
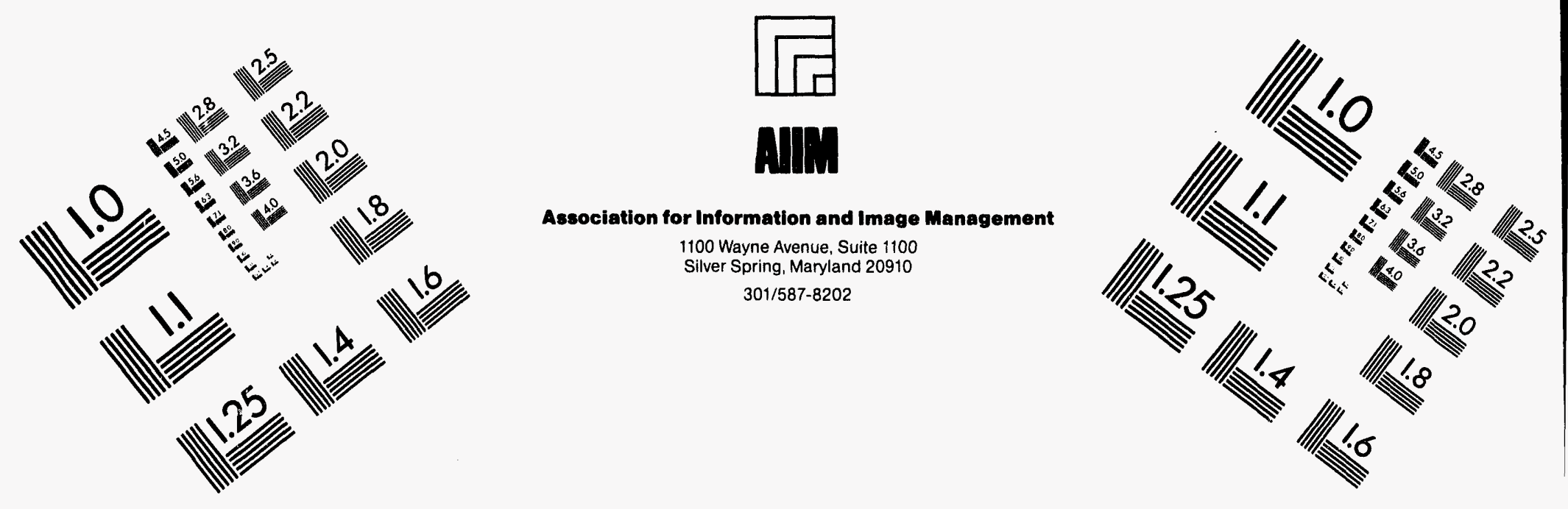

\title{
Centimeter
}

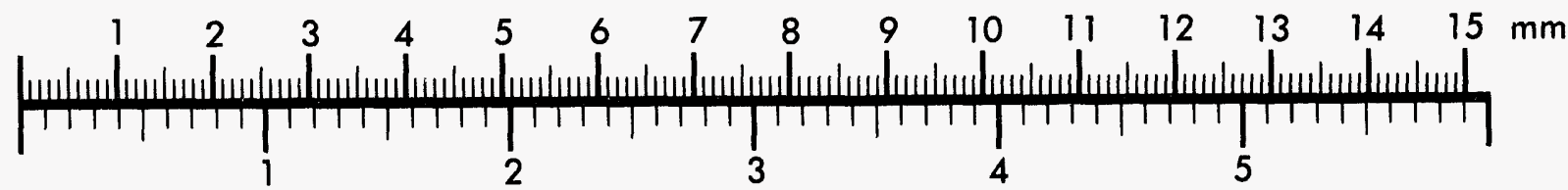
Inches
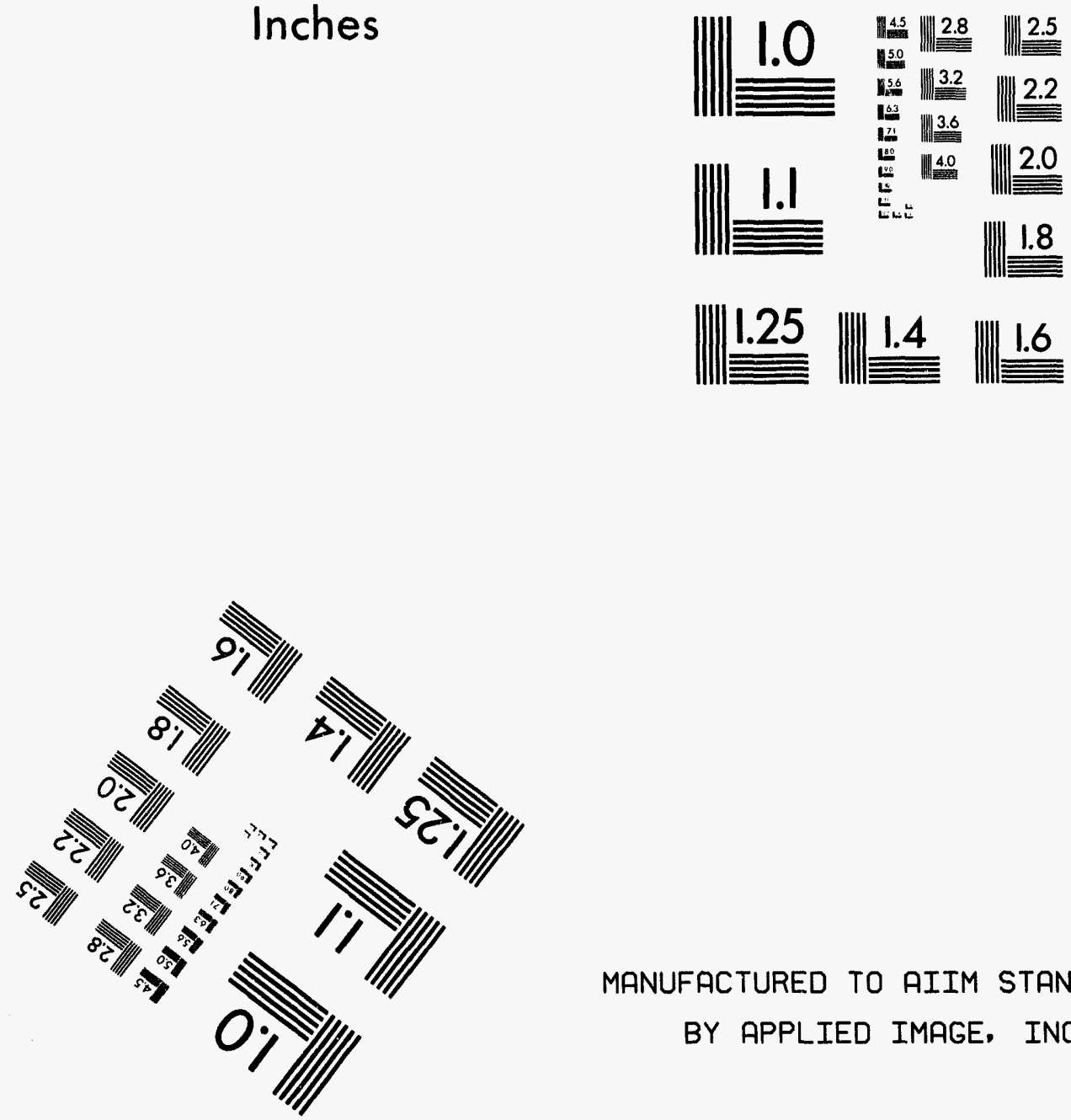

MANUFACTURED TO AIIM STANDARDS

BY APPLIED IMAGE, INC.

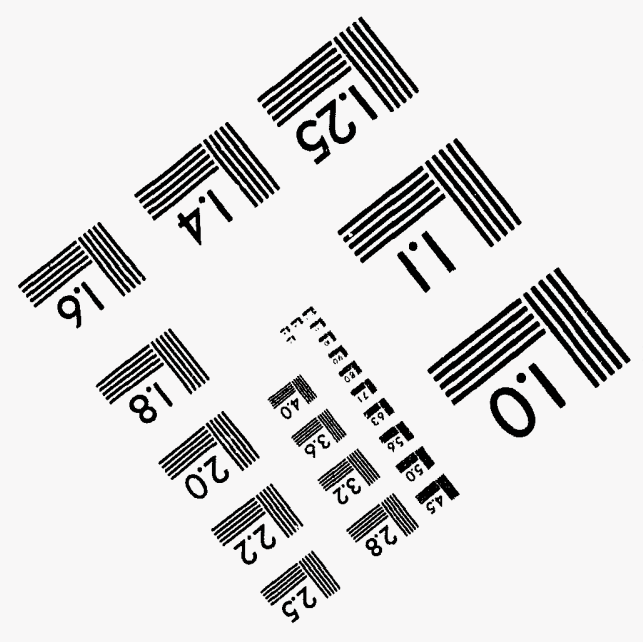



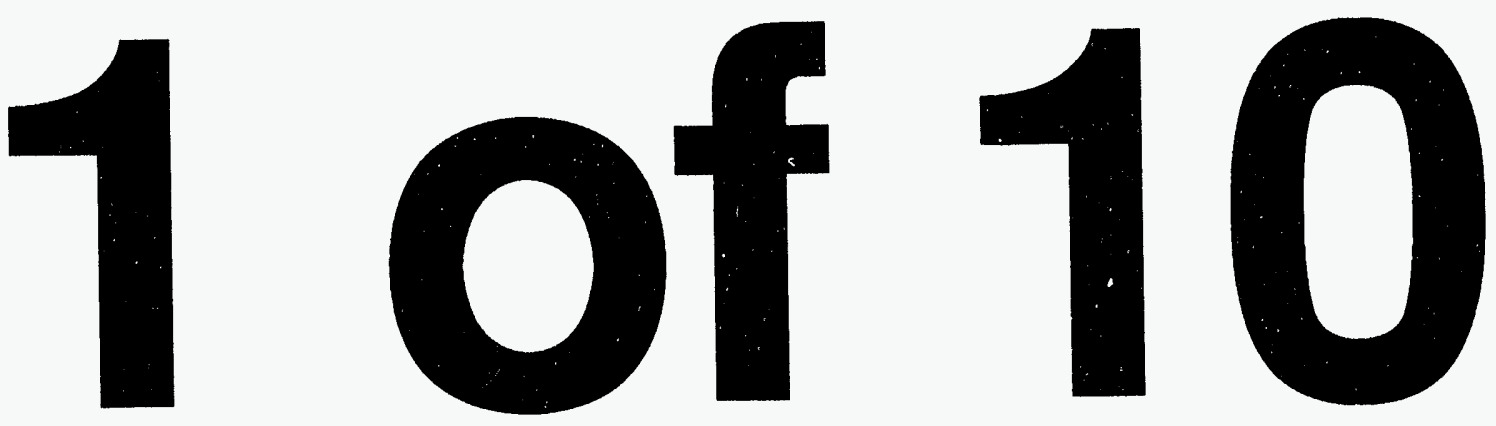
NUREG-1503

Vol. 1

\section{Final Safety Evaluation Report Related to the Certification of the Advanced Boiling Water Reactor Design}

Main Report

Manuscript Completed: July 1994

Date Published: July 1994

Associate Directorate for Advanced Reactors and License Renewal Office of Nuclear Reactor Regulation U.S. Nuclear Regulatory Commission

Washington, DC 20555-0001

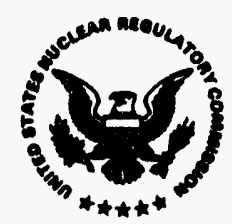




\section{ABSTRACT}

This safety evaluation report (SER) documents the tochnical review of the U.S. Advanced Boiling Water Reactor (ABWR) standard design by the U.S. Nuclear Regulatory Commission (NRC) staff. The application for the ABWR design was initially submitted by the General Electric Company, now GE Nuclear Bnergy (GE), in accordance with the procedures of Appendix $\mathrm{O}$ of Part 50 of Title 10 of the Code of Federnl Remplations (10 CFR Part 50). Later GE requested that its application be considered as an application for deaign approval and subsequent design certification pursuant to 10 CFR \& 52.45 .

The U.S. ABWR design is similar to the international ABWR design, which was being built at the Keshiwazaki Kariwa Nuclear Power Generation Station, at the time of the staff's review, by the Tokyo Electric Power Company, Inc. The ABWR is a singlo-cycle, forced-circulation, boiling water reactor (BWR) with a rated power of 3926 megawatts thermal (MWt) and a design power of $4005 \mathrm{MWt}$. Many features of the ABWR design are similar to those of BWR designs that the staff had previously approved. To the extent feasible and appropriate, the staff relied on carlier reviews for those
ABWR design features that are substentially the same as those previously considered. The SERs for the other BWR deaigns have been published and are available for public inspection at the NRC Public Document Room, 2120 L Street, N.W., Washington, D.C. 20037. Unique features of the ABWR design include internal recirculation pumps, fine-motion control rod drives, microprocessorbased digital logic and control systems, and digital safoty systems.

On the basis of its evaluation and independent analyses, the NRC staff concludes that, subject to satisfactory resolution of the confirmatory items identified in Section 1.8 of this SER, GE's application for design certification moets the requirements of Subpart B of 10 CFR Part 52 that are applicable and technically relevant to the U.S. ABWR standard design. A copy of the report by the Advisory Committee on Reactor Safeguards required by 10 CFR 52.53 is provided in Chapter 21. A final design approval, issued on the basis of this SER, does not constitute a cornmitment to issue a permit or license, or in any way affect the authority of the Commission, the Atomic Safety and Licensing Board, and other presiding officers, in any proceeding pursuant to Subpart $G$ of 10 CFR Part 2. 


\section{CONTENTS}

\section{VOLUME 1: MAIN REPORT}

ABSTRACT $\ldots \ldots \ldots \ldots \ldots \ldots \ldots \ldots \ldots \ldots \ldots \ldots \ldots$

1 INTRODUCTION AND GENERAL DISCUSSION . . . . . . . . . . . . . . . . . . 1-1

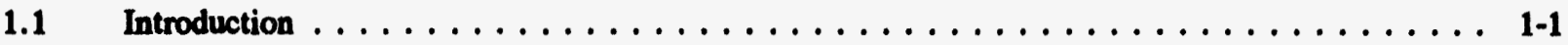

1.2 General Design Description $\ldots \ldots \ldots \ldots \ldots \ldots \ldots \ldots \ldots \ldots \ldots \ldots \ldots \ldots \ldots \ldots$

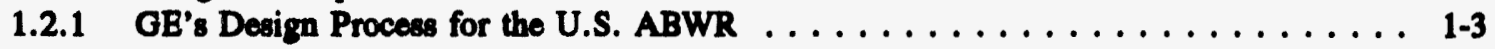

1.2.2 Precertification and Postcertification Design Control Procedures . . . . . . . . 1-3

1.2.3 The role of the COL Applicant or Licensec $\ldots \ldots \ldots \ldots \ldots \ldots \ldots \ldots \ldots \ldots$

1.2.4 Control of Design Documentation in Support of the Certified

Design ............................... 1-3

1.2.5 GE's Agreement With the Japanese $\ldots \ldots \ldots \ldots \ldots \ldots \ldots \ldots \ldots \ldots \ldots \ldots$

1.2.6 Scope of Certified Design . . . . . . . . . . . . . . . . . . . . 1-3

1.2 .7 Summary of U.S. ABWR Standard Design $\ldots \ldots \ldots \ldots \ldots \ldots \ldots \ldots \ldots \ldots$

1.3 Comparison With Similar Facility Designs $\ldots \ldots \ldots \ldots \ldots \ldots \ldots \ldots \ldots \ldots \ldots$

1.4 Identification of Agents and Contractors $\ldots \ldots \ldots \ldots \ldots \ldots \ldots \ldots \ldots \ldots \ldots \ldots$

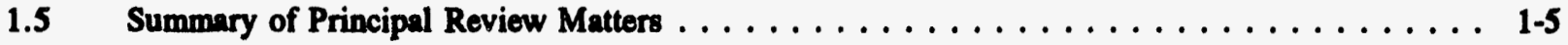

1.6 Index of Applicable Regulations and Exemptions $\ldots \ldots \ldots \ldots \ldots \ldots \ldots \ldots$

1.7 Index of Tier $2^{*}$ Information $\ldots \ldots \ldots \ldots \ldots \ldots \ldots \ldots \ldots \ldots \ldots \ldots \ldots \ldots \ldots$

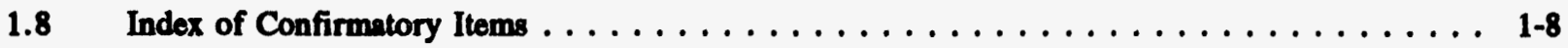

2 SITE CHARACTERISTICS ........................ $2-1$

2.1 Geography and Demography . . . . . . . . . . . . . . . . . 2-1

2.1.1 Site Location and Description . . . . . . . . . . . . . . . . . . 2-1

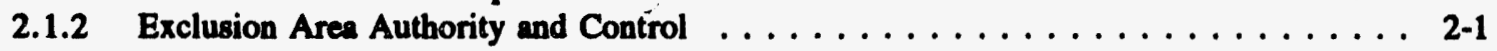

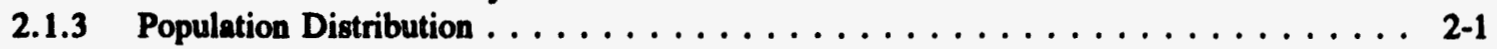

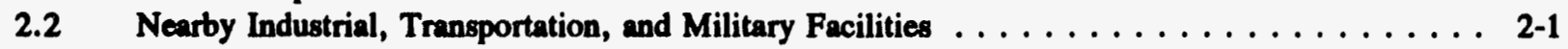

2.2.1 and 2.2.2 Identification of Potential Hazards in Site Vicinity . . . . . . . . . . 2-1

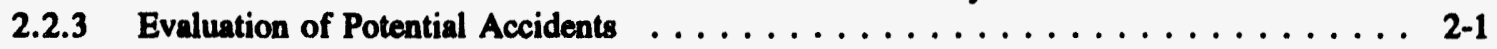

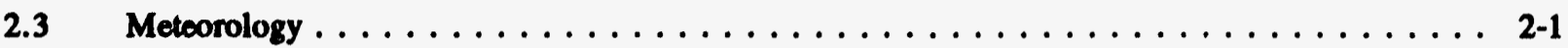

2.3.1 Regional Climatology . . . . . . . . . . . . . . . . . . 2-1

2.3.2 Local Metoorology . . . . . . . . . . . . . . . . . . . . . . . . 2-4

2.3.3 Onsite Meteorological Measurements Program . . . . . . . . . . . . . . 2-4

2.3.4 Short-Term Dispersion Estimates for Accidental Atmospheric

Releases . . . . . . . . . . . . . . . . . . . . . . . 24 24

2.3.5 Long-Term Diffusion Estimates $\ldots \ldots \ldots \ldots \ldots \ldots \ldots \ldots \ldots \ldots \ldots \ldots$

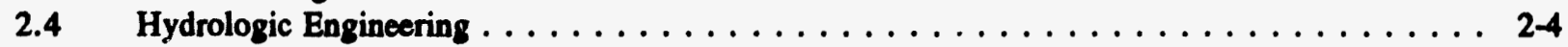

2.4 .1 Hydrologic Description . . . . . . . . . . . . . . . . . . . 2-4

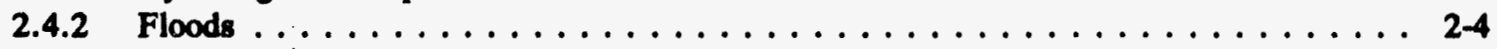

2.4.3 Probable Maximum Flood on Streams and Rivers $\ldots \ldots \ldots \ldots \ldots \ldots \ldots \ldots$

2.4 .4 Ice Effects . . . . . . . . . . . . . . . . . . . . . . . . 2-4

2.4.5 Cooling Water Channels and Reservoirs ... . . . . . . . . . . . 2-4

2.4 .6 Channel Diversion . . . . . . . . . . . . . . . . . . . . . 2-5

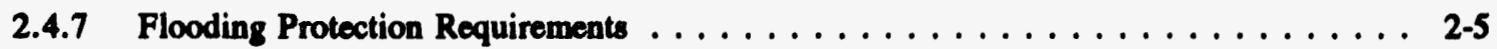

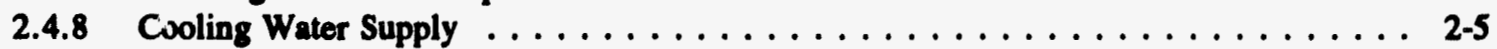

2.4.9 Accidental Release of Liquid Effluents in Ground and Surface

Waters . . . . . . . . . . . . . . . . . . . . . . . 2-5

2.4.10 Technical Specification and Emergency Operation Requirement . . . . . . . . . 2-5

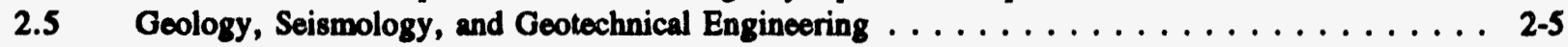

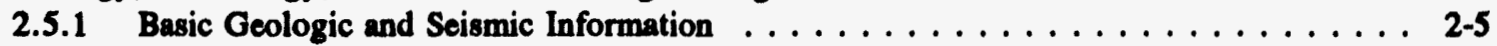

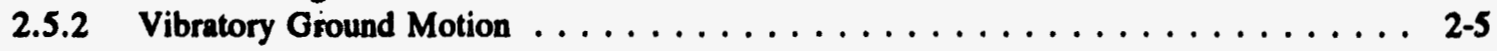


2.5.3 Surfuce Faulting $\ldots \ldots \ldots \ldots \ldots \ldots \ldots \ldots \ldots \ldots \ldots \ldots \ldots \ldots \ldots \ldots$

2.5.4 Stability of Subsurface Materials and Foundations . . . . . . . . . . . . . $2-6$

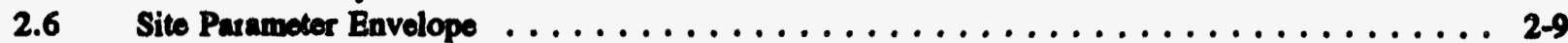

2.6.1 Wind and Tornado Design Site Parnmeters . . . . . . . . . . . . . . . 2-10

2.6.2 Water Lovel (Flood) Design Site Parameters . . . . . . . . . . . . . . . . . . 2-10

2.6.3 Seismology Site Parameters . . . . . . . . . . . . . . . . . . . 2-10

2.6.4 Soil Properties Sito Paramoters . . . . . . . . . . . . . . . . . . 2-11

2.6.5 Precipitation (for Roof Design) Site Paramoters . . . . . . . . . . . . . 2-11

2.6 .6 Design Temporature Sito Parameter . . . . . . . . . . . . . . . . 2-11

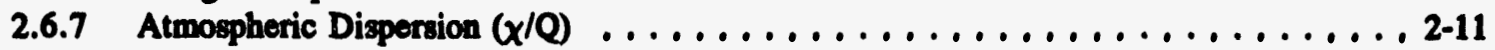

3 DESIGN OF STRUCTURES, COMPONENTS, EQUIPMENT, AND SYSTEMS $\ldots \ldots$ 3-1

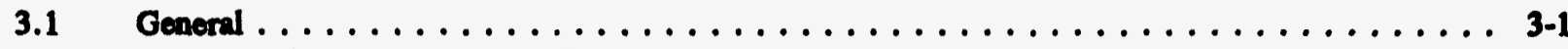

3.1.1 Elimination of Operating Basis Earthquake from Design

Consideration . . . . . . . . . . . . . . . . . . . . . . 3-1

3.2 Clessification of Structures, Systems, and Components . . . . . . . . . . . . . . 3-9

3.2.1 Seismic Classification . . . . . . . . . . . . . . . . . . . . . . 3-9

3.2.2 System Quality Group Classification . . . . . . . . . . . . . . 3-11

3.3 Wind and Tornado Loedings . . . . . . . . . . . . . . . . . . . 3-13

3.3.1 Wind Design Criteria . . . . . . . . . . . . . . . . . . . . 3-13

3.3.2 Tornado Design Criteria $\ldots \ldots \ldots \ldots \ldots \ldots \ldots \ldots \ldots \ldots \ldots \ldots$ 3-14

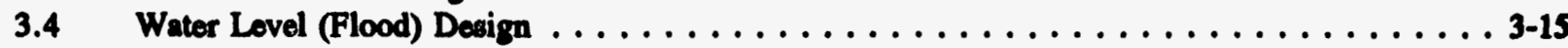

3.4.1 Flood Protection . . . . . . . . . . . . . . . . . . . . . . . . . . 3-15

3.4.2 Water Lovel (Flood) Design Procedure . . . . . . . . . . . . . . . . . 3-19

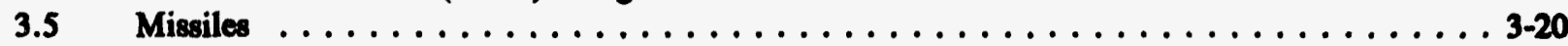

3.5.1 Missile Selection and Description . . . . . . . . . . . . . . . . . 3-20

3.5.2 Structures, Systems, and Components To Be Protected From

Externally Generated Missiles . . . . . . . . . . . . . . . . . . . . . . . . . . . . . 3-27

3.5.3 Barrier Design Procedures . . . . . . . . . . . . . . . . . . . . . . . . . . . . 3-29

3.6 Protection Against Dynamic Effects Associated With the Postulated Rupture

of Piping . . . . . . . . . . . . . . . . . . . . . . . . 3-30

3.6.1 Plant Design for Protection Against Postulated Piping Failure in

Fluid Systems Outside Containment . . . . . . . . . . . . . . 3-30

3.6.2 Determination of Rupture Locations and Dynamic Effects

Associated With the Postulated Rupture of Piping . . . . . . . . . . . 3-33

3.6.3 Leak-Before-Break Evaluation Procedures . . . . . . . . . . . . . . . . . 3-36

3.7 Seismic Design . . . . . . . . . . . . . . . . . . . . . . . 3-36

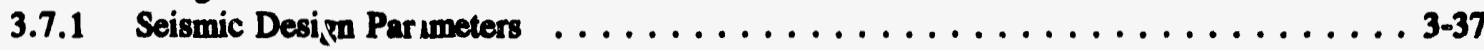

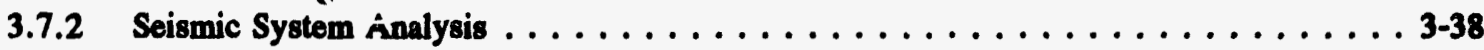

3.7.3 Seismic Subsystem Analysis $\ldots \ldots \ldots \ldots \ldots \ldots \ldots \ldots \ldots \ldots \ldots \ldots . \ldots \ldots$ 3-48 $\ldots \ldots \ldots$

3.7 .4 Seismic Instrumentation $\ldots \ldots \ldots \ldots \ldots \ldots \ldots \ldots \ldots \ldots \ldots \ldots \ldots \ldots . \ldots \ldots$

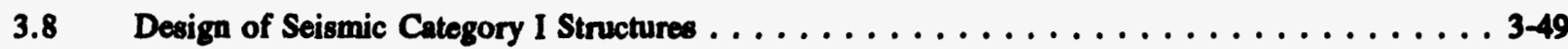

3.8.1 Concrete Containment . . . . . . . . . . . . . . . . . . . . . . 3-49

3.8.2 Steel Components of the Reinforced Concrete Containment . . . . . . . . . . 3-51

3.8.3 Concrete and Steel Internal Structures of Steel or Concrete

Containment $\ldots \ldots \ldots \ldots \ldots \ldots \ldots \ldots \ldots \ldots \ldots \ldots \ldots \ldots \ldots$ 3-51

3.8.4 Other Seismic Category I Structures $\ldots \ldots \ldots \ldots \ldots \ldots \ldots \ldots \ldots \ldots \ldots \ldots \ldots$ 3-53

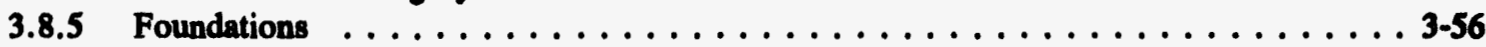

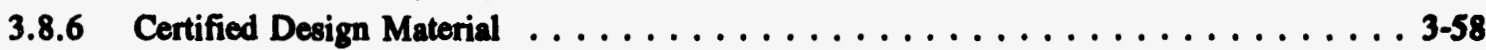

3.9 Mechanical Systems and Components $\ldots \ldots \ldots \ldots \ldots \ldots \ldots \ldots \ldots \ldots \ldots \ldots$

3.9.1 Special Topics for Mechanical Components . . . . . . . . . . . . . . 3-58

3.9.2 Dynamic Testing and Analysis of Systems, Components, and

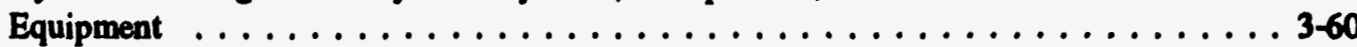


3.9.3 ASME Codo Clase 1, 2, and 3 Components, Component Supports,

and Core Support Structures . . . . . . . . . . . . . . . . . . . . . . 3-66

3.9.4 Control Rod Drive System . . . . . . . . . . . . . . . . . . . . . 3-75

3.9.5 Reactor Preecure Vecel Internals . . . . . . . . . . . . . . . . 3-76

3.9 .6 Teeting of Pumpes and Valves . . . . . . . . . . . . . . . . . . . . 3-77

3.10 Soismic and Dynamic Qualification of Mechanical and Electrical Equipment . . . . . . . . . . 3-84

3.10.1 Conclusions . . . . . . . . . . . . . . . . . . . . . . . . . 3-87

3.10.2 Mothods and Procedures of Analysis or Teeting of Supports of

Electrical Equipment and Instrumentation . . . . . . . . . . . . . . . 3-87

3.11 Environmental Qualification of Mechenical and Eloctrical Equipment . . . . . . . . . . . 3-88

3.11.1 Completeness of Qualification of Electrical Equipment Important to

Safoty . . . . . . . . . . . . . . . . . . . . . . . . . 3-89

3.11.2 Qualification Methods . . . . . . . . . . . . . . . . . . . . . . . 3-89

3.11.3 Completeness of Information in Tables of SSAR Appendix $31 \ldots \ldots \ldots \ldots \ldots$. . . . . . . .

3.11.4 Adequacy of Interface Requirements . . . . . . . . . . . . . . . 3-95

3.11.5 Conclusions . . . . . . . . . . . . . . . . . . . . . 3-95

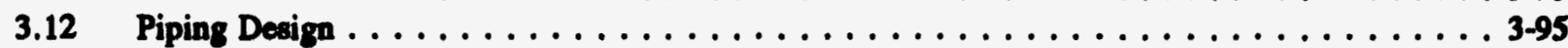

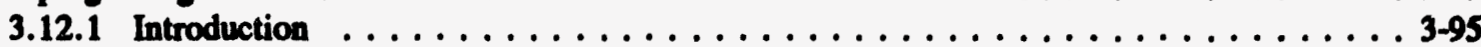

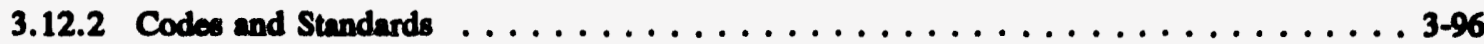

3.12.3 Analysis Mothods $\ldots \ldots \ldots \ldots \ldots \ldots \ldots \ldots \ldots \ldots \ldots \ldots \ldots \ldots \ldots \ldots . \ldots \ldots \ldots$

3.12.4 Piping Modeling . . . . . . . . . . . . . . . . . . . . . . . 3-101

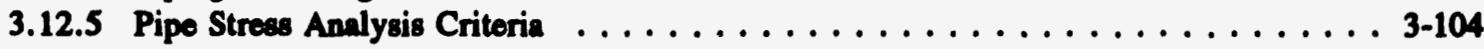

3.12.6 Pipo Support Criteria . . . . . . . . . . . . . . . . . . . . 3-112

3.12.7 High-Energy Lino-Break Criteria . . . . . . . . . . . . . . . . . 3-116

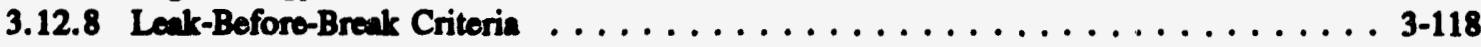

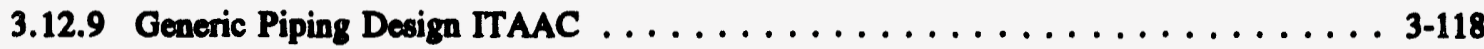

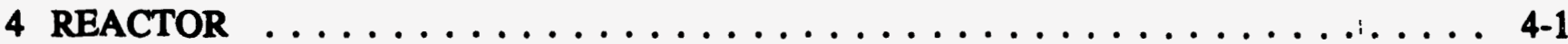

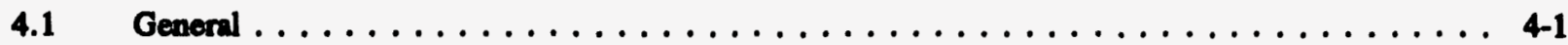

4.2 Fuel System Design $\ldots \ldots \ldots \ldots \ldots \ldots \ldots \ldots \ldots \ldots \ldots \ldots \ldots \ldots \ldots \ldots \ldots$

$4.3 \quad$ Nuclear Design . . . . . . . . . . . . . . . . . . . . . . . . . . . 4-4

4.4 Thermal Hydraulic Design . . . . . . . . . . . . . . . . . . . . . $4-6$

4.5 Reactor Muterials . . . . . . . . . . . . . . . . . . . . . . 4-8

4.5.1 Control Rod Drive System Structural Materials . . . . . . . . . . . . . . . 4-8

4.5.2 Reactor Intermal Materials . . . . . . . . . . . . . . . . . . . . 4-9

4.6 Functional Design of Fine Motion Control Rod Drive System . . . . . . . . . . . . . 4-9

5 REACTOR COOLANT SYSTEM AND CONNECTED SYSTEMS $\ldots \ldots \ldots \ldots \ldots \ldots$. $\ldots$

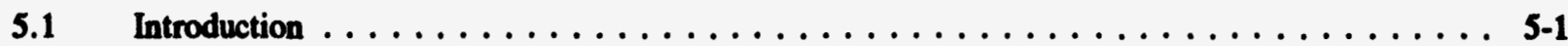

$5.2 \quad$ Integrity of Reactor Coolant Pressure Boundary $\ldots \ldots \ldots \ldots \ldots \ldots \ldots \ldots \ldots \ldots \ldots$.1 $\ldots \ldots \ldots$

5.2.1 Compliance With Code and Code Cases $\ldots \ldots \ldots \ldots \ldots \ldots \ldots \ldots \ldots \ldots$ 5-1

5.2 .2 Overpressure Protection . . . . . . . . . . . . . . . . . . . . 5-4

5.2.3 Reactor Coolent Pressure Boundary Materials . . . . . . . . . . . . . . 5 5-5

5.2.4 Inservice Inspection and Testing of the Reactor Coolant Pressure

Boundary .............................. 5 .7

5.2.5 Reactor Coolant Pressure Boundary Leakage Detection $\ldots \ldots \ldots \ldots \ldots \ldots \ldots \ldots$. . . . . . . . . . . . . . . .

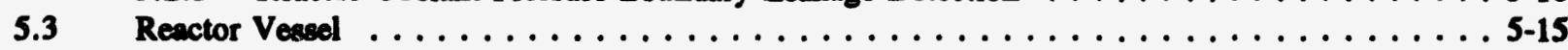

5.3.1 Reactor Vessel Materials . . . . . . . . . . . . . . . . . . 5-15

5.3.2 Pressure-Temperature Limits . . . . . . . . . . . . . . . . . 5-17

5.3 .3 Reactor Vessel Integrity . . . . . . . . . . . . . . . . . . . 5-18

5.4 Components and Subsystem Design $\ldots \ldots \ldots \ldots \ldots \ldots \ldots \ldots \ldots \ldots \ldots \ldots \ldots$

5.4 .1 Reactor Recirculation System $\backslash \ldots \ldots \ldots \ldots \ldots \ldots \ldots \ldots \ldots \ldots \ldots \ldots$

5.4.2 Steam Generators $\ldots \ldots \ldots \ldots \ldots \ldots \ldots \ldots \ldots \ldots \ldots \ldots \ldots$. . . . . . . . . . . 
5.4.3 Reactor Coolant Piping . . . . . . . . . . . . . . . . . . . . . . . 5 5-19

5.4.4 Main Steam Line Flow Reetrictions . . . . . . . . . . . . . . . . . . . . . . . . . 5-19

5.4.5 Main Steam Isolation Valvo Leakage Control System . . . . . . . . . . . . . . . 5-20

5.4 .6 Reector Core Isolation Cooling System . . . . . . . . . . . . . . . . . . . 5-20

5.4 .7 Residual Heat Removal System . . . . . . . . . . . . . . . . . 5-22

5.4 .8 Reactor Water Cleanup System . . . . . . . . . . . . . . . . . . . . . 5-24

6 ENGINEERED SAFETY FEATURES $\ldots \ldots \ldots \ldots \ldots \ldots \ldots \ldots \ldots \ldots$. . . . . . .

6.1 Engineered Safety Features Materials $\ldots \ldots \ldots \ldots \ldots \ldots \ldots \ldots \ldots \ldots \ldots \ldots$

6.1 .1 Metallic Materials ... . . . . . . . . . . . . . . . . . . . 6-1

6.1.2 Protective Conting Systems (Paints) and Organic Material . . . . . . . . . . . . 6-2

6.2 Containment Systems . . . . . . . . . . . . . . . . . . . . . . 6-3

6.2.1 Primary Containment Functional Design $\ldots \ldots \ldots \ldots \ldots \ldots \ldots \ldots \ldots$. . . . . . . .

6.2.2 Containment Heat Removal System . . . . . . . . . . . . . . . . . . . 6-19

6.2.3 Secondary Containment Functional Deaign ................... 6-20

6.2 .4 Containment Isolation System . . . . . . . . . . . . . . . . . . . . 6-22

6.2.5 Combustible Gas Control in Containment . . . . . . . . . . . . . . . 6-29

6.2 .6 Containment Leakage Testing . . . . . . . . . . . . . . . . . 6-33

6.2.7 Fracture Prevention of Containment Pressure Boundary . . . . . . . . . . 6-38

6.2.8 Severe Accident Considerations . . . . . . . . . . . . . . . . . 6-38

6.3 Emergency Core Cooling System $\ldots \ldots \ldots \ldots \ldots \ldots \ldots \ldots \ldots \ldots \ldots \ldots$. . . . . . . . . . . . .

6.3.1 System Description . . . . . . . . . . . . . . . . . . . . . 6-39

6.3.2 Evaluation of Single Failures . . . . . . . . . . . . . . . . . . . 6-40

6.3.3 Qualification of Emergency Core Cooling System . . . . . . . . . . . . . . . . 6-40

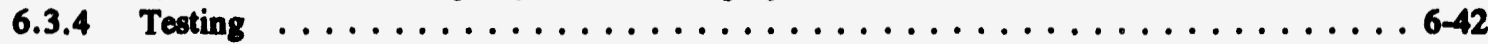

6.3.5 Performance Evaluation . . . . . . . . . . . . . . . . . 643

6.3.6 Certified Design Material . . . . . . . . . . . . . . . . . 6 6-45

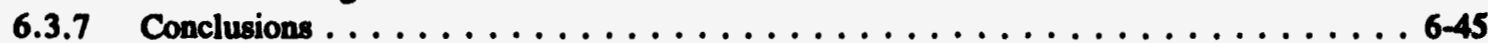

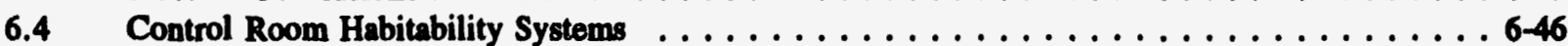

6.5 Fission Product Removal and Control Systems . . . . . . . . . . . . . . . . . . . . 6 6-48

6.5.1 Engineered Safety Features Atmosphere Cleanup Systems . . . . . . . . . . . . . . . 6-48

6.5.2 Containment Spray System . . . . . . . . . . . . . . . . . . . 6-50

6.5.3 Fission Product Control Systems and Structures . . . . . . . . . . . . . . . 6-50

6.6 Inservice Inspection of Class 2 and 3 Components $\ldots \ldots \ldots \ldots \ldots \ldots \ldots \ldots$. . . . . . . .

6.6.1 Requirements of 10 CFR 50.55a, "Codes and Standards" . . . . . . . . . . . 6-51

6.6.2 Application of the Codes and Standards Rule to Standard Design

Certification . . . . . . . . . . . . . . . . . . . . 6-52

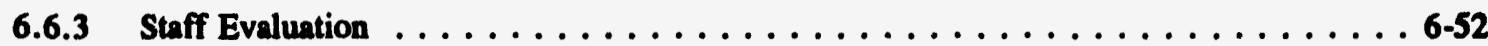

6.7 High-Pressure Nitrogen Gas Supply System $\ldots \ldots \ldots \ldots \ldots \ldots \ldots \ldots \ldots \ldots \ldots \ldots$. . . . . . . . . . . . . .

6.8 Main Steam Isolation Valve Leakage Control System . . . . . . . . . . . . . 6-53

7 INSTRUMENTATION AND CONTROLS $\ldots \ldots \ldots \ldots \ldots \ldots \ldots \ldots \ldots$

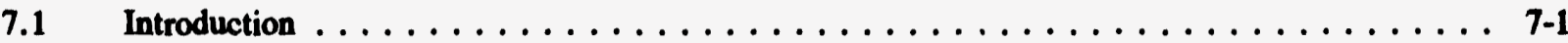

7.1.1 Acceptance Criteria ............................ 7-1

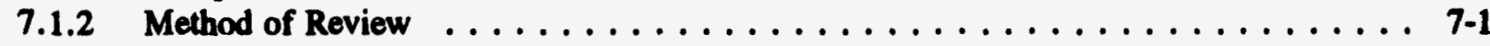

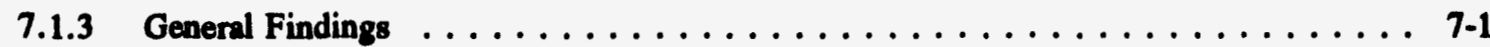

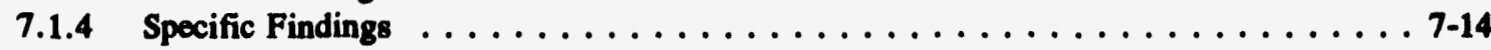

7.2 Reactor Protection System $\ldots \ldots \ldots \ldots \ldots \ldots \ldots \ldots \ldots \ldots \ldots \ldots \ldots \ldots \ldots$

7.2.1 General System Description . . . . . . . . . . . . . . . . . 7-15

7.2.2 Safety System Logic and Control and Specific Subsystem Descrip-

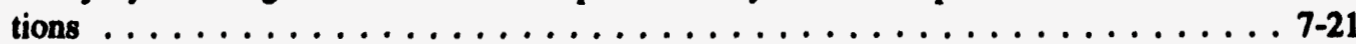

7.2.3 Indication of Bypassed and Inoperable Status $\ldots \ldots \ldots \ldots \ldots \ldots \ldots \ldots \ldots$

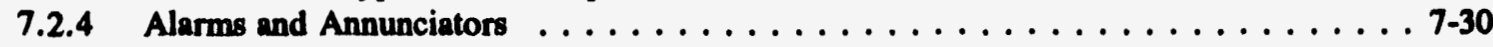




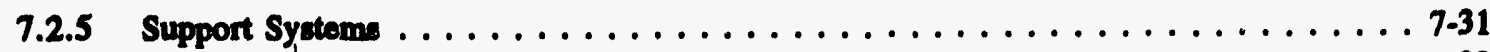

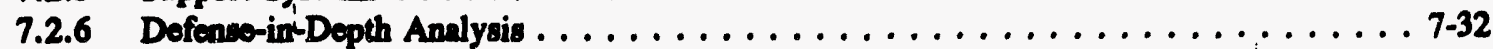

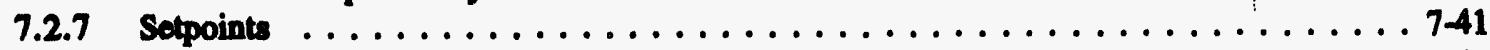

7.2.8 Handware and Software Qualification . . . . . . . . . . . . . . . 7-42

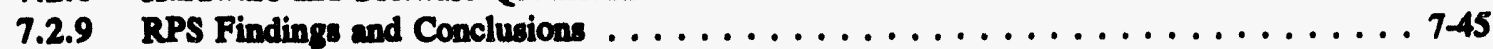

7.3 Engineered Safety Features Systems $\ldots \ldots \ldots \ldots \ldots \ldots \ldots \ldots \ldots \ldots \ldots \ldots \ldots$

7.3.1 Syetem Description . . . . . . . . . . . . . . . . . . . . 7-46

7.3.2 Safoty System Logic and Control and Specific Subsystem

Descriptions . . . . . . . . . . . . . . . . . . . . . 7-49

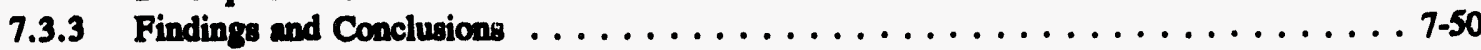

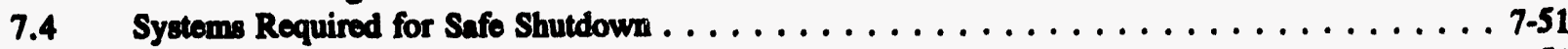

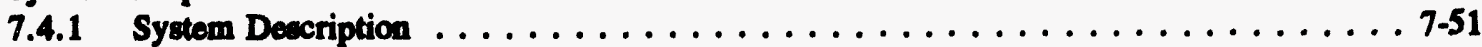

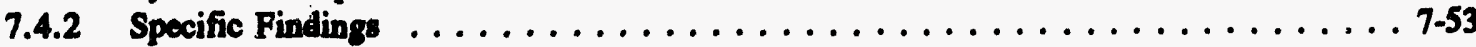

7.4.3 Evaluation Findings . . . . . . . . . . . . . . . . . . . . . 7-53

7.5 Safoty-Related Display Instrumentation and Information Systems Important to Safety $\ldots \ldots$. . 7-54

7.5.1 System Description . . . . . . . . . . . . . . . . . . . . 7-54

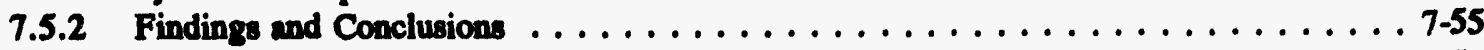

7.6 All Other Instrumentation Systems Required for Safety $\ldots \ldots \ldots \ldots \ldots \ldots \ldots \ldots \ldots \ldots$

7.6.1 System Description . . . . . . . . . . . . . . . . . . . . . .

7.6 .2 Specific Findings and Evaluation $\ldots \ldots \ldots \ldots \ldots \ldots \ldots \ldots \ldots \ldots \ldots \ldots \ldots$

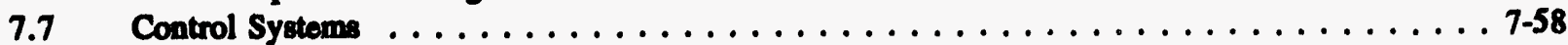

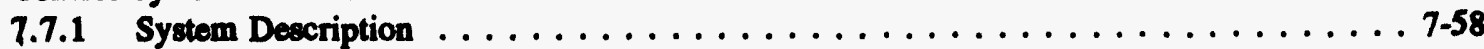

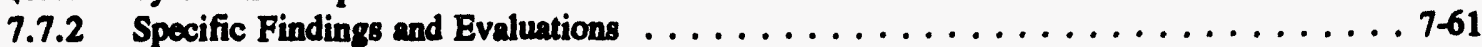

7.8 COL License Information . . . . . . . . . . . . . . . . . . . . . 7-62

7.9 Appendix 7A - Design Response to Appendix B of ABWR Licensing Review Bases . . . . . 7-62

7.10 Unresolved Safoty Iseves, Generic Safety Issues, and Operating Experience . . . . . . . . . 7-63

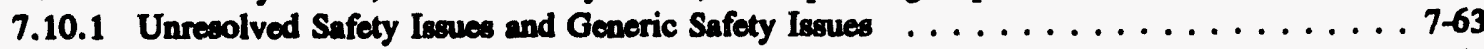

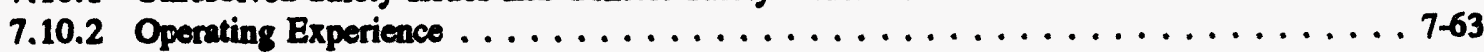

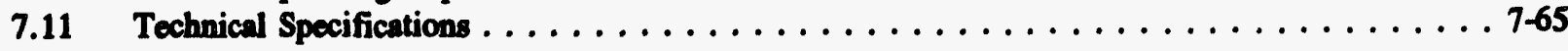

8 ELECTRIC POWER SYSTEMS $\ldots \ldots \ldots \ldots \ldots \ldots \ldots \ldots \ldots$ 8-1

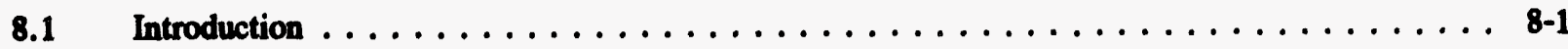

8.2 Offsite Electric Power System $\ldots \ldots \ldots \ldots \ldots \ldots \ldots \ldots \ldots \ldots \ldots \ldots \ldots \ldots \ldots$ 8-1

8.2.1 Preferred Offsite Circuits Outside the ABWR Scope of Design . . . . . . . . . . 8-1

8.2.2 Preferred Offsite Circuits Within the ABWR Scope of Design . . . . . . . . . . 8 8-5

8.2.3 Independence Between Offsite and Onsite Power Systems,

Equipment, and Components $\ldots \ldots \ldots \ldots \ldots \ldots \ldots \ldots \ldots \ldots \ldots$ 8-12

8.2.4 Power Supply for the Reactor Internal Pumps $\ldots \ldots \ldots \ldots \ldots \ldots \ldots \ldots \ldots \ldots$ 8-21

8.3 Onsite Class 1E Power System $\ldots \ldots \ldots \ldots \ldots \ldots \ldots \ldots \ldots \ldots \ldots \ldots \ldots \ldots \ldots . \ldots .21$

8.3.1 Compliance with General Design Criteria $\ldots \ldots \ldots \ldots \ldots \ldots \ldots \ldots$. . . . . . . . . . . .

8.3.2 Physical Independence $\ldots \ldots \ldots \ldots \ldots \ldots \ldots \ldots \ldots \ldots \ldots \ldots \ldots$ 8-26

8.3.3 Protection of Electrical Systems, Equipment, and Components . . . . . . . . . 8-35

8.3.4 Electrical Independence $\ldots \ldots \ldots \ldots \ldots \ldots \ldots \ldots \ldots \ldots \ldots \ldots \ldots . \ldots \ldots$

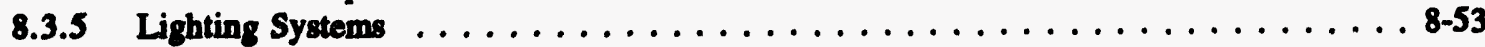

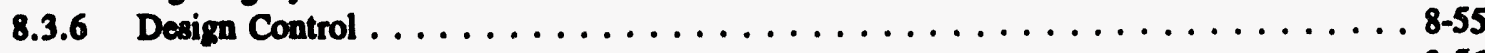

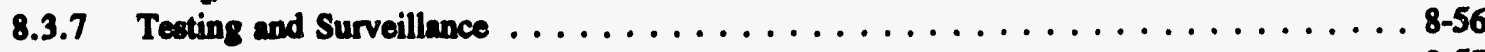

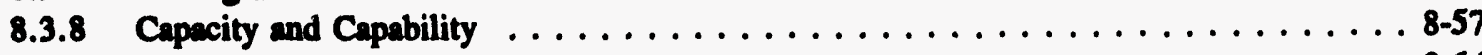

8.3.9 Station Blackout $\ldots \ldots \ldots \ldots \ldots \ldots \ldots \ldots \ldots \ldots \ldots \ldots$. $\ldots \ldots \ldots$

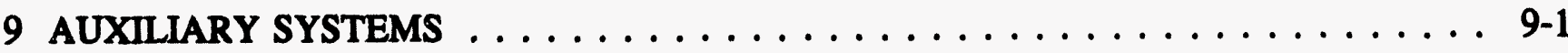

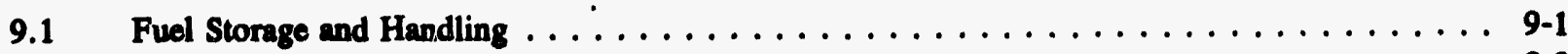

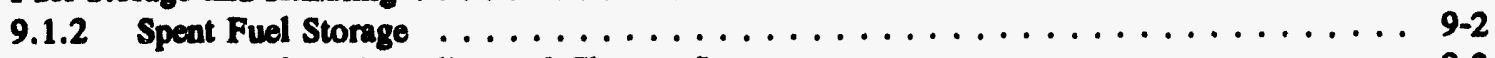

9.1.3 Spent Fuel Pool Cooling and Cleanup System . . . . . . . . . . . . . 9-3 
9.1.4 Light Loed-Handling Syetem (Rolated to Rofueling) . . . . . . . . . . . . . . 9-9

9.1.5 Overhead Heavy Loed-Handling System . . . . . . . . . . . . . . . . 9-10

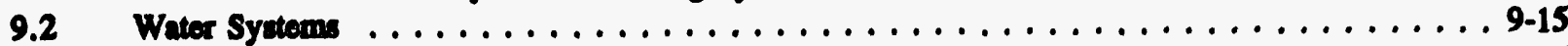

9.2.1 Station Service Water System . . . . . . . . . . . . . . . . . . . . . 9-15

9.2.2 Reactor Auxiliary Cooling Water System . . . . . . . . . . . . . . . . 9.-15

9.2.3 Demineralized Water Makeup System . . . . . . . . . . . . . . . . . 9-16

9.2.4 Potable and Sanitary Water Syatem $\ldots \ldots \ldots \ldots \ldots \ldots \ldots \ldots \ldots \ldots \ldots$. . . . . . . . . . . . . . .

9.2.5 Ultimate Heat Sink . . . . . . . . . . . . . . . . . . . . 9-16

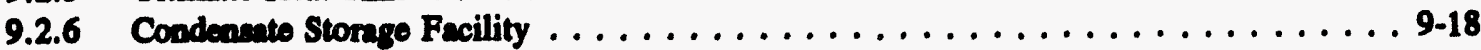

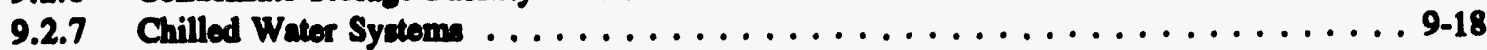

9.2.8 Makeup Water System (Preparation) $\ldots \ldots \ldots \ldots \ldots \ldots \ldots \ldots \ldots \ldots \ldots$. . . . . . . . . . . . .

9.2.9 Makeup Water System (Condeneate) . . . . . . . . . . . . . . . . . . . . . 9-18

9.2.10 Makcup Water Syatem (Purified) Dietribution Syatem . . . . . . . . . . . . . . . . 9-20

9.2.11 Reactor Building Cooling Water System . . . . . . . . . . . . . . . . . . 9-21

9.2.12 HVAC Normal Cooling Water System . . . . . . . . . . . . . . . . 9-24

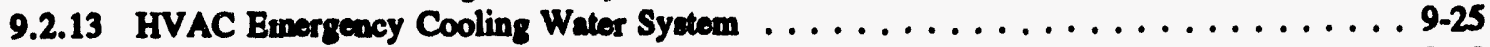

9.2.14 Turbine Building Cooling Water System . . . . . . . . . . . . . . . . 9-28

9.2.15 Reactor Service Water . . . . . . . . . . . . . . . . . . . . . . . . . 9-29

9.2.16 Turbino Service Water System . . . . . . . . . . . . . . . . . 9-31

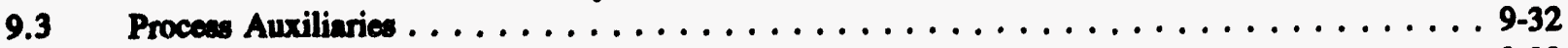

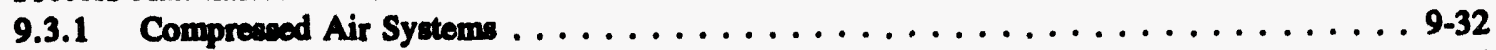

9.3.2 Process and Post-Accident Sampling Systoms . . . . . . . . . . . . . . 9-36

9.3.3 Non-Redionctive Drain System . . . . . . . . . . . . . . . . . . . . . . 9-39

9.3.4 Chemical and Volume Control System . . . . . . . . . . . . . . . . 9-40

9.3.5 Standby Liquid Control System . . . . . . . . . . . . . . . . . . . 9-40

9.3.6 Instrument Air System . . . . . . . . . . . . . . . . . . . . 9-42

9.3.7 Service Air System . . . . . . . . . . . . . . . . . . . . . 9-42

9.3.8 Radioactive Drain Transfer System . . . . . . . . . . . . . . . . 9-42

9.3.9 Hydrogen Water Chemistry System . . . . . . . . . . . . . . . . . . 9-43

9.3.10 Oxygen Injection System . . . . . . . . . . . . . . . . . . . . . . . . 9-44

9.3.11 Zinc Injection System . . . . . . . . . . . . . . . . . . . . . . . . 9-44

9.4 Heating, Ventilation, and Air Conditioping Systems $\ldots \ldots \ldots \ldots \ldots \ldots \ldots \ldots \ldots .44$

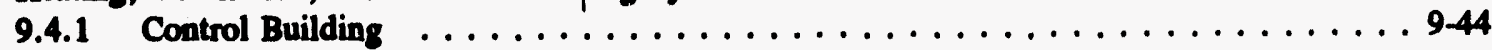

9.4.2 Spent Fuel Pool Area Ventilation System . . . . . . . . . . . . . . . 9-48

9.4.3 Auxiliary Area Ventilation System . . . . . . . . . . . . . . . . . . 9-48

9.4.4 Turbine Island HVAC System $\ldots \ldots \ldots \ldots \ldots \ldots \ldots \ldots \ldots \ldots \ldots \ldots . \ldots \ldots$

9.4.5 Reactor Building Ventilation System . . . . . . . . . . . . . . . . 9-49

9.4.6 Radwaste Building HVAC System . . . . . . . . . . . . . . . . . 9-54

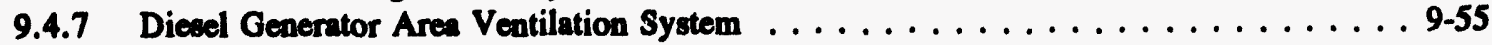

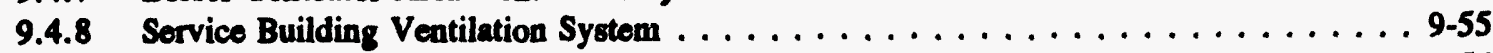

9.4.9 Drywell Cooling System . . . . . . . . . . . . . . . . . . . 9-56

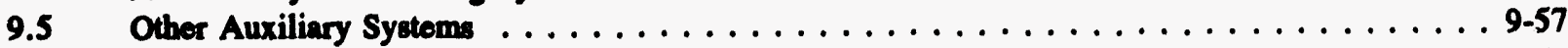

9.5.1 Fire Protection System . . . . . . . . . . . . . . . . . . . . 9-57

9.5.2 Communications Systems $\ldots \ldots \ldots \ldots \ldots \ldots \ldots \ldots \ldots \ldots \ldots . \ldots \ldots$. . . . . . . . . . . . . .

9.5.3 Lighting Systems . . . . . . . . . . . . . . . . . . . . . . . . . 9-67

9.5.4 Diesel Generator Fuel Oil Storage and Transfer System . . . . . . . . . . . . . . 9-67

9.5.5 Diesel Generator Cooling Water System . . . . . . . . . . . . . . . . . . . 9-70

9.5.6 Diesel Generator Starting Air System . . . . . . . . . . . . . . . . . . 9-72

9.5.7 Diesel Generator Lubrication System . . . . . . . . . . . . . . . . . . 9-73

9.5.8 Diesel Generator Combustion Air Intake and Exhaust System . . . . . . . . . 9-75

10 STEAM AND POWER CONVERSION SYSTEM . . . . . . . . . . . . . . . . . 10-1

10.1 Summary Description $\ldots \ldots \ldots \ldots \ldots \ldots \ldots \ldots \ldots \ldots \ldots \ldots \ldots \ldots \ldots \ldots$ 


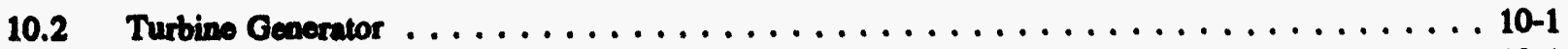

10.2.1 Turbine Generator Systom . . . . . . . . . . . . . . . . . . . 10-1

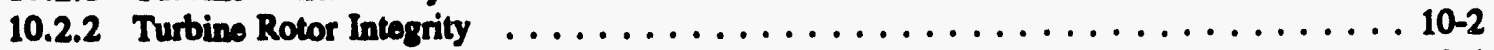

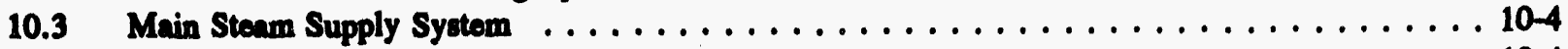

10.3.1 Syatem Description and Operation . . . . . . . . . . . . . . . . 10-4

10.3.2 Steam and Feedwater Syetem Materials . . . . . . . . . . . . . . . . 10-7

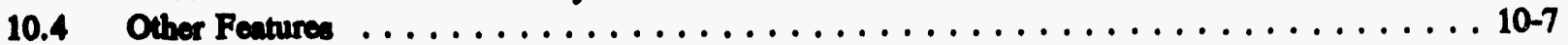

10.4.1 Main Condenser . . . . . . . . . . . . . . . . . . . . . 10-7

10.4.2 Main Condenser Evecuation System . . . . . . . . . . . . . . . . . 10-8

10.4.3 Turbine Gland Sealing System . . . . . . . . . . . . . . . . . . . . . 10-9

10.4.4 Turbino Bypass System . . . . . . . . . . . . . . . . . . . . . . . 10-10

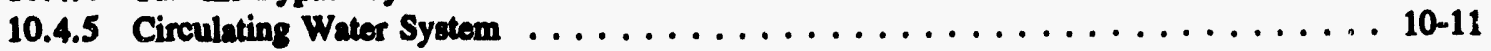

10.4 .6 Condensate Purification System . . . . . . . . . . . . . . . . 10-12

10.4.7 Condensate and Feedwater System . . . . . . . . . . . . . . . 10-13

10.4.8 Power Cycle Heat Sink . . . . . . . . . . . . . . . . . . . . . 10-14

11 RADIOACTIVE WASTE MANAGEMENT . . . . . . . . . . . . . . . . . . . . 11-1

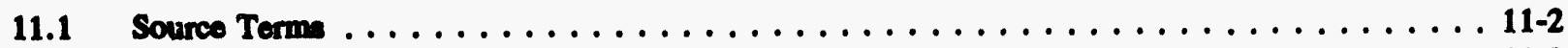

11.2 Liquid Waste Management System . . . . . . . . . . . . . . . . . . . 11-2

11.2.1 Systom Deacription and Roview Diecussion $\ldots \ldots \ldots \ldots \ldots \ldots \ldots \ldots \ldots \ldots \ldots$

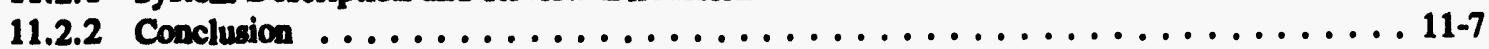

11.3 Gaseous Weste Management System . . . . . . . . . . . . . . . . . . 11-9

11.3.1 System Description and Reviow Discussion . . . . . . . . . . . . . . 11-9

11.3.2 Conclusion . . . . . . . . . . . . . . . . . . . . . . 11-10

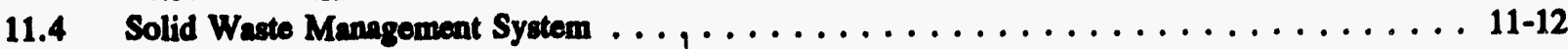

11.4.1 System Deecription and Reviow Discuseion . . . . . . . . . . . . 11-12

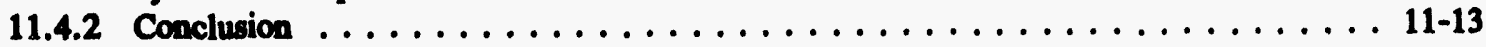

11.5 Procees and Effluent Radiological Monitoring and Sampling Systems . . . . . . . . . . . 11-15

11.5.1 System Deacription and Review Discussion ................. 11-15

11.5.2 Conclusion ...........................11-16

12 RADIATION PROTECTION . . . . . . . . . . . . . . . . . . . . . 12-1

12.1 Ensuring That Occupational Radiation Doses Are As Low As Is Reasonably

Achievable . . . . . . . . . . . . . . . . . . . . . . . . . . 12-1

12.1.1 Policy Considerations . . . . . . . . . . . . . . . . . . . 12-1

12.1.2 Design Considerations . . . . . . . . . . . . . . . . . . . . 12-1

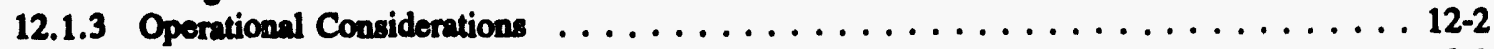

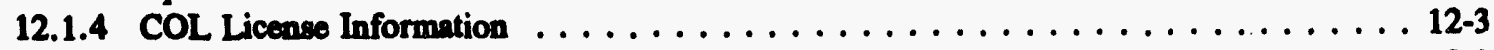

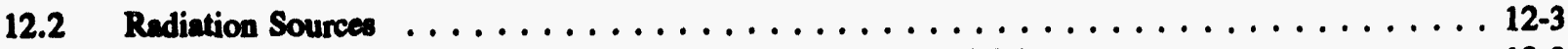

12.2.1 Contained Sources and Airborne Redioactive Material Sources . . . . . . . . . . . 12-3

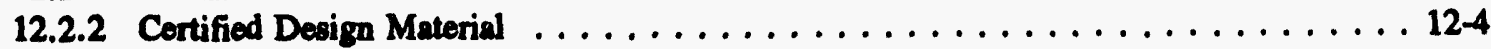

12.2.3 COL License Information . . . . . . . . . . . . . . . . . . . 12-4

12.3 Radiation Protection Design . . . . . . . . . . . . . . . . . . . . . 12-4

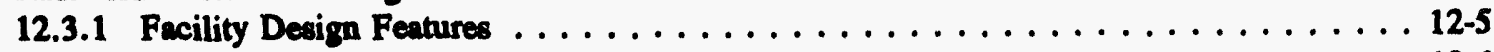

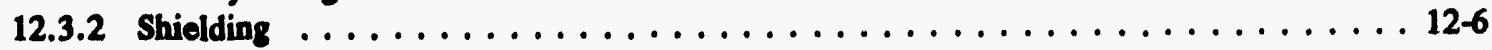

12.3.3 Ventilation . . . . . . . . . . . . . . . . . . . . . . 12-6

12.3.4 Area Radiation and Airbome Radioactive

Monitoring Instrumentation . . . . . . . . . . . . . . . . . 12-7

12.3.5 Cortified Design Material . . . . . . . . . . . . . . . . . . 12-8

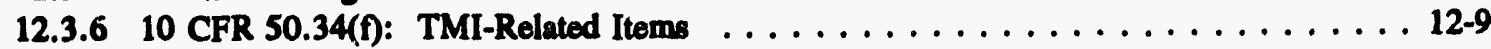

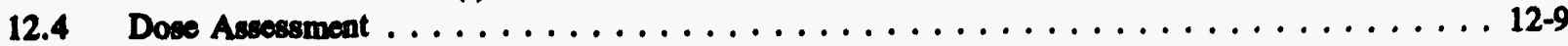

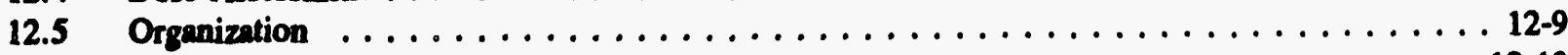

12.5.1 10 CFR 50.34(f): TMI-Related Items $\ldots \ldots \ldots \ldots \ldots \ldots \ldots \ldots \ldots \ldots \ldots$. . . . . . . . . . . 
13.1 Organizational Structure of Applicants $\ldots \ldots \ldots \ldots \ldots \ldots \ldots \ldots \ldots \ldots \ldots \ldots \ldots \ldots$ 13-1

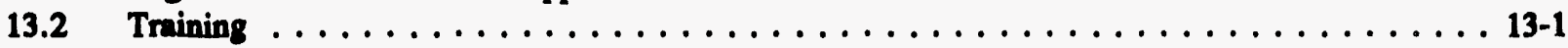

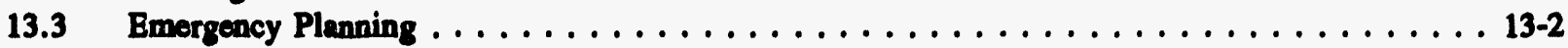

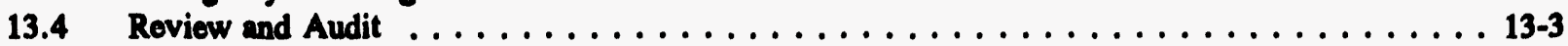

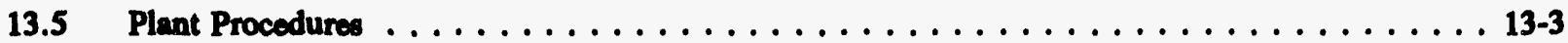

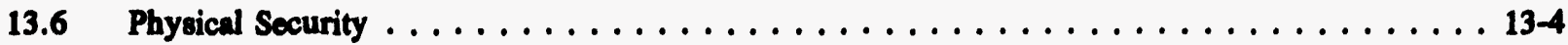

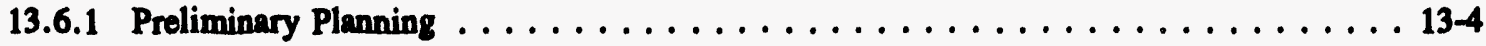

13.6.2 Security Plan . . . . . . . . . . . . . . . . . . . . . . 13-4

13.6.3 Control of Access to Areas Containing Vital Equipment . . . . . . . . . . 13-5

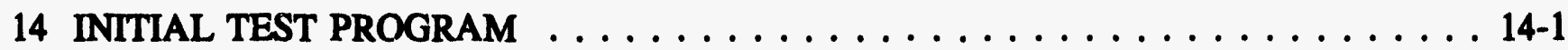

14.1 Preliminary Safety Analysis Reports Information $\ldots \ldots \ldots \ldots \ldots \ldots \ldots \ldots \ldots$ 14-1

14.2 Initial Plant Test Programs . . . . . . . . . . . . . . . . . . . . . . . 14-1

14.2.1 Summary of Test Program and Objectives . . . . . . . . . . . . . 14-2

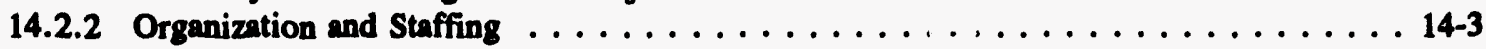

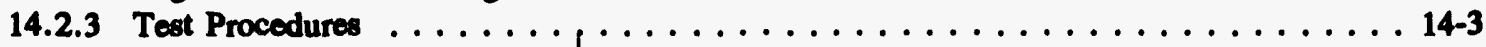

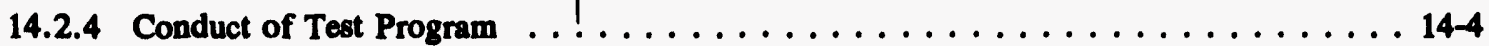

14.2.5 Review, Evaluation, and Approval of Test Results . . . . . . . . . . . 14-5

14.2.6 Test Records . . . . . . . . . . . . . . . . . . . . . . 14-5

14.2.7 Conformance of Test Program With Regulatory Guides . . . . . . . . . . . 14-5

14.2.8 Utilization of Reactor Operating and Testing Experience in the

Development of Test Program . . . . . . . . . . . . . . . . . . . 14-6

14.2.9 Trial Use of Plant Operating and Emergency Procedures . . . . . . . . . . 14-6

14.2.10 Initial Fuel Loading and Initial Criticality $\ldots \ldots \ldots \ldots \ldots \ldots \ldots \ldots \ldots \ldots$

14.2.11 Test Program Schedule . . . . . . . . . . . . . . . . . . . . . . . 14-7

14.2.12 Individual Test Descriptions . . . . . . . . . . . . . . . . . . . . . . . 14-9

14.2.13 COL License Information - Initial Test Program . . . . . . . . . . . . 14-19

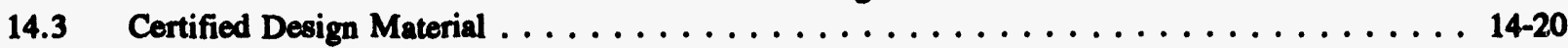

14.3.1 Introduction to CDM . . . . . . . . . . . . . . . . . . 14-23

14.3.2 Certified Design Material for Structures and Systems . . . . . . . . . . . . . 14-24

14.3.3 Additional Certified Design Material . . . . . . . . . . . . . . 14-47

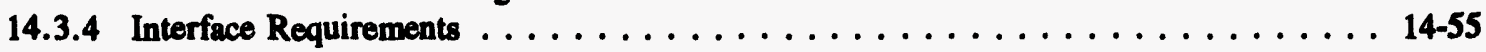

14.3.5 Site Parameters . . . . . . . . . . . . . . . . . . . . 14-56

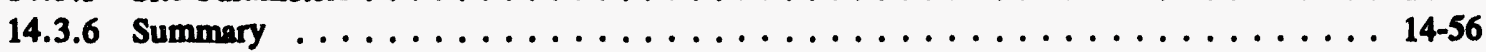

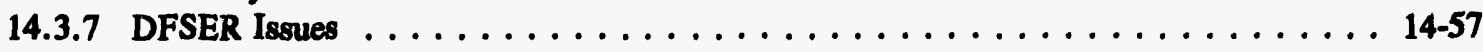

15 TRANSIENT AND ACCIDENT ANALYSIS . . . . . . . . . . . . . . . 15-1

15.1 Anticipated Operational Occurrences . . . . . . . . . . . . . . . . . 15-1

15.2 Trip of All Reactor Internal Pumps and Pressure Regulator Down-Scale Failure . . . . . . . 15-5

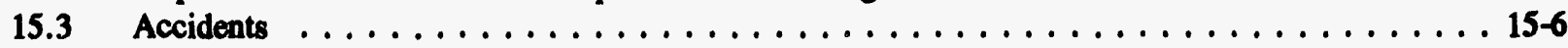

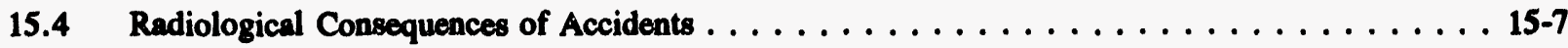

15.4.1 Control Rod Drop Accidents . . . . . . . . . . . . . . . . . . 15-16

15.4.2 Failure of Small Lines Carrying Primary Coolant Outside

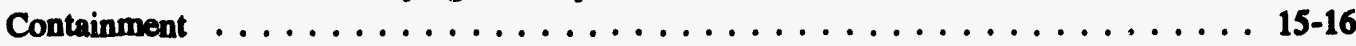

15.4.3 Main Steamline Failure Outside Containment $\ldots \ldots \ldots \ldots \ldots \ldots \ldots \ldots$ 15-17

15.4.4 Loss-of-Coolant Accidents . . . . . . . . . . . . . . . . . . . 15-17

15.4.5 Fuel Handling and Fuel Cask Drop Accidents . . . . . . . . . . . . . . . 15-24

15.4.6 Postulated Radioactive Releases Resulting from Liquid Tank

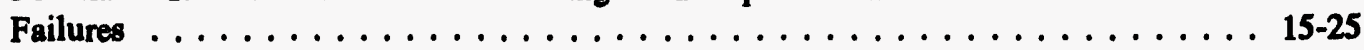

15.4.7 Reactor Water Cleanup System Pipe Break Accident $\ldots \ldots \ldots \ldots \ldots \ldots \ldots$ 15-25 


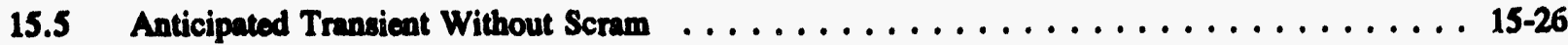

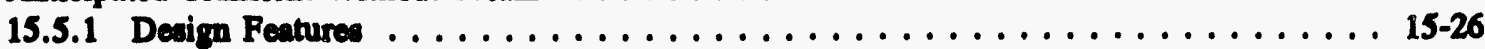

15.5.2 Analyzis ............................... 15-26

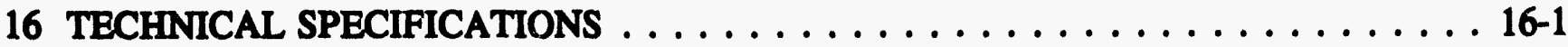

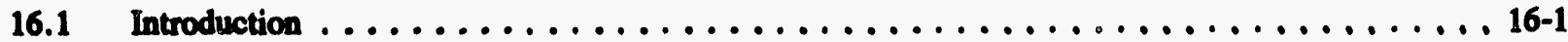

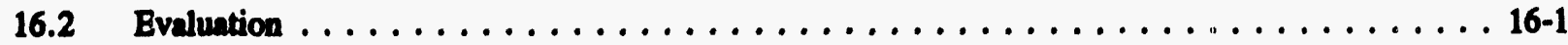

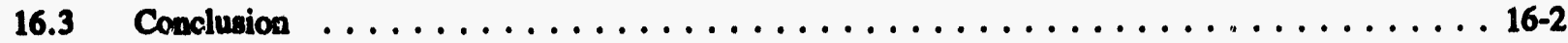

17 QUALITY ASSURANCE $\ldots \ldots \ldots \ldots \ldots \ldots \ldots \ldots \ldots \ldots \ldots \ldots \ldots$ 17-1

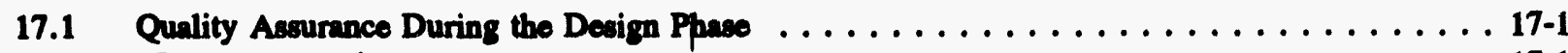

17.1.1 General . . . . . . . . . . . . . . . . . . . . . . . 17-1

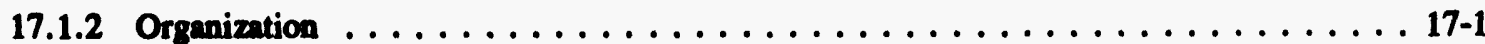

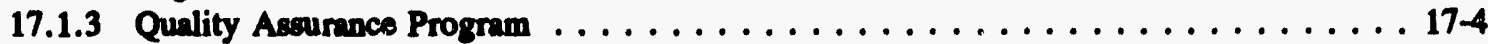

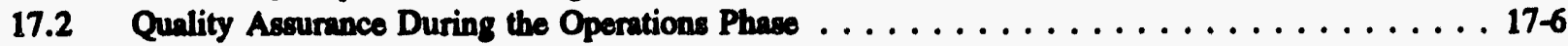

17.3 Reliability Assuranco Program ......................... 17-6

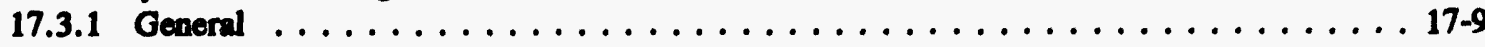

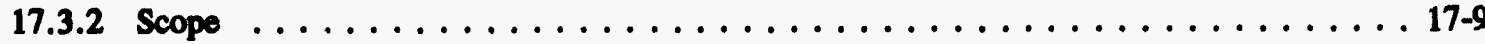

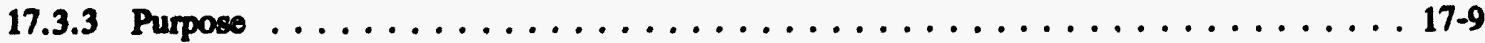

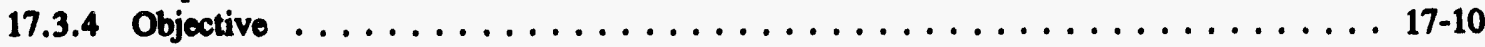

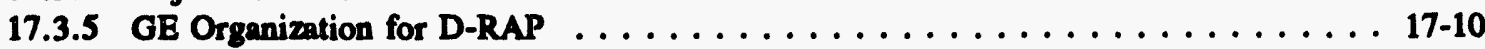

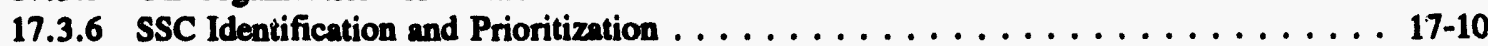

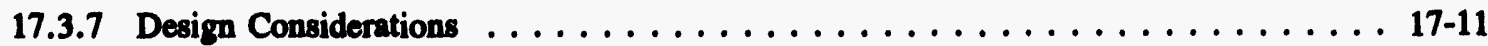

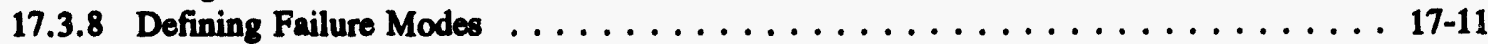

17.3.9 Operational Reliability Assurance Activities $\ldots \ldots \ldots \ldots \ldots \ldots \ldots \ldots \ldots \ldots$ 17-11

17.3.10 COL Applicant's Reliability Assurance Process $\ldots \ldots \ldots \ldots \ldots \ldots \ldots$. . . . . . . . . . . . . . . . . .

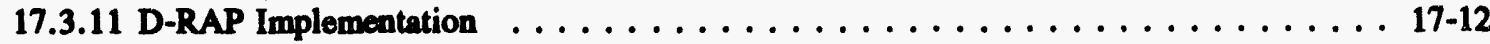

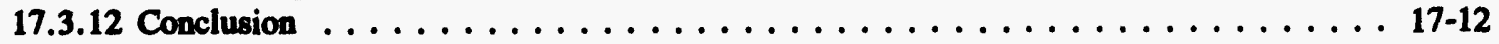

18 HUMAN FACTORS ENGINEERING $\ldots \ldots \ldots \ldots \ldots \ldots \ldots \ldots$. . . . . . . .

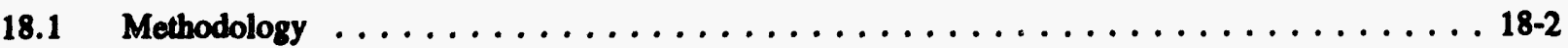

18.1.1 Preliminary Review and Draft Safety Evaluation Report Issues . . . . . . . . . . 18-2

18.1.2 Final Standard Safety Analysis Report Review . . . . . . . . . . . . . . 18-4

18.1.3 Development of Review Criteria . . . . . . . . . . . . . . 18-5

18.2 Design Goals . . . . . . . . . . . . . . . . . . . . . . . . . . 18-8

18.2.1 General Discussion in the Standard Safety Analysis Report . . . . . . . . . . . . 18-8

18.2.2 Analysis . . . . . . . . . . . . . . . . . . . . . . . . 18-8

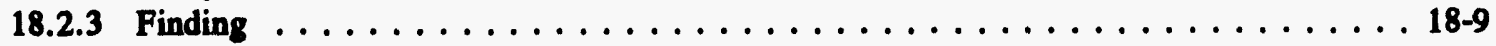

18.3 Main Control Room Standard Design Features . . . . . . . . . . . . . . . . . . . . . 18-9

18.3.1 General Discussion in the Standard Safety Analysis Report . . . . . . . . . . . . 18-9

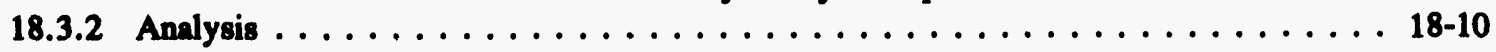

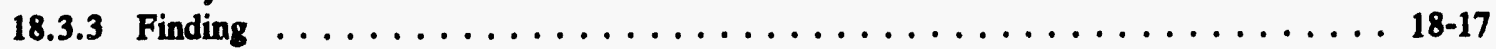

18.4 Inventory of Controls, Displays, and Alarms $\ldots \ldots \ldots \ldots \ldots \ldots \ldots \ldots \ldots \ldots$. . . . . . . . . . .

18.4.1 General Discussion in the Standard Safety Analysis Report . . . . . . . . . . . 18-17

18.4.2 Analysis . . . . . . . . . . . . . . . . . . . . . 18-18

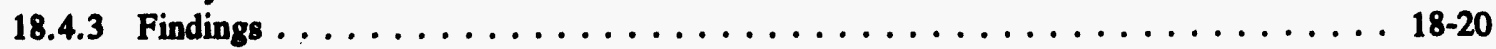

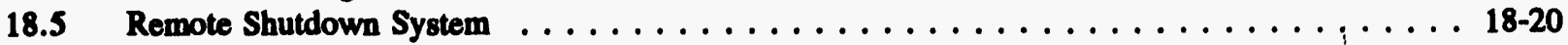

18.5.1 General Discussion in the Standard Safety Analysis Report . . . . . . . . . . 18-20

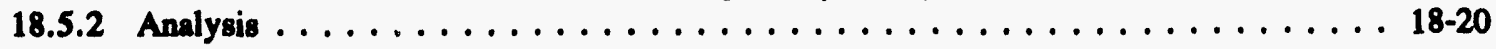

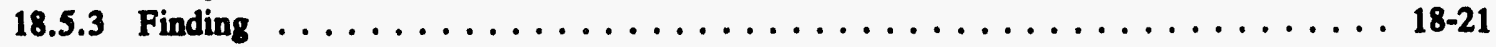

18.6 Local Valve Position Indication $\ldots \ldots \ldots \ldots \ldots \ldots \ldots \ldots \ldots \ldots \ldots \ldots \ldots \ldots \ldots$ 
18.7 Unresolved and Generic Safety Iswes $\ldots \ldots \ldots \ldots \ldots \ldots \ldots \ldots \ldots \ldots \ldots \ldots \ldots$ 18-22

18.7.1 General Discussion in the Standard Safoty Anslysis Report . . . . . . . . . . . 18-22

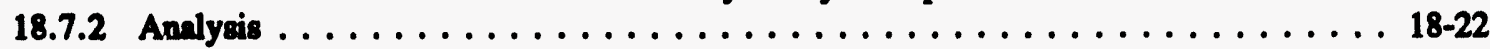

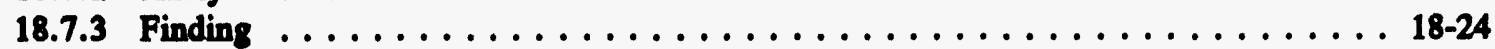

18.8 Bmergency Procedure Guidelines . . . . . . . . . . . . . . . . . . . . . . . . . 18-24

18.8.1 Containment Tempernture . . . . . . . . . . . . . . . . . . 18-24

18.8.2 Venting . . . . . . . . . . . . . . . . . . . . . . . . . 18-24

18.8.3 Drywell Spray Initiation Limit $\ldots \ldots \ldots \ldots \ldots \ldots \ldots \ldots \ldots \ldots \ldots \ldots \ldots \ldots \ldots$ 18-25

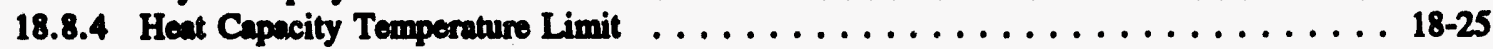

18.8.5 Primary Containment Flooding . . . . . . . . . . . . . . . . 18-27

18.8.6 ATws Stability Strategy . . . . . . . . . . . . . . . . . . . . 18-27

18.9 Decign and Implementation Procese . . . . . . . . . . . . . . . . . . . . . . 18.27

18.9.1 General Discussion in the Standard Safety Analysis Report . . . . . . . . . . . . 18-28

18.9.2 Analysis . . . . . . . . . . . . . . . . . . . . . . . 18-28

18.9.3 Deaign Decription Tier 1 ITAAC and DAC Reviow $\ldots \ldots \ldots \ldots \ldots \ldots \ldots$ 18-35

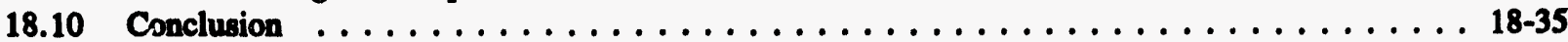

19 SEVERE ACCIDENTS $\ldots \ldots \ldots \ldots \ldots \ldots \ldots \ldots \ldots \ldots \ldots \ldots \ldots$ 19-1

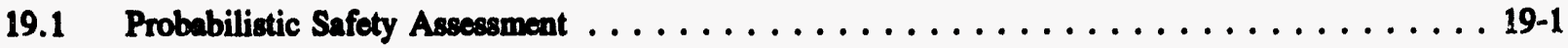

19.1.1 Executive Summary . . . . . . . . . . . . . . . . . . . 19.1

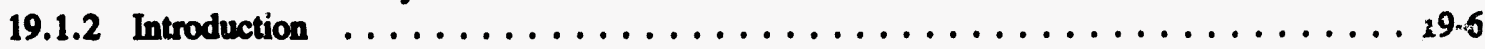

19.1.3 Advanced Boiling Water Reactor Probabilistic Risk Assessment-

Based Safaty Insights . . . . . . . . . . . . . . . . . . . . 19-7

19.1.4 Evaluation of the Quality of the ABWR Probabilistic Risk

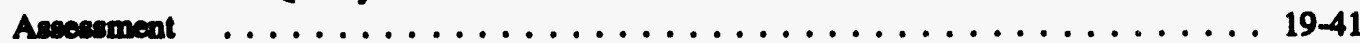

19.1.5 Open Item Closure . . . . . . . . . . . . . . . . . . . . . . . . . 19-42

19.2 Severe Accident Performence . . . . . . . . . . . . . . . . . . . . . 19-42

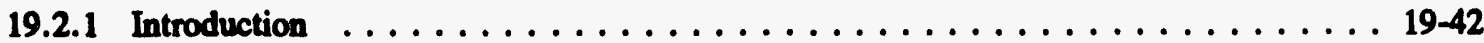

19.2.2 Deterministic Assessment of Severe Accident Prevention . . . . . . . . . . . . . 19-42

19.2.3 Deterministic Assessment of Severe Accident Mitigation . . . . . . . . . . . . 19-45

19.2.4 Contrinment Performance . . . . . . . . . . . . . . . . . . . . . 19-68

19.2.5 Accident Management . . . . . . . . . . . . . . . . . . . . . . 19-69

19.2.6 Capecity of the ABWR Primary Containment Vessel . . . . . . . . . . . . . 19-69

19.3 Shutdown Risk . . . . . . . . . . . . . . . . . . . . . . . . . . . . . . 19-74

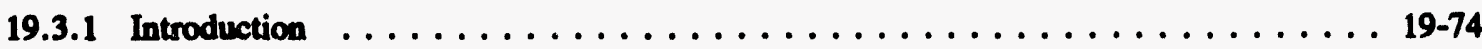

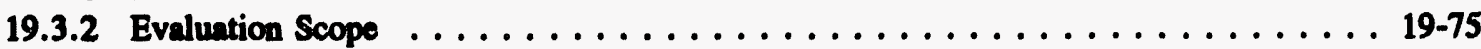

19.3.3 ABWR Design Features Minimizing Shutdown Risk . . . . . . . . . . . . 19-76

19.3.4 ABWR Reactor Instrumentation . . . . . . . . . . . . . . . . . 19-83

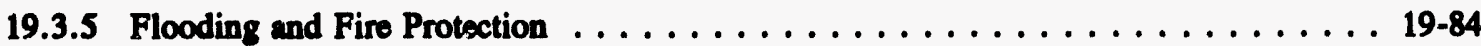

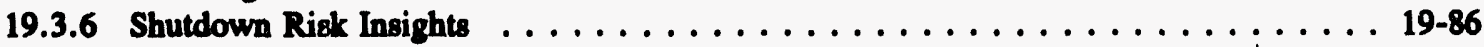

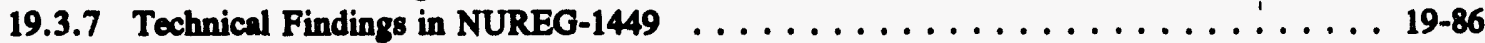

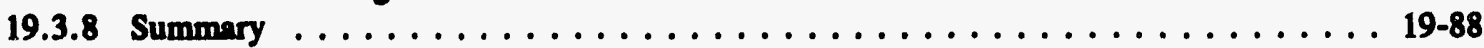

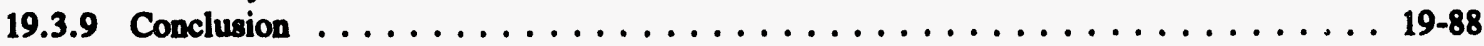

20 GENERIC ISSUES . . . . . . . . . . . . . . . . . . . . . . . . 20-1

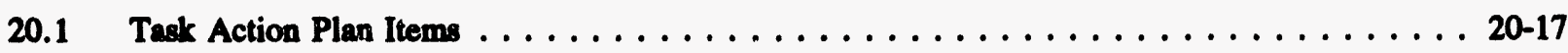

20.1.1 Issue A-1: Water Hammer (former USD . . . . . . . . . . . . . . 20-17

20.1.2 Issue A-7: Mark I Long-Term Program (former USI) . . . . . . . . . . . . . 20-18

20.1.3 Issue A-8: Mark II Containment Pool Dynamic Loads - Long-Term

Program . . . . . . . . . . . . . . . . . . . . . . . . . . . . 20-18

20.1.4 Issue A-9: Anticipated Transient Without Scram (ATWS)

(former USI) . . . . . . . . . . . . . . . . . . . . . . . . 20-19

20.1.5 Issue A-10: BWR Feedwater Nozzle Cracking (former USI) . . . . . . . . . . . . 20-19 
20.1.6 Insue A-13: Snubber Operability Avaunance . . . . . . . . . . . . . . . 20-20

20.1.7 Isve A-17: Systems Interaction (former USD) . . . . . . . . . . . . 20 20

20.1.8 Inav A-24: Qualification of Clase IE Safoty-Related Equipment

(formor USI) . . . . . . . . . . . . . . . . . . . . . . . 20-21

20.1.9 Ieve A-25: Non-Safety Loads on Clase 1E Power Sources . . . . . . . . . . . . 20-22

20.1.10 Inave A-29: Nuclear Power Plant Design for the Reduction of

Vulnembility to Industrial sabotage . . . . . . . . . . . . . . . . 20-22

20.1.11 Ineve A-31: RHR Shutdown Requirements (former USD) . . . . . . . . . . . 20-23

20.1.12 Inave A-35: Adequacy of Offaite Power Syatems . . . . . . . . . . . . . . . 20 20-24

20.1.13 Iswo A-36: Control of Heavy Loads Near Spent Fuel

(former USn) . . . . . . . . . . . . . . . . . . . . . . . . 20 20-25

20.1.14 Ieswe A-39: Determination of Safoty Relief Valve Pool Dynamic

Loads and Tempernture Limits (former USD . . . . . . . . . . . . . . . 20-25

20.1.15 Isene A-40: Seiemic Dexign Criteria - Short-Term Program (former

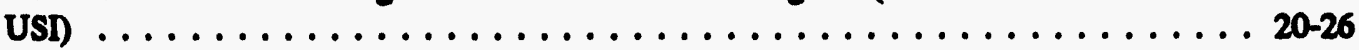

20.1.16 Iswe A-42: Pipe Cracks in BWR (formor USI) . . . . . . . . . . . . 20-26

20.1.17 Isove A-44: Station Bleckout (former USD . . . . . . . . . . . . . . . . . . . . 20-27

20.1.18 Iswo A-47: Safety Implications of Control Syatems (former USI) . . . . . . . . 20-28

20.1.19 Issue A-48: Hydrogen Control Measures and Effects of Hydrogen

Burns on Safety Equipment . . . . . . . . . . . . . . . . . . 20-28

20.1.20 Issue B-5: Ductility of Two-Way Slabs and Shells and Buckling

Behavior of Steel Containments . . . . . . . . . . . . . . . . . . . . 20-29

20.1.21 Issue B-10: Behavior of BWR Mark III Containments . . . . . . . . . . . 20-30

20.1.22 Issue B-17: Criteria for Safety-Related Operator Actions . . . . . . . . . . . . 20-30

20.1.23 Issue B-29: Effectiveness of Ultimate Heat Sinks . . . . . . . . . . . . . 20-31

20.1.24 Issue B-32: Ice Effects on Safety-Relatod Water Supplies . . . . . . . . . . . . . 20-31

20.1.25 Issue B-36: Develop Design, Teating, and Maintenance Criteria for

Atmosphere Cleanup System Air Filtration and Adsorption Units for

Engineered Safoty Features Systems and Normal Ventilation

Systems . . . . . . . . . . . . . . . . . . . . . . . 20-32

20.1.26 Issue B-55: Improved Reliability of Target Rock Safety-Relief

Valves ... . . . . . . . . . . . . . . . . . . . . . . 20-32

20.1.27 Issue B-56! Diesel Reliability . . . . . . . . . . . . . . . . . . . 20-32

20.1.28 Issue B-61: Allowable ECCS Equipment Outage Periods . . . . . . . . . . . . . 20 20-34

20.1.29 Issue B-63: Isolation of Low-Pressure Systems Connected to the

Reactor Coolant Pressure Boundary . . . . . . . . . . . . . . 20-35

20.1.30 Issue B-66: Control Room Infiltration Measurements . . . . . . . . . . . . 20-35

20.1.31 Issue C-1: Assurance of Continuous Long-Term Capability of

Hermetic Seals on Instrumentation and Electrical Equipment . . . . . . . . . 20-36

20.1.32 Issue C-8: Main Steam Line Loakage Control Systems . . . . . . . . . . . . . . . 20-36

20.1.33 Issue C-10: Effective Operation of Containment Sprays in a LOCA . . . . . . . . . . . . . . . . . . . . . . . . 20-37

20.1.34 Issue C-17: Interim Acceptance Criteria for Solidification Agents for

Radionctive Solid Wastes . . . . . . . . . . . . . . . . . . . . 20-37

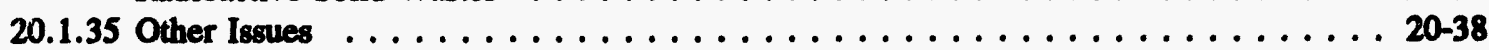

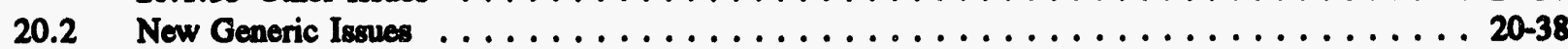

20.2.1 Issue 15: Radiation Effects on Reactor Vessel Supports . . . . . . . . . . . 20-38

20.2.2 Issue 23: Reactor Coolant Pump Seal Failures . . . . . . . . . . . . . . . 20-38

20.2.3 Issue 25: Automatic Air Header Dump on BWR Scram System . . . . . . . . . . 20-39

20.2.4 Issue 29: Bolting Degradation or Failure in Nuclear Power Flants . . . . . . . . . 20-39

20.2.5 Issue 40: Safety Concerns Associated With Pipe Breaks in the BWR

Scram System . . . . . . . . . . . . . . . . . . . . 20-40

20.2.6 Issue 45: Inoperability of Instrumentation Due to Extremo Cold

Weather ............................. 20.40 
20.2.7 Isove 51: Proposed Requirements for Improving the Reliatility of Open Cyclo Service Water Systems . . . . . . . . . . . . . . . . . . . 20-41

20.2.8 Iseve 57: Effects of Firo Protection System Actuation on SafetyRelated Equipment . . . . . . . . . . . . . . . . . . . . . . . . . 20-41

20.2.9 Ieve 67.3.3: Steam Generator Staff Actions - Improved Accident Monitoring . . . . . . . . . . . . . . . . . . . . . . . . . . 20-42

20.2.10 Isav 75: Generic Implications of ATWS Events at tho Salem Nuclear Plant . . . . . . . . . . . . . . . . . . . . . . . . . . . . . 20-42

20.2.11 Isque 78: Monitoring of Fatigue Transient Limits for Reactor Coolant System . . . . . . . . . . . . . . . . . . . . . . . . . . . . 20-43

20.2.12 Issue 82: Beyond Design-Basis Accidents in Spent Fuel Pools . . . . . . . . . . 20-43

20.2.13 Issue 83: Control Room Habitability . . . . . . . . . . . . . . . . . . . . . 20 20-44

20.2.14 Iseve 86: Long-Range Plan for Dealing with Stress Corrosion Cracking in BWR Piping . . . . . . . . . . . . . . . . 20-45

20.2.15 Iseve 87: Failure of High Preesure Coolant Injection Steam Line Without Isolation . . . . . . . . . . . . . . . . . . . . 20-45

20.2.16 Iesue 89: Stiff Pipe Clamps . . . . . . . . . . . . . . . . . . . . 20-46

20.2.17 Iseve 103: Design for Probable Maximum Precipitation . . . . . . . . . . 20 20-47

20.2.18 Reservod. . . . . . . . . . . . . . . . . . . . . . . . . . . . . . . . . . . 20-47

20.2.19 Iswe 105: Interfacing Systems LOCA at LWRs . . . . . . . . . . . . . . . 20 20-47

20.2.20 Inave 106: Piping and Use of Highly Combustible Gases in Vital Areas . . . . . . . . . . . . . . . . . . . . . . . . . . . . . 20-49

20.2.21 Issue 113: Dynamic Qualification Testing of Large Bore Hydraulic

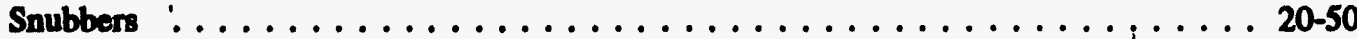

20.2.22 Issue 118: Tendon Anchorage Failure . . . . . . . . . . . . . . . 20-51

20.2.23 Issue 120: On-Line Testability of Protection Systems . . . . . . . . . . . . . 20-51

20.2.24 Issue 121: Hydrogen Control for Large, Dry PWR Containments . . . . . . . . 20-52

20.2.25 Issue 124: Auxiliary Feedwater System Reliability . . . . . . . . . . . . . 20-52

20.2.26 Issue 128: Electrical Power Reliability . . . . . . . . . . . . . . . . . . 20-52

20.2.27 Issuo 130: Essential Service Water Pump Failures at Multiplant

Site . . . . . . . . . . . . . . . . . . . . . . . . . . . . . 20-54

20.2.28 Issue 142: Leakage Through Electrical Isolators in Instrumentation

Circuits . . . . . . . . . . . . . . . . . . . . . 20-55

20.2.29 Isswe 143: Availability of Chilled Water Systems . . . . . . . . . . . 20-56

20.2.30 Issue 145: Actions to Reduce Common Cause Failures . . . . . . . . . . . . . . 20-57

20.2.31 Issue 151: Reliability of Recirculation Pump Trip During an

ATwS . . . . . . . . . . . . . . . . . . . . . . . 20-57

20.2.32 Issue 153: Loss of Essential Service Water in LWRs . . . . . . . . . . . . . 20 20-58

20.2.33 Issue 155.1: More Realistic Source Term Assumptions . . . . . . . . . . . 20-59

20.3 Human Fectors Issues . . . . . . . . . . . . . . . . . . . . . . . . . 20-60

20.3.1 Issue HF 1.1: Staffing and Qualifications - Shift Staffing . . . . . . . . . 20-60

20.3.2 Issue HF 4.4: Procedures - Guidelines for Upgrading Other Procedures . . . . . . . . . . . . . . . . . . . . . . . . . . . . 20-60

20.3.3 Issue HF 5.1: Man-Machine Interface - Local Control Stations . . . . . . . . . . 20-60

20.3.4 Iseve HF 5.2: Man-Machine Interface - Review Criteria for Human

Factors Aspects of Advanced Controls and Instrumentation . . . . . . . . . 20-60

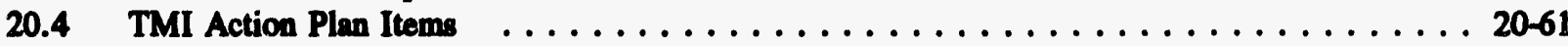

20.4.1 Issue 1.A.1.1: Operating Personnel - Operating Personnel and Staffing - Shift Technical Advisor . . . . . . . . . . . . . . . . . 20-61

20.4.2 Issue I.A.1.2: Operating Personnel - Operating Personnel and Staffing - Shift Supervisor Administrative Duties . . . . . . . . . . . . . . 20-61

20.4.3 Issue I.A.1.3: Operating Personnel - Operating Personnel and Staffing - Shift Manning . . . . . . . . . . . . . . . . . . . 20-61

20.4.4 Issue I.A.1.4: Operating Personnel - Operating Personnel and Staffing - Long-Term Upgrading . . . . . . . . . . . . . . . . . . . . . . 20-62 
20.4.5 Issue I.A.2.1: Operating Personnel - Training and Qualification of Operating Personnel - Immediate Upgrading of Operator and Senior Operator Training and Qualifications . . . . . . . . . . . . . . . . . . . 20-62

20.4.6 Issue I.A.2.3: Operating Personnel - Training and Qualifications of Operating Personnel - Administration of Training Programs . . . . . . . . . . 20-62

20.4.7 Issue I.A.2.6(1): Operating Personnel - Training and Qualifications of Operating Personnel - Long-Term Upgrading of Training and Qualifications; Revise Regulatory Guide $1.8 \ldots \ldots$. . . . . . . . . . . . . 20-62

20.4.8 Issue I.A.3.1: Operating Personnel - Licensing and Requalification of Operating Personnel - Revise Scope of Criteria for Licensing Examinations . . . . . . . . . . . . . . . . . . . . . . . . . 20-63

20.4.9 Issue I.A.4.1(2): Operating Personnel - Simulator Use and Dovelopment - Initial Simulator Improvement; Interim Changes in Training Simulators . . . . . . . . . . . . . . . . . . . . . . . . 20 20-63

20.4.10 Issue I.A.4.2: Operating Personnel - Simulator Use and Development - Long-Term Training Upgrade . . . . . . . . . . . . . . . . . . 20-63

20.4.11 Issue I.C.1: Operating Procedures - Short-Term Accident Analysis and Procedures Revision . . . . . . . . . . . . . . . . . . 20-63

20.4.12 Issue I.C.2: Operating Procedures - Shift Relief and Tumover Procedures . . . . . . . . . . . . . . . . . . . . . . . . . . . 20-63

20.4.13 Issue I.C.3: Operating Procedures - Shift Supervisor Responsibilities . . . . . . . . . . . . . . . . . . . . . . . . . 20-64

20.4.14 Issue I.C.4: Operating Procedures - Control Room Access . . . . . . . . . . . . . . 20-64

20.4.15 Issue I.C.5: Operating Procedures - Procedures for Feedback of Operating Experience to Plant Staff . . . . . . . . . . . . . . . . . . . 20-64

20.4.16 Issue I.C.6: . Operating Procedures - Procedures for Verification of Correct Performance of Operating Activities . . . . . . . . . . . . . . 20-64

20.4.17 Issue I.C.7: Operating Procedures - NSSS Vendor Review of Procedures . . . . . . . . . . . . . . . . . . . . . . . 20-65

20.4.18 Issue I.C.8: Operating Procedures - Pilot Monitoring of Selected Emergency Procedures for NTOL Applicants . . . . . . . . . . . . . 20-65

20.4.19 Issue I.C.9: Operating Procedures - Long-Term Program Plan Procedures for Upgrading of Procedures . . . . . . . . . . . . . . . . . 20-65

20.4.20 Issue I.D.1: Control Room Design - Control Room Design Reviews . . . . . . . . . . . . . . . . . . . . . . . . . 20-65

20.4.21 Issue I.D.2: Control Room Design - Plant Safety Parameter Display Console . . . . . . . . . . . . . . . . . . . . . . . . . . 20-65

20.4.22 Issue I.D.3: Control Room Design - Safety System Status Monitoring . . . . . . . . . . . . . . . . . . . . 20-65

20.4.23 Issue I.D.5(2): Control Room Design - Plant Status and PostAccident Monitoring . . . . . . . . . . . . . . . . . . . 20-65

20.4.24 Issue I.D.5(3): Control Room Design - On-Line Reactor Surveillance System . . . . . . . . . . . . . . . . . . . . . . . . . . . 20-66

20.4.25 Issue 1.F.1: Quality Assurance (QA) - Expand QA List . . . . . . . . . . . 20-66

20.4.26 Issue I.F.2: Quality Assurance - Develop More Detailed QA Criteria . . . . . . . . . . . . . . . . . . . . . . . . . . 20-66

20.4.27 Issue I.G.1: Preoperational and Low-Power Testing - Training Requirements . . . . . . . . . . . . . . . . . . . . . . . . 20-66

20.4.28 Issue I.G.2: Preoperational and Low-Power Testing - Scope of Test Program . . . . . . . . . . . . . . . . . . . . . . . . . . 20-60

20.4.29 Issue II.B.1: Consideration of Degraded or Melted Cores in Safety Review - Reactor Coolant System Vents . . . . . . . . . . . . . . . . . . . 20-67

20.4.30 Issue II.B.2: Consideration of Degraded or Melted Cores in Safety Review - Plant Shielding to Provide Access to Vital Areas and Protect Safety Equipment for Post-Accident Operation . . . . . . . . . . . . . . . 20-67 
20.4.31 Isove II.B.3: Consideration of Degraded or Melted Cores in Safety Roviow - Poet-Accident Sumpling . . . . . . . . . . . . . . . . . . . . . . . . . . 20-67

20.4.32 Isave II.B.4: Consideration of Degraded or Melted Cores in Safety Reviow - Training for Mitigating Core Damage . . . . . . . . . . . . . . . . . . 20-67

20.4.33 Inwe II.B.8: Convideration of Degrnded or Melted Cores in Safety Reviow - Rulemaking Proceeding on Degraded Core Accidents . . . . . . . . . . 20-67

20.4.34 Isove II.D.1: Reactor Coolant Syetem Relief and Safety Valves Teating Requirements . . . . . . . . . . . . . . . . . . . . . . . . . . . . . . . . . 20-67

20.4.35 Isevo II.D.3: Reactor Coolant Syotem Rolief and Safety Valves Relief and Safoty Valve Position Indication . . . . . . . . . . . . . . . . 20-67

20.4.36 Isswe II.E.1.1: System Design - Auxiliary Feedwater System Auxiliary Feedwater System Evaluation . . . . . . . . . . . . . . . . . . . . 20-67

20.4.37 Isow II.E.1.2: System Deeign - Auxiliary Feedwater System Auxiliary Poodwater System Automatic Initiation and Flow Indication . . . . . . . . . . . . . . . . . . . . . . . . . . . . . . 20-67

20.4.38 Issu II.E.1.3: System Design - Auxiliary Feedwater System Update the: Standard Reviow Plan and Dovelop Regulatory Guidance . . . . . . . . . . . . . . . . . . . . . . . . . . . . . . . . . 20-67

20.4.39 Issue II.E.3.1: System Design - Decay Heat Removal - Reliability of Power Supplies for Natural Circulation . . . . . . . . . . . . . . . . . 20-68

20.4.40 Issue II.E.4.1: System Design - Contrinment Design - Dedicated Penetrations . . . . . . . . . . . . . . . . . . . . . . . . . . . 20-68

20.4.41 Issue II.E.4.2: System Dosign -- Containment Design - Isolation Dependability . . . . . . . . . . . . . . . . . . . . . . . . . . 20-68

20.4.42 Isove II.E.4.4: System Design - Containment Design - Purging . . . . . . . . . 20-68

20.4.43 Issue II.E.5.1: System Design - Design Sensitivity of Babcock \& Wilcox (B\&W) Reactors - Design Evaluation . . . . . . . . . . . . . . . . 20-68

20.4.44 Iesue II.E.6.1: System Design - In-Situ Testing of Valves - Test Adequacy Study . . . . . . . . . . . . . . . . . . . . . 20-68

20.4.45 Reserved. . . . . . . . . . . . . . . . . . . . . . . . . . . . . 20-68

20.4.46 Issue II.F.1: Instrumentation and Controls - Additional Accident Monitoring Instrumentation . . . . . . . . . . . . . . . . . . . . . . . . . . . 20-68

20.4.47 Issue II.F.2: Instrumentation and Controls - Identification of and Recovery from Conditions Leading to Inadequate Core Cooling . . . . . . . . . . 20-68

20.4.48 Issue II.F.3: Instrumentation and Controls - Instruments for Monitoring Accident Conditions . . . . . . . . . . . . . . . . . . . . . . . . . . 20-69

20.4.49 Issue II.G.1: Electrical Power - Power Supplies for Pressurizer Relief Valves, Block Valves, and Lovel Indicators . . . . . . . . . . . . . . . . 20-69

20.4.50 Issue II.J.3.1: General Implications of TMI for Design and Construction Activities - Management for Design and Construction Organization and Staffing to Oversee Design and Construction . . . . . . . . . . 20-69

20.4.51 Issue II.J.4.1: General Implications of TMI for Design and Construction Activitie - Revise Deficiency Reporting Requirements . . . . . . . . . . . . 20-69

20.4.52 Issue II.K.1(5): Measures to Mitigate Small-Break Loss-of-Coolant Accidents and Loss-of-Feedwater Accidents - IE Bulletins - SafetyRelated Valve Position Description . . . . . . . . . . . . . . . . . . . . . . . . . 20-69

20.4.53 Issue II.K.1(10): Measures to Mitigate Small-Break Loss-of-Coolant Accidents and Loss-of-Feedwater Accidents - IE Bulletins - Review and Modify Procedures for Removing Safety-Related Systems from Service . . . . . . . . . . . . . . . . . .

20.4.54 Issue II.K.1(13): Measures to Mitigate Small-Break Loss-of-Coolant Accidents and Loss-of-Feedwater Accidents - IE Bulletins - Proposed Technical Specification Changes Reflecting Implementation of All Bulletin Items 
20.4.55 Isove II.X.1.(22): Measures to Mitigate Small-Break Lose-of-Coolant Accidents and Loss-of-Feedwater Accidents - IE Bulletins - Describe Automatic and Manual Actions for Proper Functioning of Auxiliary Heat Removal Systems When Feedwater System Not Operable . . . . . . . . . . . 20-70

20.4.56 Issue II.K.1(23): Measures to Mitigate Small-Break Loss-of-Coolant Accidents and Loss-of-Feedwater Accidents - IE Bulletins - Describe Uses and Types of RV Lovel Indication for Automatic and Manual Initiation Safety Systems . . . . . . . . . . . . . . . . . . . . . . . . . 20-70

20.4.57 Isswe II.K.2(9): Measures to Mitigate Small-Break Loss-of-Coolant Accidents and Loss-of-Feodwater Accidents - Commission Orders on B\&W Plants - Analysis and Upgrading of Integrated Control System . . . . . . . . . . . . . . . . . . . . . . 20-71

20.4.58 Issuv II.K.2(10): Measures to Mitigate Small-Break Loss-of-Coolant Accidents and Loss-of-Feedwater Accidents - Commission Orders on B\&W Plants - Hard-Wired Safety-Grade Anticipatory Reactor Trips . . . . . . . . . . . . . . . . . . . . . . . . . . 20-71

20.4.59 Issue II.K.2(16): Measures to Mitigate Small-Break Loss-of-Coolant Accidents and Loes-of-Feedwater Accidents - Commission Orders on B\&W Plants - Impact of RCP Seal Damage Following SBLOCA With Loss of Offsite Power . . . . . . . . . . . . . . . . . . . . . 20-71

20.4.60 Issue II.K.3(2): Measures to Mitigate Small-Break Loss-of-Coolant Accidonts and Loss-of-Feedwater Accidents -- Final Recommendations of Bulletins and Orders Task Force - Report on Overall Safety Effect of Power-Operated Relief Valve (PORV) Isolation . . . . . . . . . . . . . . . . . . . . . . . . . . . . 20-71

20.4.61 Issue II.K.3(3): Measures to Mitigate Small-Break Loss-of-Coolant Accidents and Loss-of-Feedwater Accidents -- Final Recommendations of Bulletins and Orders Task Force - Report Safety and Relief Valve Failures Promptly and Challenges Annually . . . . . . . . 20-71

20.4.62 Issue II.K.3(11): Measures to Mitigate Small-Break Loss-of-Coolant Accidents and Loss-of-Feedwater Accidents -- Final Recommendations of Bulletins and Orders Task Force - Control Use of PORV Supplied by Control Components, Inc., Until Further Review Complete . . . . . . . . . . . . . . . . . . . . . . . . . . . 20-71

20.4.63 Issue II.K.3(13): Measures to Mitigate Small-Break Loss-of-Coolant Accidents and Loss-of-Feedwater Accidents -- Final Recommendations of Bulletins and Orders Task Force - Separation of HPCI and RCIC System Initiation Levels . . . . . . . . . . . . .

20.4.64 Isoue II.K.3(15): Measures to Mitigate Small-Break Loss-of-Coolant Accidents and Loss-of-Feedwater Accidents -- Final Recommendations of Bulletins and Orders Task Force - Modify Break Detection Logic to Prevent Spurious Isolation of HPCI and RCIC Systems . . . . . . . . . . . . . . . . . . . . . . . . . . . . . . 20-72

20.4.65 Issue II.K.3(16): Measures to Mitigate Small-Break Loss-of-Coolant Accidents and Loss-of-Feedwater Accidents -- Final Recommendations of Bulletins and Orders Task Force - Reduction of Challenges and Failures of Relief Valves; Feasibility Study and System Modification . . . . . . . . . . . . . . . . . . .

20.4.66 Issue II.K.3(17): Measures to Mitigate Small-Break Loss-of-Coolant Accidents and Loss-of-Feedwater Accidents -- Final Recommendations of Bulletins and Orders Task Force - Report on Outage of ECC Systems; Licensee Report and Technical Specification Changes . . . . . . . . . . . . . . . . . . . . . . . . . 20-72 
20.4.67 Isevo II.K.3(18): Measures to Mitignte Small-Break Lowef-Coolent Accidents and Loss-of-Feedwater Accidents -- Final Recommendations of Bulletins and Ordere Tank Force - Modification of ADS Logic; Feasibility Study and Modification for Increased

Diversity for Somo Event Sequenced . . . . . . . . . . . . . . . . . . . . . 20-73

20.4.68 Isav II.K.3(21): Measures to Mitigato Small-Break Lowb-of-Coolart Accidents and Loss-of-Foedwater Accidents -- Final Recommeadations of Bullotins and Orden Task Force - Reaturt of Core Spray and LPCI System on Low Lovel; Design and Modification . . . . . . . . . . . . . . . . . . . . . . . . . 20-73

20.4.69 Ienve II.K.3(22): Meacures to Mitigate Small-Broak Lows-of-Coolent Accidents and Loss-of-Foedwater Accidents -- Final Recommendations of Bulletins and Orders Tack Force - Automatic Switchover of RCIC Systom Suction; Verify Procedures and Modify Design . . . . . . . . . . . . . . . . . . . . . . . . . 2v-73

20.4.70 Isswe II.K.3(23): Measures to Mitigate Small-Break Loes-of-Coolent Accidents and Loss-of-Feedwater Accidents -. Final Recommendations of Bulletins and Orders Task Force - Central Water Lovel Recording . . . . . . . . . . . . . . . . . . . . . .

20.4.71 Ievwe II.K.3(24): Moasures to Mitigate Small-Break Loes-of-Ccolant Accidents and Loss-of-Foodwator Accidents -. Final Recommendations of Bullotins and Orden Task Force - Confirm Adequacy of Space Cooling for HPCI and RCIC Systems . . . . . . . . . . . . . . 20 20-73

20.4.72 Issue II.K.3(25): Measures to Mitigate Small-Break Lose-of-Coolant Accidents and Loss-of-Feedwater Accidents -- Final Recommendations of Bulletins and Orders Task Force - Bffect of Loss of ac Power on Pump Seals . . . . . . . . . . . . . . . . . .

20.4.73 Isque II.K.3(27): Measures to Mitigato Small-Break Lose-of-Coolant Accidents and Loss-of-Feodwater Accidents -- Final Recommendations of Bulletins and Orders Task Force - Provide Common Reference Lovel for Veasel Lovel Instrumentation . . . . . . . . . . . . 20-74

20.4.74 Issue II.K.3(28): Measures to Mitigate Small-Break Loes-of-Coolant Accidents and Loss-of-Feedwater Accidents -- Final Recommendations of Bulletins and Ordon Task Force - Study and Verify Qualification of Accumulators on ADS Valves . . . . . . . .

20.4.75 Issue II.K.3(30): Measures to Mitigato Small-Break Loss-of-Coolant Accidents and Loss-of-Peodwater Accidents -. Final Recommendations of Bulletins and Orders Task Force - Revised SBLOCA Methods to Show Compliance with 10 CFR Part 50, Appendix A . . . . . . . . . . . . . . . .

20.4.76 Issue II.K.3(31): Measures to Mitigate Small-Break Loss-of-Coolant Accidents and Loss-of-Feedwater Accidents -- Final Recommendations of Bulletins and Orders Task Force - Plant-Specific Calculations to Show Compliance with 10 CFR $50.46 \ldots \ldots \ldots$

20.4.77 Issue II.K.3(44): Measures to Mitigate Small-Break Loss-of-Coolant Accidents and Loss-of-Feedwater Accidents -- Final Recommendations of Bulletins and Orders Task Force - Evaluation of Anticipated Transients with Single Failure to Verify no Significant Fuel Failure $\ldots \ldots \ldots \ldots \ldots \ldots \ldots \ldots \ldots$

20.4.78 Isewo II.K.3(45): Measures to Mitigate Small-Break Loss-of-Coolant Accidents and Loss-of-Feedwater Accidents -- Final Recommendations of Bulletins and Orders Task Furce - Evaluate Depressurization with Other Than Full ADS . 
20.4.79 Ieve II.K.3(46): Meanures to Mitigate Small-Break Loes-of-Coolant Accidents and Loss-of-Feedwater Accidents -- Final Recommendations of Bulletins and Onders Task Force - Response to List of Concerns from ACRS Consultant . . . . . . . . . . . . . . . . . . 20 20

20.4.80 Ievo III.A.1.1(1): Bmergency Preparedneas and Rediation Effects Improve Licensee Emergency Preparednees - Short Term; Upgrade Emorgency Preparednese, Implement Action Plan Requir ments for Promptly Improving Licences Emergency Proparedaces . . . . . . . . . . . . . . 20-75

20.4.81 Ineve III.A.1.2: Emergency Preparedneas and Radiation Effects Improvo Licenseo Bmergency Preparodneas - Short Torm; Upgrado Emergency Preparedness . . . . . . . . . . . . . . . . . . . . . . . . . . . . 20-76

20.4.82 Iswe III.A.2.1: Bmergency Proparedneas and Rediation Effects -Improve Licensee Emergency Preparednees - Long Term; Amend 10 CFR Part 50 and 10 CFR Part 50, Appendix E . . . . . . . . . . . . . . . 20 20-76

20.4.83 Ieeve III.A.2.2: Bmergency Preparednees and Radiation Bffects -Improve Licensee Emergency Preparedness - Long Term; Dovelopment of Guidance and Criteria . . . . . . . . . . . . . . . . 20-76

20.4.84 Iswu III.A.3.3: Bmergency Preparednees and Rediation Bffects -Improving NRC Emergency Proparednew - Communications . . . . . . . . . . . . 20 20-76

20.4.85 Issuv III.D.1.1: Rediation Protection - Rediation Source Control Primary Coolent Sources Outside the Containment Structure . . . . . . . . . . . 20-77

20.4.86 Issue III.D.3.3: Radiation Protection - Worker Radiation Protection Improvement - Inplant Radiation Monitoring . . . . . . . . . . . . . . 20-77

20.4.87 Issue III.D.3.4: Radiation Protection - Worker Radiation Prolection Improvement - Control Room Habitability . . . . . . . . . . . . . . . . 20-77

20.510 CFR 50.34(f), Additional TMI Requirements . . . . . . . . . . . . . . . . . 20-77

20.5.1 10 CFR 50.34(f)(1)(i): Considerntion of Degraded or Melted Cores in Safety Review - Rulemaking Proceeding on Degraded Core Accidents (TMI Item II. B.8), "Design Alternatives from PRA" . . . . . . . . 20 20-77

20.5.2 10 CFR 50.34(f)(1)(ii): System Design - Auxiliary Feedwater System - Auxiliary Feedwater System Evaluation (TMI Item II.E.1.1) . . . . . . . . . 20-89

20.5.3 10 CFR 50.34(f)(1)(iii):

Measures to Mitigate Small-Break Loss-of-Coolant Accidents and Lose-of-Feedwater Accidents - Commission Orders on B\&W Plants Impact of RCP Seal Damage Following SBLOCA With Loss of Offisito Power (TMI Item II.K.2(16)) and

Measures to Mitigate Small-Break Lose-of-Coolant Accidents and Loss-of-Feedwater Accidents - Final Recommendations of Bulletins and Orders Task Force - Effect of Loss of ac Power on Pump Seals (TMI Item II.K.3(25)) . . . . . . . . . . . . . . . . . . . . . . . . . . . . 20-89

20.5.4 10 CFR 50.34(f)(1)(iv): Measures to Mitigate Small-Break Loss-ofCoolant Accidents and Loss-of-Feedwater Accidents -- Final Recommendations of Bulletins and Orders Task Force - Report on Overall Safety Effect of PORV Isolation (TMI Item II.K.3(2)) . . . . . . . . . . . . . . . 20-89

20.5.5 10 CFR 50.34(f)(1)(v): Measures to Mitigate Small-Break Loss-ofCoolant Accidents and Lose-of-Feodwater Accidents -- Final Recommendations of Bulletins and Orders Task Force - Separation of HPCI and RCIC System Initiation Lovels (TMI Item II.K.3(13)) . . . . . . . . . . . . 20-90

20.5.6 10 CFR 50.34(f)(1)(vi): Measures to Mitigate Small-Break Loss-ofCoolant Accidents and Loss-of-Feodwater Accidents - Final Recommendations of Bulletins and Orders Task Force - Reduction of Challenges and Failures of Relief Valves; Feasibility Study and System Modification (TMI Item II.K.3(16)) . . . . . . . . . . . . . . . . 20-90 
20.5.7 10 CFR 50.34(f)(1)(vii): Measures to Mitigate Small-Break Loss-ofCoolant Accidents and Loss-of-Feedwater Accidents - Final Recommeadations of Bulletins and Orders Task Force - Modification of ADS Logic; Fencibility Study and Modification for Increased Diversity for Somo Event Sequences (TMI Item II.K.3(18)) . . . . . . . . . . . . . . . . 20-91

20.5.8 10 CFR 50.34(f)(1)(viii): Measures to Mitizate Small-Break Loss-ofCoolent Accidents and Lose-of-Feedwater Accidents - Final Recommendations of Bulletins and Ordors Tack Force - Reetart of Core Spray and LPCI Syatem on Low Lovel; Deaign and Modification

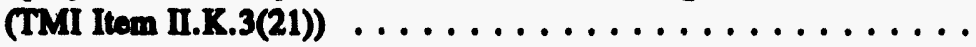

20.5.9 10 CFR 50.34(f)(1)(ix): Measures to Mitigate Small-Break Lose-ofCoolant Accidents and Low-of-Feodwater Accidents - Final Recommendations of Bulletine and Ordon Task Force - Confirm Adequacy of Space Cooling for HPCI and RCIC Systoms (TMI Itom II.K.3(24)) $\ldots \ldots$ CFR $50.34(\mathrm{f})(1)(\mathrm{x})$ : Measures to Mitigate Small-Break Lose-of-

20.5.10 10 CFR 50.34(f)(1)(x): Measures to Mitigate Small-Break Loss-of-
Coolant Accidents and Lose-of-Peedwater Accidents - Final Recommendations of Bulletins and Orders Task Force - Study and Verify Qualification of Accumulators on ADS Valves (TMI Item II.K.3(28)) . . . . . . . . . . . . . . . . . . . . . . . . . 20-92

20.5.11 10 CFR 50.34(f)(1)(xi): Measures to Mitigate Small-Break Loss-ofCoolant Accidents and Loss-of-Feedwater Accidents - Final Recommendations of Bulletins and Orders Task Force - Evaluate Depresenurization with Other Than Full ADS (TMI Item II.K.3(45))

20.5.12 10 CFR 50.34(f)(1)(xii): Evaluation of Altemativo Hydrogen Control Systems . . . . . . . . . . . . . . . . . . . . . . . . . . . . . . 20-94

20.5.13 10 CFR 50.34(f)(2)(i): Operating Personnel - Simulator Use and Dovelopment - Long-Term Training Upgrade (TMI Item I.A.4.2) . . . . . . . . . 20 20-95

20.5.14 10 CFR 50.34(f)(2)(ii): Operating Procedures -Long-Term Program Plan Procedures for Upgrading of Procedures (TMI Item I.C.9) . . . . . . . . . 20-95

20.5.15 10 CFR 50.34(f)(2)(iii): Control Room Design -Control Room Deaign Reviews (TMI Item I.D.1) . . . . . . . . . . . . . . . . . . . . 20-95

20.5.16 10 CFR 50.34(f)(2)(iv): Control Room Design -Plant Safety Parumeter Display Console (TMI Item I.D.2) . . . . . . . . . . . . . . . . . 20 20-95

20.5.17 10 CFR 50.34(f)(2)(v): Control Room Design -Safety System Status Monitoring (TMI Item I.D.3) . . . . . . . . . . . . . . . . . . . . . . . . . 20-96

20.5.18 10 CFR 50.34(f)(2)(vi): Consideration of Degraded or Melted Cores in Safety Review - Reactbr Coolant System Vents (TMI Item II. B.1) . . . . . . . . . . . . . . . . . . . . . . . . . . 20-96

20.5.19 10 CFR 50.34(f)(2)(vii): Consideration of Degraded or Melted Cores in Safety Review - Plant Shielding to Provide Access to Vital Areas and Protect Safety Equipment for Post-Accident Operation (TMI Item II.B.2) . . . . . . . . . . . . . . . . . . . . . . . . . . . . . . . . . . 20-97

20.5.20 10 CFR 50.34(f)(2)(viii): Consideration of Degraded or Melted Cores in Safety Roviow - Post-Accident Sampling (TMI Item II. B.3) . . . . . . . . . . . . . . . . . . . . . . . . . . . . . . . . . . 20-97

20.5.21 10 CFR 50.34(f)(2)(ix): Consideration of Degraded or Melted Cores in Safety Reviow - Rulomaking Proceeding on Degraded Core Accidents (TMI Item II.B.8), "Hydrogen Control System" . . . . . . . . . . . . . . 20-97

20.5.22 10 CFR 50.34(f)(2)(x): Reactor Coolant System Relief and Safety Valves - Testing Requirements (TMI Item II.D.1) . . . . . . . . . . . . . . . 20-98

20.5.23 10 CFR 50:34(f)(2)(xi): Reactor Coolant System Relief and Safety Valves - Relief and Safety Valve Position Indication (TMI Item II.D.3) 
20.5.24 10 CFR 50.34(f)(2)(xii): Syatem Deaign - Auxiliary Feedwater Syatem - Auxiliary Feodwater Syetem Automatic Initiation and Flow Indication (TMI Item II.B.1.2) . . . . . . . . . . . . . . . . . . . . . . . 20-98

20.5.25 10 CFR 50.34(1)(2)(xiii): Syatem Deaign - Decay Heat Removal Reliability of Power Supplies for Natural Circulation (TMI Item II.E.3.1) . . . . . . . . . . . . . . . . . . . . . . . . . . . . . . . . . 20-98

20.5.26 10 CFR 50.34(f)(2)(xiv): Syetem Deuign - Containment Design Inolation Dependubility (TMI Item II.E.4.2) . . . . . . . . . . . . . . . . . . . . 20-98

20.5.27 10 CFR 50.34(f)(2)(xv): Systom Deaign - Containment Deaign Purging (TMI Item II.B.4.4) . . . . . . . . . . . . . . . . . . . . . . . 20-99

20.5.28 10 CFR 50.34(1)(2)(xvi): Syetem Deaign - Deaign Sensitivity of BeW Reactors - Design Evaluation (TMI Itom II.E.5.1) . . . . . . . . . . . 20-100

20.5.29 10 CFR 50.34(f)(2)(xvii): Instrumentation and Controls - Additional Accident Monitoring Instrumentation (TMI Item II.F.1) . . . . . . . . . . . . 20-100

20.5.30 10 CFR 50.34(f)(2)(xviii): Inetrumentation and Controls Identification of and Recovery from Conditione Leading to Inedequate Core Cooling (TMI Item II.F.2) . . . . . . . . . . . . . . . . . . . . . 20-100

20.5.31 10 CFR 50.34(f)(2)(xix): Instrumentation and Controls - Instruments for Monitoring Accident Conditions (TMI Item II.F.3) . . . . . . . . . . . . . . 20 20103

20.5.32 10 CFR 50.34(f)(2)(xx): Electrical Power - Power Supplies for Preesurizer Relief Valves, Block Valves, and Lovel Indicators (TMI Itom II.G.1) . . . . . . . . . . . . . . . . . . . . . . . . . . . . 20-103

20.5.33 10 CFR 50.34(f)(2)(xxi): Measures to Mitigato Smull-Break Lose-ofCoolant Accidents and Loes-of-Feedwater Accidents - IE Bulletins Deacribe Automatic and Manual Actions for Proper Functioning of Auxiliary Heat Removal Systems When Feedwater System Not Operable (TMI Item Isove II.K.1.(22)) . . . . . . . . . . . . . . . . . . . . 20-103

20.5.34 10 CFR 50.34(f)(2)(xxii): Measures to Mitigate Small-Break Lossof-Coolant Accidents and Loss-of-Feedwater Accidents - Commission Orders on B\&W Plants - Analysis and Upgrading of Integratod Control System (TMI Item II.K.2(9)) . . . . . . . . . . . . . . . . . . . . . 20-104

20.5.35 10 CFR 50.34(f)(2)(xxiii): Mecssures to Mitigate Small-Break Lossof-Coolant Accidents and Loss-of-Feedwater Accidents - Commission Orders on B\&W Plants - Hard-Wired Safety-Grade Anticipatory Reactor Tripe (TMI Item II.K.2(10)) . . . . . . . . . . . . . . . . . . . . 20-104

20.5.36 10 CFR 50.34(f)(2)(xxiv): Measures to Mitigate Small-Break Loseof-Coolant Accidents and Loss-of-Feedwater Accidents - Final Recommendations of Bulletins and Orders Task Force - Central Water Level Recording (TMI Item II.K.3(23)) . . . . . . . . . . . . . . . . 20-104

20.5.37 10 CFR 50.34(f)(2)(xxv): Emergency Preparedness and Radiation Effects - Improve Licenseo Emorgency Preparednees - Short Term; Upgrade Emergency Preparednese (TMI Item III.A.1.2) . . . . . . . . . . . . . . . 20-104

20.5.38 10 CFR 50.34(f)(2)(xxvi): Radiation Protection - Radiation Source Control - Primary Coolant Sources Outside the Containment Structure (TMI Item III.D.1.1) . . . . . . . . . . . . . . . . . . . . . . . . . . . . . . 20-104

20.5.39 10 CFR 50.34(f)(2)(xxvii): Radiation Protection - Worker Radiation Protection Improvement -Inplant Radiation Monitoring (TMI Item III.D.3.3) . . . . . . . . . . . . . . . . . . . . . . . . . . . . . 20-105

20.5.40 10 CFR 50.34(f)(2)(xxviii): Radiation Protection - Worker Radiation Prolection Improvement - Control Room Habitability (TMI Item III.D.3.4) . . . . . . . . . . . . . . . . . . . . . 20-105

20.5.41 10 CFR 50.34(f)(3)(i): Operating Procedures - Procedures for Feedback of Operating Experience to Plant Staff (TMI Item I.C.5) . . . . . . . . . . 20-105

20.5.42 10 CFR 50.34(f)(3)(ii): Quality Assurance (QA) - Expand QA List (TMI Item I.F.1) 20-106 
20.5.43 10 CFR 50.34(f)(3)(iii): Quality Acaunnce - Dovelop More Dotailed QA Criteria (TMI Item I.P.2) . . . . . . . . . . . . . . . . . . . . . . . . . 20-106

20.5.44 10 CFR 50.34(1)(3)(iv): Consideration of Degraded or Melted Cores in Safuty Roviow - Rulemating Proceeding on Dogradod Core Acoidents (TMI Item II.B.8), ".91-Moter (3-Foot) Dirmeter Bquivaleat Dedicated Containment Penetration" . . . . . . . . . . .

20.5.45 10 CFR 50.34(P)(3)(v): Convideration of Degraded or Melted Cores in Safoty Roviow - Rulemaking Proceeding on Degraded Core Accidents (TMI Item II.B.8), "Containment Intogrity During an Accident Involving 100-Percent, Fuel Clad Metal-Water Reaction" . . . . . . . . 20-107

20.5.46 10 CFR 50.34(f)(3)(vi): System Design - Containment Design Dedicated Penctrations (TMI Item II.E.4.1) . . . . . . . . . . . . . . . . . . . 20-10

20.5.47 10 CFR 50.34(f)(3)(vii): General Implications of TMI for Design and Construction Activitios - Management for Design and Conetruction - Organization and Staffing to Overneo Deaign and Conetructican (TMI Itom II.J.3.1) . . . . . . . . . . . . . . . . . . . 20-108 


\section{FIGURES}

7.1-1

7.1-2

$7.2-1$

$7.2-2$

7.3-1

7.3-2

17.1

19.1-1

19.1-2

Integrated bandware/software dovelopment procese $\ldots \ldots \ldots \ldots \ldots \ldots \ldots \ldots \ldots \ldots \ldots$ 7-11

Flow of document through the software life cycle . . . . . . . . . . . . . . . 7-12

Safety syetem logic and control block diagram . . . . . . . . . . . . . . . . . 7-16

Safety ayetem logic and control (SSLC) control interface diagram . . . . . . . . . . . 7-18

Safoty aystom logic and control communications path for engineored anfety systoms . . . . . . 7-37 Asaignment of interfacing anfety system logic to safoty system logic and control controllers . . . . . . . . . . . . . . . . . . . . . . . . . 7-38

ABWR design organization structure $\ldots \ldots \ldots \ldots \ldots \ldots \ldots \ldots \ldots \ldots \ldots \ldots \ldots$

ABWR core damage frequency distribution $\ldots \ldots \ldots \ldots \ldots \ldots \ldots \ldots \ldots$ 19-13 $\ldots \ldots \ldots \ldots$ Breakdown of ABWR containment release frequency from CET analysis . . . . . . . . 19-34

\section{TABLES}

Design-basis tornado characteristics $\ldots \ldots \ldots \ldots \ldots \ldots \ldots \ldots \ldots \ldots \ldots \ldots \ldots$. . . . . . . . . .

Margins for straight pipe . . . . . . . . . . . . . . . . . . . . . . 3-70

Revised radiological consequences of design-basis accidents . . . . . . . . . . . . . . . 15-9 
ABWR PRA initiating ovent contributors to CDF (Lovel 1, internal events) . . . . . . . . . 19-1

Important requences for external events (eismic, firo, and internal floods) . . . . . . . . . 19-3

Examples of coet-effective PSA-inspired design/procedure modifications to the

Exnmples of configurations that moet 1E-5 CCDF goal in Modes 3, 4, and 5 . . . . . . . . 19-30

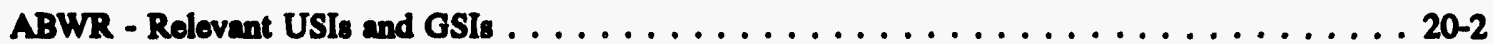

Comparison of GE and staff adjusted offsite consequences (person-Sv) . . . . . . . 20-79

Comparicon of GE and staff adjusted offsite consequences (person-rem) . . . . . . . . . 20-79 


\section{VOLUME 2: APPENDICES}

APPENDIX A $\ldots \ldots \ldots \ldots \ldots \ldots \ldots \ldots \ldots \ldots \ldots \ldots \ldots \ldots \ldots \ldots \ldots \ldots \ldots \ldots \ldots$

LIST OF ABBREVIATIONS $\ldots \ldots \ldots \ldots \ldots \ldots \ldots \ldots \ldots \ldots \ldots \ldots \ldots \ldots$ A-1

APPENDIX B $\ldots \ldots \ldots \ldots \ldots \ldots \ldots \ldots \ldots \ldots \ldots \ldots \ldots \ldots$ B-1

REFBRENCES $\ldots \ldots \ldots \ldots \ldots \ldots \ldots \ldots \ldots \ldots \ldots \ldots \ldots \ldots \ldots \ldots \ldots \ldots \ldots \ldots, 1$

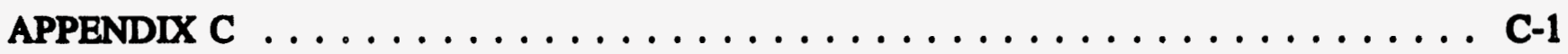

CHRONOLOGY OF CORRESPONDENCE $\ldots \ldots \ldots \ldots \ldots \ldots \ldots \ldots \ldots \ldots \ldots \ldots \ldots$ C-1

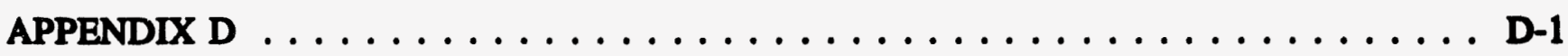

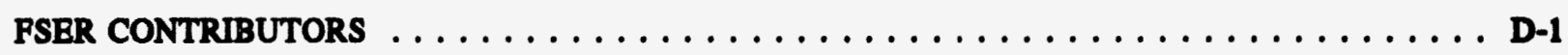

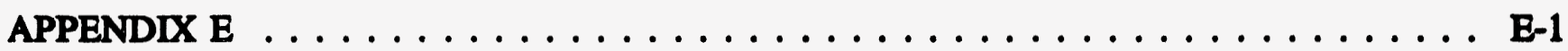

STAFF POSITION ON SHELL BUCKLING DUE TO INTERNAL PRESSURE $\ldots \ldots \ldots \ldots \ldots$-1

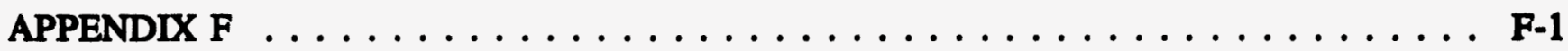

STAFF POSITION ON STEEL EMBEDMENTS $\ldots \ldots \ldots \ldots \ldots \ldots \ldots \ldots \ldots \ldots \ldots$ P-1

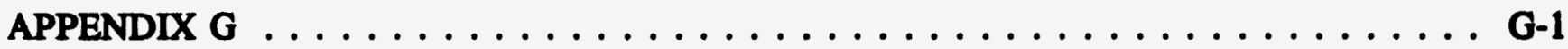

STAFF POSITIONS AND TECHNICAL BASES ON THE USE OF AMERICAN NATIONAL

STANDARDS INSTITUTE (ANSI)/AMERICAN INSTITUTE OF STEEL CONSTRUCTION

(AISC) N690, "NUCLEAR FACILITIES - STEEL SAFETY-RELATED STRUCTURES" $\ldots \ldots \ldots$ G-1

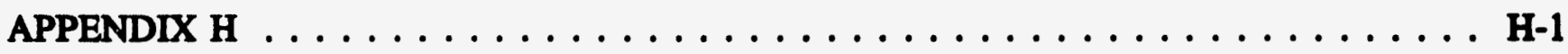

DYNAMIC LATERAL SOIL PRESSURES ON EARTH RETAINING WALLS AND EMBEDDED

WALLS OF NUCLEAR POWER PLANT STRUCTURES $\ldots \ldots \ldots \ldots \ldots \ldots \ldots \ldots \ldots$ H-1

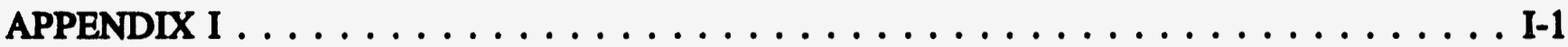

EVALUATION OF ABWR PUMP AND VALVE INSERVICE TESTING PLAN

(SSAR TABLES 3.9-8 AND 3.9-9) $\ldots \ldots \ldots \ldots \ldots \ldots \ldots \ldots \ldots \ldots \ldots \ldots$ I-1

APPENDIX J ........................

HUMAN FACTORS ENGINEERING PROGRAM REVIEW MODEL AND ACCEPTANCE

CRITERIA FOR EVOLUTIONARY REACTORS $\ldots \ldots \ldots \ldots \ldots \ldots \ldots \ldots \ldots \ldots \ldots$

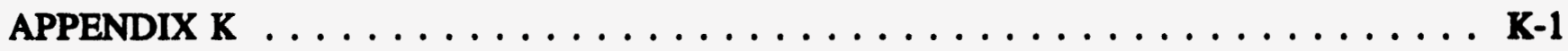

IMPORTANT SAFETY INSIGHTS $\ldots \ldots \ldots \ldots \ldots \ldots \ldots \ldots \ldots \ldots \ldots \ldots \ldots \ldots \ldots \ldots$ K-1 


\section{VOLUME 2: APPENDICES}

\section{FIGURES}

G-1 Structural ability curves for the axially loaded compression numbers. . . . . . . . . . . . G-3

J.1

HFB progrum roviow model elements ............................. J4

J.2

HFB program roviow tage

J-5 


\section{INTRODUCTION AND GENERAL DISCUSSION}

\subsection{Introduction}

On September 29, 1987, the General Blectric Company applied for certification of the U.S. advanced boiling water reactor (ABWR) atendard dosign with tho U.S. Nuclear Regulatory Commicaion (NRC) (hereinafter referred to as the NRC, the Commission, or the staff). The application was made in accordance with the procedures of Appendix 0 to Part 50 of Title 10 of the Code of Federnl Regulntion (10 CFR Part 50) and the Policy Statement on Nuclear Power Plant Standardization, dated September 15, 1987. The application was docketed on Fobruary 22, 1988 (Docket No. STN 50-605). On December 20, 1991, GE Nuclear Energy (GE) (hereinafter referred to $25 \mathrm{OE}$ or the applicant) requested that its application be considered as an application for design approval and subsequent design certification pursunat to 10 CFR 52.45. Accordingly, the staff assigned a new docket number (52-001), which became effective on March 13, 1992.

The NRC's licensing project managers that are currently assigned to the U.S. ABWR design review are Thomas $H$. Boyco, Son Q. Ninh, and David T. Tang. They may be reached by calling (301) $415-7000$ or by writing to the Office of Nuclear Reactor Regulation, Mail Stop 0-11 H3, U.S. Nuclear Regulatory Commission, Washington, D.C. 20555.

GE's application, the ABWR standard safety analysis report (SSAR), describing the design of the facility, was originally submitted in modular form between September 1987 and March 1989. Subsequently, GE supplemented the information in the SSAR through an amendment process. Amendment 35, which was submitted to the Commission on May 25, 1994, was the last amendment. GE also submitted the ABWR certified design material (CDM) on August 31, 1993. The CDM contains the so-called Tier 1 design information that GE proposes to have certified during the design certification rulemaking. GE submitted Revision 4 to the CDM on May 25, 1594. The application with all SSAR amendments and CDM revisions is available for public inspection at the NRC Public Document Room, 2120 L Street, N.W., Washington, D.C. 20555. A summary of the U.S. ABWR standard design is provided in Sections 1.2 and 1.3 of this report. Section 1.4 identifies agents and contractors.

This safety evaluation report (SER) documents the staff's review of the ABWR SSAR, up to and including Amendment 35, and the CDM, up to and including Revision 4. The staff also reviewed the SSAR, CDM, and final technical specifications to ensure that this information was internally consistent. This resolved Confirmatory

Item F1.1-1. This final SER documents the results of the staff's safety roviow of the U.S. ABWR atandard design against the requirements of Subpart B of 10 CFR Part 52 (design certification) and delinentes the scope of the tochnical details considered in evaluating the proposed design. The principal matters of the staff's review are summarized in Section 1.5 of this report.

The ataff gave the status of its initial review of the ABWR SSAR in a ceries of "draft" SERs. These draft SER, and the chapters of the SSAR that woro ovaluated were aubmitted to the Commission as follows:

Commission Paper (Date)

SECY-91-153 (May 24, 1991)

SECY-91-235 (August 2, 1991)

SECY-91-294 (September 18, 1991)

SECY $-91-309$ (October 1, 1991)

SECY-91-320 (October 15, 1991)

SECY-91-355 (October 31, 1991)

\section{SSAR Chapter}

$$
\begin{aligned}
& 2-6,17 \\
& 3,9-11,13 \\
& 7 \\
& 19 \\
& 18 \\
& 2,3,5,6, \\
& 8-10,12-15
\end{aligned}
$$

The staff also issued a "draft final" SER (DFSER) for the ABWR design, SECY-92-349, on October 14, 1992, and an advance copy of the SER related to certification of the ABWR design on December 30, 1993.

In a letter dated November 9, 1993, the NRC directed GE to revise the SSAR and CDM to conform with NRC's metrication policy, which was published in the Eederal Bepister (57 FR 46202) on October 7, 1992. The NRC requested that these rovised documents be submitted before March 4, 1994. As stated in the November 9, 1993, letter, the staff used dual units in the final SER. The staff verified that the SSAR and CDM conformed with the NRC's metrication policy.

In its application, GE stated that it was developing the $A B W R$ design to meet the requirements in the Electric Power Research Institute's (EPRI's) Advanced Light Water Reactor Program. The Commission requested, in a staff requirements memorandum (SRM) dated December 15, 1989, that the staff ovaluate deviations in the vendor designs from the EPRI "Advanced Light Water Reactor Utility Requirements Document." This was identified as Open Item 1.1-1 in the DFSER. GE stated in a letter dated April 29, 1993, that the SSAR satisfies the objectives of the policy guidance set forth by the Commission in the above SRM. The Commission designated this response to be acceptable in COMSECY-93-040, dated August 10, 1993. This resolved DFSER Open Item 1.1-1.

This SER references information in the SSAR that GE had requested to be withheld as proprietary in accordance with 
10 CFR 2.790. The staff's determination regarding OB's request was provided in a letter to GE dated June 7, 1994. This resolved Open Item F1.1-1. Severnl references to GB topical reports are aleo made in this SER. Some of these topical reports contain information that the Commission authorized to be exempt from public disclosure, as provided by 10 CFR 2.790. For each such topical report and SSAR amendmont containing proprietary information, a nonproprietary version, similar in content except for the omission of the proprietary information, is submitted to the NRC and is also available at the NRC Public Document Room. Reference to topical reports and SSAR information throughout this SER is made to the proprietary version.

Plant-specific applicants who reference the U.S. ABWR stendard design in the future will retain architect-engineers, constructors, and consultants, as needed. As part of its roview of an application for a combined license (COL), the staff will evaluate, for each plant-specific application that references the certified ABWR design, the technical competence of the applicant and its contractors to manage, design, construct, and operate a nuclear power plant. The plant-specific applicants will also be required to satisfy the requirements of Subpart C of 10 CFR Part 52 and the requirements resulting from the staff's review of this standard design, including the applicable regulations and exemptions identified in Section 1.6 of this report. GE identified additional requirements for the plant-specific applicants in the SSAR and identified them as "COL license information." The staff finds this acceptable. This resolved Open Item F1.9-1 and Confirmatory Item F1.9-1. An applicant for a COL will be required to discuss the COL license information in its application.

$A$ list and definition of the abbreviations used throughout this report are provided in Appendix A. Appendix B gives the references for this report. A chronology of the principal actions related to the processing of this application and the submittal dates of the SSAR amendments is given in Appendix C. Appendix D lists the principal reviewers who evaluated the SSAR and CDM. Appendices E, F, and $\mathbf{G}$ give staff positions on shell buckling, steel embedments, and safety-related structures, respectively. Appendices $H$ and $I$ contain the staff's evaluation of structural walls and the ABWR pump and valve inservice testing plan, respectively. The "Human Factors Engineering Program Review Model and Acceptance Criteris for Evolutionary Reactors" is given in Appendix $J$ and a list of PRA-based safety insights is given in Appendix $\mathbf{K}$.

\subsection{General Design Description}

The U.S. ABWR design is similar to the international ABWR design, which is being built at the Kashiwazaki
Keriwa Nuclear Power Generati station, Units Nos. 6 and 7 (K-6/7), by tho Tokyo Electric Power Company, Inc. OE summerized differences between the U.S. ABWR deaign and the K-6/7 project in a letter to the staff dated Fobruary 20, 1992. Since that timo, it bas mado docign changes to the U.S. ABWR etendard design. GB committed to updato the list of differences in its letter of Fobruary 20, 1992, and incorporate the find aummary of deaign differences in the SSAR. This was identified as Confirmatory Item 1.2-1 in the DFSER. GE provided the updated list in SSAR Amendment 31. The staff finds this accoptable. This resolved Confirmatory Item 1.2-1.

The design of the $\mathrm{K}-6 / 7$ project is a cooperative offort between GE, Hitachi, and Toshiba. All three parties roview and sign off on the ABWR common engineering design documents for the $\mathrm{K}-6 / 7$ project, which are generally upper-level design documents. $\mathrm{GE}$ has the lead for the reactor vessel and internals, the recirculation system, the control rod system, and the nuclear boiler system. Differences between the $\mathrm{K}-6 / 7$ design and the U.S. ABWR deaign are identified and maintained, by an internal $G E$ review process, in a controlled list for future design action and application (DAL). In addition to the design changes, this DAL process identifies other required changes for the ABWR common engineering documents (CEDs), such as U.S. code and regulatory requirements. $G E$ plans to incorporate the DALs into the supporting design documentation for the U.S. ABWR design after design certification, possibly during a first-of-a-kind engineering activity.

A significant portion of the detailed $\mathrm{K}-6 / 7$ design information used in developing the SSAR is retained at the offices of Hitachi and Toshiba in Japan. GE has stated that the contractual terms between GE and its aseociates allow GE access to the supporting design record files in Japan through October 29, 2001. In addition to the design information in GE's SSAR submittal, the staff has, in areas such as seismic, tornado, and high wind design, reviewed additional detailed design information that is not typically provided as part of a licensing submittal. Detailed design information determined to be necessary to support the staff's review findings was formally incorporated into the SSAR application.

The staff assessed GE's ABWR design process from March 30 through April 3, 1992, and summarized its assessment in a letter to GE dated May 15, 1992. It performed a subsequent inspection of the ABWR design process in September 1993. This inspection is addressed in Section 17.1.3 of this report. On June 16, 1992, GE responded to the staff's request for information in the May 15, 1992, letter on the following five issues: 


\subsubsection{GE's Dedign Proceen for the U.S. ABWR}

GE atated in its letter of June 16, 1992, that "OE and its anociates control the roviow and approval of ABWR Common Bngineering design documents with a procedure uning the Bngincering Review Momornadum .... Evidence of design verification is entered into the deaign records of the reeponsible decign organization." GE also etated that for engineering documents prepared uniquely by GB for the U.S. ABWR, changes to engineoring documents are entered into the GE design record files. A COL applicent or holder must establish the design, including the supporting detailed design documentation, consistent with the ABWR design control document (DCD) referenced in the certified design rule. The required design procese to establish the detailed design documentation in conformance with the DCD is the responsibility of the COL applicant or licensec. This was identified as COL Action Item 1.2.1-1 in the DFSER. GE provided this requirement in Section 1.1.4 of the SSAR. This is acceptablo.

\subsubsection{Precertification and Postcertification Design Control Procedures}

GE stated in its letter of June 16, 1992, that "the same design control procedures described above apply to both Common Engineering and GE documents issued before as well as after certification of the U.S. ABWR." The staff's position is that GE must certify to the NRC, before final design approval (FDA), that the U.S. ABWR DCD has not been affected by any changes to the ABWR common engineering design documents. This was designated as Open Item 1.2.2-1 in the DFSER. In a letter dated June 11, 1993, GE stated that after the completion of the DCD, GE will certify that the Tier 1 and Tier 2 information has not been affected by any subsequent changes made in the common engineering design documents since the final Tier 1 and Tier 2 submittals. This letter changes DFSER Open Item 1.2.2-1 to Confirmatory Item F1.2.2-1.

Also, GE must provide to the staff a list of the ABWR common engineering design documents and DALs that apply to the U.S. ABWR design and their effective dates. This was identified as Open Item 1.2.2-2 in the DFSER. In a letter dated June 11, 1993, GE stated that after the completion of the DCD, GE will finalize the design action list and provide the corresponding effective dates of CEDs and DALs. This letter changes DFSER Open Item 1.2.2-2 to Confirmatory Item F1.2.2-2.

\subsubsection{The role of the COL Applicant or Licensee}

In its letter of June 16, 1992, GE discuseed the change proceses for the so-called Tier 1 and Tier 2 information available to - COL applicant or licensee. The staff propoeed a change process for Tier 1 and Tier 2 information in an advanced notice of proposed rulemaking (ANPR) that was published in the Bedernl Regiter (58 FR 58664) on November 3, 1993. If a final rule certifies the ABWR deaign, then it will explicitly state the change process to be followed for the Tier 1 and Tier 2 information.

\subsubsection{Control of Design Documentation in Support of the Certified Design}

GE stated in its letter of June 16, 1992, that "GE will apply its QA [quality assurense] process throughout the dovelopment of first-of-a-kind engineering phase (as well as subeequent phases of design definition), and will insure that all commitments made in the Design Certification (i.e., Tier 1 and Tier 2) are satisfactorily being implemented."

\subsubsection{GE's Agreement With the Japanese}

GE stated in its letter of June 16, 1992, that "in general, GE's agreement with the Japanese for design information exchange and availability falls under the Technical Cooperation Agreement (TCA) which has recently been renewed through October 29, 2001. Under the TCA, GE has been able to obtain detailed design information with a lead time of about two months."

\subsubsection{Scope of Certified Design}

The regulation in 10 CFR 52.47(b)(1) requires an applicant for certification of an evolutionary nuclear power plant design to provide an essentially complete design scopo. Therefore, the scope of the U.S. ABWR design must include all of the plant that can affect safo operation except for its sito-specific eloments, such as the service water intake structure and the ultimate heat sink. This was identified as Open Item 1.2.6-1 in the DFSER. GE submitted a description of the ABWR standard plant scope, including the site-specific design elements that are either partially or completely outside the scope of the ABWR standard design, in Section 1.1.2 of the SSAR. The staff finds this acceptable. This resolved Open Item 1.2.6-1. 


\subsubsection{Summary of U.S. ABWR Standard Design}

The ABWR is a singlecyclo, forced-circulation, boiling water resctor (BWR) with a rated power of 3926 megawatts thermal (MWt) and a design power of 4005 MW. This power level exceed the guidance in Regulatory Guide (RG) 1.49, "Power Lovels of Nuclear Power Plants," which states that licensed power lovels should be limited to a reactor cone power lovel of 3800 MWt or lees until January 1, 1979, at the earliest. The intent of this regulatory guidance was to stabilize the maximum size of nuclear plents until aufificient experience whe gained with design, construction, and operation of large plants. Since the iseunnce of RO 1.49, Revision 1, in 1973, the affif has reviewed sufficient operating experience and has determined that licensing the ABWR at a rated power of $3926 \mathrm{MWt}$ is acceptable.

Unique features of the ABWR design include the internal recirculation pumpe, fine-motion control rod drives, microprocessor-based digital control and logic systems, and digital safety systems. The reactor building includes the containmeat, drywell, and major portions of the nuclear stenm supply system, steam tunnel, refueling area, diesel generators, cesential and nonessential power, emergency core cooling systems (ECCSs), and heating, ventilating, and air conditioning (HVAC) systems. The control building includes the control room, the computer facility, the cable tunnels, some essential switchgear, some essential power, the reactor building cooling water system, and the essential HVAC system. The service building houses the technical support center, the operational support center, and the counting room for analyzing post-accident samples. The turbino building includes all equipment associated with the main turbine generator. The radwaste building includes all equipment associated with the collection and processing of solid and liquid radioactive waste generated by the plant.

\section{Reactor}

The reactor design consists of the reactor pressure vessel (RPV), preseure containing appurtenances (control rod drive housings, in-core instrumentation housing, head vent and epray assembly) and internal components. The internal components include the core, the core support structure, tho shroud head and steam separator assembly, the steam dryer aseembly, the feedwater spargers, the core spray, and the core flooding spargers. Except for zircaloy in the reactor core, the internals will be made of stainless steel or other corrosion-resistant alloys.

The reactor core will consist of 872 fuel bundles in an 8-by-8 array and 205 control rods operating at a power density of $50 \mathrm{~kW} / \mathrm{liter}$. The control rods, which will enter from the bottom of the reactor core, will perform dual functions of power distribution shaping and reactivity control. Manipulation of selected pattorns of rods will control power distribution, while electro-hydrulic drive mechanisms or hydraulic rapid scram insertion will control reactivity.

\section{Reactor Coolant System}

The reactor coolant systom (RCS) includes the nuclear boiler system; the main steam, feedwater, recirculation system; the reactor core isolation cooling (RCIC) system; the residual heat removal system; and the reactor water cleanup system. The design is different from current BWR designs in that 10 reactor internal pumps (RIP8) located within the reactor vessel will forcibly circulate reactor coolant. This will eliminate large piping connections to the reactor vessel below the core and also eliminate reactor recirculation system piping. Eighteen safety/relief valves in six groups will provide RCS overpreseure protection.

\section{Beactor Protection System}

The reactor protection system (RPS) will initiate a rapid, automatic shutdown of the reactor to prevent fuel cladding damage and any nuclear system process barrier damage due to an abnormal transient. The RPS scram logic inputs are from the neutron monitoring system (NMS). The NMS is a system of in-core neutron detectors and out-ofcore electronic monitoring equipment.

\section{Containment}

The ABWR has a pressure suppression primary containment system. The primary containment includes a drywell and a wetwell. The drywell consists of two volumes, an upper drywe.' surrounding the RPV and a lower drywell that houses RIP8, control rod drives, and service equipment. The wetwell consists of a suppression pool and an air volume that will serve as a heat sink during normal and accident conditions. A secondary containment surrounds the primary containment and permits monitoring and treating of all potential radioactive leakage from the primary containment.

\section{Electrical Power Distribution Supply}

The electrical power distribution system is a complete three load group distribution system with two independent offsite power sources, the main turbine generator, three onsite standby power sources (emergency diesel generators), and a combustion turbine generator located on site. During normal plant operations, the main generator will supply power to the main power transformer (MPT) and 
throe unit auxiliary transformen (UATo) through the main generator output breaker and an isolated phase bus. When the main generator is off line, power will be aupplied to the UATs and the MPT by the proferred offisite power source.

\section{Emerrency Core Cooline System}

In the event of a breach in the reactor coolant presesure boundary that results in a lose of reactor coolent, three independent divisions of the BCCS will maintain fuel cladding below the tomperature limit as defined by 10 CFR 50.46. Each division contains one high-pressure and one low-pressure inventory makeup system. The following systems make up the ECCS:

- high-pressure core flooder (HPCF) system

- RCIC system

- low-pressure flooder (LPFL) system

- automatic depressurization system (ADS)

\section{Control Room}

The main control room incorporates monitoring and control functions for normal and emergency plant operations. It consists of a single integrated control console staffed by two operators. The console hes a low profile so that the operators can see over it from a seated position. A plant process computer system will drive onscreen control video display units (VDUs) for safety system monitoring and non-safety system control and monitoring. Two separate sets of on-screen control VDUs will be used for safety and non-safety system control and monitoring independent of the plant process computer system. Dedicated function switches are also provided on the control console. A large display panel with fixed position display of key plant parameters and major equipment status will be used by the entire control room operating staff. A supervisors console has "monitoring only" capability.

\section{Power Conversion}

The power conversion system is designed to convert the heat energy generated in the reactor to electrical energy. This system includes the main steam system, main turbine generator system, main condenser, condenser evacuation system, condensate cleanup system, and condensate feedwater pumping and heating system.

\subsection{Comparison With Similar Facility Designs}

While many features of the ABWR design are similar to those of BWR designs that the staff had previously approved, some features are unique, as discuseed in Section 1.2.7 of this report. To the extent feasible and appropriate, the staff has relied on oarlier reviews for thowe ABWR decign features that are substantially the same as those proviously considered. Where this has been dono, the eppropriate sections of this report identify the other designs. The SERs for the other designs have been published and are available for public inspection at the NRC Public Document Room, $2120 \mathrm{~L}$ Street, N.W., Washington, D.C. 20037.

\subsection{Identification of Agents and Contractors}

The ABWR common engineering design documents for the international $A B W R$ design were developed by GE and its aseociates, Hitachi and TCeniba. The U.S. ABWR design is being doveloped by $\mathrm{GE}$.

\subsection{Summary of Principal Review Matters}

The procedure for certifying a design is described in Subpart B of 10 CFR Part 52 and is implemented in two stages. The technical review stage begins with an application filed in accordance with the requirements of 10 CFR 52.45, continues with reviews by the NRC staff and the ACRS, and concludes with the issuance of a final SER related to design certification and notification that the applicable requirements of $10 \mathrm{CFR} 52.47,52.48$, and 52.53 have been met. The administrative review stage begins with a Eedernl Register notice that initiates a rulemaking, in accordance with $10 \mathrm{CFR} 52.51$, and provides a proposed standard design certification rule. The rulemaking will be conducted by the Commission and also, in the event that there is a request for a hearing and the request is granted, by an Atomic Safety and Licensing Board. The rulemaking will culminate with the denial or issuance of a design certification rule. An advance notice of proposed rulemaking on design certification was published in the Federal Register (58 FR 58664) on November 3, 1993.

The staff's technical review of GE's application for certification of the U.S. ABWR standard design was performed in accordance with Commission guidance and tho applicable requirements of Subpart B of 10 CFR Part 52. This final SER documents the results of the staff's technical review. The staff's evaluation of the tochnical information required by 10 CFR 52.47(a)(1)(i) was performed in accordance with the standard review plan (SRP, NUREG-0800) and is discussed throughout this report. The evaluation of the technically relevant unresolved safety issues, generic safety issues, and Three Mile Island requirements (10 CFR 52.47(a)(1)(ii) and (iv)) is given in Chapter 20 of this report. Site parameters required by 10 CFR 52.47(a)(1)(iii) are evaluated in Chap- 
ter 2 and listed in Section 2.6. Tho deaign-epecific probabiliatic riak ascosement (10 CFR $52.47(a)(1)(v)$ ) is ovaluated in Section 19.1. Inspoction, teots, analyeos, and ecceptance critoria (ITAAC), an required by 10 CFR $52.47(a)(1)$ (vi) and (viii), are ovaluated in Section 14.3. Interfice requirements and representative conceptual decigns (10 CFR 52.47(a)(1)(vii) and (ix)) are ovaluated in Chapters 8 and 9 and are also discuseod in Section 14.3. The ABWR tochnical spocifications aro ovaluated in Chapter 16 of this report. The staff also implemented the Commiesion's Sovero Accident Policy Statement, datod August 8, 1985, and the Commisaion's SRMs on SECY-90-016 and SECY-93-087 in its resolution of severe sccident issues. The staff's evaluation of severe accident issues is given in Section 19.2 of this report.

The regulations in 10 CFR $52.47(a)(2)$ describe the level of design information needed to certify a standard design. Determining the scceptable lovel of design detail neceseary for the staff to make its safety findings was one of the moet challenging aspects of the staff's review. The SRM for SECY-90-377, "Requirements for Design Certification Under 10 CFR Part 52," sots forth the Commission's position on what level of design information is required for a certification application, and the staff has followed that guidance in preparing this report. The staff determined that GE did not provide sufficient detail in the SSAR for the following four areas of the review: pipe stress analysis, radiation shielding and airborne concentrations, instrumentation and controls (I\&C), and control room design. The staff besed its safety decisions for these areas of the design on the use of design acceptance criteria (DAC). The staff's evaluation of the level of design information to be certified, including DAC (certified design material - CDM) is given in Section 14.3 of this report. As part of its tochnical review, the staff also made numerous requests for additional information to provide sufficient bases for its safety findings and to meet 10 CFR 52.47(a)(3). Its evaluation of the scope of the design to be certified (10 CFR 52.47(b)(1)) is given in Section 1.2.6. The requirement in 10 CFR 52.47(b)(2) does not apply because the $A B W R$ is an evolutionary reactor design and 10 CFR 52.47(b)(3) does not apply because the ABWR is not a modular design.

The staff used the safety standards in 10 CFR 52.48 as the basis for its review of the U.S. ABWR standard design. It also followed Commission guidance given in the SRMs for various Commission papers referenced throughout this report and identified in Appendix B. As a recult of this guidance, the staff proposed design-specific regulations that are applicable to the ABWR deaign and juatified exemptions from exiating regulations to complete the regulatory framowork of afety atandards. An index of thew afery standards is contained in Section 1.6 of this report.

In the DFSER and advance copy of the SER, the ataff ideatified many unrecolved or open items. These open items were resolved as described throughout this report. After iscuance of this report on the Staff's reviow of the SSAR and CDM, the applicant will submit a design control document (DCD) for the staff's review. This is Confirmatory Item F1.5-1. The DCD will consist of the CDM and Tier 2 information as described in Section 14.3 of this report. Applications that reference the certified $A B W R$ design will be required to conform with the $D C D$. The DCD will be available for public inspection at the NRC Public Document Room when the proposed rule for design certification is published in the Eederel Repister.

\subsection{Index of Applicable Regulations and Exemptions}

In sccordance with $10 \mathrm{CFR} 52.48$, the staff used the applicable regulations in 10 CFR Parts 20,50, 73, and 100 in performing its review of GE's application for design certification. During this review, the staff identified cortain regulations for which application of the regulation to the ABWR design would not serve or was not necessary to achieve the underlying purpose of the rule. These exemptions to the above regulations are discussed in the sections of this report identified below.

In the SRM pertaining to SECY-91-262, "Resolution of Selected Technical and Severe Accident Issues for Evolutionary Light Water Reactor Designs," the Commission approved the staff's recommendation to proceed with design-specific rulemakings as part of design certification rulemakings to establish selected technical and sovere accident issues as "applicable regulations" for the ABWR and System 80+ standard designs. These issues included staff positions that deviated from or were not embodied in current regulations applicable to the standard designs. These issues were proposed in various Commission papers, such as SECY-93-087, "Policy, Technical, and Licensing Isoues Pertaining to Evolution and Advanced LWR Designs." Tho "applicable regulations" that are specific to the ABWR design are identified and evaluated in this report. The proposed design certification rulo will include these "applicable regulations" for the ABWR design for the purposes of 10 CFR 52.48, $52.54,52.59$, and 52.63. These "applicable regulations" are discussed in the sections of this report identified below. 
Section Deacriotion of Ireve

3.1.1 Exemption from operating bavis earthquike design requirement

3.9.3.1.1 Applicable regulation for intersystem lowof-coolant accident

3.9.6 Applicable regulation for inservice toating of pumps and valves

3.11.1 Exemption from 10 CFR 50.49(b)(3)

7.2.6 Applicable regulation for digital instrumentation and control systems

8.2.2.9

and 8.2.3.4 Applicable regulations for electric power system

9.3.2.2 Exemption from posteccident sampling

9.5.1 Applicable regulation for fire protection

17.3 Applicable regulation for design reliability assurance program

18.3.2.2 Exemption from safety parameter display console

19.1.2 Applicable regulation for andysis of external events

19.2.2.1.2 Applicable regulation for station bleckout

19.2.3.3.2 Applicable regulation for core debris cooling

19.2.3.3.3 Applicable regulation for high-pressure core melt ejection

19.2.3.3.7 Applicable regulation for equipment survivability

19.2.4 Applicable regulation for containment performance

19.3.2 Applicable regulation for shutdown risk

20.5.44 Exemption from dedicated containment penetration requirement

\subsection{Index of Tier $2^{*}$ Information}

The ataff dotermined that certain SSAR commitments discused in the following sections of this report, if considered for a change by an applicant or licenece that references tho certified ABWR design, will require prior NRC reviow and approval beforo the change is implemented. Theee SSAR commitments (80-called Tier $2^{\circ}$ information) will bu identified in the design control document. This is Confirmatory Item F1.7-1.

\section{Section Description of Commitment}

3.8 .1

American Society of Mechanical Engincers Boiler and Pressure Vessel Code 1989 Edition for structural design and construction (referenced twice)

3.8.3, 3.8.5 American Concrete Institute 349 for structural design and construction

3.8 .4

American National Standards Institute/American Institute of Steel Construction N690 for structural design and construction

3.9.6.2.2 Design, qualification, and preoperational testing for motor-operated valves

3.10.1 Equipment seismic qualification methods

3.12 Piping DAC

4.2 First cycle fuel, control rod and design, and methods used to analyze these components

7.2.2.1 Essential multiplexing system design criteria

7.2.2.5 Self-test system design testing fentures

Instrument setpoint methodology

7.2.8 Electromagnetic interference protection criteria and standards; computer development

18.9.3 Human system interface design implementation process 


\subsection{Index of Confirmatory Items}

In the DFSER and advance copy of tho SER, the etarf ideatified many confirmetory itom. Mout of these confirmetory item were recolved as deccribed throughout this report. The following itom with an $F$ before the itom number are confirmatory at the time of isanence of this final SER. Theas item will be resolved during the etaffe. reviow of the ABWR decign control document.

Eech confirmatory item was aseigned a unique number that identifies the section in this report where the item is discused. For examplo, Confirmationy Item P1.5-1 is discused in Section 1.5 of this report.
Itom Number Decotiotion of Item

F1.2.2-1 Certification that DCD not affected by changes to CEDs

F1.2.2-2

Submittal of list of CEDs and DALs

P1.5-1 Submittal of DCD

F1.7-1 Identify Tier $2^{*}$ information

F14.3.7.5-1 Reliability Asourance Program 


\section{SITE CHARACTERISTICS}

The etaff reviowed the sito related parumetare in Standerd Safory Analyds Report (SSAR) Section 2, including the cavelope of advenced boiling water reactor (ABWR) bounding site parameter listed in SSAR Table 2.0-1. The etaff finds that OB Nuclear Bnorgy's (OB'a) list of sito charncteriatice is consiateat with that contuined in appropriato cections of the Standard Roviow Plan (SRP) Chapter 2 and 10 CFR Parts 50, 52, and 100. In its roviow of the ABWR atendand docim, the etaff finds that the ecceptance criteris in the SRP for the roviow of sito suitability for the site parameters shown in SSAR Table 2.1-1 are aufficient. The etaff hes not identified any unique fentures of the ABWR deaign that would require additional limitations for the selection of sites compatible with the ABWR deaign. Therefore, the combined license (COL) applicant may uee the applicable SRP guidelines to ovaluate the suitability of ite site for the construction of the ABWR. To canure that the ABWR deaign is caveloped by tho sito-related parametern, tho staff will roviow sito characteriatice in dotail during the COL application phase. The silo-epecific information to be provided by COL applicants referencing the ABWR deaign is discused below.

It should be noted that the sito-epecific chanacteristics, which are discussed here as required at the time of a plant apecific COL application, may also be submitted to and considered by the Nuclear Regulatory Commission (NRC) in connection with an application for an early sito permit under 10 CFR Part 52, Subpart A.

\subsection{Geography and Demography}

The COL applicant should provido sito-specific information on site location and description, exclusion area authority and control, and population distribution.

\subsubsection{Site Location and Description}

The COL applicant should provide sito-specific information on site location, including political subdivisions, natural and man-made features, population, highways, railways, waterways, and other significant features of the area. This was draft final safety ovaluation report (DFSER) COL Action Item 2.1.1-1. GE hes included this sction item in Section 2.3.2.1 of the SSAR. This is scceptable.

\subsubsection{Exciusion Area Authority and Control}

The COL applicant should provide site-specific information on activities that may be permitted within the designated exclusion area. This was DFSER COL Action Item 2.1.2-1. GE has included this action item in Section 2.3.2.2 of the SSAR. This is acceptable.

\subsubsection{Population Diateribution}

The COL applicant chould provide population data for the sito environs. This was DFSER COL Action Itom 2.1.3-1. OE has included this setion itom in Section 2.3.2.3 of the SSAR. This is sccoptablo.

\subsection{Nearby Industrial, Transportation, and Military Facillties}

The COL applicant should provide sito-epecific information on ideatifying potential hezards in the cito vicinity and ovalunting potential socidents. These itoms are diccusead in detail in Sections 2.2.1, 2.2.2, and 2.2.3 below.

\subsection{1 and 2.2.2 Identification of Potential Hamard in Site Vicinity}

Tho COL applicant should provide information on induetrial, military, and traneportation facilition and routes to catablich the prosence and magnitude of potential external harands. This was DFSER COL Action Item 2.2.1-1. OE has included this setion item in Section 2.3.2.4 of the SSAR. This is acceptable.

\subsubsection{Evaluation of Potential Accidents}

The COL applicant should identify potential accident situations in the vicinity of the plant and give the reasons why these potential accidents were or were not accommodated in the design. This was DFSER COL Action Item 2.2.3-1. GE has included this action item in Section 2.3.2.5 of the SSAR. This is acceptable.

\subsection{Meteorology}

\subsubsection{Regional Climatology}

In SSAR Table 2.0-1, GE originally proposed that the maximum tornado wind speed of $418 \mathrm{~km} / \mathrm{hr}(260 \mathrm{mi} / \mathrm{hr})$ and the tornado recurrence interval of 1 million years (tornado atrike probability of 10E-6 per year) be used for the dosign-basis tornado (DBT). These parameters are based on American National Standards Instituto/American Nuclear Society (ANSI/ANS)-2.3 (1983), "Standard for Eetimating Tornado and Extreme Wind Characteristics at Nuclear Reactor Sites." The current NRC regulatory position with regard to the DBT is contained in WASH-1300, "Technical Basis for Interim Regional Tomado Criteria (1974)," and Regulatory Guide (RG) 1.76, "Design Basis Tornado for Nuclear Power Plants," Revision 0. WASH-1300 states that the probability of occurrence of a tornado that exceeds the DBT should be on the order of 10E-7 per year per nuclear power plant, and the RG specifies maximum wind speeds of $386 \mathrm{~km} / \mathrm{hr}$ 
$(240 \mathrm{mi} / \mathrm{hr}$ ) to $579 \mathrm{~km} / \mathrm{hr}(360 \mathrm{mi} / \mathrm{hr})$ depeading on the rogions.

The etaff has not endoned ANSI/ANS-2.3. However, in 1986, the regulatory positions in RO 1.76 was reovaluated, uaing the considerable quentity of tornado data that was availablo. The reovaluation is discusen in NUREO/CR-4461. At the beart of this atudy is the tornedo data tape prepared by the National Sovero Storm Forecast Center with 30 years of data, 1954 through 1983. This tape containg the data for the approximataly 30,000 tomados that occurred during tho period.

The reovaluation showed that the tornado atrike probabilitios range from near 10B-7 per year for much of the Weatern Unitod States to ebout 10E-3 per year in the Central Stutes. As a reoult, wind apeed values aceociated with a tornado having a mean recurrence interval of 10E-7 per year were extimated to be about $322 \mathrm{~km} / \mathrm{hr}$ (200 mi/hr) for the United States weat of the Rocky Mountains and $483 \mathrm{~km} / \mathrm{hr}(300 \mathrm{mi} / \mathrm{hr})$ for the United Stated cest of the Rocky Mountrins.

The DBT requirements have been used in eetablishing structural requirements (e.8., minimum concrote wall thicknoeses) for the protection of nuclear plant safotyrelated structures, systems, and components (SSCs) against the effects not covered explicitly in RGs or the SRP. Specifically, the staff has routinely ovaluated somo aviation (general aviation light aircraft) crnehes, nearby explosions, and explosion debris or missiles by considering the tornado protection requirements. In the DPSER, the staff noted that COL applicants should evaluate the offects on the protection criteria of some external impact bazards, wuch a secenal aviation or nearby explocions. This was DFSER COL Action Item 2.3.1-1. Section 2.3.2.6 of the SSAR includes this action itom. This is scceptablo.

On the bavis of updated tornado date and the analyais in NURBC/CR-461, the ataff coacluded that it is scceptable to reduce the DBT wind epeede to $322 \mathrm{~km} / \mathrm{hr}(200 \mathrm{mi} / \mathrm{hr}$ ) for the United States weat of the Rocky Mountnin and to $483 \mathrm{~km} / \mathrm{hr}$ (300 mi/hr) for the United States east of the Rocky Mountains. In SECY-93-087, the staff gives it position on the tornedo design besis. The Commiseion in its etaff requirements memorandum of July 21, 1993, approved the stafi-recommeaded position that a maximum tornedo wind epeed of $483 \mathrm{~km} / \mathrm{hr}$ (300 mi/hr) be used for the DBT for advanced light water reactors. As a reoult, Table 2-1 shows the DBT parameters that the etaff considers scceptable for the ABWR deaign. This table, which is based on dats from NUREG/CR-4461, dieplays the geographical boundaries for the characteriatics of the DBT.

In the DSER (SECY-91-355) and DFSER, the staff requeded that OB reviee the DBT characteriatics for the ABWR to reflect the data in Table 2-1 of this report. This was DSER Outstanding Issue 146 and DPSER Confirmatory Item 2.3.1-1. GE revised Table 2.0-1, "Envelope of ABWR Standard Site Desiga Parameters," of the SSAR to reflect the DBT characteristics specified in Table 2-1 of this report. The maximum tornado wind epeed of $483 \mathrm{~km} / \mathrm{hr}(300 \mathrm{mi} / \mathrm{hr})$ is also specified in Table 5.0, "ABWR Sito Parameters," in the ABWR certifiod design matorial (CDM). This is acceptable. Therefore, DSER Outstanding Issue 146 and DFSER Confirmatory Item 2.3.1-1 are resolved.

Table 2-1 Design-basis tornado characteristics

\begin{tabular}{|c|c|c|c|c|c|c|c|c|c|c|c|c|}
\hline \multirow[b]{2}{*}{ Region* } & \multicolumn{2}{|c|}{$\begin{array}{l}\text { Maximum } \\
\text { wind speed }\end{array}$} & \multicolumn{2}{|c|}{$\begin{array}{l}\text { Rotational } \\
\text { epeed }\end{array}$} & \multicolumn{2}{|c|}{$\begin{array}{l}\text { Translational } \\
\text { spoed }\end{array}$} & \multicolumn{2}{|c|}{$\begin{array}{l}\text { Radius of } \\
\text { maximum } \\
\text { rotational } \\
\text { speed }\end{array}$} & \multicolumn{2}{|c|}{$\begin{array}{l}\text { Pressure } \\
\text { drop }\end{array}$} & \multicolumn{2}{|c|}{$\begin{array}{c}\text { Rate of pressure } \\
\text { drop } \\
\end{array}$} \\
\hline & $\mathrm{km} / \mathrm{hr}$ & $\mathrm{mi} / \mathrm{hr}$ & $\mathrm{km} / \mathrm{hr}$ & $\mathrm{mi} / \mathrm{hr}$ & $\mathrm{km} / \mathrm{hr}$ & $\mathrm{mi} / \mathrm{hr}$ & $\mathbf{m}$ & $\mathbf{f t}$ & $\mathbf{k P a}$ & pai & $\mathrm{kPa} / \mathrm{sec}$ & psi/sec \\
\hline I & 483 & 300 & 386 & 240 & 97 & 60 & 46 & 150 & 13.8 & 2.0 & 8.3 & 1.2 \\
\hline II & 354 & 220 & 274 & 170 & 80 & 50 & 46 & 150 & 6.9 & 1.0 & 3.4 & 0.5 \\
\hline III & 322 & 200 & 257 & 160 & 64 & 40 & 46 & 150 & 6.2 & 0.9 & 2.1 & 0.3 \\
\hline
\end{tabular}

"See Figure 2-1 (RG 1.76, "Design Basis Tornado for Nuclear Power Plants," Rev. 0) for a map of the tornado intensity regions. 


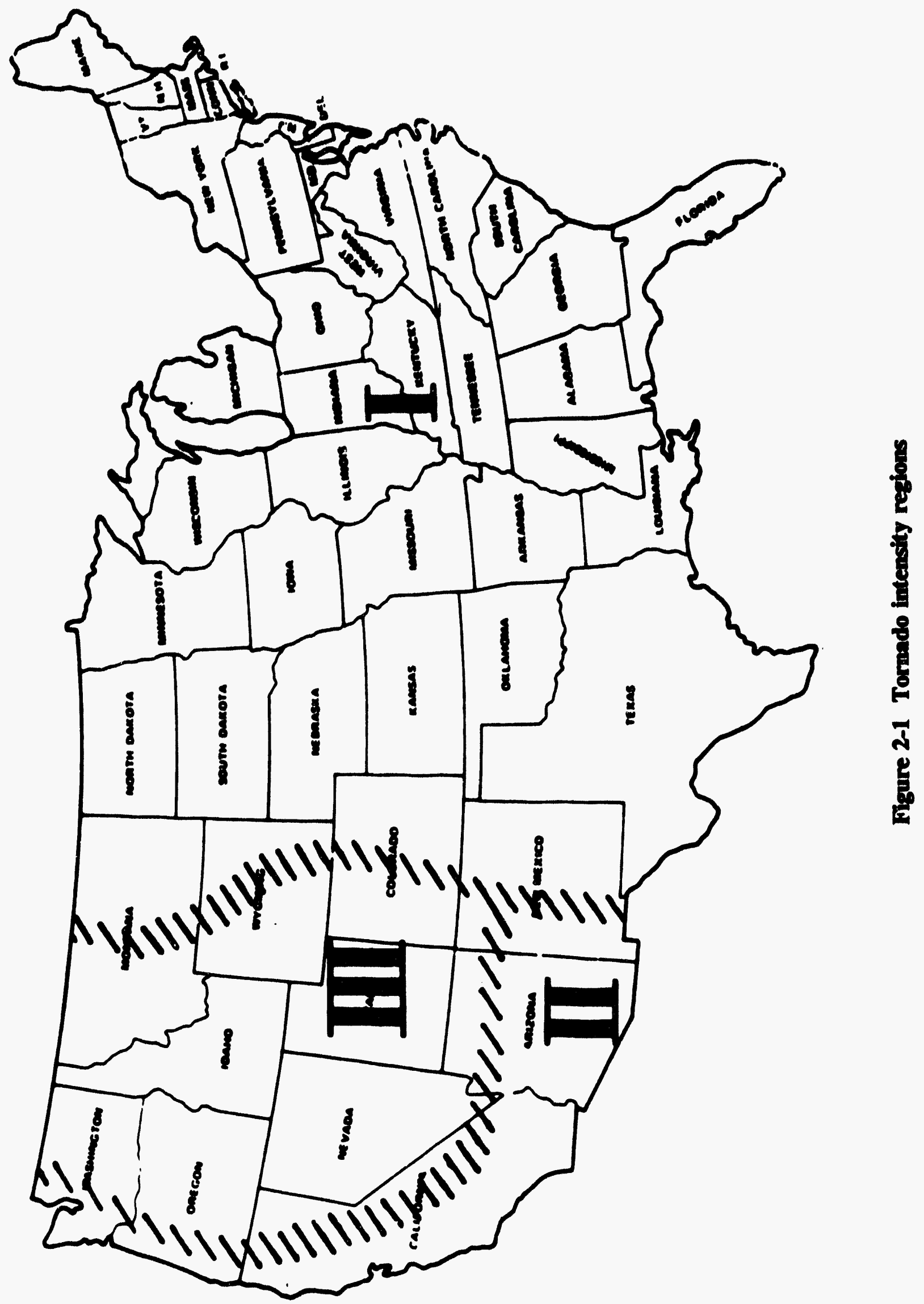




\subsubsection{Local Meteorology}

Since local moteorology is epecifically sito-related, the COL applicant will provide local meteorology for roviow by the staff on a caso-by-case besis. This was DFSER COL Action Itom 2.3.2-1. Section 2.3.2.7 of the SSAR identifies this action item. This is acceptable.

\subsubsection{Onsite Meteorological Measurtenents Program}

Details on the atmoepheric diffunion charactoristice of a proposed nuclear power plant sito are required to determine if postulated accidental, as well as routine operational, relenses of radionctive materials are within NRC regulatory guidelines. The meteorological chanacteristics of a propoesed site aro dotermined by ataff ovaluation of meteorological data collected at the site in accordence with RG 1.23, "Onsito Meteorological Programs," Rovision 0.

The COL applicant should provide the onsite moteorological measurements program for roviow by the staff. This was DFSER COL Action Itom 2.3.3-1. Section 2.3.2.8 of the SSAR identifies this sction item. This is acceptable.

\subsubsection{Short-Term Dispersion Estimates for Accidental Atmospheric Releases}

The bounding atmospheric relative concentrations $(\alpha / Q)$ for design-basis accident ovaluations aro listod in SSAR Tables 15.6.3, 15.6.7, 15.6.13, 15.6.14, and 15.6.18. The staff concludes, in Section 15.4 of this report, that these values provide a reasonable basis for ovaluating the consequences of design-besis accidents. The COL applicant should provide sito-specific short-term dispersion estimates in accordance with RG 1.145, "Atmospheric Dispersion Models for Potential Accident Consequence Assessments at Nuclear Power Plants," Revision 1, so the staff can ensure that the bounding values of atmospheric relative concentrations are not exceeded. This was DFSER COL Action Item 2.3.4-1. Section 2.3.2.9 of the SSAR identifies this action item. This is acceptable. The bounding $X / Q$ values for the 2-bour exclusion area boundary (EAB) and 2-bour low population zone (LPZ) are specified in Table 2.0-1 of the SSAR and the CDM.

\subsubsection{Long-Term Diffusion Estimates}

The staff will evaluate annual average atmospheric dispersion values for routine releases using the guidance in RG 1.111, "Methods for Estimating Atmospheric Transport and Dispersion of Gaseous Effluents in Routine Releases From Light-Water-Cooled Reactors, "Revision 1. The staff will use these values to perform its
10 CFR Part 50, Appendix I, and 10 CFR Part 20 ovaluations for a COL application. The COL applicent should provide to the NRC annual average atmospheric dispenion values for routine releases. This was DFSER COL Action Item 2.3.5-1. GE has included this action item in Section 2.3.2.10 of the SSAR. This is acceptable.

\subsection{Hydrologic Engineering}

\subsubsection{Hydrologic Description}

The COL applicant ahould provide a detailed description of all myjor hydrologic features on or in the vicinity of the site. It should also provide a specific description of the sito and critical elovations of all safety-related structures, exterior accesses, equipment, and systems from the atendpoint of hydrology considerations. This was DFSER COL Action Item 2.4.1-1. GE has included this action item in Section 2.3.2.11 of the SSAR. This is acceptable.

\subsubsection{Floods}

The COL applicant should provide sito-specific information on historical flooding and potential flooding at the plant sito, including flood history, flood design considerations, and offects of local intense precipitation. This was DFSER COL Action Item 2.4.2-1. GE has included this action item in Section 2.3.2.12 of the SSAR. This is acceptable.

\subsubsection{Probable Maximum Flood on Streams and Rivers}

The COL applicant should provide sito-specific information used for determining design-basis flooding at the power reactor sites and the extent of flood protection required for safety-related SSCs. This was DFSER COL Action Item 2.4.3-1. GE has included this action item in Section 2.3.2.13 of the SSAR. This is acceptable.

\subsubsection{Ice Efrects}

The COL applicant should provide sito-specific information on ice effects and demonstrate that safety-related facilities and water supply will not be affected by ice flooding or blockage. This was DFSER COL Action Item 2.4.4-1. GE hes included this action itom in Section 2.3.2.14 of the SSAR. This is acceptable.

\subsubsection{Cooling Water Channels and Reservoirs}

The COL applicant should provide the basis for the hydraulic design of canals and reservoirs used to transport and impound plant cooling water and for the protection of safety-related structures. This was DFSER COL Action 
Item 2.4.5-1. OB has included this sction itom in Soch tion 2.3.2.15 of the SSAR. This is scceptable.

\subsubsection{Channel Diversion}

The COL applicant should provide site-specific information on channel diversion. This was DFSER COL Action Itom 2.4.6-1. GB has included this ection itom in Section 2.3.2.16 of the SSAR. This is scceptable.

\subsubsection{Dlooding Protection Requirements}

The COL applicant should provide sito-specific information related to flooding protection requirements. This was DFSER COL Action Item 2.4.7-1. GE has included this sction itom in Soction 2.3.2.17 of the SSAR. This is acceptable.

\subsubsection{Cooling Water Supply}

The COL applicant should identify natural events that may reduce or limit the available cooling water supply and cosure that an adequate water supply will exist to operate or shut down the plant as required. This was DFSER COL Action Item 2.4.8-1. GE has included this action item in Section 2.3.3.18 of the SSAR. This is acceptable.

\subsubsection{Accidental Release of Liquid Emluents in Ground and Surface Waters}

The COL applicant should provide information on the capability of the surface water environment to disperse, dilute, or concentrate sccidental rolenses. Effocts of these releases on existing and known future uses of surface water resources should also be provided. This was DFSER COL Action Itom 2.4.9-1. GE has included this sction item in Section 2.3.2.19 of the SSAR. This is acceptable.

\subsubsection{Technical Specification and Emergency Operation Requirement}

The COL applicant should establish the tochnical apecifications and emergency procedures required to implement flood protection for safety-related facilities and provide assurance of an adequate water supply to shutdown and $\mathrm{cool}$ the reactor. This was DFSER COL Action Item 2.4.10-1. GE hes included this action item in Section 2.3.2.20 of the SSAR. This is acceptable.

\subsection{Geology, Seismology, and Geotechnical Engineering}

The COL applicant should provide sito-specific, basic geologic and seismic information and site-specific information on vibratory ground motion, surface faulting, stability of subsurface materials and foundations, slopes, and embunkments and dams as described in the following ecctions.

\subsubsection{Basic Geologic and Selsmic Information}

The COL applicent should provide site-specific information on regional and sito physiography, geomorphology, stratigraphy, lithology, and toctonics. This was DFSER COL Action Item 2.5.1-1. GE has included this action item in Section 2.3.2.21 of the SSAR. This is acceptable.

\subsubsection{Vibratory Ground Motion}

In the DFSER, the staff noted that the COL applicant should provide site-specific information on the seismicity, 8oologic, and tectonic characteristics of the site and region; correlation of earthquake activity with geologic structure or tectonic provinces; maximum earthquake potential; seismic wave transmission characteristics of the site; safe shutdown carthquake (SSE); and operating basis earthquake (OBE). This was DFSER COL Action Item 2.5.2-1. The Commission has approved the staff recommendation that the OBE be eliminated as discussed in Section 3.1.1 of this report. GE has modified SSAR Section 2.3.2.22 by stating that the COL applicant will develop site-specific geological, seismological, and gentechnical data and will compare the sito-specific SSE ground response spectra with the design ground response spectra of SSAR Section 2.3.1.2. This is acceptable.

\subsubsection{Surface Faulting}

The COL applicant should provide detailed geological and geophysical information related to the potential for surface faulting affecting the site.

Originally, GE imposed no limit for surface faulting (SSAR Table 2.1-1). However, it is the staff position, as stated in RG 4.7, "General Site Suitability Criteria for Nuclear Power Stations," Revision 1, that "sites that include capable faults, as defined in Appendix A to 10 CFR Part 100, are not suitable for nuclear power stations." Therefore, in the DFSER, the staff noted that the COL applicant should develop site-specific information to ensure that no potential exists for surface faulting affecting the site. This was DFSER COL Action Item 2.5.3-1. GE has included this action item in Section 2.3.2.23 of the SSAR. This is acceptable. 


\subsubsection{Stability of Subsurface Materials and Foundations}

In response to NRC staff Question 241.1a, GE stated that the COL applicant will provide sito-specific geotechnical data to demonstrate that they are comparable to the site design parameters given in SS/ $R$ Table 2.0-1. The staff requires that the COL applicant's aubmittals moet the guidance in Section 2.5.4 of RG 1.70, "Standerd Format. and Content of Safety Analysis Reports for Nuclear Power Plants," Revision 3. A summary of appropriate guidance is given below.

The staff will review the geotechnical engineering aspects of a COL applicant's design, design criteria, and design bases related to the stability of subsurface materials and foundations of safety-related facilities for an ABWR standard plant in accordance with SRP Section 2.5.4.

In SSAR Appendix 3A, which deals with seismic soilstructure interaction (SSI) analyses, GE characterized the site conditions in terms of (1) soil deposit depth above bedrock, (2) ground water lovel, and (3) soil profile and properties, and also gave parameter variations in each of these three areas for establishing the site envelope.

(1) GE accounted for the variations in soil deposit thickness by considering three representative soil deposit depths: (1) shallow soil deposits (46 m $(150 \mathrm{ft})),(2)$ intermediate soil deposits $(61 \mathrm{~m}$ (200 ft)), and (3) deep soil deposits (91 m (300 ft)). It assumed a minimum depth of embedment of $26 \mathrm{~m}(85 \mathrm{ft})$ for the case where the building will be supported directly by rock.

Appendix 3A of the SSAR states that the SSI analyses were performed using the same minimum embedment depths for the different site categories. Whether the reactor building will be supported onrock or soil, the minimum embedment depth will be $26 \mathrm{~m}(85 \mathrm{ft})$. GE stated that the ABWR design *does not allow for depths of embedment less than $26 \mathrm{~m}$ (85 ti) even if competent rock will be available at a site at depths much less than $26 \mathrm{~m}$ (85 ft). SSAR Tables 3A.3-2 and 3A.3-6 show that a 26-m (85-ft) embedment depth will be used in SSI analyses even when hard rock (HR) and extra hard rock (EHR) are at ground surface.

(2) GE evaluated the effects of variations in water table locations on structural response by considering three water table locations: low, intermediate, and high. It assumed the high water table will be located at $0.6 \mathrm{~m}(2 \mathrm{ft})$ below grade, while the low water table will be located at $26 \mathrm{~m}(85 \mathrm{ft})$ below grade at the base of the reactor building foundation basemat. The intermediate water table was assumed to be lecated at $12 \mathrm{~m}$ (40 ft) below grade, approximately at the midheight of the reactor building embedment.

(3) GE considered a range of soil profiles based on the shear wave velocity profiles used in GESSAR II (NUREG-0979, April 1983) and selected six velocity profiles for the SSI analyses.

- The first soil profile was assumed to consist of seven horizontal layers. The shear wave velocity, $V_{2}$, of the soil at a depth, $y$, below the ground surface was calculated as a function of the effective mean pressure at that depth and a modulus parameter.

- The second through the sixth soil profiles were selected on the basis of three generalized soil zones: a soil zone for the second profile (sands, silts, clays, and gravelly soils), a transition zone for the third and fourth profiles, and a soft rock and well-cemented soil zone for the fifth and sixth profiles. Their velocity profiles are smooth curves representative of the average variation of shear modulus with depth.

- The seventh profile represents an HR site with a uniform $V_{\text {s }}$ of $1,525 \mathrm{~m} / \mathrm{sec}(5,000 \mathrm{ft} / \mathrm{sec})$.

- The eighth profile represents an EHR site with a uniform $V_{\text {, of }} 3,050 \mathrm{~m} / \mathrm{sec}(10,000 \mathrm{ft} / \mathrm{sec})$.

GE considered the variation in shear modulus and material damping of soil with shear strain for various soil profiles. It assumed the best-estimate values of soil-shear modulus to be not less than $\mathbf{4 0}$ percent of their low-strain values. GE limited the values of hysteretic soil damping to a maximum of 15 percent of critical as recommended by SRP Section 3.7.2. On the basis of the above constraints, GE developed the shear-modulus reduction factors and damping ratios at various strain levels. The above assumptions are acceptable.

In the DFSER, the staff noted that the COL applicant should develop and submit to the NRC site-specific geotechnical data to demonstrate that they are comparable to the design assumptions. This was DFSER COL Action Item 2.5.4-1. GE has modified Section 2.3.2.24 in the SSAR by stating that the COL applicant will provide information concerning the properties and stability of sitespecific soil and rocks under both static and dynamic conditions including the vibratory ground motions associated with the site-specific SSE. This is acceptable. 


\subsubsection{Site and Facilities}

The COL applicant should provide a detailed description of the site conditions and geologic features. The description should include site topographical features and the location of various seismic Category I structures and appurtenances (pipelines, channels, and so forth) with regard to the source of normal and emergency cooling water. This was DFSER COL Action Item 2.5.4.1-1. GE has included this action item in Section 2.3.2.25 of the SSAR. This is acceptable.

\subsubsection{Field Investigations}

The COL applicant should submit to the NRC a discussion of the type, quantity, extent, and purpose of all field exploration. Logs of all borings and test pits should be provided. Results of geophysical surveys should be presented in tables and profiles. Records of field plate load tests, field permeability tests, and other special field tests (e.g., bore-hole extensometer or pressuremeter tests) should also be given. This was DFSER COL Action Item 2.5.4.2-1. GE has included this action item in Section 2.3.2.26 of the SSAR. This is acceptable.

\subsubsection{Laboratory Investigations}

The COL applicant should provide tables of the number and type of laboratory tests and the location of samples and discuss the results of laboratory tests on disturbed and undisturbed soil and rock samples obtained from field investigations. This was DFSER COL Action Item 2.5.4.3-1. GE has included this action item in Section 2.3.2.27 of the SSAR. This is acceptable.

\subsubsection{Subsurface Conditions}

The COL applicant should investigate and define the subsurface conditions and provide the engineering classifications and descriptions of soil and rock supporting the foundations. The information should include the history of soil deposition and erosion, past and present ground water levels, glacial or other preloading influences, rock weathering, and any rock or soil characteristics that may present a hazard to plant safety. Profiles through the seismic Category I structures should be provided that show the generalized subsurface fentures beneath these structures. This was DFSER COL Action Item 2.5.4.4-1. GE has included this action item in Section 2.3.2.28 of the SSAR. This is acceptable.

\subsubsection{Excavation and Backfilling for Foundation Construction}

The COL applicant should provide site-specific information on the thickness and properties of the soil between the base of the foundation and the underlying rock. The configuration, along with detailed longitudinal sections and cross-sections of other safety-related structures of the plant, including the ultimate heat sink and seismic Category I buried pipes and electrical ducts, should bo provided. The COL applicant should provide data on the extent (horizontally and vertically) of all seismic Category I excavations, fills, and slopes. The locations, clevations, and grades for excavated slopes should be described and shown on plot plans and typical cross-sections. The COL applicant should discuss, as appropriate, excavating and dewatering methods, excavation depths below grade, field inspection and testing of excavations, protection of foundation excavations against deterioration during construction, and the foundation dental fill work. The sources, quantities, and static and dynamic engineering properties of borrow materials should be described. The compaction requirements; results of test fills; and fill properties, such as moisture content, density, permeability, compressibility, and gradation also should be provided. This was DFSER COL Action Item 2.5.4.5-1. GE has included this action item in Section 2.3.2.29 of the SSAR. This is acceptable.

\subsubsection{Effect of Ground Water}

The COL applicant should analyze the ground water condition for the specific site and ovaluate the effect of ground water level on such site geotechnical properties as total and effective unit weights, cohesion and angle of internal friction, and dynamic soil properties used in dynamic response analysis. This was DFSER COL Action Item 2.5.4.6-1. GE has included this action item in Section 2.3.2.30 of the SSAR. This is acceptable.

\subsubsection{Liquefaction Potential}

GE stated in response to NRC staff Question 241.1c that one of the eight conditions in Section 3A.1 of Appendix 3A of the SSAR required that no potential for liquefaction of soils shall exist at the plant as a consequence of the OBE and the SSE as reviewed and concurred in by the NRC staff. That condition further required that the liquefaction potential of the foundation and site soils be investigated and reported for a long-duration, Now Madrid-type earthquake. GE clarified the statement regarding the New Madrid-type earthquake by stating that the maximum ground motion will be the same as the SSE 
and the actual durntion of the carthquake chocen for a specific site will be reviowed by the NRC staff and approved at the time of an individual application. $G E$ further stated that, without knowing the exact site location and its seismic hazard, it cannot specify the earthquake magnitude and the number of strong motion cycles for the liquefaction evaluation of a site.

The COL applicant should justify the selection of the soil properties used in the liquofaction potential ovaluation (0.8., laboratory tests, field tests, and publishod data), the magnitude and duration of the sito-specific earthquake, and the number of cycles of earthquakes. This was DPSER COL Action Item 2.5.4.7-1. GE has included this action item in Section 2.3.2.31 of the SSAR. This is acceptable.

\subsubsection{Response of Soil and Rock to Dymamic Loading}

In Appendix 3A of the SSAR, GE provides standard curves showing the variation in shear modulus and material damping with shear strain for the various soil and rock profiles (except for the EHR profile) described in Section 2.5.4 of this report. Further, GE limits the reduced values of the soil shear modulus to not less than $\mathbf{4 0}$ percent of their low strain values and the values of internal (hysteretic) soil damping to a maximum of $\mathbf{1 5}$ percent of critical, as shown in SSAR Tables 3A.3.3 and 3A.3.4. For the HR and EHR profiles, initial shear modulus and a nominal material damping of 0.1 percent were used in the SSI analyses.

In the DFSER, the staff noted that the COL applicant should establish and document site-specific geotechnical properties to demonstrate that they are comparable to the conditions used for the seismic design envelope discussed in Section 3.7.2 of this report. This was DFSER COL Action Item 2.5.4.8-1. GE has revised Section 2.3.2.32 determine dynamic soil properties of the site in terms of shear modulus and material damping as a function of shear strain. These strain-dependent properties will be used in determining the sito-specific SSE ground motion. This is acceptable.

\subsubsection{Maximum Soil-Bearing Pressures}

In Appendix 3H of the SSAR, GE gives a method for calculating maximum bearing pressure under the reactor building foundation mat for three load cases. Load Case 1 considers dead load, live load, and a combination of horizontal and vertical SSE components with the vertical component acting downward. Load Case 2 is the same as Load Case 1 except that the vertical seismic component acts upward and the live load is omitted. Load Case 3 is the same as Load Case 2, except for the addition of the buoyancy effect. Because the soil bearing pressure based on atatic equilibrium in the case of uplift would be very conservative, GE used the energy balance method. $\mathrm{GE}$ epecified a minimum static soil bearing capacity of 0.72 megapascal (MPa) (15 kips/ $\left.\mathrm{ft}^{2}\right)$. The maximum bearing pressure for the ABWR standard plant, which is due to dead load alone, as calculated by GE, is $0.63 \mathrm{MPa}$ $\left(13.1 \mathrm{kjps} / \mathrm{ft}^{2}\right)$. In the DFSER, the staff noted that the COL applicant should provide the sito-specific maximum soil pressures along with supporting calculations and compare them with the allowable values. This was DFSER COL Action Item 2.5.4.9-1. SSAR Table 2.0-1 lists the minimum static bearing capecity of $0.72 \mathrm{MPa}$ (15 kips/ $\mathrm{ft}^{2}$ ) as the site design parameter. GE has revised Section 2.3.2.33 of the SSAR by stating that the COL applicant will demonstrate that the site has a minimum static bearing capacity at the foundation lovel of the reactor and control buildings. For other safety-related plant facilities, the COL applicant will demonstrate that the foundation material has adequate bearing capacity to withstand the site-specific loads. This is acceptable.

\subsubsection{Earth Pressures}

The COL applicant should provide a sito-specific discussion and evaluation of static and dynamic lateral earth pressures and hydrostatic ground water pressures acting on plant safety-related facilities. This was DFSER COL Action Item 2.5.4.10-1. GE has included this action item in Section 2.3.2.34 of the SSAR. This is acceptable.

\subsubsection{Soil Properties for Seismic Analysis of Buried Pipes}

The COL applicant should provide and justify the soil properties used for the seismic analysis of seismic Category I buried pipes and electrical conduits. This was DFSER COL Action Item 2.5.4.11-1. GE has included this action item in Section 2.3.2.35 of the SSAR. This is acceptable.

\subsubsection{Static and Dynamic Stability of Facilities}

The COL applicant should perform stability evaluation or analysis of all safety-related facilities. These analyses should include foundation rebound, settlement, differential settlement, and bearing capacity. Assumptions made in stability analyses should be confirmed by as-built data. This was DFSER COL Action Item 2.5.4.12-1. GE has included this action item in Section 2.3.2.36 of the SSAR. This is acceptable.

\subsubsection{Subsurface Instrumentation}

The COL applicant should describe instrumentation, if any, proposed for monitoring of the performance of the 
foundations for eafoty-related structures. The type, location, and purpose of each inatrumeat and significant detuils of installation methods should be provided. For example, the location and tho inctallation procedures for permanent benchmarks and marker required for monitoring the settlement of Catogory I atructures should bo described. In the case of anfety-rolated, water-control structures (arch as dams, slopes, canals), the installation of instrument such as piezometers, slope indicators, and settlement plates should be described in detril. A schedule for installing and reading all instruments and for interpreting the dat should be given. Limiting values for continued safoty should be identified. This was DFSER COL Action Itom 2.5.4.13-1. GE has included this setion item in Section 2.3.2.37 of the SSAR. This is scceptable.

\subsubsection{Stability of Slopes}

The COL applicant should provide information about the static and dynamic stability of all soil and rock slopen, the failure of which could adversely affect the safety of the plant. The staff will evaluate the stability of all slopes at the site, using the stato-of-the-art procedures available at the timo of the application. This was DFSER COL Action Item 2.5.4.14-1. GE has included this action item in Section 2.3.2.38 of the SSAR. This is scceptable.

\subsubsection{Embankments and Dams}

The COL applicant should provide information about the static and dynamic stability of all embankments and dams (if used) that will impound water required for safe operation and shutdown of the ABWR plant. This was DFSER COL Action Item 2.5.4.15-1. GE has included this action item in Section 2.3.2.39 of the SSAR. This is acceptable.

\subsection{Site Parameter Envelope}

The staff reviewed GE's analysis and ovaluation of the ABWR design in terms of the bounding site parameters in SSAR Table 2.0-1. In the DFSER, the staff noted that the list of bounding site parameters in Table 2.0-1 should be comprebensive and include any additional items from the ABWR certified design material (CDM). Since this document was etill being doveloped, the staff also noted in the DFSER that GE should ensure that the final list of site parameters in Table 5.0 of the CDM agrees with SSAR Table 2.0-1. Since GE had adopted the bounding site parameters identified in Table 1.2-6 of Electric Power Research Institute's (EPRI's) "Advanced Light Water Reactor (ALWR) Utility Requirements Document Evolutionary Plant Designs," the siaff also asked GE to adequately address the issues identufied in Section 1.4 (Open Issue 1) of the SER on EPRI's ALWR requirements documeat for evolutionary plants when doveloping the final liet. This was DFSER Open Itom 2.6-1.

As part of thin opea itom, the staff aleo requested that $G E$, in ite revision to SSAR Table 2.0-1 and Table 5.0 of the CDM, include the following changes:

- All units and dimensions in these tables should be in the metric system with English units or dimensions provided in brackets.

- The following information should be added to the bounding site parameter for tornado:

- rate of pressure drop: $8.3 \mathrm{kPa}\left(1.2 \mathrm{lb} / \mathrm{in}^{2} / \mathrm{sec}\right)$

- The following additions or changes should be made for the seismology bounding site parameter:

- Note (10) should be added to the fourth bullet and modified to read: "SSE Time History: Envelope SSE Response Spectra ${ }^{(10) m}$

- Note (9) should be changed to read: "The minimum bearing capecity should be referred to as the static bearing capacity."

- Now Note (10) should read: "The response spectra of the SSE time history to be used in the free field must envelop the free field design response epectra for all damping values to be used in the response analysis. In addition, the time history should also be justified to show its adequacy by demonstrating sufficient energy at the frequencies of interest through the generation of the power spectrum density (PSD) function, which is greater than the target PSD function throughout the frequency range of significance."

GE reeponded to this open item by letters to the staff dated April 16 and June 16, 1993. The staff and GE also discussed it in several conference calls and in the meoting on ITAAC (inspections, tests, analyses, and acceptance criteria) on July 27 through 29, 1993. To provide a comprehensive list of site parameters, the following site parameters were added to SSAR Table 2.0-1, "hazards in site vicinity," and "tornado, rate of pressure drop." This is acceptable. To address the issues identified in Sections 1.4 and 4.5.2 of the SER on EPRI's ALWR requirements document for evolutionary plant, SSAR Table 2.0-1 defines minimum "static" bearing pressure and establishes a requirement, "SSE time history: envelope SSE response spectra." This is acceptable. The staff also reviewed the enveloping meteorological dispersion values 
in Table 2.0-1 of the SSAR. The staff finds that GE determined these enveloping values using acceptable methodology given in RGs 1.111, "Methods for Estimating Atmospheric Transport and Dispersion of Gassous Effluents From Light-Water-Cooled Power Reactors," Revision 1, and 1.145, "Atmospheric Dispersion Models for Potential Accident Consequence Assessments at Nuclear Power Plants, "Revision 1. The methods used by GE for determining these enveloping values are described in Sections 2.6.7 and 15.4 of this report. The staff finds the enveloping meteorological dispersion values acceptable. SSAR Section 3.7 addresses the issue noted in auggested Note (10) above. The staff's evaluation of this subject is discussed in detail in Section 3.7.1 of this report. The staff reviewed Table 2.0-1 of the SSAR and determined that it provides an adequate amount of information in support of Table 5.0 of the ABWR CDM. This is acceptable. In its letter of April 15, 1993, GE explained the use of only the Japanese metric units for the SSAR. Subsequently, GE agreed to use the International System of Units for the SSAR in eccordance with the Commissionapproved staff recommendations on implementing the metrication policy for evolutionary and revolutionary reactors. This is acceptable. On the basis of the above, DFSER Open Item 2.6-1 is resolved. The site parameter evaluation is summarized in the following sections.

\subsubsection{Wind and Tornado Design Site Parameters}

The staff's review of the wind and tornado loadings for the ABWR design is contained in Section 3.3 of this report. The bounding site parameters that were considered in the staff's evaluation are as follows:

- Basic Wind Speed: For the design of ABWR nonsafety-related structures, the basic wind speed for a 50-year recurrence interval is $177 \mathrm{~km} / \mathrm{hr}(110 \mathrm{mph})$. An "importance factor" of 1.0 should be used in accordance with the velocity pressure formula of SSAR Section 3.3.1.1. For the design of safety-related structures, the basic wind speed for a 100-year recurrence interval is $197 \mathrm{~km} / \mathrm{hr}(122.1 \mathrm{mph})$. This value is obtained by multiplying the 50-year speed of $177 / \mathrm{km} / \mathrm{hr}(110 \mathrm{mph})$ by an importance factor of 1.11 , as noted in Appendix 3H of the SSAR.

- Maximum Tormado Wind Speed: $\quad 483 \mathrm{~km} / \mathrm{hr}$ (300 $\mathrm{mi} / \mathrm{hr})$

- Translational Velocity: $\quad 97 \mathrm{~km} / \mathrm{hr}$ (60 mi/hr)

- Radius of Maximum Rotational Speed: $45.7 \mathrm{~m}$
- Meximum Atmospheric Pressure Drop: $13.8 \mathrm{kPa}$

$\left(2.0 \mathrm{lb} / \mathrm{in}^{2}\right)$

- Missile Spectm: SRP Section 3.5.1.4, Spectrum I

The staff concludes in Sections 3.3.1, 3.3.2, and 3.5.1.4 of this report that the ABWR standard plant has been adequately designed for the above bounding site parameters.

\subsubsection{Water Level (Nlood) Design Site Parameters}

The staff's review of the ABWR water level (flood) design is contrined in Section 3.4 of this report. The bounding site parameters that were considered in the staff's ovaluation are as follows:

- Eloods: The ABWR should be located on the site so that the level of the design-basis flood is no higher than $30.5 \mathrm{~cm}(1 \mathrm{ft})$ below the plant grade.

- Potential Dam Failures (Seismically Induced): Failure of existing and potential upstream or downstream water control structures should not contribute to the water level exceeding $30.5 \mathrm{~cm}$ (1 ft) below grade nor compromise the ultimate beat sink.

- Probable Maximum Surge and Seiche Flooding: The probable maximum surge and seiche flooding should be no higher than $30.5 \mathrm{~cm}(1 \mathrm{ft}$ ) below grade (see SSAR Table 2.1-1).

- Rrobable Maximum Tsunami: The probable maximum tsunami flooding should be no higher than $30.5 \mathrm{~cm}$ (1 ft) below grade (see SSAR Table 2.1-1).

- Ground Water: The ABWR is intended to be compatible with ground water levels up to $61 \mathrm{~cm}(2 \mathrm{ft})$ below plant grade.

The staff concludes in Sections 3.4.1 and 3.4.2 that the ABWR standard plant has been adequately designed for the above bounding parameters.

\subsubsection{Seismology Site Parameters}

The staff's review of the seismic design of ABWR structures, systems and components (SSCs) is contained in Section 3.7 of this repart. The bounding site parameter that was considered in the staff's evaluation is as follows:

- Vibratory Ground Motion: In SSAR Table 2.0-1, GE specifies the $0.3 \mathrm{~g}$ peak ground acceleration (PGA) value for the high frequency anchor for the SSE response spectra. The SSE response spectra are con- 
etructed in wecordance with RG 1.60, "Design Reeponse Spectru for Seismic Design of Nuclear Power Plants," Rovision 2.

Although the SSE PGA of $0.3 \mathrm{~g}$ anchoring RG 1.60 dexign responso spectru could generally be considered an edequato envelope for many sites in the Central and Eastem United States, the NRC staff knows that localized seismic sctivity exceeding this envelope cannot be ruled out catogorically. Therefore, the staff will require that sito-epecific geological, geotochnical, and seismological factors be reviewed for each application to ensure that no sito-specific seismic hazard will cause the RG 1.60 spectrum anchored at $0.30_{\text {g }}$ to be exceeded.

\subsubsection{Soil Properties Site Parameters}

The staff's roviow of the soil properties considered in the seismic design of ABWR SSCs is contained in Sections 2.5.4 and 3.7 of this report. The bounding sito parameters that were considered in the staff's evaluation are as follows:

- Minimum Shear Wave Velocity: The minimum embedment depth for the reactor building should be $26 \mathrm{~m} \mathrm{(85} \mathrm{ft).} \mathrm{The} \mathrm{minimum} \mathrm{shear} \mathrm{wave} \mathrm{velocity} \mathrm{of}$ soil should be $305 \mathrm{~m} / \mathrm{sec}(1,000 \mathrm{ft} / \mathrm{sec})$.

- Liquefaction Potential: No liquefaction potential should exist for soils under and around all seismic Category I structures, including seismic Category I buried pipelines and electrical ducts.

- Minimum Bearine Capacity (demand): The minimum (demand) bearing capacity of soil should be $0.72 \mathrm{MPa}$ (15 kips/ $\mathrm{ft}^{2}$ ).

As discussed in Section 3.7.1 of this report, the staff concludes that the ABWR standard plant design has adequately defined the above bounding parameters.

\subsubsection{Precipitation (for Roof Design) Site Parameters}

The bounding site parameters that were considered in the staff's evaluation are as follows:
- Maximum Rainfall Rat: $49.3 \mathrm{~cm} / \mathrm{hr}$ (19.4 in./hr)

- Mnximum Snow Load: $2.35 \mathrm{kPa}\left(50 \mathrm{lb} / \mathrm{ft}^{2}\right)$

The ataff concludes in Section 3.8.4 of this report that the design of the ABWR SSCs to sccommodate the precipitation site parameters is acceptable.

\subsubsection{Design Temperature Site Parameters}

The bounding site parameters that were considered in the staff's evaluation are as follows:

- Ambient 19 Exceedence Values:

- Maximum: $37.8^{\circ} \mathrm{C}\left(100^{\circ} \mathrm{F}\right)$ dry bulb/25 ${ }^{\circ} \mathrm{C}$ $\left(77^{\circ} \mathrm{F}\right)$ coincident wet bulb and $26.7^{\circ} \mathrm{C}\left(80^{\circ} \mathrm{F}\right)$ noncoincident

- Minimum: $-23.3^{\circ} \mathrm{C}\left(-10^{\circ} \mathrm{F}\right)$

- Ambient 0\% Excedance Values (Historical Limit):

- Maximum: $46.1^{\circ} \mathrm{C}\left(115^{\circ} \mathrm{F}\right)$ dry bulb/26.7 ${ }^{\circ} \mathrm{C}$ $\left(80^{\circ} \mathrm{F}\right)$ coincident wet bulb and $2 ; 2^{\circ} \mathrm{C}\left(81^{\circ} \mathrm{F}\right)$ noncoincident

- Minimum: $-40^{\circ} \mathrm{C}\left(-40^{\circ} \mathrm{F}\right)$

- Emergency Cooling Water Inlet: $35^{\circ} \mathrm{C}\left(95^{\circ} \mathrm{F}\right)$

- Condenser Cooline Water Inlet: $\leq 37.8^{\circ} \mathrm{C}\left(\leq 100^{\circ} \mathrm{F}\right)$

The staff concludes in Sections 9.4 and 9.5 of this report that the ABWR SSCs to accommodate the design temperature bounding site parameters are acceptable.

\subsubsection{Atmospheric Dispersion $(x / Q)$}

The staff's review of the use of the $X / Q$ dispersion factors for the exclusion area boundary (EAB) and the low population zone (LPZ) is given in Chapter 15 of this report. The bounding site parameters considered in the staff's evaluation are listed in Table 2-2.

Table 2-2 EAB and LPZ Atmospheric dispersion characteristics (Chi/Q)

\begin{tabular}{|c|c|c|c|c|}
\hline 0-2 Hours & $0-8$ Hours & 8-24 Hours & $1-4$ Days & $4-30$ Days \\
\hline EAB & LPZ & LPZ & LPZ & LPZ \\
\hline $1.37 E-3$ & $1.95 E-4$ & $1.22 \mathrm{E}-4$ & $4.69 \mathrm{E}-5$ & $1.12 \mathrm{E}-5$ \\
\hline
\end{tabular}




\section{Site Characteristics}

The Table 2-2 bounding atmoepheric relative concentration values for the LPZ (the 8-hour period from 0 to 8 hours, the 16-hour period from 8 to 24 hours, the 3-day period from 1 to 4 days, and the 26-day period from 4 to 30 days) were aleo determined by the moet limiting deaign basis accident lose-of-coolant sccident (LOCA) not to exceed the dose reference values given in 10 CFR Part 100 $3 \mathrm{E}+3 \mathrm{MSv}(300 \mathrm{rem})$ for the thyroid and 2.5E+2 MSv $(25 \mathrm{rem})$ for the whole body. As shown in Table 2.0-1 of the SSAR, the 2-hour LPZ atmoepheric relative concentration value and an annual average ( 8760 hours) concentration value were obtained by logarithmic extrapolation of these calculated LPZ bounding atmospheric relative concentrations.

The ettuff concludes in Section 15.4 of this report that GE's propoeed bounding atmospheric relative concentrations $(X / Q)$ for the EAB and for the LPZ of the ABWR plant, in conjunction with the engineered safety features systems provided in the ABWR design, are sufficient to provide reasonable aseurance that the radiological consequences of a postulated LOCA will be within the dose reference values in 10 CFR Part 100. 


\section{DESIGN OF STRUCTURES, COMPONENTS, EQUIPMENT, AND SYSTEMS}

\subsection{General}

The staff reviewed the information in SSAR Section 3.1 to verify that the ABWR standard plant meets the GDC of Appendix A to 10 CFR Part 50.

To reviow the design of structures, components, equipment, and systems, the staff relied heavily on industry codes and standards that represent accepted industry practice. The staff found those codes and standards citod in this report accoptable unless otherwise noted.

The staff evaluated the use of a singlo-earthquake design (i.e., elimination of operating besis earthquake (OBE)) for structures, systems, and components (SSCs). Originally, implementation of the OBE was included in applicable sections of the ABWR SSAR. After many discussions with the staff, GE stated that it might opt to use the singleearthquake design approach. In a letter to GE dated September 11, 1992, the staff gave preliminary guidance concerning what types of analyses and information would be required in the SSAR for the staff to approve design of SSCs for the ABWR without the OBE. This was Open Item 3.1-1 in the DFSER. The staff's evaluation of this issue is discussed in the following sections.

\subsubsection{Elimination of Operating Basis Earthquake from Design Consideration}

Appendix A to 10 CFR Part 100 requires, in part, that all SSCs of the nuclear power plant necessary for continued operation without undue risk to the health and safety of the public shall be designed to remain functional and within applicable stress and deformation limits when subject to an OBE. The NRC is proposing changes to Appendix $A$ to Part 100 to redefine the OBE to such a level such that the function of the OBE can be satisfied without performing explicit response analyses. In addition, Appendix A to Part 100 requires that the maximum vibratory ground acceleration of the OBE be at least one-half the maximum vibratory ground acceleration of the SSE. When the OBE is redefined to an inspection level earthquake for the $A B W R$, the maximum vibratory ground acceleration of the OBE will be established at one-third of the maximum vibratory ground acceleration of the SSE.

There exist special circumstances for granting these exemptions from the requirements of Appendix A to Part 100 pursuant to 10 CFR 50.12. The purpose of designing SSCs necessary for continued operation without undue risk to the health and safety of the public to withstand an OBE is to ensure that these SSCs remain functional and within applicable stress and deformation limits when subjected to the effects of the OBE vibratory ground motion. However, Appendix A to Part 100 also requires that theee SSCs are desizned to withstand the SSE and remain functional. Thus, when these SSCs aro decigned to remain functional for the SSE, they will also remain functional at a leseer earthquake level (ono-third the SSE) provided all dosign functions at the OBE aro accounted for. The basis for eelecting one-third the SSE as the earthquake level at which the plant will be required to shutdown and be inspected for damage was that at this level the likelihood of damage and the frequency of earthquakes occurring was judged to be low based on actual earthquake experience. It should be noted that certain design functions had been only verified for the OBE loads in the past. These design functions were the ovaluations of (1) fatigue damage caused by earthquake cycles and (2) relative seismic anchor motions in piping systems. With the elimination of the OBE from design, these design functions would not have been explicitly verified. Consequently, for the ABWR these design functions will be verified in conjunction with the SSE using applicable stress and deformation limits as described in Section 3.1.1.2 of this report.

Accordingly, the special circumstances described by 10 CFR 50.12(a)(2)(ii) exist in that the regulation need not be applied in this particular circumstance to achieve the underlying purpose of the rule because GE has proposed acceptable alternative analysis methods that accomplish the intent of the regulation. On this basis, the staff concludes that the exemption is justified because the alternative analyses performed for the SSE and the need to perform an inspection of the plant following an earthquake at or above one-third the SSE accomplish the design objectives of the OBE design analyses.

\subsubsection{Background}

In SECY-90-016, "Evolutionary Light Water Reactor (LWR) Certification Issues and Their Relationship to Current Regulatory Requirements," the staff requested the Commission's approval to decouple the level of the OBE ground motion from that of the safe-shutdown earthquake (SSE). The Commission approved the staff's position in its staff requirements memorandum (SRM) of June 26, 1990.

In SECY-93-087, "Policy, Technical, and Licensing Issues Pertaining to Evolutionary and Advanced Light-Water Reactor (ALWR) Designs, " the staff further requested that the Commission approve eliminating the OBE from the design of SSCs in both evolutionary and passive advanced reactors designs. The proposed amendment to 10 CFR Part 100, Appendix A, would allow, as an option, that the $O B E$ be eliminated from design certification when 
the OBE is cetablisbed at leas than or equal to ono-third the SSE. In this manner, the OBE corves the function as in inspection-lovel earthquake bolow which the offect on the bealth and anfery of tho public would be incignificant and wove which the licensee would be required to shut down the plant and inepect for damage. The Blectric Power Receareh Inetitute (BPR) requected the olimination of the OBB from davign and the Advicory Committeo on Reactor Safoguando (ACRS) aleo recommended OBB elimination in its letter of April 26, 1990.

In SECY-93-087, the staff discussed the eafety impact of aliminating the OBE as it pertains to civil structures, piping aystoms, and equipment soismic qualification. Tho ataff mado coveral recommendations to ensure that eliminating the OBE would not reault in a significant decrease in the overall plant anfety margin. In its July 21, 1993, SRM, the Commiasion approved and agreed with the following staff positions:

- Use two SSE events with 10 maximum stress cycles per ovent to account for earthquake cycles in the fatigue analyese of piping systems performed until the new guidance is issued; alternatively, the number of fractional vibratory cycles equivalent to that of 20 full SSB vibratory cycles may bo used (but with an amplitude not leas than ono-third of the maximum SSE amplitude) when derived in accordance with Appendix D to IEEE 344-1987.

- The effects of anchor displacements in the piping caused by an SSE be considered with the Service Lovel D limit.

- Eliminate the OBE from the design of SSCs. When the OBE is eliminated from the design, no replacement earthquake loading should be used to establish the postulated pipe rupture and leakage crack locations.

- The mechanistic pipo break and high-energy leakage crack locations determined by the piping high-stress and fatigue locations may be used for equipment environmental qualification and compartment pressurization purposes.

- With the elimination of the OBE, two alternatives exist that will eseentially maintain the requirements provided in IEEE 344-1987 to qualify equipment with the equivaleat of five OBE events followed by one SSE event. Of these alternatives, the equipment should be qualified with five one-half SSE events followod by one full SSE ovent. Alternatively, a number of fractional peak cycles equivalent to the maximum peak cycles for five ono-half SSE events may be used in accordance with Appendix D to IEEE 344-1987 when followed by ono full SSE.

- The OBE will continus to be used 2 a throubold criterion for conducting inepections following an carthquake oveat.

The following exctions contain the etaff's ovaluation of the commitments specified in the SSAR to ensure that appropriate measures and adequate eafoty margins are maintained when the OBE is eliminated from tho design. The sections evaluate (1) American Society of Mechenical Engineen (ASME) Code Class 1, 2, and 3 components and core support structures, (2) concreto and steol structures, (3) equipment soismic qualification, and (4) precarthquake planning and postearthquake operator sctions.

\subsubsection{ASME Code Class 1, 2, and 3 Components and Core Support Structures}

The dynamic analysis methods for seismic analyses of ASME Code Class 1, 2, and 3 components and core support structures in the ABWR use those methods deacribed in the ABWR SSAR as approved by the NRC staff in Sections 3.9.2 and 3.12 of this report. The loads and load combinations used for evaluating ASME Code Class 1, 2, and 3 components and coro support structures aro also stated in the ABWR SSAR and discussed in Section 3.9.3.1 of this report. Conformance to existing staff guidelines that ensure the operability of safety-related equipment under SSE loading conditions are discussed in Section 3.10 of this report. Similarly, the function of the supported system has also been taken into account. As specified in Regulatory Guide (RG) 1.124, "Service Limits and Loading Combinations for Class 1 Linear-Type Components Supports, " Revision 1, to ensure that systems - whose normal function is to prevent or mitigate consequences of events aseociated with the SSE - will operate adequately regardless of plant condition, the Code Lovel B service limits of Subsection NF or other justifiable limits approved by the staff have been used.

The elimination of the OBE from ASME Code Class 1, 2 , and 3 components and core support structure design requires all current $O B E$ design-related checks to be performed for the SSE. With regards to primary stress effects (seismic inertial stresses), the elimination of the OBE from Service Lovel B could have a potential impact on design in those cases where the load combination includes other dynamic loadings (i.e., operational transients) in Servico Lovel B but not in Service Lovel D. The staff explored this possibility specifically for piping systems and found that when the OBE is established at 
ono-third of the SSE, the loed combinations with the SSB generally control the design. Therefore, for primary stresces in piping systems, the staff finds that eliminating the OBE from piping stress load combinations will not cause a reduction in existing safety margins because the load combination with the SSE loading is generally controlling.

For cyclic and secondary stress effects (e.g., fatigue and seismic anchor motion), the elimination of the OBE would have a direct impact on the current methods used to evaluate their adequacy in piping design. Because the cyclic (fatigue) effects of earthquako-induced motions in piping systems and the relative motion effects of piping anchored to equipment and structures at various elevations are currently evaluated only for OBE loadings, the elimination of the OBE from the load combination could lead to uncertainty concerning how these effects should be evaluated. The staff's evaluation of the ABWR guidelines discussed in the SSAR for treating these effects is discussed next.

\section{Fatigue}

In order to ensure adequate design considerations for the fatigue effects of earthquake cycles, GE needs to establish a bounding load definition and the number of earthquake cycles to account for the more frequent occurrences of lesser earthquakes and their aftershocks. In Section 3.7.3.2 of the SSAR, GE used a cyclic load basis for fatigue analysis of earthquake loading for ASME Codo Class 1, 2, and 3 components and core support structures equal to two SSE ovents with 10 maximum stress cycles per event (20 full cycles of the maximum SSE stress range). This basis for analysis is acceptable because it is equivalent to the cyclic load basis of one SSE and five OBE events as currently recommended in SRP Section 3.9.2. Alternatively, an equivalent number of fractional vibratory cycles to that of 20 full SSE vibratory cycles may bo used (but with an amplitude not less than one-third of the maximum SSE amplitude) when derived in accordance with Appendix D to IEEE 344-1987.

\section{Seismic Anchor Motion}

For the ABWR, the effects of displacement-limited, seismic anchor motions (SAM) that are due to an SSE are evaluated for safety-related ASME Code Class 1, 2, and 3 components and component supports to ensure their functionality during and following an SSE. The SAM effects include (but are not limited to) relative displacements of piping between building floors and slabs, at equipment nozzles, at piping penetrations, and at connections of small-diameter piping to large-diameter piping.
For piping system, the offects of SAMs caused by an SSE are combined with the effects of other normal operational loading that might occur concurrently as specified in Table 3.9.2 of the SSAR.

\section{Piping Stroes Limits}

For ASME Code Class 1, 2, and 3 piping, GE needs to meet the design requirements in the 1989 Edition of the ASME Boiler and Pressure Vessel Code, Section III, Subsections NB, NC, and ND. In addition, the following changes and additions to paragraphs NB-3650, NC-3650, and ND-3650 will be used for piping systems when the $\mathrm{OBE}$ is eliminated from the design.

\section{ASME Codo Cless 1 Piping Stress Limits}

(a) For primary stress evaluation (NB-3654.2), earthquake loads are not required to be ovaluated for consideration of Level B Service Limits for Eq. (9).

(b) For satisfaction of primary plus secondary stress intensity range (NB-3653.1), in Eq. (10), $\mathrm{M}_{\text {s }}$ should be either (1) the resultant range of all loads considering one-half the range of the SSE or (2) the resultant range of moment owing to the full range of the SSE alone, whichever is greater. The use of the SSE is intended to provide a bounding design for the cumulative effects of earthquakes of a lesser magnitude and is therefore to be included in consideration of Level B Service Limits for Eq. (10). A reduced range (with an equivalent number of fractional vibratory peak cycles) of the SSE moment may be used for consideration of Lovel B Service Limits (but with a range not less than ono-third of the maximum SSE moment range).

(c) For satisfaction of peak stress intensity (NB-3653.2), the load sets developed in NB-3653.1 that are based on the preceding Position $b$ should be used in calculating the peak stress intensity, $S$, and the alternating stress intensity, $S$, for eval lating the fatigue effects and cumulativeltamage.

(d) For simplified elastic-plastic discontinuity analysis (NB-3653.6), if Eq. (10) cannot be satisfied for all pairs of load sets, then the alternative analysis as described in NB-3653.6 will be followed. For treatment of seismic anchor motion moments, the 
following condition chould bo atiafied in condideration of Lovel D Service Limita:

$$
s_{S A M}=C_{2} \frac{D_{0}}{2 I}\left(M_{i}^{*}+M_{i}^{*}\right) \leq 6.0 s_{m}
$$

where: $S_{\text {SAM is the nominal value of caimio sochor }}$

$$
M_{i}^{*} \text { is the mano a } M_{i}^{*} \text { in Bq. (12) }
$$

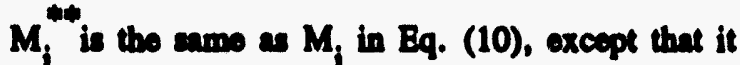
includes only momeat caured by exismic anchor motion dieplecements that are cauced by an SSB

The combined moment mage $\left(M_{i}^{*}+M_{1}^{*}\right)$ ahould be cither (1) the resultant range of thermal dxpansion and thermal anchor movementa plus coe-half the runge of the SSB anchor motion or (2) the reaultant mage of momeat owing to the full range of the SSE anchor motion alone, whichever is greater.

\section{ASME Code Class 2 and 3 Piping Streas Limits}

(a) For consideration of occasional loads (NC/ND-3653.1), earthquake loads (i.e., inertia and seismic anchor motion) an not required for atisfying Lovel B Service Limits for Bq. (9).

(b) For consideration of thermal expansion or secondary stresese (NC/ND-3653.2), $M_{c}$ in Eq. (10) is not required to include the moment offects of SAMs caused by an earthquake.

(c) For consideration of eccondary atreaces in Lovel D Service Limit (NC/ND-3655), the following condition will bo atisfied:

$$
s_{s}=i \frac{M_{c}^{*}+M_{c}}{2} \leq 3.0 \mathrm{~s}_{\mathrm{h}} \quad \text { Eq. (10b) }
$$

where: $M_{c}^{*}$ is the mage of moments owing to SAMs due to an SSE

$M_{c}$ is the range of moments owing to thermal expansion

The combined moment range $\left(M_{c}+M_{c}^{*}\right)$ should be either (1) the recultant range of moments ofwing to thermal expansion plus one-half of the range of moments owing to the SSE anchor motions, or (2) the resultant range of moment owing to the full range of the SSB anchor motion aloas, whichover is grouter.

Upoe neviowing theece aupplemental critoria to bo unod when the OBB is eliminated from the deaign of piping syatem, the ctaff finds that the criteria are inteadod to mintain tho exinting dacign margins of tho ASMB Boiler and Presure Veand Code, Section III, although rome criteria appear to be more atringeat and others more relared. The sot effoct reoults in safoty margins equivaleat to that of the ASMB Code, Section III, rules and provides a more controlled check of piping system atreeses in thow areas where sctual failures of piping systems owing to ceismic loadinge have occurred. The staff concludes that the piping criterit for the ABWR meet the staff recommendations in SECY-93-087 for considering carthquake cycles in fatigue analyese and for ovaluating the offects of anchor displacements in the piping caused by an SSE and are roceptablo.

\subsubsection{Pipe Break Postulation Without OBE}

The staff recognizes that pipe rupture is a rave ovent that might only occur under unanticipated conditions, such as those that might bo caused by possible design, construction, or operational errors; unanticipated loads or unanticipatod corrosive environments. From observation of ectual piping failures, the staff found that they generally occur at high atreses and fatigue locations, such as at the torminal eads of a piping system at its connection to componeat nozzles. Currently, in accordance with SRP (NUREG-0800) Section 3.6.2, Revision 2, dated June 1987, pipe breaks are postulated in high-energy piping at locations of high stress and high fatigue usage factor. The load combination used in calculating the high strese and high usage factor includes normal and upset load conditions (i.e., pressure, weight, thermal, OBE, and other operational transient loadings).

From a historical viowpoint, the criteria for postulating high-energy breaks at specified locations were first introduced in the carly 1970s. The besis for the mochanistic approach for selecting pipe break locations was derived from the premise that although pipe breaks could recult from random ovents induced by unanticipated conditions, the failure mochanism and the expected location of failure would likely be caused by local conditions of high atress or high fatigue in the piping. To ensure that a sufficient number of pipe breaks would be postulated, the staff recommended that breaks be postulated for a wide epectrum of events to envelope the uncertainties of unanticipated failure mechanisms. Breaks were postulated at torminal ends of the piping, at high-stress and highfatigue locations, and, as a minimum, at two additional intermediate locations when the stresses were below the 
high-etrese threbold limit. The rusulting critoria, which were incorpornied in SRP Section 3.6.2, reoulted in many poetulated pipo brenk locetions and caued the inctallation of numerous pipe rupture mitigation devices in nuclear plants.

In the mid-1980, the NRC's Bxecutive Director for Operations (BDO) initiated a comprohensive roview of nuclear power plant piping to identify areas whore changes to the piping requirements could improve the licensing proceses as well as the anfoty and reliability of nuclear power plants. The NRC's Piping Reviow Committes (PRC) in an integrated offort with the nuclear induatry under the Preasure Veacel Rewearch Council conducted comprebensive study of piping criteria, including the mecheniatic pipo break postulation guidelines. The PRC found that when an excesaive number of pipe rupture mitigation dovices (i.e., pipe whip reetraints and jet impingement shields) are installod on high-energy piping systems, the potential exists for piping systems to be overly constrained. This condition was found in several nuclear plants in which massive pipe restraints adversely affected the ability of the high temperature piping to freely expand during normal plant operation. The PRC also found through numerous dynamic tosts and field obeorvations of non-seismically designed piping systems that had undergone high seismic loadings that butt-welded piping poseseses in inherent ability to withstand large soismic inertial loadings without failure.

As a result of the PRC's effort, the NRC staff recognized that the mechanistic pipe rupture criteria for selecting locations of pipe breaks resulted in an excessive number of pipe rupture mitigation devices that could hinder the normal operation of the plant and that may not contribute significantly to the overall safety of the plant. Accordingly, the SRP was revised to reduce the number of postulated pipo breaks by (1) eliminating the need to poetulate pipe breaks at the two arbitrary intermediate locations and (2) providing a leak-beforo-break (LBB) approach in lieu of postulating pipe breaks when the system and material specific information is adequate to justify its application.

Recent dynamic pipe tests, conducted by the EPRI and NRC, have demonstrated that the piping can withstand eeismic inertial loadings higher than an SSE without rupturing. Thus, the staff believes the likelibood of a pipe break in a seismically dosigned piping system owing to an earthquake magnitude of one-third SSE is remote. Operating experience has shown that pipe breaks are more likely to occur under conditions caused by normal operation (c.g., erosion-corrosion, thermal constraint, fatigue, and operational transients).
On tho bads of the provious discuscion, the ataff concludes that no replecement earthquaks loading should be uned to extablich poetulated pipe break and lankage crack locations. Inctead, the oriteria for poetulating pipe breates and lankage crncks in mismically deaigned, high- and modento-energy piping aystem abould be based on frotors attributed to normal and operational trencieats only. SSAR Sections 3.6.1 and 3.6.2 conform to this ataff position of pipe break poctulation. However, for ectabliching pipo breake and leakage cracks cauned by fatigue effects, tho calculation of the cumulativo usage factor will continus to include seismic cyclic offects. The revised criteria aro inteoded to casure that breake and leakage cracke are pontulated to occur at the moet likely locations and to reduce the number of pipe rupture mitigation devices (e.8., pipe whip reatninte and jet impingeneent shiolda) that might hinder plant operation without providing a compensatory lovel of anfety.

The elimination of earthquake loads in the following revieed pipo break criteria is justified, in part, on the fact that the equipment covironmental qualification and compartment preseurization analyees for the ABWR are based on a worst-case broak assumption in cach compertment and aro not poetulated at mochanistic break locations. In addition, GE has committed in SSAR Section 6.6.7.2 to a monitoring program for erosion-corrosion that provides asourances that procedures or administrative controls are in plece to ensure that the NUMARC program (or another equally effective program) is implemented and the structural integrity of all high-energy (two-phese as well as singlo-phase) carbon-steel systems is maintained as discuseed in Generic Lottor (GL) 89-08 and NUREG-1344, "Erosion/Corrosion-Induced Pipo Wall Thinning in U.S. Nuclear Power Plents," April 1989.

Consistent with this staff finding, the guidelines provided in SRP Section 3.6.2, Branch Technical Position MEB 3-1, "Postulated Rupture Locations in Fluid System Piping Inside and Outsido Containment," have been revised for the ABWR as follows:

B.1.b.(1).(a): Footnote 2 should read, "For those loads and conditions in which Lovel A and Lovel B streas limits have been specified in the Design Specification (excluding earthquake loeds)."

B.1.b.(1).(d): "The maximum stress as calculated by the sum of Eqs. (9) and (10) in Paragraph NC-3652, ASME Code, Section III, considering those loads and conditions thereof for which level A and level B stress limits have been specified in the system's Design Spocification (i.e., sustained loads, occasional loads, and thermal oxpansion) excluding carthquake loeds should not exceed $0.8\left(1.8 S_{h}+S_{A}\right)$." 


\section{Design of Structures, Components, Equipment, and Systems}

The ABWR criteria are consistent with this attff position for postulating pipe breake and cracks and are scceptable.

\subsubsection{Concrete and Steel Structurve}

The current design practice for convidering OBE and SSB ground motion offects in the coirmic deaign of nuclear plant etructures was catablished in the 1960 with conceptual goals of (a) maintaining continued plant operation without damage to the structures for OBB lovel carthquakes and (b) ensuring safo shutdown of plant and maintaining the plant in a safo-ehutdown condition during and after the occurrence of an SSE. To achiove these goals, the structural responses are deaigned at or bolow the material yield streseses to preclude the onsel of plastic doformation for loed combinations owing to sccident conditions plus the SSE. For load combination owing to operating conditions plus the OBE, streaces are limited at 1/2 to 5/8 yield strees. The curreat loed combinations provided in SRP Section 3.8 wero developed from this design philosophy.

For seismic Catogory I steel structures, the staff's guidance on lond combinations is provided in SRP Section 3.8.4. The staff's review of the controlling load combinations finds that, in general, the load combinations with the SSE control the design of steel structures although there may bo apecific cases where the lond combinations with the OBE control the design. Similarly, an examination of the pertinent load combinations for concrete structures, including the containment structure, should lead to the same conclusion that the OBE loads, in most cases, do not control the outcome of the structural design.

In the design of the containment, the staff reviewed the extent to which the elimination of the OBE from the load combinations would lead to a reduction of the safety margin. An examination of the nuclear structural design practice and the SRP load combination equations, howover, show that the major dynamic load for the overall design of structures is either the OBE or the SSE. All other potential dynamic loads are conservatively accounted for in the definition of equivalent dead and live loads or only produce local effects that are handled by local reinforcement details. Therefore, the staff concludes that no reduction in safety margins of concrete and steel structures results from the elimination of the OBE as a design requirement.

For the ABWR, the following criteria for structures are used to ensure that when the OBE is eliminated from design, the structures will continue to be designed appropriately for earthquake offects.
SSB Relative Dieplacements Between Structures

In Appeadix 3A to the SSAR, the soismic respones (building dieplacements, structural momber forces, floor repones epectro (FRS), etc.) of the reactor building (RB) is discused. $\mathrm{OE}$ has considered the through-eoil, structure-to-etructure internction offect under SSB loading in the enalyeses of ABWR atructures, including the control building, ultimato bout sink pump house, radweato building, and turbine building. Therefore, io staff coscludes that the effects of through-eoil, structuro-tostructure interaction under SSE loadings for all structures bouving miamically designed piping have been adequately considered under SSE loadings to establish the relative dieplecements between buildings (seismic anchor movement for piping syetoms).

\section{Soismic Instrumentation}

GB committed in SSAR Section 3.7.4.4 to placing soismic instrumentation in the free field $s 0$ that the control room operator can be immediately informed through the event indicators when the response spectral level and the cumulative absolute velocity (CAV) experienced at this location exceed the shutdown level and can take the necessary actions. The staff concludes that the ABWR moets the etafi's recommendations for pro-earthquake planning with reepect to the location of seismic instrumentation.

\section{Use of Regulatory Guides 1.143 and 1.27}

The staff guidelines in RO 1.143, "Design Guidance for Radioective Waste Management Systems, Structures, and Components Installod in Light-Water-Cooled Nuclear Power Plants," Revision 1, and in RG 1.27, "Ultimate Heat Sink for Nuclear Power Plants," Revision 2, recommend a seismic design of radwaste buildings and ultimato heat sink features based on the OBE. With the elimination of the OBE, GE committed to designing these structures and features to withstand the SSE. The atructural design criteria, using the SSE loading, use the corresponding loads and load combinations provided in SRP Section 3.8.4. The staff finds that designing these structures and features to the SSE provides a bounding design comparable to that recommended in the regulatory guides and is acceptable. The staff will review alternative methods to ensure the seismic adequacy of these structures and features on a case-by-case basis.

\subsubsection{Equipment Seismic Qualification}

The proposed elimination of OBE from explicit design consideration affects different aspects of equipment qualification in different manners. In the area of equipment qualification, the requirements in the regulations 


\section{Design of Structures, Components, Equipment, and Systems}

(10 CFR Part 50 and 100) are interpreted by the ataff through Section 3.10 of the SRP, which deals with wismic and dynamic qualification of mechanical and electricap equipment.

When the equipment qualification is performod by analyais, the acceptance criteria are dorived from the ASME Codo. The offect of eliminating the OBE on equipment qualification by analyais ahould be negligible. It is well known that mochanical equipmeat mich as pumps and valves are, in general, seismically rugged when adequately anchored and that their operability limits are generally catablished through maximum permicaible momeats and forces or tolerance limits based on available clearances that are controlled by the SSE rather then the OBE. Therefore, for mechanical equipment, elimination of OBE from qualification analysis should not reduce any safety margin. Also, somo electrical equipment are allowed to be qualified by analysis that requires demonstration that five $O B E$ ovents followed by one SSE event do not cause it inilure to perform safety functions. With the olimination or OBE, analysis checks for fatigue effects may be performed at a fraction of the SSE (e.g., 50 cycles at ono-half of the SSE peak amplitude or 150 cycles at ono-third of the SSE peak amplitude).

When equipment qualification for seismic loadings is performed by analysis, testing, or a combination of both, the staff recommends the use of the IEEE 344-1987 as endorsed in RG 1.100, "Seismic Qualification of Electric and Mechanical Equipment for Nuclear Power Plants," Revision 2. For analysis, the selection of the level of service limit for different loading combinations should ensure the functionality of the equipment during and following an SSE. For testing, IEEE 344-1987 has detailed requirements for performing seismic qualification using five OBE events followed by an SSE event. Where complex mathematical models aro based solely on calculated structural parameters, verification testing should be performed.

With the elimination of the OBE, and in order to maintain the equivalent qualification requirements provided in IEEE 344-1987 to qualify equipment with the equivalent of five OBE events followed by one SSE event, the staff recommended in SECY-93-087 that equipment be qualified with five half SSE events followed by one full SSE event. Alternatively, the staff recommended that a number of fractional peak cycles equivalent to the maximum peak cycles for five half SSE events may be used in accordance with Appendix D to IEEE 344-1987 when followed by one full SSE. In Section 3.7.3.2 of the SSAR, GE committed to these staff recommendations as stated in SECY-93-087 and, thus, the criteria proposed for equipment seismic qualification when the OBE is eliminated from deaign are eccoptable.

\subsubsection{Pro-Earthquake Planning and Poat-Earthquake Operator Action}

The deaign certification of the ABWR, using a singlocarthquake SSE design, is predicated on the adequacy of pro-arthquake planning and poet-earthquake damage inspections that are to bo implemented by the COL applicant.

The COL applicant will be required to demonetrate to the NRC ataff as a part of its application the procedures it plans to use for pro-arthquake planning and postcarthquake actions. For design certification, the NRC staff reviewed the criteria developed by the EPRI in EPRI Reports EPRI NP-5930, EPRI NP-6695, and EPRI TR-100082 for evaluating the need to shut down the plant following an earthquake and the commitments for the ABWR for ensuring that these actions can be taken as provided in SSAR Section 3.7.4.

\subsubsection{EPRI NP-5930}

The staff finds from its review of EPRI NP-5930 that this report is adequate for and may be used by the COL applicant with the following exceptions:

1. A froe field instrument must be used for determining the CAV and the spectral acceleration level.

2. The response spectrum check is as follows:

The 5-percent damped ground response spectrum for the earthquake motion at the site exceeds (1) one-third the corresponding SSE response spectral acceleration between 2 and $10 \mathrm{~Hz}$ or it exceeds a spectral acceleration of $0.20 \mathrm{~g}$ between 2 and $10 \mathrm{~Hz}$, whichever is greater, or (2) one-third the corresponding SSE response spectral velocity between 1 and $2 \mathrm{~Hz}$ or a velocity of $15.24 \mathrm{~cm} / \mathrm{sec}(6 \mathrm{in} / \mathrm{sec})$ between 1 and $2 \mathrm{~Hz}$, whichever is greater.

3. The licensee shall consider as sufficient evidence to shut down the plant the simultaneous exceedance of the 5-percent damped ground response spectrum enumerated in Item 2 and the CAV exceedance of $0.16 \mathrm{~g}$-sec for any one frequency on any one component of the free field ground motion. The CAV shall be determined in accordance with EPRI Report TR-100082. Also, any evidence of significant damage observed during the plant walkdown in accordance with EPRI Report NP-6695 recommendations shall be sufficient cause for plant shutdown. 


\section{Design of Structures, Components, Equipment, 'and Systems}

4. The instrumentation installed at the nuclear power plant shall be capable of on-line digital recording of all three components of the ground motion and of converting the recorded (digital) signal into the standardized CAV and the 5-percent damped response spectrum. The digitizing rate of the time history of the ground motions shall be at least 200 samples per second and the band-width shall be at least from $0.20 \mathrm{~Hz}$ to $50 \mathrm{~Hz}$. The pre-event memory of the instrument shall be sufficient to record the onset of the earthquake.

5. The system must be capable of routinely calibrating the response spectrum check of $0.20 \mathrm{~g}$. Also, the CAV of $0.16 \mathrm{~g}-\mathrm{sec}$ should be calibrated with a copy of the October 1987, Whittier, Californis earthquake or an equivalent calibration record provided for this purpose by the manufacturer of the instrumentation. In the event that an actual earthquake has been recorded at the plant site, the above calibration shall be performed to demonstrate that the system was functioning properly at the time of the earthquake.

In SSAR Section 3.7.4, GE committed to these guidelines. This is acceptable.

\subsubsection{EPRI NP-6695}

The staff finds from its review of EPRI NP-6695 that this report may be used by the COL applicant with the following exceptions:

Section 3.1, Short-Term Actions

\section{Item 3, "Evaluation of Ground Motion Records"}

Within four hours, the licensee must determine if the shutdown criterion has been exceeded. After an earthquake has been recorded at the site, the licensee must provide a response spectrum calibration record and CAV calibration record to denonstrate that the system was functioning properly.

Item 4, "Decision on Shutdown"

Exceedance of the EPRI criterion as amended by the NRC or observed evidence of significant damage as defined by EPRI NP-6695 shall constitute a condition for mandatory shutdown unless conditions prevent the licensee from accomplishing an coderly shutdown without jeopardizing the health and sific ty of the public.
Add Item 7, "Documentation"

The licensee must record the chronology of events and control room problems while the earthquake evaluation is in progress.

Section 4.3, "Guidelines" (p. 4-3)

Because earthquake-induced vibration of the reactor vessel could lead to changes in neutron fluxes, the licensee need to promptly check the neutron flux monitoring instruments, which indicate whether the reactor is stable. Therefore, this check should be added to the checks listed in this section.

\section{Section 4.3.4, "Pre-Shutdown Inspection"}

Exceeding the EPRI criterion or evidence of significant damage should constitute a condition for mandatory plant shutdown, as the staff stated in its comment on Section 3.1, Iten 4, "Decision on Shutdown."

Section 4.3.4.1, "Safe-shutdown equipment" (p. 4-7)

In addition to the safe shutdown systems on this list, containment integrity must be maintained following an earthquake. Since the containment isolation valves may have malfunctioned during the earthquake, inspection of the containment isolation system is necessary to ensure continued containment integrity.

\subsubsection{Conclusions}

On the basis of the evaluation of the changes to the existing seismic design criteria previously discussed, the staff concludes that eliminating the OBE from the design of SSCs in the ABWR standard plant will not reduce the level of safety provided in current regulatory guidelines for seismic design. On the contrary, the changes enhance safety by refocusing current design requirements to emphasize those areas where failure modes are more likely to occur and by precluding the need for seismic design requirements that do not significantly contribute to the overall safety of the plant. The SSAR includes this information in Sections 3.6.1 and 3.6.2 and Tables 3.9-1 and 3.9-2. The staff further concludes that the elimination of the OBE from the design of SSCs in the ABWR standard plant meets the Commission-approved staff recommendations in SECY -93-087 and is acceptable. On the basis of these conclusions, DFSER Open Item 3.1-1 is resolved. 


\subsection{Fracture Prevention of Containment Boundary}

The ABWR primary containment vessel is a reinforced concrete structure with ferritic parts (the removable head, personnel locks, equipment hatches, and penetrations) made of materials that will have a nil-ductility transition temperature $\left(\mathrm{RT}_{\mathrm{NDT}}\right)$ of at least $17^{\circ} \mathrm{C}\left(30^{\circ} \mathrm{F}\right)$ below the minimum service temperature. GDC 51 is only applicable to parts of containment that are made of ferritic materials.

The staff requested that GE clarify the applicability of GDC 51 because in the original SSAR it seemed that GE intended to apply GDC 51 to the concrete parts of the containment (Question (Q) 251.12). Subsequently, GE responded that GDC 51 is applicable to the removable drywell head, personnel locks, equipment hatches, and penetrations that are made of ferritic materials and revised SSAR Section 3.1.2.5.2 to reflect this clarification. The staff reviewed the revision and concluded in the DFSER that the applicable revision has satisfactorily complied with the requirements of GDC 51 because ferritic parts in the concrete structure will be made of materials that will have $\mathrm{RT}_{\mathrm{NDT}}$ of at least $17^{\circ} \mathrm{C}\left(30^{\circ} \mathrm{F}\right)$ below the minimum service temperature. This ensures that the ferritic materials in the containment structure will not undergo brittle fracture and the probability of a rapidly propagating fracture will be minimized. This is acceptable.

\subsection{Classification of Structures, Systems, and Components}

\subsubsection{Seismic Classification}

GDC 2 requires, in part, that nuclear power plant SSCs important to safety be designed to withstand the effects of earthquakes without loss of capability to perform their safety functions. Certain of these features that are safetyrelated are necessary to ensure (1) the integrity of the reactor coolant pressure boundary (RCPB), (2) the capability to shut down the reactor and maintain it in a safe-shutdown condition, and (3) the capability to prevent or mitigate the consequences of accidents that could result in potential offsite exposures that are comparable to the guidelines in 10 CFR Part 100. The earthquake for which these safety-related plant features are designed is defined as the SSE in Appendix A to 10 CFR Part 100. The SSE is based on an evaluation of the maximum earthquake potential and is that earthquake that produces the maximum vibratory ground motion for which SSCs are designed to remain functional. Those plant features that are designed to remain functional, if an SSE occurs, are designated seismic Category I in RG 1.29, "Seismic Design Classification," Revision 3. In addition, regulatory Position C.1 in RG 1.29 states that the pertinent quality ssourance (QA) requirements of Appendix B to 10 CFR Part 50 should be applied to all activities affecting the safety-related functions of seismic Category I SSCs. The staff reviewed the ABWR SSAR in accordance with SRP Section 3.2.1, which references RG 1.29.

The SSC and equipment of the ABWR standard plant that are required to be designed to withstand the effects of an SSE and remain functional are identified as seismic Category I in SSAR Table 3.2-1. In addition, piping and instrumentation diagrams (P\&IDs) in the SSAR identify the interconnecting piping and valves and the boundary limits of each system identified as seismic Category I. In Section 3.2.1 of the DSER (SECY-91-153), the staff reported that the seismic classifications of the main steamline (MSL) between the seismic interface restraint and the turbine stop valve and MSL branch lines up to and including the first valve in the branch line were still under review. This was DSER Outstanding Issue 3. The staff's review also included quality group (QG) and safety class (SC) designations and QA requirements for these same components. The relationship between $Q G$ and SC is discussed in Section 3.2.2 of this report. The resolution of DSER (SECY-91-153) Outstanding Issue 3 is discussed below.

The ABWR design eliminates the main steam isolation valve leakage control system for the ABWR plant design. Instead, the design relies on the use of an alternative leakage path that takes advantage of the large volume and surface area in the main steam piping, main steam drain lines, turbine bypass line, and condenser to hold up and plate out the release of fission products following core damage. In this manner, the alternative leakage path and condenser are used to mitigate the consequences of an accident and are required to remain functional during and after an SSE.

For this reason, the staff position, which was discussed in Section II.E of SECY-93-087 and was approved by the Commission in its SRM dated July 21, 1993, is that the main steam piping beyond the outermost isolation valve up to the seismic interface restraint and connecting branch lines up to the first normally closed valve be classified as QG B (SC 2) and seismic Category I. The MSL from the seismic interface restraint up to but not including the turbine stop valve (including branch lines to the first normally closed valve) will be classified as QG B and inspected in accordance with the applicable portions of ASME Section XI. This portion of the steamline may be classified as non-seismic Category I if it has been analyzed using a dynamic seismic analysis method to demonstrate its structural integrity under SSE loading conditions. However, all pertinent QA requirements of Appendix B to 10 CFR Part 50 are applicable to ensure that the quality of 
the piping material is commensurate with its importance to safety during normal operational, transient, and accident conditions. To ensure the integrity of the remuinder of GE's proposed altornativo leakage path, the staff position is that (1) the main steam piping between the turbine stop valve and the turbine inlet, the turbino bypass line from the bypass valve to the condenser, and the min steam drain line from the first valve to the condenser are not required to be classified as safety-related or as seismic Category I, but should be analyzed using a dymamic seismic analysis to demonstrate their structural integrity under SSE loading conditions, and (2) the condenser anchorage shall be soismically analyzed to demonstrate that it is capable of sustaining the SSE londing conditions without failure.

The seismic interface restraint shall provido atructural barrier botween the soismic Category I portion of the MSL in the RB and the non-seismic Category I portions of the MSL in the turbine building. The seismic interface restraint shall be located inside the seismic Category I building. The clessification of the MSL in the turbine building as non-seismic Category I is noeded for consistency with the classification of the turbine building. Therefore, the staff positions related to the quality and safety guidelines imposed on the MSL from the outermost isolation valve up to the turbine stop valve are equivalent to the staff guidelines in SRP Section 3.2.2, Appendix A to 10 CFR Part 50, and RG 1.29.

In response to staff requests for additional information related to this issue, Amendment 23 to the ABWR SSAR, GE revised SSAR Table 3.2-1 to respond to the staff's concerns. Table 3.2-1 of the SSAR contains the following classifications:

- The MSL, including supports, from the outermost isolation valve to the seismic restraint, including branch lines up to the first valve is SC 2, QG B; QA will be in accordance with Appendix B to 10 CFR Part 50 and seismic Category I.

- The MSL from the seismic restraint to the turbine stop valve, including branch lines up to the first valve is QG B; QA will be in accordance with Appendix B to 10 CFR Part 50 and non-seismic Category I, but dynamically analyzed for the SSE. Although not explicitly stated in SSAR Table 3.2-1, the commitment to QG B requires inservice inspections in accordance with applicable portions of ASME Section XI.

- The turbine stop valve, the MSL from the turbine stop valve to the turbine, the turbine bypass valve, the turbine bypass line from the bypa'ss valve to the condenser and the main steam drain line from the first valve to the condenser, are all non-safety class, non- ceismic Category I, but dynamically analyzed for the SSE.

- The condenser is non-safety class, non-seismic Category I, but the condenser anchorage is seismically analyzed for the SSE. GE considers piping inlets to the condenser as anchor points.

Tho commitment to dynamically analyze the above components for the SSE is in Section 3.2.5.3, "Main Steamline Leakage Path" of the SSAR. The components are designed by using appropriate dynamic seismic analyses to withstand the SSE design loads in combination with other appropriate loads, within the limits specified. The mathomatical model for the dynamic seismic analyses of the main steamlines and the branch line piping includes the turbine stop valves and piping to the turbine casing. The dynamic input for the analysis and design of the main steamlines are derived from a time history analysis (or an equivalent method) of the turbine building as described in SSAR Section 3.7 .

In the DFSER, the staff noted that, to demonstrate the structural integrity of the main steam piping under SSE loading conditions, a dynamic analysis method should be used for this portion of the main steam piping. In addition, GE should discuss how the turbine building response spectra input to the main steam piping analysis will be generated when, as discussed in the following paragraph, no dynamic analysis method of the turbine building is proposed. The staff position as delineated in SRP Section 3.7.2.5 for the generation of floor response spectra (FRS) is that the development of the FRS is acceptable if a time history approach is used. Alternative methods, other than the time history approach, used for generating FRS shall be submitted to the staff for review and approval on a case-by-case basis. This was DFSER Open Items 3.2.1-1 and 3.7.2-6. The resolution of this issue is discussed in the "Turbine Building" portion of Section 3.7.2 in this report.

Note $f$ in SSAR Table 3.2-1 and SSAR Sections 3.7.2.8 and 3.7.3.13 state that equipment, structures, and piping in the ABWR that are non-seismic Category I but that could damage seismic Category I items if their structural integrity failed, are analyzed and designed to ensure their integrity is maintained under seismic loading from the SSE. At the interface between seismic and non-seismic Category I piping systems, the seismic analysis for the seismic Category I system will be extended to either the first anchor point in the non-seismic system or to sufficient distance in the non-seismic system so as not to degrade the validity of the seismic Category I analysis. In the DFSER, the staff noted that this commitment is in conformance with RG 1.29. However, as a part of the resolution of this 
issue, the staff noted that the turbine building and any other applicable structure or equipment should be seismically analyzed for the SSE (RG 1.60 ground response spectrum anchored to $0.3 \mathrm{~g}$ peak acceleration) to ensure that an earthquake will not adversely affect the structural integrity of the main steam piping, bypass line, valves, and instruments mounted on these pipes, and the main condenser. In Amendment 20 to the SSAR, GE added Section 3.7.3.16, which described a static, in lieu of dynamic, analysis for the turbine building. This proposed analysis was in accordance with the Uniform Building Code (UBC) Zone 2A, but was substantially lese conservative than the specified SSE for which the main steam and bypass lines should be analyzed. The staff asked GE to provide a clear set of criteria for the turbine building, which is designed to UBC criteria, $s$ that it will neither suffer no loss of function at the specified SSE nor adversely affect safety-significant piping, pipo-mounted equipment, or the condenser itself. This issue was DFSER Open Items 3.2.1-2 and 3.7.2-7. The resolution of this issue is discussed in the "Turbine Building" portion of Section 3.7.2 in this report.

In addition, the staff's position is that plant-specific walkdowns of non-seismically designed SSCs overhead, adjacent to, and attached to the alternative leakage path (i.e., the main steam piping, the main steam drain lines to the condenser, the bypass line to the condenser, and the main condenser) be conducted by the COL applicant before commercial operation to assess potential failures. The walkdowns, which should identify potential failure modes, will provide high confidence that the alternative leakage paths in ABWRs can retain their structural integrity during and following an SSE. In the DFSER, the staff noted that these walkdowns should be performed as a part of an inspection, test, analysis, and acceptance criteria (ITAAC) for verification of non-seismic/seismic interaction. This was DFSER Open Item 3.2.1-3 and DFSER Confirmatory Item 14.1.3.3.3.8-2. Upon further consideration, the staff found that the design detail and as-built and as-procured information for non-seismically designed SSCs in the turbine huilding as they affect the alternate leakage function of the main steam, bypass, and drain lines, and main condenser are not required for design certification, and the spacial relationship between these SSCs and the main steam piping, bypass, and drain lines, and the main condenser should be assessed to ensure compliance with GDC 2. Subsequently, GE revised the SSAR and added SSAR Section 3.2.5.3, which contains a commitment to perform plant-specific walkdowns consistent with the previously stated staff position. The commitment in SSAR Section 3.2.5.3 to perform walkdowns is acceptable. Therefore, DFSER Open Item 3.2.1-3 and DFSER Confirmatory Item 14.1.3.3.3.8-2 are resolved. The resolution of this issue is also discussed in Section 3.12.3.8 of this report.

The taff concludes that these ABWR commitments in SSAR Section 3.2.5.3, including the plant-specific walkdowns, provide reasonable assurance that the main steam piping from the outermost isolation valve up to the turbine, including the turbine stop valve and branch lines to the first normally closed valve, the turbine bypass line up to the condenser, the main steam drain line from the first valve to the condenser, and the condenser, will retain their atructural intogrity during and following an SSE. Therefore, from the structural integrity standpoint, the elimination of the MSIV leakage control system in the ABWR is acceptable, and the ABWR design meets the Commission-approved staff recommendations related to the classification of main steamlines in BWRs. The staffs evaluation of the radiological analysis for this issue is discussed in Section 15.4.4.2 of this report. On the basis of this evaluation, Outstanding Issue 3 in the DSER (SECY-91-153) is resolved.

On the basis of its review of SSAR Table 3.2.1, the applicable P\&IDs, and other relevant information in the SSAR, including the previous discussion related to the elimination of the MSIV leakage control system, the staff concludes that the safety-related SSCs of the ABWR are properly classified as seismic Category $I$ in accordance with RG 1.29 or an acceptable equivalent to ensure the structural integrity of the alternative leakage path. This constitutes an acceptable basis for satisfying, in part, GDC 2.

\subsubsection{System Quality Group Classification}

GDC 1 requires that nuclear power plant SSCs important to safety be designed, fabricated, erected, and tested to quality standards commensurate with the importance of the safety function to be performed. This requirement is applicable to both pressure-retaining and nonpressure-retaining SSCs that are part of the RCPB and other systems important to safety, when reliance is placed on these systems to (1) prevent or mitigate the consequences of accidents and malfunctions originating within the RCPB, (2) permit shutdown of the reactor and maintain it in a safe-shutdown condition, and (3) retain radionctive material.

In addition to the seismic classifications discussed in Section 3.2.1 of this report, SSAR Table 3.2-1 identifies the SC, QG, and QA requirements necessary to satisfy the requirements of GDC 1 for all safety-related SSCs and equipment. Applicable P\&IDs identify the classification boundaries of interconnecting piping and valves. The staff reviewed Table 3.2-1 and the P\&IDs in accordance with 
SRP Section 3.2.2, which references RO 1.26, "Quality Group Clasuification and Standards for Water-, Steam-, and Redionctive-Watto-Containing Components of Nuclear Power Pinnte," Revirion 3, es the principal document ueed in the staff review for identifying on a functional basis the preecuro-retaining componeats of thow systems important to sufety a NRC QO A, B, C, or D. Conformance of ASME Codo, Section III, Clues 1 components that are part of the RCPB to 10 CFR 50.55a is discusend in Soction 5.2.1.1 of this report. These RCPB components are decizmated in RG 1.26 \& QG A; certain othor RCPB components that meet the exclusion requirements of 10 CFR 50.55a(c)(2) are clasaified QO B.

GE usen American Nuclear Society (ANS) SC 1, 2, 3, and non-nuclear safety (NNS) as dofinod in Americen National Standards Inatitute (ANSI)/ANS 52.1-1983 for tho classification of syetem component as an alternative mothod of meoting RO 1.26. SSAR Tablos 3.2-2 and 3.2-3 provide a corrolation between (1) ABWR SC 1, 2 , 3 and NNS, (2) NRC QG A, B, C, and D in RG 1.26, and (3) ASME Codo Section III classes. The relationship between the three methods of classification for pressuro-retaining composents in the SSAR is shown below.

\begin{tabular}{c} 
NRC OG \\
\hline A \\
B \\
C \\
D
\end{tabular}

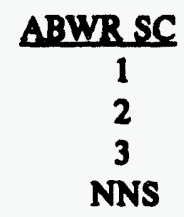

Section III
1
2
3
-

All pressivio-retaining components classified as QG A, B, or $\mathbf{C}$ are constructed in accordance with ASME Code, Section III, Class 1, 2, or 3 rules, respectively. Construction as defined in ASME, Code, Section III, Subsections NB/NC/ND-1110(a) and used herein is an allinclusive term comprising materials, design, fabrication, examination, testing, inspection, and certification required in the menufacture and installation of components. Components classified as QG D are designed to the applicable standards identified in SSAR Table 3.2-3.

Because the staff has not endorsed ANSI/ANS 52.1-1983, it cannot rely on those safety classifications for determining the rcceptability of non-pressure-retaining SSCs. Therefore, in performing the: review of SSAR Table 3.2-1 for non-pressure-retaining components, the staff concentrated on an evaluation of $Q A$ in accordance with Appendix B to 10 CFR Part 50 and seismic classifications.

In Section 3.2.2 of the DSER (SECY-91-153), the staff stated its concern about the QA requirements of the new and spent fuel storage racks and the storage container for defective fuel. This was Outstanding Issue 2 in
SBCY-91-153. The staff's position is that the now and opent fuel storage racks are important to safety and, as a minimum, should meet the applicable QA requirements of Appendix B to 10 CFR Part 50, in addition to being clatsified as seismic Catogory I. This position is consistent with RG 1.29. The storage containers for defective fuels are deaigned to the same QA requirements as the fuel storage racks. However, because these storage containers are stored in the seismic Cattegory I fuel storage racks, they do not have to be seismic Category I. Note 0 in SSAR Table 3.2-1 defines QA Catogory B, which is applicable to the new and spent fuel storage racks and the storage container for defective fuel. Category B states that elements of Appendix B to 10 CFR Part 50 are generally applied to theee components, commensurate with the importance of the component's function. This commitment satisfies the applicable guidelines in RG 1.29 and is scceptable. Therefore, DSER Outstanding Issue 3 is resolved.

In Section 3.2.2 of the DSER (SECY-91-153), the staff reported a concern about the QG classification of the containment spray piping, including the spargers, within the outermost containment isolation valve. This was identified as Outstanding Issue 1 in SECY-91-153. SSAR Table 3.2-1, Item E1.4, classifies this piping as SC 2 and QG B. The staff agrees with these classifications. However, SSAR Figure 5.4-10 originally classified this portion of piping as SC 3 and QO C. In response to Outstanding Issue 1, the SSAR, Figure 5.4-10, Sheets 2 and 7, contains the classifications which agree with those in Table 3.2-1. This is acceptable and resolved DSER Outstanding Issue 1.

The reactor internal pump (RIP) recirculation motor cooling subsystem is classified by GE as SC 2 and seismic Category I. This subsystem is connected to the RIP motor casing, which is classified as SC 1 and is part of the RCPB. In response to a staff request for GE's basis for the SC 2 classification, GE stated that in the event of a postulated failure of the RMC subsystem piping, the small annulus between the outside diameter of the RIP shaft and the inside diameter of the stretch tube in the RIP assembly acts as a flow restrictor to limit the flow of water from the reactor pressure vessel to a low level. The reactor can be shut down and cooled in an orderly manner, and reactor coolant makeup can be provided by a normal make up system (e.g., control rod drive (CRD) return or resctor core isolation cooling (RCIC) system). Therefore, per 10 CFR $50.55 a(c)(2)$, the RMC subsystem can be classified as SC 2 . This basis is acceptable.

The subject of safety and QG classification of the reactor water cleanup (CUW) system has been included as a part of several meetings between the Advisory Committee on 
Reactor Safoguards (ACRS), GB, and the taff. In the SSAR Table 3.2-1 and Figure 5.4-12, "CUW syatem P\&alD," the piping up to and including the outermost contrinment isolation valve is claseified as Safety Clase 1 and QG A. Beyond the outside inolation valvo, the piping is non-nuclear anfety, non-ceismic, but QO C. In sccordance with the SSAR Table 3.2-3, QO C components are designed to ASMB Section III, Subrection ND (ASME Clase 3) rules. Therefore, from the atructural integrity ctandpoint, this portion of the CUW piping is equivaleat to Safoty Class 3. These critoria are consistent with the acceptance critoria in SRP Section S.4.8.II.3, and aro acceptable. The transition from QG A to $\mathrm{C}$ at the outside isolation valve moots Position 2.C in RO 1.26, and is acceptable because the two containment isolation valves in this system are motor operated and are designed, qualified, and tested in accordance with the criteria discussed in Sections 3.9.2.2, 3.9.3, 3.9.6.2.2, and 3.10 of this report.

The staff concludes that the QO classifications of all pressuro-rotaining and non-preseuro-rotaining SSC important to safoty that aro identified in SSAR Table 3.2-1 are in conformance with RG 1.26 , and with etaff positions on previously licensed boiling-water reactor (BWR) plants and are acceptable. Table 3.2-1, in part, identifies major components in fluid systems (such as preesure veseels, heat exchangers, storage tanks, pumps, piping, and valves) and in mechanical systems (such as cranes, refueling platforms, and other miscellaneous handling equipment). In addition, SSAR P\&IDs identify the classification boundaries or interconnecting piping and valves. All of the above SSCs are constructed in conformance with applicable ASME Code and industry standards. Conformance to RG 1.26, previous staff positions, and applicable ASME Codes and industry standards provides assurance that component quality will be commensurate with the importance of the safety function of these systems. This constitutes the basis for satisfying GDC 1 and is acceptable:

\subsection{Wind and Tornado Loadings}

\subsubsection{Wind Design Criteria}

As described in SSAR Section 3.3.1 and Tablo 2.0-1, Amendment 32, the basic wind speed is $177 \mathrm{~km} / \mathrm{hr}$ $(110 \mathrm{mi} / \mathrm{hr}$ ) at an, elevation of $10 \mathrm{~m}$ (33 ft) above grado with a recurrence interval of 50 years. This besic wind speed is scaled by an importance factor (as defined in ANSI/American Society of Civil Engineers (ASCE) 7-88, "Minimum Design Loadings for Buildings and Other Structures") of 1.0 and 1.11, shown on SSAR Table 3.3-1, for non-safety-related and safety-related structures, respectively.
The importance factor provides basic wind epeeds ansociated with mean recurrence intervals of 100 and 25 years (annual probability of being exceeded equal to 0.01 and 0.04 , reapectively). The basic wind epeed values of the map in the ANSI/ASCB 7-88 Standard are for a s0-year mean recurrence interval (annual probability of 0.02). The etandard recommends that the basic wind apeede secociated with a 100-year mean recurrence interval be used for the deaign of buildinge and other atructures whore a high degree of harand to lifo and property exiats and when theee buildinge or other atructures aro considered to be cacential facilities. The guideline in SRP Section 3.3.1, "Wind Loadings," refore to the design wind apeed as the 100-year retum period fasteat mile of wind. Therefore, the use of importance factor of 1.11 is scceptable for the design of anfety-related structures to reeult in the basic wind spoed of $197 \mathrm{~km} / \mathrm{hr}(122.1 \mathrm{mi} / \mathrm{hr})$ because it sccounts for the recurrence interval from 50 to 100 years.

An expocure category that adequately reflects the characteriatic of ground aurface irregularities ahould be determined for the site at which the building or structure is to be constructed. Account shall bo taken of large variations in ground surface roughness that arise from natural topography and vegetation as well as constructed features. In SSAR Appendix 3H, all soismic Catogory I structures are specified to be asseseed by exposure $D$ which reprosents flat, unobstructod arees exposed to wind flowing over large bodies of water. This is accoptable.

Therefore, all seismic Category I structures within the ABWR standard plant that will be exposed to wind forces are designed to withstand the effects of the design wind that has a velocity of $197 \mathrm{~km} / \mathrm{hr}(122.1 \mathrm{mi} / \mathrm{hr})$ and exposure D.

The staff concludes that the ABWR plant design is acceptable and meets the requirements of General Desigm Criterion 2. This conclusion is based on the following:

GE meets the requirements of GDC 2 with respect to the capability of the structures to withstand deaign wind loading 80 that their design reflects the following:

(1) appropriate consideration for the SSAR Table 2.0-1 basic design wind with an appropriato margin;

(2) appropriate combinations of the effects of normal accident conditions with the effects of the natural phenomena; and 
(3) the importance of the safety function to be performed.

GE has met the requirements of GDC 2 by using ANSI/ASCE 7-88 and ASCE Paper 3269 to transform the wind velocity into an effective pressure on structures and to select pressure coefficients corresponding to the geometry and physical configuration of the structures.

The ABWR plant structures are designed with sufficient margin to prevent structural damage during the design basis wind loadings as described above so that the requirements of Item 1 listed are met. In addition, the design of seismic Category I structures, as required by Item 2 previously listed, includes, in an acceptable manner, load combinations that occur as a result of the design basis wind load and the loads resulting from normal and accident conditions.

The procedures used to determine the loadings on structures induced by the design basis wind are acceptable because they have been used in the design of conventional structures and have been proven to provide a conservative basis that ensures that the structures will withstand such environmental forces. The use of these procedures provides reasonable assurance that, in the event of design-basis winds, the structural integrity of the plant structures that have to be designed to be protected from wind will not be impaired and, consequently, safety-related systems and components located within these structures are adequately protected and will perform their intended safety functions, if needed, thus satisfying the requirements of Item 3.

In SSAR Amendment 32, as a COL applicant action item, GE added Section 3.3.3.3 and stated that all non-safetyrelated plant SSCs not designed for wind loads shall be analyzed using the 1.11 importance factor or shall be checked so that their mode of failure will not affect the ability of safety-related SSCs performing their intended safety functions. This was in response to the staff's concern in the discussion of these related subjects after issuing the DFSER. As a result of its review, the staff concludes that the action meets the guidelines of SRP Section 3.3.1 and is acceptable.

\subsubsection{Tornado Design Criteria}

In the DSER (SECY-91-153), the staff identified an open item related to the maximum wind speed for the design basis tomado (Outstanding Issue 4).

SSAR Section 3.3.2 specifies that all seismic Category I structures exposed to tornado forces are designed to resist a maximum tomado wind speed of $483 \mathrm{~km} / \mathrm{hr}(300 \mathrm{mi} / \mathrm{hr})$ and translational wind velocity of $97 \mathrm{~km} / \mathrm{hr}(60 \mathrm{mi} / \mathrm{hr})$. This also implies a maximum tangential velocity of $386 \mathrm{~km} / \mathrm{hr}(240 \mathrm{mi} / \mathrm{hr})$. Also specified are a simultaneous atmospheric pressure drop to $13.8 \mathrm{kPa}\left(2.00 \mathrm{lbf} / \mathrm{in}^{2}\right)$ at the rate of $8.3 \mathrm{kPa} / \mathrm{sec}\left(1.20 \mathrm{lbf} / \mathrm{in}^{2} / \mathrm{sec}\right)$ and the radius of maximum tornado is $45.7 \mathrm{~m}$ (150 ft). In SECY-93-087, the staff recommended that the Commission approve its position to employ a maximum tornado wind speed of $483 \mathrm{~km} / \mathrm{hr}$ (300 mph) in the design of evolutionary and passive ALWRs. In its SRM dated July 21, 1993, the Commission approved the staff's position. On the basis of this evaluation, the staff concludes that the ABWR design meets the Commission-approved staff recommendation for design basis tornado and is acceptable. This resolved Outstanding Issue 4 of the DSER (SECY-91-153).

The consideration of tornado loadings in the design of seismic Category I structures is in accordance with Bechtel Topical Report BC-TOP-3, "Tornado and Extreme Wind Design Criteria for Nuclear Power Plants," which NRC approved as a reference in plant applications. The procedures used to transform the tornado wind velocity into pressure loadings in BC-TOP-3 are similar to those used for the design wind loadings discussed in Section 3.3.1 of this report. The effects of tornado missiles are determined using the procedures discussed in Section 3.5 of this report.

The total effect of the design tornado on seismic Category I structures is determined by appropriate combinations of individual effects of the tornado wind pressure, tornado wind drop, and tomado-associated missiles. By using the maximum wind speed of $483 \mathrm{~km} / \mathrm{hr}$ (300 mph) and other associated parameters, the ABWR design meets the guidelines of SRP Section 3.3.2. This is acceptable.

By using BC-TOP-3, GE designed the ABWR plant structures with sufficient margin to prevent structural damage during the most severe tornado loadings determined to be appropriate for most sites. In addition, the design of seismic Category I structures includes load combinations involving tornado load and the loads resulting from normal plant operation and accident conditions.

The procedures of ANSI/ASCE 7-88 and ASCE Paper 3269 to determine the tornado-induced loadings on structures have been used in the design of conventional structures for the most severe winds. They are based on the performance of such structures, and are conservative. Conservative load combinations, as discussed in SRP Section 3.8.4, together with the conservative wind loading assessment ensures that the structures designed in this manner will withstand such severe environmental forces. 
Tho une of these procedures provides reasonablo asaurance that, in the event of a deaign-basis tornedo, the structural integrity of the plant atructures that have to be deaigned for tornedos will not bo impaired and, consequently, anfety-related syatems and components located within these atructures will be adequately protected to enable the performance of their intended safety functions.

In the DFSER, the staff discussed the COL applicent's action to ensure that the collapee of non-seismic Category I SSCs that are not designed for tornado loads, such as cooling towers or stacks outside the nuclear island, will not codanger seismic Catogory I SSCs, and that sito-dependent offects of blast loads will be less than those of dosign tornado pressures or provide justification for any deviations. This was DFSER COL Action Itom 3.3.2-1. In response, in SSAR Amendment 33, GB revised Section 3.3.3.4 (formerly Section 3.3.3.3) and stated, as a COL applicant action item, that all remaining plant SSCs not designed for tornado loads shall be analyzed for the sito-specific loedings to ensure that their mode of failure will not affect the ability of the seismic Catogory I ABWR standard plant SSCs to perform their intended safety functions. This is acceptable. On the sito-dependent blast loeds, as \& COL applicant action item, GE stated in SS AR Section 2.3.2.5 that if the sito-dependent blast loads are larger than those of design tomado pressures, all load combinations should be changed accordingly. This addresses the concern of site-dependent blast loads by meeting RG 1.91 and is also acceptable.

\subsection{Water Level (Flood) Design}

\subsubsection{Flood Protection}

The staff reviewed the ABWR flood design in accordance with SRP Sections 3.4.1 and 3.4.2 to ensure conformance with the requirements of GDC 2 and 10 CFR Part 100, Appendix A, "Seismic and Geologic Siting Criteria for Nuclear Power Piants," Section IV(c), as related to protecting structures, systems, and components (SSCs) important to safety from the effects of floods and investigating seismically-induced floods and water waves. The review addressed the overall plant flood protection design, including safety-related SSCs whose failure as a result of flooding could prevent safe shutdown of the plant or result in uncontrolled release of radioactivity.

SSAR Section 3.4.1 discusses the flood protoction measures that are applicable to the standard $A B W R$ plant seismic Category I SSC for both external flooding and postulated flooding from plant component failures. The reactor and control buildings are designed to seismic Category I standards. In addition, portion of the radwaste building that is below plant grade is also designed to soismic Catogory I atandards. The flood lovels and conditions are deacribed in SSAR Table 2.0-1. OB aceumed maximum ground water and flood levels to be

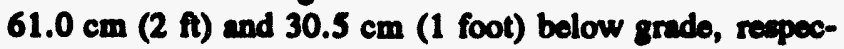
tivoly. As discuseed in SSAR Soction 3.4.2 and Table 2.0-1, GE did not consider dynamic force reculting from flooding because the design flood elevation is assumed to be below the plant finish grade. GE considered only the hydrostatic pressure caused by the design flood water level, ground water, and soil presenures in its analysis of the seismic Category I structures. However, GE indicated that the seismic Category I SSC. in the ABWR standard nuclear island were analyzed and designed for the maximum hydrostatic and hydrodynamic forces in accordance with the loads and load combinations documented in SSAR Subsections 3.8.4.3 and 3.8.5.3. In addition, GE also showed that the seismic Category I SSCs are in a stable condition with respect to either moments or uplift forces that result from the proper load combinations, including the design basis flood. GE's approach for the structural design against flooding complies with the guidelines of SRP Sections 3.7.2 and 3.8.4 and is acceptable. Furthermore, GE identified exterior or access openings and penetrations that will be below the design flood lovel in SSAR Table 6.2-9.

Safety-related systems and components that may be affected by external floods are protected either because of their location above the design flood level or because they aro enclosed in reinforced concrete seismic Category I structures that have a wall thickness of not less than $0.6 \mathrm{~m}$ $(2 \mathrm{ft})$ for portions of the structures below the flood level. The structures are provided with waterproof coating up to $8 \mathrm{~cm}$ (3 in.) above the plant ground grade level, water stops in all construction joints below flood level, watertight doors and penetrations installed below design flood level, and roofs designed to prevent pooling of large amounts of water in accordance with RG 1.102, "Flood Protection for Nuclear Power Plants." In addition, below-grade tunnels are designed with interconnecting seals such that the tunnel structural walls do not penetrate exterior building walls. In the DSER (SECY-91-235), the staff identified an open item regarding the lack of information on how safetyrelated buildings will withstand the effects of standing water on the roofs (Outstanding Issue 5). In Appendix $3 \mathrm{H}$ to the SSAR, GE stated that the design rainfall is $493 \mathrm{~mm} / \mathrm{sq} . \mathrm{km} / \mathrm{hr}(19.4 \mathrm{in} . / \mathrm{sq} \mathrm{mile} / \mathrm{hr})$, and the roof of the seismic Category I structures is to be designed to have such parapet heights that would prevent excessive ponding of water. This design rainfall together with the drainage system and suitable parapet design form a reasonable basis to conclude that there will be no roof overloading. This is acceptable, and DSER Outstanding Issue 5 is resolved. Furthermore, on the basis of the evaluation of the plant layout drawings in SSAR Section 1.2, the staff concludes 
that all the enfoty-rolated aystems and components located inside seismic Catogory I structures aro protected from ground whter seepage and external floods and mect the guidance of SRP Section 3.4.1.

OB andyzed compartmeat flooding from postulated component or syctem failures eppartidy for the reactor, control, redwete, ervice, and turbine buildings. GE considered single failure of an sctive component for compartmeat flooding. OB andyzed the failure of moderatio-energy piping larger than $2.54 \mathrm{~cm}$ (1-in.) diamoter in eccordance with ANSI/ANS 56.11 "Standard Design Criteria for Protection Against the Effects of Compartment Flooding in Light Water Reactor Plants," and Crano Co. Technical Paper 410, 1973, "Flow of Fluids Through Valves, Fittings, and Pipe." OE did not consider the effect of drain sump pump operation. In the DSER (SECY-91-235), the staff noted GE's position that high-energy line breaks (HELBs) inside the mnin steam tunnel (MST) were excluded from evaluation becauso this area will be instrumented for detection of leaks beforo a line break occurred. The staff stated that an LBB andysis should use plant-specific data such as piping geometry, materials, fabrication procedures, and pipe support locations (LBB is discussed in Section 3.6.3 of this report). In a meeting with the staff on May 5, 1992, GE committed to removing references to LBB from the SSAR. This was DFSER Confirmatory Item 3.4.1-1. In SSAR Amendment 34, GE removed all references to LBB from SSAR Section 3.4.1. The staff reviewed the SSAR and concluded that Appendix 3F of the SSAR that discussed LBB had been deleted as agreed. DFSER Confirmatory Item 3.4.1-1 is, therefore, resolved.

GE provided the results of a flooding analysis for the reactor building (RB). The analysis identified flooding hazards on a floor-by-floor basis and identified features used to ensure that multiple divisions of safety-related equipment will not be adversely affected as a result of an internal flood. The primary means of protection include divisional separation, elevation differences, and placing safety-related equipment on raised pads. Flooding in multiple divisions located below plant grade is prevented by the use of watertight doors and penetrations between divisions. Flooding above plant grade is directed to the building basement via stairways, elevator shafts, and drains. Additional features used to limit flood effects to one division include:

(1) divisional flood walls at the $-8200 \mathrm{~mm}$ ( $-26 \mathrm{ft}-107 / 8$ in.) elevation of the control and reactor buildings are $0.6 \mathrm{~m}$ (24 in.) or thicker,
(2) doors and penetrations mated as 3-bour fire barrien are sacumed to provent water spray from crosings divisional boundaries,

(3) floor are ascumed to prevent water seepenge to lower levels,

(4) penetrations between floors for pipe, cable, HVAC duct, and other equipment will be designed to provent water seepage to lower elevations from $200 \mathrm{~mm}$ of standing water through the use of seals or curbs,

(5) equipment access hatches shall prevent water sepage to lower elevations from $200 \mathrm{~mm}$ (8 in.) of standing water. Hatches to filter/demineralizer compartments may not be required to provent water seepage,

(6) water from a pipe break is assumed to flow under non-watertight doors and spread evenly over the available areas. Water sensitive safety-related equipment is raised $200 \mathrm{~mm}$ (8 in.) above the floor. The depth of water is limited to less than $200 \mathrm{~mm}$ by using available floor space and limiting the volume of water sources. As mentioned earlier, floor drains, stairways, and elevator shafts provide drain paths to the building basements.

A compliance review will be conducted of the as-built design against the assumptions and requirements that are the basis of the flood analysis in SSAR Section 3.4.1 and SSAR Appendix 19R. The, results of this review will be documented in a Flood Analysis Report and will include an assessment and disposition of any non-compliances found between the as-built facility and the design information. The criterion for determining the appropriate disposition of any non-compliances will be that the as-built facility conforms to the design criteria and flood protection characteristics in the original analysis.

GE also provided the results of a flood analysis for the control building. Both the staff and the Advisory Committee on Reactor Safeguards (ACRS) raised concerns regarding flood protection for the main control room as a result of a pipe break in the MST and as a result of a pipe break in the portion of the reactor service water (RSW) system in the control building.

GE stated that the greatest flood hazard in the MST occurs as a result of a feedwater line break. The amount of water associated with the break will be limited by manually 
closing the fectwater isolation valves. The water in the MST will collect in the large cavity at the RB and of the tunnel; any overflow from the cavity will flow to the turbine building. There are no openings or penetrations between the MST and the control building to provide a path for water to cater the coatrol building from the MST. This cosures that the control building is protected from flooding as a result of pipe failures in the MST. In the DFSER, the staff noted this to bo scceptable subject to inclusion of this information in the SSAR. This was DFSER Confirmatory Item 3.4.1-2. OE hes included this information in the SSAR. On the basis of this evaluation, DFSER Confirmatory Item 3.4.1-2 is resolved.

The control room area aits on a raised floor. The outride wall of the control room complex is sealed to prevent water in the corridor from entering the control room. Drinking wator and bathroom facilities are the only sources of water inside the control room. Fire hoses and standpipes are located in the corridors.

The evaluation of control building flooding included events that may result from the failure of fire protection systems. Flow of the water supplied from the failure of theee systems to the control areas will be prevented by diverting the water to the building basement and by locating anfetyrelated equipment in the building basement at least $400 \mathrm{~mm}$ above the basement floor. Safety-related equipment on higher levels are raised at least $200 \mathrm{~mm}(8 \mathrm{in}$.) above the floor.

Fire-fighting activities inside the control room will introduce water into this area. Because the control room is continuously manned, it is expected that fires inside the control room will be identified and quickly extinguished, thus limiting the amount of water which will accumulate. Water will either collect in the control room subfloor and drain to the building basement or flow out into the hallways, down stairways and elevator shafts, and to the building basement. The stuff expects that minimal damage to safety-related operations will occur due to the limited volume of water generated and the collection and diversion of the water.

GE also addressed control building flooding as a result of an RSW failure. A break in the RSW line inside the control building will allow water from the open cycle water source to flood the control building. The three redundant divisions of RSW supply cooling water to the reactor building cooling water (RCW) system heat exchangers located in the control building basement. Any flooding from sources above the basement that could adversely affect safe-shutdown equipment will be directed through floor drains, stairways, and elevator shafts to the basement. Each division is physically separated by watertight doors, is equipped with a sump pump, and contains two sets of safety-grado lovel seneors in a two-out-of-four logic. The firat (lower) set will slarm to alent the control room operator of the presence of excesaive water in the room. The second set of sensors will inform the control room operator that a serious flood situation exists in the RCW/RSW room. In addition, these high-level censors will trip the RSW pump and close the isolation valves for the affected division. As a result, a maximum of $\sim 5 \mathrm{~m}(\sim 16.4 \mathrm{ft})$ of water will collect in a divisional room. This amount of water will be contained in the affected divisional room and will not adversely affect the safoty function of the redundant divisions of the RCW and RSW. This analysis demonstrates that the cafecy-related equipment is adequately protected from the offects of a pipo break in the RSW system. In the DFSER, the staff noted that this ovaluation was acceptable subject to its inclusion in the SSAR. This was DFSER Confirmatory Item 3.4.1-3. The SSAR now includes this information, and Confirmatory Item 3.4.1-3 is resolved.

The radwaste building contains no safety-related equipmont and is isolated from the other plant structures with the exception of a tunnel which connects the reactor, control, turbine, and radwaste buildings. Liquid radwaste from these buildings is transferred to the waste processing system via lines running through this tunnel. The tunnel is sloped and connects to the turbine building at elevation $8,800 \mathrm{~mm}$ ( $28 \mathrm{ft}-7 / 8 \mathrm{in}$.), the radwaste building at $-1,500 \mathrm{~mm}$ (4 $\mathrm{ft}-11 \mathrm{in}$.$) , and the reactor and control$ buildings at $-8,200 \mathrm{~mm}(-26 \mathrm{ft}-10 \mathrm{7} / 8 \mathrm{in}$.). All ends of the tunnel are sealed to protect safety-related equipment from flooding which may originate in another building. All penetrations are designed to withstand the maximum expected hydrostatic and hydrodynamic loads. SSAR Subeection 3.12.3 provides design requirements for this tunnel and any other non-safety-grade tunnels that may be used in the $A B W R$ design. Tunnel design includes provisions for water tightness, accessibility, leak detection, and water removal. Failure of the tunnel will not adversely effect the ability to bring the plant to a safeshutdown condition and will not damage the seals at the interface with buildings housing safety-related equipment.

SSAR Subsection 3.12.2 provides design requirements for safety-related tunnels. These tunnels will:

(2) be routed independently or through separate compartments to assure divisional separation, 


\section{Deaign of Structures, Components, Equipment, and Systems}

(3) withetand both hydrometic and hydrodynumic affects from pipe breaks. Provisions for presurure roliof shall bo included as noceseary,

conoure the integrity of the piping peactrationes at interfacing buildinge under deaigen conditions,

allow periodic inspection of piping, cables, and penetrutions,

include provisione for leak dotection and wator removal,

provent unauthorized ascees to the tumsel,

include provisions for preventing fual oil from eccumoulating sear etructures houxing enfety-related equipment.

The service building is a non-seismic concrete structure, does not house any affety-rolated equipment, and provides access tunnels to the reactor, control, and lurbine buildings. The sccees corridors below plant grade which lead into buildinge that bouve safoty-related equipmeat have watertight doors to prevent eeepage into the corridon. The cervice building ba floor drains and two sumps to collect and transfer flood water.

In the DFSER, the ataff atated that GE had not included an annlyais of flooding in the turbine building and its potential offects on safety-rolated equipment. The staff requested that GE provide a flood analysis to characterize the nature of the hazards and the design features to protect anfotyrelated equipment from flooding in the turbino building. This wes DFSER Open Itom 3.4.1-1. Subeequently, GE provided a flood analysis for the turbine building. The major flood bezands in the turbine building occur as a recult of a failure in the circulating water aystem (CWS) or the turbine service water system (TSW). Both of thewe syetems are open-cycle systems. The CWS, because of its larger capacity, is the bounding hazard. Lak dolectors in the condenser pit will alert the control room and automatically isolate the CWS on indication of building flooding. TSW has no automatic isolation function bocause any flooding reaulting from a break in this line will be slow conough for operators to manually shut down the system on a flood alarm. A failure in either of these lines can recult in flooding of the building up to grado. A non-watertight truck door at grade lovel will allow release of the flood water onto the ground. As was stated earlier, the tunnel connecting the radwaste, reactor, and turbine buildings is sealed to prevent water from entering the RB. The staff finds the design to be an acceptable means to protect safety-related SSCs from the effects of flooding as a result of pipe failures in the turbine building. GE has also included thin information in the SSAR. Therefore, Open Itom 3.4.1-1 is resolved.

A dicenesed in SSAR Section 10.1, anfety-related inctrumeatation is provided in the turbino building to detect the fint cloaure of the turbine main steam atop and control valve oil prescure, atop valve position, turbino fint-etage presours, and main condonser preseoure. This inctrumeatation is decignod to fail safo should it be dameged dus to fire, flood, miscriles, or pipe failures. The tuff finds this scceptable.

SSAR Table 3.4-1 provides details about scceas openings between buildinge. All penetrations and scceses ways bolow flood lovel are watertight and doeigned to withetand the maximum hydroatatic loads.

In the DSER (SECY-91-235), the staff identified a noed for an interfece requirement to provide a flood analysis for arructures outside the ABWR design scope that house anfety-related equipment (Outstanding Issue 6). Upon further ovaluation, the staff determined that it is sufficient to ideatify a COL setion in the SSAR for the COL applicant to provide this information because the information is plant-epecific and is not noeded for design certification. This isove was reclassified as COL Action Irom 3.4.1-1 in the DFSER. SSAR Section 3.4.3.3 provides this information. This is accoptable and reeolved DSER Outstending Isove 6.

Based on the above review of the information provided in the SSAR, the staff concludes that safety related oquipment and instrumentation housed in the reactor, control, and turbine buildings is adequately protected from the effects of both internal and oxternal flooding and moots tho requirements of GDC 2.

The COL applicant is responsible for identifying external flood and precipitation hazards beyond those assumed in the ABWR flood analysis. With this, the applicant reforencing the ABWR design will be able to identify sitoepecific flood hazards and provide measures to protect safety-related equipment from these hazards. This will moet the requirements of 10 CFR Part 100, Appendix A, Section IV(c), regarding the required investigation for seismically-induced floods and water waves.

$G E$ originally submittod the design descriptions and the inspections, tests, analyses, and accoptance criteria (ITAAC) for the in-scope structures. These include verifications related to flood protection. During the preparation of the DFSER, the staff review was in progress. This was DFSER Open Itom 3.4.1-2. Subeequently, GE provided revised design descriptions and ITAAC. The adequacy and acceptability of the design 
decription and the ITAC are ovaluated in Section 14.3 of this report. Therefore, DPSER Open Itom 3.4.1-2 is recolved.

The stafi's flood protection reviow included all syetem and composents whose failure could prevent the afo shutdown of the plant and mainteannce thereof of reault in significant uncoatrolled release of radicactivity. From this roviow of the applicant's doaign criteria, deaign banen, and afery claseification for affety-rolated SSCe secenary for a enfo plant shutdown during and following the flood condition from either axternal or internal cuuses, the ctaff concludes that the deaign of the fecility for flood protection conforms to the Commiscion's regulations as ex forth in ODC 2 and 10 CFR Part 100 Appendix A with reepect to protection of SSCs importunt to safety from the effects of floods, tounamis, and soiches.

The staff concludes that the design provides adequate protection against floods and the effects of floods, moets the guidelines of SRP Section 3.4.1 and the requirements of GDC 2 as it rolates to flood protection, and is, therefore, scceptable.

\subsubsection{Water Lovel (Nood) Design Procedure}

GE ideatified the decign-basis flood elevation to be up to $30.5 \mathrm{~cm}(1 \mathrm{ft})$ bolow grade and the deaign-basis ground water lovel to be up to $61.0 \mathrm{~cm}(2 \mathrm{ft})$ below grade for the ABWR standard plant structures. GE performed calculations to determine the bydrostatic pressure and the bydrodynamic forces (as a result of earthquakes) on the structures that would result from theee lovels in combination with other loads as specified in the SSAR for structures. The staff finds that OE's calculations were performed using load combinations that are consistent with those apecified in SRP Section 3.8.4 and meet the requiroments of GDC 2. The staff evaluation for the design of the seismic Catogory I structures against the hydrostatic and hydrodynamic forces resulting from design-basis ground water during an earthquake is also provided in Section 3.4.1 of this report.

The staff concludes that the plant design on the basis of the specified wator lovel is accoptable.

By limiting the design-banis flood elevation to $30.5 \mathrm{~cm}$ (1 ft) below grade and the docign-basis ground water lovel to $61.0 \mathrm{~cm}(2 \mathrm{ft})$ below grado in the deaign of plant atructures, and by employing the lond combinations apecified in SSAR Section 3.8.4.3 and 3.8.5.3, the ABWR deoign provides oufficieat margin to provent atructural damage that is due to the mont eovere flood or ground water and the aseociated dynamic offects that were determined appropriate for the flood lovels. In addition, tho dadifn of ceismic Catogory I structures includes, in an coespenblo manner, load combinations that occur as a result of the moet rovere flood or ground-wneter-selated loads and the loads reaulting from normal and scoident conditions.

Because the bounding flood elovation for the ABWR is below plant srade, OB considered only the hydrostatic force in dotermining the loadinge on sismic Category I etructures. This mothod of calculating loeds is consietent with that of SRP Section 3.4.2 and provides a coneervative basis that, together with other engineering deaign considenations, auch as combination of flood loeds with other loada, and consideration of floatation as indicated in Section 3.8.5 of this report, casures that the structures will withetend auch environmental forces.

To meet the requirements of ODC 2 and Appendix A to 10 CFR Part 100, and the guidelines of SRP Section 3.4.1, the COL applicant should provide a specific description of its site and the elevations for all safoty-rolated structures, exterior acceaces, equipment, and systems, from the atendpoint of hydrological considerations and flood history (including date, level, peak discharge, and related information for major historical floods in the region of the site). To determine water lovel for the site, the COL applicant should consider the following factors, if applicablo:

- probable maximum precipitation
- runoff and stream-course models
- maximum flood flow
- coincident wind-wave activity

In the DFSER, the staff noted that the COL applicant should also domonstrato in its plant-sito-unique application that all the seismic Category I structures either will be protected againat flood damage or will not be subject to damaging flooding. Hydrostatic and hydrodynamic offects of the flood should be considered and deecribed for all postulated design flood lovels for the conditions set for the future site as previously outlined. This was DFSER COL Action Item 3.4.2-1. SSAR Section 2.3.2 states that the COL applicant shall provide identification and description of all differences from SRP Section II, "Acceptance Crileria," for aite charactoriatics (as augmentad by SSAR Table 2.1-1). Aleo, SSAR Sections 2.3.2.11 through 2.3.2.13 ideatify the COL ections related to plant-specific hydrologic dencription, floods, and probable maximum flood on streams and rivers. These addrese the staff' concern and are eccoptablo.

The staff finds that the ABWR flood decign provides reasonable eseurance that, in the event of floods or high ground water level, the structural integrity of the plant soismic Catogory I structures will not be impaired and, 
consequently, mismic Catogory I syetoms and components locatad within these atructures will be edequately protected and will bo expected to perform neceseary safety functions, as required.

\subsection{Misolles}

\subsubsection{Miadle Salection and Description}

Soismic Catogory I atructures have been analyzed and deaigned to bo protected from a wide epectrum of misciles (0.8., misailes from rotating and presourized equipmeat, gravitational miscalen, and misciles geserated from tornedo winds).

Once a potential misuilo is identified, its statistical aignificance is determined (a significant misuile is one which could cause unecceptable consequences or violate the guidelines of 10 CFR Part 100).

If the probability of occurrence of a missile $\left(P_{1}\right)$ is leas then $10^{-7}$ per year, the miseile is not considered aignificant. If $P_{1}$ is greater than $10^{-7}$ per year, the probability that it will impact a aignificant targot $\left(\mathrm{P}_{2}\right)$ is detormined. If the product of these probabilition $\left(P_{1} \times P_{2}\right)$ is leas than $10^{-7}$ per year, the missilo is not considered significant. If the above product is greater than $10^{-7}$ por year, the probability of significant damage $\left(P_{3}\right)$ is determined. If the combined probability $\left(\mathbf{P}_{1} \times \mathbf{P}_{2} \times \mathbf{P}_{3}\right)$ is leas than $10^{-7}$ per year, the missile is not considered sigmificant. Finally, if the above combined probability is greater than $10^{-7}$ per year, missile protection of safety-related SSCs is provided by one or more of the following:

(1) locating the system or component in a missilo-proof structure,

(2) separating redundant systems or components for the missilo path or range,

(3) providing local shields and barriers for systems and components,

(4) designing the equipment to withstand the impret of the most damaging missile,

(5) providing design features to prevent the generation of missiles,

(6) Orienting missile sources to prevent missiles from striking equipment important to safety.

The SSAR identified the design and operational criteria for missile protection as well as the systems requiring missile protection.

\subsubsection{Internally-generated missiles (Outside Containment)}

The etaff reviewed the ABWR devign for protecting SSCe important to mfoty against internally-generated miesiles outaide the containment in sccordance with SRP Section 3.5.1.1. Specifically, the reviow included the miscilo-protection design feature for the SSCo whoce failure could prevent enfo shutdown of the fecility or reault in significant uncontrolled release of redionctivity. The SRP scceptance critoria epecify that the deaign moet ODC 4, "Environmental and Dynamic Effects Denign Besee" as it relates to protecting the SSCe outride the contuinment againat the offocts of misailes that cas be internally senerated during facility operation, and RO 1.115, "Protection Against Low-Trajectory Turbine Miesiles," Revision 1. The staff's roviow of turbinogenerator analyses is provided in Section 3.5.1.3 of this report. The reviow included all areas outside the contrinmeat that are within the scope of the ABWR deaign.

GE ovaluated potential internally-generated misciles reaulting from failure of the plent equipment within the nuclear island and locuted outside the containment. Poteatial missiles aro categorized into two groupa:

(1) potential missiles that could result from the failure of rotating equipment such as the main turbine, reactor core isolation cooling (RCIC) turbine, pumps, fans, blowers, diesel generators, and compressors

(2) pressurized high-energy fluid system components considered potential missile sources, including valve bonnets, stems, pressure vessels, thermowells, retaining bolts, and hlowout penels

GE also performed probability calculations for certain rotating equipment and pressurized components to identify qualifying missiles. Piping failures were not included as sources of potential internally-generated missiles because the whipping section remains attached to the remainder of the pipe. The dynamic effects associated with this type of break are addressed in Section 3.6 of this report.

SSCs important to safety are protected from internallygeneratod missiles by

- placing them in individual missilo-proof enclosures

- providing localized protective shields and barriers

- physically soparating redundant components to prevent damage from a missile 
- orienting miseile cources to provent unscosptablo consequences of miscile generation

The adequacy of atructures, shiolds, and barriers provided for missile protection is evaluated in Section 3.5.3 of this report.

All electrically-powered rotating equipment wuch so pumps and fans are ac powerod and their epeods are governed by en ac power supply. Since the sc power supply frequency variation is limited to a narrow range, this rotating equipment is unlikely to attain an overepeed condition. Fan blado casinge are designed with sufficieat thickness so that a fun blado brenking off at rated apeed will not penetrate the fan caring. OE aubmitted PED-18-0389, a proprietary misaile generation study, which provides the details of the mothodology used to ensure that anfoty-related SSCs will be protectod from missiles that may be generated from rotating equipment. On the basis of the information provided in the etudy, the staff finds this methodology to be an acceptable means of prolecting anfety-related SSCs from missile damage.

Valve bonnets have sufficient design safoty factors (based on the ultimate strength of the materials) to provent them from becoming credible missiles. Valve stems have design features such as stem threads and backsents to prevent their ejection. Nuts, bolts, nut and bolt combinations, and nut and stud combinations have insufficient stored energy to require missilo-protection analysis. GE analyzed the thermowells and concluded that their maximum ejection velocity was insufficient to damage safety-related systems. Blowout panels are restrained by hinges to prevent the panels from becoming credible missiles. Air bottles are located, oriented, and restrained so as to prevent them from becoming missiles.

GB states that adoquato physical separation is provided between redundant trains for all safety-related systems. Further, each safety-related system is contained in its own room of a soismic Category I building. The walls, floor, and ceiling of this room act as the missile barrier or shield for the safety-related components in the room, protecting these components from missiles generated outside the room. Also, stored spent fuel is protected from internallygenerated missiles because no high-energy piping systems or rotating machinery are in its vicinity.

SSAR Section 3.5.1.1.1.3 and SSAR Figure 3.5-2 provide information that shows the orientation of the turbinogenerator in relation to the in-scope buildings which house safety-related equipment and identifies the low-trajectory missile strike zone. On the basis of this information, the staff concludes that no safety-related equipment is located within the turbine-generator missile strike zone. As a reault, this equipment is protected from a mistilo ejected from the turbino-genentor. Therefore, the staff concludes that the ABWR denign meets the guidelines of RO 1.115 and the requirements of ODC 4.

In the DSER (SECY-91-153), the staff stated that GE did not deacribe the means by which enfety-related systems will be protected from misciles generated by non-enfetyrelated components (Outstanding Ieswo 6). To addreas tho stafi's concern, OB stated (in responee to requeat for additional information (RAI) Q410.9) that no local barrion or shields outside the containment will be used for mitigating miscile offects. For non-safety-related componeats, so local shields and berriers will be required. Nonafoty-rolated components are arranged in such a way that any miswilo-generating component will not cause tho failure of more then one division of safety-related equipment. On the basis of GE's responses, which described the physical arrangement of equipment, the staff considered, in the DFSER, the chance of more than one division of a safetyrelated system being struck by missiles generated by nonanfety-related components to be extremoly low, and considered GE's resolution to this concern acceptable. This resolved DSER Outstanding Issue 6.

As discuseed in SSAR Soction 10.1, safety-related instrumentation is provided in the turbine building to detect the fast closure of the turbine main steam stop and control val'e oil pressure, stop valve position, turbine first-stage pressure, and main condenser pressure. This instrumentation is designed to fail safe should it be damaged due to fire, flood, missiles, or pipe failures. The staff finds this acceptable.

In the DFSER, the staff noted that the COL applicant should provide design details of all pressurized gas bottles as well as details of missile protection features for SSC. that are outside of the ABWR scope. This was DFSER COL Action Item 3.5.1.1-1. SSAR Section 3.5.1.1.2.2, subeection (3), provides design guidance to ensure that the pressurized gas bottles will not become the source of missiles. This is acceptable.

In the DSER (SECY-91-153), the staff incorrectly identified Outstanding Issue 5 related to the use of induction motors. This was deleted in the DFSER.

Verification of adequate separation of redundant divisions of safety-related systems ensures that these systems will not be rendered inoperable as a result of an intermallygenerated missile outside of containment. In the DFSER, this verification was identified as Open Item 3.5.1.1-1. Subsequently, GE submitted design descriptions and ITAAC for the buildings within the ABWR design scope. These include verifications related to missile protection for 
safety-related SSC8. The adequacy and acceptability of the design description and ITAAC aro ovaluated in Section 14.3 of this report. On the basis of the above, DFSER Open Itom 3.5.1.1-1 is resolved.

The reviow of possible effects of intermally generated missiles (outside containment) included SSCs whose failure could prevent safe shutdown of the plant or result in significant uncontrolled release of radionctivity. From its review of the SSAR design bases and criteria for safetyrelated SSCs necessary to maintain a safo plant shutdown, the staff concludes that, on the basis of the foregoing evaluation of separation of redundant divisions, the SSC will be protected from internally generated missiles (outside containment). Therefore, the ABWR design for protecting SSCs from internally generated missiles outside the contrinment meets the guidelines of SRP Section 3.5.1.1 and the dynamic effect design bases requirements of GDC 4 and is acceptable.

\subsubsection{Internally-generated missiles (Inside Containment)}

The staff reviewed the design of the facility for protecting SSCs important to safety against internally-generated missiles inside the containment in accordance with SRP Section 3.5.1.2. Specifically, the review included missileprotection design features for the SSCs whose failure could prevent safe shutdown of the facility or result in significant uncontrolled release of radioactivity. The SRP acceptance criteria specify that the design must meet GDC 4, "Environmental and Dynamic Effects Design Bases," as it relates to protecting the SSCs against the effects of missiles that can be generated inside the containment during facility operation.

GE evaluated potential internally-generated missiles resulting from plant equipment and component failures within the containment structure. The potential missiles identified by this analysis were categorized into three groups: missiles generated by rotating equipment (e.g., pump impellers, compressors, and fan blades), missiles generated by pressurized components (e.g., valve bonnets, thermowells, nuts, bolts, studs, valve stems, and accumulators), and gravitational missiles.

GE's analysis of failures of rotating equipment indicates that the equipment design prevents such equipment from becoming source of potential missiles. Pumps are unlikely to achieve an overspeed condition. All electrically-powered rotating equipment such as pumps and fans are ac powered and their speeds are governed by an ac power supply. Since the ac power supply frequency variation is limited to a narrow range, this rotating equipment is unlikely to attain an overspeed condition.
Fan blede casings are designed with sufficient thickness 80 that fan blade breaking off at rated speed will not penetrate the fan casing. GE submitted PDE-18-0389, a proprietary missile generation study, which provides the details of the methodology used to ensure that safetyrelated SSCs will be protected from missiles that may be generated from rotating equipment. On the basis of the information provided in the study, the staff finds this mothodology to be an acceptable means of protecting safety-related SSCs from missile damage.

GE stated in SSAR Section 3.5.1 that missiles generated by rotating equipment will be contained by the equipment housing. In the DFSER, the staff noted that GE should provide design information supporting this assertion or clearly state that this information will be provided by the COL applicant. This was DFSER Open Item 3.5.1.2-1. Subsequently, GE submitted the proprietary missile generation study previously discussed, which clarifies GE's approach to containment of missiles generated by rotating equipment. In addition, GE included this study as a reference in the SSAR Section 3.5.5. On the basis of the information provided in the study, the staff found this methodology an acceptable means of protecting safetyrelated SSCs from missile damage; therefore, DFSER Open Item 3.5.1.2-1 is resolved.

Pressurized components and equipment such as valve bonnets, valve stems, nuts, bolts, nut and bolt combinations, nut and stud combinations, thermowells, and blowout panels inside the containment are not considered credible missiles for the same reasons as stated in Section 3.5.1.1 of this report (e.g., design features or insufficient stored energy). Automatic depressurization system (ADS) accumulators are moderate energy vessels and are not considered as credible missile sources.

Fine motion control rod drive mechanisms under the reactor vessel are not credible missiles because the housings are designed to prevent any significant nuclear transient in the event of a drive housing break. Specifically, the pressure boundary containing the fine motion control rod drive mechanisms, including the bolted flange connections, will be stressed below the ASME Code limits and will meet all code requirements. To prevent control rod drop accidents, internal restraints will be provided to support the fine motion control rod drive housing in the event the housing-to-nozzle weld or the housing fails.

GE evaluated the potential for gravitational missiles inside the containment. Non-safety-related components are seismically supported to prevent their collapse during an SSE. These components include all cable trays for both Class 1E and non-Class 1E circuits as well as non- 


\section{Design of Structures, Components, Equipment, and Systems}

Class IE conduits ard non-safoty-rolated piping that could be potential hazards to safety-related equipmont. Also, equipment undergoing maintenance either will be removed during operation or will be seismically restrained to provent it from becoming a missile. This was DFSER COL Action Itom 3.5.1.2-1. SSAR Section 3.5.4.6 states that the COL applicant will provide these procedures. This is acceptable.

In the DFSER, the staff noted that the COL applicant should provide procedures ensuring that equipment undergoing maintenance will be removed from containment during operation or will be seismically restrained to protect it from becoming a missile. This was DFSER COL Action Item 3.5.1.2-1. In responding to this comment, SSAR Section 3.5.4.6, states that the COL applicant will provide procedures to ensure that all equipment inside containment that is required during maintenance will either be removed prior to operation, moved to a location where it is not a potential hazard to safety-related equipment, or seismically restrained to prevent it from becoming a missile. This is acceptable.

As discussed in SSAR Section 3.6.1, redundant divisions of safety-related equipment inside containment are physically separated to the extent practicable to maintain independence in order to prevent loss of safety function due to a single pipe break event. Specifically, redundant divisions of safety-related equipment are widely spaced around containment. A high-energy line separation analysis (HELSA) is used to determine which high-energy lines meet the spatial separation requirements. Although the HELSA evaluation is performed to determine if safetyrelated systems and components are adequately protected from the effects of pipe breaks, it is also helpful in determining if adequate protection is provided for these systems and components from missiles which may be generated inside containment.

As part of this evaluation, safety-related systems and components which are more than $9.14 \mathrm{~m}$ (30 ft) from any high-energy lines are considered as meeting the spatial separation requirements. Safety systems and components which are less than $9.14 \mathrm{~m}$ (30 ft) from high-energy piping are evaluated to see if damage could occur to more than one division. If damage can occur to only one division of safety-related systems, the requirement for separation of redundant equipment is met. If more than one division can be damaged by high-energy piping, barriers, shields, and enclosures will be utilized to protect safety systems and equipment. Based on this information regarding protection of safety systems and components from pipe failures, the staff concludes that this approach is equally effective in protecting these systems and components from missiles generated inside containment.
In the DSER (SECY-91-153), the staff stated that credible secondary missiles (concrete fragments) resulting from the impact of primary missiles on containment structures should be addressed in an interface requirement (Outstanding Issue 7). In the DFSER, the staff noted that this issue should be addressed as part of the ITAAC program. However, as a result of further evaluation, the staff determined that the protection of safety-related SSCs from eccondary missiles is addressed as part of the evaluation in Section 3.5.3 of this report. Thus, DSER Outstanding Issue 7 is withdrawn and resolved.

As mentioned in SSAR Section 10.1, safety-related instrumentation is provided in the turbine building to detect the fast closure of the turbine main steam stop and control valve oil pressure, stop valve position, turbine first-stage pressure, and main condenser pressure. This instrumentation is designed to fail safe should it be damaged due to fire, flood, missiles, or pipe failures. The staff finds this acceptable.

As a result of review of this information, the staff concludes that safety-related equipment is adequately protected from missiles that may be generated inside containment since each redundant division of safety-related systems is housed in its own separate missile-proof enclosure. Therefore, the requirements of GDC 4 are met.

Verification of adequate separation of redundant divisions of safety-related systems ensures that these systems will not be rendered inoperable as a result of an internallygenerated missile inside of containment. In the DFSER, this verification was identified as Open Item 3.5.1.2-2. Subsequently, GE submitted design descriptions and ITAAC for the buildings within the ABWR design scope. These include verifications related to missile protection for safety-related SSCs. The adequacy and acceptability of the design description and ITAAC are evaluated in Section 14.3 of this report, therefore, DFSER Open Item 3.5.1.2-2 is resolved.

The review of possible effects of internally generated missiles (inside containment) included SSCs whose failure could prevent safe shutdown of the plant or result in significant uncontrolled release of radioactivity. Based on the review of the SSAR design bases and criteria for safety-related SSCs necessary to maintain a safe plant shutdown, the staff concludes that the SSCs to be protected from internally-generated missiles (inside containment) meet the requirements of GDC 4 .

The staff concludes that the ABWR design for protecting SSCs from internally generated missiles inside the containment meets the guidelines of SRP Section 3.5.1.2 and 
the dynamic offect design beses requirements of GDC 4 and is acceptable.

\subsubsection{Turbine Missiles}

The staff requested that $G E$ provide additional information (Q251.13 and Q251.14) on turbine missile generation. $G E$ responded by revising SSAR Section 3.5.1.1.1.3 to include a layout of the turbine-generator building indicating the \pm 25 degree low-trajectory turbine missilo ejection zone. The turbine-generator building is favorably oriented with respect to the primary containment building so that any postulated turbine missile will not strike the primary containment building. GE also commits to meeting RG 1.115, "Protection Against Low-Trajectory Turbine Missile," Revision 1, which specifies that the probability of unacceptable damage from turbine missiles be maintained to less than $10^{-7}$ per reac.or-year.

The probability of unacceptable damage from turbine missiles is expressed as the product of (1) the probability of turbine missile generation resulting in the ejection of turbine disk (or internal structure) fragments through the turbine casing $\left(P_{1}\right) ;(2)$ the probability of ejected missiles perforating intervening barriers and striking safety-related SSCs $\left(P_{2}\right)$; and (3) the probability of struck structures, systems, or components failing to perform their safety functions $\left(\mathbf{P}_{3}\right)$.
In previous reviews of the probability calculation, the staff found that the mathematical models that were used to calculate $P_{2}$ and $P_{3}$ require numerous approximations and simplifying assumptions in order to incorporate available duta in the analysis. As a result, the calculations of $P_{2}$ and $P_{3}$ were not accurate; however, the calculation of $P_{1}$ was considered more accurate and precise. Therefore, in recent years, the staff placed emphasis on reviewing the probability of turbine missile generation $\left(P_{1}\right)$. The staff believes that if $P_{1}$ is controlled to a minimum, the final failure probability of unacceptable damage can be met. Consistent with the staff position taken in recently licensed nuclear plants, the probability of turbine missile generation should be kept to no greater than $10^{-5}$ per reactor-year for an unfavorably oriented turbine and $10^{-4}$ for a favorably oriented turbine. The staff also recommended certain actions for situations when the probability does not meet the minimum values required (see Table 3.1 of this report). The staff recommended in its DSER (SECY-91-153) that GE include the minimum requirement for the probability of turbine missile generation in SSAR Table 3.5-1. (This was not identified as an open item.) GE included this table in the SSAR and it is acceptable.

GE prepared a proprietary report in January 1984 entitled, "Probability of Missile Generation in General Electric Nuclear Turbines." The staff reviewed the report and found the methodology acceptable for calculating the

\section{Table 3.1 Criteria pertaining to the probability of turbine missile generation for a favorably} oriented turbine

\begin{tabular}{|c|l|}
\hline $\begin{array}{c}\text { Probability Criterion } \\
\left(\mathrm{yr}^{-1}\right)\end{array}$ & Required Licensee Action \\
\hline $\mathrm{P}_{1}<10^{-4}$ & $\begin{array}{l}\text { This is the general, minimum reliability requirement for loading the turbine and bringing } \\
\text { the system on line. }\end{array}$ \\
\hline $10^{-4}<\mathrm{P}_{1}<10^{-3}$ & $\begin{array}{l}\text { If this condition is reached during operation, the turbine may be kept in service until the } \\
\text { next scheduled outage, at which time the licensee is to take action to reduce } \mathrm{P}_{1} \text { to meet the } \\
\text { first criterion before returning the turbine to service. }\end{array}$ \\
\hline $10^{-3}<\mathrm{P}_{1}<10^{-2}$ & $\begin{array}{l}\text { If this condition is reached during operation, the turbine is to be isolated from the steam } \\
\text { supply within } 60 \text { days, at which time the licensee is to take action to reduce } \mathrm{P}_{1} \text { to meet the } \\
\text { first criterion before returning the turbine to service. }\end{array}$ \\
\hline $10^{-2}<\mathrm{P}_{1}$ & $\begin{array}{l}\text { If this condition is reached at any time during operation, the turbine is to be isolated from } \\
\text { the steam supply within } 6 \text { days, at which time the licensee is to take action to reduce } \mathrm{P}_{1} \text { to } \\
\text { meet the first criterion before retuming to service. }\end{array}$ \\
\hline
\end{tabular}


probability of turbins missile generation (NUREG-1048, Supplement 6). Various parameters are considered in the methodology that influence the outcome of the turbine missile generation probability, such as turbine disk design, disk material properties, turbine speed control systems, postulated crack growth rate, and inspection intervals. On the basis of parametric variations, the methodology can optimize turbine disk inspection intervals 80 that the turbine missile generation probability will be kept to the allowable limit. The staff believes that by emphasizing on the turbine disk inspection program, which includes a specified inspection interval, and an effective turbine control system maintenance program, the turbine will be operated in a safe manner.

Consistent with the staff position taken in recently licensed nuclear plants, the COL applicant should submit for NRC approval, within 3 years of obtaining a COL, a turbine system maintenance program, including probability calculations of turbine missile generation based on the methodology approved by the NRC, or commit to volumetrically inspect all low-pressure turbine rotors at the second refueling outage and every other (alternate) refueling outage thereafter until a maintenance program is approved by the staff. This position is also discussed in Section 10.2.2 of this report. In the DSER (SECY-91-153), the staff classified this item as an interface requirement. Upon further review the staff reclassified this item in the DFSER as COL Action Item 3.5.1.3-1.

GE addressed this item in SSAR Section 3.5.1.1.1.3, stating that the COL applicant shall submit for NRC approval, within 3 years of obtaining a COL, a turbine system maintenance program, including probability calculations of turbine missile generation based on the methodology approved by the NRC, or commit to volumetrically inspect all low-pressure turbine rotors at the second refueling outage and every other (alternate) refueling outage thereafter until a maintenance program is approved by the staff. This is acceptable.

\subsubsection{Missiles Generated by Natural Phenomena}

The staff reviewed the design of the facility for protecting SSCs important to safety from missiles generated by natural phenomena in accordance with SRP Section 3.5.1.4. The SRP acceptance criteria specify that the design meet GDC 2 and 4. GDC 2 requires that SSCs important to safety be protected from the effects of natural phenomena; GDC 4 requires that SSCs important to safety be designed to accommodate the effects of and to be compatible with the environmental conditions associated with normal operation, maintenance, testing, and postulated accidents, including loss-of-coolant accidents
(LOCAs). The design is considered to be in compliance with GDC 2 and 4 if it meets RG 1.76, "Design Basis Tornado for Nuclear Power Plants, " Revision 0, Positions C.1 and C.2, and RG 1.117, "Tomado Design Classification," Revision 1, Positions C.1 through C.3.

GE considered tornado-generated missiles as the most limiting hazard resulting from natural phenomena in the design of SSCs important to safety. According to the guidelines of SRP Section 3.5.1.4, this is an accoptable design basis for the standard plant. In the early SSAR amendments, the missiles considered in the ABWR design were taken from ANSI/ANS Standard 2.3. They corresponded to a design-basis tornado (DBT) with a maximum tornado wind speed of $418 \mathrm{~km} / \mathrm{hr}(260 \mathrm{mph})$ for Region I and with a probability of occurrence of 10E-6 per year. As stated in the DSER (SECY-91-153), the staff disagreed with GE's choice of the DBT for the ABWR standard design and identified this as part of DSER Outstanding Issue 8.

The staff's position on the DBT is provided in RG 1.76 . For the eastern United States, RG 1.76 specifies tornado parameters with probability of occurrence of 10E-7 per year at up to a 90-percent confidence level and maximum wind speeds in tangential and translational velocities of 531 and $113 \mathrm{~km} / \mathrm{hr}$ (330 and $70 \mathrm{mph}$ ), respectively. However, the regulatory position in RG 1.76 has been reevaluated recently by the staff using more recent tornado data. The reevaluation is documented in NUREG/CR-4461, "Tornado Climatology of the Contiguous United States," dated May 1, 1986. The reevaluation found that the tornado strike probabilities range from near 10E-7 per year for much of the western United States to about 10E-3 per year in the central United States. The wind speeds associated with a tornado having a strike probability of 10E-7 range from less than $246 \mathrm{~km} / \mathrm{hr}(153 \mathrm{mph})$ to $534 \mathrm{~km} / \mathrm{hr}(332 \mathrm{mph})$. These wind speed estimates are 48 to $161 \mathrm{~km} / \mathrm{hr}$ (30 to $100 \mathrm{mph}$ ) lower than the speed estimates presented in WASH-1300 and RG 1.76 for most of the United States. From the reevaluation, the staff concluded that it would be reasonable to reduce DBT wind speeds to $322 \mathrm{~km} / \mathrm{hr}$ (200 mph) for the United States west of the Rocky Mountains and to $483 \mathrm{~km} / \mathrm{hr}(300 \mathrm{mph})$ for the United States east of the Rocky Mountains. As a result, the Commission in its SRM of July 21, 1993, approved the staff-recommended position that a maximum tornado wind speed of $483 \mathrm{~km} / \mathrm{hr}$ (300 mi/hr) be used in the DBT for ALWRs. The revised tornado parameters are also discussed in Section 2.3.1 of this report. Subsequently, GE used the modified RG 1.76 guidelines in identifying the DBT as $483 \mathrm{~km} / \mathrm{hr}$ (300 mph) with a strike probability of $10^{-7}$ per year. The staff finds this acceptable. 
In the carly SSAR amendments, OB stated that the ABWR doaign will withetand an 1,800-kg (4000-lb) automobile, a 125-kg (280-1b), 20-cm (8-in.) armor-piencing artillery abell, and $2.54-\mathrm{cm}$ (1-in.) solid stoel sphere, all impacting at 35 percent of the maximum horizontal windspeed of the DBT. GE identified these missiles as Spectrum I. GE's proliminary ovaluation of the design revealed that the reactor building (RB) superstructure and roof should be thickened and the roof purlins strengthened. As a result, the seismic model should also be modified. The structural design sspects of this issue were discussed in Section 3.8.4 of the DFSER. This was DFSER Open Item 3.8.4-4. GE's resolution of DFSER Open Item 3.8.4-4 and the staff's evaluation of GE's responses to this open item are discussed in Section 3.8.4 of this report. In the DFSER, the staff noted that, as a result of these structural design changes, several SSAR sections and appendices that were affected need to be revised to reflect the aforementioned DBT and missile spectra. This was DFSER Confirmatory Item 3.5.1.4-1. SSAR Sections 3.3.2 and 3.5.1.4, specify the design basis tornado wind speed of $483 \mathrm{~km} / \mathrm{hr}(300 \mathrm{mph}$ ) and missile Spectrum I of SRP Section 3.5.1.4. On the basis of this information, Confirmatory Item 3.5.1.4-1 is resolved.

Based on this information, the staff concludes that GE has adequately identified and characterized the design basis natural phenomena in accordance with the modified guidelines of RG 1.76 .

Positions C.1, C.2, and C.3 of RG 1.117 state that SSCs important to safety that should be protected from the effects of a DBT are:

(1) those necessary to ensure the integrity of the RCPB,

(2) those necessary to ensure the capability to shut down the reactor and maintain it in a safe-shutdown condition (this includes both standby and cold shutdown capability), and

(3) those whose failure could lead to radioactive releases resulting in calculated offsite exposures greater than 25 percent of the guideline exposures of 10 CFR Part 100.

Compliance with Positions C.1 through C.3 of RG 1.117 was identified by the staff as a part of Outstanding Issue 8 in the DSER (SECY-91-153). In the SSAR Section 3.5.1.4 revisions that followed, GE discussed Positions C.1 and C.2. These discussions are acceptable, Subsequent to this, GE informed the staff that Position C.3 of RG 1.117 would also be met. This was DFSER Confirmatory Item 3.5.1.4-2. Systems meeting the protection guidelines of RG 1.117 have been identified in Table 3.2-1. These syetems, with the exception of the standby gas treatment system (SGTS) charcoal adsorters and certain instrumentation, are located in seismic Category I structures which are designed to withstand winds and missiles generated by the above-mentioned tornado.

As discussed in SSAR Section 10.1, safety-related instrumentation is provided in the turbine building to detect the fast closure of the turbine main steam stop and control valve oil pressure, stop valve position, turbine first-stage pressure, and main condenser pressure. This instrumentation is designed to fail safe should it be damaged due to fire, flood, missiles, or pipe failures. The staff finds this acceptable.

GE described the plant layout that provides external missile protection for the SGTS charcoal adsorber bets and the offgas system charcoal adsorber beds. The SGTS is located in the seismic Category I reactor building and is therefore protected from a tornado-generated missile. The offgas system charcoal beds are located deep within the turbine building, which is not designed to seismic Category I requirements. However, based on its review of the layout drawings of the turbine building, the staff concludes that the intervening barriers (walls and floors) between the beds and an external tornado missile provide adequate protection for the beds.

Based on this additional design information, the staff finds that the ABWR design meets the guidelines of Positions C.1, C.2, and C.3 of RG 1.117 and is acceptable. Therefore, DSER Outstanding Issue 8 and DFSER Confirmatory Item 3.5.1.4-2 are resolved.

In the DFSER, the staff noted that the COL applicant should identify missiles generated by other site-specific natural phenomena that might be more limiting than those considered in the ABWR design and should provide protection for the SSCs against such missiles. These were DFSER COL Action Items 3.5.1.4-1 and 3.5.1.4-2, respectively. To address this first COL action item, GE revised SSAR Section 3.5.4.2 by stating that the COL applicant shall identify missiles generated by other sitespecific natural phenomena that may be more limiting than those considered in the ABWR design and shall provide protection for the SSCs against such missiles. This is acceptable. To address the second COL action item, GE revised SSAR Section 3.5.4.5 by stating that a turbine system maintenance program, including probability calculations of turbine missile generation meeting the minimum requirement for the probability of missile generation, shall be submitted by the COL applicant for staff review. This is also acceptable. 
As a reoult of its reviow of the cormado and deaign information, the staff concludes that OB has identified the woret-case saturn phenomena and has provided adoquate protective decign features to ensure that SSCs important to safoty will be protected. Furthermore, OE his ideatified the SSC important to wafety which require protection from natural phenomean. Therofore, the staff concludes that $O B$ moets the guidelines of ROa 1.76 and 1.117. As a result, the requirements of ODC 2 and ODC 4 are satiofied.

Verification of adequate exparation of redundant divisions of anfoty-related aystems and location of these aystoms in structures deaigned to withetand tornadic winds and missiles generated by theee winds censure that thewe systome will not be rendered inoperable as a result of missiles generated by natural phenomena. In the DFSER, this verification was identified as Open Itom 3.5.1.4-1. Subeequently, GE submitted design descriptions and ITAAC for the buildings within the ABWR design scope. These include verifications related to missile protection for safety-related SSC and location of these systoms in structures designed to withstand tornado misailes. The adequacy and acceptability of the design description and ITAAC are evaluated in Section 14.3 of this report; therefore, DFSER Open Item 3.5.1.4-1 is recolved.

SSCs important to safety are dosigned to withstand the effects of natural phenomena without loss of the capability to perform their safety functions. The besis for acceptance in the staff review is the conformance of the ABWR design and design criteria for the protection from the effects of natural phenomena to the Commission's regulations as set forth in the GDC and to applicable regulatory guides. The staff concludes that GE's assessment of possible hazards due to missiles generated by the design besis tornado is acceptable and conforms to the requirements of GDC 2 and GDC 4 as related to tornado-generated missiles. This conclusion is based on the ABWR design meeting the requirements of GDC 2 and GDC 4 by meeting (a) RG 1.76, Positions C.1 and C.2 and (b) RG 1.117, Positions C.1 through C.3. Therefore, the ABWR design meets the guidelines of SRP Section 3.5.1.4 and is acceptable.

\subsubsection{Site Proximity Missiles (Except Aircraft)}

In SSAR Section 3.5.1.5, GE originally stated that "external missiles other than those generated by tornados are not considered design basis . . .," since the resultant event probability is $\leq 10^{-7}$. In the DPSER, the etaff identified it as a site-specific action item for the COL applicant to address. This was DFSER COL Action Item 3.5.1.5-1. Subsequently, in SSAR Section 3.5.4.3, Amendment 33, GE stated that the COL applicant shall provide an analysis that demonstrates that the probability of misciles impacting the ABWR stendard plant and cauring consequencen greater then those permitted in 10 CFR Part 100 guidelines is $\leq 10^{-7}$. This is acceptable.

\subsubsection{Aireraft Hamards}

In the SSAR Section 3.5.1.6, GE originally stated that "aircraft hazards are not a design-basis event . . .," since the recultant event probability is $\leq 10^{-7}$. In the DFSER, the enffidentified it as a sito-specific action item for the COL applicant to addrees. This was DFSER COL Action Itom 3.5.1.6-1. Subeequently, in SSAR Section 3.5.4.3, Amendment 33, GE stated that the COL applicant shall provide an analysis that demonstrates that the probability of aireraft impacting the ABWR standard plant and causing consequences greater then those permitted in 10 CFR Part 100 guidelines is $\leq 10^{-7}$. This is acceptable.

\subsubsection{Structures, Systems, and Components To Be Protected From Externally Generated Missiles}

The staff reviowed the design of the facility for protecting SSC important to eafety (within the ABWR design scope) against externally generated missiles in accordance with SRP Section 3.5.2. The SRP acceptance criteria specify that the design must moet GDC 2, "Design Bases for Protection Against Natural Phenomena," and 4, "Environmental and Dynamic Effects Design Bases." The design is considered to be in compliance with GDC 2 and 4 if it meets RG 1.13, Revision 1, "Spent Fuel Storage Facility Design Basis," as it relates to the capability of the spent fuel pool systems and structures to withstand the effects of extermally generated missiles and prevent missiles from contacting stored fuel assemblies; RG 1.27, "Ultimate Heat Sink for Nuclear Plants," Revision 2, as it relates to the capability of the ultimate heat sink and connecting conduits to withstand the offects of externally generated missiles; RG 1.115, "Protection Against Low-Trajectory Turbine Missiles," Revision 1, as it relates to the protection of the SSCs important to safety from the effects of turbine missiles; and RG 1.117, "Tornado Design Classification," Revision 1, as it relates to the protection of SSCs important to safety from the effects of tornado missiles. Protection from low-trajectory turbine missiles, including compliance with RG 1.115, is discussed in Section 3.5.1.3 of this report.

GE identified safety-related SSCs in SSAR Table 3.2-1. It corsidered the tornado-generated missiles as the limiting externally generated missiles for the ABWR design. Therefore, all the safety-related systems and components listed in the table, with the exceptions discussed in Section 3.5.1.4 of this report, are located in tornadoresistant buildings or structures. On the bases of this 
information, the staff concludes that the ABWR design meets the guidelines of RO 1.117.

The now and spent fuel storage systems are locatod in the tormado-resistant RB. Therefore, the guidelines of RG 1.13 are mot.

The ultimate heat sink (UHS) and its connecting conduits aro not considered in this mection. GE identified the UHS as being outside the scopo of the ABWR deaign and dofined it in Section 4 of the CDM as an interfacing system for COL applicants referencing the ABWR deeign. Applicante referencing the ABWR design will provide the design details of the UHS for staff review at the combined license stage. At that time, the staff will evaluate the UHS design for compliance with the guidelines of RG 1.27 and the requirements of GDC 2 and GDC 4.

SSAR Section 3.5.1.4 states that the offgas system charcoal delay beds are located deep within the turbine building and consequently will be unlikely to rupture as a result of a design basis tornado missile. From the layout drawings for the turbine building, the staff concludes that the intervening walls and barriers between the delay beds and an external tornado missilo provide adequate protection for the beds.

As was stated in Section 3.5.1.1 of this report, GE provided information in SSAR Section 3.5.1.1.1.3 and Figure 3.5-2 that shows the orientation of the turbinegenerator in relation to the in-scope buildings which house safety-related equipment and identifies the low-trajectory missile strike zone. Based on this information, the staff concludes that no safety-related equipment is located within the turbine-generator missile strike zone. As a result, this equipment is protected from a miesile ejected from the turbine-generator. Therefore, the staff concludes that the ABWR design meets the guidelines of RG 1.115.

As discussed in SSAR Section 10.1, safety-related instrumentation is provided in the turbine building to detect the fast closure of the turbine main steam stop and control valve oil pressure, stop valve position, turbine first-stage pressure, and main condenser pressure. This instrumentation is designed to fail safe should it be damaged due to fire, flood, missiles, or pipe failures. The staff finds this acceptable.

Based on the review of this information, the staff concludes that the ABWR design meets the guidelines of RGs 1.13, 1.115, and 1.117. Furthermore, the staff concludes that GE has provided adequate guidance to ensure that an applicant referencing the ABWR design will provide sufficient design information to ensure that the UHS will meet the guidelines of RG 1.27 and the requirements of GDC 2 and GDC 4. Therefore, the staff finds that the portion of the design within the ABWR scope meots the requirements of GDC 2 and GDC 4.

In tho DSER (SECY-91-153), the staff identified the need for an interface requirement to protect anfety-related equipment from failures of non-safety-rolated SSCs not boused in tornado-resistant buildings or structures (Outunding Isave 9). Upon further evaluation, the ataff determined that this action did not moet the definition of an interface requirement. This issue was reclassified as DFSER Open Itom 3.5.2-1 related to ITAAC. Verification of adequate separation of redundent divisions of safetyrelated systems and location of these systems in structures designed to withstand externally generated missiles (including those that result from the failure of non-safetyrelated SSCs not housed in tomado-resistant buildings) ensure that these systems will not be rendered inoperable as a result of the missiles. In the DFSER, this verification was identified as Open Item 3.5.2-1. Subsequently, GE submitted design descriptions and ITAAC for the buildings within the ABWR design scope. These include verifications related to missile protection for safety-related SSCs and location of these systems in structures designed to withstand externally generated missiles. The adequacy and acceptability of the design description and ITAAC are evaluated in Section 14.3 of this report; therefore, DFSER Open Item 3.5.2-1 is resolved.

In the DFSER, the staff noted that the COL applicant should design SSCs outside the ABWR design scope. Any failure of these SSCs which may result in external missile generation should not prevent safety-related SSCs from performing their intended safety function. This was DFSER COL Action Item 3.5.2-1. GE has included this action item in the SSAR. This is acceptable.

In the DSER (SECY-91-153), the staff noted that GE had not listed the design-basis tornado-generated missiles considered in the ABWR design. Subsequently, GE stated that the ABWR design will withstand an $1,800-\mathrm{kg}$ (4,000-lb) automobile, a 125-kg (280-lb), 20-cm (8-in.) armor-piercing artillery shell, and a 2.54-cm (1-in.) solid steel sphere, all impacting at 35 percent of the maximum horizontal windspeed of $483 \mathrm{~km} / \mathrm{hr}$ (300 mph) of the DBT. These missiles are identified as Spectrum I. As stated in Section 3.5.1.4 of this report, the RB superstructure and roof were thickened, the roof purlins were strengthened, and the seismic model was modified.

As was stated earlier, verification of adequate separation of redundant divisions of safety-related systems and location of these systems in structures designed to withstand externally generated missiles ensure that these systems will not be rendered inoperable as a result of the 
misailes. In the DFSBR, this verification was identified as Open Itom 3.5.2-2. Subequently, GB rubmitted doxign deceriptions and ITAAC for the buildinge within the ABWR deaign scopo. Thewe include verifications of divisional expantion for anfety-rolated SSC and location of these syctems in etructures designod to withetand externally secoerated misciles. The sdequacy and acceptability of the deaign deacription and ITAMC are ovaluated in Section 14.3 of this report; therefore, DFSER Open Item 3.5.2-2 is resolved.

The reviow of the SSCs to be protected from externally generated missiles included all safoty-related SSCs within the ABWR desizm scope provided to support the resctor facility. From reviow of the SSAR decign criteria, devign bases, and safety classifications for SSCs necoseary for afe reactor shutdown, the staff concludes that the SSC to bo protected from externally generated missiles conform to the guidelines of SRP Section 3.5.2 and the requirements of GDC 2 and 4.

\subsubsection{Barrier Design Procedures}

Missile barriers and protection structures are designed to withstand and absorb missile impact loads to prevent damage to safety-related SSCs based on the relevant requirements of GDC 2 and 4. The staff reviewed the design of seismic Category I SSCs to determine if they aro shielded from, or designed for withstunding, various postulated missiles using the guidance of SRP Section 3.5.3. SSAR Soction 3.5.3 contains information on procedures used in the design of the structures, shields! and barriers to resist the effects of missiles.

For the prediction of local damage from missiles, GE provided, in SSAR Amendment 32, information on the procedures used in the design of concrete and steel atructures. GE applied the empirical equations such as the modified Petry formula or U.S. Army Technical Manual TM 5-855-1 formula analytically for missilo protection in concrete. The staff finds that use of the Petry formula or U.S. Army Technical Manual TM 5-855-1 formula, as verified by impact tests, and with the thickness equal to or greater than the minimum required as specified for Region II listed in Table 1 of SRP Section 3.5.3 will result in sufficient concrete barrier thickness to prevent barrier perforation and, when necessary, prevent spalling or scabbing. This is acceptable.

GE used the Stanford equations for missile penetration in steel. As discussed in SRP 3.5.3, the staff finds the use of this formula accoptable. Composite barriers are not used in the ABWR design and were, therefore, not discussed.
Regarding overall damage prediction, OE sesumed that misaile impact is plastic and that all of the missilo's initial momentum is transferred to the structure or barrier, with only a portion of the kinetic energy absorbed as strain cenergy within the structure or barrier. GE evaluated the equivalent atatic load on the impacted area using an analysis for rigid misailes similar to the Williamson and Avy analyais, "Impact Bffect of Fragments Striking Structural Elements," November 1973. As stated in SRP 3.5.3, the etaff finds the secumption of plastic collisions and use of the Williams and Alvy analytical procedure, together with the use of the permissible ductility ratio as indicated in Appendix A to SRP Section 3.5.3 to dotermino equivalent static loads, acceptable.

The staff finds acceptable the procedures used for determining the offects and losdings on seismic Catogory I structures and missile shields and barriers induced by design-basis missiles selected for the plant because thoy provide a conservative basis for engineoring design to ensure that the structures or barriers will adequately withstand the effects of such forces.

The use of these procedures provides reasonable assurance that if a designbasis missile should strike seismic Category I structures or other missile shields and barriers, the atructures, shields, and barriers will not be impaired or degraded to an extent that will result in a loss of required protection. Seismic Category I systems and components protected by these structures will, therefore, be adequately protectod against the effects of missiles and will be capable of performing their intended safety functions. Conformance with these procedures is an acceptable basis for satisfying, in part, the requirements of GDC 2 and 4.

As previously discussed, GE used acceptable procedures in its barrier design. Thus, the staff finds that the barrier design is acceptable and meets SRP Section 3.5.3 and GDC 2 and 4, with respect to the capabilities of the structures, shields, and barriers to provide sufficient protection to SSCs that must withstand ine effects of natural phenomena (tornado missiles), and the environmental effects of missiles, pipe whipping, and discharging fluids.

In SSAR Section 3.5.4, GE identified the responsibilities of the COL applicant for the design of barriers and protective structures to withstand the impact of postulated missiles. The staff discusses these actions in Sections 3.5.1 and 3.5.2 of this report.

SSAR Section 3.5.4.1 identifies a COL action for the barrier design of the UHS. For this action, COL applicants should meet RG 1.27, "Ultimate Heat Sink for Nuclear Power Plants, " by demonstrating that the UHS and the connecting conduits are capable of withstanding the 
offects of externally gecoerated mieciles. This is ecceptable.

\subsection{Protection Against Dynamic Effects Associated With the Postulated Rupture of Piping}

\subsubsection{Ptant Deaign for Protection Againat Poctulated Piping Pallure in Fluid Syatems Outside Contrinsnent}

The staff roviewed the ABWR devign regarding protection of SSCs important to safoty againat postulated piping failures in fluid eystome outside the containment, but within the ABWR deaign scope, in sccordance with SRP Section 3.6.1. Specifically, the SRP scceptance criteria epecify that the deaign moet GDC 4, "Bnvironmental and Dynamic Effects Deaign Bases," as it relates to accommodating the dynamic effects of poetulated pipe rupture, including the effects of pipe whipping and discharging fluids. The design is considered to comply with ODC 4 if it conforms to Branch Technical Position (BTP) ASB 3-1, "Protection Against Postuluted Piping Failures in Fluid Systems Outside Containment," with regard to high- and modorato-energy fluid aystems outside the containment.

The staff will evaluate on a 'caso-by-case besis (1) protection against postulated piping failures outside the containment for any SSCs not within the scope of the ABWR design for each application referencing the $A B W R$ design and (2) the systems or features added to the ABWR structures by these applications.

GE discussed the analysis methodology and the offects of postulated pipo broaks in high-energy fluid systems for pipe whip, jet impingement, flooding, room pressurization, and environmental paramoters such as temperature, pressure, humidity, and radiation. However, the staff stated in the DSER (SECY-91-153) that GE did not considor pipe breaks and the resulting dynamic effects in the postulation of piping failures in main steam and feedwater systoms inside the main steam tunnel (MST). GE justified their exclusion by stating that the piping in these systems mot the LBB criterion. The staff expects that a bona fide LBB analysis should use plant-specific data such as piping seometry, materials, fabrication procedures, loads, degradation mechanisms, and pipe support locations. In its evaluation of the LBB exclusion, which is discussed in Section 3.6.3 of this report, the staff concluded that LBB could not be considered in the analysis of pipe failures. GE subsequently provided an analysis of an MSL and a main foedwater line pipe failure in SSAR Section 6.2.3; the staff's review of this analysis is found in Section 6.2.1.7 of this report. In a meeting with the staff, GE committed to removing references to LBB from the
SSAR. This was identified as Confirmatory Itom 3.4.1-1 in the DFSER and is discuseed in Section 3.4.1 of this report.

OB diweuseed pipe leakage crack events involving moderato-energy fluid syetems for wetting from epray, flooding, and other environmental effects, addressing the mothods for protecting the systems against the offects of piping failures. Physical separation is used to the extent practicable to provent the lose of redundent eafoty-rolated aysteme (including auxiliary systems) as a result of any single postulated oveat. If the required spatial separation (based on specific breaks) between redundant trains or syetome cannot be maintained, barriers, enclosures, ahiolds, or restraints will be provided. Protection aleo includes ensuring that the equipment and components important to safety are environmentally qualified for the cavironment to which they may be exposed as a result of postulated piping failures, as discuseed in SSAR Section 3.11, "Equipment Qualification Environmental Devign Criteria, " and Appendix 31. The staff's ovaluation of the protection provided against adverse environmental offects resulting from postulated piping failures is discused in Section 3.11 of this report.

GE provided lists of safety-related systems, components, and equipment both inside and outside the containment that are protected against the effects of moderate- and highenergy piping failures by the methods previously described.

GE stated that actual piping dimensions, material properties, and the equipment and associated piping stresses and regionalized environmental conditions will be the responsibility of the referencing applicants. In earlier SSAR amondments, GE included the following as interface requirements for the $\mathrm{COL}$ applicant:

(1) summary of the dynamic analyses applicable to high-energy piping systems, including sketches and data on calculated stress intensities, cumulative usage factors, and stress ranges for selecting break locations

(2) descriptions showing how safety-related systems are protected from jets, flooding, and other adverse environmental effects resulting from failures of moderate energy piping systems

identification of specific features provided for protecting each of the systems listed in the ABWR SSAR tables 
(4) detuils on protection provided againes the effects of piping fallures to conure MSL foedwater and isolation valve functional capability

\begin{abstract}
typical examplea, if any, where protection for eafety-rolated ayetoms and components againat the dynamic offects of pipe failures includes caclooures in suitably designed etructures or compartments, drainage systeme, and equipment covironmental qualifications
\end{abstract}

In the DSER (SECY-91-153), the staff atated that thew requirements were acceptable. Upon further evaluation, the staff determined that these actions did not meet the definition of a 10 CFR Part 52 interface requirement and that GE should identify these requirements as COL action items in the SSAR stating that the applicant roferencing the ABWR design should provide this information. As a result, these requirements were recladsified in the DFSER as COL Action Items 3.6.1-1, 3.6.1-2, 3.6.1-3, 3.6.1-4, and 3.6.1-5, respectively. SSAR Section 3.6.5 includep this information. This is acceptable.

In Section 3.6.2 of this report, the staff reviowed the criteria and methodology proposed by GE for the COL applicant to use to analyze the effects that breaks in highenergy fluid systems would have on adjacent safety-related SSCs with regard to pipe whip and jet impingement loads. The criteria and methodology discussed in SER Section 3.6.2 will be used by the COL applicant to ensure adequate protection against the dynamic effects of postulated ruptures of piping in the ABWR standard design.

The staff stated in the DSER (SECY-91-153) that it was unable to conclude that the ABWR design complies with GDC 4 as it relates to protection of SSCs important to safety against postulated failures outside containment. The staff's concerns were identified as Outstanding Issue 10, which consisted of the following:

(1) The staff concluded that SSAR Table 3.6-2 did not include all the systems, components, and equipment that have to be protected against piping failures. For example, the reactor service water (RSW) system and the equipment and components used to supply reactor building cooling water (RCW) system water to the residual heat removal (RHR) system, fuel pool cooling (FPC) heat exchangers, and the heating, ventilation, and air conditioning emergency chilled water (HECW) system refrigerators were not included in the SSAR table. Also, GE did not explain why certain systems such us the high-pressure core flooder (HPCF), the reactor core isolation cooling (RCIC) process ampling, and the andby liquid control (SLC) nyetem were not liated in tho SSAR Table 3.6-4. Subequeatly, OB rovieed theco tables to include all of thewe systom or provided justification for not including them in the tables. This was found to be acceptable and this isave was resolved as reflected in the DFSER.

(2) In the DSER (SECY-91-153), the ataff atated that GE had not provided the reaults of an analyais of the postulated worst-case piping failure of a moderato- or high-energy lino (including total failure of non-soismic Catogory I piping systems) for the RCIC compartment, equipment and valve room, and other applicable areas outside the containment (0.8., RHR piping areas). GE subeoquently provided subcompartment pressure analyses for compartments inside and outside of contrinment. The staff's reviow of these analyses is found in Section 6.2.1.7 of this report.

(3) As discussed above, the staff also identified that GE had not provided a subcompartment analysis for the MST. The staff was concerned that the main steam and feedwater lines would be routed in a tunnel through the control building. A steam or feedwater line failure may render the control room uninhabitable and compromise the safe-shutdown capability. Further, postulated leakage cracks in the RSW system piping may adversely affect the control room habitability systems. Subsequently, GE provided subcompartment pressure analyses (including pipe failures in the MST) in SSAR Section 6.2.3. Evaluation of the analysis can bo found in Section 6.2.1.7 of this report. The vulnerability of the main control room (MCR) as a result of flooding in the MST and failure of RSW piping in the control building basement was evaluated and discussed in Section 3.4.1 of this report. Other environmental effects of pipe failures are discussed in SSAR Section 3.11. The safety evaluation can be found in Section 3.11 of this report. Based on its review of flood protection for the MCR included in Section 3.4.1 of this report, the staff concludes that the ABWR design provides adequate assurance that the MCR can be protected from the adverse offects associated with a pipe failure. This issue was resolved as reflected in the DFSER.

The staff expressed a concern about the pressure values in SSAR Table 3I.3-15. The staff noted that the valuos appear to reflect the zone pressures that result during accident conditions, assuming that the blowout panels function properly. A more conservative scenario would assume failure of the blowout panels. In the DFSER, the 
athif noted OB's commitwent to modify the table to enurs that it roflects tho higheat anticipated preasures reaulting from accident conditions, sasuming failure of the blowout panols. This we DPSER Confirmutory Itom 3.6.1-2. Subsequently, after diccussions with $\mathrm{GB}$, the anff concluded that the blowout panels fail in a enfo condition. Specifically, the pands fail opea. Thervfore, the values in the Appendix 3I thbles scourately reflect conservative dosign conditions; therofore, DPSBR Confirmatory Item 3.6.1-2 is resolved.

Another concern expressed during moetings with $\mathrm{OE}$ involved tho ABWR design's ability to provido adequats physical separation of enfety-related systoms and equipment; anfety-roluted systems must bo protected from the offects of firs, flood, misailes, pipe failures, and advernd environments to ensure thoir ability to shut down tho reactor and mitigate the consequences of an sccident. Protection is normally ensured by providing redundant enfety-rolated systems and physical separation of tho redundant systems. The ABWR provides physical separation by either spacial separation or by housing redundant divisions of ench safety-related system in a separate compartment. Each compartment is designed to withstand the effects of the events previously identified. By providing adequate physical separation for each redundent safety-related division, at least one division will be available to perform its safety-related function assuming a single active failure in a division. GE included SSAR Section 3.13 that provides detailed information on divisional separation. All redundant divisions of safetyrelated systems are housed in separate divisional spaces inside the secondary containment. Locating these systems in these areas ensures that safety-related systems will be available to perform their safety functions given a fire, flood, missile, or pipe failure event and the adverse environmental consequences associated with such events. Each divisional space has walls, doors, floors, ceilings, and penetrations that are designed to prevent or accommodate the effects of these events and ensure system safety functions. In some cases, flood water and environments associated with failed systems in one division are allowed to reach redundant divisions. For instance flooding in the upper floors of the reactor building which may result from the failure of water systems may flow under the divisional room doors and enter other divisional areas. However, GE has evaluated the subsequent effects of these events and has shown that in no case will the water level rise to such an extent as to adversely affect equipment in the redundant division. In all cases, there is sufficient floor space and drainage capability via stairways, floor, drains, etc. to ensure that the water accumulation in any area is minimal. A second example involves the secondary containment HVAC. Unlike other plant systems, this system has common inlet and outlet headers which cerve all three plant divisional areas. The staff bas reviewed this arrangement and has concluded that the arrngement is acceptable for the following reasons:

The intersonnecting ductwork can be automatically and manually icolated during plant ovents.

(2) Tho ductwork is located high in tho divisional epaces so that flood water cannot propagate from one division to another.

Should a fire occur in a division, the smokeremoval mode of the HVAC system will minimizs the amount of smoke which can propagate to redundant diviaions (ece SSAR Sections 9.4 and 9.5.1).

(4) The environmental effects of a postulated pipe failure outside containment (CUW or RCIC) aro well within the environmental qualification limits for the equipment in each division.

As discuseed in SSAR Section 3.13, HVAC ductwork is expected to leak or poscibly fail during a pipe break ovent. However, failure of the ductwork will actually assist in minimizing the pressurization effects of the break by providing increased blowdown volume and providing additional vent pathways. In addition, as mentioned previously, safety-related equipment in each division is environmentally qualified for conditions worse than those expected during these pipe failures. Based on this information, the staff concludes that the interdivisional connection provided by the secondary containment HVAC system does not prevent the full safety function capability of any safety-related systems.

As discussed in SSAR Section 10.1, safety-related instrumentation is provided in the turbine building to detect the fast closure of the turbine main steam stop and control valve oil pressure, stop valve position, turbine first-stage pressure, and main condenser pressure. This instrumentation is designed to fail safe should it be damaged due to fire, flood, missiles, or pipe failures. The staff finds this acceptable.

As a result of its review of this information, the staff concludes that $G E$ has provided sufficient design information and supporting analyses to ensure that the guidelines of ASB BTP 3-1 are met. Specifically, the ABWR design provides protection of safety-related equipment from the effects of high- and moderate-energy pipe failures by separation of redundant divisions of these systems, by distance, or by locating safety-related systems in enclosures that provide the necessary protection. Furthermore, all safety-related systems and components 


\section{Design of Structures, Components, Equipment, and Systems}

meat the suidelines of RO 1.29 and are denigned to coismic Calogory I etendards. Piping failures aro postulated in accordance with BTP MEB 3-1, pipe rectnints are provided in accordance with the guidelines in SRP Section 3.6.2 (seo Section 3.6.2 of this report), and the effects of the poctulated piping failures, including those from nonseismic syetem, have been considered. Baced on this information, the staff concludes that the guidelines of BTP ASB 3-1 are mot, and therefore, the requirements of ODC 4 are mot.

GE originally aubmitted the design doncriptions and the ITAAC for systems within the ABWR design scope as well as for piping. These included verifications related to protection of safety-related equipment from pipe failurea and their offects. During the DFSER preparation, the staff roviow was in progrees. This was DFSER Open Item 3.6.1-1. Subeequently, GE provided revised dosign descriptions and ITAAC. The adequacy and acceptability of the design deacription and tho ITAAC are ovaluated in Section 14.3 of this report; therefore, DFSER Open Item 3.6.1-1 is resolved.

The review of the plant design for protection against postulated piping failures outside containment included all high- and moderato-energy piping systems located outside containment. The review of these high- and moderateenergy systems for the ABWR included layout drawingi, P\&IDs, and descriptive information.

The staff concludes that the ABWR design as it relates to the protection of safety-related stnuctures, systems, and components from the effects of piping failures outside containment meets the requirements of GDC 4 with respect to accommodating the effects of postulated pipe failures and the guidelines of SRP Section 3.6.1. As a result, the staff concludes that the ABWR design is acceptable.

\subsubsection{Determination of Rupture Locations and Dynamic Effects Associated With the Postulated Rupture of Piping}

GDC 4 requires that SSCs important to safety be designed to be compatible with and to accommodate the effects of the environmental conditions resulting from normal operations, maintenance, testing, and postulated accidents, including loss-of-coolant accidents (LOCAs). It also requires that they be adequately protected against dynamic effects (including the effects of missiles, pipe whipping, and discharging fluids) that may result from equipment failures and from events and conditions outside the nuclear power plant. In accordance with SRP Section 3.6.2, the staff reviewed GE's proposed criteria and methodology for the COL applicant to analyze and ensure adequate protection against and the dynamic effects that breaks in high-enorgy fluid ayctoms would have on adjecent mafoty-rolated SSC with regard to pipe whip and jot impingement loadings. Pipe whip need only be considered for thoee high-energy piping syatemi having fluid reservoire with mufficient capacity to dovelop e jot stream. OE correctly uned the criteria for dotormining high-and moderate-energy lines in SRP Section 3.6.1, Branch Technical Poaition (BTP) ASB 3-1, in SSAR Section 3.6.2.1. OB listed all high-energy syatoms in SSAR Tables 3.6-3 and 3.6-4.

One of the guidelines in SRP 3.6.2, Branch Technical Ponition (BTP) MEB 3-1, states that the analyses for the maximum stroeses, stress ranges, and usage factors to be ueed for determining postulated high- and moderato-energy pipe break and crack locations should be based on loads that include the OBE. In SECY-93-087, the staff recommended the elimination of the OBE in the design proceses on the basis that it would not result in a significant decrease in the overall plant safety margin. The detailed besis for the staff's recommendation is discussed in Section 3.1.1 of this report. In Section 3.1.1.3 of that discussion, the staff includes acceptable deviations from SRP 3.6.2 that result from pipe break postulation without the OBE. As stated in Section 3.1.1.9, "Conclusions," of this report, GE has incorporated these acceptable deviations in Sections 3.6.1 and 3.6.2 of the SSAR. Therefore, the staff's evaluation of thece sections of the SSAR have been based on the Commission-approved staff recommendations.

For ASME Class 1 piping, the staff position for postulating pipe breaks is delineated in SRP 3.6.2, BTP MEB 3-1. Before NRC issued Revision 2 of BTP MEB 3-1 in June 1987, breaks were postulated at intermediate locations between termizial ends of a pipe run if the maximum stress range as calculated by Eq.(10) $>2.4 \mathrm{~S}_{\mathrm{m}}$ and if the maximum stress range as calculated by either Eq. 12) or (13) $>2.4 \mathrm{~S}_{m}$, where Eqs. (10), (12), and (13) and $S_{m}$ are as defined in ASME Section III, Subsection NB 3653. This staff position was implemented in many plants operating today. In Revision 2 of BTP MEB 3-1, the same criteria were maintained for break exclusion in the containment penetration areas. However, for other areas, the criteria were revised to require that breaks be postulated at any intermediate locations when only Eq. (10) $>2.4 \mathrm{~S}_{\mathrm{m}}$. The use of Eqs. (12) and (13) was eliminated. This resulted in an inconsistency in the Revision 2 criteria in that they allow higher limits in the containment penetration areas than in other areas. The break exclusion areas should provide a margin greater than (or at least equal to) the margin for areas outside the break exclusion area. To determine the impact of this inconsistency, the staff obtained several independent analyses for both BWRs and PWRs that compared the number of 


\section{Design of Structures, Components, Equipment, and Systems}

pontulated pipe breaks reaulting from the use of Rovisions 1 and 2 oritaria. These analyese indicated that tho Rovision 2 oriteris will reault in a aignificant increase in the number of poetulated breike, which may be countet productive in terme of improving plant enfety. Therefore, the etaff recommendad that SRP 3.6 .2 be revieed to reinstate the Revision 1 criteria related to allowing the use of Bqs. (12) and (13) for the pontulation of intermediate pipe brentes in ASMB Claes 1 piping syetom. Sections 3.6-1 and 3.6-2 in the SSAR contains criteria that are consiateat with the Revision 1 criteris as proviously discumed. Therefore, the stafi concludes that this is an ecceptable doviation from SRP 3.6.2, Rovision 2.

In the ABWR atandard plant, breake aro not poutulated in those portions of high-ecercy piping between the contrinment isolation valves outside and insido the contuinmeat that are deaigned to meet ASME Code, Section III, Article NB-1120 and the additional design guidelines in SRP Section 3.6.2, including BTP MEB 3-1, (Rov. 2). Section 3.6.2.1.4.2 of the SSAR describes acceptable actions to address all of the applicable guidolines in SRP Section 3.6.2. Two of these guidelines are discussed below.

1. SRP 3.6.2 recommends that an augmented inservice inspection program be implemented for those portions of piping within the break exclusion region. An augmented inservice inspection was DFSER COL Action Item 14.1.3.3.7.2-1. In a letter dated March 17, 1993, GE revised SSAR Section 3.6.2.1.4.2, Item (7) and added SSAR Section 3.6.5.3 to state that the COL applicant shall perform 100-percent volumetric examination of circumferential and longitudinal pipo welds in the break exclusion region during each inspection interval as defined in Article IWA-2400, ASME Code, Section XI. The staff finds that this action for the design and examination of high-energy piping in the containment penetration area meets SRP Section 3.6.2 and is accoptable. GE has included this action item in Section 3.6.2.1.6.2 of the SSAR. The staff's resolution of this DFSER COL action item is also discussed in Section 3.12.7.2 of this report.

2. SRP 3.6.2 contains design, testing, and examination guidelines for guard pipes in the containment penetration areas. SSAR Section 3.6.2.4 states that the ABWR primary containment does not require guard pipes. This is because the ABWR design does not contain guard pipes as defined in Section 3.6.2.4 of RG 1.70, "Standard Format and Content of Safety Analysis Report for Nuclear Power Plants," Revision 3: "a guard pipe is a device to limit pressurization of the space between dual barriers of certain containmeats to ecceptable lovels." The staff notes that SRP 3.6.2 uees the torm "guand pipe" in a broader context than that in RO 1.70 to include all applieable sleoves in the containment penetration area. Section 3.6.2.1.4.2(6) in the SSAR provides deaign, teating, and examination requirements for auch sleoves. These requirements are consistent with the guidelines in SRP 3.6.2 and are acceptable.

For ASME Code Clase 1, 2, and 3 and non-seismic Catogory I high- and moderato-energy lines that are not in the containment penetration area, SSAR Soction 3.6.2 presents tho criteria for dotermining postulated rupture and crack locations and the methodology used to ovaluate the dymamic effects of pipe whip, jet thrust, and jet impingement that rosult from such breaks.

In the DPSER, the staff noted that according to SRP Section 3.6.2, the SSAR should include the following:

- sketches of applicable piping systems showing the location, size, and orientation of postulated pipe breaks and the location of pipe whip restraints and jet impingement barriers

- a summary of the data doveloped to select postulated break locations, including calculated stress intensities, cumulative usage factors, and stress ranges

This was DFSER COL Action Item 14.1.3.3.7-1. In SSAR Section 3.6.5.1, "Details of Pipe Break Analysis Results and Protection Methods," Amendment 31, GE stated that the COL applicant shall provide this information. This is acceptable. Resolution of this item is also discussed in Section 3.12.7 of this report.

In the DFSER, the staff identified an Open Item 3.6.2-1 regarding the computer programs for pipe whip analyses and the design methodology for pipe whip restraints applicable to the ABWR plant design. This open item was identified during an audit of high-energy line break criteria and pipe whip analyses. The audit was performed at the offices of GE in San Jose, California on March 23 through 27, 1992, in which GE disclosed that their pipe whip sample analysis was not yet complete but provided descriptions of the methods of analysis and design requirements for pipe whip restraints to be utilized in the sample analysis. The staff found these methods of analyses and design requirements were not in accordance with the corresponding methods and requirements in SSAR Amendment 17, Sections 3.6.2.2.2 and 3.6.2.3.3, respectively. Subsequently, in response to follow-up audits performed at the offices of GE in San Jose, California on July 28 through 31, 1992, and November 16 and 17, 1992, GE submitted Amendment 26 to the SSAR and provided 
SSAR markups in a letter dated May 26, 1993. Thees changes revied SSAR Section 3.6.2 extentively to provide comprebenaive pipe whip analyais mothods and whip retrnint deaign requirements. In the May 26, 1993 letter, GE aleo mubmitted anmplo analycis OB-NB-123-B070-0493, "Sample Anslyais for the Bffects of Postulated Pipe Break, ABWR Main Steam Piping." All of the above information provided, in aggregato, the following responses to DFSER Open Item 3.6.2-1:

1. Section 3.6.2.2.2 of the SSAR was extensively modified to permit altermative analytical approaches in accordance with ANSI/ANS 58.2 Panagraphs 6.3.1 through 6.3.5. Theas alternative appronches include the ue of the ANSYS and PDA computer program which were uned in the OE pipe whip cample analyes. This respones adequately addreases the staff's original concern about the use of the PDA program alone for pipe whip analyses.

2. Section 3.6.2.3.3 of the SSAR was modifiod to include deaign requirements for pipe whip restraints with crushable material and rigid restraints in addition to U-bar pipe whip restraints. This response results in the SSAR being consistent with the information presented to the staff during the audits mentioned, and is acceptable.

3. Appendix 3L "Procedure for Evaluation of Postulated Ruptures in High Energy Pipes" was added to the SSAR. This appendix defines an acceptable procedure for evaluation of dynamic effects of fluid dynamic forces resulting from postulated ruptures in high energy piping systems. The four major steps in the ovaluations included (1) the identification of rupture locations and rupture geometry, (2) the design and selection of pipe whip restraints, (3) the proceduro for dynamic timo-history analysis with simplified models, and (4) the procedure for dynamic time history analyais using detailed piping models.

4. The sample analysis, OE-NE-123-E070-0493, is intended to be illustrative of the GE pipe break analysis method and, although not a part of the SSAR, it supplements Appendix 3L, which is discussed above. The analysis documented the GE procedures for (i) calculating thrust forces at break locations, (2) performing nonlinear timo-history pipo whip analyses, (3) demonstrating compliance with the SRP Section 3.6.2 stress requirements for piping near containment penetration areas, and (4) demonstrating that the GE PDA computer program was adequate for selecting the size of pipe whip restraints. The staff's review found that these GE procedures are acceptable, and the intended objectives of the sample analyais wore schioved.

GB included the applicable information in Section 3.6.2 of the SSAR, and therefore, DFSER Open Itom 3.6.2-1 is resolved.

In the DFSER, the staff identified Open Itoms 3.6.2-2 and 14.1.3.3.7-1 sbout the edition of the ANSI/ANS-58.2 standard referenced in Section 3.6.2.2.1 of the SSAR, Amendment 17, and inconsiatencies betweon the criteria for evaluating the offects of fluid jets on essential SSCs upecified in Section 3.6.2.3.1 of the SSAR, Amendmeat 17, and corresponding criteria specified in SRP 3.6.2 and ANSI/ANS-58.2, 1988 Edition. The staff's evaluation of this ieswo is diecuseod in Section 3.12.7 of this report.

SRP Section 3.6.2 states that if a structure separates a high-energy line from an essential component, the separating structure should be designed to withstand the consequences of the pipe break in the high-energy line which (could) produce the greatest effoct at (to) the structure. This is irrespective of the fact that the pipe rupture criteria in SRP Section 3.6.2 might not require such a break location to be postulated.

For the ABWR, the structures are dosigned to withstand the dynamic effects of pipo breaks where the pipe rupture criteria require break locations to be postulated. In addition, for areas where physical separation of redundant trains is not practical, a high-energy line separation analysis (HELSA) is performed to determine which highenergy lines meet the spatial separation requirement and which lines require further protection. For the HELSA ovaluation, which is discussed in Section 3.6.1.3.2.2 of the SSAR, no particular break points are evaluated. Breaks are postulated at any point in all of the high-energy piping systems listed in SSAR Tables 3.6-3 and 3.6-4, and any structure identified as necessary by the HELSA evaluation are designed for worst-case loads. This was DFSER COL Action Item 14.1.3.3.7.3-1. SSAR Section 3.6.5.1, Item (8) of the SSAR states that the HELSA will be performed by the COL applicant as described, which is acceptable. The staff's resolution of this action item is also discussed in Section 3.12.7.3 of this report.

Using the above HELSA evaluation, the staff finds that an adequate level of protection is provided to ensure that the safety-related function of components, systems, and equipment will not be adversely affected by a postulated break in any $A B W R$ high-energy piping systems. Plant arrangement provides physical separation to the extent practical and the HELSA evaluation ensures that no more than one redundant train can be damaged. If damage could occur to more than one division of a redundant safety- 
related system within $9.14 \mathrm{~m} \mathrm{(30} \mathrm{ft)} \mathrm{of} \mathrm{any} \mathrm{high-energy}$ piping, other protection devices such as barriers, shields, enclosures, deflectors, or pipe whip restraints are used. When necessary, the protection requirement are met through the use of walls, floors, columns, abutments, and foundations. Thus, the staff finds that the HELSA criteria satisfy the intent of the SRP 3.6.2 guideline by ensuring that structures are adequately designed to withstand the consequences of a worst-case pipe break with no adverse impact on the safety-related function of systems, components, and equipment and are acceptable.

\subsubsection{Conclusions}

From these evaluations, the staff concludes that the criteria for postulating pipe rupture and crack locations and the methodology for evaluating the subsequent dynamic effects resulting from these ruptures comply with SRP Section 3.6.2 and meet GDC 4. The stoff's conclusion is based on the following.

The proposed pipe rupture locations will be adequately determined using the previous staff-approved criteria and guidelines. GE has sufficiently and adequately defined the design methods for high-energy mitigation devices and the measures to deal with the subsequent dynamic effects of pipe whip and jet impingement to provide adequate assurance that, upon completion of the high-energy line break analyses as part of the ITAAC process, the ability of safety-related SSCs to perform their safety functions will not be impaired by the postulated pipe ruptures.

The provisions for protection against the dynamic effects associated with pipe ruptures of the RCPB inside the containment and the resulting discharging fluid provides adequate assurance that design-basis LOCAs will not be aggravated by the sequential failures of safety-related piping and that the performance of the emergency core cooling system (ECCS) will not be degraded as a result of these dynamic effects.

The arrangement of piping and restraints and the final design considerations for high- and moderate-energy fluid systems inside and outside the containment, including the RCPB, will be the responsibility of the COL applicant. These staff-approved high-energy line break criteria and guidelines will be used to assure that the SSCs important to safety that are in close proximity to the postulated pipe ruptures will be protected. GE has developed an ITAAC to verify that the safety of the plant will not be adversely affected by the dynamic effects resulting from the postulated pipe break, as discussed in Section 3.12.7 of this report. Using these criteria and guidelines will ensure that the consequences of pipe ruptures will be aderuately mitigated so that the reactor can be safely shut down and can be maintained in a safo-shutdown condition in the event of a postulated rupture of a high- or moderato-energy piping system inside or outside the containment.

\subsubsection{Leak-Before-Break Evaluation Procedures}

SSAR Section 3.6.3 describes the evaluation procedures for the ABWR LBB methodology. The application of the LBB methodology to piping systems is permitted by GDC 4, which states, in part:

.. . dynamic effects associated with postulated pipe ruptures in nuclear power units may be excluded from the design basis when analyses reviewed and approved by the Commission demonstrate that the probability of a fluid system piping rupture is extremely low under conditions consistent with the design basis for the piping.

The analyses referred to in GDC 4 should be based on such plant-specific data as piping geometry, materials, piping loads, and pipe support locations. The staff must review the LBB analyses for specific piping designs before an applicant can exclude the dynamic effects from the design basis for the piping system.

In the DFSER, the staff noted that COL applicants seeking approval of the LBB approach for high-energy piping systems in the ABWR plant should submit an LBB plantspecific analysis in accordance with GDC 4 and include the information stated in the previous discussion. This was DFSER COL Action Item 3.6.3-1. In SSAR Section 3.6.5.2, GE stated that the COL applicant shall prepare a plant-specific LBB analysis report and submit the report to the NRC staff for approval. This is acceptable.

Although the staff is currently using the methodology and acceptance criteria provided in SRP Section 3.6.3 and NUREG-1061, Volume 3, the staff recognizes that the LBB technology is continually evolving. Therefore, the staff will review LBB requests for the ABWR plant on a case-by-case basis using the staff's methodology and acceptance criteria in effect at the time of the submittal.

\subsection{Seismic Design}

The staff reviewed the seismic design adequacy of the ABWR standard plant using SRP Sections 3.7.1 through 3.7.4 as the basis, and considered GE's responses to the open items, confirmatory items and COL action items identified in the DSER (SECY-91-153) and the DFSER. In addition, the staff conducted two design calculation audits at GE's office in San Jose, California, and two design calculation audits at Bechtel Power Corporation (consultant to GE) in San Francisco, California. The first 
design calculation audit, conducted November 28 through 30,1989, covered the design of the containment and RB. The staff's findings and concerns from the first design calculation audit and GE's subsequent resolutions are contained in Appendix 3.7A to the DSER (SECY-91-153). The second design calculation audit, conducted on March 30 through April 2, 1992, covered primarily the design of the RB, control building, and radwaste building substructure. The staff's findings and concerns from the second design calculation audit were documented in the audit report issued on May 15, 1992. The third and forth audits covered three major areas: (1) seismic reanalysis of the safety-related structures, (2) GE's response to the DFSER open and confirmatory items, and (3) designs of the safety-related structures, including the RB, the containment structure, and the control building. These two design calculation audits were conducted at the Bechtel (San Francisco) office on October 12 through 15, 1992 and February 22 through 25, 1993, respectively. These audits were to determine if the structures of the ABWR standard plant are adequately designed and if the commitments documented in the SSAR are properly implemented.

In the DFSER, the staff's evaluation covered both OBE and SSE. However, as discussed in Section 3.1.1 of this report, by implementing the Commission-approved staff recommendations on OBE elimination, unless otherwise denoted, only the SSE seismic design is evaluated on the following.

\subsubsection{Seismic Design Parameters}

In the SSAR, the input seismic design response spectra for the SSE are defined at plant finished grade in the free field. These design response spectra comply with the ground motion response spectra recommended in RG 1.60, "Design Response Spectra for Seismic Design of Nuclear Power Plants, " Revision 1. The peak horizontal as well as the peak vertical ground acceleration (PGA) is $0.3 \mathrm{~g}$. For the standard plant design, SSE (i.e., RG 1.60 response spectra anchored to $0.3 \mathrm{~g}$ ), was employed to calculate the responses of the SSCs. The staff's evaluation of the design ground motion for the SSE is discussed in Section 2.6.3 of this report.

In SSAR Section 3.7.1, Amendment 33, GE stated that the three components of the synthetic SSE ground motion time history used for the seismic analysis and design of the ABWR seismic Category I SSCs are adjusted in amplitude and frequency to obtain response spectra for damping ratios of 2-, 3-, 4-, 5-, and 7-percent of critical damping to envelop the SSE design ground response spectra at a sufficient number of frequency points as recommended by SRP Section 3.7.1 plus three additional frequencies at 40,
50, and $100 \mathrm{~Hz}$. The power spectral density function (PSDF) of the two horizontal components of the synthetic SSE ground motion time history envelops the target PSDF specified in Appendix A to SRP Section 3.7.1 for a frequoncy range of 0.3 to $24 \mathrm{~Hz}$. For the vertical component of the ground motion time history, GE followed the guideline of Appendix A to SRP 3.7.1 and developed a target PSDF for the vertical ground motion. GE also showed that the vertical component of the ground motion time history (synthetic time history) satisfied the PSDF enveloping criteris. The details of developing the target PSDF and the demonstration of PSDF enveloping process are described in a GE submittal dated May 7, 1993, (GE's responses to Item 3 of the audit report dated February 22, 1993). In addition, GE showed that the three components of synthetic time history are statistically independent of each other in that the cross-correlation coefficients at zero-time lag between these components are less than 0.16 .

From this evaluation above, the staff concludes that the SSE input ground motion (the design ground response spectra and the ground motion time history) as documented in SSAR Section 3.7.1 meets the guidelines of SRP 3.7.1 and RG 1.61 and, therefore, is acceptable.

To define the design ground motion (ground response spectra and the associated synthetic time history) at plantfinished grade in the free field, in accordance with the SRP guidelines, is acceptable for the purpose of developing the envelope of seismic responses (both structural member forces and FRS) for the design of the standard plant. However, when confirming the adequacy of the standard plant design for a specific shallow soil site, the COL applicants should define the site-specific ground response spectra and associated design time history as the free field motion at a level that complies with the guidelines of SRP Section 3.7.1.I.1. The details of the staff's review of GE's compliance with these guidelines and the staff's conclusion are discussed under "Confirmation of PlantSpecific Seismic Design Adequacy" in Section 3.7.2 of this report.

The damping ratios used in the analysis of the ABWR seismic Category I structures comply with the SSE damping ratios specified in RG 1.61, "Damping Values for Seismic Design of Nuclear Power Plants." For soils, GE determined damping values (soil material damping and energy dissipation as a result of wave propagation) on the basis of the soil shear strains induced in the free field. The approach for considering the soil damping complies with the SRP Section 3.7.2 guidelines and is, therefore, acceptable.

The ABWR seismic Category I structures have reinforced concrete mat foundations that are designed to be supported 
on soil, rock, or compacted backfill. Appeadix $3 \mathrm{H}$ to the SSAR, Amendment 33, epecifies the following embedment depths from the plant finished grado to the bottom of the besemat for each seismic Catogory I atructure:

- 25.9 m (85 ft) for RB complex (shield building, containment structure, drywell, and resctor pedestal)

- $23.2 \mathrm{~m}$ (76.1 ft) for control building

- $16.0 \mathrm{~m}$ (52.5 ft) for radwaste building substructures

These three buildings are deaigned to have independent foundations. During the design calculation audits, GB alco diccused the use of these embedment depths for the seismic analysis to determine the seismic soil-atructure interaction (SSD) effects for all soismic Category I structures except the radwaste building that is assumed to be surface-founded in the seismic analysis. The staff's evaluation regarding the adequacy of the SSI analysis, including the consideration of these embedment depths, is discussed in Section 3.7.2 of this report. However, because the depth of the embedment is an important aspect of the seismic design, the variation in the depth of embedment of an as-built plant beyond the tolerance limit of $0.3 \mathrm{~m}$ ( $1 \mathrm{ft}$ ) should be verified by calculations to reconcile the difference. The embedment depths verification is part of building-specific ITAAC. The adequacy and acceptability of the ABWR design description and ITAAC are evaluated in Section $\mathbf{1 4 . 3}$ of this report.

\section{Boundine Site Parameters}

In the DFSER, the staff identified COL Action Item 3.7.1-1 to anchor the design basis OBE to a peak ground acceleration (PGA) of $0.15 \mathrm{~g}$. Recently, the Commission approved the staff recommendation of eliminating OBE from the ABWR design. The staffs evaluation of this issue is discussed in Section 3.1 of this report, and COL Item 3.7.1-1 is withdrawn and resolved.

In SSAR Section 2.3.1.2, Amendment 33, GE stated that the COL applicant will use the following bounding sito conditions to confirm the adequacy of the ABWR standard plant seismic design for a specific site:

- The site-specific ground motion response spectra are bounded by the RG 1.60 design response spectra anchored to $0.3 \mathrm{~g}$.

- For a shallow soil site, the site-specific ground response spectra and the associated time history should be specified as the free field motion at a level that complies with the guidelines of SRP Section 3.7.1.
- The site soil static bearing capacity at the foundation level of the reactor and control building is $0.72 \mathrm{MPa}$ (15 kip/fir) minimum.

The bounding site conditions are consistent with those discused in SSAR Section 3.7.1 and are acceptable.

Certain site-specific SSCs for ABWR plants that are not part of the certified design may be designed using sitoopecific epectra. To dovelop these spectra, the horizontal and vertical free field ground surface site-specific ground motion epectra for a controlling earthquake for a site should be obtained using the procedures of SRP 2.5.2. The maximum spectral amplitude of these spectra in the frequency range 5 to 10 Hertz should be obtained. Both the horizontal and vertical design response spectra for the ABWR certified design and the RG 1.60 shapes anchored to $0.3 \mathrm{~g}$ peak ground accelerations should be scaled throughout their entire frequency range in such a manner that the minimum spectral amplitudes of the certified design spectra are equal to the maximum amplitudes of the borizontal and vertical site-specific ground motion spectra, respectively, in the 5- to 10-Hertz frequency range. The reaulting design response spectra should be used as the minimum for the design of site-specific SSCs for ABWR plants.

The staff concludes that GE meets the relevant requirements of GDC 2 and Appendix $A$ to 10 CFR Part 100 by appropriate consideration of the most severe earthquake, SSE, to which the ABWR seismic Category I SSCs are expected to be subjected. GE meets these requirements by the use of (1) SSE design response spectra that comply with RG 1.60 , (2) synthetic ground motion time histories that comply with the design response spectrum and PSDF enveloping criterion of SRP Section 3.7.1, and (3) specific percentage of critical damping values in the seismic analysis of ABWR seismic Category I SSCs that conforms to RG 1.61. This ensures that the seismic inputs to the ABWR seismic Category I SSC8 are adequately defined to form a reasonable basis for the design of such SSCs to withstand seismic loadings.

\subsubsection{Seismic System Analysis}

The staff's review of the seismic analysis of the seismic Category I SSCs includes the seismic analysis methods and acceptance criteria used for the ABWR seismic Category I structures, the reactor pressure vessel (RPV) and containment internal structures design. The radwaste building, which is not a seismic Cotegory I structure and does not house any safety-related equipment and systems, is included in this review because GE elected to design this structure for the SSE seismic loads to ensure that the embedded portion of the building retains its structural 


\section{Design of Structures, Components, Equipment, and Systems}

integrity during and after an SSE, and to provent unacceptable leakage of the radwaste material outside the building. The soismic analyses of the turbine building and the condenser, which is located inside the turbine building but has a separate foundation, are also included in this reviow although these two structures are not seismic Category I. They are within the scope of this review because a portion of the MSL, which is required to be designed for the SSE based on the discussion in Section 3.2.1 of this report, is inside the furbine building, and one end of this portion of the MSL system and branch lines is anchored at the turbine building and the condenser.

GE originally analyzed all seismic Category I structures for the OBE ground motion only and obtained the SSE responses, including the FRS of the structures by multiplying the corresponding OBE responses by a factor of two. The results of the staff review were documented in the DSER (SECY-91-153), DFSER, and the design calculation audit reports. In these reports, a number of open, confirmatory, and COL action items were identified.

In response to the DSER (SECY-91-153) and DFSER open, confirmatory, and COL action items and to address the concerns identified in the audit reports, GE initiated a seismic reanalysis for all seismic Category I structures. GE then used the results of this reanalysis to replace the original analysis results as part of the basis for the design certification application. GE explained the reasons for performing this analysis as follows:

(1) As a result of changing the design basis tornado wind speed from $418 \mathrm{~km} / \mathrm{hr}$ (260 mph) to $483 \mathrm{~km} / \mathrm{hr}(300 \mathrm{mph})$ and adopting the use of tornado missile Spectrum 'I per SRP Section 3.5.1.4, the RB superstructure and roof were thickened and the roof purlins strengthened. These structural design upgrades resulted in a need to modify the seismic models.

(2) The original SSE responses of the ABWR seismic Category I structures, including the FRS, were obtained by multiplying the corresponding OBE analysis results by a factor of two. As a result, a significant design margin was included in the SSE responses. To eliminate the: excessive design margin, GE initiated the seismic reanalyses for the RB complex and the control building to take advantage of the Commission-approved staff recommendations on OBE elimination.

(3) The original building responses used for the seismic input to subsystems such as piping were obtained by enveloping the analysis results from two dynamic models, natnely, models with and without the steel stabilizer truss between the RSW and reinforced concrete containment vessel (RCCV). Because of the protection to be provided for the personnel during reactor hot standby and shutdown for maintenance and refueling, the RSW height was raised to the height of $15 \mathrm{~cm}(6 \mathrm{in}$.) below the RCCV top slab. This change eliminated the steel stabilizer truss from design and, thus, the stabilizer truss was deleted to result in the revised model for seismic reanalysis.

(4) To address the NRC staff's concern about the use of a two-dimensional (2-D) dynamic model for the seismic analysis of seismic Category I structures, only three dimensional (3-D) soil-structure system models were used in the seismic reanalyses.

In the seismic reanalysis of the seismic Category I structures, GE regenerated the three components of the ground motion time history. In SSAR Section 3.7.1 and Figures 3.7.6 through 3.7.20 and Figures 3.7.24 through 3.7.26, GE compared the design ground response spectra and the target PSDF8 with the respective response spectra and the PSDFs obtained from these three components of the ground motion time history. As shown in these figures, the three components satisfy both the response spectrum enveloping criterion for all damping ratios to be used in the analysis and the PSDF enveloping criterion provided in SRP Section 3.7.1. Therefore, they are acceptable to the staff.

Regarding the seismic analysis of the ABWR plant structures including all seismic Category I structures, the staff found the procedures used for structural modeling, seismic soil-structure interaction analysis, development of FRS, inclusion of the effects of variation in parameters on FRS, inclusion of torsional effects, evaluation of dynamic stability of buildings (such as overturning and sliding), and determination of composite damping acceptable. The staff's basis for the acceptance of these techniques and the review of the analysis and design for each building are discussed in detail latter in the building-specific evaluations of this section.

As discussed in SSAR Section 3.7.2 and Appendix 3A and Appendix $3 \mathrm{H}$ to the SSAR, Amendment 33, GE performed dynamic analyses of the seismic Category I structures to generate the SSE responses (structural member forces and FRS) on a linear elastic basis. The seismic responses were calculated for the two horizontal directions and the vertical direction. GE did not use the technique of constant static factors for computing the vertical responses. The structural damping ratios used by GE complied with those specified in RG 1.61. For the structure of structural materials with different damping ratios and for the modal 
responso mothod of analysis used, GE calculated a composite modal damping ratio using the strain energy tochnique. The techniques used for the dynamic analyses of structures discussed above are consistent with the guidelines of SRP Section 3.7.2 and, therefore, are acceptable.

The 3-D time history method applied in the frequency domain forms the basis for the dynamic analyses of all major seismic Category I structures. The tochnique used for performing the dynamic analysis in the frequency domain moets the guidelines of SRP Section 3.7.2 and, therefore, is acceptable. GE generated the FRS, which serve as inputs for the seismic analysis, design, and test verifications of systems and components, from the time history method of dynamic analysis. To account for variation in the structural frequencies as a result of uncertainties in the material properties of the structures and in the modeling and analysis techniques, GE broadened the peaks of FRS. To develop the FRS envelopes for the subsystem design of the standard plant, $G E$, as discussed in SSAR Section 3A.10.2, Amendment 33, (1) calculated the FRS for the damping ratios of 2-, 3-, 5-, and 10percent from all 3-D analysis cases, using computer code SASSI, (2) developed the FRS envelopes from the FRS for all site conditions at the required locations in each of the three directions, and (3) at each location, developed the bounding horizontal FRS envelopes from the FRS envelopes in the two horizontal directions. In addition, GE applied a peak broadening of 15 percent to the bounding horizontal FRS envelopes and the vertical FRS envelopes to account for the uncertainties caused by structural modeling, material properties, and soil modulus. In SSAR Section 3.7.2, GE also discussed two options for the design of seismic Category I components regarding the peak broadening: (1) if a detailed parametric variation study is made, the minimum peak broadening ratio can be 10 percent, and (2) in lieu of peak broadening, the peak shifting method included in Appendix $N$ to ASME Section III can be used. GE's process for developing the FRS envelopes meets the guidelines of RG 1.122, "Development of Floor Design Response Spectra for Seismic Design of Floor Supported Equipment or Components," Revision 1, and SRP Section 3.7.2, and is acceptable. The acceptability of Appendix $\mathbf{N}$ to ASME Section III is discussed in Section 5.2.1.2 of this report.

From comparing the natural frequencies obtained from a 2-D fixed base building model and a 3-D fixed base building model with the embedment effect included, GE found that the torsional effect resulting from the eccentricity between the center-of-mass and center-ofrigidity of the seismic Category I structures (RB, control building, and embedded portion of radwaste building) on the seismic responses is negligible because of the symmotry in the geometrical layout of the buildings. Therefore, in SSAR Section 3.7.2.11, Amendment 33, GE stated that for the ABWR seismic Category I structures, the actual eccentricities are negligible and the torsional moments are due to accidental torsion only. From its review, the staff agreed that the effect of the building eccentricity is negligible. For the seismic design of structures, GE followed the approach and the procedures that comply with the guidelines of SRP Section 3.7.2 and applied an accidental eccentricity equal to 5 percent of the maximum building dimension at each floor to calculate the seismic shear for distribution to the lateral load resisting structural elements. GE evaluated the stability of the structure against seismic overturning by requirin? a minimum factor of safety of 1.1 between the potential energy needed to overturn the structure and the maximum kinetic energy of the structure during the SSE. These approaches comply with the guidelines of SRP Section 3.7.2 and are acceptable. In early SSAR amendments, GE did not describe the procedure for determining the stability of the structure against seismic sliding. This was DFSER Open Item 3.7.2-1. In Appendix $3 \mathrm{H}$ to the SSAR, Amendment 33, GE provided the analysis procedures used for the dynamic overturning of the RB, control building, and radwaste building and the evaluation results (safety factors against overturning, sliding, and flotation) of these three buildings. From the review of Appendix 3H to the SSAR and the design calculation audit conducted on February 22 through 25, 1993, the staff concludes that the reactor, control, and radwaste buildings will be dynamically stable under the specified SSE. Therefore, DFSER Open Item 3.8.5-1 is resolved. This concern is also discussed in Section 3.8.5 of this report.

From evaluation of the general approach for the seismic analysis of the seismic Category I structures discussed above, the staff concludes that the prccedures used by GE to (1) combine the modal responses, (2) combine the effects of the three earthquake components, (3) account for the effects of variation in parameters on FRS envelopes, (4) include torsional effect in the seismic design of structures, (5) evaluate stability of structures against seismic overturning and sliding, and (6) determine composite damping ratios for structures comply with the guidelines of SRP Section 3.7.2 and the applicable regulatory guides and are, thus, acceptable.

During the design calculation audit conducted on February 22 through 25, 1993, the staff was concerned about that, in its calculation of seismic loads from the live loads, GE reduced the live load on a global basis but did not provide the basis for the reduction or provide the criteria for the design of local structural elements such as slabs, beams, and columns. In SSAR Sections 3.8.1.3.1, 3H.1.4.3.1, 3H.2.4.J.1, and 3H.3.4.3.1, Amendment 33, 
GE stated that the floor area live load shall be omitted from areas occupied by equipment whose weight is specifically included in doed load and that the live load shall not be omitted under equipment where access is provided. For the computation of global soismic loads, only a portion of the live load designated as " $L$ " is used because of the overall light occupancy of power plants. The "L" loads are established in accordance with the layout and mechanical requirements. However, the live loads used in the load combinations for the design of local structural elements such as slabs and beams are the full values. In the design calculations, GE used 25 percent of the live load for computing the seismic loads owing to an SSE and used the full value of the live load for the design of structural elements. The basis for using 25 percent of the live load for computing the SSE seismic loads is provided in SSAR Section 3.8.1. As a result of its review, the staff concludes that the reduction factor of 75 percent used by GE for calculating the contribution of the live load to the overall seismic loads is consistent with the guidelines of ASCE 7-88 Standard (formerly ANSI A58.1) and the common industry practice, and is, therefore, acceptable.

On the subject associated with the interaction of nonseismic Category I SSCs with the seismic Category I SSCs, SSAR Section 3.7.2.8 states that all non-seismic Category I SSCs will meet one of the following criteria:

(1) the collapse of any non-seismic Category I structure, system, or component will not cause the non-seismic Category I structure, system, or component to strike any seismic Category I structure, system, or component.

(2) the collapse of any non-seismic Category I structure, system, or component will not impair the integrity of seismic Category I SSCs. This may be demonstrated by showing that the impact loads on the seismic Category I structure or system or component resulting from collapse of an adjacent non-seismic Category I structure or system or component, because of its size and mass are either negligible or smaller than those considered in the design (e.g., loads associated with tornado, including tornado missiles).

(3) the non-seismic Category I SSCs will be analyzed and designed to prevent their failure under SSE conditions in such a manner that the margin of safety of these SSCs is equivalent to that of seismic Category I SSCs.

Criteria (1), (2), and (3) are acceptable to the staff.
Although these criteria are used for the design of the atandard plant, during the construction phase, interforences from field run commodities and field modifications cen lead to adverse interaction between seismic Category I and other non-soismic Category I SSCs. To identify and correct such potentially adverse interaction in accordance with these described criteria, SSAR Section 3.7.5.4, Amendment 33, stated that the COL applicant will describe the process for completion of the design of balanco-of-plant and non-safety related systems and propose procedures for an inspection of the as-built plant to verify that the interaction of non-seismic Category I SSCs with seismic Category I SSCs does not cause failure of the seismic Category I SSCs to perform their intended safety function. This is acceptable. The staff will review the process and procedures as part of the COL application and the ITAAC for the COL stage.

To demonstrate that the as-built plant structures (primary containment structure, internal structures, RB, control building, radwaste building, and turbine building) are able to withstand the structural design basis loads as defined in SSAR Section 3.8, Amendment 33, GE, in SSAR Section 3H.5, Amendment 33, stated that when the construction is complete, a structural analysis report will be prepared to document the results of the review of construction records for material properties used in construction (i.e., in-process testing of concrete properties and procurement specifications for structural steel and reinforcing bars) and the inspection of as-built building dimensions. In this report, according to GE, construction deviations and design changes, if any, will be assessed to determine appropriate disposition. The as-built plant structures are considered acceptable "as-they-are," if the structural design meets the acceptance criteria and load combinations defined in SSAR Section 3.8, and the dynamic responses (i.e., FRS, shear forces, axial forces and moments) of the as-built plant structures are bounded by the responses documented in Appendices 3A, 3G, and $3 \mathrm{H}$ to the SSAR, Amendment 33. GE also stated that depending upon the extent of the deviations and design changes, compliance with the acceptance criteria can be determined by either:

a. Analyses of evaluations of construction deviations and design changes, or

b. The design basis analyses will be repeated using the as-built condition.

The staff considers that the reconciliation analysis procedures to be used by GE will ensure that the as-built plant structures are able to withstand the structural design basis loads and load combinations defined in SSAR Section 3.8, Amendment 33, and are, thus, acceptable. 


\section{Design of Structures, Components, Equipment, and Systems}

The staffs evaluations of the seismic analyses and design of the ABWR soismic Category I buildings and other atructures are discussed in the following paragraphs.

\section{Renctor Building}

GE originally developed the seismic response envelopes (shear forces, moments and FRS) for the RB considering 14 generic site conditions with soil profile depths ranging from $25.9 \mathrm{~m}$ (85 ft) to $91.4 \mathrm{~m}$ (300 ft) and averaged soil layer shear wave velocities varying from $303 \mathrm{~m} / \mathrm{sec}$ (994 ft/sec) to $3048 \mathrm{~m} / \mathrm{sec}(10,000 \mathrm{ft} / \mathrm{scc})$. These site conditions represent a range of soft-soil site, medium-soil site, stiff-soil site, and hard-rock site. The 14 site conditions with various soil profiles and the associated shear wave velocity along the soil depth were listed in SSAR Table 3A.3-6, Amendment 16. A total of 42 cases of soil-structure interaction (SSI) analyses were performed in the original seismic analysis. In the'seismic reanalysis, the site conditions (as shown in Table 3A-6 of SSAR, Amendment 33) used are basically the same as those used in the original analyses, except that Profile VP2 was eliminated, and Profiles VP6, HR, and EH were replaced by rock and hard-rock conditions that represent all site conditions with soil shear wave velocities above 1058 meters/second $(3300 \mathrm{ft} / \mathrm{sec})$. With the revised site conditions, a total of 22 SSI analysis cases were considered. The ' 14 site conditions and the 22 analysis cases were listed in Table 3A-7 of SSAR Appendix 3A, Amendment 33. The structural stick models, which represent the $\mathbf{R B}, \mathbf{R C C V}$, internal structures and reactor pressure vessel (RPV) were used in the reanalysees. In addition, one condition of the reinforced concrete structural model with the properties of cracked concrete was also considered. The Bechtel-version of SASSI computer code was used for the SSI analysis. The staff reviewed the validation documents and approved the use of this code. This code was also reviewed by the staff for the structureto-structure interaction analysis. The staff found (1) the site conditions and the SSI analysis cases covered a widp range of soil properties and site geometry, (2) the modeling tochnique used for the structural stick model is consistent with the guidelines of SRP Section 3.7.2, and (3) the version of SASSI Computer Code previously accepted by the staff for other nuclear power plant licensing applications was used for the SSI analyses of the ABWR plant structures, and, therefore, the seismic design analysis of the RB is acceptable.

As discussed in SSAR Appendix 3A, Amendment 33, the SSI analysis cases were categorized into two groups. In the first group, 3-D SSI analyses of the RB and the control building were performed individually without considering of structure-to-structure interaction effects (Cases 1 through 16 in SSAR Table 3A-7). In the second group,
2-D SSI analyses of the RB and control building were performod considering individual buildings as well as multiple buildings, including the turbine building, to ovaluato the structure-to-structure interaction effects (Cases 17 through 22 in SSAR Table 3A-7). For all these 22 SSI analyses, an embedment of $25.9 \mathrm{~m} \mathrm{(85} \mathrm{ft}$ ) from the finished grado to the bottom of the basement was used.

A 2-D structural model used in the original analyses combined with a 3-D soil-structure foundation model was used in the seismic reanalysis. The SSE damping ratios recommended in RG 1.61 were assigned to the structural elements in the reanalysis. In response to Outstanding Issue 4 of the DSER (SECY-91-153), GE increased the maximum tornado wind speed from $418 \mathrm{~km} / \mathrm{hr}(260 \mathrm{mph})$ to $483 \mathrm{~km} / \mathrm{hr}$ (300 mph) and adopted Missile Spectrum I per SRP Section 3.5.1.4 for the seismic Category I structure design. As a result, the upper portion of the RB model was modified because the building roof and the super structures were strengthened. From the design calculation audits, the staff concludes that GE's modeling techniques meet the guidelines of the SRP Section 3.7.2 and are, therefore, acceptable and that DSER Outstanding Issue 4 is resolved.

To obtain the input for the SASSI analyses, GE used computer code SHAKE to perform a computer analysis of the free-field soil column to obtain the shear modulus and material damping of soils compatible with the seismic strains induced in the free field for each site condition. In the SSI analysis, the structural model of the RB (consisting of the enclosure structure, RCCV, RPV pedestal, RPV, and internals) did not include the eccentricity of the structure. For verifying the symmetry of the RB and demonstrating the adequacy for not considering the building eccentricity in the analyses, GE compared the frequencies and modal participating factors of the fixedbase RB model both with and without the calculated eccentricity and found that the effect of eccentricity is negligible. GE also considered the effect of separation between the foundation soil and embedded wall on the structural response. During the design calculation audits conducted on October 12 through 15, 1992, and February 22 through 25, 1993, the staff found that GE compared the FRS obtained from a fixed base finite element model (unsymmetrical model) and a fixed base stick model (symmetrical model) and showed good agreement of two sets of horizontal FRS. However, in the frequency range between $20 \mathrm{~Hz}$ and $30 \mathrm{~Hz}$, the vertical FRS at the building walls generated from the finite element model significantly exceeded the vertical FRS generated from the stick model. In SSAR Section 3.7.2.1.5.1.1 and 3A.10.2, Amendment 33, GE stated that to include these excoedances in the structural models responses, the results of the finite element analysis were used as an additional 
case to obtain the sito enveloping results. From this roview, the staff concludes that GB's modoling of the RB and supporting soil modium, use of the 2-D structural model, and SSI analysis methods comply with the guidolines of SRP Section 3.7.2 and the final coismic response envelopes, including the FRS envelopes, are reasonable and accoptable.

To determine the seismic loads for the strustural deaign, the analysis results of the 16 threo-dimensional analysis cases (Cases 1 through 16) based on the computer code SASSI were enveloped to account for the effects of the 14 site conditions and the uncertainties of the relevant parameters. The enveloping maximum shears and moments along the RB walls, RCCV shell, reactor shiold wall (RSW), reactor pedestal and key internal structural elements for hprizontal excitation were given in Tables 3A-19a through 3A-19d of SSAR Appendix 3A, Amendment 33. Because this building is nearly symmetrical about the two horizontal axes, the torsional moments are obtained using the enveloping shear force at each floor multiplied by an accidental eccentricity equal to 5 percent of the respective maximum floor dimension. These forces, moments and torsional moments were used for the design of various structural elements. For the design of the structural elements below the ground surface, such as exterior walls and RCCV shell (which is structurally tied with the exterior walls), GE did not consider the reduction of the horizontal shear forces at the structural elements below the ground surface as calculated from the analyses but did consider the largest shear force above the ground surface for the design. In the vertical direction, GE expressed the loads in terms of the enveloping absolute acceleration to simplify the analyses and design of floor slabs and components. The staff reviewed the final reanalysis results (accelerations, displacements, forces and moments) as provided in SE AR Appendix 3A, Amendment 33. GE hes met the guidelines of SRP Section 3.7.2 for developing the seismic design load envelopes for the RB structure and the design loads calculated are acceptable.

In the DFSER, the staff stated that the SSAR did not completely describe the procedure for calculating the FRS and for developing the revised FRS envelopes. This was DFSER Confirmatory Item 3.7.2-1. During the design calculation audits, GE agreed to provido the basis for applying the uncertainty factors to the FRS (horizontal and vertical). This was DFSER Confirmatory Item 3.7.2-2. Also, GE agreed to include the seismic structural displacement profiles, which are needed for the seismic design of piping systems, in the SSAR. This was DFSER Confirmatory Item 3.7.2-3. These three confirmatory items are resolved.
From the audit of the deaign calculations and reanalyais reculte, and the reviow of Appendix 3A to the SSAR, Ameadment 33, the ataff found that the structural response envelopes (member forces, bending moments, and FRS) are dominated by the responses obtained from the RB SSI analysis with hard-rock sito condition (Case RZU). In other words, the atructural responses of the RB with a hand-rock foundation cavelop most of the responses calculated from the SSI analyees for other site conditions. The ABWR standard plant structures are designed using the envelopes of seismic forces and moments. The use of the etructural reeponse envelopes for the design of the plant structural eloments, systems, and components might yield unnecesearily high loads for a plant founded on a soil site. As an acceptablo alternative, GE or the COL applicant may group the 14 generic site conditions into different generic catogories of site condition (such as soft-soil site, modium-wil site, eoft-rock site, hard-rock sito, otc.) and dovelop the FRS envelopes for each generic category. The recultiag FRS envelope for the particular category of site condition most representative of a specific site may be used for the subsystem design for this site. The staff will roview the development of the category-based FRS envelope and the sito-specific design of subsystems on a caso-by-case basis.

Originally, GE did not consider the flexibility effect of the drywell equipment and piping support structure (DEPSS) when generating the FRS for the seismic input to the dosign of subsystems supported by the DEPSS. Becauso of the exclusion of the DEPSS' flexibility effect, which might cause additional amplification of the FRS, the staff believed that such subsystems supported on the DEPSS as piping and equipment could be underdesigned based on the existing FRS. This was DFSER Open Item 3.7.2-2. SSAR Section 3.8.3.4.4, Amendment 33, described the procedure for checking the applicability of the deformation criterin of framo-type pipe supports given in SSAR Section 3.7.3.3.4, from which one can determine whether the DEPSS can be considered rigid or not. The staff's roview and acceptance of the deformation criteria of framo-type pipe supports are discussed in Section 3.12.6.7 of this report. If these criteria can not be met, SSAR Section 3.7.3.3.4 further stated that the COL applicant will generato the FRS at piping attachment points by considering the DEPSS as part of the structure and using the dynamic analysis methods described in SRP Section 3.7.2 or by analyzing the piping systems treating the DEPSS as a part of pipe support. This is acceptable, and DFSER Open Itom 3.7.2-2 is resolved.

The ataff concludes that the SSI analyses performed for all site conditions and analysis cases, the development of the seismic load envelopes for the structural design of the ABWR RB, and the generation of the FRS envelopes for 


\section{Design of Structures, Components. Equipment, and Systems}

the design of the subsystoms located in the RB are acceptable.

\section{Control Building}

On the basis of the seismic design audits, the staff found that the modeling technique and analysis mothod used for the control building are essentially the samo as those used for the RB. Therefore, the staff considers the results obtained adequate and acceptable. The details of this staff review are discussed in the following paragraphs.

In the original SSI analysis, GE did not consider the effect of structure-to-structure interaction between the control building and adjecent buildings such as the RB and turbine building. The energy feedback from the adjecent buildings during an earthquake could significantly affect the seismic response of the control building because these adjecent buildings are much heavier. GE should consider the effect of structure-to-structure interaction in the SSI analysis of the control building. This was DFSER Open Item 3.7.2-3.

GE used a 2-D SSI model in the original SSI analysis. As shown in SSAR Amendment 23, GE's parametric studies for the RB indicated that the 2-D SSI analysis typically underestimated both the horizontal and vertical spectral peak accelerations at higher elevations of the building for medium-stiff-soil sites and hard-rock sites. During the design calculation audits, the staff was concerned about the significance of the difference between 2-D and 3-D SSI analyses of the control building. This was DFSER Open Item 3.7.2-4.

GE originally considered three generic site conditions to generate the envelopes of structural seismic loads and FRS. GE also applied uncertainty factors of 1.5 and 1.0, respectively, to the horizontal and vertical FRS envelopes of the control building. During the design calculation audits, GE said that a part of the uncertainty factor of 1.5 for the horizontal FRS envelope was to account for the uncertainty resulting from using only three site conditions in the standard design. The staff was concerned with the basis of the uncertainty factors and with the sufficiency of considering only three site conditions in the standard design. GE agreed to provide the basis for the uncertainty factors. This was DFSER Confirmatory Item 3.7.2-4. Also, the original SSAR did not describe the procedure to generate FRS envelopes. GE committed to document this procedure in a future amendment of the SSAR. This was DFSER Confirmatory Item 3.7.2-5.

In response to these DFSER open and confirmatory items, GE, following the same procedures that were applied to the RB, conducted seismic reanalysis of the control building. In this seismic reanalysis, the site conditions and the SSI analysis cases used are the same as those used in the RB soismic reanalysis. The 2-D structural dynamic model ahown in Figures 3A-27 through 3A-29 of SSAR Appendix A, Amendment 33, was combined with a 3-D wil-structure foundation model for the seismic reanalysis. The site conditions and the soil profiles for the 22 SSI analysis cases are documented in Table 3A-7 of SSAR Appendix 3A, Amendment 33. For all these 22 SSI analyses, an embedment of $23.2 \mathrm{~m}$ (76 ft) was included. In addition, the same approach, analysis procedures and ground motion time history that were applied to the RB were adopted for the control building analyses, and the SSI analysis computer codo SASSI was also used in this analysis. The staff concludes that the consideration of the wil site conditions and SSI analysis cases, the modeling technique used for structure and soil foundation, and the ground motion timo history used in the control building soismic reanalysis are acceptable, and DFSER Open Itom 3.7.2-4 is resolved.

To generate the FRS envelopes, GE (1) followed the same procedures that were applied to the RB, (2) generated 2-, 3-, 5-, and 10-percent damping FRS for all SASSI analysis cases shown in SSAR Table 3A-7, (3) developed the envelopes of the FRS at all required locations in each of the three directions, (4) developed the envelope FRS in the two horizontal directions at each location to form the bounding horizontal FRS, and (5) broadened the peaks of the FRS by \pm 15 percent. The uncertainty factors of 1.5 and 1.0, respectively, to the horizontal and vertical FRS envelopes used in the original seismic analyses were not applied in this reanalysis. The staff reviewed the process for developing the FRS envelopes and the resulting FRS envelope plots provided in SSAR Appendix 3A, Amendment 33, and found them acceptable, and both DFSER Confirmatory Items $3.7 .2-4$ and $3.7 .2-5$ are resolved.

In response to DFSER Open Item 3.7.2-3, GE used the 2-D soil-foundation model combined with the 2-D control building, RB, and turbine building models, and the SASSI computer code to evaluate the significance of the effects of structure-to-structure interaction (Cases 20 through 22 in SSAR Table 3A-7). The analysis results, as documented in Tables 3A-15 through $3 A-18$ and Figures 3A-122 through 3A-127 of SSAR Appendix 3A, Amendment 33, showed that the effect of structure-to-structure interaction is significant for the control building. However, these results are bounded by the structural response envelopes, which is acceptable, and DFSER Open Item 3.7.2-3 is resolved.

From the review of Appendices $3 A$ and $3 G$ of SSAR Chapter 3 ard the certified design material (CDM) for the GE ABWR design dated March 1992, the staff observed 
that the building dimensions are inconsistently specified in these documents. For example, the dimensions of the control building are specified to be $16 \mathrm{~m} \times 45 \mathrm{~m}$ (52 ft $x 147 \mathrm{ft}$ ) in plan and $12.2 \mathrm{~m}$ (40 ft) in embedment depth according to SSAR Soction 3A.2, $22 \mathrm{~m} \times 56 \mathrm{~m}$ (72 ft $x 184 \mathrm{ft}$ ) in plan and $25.9 \mathrm{~m}$ (85 ft) in embedment depth sccording to SSAR Section 3G.3.2, and $24 \mathrm{~m} \times 56 \mathrm{~m}$ (79 $\mathrm{ft} \times 184 \mathrm{ft}$ ) in plan and $23.1 \mathrm{~m}$ (75 ft and 9 in.) in embedment depth according to the CDM. In the DFSER, the staff noted that GE should verify the accuracy of all dimensions of the control building, including the embedment depth, used in the final seismic analysis of the soismic Category I structures shown in the SSAR and the CDM. This concern also applied to the dimension of all other seismic Category I building structures, including the RB. This was DFSER Open Itom 3.7.2-5.

In SSAR Sections 3.7 and 3.8, Amendment 33, GE corrected all inconsistent building dimensions, including building ombedment depths, for the seismic Category I structures. This is acceptable, and DFSER Open Item 3.7.2-5 is resolved.

\section{Radwaste Buildine Substructure}

During an earlier design calculation audit, GE indicated that the radwasto building does not house any safety-related equipment and components and bence, there is no need to generate FRS for the subsystems. To ensure that the building maintains its structural integrity during and after an SSE and to prevent unacceptable leakage of the radwaste material outside the embedded portion of the building, GE elected to analyze the radwaste building by the response spectrum analysis method and to design the radwaste building structure for the SSE seismic loads. When the modal response spectrum method was used for the analysis of the radwaste building structure and the subsystems, GE combined the modal responses by the method delineated in RG 1.92, "Combining Modal Responses and Spatial Components in Seismic Response Analysis," Revision 1. The effects of high frequency modes were considered in accordance with the guidelines of Appendix A to SRP Section 3.7.2. The co-directional responses of the radwaste building structure to the three components of the earthquake ground motion were combined using the square-root-of-sum-of-squares (SRSS) rule according to the guidelines of RG 1.92. The methods used for the combination of the modal responses and the co-directional responses to the three components of the ground motion comply with the guidelines of SRP Section 3.7.2 and are, thus, acceptable.

The seismic analysis was performed using a fixed-base freestanding stick model to represent the structure. This simplified analysis model excludes the effects of both the structural embedment and site soil conditions. The resulting fundamental horizontal frequency is within the frequency range of the maximum amplification of the input ground response spectrum. This ensures that the resulting seismic loads for the design of the structure are sufficiently conservative to preclude the need for considering the effects of structural embedment and site soil conditions. In the DFSER, the staff reported that GE had not completed the implementation of the QA program for the seismic analysis of this building. In addition, the SSAR did not include the analysis results such as the structural frequencies, seismic shear forces, and seismic moments. This was DFSER Confirmatory Item 3.7.2-6.

As a result of discussions during the audit on February 22 through 26, 1993, in SSAR Section 3H.3, Amendment 33, GE provided the analysis methods and results of the radwaste building. As a result of its review, the staff concludes that they are acseptable. Also in a letter dated September 15, 1993, GE certified that the implementation of the QA program for the design calculations of the radwaste building had been completed. Therefore, DFSER Confirmatory Item $3.7 .2-6$ is resolved.

\section{Turbine Building}

In the DFSER, the staff noted that GE had committed to perform a dynamic analysis for the portion of the MSL inside the turbine building, but neither the FRS for use as the seismic input for the MSL analysis nor the procedure to generate the FRS had been provided in the SSAR. On the basis of SRP Sections 3.7.2 and 3.7.3, the staff requested that GE perform a dynamic analysis of the turbine building and condenser to generate a set of FRS as the seismic input for the MSL analysis. The staff also noted that, according to GE, the FRS generated at the containment shell are used as the input motion at the end of MSL anchored to the containment, and the ground motion response spectrum multiplied by an amplification factor serves as the input at the end of MSL (including branch lines) anchored to the turbine building and condenser. Use of the containment FRS as the input at the containment side for the MSL analysis is acceptable.

However, the staff noted in the DFSER about the adequacy of using some multiple of the ground response spectrum as the input for the MSL analysis at the turbine building side anchor. This was DFSER Open Item 3.7.2-6. In SSAR Section 3.2.5.3, Amendment 33, GE stated that the dynamic input loads for the design of the MSLs in the turbine building are derived as follows: (1) for locations on the basemat, the amplified response spectra (ARS) (FRS in this report) shall be based upon the RG 1.60 response spectra normalized to $0.6 \mathrm{~g}$ (i.e., 2 times the SSE ground response spectra) and (2) for locations at the 
opernting dock lovel (either opernting dock or turbine dock), the ARS used shall bo the same as those used at the RB end of tho MST. SAMs chall be similarly calculated. The staff concludes that the dynnmic input loads for the design of the MSLs inside the turbine building aro acceptable because (1) a comparison of the response spectin at the RB foundation lovel with the RO 1.60 response spectra anchored to $0.68 \mathrm{ZPA}$ shows that the RG 1.60 response spectra anchored to the same 0.68 ZPA envelop the response spectrn at the RB foundation level and (2) the turbine operating deck is located at approximately the same elevation as the anchor point of the main steamline at the RB side and the response spectrn at the RB end wero genernted using an acceptable analysis approach as discussed. DFSER Open Item 3.7.2-6 is resolved.

In the markup of SSAR Section 3.7.3.16, dated May 21, 1992, GE described the seismic design of the turbind building using the UBC approach for seismic Zone $2 A$. However, the seismic design, based on UBC Zone $2 A$ rules, does not necessarily ensure that the turbine building will be structurally capable of withstanding the SSE for the standard plant design to protect the safety function of the portion of the MSL inside the turbine building. This was DFSER Open Item 3.7.2-7. In S'SAR Section 3.7.3.16, Amendment 33, GE stated that for the design of nonseismic Category I structures which are required to withstand an SSE without losing the structural integrity, the procedures described in the UBC seismic design criteria shall be followed with the following limitations:

(1) The seismic zone shall be "Zone 3."

(2) For dual systems (i.e., shear wall with braced steel frame), one of the two systems must be designed to be capable of carrying all of the seismic loading without collapse. No credit will be given for the other system for resisting lateral loads.

The seismic zone factor $Z$ for UBC Zone 3 is 0.3 , which is equivalent to a peak ground acceleration (ZPA) of $0.3 \mathrm{~g}$. Therefore, the staff concludes that GE's use of the UBC Zone 3 requirements with these restrictions as discussed for the seismic design of non-seismic Category I structures, including the turbine building, can ensure that the turbine building will retain its structural integrity under the specified SSE and is, thus, acceptable. DFSER Open Item 3.7.2-7 is resolved.

\section{Confirmation of Plant-Specific Seismic Desion Adequacy}

To confirm the site-specific seismic design adequacy of the standard plant, SSAR Section 2.3.1, Amendment 9, stated that the COL applicant shall demonstrate, according to the procedure specified therein, that it has atisfied the eight sito-dependent conditions epecified in SSAR Section 3A.1. Thewe eight sito-dependent conditions were:

(1) The peak ground acceleration is leas than $0.30 \mathrm{~g}$ SSE.

(2) The site design response spectra are lese than or equal to those given in RG 1.60 normalized to the peak ground accelerations in Condition 1.

(3) There is no potential for liquefaction at the plant site as a result of an SSE as reviewed and concurred with by the NRC staff (the liquefaction potential of the foundation and site soils will bo investigated and reported for a long duration, Now Madrid-type earthquake).

(4) There is no potential for fault movement at the plant site as reviewed and concurred with by the NRC staff.

(5) The embedment depth of the reactor building is $25.9 \mathrm{~m}(85 \mathrm{ft})$. The excavation tolerance is $\pm 15 \mathrm{~cm}( \pm 0.5 \mathrm{ft})$.

(6) The average shear wave velocity for the top $9 \mathrm{~m}$ (30 ft) of soil is $305 \mathrm{~m} / \mathrm{sec}$ (1000 ft/sec) minimum. The upper bound shear wave velocity is $3048 \mathrm{~m} / \mathrm{sec}$ (10000 ft/sec).

(7) For layered soil sites with parameters that have very abrupt variations with depth, an analysis with site-unique properties will be performed to confirm the applicability of the generic analysis.

(8) The soil-bearing capacity at the sito is adequate to accommodate plant design loads.

In letter dated August 19, 1991, GE described an evaluation procedure for the site-specific confirmation of the seismic design adequacy of the ABWR standard plant and, in SSAR Section 2.3.1.2, Amendment 18, GE revised the site-dependent conditions and the standard design adequacy confirmation procedure. The staff reviewed these submittals and identified four issues in the DFSER:

GE should provide the criteria and the confirmation procedure for the site condition classified as shallow soil site in the SSAR. This was DFSER Open Item 3.7.2-8.

(2) When a sito-specific SSI analysis is performed for the SSE case, the three components of the ground motion time history should satisfy not only the PSDF enveloping criterion, but also the response 


\section{Design of Structures, Components, Equipment, and Systems}

epectrum enveloping criterion for all damping values to be used with response analyais. This was DFSER Confirmatory Itom 3.7.2-7.

(3) In its lotter dated August 19, 1991, and in SSAR Section 2.3.1, Amendment 18, GE stated that COL applicants shall consider sito-dependent bounding Conditions 6 and 7 above as two individual ovaluation paramoters when confirming the adequacy of the standard plant design for a specific site. The effect of soil layer depth was not considered or included in the evaluation. The staff was concerned that to compare Conditions 6 and 7 with the sito-specific design parameters separately is not sufficient to confirm the design adequacy of the standard plant. The staff believed that these two conditions should be considered together with the depth of soil layers. In addition, the sitospecific responses (structural momber forces and FRS) should be compared to the response envelopes used for the standard plant design unless the sitospecific parameters (shear wave velocity, number of soil layers, and depth of soil layers) can be demonstrated to be comparable to one of the 14 generic site conditions. This wai DFSER Open Item 3.7.2-9.

(4) In SSAR Section 2.3.1.2, Amendment 18, GE stated that the FRS comparison can be made for one damping value only when confirming the seismic design adequacy of piping and equipment. According to the guidelines of SRP Section 3.7.1.1.1.b, the FRS comparison should be performed for all damping values assigned to different piping systems and equipment. This was DFSER Confirmatory Item 3.7.2-8.

To respond to these four items, in SSAR Amendment 30, GE revised the eight sito-dependent conditions by (1) moving these conditions from Appendix 3A to Section 2.3, "COL License Information," (2) eliminating Conditions 6 and 7, and (3) adding the condition for the shallow soil site. GE also revised the confirmation procedure by only comparing the site-specific SSE ground response spectrum of 5-percent damping at plant grade in the free-field with the design ground response spectrum (i.e., RG 1.60 response spectrum anchored to $0.3 \mathrm{~g}$ PGA). The staff reviewed these revisions and determined that it is acceptable to compare the ground response spectra at plant grade in the free-field for the confirmation of the design adequacy and that there is no need to specifically confirm the adequacy of the ground motion time history, local soil layering effects, and FRS for the subsystem analysis and design. The basis for the staff conclusion is that when the site-specific ground motion response spectrum is doveloped and the freo-fiold ourface ground motion is calculated, the local geotechnical propertices (coil layering, ahear module, etc.) are all considered. As far as the adequacy of site-specific ground motion time history and the generation of the FRS, the ataff will reviow it on a caso-by-case besis. Therefore, DFSER Open Items 3.7.2-8 and 3.7.2-9 and DFSER Confirmatory Items 3.7.2-7 and 3.7.2-8 are resolved.

The staff concludes that the ABWR standard plant design is acceptable and meets the requirements of GDC 2 and Appendix A to 10 CFR Part 100. This conclusion is besed on the following: the applicant has met the requirements of GDC 2 and Appendix A to 10 CFR Part 100 with respect to the capability of the structures to withstand the effects of the earthquakes so that their design reflects:

1. Appropriate consideration for the most severe earthquake recorded for the most sites east of the Rocky Mountains with an appropriato margin (GDC 2);

2. Appropriate combination of the effects of normal and accident conditions with the effect of the natural phenomena; and

3. The importance of the safety functions to be performed (GDC 2). The use of a suitable dynamic analysis to demonstrate that $\mathrm{SSC}_{3}$ can withstand the seismic and other concurrent loads.

The applicant has met the requirements of Item 1 by using seismic design parameters that meet the guidelines of SRP Section 3.7.1. The combinations of earthquake-induced loads with those resulting from normal and accident conditions in the design of seismic Category I structures meet the guidelines of SRP Sections 3.8.1 through 3.8.5 and are in conformance with Item 2.

The scope of review of the seismic system and subsystem analysis for the plant included the seismic analysis methods for all seismic Category I SSCs. It included review of procedures for modeling, seismic soil-structure interaction, development of envelope response spectra, inclusion of torsional effects, evaluation of seismic Category I structure overturning and sliding, and determination of composite damping. The review also included design criteria and procedures for evaluation of the interaction of non-seismic Category I structures with Category I structures, and the effects of parameter variations on FRS. In addition, the review included criteria and seismic analysis procedures for seismic Category I buried piping outside containment.

GE performed the system and subsystem analyses on an elastic and linear basis. Time history methods form the bases for the analyses of all major seismic Category I 
structures except the radwaste building. The seismic analyais of the radwaste building and the seismic analyais of seismic Catogory I systoms and components are besed on the response spectrum analysis mothod. When the modal response spectrum mothod was used, modal responses were combined in conformance with RG 1.92. GE's consideration of the high-frequency mode contribution to the overall structural responses met the guidelines of Appendix A to SRP Section 3.7.2. The SRSS of the maximum codirectionau responses was used in accounting for three components of the earthquake motion for both the time history and response spectrum methods. FRS inputs to be used for analysis and design of structural elements, systems, and components were generated from the timo history method, and they are in conformance with RG 1.122, "Dovelopment of Floor Design Response Spectra for Seismic Design of Floor-Supported Equipment or Components," Revision 1. A vertical seismic system dynamic analysis was employed for all $\mathrm{SSCs}$ where analyses had shown significant structural amplification in the vertical direction. Torsional effects and stability against overturning and sliding were considered.

A coupled structure and soil model was used to evaluate soil-structure interaction effects upon seismic responses. Appropriate nonlinear stress-strain and damping relationships for the soil were considered in the analysis. The staff concludes that the use of seismic structural analysis procedures and criteria delineated by GE provide an adequate basis for the seismic design, which is in conformance with the requirements of Item 3 listed.

\subsubsection{Seismic Subsystem Analysis}

The staff review of the seismic subsystem analyses included the seismic analysis methods for ABWR seismic Category I SSCs that were not explicitly included in the structural models when seismic analyses of the seismic Category I structures were performed. Such items include all seismic Category I cable trays and supports, conduit and supports, above-ground tanks, buried piping and tunnels, and structural elements that support other seismic Category I items, the dynamic effects of which could affect the seismic response of the supported items (e.g., the steel platforms, the radial steel beams, and the DEPSS in the RB). Seismic qualification of seismic Category I mechanical equipment and instrumentation and electrical equipment is evaluated, respectively, in Sections 3.9 and 3.10 of this report. The seismic analysis of piping systems is discussed in Section 3.12 of this report.

GE performed the subsystem analysis on a linear elastic basis. The modal response spectrum method and equivalent static load method formed the basis for the analyses of all major seismic Category I subsystems in both the horizontal and vertical directions. When the modal response spectrum method was used, the analygis model wes established and the procedures used for its development complied with the guidelines of SRP Section 3.7.3 for dynamic analyses. The modal responses and the spatial components of responses wero combined according to the methods delineated in RG 1.92. Theec mothods used for combining seismic responses comply with the guidelines of SRP Section 3.7.2, and are, thus, acceptable. GE used the FRS envelopes obtained from the time history analyses of the structures for the seismic input for the subsystem analyses. GE considered torsional effects of eccentric masses. These modeling techniques and analysis methods for the subsystems meet the guidelines of SRP Section 3.7.3 and, therefore, are acceptable.

Seismic Category I cable trays and conduit supports were analyzed using the modal response spectrum method of analysis. The analysis procedure and design criteria were described in more detail in SSAR Section 3.8.4, Amendment 33. The staff's evaluation of the subject is given in Section 3.10.2 of this report.

Buried seismic Category I piping systems and tunnels were analyzed using the techniques that account for the effects of seismic wave travel, differential movements of pipe anchors, bent geometry and curvature changes, local soil settlements or soil arching. The early SSAR amendments did not describe in detail the procedure for the analysis of buried piping and tunnels or provide any description of the procedure for the dynamic analysis and evaluation of the above-ground tanks. This was DFSER Open Item 3.7.3-1. In SSAR Section 3.7.3.12, Amendment 33, GE provided the design procedures for buried piping and pipe tunnels, and in SSAR Section 3.7.3.17, Amendment 33, GE provided the analysis procedures for the above-ground tanks. The procedures for the analysis and design of buried piping, pipe tunnels, and the above-ground tanks conform with the guidelines of SRP Section 3.7.3, and are, therefore, acceptable. DFSER Open Item 3.7.3-1 is resolved.

The staff concludes that the design of the subsystems of the ABWR standard plant is acceptable and meets GDC 2 and Appendix A to 10 CFR Part 100 with regard to the capability to withstand the effects of the earthquakes. Evaluation findings for SSAR Section 3.7.3 have been combised with those for SSAR Section 3.7.2 and are given in Section 3.7.2 of this report.

\subsubsection{Seismic Instrumentation}

The seismic instrumentation system specified for the ABWR plant in SSAR Section 3.7.4 is acceptable and 
meots ODC 2 and 10 CFR Part 100 Appeadix A. The applicant mot theee requirements by requiring inatallation of instrumentation that is capable of adequately moaruring the offects of an earthquake.

GE meets the requirements of $10 \mathrm{CFR}$ Part 100 , Appendix $A$, and GDC 2 by providing instrumentation that is capable of measuring the effects of an earthquake. The installation of the specified seismic instrumentation as specified in SSAR Section 3.7.4.1 in the reactor containment structure, other ABWR Category I structures, and the free field constitutes an acceptable program for recording data on seismic ground motion as well as data on the amplitude, frequency, and phase relationship of the soismic response of major structures and systpms in the event of an carthquake. A readout of pertinent data from the various seismic instruments will yield sufficient information to guide the operator on a timely basis to determine if the level of earthquake motion ground requiring plant shutdown has been exceeded. Data obtained from such installed seismic instrumentation will be sufficient to ascertain that the seismic analysis assumptions and the analytical models used in the seismic design of the ABWR were adequate and that allowable stresses have not been exceeded under conditions when continuity of operation is intended. The staff finds the design! for seismic instrumentation acceptable.

In view of the time and effort required to determine if the level of earthquake ground motion requiring plant shutdown has been exceeded, COL applicants should establish plant operating procedures that define specifically what constitutes a significant exceedance of the level of earthquake ground motion requiring plant shutdown. This was DFSER COL Action Item 3.7.4-1. GE has included this information in Section 3.7.4.4 of the SSAR. This is acceptable.

Because of the continuous enhancement in the state of the art of seismic instrumentation and the revisions to Appendix A of 10 CFR Part 100 and to RG 1.12 (Rev. 1) (currently in progress), conformity with instrumentation guidelines in existence at the time of an individual license application will be required. This was DFSER COL Action Item 3.7.4-2. GE has also included this information in Sections 3.7.4.1 and 3.7.4.2 of the SSAR. This is acceptable.

\subsection{Design of Seismic Category I Structures}

\subsubsection{Concrete Containment}

The containment is designed as a reinforced-concrete cylindrical shell structure with an internal steel liner made of carbon steel, except for wetted surfaces where stainless atcel or carbon ateel with atainloes ateel cledding will bo ueed. It is divided by the diaphragm floor and the reactor pedeetal into an upper drywell chamber, a lower drywell chamber and a suppreasion chamber. The containment is surrounded by and atructurally intogral with the $\mathbf{R B}$ through the RB floor slabs and the spent fuel pool structures. The containment wall is $2.0 \mathrm{~m}$ (6 ft $7 \mathrm{in}$.) thick with an inside radius of $14.5 \mathrm{~m}$ (47 $\mathrm{ft} 7 \mathrm{in}$.) and height of $29.5 \mathrm{~m}$ (96 $\mathrm{ft} 9 \mathrm{in}$.). The containment design pressure is $310.3 \mathrm{kPa}$ (45 psig). The containment is designed to resist various combinations of dead loads; live loads; environmental loads, including those resulting from wind, tornados, and earthquakes; normal operating loads; and loads generated by a postulated LOCA. Tho design, fabrication, construction, and testing of contrinment are in accordance with Subeection CC of ASME Code, Section III, Division 2. In the DFSER, the staff stated a concern about the use of ASME Code edition. This was DFSER Open Item 3.8.1-1. In SSAR Section 1.8, Amendment 33, GE stated that the 1989 edition of ASME Code, Section III, will be used for the containment design. The staff has reviewed the adequacy of the 1989 Edition of ASME Code, Section III, Division 2, for reinforced concrete containment design and found it acceptable with the following clarification of the criteria for the tangential shear design. With regards to the edition of the ASME code used for the ABWR containment design, Open Item 3.8.1-1 is considered closed. According to RG 1.136 (Rev. 2), the staff has not yet endorsed Subsection CC-3000 of ASME Code, Section III, Division 2, "Codo for Concrete Reactor Vessels and Containments." Specifically, the staff raised a concern that the code specified allowable tangential shear stress of $0.2 f t$ is too high for the design of reinforced concrete containments. Subsequently, SSAR Section 3.8.1.5 revised the allowable tangential shear from $0.2 f \mathrm{c}$ to $2.4 \sqrt{f \mathfrak{c}}$ (3.92 MPa (569.2 psi) for the conrete strength $f c=27.6 \mathrm{MPa}(4000 \mathrm{psi})$ to be used for containment vessel and foundation mat). The results of GE's analysis show that the maximum tangential shear stress is $3.60 \mathrm{MPa}$ (522.3 psi) and the total calculated shear strain is 0.000295 , under the factored load combinations. In addition, GE provided the staff its backup calculations on December 3, 1993, for review. As a result of its review, the staff found that the revised allowable tangential shear stress of $2.4 \sqrt{f c}$ is within the limit of in-plane shear strength $2.65 \sqrt{f c}$ for shear walls specified in ACI 318 Code and the calculated total shear strain of 0.000295 is smaller than the limit of tangential shear strain based on the tests performed for the reinforced concrete cylindrical shell. Based on this discussion, the staff concludes that the proposed allowable tangential shear stress is acceptable, and DFSER Open Item 3.8.1-1 is resolved. To follow the 10 CFR Part 52 design certification process, any change to the use of the ASME Code (1989 Edition) for the design 

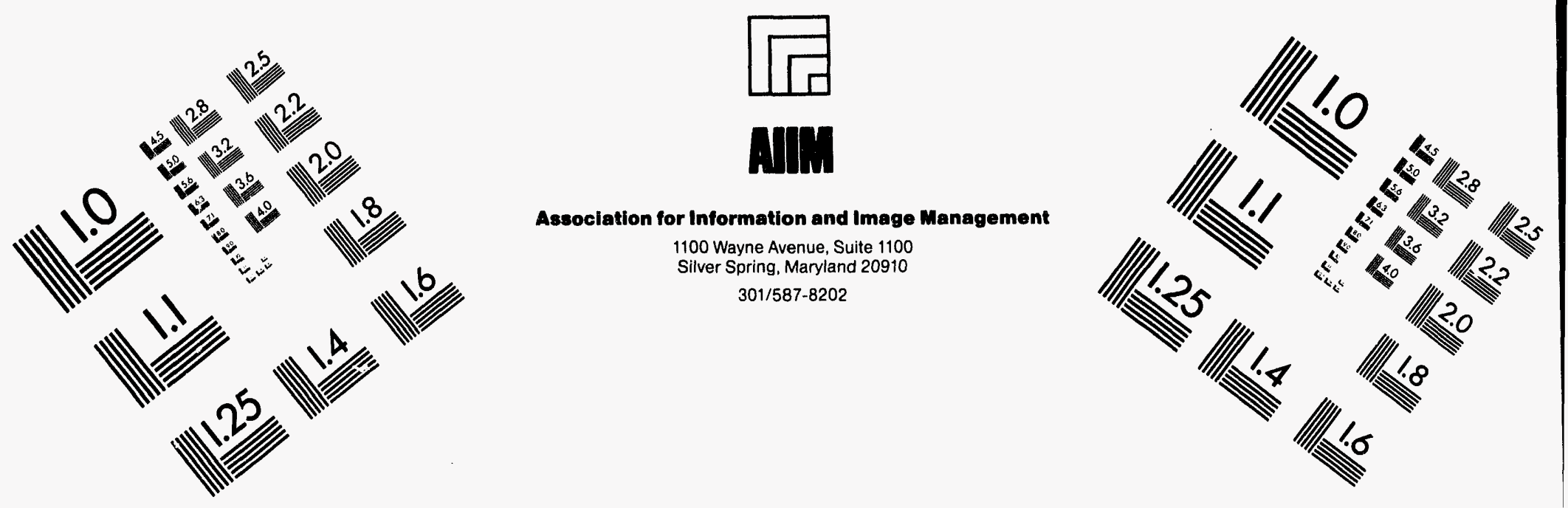

\section{Centimeter}

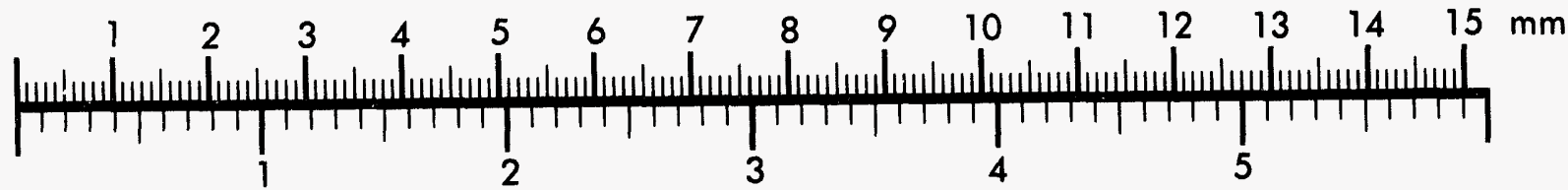
Inches
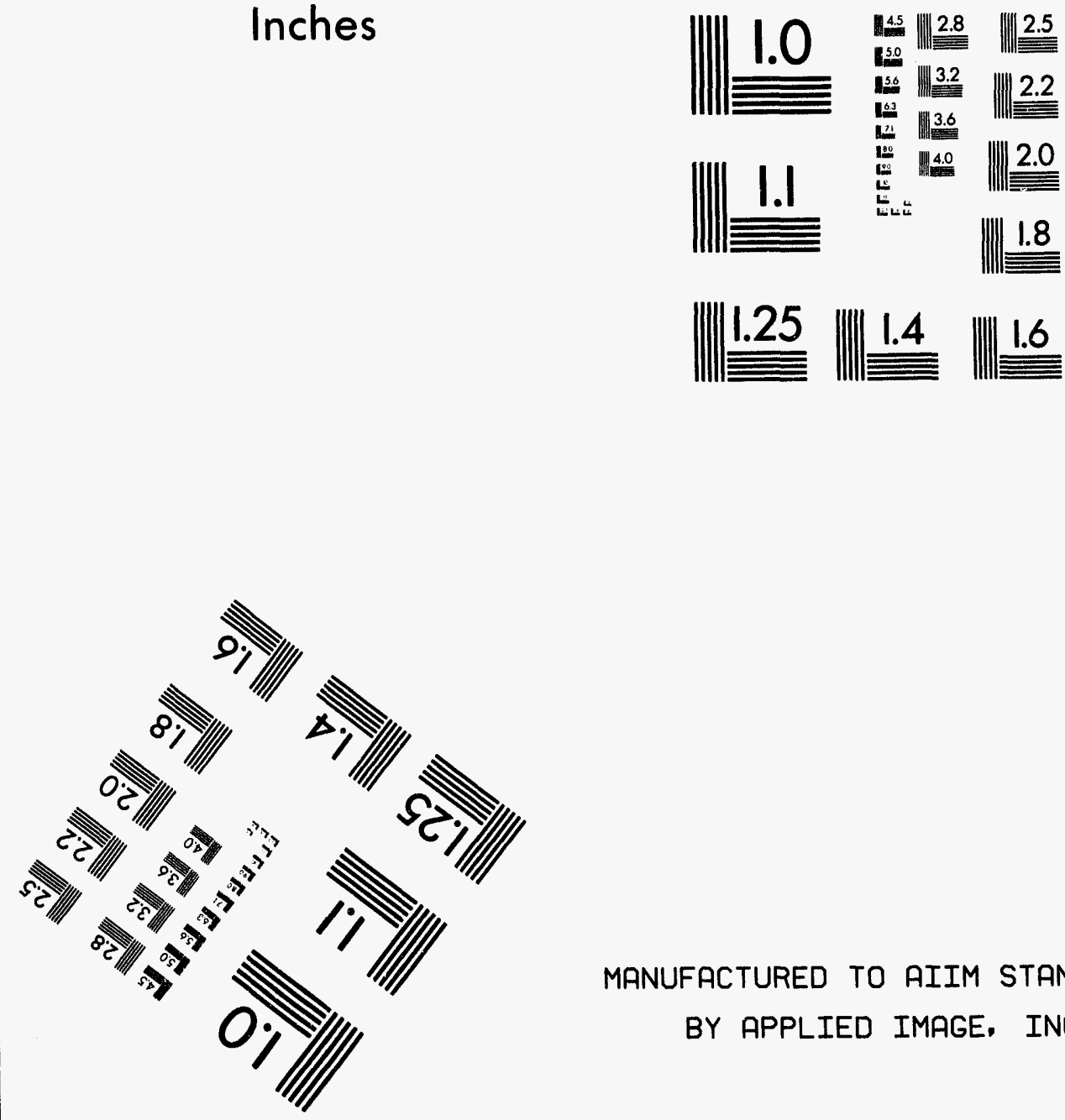

MANUFACTURED TO AIIM STANDARDS

BY APPLIED IMAGE, INC.

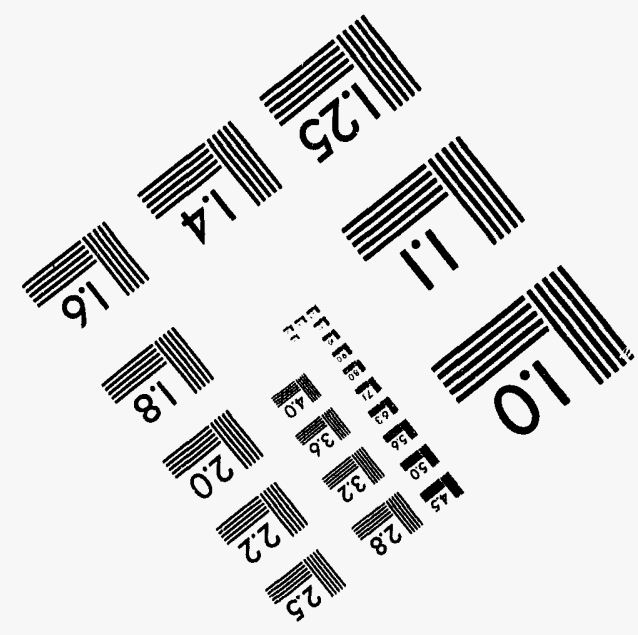



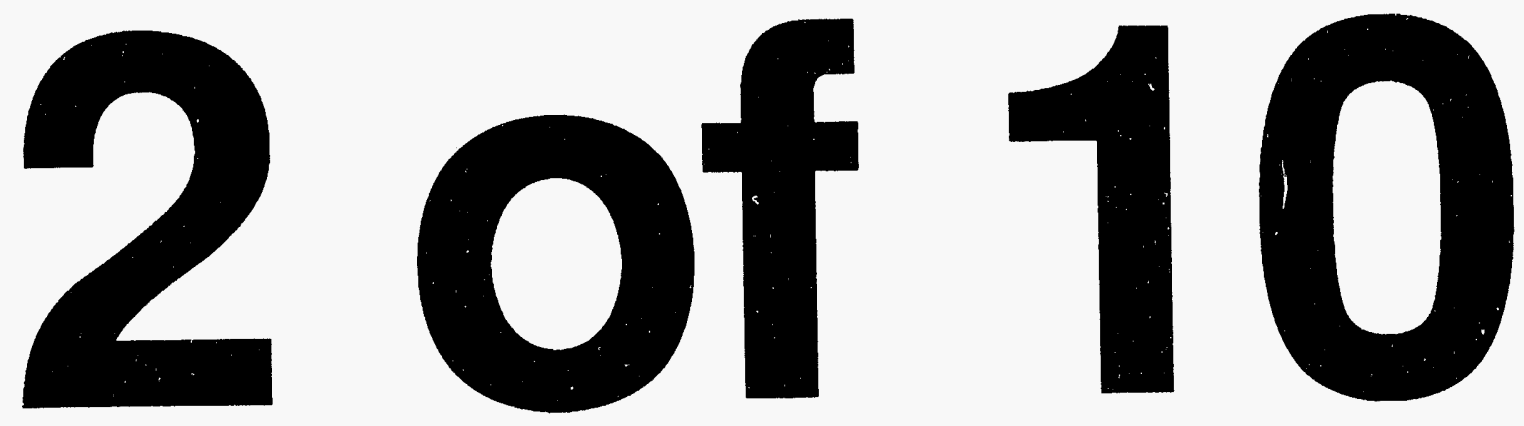


\section{Design of Structures, Components, Equipment, and Systems}

and construction of reinforced concrete containment structural elements (including the tangential shear stress limit discussed above), would involvo en unroviewed safety question and, therofore, requiro NRC review and approval prior to implementation. Furthermore, any requeeted change to the use of this code must' either be specifically described in the COL application or submitted for license amendment after $\mathrm{COL}$ issuance.

The major steel components of the concrete containment, as stated in SSAR Section 3.8.2, consist of personnel air locks, equipment hatches, penetrations, and the drywell head. These components are designed for the same loads and load combinations as those used in the design of the concrete containment shell to which these components will bo attached. These components will bo fabricated, and tested as Class MC components in abcordance with the 1989 Edition of Subsection NE of ASME Code, Section III, Division 1. Also in SSAR Section 3.8.1.7.1, GE stated that the COL applicant will perform the structural integrity test (SIT) of the ABWR containments in accordance with the provisions of Article CC-6000 and Subarticle CC-6230 of the ASME Code, Section III, Division 2 (1989 Edition). Similar to that for concrete containment, the staff raised, in the DFSER, a concern about the edition of ASME Code for the design of major steel components. This was DFSER Open Item 3.8.1-2. In Amendment 33 of the SSAR, GE stated that the 1989 Edition of ASME Code, Section III, will be used for the design and test. This edition of ASME Code is referenced in 10 CFR 50.55a and is, therefore, acceptable. DFSER Open Item 3.8.1-2 is resolved.

In SSAR Section 3.8.2.4.1.4, Amendment 33, GE stated that the drywell head, which consists of shell, finger pin closure, and drywell-head anchor system, was analyzed using a finite-element stress analysis computer program. The stresses, including discontinuity stresses induced by the combination of external pressure or internal pressure, dead load, live load, thermal offects and seismic loads, were evaluated. GE's analyses and limits for the resulting stress intensities are in accordance with Subarticles NE-3130 and NE-3200 of ASME Code Section III, Division 1 (1989 Edition). The staff found that the analysis and design approach and the use of design code are consistent with the guidelines of SRP Section 3.8.1. This is acceptable. GE also stated in the SSAR that the compressive stress within the knuckle region caused by the internal pressure and the compression in other regions caused by other loads are limited to the allowable buckling stress values in accordance with Subarticle NE-3222 of ASME Code Section III, Division 1 (1989 Edition). GE's evaluation of the potential buckling of the drywell head and the buckling criteria used are consistent with the staff position for shell buckling described in Appendix E of this report. This is acceptable. To follow the 10 CFR Part 52 design certification process, change to the use of ASME Code (1989 Edition) for the design, fabrication, and construction of drywell head against buckling would involve an unreviewed safety question and, therefore, require NRC review and approval prior to implementation. Furthermore, any requested change to the use of this code must either be specifically described in the COL application or submitted for license amendment after COL issuance.

As for the ultimate capacity of the concrete containment, including the steel drywell head, the staff evaluation is discussed in Section 19 of this report.

During the first two design calculation audits, the detailed design calculations for the containment shell were not available for reviow. This was DFSER Confirmatory Item 3.8.1-1. During the audit dated February 22 through 25, 1993, GE provided its final containment shell design calculations for staff review. The staff found the design calculations acceptable. Therefore, Confirmatory Item 3.8.1-1 is resolved.

GE considers the first ABWR containment as a prototype and requires its SIT to be performed as such. Therefore, the COL applicant is required to provide the details of the test and the instrumentation as required by the ASME Code, Section III, Division 2, Subsection 6212, for such a test to the staff for review and approval. In the DFSER, the COL applicant's action to provide the details of the test and the instrumentation as required for such a test was DFSER COL Action Item 3.8.1-1. In SSAR Section 3.8.1.7.1, Amendment 33, GE stated that the COL applicant shall perform the SIT according to Article CC-6600 of ASME Code, Section III, Division 2 (1989 Edition) and RG 1.136, "Materials, Construction, and Testing of Concrete Containments," Revision 2, after completing the containment construction. This is acceptable.

The staff review of the performance of the containment structure under the loads and load combinations beyond the design limits is discussed in Section 19 of this report.

The staff concludes that the design of the concrete containment is acceptable and meets the relevant requirements of 10 CFR Part 50, 50.55a, and GDC 1, 2, 4,16 , and 50. This conclusion is based on the following:

1. GE has met the requirements of Section $50.55 \mathrm{a}$ and GDC 1 with respect to assuring that the concrete containment is designed, fabricated, erected, contracted, tested, and inspected to quality standards commensurate with its safety function to be performed 
by meoting the guidelines of segulatory guides and industry atandards indicated below.

2. GE hes met the requirements of GDC 2 by designing the concrete containment to withstand $20.3 \mathrm{~g}$ SSE with sufficient margin, and the combinations of the effects of normal and accident conditions with the effects of environmental loadings such as earthquakes and other natural phenomena.

3. GE has met the requirements of GDC 4 by assuring that the design of the concrete containment is capable of withstanding the dynamic effects associated with missiles, pipe whipping, and discharging fluids.

4. GE has met the requirements of GDC 16 by designing the concrete containment so that it is an essentially leaktight barrier to prevent the uncontrolled release of radionctive effluent to the environment.

5. GE has met the requirements of GDC 50 by designing the concrete containment to accommodate, with sufficient margin, the design leakage rate, calculated pressure and temperature conditions resulting from accident conditions, and by assuring that the design conditions are not exceeded during the full course of the accident condition. In meeting these design requirements, $\mathrm{GE}$ bas used the recommendations of regulatory guides and industry standards indicatod below. GE has also performod an appropriate analysis that demonstrates that the ultimate capacity of the containment will not be exceoded and establisbes acceptable margin of safety for the design.

The criteria used in the analysis, design, and those proposed for construction of the concrete containment structure to account for anticipated loadings and postulated conditions that may be imposed upon the structure during its service lifetime are in conformance with established criteria, and with codes, standards, guides, and specifications acceptable to the regulatory staff. These include meeting the positions of RG 1.94, "Quality Assurance Requirements for Installation, Inspection, and Testing of Structural Concrete and Structural Steel During the Construction Phase of Nuclear Power Plants," Revision 1, and RG 1.136, "Materials, Construction, and Testing of Concrete Containments," Revision 2, and industry standard ASME Boiler and Pressure Vessel Code, Section III, Division 2 (1989 Edition).

The use of these criteria as defined by applicable codes, standards, guides, and specifications; the loads and loading combinations; the design and analysis procedures; the structural acceptance criteria; the materials, quality control programs, and special construction techniques; and the toating and inservice surveillance requirements, provide reasonable sanurance that, in the event of winds, tornados, carthquakes and various poetulated accidents occurring within and outside the containment, the structure will withstend the specified design conditions without impairment of structurai integrity or safety function of limiting the release of radionctive material.

\subsubsection{Steel Components of the Reinforced Concrete Containment}

The staff's evaluation of the design adequacy of the major steel components of the reinforced concrete containment is discussed in Section 3.8.1 of this report.

\subsubsection{Concrete and Steel Internal Structures of Steel or Concrete Containment}

In the ABWR design, the internal structures inside the containment include the reinforced-concrete diaphragm floor, the reactor pedestal, the reactor shield wall, and other structural components. The diaphragm floor separates the upper drywell from the suppression pool. The reactor pedestal consists of a ledge on a cylindrical shell that forms the reactor cavity, extending from the bottom of the diaphragm to the top of the containment foundation slab. The space enclosed by the cylindrical shell under the reactor is the lower drywell, which is connected to the suppression pool through a series of vertical and horizontal vents in the shell wall. A steel equipment platform is located in the lower drywell and is accessiblo through a steel personnel tunnel and a steel equipment tunnel from outside the containment. Other internal structures include the DEPSS and the miscelleneous floors. The major code used in the design of concrete internal structures is Americen Concrete Institute (ACI) Standard 349 (1980 Edition). The use of this code for the design of the seismic Catogory I reinforced concrete structures is acceptable, except that the utaff position on the design requirements for the steel embedments should be satisfied. The staff position on steel embedment design is described in Appendix F of this report. As described in early SSAR Amendments, GE used American National Standards Institute/American Institute of Steel Construction (ANSI/AISC) Standard N-690 (1984 Edition) for the design of all steel internal structures. In the DFSER, the staff noted that this standard had not been approved and accepted by the staff, the use of ANSI/ASCE N-690 was DFSER Open Itom 3.8.3-1. In SSAR Section 3.8.3 and Tables 3.8-4 and 3.8-9, Amendment 33, GE provided limitations of using the ANSI/AISC N-690 Standard (1984 Edition) in the design of steel internal structures. The use of this standard with these limitations complies with the staff position described in Appendix $G$ of this report. This is 


\section{Design of Structures, Components, Equipment, and Systems}

acceptable, and DFSER Open Item 3.8.3-1 is resolved. To follow the 10 CFR Part 52 design certification proceses, any change to the use of ANSI/AISC Standard N-690 (1984 Bdition) and ACI Standand 349 (1980 Edition) for the design and construction of containment internal structural elements would involve an unreviewed affety question and, therefore, require NRC roviow and approval prior to implementation. Furthermore, any requested change to the use of these codes must oither be specifically described in the COL application or submitted for license amendment after COL issuance.

The containment concrete and steel internal structures are designed to resist various combinations of dead and live loads, sccident-induced loads (including pressure and jet loads), and soismic loads. The load combinations used cover those cases likely to oxcur and include all loads that may act simultaneously. The containment internal structures are designed and proportioned to remain within the limits in accordance with SRP Section 3.8.3 for the various load combinations. These limits are based on ASME Code, Section III, Division 2, ACI Standard 349 (1980 Edition), and ANSI/AISC Standard N-690 (1984 Edition) for concrete and steel structures, respectively, modified as appropriate for load combinations that are considered extreme.

For the analysis and design, the diaphragm floor, reactor pedestal, and reactor shield wall were included in the finito element model of the RCCV. The computer code STARDYNE was used with all design basis loads considered as static loads. The analysis and design procedures are essentially the same as those used for the RCCV analysis and design. As discussed in Section 3.8.1 of this report, they are acceptable.

The DEPSS, according to SSAR Section 3.8.3.4.4, Amendment 33, is a two-level three-dimensional space frame structure that consists of columns, radial beams, circumferential beams and steel grating and is designed to support the deadweight of non-eafety-related equipment and safety-rolated and non-enfety-related piping systoms. For the analysis and design of the DEPSS, GE stated in SSAR Section 3.8.3.4.4, Amendment 33, and during the design audits, that the finite element method was used for the analysis and the design was accomplished in accordance with the ANSI/AISC N-690 Standard (1984 Edition). This is also acceptable to the staff. The staff's review and evaluation of the FRS generated through the DEPSS for the input to the piping analysis are discuseed in Section 3.7.2 of this report.

The materials of construction and their fabrication, construction, and installation are in accordance with $\mathrm{ACl}$ Standard 349 (1980 Edition) and ANSI/AISC Standare
N-690 (1984 Edition) for the concrete and steol structures, respectively. In the DFSER, the staff stated the concern about the use of the edition of ASME Code. This was DFSER Open Item 3.8.3-2. In Amendment 33 of the SSAR, GE epecified that the 1989 version of ASME Code will be used for the design. This is acceptable, and DFSER Open Item 3.8.3-2 is resolved.

The criteria specified for the analysis, design, and construction of the containment internal structures to account for anticipated loadings and postulated conditions that may be imposed on the structures during their lifetime conform to the established criteria, codes, standards, and specifications acceptable to the staff. These include meeting the guidelines of RG 1.94, Revision 1, RG 1.136, Revision 2, and RG 1.142, Revision 1.

The use of these criteria as defined by the applicable codes, standards, guides, and specifications (on the loads and loading combinations, the design and analysis procedures, the structural acceptance criteria, the materials, the quality control programs, and the testing requirements) provides reasonable assurance that, in the event of earthquakes and various postulated accidents occurring within the containment, the internal structures will withstand the specified design conditions without impairment of the structural integrity or the performance of required safety functions.

During the first two audits, the detailed design calculations for these structures were not available for roview. After the staff requested these calculations, GE committed to provide such design information on the containment internal structures. This was DFSER Confirmatory Item 3.8.3-1. Subsequently, during the audit dated February 22 through 25, 1993, the staff reviewed GE's design calculations of the internal structures and found them acceptable. Therefore, DFSER Confirmatory Item 3.8.3-1 is resolved.

The staff concludes that the design of the containment internal structures are acceptable and moets the relevant requirements of 10 CFR Part 50, Section 50.55a, and GDC 1, 2, 4, and 50. This conclusion is besed on the following:

1. GE has met the requirements of Section 50.55a and ODC 1 with respect to assuring that the containment internal structures are designed, fabricated, orectod, constructod, tested and inspected to quality standards commensurate with its safety function to be performed by meeting the guidelines of regulatory guides and industry standards indicated bolow. 
2. $\mathrm{OB}$ bas mot the requirements of ODC 2 by designing the containment internal structure to withstand the 0.38 SSE with sufficieat margin and the combinations of the effects of normal and accident conditions with offects of environmental loadings such es earthquakes and other natural phenomena.

3. GE has met the requirements of GDC 4 by assuring that the design of the intermal structures is capable of withstanding the dynamic effects associated with missiles, pipe whipping, and discharging fluids.

4. GE has mot the requirements of GDC 50 by designing the containment internal structures to sccommodate, with sufficient margin, the design leaknge rate, calculated preserure, and temperature conditions, resulting from accident conditions, and by assuring that the design conditions are not exceeded during the full course of accident conditions. In meeting these design requirements, GE has used the recommendations of RGs and industry standards indicated below in the next paragraph. GE has also performod an appropriate analysis that demonstrates the ultimate capacity of the structures and establishes acceptable margin of safety for the design.

The criteria used in the design, analysis, and those proposed for construction of the containment internal structures to account for anticipated loadings and postulated conditions that may be imposed upon structures during their service lifetimo conform with established criteria and with codes, standards, and specifications acceptable to the regulatory staff. These include meeting the positions of RG 1.57, Revision 0, RG 1.94, Revision 1, and RG 1.142, Revision 1, and industry standards ACI-349, ASME Boiler and Pressure Vessel Code, Section III, Division 2, "Code for Concrete Reactor Vessels and Containments," Boiler and Pressure Vessel Code, Section III, Subecction NE, ANSI/AISC N-690, "Specification for the Design, Fabrication, and Erection of Steel Safety-Related Structures for Nuclear Facilities," and ANSI N45.2.5.

The use of these criteria as defined by applicable codes, standards, and specifications, the loads and loading combinations; the design and analysis procedures; the structural acceptance criteria; the materials, quality control programs, and special construction techniques; and the testing and in-service surveillance requirements provide reasonable assurance that, in the event of earthquakes and various postulated accidents occurring within the containment, the interior structures will withstand the specified design conditions without impairment of the structural integrity or the performance of required safety functions.

\subsubsection{Other Seismic Category I Structures}

Other seismic Category I structures within the ABWR design scope are the balance of the RB, which is integral with the RCCV, and the control building. Because GE elected to design the radwaste building substructure to remain structurally intact during an SSE to help contain liquid from a possibly ruptured tank, the radwaste building subetructure also is included in this safety ovaluation, although it does not house any safety-related systems and components, and hence, is not seismic Catogory I.

As discussed in Section 3.7.2 of this report, the turbine building is not seismic Category I, but must be capable of withstanding the SSE 80 as not to impair the safety function of the portion of the MSL and condenser (when used as an alternative leakage path) housed within the turbino building. On May 21, 1992, GE submitted its justification for demonstrating that the turbine building will not fail during and after an SSE. In the DFSER, the staff stated the concern about the design adequacy of the turbine building. This was DFSER Open Item 3.8.4-1. In SSAR Section 3.7.3.16, Amendment 33, GE revised the design procedures for the turbine building. The staff reviewed these procedures and found them acceptable. The details of staff's evaluation is discussed in Section 3.7.2 of this report. DFSER Open Item 3.8.4-1 is resolved.

In SSAR Section 3.8.4, Amendment 33, GE describes the method of dynamic analysis, loads and load combinations, and design procedures and criteria for the design of seismic Category I cable tray, conduit, and their supports. The staff's safety evaluation of the design procedures and criteria for the seismic Category I cable tray and conduit supports is discussed in Section 3.10.2 of this report.

Seismic Category I structures within the ABWR standard plant design are constructed of structural steel or concrete, or both. The structural components consist of slabs, walls, beams, and columns. The major code used in the design of concroto seismic Category I structures is ACI Standard 349 (1980 Edition). For stoel seismic Category I structures, ANSI/AISC Standard N-690 (1984 Edition) was used. As discussed in Section 3.8.3 of this report, the use of ANSI/AISC Standard N-690 (1984 Edition) for the design of the seismic Category I structures is acceptable to the staff with the restrictions discussed in Section 3.8.3 of this report. To follow the 10 CFR Part 52 design certification process, any change to the use of ACI Standard 349 (1980 Edition) and ANSI/AISC Standard N-690 (1984 Edition) for the design and construction of the seismic Category I structural elements, would involve an unreviewed safety question and, therefore, require NRC reviow and approval prior to implementation. 
Purthermore, any requected change to the une of theas codes must either bo specifically dencribed in the COL application or aubmitted for license ameadment after COL ismunce.

The concrete and steol seismic Catogory I ctructures in the ABWR are designed and proportioned to resiat various combinations of dead loads; live loads; cavironmental loads, including winds, tornados, and SSE; and loads generated by postulated ruptures of high-energy pipes (auch as reaction and jet impingement forces, compartmeat pressures, and impact effects of whipping pipes). $\mathbf{O E}$ performod static finito-element analyses of the etructures to determine the distribution of atructural forces and moments for the various loads and load combinations. The deaign and analysis procedures ueed for them seismic Catogory I atructures are acceptable because thoy are the same as those approved for provious license applicutions and aro in accordance with SRP Section 3.8.4.

According to SSAR Section 3.8.4.2, Amendment 33, the materials of construction and their fabrization, construction, and installation are in accordance with ACI 349 Codo (1980 Edition) and ANSI/AISC Standard N-690 (1984 Edition), reepectively, for the roinforced concrete and structural stoel in the RB, control building, and radwaste building mbatructure. The use of these codes complies with SRP Section 3.8.4 and is acceptable.

During the design calculation audit conducted on October 12 through 15, 1992, the staff was concerned about the design adequacy of the reactor subcompartment walls and the removable walls under the pressure and thermal loads owing to a high-energy line (CUW lines and reactor core isolation lines) break (HELB). In respones to this staff concern, GE provided the evaluation procedures, criteria, and reoults for the reactor aubcompartment walls and removable walls in SSAR Section 3H.4, Amendment 33. From the audit recults of the deaign calculations and the reviow of the SSAR, the ataff concludes that the evaluation procedures and criteria ueed are reasonable and the design of these walls, including the removable walls are adequate.

In the early SSAR amendments, GE did not account for the effect of the hydrodymamic load on the RB reaulting from a safety/relief valve (SRV) discharge or a LOCA in the containment. Because the RB cacloses and is atructurally integral with the containment shell at each floor level and at the spent fuel grider, the offect of the hydrodynamic load on the RB as a recult of a SRV diecharge or a LOCA in the containment should be fectored into the design. This was DFSER Open Item 3.8.4-2. In SSAR Appendix 3G, Amendment 33, GE specified that the safety-related SSCs as applicable are also analyzed and designed for the dymamic excitations originating from the event of operntional transients and LOCA. The input loads considered in the etructural dynamic response analysis include condensation oncillation (CO), pool chugging (CH), borizontal vent chugging (HV), SRV discharge, and annulus pressurization (AP). The staff's ovaluation about the adequacy of these loads deacribed in SSAR Appendix 3B, Amendment 33, is discussed in Section 6 of this report. In the structural analyses, these loads wero classified as pipe nozzlo break loads, symmetric loads, and asymmetric loads. A multi-stick lumped-mass model that represents the RB, RCCV, reactor shield wall and pedeatal, and RPV was unod for the analysis. The damping values recommended in RG 1.61 were considered for SRV and LOCA loads. For the pipe nozzlo break loading casen, multi-input excitation modal timo-history analyeces were performed. For the symmetric and aymmetric loading cases, a frequency response method was uned. In SSAR Appendix 3G, GE provided the atructural reeponses (accolerations and displacements) and the FRS owing to the hydrodynamic loads applied on the RB as a reoult of an SRV discharge and a LOCA. From roviow of the SSAR and the audit conducted on Fobruary 22 through 24, 1993, the staff concludes that the atructural reaponese, including the FRS genorated and tho atructural design (RB) against these loads, are reasonable. DFSER Open Item 3.8.4-2 is resolved.

During the early design calculation audits, the staff reviewed the static analyses that calculated the structural element forces and moments resulting from the various loads and load combinations acting on the control building and radwaste building substructure. The detailed design calculations for the RB, control building, and radwasto building aubstructure, however, were not available to the ataff for review. In addition, GE did not complete the implementation of the QA programs for the static andyees and detailed design calculations for both the control building and the radwasto building substructure. GE committed to provide the detailed design calculations to the staff for roview and to complete the implementation of the QA programs for the control building and the radwaste building substructure. These two issues were DFSER Confirmatory Itoms 3.8.4-1 and 3.8.4-2, respoctively. During the audit conducted on February 22 through 25, 1993, the etaff reviowed GE's final design calculations for these buildings and the procedures for implementing the QA program and found them acceptable. Therefore, DFSER Confirmatory Itom 3.8.4-1 is resolved. In a letter dated September 15, 1993, GE certified tho implementation of the QA program for the design calculations of the reactor, control, and radwaste buildings. Therefore, DFSER Confirmatory Item 3.8.4-2 is resolved. 
During the audit conducted on October 12 through 15, 1992, in the Bechtel San Francisco office, the staff was concerned about the design of the embedded portion of the exterior walls of the seismic Category I structures. GE used the methods described in Bechtel Power Corporation Topical Report, BC-TOP-4A, "Seismic Analysis of Structures and Equipment for Nuclear Power Plants," Revision 4, to consider static soil pressure and the soil pressure induced by the carthquake and the design of these embedded exterior walls. The staff noted that these BC-TOP-4A methods for calculating the dymamic lateral earth pressures on the embedded walls had not been roviewed and accepted by the staff. As a result, GE agreed to follow the guidelines documented in the staff position for the embedded wall and retaining wall design (Appendix $\mathrm{H}$ of this report) and to design the embedded portion of the exterior walls of all seismic Category I structures. During the staff audit on February 22 through 25, 1993, in the Bechtel San Francisco office, the staff found the design methods and the design results of the exterior embedded walls acceptable.

The detailed design calculations of roof structures against severe weather phenomena, such as heavy rainfall and snow loading were unavailable during the earlier design audits. This was DFSER Open Item 3.8.4-3. In SSAR Appendix 3H, Amendment 30, GE stated that the design rainfall is $493 \mathrm{~mm} / \mathrm{hr}(19.4 \mathrm{in} . / \mathrm{hr})$ and the roof of the seismic Category I structures is designed to have parapets with scuppers to supplement roof drains or designed without parapets 80 that excessive ponding of water cannot occur. The design rainfall of $493 \mathrm{~mm} / \mathrm{hr}(19.4 \mathrm{in} . / \mathrm{hr})$ and the drainage system provisions form a reasonable design to prevent excessive roof ponding. This is acceptable, and DFSER Open Item 3.8.4-3 is resolved.

The seismic Category I structures for the ABWR standard plant were initially designed to withstand a maximum tornado wind speed of $418 \mathrm{~km} / \mathrm{hr}(260 \mathrm{mph})$. The staff raised in the DSER (SECY-91-153) its concern with the acceptance of this design tornado wind speed (Outstanding Issues 4, 8, and 9). In response, GE increased the design tornado wind speed to $483 \mathrm{~km} / \mathrm{hr}$ (300 mph). GE also revised the tornado-generated missile spectrum, specified in ANSI/ANS 2.8, to the Spectrum I specified in SRP Section 3.5.1.4. In a letter dated May 29, 1992, GE informed the staff that, based on its preliminary evaluation of the effect of the revised tornado wind and tornado missile loadings, the RB superstructure and roof design required additional thickness and the roof purlins required strengthening. These structural changes would affect the seismic model and hence the seismic response of the RB. In the DFSER, the staff was concerned that the resulting modification of the seismic model would affect the seismic analysis and design results contained in several sections and appendices in Chapter 3 of the SSAR. This was DFSER Open Itom 3.8.4-4. During the audit on Fobruary 22 through 25, 1993, the staff reviewed GE's soismic reanalysis results and design calculations and found that the resolution for this open item is acceptable. DFSER Open Item 3.8.4-4 is resolved.

GE used the NASTRAN computer code to perform the static analysis and to calculate the structural element forces and moments of the control building and radwaste building subjected to the various loads and load combinations. A finite element analysis model for each building was used in the analysis. The load combinations for the reinforced concrete structures are in accordance with ACI Standard 349 (1980 Edition).

In the DFSER, the staff noted that in analyzing the control building, GE had not considered the effects of winds; tornados, and tornado missiles and, in analyzing the radwaste building, GE had not considered the effect of winds and had used incorrectly calculated soil pressure loads. These were DFSER Confirmatory Items 3.8.4-3 and 3.8.4-4, respectively. In SSAR Appendix 3H, Amendment 33, GE documented its design results of the control building and radwaste building for the wind, tomado and tomado missile loadings, and soil pressure loads, which is acceptable; therefore, DFSER Confirmatory Items 3.8.4-3 and 3.8.4-4 are resolved. The static analysis methods and the analysis results for the element forces and moments for the control building and radwaste building are acceptable.

Sufficient descriptive and design information for the seismic Category I structures should be provided in the SSAR to meet guidelines in Section 3.8.4.1 of RG 1.70, "Standard Format and Content of Safety Analysis Report for Nuclear Power Plants, "Revision 3. Such information typically includes the floor plans, roof plans, vertical sections, and structural models used in the static analysis to calculate element forces and moments, configurations of major structural components, and arrangements of reinforcements in major concrete structural members. For the RB structure, SSAR Figures 3.8-1 through 3.8-9 and Section 3H.3 show the design information that moets the SRP guidelines. For the control building and radwaste building substructure, however, the early SSAR did not provide the descriptive and design information similar to that provided for the RB. This was DFSER Open Item 3.8.4-5. In SSAR Appendix 3H and Chapter 21, Amendment 33, GE provided the design description and design drawings for the control and radwaste buildings. The staff reviewed this information and found it acceptable; therefore, DFSER Open Item 3.8.4-5 is resolved. 


\section{Design of Structures, Components, Equipment, and Systems}

In the DFSER, the staff noted that the COL applicant should identify and describe any other seismic Category I structures that are not within the ABWR ccope es a part of its application. The staff will roviow its analysis and design on a caso-by-case besis. The ataff also noted that the COL applicant should ensure that the entloment of adjacent buildings will be such that the integrity of underground piping or tunnel will not be jeopardized. This was DFSER COL Action Item 3.8.4-1. In SSAR Sections 3.8.4 and 3.8.6.4, Amendmeat 33, GE stated that the COL applicant shall identify all seismic Catogory I structures, and in SSAR Section 2.3.2.36, Amendment 33, GE stated that the COL applicant shall perform stability ovaluation of all safety-related facilities, including foundation rebound, settlement, differential settlement, and bearing capacity. These COL actions are acceptable.

In conclusion, the design of safety-related structures other than containment or containment interior structures are acceptable and meets the relevant requirements of 10 CFR Part 50, Section 50.55a, and GDC 1, 2, and 4. This conclusion is besed on the following:

1. GE has met the requirements of Section 50.55a and GDC 1 with respect to assuring that the safety-related structures other than containment are designed, fabricated, erected, and constructed to quality standards commensurate with its safety function to be performed by meeting the guidelines of regulatory guides and industry standards indicated below.

2. GE has met the requirements of GDC 2 by designing the safety-related structures other than containment to withstand the $0.3 \mathrm{~g}$ SSE with sufficient margin and the combinations of the effects of normal and sccident conditions with the effects of environmental loadinge such as earthquakes and other natural phenomena.

3. GE has met the requirements of GDC 4 by sssuring that the design of the safety-related structures is capable of withstanding the dynamic effects associated with missiles, pipe whipping, and discharging fluids.

4. GE has met the requirements of Appendix B to 10 CFR Part 50 because their QA program provides adequate measures for implementing guidelines relating to structural design audits.

The criteria used in the analysis, design, and construction of all the plant seismic Category I structures to sccount for anticipated loadings and postulated conditions that may be imposed upon each structure during its service lifetime are in conformance with established criteria, codes, standards, and specifications acceptable to the regulatory staff. These include meeting the guidelines of RG 1.69, Revision 0 ,
RG 1.91, Revision 1, RO 1.94, Revision 1, RG 1.115, Revision 1, RG 1.142, Revision 1, and RG 1.143, Revision 1, and industry standards ACI-349 and ANSI/AISC N-690, "Specifications for the Design, Fabrication, and Erection of Steel Safety-Related Structures for Nuclear Facilities."

The use of these criteria as defined by applicable cocies, standards, and specifications, the loads and loading combinations; the design and analysis procedures; the structural acceptance criteria; the materials, quality control, and spocial construction techniques; and the testing and inservice surveillance requirements provide reasonable assurance that, in the event of winds, tornados, carthquakes, and various postulated accidents occurring within the structures, the structures will withstand the specified design conditions without impairment of structural integrity or the performance of required safety functions.

\subsubsection{Foundations}

The ABWR design employs separate reinforced-concrete mat foundations for major seismic Category I structures. The RB foundation, which is integral with the containment foundation, supports the containment structure, reactor pedestal, other interna! structures, and the balance of RB structure. Even though the containment structure foundation is integral with the RB foundation, it is a portion of the foundation within the perimeter of the containment structure. Therefore, the foundation was designed as a part of the containment boundary. The concrete foundations were designed to resist various combinations of dead loads, live loads, environmental loads (including winds, tornados, and SSE), and loads generated by postulated ruptures of high-energy pipes. The original detailed design information such as the factor of safety against overturning for the RB was calculated and provided in SSAR Appendix 3H, Amendment 4. However, in the DFSER, the staff noted that no such information was given in the SSAR for the control building and the radwaste building substructure. This was DFSER Open Item 3.8.5-1. In addition, the staff also noted that if foundation waterproofing is used, the COL applicant chould ovaluate the capability of the foundations to transfer eismic shear forces. This was DFSER COL Action Item 3.8.5-1. In SSAR Appendix 3H, Amendment 33, GE provided the loading condition used for the dynamic overturning, sliding and flotation analyses of the RB, control building, and radwaste building and the evaluation results (safety factors against overturning, sliding, and flotation) of these three buildings. From review of the SSAR Appendix $3 \mathrm{H}$ and the design calculation audit conducted on February 22 through 25, 1993, the staff concludes that the reactor, control, and radwaste buildings 
will bo dynamically stable under the apecified SSE and DFSER Open Itom 3.8.5-1 is resolved. As for COL Action Itom 3.8.5-1, which deals with the potential for the foundation mat to slide over the plastic sheots that are generally used as waterproofing material, SSAR Sections 3.8.5.4 and 3.8.6.1, Amendment 33, stated that the COL applicant will ovaluate the capability of the foundation to transfer shear loads where foundation waterproofing matorial is used. This is acceptable. In addition, based on the current practice of foundation construction and the staff's understanding, a layer of gravel will bo placed on the excavated foundation surface for the soil site and the excavated rock foundation surface will be roughened before pouring concrete and placing the waterproofing material. The treated foundation surface will increase the fiction between the structural foundation and the supporting foundation surface. Therefore, the staff concludes that the treated foundation surface will be capable to transfer the seismic shear loads.

In the DFSER, the staff noted that GE had not provided the editions of the ASME and ACI Codes. This was DFSER Open item 3.8.5-2. Subsequently, GE, in SSAR Section 3.8.5.2, Amendment 33, identified code editions. The major code used in the design of concrete mat foundations is the 1980 Edition of the ACI 349 Standard, except for the portion of the foundation within the containment boundary for which the 1989 Edition of ASME Code, Section III, Division 2, was used. The design and analysis procedures, the materials of construction and their fabrication, construction code, and installation used for the seismic Category I foundations, are in accordance with the procedures in ACI 349 (1980 Edition) and ASME Code, Section III, Division 2 (1989 Edition). The seismic Category I foundations are designed and proportioned to remain within the limits of these design codes for the applicable load combinations, including those that are considered extreme. The staff noted that this edition is referenced in 10 CFR 50.55a and is, therefore, acceptable. GE has also included this information in the SSAR; therefore, DFSER Open Item 3.8.5-2 is resolved.

To follow the 10 CFR Part 52 design certification process, any change to the use of ACI 349 Code (1980 Edition) and ASME Code (1989 Edition) for the design and construction of the seismic Category I building foundations would involve an unreviewed safety question and, therefore, require NRC review and approval prior to implementation. Furthermore, any requested change to the use of these codes must either be specifically described in the COL application or submitted for license amendment after COL issuance.

During the first two design calculation audits, the staff found that the detailed design calculations for the found- ations of all seismic Category I structures were not available for review, and in addition, GE did not complete the implementation of the QA programs for the design of the foundations of the control building and radwaste building mubetructure. In the DFSER, the staff noted that GE had committed to complete the detailed design calculations for the foundations of all seismic Catogory I structures and to complete the implementation of the QA programs for the foundations of the control building and radwaste building aubetructure. These were DFSER Confirmatory Items 3.8.5-1 and 3.8.5-2. During the audit conducted on February 22 through 25, 1993, GE provided the detailed design calculations of the seismic Category I structure foundations for review, which was acceptable. Therefore, DFSER Confirmatory Itom 3.8.5-1 is resolved. In a letter dated September 15, 1993, GE certified that the implementation of the QA program for the design calculations of the seismic Category I building foundations. This is acceptable. Therefore, DFSER Confirmatory Item 3.8.5-2 is resolved. The staff concludes that the design of the seismic Category I foundations are scceptable and meets the relevant requirements of 10 CFR Part 50, section 50.55a, and GDC 1,2 , and 4. This conclusion is based on the following:

1. GE has met the requirements of Section $50.55 \mathrm{a}$ and GDC 1 with respect to assuring that the seismic Category I foundations are designed, fabricated, erected, constructed, tested and inspected to quality standards commensurate with its safety function to be performed by meeting the guidelines of regulatory guides and industry standards indicated below.

2. GE has met the requirements of GDC 2 by designing the seismic Category I foundation to withstand the $0.3 \mathrm{~g}$ SSE with sufficient margin and the combinations of the effects of normal and accident conditions with the effects of environmental loadings such as earthquakes and other natural phenomena.

3. GE has met the requirements of GDC 4 by assuring that the design of seismic Category I foundations is capable of withstanding the dynamic effects associated with missiles, pipe whipping, and discharging fluids.

The criteris used in the analysis, design, and construction of all the plant seismic Category I foundations to account for anticipated loadings and postulated conditions that may be imposed upon each foundation during its service lifetimo are in conformance with the established criteria, codes, standards, and specifications acceptable to the regulatory staff. These include meeting the guidelines of RG 1.142 and industry standards ACI 349 and ANSI/AISC N-690, "Specification for Design, Fabrication and Erection of Steel Safety-Related Structures for Nuclear Facilities." 
The use of these criteria as defined by applicable codes, anduris, and specifications; the loads and loading combinations; the design and analysis procedures; the structural scceptance criteria; the materials, quality control, and special construction techniques; and the testing and in-eervice surveillance requirements provide reasonable assurance that, in the eveat of winds, tomados, earthquakes, and various postulated events, soismic Catogory I foundations will withstand the specified design conditions without impairment of structural integrity and stability or the performance of required safety functions.

\subsubsection{Certified Design Material}

In GB's CDM, dated May 30, 1992, GB provided design descriptions and ITAAC for soveral structural systoms. In the DFSER, the staff identified 11 open itoms related to these atructural systems. In responise to the open items, GE submitted systom- and building-8pecific ITAAC for ataff roview. The adequacy and acceptability of the ABWR design descriptions and ITAAC aro evaluated in Section 14.3 of this report.

\subsection{Mechanical Systems and Components}

SRP Sections 3.9.1 through 3.9.6 address review of the atructural integrity and functional capability of various safety-related mochanical components. The review is not limited to ASME Code components and supports, but is extended to other components such as control rod drive mechanisms, certain reactor internals, and any safety-related piping designed to industry standards other than the ASME Code. The staff reviewed such issues as load combinations, allowable stresses, methods of analysis, aummary of results, and pre-operational testing. The staff's evaluation focused on determining whether there is adequate assurance of a mechanical component performing its safety-related function under all postulated combinations of normal operating conditions, system operating transients, postulated pipe breaks, and seismic events.

\subsubsection{Special Topics for Mechanical Components}

The staff reviewed the information in SSAR Section 3.9.1 rolated to the design transients and methods of analysis used for all seismic Category I components, component supports, core support (CS) structures, and reactor intermals designated as Class 1, 2, 3 and CS under ASME Code, Section III, and those not covered by the Code. It reviewed the assumptions and procedures used for the inclusion of transients in the design and fatigue evaluation of ASME Code Cliss 1 and CS components. It also reviewed the computer programs used in the design and analysis of soismic Category I components and their supports, as well as experimental and inelastic analytical techniques.

SSAR Table 3.9-1 lists the design transients for five plant operating conditions that are applicable to the design of systems, components, and equipment, and, as an example, the number of either plant operating events or cycles for each of the design transients used in the design and fatigue enalyses of the resctor pressure vessel. The operating conditions are as follows:

\section{ASME Service Lovel A - normal conditions}

ASME Service Lovel B - upset conditions, incidents of moderate frequency

ASME Service Lovel C - emergency conditions, infrequent incidents

ASME Service Lovel D - faulted conditions, low-probability postulated events

testing conditions

The number of cycles in the original list of transients in SSAR Table 3.9.1 appeared to be based on a 40-year life. In the DFSER, the staff noted that for a design life of 60 years, the number of cycles for each transient should be increased by a factor of 1.5 (DFSER Open Items 3.9.1-1 and 14.1.3.3.5.2-1). In a letter dated October 22, 1993, GE responded to this item by providing a revision to Table 3.9-1. In this revision, the original number of cycles resulting from transients for daily and weekly reduction to 50-percent power, control rod pattern change, loss-of-feedwater heaters, and turbine stop valve full closure were increased by a factor of 1.5. The number of cycles for the remaining transients in Table 3.9-1 are identical to the original numbers. GE stated that the original number of cycles were based on BWR operating experience and are conservative for a 60-year design life. The staff agrees that BWR operating experience provides an acceptable basis for estimating the number of cycles anticipated for a 60-year design life. Therefore, Open Items 3.9.1-1 and 14.1.3.3.5.2-1 are resolved.

GE used computer codes to analyze mechanical components. The computer programs used for static and dynamic analyses to determine the structural and functional integrity of seismic Category I Code and non-seismic Category I code items are included in SSAR Appendix 3D. Design control measures to verify the adequacy of the design of safety-related components are required by Appendix B to 10 CFR Part 50. SSAR Section 3.9.1.2, states that the quality of the programs and the computer results are controlled either by $\mathrm{GE}$ or by outside computer 
program developers and the programs are verified by one or more of the methods recommended in SRP Section 3.9.1.

The NRC staff's roviow of this iecre was, in part, besed on an evaluation of the adequecy of the $\mathrm{OB}$ computer program uned in the reprementative ABWR piping analyen that were audited by the etaff on March 23 through 26, 1992, at GE's offices in San Jow, Californin. This wes sccomplished by the staff porforming in independent piping analysis to confirm the sdequacy of these GE analyses. In the DFSER, the computer program adequacy was DFSER Open Items 3.9.1-2 and 14.1.3.3.4.1-1. The recolution of these isoues is discuseed in Section 3.12.4.1 of this report.

SSAR Section 3.9.1.3 identifies several componeats for which experimental stress analyais is performed in conjunction with analytical ovaluation. The experimental atreses analycis mothods are uned in compliance with Appendix II of the ASMB Codo, Section III. This moots the guidance of SRP Section 3.9.1 and is, therefore, scceptable.

SSAR Section 3.9.1.5 states that inolantic snalysis is only applied to ABWR components to demonstrate the acceptability of three types of portulated events. Each ovent is an extremoly low-probability occurrence and the equipment affectod by theee ovents would not be reused. A discussion of ench of these three poetulated ovents follow:

\section{Postulated Pipe Rupture}

As discussed in Section 3.6.2 of this report, ruptures are postulated in certain piping systems in accordance with the conservative guidelines in SRP Section 3.6.2. For some full-diameter ruptures, pipe whip restruinte may be required to protect safety-related components or equipment from the dynamic effects of whipping pipe. Inelastic analyess are used in the design of auch reetraints to cosaure that thoy will withetand this low probability loading without loses of structural integrity. In these analyees, metallic members of the restraint are limited to an allowable strain of 50 percent of the ultimate uniform strain of the impacted material. This criterion, which is discussed in SSAR Section 3.6.2.3.3, is consistent with the guidelines in SRP Section 3.6.2, and is acceptable.
(2) Pontulated Blowout of a RIP Motor Casing a a Renult of Weld Failure

This postulated ovent is discuseed in SSAR Section 5.4.1.5. Each RIP is contained in an ASME Claes 1 presoure boundary housing that is welded to a stub tube in the reactor pressure veseel lower bead. The following low-probability failure ccenario is poatulated, and inelastic analysis is used for the design of one item. SSAR Figure 5.4-1 provides a sketch of the RIP cross section.

- A guillotine failure of the ASME Class 1 weld is sesumed. Subsequent to this ovent, the atretch tube, which normally functions to bold the pump diffuser in place, is the first member to reaiat ejection of the pump housing. On the basis of an elestic analysis, the stresses in the atretch wibe are calculated to be 85 percent of it minimum specified ultimate strength. The atretch tube could be reasonably considered to mitigate this event without failure, however, this failure scenario is continued as discussed below.

- In the event that the stretch tube also fails subsequent to the weld failure, the RIP shaft and the thrust bearing are subjected to the ejection load. The weakest link in this remaining load path is the bearing-to-shaft bolt. An olastic analysis of this bolt also results in stresses that are less than its ultimate strength. Therefore, this bolt would not be expected to fail.

- If the weld, stretch tube, and bearing-to-shaft bolt all sequentially fail, then the external vertical restraints are subjected to the ejection loads. These restraints are stainless steel rods that run from lugs on the vessel to lugs on the RIP motor cover. The structural integrity of the attachment lugs, bolts, and rod clevises under this loading condition is demonstrated by elastic analysis. The use of inelastic analysis methods is limited to the middle slender body of the rod. The allowable strain used in this analysis is identical to that used for pipe whip restraints and is acceptable as discussed in Item 1 above. 
(3) Poetulated Blowout of a CRD Housing as a Result of Wold Failure

This postulated ovent is discuseod in SSAR Section 4.6.1.2.2.9. A schematic of the internal CRD blowout support is shown in Figure 4.6.7 of the SSAR. This event begins with the poetulated full diamoter failure of the ASME Class 1 weld that attaches the CRD housing to the stub tube in the bottom head of the reactor preesure veesel (Point $A$ in Figure 4.6.7). In the unlikely event of such a failure, ejection of the CRD is prevented by the core support plate, the CRD guide tube, the CRD housing, and the CRD outer tube. Each of these components was demonstrated to be capable of sustaining this onco-in-a-lifetime ejection load without failure. This was demonstrated by use of olastic analyses in accordance with ASME Section III, Appendix F, rules for all parts of these components with the exception of the cylindrical bodies of the guide tube, housing, and outer tube. These cylindrical portions were analyzed by inelastic analysis methods. The allowable strain used in these analyses is identical to that used for pipo whip restraints and is acceptable as discussed in Item 1 above.

On the basis of these evaluations, the staff concludes that the design transients and resulting load combinations with appropriate specific design and service limits for mechanical components and supports moet the applicable portions of GDC 1, 2, 14, and 15; Appendix B to 10 CFR Part 50; Appendix A to 10 CFR Part 100; and SRP Section 3.9.1.

GE has met GDC 14 and 15 by demonstrating that the design transients and resulting loads and load combinations with the appropriate specific design and service limits for designing ASME Code, Class 1 and CS components and supports and reactor internals provide a complete basis for the design of the RCPB for all conditions and events expected over the service lifetime of the plant.

GE has met GDC 2 and Appendix A to 10 CFR Part 100 by including seismic events in design transients that serve as the design basis for withstanding the effects of natural phenomena.

GE has met Appendix B to 10 CFR Part 50, and GDC 1 by submitting information that demonstrates the applicability and validity of the design methods and computer programs used for the design and analysis of seismic Category I structures designated as ASME Code, Clase 1, 2, 3, and CS and those not covered by the Code within the present state-of-the-art limits and by having design control measures that are consistent with the applicable guidelines of SRP 3.9.1. This is acceptable for censuring the quality of the computer programs. If the COL applicant opts to use computer programe different from thoee used by GE for the design of any anfety-related itom with the exception of piping systems, the guidelines of SRP 3.9.1 must be mot for such programs. The staff's roview of the requirements for piping systems is included in its evaluation of the design acceptance criteria (DAC) and ITAAC for generic piping designs in Section 3.12 of this report.

\subsubsection{Dynamic Testing and Analysis of Systems, Components, and Equipment}

The staff reviewed the methodology, teating procodures, and dynamic analyses that GE used to ensure the structural intogrity and functionality of piping systoms, mochanical equipment, and their supports under vibratory loadings. The staff's review acceptance criteria included meeting the requirements of (1) GDC 14 and 15 by conducting the piping vibration, thermal expansion, and dynamic offects testing; (2) GDC 2 by roviowing the seismic subsystom analysis methods; (3) GDC 1 and 4 by committing to testing the dynamic responses of structural components in the reactor caused by steady-state and operational flow transient conditions; (4) GDC 1 and 4 by committing to the flow-induced vibration testing of reactor internals to be conducted during the pre-operational and startup test program; and (5) GDC 2 and 4 by committing to the dynamic analysis methods to confirm the structural design adequacy and functional capability of the reactor internals and piping attached to the reactor vessel when subjected to loads from a LOCA in combination with an SSE.

\subsubsection{Piping Pre-operational Vibration and Dynamic Effects Testing}

Piping vibration, thermal expansion, and dynamic effects testing will be conducted during a pre-operational testing program. The purpose of these tests is to ensure that the piping vibrations are within acceptable limits and that the piping system can expand thermally in a manner consistent with the design intent. During the plant's pre-operational and startup testing program, which is also described in SSAR Section 14.2.12, all ABWR plants will test various piping systems for abnormal, steady-state, or transient vibration and for restraint of thermal growth. Systems to be monitored will include (1) ASME Code, Class 1, 2, and 3 piping systems; (2) high-energy piping systems inside seismic Category I structures; (3) high-energy portions of systems whose failure could reduce the functioning of seismic Category I plant features to an unacceptable safety level; and (4) seismic Category I portions of moderatoenergy piping systems located outside the containment. Steady-state vibration, whether flow induced or caused by nearby vibrating machinery, could cause up to $10^{10}$ cycles 
of atreas in the pipe during the 60-year design life of the plant. For this reason, the staff requires that the stresses anociated with steady-atate vibration'be minimized and limited to scceptable lovels. The test program will consist of a mixture of instrumeated measurements and visual obcervations by qualified pernonnel. In SSAR Section 3.9.2.1 and Table 1.8-21, GB indicates that dotailed teat epecifications will bo prepared in eccordance ANSI/OM-1987, Part 3, and ANSI/OM-1986, Part 7.

The anff finds that these criteria will provide an acceptable lovel of afery for a piping aystem to withetand the offects of vibration and thermal expansion during the plant's 60-year design lifo. This conforms to the applicable guidolines of SRP Section 3.9.2 and is acceptable.

The tuff coacluden that $G B$ moets the relevant requirements of ODC 14 and 15 with regard to the desizn and teating of the RCPB. This provides reasonable ascurnace that there is a low probability of rapidly propagating failure and of groses rupture to casure that design conditions will not be exceeded during normal operation, including anticipated operational occurrences, by having an coceptable vibration, thermal expansion, and dynamic effects teet program that will be conducted during startup and initial operation of specified high- and modernto-energy piping, including all associated restraints and supports. Tho tests provide adequate as unce that the piping and piping aupports are deaigne ${ }^{\circ} 0$ withstand vibrational dynamic offects as a result of vauve closures, pump trips, and other operating modes associated with the decign-basis flow conditions. In addition, the tests provide aceurnace that adequate clearances and free movement of mubbers exist for unrestrained thermal movement of piping and supports during normal system beatup and cooldown operations. For the planned toets, loads similar to thowe experienced during transieat and normal reactor operations will be developed.

\subsubsection{Seismic Subsystem Analysis}

The staff's roview was performed in accordance with SRP Section 3.9.2 and consiated of an evaluation of SSAR Section 3.7.3. Areas reviewed wero seismic analysis methods, determination of the number of earthquake cycles, basis for the selection of frequencies, the combination of modal responses and spatial components of an earthquake, criteria used for damping, torsional effects of eccentric masses, interaction of other piping with seismic Category I piping, and buried seismic Catognry I piping systems.

The ABWR plant is designed for an SSE ground motion defined by a RG 1.60, "Design Response Spectra for Seismic Design of Nuclear Power Plants," Revision 1, response spectrum anchored to a peak ground accoleration of $0.3 \mathrm{~g}$. Amplified building response spectro are generated for the ABWR plant to account for varying soil properties in the United States by enveloping 14 site conditions. The enveloping amplified building response epectra provided in the SSAR are used for the dosign and analyses of the ABWR piping systems.

The ataff recognizes that the enveloping amplified building reeponse spectra for the ABWR plant contain conservatisms that might be excessive for cestain specific vito conditions. Accordingly, the staff's position is that when the SSE response spectrum is dofined by a RG 1.60 response spectrum anchored to a peak ground acceleration of 0.38 , the site-specific soil properties may be used to generate the amplified building response spectra. The method used to generate the amplified building response epectrn must be consistent with the method described in SSAR Section 3.7.2, as approved by the staff. The staff's ovaluation of the method used by GE for generating the amplified building response spectra is provided in Section 3.7.2 of this report.

GE performed the system and subsystem analyses on an elastic basis. Multidegreo-of-freedom modal response spectrum and time history methods formed the basis for the analyses of all major seismic Category I systems and components. When the response spectrum method was used, modal responses were combined by the SRSS rule. Clomely speced modes were combined using the criteria of RO 1.92, "Combining Modal Responses and Spatial Components in Seismic Analysis," Revision 1. GE considered all modes with frequencies below $33 \mathrm{~Hz}$ in computing equipment and component response for seismic loadings. For seismic analysis, consideration of highfrequency modes to preclude missing mass effects should also be included. The staff $s$ guidelines for this are provided in SRP Section 3.7.2, Revision 2, Appendix A. In the DFSER, the staff noted that the SSAR should be revised to reflect this staff position or, if an alternative mothod is used, then the details of its basis should be submitted to the staff for review and approval bofore its use. This was DFSER Open Item 3.9.2.2-1 and part of DFSER Confirmatory Item 14.1.3.3.5.6-1. In Amendment 23 to the SSAR, GE added Section 3.7.3.7.3, "Methodologies Used to Account for High Frequency Modes." The information in this new section to the SSAR is consistent with SRP 3.7.2, Revision 2, Appendix A, and is acceptable. GE has included this information in Section 3.7.3.7.3 of the SSAR. DFSER Open Item 3.9.2.2-1 is resolved. DFSER Confirmatory Item 14.1.3.3.5.6-1 is discussed in Section 3.12.5.6 of this report.

For the dynamic analysis of seismic Category I piping, each system is idealized as a mathematical model 
consiating of lumped maseen interconnectod by elastic mombers. The etiffness matrix for the piping system is dotermined using the elatic properties of the pipe. This includes the offects of torsional, bending, shear, and axial deformations as well as change in atiffinese as a result of the curved mombers. Next, the mode shapes and the undamped natural frequencies are obtained. The dynamic response of the system is calculated by using the response spectrum method of analysis. For a piping system that is supported at points with different dynamic excitations, the response analysis is performed using an enveloped response epectrum. As an alternative to the enveloped response spectrum method, $G B$ chose to use the multiplo-support excitation analysis method. When this mothod is used, the staff's position is that the responses resulting from motions of supports between two or more different support groups may be combined by the SRSS mothod if a support group is defined by supports that have the samo time history input. This usually means all supports located on the samo floor, or portions of a floor in a structure. In response to RAI Q210.26 in Amendmeat 11 to the SSAR, GE committed to use this definition. In the DFSER, the staff requested that the SSAR bo revised to include this definition. This was DFSER Confirmatory Item 3.9.2.2-1. In Amendment 23, Section 3.7.3.8.1.10, "Multiply-Supported Equipment and Components with Distinct Inputs," was added to the SSAR. This new section includes the requested definition, which is acceptable. GE has included this information in Section 3.7.3.8.1.10 of the SSAR. The staff finds this alternative to the enveloped response spectrum method acceptable, and DFSER Confirmatory Itom 3.9.2.2-1 is resolved.

The staff reviewed the method for selecting the number of masses or degrees of freedom in the piping mathematical model to determine its dynamic response. On the basis of the staff's audit conducted March 23 through 26, 1992, of GE's intermal documents, pipo and fluid masees are lumped at nodes that are selected to coincide with the locations of large masses (e.g., valves, pumps, and tanks) and with locations of significant geometric changes (0.8., pipe elbows, reducers, and tees). Additional mass points aro selected to ensure that the specing between any two adjacent piping nodes and mesees is no greator than an idealized value. This value corresponds to the length of a simply supportod beam with a uniformly distributed mass whose undamped natural frequency is equal to the cut-off frequency. Because this approach, in effect, will capture all modes up to the cut-off frequency, it is accoptable. In the DFSER, the staff noted that the SSAR should be rovisod to reflect this described approach. This was DFSER Confirmatory Items 3.9.2.2-2 and 14.1.3.3.4.2-1. In Amendment 23 to the SSAR, GE revised Section 3.7.3.3.1.2 to respond to this item. The staff's evaluation of this issue is discussed in Section 3.12.4.2 of this report.

The offect of pipe supports stiffness on the piping response is considered in the analytical model. Supports must be modeled in accordance with the SSAR. If supports are not modeled as stated in the SSAR, justification will bo provided to validate the stiffness values used in the piping model. The justification should include verification that the generic values are representative of the types of pipe supports used in the piping system. This alternative approach to use generic stiffness values and its bases should be submitted to the staff for review and approval before its use. In the DFSER, this was identified as COL Action Item 14.1 3.3.4.2-1. The resolution of this DFSER COL Action Item is discussed in Section 3.12.4.2 of this report.

Additionally, because the amplified response spectra are generally specified at discrete building nodo points, any additional flexibility between these points and the pipe support (0.8., supplesnentary steel) should also bo submitted to the staff. In the DFSER, the staff requested that the SSAR be revised to incorporate this information. This was DFSER Open Item 3.9.2.2-2 and DFSER Confirmatory Item 14.1.3.3.4.2-2. The resolution of this issue is discussed in Section 3.12.4.2 of this report.

When piping terminates at non-rigid equipment (e.g., tanks, pumps, or heat exchangers), the piping analytical model should consider the flexibility and mass effects of the equipment. In the DFSER, the staff requested that the SSAR be revised to address how the flexibility and masses of equipment attached to the piping are to be modeled. This was DFSER Open Item 3.9.2.2-3 and DFSER Confirmatory Item 14.1.3.3.4.2-3. The resolution of this issue is discussed in Section 3.12.4.2 of this report.

When analyzing piping systems, the size of the mathematical model might exceed the capacity of the computer program when large and small bore piping are included. Thus, the small bore branch lines are generally decoupled from the large bore main piping. Originally, the SSAR did not provide any criteria for the decoupling of the piping systems in the analysis model. However, in a letter to the NRC dated February 24, 1992, GE provided a decoupling critoria in a GE draft document entitled "ABWR SSAR Main Steam, Feedwater and SRVDL Piping Systems Design Criteria and Analysis Mothods," Revision 0, dated February 1992. In this document, GE stated that when the ratio between pipe diameters of the branch line to main line is less than one-third, the branch line can be excluded from the piping model of the main line. Since GE is using this criterion for all piping systems in the ABWR plant, the staff requested the basis 
for the 1:3 ratio. In addition, OE was requeated to define how the mass offect of the decoupled line is sccounted for in the model of the main line and how the frequency ratio offect (or resonant amplification of the main lino) is accounted for in the modeling and analysis of the branch line. In the DFSER, the staff noted that GE should revise its SSAR to include this information for the staff's reviow (DFSER Open Itoms 3.9.2.2-4 and 14.1.3.3.4.4-1). In Amendment 23 to the SSAR, GE revised Sections 3.7.3.3.1.3, 3.7.3.3.1.4, and 3.7.3.8.1.9 to respond to these open items. The staff's evaluation of this issue is discussed in Section 3.12.4.4 of this report.

In the DFSER, the staff noted that GE had not provided the staff with any specific information about the method to bo used for the structural design of small bore piping systems and instrumentation lines in the ABWR plant. The staff requested that this information be included in the SSAR (DFSER Open Items 3.9.2.2-5 and 14.1.3.3.3.6-1). In Amendment 23, Section 3.7.3.8.1.9, "Design of Small Branch and Small Bore Piping," was added to the SSAR. The staff's evaluation of this issue is discussed in Section 3.12.3.6 of this report.

RG 1.61, "Damping Values for Seismic Design of Nuclear Power Plants," Revision 1, contains recommended values of damping to be used in the seismic analysis of SSCs. In addition, RG 1.84 (Revision 25, May 1988) conditionally endorses ASME Code Case N-411-1. The damping values used by GE are the same as those specified in either RG 1.61 or ASME Code Case N-411-1 as permitted by RG 1.84. These criteria are acceptable.

The staff reviewed the issue of modal damping for composite structures during the audit conducted on March 23 through 26, 1992, at GE's offices in Sen Jose, California. The GE SSAR did not describe the application of modal damping for composite structures in the analysis of piping systems. However, GE's internal document entitled, "Piping Systems Design Criteria and Analysis Methods," contained a table of damping values for various types of piping supports. The damping values for the piping supports (e.g., snubbers and struts) were higher than the damping values tabulated for the piping. GE indicated that these values were presented because modal damping for composite structures could be used in a response spectrum analysis as an option. In the DFSER, the staff noted that if GE plans to use the modal damping for composite structures as an option for piping analysis, then GE has to include a description and justification of the approach in the SSAR for staff review and approval before its use. This was DFSER Open Items 3.9.2.2-6 and 14.1.3.3.5.17-1. In Amendment 23 to the SSAR, GE revised Section 3.7.3.8.1.7 to respond to these open items.
The ataffs evaluation of this isere is discussed in Section 3.12.5.17 of this report.

SSAR Section 3.7.3.12 outlines criteria for the analyais of buried soismic Catogory I piping syetems. In the DFSER, the etaff noted that GE had not given any dotailod information on how the criteria are to be appliod in the design of buried piping. Aleo, it was not clear if the buried piping within the scope of design certification will bo in contact with the soil or routed in tunnels. This information is necessary in the SSAR for the staff to complete its review. Therefore, it was identified as DFSER Open Itoms 3.9.2.2-7 and 14.1.3.3.3.9-1 in the DFSER. In Amendment 23 to the SSAR, GE rovised Section 3.7.3.12 to respond to these open items. The staffes evaluation of this isme is discuseed in Section 3.12.3.9 of this report.

SSAR Section 3 9.2.2.1 states that the minimum cut-off frequency for dynamic analysis of suppression pool hydrodynamic loads is $60 \mathrm{hz}$, based on a generic study using the missing strain energy mothod for representative BWR equipment under high-frequency input loadings. This cutoff frequency was previously used in the hydrodynamic analyses for currently operating BWR plants. Because the hydrodyramic load methodology used for the ABWR is the same as that used for the operating BWR plants, the cutoff frequency also is appropriate for the ABWR and acceptable.

On the basis of these discussions and the applicable evaluations in Sections 3.12.3, 3.12.4, and 3.12.5 of this report, the staff concludes that the ABWR plant design meets the relevant guidelines of 10 CFR Part 50, Appendix A, GDC 2, with respect to demonstrating design adequacy of all seismic Category I systems, components, equipment, and their supports to withstand the SSE by meeting the staff positions in RGs 1.61 and 1.92, and the applicable guidelines in SRP Section 3.9.2.

\subsubsection{Pre-operational Flow-Induced Vibration Analysis and Testing of Reactor Internals}

The configuration of reactor internals in the $A B W R$ is different from the configuration in previous $B W R s$, therefore, the dynamic response of reactor internals to flow-induced vibration must be predicted analytically for the $A B W R$ before final design approval (FDA). In addition, the staff's position is that the first ABWR plant will bo tested, in accordance with the guidelines in Positions C.1.1 and C.2 of RG 1.20, "Comprehensive Vibration Assessment Program for Reactor Internals During Preoperational and Initial Startup Testing," Revision 2, to evaluate the dynamic responses of reactor internals to steady-state conditions and operational flow 


\section{Design of Structures, Components, Equipment, and Systems}

transients. These tests are discused in more detail in the reet of this section.

SSAR Sections 3.9.2.3 through 3.9.2.6 and 3.9.7.1 provide information on vibration teating and andysis of reactor internals. In these actions, the firt $A B W R$ plant is referred to as a "prototypo plant." In the DFSER, the stafi reported that this chancterimation is inapplicable to ovolutionary LWR design certification applications as deecribed in 10 CFR 52.47(b)(1). To address the staff' concern, GE agreed to delete references to "prototype" from its futuro revision to SSAR Sections 3.9.2.4 and 3.9.7.1. This was identified as DFSER Confirmatory Item 3.9.2.3-1. However, the staff subsequently concluded that the word "prototype," when used in the context of conforming to the reactor internals flow-induced vibration lost guidelines of RG 1.20, does not conflict with 10 CFR 52.47(b)(1) and is acceptable. Therofore, DFSER Confirmatory Item 3.9.2.3-1 is withdrawn and resolved.

The dynamic responses of reactor internals to flow-induced vibration must be predicted for the ABWR design before FDA. One of the first steps involved in this prediction is to determine the vibration forcing functions to be used in the system and component dynamic analyses. In SSAR Section 3.9.2.3, GE outlines its appronch for determining these forcing functions. Because of the complexity of the flow conditions and structures involved, these loads are not determined by detailed analysis. Instead, a combination of analytical methods and predictions based on data from previously tested reactor internals of a similar design is used. This information on forcing functions then is used in a dynamic modal analysis to predict vibration amplitudes for each dominant response mode of components in the prototype $A B W R$ reactor internals and for interpreting the pro-operational and initial startup test results. Modal stresses are calculated and relationships between vibration measurement sensor responses and peak component stresses for each of the lower modes are obtained. The allowable amplitude in each mode is that which produces a peak stross amplitude of $\pm 68.95 \mathrm{MPa}( \pm 10,000 \mathrm{psi})$. This stress is well below the allowable stress amplitude for cycles exceeding $10^{6}$, which is defined in the design fatigue curves for austenitic stainless steels in Appendix I to ASME Code Section III.

By letter dated May 10, 1992, the staff documented a summary of this issue, which was addressed in an audit conducted at GE on February 10 through 12, 1992. As noted in the summary, GE stated that Kashiwazaki Kariwa Unit $6(\mathrm{~K}-6)$, which is currently under construction in Japan, contains renctor internals that are almost identical to those in the ABWR design. During the audit, $G E$ presented a set of documents related to the flow-induced vibration assessment program for the $\mathrm{K}-6$ reactor internals.
This information consists of an analysis for vibration prodiction, the basis and details of instrumentation for vibration monitoring, apecifications for the installation and removal of the monitoring system, and specifications for conducting the pro-operational and startup tests. In addition, GE provided a description of a full-scale, 60-degree flow test of the ABWR RIP system that was conducted in Japan.

For the vibration prediction analysis, GE took a statistical approach similar to that described in the first paragraph above to estimate the range of responses of major reactor preserure vessel intermal components in their first fow fundamental modes, based on correlations of measured reeponses of a selected group of existing BWRs with similar configurations. Parameters used in the correlation equations to estimate sample responses consisted of flow, power, stifiness, etc. As previously discussed, the acceptance criteria are more conservative than the applicable criteria in ASME Section III.

In the DFSER, the staff requested that all of the GE commitments and applicable information discussed in the staff's audit summary of May 10,1992, be included in a future revision to the SSAR. This was DFSER Confirmatory Item 3.9.2.3-2. In the ABWR CDM, dated August 31, 1993, GE submitted its ITAAC for the reactor pressure vessel system, which provided the remaining requested information (i.e., a list of principal plant design parameters and a list of documents that were referenced during the staff's audit). GE's responses in terms of the ABWR design descriptions and ITAAC are evaluated in Section 14.3 of this report. DFSER Confirmatory Item 3.9.2.3-2 is resolved.

In SSAR Section 3.9.2.4, GE states that reactor internals flow-induced vibration measurement and inspection programs are conducted during pre-operational and initial startup testing in accordance with the guidelines of RG 1.20. These tests are conducted in the following three phases:

Pre-operational tests before fuel loading Steady-state test conditions include balanced recirculation system operation and unbalanced operation over the full range of flow rates up to rated flow. Transient flow conditions include single- and multiple-pump trips from rated flow. This subjects major components to a minimum of $10^{6}$ cycles of vibration at the anticipated dominant response frequency and at the maximum response amplitudes. Vibration measurements are obtained during this test and a close visual inspection of internals will be conducted before and after the test. 


\section{Design of Structures, Components, Equipment, and Systems}

(2)

Brecritical sestine with fiel - This vibration mensurement series is conducted with the renctor assembly complete but before reactor criticality. Flow conditions include balanced, unbalanced, and transient conditions as for the first test series. The purpose of this series is to verify the anticipated effect of the fuel on the vibration response of internals.

Initial startuse testing - Vibration measurements are mado during reactor startup at conditions up to 100 percent of rated flow and power. Balanced, unbalanced, and transient conditions of recirculation system operation are evaluated. The primary purpose of this series is to verify the anticipated effect of two-phase flow on the vibration response of internals.

Vibration sensors may include strain gages, displacement sensors (linear variable transducers), and accelerometers. Accelerometers are provided with doublo-integration signal conditioning to give a displacement output. Sensor locations include the following:

- top of shroud head, lateral acceleration (displacement)

- top of shroud, lateral displacement

- control rod drive housings, bending strain

- incore housings, bending strain

- core flooder internal piping, bending strain

In addition to these components, vibration of the core flooder sparger is measured during pre-operational testing.

Only the dynamic component of strain or displacement is recorded in all vibration measurements. Data are recorded on magnetic tape, and provision is made for selective on-line analysis to verify the overall quality and level of the data. Interpretation of the data requires identification of the dominant vibration modes of each component by the test engineer using frequency, phase, and amplitude information from the component dynamic analyses. Comparison of measured vibration amplitudes to predicted and allowable amplitudes is then made on the basis of the analytically obtained normal mode that best approximates the observed mode.

The purpose of the visual inspoctions conducted before and following pre-operational testing is to detect evidence of vibration, wear, or loose parts. At the completion of prooperational testing, the reactor vessel head and the shroud head are removed, the vessel drained, and major components inspected. The inspections cover the shroud, shroud head, core support structures, recirculation internal pumps, peripheral control rod drive, and in-core guide tubes. Access is provided to the reactor lower plenum for these inspections.

The analysis and toet program, discussed in SSAR Sections 3.9.2.3, 3.9.2.4, and 3.9.2.6 previously summarized, conforms to applicable portions of SRP Section 3.9.2 and is acceptable. With respect to the availability of test results, the staff understands that, because the design of the reactor internals of K6 in Japan is almost identical to that of the ABWR, the test data discussed will be acquired during the pre-operational flow-induced vibration tests of the K6. GE also indicated that these results will include information specified in Positions C.2.1, C.2.2, C.2.3, and C.2.4 of RG 1.20 and will be submitted to the staff for review as noted in Position C.2.5, "Schedule," of RG 1.20. If the K6 preoperational flow-induced test data proves insufficient for the RG 1.20 requirements, the COL applicant will develop a test plan to ensure that any additional data is obtained and submitted to the staff. This was DFSER COL Action Item 3.9.2.3-1. SSAR Section 3.9.7.1, "Reactor Internals Vibration Analysis, Measurement, and Inspection Program," states that the first COL applicant will provide, at the time of application, the results of the vibration assessment for the ABWR prototype internals in accordance with the guidelines in RG 1.20. This information will also be submitted to the staff for review and approval. As part of the action item, SSAR Sections 3.9.2.4 and 3.9.7.1 further states that ABWR plants constructed after the first plant that have similar reactor internals will be tested in accordance with the applicable RG 1.20 positions. This is acceptable.

The staff concludes that GE meets GDC 1 and 4 with regard to the reactor internals being designed and tested to quality standards commensurate with the importance of the safety functions being performed and being appropriately protected against dynamic effects (1) by meeting RG 1.20 for the conduct of pre-operational vibration tests and (2) by having a pre-operational vibration program planned for the reactor internals that provides an acceptable basis for verifying the design adequacy of these internals under test loading conditions comparable to those that will be experienced during operation. The combination of predictive analysis, pre-test inspections, tests, and post-test inspections provides adequate assurance that the reactor internals will, during their service life, withstand the flowinduced vibrations of the reactor without loss of structural integrity. The integrity of the reactor internals in service is essential for ensuring the proper positioning of reactor fuel assemblies and the incore instrumentation system to ensure safe operation and shut down of the reactor. 


\subsubsection{Dynamic System Analysis of Reactor Internals Under Faulted Conditions}

GE performed dynamic aystem analyses to confirm the adequacy of the structural design, with no loes of function, of the reactor internals and unbroken loops of the CRD piping to withetand the loads from a LOCA in combination with the SSE. SSAR Section 3.9.2.5 describes the methodology ueod in developing the dynamic loads reaulting from tho following four significent faulted events:

- feedwater lino broak

- MSL break

- SSE

- afety/relief valvo discharge

Analyeses of other conditions existing during normal operation, abnormal operational transients, and postulated sccidents show that the loads affecting safety-related reactor internals from these other conditions are less severe than the loads affecting reactor internals as a result of any of the above four events.

The dynamic systems analyses methodology described in SSAR Section 3.9.2.5 conforms to applicable guidelines in SRP Section 3.9.2 and is acceptable. The staff's ovaluations of loading combinations and stress limits for reactor internals are discussed in Sections 3.9.3.1 and 3.9.5, respectively, of this report.

During an audit at GE on February 10 through 12, 1992, which is briefly discussed in Section 3.9.2.3 of this report, the staff reviewed dynamic system analyses of the K6 reactor internals under such postulated accidents as the MSL break at the RPV nozzle. In addition, the staff reviewed the subsequent analyses that evaluated the reactor internals components response to the loads resulting from the system analyses. The calculated pressure differentials during such an event were of a non-dynamic nature (slow variation). GE's assessment of the effects of these loads on the reactor internals is that amplification of loads is unlikely, and dynamic analyses are not required because of the large separation of component structural frequencies from the excitation frequencies. The staff concludes that the methodology implemented by GE in these analyses is consistent with that described in SSAR Section 3.9.2.5 and is acceptable.

The staff concludes that the ABWR dynamic system and component analysis meets the applicable portions of GDC 2 and 4 and SRP Section 3.9.2 with respect to the design of systems and components important to safety to withstand the effects of earthquakes and the appropriate combinations of the effects of normal and postulated accident conditions with the effects of the SSE by a dynamic system analysis which provides an acceptable basis for confirming the structural design adequacy of the reactor internals and unbroken piping loops to withstand the combined dynamic loads of a postulated LOCA and the SSE and the combined loads of a postulated main steamline rupture and the SSE. The analysis provides adequate securance that the combined stresses and strains in the components of the CRD system and reactor internals will not exceed the allowable design stress and strain limits for the materials of construction and that the resulting deflections or displacements at any structural element of the reactor internals will not distort the reactor internals geometry to the extent that core cooling may be impaired. The staff finds the mothods used for component analysis to be compatible with those used for the system analysis. The combination of component and system analyses is scceptable.

\subsubsection{ASME Code Class 1, 2, and 3 Components, Component Supports, and Core Support Structures}

The staff's review under SRP Section 3.9.3 concerns the structural integrity and functional capability of pressure-retaining components, their supports, and core support structures that are designed in accordance with ASME Code, Section III, or earlier industrial standards. The staff reviewed loading combinations and their respective stress limits, the design and installation of pressure-relief devices, and the design and structural integrity of ASME Code, Class 1, 2, and 3 components and component supports. The staff's review acceptance criteria are based on meeting (1) 10 CFR Part 50, Subsection 50.55a and GDC 1 as related to structures and components being designed, fabricated, erected, constructed, tested, and inspected to quality standards commensurate with the importance of the safety function to be performed; (2) GDC 2 as related to structures and components important to safety being designed to withstand the effects of earthquakes combined with the effects of normal or accident conditions; (3) GDC 4 as related to structures and components important to safety being designed to accommodate the effects of and to be condensible with the environmental conditions of normal and accident conditions; (4) GDC 14 as related to the reactor coolant pressure boundary being designed, fabricated, erected, and tested to have an extremely low probability of abnormal leakage, of rapidly propagating failure, and of gross rupture; and (5) GDC 15 as related to the reactor coolant system being designed with sufficient margin to assure that the design conditions are not exceeded. 


\subsubsection{Loading Combinations, Design Transients, and Stress Limits}

GE ovaluated all ASME Code, Class 1, 2, and 3 components, component supports, coro support components, control rod drive components, and other reactor internals using the loed combinations and stress limits given in SSAR Section 3.9.3.1. GE's methodology and selected allownble stress values conform to SRP Section 3.9.3 and are acceptable. Additional staff positions that are not explicitly addressed in SRP Section 3.9.3 are discuseed in the rest of this section.

The ASME Code, Section III, requires that the cumulative damage resulting from fatigue be ovaluated for all ASME Code Class 1 piping. The cumulative fatigue usage factor ahould take into consideration all cyclic offects caused by the plant operating transients listed in SSAR Table 3.9-1. As noted in Section 3.9.1 of this report, the ABWR is designed for a 60-year design life. Recent teet data to addrese fatigue concerns indicates that the effects of the reactor cavironment could significantly roduce the fatigue resistance of certain materials. A comparieon of the test data with the Code requirements indicates that the margins in the ASME Code fatigue design curves may be less than originally intended. The DFSER noted that the staff was developing an interim position, which would be available at a later date, to account for the environmental offects in the fatigue design of the affected materials. At this time, the staff is assessing the potential generic implication of this isewe on all operating plants. Depending on the severity of the isowe, certain actions may be required to generically addrese this concern. This isewe was incorrectly identified as Open Items 3.9.3.1-1 and 14.1.3.3.5.7-1 in the DFSER. The staff's evaluation of this issue is discussed in Section 3.12.5.7 of this report.

SSAR Section 3.9.3.1 states that the design life for the ABWR is 60 years. In response to a staff request, SSAR Sections 3.9.3.1 and 3.9.7.2 were revised to state that COL applicants will identify all ASME Code, Class 2, 3, and QG D components that are subjected to loadings that could result in thermal or dynamic fatigue so severo that the 60-year design life cannot be aseured by required Code calculations. If similar designs have not already been ovaluated, the COL applicant will either provide an appropriate analysis to demonstrate the required design life, or provide designs to mitigate the magnitude or duration of the cyclic loads (DFSER COL Action Items 3.9.3.1-1 and 14.1.3.3.5.8-1). The resolution of these action items is discussed in Section 3.12.5.8 of this report.

As stated carlier, the staff believes the margins built into the ASME fatigue design curves may not be sufficient to account for variations in the original fatigue test data as a result of various environmental effects. Therefore, the staff's position is that environmental effects should bo considered in the fatigue analysis for ASME Code Class 2 and 3 piping. GE should include in its SSAR the proposed approach for accounting for the environmental effects in theee fatigue analyees. In the DFSER, this was identified as a part of DFSER Open Itom 3.9.3.1-1 for ASME Class 1 components. The resolution of this issue is discuseed in Section 3.12.5.7 of this report.

In RAI Q210.42, the staff asked OE to provide the design besis that will be used to ensure the structural integrity of afety-related heating, ventilation, and air conditioning (HVAC) ductwork and its supports. In its response, GE stated that all of these components are designed in accordance with Section 8.2.1 of Chapter 9 of E.PRI's "Advanced Light Water Reactor (ALWR) Requirements Document." Section 8.2.1.2.1 of Chapter 9 in Volume II of the Requirements Document states that all safety-related HVAC systems in the ALWR will be designed to withstend an SSE and will be capable of accomplishing their intended functions assuming a single failure of an active component and a loss of preferred power (LOPP). Section 8.2.1.2.7 of Chapter 9 in Volume II of the Requirements Document specifies that the HVAC components and supports will be designed, constructed, and installed in accordance with ANSI/ASME AG-1-1988, and ANSI/ASME N509. Portions of ANSI/ASME AG-1-1988, including rules for the design of HVAC ductwork, are still being prepared. Therefore, the staff has not yet fully endorsed this standard. Until this standard is fully endorsed, the staff's interim position is that Article AA-4000 in the 1988 revision of the AG-1 Standard provides acceptable minimum design requiroments for the structural design of HVAC equipment and supports. For HVAC ductwork, in Revision 2 to RG 1.52, "Design, Testing, and Maintenance Criteria for Post Accident Engineered-Safety-Feature Atmosphere Cleanup System Air Filtration and Adsorption Units of Light-Water-Cooled Nuclear Power Plants," the staff recommends that ductwork should be designed, constructed, and tested in accordance with the provisions of Section 5.10 of ANSI N509.

The staff concludes that the design criteria required in Volume II, Chapter 9, Section 8.2.1, of the Requirements Document are consistent with current staff positions and provide an acceptable minimum design basis for ensuring that HVAC components and supports will withstand the most adverse combination of loading events without loss of structural integrity.

In eccordance with NRC Bulletin 88-08, the staff is requesting that licensees and applicants review systems 


\section{Design of Structures, Components, Equipment, and Systems}

connected to the reactor coolant system (RCS) to determine if any rections of such piping that cannot be isolated can be subjected to streeses from temperature atratification or tomperature cecillations that could be induced by leaking valves. In RAI Q210.50, the etaff requeated that $G E$ roview the ABWR decign to determine if this phenomenon could occur. In response to this request, $O E$ stated that the ABWR systems connected directly to the RCS or the RPV are the nuclear boiler system and the emergency core cooling systems. In the nuclear boiler system, GB reviewed the feodwater subsystem that supplies makeup water to the RPV to confirm that design requirements for tomperature stratifications of feodwater piping were satisfuctorily defined in aystem epecifications and piping cyclo diagrams. In the design of the ECCS, both the residual heat removal (RHR) system and high-pressure core flooder (HPCF) have piping that are directly connected to the RPV. In the unisolablo sections of RHR piping, leaking toward the RPV cannot cocur because the preacure will always be higher on the reactor side during normal plant operation when the upstream pumps are not operating. In the HPCF system design, the only unisolable piping connected to the RPV is the section of pipo between the reactor nozzlo and the upstream isolation check valve. Cold water in this system will be upstream of the injection valve (gate valve) that is outside the primary containment. The region upstream of the injection valve will operate at - pressure lower than reactor pressure except when the HPCF safety function is required. Therefore, cold water will not flow to the unisolable pipe section and stratification will not be a problem in the HPCF system. The staff concludes that the ABWR design adequately addresses the potential problems described in NRC Bullotin 88-08, Supploments 1 and 2. However, GE did not address the potential problem described in Supplement 3 to Bulletin 88-08. The staff's evaluation of GE's response to this issue is discussed in Section 3.12.5.9 of this report. Further staff ovaluations of thermal stratification are discussed as follows.

Thermal stratification is a phenomenon that can occur in long runs of horizontal piping when two streams of fluid at different temperatures flow in separate layers without appreciable mixing. Under such stratified flow conditions, the top of the pipe may be at a much higher temperature than the bottom. This thermal gradient produces pipe deflections, support loads, pipe bending stresses, and local stresses that may not have been accounted for in the original piping design. The effects of thermal stratification have been observed in both BWR and PWR feedwater piping as discussed in NRC Information Notice (IN) 84-87, and NRC IN 91-38.

During an audit conducted at GE offices in San Jose, Califormia, on March 23 through 26, 1992, the staff asked
GE to explain and demonstrate how the thermal stratification phenomenon was considered in the ABWR piping design. In reeponse, GB stated that thermal stratification is considered as a normal deaign lond in the ASME Code 1 atreas and fatigue ovaluation of the feodwater piping. In addition, GE indicated that the foedwater line will be analyzed for two thermal stratification load cases: (1) thermal atratification in the piping at the RPV nozzlo and (2) the mal stratification in the feedwater header piping. The loads will be included in the piping fatigue analysis and in the evaluations of the head fitting and RPV nozzles. The temperature differences and locations for the stratification loads are defined in the feedwater piping presenure/temperature cycle diagrams. This was DFSER COL Action Item 14.1.3.3.5.10-1. The resolution of this sction item is discuseed in Section 3.12.5.10 of this report.

The ataff reviewed and discussed the thermal stratification analyais methodology with the cognizant GE engineere and found it accoptable with the exception of an appareat discrepancy in load application. GE dofined the stratified temperature profile in the pipe cross section as a constant hot tomperature in the top half and cold tomperature in the bottom half with a step change in the temperature at the centerline. However, in the pipe stress analysis, a linear top-to-bottom tomperature profilo was applied. The linear temperature profile provides lower bending moments and streases than the step change profile. The staff asked GE to justify (1) the adoquacy of the piping analysis load input and (2) the omission of the high-cycle fatigue offects of thermal striping from the analysis. In addition, the staff asked GE to provide additional justification for their methodology including test information to support their thermal stratification load definition (DFSER Open Items 3.9.3.1-2 and 14.1.3.3.5.10-1). The staff's ovaluation of this issue is discussed in Section 3.12.5.10 of this report.

In the DFSER, the staff reported that GE had not provided information to the staff that would establish a minimum temperature at which an explicit piping thermal expansion analysis would be required. Unless GE provides this information in the SSAR, the staff would have required that thermal analyses be performed for all temperature conditions above ambient. This was DFSER Open Items 3.9.3.1-3 and 14.1.3.3.5.18-1. The staff's evaluation of this issue is discussed in Section 3.12.5.18 of this report.

In a letter dated January 28, 1993, GE revised Note 6 to SSAR Table 3.9-2 to state that all ASME Code Class 1, 2, and 3 piping systems that are essential for safe shutdown under the postulated events are designed to meet the requirements of NUREG-1367, "Functional Capability of 
Piping Syctams," dated November 1992. This report conthins methodology scceptable to the staff for ensuring the functional capability' of eacential piping systoms. has included this information in Table 3.9-2 of the SSAR.

The ASME Code requires that a decign epecification be prepared for Class 1, 2, and 3 components such as pumps, valves, and piping syatems. The deaign epecification is inteaded to becomo principal documeat governing tho deaiza and conetruction of them components and should epecify londing combinations, deaign data, and other design datn inputs. The code aleo requires a decign report for ASME Codo, Class 1, 2, and 3 piping and components. In the SSAR, GE committed to construct all safety-related components, such as veseols, pumps, valves and piping syatem, to applicable requirements of the ASME Code, Section III. During its reviow of the SSAR, the staff also roviewed selected documents related to design specifications and decign reports. Those documents were not eppecifically for the $A B W R$, but were provided by $G E$ and roviowed by the staff as a demonetration of how deaign apecifications and design reports will be prepared for ABWR plants.' The etaff determined that the demonstration documents, with modifications, would meet code requirements. However, because the documents were not epecifically for the $A B W R$, they would have to be modified before the staff can conclude that the design specification and design report requirements in ASME Code, Section III, Subsection NCA have been met. In the DFSER, the etaff noted that the plant-apecific design documentation should be prepared and made available for staff reviow by COL applicents referencing the ABWR design. This was DFSER COL Action Itoms 3.9.3.1-2 and 14.1.3.3.2.3-1. SSAR Section 3.9.7.4 states that the COL applicant will make design specifications and design seports required by the ASME Code for vessels, pumps, valves, and piping systems available to the staff for the purpose of audit. This is acceptable.

\subsection{Intersystem LOCA Design for Piping Systems}

In SECY-90-016, the staff recommended that the Commission approve the staff's resolution of the intersystem lose-of-coolant accident (ISLOCA) isuve for ALW reactor plants by requiring that low-pressure piping systems that interface with the RCPB be designed to withstand full RCS pressure to the extent practicable. As noted, in its June 26, 1990, SRM, the Commission approved the staff's recommendation provided that all elements of the low-pressure system are considered. In the DFSER, the staff noted that GE had not yet submitter the details of the piping design for the full RCS pressure. This was DFSER Open Item 14.1.3.3.5.19-1. Subsoquently, GE provided its implementation of the issue resolution for the ABWR in SSAR Section 3.9.3.1.
As an applicablo regulation deacribed in Section 1.6 of this report, the staff proposed that

the atandard design must minimize the offects of internystem lose-of-coolant accidents by designing low-prescure piping systoms that interface with the RCPB to withetand full reactor coolant system precenure to the extent prectical.

In Section 20.2.19 of this report, under Iswue 105, the staff evaluated GE's approach, in terms of the practicality for aystems, components, and equipment, for implementing the ISLOCA resolution for the ABWR. In the following, the taff evaluated the minimum pressure for which lowpresesure systems should be designed to ensure reasonable protection against burat failure should the low-pressure system be subjected to full RCS pressure. In establishing the minimum deaign preasure, the following gonls were used as tho basis for solection:

The likelihood of rupture (burst) of the pressure boundary is low, besed on a goal of approximately 10 percent failure probability for rupture;

(2) The likelihood of intolerable leakage of flange joints or valve bonnets is reasonably low although some loakage might occur;

Some piping components might undergo gross yielding and permanent deformation.

\section{Low-Pressure Piping Design}

To achieve these objectives, the staff evaluated, first, on - qualitative basis, several possible ratios of the lowpreseure system design pressure $\left(P_{d}\right)$ to the RCS normal operating pressure $\left(\mathbf{P}_{v}\right)$ to establish the margins on burst and yiold of the piping. The results of the staff's ovaluation aro depicted in Tablo 3.2 for typical carbon steol (A106 Grado B) and stainless stoel (SA312 Type 304) materials and are then discussed for three ratios of the design pressure to the reactor veesel pressure $\left(\mathbf{P}_{\mathrm{d}} / \mathbf{P}_{\mathrm{v}}\right)$. A margin of 1.0 or less represents the condition where burst or yielding is likely to occur. The higher the margin, the less likely burst or yielding is to occur. The low-pressure piping systems are assumed to be designed to the rules of the ASME Boiler and Pressure Vessel Code, Section III, Subarticle NC/ND-3600 for Class 2 and 3 piping systems. 
Design of Structures, Components, Equipment, and Systems

Table 3.2 Margins for atraight pipe

\begin{tabular}{|c|c|c|c|c|c|c|c|c|}
\hline Material & $\begin{array}{l}\text { Temp } \\
{ }^{\circ} \mathrm{C}\left({ }^{\circ} \mathrm{F}\right)\end{array}$ & $\begin{array}{c}\vdots \\
\mathbf{P}_{\boldsymbol{f}} \mathbb{P}_{\mathbf{y}}\end{array}$ & $\begin{array}{l}\mathbf{s} \\
\mathrm{MPa} \\
\text { (rai) }\end{array}$ & $\begin{array}{l}\mathrm{s}_{\mathrm{v}} \\
\mathrm{MPa} \\
\text { (kai) } \\
\end{array}$ & $\begin{array}{l}\mathbf{S}_{\mathbf{u}} \\
\text { MPa } \\
\text { (kei) }\end{array}$ & $\begin{array}{l}s_{y} \\
M_{P a} \\
\text { (cai) }\end{array}$ & $\begin{array}{c}\text { Marg } \\
\text { Burat } \\
\end{array}$ & $\begin{array}{l}\text { ins on } \\
\text { Yield }\end{array}$ \\
\hline \multirow[t]{6}{*}{ SA 106 Grado B } & $\begin{array}{l}37.8 \\
(100)\end{array}$ & $1 / 2$ & $\begin{array}{l}108.4 \\
\text { (15) }\end{array}$ & $\begin{array}{l}206.8 \\
(30)\end{array}$ & $\begin{array}{l}413.7 \\
(60)\end{array}$ & $\begin{array}{l}241.3 \\
(35.0)\end{array}$ & 2.00 & 1.34 \\
\hline & $\begin{array}{l}260 \\
(500)\end{array}$ & $1 / 2$ & $\begin{array}{l}108.4 \\
\text { (15) }\end{array}$ & $\begin{array}{l}206.8 \\
(30)\end{array}$ & $\begin{array}{l}413.7 \\
(60)\end{array}$ & $\begin{array}{l}195.1 \\
(28.3)\end{array}$ & 2.00 & 1.08 \\
\hline & $\begin{array}{l}37.8 \\
(100)\end{array}$ & $1 / 3$ & $\begin{array}{l}1034 \\
\text { (15) }\end{array}$ & $\begin{array}{l}310.3 \\
\text { (4) }\end{array}$ & $\begin{array}{l}413.7 \\
(60)\end{array}$ & $\begin{array}{l}241.3 \\
(35.0)\end{array}$ & 1.33 & 0.89 \\
\hline & $\begin{array}{l}260 \\
(500)\end{array}$ & $1 / 3$ & $\begin{array}{l}108.4 \\
\text { (1S) }\end{array}$ & $\begin{array}{l}310.3 \\
(45)\end{array}$ & $\begin{array}{l}413.7 \\
(60)\end{array}$ & $\begin{array}{l}195.1 \\
(28.3)\end{array}$ & 1.33 & 0.72 \\
\hline & $\begin{array}{l}37.8 \\
(100)\end{array}$ & $1 / 4$ & $\begin{array}{l}103.4 \\
\text { (15) }\end{array}$ & $\begin{array}{l}413.7 \\
(60)\end{array}$ & $\begin{array}{l}413.7 \\
(60)\end{array}$ & $\begin{array}{l}241.3 \\
(35.0)\end{array}$ & 1.00 & 0.67 \\
\hline & $\begin{array}{l}260 \\
(500)\end{array}$ & $1 / 4$ & $\begin{array}{l}103.4 \\
\text { (15) }\end{array}$ & $\begin{array}{l}413.7 \\
(60)\end{array}$ & $\begin{array}{l}413.7 \\
(60)\end{array}$ & $\begin{array}{l}195.1 \\
(28.3)\end{array}$ & 1.00 & 0.54 \\
\hline \multirow[t]{6}{*}{ SA312 Type 304} & $\begin{array}{l}37.8 \\
(100)\end{array}$ & $1 / 2$ & $\begin{array}{l}129.6 \\
(18.8)\end{array}$ & $\begin{array}{l}258.6 \\
(37.5)\end{array}$ & $\begin{array}{l}517.1 \\
75.0)\end{array}$ & $\begin{array}{l}206.8 \\
(30.0)\end{array}$ & 1.70 & 0.92 \\
\hline & $\begin{array}{l}260 \\
(500)\end{array}$ & $1 / 2$ & $\begin{array}{l}109.6 \\
(15.9)\end{array}$ & $\begin{array}{l}219.3 \\
\text { (31.0) }\end{array}$ & $\begin{array}{l}437.8 \\
(63.5)\end{array}$ & $\begin{array}{l}133.8 \\
(19.4)\end{array}$ & 1.70 & 0.70 \\
\hline & $\begin{array}{l}37.8 \\
(100)\end{array}$ & $1 / 3$ & $\begin{array}{l}129.6 \\
(18.8)\end{array}$ & $\begin{array}{l}388.2 \\
(56.3)\end{array}$ & $\begin{array}{l}517.1 \\
75.0)\end{array}$ & $\begin{array}{l}206.8 \\
(30.0)\end{array}$ & 1.13 & 0.61 \\
\hline & $\begin{array}{l}260 \\
(500)\end{array}$ & $1 / 3$ & $\begin{array}{l}109.6 \\
(15.9)\end{array}$ & $\begin{array}{l}328.9 \\
(47.7)\end{array}$ & $\begin{array}{l}437.8 \\
(63.5)\end{array}$ & $\begin{array}{l}133.8 \\
(19.4)\end{array}$ & 1.13 & 0.47 \\
\hline & $\begin{array}{l}37.8 \\
(100)\end{array}$ & $1 / 4$ & $\begin{array}{l}129.6 \\
\text { (18.8) }\end{array}$ & $\begin{array}{l}517.1 \\
(75.0)\end{array}$ & $\begin{array}{l}517.1 \\
(75.0)\end{array}$ & $\begin{array}{l}206.8 \\
(30.0)\end{array}$ & 0.85 & 0.46 \\
\hline & $\begin{array}{l}260 \\
(500)\end{array}$ & $1 / 4$ & $\begin{array}{l}109.6 \\
(15.9) \\
\end{array}$ & $\begin{array}{r}438.5 \\
(63.0) \\
\end{array}$ & $\begin{array}{r}437.8 \\
(63.5) \\
\end{array}$ & $\begin{array}{l}133.8 \\
(19.4) \\
\end{array}$ & 0.85 & 0.35 \\
\hline
\end{tabular}

$S=$ allowable stress per ASME Codo, Section III for Clace 2 piping

$S_{v}=$ hoop stress at $P=P_{v}$

$=S /\left(P_{d} / P_{v}\right)$

$S_{u}=$ ultimate tensile strength; from Section III, Table I-3.1 and I-3.2

$S_{y}=$ yield strength; from Section III, Table I-2.1 and I-2.2

Margin on Burst Pressure $=F \times S_{u} \times\left(P_{d} / P_{v}\right) / S$

where $F=1.00$ for SA106 Grade B

$F=0.85$ for SA312 Typo 304

Margin on Yield Fresoure $=1.15 \times S_{y} \times\left(P_{d} / P_{v}\right) / S$ 


\section{Design of Structures, Components, Equipment, and Systems}

Piping Integrity at $P_{d} / P_{v}=1 / 2 \quad$ (ASMB Code Service Lovel D)

When $P_{d} / P_{v}$ is equal to one-half, the margins on burat and yield are equivaleat to approximately those of the ASME Boiler and Presenure Veasel Code, Section III Service Lovel D condition. For carbon steel pipe, this ratio will provide a margin of 2.0 on burst and 1.08 on yield for a pipe at $500{ }^{\circ} \mathrm{F}$. For stainleas steol piping, a ratio of one-half will provide a sufficient margin on burst (1.7). However, a small amount of yielding is likely to occur with a margin of 0.70 at $500^{\circ} \mathrm{F}$. No leakage of the preasure boundary is likely to occur at $\mathbf{P}_{\mathrm{d}} / \mathbf{P}_{\mathrm{v}}$ equal to ono-balf.

As a recult, a ratio of ono-half will censure the prescure integrity of the low-preasure piping system with ample margin.

Piping Integrity at $P_{d} / P_{v}=1 / 3$

When the ratio, $\mathbf{P}_{d} / \mathbf{P}_{\mathbf{v}}$, is reduced to one-third, the margins for carbon steel piping are lowered to 1.33 and 0.72 for burst and yield at $260^{\circ} \mathrm{C}\left(500{ }^{\circ} \mathrm{F}\right)$, respectively. For stainless steel piping, the margins are 1.13 and 0.47 for burst and yield at $260^{\circ} \mathrm{C}\left(500^{\circ} \mathrm{F}\right)$, respectively. At these margins, it is expected that burst failure will not occur in either carbon steel or stainless steel piping. However, sigmificant amount of yielding might occur in stainless steel piping at all temperatures and in carbon steel piping at $260^{\circ} \mathrm{C}\left(500^{\circ} \mathrm{F}\right)$. Where the carbon steel piping is at a lower temperature, some yielding might occur although to a lesser oxtent. The consequence of significant pipe yielding (without bursting) is that gross, permanent distortion might occur in the piping components thereby resulting in some leakage through flanges, or valve bonnets. However, it is not expected that such leakage would be uncontrollable or intolerable.

In summary, a ratio of one-third will ensure the pressure boundary of the low-pressure piping although a significant amount of pipe yielding and some leakage through flanges and valve bonnets is likely to occur.

Piping Integrity at $P_{d} / P_{v}=1 / 4$

At $P_{d} / P_{v}$ equal to one-fourth, the pressure integrity of carbon steel piping becomes questionable, and for stainless steel piping, it is likely that burst failure will occur. Prior to bursting, the piping system would undergo gross plastic deformation, experience a significant amount of leakage at flanges, valve bonnets, and pump seals, and possibly lose some pipe supports due to the radial expansion of the pipe.
Therefore, at $P_{d} / P_{v}$ equal to one-fourth, the ability of the low-preacure piping ayetem to withstand full RCS preasure is queetionable for carbon steel piping and unlikely for atrainleas stoel piping aystems.

The staff further ovaluated, on a quantitative basis, the survival probabilities of the low-pressure piping at various design pressures using the methodology described in NUREG/CR-5603, "Preecure-Dependent Fragilities for Piping Components," dated October 1990. Calculations were performed by Idaho National Engineering Laboratory (INEL) under contract with the NRC's Office of Nuclear Rogulatory Rewearch.

The INEL calculations led to recults similar to the qualitative conclusions discuseed above. A temperature of $176.7^{\circ} \mathrm{C}\left(350^{\circ} \mathrm{F}\right)$ was used in the calculations of the following survival probabilities. Using a temperature of $260^{\circ} \mathrm{C}\left(500^{\circ} \mathrm{F}\right)$, the survival probabilitios decreases about 2 to 5 percent for the different materials and design presesures.

For carbon stoel piping (SA-106 Orade B material) subjected to a pressure of $2758 \mathrm{kPa}$ (400 psig) (or approximately $P_{d} / P_{v}=0.4$ ), the survival probability is 99 percent. For stainless steel piping (Type 304 material), the survival probability at $2758 \mathrm{kPa}$ (400 psig) (or approximately $P_{d} / P_{v}=0.4$ ), was found to be about 87 percent.

Using these results, the staff finds that the GE-proposed design pressure of 0.4 times the CRD pressure $2827 \mathrm{kPa}$ (410 psig) nearly achieves the staff's goal of a 90-percent survival probability under ISLOCA conditions and provides a sound besis for establisbing the design pressure of lowpreseure systems interfacing with the RCS pressure boundary. The minimum design pressure for the lowpreesure piping systems will bo identified as a certified design commitment for the ABWR.

Note, however, that the survival probabilities are based on the minimum wall thickness as calculated using Equation (3) in the ASME Boiler and Pressure Vessel Code, Section III, Subarticle NC/ND-3640. The wall thickness thus calculated does not account for manufacturing tolerances or the use of the next heavier commercial wall thickness available, which would increase the piping wall thickness and substantially increase the survival probability as well. In Section 3.9.3.1 of the SSAR, GE stated that the pipe wall thickness will be greater than or equal to schedule 40. When standard weight piping wall thicknesses are used (i.e., schedule $\mathbf{4 0}$ pipe up to and including 254-mm (10-in.) nominal pipe size), the survival probabilities at a design pressure $2758 \mathrm{kPa}(400 \mathrm{psig})$ are above 99 percent for both carbon and stainless steel piping. 


\section{Design of Structures, Components, Equipment, and Systems}

Therefore, for the ABWR, the ctaff concludes that the wes of atandard waight piping will provido a bounding danign for the ISLOCA condition.

\section{Valven in Low-Preceure Syatome}

For the valves in the low-preseaure piping syctems (excluding the preseure isolation valves), the celcotion of the valve clase rating is a primary factor for doaigning agairst full RCS proesure. For axample, ANSI B16.34 valves ane auppoeed to be shop-lested to 1.5 times their $37.8^{\circ} \mathrm{C}\left(100^{\circ} \mathrm{F}\right)$ ratod preceure. This would mean for a Clase 300 A216 WCB (cant carbon teed) valve, the teat presure is $1.5 \times 740=7,653 \mathrm{kPa}(1,110$ paig). For Clase 150, the valve teet proesure is $1.5 \times 285=$ 2,948 kPa (427.5 paig).

Clearly, the Clase 300 valve, which is teated to a preseure of 7,653 $\mathrm{kPa}(1,110$ paig), would be expected to withstand an RCS normal operating preseuro of $7,171 \mathrm{kPa}$ (1,040 paia) (or 7,067 kPa (1,025 paig)). However, it should not be ascumed that the valve in the low-preseure sysum would be able to operate with this full RCS pressure acroes the disk.

Therefore, the staff finds that a Clas 300 valve is adequate for ensuring the presoure of the low-prescure piping system under full RCS preesure (i.e., 7,067 kPa (1,025 paig)), but no credit should be taken to consider these valves operable under such conditions without further justification.

\section{Other Components in Low-Preesure Systems}

For other components in the low-preesure systems, such as pumps, tanks, heat exchangers, flanges, and instrument lines, the staff finds that eetablishing an appropriate safety factor involves everal complicating factore related to the individual component dexign. These factors include requirements for shop hydroteets, the method to determine the presenure clase rating of the component, the specific material used for bolting and the bolt teasion applied, or whether the componeat is qualified by test or analysis.

The remaining composents in the low-prescure syetems will be deaigned io a design prescure of 0.4 times the normal operating RCS pressuro (i.e., $2,827 \mathrm{kPa}$ (410 psig)). The staff finds that the margins to burat for these remaining components are at least equivalent to that of the piping at its minimum wall thickness since these components typically have wall thicknesses greater than that of the pipe minimum wall thickness.
ISLOCA Sonclusion

The staff finds for the ABWR low-preesure piping systoms that interface with the RCS preesure boundary, that using a deaign presenure equal to 0.4 times the normal operating RCS proesure of 7,067 kPa (1,025 psig) (i.e., 2,827 kPa (410 paig)) and using a minimum wall thickness of the low-preseure piping no leas than schedule 40 provide an adequate basis for acouring that these systems can withetand full reactor pressure and thus moet the Commission-approved staff recommendations in SECY-90-016 and its applicable regulation for designing sgainst internystem LOCAs. The piping design is in eccordance with the ASME Boiler and Pressure Vessel Code, Section III, Suberticle NC/ND-3600. Furthermore, the ataff will continuo to require periodic surveillance and leak rate teeting of the prescure isolation valves per technical specification (TS) requirements as a part of the inservice testing prognam.

As atated in SECY-90-016, for those low-pressure systems for which designing to withstand full reactor pressure is not practical, the design provides (1) the capability for leak teating of the preseure isolation valves, (2) valve position indication that is available in the control room when isolation valve operators are deenergized, and (3) highpreasure alarms to warn control room operators when rising RCS pressure approeches the design pressure of attached low-pressure systems and both isolation valves are not closed.

Using these design guidelines, the staff concludes that--

(1) the likelihood of the low-pressure piping rupturing under full RCS pressure is low,

(2) the likelihood of intolerable leakage is low under ISLOCA conditions although somo leakage may occur at flanges and valve bonnets, and

(3) some piping components might undergo gross yielding and permanent deformation under ISLOCA conditions.

SSAR Section 3.9.3.1 includes these design guidelines. Therefore, the staff concludes that there is reasonable aseurance that the low-pressure piping systems interfacing with the RCPB are structurally capable of withstanding the consequences of an intersystem loss-of-coolant accident. The ataff further concludes that the ABWR design moets the Commission-approved staff recommendation for ISLOCAs, as an applicable regulation as described in Section 1.6 of this report. 


\subsection{Condusion}

On the basis of the evaluation in Section 3.9.3.1 of this report, the staff concludes thet OB meets 10 CFR 50.55a and ODC 1, 2, and 4 with respect to the deaign and cervice load combinations and aseociated atrees and doformation limits epecified for ASMB Codo, Clase 1, 2, and 3 components by onsuring that systoms and components are designed to quality stendards commonsurate with thoir importance to safety and that these systems can accommodate the effects of ruch postulated ovents as LOCAs and the dynamic offects resuiting from earthquakes. The specified dosign and service combinations of loadings as applied to ASME Cods Class 1, 2, and 3 pressuro retaining components in systoms designed to meet seismic Category I standards provide assurance that, in the event of an earthquake affecting the site or other service loadings owing to postulated events or system operating transients, the resulting combined stresses imposed on system components will not exceed allowable stress and strain limits for the materials of construction. Limiting the stresses under such loading combinations provides an scceptable basis for the design of system components to withstand the most adverse combination of loading events without loss of structural intogrity.

\subsubsection{Design and Installation of Pressure-Relief Devices}

The staff roviewed SSAR Section 3.9.3.3 with regard to the design, installation, and testing criteria applicable to the mounting of pressure-relief devices used for the overpressure protection of ASME Code, Class 1, 2, and 3 components. This review, conducted in accordance with SRP Section 3.9.3, included evaluation of the applicable loading combinations and stress criteria. The review extended to consideration of the means provided to accommodate the rapidly applied reaction force when a safety/relief valve (SRV) opens and the transient fluid-induced loads applied to the piping downstream of an SRV in a closed discharge piping system. The information in SSAR Section 3.9.3.3 meets the applicable guidelines of SRP Section 3.9.3 and is acceptable.

In accordance with TMI Action Item II.D.1 of NUREG-0737, pressurized water reactor (PWR) and BWR licensees and applicants are required to conduct testing to qualify the RCS SRVs and associated piping and supports under expected operating conditions for design-besis transients and accidents. GE's response to Item II.D.1 is briefly discussed in SSAR, Appendix 1A, Section 1A.2.9. This section states that the SRV models have been tested under ABWR steam discharge conditions. It further states that if the ABWR design should contain any SRVB or discharge piping that is not similar to those that have been teated, the valves will be tated in accordance with Item II.D.1. This is scceptable.

In performing the hydraulic transient piping analyses ansocinted with the SRV discharge, GE ascumed a minimum rise time of 20 mece. Rise times faster then this value could result in higher loads than analytically predicted. The sasumed rise time is based on past SRV deaigns and existing teat data. Contingent upon the action described above to reteat the SRVs if the COL applicant should purchese any SRV or install its SRV piping in a configuration that is not similar to those that have been teated, this approach is scceptable. The COL applicant should confirm that any SRVs or discharge piping installed in the ABWR standard plant that is not similar to those that have been teeted will be teeted in accondance with TMI Action Itom II.D.1. This was DFSER COL Action Items 3.9.3.2-1 and 14.1.3.3.5.11-1. The resolution of these action items is discussed in Section 3.12.5.11 of this report.

On the basis of this ovaluation, which states that the criteria in SSAR Section 3.9.3.3 as related to the design, installation, and teoting of ASME Code, Class 1, 2, and 3 SRV mounting meet the applicable guidelines of SRP Section 3.9.3, the staff concludes that GE meets 10 CFR 50.55a and GDC 1, 2, and 4 by ensuring that SRVs and their installations are designed to standards that are commensurate with their safety functions and that they will accommodate the effects of discharge caused by normal operation as well as postulated events such as LOCAs and the dynamic effects resulting from the SSE. GE also moets GDC 14 and 15 with regard to ensuring thet the RCPB design limits for normal operation, including anticipated operational occurreaces, will not be exceeded. The criteria used by GE in the design and installation of ASME Code, Class 1, 2, and 3 SRVs provide adequate assurance that, under discharging conditions, the resulting stresses will not exceed allowable strees and strain limits for the materials of construction. Limiting the stresses under the loading combinations associated with the actuation of these pressure-relief devices provides a conservative basis for the design and installation of the devices for ensuring that the devices will withstand these loads without loss of structural integrity or impairment of the overpressure-protection function.

\subsubsection{Component Supports}

The ataff reviewed SSAR Sections 3.9.3.4 and 3.9.3.5 with regard to the methodology used in the design of ASME Code Class 1, 2, and 3 component supports. The review included an assessment of the design and structural integrity of the supports. It addressed three types of supports: plate and shell, linear, and component standard 


\section{Design of Structures, Components, Equipment, and Systems}

types. All ASME Code Class 1, 2, and 3 component supports for the ABWR plant are constructed in accordance with ASME Code, Section III, Subsection NF. In addition, the SSAR states that the design is augmented by the application of Codo Cuse N-476, Supplement 89.1, which governs the deaign of single-angle members. If eccentric loads or other torsional loads are not sccommodated by designing the load to sct through the shear center, analysee aro performod in accordance with such torsional analysis methods such as "Torsional Analysis of Stcol Mombers," AISC Publication T114-2/83. The staff position is that Subsection NF is an acceptable code for the dewign of piping supports. However, the rules must be augmented by guidelines acceptable to the ataff governing the dexign of singlo-angle members of supports and the methodology used to accommodate torsional loads. At this time, although Code Case $\mathrm{N}-476$ has not been endorsed by the staff in RG 1.84, the staff finds that it provides adequate desizn rules for the single-angle members. For torsional analysis of steel members, the staff finds that GE-proposed documents provide sufficient technical guidelines to perform a torsional analyses of steel members and are acceptable.

SSAR Section 3.9.3.4 defines the jurisdictional boundaries between pipe supports and such interface attachment points as structural steel in accordance with the ASME Code, Section III, Subsection NF, 1989 Edition. The staff's review of the jurisdictional boundaries described in the 1989 Edition finds that they are sufficiently defined to ensure a clear division between the pipe support and the structural steel and are acceptable.

SSAR Section 3.9.3.4.1 states that the loading combinations for the design of piping supports correspond to those used for the design of the supported pipe. As discussed in Section 3.9.3.1 of this report, the staff concludes that the loading combinations used for the supported pipe are consistent with SRP 3.9.3 and are acceptable. The stress limits for pipe supports are in accordance with the ASME Code, Section III, Subsection NF and Appendix F. The supports are generally designed or qualified by the load rating method as described in paragraph NF-3260 or by the stress limits specified in paragraph NF-3231. These methods and limits as specified in the 1989 Edition of the ASME Code, Section III, are acceptable.

SSAR Section 3.9.3.4 provides design criteria for the design of pipe supports using supplementary steel. The building structure component supports are designed in accordance with AISC, "Specification for the Design, Fabrication and Erection of Structural Steel for Buildings." The use of this specification is standard industry practice and has been proven to provide adequate design guidelines for the design of structural steel for use as pipe supports and is acceptablo.

SSAR Section 3.9.3.4 of earlier amendments stated that the concrete anchor bolts, which would be used for pipe support base piates, will be designed to the applicable factors of safety defined in NRC Office of Inspection and Enforcement (IE) Bullotin 79-02, Revision 1. Loading combinations for component supports are discuseed in Section 3.9.3.1 of this report. In genoral, the factors of afety for anchor bolts are acceptable. However, in the DFSER, the staff noted that GE had not discussed the use of epecific types of anchor bolts to be used for pipe support base plates in the ABWR plant. For example, under-cut type anchor bolts behave in a ductile manner but the staff's position is that the safety factors in IE Bulletin 79-02, Revision 2, are still applicable unless GE provides justification for alternative safety factors. Therefore, the use of safety factors for anchor bolts other than those provided in IE Bulletin 79-02 must be justified and submitted to the staff for reviow and approval before their use. This was DFSER COL Action Items 3.9.3.3-1 and 14.1.3.3.6.4-1. In addition, the staff reported that of the type of concrete anchor bolt used for piping supports, the action item in IE Bulletin 79-02 relative to pipe support baso-plate flexibility must be implemented. This was DFSER COL Action Item 14.1.3.3.6.4-2. The resolution of these COL action items is discussed in Section 3.12.6.4 of this report.

In the DFSER, the staff noted that GE had not provided the staff with any details about the specific analysis methods or procedures to be used for the ABWR pipe support design. For the staff to comf "ete its review, GE was requested to include the following additional details of the pipe support design in the SSAR:

(1) information that addresses the types of snubbers and their characteristics (as delineated in SRP 3.9.3, Section II.3b) to be used in the ABWR standard plant

(2) information that addresses the use of seismic restraints other than snubbers (i.e., special engineered pipe supports such as energy absorbers and limit stops, and their modeling assumptions)

(3) information that addresses the pipe support stiffness values and support deflection limits used in the piping analyses

(4) information that addresses how the seismic excitation of the pipe supports (especially large frame-type structures) are to be considered in the design of the pipe support anchorage 
(5) information that addresies the hot and cold gape to bo uved betwecia the pipe and the box-frumo-type of apport and the coefficient of friction to be used for considering friction forces between the pipes and the steol frames

(6) criteria that will ensure that the maximum defiections of the piping at aupport locations for static and dynamic loadinge are within an allowable limit to preclude failure of the pipe aupports and hangers

In the DFSER, all of these items conatituted Open Iteme 3.9.3.3-1 and 14.1.3.3.6-1. The atafi's ovaluations of thewe open itoms are diecuesed in Sections 3.12.6.5, 3.12.6.6, 3.12.6.7, 3.12.6.8, 3.12.6.10, 3.12.6.11, and 3.12.6.13 of this report.

The staff noted in the DFSER that GE had not provided any information on the deaign criteria for the structural decign of instrumentation line mupports. The was staff requested that this information be included in the SSAR. This was DFSER Open Item 3.9.3.3-2 and part of DFSER Opeen Item 14.1.3.3.6-1. SSAR Subwections 3.7.3.8.1.9 and 3.9.3.4.1 contain GB's response to then open item. The etaff's evaluation of this response is discused in Section 3.12.6.12 of this report.

The industry bas takea the position that ANS/AISC N-690 is useful in the dexign of instrumentation seneing line aupports. Its use would have the effect of reducing the QA recordkeeping requirements and codo atamping required by Subection NF of ASME Section III. The etaff's pocition on this isave is that for construction of ASME component cupports, ANS/AISC N-690 alone is not an receptable atandard; ASME Corde, Section III, Subecetion NF, chould be used. However, the etaff is curreatly participating in the ASME effort to incorporato N-690 into Subecetion NF. Subrequent to a etaff-endorsed version of NF incorporating N-690, Submection NF will also epecify the rules receptable to the staff for construction of ASME Class eupports. In the DFSER, tho staff stated that when this staff-approved version is available, tho COL applicant coeking to use it may aubmit a requeat to the ataff for approval on a plant-epecific basis. This was DFSER COL Action Itom 14.1 3.3.6.12-1. The etaff's evaluation of this iserve is discused in Section 3.12.6.12 of this report.

On the basis of the evaluation in Section 3.9.3.3, supplemented by the evaluations in applicable portions of Section 3.12.6, of this report, the staff concludee that $\mathrm{GE}$ meets the requirements of 10 CFR 50.55a and GDC 1, 2, and 4 with regard to the design and corvice load combinations and aseociated atress and deformation limits epecified for ASME Codo, Clase 1, 2, and 3 component aupports by ineuring that component aupports are designed to quality standards commensurate with their importance to safety, and that these supports can accommodate the effects of normal operation as well as postulated events such as LOCAs and the dynamic offects resulting from the safe ahutdown carthquake. The combination of loadinge (including aystom operating transients) considered for each component mupport within a system, including the deaignation of the appropriate service strees limit for each loading combination, has mot the positions and criteria of RO, 1.124 and 1.130 and are in accordance with NUREG-0484. The epecified design and service loading combinations ueed for the design of ASME Codo, Class 1 , 2 , and 3 component aupports in systems classified as ceismic Catogory I provide assurnece that in the event of an earthquake or other service loadings due to postulated ovents or system operating transients, the resulting combined atresces imposed on system components will not exceed allowable strees and strain limits for the materials of construction. Limiting the stresses under such loading combinations provides a conservative design basis to assure that auppon components cen withetand the most adverso combination of loading events without loss of structural integrity.

The staff's evaluation of Class CS components is given in Section 3.9.5 of this report.

\subsubsection{Control Rod Drive Systems}

The staff's review under SRP Section 3.9.4 included the control rod drive syotom (CRDS) up to its interfece with the control rods. Those components of the CRDS that are part of the primary preasure boundary are classified as SC 1, QO A, and are designed according to ASME Code, Section III, Clase 1 requirements and to the quality aneurence requirements of 10 CFR Part 50, Appendix B. The CRDS will be capable of reliably controlling reactivity changes either under conditions of anticipated normal plant operntional occurrences or under postulated accident conditions. The CRDS in the ABWR design consists of fine motion control rod drive mechanisms and the control rod drive hydraulic system. The staff reviowed the information in SSAR Section 3.9.4 related to the criteria uned to snoure the structural integrity of this systom during normal operation and under accident conditions. These criteria conform to SRP Section 3.9.4 and aro acceptable. Londing combinations for the CRDS are discussed in Section 3.9.3.1 of this report. The functional design and testing of these systems is discussed in Section 4.6 of this report.

The staff's review accoptance criteria are based on meeting (1) GDC 1 and 10 CFR Part 50, Subsection 50.55a requiring that the CRDS be designed to quality standard 
commensurate with the importance of the anfoty functions to bu performed; (2) ODC 2 requiring that the CRDS be dexigned to withetand the effocts of an earthquake without loes of capability to perform its safety functions; and (3) GDC 14 requiring that the RCPB portion of the CRDS be deaigned, constructed, and tested for the extromoly low probability of leakage or groes rupture.

The staff concludes that the deaign of the control rod drive syatem is acceptable for the ABWR and moets ODC 1,2 , and 14, and 10 CFR 50.55a. As stated in the first paragraph in this section, by designing the CRDS up to its interface with the control rods to acceptable loading combinations of normal operation and accident conditions using ASME Clase 1 and 10 CFR Part 50, Appendix B, requirements, $G E$ has assured the structural integrity of the CRDS. Therefore, GE meets GDC 1 and 10 CFR 50.55a with regard to deaigning components important to afety to quality standards commensurate with the importance of the anfety functions to be performed. In addition, GE moets ODC 2 and 14 with regand to designing the control rod drive systom to withstand the effects of carthquakes and anticipated normal operation occurrences with adequate margins to cosure its structural integrity and functional capability and with an extromoly low probability of leakage or groses rupture of the RCPB. The staff's evaluations of the specified dosign transients, design and service loedings, and combinations of loads, are discuseded in Sections 3.9.1 and 3.9.3.1 of this report. By limiting the stresses and deformations of the CRDS under auch loading combinations, the design conforms to the appropriate guidelines in SRP Sections 3.9.3 and 3.9.4.

\subsubsection{Reactor Pressure Vessel Internals}

The staff reviewed, in accordance with SRP Section 3.9.5, the load combinations, allowable stress and deformation limits, and other criteria used in the design of the reactor intermals. The staff's roviow acceptence criteria are based on meeting (1) GDC 1 and 10 CFR Part 50, Subection 50.55a requiring that the reactor internals shall be deaigned to quality etendards commensurate with the importance of the safety functions to be performed; (2) GDC 2 requiring that the reactor internals shall be designed to withstand the offects of earthquakes without loes of capability to perform its safety functions; (3) ODC 4 requiring that reactor internals shall be designed to eccommodate the effects of and to be compatible with the environmental conditions aseociated with normal operations, maintenance, testing, and postulated LOCA; and (4) GDC 10 requiring that reactor internals shall be designed with adequate margins to assure that specified accoptable fuel design limits are not exceeded during anticipated normal operational occurrences. SSAR Section 3.9.5.3.5 states that the core support structures for the ABWR are designed and constructed in accordance with ASME Code, Section III, Subeection NG. In accordance with Subsection NG-1100, this means that the manufacture and installation of the ABWR core support structures are in accordance with the NO rules required for materials, design, examination, and preparation of reports. This conforms to SRP Section 3.9.5 and is acceptable.

SSAR Section 3 9.5.3.6 gives the design besce for safety clase reactor internals other than the core support structures. The design criteria, loading conditions and analyses that provide the basis for the design of these components meet the guidelines of ASME Code, Section III, Subsection NG-3000. These components are constructed 80 as not to adversely affect the integrity of the core support structures as required by ASME Code, Section III, Subsection NG-1122. These criteria conform to SRP Section 3.9.5 and are acceptable!

In accordance with SSAR Table 3.2-1, the core support atructures and all othor safety-rolated reactor internals are deaigned as Safoty Class 2 components and to the quality assurance requirements of 10 CFR Part 50, Appendix B. In addition, as discuseed in Section 3.9.1, "Special Topics for Mechanical Components," Section 3.9.2.4, "Dynamic System Analysis of Reactor Internals Under Paulted Conditions," and Section 3.9.3.1, "Loading Combinations, Design Transients, and Stress Limits," of this report, the SSAR contains receptable criteria for the design of all safety-rolated reactor internals under normal, upset, emergency, and faulted loading conditions. Implementation of these criterin to the design of the reactor internal structures and components provides reasonable assurance that, in the event of an earthquake or of a system transient during normal plant operation, the resulting deflections and associated stresses imposed on these structures and components will not exceed allowable stressen and deformations under such loading combinations. This provides an acceptable design basis for ensuring that these etructures and components will withstand the most adverse loading events that were postulated to occur during their eervice lifetime without loss of structural integrity or impairment of function.

The staff concludes that the design of reactor intermals for the ABWR is acceptable and moets GDC 1, 2, 4, and 10 and 10 CFR 50.55a.

On the besis of these ovaluations related to designing all safety-selated reactor internals (1) as Safety Class 2; (2) to the quality assurance requirements of 10 CFR Part 50, Appendix B; and (3) to accoptable ASME Codo, Section III, rules, GE moets GDC 1 and 10 CFR 50.55a with regard to designing the reactor internals to quality 
andards commensurate with the importance of the safety functions to be performed.

On the basis of these ovaluations related to designing all safoty-related reactor interrals to acceptablo loading combinations and stress limits when the internals aro aubjected to the loads associated with normal, upset, emergency, and faulted conditione, GE meets ODC 2, 4, and 10 with respect to deaigning components important to anfoty to withstand the effects of carthquakes and the offects of normal operation, maintenanco, testing, and poetulated LOCAs with sufficient margin to casure that their capability to perform their safety functions is maintuined and the eppecified fuel design limits are not exceeded.

\subsubsection{Testing of Pumps and Valves}

SRP Section 3.9.6 provides guidance for review of inservice testing (IST) of certain safety-related pumps and valves typically designated as ASME Codo Class 1, 2, or 3. The staff's review acceptance criteria are based on meoting (1) GDC 37 as related to periodic functional teating of the ECCS to assure the leak tight integrity and performance of its active components; (2) GDC 40 as related to periodic functional testing of the containment heat removal system to assure the leak tight integrity and performance of its active components; (3) GDC 43 as related to periodic functional testing of the containment atmospheric cleanup systems to assure the leak tight integrity and the performance of the active components, wuch as pumps and valves; (4) GDC 46 as related to periodic functional testing of the cooling water system to assure the leak tight integrity and performance of the active components; (5) GDC 54 a related to piping systems penetrating containment being designed with the capability to test periodically the operability of the isolation and determine valve leakage acceptability; and (6) 10 CFR Part 50, Subsection 50.55a(f) as related to including pumps and valves whose function is required for safety in the inservice testing program to verify operational readiness by periodic teeting.

In Section 3.9.3 of this report, the staff discusese the deaign of anfety-related pumps and valves for the ABWR. The load combinations and stress limits used in the design of pumpe and vaives ensure that the integrity of the component prececure boundary will be maintained. In addition, a licensee will periodically test the performance and meacure performance parameters of safety-related pumps and valves in accordance with ASME Code Section XI, as required by 10 CFR 50.55a(f). Periodic measurements of various parameters will be compared to beseline measurements to detect long-term degradation of the pump or valve performance. The tests, measurements, and comparisons will ensure the operational readiness of these pumps and valves. However, as discussed in SECY-90-016, the staff determined that ASME Code Section XI requirements do not assure the necessary level of component operability that is desired for evolutionary LWR designs. Accordingly, in SECY-90-016, as supplemented by the staff's April 27, 1990, response to comments by the ACRS, the staff recommended critoria to the Commission to be used to supplement Section XI of the ASME Code. In its SRM of June 26, 1990, on SECY-90-016, the Commission approved the staff's recommendations. The staff's proposed applicable regulations, as described in Section 1.6 of this report, for inservice testing are as follows.

All pumps and valves of the standard design subject to the test requirements set forth in 10 CFR $50.55 a(f)$ are subject to the following additional limitations and modifications.

(1) Piping design must incorporate provisions for full flow testing at maximum design flow of pumps and check valves;

(2) Check valve testing must incorporate the use of advanced non-intrusive techniques to address degradation and performance characteristics;

(3) Provisions must be established to determine the frequency necessary for disassembly and inspection of pumps and valves to detect unacceptable degradation that cannot be detected through the use of advanced non-intrusive techniques;and

(4) Provisions must be incorporated to test motor-operated valves under design basis differential pressure.

The staff's evaluation of GE's responses to ASME Code Section XI issues, including the above applicable regulations, is discussed in the following sections.

SSAR Section 3.9.6 states that IST of safety-related pumps and valves will be performed in accordance with the requirements of ASME/ANSI OMa-1988 Addenda to ASME/ANSI OM-1987, Parts 1, 6, and 10. SSAR Table 1.8-21 also indicates that the applicable code of record for the ABWR is the ASME Code 1989 Edition. ASME/ANSI Part 6 of Operations and Maintenance (OM), "Inservice Testing of Pumps," and Part 10, "Inservice Testing of Valves," are referenced in Section XI, ASME Code 1989 Edition. The 1988 Addenda and the 1989 


\section{Design of Structures, Components, Equipment, and Systems}

Edition of Section XI have been incorporated by reference into 10 CFR 50.55a and are acceptable for the evolutionary LWR IST provided the analysis of leakage rates and corrective action requirements of OM Part 10, paragraph 4.2.2.3 aro applied to containment ieolation valve testing. The staff finds the containment ieolation valve leak testing to be sccoptable as discussed in Section 3.9.6.2.4 of this report.

SSAK Table 3.9-8 lists the IST parameters and frequencies for safety-related pumps and valves. This table was provided as part of the design certification and contains the information regarding the ability to teat pumps and valves in accondance with the ASME Code. The staffs assessment of the IST plen is contuined in Section 3.9.6.3 of this report. However, the dovelopment of a complete plant-specific IST program will bo the responsibility of the COL applicant. The comprehensive pump and valve IST program will provide additional information beyond that contained in the IST plen. The IST program will include the tests performed on each pump and valve and the Code requirument mot by each test; test parameters and frequency of the tests; the normal, anfoty, and fail-anfo position of each valve; component type for each pump and valve; and P\&ID coordinates for each pump and valve. In addition, the COL applicant will submit any requests for relief, which the NRC staff will reviow on the basis of the ASME Code edition referenced in 10 CFR 50.55a( $(f)$, the ABWR design, and the inservice testing mothods available at the time of the COL application. This was DFSER COL Action Item 3.9.6.3-1. SSAR Section 3.9.7.3 includes this action item and states that the COL applicant will provide a detailed pump and valve IST plan. This is acceptable.

GE's description of the primary elements of the inservice testing plan for design certification in SSAR Section 3.9.6 are discussed below.

\subsubsection{Testing of Safety-Related Pumps}

In response to the staff's concern regarding the adequacy of design and qualification for safety-related pumps, GE stated in SSAR Section 3.9.6.1 that for each safety-related pump, the design basis and required operating conditions (including tests) under which the pump will be required to function will be established. GE further stated that the COL applicant will establish the design and qualification requirements and will provide acceptance criteria for these requirements. For each size, type, and model the COL applicant will perform testing encompassing design conditions that demonstrate acceptable flow rato and corresponding bead, bearing vibration levels, and pump internals wear rates for the operating timo specified for each system mode of pump operation. From these tests the COL applicant will also develop baseline hydraulic and vibration data for evaluating the accoptability of the pump after installation. The staff finds that the planned actions provide a reasonable assurance for the adequacy of tho dosign and qualification for safety-related pumps and are, therefore, acceptable.

In response to the staff's policy concern about the adequacy of minimum-flow systems for safety-rolated pumps, GE states in SSAR Section 3.9.6.1 that safotyrelated pumps and piping configurations can accommodate insorvice testing at a flow rate at least as large as the maximum design flow for the pump. This commitment is responsive to the guidelines on this issue contained in SECY-90-016 and meets Item 1 of the staff's recommendations, as an applicable regulation, on the pump and valve inservice testing issues as described in Sections 1.6 and 3.9.6 of this report. This is acceptable. In addition, GE also stated in tho SSAR that it would ovaluate the sizing of each minimum recirculation flow path to ensure that its use under all analyzed conditions will not result in degradation of the pump and to periodically measure the minimum recirculation flow rate to verify that it is in accordance with the design specification. In response to another staff request, $\mathrm{GE}$ states in the samo SSAR section that it would provide the safety-related pumps with instrumentation to verify that the net positive suction bead (NPSH) is greater than or equal to the NPSH required during all modes of pump operation. The staff finds this acceptable because they moet SRP 3.9.6 testability requirements for eafety-related pumps.

In Section 3.9.6.1 of the DSER (SECY-91-235), the staff identified an open item relating to disassembly and inspection of safety-related pumps (Outstanding Issue 14). In its letter dated December 19, 1991, GE stated that the COL applicant will develop a program to eotablish the frequency and the extent of disassembly and inspection for all safety-related pumps, including the basis for the frequency and the extent of each disassembly. GE further stated that the program may be revised throughout the plant lifo to minimize disassembly, based on past disassembly experience. Subsequent to these clarifications, the staff concluded this program to be the responsibility of the COL applicant. Therefore, Outstanding Issue 14 was closed and was reidentified as DFSER COL Action Item 3.9.6.1-1. SSAR Section 3.9.6.1 includes this action item. This action item is responsive to the guidelines on this iesue contained in SECY-90-016 and meets Itom 3 of the staff's recommendations, as an applicable regulation, on the pump and valvo inservice testing issues as described in Sections 1.6 and 3.9.6 of this report. This is accoptable. 


\subsubsection{Testing of Safety-Related Valves}

\subsection{Check Valves}

In response to the staff's concern about the adequacy of design and qualification for safety-rolated check valves, SSAR Section 3 9.6.2.1 states that for each check valvo with active safety-related function, the design basis and required operating conditions (including testing) under which the check valve will be required to perform will be established. The SSAR further states that the COL applicant will establish the design and qualification requirements and will provide acceptance criteria for these requirements. By testing each size, type, and model, the COL applicant will ensure the design adequacy of the check valve under design conditions, including severe transient loadings expected during the life of the valve such as waterhammer or pipe break. This testing of each size, type, and model will include test data from the manufacturer, field test data for dedication by the COL applicant, empirical data supported by test, or test (such as prototype) of similar valves that support qualification of the required valve where similarity must be justified by technical data. The COL applicant will ensure that the maximum loading on the check valve under design basis and the required operating conditions is within the structural capability limits for the individual parts of the check valve. In addition, the COL applicant will ensure proper check valve applications in the piping system design. Specific considerations will include selection of valve size and type based on the system flow conditions, installed location of valve with respect to source of turbulence, and correct orientation of valve in the system (e.g., vertical versus horizontal) as recommended or required by the valve manufacturer. The qualification acceptance criteria will include baseline data developed during qualification testing and will be used for verifying the acceptability of the check valve after installation. Furthermore, during the pre-operational testing, the COL applicant will test each safety-related check valve in the open and/or closed direction, as required by the safety function, under all normal operating system conditions. The testing requirements and acceptance criteria, including leaktightness, disk stability, and correct valve sizing, are provided in the SSAR. The staff finds these planned actions provide a reasonable assurance for the adequacy of the design, qualification, and pre-operational testing for safety-related check valves and are, therefore, acceptable.

In response to the staff's concern about the full-flow testing of check valves, SSAR Section 3.9.6.2.1 states that ABWR safety-related piping systems incorporate provisions for testing to demonstrate the operability of the check valves under design-basis conditions. In response to another staff request, the SSAR states that advanced non- intrusive techniques will be used in the implementation of inservice testing program to periodically eseess degradation and the performance characteristics of check valves. These are responsive to the guidelines on these issues contained in SECY-90-016 and moots Items 1 and 2 of the staff's recommendations, as an applicable regulation, on the pump and valve inservice testing issues as described in Sections 1.6 and 3.9.6 of this report and are, therefore, acceptable.

In Section 3.9.6.2.1 of the DSER (SECY-91-235), the staff identified an open item relating to disassembly and inspection of safety-related check valves (Outstanding Issue 15). In its letter dated Decomber 19, 1991, GE stated that the COL applicant referencing the ABWR design will develop a program to establish the frequency and the extent of disassembly and inspection on the basis of saspected degradation of safety-rolated check valves, including the besis for the frequensy and the extent of each disassembly. GE also stated that the program may be revised throughout the plant life to minimize disassembly based on past disassembly experience. Subsequent to these classifications, the staff determined this to be the responsibility of the COL applicant. Therefore, Outstanding Issue 15 was closed and was reidentified as DFSER COL Action Item 3.9.6.2.1-1. GE has included this action item in Section 3.9.6.2.1 of the SSAR. This action item is responsive to the guidelines on this issue contained in SECY-90-016 and meets Item 3 of the staff recommendations, as an applicable regulation, on the pump and valve inservice testing issue as described in Sections 1.6 and 3.9.6 of this report and is, therefore, acceptable.

\subsection{Motor-Operated Valves}

In response to the staff's concern regarding the adequacy of design and qualification for safety-related motoroperated valvy (MOVs) SSAR Section 3.9.6.2.2 states that for each MOV with active safety-related function, the design basis and required operating conditions (including testing) under which the MOV will be required to perform are established for the development and implementation of the design, qualification, and pro-operational testing. For the design and qualification of MOVs, the SSAR provides commitments as follows. The COL applicant will establish the design and qualification requirements and will provide acceptance criteria for these requirements. The COL applicant will test each size, type, and model to determine the torque and thrust requirements to operate the MOV and will ensure the adequacy of the torque and thrust that the motor operator can deliver under design conditions. The COL applicant will also test each size, type, and model under a range of differential pressure and flow conditions up to the design conditions. These design conditions 


\section{Design of Structures, Components, Equipment, and Systems}

include fluid flow, differential pressure (including pipe break), system prossure, fluid temperature, ambient temperature, minimum voltage, and minimum and maximum stroke time requirements. This testing of each size, type, and model will include test data from the manufacturer, field test data for dedication by the COL applicent, empirical date supported by test, or test of similar valves (such as prototype) that support qualification of the required valve where similarity must be justified by technical data. From this testing, the COL applicant will demonstrate that the results of testing under in situ or installed conditions can be used to ensure the capability of the MOV to operate under design conditions. The COL applicant will also ensure that the structural capability limits of tho individual parts of the MOV will not be exceeded under design conditions. Furthermore, the COL applicant will ensure that the valve specified for each application is not susceptible to pressure locking and thermal binding. For the pro-operational testing of MOVs, the SSAR provides commitments as follows. The COL applicant will test each MOV in tho open and closed directions under static and maximum achievable conditions up to design basis conditions, using diagnostic equipment that measures torque and thrust and motor parameters. The COL applicant will test the MOV under various differential pressure and flow up to maximum achievablo conditions and perform a sufficient number of tests to determine the torque and thrust requirements at design conditions. The specific testing parameters and acceptance criteria for demonstrating that the adequacy of the MOV functional performance has been met are provided in the SSAR. The staff finds these commitments regarding the design, qualification, and pro-operational tosting for safetyrelated MOVs provido a reasonable assurance for demonstrating the adequacy of the MOV capability for the design basis conditions and are, therefore, acceptable.

The commitments just discussed also relate to the ITAAC information applicable to MOVs discussed in Section 3.9.6.4 of this report. To follow the 10 CFR Part 52 design certification process, any change to these commitments would involve an unreviewed safety question and, therefore, requires NRC review and approval prior to implementation. Furthermore any requested change to these commitments must either be specifically described in the COL application or submitted for license amendment after $\mathrm{COL}$ issuance.

In the DFSER, the staff noted that the COL applicant should address the design, qualification, and preoperational testing for the MOVs as discussed in SSAR Section 3.9.6.2.2, prior to plant startup. This was COL Action Item 3.9.2.2-1. SSAR Section 3.9.7.3 includes the above information. The staff finds this to be acceptable.
In the DSER (SECY-91-235), the staff identified an open item relating to justifying the use of prototype qualification testing of MOVs (Outstanding Issue 16). The staff's specific concern is the need for proper justification of the applicability of prototype test data. In response to the staff's concern, GE committed to revise the SSAR to reference GL 89-10, Supplement 1, staff responses to Q22 and Q24 through Q28, which contain staff guidelines to justify prototype testing. Therefore, Outstanding Issue 16 was resolved and was reidentified as DFSER Confirmatory Item 3.9.6.2.2-1. As described in SSAR Section 3.9.6.2.2, testing of MOVB of each size, type, and model will include test of similar valves (such as prototype) that support qualification of the required valve where similarity must be justified by technical data. The staff found that this commitment for prototype qualification testing is acceptable, and there is no need to reference GL 89-10, Supplement 1, for conducting MOV prototype qualification testing. As a result, DFSER Confirmatory Item 3.9.6.2.2 is withdrawn and closed.

In response to the staff' 8 concern about the periodic testing for MOVs, GE stated that the SSAR will be revised to address the COL applicant's program to periodically test MOVs. In the DFSER, the staff noted that the COL applicant will determine the optional frequency for valve stroking during inservice testing. This was part of DFSER COL Action Item 3.9.6.2.2-2. SSAR Section 3.9.6.2.2 states that periodic iesting per GL 89-10 Paragraphs D and $\mathrm{J}$ will be conducted under adequate differential pressure and flow conditions that allow a justifiable demonstration of continuing MOV capability for design-basis conditions. SSAR Section 3.9.7.3 also states that the COL applicant will determine the optimal frequency of this periodic verification of the continuing MOV capability for design basis conditions and will include this requirement in the development of the detailed IST program. This is responsive to the quidelines on the MOV testing contained in SECY-90-016 and meets Item 4 of the staff's recommendations, as an applicable regulation, on the pump and valve inservice testing issues as described in Sections 1.6 and 3.9.6 of this report and is acceptable. GE further stated that the ASME Code provides criteria limits for the test parameters identified in SSAR Table 3.9-8 for the ASME Code inservice testing.

In GL 89-10, the staff recommended that MOVs in a safety-related system should either be designed to prevent mispositioning or be subjected to qualification testing to demonstrate capability to recover from mispositioning. This was DFSER Confirmatory Item 3.9.6.2.2-2. The BWR Owners' Group subsequently submitted a backfit appeal on that GL 89-10 recommendation. The staff, with the assistance of Brookhaven National Laboratory, reviewed and reevaluated the issue, using probabilistic risk 
assessment techniques, and determined that the recommendations for MOVs mispositioning is not neceseary for BWRs. The staff subsequently iewed OL 89-10, Supploment 4, and stated that the staff no longer considered the recommendations for inadvertent operation of MOVs to be within the scope of GL 89-10 for BWRs. Therefore, the DFSER Confirmatory Item 3.9.6.2.2-2 is withdrawn and resolved.

In the DSER (SECY-91-235), the staff identified an open item rogarding disassembly and inspection of safety-rolated MOVs (Outstanding Issue 17). In its letter dated December 19, 1991, GE stated that the COL applicant referencing the ABWR design will develop a program to establish the frequency and the extent of disassembly and inspection besed on suspected degradation of safety-rolated MOVs, including the besis for the frequeacy and the extent of each disessembiy. GE further stated that the program may be revised throughout the plant life to minimize disassembly based on past disassembly experiendo. Subsequent to the above clarifications, the staff determined this program to be the responsibility of the COL applicant. Therefore, Outstanding Issue 17 was closed and was reidentified also as part of DFSER COL Action Item 3.9.6.2.2-2. GE has included this information in SSAR Section 3.9.6.2.2. This is responsive to the guidelines on this issue contained in SECY-90-016 and meets Item 3 of the staff's recommendations, as an applicable regulation, on the pump and valve inservice testing issues as described in Sections 1.6 and 3.9.6 of this report and is, therefore, acceptable.

SSAR Section 3 9.6.2.2 states that the inservice testing of MOVs will rely on diagnostic techniques that are consistent with the state of the art which will permit an assessment of the performance of the valve under actual loading conditions. This is responsive to the staff's guidelines on this issue and is, therefore, acceptable.

\subsection{Power-Operated Valves}

In response to the staff's concern about the adequacy of design and qualification for safety-related power-operated valves (POVs) other than MOVs, SSAR Section 3.9.6.2.3 states that for each POV with active safety-related function, the design basis and required operating conditions (including testing) under which the POV will be required to perform will be established. The SSAR further states that $\mathrm{COL}$ applicant will establish the design and qualification requirements and will provide acceptance criteria for these requirements. By testing each size, type, and model, the COL applicant will determine the force requirements to operate the POV and will ensure the adequacy of the force that the operator can deliver under design conditions. The COL applicant will also test each size, type, and model under a mage of differential presaurs and flow conditions up to the design conditions. This tecting of anch size, type, and model will include teet date from the manufacturer, field teat data for dedication by the COL. applicent, empirical data supported by test, or test of similar valves (such as prototypo) that support qualification of the required valve where similar must be justified by technical data. From this testing, the COL applicent will demonstrate that the results of testing under in-situ conditions can be used to ensure the cepability of the POV to operate under design conditions. The COL applicant will also ensure that the structural capability limits of the individual parts of the POV will not be exceeded under design conditions. The COL applicant will ensure that packing adjustment limits are specified for the valve for each application such that it is not susceptible to stom binding. SSAR Section 3.9.6.2.3 also states that during pro-operational testing, the COL applicent will test each POV in the open and closed directions under static and maximum achiovable conditions, using diagnostic equipment that measures or provides information to determine total friction, stroke time, seat load, spring rate, and travel under normal pneumatic or hydraulic pressure and minimum pneumatic or hydraulic pressure. The COL applicant will test the POV under various differential pressure and flow up to maximum achievable conditions, including design basis conditions. The COL applicant will perform a sufficient number of tests to determine the force requirements at design conditions. The specific testing parameters and acceptance criteria for demonstrating that the adequacy of the POV functional performance has been met are provided in the SSAR. The staff finds that these commitments provide a reasonable assurance for the adequacy of the design, qualification, and pre-operational testing for safety-related POVs and, are therefore, acceptable.

SSAR Section 3.9.6.2.3 also states that ABWR safetyrelated piping systems incorporate provisions for testing to demonstrate the operability of the POV 8 under design-basis conditions. Inservice testing will incorporate the use of advanced non-intrusive tochniques to periodically assess degradation and the performance characteristics of POVs. These are responsive to the staff's guidelines on these issues and are acceptable. The SSAR further states that a program will be developed by the COL applicant to establish the frequency and the extent of disassembly and inspection based on suspected degradation of safety-related POVs, including the basis for the frequency and the extent of each disassembly. The SSAR also states that the program may be revised throughout the plant life to minimize disassembly based on past disassembly experience and identified the corresponding COL applicant actions in SSAR Section 3.9.7.3. This is responsive to the guideline on this issue contained in SECY-90-016 and 
weet Itom 3 of the etafre recommondations, wh in applicable regulation, on the pump and valve inservice veting inaves as decoribed in Section 1.6 and 3.9 .6 of this report. This is scceptable.

\subsection{Inolation Valve Leak Teats}

In reponse to the enfir's concern about the leak-tight integrity of isolation valven, SSAR Section 3.9.6.2.4 etated that the leak-tight integrity of each valve relied on to provide a lenk-tight function will be verified. Thees valves includs (1) preasure icolation valves that provide isolation of precaure differential from one part of a syctom to another or between systems, (2) temperature isolation valves whose leaknge my cause unscceptable thermal treas fatigue or atratification in the piping and thermal loading on apports or whow leakage my culse stenm binding of pumps, and (3) contrinment isolation valves that perform a conthinment isolation function, including valves that are not a part of the 10 CFR Part 50, Appendix J, Type C, teding program but whose lenkage may cause lose of water inventory of a euppreasion pool. The taffe evaluations of SSAR Section 3.9.6.2.4 are a follows.

In the DSER (SECY-91-235), the etaff noted a concern about the cope of containment isolation valves (Outetanding Ieswe 18). In response, GE atated that the scope of contrinment isolation valves will be in sccordance with ODC 54 and agreed to amend the SSAR accordingly. This was DFSER Confirmatory Item 3.9.6.2.4-1. SSAR Section 3.9.6.2.4 includes this information. This is scceptablo, and DSER Outstanding Isave 18 and DRSER Confirmatory Item 3.9.6.2.4-1 are resolved. The staff's evaluation of this isswe is also discused in Section 6.2.4 of this report.

In the DSER (SECY-91-235), the staff requested that GE comply with the analysis of leakage rates and corrective sction requirements of ASME/ANSI OM Part 10, paragraph 4.2.2.3, for contrinment isolation valves (Outstanding Iesure 19). In response, GE stated that leaknge rate teating of containment isolation valves will be in sccondance with ASME Code Section XI. However, this was not completely acceptable. OM Part 10, which is referenced in ASME Code Section XI, 1989 Edition, only requires contrinment isolation valves to be tested in accordance with Appendix J to 10 CFR Part 50 and does not require that corrective action be based on exceeding individual valve leakage limits. The staff's position is that the analysis of leakage rates and corrective action requirements of paragraph 4.2.2.3 in OM Part 10 are also applicable to containment isolation valves. Subsequently, the staff requested GE to revise its response in accordance with the staff's position and reidentified Outstanding
Inese 19 a DFSER Open Item 3.9.6.2.4-1. SSAR Section 3.9.6.2.4 provides the requirements for contuinment icolation valves leakage rate teating in accordance with the ataf's position, which is scceptable, and DSER Oututanding Isors 19 and DFSER Open Item 3.9.6.2.4-1 are rewolved.

Sovenl anfety syatem connected to the RCPB have devign preanures below the rated RCS preacure. Also, somo syctems that are mited at full reactor preseure on the diccharge side of pumpe have pump auction below RCS preseure. To protect these syctems from RCS pressure, two or more isolation valves will be placed in series to form the interface between the high-pressure RCS and the low-preseure system. SSAR Table 3.9-9 provides a list of RCS preanure isolation valves. In the DSER (SECY-91-235), the theff reported that its roview of Table 3.9-9 was in progress (Outstanding Issue 20). Subsequently, the staff reviewed the RCS presoure icolation valves liet provided in the SSAR and determined that this list contains all of the RCS pressure isolation valves and was scoeptable, and that DSER Outstanding Ieave 20 was resolved.

In the DFSER, the staff also identified a concern about the periodic leak testing of all pressure isolation valves. The ataff's position is that the leak tight integrity of these valves must be ensured by periodic leak testing to provent exceeding the design pressure of the low-pressuro syatems. This was DFSER TS Item 3.9.6.2.4-1. In response, GE stated that the periodic leak rate testing of the RCS pressure isolation valves in Table 3.9-9 will be performod in accordance with the surveillance requirements of the ABWR TS. GE also stated that the final proposed ABWR TS, to be considered and approved under the design certification program, will reflect the relevant surveillance requirements of the new BWR Standard Technical Specifications. This was DFSER TS Item 3.9.6.2.4-1. Subsequently, GE included this information in the ABWR TS Section 3.4.4, "RCS Preesure Isolation Valve Leakage," dated November 12, 1992. The periodic leak rate testing requirements for ABWR RCS pressure isolation valves are the same as the relevant surveillance requirements of the new BWR Standard TS and are acceptable. As a part of the resolution of the intersystem loss-of-coolant accident (ISLOCA) issue, low pressure piping systems that interface with the RCPB are required to be designed to withstand full RCS pressure to the extent practicable. The staff's evaluation of the ISLOCA design for ABWR piping systems has been found to be acceptable as discussed in Section 3.9.3.1.1 of this report. 


\subsubsection{Review of SSAR Table 3.9-8, Ineervice Teting Pinn}

As discused previoualy in Section 3.9.6 of this report, $O B$ made certain commitmente are made regarding the teatubility of enfety-related pumpe and valves in the ABUtR deaign. In SSAR Section 3.9.6, OB atated that Code cocting flexibility in the ASME/ANSI OM Part 6 and Part 10 produced no need for reliof requeets. In SSAR Table 3.9-8, OE listed the inservice teuting parameters and frequencies for cafety-rolated pumpe and valves. In the DSER (SECY-91-235), the staff identified the roviow of SSAR Table 3.9-8 as Outatanding lewe 13. However, in the DFSER, Outetanding Item 13 was replaced by DFSER Open Itom 3.9.6.3-1, which is discuseed below.

The etaff's reviow of SSAR Table 3.9-8 to ensure that GE's commitments regarding the ability to teat pumps and valves can be met resulted in a list of questions transmitted to GE in a letter dated May 4, 1992. The staff stated that those questions should not be used to determine a comprehensive list of problem areas in SSAR Table 3.9-8 and that GE should systomatically roviow and revise its ABWR IST plan, emphasizing the deaign configuration to provide assurance that its commitmeat regarding the ability to teat pumps and valves can be met. Subeequently, a meeting with GE was held on June 8, 1992, in San Jowe, California. As a result of that moeting, $G E$ made several commitments that included addresaing those questions identified in the ataff' letter of May 4, 1992; rovising SSAR Tablo 3.9-8 as well as the associated P\&IDa; and performing a systematic roview of its. IST plan. GE also indicated that some exceptions to the Code requirements may be needed after it completes a systomatic roview of the IST plan. For the staff review of any Code exceptions, GE committed to identify the Code requirement, to provide a basis to justify the need for the codo exceptions, and to describe its proposed alternative testing method. The staff also informed GE that it would be unacceptable to leave for the COL phase certain aspects of the final design related to testability of pumps and valves. Specifically, details of the piping configuration related to additional lines, valves, and instrumentation must be provided before FDA. The development and rubmittal of an acceptable IST plan was DFSER Open Item 3.9.6.3-1.

In response to the staff s requeet, $G E$ subsequently revised SSAR Table 3.9-8. The staff, with the assistance of Science Applications International Corporation (SAIC), reviowed and evaluated the revised ABWR IST Plan as prosented in SSAR Table 3.9-8. On the basis of that evaluation, the staff determined that the ABWR pump and valve IST plan provided a reasonable seourance that GE's commitment as described in SSAR Section 3.9.6 regarding the ability to teat pumpe and valves can be met and is scceptable, and that DFSER Open Item 3.9.6.3-1 is reolved. Details of that evaluntion aro included as Appendix I to this report. Appendix I consiats of the Technical Evaluation Report prepared by SAIC that has been modified by the etaff to refiect mubeequent changes mado to Trbble 3.9-8 after SSAR Ameadment 20. Thowe changes were mado as a rewult of later design changes as well as recolutions to the staff's concerns identified in the DSER (SECY-91-235).

In the DFSER, the staff aleo identified an open item that GE should eatablish criteria to be used by the COL applicant for doveloping pump and valve deaign epecifications to ensure that theec components are capable of performing their design-besis functions. This was DFSER Open Item 3.9.6.3-2. OE provided these criteria in Sections 3.9.6.1, 3.9.6.2.1, 3.9.6.2.2, and 3.9.6.2.3 of the SSAR. The ataff bas found the criteria for doveloping pump and valve deaign epecifications to be acceptable as diecueved in Sections 3.9.6.1, 3.9.6.2.1, 3.9.6.2.2, and 3.9.6.2.3 of this report, and DFSER Open Itom 3.9.6.3-2 is resolved.

\subsubsection{Certified Design Material}

In the DRSER, the staff identified an Open Item 3.9.6.2.3-1 that requested GE to mubmit an scceptable generic ITAAC for demonstrating MOV capability. In response to the staff's requeet, GE submitted systemeepecific ITAACs that include criteria applicable to MOVs. The adequacy and acceptability of tho ABWR design descriptions and ITAAC are ovaluated in Section 14.3 of this report, and DFSER Open Item 3.9.6.2.3-1 is resolved.

In Section 3.9.6.4 of the DFSER, the staff indicated the noed for an acceptable ITAAC for POVs other than MOVs. The staff's specific concern was the inadequacy of the POV capability for the design-basis conditions. That was DFSER Open Item 3.9.6.4-1. In response to the staff's concern, GE provided information about the design, qualification, pro-operational and inservice testing requirements for safoty-rolated POVs in SSAR Soction 3.9.6.2.3. As discuseod in Section 3.9.6.2.3 of this report, the staff finds that GE's commitments provide a reasonable sesurnace for demonetrating the adequacy of the POV capability for the design-basis conditions. Therefore, the staff subsequently determined that this particular ITAAC is not necessary. The staff also dotermined that al though it was concluded that other POVB would not need Tier 1 treatment, the SSAR does not contrin sufficient information on the design and qualification and on the pro-operational toeting of other POV. In reeponse to the staff's concern, SSAR Section 3.9.6.2.3 include this information. The staff's 
Design of Structures, Components, Equipment, and Systems

ovaluation of that inave thes been found to be scoptable as divenand in Section 3 9.6.2.3 of this report. Furthermors,

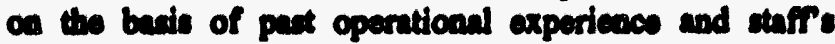
inpection, the etaff requected OB to provide on ITAC for check valves. In resposes to the staffers requed, OB mibmitted astem-epecifie ITAMCs the include criteria applicablo to check valves. The adequacy and scceptability of the ABWR check valves ITAAC is ovaluated in Section 14.3 of this report, and DPSER Open Itom 3.9.6.4-1 is resolved.

\subsubsection{Conclusion}

Based on the evaluntions described above, the ataff concludes that the pump and valve IST program dencribed in the SSAR is acceptable and meets the requiremeats of ODC 37, 40, 43, 46, and 54 and 10 CFR 50.55a(t). This conclusion is based on the commitments mado reganding the coatability of afety-related pumpe and valves in the ABWR design, which will ensure the leaktight integrity and the operational readiness to perform nocessary safoty functions throughout the lifo of the plant. The pump and valve teating will include baseline preservice testing and virual inspection for leaks and other sigms of distreas. The staff furthor concludes that the ABWR standard plant moots the Commission-approved staff positions for inservice teating of pumps and valves contrined in SECY -90-016 and its applicable regulation for inservice teating of pumps and valves as discuseed in Sections 1.6 and 3.9.6 of this report. This is acceptable. This conclusion is besed on that the commitments made in SSAR Sections 3.9.6.1, 3.9.6.2.1, 3.9.6.2.2, and 3.9.6.2.3 for safety-rolated pumpe and valves will ensure (1) the full-flow testing of pumpe and valves; (2) the use of advanced non-intrusive techniques for check valve testing; (3) the development of a disassembly and inspection program for pumps and valves; and (4) the adequacy of the MOV capability for the design-basis conditions.

\subsection{Seismic and Dynamic Qualification of Mechanical and Electrical Equipment}

SSAR Sections 3.9.2.2 and 3.10 provide information on the seismic and dynamic qualification of safety-related mechanical and electrical equipment. Section 3.9.3.2 also contains information related to pump and valve operability securance. This information includes

- rationalo uned to determino if teats, analyees, or combinations of both will be performed

- criteria used to define the soismic and other relevant dynamic load input motions
- the proposed demonatration of the adequacy of the qualification progrum

The ettaff s roviow ecouptance criteria are baced on meating (1) ODC 1 and 30 as rolated to qualifying equipmeat to appropriate quality atanderds commenourate with the importance of the anfety functions to be performed; (2) GDC 2 and Appeadix A to 10 CFR Part 100 as rolated to qualifying equipmeat to withetand the offects of natural phenomens such as earthquaken; (3) ODC 4 as related to qualifying equipment being capable of withatanding the dymamic effects anociated with oxternal misailes and internally genernted missiles, pipe, whip, and jot impingement forcen; (4) ODC 14 as related to qualifying equipment aneociated with the reactor coolant boundary so a to have an extremely low probability of absormal leakage, or rapidly propagating failure and of groes rupture; and (5) Appendix B to 10 CFR Part 50 as related to qualifying equipment using the quality asourance criteria provided.

OE will wse the seismic qualification methodology in Section 4.4 of GE report NEDE-24326-1 (propriotary) for both mechanical and electrical equipment. This program conforms to IEEE 323 as modified and cadorned by RO 1.89, "Environmental Qualification of Certain Blectric Bquipmeat Important to Safoty for Nuclear Power Plant," Revision 1. The program also meets the criteria in IEBE 344 a modified by RG 1.100, "Soismic Qualification of Electric and Mechanical Equipment for Nuclear Power Plants," Rovision 2. In Tables 1.8-20 and 1.8-21 of the SSAR, GE agrees to use RO 1.100, Revision 2, June 1988, and IEEE 344, 1987. Section 9 of IEEE 344, 1987, recognizes the use of "experience data" as a method for soismic qualification of equipment. As used in IEEE 344, experience data includes both soismic experience and previous qualifications. In accordance with RO 1.100, Rovision 2, the method of qualification will bo reviewed by the staff on a case-by-case basis. In Amendment 27 to the SSAR, GE revised Section 3.10.1.1, "Selection of Qualification Method" to permit the use of experience data for seismic qualification of seismic Category I instrumentation and electrical equipment. In a letter dated May 14, 1993, GE provided a markup of the SSAR, which further revised Section 3.10.1.1 and added Section 3.10.5.3 to state that if dynamic qualification of seismic Category I instrumentation or electrical equipment is accomplished by experience, the COL applicant will provide the following to the NRC for roview and approval:

- identification of the specific equipment

- the details of the methodology and the corresponding experience data for each piece of equipment 
This information is in SSAR Section 3.10.1.1 and 3.10.5.3. The theff concludes that the above commitment is consiatent with the applicable portion of RO 1.100, Rovision 2, and is acceptable.

The ctaff reviowed NBDB-24326-1 (propriatery) and approved the qualification methodology therein in an SER cent to OB on October 23, 1983. In repones to the stafir"s requen for information in Q 271.2, OB stated that tho mothodology in NBDB-24326-1 (proprietnry) also conforms to the above commitments as shown in Trables 1.8-20 and 1.8-21 of the SSAR. This response is ecceptablo.

The methodology in NEDB-24326-1 (propriotary), cupplomeated by the information in SSAR Sections 3.9.2.2, 3.9.3.2, and 3.9.6, provides teat and/or analyais criteria uesd to demonetrato the operability of cotive pumpes and valves (i.e., thow ASMB Clase 1, 2, or 3 components that must perform a mochanical motion to chut down the plant or mitigate the conequences of a poetulated event). The etaff concludes that the criteria deecribed are consintent with the guidelines in SRP 3.10 and applicable 'portions of SECY-90-016, and are ecceptable. To provide a more detailed basis for the atafis conclusion, in the following list are applicable guidelines from SRP 3.10 together with references to commitments in the SSAR which addreas each guideline.

(1) Teats and analyses are required to confirm the operability of all mechanical and electrical equipment during and after an earthquake of magnitudo up to and including the SSE, and for all atatic and dynamic loads from normal, transient and sccident conditions. Prior to SSE qualification, demonstrate that the equipment can withstand excitation less then the SSE without loss of structural integrity. Analyser alone, without testing, are acceptablo as a basis for qualification only if the neceseary functional operability of the equipment is assured by its structural integrity alone. When complete teating is impractical, a combination of tests and analysen is accoptable.

Equipment that has been proviously qualified by means of teats and analyses equivalent to those deacribed here aro acceptable provided that proper documentation of such tests and analyses is submitted.

Commitments to most of the above criteria can be found in the SSAR Subection 3.9.2.2, 3.9.3.2, and 3.10.1.1(B) and in NEDE-24326-1 (propriotary), Sections 4.4.2.5.1, 4.4.3.3 and 4.4.4.
In addition, consiatent with ataff positions on receatly licensed plants, Sections 3.9.3.2.1.1 and 3.9.3.2.3.1.4 in the SSAR, Ameadmeat 29, and the markup of SSAR Section 3.9.1.4.5, 3.9.1.4.11, and 3.9.3.2.5.1.2, and Table 3.9-2, Footnote (7) in - letter dated May 11, 1993, provide commitments that operability of active ASME Cleas 1, 2, and 3 valves and Clase 2 and 3 pumpe is further ascured by limiting tho streaces to the material elactic limit when the componeat is subjected to (1) the combination of normal opernting loada, (2) SSE and othor RB vibration londe, and (3) dynamic aystom loads (LOCA). Specifically, the average mombrane atress reoulting from this faulted condition (Service Lovel D) loads is limitod to 75 percent of the material yield atrees, and tho maximum mombrano plus bending streses is limited to 110 perceat of the yield atreas. Implementation of this seceptance criteria will provide sesurnace that valve bodies or pump cases will not dietort to the extent that opersbility of the component is impaired. SSAR Sections 3.9.1.4 and 3.9.3.2, and Table 3.9-2 include this information. This is acceptable.

(2) Equipment should be tested in the operational condition. Operability should bo verified during and/or after the teating, as applicable to the equipment being tested. Loadings simulating those of plant normal operation, such as thermal and flow-induced loading, if any, should be concurreatly superimpoeed upon the seismic and other pertinent dynamic loading to the extent practicablo. Particular attention should bo paid, in operability qualification of mechanical equipment subjected to flow-induced loading, to incorporate degraded flow conditions such as those that might be encountered by the presence of debris, impurities, and contaminants in the fluid systom. An example of this may be the operability of the contrinment sump pump recirculating water full of debris.

Commitments to most of the above criteria can be found in the SSAR Subsections 3.9.2.2 and 3.9.3.2 and in NEDE-24326-1 (propriotary), Sections 4.4.2.5, 4.4.2.5.1 and 4.4.2.5.2.

The characteristics of the required seismic and dynamic input motions should bo specified by response spectrum or time history methods. These characteristics, derived from the structures or systoms soismic and dynamic analyses, should bo representative of the input motions at the equipment mounting locations. 
Commitments to the above oriteris can be found in the SSAR Subuection 3.7.3.1 and in NEDB-24326-1 (proprictary), Scotion 4.4.4.1.4.6.2.

(4) For seisemio and dynamic loads, tho cotuel tent inputs motion should bo chanceteriad in the cams menner so the required inpule motion, and the conenvetion in amplitude and frequenoy conbeat should bo domonatrited (i.e., the ten repposes epectrum abould clowaly rememble and cavelope the required resposes espectrum over the eritical frequescy nange).

Commitments to the above criterita can bo found in tho SSAR Subection 3.9.2.2.1 and NEDB-24326-1 (proprictary), Section 4.4.2.5.3(b).

(5) Since seismic and the dynamic load excitation seacenlly have a broad frequecoy content, multifrequescy vibration input motion chould be und. However, single frequency input motion, wrch is sine beate, is ecoeptable provided the chanceteristices of the required input motion indicate that the motion is dominated by one frequency (0.8., by structural filtering efficets), or the anticipated repponse of the equipment is adequately repreanted by one mode, or in the cace of atructural integrity acourances, the input hes sufficient intensity and duration to produce auficicieatly high lovale of etreen for weh sevununce. Componeats that have been provioualy coted to IBEB 344-1971 should be reovaluated to juatify the sppropriateneses of the input motion used, and requalified if necesenry.

Commitments to these criteria can be found in the SSAR Subsection 3.9.3.2.3.1.4 and in NEDB-24326-1 (proprictary), Sections 4.4.2.5.3 and 4.4.2.5.6.

(6) For the seismic and dynamic portion of tho loads the teat input motion should be applied to one vertical axis and ono principal borizontal axis (or two orthogonal horizontal axee) aimultancoualy unleces it cen be demonatrated that the equipment reeponse in the vertical direction is not renaitive to the vibratory motion in the horizontal direction, and vice versa. The time phasing of the inputs in the vertical and horizontal directions must be auch that a purely rectilinear reoultant input is avoided. An acceptable alternative is to teat with vertical and horizontal inputs in-phase, and then repeat the teat with inputs 180 degrees out-of-phase. In addition, the teet must be repeated with the equipmeat rotated 90 degrees horizontally.
Components that have beca previounly tected to IBEB 344-1971 chould be requalified uaing biaxial ted inpux motions unlaso justification for ueing a ainglo axis tint input motion is provided.

Commitmente to tho above oriteria cen be found in tho SSAR Subecotion 3.9.3.2.3.1.4 and NEDE-24326-1 (proprictary), Section 4.4.2.5.4.

(7) Dynnmic coupling between the equipmont and rolated aystem, if any, wab a connected piping and other mochenical components, should bo considered. The fixture deaign should simulate the cotual corvice mounting and should not cawne any extruncous dynamic coupling to the tent itom. A commitument to this critoria can bo found in tho SSAR Subecotions 3.9.2.2.1 and Itom 7 of 3.10.1.1.

(8) For pumps and valves, the loads impoend by the atteched piping should be properly taken into sccount. To acsure opernbility under combined loadinge, the etreaces reaulting from the applied teat loads should envelope the specified corvice atreas limit for which the component's operability is intended. As discuseed in this Section 3.10, the SSAR Suberections 3.9.3.2.1.1, 3.9.3.2.3.1.4, and 3.9.3.2.5.1.2 contain criteria which addresese this inave.

(9) Selection of damping values for equipment to be qualified should bo mado in eccordance with RG 1.61, "Damping Valves for Soismic Design of Nuclear Power Plants," Revision 0, and IEEE 344-1987. Higher damping values may bo used if justified by documented teat data with proper identification of the source and mechaniem. SSAR Soctions 3.7, 3.9.2.2, 3.9.3.2, and 3.10.2 contain criteria that addreseces this issuo.

Section 3.10.2.1 of the SSAR etates that the methodology for qualifying relays shall be such that teating is performed in both the open and clowed positions.

NEDE-24326-1 (propriotary) provides qualification mothodology only and contains no plant-specific information. In the DFSER, the staff noted that each COL applicant reforencing this document should ensure that epecific cuvironmental parameters along with soismic and dynamic input responeo epectra aro properly dofined and caveloped in the methodology for its opecific plant and implemented in its equipment qualification progrnm. This was DFSER COL Action Item 3.10-1. SSAR Sections 3.9.3.2.3.2 and 3.9.3.2.5.2 of the SSAR stato that 
documentation will be prepared to dearly show that the orituris ouslined in SSAR Section 3.9.3.2 to domonetrato cotive pump and valve operability has been atiofied. This will bo included as a part of the certified atreas report for tho pump or valve anambly. In eddition, SSAR Section 3.10.5 tated thut the COL applicants shall maintain equipmeat qualification reconds in a permaneat file that aball be readily availablo for audit. Theas are soceptable sotions. The etaff will audit thew files to roviow the revilts of teats and andyees that were performed to (1) conoure that the criteria in the SSAR were properly implemeated, (2) ensure that edequate qualification was domonetrated for all equipment and thoir aupports, and (3) verify that all applicable loads were properly defined and sccounted for in the teating and analyees performed.

\subsubsection{Concluation}

On the basis of these ovaluations, the staff concludes that GB has dofined appropriate eismic and dynamic qualification of mochanical and olectrical equipment and pump and valve operability programs. Thewe programs meet applicable portion of ODC 1, 2, 4, 14, and 30, Appendix B to 10 CFR Part 50, and Appeadix A to 10 CFR Part 100 and are seceptable. This conclusion is baced on the following:

SSAR Table 3.2-1 ideatifie all ABWR afoty-rolated mochanical and electrical equipment a (1) safety Class 1, 2, or 3, (2) seismic Category I, and (3) dexigned to the quality aneurnese requirements of 10 CFR Part 50, Appendix B. As discuseod in Sections 3.2.1 and 3.2.2 of this report, the staff concludes that Table 3.2-1 is seceptable. On the basis of these evaluations, the staff concludes that OE meots GDC 1, 30, and 10 CFR Part 50, Appendix B, as they relate to qualifying affety-rolated mochanical and electrical equipment to appropriato quality standards commenourate with the importance of the safety function to be performed.

The qualification program, which will be implemented for mechanical, instrumeatation, and electric equipment moets the requirements and recommendations of IEEE 344-1987 and the regulatory positions of RGs 1.61, 1.89, 1.92, 1.100 , and SRP 3.9.3, provides edequate assurnace that auch equipment will function properly under all impoeed design and cervice loads, including the loadings imposed by the safe shutdown earthquako, postulated accidents, and loee-of-coolent eccidents. On the basis of this program, complemeated by the ataff's ovaluations of (1) soismic clasaifications in Section 3.2.1 of this report, (2) protection from extornal missiles and internally generated missiles in Section 3.5 of this report, (3) analyees to withstand dynamic offects of poetulated pipe breaks in Section 3.6.2 of this report, and (4) loading combinations and stress limits in Section 3.9.3.1 of this report, OB meets ODC 2, Appeadix A to 10 CFR Part 100, GDC 4 and 14, so they relate to qualifying equipment to (1) withatand the offects of natural phenomens such as earthquakes, (2) bo capable of withatending the dymamic effects aceociated with external misciles, internally genernted miesiles, and pipe whip and jet impingement forces, and (3) demonstrate that equipmeat aneociated with the reactor coolent presoure boundary has a low probability of abnormal leakage, mepidly propagating failure, or groes failure.

To follow the 10 CFR Part 52 design certification process, any change to the commitments involving soismic and dynamic qualification of mechanical and electrical equipment discuseed in Section 3.10 of this report would involve an unreviewed safety queation and, therefore, require NRC reviow and approval prior to implementation. Furthermore, any requeeted change to these commitments must either be specifically describe $d$ in the COL application or submitted for licenso ameadment after COL issuance.

\subsubsection{Methods and Procedures of Analysis or Teating of Supports of Electrical Equipment and Instrumentation}

SSAR Section 3.10.3, Amendment 33, deecribed the procedures and criteria for the seismic qualification and design of the nuclear steam supply system (NSSS) electrical equipment supports; seismic Catogory I supports for battery racks, instrument racks, control consoles, cabinets, and pancls; soismic Catogory I local instrument supports; and soismic Catogory I instrument tubing supports. GE provided the methods and criteria used for the design of the seismic Category I electrical raceway (cable trays and conduit) supports in SSAR Section 3.8.4.4.2, Amendment 33. The following covers only the staff's evaluation of the procedures and criteria for the design of the seismic Category I electrical racoway supports.

SSAR Section 3.10.3.2.2, Amendment 23, described the procedures and criteria for the design of the seismic Category I electrical raceway supports. GE used the response spectrum method to analyze the composite system of the electrical racownys and supports and calculate the seismic loads and the RB vibration (RBV) loads resulting from a safety relief valve (SRV) discharge or LOCA inside the containment. The input to the dynamic analysis is the soismic and RBV FRS generated for the supporting floor. In case the supports are attached to a wall or to two different locations, the input is the upper bound FRS envelope obtained by superimposing the FRS of both floors or locations. In addition, in many cases GE combined several FRS by superposition to generate an upper bound 
FRS cavolope as the input to fecilitate the decign. Tho anf found the andyais mothods and approsches for the deaign of the cable trays, conduit, and their supports ecceptablo.

However, SSAR Section 3.8.4.4.2, Amendment 33, revised the analyais mothods by stating that all seiemic Catogory I cable trays and conduit aupports aro dosigned by one of the methode discuseed in SSAR Suberection 3.7.3 or by the design-by-rule methods as approved by the NRC. On tho basis of the stafir a roviow and evaluation diecueced in Section 3.9.2.2 of this report, the methode provided in SSAR Soction 3.7.3 are acceptable for the analysis and design of the cable trays, conduit, and their mupports. As for the use of the decign by rule methods, SSAR Section 3.7.3.8.2, Amendment 33, stated that for distributive systems such as cable trays, conduit, and HVAC ducts, an alternative to qualification by analysis described in SSAR Subeection 3.7.3.8.1 is the design-by-rule method approved by the NRC at the time of COL application. This is also acceptable to the staff. The hasis to sccept the use of the design-by-rule mothod is provided as follows.

According to SSAR Section 3.8.4.2.4, Amendment 33, the design of soismic Category I electrical recoway supports uses codes, standards, and specifications applicable to the building structures to which thoy are attached. These codes include ANSI/AISC Standard N-690 (1984 Edition), AISI SG-673, "Specification for the Design of ColdFormod Steel Structural Members," and National Electrical Manufacturers Aseociation (NEMA), "Fittings and Supports for Conduit and Cable Assemblies." The supports are designed and located to withstand the dynamic loads generated from the analysee in three directions by means of vertical, transverse, and longitudinal support and bracing systems. As discussed in SSAR Section 3.8.4.3.3, Amendment 32, the design considers the dead loads, live loads, and seismic loads plus other RBV dynamic loads. SSAR Section 3.8.4.4.3.1, Amendment 33, also discussed two methods used in the analysis and design of cable tray supports:

(1) Rigid support with flexible trays - In this method, trays were modeled as flexible elastic systems and analyzed by the response spectrum method. The resulting reactions were used for the design of the supports.

(2) Flexible support with flexible trays - In this method, the composite system of trays and supports were modeled and analyzed by computer as a multidegree of freedom elastic system. The support motion was preacribed by the appropriate floor response spectrum. The resulting responses were used to obtain design loads for the supports.
Since the conduit syatem are more flexible and have comparatively leas dead load, a rigid support approach (Method (1) abovo) applied for the cable tray design was ueod.

According to the staff roviow of SSAR Section 3.8.4, Amendment 33, and the deaign audite conducted by the staff, the supports, including those for the non-seismic Catogory I cable trays and conduits, were designed to meet seismic Catogory I requiroments. These design criteria and procedures meet the guidelines of SRP Section 3.8.4 and are sccoptable. In the early ameadments of the SSAR, GE did not provide the design procedures and criteria for the seismic Catogory I cablo trays and conduit. This was DFSER Open Itom 3.10.3-1. SSAR Section 3.8.4, Amendment 33, provided the design procedures and criteria for the seismic Category I cablo trays and conduit, which are acceptable. Therefore, DFSER Open Item 3.10.3-1 is resolved.

As for the concem about the potential interaction between the non-eoismic Category I cable trays and conduit and the seismic Catogory I cable trays and conduit, SSAR Section 3.7.5.4 describes the COL applicant's action for the as-built plant assessment. The staff's roviow and evaluation are discussed in Section 3.7.2 of this report. On the basis of the previous discussion, the staff concludes that the procedures and criteria for the design of seismic Category I raceway supports are acceptable.

\subsection{Environmental Qualification of Mechanical and Electrical Equipment}

The staff reviewed the ABWR design environmental qualification requirements for mechanical and electrical equipment in accordance with SRP Section 3.11, Revision 2. Equipment that is used to perform a necessary safety function must be demonstrated to be capable of maintaining functional operability under all service conditions postulated to occur during its installed life for the time it is required to operate. This requirement, which is embodied in GDC 1 and 4 of Appendix A and Criteria III, XI, and XVII of Appendix B to 10 CFR Part 50, is applicable to equipment located inside as well as outsido the contrainment. More detailed requirements and guidance related to the methods and procedures for demonstrating this capability for electrical equipment are in 10 CFR 50.49, "Environmental Qualification of Electric Equipment Important to Safety for Nuclear Power Plants;" NUREG-0588, Revision 1, "Interim Staff Position on Environmental Qualification of Safety-Related Electrical Equipment," which supplements IEEE 323 and various NRC regulatory guides and industry standards, and RG 1.89, "Environmental Qualification of Certain Electric 
Equipmeat Important to Safecy for Nuclear Power Plante," Revision 1.

The NRC staff isured NUREG-0588 in December 1979 to promote a more orderly and syutematic implementation of equipment qualification programs by industry and to provide guidance to the NRC staff for its use in ongoing licensing roviews. The posidions in the NUREG series report provide guidance on (1) bow to extablish eavironmental service conditions, (2) how to select methods that are considered appropriate for qualifying equipment in differeat areas of the plant, and (3) other areas such as margin, aging, and documeatation. A final rule on environmental qualification of electrical equipment important to eafoty for nuclear power plants became effective on February 22, 1983. This rulo, 10 CFR 50.49, epecifies the requirements to be mot for demonetrating the environmental qualification of electrical equipment important to safety located in a harsh environment. RG 1.89, Revision 1 (June 1984), identifies the guidelines that have to be met for complying with this rule. In conformance with 10 CFR 50.49, electrical equipment for BWRs referencing the ABWR standard design may be qualified according to the criteria specified in Category I of NUREG-0588, Revision 1, and RG 1.89, Revision 1.

The qualification requirements for mechanical equipment are principally contained in Appendices A and B to 10 CFR Part 50. The qualification methods defined in NUREG-0588 can also be applied to mechanical equipment.

To document the degree to which the environmental qualification program for the ABWR complies with the NRC environmental qualification requirements and criteria, GE provided SSAR Section 3.11, "Environmental Qualification of Safety-Related Mechanical and Electrical Equipment," and SSAR Appendix 31 (proprietary), in a response deted January 13,1989, to the staff's request for additional information duted September 12, 1988.

\subsubsection{Completeness of Qualification of Electrical Equipment Important to Safety}

The following three categories of electrical equipment important to safety must be qualified in accordance with the provisions of 10 CFR 50.49(b)(1), (b)(2), and (b)(3).

- safety-related electrical equipment (relied on to remaln functional during and following design-basis events)

- non-safety-related electrical equipment whose failure under the poetulated environmental conditions could prevent satisfactory sccomplishment of the safety functions by the safety-related equipment
- certain poet-eccident monitoring equipment (Category I and II rccident- monitoring instrumentation as specified in RO 1.97, Rev. 3)

In the SSAR, GE stated that the design of the information systems important to safety will be in conformance with the guidelines of Revision 3 of RG 1.97. However, the footnote for Subsection 50.49(b)(3) references Rovision 2 for colection of the types of post-accident monitoring equipment. In issuing Revision 3, the NRC staff stated that the conformance with Revision 3 would not alier the implementation of Subsection 50.49. Therefore, conformence with Revision 2 is not required because conformance with Revision 3 moets the underlying purpose of the rulo. As a recult, an exemption from Subsection $50.49(\mathrm{~b})(3)$ is justified by the special circumstances set forth in Subection 50.12(a)(2)(ii).

In the early SSAR amendments, GE stated that for the $A B W R$, all three categories of electrical equipment mentioned above and located in a harsh eavironment will be environmentally qualified. GE also identified an interface requirement that requires COL applicants to list all electrical equipment within the scope of 10 CFR 50.49 in their plant-specific environmental qualification documents (EQDs). GE's approach for selecting and identifying electrical equipment required to be environmentally qualified for the ABWR was considered acceptable. However, following a further review, the staff determined that this item should be reclassified as a COL action item and that the staff will review specific details provided by the COL applicant to demonstrate compliance with 10 CFR $50.49(b)(1)$, (b)(2), and (b)(3). In the DFSER, the staff noted that the details will include 2 list of systems and their components that are included in the plant environmental qualification program and the design features for preventing the potential adverse consequence identified in IE Information Notice 79-22, "Qualification of Control Systems." This was DFSER COL Action Item 3.11.1-1. GE has included this action in SSAR Section 3.11.1. This is acceptable.

\subsubsection{Qualification Methods}

\subsubsection{Electrical Equipment in a Harsh Environment}

The environmental qualification program presented in GE Topical Report NEDE-24326-1 (proprietary) outlines the methodology to qualify NSSS system safety-related electrical equipment subject to a harsh environment. GE adopted this program for the ABWR (SSAR Section 3.11.2). 
Design of Structures, Components, Equipment, and Systems

The ataff reviewed the topical report and found that the qualification mothodology conforms to 10 CFR 50.49 and its ascocinted standards, except for the position on the time margin. NUREG-0588 states that the time margin for certain categories of equipment (these categories are identified in this NUREG report) chould be a minimum of 1 hour. The topical report has not addreased this requirement. While GE addressed the time margin in SSAR Section 3.11.1, Amendment 14, the staff noted in the DSER (SECY-91-153) that the report made no reforence to the 1-hour time margin requirement discussed in NUREG-0588. Therefore, the staff identified the time-margin iswe as Outotending Isswe 12 in the DSER (SECY-91-153) and required it to be resolved in accordance with NUREG-0588, Revision 1 or as amplified in RG 1.89, Revision 1.

In response to this request, $G E$ revised its position on timo-margin in Section 3.11.1 of the SSAR, Amendmeat 17. However, it was not clear that the intent is to comply with the guidance of NUREG-0588, Revision 1, Catogory 1, paragraph 3, as amplified in RG 1.89, Revision 1, Regulatory Position C.4. Therefore, in the DFSER, the staff noted that GE should confirm that SSAR Section 3.11.1 will be updated to reflect compliance with this suidance. This was DFSER Confirmatory Item 3.11.2.1-1. Subsequently, GE addressed this issue in Section 3.11.1 of Amendment 32 to the SSAR by stating that: "Some mechanical and electrical equipment may be required by the design to perform an intended safety function within minutes of the occurrence of the event but less than 10 hours into the event. Such equipment shall be shown to remain functional in the sccident environment for a period of at least 1 hour in excess of the time assumed in the accident analysis unless a time margin of less than 1 bour can be justified. Such justification will include for each piece of equipment: (1) consideration of a spectrum of breaks; (2) the potential need for the equipment later in the event or during recovery operations; (3) determination that failure of the equipment after performance of its safefy function will not be detrimental to plant safety or mislead the operator; and (4) determination that the margin applied to the minimum, operability time, when combined with other test margins, will account for the uncertainties associated with the use of analytical techniques in the derivation of environmental parameters, the number of units tested, production tolerances, and test equipment insccuracies." This is consistent with the staff position on time margin as stated in NUREG-0588, Revision 1 , and is acceptable. Therefore, DFSER Confirmatory Item 3.11.2.1-1 is resolved. As discussed in the next section, the time-margin issue for mechanical equipment is similarly resolved.

\subsubsection{Safety-Related Mechanical Equipment in a Harsh Environment}

Although no detniled requirements exist for mechanical equipment, GDC 1 and 4 and Criteris III and XVII of Appendix B to 10 CFR Part 50 contain the following requirements rolated to equipment qualification:

- Components shall be designed to be compatible with the postulated environmental conditions, including those associated with LOCAs.

- Measures shall be established for the selection and review for the auitability of application of materials; parts, and equipment that are eseential to safety-related functions.

- Design control measures shall be established for verifying the adequacy of design.

- Equipment qualification records shall be maintained and shall include the results of tests and materials analyses.

In the early SSAR amendments, GE stated that the qualification program for safety-rolated mechanical equipment for the ABWR design will include all safety-related mechanical equipment identified in SSAR Section 3.2. GE further stated that the mechanical equipment qualification program to be applied to the ABWR will use applicable portions of the NRC-approved Topical Report NEDE-24326-1 (proprietary) and RG 1.89, Revision 1, and will be consistent with the program for qualification of mechanical equipment in : harsh environment described in the NRC-approved GESSAR (GE SSAR) II design. The ABWR program scope looks not only at the metallic components of the equipment but also at the nonmetallic components. Metallic components that form a pressure boundary are considered to be qualified by the nature of their pressure retention capability as demonstrated by the application of an ASME Boiler and Pressure Vesel stamp. Nonmetallic components, wch as greases, gaskets, and lubricants, will be shown to be capable of performing their intended functions under accident environments. The design of safety-related mechanical equipment associated with the ABWR will be performed under the same internal procodural controls as that used for the design of mochanical components associated with the GESSAR II design. These controls ensure that components are designed to be compatible with their postulated operating environments, that mensures are established for the selection and review of the suitability of application of the material, parts, and equipment that are essential to safety-related functions, and that there are design control measures for verifying the adequacy of the design. As stated in NEDE-24326-1 (proprietary), a complete set of 
qualification records are developed for cach afety-related component.

In the carly SSAR amendments, $O B$ siso identified an interfice requirement that required COL applicents to provide in their plant-pecific BQDe (1) a list of all afoty-rolated mochanical equipment located in harchcenvironment plent zones and (2) tho methodology uned to qualify tho equipment located in harch wo well as mild-environment plant zones. However, following a further reviow, the etaff dotermined that this item should be reclasaified a DFSER COL Action Item 3.11.2.2-1. OE has included this setion in Soctions 3.11.1 and 3.11.6 of the SSAR. This is seceptable.

The staff concludes that the information GB provided on the seloction and ideatification of mechenical equipment required to be environmentally qualified and tho qualification mothods for the equipment for the ABWR ctandard design is acceptablo. The etaff concludes that on the basis of SSAR Section 3.11.1, the time-margin ievare as related to safoty-rolated mechanical equipment is rewolved similarly to that for the electric equipment diecuseed in the provious section.

\subsubsection{Completeness of Information in Tables of SSAR Appendix $3 I$}

SSAR Section 3.11 defines all the environmental conditions (normal, abnormal, test, sccident, and post-nccident) to which the applicable equipment may bo expoeed during plant operation. SSAR Appendix 31 contains the tables epecifying the deaign limits or timo-baced profile of thermal cavironmental parameters (preecure, temperature, and relative humidity) and/or dosign limits for radiatida cavironmental paramoters (gamma dose rate and total gamma intograted doee) for cach plant area or zono in the area under normal and/or abnormal and secident environmental conditions. The tables aleo include the neutron flux during normal operating conditions for different zones of the primery containment. The areas for which the eavironmental data are tabulated aro the primary containment, eccondary containment portion of the RB, remaining portions of the RB, turbine building, control building, radwasto building, service building, and outdoor area. Except for the radwante building and the outdoor area, all other areas are further subdivided into zones on the basis of thermal and radiation environmental conditions determined for the zones. The SSAR considen a postulated RC (steam or water) presesure boundary pipe rupture as the limiting accident for calculating the design limits or the time-besed profile for thermal environmental parameters during accident conditions for all zones. The
SSAR conciders the devign-basis LOCA as the limiting sccident for calculating the design limits for radiation environmental parumeters during accident conditions for ali applicable zones. The total normal and accident dowes in a zone is based on integrating the ambient dose rate in the zone over a 60-year period and the accident dose rate in the zone over a 6-month period, respectively.

GB thates the environmental conditions identified in the tables in Appendix 3I are upper-bound envelopes for thewe conditions in various areas or zones to which the applicable equipment has to be designed and qualified. The cavironmental parameters specified in these tables are for the upper-bound envelopes. GE states that the parameters do not include margins that may be required to eatiofy equipment qualification requirements. GE further notes that these tables include identification of significant enveloping abnormal conditions and each enveloping eccident event that affects the zone environment. $\mathrm{GE}$ provider thece tables for use by COL applicents in developing their plant-specific environmental qualification program for equipment important to safety. The staff roviowed the tables in Appendix 3I of the early SSAR amendments and found a number of deficiencies. They were collectively identified in the DSER (SECY-91-153) as Outetanding Issue 13. The reclassification of this issue to a number of DFSER open issues, confirmatory iserves, and COL action items and corresponding resolutions are diecuseod below.

In the DSER (SECY-91-153), the staff noted that the tables in SSAR Appendix 3I did not include the chemical environmental conditions (chemical composition and the resulting $\mathrm{pH}$ ) to which the applicable equipment may be exposed during accident conditions. Subsequently, GE recponded that reactor water quality characteristics for the design-basis loss-of-coolant accident (DBLOCA) are contained in SSAR Section 31.3.2.3. Additionally, in a facsimilo dated Juno 1, 1991, GE stated that SSAR Section 31.3.2.3 would be updated to include information on water quality characteristics for normal operations. This was DFSER Confirmatory Item 3.11.3-1. GE has included this information in SSAR Section 31.3.2.3. The staff reviowed this information and found it acceptable. This resolved DFSER Confirmatory Item 3.11.3-1.

The staff notes that, in the SSAR, the table and figure numbers have been resseigned as shown in Table 3.3 of this report, from those in the previous SSAR amendments. The staff reviewed these reassignments and determined them scceptable. In the discussions below, the reassigned numbers are considered unless otherwise noted. 


\section{Table 3.3 Reassigned number for tables and figures}

\begin{tabular}{|c|c|c|}
\hline $\begin{array}{l}\text { Provious } \\
\text { No. }\end{array}$ & $\begin{array}{l}\text { No.in SSAR } \\
\text { Amnt. } 32 \\
\end{array}$ & Title of Table \\
\hline 31.3-A & $3 I-1$ & $\begin{array}{l}\text { Plant Environment Data and Location Crose Roference Table of } \\
\text { Firure Numbers }\end{array}$ \\
\hline 31.3-1 & $3 I-2$ & $\begin{array}{l}\text { Thermodynamic Environment Conditions Inside primary Containment Veseel, } \\
\text { Plant Normal Conditions }\end{array}$ \\
\hline $31.3-2$ & $31-3$ & $\begin{array}{l}\text { Thermodynamic Environment Conditions Inside RB (Secondary Containment), } \\
\text { Plant Normal Operation Conditions }\end{array}$ \\
\hline 31.3-3 & $3 I-4$ & $\begin{array}{l}\text { Thermodynamic Environment Conditions Inside RB (Outside Secondary } \\
\text { Containment), Plant Normal Operating Conditions }\end{array}$ \\
\hline $31.3-4$ & $31-5$ & $\begin{array}{l}\text { Thermodynamic Environment Conditions Inside Control Building, Plant } \\
\text { Normal Operating Conditions }\end{array}$ \\
\hline $31.3-5$ & $3 I-6$ & $\begin{array}{l}\text { Thermodynamic Environment Conditions Inside Turbine Building, Plant } \\
\text { Normal Operntion Conditions }\end{array}$ \\
\hline 31.3-9 & $3 I-7$ & $\begin{array}{l}\text { Radiation Environment Conditions Insido Primary Containment Veseel, Plant } \\
\text { Normal Operntins Conditions }\end{array}$ \\
\hline $31.3-10$ & $3 I-8$ & $\begin{array}{l}\text { Radiation Environment Conditions Inside RB (Secondary Containment), Plant } \\
\text { Normal Operation Conditions }\end{array}$ \\
\hline $31.3-11$ & $31-9$ & $\begin{array}{l}\text { Radiation Environment Conditions Inside RB (Outsido Secondary } \\
\text { Containment), Plant Normal Operating Conditions }\end{array}$ \\
\hline 31.3-12 & $3 I-10$ & $\begin{array}{l}\text { Radiation Envirónment Conditions Inside Control Building, Plant Normal } \\
\text { Operation Conditions }\end{array}$ \\
\hline 31.3-13 & 31.11 & $\begin{array}{l}\text { Radiation Environment Conditions Inside Turbine Building, Plant Normal } \\
\text { Operating Conditions }\end{array}$ \\
\hline 3I.3-14 & $3 I-12$ & $\begin{array}{l}\text { Thermodynamic Environment Conditions Inside Primary Containment Vessel, } \\
\text { Plant Accident Conditions }\end{array}$ \\
\hline $31.3-15$ & $3 I-13$ & $\begin{array}{l}\text { Thermodynamic Environment Conditions Inside RB (Secondary Containment), } \\
\text { Plant Accident Conditions }\end{array}$ \\
\hline $31.3-16$ & $3 I-14$ & $\begin{array}{l}\text { Thermodynamic Environment Conditions Inside RB (Outside Secondary } \\
\text { Containment), Plant Accident Conditions }\end{array}$ \\
\hline $31.3-18$ & $3 I-15$ & $\begin{array}{l}\text { Thermodynamic Environment Conditions Inside Control Building, Plant } \\
\text { Accident Conditions }\end{array}$ \\
\hline $31.3-19$ & $3 I-16$ & $\begin{array}{l}\text { Radiation Environment Conditions Inside Primary Containment Vessel, } \\
\text { Design-basis accident }\end{array}$ \\
\hline 3I.3-20 & $3 I-17$ & $\begin{array}{l}\text { Radiation Environment Conditions Inside RB Design-basis accident (Secondary } \\
\text { Containment) }\end{array}$ \\
\hline 31.3-21 & $3 I-18$ & $\begin{array}{l}\text { Radiation Environment Conditions Inside RB Design-busis accident Conditions } \\
\text { (Outside Secondary Containment) }\end{array}$ \\
\hline $31.3-22$ & $3 I-19$ & $\begin{array}{l}\text { Radiation Environment Conditions Inside Control Building Design-basis } \\
\text { accident Conditions }\end{array}$ \\
\hline $\begin{array}{l}\text { Figure } \\
31.2-1\end{array}$ & $\begin{array}{l}\text { Figure } \\
\text { 3I-1 }\end{array}$ & Zones in Primary Containment Vessel \\
\hline
\end{tabular}


In the DSER (SECY-91-153), the staff noted that the tables in Appendix 31 did not includo tho beta radiation doce rate and the integrated beta doee for applicable zones. In reeponse, GE stated that accurate radiation environments should include consideration of the source term and the deaign and location and materials of construction of the equipment in the various environmental zones. GE further atated that while the source term is known, the COL applicant will determine the design, specific location, and materials of construction of various pieces of equipment. As a result, GE doveloped an ITAAC for this issue ("Table 3.73.11C: Bquipment Qualification for Radiation"). The etaff reviewed the ITAAC and, in the DFSER, determined that the acceptance criteria should be modified to state: "The maximum expected lifetime exposure for each piece of equipment within the scope of 10 CFR 50.49 shall not exceod the demonstrated qualified value as determined in accordance with the requirements of 10 CFR 50.49 paragraph (f)." This was DFSER Open Item 3.11.3-1. In the SSAR, GE provided revised tables for Appendix 3I that included beta radiation dose rates and intograted beta doses for applicable zones. The revised tables replace Tables 3I.3-9 through 31.3-13 and Tables 31.3-19 through 31.3-22. The staff reviewed the revised tables and found them acceptable. This resolved DFSER Open Item 3.11.3-1.

In the DSER (SECY-91-153), the staff noted that the Appendix $3 I$ tables did not identify whether the subject zone is environmentally mild or harsh and also did not list the typical equipment located in each zone. In response, GE proposed a change to SSAR Section 3.11.2 to define a mild environment as: "Mild environment is that which, during or after a design-basis event will at no time be significantly more severe than that existing during normal and abnormal events." The staff understands that IST is included as a normal or abnormal condition (IST is not en environmental qualification program requirement). This proposed definition is consistent with the requirements of 10 CFR 50.49. In the DFSER, the staff noted that it would verify the incorporation of the proposed definition for a mild environment. This was DFSER Confirmatory Item 3.11.3-2. GE has included this information in SSAR Section 3.11.2. This is acceptable and resolved DFSER Confirmatory Item 3.11.3-2. However, for current generation operating reactors, the staff's definition of what constitutes a mild radiation environment for electronic components, such as semi-conductors or any electronic component containing organic materials, is different from what it is for other equipment. The staffs's position is that a mild radiation environment for electronic equipment is a total integrated dose of $<10 \mathrm{~Gy}$ (10E3 R). For other equipment it is < $100 \mathrm{~Gy}(10 \mathrm{E} 4 \mathrm{R})$. With the expected significant increase in the quantity and variety of electronic components in newer generation plants, the staff has increating concerns about the efforts being mado to cosure that these components are environmentally qualified and the capability of the component to be environmentally qualified. As a result, in the DFSER, the staff commented that GE should confirm that its position on the environmental qualification of electronic components is consistent with the staff's. This was DFSER Open Itom 3.11.3-2. In response, GE addressed this itom in the SSAR by stating that electronic equipment subject to radiation exposure in excess of $1000 R$ and other equipment in excess of $10,000 \mathrm{R}$ is qualified in accordance with 10 CFR 50.49. This is acceptable and resolved DFSER Open Itom 3.11.3-2. In addition, to respond to DSER Outstanding Issue 13, GE proposed changes to Tables 31.3-1 through 31.3-22 to include references to P\&ID and IED drawings that will identify typical equipment for cach zone. In the DFSER, the staff found these proposed changes acceptable but noted that the changes should be incorporated into the SSAR. This was DFSER Confirmatory Item 3.11.3-3. The proposed changes are incorporated into the SSAR. Therefore, DFSER Confirmatory Item 3.11.3-3 is resolved.

In the DSER (SECY-91-153), the staff noted that the environmental conditions during abnormal plant operational conditions were placed under abnormal/accident conditions in the Appendix 31 tables. Additionally, the staff was not certain whether GE considered the adverse environmental conditions resulting from abnormal events such as SRV discharges and loss of non-safety-related HVAC and their durations in developing the environmental data for these tables for applicable zones. In response, SSAR Amendment 14 revised the Appendix 3I tables to properly include these abnormal occurrences in the normal plant operating conditions that are used for determining the qualified life of the equipment required to be qualified. This is acceptable.

In the DSER (SECY-91-153), the staff noted that the Appendix 31 tables did not explicitly identify the limiting sccident (e.g., high-energy line break such as MSL, reactor core isolation cooling, RHR, or CUW line break and DBLOCA inside the containment) for each zone (0.8., steam tunnel, RHR pump room) that results in the most severe environment, particularly thermal, in the zone. SSAR Section 3.11.1 states: "The environmental conditions shown in the Appendix $3 I$ tables are upperbound envelopes used to establish the environmental design and qualification bases of safety-related equipment. The upper-bound envelopes indicate that the zone data reflects the worse case expected environment produced by a compendium of accident conditions." The staff interprets that the SSAR considers a spectrum of break sizes and the mass and energy releases from the considered break sizes and thereby developed the environmental qualification 


\section{Design of Structures, Components, Equipment, and Systems}

profiles besed on the mot limiting combination of the considered break sizes. This is scoeptable.

In the DSER (SECY-91-153), the ataff noted that the Appendix 31 tables did not contrin information on the cavironmental conditions reaulting from epray or aubmersence or on the consequent wotting of equipment in applicable rones arising from piping failures nor the duration of the epray or enbmergence. In response, GB indicated in SSAR Section 31.3.2.3 that containment epray may continus up to 100 days. In addition, $G B$ modified SSAR Section 31.3.2.3 by thating that "equipment will bo qualified for nubmergence or will not bo nubmerged except where aubmengence is mitizated by enfety function performed by barrier eeparated redundant equipment." In the DFSER, the etaff noted that during construction, the COL applicant should ensure that issues identified in Information Notice 89-63 related to flooding above the flood lovel and equipmeat wetting are addreseod. This was DFSER COL Action Itom 3.11.3-1. OE has included this information in Section 3.11.1 of the SSAR. This is scceptable.

In the DSER (SECY-91-153), the ataff noted that the Appendix 3I tables did not contain (1) radiation environmental dati under normal plant operating conditions for the radwaste building, outdoor area, and control building zones; (2) thermal environmental data under accident conditions for the radwaste building, service building zones, and outdoor area; and (3) radiation environmental data under sccident conditions for the turbine building zones, radweste building, ervice building 200en, and outdoor area. In the DSER (SECY-91-153), the staff also indicated that if somo of theee areas identifiod are not expected to house any equipment required to be qualified and therefore not requiring environmental data, this should be stated. Subsequently, GE identified the various environmental zones within the scope of 10 CFR 50.49. However, the radiation environment that would result from normal operations and a design-basis accident was not determined. GE further commented that an sccurate determination of radiation levels in the various harch environmeatal zones requires consideration of specific equipment design details wuch as geometry and materials of construction and equipment location within each zone; therefore, radiation doee and doee rates should be determined by the COL applicant. This determination should also include the radiation contribution from recirculation fluid lines near the applicable areas. In the DFSER, the staff evaluated GE's position discuseed above and stated that it would ovaluate the relovant radiation zones on a plant-specific basis. This was DFSER COL Action Item 3.11.3-2. However, upon further evaluation, GE decided to include the relevant radiation zone data, including doses and dose rates, in the tables in
Appendix 31. This information is included in the SSAR, which is acceptable, and DFSER COL Action Item 3.11.3-2 is doleted.

In the DSER (SECY-91-153), the staff noted that the Appendix 31 tables did not contain sufficient information on thermal environmental conditions (6.g., duration of different conditions) in various zones under normal plant operating conditions to dovelop a meaningful timo-based thermal cavironmental profile for the zones. GE provided a propoend table (Table 3I.3-A) and a propoeed ameadmeat to all the tables in Appendix 31 that contrin thermodynamic environmental conditions for both normal operating conditions and doaign-basis eccidents. In the DFSER, the ataff noted that the propoeed information would bo sufficient to dovelop time-baeed profiles for the various identified zones. This was DFSER Confirmatory Item 3.11.3-4. GE has included this information in Appendix 31 of the SSAR. This is acceptable and resolves DFSER Confirmatory Item 3.11.3-4.

In the DSER (SECY-91-153), the staff noted inconsistencies in the units used to specify the pressures (0.8., $\mathrm{kg} / \mathrm{cm} \mathrm{g}, \mathrm{mm} \mathrm{Aq}$ ). Consistent units are provided in the SSAR. This is acceptable.

In the DSER (SECY-91-153), the staff noted that the moaning of the statement "the pissure will be kept negative or positive" is not clear 800 Note 2 to Tables 31.3-3 through 31.3-7). This statement was subeequently interpreted by the staff, in the DFSER, to mean that in various areas of the plant site, such as the control building, the RB, and the primary containment building, where the atmospheric pressure may be required to be negative that it will be maintained below $0.0 \mathrm{kPag}$ ( 0.0 peig) and if the atmospheric pressure is required to bo positive, that it will be maintained above $0.0 \mathrm{kPag}$ (0.0 psig).

The staff noted in the DSER (SECY-91-153) that the integrated gamma accident dose in the primary containment for the ABWR was given as $6 \times 10^{5}$ Gy $\left(6 \times 10^{7} \mathrm{rads}\right)$, which is less than the typical value of about $2 \times 10^{6} \mathrm{~Gy}$ $\left(2 \times 10^{8} \mathrm{rads}\right)$ quoted in the safety analysis reports of coveral operating reactors (e.g., Perry: $2.7 \times 10^{6}$ Gy $\left(2.7 \times 10^{6}\right.$ rads); River Bend: $1.7 \times 10^{6}$ Gy $\left(1.7 \times 10^{3}\right.$ rads); Clinton: $2.0 \times 10^{6}$ Gy $\left(2 \times 10^{8}\right.$ rads); Nine Mile Point: $1.4 \times 10^{6} \mathrm{~Gy}\left(1.4 \times 10^{8} \mathrm{rads}\right)$. It was not clear why the ABWR integrated gamma sccident dose is lower than the corresponding doses quoted for several operating reactors. As a response to the above, GE's position, which was provided in Section 5.3.2.1.5 of SSAR Amendment 15, did not adequately address this issue. In the DFSER, the staff noted that, to resolve this issue, GE must fully explain why the ABWR integrated gamma 


\section{Design of Structures, Components, Equipment, and Systems}

accident doee is lower than the corresponding doses quoted for eoveral opernting renctors. This was DFSER Open Item 3.11.3-3. Subecquently, GE determined that the integrated gamma doese for an sccident inside primary containmeat for ABWR is $2 \times 10^{6}$ Gy $\left(2 \times 10^{3}\right.$ rads). Table 3I.16 of Appendix 31 of the SSAR provides this information. The staff concludes in its engineering judgement that this is a reaconable value and is consiatent with values determined at other BWRs. This is acceptable and reeolved DFSER Open Item 3.11.3-3.

On the basis of its roview of the tables in SSAR Appendix $3 I$ the staff concludes that the tables in Appendix 3I aro scceptablo.

\subsubsection{Adequacy of Interface Requirements}

As a result of staff reviow of interface requirements, these requirements have been reclassified as ITAAC itoms that will be reviewed as part of the ITAAC program. In these instances COL applicants must (1) present e summary of environmental conditions and qualified conditions for each applicable item of equipment located in a harsh-environment zone in the system component evaluation work sheets as dxscribed in Table I-1 of GE Topical Report NEDE-24326-1-P and compile these sheets in their plant-specific environmental qualification documents and (2) record and maintain in an auditable file the results of all qualification tests for applicable equipment.

Additionally, although not identified as an interface requirement, the DFSER states that COL applicants should develop a surveillance and maintenance program for each applicable equipment item located in a mild-environment zone to ensure its operability during its design life. The vendors of equipment located in a mild environment are required to submit a certificate of compliance certifying that the subject equipment was qualified according to the requirements identified to ensure its capability to perform its safety-related function in its applicable environment. This was DFSER COL Action Item 3.11.3-3. SSAR Sections 3.11.2 and 3.11.6.3 include this action. This is acceptable.

\subsubsection{Conclusions}

On the basis of the evaluation discussed, the staff finds that the program for environmental qualification of electrical equipment for the ABWR standard design is in compliance with all the requirements of 10 CFR 50.49 and is, therefore, acceptable.

\subsection{Fiping Design}

The DPSER "Piping Deaign" section, which was undor Section 14.1.3.3, is revised and incorporated into a now ecction, Section 3.12, of this report. In the following, except for identification numbers for the DPSER open, confirmatory, COL sction, and TS items, all other donignations for mubections, paragraphs, and the like aro reaseigned and keyed to Section 3.12 of this report, as appropriate.

\subsubsection{Introduction}

This section provides the staff's safety ovaluation of GE's decign acceptance criteria (DAC) approech for the ABWR piping design. The staff used the SRP guidelines to ovalunte the piping design information in the ABWR SSAR and performed a detailed audit of the piping design criteria, including sample calculations. The staff ovaluated the adequacy of the structural integrity and functional capability of safety-related piping systems. The roview was not limited only to the ASME Boiler and Pressure Veasel Codo Class 1, 2, and 3 piping and supports, but also included buried piping, instrumentation lines, the interaction of non-seismic Catogory I piping with seismic Category I piping, and any safety-related piping designed to industry standards other than the ASME Code. The staff's evaluation of the adequacy of the ABWR pipirs design analysis methods, design procedures, acceptance criteria, and related ITAAC that are to be used for the completion and verification of the ABWR piping design is provided in the following sections of this report. The staff's evaluation includes

- applicable codes and standards

- analysis methods to be used for completing the piping design

- modeling tochniques

- pipe stress analyses criteria

- pipe support design criteria

- high-energy line break criteria

- LBB approach applicable to the ABWR

- generic piping design ITAAC

The staff must arrive at a final safety determination that, if the COL applicant successfully completes the piping design and analyses and the ITAAC as required by 10 CFR Part 52, using the design methods and acceptance criteria discussed herein, there will be adequate assurance that the piping systems will perform their safety-related functions under all postulated combinations of normal operating conditions, system operating transients, postulated pipe breaks, and seismic events. 


\subsubsection{Codes and Standards}

GDC 1 requires that etructures, syetem, and components important to eafety shall bo decigned, fabricated, erected, and teatod to quality standarda commennumato with the importance of the afety function to be performed. Where generally recognized codes and standards are ueed, they shall be ideatified and evaluated to determine their applicability, adequacy, and aufficiency and shall be aupplemented or modified as necesceary to aseure a quality product in keeping with the required anfety function. 10 CFR 50.55a requires that aystems and components of boiling and presurized water-cooled nuclear power reactors mut moet the requirements of the ASME Code. It epecifies the lateet edition and addenda endorned by the NRC and any limitations. RG 1.84 and 1.85 list ASME Code Cases that the NRC staff finds scceptable.

In SSAR Tables 1.8-21 and 3.2-3, GE identified the ASME Code, Section III, and the specific edition and addenda that will be used for the design of ASME Code, Clase 1, 2, and 3 presecure retaining components. In SSAR Table 5.2-1, the Codo Cases that may be used are also identified.

\subsubsection{ASME Boiler and Pressure Vesed Code}

For the ABWR design certification, GE has established that the ASME Boiler and Presesure Vessel Code, Section III, will be used for the design of ASME Code Class 1, 2, and 3 pressure retaining components and their supports. The specific edition and addenda are provided in SSAR Tables 1.8-21 and 3.2-3. The ASME Code is considered Tier 1 information; however, the epecific edition and addenda are considered Tier 2 information. The specific edition and addenda are considered Tier 2 information because of the continually evolving technical nature associated with the design and construction practices (including inspection and examination techniques) of the Code. Fixing a specific edition and addenda during the design certification stage may result in inconsistencies between design and construction practices during the detailed design and construction stages. The ASME Code involves a consensus process to reflect the evolving design and construction practices of the industry. Although the reference to a epecific edition of the Code for the design of ASME Code class components and their supports is suitable to reach a safety finding during the design certification stage, the construction practices and examination methods of an updated Code that would be effective at the COL application stage must be consistent with the design practices established at the design certification stage.
The ataff finda that the epecification of the ASME Code as Tier 1 information and the specific edition and addenda as Tier 2 information is appropriate because it would provide the means for the COL applicant to revise or supplement the referenced Code edition with portions of the later Code editions and addenda needed to ensure consistency between the design for the ABWR pressure retaining components and their supports and construction practices. In this manner, the updated reference Code to be used at the time of the COL application is ensured to be consistent with the lateat design, construction, and examination practices at that time. However, where the staff finds that there may bo - noed to specify certain design parameters from a epecific Code edition or addenda during its design certification reviow, particularly when that information is of importance to eatablish a significant aspect of the design or is used by the staff to reach its final safety determination, such considerations, if necessary, are reflected in the various sections of this safety evaluation.

Therefore, all ASME Code Class 1, 2, and 3 pressure retaining components and their supports must bo designed in eccordance with the requirements of ASME Code, Section III, using the specific edition and addenda provided in the ABWR SSAR. However, the COL applicant should also enaure that the design is consistent with the construction practices (including inspection and examination methods) of the ASME Code edition and addenda as endoreed in 10 CFR 50.55a in effect at the time of COL application. The portions of the later Code editions and addenda must be identified to the NRC staff for review and approval with the COL application. This was DFSER COL Action Item 14.1.3.3.2.1-1. GE has included this sction in SSAR Section 3.9.7.4, which is acceptable.

\subsubsection{ASME Code Cases}

The only acceptable ASME Code cases that may be used for the design of ASME Code Class 1, 2, and 3 piping systems in the ABWR standard plant are those either conditionally or unconditionally approved in RGs 1.84 and 1.85 in effect at the time of design certification as listed below. However, the COL applicant may submit with its COL application for staff review and approval future code cases that are endorsed in RGs 1.84 and 1.85 at the time of COL application provided they do not alter the staff's safety findings on the ABWR certified design.

- In RG 1.84, the staff has conditionally endorsed ASME Code Case N-411, "Alternative Damping Values for Respones Spectra Analysis of Classes 1, 2, and 3 Piping, Section III, Division 1." This Code Case is acceptable for the ABWR. The acceptability of the Code Case and its application is further discussed in Section 3.12.5.4 of this report. 
Other ASMB Code Cases requeated by OE that are applicable to tho $A B W R$ piping and aupport deaign aro listed bolow.

- ASME Codo Caso N-71-15, "Additional Materials for Subnection NF, Clasece 1, 2, 3, and MC Component Supports Fabricatod by Welding, Section III, Division 1." This Code Case has been eadorned by the staff in RO 1.85.

- ASME Code Caso N-122, "Streses Indices for Structure Attechments, Class 1, Section III, Division 1." This Code Case has been endorsed by the staff in RO 1.84.

- ASME Code Case N-247, "Cortified Deaign Report Summary for Component Standard Supports, Section III, Division 1, Claseses 1, 2, 3 and MC." This Code Case has been endorsed by the staff in RG 1.84.

- ASME Code Case N-249-9, "Additional Material for Subsection NF, Clasees 1, 2, 3 and MC Component Supports Fabricated Without Welding, Section III, Division 1." This Code Case has been endorsed by the staff in RG 1.85 .

- ASME Code Case N-309-1, "Identification of Materials for Component Supports, Section III, Division 1." This Code Case has been eadorsed by the staff in RG 1.84.

- ASME Code Caso N-313, "Alternate Rules for HalfCoupling Branch Connections, Section III, Division 1." This Code Case has been endorsed by the staff in RG 1.84 .

- ASME Codo Case N-316, "Alternate Rules for Fillet Weld Dimensions for Socket Wolded Fittings, Section III, Division 1, Class 1, 2, 3." This Code Case has been endorsed by the staff in RO 1.84.

- ASME Code Case N-318-3, "Procedure for Evaluation of the Design of Rectangular Cross Section Attachments on Class 2 or 3 Piping, Section III, Division 1." This Code Case has been conditionally endorsed by the staff in RG 1.84 and is discussed further in Section 3.12.5.16 of this report.

- ASME Code Case N-319, "Alternate Procedure for Evaluation of Stress in Butt Weld Elbows in Class 1 Piping, Section III, Division 1." This Code Case has been endorsed by the staff in RG 1.84 .

- ASME Code Case N-391, "Procedure for Evaluation of the Design of Hollow Circular Cross Section Welded Attachments on Class ! Piping, Section III, Division
1." This Codo Case has been endoreed by the ataff in RO 1.84.

- ASME Codo Caso N-392, "Procedure for Evaluation of the Deaign of Hollow Circular Croes Section Welded Attachments on Clasen 2 and 3 Piping, Section III, Division 1." This Codo Case has been eadoned by the ataff in RO 1.84.

- ASME Code Cavo N-393, "Repair Welding Structural Steel Rolled Shaped and Plates for Componeat Supports, Section III, Division 1." This Codo Cave has been endorsed by the staff in RG 1.84 .

- ASME Code Case N-414, "Tack Welds for Clase 1, 2, 3 and MC Components and Piping Supports." This Code Case has been endoreed by the staff in RO 1.84.

- ASME Code Case N-430, "Requirements for Welding Workmanship and Visual Accoptance Criteria for Class 1, 2, 3 and MC Linear-Type and Standard Supports." This Code Case has been endoreed by the staff in RG 1.84.

All of the above Code Cases are listed in Table 5.2-1 of the SSAR. In addition, in Sections 3.9.3.4 and 3.9.3.5 of the SSAR, Code Case N-476, "Class 1, 2, \& 3, and MC Linear Component Supports - Design Criteria for Single Angle Members, Section III, Division 1, Subecction NF," is referenced as augmenting ASME Subsection NF rules for the design of component supports. As stated in Section 3.9.3.3 of this report, the staff finds this Code Case scceptable. Therefore, the staff concludes that, since all of these Code Cases either meet the guidelines of RGs 1.84 or 1.85 , or have been reviewed and endorsed by the staff, they are acceptable for use on the ABWR design.

\subsubsection{Design Specification}

ASME Code, Section III, requires that a deaign apecification be prepared for Class 1, 2, and 3 components such as pumps, valves, and piping systems. The design specification is intended to become a principal document governing the design and construction of these components and should specify loading combinations, design data, and other design data inputs. The Code also requires a dosign report for ASME Code, Class 1, 2, and 3 piping and components. In the SSAR, GE committod to construct all safety-related components, such es vessels, pumps, valves and piping systems, to applicable requirements of the ASME Section III. During its review of the SSAR, the staff reviewed selected documents related to design specifications and design reports. Those documents wero not specifically for the ABWR, but were provided by $G E$ and reviewed by the staff as a demonstration of how design 
pecifications and daciga reports will be prepared for ABWR plante. The etaff determined that the demonetration documents, with modification, would meet Cods requiremeats. However, becules the documents were not epecifically for the ABWR, thoy would have to be modified bofore the ctafi cen conclude that the design apecification and doxign report requirements in ASMB Code, Section III, Submection NCA, have been met. In order for the staff to reach this conclusion, the COL applicant should submit representative deaign documents (0.8., decien specifications) for NRC staff roview as part of the COL application (DFSER COL Action Item 3.9.3.1-2 and 14.1.3.3.2.3-1). SSAR Section 3.9.7 thetes that COL spplicants referencing the ABWR design will mike avnilablo to the staff datign epecifications and decigen reports required by the ASMB Codo for veseds, puopes, valves, and piping aydeme for the purpose of audit. This is ecceptable.

\subsubsection{Condusions}

On the banis of thene discuscions and the evaluation of SSAR Section 3.9.3.1 and Tables 1.8-21, 3.2-3, and 5.2-1, the etaff concludes that the piping systems important to eafoty are dexigned to quality atendarde commenourato with their importance to safety. The staff's conclusion is based on the following:

(a) GE atisfice the requirements of ODC 1 and 10 CFR 50.55a by apecifying appropriate codes and atandards for the deaign and construction of eafetyrelated piping and pipe supports, and

(b) GE ideatified ASME Code Cases that may be applied to ASME Code, Class 1, 2, and 3 piping and pipe supports, which are scceptable to the staff.

\subsubsection{Analyais Methods}

The ataff reviowed the information in SSAR Section 3.9.1 related to the deaign transients and mothods of analyois used for all mismic Catogory I piping and pipo supports designated as ASME Code Class 1, 2, and 3 under ASME Code, Section III, as well as those not covered by the Code. It reviewed the sesumptions and procedures used for the inclusion of transieats in the design and fatigue evaluation of ASME Code Class 1 and core support components. It also roviewed the computer programs used in the decign and analysis of seismic Category I components and their supports, as well as experimental and inelastic analytical techniques.

\subsubsection{Experimental Stren Analyais}

SSAR Section 3.9.1.3 ideatifies evverd composents for which experimental strens analyais is performod in conjunction with analytical ovaluation. Such components in the piping area includo the piping ceismic anubbers and pipe whip retraints. The staff. evaluation of the experimental streses analysis mothods is diccused in Section 3.9.1 of this report. The etaff's evaluation of the analysis methods used to qualify these components is diecuseed further in Sections 3.12.6 and 3.12.7 of this report.

\subsubsection{Modal Reaponse Spectrum Method}

OB performed ayetem and auboyatem analyees on an olautic basis. Modal reeponso epectrum and time history mothode form the basis for the analyese of all major seismic Category I piping systems and components. SSAR Section 3.7.3.8 describes the piping dynamic analysis procedure using the modal response epectrum method. Fire a mathematical model is constructed to reflect the dynamic characteristics of the piping system. The mode shapes and natural frequencies of the piping model are computed. Uaing a given direction of earthquake motion, the modal participation factors for each mode aro calculated. Using the appropriate response spectrum curve, the spectral eccelerations for each modo aro determined. For a piping system supported at points with different dynamic excitations, an enveloped response spectrum of all attachment points is used. From the mode shapes, participation factors and spectral accelenations of each modo, the modal responses are calculated. They include the modal forces, shears, moments, stresses and deflections. For a given direction, the modal responses are combined in eccordence with the methods deacribed in SSAR Section 3.7.3.7.

The modal response calculations are performed for each of the three earthquake directions (two borizontal and the vertical). The total seismic response from the simultaneous application of the three-directional components of earthquake loading are obtained by combining the maximum codirectional responses of each of the three components by the squaro-root-of-the-sum-ofequares (SRSS) method as described in SSAR Soction 3.7.3.6. 
For piping aystem that are anchored and reatrined to floon and walls of buildinge that have differeatial movements during a colemic ovent, additional forces and momeate ase induced in the system. Additional atatio

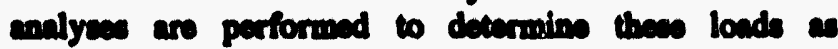
drocribed in SSAR Scotion 3.7.3.8.1.8. The maximum differseatial dieplecements are applied to the piping anchors

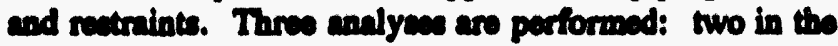
borisontal discotions and ons in the vertical direction. The

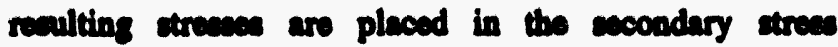
category because thoy are dieplacement induced and colflimiting. These recosdary loads are combined with the primary (inertia) loads by the SRSS mothod.

The ataff reviowed the SSAR deweription of the modal reepones spectrum method and found that it is consictent with the applicable guidelines in SRP Section 3.9.2 and is coceptable.

\subsubsection{Independent Support Motion Method}

A an alternative to the caveloped response spectrum method, the independent support motion (ISM) analysis method may be ueed. The theory and dovelopment of the governing equations of motion for this method are presented in SSAR Subection 3.7.2.1.4. Additional requirements acociated with the application of this method are deacribed in the SSAR Subection 3.7.3.8.1.10, "Multiply Supported Bquipment and Components with Distinct Inputs." This section staten that when this mothod of analyais is used, the following conditions must bo mot: (1) ASME Codo Cavo N-411-1 damping is not ueed; (2) a support group is defined by supports which have the amo time history input. This usually means all supports located on the amo floor, or portions of a floor, of a structure; and (3) The reeponses from motions of supports in two or more different groups are combined by the SRSS procedure.

The ataff finds that contingent upon these conditions, this alternative to the eaveloped reeponse eppectrum method is acceptable. More details of the ovaluation are discused in Section 3.9.2.2. of this report.

\subsubsection{Time-History Method}

A time history analysis may be performed using either the modal superposition method or the direct integration method. The modal superposition method is described in SSAR Subsection 3.7.2.1.2. This approach involves the calculation and utilization of the antural frequencies, modo shapes, and appropriate damping factors of the particular system toward the solution of the equations of dynamic equilibrium. The orthogonality of the modo shapes is used to effect a coordinate transformation of the displacements, velocitien, and eccolerations auch that the responve in ench mode is independeat of the respones of the system in any other mode. Through this tranuformation, the problem becomes ons of colving a independeat difforential equations nether than simultaneous differeatial equations. As lons as the system is linear, the principle of aperposition bolds and the total response of the syetom cesillating simultaneoualy in a modes may be determined by direct addition of the responen of the individual modes.

Tho dirsect intogration mothod is described in SSAR Section 3.7.3.1. This method involves the direct stop-byatep numerical integration of the equations of motion and does not require the solution of an eigenvalue problem. The response in all modes is calculated simultaneoualy. The numerical intogration time step, $\Delta t$, muat be afficieatly amall to accurately dofine the dynamic excitation and to render atability and convergence of the solution up to the higheat frequency of significance. The integration time step is considered scceptable when smaller time eteps introduce no more then a 10-percent error in tho total dynamic response. For moat of the commonly uned integration methods, the maximum time step is limited to ono-tenth of the emalleat period of interest, which is generally the reciprocal of the cutoff frequency. In direct integration analysis, the damping is input in the form of $\alpha$ and $\beta$ damping constents, which give the percentage of critical damping, $\lambda$ as a function of the circular frequency, w.

The total seismic response is predicted by combining the responses from the three orthogonal components (two horizontal and one vertical) of the carthquake. When separate timo-history analyses are performed for each directional component, the combined response may bo obtained by taking the SRSS of the maximum codirectional responses caused by each component. As an altermative, the combined reeponse may be obtained by algebraically adding the codirectional responses from each analysis at each time step or the total response may be obtained directly by applying the three component motions simultaneously in one analyais. When oither alternative method is used, the three component motions must be mutually statistically independent.

When the timo-history method of analysis is used, the timo-history data is broadened plus and minus 15 percent of $\Delta t$ in order to sccount for modeling uncortainties. For loads such as affety-relief valve blowdown, tests have been performed that confirm the conservatism of the analytical results. Therefore, for these loads, the calculated force time histories are not broadened.

The affe reviowed the SSAR descriptions of the modal superposition and the direct integration time-history 
analycis mothode and found them to bo in complinace with the epplicable suldolines of SRP Section 3.9.2 and ecceptablo.

\subsubsection{Inclatic Andyils Method}

OB the not provided any information on the ues of inclatic andyeis mothods for tho ABWR piping analyem. If isolatile mothods are to be uned in any ABWR piping analyese, then the etaff requires that the details of the inclatic metbod and its scceptance criteria, as woll as the coppe and exteat of its application, be nubmitted to tho etaff for approval prior to its use by a COL applicent.

\subsubsection{Small-Bore Fiping Method}

In the DPSER, the staff noted that OB had not provided sny epecific information about the mothod to be uned for the entructural deaign of amall-bore piping syatem and inetrumentation lines in the ABWR plant. The etaff requected that this information bo included in the SSAR. This was DPSER Open Items 3.9.2.2-5 and 14.1.3.3.3.6-1. SSAR Section 3.7.3.8.1.9, "Design of Small Branch and Small Bore Piping," discueses the uve of umall-bore piping handbooks in lieu of performing piping analyais for piping $50.8 \mathrm{~mm}(2 \mathrm{in}$.) and leas nominal pipe size, and amall branch lines $50.8 \mathrm{~mm}(2 \mathrm{in}$.) and leas nominal pipe sizo. It atates that (a) the amall-bore piping handbook must be curreatly accepted by the regulatory agency for use on equivalent piping at other nuclear power plants at the time of application; (b) when the handbook meets the purpose of the Design Report, it must meet all of the ASME requirements for a piping design report for piping and its supports; and (c) formal documentation oxiats showing that piping designed and installed in accordance with the handbook is conservative in comparieon to results from a detailed atrees analysis for all loads and load combinations, that it is not loes reliable owing to loas of flexibility or excessive supports, and that it atisfies required clearances around censitive components. The piping handbook methodology will not be applied when epecific information is noeded on pipe streseses, cumulative ueage factors, sccelonations, or break locations.

The staff reviewed the methodology deacribed in SSAR Section 3.7.3.8.1.9, which states that the static and dynamic analysis methods defined in Section 3.7.3 of the SSAR will bo ueed to provido the formal documentation showing that piping doaigned and installed to the small bore piping handbook is conservative in comparison to a detailed streas analysis. The staff finds this acceptable, and DFSER Open Itom 3.9.2.2-5 and 14.1.3.3.3.6-1 aro reeolved.

\subsubsection{Non-Salenic/Sciomic Internction (II/I)}

All noanteismio Catogory I piping (or other aymome and componeats) sbould be ivolated from seivmic Category I piping. This ivolation may be sobioved by designing a melemis constrint or barrier or by locating the two anfirielatly apart to proclude any internotion. If it is imprectical to isolato tho soismic Catogory I piping system, the edjecent non-ediemio Catogory I nyetem chould bo ovaluated to the eame critoria as the caismic Catogory I oyatem.

For non-seiamic Catogory I piping ayatom attached to coismic Catogory I piping system, the dynamic offects of the son-enismic Catogory I syatem should bo considered in the analyais of the seiruic Cabegory I piping. In addition, tho son-soismic Catogory I piping from the attechment point to the firet anchor should be evaluated to casure thet, under all loading condition, it will not cause a failure of the soirmic Catogory I piping syatem. Section 3.7.3.13 in the SSAR contains criteria that aro consiatent with these ataff positions and applicable portions of SRP 3.9.2 and RO 1.29, "Soismic Design Claseification, "Revision 3, and is therefore, scceptable.

\subsubsection{Main Steamline and Bypass Line in the Turbine Building}

For the ABWR plant dexign, GE eliminates the main steam isolation valve leakage control syetem and relies on the une of an alternative leakage path that takes advantage of the large volume and curfece area in the main ateam piping, drain line, bypass line, and condenner to hold up and plate out the release of fission products following core damage. In this manner, the main steam piping, drain line, bypaes line, and condenser will bo used; to mitigate the consequences of an accident and will be required to remain functional during and after a SSE.

For this reason, the staff's position is that the main steam piping boyond the recond outermost isolation valve and up to the evismic interface reatraint and the connecting branch lines up to the first normally closed valve should be slaseified as QO B (Safoty Class 2) and soismic Catogory I. The MSL from the seismic interface restraint up to but not including the turbine stop valve (including branch lines to the first normally-closed valve) should be classified as QO $B$ and inspected in accordance with the applicable portions of ASME Codo, Section XI, but may be claseified as nonsoismic Catogory I if it has been analyzed, using a dynamic seismic analysis method to demonstrate its structural intogrity under SSE loading conditions. However, all pertinent QA requirements of Appendix B to 10 CFR Part 50 are applicable to ensure that the quality of the piping material is commensurate with its importance to 
affory during sormal opentional, transicat, and cocideat conditione. To canure integrity of the remuinder of the alterenative leckage path, the main stem bypan lise, although it is not roquired to be clasedified as afety-related or es edremic Catogory I, the line from the firte valve up to the condeneser inlex, tho min steam drain live from the firet valvo to the coadeneser, and the main team piping betwean tho turbine stop valve and the turbine inlet should be analyead, uaing a dynamic soismic andyais, to demontrate itu structural intogrity undor SSB londing conditions. This wa DSER Oututinding Iene 3 in SECY-91-153 and DFSER Confirmatory Item 14.1.3.3.3.8-1.

SSAR Soction 3.2.5.3, "Main Stonmline Leakage Path," dofives the piping and composeats that make up the main ctenm leakage path and provides their claseifications and requirements for dynamic seismic analyais. It also tatee that a plant-apecific walkdown will bo conducted to confirm that the asbuilt main team piping, bypase lines to the condener, and the main condenser are not compromised by non-aviamically doaigned systom, atructures, and components. From its reviow, the etaff reviow concludes that the SSAR adequately roflects these staff positions as deacribed. On the basis of the evaluation as discuseed and the evaluation reporied in more detail in Section 3.2.1 of this report, DSER Outstanding Isave 3 and DFSER Confirmatory Itom 14.1.3.3.3.8-1 ire resolved.

Leatly, the main steam piping, drain line, and bypass line in the turbine building should be protected from the collapse of any non-soismic Catogory I structure in the event of an SSE. As a confirmatory measure, a plantepecific walkdown should be performed before operation to seeves the potential failures of non-seismically designed SSCs overhead, adjecent to, and attuched to the alternative leakage path (i.e., the main ateam piping, by-pane line, and the min condenser). In the DSER, the staff noted that this walkdown should be performod as a part of the ITAAC verification of non-seismic/seismic internction. This was later identified in the DFSER as Open Item 3.2.1-3 and Confirmatory Itom 14.1 3.3.3.8-2. Upon further consideration, the ataff found that the design dotail and a-built and as-procured information for nonseismically deaigned SSCs in the turbine building as they affect the alternative leakage function of the main atoem, bypass, and drain lines, and the main condenser are not required for dosign certification and the staff will roviow the apacial relationahip between these SSCs and the main steam piping, bypase, and drain lines, and main condenser to ensure compliance with GDC 2. Subeequently, OE revised the SSAR and added SSAR Section 3.2.5.3 that contrine a commitment to perform plant-specific walkdowns consistent with this staff position. This commitment to perform walkdowns is acceptable. Therefore, DFSER Open Itom 3.2.1-3 and DFSER
Coafirmatory Itom 14.1.3.3.3.8-2 are withdrawn and reolved. The resolution of this iens is aleo discused in Section 3.2.1 of this report.

\subsubsection{Buried Fipling}

SSAR Section 3.7.3.12 originally outlined the critoria that will bo uned in the analyais of buried soismic Category I piping ayctom. These criteria conformed to the spplicable puidelines in SRP Section 3.9.2. However, OB did not give sny detnils on bow the critoria are to be applied in the decign of buried piping. In tho DFSER, the ataff requected that the SSAR be rovised to addrees, as a minimum, (1) the maximum bearing loads, (2) the catogorization of exismic atresces in tho Codo ovaluation, and (3) the allowable streas limits for the piping. This was DFSER Open Itome 3.9.2.2-7 and 14.1.3.3.3.9-1.

SSAR Section 3.7.3.12 states that all underground soismic Category I piping systems are inatalled in tunnels. The tunnels aro analyzed a buried structures. Tho piping analyais is performed using one of the methods described in Section 3.7.3 of the SSAR. Because the SSAR states that the buried piping aystems will not be in direct contact with the soil, the staff concludes that the information requeeted in the DFSER is no longer applicable. Therefore, DFSER Open Items 3.9.2.2-7 and 14.1.3.3.3.9-1 are withdrawn and closed.

\subsubsection{ASME Code, Section III, Appendix N}

The staff bes not endorsed the use of ASME Code, Section III, Appendix N, which is non-mandatory appendix that is still ovolving and does not currently agree with come regulatory position. Therefore, for the ABWR piping deaign, if the methodology in Appendix $\mathrm{N}$ is not consistent with regulatory positions discussed herein, the regulatory positions shall be used.

\subsubsection{Conclusions}

On the basis of the ovaluations in Section 3.12.3, the staff concludes that the analysis methods to be used for all seismic Category I piping systems as well as non-soismic Catogory I piping systems that are important to safety are acceptable. The analysis methods utilizo piping design practices that are commonly used in the industry and provide an adequate margin of safety to withstand the loadings as a result of normal operating, transient, and accident conditions.

\subsubsection{Piping Modeling}

GDC 2 requires that components important to safety should bo designed to withstand effects of natural events including 


\section{Design of Structures, Components, Equipment, and Systems}

carthquakes. 10 CFR Part 50, Appeadix B requires that deaim quality ahould be controlled for enmuring atructural and functional integrity of solemic Catogory I components. For dotormining deaign adequacy, woch piping systom is idealized as a mathomation model and dynamio analyais using computer progrum is performod. Modaling techniques should be in conformance with generally recognized cagineering practice and computer progrnme should be verified per one or more methods mesected in SRP Section 3.9.1. A piping beachmart program deecribed in NUREG/CR-6049 is also provided by the NRC for aiding the verification process.

SSAR Sections 3.7.3.3 and 3.9.2.2 deecribe piping modeling techniques and SSAR Section 3.9.1.2 diecuenes quality control of computer programs and computer renults.

\subsubsection{Computer Codes}

This section addrewes the computer codes to be ued to analyze piping syetems in the ABWR deaign. SSAR Appendix 3D includes all computer pro zrams for static and dynamic analyses to determine the atrucural and functional integrity of soismic Catogory I and non-soismic Catogory I items. Design control measures to verify the adequacy of the design of safety-related components are required by Appendix B to 10 CFR Part 50. SSAR Section 3.9.1.2 states that the quality of the programin and the computer recults are controlled either by OE or by outside computer program developers. In addition, the program are verified by one or more of the methods recommended in SRP Section 3.9.1.

To reviow GE's computer verification program for ABWR piping modeling, the staff performed an independent confirmatory piping streses analysis of representative piping aystems in the ABWR standard plent. The purpose of this analysis was to verify the adequacy of the computer program used by GE to generate the eample piping analyees that were audited by the ataff on March 23 through 26, 1992, at GE's offices in San Joes, Californip. These were DFSER Open Itome 3.9.1-2, 14.1.3.3.4.1-1 and 14.1.3.3.4.3-1. The recults of the confirmatory analyeis verify that this computer program is adequato with acceptable sccuracy. The staff concludes that the computer program verification process for the ABWR is acceptable. Therefore, DFSER Open Items 3.9.1-2, 14.1.3.3.4.1-1, and 14.1.3.3.4.3-1 are reeolved.

\subsubsection{Dynamic Piping Model}

For the dynamic analysis of seismic Catogory I piping, each system is idealized as a mathematical model consisting of lumped masees interconnected by elestic mambern. The atiffneas matrix for the piping aystem is dotermined, wing the elatic properties of the pipe. This includes the offects of torrional, bending, ahear, and axial doformations as well as change in stiffness as a reault of curved members.

The staff reviowed the mothod for solecting the number of maseses or degrees of freedom in the piping mathematical model to determine its dynamic response. OB's internal documents that were audited by the staff on March 23 through 26, 1992, abowed pipe and fluid masea are lumped at nodes that are solected to coincide with the locations of large masees (0.8., valves, pumps, and tanks) and with locations of significant geometric changes (0.g., pipe olbows, reducers, and tees). Additional mass points are selected to enoure that the spacing between any two adjeceat piping nodes and maseces is no greater than an idealized value. This value correeponds to the length of a simply supported beam with a uniformly distributed mase whoce undamped natural frequency is equal to the cutoff frequency. Since this approech, in offect, would capture all modes up to the cutoff frequency, the staff finds that the ABWR method for locating mess points is ecceptable. In the DFSER, the staff requested that the SSAR be rovieed to reflect this appronch as described (DFSER Confirmatory Itoms 3.9.2.2-2 and 14.1.3.3.4.2-1). SSAR Suberction 3.7.3.3.1.2, "Selection of Mass Points," provides more detailed mass point selection criteria for dynamic piping models. The staff roviowed these criteria and dotermined that the deacription in the SSAR reflects this approach as discuseed and is, therefore, acceptable; therefore, DPSER Confirmatory Itoms 3.9.2.2-2 and 14.1.3.3.4.2-1 are resolved.

The effect of pipe support stiffness on the piping response muat be considered in the analytical model. Supports must be modeled in accordance with the SSAR. If supports are not modeled as stated in the SSAR, justification will bo provided to validate the atiffnese values used in the piping modal. The juatification should include verification that the generic values are representative of the types of pipe supports uned in the piping system. This alternative approach to use generic atiffnees values and its bases ahould be aubmitted to the staff for reviow and approval before use. This was DFSER COL Action Item 14.1.3.3.4.2-1. SSAR Section 3.7.5.3, "Piping Analysis, Modeling of Supports," states that the COL applicant will provido the information requested in this action item. This is accoptable.

Additionally, because the amplified response spectra are generally specified at discrete building node points, any additional flexibility between these points and the pipe oupport (e.8., supplementary stool) also should bo addreseed. In the DFSER, the staff requeeted that the 
SSAR be revised to incorporate this information. This was DFSER Opea Itewr 3.9.2.2-2 and DFSER Confirmatory Itom 14.1.3.3.4.2-2. SSAR Section 3.7.3.3.1.8, "Reopones Spectra Amplification at Support Attachment Points," states that the drywell equipment and pipe cupport etructures (DEPSS) should meet the criteria given in SSAR Subection 3.7.3.3.4. It further states that, if this criteria cannot be met, the COL applicant will generate the amplified response spectre at piping attachment points considering the DEPSS as part of the etructure, using the dynamic analysis method deacribed in SSAR Section 3.7.2, or will analyze the piping systems considering the DEPSS as part of the pipe eupport. The etaff reviewed this clarification and determined that it is acceptable; therefore, DFSER Open Item 3.9.2.2-2 and DFSER Confirmatory Item 14.1.3.3.4.2-2 aro resolved.

If piping terminates at non-rigid equipment (e.g., tanks, pumps, or heat exchangers), the analytical piping model should consider the flexibility and mass effects of this equipment. In the DFSER, the staff requested that the SSAR be revised to address how the flexibility and masses of equipment atteched to the piping are to be modeled. This was DFSER Open Item 3.9.2.2-3 and DFSER Confirmatory Itom 14.1.3.3.4.2-3. SSAR Subsoction 3.7.3.3.1.6, "Modeling of Piping Supports," states that stiffnesecs of supporting structures are included in the piping analysis model. Anchors at equipment such as tanks, pumps and heat exchangers are modeled with calculated stiffness properties. It also states that mass effects will bo included for equipment that have a fundamental frequency of lose then $60 \mathrm{~Hz}$. A simplified model of the equipment will be included in the piping system model. The staff concludes that this issue is adequately addressed; therefore, DFSER Open Itom 3.9.2.2-3 and DFSER Confirmatory Item 14.1.3.3.4.2-3 are resolved.

\subsubsection{Piping Benchmark Program}

To verify the adequacy of the computer program used by the COL applicent to complete the ABWR piping system design and analyses, the NRC staff established mathematical models of representative piping systems in the ABWR standardized plant that were used in a piping analysis benchmark program. The mathematical models are based on the dynamic piping model and on the piping stress analysis criteria described in Section 3.12.4.2 and Section 3.12.5, respectively, of this report. The benchmark program verifies the adequacy of linear-elastic, dynamic piping analysis methods using the enveloped response spectrum method, multiple response spectrum method, and time-history method of analyses.
The benchmark program excentially consists of constructing mathematical models of the ABWR feedwater piping ayctom inside contrinment and an SRV discharge line inside the cuppreacion pool wotwell area, using the COL applicant's computer program. The piping configuration for the piping models are deacribed in NUREG/CR-6049, "Piping Benchmark Problems for the GE ABWR," and include piping dimensions, pipe sizes, materials, valve weights, support and anchor stiffnesses, and support locations. The piping input parameters for the benchmark analyses also are specified in the piping benchmark program and include damping values, loading dofinitions, and load combinations.

When the COL applicant's dynamic piping analyees are completed, the results of the analyses must be compared with the results of the benchmark problems provided in the piping benchmark program. The piping analysis results to be compared and evaluated include the system modal frequencies, the maximum pipe moments, the maximum cupport loads and equipment reactions, and the maximum pipe deflections. The acceptance criteria or range of acceptable values are specified in the piping benchmark program and must be satisfied. The COL applicant must document and submit any deviations from these values as well as the justification for such deviations to the NRC staff for review and approval before initiating final certified piping analyses. The piping benchmark program was DFSER COL Action Item 14.1.3.3.4.3-1. In SSAR Section 3.9.1.2 states that the COL applicant will provide this information as discussed. This is acceptable. The benchmark program provides assurance that the computer program used to complete the ABWR piping design and analyses produces results that are consistent with results considered acceptable to the NRC staff.

\subsubsection{Decoupling Criteria}

When analyzing piping systems, the size of the mathematical model might excoed the capacity of the computer program if large and small-bore piping are included. Thus, the small-bore branch lines are generally decoupled from the large-bore main piping. Originally, the SSAR did not provide any criteria for the decoupling of the piping systems in the analysis model. However, in a letter to the NRC dated February 24, 1992, GE provided the decoupling criteria in a GE document entitled, "ABWR SSAR Main Steam, Feedwater and SRVDL Piping Systems Design Criteria and Analysis Methods (draft), "Revision 0, dated February 1992. This document stated that if the ratio between pipe diameters of the branch line to main line is less than one-third, the branch line can be excluded from the piping model of the main line. 


\section{Design of Structures, Components, Equipment, and Systems}

In the DFSER, the staff requested that GE provide the basis for this one-third ratio and revise the SSAR to include additional information on how mass and other effects are accounted for in the analysis (DFSER Open Items 3.9.2.2-4 and 14.1.3.3.4.4-1). SSAR Soctions 3.7.3.3.1.3 and 3.7.3.8.1.9 provide more detailed docoupling criteria. The besic criterion was changed from a ratio of run to branch pipe diameter of 3 to 1 , or more, to a moment of inertia ratio of 25 to 1 , or more. In addition, small branch lines shall bo deaigned with no concentrated masees, such as valves, in the first ono-half span leagth from the main run pipe; and with sufficient flexibility to prevent restraint of movement in the main run pipe. Quantitative requirements for aseessing the adequacy of the flexibility were provided. The staff reviowed the revised decoupling requirements and found them acceptable; therefore, DFSER Open Items 3.9.2.2-4 and 14.1.3.3.4.4-1 are resolved.

\subsubsection{Conclusions}

On the basis of these discussions and evaluation of SSAR Sections 3.7.3.3 and 3.9.2.2, the staff concludes that design control measures are acceptable to ensure quality of computer programs and design methods. The staff's conclusion is besed on the following:

(1) GE satisfies the requirements of GDC 2 py providing criteria for the seismic design and analysis of all seismic Category I piping and pipe supports using prescribed modeling techniques and design methods that are in conformance with generally recognized engineering practice.

(2) GE meets Appendix B to 10 CFR Part 50 by demonstrating the applicability and validity of the computer programs for performing piping seismic analysis.

(3) Computer programs to be used by the COL applicant to complete its analyses of the ABWR piping systems will be verified and validated using the NRC staff's piping benchmark program.

\subsubsection{Pipe Stress Analysis Criteria}

\subsubsection{Seismic Input (Envelope vs. Site-Specific Spectra)}

The ABWR standard plant is designiod for an SSE ground motion defined by a RG 1.60 response spectrum anchored to a peak ground acceleration of $0.3 \mathrm{~g}$. Amplified building response spectra are generated for the ABWR standard plant to account for varying soil properties in the United States by enveloping 14 site conditions. GE has proposed that the COL applicant use these enveloping amplified building response spectra provided in the SSAR to complete the design and analyses of the ABWR piping systoms.

The staff recognizes that the enveloping amplified building reeponse spectro for the ABWR plant contain conservatisms that may be excessive for certain specific site conditions. If amplified building response spectra are generated using site-dependent properties, then the approach and method used must be submitted to the staff for review and approval as part of the COL application. The method used to generate the amplified building response spectre should be consistent with the method deacribed in the SSAR Section 3.7.2 as approved by the staff. This was DFSER COL Action Item 14.1.3.3.5.1-1. Upon further consideration, the staff determined that a COL Action Item is not appropriate because this is only an option for the COL applicant. Therefore, DFSER COL Action Item 14.1.3.3.5.1-1 is deleted.

\subsubsection{Design Transients}

SSAR Table 3.9-1 lists the design transients for five plant operating conditions and the number of either plant operating events or cycles for each of the design transients that will be used in the design and fatigue analyses of the ASME Code Class 1 piping systems.

The operating conditions are

- ASME Service Level A - normal conditions

- ASME Service Level B - upset conditions - incidents of moderate frequency

- ASME Service Level C - emergency conditions infrequent incidents

- ASME Service Lovel D - faulted conditions low-probability postulated events

- testing conditions

The number of cycles in the original list of transients in SSAR Table 3.9-1 appeared to be based on a 40-year life. In the DFSER, the staff noted that for a design life of 60 years, the number of cycles for each transient should be increased by a factor of 1.5. GE was requested to revise the SSAR to reflect this factor. This was DFSER Open Items 3.9.1-1 and 14.1.3.3.5.2-1. The resolution of this item is discussed in Section 3.9.1 of this report.

The number of events or cycles resulting from each of the listed design transients that are applicable to other ASME 
Code Class piping systems is to be documentod by the COL applicant in its design specification and/or streas report for each component. This was DFSER COL Action Itom 14.1.3.3.5.2-1. SSAR Section 3.9.7.2 states that a COL applicant will identify ASME Class 2 or 3 piping systems under sovere cyclic loads and perform analyais to ensure integrity for 60 years. This is acceptable.

\subsubsection{Loadings and Load Combinations}

The staff reviewed the methodology used for load combinations and the selected values of allowable stress limits. GE provided the design criteria for all ASME Code, Class 1, 2, and 3 piping and piping supports, using the load combinations and stress limits given in SSAR Section 3.9.3.1. GE stated that the method used in the combination of dynamic responses of piping loadings shall be in accordance with NUREG-0484, Revision 1.

From its review, the staff concludes that appropriate combinations of normal, operating transients, and accident loadings are specified to provide a conservative design envelope for the design of piping systems. The load combinations are consistent with the guidelines provided in SRP Section 3.9.3 and are acceptable.

\subsubsection{Damping Values}

RG 1.61, "Damping Values for Seismic Design of Nuclear Power Plants," Revision 0, contains recommended values of damping to be used in the seismic analysis of SSCs. In addition, RG 1.84, Revision 25, conditionally endorses ASME Code Case N-411-1. The damping values used by GE are the same as those specified in either RG 1.61 or those specified in ASME Code Case N-411-1 as permitted by RG 1.84, which is acceptable.

The SSAR uses the damping values specified in ASME Code Case N-411 with the independent support motion (ISM) method of response spectrum analysis. The staff's position on the application of $\mathrm{N}-411$ damping values to the ISM method of analysis is that it is acceptable when the ISM method is used in accordance with the information and recommendations in Sections 2.3 and 2.4 of NUREG-1061, Volume 4. In the DFSER, the staff requested GE to confirm that $\mathrm{N}-411$ damping in an ISM analysis will be applied in accordance with the staffs position. This was DFSER Confirmatory Item 14.1.3.3.5.4-1. SSAR Subsection 3.7.3.8.1.10, "Multiple-Supported Equipment and Components with Distinct Inputs," states that when the ISM response spectrum method of analysis is used, ASME Code Case N-411-1 damping will not be used. On the basis of this new commitment, the staff concludes that GE will only use the recommended damping values given in RG 1.61 in an
ISM response spectrum analysis. This is acceptable. Therefore, DFSER Confirmatory Itom 14.1.3.3.5.4-1 is reeolved.

The staff's position on the use of $\mathrm{N}-411$ damping values with ASME Codo Case N-420 is that the two code cases may only be used in separate analyses as a further condition of RG 1.84, because the damping values established in Code Case $\mathrm{N}-411$ might not be entirely appropriate for the damping characteristics of the linear energy absorbing supports. Therefore, the two Code Cases are not to be used in the same analysis. In the DFSER, GE was requested to confirm compliance with this staff position. This was DFSER Confirmatory Item 14.1.3.3.5.4-2. SSAR Subsection 3.7.3.8.1.7, "Damping Ratio," states that the ASME Code Case N-411-1 demping cennot be used for analyzing linear energy abeorbing supports designed in accordance with ASME Code Case N-420. This is acceptable; therefore, DFSER Confirmatory Item 14.1.3.3.5.4-2 is resolved.

\subsubsection{Combination of Modal Responses}

For the response spectrum method of analysis, the modal responses are combined by the SRSS method. Closely spaced modes are combined using the criteria of RG 1.92, "Combining Modal Responses and Spatial Components in Seismic Response Analysis," Revision 1. The SSAR considers all modes with frequencies below $33 \mathrm{~Hz}$ in computing equipment and component response for seismic loadings, as stated in SSAR Sections 3.7.3.7.1 and 3.7.3.7.2. The staff concludes that this method is consistent with the applicable guidelines of SRP Section 3.9.2 and is acceptable.

\subsubsection{High-Frequency Modes}

For seismic analysis, consideration of high-frequency modes to preclude missing mass effects must be included. The staff's guidelines for this are provided in SRP Section 3.7.2, Appendix A.

For the analyses of vibratory loads (other than seismic) with significant high-frequency input (i.e., 33 to $100 \mathrm{~Hz}$ ), the staff's positions are as follows:

(1) GE should address the methodology for the combination of high-frequency modal results. The high-frequency modes must be combined in accordance with the guidelines providsd in RG 1.92. Use of other combination methods, such as the algebraic modal combination method for combining high-frequency modes, will require further justification and staff approval before use. 
(2)
GE stould addrese non-linear analyes used to eccount for saps between the pipe and its eupports when aubjected to vibratory loads with significant high-frequency. The description of and justification for such analyses must bo submitted to the staff for review and approval before use.

In the DFSER, the etaff requeeted that the SSAR be revised to reflect these two staff positions by stating that, if an alternative method is used, the details of its becis must be submittod to the staff for roviow and approval before use. This was DFSER Confirmatory Item 14.1.3.3.5.6-1. SSAR Subsection 3.7.3.7.3, "Methodologies Used to Account for High-Frequency Modes," provides a detailed procedure for calculating the responses associated with high-frequency modes above the cutoff frequency and combining them with the lowfrequency modal responses. The staff reviewed this procedure and found that it follows the guidelines provided in SRP Section 3.7.2, Appendix A, and is acceptable.

GE also revised the SSAR to address the two issues related to analyses of vibratory loads with significant highfrequency input. SSAR Subsection 3.7.3.7, "Combination of Modal Responses," addresses the first issue. It clarifies the position that modal responses for modes below the cutoff frequency will be combined in accordance with methods that follow the guidelines of RG 1.92. The combination methods are applicable for seismic loads with $33 \mathrm{~Hz}$ cutoff frequency as well as for loads with higher frequency input, such as suppression pool dynamic loads that may have cutoff frequencies as high $28100 \mathrm{~Hz}$. The responses aseociated with modes above the cutoff froquency are calculated and combined in accordance with the guidelines of SRP Section 3.7.2, Appendix A, as previously discussed. The staff reviewed this information and found that this revision adequately addressed the first issue. The second issue is addressed in the SSAR Section 3.7.3.3.4, "Analysis of Frame Type Supports," which states that nonlinear analysis methods to account for gaps between pipe and supports subjected to high frequency vibration loads, such as suppression pool loads will not be used. The staff roviewed this information and found it receptable. The SSAR does not provide an analytical method to mccount for non-linear effects of excessively large gaps. Should such large gaps exist, it would mean a change to the commitments involving piping analysis methodology discussed in the SSAR, and it would result in an unreviewed safety question. Therefore, details of non-linear analysis should be submitted to the staff for approval prior to its implementation. On the basis of this ovaluation, DFSER Confirmatory Item 14.1.3.3.5.6-1 is resolved.

\subsubsection{Fatigue Evaluation for ASME Code Class 1 Piping}

ASME Code, Section III requires that the cumulative damage from fatigue be ovaluated for all ASME Code Class 1 piping. The cumulative fatigue usage factor should take into consideration all cyclic offects caused by the plant operating transients for a 60-year design lifo. However, recent teat data indicates that the offects of the reactor environment could roduce the fatigue resistance of certain materials. A comparison of the test data with the Code requirements indicates that the margins in the ASME Codo fatigue design curves might be less than originally intended. The DFSER reported that the staff was developing an interim position, which would be available at a later date, to account for the environmental effects in the fatigue design of the affected materials. At this time, the staff is assessing the potential generic implication of this issue on all operating plants. Depending on the soverity of the issue, certain actions might be required to generically address this concern. This was inappropriately identified as Open Items 3.9.3.1-1 and 14.1.3.3.5.7-1 in the DFSER. DFSER Open Items 3.9.3.1-1 and 14.1.3.3.5.7-1 are subsumed by DFSER Open Item 14.1.3.3.5.7-2, which is discussed below.

Originally, for the ABWR, GE discussed with the staff its tentative procedure used for a foreign BWR plant design in progress. The information was provided to the staff during an audit held at the GE offices in San Jose, California, on March 23 through 26, 1992. The specified material for the ASME Code Class 1 piping in the ABWR is carbon steel. Using the GE position, additional fatigue ovaluations would not be required when certain conditions are met, such as when the fluid temperature is below $245^{\circ} \mathrm{C}\left(473^{\circ} \mathrm{F}\right)$, the oxygen content is below $0.3 \mathrm{ppm}$, or the tensile stress hold time does not exceed 10 seconds. The exemption rules also extend to piping elbows and tees and valve bodies when these components aro conservatively designed and analyzed, using the stress index method. Thus, only the circumferential girth butt welds in piping are considered to be critical by GE and are evaluated for environmental effects. The approach used by GE to sccount for the environmental effects on the girth butt welds is to modify the local peak stress through (1) the notch factor, (2) the mean stress factor, (3) the environmental correction factor, and (4) the butt-weld strength reduction factor. In the DFSER, the staff requested GE to include in its SSAR the proposed approach for accounting for the environmental effects in its fatigue analyses. This was DFSER Open Items 3.9.3.1-1 and 14.1.3.3.5.7-2. 
SSAR Subection 3.9.3.1.1.7, "Environmental Effects on Fatigue Evaluation of Carbon Stcol Piping," commits to perform additional ovaluations for environmental effects on the fatigue deaign of ASME Code, Section III, Clase 1 carbon steel piping in accordance with $O B$ document 408HA414. The SSAR describes the conditions for which these evaluations would be performed and the methodology for performing thom. Tho staff found the approach consistent with the approech presented by GE at pe March 1992 audit proviously aummarized. OE's proceduro provided aupplemental guidelines that enhence the dexign margin beyond the requirements of the ASME Code, Section III for fatique evaluation. This is acceptable; and DFSER Open Items 3.9.3.1-1 and 14.1.3.3.5.7-2 are recolved.

\subsubsection{Fatigue Evaluation of ASME Code Class 2 and 3 Piping}

SSAR Section 3.9.3.1 gtates that the design life for the ABWR is 60 years. In response to an earlier staff requeat, SSAR Sections 3.9.3.1 and 3.9.7.2 stated that COL applicants will identify all ASME Code Class 2, 3, and QG D components that will be subjected to loadings that could result in thermal or dynamic fatigue and provide the analyses that are similar to those required by ASME Code, Section III, Subsection NB (ASME Class 1). This was DFSER COL Action Items 3.9.3.1-1 and 14.1.3.3.5.8-1. In the SSAR, GE modified these COL actions by further revising Sections 3.9.7.2 and 3.9.3.1 to state that COL applicants will identify ASME Code Clase 2 or 3 or QG D components that are subjected to cyclic loadings, including operating vibration loads and thermal transient effects, of a magnitude and/or duration so severe that the 60-year design life cannot be assured by required Codo calculations and, if similar designs have not already been evaluated, either provide an appropriate analysis to demonstrate the required design life or provide designs to mitigate the magnitude or duration of the cyclic loads. SSAR Section 3.9.3.1 provides criteria on the magnitude of covere thermal transients that should be ovaluated for possible offect on plant life. These transients are temperature rate changes faster than $830^{\circ} \mathrm{C}$ bour (1494 ${ }^{\circ} \mathrm{F} / \mathrm{hour}$ ), when the total fluid temperature change is greater than $55^{\circ} \mathrm{C}\left(100^{\circ} \mathrm{F}\right)$. It also states specifically that COL applicants will perform ASME Code Class 1 fatigue analysis of the SRV discharge piping in the wetwell and the SRV quenchers. This is acceptable.

On the basis of current data, the staff belioves that the margins built into the ASME fatigue design curves may not be sufficient to account for variations in the original fatigue test data becuuse of various environmental effects. Therefore, consistent with the staff position discused in Section 3.12.5.7 of this report, the staff's position for
ASME Code Clase 2 and 3 piping for which a fatigue analyais is performod is that the environmental offects ahould be considered in the fatigue analysis. This was DFSER Open Itom 14.1.3.3.5.8-1. SSAR Section 3.9.3.1 thates that environmental offects will be considered in the fatigue andyece of the SRV discharge piping and SRV queschere in sccordance with the requirements for ASME Code, Soction III, Clase 1, carbon stoel piping discuseed in Section 3.9.3.1.1.7 of this report. This is scceptable, and DFSER Open Item 14.1.3.3.5.8-1 is resolved.

\subsubsection{Thermal Oscillations in Piping Connected to the Reactor Coolant System}

In sccordance with NRC Bulletin 88-08, the staff requests that licenseses and applicants review systems connected to the RCS to determine whether any sections of this piping that cannot be isolated can be subjected to temperature oecillations that could be induced by leaking valves.

In the design of the ABWR emergency core cooling systems, both the residual heat removal (RHR) system and high-preserure core flooder (HPCF) have piping that will bo directly connected to the reactor pressure vessel (RPV). In the unisolable sections of RHR piping, leaking toward the RPV cannot occur because the pressure will always be higher on the reactor side during normal plant operation when the upstream pumps are not operating. In the HPCF system design, the only unisolable piping connected to the RPV will be the section of pipe between the reactor nozzle and the upstream isolation check valve. Cold water in this syctom will be upstream of the injection valve (gate valve) that is outside the primary containment. The region upstream of the injection valve will operate at a pressure lower than reactor pressure except when the HPCF safety function is required. Therefore, cold water will not flow to the unisolable pipe section and stratification will not be a problem in the HPCF system.

In the DFSER, the staff concluded that GE had adequately addreased the potential problems described in Builetin 88-08. Subsequently, however, the staff noted that GE did not address the potential problem described in Supplement 3 to Bulletin 88-08, although Supplements 1 and 2 were addressed adequately. It involved the development of potential cyclic stratified flow and associated thermal striping that may occur because of possible leakage past the valve disk and out the valve stem packing gland. This flow stratification and striping may occur when the pressure on the upstream side of the valve is less than the RPV system pressure during normal operation. Supplomeat 3 reported an incident in which this phenomenon induced thermal fatigue, which led to a through-wall pipe crack in a foroign reactor. The staff reviewed the SSAR and requested that $\mathrm{GE}$ provide additional information to 
addrese this concern. GE then identified the ABWR piping cections that could be ausceptible to unecceptable thermal atreseses, owing to this phenomenon. They includo coctions of the RHR ayetem and the HPCF syctem. For the affected piping sections, $\mathrm{OB}$ will require that either (1) the gate valve in each of the unisolable piping sections be located at a dietance equal or greater then 25 pipo diametere from the RPV nozalo or (2) atress analyais be performed to. show that atrecees and fatigue from potential stratification and thermal atriping aro acceptable per the ASME Codo. The SSAR incorporated these now requiremeats by including an additional noto on the P\&ID's of the RHR system (SSAR Figure 5.4-10) and the HPCF system (SSAR Figure 6.3-7). This is acceptable; therefore, the theff concludes that $\mathrm{GE}$ has adequately addreased the potential problem deccribed in Supplement 3 to Bulletin 88-08.

\subsubsection{Thermal Stratification}

Thermal atratification is a phenomenon that can occur in long runs of borizontal piping when two streams of fluid at different temperatures flow in separate layers without appreciable mixing. Under these stratified flow conditions, the top of the pipe may be at - much higher temperature than the bottom. This thermal gradient produces pipe deflections, support loeds, pipo-bending streeses, and local stresees that may not have been sccounted for in the original piping design. The effects of thermal stratification have been obeerved in both BWR and PWR feedwater piping as discused in NRC Information Notice (IN) 84-87 and NRC IN 91-38.

During an audit conducted at GE's offices in San Jose, California, on March 23 through 26, 1992, the staff asked GE to explain and demonstrate how the thermal stratification phenomenon was considered in the ABWR piping design. In response, GE stated that thermal stratification will be considered as a normal design load in the ASME Code Clase 1 etreses and fatigue evaluation of the feedwater piping. The ABWR sample problem criteria document states that the feedwater line will be analyzed for two thermal stratification load canes: (1) thermal stratification in the piping at the RPV nozzle and (2) thermal stratification in the feodwater header piping. The loads will be included in the piping fatigue analysis and in the evaluations of the head fitting and RPV nozzles. The temperature differences and locations for the stratification loads were defined in the feedwater piping pressure/tomperature cycle diagrams. This was DFSER COL Action Item 14.1.3.3.5.10-1. SSAR Section 3.9.3.1 atates that the COL applicant shall design for thermal stratification in sccordance with the requirements of that ecction. This is acceptable.
The ataff reviewed and discussed the thermal atratification analyais methodology with the cognizunt $G E$ engineers. The staff found the analysis method accoptable with the exception of an apparent diecrepancy in load application. OE defined the atratified temperature profile in the pipe croes coction as a conetent bot temperature in the top half and cold temperature in the bottom half, with a step change in temperature at the centerline. However, in the pipe etrees analysis, a linear top-to-bottom temperature profile was applied. The linear temperature profile provides lower bending moments and streeces than the step change profile. OE was acked to justify (1) the adequacy of the piping analysis load input and (2) the omission of the high-cycle fatigue effects resulting from thermal striping and why it should not be considered in the analyais. The staff aleo asked GE to provide additional juatification for their methodology, including tout information to support their thermal stratification load definition. This was DFSER Open Items 3.9.3.1-2 and 14.1.3.3.5.10-1.

SSAR Section 3.9.3.1 states that thermal stratification is one of the specific operating conditions that is included in the laads and loed combinations contained in the piping desiga specifications and design reports. Stratification can occur in the feedwater piping during plant startup and during hot standby conditions following scram. If evidence of stratification is detected in any other piping system during design or startup, it will be evaluated to determine whether it is significant in terms of strese and deflection. As a general guideline, if temperature differences between the top and bottom of the pipo are leas than $27^{\circ} \mathrm{C}\left(48.6^{\circ} \mathrm{F}\right)$, it is assumod insignificant and not included in the design specification and design reports. The staff reviowed this information and found it acceptable.

In addition, SSAR Section 3.9.2.1.3, "Thermal Stratification in Feedwater Piping," describes a special teat that will bo performed as part of the startup program to monitor the conditions and effects of thermal stratification in sections of the feedwater piping where stratification is anticipated. The test program will meature temperatures around the pipe circumference, strains at points of high atress, and pipe displacements, which are duo to bowing caused by stratification. GE committed to perform this test to address the staff concern over the adequacy of the linear temperature profile assumed in the thermal stratification analysis. From its review, the staff concludes that the tost should provide appropriate dats to evaluate the adequacy of the sssumed temperature profile.

In a letter datod April 19, 1993, GE presented thermal striping ovaluation for the foedwater header pipe. Calculations summarized in the letter report show that 
arecees at the pipe wall cauced by triping are well below the motal cadurnoco limit and are, therofore, negligible. The etaff concluded that GE had provided a technical approsech to adequately addrese the iseave of thermal itratification in the ABWR feedwater piping aystems. $\mathrm{GB}$ hes also included this information in the SSAR. On the basis of this ovaluation, DFSER Open Itoms 3.9.3.1-2 and 14.1.3.3.5.10-1 are resolved.

\subsubsection{Safety-Relief Valve Deaign, Installation, and Teating}

SSAR Section 3-9.3.3 contains the design, intallation, and teating criteria applicablo to tho mounting of presurure reliof devices used for the overpreseure protection of ASMB Code Class 1, 2, and 3 components. The ataff reviewed this information in sccordance with SRP Section 3.9.3, including en evaluation of the applicable loading combinations and atress criteria. The review extended to consideration of the means to sccommodate the rapidly applied reaction force when a safety valve or relief valve opens and the transient fluid-induced loads are applied to the piping downstream of a safety valve or relief valve in a cloeed discharge piping system. The information in Section 3.9.3.3 of the SSAR meets the spplicable guidelines of SRP Section 3.9.3 and is, therefore, ecceptable.

In eccordance with TMI Action Item II.D.1 of NUREG-0737, both PWR and BWR licensees and applicants are required to conduct testing to qualify the RCS relief and safety valves and associated piping and supports under expected operating conditions for design-basis transients and accidents. GE's response to Item II.D.1 is discussed in SSAR Section 1A.2.9. This section states that the safety-relief valve models that will be used for ABWR plants have been tested under ABWR team discharge conditions. It further states that if the ABWR design should contain any safety-relief valves or discharge piping that is not similar to those that have been tested, the COL applicant will test the valves in accordance with TMI Item II.D.1. This is scceptable.

In performing the hydraulic transient piping analyses aseociated with the SRV discharge, the SSAR assumes a minimum rise time of $20 \mathrm{msec}$. Rise times faster than this value could result in higher loads than analytically predicted. The assumed rise time is based on past SRV designs and existing test data. The COL applicant must retest the SRVs if it should purchase any SRV or install its SRV piping in a configuration that is not similar to those that have been tested. This was DFSER COL Action Items 3.9.3.2-1 and 14.1.3.3.5.11-1. In Amendment 33 to the SSAR, GE added Section 1A.3.7, "Testing of SRV and Discharge Piping, " to state that the COL applicant will confirm that any SRVs or discharge piping inetalled that is not aimilar to those that have been teated will be teeted in eccordance with SSAR Section 1A.2.9. The etaff considers this acceptable. Therefore, COL Action Items 3.9.3.2-1 and 14.3.3.5.11-1 are resolved.

\subsubsection{Tunctional Capability}

Note 9 to the SSAR, Table 3.9-2, states that all ASME Code Class 1, 2, and 3 piping systems that are eseential for safe shutdown under the postulated events listed in the table are designed to meet the recommendations in NUREG-1367, "Functional Capability of Piping Systoms," dated November 1992. In no case shall the piping stress exceed the limits designated for Service Lovel D in the ASME Code, Section III. The Service Lovel D limits are 3.0 $\mathrm{S}_{\mathrm{m}}$ (not to exceed $2.0 \mathrm{~S}_{\mathrm{y}}$ ) for ASME Code Class 1 piping and $3.0 \mathrm{~S}_{\mathrm{h}}$ (not to exceed 2.0 $\mathrm{S}_{\mathrm{y}}$ ) for Class 2 and 3 piping. Dynamic testing conducted by EPRI, $G E$, and the NRC has cetablished that these stress levels do not result in a loss of piping functional capability. Thus, the staff concludes the methodology and stress levels for ensuring the functional capability of piping systems acceptable.

\subsubsection{Combination of Inertial and Seismic Motion Efrects}

Piping analyses must include the effects caused by the relative building movements at supports and anchors (seismic anchor motion) as well as the seismic inertial loads. This is necessary when piping is supported at multiple locations within a single structure or is attached to two separate structures.

The effects of relative displacements at support points must be evaluated by imposing the maximum support displacements in the most unfavorable combination. This can be performed, using a static analysis procodure. Relative displacements of equipment supports (e.8., pumps or tanks) must be included in the analysis along with the building support movements.

When required for certain evaluations, such as support design, the responses that are due to the inertia effect and relative displacement effect should be combined by the absolute sum method.

In lieu of this method, time histories of support excitations may be used, in which case both inertial and relative displacement effects are already included. Consideration of these effects and analyses was DFSER Open Item 14.1.3.3.5.13-1.

Section 3.7.3.8.1.8 of the SSAR describes the methodology for considering the effects caused by relative 
building movemeats. The dieplacements that are obtained from the dynamic building analyais are applied to the piping anchors and reetraints correaponding to the maximum differential displacements that could occur. Three analyses are performed: one for each of the two horizontal differential displacements and one for the vertical. The reculting streases in the piping are treated as cecondary stresace because they are colf-limiting. The primary loads owing to inertia are combined with the eccondary loads owing to the rolative displacements by the SRSS mothod.

The SRSS combination of these respones doviate from the scceptunce criteria of SRP Section 3.9.2, which specifies the more conservative abeolute sum method. To juatify this deviation, SSAR Section 3.7.3.8.1.8 states that the inertia and relative aupport displacement responses are dynamic in nature and their peak values are not expected to occur at the sume time. Anchor movement offects are computed from static andyese in which the eupport movemeat effects aro applied to produce the moet conservative loads on the piping. 'In viow of this, GE bolieves that an SRSS combination is appropriate. OE provided a description of the theoretical basis for this position based on an independent support-motion timohistory analysis. The staff found the approach tochnically justifiable and consistent with the recommendations of NUREG-1061, Volume 4, for independent support motion analysis. Therefore, the staff concludes that the SRSS combination of responses owing to inertia and relative displacements is acceptable for the ABWR. On the basis of the sbove, DFSER Open Item 14.1.3.3.5.13-1 is resolved.

\subsubsection{Cutoff Frequency for Hydrodynamic Losdings}

SSAR Section 3.7 states that the cutoff frequency for dynamic analysis is $60 \mathrm{~Hz}$ for cuppression pool bydrodynamic loads. For piping aystems with a fundamental frequency greater then $20 \mathrm{~Hz}$, the cutoff frequency is $100 \mathrm{~Hz}$ for suppression pool hydrodynamic loeds. These cutoff frequencies were previously used in the hydrodynamic analyses for currently operating BWR plants. Because the hydrodynamic load methodology used for the ABWR is the same as that used for the operating BWR plants, the cutoff frequency is acceptable for the ABWR.

\subsubsection{OBE as a Design Load}

In SECY-93-087, the staff recommended eliminating the OBE from the design for advanced light-water reactors. The Commission approved the staff recommendations in its SRM dated July 21, 1993. For the ABWR, GE originally proposed that the OBE be equal to ono-thind of the SSE. The DFSER noted that the staff was discuscing dotaila with $O B$ for the neceecary actions that will be required for oliminating the OBE from the dovizn of SSC in the $A B W R$ and that the ataff s ovaluation of uaing a ainglocarthquake design based on only the SSE will be addreaned in the FSER. This wa DFSER Open Itoms 3.1-1 and 14.1.3.3.5.15-1.

In a lotter to GE datod Septomber 11, 1992, the atuff transmitted a guidance document that identified the necessary changes to existing seismic dosign criteria that are scceptable for implemeating the proposed rulo chenge as it pertains to tho docizm of anfety-related SSCe in the GE ABWR. This document included epecific supplemental criteria for fatigue, miemic anchor motion, and piping streas limits that should be applied when the OBE is olimimatod. A detailed discussion of this document is in Section 3.1.1 of this report. For fatigue evaluation, two SSE events with 10 maximum streses cycles per ovent (or an equivalent number of fractional cycles) should be considered. The effects of SAM owing to the SSE should be considered in combination with the effects of other normal operational loadings that might occur concurreatly. For Class 1 primary stress eyaluation, seismic loads noed not be ovaluated for consideration of Lovel B Sorvice Limits for Bq. (9). However, for satisfaction of primary plus secondary stress range limits in Eq. (10), the full SSE stress range or a reduced range correeponding to an equivalent number of fractional cycles must be included for Lovel B Service limits. These loed sets should also be used for evaluating fatigue offects. In addition, the stress that is due to the larger of the full range of SSE anchor motion or the resultant nange of thermal expansion plus half the SSE anchor motion range, must not excood $6.0 \mathrm{~S}$. For Class 2 and 3 piping, soismic loads aro not required for considention of occasional loads in satisfying the Lovel B Servico Limits for Eq. (9). Soismic anchor motion stresses are not required for consideration of secondary stresses in Eq. (10). However, stresses that are due to the combination of range of moments caused by thermal expansion and SSE anchor motions must not excoed $3.0 \mathrm{~S}_{\mathrm{h}}$.

SSAR Section 3.9, defines a number of revised requirements associated with the elimination of the OBE. SSAR Section 3.7.3.2, "Determination of Number of Earthquake Cycles," states that the SSE is the only design carthquake considered for the ABWR. The fatigue ovaluation of ASME components would take into consideration two SSE events with 10 peak stress cycles per event. Alternately, an equivalent number of fractional vibratory cycles may be used (but with an amplitude not less than one-third of the maximum SSE amplitude) when derived in accordance with Appendix D of IEEE Standard 
344-1987. The etaff found this commitment consistent with the NRC guidance documeat provioualy discused above and the Commission-approved staff recommendations on the iseve of OBE elimination as diecused in Section 3.1.1 of this report. This is seceptable.

SSAR Table 3.9-1, "Plant Bveats," was revised to replece the OBE cycles with 20 peak SSE cycles for ovaluation of Service Lovel B limits. A footnote was added to require the effects of SAMs owing to SSE to be ovaluated to casure functionality during and following an SSE. The etaff finds this commitment consiatent with the NRC suidance document and the Commission-approved ataff recommendations on the issue of OBE elimination $*$ discussed in Section 3.1.1 of this report. This is scceptable.

SSAR Table 3.9-2, "Loed Combinations and Accoptance Criteria," was revised to replace the normal operation and OBE load combination with a normal and SSE combination for fatigue evaluation of Class 1 components under Service Lovel B. Footnote 7 of this table defines the changes and additions to the atrees limits of ASME Code, Section III, Subections NB-3600 and NC/ND-3600. For Clase 1 piping, the streas owing to the larger of the full range of SSE SAM moment or the resultant range of thermal plue ono-half the SAM moment must not exceed $6.0 \mathrm{~S}_{\mathrm{m}}$. SSE inertia and SAM loads must bo included in NB-3600 Eqs. (10) and (11). For Class 2 and 3 piping, the stress that is due to the larger of the full range of SSE SAM moment or the resultant range of thermal plus ono-half the SAM moment must not exceed 3.0 $\mathrm{S}_{\mathrm{h}}$. SSE inertia and SAM loads must not be included in NC/ND-3600 Eqs. (9), (10), and (11). The staff finds these revised stress limits consistent with the requirements of the NRC guidance document. On the basis of this information and the more detailed discussion of this issue in Section 3.1.1 of this report, DFSER Open Items 3.1-1 and 14.1.3.3.5.15-1 aro resolved.

\subsubsection{Welded Attachments}

For the analysis of local stresses at welded attachments to piping (e.g., lugs, trunnions, or stanchions), the SSAR presents several ASME Code Cases. Code Case N-318-3 is acceptable to the staff and is endorsed in RG 1.84. The staff noted that this Code Case is conditionally approved in RG 1.84 on the basis that the applicant specifies (1) the method of lug attachment, (2) the piping system involved, and (3) the location in the system where the case is to be applied. The staff concludes, however, that for the ABWR design certification, these conditions in RG 1.84 are not needed to reach a safety conclusion and, therefore, are not required.
Code Caves N-391 and N-392 are endored by the ataff in RO 1.84 and are acceptable.

\subsubsection{Modal Damping for Composite Structure}

The etaff reviewed the isoue of modal damping for composite structures during its audit on March 23 through 26, 1992, at GE's offices in San Jose, Califomia. At that time, the SSAR did not describe the application of modal damping for composite structures in the analyais of piping systoms. However, a roviow of a GE internal document entitled, "Piping Systems Design Criteria and Analyais Methods, " contrined a table of damping values for various types of piping supports. The damping values for the piping supports (0.8., seubbers and struts) were higher than the damping values tabulated for the piping.

GE indicated that these values were presented because modal damping for composite structures could be used in a response spectrum analysis as an option. In the DFSER, the staff reported that if GE plans to use the modal damping for composite structures as an option for piping analysis, then a description and justification of the approach must be provided in the SSAR. This was DFSER Open Items 3.9.2.26 and 14.1.3.3.5.17-1.

SSAR Section 3.7.3.8.1.7, "Damping Ratio," states that strain-energy-weighted modal damping can aleo bo used in the dynamic analysis of piping systems. Strain-energy weighing is used to obtain the modal damping coofficient owing to the contributions of damping from different elements of the piping system. The element damping values are specified in SSAR Table 3.7-1. The procedure for calculating strain-energy-weighted modal damping is given in SSAR Section 3.7.2.15. The staff reviowed the information in the SSAR and found it acceptable; therefore, DFSER Open Items 3.9.2.2-6 and 14.1.3.3.5.17-1 are resolved.

\subsubsection{Minimum Temperature for Thermal Analyses}

In the DFSER, the staff noted that GE had not provided any information that would establish minimum temperature at which an explicit piping thermal expansion analysis would be required. Unless GE had provided this information in the SSAR, the staff would have required that thermal analyses be performed for all temperature conditions above ambient. These were DFSER Open Items 3.9.3.1-3 and 14.1.3.3.5.18-1.

SSAR Section 3.9.3.1, "Loading Combinations, Design Transients and Stress Limits," states that piping loads due to the thermal expansion of the piping and thermal anchor movements at supports are included in the piping load 
combinations. All operating modes, are ovaluated, and the maximum moment ranges ase included in the fatigne ovaluation. Piping systom with maximum operating comperatures of leas than or equal to $65.6^{\circ} \mathrm{C}\left(150^{\circ} \mathrm{F}\right)$ aro not required to be analyzed for thermind expansion loading because, when below this temperature, thermal-induced trecenes will be low and inconeequential to piping decizns. The ataff reviowed this information and concluded that $O E$ bad dofined a reasonablo and acceptable minimum tempernture at which an explicit thermal analysis would be performod. On the badis of this evaluation, DFSER Open Ilem 3.9.3.1-3 and 14.1.3.3.5.18-1 are recolved.

\subsubsection{Internystem LOCA}

In SECY-90-016, dated January 12, 1990, the NRC ataff diecused the resolution of the intersyatem LOCA isave for advenced light-water reactor plants by requiring that lowpreseure piping syetems that interface with the RCPB be decigned to withetend full RCS preseure to the extent practicable. In its June 26, 1990, SRM, the Commission approved thew etaff recommendations provided that all olemeats of the low-presenure systems are considered. In the DPSER, the staff noted that GE had not yot aubmitted the details of the piping deaign for the full RCS proesure. This was DFSER Open Item 14.1.3.3.5.19-1.

SSAR Subection 3.9.3.1, "Loading Combinations, Dexign Transients, and Streas Limits," requires that low-preseure piping syatems that interface with the RC boundary be designed with a pipo wall thickness calculated for a presecure equal to 0.4 times the RCS pressure but not less than that of a schedulo 40 pipe. On the basis of a staff review and discusaions with GE and the more detailed ovaluation in Section 3.9.3.1.1 of this report, the staff finds this requirement acceptable. Therefore, DFSER Open Item 14.1.3.3.5.19-1 is resolved.

\subsubsection{Condusions}

One the basis of its reviow, the staff concludes that-

(1) GE meets GDC 1 and 10 CFR Part 50, Appendix B with regard to piping systems being designed, fabricated, constructed, tested, and inspectod to quality standards commensurate with the importance of the safety function to be performed, and with appropriate quality control.

(2) GE moets GDC 2 and 10 CFR Part 100, Appendix A with regand to design transients and resulting load combinations for piping and pipe supports to withstand the effects of earthquakes combined with the effects of normal or accident conditions.
(3) GE meets ODC 4 with regard to piping system important to safety being decigned to sccommodate the offects of and to be compatible with the covironmental conditions of normal and accident conditions.

(4) GE moets GDC 14 with regand to the reactor coolant prescure boundary of the primary piping systoms boing deaigned, fabricalod, constructed, and toeted to have an extremely low probability of abaormal leakage, of rapid propagating failure, and of groes rupture.

OE mocte ODC 15 with regard to the reactor coolent piping aystem being designed with specific deaign and sorvice limits to assuro sufficient margin that the deaign conditions are not exceoded.

\subsubsection{Pipe Support Criteria}

\subsubsection{Applicable Codes}

The etaff reviowed the methodology used in the design of ASME Code Class 1, 2, and 3 component supports as deecribed in SSAR Sections 3.9.3.4 and 3.9.3.5. The ataff also aseceed the deaign and atructural integrity of three types of aupports: plate and shell, linear, and component etendard types. All ASME Codo Clase 1, 2, and 3 component supports for the ABWR standard plant will be constructed in accordance with ASME Code, Section III, Subection NF. In addition, the SSAR states that the dosign is algmented by the application of Code Case $\mathrm{N}-476$, Supplement 89.1, which governs the design of singlo-angle members. It further states that if eccentric loads or other torsional loads are not accommodated by designing the load to act through the shear center, analyeos will be performed in eccordance with such torsional analyais methods as "Torsional Analysis of Steel Members," AISC Publication T1142/83.

Although Code Case N-476 has not been endorsed by the staff in RG 1.84, the staff finds that it provides adequate design rules for the single-angle members. The stuff finds that GE's proposed documents provide sufficient technical guidelines to perform a torsional analysis of steel members and are acceptable.

The staff finds Subsection NF scceptable for the design of piping supports. The staff bas not endorsed the use of ANSI/AISC N-690, "Specification for the Design, Fabrication and Erection of Stool Safety-Related Structures for Nuclear Facilities," in lieu of Subsection NF ( 100 Section 3.12.6.12 of this report for more information). 


\subsubsection{Jurbdictional Boundarive}

SSAR Section 3.9.3.4, defines the juriedictional boundaries between pipe aupports and interface attechmeat points, weh as atructural ateel, in sccordance with the ASMB Code, Section III, Subection NF (1989 edition). The ataffe reviow of the juriedictional boundarion demeribed in tho 1989 edition finds that thoy are sufficieatly dofined to conure a clear division between the pipe aupport and the atructural ateel and are acceptable.

\subsubsection{Loads and Load Comblnation}

SSAR Section 3.9.3.4.1 the londing combinations for the deaign of piping aupports correspond to those used for the dexign of the rupported pipe. The ataff'z evaluation of this load combinations for the mupported pipe is contained in Section 3.12.5.3 of this report. The strese lirnits for pipe supports are in scocordance with the ASME Code, Section III, Subuection NF and Appendix F (1989 Edition). The aupports are generally designed or qualified by the load nating mothod as described in NF-3260 or by the stress limits specified in NF-3231. This is scceptable.

\subsubsection{Pipe Support Baseplate and Anchor Bolt Design}

SSAR Section 3.9.3.4 of carlier amendments statod that the concrete anchor bolts, which would be used for pipe support base plates, will be designed to the applicablo factors of safety defined in Office of Inspection and Enforcement (IE) Bulletin 79-02, Revision 1. Loeding combinations for component aupports are discused in the previous soction. In general, the factors of anfety for anchor bolts are scceptable. However, in the DFSER, the staff noted that in SSAR Section 3.9.3.4, "Component Supports, " GE had not discuseed the uee of eppecific types of anchor bolts to be used for pipe support base plates in the ABWR standand plant. For example, under-cut-type anchor bolts behave in a ductile manner, but the atafi's position is that the safety factors in IE Bulletin 79-02, Revision 2, are still applicable unless justification for alternative safety factors is provided. Therefore, the COL applicant should justify the use of anfety factors for anchor bolts other than those provided in IE Bulletin 79-02, Revision 2, and submit the justification to the staff for review and approval before their use. These were DFSER COL Action Items 3.9.3.3-1 and 14.1.3.3.6.4-1. In addition, the staff noted that irrespective of the type of concrete anchor bolt used for piping supports, the COL applicant should implement the sction item in IE Bulletin 79-02 related to pipe support baseplate flexibility. This was DFSER COL Action Item 14.1.3.3.6.4-2.
SSAR Section 3.9.3.4 atates that concreto suchor bolts (inoluding under-cut-type anchor bolts) that are used for pipe aupport base plates will be designed to the applicable factorn of anfety that are dofined in IB Bullotin 79-02, Revision 2. SSAR Section 3.9.3.4 further atates that pipe aupport baes plate flexibility will be accounted for in the calculation of concrete anchor bolt loads, in sccordance with IB Bullotin 79-02, Revision 2. On tho basis of these ctatements, the staff concludes that the ABWR pipo support beseplate and anchor bolt deaigns will bo in accordances with applicable portions of IE Bulletin 79-02, Revision 2, and are scceptable. Loading combinations for component aupports are discuesed in the coction above.

In addition, SSAR Section 3.9.3.4 states that the COL applicants shall provide juntification for the use of anfety factors for concrete anchor bolts other than those specified in IE Bulletin 79-02. This justification must bo submitted to the NRC for reviow and approval prior to installing of the bolts. SSAR Section 3.9.3.4 also states that COL applicants shall eccount for pipe eupport bace plate flaxibility in sccordance with IE Bulletin 79-02. This is ecceptable.

\subsubsection{Use of Eneres Absorbers and Limit Stops}

The DFSER noted that GE had not provided the specific analysis methods or procedures to be used for the ABWR pipe aupport design. The staff requested that GE addrees in the SSAR the use of soismic restraints other then subbers and thoir modeling assumptions. This was part of DFSER Open Items 3.9.3.3-1 and 14.1.3.3.6-1.

SSAR Section 3.7.3.3.1.7, "Modeling of Special Engineered Pipo Supports, "states that modifications to the normal linear-elestic piping analyais methodology used with conventional pipo aupports aro required to calculato the loads acting on the supports and on the piping components when apecial engineered supports are ueod. Thewe supports include energy absorbers and limit stope, which are deacribed in SSAR Section 3.9.3.4.1(G). The modifications are noeded to account for greater damping of the energy abeorbers and the non-linear behavior of the limit stops. If these special devices are used, the modeling and analytical mothodology will be in accordance with urethodology accepted by the regulatory ageacy at the timo of design certification or at the time of COL application, per the discretion of the COL applicant. In addition, the information required by RG 1.84 related to the use of energy abeorbers (ASME Code Case N-420) will be provided to the regulatory agency. This is acceptable. Although the staff has not yet endorsed the use of limit stops, the commitment in SSAR Section 3.7.3.3.1.7 to use design criteria in accordance with that accepted by the regulatory agency at the timo of either design certification 
or COL spplication, is aleo scoeptable to the etafi. On the bads of this ovaluation, the spplicable parts of DPSBR Open Itemen 3.9.3.3-1 and 14.1.3.3.6-1 are recolved.

\subsubsection{Une of Snubbers}

The DFSER noted that OB had not providad the epecific analyais mothods or proceduren to be uned for the ABWR pipe mupport decipen. The staff requented that OE addrow in the SSAR tho types of mubbers to be unod in the ABWR standand plant and thoir chernoteriatice. This wes part of DFSER Open Itam 3.9.3.3-1 and 14.1.3.3.6-1.

SSAR Section 3.9.3.4.1, "Piping," provides a dencription of the mubbers, dexign criteria and teating, installation,

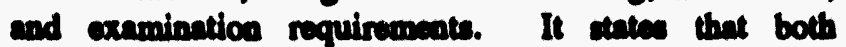
mochenical and bydraulio type aubbers will bo ued. If describes how thair operational and performances chancteristics will be verified by teat. From its roviow of the description, the staff concluded that the information provided is comiatent with applicable portions of SRP Section 3.9.3 and is ecceptable; therefore, the applicable parte of DPSER Opea Item 3.9.3.3-1 and 14.1.3.3.6-1 are recolved.

\subsubsection{Fipe Support Stifnewes}

The DFSER noted that OE had not provided the eppecific analyais methode or procedures to be ueed for the ABWR pipe mupport design. The staff requected that $\mathrm{OE}$ addrees in the SSAR the pipe support atiftwees values and aupport deflection limits uned in the piping analyees. This was part of DFSER Open ltoms 3.9.3.3-1 and 14.1.3.3.6-1.

SSAR Soctions 3.7.3.3.1.6, "Modeling of Piping Supports," and 3.7.3.3.4, "Analysis of Frumo Typo Supports," deweribe the criteria for using equivalent atifneases for mubbers and atruts, including their supporting atructures, and for framo type cupports. Methods for dotermining the atiffinesese of each aupport type were provided. Stifficeses for frame type aupports and for mpporting atructures must be included unlees they can bo shown to be rigid. OE provided a deflection limit critoria that muat be mot for aupports that aro modeled as rigid. The ataff roviowed this information and found it acceptablo. Therefore, DFSER Open Itoms 3.9.3.3-1 and 14.1.3.3.6-1 are reeolved with regard to the iseve of pipe aupport stiffinees.

\subsubsection{Selomic Self-Woight Excitation}

The DFSER reported that OE had not provided the specific analyeis methods or procedures to be used for the ABWR pipe aupport design. The staff requeated that $G E$ address in the SSAR the seismic excitation of the pipe supports (epecially large frame-type atructures) in the deaign of the pipe expport anchorage. This wes part of DFSER Open Irom 3.9.3.3-1 and 14.1.3.3.6-1.

SSAR Section 3.7.3.3.4 includes a description of the deaign loade to be considered in the analyais of fremo-type aupports. It explains that in addition to the loads transmittod from tho piping to the support, the rupport internal loads cauned by the weight, thormal, and inertia offects, which are due to the support structure itself, must bo included in the mpport analyais. Therefore, the seismic self-waight excitation will bo included, which is seceptable; therefore, DFSER Itom 3.9.3.3-1 and 14.1.3.3.6-1 are recolved with regand to this isave.

\subsubsection{Deaign of Supplementary Sted}

SSAR Section 3.9.3.4 provide deaign criteria for the deaign of pipe supports, using supplementary eteel. Supplementary etcol for pipe supports are decigned in accordance with ASME Code, Section III, Subwection NF. The une of Subeoction NF is standard induetry practice and hes been proven to provide adequate design guidelines for the decign of structural steel for use as pipo supports. This is ecceptable.

\subsubsection{Consideration of Friction Forces}

The DFSER reported that GE had not provided the specific analysis methods or procedures to be used for the ABWR pipe mupport design. The staff requeated that GE address in the SSAR the coefficient of friction to be used for considering friction forces between the pipe and the steel frumes. This was part of DFSER Open Items 3.9.3.3-1 and 14.1.3.3.6-1.

SSAR Section 3.7.3.3.4, "Analysis of Framo Type Supports," includes a description of the design loads that must bo considered in the analysis of framo-type aupports. One of the design loads includes friction loads caused by a pipo aliding on the support. In calculating these loads, GE will ues atatic coefficients of friction of 0.80 for steel on ateel and 0.15 for lubricated plates. The ataff finds this acceptable because the megnitude of these specified static coefficients is sufficiently conservative to define the friction force doveloped at different kinds of contact surfaces of a sliding pipe on its support; therefore, the applicable parts of DFSER Open Items 3.9.3.3-1 and 14.1.3.3.6-1 are resolved.

\subsubsection{Pipe Support Gaps and Clearances}

The DFSER noted that GE had not provided the specific analysis methods or procedures to be used for the ABWR pipe support design. The staff requested that $G E$ address 


\section{Design of Structures, Components, Equipment, and Systems}

the hot and cold gaps to be uned betwean the plpo and the box-frame-type of eupport. This was part of DFSBR Opea Itame 3.9.3.3-1 and 14.1.3.3.6-1.

SSAR Section 3.7.3.3.4 includan information on allowable sape. It thates that the total gap or diamedral clearance between the pipe and frame aupport thall be between $1.6 \mathrm{~mm}(1 / 16 \mathrm{in}$.) and $4.76 \mathrm{~mm}$ (3/16 in.) when the pipe is in either the hot or cold condition. The etaff finde this coceptable becaues a small gap will conure validity of ueing the linear analyais mothodologies prewented in the SSAR for piping deaiga; therefore, the applicable parts of DFSER Open Iteme 3.9.3.3-1 and 14.1.3.3.6-1 are recolved.

\subsubsection{Instrumentation Line Support Criteria}

In the DFSER the ataff noted that GE had not provided any information on the design critoria for the structural design of instrumentation line supports. The stafi requected that this information bo included in the SSAR. This was DFSER Opea Itom 3.9.3.3-2 and part of DFSER Open Itom 14.1.3.3.6-1.

SSAR Sections 3.7.3.8.1.9 and 3.9.3.4.1 thato that eupportu for ASMB Code, Section III inctrumentation lines are analyzed in sccordance with SSAR Subecetion 3.7.3, "Soismic Subsystem Analyais," and decirmed in sccordance with SSAR Section 3.9.3.4, "Component Supports." Thus, these instrumeatation lines will be snalyzed, using the ame methodology that will be applied to amall-bore piping, and will be deaigned in accordance with ASN B Code, Section III, Subsection NF. The taff finds this acceptable because these criteria and this guidance are sufficient to ensure codo complinence and evismic deaign adequacy of the instrumentation line aupports; therefore, DFSER Open Itom 3.9.3.3-2 and the applicable part of DFSER Open Itom 14.1.3.3.6-1 aro resolved.

The industry hes taken the position that ANS/AISC N-690 is useful in the design of instrumentation sensing line supports and has recommended that the industry bo allowed to use it. Its use would have the effect of reducing the QA recordkeeping requirements and Code atamping required by Section NF of ASME Codo, Section III. The staff believes that ANS/AISC N-690 alone is not an acceptable standard for construction of ASME componeat mupports. ASME Code, Section III, Subuection NF, should bo used. However, the ataff is currently participating in the ASME effort to incorporato N-690 into Subsection NF. Subsequent to a etaff-endorsed version of NF incorporating N-690, Subsection NF will specify the rules acceptable to the staff for construction of ASME Code Class supports. In the DFSER, the staff stated that when this staff-approved version is available, the COL appliesat cacking its ues may mubmit a roquat to the etaff for approval on a plant-epecific bacis. This was DFSER COL Action Itom 14.1.3.3.6.12-1. Upon further considenation, the ctaff determined that a COL action item would not be appropriate becaune, as discuesed in Section 3.12.2.1 of this report, DRSER COL Action Item 14.1.3.3.2.1-1 provides a commitment for tho COL applicant to ensure that the deaign will be consiatent with ASMB Code and addeade as codorwed in 10 CFR 50.55a in effect at the time of application. Therefore, DFSER COL Action Itsm 14.1.3.3.6.12-1 is deleted.

\subsubsection{Fipe Dafaction Limits}

In the DFSER the ataff noted that OB had not provided the epecific analyais mothods or procedures to be uned for the ABWR pipe cupport design. The staff requected that $G B$ include this information in the SSAR design critoria that will casure that the maximum deflections of the piping at aupport location for static and dynamic loadinge aro within an allowable limit to preclude failure of the pipe aupports and hangers. This was part of DFSER Open Item 3.9.3.3-1 and 14.1.3.3.6-1.

SSAR Section 3.9.3.4.1, "Piping," includes deaign critoria to consure that maximum doflections at pipe aupports will be within allowable limits. The staff roviewed the deflection criteria and found them acceptablo because thoy are compatible with doaign acoumptions and atandard engineering practice; therefore, the applicable portions of DFSER Open Itoms 3.9.3.3-1 and 14.1.3.3.6-1 are resolved.

\subsubsection{Conclusions}

On the basis of these discusaions and the evaluation of SSAR Sections 3.9.3.3, 3.9.3.4, 3.9.3.5, 3.7.3.3, the ataff concludes that aupports of piping systems important to afety aro designed to quality standards commensurate with their importance to safoty. The staff's conclusion is based on the following:

(1) OE antisfies the requirements' of GDC 1 and $10 \mathrm{CFK} 50.55$ a by specifying mothods and procedures for tho design and construction of anfety-related pipe supports in conformance with general engineering practico, and

(2) OE satiefies the requirements of ODC 2 and ODC 4 by designing and constructing safety-rolated pipe supports to withstand the offects of normal operation as well as postulated ovents such ws LOCAs and dynamic effects resulting from the SSE. 


\subsubsection{Aligh-Enerey Lime-Break Criteria}

ODC 4 requires that SSCr important to enfety bo deaigned to be compatible with and to accommodate the effects of the cavironmental conditions realting from oormal operntion, mintenance, teeting, and poetulated sccidents, including LOCAs. It also requires that they bo edequately protected againat dynamic effects (including the effects of misciles, pipe whipping, and discharging fluide) that may result from equipmeat failures and from oveats and conditions outride the nuclear power plant.

In eccordance with SRP Section 3.6.2, Revition 2, the etaff reviowed OB's proposed criteria and methodology to poetulato pipo breake and leakage cracks and to analyzo tho offects of brouks in high-enorgy fluid aystems on adjecent afoty-rolated SSC with regand to pipe whip and jet impingemeat loedinge. In the DFSER, the staff noted thet the COL applicant should ues them criterita and mothodology to poctulate locations of pipe breake and leakage crecks to canure edequate protection against the dynamic effects of pontulated ruptures of piping in the ABWR standard dexign. This was DFSBR COL Action Item 14.1.3.3.7-1. SSAR Section 3.6.5.1, "Detrils of Pipo Break Analyais Reaults and Protection Methoda," states that the COL applicant shall provide a summary bf the dynamic analyees applicable to high-and modertioenergy piping systems in accordance with Section 3.6 2.5 of RO 1.70. This is acceptable.

In tho DPSER, the ataff also ideatified Open Iteme 3.6.2-2 and 14.1.3.3.7-1 regarding the edition of ANSI/ANS-58.2, "Design Basis for Protection of Light Water Nuclear Power Plants Against the Effests of Pipe Rupturo," which is referenced in SSAR Section 3.6.2.2.1. Originally, there were inconsistencies between the criteria for ovaluating the effects of fluid jets on essential SSCs specified in SSAR Section 3.6.2.3.1 and corresponding criteria specified in SRP 3.6.2 and ANSI/ANS-58.2, 1988 Edition. SSAR Table 1.8-21, "Industrial Codes and Standards Applicable to ABWR," specifies the current 1988 Edition of the ANSI/ANS-58.2 Standard. In addition, the criteria described in SSAR Section 3.6.2.3.1 are consistent with SRP Section 3.6.2 and ANSI/ANS-58.2, 1988 edition. This is acceptable; therefore, DFSER Open Items 3.6.2-2 and 14.1.3.3.7-1 are resolved.

By letter dated September 11, 1992, the staff provided GE with guidance for the use of a single-earthquake design for SSCs in the ABWR. This guidance proposes that the criteria for postulating pipe breaks in seismically designed, high-energy piping systems be based on normal and operational transients only, excluding earthquake loadings. SSAR Sections 3.6.1 and 3.6.2 and Tables 3.9.1 and 3.9.2 incorporate the staff guidance for the use of a single- earthquake for the postulation of pipo break locations. On the basis of this incorporation and the staff's evaluntion of this isave in Section 3.1.1.3 of this report, the ctaff concludes that the ABWR criteria are consiatent with ataff positions discuseed in Section 3.1.1 of this report, which is ecceptable.

The taff also told OE that rolaxation of the curreat BTP MEB 3-1, Revision 2, June 1987, Section B.1.c.(1)(b) criteria to the provious BTP MEB 3-1, Rovision 1, July 1981 criteria would be scceptable. These critoria aro for the poctulation of pipe breaks in ASME Code, Section III, Clas 1 high-energy fluid-eyetem piping in arens other than containment penetration. This etaff position atated is based on the following rationale:

For ASME Code Clase 1 piping, the NRC position for poetulating pipe breaks is dolineated in the Branch Tochnical Ponition MEB 3-1 of the SRP 3.6.2. Prior to isaunce of Rovition 2 of BTP MEB 3-1 in Juno 1987, breaks were postulated at intermediate locations between terminal ends of a pipe run if tho maximum atreas range as calculated by Codo Bq. (10) $>2.4 \mathrm{~S}_{\mathrm{m}}$ and either by Eq. (12) or Eq. (13) $>2.4 \mathrm{~S}_{\mathrm{m}}$. These stated were implemented in many plants operating today.

In Rovision 2 of BTP MEB 3-1, the same criteria are muintained for break exclusion in the containment penetration areas. However, for other areas, the criteria were revised requiring that breaks be postulated at any intermedime locations when only Eq. (10) exceeds 2.4 S. The use of Eq. (12) and Eq. (13) was eliminated.

The staff reviewed the impact of BTP MEB 3-1, Rovision 2, and found that the Rovision 2 criteria aro inconsistent in that they allow higher limits in the containment penetration areas than in other areas. It would appear that the break exclusion area should provide a margin greater than (or at least equal to) the margin for areas outside the break exclusion area. In addition, the Revision 2 criteria will reoult in a significant increase in the number of postulated pipo breaks, which may be counter-productive in torms of cohrancing plant safety.

For these reasons, the staff concludes that the Revision 1 criteria related to allowing the use of Eq. (12) and Eq. (13) should be reinstated for the postulation of intermediate pipe breaks in ASME Code Cless 1 piping systems. SSAR Section 3.6.2 includes the use of Revision 1 of BTP MEB 3-1 criteria in B.1.c.(1).(b). On the basis of this evaluation and a similar evaluation in Section 3.6.2 of this report, the staff concludes that these 
criteria are an acceptable deviation of applicable criteria in SRP 3.6.2, Rovision 2.

During the audit performed at GE in San Jose, California, oa March 23 through 27, 1992, the staff discussed with GE the as-yet-developed procedures for the ABWR for postulated pipo break analyses. This was a part of DFSER Open Itom 3.6.2-1. SSAR, Appendix 3L, "Evaluation of Poetulated Ruptures in High Energy Pipes," dofines a procedure for ovaluating dymamic effects of fluid dymamic forces reaulting from poctulated ruptures in high-energy piping systoms. The four major steps in the evaluations include: (1) the identification of rupturo locations and rupture geometry, (2) the design and selection of pipe whip reatraints, (3) the procedure for dynamic timo-history analysis with simplified models, and (4) the procedure for dynamic timo-history analysis, using detailed piping models. The staff's reviow concludes that the procedure in Appendix 3L is consistent with applicablo guidelined in SRP Sections 3.6.2 and 3.9.2 and are acceptable; therefore, this part of DFSER Open Item 3.6.2-1 is rosolved. The remainder of DFSER Open Item 3.6.2-1 is discussed in Section 3.6.2 of this report.

\subsubsection{High-Energy Piping Systems}

Pipe whip need only be considered for those high-energy piping systems having fluid reservoirs with sufficient capacity to develop a jet stream. The criteria for determining high- and moderato-energy lines in SRP Section 3.6.1, Branch Technical Position (BTP) ASB 3-1, are adequately defined in Section 3.6.2.1 of the SSAR. All high-energy systems are listed in SSAR Tables 3.6-3 and 3.6-4.

\subsubsection{Pipe Break Criteria Within the Containment Penetration Areas}

Breaks are not postulated in the ABWR design for those portions of high-energy piping between the isolation valves outside and inside the containment that are designed to moet ASME Code, Section III, Article NE-1120, and the additional design guidelines in SRP Section 3.6.2, including BTP MEB 3-1, Revision 2, June 1987. These guidelines recommend that an augmented inservice inspection program be implemented for those portions of piping within the break-exclusion region. In the DFSER, the staff noted that the COL applicant should perform a 100-percent volumetric examination of circumferential and longitudinal pipe welds in the break-exclusion region during each inspection interval as defined in Article IWA-2400, ASME Code, Section XI. This was DFSER COL Action Item 14.1.3.3.7.2-1. SSAR Section 3.6.5.3, "Inservice Inspection of Piping in Containment Penetration Areas," states that the COL applicant shall perform an augmented inservice inepection program, as defined. This is acceptable.

\subsubsection{Pipe Break Criteria Outside the Containment Penetration Areas}

For ASME Code, Class 1, 2, and 3, and non-ASME soismic Catogory I high- and moderate-energy lines that are not in the containment penetration area, Section 3.6.2 of the SSAR provides the criteria for determining postulatad break and crack locations and the methodology used to ovaluate the dynamic effects of pipe whip, jet thrust, and jet impingement that result from such breaks.

SRP Section 3.6.2 guidelines state that if a structure separates a high-energy line from an essential component, the separating structure should be designed to withstand the consequences of the pipe break in the high-energy line that produces the groatest effect at the structure, irrespective of the fact that the pipe break criteria in SRP Section 3.6.2 might not require such a break location to be postulated.

The ABWR structures are designed to withstand the dynamic effects of pipe breaks where the pipe rupture criteria require break locations to be postulated. In addition, for areas where physical separation of redundant trains is not practical, a high-energy line separation analysis (HELSA) will be performed by the COL applicant to determine which high-energy lines meet the spatial separation requirements and which lines require further protection. For the HELSA evaluation, which is discussed in Section 3.6.1.3.2.2 of the SSAR, no particular break points are evaluated. Breaks aro postulated at any point in the piping system and any structure identified as necessary by the HELSA evaluation are designed for worst-case loads. This was DFSER COL Action Item 14.1.3.3.7.3-1. SSAR Section 3.6.5.1, Item (8), states that the COL applicant will perform the HELSA as described. This is acceptable.

Using this HELSA evaluation, the staff finds that an adequate level of protection is provided to ensure that the safety-related function of components, systems, and equipment will not be adversely impacted by a postulated high-nergy line break. Plant arrangement provides physical separation to the extent practical and the HELSA evaluation ensures that no more than one redundant train can be damaged. If damage could occur to more than one division of a redundant safety-related system within $9.14 \mathrm{~m}$ (30 ft) of any high-energy piping, other protection devices such as barriers, shields, enclosures, deflectors, or pipe whip restraints are used. When necessary, the protection requirements are met through the use of walls, floors, columns, abutments, and foundations. Thus, the staff finds that the HELSA criteria satisfy the intent of the SRP 3.6.2 
guideline by ensuring that structures ase adequately deaigned to withstand the consequences of a woret-ane pipe break with no adverse impect on the anfety-related function of systems, components, and equipment and are acceptable.

\subsubsection{Conclusions}

The stafi concludes that the criteria for postulating pipe rupture and crack locations and the mothodology for ovaluating the subsequent dynamic effects resulting from these ruptures comply with SRP Section 3.6.2, med GDC 4 and, are therefore, acceptable. The staft? conclusion is bessed on the evaluations in Section 3.12.3.7 of this report and the following:

The propoeed pipe rupture locations are adequately determined, using the ataff-approved criteria and guidelines. GE has sufficiently and adequately defined the design methods for high-energy mitigation dovices and the measures to deal with the aubeequent dynamic effects of pipe whip and jet impingement to provide adequate assurance that if the COL applicant completes the highenergy line break analyses, the ability of anfety-related SSCs to perform their safety functions will not be impaired by the postulated pipe ruptures.

The provisions for protection against the dynamic effects associated with pipe ruptures of the RCPB inside the containment and the resulting discharging fluid provides adequate assurance that design-basis LOCAs will not be aggravated by the sequential failures of safety-relatod piping, and that the performance of the emergency core cooling system will not be degraded as a result of these dynamic effects.

The COL applicant is responsible for the arrangement of piping and restraints and the final design considerations for high-and moderato-energy fluid systems inside and outside the containment, including the RCPB. The COL applicant should use these staff-approved high-energy line break criteria and these guidelines to ensure that the SSCs important to safety that are in close proximity to the postulated pipe ruptures will be protected. Using these will ensure that the consequences of pipe ruptures will be adequately mitigated so that the reactor can be safely shut down and be maintained in a safo-shutdown condition in the event of a postulated rupture of a high- or moderateenergy piping system inside or outside the containment.

\subsubsection{Leak-Before-Break Criteria}

SSAR Section 3.6.3 and Appendix 3E provide a description of the evaluation procedures for an LBB methodology. Since no LBB analysis was submitted for ataff reviow and approval, the weo of the LBB approach hes not been pro-approved by the etaff in the $A B W R$ design certification phase. Hence, it is a design option for the COL applicant to consider in lieu of performing highcoergy line break analyses as diecuseod in Soction 3.12.7 of this report.

GDC 4 permits the application of the LBB methodology to piping systems. It states, in part, that "dynamic effects aseociated with postulated pipe ruptures in nuclear power units may be excluded from the deaign basis when analywe reviewed and approved by the Commission demonatrate that the probability of fluid system piping rupture is extremely low under conditions consistent with the dexign besis for the piping." The andyess referred to in ODC 4 (52 Eedernl Repister, 41288-41295, October 27, 1987) ahould be based on apecific plant data, such as piping geometry, materials, piping loads, and pipe aupport locations. The staff must reviow the LBB analyese for epecific piping deaigns before the epplicent cen excludo the dynamic effects from the design basis for the piping syatem.

The staff concludes that COL applicants soeking approval of the LBB approach for high-energy piping systems in the ABWR standardized plent must submit to the NRC staff an LBB plant-specific analysis in accordance with GDC 4. The staff recognizes that the LBB technology is continually evolving, therefore, the staff will reviow LBB requests for the ABWR plant on a case-by-case basis, using the staff's methodology and acceptance criteria in effect at the timo of the submittal.

\subsubsection{Generic Piping Design ITAAC}

In Section 3.3 of the CDM, dated June 17, 1992, GE provided its ITAAC for piping design. Table 3.3 therein identified 12 certified design commitments (design elements) for the ABWR piping design and the corresponding ITAAC. In a meeting held at GE's offices in San Jose, California, on January 11 through 21, 1993, the staff and GE reached agreement on the resolution of comments from the industry/NUMARC on the generic piping dosign ITAAC (also referred to as the Piping DAC). The piping design description has been substantially expended to include additional certified design commitments. The ITAAC design commitments have been reduced in number to consolidate those design commitments that are implicit in the ASME Code, Section III, requirements and to eliminate some design criteria that were deemed not appropriate for inclusion into ITAAC. GE gave the NRC additions and changes to the SSAR to support the piping DAC/ITAAC changes. 
The stafi's ovaluation of the certified design commitments and ITAAC for piping deaign is given in the following rections.

\subsubsection{Patigue}

GE provided a certified design commitment that the pipitg will be designed for a fatigue life of 60 years. The COL applicant will perform a fatigue analyais for ASME Code Class 1 piping systems in accordance with the applicable requirements of ASME Code, Section III. Section III rules will be followed for ASME Codo Class 2 and 3 piping, using a stress runge reduction factor of 1.0 for those piping systems expected to experience less then 7000 thermal cycles in their 60-year design life.

The COL applicant will be required to ensure that the fatigue analysis meets the ASME Code requirements for the 60-year design life. The acceptance criteria for the fatigue design of ASME Code Class 1 piping will be that the cumulative usage factor is leas than 1.0 as specified in tho ASME Codo, Section III.

The staff finds that a fatigue analysis of safety-related piping is a necessary certified design commitment to ensure the integrity of the RCPB and the ability of the piping systems to perform their safety function for a 60-year design life. The design acceptance criterion for a cumulative usage factor to be lese than 1.0 is consistent with curreat ASME Code requirements for fatigue ovaluation as stated in Subparagraph NB-3222.4. The COL applicant will consider in its fatigue analysis the environmental offects as discussed in Section 3.12.5.7 of this report.

The inspection of the ASME Code certified stress report, including the fatigue analyses ensures that the ASME Code requirements for fatigue will be satisfied. However, in the DFSER, the staff reported that an additional certified design commitment is needed for any ASME Code Class 2 and 3 piping system that is expected to experience 7000 or more thermal stress cycles in its 60-year design life. For any such piping, the COL applicent should use a stress reduction factor of less than 1.0 as required by Subparagraph NC/ND-3611.2 of the ASME Codo, Section III. In addition, if an ASME Code Class 1 fatigue evaluation is required for ASME Code Class 2 and 3 piping systems, as discussed in Section 3.12.5.8 of this report, a cumulative usage factor of 1.0 should be met and environmental effects should be considered. This was DFSER Open Item 14.1.3.3.9.1-1.

Section 3.9.3.1 of the SSAR provides information on loading combinations, design transients, and stress limits for ASME Code Class 1, 2, and 3 components and cupports. SSAR Soction 3.9.3.1.19 states that the Clase 1, 2, and 3 piping is conetructed in accordance with the ASME Boiler and Pressure Veceel Codo, Section III. For Clase 1 piping, streases are calculated on an elastic basis and ovaluated in accordance with NB-3600 of the ASME Code, Section III. For Cless 2 and 3 piping, streases are calculated on an elastic basis and evaluated in accordance with NC/ND-3000 of the Code. From GE's commitment, the staff concluded that any Class 2 or 3 piping that is expected to experience 7000 or more thermal stress cycles must be designed to meet the allowable expansion stress mage defined in NC/ND-3611.2(e) and based on the appropriate streas range reduction factor given in Table NC/ND-3611.2(e)-1 for the total number of full temperature cycles in its 60-year design life. The staff also concluded that for any piping system in which an ASME Colo Class 1 fatigue evaluation will be performed, the evaluation must be performed in accordance with the requirements of NB-3653 and a cumulative usage factor of 1.0 must not be exceeded, considering the total number of stress cycles in its 60-year design life. In SSAR Section 3.9.3.1.1.7, GE commits to performing additional evaluations for environmental effects on fatigue design. The staff evaluation of this issue is discussed in Sections 3.12.5.7 and 3.12.5.8 of this report.

On the basis of these commitments, the staff concludes that there is reasonable assurance that the design of the ABWR piping systems will be adequately evaluated for fatigue effects.

\subsubsection{Pipe-Mounted Equipment Allowable Loads}

GE provided a certified design commitment that the loads imposed by the piping system on pipe-mounted equipment will meet the vendor allowable loads. The COL applicant will inspect the design documents and document that the as- designed interface loads meet the vendor's specified allowable loads. This was DFSER COL Action Item 14.1.3.3.9.2-1. SSAR Section 3.9.3.1.21, "PipoMounted Equipment Allowable Loads," states that the COL applicant shall inspect the piping design reports and document that the pipe applied loads on attached equipment are less than the equipment vendor's specified allowable loads.

The staff finds it necessary to ensure that the calculated loads imposed by the piping on the equipment nozzles and other attachment interfaces are within the vendor's recommended allowable values. This verification will ensure that the equipment and supports will function as intended under normal operating, transient, and accident conditions. 


\section{Design of Structures, Components, Equipment, and Systems}

On the basis of these commitments for a COL applicantyto verify that the calculated piping loads are within the equipment and interfuce allowable loads, the staff concludes that there is rensonable assurance that the ABWR pipe-mounted equipment and piping attachment interfaces will adequately satisfy the vendor interface allowable limits to ensure that the equipment can perform its intended anfety functions under normal, operating, transient, and accident loading conditions.

\subsubsection{Piping Analysis Methods}

GE provided a certified design commitment that would require that the analytical methods and load combinations be referenced or specified in a certified stress report. The COL applicant will use a suitable dynamic analysis method or an equivalent.etntic load method in the andysis of the piping system.

The analytical methods to be used to complete the ABWR piping design will ensure the pressure integrity, structural integrity, and the functional capability of the piping systom under normal operating and accident loading conditions and will use a suitable dynamic analysis or an equivalent static analysis method as approved by the staff. The analysis methods approved by the staff for the ABWR piping design are discussed in Section 3.12.3 of this report. The key analysis input parameters approved by the staff for the ABWR piping analysis are discussed in Section 3.12.5 of this report.

On the basis of these commitments for a COL applicant to use the above staff-approved analysis methods and input parameters for the ABWR piping analyses, the staff concludes that there is reasonable assurance that the ABWR analysis methods are adequate to ensure the pressure integrity, structural integrity, and functional capability of the piping.

\subsubsection{High-Energy Line Break Analysis}

GE provided a certified design commitment that would require an analysis demonstrating that safety-related systems, components, and structures are protected against the dynamic effects associated with the postulated rupture of high-energy piping systems.

The COL applicant will prepare a pipe rupture analysis report or an LBB analysis report to verify that the safety of the plant will not be adversely affected by the dynamic effects resulting from the postulated pipe breaks. For those impacted components needed to safely shut down the plant, the ASME Code requirements for faulted plant conditions and operability limits must be met. Pipe rupture mitigation devices (e.8., pipe whip restraints and jet impingement shields) will be used to restrain tho whipping pipe and deflect the blowdown loads. The COL applicant will inspect to verify the existence of a pipe break analysis report or LBB report as stated in SSAR Section 3.6.5.1. The COL applicant will also inspect the a-built high-energy pipe break mitigation features as discusced in SSAR Section 3.6.4.

A pipe rupture analysis will be completed by the $\mathrm{COL}$ applicant to demonstrate that safety-related SSCs will be protected against the dynamic effects of a postulated pipe break, using the methods described in Sections 3.6.2 and 3.12.7 of this report. As an alternative, the COL applicant may submit request for staff approval to eliminate breaks, using an LBB approach as discuseed in Section 3.12.8 of this report.

On the basis of these commitments for a COL applicant to perform high-energy line break analyses, using the staffapproved analysis methods, and to verify the results of the analyses, the staff concludes that there is reasonable assurance that the safety-related SSCs in the ABWR are adequately protected against the dynamic effects of postulated HELBs.

\subsubsection{Functional Capability}

GE provided a certified design commitment that all ASME Code Class 1, 2, and 3 piping systems essential for the safe shutdown of the plant must be designed to ensure that they will maintain sufficient dimensional stability to perform their required function under all loading conditions. In Section 3.12.5.12 of this report, the staff evaluated the stress limits GE specified to ensure the functional capability of safety-related piping systems. In no case will the piping stress exceed the primary stress limits designated for Service Level D in the ASME Code, Section III. The Service Level D limits are $3.0 \mathrm{~S}_{\mathrm{m}}$ (not to exceed $2.0 \mathrm{~S}_{\mathrm{y}}$ ) for ASME Code Class 1 piping and $3.0 \mathrm{~S}_{\mathrm{h}}$ (not to exceed $2.0 \mathrm{~S}_{\mathrm{y}}$ ) for Class 2 and 3 piping.

The staff finds that the limits specified by GE to ensure functional capability of piping as discussed in Section 3.12.5.12 of this report are acceptable. The use of Service Level D limits (not to exceed $2.0 \mathrm{~S}_{\mathrm{y}}$ ) are consistent with the staff recommendations as documented in NUREG-1367, "Functional Capability of Piping Systems," for ensuring the functional capability of piping systems that were based on high-level dynamic tests sponsored by the EPRI and the NRC staff.

On the basis of these commitments for a COL applicant to limit piping stresses in the certified stress report to the design acceptance criteria discussed above, the staff concludes that there is reasonable assurance that the piping 
is capable of performing its safety function under all normal operating, transieat, and accident conditions.

\subsubsection{Analytical Modeling of Piping}

GE provided a certified design commitment to verify the piping analysis modeling technique for the computer code to be used by the COL applicant to complete its piping stres analyees. The piping analysis model must address the key parameters needed to ensure adequate static and dynamic characteristics of the piping system. The key parameters for the piping model are discuseed in Section 3.12.4.2 of this report. The computer program and the modeling techniques must be evaluated, using the NRC benchmark program discussed in Section 3.12.4.3 of this report.

The COL applicant will verify the sufficiency of the computer code and modeling tochniques in conjunction with the piping benchmark program.

On the basis of these commitments for a COL applicant to verify that the piping benchmark results are within the scceptable range of values epecified in the benchmark program, the staff concludes that there is reasonable assurance that the computer code and analytical modeling techniques to be used to complete the ABWR piping design and analyses are adequate.

\subsubsection{ASME Code Classification}

GE provided a certified design commitment that the ABWR piping, its appurtenances, and its supports must satisfy the ASME Code class, seismic category, and QG requirements commensurate with their classification. The COL applicant will review the ASME Codo-required design documents for installed components to verify the completion of a certified stress report and related Codorequired documents.

On the basis of this commitment for a COL applicant to verify the existence of Code-required documents, the staff concludes there is reasonable assurance that the piping and its subcomponents will be adequately designed, fabricated, and examined in accordance with the applicable ASME Code requirements.

\subsubsection{Fracture Toughness}

GE provided a certified design commitment that the piping systems made of ferritic material must not be susceptible to brittle fracture. Only intrinsically tough grades of ferritic materials will be used. The COL applicant will perform fracture toughness tests in accordance with the requirements of the ASME Code, Section III.
On the basis of these requirements for a COL applicant to verify that ferritic materials satisfy the requirements of ASME Code, Section III, the staff concludes that there is reasonable assurance that the material for piping systems will be adequately specified to preclude brittle fracture under pressure loadings for the expected service conditions.

\subsubsection{Cracking in Stainless Steel Piping}

GE provided a certified design commitment that the fabrication procese for piping systems made of austenitic atainleses steel will be selected to minimize the possibility of cracking during their 60-year design life. Special chemical, fabrication, handling, welding, and examination requirements will be satisfied to minimize the potential for cracking. The guidelines in NUREG-0313, Revision 2, will be followed as stated in SSAR Section 5.2.3.4.

On the basis of these commitments for a COL applicant to use the material and processes that satisfy the ASME Code and special requirements, the staff concludes that there is reasonable assurance that the austenitic stainless steel piping systems will be adequately fabricated to minimize the potential for cracking during service.

\subsubsection{As-Built Piping Verification}

GE provided a certified design commitment that the asbuilt piping system must be reconciled with the certified piping design. The COL applicant will perform an inspection to verify the pipe routing configurations, as well as the location, size, and orientation of piping supports, valves, and equipment, and to identify deviations from the as-designed condition as described in SSAR Section 3.9.3.1.20. The piping configuration and component location, size, and orientation will be within the specified tolerances. Deviations (outside the tolerances) will be evaluated to ensure that the vendor-allowable loads and ASME Code, Section III, stress limits are satisfied.

The tolerances to be used for the reconciliation of the asbuilt installation of piping systems will be obtained from the EPRI report, "Guidelines for Piping System Reconciliation (NCIG-05, Revision 1)," NP-5639 dated May 1988. The staff's acceptance of this approach is documented in a letter from G. Arlotto (NRC) to W. Weber (Nuclear Construction Issues Group) dated February 3, 1988. The staff's endorsement of the EPRI report is subject to the restriction that (1) the acceptable as-built piping tolerances not be increased beyond those stated in NP-5639 and (2) they be limited to the piping systems analyzed using linear-elastic methods and qualified on the basis of the staff-approved design criteria specified in this report. 
On tho basis of thea commitments for a COL applicant to verify that the installation tolerances are satisfied and that all deviations are reconciled uning the etaff-approved mothods and deaign acceptance criteria discussed in this report, the taff concludes that there is reasonable seaurance that the ABWR piping system will bo constructed in eccordance with the design documents.

\subsubsection{Presoure Integrity}

OE provided a certified deaigm commitmeat that the ASME Code Clase 1, 2, and 3 piping will be deaigned to the requirements of ASME Code, Section III, as discussed in Section 3.12.2.1 of this report to retain its preseure integrity for its 60-year design life.

The COL applicant will inspect the ASME Codo-required documents to verify that ASME Code, Soction III, requiroments are atisfied for ASME Code Class 1, 2, and 3 piping systems. The COL applicant will perform hydrostatic presenre treets of the ASME Code Clase 1, 2, and 3 piping in eccordance with the ASME Codo requirements. In addition, the COL applicant will ensure that the low-pressure piping systems that interface with the RCS pressure are adequately designed to withstand full RCS pressure in the ovent of an intersystem LOCA as discussed in Section 3.12.5.19 of this report.

On the basis of these commitments for a COL applicant to perform these inspections and tests, the staff concludes that the ASME Code Class 1, 2, and 3 piping systems will be designed, constructed, and tested to ensure their pressure integrity in service under normal operating, testing, transient, and accident conditions.

\subsubsection{Interferences}

GE provided a certified design commitment that piping will be designed with adequate clearances to preclude interferences with nearby SSCs resulting from piping displacements.

The COL applicant will verify that the maximum calculated pipe deflections under normal operating, transient, and eccident conditions do not exceod the minimum specified clearances between the piping and nearby SSCs as stated in SSAR Section 3.9.3.1.22.

On the basis of these commitments for a COL applicant to verify that maximum calculated pipe deflections aro within the minimum specified clearances or do not impact nearby SSCs, the staff concludes that there iz reasonable assurance that the piping deflections under normal operating, transient, and accident conditions will not cause interferences with nearby SSCs.

\subsubsection{Erosion-Corroaion}

OE provided a certified design commitment that piping system will be designed to minimize the effects of erosicn-corrosion. Erosion-corrosion will be controlled as diecuseed in SSAR Section 5.2.3.2.2.3. The EPRIdoveloped code CHECMATE will be used for two-phase environments to predict corrosion rates and to identify areas where design improvements to the material selection, hydrodynamic conditions, oxygen content, and temperature may be required to ensure adequate margin for exteaded piping performance.

On the basis of this certified design commitment for a COL applicant to ovaluate the erosion-corrosion effects in piping systems, the staff concludes that there is reasonable aseurance that the effects of erosion-corrosion are minimized in the piping design for the 60-year plant life.

\subsubsection{Conclusions}

In the DFSER, the staff requested that GE revise the CDM for piping design to ensure that all its certified design commitments in Table 3.3 of the CDM are included in the design description. This was DFSER Open Itom 14.1.3.3.9.13-1. In a rovision to Section 3.3, "Piping Design," of the Tier 1 CDM document, GE expanded the design description to include the certified design commitments. GE has also included this information in the final CDM. On the basis of this evaluation, DFSER Open Item 14.1 3.3.9.13-1 is resolved.

The staff concludes that the certified design commitments and ITAAC for piping design incorporate the staffapproved piping design criteria and analysis methods for ensuring that the piping systems will be adequately designed to perform their safety-related functions for all postulated combinations of normal operating, operating transient, and accident conditions, and provide reasonable assurance that the piping systems are built in conformance with the certified design.

\subsubsection{Overall Conclusions}

The staff concludes that GE has provided sufficient information in the SSAR for the staff to reach a safety determination in ABWR piping and pipe support design. The staff's conclusion is based on the following:

(1) GE satisfies 10 CFR Part 50 requirements by identifying applicable codes and standards, design and analysis methods, design transients and load combinations, and design limits and service 
conditions to canure edoquate dacign of all safotyrelated piping and pipe aupports in ABWR for thoir enfery functions.

(2) OB atiofies 10 CPR Part 52 requirements by providing rencomable securance that the piping aystom will be deaigned and built in accordance with the certified deaign. The implementation of these preapproved methods and antiafaction of tho ecceptence criteria will be verified through the performance of the ITACC by the COL applicant to cosure that the as-conetructed piping systom are in conformance with the certified deaign for their anfory functions.
(3) OB mation 10 CFR Part 100, Appendix A, requiremeats by deaigning the mafoty-rolated piping oyetem, with reaconable aceurance to wishetand the dymamic offects of earthquakes with appropriate combination of otber loads of normal operation and poctulated oveats with adequate margin for casuring their mafety functions.

Any change to the commitments involving the piping analyair methodology discused in Section 3.12 of this report would involve an unreviowed anfety queation and, therefore, requires NRC roviow and approval prior to implementation. Any requeated change to these commitments must either be specifically deacribed in the COL application or be rubmitted for license amendment after COL isaunce. 


\section{REACTOR}

\subsection{General}

The reactor asembly consiats of the resctor preacure veseol, preseure containing sppurtenances that include control rod drive (CRD) bousings, in-core inetrumentation housing, and the hoed vent and epray anembly. The resctor preseure veasel includes the renctor internal pump (RIP) casing and flow reatrictore in cach of the eteam outlet nozeden and tho shroud aupport and pump deck that form the partition between the RIP arction and discharge. The docign and description of the resctor preseure veseel are diesuesed in Section 5.3 of this report.

The major reactor internal components are the core (fuel, chmonela, control blades, and inetrumentation), the core support structure (including the shroud, top guide, and core plate), the shroud head and steam separator aseombly, the steam dryer aseembly, the feedwater spargers, and the core flooding spargers. Except for the Zircaloy in the reactor core, these reactor internals are stainless steel or other corrosion-resistant alloys. The fuel asemblies (including fuel rods and channel), control blades, shroud head and steam separator aseembly, and steam dryers and in-core inetrumentation dry tubes are removable when the reactor veseol is opened for refueling or maintenance.

A fuel and control rod design and core loading paltern typical of many currently operating boiling water reactors (BWRs) was used as the basis for the core dosign for the first cycle and for the system reeponse analysis for standard safoty analysis report (SSAR) Chapters 6 and 15. These elements of the core design meet criteria approved by the Nuclear Regulatory Commission (NRC) as presented in SSAR Appendices 4B, 4C, and 4D.

\subsection{Fuel System Design}

The staff reviewed the fuel syetem design in sccordance with Standard Review Plan (SRP) Section 4.2, which includes the acceptance criteria of General Design Criteria (GDC) 10, 12, and 27, as discuseed below and the reference to fuel designs approved by the NRC or to fuel that meets acceptance criteria approved by the NRC for GE Nuclear Energy (GE) fuel (NEDE-31152P, "GE Fuel Bundle Designs Evaluated with GESTAR - Mechanical Analysis Beses," SSAR Appendix 4B and SSAR Reference 4.2-2).

GDC 10 requires that acceptable fuel design limits be specified that are not to bo excoeded during normal operation, including the effects of anticipeted operational occurrences.

(2) GDC 12 requires that power oscillations which could result in conditions exceeding specified scceptable fuel design limits are not possible or can be reliably and readily detectod and suppreseed.

(3) GDC 27 requires that the reactivity control systems have a combined capability, in conjunction with poison additioxis by the omergency core cooling system, of reliably controlling reactivity chenges under postulated accident conditions, with appropriate margin for stuck rods.

Tho fuel for the advanced boiling water reactor (ABWR) is similar in design, including most geometrical and material details, to the fuel commonly used for roloading moet BWR cores. The fuel design bases, limits, analysis methodologies, and evaluations for the ABWR also are the ane as those ueed and approved for initial loading and reloading of previous BWR cores. The ABWR fuel and core design provides the basis for the representative first cycle power distributions and rod patterns as presented in SSAR Appendix 4A and as used in the safety analyses of SSAR Chapters 6 and 15. The ABWR Cycle 1 core deaign, along with the fuel and control rod design (800 below) are desigmated Tier 2 items and no inspections, teots, analysis, and acceptanco criteria (ITAAC) aro involved. However, pertinent elements of the fuel and control rod design criteria (SSAR Appendices 4B and 4C) are Tier 1 items and are included in the design deecriptions. GE submitted the design description for the fuel and control rod. The adequacy and acceptability of these design descriptions are evaluated in Section 14.3 of this report.

Although the areas are Tier 2, the staff review has concluded that the fuel and control rod design criteria (of SSAR Appendices 4B and 4C), the first cycle fuel, control rod and core design, and the methods used to analyze these components may not be changed without prior NRC review and approval. The specific fuel, control rod, and core designs presented in SSAR Chapter 4 will constitute, based on this staff review and approval, an approved design that may be used for the COL first cycle core loading, without further NRC staff review. If any other design is requested for the first cycle, the COI, applicant will be required to submit for staff review that specific fuel, control rod, and core design analysis and corresponding safety analysis described in SSAR Chapters 6 and 15. The review for the fuel, control rod, and core design will be based on fuel and control rod design criteria as described below.

Although it is not specifically referenced in the SSAR, GE customarily presents relevant generic information relating to core initial and roload cycle designs and analyses, including methodology related to fuel and control rod thermal-mechanical, nuclear, and thermal-hydraulic phenomena, in the licensing topical report NEDE-24011-P, 
"General Bloctric Standard Application for Remotor Fud" (OESTAR II) (proprictary). Currently approved OB BWR fual deaigns ane deceribed in the OB report NEDB-31152P, "General Bloctric Fual Bundlo Deaigns Bvaluated with OESTAR-Mechanical Amalycis Baces" (proprietery). OB ctates in SSAR Section 4.2 that BP 8 × $8 R$ fucl is uned for the reference core deaign. The BP $8 \times 8 R$ is a ctandard fual dovign froquently uod in current BWRe for cycle reloads. An cight-by-eight army of prepreweurized fual pins and a barrier conting on the inner aurface of the fuel cladding are ueed. A diccusesion and NRC ataff approval of features of the fuel may be found in OESTAR II, Supplameat for United Staten, Appendix C, and in Referane 4.2-2 of the ABWR SSAR. The fuel senembly deucriptions are in Section AY of NEDB-31152P, Volume 3, Revision 3. Thew roviows covered all of the areas in SRP Section 4.2. Compliance of the fuel dexign with the fuel decign criteris (diccused below) is prewented in SSAR Appendix 4D, and the decign is ahown to meet all requirements. This fual is scceptable for the ABWR.

GB provided the primary roference to acceptable fuel dexign for the ABWR in SSAR, Appendix 4B. This appendix provides a of of acoptance criteria to bo satisfied by now fuvel deaigns for the ABWR. These criteria were doveloped from preceding generic work in reeponse to the NRC etaff generic requeet that wuch ecceptance criteria be extablished by each fuel veador. With the NRC approval of the generic criteria, now fuel dovigns (or chnogen) satisfying the criteria would not require explicit ataff roviow for current reactors.

In response to the NRC staff generic requed, $\mathrm{GB}$ submitted Amendment 22 to GESTAR II, containing proposed fuel licensing acceptance criteria for current BWRs. These criteria include considerations of fuel thermal-mochanical, nuclear, and thermal-hydraulic aspects of design analyeses. The NRC ataff and the Committeo to Reviow Generic Requirements reviewed and approved thewe critoria. The taff afety ovaluation report (SER) eccepting thewe criteria cen be found in GESTAR II, Revision 10, Supplement for Unitod Stuter, Appendix C. However, the ataff hes noted deficiencies in the generic fuel licensing criteria. In its audit nummary, "Audit Team Audit of GE II Fuel Dexign Compliance With NEDE-24011-P-A," dated March 25, 1992, the staff noted the lack of a burpup limit requirement in the fuel criteria at that time. A parallel fuel burnup problem area (DFSER Confirmatory Itom 4.2-1) for the ABWR is discussed below.

For the $A B W R, G B$ has not directly referenced GESTAR II or the fuel criteria amendment. Instead GE hes provided SSAR Appendix 4B which provides a similar set of criteria for the ABWR. Since the Appendix 4B criteria are cementially ideatical to the criteria approved by the ataff for OESTAR II, thoy are generally acceptable. However, come additions or reatrictions are neceecary. The etaff roviow of the Appendix 4B criteria and the ataff audit of the generic criteria have indicated that the following reatriction are neceacary for the long-term ueo of the criteria:

- NRC-approved analytical modols and analyais procedures of General Criterion (1) to be used without further reviow must be limited to those referenced in GESTAR II, Revision 10, or provious revisions. Methode doveloped and approved in later GESTAR II revisions will not automatically apply to the ABWR and will have to be specifically roviowed and approved for ABWR uve.

- Fuel burnup limits must bo apecified and justified on the basis of material properties versus exposure data for anch fuel type used in the ABWR and may bo extended only with NRC review and approval. This was identified as DFSER Confirmatory Item 4.2-1.

In response to the staff request for burnup limit and review statements in the fuel criteria, GE stated that such criterion is unnecessary and not a safety issue. However, they propoeed the following statement for the SSAR.

Burnup limits will be specified for each fuel type uned in the ABWR. The current maximum exposure limit for any GE fuel design is $\mathbf{7 0}$ Giga watts days metric ton of uranium (GWd/MTU) $(6,048 \mathrm{MJ} / \mathrm{gu}(3,214 *$ 10EG BTU)LbU peak pellet exposure $(\sim 60 \mathrm{GWd} / 5,184 \mathrm{MJ} / \mathrm{gU}$ $(2,755 * 10 \mathrm{E} 6 \mathrm{BTU} / \mathrm{LbU}$ or $60 \mathrm{GWd} / \mathrm{MTU}) \mathrm{rod}$ average exposure). Any extension to this maximum exposure limit in excess of $10 \mathrm{GWd} / \mathrm{MTU}$ will be submitted to the NRC for review and approval besed on the availablo supporting materials propertices ve. exposure information and planned surveillence program. In no ovent will the GE fuel doeign maximum exposure limit required by the NRC be lower then the maximum of all exposure limits approved by the NRC for LWR fuel vendors.

The staff found that the proposed fuel burnup limit in this aubmittal is higher than that previously approved for GE $(5,184 \mathrm{MJ} / \mathrm{gU}(2,755 * 10 \mathrm{E} 6 \mathrm{BTU} / \mathrm{LbU}$ or $60 \mathrm{GWd} / \mathrm{MTU})$, peak pellet), that an unreviewed extension of $10 \mathrm{GWd} / \mathrm{MTU}$ is excessive, and that limits approved for other veadors do not necessarily apply to GE fuel without specific review for GE. The staff considers the burnup limit a safoty question and has several fuel operating concerns at burnup levels above those currently approved for BWRs (about 5,184 MJ/gU (2,755*10E6 BTU/LbU of 
$60 \mathrm{OWdMTU}$ ) peak-pellet burnup). These concerns impect normal operation, off-normal trensients, and sccidents.

A briof summery of the concerns are:

- no prototypical LWR operating data above about $5,357 \mathrm{MJ} / \mathrm{gU} \quad(2,847 * 10 \mathrm{~B} 6 \mathrm{BTU} / \mathrm{LbU}$ or 62 GWd/MTU)

- no fuel transient data above about $3,974 \mathrm{MJ} / \mathrm{gU}$ $(2,112 * 10 \mathrm{~B} 6 \mathrm{BTU} / \mathrm{LbU}$ or $46 \mathrm{GWd} / \mathrm{MTU})$

- significant drop in cladding ductility obeorved at about $5,184 \mathrm{MJ} / \mathrm{gU} \quad(2,755 * 10 \mathrm{~B} 6 \mathrm{BTu} / \mathrm{LbU}$ or $60 \mathrm{GWd} / \mathrm{MTU})$

- decrease in fuel thermal conductivity and changes in other physical properties

- changes in loss-of-coolant accident (LOCA) rod behavior at higher burnup levels

- fission gas release

Other issues that noed to limits be addressed on a design specific basis for an extension in fuel burnup are the following:

- assembly and cladding corrosion .

- fuel rod and aseombly axial growth

- grid spacer spring relaxation

Since GE has provided a fuel burnup limit, the staff considers DFSER Confirmatory Item 4.2-1 resolved. However, GE has been requested to augment its proposed fuel design criteria for the $A B W R$ to include fuel burnup limits and to indicato that these limits may bo extendpd only with NRC reviow and approval. In its later submittal on this subject, GE omitted previous objections that the staff has not imposed explicit burnup limits in the past. (They had appeared indirectly in the maximum average planar linear heat generation rate (MAPLHGR) TS maximum burnup listing, but this would effectively disappear in the core operating limit report.) However, they proposed a peak burnup limit of $6,048 \mathrm{MJ} / \mathrm{gU}$ $(3,214 * 10 \mathrm{E} 6 \mathrm{BTU} / \mathrm{LbU}$ or $70 \mathrm{GWd} / \mathrm{MTU}$ (peak pellet) which is greater than the limit previously approved by the staff (60), and they also proposed that extensions to approved values that would not need staff review and approval should be at least $10 \mathrm{GWd} / \mathrm{MTU}$, which the staff considers to be highly excessive. This was an Open Item F4.2-1 for the ABWR review. In response to this open item, GE provided changes to the fuel licensing acceptance criteria Section 4B.3(2)(j), "Submittal
Supporting Accelerated ABWR Schedulo-Reaponse to Opee Item P4.2-1," dated Fobruary 4, 1994, which now states that (1) ful burnup limits will be epecified for fuel uned in the ABWR deaign, (2) the current limit for the ABWR ful is 60 GWd/MTU rod average oxposure, and (3) eny extension of this limit will bo nubmitted to the NRC for roviow and approval. These changes provide an acceptable reeolution of the need for bumup restrictions indicated in the etaff reviow. Tho 60 OWd/MTU limit is acceptable based on the etaff reviow of high performance data for $O B$ full during the NRC audit of the fuel design process for the GB 11 fuel referenced above. The data supporting the high burnup performance that were examined during the audit included GB $8 \times 8$ fivel of the type uned in the ABWR reference core. This submittal resolved Open Itom F4.2-1.

With spproval of the ABWR fuel criteria, now ABWR fuel designs (or changes) satisfying the criteria would not require explicit staff reviow, other than that required by its us. 3y a COL applicant for the first cyclo core londing.

Similar to the presentation of the ABWR fuel design, GB has provided a specific dosign for the control rod. This dosign was used in the safety analyses of SSAR Chapters 6 and 15. OE aleo has proposed control rod design criteria, similar in concept to those for the fuel designs, to be used as a basis for the proposed control rods or future now design submittals. Just as for the fuel design, the specified control rod design used in the ABWR safety analyees will constitute, based on the staff zoview and approval, an approved design that may be used by the COL applicant for the first cycle without further staff review. If the COL applicant changes the design, the staff will require new submittals for roview and approval.

The ABWR control rod design has, for the most part, the same geometrical and material design characteristics of those approved and used for current reactors for the first cycle and for replacement, including current improvements for corrosion-cracking control. The ABWR design differs significantly from current control rod designs only in that it does not provide a velocity limiter for the rod drop accident event. GE believes that this event is not credible because information on the blade-drive uncoupling signal will be provided in the new ABWR rod drive design. In any case, the velocity limiter has become much lese significant with axial reactivity shaping Gadolinia burmable poison in the fuel than with the early fuel designs that required the velocity limiter. Because of the burnable poison distribution or, later in the cycle, burmup distribution, most of the available reactivity increase from the dropped rod is inserted in a short distance and appears in the transient without significent dependence on the velocity limitor action. NRC consultant analyses (Brookhaven National Laboratory (BNL) - NUREG-36891, 
"Bficetes of Rod Worth and Drop Speed on the BWR OffCenter Rod Drop Accident," and ANS Transuctions, November 1985) have shown little censitivity to drop velocity. Thus removal of the velocity limiter is eccoptable.

In SSAR Appeadix 4C, OE mbmitted the ext of control rod licenting ecceptance criteria for the ABWR. Theee critoria deccribe the afoty-rolated functional performance requiremente for the control roda.' The etaff reviowed these criteria in Appendix 4C and proponed additions and modifications neceseary to provide scceptable criteria. The changes which wero submitted in the OB reeponse were (1) removal of a statement from the seneral criteria indicating that a control rod deaign mooting tho criteria did not require specific NRC roviow and (2) indicating that aurveillance programs aro to be implemented when changes in design features could impect the control function. Aleo added to the bases for the criteria were (1) inclusion of irradiation effects to the streae and strain limits, (2) further detrils of inspection of lead depletion rods with now deaign features, and (3) inclusion of crudding, crovices, and atreas corrosion effects upon control rod material. The GE responses were reeponsive and satisfactory, and these criteria, as revised, vere scceptable. This was DPSER Confirmatory Item 4.2-2. GE incorporated the appropriate changes have been in SSAR Amendment 31. The staff finds it to be acceptable. Therefore, DFSER Confirmatory Item 4.2.2 is resolved.

Current GE control rod designs that have been reviewgd and approved by the NRC are suitably adaptable for the ABWR (when modified by whe elimination of the velocity limiter). GE has provided a description of the reference control rod blade design in SSAR Section 4.2. GE has provided an evaluation of the design via a comparison with the Appendix 4C criteria. GE has revised SSAR Section 4.2.3.2.2.1 to indicate they have completed the evaluation of the control rod design, based on the criteria of SSAR Appendix 4C. GE has stated that the control rod evaluations deecribed in Section 4.C.3 have been completed for the reforence control rod design, and the criteria are satisfied. The control rod evaluation, performed by GE using proprietary Japanese data, was not submitted for staff review but is available for audit. It was not necessary to audit this data because the reference control rod blade design is similar to previously approved GE control rod designs. As discussed above, the staff finds GE's conclusions to be reasonable. The control rod design and evaluation were Open Item 14 in the draft safety evaluation report (DSER), and DFSER Confirmatory Item 4.2-3, respectively. Both items are now resolved.
The staff concludes that with approval of the specific fuel deaien type and of the fuel licensing accoptance criteria of SSAR Section 4B, as indicated above, and with the staff ecceptance of the control rod design criteria in SSAR Section 4C, the ABWR core design appronch meets the requirements of SRP Section 4.2 and is acceptable.

\subsection{Nuclear Design}

The etaff roviewed the nuclear deaign in eccordance with SRP Section 4.3 which includes the relevant requirements of the ODC rolated to the reactor core and reactivity control ayetoms. The relovant requirements are as follown:

(1) ODC 10 requires that acceptable fuel design limits be specified that are not to be exceeded during normal operation, including the offects of anticipated operational occurrences.

(2) GDC 11 requires that in the power operating range, tho prompt inhereat nuclear feedback characteristics tend to compensate for a rapid increase in reactivity.

(3) GDC 12 requires that power oscillations which could result in conditions exceeding specified acceptable fuel design limits are not possible or can be reliably and readily detected and suppressed.

(4) GDC 20 requires automatic initiation of the reactivity control systems to assure that acceptable fuel design limits are not exceeded as a result of anticipated operational occurrences and to assure automatic operation of systems and components important to safety under accident conditions.

GDC 25 requires that no single malfunction of the reactivity control system (this does not include rod ejection or dropout) causes violation of the acceptable fuel design limits.

(6) GDC 26 requires that two independent reactivity control systems of different design be provided, and that each system have the capability to control the rate of reactivity changes resulting from planned, normal power changes. One of the systems must bo capable of reliably controlling anticipated operational occurrences. In addition, one of the systems must be capable of holding the reactor core subcritical under cold conditions.

(7) GDC 27 requires that the reactivity control systems have a combined capability, in conjunction with 
poicon addition by the emiergency core cooling aystom, of reliably controlling reactivity changes under postulated eccident conditions, with appropriate margin for stuck rods.

ODC 28 requires that the offects of postulated reactivity eccidents neither recult in demage to the reactor coolant preasure boundary greater then limited local yiolding, nor cause mufficient damage to impair significantly the capability to cool the core.

In SSAR Section 4.3, GE deacribes how the ABWR meets ODC 10, 11, 12, 20, 25, 26, 27, and 28 and the other requirements of SRP Section 4.3 by direct roference to the fuel licensing scceptance criteria in SSAR Appendix 4B. Appendix 4B contains proposed criteria on fuel design and on related neutronic and thermal-hydraulic aspects of the fuol design. As discuseed in Section 4.2 of this report, the ataff approved theee criteria in its roviow of the ABWR fual systom deaigin.

As discuseed in Section 4.2 of this report, $O E$ used a apecific core deaign for the firet cycle and for the ABWR system response analysis and provided apecific designs bf first core fuel assembly enrichment patterns based on the core design. GE has also doveloped, with staff approval, a slightly revised fuel assembly earichmeat pattern with neutronic parameters falling within the bounds of the reference design but with decreased local power peaking. This is to be used for the first cyclo as required by the staff review of the fuel misorientation event, as discussed in Section 15.3(2) of this report. In SSAR Appendix 4A, GE describes use of an example control rod pattern throughout a cycle and the resulting power distributions for the cycle. The core operating limits on process variables determined from the reference core safety evaluation are incorporated in the core associated technical specifications (TS). SSAR Chapters 6 and 15 provide the analyses to satisfy the acceptance criteria tor all design-basis transients and accidents initiated from worst-case steady-state operating conditions within TS operating limits for the design life of the core.

The core design and control rod pattern operations are generally similar to current BWR designs. They only differ in relatively small ways, in details of the geometry and operating limits, which result in small differences in neutronic parameters and characteristics. These differences are generally in a direction of a more conservative core neutronic design and operation than, for example, a BWR/6. They are designed with slightly lower average power densities. The ABWR control rod pitch will be slightly greater than current designs and this will result in a six percent larger core water to $\mathrm{UO}_{2}$ volume ratio (a moderation ratio increase), which in turn will recult in a amaller (abeolute magnitude) void reactivity cosfficient througbout the range of power operating conditions. Both the lower average power denuity and amallor void reactivity coefficient tead to improve core thermal bydraulic stability and pressurization transient responso. The moderation ratio increase tends to make the cad-of-cycle low power (low tempernture) moderator temperature reactivity coofficient leas negative and poscibly alightly positive. But the increase is not eufficient to cause an operational problem during startup or shutdown or a reactivity incortion problem, oven asouming the maximum potential integrated positive reactivity is available for rapid insertion into the core.

In the operations examples, the ABWR control rods are withdrawn in patterns that are generally similar to curreat reactor withdrawal patterns using the banked position withdrawal eequence (BPWS). The primary difference is that, throughout the withdrawal patterns, multiple rods will be withdrawn simultaneously. Rather than pulling rods individually to provide the step banked patterms of BPWS, the roda in a group will be withdrawn simultaneously by the electric-drive motor aystems. Similar to curreat BPWS patterns, about $1 / 8$ of the 205 control rods in each of the 4 rod groups will be withdrawn to a 50-percent rod density checkerboard pattern (to about hot critical conditions). Because of the rod distribution in the patterns, the total group reactivity worths will not be very large (about 2 percent delta-K each for groups 2, 3, and 4 withdrawal when criticality might be expected). Operational control with this reactivity magnitude, and its accompanying differential reactivity worth, will be straightforward and not significently different from current operation. Groups 3 and 4 (covering cold to hot critical) will be operated in a jog mode to avoid any approach to period scram levels. Beyond 50-percent rod density, the groups will bo divided into groups of four or eight rods that will moved simultaneously, with patterns similar to BPWS and operation similar to BWR/6s. The simultaneous withdrawal for the first 50-percent groups will reduce the maximum reactivity worth, which could be associated with a (postulated) rod drop accident to insignificant levels. In the power range, the ABWR examples use a "control cell core" strategy, which, combined with axial zoning of fuel enrichment and bumable poison, will result in very littlo movement of the control rods over most of the cycle in the normal power operation range. These various control rod operational characteristics are either very similar to current approved operation or are improvements. The operation and characteristics are acceptable.

Design criteria for the core neutronics for the ABWR are included in the fuel design criteria in SSAR Appendix 4B. The nuclear criteria are 4B.4, 1 through 8 . These criteria 
provide for fral and moderator renctivity cosfricieats, shutdown margin, and ful storage, reactivity. Thewe eriteris are in OBSTAR Ameadmeat 22 and are discusead in Section 4.2 of this report in connection with the fuel deaign. Thoy are soceptable.

The staff concludes that on the beris of (1) moeting the relovant fuel licensing acceptance criteria of SSAR Appeadix 4B, (2) the geosenl similarity to curreat operating OB BWR cores, and (3) the additional coneervatian relative to curreat BWRs in the area of power density abd leas negative void coefficient, the ABWR nuclear deaign meets the requiroments of SRP Section 4.3 and is scceptable.

\subsection{Thermal Hydraulic Design}

The NRC anff roviowed the thermal-hydnulic design of the ABWR reactor core in eccordance with SRP Section 4.4. SSAR Section 4.4 describes bow the ABWR mocts ODC 10 and the other requirements of SRP Section 4.4 by direct reference to the fuel licensing scceptunce criteria in SSAR Appendix 4B. As discuned in Section 4.2 of this report, SSAR Appendix 4B contrins criteria on full deaign and rolated noutronic and thermalhydraulic aepects of the fuel deaign. The staff approved these criteria after its reviow of the ABWR fuel system deaign.

OB provided a epecific first cyclo coro design for the ABWR and used this design for system response analysis. As discussed in Section 4.2 of this report, the fuel used in this design is the same as currently approved fuel used in existing BWRs and the core fuel arrangement is similar to current fuel loadings. Alternate fuel loading designs for the first or aubsequent cycles will have to conform to the fuel criteria of SSAR Appendix 4B, or be specifically reviewed and approved by the staff; for the first cycle any changes will have to be reviewed and approved by the NRC, along with any changes nocessary for the analyses of SSAR Chapters 6 and 15. These criteria include the requirements for providing now thermal-hydraulic data such as critical power ratio correlations and limits on fuel stability chanacteristics.

The reference core design is generally similar to current BWR designs. It only differs in relatively small ways in details of the geometry and operating limits, and which result in small differences in neutronic and thermalhydraulic parameters and characteristics. These differences generally reflect a more conservative core neutronic and thermal-hydraulic design and operation than, for example, a BWR/6. The core has a with slightly lower average power density. The fuel bundle and overall core parameters for this deaign fall within the range of applicability of exiating critical power correlativas.

The caly rignificant new dosign feature of the recirculation flow system is the wes of the reactor internal pumpe (RIP). This syetom is discuesed in Section 5.4.1 of this report. This change from current GE BWR design does not produce a significantly different power/flow operation map for the ABWR then that produced by curreat GE BWR, although map paramotors aro slightly changed in some areas. GB provided a power/flow map, corresponding to the coro design (discuseed in SER Sections 4.2 and 4.3 of this report), to be used in systoms reepones analyees. Each COL applicant should provide a plant-epecific power/flow map at the timo of application and for core reloads. This was DFSER COL Action Itom 4.4-1. OB has aleo included this action itom in the SSAR and the staff finds it to bo acceptable. Flow lines and control rod lines of the power/flow map generally will be within the range of operation currently permitted for BWR/6s, although natural circulation occurs at a slightly lower flow. The ABWR is expected to operate with a minimum pump epeed of 30 percent of nominal full-flow epeed, providing a minimum (all pumps operating) flow of about 40 percent. The ABWR design replaces the usual cavitation restriction region with a steam separation limit region to provide for acceptable moisture carryover. There is an interlock to reduce RIP speed to prevent operation in this restricted region. The maximum expected flow for the RIP system is about 115 percent of normal full flow. For the submitted design power/flow map, $G E$ did not consider operating above the 102-percent power control rod line. These power/flow parameters generally are within expected bounds and present an acceptable region for normal operation. As indicated in SSAR Section 4.4.3.2, for normal operation at least 9 of the $10 \mathrm{RIPs}$ are required to be operating. GE has provided a power/flow map for both 9 and 10 RIP operation.

In addition to the above boundaries of the power/flow map, there is a restricted region in the low-flow/high-power areas of the map that is intended to eliminate possible problems with thermal-hydraulic stability. (This is Region III on the map, generally considered to be approximately above the 80-percent control rod line and below the 40-percent flow line.) Operation will not be permitted in this region. Automatic startup logic will be programmed to block rod withdrawal in this region during low power and startup operation and to insert rods to withdraw from the region if entered inadvertently from higher power/flow regions.

In addition to this automatic control, the $A B W R$ has several design features intended to improve the stability 
status of the reactor that are not preseat in curreat resctors. Theme fratures are (1) emaller inlet orifices (lose cosficieat doubled) to incrence singlo-phaco prescure drop, (2) wider control rod pitch to increace flow aren and increases the moderator/fuel ratio and reduce the void reactivity coefficient, (3) more atcam esparators to reduce the two-phese preanuro drop, (4) multiplo RIPs on multiple power aupplies along with minimum pump epeed logic to reduce the likelihood of significant flow low, and (5) regional local power rage monitor (LPRM) and avernge power rnoge monitor neutron flux time hietories available for operator dieplay to dotect oscillations.

The control rod insertion to withdraw from Region III, if entered, will bo provided by the selected control rod run-in system. This system is described in SSAR Section 7.7.1.2. Multiple control rods will be automatically incerted (simultaneously) to move to a stable region (0.8., from the 100-percent control rod line to below 25-percent power if two or more RIPs trip and flow is below the trip en point). Set points for power and flow will be adjuetable and may be changed if stability analyea require it.

The NRC, in parallel with work by the BWR Owners' Group (BWROC) stability sub-committce, hes for somo time bece reviowing generic questions relating to BWR stability. This soviow is atill in progress. Questions concerning the need and the mothods for improved stability control so as not to exceed coro thermal-hydraulic safety limits and to understand and control, if necessary, adverse affects of power oscillation during anticipated transient without scrum (ATWS) events are escentially complete. The ABWR design features indicated above are desirable for improving inherent stability and the system for control rod blocking and insertion to provide exclusion from Region III are consistent with some of the proposed long term solutions (LTS) for current BWRs. The BWROG has developed several (LTS that have been approved by the NRC for application to operating reactors. The region exclusion system for the ABWR is similar to the BWROG LTS Option IA. In response to a staff question requesting reviow of the recent LTS work and the possibility of its application to the ABWR, GE has stated that in addition to the region exclusion syatem, the BWROO Option III system, the oscillation power range monitor, which is based on the detection of oscillation signals by the LPRMs, will be implemented in the ABWR design (seo SSAR Section 7.6.1.1.2.2). This LTS methodology has been accepted by the staff (letter from A. Thadani, NRC, to L. England, BWROG, "Acceptance for Referencing of Topical Reports NEDO-31960 and NEDO-31960 Supplement 1, 'BWR Owners Group Long-Term Stability Solution Licensing Methodology ") and is considered to be accoptable for the ABWR.
In the DFSER, the staff stated that the information presented by $G E$ and the staff review of the subject of instability during ATWS tnasients was not complete. This Wes DFSER Open Itom 4.4-1. GE subsequently submittod - report deacribing their analyeses of oscillations during limiting ATWS tranients susceptible to thermal-hydraulic instability and possibly large oscillations (Ref: GE ATWS Stability study, February 19, 1993, OE transmitted by letter dated Fobruary 22, 1993). GE performed calculations using the TR ACr code, which has been used for atability studies for operating BWRs and has been auditod by the staff. The ABWR calculations were reviewed by the staff and its consultants, and the stability characteristics of the ABWR have been explored using the Oak Ridge National Laboratory LAPUR code, commonly used by the stuff for stability analyses. The LAPUR calculations showed, in accord with GE findings, that the $A B W R$ is more stable than most current BWRs and will have smaller power oscillations, if any, at comparable operating conditions. The GE TRACG calculations appear to bound the worst expected ATWS conditions for instability and do not result in exceeding ATWS fuel failure limit criteria. The ABWR mitigating actions are similar to the BWROG proposed actions for current BWRs, and in SSAR Section 4.4.3.7 states that the ABWR omergency procedure guidelines will incorporate any changes recommended by the BWROG committee on thermal-hydraulic stability. There is automatic feedwater reduction and boron injection via the standby liquid control system. The feedwater runback and lowering of reactor lovel below the feedwater spargers are very effective in reducing oscillations magnitudes. The TRACG modelling and input for these calculations were found to be acceptable. The staff concludes that the issue of instability induced large power oscillations during ATWS has been properly addressed for the ABWR. GE has also included this information in the SSAR and the staff find it to be acceptable. On the basis of this evaluation, this item is resolved.

The ABWR design, as initially presented, did not include a looso-parts monitoring system (LPMS). However, in response to the staff position that an LPMS is required, GE submitted an LPMS general description, including a design basis, system description, system operation, safety ovaluation, test, and inspection and application. This system is designed in conformance with Regulatory Guide (RG) 1.133, "Loose-Parts Detection Program for the Primary System of Light-Water-Cooled Reactors," Revision 1. The system includes sensors (accelerometers located at natural loose parts collection regions, e.g., steam outlet nozzle, feedwater inlet nozzle, control drive housings), signal conditioning, signal analysis, alarms, and calibration. The sensitivity is such that a sensor will bo able to detect a metallic part between $0.1-14 \mathrm{~kg}$ (0.25 to 
$30 \mathrm{lbs}$ ) with a kinetic energy of 0.7 joule $(0.5 \mathrm{ft}-1 \mathrm{~b})$ on an inside surface within $1 \mathrm{~m}$ (3 ft) of a sensor. There will be provisions for online channel checks and functional tosts and offline calibration. The system is designed to moet the seismic and environmental operability recommendations of RG 1.133, Revision 1. OE has provided an ITAAC for the LPMS as part of its Tier 1 certified design material submittal. It provides for design commitment for detector locations and sensitivity with appropriate accompanying inspections, tests, and criteria. In the DFSER, the staff stated that, as DFSER Open Item 4.4-2, Certified Design Commitment 1 in the LPMS ITAAC should be expanded to explicitly state that the LPMS design is consistent with the requirements of RG 1.133, Revision 1. This has been done; therefore, DFSER Open Item 4.4-2 is resolved. GE has submitted the Design Description, the ITAAC for the LPMS. The adequacy at acceptability of the ABWR Design Description and ITAAC are evaluated in Section 14.3 of this report. On the basis of this evaluation, this open item is resolved.

Core flow patterns are expected to be uniform at the core inlet during normal operations as a result of flow distributions from the downcomer through the RIPs, into the lower plenum, up through the orifices of the lower core plate, and into the fuel assemblies. TS will require for normal operation that at least 9 of the 10 RIPs are operating. Operation with fewer than 9 RIPs operating will require supporting analyses and justification by the COL applicant. This was DFSER TS Item 4.4-1. GE asserts that, with the allowed number of RIPs inoperable, pump operation will be close to normal and bounded by one recirculation loop operation in current jet pump BWRs (with, in effect, half the pumps out) for which there are no restrictions other than similar-type LOCA power-density restrictions. The restriction to no fewer than 9 RIPs operating is a recent modification of SSAR Section 4.4 and of the TS, and therefore, DFSER TS Item 4.4-1 is resolved. The restriction and specification are acceptable. The staff requested GE to provide existing flow test information. This was DFSER Confirmatory Item 4.4-1. GE has provided references in SSAR Section 4.4 to such information on current reactors relevant to the above restricted modes of operation. GE has also included this information in the SSAR and the staff finds it to be acceptable. Therefore, DFSER Confirmatory Item 4.4-1 is resolved.

\subsection{Reactor Materials}

\subsubsection{Control Rod Drive System Structural Materials}

The acceptence criteria used as the bases for the staff's evaluation of control rod drive (CRD) structural materials are SRP Section 4.5.1. The CRD structural materials are acceptable if they meet the relevant requirements of: GDC 1 as it relates to structures, systems, and components important to safety being designed, fabricated, orected, and tested to quality standards commensurate with the importance of the safety functions to be performed; ODC 14 as it relates to the reactor pressure boundary being designed, fabricated, erected and tested 80 as to have an extremely low probability of abnormal leakage, of rapidly propagating failure and of gross rupture; GDC 26 as it relates to the control rod being capable of reliably controlling reactivity changes so that specified acceptance fuel design limits are not exceeded; and Section 50.55a, of Title 10 of the Code of Federal Regulations, Part 50 as it relates to structures, systems, and components shall be designed, fabricated, erected, constructed, tested, and inspected to quality standards commensurate with the importance of the safety functions to be performed.

The SSAR states that the properties of the materials selected for the ABWR CRD mechanism will be equivalent to those given in Appendix I to Section III of the American Society of Mechanical Engineers (ASME) Code; Parts A, B, and C of Section II of the ASME Code; and RG 1.85. No cold-worked austenitic stainless steels except those with controlled hardness or strain are employed in the CRD system. All materials used in this system will be selected for their compatibility with the reactor coolant as described in Articles NB-2160 and NB-3120 of the ASME Code. The materials selected as identified in SSAR Section 4.5.1 will be resistant to stress corrosion in a BWR environment. The controls imposed on the austenitic stainless steel of the CRD mechanism conform to the recommendations of RGs 1.31, "Control of Ferrite Content in Stainless Stoel Weld Metal," (Revision 3) and 1.44, "Control of the Use of Sensitized Stainless Steel," (Revision 0).

All materials selected for application in CRD mechanism components will conform with the ASME Code Section III or RG 1.85. Fabrication and heat treatment practices performed in accordance with the Code and regulatory guide provide added assurance that stress corrosion cracking will not occur during the design life of the components. Both martensitic and precipitation-hardening stainless steels will be given tempering or aging treatments in accordance with staff positions. Cleaning and cleanliness control will be in accordance with American National Standards Institute Standard N 45.2.1-1973, "Cleaning of Fluid Systems and Associated Components During Construction Phase of Nuclear Power Plants, " and RG 1.37, "Quality Assurance Requirements for Cleaning of Fluid Systems and Associated Components of WaterCooled Nuclear Power Plants," Revision 0.

The information in the SSAR meets the criteria in SRP Section 4.5.1. The staff concludes that the structural 
materials for the CRD mechanism conform to the staff's regulatory guidance to ensure that the requiroments of GDC 1, 14, and 26 of Appendix A to 10 CFR Part 50 and the requirements of 10 CFR 50.55a are satisfied. This is ecceptable.

\subsubsection{Reactor Internal Materials}

The acceptance criteria used as the bases for the staff's evaluation of reactor internal materials are SRP Section 4.5.2. The reactor internals are acceptable if the design, fabrication, and testing of the materials used in the reactor internal and core support structures meet the code and standards commensurate with the safety function to be performed so that the relevant requirements of GDC 1 and Section 50.55a of Title 10 of the Code of Federal Regulations, Part 50 are met.

The SSAR states that the requirements of GDC 1 and 10 CFR 50.55a will be met with regard to ensuring that the design, fabrication, and testing of the materials used in the reactor internal and core support structures are of high quality standards and adequate for structural integrity. The controls imposed on components constructed of austenitic stainless steel will satisfy the recommendations of RGs 1.31 and 1.44 .

The materials to be used for the construction of components of the reactor internals and core support structures were identified in SSAR Section 4.5.2 by specification and found to be in conformance with the requirements of NG-2000 of Section III and Parts A, B, and $C$ of Section II of the ASME Code. Extensive tests and satisfactory performance have shown that the specified materials are compatible with the BWR environment. The controls imposed on the reactor coolant chemistry satisfy the chemistry limits specified in EPRI report NP-4947, "BWR Hydrogen Water Chemistry Guidelines 1987 Revision," December 1988. This will provide reasonable assurance that the reactor internal and the core support structures will be adequately protected during operation from conditions that could lead to stress corrosion, including irradiation-assisted stress corrosion cracking and loss of component structural integrity.

The materials selection, fabrication practices, examination and testing procedures, and control practices provide reasonable assurance that the materials used for the reactor internal and core support structures will be maintained in a metallurgical condition that will preclude inservice deterioration. Conformance with the requirements of the ASME Code constitutes an acceptable basis for meeting, in part, the requirements of GDC 1 and 10 CFR 50.55a.
The staff finds that the information in the SSAR related to reactor internal materials meets the criteria of SRP Section 4.5.2 and is, therefore, acceptable.

\subsection{Functional Design of Fine Motion Control Rod Drive System}

The staff reviewed the fine motion control rod drive (FMCRD) system in accordance with SRP Section 4.6. The staff performed an audit review of each of the areas listed in the "Areas of Review" portion of the SRP section according to the guidelines provided in the "Review Procedures" section of the SRP section. Conformance with the acceptance criteria formed the basis for the staff's evaluation of the CRD system with respect to the applicable regulations of 10 CFR Part 50.

The ABWR incorporates electric-hydraulic FMCRDs, which provide electric fine rod motion during normal operation and hydraulic pressure for scram insertion. Fine motion during normal operation is provided by a ball nut and spindle arrangement driven by the electric stepper motor. In response to a scram signal, the control rods are inserted hydraulically via the stored energy in the scram accumulator similar to the current operating BWR CRDs.

A scram signal is also given simultaneously to insert the FMCRDs electrically via the FMCRD motor drive. This diversity, hydraulic and electric methods of scramming provides a high degree of assurance of rod insertion on demand.

The FMCRD and recirculation flow control system (RFCS) are designed to control reactivity during power operation. Reactivity will be controlled in the event of fast transients by automatic rod insertion. During ATWS conditions, the internal recirculation pumps will be tripped automatically. In the event the reactor cannot be shut down with the control rods, the operator can actuate the standby liquid control system (if not automatically started) that pumps a solution of sodium pentaborate into the primary system. The evaluation of the functional design of the standby liquid control system is addressed in Section 9.3.5 of this report. This evaluation resolved Open Item 15 from the DSER (SECY-91-153). Compliance with the ATWS rule is discussed in Section 15.5 of this report.

Reactivity in the ccre will be controlled by the FMCRD by moving control rods interspersed throughout the core. These rods will control the reactor's overall power level and will provide the principal means of quickly and safely shutting down the reactor. 
GE submittod a proprietary failure modes and offects analysis for the FMCRD system. The singlo-failure analysis of the FMCRD and hydraulic control unit (HCU) components indicates that the system design is satisfactory. This resolved Open Item 17 from the DSER (SECY-91-153). A supply pump (with a spare pump on standby) will provido the HCUs with water from the condensato treatment system and/or condensate storage tank to supply CRD purge water and to supply the purge water to the RIPs and reactor water cleanup pumps. The supply pump also will provide water to a scram accumulator in each HCU to maintain the desired water inventory. When necessary, the accumulator will force water into the drive system to scram the control rods connected to that HCU; the volume of water in the scram accumulator will be sufficient to scram two rods. A single failure in an HCU would result in the failure of two rods only. The failed rods would not be adjacent; they would be sufficiently separated $s 0$ that the reactivity offect would essentially be the same as for the failure of one rod in current BWRs. Therefore, adequate shutdown margin exists with a single HCU failure even though the HCU is shared by two drives.

The FMCRD is designed to permit periodic functional testing during power operation with the capability to independently test individual scram channels and motion of individual control rods. The FMCRD is also designed so that failure of all electrical power or instrument air will cause the control rods to scram, thereby protecting the reactor. This satisfies the protection system failure modo requirements of GDC 23.

Preoperational tests of the CRD hydraulic system will be conducted to verify the capability of the system. Startup tests will be conducted over the range of temperatures and pressures from shutdown to operating conditions to determine compliance with applicable TS. Each rod that is partially or fully withdrawn during operation will be exercised one notch at least once each week. After each refueling shutdown, control rods will be tested for compliance with scram time criteria from the fully withdrawn position.

The FMCRD is designed to control reactivity under normal operating conditions and during articipated operational occurrences. This capability is demonstrated by the safety analyses discussed in SSAR Chapter 15 (including effects of stuck rods). This CRD system also will be capable of holding the core subcritical under cold shutdown conditions. The RFCS will be capable of accommodating reactivity changes during normal operating conditions. The standby liquid control system will be capable of bringing the reactor subcritical under cold shutdown conditions in the event the control rods cannot be inserted.
These protection and renctivity control systems, taken together, satisfy the requirements of GDC 26, 27, and 29 pertaining to reactivity control system redundancy and capability, combined reactivity control system capability, and protections against anticipated operational occurrences.

The control rod system design incorporates appropriate limits on the potential amount and rate of reactivity increase. Control rod withdrawal sequences and patterns will be selected to achieve optimum core performance and low individual rod worths. The rod control and information system (RCIS) will reduce the chances of withdrawal other than by the preselected rod withdrawal pattern. The RCIS function will assist the operator with an effective backup control rod monitoring routine that enforces adherence to established control rod procedures for etartup, shutdown, and low-power-level operations.

A malfunction in the FMCRD could result in a reactivity change. GE demonstrated in SSAR Chapter 15 that the FMCRD system will limit these postulated transients to within acceptable fuel design limito, as required by GDC 25.

The control rod mechanical design incorporates a brake system and ball check valve, which will reduces the chances of rapid rod ejection. This engineered safeguard will protect against a high reactivity insertion rate from a potential control rod ejection. Normal rod movement and the rod withdrawal rate will be limited through the FMCRD.

GE adopted an internal CRD housing support to replace the support structure of beams, hanger rods, grids, and support bars used in current BWR designs. This system will use the outer tube of the drive to provide support. This tube will be welded to the drive middle flange and will attach by a bayonet lock to the guide tube base. The guide tube, supported by the housing extension, will prevent downward movement of the drive in the event of housing failure. The CRD housing support is designed to prevent ejection of a CRD and attached control rod.

The FMCRD is designed to detect separation of the control rod from the drive mechanism. Two redundant and separate Class 1E switches will be provided to detect the separation of either the control rod from the hollow piston or the hollow piston from the ball nut. Actuation of either of these switches will cause an immediate rod block and will initiate an alarm in the control room, thereby reducing the chances of a rod drop accident. The ABWR control rod design does not include a velocity limiter because of the design features described. The design features of the reactivity control system will limit the potential amount 
and rate of reactivity increase to ensure that GDC 28 is satisfied for postulated reactivity accidents.

Tho safety concerns associatod with a pipo break, given in NUREG-0803, "Safety Concerns Associated With a Pipe Break in the BWR Scram System," are not applicable for the ABWR. The ABWR design does not include scram discharge volume piping. The water displaced by the CRD during the scram will be routed to the reactor pressure vessel.

Nitrogen charge pressure for the CRD accumulator is substantially increased in the ABWR design. The initial $\mathrm{N}_{2}$ charge pressure will be $1,4817 \mathrm{kPa}(2,134 \mathrm{psig})$ compared with a maximum of $10,446 \mathrm{kPa}(1,500 \mathrm{psig})$ for the operating BWRs. GE's calculations have verified that even with initial $\mathrm{N}_{2}$ charge pressure of $12,859 \mathrm{kPa}$ (1,850 psig), there is sufficient differential pressure to drive the CRD fully with a reactor pressure of $9,584 \mathrm{kPa}$ (1,375 psig). (The peak calculated reactor pressure for a main steam isolation valve closure event during ATWS is leas then 9,584 $\mathrm{kPa}(1,375$ psig)). The calculations have shown that at 4.53 seconds, when the CRD is fully inserted, the accumulator $\mathrm{N}_{2}$ charge pressure is calculated 2s $10,625 \mathrm{kPa}(1,526 \mathrm{psig})$ with reactor pressure at $9,584 \mathrm{kPa}(1,375 \mathrm{psig})$. There is a remaining differential pressure of $166 \mathrm{kPa}$ (151 psid), demonstrating that accumulator pressure is more than adequate for the rod insertion.
GE submitted the LaSalle test report on FMCRD in-plant toet program by letter dated October 12, 1989. This report is proprietary. The in-plant tost shows that the basic design of the FMCRD is acceptable. There is significant operating experience with the FMCRDs. In Europe, 2,700 drives are in service with over 15,000 drive years of experience. Thus, FMCRDs in BWRs, are a proven tochnology. Open Item 16 in the DSER (SECY-91-153) was resolved in the DFSER.

GE submitted the design description and the ITAAC for the FMCRD system. This was DFSER Open Item 4.6-1. GE has provided a revised set of design descriptions and ITAAC. The adequacy and acceptability of the ABWR design descriptions and ITAAC are evaluated in Section 14.3 of this report. On the basis of this evaluation, this open item is resolved.

The staff concludes that the functional design of the reactivity control system conforms to the requirements of GDC 23, 25, 26, 27, 28, and 29 with regard to demonstrating the ability to reliably control reactivity changes under normal operation, anticipated operational occurrences, and accident conditions, including single failures. The design of the reactivity control system conforms to the applicable acceptance criteria of SRP Section 4.6, and is acceptable. 


\section{REACTOR COOLANT SYSTEM AND CONNECTED SYSTEMS}

\subsection{Introduction}

The reactor coolent systems (RCS) and connected absystems are evaluated in the following sections.

\subsection{Integrity of Reactor Coolant Pressure Boundary}

\subsubsection{Compliance With Code and Code Cases}

The staff reviewed the measures used to provide and maintain the integrity of the reactor coolant pressure boundary (RCPB) and other pressure-retaining components and their supports that are important to safety for the design lifetime of the plant.

\subsubsection{Compliance With 10 CFR 50.55a}

According to 10 CFR 50.55a, components important to safety are subject to the following:

(1) RCPB components must meet the requirements for Class 1 (Quality Group (QG) A) components specified in ASME Code, Section III, except for those components that meet the exclusion requirements of 10 CFR $50.55 a(c)(2)$.

(2) Components classified as QG B and C must meet the requirements for Class 2 and 3 components, respectively, specified in ASME Code, Section III.

SSAR Table 3.2-1 classifies the pressure-retaining components of the RCPB as ASME Code, Section III, Class 1 components. These Class 1 components are designated QG $A$ in conformance with Regulatory Guide (RG) 1.26, "Quality Groups Classifications and Standards for Water-, Steam-, and Radiosctive-Waste-Containing Components of Nuclear Power Plants," Revision 3. The staff reviewed the QG A RCPB components in accordance with SRP Section 5.2.1.1, as discussed below.

In addition to the QG A components of the RCPB, certain lines that will perform a safety function and that meet the exclusion requirements of $10 \mathrm{CFR} 50.55 \%(c)(2)$ are classified as QG B in accordance with Position C.1 of RG 1.26, Revision 3, and will be constructed as ASME Code, Section III, Class 2 components. The staff's review of these components and other pressure-retaining components that will be constructed to ASME Code, Section III, Class 2 and Class 3 specifications, is discussed in Section 3.2.2 of this report.

SRP Section 5.2.1.1 recommends that safety analysis reports for both construction permits and operating licenses contrin a table identifying the ASME component code, code edition, and applicable addenda for all ASME Code, Section III, Cless 1 and 2 pressure vessel components, piping, pumps, and valves in the RCPB. SSAR Section 5.2.1.1 states that the ASME Code edition, applicable addenda, and component dates will be in accordance with 10 CFR 50.55a and that ASME Code, Section III, will be used for the design of ASME Code Class 1, 2, and 3 pressure retaining components and their supports. The epecific edition and addend are given in SSAR Tables 1.8-21 and 3.2-3. The ASME Code is considered Tier 1 information; however, the specific edition and addenda are considered Tier 2 information partly because of the continually evolving design and construction practices (including inspection and examination techniques) of the Code. Fixing a specific edition and addenda during the design certification stage might result in inconsistencies between design and construction practices during the detailed design and construction stages. The ASME Code involves a consensus process to reflect the evolving design and construction practices of the industry. Although reference to a specific edition of the Code for the design of ASME Code Class components and their supports is suitable to reach a safety finding during the design certification stage (as reflected in the discussion of the reactor pressure vessel (RPV) design in Section 5.2.4 of this report), it is necessary that the construction practices and examination methods of an updated Code that would be effective at the COL stage be consistent with the design practices established at the design certification stage.

To avoid this potential inconsistency for the advanced boiling water renctor (ABWR) pressure-retaining components and their supports, it is appropriate that the ASME Code be specified as Tier 1 information and the specific edition and addenda as Tier 2 information so that the COL applicant has the option to revise or supplement the referenced Code edition with portions of the later Code editions and addenda and still ensure consistency between the design and construction practices. In this manner, consistency with the latest design, construction, and examination practices also is ensured. However, the staff finds that there might be a need to fix certain design parameters from a specific Code edition or addenda during its design certification review particularly when that information is important for establishing a significant aspect of the design or is used by the staff to reach its final safety determination. Such considerations, if necessary, are reflected in the various sections of this report.

Therefore, all ASME Code, Class 1, 2, and 3 pressure-retaining components and their supports shall be designed in accordance with the requirements of ASME Code, Section III, using the specific edition and addenda 
given in the SSAR. The COL applicent should ensure that the design is consistent with the construction prectices (including inspection and examination mothods) of the ASME Code edition and addeadn in effect at the timo of the COL application, as eadoreed in 10 CFR 50.55a. Tho COL applicant should ideatify in its application the portions of the later code editions and addenda for NRC staff roviow and approval. This was DFSER COL Action

\section{NCA-1140 Rules}

NCA-1140(a)(1) - Under the rules of this Section, the owner or his designes shall establish the Code edition and addenda to be included in the Design Specifications. All items of a nuclear power plant may be constructed to a singlo Code edition and addenda, or each item may be constructed to individually specified Code editions and addenda.

NCA-1140(a)(2) - In no case shall the Codo edition and addenda dates established in the Design Specifications bo earlier than 3 years prior to the date that the nuclear power plant construction permit application is docketed.
NCA-1140(b) - Code oditions and addenda later than those established by (a) above may be used by mutual consent of the owner or his designee and certificate holder. For Division 2 design and construction, the consent of the designer shall also be obtained. Specific provisions within an odition or addenda later than those established in the design specifications may be used, provided that all related requirements are met.

NCA-1140(c) - Codo Cases are permissible and may be used beginning with the date of approval by the ASME Council (and the American Concrete Institute for Division 2 design and construction). Only Code Cases that are specifically identified as being applicable to this Section may be used.
Item 14.1.3.3.2.1-1. The resolution of this item is discuseed in Section 3.12.2.1 of this report.

Since the above position is not totally consistent with ASME Code, Section III, Subeection NCA-1140, "Use of Code Editions, Addenda, and Cases," the following comparison is provided:

\section{Design Certification Position}

(1) The vendor must specify the Code edition and addenda in the SSAR during design certification. The COL applicant may update the Code edition or addenda (or portions thereof) referenced in the SSAR using a process similar to that specified in 10 CFR 50.59 without prior NRC approval unless the proposed change involves change to the certified design or an unreviewed safety question. The COL applicant may update the referenced edition or addenda for all items of a nuclear power plant or a specific item if the construction practices (including fabrication, inspection, and examination methods) are not compatible with the design requirements. All changes to the referenced edition and addenda must be documented and maintained by the COL applicant and must be available for audit.

(2) The specific Code edition and addenda are required to be established during design certification except for Section XI requirements related to inservice inspection (ISI), inservice testing, and system pressure tests, which must meet the requirements of 10 CFR $50.55 \mathrm{a}(\mathrm{f})$ and $(\mathrm{g})$. Further discussions and any exceptions to 10 CFR $50.55 \mathrm{a}(\mathrm{f})$ and $(\mathrm{g})$ are noted in Sections 5.2.4 and 6.6 of this report.

(3) This is acceptable subject to the conditions noted in Position (1) above.

(4) As discussed in Section 5.2.1.2 of this report, only those Code Cases identified in RG 1.84, Revision 24, or 1.85, Revision 24, as specified in the SSAR may be used. The COL applicant may submit for staff review and approval future Code Cases that are endorsed in future revisions of RGs 1.84 and 1.85 with its COL application, provided these cases do not involve a change to the certified design or an unreviewed safety question. 


\section{NCA-1140Rule:}

NCA-1140(d) - Codo Cases may be used by mutual consent of the owner or his deaignee, and the certificate holder on or after the date permitted by (c) above. For Division 2 design and construction, the consent of the deaigner shall also be obtained.

NCA-1140(e) - Existing materials previously produced and certified in accordance with Code editions and addenda carlier than the one specified for construction of an item may be used, provided all of the following requirements are satisfied.

(i) The material (NCA-1220) moets the applicable requirements of a material epecification permitted by paragraph 2121 of the applicable subecction of the Section III edition and addenda specified for construction.

(ii) The material meots all the requirements of Article 2000 of the applicable Subeection of the Section III edition and addenda spocified for construction.

(iii) The material was produced under the provisions of a quality systom program that had been acceptod by the society or qualified by a party other than the rociety (NCA-3820), in accordance with the requirements of the lateet Soction III edition and addenda iseved at the time the material was produced. Material exempted from portions of the provisions of NCA-3800 by paragraph 2610 of the applicable Subsection of Section III may be used, provided the requiroments of (i) and (ii) above are met.

NCA-1140(t) - Code editions, addenda (including the use of specific provisions of editions addenda permitted by (b) and (e) above), and Cases used shall be reviewed by the owner or his designee for acceptability to the regulatory and enforcement authorities having jurisdiction at the nuclear power plant aite.

\section{Deain Certification Position}

(5) Codo Cases to be used in the design of the standard plant must be identified by the vendor in the SSAR during deaign certification.

(6) Does not apply to design certification.

(7) The vendor must specify the Code edition and addenda in the SSAR during design certification. Use of later editions and addenda (or portions thereof) and Code Cases not approved during design certification must be reviewed by the COL applicent or its designee for acceptability to the regulatory and enforcoment authorities having jurisdiction at the nuclear power plant site. 


\subsection{Conclusion}

The staff concludes that the construction of all ASMB Code, Clase 1, 2, and 3 components and their aupports will conform to the appropriate ASME Code editions and addeade and the Commisaion's regulations and that component quality will be commensurate with the importance of the anfoty function of all auch components and their supports. This constitutes an scceptable basis for satisfying GDC 1 and is acceptablo.

\subsubsection{Applicable Code Cases}

SSAR Table 5.2-1 identifies specific ASME Code Cases that will bo applied in the construction of pressure-retaining ASME Code, Section III, Class 1, 2, and 3 components. The staff's review of this table is based on the guidolines in RG 1.84, "Design and Fabrication Code Case Acceptability - ASME Soction III, Division 1," and RG 1.85, "Materials Codo Caso Acceptability - ASME Section I!, Division 1." All ASME Code Cases that have been either conditionally or unconditionally cadoreed by the staff are discused in one of these RGs, as applicable. Table 5.2-1 of the SSAR lists 15 code cases that will be used in the design of the ABWR. All of these code cases have been endorsed by the staff and are included in one of the above RGs.

In SSAR Sections 3.9.3.4 and 3.9.3.5, Code Case N-476, "Class 1, 2, 3, and MC Linear Component Supports Design Criteria for Single Angle Members, Section III, Division 1, Subsection NF," is referenced as augmenting ASME Subsection NF rules for the design of component supports. As stated in Section 3.9.3.3 of this report, the staff finds this code case acceptable. Therefore, it will be an acceptable addition to SSAR Table 5.2-1.

The only acceptable ASME Code Cases that may be used for the design of ASME Code, Class 1, 2, and 3 piping systems in the ABWR standard plant are those either conditionally or unconditionally approved in RGs 1.84 and 1.85 in effect at the time of deaign certification. However, the COL applicent may submit, with its $\mathrm{COL}$ application, future code ceses that are endoreed in RGs 1.84 and 1.85 at the time of the application provided they do not alter the staff's safety findings on the ABWR certified design. In addition, the COL applicant should submit those Code Cases that are applicable to RG 1.147, "Inservice Inspection Code Case Acceptability - ASME Section XI, Division 1," which is in effect at the time of the COL application.

The staff concludes that all of the Code Cases in SSAR Table 5.2-1 either meet the guidelines of RG 1.84 or 1.85 or have beew reviewed and endorsed by the staff and are acceptable for use on the ABWR design. Compliance with the requirements of these Code Cases will result in a component quality that is commensurate with the importance of the eafety functions of these components, conetitutes the besis for satisfying GDC 1, and is ecceptable.

\subsubsection{Overpressure Protection}

The staff evaluated overpressure protection in the ABWR in accordance with SRP Section 5.2.2, which states that the acceptance criteria also are based on GDC 31 as it relates to the fracture behavior of the RCPB. This roview area is addressed in Section 5.3.1 of this report. SRP Section 5.2.2 also states that overpressure protection during low-temperature operation need not be considered for BWRs, since BWRs never operate in water solid conditions. Hence, overpressure protection during low-temperature conditions is not addressed for the ABWR.

The RCPB is designed with a pressure relief system to:

- prevent the pressure in the RCPB from rising beyond 110 percent of the design value

- provide automatic depressurization if small breaks in the nuclear system should occur together with failure of the high-pressure core flooder (HPCF) and reactor core isolation cooling (RCIC) system. (This depressurization will allow operation of the low-pressure flooder systems to protect the fuel barrier.)

To be acceptable, the pressure relief system must permit verification of its operability and must withstand adverso combinations of loadings and forces resulting from normal; upset, emergency, and faulted conditions.

Overpressure protection in the ABWR will be provided using 18 afety/relief valves (SRVs); of which 8 are part of the automatic depressurization system (ADS). The 18 SRVs are divided into six nominal pressure set point groups and mounted on the four main steamlines (MSLs) between the reactor vessel and the first isolation valve inside the drywell. The SRVs will discharge through piping to the suppression pool. The design of the ABWR pressure reliof system is similar to that for BWR 4, 5, and 6 plants.

The SRV8 are classified as QG A and seismic Category I, as shown in SSAR Table 3.2. The SRV s are designed to moet RGs 1.26, Revision 3, and 1.29, "Seismic Design Classification," Revision 3. 
The nominal presaure set points of the SRVs will be distributed in six valve groups with a minimum set point of 7.9 MPa (1,149.2 psig) and a maximum of 8.2 MPa (1,189.0 paig) in the safety mode of operation. The nominal preseure set points of the SRVs in the relief mode of operation will be at a minimum of $7.5 \mathrm{MPa}$ (1,089.5 paig) and maximum of $7.9 \mathrm{MPa}(1,139.2 \mathrm{prig})$. The SRVs can also be operated in the relief mode by remoto-mnnual controls from the main control room. Four SRV s can aiso be operated from the remoto shutdown panol. The offects of flow-induced SRV diecharge line beckpresure on the performance of the SRV are addresed by sixing the line to ensure that the steady-etate beckpreserure does not exceed 40 percent of the SRV inlet pressure. These sizing criteria control the effective beckpreacure buildup and maintain the required forco balance needed to keep the SRV open and to permit proper blowdown.

In the DFSER, the staff noted that before the valves are installed, the SRV manufacturer will test them hydrostatically sccording to ASME Code, Section III requirements. During startup testing, opening response time and set pressure tests will be conducted to verify that design and performance requirements havo been met. This was DFSER COL Action Item 5.2.2-1. Since these tests are being addreseed in Chapter 14 of the SSAR, they need not be specified as a COL action item. Therefore, COL Action Item 5.2.2-1 is resolved.

GDC 15 defines the basis for overpressurization protection in a nuclear resctor. It requires that the RCPB design conditions not be exceeded during any condition of normal operation, including anticipated operational occurrences. To satisfy this criterion, the overpressurization protection system for the $A B W R$ is designed in compliance with ASME Code, Section III, which requires that the maximum pressure reached during the most severe pressure transient be less than 110 percent of the design pressure. For the ABWR, that pressure limit is $9.5 \mathrm{MPa}$ (1,375.3 psig). GE analyzed the series of transients that would be expected to require SRV actuation to prevent overpressurization. The analysis was performed using the computer-simulation model ODYNA. ODYNA is the $A B W R$ version of ODYN incorporating changes unique to the ABWR such as reactor internal pumps (RIPs). ODYN is described in GE Topical Report NEDO-24154. The ataff reviewed ODYN and found it acceptable as documented in "Safety Evaluation for the General Electric Topical Report Qualification of the One-Dimensional Core Trunsient Model for Boiling Water Reactors, NEDO-24154 and NEDO-24154-P Volumes I, II, III, June 1980." The staff performed an audit of ODYNA and found the changes to be acceptable. The acceptability of ODYNA for ABWR transient analysis is discussed in Section 15.1 of this report. The analysee show that the maximum pressure will remain below the 9.5-MPa (1,375.3-psig) limit. For the most severe transient (i.e., closure of all main steam isolation valves (MSIV8) with a high neutron flux scram), the maximum vessel bottom pressuro is calculated to be 8.8 MPa (1274.4 psig) when all 18 SRVs are assumed to operato in the safety mode. The analysis acoumed that the plant was operating at 102.7 percent of rated steam flow of $7.85 \times 10 \mathrm{E}+6 \mathrm{~kg} / \mathrm{hr}$ (about $17 \times 10 \mathrm{E}+6 \mathrm{lb} / \mathrm{hr}$ ) and a veeeel domo preseure of $7.2 \mathrm{MPa}(1,040 \mathrm{psig})$. This is consistent with SRP Section 5.2.2 and is acceptable.

GE besed the sizing of the SRVB on the initiation of a reactor scram by the high-neutron flux scram, which is the second safety-grade scram signal from the reactor protection system following MSIV closure. The staff believes that the qualification and redundance of reactor protection system equipment, coupled with the fact that the reactor vessel pressure is limited to less than 110 percent of design pressure, provides adequate assurance that the rewctor vessel integrity will be maintained for the limiting transient event.

The staff evaluation of TMI-2 Action Items (NUREG-0737 requirements that are incorporated into 10 CFR 50.34(f)(1)(vi), (1)(v), (2)(vi), 2(x), and (2)(xi)), as related to SRVs, is discussed in Chapter 20 of this report.

GE performed the overpressure protection analysis for a core loading pattern, which is described in Chapter 4 of the SSAR.

GE originally submitted the design description and the inspection, test, analysis, and acceptance criteria (ITAAC) for SRVB. At the time the DFSER was issued, the ITAAC review was in progress. Therefore, this was DFSER Open Item 5.2.2-1. GE has since submitted revised design description and ITAAC in its certified design material (CDM). The adequacy and acceptability of the CDM are evaluated in Chapter 14.3 of this report. Therefore, this item is resolved.

The staff concludes that the pressure relief system, in conjunction with the reactor protection system, will provide adequate protection against overpressurization of the RCPB and that the overpressurization system is acceptable and meets the relevant requirements of GDC 15.

\subsubsection{Reactor Coolant Pressure Boundary Materials}

The staff reviewed RPCB materials in accordance with SRP Section 5.2.3. The RPCB materials are acceptable if they meet the requirements of (1) GDC 1 and 30 as related 
to quality standards for design, fabrication, orection and tosting; (2) GDC 4 as related to compatibility of components with environmental conditions; (3) ODC 14 and 31 as related to extremely low probability of rapidly propagating fracture and gross rupture of the RCPB; (4) Appendix B to 10 CFR Part 50 as relatod to onsito matorial cleaning control; (5) Appendix G to 10 CFR Part 50 as related to material teating and acceptance criteria for fracture toughnese of the RCPB; and (6) 10 CFR 50.55a as related to quality standards and fracture toughneas.

In the DSER (SECY-91-153), the staff noted that the materials used for the construction of RCPB components had been identified by specification and were in conformance with Section III of the ASME Code and NUREG-0313. However, the staff requested that GE use Revision 2 (not Revision 1 as proposed by GE) of NUREG-0313. GE revised the SSAR (Amendment 14) to reference NUREG-0313, Revision 2. GE's compliance with the provisions of the Code for material specifications and conformance with NUREG-0313, Revision 2, satisfy the quality standards of GDC 1 and 30 and 10 CFR 50.55a.

In the DFSER, the staff noted that the construction materials for the RCPB had been identified in SSAR Table 5.2-4 and were compatible with the primary coolant water, which will be chemically controlled in accordance with appropriate technical specifications (TS). This was DFSER TS Item 5.2.3-1.

GE addressed DFSER TS Item 5.2.3-1 in its April 16, 1993, submittal, "Responso to TS Items in ABWR DRAFT FSER," which stated that the reactor coolent chemistry limits had been removed from the improved TS (NUREG-1433 and -1434) and thus would not bo included in the ABWR TS. The reactor coolant chemistry limits are to be controlled by appropriate administrative controls outside of TS. This is acceptable. Therefore, this item is resolved.

The RCP materials of construction identified in the SSAR that will be exposed to the reactor coolant have been identified and are compatible with the primary coolant water, which will be chemically controlled to maintain adequate water purity. This compatibility has been proven by extensive testing and satisfactory performance. This includes conformance with the recommendations of RG 1.44, "Control of Sensitized Stainless Steel," Revision O, and with the staff guidelines of NUREG-0313, Revision 2. General corrosion of all materials, except unclad carbon and low-alloy steels will be negligible. For unclad carbon and low-alloy steel, GE has provided conservative corrosion allowances for all exposed surfaces in accordance with ASME Codo, Section III. This compatibility with the reactor coolant and compliance with the ASME Code satisfy the requirements of GDC 4 as related to the compatibility of components environmental conditions.

The main source of radiation buildup in operating plants is cobalt-60, which is formed by neutron activation of cobalt-59. GE roduced the cobalt content in alloys to be used in high-fluence areas such as fuel assemblies and control rods. It replaced cobalt-bese alloys, used for pins and rollers in control rods, with non-cobalt alloys. This will reduce occupational exposure from cobalt-60 during operation and maintenance of plant components.

The materials to be used for the construction of the RCPB are compatible with the thermal insulation used in these areas and conform to the recommendations of RG 1.36, "Nonmotallic Thermal Insulation for Austenitic Stainless Steels," Revision 0 . They satisfy the requirements of GDC 14 and 31 as they relate to the prevention of RCPB failure.

The ferritic steel tubular products and the tubular products fabricated from austenitic stainless steel that GE proposes to use will be examined nondestructively in accordance with the provisions of ASME Code, Section III. This is acceptable and satisfies the quality standards of GDC 1 and 30 and 10 CFR 50.55a.

The fracture toughness tests, required by the ASME Code and augmented by Appendix G to 10 CFR Part 50, provido reasonable assurance that adequate safety margins against nonductile behavior or rapidly propagating fracture can bo established for all pressure-retaining components of the RCPB. The use of Appendix G to ASME Code, Section III, and the results of fracture toughness tests performed in accordance with the ASME Code and NRC regulations in establishing safe operating procedures provide adequate safety margins during operations, testing, maintenance, and postulated accident conditions. This satisfies the requirements of GDC 14 and 31 and 10 CFR 50.55 a regarding the prevention of RCPB fracture and of groses rupture. The use of low-alloy steel is restricted to the RPV. The controls imposed on preheat temperatures for welding of ferritic stoels conform to the requirements of ASME Code, Section III, and provide reasonable assurance that components made from ferritic steels will not crack during fabrication. These controls also minimize the possibility of subsequent cracking due to the retention of residual stresses in the weldment and satisfy the quality standards requirements of GDC 1 and 30 and 10 CFR 50.55a. 
The controls imposed on electroslag welding of ferritic steols aro not neceesary because electroslag wolding will not be used for RCPB components.

The controls imposed on the welding of RCPB materials under conditions of limited accessibility are in accordance with the recommendations of RO 1.71, "Wolder Qualification for Aress of Limited Accessibility," Revision 0, and provide assurance that proper requalification of welders will be required in accordance with the welding conditions. These controls also satisfy the quality standards requirements of GDC 1 and 30 and 10 CFR 50.55a. The controls imposed on stainless steel weld cladding are not necessary bocause the use of lowalloy steels is restricted to the RPV.

The controls to avoid stress corrosion cracking in RCPB components constructed of austenitic stainless steels conform to the recommendations of RGs 1.44 and 1.37, "Quality Assurance Requirements for Cleaning of Fluid Systems and Associated Components of Water-Cooled Nuclear Plants," and NUREG-0313, Revision 2. Cold work of austenitic stainless steel is controlled by applying limits on hardness, bend radii, ind surface finish on ground surfaces. The controls to be followed during material selection, fabrication, examination, and protection, in accordance with these recommendations, in order to prevent excessive yield strength, sensitization, and contamination provide reasona/le assurance that the RCPB components of austenitic stuinless steels will be in a metallurgical condition that minimizes susceptibility to stress corrosion cracking during service. These controls moet the requirements of GDC 4 pertaining to the compatibility of components with environmental conditions and those of GDC 14 pertaining to the prevention of leakage and failure of the RCPB.

Since hydrogen water chemistry will be used, a hydrogen injection of less than 1 part per million (ppm) in the feedwater will also be used to minimize intergranular stress corrosion cracking (IGSCC) of the reactor internals in the $A B W R$. To suppress IGSCC, the reactor coolant conductivity will be maintained below $0.3 \mathrm{microsiemen} / \mathrm{cm}$ and sufficient hydrogen will be added to the feedwater to reduce the electrochemical potential below -0.23 volt (standard hydrogen electrode). These controls will further ensure that the materials exposed to the reactor coolant will not be subject to IGSCC. This is acceptable.

The staff concludes that the RCPB materials are acceptable because of the above reasons and because they meet the requirements of GDC 1,4,14,30, and 31 of Appendix $A$ to 10 CFR Part 50; of Appendices B and G to 10 CFR Part 50; and of 10 CFR 50.55a.

\subsubsection{Inservice Inspection and Testing of the Reactor Coolant Presoure Boundary}

SSAR Section 5.2.4 and Table 5.2-8 deacribe certain commitments and plans for the preservice inspection (PSI) and inservice inspection (ISI) programs. GE diecused basic inspection concepts and general ASME Codo provisions because it had reasoned that the requiroments of the NRC regulations might be controlled by the date of order of each specific component subject to examination. The staff reviow was performed in accordance with SRP Section 5.2.4, except as discussed below.

Throughout the service lifo of the plant, the COL applicant will have the overall reeponsibility for the ISI of the RCPB although other organizations also will contribute to the examination activity (0.8., the reactor vendor, the architect-engineer and the inspection agency). The staff and GE representatives discussed the issue of ISI requirements during moetings on March 25 and 26, 1992, as documented in an NRC meeting summary dated April 28, 1992. It was determined that GE is responsible for designing the RPV for accessibility to perform PSI and ISI. For all ASME Code, Class 1, 2, and 3 components, the development of the PSI and ISI programs is the responsibility of the COL applicant.

Pursuant to 10 CFR 50.55a(g)(3), "Components which are classified as ASME Code Class 1 shall be designed and be provided with access to enable the performance of inservice examination of such components and shall meet the preservice examination requirements set forth in Section XI of editions of the ASME Boiler and Pressure Vessel Code and Addenda applied to the construction of the particular component." The applicable construction code should be determined by Paragraph NCA-1140 of ASME Code, Section III, but the construction code that is selected must be incorporated by reference in 10 CFR 50.55a(b).

Throughout the service life of a nuclear power facility, components (including supports) that are classified as ASME Code Class 1 must meet the requirements in ASME Code, Section XI, that become effective after the editions specified in 10 CFR 50.55a(g)(2) and are incorporated by reference in 10 CFR $50.55 a(b)$, to the extent practical within the limitations of design, geometry, and materials of construction of the components. The inservice examination of components conducted during the initial 10-year interval must conform to the requirements of the latest edition and addenda of ASME Code, Section XI, incorporated by reference in 10 CFR 50.55a(b) on the date 12 months before the date of issuance of the operating license. The regulations also require that the ISI program be updated for each subsequent 10-year interval to comply 
with the ASMB Codo incorporated by reference in 10 CFR 50.552 .

Compliance with the requirements of the regulations for the PSI and ISI must be based on commitments for or by the COL applicant. The applicable ASME Code or Codes for both design and ISIs aro not known at the time of design certification. In addition, the regulation permits the COL applicant the option to change to a newer edition of ASME Code, Section XI, by component, during the construction of the plant.

The staff review of the information in the SSAR emphasizod design access and the use of an offective nondestructive examination (NDE) methodology. Since the PSI requirements are established and known at the time eech component is ordered, 10 CFR $50.55 a(g)$ does not have provisions for "relief requests" for impractical examination requirements. ASME Code, Section XI has provisions to use certain shop and field examinations in lieu of the onsite preservice examination. Therefore, the NRC staff concluded in the DFSER that the COL applicant must incorporate plans for NDE during construction in order to meet all access requirements of the regulations. This was DFSER COL Action Item '..2.4-1.

GE responded to this $\mathrm{COL}$ item by including additional information in SSAR Section 5.2.6.2, "Plant-Specific ISI/PSI." This section states that the COL applicant will submit the complete plant-specific ISI/PSI program to the NRC including references to the edition and addenda of ASME Code, Section XI, that will be used for selecting components subject to examination, a description of the components exempt from examination by the applicable code, and isometric drawings used for the examination. This is acceptable. Further, SSAR Section 5.2.4.2 states that all items within the Class 1 boundary are designed to provide access for the examinations required by ASME Code, Section XI, IWB-2500. This is also acceptable.

ASME Code, Section XI, states that the PSI should be conducted with equipment and techniques equivalent to those that are expected to be used for subsequent ISIs. Ultrasonic testing of RCPB components will improve in the near future, as indicated by ASME Code, Section XI, Appendix VII, "Qualification of Nondestructive Examination Personnel for Ultrasonic Examination," and Appendix VIII, "Performance Demonstration for Ultrasonic Examination Systems." The NRC has referenced in 10 CFR 50.55a(b) the ASME Code, Section XI edition that includes the published Appendix VII. In addition, the NRC staff has established a technical contact to coordinate the implementation of Appendix VIII. Therefore, the staff concluded in the
DFSER that GB should include in its SSAR PSI program provisions that ultrasonic testing be performed in accordance with Appendices VII and VIII pursuant to 10 CFR 50.55a(g)(3). This was DFSER Open Item 5.2.4-1. However, on further review the staff determined that this open item could be resolved by the action taken by the COL applicant.

GE responded to this open item by including additional information in SSAR Section 5.2.6.2. This section states that the COL applicant will submit, for staff review, the complete plant-specific ISI/PSI program, including references to the edition and addenda of ASME Code, Section XI, that will be used for selecting components subject to examination, a description of the components exempt from examination by the applicable code, and isometric drawings used for the examination. This is acceptable. Therefore, DFSER Open Item 5.2.4-1 is resolved.

The requirements for the initial ISI program will be determined by the ASME Code in effect 1 year before issuance of the COL. The COL applicant is required to meet the ISI requirements "to the extent practical within the limitations of design, geometry and materials of construction of the components." The regulations have provisions for staff evaluation, on written request, of new ASME Code requirements determined by a licensee to be impractical for its facility.

In the DSER (SECY-91-355), the staff found that the SSAR information pertaining to compliance with 10 CFR 50.55a(g), design access, PSI requirements, and proposed methodology for ISI was unacceptable. This was DSER Outstanding Issue 1. In SSAR Section 5.2.4, GE addressed the topics discussed in SRP Section 5.2.4. GE described the access provisions for examining the major components of the RCPB including the reactor vessel, closure head, RPV studs, nuts and washers, reactor vessel support skirt, piping, pumps, valves, and component supports. GE stated that all items within the Class 1 boundary are designed to provide access for the examinations required by ASME Code, Section XI, IWB-2500. This is acceptable and resolved DSER Outstanding Issue 1.

SSAR Table 5.2-1 lists the applicable ASME Code Cases for the major RCPB components. In a letter dated March 11, 1992, GE stated that the Code addenda requirements for the ABWR plants will comply with 10 CFR 50.55a, except for the RPV, because as of that date the 1989 Edition of the ASME Code had not been referenced by the regulation. The 1989 Edition was subsequently referenced by 10 CFR 50.55a. As a result of a meeting on March 25 and 26, 1992, it was determined that the COL applicant 
would be responsible for the development of the PSI and ISI programe for all ASME Codo, Class 1, 2, and 3 components. Since the applicablo ASME Code edition for the PSI and ISI programs at the timo of the COL application cannot bo determined at the time of design certification, pursuant to 10 CFR $50.55 \%(8)$, the dovolopment of the PSI and ISI programs for ASME Code, Class 1, 2, and 3 components for the ABWR was DFSER COL Action Item 5.2.4-2. In the DSER (SECY-91-153), the staff noted that its reviews of the PSI and ISI programs were in progrose. These were DSBR Outstanding Issues 20 and 23. In response to the above items, $\mathbf{O B}$ included additional information in the SSAR to state that the COL applicent will submit the complete plant-specific ISI/PSI program to address a number of concerns including those discussed above. This is acceptable. The staff concludes that the SSAR enables the COL applicant to meet the requirements of the NRC regulations defined in 10 CFR 50.55a, except for the RPV, which is evaluated below as an individual component pursuant to 10 CFR Part 52. Therefore, DSER Outstanding Issues 20 and 23 are resolved.

GE committed to design the RPV so that PSI based on the requirements of ASME Code, Section XI, 1989 Edition, can be performed. This edition is specified in the RPV ITAAC, Section 2.1.1, "Reactor Pressure Vessel System." The RPV shell welds are designed for 100 percent accessibility for both PSI and ISI. The RPV nozzle-toshell welds will be 100 percent accessible for PSI but might have limited areas that will not be accessible from the outer surface for inservice volumetric examination using current examination techniques. The staff will review the ISI program in accordance with the ASME Code edition in effect and the ISI tochniques available at the time of the COL application.

The staff reviewed GE's use of the 1989 Edition of ASME Code, Section XI, and evaluated the extent of examination, design access, methodology for NDE, and personnel qualifications. Subarticle IWB-2200 "Preservice Examination" of the 1989 Edition states that examinations required for Class 1 components shall be completed before initial plant startup. In addition, these PSIs should be extended to include essentially 100 percent of the pressure- retaining welds in all Class 1 components except in those "components exempt from examination" as defined by IWB-1220(a), (b), or (c). GE's use of the 1989 Edition of ASME Code for design of the RPV should not significantly change the extent of examination required by 10 CFR $50.55 a(g)$.

GE committed to design the RPV with essentialiy 100 percent of the shell welds accessible for both PSI and ISI. The RPV nozzle-to-shell welds, a different examin- ation category dofined by ASIME Codo, Section XI, will bo 100 percent accessible for PSI. The staff assumes that PSI of the nozzlo-to-sholl regions will be accomplished by shop and field inspections during construction as permitted by the Code. Although the RPV nozzlo-to-shell welds might have limited areas that will not be accessible from the outer surface for inservice volumetric examination using current examination techniques, the actual Code edition for ISI, as defined by 10 CFR 50.55a(g), cannot be determined until the construction of the ABWR plant is cesentially completo. Therefore, the staff will reviow all examination limitations with the COL application. This is scceptable because the concepts described above are equivalent or superior to examinations performed on existing operating BWRs. However, the staff concluded in the DFSER that the COL applicant must monitor the construction of structural supports around the RPV and the installation of auxiliary equipment to ensure that the design access that will be provided is not adversely affected. This was DFSER COL Action Item 5.2.4-3.

GE responded to this item in SSAR Section 5.2.6.2, which states that the COL applicant will submit the complete plant-specific ISI/PSI program to the NRC including references to the edition and addenda of ASME Code, Section XI, that will be used for the selection of components subject to examination, a description of the components exempt from examination by the applicable code, and isometric drawings used for the examination. This is acceptable. GE also stated that the COL applicant will submit plans for preservice examination of the RPV welds to address the degree of compliance with RG 1.150, "Ultrasonic Testing of Reactor Vessel Welds During Preservice and Inservice Examinations," Revision 1. Further, SSAR Section 5.2.4.2 states that all items within the Class 1 boundary are designed to provide access for the examinations required by ASME Code, Section XI, IWB-2500. This is also acceptable.

The SSAR Section 5.2.4.3.2.1 states that ultrasonic testing of the reactor vessel welds will be performed in accordance with RG 1.150 and that personnel performing ultrasonic examinations shall be qualified in accordance with ASME Code, Section XI, Appendix VII. Ultrasonic examination systems will be qualified in accordance with an industry-accepted program for implementing ASME Code, Section XI, Appendix VIII. GE does not consider the supplemental examinations recommended in GE service information letters (SILs) and rapid communication service information letters (RICSILs) for previous BWR designs applicable to the ABWR. In the ABWR design either the components addressed by the SIL or RICSIL (e.g., jet pumps) have been eliminated or the need for the examination no longer exists because of the elimination of crevices and the use of materials resistant to the known 
degradation mochaniums (0.8., IOSCC) on which the SIL and RICSIL araminations were baend. OB's proposed mothodology for 'NDB of the reactor veacel and perionel qualifications are scceptable beculue the concepts described above have been anccesafully used in exiating operating BWRs.

Periodic examinations and bydroetatic teating of preceuroretaining components of the RCPB by the COL applicent in eccordance with ASME Code, Section XI, and 10 CPR Part 50 will provide reasonable securnence that structural degradation or low of lenktight intogrity during wervice will be detected in time to permit corrective sction before tho anfoty functions of a component aro compromiead. Compliance with the PSI and ISI requirements of ASME Code and 10 CFR Part 50 constitutes an acceptable basis for atisfying ODC 32.

As a vendor-apecific isewe, OB based its deeign of the RPV on the 1989 Bdition of the ASME Code, which is a national atandard roforenced by 10 CFR 50.55a(b). Tho ataff roviowed the deaign of the RPV uning the 1989 Edition of the ASME Code to determine if the deaign is cochnically soceptiblo. In the DFSER, the staff concluded that OE's proposeal rolated to the examination of the RPV will bo technically scceptable, if it is properly deacribed in the SSAR and the Tier 1 document. GE was aked to revise the SSAR to indicate that it had based its design of the RPV on the 1989 Edition of the ASME Code and that PSI will be performed in accordance with that samo code edition, rather than the code in effect at the time of COL application (as required by 10 CFR $50.55(\mathrm{~g})$. In addition, discussion of the PSI and the 1989 Edition of the Code will be added to the RPV Tier 1 document design information. This was DFSER Confirmatory Item 5.2.4-1.

GE responded to this itom in SSAR Section 5.2.4 by ctating that the design for performing PSI on the reactor veceel shall be based on the requirements of ASME Code, Section XI, 1989 Edition. For the required preservice examination, the reactor vesed shall moet the acceptance standards of Section XI, IWB-3510. The RPV shell welds are designed for 100-percent accessibility for both PSI and ISI. The RPV nozzlo-to-shell welds will be 100-percent acceasible for PSI but might have limited areas that will not be accessible from the outer surface for performing inservice exsmination techniques. The staff reviewed rovised SSAR Section 5.2.4 and found it acceptable. After - discussion with the applicant, the staff docided that PSI requirements will include ultresonic examination in addition to the radiographic examination required by Section III of the Code. These requirements are included in the RPV Tier 1 design description. However, the specific editios of the ASME Code (1989) is considered
Tier 2 information as previously discuseod in Section 5.2.1.1 of this report. This itom is recolved.

\subsubsection{Reactor Coolant Pressure Boundary Leakage Detection}

The staff reviowed the RCPB leakage dotection systems in cocordance with SRP Section 5.2.5. Staff acceptance of the RCPB leakage detection systems is based on the design mooting the requirements of GDC 2 as it relates to the ability of syatems to mantain and perform their safoty functions following an carthquake and moeting the requirements of ODC 30 as it relates to the detection, identification, and monitoring of the source of resctor coolant leakage. Conformance with ODC 2 is besed on the devign meeting the guidelines of RG 1.29, Positions C. 1 and C. 2 while conformance with GDC 30 is based on the deaign meoting the guidelines of RG 1.45, Positions C.1 through C.9.

A limited amount of leaksge is to be expected from components forming the RCPB. Loakage is classified into two types, identified and unidentified. Components such a valve atem packing, pump ahaft ceals, and flanges will not bo completely leaktight. Because some leakage is expected from them, it will bo collected and monitored. This leakage from the selected components (1) is considered identified leakage and (2) its total flow rato will be monitored separately from unidentified leakage (which may be symptomatic of an unexpected failure of the RCPB). Items (1) and (2) above are requirements of Position C.1 of RG 1.45, "Reactor Coolant Pressure Boundary Leakage Detection Systems," Revision 0. The sensitivity of detection methods $(3.79 \mathrm{~L} / \mathrm{min}(1 \mathrm{gpm}))$ and loekage limits (ranging from $3.79 \mathrm{~L} / \mathrm{min}(1 \mathrm{gpm})$ to $19 \mathrm{~L} / \min (5 \mathrm{gpm})$ ) for unidentified leakage will bo selected to detect and correct potential through-wall flaws (cracks) in the RCPB before such cracks can grow sufficiently to threaten the safety of the plant.

Reactor coolant leakage for the ABWR involves leakage within the drywell, leakage external to the drywell (i.e., in the equipment areas in the reactor buildirg, the main steam tunnel, and the turbine building) and intersystem leakage. These are discussed below.

\section{(1) Leakgae Within the Drowell}

Identified Leaksge; Within the drywell, the drywell equipment drain sump will collect leakage from the reactor vessel head flange inner seal, stem inner packing for large remote power-operated valves, and other known leakage sources. The sump is designed with two pumps, timers, and 

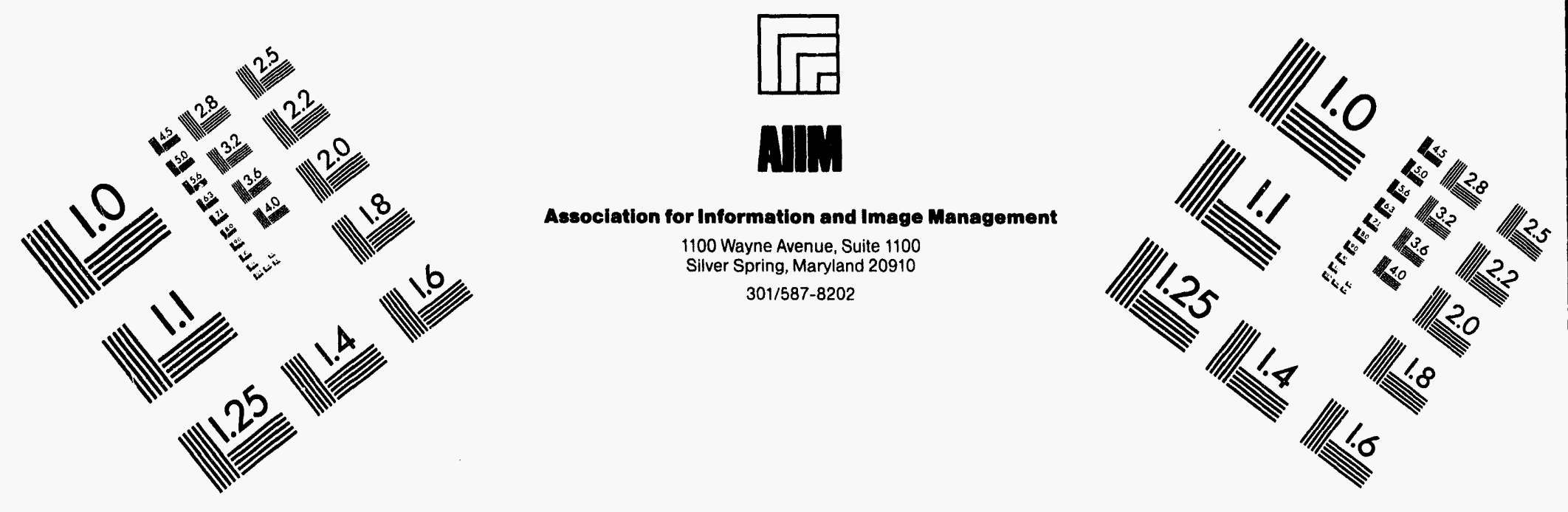

\section{Centimeter}

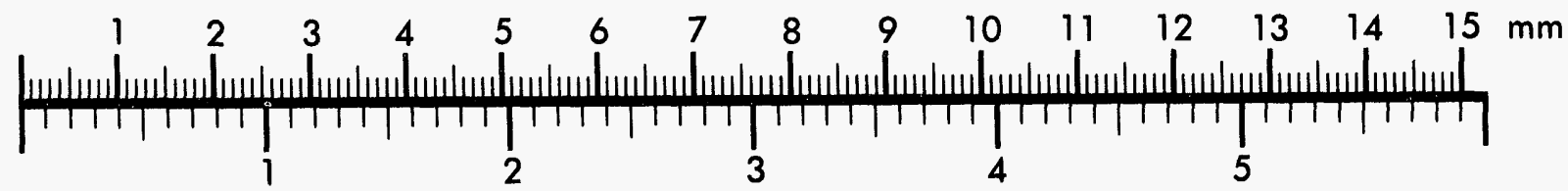
Inches
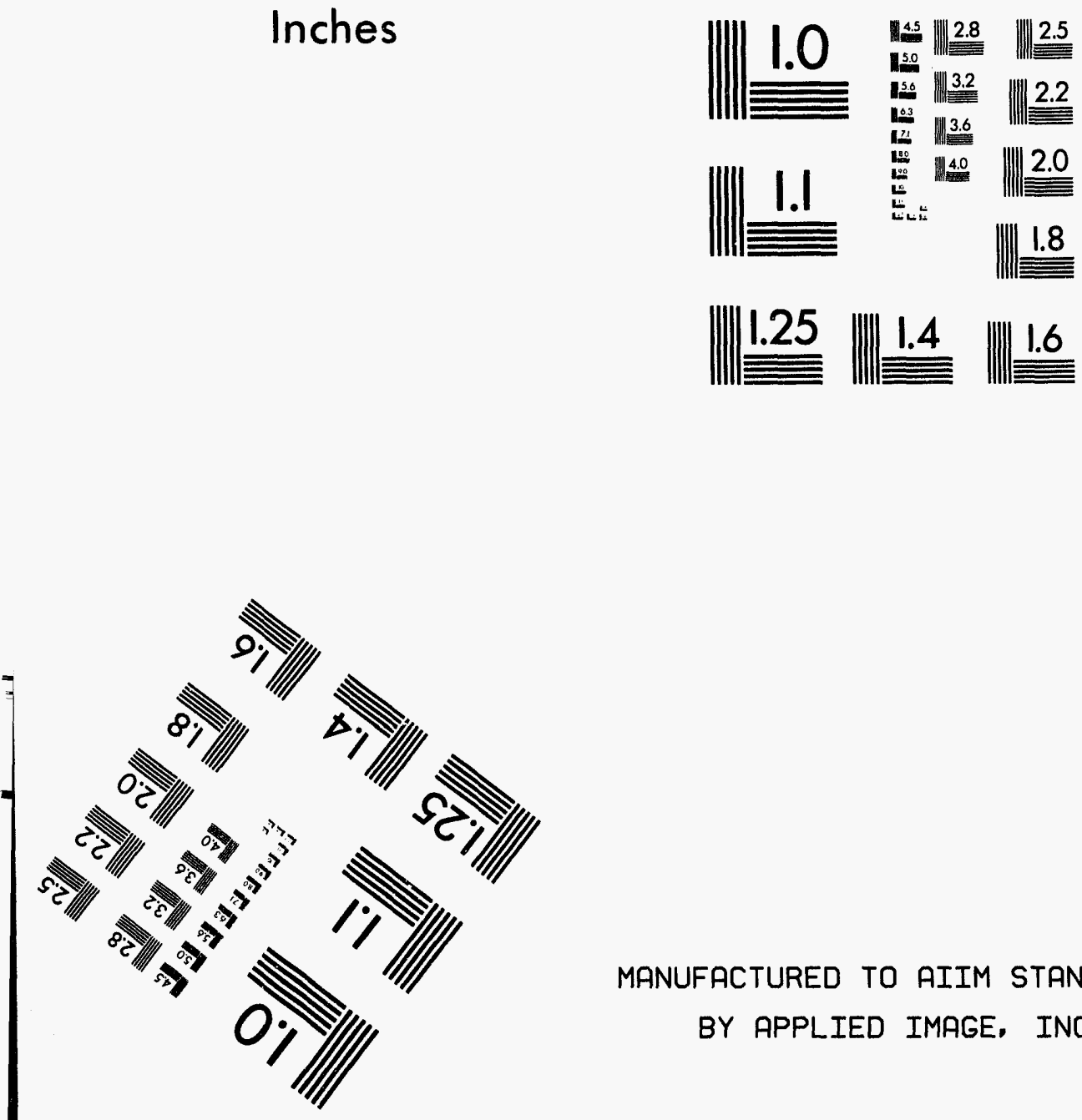

MANUFACTURED TO AIIM STANDARDS BY APPLIED IMAGE, INC.

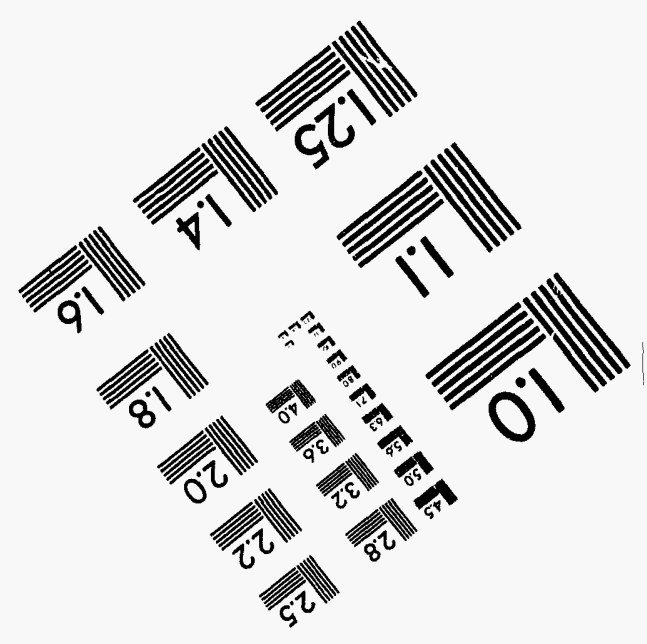



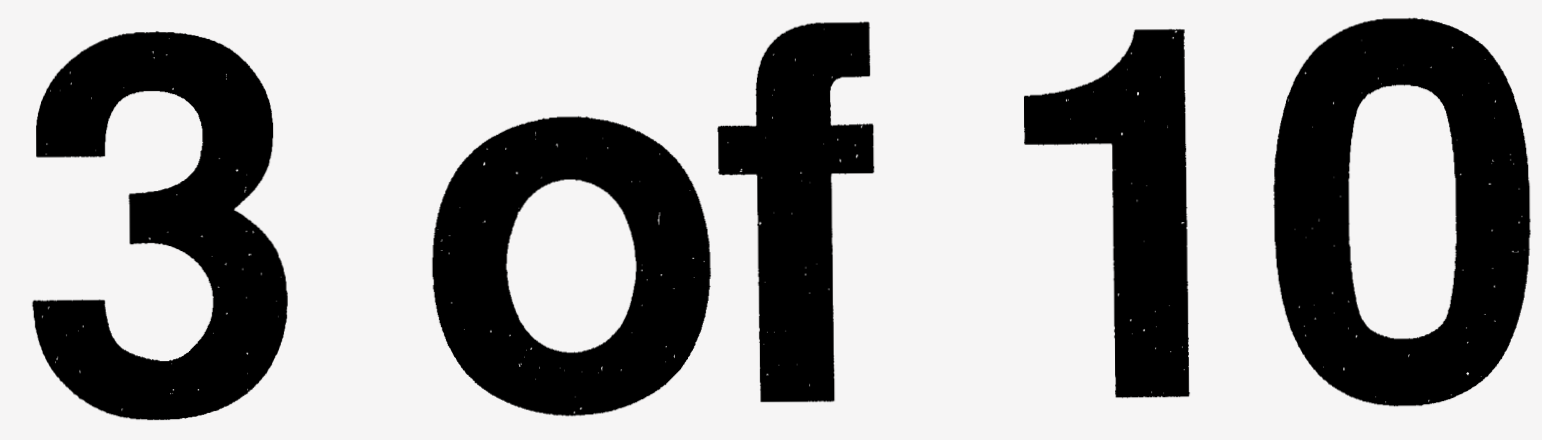
instrumentation for control room monitoring. The sump instrumentation and timers will monitor identified leakage by measuring the rate of change in sump lovel and the sump's fill-up and pump-out times. The ABWR design provides control room indication and alarm capabilities. The cump lovel monitoring instrument and the fill-up and/or pumpout timer will activato an alarm in the control room when the total leak rate reaches $95 \mathrm{~L} / \mathrm{min}$ (25 gpm). Different parameters will monitor leakage from individual sources. The leakage from the head flange inner seal will be monitored by means of a seal drain lino prossure instrument. Safety/ relief valvo (SRV) and valvo stom leakage will be monitored by temperature seneors provided on each SRV discharge line. These monitors will continuously indicate and/or record leakage in the control room. In addition, the mnnitors will trip and activate an alarm in the control room if leakage from the monitored components is detected. The stems for large power-operated valves will be equipped with drain lines to the sump. A remotooperated solenoid valve installed in each drain line can be used during plant operation, in conjunction with additional sump instrumentation, to identify leaking valve packing and to isolate leakage flow from the valve stem's inner seal.

Unidentified Leakgre: Within the drywell, the drywell floor drain sump will collect unidentified leakage from sources such as control rod drives, valve flanges, closed cooling water for reactor services (e.g., cooling of RIP motor), condensate from the drywell atmosphere coolers, and other leakage not collected in the drywell equipment drain sump. The sump is designed with two pumps, timers, and instrumentation for control room monitoring. Sump fill-up and pump-out times will be monitored. The instrumentation will activate an alarm in the control room when preset limits are reached. The rate of change in sump level will be indicated continuously in the control room. Other primary detection methods for small unidentified leaks will include increases in condensate flow rate from the drywell air coolers and increases in the radionctivity count level for noble gases, iodines, and particulates in the drywell atmosphere. The flow rate for condensate, which results from condensation of thermally hot leakage inside the drywell, will be monitored by flow instrumentation provided on the common drain line for the condensate from all the coolers. The radionctivity count levels will be monitored by drywell radiation monitors. These variables will be continuously indicated and/or recorded in the control room. The monitors will activate alarms in the control room when their preset limits are reached. The mensitivity and response timo for all these primary detoction systoms is $3.79 \mathrm{~L} / \mathrm{min}$ (1 spm) or its equivaleat in lees than 1 hour, thus satisfying Positions C.2 and C.5 of RG 1.45, Revision 0. Secondary detection methods will include monitoring the drywell temperature and pressure for gross unidentified leakage. These variables will bo recorded in the control room and will activate control room alarms when they are high. Excessive leakage inside the drywell (0.8., during a lous-of-coolant accident (LOCA)) will be detected by high drywell pressure, low reactor vessel preasure, or high steamline flow (for breaks downstream of the flow eloments). The instrumentation for these monitored variables will trip, activate alarms and isolate the appropriate valves when their predetermined limits are exceeded. Position C.3 of RG 1.45, Revision 0, states that at least three methods of leak detection should be used in the design. Position C.7 of RG 1.45, Revision 0, states that indicators and alarms for cach leakage detection system should be provided in the main control room. Also, it states that procedures for correcting various indications to a common leakage equivalent should be available to reactor operators. The leakage detection methods described above meet Position C.3 of RG 1.45, Revision 0, and are acceptable. The instrumentation and alarms discussed in the SSAR meet the indicator and alarm provisions of Position C.7 of RG 1.45, Revision 0 and are acceptable. The applicant referencing the $\mathrm{ABWR}$ design will provide the procedures to convert leakage indicators to a common leakage equivalent.

The total leakage rate from the RCPB consists of all leakage, identified and unidentified, that flows into the drywell floor drain and equipment drain sumps. GE specifies an identified leakage rate limit of $95 \mathrm{~L} / \mathrm{min}(25 \mathrm{gpm})$ and an unidentified leakage rate limit of $3.79 \mathrm{~L} / \mathrm{min}(1 \mathrm{gpm})$ from the RCPB. GE also states that the total leakage rate from both categories from the RCPB is limited to $95 \mathrm{~L} / \mathrm{min}$ (25 gpm).

Position C.9 of RG 1.45, Revision 0, requires that the TS include limiting conditions for identified and unidentified leakage and address the availability of various instruments to ensure adequate coverage. The technical specification limits on RCS leakage are $3.79 \mathrm{~L} / \mathrm{min}(1 \mathrm{pgm})$ for unidentified leakage and $98.4 \mathrm{~L} / \mathrm{min}(26 \mathrm{gpm})$ for total leakage. Since the above limits are either equal to or less than 
curreat BWR standard TS limits for RCPB leakage limits, the systom meets Position C.9 of RG 1.45, Revision 0, and is accoptable. This was DFSER TS Itom 5.2.5-1. OE has provided the applicable TS. Therefore, DFSER TS Itom 5.2.5-1 is recolved.

\section{Lenke Externl to the Drwwell}

The areas designated as external to the drywell that are monitored for reactor coolent leakage include the equipment areas in the reactor building, the main steam tunnel, and the turbino building. The proceses piping for ench monitored system is locatod in exparnto compartments of rooms, where fassible, to ficilitute tho detection of the leak through area temperature indications. Ench leakage detection aystem has the capability to detoct leak rates that are less then tho cetublished limits for identified and unidentified leakage from the RCPB. Many detection and monitoring systems will be used to detect leakage external to the drywell.

\section{- Equipment Areas in the Reactor Building}

Leakage from unknown or unidentified sources, including shutdown cooling system piping, resctor water cleanup system (CUW) piping, proceses inatrumentation piping, and control rod drive hydraulic control unit (HCU) piping is collected in soveral reactor building floor drain sumps. Identified leakage from known sources will be collected in reactor building equipment drain sumps.

Pumps, timers, and instrumentation used for procesesing and monitoring the reactor building equipment and floor drain cumps will be the same a those provided for the drywell equipment and floor drain sumps. Sump levels and sump fill-up and pump-out times will be monitored. Alarms will be initiated in the control room when the applicable set points are renched.

In addition to the above parameters (i.e., sump levels and sump fill-up and pump-out times), other parameters also will be used for detocting leakage. Equipment rooms that house the RCIC, RHR, and CUW components will be monitored by dual-element thermocouples that sense high ambient temperature. These sensors will indicate possible reactor coolant leaks in these areas. The high-temperature conditios will be indicated, alarmed, and recorded in the control room. In somo cases, a high-temperature condition will provide isolation signals to close appropriate valves. These monitors will be suitable to detect leakage of $95 \mathrm{~L} / \mathrm{min}(25 \mathrm{gpm})$ or lese into the monitored areas. In addition to area temperature monitoring, leakage external to the drywell originating from specific systems can be detected by monitoring other parameters such as low steam pressure and high steam flow in the RCIC system and main steamlines (MSLs), high RCIC exhaust line diaphragm presoure, and high differential flow between suction and discharge lines of the CUW system. These detection systems will activate alarms in the control room and/or initiate closure of applicable valves when the preset limits for the corresponding parameters are reached.

\section{- Mrin Steam Tunnel}

Leakage within the main steam tunuel will be detected by monitoring area temperatures and radiation. MSL area temperature will be monitored by thermocouples located in the aren of the main steam and RCIC pipelines. All temperature elements will bo located and shielded 80 that they will be sensitive to ambient air temperature rather than the radiated heat from hot equipment. The monitors will alarm in the control room and provide isolation signals to the MSL and the MSL drain line isolation valves as well as the CUW isolation valves. If the leakage is from the feedwater system, the system will be isolated manually. These monitors will be suitable to detect leakage of $95 \mathrm{~L} / \mathrm{min}$ (25 gpm) or less into the monitored areas. MSL radiation will be monitored by the process rediation monitoring systom (PRMS). The PRMS trip functions will include isolation of the MSIVs and reector scram. The PRMS will initiate control room readouts and alarms.

\section{- Turbine Building}

Reactor coolant leakage in the turbine building will be detected by monitoring MSL pressure, main condenser vacuum, and turbino building ambient temperature in areas traversed by the MSL. These monitors will alarm and indicato in the control room and, in some cases, will also provide sigmals for isolating the MSIV and MSL drain lines. 
Large leaks external to the drywell will be detected by monitoring MSL flow rate, reactor vesul level, RCIC eteamline flow rate, and low preasure on the RCIC steamline or the RCIC turbine. Abnormal conditions detected by any of the above monitors will aiarm in the control room, and isolation of appropriate systom(s) will bo initiated.

\section{(3) Intereystem Leaknoe}

Position C.4 of RG 1.45, Revision 0, states that provisions should be made in the design to monitor systems connected to the RCPB for signs of intersystom leakago.

The ABWR design provides for monitoring interaystem leakages (i.e., leakagen from the reactor coolant system (RCS) into other connectod systems). Detection of leakage into systems connected to the RCS is necessary because intersystem leakage could result in damage to those systems. The systems of concern are:

- HPCF system

- RCIC aystem

- RHR shutdown cooling (SDC) system

- RHR low-preecure core flooder (LPFL)

- sccondary sido of RHR heat exchangers

- socondary side of RIP heat exchrngers

- econdary side of CUW heat exchangers

- cecondary side of fuel pool cooling (FPC) heat exchangers

In response to request for additional information (RAI) Question (Q)430.2c, GE submitted information regarding the detection of intersystem leakage for aystems connected directly to the RCS. In the DFSER, the staff stated that this information should be incorporated into SSAR Section 5.2.5. This was identified as Confirmatory Item 5.2.5-1. GE added a reference to the response to RAI Q430.2c in the text of SSAR Section 5.2.5.2.2(11). Since the response is presented in SSAR Chapter 20 and is adequately referenced in Section 5.2.5, Confirmatory Item 5.2.5-1 is resolved. GE's response to the RAI is summarized below.

The ABWR high-pressure safety injection system consists of two HPCF divisions (Divisions B and C) and the RCIC system. There is no connection between the RCS and the inlet suction of HPCF divisions $B$ and $C$. Both divisions will draw their suction flow from the condensate storage pool or muppreasion pool, and not from the RCS. The discharge lines of the HPCF divisions connect to the RCS through normally closed discharge check valves and injection valves. Substantial (potential) leakage through the clowed discharge check valves and cloced injection valves into either of the discharge lines would result in prescurization of both the discharge line and the HPCF pump suction line, leading to a control room alarm indicating high HPCF B (or C) suction pressure. Significent prescurization of the suction piping would result in - discharge to the suppression pool via a prescure relief valve.

There is no connection between the RCS and the auction or diecharge of the RCIC syetem. The syetem will draw its auction flow from the condenate atorage pool or auppreacion pool, and not from the RCS. The diecharge line of the RCIC system connects to feedwater line B through normally closed discharge chock and injection valves and is not considered to be connectod to the reactor system preseure boundary. Therefore, the provisions of SRP Section 5.2.5 are not applicable to the RCIC aystem.

Each of the three suction lines for the shutdown cooling mode of the RHR system connect to the RCS through a shutdown cooling line suction valve and through both an inboard and an outboard contrinment isolation valve. Substantial (potential) leakage through both of the cloeed containment isolation valves into any of the suction lines would be detected by prescure rensors located between the outboard containment isolation valve and the keylocked closed RHR shutdown cooling mode suction valve. High pressure in this section of piping would reault in a control room alarm. Significant prescurization of this section of piping would result in a diecharge to the auppression pool via a pressure relief valve.

In the LPFL mode of RHR, suction flow will be drawn from the suppression pool through normally opened RHR pump suction valves, and not from tho RCS.

The RHR discharge lines will be used by all three RHR divisions to return flow to the reactor for both the shutdown cooling mode or LPFL mode of operation. The discharge lines normally will be filled with water by the RHR discharge line fill pumps. Only RHR divisions B and C will discharge directly into the RPV; division $A$ will discharge into feedwater line A. Therefore, 
intersystem leakage is only postulated to occur in RHR divisions B and C. The diecharge lines of RHR connect to the RPV through normally closed discharge check valves and injection valves. Substantial (potential) leakage through the closed discharge chock valves and closed injection valves into either of the discharge lines would result in pressurization of the discharge line, leading to a control room alarm. Significant pressurization of the discharge piping would result in a discharge to the suppression pool via a pressure relief valve.

Radiation monitors will detect reactor coolant leakage into the reactor building cooling water (RCW) system, which will provide cooling water to the RHR heat exchangers, the RIP heat exchangers, the CUW nonregenerative heat exchangers (NRHXs), and the fuel pool pooling and cleanup (FPC) heat exchangers. At least two process radiation monitoring channels will monitor leakage into each of the two common cooling water headers that will receive $\mathrm{RCW}$ return flow from the above heat exchangers. Each channel will alarm on highradiation conditions that indicato process leakage into the CUW system.

The staff concludes that intersystem leakage applicable to the ABWR, such as that into the RHR, HPCF, and RCIC systems, would be highly unlikely because it would have to occur through closed check valves and/or closed containment isolation valves. All potential intersystem leakage from the RCPB will bo into closed systems, normally filled with water. Therefore, indicators for abnormal water levels or flows in the affected areas will not be used for monitoring intersystem leakage. For these systems, high-pressure alarms will be used. Thus, the ABWR design satisfies the requireraents of Position C.4 of RG 1.45, Revision 0, and is acceptable.

Position C.8 of RG 1.45, Revision 0, states that leakage detection systems should be equipped with provisions to permit testing for operability and calibration during plant operation.

The ABWR leakage detection systems are equipped with features to permit operability testing and calibration during plant operation using the following methods:

- simulation of input signals into trip units

- comparison of methods (e.g., comparison of airborne particulate monitoring or air cooler condensate flow with sump fill-up rate)
- comparison of channels when more than one channel is used for any one detection method (e.8., area temperature monitoring)

These methods meet Position C.8 of RG 1.45, Revision 0, and are acceptable.

However, in the DFSER, the staff noted that the COL applicent should provide information regarding the sensitivity of detection methods and leakage limits for unidentified leakage and procedures and graphs for converting various indicators into a common leakage equivalent to meet the procedures portion of Position C.7 of RG 1.45. This was DFSER COL Action Item 5.2.5-1. GE has included this action in SSAR Section 5.2.5.9. This is acceptable.

GE originally submitted the design description and the ITAAC relating to RCPB leakage detection. At the time the DFSER was issued, the ITAAC roview was in progress. Therefore, this was DFSER Open Item 5.2.5-1. GE has since provided revised design description and ITAAC. The adequacy and acceptability of the design description and the ITAAC are evaluated in Chapter 14.3 of this report. Therefore, DFSER Open Item 5.2.5-1 is resolved.

The leakage detection systems proposed for the ABWR design meet RG 1.45, Revision 0, Positions C.1 through C.5, C.8, and C.9. RG 1.29, Revision 3, states in Positions C. 1 and C. 2 that systems required for monitoring systems important to safety should be designed to meet seismic Catogory I standards and to withstand the effects of a safe shutdown earthquake (SSE) without failure. RG 1.45, Revision 0, indicates in Position C.6 that the airborne particulate monitoring system should function when subjected to an SSE, and the leakage detection system should be capable of performing its functions following seismic events not requiring shutdown. The ABWR leakage detection systems are designed to remain functional following seismic events. Specifically, the drywell airborne particulate radioactivity monitoring system is designed to seismic Category I standards. Thus, the requirements of GDC 2, "Design Basis for Protection Against Natural Phenomena," and the guidelines of RG 1.29, Revision 3, Positions C.1 and C.2, and of RG 1.45, Revision 0, Position C.6, are satisfied.

Indicators and alarms for each leakage detection system are provided in the control room. Level and flow from floor and equipment drain sumps, both internal and external to the drywell, will be monitored for leakage. Condensate flows from the drywell air cooler also will be monitored and will alarm in the control room on high flow. 
The staff concludes that the leakage dotection systems provided to detect leakage from components of the RCPB furnish ressonable sssurance that structural degradation that may dovelop in pressure-retaining components will be dotected on a timely basis. Thus, corrective sction can be taken before such degradation becomes sufficiently sovere to jeopardize the safety of the system, or before the leakage increases to a level boyond the capability of the makeup system to replenish the loes. On the besis of the information in the SSAR and the ovaluation above, the staff concludes that the systems are in conformance with the guidalines of RG 1.29, Revision 3, Positions C.1 and C.2, and RG 1.45, Revision 0, Positions C.1 through C.9, and satisfy the requirements of GDC 2 and 30. Therefore, the RCPB leakage detection systems meet the acceptance criteria of SRP Section 5.2.5 and are acceptable.

\subsection{Reactor Vessel}

\subsubsection{Reactor Vessel Materials}

The materials specified for construction of the reactpr vessel and its appurtenances have been identified by specification on SSAR Table 5.2-4 and found to be in conformance with Section III of the ASME Code. GE has identified special requirements with regard to the control of residual elements that the staff considers acceptable. Compliance with the provisions of the Code for material specifications satisfies GDC 1 and 30 and 10 CFR 50.55a.

Ordinary processes will be used for the manufacture, fabrication, welding, and NDE of the reactor vessel and its appurtenances. Fabrication processes and NDEs will be performed in sccordance with the requirements specified in the ASME Code. Compliance with these ASME Code provisions meets GDC 1 and 30 and 10 CFR 50.55a.

In the DSER (SECY-91-153), the staff noted that GE should discuss the onsite cleaning and cleanliness controls for austenitic stainless steel. This was DSER Outstanding Issue 21. As discussed in SSAR Section 5.3.1, the controls to be used during all stages of welding to prevent contamination and sensitization that could cause stress corrosion cracking in austenitic stainless steel conform with the recommendations of RGs 1.37, Revision 0, and 1.44, Revision 0, and NUREG-0313, Revision 2. These controls will provide reasonable assurance (1) that austenitic stainless steel components will be properly cleaned on site, thus satisfying Appendix B to 10 CFR Part 50, and (2) that welded components will not be contaminated or excessively sensitized before or during the welding process, thus satisfying GDC 1, 4, and 30 and 10 CFR 50.55a. This is acceptable and resolved DSER Outstanding Issue 21.
When components of austenitic stainless steels are welded, ASME Codo controls will be supplemented by conformance with the recommendations of RG 1.31, "Control of Ferrite Content in Stainless Steel Weld Metal," Revision 3, and NUREG-0313, Revision 2. These controls will provide reasonable assurance that the wolds will not contain microcracks and will be resistant to IGSCC and satisfy GDC 1, 14, and 30 and 10 CFR 50.55a as related to the integrity of the RCPB.

When components of low-alloy steels are welded, ASME Code controls will be supplemented by conformance with the recommendations of RG 1.50, "Control of Preheat Temperature for Welding of Low-Alloy Steel," Revision 0. Low-alloy steel components either will be held for an extended time at preheat temperatures to ensure the removal of hydrogen, or preheat will be maintained until postweld treatment. This will provide reasonable assurance that components made from low-alloy steels will not crack during fabrication and will minimize the potential for subsequent cracking. Adherence to the recommendations of RG 1.43, "Control of Stainless Steel Weld Cladding of Low-Alloy Steel Components," Revision 0, is not necessary because the RPV specifications require that all low-alloy steel be produced in accordance with fine grain practice. This will provide reasonable assurance that underclad cracking will not occur during the weld cladding process. These controls satisfy GDC 1 and 30 and 10 CFR 50.55a.

Integrity of the reactor vessel studs and fasteners is ensured by conformance with the recommendations of RG 1.65, "Materials and Inspections for Reactor Vessel Closure Studs," Revision 0, which satisfies GDC 1, 30, and 31 and 10 CFR 50.55a and the requirements of Appendix $G$ to 10 CFR Part 50.

The staff reviewed the fracture toughness of the reactor vessel materials, the RCPB materials, and the materials surveillance program for the reactor vessel beltline region according to SRP Section 5.3.1.

GDC 31 require that the $\mathrm{RCPB}$ be designed with sufficient margin to ensure that, when stressed under operating, maintenance, and test conditions, the boundary behaves in a nonbrittle manner and the probability of rapidly propagating fracture is minimized. GDC 32 require that the RCPB be designed to permit an appropriate material surveillance program for the RPV. The fracture toughness requirements for the ferritic materials of the RCPB are defined in Appendices $G$ and $H$ to 10 CFR Part 50.

The edition and addenda of the ASME Code that are applicable to the design and fabrication of the reactor vessel and RCPB components are specified in 10 CFR 
50.55a. The ASME Codo edition and addenda that are applicable to the ABWR are specified in SSAR Tablos 1.8-21 and 3.2-3.

In the ABWR SSAR, GE states that the reactor vessel will comply with the fracture toughness requirements of Appendix G to 10 CFR Part 50. However, the staff concluded in the DFSER that to confirm this conclusion, the COL applicant must provide frecture toughness data based on the limiting reactor vessel materials. This was DFSER COL Action Item 5.3.1-1.

GE responded to this item in SSAR Section S.3.4 by stating that the COL applicant will provide fracture toughness data based on the limiting reactor vessel materials. This is acceptable.

Appendix G, "Protection Against Nonductile Failures," to Section III of the ASME Code is used, together with the fracture toughness test results required by Appendices G and $H$ to 10 CFR Part 50, to calculate the pressurotemperature limits for the ABWR reactor vessel. The fracture toughness tests required by the ASME Code and Appendix G to 10 CFR Part 50 provide reasonable assurance that adequate safety margins against the possibility of nonductile behavior or rapidly propagating fracture can be established for all pressure-retaining components of the RCPB. These methods will provide adequate safety margins during operating, testing, maintenance, and anticipated transient conditions. Compliance with these code provisions and NRC regulations is acceptable and satisfies GDC 31.

The materials surveillance program will be used to monitor changes in the fracture toughness properties of ferritic materials in the reactor vessel beltline region resulting from exposure to neutron irradiation and the thermal environment, as required by GDC 32 . The ABWR surveillance program, which must comply with Appendix $\mathrm{H}$ to 10 CFR Part 50 and American Society for Testing and Materials (ASTM) E-185-82, "Standard Recommended Practices for Surveillance Tests for Nuclear Reactor Vessels," requires that fracture toughness data be obtained from material specimens that are representative of the limiting base weld and heat-affected-zone materials in the beltline region. These data will permit the determination of the conditions under which the vessel can be operated with adequate margins of safety against fracture throughout its service life.

In the SSAR, GE states that the reactor vessel materials surveillance program will comply with the requirements of Appendix H to 10 CFR Part 50 and ASTM E-185-82. However, the staff concluded in the DFSER that to confirm this conclusion, the COL applicant must provide details of its surveillance program including the specific materials in each surveillance capsule, the capsule lead factors, the withdrawal schedule for each capsule, the neutron fluence to be received by each capsule at the time of its withdrawal, and the vessel end-of-life peak neutron fluence. This was DFSER COL Action Item 5.3.1-2.

GE reeponded to this item in SSAR Section 5.3.4 by atating that the COL applicant will submit the following information to the NRC: the specific materials in each surveillance capsule, the withdrawal schedule for each surveillance capsule, the neutron fluence to be received by each capsule at the time of its withdrawal, and the vessel end-of-life peak neutron fluence. This is acceptable.

The materials surveillance program will generate information on the effects of irradiation on material properties 80 that changes in the fracture toughness of the material in the ABWR reactor vessel beltline region can be properly assessed and adequate safety margins against the possibility of vessel failure can be provided. The surveillance program must generate sufficient information to permit the determination of conditions under which the reactor vessel will be operated with an adequate margin against rapidly propagating fracture throughout its service lifetime. On the basis of a 40-year design life, ASTM E-185-82 recommends that three materials surveillance capsules be installed in the reactor vessel beltline. However, in the DFSER, the staff noted that for the ABWR, the design life is expected to be increased to 60 years. Accordingly, GE needed to reassess the number of materials surveillance capsules to be provided to account for the additional 20-year increase in the expected life of the vessel. The staff noted that GE should revise its SSAR to address changes to the materials surveillance program, including the number and location of the vessel surveillance capsules, for the ABWR reactor vessel to account for the 60-year design life of the plant. This was DFSER Open Item 5.3.1-1.

GE addressed this open item in the SSAR. Specifically, GE committed to provide four surveillance capsules instead of the three previously proposed capsules. GE also required that the capsules be placed to produce a lead factor of approximately 1.2 to 1.5 . Furthermore, GE specified that the weld metal specimens be made from the same heat of weld wire and lot of flux and that the same welding practice as that for the beltline weld be used. GE also calculated that the predicted end-of-license adjusted reference temperature of the reactor vessel will be less than $38^{\circ} \mathrm{C}\left(100^{\circ} \mathrm{F}\right)$. The staff finds this response acceptable because these requirements will ensure that the surveillance program will generate sufficient information 
to determine the conditions under which the reactor veasel will bo operated throughout its 60-year service lifetimo. Therefore, this open item is reeolved.

Compliance with Appendix H to 10 CFR Part 50 and ASTM E-185-82 ensures that the surveillance program will be capable of monitoring radiation-induced changes in the fracture toughness of the reactor vessel material and will satisfy the requirements of GDC 32 regarding the design of an appropriate materials surveillance program for the reactor pressure vessel.

\subsubsection{Pressure-Temperature Limits}

The acceptance criteria for reviowing the pressure-temperature limits are given in SRP Section 5.3.2 and Appendices $G$ and $H$ to 10 CFR Part 50. Appendices $\mathbf{G}$ and $H$ describe the operating conditions that require pressuro-temperature limits and provide the bases for these limits, specifically requiring that pressure-temperature limits provido safety margins at least as great as those recommended in ASME Code, Section III, Appendix G. Appendix G to 10 CFR Part 50 requires additional safety margins whenever the reactor core is critical (except for low-level physics tests) for the materials in the closure flange and beltline regions.

The staff reviewed the pressure-temperature limits that will be imposed on the RCPB during the following operations and tests to ensure that there will be adequate safety margins against nonductile behavior or rapidly propagating failure of ferritic components as required by GDC 31:

- preservice hydrostatic tests

- inservice leak and hydrostatic tests

- heatup and cooldown operations

- core operation - criticality

Appendices $\mathrm{G}$ and $\mathrm{H}$ to $10 \mathrm{CFR}$ Part 50 require the applicant to predict the amount of increase in reference temperature, $\mathbf{R T}_{\mathrm{NDT}}$, resulting from neutron irradiation. The increase in $\mathbf{R T}_{\text {NDT }}$ resulting from neutron irradiation is then added to the initial $\mathrm{RT}_{\mathrm{NDT}}$ and the margin to establish the adjusted reference temperature. The staff's recommended method for calculating the increase in $\mathrm{RT}_{\mathrm{NDT}}$ resulting from neutron irradiation is contained in RG 1.99, "Radiation Embrittlement of Reactor Vesed Materials," Revision 2. The relationships in the guide were derived by statistical analysis of 216 material data points that were reported from the testing of irradiated materials.

These materials were contained in surveillance capsules and had been irradiated inside U.S. commercial nuclear reactor vessels. As more surveillance data become available, this guide may noed additional revision, since the relationship between the increase in RT $_{\text {NDT }}$ and neutron fluence is empirically derived from analysis of material surveillance data on U.S. commercial nuclear renctor vessels.

The preecure-temperature curves in SSAR Figure 5.3-1 are system hydrotest limits with fuel in the vessel, non-nuclear beating limits, and nuclear (core critical) limits. In the DFSER, the staff noted that these three limits were different from the suggested limits on preservice hydrostatic tests, inservice leak and hydrostatic tests, heatup and cooldown operations, and core operation in SRP Section 5.3.2. The pressure-temperature curves in the SSAR were generic and were not valid for any specific effective full-power years. The staff found that the general shapes of the curves are acceptable, but the curves should be used as a reference only. For approval of any COL, COL applicants must submit plant-specific calculations of $\mathrm{RT}_{\text {NDT }}$, stress intensity factors, and pressure-temperature curves similar to those in RG 1.99 and SRP Section 5.3.2. This was DFSER COL Action Item 5.3.2-1.

GE responded to this item in the SSAR, Section 5.3.4, by stating that the COL applicant will submit plant-specific calculations of $R T_{\mathrm{NDT}}$, stress intensity factors, and pressure-temperature curves similar to those in RG 1.99 and SRP Section 5.3.2. This is acceptable.

In response to the staff's questions, GE submitted a calculation of the RT NDT $_{\text {shift for the vessel plate and weld }}$ metal. The calculation followed RG 1.99, closely. The calculated $\mathrm{RT}_{\mathrm{NDT}}$ was low $\left(-22^{\circ} \mathrm{C}\left(-8^{\circ} \mathrm{F}\right)\right.$ for the weld metal and $-8.4^{\circ} \mathrm{C}\left(17^{\circ} \mathrm{F}\right)$ for the plate) because of the low neutron fluence and the low copper and nickel contents used in the calculation.

GE predicted the neutron fluence at end of life to be $6 x$ $10^{17} \mathrm{n} / \mathrm{cm}^{2}$, which is low in comparison to the existing BWR design. In the DFSER, the staff noted that GE should submit additional information to show how the fluence value of $6 \times 10^{17} \mathrm{n} / \mathrm{cm}^{2}$ was predicted. This was DFSER Open Item 5.3.2-1.

GE responded to this item in SSAR Section 5.3.2.1.5. It stated that fast neutron fluence for the ABWR vessel was evaluated using the Oak Ridge National Laboratory code on the CRAY X-MP Super Computer based on an eighth core symmetry fixed source model. The neutron source was based on a three-dimensional nodal fuel model of ABWR for an integrated equilibrium core with a 26-group neutron spectrum. The results were found to be reasonable in comparison to the BWR/6 calculations performed earlier by the Department of Energy (DOE). In evaluating the relative fluence, the power level and shroud- 
to-veseal water thicknese were taken into sccount. The incorporation of integral pumpe increased the annulus between the shroud and the vesed walls for the ABWR. This led to an order of magnitude reduction in expected fluence. Therefore, this item is resolved.

The enff concludes that the preseuro-temperature limits imponed on the RCS for operating and testing conditions to ensure adoquate safoty margine against nonductile or rapidly propagating failure will bo in conformance with the fracture toughness criteria of Appendix O to 10 CFR Part 50 and Section III, including Appendix G, of the ASMB Code. The use of operating limits, based on the criteria in SRP Section 5.3.2, provides reasonablo eseurance that nonductilo or rapidly propagating failure will not occur and constitutes an acceptable basis for antisfying the requirements of 10 CFR 50.55a and GDC 1 , 14,31 , and 32 .

\subsubsection{Reactor Vesed Integrity}

Although the staff reviowed most areas separately in sccordance with its review plans, reactor vessel integrity is of auch importance that a special summary reviow of all factors relating to it was warranted. The staff reviowed the fracture toughness of the ferritic materials for the reactor veseel and the RCPB, the pressure-temperature limits for operation of the resctor vessel, and the materials arveillance program for the reactor veseol beltline. Tho acceptance criteria and reforences that aro tho basen for this evaluation are given in SRP Section 5.3.3.

The ataff reviewed the information in each area to ensure that no inconsistencies existed that would reduce the certainty of veseel integrity. The areas reviewed and the sections of this report in which they are discussed are given below.

- RCPB materials design (Section 5.2.3)

- ISI and teating of RCPB (Section 5.2.4)

- reactor vessel materials fabrication methods (Section 5.3.1)

- pressure-temperature limits and operating conditions (Section 5.3.2)

The staff concludes that the structural integrity of the reactor veseel is acceptable and meets the requirements of GDC 1, 4, 14, 30, 31, and 32 of Appendix A to 10 CFR Part 50; Appendices B, G, and H to 10 CFR Part 50; and 10 CFR 50.55a.

The basis for this conclusion is that the design, materials, fabrication, inspection, and quality assurance requirements for the ABWR plant satisfy the NRC reg lations and regulatory guides and the rules of the ASME Code, Section III. The stringent fracture toughnees requirements of the regulations and the ASME Codo, Section III will be met, including requirements for wurveillance of vescel materials properties throughout service life, in eccordance with Appendix H to 10 CFR Part 50. Also, operating limitations on temperature and preasure will be cetablished for the plant in sccordance with Appendix G, "Protection Againat Nonductile Failure," to ASME Code Section III and Appendix G to 10 CFR Part 50.

The integrity of the resctor veseel is aseured because the veased

(1) will be designed and fabricated to the high standards of quality required by ASME Code and by any pertinent Code Cases;

(2) will be made from material of controlled and demonstrated high quality;

(3) will be subjected to extensive preservice inspection and teating to provide aseurance that the vessel will not fail because of material or fabrications deficiencies;

(4) will operate under conditions and procedures and protective devices that provide assurance that the vereel design conditions will not be exceeded during normal reactor operation, maintenance, testing, and anticipated transients;

(5) will be subjected to periodic inspection to demonstrate that the high initial quality of the reactor vessel has not deteriorated significantly under service conditions;

(6) will be subjected to surveillance to account for neutron irradiation damage 80 that the operating limitation may be adjusted.

\subsection{Components and Subsystem Design}

\subsubsection{Reactor Recirculation System}

This system is not addressed in the SRP. However, since the ABWR reactor recirculation system is unique, as compared to the current BWR designs, an evaluation of the system is provided.

A significant change in the ABWR from current BWR designs is the elimination of the external loops and the incorporation of RIPs for reactor coolant recirculation. The containment volume is reduced as a consequence of 
uxing RIPs instead of external pumps becuuse the external large pipes of the reactor recirculation syetom are diminated. (Rupture of largo-bore external pipes in the lower part of the reactor vessel is eliminated as the deaignbesis accident). There is no pipe larger than approximatoly $5 \mathrm{~cm}$ ( 2 in.) below the core; thus, the probability of fuel uncovery is reduced during a loss-of-coolant (LOCA). This improves plant safety performance. The use of RIPs requires a veseol with a larger diameter, approximately $706 \mathrm{~cm}$ (278 in.), to allow pump impeller removal. However, this results in reduced neutron flux at the veseel beltline and reduced reactor preseure sates during trancients. Full-power operation will be poseible with one RIP out of service, improving plant availability. Maintenance of RIPs will be easier than that of current recirculation pumpe with leses radiation exposure to plant personnel.

The reactor recirculation system consists of $10 \mathrm{RIPs}$ with their shafts, impellers, and diffusers internal to the reactor veseel and will be removed from above for service. The RIPs are mounted vertically onto and through the pump nozzles which aro arranged in an equally spaced ring pattern on the bottom head of the RPV. The RIPs are singlo-etage, vertical pumpe driven by variablo-speed induction motore. The pump speed will be changeable by varying the voltage and frequency output of the individual pump motor's electrical power supply. The RIPs will provide recirculation flow from the downcomers through the lower plenum and up through the lower grid, the reactor core, and steam separators. The flow rate will range from minimum flow, established by the pump characteristics, to above the maximum flow required to obtain rated reactor power.

The RIP motors are variable-speed, four-pole, ac induction wet-motor type. The operating speed of the pump motor will depend on the variable voltage and the variable frequency output of the adjustable speed driven. The RIP motors will be cooled by circulating water in the motor cavity through the shell side of the recirculation motor beat exchanger. Hot water in the shell side of the beat exchanger will be cooled by the reactor building cooling water system. There is one heat exchanger per motor. A clean purge flow will be provided by the control rod drive systom to prevent reactor water from entering the motor cavity region, thereby preventing any impurity buildup. Also, anti-reverse rotation devices will be installed on the motor shaft to prevent poesible damage of the motor caused by reverse pump flow. For service, the motors will be removed from below the RPV.

The staff discusses acceptability of the flow coastdown characteristics to maintain fuel thermal margins during abnormal operational transients in Chapter 15 of this report. The RIP inertia is significantly less than the pump inertia for operating BWRs (i.0., about 0.7-8econd inertia timo constant for the ABWR compared with about 3 to 5 seconds for operating BWRs). The ABWR design also uees motor generator (MG) sets as pass-through energy devices on 6 of the 10 RIPs. The MG sets will be powered from two separato olectrical distribution systems and ueed to lengthen the coastdown of two groups of three RIPs on lose of offeite power (LOOP), thus preventing the departure from nucleate boiling on an all-pump trip. No now safety concerns are associated with the use of RIPs, as compared with external recirculation loops. There is aignificant operating experience with the RIPs. In Europo, nearly 100 pumps are operating in BWRs, approaching 600 pump-years of experience. Fow major forced outages have been reported as a result of pump-related problems. Thus, RIP operation did not require the development of new tochnology.

Teats conducted to verify that the core flow pattern for 9-pump operation is not significently different from 10-pump operation showed that the flow distribution to the reactor core is uniform even if one RIP is idle.

GE originally submitted the design description and the ITAAC for the recirculation flow control system. At the time the DFSER was issued, the ITAAC review was in progreas. Therefore, this was DFSER Open Item 5.4.1-1. GE has since provided revised design description and ITAAC. The adequacy and acceptability of the ABWR design descriptions and ITAAC are evaluated in Chapter 14.3 of this report. Therefore, this item is resolved.

Since the operating limits such as maximum critical power ratio are calculated in Chapter 15 of this report for abnormal transients using RIP coastdown and are found to bo scceptable, the staff concludes that the ABWR reactor recirculation system is acceptable.

\subsubsection{Steam Generators}

This section is not applicable because the ABWR does not use steam generators for power generation.

\subsubsection{Reactor Coolant Piping}

This eection does not apply because the reactor internal pumps (RIPs) aro located inside the reactor pressure vessel (RPV) and there is no major external reactor coolant piping connected to it.

\subsubsection{Main Steam Line Flow Restrictions}

The functional requirements of the main steam line restrictors are reviewed in Section 15.4.3 of this report. 


\subsubsection{Main Steam Isolation Vaire Leakage Control System}

This section is not applicable to the ABWR because a main steam isolation valve leakage control ayctem is not uead. This is discused in Section 10.3 of this report.

\subsubsection{Reactor Core Isolation Cooling Syetem}

The staff ernluated the reactor core isolation cooling (RCIC) system for conformance to SRP Section 5.4.6. The staff's roviow critoria are based on meeting the following:

(1) GDC 4 as rolatod to dynamic offects aseociatod with flow instabilities and loads.

(2) GDC 5 as related to structures, systems, and components important to safety not being shared among nuclear power units unless it can be demonstrated that sharing will not impair its ability to perform its safety function.

(3) GDC 29 as related to the system being desizned to have an extremoly high probability of performing its safety function in the ovent of anticipatod operational occurrences.

GDC 33 as related to the system capability to provide reactor coolant makeup for protection against small breaks in the reactor coolant presoure boundary so the fuel design limits are not exceeded.

GDC 34 as related to the system design being capable of removing fission product decay heat and other residual heat from the reactor core to preclude fuel damage or reactor coolent preseure boundary overpressurization.

GDC 54 as related to piping systems penetrating primary containment being provided with leak detection and isolation capabilities.

Unlike most current BWR designs, the RCIC system in the ABWR is a part of the emergency core cooling system (ECCS). The initiation logic is diversified by adding a high drywell pressure input as well as by maintaining the typical system initiation on RPV Lovel 2. In the ABWR design, system reliability is improved by including a bypass line to the turbine steam inlet valve (F045 dc powered) to provide for a smoother turbine start and reduce the possibility of an overspeed trip. Since the RCIC system is a part of the ECCS, full-flow tosting capability is provided using the safety-related action source (i.e., suppression pool).

The RCIC system is designed as a high-presenure reactor coolent makeup system that will start independent of the ac power supply. All motor-operated valves will be de operated, except the inboard steam isolation valves. Steam supply inboard isolation valve F035 and inboard bypase valve F048 will be powered from ac power cources; however, valve F035 will normally open and fail as is; therefore, lows of ac power will not prevent RCIC syetem operation. Inboard bypass valve F048 will be closed during the system operation; and hence, loss of ac power will not prevent RCIC system operation. The syetem will provide sufficient water to the reactor veceel to cool the core and to maintain the reactor in a standby condition if the vessel becomes isolated from the main condenser and experiences a loss of feedwater flow. The system also is designed to maintain reactor water inventory, in the event of a loss of normal feedwater flow, while the veseel is depressurized to the point at which the RHR system can function in the shutdown cooling mode.

In reviowing Amendment 32 to the SSAR, the staff notod that the previously described RCIC system capability, without ac power, of " 8 hours" had been changed to "at least 2 hours." The staff raised a concern to GE that changing the capability from 8 hours to 2 hours would result in a measurable increase in the core damage frequency estimate as related to station blackout. To clarify the changed position, GE stated and the staff agreed that an RCIC system capability of up to 8 hours could only be adequately demonstrated during startup tests when plant steam is available after fuel loading. SSAR Section 5.4.6 stated that the RCIC system is designed to perform its function without ac power for at least 2 hours with a capability up to 8 hours. It further stated that the COL applicant will provide analyses for the as-built facility to demonstrate the 8-hour capability. This is acceptable and resolved the staff's concern.

The RCIC system consists of a steam-driven turbine-pump unit and associated valves and piping capable of delivering makoup water to the reactor vessel through the feedwater system. The steam supply to the RCIC turbine is taken from main steamline B at the upstream side of the inboard MSIV. The steam supply to the RCIC turbine will be ensured even if MSIVs are closed. Fluid removed from the reactor vessel following a shutdown from power operation will be normally made up by the feedwater system and supplemented by inleakage from the control rod drive system. If the feedwater system is inoperable, the RCIC system will start automatically when the water level in the reactor vessel reaches the Level 2 (L2) trip set point or 
will be atarted by the operator from the control room. The syctem is capable of delivering ratod flow within 29 reconds of initiation. Primary water mpply for the RCIC syatem comes from the condensate storage tank (CST), and a secondary supply comes from the suppreasion pool.

The RCIC syetem decign operating parameters, as shown in SSAR Figure 5.4-9b, are consistent with expected cperational modes.

Bewatial components of the RCIC aystem are deaignated caismic Catogory I (in eccordance with RO 1.29, Revision 3) and QO B (in accordance with RG 1.26, Revision 3), as discuseed in Section 3.2 of this report. The propoesd initial test programs are discuseed in Chapter 14 of this report.

The RCIC system is housed in the reactor building, which will provide protection against wind, tornados, floods, and other weather phenomena. Compliance with the requirements of GDC 2 is discuseed in Section 3.8 of this report. In addition, the system is protected against pipe whip inside and outside the containment, as required by ODC 4 and as discussed in Section 3.6 of this report.

The HPCF and RCIC systems are located in different rooms of the reactor building for additional protection against common-modo failures. Different energy sources will be used for pump motivation (steam turbine for RCIC pump, electric power for HPCF pumpe) and different power aystems for control power. This diversity conforms to SRP Section 5.4.6.

To protect the RCIC pump from overheating, the RCIC system contains a miniflow line that will discharge into the cuppression pool when the line to the reector vesed is isolated. When sufficient flow to the vesed is schieved, a valve in the miniflow line will automatically close, thus directing all flow to the reactor.

The makeup water system connection to the RCIC system will maintain the pump discharge line in a filled condition up to the injection valve. The makeup water system operation eliminates the possibility of an RCIC pump discharging into a voided pipe and minimize waterhammer offects. A high point vent is provided, and the system will bo vented periodically. The RCIC system includes a fullflow teat line with water return to the suppression pool for periodic lesting. The periodic tests will be performed according to ASME Code, Section XI, as required by the TSs. The staff requires, for any emergency core cooling system (ECCS), that the TSs include a system functional teet at least overy refueling outage, with simulated automatic actuation and verification of proper automatic valve poaition to verify that the RCIC pump will develop - minimum flow of $182 \mathrm{~m}^{3} / \mathrm{hr}(800 \mathrm{gpm})$. This was DFSER TS Itom 5.4.6-1. GE has nubmitted the ABWR TS which include the functional teating; this is scceptable. Therefore, DFSER TS Itom 5.4.6-1 is resolved.

The auction piping of the RCIC system is designed for low preacure. A relief valve, therefore, is provided to protect against overpresourization of the line from the highpreacure piping. The suction preesure piping was upgraded from $1.37 \mathrm{MPa}$ (200 paig) to $2.82 \mathrm{MPa}$ (410 paig) for reolving the generic issue pertaining to interfacing aysteme low-of-coolant-accident (ISLOCA) a discuseed in Chapler 20 of this report.

Suitable provisions will be provided for isolation of the RCIC system from the RCS by one testable valve and a closed dc-powered valve in the RCIC system discharge line, and two normally open motor-operated valves with appropriate closure signals to terminate the leakage of the pipe as a result of a break outside containment. Inservice tosting of pumps and valves is discussed in Section 3.9.6 of this report.

The RCIC system will have controls that will shut down the system if operating conditions exceed certain limits. A loak detection system is provided to detect leakage in the RCIC system.

The CST lovel transmitter will be supported and mounted in such a way that automatic suction transfer to the suppression pool from the non-seismic tank will take place without failure during a soismic event.

The RCIC system design moets RG 1.1, "Net Positive Suction Head for Emergency Coro Cooling and Containment Heat Removal System Pumps," Revision 0.

In the DSER (SECY-91-153), the staff identified Outstanding Issue 24, which required an evaluation of the TMI-2 Action Items as related to the ECCS. The staff's evaluation of these items (NUREG-0737 requirements that are incorporated into 10 CFR 50.34(f)(1)(v) and (1)(ix)), as related to the RCIC system, is provided in Chapter 20 of this report. Therefore, DSER Outstanding Issue 24 is resolved.

During an earlier review, the staff found that the testing of steam isolation valves (F035 and F036) leading to the RCIC turbines in currently operating BWRs did not include actual operating conditions such as a differential pressure of about $7,000 \mathrm{kPa}(1,000 \mathrm{psig})$ and a temperature of $286^{\circ} \mathrm{C}\left(546^{\circ} \mathrm{F}\right)$ expected during steam pipe break 
downstroam of the valves. Thus, there is no verification that the isolation valves will cloes during a break as a recult of dynamic steam flow forces. Generic Invese (GI)-87, "Failure of HPCI Steamline Without Isolation," addreseses this concern. Teats performed as part of tho NRC effort to recolve GI-87 huve reinforced concerns about the opernbility of motor-operated valves (MOV)) under these deaign-basis conditions. The etaff concerms reganding operibility of MOVs are given in Generic Letter 89-10 (June 1959) and its aupplements. OB semumed clocure of theee valves in the stenmiine break analyais. Therefore, this functional requirement is incorporated into the ITAAC. In the DFSER the etaff noted that the COL applicant refereacing the ABWR docign should verify teat data showing the steam iscidtion valves (F035 and F036) will isolate under actual operating conditions of a differcutial preasuns at about $7,000 \mathrm{kPa}(1,000 \mathrm{paig})$ and a temperature of $286^{\circ} \mathrm{C}\left(546^{\circ} \mathrm{F}\right)$. This was DFSER COL Action Item 5.4.6-1. Since verification of the valves performance by the preoperational and power accention teeting is discuseed in Chapter 14 of the SSAR, it need not bo specified as a COL sction item.

GE originally submitted the design description and the ITAAC for the RCIC system. At the timo the DFSER was iscuod, the ITAAC reviow was in progreas. Therefore, this wes DFSER Open Itom 5.4.6-1. GE has since provided a revieed deaign description and ITAAC. The adequacy and acceptability of the ABWR deaign description and ITAAC are ovaluated in Chapter 14.3 of this report. Therefore, this item is resolved.

The RCIC syctem meets GDC 4, 5, 29, 33, 34, and 54 as identified in SRP Section 5.4.6. Compliance with ODC 4 on protecting the system against dynamic effects associnted with flow instabilities and loads is discuseed in Section 3.6 of this report. Since the ABWR is a single-unit plant, ODC 5 are not applicable. Tho RCIC ayetem moots ODC 29 and 34 because it is designed to performed its function without the availability of any ac power and, in conjunction with the high-preacure core flooder system, is designed to ensure an extremely high probability of sccomplishing its safety function. Tho RCIC system is used to supply reactor coolant makeup for small leaks. Accordingly the system meets GDC 33. Compliance with GDC 54 is discussed in Section 6.2 of this report.

The ataff concludes that the design of the RCIC aystem conforms to the Commission's regulations and is, therefore, acceptable.

\subsubsection{Residual Heat Removal System}

The ataff ovaluated the residual heat romoval (RHR) ayetem according to SRP Section 5.4.7. The staff' s review criteria are based on moeting the following:

(1) ODC 2 with respect to the seismic design of systoms, atructures, and components whose failure could cause an unsccoptable reduction in the capability of the residual heat removal system. Acceptability is based on meeting position C-2 of RO 1.29 or its equivalent.

(2) GDC 4 as related to dynamic offects aseociated with flow instabilities and loads (0.8., water hammer).

(3) GDC 5 which requires that any sharing among nuclear power units of structure, systoms and components importent to safety will not significantly impair thoir safety function.

(4) GDC 19 with respect to control room requiremeats for normal operations and shutdown.

GDC 34 which specifies requirements for a residual beat romoval system.

The RHR system consists of three independent loops subsyetems A, B, and C. Each loop contains a motordriven pump, heat exchanger, piping, valves, instrumentation and controls. Each loop can take suction from either the RPV or the suppression pool and will be capable of diecharging water to oither the RPV or back to the auppreasion pool through a full-flow test line. Each shutdown cooling loop has its own heat exchanger, which will be cooled by the reactor building cooling water syctem. RHR subsystems B and C can be used for wetwell and drywell sprays. The RHR system will operate in the following modes:

(1) shutdown cooling

(2) euppression pool cooling

(3) wetwell and drywell spray cooling

(4) low-pressure flooder mode

(5) fuel pool cooling

(6) ac independent water addition 
During all six modes of operation, the same major hardware components (0.8., RHR pump, heat exchanger) will be used. Shutdown cooling, fuel pool cooling, wetwell spray cooling, drywell spray cooling, and ac independent water addition will all bo started menually. The low-presesure flooder mode and the suppression pool cooling mode will be started automatically. Modes (2), (3), and (4) are roviewed in Sections 6.2 and 6.3 of this report; Mode (5) is reviewed in Section 9.1.3 of this report.

The normal operational mode of the RHR system is the shutdown cooling mode, which will be used to remove decay heat from the reactor core to achiove and maintain a cold shutdown condition. Shutdown cooling will be started manually when the RPV is depressurized to about $931 \mathrm{kPa}$ (135 psig). The heat removed in the RHR heat exchangers will be transported to the ultimate heat sink by the reactor building cooling water system.

There are throe suction lines directly from the RPV for shutdown cooling rather than from the external reactor cecirculation loop. This design is an improvement over the present single suction line in current operating BWRs because the single line is more vulnerable to a loss of shutdown cooling by single failure of valves in the line. The RHR shutdown cooling return line for RHR subsystem $A$ is routed to the RPV through the feedwater system. The RHR shutdown cooling return lines for RHR subsystems $B$ and $C$ are routed to the RPV directly.

The RIR system also includes an ac-independent water addition subsystem that consists of piping and manual valves connecting the fire protection system to the RHR pump discharge line on loop C downstream of the pump's discharge check valve. This flow path will allow water to be injected into the reactor vessel and the drywell spray during postulated beyond-design-basis conditions where all ac power and all ECCS pumps are unavailable. Additionally, an external hookup outside the reactor building is provided so that a fire truck pump can be connected as an alternative water source.

In Branch Technical Position (BTP) RSB 5-1 of the SRP, the staff recommends that the valves provided in the suction line (valves F010 and F011) of the RHR system to isolate it from the RCS have independent and diverse interlocks to protect the RHR system. Although the ABWR design does not explicitly meet the guidance on diversity, it does meet the intent of the guidance to provide high reliability against inadvertent opening of the isolation valves. The pressure signal that provides the interlock function will be supplied from 2-out-of-4 logic, which has four independent pressure sensor and transmitter inputs. The independence is provided by each being in a separate instrument division. Furthermore, the inboard and outboard valves of the shutdown cooling system aleo will clowe on low reactor water lovel and will be powered from different electrical divisions. This meets the intent of BTP RSB 5-1 and, therefore, is scceptable. High-preseure/lowpresaure aystem interaction protection functions aro discuesed in Section 7.6.1.3 of this report.

In the DSER (SECY-91-153), the staff noted that GE should describe in dotail how the RHR syetem design meets the pressure relief requirements of BTP RSP 5-1. This was Outstanding Issue 22. This same issue was also identified as Outstanding Isouv 31 in a follow up DSER (SECY-91-235). GE investigated potential overprescurization transients when the RHR system is not isolated from the RCS. GE also evaluatod all the reactor nozzlo penetrations to determine if they could be a source of high pressure into the RPV during shutdown. GE concluded that relatively cold water from the feedwater (condensate pump) system could be injected into the RPV through either of two valves in the feodwater line by inadvertent operator action or by a valve failing open. The condensate pumps are rated for approximately 49,210 L/min $(13,000 \mathrm{gpm})$, which is one-third feedwater flow, with a shutoff head of approximately $4,137 \mathrm{kPa}$ (600 psig). A pressure in the range of 2,758 to $3,447 \mathrm{kPa}$ (400 to 500 peig) could occur upstream of the feedwater inlet valves in the RPV by inadvertent operation of the condensate pumps. This high pressure could lift the RHR pressure relief valve set at $2,275 \mathrm{kPa}$ (330 psig). To provide protoction against this situation, which would cause an overpressure condition in the RHR low-pressure piping, a design change was made by GE that will close all feed pump discharge and bypass valves by a reactor water level (LS) signal. The staff concludes that the pressure relief requirements of the RHR system satisfy BTP RSB 5-1 and are acceptable. This resolved DSER (SECY-91-235) Outstanding Issue 31.

Inservice testing of pumps and valves is discussed in Section 3.9.6 of this report. Relief valves are provided in each of the low-pressure lines that interconnect with the RCS to protect against overpressurization from RCS leakage.

The RHR pumps are motor-driven centrifugal pumps and are sized for the low-pressure flooder mode of operation. The available net positive suction heed for the RHR pumps is adequate to prevent cavitation and to ensure pump operability in accordance with RG 1.1, Revision 0. Environmental qualification for long-term operability of the RHR pumps is discussed in SSAR Appendix 3I and evaluated in Section 3.11 of this report. 
Three discharge line fill pumps are provided to maintain the RHR discharge header full of water and preseurized to reduce waterhammer during system initiation.

Each train of the RHR system can be teeted during normal plant operation by pumping water from the euppression pool back into the pool. In the DFSER, the staff noted that the TS should include (1) verification of low-presoure flooder mode operability, (2) demonstration of the capability to start each pump from the control room, and (3) performance of a system functional test without requiring coolent injection into the reactor veesel. This was DFSER TS Item 5.4.7-1. GE has submitted the ABWR TS, which include the above three areas in Section 3.5.1. Hence, DFSER TS Item 5.4.7-1 is resolved.

The preoperational test program for the RHR system is discussed in Chapter 14 of this report.

The RHR system is designed to operate with or without offsite power. The RHR system will be controlled from the control room. RHR shutdown cooling subsystems $A$ and $B$ also can be operated from the Remote Shutdown Panel.

The staff concludes that the RHR system has the capability to bring the reactor to cold shutdown conditions in a reasonable time (within 36 hours as specified by SRP Section 5.4.7).

GE originally submitted the design description and the ITAAC for the RHR system. At the time the DFSER was issued, the ITAAC review was in progress. Therefore, this was DFSER Open Item 5.4.7-1. GE has since provided a revised design description and ITAAC. The adequacy and asceptability of the ABWR design description and ITAAC are evaluated in Chapter $\mathbf{1 4 . 3}$ of this report. Therefore, this item is resolved.

The staff finds that the RHR system is designed to minimize the possibility of an ISLOCA in the following ways. The low-pressure systems at pump discharge directly interfacing with the RCS are designed with $3,447-\mathrm{kPa}$ (500-psig) piping that provides for a rupture pressure of at least $6,895 \mathrm{kPa}(1,000 \mathrm{psig})$. In addition, the high-/low-pressure motor-operated isolation valves have safety-grade, redundant pressure interlocks. Also the motor-operated valves will only be tested when the reactor is at low pressure. All inboard check valves on the RHR system are testable and have position indication.
As a part of the high-/low-pressure interface design review (Generic Issue 105, "Interfacing Systems LOCA at LWRs"), GE originally proposed to change the design preesure of the RHR suction piping from 1379 to $2827 \mathrm{kPa}$ (200 paig to 410 paig). At the time the DFSER was ieruod, GE was still assessing this change and other interfaces in the design. Therefore, this was DFSER Open Item 5.4.7-2. The SSAR now describes design improvements to reduce the possibility of an ISLOCA. The adequacy and acceptability of the ABWR design with regard to the ISLOCA concerns are evaluated in Chapter 20 of this report. Therefore, this item is resolved.

RHR system vulnerabilities during shutdown snd lowpower operation are addressed in Section 19.4 of this report.

The RHR system meets the requirements of GDC $2,4,5$. 19, and 34 as identified in SRP Section 5.4.7. It is designed to the seismic Category I recommendations of RG 1.29, as discussed in Section 3.2 of this report. It is housed in the reactor building for protection against the effects of flooding, tornados, hurricanes, and other natural phenomena. Compliance with GDC 2 is discussed in Section 3.2 of this report. Compliance with GDC 4 on protecting the system against dynamic effects associated with flow instabilities and loads are discussed in Section 3.6 of this report. Since the ABWR is a singlo-unit plant, GDC 5 are not applicable. The RHR system moets GDC 19 because its design includes necessary instrumentation and controls with respect to control room requirements. By meeting BTP RSB 5-1, the RHR system complies with GDC 34.

The staff concludes that the design of the RHR system conforms to the Commission's regulations and is, therefore, acceptable.

\subsubsection{Reactor Water Cleanup System}

The staff reviewed the reactor water cleanup system (CUW) description and piping and instrumentation diagrams in accordance with SRP Section 5.4.8. Staff acceptance of the design is based on compliance with the requirements of (1) GDC 1 as related to the design meeting standards commensurate with the system's safety function; (2) GDC 2 as related to the system being able to withstand the effects of natural phenomena; (3) GDC 14 as related to assuring the integrity of the RCPB; (4) GDC 60 as related to the capability of the system to control the release of radioactive effluents to the environment; and (5) GDC 61 as related to designing the system with appropriate confinement. 
The CUW performs the following function:

(1) Removes solid and dissolved impurities from the reactor coolant.

(2) Provides containment isolation which ensures that the major portion of the system is outside the RCPB.

(3) Discharges excese reactor water durings startup, shutdown, and hot standby 'conditions to the rudwasto system or the main condenser.

(4) Provides flow to the RPV head spray for rapid RPV cooldown.

Minimizes RPV temperature gradients by maintaining circulation in the bottom head of the RPV during periods when the reactor internal pumps are not operating.

The CUW is a closed-loop system comprised of a regenerative heat exchanger, two nonregenerative heit exchangers (cooled by RCW), two filter-demineralizers, two circulating pumps, system isolation valves, and other piping, valves, and instrumentation. The system takes its suction from the shutdown cooling suction line of RHR loop "B" and the RPV bottom head drain line. CUW discharges back to the vessel via either the feedwater system or the RPV head spray line. The system capacity is 2 percent of rated feedwater flow, which is twice the capacity of previous BWRs.

The majority of the system (including all safety-related components) is located in the nondivisional quadrant of the secondary containment portion of the reactor building. The system is classified as non-safety related with the exception of the containment isolation valves. System piping and components in the drywell, up to and including the outboard containment isolation valves, form part of the RCPB are classified as seismic Category I, QG A. The remainder of the system is classified as nonseismic, QG C. Low-pressure piping in the backwash and precoet area driwnstream of the block valves is classified as QG D. Nonsafety components receive power from non-class $1 E$ supplies. Based on this QG and seismic classification design information, the staff concludes that the CUW system meets the guidelines of RGs 1.26 and 1.29 and, therefore, the requirements of GDC 1 and GDC 2 as they relate to the CUW design meeting the standards commensurate with the system's safety function and the system being able to withstand the effects of natural phenomena.
The two afety-related containment isolation valves on the arction line of the CUW system and the isolation valve on the RPV head spray line recoive isolation signals from the leak detection system (LDS). These valves are powered by class-1E power sources and automatically isolate on indications of low reactor water level, high ambient main steam tunnel are temperature, high mass differential flow, high ambient CUW equipment area temperature, or initiation of the standby liquid control (SLC) system. The icolation valves are designed and tested to ensure that they close during maximum flow and differential pressure conditions. Based on this information, along with the coismic and quality group classifications for that portion of the system up to and including the containment isolation valves discussed earlier, the staff concludes that the system meets the requirements of GDC 14 as it relates to assuring the integrity of the RCPB.

GE performed pressure and temperature and cooldown analyses for CUW breaks inside the secondary containment. The resulting pressures and temperatures were within the environmental qualification envelope for components which would be affected by the breaks and were within the design pressure and temperature limits for the primary and secondary containment structures (see Chapter 6 of this report).

The CUW suction line contains a flow restrictor inside the containment to monitor flow and to restrict flow during a line break, as well as a motor-operated shutoff valve for long-term system isolation. In addition, upon indication of high radiation levels in the secondary containment, SGTS actuates and processes potentially radioactive effluents before release to the environment. FDU vents are routed to the beckwash receiving tank while piping vents and drains are routed to the low conductivity portion of the liquid radwaste system. Unidentified leakage from CUW piping is collected and monitored in the reactor building floor drain sumps. These design features, along with the automatic system isolation features discussed earlier, ensure that releases of radioactive effluents to the environment are limited. This satisfies the requirements of GDC 60 as it relates to controlling the release of radicictive material.

The filter demineralizers are of the pressure precoat type using filter aid and powdered mixed ion-exchange resins as a filter and an ion-exchange medium. Spent resins cannot be regenerated and will be sluiced from the filterdemineralizer unit to a backwash-receiving tank from which they will be transferred to the radwaste system for processing and disposal. Resins will be discarded on the basis of filter-demineralizer performance, as indicated by monitored effluent conductivity, differential pressure across the unit, and sample analysis. A strainer is installed in the 
offilvent line of each filter domineralizer to provent rexins from entering the syetem in the ovent of failure of a filter-deminoralizer reein support. Each strniner and filterdeminoralizer veseal has a control room alarm that will be coergized by high differential preasure. If difforential preanure increases beyond the slarm point, the filter demineralizer will isolate automatically. Based on this information (along with the information discuseed carlier regarding ayatem' vents and drains), the staff concludes that the CUW deaign meets the requirements of GDC 61 as it relates to deaigning the system with adequate confinement features.

Hydrogen water chemiatry that conforms to with the guidolines contained in Electric Power Reweurch Institute (EPRI) Report NP-4947-SR, "BWR Hydrogen Water Chemistry Ouidalines," 1987 Rovision, will be used. This document sio includes hydrogen water chemistry limits, responses to out-of-epecification water chemistry, chemical analysis methods, dat management and aurveillance schemes, and management philoeophy required to ectablish and implement a arcecenful water chemiatry control program. Therefore, the CUW system design satisfies the reactor chemistry limits specified in RG 1.56, "Maintenance of Water Purity in Boiling Water Reactors," Revision 1, and EPRI Report NP-4947-SR.

The Advieory Committee on Reactor Safeguards (ACRS) performed an independent reviow of the CUW system and provided the reaults to both GE and the NRC staff. GE roviowed the reaults and provided responses to cach of the ACRS concerns identified in the ACRS report. The staff has reviewed GE's responses and has concluded that the modified CUW design adequately addresses the issues mised during the ACRS independent roview and documented in the report.

Major concerns in the ACRS report included (1) CUW configuration and design features, (2) CUW processing capacity, (3) quality group and seismic classification of components, (4) quality and consistency of information in the SSAR, (5) design of system isolation valves, and (6) role of the system in safety analyses.

\section{(1) CUW Confiquration and Desien Features}

The ACRS concerns in this area included (a) the lotdown path for excess water during plant heatup, (b) reverse flow from the feedwater system into the main steam tunnel (MST) or secondary containment on a CUW pipe break, and (c) high-temperature isolation of the system's filter-demineralizer units (FDUs) and resin retention in the FDUs. (a)

\section{LETDOWN PATH FOR EXCESS WATER}

It was unclear whether the CUW system provided letdown to the condensate storage tank. GE clarified that CUW discharges excess water to the main condenser or to the liquid waste management oystem.

\section{(b) REVERSE FLOW FROM THE FEEDWATER SYSTEM}

GE modified the system design to ensure that reverse flow from the feedwater system to the cecondary contrinment and steam tunnel would not occur as a recult of a CUW line break in these areas. Proviously, check valve G31-F014 and motor operated valve G31-F015 were located inside eccondary containment with G31-F014 upstream of G31-F015. In this configuration, break in the CUW line upstream of these valves, along with a failure of G31-F015 to close, could result in excessive blowdown of the CUW line into the secondary containment area. In response to this concern, GE modified the valve arrangement so that G31-F014 is now inside the MST next to the tunnel wall and G31-F015 is located against the outer MST wall. In this configuration, a CUW line break with a failure of G31-F015 will not result in excessive system blowdown into the secondary containment because check valves in the nuclear boiler system (NBS) (B21-F006A and B21-F006B) as well as G31-F014 are available to prevent reverse flow. In addition, two motor-operated valves in the NBS (B21-F007A and B21-F007B) are available to provide additional long-term manual isolation. These NBS valves are classified as safety-Class 2, Quality Group B, and seismic Category I.

The three containment isolation valves for CUW are designed to close on a signal from the Leakage Detection and Isolation System (LDS). The LDS provides this signal on low reactor water level, high ambient MST are temperature, high mass differential flow, high ambient CUW equipment are temperature, and SLCS actuation. Based on this information, the staff concludes that the modified CUW design provides assurance that excessive feedwater or CUW blowdown will not occur a result of a CUW pipe failure inside secondary containment. 
(c) HIGH-TEMPERATURE ISOLATION OF THE SYSTEM'S FILTER-DEMINBRALIZER UNITS (FDU\&) AND RESIN RETENTION IN THE FDU:

Tho ACRS report identified a concern regarding protection of the FDU resins from high temperature water. The high tomperature ectpoint for automatic bypass of the FDUs was not provided in the SSAR. GE later clarified that the FDUs aro isolated and bypassed at $54^{\circ} \mathrm{C}$ as shown on SSAR Figyro 5.4-13, sheet 2.

\section{CUW Processing Capacity}

The ACRS identified soveral concerns related to CUW flexibility and processing capecity. Theee included (a) increased processing capacity and (b) the effectiveness of the nonregenerative heat exchanger (NRHX) when used as an alternate means of docay heat removal.

\section{(a)}

\section{INCREASED PROCESSING CAPACITY}

The ABWR design doubles the traditional CUW procesesing capacity from 1 percent in current BWR to 2 percent in the ABWR. The ACRS report expreseed concern regarding the impect of this increase. Specifically, the ACRS was concerned that design details such as resin bed volumes, resin types, and resin bed replacement criteria were not provided in the SSAR. Subsequently, GE clarified that the ABWR commits to maintaining the water chemistry requirements stated in the SSAR. The COL applicant will determine the proper components to meet the chemistry requirements.

EFFECTIVENESS OF THE NON-
REGENERATIVE HEAT EXCHANGER
(NRHX) WHEN USED AS AN
ALTERNATE MEANS OF DECAY HEAT
REMOVAL

The ACRS report stated that additional heat exchanger parameters are needed to determine if the NRHX can be used as an effective means of removing decay heat during high pressure conditions with RHR unavailable. Subsequently, GE provided information which showed that the use of the NRHXs is not a primary means of accomplishing the heat removal function and that this method of heat removal has only a small impact on the PRA core damage frequency.

\section{(3) Ouslity Group and Seismic Classification of Components}

The ACRS report identified a concern relating to the conversion of Japanese safety classification codes to equivalent domestic codes. Specifically, umbiguities wero identified in noto 11 of SSAR Table 1.7-1 (this table corrolates the Japanese and domestic codes). As a result, GE modified this table to remove any ambiguities.

\section{Ouality and Consistency of Information in the SSAB}

The ACRS expreseed a concern regarding the quality and consistency of information not only in the SSAR section relating to CUW, but also in other SSAR sections. The staff has worked with GE throughout the review process to identify any ambiguities and inconsistencies found in the SSAR. These have largely been identified and corrected.

\section{(5) Desian of System Isolation Valves}

The ACRS report identified a concern regarding the design adoquacy of the system isolation valves. Specifically, current BWRs must meet Generic Letter 89-10 regarding reliable containment isolation valve closure against maximum differential pressure and flow. However, despite this, problems still exist. Demonstration of the reliability and capability of these valves through the use of in-service testing cannot be achieved since the worst-case conditions cannot be created in-situ. As a result, the assumptions used in the safety analysis and PRA may not be valid. In response, GE clarified that type-testing of all isolation valves are conducted in the shop at worst-case design conditions and each installed valve is tested in-situ. The requirements on these valves are provided in SSAR Section 3.9.6 and evaluated in Section 3.9.6 of this report. In addition, verifications are made as part of the ITAAC process.

\section{(6) Bole of the System in Safety Analyses}

The ACRS report identified concerns related to system failure as it relates to the safety analysis. This included (a) maximum inventory loss and (b) isolability of the bottom head drain line.

\section{(a) MAXIMUM INVENTORY LOSS.}

The ACRS report stated that because of the uncertainty of whether the CUW line break was 
evaluated in Chapter 6 of the SSAR, it appeared that the tothl inventory low from this break (areuming a 30-recond CUW lino isolation) may be more then that from a main ateem live (MSL) break with rubequent MSIV isolation. Subeequently, GB clarified that the wort-cane broak outside contrinment (from a loae-of-mins perapective) cocurred as a result of a feedwater lino break. The CUW line break analysis ascumed a 75-eecond isolation time (45 second time delay on system differential flow indication and 30 second cloaure time). In this conservative analysis the total inveatory loes was leas than that from a MSL break with aubeequent MSTV isolation.

\section{(b) ISOLABILITY OF THE BOTTOM HEAD DRAIN LINE}

The original CUW design included a manuallyoperated valve on the reactor pressure veseel (RPV) bottom head drain line inside containment. The ACRS report identified a concern regarding isolability of this line. Subeequently, OE modified the dexign to make this a remote manually-operated shutoff valve and moved the valve to a position immediately upstream of the inboard containment isolation valve on the CUW suction line. In addition, the RPV bottom head drain line connects to the main CUW suction line at a "toe." The centerline of this connection is at least $389 \mathrm{~mm}$ (15.3 in.) above the top of active fuel. If an unisolated CUW line break should occur, the shutoff valve can be used to isolate the break. If this were to fail, the RPV water level would be maintained at the level of the "tee" connection. An isolated line break is discussed in SSAR Subsection 19.9.1.

Other concerns identified in the ACRS report related to the treatment of CUW in the PRA and the ITAAC. In both cases GE provided information which reeolved the concerns.

Based on the information provided by $G E$ in response to the concerns raised in the ACRS report, the staff concludes that the issues have been adequately addressed.

In the DFSER, the staff requested GE to provide adequate design description and inspections, tests, analyees, and acceptance criteria (ITAAC) relating to CUW. GE provided a revised set of design description and ITAAC. The adequacy and ecceptability of the deaign deacription and ITAMC are ovaluated in Section 14.3 of this report.

The reactur water cleanup aystem (CUW) will bo uned to aid in maintrining the reactor water purity and to soduce the reactor water inventory as required by plant operations. The reviow hes included piping and inotrumentation diagram and proceses diagram along with descriptive information concerning the syatem design and operation.

The ataff concludes that the proposed dexign of CUW is acceptable and moets the relovant requirements of General Design Criteria 1, 2, 14, 60 , and 61. This conclusion is based on the following:

(1) GE has met the requirements of GDC 1 by designing, in accordance with the guidelines of RG 1.26, the portion of the CUW extending from the reactor vesel to the outermoet primary containment isolation valves to Quality Group A and by designing, in accordance with position C.2.C of RO 1.26, the remainder of the CUW outside primary containment (excluding the precont unit) to Quality Group C.

GE has met the requirements of GDC 2 by designing, in sccordance with positions C.1, C.2, C.3, and C.4 of RG 1.29, the portion of the CUW extending from the reactor veseel to the outermost primary containment isolation valves to seismic Category I.

(3) GE has met the requirements of GDC 14 by meeting RG 1.56 in maintaining reactor water purity and material compatibility to reduce corrosion probabilities, and thus reducing the probability of RCPB failure.

GE hes met the requirements of ODC 60 and 61 by designing a system containing radioactivity with confinement and by venting and collecting drainage from CUW components through closed systems.

Based on this information, the staff concludes that the CUW design for the ABWR is acceptable. 


\section{ENGINEERED SAFETY FEATURES}

\subsection{Engineered Safety Features Materials}

\subsubsection{Metallic Materials}

Tho etaff reviowed the engincered mafoty features (BSF) meterials in eccordance with SRP Section 6.1.1. The caginoered affety fotturen materials are acoeptable if thoy mece the requirements of: ODC 1 and Section 50.55a of 10 CFR Part 50 as thoy relate to quality etandarits being urd for deaign, fabrication, erection, and teating of ESF cumponents and the identification of applicable codes and ctusdarda; GDC 4, as it relates to compatibility of ESF components with environmental conditions sesocinted with normal operation, maintenance, toeting, and poetulated scoidenu, including low-of-coolent eccidente; GDC 14, a it relatis to doaign, fabrication, and toating of reactor coolant preseure boundary so 2 to have extremely low probability of abnormal leakage, of rapidly propagating failuro, and of groes rupture; GDC 31, a it relates to extromely low probability of rapidly propagating fracture and groes rupture of the reactor pressure coolant boundary; ODC 35, as it rolates to ascurance that the clad metalwater reaction is limited to nogligible amounts; GDC 41 as it relates to control of the concentration of hydrogen in the containment atmosphere following poctulated sccidents to ascure that the containmeat intogrity is maintained; and Appendix B to 10 CFR Part 50 as it relates to the requiremeat that measures should be catablished to control the cleaning of material and equipment in sccordance with work and inspection instructions to provent damage or deterioration.

To moet the requirements of GDC 1, 14, and 31 of Appendix A to 10 CFR Part 50, the requirement of 10 CFR 50.55a and to enoure that the BSF materials perform the neceseary sefety function, the ASME Code and industry atandands should be satiefied for the ABWR decign. SSAR Table 5.2-4 lists the pressuro-rotaining materials and materials specifications for the reactor coolant pressure boundary components. SSAR Table 6.1-1 lists the pressuro-retaining materials' and materials specifications for the primary containment system, emergency core cooling systems (ECCS8) and their auxiliary syatems, and the standby liquid control system. In the DSER (SECY-91-153), the staff atated that the ESF materials should atisfy GDC 1, 14, and 31 and 10 CFR 50.55a to ensure low probability of leakage, rapidly propagating failure, and groes rupture. To do so, the ESF materials celected should aatiefy Appendix I, "Design Strees Intensity Values, Allowable Streseses, Material Properties, and Deaign Fatigue Curves, "to Section III of the ASME Code and Parts A, B, and C of Section II of the code. In its transmittal of October 9, 1991, GE addressed this item by revising SSAR Section 6.1.1.1.1 to state that the ESF meterials will matinfy Appendix I to Section III of the ASMB Cods and Parts A, B, and C of Section II of the code. This revision was soceptable and resolved part of Open Iteon 25 from tho DSER (SECY-91-153).

To meet the requirements of ODC 4,14, and 41, the water uned in the ESF aysteme should be controlled to provide ascurnece that ntrese corrotion cracking of unstabilized autenitic atrinlees eteol components will not occur. In the DSER (SBCY-91-153), the ataff made the following recommendation:

- OB should follow Blectric Power Rsecearch Institute (BPRI) report, "Boiling Water Reactor (BWR) Water Chemietry Guidalines," NP-3589-SR-LD, April 1985, for the water ueed for BCCS and sprny systems.

- GE should follow EPRI report, "Guidelines for Permanent BWR Hydrogen Water Chemistry Inetallations - 1987 Revision, "NP-5283-SR-A, September 1987, for the deaign, construction, and operation of hydrogen water chemistry installations.

- GE should follow EPRI report, "BWR Hydrogen Water Chemistry Guidelines: 1987 Revision, " NP-4947-SR, October 1988, for water chemistry limits, responses to out-of-epecification water chemistry, chemical analysis mothods, and data management and surveillance and management philosophy required to establish and implement a succeseful water chemistry control program.

In the DSER (SECY-91-153), the staff also stated that SSAR Sections 6.1.1.1.2 and 6.1.1.2 should have adhered to the above recommendations. This was DSER Open Itom 25.

In its letter of March 11, 1992, GE responded to this item by revising SSAR Section 9.3.9 (SSAR Amendment 21) to etate that the hydrogen water chemistry system will conform to the guidelines in EPRI reports NP-5283-SR-A and NP-4947-SR. This response was acceptable and resolved Open Item 25 from the DSER (SECY-91-153); however, because (JE also might use pure water chemistry, the staff concluded in the DFSER that GE should commit to follow EPRI Report NP-3589-SR-LD. This was identified a DFSER Confirmatory Itom 6.1.1-1. GE advised the staff in its letter of March 8, 1993, that compliance with EPRI report NP-3589-SR-LD was no longer appropriate because it had committed to use hydrogen water chemistry and was following the guidelines of EPRI report NP-4947-SR. The staff finds this commitment acceptable. This resolved DFSER Confirmatory Itom 6.1.1-1. 
SSAR Section 6.1.1.1.3 adheres to the materials epecifications that antisfy Appendix I to Section III of the ASMB Code and Parts A, B, and C of Section II of the code; therofore, Section 6.1.1.1.3 atiofies ODC 4, 14, and 35 and Appendix B to 10 CFR Part 50 as thoy pertain to matterials epecifications.

The controls to be pleced on concentrations of leachable impurition in nonmetallic thermal inmulation uned on BSF components comply with the guidalines of RO 1.36, "Nonmotallic Thermal Inmulation of Aurtenitic Strinleas Steals," Revition 0 . Therefore, by complying with RG 1.36, the ESF thermal inculation epecification meet the requiremente of ODC 1, 14, and 31 .

OB thes mot ODC 1, 14, and 31 and 10 CFR 50.55a with reepect to concuring an extromoly low probability of leakage, of mpidly propagating failure, and of groves rupture, since the materials selocted for the ABWR ESF atiofy Appendix I to Section III of the ASME Code and Parts A, B, and C of Section II of the code. During beading and fabrication, the bead radius, the material hardnese, and the surfece finish or ground aurface aro to be controlled. If the controls are not met, the materials are required to be solution heat-treated again. Frncture toughness specifications for the forritic materials meet the requirements of the code.

The controls on the ues and fabrication of the austenitic athinleses atool of the systom satiofy the guidence of RO 1.31, "Control of Ferrite Content of Strinleses Steol Wold Motal," Revision 3, and RO 1.44, "Control of the Use of Sensitized Stainleas Steel, "Revixion O. Fabrication and he at treatment practices performed in eccordance with these requirements provide added acournece that the probability of stress corrosion cracking will be reduced during the postulated eccident time interval.

Conformance with the code and RGs and with the ataff positions mentioned above constitutes an acceptablo basis for meeting the requirements of GDC 1, 4, 14, 35, and 41; Appendix B to 10 CFR Part 50; and 10 CFR 50.55a, according to which the system are to be decigned, fabricated, and erected so that they can perform their functions as required.

As discuseed above, GE hes met GDC 1, 14, 31, and 35 and Appendix B to 10 CFR Part 50 with respect to ensuring that the ABWR reactor coolant boundary and associated auxiliary syetems will have an extremoly low probability of leakage, of rapidly propagating failures, and of gross rupture.

Based on the above discusaion, the staff concludes that the ESF metallic materials satiafy the requirements of ODC 1 ,
$4,14,31,35$, and 41; and the requirements of $10 \mathrm{CFR}$ Part 50.

\subsubsection{Protective Coating Systems (Paints) and Organic Material}

The ataff performod its roviow in sccordance with SRP Section 6.1.2. The protective coating systems are scoeptable if the protective coatings that will be applied incide the containment meet the requirements of Appeadix B to 10 CFR Part 50 as it relates to the quality amunnce (QA) requirements for the design, fabrication, and conetruction of anfety-related structures, systems, and composents. The Appendix B to 10 CFR Part 50 requirements are satisfied if the protective coatings conform to the teeting requirements of ANSI N101.2-1972, "Protective Coatinge (Paints) for Light Water Reactor Containment Facilitien," and the QA guidelines of RO 1.54, "Quality Asournee Requirements for Protective Conting Applied to Water-Cooled Nuclear Power Plants." This provides sasurance that the protective coatings will not fail under design-basis-accident (DBA) conditions and genernto significant quantities of solid debris that would impair the performance of the ESF.

GE atated that the coating system materials to be used on the exponed surfaces within the drywell will bo qualified in sccordance with ANSI N101.2-197\%. The protective conting aystem for the containment will be applied in cocondance with RO 1.54. However, GE has indicated that the COL applicant may use materials in relatively amall areas in the drywell that will not conform to RO 1.54.

Since GE will meet the QA requirements of Appendix B to 10 CFR Part 50 and since the containment coating systems have been evaluated for suitability to withstand a postulated DBA cavironment, the staff concluded in the DFSER that the protective coating systoms and their applications were ecceptable.

However, the staff also concluded in the DFSER that the COL applicant referencing the ABWR design should indicato the total amount of protective coatings and organic materials used inside the containment that did not meet the requirements of ANSI N101.2-1972 and RG 1.54. This was identified as DFSER COL Action Item 6.1.2-1.

GE included this information in SSAR Section 6.1.3, which requires that the COL applicant indicate the total amount of protective coatings and organic materials used inside the containment that do not meet the requirements of ANSI N101.2 and RG 1.54. This is acceptable. 


\subsection{Containment Systems}

The containment systems for the ABWR include a contrinment etructure as the primary contrinmeat, a cecondary containment (resctor building) currounding tho primary contrinment and housing equipment cesential to afo shutdown of the renctor and ful tornge facilitien, and aupporting systoms. The primary contrinment is deaigned to provent the uncontrolled releave of radionctivity to the environmeat with a leakage rato of 0.5 percent by weight per day at tho calculated peak containment presauro rolated to the DBA. The secondary contrinment is deaigned to confine the leaknge of airborne radionctive materials from the primary containment. SSAR Figure 6.2.1 shows the principal features of the ABWR containment.

\subsubsection{Primary Contrinment Functional Design}

The ABWR primary containment is desizned with the following main features:

- A drywell that consists of two volumes: (1) en upper drywell (UD) volumo surrounding thu reactor preesure vesel (RPV) and housing the steam and feodwater lines and other connections of the reactor primary coolant system, safety/rolief valves (SRVs), and tho drywell heating, ventilation, and air conditioning (HVAC) coolers; and (2) a lower drywell (LD) volume housing the reactor internal pumps (RIPB), control rod drives, and under-veseel components and servicing equipment.

The UD is a cylindrical, steel-lined, reinforcedconcrete structure with a removable steol bead and a reinforced-concrete steol diaphragm floor. The cylindrical RPV pedeetal, which is connected rigidly to the steel diaphragm floor, separates the LD from the wetwell. Ten UD-to-LD connecting vents (DCVs), approximately $1 \mathrm{~m} \times 2 \mathrm{~m}(3.3 \mathrm{ft} \times 6.6 \mathrm{ft})$ in cross-section, are built into the RPV podestal. The DCVs extend downward through steel pipes with an inside diameter of $1.2 \mathrm{~m}(4 \mathrm{ft})$, each of which has three horizontal vent outlets into the suppression pool.

The drywell, which has a net free volume of $7,350 \mathrm{~m}^{3}$ $\left(259,563 \mathrm{ft}^{3}\right)$, is designed to withstand design presesure and temperature transients following a loss-of-coolant accident (LOCA) and also the rapid reversal in pressure when the steam in the drywell is condensed by ECCS flow during post-LOCA flooding of the RPV. A wetwell-to-drywell vacuum relief system will prevent beckflooding of the suppression pool water into the LD and protect the integrity of the steel diaphragm floor slab between the drywell and wetwell and the drywell structure and liner. The drywell design pressure and temperature are 310 kilopacal (kPa) (45 pounds per equare inch gauge (paig)) and $171^{\circ} \mathrm{C}\left(340^{\circ} \mathrm{F}\right)$, reapectively. The deaign drywell-to-wetwell differeatial preasures aro +172.4 kPa (25 paig) and $-13.8 \mathrm{kPa}$ (-2 paig). Tho decign drywell-to-roactor building negative differeatial pressure is $-13.8 \mathrm{kPa}$ (-2 psig).

- A syatem of drywell-to-wetwell veat channels that will blow down from the drywell and diecharge into the auppreasion pool following LOCA. There are 30 vents in the vertical section of the LD below the aupprescion pool water level, each with a nominal diameter of $0.7 \mathrm{~m}(2.3 \mathrm{ft})$. These vents are arranged in 10 circumferential columns, each containing threo vents. The three-vent centerlines in each column are located at $3.5 \mathrm{~m}$ (11.48 ft), $4.87 \mathrm{~m}$ (15.98 ft), and $6.24 \mathrm{~m}(20.48 \mathrm{ft})$ below the suppression pool water level when the suppression pool is at the low water lovel.

- A wetwell that consiats of an air volume and auppreacion pool, with a not freo-air volume of $5,960 \mathrm{~m}^{3}\left(210,475 \mathrm{ft}^{3}\right)$ and a minimum pool volume of $3,580 \mathrm{~m}^{3}\left(126,427 \mathrm{ft}^{3}\right)$ at low water level.

The wetwell is designed for an internal pressure of $310 \mathrm{kPa}$ (45 psig) and a temperature of $103.9^{\circ} \mathrm{C}$ $\left(219^{\circ} \mathrm{F}\right)$. The design wetwell-to-reactor building negative differential pressure is $-13.8 \mathrm{kPa}$ (-2 psig). The auppression pool, which is locatod inside the wotwell annular region between the cylindrical RPV pedectal wall and tho outer wall of the wetwell, is a large body of water that will serve as a heat sink for poatulated transients and accidents and as a sourco of cooling water for the ECCS. In the case of transients that result in a lose of the ultimate heat sink, energy will be transferred to the pool by the discharge piping from the reactor system's SRVs. In the event of a LOCA in the drywell, the drywell atmosphere will be vented to the suppression pool through the system of diswell-to-wetwell vents.

This primary containment design basically uses combined features of the Mark II and Mark III designs, excopt that the drywell consists of UD and LD volumes. The vents to the suppreesion pool are a combination of the vertical Mark II and horizontal Mark III systems. The wetwell is similar to a Mark II wetwell.

\subsubsection{LOCA Chronology}

Following a postulated LOCA, the drywell pressure increases as a result of blowdown of the reactor coolant system. Pressurization of the drywell causes the water initially in the vent system to be accelerated into the pool 
until the vents are cleared of water. During this clearing procees, the water leaving the borizontal vents forms jets in the mppreacion pool and caves water jet impingement loads on tho atructures within tho auppreseion pool and oa the contrinment wall opposito the vents.

During the vent-clearing transient, the drywell aleo is arbjected to a preacure differeatial and tho RPV pedectal wall experiences a vent-clearing reaction force.

Immodiately following vent clearing, an air and ateam bubble forms at the exit of the vent. The bubble preseare initially is ascumed equal to the exiating drywall and wetwell differential preseurs. This bubble transmits a preanure wave through the auppreseion pool water and recults in a loading on the suppreacion pool boundaries and on equipment located in the auppreacion pool.

As the air and ateam flow from the drywall becomen extablished in the vent system, the initial veat exit bubble expands to equalize tho mppreacion pool hydroetatic preenure. GE's largo-ecalo preacure auppresaion toat facility (PSTF) teets show that the steam fraction of the flow is condensed, but continued injection of drywell air and expension of the air bubble results in a rise of the suppression pool surface. During the early stages of this process, the pool swells in a bulk mode (i.e., a slug of solid water is sccelerated upward by the air prescure). Structures clowe to the pool surfece experience loads as the rising pool surfice impacts the lower surface of the structure. In addition to these initial impect loads, these structures experience drag loads as water flows past them. Equipment in the suppression pool also experiences drag loads.

Data from PSTF air teots indicate that after the pool aurfice has risen approximately 1.6 times the initial aubmergeace of the top veat (which trunalates to $3.66 \mathrm{~m}$ (12 fi) above the initial pool surfece for the Mark III design) the thickneas of the water ligameat could be as small as $0.61 \mathrm{~m}(2 \mathrm{ft})$ or lese, significantly reducing the impect loads. This phase is referred to as "incipient breakthrough," that is, the ligament begins to break up. To account for poesible nonconservatism in the teet facility arrangement and indrumeatation error bands, the ataff has determined that the breakthrough beight should be set at $5.5 \mathrm{~m}$ (18 ft) above the initial pool aurface for the Mark III design. The etaff's ovaluation of the brenkthrough height for the ABWR design is given in Section 6.2.1.6 of this report.

As the drywoll air flow through the horizontal vent gystem decreases and the air/water suppression pool mixture experiences gravity-induced phase separation, pool upward movement stops and the fallback proceses starts. During this procese, floore and other flat structures experience downward loading, and therefore, the containment wall theoretically can be aubjected to a small preseure increase. However, this preecure increase has not been observed experimeatally.

As the reactor blowdown proceeds, the primary system is depleted of high-energy fluid inventory and the steam flow nito to the vent system decreases. This reduced steam flow rate leads to a reduction in the drywell-to-wetwell preceure differential that, in turn, results in a sequential recovering of the horizontal vents. Suppression pool recovery of a particular vent row occurs when the vent etagnation differential pressure corresponds to the auppreation pool hydroetatic pressure at that row of vents.

Toward the end of the reactor blowdown, the top row of vents is capable of condensing the reduced blowdown flow and the two lower rowe are totally recovered. As the blowdown steam flow decreases to very low values, the water in the top row of vents starts to oecillate, causing what has becomo known as vent chugging. This action results in dynamic loads on the top vents and on the RPV pedestal wall opposite the upper row of vents. In addition, an oecillatory pressure loading condition can occur on the drywell and wetwell. Because this phenomenon is dependent on a low steam mass flux (the chugging threebold appears to be in the range of $49 \mathrm{~kg} / \mathrm{sec} / \mathrm{m}^{2}$ $\left(10 \mathrm{lb} / \mathrm{sec}^{\mathrm{ft}} \mathrm{\textrm {t } ^ { 2 }}\right)$ ), it is expected to occur for all break sizes. For smaller breaks, it may be the only mode of condensation that the vent system will experience.

The staff's evaluation of these LOCA-related pool dynamic loads is given in Section 6.2.1.6 of this report.

Shortly after onset of a DBA, the ECCS pumps automatically start and pump suppression pool water into the RPV. This water floods the reactor core, and the water starts to cascade into the drywell from the break. When this occurs will depend on the size and location of the break. Because the drywell is full of steam at the time of veseel flooding, the sudden introduction of cool water cauces rapid steam condensation and drywell depresecurization. When the drywell pressure falls below the wetwell airspace preesure, air from the wetwell redistributes between the drywell and wetwell through the wetwell-to-drywell vacuum relief system. Eventually enough air returns to equalize the drywell and wetwell pressures; bowover, during this drywell depressurization transient, there is a period of negative pressure on the drywell structure. A negative load condition of $-13.8 \mathrm{kPa}(-2 \mathrm{psig})$ is, therefore, specified for drywell design. The staff's evaluation of this drywell-to-wetwell negative differential pressure is given in Section 6.2.1.5.1 of this report. 


\subsubsection{Containment Amalysis}

The staff's review of the containment deaign included the tomperature and preseure responses of the drywell and wetwell in a spectrum of LOCAs, the capability of the containment to withstand the offects of steam bypees from the drywell directly to the air region of the auppreacion pool, the capability of the drywell and wetwell to withetand external pressure, and the negative drywell-to-wetwell differential preserure. In addition, the etaff considered GE's proposed design bases and criteria for the containment, the analyses and test date in support of the criteria and bases, and the loads reoulting from pool dynamic phenomena.

\section{Contrinment Analytical Model}

In its slculation of the short-term and long-term containment pressure-temperature response to postulated high-energy line breaks, GE used the same analytical models and conservative assumptions that were prescented and reviewed for the Mark III containment in General Electric Standard Safety Analysis Report (GESSAR) II (NUREG-0979). The staff found these to be acceptable, using independent confirmatory analyses with the CONTEMPT-LT28 computer code. These models and assumptions are discussed in the ABWR SSAR and NEDO-20533 and its Supplement 1, "The G.E. Mark III Pressure Suppression Containment Analytical Model." In response to the staff's request for additional information (RAI), GE stated that the analytical models described in NEDO-20533 are appropriate to calculate the ABWR containment responses to postulated accidents. Although originally written for predicting of Mark III transients, these models, which simulate the transient conditions in the containment, can be adapted for the ABWR containment configuration. These models simulate the drywell, vent systems, and wetwell (suppression pool and airspace). They are, therefore, adaptable to other containment configurations having the same basic components.

As indicated earlier, the ABWR containment design uses combined features of Mark II and Mark III designs, except for the unique feature of two drywell volumes (upper and lower). The vent system is a combination of vertical (Mark II design) and horizontal (Mark III design) drywell-to-wetwell vent systems, and the wetwell (suppression pool and airspace) is similar to a Mark II.

The staff was unable to conclude in the DSER (SECY-91-355) that the assumptions and models used to predict the containment pressure and temperature transients following a LOCA in the ABWR containment were acceptable. In the DSER (SECY-91-355), the staff identified the issue of containment pressure and temperature analysis as Open Items 3 and 10. Specific concerns are discuesed below.

As diecusead in the DSER (SECY-91-355), GE had not provided a dotailed discussion to describe how the two ABWR drywell volumes (Open Itom 3) and the combination vertical and horizontal vent system are modeled in the computer code to represent the physical geometry of the containment, and how the air carryover from the two drywell volumes to the wetwell is treated in the computer code. The impact of any difference in the hydrodymamic force, caused by venting, between the Mark III design (vent annulus) and ABWR design (pipe vents) was also unclear. In addition, the staff required teots or analyses to verify that following a LOCA:

- the combination vertical and horizontal drywell-towetwell vent system will perform (to demonstrate venting clearing, condensation, and chugging) as predicted

- the containment will perform (air carryover and containment pressure and temperature responses) as predicted by the analytical model

In a meeting held on May 6, 1992, GE clarified its model assumed for drywell volumes and the vent system. The same as for the Mark III containment model, GE assumed that the UD and LD volumes act as a single node and the drywell-to-wetwell vent system as a horizontal vent for its ABWR analysis. The contents of the LD start transferring to the wetwell as soon as the pressure starts decreasing. GE assumed 50 percent of the LD contents is transferred into the wetwell. The staff raised questions $x^{\circ}$. Jut the validity of these assumptions because they do not reflect the actual ABWR configuration. By a letter dated May 22, 1992, GE provided additional information to justify the conservatism of those assumptions. GE calculated the drywell pressure using a more realistic two-node drywell model and compared it with the drywell pressure described in the SSAR using the single-node drywell model. The results show that the single-node model results in a higher peak drywell pressure. Therefore, the single-node model is acceptable in that it is more conservative. This resolved Open Item 3, which was identified in the DSER (SECY-91-355). Furthermore, because the peak containment presoure occurs substantially later, after the ventclearing process is complete, the slight geometrical differences are expected to result in negligible effects on the containment peak pressuro and overall vent-clearing process. GE's use of NEDO-20533 for the ABWR is acceptable.

Regarding the test programs, GE stated that the ABWR test program is described in SSAR Appendix 3B. The test 
program includes 24 toets of LOCA condenention cecillation and chugging loads. Theee loads for the ABWR are identified to be potentially different from those for the MARK III deaign. GE expects other test datn that wero doveloped for the Mark III to bo applicable for the ABWR because the total area ratio of the horizontal vents and vertical veats in the ABWR will be comparable with that in the Mark III. This was ideatified as Open Item 3 in the DSER (SECY-91-355), which is resolved. The hydrodynamic loads described in Appendix 3B aro ovaluated in Section 6.2.1.6 of this report. DSER Open Item 10 is dealt with in that esction. Tho staff concludes that GE's ascumptions and models for ABWR contrinment response analyais are acceptable.

\subsubsection{Short-Term Pressure Response}

The maximum drywell-to-wetwell differential precenure occurs during the blowdown phase (short term) of a LOCA. GE has performed analyses of various postulated primary system breaks, including a double-ended rupture of the main feedwater line, a doublo-eaded rupture of the main steamline, and small-break accidents. The analyees show that the main feedwater line break (FWLB) yiolds the limiting drywell-to-wetwell differential preseure and peak drywell and wetwell prosesure and is, therefore, the design-basis accident for the drywell and wetwell. The main steamline break (MSLB) yields the limiting drywell temperature. GE has provided comparative plots of drywell and wetwell ahort-term preseurs and tomperature reoponese to design-banis, $0.0465 \mathrm{~m}^{2}\left(0.5 \mathrm{ft}^{2}\right), 0.093 \mathrm{~m}^{2}$ $\left(0.1 \mathrm{ft}^{2}\right)$, and $0.0093 \mathrm{~m}^{2}\left(0.01 \mathrm{f}^{2}\right)$ breaks in both the main feodwater and main steamlino piping inside the drywell. These figures wabetentiate the large guillotine breake resulting in tho higheet drywell and wetwoll preasure and temperature. However, in the DSER (SECY-91-355), the ataff stated that these figures, comparing different size pipe breaks, did not indicate the same value of peak drywell and wetwell pressure as reported in SSAR Table 6.2-1. The staff asked $\mathrm{OE}$ to clarify these discrepancies.

In a letter dated May 22, 1992, GE compared the reported values in Table 6.2-1 and the corresponding calculated values in SSAR Figures 6.2-6, 6.2-8, 6.2-13, and 6.2-17. It demonstrated the consistency of the reported values between the table and figures in the SSAR. This is acceptable and this item is resolved. It was not tracked in the DSER or DFSER as an open item.

SRP Section 6.2.1.1C states that, for Mark III plants at the construction permit stage, the containment design pressure should provide at least a 15-percent margin above the peak calculated containment pressure and the design differsatial preseure between the drywell and tho containment should provide at least a 30-percent margin above the peak calculated differential preecure. OE's calculistod drywell peak pressure for the FWLB is $268 \mathrm{kPa}$ (39 psig) and maximum calculated tomperature is $170^{\circ} \mathrm{C}\left(338^{\circ} \mathrm{F}\right)$ reculting from the MSLB. The design pressure for the drywell is $310 \mathrm{kPa}$ (45 poig), which provides a margin of 15 percent above the peak calculated pressure in the drywall and is equal to the margin recommended in the SRP. Therefore, this devign margin for containment preasure is acceptable.

The calculated wotwell peak preasure and maximum temperature are $179 \mathrm{kPa}\left(26\right.$ poig) and $97.2^{\circ} \mathrm{C}\left(207^{\circ} \mathrm{F}\right)$, which is $6.7^{\circ} \mathrm{C}\left(12^{\circ} \mathrm{F}\right)$ below the design tomperature of $103.9^{\circ} \mathrm{C}\left(219^{\circ} \mathrm{F}\right)$ resulting from the FWLB. The design presoure for the wetwell is $310 \mathrm{kPa}: 45$ psig), which provides a margin of $\mathbf{4 2}$ percent above the peak calculated presenure in the wetwell.

The calculated drywell-to-wetwell peak differential presure is $110.3 \mathrm{kPa}$ (16 psig) and the design drywell-to-wetwell differential pressure is $172.3 \mathrm{kPa}$ (25 paig), which provides a design margin of 56 percent.

The staff concludes that the ccntainment pressure and temperature transients following a LOCA in the ABWR containment are consistent with SRP Section 6.2.1 and, therefore, are acceptable.

\subsubsection{Long-Term Response}

Following the short-term blowdown phase of the accident, the suppression pool temperature and containment pressure continuously increase bocause of the input of decay heat and consible energy into the containment. During this period, the ECCS pumps, which take suction from the suppression pool, reflood the RPV up to the level of the main steam nozzles. Subsequently, ECCS water flows out of the break and fills the drywell, establishing a recirculation flow path for the ECCS. The relatively cold ECCS water condenses the steam in the drywell and rapidly brings the drywell pressure down. After approximately 10 minutes, the residual heat removal (RHR) heat oxchengers are automatically activated to remove energy from the containment by using the RHR service water systom for recirculation cooling of the suppression pool. This is a conservative assumption because the RHR design permits automatic initiation of containment cooling well before 10 minutes. The containment spray also is conservatively assumed not to be used.

In the long-term analysis, GE accounted for potential postaccident energy sources, including decay heat, pump heat rate, sensible heat, and motal-water reaction energy. GE's long-term model also assumed that the containment 
atmoephere would be saturated and equal to tho ouppreacion pool temperature at any timo. Therefore, the containment preasure is equal to the eum of the partial preacure of air and the saturation preacure of water correeponding to the pool temperature.

GE calculated a peak suppreasion pool temperature of $96.9^{\circ} \mathrm{C}\left(206.46^{\circ} \mathrm{F}\right)$. The calculated long-term mecondary peak containment drywell and wetwell preasures are well below the calculated short-term peak preseures. OB's analysis for long-term response following a LOCA in the ABWR containment is acceptable in accordance with SRP Section 6.2.1.

\subsubsection{Reverse Containment Pressurization}

Cortain events in the primary containment cause depressurization transients that can creato negative drywell-to-wetwell, drywell-to-reactor building, or wetwell-to-reector building preesure differentials. Therefore, vacuum relief provisions may be necescary to limit these negative pressure differentials within deaign values. The events that cause containment depreacurization are

- inadvertent drywell/wetwell spray actuation during normal operation

- post-LOCA drywell depressurization as a result of condensation of the steam by the spilled ECCS subcooled water

- wetwell spray actuation following a stuck-open rolief valve

\subsection{Drywell Depressurimation}

Drywell depressurization, which creates negative drywell-to-wetwell pressure differential and/or a negative drywell-to-reactor building presecure differential, is caused by two major events:

- post-LOCA drywell depressurization as reoult of condensation of the steam by the spilled ECCS subcooled water

- inadvertent drywell epray sctuation during normal operation

GE states that drywell deprescurization following an FWLB results in the most sovere negative pressure transient in the drywell. Without vacuum relief, this negative pressure transient may create a drywell-to-wetwell negative pressure differential of $-275.8 \mathrm{kPa}$ ( $-40 \mathrm{psig}$ ). This pressure differential is much greater than the design negative drywell-to-wetwell preesure differential of $-13.8 \mathrm{kPa}$ (-2 paig). Therofore, this transient is used to determine the size and the number of wetwell-to-drywell vacuum breakers.

On the badis of its analysis, GE further states that with a typical vacuum breaker diameter of $50.8 \mathrm{~cm}(20 \mathrm{in}$.), * lose coefficient, $\mathbf{K}$, of 3 , and one single failure, eight wetwell-to-drywell vacuum breakers are required to muintain the drywell-to-wetwell and drywell-to-reactor building negative pressure differentials below the design negative proesure differentials of $-13.8 \mathrm{kPa}(-2 \mathrm{psig})$.

In the DSER (SECY-91-355), the staff identified Open Item 4 regarding the adequacy of the vacuum breaker deaign. Specifically, GE needed to clarify the arrangement of vecuum breakers (0.8., LD or UD, two valves in series for bypase singlo-failure protection) and the test program that would demonstrate the performance of the vacuum breaker system.

In a telephone conversation on August 9, 1991, GE stated that analyses had been performed using first-principle analytical models. These analyses were similar to those performed for other BWRs and assumed that the spray efficiency was 100 percent. Subsequently, in a letter dated May 22, 1992, GE explained that there are eight vacuum breaker valves, including one valve to moet the singlefailuro criterion.

Each penetration opening into the $L D$ has one valve. Thew 50.8-cm (20-in) swing check valves open passively on negative differential pressure and require no external power to sctuate them. They will be installed horizontally in the wetwell airepace. Position locations of these valves are shown in Figures 1.2-3C and 1.2-13K in SSAR Amendment 6. Also, vacuum breakers are equipped with pocition switches facilitating the monitoring of valve position inside the control room. The design of the wetwell-drywell vacuum breakers is acceptable.

Concerning the testing aspect of the DSER (SECY-91-355) open item, the ABWR technical specifications (TS) must require the periodic inspection and testing of vacuum breakers during outages to ensure their operability. This was DFSER TS Itom 6.2.1.5.1-1. Such testing is included in the BWR Owners Group Standard Technical Specifications, which GE is adopting for the ABWR. Since GE has included an acceptable testing requirement, this itom is resolved.

DSER Open Itom 4 is resolved because the design of the wetwell-drywell vacuum breakers has been found to be acceptable in accordance with SRP Section 6.2.1, and 
because the syctem will be teated as epecified in the TS for the ABWR.

In a latter dated May 26, 1994, GB provided the reaults of an andytis that ovalunted the offect of drywell epray sctuntion following a LOCA. The realte of this analyais are bounded by the poet-LOCA drywell depreasurintion cuss realting from team cordensation by the epilled BCCS aubcooled water.

\subsection{Wetwell Depreseuriation}

Wetwell depressurization, which creates a wetwell-to-reactor building negative presinure differeatial, can bo caused by the following ovents:

- insdvertent drywell and/or wetwell epray sctuntion during normal operation

- wetwell epray sctuntion following a stuck-open rolief valve

- drywell and wotwell epray sctuntion following a ?.OCA

GE states that the limiting negative prescure transient in the wetwell correxponds to wetwell epray sctuation following a ctuck-open relief valve. The effect of relief valve diecharge into the aupreasion pool also heats the wetwell airepece, thus iscreasing its presire. When the preseure in the wetwell becomes greater then the drywell preacure of $1.7 \mathrm{kPa}$ (+0.25 paig), the wetwell-to-drywell vacuum relief system allow the flow of air from the wetwell to the drywell, theroby preasurizing both drywell volumes. Wetwell preseure and temperature peak when the reactor decay heat decreases bolow the heat removal capebility from continued pool cooling and wetwell spray. Wetwell tomperature and preacure docrease, but tho drywell pressure remains at its peak value. When the presure difference between the two volumes becomes greater than the hydrostatic head of water above the top vent, air flows back into the wetwell airepace, slowing down wetwell depreacuriention. The preweure differential between the drywell and the wetwall is mintained constant at the hydrostatic head above the top row of horizontal vents. The find preacure in the wetwell is lower then the drywell preasure because more air is transferred to the drywell during wetwell pressurization than is recoived during wetwell depressurization.

Inadvertent drywell or wetwell epray schation during normal cperation can cause deprensurization of the eprayed volume because of the resultant condensation of vapor present in the airepece. However, the magnitude of this depressurization is less than the post-LOCA or stuck-open relief valve cases because of the relatively amaller mass of condensable vapor present during normal operation.

Calculation of the peak wetwell-to-reactor building negative differential preseure is based on an energy balance of the conthinment atmoephere before and after spray sctivation, asauming that the find air-vapor mixture is at 100-percent relative humidity (RH) and that there are no reactor building-to- wetwell vacuum breakers. Using these ascumptions, the peak calculated wetwell-to-reactor building negative differential pressure was determined by GE andysis, escuming worse-accident conditions, to bo $-12.2 \mathrm{kPa}(-1.77$ poig). This is 10 percent less than the ABWR design value of $-13.8 \mathrm{kPa}(-2.0 \mathrm{psig})$. In a meeting with GE on May 6, 1992, the ataff questioned the appropriateness of the ssaumption of 20-percent initial drywall RH in the analyais. In response to the atafis concem, OB performed a sensitivity study aseuming a conservative drywell RH of 60 percent and a minimum appression pool temperature of $23.9^{\circ} \mathrm{C}\left(75^{\circ} \mathrm{F}\right)$ for the postulated drywoll and wetwell spray actuntion during normal operntion. The resulting maximum negative differential pressure shown in a letter dated June 10, 1992 , is $-10.2 \mathrm{kPa}(-1.48 \mathrm{psi})$, which is less limiting then the case reported in the SSAR. The limiting case of wetwell spray sctuation following a stuck-open relief valve is independent of the drywell humidity.

From its analysis given in the SSAR, GE concluded that vecuum relief from the reactor building to the wetwell was not required. The staff asked GE in what way was the deaign of the ABWR different from the designs of Mark II and III plants, which do require vacuum rolief. GE stated that the wetwell spray system flow will be limited by design to a maximum flow of $1,893 \mathrm{~L} / \mathrm{min}(500 \mathrm{gpm})$, which has the effect of limiting the negative pressure transient response to $-12.2 \mathrm{kPa}(-1.77 \mathrm{psig})$. Therefore, the staff concludes that the limiting case reported in the SSAR is acceptable. The staff also finds that the initial conditions, assumptions, and mathodology used in the GE analysis are acceptable, as discussed above, and that vacuum relief from the reactor building to the wetwell is not needed.

\subsubsection{Suppression Pool Dynamic Loads}

GE submitted proprietary SSAR Appendix 3B to address the issue of suppression pool dynamic loads for the ABWR. The scope of Appendix 3B encompasses SRV actuation and LOCA phenomena, SRV discharge loads, LOCA loads, submerged structure loads, and load combinations. Although similar to the Mark III containment design, the ABWR has the following diatinctive features that affect suppression pool dynamic loads: wetwell airspace pressurization, an LD volume, a 
emaller number of horizontal vents (30 in the $A B W R$ compand with 120 in the Mark III), horizontal vent extension into the pool, vent aubmergence, and auppression pool width.

SRV sctuation and LOCAs are the eveats that can impose dyanumic loads on the auppreacion pool. SRVs diccharge eteam from the RPV through diccharge piping that is routed into the suppreasion pool and fitted at the auppression pool and with a quencher to enhance beat trunsfer between the hotter SRV discharge fluid (etceam and air) and the cooler suppreesion pool water.

SRV discharge into the suppression pool consists of the following throe phases, which are listed in the order in which they occur: water cloaring, air clearing, and steam flow. The discharge pipe standing column of water first is pushed out, or cleared, into the pool by blowdown team preceure. Water clearing creates SRV pipe precesure and thermal loads, pipe reaction forces, drag loads on structures aubmerged in the pool, and pool boundary loads. After water clearing, air clearing occurs as air above the water column in the pipe is forced out the pipe and into the pool. The air-clearing phase generates expanding bubbles in the pool that cause transient drag loads on submerged structures as a result of both the velocity and accoleration fields and oecillating pressure loads on the pool boundary. Finally, the steam-flow phase creates pipe reaction forces, quencher thrust forces, structure thermal loads, and oscillating pool boundary loads as a result of steam jet condensation at the quencher.

For the ABWR, the FWLB and MSLB cause dynamic loads in the suppression pool. As with the SRV discharge, these events can be characterized by several phenomena that occur in the following order: vent clearing, pool swell, high steam flow, and chugging. After an FWLB or MSLB, with sufficient pressurization of the drywell, water in the vents is forced out into the pool. This vent water clearing causes submerged jet-induced loeds on nearby structures and the pool besemat. After vent clearing, an air and steam bubble flows out the vents. The air component, originating from the drywell air, expands in the pool causing a rise in pool surface level called pool swell. Pool swell imposes loads on wubmerged structures and pool boundaries. After pool swell, a period of high steam flow occurs and steam is condensed in the pool vent exit area, imposing no significant loads on the pool system. Later, as vent steam flow decreases, the steam condensation process causes the steam bubble, which has been growing, to suddenly collapse, creating oscillatory loads. This process is called chugging and imposes significant vent and suppression pool boundary loads.
The ABWR SRV discharge is directed to the suppression pool through X-quenchers that GE has stated are identical to the quenchers used for the Mark II and Mark III designs. Therefore, GE concluded that the hydrodymamic load methodology, doveloped for the Mark II and III designs, was applicable for both the ABWR suppression pool geometry and the $X$-quencher configuration. However, in the DSER (SECY-91-355), the staff queationed how GE had addressed the SRV loads that would result from a second opening of the SRV while the SRV tailpipe is still hot from the initial SRV discharge (commonly referred to by the staff as "subsequent actuation" or "consecutive actuation" in NUREG-0802, "Safety/Relief Valve Quencher Loads: Evaluation, for BWR Mark II and III Containments") (Open Item 5). A aubeequent SRV valve actuation becomes a concern because following the first actuation of the SRV, the second actuation could generate higher loads on the structure.

The water reentering the tailpipe (reflood) after the initial actuation of the SRV has been found in experiments to be transitory because the water column within the tailpipe does not reech equilibrium quickly. In addition, the tailpipe wall has not cooled to its initial temperature before the second actuation of the SRV. If the reactor system pressure should rise again to greater than the SRV set point, the SRV would discharge. However, the noncondensable gas from the drywell atmosphere that reentered the tailpipo through the vacuum breaker would have boen heated by the tailpipe wall. This discharge (commonly called SRV air-clearing loads) could produce hydrodynamic wall pressures in the pool that might be significantly different from the initial air-clearing loads because of the higher noncondensable gas temperature in the tailpipe. As a result, the staff concluded that loads from both the initial and second actuation should bo considered in the design of the system. GE stated in its submittal of June 1, 1992, that both the first and possible second actuation were considered and the structures will be analyzed to accommodate these second actuation loads. GE stated that these analyses are scheduled to be completed before final design approval. This item became DFSER Open Item 6.2.1.6-1.

GE stated in SSAR Section 3.9.3.3.1 that loading of the main steam and discharge piping resulting from SRV discharge was calculated on the basis of simultaneous actuation of all SRVs followed by a second actuation of all SRVB. The methodology used by GE to calculate hydrodynamic loading on SRV discharge piping resulting from initial and subsequent SRV actuations is consistent with the methodology used for earlier BWR (Mark II and III) designs. The effect of subsequent valve actuation is considered by assuming the SRV discharge pipe has been 
beated by the initial SRV actuntion. GE asumed an initid SRV pipe tomperature of $149^{\circ} \mathrm{C}\left(300^{\circ} \mathrm{F}\right)$ for the drywell piping and $93^{\circ} \mathrm{C}\left(199^{\circ} \mathrm{F}\right)$ for the wetwoll piping. These temperature values are, besed on measured data from inplant SRV blowdown tests. This mothodology, which the staff finds acceptable, is consistent with that used for earlier BWRs and resolved DFSER Open Item 6.2.1.6-1.

The staff also questioned, in the DSER (SECY-91-355), the acceptability of the complete olimination of appreasion pool temperature limits. GE had stated in its earlier submittal that suppression pool temperature limits for steady-state steam condensation were no longer needed. In the basis for this conclusion, GE referenced an analysis submitted to the staff by the BWR Owners Group. However, the staff had not yet completed its review of the BWR Owners Group request for the elimination of suppression pool temperature limits. This was Open Item 6 of the DSER (SECY-91-355). In addition, the date for completing the staff's review was shown to be very close to the date neceseary for find closure of all iesues for the ABWR. In light of these uncertainties, $G E$ documented in its submittal of June 1, 1992, that the same suppression pool temperature limits will bo used for the ABWR as those used in current Mark I, II, and III plants to ensure steady condensation of the SRV discharge. These criteria are documented in NUREG-0783, "Suppression Pool Temperature Limits for BWR Containments."

As currently implemented in the Mark I, II, and III designs, the suppression pool temperature limits involve a three-tier approach. The lowest temperature threshold requires the operator to take such actions as activating pool cooling to reduce the suppression pool temperature. The plant, however, can continue to operate at power during this time. The intent of this threshold is to ensure that the operator takes action to reduce pool temperature. This temperature is typically $35^{\circ} \mathrm{C}\left(95^{\circ} \mathrm{F}\right)$. Operation can continue until the suppression pool reaches $43^{\circ} \mathrm{C}$ $\left(110^{\circ} \mathrm{F}\right)$. At this temperature, an automatic scram on high suppression pool temperature occurs. Finally, if the pool reaches $49^{\circ} \mathrm{C}\left(120^{\circ} \mathrm{F}\right)$, the TS require depressurization of the reactor coolant system and initiation of cold shutdown conditions. This was DFSER TS Item 6.2.1.6-1. GE included this item in its TS, which the staff has found are acceptable in Chapter 16 of this report, thus resolving this TS item.

This process ensures that suppression pool temperature limits for reactor scram and reactor depressurization, as defined in NUREG-0783, will not be reached. The staff finds acceptable GE's commitment to maintain current suppression pool temperature limits. This part of Open Item 6 in the DSER (SECY-91-355) is resolved.
Another part of Ope: Item 6 from the DSER (SECY-91-355) was aseociated with the justification used to eatablish the pool dymamic loads for the ABWR. Tho ABWR auppression pool contains structures above and below the normal level of the pool (such as SRV trilpipes, scceses tunnels to the LD, and a wallwway in the auppreasion pool) that would be subject to pool drag and pool swell impect loads during the initial vent clearing and pool awell phenomenn. The staff requested that $\mathrm{GE}$ provide the epecific tests used to support the methodology to eatablish the hydrodynamic loads for the ABWR. GE committed to provide these tests in the SSAR. GB had identified the general database that will bo used and the methodology to dovelop the hydrodynamic loarls, but had not submitted data on the actual primary or secondary loads (wall pressure, thermal, drag, impact, etc.). This mathodology for defining hydrodynamic loads was considered acceptable in the DFSER. This resolved both parts of Open Item 6 identified in the DSER (SECY-91-355). This resulted in DFSER Confirmatory Itom 6.2.1.6-1 - GE would provide the specific load definition design information in a future SSAR amendment.

GE provided a typical pressure time history at the bottom of the pool boundary in SSAR Figure 3B-29. The staff finds this plot to be an acceptable hydrodynamic load definition for design certification. This resolved DPSER Confirmatory Item 6.2.1.6-1.

The ABWR configuration is similar to the Mark II contrinment design in that the suppression pool volume of the ABWR wetwell is approximately equal to the Mark II and III suppression pool volumes. Also, the sizes of the drywell volumes are quite similar. GE stated in its submittal of June 1, 1992, that the ABWR wetwell airspace volume is $5,947 \mathrm{~m}^{3}\left(210,000 \mathrm{ft}^{3}\right)$ as compared with a Mark II wetwell volume of 4,672 $\mathrm{m}^{3}\left(165,000 \mathrm{ft}^{3}\right)$. Therefore, it considered the methodology used to evaluato the bulk backpressure due to suppression pool gas space compression from pool swell for the Mark II design to be equally applicable for the ABWR.

The PICSM cornputer code, which models the transient behavior of suppression pool swell surface elevation, pressure in the wetwell airspace, and pool surface velocity, is described in GE technical report NEDE-21544 (proprietary). GE validated test data generated for the Mark II design; however, the code was not reviewed and approved by the staff.

The staff identified Open Item 10 in the DSER (SECY-91-355), related to modeling assumptions used by GE. For ABWR applications, the PICSM code was used to compare Mark III suppression pool swell test data from the pressure suppression test facility (PSTF) with analytical 
prodictions from PICSM. The parameter that were compared were gas beckpreasure, water alus volocity, and water alug awell boight. OE concluded thet the PICSM code was tochnically adequate to model the euppreacion pool gas epace preasure; however, the calculated water slug aurface elevation required somo modoling adjuatments because of the horizontal vent configuration of the Mark III. A borizontal vent configuration introduces an air bubble into the suppresaion pool that does not spread uniformly acroes the entire auppreasion pool; therefore, it produces a swell that is not radially uniform. The pool swell has a higher rise on the inside radius of the pool.

The Mark III vent design is quite similar to that of the ABWR. Because of this similarity, GE felt that comparison with the Mark III data would be sufficient to validate the program for use on the ABWR design. This type of comparison also was necessary to determine if the difference in vent design (such as submergence of the vent and number of vents) would significantly affect the calculated results using the PICSM code.

Because of the horizontal vents for both the ABWR and the Mark III, the air bubble does not penetrate the entire width of the pool as was described above. As a result, the suppression pool water slug is not a constant thicknoses. The PICSM code does not implicitly model this nonuniform pool swell elevation. This nonuniform pool swell is different from the Mark II design in which the air bubble is uniformly distributed over the entire suppression pool. The vertical Mark II downcomers then distribute the air bubble throughout the entire pool crose-section. As a result, the air is injected into the pool in an almost uniform manner yielding an almost constant water slug thickness.

Because of the difference in vent configuration between the Mark II (which the PICSM code would model accurately) and the Mark III, GE found it necessary to develop a correlation for the PICSM code to account for the uneven pool slug rise observed in the Mark III PSTF tests. GE stated that by modeling 80 percent of the suppression pool horizontal surface area, it achieved agreement betwoen PICSM calculated pool swell velocity and elevation and the PSTF test results. GE included this comparison in its submittal of June 1, 1992.

GE showed that the PICSM code without the correction factor can correctly predict the suppression pool airspece pressure time histories resulting from a reactor system blowdown in the drywell. By using a reduction factor of 80 percent for pool surface area, GE correctly prodicted the swell elevation. On the basis of these comparisons, GE believes that the PICSM code has been validated for use on the ABWR.
OE sileo noted that the pool swell phenomenon is depeadeat on a reactor aystem blowdown into tho drywell and that the largeat poctulated pipe break in the ABWR is a foedwater line broeis (FWLB). The Mark II and III dexigns must sccommodate a recirculation line break that OB has eliminated in the design of the ABWR. A poctulated FWLB into the ABWR drywell is calculated to be a lower preseurization ovent, causing leas blowdown flow, because of the smaller pipe break size and energy input than was considered for Mark II and III designs. Becauve of the lower mase and energy input into the drywell from an FWLB, the suppression pool response is expected to bo lese sovere.

GE also atated that the pool-to-vent area natio is larger for the ABWR than for the Mark II and III designs. For the ABWR, the pool-to-vent aree ratio is 38.5, for Mark II the ratio is typically 20.0, and for Mark III it is typically 12.0. GE believes that the larger pool relative to the vent area will cause the pool hydrodynamic loads to be reduced. This position is supported by NUREG-0808, "Mark II LOCA-Related Hydrodynamic Loed Definition."

The staff documented its evaluation of definition of the Mark II design containment hydrodynamic load in NUREG-0808. In the ovaluation of the pool swell phenomens (discussed in Section 2.1 of the NUREG report), the staff relied on comparisons with a substantial amount of data from tests conducted by both GE and Japan Atomic Energy Research Institute. These tests were directly applicable to the Mark II design. The computer code used for these comparisons was a GE-doveloped program called PSAM (GE topical report NEDO-21061, Revision 0, November 1975). It was used as part of the Mark II hydrodynamic load evaluation program. The staff has reviowed the Mark II program and approved the methodology and PSAM in NUREG-0808. However, it did not find GE's methodology within PSAM acceptable. Rather, the staff based its acceptance on the favorable comparisons with the database. As a result, the use of the program for configurations other than those encompased by the test data would not be accepted without further comparisons with applicable test data.

The PICSM code, which GE referenced in its submittal of June 1, 1992, had not been reviewed by the staff. In addition, the use of the 80-percent area reduction factor may significantly alter the results of the program. GE's justification for use of an 80-percent reduction on pool surface area to schieve correct swell heights is based on the comparison with PSTF test heights for a Mark III-typo suppression pool. However, GE did not discuss other such critical panameters of pool swell as water slug velocity and the way velocity is affected by the 80-percent reduction factor. In addition, the 80-percent reduction factor also 
may affect such factors as the effect of gas backpresoure on the water slug because of the reduced water slug surfece area exposed to the gas backpreseure and inertia of the water alug may be affected by the reduced surface area. GE did not discuss these effects or the PICSM code's treatment of them in its submittal. PICSM is a newer version of the PSAM computer code; however, GE has not indicated the specific differences between the codes.

The staff agrees that the ABWR suppression pool design is similar to the Mark III design in terms of the water slug shape and that PSTF test data for Mark III may have limited applicability to the ABWR. This closes out Open Item 18 identified in the DSER (SECY-91-355). However, since the database discussed in the submittal of June 1, 1992, did not contain specific test results for an ABWR geometry (actual vent sizo and configuration were not used for ABWR-specific tests), the staff evaluated the uncertainties of the test results and whether these uncertainties can be tolerated in the ABWR design.

As a result, the staff evaluated the ABWR design and the PICSM load predictions to determine the degree of margin associated with each safety-related component. At a height

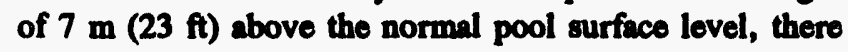
are eight drywell-to-wetwell vacuum breakers that are mounted on the suppression pool wall and potentially subject to pool swell loads. The design indicates $7 \mathrm{~m}$ $(23 \mathrm{ft})$ from the normal liquid level in the suppression pool to the bottom of the valve. The vents are equally spaced around the circumference of the suppression pool. Underneath the vacuum breakers, a continuous catwalk surrounds the pedestal wall within the suppression pool at the 6-m (20-ft) elevation, which is approximately $1 \mathrm{~m}$ $(3 \mathrm{ft}$ ) below the vacuum breakers. The flooring is grating except for the area immediately below each vacuum breaker. GE states that a solid steel plate in this area will protect the valves from any direct effect of the pool swell water slug.

PICSM predicts liquid impact up to $6 \mathrm{~m}(21 \mathrm{ft})$ and froth impact beyond $6 \mathrm{~m}(21 \mathrm{ft})$. As a result, the design is based on the solid decking of the catwalk absorbing 100 percent of any possible liquid pool swell load. Additionally, the valves are designed to withstand froth loads assuming no load reduction as a result of the steel plate. This approach seems to be bounding in nature, and the loadings assessed for the valves are acceptable. However, GE has not specified the method for calculating the load to which the steel plate is designed or the specific load to which the plate will be subjected. This was DSER (SECY-91-355) Open Item 6.2.1.6-2, which was not tracked in the DFSER. The staff also stated in the DFSER that Tier 1 design information and inspections, tests, analyees, and acceptance criteria (ITAAC) were required for pool swell impact loads. (The ABWR ITAAC are discuseed in Chapter 14 of this report.) The staff has determined that the design of the plate and supporting analysis are not needed for design certification but can be provided in the COL application, because of GE's commitment to have the analysis performed in accordance with the Mark II and III design methodology.

As spocified in SSAR Section 6.2.7.4, the COL applicant will review the issue of providing appropriate structural features for protecting these vacuum breakers from pool awell loads and propose to the NRC staff an appropriate design for ensuring that these valves are adequately protected. The structural shielding features for pool swell loads will be determined on the basis of the methodology approved for the Mark II and III designs. For design of structural shielding features, pool swell loads will be defined to the maximum practical extent possible. This commitment to a COL action item is acceptable, and resolved DSER Open Item 6.2.1.6-2.

In the DSER (SECY-91-355), the staff raised an issue concerning the modeling assumptions used for calculating suppreesion pool boundary loads during the pool swell period occurring as a result of a postulated hydrodynamic ovent caused by a LOCA. The question was raised concerning the modeling assumptions used for conducting the tests to determine the resultant pool loads.

GE stated in its submittal of June 1, 1992, that it conducted a test program for suppression pool hydrodynamic loads specific to the ABWR because of anticipated differences in condensation oscillation $(\mathrm{CO})$ and churging (CH) loads in the ABWR design when compared to the Mark III design. GE anticipated differences in loads because the airspace $\left(5,947 \mathrm{~m}^{3}\left(210,000 \mathrm{ft}^{3}\right)\right)$ in the ABWR suppression pool is much smaller than that in the Mark III design $\left(4,672 \mathrm{~m}^{3}\left(1,140,000 \mathrm{ft}^{3}\right)\right)$. This smaller wetwell airspace volume increases the pool backpressure and may dampen pool response. Also, the LD in the $A B W R$ may have an effect in that the total drywell volume of the ABWR is $7,334 \mathrm{~m}^{3}\left(259,000 \mathrm{ft}^{3}\right)$ compared to $7,787 \mathrm{~m}^{3}\left(275,000 \mathrm{ft}^{3}\right)$ for Mark III. However, the LD is a physically separate volume from the UD and is connected to the UD through the vent duct system compared with Mark III, where the drywell is one large volume. The $A B W R$ also has a reduced number of horizontal vents (30) at a deeper submergence of $3.5 \mathrm{~m}$ (11.48 ft) from the top vent relative to the Mark III, which has 120 vents at a submergence of $2 \mathrm{~m}(7 \mathrm{ft})$. The suppression pool for the ABWR is also wider $(7.5 \mathrm{~m}$ $(24.6 \mathrm{ft})$ ) than that in the Mark III (6.2 $\mathrm{m}(20.5 \mathrm{ft}))$. 
The staff identified Open Itom 9 in the DSER (SECY-91-355) concening the coaling laws used by GB for doveloping the ABWR load dofinition. GE conducted 24 simulated blowdown toets on a singlo-cell model (a 36-dogree sector of the ABWR euppreseion pool) that represented a single vent pipe system. The test facility used wes scaled for two sizes of blowdown experiments. The subscalo (SS) toets represented the ABWR realod by a reduction factor of 2.5 and a acaled single vertical and single horizontal vent pipe ayatem. Tho partial full-ecalo (FS) teets were conducted with tho samo scale factor for pool dimensions but a full-ecale vertical and horizontal vent system and two horizontal vent pipes into the pool. The ABWR has three horizontal vent pipes into the suppression pool.

Using the SS and FS configuration in its test facility, GE ran 24 blowdown tests to obtain data on $\mathrm{CO}$ and $\mathrm{CH}$ loads to produce wall pressure data to be used to generate the load definition. Thirteen tests were conducted for CO loads on the SS test configuration and eleven were conducted for CH loads on the FS teet configuration. For the SS tests, GE stated that linear dimensions were scaled, but thermodynamic properties associated with steam condensation such as pressure, temperature, and enthalpy were maintained at full-scale values.

The staff evaluated the above approach and concludes that these additional tests have added to the overall database relative to pool condensation loads and are acceptable. This resolved Open Items 7, 8, and 9, as identified in the DSER (SECY-91-355). However, GE had not addreseed the use in the ABWR design of Mark III data from the PSTF blowdown tests that were conducted to verify the GE methodology used for the Mark III load definition studies. These tests were conducted and demonstrated the use of scaled tests, as reported in NUREG-0978, which showed close agreement between 1/3 and 1/9 scaled tests. Tho PSTF tests for Mark III on all scaled tests reported in NUREG-0978 were conducted with full-scale vent lengths and all three horizontal vents.

GE also had not demonstrated that the past condensation tests can or should be neglected in the development of the load definition for the ABWR. In addition, the staff was concerned about the adequacy of using only the SS and FS tests for which one and two horizontal vent pipes into the pool were used instead of the three vent pipes used in the ABWR and the PSTF tests for Mark III.

For previous tests conducted for Mark III at the PSTF, three horizontal vent pipes that were full scale were used. For the ABWR SS tests, the vent system was scaled, which the staff believes will affect the measured frequency spectrum. The use of scaled frequency responses for CO has not been demonstrated, nor has there been any attempt to juatify the approach on the ABWR docket. The Mark III tests for unstable CO were conducted on a fullsizo vent system, which would not interfere with the frequency content of the measured wall pressures in the teet facility.

Therefore, to resolve DSER Open Item 10, the staff concluded that GE should addreas the differences in load dofinition uaing the Mark III and II test databases and determine the offect on structural response of possible differences from frequency signatures for both $\mathrm{CO}$ and $\mathrm{CH}$ loads. The use of the ABWR SS and FS tests without correlation to the Mark III test database had not been demonstrated to be sufficient for modeling without the fullscalo vent pipe configuration and was unacceptable. This was DFSER Open Item 6.2.1.6-3.

SSAR Figure 3B-22 shows a pressure time history representative of CO loads associated with the ABWR using the source load approach. SSAR Figure 3B-23 shows a pressure timo history representative of Mark III CO loads. This pressure time history is based on the Mark III CO correlation as described in the GESSAR II (NUREG-0979). This comparison showed higher pressure amplitudes in the ABWR that were attributed to (1) a greater submergence depth (3.5 m (11.5 ft) compared with $2.3 \mathrm{~m} \mathrm{(7.5} \mathrm{ft)),} \mathrm{(2)} \mathrm{all} \mathrm{three} \mathrm{horizontal} \mathrm{vents} \mathrm{remaining}$ open in the ABWR tests whereas the bottom two vents were closed in the Mark III tests at the onset of CO conditions, and (3) the contribution from increasing wetwell overpressure during the $\mathrm{CO}$ period in the $\mathrm{ABWR}$ teets. ABWR CO loads were not compared to Mark II test data because Mark II has a vertical vent while the ABWR has a horizontal vent. GE stated that a typical large chug from the full-scale database as shown in Figure 3B-24 exhibited characteristic features similar to chugging data from Mark II and Marts III testing. For the ABWR, GE defined the chugging load by using the key-chug approach, which was the same approach as that used for Mark II. GE also stated that the data supported the understanding (observed from prior tests) that chugging has some dependence on system parameters, such as mass flux and pool temperature, along with a substantial degree of randomness.

The staff believes that GE has adequately considered the differences between the Mark II, Mark III, and ABWR databases to determine that the suppression pool wall pressures for ABWR do not exhibit any unusual characteristics when compared to the Mark III wall pressures. The SS and FS tests appear to be adequate representations of the ABWR downcomer vents for predicting the suppression pool hydrodynamic response for unstable $\mathrm{CO}$ and $\mathrm{CH}$ loads. The staff finds that the 
proponed load definition methodology for unstable CO and CH loads scoeptable. This resolved DFSER Open Itam 6.2.1.6-3.

\subsubsection{Subcompartment Presoure Analyals}

Internal structures in tho drywell, wetwell, and secondary containment form mibcompartments or rectricted volumes that are cubjected to differential preseure after poetulated pipe ruptures. In the drywall there are two auch volumea: (1) tho RPV annulus, which is the annular rogion formod by the RPV and the resctor shield will, and (2) tho drywell bead, which is a cavity aurrounding tho RPV hoed.

The deaign of the containment cubcompartments was besed on the postulated wort-case decign-basis sccident (DBA) occurring in each mubcompartment. For each contrinment abcompartment in which high-energy lines will be routed, mese and energy release data correeponding to a poctulated line break were calculated. All breales were considered to be full doublo-ended breaks.

In response to RAI Question (Q) 430.17 regarding abcompartment proesurization from high-energy lino breaks, GB submitted SSAR Tables 6.2-3 and 6.2-4 and Figures 6.2-37a through 6.2-370. Thewe tables and figures present subcompartment node and vent path initial conditions, break conditions, and physical characteriatics as wall as a flow chart showing the volume and junction connections between each aubcompartment. GE modoled - total of 23 subcompartments connected with 35 separate flow path vents for the subcompartment analysis. Moet of the vents are blowout panels that have a characteriatic opening pressure and time. The mubcompartments enclowe some compartments of the RHR, ECCS, reactor water cleanup (RWCU), main steam, and main turbino systoms. GE presented the calculated peek differeatial presesure for each aubcompartment in SSAR Table 6.2-3.

The staff ovaluated the aforementioned information in accordance with the requirements and guidance in RG 1.70 (Rev. 3) and SRP Section 6.2.1.2. The staff requestod in Open Item 11 in the DSER (SECY-91-355) the following additional information:

- mass and energy release rates assumed for the subcompartment analyses

- mothodology (i.e., computer codes), if any, used in calculating subcompartment pressurization

- nodalization censitivity studies for the individual subcompartments to justify the final model
- basis for solecting subcompartment initial thermodynamic conditions

- individual aubcompartment desion presenure differential

Within the limitations of the available information, the ataff made the following additional obeervations in Open Item 12 in the DSER (SECY-91-355).

- The selected aubcompartment initial humidity epecified in SRP Section 6.2.1.2, Itom II.B.1, is 0 percent. Becauve of the capability of water vapor to abeorb more energy than dry air, a humidity lovol of 0 percent reaults in a maximum peak differential preecure during a high-energy line break in a cubcompartment. In its analysis, GE used a higher valuo for initial humidity.

- On the besis of subcompartment volume and relief vent propertien, the trend of calculated peak differential preceure for rooms with the same pipe break was analyzed. A number of calculated subcompartment peak prescures did not follow the basic trend that was expected (thut is, for the same pipe break, peak presecure should incresse with smaller room volume and/or amaller vent area). The subcompartments with queationable peak pressures were SA7, SA4, SR5, SR4, and SR9.

- Using the COMPARE MODE 1A computer code, aubcompartment and vent properties from SSAR Tables 6.2-3 and 6.2-4 and main steamline break mass and coergy release data from SSAR Figures 6.2-24 and 6.2-25, the staff performed a reviow calculation for the preacurization of rooms SS1 and ST1 (ateam tunnel and turbine building). This analysis showed preseures for the ateam tunnol and for the turbine building that were significently different from those reported in the SSAR.

These observations showed inconsistencies in aubcompartment peak prescure treads, subcompartment preserures, and analytical assumptions. These differences, when considered collectively, may result in a less conservative structural design of containment subcompartments. The staff identified the above concerns as Open Items 11 and 12 in the DSER (SECY-91-355).

In a letter dated May 22, 1992, GE stated that its propriotary computer code, SubCompartment Analysis Method (SCAM), was used for the subcompartment analyses. GE stated that the SCAM code was used for the Mark III standard plant and was benchmarked against 13 NRC-specified subcompartment standard problems. GE hes not submitted SCAM to the NRC for computer code reviow and approval. SCAM calculates the transient thermal-hydraulic response of connected subcompartments 
to high-energy line breaks. Eech volume is modeled as a bomogenous mixture with connecting flow pathe using a welfechoking compreasible flow modal and tho volume proceure and temperature calculated for each tim etep. The vent flow modal was extensively verified by experimental comparieon in OB report NEDO-20533. SCAM treats air as an ideal gas and initializes the contents of each volume as a homogeneous mixture of air and water vapor. SCAM does not include gravitational potential energy in its flow energy equation and does not include the offects of heat transfor between materials in the volumes and the flowing fluid.

By a letter dated May 11, 1992, GE provided additional information on mass and energy releace rates anoumed for its subcompartment analyeses. GE calculated the mase and conergy release rato for main steam and RWCU lino brealce by including friction losese in the pipe regment between the RPV and the poetulated break location as well as flow choking (i.e., critical flow) and inventory depletion effects. Isolation valve closure determines the time for cesation of break flow. Friction losees included pipe leagth, fittinge, elbows, valves, and other equipment with a hydruulic resistance in the pipe segment. This mothodology reculted in different mass and energy release rates being calculated for the same pipo type and sizo break in differeat subcompartments. GE indicated in a telephone converation on May 19, 1992, that the inconsiatency identified in Open Itom 12 of the DSER (SECY-91-153), may be explained by the use of these mass and energy release data. The pipe break mass and energy release data used by GE are based on cetimated pipe leagths, fittings, elbows, valves, and other hydraulic resistance components in the pipeline. This assumed hydraulic resistance (i.e., fl/D) constitutes part of the design besis for the ABWR and must bo confirmed and adhered to in the actual as-built plant, since deviations in such parameters as pipe routing and numbers and types of valves could affect the results of the subcompartment analysis. The staff indicated in the DFSER that this information should bo included in the ITAAC for the ABWR containment. This was identified as a part of DFSER Open Item 6.2.1.7-1. On further ovaluation, the staff revised its previous position and determined that the information on $f / D$ should be included in the SSAR rather then the ITAAC. In Amendment 30, GE provided this information (fI/D) in Table 6.2-4A and mass and energy release data in Table 6.2.4B of the SSAR. This is acceptable. This part of DFSER Open Item 6.2.1.7-1 is resolved. In addition, the staff and GE agreed that subcompartment analyses using as-built fl/D data and effects on the mass and energy releases should bo included in the ITAAC. This is discussed below.

The GE SCAM subcompartment model for the ABWR consisted of a total of $\mathbf{2 3}$ volumes and 35 flow junctions.
Moat of the flow junctions are blowout panels that have a blownout precaure of $\$ 1.45 \mathrm{kPa}(0.5$ paig). Three different typen of doublo-ended pipe breaks were anclyzed in the abeompartment andycis: $71.1 \mathrm{~cm}$ (28 in.) main stoum, $15.2 \mathrm{~cm}$ (6 in.) main stan, and $20.3 \mathrm{~cm}$ (8 in.) RWCU. All blowdowne and correcponding peak wubcompartment preacures cocurred over a period of lese than 1 minute. All eubeompartmeats were initialized at maximum expected air temperafure and presaure and a humidity of 10 percent. Junction were modoled with their flow area, forward and revern low coefficient and ascociated inertia based on flow length and area. Tho SCAM analyees did not include any nodalization ensitivity studies and relied on internal time etep ealoction routines.

As part of the review of the ABWR aubcompartment analyces, the etaff performod independent audit calculations with the COMPARB MOD1A computer code, which is a abcompartment analyais codo doveloped by $\mathrm{Los}$ Alamos National Laboratory for the NRC and approved for this application in SRP Section 6.2.1.2 (Item III). The staff doveloped a model of the ABWR subcompartment volumen, juaction vents, and mass and energy rolease data based on the information provided by GE. Five of the pipe breaks were analyzed using COMPARE. These five pipo breake reaulted in peak preesures for 8 of the 23 abcompartments in the ABWR. The results of the COMPARE calculations of peak differential pressure were similar in magnitude and trend to those reported by GE. In all cases, the GE-calculated peak differential pressure was larger then that calculated by COMPARE. This is attributed to differences in modeling blowout panels and vent flow corrolations between SCAM and COMPARE. However, the SCAM results were all bounding. Based on the COMPARE audit calculations, the staff confirmed in the DFSER that the results of the GE subcompartment preasure analyses were acceptable.

Review of the ABWR subcompartment analysis shows that the analyais was performed in accordance with SRP Section 6.2.1.2. Independent check calculations with the COMPARE MOD1A computer code confirmed both the treads and magnitude of the peak subcompartment differential pressures reported by GE in the SSAR.

Although SRP Section 6.2.1.2 states that zoro initial humidity should be assumed for volumes, GE assumed a 10-percent bumidity. GE stated that the subcompartment initial thermodynamic conditions were those corresponding to plant normal operating conditions, as defined in SSAR Appendix 3I. The staff's COMPARE analyses confirm that the effect of the 10-percent initial bumidity is insignificant. 
Item II.B.2 of SRP Section 6.2.1.2 requires that in eppropriato sodalization echeme be chomen and confirmed

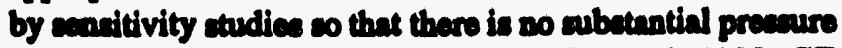
gradient within a node. In a moeting of May 6, 1992, GB atatod that on the baris of its judgement of adequecy, so epecific nodalization enesilivity andies were performod.

Purthermore, in a conference call on May 19, 1992, and in a letter datod May 22, 1992, GB committed to rovico the SSAR to include the values of decign differential preasure for each mabcompartment in order to confirm that the margin between calculated and deaign poak differential preseure of 40 percent required by SRP Section 6.2.1.2 (Item II.B.5) is schioved for the ABWR. The staff found this 40-percent deaign margin scceptable aubject to the SSAR revision to reflect this commitment. This was identified as Confirmatory Itom 6.2.1.7-1 in the DFSBR. In Amendment 30, GE provided this information in SSAR Table 6.2-3. There are a fow exceptions in which the 40-percent margin cannot be atiafied. However, there atill oxist subetantial margins auch a 28 percent, 34 percent, or 38 percent shown in Table 6.2-3. The staff hes dotermined that these fow exceptione are scceptable provided the subcompartment analyeses using ab-built data are included in the ITAAC. Therefore, the etaff concludes that DFSER Confirmatory Itom 6.2.1.7-1 is resolved. In addition, DSER Open Itoms 11 and 12 (SECY-91-153) were resolved in the DFSER.

Following the isuance of the DSER (SECY-91-355), OE modified the reactor shield wall, extending it to a beight of $0.1 \mathrm{~m}(0.33 \mathrm{ft})$ below the contrinment top slab. This recults in a smaller vent area for a pipe break in the shield annulus. The staff requested GE to confirm the adequacy of the rovised shield wall design. In Amendmeat 30, GE states that the results of its subcompertment pressurization ro-analysis, accounting for the reduced vent area and redofined DBA break in the annulus, demonstrate the adequacy of the shield wall structure and the RPV and its internal structures. Therefore, this now ieswe of annulus presaurization resulting from the modification of the ahield wall is recolved.

Therefore, on the basis of the above diecusaion, the ataff concludes that GE's subcompartment analycis is acceptable.

GE aubmitted the deaign deacription and ITAAC for the ABWR containment. The ITAAC were being reviowed by the staff when the DFSER was iseued. This wes identified as DFSER Open Itom 6.2.1.7-1. OB subequently aubmitted a rovised design deacription and ITAAC. In ITAAC Section 2.14.1, "Primary Containment Syetem," GE has included containment preseure and temperature analyses of the DBA using as-built data. In addition, the verification of the eubcompartment analyais of the recetor building is included in ITAAC Section 2.15.10, "Reactor Building," as part of the structural analyais reconciling atbuilt dath, which is described in Section 3H.5.3 of the SSAR. The ctaff findo the abovo commitments rogarding abeompartment andyeces ecceptablo. Therefore, DFSBR Open Item 6.2.1.7-1 is recolved. The adoquecy and acceptability of the dexign dencription and the ITAAC are ovaluated in Soction $\mathbf{1 4 . 3}$ of this report.

\subsubsection{Steam Bypase of the Suppresilon Pool}

The staff ovaluated GE's analysis of ateam bypase of the auppreasion pool provided in SSAR Section 6.2.1.1.5 in eccordance with SRP Section 6.2.1.1.C. Contrinment presaurisation from steam bypass of the suppreacion pool is atrongly affected by tho containment size and wetwoll-todrywell volums ratio. Of the Mark I, II, and III containments, the ABWR contrinment deaign is most similar to the Mark II in size and wetwell-to-drywall volume retio. Therefore, the etaff concludes that the ecceptence critoria in SRP Section 6.2.1.1.C for Mart II containments are the moet applicable. These scceptance criteria epecify (1) an offective steam bypass capability for small breaks $\left(\mathrm{A} / \mathrm{K}^{1 / 2}\right)$ of $46.5 \mathrm{~cm}^{2}\left(0.05 \mathrm{ft}^{2}\right)$ (2) automatic initiation of wetwell eprays, (3) preoperational highprescure leak teet, (4) periodic low-preesure leak teets, (5) periodic visual inspection of the vecuum relief system, (6) redundant position indicatiors and alarme on all vacuum breaken, and (7) monthly operability teet of vecuum breakers.

In a presoure suppression-type containment, wach as the $A B W R$, steam released from the primary systom following a postulated LOCA is collected in the drywell volume and directed through the drywell connecting vents to the suppression pool where it is condensed. Therefore, no steam is supposed to enter the wetwell air volume. However, the potential exists for steam to bypase the auppreacion pool by leakage through the vacuum breakers or directly from leak pathe in the drywoll-to-wetwell boundary. Such bypases could lead to undecirable precenurizntion of the containment, as the pressure auppreseion function has been loet. BWRs have tho capability to eccommodato limited amounts of suppreasion pool bypase. An allowable amount of auppreseion pool bypass can be defined as the amount that will not recult in the containmeat presevure exceeding the containment decigm preseure.

\subsection{Analyses}

GE performed the analyses given in SSAR Sections 6.2.1.1.5.3 and 6.2.1.1.5.4 to inveetigate the sensitivity of the containment design to suppression pool 
bypase. In general, dow reactor depresenurization ovents land to more limiting auppreacion pool bypeses cacen. This is the case because the borizontal vents in the muppresion pool remin covered and all of the etenm releand from the reactor paeseas through the bypaes pathway into the wetwell airepace.

For the firt analycis, OB acaumed a controlled reactor cooldown rate of $55.6^{\circ} \mathrm{C}\left(100^{\circ} \mathrm{F}\right)$ per hour for approximataly 6 bour. The anumptions were conservative, and credit was not tiken for etructural beat sinks or ecturation of the contrinment eprays. The analyais indicates a maximum allowable offective leakage path $\left(A / K^{1 / 2}\right)$ of $5 \mathrm{~cm}^{2}\left(0.0054 \mathrm{f}^{2}\right)$.

For the recond analyain, $\mathrm{GB}$ aleo anoumed a controllod reactor cooldown rate of $55.6^{\circ} \mathrm{C}\left(100^{\circ} \mathrm{F}\right)$ per bour for approximately 6 bours and credited operation of the wetwoll portion of containment epprays with a flow rate of $114 \mathrm{~m}^{3} / \mathrm{hr}\left(4,026 \mathrm{ft}^{3} / \mathrm{hr}\right)$ and beat transfor to the containment boundary surfaces. A spectrum of postulated resctor coolant syetem pipe breald were ovalunted to dotermine the moet limiting case. The containment eprays were sesumed to initiate 30 minutes after the contrinment reached a presaure of $103.0 \mathrm{kPa}$ O (14.9 paig). This presure is above the emergency operating procedure spray sctuation preseure as specified in SSAR Section 18A. This analyais is similar to that performod for tho Mark II contrinments. The andyeis indicates a maximum allowable effective leakage path $\left(A / K^{1 / 2}\right)$ of $50 \mathrm{~cm}^{2}$ $\left(0.054 \mathrm{ft}^{2}\right)$.

The staff concludes that eufficient capability exists in the containment to handle limited amounts of steam bypass of the auppression pool.

\subsection{Wetwell Sprays for Mitigation of Steam Bypare}

As discuseod in Section 6.2.1.8.1 above, GE ascumed a wetwell spray flow of $114 \mathrm{~m}^{3} / \mathrm{hr}\left(4,026 \mathrm{ft}^{3} / \mathrm{hr}\right)$ to mitigate the consequences of ateam bypase. Wetwell epray cannot be operated in isolation. Combined wetwell and drywell apraye are the normal mode of operation. With operator intervention, the wetwell sprays could be combined with cither the muppression pool cooling mode or low presecure veesel injection mode. An orifice is included in the wetwell epray line to limit the flow to the stated amount. Wotwell epray flow is balanced by the orifice to provide (1) cnough flow to mitigate preesurization of the wetwell due to ateam bypase and (2) not 100 much flow to exceed the negative deaign prescure of the wetwell as discussed in SSAR Section 6.2.1.1.4.
OE doviates from the SRP in Section 6.2.1.1.5.6.1 of the SSAR by not requiring automatic sctuation of tho wotwell eprays 10 minutes after a LOCA aignal. OB's analyees in Section 6.2.1.1.5.3 of the SSAR show that approximately 30 minutes is available for initiation of the containment eprays after the wetwell preasure has paced the lower limit of the containmeat epray sctuation lovela.

The etaff concludes that $G B$ hes demonstrated that anfiticient timo is available to initiate containment eprays for the analyzed bypase scenario. Therefore, the ataff agreses that sutomatic initiation of containmeat epray is not neceecary.

\subsection{Periodic Teutins and Inspection}

The ecceptance criteria in SRP Section 6.2.1.1.C indicate the need for a preoperntional high-preacure leak leat, periodic low-prensure leak teets, and periodic visual inspection of the vecuum roliof systom. In Section 6.2.1.1.5.7 of the SSAR, GE committed to perform thene toets and inspection. The acceptance criterion for both the high- and low-prencure leak teate is a measured bypass leakage area that is leas than 10 percent of the effective muppreacion pool bypass capability $\left(A / K^{1 / 2}\right)$ of $50 \mathrm{~cm}^{2}\left(0.054 \mathrm{f}^{2}\right)$

The preoperational high-preseure leak test is discuseed in SSAR Sections 6.2.1.1.5.7.1 and 14.2.12.1.41. Tho lowpressure leak tost is discussed in SSAR Section 6.2.1.1.5.7.2 and is included in Survoillance Requiremeat 3.6.1.1.3 of TS 3.6.1.1, "Primary Containment. "The periodic visual inspection of the vacuum roliof system is discussed in SSAR Section 6.2.1.1.5.7.4 and will be performed each refueling outage in accordance with TS 3.6.1.6, "Wetwell-to-Drywell Vacuum Breakers."

The etaff concludes that these testing and inspection requirements will ensure that the suppression pool stoam bypass capability of the containment is not exceeded.

\subsection{Vacuum Breaker Position Indicators and Alarms}

In Section 6.2.1.1.5.8.1 of the SSAR, GB committed to provide redundant position indicators on all vacuum breakere with redundant indication and alarm in the control room. The sensitivity of the indicator system is adequate to detect a total valve opening, for all valves, that is leas than the doaign bypass capability for a small break. Tho detectable valve opening is based on the assumption that it is evenly divided among all vacuum breakers.

In its discussions with $G E$, the staff stated that the redundant indicator and alarm system should be tested and 
calibrated periodically and included in the TS. TS 3.6.1.6 requires a chennol calibration of the vecuum brenker position indicator syctem overy 18 monthe, thus encuring the system's manitivity. The staff finde this cocoptebblo.

The etaff coscludes that the vecunum brestrer poilion indicator and alarm aystem will ensuro that the contribution of etoum bypace of the auppreaion pool through the vecuum breaker system is within the contrinment decign baris.

\subsection{Monthly Vecuum Breaker Operabillty Text}

OB doviates from the SRP in Section 6.2.1.1.5.6.2 of the SSAR by not requiring the monthly operability teet of the vecuum breaken. This teat was decigned to ensure that the vecuum breakers edequataly parform the dacign function of opening and then returning to a fully cloned position.

There are eight vecuum breaker lines in the ABWR containment with one owing chock valve per line, a opposed to most operating BWRs, which have two valves per penetration. In the DFSER, the ptaff concluded that the wetwell-drywell vacuum breaker aystom was acceptable. Failure of one of the vacuum breaken to opea is within the deaign basis of the plant, 20 only seven are required to relieve preseure differeatials.

Given the scceptability of a single barrier in the vecuum breaker lines, monthly opernbility teating could reault in one of the valves failing to recent becaune of the binding of the mechanical operator. Failure of one of the vacuum breakers to close could result in the containment preceure exceoding its design basis.

With only one barrier per vecuum broaker line, the ctaff concludes that monthly operability teating, which could recult in failure of the valves to reseat or in binding of the mechenical operators, may not be necenary becaure tho valves are deaigned for single failure to open. However, the staff believes that the singlo burrier per line pleces additional importance on the vacuum breaker position indicator and alarm system and wotwell epray systom a discussed above. These aystems will casuro that the design-basis steam bypass of the suppreacion pool is not exceeded through the vecuum breakers. In addition, TS 3.6.1.6 requires a plant shutdown within 12 hours when one vacuum breaker is not closed or cannot be demonstrated to be closed.

\subsection{Conclusion}

The staff concludes that GE's analyais, provisions for periodic testing and inspection, and vacuum breaker pocition indicator and alarm are scocoptable and mon SRP Section 6.2.1.1.C (Rov. 6), "Prencure-Suppreceion Type BWR Containments," selative to team bypaes of the apprevion pool. In addition, OB has provided edequate juctification for sot providing automatic setuation of wetwell epraye and sot requiring monthly opersbility (ctroks) teets of the vecumm breakers. Since failure of ono of the vecuum breakers to clowe could recult in the contrinment prosenurs exceoding its deaign bacis, this scopptability ralies greatly on the inctrumentation provided to detect opening of tho vecuum breaker lines and places added importances on the wotwall epray aystem.

\subsubsection{Conthinment Debrib Protection for ECCS Strainere}

The emergenoy core cooling aytem (BCCS) suction atrineses are locatod in the auppreseion pool, and their function is to ensure that dobris in the ruppresaion pool does not lead to clogring of BCCS pumps, beat exchengern, valves, and epray nozales. To eccomplish this function, debris in the cupprecesion pool will be filtered out on the aurface of the muction strainers. An exceesive sccumulation of debris on the strainer aurfece could lead to inadequate net pocitive auction bead (NPSH) and failure of the BCCS pumps.

In 1985, the NRC inuned RG 1.82, Rovision 1, "Water Sources for Long-Term Recirculation Cooling Following - Lom-of-Coolent Accident," which contains guidence on the sixing criteris for BCCS atriners. Recent events at operating renctore involving the clogeging of BCCS atraines have led the etaff to conclude that the guidance in RO 1.82, Revision 1, may not be coneervative enough to diminate this concern. To addrese this iscue for operating reactor, the NRC isoued Information Notico (IN) 92-71, "Partial Plugging of Suppreasion Pool Strainer at a Foreign BWR"; IN 93-34, "Potential for Loes of Bmergency Cooling Function Due to a Combination of Operational and Poet-LOCA Dobris in Contrinment"; Supplement 1 to IN 93-34; and Bulletin 93-02, "Debris Plugging of Bmergency Core Cooling Suction Strniners." The etaff is etill working on resolving this isowe for operating reactors.

To address this iseve for the ABWR, GE committed to the following: (1) the guidance for atrainer sixing in RG 1.82, Revision 1, will be mot; (2) for surfaces in contect with tho auppreasion pool, strinleses ateol will be used; (3) the upper drywell connecting vent openings will be protected with horizontal plates and vertical tresh racks; (4) the atrainere will bo in a " $T$ " configuration; (5) a auppression pool cleanup syetem will be used; and (6) the COL applicant will dovelop a program for maintaining auppresaion pool cleanlineses. 


\section{Bngineered Safety Features}

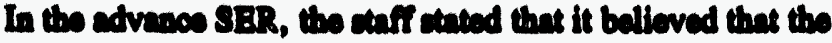
setione receified by OB wers eppropriate; however, OB did not addrese the poseible lock of conservatien in RO 1.82, Rovision 1, due to the daleterious efficet of finoly frngmented inculation. Reducing the totel amoount of inculation in the contrinment would not reolve this problem becausen the sizing eritorion is bend on corrslations in the regulationy suide. Therofore, lense inculation would lead to emaller etrimen. The taff

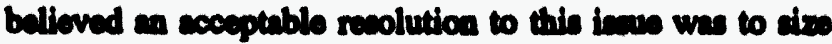
the etrinines in ecoordance with RO 1.82, Rovicion 1, but provide a fretor of 3 alzing marin to rocount for uncertainty in the ayserzetic effects of thiner clocring from inaulation, corrocioa products, and other dobris. In the edvence SER, the etaff identified this as Open Itom F6.2.1.9-1.

In Ameadment 35, GB committed to sire the RHR avetion trainers 3 times tho area that reault from RO 1.82 for all break. Tho HPCF and RCIC aystem arction atriners are airod scoording to RO 1.82, but with conservatien in the man of debris seumed to be deposited on the striners from a dexign basis aspect. OB also committed to provide - 10 percent margin in the net positive arction head available from the etatic head of the auppreacion pool for conservatiem. Based on the commitments in Ameadment 35, the etaff finds this ecceptable. This reolved Opea Item F6.2.1.9-1.

\subsubsection{Containment Heat Removal Sratem}

Tho containmeat heat removal eystem, which is an intogral part of the RHR systom, consiats of three rodundant loops. Each loop is designed so that a failure in one loop cannot cause a failure in another. In addition, each of the loops and aseociated equipment aro located in a separate protectod area of the reactor building to minimize the potential for single failure, including the lose of onsite or officito power causing the low of function of the eatire system. The system equipment, piping, and cupport atructures are deaigned to eeismic Category I criteria.

The containment beat removal system encompasese the following RHR operating modes:

- Low-Prescure Flooder (LPFL) Mode

After a LOCA, contrinmeat cooling starts as 2000 as the LPFL injection flow begins. During this modo, water from the suppreasion pool is pumped through the RHR beat exchangers and injected into the reactor veasel. The LPFL modo is automatically initiated by - low water lovel in the reactor veesel or high pressure in the drywell. In addition, each loop in the RHR ayctom can be pleoed in opention by moans of a manul initiation puch-button awitch.

\section{- Supprouidon Pool Cooling Mode}

After \& LOCA, the muppreasion pool cooling cubuyeteen provides a means to remove heat releaced into the apprescion pool. During this mode of operation, water is pumped from the aupprosion pool through the RHR heat exchengen and back to tho euppreacion pool. This mode is automatically initiated, as seoded, by cloains the LPFL injection valves and opening the aupreacion pool return valves. In reposere to a requeat for additional information (RAD), OB etated that the beat removal function will be initiated within 10 minutes after a LOCA. The staff found this to be aufiticiently conservative and adequate to echiove the necesuary contuinment cooling function.

- Containmeat (Wetwell and Drywell) Spray Cooling Mods

Two of the RHR loops include contrinment spray cooling aubayatems. Bach subayetem provides both wetwoll and drywell epray cooling. This aubaystom provides steam condensation and primary containmeat atmoepheric cooling after a LOCA by pumping water from the supprestion pool, through the RHR heat exchangers, and into the wotwell and drywell apray epargers in the primary containment. The normal mode of containment epray operation is combined wetwell and drywell eprays. However, the wetwell eprays can be operated in conjunction with either the muppreacion pool cooling mode or low preasure flooder modo. The drywell eprays can be operated in ieolation through a series of operator actions; however, this is not intended to to used in isolation following in eccident.

Provisions have been made to permit inservice inspection (ISI) of the RHR system components and functional toating of ective componeats.

The location of action and return lines in the suppreasion pool will facilitate mixing of the return water with the total pool inventory before the roturn water becomes available to the auction lines.

RO 1.1, "Net Positive Suction Head (NPSH) for Bmergency Core Cooling and Containment Heat Removal System Sumps," prohibits design reliance on preseure or temperature transients expected during a LOCA for cosuring NPSH. The ABWR NPSH design ascumes 0-kPa (O-paig) containment preseure and the maximum expected fluid temperatures reaulting from a LOCA and, therefore, 


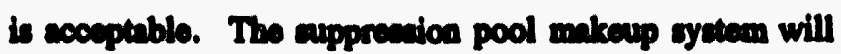
provide additional water from the condenente etornge tonk (CST) through the auppresion pool cleanup (SPCU) systom to the auppreation pool by gravity flow during normal conditions. Following a LOCA, the BCCS will take suction from the auppresion pool. The quentity of whter is aufficient to scoount for all conceivable poeteccident centrapment volumes (i.e., pleces where water cen be stored whilo maintaining long-term of the drywell veats with water).

The etaff concludes that the contrinment boat removal systeme satisfy SRP Section 6.2.2 and RO 1.1 and are ecceptable.

\subsubsection{Secondary Contrinment Punctional Dedigm}

The ABWR secondary containmeat boundary completely currounds the primary containment and is doaigned to remove fiseion products released from the primary containment during a DBA to limit the wholo-body and thyroid doees to 10 CFR Part 100 requirements at the vite boundary and the GDC 19 limit for the control room operator, as discussed in Chapters 12, 15, and Section 6.4 of this report. The etaff reviewed the secondary containment functional design in accordance with SRP Section 6.2.3. The design is considered acceptable if the relevant requirements of ODC 4, 16, and 45 and Appendix J to 10 CFR Part 50 are complied with. The relovant requirements are as follows. ODC 4 as it relates to structures, systems, and components important to safety being designed to accommodate the effects of normal operation, maintenance, teeting and poetulated accidents, and being protected against dynamic effects (e.8., the offects of missiles, pipo whipping, and discharging fluids) that may result from equipment failures. GDC 16 as it relates to reactor containment and aseociated syetems being provided to eatablish an esecentially leak-tight barriers against the uncontrolled release of radionctivity to the environment. GDC 43 as it relates to atmosphero cleanup systoms having the dosign capability to permit periodic functional teating to assure system integrity, the operability of active components, and the operability of the system as a whole and the performance of the operational sequence that brings the systom into operation. 10 CFR Part 50, Appendix $\mathrm{J}$ as it relates to the secondary containment being designed to permit preoperational and periodic leakage rato testing so that bypess leakage paths are identified.

The components of the secondary containment are designed to withstand missiles, pipe whip, postaccident environments, seismic events, a single active failure, and a loss of offsite power coincident with an accident, in accordance with GDC 4. The two systems that fulfill this function are the secondary containment heating, ventilation and air cooditioning (HVAC) ayctom and the standby gas ircetment syctem (SOTS). Thoy aro both located incide eccondary coatuinment.

The HVAC oystem will maintain a slightly negative preneure in the ecoondary containment during normil opention to prevent any radionctivity from eaceping to the eaviroament. The SCTS will provide poutaccident filention and removal of airborno halogens and particulates from the ecocondary contrinment. The SOTS is dexigned to maintain a negative preasure of -0.25 in. water gauge (cocondary contrinment to environment) after any poctulated eccident. $O E$ indicates that toeting and inepection of the integrity of the eccondary containment is part of the teating of the SOTS. The atafi's evaluation of the SOTS is given in Section 6.5.3 of this report.

SRP Section 6.2.3 tates that all Openings, wach as perconnel doors and equipment hatches, should be undor edministrative control. Theese openings should be provided with position indicators and alarms having readout and alarm capability in the main control room (MCR). The effect of open doors or hatches on the functional capability of the depressurization and filtration systems should be evaluated. The staff requeated (in RAI Q430.34) that GE provide a list of the secondary containment openings and the instrumentation used to ensure that each one is closed during a postulated DBA. In response to RAI Q430.34, GE aubmitted SSAR Table 6.2-9, which lists all secondary containment penetrations along with their elevation and diameter; however, $O E$ did not sufficiently address the etaff concerns. The staff identified this issue as Open Itom 14 in the DSER (SECY-91-355).

To eddreses the stafi's concern, GE rovised SSAR Table 6.2-9 and provided notes to the table, marking the applicable penotrations with an asterisk. The notes state that (1) the HVAC openings have safety-related isolation valves with both local monitoring and remote (in control room) monitoring and (2) the doors are monitored in the control room in accordance with SSAR Section 13.6.3.4. The ataff finds that GE's reeponse is acceptable because the other penetrations, not covered by the notes, are fluid piping systems that aro designed under containment isolation provisions. Therefore, DSER Open Item 14 is reeolved.

Furthermore, in RAI Q430.32 and Q430.34, the staff asked for information on the capability of the SGTS to draw a negative pressure following an accident assuming that all lines that do not receive an isolation signal are open and assuming the worst-case single failure of a secondary containment ieolation valve (CIV) to close. In addition, the staff asked GE to identify the instrumentation used to ensure that the CIVs shut. GE's initial response 
did not pecify the slarm capability for these indication and did not addrese slarms available in the control room.

In reeponse to RAI Q430.32, OB reviced SSAR Section 6.5.1.3.1 to state that a cocondary contrinment draw-down andycis will be performed to demonetrate the capability of the SOTS to maintuin the dacipoed negative preacurv following a LOCA, including inleakage from the open, nosirolated penetration lines identified during construction eagineering and in the eveat of the wort single failure of a recondary CIV to clow. GE aleo added SSAR Section 6.5.5.1 to atute that the COL applicant will parform an SOTS dow, functional damage, and drawdown enalywis in eccordance with SSAR Sections 6.5.1.2.3.7 and 6.5.1.3.1(5). The ataff found OE's respones scceptable. This we identified a COL Action Item 6.2.3-1 in the DFSER.

To further addres this isew, $\mathrm{OB}$ nubmitted a list of econdary contrinment pecelrations in SSAR Trble 6.2-9. All piping and cablo-tray penetrations will bo sealed with a cealing compound for leakage and fire protection and are all provided with contrinment isolation features. To censure that the SOTS is capablo of maintaining the design negative presecuro, $\mathrm{OB}$ atated that the draw-down analysis would aseume 50-percent containment inleakage regardlese of valve positions. During construction engineering, the COL applicant will identify the piping that could cauve inloakage. SSAR Section 6.5.1.3.2 tates that each SOTS fan is sized to individually cetablich a continuously negative differential pressure (considering the effect of wind) within 10 minutes after SGTS initiation. The doese analysis assumes direct leakage from the contrinment to the environs for twice the required draw-down period. The staff finds that the SGTS design includes some conservatism when considering any malfunction of secondary containment isolation features. The staff concludes that it does not need to evaluate the reaults of the draw-down analyais for its FSER afety finding. Therefore, COL Action Item 6.2.3-1 is acceptable as included in the SSAR.

The staff has reviewed the secondary containment functional design and the capability of the SGTS to maintain a negative pressure in the secondary containment following a LOCA. The SGTS hes two parallel and redundent filter trains, both of which will bo automatically actuated (one train will be placed in the standby mode) by a high drywell pressure signal or a low reactor water level signal, or when high radionctivity is detocted in the secondary containment or refueling floor ventilation exhaust. The system will be on standby during normal plant operation and may bo menually initiated from the control room for primary containment do-inerting prior to plant shutdown. Normal operation of the SGTS at power is limited to 90 bours per year for both trains combined. There are alarme and indicators for all LOCA and highmdiation mitigation systoms.

The taff concludes that the secondary design and the SOTS meet the requirements of ODC 16 as it relates to catablishing an cacentially leak-tight barrier against the uncontrolled releace of radionctivity to the environment, and are adoquately deaigned to ensure that failure of any ective component, aseuming lose of offsite power, cannot impair the capability of the system to perform its safety function and, therefore, is acceptable.

\section{Secondury Contrinment Bypass Leakage}

Nthough the primary containment is enclosed by the ecoondary contrinment, there are systems that penetrate both the primary and secondary containment boundaries, creating potential paths through which radionctivity in the primary contrinment could bypass the leakage collection and filtration system aseociated with the secondary containment. A number of the system lines contain phyaical barriere or design provisions that can offectively oliminate bypass leakage. These include water seals, containment isolation provisions, and vent return lines to the controlled regions. The acceptance criteria by which potential bypass leakage paths are reviewed are given in Branch Technical Position (BTP) CSB 6-3, "Determination of Bypass Leakage Paths in Dual Containment Plants, " of the SRP.

BTP CSB 6-3 states that the evaluation of bypass leakage involves both the identification of bypass leakage paths and the determination of leakage rates. Potential bypass leakage peths are formed by penetrations which pass through both the primary and secondary containment boundaries. Penetrations that pass through both the primary and secondary containment may include a number of barriers to leakage (e.g., isolation valves, seals, gaskets, and welded joints). While each of these barriers aid in the reduction of leakage, they do not necessarily eliminate leakage. Therefore, in identifying potential leakage paths, each of these penetrations should be considered, together with the capability to test them for leakage in a manner similar to the containment leakage tests required by Appendix J to 10 CFR Part 50.

In RAI Q430.33, the staff requested GE to specify and justify the maximum allowable fraction of primary containment leakage that may bypass the secondary containment boundary. In its response, GE stated that only valve leakage through process piping can bypass the secondary containment and that leakage will be monitored via the containment local leakage test (Typo $\mathrm{C}$ test) on the outboard CIV valves. In response to the related RAI 
Q430.52 (b and c), OB atted that information on potential bypaen leakage pathe is given in SSAR Section 6.2.3 and SSAR Table 6.2-10.

GE has ovaluated each penetration in the recondary containment in eccondance with the guidance of BTP CSB 6-3. SSAR Table 6.2-10 identifies whero each path Cerminates, the leakage herriers for the path, and whother the path is considered a potential bypans lenkage path. The potential bypase leakage paths identified in SSAR Table 6.2-10 are the drywell and wetwell purge syatems and the main steam system. Bach of thewe paths bus redundant contrinmeat isolation valves which are Type C touted in eccordance with Appendix J. Additionally, the drywell and wetwell purge systems terminate inside the eccondary containment where the SGTS collects and treats any leakage. GE has accounted for $4.2 \mathrm{~m}^{3} / \mathrm{hr}$ (140 standard cubic foet per hour (SCFH)) leakage through the MSIVs as the secondary containment bypass leakage rate to the environmeat, and this leakage has been treated ceparntely in the offisite doee analyais. The toeting and inepection of the integrity of the excondary containment will be part of the teeting of the SGTS a described in SSAR Section 6.5.1. Therefore, the staff finds that the ABWR moets the requirements of GDC 43 and 10 CFR Part 50, Appendix $\mathrm{J}$ regarding the inspection and cesting of the secondary containment system, and is acceptable.

Tier 1 deaign information and ITAAC are required for the functional dexign of the secondary contrinment. GE submitted the design description and ITAAC for the cocoadary containment. However, the recults of the staff's noviow was not complete when the DFSER was iscued. This was ideatified as Open Item 6.2.3.1-1 in the DFSER. GE aubequently submitted a revised design description and ITAAC. The adequacy and acceptability of the design deacription and ITAAC are evaluated in Soction 14.3 of this report. Therefore, DFSER Open Item 6.2.3.1-1 is resolved.

The etaff concludes that the secondary containment functional deaign and the SGTS aro in compliance with GDC 4, 16, and 43, and Appendix J to 10 CFR Part 50, and with the guidance in SRP Section 6.2.3 and BTP CSB 6-3 and, therefore, are acceptable.

\subsubsection{Containment Isolation System}

The contrinment isolation system includes containment isolation valves (CIVs) and aseociated piping and peretrations neceecary to allow normal or emergency pasange of fluida through the primary containment while preserving the capability to provent or limit the escape of fission products from the containment boundary in the oveat of a LOCA. The staff's review of this system includes the number and location of isolation valves, valve ectuntion aignals and valve control featuren, the positions of valves under various plant conditions, the protection afforded isolation valves from misciles and pipo whip, and the cavironmental deaign conditions specified in the deaign of components. The containment isolation system deaign bases and containmeat isolation provisions should conform to ODC 1, 2, 4, 16, 54, 55, 56, and 57, as appropriate. Juatification ahould be provided if deviations from these requirements exist.

GDC 1, 2, and 4 as thoy relate to systems important to ufety being designed, fabricated, erected, and tested to quality atendards commeneurate with the importance of the afoly function to be performed; systems being designed to withetand the effects of natural phenomenn (e.g., carthquakes) without lose of capability to perform their anfety functions; and systems boing designed to eccommodate postulated environmental conditicas and protocted against dynamic offects (0.8., missiles, pipe whip, and jet impingement), respoctively. ODC 16 as it relates to aystom, in concert with the reactor containment, being provided to establish an essentially leak-tight barrier against the uncontrolled release of radioactivity to the environment. GDC 54 as it relates to piping systems penetrating the containment being provided with leak detection, isolation, and containment capabilities having redundant and reliable performance capabilities, and as it relates to design provision incorporated to permit periodic operability testing of the containment isolation system, and leak rate testing of isolation valves. GDC 55 and 56 as it relates to lines that penetrate the primary containment boundary and either are part of the reactor coolant pressure boundary or connect directly to the containment atmosphere being provided with isolation valves as follows:

(a) One locked closed isolation valve inside and one locked closed isolation valve outside containment; or

(b) One automatic isolation valve inside and one locked closed isolation valve outside containment; or

(c) One locked closed isolation valve inside and one automatic isolation valve outside containment; or

(d) One automatic isolation valve inside and one automatic isolation valve outside containment.

GDC 57 as it relates to lines that penetrate the primary containment boundary and are reither part of the reactor coolent pressure boundary nor connected directly to the containment atmosphere being provided with at least one 
locked closed, remoto-manual, or automatic isolation valve outside containment.

The containment icolation provisions of the ABWR for nyetom lines that penetrato the contuinment can be classified into three areas:

(1) system lines that meet the explicit requirements of GDC 54, 55, 56, and 57 rogarding leak detection, isolation, and valve location and testing

(2) systom lines that differ from the explicit requirements of GDC 54,55,56, and 57, but that difference has been justified under the specific guidolinos given in SRP Section 6.2.4, which constitute scceptablo alternate containment isolation provisions

(3) Other lines that must be reviewed on a caco-by-case besis to determine if an acceptable alternative basis exists for allowing a doviation from the explicit GDC on grounds not previously articulated in SRP Section 6.2.4.

During its review, the staff requested GE to provide additional information regarding the containment isolation provisions. RAI Q430.31, Q430.32, Q430.34, Q430.35, Q430.36, Q430.37, Q430.39, Q430.40, Q430.41, Q430.43, and Q430.44, all involve isave affecting the containment isolation system design. OE reeponded to all of these questions, and its responses aro acceptable with the exception of those to Q430.34 and Q430.36.

Portions of GE's responses to Q430.32 and Q430.34, regarding secondary containment isolation related to the SGTS draw-down analysis, are evaluated in Section 6.2.3 of this report. In the DSER (SECY-91-355), the staff stated that the SGTS draw-down analyses should be included in the SGTS ITAAC. This was incorrectly identified in the DFSER as Open Itom 6.2.4.1-1. It should have been DFSER Open Itom 6.2.4-1. GE submitted a revised set of design descriptions and ITAAC. The adequacy and acceptability of the design description and ITAAC are ovaluated in Section 14.3 of this report. On the besis of this evaluation, DFSER Open Item 6.2.4-1 is resolved.

In its submittal of March 11, 1992, GE further responded to RAI Q430.34 by stating that instrumentation requirements for the secondary containment openings were contained in SSAR Section 6.2.3.5. Subeequently, GE added a statement in SSAR Section 6.2.3.2 that all piping and cablo-tray penotrations will be sealed with a sealing compound for leakage and fire protection. All doors are vestibule type with card reader access security systems that are monitored. The HVAC penetrations are designed to clowe in the event of a design-basis accident. The required teating procedures and frequency are included in the TS.

In Q430.36, the ataff aked GE to identify the systems and the relovent interfuce requirements for CIVs not within the ABWR scope and discuse escential and nonessential syetem in accordance with RG 1.141, "Containment Isolation Provisions for Fluid Systems," Revision 0. GE stuted that all isolation valves are within the scope of the ABWR standard plant. However, it did not provide containment isolation provisions for the essential and nosessential systems. This was identified as Open Item 15 in the DSER (SECY-91-355).

In response to DSER Open Itom 15, GE stated that containment isolation provisions for the isolation valves were specified in SSAR Table 6.2-7, which gives information on CIVs on a system-by-system basis. However, the table did not identify the system lines as cesential or nonessential to address the Three Mile Island (TMI) ection plan requirements (NUREG-0737, Item II.E.4.2). RG 1.141 contains guidance on the classification of essential versus nonessential systems. Exch nonessential penetration (except instrument lines) is required to meet GDC 54, 55, 56, and 57 and will be isolated automatically by the containment isolation signal. Escential systems, such as systems related to engineered wafety features (ESF) or systoms needed for safe shutdown of the plant, may include remoto-manual CIVs.

The staff finds that SSAR Table 6.2-7 contains the valve information on a system-by se"stem basis with containment isolation provisions for both ESF and non-ESF systems. It concludes that the valve actuation for the ESF system reflects the function of the essential system, and is acceptable. Therefore, DSER Open Item 15 is resolved.

In the DSER (SECY-91-355), the staff stated that although GE had specifically committed to meet GDC 54, 55, 56, and 57, there was no commitment to meet GDC 1, 2, 4, and 16 in accordance with SRP Section 6.2.4. GDC 1 requires that structures, systems, and components (SSCs) important to safety be designed, fabricated, erected, and tested to quality standards commensurate with the importance of the safety functions to be performed. GDC 2 requires that SSCs important to safety be protected from the effects of natural phenomena. GDC 4 requires that thewe SSCs be protected against dynamic effects. GDC 16 requires that the reactor containment and sesociated systoms be provided to establish an essentially leaktight barrier against the uncontrolled release of radioactivity to the environment. This lack of commitment to meet GDC wes identified as DSER Open Item 16. 
In its reeponse to this open item, OB stated that tho ABWR commitments to GDC 1, 2, 4, and 16 aro contained in SSAR Section 3.1.2.1.1, 3.1.2.1.2, 3.1.2.1.4, and 3.1.2.2.7, reepectively. The tuff roviowed SSAR Section 3.1 and found that GE had mot the above-cited GDC in the ABWR decign. However, SSAR Soction 3.1.1 tates that the ODC are intendod to guide the deaign of all water-cooled nuclear powver plants and the ODC are aubject to a variety of interpretations. In reviowing these criteria in SSAR Section 3.1.2, the staff noted that some of the wording pertaining to the GDC did not match the wording in 10 CFR Part 50. The etaff pointed out these dimerepancies and asked $O B$ to change the wording. GB mado the changes in SSAR Section 3.1.2. The staff finds this acceptable. Therefore, DSER Open Itom 16 is reeolved.

In addition, in response to Q430.41, GE stated that instead of meoting the requirements of GDC 56 for the highpreseure core flooder (HPCF) and residual heat removal (RHR) test and pump miniflow bypess lines, reactor core isolation cooling (RCIC) turbine exhaust and pump miniflow bypaes lines, and suppreasion pool cleanup (SPCU) suction and discharge lines, it will use GE Safoty Standard 20, Nos. 8 and 9. The staff stated that these standards did not meet the explicit requirements of GDC 56 and GE must provide justification for this deviation. This was identified as Open Itom 17 in the DSER (SECY-91-355) and as Open Item 6.2.4-3 in the DFSER.

GE atated that GE Standard 20, Nos. 8 and 9, are GE's criteria to meet GDC 56 on another defined basis. Specifically, No. 8 is the criterion applicable to a line that (1) penetrates the containment, (2) communicates with the containment interior, (3) is not an instrument line, and (4) is not a suppression pool effluent line. No. 9 is similar to No. 8, but is applicable to the effluent line that communicates with the suppression pool. The term "communicates" is intended to mean that these lines are not closed loops, they may leak, or open to the containment interior or the suppression pool.

GE Safety Standard 20, No. 8, requires that each of these lines be provided with two isolation valves. At least one valve should be located outside the containment; the other valve may be located either inside or outside the containment. Alternative, one isolation valve outside the containment, which will be normally closed (or a blind flange) and will not receive a signal to open after an accident, may be used. On influent lines having two valves, one may be a check valve, and the valvo outside the containment must be capable of automatic or remotomanual closure, or should be normally locked closed. Gn effluent lines or where a second valve is not provided on an influent line, these valves should be capable of automatic and remoto-manual closure or should be normally locked closed. The valves should be located as clow as practicable to the containment. GE Safety Stundard 20, No. 9, requires that the cuppression pool effluent lines be provided with one remoto-manual valve outside the contrinment that should be located as close to the containment as practicable. GE also provided additional information in SSAR Table 6.2-7 (Amendment 34) by adding notes $h, i, j, k, l, q$, and $r$ to addreses the containment isolation provisions for these system lines.

The etaff has reviewed the valve arrangement in SSAR Table 20.3.2-3 and SSAR Section 6.2.4.3.2.2 (Amendment 34) and finds that these system lines should not be automatically isolated following a containment isolation signal because of the specific safety function they will perform. Specifically, the RCIC system, in conjunction with the HPCF and RHR system, will provide core cooling to prevent excessive fuel temperature during - LOCA. To protect the RCIC pump from overheating, the RCIC system contains a pump miniflow bypass line that will discharge into the suppression pool when the line to the reactor vessel is isolated. When flow through the pump to the vessel is sufficient, the isolation valve in the miniflow line will close automatically, thus directing all flow to the reactor. The HPCF and RHR test and pump miniflow bypass lines have isolation capabilities commensurate with the importance to safety of isolating these lines. The RCIC pump miniflow bypass line will be isolated by a normally closed, remote manually actuated valve outside the containment. The RCIC turbine exhaust line, which penetrates the containment and will discharge to the suppression pool, is equipped with a normally open, motor-operated, remoto-manual gate valve. The RHR and HPCF test and miniflow bypass lines each has a motoroperated valve outside the containment. The SPCU suction and discharge lines each has two isolation valves outside the containment because the penetration is under water. All these lines terminate below the suppression pool water level and will be sealed from the containment atmosphere following a LOCA.

Bocause of the specific safety function that these system lines will perform, their automatic isolation following a containment isolation signal is not appropriate. The staff finds that the containment isolation provisions do not dogrado containment isolation capability and conform with the system's function. SRP Section 6.2.4 contains guidance for satisfying the GDC on another defined basis in that remoto-manual actuation is provided for accident protection. Therefore, the staff concludes that the containment isolation design for the system line moets GDC 56 on another defined basis (GE Safety Standard 20, 
Now. 8 and 9) and is scoeptublo. This reoolved DFSER Open Itom 6.2.4-3.

During its reviow of SSAR Tablo 6.2-7, which dalineatices CIV information in respones to Q430.35, the staff identified como icolation valve dexign fentures that did not conform to SRP Section 6.2.4. In the table, the normal valve ponitions are either "open" or "clowed." There is no way to dotermine if cloced is the same as locked cloced as it is rtipulated in SRP Section 6.2.4. In eddition, GB did not juetify the icolation valve clonure times of leas than 30 ecconds for some relatively large-diameter valves for the drywall atmoephere syatem, auch as atmorpheric control syetem (ACS) $55 \mathrm{~cm}$ (22 in.)-dinmeter valve T31-FOO4 and flammability control aystem (PCS) $15 \mathrm{~cm}$ (6 in.)-diameter valve T49-F006A. The selection of the drywell atmoephere systems closure times, as epecified in SRP Section 6.2.4, should be based on the analysis of rediological consequences for the DBA. In the DSER (SECY-91-355), the etaff asked GE to identify which valves were "open," "clowed," or "locked closed" and provide the technical basis for drywell atmosphere closure times. This was identified as part of Open Item 17 in the DSER (SECY-91-355).

GE stated that valve condition is given on the system piping and instrumentation diagram (P\&ID) as locked open/cloeed, normally opea/clobed, and normally energized/deenergized. For clarity, the staff prefers that thewe valve positions are also epecified in SSAR Table 6.2-7. In diecuesions with the etaff, GE committed to make the change and this became Confirmatory Item 6.2.4-1 in the DFSER. In a cubsequent amendment, GE added a note to SSAR Table 6.2.7 which atates that the P\&ID's identify which CIV's are locked closed. This is scceptable. This reeolved DFSER Confirmatory Itom 6.2.4-1.

In its aubmittal of March 11, 1992, GE stated that ACS isolation valves (T31-F001, -F002, -F004, -FO06, and F009) are $55 \mathrm{~cm}$ (22 in.)-diameter butterfly valves with an air operator that can travel $90^{\circ}$ to close. These valves will be normally cloeed because their main function is to aupport containment purging and nitrogen inerting when the reactor is at lese then 15-percent power. The smaller valves (T31-F005, -F039, -F040, and -F041) are $5 \mathrm{~cm}$ (2 in.)-diameter, air-operated globe valves that will close within 15 seconds. These air-operated valves may be opened for short periods during reactor operation to lower primary containment pressure or to keep the primary containment pressurized (by adding nitrogen) for preventing any air in-leakage. T31-F008 is $25 \mathrm{~cm}$ (10 in.)-diameter, normally closed outboard air-operated butterfly icolation valve that will be connected to the SGTS and opened in series with T31-F005. T31-F025 is a $41 \mathrm{~cm}$
(16 in.)-diameier, normally closed ousboard butterfly icolation valve that will bo opened only during initial inerting of the primary containment when the reactor is below 15-percent power. Open/clowe times of 20 seconde or bes are planned for all except tho $5 \mathrm{~cm}(2 \mathrm{in}$.)-diameter valves.

FCS ieolation valves (T49-F001, -F002, -F006, and -F007) are normally clowed $15 \mathrm{~cm}(6 \mathrm{in}$.)-diamoter gate valves. These valves my be ectuatod individually for teating during reactor operation. Two of these valves will be air or nitrogen operated and two valves will be motor operated. This ayetem will not be setivated for days following a LOCA and a clowure time of lees than 30 ecoonds is planned.

In the DSER (SBCY-91-355), the staff stated that the closure times for these valves, including instrumentation delay, thould be determined by demonstrating complinnce with 10 CFR Part 100 rogarding offeite radiological conequences. The closure time should be justified on the baris of an analysis of the radiological consequences of a LOCA. However, GE had not explained how the valve open/close times were determined, or that the radiological consequences following a LOCA meet the requiroments of 10 CFR Part 100. This was identified as Open Itom 6.2.4-4 in the DFSER, which was part of Open Item 17 in the DSER (SECY-91-355).

GE stated that the FCS is a closed-loop system that will bo capable of controlling combustible ges concentrations in the containment atmosphere for the design-basis LOCA without relying on purging and without releasing radionctive material to the environment. The timo limit for valve clowure is not importent, since offaite radiological consequences need not be considered for a closed-loop system. Therefore, the staff finds that the closure time of leas than 30 seconds for the FCS is acceptable.

SRP Section 6.2.4 states that the closure times of the containment purge and vent isolation valves should be cetablished on the basis of minimizing the release of contrinment atmosphere to the environs and that isolation valve closure times of about 5 seconds or less may be necessery. SSAR Section 6.2.4.3.2.2.2.3 (Amendment 34) states that the ACS CIV closure timo is equal to or lese than 20 seconds. The ABWR TS require the $55 \mathrm{~cm}$ (22 in.)-diameter ACS CIVs to be normally sealed cloeed and to be opened only when reactor power is less than 15 percent during the 24-hour period following entry into Mode 3 for inerting the containment (startup) and the 24-hour period before entering Mode 4 for do-inerting the containment (shutdown). If open, they will sutomatically close on drywell high pressure or high radiation detected in the exhaust flow. The exhaust radiation detectors are 
deaigned to be very censitive and will be cet at a lower setpoint compared to the ones inside the containment to ensure early detection. GB stated that the difierence between 5 and 20 eeconds is considered to be insignificant and that on the basis of its annlyais, the clocure times of theee valves are significantly shorter then neceesary to prevent any radiological impact. Additionally, GB etated that valves with moderate eppeed will be moro reliable and, therefore, ensure contrinment integrity.

The staff finds that the closure time of 20 reconds or lese for the ACS isolation valves is scceptable based on GE's sccident analysis and juatification that alower seting valves are more reliable. The sccident analysis in Chapter 15 of the SSAR ascumen, smong other thinges, that all containment isolation valves isolate within 60 reconds following a poetulated LOCA for calculating the offivite doses. The 20-necond or lase cloture time of the ACS CIVs is amall compared to this seaumption. Additionally, the analyais secumes primary containment releases through the penetrations to be 0.5 -percent by waight per day of the containment free volume. The contribution to the officite doses due to the leakage through the ACS CIVB for the period from 5- to 20-seconds following a LOCA is insignificant when compared to the offaite domes due to the assumed leakage through the penetrations, and is scceptable. This resolved Open Iten 6.2.4-4.

\section{Contrinment Purce System}

The staff requeated GE (in RAI Q430.42) to addrees the containment isolation provisions for the purge lines that show conformance with BTP CSB 6-4, "Containment Purging During Normal Plant Operations," of the SRP. In its initial reeponee, GE incorporatod a now proprictary SSAR Section 9.4.5.6, "Primary Containment Supply/Exhaust System," which gives design information on the primary containment purge aupply/oxhaust syetop. The system consists of the mupply fan, a high-officiency particulate air (HEPA) filter, a purge fan, duct work, and controls. GE also provided additional information in SSAR Table 6.2-7 and Figure 6.2-39a (the atmoepheric control system P\&ID).

In response to RAI Q430.42, GE stated that the containment purge supply and exhaust lines, connected to both the drywell and wetwell, consiet of one aupply and one exhaust penetration each for the drywell and wetwell. Both the purge supply and exhaust lines, each of which is connected to both the drywell and wetwell, have two parallel isolation valves that will be located as close as possible to the outside of the primary containment. One of these valves (55 cm (22 in.)-diameter) is intended for use for (high-volume) inerting and purging. The other valve (5 cm (2 in.)-diameter) will bo ueed for any noceasary nitrogen makeup during power operation. The two $5 \mathrm{~cm}$-diameter exhnust valves will be used for any noceseary veating (e.8., for pressure control) during operation. All these ivolation valves are sir operated and will automatically be cloced by high drywell pressure or Lovel III low renctor veceel water level signals. They also will fiil in the clowed position if actuating power is loct. Tho largo-diameter valves aro butterfly-typo valves with a clocure time of lees then 20 reconds. The small-diameter valves are globo-type valves and have closure times of leas then 15 reconds. The staff finds that the containment isoletion provisions for the purge valves are in confurmance with BTP CSB 6-4. However, this valve configuntion does not comply with GDC 56, which requires one isolation valve inside and one isolation valve outride the contrinment for each penetration. This was identified as Open Item 6.2.4.1-1 in the DFSER and as Open Item 18 in the DSER (SECY-91-355).

GE atated that purge and vent lines do not extend into the containment and have both inboard and outboard containment isolation valves (CIVs) located outside the primary containment 80 that they are not exposed to the hareh environment of the wetwell and drywell and are accessible for inspection and testing during reactor operation. SSAR Section 6.2.4.3 (Amendment 34) states, in part, that the CIVs for the atmospheric control system located outside the containment will be located as close to the containment as practical. The piping from the containment up to and including both valves is an extension of the primary containment boundary and is designed in accordance with ASME Code, Section III, Class 2 requirements. The CIVs are protected from the effects of flood and dynamic offects of pipe breaks in accordance with SSAR Sections 3.4 and 3.6. The arrangement of the isolation valves and connecting piping is such that a single failure of an inboard valve, or a single active or passive failure in the connecting piping or an outboard valve, cannot provent isolation of the ACS. The valves are air operated with a pilot dc solenoid valve that will fail closed on loses of air or loss of electrical power. The power for the de solenoids will be supplied from independent electrical divisions.

The affe's position on this issue is that locating both ieolation valves outside the containment is acceptable if piping and valve design criteria are sufficiently conservative to preclude a breach of integrity. In general, the isolation barriers should be designed to ESF criteria and protected against floods, missiles, pipe whip, and jet impingement. GDC 56 permits containment isolation provisions for lines penotrating the primary containment boundary that differ from GDC 56, provided the besis for scceptability is defined. The staff concludes that this valve arrangement precludes a breach of piping integrity, meets 
the single-sailure criterion, and is protected aginet the offects of flooding, mimilen, pipe whip, and jet impingement and moet. ODC 56 on another dofined basis, and is coceptable. Therefore, DFSBR Open Item 6.2.4.1-1 is resolved.

In the DSER (SECY-91-355), tho etaff identified a number of criteria that are delineated in BTP CSB 6-4, but that GB did not addrew, including

- radiological consequeace analysis for a LOCA with the purge system initially open (BTP CSB 6-4, B.5.a)

- system structural intogrity decign under LOCA thermal-bydraulic conditions (BTP CSB 6-4, B.5.b)

- deaign provisions to ensure that isolation valve closure is not prevented by dobris entrained in eccaping air and steam (BTP CSB 6-4, B.1.8)

- during emergency core cooling system (ECCS) backproesure contrinment preesure reduction analyais for a LOCA which the purge system is initially open (BTP CSB 6-4, B.5.c)

- evaluation of case-by-case purge isolation valve maximum allowable leak rate (BTP CSB 6-4, B.5.d)

- technical justification for a purge system isolation valve closure time of more than 5 seconds (BTP CSB 6-4, B.1.f)

- design provisions to ensure that simultaneous venting of the wetwell and drywell will not occur

In its submittal of March 11, 1992, GE addreseed these criteria as follows:

- Radiological consequence analysis for a LOCA with the purge system initially open relates to SSAR Section 16.3.6.3.2, regarding the tochnical specification requirements for the oxygen concentration in the primary containment. The atmospheric control syatem (ACS) $55 \mathrm{~cm}(22 \mathrm{in}$.)-diameter purge isolation valves normally will be sealod closed during plant operation and will be opened only during the inerting (startup) and do-inerting (shutdown) process when reactor power is less than 15 percent and within 24 hours of reactor shutdown or startup. Within such a limited time, if a LOCA does occur, these valves will have closed before the onset of fuel failure. In the event of a radionctivity leak during inerting/de-inerting, the radiation detectors at the purge and vent exhaust line will detect the condition and isolate the ACS CIVs. GE stated that the exhaust radiation detectors are designed to be very canitive and will be ex at a lower setpoint compared to the onee insido the containment to eneure carly detection. Therefore, the potential for a LOCA to cocur while the ACS $55 \mathrm{~cm}$ (22 in.)-diameter purge irolation valves are opened is emall because the valves are allowed to be opened for limited times and tho radiological consequence analysis shows that should a LOCA occur whilo they are open, site radiological limits will not exceed the limits of 10 CFR Part 100.

- Penetrations, piping, ieolation valves, and rupture diece will maintain their structural intogrity for all sccident conditions. Periodic Type C teats of the isolation valves will bo conducted at the contrinment peak presaure. The design meets seismic Category I and anfety Clase 2 requirements. Isolation valves will clowe automatically following LOCA signals and will fail clowed on lose of instrument air. Purge system isolation valves (AO-FOO1, AO-FOO2, AO-FO03, AO-FOO4, AO-FOO6, and AO-FO25) will be locked closed whenever the reactor is above 15-percent power. Purge exhaust isolation valve AO-FOO5 normally will be closed and will open only for 90 hours per year aloag with operation of the slendby gas treatment systems (SGTS) for containment pressure control. Nitrogen will be added to the prima - $v$ containment during reactor operation by opening isoistion valves AO-FOO39 and AO-FOO40 for the drynell and AO-FOO39 and AO-FOO41 for the wetwell.

- Drywell and wetwell purge penetrations will have seismic Category I debris screens.

- ECCS systems with suction from the suppression pool are designed with the primary containment at atmoepheric pressure and without crediting net positive suction head for containment backpressure.

- Caso-by-case maximum allowable leakage rates for isolation valve are based on valve size, type, and containment peak pressure for Type $C$ tests as required by the TS. Test connections are provided. This was DFSER TS Item 6.2.4.1-1. Since GE included the leeting requirements in the ABWR TS, the TS item is resolved.

- Purge system isolation valves AO-F005, AO-F040, and AO-F041 will bo opened for short periods during reactor operation for containment pressure control. These valves are all $5 \mathrm{~cm}$ ( 2 in.)-diameter and are capable of full closure within 5 seconds.

GE provided adequate information to address these criteria with the exception of simultaneous venting of the drywell and wetwell. BTP CSB 6-4 prohibits simultaneous venting 
of tho drywell and wotwell. In tho DFSER, the etaff atated that $G E$ should show how this will be ensured. This was identified as Open Itom 6.2.4.1-2.

In its aubmittal of January 22, 1993, GB proposed to add Section 6.2.4.3.5 to the SSAR. This coction (Amendment 34) atates, in part, that the large $(55 \mathrm{~cm}$ (22 in.)) purge and vent lines for the ACS will not be used for purging or venting during normal reactor operation. The isolation valves in these lines are normally closed and thoy are not needed for preasure control of the containment during normal operations. Presaure control of the containmeat during operation will be maintained by a single, small (5 cm (2 in.)) nitrogen line and o single, small (5 cm (2 in.)) vent line. The small vent line will be attached to the $55 \mathrm{~cm}(22 \mathrm{in}$.) drywell purge exheust line and bypass the cloeed $55 \mathrm{~cm}$ (F004) valve. There is no equivalent vent line from the wetwell. Therefore, the drywell and wetwell will not be vented simultaneously during operation, and the syetem has only one supply and one exhaust line as required by BTP CSB 6-4. The ataff finds that GE's justification is scceptable. DFSER Open Item 6.2.4.1-2 is resolved.

The staff also requested (in RAI Q430.254) that of explain how the drywell and wetwell purge aupply and exhaust subsystems can meet BTP CSB 6-4. OE committod to provide such information. This was identified as Confirmatory Item 6.2.5-1 in the DFSER and as part of Open Item 21 in the DSER (SECY-91-355).

In response, GE stated that drywell and wetwell purging is not required during normal operation. The staff finds that BTP CSB 6-4 does not apply to the plant that does not have an online purge system. Therefore, DFSER Confirmatory Item 6.2.5-1 is resolved.

GDC 54 requires "containment capability having redundancy" for piping that penetrates the containment. However, SSAR Figure 6.2-39 shows common CIVs for the containment purge supply (T31-F001 from the reactor building HVAC system, T31-F025 from the $40 \mathrm{~cm}$ (16 in.) nitrogen purge line, and T31-F039 from the $5 \mathrm{~cm}$ (2 in.) nitrogen supply line) and exhaust (T31-F009 to the reactor building HVAC system and T31-F008 to the SGTS). The staff was concerned that this valve arrangement would leave the system vulnerable to common-mode failures. Each purge and exhaust line should have redundant and independent CIVs to comply with GDC 54. This was identified as Open Item 6.2.4.1-3 in the DFSER and as part of Open Item 18 in the DSER (SECY-91-355).

In its submittal of January 22, 1993, GE stated, in part, that the containment purge system has redundant CIVs, cach powered from an independent electrical division, and the CIV are arranged eo that any single active failure will not compromice the integrity of the containment. GE also stated that this arrangement has adequate redundancy and independence and is not unduly vulnerable to common mode failures.

The tuff reviewed the valve arrangement in SSAR Figure 6.2-39 and finds that the common $\mathrm{CIV}_{8}$ mentioned above are the outboand CIVs, which are redundant. There are independeat inboard CIVs for containment purge aupply (T31-F002, -F003), nitrogen supply (T31-F040, -F041) and exhaust (T31-F004, -F005, -F006, -F007). All of theee inboard CIVs will be closed automatically on receipt of a containment isolation signal and are designed to fail in the closed position on loss of air or loss of power to the pilot solenoid valves. Therefore, the staff concludes that the valve arrangement does not degrade containment integrity, meets the single-failure criterion, and is acceptable. DFSER Open Item 6.2.4.1-3 is resolved.

10 CFR 52.47(a)(1)(ii) requires that an application for a standard design cortification to include a demonstration of compliance with any tochnically relevant portions of the TMI-related requirements identified in 10 CFR 50.34(f). In accordance with $10 \mathrm{CFR} 50.34(f)(2)$ (xiv), GE has incorporated the following containment isolation provisions in the ABWR design:

- The design ensures all nonessential systems will be automatically isolated by the containment isolation system on receipt of a containment isolation signal.

- Each nonessential system line (except instrument lines) is designed with two isolation barriers in series.

- The design allows resetting the isolation sigyeal without automatically roopening the CIVs. The ABWR system design ensures that resetting the isolation signal will not result in the automatic reopening of the CIVs. The reopening of any CIV is on a valve-by-valve basis once the isolation signal has cleared and following a subeequent logic reset.

- The design utilizes a contrinment pressure setpoint for initiating containment isolation that is as low as compatible with normal operation. Specifically, GE has committed to a high drywell setpoint pressure of $0.14 \mathrm{~kg} / \mathrm{cm}^{2} \mathrm{~g}$ (2 psig) to isolate nonessential penetrations.

- The design includes automatic closing on a high radiation signal for all systems that provide a path to the environs. Specifically, the containment purge and vent isolation valves will close on high radiation levels 
in the secondary contrinment HVAC air exhaust or in the fuel handling area HVAC air axhauat.

The staff finds that the contrinment icolation provisions for the ABWR dexign meet the requirements of 10 CFR 50.34(f)(2)(xiv).

GE rubmitted the design description and the ITAAC relating to the containment isolation aystem. The staff's roviow of this material was not complete whea the DFSER was issued. This was identified in the DFSER as Open Itom 6.2.4.14. GE subeequently provided a rovised design deecription and ITAMC. Tho adoquacy and acceptability of the design description and the ITAAC are ovaluated in Section 14.3 of this report. On the basis of this evaluation, DFSER Open Item 6.2.4.14 is resolved.

The ataff has reviowed the information in the SSAR apd information submitted in response to staff quections concerning the containment isolation system to enoure conformance to SRP Section 6.2.4 and BTP CSB 6-4. It concludes, as deecribed in the preceding soction, that the containment isolation system meets GDC $1,2,4,16,54$, 55,56 , and 57 .

\subsubsection{Combustible Gas Control in Containment}

Following a LOCA, hydrogen may accumulate within the containment as a result of the following phenomena: (1) metal-water reaction between the zirconium fuel cladding and the reactor coolant, (2) radiolytic decomposition of the water in the reactor core and the containment, and (3) corrosion of metals by ECCS spray solutions. If a sufficient amount of hydrogen is generated, it may react with the oxygen present or generated in the containment following an accident. To monitor and control the buildup of hydrogen and oxygen within the containment, GE has incorporated the following aystems and capabilities in the ABWR design:

\section{Atmospheric Control System}

The atmospheric control system (ACS) is designed to maintain the primary containment oxygen concentration below the maximum permissible limit (3.5 percent) in accordance with RG 1.7, "Control of Combustible Gas Concentrations in Containment Following a Loss-of-Coolant Accident, " Revision 2, during normal, abnormal, and accident conditions to ensure an inert atmosphere. The containment atmosphere will be inerted using adequately sized nitrogen storage tanks that are provided with makeup capability. The ACS is designed to withstand missiles, pipe whip, flooding, tornados, a safe shutdown earthquake, LOCA environment, and a single active failure. However, GB states that the ACS is non-anfety grade, whereas the SRP Section 6.2.5 scceptance criteria to satisfy ODC 41 thete that the combustible gas control system should be cafoty grado because this aystem is relied on to cenure that containment integrity is maintained following an sccident. The staff identified this as Open Item 19 in the DSER (SECY-91-355).

OE atated that the ACS consists of a nitrogen aupply, injection, and exhaust lines and the contrinment overpreesure protection system. The enfoty-related functions normally aseociated with the ACS will be performed by the safety-related highpreacure nitrogen systom (HPIN). The only portions of the ACS that are afety related are the containment penetrations and isolation valves that inolate the ACS from the HPIN. This is cccoptable. In addition, the staff's review of the HPIN design is contained in Section 9.3.1 of this report, and the staff finds this HPIN design is ecceptable. This resolved DSER Open Item 19.

Containment Atmosphere Monitoring System

The containment atmosphere monitoring system (CAMS), as addressed in SSAR Section 7.6.1.6, is a safety-grade, soismic Category I system designed to meet GDC 41 by monitoring the drywell and suppression chamber for high levels of hydrogen, oxygen, and radiation during accident conditions. The system will allow operators to confirm that the containment is inerted so that containment nitrogen purging can be terminated and also to verify that do-inerting is complete to ensure safe personnel entry into the primary containment. The system has a measurement range of 0 to 25 percent (by volumo) at 100-percent relative humidity.

The CAMS consists of two independent but rodundant Class IE divisions, which are electrically and physically independent to remain operable as a result of a single active failure coincident with a loss of offsite power. The system has two subsystems: radiation monitoring subsystem and hydrogen/oxygen monitoring subsystem. The radiation monitoring subsystem contains two channels per division; one for monitoring the drywell and the other for monitoring the suppression chamber. Each monitoring channel consists of an ionization chamber, a log rate meter, and a recorder. Each channel has a range of 1 to $10 \mathrm{E}+7 / \mathrm{R} \mathrm{hr}$ and will initiate an alarm in the control room on high radiation level or on system failure. This subsystem can be initiated auto- 
matically on a LOCA signal of manually ectuated from the control room. The radiation monitors do sot provide any bypaes or interlock capability.

The bydrogea/oxyen monitoring aubayctem coneines of two divisions that will thise amples of tho drywell and wetwell and fead them to monitors for manurement, reconding, and control room alerm. The piping is atuinlow ated and continuounly beet treced to remove moiture from the ayebon during monaurementa. Gas calibration nolbe are provided to perform equipmepte calibrations during operating conditions. A thermal dolay bypan feature will sllow syetem teating during powver operation. There are no automatic inolation functions anocinted with the syctem.

Bech CAM abbyetem will be powered from a divisional 120-V ec Clase 1B instrument bus. This power cource also will aupply the beat-tracing bleaket ued for the campling lines.

The athef concludes that the CAMS bas adequate capability for monitoring the contrinment atmoephere for hydrogen/oxygen control, thus eatisfying ODC 41 regarding containment atmoephere cleanup.

(3) Capability of Pout-LOCA Purging of the Containment

Poet-LOCA primary containment backup purging capability is required in eccordanco with RO 1.7 a an aid for containment atmosphere cleanup following a LOCA. During normal plant operation, the bleed line will function, in conjunction with the nitrogen purge line, to maintain primary contrinment preseure at about $5.2 \mathrm{kPag}$ (0.75 psig) and oxygen concentration below 3.5 percent by volume. This will be done by making up the required quantity of nitrogen in the primary contrinment through the makeup line or relieving preasure through the bleed line. Flow through the bleod line will be directed through either the SOTS or tho renctor building econdary containment HVAC ayetem and will be monitored for radiation. However, GE provided neither the purge rate that would be required to maintain the oxygen concentration below 3.5 percent by volume nor the redionctive consequence analysis for the staff to reviow. This was ideatified as Open Item 6.2.5-1 in the DFSER and as Open Item 20 in the DSER (SECY-91-355).
OB tated thet postucoident containment beckup purging ceppability is not needed to maintain the oxycen concentrition below 3.5 percent because the costainmeat is inerted. Pressure in the containment during normal operation will be mintained by a $5 \mathrm{~cm}$ (2 in.) nitrogen aupply lino and a $5 \mathrm{~cm}$ (2 in.) veat lino. No continuous purging is required during normal operation. The utaff finds this scoeptable. This recolved DFSBR Open Item 6.2.5-1.

With respect to postaccideat hydrogen generation andysis, $O B$ stated that the andiytical model described in GB report NEDO-22155, "Generation and Mitigation of Combuetible Gas Mixtures in Inerted BWR Mark I Containment" (nonproprietary) whe uned to compute hydrogen and oxygea generation from radiolysis. NEDO-22155 was roviowed by the etaff for the EPRI requiremente document certification and found unscceptable. As a recult, GE performed a now hydrogen generation analysis using the RG 1.7 methodology. The reaults of the analysis are provided in Appendix B of SSAR Chapter 19. On the basis of its reviow of GE's analysis, the staff concludes that the ABWR will be ablo to withstand a 100-percent fuel-clad motal-water reaction.

Flammability Control System (Hydrogen
Recombiner)

SSAR Section 6.2.5.2.7 states that there will be two permanently installed recombiners in the secondary containment. However, GE did not provide information on dedicated redundent contrinment penetrations to demonstrate that the recombiners could perform their safety function assuming a single sctive failure. Also, GE did not indicate whether the recombiners are safoty grade. This was identified as Open Item 6.2.5-2 in the DFSER and as Open Item 21 in the DSER (SECY-91-355).

In Amendment 34, GE revised SSAR Section 6.2.5.2.7 which states, in part, that the flammability control system (FCS) consists of two permanently installed safety-related thermal hydrogen recombiners located in separate rooms in the secondary containment and controlled from the main control room. Independent drywell and auppreesion chamber penetrations are provided for the two recombiners. Eech penetration has two normally closed isolation valves. The staff has reviewed GE's FCS design and finds that the recombiner configuration meets the single-failure criterion and is acceptable. Therefore, DFSER Open Item 6.2.5-2 is resolved. 
10 CFR 52.47(a)(1)(ii) requires thet an application for a ctandard decien certification include a domonetration of complience with any technically relovent portions of the TMI requirements forth in 10 CFR 50.34(f). The atafi's evaluation of the TMI-related requirements on bydrogen control is provided as follows:

(a) 10 CFR 50.34(f)(1)(xii), "Bvaluation of Alternative Hydrogen Control Syetems," requires the applicant to perform an evaluation of alternative hydrogen control ayctoms that would satisfy the requirements of 10 CFR 50.34(f)(2)(ix). At a minimum, consideration chould be given to a hydrogea ignition and poutaccident inerting aystem and the oveluation should includo

- a compariecen of coets and besofits of the alternative nystems considered

- analyeses and test data to verify compliance with the requirements of 10 CFR 50.34(f)(2)(ix) for the selected system

- preliminary design descriptions of equipment, function, and layout for the selected aystems

OE has provided information for the lat two itoms as identified above but has not provided coet and benefit information for alternative systems. If the alternative systems are used in the design, this information must be provided by the COL applicant. This was identified as COL Action Item 6.2.5-1 in the DFSER.

In its submittal of Manch 5, 1993, GE addod Section 6.2.7 to the SSAR. SSAR Section 6.2.7.1 (Amendment 32), reganding alternative hydrogea control, states that the COL applicant will provide a comparison of costs and benefits for alternative hydrogen control in sccordance with SSAR Section 6.2.5. Therefore, COL Action Item 6.2.5-1 hes been clarified and found to be acceptable. The staff concludes that the ABWR design meets the requirements of 10 CFR $50.34(f)(1)(x i i)$.

(b) 10 CFR 50.34(f)(2)(ix), "Hydrogen Control Syatem Proliminary Design," requires the applicant to provide a system for hydrogen control that can cafely eccommodate hydrogen generated by the equivalent of a 100-percent fuel-clad metal-water reaction. This system and any associated systems should provide, with reasonable assurance, that
- uniformly dietributed hydrogen concentrations in the containment do not exceed 10 percent during and following in eccident that releases an amount of bydrogen that would be equivaleat to that senerated from a 100-perceat fuel-cled metal-wator renction, or that the poet-accident atmoephere will not eupport hydrogen combuation

- combustible concentrations of hydrogen will not collect in areas where unintended combustion or detonation could cause loss of contrinment intogrity or lows of appropriato mitigating features

- equipment necescary for achioving and maintaining anfo shutdown of the plant and maintaining containment integrity will perform its safety function during and after its exposure to the environmental conditions attendant with the release of hydrogen generated by the equivalent of a 100-percent fuel-clad motalwater reaction including the environmental conditions created by activation of the hydrogen control systom

In SSAR Section 19B.2.18, GE state that the ABWR containment will have an inert atmosphere and will be ablo to withstand the prescure and cenergy addition from a 100-percent fuel-clad metalwater reaction. The staff concludes that the inerted containment and the provision for permanently installed hydrogen recombiners are acceptable as hydrogen control measures and adequately address 10 CFR 50.34(f)(2)(ix).

(c) 10 CFR 50.34(f)(3)(iv) requires the applicant to provide one or more dedicated containment penctrations, equivalent in size to a single $0.9 \mathrm{~m}$ (3-ft)-diameter opening, in order not to preclude future installation of systems to proveat containmeat failure, such as a filtored ventod containment system. This requirement is a followup of one of the requirements identified under TMI action plan, Item II.B.8 of NUREG-0660.

The staff's evaluation of the size of the penetration that can be used for venting the containment is provided in Section 20.5.44 of this report.

(d) 10 CFR $50.34(f)(3)(v i)$, "Dedicated Hydrogen Penetrations (Hydrogen Recombiners), "requires the applicant to provide redundant dedicatod containment penetrations for plant designs with external bydrogen recombiners so that, assuming * 


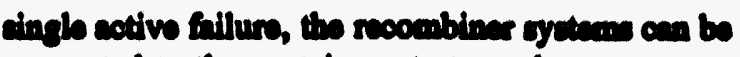
consected to the contrinmeat atenophers.

SSAR Figure 6.2-40 dhow rectuadent dediceted bydrogen recombiner penetrutions. This entiafles 10 CFR 50.34(1)(3)(vi). However, in the DFSER, the ataff etatod that OB had not provided decipn information for the recombinese in the SSAR, but had committed to ioclude this informetion in a future SSAR amendment. This was identified a Confirmationy Item 6.2.5-2 in th DFEER.

In Ameadeneat 32, OB providad this informetion in SSAR Section 6.2.5.2.7. The ctafi reviowed this coction and PEID Figure 6.2-40 (Amendmant 34) and finds that OB hes addrened tho FCS decion requirements in the SSAR. This is ecoeptiblo. Therefore, DFSER Confirmationy Item 6.2.5-2 is recolved.

(6) 10 CFR 50.34(f)(2)(xv), "Containment Purging/Venting," requires the spplicant to provide - capability for contrinment purging/venting decigned to minimize purging time consistent with ALARA (as low as is reacomably schiovable) principles for occupational exponure. It also requires anurance that the purge system will reliably isolate under eccident conditions.

In SSAR Section 19A.2.27, OB ataten that during normal operation, all large valves in contrinment ventilation lines will be cloced and only small, $5 \mathrm{~cm}$ (2 in.), nitrogen makeup valves will be opened. These are air-operated valves with rapid elocure times that provent abratatial releases from the containment in the ovent of a trensient requiring contuinment isolation. OB aleo states that the $5 \mathrm{~cm}$ (2 in.) nitrogen bleed lines will be aufieicent to maintain normal contrinment preseure during normal operation when ued in conjunction with containment epray and the drywell cooling syetem. Howover, SSAR Figure 6.2-39 shows that T31-F007 and T31-F010 (36 cm (14 in.) valves) aleo will be open during normal operution. In the DFSER, the etaff requedted OB to correct this diecrepancy. This was ideatified as Confirmatory Item 6.2.5-3.

In its aubmittal of March 5, 1993, OB rovised SSAR Section 19A.2.27 to etate, in part, that all large valves in containment veatilation lines will bo clowed during normal operation with the exception of two large valves in the contrinment overpreesure protoction aystom (COPS) where flow will bo provented by rupture dices in the piping.
Furthermono, th a cubmitud deted May 7, 1993, OB roviend SSAR Table 3.9-8 to epecify that valves T31-F007 and T31-F010 will bo leakage rato tented crery 2 yeare during rofueling outages in cocordence with the requiremente of the of the Americen Society of Mechenical Bugincen Boiler and Premaure Vecoul Codo (ASME Codo). The ettaff finds thet this dicerepency is clarified, and is scosptuble. Therefore, DPSBR Confirmetory Item 6.2.5-3 is resolved.

In SSAR Section 19A.3.3, OB thates that a tecting program will be provided to enmure that the lange ventilation valves will close within the limits canaured in the radiological doaign bases. In the DFSER, the ctaff ctated that the teat program chould include valven T31-F007 and T31-F010 and that the COL applicant should aubmit dotails of then tads. This was identified a COL Action Itom 6.2.5-1 in the DFSER.

In response, OB atated that valves T31-F007 and -F010 will normally be open and will be cloned every 2 years for leakage rate teeting in accordance with the requirements as addreseod in SSAR Table 3.9-8, "In-ervice Teeting of Safoty Related Pumpe and Valves." The ataff finds that these valves are pacaive preseure control valves, not the primary containmeat isolation valves. Contrinment integrity is preserved by the rupture discs downetream of the valves. Theee valves are subject to loak rate teats in sccordance with ASME/American National Standards Institute (ANSI) OM-1987, Part 10, to verify their normally open pocition and their capability to close. Therefore, theme valvee should not be included in the veatilation valve teating program. On the basis of this reviow, COL Itom 6.2.5-1 is deloted and need not be included in the SSAR.

In response to a requeet for additional information (RAD, OE agreed to amend the ABWR TS to allow a 24-bour (rnther than a 72-hour) window at the beginning and ead of a fuol cycle, during which the largo-diameter (55-cm (22-in.)) purge lines can be open. GE has made this modification. This was DFSER TS Item 6.2.5-1 and is resolved.

The ataff finds that the methods used to maintain contrinment preesure without backup purging capability meet the requirements of 10 CFR $50.34(f)(2)(x v)$. 
Thres RAI quentions (Q430.45, Q430.46, and Q430.47) on the combuntible ene control syctem were tranemitted to OB. Then questiones dealt with the subjects of reope and interfince, compliances with RO 1.7, and BTP ASB 9-2 of tho 3RP regurding hydrogea and oxyerea production and cocumulation. OB has reponded to all of then quectione and ameaded SSAR Soction 6.2.5. OB thates in that cection that the combuntible gas control aystem, consiating of the FCS and atmospheric control eyctem, ase completely within the soope covered by the ABWR SSAR and that there ase so interficen with equipment or aystems outride the seope of this cubmittal. GB aleo states that the analyais of hydrogen and oxysen production is based on the parameter listod in RG 1.7. The firsion product docay coergy model uned is that presented in SRP Section 9.2.5, BTP ASB 9-2, and inputs to the andyais aro provided in SSAR Section 6.2.5.3. Tho etaff finde that OE's reapones and the SSAR a amended adequately addreses the iseves identified in the stafirs RAls.

Generic Letter (GL) 89-16, "Installation of Hardened Wetwell Vent," addresend the need for modifications of BWR containment deaigns to reduce their vulnerability to sovere sccident challeages. The stuff finds that the ABWR dexign the included the containment overpromare profection syetem which addreacen this OL. Tho ABWR deaign for severe accident conditions is evaluated in Section 19.2 of this report.

The ataff concludes that the design of the combuatible gas control aystem including the containment ACS and FCS are acceptable and meet the requirements of 10 CFR Part 50, Sections 50.44 and 50.34 and GDC 41, 42, and 43 besed on the following:

(1) GE has resolved all the open isences on combuatible gas control. The design meots the requirements of 10 CFR 50.44 with respect to means for controlling hydrogen and capability for meanuring hydrogen concentration and inerting in the containmeat.

(2) GE has demonstrated compliance with all technically relovant portions of the TMI requirements set forth in 10 CFR 50.34(f).

(3) GE has mot the requirements of GDC 41 with respect to systems being provided to control hydrogen and oxygen concentration in the contrinment following postulated sccidents, GDC 42 with respect to periodic inspection of the systems, and ODC 43 with respect to periodic teating of the systems.
(4) The deaign of the combuatible gas control syctom mente the ecceptance oriteria sot forth in SRP Scotion 6.2.5 and the limitation of hydrogen and oxyeer concentration eppecified in RO 1.7.

\subsubsection{Containment Leakege Trating}

The cheff reviowed OB's containment lenkage teating program decoribed in tho SSAR for compliance with the contininment leckace teating requirement in Appendix $\mathrm{J}$ to 10 CFR Part 50 (Appeadix J). Such complianco provides adoquato securuseo that tho containmeat leaktight integrity cen be verified throughout the service lifetime and that the leakage mes will be chocked periodically during service on a timely basis to muintain much leakage within the epeciffed limits. Maintaining contrinmeat leaknge within limits providen reacosable anaurance that, if any radiocotivity is released within the containment, the lose of the contrinment atmoephere through poteatial loak paths is not in excess of the limits specified for the sito.

The ataff roviowed the containment leakage testing program to ensure that the containment penetrations and syatem icolation valve arrangements are designed to satisfy the containment integrated and local leakage rate testing requirements of Appendix J.

\section{Tym A Tet}

The preoperational containment integrated leakage rato (Typo A) teat is intended to moasure the primary containment overall integrated leakage rate after the containment has been completed and is ready for operation and the local leak rato teets (LLRTs) of all mochanical, fluid, electrical, and instrumentation systems penotrating the contrinmeat preasure boundary have been performed.

The objectives of the initial integrated leakage rate test (ILRT) are to

- verify that the containment integrated leakage rate does not exceed the contrinment design-basis accident DBA leakage rato, $\mathrm{L}_{a}$, which is 0.5 percent by weight of the containment atmosphere in 24 hours, at peak containment accident pressure, $P_{a}$ related to DBA

- cetablish a minimum allowable leakage rate, $L_{4}$, at reduced presenure, $P_{t}$, which is used during subsequent ILRTs

- obtain data that may be used to develop the leakage rate characteristics and history of the containment syctem 
- demonetrito by a verification bet the cocurnoy of the integrated leatrage rato inctrummatation to entiafictorilly determino tho containment tategrated leskage rato

The preoperational text will bo performed at both the reduced presaure, $P_{l}$ and the pents contuinment cocidente preasure, $P_{a} . P_{1}$ will be abouse 20 that it is greater then $0.5 \mathrm{P}_{\mathrm{a}}$. After the initial ILRT, a ent of thres Typo $A$ tenta will bo performod at approximately equal intervals during ench 10-your service period with the thind text of ench we coinciding with the end of each 10-year myjor incervice inspection shutdown. The total mearaured containment leakage rate, $\mathrm{L}_{\mathrm{m}}$, at reduced presenure, $\mathrm{P}_{\mathrm{f}}$ chould sot axceed $0.75 L_{4}$ an cotabliched by the initial ILRT. Tho cocurnoy of tho leakage rato tedt will be verified by uains - cupplemental method of leakage meacurement.

In conducting a Type A teot, certuin systom that ars normally filled with water and operating under pou-LOCA conditions need not be vented to the contuinment atmoephere. In addition, syetem required to function during the Type A teat should be operable in thoir normal modo and noed not bo vented, but the teat reaults for auch systems should be added to the Type A teat total. OE has confirmed that the leakage teat values of auch aydem lines will bo added to the Typo A teat reaults. All other aystem lines will be vented or drained before the Type A teat. However, during its initial reviow, the etheff found that although OB's Typo A teat program was scceptable, OB had not ideatified the aystems or the reasons why these aystems would not be vented or drained during the ILRT. This iseve was identified as a part of Open Item 27 in the DSER (SECY-91-153).

In reeponse to this concern, GE atated that SSAR Section 6.2.6.1.3 provides additional criteria for the intograted leak rato teat, thus addreacing this isene. The ataff roviewed SSAR Soction 6.2.6.1.3 and finds that the criteria for syetem lines not to bo vented or drained durins a Typo A teet are scceptable. This part of DSER Opea Item 27 is recolved.

In roviowing the cortified deaign material for the primary contrinment aystem, the ettaff found that the daxign description and ITAAC atated that the main atcam isolation valve (MSIV) loakage was not included in the primary contrinment allowable leakage of 0.5 percent. GE atated that the analytical predictions of radiological consequences in the SSAR had been besed on the asoumption of a containment leakage of 0.5 percent per day plus a ceparato MSIV loakage. The next revision of the SSAR was to clarify that MSIV leakage is to be excluded from the 0.5 percent per day. The staff reviowed SSAR Section 6.2.1.1.2 and finds that this iscuo has been adoquately clarified.

\section{Tron R Trin}

Contuinment pesctutions whose dexigns incorpornte

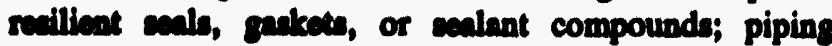
penetintions fitted with axpansion bellows serving as the contrinment boundary; airlock door ceala; equipment and mocen doors with remilient coaln; and other teatable penetrations are to be Typo B tectod during preoperational reting and thereatter at periodic intervals during the lifetime of the unit in eccordance with Appendix J. The Type B tode are neceseary to enoure the continuing integrity of the penetrations.

To facilitate LLRT, OB has propoed a permanently inctalled aystem conainting of a presaurized gas source (nitrogen or air) and the manifolding and valving neceacary to cubdivide the teatable penctintions into groupe of two to five. Bech group will then be preacurized, and if any lealarge is detected (by presenure decay or flow moter), individual penctrations can be isolated and teated until the cource and nature of the leak is determined.

OB atutes, in SSAR Section 6.2.6, that the combined local leakage rato of all components subject to Typo B and Typo C teats (dencribed in subeequent paragraphs) will not arceed 60 percent of $L_{n}$. Typo B tests will be performed at peak containment eccident preesure during each reactor chutdown for major fuel reloading, but in no case at intervals greater than 2 years. Airlocks will bo teeted at initial fual loading and at least once overy 6 months thereafter. Additionally, whenever they are opened during periods when containment integrity is required, they will be teeted within 3 days of opening in accordance with Appendix J. Thees teats are required for the airlocks since thoy contain inflatable seals.

In the DSER, the staff stated that because the intent of the Appeadix J teating program has nover been to require a forced reactor shutdown just to conduct these tests within presed teat intervals, GE would oither have to clarify whether provisions for conducting all Type B tests at power axiat in the ABWR design or request an exemption from the requirement for conducting Typo B toets at 2-year intervals and justify the requeet. Also, GE had not provided (1) the sccoptance criteria for tosting the airlocks, (2) a list of all containment penetrations that are subject to Type B teats, and (3) a liat of all penetrations that are excluded from Type B tests (if any) and the rationale for auch excluaions. In the DSER, the staff stated that it could not conclude that the proposed Type B testing program for the ABWR was acceptable. These issues were identified as part of Open Itom 27 in the DSER (SECY-91-153).

GE aubeequently provided information on Type B test criteria and listed all containment penetrations in SSAR 
Tablo 6.2-8. The etaff finds that the Type B tect erituria epecified in SSAR Section 6.2.6 comply with Appendix J and SRP Section 6.2.6. SSAR Scation 6.2.6.2 epecifies that contuinment pescetrations whom dodigne incosporats

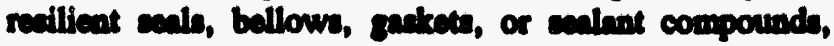
airlocke and lock door ceals, equipment and socein hath mals, and alectric caniaters, and other wah penetrations are to be leak tented during preoperational teating and at periodic intervals thereafter in conformence with Type B leakage rate toete defined in Appendix J. SSAR Section 6.2.6.4 etates that Type B and C teets may bo conducted at any time during normal plant operations or during shutdown periode, a long as the tim interval between tecte for any individual Typo B or C teat does not axceed 2 your. Tho taff reviowed SSAR Scetion 6.2.6 and SSAR Tablo 6.2-8 and finds that the Typo B text requirementes are ecceptable. This part of DSER Opea Ilem 27 is resolved.

\section{Trpe C Tests}

All primary containment isolation valves whowe seats are expoeed to the containment atmoephere after a LOCA will be Type $C$ toeted pacumatically with air or nitrogen at $P_{\text {. }}$. Valvee that are cealed by water will bo leak teeted with water as the teat modium. The teat preseure will be applied in the same direction as when the valve is required to perform its safety function, unless it can bo shown that reaults from tects with presenure applied in a different direction are equivalent or more conservative. Type C toeting will be performed by local prescurization, using either the preasure decay method (for pnoumatic tosting) or the flowmeter mothod (for both pnoumatic and hydroetatic teating).

SSAR Section 6.2.6.3.1 states that Type C tests will be performed on all containment isolation valvee required by Appendix J. All teeting will be performed pneumatically, except that hydraulic teeting might be performed on isolation valves using water as a coalant provided the valves were demonstrated to exhibit leakage rates that did not exceed those in the ABWR technical specifications. However, the SRP states that Type C lesting with water is permissible only if the system line for the valve is not a potential containment atmosphere leak path. This was identified as Open Itom 6.2.6-1 in the DFSER.

In response to the staff's concern, GE rovised SSAR Section 6.2.6.3.1 (Amendment 21) to state that all teeting will be performed pnoumatically, except that hydraulic teating using water as a cealant may be performed during isolation valve Type C tests provided the system line for the valve is not a potential contrinment atmosphere leak path. The staff finds the statement accoptable and DFSER Open Item 6.2.6-1 is resolved.
During its initial roviow, the staff found that GB had not adequately reponded to the ctarre RAI of July 7, 1988, on a musber of ivanes. Then inoves inoluded (1) Type C

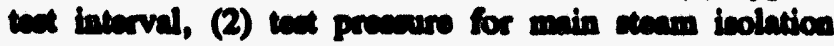
valves, (3) the methodolosy for BCCS icolation valves, (4) tont procechures for valves not covered by Appendix J procedure and a lixt of ach valven, (5) a lint of all primary containment isolation valves that will be Type C leak tanced, (6) a line of all valves that will bo bydroctatically teatad and tho tent presoure, and (7) a liet of all valves that will be tented in the reverso direction and tho juetification for anch teating. Additionally, it was not clear whother lines that contria valves that do not have 30-day weter-leg eals will bo drained and the valves then

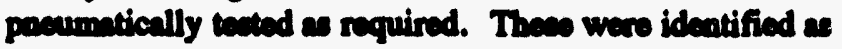
part of Opea Item 27 in the DSBR (SBCY-91-153).

GE's response and the etafi's ovaluation of these isenses follows:

(1) SSAR Section 6.2.6.4 atates that Type B and C toets may be conducted at any timo during normal plant operations or during shutdown perioda, as long as the time interval between teets for any individual Type B or C teat doen not exceed 2 years. GE has epecified a Type C tect interval. The ataff finds this scceptable, and this part of DSER Open Item 27 is reeolved.

(2) SSAR Section 6.2.6.3.1 epecifies that MSIVs and isolation valves isolated from a sealing system are to use a preseure of at least $P_{a}$. The staff finds that the teet presenure moets Appendix J and is scceptablo. This part of DSER Open Itom 27 is resolved.

(3) GE did not addreen teat mothodology for BCCS inolation valves. SSAR Section 6.2.6.3 does not mention this issue. This was identified as Open Item 6.2.6-2 in the DFSER.

GE stated that the test information is provided in revised SSAR Table 6.2-7. The ataff reviowed SSAR Table 6.2-7 and finds that the teat requirements for the ECCS isolation valve are eddreesed in its aseociated noten $g, h, i, j, k$, and $u$. This is scceptable. DFSER Open Item 6.2.6-2 is resolved.

(4) OB did not provide teet procedures for valven not covered by Appendix J and a liat of auch valves. This was identified a Open Itom 6.2.6-3 in the DFSER. 
OE ented thet the teet requirements for icolation valves not covered by Appendix J are eddreaned in SSAR Section 3.9.6.2 (insarvice tecting of enfotyrolated valvea), SSAR Section 3.9.7.3 (pump and valve inservice tecting), and SSAR Trble 3.9-8. Thees vilves are cubject to ASME Code, Section XI leale mato tents. The etnff's eveluation of these valves is provided in Chepter 3 of this report. In reeponse to RAI Q430.50h, GE stated that those valves not epecifically Typo C teated will bo teated as part of the Type A taet. GE hes addreased the teet requirements for the valves not covered by Appendix J. The etaff finds this acceptablo. Therefore, DFSER Open Item 6.2.6-3 is reodved.

GE listed all containment isolation valves thet require Type $\mathrm{C}$ teeting in SSAR Table 6.2-7. The staff finds that the teet provisions for the valuen listed in the table meet Appendix $J$ and are scceptable. This part of DSER Open Item 27 is resolved.

(6) GE did not list all the valves subject to hydroetatic test as addreased in SSAR Section 6.2.6.3.1. This wes identified as Open Item 6.2.6-4 in the DFSER, which was part of Open Item 27 in the DSER (SECY-91-153).

GE ctated that the teet requirements are provided in revised SSAR Table 6.2-7. The staff reviowed SSAR Table 6.2-7 (Amendment 34) and finds that GE has identified, in notes $d, 8, h, j, k, n$, and $q$, those ieolation valves that will be filled with water following a LOCA. SSAR Section 6.2.6.3.1 (Amendment 34) states that these valves are in lines deaigned to be, or remuin, filled with a liquid for at least 30 days following a LOCA and will be leakage mite tested with that liquid. The liquid leaksge measured will not be converted to equivalent air leakage or added to the Type B and $C$ test total. The staff finds that the hydrostatic teet criterion meets Appendix $J$ and is acceptable. DFSER Open Item $6.2 .6-4$ is resolved.

(7) GE did not justify and list the valves to be tested in the reverse direction. This was identified as a part of Open Item 27 in the DSER (SECY-91-153).

GE stated that SSAR Table 6.2-7, note e, provides the criterion for valves to be testud in the reveree direction and the valves listed in the table with that note will be teated in the revicat direction. The etaff finds that the teet requirement complies with Criterion III.C.1 of Appendix J and is acceptable. This part of DSER Open Item 27 is resolved.
(8) GE did not epecify whether lines that contrin valves that do not have 30-day water-leg seals will be drained bofore the valves are proumatically teeted. This wa identified as Open Item 6.2.6-5 in the DFSER and as part of Open Item 27 in tho DSER (SECY-91-153).

GB atuted that the valves that do not have 30-day water-log seal are indicated in SSAR Table 6.2-7 by note (u) in the Typo C teet requirements entry. The ataff verified that the isolation valves to bo peoumatically tested are indicated by note (u) in the teat requiremente entry of the table, and finds that thoy are scceptable. DFSER Open Item 6.2.6-5 is resolved.

During its initial reviow of SSAR Section 6.2.6 regarding contrinment leaknge teating, the staff also identified the following open items in the DSER

(SECY-91-153).

(1) GE did not indicate whether the test, vent, and drain connections used to facilitate ILRTs and LLRTs will be kept closed and under administrative control during normal plant operations and whether they would be subject to periodic surveillance teating to ensure their integrity and to verify the effectiveness of administrative controls. In the DFSER the staff stated that SSAR Section 6.2.6.3.1 did not address its concern. This issue was identified as Open Item 6.2.6-6 in the DFSER.

In its submittal of March 5, 1993, GE added Section 6.2.7.2 (Amendment 32) to the SSAR to state that the COL applicant will maintain the primary containment boundary by administrative controls in accordance with SSAR Section 6.2.6.3.1. SSAR Section 6.2.6.3.1 (Amendment 34) states, in part, that all test connections, vent lines, or drain lines consisting of double barriers (e.g., two valves in series, one valve and a cap, or one valve and a flange), which are connected between isolation valves and form a part of the primary containment boundary, need not be Type $\mathbf{C}$ tested because of their infrequent use and multiple barriers as long as the barrier configurations are maintained using an administrative control program. These lines will be surveillance inspected at cold shutdown and at 31-days intervals (internal and external to the primary containment, respectively) as required by the TS. The staff finds that these test connections are designed with multiple barriers, are under an administrative control program, and will be surveillance inspected 80 that any leakage can be 
detected. In addition, Appendix J does not epecify toest requirements for these lines. This is ecceptable. DFSER Open Item 6.2.6-6 is recolved.

(2) GE relies on closed loops outside the contrinment as contrinment isolation barriers for some engineered safety feature (ESF) system containmeat penetrations. The staff's position is that a cloced loop outside the contrinment thut meets the criteria of Section 3.6 of ANSI/American Nuclear Society 56.2-1976 can be considered a cocond contrinment isolation barrier, thereby oliminating the need for a socond contrinment isolation valve at the penetration. However, each barrier (i.e., the single isolation valve at each penetration and closed piping loop outsido the containment) is aubject to loak rate testing. Inclusion of this position in the SSAR was identified as Open Item 6.2.6-7 in the DFSER.

In its submittal of April 26, 1993, GE statod that there are two closed-loop systems in the ABWR design that provide an extension of the containment. These are the containment atmosphere monitoring system and the fuel pool cooling system. These systems will be leak tested by opening their lines to the containment atmosphere during the containment ILRT. The staff finds that their test requirements have been specified in SSAR Table 6.2-7 (Amendment 32), and are acceptable. DFSER Open Item 6.2.6-7 is resolved.

(3) In response to the staff's RAI Q430.52b of July 7, 1988, GE submitted information regarding secondary containment inleakage and potential bypass leakage paths. However, it did not indicate whether the bypass leakage paths will be leak tested as specified in BTP CSB 6-3, "Determination of Bypass Leakage Paths in Dual Containment Plants," of the SRP. The staff found that SSAR Table 6.2-10, Table 6.5-2, and Section 6.5.1.3.2 did not address this issue adequately. Clarification of this issue was identified as Open Item 6.2.6-8 in the DFSER.

In response to this issue, $G E$ identified all the potential leakage paths that could bypess the secondary containment in revised SSAR Table 6.2-10. The staff reviewed SSAR Table 6.2-10 (Amendment 34) and finds that the potential bypass paths are the main steamlines, feedwater lines, drywell purge suction and exhaust lines, and wetwell purge suction and exhaust lines. The staff noted that the leakage rate through the main steam isolation valves (MSIVs) has been considered as the secondary containment bypass leakage rate and has been treated exparately in the offisite dose analysis. Loakage through feedwater isolation valves (FWIVs) will be monitored by Type C test. Leakage from the purge lines also will be monitored by Type C teet and can bo detected by the radiation detectors at the purge and vent exhaust lines. In addition, SSAR Table 6.5-2, regarding source terms used for the stendby ges treatment syetem (SGTS) charcoal adeorber design, specifies that leakage rates assumed for calculation are 0.5 percent per day for the primary containment and 50 percent per day for the secondary containment.

Additionally, primary containment leakage could circumvent the cecondary containment and bypase tho leakage colloction and filtration systems. This leakage is generally not quantifiable through LLRTs, but must bo considered in the radiological consequence analysis of a DBA. SSAR Section 6.5.1.3.2 (Amendment 34) states that, for the ABWR dose analysis, direct transport of containment leakage to the environment was assumod for the first 20 minutes after initiation of a LOCA (in addition to the leakage through the MSIVs). Each SGTS fan is sized to establish a continuously negative pressure within 10 minutes after SGTS initiation.

The staff finds that GE has provided all the necessary measures to control bypass leakage in the ABWR design in conformance with BTP CSB 6-3 and provide acceptable margins in the offsite dose analysis. This is acceptable. DFSER Open Item 6.2.6-8 is resolved.

GE did not provide procedures for factoring potential contributions from the hydrogen recombiners into the ILRT results. However, the staff considered this to be a COL action item. In the DFSER, the staff stated that it would ensure that COL applicants factored the potential contributions from the hydrogen recombiners into the ILRT results in accordanco with SRP Section 6.2.6. This was identified as COL Action Item 6.2.6-1.

In response to this concern, GE added note (v) in SSAR Table 6.2-7 (Amendment 32) to state that the flammability control system (FCS) is a closed-loop, safety-grade system required to be functional following an accident. Whatever leakage (if any) will be returned to the primary containment. In addition, during an ILRT, these valves will be opened and the lines will be subjected to Type A tests. The staff finds that any leakage from the 
penetrations or the lines connected to the hydrogen recombiness will be included in the ILRT reaults. Therefore, COL Action Item 6.2.6-1 is deleted and will not be included in the SSAR.

In Bulletin 82-04, "Doficiencies in Primary Containment Electrical Penctration Asemblies," was identified as a condidato opernting axperience isavo. This bulletin eddreseces potential generic enfety concerns related to doctrical penetration asemblies aupplied by the Bunker Ramo Company. However, the aneemblies are no longer manufactured by Bunker Ramo and are not uned in the ABWR design. Therefore, this operating experience issue is not applicable to the ABWR deaign.

GE rubmitted the design dencription and the ITAAC relating to containment leakage teating. The staff's roview of this material wes not complete when the DFSER was isered. This was identified in the DFSER as Open Itom 6.2.6-9. OB mubequently provided a rovised decign description and ITAAC. The sdequecy and acceptability of the deaign deceription and the ITAAC are ovaluated in Section 14.3 of this report. On the bexis of this ovaluation, DFSER Open Itom 6.2.6-9 is resolved.

On the basis of this reviow, the ataff concludes that the ABWR containment leakage teeting program complies with Appendix J to 10 CFR Part 50. Such complinece provides adequate seaunnce that leaktight intogrity of the containmeat can be verified periodically throughout its service lifo to ensure that leakage rates are maintained within the limits of the TS. Maintaining containment leakage rates within auch limits provides reasonable ascurnnce that, in the event of any radionctivity releases within the containment, the lose of the containment atmosphere through the leak paths will not be in excess of the acceptable limits epecified for the site. Compliance with Appendix J as described in this section constitutes an acceptable basis for satisfying the requirements of GDC 52 with respect to tho capability for containment leakage rate teeting, the requirements of GDC 53 with respect to provisions for containment testing and inspection, and the requirements of GDC 54 with respect to the capability for detecting piping leakages.

\subsubsection{Fracture Prevention of Containment Pressure Boundary}

The staff reviewed the ABWR measures involving fracture prevention of ferritic materials used in the containment pressure boundary in accordance with SRP Section 6.2.7. Containment pressure boundary ferritic materials are acceptable if they meet the requirements of GDC 51 as it relates to the reactor containment pressure boundary being designed with sufficient margin to assure that under operating, maintenance, testing, and postulated accident condition the forritic materials will behave in a nonbrittle manner and the probability of rapidly propagating fracture is minimized.

The primary containment vessel of the ABWR is a reinforced-concrete structure with ferritic parts (the removable beed, pereonnel locks, equipment hatches, and penetrations), which will be made of material that has a nilductility transition temperature, $\mathbf{R T}_{\mathrm{NDT}}$, of at least $-17^{\circ} \mathrm{C}\left(30^{\circ} \mathrm{F}\right)$ below the minimum service temperature. This meets the requirements of GDC 51. GDC 51 is only applicable to parts of the containment that are to be made of ferritic materials.

In RAI Q251.12, the staff requested that GE clarify the applicability of GDC 51 because it appeared that GE intended that GDC 51 be applied to the concrete portion of the containment. GE responded that GDC 51 is applicable to the removable drywell head, personnel locks, equipment hatches, and penetrations, which will be made of ferritic materials. GE responded satisfactorily to the staff's iequeat and revised SSAR Section 3.1.2.5.2.2 accordingly. Therefore, GE's commitment to GDC 51 for the items listed above in the containment design meets SRP Section 6.2.7 and is ecceptable.

\subsubsection{Severe Accident Considerations}

GE addreseses containment performance during severe accidents in SSAR Chapter 19, and the staff's review is documented in Chapter 19 of this report.

\subsection{Emergency Core Cooling System}

The staff reviewed the emergency core cooling system (ECCS) in accordance with SRP Section 6.3. The staff acceptance criteria are based on meeting the relevant requirements of the following regulations:

(1) GDC 2 as it relates to the seismic design of structures, systems, and components (SSC) whose failure could cause an unacceptable reduction in the capability of the ECCS to perform its safety function. Acceptability is based on meeting Position C2 of RG 1.29.

(2) GDC 4 as related to dynamic effects associated with flow instabilities and loads (e.g., water hammer).

(3) GDC 5 as it relates to SSC important to safety shall not be shared among nuclear power units unless it can be demonstrated that sharing will not impair their ability to perform their safety function. 
(4)

GDC 17 as it relates to the deaign of the BCCS having aufficient capacity and capability to anaure that epecified acceptable fuel dotign limite and the design conditions of the reactor coolant preseure boundary are not exceeded and that the core is cooled during anticipated operational occurrences and accident conditions.

GDC 27 requires that the resetivity control syetem have a combined capability, in conjunction with poison addition by the emergency core cooling system, or reliably controlling reactivity changes under postulated sccident conditions, with appropriato margin for stuck rods.

GDC 35, 36, and 37 as they relate to the BCCS being designed to provide an abundance of core cooling to transfer heat from the core at a rite $s 0$ that fuel and clad damage will not interfere with continued effective core cooling, to permit appropriate periodic inspection of important components, and to permit appropriate periodic prossure and functional tosting.

10 CFR Part 5, Subsection 50.46, and Appendix K to 10 CFR Part 50 as it relates to the ECCS being designed so that its cooling performance is in accordance with an accoptable ovaluation model.

The ECCS is designed to provide coolant inventory to the reactor coolant syetem in the eveat of a loev-of-coolant accident (LOCA) in the preseure boundary. The ECCS capability extends to failures as large as a double-ended rupture of the largest piping carrying water or steam, and spurious safety/relief valvo operation.

\subsubsection{System Description}

The ECCS consists of the following:

- reactor core isolation cooling (RCIC) system

- high-pressure core flooder (HPCF) system

- automatic depressurization systom (ADS)

- low-pressure flooder (LPFL) system

Unlike that in current BWR designs, the RCIC system in an ABWR design is a part of the ECCS. The initiation logic is diversified by adding a high drywell preseure input af well as maintaining the typical system initiation on reactor pressure vessel (RPV) level 2.

The RCIC system is a high-pressure reactor coolant makeup system that will start independently of the 20 power supply. The system will provide sufficient water to the reactor vessel to cool the core and to maintain the resetor in a standby condition if the veecel becomes icolated from the main condenser and experiences a lows of foodwater flow. The syctem aleo is designed to maintain resctor water inventory, in the ovent of a loes of normal foedwater flow, while the veseel is depressurized to the point where the revidual heat removal (RHR) system can function in the shutdown cooling mode at a reactor precurare of $1,034 \mathrm{kPa}$ (150 paig).

The RCIC ayctem consiats of a steam-driven turbino-pump unit and amociated valves and piping capable of delivering $3,028 \mathrm{~L} / \mathrm{min}(800 \mathrm{gpm})$ of makeup water to the reactor veasel through the foedwater system. Fluid removed from the reactor veceel following a shutdown from power operation normally will be made up by the foedwater oyatem and aupplemented by inleakage from the control rod drive system. If the feedwater system becomes inoperable, the RCIC system will start automatically when the water level in the reactor vessel reaches the level 2 (L2) trip set point or drywell pressure reaches the high drywell prescurre trip ext point. The RCIC system also can be etarted by the operator from the control room. The syatem is capablo of delivering rated flow within 29 reconds of initiation. Primary water supply for the RCIC system will be from the condensate storage tank (CST), and a secondary supply will be from the cuppresion pool.

A detailed ovaluation of the RCIC system is given in Section 5.4.6 of this report.

The HPCF aystem will maintain the reactor vessel water lovel above the top of the active core in the event of a break of a $2.54 \mathrm{~cm}$ (1 in.)-diameter pipe or smaller and will provide cooling in the ovent of largo-pipe breaks. Actuation of the HPCF system will not require the depressurization of the reactor vessel. The HPCF system consists of two loops. Each loop includes a single motordriven centrifugal pump that will take suction from the CST or the primary containment suppression pool. An automatic switching feature is based on indication of low CST lovel. The HPCF flow rate is dependent on the reactor pressure. SSAR Table 6.3-1 states that the rated HPCF flow of $12,113 \mathrm{~L} / \mathrm{min}(3,200 \mathrm{gpm})$ will be attainod at a reactor preceure of approximately $689 \mathrm{kPa}(100 \mathrm{psig})$, which is consistent with accident analysis assumptions. The HPCF system is designed to operate from normal officito auxiliary ac power or from the omergency diesel generators. Each HPCF pump will be powered from a differeat diesel generator. The system will initiate automatically by either low water level 1.5 or high drywell prensure signals. The system also can be placed in operation manually from the main control room and the remote shutdown panel (loop B only). 
If the RCIC and HPCF aystoms do not maintain the reactor water lovel, the ADS will reduce the reactor presesure so that flow from the RHR syetem, which will be operating in the LPFL mode, enters the reactor veceel in timo to cool the core and limit fuel cladding tempernture.

Of tho 18 nuclear syctem preasure reliof valves, eight ADS relief valves will relieve high-presaure team to the suppression pool. Tho ovaluation of the preacure relief valves is given in Section 5.2.2 of this report. The ADS will bo actuated when the following conditions ax satisfied: (1) drywell high presenure, (2) reactor low water lovel (level 1), and (3) a permianive sigal of high RHR or HPCF pump discharge presaure. A timo delay of 29 soconds will be used to confirm that the low water level 1 signal is present and is consistent with the ECCS pump startup time. The instrumentation and controls for the ADS are discuseed in Chapter 7 of this report.

The LPFL system will replece resctor veseel water inventory following largo-pipe breaks. The syetem is part of the RHR system, which consists of three independent loope (A, B, and C). Each loop has a motor-driven pump with a capacity of $15,900 \mathrm{~L} / \mathrm{min}(4,200 \mathrm{gpm})$ that will take suction from the suppression pool and supply water to the reactor vessel. All three RHR loops include heat exchangers that will be cooled by the RHR reactor building cooling water system and transfer the docay heat from the reactor core to the ultimate heat sink. The three LPFL (RHR) pumps will be powered from ac power buses that heve standby backup sources of power. RHR pumpe A, $B$, and C will receive emergency power from the three separate diesel generators. The RHR system valve logic will require LPFL systom alignment in the oveat of a LOCA. The LOCA event takes precedence over other RHR system functional modes. The system will initiato automatically by either low water lovel 1 or high drywell pressure siganals. The reactor must be depresenrized below the reactor low-pressure permissive signal before LPFL injection to the reactor occurs. Each of the two highpressure core flooding loops and two of the three lowpressure flooding loops will diecharge water into the core through a separate overhead flooder sparger. Lowpreseure flooding loop A will diechirge into the RPV through the feedwater syctom. Internal veced piping connects each sparger to the veasel nozzlo. The ABWR flooder design and relative location will reoult in reduced personnel radiation exposure ss compared to the current BWR core spray design because the peripheral location of the flooder minimizes the need for work over the fuel during inservice inspection. Spray distribution in the core is not critical because there will be no core rncovery during a LOCA.

\subsubsection{Evaluation of Single Failures}

The ataff reviewed the SSAR system description and piping and inatrument drawings to ensure that abundant core cooling will be provided during the injection phase with and without offaito power and asuming a limiting single failure as required by GDC 35. A low reactor vecsel water lovel and/or containment high pressure signal is required to atart pumpe and open discharge valves.

OB provided in SSAR Section 6.3.3 in analysis to demonatrate that the moet limiting break size, break location, and single failure had been considered for the ABWR. The most limiting combinations are given in Table 6.1 of this report. The ataff finds that the SSAR information supports the finding that the ECCS systems meet the singlo-failure criterion.

\subsubsection{Qmalification of Bmerzency Core Cooling Sydtem}

The ECCS is designed to meet seismic Category I requirements in compliance with RG 1.29, "Soismic Design Classification," (Rev. 3), as discussed in Section 3.2 of this report. The ECCS is housed in structures designed to withstand seismic events, tornados, floods, and other phenomena, in accordance with the requirements of GDC 2, as discussed in Section 3.2.1 of this report. ECCS equipment is designed in compliance with RG 1.26, "Quality Group Classifications and Standards for Water-, Steam-, and Radioactivo-Waste-Containing Components of Nuclear Power Plants," (Rov. 4), as discussed in Section 3.2 of this report.

Prolecting the ECCS against pipe whip and against discharging fluids, in compliance with the requirements of GDC 4, is discussed in Section 3.6 of this report. Evaluation of the instrumentation and controls for the ECCS, including compliance with RG 1.47, "Bypass and Inoperable Status Indication for Nuclear Power Plant Safety Systems, "in accordance with the applicable requiroments of GDC 27, is discuseed in Section 7.3 of this report. Compliance with the inservice inspection requirements of GDC 36 is discussed in Section 6.6 of this report.

Environmental qualification of the ECCS equipment for operation under normal and accident conditions, as required by GDC 4, is discussed in Section 3.11 of this report. 
Table 6.1 Single fallure evaluation

\begin{tabular}{|c|c|c|}
\hline \multicolumn{3}{|c|}{ Areumed Failure } \\
\hline \multicolumn{3}{|c|}{ Emergency diewel generator A } \\
\hline \multicolumn{3}{|c|}{ Emergency diewel generator B or C } \\
\hline \multicolumn{3}{|c|}{ RCIC injection valve } \\
\hline \multicolumn{3}{|c|}{ One ADS valve } \\
\hline Note: & $\begin{array}{l}\text { ADS = } \\
\text { HPCF = } \\
\text { LPFL = } \\
\text { RCIC = } \\
\text { RHR = }\end{array}$ & $\begin{array}{l}\text { automatic depreacurimation system } \\
\text { high-preesure core flooder } \\
\text { low-preseure flooder } \\
\text { reactor core isolation cooling } \\
\text { reaidual heat removal }\end{array}$ \\
\hline
\end{tabular}

In sccordance with the pertinent requirements of GDC 35, the available net positive auction hoad (NPSH) for the pumps in the ECCS, as reflected in calculations submitted by GE, is adequate to prevent cavitation and ensure pump operability in accordance with RG 1.1, "Net Positive Suction Head for Emergency Core Cooling and Containment Heat Removal System Pumps (Safety Guide 1)," (Rev. 0). The pump head and NPSH requirements for ECCS pumps are included in the ITAAC for verification by the COL applicant.

Each of the low-pressure lines that will discharge into the reactor coolant system has a teatable check valve inaide the primary containment backed up by a normally clowed motor-operatod gate valve outsido the containment. Reliof valves in the low-preseure lines will protect againd leakage from the reactor coolant system. An interlock on the motor-operated valves will prevent them from opening until the reactor copolant pressure is below the low-presaure ECCS design presoure.

Containment isolation in accordance with the requirements of GDC 55 is discuseed in Section 6.2 of this report. The periodic teating and leak-rate criteria for thow valves that isolate the reactor syetem from the BCCS are diecunead in Section 3.9.6 of this report. Detection of leaks from thom portions of the ECCS within the primary coolant presaure boundary is diecuseed in Section 5.2.5 of this report.

To protect the pumps from overheating, all the ECCS pumpe have minimum flow bypass lines to permit a limited amount of flow if an isolation valve between the reactor coolant system and the ECCS is closed for any reason.
Syctems Remaining

All ADS, RCIC, 2 HPCF, 2 RHR/LPFL

All ADS, RCIC, 1 HPCF, 2 RHR/LPFL

All ADS, 2 HPCF, 3 RHR/LPFL

All ADS minus 000, RCIC, 2 HPCF, 3 RHR/LPFL
When flow in the injection lines is sufficient for pump cooling, valves in the minimum flow bypess lines will close automatically, diverting all flow to the pressure veseol. Each LPFL pump suction line from the suppreasion pool has an open motor-operated valve outside the contrinment. The suction line of the HPCF from the suppreesion pool contains a closed motor-operated valve so the HPCF initially will draw water from the CST. When the CST water is exhausted, the suppression pool suction valve will open automatically.

Isolation of the suppression pool from the reactor building in sccordance with GDC 56 is discussed in Section 6.2 of this report.

As a beckup to the HPCF system, the ADS will be used to deprescurize the reactor and allow the LPFL to function in the event of a small break. Nitrogen will be supplied to the valves of the ADS from seismically qualified sccumulators.

One of the design requirements of the ECCS is that cooling water flow be provided rapidly following the initiation signal. By always keeping the ECCS pump diecharge lines full, the lag time between the signal for pump start and the initiation of flow into the RPV can be minimized. In addition, full discharge lines reduce potentially damaging waterhammer occurrences on systom startup. The RHR systom has three jockey pumps, one in each loop (discharge line fill pump). Maintaining the filled status of the systom is ensured by continuous indication of pump operation and pump discharge pressure. The makeup water system connections to the RCIC and HPCF 
gyctom will mointuin the pump diechnrge line in a filled condition up to the injection valve.

The capability of the BCCS pumpe to operate for an extended period of time during the long-term recirculation phes following a LOCA is discunsed in Section 3.9.6.1 of this report.

Sufoty/reliof valve (SRV) operability will be demontented during the power ascension phase of the plent atartup tect program by manully sctuating each SRV (including the ADS valves) one at a time to show that no blockage existe in the valve diecharge line. After commercial turnover, all of the SRVs will be teeted in sccordence with Section XI, Article IWV, of the ASME Codo. Linoar variable differential transformers and thermocouples are to be installed in the discharge line of each SRV to monitor valve poaition and SRV leakage in sccordance with TMI-2 Action Plan Item II.D.3 (NUREG-0737) and are diecusead in Section 20.5.23 of this report.

Environmental qualification of the SRVs is discussed in Section 3.11 of this report.

The ADS time delay is set at 29 seconds rather than 120 seconds (as in present BWRs) to satisfy the design goal of no core uncovery during a LOCA. The ADS moet likely will not be initiated because of the availability of threo high-preseure core injection systems. The ABWR emergency procedures guidelines (BPGB) (which aro provided in SSAR Chapter 18) tates that the operator is allowed to prevent ADS acturtion in two instances. Tho first is during an anticipated transient without scram (ATWS) event. Because the ABWR design incorporates an automatic ADS inhibit signal following an ATWS, operator action is to verify the automatic ADS inhibit signal as addresed in SSAR Chapter 18 (EPGs). The eccond case is when the operator believes that tho reactor water level may go below the reactor low water lovel 1 setpoint but will remain above the top of the active fuel (TAF) without ADS actuation. Because no ADS timer is provided for LOCAs in the containment, where high drywell preesure occurs, and because the ADS time delay is short, operator intervention is unlikely. However, during LOCAs outside the containment or LOCAs that do not result in a high drywell pressure signal, an 8-minute timer will be initiated and the EPGs allow the operator to assess whether the level is maintained above TAF. If the high-pressure ECCS cannot control the reactor water level, it is prudent to allow the ADS to actuate and quickly depressurize the vessel to gain the additional reflooding capacity of the low-pressure ECCS. The EPGs provide sufficient guidance to ensure that operating procedures will reflect the importance of allowing ADS sctuation when high-preasure makeup ayctems are not available.

For transient and sccident ovents that do not directly produce a high drywell preacure signal (e.g., stuck-open reliof valve or eteamline break outside the contrinment) and that are further complicated by the lose of all highpreasure ECCS syatems, munual sctivation of the ADS wn originally required to provide adequate core cooling. However, TMI Action Plan Item II.K.3.18 (NUREG-0737), as incorpornted in 10 CFR 50.34f(1)(vii), require ADS logic modification to eliminate operntor sction. GE's proposed design modification is consistent with Option 4 of the BWR OWner's Group response to TMI Action Plan Item II.K.3.18. This option requires the addition of a timer that bypasses the high drywell preacure permisuive if the reactor water lovel is low for a susthined period and the addition of a manual inhibit switch. An 8-minute high drywell pressure bypass timer has been added to the ABWR ADS initiation logic. (An andyais was performed to evaluate the adequacy of the 8-minute bypan timer.) This timer will initiate on a low water lovel 1 aignal. When the timer runs out, it will bypase tho need for a high drywell pressure signal to initiate the atendard ADS initiation logic. The bypass timer will bo tested periodically. This teat is required by the TS. This was DFSER TS Item 6.3.3-1. (This itom has been added to the ABWR TS and has been found to be acceptable.) This timer can bo inhibited as indicated in tho ABWR EPGs if the operator determines that water level can be maintained above TAF. The proposed GE modification to ADS logic is consistent with the ataff-approved resolution of Itom II.K.3.18 and is scceptable because it ensures the initiation of the ADS and low-pressure injection systems when high drywell pressure does not occur. In the DSER (SECY-91-153) the staff identified a concern about the ADS in Open Item 28. The above discussion on bypass timers shows that DSER Open Item 28 has been reeolved. Assurance of the proposed modification to the ADS logic was DFSER Confirmatory Itom 6.3.3-1. GE submitted the required changes in the SSAR in Section 6.3.3.4, which is scceptable to the staff. GE also included this action item in the SSAR. This Confirmntory Item 6.3.3-1 is resolved.

\subsubsection{Testing}

RG 1.68, "Initial Test Programs for Water-Cooled Nuclear Power Plants," (Rov. 2) and GDC 37 require that the ECCS system be designed to permit appropriate periodic pressure and functional testing to assure the integrity of components, and the operability and performance of the components and ECCS systom. GE states that ECCS integrity, operability, and performance are demonstrated by preoperational and periodic testing, which is acceptable to the staff. 


\subsubsection{Preopernational Teet}

Proppentional tode will encure proper functioning of controls, inetrumentation, pumpe, piping, and valves. Precoure differeatials and flow rates are meacured for later use in determining ecceptable performance in periodic weth. $G E$ commits to conform to the suidalines of RO 1.68 for preoperational and initial startup teating of the BCCS, as noted in Section 14.2 of this report.

\section{3.‥2 Periodic Component Teats}

The etaff etated in the DFSER that the TS should state that the ECCS aubaystem (axcept for the ADS) will bo tected periodically to show that epecified flow rates are attained. This was DFSER TS Item 6.3.4.2-1. GB has included this ctatement in the TS. The ataff aleo atated in the DFSER that the COL applicant should perform a teet overy rofualing outage in which all subeystems are sctuated through the emergency operating sequence. This was DFSER COL Action Itom 6.3.4.2-1. GE provided this procedural COL ection item in Amendment 31 of the SSAR.

\subsubsection{Performance Evaluation}

GE's ABWR-epecific LOCA analyais demonetrates that the reference fuel deaign meets the requirements of 10 CFR 50.46 and is based on the initial core deaign.

The staff expected the expoeuro-dependent maximum average planer linear heat generation rato (MAPLHGR) to be provided in the TS. This was DFSER TS Item 6.3.5-1. GE rubmitted the MAPLHGR in TS 3.2.1; hence this item is reeolved. In Section 4.2 of this report, the specific ful and core doaign used for the analyees of SSAR Sections 6 and 15 is described. Section 4.2 of this report also deecribes fuel decign criteria that epecify requirements for any alternative fuel that may be ueed by the COL applicant or licensees in relond cycles.
Tho ctaff uned the information in tho SSAR, the reaults of tho LOCA analyese, alons with tho revults of its reviow of ach BCCS aystom to verify that the propóned BCCS moets the performance criteria in 10 CFR 50.46. Complience with the firct three criteria below is demonetrated analytically. Coolable geometry is maintained if the firt two criteria are mot. Long-term cooling capability is verified by the composite reviow of the BCCS and the various aupport aystem. The five scceptance criteria for the BCCS, as epecified in 10 CFR 50.46, are the following:

(1) The calculated maximum peak cladding temperature (PCT) shall not exceed $1204^{\circ} \mathrm{C}\left(2200^{\circ} \mathrm{F}\right)$.

(2) The calculated total oxidation of the cladding chall nowhere exceed 0.17 times the total cladding thickneses before oxidation.

(3) The calculated total amount of hydrogen geaerated from the chemical reaction of the cladding with water or steam shall not exceed 0.01 times the hypothetical amount that would be generated if all of the motal in the cladding cylinders murrounding the fuel, excluding the cladding aurrounding plenum volumo, were to react.

(4) Calculated changes in core geometry shall be wuch that the core remains amenable to cooling.

(5) The calculated core temperature shall be maintained at an acceptably low valuo, and decay heat shall bo removed for the extended period of time required by the long-lived radioactivity remaining in the core after any calculated successful initial operation of tho ECCS.

GE hes demonstrated compliance with the firet three of these criteria as shown in Table 6.2 of this report.

Table 6.2 Demonstration of compliance with ECCS criteria

\begin{tabular}{lll}
\hline & \multicolumn{2}{c}{ Maximum } \\
\cline { 2 - 3 } Criterion & Prom Break Analyses & Allowable \\
\hline Peak cladding temperature, ${ }^{\circ} \mathrm{C}\left({ }^{\circ} \mathrm{F}\right)$ & $621(1149)$ & $1204(2200)$ \\
Maximum cladding oxidation, $\%$ & 0.03 & 17 \\
Maximum total hydrogen generation, $\%$ & 0.03 & 1 \\
\hline
\end{tabular}


There is no cose uncovery and heace the core geometry is maintained. Moreover, a coolable seometry wa demonstrated by complinnce with the criteris for PCT and maximum cladding oxidation as discused in NEDO-20566, "Analytical Modal for Lose-of-Coolant Analysis in Accordance with 10 CFR Part 50, Appendix K," proprietary, November 1975.

Because there are no jet pumpe in the ABWR, the core flow pattern is similar to that in BWR/2 plants that do not use jot pumps (0.8., Oyster Creck, Nine Milo Point Unit 1). The GB thermal-hydraulic codo SAFBR, which was approved for BWR/2 plants without jet pumpe (NEDE-30996P-A, "SAFER Model for Bvaluation of Loss-of-Coolant Accidents for Jet Pump and Non-Jet Pump Plants," (Volumes I and II) October 1987), was used to perform LOCA analysis for the ABWR. The SAFER code was used to calculate the long-term thermal-hydraulic behavior of the coolant in the veesel during a LOCA. Somo important system parameters calculated by SAFER aro veseel pressure, veseel water lovel, and BCCS flow rates. The SAFER codo also calculates PCT and local maximum oxidation. The staff's SER (datod Fobruary 19, 1987, "Roview of NEDE-30996(P), 'SAFER Modals for Evaluation of Loes-of-Coolant Accident for Jet Pump and Non-Jet Pump Plants,' Volumes I and II") on NEDE 30996A-P documents sgreement between SAFER predictions and teet results from the ABWR full integral simulation test (FIST) facility. GE made some modifications to the FIST facility for the ABWR and conducted additional teats. Jet pump olimination and reactor internal pump (RIP) flow were simulated. GE also modified ECCS capacities, brenk sizes, and locations. The SAFER code was compared to TRACG-P (proprietary) for the ABWR plant. (See staff SER of February 19, 1987.)

ABWR-specific date based on tests for the RIP constiown time following a pump trip and flow are and pressure losses through the RIPs were used as input to the SAFER model.

GE computer codes LAMB, SCAT, and GESTR were used for the ABWR LOCA analysis.

The LAMB code is used to analyze the short-term thermodynamic and thermal-hydraulic behavior of the coolant in the vesel during a postulated LOCA. In particular, LAMB predicts the core flow, core inlet enthalpy, and core pressure during the initial phase of the LOCA event (i.e., the first 5 seconds). GE used the LAMB computer model (documented in NEDE 20566P-A, "Analytical Model for Loss-of-Coolant Accident Analysis in Accordance with 10 CFR Part 50, Appendix K," January 1976, and approved by the staff) to perform analyces precented in tho ABWR SSAR. Tho ABWR input to the LAMB computer model is the samo input as that used for operating plants except for recirculation syetem modeling. Becauve the ABWR has RIPs inctead of jet pumps, the recirculation aystom is modeled secuming no induced flow from a jot pump. Thus, the drive flow from the recirculation pumps is sot equal to the total recirculation flow.

The SCAT codo is used to evaluate the short-term thermalbydraulic response of the coolant in the core during a potulated LOCA. Using the LAMB recults as input, SCAT analyzes the convective heat trunsfer process in the thermally limiting fuel bundlo during the initial phase of the LOCA event. In particular, SCAT predicts the departure from nucleate boiling at any one of the 24 axial nodes in the fuel bundle. GE used the SCAT computer model (documented in NEDE 20566P and approved by the stafi) to perform analyses presented in the ABWR SSAR. Specifically, GE used SCAT to determine the transient thermal-hydraulic conditions within a bundle and predict the time when the loss of nucleate boiling occurs. The SCAT program only models the hot bundle and sets the boundary conditions based on LAMB results. The ABWR core dosign is besed on a GE standard fuel that is similar to BP $8 \times 8 R$ with two water rods. This type of fuel has already been analyzed using SCAT for operating BWRs. Therefore, the differences in the ABWR from previous BWRs do not represent any special application of the SCAT model.

The GESTR code is used to provide bestestimate predictions of the thermal performance of GE nuclear fuel rods experiencing variable power histories. For LOCA analysis, the GESTR code is used to initialize the fuel stored energy and fuel rod fission gas inventory at the onset of a postulated LOCA. GE used the GESTR computer model (documented in NEDE 30996P-A and approved by the staff) to perform LOCA analyses presented in the ABWR SSAR. GE used the results from GESTR to establish the initial conditions (i.e., stored energy and rod internal pressure) at the start of the LOCA within each fuel rod. As stated above, GE based its ABWR core design on a GE standard fuel, which also has been analyzed using GESTR for operating BWRs. The differences in the ABWR from previous BWRs do not affect the fuel thermal-mechanical performance predicted by the GESTR model. Therefore, the use of GESTR for the ABWR does not represent any special application of the GESTR model.

No model changes were made to any of the GE codes used in the LOCA analysis; only input data were changed for ABWR-specific design features. 
The OB analyese includad breat tine ranging from a bottom heed drain line break $0.0020 \mathrm{~m}^{2}\left(0.0218 \mathrm{~A}^{2}\right)$ to the main iteamline brenk outride the contrinment $0.39 \mathrm{~m}^{2}$ $\left(4.24 n^{2}\right)$. (Since the bottom bead drain line will tio into the RHR/cleanup system lines, the total break flow for the maximum bottom head drain line break includes flow from the veael through the bottom boad drin line pesetration as well as through tho RHR/cleanup system lines.) $\mathrm{OB}$ analyzed different break sizen in conjunction with BCCS failure combinations. The cases were ovaluated to extublish the treend of PCT curves (Appendix K to 10 CFR Part 50 and bounding valuee) veraus brealk aize. Eight break sizes are summarized in SSAR Table 6.3-4. The moet limiting break is the main steamline break outside the contrinmeat, which reaults in a PCT of $621^{\circ} \mathrm{C}\left(1149^{\circ} \mathrm{F}\right)$. This is well below the $1204^{\circ} \mathrm{C}\left(2200^{\circ} \mathrm{F}\right)$ sceeptance criterion. Because there will be no large pipe below the top of the core and no core uncovery for any size LOCA, the calculated PCT of $621^{\circ} \mathrm{C}\left(1149^{\circ} \mathrm{F}\right)$ is low compared to the PCT for current BWRs.

The staff confirmed that the LOCA analysis methodology used by GE for the ABWR was consistent with and bounded by the staff's generically approved LOCA analysis methodology. The staff concluded that the PCT, peak local oxidation, and coro-wide metal-water reaction values were well below staff scceptance criteria. Thus, the analyses and results are in accordance with NRC requiroments and GE has demonstrated conformance with the ECCS acceptance criteria of 10 CFR 50.46 and Appendix K to 10 CFR Part 50.

Long-term cooling is ensured by the use of redundant RHR systems that have adequate water sources available to remove the decay heat generated in the reactor core and transfer the heat to the ultimate heat sink. $G E$ identified no single failure that would prevent the ECCS from meeting this criterion. The systems are designed to prevent any core uncovery.

The LPFL flow will be diverted manually to wetwell spray cooling for containment pressure control. The ABWR EPGs require cautions in the emergency operating procedures to deter the operator from premature flow diversion. These guidelines, which caution the operator against diversion unless adequate core cooling is ensured, have been accepted by the staff (NUREG-0737, TMI-2 Action Plan Item I.C.1, discussed in Chapter 20 of this report). LPFL diversion is identified in the procedure as secondary to core cooling requirements, except in those instences outside the design envelope involving multiple failures for which maintenance of containment integrity is required to minimize risk to the environment.
The BCCS moet ODC 17 in that its ceppocity and capability are maficicient to ensure that scopptable fuel deaign limits and datign conditions of the resctor coolent presurure boundary are not exceeded as a recult of anticipated opentional cocurrences; and the core will bo cooled and vital functions will be maintained in the ovent of poetulated secidents as given in SRP Section 6.3.

\subsubsection{Certined Dedizm Material}

OB abmitted tho dexign dencription and the inspections, tects, analyeses, and ecceptance criteria (ITASC) for the HPCF eysecen. This was DFSER Open Item 6.3.6-1. OB abmequently providad a rovised decign deweription and ITAAC. The adequacy and tho scceptability of the ABWR deaign descriptions and ITAAC aro ovaluated in Section 14.3 of this report. On the basis of this ovaluation, this itom is resolved.

\subsubsection{Conclusions}

As discused above, the staff finds the design of the BCCS scceptable. The ECCS conforms with the roview guidelines and accoptance criteria of SRP Section 6.3 and its pertinent RGs. Therefore, the ECCS moets the performance criteria of 10 CFR 50.46 and the pertineat requirements of ODC 2, 4, 17, 35, 36 and 37 as set forth in the SRP, as summarized bolow:

(1) 10 CFR 50.46 and Appendix $K$ performance requirements, as described in Section 6.3.5 of this report.

(2) GDC 2, as it relates to the seismic design of SSC whowe failure could cause an unacceptable reduction in the capability of the ECCS to perform its safety functions, as discuseod in Section 3.2.1 of this report.

(3) GDC 4, as related to dynamic effects aseociated with flow instabilities and loads, as discussed in Section 3.6 of this report.

(4) GDC 5 is not applicable since the ABWR is a single unit plant.

(5) GDC 17, ss it relates to the ECCS design for aufficieat capacity and capability to essure that epecified acceptable fuel design limits and decign conditions of the reactor coolant pressure boundary are not exceeded and that the core is cooled during anticipated operation occurrences and sccident conditions, es discussed in Section 6.3.5 of this report. 
(6) ODC 27, w it selates to the rectivity control oymen to have a combinad capability, in conjunction with poicon eddition by the energency core cooling syntem, or reliably controlling runctivity changes under poetulated socident condition, with appropriats mangin for stuck rods is discusend in Sections 4.2, 4.6 and 9.3.5 of this report.

(7) ODC 35, 36, and 37, an thoy relate to the BCCS deaign to provide an abuedanco of core cooling to trunafor beat from tho core at a rite 10 that fuel and clad damase will sot interfore with continued effective core cooling, to permit eppropriate periodic inepection of important composente, and to permit appropriate periodic provare and functional teating, as diecuened in Sections 6.3.2, 6.3.4, and 6.6 of this report.

\subsection{Control Room Habltability Systems}

The ataff reviowed the control room habitability syctem in scoordance with SRP Section 6.4. Conformence with the ecceptanco criteria formed the bavis for the etafis: ovaluation of the control room habitability syetems with repect to the applicable regulations of 10 CFR Part 50. Specifically, the SRP soceptance criteria require the deaign to meet ODC 4 as it relates to sccommodating the offects of and boing compatible with the environmental conditions anociated with poctulated accidents, including the offects of the release of toxic sanes; ODC 19 as it relates to maintaining the control room in a afo, habitable condition under socident conditions by providing adequate protection againat rodiation and toxic gaven; additional TMI requirement 10 CFR $50.34(1)(2)$ (xxviii) as it relates to the ovaluation of potential pathways for radionctivity and radiation that may load to control room habitability problem; and TMI Action Plan Itom III.D.3.4 (NURBO-0737) requirements as thoy relate to providing protection againd the offects of the release of toxic aubetances, cither on or off the site. Since the ABWR deaign is applicable only for a single unit, ODC 5 is not applicable.

The control room habitability syctoms will provide (1) misailo provection, (2) radiation chielding, (3) radiation moniloring, (4) air filtration and ventilation, (5) lighting, (6) pereonnel and administrative aupport, and (7) firt prolection. The control building heating, ventilating, and air conditioning (HVAC) system and components aro located in a coismic Catogory I structure that is protocted from tomado, misaile, pressure and flood damage. The HVAC ducting is ESF grado. HVAC hangers are dexigned to soismic Category I standards. The HVAC system will maintain the control room atmosphere tempera- ure at a babitable lovel to permit prolonged penconnal cocupanoy throughout a poetulated deaign-bacis cocident (DBA). The ayctem dacien provides for control room premarimition with reppect to tho murrounding epeces and fillered intaks during eccident situations and for purging of anoles and toxic geves. The system is capable of cutomatic tranofer from its normal operating mode to its energency or isolation modes on detection of adveres conditions (0.8., high rediation, amoke). The ayetem hes cufficical redundancy to ensure operation under emergency condition, sauming the single failure of any one sctive componeat. Beckup powver nources are provided for the cencential composente of the HVAC syetom. Section 9.4.1 of this report provides more information on the control room HVAC ayctem. The habitability syatems are deaigned to detect and limit the introduction of redionctive material and amoke into the control room. The ABWR deaign relies on noncombuetible conetruction and heat- and flamo-reaimant materials throughout the plant to minimizo the likelibood of fire and consequent fouling of the atmouphere with moke or noxious vapor. Further, the number of individual respirator (subject to periodic operational teating) is mufficient to protoct againat tho intrucion of toxic gases into the control room. Nonseiamic pipe, ductwork for kitchen and sanitary facilities, and other noncesential components in the control building are deaigned to onsure that their failure during a eafo shutdown carthquake will not adversely affect cesential components. Potential sources of danger wuch as pressure vereols and carbon dioxido firefighting containers will be located outside the control room and the compartments contrining control building lifo aupport syetems. There are no high-energy lines near the control room; therefore, the habitability ayatems are protected against the dynamic offects that may reault from poesible failures of auch lines. Section 3.6.1 of this report addreseses protection of safotyrelated equipment from the offects of pipe breaks. The etaff coacludes that the control room habitability systems catiafy GDC 4.

By lotter dated July 7, 1988, the staff requeeted additional information on a number of iserues (0.8., makeup air inlet for control room emergency zone, locations of control room ventilation inlets relative to major potential plant release points, rediation protection instrumentation, and minimum positive preecure during the presesurization mode) regarding the design features provided for compliance with GDC 19. This was identified as Open Item 29 in tho DSER (SECY-91-153). GE has provided the requeeted information. The staff hes roviewed and finds it ecceptable as discussed below. Therefore, DSER Open Item 29 is resolved.

The ABWR main control room (MCR) is physically integrated with the reactor building and turbino building 
and is locand between then two ctructures. During and following a LOCA, which is tho controlling DBA for the radiologital conesquesces to the control room opentions, mediation exposure to the operntors will consint of contributions from sisborm fivion products entrined in the control room veatilation eystem and direct gamme radiation from the aurrounding building and process equipment.

ODC 19 requires that the control room be deaigned to permit perconnel to cocupy it under eccident conditions. OB has propoced that this requiresent be mot by incorporating shiolding and energency veatilation aystom into the control room deaign, and by two roof-mounted and astomatically sontrolled room air intaken. OB has stated that the etructure bousing the control room is decigened and will bo conetructed to meet edemio Catogory I criteria, as is the emengeacy veatilation aystem, which is also deaigned to mod the singlo-failure criterion.

OE has provided for the rediation protection of control room occupents by the uno of ahielding walls and by the installation of redundint eafety grade emergency veatilation syctems. The inhabited portions of the ABWR control room are located underground ( $4.3 \mathrm{~m}$ (14 $\mathrm{t}$ ) below grade). A diatance of more than $11.3 \mathrm{~m}$ (37 ft) (including $2 \mathrm{~m}$ (6.5 ft) of concrete shialding and $0.46 \mathrm{~m}$ (1.5 ft) of floor) separates the control room and ateamlines. GB stated that the expected radiation expoaure rate in the control room resulting from direct gamma radiation during normal operntion and after an eccident is leas then $0.006 \mathrm{mSv} / \mathrm{hr}$ $(0.6 \mathrm{mR} / \mathrm{hr})$. The ctaff secepted OE's cetimate of direct gamme radiation of lees then $0.006 . \mathrm{mSv} / \mathrm{hr}(0.6 \mathrm{mR} / \mathrm{hr})$ after an eccident because of the decay of short-lived isotopes and the immodiate clocure of the main stam icolation valves that are upetream of the pipes above the MCR.

If a significant concentration of sirborne rndionctive materials is detocted at the normal control room ventilation gystem air intake, the air intake will isolato automatically. Automatic control room proseurization will cocur immediately, and filtered air will bo takea in by aither of two exparito emergency ventilation systems. Bach emergency veatilation syatem consiets of, at a minimum, a $50 \mathrm{~mm}$ (2 in.)-thick charcoal adeorber for romoval of iodines. The intakes for these syatems are ceparated from each other and from the plant stack. It is not likely that both air intakes would simultaneously admit equivalent lovels of radionctive contaminated air.

The viability of the dual-inlet concept depends on whether or not the plecement of the inlets cosures that airtorne radionuclide concentrations in one inlet will always bo relatively low. The capability to encure that this condition exits at en inlet depeods, in part, on building wake offects, stompecific tormin, and wind etagnation or rovernel. For the ABWR deaign, the inlete are located at the extreme edges of the control building. However, the taff findo that it is posedible, under certain low-probability condition, for both inlets to be draving air from the same cource of radionative materials, and that the location of the air inlets is leas then idenl, since thoy aro not on opposite sides $\left(180^{\circ}\right)$ of potential rediation release points.

In Amendment 8, OB claimed a factor of 4 reduction in the extimate of the atmoepheric dispertion parameter for the control room to account for dilution offectu aseociated with the ABWR air inlet configurations and the ABWRpecific building amangement. SRP Section 6.4 allows a factor or 10 for reduction of the parameters for a dual air interts design with automatic solection control features and with tho inlets pleced on plent etructures on opposito sides. Therefore, the etaff atated in the DFSER that GB's proponed reduction factor of 4 (instond of 10) was reasonable and acceptable because the lower reduction factor consecutively accounts for air inlets not being on oppoaite $\left(180^{\circ}\right)$ sides of potential radiation.

In Ameadment 24, OE changed the control room HVAC systom deaign by doleting automatic selection features of the mont favorable (lese radionctive) air intake from either of two separate emergency air intakes to the control room. In addition, OE rovised (1) the filtered emergency sir intake flow rate into the control room, (2) the control room air recirculation flow rate, and (3) the control room limiting atmoepheric dispersion values provided in Table 15.6-14 of the SSAR. Therefore, the staff diallowed a factor of 4 reduction given in tho DFSER for cetimating the atmospheric dispersion parameters for the control room, since GE had deleted the automatic solection features of the moet favorable air intakn from the ABWR deaign. Bven though SRP Section 6.4 allows a factor of 2 for reduction of the parumoters for a dual air intake deaign without manual or automatic selection features, the ataff has not provided, and GB did not requeet in Amendment 24, any reduction factors because the emergency control room air intakes are not placed on opposite sides of potential radiation rolease points.

The ataff recalculated the control room operator doeses using the deaign-basis LOCA described in Sestion 15.3.1 of this report and rovised control room design paramotorn provided in Amendment 24. The revised staff sesumptions and dose estimates are listed in Table 15.10 of this report. The ataff concludes that the calculated doses still meet the radiological consequences values of GDC 19 and TMI Action Plan Itom III.D.3.4, "Control Room Habitability." The atuff further concludes that the ABWR control room deaign atill provides an scceptable means of maintaining 
to control room in a we and mabituble condition by providing edequate probetion under ecoldent conditions in cocontences with TMI requirement 10 CFR SO.34(f)(2) (exviii).

OS idendifed en invertices requirement demeribed below for

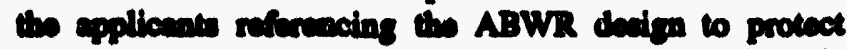

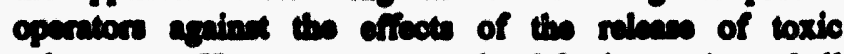
sebetences. Hownver, 20 a reall of further roviow of all

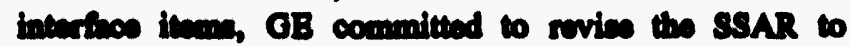

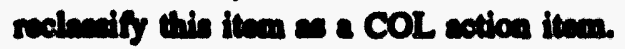

By lower dented April 16, 1993, OB wand thet the ABWR andard pleat elo dacion parnmeters (SSAR Tablo 2.0-1) did sot bolude trevis enem in tho site vicinity. A COL cotion item has bere included in Section 6.4 .7 of the SSAR requiring utility epplicante reforweing the ABWR dodign to domonetrete thet coatrol room opertion are edequatoly provectad apainat the effects of the relanes of toxic cubetunces, cither on or off tho sito, and that the plent can be enfely operated or shut down under conditions created by a DBA. The sead for aiboepecifid toxic gas protection will be revioured to eneure that the control room opentions

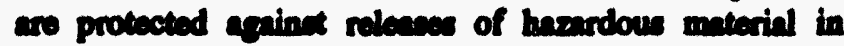
cocondanco with TMI Action Plen Item III.3.D.4. The amounts and bocations of any posaiblo cources of toxic subanneses in ench plent vicinity will be ideatified following the methods outlined in ROe 1.78 and 1.95. Specific detectors to permit automatic control room isolation will bo provided, where neceneary.

In the DPSER, the saff atated that the following were to bo included in the ITAAC. The COL applicant will need to verify that the following are consirtent with the licenaing bais documeatution: the abuilt dexign; the operating, minteanence, and emergency procedures and trining; the performance chameterintices of the control room habitability syetem; and the TS and aurveillence procedures. This was identified as Open Itom 6.4-1 in the DFSER. OB provided a revieed decien deccription and ITAAC. The adequacy and acceptability of tho dexign deacription and the ITAAC are evaluated in Section 14.3 of this report. On the basis of this ovaluation, DFSER Open Item 6.4-1 is recolved.

The ctaff revioned the ITAAC for the control room habitability area (CRHA) HVAC aystem (Tablo 2.15.5a, Deaign Commitmeats 1 through 10) and the control building (Tablo 2.15.12, Dexign Commitments 1 through 13) as thoy relate to control room habitability. In the DFSER, the ataff found them to be scceptable with some axceptions. Thewe were ideatified as DFSER Open Item 6.4.2. OE providad a revised deaign deacription and ITAAC. The adequacy and ecceptability of the design deccription and the ITAAC are ovaluated in Chapta 14.3 of this report. On the bacis of this ovaluation, DPSER Open liom 6.4-2 is reolved.

The anf concluden that the control room habitability

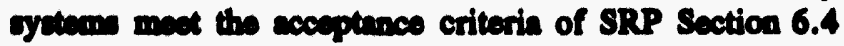
and are, therefore, receptable.

\subsection{Fiaton Product Removal and Control Syctems}

\subsubsection{Engincered Safoty Features Atmoephere Clean up Syetoun}

The ethfi reviowed the engincered mfety fecture (BSF) atmoghere clannup aytem in eccordence with SRP Section 6.5.1. Conformence with the scceptinnce crituria formed the bacis for the ctaff's ovaluation of these syctem with rempect to the applicable regulations of 10 CFR Part So.

The ABWR doaign hes two BSF filter syatems: the emergency air filtution system of the CRHA HVAC syctem and the standby gas treatment gyotem (SOTS).

SRP Section 6.5.1 ecceptence criteria applicable for tho emergency air filtration system's high-rndiation mode of the CRHA HVAC aystem are GDC 19 se it relates to the aystem being dexigned to ensure habitability of the control room under eccident and LOCA conditions and ODC 61 as it relates to the dexign of the syetem for radionctivity control under sormal and postulated accident conditions. As the staff concluded in Section 6.4 of this report, the energeacy air filtration syetem, which is part of the CRHA HVAC ayctem, complies with GDC 19 radiation exponure limits for the control room operators. The SRP atates that the epecified scceptance criteria are met by conforming with the guidelines of RO 1.52, "Deaign, Teating, and Maintenance Criteris for Poet Accident Engineered-Safoty-Feature Atmosphero Cleanup System Air Filtration and Adsorption Units of Light-Water-Cooled Nuclear Power Plants, "Revision 2, and SRP Table 6.5.1-1 regarding the systom instrumentation. Therefore, the staff has ueod aystem compliance with RG 1.52 and SRP Tablo 6.5.1-1 as the basis for concluding that the ESF filter aystem meets the applicable GDC and consequently the applicablo SRP scceptance criteria. The above compliance ovaluation is discused in Section 9.4.1 of this report for the emergency air filtration system of the CRHA HVAC syatem and in this section for the SOTS.

SRP Section 6.5.1 scceptance criteria applicable for the SOTS are GDC 41 as it relates to the decign of the system as it will be used for containment atmosphere cleanup following postulated accidents and for the control of releases to the cavironment, ODC 42 as it relates to the 
inspection and reding of the SOTS, ODC 61 (we the above pangraph) and ODC 64 as they relate to monitoring redionetive releanes vil the SOTS under sormal, enticipeted opentional oscurrencen and poetulated socideat conditions. As the etaff concludes in Section 11.5 of this report, the system complies with ODC 64.

The etaffe evaluation of the two BSF filter aystom is given below.

Emexpency Air Biltention Sytrm: The function of this aystem is to apply filtered outride air to the main control aren envelope (MCAB) and to preacirize the coatrol room after a deaign-bacis socideat (DBA). This system is ovaluated in Section 9.4.1 of this roport. In Section 9.4.1 of tho SSAR and the DFSER, tho emergency air filtration syetem of the CRHA HVAC system was erroncouraly identified as the control building outdoor air cleanup system. GE has corrected this orror in SSAR Amendment 20, and SSAR Amendment 32 ideatified exparato and independent diecharge and return pathe to and from the MCAB for the emergency filtration ayetom.

Stundby Gre Treatment System: The primary function of the SCTS is to filler and thereby reduce offitito airborno releanes of radioiodine and particulaten following a DBA (e.8., LOCA, fuol-handling sccident, fuel cask drop sccideat). This will be eccomplished by automatic isolation of the econdary containment from its normal HVAC air paths and automatic sctuation of the SOTS on receipt of a LOCA signal, detection of high radiation lovels in the recondary containment normal HVAC exhaust or in the refueling floor exhaust or loss of socondary contninment HVAC supply/exhaust fans signal. The system can also be manually initiated from the control room (0.8., for do-inerting during power operation) to reduce sirborne radionctive iodine and particulate relenses. The SOTS will maintain the socondary containmeat at a negative preseure of $6.4 \mathrm{~mm}$ (1/4 in.) of water gauge or greater relative to the surrounding speces within 20 minutes from the time the eccondary containment is isolated and proceses the offluent gases through a filter train to remove sirborme iodines and particulates. The system consist of two identical, parallel, physically separated, 100-percent-capecity subsyetems, $6,800 \mathrm{~m}^{3} / \mathrm{hr}(4,000 \mathrm{cfm})$ each, with aseociated piping and ducts, valves, dampers, and controls. Each aubsystom consists of a moisture eeparator, electric process heater, prefilter, pro-high-efficieacy particulate air (HEPA) filter, charcoal adeorbor (15-cm (6 in.) depth), poet-HEPA filter, procees fan $\left(6,800 \mathrm{~m}^{3} / \mathrm{hr}(4,000 \mathrm{cfm})\right.$ at 1 atmosphero and $21^{\circ} \mathrm{C}$ $\left.\left(70{ }^{\circ} \mathrm{F}\right)\right)$ and cooling fan $\left(700 \mathrm{~m}^{3} / \mathrm{hr}(412 \mathrm{cfm})\right.$ at 1 atmoephere and $21^{\circ} \mathrm{C}\left(70^{\circ} \mathrm{F}\right)$ ). IE Bulletin 80-03 has been mot since GE has revised SSAR Se tion 6.5.1.3.3 to state that the charcoal tray and screen will be all welded con- itruction in eccordance with the bulletin. Therefore, the SOTS filter trains will preclude the posible low of charconl from adeorber colls. The aystom is dacigned to culemic Category I requirements and will bo housed in a siemic Catogory I atructure.

In the DSER (SECY-91-153), the etaff etated that Appendix 6A to Chapter 6 of tho SSAR demonatunted the ayctem's compliance with each of the regulatory pocitions in RO 1.52, (Rov. 2), except one relating to the requirement for redundancy in filter trains. Originally, the SOTS deaign included only a single filter trin. In the DSER (SECY-91-153), the staff identified the use of a single filter train in the SOTS as Open Itom 30. Before the DFSER was ieved, GE submitted in a letter dated February 13, 1992, piping and instrumentation diagrams (P\&ID's) for a number of aystems including the SCTS. The SCTS P\&ID showed two filter trains. Therofore, in the DFSER, DSER Opea Itom 30 was rewolved. However, at a followup to GE's proposed design change, the etaff required $G E$ to confirm the deaign change by (1) rubmitting layout drawings showing the locations of the two filter trains and explaining the adequacy of the spatial exparation between the trains, and (2) revising SSAR Section 6.5.1, Table 6.5-1. and Appeadices 6A and 6B. The staff identified the woovo requirements as Confirmatory Item 6.5.1-1 in the DFSER. GE provided tho required information and SSAR section, table, and appendices in an amendment to the SSAR. The staff has reviewed them and finds them acceptable. Therefore, DFSER Confirmatory Item 6.:.1-1 is rosolved.

Appendix 6B to Chapter 6 of the SSAR addresese the compliance of the instrumentation for the SGTS with the requirements in Table 6.5.1-1 of SRP Section 6.5.1. Before the DFSER was issued, GE identified in Appendix 6B several doviations from the instrumentation requirements listed in SRP Table 6.5.1-1. GE attributod these deviations as being partly duo to the single filter train propoeed for the SOTS. In the DFSER, the staff etated that in addition to its concern regarding the deviations that atem from the use of a single filter train, it was concerned about doviations that cannot bo attributed to a single filter train design. Therefore, as stated above, the staff required GE to revise Appendix 6B to reflect the redundant filter trains and additionally justify any remaining deviations from SRP Table 6.5.1-1. The staff identified its concern regarding the deviations as Open Item 6.5.1-1 in the DFSER. GE has amended Appendix 6B and has provided ecceptable justifications for the deviations. The staff has roviewed GE's justifications for compliance of the SGTS with SRP Table 6.5.1-1 (minimum instrumentation, readout, recording and alarm provisions for ESF atmosphere cleanup systems) and finds that the propoeed instrumentation and controls in the main control room 
(MCR), as well as eelected local panels, meet the above guidance, and are acceptable. Although it would prefor that GE provide all of the local instrumentations and controls described in the above guidance for operational efficieacy and convenience, the ettaff finds that the SGTS instrumentation and controls moet the above guidance on the basis of the following:

(1) The instrumentation and control (i.e., readout, recordings, and alarms) provisions for the related paramoters (i.e., preesure drop, temperature, humidity, flow, etc.) are available and would be made accessible in the MCR.

(2) Plant-specific procedures will be developed to respond to these instrumentation and controls.

(3) The filtration train fully complies with the regulatory position of RG 1.52.

The acceptance, preoperational, and aurveillance testing meet the intent of ASME N509 and N510.

Unfiltered inleakage will be controlled by the use of welded filtration housings (GE hes stated that the advanced design of the filter housing and flow pattern would virtually eliminate any untreated filter bypass).

SGTS dose analysis is bounded by the maximum system flow.

Therefore, DFSER Open Item 6.5.1-1 is resolved.

During its meeting with the staff on May 5, 1992, GE committed to provide an analysis to demonstrate that the use of the system during the inerting, do-inerting, preserure control, or purging of the primary containment during normal plant operation will not impair its functional capability during a DBA. Therefore, the staff identified the submittal of the analysis as Open Item 6.5.1-2 in the DFSER. However, the staff considers that the analysis need not be performed, provided the use of the SGTS during power operation is limited to no more than 90 hours per year (approximately 1 percent of tho timo). BY SSAR Amendment 32, GE stated that normal operation of the SGTS would be much less than 90 hours per year for both trains combined during startup, power, and hot shutdown modes of operation. However, if 90 hours of operation per year for either train is to be exceeded, the COL applicant is required to provide functional damage analyses to demonstrate that the SGTS is capable of performing its intended function in the event of a LOCA, since this would be a change to SSAR certified design information. The atuff finds this acceptable. Therefore, DFSER Open Item 6.5.1-2 is resolved.

The ataff concludes that the SOTS has a removal efficiency of 99 percent for all forms of radioiodine. It further concludes that the system moets the acceptance criteria of SRP Section 6.5.1 and is, therefore, acceptable.

\subsubsection{Containment Spray System}

SRP Section 6.5.2 does not apply to the ABWR plant.

\subsubsection{Fission Product Control Systems and Structures}

The staff reviewed fission product control systems and structures in accordance with SRP Section 6.5.3. The ABWR design includes two fission product control systems and structures. These are the primary containment, which includes the suppression pool with scrubbing and retention capability, and the socondary containment, which includes the SGTS with filtration capability.

Primary Containment: The primary containment is a cylindrical steel-lined reinforced-concrete structure that forms a limited leakage boundary for fission products released to the containment atmosphere following a LOCA or any other accident that releases lesser amounts of fission products. The structure is divided by a reinforced-concrete diaphragm floor and the reactor vessel pedestal into the upper and lower drywell, and a suppression chumber (wetwell). The diaphragm floor will be rigidly attached to the reactor pedestal and the contrinment wall. The diaphragm floor includes a liner to provent steam bypass from the upper drywell to the suppression chamber airepace during any accident. The primary containment is totally enclosed within the reactor building, a portion of which forms the secondary containment. GE has assumed a design leak rate of 0.5 percent per day of the free containment volume for the duration of the accident (for further discussion on leak rate, see Section 15.4.4.1 of this report). A test program will be implemented to confirm leak integrity of the primary containment structure (see Section 6.2.6 of this report). The primary containment provides a passive barrier to limit leakage of airborne radioactive material following $a$ LOCA by immediate closure of containment isolation valves except for those neceseary for ECCS and ESF functions. Information on the primary containment design, its isolation methods, and isolation times are given in Sections 6.2.1 and 6.2.4 of this report. This information includes an evaluation of the suppression pool bypass leakage area of $0.0046 \mathrm{~m}^{2}$ $\left(0.05 \mathrm{f}^{2}\right)$ assumed by GE. GE originally assumed a decontamination factor (DF) of 10 for the elemental and particulate forms of iodine resulting from scrubbing and retention in the suppression pool. In its radiological 
consequence analysis, the staff conservatively assumed a decontamination factor of 2 (equivaleat to suppression pool steam bypass of 50 percent). The staff finds that the assumed pool DF of 2 for elemental and particulate forms of radionctive iodine meets the regulatory position in SRP Section 6.5.5, "Pressure Suppression Pool as a Fission Product Cleanup System," and is acceptable as discussed in Section 15.3 of this report. Therefore, the design features of the primary containment discuseed in this section are scceptable for controlling fiation product release during on accident.

Secondary Conteinment: The secondary containment is a reinforced-concrete building that forms an envelope surrounding the primary containment above the basemat. It encloses the penetrations through the primary containment and all those systems external to the primary containment that could become a potential source of radionctive release after an accident. Following an accident, the secondary containment normal HVAC paths are secured. The SGTS will maintain the secondary containment at a negative pressure of $6.4 \mathrm{~mm}(1 / 4 \mathrm{in}$.) of water gauge or greater relative to the surrounding speces within 20 minutes from the time the secondary containment is isolated and process the effluent gases through a filter train to remove airborne iodines and particulates. GE has rssumed a draw-down time of 20 minutes for achieving this negative pressure in its LOCA dose analysis. GE states in SSAR Section 6.5.1.3.1(5) that the COL applicant will perform a secondary containment draw-down analysis to demonstrate tho sapability of the SGTS to maintain the design negative pressure following a LOCA, including inleakage from the open, nonisolated penetration lines identified during construction engineering and in the event of the worst single failure of a secondary isolation valve to close. The SGTS will filter airborne fission products (iodines and particulates) leaking from the primary containment before their release to the environs. GE assumed an inleakage rate of 50 percent of the secondary containment free volume per day at a differential pressure of $6.4 \mathrm{~mm}$ (1/4 in.) water gauge with respect to the surrounding spaces. The design of the secondary containment is discussed in Section 6.2.3 of this report. The design of the SGTS is discussed in Section 6.5.1 of this report.

On the basis of the above information and its evaluation of the SGTS in Section 6.5.1 of this report, the staff concludes that GE has demonstrated 99-percent removal efficiency by the SGTS filter train for all forms of iodine. The staff further concludes that the fission product control systems and structures provided in the ABWR design have the capability to reduce the DBA doses to within 10 CFR Part 100 limits (for further information, see Chapter 15 of this report).
The staff concludes that the fission product control systems and etructures provided for the ABWR meet the scceptunce criteria of SRP Section 6.5.3 and are, therefore, acceptable.

\subsection{Inservice Inspection of Class 2 and 3 Components}

A detailed evaluation of the inservice inspection (ISI) of the reactor coolent presesure boundary is given in Section 5.2.4 of this report.

The staff's evaluation of SSAR Soction 6.6 was not complete in the DSER (SECY-91-153) and was therefore identified as Open Item 31. The staff reviewed SSAR Section 6.6, and Open Item 31 was resolved based on the following discussion.

SSAR Section 6.6 and Table 6.6-1 describe certain commitments and plans for the preservice inspection (PSI) and ISI programs for ASME Code, Class 2 and 3 components. GE discussed basic inspection concepts and general ASME Code provisions because the requirements of the NRC regulations might be controlled by the date of order of each specific component subject to examination. The staff review was performed in accordance with SRP Section 6.6, except as explained below.

Throughout the service life of the plant, the COL applicant has the overall responsibility for the ISI of the Class 2 and 3 components. Howover, other organizations aleo contribute to the examination activity, including the reactor vendor and the architect-engineer. The NRC staff and GE discussed the issue of ISI requirements on March 25 and 26, 1992, and decided that the COL applicant is responsible for the development of the psi and ISI programs for all ASME Codo, Class 2 and 3 components. This was identified as DFSER COL Action Item 6.6-1.

GE included this information in SSAR Section 6.6.9, which states that the COL applicant will develop psi and ISI program plans as outlined in Section 6.6 of the SSAR. This is acceptable.

\subsubsection{Requirements of $10 \mathrm{CFR}$ 50.55a, "Codes and Standards"}

Pursuant to 10 CFR 50.55a(g)(3), ASME Code Class 2 and 3 components should be designed and provided with access to enable the performance of inservice examination of such components and should meet the preservice examination requirements in ASME Code, Section XI, applied to the construction of the particular component. The applicable construction code will be determined by paragraph NCA-1140 of ASME Code, Section III, but the 
construction code that is selected must bo incorporated by reference in 10 CFR 50.55a(b).

All items of a nuclear power plant may be constructed to a single edition of the ASME Code, or each itom may be constructed to individually specified codo editions and addenda. NCA-1140 of ASME Code, Section III, states, in part, that in no case should the ASME Code edition established in the design specification be carlier then 3 years before the date that the nuclear power plant construction permit application is docketed. In addition, NCA-1140 permits the use of later code editions by mutual consent of the owner and certificate holder, that is, an organization holding valid N, NV, NPT, or NA certificate of authorization issued by ASME.

Throughout the service life of a boiling or pressurized water-cooled nuclear power facility, components (including supports) that are classified as ASME Codo, Class 2 and 3, must meet the requirements, except design and access provisions and preservice oxamination requirements, sot forth in ASME Code, Section XI, that become effective after the editions specified in 10 CFR 50.55 a(g)(3) and are incorporated by reference in 10 CFR 50.55a(b), to the extent practical within the limitations of design, geometry, and materials of construction of the components. The inservice examination of components conducted during the initial 10-year interval must comply with the requirements of the latest edition and addenda of ASME Code, Section XI, incorporated by reference in 10 CFR 50.55a(b) on the date 12 months before the date of issuance of the operating license. The regulations also require that the ISI program be updated for each subeequent 10-year interval to comply with the ASME Code incorporated by reference in 10 CFR 50.55a.

\subsubsection{Application of the Codes and Standards Rule to Standard Design Certification}

Compliance with the requirements of the regulations for PSI and ISI must be based on commitments for or by the COL applicant. The applicable ASME Code(s) for both design and ISI are not known at the time of the design certification application. In addition, the regulation permits the COL applicant the option to change to a newer edition of ASME Code, Section XI, by component, during the construction of the plant.

The staff reviewed the information in the SSAR that emphasized design access and the use of effective nondestructive examination (NDE) methodology. Because PSI requirements are established and known at the time each component is ordered, 10 CFR $50.55 a(g)$ does not have provisions for relief requests for imprectical examination requirements. ASME Code, Section XI, does have provisions to use certain shop and field examinations in lieu of the onsite preservice examination. Therefore, the COL applicant will incorporate plans for NDE during design and construction in order to meet all access requiroments of the regulations. This was identified as DFSER COL Action Item 6.6.2-1.

OE included this information in SSAR Soction 6.6.9, which states that the COL applicant will incorporate plans for NDE during design and construction in order to meet all eccess requirements of the regulations. This is acceptable.

ASME Code, Section XI, states that the preservice examination should be conducted with equipment and techniques equivalent to those that are expected to be used for subeequent inservice examinations. Improvements in the ultrasonic testing of Class 2 and 3 components will occur in the near future. ASME has publishod ASME Code, Section XI, Appendix VII, "Qualification of Nondestructive Examination Personnel for Ultrasonic Examination," and Appendix VIII, "Performance Demonstration for Ultrasonic Examination Systems." The NRC staff has published in the Federal Rerister its intent to reference in 10 CFR 50.55a(b) the edition of ASME Code, Section XI, that includes the published Appendix VII. In addition, the staff has established a technical contact to coordinate the implementation of Appendix VIII. Therefore, the PSI program for the ARWR should include provisions that ultrasonic testing be performed in accordance with Appendices VII and VIII pursuant to 10 CFR $50.55 \mathrm{a}(\mathrm{g})(3)$. However, the staff did not identify the above as a separate issue because it was covered by DFSER Open Item 5.2.4-1. See Section 5.2.4 of this report.

The requirements for the initial ISI program will be determined by the ASME Code in effect 1 year before the issuance of an operating license. The COL applicant is required to meet the ISI requirements "to the extent practical within the limitations of design, geometry and materials of construction of the components." The regulations have provisions for the staff evaluation, on written request, of new ASME Code requirements determined by a licensee to be impractical for its facility.

\subsubsection{Staff Evaluation}

A PSI program and an ISI program will be prepared for each ABWR plant. GE states that provisions have been made in the design and layout of ASME Code, Class 2 and 3 systems to allow for access for the examinations required in ASME Code, Section XI, Articles IWC-2000 and IWD-2000, and as defined in the ISI program. As a result of a meeting between GE and the NRC staff on March 25 
and 26, 1992, it was determined that the COL applicant is responsible for the development of the PSI and ISI programs for all ASME Code, Class 1, 2, and 3 scomponents. The NRC staff reviewed the above information regarding design sccess for the preservice examination and finds the information pertaining to planning adequate. The staff notes that the SSAR Section 6.6 states that the COL applicant will moet the

requirements of the NRC regulations defined in 10 CFR $50.55 a$.

The SSAR Section 6.6.3.2 states that the examination techniques to be used for ISI will include radiographic, ultrasonic, magnetic particle, liquid penetrant, eddy current, and visual examination methods. For all examinations, both remote and manual, specific procedures will be prepared describing the equipment, inspection technique, operator qualifications, calibration standards, flaw evaluation, and records. These techniques and procedures will meet the requirements of Articles IWC-2000 and IWD-2000 in the edition of ASME Code, Section XI, in effect as stated in $10 \mathrm{CFR} 50.552(\mathrm{~g})$. GE has revised SSAR to state that personnel performing ultrasonic examinations will be qualified in accordance with ASME Code, Section XI, Appendix VII. Ultrasonic examination systems will be qualified in accordance with an industryaccepted program for implementing ASME Code, Section XI, Appendix VIII. GE considered the supplomental examinations recommended in GE service information letters (SILs) and rapid communication service information letters (RICSILs) for previous BWR designs as not applicable to the ABWR. In the ABWR design either of the following has been eliminated: components addressed by the SILs or RICSILs or the need for the examination by eliminating crevice designs and using materials resistant to the known degradation mechanisms, auch as intergranular stress corrosion cracking, on which the SIL and RICSIL examinations were based.

The staff finds these commitments acceptable.

\subsection{High-Pressure Nitrogen Gas Supply System}

The ABWR design includes four compreseed air systems: the instrument air system, the service air system, the highpreesure nitrogen (HPIN) gas supply system, and the atmoepheric control system (ACS). In SSAR Section 6.7, GE aupplies information on the design of the HPIN system. The staff reviewed the information in accordance with SRP Section 9.3.1.

The HPIN system consists of both a nonessential (i.e., non-safety-related) and an eseential systems. A single nonessential system will provide a continuous nitrogen supply to all pneumatically operated components in the primary containment during normal operation. As noted in Section 6.5.2 of this report, during normal operation, the nitrogen gas evaporator/storage tank will supply the HPIN system via the makeup line to the ACS. The eseential system has two independent divisions. Each division contains safety-related emergency stored nitrogen supply capable of supplying 100 percent of the requirements of the division being serviced. Nitrogen gas for the escential system will be supplied from HPIN gas storage bottles. There are tielines between the nonessential system and each division of the essential system. Each tieline has a motor-operated shutoff valve.

Because the HPIN system is one of the four systems that will perform the functions addressed in SRP Section 9.3.1, the review of this system was performed as part of an integrated review of the ABWR compressed air systems. The results of this review are given in Section 9.3.1 of this report.

\subsection{Main Steam Isolation Valve Leakage Control System}

An MSIV leakage control system will not be used in the ABWR, as discussed in Section 10.3 of this report. 


\section{INSTRUMENTATION AND CONTROLS}

\subsection{Introduction}

The staff hes reviewed the GE Nuclear Bnergy (GE) advanced boiling water reactor (ABWR) atendurd afeaty analyais report (SSAR) and secocinted reference matarial. A draft eafoty ovaluation report (DSER) was ieaved on September 18, 1991, attached to SECY-91-294, "Draft Safety Evaluation Report on the Generd Blectric Boiling Water Reactor Design Covering Chapter 7 of the Standard Safety Analysis Report." The applicant responded to the open issues identified in the DSER by letter dated Fobruary 3, 1992. A copy of the DSER was aleo provided to the Advisory Committee on Reactor Safeguards (ACRS).

A draft final safoty evaluation report (DFSER) whe isaued on October 14, 1992, attached to SECY-92-349, "Draft Final Safoty Evaluation Report on the General Electric Boiling Water Reactor Design Covering Chapter 7 of the Standard Safety Analysis Report." The DFSER has also been provided to the ACRS. The applicant responded to the open issues identified in the DFSER by soveral submittals described in this report. The following sections describe the staff's final safety evaluation findings. This report describes the resolution of the open items from the DSER and DFSER.

The staff has reviewed Chapter 7 of the SSAR submittal through Amendment 35. Chapter 7 contains the primary instrumentation and control (I\&C) descriptions and commitments. Chapter 1 of the SSAR contains most of the associated instrumentation block diagrams. A few items from other chapters of the SSAR are included in this evaluation, as indicated. The staff has reviewed both proprietary and non-proprietary information from the SSAR and other docketed materials.

\subsubsection{Acceptance Criteria}

The acceptance criteria used as the basis for the staff's evaluation of the I\&Cs for the ABWR are set forth in NUREG-0800, "Standard Review Plan for the Review of Safety Analysis Reports for Nuclear Power Plants, LWR Edition," and 10 CFR Part 52. The primary sections of NUREG-0800 used for this portion of the review are Section 7, "Instrumentation and Control," and Section 9.5.2, "Communications Systems." The Commission issued review guidance in staff requirements memoranda (SRM), dated June 26, 1990, and February 15, 1991, pertaining to SECY-90-016, "Evolutionary Light Water Reactor Certification Issues and Their Relationship to Current Regulatory Requirements," and SECY-90-377, "Requirements for Design Certification under 10 CFR Part 52," respectively.
The etaff developed the necoseary acceptance criteria to cover the cortification of those systems beceuse the SRP presently does not addrese design certification, or the nower digital technology used in these ABWR I\&C oyetem (the SRP was last revised in 1984). The additional acceptance criteria and conformance to the SRP are discused in the applicable sections of this report. This report also deacribes certain items which will be included in the cortified design material (CDM) which includes the design description; inspections, tests, analyses and acceptance criteria (ITAAC), sito parameters, and interface requirements for design certification. The description of the CDM development process, bases, and acceptability is primarily discuseed in Section 14.3 of this report. This report diecuseces only thoee CDM areas which relate to the I\&C syetems' certified design process in addition to epecific deaign charecteristics.

The etaff referenced its evaluation of previously-reviewed plant designs and topical reports, as stated.

\subsubsection{Method of Review}

In the DSER (SECY-91-294) the staff discussed the following items: systems which have had significant design changes compared to previously-reviewed andsccepted designs; the appropriate level of detail necessary for design certification; and design issues where more information was needed in order for the staff to make a finding of acceptability. Since issuing the DSER the staff has concentrated on resolving the open issues in the DSER and reviewing the submittals of the CDM and technical specifications (TS). The DFSER (SECY-92-349) described the remaining open issues and the acceptance of design process commitments in lieu of design details for certain rapidly developing technologies such as software design.

In addition to reviewing the SSAR, the staff also visited GE's offices and reviowed documents associated with the SSAR material. All documents relied upon for the safety ovaluation that are not included in the SSAR have been docketed.

\subsubsection{General Findings}

GE has identified the I\&C systems which are important to safety in accordance with Regulatory Guide (RG) 1.70 , Revision 3, "Standard Format and Content of Safety Analysis Reports for Nuclear Power Plants," November 1978. Each of the safety systems identified in the SSAR also has an associated Design Description and ITAAC. Some aspects of the design which affect all of the I\&C systems (such as the software design process) are addressed in an I\&C CDM section rather than repeated for 
cach individual I8C syetem CDM. Moet of tho non-eafety syetems are aleo described in a CDM.

The ABWR IEC aystems are aignificantly different from IeC ayetem in provioualy-approved deaign. The primary differences reault from using digital microproceseor-baced IEC aystems with multiplexed data links in plece of the analog electronics, rolay logic, and hardwired aystems previously approved by the staff. The staff previously reviowed designs using digital equipment similar to that proposed for the ABWR; however, the ABWR significantly extends the quantity and scope of system coverage of the digital microprocessor applications and, in conjunction with the 10 CFR Part 52 design certification process, requires anique review which is not directly comparable with any past licensing review. The differences from past license reviows are addrees in greater detail in this chapter.

The comparison of the ABWR to the GESSAR II deaign in SSAR Table 7.1-1 is not a sufficient besis for accepting the ABWR I\&C design because, as the table shows, of the significant differences in the implementation of the I\&C system design when using the ABWR digital equipment.

\subsubsection{Standard Review Plan Criteria}

The acceptance criteria listed in Table 7.1 of this report are identified in the Commission regulations and Standard Review Plan (SRP) Chapter 7, "Instrumentation and Controls." The SRP also provides some review guidance and acceptance criteria not found in the specified standards, General Design Criteria (GDC) and other references. Table 7.1 does not consider the degree of conformance of the $A B W R$ with the requirements or the method of implementation of the I\&C aystem design, but simply lists the SSAR sections where the standards and criteria are mentioned in the SSAR. Many of the standards and criteria discussed in SSAR Chapter 7 and Appendices A, B, and C are applicable to the provious SSAR sections which describe the I\&C systems without being specifically listed and discussed in those sections. The request for additional information (RAI) column refers to the staff RAI and the GE response to them which relate to specific standards and criteria. The RAIs and responses are provided in Chapter 20 of the SSAR. The conformance to and any exceptions from the standards and criteria are discussed in this chapter. SSAR Table 7.1-2, "Regulatory Requirements Applicaility Matrix for I\&C Systems," also provides a similar matrix of the SRP criteria to that in this report, but compares them with the I\&C systems rather than the SSAR sections. In general GE committed to meet the SRP requirements without exception. The fow exceptions GE requested are noted in
SSAR Section 1.8 and the applicable soctions of this chaptor.

10 CPR Part 50, Appendix A, "General Deaign Criteria for Nuclear Power Plants," contains the GDC. Chapter 3.1 of the SSAR diecueses compliance with the ODC generally and references other SSAR chapters for epecifics. Table 7.1-2 of the SSAR lists the GDC applicable to the I\&C systems.

The SSAR Chapter 3 discussion of GDC 3, "Fire Protection;" GDC 26, "Reactivity Control System Redundancy and Capability;" ODC 27, "Combined Reactivity Control Syatem Capability;" ODC 30, "Quality of Reactor Coolent Preseure Boundary;" GDC 37, "Teating of Emergency Core Cooling System;" GDC 42, "Inspection of Containment Atmoephere Cleanup Syetems;" GDC 43, "Texting of Containment Atmosphere Cleanup Systems;" GDC 55, "Reactor Coolant Pressure Boundary Penetrating Containment;" and GDC 56, "Primary Containmeat Isolation; " referred to Chapter 7 of the SSAR for further discussion of each GDC. However, these GDC did not appear in the SSAR Chapter 7 GDC discussions. The topics generally are discussed in other sections of the SSAR.

GDC 2, "Design Bases for Protection Against Natural Phenomena;" GDC 15, "Reactor Coolent System Design;" GDC 16, "Containment Design;" GDC 38, "Containment Heat Removal;" and GDC 44, "Cooling Water," were listed in Chapter 7, but there was no corresponding reference to Chapter 7 in the Chapter 3 evaluations. The GDC discrepancies were listed as Open Item 7.1.3.1-1 in the DFSER. GE revised the SSAR to include references in Chapter 3 to Chapter 7 for GDC 2, 15 and 38. GE also clarified that the GDC discussed in Chapter 3 apply to the equipment included in Chapter 7, regardless of whether there is a specific discussion in the I\&C sections in Chapter 7 or not. The staff concludes that this is acceptable; therefore, this open item is resolved.

The specific standards to which GE has committed are a significant consideration for the staff's safety findings. The most important aspects of those criteria, which are required to be certified by rulemaking, are included in the CDM and are discussed in the staff's evaluation.

\subsubsection{Electric Power Research InstituteRequirements Document}

Electric Power Research Institute (EPRI) prepared a document of technical requirements, referred to as the advanced light water reactor (ALWR) Utility Requirements Document (ALWR RD), intended by EPRI to be applies to the design of ALWR power plants, including the ABWR. 
Table 7.1 SRP Acceptance Criteria

\begin{tabular}{|c|c|c|c|c|c|c|c|c|c|c|c|c|}
\hline \multirow{2}{*}{ SRP CRITERIA } & \multicolumn{12}{|c|}{ ABWR SSAR Chapter 7} \\
\hline & 7.1 & 7.2 & 7.3 & 7.4 & 7.5 & 7.6 & 7.7 & 7.8 & $7 . A$ & 7.8 & 7.6 & RAI \\
\hline 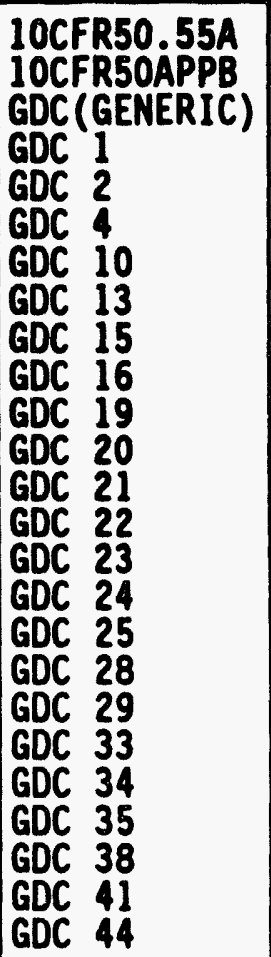 & $\begin{array}{l}x \\
x \\
x \\
x \\
x \\
x \\
x \\
x \\
x \\
x \\
x \\
x \\
x \\
x \\
x \\
x \\
x \\
x \\
x \\
x \\
x \\
x \\
x \\
x \\
x\end{array}$ & $\begin{array}{l}x \\
x \\
x \\
x \\
x \\
x \\
x \\
x \\
x \\
x \\
x \\
x \\
x \\
x \\
x \\
x \\
x \\
x\end{array}$ & \begin{tabular}{|l|}
$x$ \\
$x$ \\
$x$ \\
$x$ \\
$x$ \\
$x$ \\
$x$ \\
$x$ \\
$x$ \\
$x$ \\
$x$ \\
$x$ \\
$x$ \\
$x$ \\
$x$ \\
$x$ \\
\\
$x$ \\
$x$ \\
$x$ \\
$x$ \\
$x$ \\
$x$ \\
$x$
\end{tabular} & $\begin{array}{l}x \\
x \\
x \\
x \\
x \\
x \\
x \\
x \\
x \\
x \\
x\end{array}$ & \begin{tabular}{|c|}
$x$ \\
$x$ \\
$x$ \\
$x$ \\
$x$ \\
$x$ \\
$x$ \\
$x$ \\
$x$
\end{tabular} & $\begin{array}{l}x \\
x \\
x \\
x \\
x \\
x \\
x \\
x \\
x \\
x \\
x \\
x \\
x \\
x \\
x \\
x \\
x \\
x \\
x \\
x \\
x \\
x \\
x \\
x \\
x \\
x\end{array}$ & $\begin{array}{l}x \\
x \\
x\end{array}$ & & \begin{tabular}{|l|}
$x$ \\
$x$ \\
$x$ \\
$x$ \\
$x$ \\
$x$ \\
$x$ \\
$x$ \\
$x$ \\
$x$ \\
$x$ \\
$x$
\end{tabular} & $\begin{array}{l}x \\
x \\
x\end{array}$ & & $\begin{array}{l}x \\
x \\
x \\
x\end{array}$ \\
\hline \multirow{2}{*}{$\begin{array}{l}\text { IEEE } \\
\text { STANDARDS } \\
\text { IN SRP }\end{array}$} & \multicolumn{12}{|c|}{ ABWR SSAR Chapter 7} \\
\hline & 7.1 & 7.2 & 7.3 & 7.4 & 7.5 & 7.6 & 7.7 & 7.8 & $7 . A$ & $7 . B$ & $7 . C$ & RAI \\
\hline $\begin{array}{l}279-1971 \\
317-1972 \\
323-1974 \\
336-1971 \\
338-1971 \\
379-1972 \\
384-1974\end{array}$ & $\begin{array}{l}x \\
x \\
x \\
x \\
x \\
x\end{array}$ & $\begin{array}{l}x \\
x \\
x \\
x \\
x \\
x\end{array}$ & $\begin{array}{l}x \\
x \\
x\end{array}$ & $\begin{array}{l}x \\
x\end{array}$ & $\begin{array}{l}x \\
x\end{array}$ & $\begin{array}{l}x \\
x\end{array}$ & $x$ & & $\begin{array}{l}x \\
x \\
x \\
x\end{array}$ & & & $x$ \\
\hline \multirow{2}{*}{$\begin{array}{l}\text { OTHER } \\
\text { GUIDANCE } \\
\text { IN SRP }\end{array}$} & \multicolumn{12}{|c|}{ ABWR SSAR Chapter 7} \\
\hline & 7.1 & 7.2 & 7.3 & 7.4 & 7.5 & 7.6 & 7.7 & 7.8 & $7 . A$ & 7.8 & 7.6 & RAI \\
\hline $\begin{array}{l}\text { ANSI/ANS } 4.5 \\
\text { ANSI N41.15 } \\
\text { ISA } 67.02 \\
\text { NUREG-0694 } \\
\text { NUREG-0696 } \\
\text { NUREG-0718 } \\
\text { NUREG-0737 }\end{array}$ & $\begin{array}{l}x \\
x \\
x \\
x \\
x \\
x\end{array}$ & $\begin{array}{l}x \\
x \\
x \\
x \\
x \\
x\end{array}$ & $\begin{array}{l}x \\
\hat{x} \\
\mathbf{x} \\
\hat{x} \\
\hat{x} \\
\hat{x}\end{array}$ & $\begin{array}{l}x \\
\dot{x} \\
x \\
x \\
x \\
x\end{array}$ & $\begin{array}{l}x \\
x \\
x \\
x \\
x \\
x \\
x\end{array}$ & $\begin{array}{l}x \\
x \\
x\end{array}$ & $\begin{array}{l}x \\
x \\
x\end{array}$ & & $\begin{array}{l}x \\
x \\
x \\
x\end{array}$ & & & \\
\hline
\end{tabular}


Table 7.1 SRP Acceptance Criteria (continued)

\begin{tabular}{|c|c|c|c|c|c|c|c|c|c|c|c|c|}
\hline \multirow{2}{*}{$\begin{array}{l}\text { TMI } \\
\text { ACTION PLAN } \\
\text { ITEMS IN SRP }\end{array}$} & \multicolumn{12}{|c|}{ ABWR SSAR Chapter 7} \\
\hline & 7.1 & 7.2 & 7.3 & 7.4 & 7.5 & 7.6 & 7.7 & 7.8 & $7 . A$ & $7 . B$ & $7 . c$ & RAI \\
\hline $\begin{array}{l}\text { II.D.3 } \\
\text { III.E. } \\
\text { II.E. } 4.2 \\
\text { II.F.1 } \\
\text { II.F.3 } \\
\text { III.K.1 } \\
\text { II.K. } \\
\text { II.K.3 }\end{array}$ & \begin{tabular}{l|}
$x$ \\
Not \\
$X$ \\
$X$ \\
$X$ \\
$X$ \\
Not \\
$X$
\end{tabular} & $\begin{array}{l}x \\
\text { AP } \\
X\end{array}$ & \begin{tabular}{|l|}
$x$ \\
LIC \\
$x$ \\
$x$ \\
$X$ \\
LIC \\
$x$
\end{tabular} & ABLE & $\begin{array}{l}x \\
x\end{array}$ & $\begin{array}{l}x \\
\dot{x}\end{array}$ & $x$ & & & & & $x$ \\
\hline \multirow{2}{*}{$\begin{array}{l}\text { REGULATORY } \\
\text { GUIDES } \\
\text { IN SRP }\end{array}$} & \multicolumn{12}{|c|}{ ABWR SSAR Chapter 7} \\
\hline & 7.1 & 7.2 & 7.3 & 7.4 & 7.5 & 7.6 & 7.7 & 7.8 & $7 . A$ & 7.8 & $7 . C$ & RAI \\
\hline $\begin{array}{ll}R G & 1.22 \\
R G & 1.47 \\
R G & 1.53 \\
R G & 1.62 \\
R G & 1.75 \\
R G & 1.89 \\
R G & 1.97 \\
R G & 1.105 \\
R G & 1.118 \\
R G & 1.151\end{array}$ & $\begin{array}{l}x \\
x \\
x \\
x \\
x \\
x \\
x \\
x \\
x \\
x \\
x \\
x\end{array}$ & $\begin{array}{l}x \\
x \\
x \\
x \\
x \\
x \\
x \\
x \\
x \\
x\end{array}$ & $\begin{array}{l}x \\
x \\
x \\
x \\
x \\
x \\
x \\
x \\
x \\
x \\
x\end{array}$ & $\begin{array}{l}x \\
x \\
x \\
x \\
x \\
x \\
x \\
x\end{array}$ & $\begin{array}{l}x \\
x \\
x \\
x \\
x \\
x \\
x\end{array}$ & $\begin{array}{l}x \\
x \\
x \\
x \\
x \\
x \\
x \\
x \\
x \\
x \\
x\end{array}$ & $x$ & $x$ & $\begin{array}{l}x \\
x \\
x \\
x \\
x\end{array}$ & & & $x$ \\
\hline \multirow{2}{*}{$\begin{array}{l}\text { BRANCH } \\
\text { TECHNICAL } \\
\text { POSITION } \\
\text { IN SRP }\end{array}$} & \multicolumn{12}{|c|}{ ABWR SSAR Chapter 7} \\
\hline & 7.1 & 7.2 & 7.3 & 7.4 & 7.5 & 7.6 & 7.7 & 7.8 & $7 . A$ & $7 . B$ & $7 . c$ & RAI \\
\hline $\begin{array}{lll}\text { BTP } & \text { ICSB } & 3 \\
\text { BTP } & \text { ICSB } & 4 \\
\text { BTP ICSB } & 12 \\
\text { BTP I ICSB } & 13 \\
\text { BTP } & \text { ICSB } & 14 \\
\text { BTP } & \text { ICSB } & 16 \\
\text { BTP } & \text { ICSB } & 20 \\
\text { BTP } & \text { ICSB } & 21 \\
\text { BTP } & \text { ICSB } & 22 \\
\text { BTP ICSB } & \text { ICSB }\end{array}$ & $\begin{array}{l}X \\
\text { NOT } \\
X \\
\text { NOO } \\
\text { NOT } \\
\text { DEL } \\
X \\
X \\
X \\
X \\
X\end{array}$ & $\begin{array}{l}\text { APF } \\
X \\
\text { APF } \\
\text { APF } \\
\text { ATEL } \\
x \\
x \\
X \\
X\end{array}$ & $\begin{array}{l}x \\
\text { LICA } \\
\text { LICA } \\
\text { LICA } \\
x \\
x \\
x\end{array}$ & \begin{tabular}{|c|}
$X$ \\
$A B L E$ \\
$A B L E$ \\
$A B L E$
\end{tabular} & & $\begin{array}{l}x \\
x\end{array}$ & & & & & & \\
\hline
\end{tabular}

Volume II, "Evolutionary Plant," specifically applies to the ABWR design. By letter dated June 12, 1990, GE previded a comparison of the ALWR RD, Volume II, and the ABWR SSAR. The EPRI requirements pertaining to the I\&C systems are contained primarily in Chapter 10 of Volume II of the ALWR RD, "Man-Machine Interface Systems." GE concluded in their letter that a detailed comparison of the ABWR SSAR to the many ALWR RD requirements showed that the $A B W R$ complied with all but a few of the EPRI ALWR requirements.
GE did not document its detailed comparison, nor did the staff compare the EPRI's requirements to the entire ABWR design for applicability. In addition, there are many requirements in the ALWR RD without any corresponding references to published standards. There are also many requirements in the ALWR RD which allow vendor different options for implementation in a design, or provide a caveat that the requirement should be implemented to the extent practical. In August 1992, the staff issued the final safety evaluation report for the 
Volume II of the ALWR RD, and requeded the $O B$ clearly document in detail how the ABWR deaign differe from that in the ALWR RD and also how it complies with BPRI's requirements. This was identified as DRSER Open Item 1.1-1. The resolution of this iaves is dencribed in Section 1.1 of this report.

\subsubsection{Additional Criteria}

Table 7.2 of this report lists criteria and etendards discuseed in the ABWR SSAR but are not included in the SRP criteria in Table 7.1 of this report. Howover, como of the etandards in Table 7.2 are refereaced in atundards included in Table 7.1 and, therefore, could be considered 28 part of the SRP listings. They are liated in Table 7.2 for convenience and completeness. Table 7.2 also includen the standards and criteria which GE has committod to uve since the DSER was iscued to addrese the new technology issues not addressed in the SRP. Some of these items are included in SRP chapters other then Chapter 7. Additional comments regarding use of future standards to accommodate changing I\&C digital technology are discussed elsowhero in this chapter.

ABWR SSAR Table 7.1-2, "Regulatory Requiremente Applicability Matrix for I\&C Syetems," liets the ABWR I\&C systems and the requirements which apply to each system. The safety system logic and control (SSLC) and escential multiplexing system (EMS) are not explicithy defined in SSAR Table 7.1-2. The staff noted that GE has defined the "reactor protection (trip) system (RPS)" as a system that provides sensor signals and reactor trip outputs, and that uses the SSLC as the means for implementing trip logic. The SSLC in turn uses the EMS as the means for interfacing with sensors and sctuatod equipment except where the devices are hardwired. Since the commitment to the SRP standards and criteria as shown in SSAR Table 7.1-2 includes the SSLC and EMS, the staff finds the commitment acceptable.

In the DSER, the staff determined that SSAR Table 7.1-2 provides commitments to the acceptance criteria prescribed by the SRP with one exception. The table in the SSAR did not include an explicit commitment to GDC 1, "Quality Standards and Records," of 10 CFR Part 50. Although GDC 1 was addreseed in Chapter 3 of the SSAR, the staff believed that an explicit commitment should be provided in Chapter 7 and identified this as an open issue in the DSER (Open Item 5). Specifically, GDC 1 requires that systems and components important to safety be designed, fabricated, and tested to quality standards commensurate with the importance of the eafety functions to bo performed. In addition, this criterion also requires that $G B$ identify and ovaluato applicability, edequacy, and mufficiency of generally recognized codes and atendards.

In the DSER, the etaff concluded that scceptance criteria for softwero-bened digital I\&C aystems were not addreaced in sufficient detail by the regulatory positions and tho induntry atudande rofereaced by GE in the SSAR at the timo the DSER was written. No standards were identified regarding electromagnetic compatibility (BMC), multiplex or architecture, communications protocols, and coftware decign. GB has since committed to induetry atendards listed in SSAR Appendix 7A for thees areas, and the ataff concludes that the ABWR design conform with GDC 1 in that GE has committed to use the appropriate induetry atandards for the type of equipment to be used in the implementing the design. Therefore, this open issue is reeolved.

SRP Appendix 7-B, "General Agenda, Station Site Visits," includes the following statement:

An important part of the reviow at the operating license atage is a site visit. It is preferable to have the site visit sometimo before the completion of the drawing roview. The purpose of the site visit is to supplement the reviow of the design based on the drawings and to evaluate the actual implementation of the design as installed at the site. The NRC Regional Office having jurisdiction over the plant under consideration should be notified ahead of time of the visit so that the regional inspectors can become familiar on a first-hand basis with findings that may require followup action. Since proper implementation of design is the ultimate goal of the tochnical review process, the importance of a site visit is self-evident.

SRP Appendix 7-B provides a general agenda for the station site visit which includes verification of layouts, separation and isolation, test features and potential for damage due to fire and flooding, or other environmental offects. Because the design certification will be issued prior to the selection of a construction site, this SRP reviow item cannot be completed at this time. The method to be used to address the necessary inspection tasks for design certification will be addressed through the ITAAC process and commitments to preoperational tests described in SSAR Chapter 14. The reviow described in SRP Appendix 7-B will be accomplished as part of the testing done for the combined license (COL). 
Table 7.2 Chapter 7 Additional Requirements

\begin{tabular}{|c|c|c|c|c|c|c|c|c|c|c|c|c|}
\hline \multirow{2}{*}{$\begin{array}{l}\text { CRITERIA/ } \\
\text { STANDARD }\end{array}$} & \multicolumn{12}{|c|}{ ABUR SSAR Chapter 7} \\
\hline & 7.1 & 7.2 & 7.3 & 7.4 & 7.5 & 7.6 & 7.7 & 7.8 & $7 . A$ & 7.8 & $7 . c$ & RAI \\
\hline $\begin{array}{ll}\text { GDC } & 12 \\
\text { GDC } & 17 \\
\text { GDC } & 18 \\
\text { GDC } & 54 \\
\text { GDC } & 55 \\
\text { GDC } & 56 \\
\text { GDC } & 57 \\
\text { RG } & 1.26 \\
\text { RG } & 1.28 \\
\text { RG } & 1.30 \\
\text { RG } & 1.32 \\
\text { RG } & 1.38 \\
\text { RG } & 1.58 \\
\text { RG } & 1.64 \\
\text { RG } & 1.70 \\
\text { RG } & 1.74 \\
\text { RG } & 1.88 \\
\text { RG } & 1.100 \\
\text { RG } & 1.123 \\
\text { RG } & 1.144 \\
\text { RG } & 1.146 \\
\text { RG } & 1.152 \\
\text { RG } & 1.153 \\
\text { IEC } & 801-2 \\
\text { IEC } & 880 \\
\text { IEEE } & 344 \\
\text { IEEE } & 352 \\
\text { IEEE } & 472 \\
\text { IEEE } & 518 \\
\text { IEEE } & 603 \\
\text { IEEE } & 730 \\
\text { IEEE } & 7-4.3 .2 \\
\text { IEEE } 802.2 \\
\text { IEEE } 802.5 \\
\text { IEEE } 828 \\
\text { IEEE } & 829 \\
\text { IEEE } & 830 \\
\text { IEEE } & 1012 \\
\text { IEEE } & 1033 \\
\text { IEEE } & 1042 \\
\text { IEEE } & 1228 \\
\text { NEMA } & 4 \\
\text { ASME } & \text { NQA } \\
\text { NEDO } & 24708 \\
\text { NEDC } & 31336 \\
\text { NEDO } & 31439\end{array}$ & $\begin{array}{l}x \\
x \\
x \\
x \\
x \\
x \\
x \\
x \\
x \\
x \\
x \\
x \\
x \\
x \\
x \\
x \\
x \\
x \\
x \\
x \\
x \\
x \\
x \\
x \\
x \\
x \\
x \\
x \\
x \\
x\end{array}$ & $\begin{array}{l}x \\
x \\
x \\
x \\
x \\
x \\
x \\
x \\
x \\
x \\
x \\
x \\
x \\
x \\
x \\
x \\
x \\
x \\
x \\
x \\
x \\
x \\
x \\
x \\
x \\
x \\
x \\
x \\
x \\
x \\
x \\
x\end{array}$ & $\begin{array}{l}x \\
x \\
x \\
x \\
x \\
x \\
x \\
x \\
x \\
x \\
x \\
x \\
x \\
x \\
\\
x \\
x \\
x \\
x \\
x \\
x \\
x \\
x \\
x \\
x \\
x \\
x \\
x \\
x\end{array}$ & $\begin{array}{l}x \\
x \\
x \\
x \\
x \\
x \\
x \\
1 \\
x \\
x \\
x \\
x \\
x \\
x \\
x \\
x \\
x \\
x \\
x \\
x \\
x \\
x \\
x \\
x \\
x \\
x \\
x \\
x \\
x \\
x \\
x\end{array}$ & $\begin{array}{l}x \\
x \\
x \\
x \\
x \\
x \\
x \\
x \\
x \\
x \\
x \\
x \\
x \\
x \\
x \\
x \\
x \\
x \\
x \\
x \\
x \\
x \\
x \\
x \\
x \\
x \\
x \\
x \\
x \\
x \\
x \\
x \\
x \\
x \\
x \\
x \\
x\end{array}$ & $\begin{array}{l} \\
x \\
x \\
x \\
x \\
x \\
x \\
x \\
x \\
x \\
x \\
x \\
x \\
x \\
x \\
x \\
x \\
x \\
x \\
x \\
x \\
x \\
x \\
x \\
x \\
x \\
x \\
x\end{array}$ & $x$ & $x$ & $\begin{array}{l}x \\
x \\
x \\
x \\
x \\
x \\
x \\
x \\
x \\
x \\
x \\
\\
x \\
x \\
x\end{array}$ & $\begin{array}{l}x \\
x \\
x \\
x \\
x \\
x \\
x \\
x\end{array}$ & & $\begin{array}{l}x \\
x \\
x \\
x \\
x \\
x \\
x \\
x \\
x \\
x \\
x \\
x \\
x\end{array}$ \\
\hline
\end{tabular}


Table 7.2 Chapter 7 Additional Requirements (continued)

\begin{tabular}{|c|c|c|c|c|c|c|c|c|c|c|c|c|}
\hline \multirow{2}{*}{$\begin{array}{l}\text { CRITERIA/ } \\
\text { STANDARD }\end{array}$} & \multicolumn{12}{|c|}{ ABWR SSAR Chapter 7} \\
\hline & 7.1 & 7.2 & 7.3 & 7.4 & 7.5 & 7.6 & 7.7 & 7.8 & 7.A & 7.8 & 7.C & RAI \\
\hline $\begin{array}{l}\text { NEDE } 31906 \\
\text { ANS } 4.5 \\
\text { NUREG } 0493 \\
\text { NUREG } 0588 \\
\text { NUREG CR3453 } \\
\text { NUREG }-0308 \\
\text { NUREG }-0491 \\
\text { ISA } 67.04 \\
\text { IOCFR21 } \\
\text { MIL HDBK } 251 \\
\text { MIL HDBK } 217 \text { E } \\
\text { MIL STD } 2167 \\
\text { MIL STD } 461 \text { C } \\
\text { MIL STD } 462 \\
\text { IOCFR50.46 } \\
\text { IOCFR50.49 } \\
\text { IOCFR50.62 } \\
\text { GL } 83-08 \\
\text { GL } 84-23 \\
\text { ISO } 7498 \\
\text { ANSI C37.90.2 } \\
\text { ANSI C62.41 } \\
\text { ANSI C62.45 } \\
\text { ANSI C63.12 } \\
\text { ANSI X3T9.5 }\end{array}$ & $\begin{array}{l}x \\
x \\
x \\
x \\
x \\
x \\
x \\
x \\
x \\
x \\
x\end{array}$ & $\begin{array}{l}x \\
x \\
x \\
x \\
x \\
x \\
x \\
x\end{array}$ & $\begin{array}{l}x \\
x \\
x \\
x \\
x \\
x \\
x \\
x \\
x \\
x\end{array}$ & $\begin{array}{l}x \\
x \\
x \\
x \\
x \\
x \\
x \\
x \\
x\end{array}$ & $\begin{array}{l}x \\
x \\
x \\
x \\
x \\
x \\
x \\
X\end{array}$ & $\begin{array}{l}x \\
x \\
x \\
x \\
x \\
x \\
x \\
x\end{array}$ & $x$ & $x$ & $\begin{array}{l}x \\
X \\
x \\
X \\
X \\
X \\
X\end{array}$ & $\begin{array}{l}x \\
x \\
x \\
x \\
x \\
x \\
x \\
x \\
x \\
x \\
x \\
x \\
x \\
x \\
x \\
x \\
x \\
x\end{array}$ & $x$ & $\begin{array}{l}x \\
x \\
x \\
x \\
x \\
x \\
x \\
x \\
x \\
x \\
x \\
x \\
x \\
x \\
x \\
x \\
x \\
x\end{array}$ \\
\hline
\end{tabular}

Because the ABWR has been submitted for design certification, the requirements of 10 CFR Part 52 apply in addition to those of 10 CFR Part 50. 10 CFR Part 52 requires a level of design detail beyond a simple commitment to conformance with the existing requirements. 10 CFR $52.47(a)(2)$ requires that:

The application must contain a level of design information sufficient to enable the Commission to judge the applicant's proposed means of assuring that construction conforms to the design and to reach a final conclusion on all safety questions associated with the dissign before the certification is granted. The informition submitted for a design certification must incluite performance requirements and design information sufficiently detailed to permit the preparation of acceptance and inspection requirements by the NRC, and procurement specifications and construction and installation specifications by an applicant. The Commission will require, prior to design certification, that information normally contained in certain procurement specifications and construztion and installation specifications be completed and available for audit if such information is necessary for the Commission to make its safety determination.

10 CFR 52.47(b)(1) also states that, ". . . this rule must provide an essentially complete nuclear power plant design except for site-specific elements." The following sections of this report describe the information provided by GE and the staff's conclusions concerning conformance with the SRP criteria, additional criteria necessary to address newer digital I\&C technology, and the above requirements of 10 CFR Part 52. 
In the DSBR, the etaff conoluded thet OB had adequately committed to the SRP requirements but had not provided docign information detailed eacugh for the ataff to conclude that the plant will be built in sccorduace with thom standards. This was identified 25 an open iseve in the DSER. The resolution of this open iseve was beed on a digital IezC syetem deaign procens and the uso of a phemed approech to decien implementation through the ITAAC. In addition, certain rectrictions on changing SSAR commitments have been incorporated to ensure atafi agreameat prior to sny changes to koy details of tho design proceses. This approach formed a cubetantial part of the basis for stafi's scceptance of the I\&C syetem for certification under 10 CFR Part 52.

The CDM describes the baxic deaign procees to be followed during the deaign of the I\&C hardware and software and will include apecific acceptance criteria. The dexign proces CDM will bo in the same format as the syetem CDMs. Tho I\&C syetem deaign process is described below. Additional general information on this appect of the roviow proceses is provided in SECY-92-287, "Form and Content for a Design Certification Rule."

\section{CDM Procees}

The ABWR I\&C systems described in the SSAR lack cubetantial design detail. Therefore, the following descriptions of the process in the SSAR and CDM for development of the detailod design, together with certain SSAR change reetrictions are key features of the final safety determination for the I\&C systpms in this report and are included in the design certification rule for the ABWR. The ataf's audit and approval function following design certification is also a critical feature of the scceptance of the CDM and SSAR deccriptions for the I\&C systems. The etaff proposed in the DFSER that this design procese be deecribed in the appropriate CDM. The CDM has been revised to include the phased development process, however, the staff audit participation is only described in this report.

In the design description section of the CDM, a textual and graphical description of the fundamental characteristics of the various I\&C systems is provided. The CDM includes a summary of the systems and design commitments which will be certified for the life of the plant. The items in the design description cannot be changed over the life of the plant without rulemaking and, therefore, the details of the design which can be changed are not described. The ITAAC section of the CDM provides a general description of the activities that will be performed by the $\mathrm{COL}$ applicant to verify that the $1 \& \mathrm{C}$ system has been built in accordance with the certified design description and commitments. The SSAR provides additional information on the implementation of the design. The SSAR provides additional detail (unlike the CDM) by reference to epecific atandand for the deaigners (COL applicent) to follow. The anf will audit the COL applicant's activitios at appropriato roviow points to enaure that the dotailed deaign is in conformance with the deaign descriptions and ITAAC.

It is premature to complete the final deaign details for the microproceneor and digital control tochnology apecte of the IRC system deaign of the ABWR before the COL is iesued. This is because the technology in this aren is rapidly ovolving and it is, therefore, important that the certified deaign deacription and ITAAC not "lock in" a design which could be obsolete at the time of construction. The appronch that will be used is to "lock in " deaign process and the specific acceptance criteria which, if mot, would reoult in a design which is acceptable. At the same time, the functional system description, commitment to stendards, and commitment to a structured design process in the CDM must be sufficient for the staff to make its final affety determination. This process was deecribed in SECY-92-053, "Use of Design Acceptance Criteria During 10 CFR Part 52 Design Certification Reviews."

The CDM was not submitted by GE as part of the original design certification application. Subsequently, a small group of system design description and ITAAC were submitted as a pilot program in an effort to reach agreement on the general scope of the design description and ITAAC for all systems. The staff reviewed the RPS design description and ITAAC as representative of the I\&C systoms. The staff provided comments whose resolutions were incorporated into the documents. In general, the descriptions and ITAAC that were proposed by GE were not sufficiently detailed or complete for a staff safety finding. Therefore, the staff concluded that it was necessary to roview both the SSAR and the CDM and to require more CDM information in order to reach a safety conclusion. Because the CDM was still under review when the DFSER was issued, the staff identified this as DFSER Open Item 7.1.3.3-1. The CDM has been submitted, reviewed, and found acceptable. The acceptance of the CDM is addressed in Section 14.3 of this report. Therefore, this item is resolved.

GE has not finalized the hardware and software design for the ABWR digital I\&C systems. Therefore, the staff used the two-part approach described in SECY-92-053 to reach its safety finding for design certification. In reviewing the I\&C systems, the first part of this approach involved a detailed functional review at the block diagram level to ensure the applicant has appropriately implemented the Commission's requirements related to postulated single failures, common mode failures, signal isolation, and other 
appects of the ataff' reviow that are typical for any anfotyrelated LeC ayatom, inoluding analog control ayetems auch as those in curreat operating nuclear plants. This roviow confirmod that tho dotailed functional requirements for the IEC aystems are extablished.

The second part of the staff's approach to reach certification enfoty finding addreases the edequacy of the digital control ayetem implementation with respect to the syetem functional requirements. This relies upon a formal deaign implementation process with a phased ITAAC program for doaiga dovelopment within certain predofined constraints and limits.

This report documents the results of the staff' seviow of tho ABWR I\&C systems at the functional block diagram lovel as deecribed above for the firat part of the two-part approesch documented in SECY-92-053.

\section{Centified Desion Material}

Because the CDM and SSAR roviews are interrelated, it is neceseary for the two parts of the review to be considered integrally rather than individually. The following section uses the computer dovelopment process to illustrate the implementation of the CDM and the NRC staff involvement. This process is also used for multiplexor design, setpoint methodology, and BMC and equipment qualification verification.

\section{Computer Development}

The primary function of the computer is to implement the functional I\&C requirements described in the CDM and the SSAR for the ABWR systems. The decomposition of the functional system (SSLC, RPS, ARI, etc.) requirements to specific computer hardware and software components to accomplish the various tasks is accomplishod using the structured design process described below.

The CDM includes the description of the design process to be followed for hardware and software development, design commitments, the ITAAC to be performed, and the appropriate acceptance criteria. The ITAAC for computer hardware and software (included in the I\&C CDM) differs from the majority of the system ITAAC in that the acceptance criteria include accoptance criteria for the certified design process (referred to as design acceptance criteria in SECY-92-053). This ITAAC describes attributes of the process to be used to develop the software as well as attributes of the final software product. The ITAAC for software and hardware (included in the CDM Section 3.4, "Instrumentation and Control") describes several design stages.
The following deaign atages (the software lifecycle) are necenary for the dovelopment and operation of both afoty-rolated and non-anfoty-related softwaro.

(1) planning

(2) requirements

(3) decign

(4) implementation

(5) intogration

(6) validation

(7) Installation

(8) Operation and maintenance

The etaff considers these stages to be neceseary for the dovelopment of a computer system of sufficient quality to adequately perform its design function. The stages are based on generic activities that represent software and system lifecycle models, and encompass existing national standards and input from ongoing offorts in the revisions of national and international standards for computer systems in nuclear power plants, and expert opinion.

GE has rovised the CDM and SSAR to provide a similar lifecycle definition but solected the following categories:
(1) planning
(2) design definition
(3) software design
(4) software coding
(5) integration
(6) validation
(7) change control

The CDM and SSAR contain criteria which describe the method to develop plans and procedures that will guide the design process throughout the lifecycle stages. The ITAAC provides the acceptance criteria for verifying the design through the stages, while the SSAR adds the set of guidelines and standards that will provide more detailed criteria for the development of the design process. The CDM has been written to encompass the most important aspects from the standards. The SSAR set of standards and criteria encompass the guidance that will be used to start the computer software and hardware design process by generating the plans for the computer design throughout the lifecycle. Therefore, the staff concludes that these stages are accoptable for the development and operation of safety-related and non-safety-related computer systems.

The software QA (SQA) plan describes the softwarespecific activities that are to be performed and controlled in addition to the approved QA plan (in accordance with Appendix B of 10 CFR Part 50, "Quality Assurance Criteria for Nuclear Power Plants and Fuel Reprocessing Plants") for the total ABWR design. The SQA plan 
eatablishes the criteria under which the other coftware development plens will bo senernted. The DFSER ideatified the following documents which are typical of a coftware dovelopmeat program.

- The coftwere management plan (SMP) eatabliches the organization and authority structure for the decigm, the procedures to be used, and the interrelationships between major activitien.

- The coftwaro configuration management plen (CMP) provides the means to ideatify coftware products, control and implement changes, and record and report change implementation atatus.

- The software dovelopment plan deecribes dovelopment process, tool documentation, and products doveloped according to the software lifecycle.

- The verification and validation (V\&V) plan deacribes the mothod to ensure that the requirements of each phase or atage are fully and accurately implemented in the next phese.

- The softwaro afoty plan describes the eafoty and hazards analyses that will bo performed.

- The software operation and maintenance plan (SOMP) includes the procedures required to ensure that the software will be operated correctly and that the quality of the software is maintained.

GE combined these plans into an SMP, a CMP, and a V\&V plan. The NRC will perform audits and inspections of these plans and their implementation at each appropriate phase or stage of the lifecycle.

The ITAAC activities completed by the COL applicant will be inspected by the NRC to verify conformance with the requirements at several stages during the digital control system design process. The documents which demonstrate satisfactory implementation of the ITAAC will be available for inspection during the NRC audit at the completion of each of the above stages. Figure 7.1-1 (from Section 3.4 of the CDM) of this report shows the stages or phases described by GE. The stages described in the DFSER, including the Figure 7.1-2 shows the stages described in the DFSER, including the NRC audit and the COL applicant conformance review points. These stages correspond closely with the phases described by GE in the CDM. The actual stages, including the conformance review and audit points, will be determined for each of the coftware products to be developed when the deaiza implementation is cehoduled to begin. The COL applicant is required to atiofictorily complete ITAAC activities at each atage prior to prosceding to the next atage of the deaign dovelopment proceses. Failure to mecenefully complete the ITAAC at a atage, 2 dotermined by the conformance reviow or the NRC audit, may require repenting an carlier atage ITAAC and/or changing the system design. The NRC staff will iscue an inspection report for cach etage ITAAC and will identify any open isoves which require resolution. Significant open ieswes which are not remolved could reault in the NRC staff conciuding that the ITAAC has not been satisfactorily completed.

At each atage, the COL applicant must verify that the deaign dovelopment is in accordance with the certified deaign process and that the detailed design developed (through that stage) is in conformance with the certified design. Upon completion of ITAAC activities for each stage, the COL applicent will certify to the NRC that the stage has been completed and the design and construction completed up through that stage is in compliance with the certified design.

Certain ITAAC, such as those for software development, will be repeated for ali the products which use software. All of the products to be verified by the ITAAC process must be complete before the ITAAC itself is complete. The COL applicant will also provide a description of the next stage of design development and associated testing, analysis, and acceptance criteria in enough detail that the NRC staff can determine whether or not the proposed design development and testing are consistent with the certified design process and the subsequent ITAAC. This phased process will continue until all ITAAC steps for all the safety-related software are complete.

The certified design description and design development process will continue for the lifetime of the plant. Any safety-related software that is changed or added after plant startup is required to either be developed using the certified design development process described in the CDM, or the applicant must submit a design process (together with the design bases) description that will produce software of the same or higher quality than the original certified design process. The applicant will be required to use the approved soft-ware change procedure besed upon the certified design development process for the operation stage of the lifecycle. The method of incorporating software changes will be consistent with the SSAR chango limitations defined in this report. 


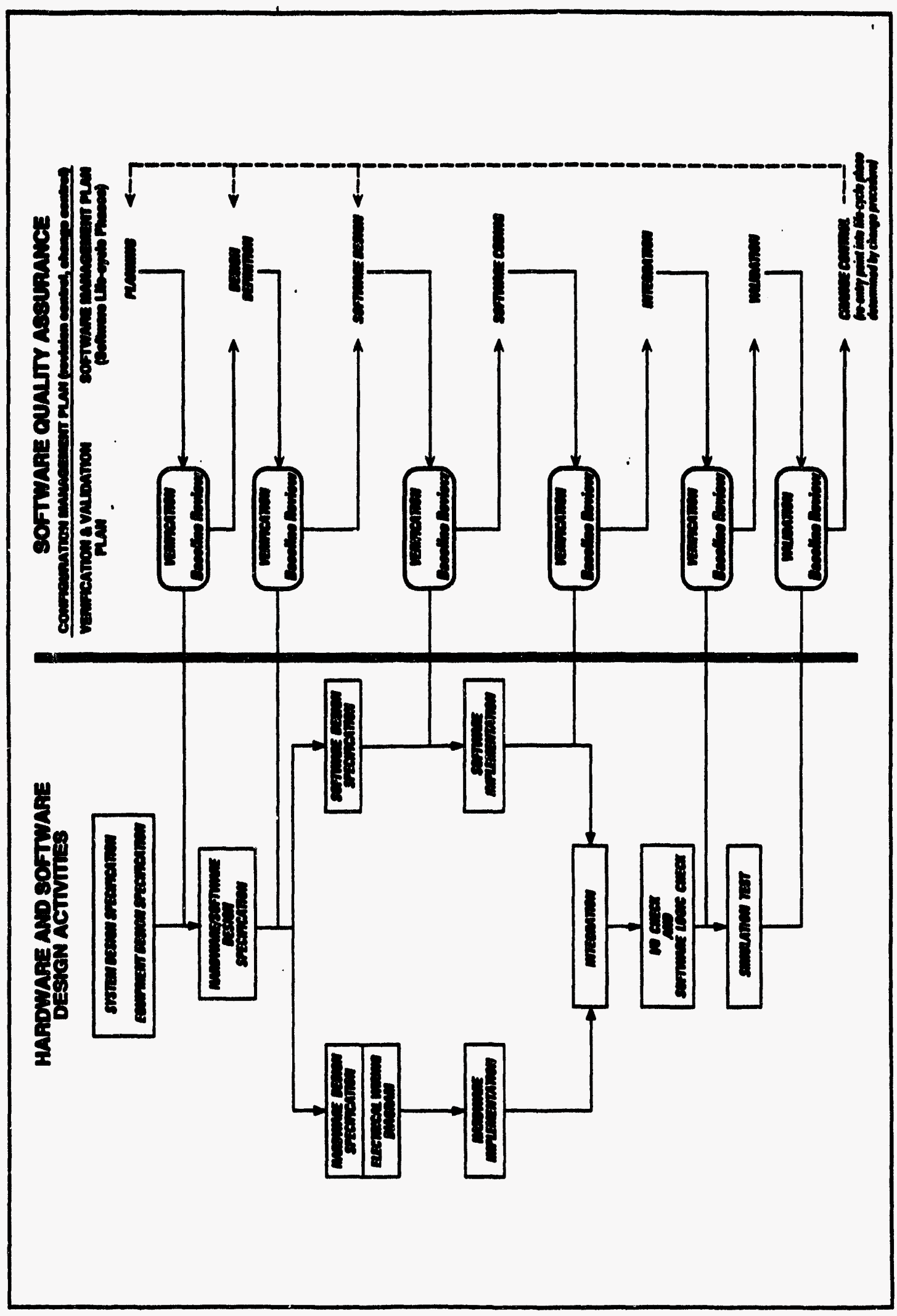

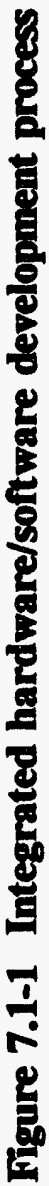


upny euemulos
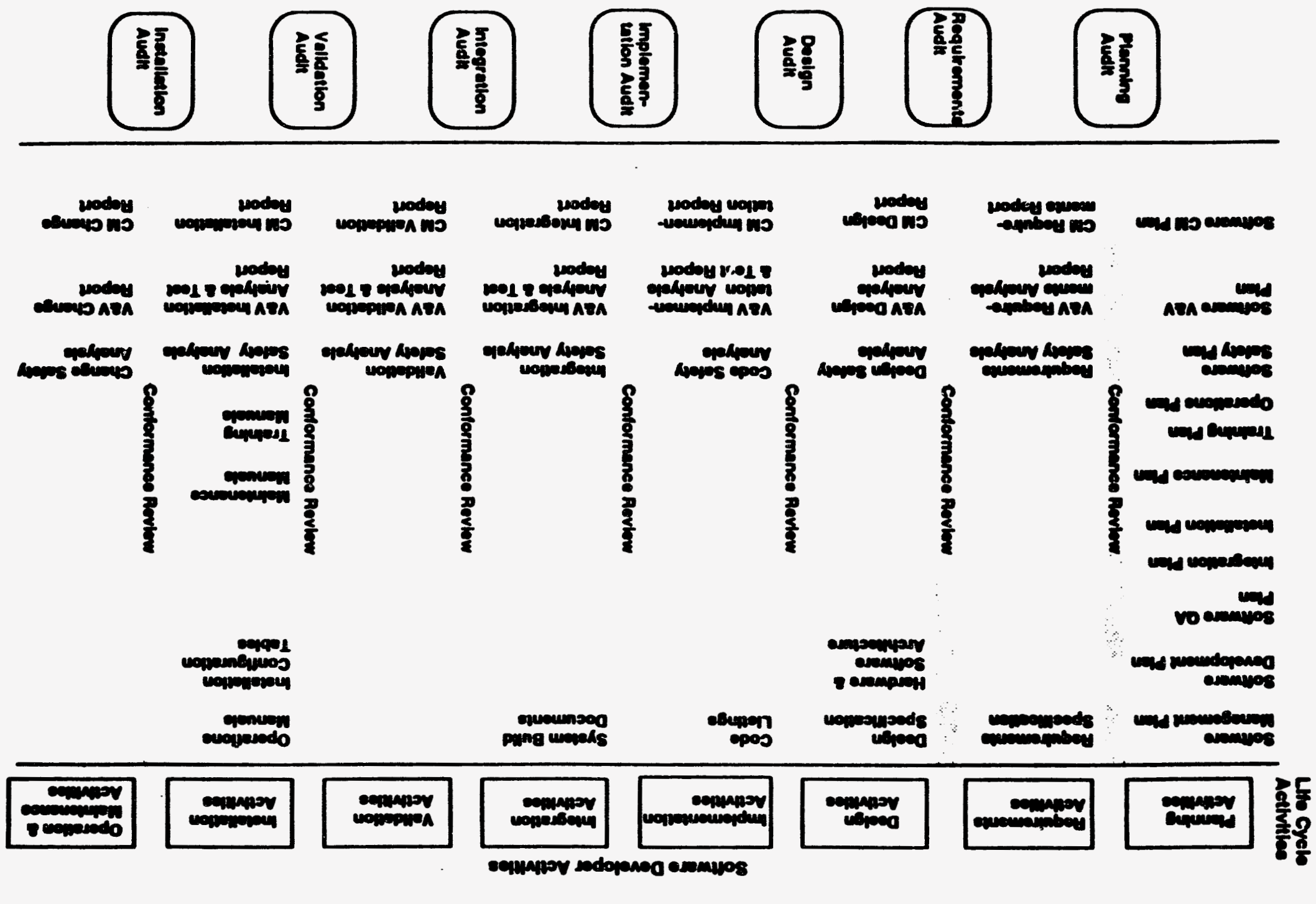
The commitments described in the SSAR and related (docketed) documents provide acceptable mothods and descriptions of the implementation of the CDM. The determination that the plant has been constructed in accordance with the CDM will require the use of the more detailed information contained in the SSAR and the documents which will be produced during the design phases. The SSAR commitments are besed on postulations of how the design will be implemented which may change when detailed design begins. Therefore, some of the SSAR commitments may be changed. The acceptance of the ABWR design is based upon assumptions by the staff that the criteria that have been accepted will still be the proper criteria when the design is implemented. If a significant change in design process is selected by the design implementer, it may be appropriate to select different standards. Changes to SSAR commitments that affect the technical design of the I\&C systems, including the design process, design implementation, and the NRC staff review as described in this report, must be submitted to the NRC for review prior to implementation. The majority of the SSAR material may be revised through a "50.59-like process" as described in SECY-92-287. This report specifically identifies those areas which must be reviewed by the staff prior to change by a licensee. The areas that the staff has determined must be submitted for reviow of proposed changes include computer design (hardware and software), multiplexor design, setpoint methodology, and EMC. These areas are designated with the following statement:

Any changes to this commitment would involve an unreviewed safety question and, therefore, require NRC review and acceptance prior to implementation. Any requested changes to this commitment shall either be specifically described in the $\mathrm{COL}$ application or submitted for license amendment after $\mathrm{COL}$ issuance.

The process to be used for software development and implementation is in compliance with the specified industry standards governing those activities (Tables 7.1-1 and 7.1-2), the requirements of 10 CFR Part 50, Appendix B, QA program for I\&C systems and the requirements listed in CDM 3.4. In particular, the vendor implementation and the NRC evaluation of the safetyrelated software QA program is accomplished under a 10 CFR Part 50, Appendix B, QA program.

Based on the additional commitments to standards in the SSAR, increased level of design detail in the design description submitted, and the use of ITAACs (including NRC inspections at various stages) to allow design detail to be developed after design certification, the DSER open issue on level of detail for digital I\&C system design is resolved.

\section{Prototyping}

In diccussing the level-of-detail open issue in the DSER (Open Item 1), the staff stated that it expected prototype testing of new technology to confirm expected safety performance would be required to confirm potential systems interactions, and to allow the staff to reach its safety determination on systems which may not have extensive operating experience. Based on the limited design information available for the interconnected RPS, ESF, EMS, and SSLC systems, the staff concluded that prototypes would be needed to demonstrate acceptable performance of these systems.

The term "prototype" has been used in soveral different ways. The staff identified several types of feasibility or demonstration testing that have at times been referred to by various parties, including the NRC, as prototype testing or prototyping. There are probably types other than the ones listed below that could be referred to as prototyping, but the staff believes that the following discussion will serve to clarify the issue of prototyping in the level-of-detail issue. The first example of prototyping, which occurs prior to design certification, is the need for a demonstration of the basic technology, or a demonstration of an example of a possible implementation of the proposed system. An example of this is the GE NUMARC digital equipment product line as a demonstration that microprocessors can be used to perform a function such as neutron monitoring which requires data transmission, comparison to setpoints, and logic decisions similar to the functions that will be required for the $A B W R$ design. The staff considered the previous demonstrations of digital technology and does not require further demonstration of the feasibility of digital implementation of the I\&C design. The staff also does not believe that there is a need to put acceptance criteria into the ITAAC for this prototype point. The design process description and the assessment of proven technology required in the equipment selection process is adequate.

The second example of prototyping occurs during the selection of the equipment vendors. There may be some prototyping to demonstrate capabilities or compatibility of specific hardware selected with the rest of the design. The staff does not believe that this demonstration is necessary to make a safety determination based on the system integration incorporated into the digital system design process.

The third prototyping example (probably at many places along the design implementation process) could include the development of specific system- aspect prototyping. For 
example, this may include breadboarding and testing specific components and different software languages to offectively implement the neutron monitoring algorithms. The staff does not believe that this type of prototyping needs to be described in the ITAAC because the final selected process or component will be assesed under the design process without a need to assess unethods not selected for the design.

The fourth prototyping example could be identified on a typical design process as "perform hardware/software integration testing." The staff has concluded that this is an appropriate point to audit in the design process, and it will be part of the verification of the ITAAC at that stage to demonstrate that the design has been implemented correctly. This point includes a verification of the realtime performance capabilities of the system.

The items incorporated in the ITAAC include the development of the test and evaluation procedures as the design commitment, inspections to verify that the procedures are being used correctly as the inspection activity, and the completion of the testing, documentation of the results, and the feedback of the results to the design process as the acceptance criteria. The staff believes that the inclusion of this prototyping (hardware/software integration testing) in the ITAAC serves two primary purposes. The first is to verify that the design process is being implemented as certified and that the previous requirements have been met. The second is to establish the more detailed acceptance criteria for the next stage of the design process. The staff believes that this prototype needs, as a minimum, one full channel of the SSLC using hardware and software similar to the intended final product to adequately demonstrate that the design process stage has been completed.

The fifth example of prototypind (not usually referred to as prototype) is the final factory acceptance test. Factory acceptance testing will be covered by the ITAAC and has similar requirements to the previous prototype example, except that the test will be with the final software and hardware to be installed in the plant and would include all channels of the I\&C system.

The last prototype example (also not usually referred to as prototype) is the final test and inspection, prior to fuel load, as installed in the plant. This test will be in the ITAAC and the SSAR Chapter 14 preoperational test program. The acceptance criteria will be a successful demonstration that all the original criteria in the design certification have been met.

GE agreed with the use of prototypes as described above and included prototyping in the ITAAC, as previously stated. The required I\&C system testing is described in the ITAAC and SSAR. The COL applicant will also perform a series of tests of the I\&C system following fuel load under 10 CFR Part 50 guidelines that are not included in the ITAAC. Therefore, the issue of prototyping in the level-of-detail open issue (Open Item 1) is resolved.

\subsubsection{Specific Findings}

In DSER Section 7.4.1.2, the staff stated that the standby liquid control system (SLCS) lacked automatic initiation capability. Subsequently, GE added automatic initiation capability to this system and revised SSAR Section 7.4.1.2 to reflect this addition. However, SSAR Section 7.1.1.4.2, SLCS, was not revised to include the automatic initiation feature. Therefore, GE's commitment to revise SSAR Section 7.1.1.4.2 was identified as DFSER Confirmatory Item 7.1.4-1. The automatic initiation feature is also included in the CDM and will be verified during the ITAAC process. GE revised SSAR Section 7.1.1.4.2 to reflect automatic initiation capability for the SLCS. GE has also included this information in the SSAR and the staff finds it to be acceptable. This item is resolved.

In response to NRC Bulletin 88-07 (June 15, 1988), "Power Oscillations in Boiling Water Reactors (BWRs)," GE committed to implement the BWR Owners Group (BWROG) resolution which includes the installation of an Oscillation Power Range Monitor (OPRM) system. This was identified as DFSER Confirmatory Item 7.2.1-2. The SSAR and CDM have been revised to reflect this change and, therefore, this item is resolved. The resolution is discussed further in Sections 7.2.1 and 7.6 of this report.

The CDM for the neutron monitoring system (NMS) (including the OPRM) had not been submitted for review in time for the DFSER and, therefore, the OPRM CDM was DFSER Open Item 7.1.4-1. GE revised the SSAR to incorporate this information; therefore, this item is resolved.

The OPRM had not been included in the draft RPS ABWR TS and, therefore, this was listed as DFSER technical specification (TS) Item 7.1.4-1. The OPRM has since been added to the TS, therefore, this TS item is resolved. The TS is described in Chapter 16 of the SSAR.

SSAR Section 7.1.2.1.6, "Protection System Inservice Testability," described an integrated self-test provision built into the SSLC microprocessors. The SSAR described this feature as "safety associated" rather than "safetyrelated" consistent with the SSLC. The DSER identified this as an open issue (Open Item 7). GE committed to qualify the self-test features as Class 1E (safety-related) for 
microprocessors performing safety functions and has revised the SSAR to reflect this commitment. This DSER open issue is, therefore, resolved.

Based on the above discussion, the staff concludes that $G E$ has proposed an acceptable approach for design certification of the I\&C systems under 10 CFR Part 52. All DSER and DFSER open items specific to the I\&C systems design are resolved.

\subsection{Reactor Protection System}

\subsubsection{General System Description}

The reactor protection system (RPS) is described in Section 7.2 of the SSAR. Certain aspects of the RPS design are also discussed in SSAR Appendices 7A, 7B, and 7C. The RPS is also described in the CDM and is included in the TS. As with the other I\&C systems, the RPS CDM provides the design description and ITAAC for the functional requirements of the RPS. Other CDM sections that also apply include the general I\&C and EMS descriptions. The RPS includes those power sources, sensors, communication links, software/firmware, initiation circuits, logic matrices, bypasses, interlocks, racks, panels and control boards, and actuation and actuated devices that are required to initiate a reactor trip. The RPS is designed to automatically initiate the rapid insertion of the control rods of the reactivity control system to ensure that the specified acceptable fuel design limits are not exceeded. Manual initiation is also provided. The RPS also provides status information to the operator and status and control signals to other systems and annunciators. The RPS is qualified as a Class 1E safety system and will be environmentally and seismically qualified. The alternate rod insertion (ARI) capability via the fine motion rod control drive is discussed in Section 7.4 of this report.

The RPS is an open loop system with no feedback control other than operator initiation in response to display indication. The RPS performs four major functions: sense, command, execute, and display. At this highest level functional description, the ABWR RPS is similar to that previously reviewed and accepted for the GESSAR II design. The primary differences in the I\&C portion of the ABWR design are: (1) the technology of the digital microprocessor-based logic and multiplexed data communications systems which is now used for most of the I\&C design, and (2) the sharing of equipment for logic and display functions with other safety systems. A representation of the RPS configuration is provided in Figure 7.2-1 of this report for reference.

The RPS is implemented in the ABWR using the SSLC system which is also shared with the main steamline
(MSL) isolation valves (MSIV) and the engineered safety feature (ESF) systems. ESF systems which will share the SSLC are:

(1) neutron monitoring system

(2) process radiation monitoring (PRM) system

(3) nuclear boiler system (NBS)

(4) leak detection and isolation system (LDS)

(5) residual heat removal (RHR) system

(6) reactor core isolation cooling (RCIC) system

(7) high-pressure core flooder system

(8) reactor building cooling water

(9) reactor service water (RSW)

(10) HVAC emergency cooling water

(11) diesel generator

(12) electrical power distribution system

(13) standby gas treatment system (SGTS)

(14) atmospheric control system

(15) safety-related heating, ventilation, and air conditioning (HVAC)

(16) suppression pool temperature monitoring (SPTM) system

(17) automatic depressurization subsystem

(18) high-pressure nitrogen gas supply

(19) fuel pool cooling and cleanup

(20) radioactive drain transfer system

(21) flammability control system

The following descriptions generally apply to the above ESF systems and the RPS. Differences are discussed in the ESF system Section 7.3 and other applicable sections of this report.

The SSLC is included in the I\&C CDM. Figure 7.2-2 of this report is a representation of the SSLC logic and control block diagram (from the CDM) which shows the interconnection of the RPS and ESF systems. The figure also shows the inherent interrelationship with the EMS. Specific components and attributes of the SSLC are discussed in the following sections of this report.

The first primary function of the RPS is to sense the condition of certain parameters of the plant and provide accurate information to the command (comparison and calculation) section of the RPS, which in turn will initiate the execution of a reactor trip (scram) when the predetermined conditions have been met. The RPS will initiate a reactor scram when any one of the following conditions occur: neutron monitoring system conditions exceed acceptable limits

high reactor pressure

low reactor water level (level 3)

high drywell pressure 


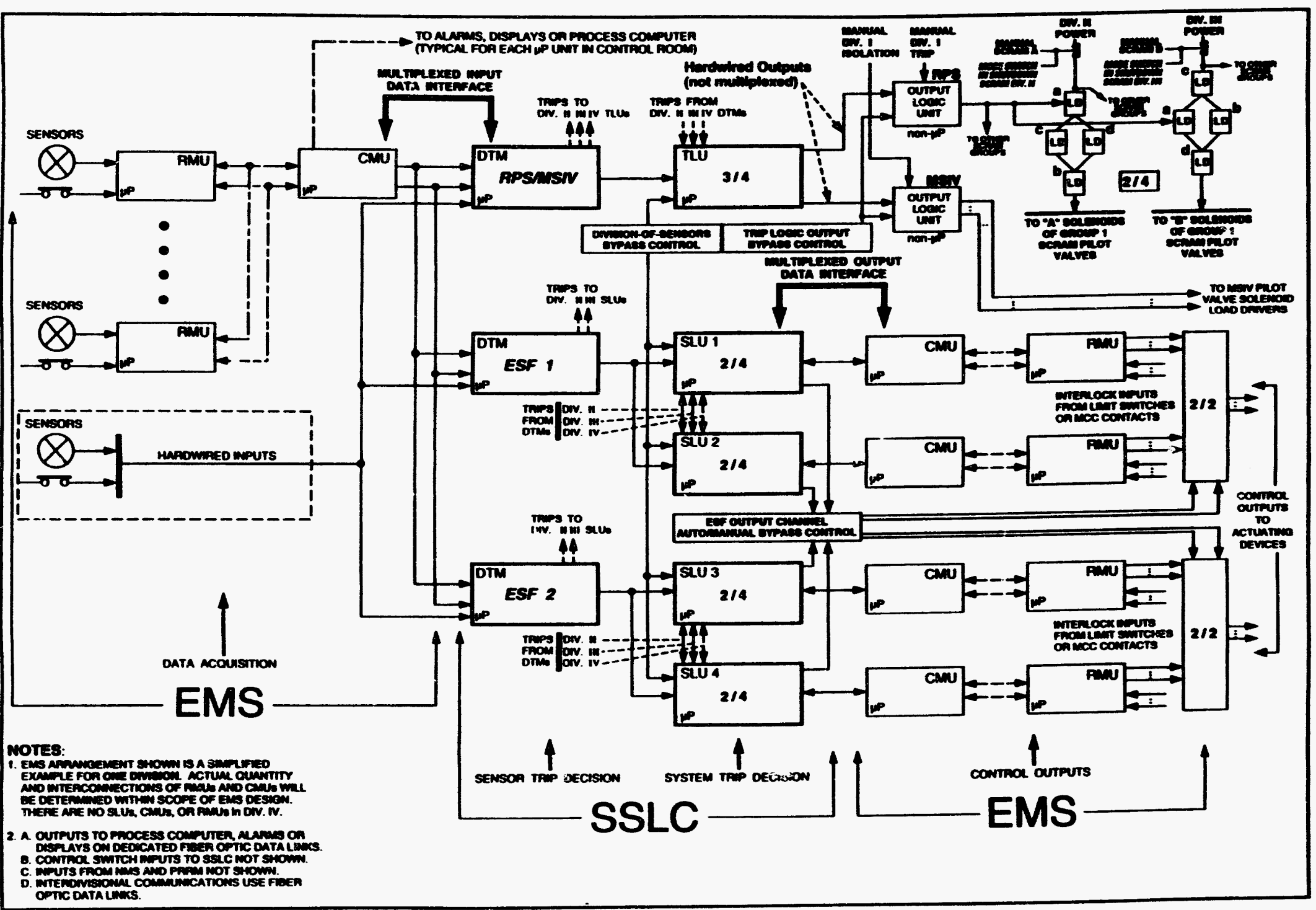


(5) MSL isolation

(6) low control rod drive (CRD) charging header pressure

(7) high MSL radiation

(8) turbine stop valve closed

(9) turbine control valve fast closure

(10) operator initiated manual scram

(11) high suppression pool temperature

The specific setpoints at which a reactor trip decision js reached are discussed in the setpoint (Section 7.2.7) and TS (Section 7.11) sections of this report. The setpoint methodology is also included as a part of the I\&C CDM and SSAR Appendix 7B. The specific setpoints to be used for plant operation will be determined and verified using a structured process described in the CDM after design certification but prior to reactor fuel load.

SSAR Section 7.2.1.1.4.2 lists the initiating RPS circuits. When the DFSER was prepared, the SSAR list included most of the above listed items plus a reactor scrum on high seismic activity. GE has stated that this latter item was inadvertently included and would be deleted. This is acceptable to the staff and was identified as DFSER Confirmatory Item 7.2.1-1. The SSAR figures and several additional textual sections throughout SSAR Section 7.2 have been revised to reflect the removal of the seismic trip. This confirmatory item is resolved.

The high suppression pool temperature trip was added as an RPS signal after the DFSER was issued.

The NMS will provide separate, isolated, bistable startup range neutron monitor (SRNM) trip and average power range monitor (APRM) trip signals to all four divisions of RPS trip logics. The NMS provides trip signals directly to the divisional trip logic units (TLU). The NMS does not use the EMS to transmit its data. The NMS will also not use the digital trip modules (DTMs) for the determinstion of tripped or non-tripped status, but will perform that function within the NMS modules themselves.

The NMS provides trip signals and information from the SRNM and power range neutron monitor (PRNM). The PRNM includes both the local power range monitor (LPRM) and the APRM. The NMS monitors neutron flux from a source range of $1 . \mathrm{E}+3 \mathrm{nv}$ to 125 percent of rated power. Trip signals will be provided for SRNM upscale, SRNM short period, SRNM and APRM inoperative, APRM rapid flow decrease (reactor internal pump trip), and APRM upscale (flux and thermal power).

The staff determined that the SSAR includes commitments for compliance with IEEE 279-1971 for the NMS. In addition, in response to NRC Bulletin 88-07, "Power
Oscillations in Boiling Water Reactors," GE committed to implementing the BWROG resolution by incorporating an OPRM system in the ABWR design. This was DFSER Confirmatory Item 7.2.1-2. The OPRM has been added to the ABWR SSAR, and therefore, this item is resolved. The NMS (and the OPRM) is described in more detail in Section 7.6 of this report.

The second primary functions of the RPS is the command function, which is implemented using the logic of the SSLC. The RPS automatically initiates rapid insertion of the control rods to scram the reactor when warranted by any one of the predetermined conditions (listed above). The scram is initiated by means of four redundant divisions of sensor channels, trip logic, and trip actuators, and two divisions of manual scram controls and scram logic circuitry. In most instances, the EMS (described in Section 7.2.2.1 of this report) encodes the analog sensor channel output signal or contact position into a digital message, then transmits the message through an optical data link to a central decoder, which presents the signal to the DTM. In this manner, the EMS transmits data to the DTM (described in Section 7.2.2.2 of this report) from the reactor pressure transducer, reactor water level (Level 3) transducer, drywell pressure transducer, and CRD charging header pressure transducer. One exception to this EMS-to-DTM pathway is the manual scram, which bypasses both the EMS and DTM, since it is hardwired from the main control panel directly to the output logic unit (OLU). Other exceptions include the main steam isolation valve position switches, which are hardwired to the DTM, as are the MSL radiation monitors, turbine stop valve closure sensors, and turbine control valve fast closure sensor. Signals from these sensors are transmitted directly to the DTM, without passing through the EMS. However, the SSAR text and figures originally stated that the turbine inputs were multiplexed. This was DFSER Confirmatory Item 7.2.1-3. GE revised the SSAR to state which sensor inputs use the EMS and which are hardwired. The revised SSAR states that the turbine inputs are hardwired. This item is, therefore, resolved.

The DTM compares the sensor data (either received directly from the sensor or through the EMS) to a preestablished setpoint and determines if the individual sensor is in a tripped or non-tripped state. The data link between the sensors and the DTM is a fiber distributed data interface (FDDI), a bi-directional, fiber optic link in which two redundant token ring networks provide the data path protocols. Each sensor input is multiplexed through each of the two links so that the loss of a single direction of an EMS link will not prevent the SSLC from receiving the sensor information. 


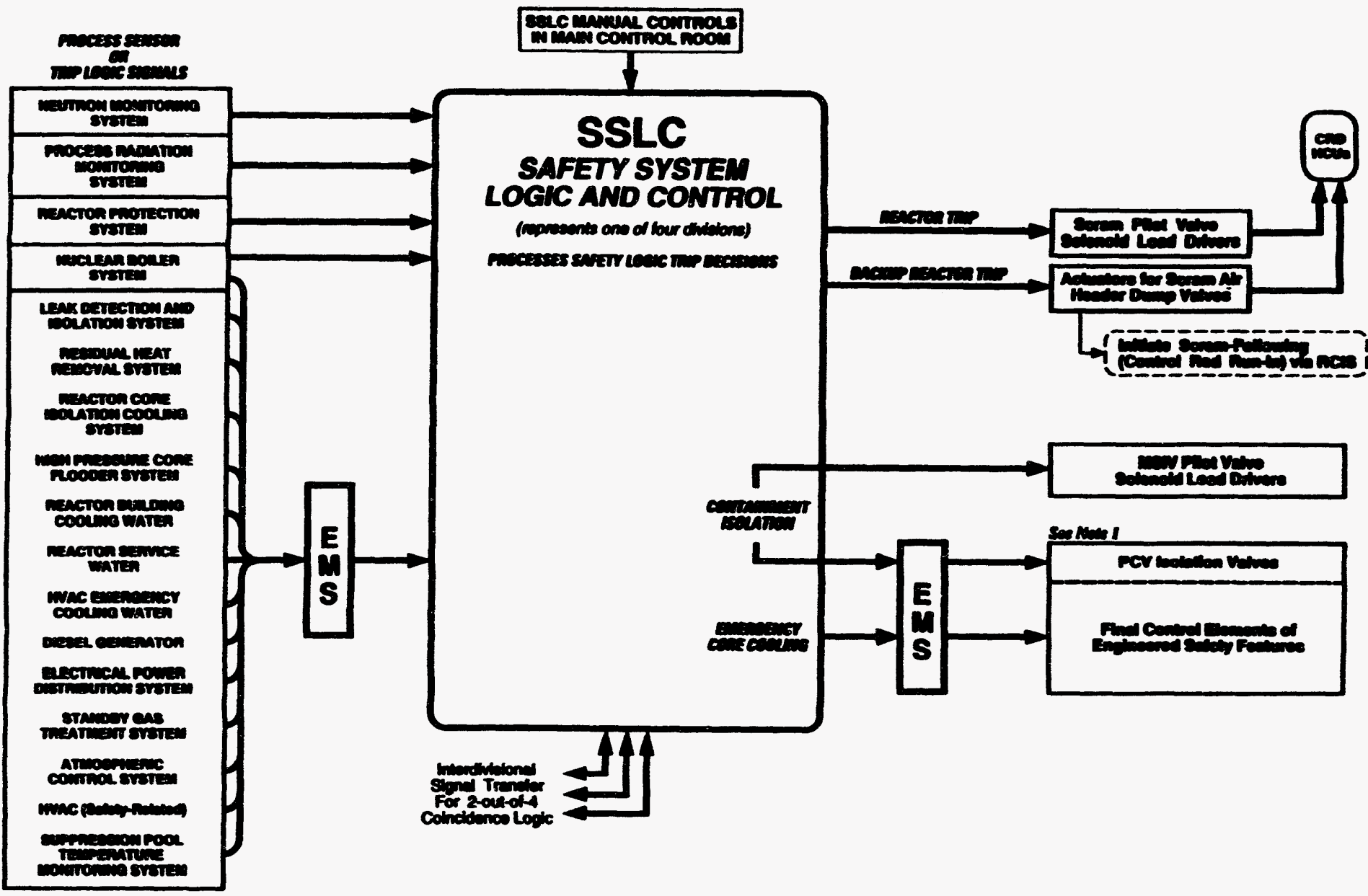

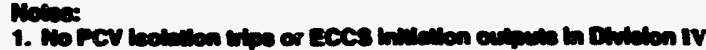

Figure 7.2-2 Safety system logic and control (SSLC) control interface diagram 
The RPS is a four division syctem where each panmeter is monitored by four sensor channele, one in each division. GE defined "sensor channel" in the TS as sensor, data acquisition, and data transmission hardware and software to the input of a bistabie or voter in the TLU or safety system logic unit (SLU). A division of sensor channols is the total set of sensor channels which are input to the SSLC for the RPS, MSIV actuation and ESF. Bach division of sensor channels is powered from the reepective Class 1E power supply. Unless otherwise specified, a "division" of RPS (or MSIV or ESF) is the set of sensor channels, the logic channel, and output channel which are powered from the same division of electrical power. This definition of division also specifies physical and electrical separation. To ensure consistency, a "logic channel" is defined as the hardware and software that process the sensor channel inputs to produce an identifiable actuation signal within a division.

Certain sensed parameters have more than the four individual division sensors which would provide one signal per logic per channel input. The SRNM, for example, has ten channels which feed into the four RPS logic channels (three each to Divisions I and III and two each to Divisions II and IV). The MSIV position and turbine control valve fast closure each provide eight logic channel inputs.

Trip signals from the four channels of DTMs (and the NMS input) form four two-out-of-four coincidence logic matrices, one for each division of trip logis. A trip output from a DTM will also indicate the parameter which has exceeded its setpoint. If the parameter is the NMS, the indication to the operator will be that the trip was caused by the NMS without specifying the particular aspect within the NMS which caused the trip. The two-out-of-four comparison is accomplished in the TLU and the voting is done by local coincidence logic which requires the two tripped signal inputs to be from the same parameter. Because the RPS is designed to be fail-safe, the actual implementation of the logic is three-out-of-four channels not tripped. The TLU is described in Section 7.2.2.3 of this report. Trip signals from each division TLU go to the RPS OLU where a hard logic (not software/firmware) unit (similar in concept to the GESSAR II design) interconnects the divisional two-out-of-four TLU trip signals to the control rod scram pilot valves. The OLU is described in Section 7.2.2.4 of this report. Each final scram logic provides four output signals, each of which operates a load driver. A scram occurs when two or more divisions of TLUs are tripped. The two-out-of-four vote will occur twice -- once in a vote of sensor parameters in each TLU and again in a vote of RPS division output logic at the load drivers.
The RPS interfeces with the CRDs through its own pair of solenoid scrum pilot valves to perform the "executo" function. There are two scram valves for each CRD. A rod scrum is initiated when both (two-out-of-two) solenoids of a scram pilot valvo are do-energized. When docaergized, the scram pilot valve vents the air that holds the scrum valve closed. Opening of the scram valve allows the presecurized (at greater than RCS pressure) control rod water to act on the CRD piston resulting in the rapid insertion of the rods. With this arrangement, a scram of all rods is initiated if any two (or more) of the four divisional logics (TLUs) are tripped.

The OLU output is used as an input to two backup scram logic circuits. The backup scram is an energize-to-scram logic arrangement. The backup scram logic is $125 \mathrm{Vdc}$ powered rather than the de-energize to scram $120 \mathrm{Vac}$ power of the scram pilot valves discussed above. When the relays for the backup logic are tripped, the relay contacts will energize the air header dump valve solenoids and initiate the scram. This is a diverse means of reactor scram.

The ARI can also automatically (and manually) insert the control rods by means of the fine motion control rods or the ARI scram valves in case of off-normal conditions and is discussed in Section 7.4 of this report. The SLCS can also automatically (and manually) shut down the reactor and is discussed in Section 7.4.1.2 of this report.

For manual scram, four push-button switches are provided, one for each divisional trip logic. Additionally, hardwired manual scram is provided by two pushbuttons in the power supply circuits for the pilot scram solenoids. Actuation of any two (or more) of the four divisional switches or both hardwired manual scram pushbuttons will scram the reactor by means of the load drivers for eutomatic scram. The reactor can also be scrammed by setting the mode switch to the "shutdown" position. These provisions in the RPS design for manually scramming the reactor conform with the requirements of IEEE-279 and the guidelines of RG 1.62 on manual initiation of protective actions.

The display function of the RPS will be accomplished with a combination of Class 1E fixed mimic displays and Class 1E divisional visual display units (VDUs). SSAR Table 18F-1 (also 18F-2 and 3), "Inventory of Controls (displays and alarms) based upon the ABWR EPGs and PRA, " provides a listing of the inventory of controls and displays required to execute all emergency procedure guideline (EPG) steps, the alarms required to alert the operator to perform the steps, and the displays to judge that the actions have been initiated or accomplished. The human factors aspects of the controls and displays, and the staff conclusions are addressed in SSAR Chapter 18 and 
the corresponding section of this report. There are also RPS inputs to tho non-Class 1E plant computer through isolation devices.

The RPS will be periodically tested during plant operation as defined by the TS discussed in Section 7.11 of this report. In addition to the standard operator initiated surveillance, the safety system logic portion of the RPS is tested by the self-test subsystem (STS). The STS is a software-based self diagnostic system which continuously and automatically tests the SSLC components and interconnections. A more complete description of this system is discussed in Section 7.2.2.5 of this report. Tho provisions for testing in the design of the RPS and the periodic testing of the RPS, as described in the SSAR, conform with guidelines of RG 1.22, "Periodic Testing of Protection System Actuation Functions" dated Fobruary 1972 and IEEE Standard 338, "Criteria for the Periodic Testing of Nuclear Power Generating Station Safety Systems" as supplemented by RG 1.118, "Periodic Testing of Electric Power and Protection Systems" Revision 2. The commitments in the SSAR to the design basis requirements for the capabilities for sensor checks and test and calibration are consistent with the requirements of GDC 21, "Protection System Reliability and Testability."

Complete electrical and physical separation must bo maintained between the four RPS divisions in order to meet the criteria of IEEE Standard 279-1971. This requirement is included in the CDM and will be verified during the implementation of the ITAAC. The staff concluded in the DSER that isolation of information (error handling) must also be addressed because of the extensive use of multiplexors and software. This aspect of the multiplexors is discussed in Section 7.2.2.1 of this report.

A trip of any sensor or logic channel will be annunciated and will cause that channel to lock in the trip mode until manually reset. The RPS will be fail-safe in that a loss of power to a channel will result in that channel going to the tripped condition. Other failures such as a break in a communications link will be detected and the self diagnostic of the individual microprocessor will put the output to the tripped state.

The design of the ABWR RPS is significantly different than in previous BWRs in the mothod the high level functional design is implemented. The staff reviewed the SSAR and found that conceptual design description to be a functional block diagram level of detail. The staff found that the hardware design documents for the SSLC did not state details such as bus protocol, bus data capacity, provisions for hardware level interrupts, the size of the memory, the speed and size of the microprocessor, the format of the status panel, hardware based interlocks, and type of display modia. The means of addreasing the above design dotails for design certification is described in Section 7.1 of this report and is discussed further below.

The functional level block diagram of the safety-related signal paths is simple and direct. However, in a microprocessor-based system, the software implied in the blocks of the system diagram can mask much of the safety system's design complexity. Several of the significant issues involving the use of microprocessor-based systems and safety functions have been presented to the Commiasion in SECY-91-292 (September 16, 1991), "Digital Computer Systems for Advanced Light Water Reactors."

The staff concluded in the DSER that the SSLC design was not "essentially complete" as required by 10 CFR Part 52 because of the complexity of the ABWR I\&C system design and the lack of design details for certification. The staff found that the design description presented for the SSLC was ambiguous because the design material was dispersed in the submittal and often contradictory. For example, data about the TLU trip (RPS division trip) status was not originally listed in the SSAR as an output to the operator.

The staff reviewed the SSLC system design specification, which was described by GE as a procurement level document. The staff considered the documentation for the SSLC to be inadequate for design evaluation and not in conformance with the design certification requirements for level of detail. The staff, therefore, concluded that the software design and development aspects of the SSLC were not described to a sufficient level of detail. GE did not adequately disclose the details of the design to enable the staff to reach a final conclusion on the acceptability of the design for certification, and this was an open issue in the DSER.

Since the issuance of the DSER, GE has provided additional detail, committed to industry standards appropriate for the digital system design, and submitted the CDM which includes the I\&C system design process. The staff concludes that the combination of the improved level of detail provided, the commitments to standards, and the incorporation of the design process into ITAAC with extensive NRC auditing during design development and implementation provides the basis for a final safety determination for certification, and is sufficient to resolve this issue. In Section 7.1, the staff discusses the issue of level of design detail. This open issue from the DSER is, therefore, resolved.

The staff also reviewed the SSAR for conformance to IEEE Standard 279-1971 and ancillary requirements for 
meeting the singlo-failure criterion, independence, control and protection system internction (isolation), teating, bypases and bypass indication (including removal of bypass), and manual initiation. To moet the single-failure criterion described in Section 4.2 of IEEE-279 and IEEE-379, "Standard Application of the Singlo-Failure Criterion to Nuclear Power Generating Station Class 1E Systems," GE committed in the SSAR to compliance with RG 1.53, "Application of the Single-Failure Criterion to Nuclear Power Plant Protection Systems." The SSAR states that the RPS will comply with GDC 22 on protection system independence, the requiroments in IEEE-279 on chennel independence, and the guidance for phyaical and electrical independeace of the instrumentation syetem in RO 1.75, which codorses IEEE Stundard 384. Conformance to RG 1.47, "Bypassed and Inoperable Status Indication for Nuclear Power Plant Safety Systems," is described in the SSAR and discussed further in Section 7.2.3 of this report. The RPS design includes provisions to meet the requirements of IEEE-279 on channel and operating bypasses. The RPS performs no control functions, interlocks with control systems are to be through isolation devices, and the channels of the RPS are to be electrically isolated and physicaly separated in order to meet the criteria of GDC 24 on separation of protection and control systems and the requirements of IEEE-279 for control and protection system interaction. The RPS description and drawings in the SSAR describe a clear commitment to the above requirements. The CDM describes the GE commitments to the most significant requirements from the various standards and criteria (though not the specific stendards themselves). These commitments will be verified during the ITAAC implementation. The standards themselves and other less significant criteria referenced in the SSAR and this report are expected to change over time and are not "locked in" by the CDM.

In the DSER, the staff noted that the SSAR did not present a detailed failure modes and effects analysis (FMEA) to ensure that all postulated failures result in a known safe state if the RPS experiences conditions such as disconnection of the system, loss of power, or exposure to a postulated adverse environment. Therefore, the staff could not evaluate conformance to GDC 23, "Protection System Failure Modes." This was Open Issue 3 in the DSER. Open Issue 3 has since been resolved by the FMEA submitted by GE and included in the SSAR, and additional studies performed by the staff. As a result of these studies, the staff determined that some aspects of this issue relate to the potential for common-mode failure of the I\&C system. Consequently, the DSER issue concerning the lack of a FMEA was resolved, but the potential common-mode failure and the required redundancy and diversity issues were identified as DFSER
Open Items 7.2.6-1 and 7.2.6-2. These open itoms ane resolved in Section 7.2.6 of this report. The etaff concludes that the RPS dexign meets the requirements of GDC 23, "Protection Syetom Failure Modes."

When the a staff iseved the DFSER, the figures (interface eloctrical diagrams (IEDB)) and interface block diagrams in SSAR Section 7.2 lacked many dotails to be aubmittod lator. This was DFSER Confirmatory Item 7.2.1-4. The figures have been corrected in the SSAR and this item is, therefore, resolved.

\subsubsection{Safety Syatem Logic and Control and Specific Subsystem Descriptions}

The SRP and tho SSAR format are ustablished along functional system boundaries. The ABWR I\&C aystem is significantly different from the I\&C system designs in plants when the SRP was last revised in 1984 in that the safety functions aro combined the SSLC, into a common computer-based logic, control, display system. Consequently, the ABWR I\&C system does not follow the discrete system boundaries assumed in the SRP. The SSLC serves both the RPS/MSIV and ESF systems. The following sections describe common elements of the SSLC which are used for the RPS. Although GE does not consider the EMS to be part of the SSLC, it is inherently interconnected with the SSLC and, therefore, is included in this section of this report.

The staff reviewed some of the I\&C system documents referred to as master parts list (MPL) documents. These documents are referenced as supporting documents in the IED figures in the SSAR. The MPL documents reviewed and discussed throughout this report were prepared for the Tokyo Electric Power Company, Inc., Kashiwazaki Kariwa Nuclear Power Generation Station, Units Nos. 6 and 7. These documents list applicable Japanese laws, regulations and standards. In addition, the Japanese standards list the U.S. standards which are either specifically accepted in the MPL documents or are referenced as guidelines. For example, MPL C71-4010 (Rev. 1, July 2, 1990), "Reactor Protection System Design Specification," states acceptance of 10 CFR Part 50, Appendix A (GDC) but refers to IEEE 279, IEEE 603, and RG 1.152 as standards that form a part of the document or are listed as references without a specific statement of acceptance or conformance. Several items in the MPLs are specific to the Japanese design and, therefore, will require revisions to refer to U.S. criteria if these documents are used in the ABWR design. For example, the Japanese plant RPS is specified to use a $50 \mathrm{HZ}, 120 \mathrm{Vac}$ power supply instead of a $60 \mathrm{HZ}$ supply as specified in the ABWR SSAR. The MPL document also includes the seismic scram function which is not 
included in the ABWR deaign. The ataff has not listed all weh diecrepancies in this report. The verification process in the ITAAC will bo ueed to confirm that the MPL deaign documents, when doveloped and ueed by the COL applicant, will be in eccordunce with the SSAR and CDM. Where neceseary, the ataff has requected OB to clarify the standards commitments in the SSAR for the ABWR 20 reliance in the SSAR is aufficient for the safoty finding. Standards commitments are discused throughout this report.

MPL ABBE-4080 (Rev. 0, April 25, 1990), "EMS/SSLC Interface Requirements, Requirements Specification," states that system timing shall be a synchronous between the EMS and the SSLC. The interface between any one channel of the BMS and the corresponding channel of the SSLC may be either by hardwired or by fiber optic cable. The SSLC will determine from which of the dual EMS channels (per division) to select the information. The selection will be besed upon data quality che 28 . The dats quality checks may include chocksums, parity checks, nte limiting checks, and the do-bouncing of digital inputs. The DTM will perform these functions except for the display functions which are taken directly to the displays from the control room multiplexing unit (CMU). Typical data formats are presented with options from which to select, dependent on tho final design input and output parameters. The above information is consistent with the SSAR description.

The staff reviewed MPL A32-4080 (Rov. 1, April 24, 1990), "Safety System Logic and Control Design Specification." The document is in general conformance with the SSAR and CDM but does not add a significant amount of design information about the SSLC. Many of the design procedures are described as items to be developed later. This document lists topics to be considered when the design is doveloped and is similar to the SSLC CDM. The MPL document is, therefore, appropriate for the intended purpose.

\subsubsection{Escential Multiplexing System}

As deecribed in SSAR Chapter 7.2, the EMS portion of the RPS system transmits data to the SSLC from the censors that are not hardwired or part of the NMS. SSAR Appendix 7A discusses the EMS system. Additional information is included in SSAR Appendix 19N, "Analygis of Common-Cause Failure of Multiplexing Equipment," SSAR Chapter 7 Appendix C, and the MPL documents discussed below.

Data multiplexing is an integral part of the ABWR I\&C system design. Multiplexing systems will transfer data between sensors and actuation control devices distributed throughout the plant, and the logical proceasing units in the control room. The multiplexing syetem applications procedure (MPL Document No. A11-4120) and the SSAR dofine two multiplexor systoms. The multiplexing system taske are divided between the EMS and tho Non-Eseential Multiplexing Systom (NEMS).

The EMS receives inputs only from safety systems. Any outputs to non-safety systems are electrically isolated. The BMS is not listed as a separato safety system in GE Table 7.1-2 of the SSAR, but is considered part of each safety system for which it provides data communications. The EMS interfaces with the RPS/MSIV and ESF systems, and is qualified to the samo quality standards as the RPS, ESF, and SSLC systems. The EMS is powered from the Clase 1E 125 Vdc buses. The EMS transmits approximately 1500 signals either from the sensors to the SSLC or from the SSLC to the actuated equipment (for the ESF functions only). The EMS has a separate CDM description in addition to those aspects of the EMS included in the functional requirements of the RPS CDM and functional and design process requirements of the SSLC (I\&C) CDM.

The SSAR states tant the NEMS is used in the non-safetyrelated control systems and is not considered a safety system. The NEMS is discussed further in Section 7.7 of this report.

The EMS is comprised of four independent divisional multiplexing systems, ench of which has redundant data links within the channel. In the DSER, the staff concluded that GE had not committed to appropriate industry standards for certain aspects of the EMS design, including the multiplexors themselves. GE has since committed to a deterministic, dual redundant, fiber optic ring structure which will follow the guidelines of industry accepted Standard American National Standards Institute (ANSI) ASC X3T9.5 (1988), "Fiber Distributed Data Interface (FDDI)." As noted in previous GE responses to staff requests for additional information, the design is not specifically constrained to this particular format and configuration. Specifically, the CDM does not require a epecific design at this time. Rather, the CDM provides functional requirements with the SSAR providing more specific information at the functional level of detail. The SSAR also refers to IEEE 802.5 (1985), "Token Ring Access Method and Physical Layer Specifications," if a lower throughput of information is incorporated in the EMS design. Both options are consistent with International Standard Organization (ISO) 7498 (1984), "Open Systems Interconnection - Basic Reference Model," as the data link layer and physical layer. IEEE $\mathbf{8 0 2 . 2}$ (1985), "Standard for Local Area Networks: Logical Link Control," will define the protocols necessary to move data 
to the higher levels of the ISO model. Any changes to these standarde commitmente would involve en unreviowed afoty queation and, therefore, require NRC roviow and ecceptance prior to implementation. Any requested chenges to this commitment shall either bo epecifically deccribed in the COL application or aubmitted for license amendment after COL issuance. For example, if a now ANSI FDDI standard is doveloped wiich uees a shorter wavelength than the current standard, the COL applicent or holder will need to verify to the staff that the dispersion will still be small enough to meet the FDDI's bit error rate.

The data link and physical layers are part of the general seven-layer hierarchical model of the open systems interconnection which the FDDI protocol conforms to. The seven layers are application, presentation, transport, network, datalink (including logical link control and media-access control), and physical (including physical and physical medium dependent). The FDDI standard (ANSI ASC X3T9.5) also requires a station management function at each station to supervise sub-layer and ring management operations. The descriptions that GE has presented, with the caveat that this is but one of a numbbr of possible implementations, are in general conformance to the above standard to $\mathrm{L}$ - - level of detail provided. These standards are supported by the industry.

Vendors currently offer chip sets to implement the individual FDDI sublayers, as well as complete systems that conform with the above standards. FDDI controllers are available with several different computer buses. The staff concurs with GE that no additional prototyping is required to demonstrate the feasibility of the design because the EMS will use proven technology. The capacity of the FDDI should be capable of handling the quantity of inputs/outputs at the rates necessary for proper operation of the SSLC. This will be verified by testing during the ITAAC implementation. The prototype requirements described in Section 7.1 of this report still apply.

The staff concludes that the ABWR SSAR references and contains commitments to appropriate standards for the EMS design at this level of design detail and, therefore, this open issue (Open Issue 5 regarding adequate commitments to industry standards) from the DSER is resolved. The implementation of the design in accordance with the standards referenced above and other ABWR SSAR statements will be verified during the ITAAC. The multiplexor design will also be verified through a staged ITAAC as discussed in Section 7.1.3.3 of this report. When the final design development is initiated, the COL applicant will submit the design plans for staff review and for development of the ITAAC verification audit points.
As a date highway, the EMS multiplexes data from the eensors to the control room logic units, and multiplexen the commends from the control room computers to the appropriate scturtion control dovices (for the BSF actuation only). The RPS (and the MSIV initiation) does not ueo the BMS for the output of the SSLC to the scrum pilot valve initiation. With the exception of hardwired input connections (turbine stop valve closed, turbine control valve fast closure, MSIV position, manual scram, and the noutron monitor systems input) all of the RPS (and most of the ESF) sensor inputs will be processed by the EMS.

The hardware anchitecture of the EMS described in the SSAR uses fiber optics for the communications medium and microproceseors for the node controllers. The SSAR also states that the ABWR EMS may use coaxial cable or twisted-pair connections. If copper wire is used in place of the fiber-optic cable, electrical isolation will bo maintained and provided where necessary (and demonstrated by testing of the devices in accordance with the Licensing Review Bases (LBB), Appendix B) thus resulting in potentially additional isolation devices. Fiberoptic cable is an inherently excellent electrical isolator, and its use to the extent practical will reduce the need for additional isolation devices.

The major components of the EMS are the remote multiplexing units (RMU), the CMU and the fiber-optic (or copper) cables. The RMU and CMU will contain the following items: transmission line interface circuits, processors, memories, signal conditioning circuitry, analog to digital conversion, and watchdog timers. The specific number of RMUs has not been determined. The only specific EMS requirement identified at this time is that within each division of EMS, the wide-range and narrowrange reactor water level sensors will be processed by different RMUs. This will provide an additional level of defense-in-depth such that any single RMU failure will only disable one of the water level indications and SSLC inputs. All of the components of the EMS are identified as Class 1E. At the RMU, an input sensor interfacing is provided to switch contacts, 4-20 ma current loops, thermocouples, RTD devices, pulse inputs, and voltage inputs. The RMU output interface (which is not used for RPS functions) is to relays, solenoids, voltage to current converters, panel meters, and indicator lights. All equipment will be rack mounted and operated from the divisional 125 VDC Class 1E power sources.

The RMU will be locuted in mild environment areas throughout the plant near the sensors and the actuation control devices with which they interface. The RMU and CMU are connected to the fiber-optic cable, and together control transmission to assign which RMU/CMU transmits or receives signals. The RMU multiplexes and sends data 
monages to the control room vit the fiber-optic cable. In the control room, the CMU demultiplexes the meange and cende it to the appropriate DTM of the SSLC. The DTM will celect which of the rodundant CMU signals it will woo. Control aimals from the SLU for the BSF functions of the SSLC are cent to the CMU which in turn trunumits thewe control signals to the appropriato RMU.

The BMS deaign concept identifies the RMU and CMU as sharing a modular, microprocessor-basod, bue-oriented architecture, ueing similar modules. The RMU and CMU are configured eomewhat differently with tho CMU having additional communications modules instead of input and output modules. Tho following functional modules will be in a typical RMU/CMU:

a. Input - acquires andog and digital data from the censors.

b. Output - transmits control signals to equipment setuation control devices (BSF function only).

c. CPU - proceseses the signal data, coordinates I/O and communications, and performs calibration and diagnostics.

d. Memory - contains the stored program executed by the microproceseor and stores intermadiate data.

0. Communications - formats and multiplexes data that is sent through the werial optical link.

f. Front Panel Interface - permits technician access to calibration and diagnostic functions.

GE stated in SSAR Chapter 20, that the RMU failure mode was dependent on what sensors were connected to it, either fail-afe (negative, low) or fail-es-is (last reading). The particular failure state for the RPS will be fail-eafo and will bo verified during the ITAAC implementution.

GE stated in SSAR Chapter 20, that the EMS includes celf-test software that detects malfunctions in the hardware modules and provides alarms in the control room. GE has not presented specific information on the types of malfunctions for which testing is being provided for or the EMS reaction to each malfunction (0.g., restart, alarm, fail-safe, or fail-es-is). However, GE has provided a listing of typical parameters that are monitored. These include the status of the central processing unit, parity checks, data plausibility checks, watchdog timer checks, memory checks, voltage level checks, and data range and boundary checks. The self tests also provide the capability for internal teating and error checking within the EMS. In addition, the EMS is subject to routine periodic operator initinted curvoillance checke required by the TS. Aleo, as decoribed in the simplified FMEA in Chapter 15.B.4 of the SSAR, the EMS will reject corrupted rignals in the transmiecion. Further, the DTM, which receives inpute from the BMS, ues a data quality check to dotermine which of the CMUs it will sccept date from.

The selection of the EMS hardware was not identified in tho SSAR or aupporting material. However, the top lovel epecification documents referenced the design control and hardware reliability andards and critoria required to be met. In responso to etaff questions (Q) (Q420.92, Chapter 20 of the SSAR), ER committed to MIL-HDBK-251 and to MIL-STD-217B for EMS hardware reliability and thermal effects.

The ataff ideatified an open issuo in the DSER based on a concern that common- mode failure from effects whe a electromagnetic interference (EMI/EMC) or design error could cause the lose of the EMS in more than one division. In reepones, $G B$ performed an asseesment of the offect on the ABWR I\&C systems for a loss of all four divisions of the EMS. The GE study (SSAR Section 19n) concluded that under such a condition, the plant could be safely shut down from the remote shutdown system. This response was insufficient to fully resolve the common-mode failure concern, and further information was requested from $G E$. The concern about EMI/EMC, reliability and thermal offects was eventually resolved as discuseed in Section 7.2.8 of this report. The concern with potential common-mode failure of the EMS (and other equipment) was also oventually resolved as addreseed in Section 7.2.6 of this report.

The SSAR defines the top level hardware architecture for the EMS but presents limited information for the software that runs in the EMS microprocessors. GE stated the following high lovel design goals for the EMS esftware:
a. real time executive kernel
b. hierarchical task structure
c. simple modules
d. on-line calibration with bypass
o. self-test as background process
f. automatic recovery

The ABWR EMS uses microprocessors to control the movement of data from the sensors to the SSLC, between the different components in the EMS itself, and from the SSLC logic to the actuated dovices (for the ESF systems). The high level block diagrams of the data signal paths are simple and direct. However, in a microprocessor-based system, the software implied in the blocks of the system diagram can mask much of the safety system's design complexity. In a microprocessor-based data transport 

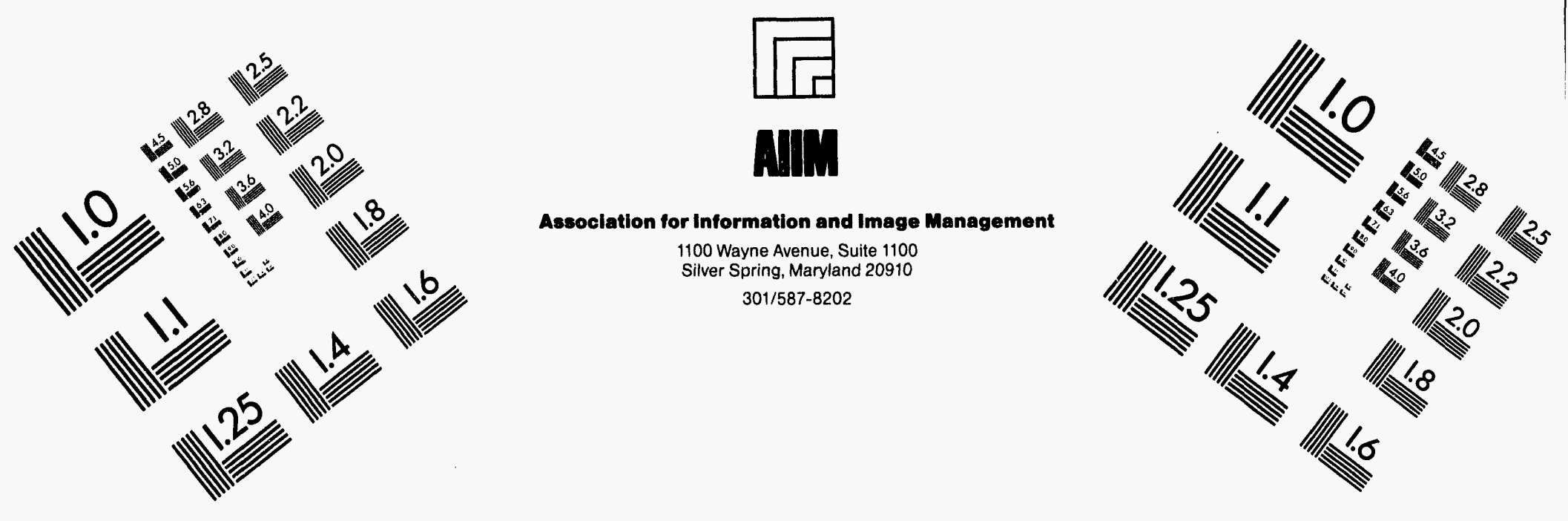

Centimeter

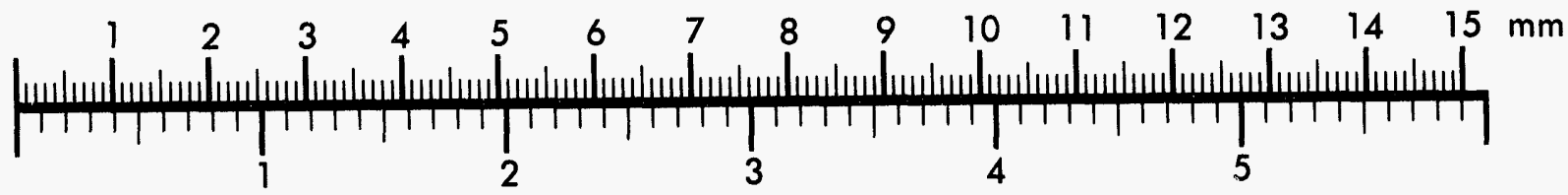

Inches
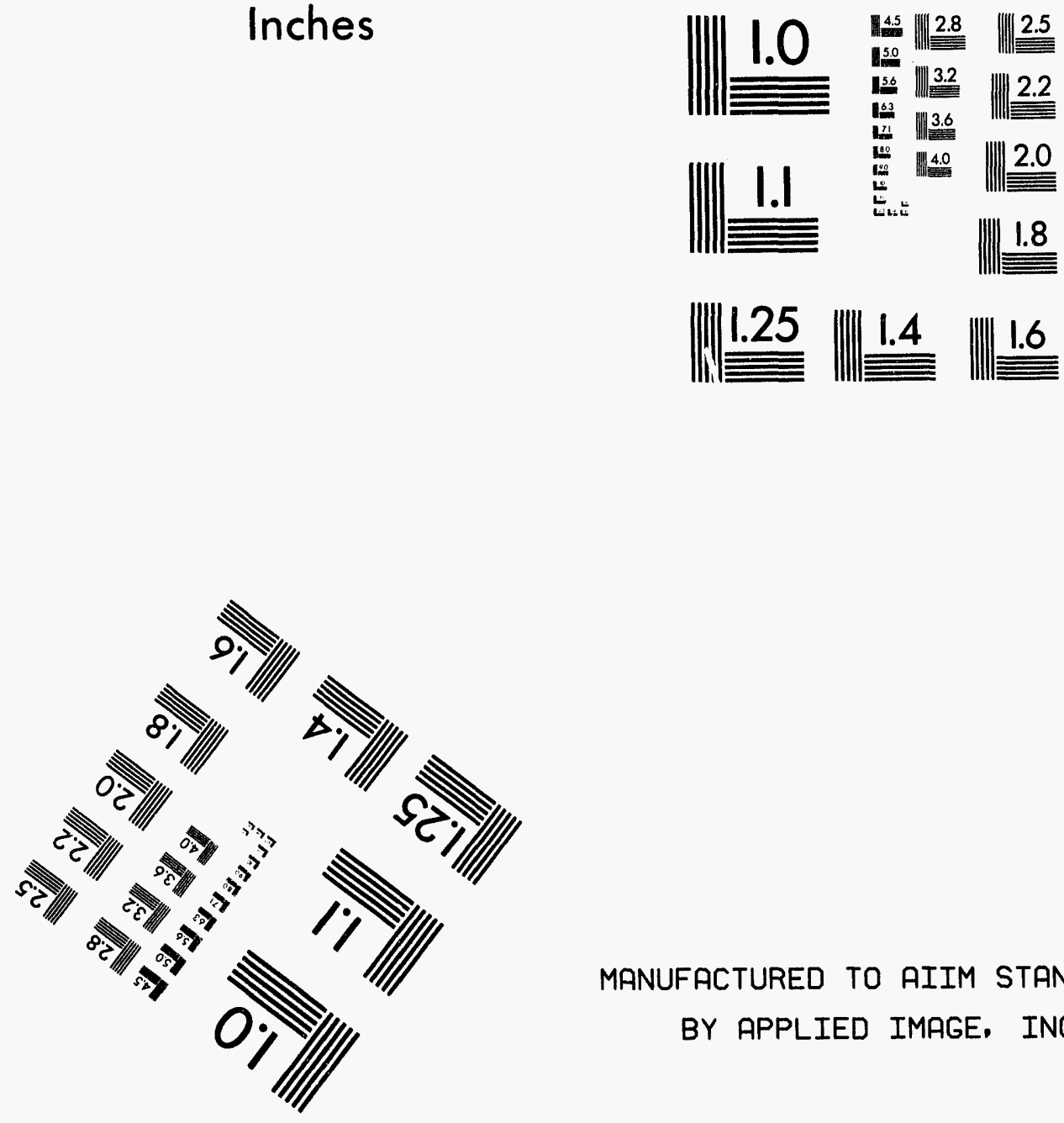

MANUFACTURED TO AIIM STANDARDS

BY APPLIED IMAGE. INC.

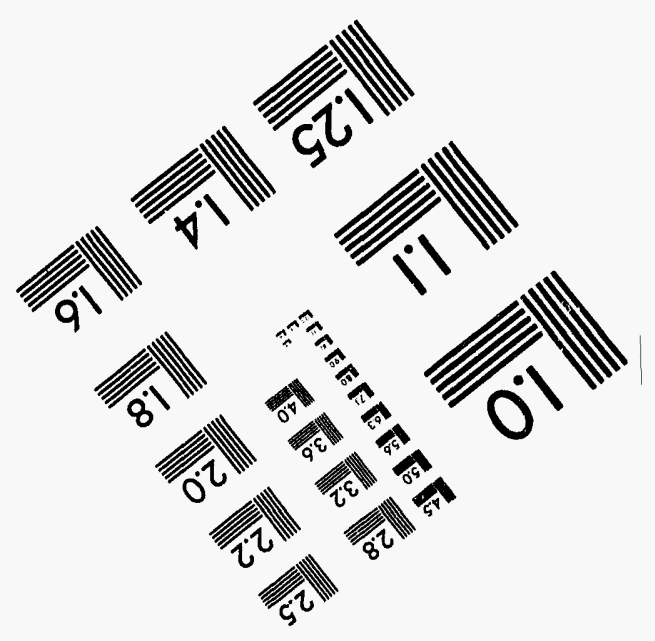



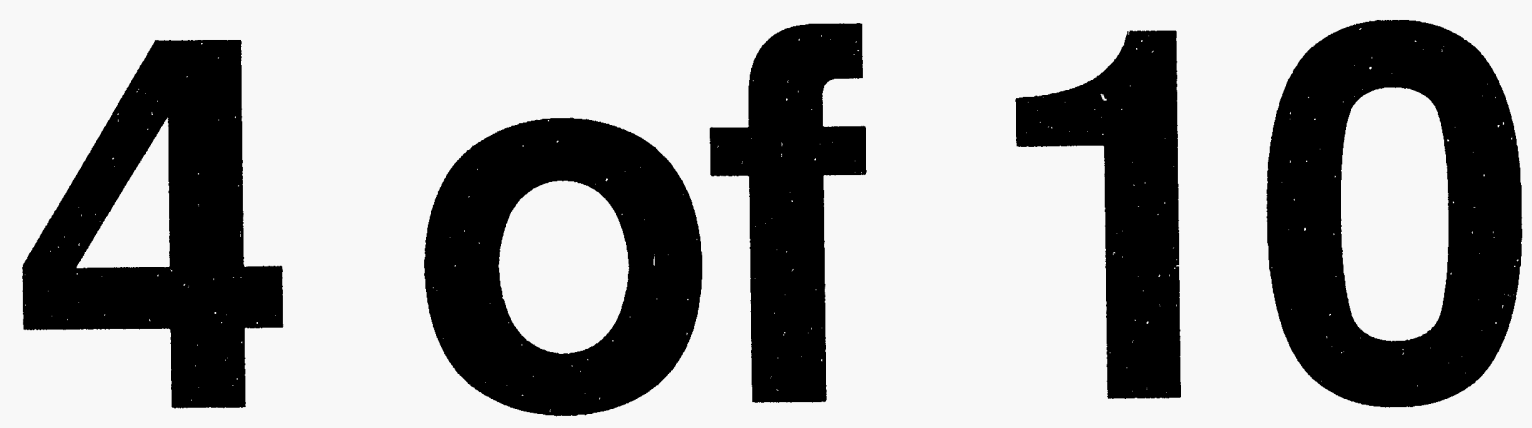
syetem, the softwere is an escential line eloment in the execution of the safoty syetem functions. For this reason, the etaff concluded in the DSBR that the design of the BMS did not provide the appropriate level of detril cusertial to tho staff's roviow. This was ideatified as Open Inswe 1 in the DSER. Since the DSER, GB has committed to the use of several additional software development standards as statod in the SSAR. This commitment, in conjunction with the design process, correoponding ITAMC steps, and staff audit verification, resolved this isow. The topic of hardware and software qualification is addreaned further in Section 7.2.8 of this report.

The SSAR initially did not present an architecture for the software deaign. GE had not demonstrated how the decision logic, a parallel process in an analog aystem, would bo implemented by the software, which is uaully a serial proceses. The staff considered this an open iscue in the DSER rolated to level of detail. GE has reeponded to this issue by providing the timing requirements for each stage of the control process from sensor to scrum initiation, and demonstrating that the scrmm time requirements $(50 \mathrm{meoc})$ can be mot with tho BMS and the SSLC. The decision logic will be sccomplished using a deterministic serial process. The timing requirements will also be demonstrated in the ITAAC implementation. This is acceptable to resolve the iseve of serial vs. parallel procesesing.

The following is a list of software elements that process a signal as it moves from the sensor through the EMS to the SSLC control logic for the RPS.

a. Remote multiplexer unit - input

1. operating system/executive

2. signal acquisition

3. signal conditioning

4. analog to digital conversion

5. digitized signal data preparation for transmission

6. digitized data transmission on fiber optic link

b. Control room multiplexer unit - input

1. operating system/executive

2. digitized data acquisition from fiber optic link

3. data preparation for SSLC/DTM

4. data transmission to SSLC/DTM

5. multiplexed date transfer control

6. display information transmission

c. DTM processing by SSLC software modules.
A basic design parameter of a local area network is whether synchronous or asynchronous transmission is used. The staff identified concerns about this issue in the DSER, and in particular was concerned about the use of synchronization scroses channels which could violate the singlo-failure requirements of IEEE-279 and IEEE-603. GE responded by stating in the SSAR and CDM that the EMS will run aynchronously. There will be no common clock shared between channels. The inherent time skew in the logic processing that will result by not synchronizing the channols will be controlled by maintaining a significantly high sample rate and storing the last four validated variables in each TLU for each vote. There is also no common clock within a division, however, the RMUs will append timing information to the sensor information to be multiplexed to the CMUs. The staff finds this acceptable, and the DSER issue of synchronization is, therefore, resolved.

Although the detailed design of the EMS depends on the hardware that is selected, the functional requirements for the EMS as part of the ABWR safety systems are not hardware dependent. Because the detailed BMS hardware design was not provided, a concern regarding lovel of dotail was identified es part of Open Item 1 in the DSER. In addition, Open Itom 2 identified the need for design information about the isolation of corrupted data in multiplexors. In response to these issues, GE has defined the high level functional requirements of the EMS, the major parameters that define the data transmission attributes, and the criteria for selecting the data transmission hardware.

GE stated several functional requirements for the EMS as follows:

1. The EMS is to be implemented such that any single failure or any single channel removal within the system shall not prevent proper action of the RPS at the system lovel.

2. The EMS in each division will be independent, and physically and electrically separated from the other divisions to preclude failures in one EMS from propagating to another division.

3. Non-safety system failures are to be isolated from the safety systems.

4. The capability for testing during power operations is to be provided. 
5. The EMS will satisfy all the environmental operability requirements (soismic, temperature, humidity, rediation levol).

6. The EMS will have adequate capability to withstand surges in sccordance with IEEE-472.

7. The EMS will have a designated temperature range of 10 to $40^{\circ} \mathrm{C}$. ( 50 to $104^{\circ} \mathrm{F}$ ), for relative humidity of 10 to 60 percent for the CMU and of 10 to 90 percent for the RMU.

The staff concludes that the combination of additional information on EMS functional requirements, commitment to appropriate additional standards and the ITAAC process provide the necessary information on the EMS design and, therefore, the related part of DSER (SECY-91-294) Open Items 1 and 2 are resolved.

The two loops of the network are designated "master" and "standby" by the receiving fiber optic interface. The designation of which loop is "master" is on the basis of transmission errors, checksum errors, and other tests in the self diagnostics. The diagrams that the staff has reviowed showed that each DTM in the SSLC has two fiber optic interfaces. The "master" designation is also applicable at the RMU level where ESF equipment actuation commands are received. It was not initially clear to the staff how these two fiber optic units arbitrate between themselves to determine which is to be the "mester" loop. GE stated that the decision will be based upon a data validity check at the DTM. The specifics of what will be valid data for each parameter was not provided. This was Open Item 6 in the DSER. GE has committed to the FDDI standard for data validation guidance which the staff finds acceptable to resolve this issue. The correct implementation and demonstration by test of the master/slave switch will be included in the ITAAC for multiplexors. DSER Open Item 6 is, therefore, resolved.

MPL DMH-4270 (Rev. 2, February 3, 1989), "Essential Multiplexing System Design Specification," provides various EMS design details. It states, for example, that the bit orror rate shall be under 10E-9 "theoretically." This is consistent with the FDDI guidelines. The CDM commitment is to a functional demonstration of capability without specifying particular throughput or error rates. The MPL document also states that the RMU and CMU shall have the capability to transmit the data at the rate of one megabit/sec (Mbps). The FDDI standard is written for essentially an $100 \mathrm{Mbps}$ system. The difference in data transmission rate between the GE MPL and the FDDI standard is an example of an MPL revision that will ive required and verified during the ITAAC implementation in order to ensure consistency with the CDM. The EMS will be capable of sampling a sensor with a 10-msec sampling ruto, but the actual sampling rate for each sensor has not yot been determined. The sampling rate vill be extablished as part of the detailed design by the COL applicant. The maximum transmission distance for any single multiplexing station is apecified in the MPL as $500 \mathrm{~m}$ (approx. $1640 \mathrm{ft}$ ). A maximum dietance verification was to bo included in the ITAAC. This was DFSER Confirmatory Item 7.2.2.1-1. Although the CDM has not been revised to eppecifically reflect the distance verification, the functional requirements in the CDM and an SSAR change restriction are acceptable to the staff and this item is, therefore, resolved.

The need to incorporate consideration of instrument channel inaccuracies due to A/D converter in the setpoint methodology was DFSER Confirmatory Itom 7.2.2.1-2. GE revised CDM Section 3.4, "Instrumentation and Controls" to include setpoint methodology and specifically includes consideration of the A/D converter accuracy. This item is, therefore, resolved.

MPL A32-4080 (Rev. 0, April 25, 1990), "EMS/SSLC Interface Requirements, Requirements Specification," specifies that the four channels of the EMS be asynchronous. This is consistent with the SSAR and the CDM. It also requires a fixed format for both the messages and the sequence of the messages. This is consistent with the general GE commitment to use a deterministic EMS. The MPL notes that the RMUs shall provido appropriate filtering without providing a specification of what is appropriate. Providing appropriate filters will be part of the design development and implementation process which is the responsibility of the COL applicant.

The EMS design of the ABWR uses microprocessors and related software throughout the safety systems. While promising improvements in performance and reliability, this advanced technology also can introduce problems and failure modes that had not been addressed before in reactor safety system design. Several of the communications control functions performed within the EMS are implemented by software. RG 1.152, which endorses ANSI/IEEE ANS Standard 7-4.3.2 (1982), has been promulgated as the standard for developing software for safety systems. However, GE's commitment to this standard was ambiguous. There was no evidence in the SSAR that the software development for the EMS would be in accordance with IEEE Standard 7-4.3.2. This was an open issue in the DSER (SECY-91-294). GE subsequently removed the ambiguity from the SSAR commitment to IEEE Std. 7-4.3.2 and added additional software requirements to the SSAR which are discussed in Section 7.2.8 of this report. This issue is, therefore, resolved. 
In the DFSER, the staff stated that the sensor data transmitted through the EMS should be clarified in Chapter 7.2 of the SSAR. For example, the turbine stop valve closure input was described in Section 7.2.1.1.4.2 (6) as using the EMS, which was not consistent with other information provided by GE. This was DFSER Confirmatory Itom 7.2.2.1-3. GE has revised the SSAR to specifically state which types of data are transmitted through the EMS and which types one not. This item is, therefore, resolved.

GE has committed in the SSAR that the EMS design will moet the relovant SRP criteria and will moet current industry standards for multiplexing. GE also committed to additional hardware and eoftware criteria beyond those contained in the SRP. Based on the above, the staff concludes that the EMS will be capable of accomplishing the RPS performance requirements. Verification of the final design against the above criteria will be performed during the ITAAC implementation. Any changes to the commitments described above concerning the performence specifications and architecture of the EMS would involve an unreviewed safety question and, therefore, require NRC review and acceptance prior to implementation. Any requested changes to commitments involving the EMS performance specification or architecture shall either be specifically described in the COL application or submitted as a license amendment after COL issuance.

\subsubsection{Digital Trip Module}

The digital trip module (DTM) is \& microprocessor-based unit which performs the basic comparison of the sensors to the preestablished setpoint, and provides a trip or no-trip output for that parameter. For the RPS, there is one DTM for each set of sensor channels (a division of sensors, refer to Figures 7.2-1 and 7.2-2 in this report). The DTMs for the ESF functions are separate and are not shared as was the case for the EMS. The DTM, as with all of the SSLC, is Class 1E. The hardware and software requirements for the DTM are addressed in Section 7.2.8 of this report. The RPS DTM is designed to be fail-safe. A loss of power to the DTM will result in a trip signal to cach of the TLUs until that division is placed in bypass by the operator.

The DTM will receive input from both the EMS and directly hardwired sources. The hardwired sources include both the traditional hardwired inputs (discussed previously in this rection) and the process PRM which provides the MSL high radiation input. The only RPS scram signals not procesed through the DTM are from the manual operator controls and the NMS.
The DTM will send a trip or no-trip signal for each of the sensed parameters to each of the four TLUs. The signal to the TLUs which are not in the same electrical division will be electrically isolated and separated. The DTM will also provido data to the Class $1 E$ divisional display units, the Clase IE mimic board, and isolated outputs to the plant computer and non-Class 1E alarms and annunciators.

GE described the following elements of the DTM:

1. Operating system/executive

2. Setpoint check

3. Trip decision transmission if setpoint exceeded

4. Serial data transmission to all divisions

For the items that are multiplexed, both multiplexor loops within a division and the identical sensor information contained on both is available to the DTM. As described in the previous section on the EMS design, the DTM will perform a data validity check and select from which CMU it will receive information.

As part of the data checking, the DTM will also verify that it is receiving the correct parameter and will ignore any other signals, such as those for the ESF DTMs. The DTM will also perform a data validity check on the nonEMS inputs and provide alarms if the checks fail.

Figure 7.A.2-1 in SSAR Appendix 7A shows all the sensor signals sent via the EMS. This drawing was listed in the DFSER as needing revision to be consistent with the distribution of the sensor inputs to the DTM as described above. This was DFSER Confirmatory Item 7.2.2.2.2-1. The SSAR has been revised to properly show the DTM sensor inputs, and this item is, therefore, resolved.

MPL A32-4080 (Rev. 0, April 25, 1990), "EMS/SSLC Interface Requirements, Requirements Specification," requires that the DTM permit manual trip of individual plant date inputs when an inoperable condition is detected in the incoming EMS data. This is consistent with the SRP criteria for a manual trip.

MPL C71-4010 (Rev. O, May 18, 1990), "Reactor Protection System, Hardware/Software System Specification," lists the 11 sensor inputs and 34 outputs to the TLUs (if seismic inputs/outputs are not used) for each DTM. In addition to the sensor tripped/not-tripped status, the DTM output will include the mode switch MSL isolation trip bypass permissive to the TLU in its own channel. The DTMs are essentially identical between the four RPS divisions. There will be sensor identification and small timing differences that provide for some emall differences, however, most of the dovice's hardware and coftware is identical between divisions. The DTMs are 
also similar to the DTMs of the ESF functions. The software algorithms will be significently different between the RPS/MSIV and ESF functions but the opernting system, the self diagnostics, and the input/output will be identical. The staff wes concerned that the DTMs could be vulnerable to a potential common-mode failure of all divisions and between the RPS/MSIV and ESF due to a hardware or software design error. This was an open issue in the DFSER and the resolution is discuseed in Section 7.2.8 of this report.

\subsubsection{Trip Logic Unit}

The trip logic unit (TLU) is a microprocessor-based unit which performs two-out-of-four coincidence logic calculation based upon the signals it recoives from the four DTMs and the four divisions of NMS. There is one TLU for each of the RPS logic channels and it does not share any functions with the BSF system with the exception of the ability to bo bypaceed by the operator. The TLU aleo receives the manual operator division scram inputs and the sensor channel bypass command. The primary TLU output is to the MSIV and RPS OLUs. The TLU aleo hes outputs to the Class 1E displays and icolated outputs to the non-Class IE displays and annunciators. The TLU is Class 1E.

MPL C71-4010 (Rov. 0, May 18, 1990), "Reactor Protection System, Hardware/Software System Specification," lists the approximately 106 interfaces (inputs and outputs) for each TLU.

MPL A32-4080 (Rev. 0, April 25, 1990), "EMS/SSLC Interface Requirements, Requirements Specification," requires that the TLU include a watchdog timer function on all outputs to ensure constant updating. Timo-out shall cause outputs to assumo predetermined safe states. These predetermined states were not atated in this MPL and, therefore, the DPSER stated that information on this matter is to be included in the ITAAC verifications. This was DFSER Open Item 7.2.2.5-1. In response to this issue, GE stated that tests have been added to the ITAAC to demonstrate that the failure state is fail-safo for the RPS. In addition, the MPL for the SSLC design specification provides the system failure modes and specifies that the RPS is fail-safe. Therefore, this open item is resolved.

GE identified the operating system/executive and the functional software as the two elements of the TLU software. The TLU configuration is characterized by the nine 1/O interface boards connected to the central bus. There are a total of 21 input channels and nine output channels physically connected to each TLU. The details of the configuration are as follows: a. There are four fiber optic communications interface boards that handlo tho following data channela:

1. bypess control inputs - 4 channels

2. DTM inputs (other divisions) - 3 channels

3. NMS inputs (other divisions) - 3 channels

4. recirculating pump trip output - 1 channol

5. data output to plant computer - 1 channel

b. There are two signal interface boards that handle the following data channels:

1. DTM input (own division)

2. NMS input (own division)

3. operator control input

4. TLU control output (adjecent division)

c. There are two logic level interface boards that handle the following data channels:

1. MSIV input - 4 channels

2. auto reactor trip output - 1 channel

3. auto MSIV closure output - 1 channel

4. MSIV test close output - 4 channels

d. There is one contact input interface board that bandles the following data channels from the SSLC panel switches:

1. non-coincidental trip disable input

2. main condenser vacuum bypess input

3. auto trip test input

4. auto isolation test input

The TLUs are essentially identical between the four RPS divisions. There will be identification and small timing differences in some TLUs, however, most of the devices are identical. The TLUs are also similar to the SLUs of the ESF functions. The TLU software algorithms will be significantly different but the operating system, the solf diagnoetics, and the input/output will be identical. The staff was concerned that the TLUB could be vulnerable to a potential common-mode failure similar to the DTMs. This was an open issue in the DFSER and the resolution is discuseed in Section 7.2.8 of this report.

\subsubsection{Output Logic Unit}

MPL C71-4010 (Rev. 0, May 18, 1990), "Reactor Protection System, Hardware/Software System Specification," lists the 6 inputs and 12 outputs for each OLU. The OLU is a Class IE solid state electronics device (non-microprocessor-based) which receives signals from the TLU within its own electrical division. There are 
separate units for the MSIV and RPS initiation functions. The OLU aleo receives the division bypase commands, the manual division trip input for the RPS OLU and manual division isolation input for the MSIV OLU. The output of the OLU units is to the MSIV and RPS loed drivers which provide a division lovel two-out-of-four vote. This is in addition to the separate two-out-of-four sensor input vote which occurs in the TLU.

\subsubsection{Self-Test System}

The self-test system (STS) feature of the SSLC is described in Section 7.1.2.6 of the SSAR. The STS performs testing on both the RPS and ESF functions of the SSLC. The STS was originally presented in the SSAR as an overlay testing and surveillance system which continually and automatically performs end-to-end testing of all active circuitry in the SSLC using short test pulses similar to the Clinton nuclear system protection system design. GE has substantially revised the SSAR description since the DSER was issued to tailor the STS for a multiplexed microprocessor-based design.

GE originally classified the STS as safoty-associated and stated that Class 1E equipment would bo used wherever the STS interfaced with safety-related equipment. The staff was concerned that the test features were not classified as Class 1E and could potentially degrade the safety function. This issue was identified as an open item in the DSER (SECY-91-294). The staff was also concerried about the potential interaction between the STS and the master/sleve configuration in the SSLC causing problems with the SSLC operation and possibly violating the separation requirements of the SRP. The design of the STS as described in the SSAR is now substantially integrated into the SSLC, and GE has committed that all STS equipment will be qualified as part of the SSLC (Class 1E). The revised description and Class $1 \mathrm{E}$ designation have also resolved the configuration and separation issues identified in the DSER. This is acceptable and the DSER open issue is, therefore, resolved.

The STS for safety-related systems and the SSLC are required to be Class $1 \mathrm{E}$ in accordance with the criteria of the SRP. This had not been explicitly stated in the SSAR and was identified as DFSER Confirmatory Item 7.2.2.5-1. The SSAR has been' revised to clarify that the Class IE requirement will apply for all safety-related self-test or self-diagnostic features and, therefore, this item is resolved. The Class 1E requirement applies to self-test features imbedded in the software of safety-related systems. However, it is acceptable to use non-Class IE testing equipment in typical configurations where a safetyrelated I\&C channel or system under test is taken out of service to perform manual tests.
The protection system in-service testability requirement comprises a sot of aix soparate tests, which together constitute a complete system teat:

1. A manual scram test will de-energizo one set of scram pilot valve solenoids at a time. This teet will aleo verify the indications in the main control room and the plant computer input.

2. A calibration check of the NMS will verify calibration of setpoints.

3. The single rod scram test will include a physics review performed before insertion of each rod.

4. A calibration check of the analog sensor inputs at the inputs to the RMUs will verify, by injecting calibrated sensor signals in place of the normal sensor inputs and monitoring the SSLC control room panels, linearity, accuracy, fault response, and downscale and upecale trip responses. This test is accomplished by placing a division of sensors in the bypass position.

5. A check of sensor operation will verify sensor inputs by cross comparison of other channels, by varying the monitored variable, or by substituting a test source. If the test requires disconnecting the sensor from the system, an out-of-service alarm will be given in the main control room.

6. A self-diagnostics test of the SSLC equipment will be run to detect and determine the location of a failure in the functional SSLC system. The self-test provision within each division of the SSLC system consists of an on-line, continuously operating, self-diagnostic monitoring network, and an off-line semi-automatic, end-to-end surveillance program. The self-diagnostic software within each logic processing unit will monitor critical circuit nodes and timing functions, as well as states of registers, memory locations, and program flow and timing. These monitoring functions are designed so detect both internal problems and cortain external problems such as corrupted data input. The self-diagnostics will include hardware techniques such as watchdog timers.

The capability to perform on-line protection system testing is included in the CDM. The specific implementation is described in the SSAR. Specifics of the system design features to permit testing are not available. The ITAAC process will verify that the above tests can be accomplished and includes use of the test equipment indicated for the above tests itself to demonstrate some of the other I\&C functional requirements in the ITAAC. 
One significant feature of the testing that has been deacribed by GE is the elimination of the need to lift leads and install jumpers to perform testing. Such actions have been a significant problem area at currently operating plants. The DFSER stated that this feature should be included as a CDM requirement, which was identified as DFSER Confirmatory Item 7.2.2.5-2. The SSAR has been revised to include the ABWR design testing features that eliminate jumpers and lifting leads, and the TS have been propared besed on these design features. The CDM has been revised to roflect the technician interfaces for teeting, and the staff finds it to be acceptable. This confirmatory item is resolved.

Any changes to the design testing features and commitments identified in the SSAR would involve an unreviewed safety question and, therefore, require NRC review and acceptance prior to implementation. Any requested changes to these commitments shall either be specifically described in the COL application or submitted for license amendment after COL issuance.

\subsubsection{Indication of Bypassed and Inoperable Status}

MPL C71-5030 (Rov. 0, April 23, 1990), "Reactor Protection System Verification and Validation Criteria Design Specification," requires that only one sensor channel be bypassed at a time. However, the ABWR design does not include the capability to bypass an individual sensor. The sensor bypass referred to in this MPL is the same as that which the staff and GE have defined as a division of sensors bypass. The ITAAC in CDM 3.4, Instrumentation and Control, includes a verification that only one division of sensors may be bypassed at a time.

MPL C71-4010 (Rev. 1, July 2, 1990), "Reactor Protection System Design Specification," states that one sensor channel may be bypassed and the coincidence logic will go to a two-out-of-three vote at the TLU. This bypass is implemented at the input to the TLU. Bypass of one division of output logic at the OLU will result in a twoout-of-three coincidence logic. This bypass is implemented at the input to the OLU. The above MPL document also requires that bypass status be readily apparent and under direct control of the operator.

When any part of the RPS or supporting systems is bypassed or made inoperable, a continuously displayed status of this condition is required in the main control room. SSAR Section 7.2.2.2.1 states that this requirement is met with individual indicator lights grouped near the affected equipment. The following alarms and annunciators are provided for the RPS bypass and inoperable status and are qualified as Class 1E:
RPV level 3 scram bypassed

RPV pressure high scram bypassed

Drywell pressure high scram bypassed

Noutron flux high scram bypassed

MSIV closure scram bypassed

CRD charging water pressure low scram bypassed

MSL radiation high scram bypassed

The following alarm is provided for the RPS inoperable function as non-Class 1E:

\section{Indicated RPV water level invalid}

There are also additional commitments for all bypasses to bo annunciated, however, the alarm and annunciator list from which this information was extracted did not list all of the non-Class $1 \mathrm{E}$ alarms and annunciators but only those specifically identified in the Emergency Planning Guidelines (EPGs). To address this issue, the staff reviewed the ABWR SSAR for commitment to RG 1.47, "Bypassed and Inoperable Status Indication for Nuclear Power Plant Safety Systems, " Position C.2, which requires that the bypassed and inoperable status of RPS auxiliary or supporting systems be automatically indicated in the main control room. The description in the SSAR indicates that adequate indication and annunciation for these systems will be provided in the main control room. The indication is automatic at the system level when the system loses power or when it is out of service. A switch will be provided for manual initiation of bypass indication for out-of-service conditions which could not be automatically annunciated. The staff concludes that GE has provided adequate commitment to RG 1.47. The DFSER listed the verification that all bypasses are appropriately annunciated as DFSER Confirmatory Item 7.2.3-1. Bypass testing has been included in the CDM, and this item is, therefore, resolved.

\subsubsection{Alarms and Annunciators}

For the ABWR, the most significant change in alarm and annunciator design from previous designs is that many of the alarms are now Class $1 \mathrm{E}$ and as such will be powered from the divisional Class 1E power sources. These Class 1E alarms are distributed between the fixed display (fixed alarm tiles above the mimic section) and the VDU. As a part of the. ABWR design, the RPS channel trips will annunciate and identify the variable which caused the trip. Loss of annunciator events at currently operating plants have demonstrated that this is important information for the operator. SSAR Chapter 18 and the corresponding section of this report for the human factors review provide a discussion and evaluation of the displays. 
The ABWR bas committed to using non-Class 1E "uninterruptable power supplies" for the non-Clase IB annunciators. Dotnils on the distribution of the nonClase 1E power loads were not provided by GE in the SSAR. However, independence of Class IE and nonClass 1E power supplies and isolation of non-Class 1E alarms from Class 1E alarms will ensure that the Class IE alarms would be available in the event of loss of the uninterruptable power supplies.

At the staff's request, GE provided an inventory of control room instrumentation, including a list of Class IE alarms, besed upon the EPGs. Because the inventory is emergency mitigation besed, it does not include a list of the nonClass 1E alarms that are not required for entry conditions into the EPGs. Additional discussion on the inventory is provided in Section 18.0 of this report.

The number of fixed position alarm tiles in the ABWR control room has been significantly reduced compared to current operating plants by employing alarm prioritization and filtering. In the ABWR, the fixed alarm tiles are only used for important plant-lovel alarm conditions that potentially could affect plant availability and plant safety, or indicate the need for immediate operator action. Less critical alarms are presented on the operator console VDUs. In addition, the large control room overviow display panel will include important safety-related (Class 1E) system-level alarms and some non-Class 1E system-level alarms.

The following is a list of Class 1E alarms for the ABWR. The fixed displays will be primarily alarm tiles near the large overhead mimic. The term "VDU" refers to the CRTs or plasma screens on the control room consoles. (There are several VDUs, and this list is not intended to imply that all the alarms are on one screen.)

The Class 1E alarms that indicate RPS information include:

(1) RPV water level (fixed)

(2) drywell pressure high (fixed)

(3) drywell pressure high (VDU)

(4) RPV water level 3 (fixed)

(5) RPV water level 3 (VDU)

(6) RPV pressure high (fixed)

(7) RPV pressure high (VDU)

(8) neutron flux high (fixed)

(9) neutron flux high (VDU)

(10) MSIV closure (fixed)

(11) MSIV closure (VDU)

(12) CRD charging water pressure low (fixed)

(13) CRD charging pressure low (VDU)

(14) main turbine stop valve closure (VDU)
(15) main turbine control valve fast closure (VDU)

(16) MSL radiation high (fixed)

(17) MSL radiation high (VDU)

(18) RPS Div I trip (VDU)

(19) RPS Div II trip (VDU)

(20) RPS Div III trip (VDU)

(21) RPS Div IV trip (VDU)

(22) RPS Div I menual trip (VDU)

(23) RPS Div II manual trip (VDU)

(24) RPS Div III manual trip (VDU)

(25) RPS Div IV manual trip (VDU)

(26) menual scram (A) initiated (VDU)

(27) manual scram (B) initiated (VDU)

(28) reactor acram (fixed)

(29) reactor period short (fixed)

(30) SRNM neutron flux upscale rod block (VDU)

(31) SRNM neutron flux upecale reactor trip (VDU)

The non-Class 1E alarms that annunciate RPS information include:

(1) drywell pressure high (fixed)

(2) RPV pressure high (fixed)

In addition to the above displays of alarm conditions, access to the plant computer will aliow the operator in the control room to identify the specific senspr or sensors that caused a channel trip. The plant computer will also maintain the sequence of events log. This $\log$ will contain both nuclear steam supply system and balance of plant inputs. The plant computer is not part of the safety systems and no credit is taken for this system in meeting SRP acceptance criteria. The plant computer is described in Section 7.7.1.5 of this report.

The ABWR design provides for the distribution of alarms between the fixed displays, the VDUs, and the large overview panel; the independence of divisionalized Class IE and uninterruptible non-Class 1E power supplies that provide power to the alarm systems; and the isolation of non-Class $1 E$ alarms from the Class $1 E$ alarms. These provisions in the design minimizes the potential for total loss of annunciators due to single failures as experienced by operating nuclear plants and meet the requirements of redundancy, independence, and separation of alarm systems of the Commission's position on control room annunciator reliability in SECY-93-087.

\subsubsection{Support Systems}

The support systems discussed in this section include the line power supplies and the HVAC systems.

SSAR Chapter 8 and the corresponding section of this report discuss the plant station power. For the SSLC, the 
power is aupplied by four independent and separated Clase 1E 120 Vec sources, each of which is becked up with a Clase 1E 125 Vde battery cource through an invertor. Divisions I and III of the $120 \mathrm{Vec}$ sources are each supplied power from the corresponding division 480 Vac power source; 120 Vac Divisions II and IV are supplied from the Division III 480 Vac source as indicated by SSAR Figure 8.3-3. SSAR Figuro 7.2-1 initially incorrectly showed a fourth division of $480 \mathrm{Vac}$ power and, therefore, needed to be revised to reflect the power supply design. This whe DFSER Confirmatory Item 7.2.5-1. SSAR Figure 7.2-1 was subsequently corrected and this item is, therefore, resolved.

MPL C71-4010 (Rov. 1, July 2, 1990), "Reactor Protection System Design Specification, "is consistent with the SSAR and the CDM in that it calls for four Class 1E $120 \mathrm{Vac}$ systems. However, the specifications in the MPL identified only two $125 \mathrm{Vdc}$ systems whereas the ABWR CDM and SSAR stated that there are four $125 \mathrm{Vdc}$ systems provided. GE indicated in the SSAR that the four 125 Vdc system configuration is the one for the ABWR design, and this is acceptable to the staff.

The scram pilot valve solenoids are powered from the Divisions II and III 120 Vac SSLC buses.

A potential Division II $6.9 \mathrm{KV} / 480 \mathrm{Vac}$ transformer or 480 Vac switchgear failure could disable the 480 Vac power sources to the inverters associated with Divisions II and IV 120 Vac SSLC buses. Such a failure could also affect the inverters and result in disabling the capability to use the beckup $125 \mathrm{Vdc}$ sources. The failure of the inverters would lead to degradation or loss of power to the two 120 Vac SSLC buses. This issue was addressed in two ways. The first is by incorporating a TS requirement that limits the bypass of SSLC channels. This was an open item in Chapter 16 (Item 16-2) of the DFSER and the resolution is discussed further in Section 7.11 of this report. The second way is by providing electrical protection assemblies (EPAs) for the SSLC buses in the ABWR electrical distribution system design. EPAs provide an additional level of protection to the SSLC power supplies. Each ascembly consists of a circuit breaker with a trip coil driven by logic circuitry which senses line voltage and frequency, and trips the circuit breaker open on a condition of overvoltage, undervoltage, or underfrequency. The EPAs will detect a spectrum of degraded conditions of the SSLC bus power supply end open the power supply line in time to prevent serious damage to connected equipment. Another area of benefit by using EPAs is reduction in the possibility of the scram pilot solenoid valves sticking as a result of damage caused by insufficient voltage supply to the solenoid coils. The ABWR design requires the coils of both scram pilot solenoid valves of each CRD to disengage when power is removed, to initiate a scram. The EPAs will detect an undervoltage condition and remove power prior to possible damage to the coils. Normal voltage drop between the location of the EPAs and the solenoid coils will be included in the design considerations. The ITAAC for the EPAs will include a verification that the wiring to the solenoid valves is sized 80 that the voltage drop in the cables will not result in insufficient voltage being supplied to the solenoid coils. The ITAAC will also include a verification that the neutral leads of the scram pilot solenoid valve coil windings are configured such that credible faults (e.g., hot shorts) will not prevent the valves from performing their safety function. The above ITAAC considerations were identified as DFSER Confirmatory Item 7.2.5-2. GE has included this information in the SSAR and the staff finds it to be acceptable. Therefore, this item is resolved.

The four primary SSLC cabinets (or set of cabinets) are installed in the main control room. Portions of the RPS and SSLC (in particular, the RMUs) are located in other mild environment areas such as the control building equipment rooms. The RPS I\&C equipment which is designed for harsh environments and will be required to meet the electric equipment environmental qualification requirements of 10 CFR Part 50.49 are certain sensors, sensor lines, transmitters, and associated cabling. None of the microprocessor-based equipment, multiplexor units, or fiber optic links will be in areas designated as a harsh environment area. All of the SSLC equipment is qualified to the environment of the room in which it is located. The support system is the HVAC system for the specific area. Section 7.2.8 of this report describes the hardware and software qualification.

\subsubsection{Defense-in-Depth Analysis}

The I\&C systems for the ABWR help ensure that the plant operates safely and reliably by monitoring, controlling, and protecting critical plant equipment and processes. Both safety and non-safety I\&C systems for the ABWR are primarily digital-based and differ significantly from the primarily analog systems used in currently licensed operating plants. The digital I\&C system shares more data transmission functions and process equipment than was the practice with the analog systems. The ABWR I\&C systems use the same software and processing equipment (hardware) across the safety divisions, and therefore, a hardware design error, a software design error, a software programming error, or a maintenance error may affect all of the I\&C system divisions and result in a common-mode or common-cause failure of redundant equipment. The staff was concerned that the use of digital computer technology in I\&C systems could result in safetysignificant common-mode failures. Because of these 
concerns, which wero expreseced carly in the proliminary reviewe of the ABWR, the etaff requented that $O E$ prepare an analyais of ABWR I\&C aysteen dofeneo-in-depth based upon NURBO-0493, "A Defenco-in-Depth and Divernity A excedement of tho RBSAR-414 Intograted Protection System" (1979). The etaff believes that a lovel of divernity is neceneary to provido dofeneo-in-depth againat potential common-mode coftware errors so that nececeary eafety functions can be performed reliably. The staff considers common-modo coftware errors to be a epecial case of aingle failure and, therefore, protection againat wach errors is to be part of the design baces.

To complicate tho concern with regand to common-mode fillure, the initial SSAR did not include tho dexign dotails that would allow the staff to independently awees tho diventity and defenco-in-depth of the deaign and conformance with the guidelines of NUREG-0493. Therefore, the etaff concluded that the common-mode failure potential of software had not been adequately addreesed, and this was identified as an open itom in the DSER. Subsequently, GE provided the results of analyses done to address the dofense-in-depth isoue as amendments to tho SSAR. Reeolution of this item is discussed further in this soction of the report.

\section{BACKGROUND}

The firet design reviowed by the staff epecifically to addrese defenes againet potential common-mode failures in digital systems was the Weatinghouve RESAR-414 deaign. The recults of this atudy were published in NUREG-0493, "A Dofener-in-Depth and Diversity Anecesment of the RESAR-414 Integrated Protection Systom," (March 1979). NUREG-0493 discuseed common-modo failures and differeat types of diversity, and presented a method for asecessing the dofenso-in-depth of the design.

The staff described concerne with common-modo frilures and other digital ayetem design isoues in SBCY-91-292, "Digital Computer Syatems for Advanced Light Water Reactors." SECY-91-292 describes how common-mode failures could defeat not only the redundancy achieved by the hardware architectural structure, but also could result in the lose of more than one echelon of defense-in-depth provided by the monitoring, control, reactor protection, and enginoered anfety functions performed by the digital I\&C syatems. The two principle factors for defense against common-mode/common-cause failures are quality and divervity. Maintaining high quality will increase the reliability of both individual components and completo system. Divertity in asigned functions for both equipment and buman ectivities, equipment, hardware and coftware, can reduce the probability that a common-modo failure will propagate.
The modules in the ABWR SSLC are to be implemented by microproceneor-based designe with identical or similar handware and coftware ueed in all four divisions. Because of this similarity the concerns expressed in NUREG-0493 and SECY-91-292 apply directly to the SSLC.

Tho ataff reviowed the ABWR I\&C aystom design and concludes that common-mode failure concerns were valid for coveral reasons.

1. The commonality of the timing between channels is wuch that an error in one channel is expected to occur in all ideatical channels and equipment within a fow milliecoconds of each other.

2. The pousibility exist that an initiating transient or sccident itcelf creates the set of circumstances that reveal a eoftware error. The staff considers that the models of the systems used to develop the test sets may not contain sufficient inputs for all transient and accident situations, and therefore, certain situations may not be adequately tested. In most software applications, including the ABWR design, it is not possible to include a 100-percent tost of all software inputs due to the very large number of poseiblo input combinations.

3. There is presently no general consensus as to a mothod to demonstrate a quantitative measurement of software reliability. Somo escumptions, such as the GE ABWR PRA assumption of $4.25 \times 10^{-6}$ failures per demand for the EMS, cannot be demonstrated with the current software metrics or existing data bases, and are likely unrealistically low.

4. Redundancy in software does not necessarily increase the reliability and availability of the overall syetem to an acceptablo level as it can in analos systems. Some of the failure modes of a softwarebesed system (particularly the common-mode failures mentioned above) are fundamentally different from those of an analog system.

5. Self-diagnostics and periodic teating provido a significant safety improvement by reducing the possibility of undetected failures during plant operation, but thoy do not provent the failures from occurring. The improved self-diagnostics of digital systeme do not reeolve the common-mode failure isave. The analysis described subsequently in this report explains the common-mode vulnerabilities of the ABWR design, and the attributes which mitigate those failures. 
Several NRC regulations and industry standards addreses the need for dofense againet potential common-mode failures. ODC 22 requires that "design techniques, such as functional diversity or diversity in component decign and principles of operation, shall be ueed to the extent prectical to provent loses of the protection function." IEEE Standard 279-1971 requires that "equipment, not subject to failure caused by the samo credible ovent, shall bo provided to dotect the ovent . . . ." IEEE Standard 603-1980 has the samo requirement as IEBE-279. IEEB Standard 379-1968 states that "certain common-cause failures shall be treated as single failures when conducting the single failure unalysis. Such failures cen be in disaimilar components and cen have discimilar failure modes. Failures resulting from cascaded failures and from docign beses events have already been discuseed and are those which shall be included in the analyais. Commoncause failures not subject to single-failure analysis include thoee that can result from external environmental effects, design deficiencies, manufacturing errors, and operator errors. Design qualification and quality aseurance programs are intended to afford protection from external onvironmental offects, design deficiencies, and manufacturing errors. Personnel training, proper control room design, and operating and maintenance procedures are intended to afford protection from maintenance and operator errors." Common-mode failure issues are also addresed in the requirements of 10 CFR 50.62 concerning mitigation of anticipated transients without scram (ATWS).

There are several different types of diversity, eact of which offers certain protection against the common-mode failures. Various forms of diversity include signal diversity, equipment diversity, aspect diversity, and people diversity. Signal diversity includes the use of different signals (censors) to initiate an sction, wach as neutron flux and resctor preasure as diveres signals for initiation of reactor scram. Equipment diversity includes using different kinds of equipment to perform a function. An example of equipment divervity described in NUREG-0493 is the use of relay ve solid-state logic in the I\&C syetem. The ABWR dosign employs equipment diversity in that the remote shutdown station (RSS) is a hardwired analog system and is, therefore, diveree from the microprocessorbaeed SSLC. Included in the equipment diversity category is the uee of different software languages. Aspect diversity involves using different logic lovels. An example for the ABWR is the functional algorithm diversity between the DTM functions within a channel. Another example of espect diversity in the ABWR design is the do-energize to actuate (fail-eafo) aspect for the RPS actuation v8. the corgize to actuate (fail as-is) aspect of the ARI. People divervity refers to using different groups of people to design, verify, validate, and maintain an I\&C system. Examples of people diversity required in the ABWR design are the different groups performing the I\&C syetem design ve. thowe performing the QA function, and tho independence between the software verifier and the software designer. It is difficult to define how much improvement in safety recults from a given kind or degree of diversity. For microprocessor design, this is especially difficult because there is no industry consensus on a method to quantify software reliability and/or availability.

\section{DISCUSSTON OR THE RBSOLUTTON}

GE's initial analysis of common-mode failure was provided in Appendix 7A of the SSAR. In the SSAR, GB stated that the use of shared sensors in the design may increase the effects of potential common-mode failures. Therefore, the SSLC system architecture is designed to provide maximum segrogation of system functions by using separate DTMs and TLUs within each of the four I\&C divisions. In the analysis it was also noted that for the reactor shutdown function there are five different methods for controlling reactivity including the RPS hydraulic scram, the air header dump valves of the ARI system, the fine motion control rod drive (FMCRD) insert function of the ARI system, the SLCS, and the CRD system. The reactor core cooling function can be accomplished as described in the SSAR by four different systems including the motor driven (FDWC) system, the motor driven highpressure core flooder system (HPCF), the turbine driven RCIC system, and the low-pressure mode of the RHR system. Appendix 7A also described the RSS which provides diverse (hardwired) core cooling control functions. GE concluded that the ABWR meets the intent of NUREG-0493 for I\&C system diversity. The staff, however, concluded in the DSER that the GE analysis did not adequately addrese potential loss of safety functions due to postulated common-modo failures, and that this was an open issue.

The staff conaiders the two principle factors for dofence against common-modo failures to be quality and diversity. The quality aspects of the ABWR I\&C systoms are addressed in other sections of this report. Quality, in part, is achioved by the use of quality design standards for the hardware and software, and the I\&C aystem teating to be performed. With fow exceptions, the staff concluded in the DFSER that the quality issues had been substantially resolved.

Though there were some studies performed by GE in the design process, no analyses were presented to the staff which adequately demonstrated how the SSLC design complied with NUREG-0493, and thereby provided adequate defense against potential common-mode failures. The staff concluded in the DFSER that this concern had 
not yet been addreaned adequatoly by $\mathrm{OB}$. The ataff identified the dofeneo-in-depth jenve an DFSER Open Items 7.2.6-1, 7.2.6-2, and 7.2.6-3.

Because the staff determined that the ABWR SSAR and related documentation had not adequately addreaced the common-mode failure and defeneo-in-depth concern, the etaff performed its own common-mode failure asicesment of the ABWR besed upon the guidence of NUREG-0493. Somo additional considerations were added to the original NUREG-0493 approach, such as evaluation of information available to the operator, common-mode failures during accidents as well as transients, the time available for syatems actuation, and tho use of non-Class IE systems to provide a diverse means of accomplishing safoty functions if the first-line safoty systems failed. The ataffe dofensein-depth and diversity asecesment of the ABWR devign was performed by the Lawrence Livermore National Leboratory (LLNL) (under contract to the staff - reforred to as the LLNL diversity study). The results were made available to GE for determination of any factual errors in the design asecesment. $G E$ informed the staff of some orrors in the study which have been correctod.

The LLNL diversity study ovaluated I\&C system function for all of the SSAR Chapter 15 events. This set of events was judged by the staff to be sufficiently complete to bound these situations requiring initiation of safety systems based on the NUREG-0493 methodology. The study ovaluated each ovent in conjunction with a set of postulated common-mode failures. Two specific ovents wero selected for detailed study in the preliminary stages of the review. Those events were generntor load rejection with normal bypass, and steam system piping break outside containment. Aseumptions made by LLNL in the analysis during the reviow were documented in the LLNL diversity study. Ono aspect that was not specifically ovaluated in the study was anticipated operator actions. As described later in this report, opentor actions have now been considered.

In the LLNL diveraity study several areas of concern were identified. The use of the EMS for the RPS, ESF and information to the operator was a particular vulnesability, along with the common elements shared by the DTMs and TLUs. In the study it was concluded that, in general, there was information and system controls to mitigate each of the transients investigated, however, there may not be sufficient time and information to complete all necessary activities manually to maintain safety functions, especially if the actions required the use of the RSS.

Due to the significance of the EMS to the proper functioning of both the RPS and ESF, a common-modo failure of the EMS was a significant concern of the staff in the resolution of the defenes-in-depth and diversity iscus. The modules identified in the EMS are to be implemented by microproceseor baeed designs with similar hardware in all four divisions. MPL A11-4121 (Rov. a (preliminary), January 19, 1988), "Multiplexing Syetem Application Procedure, Design Procedure," opecifically states that the individual multiplexing systems shall be designed with a high dogree of atandardization. The DTM and TLU/SLU component of the SSLC also share common software design features which would result in a failure of all four channels if there is a software error.

In roviowing the results of the study, the staff found diverw I\&C system features in the ABWR design, several of which GE had previously presented as solutions to the potential common-mode software error concern. In the study, credit was given to non-Class 1E systems to mitigate an event if tho non-safety systems were reasonably expected to be available. Thus, from the study the staff determined that the ABWR design has a number of attributes which provide defenso-in-depth and protection against a potential software error as follows:

1. The turbine inputs to the RPS are hardwired (do not use the EMS). Further, the NMS and the PRM system RPS inputs use microprocessors but are directly wired to the SSLC and do not use the EMS. Therefore, an EMS common-mode failure would not disable these inputs.

2. Manual scram functions and manual MSIV actuation are hardwired from the control room, do not use the EMS, and are not dependent upon microprocessors.

3. The ARI function, that is part of the ATWS system, is independent of the EMS. The ARI system is a twoout-of-three logic initiation non-Class $1 E$ system that is separate and independent from the RPS. By lettor dated June 2, 1993 (on important features identified by the ABWR PRA), GE identified this feature as providing a aignificant factor in the reduction in the probability of an ATWS.

4. The NEMS is diverse in both hardware and software from the EMS. The NEMS is a non-Class $1 E$ system.

5. The RSS is conventionally hardwired from the station itself to the actuation devices (does not use the EMS) and does not use microprocessors. The RSS is outside of the main costrol room as required for its primary dosign function of shutting down the reactor upon abendoning the main control room. The RSS is a two chaunel control and indication station which contains most of the ESF capabilities. 
6. Final dieplay information for the operntor is provided by a exparate, diverse means - the Clase IE fixed mimic display and the Clase 1E divisional VDUs. Alarme and paramoter information are also available on the non-Clase 1B VDUs and from the plent computer.

7. The NMS bypaeses the DTM and is input directly to the TLU. A common DTM filure will not fail the NMS ecram function. The ARI aystem controls aleo bypese the DTM because the ARI aystom is not part of the SSLC.

8. The DTMs and TLU/SLUs have a aignificant lovel of functional diveraity between the RPS and ESF functions and between portions of the ESF. As shown on Figuren 7.3-1 ard 7.32 of this report, there are three DTMs, one TLU and two SLUs per channel of the SSLC. The coftware algorithms within the SSLC are functionally diveres between the RPS and ESF functions as reoult of the equipment to bo tripped/actuated, i.e., deenergizo-to-operate function for RPS and MSIV, and energizo-to-operate function for ESF.

9. GB stated in the SSAR that the SSLC cottware will bo relatively simple which will reoult in a high degreo of aseourance that the required teating will reveal virtually all of the coftware errors. The BMS eoftware is oven simpler. However, no supporting analysis has been provided to support these conclunions. All the anfotyrelated coftware will be verified and validated. The staff concludes that eoftware, oven that which hes been verified and validated with a high-quality program may still bave undetected errors. This was DFSER Open Item 7.2.6-4. In a letter dated April 30, 1993, GE provided a deecription of the software development program, a commitment to provide a set of hardwired backups, and a rovised common-mode frilure analysie. In the letter, GE concluded that a softwaro simplicity analyais was no longer relovant aince the quality and diversity ievuce for software will addrees the staff's concerns regarding software reliability and digital system dofenso-in-depth. The staff agrees that this analysis is no longer neceseary as the besis for resolving the defense-in-depth questions. These concerns are addreseed in the computer ITAAC and overall digital system diversity, and, therefore, Open Item 7.2.6-4 is resolved.

Based on the two examples reviewed in detail in the LLNL diversity study, the staff and $\mathrm{OE}$ conclucied that nome postulated failures in the SSLC (and EMS) would disable the displays and controls of the ESF systems in the main control room. Some postulated failures would also result in the loss of a significant amount of information to the operator in the control room. Another conclusion was that it would be neceneary to sccess the RSS in order to initiate the BSF equipmeat and mitigate the ovents under concideration. For the events reviowed, there was dieplay and mitigation capability available for all postulated failures. The mitigation control function was occasionally at the RSS or was provided by a non-Class 1E system. Normally available control systoms, wch es the FDWC syctem, were credited in the analysis, while systems not normally ueed, wuch as the fire water system for reactor water injection, were not.

The reaults of tho LLNL diversity study were precented to OB. The etaff identified the following four primary concerns arising out of the study:

1. The reeponse to the initiating ovent needed to be confined to the main control room.

2. Consideration of the time available for manual operator actions was incomplete in the analysis.

3. Syatem lovel actuation capability from the ccistrol reom for the ESF functions was lacking.

4. Display of the necessary Class IB variables in the main control room was lecking.

The ataff requested OE to complete its roviow of the LLNL diversity study and respond to the above concerns. The above results were also provided to the Commiscion for approval in SECY-93-087, "Policy, Technical, and Licensing Iswues Pertaining to Evolutionary and Advanced Light-Water Reactor (ALWR) Designs," April 2, 1993, as the staff's generic position for digital system defense against common-mode failures for advanced light-water reactors.

Tho staff position on I\&C system diversity for ALWRs as approved by the Commission in a SRM dated July 21, 1993, is as follows:

1. The applicant shall assess the dofense-in-depth and diversity of the proposed I\&C system to demonstrate that vulnerabilities to common-mode failures have been adequately addressed.

2. In performing the assessment, the vendor or applicant ahall analyze each postulated commonmode failure for each ovent that is ovaluated in the accident analysis cection of the safety analysis report (SAR) using best-estimate methods. The veador or applicant shall demonstrate adoquate diversity within the design for each of these events. 


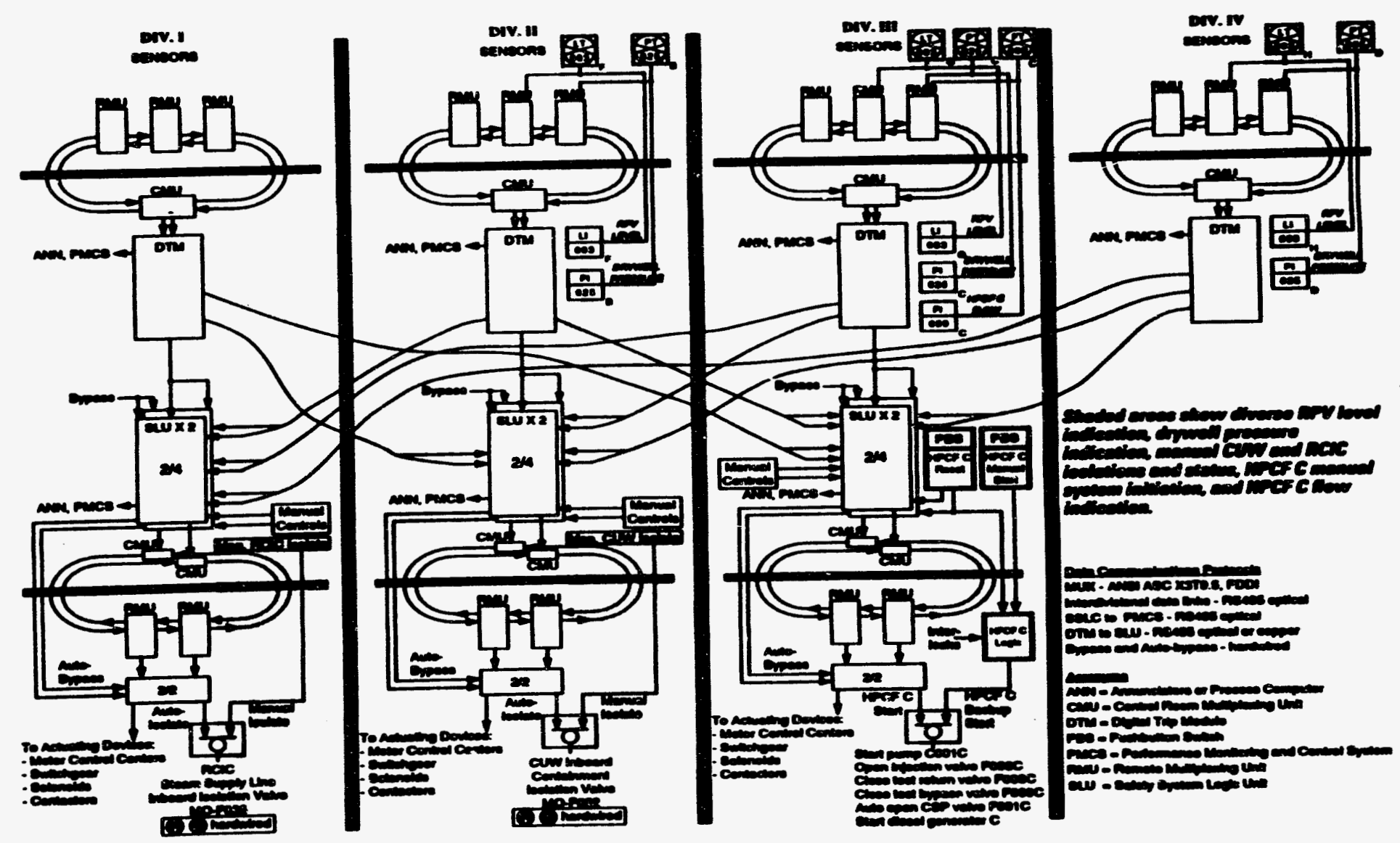

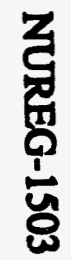

Figure 7.3-1 Safety system logic and control communications path for engineered safety systems 


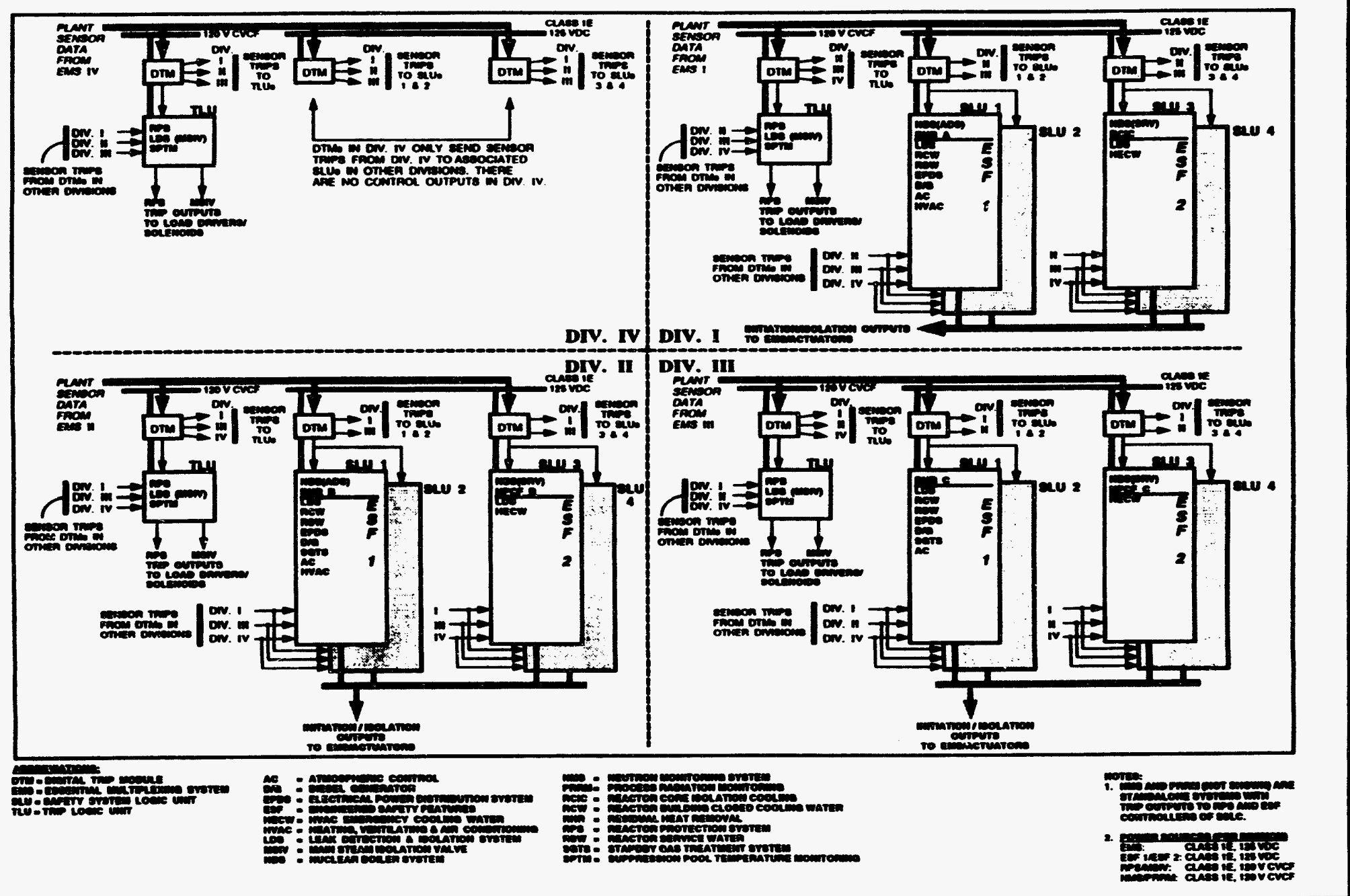


3. If a postulated common-mode failure could disable a safety function, then a diverse means, with a documented beses that the diverse means is unlikely to be subject to the same cormon-mode failure, shall be required to perform either the samo function or a different function that provides adequate protection. The diverse or different function may be performed by a non-safety system if the system is of sufficient quality to perform the necessary function under the associated event conditions.

4. A set of displays and controls located in the main control room shall be provided for menual system-level actuation of critical safety functions and monitoring of parameters that support the safety functions. The displays and controls shall be independent and diverne from the safety computer system identified in Items 1 and 3 above.

The staff's proposed applicable regulation for digital system defense against common-mode failures for the ABWR design is, as follows:

Digital instrumentation and control systems provided for the standard design must include:

(1) an assessment of the defense-in-depth and diversity of instrumentation and control systems,

(2) a demonstration of adequate defense against common-mode failures, and

(3) provision for independent backup manual controls and displays for critical safety functions in the control room.

GE completed its review using events that GE believes envelope the Chapter 15 events. GE disagreed with the staff's position and indicated that adequate defense-in-depth and diversity should consider the likelihood of the postulated events in conjunction with the assumed commonmode failures. Under these circumstances, credit for the RSS to mitigate the event should be permitted.

In response to the GE position, the staff prepared a list of the set of equipment which it believed was necessary to bring the ABWR design into compliance with the proposed staff position and which were necessary for a demonstration of appropriate diversity. The list was based on a functional, symptom-based approsech to accident mitigation to assure that adequate reactivity control, core cooling, reactor coolant system integrity, and primary containment integrity are maintained for all events. This list was also based upon a review of the control functions identified in the EPGs and the post-accident monitoring indications identified in RO 1.97.

GE completed three studies related to furthering the issue of dofense against common-mode/common-cause failures in the ABWR I\&C systems. The first was an analysis of the common-mode failure of ABWR multiplex equipment (SSAR Appendix 19N, Amendment 22). This study identified the following potential common-mode failure mochanisms:

(1) Earthquake

(2) Loss of dc power

(3) Loes of cooling

(4) Sensor miscalibration

(5) RMU miscalibration

(6) Set point drift

(7) Maintenance/tost error

(8) Manufecturing orror

(9) EMI

(10) Fire

(11) Software fault

In the study, GE addressed each of the above issues. Most were evaluated as not being credible causes due to the qualification of the I\&C equipment, physical separation, or administrative controls. The study contained the conclusion that common-mode software fault is a credible, although unlikely, possibility. GE committed to administrative controls to minimize errors, TS requirements to assure failure detection, and symptombased procedures to assure that adequate core cooling is maintained in the event of a common-mode EMS failure.

The second GE study relating to the issue of defense against common-mode failures was the preparation of an inventory of controls, displays, and alarms relied upon for accident mitigation based on the EPGs, including their locations. This information was submitted as SSAR Appendix 18F. Based on the information provided in the SSAR, GE demonstrated that the displays will have separation and some diversity. The diversity for the safety-related displays is primarily provided between the fixed mimic panel and the safety channel VDUs.

The third study prepared by GE was an event-based common-mode failure evaluation. (The result of the study was presented to the staff at a meeting held at the GE offices in San Jose, California on August 26, 1992, and was documented as part of the minutes of that meeting). In performing the study, GE evaluated 14 events from the SSAR Chapter 15 transients and accidents, considering the emergency operating procedure entry conditions and a postulated common-mode failure in the ABWR I\&C system. The study addressed the automatic actions that 
would occur following each ovent coincident with the poetulated common-mode failure. The common-modo failure poetulated for each of the ovents wes an undiscovered fault in the EMS resulting in all valid and correct control and monitoring data transmissions being loet. The emergency opernting procedure (EOP) entry conditions were then considered. In eoveral ovents, moro than one monitored parameter is expected to indicate the need to enter the BOPs. Indication of reactor preesure vecal water lovel low was the entry condition for many of the eveats; drywell preesure high indication was the entry condition for everal others. The etudy considered operutor actions described in the EOPa, with the equipment which was not disabled by the pottulated common-mode failure. The reactor and containment response was ovaluated for each ovent and was compared to the SSAR Chapter 15 snalysis (which does not ascume common-mode failure of LEC equipment). A summary of each svent was provided which concluded that, for one hour or more, refficient water was available for decay heat removal.

A significant factor considered in this analysis was the function of the feedwater system during the postulated transient or eccident. For each of the ovents (except for feedwater line breaks or failures) the feedwater system was aseumed to remain operational. The feodwater system was also assumed to function properly in response to the specific oveat ecenario. For example, a loss-of-coolant accident (LOCA) inside containment, a lows of condenser vacuum, or a loes of the auxiliary power transformer requires a reduction in feedwater flow to the reactor veseel., GE stated that reduced flow was a normal expected function of the feedwater system under the above event condition. If the feedwater system continues to run at 100 percent flow, the available water inventory would be exhausted in approximately 4 minutes. If the feedwater system responds as assumed in this study, water inventory would be available for over an hour. Based on this study, GE concluded that there was adequate capability in the ABWR design to mitigate each ovent for sufficient time until the RSS capabilities could be used.

The staff reviewed the GE study as documented in the SSAR and agreed with the conclusions. However, the staff believes that GE relied too heavily upon the feedwater system as a backup to safety-related RPV inventory means; therefore, additional backup capability should be provided in the main control room. This was discussed further in the DFSER.

\section{CONCLUSION}

The staff concludes in the DFSER that the following additions to the ABWR design are needed in order to provido acceptable defengo-in-depth against potential common-mode failures of the I\&C systems:

1. The following control capability will be added in the control room:

a. clean up water line isolation valve (inboard) manual initiation. This is required by both Itoms 3 and 4 of the above staff diversity position.

b. RCIC steamline isolation valve (inboard) manual initiation. This item is required by both Items 3 and 4 of the staff position listed above.

c. HPCF system manual initiation. 'In the diversity analyses, many of the events rely on the feedwater system to mitigate the event in combination with the postulated common-mode failure. Experience with feedwater systems at operating plants raises a concern that they may not be reliable enough to satisfy the Item 3 requirement that the backup system be of sufficient quality to perform the necessary function under the associated event conditions. The ABWR feedwater system uses a triplicated I\&C system and electric motor-driven pumps which should provide a higher degree of reliability than in currently operating plants. However, the reliability of the I\&C system, especially responding to transients and accidents for which it was not specifically designed, cannot be determined. By letter dated June 2, 1993, GE provided a description of the important features identified by the ABWR PRA. This report identified the HPCF logic and control as an important item and stated that "although the probability of a common cause failure of the SSLC is very low, an independent and diverse means of HPCF operation further reduces the risk associated with system operation through the multiplexed digital SSLC." Therefore, the staff concluded that it is prudent to require HPCF backup capability to provide water to the reactor vessel. HPCF backup control in the main control room provides additional assurance that long term core cooling will continue to permit additional time for implementation of the emergency action plan, manning of the RSS, or other long term actions. The staff concluded that only one channel of HPCF capability was needed, and that system-level actuation be provided at the lowest level in the safety computer system architecture. The controls may be hardwired either to analog components or to simple, dedicated, and diverse software-based digital equipment that performs the system-level actuation logic. The above staff conclusions are consistent with the Commission approved diversity position. 
2. The following dieplay capability will be added in the control room:
a. RPV water lovel
b. RPV water lovel (lovel 3) alarm
c. Drywell pressure
d. Drywell pressure (high) alarm
- CUW isolation valve status
f. RCIC atoumlino icolation valve status
8. HPCF flow.

The displays may be analog components or simple, dedicated, and diveres coftwaro-based digital displays.

3. The RSS dieplays will be operable during normal operntions. This will permit an operntor to aseees the status of the displayed peramoters without transferring control from the main control room.

4. The FDWC aystom will be designed and teeted to verify its availability consiatent with the oveat analyees deccribed above. Teeting is required to provide an appropriato lovel of ascurance that the feedwater systom can reepond to the conditions ancumed in the analyses which are beyond the aystem's normal design basit. The inclusion of only angle I\&C channel of highprecerure water injection capability in the main control room is predicated upon eatisfactory operation of the feedwater system during the analyzed ovents as demonetrated by testing. For each ovent analyses of SSAR Chapter 15 (the GE and LLNL analyseo referenced above) which shows that foedwater provides mitigation following the postulated common-mode failure of the anfety-related I\&C aystems function, the FDWC system shall be tented using simulated inputs to demonetrate that it will porform as acoumod in the analyeses. This requirement is added to the ITAAC.

The above staff conclusions were provided to $G E$. GE bes completed the last of the analyses demonstrating adequate core cooling. The sanlysis tochnique was recently revised when GB discovered that the code being used to model the ovents was not adequate for the steam cooling modo. Uaing a model that provided steam cooling analysis, GE concluded that the CRD pumps did not provide adequate inventory to mitigate a feedwater line break and, therefore, OE agroed to add hardwired HPCF pump initiation control and flow indication as diverse beckup capability. This was the last remaining area of disagreement between the staff and $G E$, and this isoue is now resolved. $G E$ hes provided an Appendix C to SSAR Chapter 7 which includes the above commitments to provide adequato defense against potential common-modo failures. Appendix C addresses the iscues identified above and specifies the diversity and et of equipment that will not be subject to potential common-mode failures. Therefore, DFSER Open Iteme 7.2.6-1, 7.2.6-2, and 7.2.6-3 are reeolved and the design meets the staff's propoeed applicable regulation for digital instrumentation and control systems.

\section{REACTOR VESSEL WATER LEVEL INSTRUMENTATION}

One ienve aseociated with defenso-in-depth and the diversity of design required to provide adequate protection against common-mode failures remains open. This issue concerns the RPV water level menourement. The issue was DFSER Open Item 20.3.8. The primary issue concerns the use of identical messurement techniques using condensing chambers and differential preseure transmittern to mensure the water level and provide aignals to I\&C logic. Resolution of this item is discussed in Chapter 20 of this report.

\subsubsection{Setpoints}

The RPS setpoints will bo listed in the RPS TS. The actual setpoints will not be established at this timo beceuse the design has not been completed, and the equipment hes not been selected. The COL applicant will provide the specific eetpoints besed on the I\&C system design and equipment prior to fuel loed. The general requirement is that the ectpoints be established high enough to preclude inadvertent actuation, but low enough to assure that proper margin is maintained in the setpoint determination. The TS (SSAR Chapter 16) have been submitted for review and are addreased in Section 16 of this report. Additional TS diecusajion is also included in Section 7.11 of this report.

OE has committed in the SSAR to meet the guidelines of RG 1.105, which govern instrument setpoints. RG 1.105 endores ISA S67.04-1982, "Setpoints for Nuclear SafetyRelated Instrumentation Used In Power Plants, " with somo exceptions. This is an acceptable commitment since ISA S67.04 defines a structured analysis acceptable to the staff to determine specific setpoints that adequately considers inaccuracies. This standard is currently undergoing revision and is expected to be issued in the near future. This is an example of a SSAR commitment which may bo changed at come later time. The ITAAC for setpoints (which are included in the I\&C CDM) requires a plant specific setpoint analysis which details the procedure for establishing specific setpoints. This plant specific analysis will bo audited by the NRC during ITAAC implementation. Any changes to the setpoint commitments in the SSAR would involve an unreviowed safety question and, therefore, require NRC review and acceptance prior to implementation. Any requested changes to this commitment shall either be specifically described in the 
COL application or aubmitted for license amendment after COL ismunce.

\subsubsection{Hardware and Software Qualification}

The SSLC will be qualified a a Clas IB syatem. All SSLC components aseociated with protection systems are Class IE and will be qualified to the sume standands as the protection syctoms. All programmable digital equipment used for afoty-related functions will be qualified in sccordance with the safoty aystem doaign basis with which they interface. This includes cavironmental and soismic qualification. The SSAR dencribes commitment to the SRP qualification criteria. The etafi reviewed the commitments and has concluded that, for the topica that are addressed by the SRP, the commitments are adequate. The staff identified three additional areas of qualification that are not fully addreesed in the SRP criteria. These issues are discuseod in SSAR Appendix 7A, and are software qualification, electro-magnutic auceptibility, and mild environmental qualification. Thewe issues were identified in the DSER as open issues.

The ABWR SSLC is dependent upon the proper functioning of the software to perform its safety functions. The standard for software which bes been formally endorsed by the staff to specifically address software qualification is ANSI/IEEE ANS-7-4.3.2 (1982), "Application Criteria for Programmeble Digital Computer Systems in Safety Systems of Nuclear Power Generating Stations," which was endoreed by RG 1.152 in 1985. The ABWR SSAR stated that, coftware development will, in general follow this standard. The etaff considered this statement unclear and requested GE to provide a clear commitment to the software development process to be followed for the ABWR I\&C system. This isene is also related to the GDC 1 issue previously discuseed in this report concerning commitments to industry standards, and the iseuve concerning level of detail identified in the DSER. Because the software products and the software development plans for the SSLC have not been developed yet, there was no method available to the ataff to independently verify that the coftware was in conformance with ANSI/IEEE ANS 7-4.3.2.

ANSI/IEEE ANS 7-4.3.2 is high lovel deccription of a software V\&V proceses. Since it was published in 1982 there have been eoveral other standards iseued which provide additional guidance for V\&V. In addition, there are other apects to eoftware qualification in addition to V\&V. ASNI/IEEE ANS 7-4.3.2 has undergone significant revision and was roissued in November 1993.

To resolve the above issue on software qualification, $G B$ hes committed in the SSAR to software development, documentation and verification, in sccordance with the 10 CFR Part 50, Appendix B requirements for quality acaurance for anfety-related aystems and the following ctandurda:

1. ASME NQA2a, Part 2.7, "Quality Aemunance Requirements of Computer Software for Nuclear Facility Applications."

2. ANSI/IEEE ANS 7-4.3.2-1982, "Application Criteria for Digital Computere in Safety Syetems for Nuclear Facilities." GE has also committed to the revised version of this standard.

3. IEEE 730-1984, "IEEE Standard for Softwaro Quality Ascurance Plans."

4. IEEE 828-1983, "IEEE Standand for Software Configuration Management Plans."

5. IEEE 829-1983, "IEEE Standard for Softwaro Teat Documentation."

6. IEEE 830-1984, "IEEE Standard for Software Requirements Specifications."

7. IEC 880-1986, "Software for Computers in the Safoty Systems of Nuclear Power Stations."

8. IEEE 1012-1986, "IEEE Standard for Software Verification and Validation Plans."

9. IEEE 1033-1985, "IEEE Recommended Practice of Application of IEEE Standard 828 to Nuclear Power Generation Stations."

10. IEEE 1228 (draft), "Standard for Software Safety Plans."

11. IEEE 1042-1987, "Guide to Software Configuration Management."

12. Standard 2167A-1988, "Defense Syetem Software Development."

GB has provided a diecuesion of coftware development in Table 7B.1 of the SSAR. In addition to a deacription of the process, and the commitment to standards, $O E$ has added the following caveat:

Note that the documents listed above may differ regarding apocific mothods and criteria applicablo to tho SMP. In situations where such differences exiat, all of the mothods and criteria presentod within those documents are considered to be equally 
approprinte and valid and, therefore, any of the sbove listed documents my bo solected as the basis for elemente of the SMP.

The staff finds the list of standard scceptable. The coftwar developmeat for the ABWR is included in the IAC CDM. The CDM outlines a coftware dovelopment plan which follows the guidence of the atandurd included in the SSAR. Tho atendards lieted in the SSAR are expected to chnnge over the lifecims of the deaign certification. The etafi expects the COL epplicent to use the curreat vercion of atndards which are avainble when the cofware implementation is sturted. Section 7.1 of this report provides a diecussion of the uppronch to implementation of the ITAAC process for the I8C sytams. The stafi consider the first step in the staged ITAAC involving development of softwhre design plans to bo critical to ruccessful completion of the ABWR I\&C eyctem because of the rapidly chnnging technology in digital I\&C syatoms, and the many different vendors that my be invelved in implementation of the ABWR design.

GE has committed to several additional software dovelopment mothods and features as discuseed below. GB committed to uss formal mothods for the SSLC when formal mothods are doveloped aufficiently. Formal methods are typically defined as entailing a mathematical or occasionally a graphical software specification rather than natural langunge specification. The outputs would be able to be verified mathematically. Use of formal mothods is in a rolatively early stage of dovelopment at this tims. The staff agrees with GE that it is premature to epecifically commit to a particular formal mothod in tho SSAR and, therefore, the etaff finds the commitmont by GB to use the cccepted industry software design practices at the time that the coftware is doveloped to be appropriate.

GE has committed to provide a cafoty and beords andysis, a anouk circuit andysis, and a timing analysis for the digital I\&C syatoms. GE was requested to provide a deacription of the specifice of the progrnm in these areas. This was DPSER Open Itom 7.2.8-1. GE has provided additional detrile on these items in the CDM and the SSAR, and this item is, therefore, resolved.

GE he committed to the use of sofware metrics to track error rates during coftware development. GE has not specified a particular software motric as this will probably be selected by the find software vendor, and is an area that may change over the lifetime of the design certification. This was DFSER Confirmatory Itom 7.2.8-1. Tho SSAR and the CDM have been revised to include the selection of eoftwere metrics during the development process. This item is, therefore, resolved. The ataff also identified COL Action Itom 7.2.8-1 for this iene rince a posaible resolution considered when the DFSER was written was for tho COL applicant to select the software metrics. The solection of software metrics is now included in the CDM, SSAR and NRC audit of the ataged ITAAC. Therefore, this COL action item is no longer applicable and is resolved.

GB etated that "proven technology" will be employed in the deaign and development of the ABWR I\&C systems. The etaff requeated OB to clarify what was meant by proven technology. In response, GB stated that tho dofinition of proven technology provided in the EPRI RD wes appropriate for the ABWR. This EPRI requirement atates that three years of successful experience in an application (nuclear or non-nuclear) very similar to the nuclear power plent application is adequate to demonstrate proven technology. The staff agrees with this definition and finds this scceptable. The stated goal, to which both the staff and GE agrees, is to use the best available technology without using unproven designs.

GE has committed to simple modular software programs that follow the guidance of DOD-STD-2167. The staff agrees that safety systems should have simple modular progrums and finds this acceptable. GE has not specifically committed to follow DOD-STD-2167 for any other design requirements, though there are similar requirements for atructured design process between DOD-STD-2167 and the GE ABWR SSAR commitments.

At the time of issunnce of the DFSER, the issue of commercial dedication of software for use in safety systems had not been adequately addressed by GE. GE subequently made several commitments regarding commorcial dedication of software, and the specific wording to be included in the SSAR. These commitments were identified as DFSER Confirmatory Item 7.2.8-2.

The firet aspect of the commercial dedication issue is the use of woll- developed operating systems in the development of a plent epecific digital system, such as the SSLC. The staff agrees with GE that it is not necessary for the SSLC doveloper to perform a formal V\&V of the opernting system. However, it is essential that the SSLC developer aserure that the operating system was developed under atrict guidelines and has the quality necessary for a enfety systom.

The eccond aspect of the commercial dedication issue is the use of a complete component, such as a programmable logic controller, where most of the software has been developed prior to the decision to use it in a nuclear application. As with the operating systems described above, it is necesenry for the developer to verify that the equipment selected is of aufficiently high quality for use in 
a safety system. It is not nocesany for the find doveloper to repent the M\&V activities, but it is necesanary for the doveloper to verify that the original equipment deaigner hes followed equivalent critoria. This concern was resolved with SSAR commitmeats which were ideatified as DPSBR Confirmatory Item 7.2.8-2.

Included in the commercial dedication inase is the qualification of the automated tools and denign aupport software. It is neceseary for the Iaz eyctem developer to verify that the tools are sccurato. The etaff expects the doveloper to verify the quality of the tools used in the deaign.

Also related to the iswe of commercial dedication is the atafi concern regarding communication by the eupplien of errore discovered in the suppliers' tools or softwane to the end user. This is similar to the 10 CFR Part 21 defect reporting required for Class 18 vendors. This whe identified as DFSER Confirmatory Item 7.2.8-3. Tho CDM and the SSAR have been reviced to include the selection criteria for commercial softure, sccuracy of tools, and notification of the end user by the developer of changes. Therefore, DFSBR Confirmatory Items 7.2.8-2 and 7.2.8-3 are resolved.

Any changes to the hardware and software developmeat commitments deecribed in this section of this report would involve an unreviewed safoty question and, therefore, require NRC review and acceptence prior to implementation. Any requested changes to this commitment shall bo either specifically described in the COL application or submitted for license amendment after COL iesunce.

The MPL documeats do not add cubatentially to the irformation concerning hardware and software qualification. MPL C71-4010 (Rov. 0, May 18, 1990), "Reactor Protection System, Hardware/Softwaro System Specification," lists the inputs and outputs for the DTM, TLU, and OLU but does not provide any additional hardware or software descriptions or specifications.

The second aren of digital syatem qualification not addresecd in tho SRP criteria and which was an open ieves in the DSER, concerns the qualification of the RPS and the other digital I\&C equipment for the electromagnetic environment to which it will be exposed. This ienese includes EMI, surge withstand cepability, electrostatic diecharge (ESD), radio frequency interfereace, and EMC. GE noted in the SSAR that one of the effective means of protection against EMI offects is the redundancy and separation of the divisions of the SSLC. GE committed in the SSAR to the following standards. for electromagnetic environmental considerations:
1. ANSI IEEB C63.12-1987, "Americen National Standard for Blectromagnetic Comparability Limits Recommended Practice."

2. ANSI/IREB C37.90.2-1987, "IEEE Trial - Uno Standard, Withetand Capability of Relay Syatem to Rediated Blectromagnetic Interference from Trunsceivors."

3. ANSI/IBEB C62.41-1980, "Guide for Surge Voltages in Low-Voltage AC Power Circuits."

4. ANSI/IEEE C62.45-1987, "Guide on Surge Teeting for Bquipment Connected to Low-Voltage AC Power Circuits."

5. MIL-STD 461C-1987, "Electromagnetic Emission and Susceptibility Requirements for the Control of Blectromagnetic Interference."

6. MIL-STD 462-1987, "Measurement of Electromagnetic Interference Characteristics."

7. IEC 801-2, "Electromagnetic Comparability for Induatrial-Process Measurement and Control Equipment, Part 2: Electrostatic Discharge Requirements."

8. IEEE 518-1982, "Guide for the Installation of Blectrical Equipment to Minimize Electrical Noise Inputs to Controllers from External Sources."

Commitment to the above standards resolved the DSER open isave. The standards listed above require the selection of epecific toet categories. Verification of the appropriate selection will be performed during the ITAAC implementation. The seloction at the planning stages includes consideration of installation techniques (wuch as indicated in IEEE-1050 for shielding and grounding), and verification at the sito that the installed condition is enveloped by the qualification testing.

BMI protection is included in the I\&Cs CDM. One specific feature that the staff requested be included in the CDM is that the digital equipment be tested for the low range of the EMI spectrum as well as the mid to upper runges. This wes DFSER Confirmatory Item 7.2.8-4. The CDM was revised to include the solection of the EMI teating ranges when the equipment has been eelected. This is acceptable to the staff and, therefore, this item is resolved. Any changes to these EMI commitments would involve an unreviewed safety question and, therefore, require NRC reviow and acceptance prior to implementation. Any requested chenges to this commitment shall 
aither be apecifically doscribed in the COL application or submitted for license amendmeat after COL iesuance.

The third area of digital system qualification concerns the qualification of the SSLC equipment for the mild environment temperature profiles to which the equipment could be subjected during plant opention. One isoue in particular concerned the poesibility of local hot epots as a renult of higher current densitie when using digital chip designs. OB committed to qualification of the SSLC internal panel components to a temperature rice of $15{ }^{\circ} \mathrm{C}$ $\left(27^{\circ} \mathrm{F}\right)$ above the normal ambient operating conditions. The electronic equipment panel cooling to meintain qualification is achieved by natural convection of the room air in the panels. Fans may be used to improve long term reliability of electronic equipment, but no credit is taken for forced air circulation for thermal qualification purposes. MPL DMH-4270 (Rev. 2, February 3, 1989), "Esecential Multiplexing System Design Specification," liste the CMU and RMU environmental qualification requirements as $10-^{\prime} 40^{\circ} \mathrm{C}\left(50-104^{\circ} \mathrm{F}\right)$ temperature, 10 - 60 percent relative humidity, and seismic Category I.

OE stated in the SSAR that the SSLC will be constructed from electronic components purcinesed to military specifications to the extent practical, and the components will be qualified by teating to higher tomperatures than specified in the SSAR for a given room cavironment. The staff agrees that it is desirable to have this additional margin built into the design. This was DFSER Confirmatory Item 7.2.8-5. The SSAR, has been revised to include this information and, therefore, this item is resolved.

Based on the above ovaluation of the RPS qualification, the staff concludes that the commitments in the SSAR meet the requirements of IEEE-279 for equipment qualification and quality of components and modules.

\subsubsection{RPS Findings and Conclusions}

The design description of the RPS in the SSAR was ovaluated to confirm commitments to the SRP and the applicable regulatory guides and industry codes and standards. This review was concerned with the trip parameter sensors, EMS, SSLC and the protection actuation circuits. Based on staff review of the information provided for the sensor and protection actuation circuits, the staff concludes that the SSAR provides acceptable commitments to the appropriate SRP criteria.

The RPS includes systems and components that GE has committed to be designed to survive the effects of carthquakes, other sutural phesomena, abnormal cavironments and misailes. The etaff, therefore, concludes that the $O B$ commitments meet the requirements of ODC 2, "Deaign Bases for Protection Againat Natural Phenomenn," and ODC 4, "Environmental and Mieaile Deaign Baees," for the RPS.

Baned on the review, the etaff concludes that the deaign and the deaign procees for the RPS a described by OE in the SSAR and CDM provides instrumentation to monitor variables and aysteme over their anticipated ranges for normal operation, for anticipated operational occurrences, and for accident conditions as appropriate to maure adequate anfoty, including those variables and aystems that can affect the fiscion procese, the integrity of the reactor core, the reactor coolent prousure boundary, and the containment and its ascociated systoms. It appears that appropriate controls have beo provided to maintain the variables and aystems within preacribed operating ranges. Therefore, the staff finds that the RPS design satiafies tho requirements of ODC 13.

The staff also concludes, as discuseed in Section 7.2.1 of this report, that the $\mathrm{OB}$ commitments to the requirements of 10 CFR 50.55a(b) (IBEE-279) and the requirements of GDC 20, "Protection Syatom Functions," for the functional requirements of the RPS are acceptable.

The etaff concludes that periodic testing of the RPS as described in the SSAR, and as discussed in Section 7.2.1 of this report, conforms with the criteria of RG 1.22 and IEEE Standard 338 as supplemented by RG 1.118 and is, therefore, acceptable. The staff further concludes that $\mathrm{GE}$ commitments to IEEE-279 with regard to system reliability and testability are consistent with the requirements of GDC 21, "Protoction System Reliability and Testability," and are acceptable.

The staff concluden, as discussed in Section 7.2.1 of this report, that the RPS as defined by GE moets the criteria of IEEE-384 as supplemented by RG 1.75 for protection system independence with the exceptions noted in SSAR Table 1.8-7, "Summary of Differences from SRP Section 7," and discussed in the SSAR. The staff finds the identified exceptions acceptable, and therefore, the staff concludes that the RPS moets the requirements of GDC 22, "Protection System Independence."

Based on the staff roview of results of the FMEA of the RPS in conjunction with the results of the studies of the RPS design for dofense against common-mode failures, the staff concludes, as discussed in Section 7.2.1 of this report, that the RPS design adequately meets the requirements of GDC 23, "Protection System Failure Modes." 
Baned on the reviow of the reactor protection syatem deaign, tho etaff finds that the syetem is deaigned to mod the requirements of IBEE-279 regarding control and protection system internetion meets the requirements of GDC 24, "Separation of Protection and Control Systoms."

Based on the roviow of the reactor protection system, the ataff concludes that the oystem entisfies the protection system requirements for malfunctions of the reactivity control system auch as accidental withdrawal of control rods. Therefore, the staff finds that the RPS satisfies the requirements of ODC 25.

Based on the reviow of the protection and reactivity control systems, the staff finds ibat these systems are designed to assure a high probability of accomplishing their safety functions in the event of anticipated operational occurrences. The staff, therefore, concludes that the design meets the requirements of GDC 29.

The staff roviow also included considenation of the RPS quality and diveraity, as discuesed proviously in Section 7.2.1 of this report. Based on this review, the staff concludes that $\mathrm{OE}$ has specified the appropriato quality requirements, and has provided adequato defensoin-depth and diversity for postulated common-mode failures. The staff has determined that changes to commitments involving (1) computer hardware and software development and quality standards, (2) essential multiplexor design and standards criteria, (3) electromagnetic environment protection criteria and standards, (4) design features and commitments of the SSLC self-test system, and (5) setpoint methodology, would involve an unreviewed safety question and, therefore, require NRC reviow and acceptance prior to implementation. Any requested changes to these commitments shall either be specifically described in the COL application or submitted for license amendment after COL issuance.

The staff also concludes that the staged audit approach of the ITAAC implementation discussed in Section 7.1.3.3 of this report is an important espect in the final acceptance of the RPS.

Based on the above discussions and findings, the staff concludes that the design and the design proceses of the RPS as described by GE in the SSAR and CDM meets the requirements of GDC 2, 4, 13, 20, 21, 22, 23, 24, 25, and 29 and 10 CFR 50.55a(b) (IEEE-279). The RPS design is, therefore, acceptable.

\subsection{Engineered Safety Features Systems}

\subsubsection{Syatem Description}

This section describes the I\&Cs for equipment in the various ESF systems. ESF system deecriptions are provided in SSAR Chapter 6. The ESF systems for the ABWR utilize the SSLC system which is shared with the RPS. Figures 7.3-1 and 7.3-2 of this report provide an overview of the ESF implementation with the SSLC. Section 7.2 of this report discusses the components of the SSLC. Difierences between the RPS design implementation and the ESF design are discused in tho following rection.

This rection deecribes application to the ESF system of the design bases information identified in IEEE-279, and the various new technology criteria identified by RG 1.152, NUREG-0493 and the ABWR CDM. The additional RPS criteria discussed in Section 7.2 for software, EMI and mild environment qualification also apply to the ESF systoms.

The ESF systems are:

(1) emergency core cooling systems

(2) LDS

(3) wetwell and drywell spray mode of RHR

(4) suppression pool cooling mode of RHR

(5) SGTS

(6) emergency diesel generator support systems

(7) reactor building cooling water system

(8) essential HVAC emergency cooling water system (HECW)

(9) high-pressure nitrogen gas supply system

The systems that provide the ESF functions for the ABWR are similar to those of operating BWR designs previously roviowed by the staff. As with the RPS, the primary differences are in the method of implementation of the I\&C aspects of the design. The focus of this review was on the use of the EMS and the SSLC system in place of the relay, solid state logic, and copper wire cable of previous I\&C system designs.

\subsubsection{Emergency Core Cooling Systems}

The ECCS consists of the HPCF system, the automatic depreseurization (ADS), including the safety/rolief valvo (SRV) electrical actuation logic system, RCIC system, and low-preesure flooder (LPFL) mode of the RHR system. The ECCS I\&C (ESF actuation) systems sense the need for ECCS action and initiate appropriate equipment as required. Though the ESF systems share the SSLC and EMS with the RPS, the ESF systems are described in the 
SSAR and CDM as esparate I\&C systems which use the SSLC and EMS.

\subsection{Aligh-Presoure Core Dlooder System}

Four reactor water lovel and drywell preseure transmitters (one for each division) provide inputs to the SSLC logic, aither of which logic sigmal setivates the HPCF aystem upon I two-out-of-four coincidence of the parameter setpoint. The logic arrangement permits on-line teating of the electronics. After activation, the two HPCF pumps reach rated flow within 36 seconds. The HPCF pumpe automatically atop on reactor high water level, or can bo manually shutdown. The HPCF pumpe are interlocked to prevent etarting if an open suction path from the condensate storage tank or suppreacion pool is not available.

Separation within the HPCF sctuation logic system is such that no single failure can proveat system actuation. The logic system is also designed so that no single fuilure resui 's in a spurious actuation. While the initiating logic is a four-channel system, the sctuated system is a twochannel system. The HPCF control is powered by Divisions II and III of the SSLC as shown in Figure 7.3-2 of this report. Divisional separation is maintained between the four sensor inputs (Divisions I, II, III, and IV sensor channels) to tho logics, the Divisions II and III logic channels, and the Divisions II and III output controls (output channels).

\subsection{Automatic Depressurization System}

The MSL inside the drywell have a total of 18 SRV which discharge to the suppression pool. Eight of these valves are designated for use as the ADS. ADS consists of redundant trip chennels in two separate logics that control two separate solenoid-operated pilot valves on each ADS valve. Either pilot valve can operate its aseociatod ADS valve. ADS initiation signal is either reactor low water level (L1) and high drywell pressure or a sustained reactor low water level (sustained for 8 minutes). Both parameter eotpoints must be reached before ADS is initiated. The valves are interlocked with the HPCF and RHR pump discharge prescure sensors to assure that an HPCF or RHR pump is running prior to depressurization. There is also a time delay (29 seconds) between the completion of the logic voting and the initiation signal. This time delay allows the HPCF or RCIC systems to restore reactor vessel water lovel if they are available before depressurizing the reactor by actuating ADS. Manual initiation of ADS is also available.

Sensors provide inputs to the four-division SSLC. The ADS actuation output signal to the valves is via Divisions I and II output channels (electrical divisions) of the SSLC. The SSLC unes eight reactor veceel water lovel sensors; four different ecenons for Divisions I and II. Both electrical divisions are routed to each of the eight ADS valves. The ADS Division I ectuntion output energizes a solenoid pilot valve on each ADS valve. Similarly, the ADS Division II ectuation output energizes the recond pilot valve on each ADS valvo. Actuation of either solenoid pilot valve opeens the ADS valve.

\subsection{Reactor Core Isolation Cooling}

The RCIC system is a high-preanure injection system which uees a eteam turbino-driven pump. The ectuated equipment is a aingle train aystem. This system is initiated when either high drywell preesure or low reector water lovel (L2) cotpoints are met. Bach parameter has four sencore which provide input via the EMS to the SSLC. The output is via electrical Division I of the SSLC and the EMS.

The RCIC pump turbine is automatically shutdown on turbine overepeed, high turbine exhaust pressure, RCIC auto-isolation signal, low pump suction pressure, reactor water level high (L8), or manual trip if the initiation sigmal is not prosent. The RCIC systom fails-as-is upon loss of power to the SSLC or loss of input signals. Automatic and manual isolation capability for the RCIC systom is provided as part of the leak detection and isolation system.

The RCIC system itself is not redundant because the HPCF system provides functionally redundent capability. Some RCIC system valves are Division II components and appropriate separation of these devices and circuits from the Division I equipment is maintained. System tests aro sccomplished with a division-of-sensors bypass in place, as discuseed in Section 7.2 of this report. On-line signal verification is accomplished by the SSLC. S $\because$ stem status annunciation and performance indicators are provided in the control room.

\subsection{RHR/Low-Pressure Flooder}

The LPFL is an operating mode of the RHR system which is designed to provide water to the reector vessel following a design basis LOCA. The LPFL is initiated automatically on reactor low water level (L1) signals from the eight water level transmitters of the NBS. The LPFL injection valve actuation logic requires a reactor low-pressure permisaive for automatic actuation. These transmitters ase separated into four divisions, as discussed in Section 7.2 of this report. Four transmitters provide signals (one from each division) to RHR Divisions I and III, while the other four supply similar signals to RHR Division II. The LPFL systom is also initiated on high drywell preseure as sensed 
by four tranemilters (one from each divinion) of the NBS. The aignals from each parnmeter are combined, through fiber optic isolators, in two-out-of four logic for each division of LPFL in order to moet the singlo failure criterion. The RHR/LPFL flow pathe are redundant with functional divernity provided by the HPCF and RCIC systems. The SSLC incorporates sutomatic teating of the instrumentation and verification of the output signals. Syetem status annunciation and performence indicators are provided in the control room. The equipment will be environmentally qualified for the location in which it is to bo installed.

\subsubsection{Leak Detection and Isolation System}

The LDS I8C consist of temperature, preseure, radiation, and flow ecessors to detect, indicate, and alarm leakage from the reactor primary preasure boundary, and, in certain cases, also. clowe isolation valves to shut off leakage outside the containment. Manual control is provided in the control room for system level isolation of leakage. Each power-operated isolation valve is also provided with a eoparate manual control switch in the control room independent of the automatic and system level manual logic. All LDS isolation valves are actuated with doenergize to isolate logic.

The LDS system has several isolation capabilities. Containment isolation is initiated on high drywell pressure, low reactor water level (L1, L1.5, L2, L3), manual operator action, and high radiation from the PRM system. Direct operntor action, via manual logic reset control, is required to reeet the trip condition, provided the initiating signal is cleared. Reactor water cleanup system isolation is initiated on high differential flow and high equipment are temperature. RHR system shutdown cooling suction lines are isolated on low reactor water lovel (L3) and high ambient temperature. RCIC is isolated on high ambient temperature and high turbine exhaust preseure. The MSL is isolated on low reactor water level (L1.5), high MSL differential presesure, high MSL radiation, high MSL tunnel ambient temperature, high MSL tunnel area temperature in the turbine building, low main condenser vacuum, and low MSL preseure.

\subsubsection{RHR/Wetwell and Drywell Spray Cooling}

The wetwell and drywell epray cooling is an operational mode of the RHR system. This mode uses RHR pumps B and C. The wetwell and drywell spray cooling is manually initiated from the control room, with drywell pressure providing permissive interlocks from NBS sensors and EMS and SSLC system functions for the drywell cooling mode. The sensor circuits and logic are provided with ceparation, redundancy and testability consistent with other ESF circuits described in this soction and in Section 7.2 of this report. The menual initiating sequence begins with en LPFL initiation signal (low reactor water lovel). If high drywell preseure and/or high wetwell pieseure is also present, the operator will manually close the reactor injection valves, and manually open the spray valves. If low water level occurs again, the system will automatically realign to the reactor injection mode.

\subsubsection{RHR/Suppression Pool Cooling Mode}

The suppression pool cooling mode of RHR uses the same IRC as the LPFL previously described. Redundancy is provided by three separate logic divisions. However, unlike the LPFL, no functional or equipment diversity is identified. This systom is automatically initiatod upon receipt of a high temperature signal from the SPTM system. The suppression pool cooling mode is also initiated menually. Annunciators and indicators of the RHR systems' operation status in the suppression pool cooling mode are non-safety and available in the control room.

\subsubsection{Standby Gas Treatment System}

The SGTS is initiated automatically upon the detection of high drywell pressure, low reactor water level, high radiation in the fuel handling area or secondary containment HVAC exhaust air. Manual initiation is also available. Two logic divisions are powered from separate ESF buses. The SGTS I\&C are supplied power from the Divisions II and III emergency power supplies. Both electrical isolation and physical separation of the divisions are maintained. The system electronics are tested by signal ineertion. The SSAR states that SGTS electrical equipment is conformod to the environmental conditions for the area in which it is to be installed. Non-safetyrelated system status indicators and annunciators are provided in the control room.

\subsubsection{Emergency Diesel Generator Support Systems}

The three emergency diesel generators provide power to and are controlled by Divisions I, II, and III of the Cless 1E power supplies. The EDG support systems are described in SSAR Chapter 9 and the associated section of this report. The support systems include the jacket water system, the starting air system, the lube oil system, and the fuel transfer system. Though not specifically mentioned in the SSAR, the support systems also include the EDG HVAC system. The I\&C for the support systems are designed to the same criteria as the primary system. 


\subsubsection{Reactor Building Cooling Water System}

The I8C system for the reactor building cooling water syetem consint of two-out-of-four logic with syctom initiation cocurring on low resctor water lovel or high drywall presarure sigmals. The inetrumentation syctem's output to the ectuated equipment is exparated into three divisions wach that no single failure can dieable this system. Annunciators and indicators of syatem status are non-eafety-related.

\subsubsection{Ereential HVAC Emergeney Cooling Water System}

The HECW systom supplies domineralized chilled water to the cooling coils of the control building anfety-related olectrical equipment rooms and main control room coolers, and the diesel generator zone air conditioning systems. The HECW syetem is composed of three divisions, each of two divisions containing two 50-percent capacity refrigeratore and chilled water pumps and one division containing one refrigerator and chilled water pump. The systems' I\&C output to the actuatod equipment are aupplied from Divisions I, II, and III power buses.

The HECW syatem divisions are mochanically and electrically separate. The system is dosigned to operate during both accident conditions and normal plant operation and during all modes of operation for the control building and diesel generator zone cooling syetems. The HECW system operation is initiated automatically when the controls in the main control room are sot for automatic operation and any of the HVAC systems located in the control building or diesel generator areas are started. The HECW system can aleo bo startod manually from the control room. The HECW system I\&C will be teated manually.

The HECW system I\&C equipment will be qualified for the particular environment in the area in which it is located ss described in Section 7.2 of this report. The environmental qualification of the electrical equipment is also verified vis the ITAAC. DFSER COL Item 7.3.1.11-1 discussed the testing and temperature verification that the COL applicant is to include in its prooperational test procedures in order to confirm electrical equipment environmental qualification. GE rovised SSAR Section 7.3.3.1 to add the requirement that the COL applicant include temperature profiles for racke containing Class 1E microproceseor equipment (for various loss of HVAC conditions) in the pro-operational test procedures. This is acceptable to the staff. The COL applicant items aseociated with I\&C equipment cooling are discussed in Section 7.8 of this report.

\subsubsection{High-Preasure Nitrogen Gas Supply System}

The high-preasure nitrogen gas supply system provides compreaced nitrogen to the ADS SRV, the MSIVs (for teating only), and other instruments and valves. This syctem supports both afety- and non-eafoty-rolated portions of the plant. The safety-related portion of the syatem consiats of two redundant banks of high-preecure nitrogen bottles and associated piping, valves, and controls powered from separate escential power supplies (Divisions I and II). Upon detection of low nitrogen preesure to the ADS sccumulators, this system will automatically isolate the safety-rolated portion of the system from the non-afety-related portion by isolation valven which automatically terminato the normal nitrogen supply and open the emergency nitrogen gas bottle supply to the ADS sceumulators.

\subsubsection{Safety System Logic and Control and Specific Subsystem Descriptions}

The SSLC is discused in detail in Section 7.2 of this report. This section discuseses the differences between the RPS and ESF portions of the SSLC. The primary difference is the uee of anfety SLUs in place of the RPS TLUs. As shown in Figure 7.3-2, there are a total of 12 SLUs with four in each of the three SSLC divisions. The SLUs are contained in the portion of the SSLC designated as the logic channol in the TS. The actuated ESF equipment controlled from the SLUs may be in single, redundant or triplicated systom trains as described in the syetem descriptions above. The ESF equipment is divided between the SLUs $1 \& 2$ and SLUs 3\&4 logic functions to provide some diversity in case of a failure. For example, the HPCF and RCIC high-pressure reactor injection functions are provided by different SLUs than the RHR low- preseure reactor makeup function. The full distribution of systems on the various output channels is presented in the MPL design specifications.

The SLU architecture is arranged so that each ESF logic function has two SLUs performing the same function. Both SLUs (1\&2 or 3\&4) recoive the same input from the DTM, manual controls and bypasses, and in some cases they receive the same direct sensor inputs for interlock protection. The logic in both SLUs must agree before the initiation signal is processed via the output channel to the actuated equipment. This two-out-of-two voting arrangement occurs at the remote multiplexing unit. A single failure of an SLU or EMS channel (one of the two links within an electrical division) will not initiate an ESF function. With the exception of the containment isolation signals which aro fail-safe, the logic for the ESF systems is designed to a fail-as-is condition. 
MPL A32-4080 (Rev. 0, April 25, 1990), "EMS/SSLC Interface Requirements, Requirements Specification," Figuro 1, "EMS/SSLC Interface Block Diagram," uses the term "Auxiliary Supporting Features Logic" (ALU) for part of the SSLC while the SSAR and the CDM use the term "Safety System Logic Unit" for the same dovice. This inconsistency was identified as DRSER Confirmatory Item 7.3.2-1. OE committed to revise the MPLs which use the ALU terminology to be consistent with the SLU terminology as used in the CDM and SSAR. The ITAAC will verify that these documents are consistent when the design is implemented. Therefore, this item is resolved.

\subsubsection{Findings and Conclusions}

The general ESF design and arrangements are in accordance with the requirements of the SRP to the extent information was available for roview. Many of the issues that are identified in Section 7.2 concerning the RPS also apply to the ESF systems. The level of detail for the ESF systems was an open isene in the DSER. The staff found the level of detail available fos reviow inadequate in the DFSER. However, because theee systems will be $i$ iscluded in the digital I\&C design development and ITAAC prucess, the DSER open issue is resolved. The potential for common-mode software problems may also exist with the ESF systems. This was an open issue in the DFSER. The issue of defense against common-mode failures was resolved as discussed in Section 7.2 of this report.

GE had not providad a detailed FMEA for I\&C of the ESF systems as required to demonstrate conformance with the requirements of IEEE-279 and the guidelines of NUREG-0493 regarding defenso-in-depth analysis. This was identified as an open issue in the DSER und was part of the common-mode failure discussion (DFSER Open Item 7.2.6-1). This item is resolved as discussed in Section 7.2 of this report.

The design description of the ESF I\&C systems in the SSAR was evaluated to confirm commitments to the SRP and the applicable regulatory guides and induatry codes and etandards. This review was concerned with the EMS, SSLC, and the ESF aystem initiation and actuation circuits. Based on staff review of the information provided for the initiation and actuation circuits, the staff concludes that the SSAR provides acceptable commitments to the appropriase SRP criteria.

The ESF actuation systom includes systems and components that GE has committed to be designed to survive the effects of carthquakes, other natural phenomenn, abnormal environments, and missiles. The buildinge containing ESF systems and components will be designed to meet and withetand the probable maximum flood at the site, and meteorological events. The structures contraining the ESF components and the ESF instrumentation and electrical equipment will bo soismically qualified. To protect the ESF systems in the event of a postulated fire, the redundant portions of the systems will be eeparated by fire barriers. The ESF system instrument tape and sensing lines located inside the drywell will be qualified to remain functional during and following a LOCA. The staff, therofore, concludes that the GE commitments meet the requirements of GDC 2, "Design Bases for Protection Against Natural Phenomena," and GDC 4, "Environmental and Missile Design Bases," for the ESF systems.

As discussed above, in Sections 7.3.1 and 7.3.2 of this report, GE has committed that all components of the ESF systems are qualified for the environments in which they are located. Separation and isolation will be preservod, both mechanically and electrically, in accordance with IEEE-279 and RG 1.75. Commitments to other requirements of IEEE-279, such as testing, bypasses, and menual initiation, and corresponding provisions in tho design are also described in the SSAR and discused above. The staff concludes that the GE commitments to the design basis requirements of IEEE-279 and the requirements of GDC 20, "Protection System Functions," for the functional requirements of the ESF actuation systems are acceptable.

In conjunction with SSLC discussed in Section 7.2 of this report, ESF system logic and component testing capabilities will be pre'-ided to fully test ESF systems during reactor operation. The staff concludes that periodic testing of the ESF I\&C system as described in the SSAR conforms with the criteria of RG 1.22 and IEEE-338 as supplemented by RG 1.118 and is, therefore, acceptable. The staff further concludes that GE commitments to IEEE-279 with regard to system reliability and testability are consistent with the requirements of GDC 21, "Protoction System Reliability and Testability," and aro ncceptable.

Divisional separation of sensor inputs and output channels that will be provided in the design of various ESF aystems are discussed above. The evaluation of the SSLC regarding channel separation and electrical isolation is discussed in Section 7.2 of this report. The staff concludes that the ESF actuation systems as defined by GE meet the criteria of IEEE-384 es supplemented by RG 1.75 for protection system independence with the exceptions noted in SSAR Table 1.8-7, "Summary of Differences from SRP Section 7," and discuseed in the SSAR. The staff finds the identified exceptions scceptable, and the staff concludes that the ESF sctuation syetems moet the requirements of GDC 22, "Protection System Independence." 
Based on the staff's review of results of the FMEA of the ESF I\&C systems in conjunction with the results of the studies of tho digital I\&C system design for dofenso against common-mode failures, the staff concludes that the design of the I\&C of ESF systems adequately meets the requirements of GDC 23, "Protection Syetem Failure Modes." The ESF systoms and components fail in the asis position in that they require power to operate (i.e., energize to operato). Electrical power is required to perform the emergency functions of the ESF systems and components. The redundancy provided in the design of the ESF I\&C, as discussed above, assure that no single failure can cause ESF system failure when required, or inadvertent initiation. The evaluation of defense against common-mode failure in the I\&C systems is discussed in Section 7.2 of this report.

The I\&C system for ESF has no control function of nonsafoty systoms. However, it does provido isolation sigmals and inputs to non-eafety portions of cooling systems, and annunciators and computers through appropriato isolation dovices. Such circuits will be treated as associated circuits or non-Class 1E circuits. Associated circuits will be in sccordance with Class 1E circuit requirements up to and including the isolation devices. Non-Clase IE circuits will be separated and isolated from Class IE circuits or be treated as associated circuits. The staff also concludes that the GE commitments to the design besis requirements of IEEE-279 regarding control and protoction system interaction meets the requirements of GDC 24, "Separation of Protection and Control Systems."

The staff's review also included consideration of the ESF system quality and diversity as discussed previously in Section 7.2 of this report. The staff also concludes that the staged audit approach of the ITAAC implementation discussed in Section 7.1 of this report is an important aspect in the final acceptance of the ESF I\&C systems.

Based on the above discussions and findings, the etaff concludes that the design and the design proceses of the ESF I\&C systems as described by GE in the SSAR and CDM meets the relevent requirements of GDC 2, 4, 20, 21, 22, 23, and 24, and 10 CFR 50.55a(b) (IEEE-279). The design of the ESF I\&C systems is, therefore, acceptable.

\subsection{Systems Required for Safe Shutdown}

\subsubsection{System Description}

The following systems are identified in the SSAR as required for safo shutdown of the reactor:
(1) alternate rod insertion function

(2) standby liquid control system

(3) reactor shutdown cooling mode of the RHR system

(4) remoto shutdown system

This ection provides a discussion of the I\&C aspects of thewe syatems, with a roviow of the interface offects between these systems and the RPS, ESF, EMS, and the SSLC. The four systems addressed in this section have a corresponding CDM section. The review of the CDM for these systems had not been completed at the time the DFSER was issued, and this was identified as DFSER Open Item 7.4.1-1. GE provided the CDM for these systems. The adequacy and acceptability of the CDM is evaluated in Section 14.3 of this report. On the basis of this evaluation, this item is resolved.

\subsubsection{Alternate Rod Insertion System}

The ARI function is accomplished by the rod control and information system (RC\&IS), the reactor flow control (RFC) system, and the FMCRD. The ARI system provides the capability for automatic insertion of all rods by an alternate and diverse method from the RPS as necessary for mitigation of an anticipated transient without scram on receipt of high reactor domo pressure and low reactor water lovel (Lovel 2) signals. The RC\&IS, including the portion for ARI actuation, is not classified as a safetyrelated system, but is singlo-failure proof and incorporates features in its design for high reliability and availability. (RC\&IS is discussed further in SSAR Section 7.7 and Section 7.7 of this report.) The Lovel 2 low reactor vessel water level signal is provided via the SSLC (ESF portion) and, therefore, the sensors for this input are Class 1E. In the ARI SSAR description, GE did not indicate whether the RPV water Lovel 2 inputs to the SSLC are hardwired and, therefore, would not share common equipment with the RPS input. The SSAR needed to clearly state the design for this feature. This was DFSER Confirmatory Item 7.4.1.1-1. GE subsequently revised the SSAR to specify which SSLC signals are multiplexed and which are handwired. Therefore, this item is resolved.

The requirement for a reactor shutdown system for operational transients is identified in 10 CFR 50.62, "Requirements for Reduction of Risk from Anticipated Transients Without Scram Events for All LWR Designs." Topical Report NEDE-31096-A was submitted by GE to address ATWS ovents for currently operating BWRs and was approved by the staff. GE indicated, in response to staff questions, their intent to fully conform to NEDE-31096-A for the ABWR. This was identified as DFSER Confirmatory Item 7.4.1.1-2. GE revised the SSAR to include a commitment to the topical report. 
Therefore, this item is resolved. The staff concludes that the ARI design meots the requirements of 10 CFR 50.62.

The ARI thensor trip ectpoints are seve the corresponding RPS rettings to allow the RPS trip to occur first. The RPS reactor water lovel trip is at Lovel 3 compared to Lovel 2 for the ARI. The reactor domo presesure trip setpoint is higher then the RPS reactor presesure trip setpoint. Manual sctuation of rod insertion requires two manual actions to be taken in order to avoid inadvertent actuation of the rod trips. The logic for the ARI function as deecribed in the SSAR is designed auch that no single failure recults in the failure to insert more then one operable control rod when the ARI is actuated.

The RPV Lovel 2 signal from the SSLC is provided to each of the triple redundant recirculation flow control (RFC) system controllers where a two-out-of-four vote is taken in each controller. The reactor dome pressure signals from the ateam bypass and precsure control (SB\&PC) system are provided to each of the RFC controllors where a two-out-of-three vote is taken. Manual ARI initiation is provided to the same controllers where a two-out-of-two vote is taken. Any of thewe three RFC controller output signals will initiate the ARI function. The output (trip or no-trip) from each of the RFC controllers is provided as input to the redundant RC\&IS controllers where a two-out-of-three vote is taken to initiate FMCRD run-in. (Scrum-follow input signals are also provided to the RC\&IS.) The output of the two channels of the RC\&IS aro provided, along with the output of the FMCRD emergency insertion logic channel, to the FMCRD inverter controllens where they are combined in a three-out-of-three vote logic to initiate rod insertion. The output from the RFC controllers also provides input to a two-out-of-three vote logic for the ARI function performed by the redundant scram air header exhaust valves. The ARI system also initiates a recirculation pump trip as described in Section 7.7 of this report.

\subsubsection{Standby Liquid Control System}

The SLCS I\&C are designed to initiate the injection of liquid neutron abeorber (borated water) into the reactor. The SLCS is a two-train system with one pump for each train. The I\&C system is designed to withstand seismic Category I carthquake loads and I\&C equipment is mounted in seismically qualified panels. Power for the I\&C is provided from the Class $1 \mathrm{E}$ instrument bus. Tho system is designed to be highly reliable with many safetyrelated system features but it is not classified as a safetyrelated system. In response to Q420.125 (SSAR Chapter 20), GE stated that the SLCS is hardwired and does not interface with the EMS. Therefore, the SLCS I\&C aystem does not shi'o any components with the RPS.

Reactor preanure and SLCS borated water attorage tank lovel censing equipment are ueed to determine that the liquid neutron abeorber is being pumped into the reactor. Tho aystem is capable of boing teeted while the plant is operational by using the SLCS pumps to inject demineralized water into the resctor vessel. Indicutions, controle and annunciatore for SLCS atatus and control are located in the control room. SLCS status indicators are also provided at the SLCS local control panel to indicato syctem operating conditions.

The SLCS was initially deccribed in the ABWR decign as a manually-initiated system with no capability for automatic initiation. By letter dated June 2, 1993, (regarding important features identified by the ABWR PRA) GE atated that the SLCS would be automatically initiated in order to avoid tho potential for operator error and further reduce the probability of adverse consequences due to an ATWS. This change is consistent with the requirements of $50.62(c)(4)$ for the SLCS automatic initiation. The two SLCS pumps and associated valves will be initiated upon an ATWS initiation signal derived from high RPV preseure and SRNM ATWS permisaive for 3 minutes, or low RPV lovel and SRNM ATWS permissive for 3 minutes. If the control sods have been inserted by the RPS or ARI (automatically or manually) the APRM should indicate downscalo before 3 minutes and, therefore, the SLCS would not initiate. The staff finds the SLCS design modification to be in conformance with the requirements of $50.62(\mathrm{c})(4)$, therefore, acceptable.

\subsubsection{Reactor Shutdown Cooling Mode of the RRR System}

The reactor shutdown cooling mode of the RHR system is initiated by manual operator action with interlocks on the RHR valves to ensure correct cooling mode alignment. The RHR reactor shutdown mode is entered during both normal and emergency shutdown. Normal shutdown is sccomplished with all three of the RHR trains in operation and brings the reactor to approximately $51.7^{\circ} \mathrm{C}\left(125{ }^{\circ} \mathrm{F}\right)$ within 20 hours following a reactor scram. Emergency shutdown operation brings the reactor to cold shutdown (lees then $100^{\circ} \mathrm{C}\left(212^{\circ} \mathrm{F}\right)$ ) with two RHR pumps operating within 36 hours after control rod insertion. The RHR equipment is Class 1E and redundant, and is seismically and environmentally qualified for the installed location. RHR system controls are located in the control room. The staff finds the reactor shutdown cooling mode I\&C design acceptable. 


\subsubsection{Remote Shutdown System}

The remote shutdown system provides a means to accomplish reactor shutdown functions (controls and indications) from outside the main control room and bring the reactor to cold shutdown. By letter dated June 2, 1993, (regarding important features identified by the ABWR PRA) GE identified the RSS as an important feature for reducing ABWR core damage frequency dus to a control room fire.

The RSS does not include reactor scram capability or complete control of ESF systems. The RSS deaign assumes that the operator scrams the reactor from the main control room prior to going to the RSS, and that there is no coincident design-basis accident. Two divisionalized RSS panels are provided at separate locations. Their operation is administratively and procedurally controllod. The remote shutdown controls include manual transfer switches to transfer control functions from the control room to the RSS. In addition, on transfer of controls to the RSS, an alarm actuates in the control room.

The staff requested (Q420.15) additional clarification of the intended use of the RSS and the degree of isolation and independence of the RSS from the SSLC and EMS. In the response, GE stated that the RSS is totally separate and independent from the SSLC and EMS because it is hardwired from the sensore to the RSS panels and from the RSS panels to the actuated devices, and does not use multiplexed signal interfaces. Inclusion of this clarification into the SSAR was DFSER Confirmatory Item 7.4.1.4-1. GE revisod the SSAR to incorporate the above clarification and, therefore, this item is resolved. The RSS capability is a consideration in the staff's resolution of the commonmode failure issue as discussed in Section 7.2.6 of this report.

The two RSS panels are powered by separate Divisions I and II Class 1E power. Equipment controlled from these panels is powered from the same divisions as when normally controlled from the SSLC. The RSS includes controls for one train of HPCF, two trains of RHR, two trains of RCW, two trains of RSW system, two trains of electrical power distribution system, and the flammability control system. Transfer switches that transfer controls from the control room for these trains of equipment and the emergency diesel generators, are located in the RSS. Indication is also provided to monitor shutdown functions.

\subsubsection{Specific Findings}

The ARI function and the SLCS instrumentation are part of the resolution of the issue of potential common-mode failure of the EMS and SSLC components. The analysis to resolve this iseve also considered the function of the system discuseed above for mitigation of SSAR Chapter 15 events in combination with postulated commonmode failure in the safety-related digital I\&C system, and how operation of these shutdown systems may need to be reconsidered. Specifically, the RSS operation may require reconsideration of the equipment required or the time available to the operator to achiove shutdown using the RSS. This was part of the I\&C systom common-mode failure analyeis which was an open issue in the DSBR (SECY-91-294) and DFSER Open Item 7.4.2-1. The uee of the equipment deecribed in this ection to sarist in mitigation of the consequences of a common-mode failure is addreseod in Section 7.2 of this report. This open item is, therefore, resolved.

The SSAR did not initially describe how the transfer of sensor outputs from the control room to the RSS would occur without the loss of the calibration data updates stored in the SSLC system microprocessors. The information required to address this issue was part of Open Isswe 1 in the DSER (SECY-91-294). GE subsequently rovised the SSAR to state that when transfer is made to the RSS, the 4-20ma outputs are routed directly to the RSS, and the automatic calibration function in the RMUs is no longer part of the input signal to the RSS. During the use of the RSS, the automatic calibration function will not be available. Conventional, manual calibration of I\&C equipment is available if the length of time of operation of the RSS requires recalibration. This is acceptable to the staff, and this DSER (SECY-91-294) open issue is, therefore, resolved.

\subsubsection{Evaluation Findings}

The review of the system interfaces for the systems required for safo shutdown included the sensors, circuitry, redundancy features and the actuated devices that provide the I\&C functions to prevent the reactor from returning to criticality and provide means for adequate residual heat removal. The review also addressed the interfaces between the safe shutdown systems and the RPS. The primary characteristics of these systems and requirements are included and verified in the CDM.

The staff concludes that the systems required for safe shutdown are acceptable and meet the relevent requirements of General Design Criteria (GDC) 2, 4, 13, $19,34,35,38$, and 44 and the applicable standards and regulatory guides. This conclusion is based on discussions above and summarized as follows:

The staff examined the information submitted for this design to determine its conformance to the GDC, standards and guidelines identified in the SSAR Section 7.1 and the 
SRP. The chiff finds that there is rensonable asmunnce the systems conform fully to the guidelines applicable to these systoms.

The staff's reviow has included the identification of those systems and components required for safo shutdown which are deaigned to survive the effects of earthqunkes, other natural phenomenn, abnormal environments and missiles. Based upon our review we conclude that the design of those systems and components is consistent with the design beses. Additional evaluation is provided in Section 7.1 of this report. Therefore, the staff finds that the design of these systems and components satisfies this aspect of the GDC 2 and 4.

Based on the review, the staff concludes that instrumentation and controls have been provided to maintain variables and systems which can affect this fission process, the integrity of the renctor core, the reactor coolant pressure boundary, and the containment and its associated systems within prescribed operating ranges during plant shutdown. Therefore, the staff finds that the systoms required for safo shutdown satisfy the requirements of GDC 13.

Instrumentation and controls have been provided within the control room to allow actions to be taken to maintain the nuclear power unit in a safo condition during shutdown including a shutdown following an accident. Equipment at appropriate locations outside the control room have been provided (1) with a design capability for prompt hot shutdown of the reactor, including necessary instrumentation and controls to maintain the unit in a safe condition during hot shutdown, and (2) with a potential capability for subsequent cold shutdown of the reactor through the use of suitable procedures. Therefore, the staff concludes that the systems required for safe shutdown satisfy the requirements of GDC 19.

The staff roview of I\&C required for safe shutdown systems included determination of conformance to the requirements for testability, operability with onsite and offsite electrical power, and single failure. The staff concludes that these systems as described above incorporate provisions for testability and operability with onsite and offaite power, and to cope in the event of a single failure where applicable and, therefore, meet the relevant requirements of GDC 34, 35, 38, and 44 .

\subsection{Safety-Related Display Instrumentation and Information Systems Important to Safety}

\subsubsection{System Description}

Safoty-related display aystems are those which provide information (1) for manually initiated and manually controlled safety functions, (2) to indicate that the plent safety functions are being accomplished, and (3) to provide information from which appropriate action can be taken to mitigate the consequences of anticipated operational occurrences and accidents.

The information systems important to safety provide the operator with the status of the plant to allow manual safety actions to be performed when necesenry. The following systoms are identified in the SSAR as information systoms important to safety:

\section{a. Safety parameter display system (SPDS) \\ b. Information systems associated with emergency response facilities}

\section{c. Nuclear data link}

The plant site emergency response center and communications links with the NRC emergency response center are conditions of the COL and are not addressed in this section.

This report ovaluates the instrumentation aspects of the information aystems with emphasis on interfaces between theoe symand and the SSLC and EMS as well as the application of advanced technology to processing and display of data important to safety. GE presented in the SS. UR a comprehensive list of variables that were considered essential for providing safety-related informtion to the operators. Tables of conformance and specific exceptions to the guidelines of RG 1.97 were provided in the SSAR, and functional requirements for display of data were provided in the SSAR process system descriptions. One difference between the ABWR and currently operating BWRs is the incorporation of a Class 1E NMS that is in conformance with RG 1.97 Category I instrumentation criteria. 
The manner in which the required data is proceseed and displayed, and dependencies on aupporting handware and software were not deecribed in the SSAR. This was ideatified as part of the open itom in the DSER (SECY-91-294) concerning lovel of detail (Open Item 1). The details of the dieplays will be determined during the implementation of the humin factor CDM process described in Section 18 of this report. GE hes committed to provide the displays for Catogory 1 RO 1.97 parumeters on the fixed mimic panel. These panumeters are also available at the operatore display console. SSAR Chapter 18, Table 18F, provides a lieting of the parumeters and the general location of the aseociatod display equipment. The supporting I\&C display system equipment is described in Section 7.2 of this report with a similar emphasis on the use of the ITAAC process to implement the I\&C design.

The sccuracy of the RG 1.97 displays is not specified in the RG 1.97 guidelines or in the SSAR. However, the Emergency Procedure Guidelines imply an sccurncy in the displays. For example, the Primary Containment Control Guideline (Ref. SSAR 18A.5) spocifies en entry condition when the suppresaion pool water lovel is above 7.1 meters or below 7.0 meters. The TS also bave similar sccuracy requirements. The staff finds that the sccuracy requirements implied will bo met with the expected equipment. However, bocause the equipmeat has not been selected, accuracy will be confirmed in the ITAAC process. The final TS prepared by the COL applicant prior to fuel load will also include the specific setpoints and accuracy for the selected equipment.

NUREG-0737 Item I.D.2 requires that each applicant install a SPDS that will display to operating personnel a minimum set of parameters which define the safety status of the plant. This can be attained through continuous indication of direct and derived variables as necessary to assess plant safety status. Operating reactors have implemented the SPDS with a stand-alone display design. The ABWR is significantly different in that the SPDS parameters are integrated into the total main control room information display design as are the RG 1.97 parameter displays. The staff finds this acceptable. Additional discussion on the SPDS design is provided in Section 18 of this report.

\subsubsection{Findings and Conclusions}

The scope of the staff's review included an assessment of the proposed application and design of the EMS and SSLC to support operator displays important to safety. Other documentation normally reviewed for information system design such as component states, functional control diagrams, eloctrical and physical layout drawings, and deacriptive information were not available and will bo part of the ITAAC. The etaff the considered applicable critoria, guidelines, and design bases, including thowe for indication of bypased or inoperable safety systems, in the roviow discuseed in this section.

The etaff evaluated the information submitted for the ABWR information system design to dotermine its conformance to the guidelines identified in the SSAR Section 7.1 and the SRP. The review was concerned with the interfaces between the eafety-related information system and the safety-related I\&C for systems auch as the RPS, LDS, and ECCS.

Table 7.5-7 of the SSAR lists drywell preseure as one of the variables required for indication of manual actions neceseary for reactor shutdown from outside the control room. However, the parameters listed in SSAR Section 7.4 for display on the remote shutdown panel do not include this parameter. GE stated that this parameter is not required for shutdown using the RSS in the abseace of o poetulated deaign-basis ovent and should, therefore, not be listed in Table 7.5-7. Revision of this table was identified as DFSER Confirmatory Itrem 7.5.2-1. Table 7.5-7 was revised to remove the extraneous reference to drywell pressure and, therefore, this item is resolved.

The safety-related display information provided to the operator is derived from the SSLC and EMS. Additional display information is provided from the non-essential systems. The display information was considered in the resolution of the I\&C system common-mode failure issue addressed in Section 7.2 of this report because the analysis of a common-mode failure in conjunction with an ovent included the information available to the operator.

Based on the above discussions and findings, the staff concludes that the ABWR design includes the necessary operator display information and, therefore, meets the requirements of RG 1.97 for post-accident monitoring instrumentation and TMI Action Plan Item I.D.2 for the SPDS, and is acceptable. The detailed information on the safety-related display instrumentation will be reviewed during the implementation of the ITAAC.

The staff concludes that the safety-related display instrumentation and information systems important to safety are acceptable and meet the requirements of GDC 2, 4, 13 and 19. This conclusion is based on discussions above and summarized as follows:

The staff concluded in Section 7.1 of this report that GE has identified in the SSAR the I\&C systems which aro 
importent to enfery. Additional ovaluation is provided in Soction 7.1 of this report.

The etaff bes reviound the dacign of those aystam and componente which are required to survive the offects of carthquaken, other netural phesomena, abnormal cavironmeats and mimiles. Based on the etafips reviow, the ctaff concludes that the dexign of thow syctoms and componente is consintent with tho design beces. Therefore, the etafi finds that the deaign of thees syetem and components atisfies this aspect of the ODC 2 and 4.

The athf concluden that the display and information syatem to enfety include approprinte variables and that thoir rnage and accurncy are consisteat with the plant afoty analyais. Therofore, wo find that the information aystem satiofy the requirements of GDC 13 and the applicable guidolines eatisfy the requirements of GDC 19 with reepect to information to operate tho unit afely under normal conditions and to mantain it in a me condition under sccident conditions.

\subsection{All Othe: Instrumentation Systems Required for Safety}

The instrumentation systems included in this section are thome required for affety but not previously diecuesed in other section of this report, slthough some sepects of these systom are included in provious sections of this report.

\subsubsection{System Description}

The following systems are deacribed in this section:

(1) neutron monitoring system

(2) PRM syetem

(3) high-preseure/low-preseure interlocks

(4) drywell vecuum relief systom

(5) contrinment atmosphere monitoring (CAM) system

(6) SPTM Systom

All of these syatems are included in the CDM. The CDM had not been reviewed at the time of issuance of the DFSER, and this was identified as DFSER Open Item 7.6.1.1. Descriptions of the above systems have been included in the CDM and this open item is, therefore, resolved. Section 14.3 of this report discusses the scceptability of the CDM.

\subsubsection{Neutron Monitoring System}

The affety-related rubsystems of the NMS consist of the SRNM, the LPRM, and the APRM subsystems. The LPRM and the APRM together are referrod to as the
PRNM. The non-afory-rolated portions of the NMS (the automatic traverning in-cose probe (ATIP) and multichannol rod block monitor (MRBM)) are discuened in Seotion 7.7 of this report.

Tho SRNM monitore neutron flux from the cource range (1.E+3nv) to 15 percent of rated power. The SRNM aubaystem bas 10 SRNM channols with each channol having one fixed in-core regenorative fiecion chamber cencor. The SRNM preamplifier signals are tranemitted to the SRNM digital measurement and control (DMC) units in the main control room. The DMC units contain tho coftware algorithm for sigmal proceasing, neutron flux, and power calculations. The SRNM was described by OE as being functionally the ame as the wide range NMS in currently operating BWR plants. The SRNM provides trip signals to the RPS, and rod block signals to the rod controls. Each of the four trip channels receives input signalu from a different set of SRNM channels. Unlike the other weneor inputs to the SSLC, the NMS provides a trip/non-trip decision directly to the TLU without use of the DTM to process the eensor data.

Three SRNM channels provide input to each of SSLC Divisions I and III, and two SRNM chnnnels provido input to anch of SSLC Divisions II and IV. The 10 SRNM chanools are divided into three bypase groups. A total of three SRNM channela can bo bypaseed with no more than one SRNM bypaseed per SSLC channel. No additional divisional bypass is allowed. If two (in Divisions II and IV) or three (in Divisions I and III) of the SRNMs are out of service, one channel of the RPS will be tripped.

Tho PRNM consists of the LPRM and APRM subsystems. The LPRM monitors power in the power range. The LPRM provides signals to the APRM and to the plant computer. The LPRM consists of 52 detector assemblies, anch with four fiesion chamber detectors. The LPRM channols provide trip sigmals when an LPRM is upecale, downecale, or bypessed. The APRMs consist of four DMC APRM channols, each of which receives the 52 LPRM signals as inputs. The APRM DMC units average the inputs to provide a core average neutron flux which corresponds to the core average power. Each APRM channel is associated with a single RPS trip channel. The APRM also provides rod block functions.

GDC 12 requires that the reactor core and associated coolant, control, and protection systems be designed to ascure that power oscillations which result in conditions exceeding specified acceptable fuel design limits aro not possible, or can bo reliably and readily detected and suppreseed. BWR licensees were requested in NRC Bulletin No. 88-07 to take actions to provent the occurrence of uncontrolled power oscillations during all 
modes of operation. The NRC sloo requeded that the BWROC perform generio cvaluation of the BWR plant respones to core thermal hydruulic intabilitien, and provide long-term solutions to provent or quickly mitignte cecillations or operation in potentially untable power/flow regions. The BWROO committes on thermal hydraulic ctability bas developed a long-term atability solution. A licensing Topical Report, NEDO-31960, "BWR Owner's Group Long-Term Stability Solutions Liceaning Methodology," has been mubmitted for NRC roview and epproval. This topical report describes weveral options for BWR licenseses to choose to deal with etability concerns.

In response to NRC Q440.187, OE atuted that in order to moet the etability deaign requirements epecified in the ALWR Utility Requirements Document, Option III, the OPRM aystom, a microprocencor-based protection system, will be implemented in the ABWR detign. The OPRM system uses microprocescion to monitor groups of APRM sizmals. Upon detection of neutron flux ancillations charncteristic of a thermal-hydrullic instability, the system will initiate an automatic auppreacion function (ASF) to aupprese oncillations prior to exceeding enfety limits.

Licensing Topical Report NEDO-31960 tatee that the OPRM which aloo uses the LPRM input is a Clan IE protection aystem and conforms to all applicable requiremeats of IBEE-279-1971. There are four OPRM chennels, each of which provides inputs to trip logice which initiate an ASF. The OPRM function is in parallel with, and independent of, the existing Class 1E and nonClase 1E functions of the power range NMS. The OPRM does not affect the design bases for the existing power nage monitoring components, their calibration, or their espanation.

The OPRM function provides inpute to the ASF for the purpoce of auppreating occillations prior to axceeding the plaat minimum critical power ratio mafety limit. The OPRM is installed and maintained as an RPS protection function or for a select rod insert (SRI) function. The SRI function is inteaded to reduce core power to leas then the turbine bypase capacity, so that the unit avoids a scram during a loed rejection event. For implementation as an RPS function, four OPRM channels provido four separate inputs, one for each RPS trip channel. Any two channels in trip will reault in a reactor scram.

GE has indicated and the etaff concurs that Option III, LPRM-besed, OPRM system is the preferred method of addreasing atability. The ABWR OPRM system meets the requirements specified in the EPRI URD for ALWR and is consistent with the guidelines in Topical Report NEDO-31960. The etaff, therefore, finds the OPRM syctem in the ABWR design to bo scceptable. This was identified a DRSER Confirmatory Itom 7.2.1-2. The SSAR and the CDM have been rovieed to include the OPRM. This item in, therefore, recolved.

\subsubsection{Procean Radiation Monitoring System}

Rediation monitoring is provided on a number of process lines, HVAC ducts, and vents. The following radionetive material diecharge routes are monitored for radiation:

(1) MSL tunnel area

(2) reactor building veatilation exhaust (including fuol exchange area)

(3) redwato liquid dicherge

(4) off-gas diecharge

(5) sland ateam condenser and mechanical vacuum pump off-gas discharge

(6) atuck discharge

(7) turbino building veat exhaust

(8) tandby gas treatment ventilation exhaust

(9) drywoll cump liquid diccharge

(10) control building air intako supply

(11) radwasto building ventilation exhaust

The four MSL tunnol monitors are Clase IE inputs to tho RPS and are input to the DTMs for thoir respective channols.

The reactor building ventilation system radiation monitoring is Clase 1B and includes the four exhnust air radiation monitors, the four fuel bandling area exhaust maliation monitors, and the eight control building air intake radiation monitors. The oxhaust air and the fuel area provide inputs to the leak detection system, and trip the ventilation eyetems on indication of high radiation. The control building air intake monitors isolate the HVAC for the control room upon indication of high radiation.

\subsubsection{Figh-Preseure/Low-Prewsure Systems Interlock Protection Iunction}

The only high/low-preacure interfeces for the reactor veseal involve the low- preserure modes of the RHR aystem. The logic for the preasure and level sensor inputs which provide the RHR systom isolation valve closure signals is a two-out-of-four high reactor pressure or low RPV water lovel aigmal.

The inboand and outboard containment/presenure isolation valves for each of the three trains of the RHR system are powered from eeparate electrical divisions. The valves have permissive logics which provent them from being opened when reactor preecure is greater than RHR oystom devign prescure or when reactor water lovel is lees then Lovel 3. These valve closure sigmals are provided by four 
divisionalized seaver in a two-out-of-four logic. An additional interlock is provided for the RHR syetem isolation valves from the RHIR syetem area smbieat cemperature. The SSAR deceription of tho valve interlocke origianlly contained an inconsistency concerning tho RPV water lovel at which isolation cocum. This was DFSBR Confirmatory Item 7.6.1.3-1. OB albequently revised the SSAR to resolve tho inconcistency. Therofore, this item is recolved.

\subsubsection{Duel Pool Coolins and Cleanup Sratem}

Tho fual pool cooling and cleanup systom is clasaified as a non-enfety-rolated systom and is diecuesed in Section 7.7 of this report.

\subsubsection{Wetwell-to-Drywell Vacuum Breaker System}

Direct control of the wetwell-to-drywell vecuum breakers is not provided. However, the open/close position of these vecuum breaker valves is monitored. The related instrumentation which indicates proper function of the vacuum breakers is deecribed in Section 6.2.1.7 of the SSAR. This instrumentation includes the opea/clowe position indicatore for the wetwell-to-drywell vacuum breaker valves and indications of wetwell-to-drywell difforential presesure.

\subsubsection{Containment Atmosphere Monitoring System}

The CAM system is a two-train Class IB system. Each CAM system division monitors the total gamma-ray does rate and concentration of hydrogen and oxygen in the drywell and/or the suppression chamber. The CAM system is a microproceseor-based system which provides measurement, recording, and alarms in the control room for operator information. Each divisional gamma radiation monitoring channel can be energized manually by the operator or automatically by tho LOCA signal. Each divisional hydrogen/oxygen monitoring aubsystem is powered continuously during plant operation.

\subsubsection{Suppresion Pool Temperature Monitoring System}

The two-train SPTM system consists of eight eensor locations around the circumference of the pool, each of which has a group of four sensors for the two trains. The signal procesting for the SPTM aystem is performed by microprocesesors. The I\&C of the SPTM system are powered by four divisionally separated electrical buses. The SPTM system initiates RHR suppression pool cooling, RCW load shodding, and RPS trip sigmaling. It also provides information for the operator in the control room and the remote shutdown panel.

\subsubsection{Specinc Finding and Evaluation}

The SSAR inoludes an analyais of the mefoty-rolated portions of all inctrumentation systemen required for mefety diceuned above. The analyais is to show conformenes to general functional requirements and epecifie regulatory requirements. The etaff reviewed the information aubmitted for thece systems to determino their conformance to the geoeral deaign criteria, stundards, and guidelines identified in tho SSAR Section 7.1 and the SRP. Bawed on the reviow, the staff concludes that the decign of the instrumentation for the syetems in Section 7.6 of tho SSAR and discuseed in this coction meet the requirements of ODC 2, 4, 10, 12, 13, 19, 23, 24, 28, 33 and 44, and tho guidelines of applicable tandards, regulatory guides, and branch technical positions, as applicablo and are, thereforo, scceptable. The additional requirements listed in Sections 7.1 and 7.2 of this report for SSLC qualification aleo apply to the affety-related portions of thew syctems. Theas aystoms are included in the CDM.

\subsection{Control Systems}

\subsubsection{Syetem Deccription}

This section discuseces control systems which are considered by GE to be not cesential for the safoty of the plant. These systoms primarily use microproceseor-based equipment and transmit information via non-esecential multiplexors. These systems include:

(1) NBS reactor veceel instrumentation

(2) RC\&IS

(3) RFC system

(4) FDWC system

(5) process computer system and power generation control system (PGCS)

(6) NMS, ATIP and MRBM subsystems

(7) automatic power regulator (APR) syatem

(8) SB\&PC systom

(9) non-eseential multiplexing systom

(10) fire protection system

(11) drywell cooling systom

(12) instrument air systems

(13) makeup water system

(14) atmoepheric control system

(15) fuel pool cooling and cleanup systom

(16) communications system

Nthough these systoms are not directly needed for the performance of safoty functions, their operation is important to the reliability of the plant. The non-eafety systems are designed such that their failure will not provent the proper operation of the safety systems. These system are also designed to be of high quality to minimizo the 
challeages to enfoty aystem functions. Becanes the CDM for them ayetom had not been reviewed when the DFSER was written, the ctaff ideatified the inoomplete roviow of the CDM and ITAMC a DFSER Open Item 7.7.1-1. The key features of thene aystem aro now inoluded in the CDM and this itrom in, therofore, revolved. The codes and

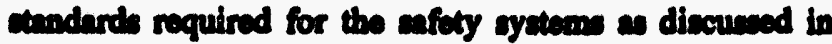
Section 7.1 of this report do not apply to thew aystem unlaw otherwite apecified. The digital ayetom deaign procese for the cafery ayetems are similar for thew nonafoty symberm, except that documentation requirsments aro not es etringent.

\subsubsection{Nuclear Boller Syctem Reactor Venda Instrumentation}

Only the son-anfory portion of the NBS is included in this coction. This part of the NBS provides monitoring and control input of variables during normal plant operations. The variables monitored include:

(1) reactor veceel temperature,

(2) renctor veceel water lovel (chutdown, narrow, wide, and fuel zone ranges),

(3) renctor core differential proecure,

(4) resctor veasel proesure,

(5) SRV sool loak detection,

(6) feedwater tomperature

Sensors for the above variables ahare ensing lines with the safoty systom seneors. Separation and isolation is maintained between the sufety and non-arfety portions of the system.

\subsubsection{Rod Control and Information Syatem}

The RCIS is a son-enfety-related aystem which provides the operator with the information necessary to make changes in nuclear reactivity 80 that reactor power level and power distribution can be controlled by manipulating the control rods. This system includes those interlocks which inhibit rod movement (rod block) under certain conditions. The RCIS is also used to implement the ARI control rod insertion function, and a backup ecram follow function. Upon an RPS scrnm, this system is initisted and atarts the motor-driven FMCRD, to follow the RPS hydraulic scram of the rods.

The RCIS consists of two independent channels for monitoring and control rod positioning during normal
Opentions. Disagreoment between the two chennede results in a rod block. The RCIS is dexigned to be a singlefillure proof aystem. The CRD components which are requind for shutdown of the plant and/or whose frilure can reault in grows fival damage, are decigned to moek the requinuments of a cafety-related ayctom.

The two RCIS cabinets contrin the rod worth minimizer, automatad thermal limit monitor, and rod block functions. The RCIS recoiven the cernm follow commend from the RPS. It aleo recoives the celected control rod run-in signal from the RFC aystem and the APR systom. The RCIS aleo provides the signals to the RFC system to reduce flow when the RCIS fully incerts tho rods as the recult of an ARI initiation or corum follow.

The RCIS allowe the operator to complotely bypan up to dight control rods by declaring them inopernble and placing them in bypass. The operntor can rubatitute a ponition for tho bypaened rod into tho RCIS. The RCIS has a dedicated control interface in the main control room.

\subsubsection{Recirculation Dlow Contrul System}

The RFCS provides each of the two chunnels of the RCIS with separate isolated trip signals indicating the need for automatic selected control rod run-in upon trip or run-back of the recirculation pumps. This aystem recoives reference power level signals from the NMS and compares the reference power level signals with tho power level setpoint. The sigmale provided represent the validated total core flow. The primary purpose of this system is to control the speed of the 10 reactor internal pumps.

In the DSER (SECY-91-294), the staff expressed concern regarding GE's request to change the normal clasaificution of a low of all forced circulation from a moderato frequency ovent to an ovent not expected to occur in the lifetime of the plant. The staff presented a discussion of the reseons that it did not agree with GE's position. Included in that discussion was the concern that a potential common-mode software error could recult in a loss of all forced circulation. In response, GE provided information concerning potential common-mode software failures and the reliability of the RFCS.

The frilures addressed by GE included those of sensors, control modules, power supplies, multiplexor links, and apeod controllers. Other failure mechanisms such as incorrect operator action, or maintenance and commonmode coftware errors, were also addreseed with means indicated to reduce their likelihood, but such mechanisms are still possible causes of simultaneous reactor internal pump trip. The etaff concluded that improvements were made in the reactor recirculation system of the ABWR 
when compered to curreatly operating plante; bowever, the

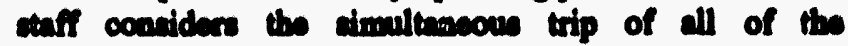
reoirculation pumpe dus to a common-modo fillure to be a crodible ovent that is expected to ocour during the lifetime of the plant. Therefore, menemes are required io mitigato such an ovent, or andycils providad to verify that the consequences are ecceptable. This ovent is ovelunted in Chapter 15 of this report.

\subsubsection{Feedwater Control Syatem}

Tho FDWC aystem is a threo-trin oystem that controls the flow of foectwater into the RPV. The IEC aystom for foectwator operation is a triplicated aystem which is ainglefailure proof. The feedwater syetem cen be controlled manually or automatically. Normal mutomatic control is based on resctor water lovel (when steam flow is very low) or on reactor water lovel, main feedwater line flow, and feedpump action flow meacurements during power operation.

\subsubsection{Procen Computer Syctem and Power Genentor Control Syotem}

The proceses computer is intended to provide a determination of core thermal performbence, and to improve data reduction, eccounting, and losging functions. The PGCS, a separato function of the process computer aystem, monitore overall plant conditions, iscuses control commende, and adjuets setpoints of lower lovel controllen to euppost sutomation of the normal plant ctartup, shutdown, and power range operations. The POCS inoves commend signals to the turbine master controller.

The etaff has reviowed MPL C71-4010 (Rov. 1, July 2, 1990), "Reactor Protection Systom Design Specification," which requires that both the tripped and react conditions of the RPS-rolated sensor instrument channols and the RPS eutomatic or manul trip aystem bo losed by the procens computer. For all conditions that cauve reactor trip, the computer shall identify the epecific trip variable, the divisional channel identity and the epecific automatic or manual trip syetem. The ataff identified the inputs to the plant computer a DFSER Confirmatory Itom 7.7.1.5-1. The plant proceses computer and its inputs to tho trip ecram data logger are included in the CDM and the SSAR. This itom is resolved.

GE indicated that the plant computer will have the capability to trend performance of all enfety-rolated seneors. This will provide the capability for detection of problems which have occurred previounly reganding loss of oil in oil-filled trunsmitters at operatiog plants. This resolved the operating experience concern diecused in NRC Bulletin 90-01, and Supplement 1 to Bullotin 90-01.

\subsubsection{Noutron Monitorimes Syctem, ATIP and MRBM Subogatame}

The ATIP anbaystem of the NMS is compriced of threo TIP mechines, each with a seutron ceneor atteched to a floxibie cable. The syctem inoludes tho secociated dive mechenisom and guide tuben, and is uead to obtain flux readinge along the axial leagth of tho cors. The MRBM

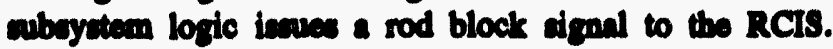
This microprocececorbened eyctem receives input neutron flux tirnals from the LPRMe and APRMs, core flow dath from the NMS, and control rod atatus to determine when rod block aigmals are required.

\subsubsection{Automatic Powrer Regulator Syctem}

The APR syctem controle resctor power by providing commende to rod podition or resctor RPC inctrumentation. The APR receives input from the plent proceses computer, the POCS, the SBEPC syctom, and the operator's control coneole. The output demand aigals from tho APR aro to the RCIS and the RPC and SBAPC aystems. The APR logic is performed by redundant microprocesenon.

\subsubsection{Steam Bypan and Presoure Conterl Syctem}

The SBAPC ayetem controls the reactor aystem presaure during normal operation. The ayetem regulates the poxition of the turbine control and/or ateam bypaes valves.

\subsubsection{Non-Decential Multiplexing System}

The NEMS is coparate from the BMS but is similer in function. The NEMS supports communication between the non-anfety I\&C systems. The NEMS will be diverno from the BMS (hardware and coftware).

\subsubsection{Fire Protection Syatem}

The IEC aspects of the fire prolection syetom convist of the detection and auppreacion portions. This ayetem is automatically sctuated by smoke, infrured, or tompernture detectors when firo is indicated.

\subsubsection{Drywell Cooling System}

The drywell cooling aystem is ued to limit the termperature of the various drywell zones within ranges dictated by the equipment requirements.

\subsubsection{Instrument Air System}

Tho instrument air system is diecuseced in Section 9.3.6 of the SSAR and is not diecuesed in this cection. 


\subsubsection{Mrokeup Water Syatom}

The makeup water syctom is dicoused in Section 9.2.3 of the SSAR and is not diecusend in this rection.

\subsubsection{Atmoeptraric Control Syatem}

The etmoepheris control syctem is dicousend in Scotion 6.2.5 of the SSAR and is not discuesed in this section.

\subsubsection{Dud Pool Cooling and Clcanup Syatem}

The fual pool cooling and cleanup syatem was reclasaified as a completely noa-Clase IB syetem since the DFSER was written. It is sa independeat oyitem which monitor and controls the frel pool tomperature and maintain the wher quality of the pool. This syetem consiats of redundant trins with power eupplies that are becked by the combuation turbino generator.

\subsubsection{Communication System}

The paging aystom is deaigned to provido facilities for mutual communication and simultuneous broadeneting within the plant. The cound-powered tolephone aystem providen communications primarily for fuel trunafor, teating, calibration, and maintenanco.

The communication aystems consiat of a power-ectunted paging facility and a separate network of cables and jecks to facilitate the use of cound-powered telephones for maintenance and repair. The paging aystom is primarily ueed for intraplent communication during plent operation. Handeets and speakers aro installed in the rooms indicated bolow:

(1) main control room

(2) electrical equipment room

(3) fuel replecement area

(4) turbine operntion area

(5) periphery of control rod hydraulic units area

(6) foedwater pump room

(7) elovator

(8) exterion of plant buildings

In addition to the basic paging function, the paging equipment can be used for automatic surveillance of the main amplifier and manual switching to a spare amplifier a neceecary. The paging equipment produces an omergency signal (siren) upon sctuation of an emergency pusbbutton. The circuits from the main paging equipment to each junction box are wired in separate routes.
A expants tolephose communication syctem ueins portable cound-powered teleptones is provided, but is outside the coops of the ABWR dacign. The ayetem providas communication between bonds in the muin control room, between the main control room and fiald atations, and between fiold atations during lating or inspections.

The communication aystem do sot have a cafixy-rolated function. However, thoy aro uned during enengunoico and because the communication aystem is required whea plent coatrol is at the remote shutdown atation, its availability muat be demonetrated anouming a main control room fire. This was DFSER Opea Item 7.7.1.15-1. OB aubequendly revieed SSAR Chapter 9.5.2 to decocribed the aurvivability of the cound-powered phones in the evpat of a control room fire. This item in, therefore, resolved.

No identification of the BMI mdiation lovels or froquency range is identified for the communication unnomitter/roceivers to bo inctalled in the plant. In addition, tho ecescitivity of the enfety computer system to the electromagnetic fields is undefined. Therofore, a teat program with field measurements and operntional dewcription is required if spurious offects upon afotyrelated I\&C equipment dus to communications is to be avoided. This was identified as DFSBR Open Item 7.7.15-2. This will be verified as part of the BMI ITACC that is included in tho instrumeatation and controls CDM. Therefore, this itom is resolved.

Baced on the above, the staff concludes that the deaign of the paging communication system ensures its availability as required and is, therefore, acceptable.

\subsubsection{Specific Findings and Evaluations}

In the SSAR, GE provided en analysis to demonstruto that the above non-eafety-related I\&C systems are not required for any plant anfety function, and that the plant protection syatems are capable of coping with all failure modes of these I\&C aystems. The analyais shows how the docign of the above I\&C aystoms conforms to general functional requirements and epecific regulatory requirements. The staff reviewed the information submitted for thees system to determine their conformance to the GDC, atandards, and guidelines identified in the SSAR Section 7.1 and the SRP. Based on the review, the staff concludes that the dotign of the I\&C syetems in Section 7.7 of the SSAR and discusaed in this section meet the requiroments of ODC 13 and 19, and the guidelines of applicable standards and regulationy guides and is, therefore, scceptable. 


\subsection{COL License Information}

Section 7.8 of the SSAR provides a discustion of topice that are sot apecifically addreaned in the SRP but aro important to the dacign and operation of afoty-rolated cquipmeat. These topice will bo sddrened by the COL applicant in its epplication. Thece topice include: (1) effects of atation bleckout on HVAC aystems and the suberqueat offects on plant dectronica; (2) offects of BSD on exponed electrical and electronic equipmeat composenta; (3) offects of localized high heat epots in cemiconductor materials for computing dovicen; (4) criteria for interfaces between the ABWR I\&C aystem and yystems outride of the coope of the ABWR deaign cortification; and (5) comprebensive functional teots neceeceary to moet tho plant TS.

The ataff requected $(Q 420.014)$ that $O B$ addreas the efficets of atation bleckout on that portion of the HVAC aystom which is required to maintain the function of plant electronics. OB responded that this iseve will be addreaned a a COL applicant requirement by performance of a temperature/beat rise analysis for the etation blackout (no HVAC) ecenario using the reculting cevironmental cemperatures for the epecific plant location as a basis for confirming appropriate olectronic equipment performanco. The beat rise andysis will verify that the required eloctronic equipment has been qualified to the higheat expected temperature aseuming station blackout. This is acceptable and will be verified as part of the ITAAC process by the COL applicant.

The staff requected (Q420.90) that GE addrese the posaible effects of ESD on the proper performance of koyboands, keyed switchen, and other exponed alectrical equipment components. OE's response described the damage to components and aystem upeets that ESD can caure. The response deccribed the steps used in modern equipment devign to protect the equipment from ESD and precautions that should be used in their installation. The equipment design standards, installation and maintenance procedures are included as part of the EMC ITAAC. The COL applicant will verify by the EMC ITAAC that the GE recommendations for grounding and shielding are followed or provide an scceptable alternative.

The staff requected (Q420.92, Q420.94, Q420.95) that GE addreas poseible localized hot epots in semiconductor matorials dwo to high current densities and their offects on equipment reliability. OE's response described the requirement for a thermal analysis which will follow the methods of MIL-HDBK-217 and MIL-HDBK-251. Because the worst case for potential bot eppots occurs during a poetulated station blackout acenario (no HVAC) and, therefore, will require plant-epecific information to be incorporated in the thermal analyais, the staff agrees that this inave will bo uddreaced as part of the ITAAC proceses. Tho COL applicent will verify that adequato compensation is provided for internal heat rise to eneure proper dectronic equipment performanco.

OB performed an interface study of each of the IRC aystem included in Chapter 7 of the SSAR, and determined that there are no enfety-selated electrical aignal interfices between afoty syatems and eyctoms that aro sito epecific that have not already been included in the requirements of the provious ecctions. Therefore, $\mathrm{OB}$ indicatod that there are no intorface requirements neceasary to carure safety-related system performance. However, the SSAR did not epecifically addreas non-enfoty I\&C oyetem interfaces with cafoty-rolated systems outside the ABWR scope. If there are any wich interfaces with equipmeat outside of the scope of the ABWR SSAR, the exinting requirements for afoty/non-afoty I\&C system isolation will apply and will bo verified during the ITAAC phase. The COL applicant will verify that any safety/nonafety I\&C interfaces are adequately separated and isolated.

The TS contain several different surveillance toet requiromeats. One of those teets is a comprebensive functional teet of the safety-rolated I\&C systems that will bo performed during each refueling outage. The TS require the teata, and the bases for the TS provido a short description of the teating that is to be done. GE has also included a detailed description of the comprehensive functional teat in the SSAR. This description will be included by the COL applicant in its maintenance program.

\subsection{Appendix 7A - Design Response to Appendix B of ABWR Licensing Reviev Bases}

Appendix B to the GE ABWR LRB, dated August 1987, noted that the SRP did not provide standards and criteria for the review of stato-of-tho-art fiber optics, multiplexing, and computer controls. LRB Appendix B contains questions from the staff regarding digital $1 \& C$ systems. The questions were intended to solicit additional information from the applicant boyond that normally provided in SAR because of the use of digital tochnology in the design. GE provided their responses to these questions in Appendix 7A of the ABWR SSAR. Since the DFSER was issued, GE also added SSAR Chapter 7 Appendices B and C to further addrese digital I\&C system design issues, including defenso-in-depth.

The responses in Appendices 7A, 7B, and 7C provide a level of design information similar to that provided in the I\&C systoms soctions of the SSAR and in responses to 
other etaff requedt for additional information. The information provided was not aufficiently detailed in and of itsalf to permit the ettaff to reach its anfety conclusions. An example is the OB atatemeat in the response to NRC Requeat 11 (SSAR Appendix 7A) that "roftware development will, in general, follow RO 1.152." The etaff coscludes that the Appendix 7A respones provides a commitment to sddress the ireves involving digitul ayetem denign as identified in Appendix B to the LRB, but does not present mufficient description of the design to demonetrate bow the commitments are to be met. Appendix 7A was rovised following the DSER (SECY-91-294) to include a commitment that the ABWR digital syetems will meat the criteria of the additional atandands listed in Section 7.1 and 7.2 of this report. Verification that tho IEC syetem dexign conforms with this commitment will bo scomplisbed during the ITAAC phase.

In addition to the hardware and software aspects of the afoty-related I\&C systom dosign that have boen discuseod previoualy in this report, SSAR Appeadix 7A provides a commitment to the guidalines of RO 1.153 which endorses IEBE-603. For the I\&C aystems of the ABWR deeigm, IEEE-603 provides guidance which is similar to that of IEEE-279. GE atated that the ABWR afety-related I\&C system design be in conformance with IEEE-603, and the implementation of the I\&C design will be verified during the ITAAC. This is acceptable to the staff.

Based on the review of the information provided in the SSAR (Appendices 7A, 7B, and 7C) and in related CDM, the etaff considen that isaves rogarding standarda and criteria for digital equipment, nised by the LRB Appendix B questions, have been adequately addreseed.

\subsection{Unresolved Safety Issues, Generic Safety Issues, and Operating Experience}

\subsubsection{Unresolved Safety Issues and Generic Safety Issues}

USIs and GSIs are discussed in Chapter 20 of this report.

\subsubsection{Operating Experience}

The EPRI ALWR Utility Requirements Document, Volume II, for evolutionary reactor design provides a general description of the operating experience that is necessary before equipment should be considered for use in future nuclear power plants. The general guidelines specify that approximately 3 years of successful experienco in applications similar (but not necessarily nuclear plantrelated) to the intencied nuclear power plant installation is appropriate. Failure to meet this EPRI requirement results in increased prototyping as specified in the EPRI requirements. OB has committed to the BPRI requiromeats and the staff finds this seceptable. This was DFSER Confirmatory Itom 7.10.1-1. The SSAR has been revied to addres operating experience as indicated above, and this is acceptable. DFSER Confirmatory Itom 7.10.2-1 is, therefore, resolved.

In addition, as part of the operating experience roviow, the anff reviowed the following NRC bulletins and generic letten (GL) which have been isaved since 1980. Tho primary inteat of this roviow offort was to aesure that the operating experience sained as described in thew documents is incorporated into the deaign and operating features for the ABWR.

The generic communications reviewed by the staff for operating experience in the I\&C systems area and a discuseion of the review follows:

\section{NRC Bulletins}

a. Bulletin 80-01 (January 11, 1980), "Operability of ADS Valvo Pneumatic Supply."

This item is not applicable to the SSAR Chapter 7 I\&C system review.

b. Bulletin 80-06 (March 13, 1980), "Engincered Safoty Feature Reset Controls."

Bulletin 80-06 listed three actions to be taken by the licensee. The firat was to roviow the I\&C system schematics and verify that upon reset of an ESF actuation signal, the safety-related equipment remains in its emergency mode. For the ABWR, the ESF systems are recet individually and manually, and will remain in thoir emergency mode. This is acceptable.

The second item requires verification that the as-built I\&C system configuration is in conformance with the schematics. This will be verified by the COL applicant during the ITAAC phase, and is acceptable.

The third item pertains to plant-specific corrective actions by operating plants and does not affect the ABWR. The concerns of Bulletin 80-06 have been adequately addressed in the ABWR design.

s. Bulletin 80-20 (July 31, 1980), "Failures of Westinghouse Type W-2 Spring Return to Neutral Control Switches."

Based on the information provided by GE, this type of switch will not be used in the ABWR design and, therefore, Bulletin 80-06 is not applicable. 
d. Balletin 81-02 (April 9, 1981), "Failure of Gato Typo Valves to Clow Against Diffecential Preesure."

This item is not epplicable to the SSAR Chapter 7 IEC sydem roviow.

- Bulletin 82-04 (December 3, 1982), "Doficiencies in Primary Containment Blectrical Penetration Anemblies."

This item is not applicable to the SSAR Chapter 7 IRC sydem roviow.

f. Bulletin 88-07 (June 15, 1988), "Power Oacillations in Boiling Water Reactors."

The mencures provided in the ABWR IRC syetem deaign to deal with powver oecillations are addreseed in Sections 7.2 and 7.6 of this report.

8. Bulletin 90-01 (March 9, 1990), "Loes of Fill Oil in Transmitters Manufactured by Rosemount."

GE committed for the ABWR I8C system design not to uce the transmitters of concern identified in the bulletin which were built before July 1989 . In addition, the plant computer for tho ABWR will have the capability to trend the operational datu of all safoty-related transmitters. This trending is capable of detecting the type of problems described in Bulletin 90-01. This is, therefore, scceptable.

\section{NRC Generic Letten}

2. GL 80-03 (April 10, 1980), "Chrification of the Term "Operable" as it Applies to Single Failure Criterion for Safety Syetems Required by TS."

This item is not applicable to the SSAR Chapter 7 I\&C syctem reviow.

b. GL 83-27 (July 6, 1983), "Surveillance Intervals in Standand Technical Specifications."

This item. is not applicable to the SSAR Chapter 7 I\&C system reviow.

c. GL 88-02 (January 20, 1988), "Integrated Safety A

This item is not applicable to the SSAR Chapter 7 I\&C system review.

d. GL 88-20 (November 23, 1988), "Individual Plant Examination of Sovere Accident Vulnerabilitios."
This item is not applicable to the SSAR Chapter 7 I\&C syetem roviow.

6. GL 89-14 (August 21, 1989), "LineItem Improvements in Technical Specifications Removal of 3.25 Limit on Extending Surveillance Intervals."

Iseves in GL 89-14 related to I\&C system TS are discuseed in Section 7.11 of this report.

f. GL 91-04 (April 2, 1991), "Changes in Technical Specification Surveillance Intervals to Accommodato a 24-Month Fuel Cycle."

Inowes in GL 91-04 related to I\&C system TS are discuseed in Section 7.11 of this report.

8. GL 91-09 (June 27, 1991), "Modification of Surveillance Interval for Electrical Protection Assemblies in Power Supplies for the Reactor Protection Systems."

Iscues in GL 91-09 related to I\&C system TS are discussed in Section 7.11 of this report.

One issue associated with operating experience concerns an aspect of the adequacy of the defense-in-depth and the diversity of the instrumentation design required to provide defense against common-mode failures remains open. Specifically, the issue concerns the need for diverse reactor pressure vessel water level measurement instrumentation. This issue was Open Item 20.3.8 in the DFSER and is also addreseed in Section 7.2 of this report. The primary concern is in identical measurement instrument techniques used (condensing chambers and differential pressure transmitters) to measure the RPV water level and provide signals to the I\&C logic.

Recent anomalies have been observed in RPV level instrumentation (and discussed in GL 92-04, "Resolution of the Issues Related to Reactor Vessel Water Level Instrumentation in BWRs Pursuant to 10 CFR 50.54(f)," Information Notice 92-54, "Level Instrumentation Inaccuracies Caused by Rapid Depressurization," and Bulletin 93-03, "Resolution of Issues Related to Reactor Veesel Water Lovel Instrumentation in BWRs") that were caused by the effects on non-condensible gas in the condensing chamber and reference leg of the water level instrumentation. GE committed to a modification of the design for the ABWR water level instrumentation by revising the sensing line connections and adding a water backfill capability to minimize the possibility of entrapping non-condensible gas in the reference legs and condensing chambers. The proposed modifications will be tested to 
validate the appropriatenceses of the modification. This isnes is discuesed in more detnil in Chapter 20 of this report.

Operating axperience at Grund Gulf Station (found during beting) has domonstrated that the solenoid coils on scrum pilot valves can be damaged by undervoltage and thereby proveat the cernm function. During the provious licensing roviow of Hatch 2, this irano was aleo rniced and included quentions of posaible damage due to undervoltage to the RPS equipmeat in geseral, sot just to the cernm pilot valve solesoid coils. Rewolution of this concern is addreased in Section 7.2.5 of this report.

A rignificant feature of tho I\&C system thating capability for the ABWR deecribed by GB in the SSAR is the climination of the seed to lift leade and install jumpers when performing teats. Lifting leads and installing jumpers has been a cource of problems at operating plants. This inase was part of DFSER Confirmatory Itom 7.2.2.5-2. OB provided moro detailed dencriptions in tho SSAR of the I\&C syetem colf-diagnoutice and teating equipment to be ued for aurveillance and maintenance. The ABWR devign has diminated the necensity to lift leads or add jumpers for sormally cheduled aurveillance and maintennece. This item is, therefore, recolved.

Baced on the above, the etaff concluden that $O B$ had adequately addreaned and incorporated into the ABWR deaign for the ILC aystoms, features which daal with concerms identified from past operating experience. Therofore, operating experience ievues are revolved.

\subsection{Technical Specincations}

The enffi reviowed the drat ABWR TS provided prior to the isarence of the DFSER. Subetential quections were identified as discuened below, which required resolution prior to the ataff finding the ABWR TS scceptable and, therofore, the TS were an open inawe in the DFSER.

The dexign of the ABWR I\&C aystems is mbetentially differeat from that used in curreatly operating BWR plants and, therefore, the current BWR atandard TS sections for the IQZC aystem were not readily applicable to the ABWR IezC systom. OB has mubetantially revieed the ABWR TS to reflect the epecific deaign of the ABWR.

Because the proposed ABWR IRC syetems have not yet been in operntion, there is no epecific equipmeat history that cen bo used to aceess the equipment curveillence intervals. The eppecific I\&C equipment and veadors have not been eelected, and are not required to be eclectod until after the COL is isaued. The epecifics of the 1\&C system equipmeat colf-dingroutices are to be considered in asseating the TS murveillance intervals.
Prior to the isanance of the DFSER, GE had not claimed credit for tho celf- diagnoctics to meet any particular TS requirements. The celf-diagnoctices are an intogral part of the deaign, and form a significant basis for the cetablishmeat of surveillance intervals for equipment beyond the colf-diagnontica. The inclurion of the self-diagnostice in the deaign is neceseary to the seceptence of the TS a diccused in Section 16 of this report.

MPL C71-5030 (Rov. O, April 23, 1990), "Reactor Profection Syatem Verification and Validation Criteria Decign Specification," atates that fiold installation and validation teet for the RPS will be performed while the multiplexing loops for each RPS division are operational. The DFSER atated that the limiting conditions for plant operntion muat addreas the posesibility of a multiplexor loop being out of ervice. The ABWR TS incorporate limiting conditions for this situation, and therefore, this item is recolved.

MPL C71-4010 (Rov. 1, July 2, 1990), "Reactor Protection Syetem Dexign Specification," states that one ceasor channel may be bypaneed and the systom actuation will bo based on a two-out-of-three logic. This bypass is implemented at the input to the TLU. Bypass of ose division of output logic will aleo result in a two-out-ofthree coincidence logic. This bypass is implemented at the input to the OLU. There is no indication in the MPL document if both bypaseses are allowed at the same timo. The initial draft ABWR RPS TS referred only to the traditional chennel check calibration and functional tests. In the DFSER, the ataff atated that a deecription of how these IRC channel and division bypecees are to be implemented on the $A B W_{k x}$ was required. A functional channol teat chould be dofined. Subsequent versions of the ABWR TS added the dofinitions of ensor, logic, and output channols as well as a discusaion of the various curvoillance requirements including bypass conditions. This itom is, therefore, resolved.

Plent operation in the event of power supply failures needed to be connidered in the I\&C syetem TS. A lows of one channel of SSLC power not only dieables one channel of ceneors and one channel of coincidence logic, but also dieables $1 / 4$ of the inputs to the other three coincidence logics. The DFSER atated that the TS needed to consider cach of the credible equipment failures and the specific TS ecticn that it invoken, if eny. The TS were reviced to consider credible failures and the appropriate statements of sction have been incorporated. This item is, therefore, recolved.

The dnaft ABWR TS initially indicated that an indofinite bypas (no repair reguired until the next refueling outage) was appropriate for a chennel out of service. No basea 
were provided to justify this coadition. The etaff noted that there is a potential single frilure of the Division II, $6.9 \mathrm{KV} / 480 \mathrm{Vac}$ trunsformer or $480 \mathrm{Vac}$ awitchgear which could diable both the Divisions II and IV SSLC, and at the came time not cause a resctor coram. If a Division I or III SSLC channol is in bypass at the came time, the recult could be a loes of RPS function.

By lecter dated June 2, 1993, on important features ideatified by the ABWR PRA, GE identified that the four divisions of the SSLC are doxigned to be highly reliable with features that reduce the poenibility of inadverteat sctuations. The PRA ancumed a celf-diagnostic fuult detection rate for the SSLC of 0.95 with the remainder of the fuults expected to be found during the quarterly SSLC surveillance required by TS. As diecuseed earlier, there is a leck of operational data for the SSLC equipment to cupport the PRA number.

Because of the above reasons, GE has revised the ABWR TS to remove the indefinite bypass of an SSLC channel. This is ecceptable to the staff.
In the DFSER, the etaff noted that epecific operability apects of the ABWR I\&C syetem digital technology needed to be further ovaluated when doveloping the TS. For example, if a failure of a afety-related I\&C aystem (channel or division) during aurveillance can be attributed to a coftware error, the appropriate TS operability requirements for other ayetems which may aleo be mbject to failure as a recult of the mene software error are needed to be cetabliched. The TS were revised to include limits on continued operation and programmatic consideration (ineluding reporting to the NRC) of coftware erron when they are diecovered. This is acceptable to the staff.

The TS for deaign certification include I\&C syctem etpoints that will be eatablished by the COL applicant during tho I\&C system detailed design dovelopment. The cetpoint methodology is included in the CDM and its implementation is included in the ITAAC.

Based on the above, the staff concludes that the ABWR TS for deaign certification incorporate the necessary operability and surveillance requirements for digital I\&C systems and are, therefore, acceptable. 


\section{ELECTRIC POWER SYSTEMS}

\subsection{Introduction}

The etaff reviownd the advanced boiling water reactor (ABWR) decien decoriptions and commitmente documented in Chepter 8 of OB Nuolour Energy's (OB's) atudand metoy amalyais report (SSAR) Ameadment 32. The baces for ovaluating tho edequacy of ABWR electric power oyetem presented in SSAR Chopter 8 were the scoeptences criteria and guidalines for electric power aystem contrined in etandand roviow plan (SRP) Chapter 8 and Regulatory Ouides (ROs) 1.153 (Rev. 0), "Criteria for Power, Intrumentation, and Control Portions of Safoty Systame," and 1.155 (Rov. 0), "Stution Bleckout." The Nuclear Regulatory Commistion (NRC) approved thewe regulatory guides following the inanes of SRP Revision 3 (July 1983), and they apply to the ABWR dectric power oyctem deaign.

The stafi's initial findinge were included in tho draft safoty ovaluation report (DSER), SECY-91-355. In addition, the ctaffe interim findinge were included in the draft final anfoty evaluation report (DFSER), SECY-92-349. Open, confirmatory, and COL setion itome from thece documents have been rofereaced in the discuscions below.

\subsection{Orfsite Electric Power System}

The offite electric power aystem is commonly called the "proferred" power system. The staff's evaluation of this system focused on the system's importance as the proferred supplier of olectric power for the onsite power syatem (that is, the Clase 1E ac-distribution syetem), which supplies power to anfoty systems.

For the ABWR, the preferred power aystem compriese the following circuitu:

- Normal proferred power circuit - a back-feed circuit from the tranemiecion notwork to the input terminals of each of the three redundant, onsite Class IE ac-diatribution aystems through the main transformer and three unit auxiliary traneformors.

- Alternate proferred power circuit - from the trensmiscion network through one rewerve auxiliary transformor to the input torminals of each of the three redundant, onsite Clese IE sc-distribution systoms.

Because GE shares the ABWR design responsibility for this system with the combined license (COL) spplicants, those parts that are outside the scope of deaign of the ABWR standard plant, and those parts that are within the scope of design of the ABWR standard plant are described and ovaluated as follows.

\subsubsection{Prelarred Ondte Circuits Outaide the ABWR Scope of Deaign}

The following portions of the preforred power circuits are outride the coope of dexign of the ABWR ctendard plent:

- Normal preforred power circuit from the treneminsion networt through the main power tranuformer to the low-voltage terminals of the main transformor.

- Nlernato preferred power circuit from the tranemiecion networts through the reserve auxiliary traneformer to the low-voltage terminals of the rewerve auxiliary tounsformer.

\subsubsection{Scope of GE Deaign of Orfite Preferred Circuits}

Section 3.1.2.2.8.2.2 and Sections 8.2.1, 8.2.2, and 8.2.3 of SSAR Amondments 7 and 10 were inconsistent with regand to which parts of the offisite system are within (or outside) the ABWR etandard design ecopo (DSER (SECY-91-355) Open Itom 22). Subeequently, GE committed to revise Section 3.1.2.2.8.2.2 of SSAR Ameadment 7 so that it would be consistent with the above dofined scopo of design.

Verification that GE included appropriate changes in a future SSAR amendment to reflect the above information was DFSER (SECY-92-349) Confirmatory Item 8.2.1.1-1. GE included this information, in Sections 3.1.2.2.8.2.2 and 8.2.1 of SSAR Amendment 32, which is acceptable.

\subsubsection{Definition of Offsite System}

OE's draft SSAR mbmittal of April 3, 1992, indicatod that the offaito power syetem begins at the terminals on the tranemisaion network side of the circuit breakers connecting tho switching stations to the offuito transmicsion network. That draft also indicated that the offsite power system ends at the terminals of the plant's main generator and at the circuit breaker input terminals of the mediumvoltage $(6.9 \mathrm{kV})$ switchgear. This doscription is not consiatent with the NRC SRP definition of an offaite syetem DSER (SECY-91-355) Open Item 27. Specifically, GE's dofinition appeared to excludo the transmiscion network, as well as the plant's main generator and gas turbine generator. GE committed to revise the SSAR in a future amendment to be consistent with the NRC SRP definition of an offsite system.

Verification that GE included appropriate changes in a future SSAR amendment to reflect the above information was DFSER (SECY-92-349) Confirmatory Item 8.2.1.2-1. GE included this information, in Sections 8.1.2.1 and 
8.2.1.1 of SSAR Ameadment 32, which is scceptable. Therefore, this itom is resolved.

\subsubsection{Onsite Power Syctem Interfaces}

This cection eddresece the etafis ovaluation of OB's reeponse to DSER SECY-91-355 Open Item 24.

In the draft SSAR abmittal datad April 3, 1992, OB reeponded to Open Item 24 from the DSER (SECY-91-355) by defining interfece requiremente for the offrite circuitu outside the scope of dexign of the ABWR tandard plant. OB committed to document rimilar interfroes in the SSAR in a future ameadment. Verification that $\mathrm{OB}$ included appropriate changes in a future SSAR amendment was DFSER (SECY-92-349) Confirmatory Itom 8.2.1.3-1. OE included the appropriato changes in Section 8.2.3 of SSAR Ameadment 33, which is ecceptable. Therefore, this itom is recolved.

Section 8.2.3.1 of GB's drat SSAR wubmittal of April 3, 1992, indicated that a COL applicant "should" moet the interfice requirements dofined in Section 8.2.3 of the ABWR SSAR. Applicants who reference the ABWR deaign will be required to addrese all interface requiroments in its dexign ecopo. GE committed to revico the SSAR in a futuro ameadmeat to indicate that interface requiremeats "shall" be met by the applicant. Verification that GE included this change in a future SSAR amendment was DFSER (SECY-92-349) Confirmatory Item 8.2.1.3-2. GE included this change in Section 8.2.3 of SSAR Amendment 32, which is sccepteble. Therofore, this item is recolved.

GB also committed to rovico in a future SSAR ameadmeat the wection on interfice requirements to include a lieting of the regulatory requirements and anociated regulatory and induetry guidance, which a COL applicant must addrees in its deaign reope as part of tho COL application. For the offinito system, these should include, as a minimum, the requirements of General Deaign Criterion (ODC) 17 and 18 of 10 CFR Part 50, Appeadix A, 20 well as the guidelines of IEBB 765-1983. Verification that $\mathrm{OB}$ provided the above deaign information in a future SSAR ameadmeat was DFSER (SECY-92-349) Confirmatory Itom 8.2.1.3-3.

Subequeotly, during a November 18, 1992 mocting, OB indicated that SSAR interfice requiroments were pot moent to define the totality of the requirements (including regulatory requiremeats) which a COL applicant's interfacing deaign must ultimatoly meet. The deaign interface requirements need only include those requirements that are needed by the ABWR dexign to aseure that the devign as completed by the COL applicant mocts tho in scope deaign bacis requirements in the SSAR. The etaff asrees with this scescement. COL applicant dexign will bo required to moet all applicable regulatory requirements and ascociated regulatory and induntry suidence as part of its COL application. The applicable regulatory requirements and ascociated regulatory and induatry suidance are delineated in the code of federnl regulations, the NRC SRP, and industry etandands and codes. Thene requirements and guidance do not need to be repeated as interface requirements. DFSER (SECY-92-349) Confirmatory Item 8.2.1.3-3 is therefore recolved. The etaff's ovaluation of deaign interfuce requirements is aleo addreseed in Soction 8.2.1.3.1 of this report.

In interfece requirement (2), Section 8.2.3.1 of the draft SSAR mubmittal dated April 3, 1992, indicated that \& COL applicant who references the ABWR design is expected to cutablich the size of the unit auxiliary transformers to cencure a voltage dip of no more then 20 percent during motor starting. It wat tho etaff's undoretanding, babod on discrascions with $\mathrm{OE}$, that the aixing of the unit suxiliary treneformen is within the ABWR rcope of deaign responsibility. GE committed to revise the SSAR in a future amendment to reflect the above as part of GE's scope. Verification that GB included this change in a future SSAR amendment was DFSER (SECY-92-349) Confirmatory Item 8.2.1.3-4. $\quad \mathrm{E}$ included this change in Section 8.2.1.2 of SSAR Amendment 32, which is scceptable. Therefore, this item is resolved.

In interfice requirement (4), Section 8.2.3.1 of the draft SSAR aubmittal dated April 3, 1992, GE indicated that it is ecceptable and recommended to normally power all three divisions of the Clace 1E ac-diatribution system from the normal preferred power cource. This interface requirement is not consietent with design commitments that aro curreatly documented in other rections of the SSAR (cee Section 8.2.3.5 of this report). GE committed to deleto this requirement (epecifically, the wecond reatence of interfice requirement (4) in Section 8.2.3.1 of the draft SSAR rovision dated April 3, 1992) when tho SSAR was revieed in the future. Verification that $\mathrm{GE}$ included this change in a future SSAR amendment was DFSER (SECY-92-349) Confirmatory Itom 8.2.1.3-5. OB included this change in Section 8.2.3 of SSAR Ameadmeat 32, which is rcceptable. Therefore, this item is resolved.

In interfece requirement (5), Section 8.2.3.1 of the dint SSAR nubmittal datod April 3, 1992, GB indicated that the two offeite circuits will be connected to different transmission systems. It was the staff's underetanding, based on diecuserions with $\mathrm{GE}$, that there is only one trensmisaion system. GB committed to clarify the interface 
requirement in a future ansodment to indicato that the min and reserve offaito power circuits will be connocted to different trenemiscion circuits or lines (nther than syctems) and that the tranemiesion circuits or lines will be independent and exparato. Verification that GE provided the abovo deaign information in a future SSAR amendmeat was DFSER (SECY-92-349) Confirmatory Itom 8.2.1.3-6. GE included this information in Section 8.2.3(5) of SSAR Amendment 32, which is scceptablo. Therefore, this itom is roeolved.

Section 8.2.3.1 of GE's draft SSAR rubmittal dated April 3, 1992, did not include additional interfice requirements dofining what is required of the COL applicant in order to have independent and separate transmission circuits and switching stations. GE committed to include in a future SSAR ameondment oxplicit interface requirements dofining independence and separation of transmission lines and switching stations or switchyands. Verification that GE 'rovised the SSAR to reflect as a minimum the following decign commitments in a future amendment was DFSER (SECY-92-349) Confirmatory Item 8.2.1.3-7:

- The two decignated preferred power circuits will not have a common take-off structure or use common structures for support.

- The two lines from the transmission network that are designated as the preferred power circuits will be designed to minimize their simultanieous loes as a reault of failure of any transmission tower or failure from crossing lines.

- The preferred power circuits originating from the transmission network will be designed to minimize their simultaneous failure as a result of failure of a single breaker, switchyard bus, switchgear bus, or cable.

- System studies will be performed to demonstrate that the preferrod power supply will not degrade below a level consistent with the availability goals of the plant as a recult of contingencies such as loss of any of the following elements

- nuclear power generating unit

- largeat generating unit

- moet critical transmission circuit or intertie

- largeet loed

- The interconnection between the transmission network and the switchyard will consist of a minimum of two transmission lines that are designated as the preferred power aupply circuits. Where more than two lines are available from the tranomiecion network, eny combination of two lines may bo dexignated and used as the preferred power aupply circuits, provided that each combination of two circuits meets the offaito syetem deaign requirements.

- Switchyard equipmeat will be designed to adequately withetand streases from the worst-case faults.

- The physical decign of the switchyards will minimize the probability that a singlo equipment failuse will caves the simultanecuss or subeequent lose of both proferred power aupply circuits.

OB indicated in response to this item that SSAR interfece requirements were not meant to define the totality of the requirements (including the requirements noeded to serurv independence and separation between transmission circuits) which a COL applicant's interfacing design may ultimately have to moet. The staff agrees with; this asecesmeat. Under 10 CFR Part 52, the sito-specific portion of a COL applicant's deaign will be required to meet all applicable regulatory requirements and ascociated regulatory and induatry suidance an part of their COL application. The applicable regulatiory requirenents and aceociatod regulatory and industry guidelina: are delinented in the code of federal regulations, the NRC SRP, and the industry standards and codes. These sinuirements and guidelines, therefore, do not need to be repented as interface requirements in ABWR SSAR. In zatition, GE indicated that the above listed items that were id atified in the DFSER (SECY-92-349) to assure independence between offsite circuits would be considered as part of their propoeed conceptual design deecription to be included in the sito-epecific part of the SAR for a facility referencing the certified design. The staff concludes that interface requirements defining what is required of the COL applicant in order to have independent and separato transmission circuits and switching stations are not required to be included as interface requirements in the ABWR SSAR. DFSER (SECY-92-349) Confirmatory Item 8.2.1.3-7 is therefore resolved. The staff's ovaluation of interface requirements relating to capacity, capability, and independence of offsite circuits is in Section 8.2.2 of this report. The staff's evaluation of GE's conceptual dexign for the offaite syetem is in Section 8.2.1.3.2 of this report.

In interface requirement (4), Section 8.2.3.1 of the draft SSAR aubmittal of April 3, 1992, GE indicated that the COL applicant will analyze incoming transmission lines to ensure that their expected availability is as good as ascumed in performing the plant's probability risk analysis (PRA). Based on discussions with GE, the staff contended that the sacumptions made in performing the plant's PRA 
are within the coope of the ABWR deaign. OB committed to explicitly state as part of this interfices requirement, the axpected availability of incoming trensmiscion lines, in a future SSAR amendment. Verification that $O B$ provided the above deaign information in a future SSAR amendment was DFSER (SECY -92-349) Confirmatory Item 8.2.1.3-8. OB included this information in Section 8.2.3(4) of SSAR Amendment 32, which is scceptable. Therefore, this item is resolved.

Dexign commitments documented in tho SSAR indicated that the conceptual deaign of the ABWR officto preferred power syatem will include two separate and independent owitching atations (or awitchyands). Given that there will be two separato and independeat switchyands, the interfice requirements within individual switchyards presented in GE's draft aubmittal of April 3, 1992, 80 beyond industryrecommended practice for offaite preferred circuits. The staff understood that GE will revise the SSAR to describe the parts of the offeite system switchyand not subject to interface requirements specified in Section 8.2.3 of the draft submittal of April 3, 1992 . Verification that OE provided the above design information in a future SSAR amendment was DFSER (SECY-92-349) Confirmetory Item 8.2.1.3-9. GE indicated that they would ro-evaluate their proposed interface requirements and conceptual dexign for the portion of the officite syetem that is outside of their coope of aupply. Interface requirements and the conceptual design are evaluated in Sections 8.2.1.3.1 and 8.2.1.3.2 of this report respectively. On the basis of these ovaluations, this item is resolved.

\subsection{Interface Requirements}

This section addreseses, in part, the staff's evaluation of GE's reeponse to DSER (SECY-91-355) Open Itom 24 and DFSER (SECY-92-349) Confirmatory Items 8.2.1.3-3 and 8.2.1.3-9 and complements the resolution of these items.

GE revised their interface requirements included in Section 8.2.3.1 of GE's draft SSAR submittal of April 3, 1992, and moved interface requirements that were included in Section 8.2.4 of SSAR Amendment 21 to Section 8.2.3 of SSAR Amendment 33. In addition, GE provided a representative conceptual design for the portion of the offsite system outside of their scope of supply ( 800 Section 8.2.1.3.2 of this report).

Section 52.47(a)(1)(vii) of 10 CFR dictates that interface requirements be provided (for those portions of the offsite power system design for which GE's application does not seok certification) that are sufficiently detailed to allow completion of the final safety analysis. The staff concludes that GE has provided interface requirements in Section 8.2.3 of SSAR Amendment 33. The design, therefore, moets the above dofined requiremeats of Section 52.47(a)(1)(vii) of 10 CFR and is scceptable.

The stafi's asceument of the adequacy of these interfice requirements is addresed in Section 8.2.2 of this report.

\subsection{Conceptual Design}

This cection addreaces, in part, the etaffe ovaluation of OE's reepones to DSER (SECY-91-355) Open Item 24 and DFSER (SECY-92-349) Confirmatory Items 8.2.1.3-7 and 8.2.1.3-9 and complements the revolution of thewe items.

GE added a Section 8.2.5 to SSAR Amendment 33 to addrees their conceptual deaign for the offisite system outride of ite design rcope. The conceptual design will consiat of two independent offisite circuits from the transmisaion network to the electrical systems for which GE is soeking cortification. These offsite circuits, including their associatod I\&C circuits, will bo independent. Each circuit will have sufficient capacity and capability. Each circuit will have redundant I\&C circuits including their ac and dc power supplies. In addition, the total offeite power system will have an expected availability that is as good as the assumptions made in performing the plant PRA.

To aid the staff in its review of the SSAR and to permit asecesment of the adequacy of the interface requirements, Section 52.47(a)(1)(ix) of $10 \mathrm{CFR}$ dictates that a representative conceptual design be provided in the ABWR SSAR for those portions of the plant's offsite power system design for which the GE's application does not soek certification. The staff concludes that GE has provided a representative conceptual design described above. The design, therofore, moets the above defined requirements of Section 52.47(a)(1)(xi) of 10 CFR and is acceptable. GE has included the above described conceptual design in Section 8.3.5 of SSAR Amendment 33 which is ecceptable.

The staff's assessment of the adequacy of the interface requirements with the aid of the above described conceptual design is addressed in Section 8.2.2 of this report.

\section{Certified Desion Materisl}

The certified design material (CDM) for the GE ABWR Design Stage 2 Submittal, transmitted by letter dated April 6, 1992, did not specify the appropriate interfacerelated ITAAC material for the offsite systems outside the ABWR scope of design. In the ITAAC, (GE) must address this interface area. This was DFSER Open Itom 8.2.1.4-1. GE provided a revised set of design 
descriptions and ITAAC. The edequacy and seceptability of the ABWR decign descriptions and ITAAC are ovaluated in Chapter 14.3 of this report. On the basis of this ovaluation, this item is resolved.

\subsubsection{Preferred Onsite Circuits Within the ABWR Scope of Dedign}

This ecction eddreseces, in part, tho etafi's ovaluation of GE's reeponse to DSER (SECY-91-355) Open Item 24 and DSER (SECY-92-349) Confirmatory IItom 8.2.1.3-7 and complements the resolution of these items.

The following portions of the preferred power circuits are within the scope of design of the ABWR standard plant:

- Preferred power circuit from the low-voltage terminals of the main transformer through the three unit auxiliary transformens to the input terminals of each of the three redundant, onsite Class IE ac-distribution systems.

- Alternato preferred power circuit from the low-voltage terminals of the reverve auxiliary transformer to the input terminals of each of the three redundant, onsite Class IE ac-distribution systems.

\subsubsection{Physical Separation (Transformers and Circuits)}

\section{Physical Sepantion of Trnoformen}

By its draft aubmittal dated April 3, 1992, GE rovised the SSAR to indicate that the reserve auxiliary transformer will be separated from the unit auxiliary transformers by a minimum distance of $15 \mathrm{~m}$ (50 ft) and that each transformer will be provided with an oil collection pit and drain to a safo disposal area. In addition, GE indicated by letter dated April 6, 1992, that the reserve auxiliary transformer and its input feoders will be separated from the main power transformer and its input feeders and from the unit auxiliary transformers by a minimum of $15 \mathrm{~m}$ (50 ft). Section 9A.4.6 of SSAR Amendment $14 \mathrm{also}$ indicated that the main, unit auxiliary, and reserve transformers will have oil collection pits and that each of theee transformers will have automatic deluge water spray systems. This information was provided in responso to DSER SECY-91-355 Open Item 23.

In order to assure that the COL applicant's design for offsite systems does not negate their proposed design for physical separation of transformers, GE indicated that the COL applicant's design will be required (i.e., by interface requirement) to be independent and compatible with the above described design commitmeats.
GDC 17 of 10 CFR Part 50, Appendix A, requires that provisions be included in the deaign of the offinte electric power aystem which will minimize to the extent precticable the likelihood of simultaneous failure of both normal and altermate offaite preferred power circuits under operating and postulated eccident and environmental conditions. The utaff concludes that a doeign which moets the above dencribed commitments will provide reasonable aneurnece that the energy available from a credible failure of one of the officte circuit tranaformen (such as, fillure by fire or by explocion) will not propagate to the other offisite circuit and canso its failure. The oil collection pit will contain a tranaformer oil fire at the transformer. The automatic deluge water epray eystem will minimize the intensity of the beat that may be generated by a transformer fire. In addition, the $15 \mathrm{~m}$ (50 ft) of distance to other offsito circuit transformen will dissipate the cenergy from heat that may be generated by a transformer fire or by missiles that may be generated by transformer explosion.

Consequently, the design moets the above defined requirement of GDC 17 and is acceptable. Verification that GE incorporated the above commitments into a future Chapter 8.0 SSAR amondment was DFSER (SECY-92-349) Confirmatory Item 8.2.2.1-1. GE has included these commitments in Sections 8.2.2.1(2) and 8.2.3(6) of SSAR Amendment 33, which is acceptable. Therefore, this item is resolved.

\section{Certified Desimn Material}

DFSER (SECY-92-349) Open Item 8.2.2.1-1 related to the design description and the inspections, tests, and analyses, and acceptance criteria (ITAAC) for the physical separation of transformors. The adequacy and acceptability of the ABWR design descriptions and ITAAC are evaluated in Chapter 14.3 of this report. Therefore, this item is resolved.

\section{Physical Separation of Circuits}

By its draft submittal dated April 3, 1992, in response to DSER Open Item 23, GE revised the SSAR to indicate that separation of the normal and alternate preferred power feeds within the turbine, control, and reactor buildings will be accomplished by floors and walls, except within the switchgear rooms where they must be routed to the same owitchgear lineups. Besed on discussions, GE further indicated that normal and alternate circuits in the switchgear rooms will be separated to the maximum extent feasible; that is, the circuits will be routed on opposite sides of the room and will be connected to the switchgear lineup on opposite ends. Also, based on discussions, GE indicated that the isolated phase bus duct and/or cables located outside the turbire, control, and reactor buildings 


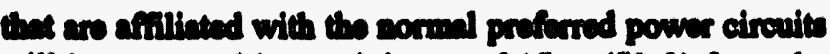
will be ceparated by a minimun of $15 \mathrm{~m}$ (50 $\mathrm{A})$ from the

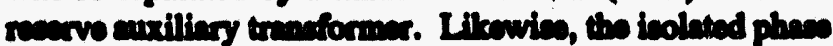

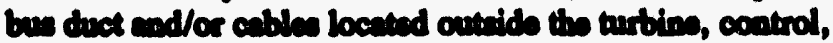
and rector buildinge thet ane afillined with the altemente

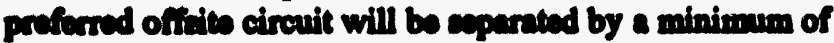
$15 \mathrm{~m}$ (50 is) from the unit anxiliery and min uneformase.

In order to enere thet the COL applient's danign for

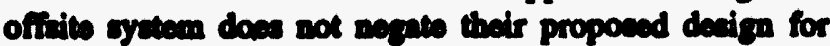
phycieal expartion of circuite, OB indiented thet the COL epplicent's dacion will bo requind (i.e., by interiace requirsmant) to be indepeadent and compatible with the sbove dacaribed datim commitmente.

GDC 17 of 10 CFR Part 50, Appendix A, requires that provision be included in the decion of the offite electric power syctem which will minimize to the extent practicable the likolihood of cimulteneous fillure of both normal and altemnte officite preferred power circuits under operating and poesulated accident and environmental conditions.

The etafi concludes that a deaign which moets the above deccribed commitmente will provide reasoable anannoce thet frilure of one circuit will not propagate and cauns filure of the other officite circuit. consequently, the dexign moets the sbove dofined requirements of GDC 17 of 10 CFR Part 50, Appendix A, and is scoptable. Verification that OE has included appropriate changes in - future SSAR amendment to reflect the above commitmeats wes DFSER (SECY-92-349) Confirmatory Item 8.2.2.1-2. GE has included thew commitments in Section 8.2.1.3 and 8.2.3 of SSAR Amendment 33, which is acceptable. Therefore, this item is resolved.

\section{Centified Derion Meterinl}

DFSER (SECY-92-349) Open Item 8.2.2.1-2 related to the deaign deccription and the ITAAC for the physical eeparation for offaito preferred circuit. The adequacy and scoeptability of the ABWR design descriptions and ITAAC are evaluated in Chupter 14.3 of this report. Therefore, this item is resolved.

\subsubsection{Phycien Separation of Instrumentation and Control (IEC) Cables for the Onsite Power Sritem}

Baced on OB's draft aubmittal datod April 3, 1992, in rexponso to DSER (SECY-91-355) Open Item 23 and aubeequent discuecions, OE indicated that instrumentation and control cables that are affiliated with the normal and alternate preferred offeite circuits will be separated as follows:
- The indrumentution and control cables that are afflievad with the normal proferred officte cireuit will be routed in recowny correeponding to the loed group of their power cource.

- The inctrumentiation and control cables that ase afrilintad with tho alternato proferred officito circuit will bo routed in dedicated recownys. The alternate proferred officite inetrumentation and control circuit cables will not share moevaye with any other cables.

- The exparation between the normal and sliernato preferred offitto inetrumentation and control cables will bo the eamo es the exparation between tho normal and slternate preferred offitite power circuits (that in: flocm, walle, or $15 \mathrm{~m}$ (50 ft) of phyrical separation).

In order to aseure that the COL applicant's design for offivite aystem does not negate their proposed design for physical separation of 18C circuits, GE indicated that the COL applicant's deaign will be required (i.e., by interface requirement) to be independent and compatible with the above described design commitments.

ODC 17 of 10 CFR Part 50, Appendix A, requires that electric power from the transmiesion network to the onsite eloctric distribution syctem shall be supplied by two physically independent circuits decigned and located so as to minimize to the extent practicable the likelihood of their simulteneous failure under operating and poetulated eccident and environmental conditions.

The staff concludes that a design which meets the above commitments will provide reasonable assurance that failure of one circuit will not cause the failure of the other circuit. The deaign, therefore, meets the above defined requiremeats of ODC 17 of 10 CFR Part 50, Appendix A, and is acceptable. Verification that GE has provided the above commitments in a future SSAR amendment was DFSER (SECY-92-349) Confirmatory Item 8.2.2.2-1.

GE included the above design commitments in Section 8.2.1.3 of an SSAR markup dated March 31, 1993, and Section 8.2.3 of SSAR Amendment 33 with the exception of I\&C circuits located in the control room area and interlock circuitry required to prevent paralleling of the two offeite sources. GE indicated that these circuits are not eeparated by floors, walls, or $15 \mathrm{~m}$ (50 ft) but intend indicated that these circuits will be eloctrically isolated and will not be routed together in the same secoway. The staff concludes that a design which moets the above described commitments as revised will also provide reasopable sesurance that failure of one circuit will not cause failure of the other circuits. Consequently, the revised offsite system design also meets the above defined 
requiramente of ODC 17 of 10 CFR Part 50, Appeadix A, and is cocoptable. OB boluded the additional decipo provitions in Scotion 8.2.1.3 of SSAR Amendement 32, which is coseppeblo. Therefore, this item is recolved.

During ITAAC dovelopment, OB reopmizad that the

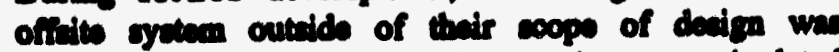

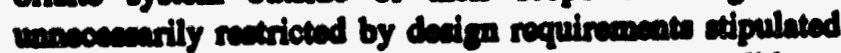
within their socpe of docign. Tho requircments did not allow charing the son-Clew 18 do aystemen within OB's cope of desipm between the independent officito circuito. During ITAAC roviow, the taff agread that en officito

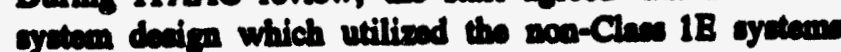
within OB's woops of decign and shand then oyctem betweren the independent offitio circuits could maet regulationy requirementes and could thw be found scoeptable. In order to remove this limitation, OB further rovinad Section 8.2.1.3 of it SSAR markup dated March 31, 1993, to indicato the following:

a. Inetrumentution and control circuite at their de power sources may be dectrically isolated, and not routed together in the came recowny inetead of being cepanted by floon, walls, or $15 \mathrm{~m}(50 \mathrm{n})$.

b. Inetrumentation sad control circuite for tho independent oftitis circuite will not rely on a singlo common de power cources.

The etaff agnes that these revisione will allow utilization of the noc-Clace 18 de aystem within OB's coope of deaign and sharing of these do syctem between independent officito circuits within a COL applicant's offitito syctom doaign.

If non-Clas IE de power aystem within GB's coope of dacign are utilizad as the de coures for inctrumeatation and control in a COL applicant's propoend ofivite syetom deaign and these de power cources are chared between the independeat offitit circuits, the staff concludes above a deaign which meets the above demeribed commitmente a further revied will aleo provido reneomable eneurnece that failure of ans circuit will not calle frilure of the other circuit.

Conenqueatly, the decipen mocts tho above dofinod ruquirements of ODC 17 of 10 CFR Part 50, Appendix A, and is ecceptible.

\section{Corified Darion Mntroil}

DFSER (SBCY -92-349) Opea Itom 8.2.2.2-1 related to the decipm deacription and the ITAAC for the phyaical exparation of powner, inctrumentation, and control cables for the offite proferred power syctem. The adequacy and coceptebility of the ABWR decign descriptions and ITAAC are eviluated in Chapter 14.3 of this repart. Therofore, this item is reolved.

\subsubsection{Electrical Independence}

Baced on OB's drat SSAR mbmittal dated April 3, 1992, in repons to DSER (SBCY-91-355) Open Item 23 and diccumion, $O B$ indicated that there will bo no electrical intureonsections between the normal and alternate proferred power, inetrumentation, and control circuits except where the power circuits connect to common Clen 18 and non-Clace 1B awitohgean lineups. At the common awitchgear, one open and one cloned circuit brenter will mainituin the electrical independence. Them circuilt breskes will be interlocked so that the clomed breaker munt be opened bofore the open breaker can bo cloued. Trunserer from pormal to alternato (or alternuto to normal) proferred power circuits will be manual. Intrumentation and control circuits (including thoir power apply) that are affiliated with the normal proferred offuite eireuit will be electrically independent from (that is, they will bo dectrically icolated from or will have no electrical interconnection with), tho inetrumentation and control circuito (including thoir power mupply) affiliated with the alternato preferred power mupply.

In order to asours that the COL applicent's deaign for officte aystem does not negate thoir proponed devign for dectrical independence, OB indicated that the COL applicant's docign will bo required (i.e., by interface requirement) to be independent and compatible with the abovo described deaign commitments.

ODC 17 of 10 CPR Part 50, Appeadix A, requires that dectric power from the trunemiecion network to the onaito dectric diatribution oystem shall bo mpplied by independeat circuits designed and located so as to minimizo to the extent precticable the likelibood of their simultuncous fallure under operating and postulated sccideat and eavironmeatal conditions.

The atafi concludes that a deaign which moets the above deccribed devign commitments will provide reasomable ancurnes that failure of one circuit will not cause failure of the other circuit. Consequently, the deaign meets the above dofined requirements of GDC 17 of 10 CFR Part 50, Appendix A, and is acceptable.

Verification that $\mathrm{OB}$ provided the above deaign commituments in a futuro SSAR ameadmeat was DFSER (SBCY-92-349) Confirmatory Itom 8.2.2.3-1. GB included thece commitmentu in Sections 8.1.3.1.1.1, 8.2.3, and 8.2.1.3 of SSAR Ameodment 33 which is acceptable. Therefore, this item is rewolved. 
As indicated above in section 8.2.2.2 of this report, $\mathrm{OB}$ further roviend scotion 8.2.1.3 of 8SAR matrop dated March 31, 1993, to remove dadpm restrietions within its coppo of dadifm which did not allow sharing of the now-

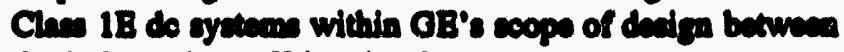
tho indepeadeat offeito circuits.

If son-Clem 1B de powner aystem within OB's scope of decigen are utilined as the do powrer ecurce for instrumentation and control in a COL explicant's proposed ofitite aystem dacion and these do power cources are chared between the independeat offisito circuite, the etaff concludes that a decign which mode the above described

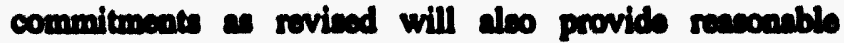
aceurnace that failure of ose circuit will not canco failuse of the other circuit.

Consequently, the deaign moets the above defined requirements of ODC 17 of 10 CFR Part 50, Appendix A, and is acceptable.

\section{Contified Denim Mnteriv}

DPSER (SBCY-92-349) Opea Itom 8.2.2.3-1 relatad to the decign description and the ITAAC for the electrical independence. The edequecy and scoeptibility of the ABWR decign deacriptions and ITAAC aro ovaluated in Chapter 14.3 of this report. Therefore, this item is recolved.

\subsubsection{Teating for the Ondite Power Syatem}

Based on GE's draft aubmittal dated April 3, 1992, in resposes to DSER (SECY-91-355) Open Item 25 and discuscions, $O B$ indicated that all syatem, equipmeat, and componeats that aro affiliated with the normal and alternato offaite proferred power circuits within the OB scope of docign - except generator breaken - will have the capability to be teated periodically during normal piant operation. Based on this commitmeat, GB indicated that the deaign will permit verification of the following offaite power system capabilities:

- The generator breaker can open on demend.

- The instrumentation, control, and protection syatems, equipment, and composents that aro affiliated with tho normal and altornato offinite preferred cincuits are properly calibrated and perform their required functions.

- All required Clase 1E and non-Clase IE loads can be powered from their deaignated proferrod power supply within the capacity and capability margins specified in the SSAR for the offaite system, circuits.

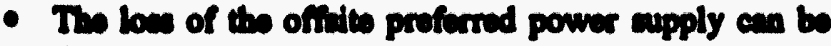
deverad.

- Trunder between proferred power aupplies cen bo cocompliched.

- The battarias and chargers that are afriliatod with the preforred powner ayctem can modt the requiremente of their dovign loads.

In addition, OB indicated that the dosign of high- and modium-voltage bue ducte and cables provide ready scomen for rogularly inpecting, cleaning, and tightening torminals, and for inspecting and cleaning insulation. The bus duct decion aleo includes provisions for excluding dobris and fluida, and for draining condensate.

ODC 18 of 10 CFR Part 50, Appendix A, requires that the offitio dectric power aystems bo deaigned (1) to permit eppropriate periodic inspection and teating of important ances and fratures (auch as wiring, inculation, consections, and awitchboands) to ancese the continuity of the aystem and the condition of thair componente, (2) the ceppability to tex periodically the operability and functional performance of the composeats of the aystem, and (3) the capability to an pariodically tho opernbility of the aystome as a wholo and (under conditions as clow to design a prectical) the full operntion exquesce that brings the systems into opention.

The ctaff concludes that a dosign which moets these tectability requirements will consure that the officito olectric powrer systems, equipment, and components will be deaigned with the capability to bo periodically teeted. Consequeatly, the decign moets the above defined requiroments of ODC 18 of 10 CFR Part 50, Appendix A, and is eccoptable.

Verification that $\mathrm{OB}$ provided the above teatability requirements in a future SSAR ameadmeat was DPSER (SBCY-92-349) Confirmatory Itom 8.2.2.4-1. OB included these teatability requirements in Section 8.2.2.1(3) of SSAR Amendment 32, which is acceptable. Therefore, this item is renolved.

With regard to periodic teating of the systems, equipmeat, and composents, $O E$ indicated the following:

- Periodic verification will ensure that the normal and alternate offsite power circuits are coergized and connected to the appropriate Clase IE distribution system division at least once every 12 hours. 
- Tous and inpections will be parformed a appropriately coboduled intervale for cach of the ituen highlighted above.

- The bent and inspection intervalo will bo cutablicted and mintuined ecoording to induatry recommendod practico dofined in Scotion 6.5, "Tect Intervals," of IBEE 338-1977.

Verification that OB epecified in a future SSAR ameadment a ctetement that the COL applicant must inolude the sbove epecified periodic trote and inspections in appropriate plant procedures was DPSER (SBCY-92-349) COL Action Item 8.2.2.41. OB includad this setion item in Section 8.2.4.1 of SSAR Amendment 32, which is ecceptable.

\section{Centified Darim Mnterin}

DFSER (SBCY-92-349) Open Item 8.2.2.4-1 was related to the decigen dencription and the ITAMC for tecting for the offite power aystem. The adequacy and coceptability of the ABWR decipgn deccriptions and ITAAC are cvaluated in Chepter 14.3 of this report. Therefore, this itom is revolved.

\subsubsection{Generator Breaker}

The low-voltage generator breaker must open on a turbine trip to maintain the normal preferred power mupply to the safety buses. The generator breaker cannot be teeted during normal plant operation without tripping the main turbine generntor.

Bawed on discuscions, GE indicated that the opeaing of the generntor breaker to eatablich the normal offsite preferred power circuit to affety busen will be verified each timo the renctor is shutdown (at intervals in eccordance with the plant's technical spocifications (TS)). In addition, besed on information presented in the draft SSAR submittal of April 3, 1992, GE indicated that there are industry published test results showing a reliability number of 0.9967 for the generator breaker.

The draft SSAR rubmittal of April 3, 1992, aleo indicated that during all modes of plant operation (including shutdown, refucling, startup, and run), the normal proferred power aupply will be connected to two of the three affety buen, and the alternate proferred power mupply will be connected to one of the three safety buese. If the normal preferred supply is lost because the generator breaker fails to open, offrite power will still be available immodiately through the alternate preferred power supply to one of the three safety buses. It will also be available on a delayed basis (within minutes by manual action from the coutrol room) to the two other afety buen through the alternets proferred pouver aupply.

ODC 17 of 10 CFR Part 50, Appendix A, requires provisions be included in tho doaign to minimize the probability of losing dectric power from any of the remining eupplies as a recult of, or coincident with, the low of power gesernted by the nuclear power unit, the low of pown from the tranemicuion networt, or the lowe of power from the ondite dectric power aupplies. ODC 18 of 10 CFR Part 50, Appeadix A, requires that the offaite clectric power aystem bo decigoed (1) to permit approperiate periodic inspection and tecting of important arese and fectures (woch es wiring, insulation, connections, and awitchbourdo) to ancese the continuity of the aystems. and the condition of thair components, (2) the capability to teat periodically the operability and functional performance of the components of the syctems, and (3) the capability to tont periodically the operability of the systems as a whole and (undor conditions as clow to deaign as practical) the full operation exquence that bringe the systems into operation.

The ataff concludes that a deaign which moets the sbove dewcribed provisions, will minimizo to the extent feasible the likelihood of simultaneous failure of both normal and alternate offaite proferred power circuits and will be teatable. Consequently, the design meots the above defined requirements of ODC 17 and 18 of 10 CFR Part 50, Appendix A, and is acceptable.

Verification that GE specified in a future SSAR amendment a statoment that the COL applicant must include aurveillance requirements for generator breakers and the above design provisions in appropriate plant procedures was DFSER (SECY-92-349) COL Action Item 8.2.2.5-1. GB included this action item in Sections 8.2.4.1(7) and 8.3.4.9 of SSAR Amendment 32, which is acceptable.

\subsubsection{Capacity and Capability of the Offsite Power System}

Based on discussions with GE and information presented in the April 3, 1992, draft submittal of SSAR Chapter 8.0, in reeponse to DSER (SECY-91-355) Open Item 26, GE indicated that the offsito power system will be designed to provide the following capacity and capabilitios:

- Each circuit of the preferred power supply will be designed to provide sufficient capacity and capability to power equipment required to ensure that

- fuel design limits and design conditions of the reactor coolant pressure boundary will not be 
ancoudad an a revelt of antioipated opantional cocurnuces

- in the eveat of plant deaign-bads cocideate, the cors will bo cooled, and contninment intogrity and other vitul functions will be mintnined

- Whea uead for normal operation, ach profierred power auply will be ated to aupply the maximum axpected coincident Clan 18 and noa-Clan 1B loada.

- The cecondary winding of the rearve auxillary traneformer, which aupplies tho Claen IB load groupa, will have an oll/air nating greater then or equal to the combined load of the three Clan 1B lond groups.

- The normal and alternate offisto proferred pown circuits will bo deaigned with mufficicat capacity and cappability to limit variations of the openting voltage of the onsite power distribution syctem to ange appropriate to enrure

- normal and afe ateady-atate operation of all plant loads

- atarting and eccoleration of the limiting drive syztem with the remainder of the loads in cervice

- reliablo operation of the control and protection aystoms under conditions of degraded voltage

Specifically, when measured at the load terminala, the voltage variation at any voltage lovel will bot exceed the following limits

- plus or minus 10 percent of the lond-rated voltage during all modes of attendy-atato operation

- minu 20 percent of the motor-rated voltage during motor ctarting

- Voltage lovels at the low-voltage torminals of the auxiliary and reserve transformers will be analyzed to determine the maximum and minimum load conditions that are expected throughout the anticipated rnage of voltage variations of the offoito transmiasion aystem and the main generator. Separate analyees will be performed for ach pocaible circuit configuration of the offuite power supply syatom.

- During their operation, normal and alternate proferred power circuits are rubject to environmental conditions (wuch a, wind, ice, now, lightning, tomperature variations, or flood). Thewe circuits will be deaigned in eciordance with industry-recommended practice in onder to minimin the likelibood that thoy will fail whilo openting under the environmental conditions to which thoy aro aubject.

- During their operation, normal and alternate proferrud pown circuits cen bo aubjected to the tranemiecion syctem's atcady-tato and trancicat conditions (wuch as awitching and lightning aurgen, maximum and minimum voltage mages for havy and light load condition, frequency variation, or atability limits). The proferred power circuits will to deaigned aveh that them conditions will not abject the onsite Clane 18 ayteme, equipment, and components to conditions that are beyoad the limits for which they are deaigned and qualifiod. Theos dosign conniderations apply to all conito Clan 1E loads and ayetoms that weo the services of the preforred power aupply during etartup, normal operntion, safo shutdown, accident, and post-accident operntion. The etaff's evaluation of this itom is addreand in Section 8.2.3.8 of this report.

- Performance sad operating characteristics of the normal and alternate preferred power circuits will bo required to moet operability and doaign-bacis requirements. Thew requirements include but are not limited to; the ability to withetand sbort-circuits, equipment capacity, voltage and frequency tranaieat reepones, voltage regulation limits, step load capability, coordination of protective rolaying, and grounding.

- The generator circuit breaker will be deaigned to withatand the maximum root mean equared and creat momentary currents. Further, the breaker will be deaigned to interrupt the maximum anymmotrical and oymmotrical currents dotermined to be produced by a threophase fault at the location that results in the maximum fault currents.

- The main stop-up transformors and the unit auxiliary and recerve transformen will be deaigned and constructed to withatand the mechanical and thermal atreacen produced by external short circuits. In addition, thewe transformers will meet the correaponding requirements of the lateat revisions of ANSI C57.12.00, "General Requirements for LiquidImmenced Distribution, Power, and Regulating Truneformens."

- Circuit breakers and disconnocting awitches will be sizad and designed according to the latest revision of ANSI C37.06, "Preferred Ratings and Rolated Capabilities for ac High-Voltage Circuit Breaken Rated on a Symmetrical Curreat Basis." 


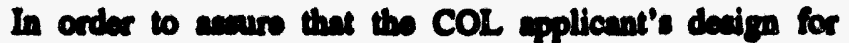

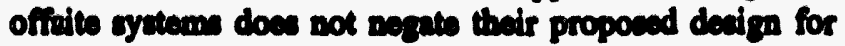
capecity and capability of tho officite ayetem, OE indicated the the COL applicant's doaign will be required (by interfice requirements) to moet the following:

- Voltage variations of the offeite tranemienion network during steady atate operation will not cause voltage variations at the loade of more then plue or minus 10 percent of the loads nominal ratings.

- The normal ctendy state frequency of the offito transmizaion network will be within plus or minue 2 bertz of 60 bertz during recoverable periods of aystem inatability.

- The offsito transmissica circuits from the transmission network through and including the main step-up power and recerve auxiliary transformers will be sized to supply thoir load requirements, during all dosign operating modee, of their respective Clase IB divisions and non-Clase IE lond groups.

- The impedance of the main step-up power and reserve transformers will be compatible with the interrupting capability of the plant's circuit interrupting dovices.

- Instrumentation and control system loads will bo compatible with the capacity and capability design requirements of dc systems within the ABWR standard plant scope.

GDC 17 of 10 CFR Part 50, Appendix A, requires that the offsite eloctric power system have sufficient capacity and capability to permit safety systems to : Iform their required safety function.

The staff concludes that a design which meets the above described commitments and characteristics will have sufficient capacity and capability to ensure that:

- Specified acceptable fuel design limits and design conditions of the reactor coolant pressure boundary will not be excoeded as a result of anticipatod operational occurrences.

- The core will be cooled, and containmeat integrity and other vital functions will be maintained in the event of postulated accidents.

The design, therefore, meets the above defined requirements of GDC 17 of 10 CFR Part 50, Appendix A, and is acceptable.
Verification the OB providad the above soted devign commitmeats and cheneteriatice in a future SSAR anneadment was DFSER (SBCY-92-349) Confirmatory Item 8.2.2.6-1. OB included this information in Section 8.1.2.1, 8.2.1.2, 8.2.2.1(2), and 8.2.2.1(8) of SSAR Amendmeat 32, which is scceptable. Therefore, this itom is resolved. (Note: A portion of this confirmetory itom is discused in Section 8.2.3.8 of this report.)

In reppones to DFSER (SBCY-92-349) COL Action Itom 8.2.2.6-1, OB clarified operational reatrictions a follows for the offite systom:

- Openational rectrictions will require the recerve auxiliary truneformer to aupply ose of three Clese 1E load groups during sormal plant operation.

- Operational reatrictions will secure that the forced oil/air ratings of the recerve auxiliary transformer, or any unit auxiliary tranoformer, will not be exceeded under any operating mode.

- Continued plant operation will bo sppropriately limited when one of the three unit auxiliary transformers is inoperable (that is, when one of the three safety buses will not have acceses to both normal and proforred offaite circuits).

- Continued plant operation will be appropriately limited when the reserve auxiliary transformer is inoperable.

GE included the above listed aspects of this action item in Sections 8.2.4.2, 8.2.4.5, and 8.3.4.9 of SSAR Amendment 32, which is acceptable.

As indicated above in Section 8.2.2.2 of this report, $G B$ further rovised Section 8.2.1.3 of SSAR markup dated March 31, 1993, to remove design reatrictions within its scope of design which did not allow sharing of the nonClass IE de systoms within GE's scope of design between the independent offsite circuits.

If non-Class IE de power systems within GE's scope of design are utilized as the de power source for instrumentation and control in a COL applicant's proposed offaite system design and if these dc power sources are (or are not) shared between the indepeasent offsite circuits, the staff concludes that a design which moets the above design commitments and characteristics as revised will also have sufficient capacity and capability to ensure that:

- Specified accoptable fuel design limits and design conditions of the reactor coolant pressure boundary will not be exceoded as a result of anticipated operational occurrences. 
- The core will bo cooled, and contninment integrity and other vital functions will be maintained in the ovent of poetulated eccidents.

The design, therefore, meets the above defined requirements of GDC 17 of 10 CFR Part 50, Appendix A, and is acceptable.

\section{Cortified Desion Mnterin}

DFSER (SECY-92-349) Open Item 8.2.2.6-1 was related to the design deacription and the ITAAC for the capacity and capability of the offsite power system. The adequacy and acceptability of the ABWR deaign doscriptions and ITAAC are ovaluated in Chapter 14.3 of this report. Therefore, this item is resolved. (Note: This open item is also addreesed in Section 8.2.3.8 of this report).

\subsubsection{Grounding and Lightning Protection}

This section was moved to section 8.2.3.6 of this report.

\subsubsection{Compliance With IEEE 765}

Complisance with the guidelines of IEEE 765-1983 is addreseed in Section 8.3.1.1 of this report.

\subsubsection{Alternate Source of Power for Non-Safety Loads (NRC Policy Isaue SECY-91-078, Section II.B of Enclosure 1 to SECY-93-087)}

In SECY-91-078, the staff recommended that the Commission approve its position that an evolutionary plant design should include an alternate power source to the nonsafety loads unlese it can be demonstrated that the design margins will result in transients for a lose of non-safoty power event that are no more severe than those aseociated with the turbino-trip-oaly event in current existing plant designs. In its August 15, 1991, SRM, the Commission approved the staff' 8 position. The staff in NUREG-1242, "NRC Review of Electric Power Research Institute's Advanced Light Water Reactor Utility Requirements Document," Volume 2 (August 1992), clarified the intent of this position. Further, the staff has evaluated the electrical design for the ABWR relative to the provision of an alternate source of power for non-safety loeds against the following proposed applicable regulation, which is based on the position included in NUREG-1242: "The electric power system of the standard design must include an alternate power source that is provided to a sufficient string of non-safety loads so the forced circulation could be maintained, and the operatur $\&$ available the complement of non-safety equipment that would most facilitate the ability to bring the plant to a stable shutdown condition, following a loes of the normal power supply and plant trip."
GE revised the SSAR to indicate that the ABWR reserve auxiliary tranoformer provides the required alternate power cource. The staff concluded that the ABWR design moets the requirements of this spplicable regulation, and is coceptable. GE included this information in Section 8.3.1.2(4)(b) of SSAR Amendment 32.

\subsubsection{Independence Between Ofisite and Onsite Power Systems, Equipment, and Components}

The preferred power supply furnishes electric power from the offsite system's transmission network (a common source of electric power) to redundant, onsite Class 1E systems, equipment, components, and loeds. This common source of electric power may be used during all modes of plant operation to supply power to redundant Clase 1E load groups. Because redundant load groups are powered from a common power source, they can be subjected to conditions which may

cause their common failure due to single events or failures of this single source of electric power. This section of the staff's evaluation addresses ABWR design provisions for minimizing the probability of: (1) common mode failure of redundant onsite Class 1E systems due to single events or failures of this common source of electric power; and, (2) failure of the onsite system from causing loss of the offsite system in accordance with the requirements of GDC 17 of 10 CFR Part 50, Appendix A. The staff's DSER (SECY-91-355) addressed this part of the design in Open Item 28.

The following sections discuss the areas addressed in the staff's evaluation of ABWR design provisions intended to ensure an adequate level of independence between offsite and onsite systems.

\subsubsection{Independence Between Orisite Circuits and Onsite Class 1E dc Systems}

DC control, protection, and instrumentation power for offsite circuits, (originally proposed for the ABWR design), were derived from the Class $1 E$ dc system through dc to dc converters that GE considered isolation devices. By the draft SSAR revision of April 3, 1992, GE eliminated all electrical interconnections between the offsite control, protection, and instrumentation circuits and the onsite Class 1E dc systems, equipment, and components.

GE indicated that the offsite system circuits will derive their control, protection, and instrumentation power from a non-Class 1E dc system that is independent of the onsite Class 1E dc system. GDC 17 of 10 CFR Part 50, Appendix A, requires provisions be included in the design to minimize the probability of losing electric power from any of the remaining supplies as a result of, or coincident 
with, the loes of power generated by the nuclear powver unit, the loses of power from the trunsmiscion network, or the loes power from the onsite electric power aupplies. The etaff concludes that a docign which meets the above described deaign commitment (1) will provido reaconable securance that failure in the offisite system will noither challenge nor possibly cause the lows of onsite Cles IB de syctems, (2) will provide reacomable securance that eny single failure of a Clase 1E de system or its component part will not calles loes of offite power, and (3) will provide reasonable sesurance that common-cause fillure will not occur between offsite and onsite power cources that are affiliated with a single load group. Therefore, the design meets the above defined requirements of GDC 17 of 10 CFR Part 50, Appendix A, and is acceptable.

Verification that GE provided the above deaign commitments in a future SSAR amendment was DFSER (SECY-92-349) Confirmatory Item 8.2.3.1-1. GE ha included these commitments in Section 8.2.1.2 of SSAR Amendment 32, which is scceptable. Therefore, this item is resolved.

\section{Certified Desion Material}

DFSER (SECY-92-349) Open Item 8.2.3.1-1 was related to the design description and the ITAAC for the electrical independence between offsite circuits and onsite Clase IE DC system. The adequacy and scceptability of the ABWR design descriptions and ITAAC are ovaluated in Chapter 14.3 of this report. Therefore, this item is resolved.

\subsubsection{Independence During Loss of or Degraded Offsite Voltage}

The ABWR design incorporates two distinct levels of protection to ensure the independence of offsite and onsito systems during loss of offsite voltage or degraded offsite voltage conditions:

\section{Loss of Offsite Voltage (First Lovel of Protection)}

In the draft SSAR revision of April 3, 1992, Section 8.3.1.1.7(1), GE indicated that the onsite Class 1E systems will be normally energized from the offsite normal and alternate preferred power system. Should the voltage on the Clase IE bus decay to less than 70 percent of its nominal rated value for a predetermined time, a bus transfer will be initiated. As a result of this trassfer, the onsite Class 1E buses will be transferred so that they are powered by the onsite standby diesel generators (rather than the offsite normal and alternate preferred power systems). Upon initiation of a bus tranefer, a rignal will be geserated to open the officite rupply breaker to the Clave IE bus.

In the draft SSAR revision of April 3, 1992, the firnt paragraph of Section 8.3.1.1.7 indicated that the time dolay for bus tranofor initiation will change (be reduced) from 3 to 0.4 econds if a loss-ofcoolent sccident (LOCA) signal is present when a low of proferred power (LOPP) occurs. (The 3 and 0.4 recond time delay retpoints for initiation of bus transfor are considered to be approximations of the sctual setpoint that will be in effect during plant operation. Tho actual setpoints will be established as part of an overall system voltage and load analyais.) Discuseions with GE confirmed that the proposed ABWR decign will include a time delay rolay to cetablish the prodetermined timo before bus transfor initiation. When only a LOPP signal is prewent, the timo delay relay will be set for 3 coconds. When both LOPP and LOCA signals are prewent, the time dolay relay will be sot for 0.4 ecoonde. The purpose of the time delay is to reduce unnecescary trunsfer from offsite to onsite sources during offsite power system transients. If voltage on the offsite system drops below 70 percent for less than 3 seconds (or 0.4 seconds when both LOCA and a LOPP signals are present), both the LOPP and timo delay relay will reset after voltage recovery and transfer will not be initiated.

\section{Degraded Offsite Voltage (Second Lovel of Protection)}

In draft SSAR revision of April 3, 1992, Section 8.3.1.1.7(8), GE indicated that when the bus voltage degrades to 90 percent or less of its rated value and remains degraded throughout a time delay, an undervoltage condition will be annunciated in the control room. Simultaneously, a 5-minute timer will be started, allowing the operator to take neceseary corrective action. (The 5 minute time delay setpoints for initiation of bus transfer are considered to be approximations of the ectual setpoint that will be in offect during plant operation. The sctual setpoints will be established as part of an overall system voltage and load analysis.) After 5 minutes, the feeder breaker affectod by the degraded voltage will be tripped. Should a LOCA occur during the 5 minute time delay, the affected foeder breaker will be tripped immediately.

In draft SSAR submittal of April 3, 1992, Section 8.3.1.2.1(3)(d), GE indicated that the design for degraded offsite voltage will meet the 
guidalines of Branch Technical Poaition, Power Syctem Branch 1.

OB indicated that the ABWR dectric aystem doaign will comply with the guidalines of IEEB 308-1980 and IEEE 603-1980, a epecified by Section 8.3.1.2.1(2)(c) of tho April 3, 1992, drat SSAR revision and Section 1.8.2 (Tables 1.8-20 and 1.8-21) of SSAR Amendment 17. Becalue both lovels of protection ene required to support safety-rolated syctem, the staff concluded that OE's commitment to IREE standards indicates that the olectric system design will meet the requirements of Section 5.2 of IEEE 308-1980. Section 5.2 of IEEE 308-1980 requires that composents, equipment, or systems required to provide exme protective sction, whe a containment integrity protoction, or utilized to provide icolation protection are covered by all afoty system requirements which are defined in IEEE 603-1980. The system described above protect afety-related electrical systems from degraded or lows of voltuge conditions. Thus, they provide como protective action and are covered by all safety syetem requirements defined in IEEE 603-1980. The etaff, therefore, concluded that GE's commitment to IREE ctandards indicutes that syetems, equipmeat, and components included in the design for both the first and second lovels of voltage protoction will moot all requirements of IEEE 603-1980.

GE's expreseed commitment to IEEE Standards also applies to safety-related equipment (including the reactor trip system, engineered safety feafures, auxiliary supporting features, and other auxiliary features equipment) that requires ac power from the offsite system to perform afety functions. Specifically, GE indicated that such safety-related equipment will bo decigned and qualified (by type test, provious operating experience, analysis, or any combination of these three methods) to be capable of performing their required safety functions before, during, and after the following design besis opernting conditions:

- voltage at the load at either +10 percent or -10 percent of the nominal voltage rating

- for 5 minutes with voltages at the load at 70 percent of the nominal voltage rating

- for 3 seconds with voltages at the load below 70 percent (0.8., for 3 seconds at 35 percent) of the nominal voltage rating

GDC 17 of 10 CFR Part 50, Appendix A, requires provisions be included in the design to minimize the probability of lowing dectric powver from any of the remining aupplies as a reoult of, or coincident with, the low of power generated by the nuclear power unit, the loes of power from the trunemiseion network, or the lows of power from the onsite electric power supplies. The ataff concluden that a denign which meots the above commitments will provide reaconable asourance that the common failure of both offaite and onsite systems will not occur as a recult of lows of or degraded voltage conditions. The design, therefore, meets the above defined requirements of GDC 17 of 10 CFR Part 50, Appendix A and is scceptable.

Verification that GE provided the above deaign commitments in a future SSAR amendment was DFSER (SECY-92-349) Confirmatory Item 8.2.3.2-1. GE included this information in Section 8.3.1.1.7 of SSAR Amendmeat 32, which is ecceptable. Therefore, this item is resolved.

GE also indicated that both first- and second-level voltage protection will be tested periodically. Verification that $G E$ included a COL action item to include these periodic tests in appropriate plant procedures was DFSER (SECY-92-349) COL Action Item 8.2.3.2-1. GE included this action item in Section 8.3.4.20 of SSAR Amendment 32, which is acceptable.

During the process of verifying inclusion in the SSAR of the above design information and periodic tests, the staff noted and expressed the concern that the diesel generator may be overloaded if there is a LOCA with a delayed LOPP. Section 8.3.1.1.7(3) of SSAR Amendment 21, LOPP following LOCA, indicates that all loads that have been connected to the Class IE bus and are operating from the offsite power supply in response to the LOCA will be connected in one block to the standby diesel generator (operating at no load due to the LOCA) if there is a LOPP. The diesel generator may not have sufficient capacity to supply, in one block, the loads which may be operating on the Class 1E bus at the time of the LOPP. Because this item involved the capacity of the diesel generator, it has been moved to Section 8.3.8.4 of this report which addresses the capacity of the diesel generator.

\section{Certified Desion Material}

DFSER (SECY-92-349) Open Item 8.2.3.2-1 related to the design description and the ITAAC for the electrical independence during loss of, or degraded, offsite voltage. The adequacy and acceptability of the ABWR design descriptions and ITAAC are evaluated in Chapter 14.3 of this report. Therefore, this item is resolved. 


\subsubsection{Independesce During Parallel Operation of the Orfaite and Ondte Syatems During Pariodic Land Tests of the Diesd Generator}

\section{(1) LOCA During Parallel Operation}

Soction 8.3.1.1.7(5) of SSAR Ameadment 4 states that if - LOCA occurs when the diesel generntor is being operated in parallel with the preferred power cource during teating, and the test is being conducted from the local control panel, control muat be returned to the main control room or the teat operator must trip the dical generntor breaker. GE aubequently revised Section 8.3.1.1.7(4) of SSAR Amendment 4 in Section 8.3.1.1.7(5) of the draft SSAR revision dated April 3, 1992 (100 the reeponve to Queation 435.19). Through that revision, GB changed the dexign commitment to indicato that if a LOCA occurs when the diesel generator is being opernted in parallel with the offaite systom, the diesel generntor will automatically be disconnected from the $6.9 \mathrm{kV}$ emergency bus, regardless of whther the teet is being coinducted from the local control panel or the main control room.

In addition, Section 8.3.1.1.8.8 of the draft SSAR revision dated April 3, 1992, indicated that the ABWR decign will include interlocks to the LOCA and LOPP cenaing circuits, in order to terminato parallel operation and cause the dienel generator to automatically revert to its standby mode if oither a LOCA or a LOPP signal appears during a teat. GE further indicated that the interlock design will have the capability to be tested periodically.

The ABWR design will include provisions for automatic switchover from system test mode to operating mode in case of either an accident signal or a lose of proferred offeite power signal, regardleas of whether the teat is being conductod from the local control panel or the main control room. GDC 17 of 10 CFR Part 50, Appendix A, requires provisions be included in the design to minimize the probability of losing electric power from any of the remaining supplies as a result of, or coincident with, the loses of power generated by the nuclear power unit, the loes of power from the transmission network, or the loss of power from the onsite electric power supplies. The staff concludes that a design which meets the above described commitments will provide reasonable essurance that lose of electric power from the offsite and onsite systoms will not occur due to loss of power from the nuclear power unit due to a LOCA. The design, therefore, meets the above defined requirements of GDC 17 of 10 CFR Part 50, Appendix A, and is acceptable.

Verification that GE provided the above design commitments in a future SSAR amendment was DFSER (SECY-92-349) Confirmatory Item 8.2.3.3-1. GE has included thewe commitments in Soctions 8.3.1.1.7(5), 8.3.1.1.7(6), and 8.3.1.1.8.8 of SSAR Amendment 32, which is scceptable. Therofore, this item is resolved.

OB also indicated that tho interlock dexign (which terminates parallel operation and causes tho diend generator to automatically revert to its standby modo) will periodically be tested. Verification that GE would include - COL setion item to include this periodic teat in appropriate plant procedures was DFSER (SECY -92-349) COL Action Item 8.2.3.3-1. GE included this sction item in Section 8.3.4.21 of SSAR Amendment 32, which is ecceptable.

\section{Centified Denion Mnteril}

DFSER (SECY -92-349) Open Item 8.2.3.3-1 was related to the decigan description and the ITAAC for LOCA during parallel operation. The adequacy and acceptability of the ABWR design descriptions and ITAAC aro ovaluated in Chapter 14.3 of this report. Therefore, this item is resolved.

\section{(2) LOPP During Parallel Operation}

In Section 8.3.1.1.7(6) of the draft SSAR revision dated April 3, 1992, GE indicated that the diesel generator circuit breaker will automatically trip on overcurrent if the offisite power supply is lost during the diesel generator paralleling test. In addition, Section 8.3.1.1.8.8 of that revision indicated that interlocks to the LOPP sensing circuits will terminate a parallel operation test, causing the diesel generator to automatically revert to its standby modo if a LOPP signal appears during a test.

When a standby power supply is being operated in parallel with the preferred power supply, Section 5.1.4.3 of IEEE 741-1986 requires that protoction be provided to coparate the two supplies if either degrades to an unecceptable lovel. However, this protection shall neither lock out nor prevent the availability of the power supply that is not degraded. In addition, Section 6.2.4.6.3 of IEEE 308-1992 requires provisions to detect a LOPP during testing, when the standby generator is connected to the offisite power source.

The ataff concluded that a design complying with these industry-rocommended IEEE practices will minimize the probability of losing electric power from any of the remaining supplies as a result of, or coincident with, the loss of power from the transmission network. This design meets the above defined requirements of GDC 17 of 10 CFR Part 50, Appendix A, and is acceptable. 
Based on OB's dexige commitmeat that interlocks to the LOPP cenciag circuitu will be included in the ABWR dosign to terminate a parillel operation teat and cunse the diesal generntor to automntically revert to its anndby modo if LOPP aignal appears during a toot, the etaff concluded that the ABWR design meets the above deceribed industryrecommended interlock prectice.

The stuff concludes that a danign that moets the above described deaign commitments will provide reaconable sesurnace that electric power from the onvite diesel generator supplies will not be loct dus to lows of the officite transmission notwork. The deaign, therofore, moet the above dofined requirements of GDC 17 of 10 CFR Part 50, Appendix A, and is scceptable.

Verification that $\mathrm{GE}$ provided the above deaign commitments in a future SSAR ameadment was DFSER (SECY-92-349) Confirmatory Item 8.2.3.3-2. GE has included these commitments in Section 8.3.1.1.7(6) of SSAR Amendment 32, which is scceptable. Therefore, this item is resolved.

\section{Centified Desion Mnterial}

DFSER (SECY-92-349) Open Item 8.2.3.3-2 was related to the design description and the ITAAC for LOPP during parallel operation. The adequacy and scceptability of the ABWR design descriptions and ITAAC are evaluated in Chapter 14.3 of this report. Therefore, this item is resolved.

\section{(3) Duration of Parallel Operation}

Table 1.8-21 of SSAR Amendment 17 and Section 1.8.2 of SSAR Amendment 12 indicated that the ABWR design complies with IEEE 308-1980. Based on this statement of compliance, GE indicated that the ABWR design will satisfy Section 6.1.3 of IEEE 308-1980, which requires that the design minimize the duration of the connection between the preferred and standby power supplies. In addition, Section 8.3.1.1.8.1 of the draft SSAR revision dated April 3, 1992, indicated that the ABWR design requires that each diesel generator set be operated independently of the other sets and be connected to the utility power system only by manual control during testing or for bus transfer.

The staff concludes that a design which meets these commitments will minimize the probability of losing electric power from any of the remaining supplies as a result of, or coincident with, the loss of power generated by the nuclear power unit, the loss of power from the transmission network, or the loss of power from the onsite electric power supplies. Consequently, this design meets the above dofined requirements of ODC 17 of 10 CFR Part 50, Appendix A, and is roceptablo.

Verification that GE included in a future SSAR ameadment an action itom that the COL applicant include the above commitments in appropriate plant procedures was DFSER (SBCY-92-349) COL Action Itom 8.2.3.3-2. GB included this setion item in Section 8.3.4.21 of SSAR Ameadment 32, which is scceptable.

(4) Diecel Generntor Protective Relaying with the Diesel Generator Operating in Parallel with the Offrite System

Section 8.3.1.1.6.4 of the draft SSAR revision dated April 3, 1992, indicated that protective relaying of the diesel generator (generator differential, engine overspeed; low jacket water pressure, loss of excitation, anti-motoring (reverse power) overcurrent voltage restraint, high jacket water temperature, and low lube oil pressure) will be usod to protect the machine when it is operated in parallel with the normal power system during periodic tests. In eddition, Section 8.3.1.1.6.2 of the draft SSAR revision dated April 3, 1992, indicated that each diesel generator will be high-resistance grounded to maximize availability.

Section 8.3.1.2.1(2)(c) of the draft SSAR revision dated April 3, 1992, and Section 1.8.2 (Tables 1.8-20 and 1.8-21) of SSAR Amendment 17 indicated that the ABWR electric system design will comply with the requirements of IEEE 308-1980 and IEEE 603-1980. Through this commitment to these IEEE standards, GE indicated that the electric system design will satisfy the requirements of Section 5.2 of IEEE 308-1980, and that systems, equipment, and components included in the design for protective relaying will satisfy all requirements of IEEE 603-1980. Because protective relaying is required to minimize the likelihood of simultaneous loss of both offsite and onsite sources during testing, these components are required to satisfy all requirements of IEEE 603-1980 during parallel operation of offsite and onsite power supplies.

The staff concludes that a design which moets the above described commitments will provide additional assurance that there will not be a common failure between onsite and offsite power supplies during testing. The design, therofore, meets the above defined requirements of GDC 17 of 10 CFR Part 50, Appendix A, and is acceptable.

Verification that GE provided the above design commitments in a future SSAR amendment was DFSER (SECY-92-349) Confirmatory Item 8.2.3.3-3. GE included this information in Sections 8.3.1.1.6.2 and 
8.3.1.1.6.4 of SSAR Amondmeat 32, which is scoeptuble. Therefore, this itom is resolved.

OB also indicated that protective rolaying of the dienel reserator will bi tected periodically. Verification that $\mathrm{OB}$ included in a future SSAR amsadment a ctatement that the COL applicant will include these periodic teets in approprito plant procodures wes DFSBR (SBCY-92-349) COL Action Item 8.2.3.3-3. OB included thin setion itom in Section 8.3.4.22 of SSAR Amendmeat 32, which is eccoptablo.

\section{Cextified Desim Mntericl}

DFSER (SECY-92-349) Opeen Itom 8.2.3.3-3 was related to the dexign dencription and the ITAAC for the dieal generntor protective relaying when the dienel generntor is operating in parallel with the offaite system. The adequacy and acceptability of the ABWR deaign deacriptions and ITAAC aro ovaluated in Chapter 14.3 of this report. Therefore, this item is recolved.

\section{(5)}

\section{Synchronizing Interlocks}

Baced on discuscions, GE indicated that the ABWR decign will meet the guidelines of Section 5.1.4.2 of IEBE 741-1986 which requires sypchronizing interlocks to provent incorrect synchronizntion whenover a standby power source is required to operate in parallel with the preferred power supply. GE also indicated that the synchronizing interlocks will have the capability to be tested periodically.

The staff concludes that a design complying with the above described commitments will reduce the likelihood of simulteneous lose of both offeite and oncite power aupplies as a reault of synchronization. The deaign, therefore, meets the above defined requirements of ODC 17 of 10 CFR Part 50, Appendix A, and is accoptable.

Verification that $G E$ provided the above deaign commitments in a future SSAR ameadment was DFSER (SECY-92-349) Confirmatory Itom 8.2.3.3-3. GE included this information in Section 8.3.1.1.6.4 of SSAR Amendment 32, which is receptable. Therefore, this item is resolved.

GE also indicated that aynchronizing intertocks will bo teated periodically. Verification that GE included in a future SSAR amendment a statement that the COL applicant will include these periodic teats in appropriate plant procedures was DFSER (SECY-92-349) COL Action Item 8.2.3.3-4. GE included this setion itom in Section 8.3.4.23 of SSAR Amendment 32, which is accoptable.

\section{Crtified Darim Mnterin}

DFSER (SECY -92-349) Open Itom 8.2.3.3-4 was rolated to the deaign dencription and the ITAAC for the synchronizing interlocks. The adequacy and ecceptability of the ABWR deaign deccriptions and ITAAC are ovaluated in Chapter 14.3 of this report. Therefore, this item is resolved.

\subsubsection{Independence of Safety Syetems During Operation or Pallure of Non-Clans IE Loads (NRC Polley Irove SECY-91-078, Section II.B of Encloaure 1 to SECY-93-087)}

The ABWR deaign must minimize the offects that operation or failure of non-Class 1E loads may have on Class 1E systems. To schieve this design objective, the ataff took the potition that the Class IE system should be connected directly to a winding of the offisito power syctem's transformen that is exparate from the winding that foeds the non-Clase 1E loads. In other words, Clan IE and non-Clase IE ionds should not be powered from the ano traneformer winding.

In SECY-91-078, the raff recommended that the Commistion approve this position for evolutionary plant deaigns. The ovolutionary plant deaign should include at least one offaite circuit to each redundant safety division cupplied directly from one of the offisite power sources with no intervening non-aafety buses in such a manner that the offaite source cen power the safety buses upon a failure of any non-anfoty bus. In its August 15, 1991, SRM, the Commicaion approved the staff's position.

Therefore, the atafi's proposed applicable regulation for offisito power cources is as follows:

The electric power system of standard plant design must include at least one offsite circuit to each redundant anfety division aupplied directly from one of the offeite power sources with no intervening nonsafoty bues in such a manner that the offsite source can power the safety buses upon a failure of any nonanfoty bus.

The initial design proposed by GE for the ABWR offsite preferred power system satisfied this staff position. However, by the draft SSAR revision dated April 3, 1992, GE changed the design to use a singlo transformer winding to supply power to both Class IE and non-Class IE loads. As a rexult, the staff became concerned that operation or failure of non-Class IE loads could adversely affect operation and thus the independence of Class IE systems. 
Baned on diccusaions, $O B$ indicated that any single failure of a non-Clan 1E load or load group will affect only one of the three Cles 1B redundent load groups. The ABWR dexign will consiat of three, non-Clem IB loed groupe, a well as three Clane 1B divisional load groups and three truneformers. Each of the three son-Claes IB loed groups will be affiliated with only one of the three Clace IB divisional load group by being powered from the sure offisite power system transformer winding. Thus, failure of any one of three transformere due to failure of nonClase IE loads or load groupe can affect only one of the three Class IE divisional load groups. In addition, the alternate offisite proferred circuit design (which does not include provicion for powering of non-Clase $1 E$ loads from the same transformer winding a Clase IB loads) and operating procedures (which require that one of the three divisional buses bo fed by the alternate offaite power source during normal operation) will also provide assurance that the three Class IE divisional loed groups will not be subjected to common abnormal conditions due to failure of non-Class IE loads or lond groups.

In eddition, GE indicated during discuseions with the staff that the ABWR design will include provisions to limit the harmonic offect on the Clase 1E divisional loed group power supply to lese then 5 percent for operation or failure of reactor intermal pumpe (RIPs) or other non-Clase 1E loads.

ODC 17 of 10 CFR Part 50, Appendix A, requires provisions be included in the deaign to minimizo the probability of losing electric power from any of the remaining supplies as a result of, or coincident with, the loss of power generated by the nuclear power unit, the lose of power from the transmission network, or the loss of power from the onsite electric power supplies. The ctaff concludes that a design which meets the above deacribed commitments will minimize the offects of non-Class $1 E$ system operation/failure causing loes of electric power to safety systems or failure of Clase IE safety systems and loeds. The design, therefore, moets the above defined requirements of GDC 17 of 10 CFR Part 50, Appendix A, and the staff's proposed applicable regulation for offeito power sources is acceptable.

Verification that $G E$ provided the above deaign commitments in a future SSAR amendment was DFSER (SECY-92-349) Confirmatory Item 8.2.3.4-1. GE included this information on Figure 8.3-1 and in Sections 8.3.1.0.1 and 8.3.4.9 of SSAR Amendment 32, which is acceptable. Therefore, this item is resolved.

\section{Centified Darion Mnterial}

DFSER (SECY-92-349) Opea Item 8.2.3.4-1 was rolated to the deaign dencription and the ITAAC for the independence of Clan 1B aystem from the influences of non-Clam IB loada. The edequacy and scceptability of the ABWR deaign deccriptions and ITAAC are evalunted in Chapter 14.3 of this report. Therefore, this item is recolved.

\subsubsection{Physical Separation Between Oraite and Ondite Class 1E Circuits}

Banod on discuseions with $O E$ and information presented in Section 8.2.1.3 of the April 3, 1992, draft rovition to the SSAR, the ABWR deaign is anch that the offivite circuits will be physically separated from any Clase IE syetems, equipmeat, components, cables, or loeds by floor or walls up to the point where the offsite circuits enter the reactor building. From the point where the alternate preferred circuit enters the Division II side of the reactor building to tho Cless IE awitchgear rooms, and from the point where the normal preferred circuit enters the Divisions I and III side of the reactor building to the Clase IE switchgear rooms, OE has indicated (by their commitmeat to IEEE 384), that the offrite circuits would be phycically separated from circuits of the Clase IE syatem by a minimum physical separation distance of

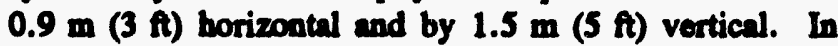
addition, GE indicated that safoty systems (for examplo, rotating equipment with potential for boing a miscilo hesard) whose failure could potsatially affect the operation of an offrite circuit will not be located in the eame rooms with the normal or altermato offeito circuits, or barriers will bo installed to preclude possible interaction between offsite and onsito systoms.

GDC 17 of 10 CFR Part 50, Appendix A, requires provisions be included in the design to minimize the probability of losing electric power from any of the remaining supplies as a recult of, or coincident with, the loss of power genernted by the nuclear power unit, the lose of power from the transmiscion network, or the loss of power from the onsite electric power supplies. The staff concludes that a design which meet the above deacribed commitmente will provide reasonable assurance that failure of offeite circuits will not cause loes of onsite circuits and failure of onsite safety-related equipment will not cause loss of offaite circuits. The design, therefore, meets the above defined requirements of GDC 17 of 10 CFR Part 50, Appendix A, and the staff's proposed applicable regulation for offrite power sources, and is acceptable. 
Verification that GE provided the above decign commitments in a future SSAR smendment was DFSER (SBCY-92-349) Confirmatory Item 8.2.3.4-2. OB has included thees commitments in Sections 8.2.1.3 and 8.3.3.1 of SSAR Amendmeat 32, which is scceptable. Therefore, this item is resolved.

In eddition, Figure 8.3.1 of the draft SSAR revicion dated April 3, 1992, indicated that the offitito power connection from the recerve auxiliary tonnsformer is normally supplied through the Division II Clave IB equipment areas to the Division III load group. Similarly, OB indicated that the offeite connection from the unit auxilinry transformers is normally supplied through the Divisions I and III Clase IE equipmeat areas to the Divisions I and II load groups. To further minimize the likelihood of interaction between the offisite and onsito system during operation, the ataff contended that the normal configuration for the connection of the offsite circuit to the onsite Class IE distribution syetem should be configured with the reserve auxiliary transformer normally connected to the Division II load group and the unit auxiliary transformers normally connected to the Divisions I and III load groups. This was DFSER (SECY-92-349) Open Itom 8.2.3.4-2.

This is an operation rather than design issue. Therefore, in response to this item, GE specified that the COL applicant would establish the preferred configuration of offsite circuits for normal operation based on the reliability/stability of offsite circuits, the Class IE bus loads, and the separation of the offsite foeds as they pass through the divisional areas. Based on this requirement, the staff concludes that the operational configuration of offsite circuits will minimize the probability of losing electric power from any of the remaining supplies as a result of, or coincident with, the loss of power generated by the nuclear power unit, the loss of power from the transmission network, or the loss of power from the onsite electric power aupplies. GE has included this COL action item in Section 8.3.4.9 of SSAR Amendment 32, which is scceptable. Therefore, DFSER Open Item 8.2.3.4-2 is resolved.

\section{Certified Desion Material}

DFSER (SECY-92-349) Open Item 8.2.3.5-2 was related to the design description and the ITAAC for the physical separation between offsite and onsite class IE circuits. The adequacy and acceptability of the ABWR design descriptions and ITAAC are ovaluated in Chapter 14.3 of this report. Therefore, this item is resolved.

\subsubsection{Grounding and Lightning Protection}

This section addreaces the staff's evaluation of OB's repones to DFSER (SECY-92-349) Confirmatory Itom 8.2.2.7-1 and Open Itom 8.2.2.7-1.

The ACRS, in an April 13, 1992, letter to the etaff dicenesed a concern that SSAR Chapter 8 did not discun eny requirements or deaign considerations for etation grounding. In response $O E$ has committed to moet the following Blectric Power Rewearch Inetituto (BPRD) plant grounding guidelines:

- A station grounding grid, consiating of bare copper cables, will be provided that will limit atep-and-touch potentials to safo values under all fault conditions.

- Baro copper risen will be furnished for all underground olectrical ducts and equipment, and for connections to the grounding systems within buildings.

- The deaign and analysis of the grounding system will follow the procedures and recommendations specified by the latest revision of IEEE 665, "Guido for Generation Station Grounding."

- Eech building will be equipped with grounding systems connected to the station grounding grid. As a minimum, overy other steel column of each building perimeter will connect directly to the grounding grid.

- The plant's main generator will be grounded with a noutral grounding dovice. The impedance of that device will limit the maximum phase current under short-circuit conditions to a value not greater than that for a threo-phase fault at its terminals.

- Provisions will be included to ensure proper grounding of the isophase buses when the generator is disconnected.

- The onsite, modium-voltage ac-distribution systom will be resistance grounded at the neutral point of the lowvoltage windings of the unit auxiliary and reserve transformers.

- Grounding of the neutral point of the generator windings of the onsite standby power supply units (Class 1E diesel generators and non-Class 1E combustion turbine generator (CTG)) will be through distribution-type transformers and loading resistors, sized for continuous operation in the event of a ground fault. 
- Tho neutral point of the low-voltage sc-diatribution ayctem will be either colidly or impedance grounded, as necescary, to casure proper coordination of ground fault protection.

- The de systams will be left ungrounded.

- Eech major piece of equipment, metal atructure, or motallic tank will be equipped with two ground connections diagoenally opposito each other.

- The ground bus of all awitchgear anemblies, MCCs, and control cabinets will be connected to the station ground grid through at least two parallel paths.

- One bare copper cable will bo installed with cach underground electrical duct run, and all motallic hardware in each manhole will be connected to this cable.

- Plant instrumentation will be grounded through soparate radial grounding yytems consiating of isolated instrumentation ground buses and insulated cables. The instrumentation grounding systems will be connected to the station grounding grid at only one point and will be insulated from all other grounding circuits.

- Separate instrumentution grounding systems shall be provided for plant analog and digital instrumentation systems.

- A lightning protection system will be provided for ach major plant atructure, including the contrinment enclocure building. The design and installation of these systems will comply with the National Firo Protection Association's Lightning Protection Codo, NFPA-78, and the Nuclear Energy Property Insurance Association's "Besic Fire Protection for Nuclear Power Plents" document.

- Lightning arresters will be provided in each phase of all tie lines connecting the plant electrical systems to the switching station(s) and offsite transmission system. These arresters will be connected to the high-voltage terminals of the main step-up and recerve transformers.

- Plant instrumentation and monitoring equipment located outdoors or connected to cabling that runs outdoors will be equipped with built-in surge suppression devices to protect the oquipment from lightning-induced surges.

GDC 17 of 10 CFR Part 50, Appendix A, requires provisions be included in the desitgn to minimize the probability of losing electric power from any of the remaining supplies as a result of, or coincident with, the low of power generated by the nuclear power unit, the low of power from the transmiscion network, or the low of power from the onsite electric power aupplies. The etaff concludes that a deaign for plant atructures, syetems, and equipment which moets the above deacribed commitments will be appropriataly grounded and protocted from lightning. The dexign, therefore, meets the above defined requirements of ODC 17 and is scceptable.

Verification that $\mathrm{OB}$ included the above dewign commitments in a future SSAR amendment was DFSER (SBCY-92-349) Confirmatory Itom 8.2.2.7-1. GE has included these commitments in Section 8.3.1.1.6.2 and Appendix 8A.1 of SSAR Amendment 32, which is acceptable. Therefore, this item is resolved.

\section{Certified Desion Material}

DFSER (SECY-92-349) Open Item 8.2.3.6-2 rolated to the dexign deacription and the ITAAC for the grounding and lightning protection. The adequacy and acceptability of the ABWR design deacriptions and ITAAC aro evaluated in Chapter 14.3 of this report. Therefore, this item is resolved.

\subsubsection{Operating Restrictions on the Offsite Preferred Power Circuits}

Section 8.3.1.1.1 of the draft SSAR revision dated April 3, 1992, in reeponse to DSER (SECY-91-355) Open Item 28, indicated that during normal operation (which includes: shutdown, refueling, startup, and run modes of plant operation), the normal preferred power supply feeds two of the three Class 1E lond groups. The remaining load group is fod from the alternate power source. SSAR Section 8.3.4.9 specifies that COL applicants that imploment the ABWR design must include in their operating procedures that one of the three divisional buses must be fed by the alternate power source during normal operation. The intent of this provision is to arrange the offsite power supply circuits to the Class IE buses so that all three Class 1E divisional buses are not simultaneously doenergized on the loss of only one of the offsite power supplies.

GDC 17 of 10 CFR Part 50, Appendix A, requires provisions be included in the design to minimize the probability of losing electric power from any of the remaining supplies as a result of, or coincident with, the lose of power generated by the nuclear power unit, the loss of power from the transmission network, or the loss of power from the onsite electric power supplies. The staff concludes that a design which includes this operating procedure will minimize the probability of losing all Class IE buses as a result of, or coincident with, the loss 
of power generated by the nuclear power unit or the low of power from the trenemisuion network. The deaign, therofore, mects the above defined requirements of ODC 17 of 10 CFR Part 50, Appendix A, and is eccoptablo.

Verification that OB included in a future SSAR ameadmeat the statement that the COL applicant include the above operating procedure we DFSBR (SBCY-92-349) COL Action Itom 8.2.4-1. OE included this setion item in Sections 8.2.4.2 and 8.3.4.9 of SSAR Amendmeat 32, which is scooptable.

\subsubsection{Protection of Onsite Syatems}

The normal and alternate preferned offaito power circuits can be subjected to transmiscion syetom's steady-etato and transient conditions (such ss switching and lightning surges, maximum and minimum voltage ranges for heavy and light load conditions, frequency variation, or stability limits). GE indicated that provisions will be included in the design of the offrite and consite syetoms to minimize the probability of loaing electric power from any of the remaining sources a recult of these conditions in eccordance with the requirements of GDC 17 of 10 CFR Part 50, Appendix A. In reeponse to DSER (SECY-91-355) Open Item 26, OE revised the SSAR to indicate that these provisions include:

- Switching and lightning surge protection is provided by the station grounding and surge protoction systems described in Appendix 8A of the SSAR, by independent feeds (i.e., normal and alternate preferrod power circuits described in SSAR Section 8.2.1.2), and by grounding and lighting protection spocified in SSAR Section 8.2.3.

- Maximum and minimum voltage ranges are specified in SSAR Section 8.2.3 and transformers are designed per SSAR Sections 8.2.1.2 and 8.2.3. Allowable frequency variation or stability limitations are addressed in SSAR Section 8.2.3.

- Protection for degraded voltage conditions is discussed in SSAR Section 8.3.1.1.7(8).

GDC 17 of 10 CFR Part 50, Appendix A, requires provisions be included in the design to minimize the probability of losing electric power from any of the remaining supplies as a result of, or coincident with, the loss of power generated by the nuclear power unit, the loss of power from the transmission network, or the loss of power from the onsite electric power supplies. The staff concludes that a design which meets these design provisions will minimize the probability of losing electric power from any of the remaining courcen as andt of trenemincion syctom's steady-atato and trensient conditions. The deaign, therofore, meets the sbove dofined requirements of ODC 17 of 10 CFR Part 50, Appendix A, and is scoeptable.

Verification that thea deaign provisions were included in - future SSAR Amendment was part of DFSER (SECY-92-349) Confirmatory Itom 8.2.2.6-1. OB included them proviaions in Section 8.2.2.1(2) of SSAR Ameadment 32, which is accoptable. Therefore, this item is resolved.

\section{Centified Deaim Mntericl}

This part of DFSER (SBCY-92-349) Open Item 8.2.2.6-1 related to the deaign description and the ITAAC for the protection of offaito and onsite circuits from transmission system's steady-state and transient conditions. The adequacy and acceptability of the, ABWR dosign descriptions and ITAAC are ovalunted in Chapter 14.3 of this report. Therefore, this itom is resolved.

\subsubsection{Power Supply for the Reactor Internal Pumps}

Section 15.3.1.1.1 of SSAR Amendment 10 stated that, since four buses are used to supply power to the ten reactor internal pumps (RIPs), the worst single failure can only cause three RIPs to trip. In addition, the response to Question 435.4 of SSAR Amendment 10 stated that the probability of any additional RIP trips is low (less than 10B-6 per year). Therefore, the simultaneous trip of more than throe RIPs was classified by GE as a limiting fault. This classification was identified as DSER (SECY-91-355) Open Itom 29.

The etaff subsequently classified this postulated event in the epecial catogory of anticipated transients involving a common-mode software failure, and developed special acceptance criteria for the radiological dose calculation. The staff's evaluation of this postulated event in a special catogory is addrosed in Section 15.2 of this report.

\subsection{Onsite Class 1E Power System}

GE provided in tho SSAR markup dated March 31, 1993 as amended by SSAR markup dated May 11, 1993, a description of the ABWR design of the onsite Class 1E power system as being comprised of the following systems:

\section{- Class IE Altematine Current (ac) Power System}

The Class 1E ac power system will consist of throe redundant Class IE ac safety system divisions (Divisions I, II, and III). Each of these divisions will 


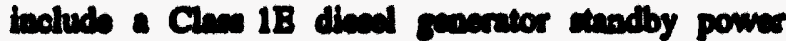

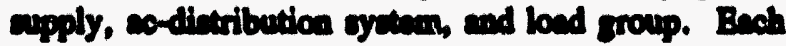
of the thres Claw 1B diecel serentor tendby pown applites will condat of all componeate from the troced conery (fivi) to the connection to the distribution arteon's aupply circuit breaker. Bech Clan IB scdiveribution system will consiat of the following Cher 1B co-didribution syetem:

\section{- $6.9 \mathrm{kV}$ medium voliage so-didtribution system}

Bech of the three Clan 1B 6.9 kV medium voltage co-dintribution system (cose per division) will consin of all equipmeat in the dietribution circuit, from the pawer side of the offidite and cosite power apply brenkers to and including the $6.9 \mathrm{kV}$ Chm 1B afiety ayctem loeds. Bquipment in each of the three Clam 1B 6.9 kV so-dietribution cireuits will include; ono Clas 1B circuit connection from the Clan 1E dienel generator atendby power aupply, three circuit connections from non-Claes IB power applien (the normal proferred offaito power cireuit, the alternito preforred offisite ppwer circuit, and the CTO), one $6.9 \mathrm{kV}$ medium voltage Claso IB ec owitchgear, the Clas 1B circuit connections to and including one or more $6.9 \mathrm{kV}$ medium voltage Clase IB anfety system londs, the Clace IE circuit connections to two Clase 1B 480-volt low voltage a distribution syetem, ons Clan 1B circuit connection to ground, and the Clas IB circuit connection through the Clan IB 480-volt low voltage ap-diatribution systems to ench of the following ayctema:

- one Clase 1E 120-volt ac I\&C distribution system,

- cose or more Che IB 120/240-volt scdietribution syctem,

- one or two Clase 1E de power aystems, and

- one or two Clase IB vital 120-volt ac LeC power syetems.

Equipment in Division I of the Clace IE $6.9 \mathrm{kV}$ acdiatribution circuits will aleo include throe circuit connections to non-Clase 1E fine motion control rod drive (FMCRD) motor loeds (one circuit connection to each of the three FMCRD motor load groupu). Each of the three circuit connections will consiat of all equipment in the distribution circuit from the 6.9 KV modium voltage switchgear to and including the 480-volt FMCRD motor loads. Equipment contained in the circuit will include a Clase 1B zone coloctive interlock circjit between the Clas IB medium voltage supply and lond brokkers, a pair of Clase 1B 6.9 kV interlocked breaken, one non-
Clam 18 6.9 kV/480-volt tranaformor, one nomClaw IB 480-volt MCC, and circuit connectione from modium voltage owitchgear through the interlocked breaken, $6.9 \mathrm{kV} / 480$-volt trenoformer, and 480-volt MCC to FMCRD aystam motor londs. The circuit connection between the Clase IE modium voltage mwitchgear load brewker and the pair of interlocked brekters will be claseified a ancolated. The circuit connections from interlocked breaken to the FMCRD londe and from the non-Clen IB medium voltage switchgeer to the interlocked breaken will bo clacaified a nonChes 1B. Control power for the interlocked breaken will be from the Division I Clam 1B 125-volt de sydtem.

- 480-volt low-voltage ec-dietribution ayetom

Bech of the aix Clase 1E 480-volt low voltage sodistribution aystome (two per division) will consiat of all equipmeat in tho distribution circuit from the $6.9 \mathrm{kV}$ medium voltage side of the $6.9 \mathrm{kV} / 480$-volt transformer to and including the 480-volt Clase 1B enfoty syatem loads. Bquipment in each of the six Clan IE 480-volt ec-distribution circuits will include one Class IE circuit connoction from the Clase 1E medium voltage distribution system, one Clase 18 $6.9 \mathrm{kV} / 480$-volt trensformer, one Chase 1E 480-volt switchgear, Clase 1E circuit connection 10 and including one or more 480 -volt Clase IE anfety system loeds, one Class 1B circuit connection to ground, and Class 1B circuit connection to and including one or more Clase 1E 480-volt ac MCCe and their affiliated 480-volt Clase 1B eafety system loads.

\section{- 120-volt I\&C ac-dietribution systom}

Each of the three Clase 1E 120-volt I\&C acdietribution systems (one per division) will consist of all equipmeat in the distribution circuit from tho 480-volt side of the 480/120-volt transformer to and including the 120-volt Clase 1E safoty system I\&C loads. Equipment in each of the three Class 1B I\&C ac-distribution circuits will include one Class 1E 480/120-volt transformor, two Clase 1E 120-volt ac-distribution panels, and Class 1E circuit connection to and including 120-volt Class IE anfety systom I\&C loads.

- 120/240-volt low-voltage sc-distribution syatem

Each of the Clase 1E 120/240-volt low voltage acdietribution systems (one or more per division) will consist of all equipment in the distribution circuit 
from the 480-volt ald of the Clew IB 480/120/240-volt tranaformer to and including Clem IB afty ayctem loade. Bquipment in each of the Clas 18 120/240-volt distribution circuits will includs ons Clem IB 480/120/240-volt trenaformer, cas or more Clim IB 120/240-volt se dietribution panele, and Clan IE circuit connection to and including Clan 1B 120- and 240-volt afety syctem loads.

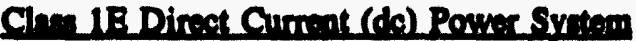

The Claw 1B de power ayetem will concist of four redundant 125-volt Claes 1B de enfety aycteon divisions (Divisions I, II, III, and IV). Bech of then divisions will include a Clan 1B battery and battery charger power aupply, 125-volt de-dietribution systom, and load group. Bech of the four Chas 1B battery pown aupplies will coneint of tornge celle, connectorn, and connections to the distribution system mupply circuit interrupting dovice. Bech of the four Clave IB bettery charger power auplien will consist of all equipment from the connection to the 480-volt Clase 1B c-dietribution oy atom to its dintribution sy stem's apply breaker. Bech of the four Clan 1B 125-volt de-diatribution systom will convist of all equipmeat in the distribution circuit, from the power side of the battery intermupting dovice and the battery charger aupply breaker to and including the 125-volt Clane IB de anfery syatom loads. Bquipmeat in wach of tho four distribution circuits will include one or more Class IB diatribution panels and connoctions to and including 125-volt Clase 1E de safoty system loads.

Divisions I and III of the 480-volt Clase 1B ac-dietribution ayetem will foed tho Divisions I and III battery charger power supplien, respectively. Division II of the 480-volt Clew IE ec-dietribution syatem will food the Divisions II and IV battery charger power aupplies.

\section{Chm IR Vinl ac JezC Powner Syntem}

The Clas IB vital ac I\&C power system will consiat of four rodundant Clase 1B vital 120-volt «c I\&C safoty ayatom divirions (Divisions I, II, III, and IV). Each of thew divisions will include a Clase IB Conotent Voltage Constant Frequeacy (CVCF) power aupply, a 120-volt Clas 1E ac-distribution aystem, and a lond group. Bech of the four CVCF power aupplies will consist of the power source (tho static inverter, $2 c$ and de atatic transfor owitches, and a regulating atep down tranaformer as an alternute ac power aupply) and its connection to the distribution supply circuit interrupting devico. Each of the four Clese IE vital 120-volt c LCC ditribution sydem will consiat of all cquipment in the dietribution circuit from tho power ide of the conetent CVCF power mupply bronker to and including the Clen IB cafoty syetem IezC londs. Bquipmeat in cach of tho four Claw IB vital 120-volt sc distribution circuits will include one or more 120-volt $2 c$ dietribution punols and connections to and including vital 120-volt Clase 1B enfety syetem IRC loads.

Each divisional CVCF power aupply will be aupplied power from ite affiliated divisional de power ayetom. (For example, the Divicion I CVCF power aupply will bo aupplied from Division I 125-volt de-dintribution aycuem.) In addition, Divisions I and III of tho 480-volt ec-dietribution aydtem will aupply power to the Divicione I and III CVCF power mupplien, respectively. Similarly, Division II of the 480-vole ec-diatribution ayctem will aupply power to the Divisions II and IV CVCF power aupplies.

The ataff concludes that the above deaign is consiatent with the typieal electrical syetem decipn dofined by IBBB 308-1980. The staff? reviow of the ABWR dectrial aystom doxign wes based on this typical decign. OE he included the above typical desion in SSAR Ameodment 32, which is scceptable.

In addition, $O B$ indicated that operational reatrictions would apply to tho ues of Clane 1E receptacles which are powered from each of the Clese IE 120/240-yolt diatribution aystems. Verification that theee operational reatrictions will be included in appropriate COL procedures to enoure compliance with the capacity, independence, and protection provisions required by GDC 2, 4, 17, and 18 of 10 CFR Part 50, Appendix A for Clase IE power systoms was DFSER (SECY-92-349) COL Action Item 8.3-1. In repones to this item, GE rovised their electrical syetem decign to diminato Clace IB electrical receptacles. $\mathrm{OB}$ included their revised decign in Section 8.3.1.1.3 of SSAR Amendment 32 negating the need for a specific COL sction itom which is scceptable.

ODC 17 of 10 CFR Part 50, Appendix A, requires that the Chas 1B oystems have aufficient (1) capacity and capability to permit enfety systems to perform their required affety function and (2) sufficient independence and redundancy to perform their safoty functions asouming a singlo failuro. With the elimination of Clase 1E receptacles, the potential for loses of independence between redundant Clase 1E divisions and lose of sufficient capacity of the Clase 1B power mupplies due to incorrect use of the receptecles was eliminated from the design. Consequently, the deaign meots the above defined requirements of GDC 17 and is acceptable. 
Cotified Datim Menterin

DFSER (BBCY-92-349) Open Itom 8.3-1 related to the deaign deceription and the ITAAC for the onsite Clase $1 \mathrm{~B}$ power eyctem deaign. The edequncy and scceptability of the ABWR denign decoriptions and ITAAC are ovalunted in Chapter 14.3 of this report. On the basis of this ovaluation, this itom is recolved.

To canare thet the ABWR deaign incorporntes sufficient capacity, capability, independence, redundancy, and

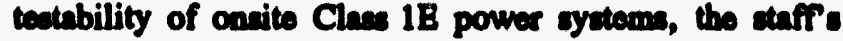
ovaluation also addresed the areas diecuseed in the following rections.

\subsubsection{Compliance with General Decign Criteria}

This esction addreseces the atafi's evaluation of OB's response to DSER (SECY-91-355) Open Items 27 and 30.

Itom (1)(b) of Section 8.3.1.2.1 of SSAR Amendmeat 10 indicated that the Clase 1B ac power syetem complies with GDC 2, 4, 17, and 18 in part or as a whole, as applicable. GE's reeponse to Queation 435.26 (aleo of Amendment 10) provided clarification that there are no non-compliances, but also indicated that some portions of the GDC do not apply to the CVCF power supplies (for example, the statement in GDC 17 about two physically independent circuits from the transmission network). Based on the information procented, the staff could not sscertain which parts of the GDC GE considered not applicable to the CVCF power supplies.

In its draft submittal dated September 4, 1991, GE proposed modifying the response to Question 435.26 and Section 8.3.1.2.1 to indicate full compliance with the GDC. The proposed modification deleted (1) certain conflicting statements in the SSAR, (2) the example of non applicability to GDC 17, and (3) the phrase "the subetance and intent of" from Section 8.3.1.4.2.1. In addition, $G E$ agreed to revise Itom 11 of Section 1.2.1.1.2 of SSAR Amendment 1 to clarify the systems or components to which IEEE 279, "Critoria for Protoction Systems for Nuclear Power Generating Stations" (1971) applies and to correct inconsistencies concerning applicable SRP criteria within Table 8.1-1 and between Table 8.1-1 and Section 8.1.3.1.2.

The staff concludes that the ABWR electrical system design with the above mentioned changes will comply with ODC 17 requirements to ODC commitments and is acceptable. Verification that $\mathrm{GE}$ provided the above clarifications in a future SSAR amendment was DFSER (SECY-92-349) Confirmatory Item 8.3.1-1. GE included this information in Table 8.1-1 of SSAR Amendment 21 and in Section 1.2.1.1.2(11), 8.3.1.2(1)(b), 8.3.3.6.2.1, and 8.1.3.1.2 of SSAR Amondment 32, which is coceptable. Therefore, this itom is recolved.

\subsubsection{Compliance with IETE Standards (NRC Polley Inew SXCY-91-273, Section II.A of Enclosure 1 to SECY $-33-087$ )}

In the draft SSAR aubmitual dated September 4, 1991, GB indicated that there will be no limitation on the ues of IBEB 384-1981 "IEEE Stundard Criteria for Independence of Clase 1E Equipment and Circuits," for exparation in the ABWR deaign. The NRC ataff has not formally roviowed and eccepted the changes between the 1974 and 1981 vercions of this standard. Also, IEEB 384 is not the only andard in this claseification for which the NRC has not completed it formal ovaluation and regulatory guide codornemeat of the nower version of the atandard. Thus, to allow the use of an updated IEEE standard which the NRC ataff has not formally reviowed or cadorned, the atafi folt that each differeaces between the old and now standard neaded to be identified, juntified, and approved for un. Such roviow is required in order to ensure that the deaign criteria of the now atandards are equally conservative as thow included in the standards currently approved by the staff. This was DSER (SECY-91-355) Open Item 41.

In order to identify, justify, and approve the differeaces between the old and new standards for use on the ABWR and also complete the evaluation of the electrical system decign for the ABWR, the staff ovaluated the guidelines in two of the nower standards with respect to tho intent of criteria and guidelines contained in the SRP and existing regulatory guides. The staff believes that these two standards provide the majority of the basic criteria for the electrical power systems. The electrical design proposed for the ABWR was then evaluated using the newer standards.

The nower standards were revised to be consistent with IEEE 603-1980. The newer standards involved primarily clarificrtion and amplification of guidelines contained in prior standands and were thus considered the more relevant base from which to evaluate the ABWR design. The nower atandards included

- IEEE 308-1980, "IEEE Standard Criteria for Class IB Power Systems for Nuclear Power Generating Stations" (This standard was specifically revised to be consistent with IEEE 603-1980, which was endoreed by the NRC staff in RG 1.153 in 1985.)

- IEEE-384-1981 "IEEE Standard Criteria for Independence of Class 1E Equipment Circuits" 
In addition, IBEB has dovoloped and inned other companion standards to provide additional guidance for certain arese. Thees standards includo

- IBBB 741-1986, "Standard Criteria for the Protection of Clas IB Power Syatoms and Bquipment in Nuclear Power Generating Statione"

- IEBB 765-1983, "Standard for Proforrod Power Supply for Nuclear Rower Gesernting Stations"

- IEEB 485-1983, "Recommended Practice for Sizing Large-Laed Storage Batteries for Generating Stations and Subutations"

- IEEB 946-1985, "Recommended Practice for the Design of Safoty-Relatod de Auxiliary Power Syatome for Nuclear Power Generating Stations"

Like the two atandarde cited sbove, thewe other companion atandards have not been eadorned by an NRC regulatory guide. However, these atandards were developed to be used with IEEE 308-1980 and they aleo clarify and amplify current SRP critoria and guidolines. The staff therefore considere thewe standards the more relevant base from which to evaluato the ABWR doaiga.

In some cases, GE had not roferenced these other compenion etandards in the ABWR SSAR. The staff proceoded with its roview with the understanding that $G E$ intended to use these other standards. Verification of this underatanding in a future SSAR amendmeat was DFSER (SECY-92-349) Confirmatory item 8.3.1.1-1. GE included a statement of conformance to these standards in Sections 8.3.1.2(5), 8.2.2.1(9), and 8.3.2.2.2(5) of SSAR Amendment 32, which is acceptable. Therefore, this item is resolved.

\subsubsection{Compliance with GDC 2 and 4}

ABWR SSAR Chapter 8 was modified, in response to DSER (SECY-91-355) Open Itom 31 and 63, by the draft revision dated April 3, 1992, as amended by an SSAR markup dated March 31, 1993, to include the following statements related to the compliance of the electrical system design to the requirements of GDC 2, "Design Bases for Protection Againat Natural Phenomena," and GDC 4, "Environmental and Missiles Design Bases," of 10 CFR Part 50, Appendix A:

- "Electrical equipment and wiring for the Class IE systems which are segregated into separate divisions are separated 80 that no design-basis event is capable of disabling more than one division of any ESF total function."
- "Redundant parte of the syetem are phyvically eeparated and electrically independent to the exteat that in any dealgo-basis oveat with any resulting loes of equipmeat, tho plant can atill be shut down with the remaining two divisions."

- "Ches 18 eloctric equipmeat and wiring is sogregated into coparato divisions so that no single crediblo oveat is capable of dieabling coough equipmeat to hinder reactor shut down and removal of docay heat by either of two unaffected divisional load groupe or proveat ieolation of the containment in the oveat of 20 eccident."

- "Bquipment arrangement and/or proloctivo barriers are provided such that no locally generated force or misuile cen deatroy any reactor protoction syatom (RPS), nuclear steam supply systom, (NSSS), emergency core cooling syctem (BCCS), or engineered safoty feature (BSF) functions. In addition, arrangement and/or espanation barrien are provided to canure that much disturbunces do not affect both high presecure core flooder (HPCF) and reactor core ieolation cooling (RCIC) aystoms."

- "Containment peretrations aro 80 arranged that no dowign-basis ovent can disable cabling in more then one divinion."

- "Tho protection system and ESF control, logic, and inetrument panels/racks shall be located in a safoty clase structure in which there are no potential sources of missiles or pipe breaks that could jeopardize redundant cabinets and racoways."

- "The standby ac power system is capable of providing the required power to safoly shut down the reactor aftor LOPP and/or LOCA and to maintain the safo-shutdown condition and operato the Class IE auxiliaries necessary for plant safety after shutdown."

Based on the above stated capability to safely shut down, other SSAR commitments regarding physical protection of electrical divisions, and discuseions, GE indicated that there will be a limited number of design-basis ovents for which Class 1B systems, equipment, and components will be protected by the capability to maintain safo plant shut down with any one of the three load groups.

GDC 2 and 4 of 10 CFR Part 50, Appendix A, requires that Class 1E systems, equipment, and components be designed (1) to withstand the effects of natural phenomena without loss of capability to perform their safety functions, (2) to accommodate the effects of and to be compatible with the environmental conditions associated with normal 
operation, mainteanance, teeting, and postulated sccidents, and (3) be epproptiately protected against dynamic effects. GDC 17 of 10 CFR Part 50, Appendix A, requires that the Class 1E syctems, equipment, and components have auficieat independence to perform thoir afoty function anuming a single failure. The athif conclude that a deaign that meats the above described commitments will reasonably asaure that no deaign basis event (that is, failure of any one anfety-related syctem division or failure of nonClass 1E equipment) will cause failure of more than one anfety-related system division. The design, therefore, meets the above defined requirements of GDC 2, 4, and 17 of 10 CFR Part 50, Appendix A, and is acceptable. Verification that GE has provided the above design commitments in a future SSAR ameendment was DFSER (SECY-92-349) Confirmutory Itom 8.3.1.2-1. GE has included information in Sections 8.3.3.1, 8.1.3.1.1.1, 8.3.3.6.1.1, 8.3.3.6.2.3.2, 8.3.3.6.2.2.3, and 8.1.2.2 of SSAR Amendment 32, which is acceptable. Thereforo, this item is resolved.

\section{Certified Design Meterial}

DFSER (SECY-92-349) Open Item 8.3.1.2-1 related to the design description and the ITAAC for the capability of performing a safe shutdown (performing the required minimum safety function). The adequacy and acceptability of the ABWR design deecriptions and ITAAC are evaluated in Chapter 14.3 of this report. Therefore, this item is resolved.

\subsubsection{Physical Independence}

\subsubsection{Conduits to Open Tray Separation (Scram Cables)}

Section 8.3.3.6.2.3.1 of the dnft SSAR revision dated April 3, 1992, documented the following design commitments in response to DSER (SECY-91-355) Open Item 32:

- The reactor protective system scram solenoid circuits, from the actuation devices to the solenoids of the scram pilot valves of the control rod drive hydraulic control units, will be run in grounded steel conduits, containing no other wiring.

- Separate grounded steel conduits will bo provided for the scram solenoid wiring for each of four scram groups.

- Separate grounded steel conduits will also be provided for both the A and B solenoid wiring circuits of the same scram group.
- Scram group conduits will have unique identification and will be separately routed as Divisions II and III conduits for the A and B solenoids of the scram pilot valves, respectively. This corresponds to the divisional seaignment of their power sources.

- Conduits containing the circuits for the A colenoids of the ecrnm pilot valves (Division II) will be separated from their B eolenoid counterpart (Division III) by a minimum separation distance of $2.54 \mathrm{~cm}$ (1 in.), in accordance with divisional separation requirements.

- The scram group conduits will not be routed within the confines of any other tray or raceway system.

- The conduits containing the scram solenoid group wiring of any one scram group will also be physically separated by a minimum distance of $2.54 \mathrm{~cm}(1 \mathrm{in}$.) from the conduit of any other scram group and from conduits or metal-enclosed raceways affiliated with any of the four Cless 1E divisions or any non-Class IE (non-divisional) circuits.

- The conduits containing the scram solenoid group wiring of any one scram group will also be physically separated from non-enclosed raceways associated with any of the four safety-related electrical divisions or any non-safety-related (non-divisional) circuits in accordance with IEEE 384 and RG 1.75, Revision 2.

- Separation "in accordance with IEEE 384" means that conduits containing scram solenoid group circuit wiring will be separated from any non-enclosed raceway containing either safety or non-safety-related circuits. Specifically, the vertical separation distance will be 1.5 or more $m$ (5 or more $\mathrm{ft}$ ) and the horizontal separation distance will be .9 or more $\mathrm{m}$ ( 3 or more $\mathrm{ft}$ ).

GDC 4 of 10 CFR Part 50, Appendix A, requires that Class IE systems, equipment, and components be designed to accommodate the effects of and to be compatible with the environmental conditions associated with normal operation, maintenance, testing, and postulated accidents. GDC 17 of 10 CFR Part 50, Appendix A, requires that the onsite electric distribution system have sufficient independenco to perform their safety function assuming a single failure. The staff concludes that a design that meets the above described commitments will reasonably preclude the common failure of reactor protection system scram solenoid circuits and other Class IE or non-Class IE circuits. The design, therefore, meets the above defined requirements of GDC 4 and 17 of 10 CFR Part 50, Appendix A, and is acceptable. 
Verification that $\mathrm{GE}$ provided the above design commitments in a future SSAR amendment was DFSER (SECY-92-349) Confirmatory Item 8.3.2.1-1. In responso to this itom, GE further clarified their design commitment for separation in accordance with IEEE 384. Specifically GE indicated that the RPS conduits containing the scram group wiring for the A and B solenoids of the scram pilot valves (associated with Divisions II and III, respectively), will be separated from non-enclosed raceways associated with any of the four olectrical divisions or non-divisional

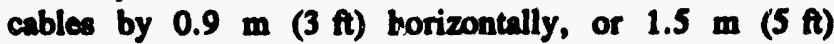
vertically, or with an additional barrier that is separated from any raceway by $2.5 \mathrm{~cm}(1 \mathrm{in}$.). The staff concludes that a design that meets the abovo described commitments as revised will also ressonably preclude the common failure of resctor protection system scram solenoid circuits and other Cless 1E or non-Class 1E circuits. The design, therefore, meets the above defined requirements of GDC 4 and 17 of 10 CFR Part 50, Appendix A, and is acceptable. GE has included the revised design commitments in Section 8.3.3.6.2.3.1 of SSAR Amendment 32, which is acceptable. Therefore, this item is resolved.

\section{Certified Design Material}

DFSER (SECY-92-349) Open Item 8.3.2.1-1 related to the design description and the ITAAC for separation between scram cables and between scram and other cables. The adequacy and acceptability of the ABWR design descriptions and ITAAC are evaluated in Chapter 14.3 of this report. Therefore, this item is resolved.

\subsubsection{Dedicated Neutron Monitoring Raceways}

Section 8.3.1.3.1.3 of the draft SSAR revision dated April 3, 1992, (in response to DSER (SECY-91-355) Open Item 32) indicated that neutron monitoring cables will be routed in their own divisional conduits and cable trays, separate from all other power, instrumentation, and control cables.

GE also committed that neutron monitoring cables will be routed in their own dedicated raceways from termination to termination. These dedicated raceways will be separated from raceways containing all other Class 1E or non Class $1 E$ power, instrumentation, and control cables by the same separation provided between scram and other cables described in Section 8.3.2.1 of this report.

GDC 4 of 10 CFR Part 50, Appendix A, requires that Class 1E systems, equipment, and components be designed to accommodate the effects of and to be compatible with the environmental conditions associated with normal operation, maintenance, testing, and postulated accidents. GDC 17 of 10 CFR Part 50, Appendix A, requires that the onsite electric distribution system have sufficient independence to perform their safety function aseuming a single failure. The staff concludes that a design that moets the above described commitments will reasonably preclude the common failure of neutron monitoring circuits and other Class 1E or non-Class 1E circuits. The design, therefore, meets the above defined requirements of GDC 4 and 17 of 10 CFR Part 50, Appendix A, and is acceptablo.

Verification that $\mathrm{GE}$ provided the above design commitments in a future SSAR amendment was DFSER (SECY-92-349) Confirmatory Item 8.3.2.2-1. In response to this item, GE further clarified in its design that neutron monitoring cables will be routed in their own dedicated raceways for the purpose of assuring their protoction from the offects of electromagnetic interference (EMI). GE indicated that additional physical separation requirements are not necessary to assure protection from the offects of EMI.

The staff concludes that a design that meets the above described commitments as modified will also reasonably preclude the common failure of neutron monitoring circuits and other Class 1E or non-Class 1E circuits. The design, therefore, meets the above defined requirements of GDC 17 of 10 CFR Part 50, Appendix A, and is acceptable. GE has included this commitment in Section 8.3.3.5.1.3 of SSAR Amendment 32, which is acceptable. Therefore, this item is resolved.

The issue related to protection of circuits from EMI is resolved in Chapter 7.0 of this report.

\section{Certified Design Material}

DFSER (SECY-92-349) Open Item 8.3.2.2-1 related to the design description and the ITAAC for routing of I\&C neutron monitoring circuits in dedicated raceways. The adequacy and acceptability of the ABWR design descriptions and ITAAC are evaluated in Chapter 14.3 of this report. Therefore, this item is resolved.

\subsubsection{Separation of dc Emergency Lighting Raceways}

In Section 9.5.3 of the draft SSAR revision dated April 3, 1992, in response to DSER (SECY-91-355) Open Item 32, GE indicated that dc emergency lighting cables will bo routed in their own divisional conduits and cable trays, separate from all other power, instrumentation, and control cables.

GE indicated that the dc emergency lighting cables will be routed in their own dedicated raceways from termination to termination. These dedicated raceways will be separated from raceways containing all other Class 1E or 
non-Clase 1B power and I\&C cables by the eamo separation provided between scrmm and other cables, as described in Section 8.3.2.1 of this report.

ODC 4 of 10 CFR Part 50, Appendix A, requires that Class 1E systems, squipment, and components bo designed to sccommodate the effects of and to be compatible with the environmental conditions aseociated with normal operation, maintennnce, testing, and postulated accidents. GDC 17 of 10 CFR Part 50, Appendix A, requires that the onsite electric distribution system have sufficient independence to perform their anfety function asuming a single failuro. The staff concludes that a design that moets the above described commitments will minimize to the extent practicable the common failure of the standby and dc emergency lighting circuits. The design, therefore, meets the above defined requirements of GDC 4 and 17 of 10 CFR Part 50, Appendix A, and is acceptable.

Verification that GE provided the above design commitments in a future SSAR amendment was DFSER (SECY-92-349) Confirmatory Item 8.3.2.3-1. In response to this item, GE clarified their design to indicate that emergency dc lighting circuits will not share raceways with any other circuits in order to enhance lighting reliability. GE indicated that physical separation of these raceways within the same division is not required.

The staff concludes that a design that meets the above described commitment as modified will also minimize to the extent practicable the common failure of the standby and dc emergency lighting circuits. The design, therefore, meets the above defined requirements of GDC 4 and 17 of 10 CFR Part 50, Appendix A, and is acceptable. GE has included this design commitment in Sections 9.5.3 and 9.5.3.1.1(7)(d) of SSAR Amendment 32, which is acceptable. Therefore, this item is resolved.

\section{Certified Desion Material}

DFSER (SECY-92-349) Open Item 8.3.2.3-1 related to the design description and the ITAAC for routing of emergency dc lighting in dedicated raceways. The adequacy and acceptability of the ABWR design descriptions and ITAAC are evaluated in Chapter 14.3 of this report. Therefore, this item is resolved.

\subsubsection{Separation of Containment Electrical Penetrations}

Separation Between Class 1E Penetrations of Redundant Divisions

Item (7) of Section 8.3.1.4.1.2 of SS $: \mathbb{R}$ Amendment 10 indicated that electric penetration assemblies of different
Clase IE divisions will be separated by distance, barriers, and/or location in sepante rooms or on separate floors. The use of barriers and/or location in separate rooms or on separate floors exceods separation guidelines for penetrations and are acceptablo approaches. Separation by distance may also moet separation guidelines; however, SSAR Amendment 10 did not clearly define what conatitutes the minimum allowable distance between penotrations. This was DSER (SECY-91-355) Open Item 33.

In the draft SSAR revision dated April 3, 1992, itom (7) of Section 8.3.1.4.1.2 similarly indicated that electrical penetration assemblies of different Class IE divisions will bo separated by 3-hour fire-rated-barriers (that is locations in separate rooms or on separate floors). Separation by distance (without barriers) will be allowed only within the inerted containment. Section 8.3.1.1.5.1 of the April draft revision further indicated that penetration assemblies will be located around the periphery of the containment and at different elevations to facilitate reasonably direct routing of cables to and from the equipment.

GDC 4 of 10 CFR Part 50, Appendix A, requires that Class 1E systems, equipment, and components be designed to accommodate the effects of and to be compatible with the environmental conditions associated with normal operation, maintenance, testing, and postulated accidents. GDC 17 of 10 CFR Part 50, Appendix A, requires that the onsite electric distribution system have sufficient independence to perform their safety function assuming a single failure. The staff concludes that a design that meets the above described commitments will reasonably ensure that failure of Class 1E (or associated) penetration circuits in any one division will not cause failure of Class 1E (or associated) penetration circuits in a different Class 1E division. The design, therefore, meets the above defined requirement of GDC 17 of 10 CFR Part 50, Appendix A, and is acceptable.

Verification that GE provided the above design commitments in a future SSAR amendment was DFSER (SECY-92-349) Confirmatory Item 8.3.2.4-1. GE has included these commitments in Sections 8.3.3.1 and 8.3.3.6.1.2 of SSAR Amendment 32, which is acceptable.

\section{Certified Desion Material}

DFSER (SECY-92-349) Open Item 8.3.2.4-1 related to the design description and the ITAAC for the separation between Class 1E penetrations of redundant divisions. The adequacy and acceptability of the $A B W R$ design descriptions and ITAAC are evaluated in Chapter 14.3 of this report. Therefore, this item is resolved. 
Sepantion of Clrse 1B Penetrations From Non-Clace 1B Penetritions

Section 8.3.1.4.1.2 of the drat SSAR revision dated April 3, 1992, in reeponeo to DSER (SECY-91-355) Open Irem 34 indicated that exparation between penetrations containing non-Clase 1E circuits and thowe contrining Clase 1E or aseocinted circuits will be in sccordance with IEEE 384. GB indicated that "espanation in sccordance with IEEE 384" means a vertical separation of 1.5 or more m (5 or more ft) and a horizontal separation distance of 0.9 or more $m$ ( 3 or more $\mathrm{ft}$ ).

The staff concludes that a design which meets the above doecribed commitmeats will reasonably ensure that failure of non-Clase 1E system penetration circuits will not cause failure of Clase 1E (or aseociated) pesetration circuits. The decign, therefore, moets the sbove defined requirements of GDC 4 and 17 of 10 CFR Part 50, Appendix A, and is scceptable.

Verification that GE provided the above design commitments in a future SSAR amendment was DFSER (SECY-92-349) Confirmatory Item 8.3.2.4-2. In response to this item, GE further clarified their design to indicate that the separation between Electrical penetration assemblies contrining non-Class $1 E$ circuits and penetration assemblies containing Class 1E or associated Class 1E circuits is by walls, barriers, or floors that have : threo-hour firo-rating. The staff concludes that a design which meets the above described commitments will also reasonably ensure that failure of non-Class $1 E$ penetration circuits will not cause failure of Class IE (or associated) penetration circuits. The design, therefore, meets the above defined requirements of GDC 4 and 17 of 10 CFR Part 50, Appendix A, and is acceptable. GE has included this design commitment in Section 8.3.3.6.1.2(7) of SSAR Amendment 32, which is acceptable. Therefore, this item is resolved.

\section{Certified Desien Material}

DFSER (SECY-92-349) Open Item 8.3.2.4-2 related to the design description and the ITAAC for the separation between Class IE and non-Class IE penetrations. The adequacy and acceptability of the ABWR design descriptions and ITAAC are evaluated in Chapter 14.3 of this report. Therefore, this item is resolved.

\section{Separation of Clas $1 \mathrm{E}$ Penetrations from Non-Class 1E Cables or Other Divisional Cables}

This section addresses the staff's evaluation of GE's response to DSER (SECY-91-355) Open Item 35.
GB indicated that penetrations contrining Class 1E circuits will be exparated from other divisional cables by routing through separate rooms and/or different floors outside containment and by maintaining a minimum separation of

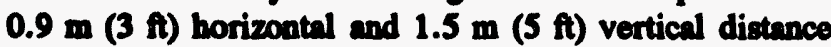
inside the inerted containment. In addition, separation between penetrations containing Clase 1E circuits and nondivisional cables will be maintained at a minimum

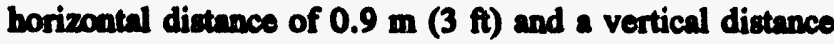
of $1.5 \mathrm{~m} \mathrm{(5} \mathrm{ft)} \mathrm{both} \mathrm{inside} \mathrm{and} \mathrm{outside} \mathrm{of} \mathrm{containment.}$

The ataff concluded that a design which meets the above deecribed commitments will also reasonably ensure (1) that failure of Class IE (and aseociated) circuits of one division will not cause failure of Clase 1E (or associatod) pesetration circuits in a different division and (2) that failure of non-Clase 1B circuits will not cause failure of Clase 1E (or aseociated) penetration circuits. The design, thereforo, meets the above requirements of GDC 4 and 17 of 10 CFR Part 50, Appendix A, and is acceptable.

Verification that GE provided the above design commitments in a future SSAR amendment was DFSER (SECY-92-349) Confirmatory Item 8.3.2.4-3. In response to this item, GE further clarified their design to indicate that the separation between Electrical penetration aseemblies containing Class 1E or associated circuits from other divisional or non-divisional cables is by walls, barriers, or floors that have a three-hour fire-rating. The staff concluded that this separation exceeds the guidelines of IEEE 384, moets the protection and independence requirements of GDC 4 and 17 of 10 CFR Part 50, Appendix A, and is acceptable. GE included this design information in Section 8.3.3.6.1.2(7) of SSAR Amendment 32, which is acceptable. Therefore, DFSER (SECY-92-349) Confirmatory Item 8.3.2.4-3 is resolved.

\section{Certified Desien Material}

DFSER (SECY-92-349) Open Item 8.3.2.4-3 related to the design description and the ITAAC for the separation between Class 1E penetrations to non-Class $1 \mathrm{E}$ cables or to other divisional cables. The adequacy and acceptability of the ABWR design descriptions and ITAAC are evaluated in Chapter 14.3 of this report. Therefore, this item is resolved.

\subsubsection{Separation and Protection of Cables Located Outside Cabinets and Panels}

Section 8.3.1.1.5.1 of the draft SSAR revision dated April 3, 1992, documents the following design commitments related to separation of Class $1 \mathrm{E}$ cables in response to DSER (SECY-91-355) Open Item 36: 
(1) Bnclosed solid metal racownys are required for esparation between Clase 1B or ancociated cables of different anfoty divisions and between Clase 1E or aseociated cables and non-Clase IE cables, if: the vertical separation is lese than $1.5 \mathrm{~m}(5 \mathrm{ft})$, the horizontal separation distance is less than $.9 \mathrm{~m}$ (3 ft), and the cables aro located in the same fire area.

Both groupings of cables requiring separation (as specified in item 1) must be cenclosed in solid metal recoways.

GB indicated that all power, control, and inetrumentation cables (including fiber optic cables) located outside cabinets and panels throughout the plant will be supported in recowaye in sccordance with IEEE-recommended practice for aupport of cable systems. When Class 1E (or aseociated) cables of different Class 1E divisions are separated from each other or from non-Class 12 cables by less than $1.5 \mathrm{~m}(5 \mathrm{ft})$ vertically or $.9 \mathrm{~m}(3 \mathrm{ft})$ horizontally, the cables will be supported in enclosed solid metal raceways (such as rigid or flexible metal conduits or totally caclosed cable trays).

In addition, Section 8.3.1.2.1(2)(f) of the draft SSAR revision dated April 3, 1992, and Section 1.8.2 (Table 1.8-21) of SSAR Amendment 17 indicated that the ABWR electric system design will comply with the requirements of IEEE 384-1981. Based on this commitment, $G E$ indicated that the separation distance will be at least $2.54 \mathrm{~cm}(1 \mathrm{in}$.) between solid metal raceways containing Class 1E (or associated) cables of different Class 1E divisions or between solid metal raceways containing Class 1E (or associated) cables and nonClass 1E cables.

GDC 4 of 10 CFR Part 50, Appendix A, requires that Class 1E systems, equipment, and components be designed to accommodate the effects of and to be compatible with the environmental conditions associated with normal operation, maintenance, testing, and postulated accidents. GDC 17 of 10 CFR Part 50, Appendix A, requires that the Class 1E systems, equipment, and components have sufficient independence to perform their safety functions assuming a single failure. The staff concludes that a design which meets the above described commitments will reasonably ensure (1) that failure of Class 1E (or associated) cables in any one division (located outside of cabinets and panels and in any single raceway) will not cause failure of Class $1 E$ (or associated) cables in a different Class 1E division and (2) that failure of nonClass 1E cables (located outside of cabinets and panels and in any single raceway) will not adversely affect Class $1 \mathrm{E}$ (or associated) cables. Consequently, the staff concludes that the design moets the above defined requirements of GDC 4 and 17 of 10 CFR Part 50, Appeadix A, and is ecceptable.

Verification that GE provided the above design commitments in a future SSAR amendment was DFSER (SECY-92-349) Confirmatory Item 8.3.2.5-1. GE has included these commitments in Section 8.3.3.1 of SSAR Amendment 32, which is acceptable. Therefore, this item is reeolved.

\section{Certified Desion Mnteria!}

DFSER (SECY -92-349) Open Item 8.3.2.5-1 related to the design description and the ITAAC for the separation and protection of cables located outside cabinets and panels. The adoquacy and scceptability of the ABWR design descriptions and ITAAC are evaluated in Chapter 14.3 of this report. Therefore, this item is resolved.

\subsubsection{Separation of Cables Inside Cabinets and Panels}

In response to DSER (SECY-91-355) Open Item 37, Sections 8.3.1.4.1, 8.3.1.4.1.2, 8.3.1.4.2, 8.3.1.3.1.3, and 8.3.1.4.2.2.3 of Amendment 10 to the SSAR and draft SSAR revision dated April 3, 1992, document the following design commitments related to separation of power, control, and instrumentation cables inside panels, racks, cabinets, and other enclosures located in the main control room and other areas of the plant.

- Single panels or instrument racks will not contain circuits or devices of different Class IE safety system divisions, except under the following conditions:

- Certain operator interface control panels may have operational considerations which dictate that Class 1E safety system circuits or devices of different divisions must be located in a single panel. These circuits and devices will be separated horizontally and vertically by a minimum distance of $15.2 \mathrm{~cm}$ (6 in.) or by steel barriers or enclosures.

- The input and output circuits of isolation devices will be separated horizontally and vertically by a minimum distance of $15.2 \mathrm{~cm}(6 \mathrm{in}$.$) or by steel$ barriers or enclosures.

- Class 1E circuits and devices will also be separated from the non-Class 1E circuits and devices which are present inside a panel. These circuits and devices will be separated from each other horizontally and vertically 
by a minimum distunce of $15.2 \mathrm{~cm}(6 \mathrm{in}$.) or by steel barriens or enclomures.

- If two panals containing circuits of different divisions are leas than $.9 \mathrm{~m}$ (3 ft) apart, there will be a ateel barrier between the two panols. Panel ands cloned by atoel end plates will be considered to be ecceptable barrien provided that terminal boands and wirowaye are epeced a minimum of $2.5 \mathrm{~cm}$ ( 1 in.) from the cad plato.

- Penetration of expantion barriers within a aubdivided panel will be permitted, provided that auch penetrations are cealed or otherwise treated so that fire generated by an electrical fault could not reasonably propagato from one exction to the other and dieable a protective function.

Based on the commitment to moet the guidelines of IEEE 384-1981 and RG 1.75, Rovision 2, GE indicated that Cless 1E or non-Chase 1E power circuits located inside panols and cabinets will be limitad to those required to operate systems, equipment, or components located inside the panols and cabinets. Power cables will not be permitted to traverse from cose side of a panel or cabinet to the other without being terminated inside the panel. In addition, these circuits will be routed inside rigid or flexible conduits that will bo physically separated from instrumentation and control cables by minimum horizontal and vertical distances of $15.2 \mathrm{~cm}(6 \mathrm{in}$.$) or by steel$ barriens or additional caclosures.

GDC 4 of 10 CFR Part 50, Appendix A, requires that Clase IB eystems, equipment, and components be designed to accommodate the offects of and to be compatible with the environmental conditions sseociated with normal operation, maintenance, teeting, and postulated accidents. GDC 17 of 10 CFR Part 50, Appendix A, requires that the Class IE systems, equipment, and components have sufficient independence to perform their safety functions seauming a single failure. The staff concludes that a devign which moets the above described commitments will reasonably sure (1) that failure of Clase 1E (or aseociated) cables in any one division (located inside of cabinets or panels) will not cause failure of Clase IE (or expociated) cables in a different anfoty division, (2) failure of non-Clase 1B cables (located inside cabinets or panels) will not adversely affect Class IE (or associated) cables, and (3) normal operation and/or failure of power circuits (Class 1E, aseociated Class 1E, or nonClass IE) will not adversely affect ISC circuits. The design, therefore, meets the above defined requirements of ODC 4 and 17 of 10 CFR Part 50, Appendix A, and is acceptable.
Verification that $G B$ provided the above deaign commitments in a future SSAR ameadmeat was DFSER (SECY-92-349) Confirmatory Item 8.3.2.6-1. In response to this item, GE indicated that it was not their intent to commit to the routing of power circuits inside rigid or flexible conduits that will bo physically separated from inutrumentation and control cables of tho samo division by minimum borizontal and vertical distances of $15.2 \mathrm{~cm}$. (6 in.) or by atoel barriers or additional enclocures. $\mathrm{OE}$ further indicated that the IEEE guideline "installed in acloeed ncownys that qualify as barriers" has been interpreted to mean that for EMI considerations, power cables will be routed in metallic conduit wherever they come in clowe proximity with low lovel (V1) cables. For independence between power and I\&C cables within the mome division, the ataff agreed with GE's interpretation. The staff concludes that a design that meets the above described commitments as clarified will reasonably ensure that normal operation and/or failure of power circuits (Claw 1E, anociated Cleen 1E, or non-Class 1E) will not advernely affect I\&C circuits. The design, therefore, moets the above defined requirements of GDC 4 and 17 of 10 CFR Part 50, Appendix A, and is scceptable. The staff's evaluation for the protection of circuits from EMI is addreseed in Chapter 7.0 of this report. GE has included the above design commitments in Sections 8.3.3.6.1.1, 8.3.3.6.2.2.3, and 8.3.3.6.2.2.4 of SSAR Amendment 32, which is acceptable. Therefore, this item is resolved.

\section{Certified Desien Material}

DFSER (SECY-92-349) Open Item 8.3.2.6-1 related to the deaign description and the ITAAC for the separation of cables inside cabinets/panols. The adequacy and acceptability of the ABWR design descriptions and ITAAC are ovaluated in Chapter 14.3 of this report. Therefore, this item is resolved.

\subsubsection{Separation of Cables Approaching and/or Exiting Cabinets and Panels}

The response to Question 435.30 in SSAR Amendment 10, DSER (SECY-91-355) Open Itom 40, stated that cable apreading areas do not apply to the ABWR and are not included in the plent layout because the majority of the I\&C signals will be multiplexed to the control room. This reeponse implied that the $0.3 \mathrm{~m}(1 \mathrm{ft})$ by $0.9 \mathrm{~m} \mathrm{(3 \textrm {ft } )}$ separation guidelines allowed by Section 5.1.3 of IEEE 384-1974 (Section 6.1.3 of IEEE 384-1981) will not apply to the ABWR. The guidelines of Position C12 of RG 1.75 Revision 2, also will be irrelevant. The ABWR SSAR did not clearly address the criteria for the separation and protection of cables approaching or exiting cabinets and panels. 
In dimonacions with the anff and in Section 8.3.1.4 of tho dran SSAR rovision dated April 3, 1992, OB clarified its deaign commitmeats as follows:

- I\&C and optical cables (including motallic and fiberoptic cables) will be treatod the anmo with reppect to exparation and protection throughout the plant.

- Each division of Clase 1E power, inctrumentation, and control cables will be routed to the control room complex through a cable chace or other meane, to that different divisional areas will bo mepurated by a 3-bour firo-nated barrier.

- Each cable chase will be ventilated.

- Separation between Claes IE and non-Clase IE cables within the cable chase will be the same as reparation of cables located outside cabinots apd panels as described in Section 8.3.2.5 of this report.

- Clase 1E, ascociated, or non-Clase IE power circuits routed in a cable chase serving the control room or in the control room aren will be limited to those required to operate syatems, equipment, or components located in the control room aren (power cables will be not be permitted to traverse through from one side of the control room are to the other without being terminated in the control room area).

- Class 1E, associated, or non-Clase 1E power circuits routed in a cable chase or the control room area will be routed inside rigid or flexible conduits that will bo physically separated borizontally and vertically from any I\&C cables by a minimum distance of $15.2 \mathrm{~cm}$ (6 in.) or by steel barriers or additional caclosures.

- Power cables may be routed in flexible metallic conduit under the raised floor of the control room.

- Separation between divisional and between divisional and non-divisional power, instrumentation, and control cables within the control room area will be separated in the amo way as cables located outside cabinets and panels dencribed in Section 8.3.2.5 of this report.

- Power, instrumentation, and control cables of differeat Class 1E divisions will enter cabinets and panels through separate apertures. Similarly, Class IE and non-Class 1E power, instrumentation, and control cables will enter cabinets or panels through separate apertures.
- Cable chanes and the control room area will be nonharend areas (Section 6.1.3 of IEEE 384-1981 dofines son-beond areas).

- Cablo chases and the control room area will not contain poteatial hasard auch as high energy owitchgear, power distribution panels, transformers or rotating equipment, potential cources of miesiles, pipe failure hasands, or fire hazards.

GDC 4 of 10 CFR Part 50, Appendix A, requires that Claes IE ayetem, equipment, and components bo deaigned to accommodate the effects of and to be compatible with the environmental conditions secociatod with normal operation, maintennnce, teating, and postulated eccidents. GDC 17 of 10 CFR Part 50, Appendix A, requires that the Clace IE systems, equipment and components have wifficient independence to perform their safety functions asauming a single failure. The staff concludes that a design which meots the above deecribed commitments will renconably ensure (1) that failure of Cless 1E (or associated) cables in any one division (located in a cable chese or the control room area) will not cause failure of Class 1E (or aseociated) cables in a different anfoty division, (2) that failure of non-Clase 1E cables (located in a cable chase or the control room area) will not adversely affect Class 1E (or aneciated) cables, and (3) normal operation and/or failure of power circuits (Class 1E, associated, or nonClase 1E) will not adversely affect I\&C circuits. The deaign therefore meets the above defined requirements of GDC 4 and 17 of 10 CFR Part 50, Appendix A, and is acceptablo.

Verification that $\mathrm{GE}$ provided the above design commitments in a future SSAR amendment was DFSER (SECY -92-349) Confirmatory Item 8.3.2.7-1. In response to this item, GE indicated that it was not their intent to commit to the routing of power circuits inside rigid or flexible conduits that will be physically separated from instrumentation and control cables of the same division by minimum borizontal and vertical distances of $15.2 \mathrm{~cm}$ (6 in.) or by steel barriers or additional enclosures. GE further indicated that the IEEE guideline "installed in cacloned racoways that qualify as barriers" has boen interpreted to mean that for EMI considerations, power cables will be routed in metallic conduit wherever they como in close proximity with low level (V1) cables. For independence between power and I\&C cables within the same division, the staff agreed with GE's interpretation. The etaff concludes that a design which meets the above described commitments as clarified will reasonably ensure that normal operation and/or failure of power circuits (Class 1E, associated, or non-Class 1E) will not adversely affect $1 \& \mathrm{C}$ circuits. The design, therefore, moets the above defined requirements of GDC 4 and 17 of 10 CFR 
Part 50, Appendix A, and is soceptablo. The atafits ovaluation for the protection of circuitu from BMI is eddreaned in Chapter 7.0 of this report. OB has included the above decien commitmente in Sections 8.3.3.1, 8.3.3.6.1.1, 8.3.3.6.1.2, 8.3.3.6.2.2.3, and 8.3.3.8.2 of SSAR Amendmeat 32, which is rcceptable. Therefore, this itom is recolved.

In addition, based on the deaign commitment to moet the guidalines of IEEE 384-1981, GE indicated that administrative control of operntions and maintenance sctivities will be uned to control and limit introduction of potential besurds into cable chases and tho control robm area. Verification that GE included in a future SSAR ameadment the statement that the COL applicant include these adminietrative controls in appropriate plant proco dures was DFSER (SECY-92-349) COL Action Item 8.3.2.7-1. GE included this action item in Section 8.3.4.26 of SSAR Amendmeat 32, which is scceptable.

\section{Certified Deaion Mnterial}

DFSER (SECY-92-349) Open Item 8.3.2.7-1 related to the design description and the ITAAC for the separation of cables approeching and/or exiting cabinots/panels. The adequacy and acceptability of the ABWR deaign descriptions and ITAAC are evaluated in Chapter 14.3 of this report. Therefore, this item is resolved.

\subsubsection{Independence and Physical Separation of Equipment}

This discussion addresses DSER (SECY-91-355) Open Item 36.

GE indicated in the draft SSAR revision dated April 3, 1992, and in discussions with the staff that Clase 1E power supply and distribution systems, equipment, and components from the power supply through the power distribution panels of different Class 1E divisions will be separated by a 3-hour rated fire barrier and a missile barrier when the potential for missiles exist.

GDC 17 of 10 CFR Part 50, Appendix A, requires that Class 1E systems, equipment, and components have sufficient independence to perform their safety functions assuming a single failure. The staff concludes that a design which meets the above described commitment will exasure that any failure of or within one division of the Alase 1E power system or its loed group will not cause a loss of function in another division of the Class 1E power system. The design, therefore, moets the above defined requirements of GDC 17 of 10 CFR Part 50, Appendix A, and is acceptable.
Verification that $\mathrm{OB}$ provided the above deaign commitmeats in a future SSAR ameadmeat was DFSER (SECY-92-349) Confirmatory Itom 8.3.2.8-1. (Section 8.3.3.5 of this report addreases sceseptable redundent circuits independences and protection from distribution ayctom power panele to connected equipment loads which are aot ecparnted by fire and/or misaile barriers.) $\mathrm{GE}$ included this commitment in Section 8.3.3.6.2.2.2 of SSAR Amendment 32, which is acceptable. Therefore, this itom is reeolved.

\section{Certified Deaion Material}

DFSER (SECY-92-349) Open Item 8.3.2.8-1 related to the design deacription and the ITAAC for the independence/physical separation of equipment. The adequacy and acceptability of the ABWR design deacriptions and ITAAC aro ovaluated in Chapter 14.3 of this report. Therefore, this item is resolved.

\subsubsection{Equipment, Cable, and Raceway Identification}

This ecction addresses the staff's evaluation of GE's reeponse to DSER (SECY-91-355) Open Item 39.

Identification of Power. Instrumentation. and Control Equipment. Cables, and Raceways

GE indicated in Section 8.3.1.3 of the draft SSAR rovision dated April 3, 1992, that the ABWR electrical system design related to identification of power, control, and instrumentation systems, equipment, and components will moet the following commitments:

- The background of the nameplate for a division's equipment will be the samo color as the electrical cable jacket markers and the cable raceway markers affiliated with that division.

- All exposed Class 1E and associated circuit raceways will be marked with the division color at $4.5 \mathrm{~m}$ (15 ft) intervals on; straight sections, at tuming points, at points of entry to and exit from rooms and enclosed areas, at discontinuities, at pull boxes, and at origins and destinations of equipment.

- Class 1E and associated circuit raceways will bo marked before their cables are installed.

- Before or during installation of all cables, for Class $1 E$ and associated circuits, will be marked with the division color at intervals of approximately $1.5 \mathrm{~m}$ (5 ft). 


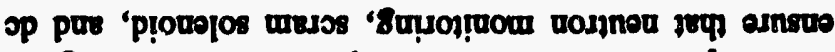

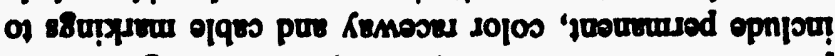

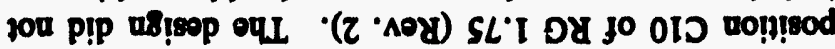

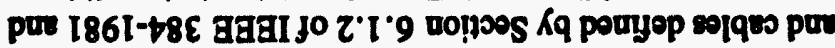
akemoses yo no!̣voy!pwop! oup 103 sou!

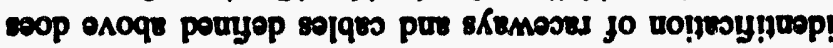
pesodord oup seq mo!̣

- voịverịisep

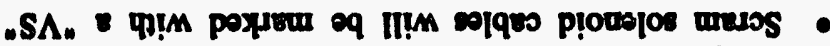
- voigunipgop

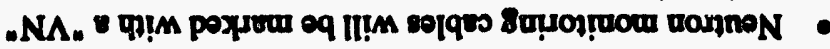

:eedas

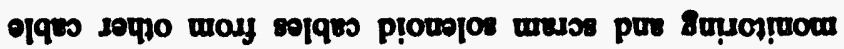

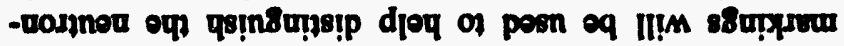

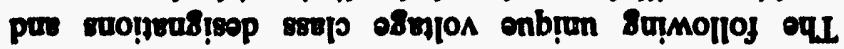

-dnars

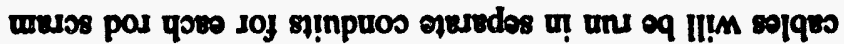

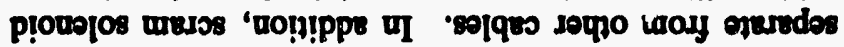
sKuี

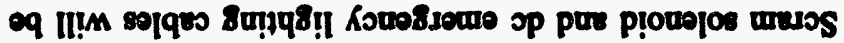
-

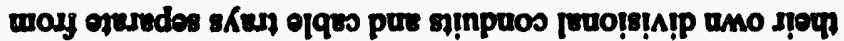

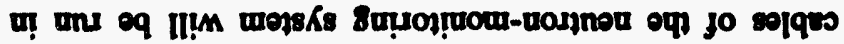

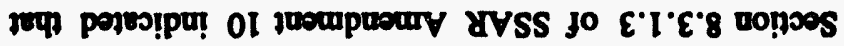

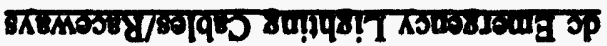

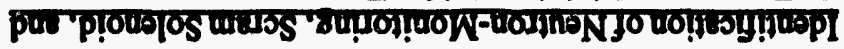

ponjoras

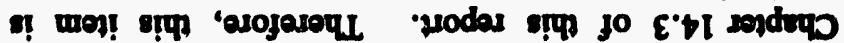

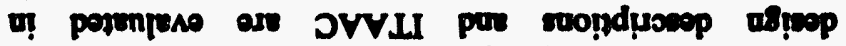

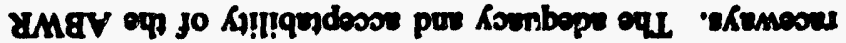

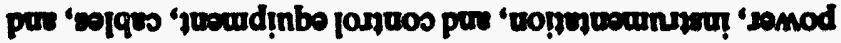

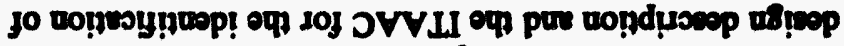

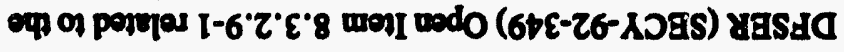

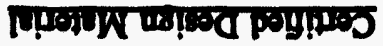

'ponjoses 8! I-6'Z'E'8 mell kJonwurywos

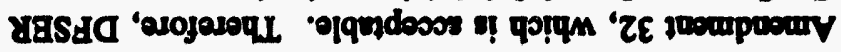

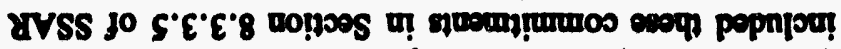

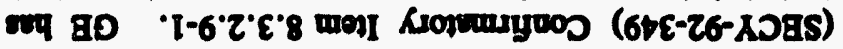

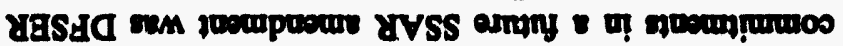

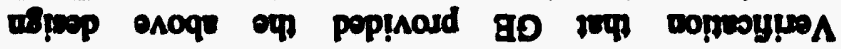

- olquidoos s! pur 'v xypueddy

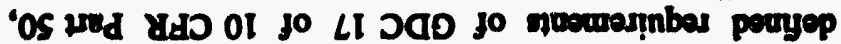

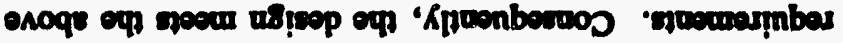

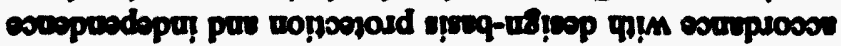

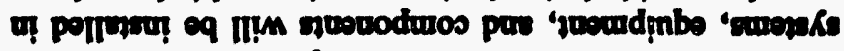

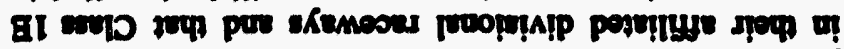

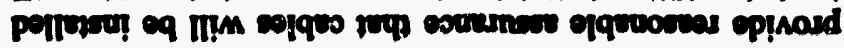

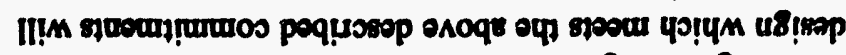

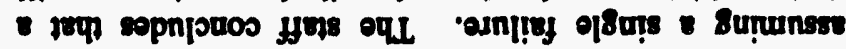

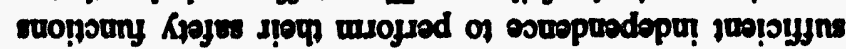

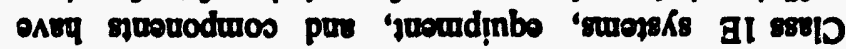
ruq earnbes ' $\forall$ xupuoddy 'OS भred yas ol jo LI Jas

- parịnbar oq II!̣

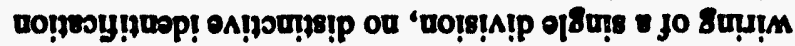

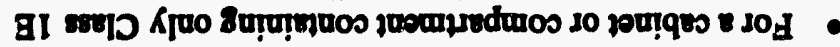

-8тبти

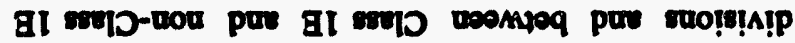

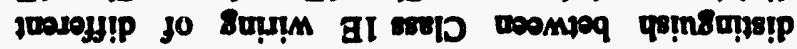

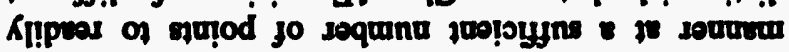

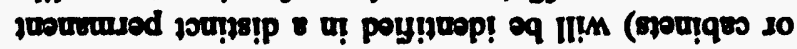

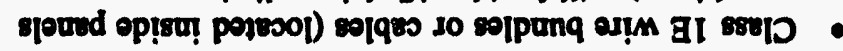

- $90 ; q 00$ pruot!i!n!p

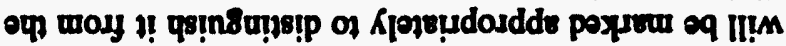

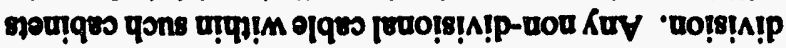

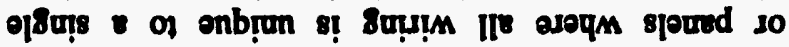

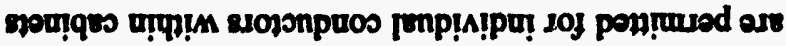

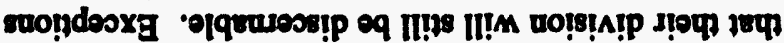

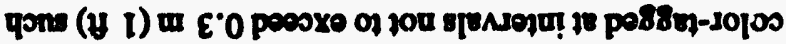

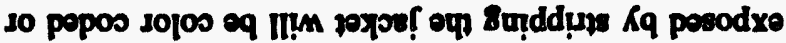

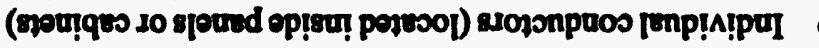

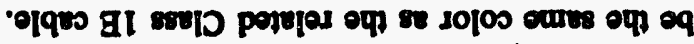

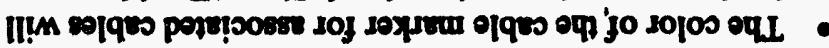

'poqpear popos-sojos soqpo so adup puipri!ruol

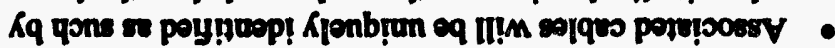

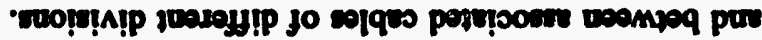

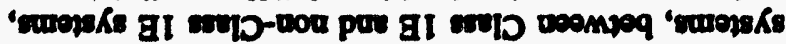

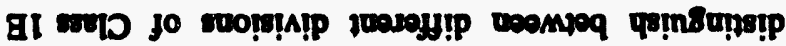

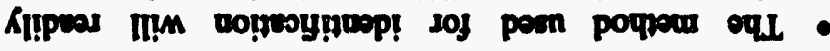

- ompogos өlqu

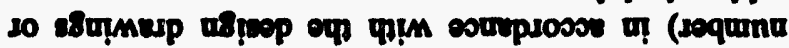

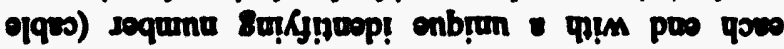

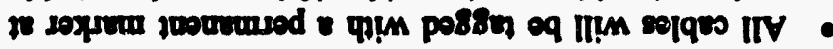

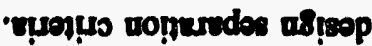

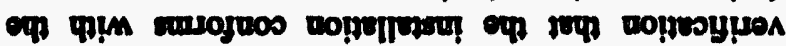

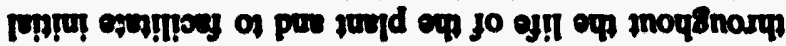

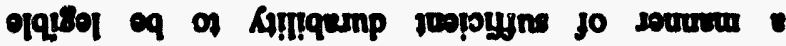

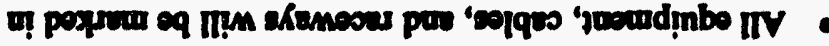

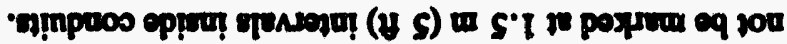

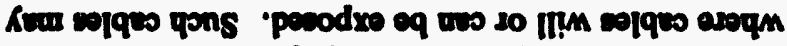

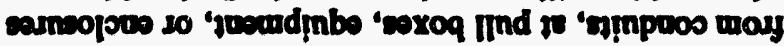

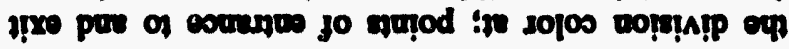

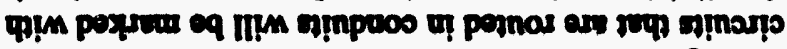

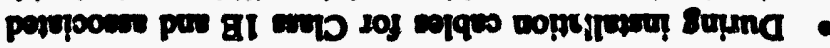




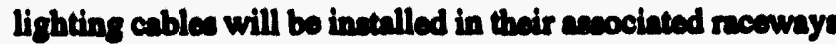
in scoordance with deaign beais protection and independence requiremente. This we DFSBR (8ECY-92-349) Open Item 8.3.2.9-2.

In reepones to this item, OE indicated that the "VN" or "VS" deaignation would be euperimponed on tho divisional color markinge on the cable and racowny. Similarly, $O B$ indicatod a "DCL" designation would be auperimponed on the color mark for de emergency lighting cables and their dedicated meeways. The etaff concludes that these designations and color coding meet the guidalines of RO 1.75 (Rov. 2). This appect of the decigat therefore consures that cables will bo inetalled in their decignated receways in sccordance with decign beais requirements and is acceptable. OB included this decign information in Sections 8.3.3.5.1.3 and 9.5.3 of SSAR Amoedment 32, which is scceptable. Therefore, this item is resolved.

\section{Certified Desion Mnterial}

DFSER (SECY-92-349) Open Item 8.3.2.9-3 related to the design description and the ITAAC for the identification of neutron-monitoring, scram solenoid, and de emergency lighting cablea/racoways. The adequacy and seceptability of the ABWR dexign deccriptions and ITAAC are evaluated in Chapter 14.3 of this report. Therefore, this item is resolved.

\subsubsection{Protection of Electrical Systems, Equipment, and Components}

Protection of Class 1E cable systems from non-Class IE cable systems by spatial separation or barrier is addressed in Section 8.3.2. Protection of Class IE cable systems by isolation devices is addressed in Section 8.3.4.

\subsubsection{Protection of Electric Penetration}

This section addresees DSER (SECY-91-355) Open Item 43.

Item 7 of Section 8.3.1.4.1.2 of SSAR Amendment 10 indicated that power circuits passing through electric penetration aseomblies are protected against overcurrent by redundent interrupting dovices. In addition, GE's response to Question 435.31(b) of SSAR Amendment 10 indicated that the ABWR design requires that redundant interrupting devices be provided for electrical circuits passing through containment penetrations, if the maximum available fault curreat (including failure of upstream dovices) is greater than the continuous current rating of the penetration.

Based on these design requirements, GE indicated that the proposed design will include redundant interrupting devices co all IsC circuits a woll a power circuits that paen through containmeat when thew circuits can produce curficient energy (maximum availeblo fult cument) to exceed the current carrying capability of containmeat penetrations. When calculating maximum available fult curreat at the pesetration, GB further indicated that curreat limiting dovicen will not bo ued in tho calculation. For example, the wort cave failure or shorting of the upatream or current limiting dovices will be sesumed as a given in the calculation. The etaff concluded that the proposed dosigen will include redundent protective devices (that is, curreat limiting and/or curreat interrupting) on all contuinment pesetration circuits in eccordance with guidalines in RO 1.63 (Rov. 3) as discuseed bolow.

Baced on the above, diccuscions with $\mathrm{GE}$, and information presented in Section 8.3.4.4 of the draft SSAR rovicion dated April 3, 1992, GB indicated that protection of eloctrical penetrations will meet the following commitmeats:

- The thermal capability of all electrical conductors within containment penetrations will be preserved and protected by two independent devices which meet requirements of IEEE 603-1980.

- The two independent dovices will be located in separate panols or will be separated by barriers.

- The two independent devices will be independent such that failure of one will not adversely affect the other.

- The two independent devices will not depend on the same power supply to accomplish their safety-related function of protecting the containment penetration.

- Analysis will demonstrate that the maximum available fult current in the event of failure of either of two dovices (that is short or open between input and output of a current limiting device or protective device fails open or closed) will be less than the maximum continuous current capecity of the conductor within the penetration and the maximum continuous current capacity rating of the penetration.

- Fault current clearing-time curves of the electrical penetrations' primary and secondary current interrupting dovices plotted against the thermal capability $\left(\mathbb{R}^{2} t\right)$ curve of the penetration will show proper coordination.

- A simplified, one-line diagram will show the location of the protective or current limiting devices in the penetration circuit, the maximum available fault current of the circuit, and specific identification and location of 
power eupplies uned to provide axternal control power for tripping primary and backup electrical penctration breakers (if utiliand).

- The dovices will be cappable of boing functionally teeted and calibrated.

In addition, Section 5.2 of IBEB 308-1980 indicates that components, equipmeat, or aysteme required to provido come protective sotion, wach as containment integrity protection, are covered by safety syetem requirements dofined in IBEB 603-1980. Based on OB's commitment to meet the guidelines of IEEB 308-1980, GB indicated that tho dovices used to protect conthinment intogrity will be covered by all afoty aystem requirements defined in IBEB 603-1980.

ODC 50 of 10 CFR Part 50, Appendix A, requires that the reactor containment structure, including penetrations, bo designed $s 0$ that the containment structure cen, without exceeding tho design leakage rate, accommodate the calculated preesure, temperature, and other environmental conditions resulting from any lose-of-coolant accident. The staff concludes that a design that meets above described commitments will provide protection of contrinment electrical penotration such that a failure of a circuit (i.e., the single failure during a design basis eveat) and single failure of a device providing protection to contrinmeat penetrations will not cause lose of contrinment integrity. The design, therefore, meets the above defined requirements of GDC 50 of 10 CFR Part 50, Appendix A, and is acceptable.

Verification that GE provided the above design commitments in a future SSAR amendment was DFSER (SECY-92-349) Confirmatory Item 8.3.3.1-1. GE has included these commitments in Sections 8.3.1.2(2)(c), 8.3.3.6.1.2, and 8.3.3.7 of SSAR Amendment 32, which is acceptable. Therefore, this item is resolved.

In addition, GE indicated that the protective devices will periodically be tested to demonstrate their functional capability to perform their required safety functions. Verification that GE included in a future SSAR amendment a statement that the COL applicant will include periodic test and calibration of protective devices in appropriate procedures was DFSER (SECY-92-349) COL Action Item 8.3.3.1-1. GE included this action item in Section 8.3.4.4 of SSAR Amendment 32, which is acceptable. Therefore, this item is resolved.

\section{Certified Desion Material}

DFSER (SECY-92-349) Open Item 8.3.3.1-1 related to the design deacription and the ITAAC for the protection of electric peactrations. The edequacy and acceptability of the ABWR doaign demeriptions and ITAAC are ovaluated in Chapter 14.3 of this report. Therofore, this item is recolved.

\subsubsection{Dedow/Qunlineation of Electrical Equipment}

Section 8.3.1.2.4 of tho drat SSAR revicion datod April 3 , 1992, in reeponse to DSER (SECY-91-355) Open Itom 45, indicated that all Clase 1E equipment is designed to operate in its normal service environment as well as in the environment expected in the aren in which it is located during and after any deaign-basis ovent. In addition, by committing to meet the guidelines of IEEE 308-1980 (Table 1.8-21 of SSAR Amendment 17), GE indicated compliance with the requirements of Section 5.9, Equipment Qualifications of IEEE 308-1980. Section 5.9 of IBEB 308-1980 requires that all Clase 1E power systom equipment shall be qualified in eccordance with IEEE 323-1974 to substantiate that it will be capable of meoting the performance requirements spocified in the design basis.

Based on this commitment, information presented in the draft SSAR revision dated April 3, 1992, and discussions with the staff, GE indicated that each type of Class 1E equipment will be

- qualified by; analysis, successful use under similar conditions, or by actual teat to demonstrate its ability to perform its function under normal and design-basis event eavironmental and operational conditions

- designed and qualified to survive the combined effects of temperature, humidity, radiation, and other conditions associated with a LOCA or other designbasis event environments at the end of their qualified and/or design life

- qualified to IEEE 344-1987, "Recommended Practices for Seismic Qualifications of Class 1E Equipment for Nuclear Power Generating Stations"

- qualified by test and/or analyzed to demonstrate its ability to meet its performance requirements during and following the design-basis seismic event

- located in seismic Category I structures

- seismically supported

- designed and qualified to operate within allowable design basis limits; (for example, able to operate for predetermined time when subject to voltage below 90 percent, to operate for a predetermined time when 
voltage is below 70 perceat, or to operate continuoualy when subjected to voltage variations of \pm 10 perceat of nominal).

All atructures, syetome, equipmeat, components, pipes and loads that aro not Claen IB and whose failure could poesibly provent Clase IB systom, equipment, componente, and circuitu including connected loads from performing thoir required afoty function will be appropriataly deaigmed and qualified to not fail in the normal and deaign-busis oveat cavironmeat for which the structures, systems, equipment, componente, pipes and loads will bo expected to function. In addition, variations of voltage, frequency, and wavoform in the Class IB power systems, during any mode of plant operation, will not dograde the performance of any eafety-related ayatem load below an acceptable level. The de systom equipment and loads will bo designed and qualified to perform their required safotyrelated function while operating with voltages between 100 to 140 volts at the dc system's 125-volt distribution proels.

GDC 2 and 4 of 10 CFR Part 50, Appeadix A, requires that Class 1E systems, oquipment, and componeats be designed (1) to withetand the effects of natural phenomena without lose of capability to perform their safoty functions, (2) to accommodate the effects of and to be compatible with the environmental conditions aseociated with normal operation, maintenance, teating, and postulatod accidents, and (3) bo appropriately protected against dynsmic offects. GDC 17 of 10 CFR Part 50, Appendix A, requires that the Class 1E systems, equipment, and compunents have sufficient independence to perform their safety functions assuming a single failure. The staff concludes that a design that meets the above commitments will provide protection to Class 1E systems, equipment, and componeats during design basis events such that there will be reasonable assurance that Class 1E systems will bo capable of performing their required function. The electrical system design, therefore, meets the above defined requirements of GDC 2, 4, and 17 of 10 CFR Part 50, Appendix A, and is acceptable.

Verification that $G E$, provided the above design commitments in a future SSAR amendment was DFSER (SECY-92-349) Confirmatory Item 8.3.3.2-1. In response to this item, GE further modified their design to indicate that the Class 1E systems, equipment, and components conform to seismic Category I requirements and are housed in seismic Category I structures in accordance with the above design information except for some control sensors associated with the reactor protection system and the leak detection system which are housed in the turbine building which is not a seismic Category I structure. For these exceptions, GE has indicated that the feeders between Class 1E systems located in seismic Category I structures (cafety clans atnctures) and syotems that are not located in enimic Catogory I taructures will bo providod with Claw 1B protective devices (wich as coordinated circuit breakens) located in a seismic Catogory I atructure. By committing to moet the suidelines of IBEE 308-1980 (Tablo 1.8-21) of SSAR Amendment 17), GB indicated complience with the requirements of Section 5.2 of IEEB 308-1980. Section 5.2 of IEEB 308-1980 requires that components, equipment, or aystoms utilized to provide isolation protection are covered by safety syctem deaign requirements dofined in IBEB 603-1980. The etaff coacluded that the Clase 1B claecification for the protective devioes utilized to provide an ieolation protection function in the proposed modified dosign meots the guidelines of Section 5.2 of IEEE 308-1980. The staff concludes that a deaign that meots the above deacribed commitments will also provide prolection to Class IE systems such that there will be reasonable aseunance that Clase IE systems will be capable of performing their required function. Tho electrical system design, therefore, meets the above defined requirements of GDC 2, 4, and 17 of 10 CFR Part 50, Appendix A, and is acceptable. OE has included tho above design commitments in Sections 3.11.2, 8.1.3.1.1.1, 8.3.1.1.5, 8.3.1.1.7, 8.3.2.1.3.1, and 8.3.3.4 of SSAR Amendment 32, which is acceptable. Therefore, this itom is rosolved.

\section{Certified Desion Material}

DFSER (SECY-92-349) Open Itom 8.3.3.2-1 related to the design description and the ITAAC for the design/qualification of Class IE electrical equipment. The adequacy and accoptability of the ABWR design descriptions and ITAAC are evaluated in Chapter 14.3 of this report. Therefore, this itom is resolved.

\subsubsection{Seismic Qualification of Light Bulbs}

In response to DSER (SECY-91-355) Open Item 45, GE provided draft SSAR revision dated April 3, 1992, Section 8.3.2.2.2, identifying an exception to the requirement that all Class IE equipment is seismically qualified. $G E$ indicated that the safety-related dc standby lighting system is powered from the Class $1 E$ dc system and that the lighting system circuits from the Class $1 E$ de system power source to the lighting fixtures will be treated as Class 1E circuits (that is, these circuits will be classified as aseociated) and will be routed in seismic Category I noceways. The lighting fixtures themselves will not be seismically qualified, but will be seismically supported. The bulbs cannot be seismically qualified.

To justify this exception, GE indicated that bulbs can only fail open, and, therefore, do not represent a hazard to the Class IE power source. 
Band on albeaqueat discustions with $O B$, the ataff determined that lighting fixtures will be coismically qualified. Light bulbe may fril during and/or following a ciemio oveat thescby extinguishing the light; bowover, tho light bullbe will be replecenble. (The etafire eveluation of lighting requiremente is in Section 8.3.5 of this report.) In addition, bulbe will sot fail in a manner that could cause fillure of other eafety-rolated syatems and will not becomo a hemard to perconeol or affety-related equipment during or following a coismic oveat.

ODC 4 of 10 CFR Part 50, Appeadix A, requires that Clan 1B system, equipment, and components bo designed to eccommodate the effects of and to be compatible with the covironmental conditions aneociated with normal operation, maintenunce, teating, and pontulated eccidents. ODC 17 of 10 CFR Part 50, Appeadix A, requires that the Clase 1B syetems, equipment, and composents have arficient independence to perform their afoty functions seouming a single failure. The staff concludes that lighting circuits that are treated as Clase IB except for the soismic qualification of light bulbs and which include seismically qualified light bulb fixtures will provide protection to Clase 1E systems auch that there will be reasonable sesurance that the lighting systems will not prevent the Clase 1B systoms from performing their required function. Consequently, the design meets the above dofined requiroments of GDC 4 and 17 of 10 CFR Part 50, Appendix A, and is acceptablo.

Verification that $O B$ provided the above design commitments in a future SSAR amendment was DFSER (SECY-92-349) Confirmatory Item 8.3.3.3-1. In response to this item, GE indicated that lighting fixtures are seismically supported but not seismically qualified as indicated above. GE further indicated tbat overcurrent protective devices and their coordination would provide protoction and isolation of the Class 1E power supply from possible failure of non-seismically qualified fixtures during a seismic ovent. The staff concluded that Class IE systems will be adequately protected from failure of the non-seismically qualified fixtures as well as the nonseismically qualified light bulbs during a soismic ovent. By committing to meet the guidelines of IEEE 308-1980 (Table 1.8-21 of SSAR Amendment 17), GE indicated compliance with the requirements of Section 5.2 of IEEE 308-1980. Section 5.2 of IEEE 308-1980 requires that components, equipment, or systems utilized to provide isolation protection are covered by safety system design requirements defined in IEEE 603-1980. The staff concluded that the overcurrent protective devices and their coordination which are utilized to provide an isolation protection function to the Class IE system from failure of the non-seismically qualified fixtures will meet the guidelines of Section 5.2 of IEEE 308-1980 and thus will mod cafoty syetom deaign requiroments dofined in IEBE 603-1980.

The ataff concludes that lighting circuits that are treated as Claw 1B except for coismic qualification of light bulbs and fixtures and include profective dovices which moot enfety ayetem requirements will provide protection to Clas 1B aystoms ach that thero will be reasonable seourance that the lighting systoms will not prevent the Clase 1B syeteme from performing their required function. Conequently, the deaign moets the above defined requirements of ODC 4 of 10 CFR Part 50, Appendix A, and is eccoptable. GE hes included the above design commitments in Soctions 8.3.2.2.2, 9.5.3.1.1,9.5.3.2.2.1, and 9.5.3.2.3.1 of SSAR Amendment 32, which is ecceptable. Therefore, this item is resolved.

\section{Cortified Desion Mnteris}

DFSER (SECY-92-349) Open Item 8.3.3.3-1 related to the design description and the ITAAC for the protection of Class 1E aystems from the non-seismically qualified light fixtures and bulbs. The adequacy and acceptability of the ABWR design descriptions and ITAAC are ovaluated in Chapter 14.3 of this report. Therefore, this item is recolved.

\subsubsection{Submergence}

Ilem (6) of Section 8.3.1.4.2.3.2 of SSAR Amendment 10 stated that any RPS or ESF electrical equipment and/or racoway located in the suppression pool level swell zone will bo designed to satisfactorily complete its function before being rendered inoperable due to exposure to the environment created by the level phenomena. In response to staff Question 435.36 of SSAR Amendment 10, GE identified electrical equipment that may be submerged as a result of suppression pool level swell phenomena or as a result of a LOCA. GE further indicated that the design specifications associated with this electric equipment would require that electrical terminations be sealed such that equipment operation would not be impaired by submersion. However, GE did not specifically address the qualification of this equipment in accordance with the guidelines of Section 4.7 of IEEE 308-1974.

Based on information presented, it appeared that electrical equipment subject to submergence was not qualified and only partially designed for submergence. This conclusion contradicted Section 8.3.1.2.1 of Amendment 10 to the SSAR which stated that all Class 1E equipment is qualified.

The staff was concerned that equipment failure due to submergence could adversely affect the safe operation of 


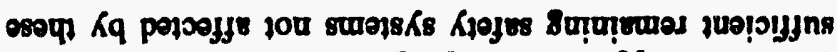

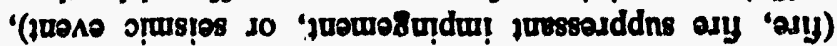

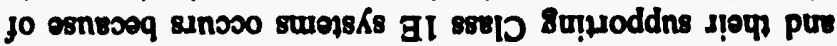

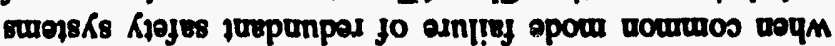
j84 pornsse s?

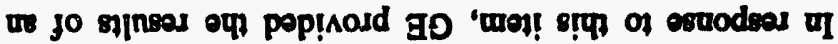

I-S.E. E'8 menI

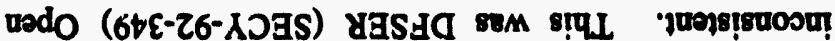

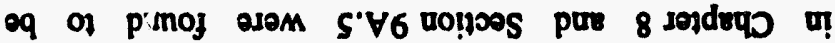

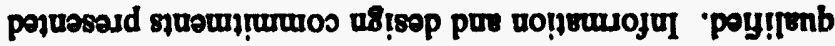

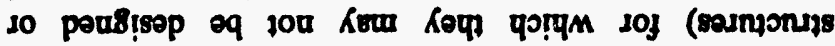
ọms!es-uod pue "jussserddns asy 'asy 8ụpnjou!)

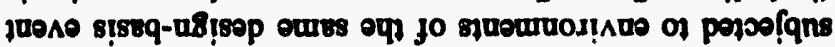

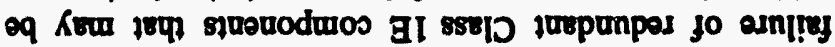
of onp swejsks remod al sselp popsojfe oq of uonponard

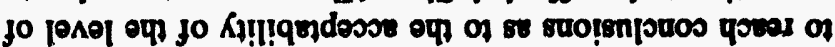

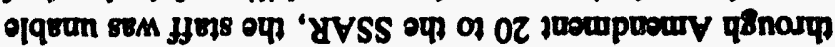

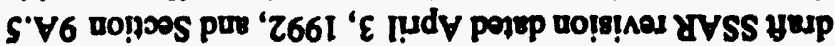

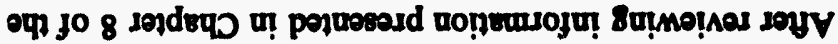

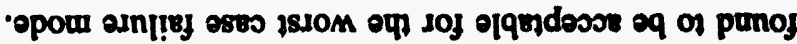

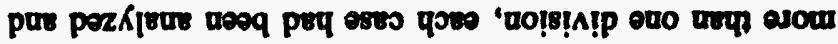
jo solq"o vo posurdu! juvseasddins ary asoym jwप popwo!pu!

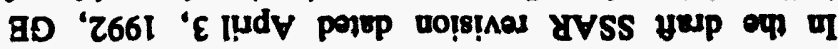

Lb menI nedo (SSE-16-XOAS) yaSa

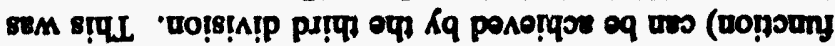

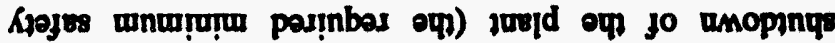

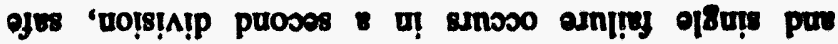

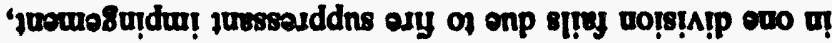

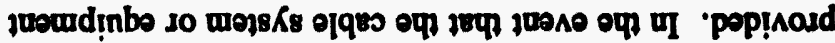

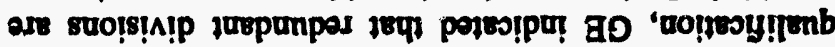

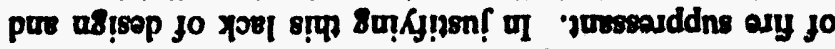
juowosụdu! joel!p oqp of popor!qns sụeq o!̣m vo!̣ouny

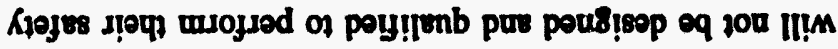

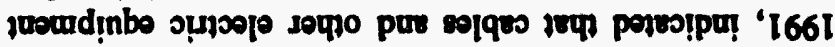

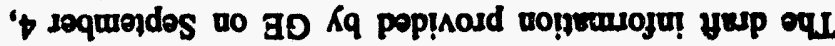

'jussouddns ayy jo jwowesundu!

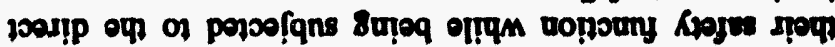

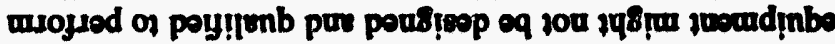

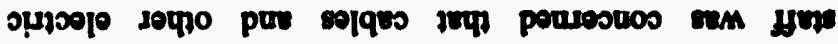

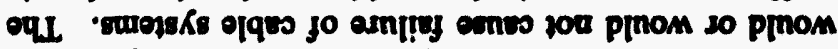

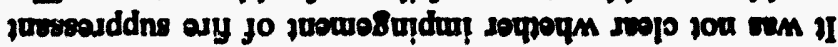
- umopjnqe sosoves ojes jossasd jou IIIM jurseasddns ary jo

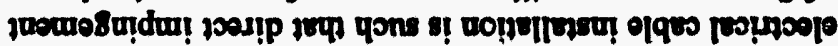

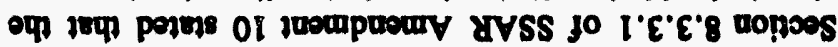

gquounadyag ģoeg ufigea uoumuos

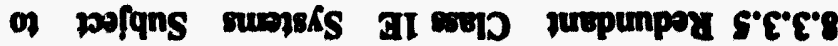

penjorar

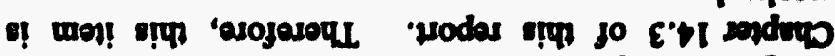

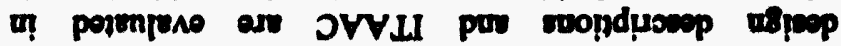

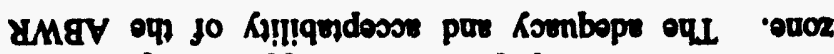

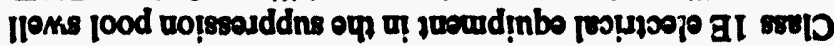

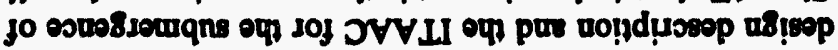

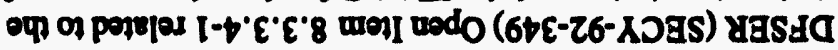

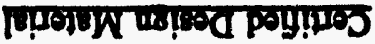

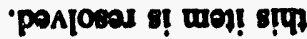

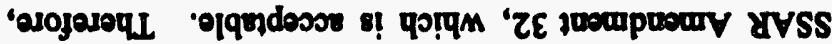

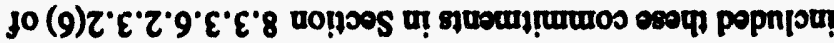

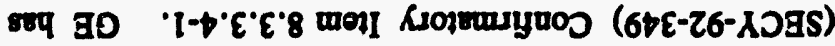

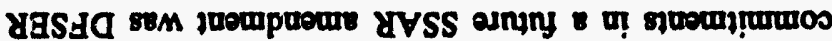

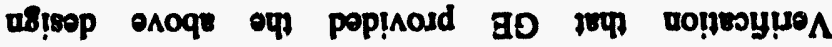

-

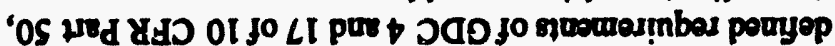

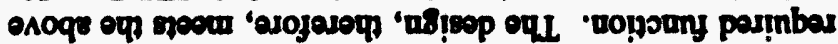

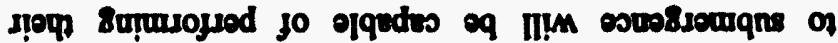

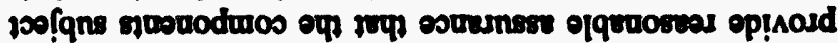

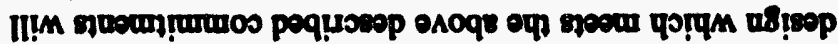

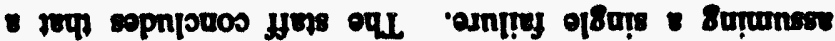

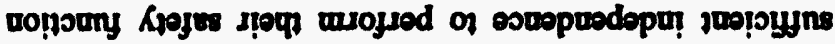

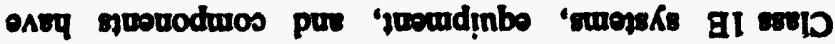

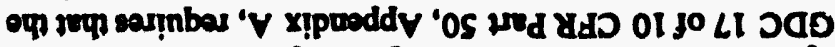

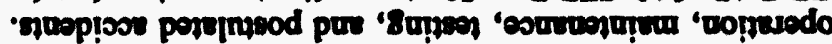

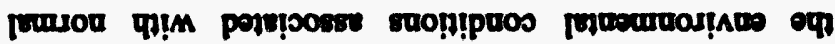

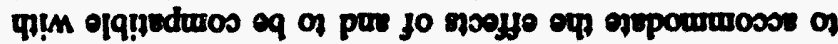

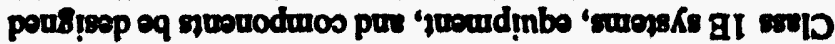

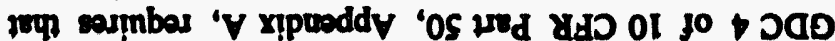

- equedo

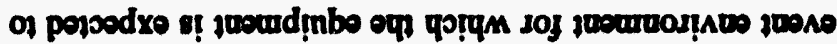

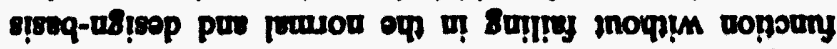
Kiojes parmbas a! usojed of poy!lmb pur powitiop

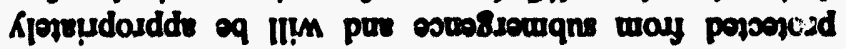

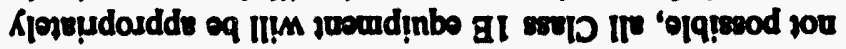

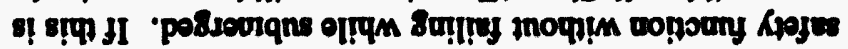

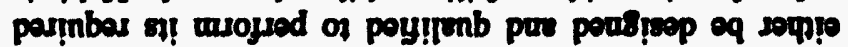

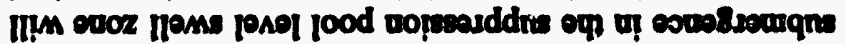

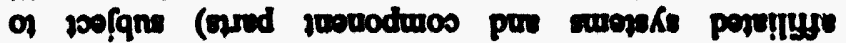

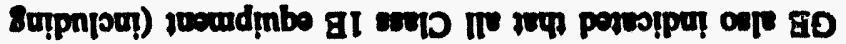

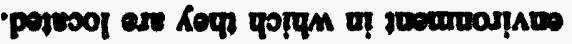

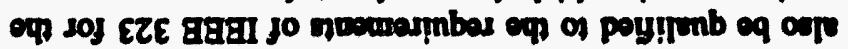

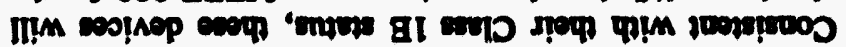

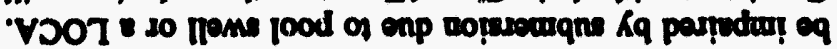

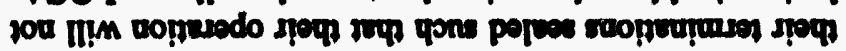

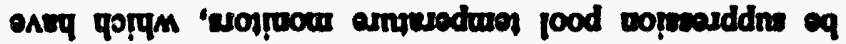

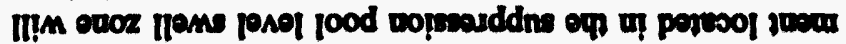

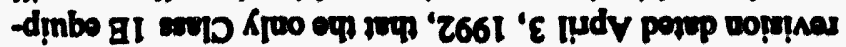

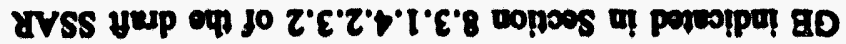

-9t won ado (SSE-I6-XOES)

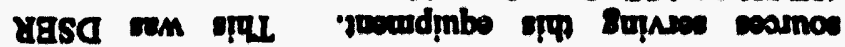

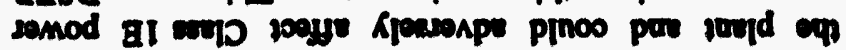


sume events are available to accomplish the required enfety function. The results of this analysis, indicated that Clase IE power systems will be protected by circuit protective dovices and thoir coordinntion or current limiting dovices, in onder to senure the continued operntion of Clase 1B system in sccordance with thoir required anfoty function. By committing to meet the guidelines of IEEE 308-1980 (Table 1.8-21 of SSAR Amendment 17), GE indicated complience with the requirements of Section 5.2 of IEEE 308-1980. Section 5.2 of IEEE 308-1980 requires that components, equipment, or systems utilized to provide isolation protection are covered by safety system design requirements defined in IEEE 603-1980. The staff concluded that the overcurrent protective devices and their coordination or current limiting dovices which are utilized to provide an isolation protection function to the Clase 1B syetoms will meet the guidelines of Section 5.2 of IEEE 308-1980 and thus will meet safety system design requirements defined in IEEE 603-1980.

GDC 4 of 10 CFR Part 50, Appendix A, requires that Class 1E systems, equipment, and components bo designed to accommodate the effects of and to be compatible with the environmental conditions associated with normal operation, maintenance, testing, and postulated accidents. GDC 17 of 10 CFR Part 50, Appendix A, requires that the Class 1E systems, equipment and components have sufficient independence to perform thoir safety function assuming single failure. The staff corsludes that a design that meets the above commitments will adequately protect Class 1E systems such that there will be reasonable assurance that redundant system will not fail. Consequently, the design meets the above defined requirements of GDC 4 and 17 of 10 CFR Part 50, Appendix A, and is acceptable. GE has included the results of this analysis and the above commitments in Sections 8.3.1.2(2)(c) and 9A.5 of SSAR Amendment 32, which is acceptable.

\section{Certified Desien Material}

DFSER (SECY-92-349) Open Item 8.3.3.5-2 related to the design description and the ITAAC for the protection of redundant Class 1E systems subject to common design basis environments. The adequacy and acceptability of the ABWR design descriptions and ITAAC are evaluated in Chapter 14.3 of this report. Therefore, this item is resolved.

\subsubsection{Associated Circuits}

Based on discussions with GE and information presented in Section 8.3.1.1.5.1 of the draft SSAR revision dated April 3, 1992, in response to DSER (SECY-91-355) Open Item 38, GE indicated that the ABWR electrical system deaign related to associated circuits will meet the following commitments:

- Amecinted circuits will remain with or be physically ceparated in the same manner as those Class $1 E$ circuits with which they are associated;

or

Associated circuits, will remain with or be physically separated in the same manner as those Class 1E circuits with which they are associated, from the Class 1B equipment to and including an isolation device.

- Arsociated circuits (including their isolation dovices or their connected loeds without isolation devices) will be abject to all requirements placed on Class $1 E$ circuits.

- Non-Class 1E circuits powered from a Class 1E power supply will be limited to power circuits related to the FMCRDs and lighting systems.

GDC 4 of 10 CFr. Part 50, Appendix A, requires that Class 1E systems, equipment, and components be designed to sccommodate the effects of and to be compatible with the environmental conditions associated with normal operation, maintenance, testing, and postulated accidents. GDC 17 of 10 CFR Part 50, Appendix A, requires that the Class 1B systems, equipment, and components have sufficient independence to perform their safety function assuming a single failure. The staff concludes that a design which meets the above described commitments will provide adequate protection and independence for Class 1E systems. The design, therefore, meets the above defined requirements of GDC 4 and 17 of 10 CFR Part 50, Appendix A, and is acceptable.

Verification that GE provided the above design commitments in a future SSAR amendment was DFSER (SECY-92-349) Confirmatory Item 8.3.3.6-1. GE has included the above design commitments in Sections 8.3.3.1 and 8.3.1.1.1 of SSAR Amendment 32, which is acceptable. Therefore, this item is resolved.

\section{Certified Desion Material}

DFSER (SECY-92-349) Open Item 8.3.3.6-1 related to the design description and the ITAAC for associated circuits. The adequacy and acceptability of the ABWR design descriptions and ITAAC are evaluated in Chapter 14.3 of this report. Therefore, this item is resolved.

The staff determined that a commitment was required in the design description of electrical systems that states that non-Class IE circuits connected to the Class IE system 
shall be limited to circuits in the FMCRD and lighting subsystems. This wes Open Item F8.3.3.6-1 identified in the advance version of the SER. GE has included this commitment in the design description of Section 2.12.1 and 2.12.12 of the certified design material. The staff finds this scceptable. This resolved Open Itom F8.3.3.6-1.

\subsubsection{Diesel Generator Protective Relaying Bypass}

Section 8.3.1.1.6.4 of SSAR Amendment 10 indicated that the following identified protective relaying will trip the diesel generator and will be retained under LOCA conditions. This relaying included the generator differential, bus differential, engine over speed, low diesel cooling water pressure (two out of two sensors), and low differential pressure of secondary cooling water (two out of two sensors). Other diesel generator protective trips will be bypassed during LOCA conditions.

GE responded to DSER (SECY-91-355) Open Item 49 in Section 8.3.1.1.6.4 of the draft SSAR revision dated April 3, 1992, where they indicated that only the generator differential relays and engine overspeed trip would be retained under accident conditions. Other protective relays, such as loss of excitation, antimotoring (reverse power) overcurrent voltage restraint, low jacket water pressure, high jacket water temperature, and low lube oil pressure are automatically removed from the tripping circuits during LOCA conditions.

By committing to meet the guidelines of IEEE 308-1980 (Table 1.8-21 of SSAR Amendment 17), GE indicated compliance with the requirements of Section 5.2 of IEEE 308-1980. Section 5.2 of IEEE 308-1980 requires that components, equipment, or systems that provide some protection to Class $1 E$ systems are covered by safety system design requirements defined in IEEE 603-1980. The staff concluded that the diesel generator protective relying bypass circuitry which are utilized to provided protection to the Class 1E systems will meet the guidelines of Section 5.2 of IEEE 308-1980 and thus will moet safety system design requirements defined in IEEE 603-1980. By committing to meet the guidelines of RG 1.9 (Rev. 3) (Table 1.8-20 of SSAR Amendment 33), GE indicated compliance with the requirements of Position C-1.8 of the RG. Position C-1.8 requires that the diesel generator protective relay bypass system design include the capability for testing the status and operability of the bypass circuitry, for alarming in the control room for abnormal values of all bypass parameters, and for resetting the trip bypass function manually (automate reset is not acceptable). Based on the above commitment and the commitment to meet the guidelines of Position C-1.8 of RG 1.9 (Rev. 3) and Section 5.2 of IEEE 308-1980 contained in Section 8.3.1.2.1(2)(b) of the draft SSAR revision dated April 3, 1992, and Table 1.8-21 of SSAR Amendment 17, information presented in the draft SSAR rovision dated April 3, 1992, and discussions, GE's indicatod that:

- the dosign of the bypass circuitry will moet all the requirements of IEEE 603-1980

- abnormal values of all bypassed parameters will be alarmed in the control room so that the control room operator can react appropriately to the abnormal condition on the diesel generator unit

- the trip bypass function will be capable of being reset menually (capability for automatic reset is not acceptable)

- the protoctive relaying and its bypass circuitry will have the capability to be tested periodically

GDC 4 of 10 CFR Part 50, Appendix A, requires that Class 1E systems, equipment, and components be designed to accommodate the effects of and to be compatible with the environmental conditions associated with normal operation, maintenance, testing, and postulated accidents. GDC 17 of 10 CFR Part 50, Appendix A, requires (1) that offsite and onsite power systems have sufficient capacity and capability to permit safety systems to perform their required safety function and (2) that the Class $1 E$ systems, equipment and components have sufficient independence and testability to perform their safety functions assuming a single failure. GDC 18 of 10 CFR Part 50, Appendix A, requires that electric power systems important to safety be designed to permit appropriate periodic inspection and testing of important areas and features. The staff concludes that a design which meets the above described commitments will provide reasonable assurance that the protective relaying (to be installed on Class 1E diesel generators to protect the diesel generator from failure) will be bypassed during accident conditions so that the diesel generator will not be prevented from performing its required safety function under accident conditions due to operation or failure of the protective scheme. Consequently, the design meets the above defined requirements of GDC 4,17, and 18 and is acceptable.

Verification that GE provided the above design commitments in a future SSAR amendment was DFSER (SECY-92-349) Confirmatory Item 8.3.3.7-1. GE included this information in Secticn 8.3.1.1.6.4 of SSAR Amendment 32, which is acceptable. Therefore, this item is resolved.

In addition, GE indicated that the protective relays and their bypass circuitry will be periodically tested. 
Verification that GE specified in - future SSAR amendment that the COL applicant will include periodic teeting of protective relays and their bypess circuitry in appropriate procedures was DFSER (SECY-92-349) COL Action Item 8.3.3.7-1. GE included this action item in Section 8.3.4.22 of SSAR Amendment 32, which is acceptable.

\section{Cortified Desion Material}

DFSER (SECY-92-349) Open Item 8.3.3.7-1 related to the design description and the ITAAC for the diesel generator protective relaying and their bypass. The adequacy and acceptability of the ABWR design doecriptions and ITAAC are evaluated in Chapter 14.3 of this report. Therefore, the above open item is resolved.

\subsubsection{Thermal Overloads}

GE's response to Question 435.60 in SSAR Amendment 10 indicated that thermal overload protection for Class 1E motor operated valves (MOVs) is in effect only when the MOVs are in test mode. The thermal overload protection is bypassed at all other times by means of closed contacts in parallel with the thermal overload contacts.

GE responded to DSER (SECY-91-355) Open Item 50, in Section 8.3.1.2.1(2)(g) and Section 8.3.2.2.2(2)(f) of the draft SSAR revision dated April 3, 1992, where it was indicated that the thermal overload protection for Class 1E MOVs will be in effect during normal plant operation but the overloads will be bypassed under accident conditions as specified by Position 1.(b) of RG 1.106 (Rev. 1).

By committing to meet the guidelines of IEEE 308-1980 (Table 1.8-21 of SSAR Amendment 17), GE indicated compliance with the requirements of Section 5.2 of IEEE 308-1980. Section 5.2 of IEEE 308-1980 requires that components, equipment, or systems that provide some protection to Class 1E systems are covered by safety system design requirements defined in IEEE 603-1980. Based on this commitment, the staff concluded that the thermal overload protection bypass circuitry for Class 1E MOVs (which is utilized to provide protection to motors of MOVs in the Class 1E system) will meet the guidelines of Section 5.2 of IEEE 308-1980 and thus the safety system design requirements defined in IEEE 603-1980. In addition, GE indicated that the thermal overload and its bypass circuitry will have the capability to be tested periodically.

GDC 4 of 10 CFR Part 50, Appendix A, requires that Class 1E systems, equipment, and components be designed to accommodate the effects of and to be compatible with the environmental conditions associated with normal operation, maintenance, teating, and postulated accidents. GDC 17 of 10 CFR Part 50, Appendix A, requires (1) that offisito and onsito power systems have sufficient capacity and capability to permit safety systems to perform their required anfety function and (2) that the Class 1E systems, equipment, and components have sufficient independence to perform their safety function assuming a single failure. GDC 18 of 10 CFR Part 50, Appendix A, requires that Class 1E power gystems be designed to permit appropriate periodic inspection and testing of important areas and features. The staff concludes that a design which moets the above doscribed commitments will provide reasonable aesurance that the thermal overload protection to be installed on Clase IE motor operated valves will be bypassed during accident conditions so that the Class 1E valve motor will not be prevented from performing its required safety function under accident conditions due to operation or failure of the thermal overload devices. Consequently, the design meets the above defined requirements of GDC 4, 17, and 18 and is acceptable.

Verification that GE provided the above design commitments in a future SSAR amendment was DFSER (SECY-92-349) Confirmatory Item 8.3.3.8-1. GE has included these commitments in Sections 8.3.1.2(2)(g) and 8.3.2.2.2(2)(f) of SSAR Amendment 32, which is acceptable. Therefore, this item is resolved.

In addition, GE indicated that the thermal overloads and their bypass circuitry will periodically be tested. Verification that GE specified in a future SSAR amendment that the COL applicant will include periodic testing of thermal overloads and their bypass circuitry in appropriate procedures was DFSER (SECY-92-349) COL Action Item 8.3.3.8-1. GE included this action item in Section 8.3.4.24 of SSAR Amendment 32, which is acceptable.

\section{Certified Desien Material}

DFSER (SECY-92-349) Open Item 8.3.3.8-1 related to the design description and the ITAAC for the thermal overloads. The adequacy and acceptability of the ABWR design descriptions and ITAAC are evaluated in Chapter 14.3 of this report. Therefore, this item is resolved.

\subsubsection{Breaker Coordination}

Section 8.3.1.1.2.1 of SSAR Amendment 10 stated that tripping of the Class 1E bus feeder breaker is normal for faults that occur on its Class IE loads. The staff disagreed with this statement. Class 1E load breakers should be coordinated with the Class $1 E$ bus feeder breaker so that faults which occur on its Class IE loads will, to the extent 
possible, not cause the bus feeder breaker to trip. A design which utilizes coordinated breakers minimizes the potential for lose of safety-related systems. This whes DSER (SECY-91-355) Open Itom 51.

The draft information provided by GE on September 4, 1991, revised the SSAR to delete the statement that tripping of the bus supply breaker is normal for faults that occur on its Class 1E loads. GE further indicated that the Class IE load and bus supply breakers will be coordinated.

GDC 4 of 10 CFR Part 50, Appendix A, requires that Class 1E systems, equipment, and components be designed to accommodate the offects of and to be compatible with the environmental conditions associated with normal operation, maintenence, teating, and postulated accidents. GDC 17 of 10 CFR Part 50, Appendix A, requires (1) that offsite and onsite power systems have sufficient capacity and capability to permit safety systems to perform their required safety function and (2) that the Class IE systems, equipment, and components have sufficient independence to perform their safety function assuming a single failure. The staff concludes that a design which meets the above commitment will minimize to the extent practicable the effect of single Class 1E components or equipment failure. The design, therefore, meets the above defined requirements of GDC 4 and 17 of 10 CFR Part 50, Appendix A, and is acceptable.

Verification that GE provided the above design commitment in a future SSAR amendment was DFSER (SECY-92-349) Confirmatory Item 8.3.3.9-1. GE has included these commitments in Section 8.3.1.1.1 of SSAR Amendment 32, which is acceptable.

\subsubsection{Protective Relaying}

This section addresses DSER (SECY-91-355) Open Item 52.

Experience with protective relay applications has established that relay trip setpoints will drift with conventional relays. Setpoint drift at nuclear power plants has resulted in premature tripping of redundant, safetyrelated pump motors when they were required to be operative. While the staff recognizes the basic noed for proper fault protection for feeders and equipment (and while such protection may be required for some designbasis events such as fire), the total non-availability of redundant safety systems due to spurious trips of protective relays is not acceptable. GE responded to this concern (Question 435.58 of SSAR Amendment 10) and indicated Ciat loads, such as motors, will be designed with sufficient current carrying capability or overload margins so that setpoints of protective devices can be set sufficiently above the operating current point of loads to allow for setpoint drift. The use of loads, such as motors, with sufficient overlond margins resolves the staff's concern if one ascumes the following:

- Specific design parameters clearly define the overloed margin requirements with respect to; protective devico trip setpoints, the margin between the trip setpoint and operating current point of loads, setpoint drift, and the margin between the trip setpoint and overload rating of loads.

- The protective device trip setpoint is periodically verified and calibrated.

- The protective device is periodically subjected to a functional test to demonstrate that it does not trip at its design rating (the normal operating current of load plus margin) and that it does trip when subjectod to a fault current.

The staff was concerned earlier in the review that the ABWR design may not satisfy the above assumptions.

By committing to meet the guidelines of IEEE 308-1980 (Table 1.8-21 of SSAR Amendment 17), GE indicated compliance with the requirements of Section 5.2 of IEEE 308-1980. Section 5.2 of IEEE 308-1980 requires that components, equipment, or systems that have no direct safety function and are only provided to increase the availability or reliability of the Class $1 \mathrm{E}$ power systems shall meet those safety system design requirements defined in IEEE 603-1980 to assure that those components; equipment, and systems do not degrade the Class 1E power system below an acceptable level. Based on the design commitment to meet the guidelines of Section 5.2 of IEEE 308-1980, information presented in the draft SSAR revision dated April 3, 1992, and discussions, GE indicated that:

- protective relaying design will meet the above defined assumptions (that is, there will be protective device trip setpoint margin and capability to functionally test and calibrate the protective relaying)

- protective relaying-as well as all other components, equipment, and systems within the Class $1 \mathrm{E}$ power system (that have no direct safety function and are only provided to increase the availability or reliability of the Class 1E power systems) including the diesel generator protective relaying and thermal overload protective devices which are bypassed during accident conditions-will meet those requirements of IEEE 603-1980 that assure that the consequences of 
any operntion or failure is acceptable to the Clase IE power syetem

GDC 4 of 10 CFR Part 50, Appendix A, requires that Class 1B aystems, equipment, and components be designed to accommodato the effects of and to be compatible with the environmental conditions associated with normal operation, maintenance, testing, and postulated accidents. GDC 17 of 10 CFR Part 50, Appendix A, requires (1) that offsite and onsito power systems have sufficient capacity and capability to permit safety systems to perform their required safoty function and (2) that the Class IE systoms, equipment, and components have eufficient independence and testability to perform thoir safety functions assuming - single failure. GDC 18 of 10 CFR Part 50, Appendix A, requires that Clase 1E power eystems be designed to permit appropriate periodic inepection and testing of important areas and features. The staff concludes that a design that meets the above commitments will assure that when these components, equipment, or systems are used that have no direct safety function their operation or failure will not significantly reduce the capability of the Class $1 E$ power system from performing its safety function when required. The design, therefore, meets the above defined requirements of GDC 4,17 , and 18 of 10 CFR Part 50, Appendix A, and is acceptable.

Verification that GE provided the above design commitments in a future SSAR amendment was Confirmatory Item 8.3.3.10-1. GE has included these commitments in Sections 8.3.1.2(2)(c) and 8.3.2.2.2(2)(b) of SSAR Amendment 32, which is acceptable. Therefore, this item is resolved.

In addition, $G E$ indicated that the protective relaying will periodically be tested. Verification that GE specified in a future SSAR amendment that the COL applicant will include these periodic tests in appropriate plant procedures was DFSER (SECY-92-349) COL Action Item 8.3.3.10-1. GE included this action item in Section 8.3.4.27 of SSAR Amendment 32, which is acceptable.

\section{Certified Design Material}

DFSER (SECY-92-349) Open Item 8.3.3.10-1 related to the design description and the ITAAC for protective relaying. The adequacy and acceptability of the ABWR design descriptions and ITAAC are evaluated in Chapter 14.3 of this report. Therefore, this item is resolved.

\subsubsection{Fault Interrupting Capacity}

Section 8.3.1.1.5.2(4) of SSAR Amendment 10 stated that the interrupting capacity of switchgear, load centers,
MCC, and distribution panels is compatiblo with the short-circuit current available at the Class IE buses. It was not clear whether the interrupting capacity of this equipment would be equal to or greater than the maximum available fault current to which it would be exposed for all modes of operation (for example, with the diesel generator operating in parallel with the grid).

Section 8.3.1.1.5.2(4) of the draft SSAR revision dated April 3, 1992, in response to DSER (SECY-91-355) Open Item 53, indicated that the interrupting capacity of switchgear, load centers, MCCs, and distribution panels will be equal to or greater than the maximum available fault curreat to which the equipment is exposed under all modes of operation.

GDC 4 of 10 CFR Part 50, Appendix A, requires that Class 1E systems, equipment, and components be designed to accommodate the effects of and to be compatible with the environmental conditions associated with normal operation, maintenance, testing, and postulated accidents. GDC 17 of 10 CFR Part 50, Appendix A, requires (1) that offsite and onsite power systems have sufficient capacity and capability to permit safety systems to perform their required safety function and (2) that the Class 1E systems, equipment, and components have sufficient independence and testability to perform their safety functions assuming a single failure. The staff concludes that a design which meets the above described design commitments will have sufficient capacity and capability to interrupt the worst case fault. The design, therefore, meets the above defined requirements of GDC 4 and 17 and is acceptable.

Verification that GE provided the above design commitments in a future SSAR amendment was DFSER (SECY-92-349) Confirmatory Item 8.3.3.11-1. GE has included these commitments in Section 8.3.1.1.5(4) of SSAR Amendment 32, which is acceptable. Therefore, this item is resolved.

\section{Certified Desion Material}

DFSER (SECY-92-349) Open Item 8.3.3.11-1 related to the design description and the ITAAC for the fault interrupting capacity of Class $1 \mathrm{E}$ protective equipment. The adequacy and acceptability of the ABWR design descriptions and ITAAC are evaluated in Chapter 14.3 of this report. Therefore, this item is resolved.

\subsubsection{Control of Design Parameters for Motor Operated Valves}

Valve problems such as excess friction which may be caused by excessively tight packing can result in an operational condition where the current drawn will exceed 
the design rating or capability of tho insulation system uned in the valve motor winding. Operating experience has shown that excessive current, if undetected during operation, can cause premature or unexpected failure when the valve is next operated. The ABWR SSAR did not present methods, design provisions, alarms, or procedures to ensure that the valve motor will not be operated with excessive currents without operator knowledge (or will always be operated within their design limits).

The draft information provided by GE on September 4, 1991, indicated that thermal overloads will provide protection at all times for non-Class 1E MOVs and will provide protection during testing or maintenance for Class 1E MOVs. At all other times, the Class 1E MOVs will not be protected. The staff was concerned by this lack of protection for Class 1E MOV8. This was DSER (SECY-91-355) Open Item 54.

Section 8.3.1.2.1(2)(g) of the draft SSAR mvision dated April 3, 1992, indicated that Class 1E MOVs which are required to open and/or close to satisfy their safety function, will have the thermal overload protective device on the valves' motor in force during normal plant operation. The thermal overload protective device for these valves will be bypassed under accident conditions provided that safety function completion is not jeopardized or that other safety systems are not degraded as per Regulatory Position 1.(b) of Revision 1 of RG 1.106.

GDC 4 of 10 CFR Part 50, Appendix A, requires that Class 1E systems, equipment, and components be designed to accommodate the effects of and to be compatible with the environmental conditions associated with normal operation, maintenance, testing, and postulated accidents. GDC 17 of 10 CFR Part 50, Appendix A, requires (1) that offsite and onsite power systems have sufficient capacity and capability to permit safety systems to perform their required safety function and (2) that the Class 1E systems, equipment, and components have sufficient independence and testability to perform their safety functions assuming a single failure. The staff concludes that a design, which keeps the thermal overload in force during normal plant operation as well as during rest and maintenance in accordance with the above described commitments, will provide reasonable assurance that the MOV will not be operated with excessive currents without operator knowledge (or will be operated within their design limits). The design, therefore, meets the above defined requirements of GDC 4 and 17 of 10 CFR Part 50, Appendix A, and is acceptable.

Verification that GE provided the above design commitments in a future SSAR amendment was DFSER (SECY-92-349) Confirmatory Item 8.3.3.12-1. GE included these commitments in Sections 8.3.1.2(2)(g) and 8.3.2.2.2(2)(f) of SSAR Amendment 32, which is icceptable. Therefore, this itom is resolved.

\section{Certified Desion Meterial}

DFSER (SECY-92-349) Open Item 8.3.3.12-1 related to the design description and the ITAAC for the control of design parameters for MOVs. The adequacy and acceptability of the ABWR design descriptions and ITAAC are evaluated in Chapter 14.3 of this report. Therefore, this itom is resolved.

\subsubsection{Protection of Cable Systems from Internally - Generated Fires}

Section 8.3.3.2 of SSAR Amendment 10 indicated that spatial separation is used as a method of preventing the spread of fire between adjacent cable trays of different divisions (for example, inside primary containment). The design objective should be to separate cable trays of different divisions with structural fire barriers such as floors, ceilings, and walls. Where such barriers are not possible, divisional trays should be separated spatially by $.9 \mathrm{~m}(3 \mathrm{ft})$ horizontally and $1.5 \mathrm{~m}(5 \mathrm{ft})$ vertically. Where this .9 by $1.5 \mathrm{~m}$ ( 3 by $5 \mathrm{ft}$ ) spatial separation is not possible, firo-rated barriers aro used to separate divisional cable trays.

GDC 17 of 10 CFR Part 50, Appendix A, requires that the onsite electric distribution systems have sufficient independence to perform their safety function assuming a single failure.

For a fire initiated by a cable fault within one division, the staff concludes that a design which moets the above described commitments will provide reasonable assurance that a fire in one division will not propagate to a redundant division. The design, therefore, meets the above defined requirements of GDC 17 of 10 CFR Part 50, Appendix A, and is acceptable. This was DSER (SECY-91-355) Open Item 24.

In the draft SSAR revision dated April 3, 1992, GE revised Section 8.3.3.2 of SSAR Amendment 10 to indicate that separation will be achieved by using totally enclosed raceways separated by a least $2.54 \mathrm{~cm}$ ( $1 \mathrm{in}$.) when spacial separation is less than .9 by $1.5 \mathrm{~m}$ ( 3 by $5 \mathrm{ft}$ ). The staff concludes that a design which meets this commitment will provide reasonable assurance that a fire initiated in one division will not propagate to a redundant division. Consequently, the design meets the above defined requirements of GDC 17 of $10 \mathrm{CFR}$ Part 50, Appendix A, and is acceptable. 
Verification that GE hen provided the above deaign commitment in a future SSAR amendment was DFSER (SECY-92-349) Confirmatory Item 8.3.3.13-1. GE has included thew commitments in Section 8.3.3.8.2 of SSAR Ameadment 32, which is acceptable. Therefore, this item is resolved.

\section{Certified Dexion Mnterin}

DFSER (SECY-92-349) Open Item 8.3.2.5-1 related to the design description and the ITAAC for separation of racoways. The adequacy and scceptability of the ABWR design descriptions and ITAAC are evaluated in Chapter 14.3 of this report. Therefore, this item is resolved.

\subsubsection{Electrical Protection for Seram and MSIV solenoids Electrical Protection Assemblies (EPAs) (The need for EPAs was established as part of the stafr's evaluation of I\&C Systems. I\&C Systems are addresed in Chapter 7 of this SER.)}

A generic letter issuod to all operating BWRs on September 24, 1980, requires two independent EPAs on the output of RPS power supplies. Two EPAs are required to eatisfy the singlo-failure criterion for nonfail-safe type failures, which may be caused by undervoltage, over- voltage, and under-frequency conditions.

GE's response to Question 435.7 included in SSAR Amendment 10 indicated that EPAs will not be used in the ABWR design because of special design features. These special features included voltage and frequency monitoring, automatic transfer of power supply input sources when the voltage or frequency exceeds pre-established limits, control room alarm for abnormal conditions, operator action in response to alarm of abnormality, and design and qualification of equipment to preclude failure after operation for a period of time under the allowable abnormality of voltage and frequency.

The staff determined that these special features should provide reasonable assurance that any abnormality in voltage and frequency (which can cause failure of fail-safe-type equipment) will be promptly disconnected by alarms and operator action. The special features, however, do not meet the single failure criterion. Failure of the special features to alarm or failure of the operator to take prompt appropriate action are single failures which may cause a non-fail-safe type failure. The capability to scram the reactor could thus be compromised. This was DSER (SECY-91-355) Open Item 55.
Baned on discuseions, GE indicated that one EPA will be installed in each of the distribution circuits between the CVCF power supply and the RPS scram and main steam isolation valve (MSIV) solenoid valves (the fail-safo-type equipment). The CVCF abnormality in voltage or frequency alarm will bo a Class IE circuit and the CVCF alarm systom and EPAs will be designed with the capability of boing tested periodically.

The staff concludes that single failure of the EPA or the Clase 1E CVCF power supply will not cause a non-failsafe type failure of RPS scram or MSIV solenoid valves and is acceptable.

Verification that GE provided the above design commitments in a future SSAR amendment was DFSER (SECY-92-349) Confirmatory Item 8.3.3.14-1. GE included this information in Sections 8.3.1.1.4.2.1 and 8.3.1.1.4.2.2 of SSAR Amendment 32, which is ecceptable. Therefore, this item is resolved.

In addition, GE indicated that the CVCF alarm system and the EPA will be tested periodically. Verification that GE specified in a future SSAR amendment that the COL applicant will include these periodic tests in appropriate plant procedures was DFSER (SECY-92-349) COL Action Item 8.3.3.14-1. GE included this action item in Section 8.3.4.28 of SSAR Amendment 32, which is acceptable.

\section{Certified Desion Material}

DFSER (SECY-92-349) Open Item 8.3.3.14-1 was related to the design description and the ITAAC for the electrical protection for scram and MSIV solenoids. The adequacy and acceptability of the ABWR design descriptions and ITAAC are evaluated in Chapter 14.3 of this report. Therefore, this item is resolved.

\subsubsection{Safety Bus Grounding}

On every bus shown in Figure 8.3-1 of the draft SSAR revision dated April 3, 1992, there is shown one circuit connected to ground through a circuit breaker. The circuit breaker or bus grounding device provides a safety ground on buses during maintenance operations. The bus grounding device includes the following interlocks

- under-voltage relays must be actuated

- related breakers must be in the disconnect position

- voltage for bus instrumentation must be available

The staff agreed that the proposed grounding device should be included in the design because it may be an important protection enhancement for personnel performing mainte- 
nance on Class IE buses. The staff was concerned, however, that the proposed interlocks may not be sufficient to provent inadvertent closing of the dovice during non-maintenance operation. This was DSER (SECY-91-355) Open Itom 44.

GE indicated that annunciation will bo provided in the design to alarm in the control room whepever the breakers are racked in for service. The staff concludes that a design which meets the above described commitments, together with administrative control and annunciation of the bus grounding system, will be sufficient to prevent inadvertent actuation of the grounding system. Consequently, this design is acceptable.

Verification that GE provided the above design commitments in a future SSAR amendment was DFSER (SECY-92-349) Confirmatory Item 8.3.3.15-1. GE included this information in Section 8.3.1.1.1 of SSAR Amendment 32, which is acceptable. Therefore, this item is resolved.

In addition, $G E$ indicated that there will be administrative controls to keep these circuit breakers racked out (that is in the disconnect position) whenever corresponding buses are energized. Verification that GE specified in a future SSAR amendment that the COL applicant will include these administrative controls in appropriate plant procedures was DFSER (SECY-92-349) COL Action Item 8.3.3.15-1. GE included this action item in Section 8.3.4.14 of SSAR Amendment 32, which is acceptable.

\section{Certified Desien Material}

DFSER (SECY-92-349) Open Item 8.3.3.15-1 related to the design description and the ITAAC for the safety bus grounding systems. The adequacy and acceptability of the ABWR design descriptions and ITAAC are ovaluated in Chapter 14.3 of this report. Therefore, this item is resolved.

\subsubsection{Control of Access to Class 1E Power Equipment}

By committing to meet the guidelines of IEEE 308-1980 (Table 1.8-21 of SSAR Amendment 17), GE indicated compliance with the requirements of Section 5.12 of IEEE 308-1980. Section 5.12 of IEEE 308-1980 requires that the plant design permit the administrative control of access to Class 1E power equipment. Based on this design commitment, information included in the draft SSAR revision dated April 3, 1992, and discussions, GE indicated that Class 1E power supplies and distribution equipment (including diesel generators, batteries, battery chargen, CVCF power supplies, $6.9 \mathrm{kV}$ switchgear; 480-volt loed centers, and 480-volt MCCs) will be located in areas with accoss doors that can be administratively controlled. In addition, ac and dc distribution panels will bo located in the same or similar areas as Class 1E power supplies and distribution equipment; otherwise, the diatribution panels will be designed to be locked 80 that access to circuit breakers located inside the panel can be administratively controlled. The plant physical design of the ABWR will permit the administrative control of access to Class 1E power equipment areas.

GDC 4 of 10 CFR Part 50, Appendix A, requires that Class 1B systems, equipment, and components be designed to accommodate the effects of and to be compatible with the environmental conditions associated with normal operation, maintenance, testing, and postulated accidents. The staff concludes that a design which meets the above described design commitments will permit control of the conditions that equipment may be subjected to during normal operation, maintenance, testing, and postulated accidents. The design, therefore, meets the above defined requirements of GDC 4 and is acceptable.

Verification that GE provided the above design commitments in a future SSAR amendment was DFSER (SECY-92-349) 8.3.3.16-1. GE has included these commitments in Section 8.3.3.6.1.1(5) of SSAR Amendment 32, which is acceptable. Therefore, this item is resolved.

In addition, $G E$ indicated that there will be administrative control of access to Class 1E power equipment areas and/or distribution panels. Verification that GE specified in a future SSAR amendment that the COL applicant will include these administrative controls in appropriate plant procedures was DFSER (SECY-92-349) COL Action Item 8.3.3.16-1. GE included this action item in Section 8.3.4.19 of SSAR Amendment 32, which is scceptable.

\section{Certified Design Material}

DFSER (SECY-92-349) Open Item 8.3.3.16-1 related to the design description and the ITAAC for control of access for Class $1 E$ power equipment. The adequacy and acceptability of the ABWR design descriptions and ITAAC are evaluated in Chapter 14.3 of this report. Therefore, this item is resolved.

\subsubsection{Electrical Independence}

Based on discussions with GE and information included in the draft SSAR revision dated April 3, 1992, GE indicated 
that electrical independence is addreesed in the deaign as follows:

- The prolective actions (that is, the initiation of a signal with the sense and command features, or the operation of equipment within the execute fentures, for the purpose of sccomplishing a safety function) of each lond group will be independent of the protective actions proyided by redundant load groups.

- Each onsite Class $1 \mathrm{E}$ power aupply (for example, the diesel generatior) will have provisions for automatic connection to one Class 1B load group, but will have no automatic connection to any other rodundant Class 1E or non-Class 1B load group. If nonnutomatic (mnnual) interconnecting menns aro furnished, provisions that prevent paralleling of the redundant onsite Class 1E power supplies will be included.

- The ABWR electrical system deaign will not include provisions for the manual connection of the onsite Class IE power supply of one Class 1E divisional loed group to any other redundant Class 1E divisional or non-Class IE non-divisional load group (except for the spare battery chargers)

+ The ABWR design will include provisions to allow one spare battery charger to be connected to either of two divisions and another spare battery charger to be connected to either of two other divisions.

+ The spare chargers for the de power supply may be manually connected to either of two designated divisions, but only when their loads are switched to the same division. Key interlocks will mechanically ensure that these standby chargers can only be used in one division at a time.

- The ABWR electrical system design will not have interconnections between redundant Class 1E divisions except as noted in Sections 8.2.2.3 and 8.3.4.1 of this report.

- The divisional battery charger will normally bo fed from its assigned Class $1 E$ divisional 480-volt MCC bus.

- Each standby power system division includes the diesel generator, its auxiliary systems, and the distribution of power to various Cless $1 \mathrm{E}$ losds through the $6.9 \mathrm{kV}$ and 480-volt systems. Each of these divisions will be segregated and separated from the other divisions. No automatic interconnection will be provided between the
Class 1E divisions. Each diesel generator set will operato independently of the other sets.

- Control power (for the Class IE 480-volt auxiliaries) will be from the Class 1E 125-volt de power system of the same division.

- Each Class 1E dc system load group will have its own battery charger with no provision for automatic interconnection with other redundant Class 1E load groups.

- There will be no provision for automatically interconnecting redundant de system load groups.

- No provision will be mado for automatically transferring loads between Class 1E dc power sources.

- The ABWR design will not have manual interconnections between redundant Class $1 \mathrm{E}$ divisions of the dc system except those that involve the battery chargers.

- Each Class 1E battery will be independent of other redundant battery supplies.

- Each Class 1E battery charger will be independent of other redundant battery chargers.

- The ac and dc switchgear power circuit breakers in each division will receive control power from their respective load groups to provide the following assurances

- loss of one Class 1E 125-volt de system division will not jeopardize the Class $1 \mathrm{E}$ power supply to the Class 1E buses of the other load groups

- the differential relays in one division and all the interlocks affiliated with these relays will be from one 125-volt Class 1E dc system division. There will be no cross connections between the redundant dc system divisions through protective relaying

GDC 17 of 10 CFR Part 50, Appendix A, requires that the Class 1E systems, equipment, and components have sufficient independence and redundancy to perform their safety functions assuming a single failure. The staff concludes that a design which meets the above described commitments will include sufficient independent and redundant systems such that their will be reasonable assurance that a single failure of one set of systems (that is, one Class $1 \mathrm{E}$ division) will not prevent the remaining sets of interconnected system components, modules, and equipment from accomplishing the minimum required 
safoty function. The design, therefore, meets the above defined requirements of GDC 17 of 10 CFR Part 50, Appendix A and is acceptable.

Verification that GE provided the above deaign commitments in a future SSAR amendment was DFSER (SECY-92-349) Confirmatory Item 8.3.4-1. In reeponve to this itom, GE further clarified their design to indicate that, (in addition to the manual transfer capability of the battery chargers discussed above) the ABWR electrical design will permit the manual transfor capability of the FMCRDs motors from a non-divisional to a divisional supply as well as the manual transfer capability of any one of the Class 1E diesel generators to any one of the Class IE divisional or non-divisional load groups by beckfeeding power from the diesel generator through the combustion turbine bus. For these deaign clarifications, the staff also concludes that a design which meots the above described commitments as clarified will include sufficient independent and redundant systems auch that there will be reasonable assurance that a single failure of one set of systems (that is, one Class 1E division) will not prevent the remaining sets of interconnected system components, modules, and equipment from accomplishing the minimum required safety function. The design, therefore, meets the above defined requirements of GDC 17 of 10 CFR Part 50, Appendix A and is acceptable.

GE included the above design commitments in Sections 8.3.3.1, 8.3.1.1.8.1, 8.3.1.1.2.1, 8.3.1.2(4)(b), 8.3.2.1.3, 8.3.2.1.3.1, and 8.3.2.2.1 of SSAR Amendment 32, which is acceptable. Therefore, this item is resolved.

In addition, GE indicated that the keys for the above described interlocks, manual interconnections, and manual transfer of power supplies will be administratively controlled by the COL applicant. Verification that GE specified in a future SSAR amendment a statement that the COL applicant will include these administrative controls in appropriate plant procedures was DFSER (SECY-92-349) COL Action Item 8.3.4-1. GE included this action item in Sections 8.3.4.15 and 8.3.4.18 of SSAR Amendment 32, which is acceptable.

\section{Certified Desion Material}

DFSER (SECY-92-349) Open Item 8.3.4-1 related to the design description and the ITAAC for electrical independence. The adequacy and acceptability of the ABWR design descriptions and ITAAC are ovaluated in Chapter 14.3 of this report. Therefore, this item is resolved.

\subsubsection{Interconnections}

Chapter 7 of this SER addresses design requirements for I\&C system isolation devices. These devices are to be used to maintain independence between Class 1E and nonClass 1E circuits (such annunciators or data loggers and computer circuits) and between redundant Class IE trip channols.)

Figure 8.3-8 of SSAR Amendment 10 showed two interconnections between redundent safety divisions:

(1) The Division III 480-volt bus is connected to the Division I 480-volt bus through circuit breakers and a mechanical interlock. Section 8.3.2.1 of SSAR Amendment 10 indicates that this interconnection is used to transfer the 250-volt de normal battery charger between Division I and III load centers.

(2) The Division III 480 -volt MCC is connected to Division I 480-volt MCC through battery chargers, breakers, and key interlocked breakers. Section 8.3.2.1 of SSAR Amendment 10 indicates that this interconnection is used for selection of the normal or standby battery chargers.

A staff concern over this issue was discussed in DSER (SECY-91-355) as Open Item 56.

In Section 8.3.2.1.4 and Figure 8.3-7 of the draft SSAR revision dated April 3, 1992, GE eliminated the interconnection between Divisions III and I (item 1 above), which was to be used to transfer the 250-volt dc battery charger between Class 1E divisions. In the new proposed design, power for the non-safety-related 250-volt dc battery charger is supplied from either the non-safety-related load group $\mathbf{A}$ or $\mathbf{C}$ turbine building load centers. With the elimination of the interconnection, this item was considered resolved.

Verification that GE provided the above design information in an SSAR amendment was one aspect of DFSER (SECY-92-349) Confirmatory Item 8.3.4.1-1. GE included this information in Section 8.3.2.1.3.3 of SSAR Amendment 32, which is acceptable.

In regard to the interconnection described in item 2 above, Section 8.3.2.1.2 and Figure 8.3-7 of the draft SSAR revision dated April 3, 1992, indicates that electrical interconnections will continue to exist between Divisions I and II and between Divisions I and III, so that two redundant divisions can share one standby charger. Similarly, Division I, and Division II, Division III, and Division IV, and Division I and Division III can be interconnected through the standby charger. 
ODC 17 of 10 CFR Part 50, Appendix A requires that the Cles 1B systems, equipment, and components have sufficient independence to perform their afety functions ascuming a single failure. To moet this ODC 17 requirement with respect to electrical interconnection between redundant Class $1 \mathrm{E}$ divisions, it is the staff position that two independent open dieconnect links, locked open breakers, or other equivalent open dovices shall be maintained between the redundant Class IE divisions. To meet this staff position, GE indicated that koy interlocks will be installed as part of their electrical system design which will mechanically ensure that two open devices are always maintained between redundant divisions in accordence with the above staff position. (Also see Section 8.3.4 of this report.)

The staff concludes that the proposed key interlock design which meets the above described design commitments will maintain independence between them by using two open devices. Failure of one device will not challenge or cause failure of the remaining redundant divisions. Therefore, this design meets the above defined requirement of GDC 17 of 10 CFR Part 50, Appendix A, and is acceptable.

Verification that GE provided the above design commitments in a future SSAR amendment was the second espect of DFSER (SECY-92-349) Confirmatory Item 8.3.4.1-1. GE has included thees commitments in Section 8.3.2.1.3.1 of SSAR Amendment 32, which is acceptable. Therefore, thic item is resolved.

In addition, GE indicated that the keys for the interlock described above will be administratively controlled. Verification that GE specified in future SSAR amendment that the COL applicant will include these administrative controls in appropriate plant procedures was DFSER (SECY-92-349) COL Action Item 8.3.4.1-1. GE included this action item in Section 8.3.4.18 of an SSAR markup dated March 31, 1993, which is acceptable.

\section{Certified Desion Material}

DFSER (SECY-92-349) Open Item 8.3.4.1-1 related to the design description and the ITAAC for interconnections between redundant divisions. The adequacy and acceptability of the ABWR design descriptions and ITAAC are evaluated in Chapter 14.3 of this report. Therefore, this item is resolved.

\subsubsection{Constant Voltage Constant Frequency Power Supplies}

Section 8.3.1.1.4.2 of SSAR Amendment 10 indicated that each of the four independent trip systems of the reactor protection logic and control systom is powered by four CVCF control power busen (one each for Divisions I, II, III, and IV). This soction stated that ench of these buses is independently supplied from an inverter which, in turn is applied from one of four independent and redundant ac and de power supplies. Subsequent sections and Figure 8.3-6 of SSAR Amendment 10, however, indicate that the sc supply for Divisions I and IV originates from a single 480-volt MCC (C14). A singlo 480-volt MCC is not "independent and redundant" as stated in Section 8.3.1.1.4.2. This was DSER (SECY-91-355) Open Itom 57.

Based on discussions with and draft information provided by GE on September 4, 1991, November 26, 1991, and April 3, 1992, GE indicated that ac power to Divisions I and IV is eupplied from the $6.9 \mathrm{kV}$ Division I bus through aingle $6.9 \mathrm{kV}$ to 480 -volt ac transformer and MCC to the vital ac system's CVCF power supplies and the dc system's battery charger power supplies for Divisions I and IV. GE indicated that Divisions I and IV ac and dc systems may be subject to a single common failure of the $6.9 \mathrm{kV}$ to 480-volt transformer. In addition, GE indicated that they would revise the SSAR to indicate that there are four independent and redundant de systems and three (versus four) independent and redundant ac systems.

Verification that $G E$ provided the above design information in a future SSAR amendment was DFSER (SECY-92-349) Confirmatory Item 8.3.4.2-1. GE included this information in Section 8.3.1.1.4.2.1 of SSAR Amendment 32, which is acceptable. Therefore, this item is resolved.

Subsequently, GE revised their design so that the ac supply for Division IV originates from a Division II (versus Division I) 480-volt MCC.

Because ac power to Divisions II and IV is supplied from aingle $6.9 \mathrm{kV}$ Division II bus through a single 6.9 to 480-volt ac transformer and MCC, Divisions II and IV ac and de systems may be subject to common failure due to the single failure of the $6.9 \mathrm{kV}$ to 480 -volt transformer. The issuve related to the lack of independence between Divisions II and IV of I\&C equipment is resolved in Chapter 7 of this report.

\section{Certified Desian Material}

DFSER (SECY-92-349) Open Item 8.3.4.2-1 related to the design description and the ITAAC for constant voltage, constant frequency power supplies. The adequacy and acceptability of the ABWR design descriptions and ITAAC aro evaluated in Chapter 14.3 of this report. Therefore, this item is resolved. 


\subsubsection{Power Supply Cireuits for Safety/Relief Valres}

Section 19B.2.1.2.2.2 of SSAR Amendment 10 indicated that portions of each safety relief valve (SRV) control circuit use non-eafety grade power. This power is taken from the Clase 1E de system through de to de converters or isolation devices connectod to each of the four redundant and independent Class IE de syatom buses. Section 19E.2.1.2.2.2 implied that control power for each SRV comes from a minimum of two different Clase 1B power source divisions. One source directly from the Class 1E dc bus, and the other from a different Class 1E dc bus through the dc-to-dc converter. The staff was concerned that the proposed design for powering the SRV may not provide sufficient independence between the redundant de power sources, as required by GDC 17. This was DSER (SECY-91-355) Open Item 58.

Draft information provided by GE on September 4, 1991, modified SSAR Section 19E.2.1.2.2.2 to deloto a reference to the use of non-safety grade power taken from safoty grade batteries for a portion of each SRV control circuit. In addition, the information indicated that non-divisional power is not utilized in either the SRV or the automatic depressurization system (ADS) functions.

GE indicated that $S R V_{8}$ will bo powered only from Class 1E sources and that there will be no electrical interconnection between power supplies. This design will ensure electrical independence between the redundant power supplies, and is acceptable.

Verification that GE provided the above design commitments in a future SSAR amendment was DFSER (SECY-92-349) Confirmatory Item 8.3.4.3-1. GE included this information in Section 19E.2.1.2.2.2 of SSAR Amendment 32, which is acceptable. Therefore, this item is resolved.

\subsubsection{Isolation Between Class 1E Buses and Loads Designated as non-Class $1 E$}

Section 8.3.1.1.2.1 of SSAR Amendment 10 indicated that isolation breakers will be provided between the Class IE and non-Class 1E buses. In addition zone-selective interlocking was provided between each isulation breaker and its upstream Class IE bus feeder breaker. Section 8.3.1.2.1 of SSAR Amendment 10 indicated that even though the isolation breaker is only fault current actuated and does not meet the guidelines of Position 1 of RG 1.75 (Rev. 2), the zone selective interlocking technique met the intent of this RG. GE therefore concluded that this design met the recommendations of RG 1.75 (Rev. 2).
With respect to protecting Clase IB system from failure of non-Class IE systems and components, the staff agreed with OE that coordinated breakers with zone selective interlocking mot the intent of Position 1 of RO 1.75 (Rov. 2), ws well as the protection requirements of ODC 2 and 4. However, with respect to the independence requirement of GDC 17, the staff disagreed with GB's sesesement (DSER (SECY-91-355) Open Itom 48). Figure 8.3-5 of SSAR Amendment 10 showed non-safetyrelated computers and transient recorder loads with provisions included in their power supply design for automatically transforring these loads from Class 1B Divisions I to Division III and from Class IE Divisions II to Division III. In addition, it appeared that the power supply design may have included provision for automatic transfer of loads between Divisions I and II. This design did not meet the guidelines of RG 1.6 or the intent of Position 1 of RG 1.75 (Rev. 2).

Subeequently, in Section 8.3.1.1.1 of the draft SSAR revision dated April 3, 1992, GE eliminated automatic transfer of loads between redundant divisions by indicating that only Class 1E Division I will have a non-safety-related load and this is acceptable. Verification that GE provided the above design information in a future SSAR amendment was DFSER (SECY-92-349) Confirmatory Item 8.3.4.4-1. GE included this information in Sectinn 8.3.1.1.1 of SSAR Amendment 32, which is acceptable. Therefore, this item is resolved.

By SSAR markup dated March 31, 1993, GE revised their design described in Section 8.3.1.1.1 of the draft SSAR revision, dated April 3, 1992, for supplying power to the Non-Class 1E FMCRD motors from the Class IE system. The following evaluation addresses GE response to DFSER (SECY-92-349) Confirmatory Item 8.3.4.4-2.

GE indicated that the non-Class 1E loads, to be connected to the Class 1E power system through isolation devices, will consist of three separate groups of non-Class $1 E$ FMCRD motors. The rod drive motors are considered non-Class 1E but important to safety because of their backup scram function. In addition, GE indicated that these non-Class 1E loads will be restricted to Division I and will be isolated from Class 1E systems by a Class 1E fault-actuated breaker, a zone-selective interlock, and a design restriction that the circuits on the load side of the transfer switch be classified non-Class 1E (so that these circuits will not he routed as associated circuits with cables of any Class 1E division). Upon loss of power from the Class 1E source, the non-Class 1E FMCRD loads will automatically be transferred between the Class 1E Division I power supply and a non-Class IE power supply, The design will not allow automatic transfer of this nonClass 1E load back from the non-Class 1E to the Class 1E 
power mpply. This non-Clase 1B load can only be manually transforred from the non-Clase IE to the Class 1B power supply.

GE indicated in Section 8.3.1.1.1 of the SSAR markup dated March 31, 1993, the following

- the fault interrupt capability of breakers supplying Class 1B loads, including the Class 1B breakers supplying the Division I non-Class IE FMCRD loads, will be coordinated with the fault interrupting capability of each load's upstream supply breaker so that failure of a greater part of the Class 1E division due to the single failure of a load will be minimized to the extent feasible

- the Class 1E load breakers for the non-Class IE FMCRD loads will have zone selective interlocks with the Class 1E supply breaker to provide additional assurance that failure of a portion of a Class IE division due to the failure of the non-Class $1 E$ load will be minimized to the extent feasible

- the FMCRD motor circuits from the output of the 6.9 KV switchgear through the transfer switch will be classified as associated

- the FMCRD motor circuits from the associated transfer switch through the load and the feeder circuits from the non-Class 1E bus to the transfer switch will be classified non-Class IE

- the fault interrupt capability of all Class IE breakers, fault interrupt coordination between the supply and load breakers for each Class IE load and each Division I non-Class IE load, the zone selective interlock feature of the breaker for the non Class 1E loads, and the transfer of power from Class IE to non-Class IE sources will have the capability of being tested

- the Division I Clase 1E onsite power supplies, the nonClass 1E offsite power supplies, and the Division I distribution system will have sufficient capacity and capability with margin to supply all Class $1 E$ loads and the additional non-safety loads during all modes of plant operation

- each FMCRD power train has current limiting features that are Class 1E to limit the FMCRD motor fault current

- continuous operation of the FMCRD motors at the limiting fault current will not degrade operation of any Class IE loads
- the Division I diesel generator has sufficient capecity margin to supply overload currents up to the trip setpoint of the Class IE foeder breaker to FMCRDs

In addition, by committing to meet the guidelines of IEEE 308-1980 (Table 1.8-21 of SSAR Amendment 17), OE indicated compliance with the requirements of Section 5.2 of IBEE 308-1980. Section 5.2 of IEEE 308-1980 requires that components, equipment, or systoms utilized to provide isolation protection are covered by all the safety system design requirements defined in IEEE 603-1980. The staff concluded that the overcurrent protective devices and their coordination together with the zono select interlocks which are utilized to provide an isolation protection function to the Class $1 E$ systems will meet the guidelines of Section 5.2 of IEEE 308-1980 and thus will meet safety system design requirements defined in IEEE 603-1980. By committing to meet the guidelines of IEEE 384-1981 (Table 1.8-21 of SSAR Amendment 33) and RG 1.75 (Rev. 2) (Table 1.8-20 of SSAR Amendment 33), GE indicated compliance with the guidelines of Sections 5.5.2(1) and 5.5.2(2) and Position 4 of RG 1.75, Revision 2. These guidelines require that associate circuits should be subject to all requirements placed on Class 1E circuits. The staff concluded that the non-Class $1 E$ circuit that have been classified as associated will meet safety system design requirements defined in IEEE 603-1980. Also, by committing to the guidelines of IEEE 384-1981, GE indicated compliance with Section 7.1.2.1 of IEEE 384-1981. Section 7.1.2.1 requires that the circuit breaker being used for isolation shall be coordinated with upstream breakers, requires that the isolation breakers and their coordination be testable and be periodically tested, and requires that the Class IE power supply to the loads being isolated have sufficient capacity and capability to supply fault current. The staff concluded that GE's proposed design for isolating nonClass 1E circuits includes design commitments which are in accordance with these guidelines of IEEE 384.

GDC 4 of 10 CFR Part 50, Appendix A, requires that Class $1 E$ systems, equipment, and components be designed to accommodate the effects of and to be compatible with the environmental conditions associated with normal operation, maintenance, testing, and postulated accidents. GDC 17 of 10 CFR Part 50, Appendix A, requires (1) that offsite and onsite power systems have sufficient capacity and capability to permit safety systems to perform their required safety function and (2) that the Class $1 E$ systems, equipment and components have sufficient independence to perform their safety functions assuming a single failure.

The staff concludes that an isolation system design which meets the above described commitments will adequately 
protect the Class 1E power system from the failure of the non-Clase IB rod control loads, provides eufficient capability and capacity from either the non-Claw $1 E$ offaito or the Class 1B onsito power systoms to supply Class 1B loads in addition to the non-Clase 1B rod control loads, and providen sufficient independence between redundant Class 1B divisions. The proposed ABWR design, for isolating the non-Cless 1B FMCRD motor loeds from the Class $1 \mathrm{E}$ power system, therefore, meets the above defined requirements of GDC 4 and 17 of 10 CFR Part 50, Appendix $A$ and is acceptable. $G B$ included the above design commitments in Section 8.3.1.1.1 of SSAR Amendment 32, which is acceptable. Therefore, this item is resolved.

In addition, GE indicated that the design permits periodic calibration and testing of the fault interrupt capability of all Class $1 \mathrm{E}$ breakers, fault interrupt coordination between the supply and load breakers for each Class 1E load and the Division I non-Class 1E load, and the zone selective interlock feature of the breaker for the non-Class 1E load. Verification that GE specified in a future SSAR amendment that the COL applicant must include these periodic calibrations and functional tests in appropriate plant procedures was DFSER (SECY-92-349) COL Action Item 8.3.4.4-1. GE included this action item in Section 8.3.4.29 of SSAR Amendment 32, which is acceptable.

\section{Certified Desion Material}

DFSER (SECY-92-349) Open Item 8.3.4.4-1 related to the design description and the ITAAC for the isolation between Class 1E buses and non-Class IE loads. The adequacy and acceptability of the ABWR design descriptions and ITAAC are evalusted in Chapter 14.3 of this report. Therefore, this item is resolved.

\subsubsection{Lighting Systems}

In its DSER (SECY-91-355), the staff identified 17 concerns in Open Item 59. GE provided a response in the draft SSAR revision dated April 3, 1992. In that document GE indicated that there will be four lighting systems: the normal ac lighting system, the standby ac lighting system, the emergency dc lighting system, and the guide lamp lighting system.

\section{The Normal Lighting System}

The normal ac lighting system will be used to provide up to 50 percent of the lighting needed for operation, inspéction, and repairs during normal plant operation. Normal lighting will be installed throughout the plant in areas containing non-safety-related equipment. Normal lighting will not bo installed in pasaagoways and stairwells. The normal lightins syatem will be part of the plant's nonanfoty-rolated oyatem and as such will be supplied by the non-safoty-rolated power systom buses and will be energized as long as power from an offsite power source is available. Normal lighting will not be available following a LOPP event.

\section{The ac Standby Lightine System}

The ac standby lighting system will be comprised of two parts. The non-Class IE ac standby systom and the associated ac standby system. The Class IE associated ac standby system will serve the safety-related equipment areas and their passageways. The non-Class 1E ac standby system will serve both safety and non-safety-related equipment areas and their passageways.

The associated ac standby system will be comprised of three subsystems. Each subsystem will be supplied from a different Class 1E standby divisional power supply (diesel generator). Each subsystem will supply a minimum of 50 percent of the lighting needs for the areas containing safety-related equipment in its respective division. Each subsystem will also supply $\mathbf{5 0}$ percent of the lighting in passageways and stairwells leading to its respective equipment areas. In addition, the subsystem associated with Division II will supply a minimum of 50 percent of the lighting needs for areas containing Division IV safetyrelated equipment (the Division IV battery room and other Division IV I\&C areas). The subsystems associated with Divisions II and III will each supply a minimum of 50 percent of the lighting needs of the main control room. Each of the subsystem circuits will be treated as Class 1E (that is, they will be classified as associated) and as such will meet all requirements of a Class $1 E$ circuit. In regard to the lighting system's fixtures and bulbs, GE has taken exception to the Class $1 E$ requirement for seismic qualification. The staff's evaluation of this exception is addressed in Section 8.3.3.3 of this report.

The non-Class $\mathrm{IE}$ ac standby system will be comprised of three non-Class 1E load groups. Each load group will be supplied from a different plant investment protection bus, which can be connected to the non-Class $1 E$ standby power supply CTG. The non-Class 1E ac standby lighting system will supply a minimum of 50 percent of the lighting needed for its affiliated equipment areas and will supply 100 percent (50 percent from each of two different plant investment protection buses) of the lighting needs in passageways and stairwells leading to equipment areas containing non-safety-related equipment. In addition, the non-Class $1 E$ ac standby lighting system will supply up to 50 percent of the lighting needs in areas containing safetyrelated equipment and in passageways and stairwells 

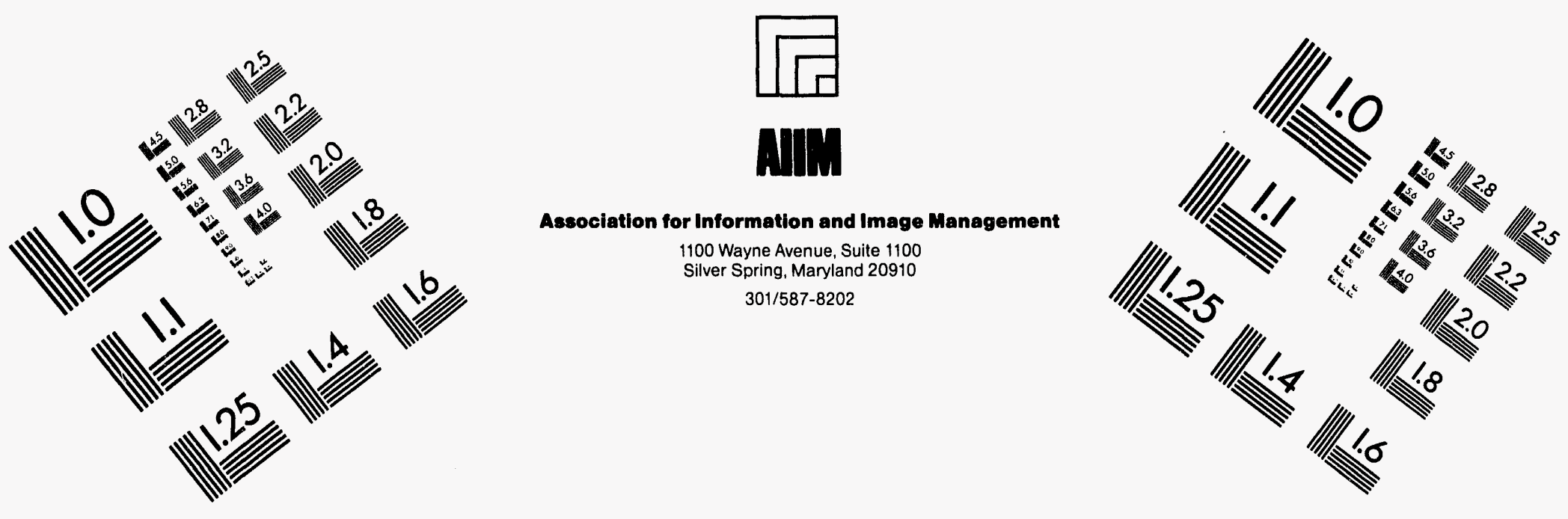

\section{Centimeter}

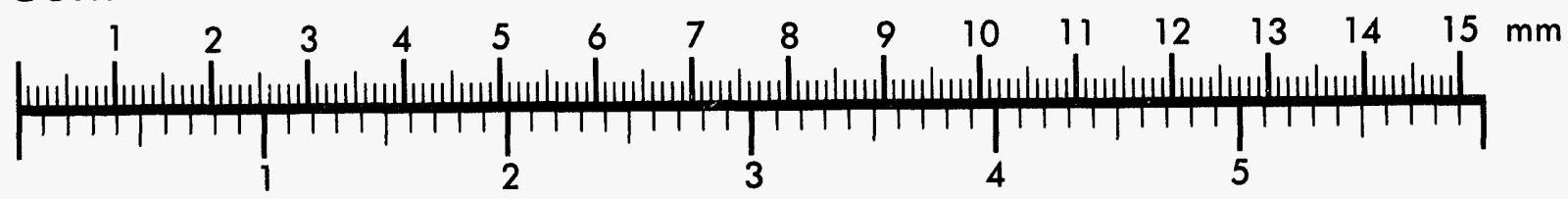

Inches
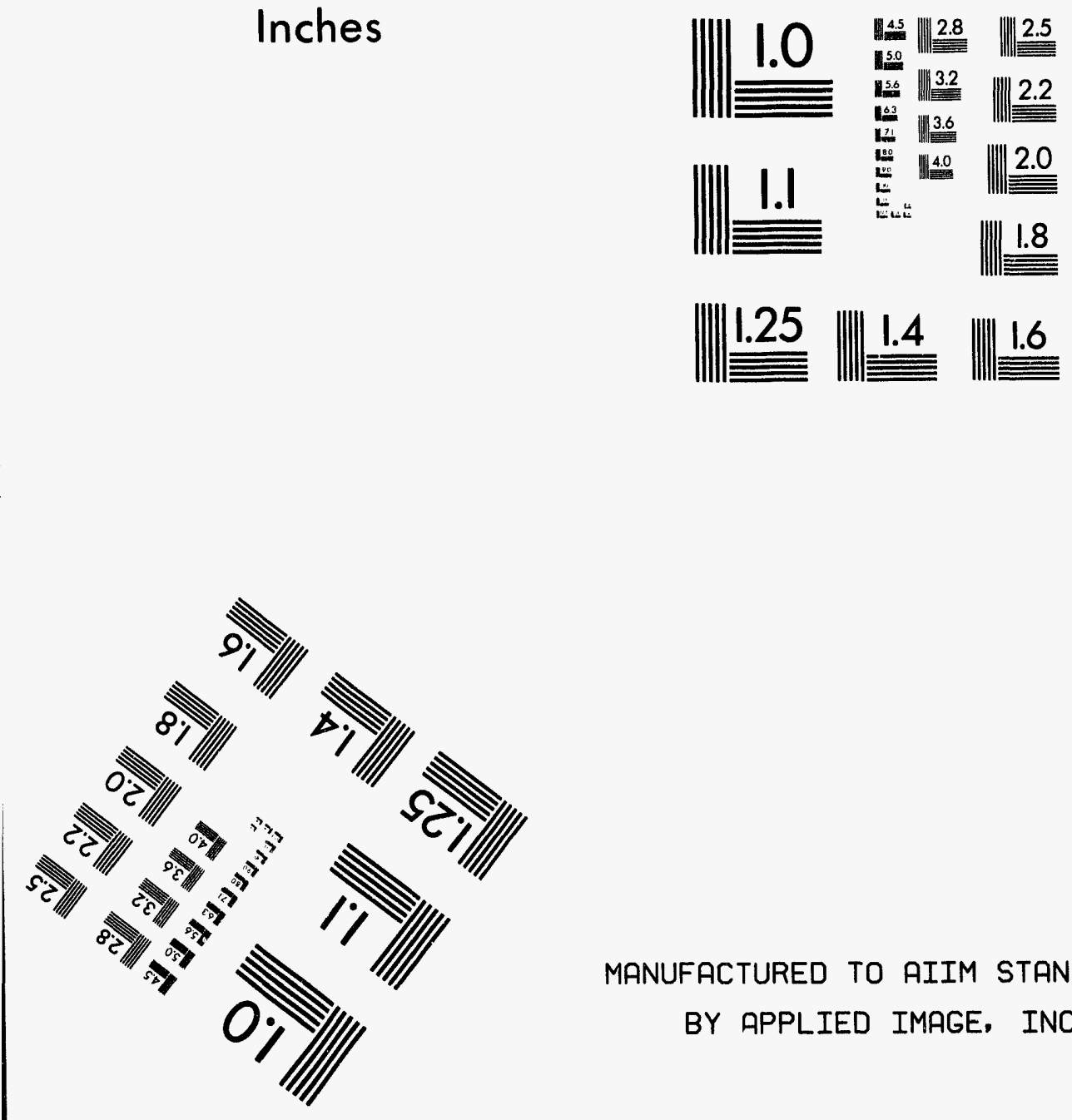

MANUFACTURED TO AIIM STANDARDS

BY APPLIED IMAGE, INC.

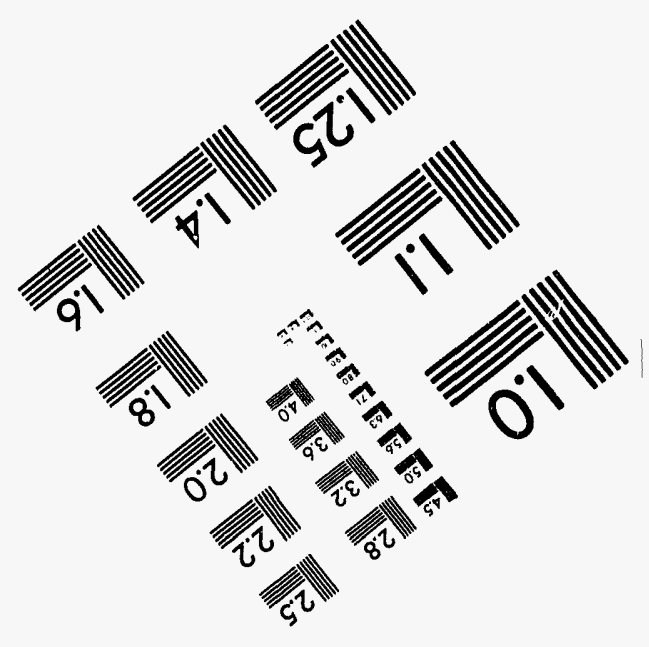



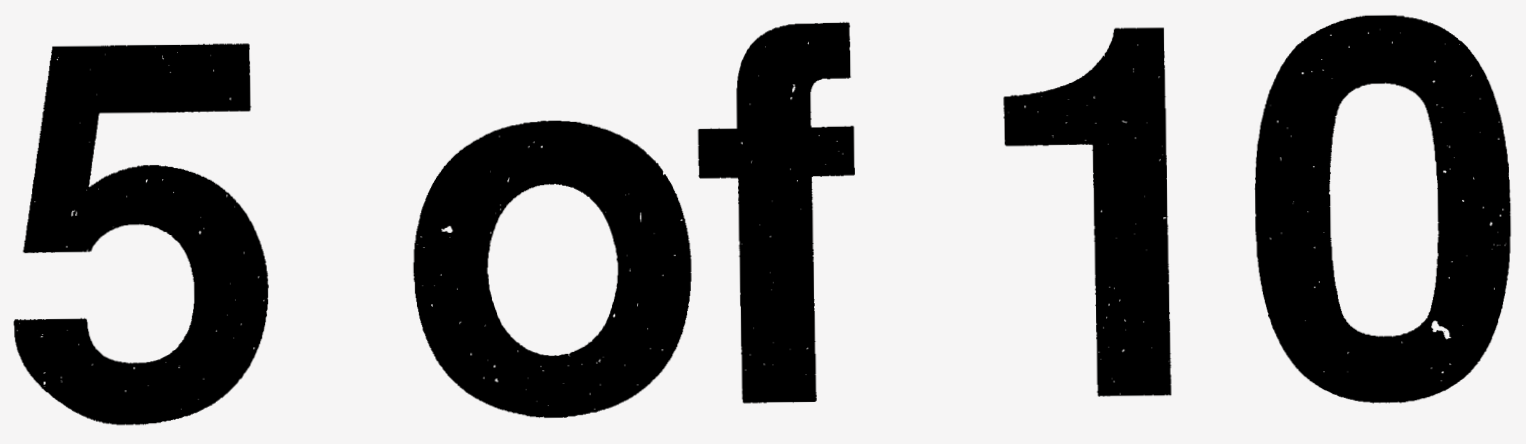
leading to them. The non-Class IE lighting in the areas containing safety-relatod equipment and the passageways and atairwells leading to them will be supplied from the same unit auxiliary transformer power source as the safetyrelated equipment in the area. (Eech unit auxiliary transformer cen supply a Cless 1E and non-Cless 1E distribution system and load group. For example, the unit auxiliary transformer that supplies power to Division I of the Class 1E distribution system and load group will also supply a non-Class $1 E$ distribution system and load group.) The non-Class 1E lighting system's fixtures in areas containing safety-related equipment and in the passageways and stairwells leading to them will be seismically supported and will be designed with appropriate grids or diffusers such that broken material from either the fixture or bulb will bo contained and will not become a hazard to personnel or safety equipment during or following a seismic event.

\section{The dc Emergency Lightine System}

The dc emergency lighting system will provide dc powered beckup lighting to prevent total blackout in areas which are or may be occupied during periods when ac lighting is lost until the normal or standby lighting systems are energized. The dc emergency lighting system will be comprised of two parts. The non-Class 1E dc emergency lighting system and the associated dc emergency lighting system. The non-Class 1E de emergency lighting system supplies the lighting needed in plant areas containing non-safety-related equipment. The associated dc emergency lighting system supplies the lighting needed in plant areas containing safety-related equipment.

Plant areas containing, safety-related equipment and associated dc emergency lighting include the main control room, the remote shutdown panel rooms, the diesel generator areas and associated control rooms, the safetyrelated electrical equipment rooms, and dc electric equipment rooms (including battery rooms). Electrical power for the associated dc emergency lighting system in these safety-related equipment areas (except the main control room) is supplied from the Class IE 125-volt dc system in the same division as the equipment in the area (for example, Class 1E dc Division I will supply power to the associated dc emergency lighting system in those rooms containing Division I safety-related equipment). Electrical power for the associated dc emergency lighting system in the main control room will be supplied from the Divisions II and III Class 1E 125-volt dc systems. Each of the dc emergency lighting circuits will be treated as Class IE (that is, they will be classified as associated) and as such will meet all requirements of a Class $1 \mathrm{E}$ circuit. In regard to the lighting system's fixtures and bulbs, GE has taken exception to the Class $1 E$ requirement for the soismic qualification. The staff's evaluation of this exception is addressed in Section 8.3.3.3 of this report.

Plant areas containing non-safety-related equipment and non-Class 1E dc emergency lighting include the radwaste building control room, the CTG area and control room, and the non-safety-related electrical equipment areas (both ac and dc). Electrical power for the non-Class 1E dc emergency lighting system in the radwaste building control room will be supplied from the non-Class 1E 250-volt de system. Electrical power for the non-Class 1E dc emergency lighting system in electrical equipment rooms containing non-safety-related equipment will be supplied from the same non-Class 1E 125 -volt dc system that supplies power to equipment in the room. Electrical power for the non-Class 1E dc emergency lighting in the non-Class IE CTG area and control room will be supplied from one of the three non-Class 1E 125-volt de systems. The non Class 1E dc emergency lighting system circuits providing the needed lighting in non-safety-related equipment areas will be classified as non-Class 1E. (By letter dated March 31, 1993, GE modified their design to remove security lighting from their scope of design.)

\section{The Guide Lamp Light System}

The guide lamp light system will illuminate stairways, exit routes, and major control areas such as the main control room and remote shutdown panel areas. Each guide lamp unit will have a lighting fixture with two incandescent sealed-beam lamps and a self-contained battery pack unit containing a rechargeable battery with an 8-hour capacity. Each guide lamp unit will also contain a charger and an initiating switch, which energizes the fixture from the battery in the event of loss of the ac power supply and deenergizes the fixture upon return of ac power to the standby light following a time delay of 15 minutes. The guide lamp units will be supplied ac power from the same power source that supplies the associated standby lighting system in the area in which they are located. The guide lamp light system will be seismically qualified and will meet Class IE requirements in plant areas containing Class 1E equipment.

GE provided information pertaining to the design of the normal, standby, emergency, and guide lamp lighting systems to demonstrate that the lighting is adequate in plant areas containing safety-related equipment as well as passageways to and from these areas. GE indicated that the ABWR design for each of these lighting systems will meet or exceed the lighting level requirements of the Illuminating Engineering Society Lighting Handbook and will have the capability of being functionally tested on a periodic basis. 
The ataff concluded that a lighting system that meets tho above described commitments will provide adequate lovels of light to permit the required operation and maintenance of equipment in safety-rolated equipment areas, and paseagoways to and from these areas, under normal operating conditions. This design is, therefore, scceptable. Verification that GE provided the above design commitments in future SSAR amendment was DFSER (SECY-92-349) Confirmatory Item 8.3.5-1. GE included this information in Section 9.5.3 of SSAR Amendment 32, which is acceptable. Therefore, this item is resolved.

In addition, GE indicated that the ac standby and dc emergency lighting systems which aro normally energized will be periodically inspected and bulb replacement will be performed. In addition, the guide lamp system will be inspected and tested periodically to ensure operability of lights and switching circuits. Verification that GE has specified in a future SSAR amendment the requirement that the COL applicant must include these periodic tests, inspections, and bulb replacement in appropriate plant procedures was DFSER (SECY-92-349) COL Action Item 8.3.4.4-1. GE included this requirement in Section 8.3.4.25 of SSAR Amendment 32, which is acceptable.

For other off-normal conditions, it was not clear that the design adequately considers lighting needs for areas containing safety-related equipment and for passageways to and from these areas where plant operations are or may be required by emergency procedures. For example, under certain failures, it appears that the main control room may have only a portion (50 percent) of its lighting. Therefore, GE needed to further address the adequacy of the lighting in areas containing safety-related equipment under offnormal conditions. This was DFSER (SECY-92-349) Open Item 8.3.5-1.

GE indicated that because of the redundancy provided by the four lighting systems described above, the complete loss of lighting in any of the critical areas is not credible. The standby lighting and emergency lighting systems provide totally independent low level illumination in areas vital to safe shutdown of the reactor. In addition, the safety-related control systems will automatically bring the plant to safe-shutdown conditions. The control systems do not require the lighting system to perform their safety function of bringing the plant to a safe-shutdown condition.

The staff concluded that a lighting system design which meets the above described commitments will provide reasonable assurance that sufficient illumination will be available to perform emergency procedures as may be required during off normal conditions. The lighting system design is, therefore, acceptable. GE included the above commitments in Section 9.5.3.2.5 of SSAR Amendment 32, which is acceptable. Therefore, this item is resolved.

\section{Centified Desion Mnterial}

DFSER (SECY-92-349) Open Item 8.3.5-2 related to the design deacription and the ITAAC for the lighting system. The adequacy and acceptability of the ABWR design deacriptions and ITAAC are ovaluated in Chapter 14.3 of this report. Therefore, this item is resolved.

\subsubsection{Design Control}

\subsubsection{Control of the Electrical Design Process}

Recently, a number of problems have been identified with the electrical system design at nuclear power plants. Although the majority of these problems arose as a result of modifications performed after plant licensing, some were (and all could have been) the result of poor original design. OL 88-15 dated September 12, 1988, addressed a number of these problems that have occurred primarily as a result of inadequate control over the design process. These problems have occurred in areas of electrical system design which have historically well-established, comprehensive design criteria and guidelines available for the design engineer such as circuit breaker coordination and fault current interruption capability. The adequacy of the design is a function of the designers proper exercise of the well-established design criteria and guidelines.

In Sections 8.3.4.17 and 8.3.5 of draft SSAR revision dated April 3, 1992, GE indicated that purchase specification for both Class 1E and non-Class 1E equipment will contain a list of appropriate common industrial standards to ensure quality manufacturing. Based on this commitment, the staff concluded that this concern (DSER SECY-91-355 Open Item 60) is resolved. Verification that GE provided the above design information in a future SSAR amendment was DFSER (SECY-92-349) Confirmatory Item 8.3.6.1-1. GE included this information in Sections 8.3.4.17 and 8.3.5 of SSAR Amendment 32, which is acceptable. Therefore, this item is resolved.

\section{Certified Desion Material}

DFSER (SECY-92-349) Open Item 8.3.6.1-1 related to the design description and the ITAAC for the control of the electrical design process. The adequacy and acceptability of the ABWR design descriptions and ITAAC are evaluated in Chapter 14.3 of this report. Therefore, this item is resolved. 


\subsubsection{Control of the Electrical Design Bases}

The design bases described and presented in the ABWR SSAR should, for the most part, be useable as the bases by which the NRC issues a plant combined operating license. However, a reviow of the bases presented in Chapter 8 and other related chapters, revealed numerous inconsistencies as noted in DSER '(SECY-91-355) Open Item 61. Consequently, it appears that $G E$ used a deficient process to control the design bases presented in the ABWR SSAR.

At the time the DFSER was issued, GE had indicated that a formal engineering review and update of the SSAR was in progress to identify and correct inconsistencies within and between sections of the SSAR. Verification that GE revised the design bases in a futuro SSAR amendment to eliminate conflicting information was DFSER (SECY-92-349) Confirmatory Item 8.3.6.2-1. Staff review of SSAR Amendment 32 did not show these that inconsistencies had been resolved. Subsequently, the staff has reviewed the SSAR through Amendment 34 and found no significant inconsistencies which affect safety findings in this chapter. Therefore, Confirmatory Item 8.3.6.2-1 is resolved.

\subsubsection{Testing and Surveillance}

This section addresses DSER (SECY-91-355) Open Item 62. By committing to meet the guidelines of IEEE 308-1980 (Table 1.8-21 of SSAR Amendment 17), GE indicated compliance with the requirements of Section 7 of IEEE 308-1980. Section 7 of IEEE 308-1980 defines the guidelines for surveillance and preoperational and periodic equipment and system tests for electrical systems. Based on this commitment to Section 7 of IEEE 308-1980, information presented in the draft SSAR dated April 3, 1992, and discussions, GE indicated the following:

- The ABWR electrical system design will provide controls and indicators in the main control room.

- The design will include provisions for control and indication outside the main control room for

- circuit breakers that switch Class 1E buses between the preferred and the standby power supply

- the standby power supply

- circuit breakers and other equipment as required for safety systems that must function to bring the plant to a safe-shutdown condition.
- Operational status information will be provided for Class IE power systems.

- Class 1E power systems required to be controlled from outside the main control room will also have operational status information provided outside the central control room at the equipment itself, at its power supply, or at an aliernate central location.

- The operator will bo provided with accurate, complete, and timely information pertinent to the status of the execute features in the control room.

- Indication of protective actions and execute features unavailability, will be provided in the control room.

- Electric power systems and equipment will have the capability of being periodically tested.

- Testability of electrical systems and equipment will not be so burdensome operationally that required testing at intervals of 1,2 , or 3 months cannot be included in the TS if doemed necessary.

GDC 17 of 10 CFR Part 50, Appendix A, requires that Class 1E systems, equipment, and components have sufficient testability to perform their safety functions assuming a single failure. GDC 18 of 10 CFR Part 50, Appendix A requires that Class 1E power systems be designed (1) to permit appropriate periodic inspection and testing of important areas and features (such as wiring, insulation, connections, and switchboards) to assess the continuity of the systems and the condition of their components, (2) the capability to test periodically the operability and functional performance of the components of the systems, and (3) the capability to test periodically the operability of the systems as a whole and (under conditions as close to design as practical) the full operation sequence that brings the systems into operation.

Except as noted below, the staff concludes that an electrical system design which meets the above commitments will be testable. The design, therefore, meets the above defined requirements of GDC 17 and 18 of 10 CFR Part 50, Appendix A and is acceptable.

Verification that GE provided the above design commitments in a future SSAR amendment was DFSER (SECY-92-349) Confirmatory Item 8.3.7-1. GE has included these commitments in Section 8.1.3.1.1.3 of SSAR Amendment 32, which is acceptable. Therefore, this item is resolved.

GE also indicated that the electrical systems and equipment will be periodically tested. Verification that GE specified 
in a future SSAR amendment that the COL applisant will include this periodic testing of electrical systems and equipment in appropriate plant procedures was DFSER (SECY-92-349) COL Action Item 8.3.7-1. GE included this action item in Section 8.3.4.30 of SSAR Amendment 32, which is acceptable.

Section 8.3.1.1.5.3, of SSAR Amendment 10 indicated that the ABWR design of Class 1E equipment permits periodic testing of the chain of system elements from sensing dovices through driven equipment. This teeting ensures that Class 1E equipment is functioning eccording to design requirements. This section aleo impliss that the requirements of the single-failure criterion described in IEEE 379-1977, "Standard Application of the Single Failure Criterion to Nuclear Power Generating Station Safety Systems," will be met with respect to testing of Class 1E equipment.

The staff interpreted these statements to mean that one complete olectrical aystem division may be taken out of service for maintenance, testing, and/or repair during any mode of plant operation and still leave the remaining eloctrical systems in compliance with the single-failure criterion. The staff, therefore, concluded that the design provision for testability of electrical systems (as interpreted) meets the sufficient testability requirement of GDC 17 and is acceptable.

To confirm this interpretation, the staff further evaluated the capability of the electric power system to be tested during normal plant operation while moeting single failure requirements with remaining systems for any design-basis event.

GE's design commitment that the ABWR design meets Section 5 of IEEE 338-1977, which is endorsed by RG 1.118 (Rev. 2), reflected the following:

- On-line testing will be greatly enhanced by the design which utilizee three independent divisions, any one of which can safely shutdown the plant. However, the design will not meet the single-failure criterion with respect to all required safety-related systems for all design-basis events with one of the three electrical system divisions out of service.

- An acceptable level of reliability for the remaining operable safety systems will exist when one train is taken out of service for a specified period of time for preplanned or unplanned maintenance while the singlefeature criterion is not met.
- When one Class 1E division is out of service, an acceptable level of reliability will be established by $G E$ for the remaining operable safety systems by a PRA.

Based on the information presented in the ABWR SSAR, the staff was unable to determine what constitutes an acceptable lovel of reliability. This was DFSER (SECY-92-349) Open Item 8.3.7-1.

GE rovised Sections 8.2.2.1(3) and 8.3.1.1.5.3 of SSAR Amendment 21 to indicato that all equipment can be tested, as necescary, to assure continued and safe operation of the plant. For equipment which will not be tested during operation, GE indicated that the equipment's reliability will be such that testing can be performed during plant shutdown. Based on the above commitment as revised, the staff concludes that all systems and component parts of an electrical system design which met the above commitments as revised will have the capability of being tested. In addition, the reliability assurance program as discussed in Chapter 17.3 of this roport will ensure that important reliability assumptions of the probabilistic risk assessment will be considered throughout the plant life. The design therefore meets the above defined requirements of GDC 17 and 18 of 10 CFR Part 50, Appendix A, and is acceptable. GE included the above design commitments in Sections 8.2.2.1(3) and 8.3.3.2 of SSAR Amendment 32, which is acceptable. Therefore, this item is resolved.

\section{Certified Design Material}

DFSER (SECY-92-349) Open Item 8.3.7-2 related to the design description and the ITAAC for the testing and surveillance of electrical equipment. The adequacy and acceptability of the ABWR design descriptions and ITAAC are evaluated in Chapter 14.3 of this report. Therefore, this item is resolved.

\subsubsection{Capacity and Capability}

\subsubsection{Non-Class 1E dc Power Systems}

In response to DSER (SECY-91-355) Open Item 64, regarding interaction between safety and non-safety-related systems, GE provided in Sections 8.3.2.1.3 and 8.3.2.1.4 of the draft SSAR revision dated April 3, 1992, a description of the non-Class 1E 125-and 250-volt de systems. The 125-volt de non-Class IE system will provide power to non-Class 1E switchgear, valves, converters, transducers, controls, and instrumentation. The non-Class 1E 125-volt de system will have three load groups with one battery, charger, and bus per load group. The 250-volt dc 
non-Class IB system will provide power for non-anfetyrelated computers and the turbine turning gear motor. The 125- and 250-volt de systems will provide power only to non-eafety-rolated loads and will be physically and electrically independent of the Class IE ac and de syetems.

Based on the design commitments included in the draft SSAR revision, staff concerns relating to interactions between safety and non-safety-related aystoms aseociated with the proviously proposed common de power aupply have been resolved.

Verification that GE provided the above dexign commitments in a future SSAR ameadment was DFSER (SECY-92-349) Confirmatory Item 8.3.8.1-1. OB included this information in Sections 8.3.2.1.3.2 and 8.3.2.1.3.3 of SSAR Amendment 32, which is scceptablo. Therefore, this item is resolved.

\section{Certified Desian Material}

DFSER (SECY-92-349) Open Itom 8.3.8.1-1 related to the design description and the ITAAC for the independence between Class 1E and non-Class 1E de power systems. The adequacy and acceptability of the ABWR design descriptions and ITAAC are evaluated in Chapter 14.3 of this report. Therefore, this item is resolved.

\subsubsection{Capacity of the Class 1E 125-volt de Battery Supply}

This section addresses the staff's evaluation of GE's response to DSER (SECY-91-355) Open Item 65.

Based on information presented in Section 8.3.2.1.1.1 of the draft SSAR revision dated April 3, 1992, GE indicated that each of the four Class 1E 125-volt batteries will

- be capable of starting and operating its required steady state and transient loads

- be immediately available during both normal operations and following the loss of power from the alternating current system

- have sufficient stored energy to provide an adequate source of power for starting and operating all required LOCA and/or LOPP loads and circuit breakers for two hours with no ac power

- have sufficient stored energy to provide power in excess of the capacity of the battery charger when needed to supply transient loads
- bo sized in accordance with industry recommended prectice defined in IEEE 485-1983

- have a capacity design margin of 5 to $\mathbf{1 5}$ percent to allow for less than optimum operating conditions

- have 25-percent capacity design margin to compensate for battery aging

- have a 4-percent capacity design margin to allow for the loweat expected electrolyte temperature of $21^{\circ} \mathrm{C}$ $\left(70^{\circ} \mathrm{F}\right)$

- have a number of battery cells that matches the batteryto-ayetem voltage limitations

- base the firat minute of the batteries' duty cycle on the sum of all momentary, continuous, and noncontinuous loads that can be expected to operate during the one minute following a LOCA and/or LOPP

- be installed in accordance with IEEE 484-1987

- moet the recommendations of Section 5 of IEEE 946-1985

- be designed so that each hattery's capacity can periodically be verified

In addition to having sufficient stored energy to operate all required LOCA and/or LOPP loads and circuit breakers for 2 hours, GE indicated that the Division I battery will have aufficient stored energy to provide an adequate source of power to atart and operate all required loads and circuit breakers for approximately 8 hours with no ac power. Further, the heating/ventilation system will maintain battery electrolyte temperature above $21^{\circ} \mathrm{C}\left(70^{\circ} \mathrm{F}\right)$.

GDC 17 of 10 CFR Part 50, Apperdix A, requires that the Clase 1E 125-volt de battery supply have sufficient (1) capacity and capability to permit safety systems to perform their required safety function and (2) testability to perform their safety function assuming a single failure. GDC 18 of 10 CFR Part 50, Appendix A requires that the Class IE 125-volt dc battery supply systems be designed (1) to permit appropriate periodic inspection and testing of important areas and features (such as wiring, insulation, connections, and switchboards) to assess the continuity of the systems and the condition of their components, (2) the capability to test periodically the operability and functional performance of the components of the systems, and (3) the capability to test periodically the operability of the systems as a whole and (under conditions as close to design as practical) the full operation sequence that brings the systems into operation. The staff concludes that Class 1E 
125-volt battery supply doaign that moets the above commitments will have sufficient capacity and capability to supply required loads following a LOCA and/or LOPP and a station blackout event and will be testable. The design, therefore, moets the above defined requirements of GDC 17 and 18 of 10 CFR Part 50, Appendix A, and is acceptable.

Verification that $\mathrm{GE}$ provided the above design commitments in a future SSAR amendment was DFSER (SECY-92-349) Confirmatory Itom 8.3.8.2-1. In response to this itom, GE modified the above commitments to indicate that the batteries' capacity design margin to allow for the lowest expected electrolyto temperature was changed from $21^{\circ} \mathrm{C}\left(70^{\circ} \mathrm{F}\right)$ to $10^{\circ} \mathrm{C}\left(50^{\circ} \mathrm{F}\right)$. This change was based on the capability of the beating and ventilation system to maintain room temperature above $10^{\circ} \mathrm{C}\left(50^{\circ} \mathrm{F}\right)$. The capability of the heating and ventilation system to maintain a temperature range of 10 to $40^{\circ} \mathrm{C}$ ( $50^{\circ} \mathrm{F}$ to $104^{\circ} \mathrm{F}$ ) is addresesed in Chapter 9.0 of this SER.

The staff concludes that a Class 1E 125-volt battery supply design that meets the above commitments as modified, will also have sufficient capacity and capability to supply required loads following a LOCA and/or LOPP and a station blackout event and will be testable. The design, therefore, meets the above defined requirements of GDC 17 and 18 of 10 CFR Part 50, Appendix A, and is acceptable. GE has included the above design commitments in Sections 8.3.2.1.1.1, 8.3.2.1.3.1, and 8.3.2.2.2(5)(c) of SSAR Amendment 32, which is acceptable.

In addition, GE indicated that the capacity and capability of the dc system batteries and the capability of the batteries to supply power to their connected loads will periodically be tested in accordance with the recommendation of IEEE 450-1985. Verification that GE specified in a future SSAR amendment that the COL applicant will include these periodic tests in appropriate plant procedures was DFSER (SECY-92-349) COL Action Item 8.3.8.2-1. GE included this action item in Sections 8.3.4.32 and 8.3.4.33 of SSAR Amendment 32, which is acceptable.

\section{Certified Desion Material}

DFSER (SECY-92-349) Open Item 8.3.8.2-1 related to the design description and the ITAAC for the Class IE 125-volt dc battery supply. The adequacy and acceptability of the ABWR design descriptions and ITAAC are evaluated in Chapter 14.3 of this report. Therefore, this item is resolved.

\subsubsection{Use of Silicon Diode in the de System}

Figure 8.3-7 and GE's response to Question 435.51 in SSAR Amondment 10 indicated that a silicon diodo would be installed in series with the output of the battery and battery chargers to create a voltage drop of 10 volts. During normal operation (that is, when battery charger output voltage is set at 140 volts to equalize the charge of battery cells) the switch in parallel with the silicon diodo will be open 80 that the voltage from the battery charger to the de bus will remain at 130 volts (140 volts minus the 10-volt drop across the silicon diode), while 140 volts is supplied to the battery to equalize the charge of battery colls.

In response to DSER (SECY-91-355) Open Item 66, GE provided the draft SSAR revision dated April 3, 1992, which removed the use of the silicon diode from the ABWR design and restated the commitment to design the de system distribution equipment, component, and loads to function at 140 volts during equalization chargo.

This item is, therefore, considered resolved. Verificstion that GE revised the SSAR in a future amendment, indicating the removal of the silicon diode from the ABWR design was DFSER (SECY-92-349) Confirmatory Itom 8.3.8.3-1. GE included this revision in SSAR Amendment 32, which is acceptable. Therefore, this item is resolved.

\subsubsection{Class 1E ac Standby Power System (Diesel Generator)}

This section addresses the staff's evaluation of GE's response to DSER (SECY-91-355) Open Item 67.

Based on discussions with $G E$ and information presented in the draft SSAR revision dated April 3, 1992. GE indicated that each standby (diesel generator) power source will

- be capable of starting, accelerating to rated speed, and supplying, in the required sequence, all the required safety system loads

- be capable of attaining rated frequency (i.o., full speed) and voltage within 20 seconds after receipt of a start signal

- have a continuous load rating of 6.25 megavolt amps (MVA) 0.8 power factor 
- have a short time rating (operation at this rating does not limit the use of the diesel generator unit at its continuous rating) of 110 percent of the continuous load rating for a 2-hour period out of any 24-hour period, without exceeding the manufacturer's design limits and without reducing the maintenance interval established for the continuous rating

- be available following the loss of the preferred power supply within a time consistent with the requirements of the safety function under normal and accident conditions

- have stored energy (fuel) at the site in its own storage tank with the capacity to operate the standby diesel generator power supply, while supplying post-accident power requirements to a unit for seven days

- have stored energy (fuel) at the site in its own day tank with the capacity to operate the standby diesel generator power supply while supplying post-accident power requirements for 8 hours

- have a fuel transfer system with the capability of automatically replenishing the day tank from the storage tank such that the 8-hour fuel capacity of the day tank is maintained

- be capable of operating in its service environment during and after any design-basis event, without support from the preferred power supply

- be capable of starting, accelerating, and being loaded with the design load, within an acceptable time

- from the diesel engine's normal standby condition

- with no cooling available, for a time equivalent to that required to bring the cooling equipment into service with energy from the diesel generator unit

- on a restart with an initial engine temperature equal to the continuous rating full load engine temperature

- be capable of accepting design load following operation at light or no load for a period of 4 hours

- be capable of maintaining voltage and frequency at the generator terminals within limits that will not degrade the performance of any of the loads comprising the design lond below their minimum requirements, including the duration of transients caused by load application or load removal
- be capable of carrying its continuous load rating for 22 bours following 2 hours of operation at its short time rating

- start from each automatic and remote manual signal and then accelerate to rated voltage and frequency, and then properly sequence its loads if there is no offsite power available or operate at no load if offsite power is available

- start but not sequence its loads by a local manual start signal

- be capable of being manually started without ac external electric power

- be capable of automatic acceleration to rated voltage and frequency without ac external electric power

- be capable of allowing the bus to be manually energized without ac external electric power

\section{GE also indicated that}

- the maximum loads expected to occur for each division (according to nameplate ratings) will not exceed 90 percent of the continuous power output rating of the diesel generator

- each diesel generator's air receiver tanks will have sufficient capacity for five starts without recharging

- following one unsuccessful automatic start of the diesel generator with and without ac external power, each diesel generator's air receiver tanks will have sufficient air remaining for three more successful starts without recharging

- automatic load sequence will begin at $\leq \mathbf{2 0}$ seconds and will end at $\leq 65$ seconds

- following application of each load during load sequencing, voltage will not drop more than 25 percent from nominal voltage measured at the bus

- following application of each load during load sequencing frequency will not drop more than 5 percent from nominal frequency measured at the bus

- frequency will be restored to within 2 percent of nominal, and voltage will be restored to within 10 percent of nominal within 60 percent of each load sequence time interval 
- during recovery from transients caused by step load increases or resulting from the disconnection of the largest single load, the speed of the diesel generator unit will not exceed the nominal speed plus 75 percent of the difference between nominal speed and the overspeed trip setpoint or 115 percent of nominal, whichover is lower

- the transient following the complete loss of load will not cause the speed of the unit to attain the overspeed trip setpoint.

- bus voltage and frequency will recover to $6.9 \mathrm{kV} \pm 10$ percent at $60 \pm 2$-percent $\mathrm{Hz}$ within 10 seconds following trip and restart of the largest load

- each of the above design commitments will have the capability of being periodically verified

GDC 17 of 10 CFR Part 50, Appendix A, requires that the Class 1E ac standby power supply (the diesel generator power supply) have sufficient (1) capacity ard capability to permit safety systems to perform their required safety function and (2) testability to perform their safety functions assuming a single failure. GDC 18 of 10 CFR Part 50, Appendix A, requires that the Class 1E ac standby electric power system be designed (1) to permit appropriate periodic inspection and testing of important areas and features (such as wiring, insulation, connections, and switchboards) to assess the continuity of the systems and the condition of their components, (2) the capability to test periodically the operability and functional performance of the components of the systems, and (3) the capability to test periodically the operability of the systems as a whole and (under conditions as close to design as practical) the full operation sequence that brings the systems into operation. The staff concludes that a diesel generator power supply design that meets the above described commitments will have sufficient capacity and capability to supply required loads and will be testable. The design, therefore, meets the above defined requirements of GDC 17 and 18 of 10 CFR Part 50, Appendix A, and is acceptable. Verification that GE has revised the SSAR to include the above design commitments in a future SSAR amendment was DFSER (SECY-92-349) Confirmatory Item 8.3.8.4-1. GE has included these commitments in Sections 8.1.3.1.1.3, 8.3.1.1.8.2, 8.3.1.1.8.3, and 8.3.1.1.8.6 of SSAR Amendment 32, which is acceptable. Therefore, this item is resolved.

GE indicated that each of the above design commitments will be verified periodically and that testing or analysis will be performed periodically to demonstrate the capability of the diesel generator to supply the actual full design basis load current for each sequenced load step. Verification that GE specified in a future SSAR amendment that the COL applicant will include these periodic tests and analysis in appropriate plant procedures was DFSER (SECY-92-349) COL Action Item 8.3.8.4-1. GE included this action itom in 8.3.4.36 of SSAR Amondment 32, which is acceptable.

\section{Start time for the diesel senerators}

As part of DSER (SECY-91-355) Open Item 67, the staff identified inconsistencies between Sections 8.3.1.1.8.2 and 8.3.1.1.8.3 of SSAR Amendment 10 with regard to the design capability of the diesel generator to start and attain rated voltage and frequency. Section 8.3.1.1.8.2 of SSAR Amendment 10 indicated a 13-second design capability, whilo Section 8.3.1.1.8.3 indicated a 20-second capability.

GE's SSAR Amendment 17 corrected the inconsistency by changing the 13-seconds start time for the diesel generator to 20 seconds, with the sequence start times for loads changing accordingly. GE indicated that this change was made to be consistent with EPRI/advanced light water reactor requirements.

GE indicated that the accident analysis requires the residual heat removal (RHR) and HPCF injection valves to be open 36 seconds after the receipt of a high drywell or low reactor vessel level signal. Since the motor operated valves are not tripped off the buses, they start to open (if requested to do so by their controls) when power is restored to the bus at 20 seconds. This gives them an allowable travel time of 16 seconds.

Changing the allowable start time for the diesel generator from 13 to 20 seconds has changed the allowable travel time for the RHR and HPCF injection valves to move from the close to open position from 23 to 16 seconds. GE indicated that this reduction to a 16 second travel or opening time is attainable for the RHR and HPCF injection valves. The staff therefore concluded that the longer start time for the diesel generator is within the accident analysis limits and is acceptable. GE included this information in Section 8.3.1.1.8.2 of SSAR Amendment 32, which is acceptable. Therefore, this item is resolved.

Load Sequencine on the Diesel Generator following 8 LOCA with a delayed LOPP

This section addresses, in part, the staff's evaluation of GE's response to DSER (SECY-91-355) Open Item 28 and DFSER (SECY-92-349) Confirmatory Item 8.2.3.2-1.

As noted in Section 8.2.3.2 of this report, the diesel generator may be overloaded if there is a LOCA with a delayed LOPP. Section 8.3.1.1.7(3) of SSAR 
Amendment 21, LOPP following LOCA, indicated that all loads that have been connected to the Clase 1E bus and are operating from the offaite power supply in response to the LOCA will be connected, in one block loed, to the standby dievel generator (operating at no load due to the LOCA) if there is a LOPP. The staff was concerned that the diesel generator may not have sufficient capecity to supply, in one block, the loads which may be operating on the Class IB bus following a LOCA with a delayed LOPP.

Subsequently, GE indicated that the diesel generator breaker will not close until after large motors loads aro tripped. Thus, loads will be reloaded onto the bus in a controlled sequence which will not overload the diesel generator power supplies.

If there is a LOCA with a delayed LOPP, if there is a coincident LOCA and LOPP, or if there is a LOPP with a subsequent LOCA, the staff concludes that a diesel generator power supply design that meets the above commitments (as clarified) will have sufficient capacity and capability to supply required loads for all modes of plant operation and will be testable. The design, therefore, meets the above defined requirements of GDC 17 and 18 of 10 CFR Part 50, Appendix A, and is acceptable. GE has included the above clarification in Section 8.3.1.1.7 of SSAR Amendment 32, which is acceptable. Therefore, this item is resolved.

\section{Cortified Desion Material}

DFSER (SECY-92-349) Open Item 8.3.8.4-1 was related to the design description and the ITAAC for the capacity and capability of the Class IE ac standby power system. The adequacy and acceptability of the ABWR design descriptions and ITAAC are evaluated in Chapter 14.3 of this report. Therefore, this item is resolved.

\subsubsection{Constant Voltage Constant Frequency Power Supply Capacity}

Based on information presented in the draft SSAR revision dated April 3, 1992, and discussions; GE indicated that each of the four redundant Class IE CVCF power supplies will have a capacity based on the largest combined demands of the various continuous loads, plus the largest combination of noncontinuous loads that would likely be connected to the power supply simultaneously during normal or accident plant operation, whichever is higher. The design will also permit periodic verification of this capacity for each of the CVCF power supplies.

GDC 17 of 10 CFR Part 50, Appendix A, requires that the Class 1E CVCF power supplies have sufficient (1) capacity and capability to permit safety systems to perform their required anfoty function and (2) testability to perform their safoty functions seauming a single failure. GDC 18 of 10 CFR Part 50, Appendix A, requires that the Class 1E CVCF power supply syetems be designed (1) to permit appropriato periodic inspection and testing of important areas and foatures (such as wiring, insulation, connections, and switchboards) to assees the continuity of the systems and the condition of their components, (2) the capability to teat periodically the operability and functional performance of the components of the systems, and (3) the capability to teat periodically the operability of the systems as a whole and (under conditions as close to design as practical) the full oreration sequence that brings the systems into operation. The staff concludes that a CVCF power supply design that moets the above commitments will have sufficient capacity and capability to supply required loads and will be testable. The design, therefore, meets the above defined requirements of GDC 17 and 18 of 10 CFR Part 50, Appendix A, and is acceptable.

Verification that GE provided the above design commitments in a future SSAR amendment was DFSER (SECY-92-349) Confirmatory Item 8.3.8.5-1. GE has included these commitments in Section 8.3.1.1.4.2.1 of SSAR Amendment 32, which is acceptable. Therefore, this item is resolved.

GE also indicated that the above capacity commitment for the CVCF power supplies will periodically be verified. Verification that GE specified in a future SSAR amendment that the COL applicant will include these periodic tests in appropriate plant procedures was DFSER (SECY-92-349) COL Action Item 8.3.8.5-1. GE included this action item in Section 8.3.4.34 of SSAR Amendment 32, which is acceptable.

\section{Certified Desion Material}

DFSER (SECY-92-349) Open Item 8.3.8.5-1 related to the design description and the ITAAC for the capacity of the CVCF power supplies. The adequacy and acceptability of the ABWR design descriptions and ITAAC are evaluated in Chapter 14.3 of this report. Therefore, this item is resolved.

\subsubsection{Battery Charger}

Based on information presented in the draft SSAR revision dated April 3, 1992, and discussions, GE indicated that each of the four redundant Class 1E dc battery chargers will have sufficient capability and will be testable. The battery chargers will have a capacity based on the largest combined demands of the various continuous steady-state loads, plus charging capacity to restore the battery from the design minimum charge state to the fully charged state 
within the time stated in the dexign-bexis, regardleas of the atatus of the plant during which these demends occur. The de battery chargers will have a disconnecting dovice in the incoming ec power feed and in its dc-power output circuit for isolating the charger. The de battery chargers will be deaigned to provent the ac power aupply from becoming a load on the battery. The de bettery chargers will aleo have provisions to isolate transients from the sc aystem from affecting tho dc system and; conversely, provisions will be included to isolate transients from the de aystem from affecting the ac system. The de battery charger system will be sized in accordance with the guidelines defined in Section 6.1 of IEEE 946-1985 for eetablishing the required rating for battery chargers. The design of the de aystem will include the capability to periodically verify the required capacity for each of the battery charger power supplies.

GDC 17 of 10 CFR Part 50, Appendix A, requires that the Clase IE battery chargers have sufficient (1) capacity and capability to permit safety systems to perform their required safety function and (2) testability to perform their safety functions assuming a single failure. ODC 18 of 10 CFR Part 50, Appendix A, requires that the Class 1E dc system battery chargers be designed (1) to permit appropriate periodic inspection and teating of important areas and features (such as wiring, insulation, connections, and switchboards) to aseess the continuity of the systoms and the condition of their components, (2) the capability to test periodically the operability and functional performance of the components of the systems, and (3) the capability to test periodically the operability of the systems as a whole and (under conditions as close to design as practical) the full operation sequence that brings the systems into operation. The staff concludes that a dc system battery charger deaign that moets the above described commitmeats will have sufficient capacity and capability to supply required loads and will be testable. The design, therefore, meets the above defined requirements of GDC 17 and 18 of 10 CFR Part 50, Appendix A, and is ucceptable.

Verification that $\mathrm{GE}$ provided the above design commitments in a future SSAR amendment was DFSER (SECY-92-349) Confirmatory Item 8.3.8.6-1. GE hes included these commitments on Figure 8.3-4 and in Sections 8.3.2.1.1 of SSAR Amendment 32, which is acceptable. Therefore, this item is resolved.

GE also indicated that the above capacity commitment for the battery charger power supplies will be periodically verified. Verification that GE specified in a future SSAR amendment that the COL applicant will include this periodic teating of the battery capacity in appropriate plant procedures was DFSER (SECY-92-349) COL Action
Itom 8.3.8.6-1. GE included this action item in Section 8.3.4.35 SSAR Amendment 32, which is acceptablo.

\section{Certified Denion Meterial}

DFSER (SECY-92-349) Open Itom 8.3.8.6-1 related to the deaizn description and the ITAAC for the capecity of the bettery charger. The adequacy and acceptability of the ABWR design descriptions and ITAAC are evaluated in Chapter 14.3 of this report. Therefore, this item is resolved.

\subsubsection{Distribution Systems}

Based on information presented in the draft SSAR revision dated April 3, 1992, and discussions, GE indicated that each Class 1E distribution circuit will be capable of transmitting sufficient energy to start and operate all required loeds in that circuit for all plant conditions described in the design basis. GE also indicated that the design will also permit periodic verification of this required capacity for each distribution circuit.

ODC 17 of 10 CFR Part 50, Appendix A, requires that the Claw 1E distribution system have sufficient (1) capacity and capability to permit safety systems to perform their required safety function and (2) testability to perform their safety functions assuming a single failure. GDC 18 of 10 CFR Part 50, Appendix A, requires that the Class 1E distribution systems be designed (1) to permit appropriate periodic inspection and testing of important areas and features (such as wiring, insulation, connections, and switchboards) to assess the continuity of the systems and the condition of their components, (2) the capability to test periodically the operability and functional performance of the components of the systems, and (3) the capability to test periodically the operability of the systems as a whole and (under conditions as close to design as practical) the full operation sequence that brings the systems into operation.

The staff concludes that a Class 1E distribution system design that meets the above described commitments will be capable of supplying sufficient energy to Class 1E safety system loads for their operation, and will be capable of being tested. The design, therefore, moots the above defined requirements of GDC 17 and 18 of 10 CFR Part 50, Appendix A, and is acceptable.

Verification that $\mathrm{GE}$ provided the above design commitments in a future SSAR amendment was DFSER (SECY-92-349) Confirmatory Itom 8.3.8.7-1. GE has included these commitments in Sections 8.3.1.1.5(2) and 
8.3.3.2 of SSAR Amendment 32, which is acceptable. Therefore, this item is resolved.

GE also indicated that the above capecity commitment for each jistribution circuit will periodically bo verified. Verification that GE has specified in a future SSAR amendment that the COL applicent will include this periodic testing in appropriate plant procedures was DFSER (SECY-92-349) COL Action Itom 8.3.8.7-1. GE included this action item in Section 8.3.4.30 of SSAR Amendment 32, which is acceptable.

\section{Certified Desion Material}

DFSER (SECY-92-349) Open Item 8.3.8.7-1 related to the design description and the ITAAC for capacity of distributions systems. The adequacy and acceptability of the ABWR design descriptions and ITAAC are ovaluated in Chapter 14.3 of this report. Therefore, this item is resolved.

\subsubsection{Station Blackout (SBO)}

In SECY-90-016, dated January 12, 1990, the staff recommended that the Commission approve its position that a diverse, AAC source, be provided for SBO in evolutionary LWRs. In; its June 26, 1990, SRM, the Commission approved the staff's position.

In response to the above staff position and DFSER (SECY-92-349) Confirmatory Items 8.3.9.1-1, 8.3.9.2-1, and 8.3.9.3-1 and open items 8.3.9.1-1, 8.3.9.2-1, and 8.3.9.3-1, GE indicated that they planned to change their commitment for meeting the SBO rule from a design that met the SBO rule through the use of coping to a design that meets the SBO rule through the use of an alternate ac (AAC) power source in accordance with NRC Policy Issue SECY-90-016.

In an SSAR draft version dated July 2, 1993, GE indicated in accordance with RG 1.115, that the AAC power source will

- be a CTG

- be capable of automatically starting, accelerating to rated speed, of reaching nominal voltage, and to begin accepting load within two minutes of receipt of its start signal

- be capable of being manually connected to Class $1 E$ $6.9 \mathrm{kV}$ buses and safety-related loads

- be capable of being manually reconfigured such that non safety investment protection loads can be shed and safety-related shutdown loads can bo connected (via nuy one of the Class 1E $6.9 \mathrm{kV}$ buses) from the main control room within ten minutes

- be a solf-contained unit equipped with its own auxiliary control and support systems such that external ac power is not required for its operation

- be physically and electrically independent and diverse from the Class 1E standby diesel generators such that weather-related failures, common cause failures, or single point vulnerabilities are minimized to the extent practicable

- be electrically isolated from each $6.9 \mathrm{kV}$ bus by two normally open circuit breakers in series (one Class $1 E$ and one non-Class 1E) ,

- require DC control power from the Class $1 E$ and nonClass 1E dc power systems so that the AAC power source can be connected to the Class $1 E 6.9 \mathrm{kV}$ bus (to close the two normally open circuit breakers) from the control room within the 10 minute time requirement

- be capable of operating during and after a station blackout without any ac support systems powered from the preferred power supply or the blacked-out units Class 1E power sources affected by the event

- have sufficient capacity and capability to power one safety-related bus within 10 minutes of the onset of a station blackout, such that the plant safety systems will be capable of maintaining core cooling and containment integrity

- not normally or automatically be connected to the offsite power sources or the on-site Class 1E $6.9 \mathrm{kV}$ buses thus minimizing the possibility of a common cause failure

- be designed to assume non-safety plant investment protection (PIP) loads automatically, to shed loads manually, and assume safety system loads manually while maintaining voltage and frequency within design requirements of safety system loads

- be capable of powering required shutdovm loads with margin

- be capable of powering HVAC systems, chillers, battery chargers, and other support/auxiliary equipment during the station blackout event such that the environment during and following a station blackout event will not exceed the environment for vluch the 
equipment is designed and the habitable cavironment for perconnel

- undergo factory testing, similar to the Class IE standby diecel generator, to demonstrate its ability to reliably start, eccolerate to rated speed, voltage, and supply power within two minutes

- bo aubject to site acceptance tecting, periodic proventive mainteance, inspection, testing and operational reliability asourance program goals

- be designed to quality assurance requirements commensurnte with its importance to safety

- be located above the maximum flood level in the turtine building

- be provided with an oil storage and transfer system that will be physically and mechanically independent of the Class 1E atandby diesel generator oil storage and transfer system

- have its fuel sampled and analyzed consistent with applicable standards

- have sufficient fuel oil stored on-site to support 7 days operation

- be capable of being periodically inspected, tested, and maintained
In addition, GE indicated that required plant core cooling and containment integrity during the station blackout duration (10 minutes) will not depend on any ac power sources.

Section 50.63(c)(2) of 10 CFR Part 50 requires (1) the time required for startup and alignment of the AAC to required shutdown equipment be demonstrated by test, (2) the ACC source have aufficient capacity and capability to permit required shutdown equipment to perform their required function, and (3) the AAC can be started and aligned within 10 minutes to the buses that distribute power to required shutdown equipment.

The staff concludes that a design, which meets the above deacribed commitments, will have sufficient capacity, capability, and testability to provide power to required shutdown loads within specified station blackout timo limitations. The design, therefore, meets the above defined requirements of Section 50.63(c)(2) of 10 CFR Part 50 and is acceptable. GE has included the arovm deaign commitments in Section 8.3.1.1.7(9) of SSAR Amendment 32, which is acceptable.

GE also indicated that the COL applicant must include periodic testing and/or analysis to verify the adequacy of the CTG to meet AAC requirements for station blackout in appropriate plant operating procedures. GE included this requirement in Section 9.5.13.19 of SSAR Amendment 32, which is acceptable.

\section{Certified Desian Material}

The adequacy and acceptability of the ABWR design descriptions and ITAAC for the AAC are evaluated in Section 14.3 of this report. 


\section{AUXILIARY SYSTEMS}

\subsection{Fuel Storage and Handling}

\subsubsection{New Fuel Storage}

The staff reviowed the now fuol storage capability in accordance with Standard Roview Plan (SRP) Section 9.1.1. Staff acceptance of the new fuel storage facility design is besed on the design moeting the requirements of General Design Criteria (GDC) 2 as it relates to the ability of structures housing the facility and the facility itself to withstand the effects of natural phenomena such as earthquakes; the position in Regulatory Guide (RG) 1.29, "Seismic Design Classification," Revision 3, Section C, which lists the systems which need to be designed to operate following a safe shutdown earthquake (SSE); GDC 5 as it relates to shared structures, systems, and components (SSCs) important to safety being capable of performing required safety functions; GDC 61 as it relates to the facility design for fuel storage; and GDC 62 as it relates to the prevention of criticality.

New fuel storage is provided in the new fuel storage vault located in the reactor building. The vault will contain storage racks for up to $\mathbf{4 0}$ percent of one full core fuel load. New fuel normally will be in dry storage; however, the storage racks can be used in either a wet or dry mode. The storage racks, vault, and the reactor building that houses the facilities are designed to seismic Category I criteria. The reactor building also is designed to provide protection against flooding and tornado missiles as evaluated in Sections 3.4.1 and 3.5.2 of this report, respectively. Therefore, the design satisfies the requirements of GDC 2 and the guidelines of Position C.1 of RG 1.29, Revision 3 because the reactor building provides the required protection.

The ABWR is designed as a single-unit facility. Therefore, the requirements of GDC 5 regarding the sharing of SSCs are not applicable. An application for a multi-unit facility will require review of the design for compliance with GDC 5.

The facility is designed to store unirradiated, low-emission fuel assemblies. Accidental damage to the fuel would release only minor amounts of radioactivity. These amounts would be treated by the standby gas treatment system (SGTS) which will limit any possible release of radioactivity from a fuel- handling accident to below acceptable values. Thus, the design meets the requirements of GDC 61 regarding appropriate containment, confinement, and filtering systems for a fuel storage facility.

The new fuel racks are not located near any high-energy lines, rotating machinery, or non seismic Category I SSCs and thus are protected from internally-generatod misailos and the effects of pipe breaks by physical separation. Applicants referencing the ABWR design will be required to provide features which prevent placement of a now fuel assembly in other than its prescribed location. Because the racks are freestanding (i.e., no supports above the base of the racks), the racks and rack support structure provide the necessary dynamic stability for the racks, thus preventing them from tipping.

The new fuel racks are designed to ensure that $\mathbf{k}_{\text {eff }}$ does not exceed 0.95 under all normal and abnormal conditions. The standard safety analysis report (SSAR) states that the new fuel storage racks are purchased equipment. In the draft safety evaluation report (DSER) (SECY-91-235), interface requirements were identified for the combined license (COL) applicant to provide:

- An analysis of design details that prevent inadvertent placement of a fuel assembly in other than prescribed locations.

- Confirmatory dynamic and impact analyses. The input excitation for these analyses should utilize the horizontal and vertical response spectra provided in SSAR Section 3A.10.2.

- An analysis showing that the design of the new fuel storage racks will be such that $k_{\text {eff }}$ will not exceed 0.98 with a fuel load of the highest anticipated reactivity, assuming optimum moderator conditions (fosm, small droplets, spray, or fogging), as described in SRP Section 9.1.1.

In the DSER, the staff identified these requirements as Interface Information Items 28 and 29 . They were later reclassified as Open Item 9.1.1-1 in the draft final safety evaluation report (DFSER). Upon further evaluation, the staff determined that these requirements can be accomplished by $\mathrm{COL}$ actions and are not needed for design certification. SSAR Sections 9.1.6.1 and 9.1.6.2 state that the COL applicant shall provide a confirmatory criticality analysis and dynamic and impact analyses of the new fuel storage racks. This is acceptable as information which will be evaluated during the COL review. On the basis of the above, DFSER Open Item 9.1.1-1 and DSER Interface Information Items 28 and 29 are resolved. Therefore, the staff concludes that design commitments in the SSAR meet GDC 62 as it relates to prevention of inadvertent criticality for fuel storage facilities.

In the DFSER, the staff requested GE to provide adequate design description and inspections, tests, analyses, and acceptance criteria (ITAAC) for the new fuel storage facility. This was part of DFSER Open Item 9.1.2-2. GE 
submitted a revised set of design description and ITAAC. The adequacy and acceptability of the design description and the ITAAC are evaluated in Section 14.3 of this report. On the basis of the above, the applicable part of DFSER Open Item 9.1.2-2 is resolved.

The now fuel facility includes the fuel assembly storage racks and the concrete storage vault that contains the storage racks. The staff reviewed the applicant's proposed design criteria, design bases, and seismic classification for the new fuel storage facility related to the provisions necessary to maintain a subcritical array. The staff concludes that the design of the new fuel storage facility and supporting systems is acceptable and meets the requirements of GDC 2 as it relates to the ability of structures housing the facility (the reactor building) and the facility itself (designed to seismic Category I) to withstand the effects of natural phenomena such as earthquakes and GDC 61 as it relates to the facility design for fuel storage. GE adequately incorporated a COL action item requiring the applicant referencing the ABWR to provide information to ensure compliance with GDC 62 during the COL review. Therefore, the staff concludes that the design and related commitments comply with the guidelines of SRP 9.1.1 and are acceptable.

\subsubsection{Spent Fuel Storage}

The staff reviewed the ABWR spent fuel storage facility in accordance with the guidelines of SRP Section 9.1.2 to verify that is meets the requirements of GDC 2 as it relates to structures housing the facility and the facility itself being capable to withstand the effects of natural phenomena; GDC 4 as it relates to structures housing the facility and the facility itself being capable of withstanding the effects of environmental conditions, missiles, pipe whip, and jet impingement forces associated with pipe breaks; GDC 5 as it relates to shared SSCs important to safety being capable of performing required safety functions, GDC 61 as it relates to the facility design for fuel storage and handling of radioactive materials, GDC 62 as it relates to prevention of criticality, and GDC 63 as it relates to monitoring systems to detect conditions that could result in the loss of decay heat removal capabilities, to detect excessive radiation levels, and to initiate appropriate safety actions.

The spent fuel storage facility consists of fuel storage racks contained in the spent fuel storage pool in the reactor building. The spent fuel pool can store 270 percent of one full core load, in accordance with American Nuclear Society (ANS) $\mathbf{5 7 . 2}$ for the capacity of a single-unit facility. As stated in SSAR Section 9.1.4.2.8, defective fuel assemblies are placed in special fuel storage containers which are stored in equipment storage racks. Both the containers and the racks are designed for defective fuel.
The reactor building housing the facility is designed to seismic Category I criteria, as are the storage racks and other fuel storage facilities, including the gates between the spent fuol pool and other areas. In the DSER (SECY-91-235), the staff commented on the lack of information in the SSAR regarding the seismic classification of the spent fuel pool liner. This was DSER Open Item 44. Table 3.2-1 of the SSAR states that the liner will be seismic Category I. This meets the guidelines of SRP Section 9.1.2 and resolved DSER Open Item 44.

Applicants referencing the $A B W R$ design will be required to provide features which prevent placement of a spent fuel assembly in other than its prescribed location. Because the racks are freestanding (i.e., no supports above the base of the racks) the racks and rack support structure provide the necessary dynamic stability for the racks, thus preventing them from tipping.

The reactor building is also designed to provide protection against flooding and tornado missiles as discussed in SSAR Sections 3.4.1 and 3.5.2 and evaluated in Sections 3.4.1 and 3.5.2 of this report. Therefore, the design satisfies the requirements of GDC 2 for protection of safety-related SSCs from natural phenomena and the guidelines of Position C.3 of RG 1.13, "Spent Fuel Storage Facility Design Basis, "Revision 1, Positions C.1 and C.2 of RG 1.29, and Positions C. 1 through C.3 of RG 1.117, "Tornado Design Classification," Revision 1.

The spent fuel pool is not located near any high-energy lines, rotating machinery, or non seismic Category I SSCs, and thus is protected from internally-generated missiles and the effects of pipe breaks by physical separation. The reactor building provides protection against externaily generated missiles. Therefore, the design of the spent fuel facility satisfies GDC 4 and Positions C.1 through C.3 of RG 1.117.

The ABWR is designed as a single-unit facility. Therefore, the requirements of GDC 5 regarding the sharing of SSCs are not applicable. An application for a multi-unit facility will require review of the design for compliance with GDC 5.

Accidental damage to the fuel could release radioactive material. These amounts would be treated by the SGTS to limit any possible release of radioactivity from a fuel-handling accident to below acceptable values. Thus, the design meets the requirements of GDC 61 regarding appropriate containment, confinement, and filtering systems.

The fuel storage racks are designed to meet design requirements specifying that the fuel assemblies will be stored in 
an array that limits $k_{\text {off }}$ to 0.95 or less under all normal and abnormal conditions, such as a dropped fuel assembly, earthquake, or stuck fuel asseribly. The SSAR specifies the design requirements.

In the DSER (SECY-91-235), the staff included interface requirements, that the COL applicant's purchase specification for the spent fuel storage racks should require the vendor to submit:

- Confirmatory criticality analysis, including the uncertainty value and associated probability and confidence level for the $k_{\text {eff }}$ value determined by the analysis.

- Confirmatory load drop analysis, including the free fall of a fuel assembly and its associated handling tool.

These were identified as Interface Information Item 30 in the DSER and later reclassified as Open Item 9.1.2-1 in the DFSER. Upon further evaluation, the staff determined that these requirements can be accomplished by COL actions and are not needed to be met for design certification. SSAR Sections 9.1.6.3 and 9.1.6.4 state that the COL applicant shall provide a confirmatory criticality analysis and load drop analysis of the spent fuel storage racks. This is acceptable. On the basis of the above, DFSER Open Item 9.1.2-1 and DSER Interface Information Item $\mathbf{3 0}$ are resolved. Therefore, the staff concludes that the design and associated commitments meet GDC 62 as it relates to prevention of inadvertent criticality.

In the DSER, the staff determined that the design of the storage pool includes the provisions for radiation monitoring systems described in SSAR Section 11.5 that satisfy, in part, the requirements of GDC 63 regarding the monitoring of spent fuel. In the DSER, the staff identified, as Open Item 45, a lack of information regarding pool level indication. Subsequently, GE provided additional information which states that the pool level will be monitored and alarmed (on high and low level) locally and in the control room. Leakage flow detectors in the pool drains and pool liners are also provided and alarmed in the control room. The staff concludes that these provisions will provide adequate nonitoring capability and meet the requirements of GDC 63. Therefore, DSER Open Item 45 is resolved.

In the DFSER, the staff requested GE to provide adequate design description and the ITAAC relating to the spent fuel storage facility. This was part of DFSER Open Item 9.1.2-2. Subsequently, GE provided a revised set of design description and ITAAC. The adequacy and acceptability of the design description and the ITAAC are evaluated in Section 14.3 of this report. On the basis of the above, the applicable part of DFSER Open Itom 9.1.2-2 is resolved.

The spent fuel storage facility includes the spent fuel storage racks and the spent fuel storage pool that contains the racks. The staff reviewed the design criteria, design bases, and safety classification for the spent fuel storage facility and the provisions necessary to maintain a subcritical array. The staff concludes that the design and relatod commitments of the spent fuel storage facility and supporting systems conform with the Commission's regulations as set forth in GDC 2, 4, 5, 61, and 63. GE adequately incorporated a COL action item requiring the applicant referencing the ABWR to submit information to ensure compliance with GDC 62.

The staff concludes that the spent fuel storage design and commitments meet the guidelines of SRP 9.1.2 and the requirements of GDC 2 as it relates to structures housing the facility and the facility itself being capable of withstanding the effects of natural phenomena; GDC 4 as it relates to structures housing the facility and the facility itself being capable of withstanding the effects of environmental conditions, missiles, pipe whip, and jet impingement forces associated with pipe breaks; GDC 5 as it relates to shared SSCs important to safety being capable of performing required safety functions; GDC 61 as it relates to the facility design for fuel storage and handling of radioactive materials; GDC 62 as it relates to prevention of inadvertent criticality; and GDC 63 as it relates to monitoring systems to detect conditions that could result in the loss of decay heat removal capabilities, to detect excessive radiation levels, and to initiate appropriate safety actions. The design and related commitments, therefore, are acceptable.

\subsubsection{Spent Fuel Pool Cooling and Cleanup System}

The staff reviewed the spent fuel pool cooling and cleanup (FPC) system and its makeup system in accordance with SRP Section 9.1.3 to verify that they meet the requirements of GDC 2 as it relates to structures housing the system and the system itself being capable of withstancing the effects of natural phenomena; GDC 4 as it relates to structures housing the system and the system itself being capable of withstanding the effects of external missiles; GDC 5 as it relates to shared SSCs important to safety being capable of performing required safety functions; GDC 44 as it relates to the system's ability to reliably transfer heat loads from safety-related SSCs (including suitable redundancy and isolability); GDC 45 and 46 as they relate to inspection and functional testing, respectively; GDC 61 as it relates to the facility design for fuel storage and handling of radioactive materials; GDC 63 as it relates to monitorirg i systems provided to detect 
conditions that could result in the lose of decay heat removal capabilities, to detect exceusive radiation lovels, and to initiate appropriate safoty actions; and 10 CFR Part 20 as it relates to keeping radiation doses as low as reasonably schiovable (ALARA).

The FPC system is a non-rafoty-related aystom designed to remove docsy heat generated by spent fuel assemblies in the spent fuel storage pool; to maintain water quality and clarity; and to remove corrosion products, fission products, and other impuritios from the pool water. The system consists of all components and piping from the system inlet at the fuel pool to the system outlet at the fuel pool, piping used to carry the fuel pool makeup water, and the cleanup filter/demineralizers (shared with the suppression pool cleanup (SPCU) system) to the point of discharge to the radwaste syetom. Specifically, the system includes two 50-percent capacity circulating pumps, two 50-percent capacity heat exchangers, two filter/demineralizers, one postdemineralizer strainer, two skimmer surge tanks, piping, valves, controls, and instrumentation. The pool water is circulated by means of overflow through skimmers around the periphery of the pool and a scupper at the end of the transfer canal; the overflow is collected in the surge tanks. Normally, one of the two circulating pumps draws water from these tanks and discharges it through a common header to either of two filter/demineralizers connected in parallel. System flow then passes through two heat exchangers in parailel, cooled by water from the reactor building cooling water (RCW) system, and returns to the spent fuel storage pool. The system includes a bypass line around the cleanup portion of the system (the filter/demineralizers). Circulating pumps can be powered from the combustion turbine generators (CTGs) if normal power is not available.

The requirements of GDC 5 regarding the sharing of SSCs do not apply because the ABWR is designed as a singleunit facility. An application for a multi-unit facility will require review of the design for compliance with GDC 5.

Filtering and ion exchange together maintain clarity and purity of pool water. The filter/demineralizers maintain total corrosion product metals at 30 parts per billion (ppb) or less with a $\mathrm{pH}$ range of 5.6 to 8.6 at $25{ }^{\circ} \mathrm{C}\left(77^{\circ} \mathrm{F}\right)$ for compatibility with fuel storage racks and other equipment. Conductivity is maintained at less than 1.2 micro siemens $(\mu \mathrm{S}) / \mathrm{cm}(3.0 \mathrm{micro} \mathrm{Mho} / \mathrm{in}$.) at $25 \circ \mathrm{C}$ and chlorides less than $20 \mathrm{ppb}$. Maintaining the pool water|purity within these levels will ensure that there are no adverse chemical interactions with the fuel storage racks and other pool equipment supplied by the applicant. Each filter unit in the filter/demineralizer subsystem has adequate capacity to maintain the desired purity of the pool under normal operating conditions.
The FPC system is housed in the reactor building (eocondary containment area), a seismic Category I structure designed to protect against flood and tornado missiles. Thus, the system meets Position C.2 of RG 1.13 for protection of this support system for the fuel storage facility from natural phenomena such as tornados, winds, and externally-generatod missiles.

Normal makeup water is supplied to the storage pool by the non-safety-related makeup water (condensate) system (MUWC). Backup to the normal makeup will also be available from the nonsafety-related SPCU system. Additionally, an emer jency safety-related, seismic Category I makeup water source to the spent fuel pool will be provided by FPC connections to the residual heat removal (RHR) systom, which draws water from a safety-related water source, that is, the suppression pool. FPC system piping from the spent fuel pool to the RHR system is classified as safety related. In a letter dated July 23, 1990, GE stated that the FPC system, except for the filter demineralizers, is designed to seismic Category I, Quality Group (QG) C standards. Althuugh the entire system is not classified as seismic Category I, QG C standards, the nonsafety-related portions of the system that could affect any SSCs important to safeiy if they failed during a seismic event, are designed to ensure their integrity under seismic loading. Thus, the system meets Positions C. 1 and C.2 of RG 1.29 with respect to the seismic design of the safety-related and nonsafety-related portions of the system, respectively.

There are no connections to the spent fuel pool that would cause the pool water to be drained below a safe shielding level. All lines that connect to the pool and extend below the safe level of the pool are equipped with siphon breakers, check valves, or other suitable devices to prevent inadvertent pool draining. Drainage paths are interconnected behind the liner welds. Leakage through the pool liner is collected in a drain system and transferred to an equipment drain tank. No piping connections penetrate the fuel pool liner to the fuel storage pool. The FPC system is designed so that no single failure, malfunction, or misoperation of the active components will uncover the stored fuel. Thus, the system meets Position C.6 of RG 1.13.

As mentioned above, the isystem includes a seismic Category I makeup water source that uses a safety-related piping segment of the FPC system return line. Check valves in the return lines that lead to the submerged FPC water return diffusers protect against backflow. Also, the system includes redundant safety-related isolation devices to facilitate isolation of the safety-related makeup portion of the system from the nonsafety-related SPCU system. The SPCU system makeup uses the same FPC system 
afoty-related piping segment that the RHR makeup uses, and is, therefore, equally vulnerable to a passive failure. In the DSER (SECY-91-235), the staff noted that such a failure will also affect the docay heat removal capability of both the FPC and the RHR systems, because both of these use the sume safety-rolated piping regment of the FPC system return line. Subeequently, GE indicated that the pipe segments are protected from the effects of the failure of other components and systems. $O E$ also submitted the recults of an analysis that show that given a failure of this pipe sogment, alternativo cooling and makeup capabilities exist that will maintain the pool level and tomperature within acceptable limits. The SSAR Section 9.1.6.10 clarifies the common piping through which FPC, RHR, and SPCU flow by stating that the COL applicant will ensure that the RHR system connections are adequately protected from the offects of pipe whip, intermal flooding, internally-generatod missiles, and the offects of a moderate energy pipe rupture in the vicinity. This is acceptable. Furthermore, responding to an early staff request (request for additional information (RAI) Question 410.37), GE stated that fire hoses will also be available to supply makeup water to tho pool. This is also scceptable. The staff concludes that the FPC systom design meets Position C.8 of RG 1.13.

Acceptance Criteria II.1.2 and b of SRP Section 9.1.3 state that GDC 2 and 4 noed not apply to the FPC system design if the design includes a safety-related makeup water system, including its source, and a safety-related fuel pool area ventilation and filtration system designed in accordance with the guidelines of RG 1.52. As noted above, a major portion of the FPC system is not safetyrelated and, therefore, does sot moet Position C.1 of RG 1.13. The design relies instead on the SGTS, a safety-related ventiletion and filtration system for the fuel pool area and relies on a safety-related makeup water system. In Section 6.5.1 of the DSER (SECY-91-235), the staff stated that the design of the SGTS had been identified as Open Item 30 in SECY-91-153 because GE had not demonstrated its compliance with all the applicable positions of RO 1.52 (e.8., redundancy of filtors in the SGTS). The staff stated its concerns about safety-rolated makeup capability for the fuel pool and the SGTS design in the DSER (SECY-91-235) as part of Open Item 46 (Section 1.8 of the DSER (SECY-91-235) grouped four concerns of DSER Section 9.1.3 as Open Item 46.).

GE subsequently committed to revise the design of the SGTS to include a second redundant filter train. Because the safety-related makeup for the pool is not totally independent, but relies on the safety-related portion of the FPC system, GDC 2 and 4 are applicable for that portion of the FPC system. As stated above, the system is protected against the effects of adverse natural phenomena by virtue of its location in the reactor building. Also, SSAR Sections 3.5.1 and 3.6.1, and SSAR Table 3.6-2, include spent fuel pool cooling for protection against the offects of missiles and piping failures. The staff noted that GE's submittal dated June 2, 1989, further stated that the major components of the FPC system are located in eeparatoly-ahielded rooms and that barriers, restraints, and equipment compartments protect fuel pool cooling components against failure of high-energy piping systems. In the DSER (SECY-91-235), the staff stated, as part of Open Item 46, the need for GE to confirm that the safotyrelated portion of the system is protected from moderateenergy piping failures in the vicinity. The SSAR states that the safety-related portions of the system are protected from moderato-energy pipe breaks. This resolved this part of DSER (SECY-91-235) Open Item 46. GE also committod to modify the design of the SGTS to resolve the part of DSER (SECY-91-235) Open Itom 46 associated with the SGTS design, and include the required ventilation and filtration system required as an alternative to designing the entire FPC system as a safety-grade system. Incorporation of the identified changes to the SGTS into the SSAR was DFSER Confirmatory Item 9.1.3-1. The staff reviowed the SSAR and concluded that the SGTS has been modified to include two redundant safety-grade filtor trains and that the system complies with RG 1.52. This modification allows the ABWR FPC system to meet the alternate design guidance provided in SRP Sections 9.1.3.II.1.a and $b$. The SSAR clarifies the common piping through which FPC, RHR, and SPCU flow. SSAR Section 9.1.6.10 notes that the COL applicant will provide the protective features for this section of piping. The staff finds this approach and commitment acceptable. Therefore, DFSER Confirmatory Item 9.1.3-1 is resolved.

Based on the discussions above, the staff concludes that the design of the FPC system and the structures housing the system moet the criteria in GDC 2 and 4.

The staff based its evaluation of the capability of the FPC systom to handle the decay heat load in the fuel pool on the guidelines in SRP Section 9.1.2, Paragraphs II.1.d.(4) and III.1.h. Each of the two FPC system heat exchangers is rated at $6.91 \mathrm{E}+9 \mathrm{~J} / \mathrm{h}(6.55 \mathrm{E}+6 \mathrm{BTU} / \mathrm{hr})$ at the design temperature of $52{ }^{\circ} \mathrm{C}\left(125^{\circ} \mathrm{F}\right)$. Based on an independent staff calculation of the spent fuel heat load using Branch Tochnical Position (BTP) ASB 9-2, the maximum normal heat load at 150 hours after shutdown is approximately $18 \mathrm{E}+9 \mathrm{~J} / \mathrm{h}(1.7 \mathrm{E}+7 \mathrm{BTU} / \mathrm{hr})$. This heat lond is based on the decay heat generated by one refueling load (35 percent of the core) at equilibrium conditions 150 hours after shutdown, plus a refueling load at 365 days, and one at 400 days after shutdown in accordance with SRP Section 9.1.3.III.1.h.iv for pools with storage capacity greater than 1.3 cores. The FPC heat exchangers are inadequately 
sized to handle the decay heat loed in the fuol pool at 150 hours after shutdown as outlined by SRP Section 9.1.3, Paragraphs II.1.d.(4) and III.1.h, to meet GDC 44. The heat load beyond the FPC heat exchenger capacity is to be handled by the RHR system, which includes a segment of the non-safoty-related suction portion of the FPC systom and a safety-related piping segment of the FPC system return line for performing its decay heat removal function. The RHR system also supplements the FPC system capabilities to maintain pool water tomperature below $66^{\circ} \mathrm{C}\left(150^{\circ} \mathrm{F}\right)$ under the maximum abnormal heat load, that is, a full core offloed. GE has based the FPC heat exchanger design on the heat loed at 21 days after shutdown, the time at which the fuel transfer canal can be closed without requiring supplemental cooling. Independent calculations of the heat load at this time confirm the GE-calculated value of $12.0 \mathrm{E}+9 \mathrm{~J} / \mathrm{h}\left(1.14 \times 10^{7} \mathrm{BTU} / \mathrm{hr}\right)$. At this time after shutdown, the FPC system is adequately sized to handle the decay heat load of the fuel pool.

In the DSER (SECY-91-235), the staff stated that the FPC system design does not accommodate any single active failures. A single heat exchanger has insufficient heat removal capability to maintain the fuel pool temperature at an acceptable lovel at all times. GE also indicated that for some active single failures, using the RHR system may be necessary to limit the temperature of the fuel pool to less than $60^{\circ} \mathrm{C}\left(140^{\circ} \mathrm{F}\right)$. As a result, in addition to this concern, the DSER (SECY-91-235) identified as part of Open Item 46, the apparent undersizing of the FPC heat exchangers for the ABWR. The staff also identified as a concern the sole reliance on the RHR system to supplement the FPC system's normal maximum spent fuel heat load removal capability during certain situations (e.g., all times preceding 21 days after shutdown and after 21 days when there is a single active failure coincident with a loss of all offsite power). To address this concern, the SSAR provides additional commitments regarding the design of the RHR connection and alternative makeup capabilities so that the connection will te protected from the effects of high-energy and moderate-energy pipe breaks, and any other hazards to limit the likelihood of failure of the SPCU and RHR spent fuel pool makeup and cooling capability. The SSAR also addresses the capability to provide alternative makeup within an acceptable time limit. Fire water makeup to the spent fuel pool will be available within 30 minutes after the failure of the fuel pool cooling capability. GE's analysis showed that the spent fuel pool would not reach $60^{\circ} \mathrm{C}\left(140^{\circ} \mathrm{F}\right)$ under the maximum normal heat load at 21 days in less than this time. It concluded that over 6 hours would be required for the pool to heat up to this level. Under conditions of a full core off-load at 21 days after shutdown, the time to reach boiling was estimated to be over 16 hours. The staff's independent calculations verify that the results are representative of the times available to provide additional makeup. The available time to realign the fire water system appears to be sufficient to make the configuration changes. Incorporation of this information into the SSAR was DFSER Confirmatory Item 9.1.3-2. The SSAR provides this information which adequately addresses the part of DSER Open Item 46 (SECY-91-235) regarding the use of the RHR system as an integral part of the FPC system from 150 hours after shutdown to 21 days after shutdown, and under the conditions of a loss of offsite power (LOOP) and a single active failure. This resolved the applicable part of DSER Open Item 46 and DFSER Confirmatory Item 9.1.3-2. Therefore, the st iff concludes that the FPC system design complies with GDC 44 regarding the system's ability to transfer heat from systems important to safety under both normal and accident conditions and also complies with the RHR capability and coolant inventory maintenance requirements of GDC 61 .

The pumps, heat exchangers, and the filter/demineralizers are each located in separate shielded rooms within the secondary containment portion of the reactor building. Individual components can be isolated from the rest of the system during operation. The system design allows for isolation and accessibility of the components. This complies with the requirements of GDC 61 for shielding, containment, and confinement.

One division of the FPC system (pump, heat exchanger, and filter-demineralizer) is normally in operation. The second pump will be operated periodically to ensure its operability or to allow the operating pump to be removed from service. Periodically, the FPC system components will be visually inspected. From this discussion, the staff concludes that the requirements of GDC 45 and 46 regarding the inspection and testing of cooling water systems are satisfied for the components in the safety-related portion of the FPC system. The design also complies with the testing and inspection requirements of GDC 61.

The components of the FPC system are accessible and can be isolated to allow for periodic testing. The FPC system is located within the secondary containment portion of the reactor building, thus providing adequate containment. The FPC system contains design features to prevent reduction in fuel storage coolant inventory under accident conditions in accordance with Position C.6 of RG 1.13. The decay heat removal capabilities of the FPC system are designed to meet the heat load requirements of the fuel pool at 21 days after shutdown, not the requirements at 150 hours after shutdown. Use of the RHR system is required to meet the heat load requirements of the FPC 
system during the period between 150 hours and 21 days after shutdown. Additionally, as identified in the DSER, the FPC system is not capable of handling the decay beat load ascuming both a LOOP and a single active failure. Again the RHR systom, in conjunction with the operable portions of the FPC systom, is the system used to moet the heat load requirements. As indicated proviously, GE has provided information justifying this system arrangement. The design includes measures to ensure RHR system operability in the spent fuel cooling mode and aliernative makeup and cooling capabilities. Therefore, the staff conclivdes that the FPC system meets all requirements of GDC 61.

The control room includes instrumentation to monitor the fuel pool level and temperature and area radiation for the fuel storage and handling areas. The control room also includes high and low fuel pool level and high-radiation alarms. Interconnected drainage paths behind the liner welds include instrumentation to detect and measure liner leaks. Several FPC system parameters are also displayed and recorded in the control room and locally. These include pump suction pressure and pump flow and system water discharge temperature. The pump suction pressure and flow are also alarmed in the control room. These monitoring and alarming devices enable plant personnel to quickly begin appropriate safety actions such as erecting temporary shields to reduce radiation, supplying makeup water to the pool through a remotely operated valve, and actuating the SGTS on a high radiation signal on the refueling floor). Indications of high system temperature allow the operator to manually bypass system flow from the filter-demineralizers to protect the resins from damage. Thus, the system instrumentation meets the requirements of GDC 63 regarding the monitoring of fuel storage facilities and the initiation of appropriate safety actions.

Based on its review as discussed above, the staff concludes the following:

1. Designing the FPC system for the ABWR as a nonsafety-related system, except as stated above, meets the applicable acceptance criteria of SRP Section 9.1.3.

2. The cooling portion of the FPC system complies with the requirements of GDC 44 and 61 for decay heat removal, inspection and testing, containment and confinement of stored fuel, maintenance of fuel storage coolant inventory, and shielding requirements.

3. The safety-related portion of the FPC system complies with the requirements of GDC 4 for its protection from the effects of missiles and high- and moderate-energy piping failures in the vicinity.
4. The safety-rolated portion of the FPC system complies with the requirements of GDC 2 for its protection from the effects of adverse natural phenomena.

5. The cooling portion of the FPC system complies with the requirements of GDC 45, 46, 61, and 63, for inspection, hating, and monitoring.

In the DSER (SECY-91-235), the staff stated that conclusions 1,2 , and 3 are subject to:

1. GE's confirmation of protection of the system's anfety-related portions from the effects of modernte-energy piping failures in the vicinity. The SSAR includes a commitment that the COL applicant will include features to protect the common portion of FPC piping from pipe and equipment failures. This commitment is acceptable.

2. Resolution of the staff's concerns relating to (a) the system's decay heat removal capability, and (b) the SGTS design as it pertains to the requirement for redundant filters. The information provided in the SSAR regarding the capability of the operators to align the fire water system to supply pool makeup and cooling and the temperature response of the pool water after the loss of all cooling, adequately addresses the staff's concern about the system's decay heat removal capability. The staff's concern regarding the design of the SGTS was identified as Confirmatory Item 9.1.3-3 in the DFSER. Subsequently, the SGTS design was modified (see SSAR Section 6.5.1 for a full discussion of the SGTS and Section 6.5.1 of this report for the staff evaluation of the SGTS). As a result of the design modifications, the staff concludes that the SGTS provides adequate redundancy. Therefore, Confirmatory Item $\mathbf{9 . 1 . 3 - 3}$ is resolved.

In the DSER, the staff raised the issue of the technical specification (TS) implications of using the RHR system as an integral part of the FPC system, as part of Open Item 46. In the DFSER, the staff stated that GE's response did not explain how the RHR system can be used for the maximum normal heat load removal without violating the TS requirements for availability of the system for other purposes in Mode 5 (refueling mode). This was DFSER Open Item 9.1.3-1. Subsequently, GE submitted information in which it explained that, during refueling, containment is not required to be operable unless fuel is being moved. Therefore, suppression pool cooling and wetwell/drywell spray is not required while in the refueling mode. In a situation where augmented fuel pool cooling may be required, the shutdown cooling function is not affected since in this mode, the pool gates are removed and the reactor and spent fuel pool are common. RHR in the 
low-pressure flooder (LPFL) mode may be needed during refueling. In this case, TS require only two emergency core cooling system (ECCS) divisions to be operable. Five divisions are available in the ABWR design to meet this need (two divisions of high-prescure core flooder (HPCF) and three divisions of RHR). TS consider an RHR division aligned in the shutdown cooling mode to be considered operable if it can be manually realigned to the LPFL mode. The staff notes that the ABWR design allows this reconfiguration. Therefore, based on the evaluation above, the staff concludes that the ABWR design is capable of providing adequate availability of RHR for all required heat removal functions during all modes. This resolved DFSER Open Item 9.1.3-1.

The ACRS inquired about the ability of the ABWR design to initiate and/or maintain spent fuel pool cooling during and following an accident, including a LOCA. This question arose as a result of design concerns identified at an operating reactor in a 10 CFR Part 21 notification. Specifically, it was postulated that if a LOCA occurred, the resulting environmental conditions in the secondary containment would render the fuel pool cooling and cleanup system (FPC) equipment inoperable while, at the same time, preventing implementation of rocovery actions. Should this occur, water in the spent fuel pool would boil, resulting in excessive condensation leading to flooded conditions. In addition, boiling conditions could render the standby gas treatment system (SGTS) inoperable, so that any radioactive material resulting from failed fuel in the pool (due to lack of pool cooling) could be released to the environment without first being processed by the SGTS.

The staff discussed the postulated scenario with $G E$ and askec whether the ABWR design would be able to initiate and/or maintain spent fuel pool cooling during and following an accident, including a LOCA, in accordance with GDC 44 and 61. Subsequently, GE stated that the ABWR design can accommodate this accident for the following reasons:

(1) GE determined that a break in the reactor water cleanup system (CUW) presents the most limiting environmental conditions inside secondary containment for all design-basis accidents, including a LOCA. Safety-related equipment located inside the secondary containment is environmentally qualified to remain functional given a CUW pipe failure inside the secondary containment. Therefore, this equipment would remain available to perform its safety-related functions following an accident.

(2) In Section 9.1.3 of the SSAR, GE provided the results of a pool heatup analysis. The results showed that, should pool cooling fail with the maximum abnormal heat load in the pool, it would take approximately 16 hours for the pool to reach boiling conditions. This allows sufficient time for operators to implement manual recovery actions (manipulation of manual valves, etc.) well before boiling conditions develop. The system connections to each of the two residual heat removal (RHR) system divisions connected to the FPC utilizes a motor-operated valve (MOV) on the FPC inlet from the RHR system and a manual valve on the FPC outlet to the RHR system. The inlet valves are remotely operated; the outlet valves, however, require the operator' to manually manipulate the valves. GE states in the SSAR that these manual valves will be accessible following an accident in aufficient time to permit an operator to align the RHR system to prevent the SFP from boiling.

Two of the three safety-related RHR divisions are available to provide cooling water to the spent fuel pool. Either division is sufficient to cool the spent fuol pool given the worst-case heat load in the pool. Therefore, given a single failure of an RHR division, one remaining division can provide spent fuol pool cooling while the other provides cooling for the reactor.

In the unlikely event that pool boiling were to occur, safety-related makeup water can be provided from the suppression pool through either of the MOVs on the FPC inlet from RHR. The resulting environmental conditions are bounded by the worstcase environmental conditions postulated in the CUW line break discussed earlier. Each division of safety-related equipment inside the secondary containment is physically and electrically separated to prevent flood conditions from affecting more than one division of safety-related equipment.

The system is not safety related except for those portions from RHR to the FPC system and from the FPC system to the RHR system. However, the FPC system is designed to seismic Category I standards (with the exception of the filterdemineralizers) to ensure it remains functional during seismic events. Alternative means of power to the system is available through the combustion turbine generator (CTG) which is the alternate ac (AAC) power source for the ABWR design. Should a loss of preferred power (LOPP) or station blackout (SBO) occur, the CTG can be used to provide power to the FPC system. Therefore, the system will be available to provide spent fuel pool cooling under both normal and accident conditions. 
On the besis of this information, the etaff concludes that the ABWR decign ensures that cooling can be initiated and/or maintained during both normal and sccident conditions, including a LOCA.

In the DFSER, the staff requested GB to submit adequate design description and the ITAAC relating to the FPC system. This was DFSER Open Item 9.1.3-2. The adequacy and acceptability of the deaign description and the ITAAC are evaluated in Section 14.3 of this repcrt. On the basis of the above, DFSER Open Item 9.1.3-2 is resolved.

The staff's review of the FPC system included all components and piping of the system from the inlet to and the exit from the storage pool, the seismic Catogory I makeup source and piping used for the fuel pool makeup, the cleanup system filter/demineralizers, and the regenerative process to the point of discharge to the radwaste system. The scope of the FPC system review included layout drawings, process flow diagrams, piping and instrumentation diagrams, and descriptive information for the system and supporting systems that are essential to safe operation. The cooling portion of the system and the omergency primary makeup system are designed to seismic Category I, QG C requirements, since they are necessary to remove decay heat from the spent fuel and to prevent fuel damage that could lead to unacceptable relenses of radionctivity. The staff concludes that the design of the FPC system and its makeup systems meet the guidelines of SRP 9.1.3 and the requirements of GDC 2, 4, 5, 44, 45, 46,61 , and 63 , subject to incorporation of information regarding protection of the filter-demineralizer resins.

\subsubsection{Light Load-Handling System (Related to Refueling)}

The light load-handling system (LLHS) provides the means of transporting, handling and storing fuel (both new and spent fuel) in the reactor building. The staff reviewed the fuel-handling system, in accordance with the guidelines of SRP Section 9.1.4. Staff acceptance of the LLHS is based on meeting the requirements of GDC 2 as it relates to structures housing the system, and the system itself being capable of withstanding the effects of natural phenomena; GDC 5 as it relates to shared SSCs important to safety being capable of performing required safety functions; GDC 61 as it relates to radioactivity release as a result of fuel damage, and the svoidance of excessive personnel radiation exposure; and GDC 62 as it relates to prevention of inadvertent criticality.

The transfer of new fuel assemblies between the uncrating area and the new fuel inspection stand and/or the new fuel storage vault is accomplished using $4500-\mathrm{kg}$ (5-ton) auxiliary hook on the reactor building crane equipped with a mitable grapple. A 450-kg (1000-lb) auxiliary hoist on the reactor building crane is used with an auxiliary fuel grapple to transfor now fuel from the new fuel vault to the fuel atorage pool. From these, the fuel is handled by the tolescoping grapples on the refueling platform or auxiliary hoists.

The refueling machine is a gantry crane used to transport fuol and reactor components to and from pool storage and the reactor veseel. The platform spans the fuel storage and vessel pools. A telescoping mast and grapple suspended from a trolloy system is used to lift and orient fuel bundles for placement in the core or storage rack. The fuel grapplo hoist has a redundant load path so that no single component failure can result in a fuel bundle drop. Interlocks on the platform (1) provent hoisting a fuel assembly over the vessel with a control rod removed, (2) provent collision with fuel pool walls or other structures, (3) limit travel on the fuel grapple, (4) interlock grapple hook engagement with hoist load and hoist up power, and (5) ensure correct sequencing of the transfer operation in the automatic or manual mode.

The refueling machine also has two $(4.71 \mathrm{kN}$ (1060 lbf) and $9.87 \mathrm{kN}(2200 \mathrm{lbf}))$ auxiliary hoists. The hoists can be used normally with appropriate grapples to handle control rods, guide tubes, fuel support pieces, sources, and other internals of the core.

The refueling machine is designed structurally to seismic Category I standards and the entire system is housed within the reactor building, which is a seismic Category I structure designed to protect against flood and tomados.

In the DSER (SECY-91-235), the staff identified as Open Item 47, the impact of the failure of the fuel inspection stand during a safe-shutdown earthquake (SSE) because the stand was not classified as seismic Category I, and the radiological and criticality impact of the fall of the new fuel stand was not satisfactorily addressed in the SSAR. The SSAR commits the new fuel inspection stand to be firmly attached to a wall so that it does not fall or dump personnel into the fuel pool during an earthquake. This is acceptable and resolved DSER Open Item 47.

The final inspection stand design meets the requirements of GDC 2 and the guidelines of Positions C. 1 and C.6 of RG 1.13, and Positions C. 1 and C.2 of RG 1.29, relating to the protection of safety-related equipment and spent fuel from the effects of earthquakes, because it is housed and attached to a seismic Category I structure.

The reactor building crane main hook is used to move the spent fuel cask, and the auxiliary hook is used to move 
now fuel from the now fuel vault to the epent fuel storage pool. Interlocks and procedures prevent the main hook of the reactor building crane from travensing over the speat fuel pool or the now fuel storage vault while carrying a heavy load. This is acceptablo.

The requirements of GDC,5 for sharing SSCe do not apply because the ABWR is designed as a singlo-unit facility. An application for a multi-unit facility will require review of the deaign for compliance with GDC 5.

In Section 9.1.2 of the DSER (SECY-91-235), the staff stated that the COL applicant's purchase epecification should include an interface requirement for the vendor to submit a confirmatory anilysis of the consequences of dropping a fuel assembly and its aseociated handling tool from above the spent fuel storage racks. The staff determined that this requirement can be accomplished by COL actions as resolved in Section 9.1.2 of this report.

This additional information will ensure compliance with GDC 62 regarding protection of the fuel from inadvertent criticality.

The fuel-handling machine grapple retracts to a maximum position which ensures that the fuel will not be lifted beyond a safe-shielding height. Various electrical and mochanical interlocks prevent excessive cable load, movement over the core with a control rod removed, withdrawal of a control rod with fuel of the core, and collisions of fuel with surrounding structures. The refueling machine has redundent load paths and is designed to retain its load during a seismic event. Finally, the ABWR design includes instrumentation to monitor radiation levels on the refueling floor and initiated protective actions on a high-radiation level (realignment of heating, ventilation, and air conditioning (HVAC) systoms and SGTS initiation). The staff concludes that the design of the light load-handling system moets the guidelines of Position C.3 or RG 1.13 and ANS 57.1, and the requirements of GDC 61 for the release of radioactivity resulting from fuel damage and protection of personnel from excessive radiation exposure.

In the DFSER, the staff requested GE to submit adequate design description and the ITAAC for the LLHS. This was DFSER Open Item 9.1.4-1. GE submitted a revised set of design description and ITAAC. The adequacy and acceptability of the design description and the ITAAC are evaluated in Section 14.3 of this repori. On the basis of the above, DFSER Open Item 9.1.4-1 is resolved.

The LLHS includes all components and equipment used in moving fuel and other related light loads between the receiving area, storage areas, and reactor vessel. Based on the review of the applicent's proposed design criteria and deaign bases for the LLHS, and the requirements for the safe opention of the LLHS, as discussed above, the staff concludes that the design of the LL.HS and supporting syetems are in conformance with the guidelines of SRP 9.1.4, and the Commission's regulations as set forth in GDC 2 (protoction from natural phenomena), GDC 5 (aharing of SSCs), and GDC 61 (fuel storage handling and radionctivity control) and will conform to GDC 62 (protection of criticality in fuel storage handling), and are acceptablo.

\subsubsection{Orerhead Heavy Load-Handling System}

Inadvertent operations and equipment malfunctions caused by a load drop during critical load-handling operations could cause (1) a release of radioactivity to the environment above acceptable limits, (2) a criticality accident, (3) the inability to cool fuel within the reactor vesed or spent fuel pool, or (4) the inability to achieve safe shutdown of the reactor when needed. Therefore, critical load-handling equipment and operations are required to prevent these problems by built-in design features and operating procedures. Additionally, safe handling of loads includes design considerations for maintaining occupational radiation exposures as low as practicable during transportation and handling. The overhead heavy load-handling system (OHLHS) consists of all components and equipment used in moving all heavy loads, that is, loads weighing more than one fuel assembly and its associated handling device.

The staff reviewed the system in accordance with SRP Section 9.1.5. Staff acceptance of the OHLHS design was besed on meeting the requirements of GDC 2 as it relates to the ability of structures, equipment, and mechanisms to withstand the effects of natural phenomena; GDC 4 as it relates to protection of safety-related equipment from the effects of dropped loads; GDC 5 as it relates to sharing of equipment and components important to safety; and GDC 61 as it relates to the safe handling and storage of fuel. In addition, the acceptance criteria for the OHLHS includes meeting the guidelines of ANS 57.1, "Design Requirements for Light Water Reactor Fuel Handling System," and 57.2, "Design Objectives for Light Water Reactor Spent Fuel Storage Facilities at Nuclear Power Plants." The staff used the guidelines contained in the SRP Section III titled "Review Procedures" and in NUREG-0612, "Control of Heavy Loads at Nuclear Power Plants."

The OHLHS includes equipment necessary for the safe disassembly and reassembly of the reactor vessel head and internals during refueling operations and for the safe handling of the spent fuel cask. The reactor building crane 
will handle heavy loads in the containment and fuel-handling area of the reactor building. This singlo-failure-proof crane will handle the reactor veesel head, shroud head, steam separator, steam dryer, pool gates, now fuel from the reactor building entry hatch to now fuel storage, spent fuel shipping cask, emo reactor internal pump (RIP) components during pump sorvicing, and other miscellaneous loads during operation and outage. Also, the OHLHS includes reactor servicing equipment, upper and lower drywell servicing equipmbent, and main steam tunnel (MST) area servicing equipment, which are used for safe handling of main steam isolation valves (MSIVs), safoty/reliof valves (SRVs), RIP motors, heat exchangers and pump components, control rod blades and guide tubes, and fine motion control rod drive (FMCRD) components during their removal and reinstallation or replacement. This servicing equipment includes among other things, monorail and its hoist, transportation carts, equipment hatchway hoist, steam tunnel crane and its hoist, servicing platform, refueling platform, equipment platform, and lower drywell RIP hoist.

The OHLHS equipment described above is housed in the reactor building in which the associated heavy load-handling operations are performed. The building is a flood-protected and tomado-protected structure and thus, the OHLHS described above is protected against the effects of adverse natural phenomena. The spent fuel storage facility and the new fuel storage vault are seismic Category I. Also, as stated in Section 9.1.3 of this report, the spent fuel storage facility meets Position C.6 of RG 1.13, "Spent Fuel Storage Facility Design Basis." The OHLHS equipment and components are not seismic Category I except for the upper and lower drywell servicing equipment, refueling platform, equipment platform, and reactor service platform. Though the load-handling equipment need not be seismic Category I, the non seismic Category I equipment that can adversely impact SSCs important to safety should they fail during a seismic event, have to meet Position C.2 of RG 1.29. SSAR Table 3.2-1 states that the reactor building and refueling platform cranes are designed to hold their positions during an SSE. The table further indicates that the non seismic Category I system equipment that can adversely impact safety-related SSCs during an SSE, are designed to ensure their integrity under seismic loading resulting from an SSE. The staff identified in the DSER (SECY-91-235), as part of Open Item 48, (Section 1.8 of the DSER grouped eight concerns of DSER Section 9.1.5 as Open Item 48. Five are addressed in the items that follow. The remaining three are addressed in subsequent paragraphs.) several concerns pertaining to compliance of the OHLHS with GDC 2 as it relates to protection of safety-related equipment from the effects of adverse natural phenomena:
1. In the DSER (SECY-91-235), the staff noted that Note $x$ for SSAR Tablo 3.2-1 needed to be clarified to show that the reactor building and refueling platform cranes will hold their loads under the dynamic effects of an SSE.

Note $x$ of Table 3.2-1, SSAR Amendment 20, stated that the cranes are capable of holding their loads under operating-basis earthquake (OBE) conditions but did not address the SSE. This part of DSER Open Item 48 was not resolved and was reclassified as Open Item 9.1.5-1 in the DFSER. In the SSAR, Note $x$ of Table 3.2-1, states that the cranes are designed to hold their load and maintain their position during an SSE. This is acceptable and resolved DFSER Open Itom 9.1.5-1.

2. In the DSER (SECY-91-235), the staff noted that the above criterion should be applied for all other applicable (i.e., affecting safe-shutdown equipment) non soismic Catogory I load-handling equipment.

In response, GE indicated that the use of the steam tunnel handling equipment is limited to times when the reactor is shut down. Failure of the handling equipment at this time would not result in the loss of safoty functions (identified in SSAR Amendment 17). The rationale for not requiring this equipment to have the capability of holding its loads during an SSE is acceptable. However, sufficient justification for the lack of the application of a seismic criterion, such as that identified in item 1 above, has not been provided for the remaining devices in the control building, secondary containment, and clean zone of the reactor building. This part of DSER Open Item 48 was not resolved and was reclassified as Open Item $9: .5-2$ in the DFSER. GE later added Amendment 24 to the SSAR which stated that, with the exception of containment, the MST, and the refueling floor, no safetyrelated components of one division shall be routed over another safety-related division. Therefore, a dropped load cannot adversely effect more than one safetyrelated division.

GE also indicated that the amount of safety-related equipment present inside primary containment, and the divisional equipment is widely separated (120 degrees) around the containment. Therefore, the likelihood of a dropped load damaging more than one train of safetyrelated 'equipment is minimized. Load-handling equipment in the MST is operated only during shutdown conditions. During this condition, systems located in the tunnel are isolated and not required to be operable. In addition, isolation valves inside the tunnel have redundancy with valves inside containment. 
Therefore, a dropped load in the MST could damage components inside the tunnel, but the redundent components ineide the contrinment will maintain the anfety function. Finally, regarding the rdfueling floor, the reactor building crane meots the singlo-failure-proof design requirements of NUREG-0554 and is interlocked to prevent movement over the epent fuel stornge pool. The SSAR incorporates the above information. The staff reviewed the information and concluded that the design features for the loed-handling equipment in all certified buildings ensure that both now and spent fuel, as woll as safety-related equipment, will not be damaged to such an exteat as to inhibit or prevent safoty functions. This is acceptable and resolved DFSER Open Item 9.1.5-2.

3. In the DSER (SECY-91-235), the staff noted that terms such as "refueling bridge crane," "automatic refueling machine," and "spent fuel bandling crane" were used in the SSAR to represent possibly the same loadhandling device. Also, it wes not clear whether the ABWR used a jib crane and whether the fuel-handling platform was different from the refueling platform. Further, SSAR Tables 3.2-1 and 9.1-2 gavo different seismic classifications for the refueling platform crane (automatic refueling machine) and the jib crane.

In the DFSER, the staff stated that many of the discrepancies had been corrected. However, neither the jib crane nor the refueling platform crane were referred to in the text of SSAR Section 9.1, although both were listed in SSAR Table 3.2-1. While the term "Refueling Bridge," was used only in Table 3.2-1, the term "Refueling Platform," was used throughout Section 9.1. The text of Section 9.1 appeared to be internally consistent. References to a refueling platform consistently referred to the fuel-handling equipment. The staff requested GE to clarify the remaining discrepancios in the nomenclature in SSAR Table 3.2-1 and Section 9.1. The staff reclassified this part of DSER Open Item 48 as Open Item 9.1.5-3 in the DFSER. Subsequently, GE provided clarifying information which corrected the remaining discrepancies and changed "refueling platform" to "rofueling machine." This is acceptable and resolved DFSER Open Item 9.1.5-3.

4. The staff noted in the DSER (SECY-91-235) that SSAR Section 9.1.5.2.1 implies that the load-handling equipment for steam tunnel servicing (MSIVB and SRVs) is housed in the reactor building, while SSAR Table 3.2-1 shows the equipment to be located in "any other location." The staff requested GE to correct the location of the subject equipment, as appropriate and, if the location is "any other location," to state why bousing the equipment in non seismic Category I structure is acceptable.

In response, SSAR Section 9.1.5.2.2.3, Amendment 17, stated that the MST servicing equipment is a permanently installed monorail system. Note $\mathrm{c}$ in SSAR Table 3.2-1, which indicated the MST tunnel servicing cranes and hoists are in "any other location," is interpreted to mean that the monorail is not in any of the locations specifically identified in Note c, and does not contradict the statement in SSAR Section 9.1.5. The clarification shows that the equipment is boused in a seismic Category I structure. This is acceptable and resolved this part of DSER Open Itom 48.

5. The staff stated in the DSER (SECY-91-235) that SSAR Table 3.2-1 showed load-handling equipment for special service rooms being housed in the non seismic Category I radwaste and turbine buildings, and requeuted GE to clarify why such locations are scceptable.

In response, GE indicated that the load-handling equipment in the turbine and radwaste buildings will handle only the equipment in those structures. In the DFSER, the staff requested GE to incorporate this information into the SSAR by reclassifying it as Confirmatory Item 9.1.5-1 in the DFSER. The SSAR adds information in Sections 9.1.5.3 and 9.1.6.6 clarifying that all load-handling devices, including those in the radwaste building and turbine buildings, must be designed and procedures must be used which ensure that the loads they carry will not damage more than one division of a safety-related system. Further, the load-handling devices in the turbine and radwaste buildings are intended to handle only equipment in these buildings and that the loads will not be moved over safety-related equipment. Therefore, failure of this equipment or dropping of any loads moved by this equipment will not adversely affect safety-related SSCs. The staff finds this additional clarification acceptable. Therefore, DFSER Confirmatory Item $9.1 .5-1$ is resolved.

The OHLHS meets Positions C. 1 and C.2 of RG 1.29, and Positions C.1 and C.6 of RG 1.13 for the spent fuel storage facility and therefore, complies with the requirements of GDC 2 with regard to protection of the system from the effects of adverse natural phenomena.

The spent fuel cask pool is separated from the spent fuel storage pool by a water-tight gate. Redundant safety interlocks and limit switches in the reactor building crane prevent transport of any heavy load, including the spent 
fuel cask, over the spent fuel pool. Administrative control and a coverage area prevent transport of any heavy load over the now fuel storage vault. A dropped cask cannot, therefore, result in any fuel damage. Additionally, as mentioned above, the reactor building crane and the refueling platform crane are single-failure-proof cranes. The staff in the DSER (SECY-91-235) identified sovernal concerns, as part of Open Item 48, pertaining to compliance of the OHLHS with the requirements of GDC 4 as it relates to protection of safoty-related equipment from the effects of internally-generated missiles (i.e., dropped loads) during load-handling operations:

1. The staff stated in the DSER (SECY-91-235) that SSAR Section 9.1.4.3 incorrectly stated that the spent fuel-handling crane's lifting height for the spent fuel cask is limited to 30 feet on the operating floor, and that this should be corrected to refer to the reactor building crane.

GE subsequently modified the SSAR to eliminate inconsistent terms. This modification resolved this part of DSER Open Item 48.

2. The staff noted in the DSER (SECY-91-235) that SSAR Amendment 7 (response to RAI 410.43) gives contradictory statements: "While carrying heavy loads, such as the spent fuel cask, the reactor building crane is prohibited from moving the heavy load over the spent fuel pool," and "No other heavy loads other than the spent fuel cask, need to be carried above the top of the spent fuel storage pool." The staff requested GE to correct this as appropriate.

In response, $\mathrm{GE}$ committed to revise the response to RAI 410.43 to eliminate the contradictory statements regarding movement of the spent fuel cask. Incorporation of the revisions to the response to RAI 410.43 was identified as Confirmatory Item 9.1.5-2 in the DFSER. SSAR Section 9.1.5.2.1 states that the reactor building crane will be interlocked to prevent movement over the spent fuel pool while carrying heavy loads. This is acceptable and resolved DFSER Confirmatory Item 9.1.5-2.

3. The staff noted in the DSER (SECY-91-235), as part of DSER Open Item 48, that GE had not identified how safety-related equipment would be protected during all heavy load-handling operations involving non-singlefailure-proof load lifting devices (e.g., MSIVs, SRVs, RIP motors and hoists, load-handling operations in control, radwaste, and turbine buildings).

In response, SSAR Amendment 20 identified the criteria to assess the safety impact of the failure of the load-handling devices. The lower drywell load-lifting device does not carry loads over safety-related equipment. The failure of the upper drywoll loed-lifting device, used only during maintenance at shutdown, can affect only the one division of an ECCS. Safo-shutdown conditions can be maintained with the failure of the one ECCS division. The MST equipment is used only during shutdown, and its failure will not impact any safety-related equipment needod to maintain safo-shutdown conditions. Load-handling equipment in the turbine and radwaste buildings is not used near safety-related equipment because such equipment is restricted to use in these structures. However, the use of heavy load-handling equipment in the control building was not addressed. As discussed in the DFSER, all items identified in this portion of DSER Open Item 48 are resolved with the information provided by SSAR Amendment 20 except for the concern regarding the control building. Identification of how safety-related equipment would be protected during all heavy load-handling operations involving non-single-failureproof loed lifting devices in the control building was identified as Open Item 9.1.5-4 in the DFSER. Subsequently, GE provided clarifying information in SSAR Sections 9.1.5.3, 9.1.5.4, 9.1.5.5, and 9.1.6.6. The design of all heavy load-handling equipment will meet the guidelines of NUREG-0612, including the guidelines of NUREG-0554 regarding single-failureproof cranes. Based on the additional information provided in these SSAR subsections, the staff concludes that safety-related equipment will be adequately protected during all heavy load-handling operations. Therefore, DFSER Open Item 9.1.5-4 is resolved.

Based on the above information, the staff concludes that the OHLHS design will meet the guidelines of Positions C.3 and C.5 of RG 1.13, with respect to protection of the spent fuel storage facility from the effects of internallygenerated missiles and for the safe handling and storage of fuel, and further concludes that safety-related equipment is protected from the effects of internally-generated missiles during load-handling operations. Therefore, the OHLHS design for the ABWR will comply with GDC 4 as it relates to protection of safety-related equipment from internallygenerated missiles.

The requirements of GDC 5 regarding the sharing of SSCs do not apply because the ABWR is designed as a singleunit facility. An application for a multi-unit facility will require review of the design for compliance with GDC 5.

As mentioned above, the reactor building and refueling platform cranes are single-failure-proof cranes. SSAR Section 9.1.5.5 further states that all the cranes, hoists, and related lifting devices for handling heavy loads either 
satisfy the singlo-failuro-proof guidelines of NUREG-0612, Section 5.1.6, including NUREG-0554, or evaluations aro mede to demonstrate compliance with guidelines of NUREG-0612, Section 5.1, including Sections 5.1.4 and 5.1.5. GE stated that the applicable components of the OHLHS will comply with the guidelines of the following industry standards: American National Standards Institute (ANSI) N14.6, ANSI B30.9, ANSI B30.10, ANSI B30.2, ANSI B30.16, ANSI B30.11, and Crane Manufacturers Association of Americe (CMAA) Specification 70. NUREG-0554 and NUREG-0612 recommend the standards specified in ANSI N14.6, ANSI B30.2, ANSI B30.9, and CMAA 70 for the design and performance of a nuclear power plant OHLHS. Additionally, GE states that the design of special lifting devices and slings will comply with the guidelines of NUREG-0612, Sections 5.1.1(4) and 5.1.1(5).

GE submitted general description of the inspection, operation, maintenance, service, and teet requirements for the OHLHS equipment. The COL applicant is responsible for supplying operating, maintenance, and test proxesdures and instruction manuals that will comply with NUREG-0612, Soctions 5.1.1(2) and 5.1.1(6) for heavy loed-handling equipment components (e.g., cranes, hoists, refueling plaiform). In accordance with the requirements of 10 CFR Part 50, Appendix B, the COL applicant will subject the OHLHS equipment to qualification load and performance tests, dimensional inspection, and nondestructive examination before the equipment is accepted by the applicant's quelity assurance group. The applicant will also ensure that lifting components are appropriately inspected and tested before shipment, after receipt at the site, before use, and at periodic intervals. The tests will be conducted in accordance with the requirements of ANSI B30.2 and NUREG-0612, Section 5.1.1(6). For each item of equipment requiring servicing, the applicant will develop an interface control diagram (ICD) delineating the space around the equipment required for servicing. The ICD will include pull space for internal parts and access space for tools, handling equipment, and alignment requirements. The ICD will specify the weights of large removable parts, show the locations of their centers of gravity, and describe installed lifting accommodations such as eyes and trunnions. The COL applicant will develop safe load paths and routing plans for each heavy load to be handled, which will show, among other things, frequency of transportation and usage of the route. The safe load paths/routing wil! comply with NUREG-0612, Section 5.1.1(1), guidelines. These items are DFSER COL Action Item 9.1.5-1.

The staff stuted in the DSER (SECY-91-235) that the information provided in SSAR Section 9.1.5 (also Section 9.1.4, which is cross-referenced in Section 9.1.5), lacked details with respect to OHLHS compliance with the applicable guidelines of NUREG-0612. The staff's concerns, identified as DSER Open Item 49 (Section 1.8 of the DSER grouped four concerns of DSER Section 9.1.5 as Open Item 49.) in this regard, are as follows:

1. In the DSER (SECY-91-235), the staff noted that GE had not identified all the hoists for the reactor building, refueling platform, and steam tunnel cranes and any other crane, nor the load-handling capacity for all the hoists, including the monorail hoist, equipment hatchway hoiet, equipment platform/lower drywell RIP hoist. In the DFSER, the staff further noted that GE had not provided this information, therefore, this part of DSER Open Item 49 was reclassified as Open Item 9.1.5-5 in the DFSER. Upon further review, the staff determined that the issue can be addressed by COL actions. The SSAR, Section 9.1.6.6, states that the COL applicant will provide this information. This is acceptable and resolved DFSER Open Item 9.1.5-5.

2. In the DSER (SECY-91-235), the staff noted that GE had not identified which of the hoists and related lifting devices associated with all heavy load-handling systems moet single-failure-proof criteria and which of these components meet the alternative criteria specified in applicable sections of NUREG-0612. The staff indicated that GE should identify the specific alternative criterion applicable to the chosen heavy load- handling device, or if neither of the above criteria is applicable for some heavy load-handling devices (because they do not affect required safety-related equipment). GE should include justification for such a conclusion for the applicable devices.

As previously noted, SSAR Amendment 20 identified the criteria to be applied to each heavy load-bandling system except for those in the control building. With the exception of this area as discussed separately in item (4) below, this information resolved the applicable part of DSER Open Item 49.

3. In the DSER (SECY-91-235), the staff noted that GE did not identify the specific limit and safety devices (e.g., interlocks and limit switches) provided for automatic and manual operation of all the heavy load-handling equipment (within ABWR scope) under both normal and emergency conditions. Further, the staff noted that GE did not submit a failure modes and effects analysis for the OHLHS instrument and control system to demonstrate that the control system will adequately limit the loads or limit the crane load movement, assuming a single failure, without affecting the function of safety-related equipment or causing the release of radioactivity. 
Section 9.1.5.5 of SSAR Amendment 20 states that limit switches and safety interlocks are provided to provent transporting heavy loads over spent fuel. However, the amendment does not include the lovel of detail requested by the staff in the DSER (SECY-91-235) and does not specify this information as the action of the COL applicant. In the DFSER, the staff stated that GE should either submit this information or designate this as the action of the COL applicant. The staff reclassified this part of DSER Open Item 49 as DFSER Open Item 9.1.5-6. SSAR Section 9.1.6.6 states that the COL applicant will submit this information. This is acceptable and DFSER Open Item 9.1.5-6 is resolved.

4. The staff stated in the DSER (SECY-91-235) that GE had not indicated the heavy load-handling operations which may involve areas other than the reactor building which are within ABWR scope (e.g., control building). Specifically, GE had not identified the heavy load-handling equipment, its handling capacity, the load required to be handled, when such operations have to be performed, and how safety-related equipment is protected during such operations.

In the DFSER, the staff stated that GE did not submit the information requested in the DSER (SECY-91-235) and did not state guidelines for load- lifting systems outside the scope of the ABWR (e.g., the reactor service water (RSW) pump house). The staff further noted that this information should include the identification of the load-handling systems, the system characteristics, and the ability to meet the guidelines of NUREG-0612. The staff reclassified as DFSER Open Item 9.1.5-7 the submission of the previously requested information and the identification of the requirements for load lifting systems outside the ABWR scope. Upon further evaluation, the staff determined that the issue can be resolved by COL actions. SSAR Section 9.1.6.6 clarifies that the COL applicant will submit design and operational details for all load-handling devices both in and out of the design scope. The staff concludes that this clarification will ensure that the design and operational details associated with the movement of heavy loads will be provided. This is acceptable and resolved DFSER Open Item 9.1.5-7.

The staff finds that the OHLHS design and commitments meet the guidelines of NUREG-0612 and requirements of GDC 61 for the safe handling and storage of fuel.

In the DFSER, the staff requested GE to submit adequate design description and the ITAAC for the OHLHS. This was DFSER Open Item 9.1.5-8. GE submitted a revised set of design description and ITAAC. The adequacy and acceptability of the design description and the ITAAC are ovaluated in Section 14.3 of this report. On the basis of the above, DFSER Open Item 9.1.5-8 is resolved.

The staff concludes that the design of the OHLHS for the ABWR conforms with the requirements of GDC 2, 4, 5, and 61 for protection against natural phenomena, protection of safety-related equipment from the effects of internal missiles, the sharing of important systems, and the safe handling and storage of the fuel. The design also conforms with the guidelines of Positions C.1, C.3, C.5, and C.6 of RG 1.13 and Positions C.1 and C.2 of RG 1.29. The staff further concludes that the OHLHS equipment within the ABWR scope conforms with the guidelines of NUREG-0612. However, since a major portion of NUREG-0612 is outside the scope of the ABWR standard design (the part which deals with crane operation, operator training, operating and maintenance procedures, and physical marking of safe load paths), the staff stated in the DFSER that the COL applicant will provide the specifics of compliance and final implementation of NUREG-0612 guidelines on a plant-specific basis. This was DFSER COL Action Item 9.1.5-2. SSAR Section 9.1.6 states that the COL applicant will submit this information.

The OHLHS includes all components and equipment used to handle all heavy loads at the plant site over the lifetime of the facility. Based on the review of the SSAR design criteria and design bases for the OHLHS, the staff concludes that the design of the OHLHS, as discussed in detail above, is in conformance with the guidelines of SRP Section 9.1.5 and the Commission's regulations as set forth in GDC 2, 4, 5, and 61, and is acceptable.

\subsection{Water Systems}

For some systems listed in the SRP, the functions in the ABWR design will be performed by one or more different systems. For example, the functions of the closed cooling water system also will be performed by the RCW system, the heating, ventilation, and air conditioning normal cooling water (HNCW) system, the HVAC emergency cooling water (HECW) system, and the turbine building cooling water (TCW) system.

\subsubsection{Station Service Water System}

See Section 9.2.15, "Reactor Service Water."

\subsubsection{Reactor Auxiliary Cooling Water System}

See Sections 9.2.11 "Reactor Building Cooling Water System," and 9.2.12, "HVAC Normal Cooling Water System" of this report. 


\subsubsection{Demineralized Water Makeup System}

See Sections 9.2.8, "Makeup Water Systom (Preparation)," 9.2.9, "Makeup Water System (Condensate)," and 9.2.10 "Makeup Water System (Purified)" of this report.

\subsubsection{Potable and Sanitary Water System}

The staff reviewed the design requirements for the potable and sanitary water (PSW) system in accordance with SRP Section 9.2.4. Staff's acceptance of the design is besed on meeting the requirements of GDC 60 as it relates to preventing the release of liquid effluents containing radioactive material into the PSW system. Compliance is met if there are no interconnections between the PSW system and any potentially contaminated systems and if the PSW system is protected by an air gap, if necossary.

GE stated that only the portion of the PSW system located in the buildings of the certified standard plant is within the design scope, while the remainder of the system is not. The out-of-scope portion of the system will be designed by the applicant referencing the ABWR design. The DFSER noted that the staff's review was in progress. This was DFSER Open Item 9.2.4-1. SSAR Section 9.2.4 includes a conceptual design and interface requirements for the outof-scope portion of the system. The staff reviewed the conceptual design and interface requirements and concluded that sufficient guidance has been provided to allow an applicant referencing the ABWR to design the out-of-scope portion to meet all applicable regulatory requirements. This is acceptable and resolved DFSER Open Item 9.2.4-1.

The PSW system is a non-safety-related system designed to provide a minimum of approximately $45 \mathrm{~m}^{3} / \mathrm{hr}$ (200 gpm) of potable water during peak demand periods. The system is composed of a potable water subsystem, a sanitary drainage subsystem, and a sowage treatment subsystem.

Water is supplied to the potable water subsystem from the makeup water system (preparation) (MWP) to a potable water storage tank. The water is chemically treated, pressurized, heated, and distributed throughout the plant. According to SSAR Table 3.2-1, the system serves all areas of the plant within the ABWR scope except the primary containment and the MST.

Liquid wastes (including those from the nonradioactive drain system) are collected in the sanitary drainage subsystem and sent to the sewage treatment subsystem. The sewage treatment subsystem uses the activated sludge biological treatment process. The subsystem contains a comminutor, aeration tanks, aerobic digesters, air blowers, clarifiers, a froth spray pump, a hypochlorite pump, and associated equipment. This subsystem can be operated in the extended aeration mode or the contact stabilization mode (used during high demand periods (e.g., refiveling outages) when additional personnel are on site).

The PSW system does not include any connections to systems which may contain radioactive material. Where necessary, additional protection is provided through the use of air gaps.

The system contains adequate controls, instrumentation, and alarms to ensure adequate operation during normal conditions and to alert operators to abnormal conditions. Drainage piping will be hydrostatically tested.

In the DFSER, the staff requested GE to submit adequate design description, ITAAC, and interface requirements for the PSW system. This was DFSER Open Item 9.2.4-2. Subsequently, GE provided a revised set of design description, ITAAC, and interface requirements. The adequacy and acceptability of the design description, the ITAAC, and the interface requirements are evaluated in Section 14.3 of this report. On the basis of the above, DFSER Open Item 9.2.4-2 is resolved.

The PSW system includes all components and piping from the supply connection to the municipal or other water source to all points of discharge to sewage facilities or other plant systems. Based on the review above, the staff determined that adequate design provisions have been made to prevent the inadvertent contamination of the system with radioactive material. The staff concludes that the design of the PSW system meets the guidelines of SRP Section 9.2.4, and since there are no interconnections between the PSW system and any contamination systems it also meets the requirements of GDC 60, and is acceptable.

\subsubsection{Ultimate Heat Sink}

The staff reviewed the design requirements for the ultimate heat sink (UHS) in accordance with SRP Section 9.2.5. Staff acceptance of a UHS design is based on meeting GDC 2 as it relates to structures housing the system and the system itself being capable of withstanding the effects of natural phenomena; GDC 5 as it relates to the capability of shared SSCs to perform required safety functions; GDC 44 as it relates to the capability to transfer heat loads from safety-related SSCs to the heat sink under normal and accident conditions, providing suitable redundancy of components to ensure adequate safety function given a single active component failure, and the capability to isolate parts of the system so that the safety function is not compromised; and GDC 45 and 46 as they relate to 
inservice inspection and operational functional teating, respectively, of safety-rolated systems and components.

The SSAR states that the design of the UHS is outside the scope of the ABWR design. The SSAR includes a conceptual design and interface requirements, as required by 10 CFR Part 52, to allow an applicant reforencing the ABWR design to provide a plant-specific UHS design that is capable of dissipating reactor decay heat and eceential cooling loads after a normal reactor shutdown or a shutdown after an accident, including a loss-of-coolant sccident (LOCA). The UHS must be designed to sccept the heat loads of the RSW system (Section 9.2.15 of this report), which in turn accepts the heat loads of the RCW system (Section 9.2.11 of this report) under both normal and accident conditions.

The conceptual design for the UHS consists of a seismic Category I spray pond from which the RSW system will receive cooling water. The spray pond will be excavated below grade and contain adequate water volumo to supply cooling for 30 days under design-basis conditions. Six spray networks, three functioning during normal operation, will cool the RSW return water. The spray nozzles may be bypassed during cold weather conditions allowing RSW return water to be returned directly to the pond. RSW pumps will be located in the spray pond pump structure, each pump in its own bay. The pond will also have a seismic Category I overflow weir to accommodate normal level fluctuations. The spray pond will receive makeup from a power cycle heat sink makeup line.

The structures and components of the UHS will be designed to seismic Category I requirements and will be designed to withstand the effects of natural phenomena such as floods, earthquakes, and tornados. The system desigp should ensure that the UHS can perform its safety function given the occurrence of any of the following: (1) the most severe natural phenomena appropriate with site conditions, (2) site-related events that have historically occurred, (3) reasonable combinations of natural phenomena and site-related events, and (4) a single failure of man-made structures. These interface requirements will allow an applicant to design a UHS that moets the requirements of GDC 2 regarding protection from natural phenomena and RG 1.27, "Ultimate Heat Sink for Nuclear Power Plants," Revision 2 and RG 1.29, "Seismic Design Classification," Revision 3.

The UHS design will ensure that safety-related portions of the system are protected from spraying, steam impingement, pipe whip, jet forces, missiles, fire, internal flooding, and the effects of failure of non seismic Category I equipment. Thus, the interface requirements meet the requirements of GDC 4 for protection of systems from the environmental and dynamic offects aseociated with equipment failures.

The requirements of GDC 5 for the sharing of SSCs do not apply because the ABWR is designed as a singlo-unit facility. An application for a multi-unit facility will require reviow of the design for compliance with GDC 5.

The UHS must have the capability to transfer heat loads from safety-related structures and systems during normal and accident conditions, and suitable redundancy so that it will function given single-failure coincident with a LOOP. It must also be capable of isolating portions of the system in such a way as to not interfere with the system's safety function. The UHS will provide cooling capability for $\mathbf{3 0}$ days.

The requirements of RG 1.72, "Spray Pond Piping Made from Fibergless-Reinforced Thermosetting Resin," Revision 2, apply to the design of a spray pond as an UHS. The staff established Open Item 50 in the DSER because these requirements were not referenced in the SSAR submitted before the staff completed the DSER (SECY-91-235). SSAR Section 9.2.5.8 states that the COL applicant will submit information to sho $N$ that all applicable requirements of RG 1.72 are met. This is acceptable and resolved Open Itum 50.

The SSAR requires the COL applicant to prepare a preoperational test program in accordance with the requirements of Chapter 14 and shall perform inspections and tests during normal operations. Based on these commitments, the staff believes that the applicant referencing the $A B W R$ design can perform inspections and tests which meet the requirements of GDC 45 and 46 , respoctively.

In the DFSER, the staff requested GE to include interface requirements for the UHS system in the Tier 1 information. This was DFSER Open Item 9.2.5-1. The adequacy and acceptability of the Tier 1 information is evaluated in Section 14.3 of this report. On the basis of the above, DFSER Open Item 9.2.5-1 is resolved.

The staff found the conceptual design and interface requirements for the UHS to be acceptable. They include adequate guidelines to ensure that the plant-specific design can meet the requirements of GDC 2, 5, and 44 with respect to protection against natural phenomena, sharing of SSCs and heat transfer, redundancy, isolation capabilities, and ability to transfer heat loads. The system must be designed by the COL applicants to allow periodic inspections and tests and must, therefore, meet the requirements of GDC 45 and 46 with respect to inspection and testing requirements for cooling water systems. The interface 
requirement in the ABWR SSAR should enable an applicant referencing the ABWR to design an acceptable UHS.

\subsubsection{Condensate Storage Facility}

Soo Section 9.2.9, "Makeup Water System (Condensate)," of this report.

\subsubsection{Chilled Water Systems}

See Sections 9.2.12, "HVAC Normal Cooling Water System," and 9.2.13, "HVAC Emergency Cooling Water System," of this report.

\subsubsection{Makeup Water System (Preparation)}

The staff reviewed the requirements for the makeup water system (preparation) (MWP) in accordance with SRP Section 9.2.3. Staff acceptance of the MWP system design is based on meeting GDC 2 as it relates to safety-related portions of the system being capable of withstanding the effects of natural phenomena, GDC 5 as it relates to the capability of shared SSCs to perform required safety function, and position C.2 of RG 1.29, Revision 3 (September 1978) relative to protection of safety-related SSCs from failure of the system following an SSE.

The MWP system is not within the certified design scope of the ABWR. As required by 10 CFR Part 52, the SSAR provides a conceptual design and interface requirements for the MWP system. This design information and commitments provide sufficient detail to ensure that the system can be designed and built to meet the applicable regulatory requirements.

The MWP system is a non-safety-related system that supplies water for the makeup water system (purified) distribution system (MUWP) and the portable and sanitary water system (PSW). The MWP system design includes a requirement for two system divisions, each capable of producing approximately $45 \mathrm{~m}^{3} / \mathrm{hr} \quad(200 \mathrm{gpm})$ of demineralized water and each with a storage capacity of at least $760 \mathrm{~m}^{3}$ (200,000 gallons).

The system will consist of both a permanently installed water treatment system and a mobile water treatment system. The permanently installed system will consist of a well, filters, reverse osmosis modules, demineralizers, storage tanks, and pumps to treat and store well water for use as demineralized water. The mobile water treatment system will be used before the permanent system is operable and if needed to supplement the permanent system. Therefore, the system does not require a seismic Category I makeup source.
The MWP system will be located in a building that does not contain any safety-related components, systems, or structures. Any failure of the system (including failures that could cause flooding) will not result in the failure of any safety-related SSCs and consequently will not adversely affect any safety-related function of the ABWR design. Therefore, the staff concludes that the conceptural design meets the requirements of GDC 2 with regard to protection of safety-related equipment from natural phenomena, and Position C.2 of RG 1.29, Revision 3 (September 1978).

The requirements of GDC 5 for the sharing of SSCs do not apply because the ABWR is designed as a single-unit facility. An application for a multi-unit facility will require review of the design for compliance with GDC 5.

In the DFSER, the staft requested GE to submit adequate design description, ITAAC, and interface requirements for the MWP system. This was DFSER Open Item 9.2.8-1. GE submitted a revised set of design description, ITAAC and interface requirements. The adequacy and acceptability of the design description, ITAAC, and interface requirements are evaluated in Section 14.3 of this report. On the basis of the above, DFSER Open Item 9.2.8-1 is resolved.

Based on the SSAR commitments discussed above, the staff concludes that GE has described an acceptable conceptual design and interface requirements sufficient to ensure that an applicant referencing the ABWR can design a MWP system that will meet the requirements of Position C.2 of RG 1.29, Revision 3 (September 1978); GDC 2 with regard to the ability of the non-safety-related portions of the system to withstand the effects of natural phenomena without affecting safety-related systems; and GDC 5 with regard to the sharing of SSCs important to safety. The int rface requirements in the SSAR will enable an applicant referencing the $A B W R$ to design an acceptable MWP system in compliance with the guidelines of SRP 9.2.3. The conceptual design is acceptable.

\subsubsection{Makeup Water System (Condensate)}

The staff reviewed the MUWC system (the condensate storage and transfer system) in accordance with SRP Section 9.2.6. Staff acceptance of the MUWC system design is based on meeting the requirements of GDC 2 as it relates to the system being able to withstand the effects of natural phenomena; GDC 5 as it relates to the capability of shared systems and components to perform required safety functions; GDC 44 as it relates to redundancy and isolability of components as well as the capability to provide makeup to safety-related systems; and GDC 45 and 46 as they relate to inservice inspection and testing, 
respoctively, of safety-related systems and components. The design of the entiro MUWC eystem is within the scopo of the ABWR certified deaign.

Tho MUWC syatem will supply condeneato quality water and will include a piping dietribution ayctem from the source to the components that require this water during normal and emergency operations. MUWC syatem water will be stored in the condensate storage tank (CST) with a capacity of at least $2,100,000 \mathrm{~L}(555,000$ gallons). The CST, is located outdoors adjecent to the turbino building. The CST will reserve approximately $570,000 \mathrm{~L}$ (150,000 gallons) of this capacity to removo docay heat for up to 8 hours after a station blackout (SBO). Water will be supplied to the CST from the MUWP system. Lovolsensing instrumentation and transmitters will sutomatically switch over the HPCF and reactor core isolation cooling (RCIC) pumps from the preferred CST to the safety-related suppression pool when the CST water lovel is low. The tank will also supply water for the control rod drive (CRD) supply pump (the preferrod water source being the condensate treatment system) and the SPCU pump, which will be used for fuel pool makeup, when required. The MUWC system will normally supply water through three system transfer pumps for charging, flushing, pump sealing, surveillance teeting, room docontamination, and makeup, as appropriate, for systems including RHR, HPCF, RCIC, fuel pool skimmer surge tanks, and the main condenser hotwell.

The MUWC system is not safety-related, except as noted below, because it will not affect the integrity of the reactor coolant system pressure boundary, prevent achieving and maintaining safe shutdown, or affect the capability to prevent or mitigate the consequences of accidents, which could result in unacceptable offsite radiological exposures. Therefore, GDC 44, 45, and 46 do not apply to the nonsafety-related portions of the system.

The safety-related portions of the system discussed below meet the redundancy, inservice inspection, and inservice testing requirements for safety-related equipment and therefore moet the requirements of GDC 44,45 , and 46.

As stated in SSAR Table 3.2-1, for the MUWC, RCIC, and HPCF systems, certain parts of MUWC system piping, including supports and valves, will be designed to seismic Category I and QG B standards and will be located in seismic Category I, flood-protected and tormado-missile-protected structures. The safety-related portions include those forming part of the contajinment boundary and those system piping portions that interface with the safety-related RCIC and HPCF systems, up to and including the isolation/suction valves for the systems from the MUWC. The non-safety-related portions of the system that could affect any SSC important to safety if thoy fail during a seismic ovent aro dosigned to encuro their integrity under soismic loading conditions resulting from an SSE. The level instrumentation in the MUWC syetem that facilitate the automatic switchover of the HPCF and RCIC pumpa auction from the CST to the suppreesion pool and their power aupplies are safoty-related. The SPCU pumps will be switched over manually. The staff concludes that the safety-rolated and non-safety-related portions of this syetem moet Positions C.1 and C.2, respectively, of RO 1.29.

The thaff etated in the DSER (SECY-91-235) that GE did not mubmit an analysis for flooding that could reault from a possible failure of the non-safety-related portion of the MUWC system, including the CST, and how safety-related SSC are protocted from such flooding. This was DSER Open Item 51. SSAR Section 3.4.1.1.1 reports the results of a flood analysis and deacribes the safety features that will protect safety-related SSCs from external floods (including the failure of the CST) as discussed in Section 3.4.1 of this report. The instrumentation used to initiate the sutomatic switchover of HPCF and RCIC suction from the CST to the suppression pool is safetyrolated and is housed in a safoty-grado standpipe in tho reactor building, a seismic Category I structure designed to withstand tornadic winds and missiles, flooding, hurricanes, and an SSE. On the basis of this information, the staff concludes that the system meets the requirements of GDC 2 as it relates to the protection of safety-related portions of the system from the effects of natural phenomena. Therefore, DSER Open Item 51 is resolved.

The ABWR is designed as a single-unit facility. Therefore, the requirements of GDC 5 regarding the sharing of SSCs are not applicable. An application for a multi-unit facility will require review of the design for compliance with GDC 5.

Normal alignment for removal of decay heat is with the CST. Water for RCIC operation is taken from either the CST or the suppression pool as described in the emergency procedure guidelines of SSAR Appendix 18A. The volume of water in these two sources is sufficient to permit core cooling during SBO for a duration of 8 hours. The switchover from the CST to the suppression pool (or the reverse) is performed using station dc power and is not dependeat upon either offsite ac power and systems or onsite emergency power systems. Therefore, the MUWC system complies with the applicable guidance of RG 1.155, "Station Blackout," Revision 0 (August 1988).

MUWC is demonstrated to be operable by normal system operation. Those portions of the system normally closed 
to flow can be teeted to ensure syatom operability and intogrity.

Based on this information, the ataff concludes that MUWC moets the applicable requirements of ODC 44,45 , and 46.

In the DPSER, the staff requested GE to provide adequate design description and the ITAAC relating to the MUWC system. This was DFSER Open Itom 9.2.9-1. Subeequently, OB provided a revised eet of design description and ITAAC. The adequacy and acceptability of the deaign description and the ITAAC are evaluated in Section 14.3 of this report. On the basis of the above, DFSER Open Item 9.2.9-1 is resolved.

The MUWC system includes all components and piping sesociated with the system to the points of connection with other systems. The staff determined that the SSAR design criteria and bases for the MUWC and the requirements for a sufficient water supply to safety-related systems during normal and emorgency conditions are acceptable.

The staff concludes, as discussed above, that the MUWC system design complies with Positions C.1 and C.2 of RG 1.29, GDC 2, 5, 44, 45, 46, and, therefore, with the applicable acceptance criteria of SRP Section 9.2.6 and is scceptable.

\subsubsection{Makeup Water System (Purified) Distribution System}

The staff reviewed the MUWP system in accordance with SRP Section 9.2.3. The design is acceptable if it complies with the requirements of GDC 2 as it relates to protection of the safety-related portions of the system from natural phenomena, and GDC 5 as it relates to the capability of shared SSCs to perform required safety funptions.

The design of the MUWP system is fully within the scope of the ABWR design. The staff evaluated the ABWR capability to prepare, store, and transport demineralized water to this system as described in Section 9.2.8 of this report. The MUWP system is not safety-related, except as noted below.

The MUWP system will supply demineralized makeup quality water and will include a piping distribution system from the source to the components that require this water. The MUWP system will receive makeup water from the MWP system and will normally supply demineralized water for flushing, sealing, surveillance testing, area decontamination, sampling, and makeup as appropriate. The MUWP system will supply makeup water to systems such as the MUWC system, the RCW system, the TCW system, the diesel generator cooling water (DGCW) syctem, the liquid waste management aystem (LWMS), the standby liquid control system (SLCS), and other plant auxiliary systems. Protection from flooding for safety-related SSCs is discussed in Section 3.4.1 of this report.

The MUWP system is not safoty-related, except as noted below, because it will not affect the capability of the reactor coolant system preesure boundary, the capability to achiove and maintain safe shutdown, or the capability to prevent or mitigate the consequences of accidents that could result in unacceptable offsite radiological exposures. The MUWP system caters the primary containment through one penetration. The system piping through this penetration has a locked-closed manual valve outside the contrinment and a check valve inside the containment. The portions of the system penetrating the containment (including these two valves) are designed to seismic Category I, QG B requirements in accordance with Position C.1 of RG 1.29.

Although it is not safety-related, this system is designed to prevent any radioactive contamination of the purified water. SSAR Table 9.2-2a presents chemistry requiroments for the purified makeup water.

In the DSER (SECY-91-235), the staff stated, as part of Open Item 52, that it was not clear whether the non-safetyrelated portions of the system, which upon their failure during a seismic event can adversely impact SSC. important to safety, will be designed to ensure their integrity under seismic loading resulting from an SSE. SSAR Section 9.2.10.1 states that the portions of the MUWP whose failure can impact safety-related SSCs will be designed to ensure their integrity under seismic loeding conditions resulting from an SSE. This is acceptable. Therefore, the design of the MUWP system complies with Positions C. 1 and C.2 of RG 1.29 for the safety-related and non-safety-related portions of the system, and GDC 2 for protection against natural phenomena. This resolved the applicable part of DSER Open Item 52.

In the DSER (SECY-91-235), the staff also stated, as part of Open Item 52, that it was not clear whether the portions of the MUWP system in buildings other than the reactor building (e.g., turbine building) and the transport of the demineralized water to these buildings were within GE's scope or the scope of the applicant referencing the ABWR design. SSAR Section 9.2.10.1 states that the interfaces between the MUWP system and safety-related systems are located in the control building or reactor building which are seismic Category I, tomado-missile resistant and floodprotected structures. Therefore, the MUWP system complies with Positions C.1 and C.2 of RG 1.29 and with GDC 2 and, therefore, with the applicable acceptance 
criteria of SRP Section 9.2.3. This is acceptable and the applicable part of DSER Open Item 52 is resolved.

In the DFSER, the staff statod that the applicant reforencing the ABWR decign should aupply the following: toating capability for air-operated valves; adoquate pump net ponitive suction bead (NPSH), purified water atorage tank overflow/drainage diversion to the radwaste syetem; material corrosion resistance; adequato distribution piping, valves, instrumentation, and controls; control room instrumentation that indicats the water lovel in the purified water storage tank; outdoor piping freeze protection; and adoquate diking and other means to control spill and leakage from the demineralized water storage tank that will be located outdoors. This was DFSER COL Action Itom 9.2.10-1. Upon further roviow, the staff has dotermined that the listing of this information as a COL action item is not neodod in the SSAR because it will be provided as a normal part of the licensing process. Therefore, COL action item 9.2.10-1 is appropriately deleted from the SSAR.

The requirements of GDC 5 for the sharing of SSCs do not apply because the ABWR is designed as a single-unit facility. An application for a multi-unit facility will require review of the design for complience with GDC 5.

In the DFSER, the staff requested GE to supply adequate design description and ITAAC for the MUWP system. This was incorrectly identified in the DFSER as Open Item 9.2.10-2. This designation was latet corrected to DFSER Open Item 9.2.10-1. Subsequently, GE provided a revised set of design description and ITAAC. The adequacy and acceptability of the design description and the ITAAC are evaluated in Section 14.3 of this report. On the basis of the above, DFSER Open Item 9.2.10-1 is resolved.

Based on information in the SSAR and that discussed above, the staff concludes that the MUWP system complies with Positions C.1 and C.2 of RG 1.29, GDC 2, and GDC 5, and therefore, with the applicable acceptance criteria of SRP Section 9.2.3 and is acceptable.

\subsubsection{Reactor Building Cooling Water System}

The staff reviewed the RCW system in accordance with SRP Section 9.2.2. Staff acceptance of the design of the RCW system is based on meeting the requirements of GDC 2 as it relates to the system withstanding the effects of natural phenomena; GDC 4 as it relates to the systom withstanding the effects of failed equipment and piping during both normal and accident conditions; GDC 5 as it relates to the capability of shared SSCs to perform required safety functions; GDC 44 as it relates to the capability to transfor heat loads from safety-related SSC. to the heat sink under normal and accident conditions, providing suitable iedundancy for components given a single active compunent failure, and the capability to icolate part of the system 80 that the safety function is not compromised; and ODC 45 and 46 as they relate to permitting inservice inspection and testing, respectively, for anfety-related equipment.

The requiruments of GDC 5 for the sharing of SSCs do not apply because the ABWR is designed as a singlo-unit facility. An application for a multi-unit facility will require review of the dosign for compliance with GDC 5.

The function of the RCW system is to remove heat from plant auxiliaries (some of which are required for safe shutdown) during normal operation and after a LOCA. The RCW system is required to operate, with and without preferred ac power available, at normal power, reactor shutdown, hot standby, and after a postulated LOCA has occurred. The RCW system is a closed cooling water system that provides cooling water to the following cosential systems and components: RHR and fuol pool cooling hoat exchangers; mechanical seals and motor bearings for RHR and HPCF pumps; air conditioning units (ACUs) for pump rooms (RHR, HPCF, FPC, and RCIC) and syatem rooms (SGTS, containment atmospheric monitoring system (CAMS), and flammability control system (FCS)); jacket water coolers and filtered water and lubricating oil coolers for diesel generators; and HECW system refrigerators. The RCW system supplies cooling water to the non-essential RIP pump motor coolers and motor generator sets, drywell coolers, reactor water cleanup (CUW) pump coolers, instrument air (IA) and service air (SA) system coolers, CUW non-regenerative heat exchangers, CRD pump oil coolers, and other nonessential auxiliary components in the reactor, turbine, and radwasto buildings (e.g., radwaste components, condenser offgas, and reactor building and turbine building sampling coolers).

The RCW system supplies cooling water, which absorbe heat from the plant auxiliaries it serves, and rejects the heat through the RCW system heat exchangers to the reactor service water system. The RSW system, in tum, rejects the heat to an UHS that will be designed by the COL applicants. The GE scope of the RCW system includes all the piping, valves, pumps, heat exchangers, instrumentation, and controls from the RCW system heat exchangers to their loads in the reactor, turbine, and radwasto buildings. GE specified the total heat removal rate, total flow rate, temperature drop, and pressure drop at the RCW system heat exchangers for all modes of operation identified above. These parameters provide the heat removal requirements for the referencing applicant to 
dovign the plant-epecific UHS aystem that would be connected to the RSW aystem.

The RCW syetem consiate of three mechenically and dectrically independeat divicion, ench consiating of it own separate piping (including mupply and return beaders), two pumps, three heat exchungers, valves, and instrumentation. Bech division of the RCW syctem is powered by a different division of the engineered afety features (BSF) power ayctom. Bech division of the RCW system aupplies cooling water to the auxiliarion of a separate emorgency dievel generator, RHR beat exchanger, RHR pump room ACU, RHR pump motor and soal coolen and HBCW refrigerntors. Other afety loads and noncesential cooling loads are distributed among the three divisions; two divisions share the loads for system with redundant components (0.8., HPCF and SGTS). Each division has one isolable train for nonessential loads.

Bach division of the RCW system is equipped with a surge tenk (chared with the HECW syetem) which the SSAR states is designed to accommodate 30 days of system design leakage without makeup water (GB reeponse, dated March 7, 1989). Also, the system is designed to detect system leakage by aseociated level monitors, to provide adoquato proesure for pump auction, and to allow for changes in system water volume without significant pressure variations. The system is initially filled with demineralized water from tho MUWP system. Eech division is further equipped with a chemical addition tank to add chemicals to the RCW syetem to protect it from corrosion or organic fouling.

The system is protected from water-hammer by high point vents in isolable portions of the systom and operational procedures requiring filling and venting of any sections of the system before operation. During a LOCA, noncesential RCW system cooling loads aro automatically isolated by the closure of valves except for system cooling loads to IA and SA system coolers, CRD pump oil coolers, and CUW pump coolers; these are isolated by the operator, if neceseary. Lovel switches for the surge tank enable the automatic isolation of nonessential cooling loads in the ovent of significant system leakage results from piping failures in the non-safety-related portions of the system. One valve on each supply and discharge line, with suitable power and coptrols from applicable divisional sources, ensures isolation if a single active component fails. GE described the methods for determining whether the system leakage occurs in the nonessential portion of the systom as indicated by a falling surge tank lovel. Radiation monitors located downstream of the RCW system pumps and heat exchangers indicate that radiation has leaked into that division. The ABWR design includes remote manual isolation capability for any division. The two remaining operable divinions will be rufficient to med the total eacential cooling load.

The RCW syetom consiats of afoty-related and nonafety-related portions. Portions of the system piping (including valves forming part of the primary containment boundary and other afety-related portions of the ayatem piping up to and including the isolation valves that isolate the aystom from its non-anfoty-rolated portions) are deaigned to the requirements of soismic Catogory I, QO B or C, and 10 CFR Part 50, Appendix B. The afety-related portions include the RCW syetem pumpe, beat exchangers, aurge tanks, and the division isolation valves. Instrumentation and controls performing afotyrelated functions (0.8., surge tank lovel switches) aro located in the safoty-related portions of the syatem. Electric modules (0.8., censors, power mupplies, signal proceseors) and cables performing anfety-related functions are all designed to seismic Category I and QG B requirements. Non-safety-related portions of the syetem that can adversoly impact anfety-rolated SSCa if thoy fail during a seismic ovent, are designed to ensure their intogrity under soismic loads reculting from an SSB. The safoty-related portions are locatod in soismic Catogory I atructures designed to protect against flood and tornado misciles. In the DSER (SECY-91-235), staff requeeted GB to aubmit confirmatory information that the safoty-related electric modules and afety-related cables are locatod in soismic Catogory I, flood-protected, and tornado-protected structures. The SSAR incorporates this information. This is acceptable and resolved the unnumbered DSER (SBCY-91-235) confirmatory item. Therefore, the staff concludes that the design of the RCW systom complies with GDC 2 with respect to protoction from natural phenomena, and moets Positions C.1 and C.2 of RO 1.29 with respect to its seismic requirements for the safety-relatad and non-safety-related portions.

Tho SSAR states that both the mechanical equipment and piping and electrical equipment, including instrumentation and controls of the redundant divisions of the RCW system, are sufficiently separated and protected to ensure availability of the needed equipment to shut the reactor down in the event of any of the following occurrences: pipe rupture or equipment-failure-induced flooding, spraying or steam release; pipe whip and jet forces from a postulated nearby high-energy pipeline break; misciles from equipment failure; firo; non soismic Catogory I equipment failure; or a single active component failure in the system. The amendments included the recults of a failure analysis of the RCW system to demonstrate that a single active or applicable passive component failure will not compromise the ability of the RCW system to transfor heat loads from safety-related components to the RSW during all modes of operation. GE submitted dosign char- 
soteristics for RCW system composents (0.8., pump deaign flow rato; heat oxchanger heat romoval capacity) to show that the system will transfor the expected heat loads to the RSW system under all operating conditions.

The staff stated, as Open Itom 53 in DSER (SBCY-91-235), the following three concerna:

1. The heat removal decign capecity of the RCW aystem heat exchanger may be inadequate for the hoat load required to be removed during auppreasion pool cooling, when the pool temperature reaches $97^{\circ} \mathrm{C}$ $\left(207^{\circ} \mathrm{F}\right)$ after a LOCA. The ataff boted that a reactor shutdown at 4 hours after a blowdown to the main condenser may be the bounding case, which may roquire a greater beat removal rate and, consequently, a higher deaign capacity than that atated for the heat oxchangers (seo GE's reeponse to RAI 440.73).

In the DFSER, the staff reclassified this concern as Open Item 9.2.11-1 because it had not yet been addreseed by GB. The ataff reviewed the SSAR and found that the RCW heat exchanger capacity dosign hed been modified to casure that the RCW aystem will be able to remove the worat anticipated heat loads as stated in SSAR Table 9.2-4. This is acceptable and resolved DFSER Open Item 9.2.11-1.

2. The staff stated in the DSER (SECY-91-235) that the projected heat loads and flow rates for hot standby conditions with a loss of ac power indicate that both RCW pumpe and all threo beat exchangers in a division are required. The staff also stated that this will also be the case for shutdown at 4 hours.

Data in SSAR Table 9.2-4 clearly indicato that this equipment is required for successful operation of each division for this mode of operation. This is acceptable and resolved the applicable part of DSER (SECY-91-235) Open Item 53.

3. The staff questioned in the DSER (SECY-91-235) whether the loss of an RCW system division during normal operation would result in plant shutdown or operation at reduced power.

In response, the SSAR states that the loss of one division of RCW to the drywell coolers will not affect plant operation and the lose of cooling to the RIP coolers will reduce plant power output but will not result in a reactor trip. This clarification is acceptable and resolved the applicable part of DSER Open Item 53.
All three divisions of the RCW system will have at least one RCW system pump operating. This configuration enaures the immediate availability of the RCW system for plant shutdown in the event of a LOCA. A LOOP concurrent with a LOCA will result in a temporary lows of pumping until the automatically sequenced reatart of RCW system pumps from the emergency diecel generator louding sequence. A LOCA will result in the automatic ieolation of moet non-eafoty-rolated RCW system loeds, the starting of the rocond RCW system pump, and the placing of the third heat exchanger in each division in service.

The staff concludes that the safoty-rolated portions of the RCW syatem comply with the requirements of GDC 4, with respect to protection against the dynamic offects of poetulated piping failures and internally- and externallygenerated missiles, and with GDC 44 for the provisions of a system to transfor heat from SSCs important to safety to an UHS.

As stated in Section 9.2.5 of this report, $G E$ submitted interface requirements for an applicant to design the UHS. The RCW system water quality requirements are cetablished by the MUWP because this system supplies makoup water for the RCW systom as discussed in Section 9.2.10 of this report. All three divisions of the RCW system are designed to allow periodic inservice inspection of all the system components. The inspections consist of structural and leak-tightness visual inspection, inspection of the entire system for operability, and inspection of the system components for operability and performance. Testing will be conducted to simulate as closely as possible the entire operational sequence of the RCW system for reactor shutdown and LOCA. The system design incorporates provisions for accessibility to permit inservice inspection as required. The staff finds that the system complies with GDC 45 and 46 for inspection and testing requirements for cooling water systems.

In the DFSER, the staff requested GE to submit adequate design description and the ITAAC for the RCW system. This was DFSER Open Item 9.2.11-2. Subsequently, GE provided a revised set of design description and ITAAC. The adequacy and acceptability of the design description and the ITAAC are evaluated in Section 14.3 of this report. On the basis of the above, DFSER Open Item 9.2.11-2 is resolved.

The RCW system includes pumps, heat exchangers, valves and piping, surge tanks, makeup piping, and the points of connection or interfaces with other systems. Portions of the RCW system that are necessary for safe shutdown, accident prevention, or accident mitigation are designed to soismic Category I and QG B or C requirements. The staff reviewed the SSAR design criteria, design beses, and 
safecy classification for the RCW syctom againat the requirements for aupplying adequate cooling water for the afety-related BCCS components and reactor auxiliary equipmeat for all conditions of plant operation.

Baced on the above the etaff concludes that the deaign of tho $\mathbf{R C W}$ syetem is acceptable and moets the requirements of ODC 2, 4, 5, 44, 45, and 46 and the guidelines of SRP Section 9.2.2.

\subsubsection{HVAC Normal Cooling Water Syetem}

The ataff reviowed the HNCW ayetem in ecordance with SRP Section 9.2.2. Staff ecceptance of the HNCW deaign is based on moeting ODC 2 as it relates to the aystom withstanding the offects of natural phenomena; GDC 4 as it relates to the syetem withetanding the offects of failed equipment and piping during both normal and sccident conditions; ODC 5 as it rolates to the sapability of shared SSCs to perform required safoty functions; ODC 44 as it relates to the capability to transfer beat loads from afotyrelated SSC, to the beat aink under normal and sccident conditions, providing muitable redundancy for components given a aingle active component failure, and tho capability to isolate part of the aystom 20 that the afoty function is not compromiced; and GDC 45 and 46 as thoy relate to permitting inservice inspection and teeting, respectively, for safety-related equipment.

The entire HNCW system is within the scope of the ABWR. The HNCW dystem is not mfety related except for portions of the system that penetrate the primary containment, the portions of the syetem that are part of the secondary containment boundary, and the aseociatod isolation valves.

The major components of the HNCW syatem are five 25-percent-capacity chillers (one standby), each with an HNCW pump (one standby), a surge tank (thared with the corresponding division of the TCW system), and the associated piping, valves, and instrumentation. Cooling water to the chiller-condenser is supplied by the TCW systom.

The requirements of GDC 5 for the sharing of SSCs do not apply because the ABWR is designed as a single-unit facility. An application for a multi-unit facility will require review of the design for compliance with GDC 5.

The function of the HNCW system is to provide chilled water to the drywell cooler cooling coils and cooling coils of other non-safety-related air conditioners, primarily in the reactor, control, radwaste, and service buildings. The HNCW system is not safety-related because it is not required to ensure (1) integrity of the RCS presoure boundary, (2) capability to achieve and maintain afe shutdown, or (3) the ability to prevent or mitizate offisite radiological exposures during eccidents. Therefore, ODC 44, 45, and 46, identified as acceptance critoria in SRP Section 9.2.2 do not apply to the non-enfoty-rolated portion of the HNCW system. The HNCW systom joins the primary containment through two penotrations: one for the aupply line and the other for the return line. The supply line penetration has ono motor-operated isolation valve outaide the containment and a check (ieolation) valve inside the containment. The return line penetration has two motor-operated isolation valves, one inside and one outside the containment. Ieolation valves and piping for the primary containment penetrations are safety-related and aro deaigned to seismic Category I, QO B, and 10 CFR Part 50, Appendix B, standards. Piping for penetrations for secondary containment is designed to soismic Category I and 10 CFR Part 50, Appendix B, standards. Based on this information, the staff concludes that the cafety-related portions of the HNCW system meet the requirements of ODC 44 regarding the provision for roliable systems for transferring heat loads to a heat aink.

The reat of the HNCW system is not safoty-related, ss atated above, and is designed to non soismic Catogory I standards. However, the non-safety-related portions of the system whose failure during a seismic event could affect any structure, system, or component important to safety, aro designed to ensure their integrity under seismic loads reoulting from an SSE. In the DSER (SECY-91-325), the staff stated that, subject to GE's confirmation that the safoty-related portions include the isolation valves for the primary containment penetrations, the design of the HNCW system moets Positions C.1 and C.2 of RO 1.29, as addreseod by the SRP Section 9.2.2 acceptance criterion with respect to the seismic requirements for the safoty-relatod and non-sufety-related portions of the system. This was DSER Confirmatory Item 6 and DFSER Confirmatory Item 9.2.12-1. SSAR Section 9.2.12.3 clarifies the safety classification of the containment penetrations, which is acceptable. This resolved DSER Confirmatory Item 6 and DFSER Confirmatory Itom 9.2.12-1.

By virtue of their location in seismic Category I, tomado-missile-protected and flood-protected structures, the safety-related portions of the system are protected against damage from adverse natural phenomena. Further, as concluded in Section 3.4.1 of this report, all safoty-related systems are protected against flooding that may result from system failure. Therefore, the system design complies with GDC 2 with respect to protoction of its safoty-related portions against natural phenomena and protoction of other safety-related systems against the conso- 
quences of filure of the non seismic portions of the system, as required by the SRP Section 9.2.2 ecceptance critarion.

The major components of the HNCW aystem are located in the turbine building. Therefore, fillure of any of thewe components will not advernoly effect enfety-related SSC. Safoty-related portions of the aystem aro locuted wach that tho adveres consequences of a pipe or other component failure will not prevent the safoty-related portions of tho system from performing their safoty function. Thu the system design moets the requirements of GDC $4=$ it relates to the system's capability to withatand the effects of adverse cavironmental and dynamic offects.

This systom is designed to allow periodic toeting and inspection of major components. Appropriato Americen Socioty of Heating, Rofrigoration, and Air Conditioning (ASHRAE), American Society of Mechanical Engincors (ASME), Tank Equipment Manufecturers Aseociation (TEMA), and Hydraulic Instituto (HI) standards aro used for all tests. Based on this inspection and teat information, the staff concludes that the HNCW systems meets the inspection and testing requirements of GDC 45 and 46 , respectively.

Makeup water to the system is supplied by the TCW systom surge tank which, in turn, receives water from the MUWP system. The MUWP system and the TCW systems are evaluated in Sections 9.2.10 and 9.2.14 of this report, respectively. The SSAR states design charactoristics for the system (0.8., cooling capacity of the chillers, pump design flow rato, chillod water supply tomperature) and the heat loads required to be removed from the components served by the system. These characteristics indicate that the system is capable of meeting the cooling water noeds of the components it serves during normal plant operation and rofueling shutdown. The chiller units are controlled individually by remote manual switches. The containment isolation valves for the system close automatically on a LOCA signal. These valves can also be operated manually by remote means. In the DSER (SECY-91-235), the staff stated, as Open Item 54, a discrepancy regarding the number of HNCW pumpe and chillers. The SSAR piping and instrumentation diagram (P\&ID) correctly shows five HNCW pumps and associated chillers. This resolved DSER Open Item 54.

In the DFSER, the staff requested GE to provide adequate design description and the ITAAC relating to the HNCW system. This was DFSER Open Item 9.2.12-1. Subsequently, GE provided a revised set of design description and ITAAC. The adequacy and acceptability of the design description and the ITAAC are ovaluated in
Section 14.3 of this report. On the basis of the above, DFSER Open Itom 9.2.12-1 is resolved.

The HNCW aystom includes pumpo, chillen, valves and piping, curge tanks, makeup piping, and the points of connection or interfaces with other systoms. The ataff roviewed the SSAR deaign criteria, design baces, and wefey claseification for the HNCW system againat the requiremente for aupplying adequate cooling water for waxiliary equipment for all conditions of plant operation. Tho ataff concludes, as discused above, that the design of the HNCW systom is accoptable and moets the applicable requirements of GDC 2, 4, 5, 45, and 46, and the guidolines of SRP Section 9.2.2.

\subsubsection{HVAC Emergency Cooling Water System}

The staff reviowed the HECW systom in accordance with SRP Section 9.2.2. Staff acceptance of the HECW design is based on moeting GDC 2 as it relates to the system withetanding the effects of natural phenomena; GDC 4 a it relates to the system withstanding the effects of failed equipment and piping during both normal and accident conditions; GDC 5 as it relates to the capability of shared SSCS to perform required safoty functions; GDC 44 as it relates to the capability to transfer heat loads from safetyrelated SSCs to the heat sink under normal and accident conditions, providing suitablo redundancy for components given a single active component failure, and the capability to isolate part of the system so that the safety function is not compromised; and GDC 45 and 46 as they relate to permitting inservice inspection and testing, respectively, for safety-related equipment.

The requirements of GDC 5 regarding the sharing of SSC do not apply because the ABWR is designed as a singlounit facility. An application for a multi-unit facility will require review of the design for compliance with GDC 5.

The HECW is a closed cooling water system whose function is to provide cooling water to the main control room (MCR) air conditioners, reactor building essential electrical equipment room (diesel generator zone) coolers, and control building essential electrical equipment room coolers. The HECW system is required to operate at normal power, reactor shutdown, and after any postulated abnormal reactor conditions, including a LOCA. The HECW system has no primary or secondary containment penetrations. GE states that the entire HECW system is safety-rolated and is within the scope of the ABWR design. The GE scope of the HECW system includes all piping, valves, pumps, chillers, instrumentation, and controls from the HECW system chillers to their cooling loads. 
The HICCW syatem consiats of three mechanically and electrically independent and completely redundant divisions. HBCW Division "A" serves Divition "A" dieed generator (DG) 2000 coolers and control building cencential electrical equipment room coolers. Division "A" consist of one refrigerator and pump, a aurge tank (shared with the correeponding diviaion of RCW), piping, valves, and instrumentation. Divisions "B" and "C" servo thoir respective DG zone coolers, control building esential electrical equipment room coolers, and MCR air conditioners. Bach division consiets of two refrigeratore and two pumpe, a surgo tank, and separate piping, valves, and instrumentation. Bech refrigeration unit includes a condenser, an ovaporator, a centrifugal compreceor, refrigerant, piping, and package chiller controls. Cooling water is supplied to the condensers by the corresponding RCW systom divisions. Each HBCW system division is powered by a different division of the ESF power system. The systom also has a chomical feed tank to add chemicals to each division to protect the system components from fouling.

The HECW system and the cooling water lines from the RCW system are designed to the requirements of seismic Category I, 10 CFR Part 50, Appendix B, and QG C. Thus, the system meets Position C.1 of RG 1.29 for seismic classification for safety-related systems. The system is located in the control building, a soismic Catogory I structure that protects against flood and tornadomissiles. Therefore, the system complies with GDC 2 with regand to protection of safety-related systems against adverse natural phenomena.

Each'HECW system division is equipped with a surge tank that GE states is designed to eccommodate more than 100 days' system leakage without mekcup water during an emergency. The surge tank is connected to the MUWP system, which supplies normal makeup water. The tank includes level switches to detect system leakage and to allow makeup water to be supplied to the tank when required. These switches actuate the makeup water supply valves (open or clceed on low or high tank water level, respectively) and annunciate control room alarms for high-high or low-low tank water levels.

The design of the HECW system includes sufficient separation and independence for both mechanical and electrical components of the redundant trains and protection for the system to perform its function under all reactor conditions, including a LOCA, loss of normal ac power, or a single active component failure in the system, or any combination of the above. GE performed a failure analysis of the HECW system and presented the results in the SSAR to demonstrate that failure of a single active component, failure of all power to a single Class IE power syctem bus, or a failure-of-refrigerator signal will not compromise the ability of the systom to perform its function. With the system controls set for automatic operation, the systom is automatically initiated whenever the HVAC syatems in the control building or diesel generator areas are started. The system can also bo manually started from the control room. Interlocks for the chillen automatically start the redundant division whenover the operating division fails (0.g., high temperature of the returned cooling water or inadequate chilled water flow). The system flow switches prevent the chiller from operating unless sufficient water is flowing through both the evaporator and the condenser. The chiller units can be controlled individually from the control room by remoto-manual switches. The system includes instrumeatation and controls for monitoring and controlling syetem paramoters, auch as chilled water flow and temperature, condenser water flow, and ovaporator diecharge flow and temperature. Since the syetem is not expected to contain any significant level of radioactivity, it has no radiation monitors. GE has provided the design characteristics for the system components (e.8., capecity of the HECW system refrigeration units, chilled water pump flow rate, chilled water and condenser water supply temperatures). GE also submitted the heat removal and flow requirements for the individual system components. This information indicates that any single division of the system is by itself capable of rejecting the total heat from the components the system serves via the refrigerant to the RCW cooling water under all reactor conditions.

From its initial review, the staff stated in the DSER (SECY-91-235) the following three concerns of DSER Section 9.2.12 as Open Itom 55:

1. SSAR Table 9.2-9 did not indicate that a single HECW system pump by itself could deliver the required total chilled water flow rate. The staff noted that the statoment in SSAR Section 9.2.13.2 that each division contained two 100-percent capacity pumpe was contradictory.

In response, GE committed to provide information to reflect that Divisions " $B$ " and " $C$ " consist of two 50-percent capacity pumps and that Division " $A$ " consists of one pump capable of meeting the hydraulic requirements of the division, which would be consistent with the information provided in revised SSAR Table 9.2-9. Incorporation of this information into the SSAR was Confirmatory Item 9.2.13-1 in the DFSER. The SSAR states that each HECW pump has a capacity of approximately $950 \mathrm{~L} / \mathrm{M}(250 \mathrm{gpm})$. This capacity is sufficient to supply 100 percent of the needs of Division " $A$ " and 50 percent of the neods for Divisions "B" and "C," which is accoptable. Therefore, the 
applicable part of DSER Open Item 55 and DFSER Confirmatory Itom 9.2.13-1 are reeolved.

2. It was not cloar whether the single chomical foed tank provided for the system is safety-related. The staff also noted that GB had not indicated whether the aseociatod icolation valve and its piping are anfetyrelated, or whether any non-afoty-rolated portions of the system are isolated from the safety-related portions of the systom if isolation is warranted.

In reeponee, GE indicated that the only non-eafetyrelated portions of the HECW divisions are the chemical addition tank and the piping from the tank to the safoty-related valves which isolato tho tank from the safety-related portions of the syetom. This addreesed the applicable part of DSER (SECY-91-235) Open Itom 55. In the DFSER, the staff requested that the piping and instrumentation diagrams (P\&IDs) be appropriately updated and that the above information be incorporated into the system description. This was DFSER Confirmatory Item 9.2.13-2. The staff reviewed Figure 9.2-3 of the SSAR and concluded that the surge tenk isolation valves are included in the safoty-related portion of the system. This is acceptable and resolved DFSER Confirmatory Item 9.2.13-2 and the applicable part of DSER (SECY-91-235) Open Item 55.

3. The staff noted that it was not clear which division of the HECW supplies chilled water to the DG in Zone C. The staff also noted that SSAR Figure 9.4-4 and Section 9.2.13 were inconsistent in showing the number of divisions for the system.

SSAR Section 9.2.13 currently shows the three divisions of the HECW system. Divisions A, B, and C support diesel generator areas A, B, and C, respectively. This eliminates the discrepancy in the DSER (SECY-91-235) and is acceptable. Therefore, the applicable part of DSER Open Item 55 is resolved.

Based on the above information, the staff finds that the HECW system will comply with GDC 4 regarding protoction for the system against dynamic effects resulting from postulated piping failures and internally- and externally-generated missiles, and with GDC 44 regarding system reliability.

The HECW system water quality requirements are established by the MUWP system, as this system is the source of the water for the HECW system surge tanks. (See Section 9.2.10 of this report.)
The deaign of the HECW system includes provisions to allow periodic inservice inspection of all the aystom components to ensure the integrity of the system and its capability to perform its intended function. Local display dovices indicate vital parameters required in teeting and inspections. For example, chilled water flow rate and temperature of the systom can be checked by viewing the dieplay of locally-mounted preasure and temperature gauges at the main control panel. The staff reviewed the SSAR and concluded that the system aleo includes provisions to permit periodic testing of system components as well as the system as a whole. The SSAR states that this teating capability includes structural and leak-tightness visual inspection, tests of entire system operability, and teats of system component operability and performance. This is acceptable. The staff finds that the design of the system complies with the requirements of GDC 45 and 46 for inspection and testing of safety-related cooling water systems.

As a result of further staff review, an additional concern was identified regarding the HECW system. Because of the properties of the refrigerant used in the HECW chiller units, unique problems may arise in recovering the units following a SBO. In the DFSER, the staff requested GB to provide an analysis regarding the HECW system's ability to recover following a postulated SBO condition. This was DFSER Open Item 9.2.13-1. As described below, the SSAR, Appendix 1C, provides information regarding the HECW system's response during an SBO. The system can be connected to an alternate ac (AAC) power source within 10 minutes after the initiation of an SBO. The CTG serves as the AAC source. During the SBO, little heat will be generated in the areas served by the HECW since only battery-powered equipment will be running. The temperature increase in the rooms over the 10-minute period will not exceed the qualification limits for the equipment in these areas. Once AAC is available, fans (which are normally powered from Class $1 E$ sources) will be available to remove heat from the areas served by the HECW. As the chillers become available, normal area temperatures will be restored. Furthermore, the SSAR states that the applicant referencing the ABWR will provide the necessary means for restarting the system on an SBO after the AAC is available. The staff concludes that the design provisions in the SSAR give adequate assurance that, during an SBO condition, safety-related equipment served by the HECW system will not exceed its environmental operability limits. This is acceptable and resolved DFSER Open Item 9.2.13-1.

In the DFSER, the staff requested GE to provide adequate design description and the ITAAC relating to the HECW system. This was DFSER Open Item 9.2.13-2. Subsequently, GE provided a revised set of design 
description and ITAAC. The adequacy and acceptability of the deaign description and the ITAAC are evalunted in Section 14.3 of this report. On the basis of the above, DFSER Open Itom 9.2.13-2 is resolved.

The HECW system includes pumps, chillers, valves, piping, surge tanks, makeup piping, and the points of connection with other systems. Portions of the HECW system that are necessary for safe shutdown, acoident prevention, or accident mitigation are designed io saismic Catogory I and QG B requirements. The staff reviewed the SSAR design criteria, design bases, and safoty classificution for the HBCW system aguinst the requirements for supplying adequate cooling water for the safety-related ECCS components and reactor auxiliary equipment for all conditions of plant operation. The staff concludes, as discuseed above, that the design of the HECW system is acceptable and meets the requirements of GDC 2, 4, 5, 44, 45, and 46, the applicable criteria of SRP Section 9.2.2.

\subsubsection{Turbine Building Cooling Water System}

The staff reviewed the non-safety-related TCW system in sccordance with applicable portions of SRP Section 9.2.2. Staff acceptance of the TCW system design is based on meeting GDC 2 as it relates to the system withstanding the effects of natural phenomena; GDC 4 as it relates to the system withstanding the effects of failed equipment and piping during both normal and accident conditions; GDC 5 as it relates to the capability of shared SSCs to perform requires safety functions; GDC 44 as it relates to the capability to transfer heat loads from safety-related SSCs to the heat sink under normal and accident conditions, providing suitable redundancy for components given a single active component failure, and the capability to isolate part of the system so that the safety function is not compromised; and GDC 45 and 46 as they relate to permitting inservice inspection and testing, respectively, for safety-related equipment.

The TCW system is a non-safety-related system designed to remove heat for various turbine island auxiliary equipment. The TCW is a closed-loop system consisting of three 50-percent capacity pumps, three 50-percent capacity heat exchangers, a surge tank (shared with the corresponjing division of the HNCW system), and associated piping, valves, and instrumentation. In Section 9.2.14 of the DSER (SECY-91-235), the staff noted, as part of Open Item 56, that the description of the TCW in SSAR Section 9.2.14 contained several inconsistencies. The component and system descriptions in SSAR Section 9.2.14.2.3 and in SSAR Figure 9.2-6a did not agree with the descriptions of SSAR Sections 9.2.14.2.1 and 9.2.14.2.2 and GE's responses to RAIs. The discrepancies (in particular, the number of heat exchangers and pump capecities) required correction. GE submitted information and committed to update the SSAR to eliminate the discrepancies between the figures and the text. GE stated that the system will be a single-loop system consisting of three pumps and three heat exchangers, each of 50 -percent-capacity as stated above. Incorporation of the corrected information into the SSAR was Confirmatory Item 9.2.14-1 in the DFSER. The staff reviewed the SSAR and concluded that the inconsistencies had been corrected. This is acceptable and resolved the applicable part of DSER Open Item 56 and DFSER Confirmatory Itom 9.2.14-1.

The SSAR includes pump flow requirements, heat exchanger capacity, and turbine service water temperature limits for TCW operation. Demineralized water is added automatically based on surge tank level indications. During normal operation, two pumps are in operation and the third is in standby. The third pump automatically starts on low pump discharge pressure. There are no connections between the TCW and safety-related water systems, and the TCW system is designed in accordance with QG D standards.

The TCW system is located in and near the turbine building, away from safety-related systems. In response to RAIs 430.206 and 430.207, GE indicated that failure of any TCW components, including the atmospheric surge tank, would not cause any safety-related equipment to fail. In the DSER (SECY-91-235), the staff noted that, from equipment layout diagrams reviewed, this statement appears to be true for all equipment shown on the diagrams. The staff also noted that the atmospheric surge tank did not appear on these diagrams and the staff verification that failure of this component would not affect safety-related systems was not possible. The SSAR identifies the surge tank as being located above the TCW pumps in the turbine building. This location would place the tank in an area away from safety-related components, and failure of the tank would not affect any safety-related components, which is acceptable. This description meets Position C.2 of RG 1.29, "Seismic Design Classification," Revision 3, and resolved the remaining part of DSER Open Item 56.

Based on this information, the staff concludes that the TCW system design meets the guidelines of Position C.2 of RG 1.29, pertaining to seismic requirements for non-safety-related systems and components. Therefore, the design meets the requirements of GDC 2 in accordance with SRP 9.2.2.

The requirements of GDC 5 regarding the sharing of SSCs do not apply because the ABWR is designed as a single- 
unit facility. An application for a multi-unit facility will require review of the design for compliance with GDC 5.

Because the TCW system is non-safety-related and does not interface with a safety system, the remaining requirements (GDC 4, 44, 45, and 46) of SRP Section 9.2.2 do not apply since they addrese requirements of safety-related systems.

In the DFSER, the staff requested GE to provide adequate design description and the ITAAC relating to the TCW system. This was DFSER Open Item 9.2.14-1. Subsequently, GE provided a revised set of design description and ITAAC. The adequacy and acceptability of the design description and the ITAAC are evaluated in Section 14.3 of this report. On the basis of the above, DFSER Open Item 9.2.14-1 is resolved.

The TCW system includes pumps, chillers, valves, piping, surge tanks, makeup piping, and the points of connection with other systems. The staff reviewed the applicant's proposed design criteria, design bases, and safety classification for the TCW system against the requirements for supplying adequate cooling water for the auxiliary equipment for all conditions of plant operation. The staff concludes, as discussed above, that the design of the TCW system is acceptable and meets the applicable requirements of GDC 2, 4, 5, 44, 45, and 46 and the guidelines of SRP Section 9.2.2.

\subsubsection{Reactor Service Water}

The staff reviewed the reactor service water (RSW) system in accordance with SRP Section 9.2.1. Staff acceptance of the RSW system design is based on meeting the requirements of GDC 2 as it relates to protecting SSCs important to safety from the effects of natural phenomena; GDC 4 as it relates to protecting SSCs important to safety from the effects of piping and equipment failures during both normal and accident conditions; GDC 5 as it relates to the capability of shared SSCs to perform required safety functions; GDC 44 as it relates to the capability to transfer heat loads from safety-related SSCs to the heat sink under normal and accident conditions, providing suitable redundancy for components given a single active component failure, and the capability to isolate part of the system so that the safety function is not compromised; and GDC 45 and 46 as they relate to inservice inspection and testing of safety-related systems and components.

The portion of the RSW system within the ABWR design scope includes all the piping, valves, instrumentation, and controls within the control building. All other equipment outside the control building, including the RSW pumps, are outside the ABWR design scope and are the responsibility of the COL applicent.

The SSAR includes a conceptual design and interface requirements for that portion of the RSW system outside the ecope of the ABWR design as required by 10 CFR Part 52.

The function of the RSW system is to provide cooling water to the RCW system (reviewed in Section 9.2.11 of this report) for distribution to several safety-related and non-eafety-related loeds. The RSW is required to operate at normal power, reactor shutdown, hot standby, and after a postulated LOCA. Under each of these conditions, the RSW is required to function both with and without preferred ac power available and with a single active failure.

The RSW system is an open-cycle system that provides cooling water to the RCW heat exchangers. The RSW system supports no other heat loads. The RSW system picks up heat from the RCW heat exchangers and rejects the heat to the UHS, which is to be designed by COL applicants referencing the ABWR design as discussed in Section 9.2.5 of this report. Although earlier SSAR amendments discussed the total heat rate, total flow rate, temperature drop, and pressure drop at the RCW heat exchangers for all identified modes of operation for the RCW system, the staff completed the DSER (SECY-91235) before receiving in an amendment similar parameters for the RSW system (including identification of sufficient NPSH at pump suction locations for low water levels). This was identified in Section 1.8 of the DSER (SECY-91-235) as Open Item 57. GE submitted information and committed to update the SSAR, identifying these parameters as actions by the COL applicant. This was DFSER COL Action Item 9.2.15-1. SSAR Section 9.2.15.2 requires the $\mathrm{COL}$ applicant referencing the ABWR design will submit sufficient information to allow the staff to perform a plant-specific safety evaluation on that portion of the RSW system outside of the ABWR design scope. This is acceptable. On the basis of the above, the applicable part of DSER Open Item 57 is resolved.

The RSW system is composed of three mechanically and electrically independent divisions. Each division consists of its own separate piping from intake to discharge, two pumps, two strainers, valves, and instrumentation. Each RSW division supplies cooling water to one division of the RCW system.

The SSAR states that the RSW system will be able to function during abnormally low or high water levels and that steps are taken to prevent organic fouling that may degrade 
system performance. These steps include installing trash racks, biocide treatment (or non-biocide treatment where biocide treatment is not allowed), and thermal beckwash capabilities. In the DFSER, the staff stated that solection of appropriate mensures is sito-specific and, therefore, the responsibility of the COL applicant. This was DFSER COL Action Itom 9.2.15-2. SSAR Section 9.2.15.2.2 states that the COL applicent will design the out-of-scope portion of the RSW system to prevent excessive organic fouling, erosion, and corrosion of the RSW piping. This is acceptable and resolved the applicable portion of DSER Open Itom 57.

In the DFSER, staff reviow of the interfece requirements in the SSAR and the certified design material (CDM) was in progress. This was DFSER Open Item 9.2.15-1. Subsequently, GE submitted the design description, the ITAAC, and the interface requirements relating to the RSW system. The adequacy and acceptability of the design description, the ITAAC, and the interface requirements are evaluated in Section 14.3 of this report. On the basis of the above, DFSER Open Item 9.2.15-1 is resolved.

System protection from water-hammer is achieved through the use of high point vents and operational procedures requiring filling and venting of any sections of the system before operation. In the DFSER, the staff stated that the COL applicant should supply these procedures. This was DFSER COL Action Item 9.2.15-3. SSAR Section 9.2.15.2.1(6) states that the COL applicant will submit the above information. This is acceptable.

All portions of the RSW system are designed to seismic Category I, QG C, requirements. SSAR Table 3.2-1 states that the RSW pumps are located in the structures associated with the UHS; therefore, all portions of the system will be located in seismic Category I, flood- and missile-protected structures. The design of the RSW system complies with the requirements of GDC 2 with respect to its protection from natural phenomena, and meets Position C.1 of RG 1.29 with respect to its seismic requirements.

The SSAR states that both the mechanical equipment and piping and electrical equipment, including instrumentation and controls, of the redundant divisions of the RSW system are sufficiently separated and protected to ensure availability of the needed equipment to shut down the reactor in the event of any of the following occurrences: flooding or spraying steam release induced by pipe rupture or equipment failure, pipe whip and jet forces from a postulated nearby high-energy line break, missiles from equipment failure; fire; non seismic Category I equipment failure, or a single active component failure in the system.
In the earlier SSAR amendments, insufficient detail was provided to ensure that this design criteria can be mot. Specifically, location and design features for the RSW pump and associated equipment were not specified prior to DSER (SECY-91-235) completion. This was identified in Section 1.8 of the DSER (SECY-91-235) as part of Open Item 57. The SSAR provides this information as an interface requirement and establishes interfece criteria to sssure an appropriate design. The staff reviewed this information and found it acceptable. This resolved the applicable part of DSER Open Item 57.

A portion of each division of the RSW system is located in separate divisional areas in the control building besement. An RSW pipe break in this area would expose the safetyrelated RCW heat exchangers to flood water from the UHS through the RSW system. GE incorporated a flood protection feature to isolate the affected division of the RSW system on a high water level signal in the divisional spece within the control building. In this way, only the division experiencing the break and subsequent flooding will be affected. The redundant divisions of RCW and RSW will still be available to perform their safety functions. Based on this information, the staff concludes that the ABWR RSW design and related commitments are adequate to ensure compliance with GDC 4 as it relates to protection of safety-related equipment from the dynamic effects resulting from postulated pipe failures, floods, and intermally- and externally-generated missiles. This resolved the second part of DSER Open Item 57. Incorporation of this information into the SSAR was identified as Confirmatory Item 9.2.15-1 in the DFSER. SSAR Section 9.2.15.2.1 states that the COL applicant referencing the ABWR will design the out-of-scope portion of the RSW system to withstand the effects of piping and equipment failures. This is acceptable and resolved DFSER Confirmatory Item 9.2.15-1.

The staff notes that, in addition to the interface criteria identified above, the portion of the RSW system within the scope of the COL applicant's action must meet the following:

- the system will be sized to remove the heat associated with the worst-case condition listed in Table 9.2-4 in the SSAR.

- RSW piping length will not exceed $2000 \mathrm{~m}$ ( 6600 ft) and redundant system isolation capability will be designed to ensure that flooding in the control building resulting from the failure of RSW piping is within the bounds of the flood analysis. This is discussed in Section 3.4.1 of this report. 
The requirements of GDC 5 for the sharing of SSCs do not apply because the ABWR is designed as a singlo-unit facility. An application for a multi-unit facility will require review of the design for compliance with GDC 5.

At least one RSW pump in each of the three divisions of the RSW aystem will be operating. This configuration ensures immodiate availability of the RSW system for plant shutdown in the event of a LOCA. A LOPP concurrent with a LOCA will reoult in a tomporary lows of pumping until the sutomatically sequenced restart of RSW pumps from the emergency diesel generator londing sequence. Upon the occurrence of a LOCA, the socond RSW pump starts and the third heat exchanger in each division is placed in service. The design criteria for the RSW include the requirement that a single sctive or applicable passive component failure will not compromise the ability of the RSW system to transfer heat loads from the RCW system to the UHS.

GE discussed protection from adverse environmental conditions, such as freezing, icing, and biofouling in its response to Unresolved Safety Issues B-29 and B-32 and Generic Isoue (GI) 51. The staff discusses the adequacy of the ABWR design provisions and interface requirements with regard to these issues in Sections 20.1 and 20.2 of this report.

The staff reviowed design information and interface criteria supplied by GE and concludes in viow of the above that the RSW system design ensures that the heat removal requirements of GDC 44 will be met and are acceptable.

All throe divisions of the RSW system are designed to allow periodic inservice inspection of all the system components. This testing capability consists of structural and leak-tightness visual inspection, tests for entire systom operability, and tests for system component operability and performance. Teeting will be conducted to simulate as closely as possible the entire operational sequence of the RSW system from reactor shutdown to LOCA. The system design also incorporates provisions for accessibility to permit inservice inspection as required. Therefore, the system complies with the requirements of GDC 45 and 46 with respect to inspection and testing requirements for cooling water systems.

In the DFSER, the staff requested GE to provide adequate design description, the ITAAC, and interface requirements relating to the RSW system. This was DFSER Open Item 9.2.15-2. Subsequently, GE provided a revised set of design description and ITAAC. The adequacy and acceptability of the design description, the ITAAC, and the interface requirements are evaluated in Section 14.3 of this report. On the basis of the above, DFSER Open Item 9.2.15-2 is resolved.

The design and related commitments of the RSW aystem comply with the applicable requirements of GDC 2, 4, 5, 44, 45, and 46, and the guidelines of SRP Section 9.2.1 discuesed above, and are acceptable.

\subsubsection{Turbine Service Water System}

The staff reviewed the non-safety-related turbine service water (TSW) system in accordance with applicable portions of SRP Section 9.2.1. The TSW system design is scceptable if it meets the requirements of GDC 2 as it relates to protecting SSCs important to safety from the offects of natural phenomena; GDC 4 as it relates to protecting SSCs important to safety from the offects of piping and equipment failures during normal and accident conditions; GDC 5 as it relates to the capability of shared SSCs importent to perform safety functions; GDC 44 as it relates to the capability to transfer heat loads from safetyrelated SSCs to the heat sink under normal and accident conditions, providing suitable redundancy for components if a single active component fails, and the capability to isolate part of the system 80 that the safety function is not compromised; and GDC 45 and 46 as they relate to insorvice inspection and testing of safety-related systems and components.

The portion of the TSW system design within the ABWR design scope includes all the piping, valves, instrumentation, and controls within the turbine building. All other equipment outside the turbine building, including the TSW pumps, are outside the ABWR design scope and are the responsibility of the COL applicant.

The SSAR includes a conceptual design and interface requirements for that portion of the TSW system outside the scope of the ABWR design as required by 10 CFR Part 52.

The TSW system is a non-safety-related system designed to transfer heat from the TCW system heat exchangers to the power cycle heat sink. The TSW includes three 50-percent capacity pumps, three duplex strainers, and associatod piping, valves, and instrumentation. In the DSER (SECY-91-235), the staff stated that GE did not provide system parameters, (pump flow requirements, system design pressure) but submitted a requirement that water supplied to the TCW heat exchangers be at a temperature not to exceed approximately $40^{\circ} \mathrm{C}\left(100^{\circ} \mathrm{F}\right)$. In response, GE committed to update the SSAR concerning the design of the TSW system. SSAR Table 9.2-16 provides the specific system parameters described above. 
This is acceptable and resolved DFSER Confirmatory Item 9.2.16-1.

In the DFSER, the staff noted contradictory information concerning the number of pumps in the system. The text of SSAR Section 9.2.16 referred to two pumps and two duplex strainers. However, SSAR Figure 9.2-8 and Table 9.2.17 both showed three 50-percent capecity pumps. Resolution of this discrepancy was identified as Open Item 9.2.16-1 in the DFSER. The SSAR clarifies that the system consists of a single loop containing three vertical wet pit pumps. During normal operation, two pumps are operating and the third is in standby. The standby pump starts automatically if an operating pump trips or if the pump discharge preseure drops below a preselected limit. This clarification is acceptable and resolved DFSER Open Item 9.2.16-1.

The TSW system is located in the intake structure (the power cycle heat sink pump house) and the turbine building. The system does not have any connections with safety-related systems. The applicant must demonstrate that all safety-related components, systems, and structures are protected from flooding in the event of a pipeline break in the TSW system in order to meet Position C.2 of RG 1.29, and thus, comply with GDC 2. The staff recognized the site-specific location of some TSW components and stated in the DSER (SECY-91-235) that this requirement may noed to be specified as an interface requirement. This was identified in Section 1.8 of the DSER as Open Item 58. Incorporation of this requirement in the SSAR was identified as Confirmatory Item 9.2.16-2 in the DFSER. GE stated that the COL applicant should submit an interface requirement for flood protection of safety-related SSCs in case of TSW component failures. The SSAR includes sufficient information to ensure that an applicant referencing the ABWR can design the out-of-scope portion of the TSW system to prevent flood damage to safety-related equipment as a result of a break in the TSW piping. The staff notes that in the SSAR, Section 3.4.1 includes a flood analysis which indicated that any flooding resulting from a break in the TSW system will be prevented from affecting safetyrelated equipment by several means. First, a break in the TSW line will result in a high water level alarm in the condenser pit. The operator can then isolate the system. If the operator is unsuccessful in isolating the system, flood waters would rise to plant grade where it would flow out of the truck door and onto the ground at this elevation. Second, the below-grade tunnel which connects the turbine, radwaste, and reactor buildings is sealed at all ends to prevent water from entering any of the buildings. On the basis of this information, the staff concludes that flooding as a result of a break in the TSW line will not adversely affect any safety-related equipment. Therefore, the guidelines of Position C.2 of RG 1.29 and the requirements of GDC 2 can be met, and DFSER Confirmatory Item 9.2.16-2 is resolved. The CDM aspects are addressed in the discussion of DFSER Open Item 9.2.16-2 below.

The requirements of GDC 5 for the sharing of SSCs do not apply beceuse the ABWR is designed as a single-unit facility. An application for a multi-unit facility will require review of the design for compliance with GDC 5.

The remaining requirements of SRP Section 9.2.1 (GDC 4, 44, 45, and 46) do not apply because the TSW systom is non-safety-related and has no connections to safety-related systems.

In the DFSER, the staff requested GE to provide adequate design description, interface requirements, and the ITAAC relating to the TSW system. This was DFSER Open Item 9.2.16-2. Subsequently, GE provided a revised sot of design description and ITAAC. The adequacy and acceptability of the design description and the ITAAC are evaluated in Section 14.3 of this report. On the basis of the above, DFSER Open Item 9.2.16-2 is resolved.

The design and related commitments of the TSW system comply with the requirements of GDC 2 as discussed above. The requirements of GDC 4, 5, 44, 45, and 46 do not apply. In view of the above the staff concludes that the system design and related commitments meet the applicable acceptance criteria of SRP Section 9.2.1 and are acceptable.

\subsection{Process Auxiliaries}

\subsubsection{Compressed Air Systems}

The design of the compressed air (CA) systems are discussed in SSAR Sections 6.2.5 (Atmospheric Control System), 6.7 (High Pressure Nitrogen Gas Supply), 9.3.6 (Instrument Air), and 9.3.7 (Service Air) and were reviewed in accordance with SRP Section 9.3.1. The review of the CA systems involved a review of information in the SSAR and GE's responses to staff RAIs. The acceptance criteria for the safety-related portions of the CA systems is provided in SRP Section 9.3.1 and includes compliance with GDC 1 as it relates to systems and components important to safety being designed, fabricated, and tested to quality standards in accordance with the importance of the safety functions to be performed; GDC 2 as it relates to safety-related CA systems being capable of withstanding the effects of natural phenomena; and GDC 5 as it relates to the capability of shared systems, and components to perform required safety functions. The 
staff roviowed the CA systems for compliance with GDC 1 as discuseed in Section 3.2 of this report.

The requirements of GDC 5 for the sharing of SSCs do not apply because the ABWR is designed as a singlo-unit facility. An application for a multi-unit facility will require reviow of the design for compliance with GDC 5.

The CA system consists of four subsystems: (1) the atmospheric control system (ACS), (2) the high-pressure nitrogen gas supply (HPIN) system, (3) the instrument air (IA) system, and (4) the service air (SA) system. These systems provide compressed gas (either air or nitrogen) to operate safety-related equipment relied upon to mitigate the consequences of design-basis events and plant equipment used for normal facility operation. The non-safety-related portions of the system are interconnected with the safetyrelated portions of the system; the designs of the four subsystems are summarized below.

The ACS system establishes and maintains an inert atmosphere within the primary containment during all plant operating modes except (1) during shutdown for refueling or equipment maintenance, and (2) during limited periods of time to permit access for inspection at low reactor power (15 percent). The ACS is non-safety-related except as necessary to ensure primary containment integrity (e.g., penetrations and isolation valves). The ACS includes nitrogen storage tanks, vaporizers, valves and piping carrying nitrogen to the containment, valves and piping from the containment to the SGTS and reactor building HVAC exhaust line, non-safety oxygen-monitoring, and all related instrumentation and controls. The ACS provides nitrogen from the nitrogen evaporator to the HPIN system during normal operation.

The HPIN system consists of both safety-related and nonsafety-related portions. A single non-safety-related line provides a continuous nitrogen supply to all pneumatically operated components in the primary containment during normal operation. During normal operation, the HPIN system is supplied from the nitrogen ges evaporator/storage tank through the makeup line from the ACS.

The safety-related portion of the system consists of two independent divisions; each division contains a safety-related nitrogen supply capable of supplying 100-percent of the requirements of the division being serviced. High-pressure nitrogen gas storage bottles supply nitrogen gas for the safety-related portion of the system. Tielines connect the non-safety-related portion of the system to each division of the safety-related portion of the system. Each tieline has a motor-operated isolation valve.
The IA system provides dry, oil-free, CA for valve sctuators, non-safety-rolated instrument control functions, and general instrumentation and valve services outside the containment. (All instrumentation and control systems inside the containment are supplied with nitrogen gas during normal plant operation.) The primary containment penetrations of the IA system are of seismic Catogory I, QG B, design and are equipped with sufficient isolation valves to satisfy single-failure criteria. In GE's responses to RAI 430.215, the staff noted in the DSER (SECY-91-355), as an unnumbered confirmatory isewe, that the reference to ". . . containment penetrations and drywell penetrations of the instrument air system . . ." in SSAR Section 9.3.6.1.1 should be revised to reference primary containment penetrations only. The correction of the SSAR text was identified as DFSER Confirmatory Item 9.3.1-1. GE subsequently made this correction in Amendment 24 of the SSAR. DFSER Confirmatory Item 9.3.1-1 is resolved.

The SA system is designed to provide CA of suitable quality for non-safety-related functions. The SA system provides CA for services requiring air of lower quality than that provided by the IA system. The containment penetrations and drywell penetrations of the SA system are of seismic Category I, QG B, design and are equipped with sufficient isolation valves to satisfy single-failure criteria. The SA system does not directly inte face with the HPIN system and does not perform any safety-related function.

As noted earlier, only the HPIN system provides compressed gas to safety-related components. However, the ACS and the IA system directly interface with the HPIN system and could affect the reliability of safetyrelated components relied upon to mitigate the consequences of design-basis events. Therefore, the staff reviewed these three systems in assessing the adequacy of the CA systems in accordance with acceptance criteria in SRP Section 9.3.1.

The staff reviewed the SSAR to determine the safetyrelated portions of the CA system and stated in the DSER (SECY-91-355) that the text and figures in SSAR Section 6.7 did not clearly state which portions of the HPIN system are safety-related. However, the response to an RAI, and the valve and instrument numbers on a revision to SSAR Figure 6.7-1 specify which portions of the system are safety-related. These portions include the nitrogen storage bottles and their headers up to and including valves FOO2A through FOO2D, piping and valves from F002 (A through D) to the accumulators for the automatic depressurization system (ADS) valves, and piping from the cross-tie valves F012A and F012B to the piping leading to the accumulators (identified previously). Additional safety- 
related piping in the IA system and ACS include piping and valves from $\mathrm{F} 200$ to $\mathrm{F208}$, incluaive.

The staff noted an inconsistency in the deaignation of the inboard isolation valve. GE roferred to this valve as F209 in all drawings and as F208 in the responses to RAIs. In DSER (SBCY-91-355) Table 9.3.1-1, the ataff identified (DSER Open Itom 69) additional numbering inconsistencies, including valve numbers and valve operator types. The staff aleo atated [DSER (SECY-91-355) Open Itom 70] that the SSAR toxt and figures did not include all information on the safety classification of components before the ataff completed DSER (SECY-91-355). While the information in response to requests for information is acceptable, the staff stated in the DSER (SECY-91-355) that this information should be fully incorporated into the SSAR. The inconsietencies and lack of information noted in the DSER (SECY-91-235) were addreseed in revised figures to be incorporated into the SSAR. This information resolved DSER Open Items 69 and 70; however, the etaff identified incorporation of this information into the SSAR as'Confirmatory Item 9.3.1-2 in the DFSER. GE submitted Amendment 20 of the SSAR which corrected the inconsistencies and included the additional information. This is acceptable, and resolved DFSER Confirmatory Item 9.3.1-2.

Contrary to the guidelines of the SRP, the SSAR does not indicate the failure mode for the valves in the HPIN system. Except as noted below, and assuming that the MOVs fail "as-is," the system configuration is scceptable. In the DSER (SECY-91-355), the staff stated as Open Item 71 that information related to the failure mode of components should be incorporated into the SSAR text and drawings. GE indicated in a letter dated March 11, 1992, that the motor-operated valves in the air systems fail as-is; air-operated valves fail open (unless otherwise indicated) in the HPIN, IA, and SA systems and fail closed in the ACS. This information resolved DSER Open Item 71; however, identification of the failure modes of the valves in the CA systems (i.e., confirmation of the failure states) in the SSAR was identified as DFSER Confirmatory Item 9.3.1-3. GE modified SSAR Figures 6.7-1, 6.2-39, 9.3-6, and 9.3-7 to include the failure modes of all pneumatically-operated valves in the CA systems. All motor-operated valves fail as-is. This is acceptable to the staff and resolved DFSER Confirmatory Item 9.3.1-3.

In the DSER (SECY-91-355), the staff stated that Valves AO F018A and B in SSAR Figure 6.7-1 were identified as "NC, FO" (i.e., normally closed and fail open) and that this was inconsistent with Section 19E.2.1.2.2.2(2)(b), which states that upon a loss of power, the operator will have to manually open these valves. The staff noted that this is also inconsistent with a design which should protect the storage bottles from inedvertent depreseurization due to a postulated line break. Confirmation that these valves do not fail in the open position was identified as DSER (SECY-91-355) Open Item 72. In a letter dated March 11, 1992, GE changed these valves to motor-operated valves that aro normally locked closed and as such they will fail an-is, cloeed. This resolved the DSER Open Itom 72. Incorporation of this information into the SSAR was identified as DFSER Confirmatory Item 9.3.1-4. In reeolving DFSER Confirmatory Item 9.3.1-2, GE changed the designation of valves F018A and B to F003A and B in SSAR Amendment 20 and changed these valves from pneumatically-operated valves to motor-operated valves which are normally closed. The staff found the modifications acceptable. DFSER Confirmatory Item 9.3.1-4 is reeolved.

The vessels, piping, and fittings of the safety-related portions of the HPIN system (except penetrations) are designed to the requirements of seismic Category I, ASME Code Section III, Clase 3, QG C, and Quality Assurance B. The SSAR states that the cross-tio valves (i.e., F012A and B) that connect the safety-related portions of the HPIN system to the non-safety-related portions are safoty-related. While two isolation valves are not provided on the non-safety-related/safety-related interface within the HPIN system, the system is deemed adequate in accordance with information GE provided in the response to RAI 430.211. One isolation valve is provided between each division of the safety-related HPIN system and the non-eafety-related portion of the system. Additionally, check valves are provided to prevent backflow of nitrogen from the accumulators through any possible break in the non-safety-related portion of the system. The inboard isolation valves are check valves and each safety-related accumulator is downstream of a separate check valve. The accumulators are sized to perform their function. The combination of isolation valves, check valves, and the sizing of the accumulators ensures that the system would fulfill its function in the event of a rupture in the nonsafety-related portion of the piping.

The piping and valves for the containment and drywell penetrations for the HPIN and IA systems are designed to the requirements of seismic Category I, ASME Code Section III, Safety Class 2, QG B, and Quality Assurance B. The isolation provisions for the ACS primary containment penetrations include two isolation valves that are both located outside the primary containment, which is not strictly in conformance with GDC 56. However, the penetrations do not extend inside the containment, and an inboard isolation valve would not be practical (as described by GE in the response to RAI 430.209). An inboard isolation valve for the ACS would be exposed to a more severe envirüriment and would not be easily accessible for 
inspection, surveillence, and maintenence. The staff approved a similar decign for the GESSAR II BWR/6 design. Therefore, the staff determined that the icolation design is acceptable. The containment ieolation valve provisions are reviowed in detail in Section $\mathbf{6 . 2 . 6}$ of this report.

Based on this information, the staff concluded that the CA system complies with Positions C.1 and C.2 of RG 1.29 regarding the ability of the system to withstand the effects of earthquakes.

The safoty-related portions of the HPIN system are located within the reactor building. The reactor building is designed to withstand and protect equipment from tomados, externally-generated missiles, flodds, and other natural phenomena. In a'ddition, the safety-related portions of the HPIN system will retain their function during a LOCA and seismic events in which non-safety-related portions may be damaged. SSAR Section 6.7.3 states that the space separating the pipe routing of Divisions I and II of nitrogen gas is sufficient to prevent a strike by a single high-energy whipping pipe, the jet force from a single broken pipe, or an internally-generated missile from preventing the other division from accomplishing its safety function. Thus, the system satisfies GDC 2 regarding protection of the system from natural phenomena.

The ADS valves will perform their safety-related functions using compressed gas that will be provided by the HPIN under most conditions. This nitrogen is supplied during normal operation from the ACS nitrogen storage tank. During design-basis events, nitrogen is supplied by accumulators charged by either the ACS, during normal operation, or by nitrogen bottles during periods when the ACS ' is unavailable. In addition, stored nitrogen can be used to replenish the accumulators or to supplement their operation. The ABWR design uses nitrogen containing particles up to 5 microns. As discussed in DSER Open Item 73 (SECY-91-355), this does not comply with the guidance of ANSI MC 11.1-1976, which recommends that nitrogen used by safety-related components contain particles no larger than 3 microns. In response to this issue, GE indicated that the filters in the HPIN system will be able to remove particles larger than 5 microns from the system, and the nitrogen supply subsystem will supply oilfree nitrogen with a moisture content of less than 2.5-ppm. The 5-micron capacity of the filters is not in compliance with the requirements of ANSI MC 11.1-1976, and GE had not provided sufficient justification for the staff to allow deviation from the 3-micron criterion. In the DFSER, the staff stated that GE should either commit to the 3-micron requirement of the standard or provide a commitment to use equipment demonstrated to be unaffected by the use of nitrogen containing particulates of the larger size. DSER Open Item 73 (SECY-91-355) was identified as DFSER Open Item 9.3.1-1. Subeequently, GE modified the SSAR to clarify the design requirements for components using this nitrogen source. GE submitted Amendment 24 to the SSAR. The staff reviowed Saction 6.7.2 of this amendment and concludes that $G E$ had clarified that any equipment using this nitrogen will be capable of operating with nitrogen containing 5-micron particulates. The staff finds the modification acceptable. DFSER Open Item 9.3.1-1 is resolved.

IE Bulletin No. 80-01 concerns the operability of the ADS pneumatic supply. The bulletin states that the ADS pneumatic supply may not be operable for all possible events because of a combination of misapplication of chock valves, a lack of testing of the accumulator system backing up each ADS valve operator, and questions about the continued operability of the pneumatic supply in a seismic ovent.

The bulletin requires licensees of GE BWR facilities which use a pneumatic operator for ADS function to:

(1) Determine if the facility has installed hard-seat check valves to isolate the ADS accumulator system from the pneumatic supply system.

Determine if periodic leak tests have been performed in the ADS accumulator systems to essure emergency pneumatic supply for the PSARrequired number and duration of valve operations.

(3) Review seismic qualifications of the ADS pneumatic supply system:

(a) from accumulator system isolation check valve to ADS valve operator,

(b) from isolation valve outside containment up to ADS accumulator check valve.

(4) Based upon determination of Items 1, 2, and 3 above, evaluate the operability of the ADS for the conditions under which it is required to be operable, including a seismic event. If operability cannot be established, adhere to appropriate tochnical specification action statement.

Operational experience has shown that check valves with hard seats may lead to excessive valve leakage, thus undermining the ability of the accumulators to provide the required pneumatic fluid to ensure that the ADS valves actuate. The ABWR design may use check valves with a hard seat. GE states that accumulator operability will be 
mowred by ensuring that aystem leakage doen not exceed $28 \mathrm{~L} / \mathrm{h}(1 \mathrm{ecth})$ per valve. SSAR Sections 6.7.2 and 6.7.4 state that periodic loakage teating will be performed to ensure that the leakage rato does not exceed $28 \mathrm{~L} / \mathrm{h}$ (1 scfh) for each valve. Section 6.7.3 states that the safety-rolated portions of the ADS syetem are seismic Category I. The section of syetem piping addreseed in the bulletin is classified as eafoty-related for the HPIN system. Thus, these sections of the system will be ablo to withetand the conditions aseociated with a seismic ovdat. Based on this information, the staff concludes that the HPIN deaign is sufficient to censure that the ADS SRV cccumulators will supply edequate nitrogen to the ADS SRVE to conoure proper valve actuation. The system deaign adequately addreseses the iscues in IE Bullotin No. 80-01.

The staff stated in the DSER (SECY-91-355) that SSAR Section 9.3.6.1.2 indicated that the non-safety-related IA system is also used as a backup to the nitrogen system when, during normal operation, the nitrogen gas supply pressure drops below a specified setpoint. The staff noted that this conflicted with GE's carlier reeponse to RAI 430.218, dated March 11, 1992, which states: "Instrument air system does not serve as a backup to HPIN system during normal operation . . . . The resolution of this discrepancy was identified as Open Itom 74. Subsequently, GE committed to revise the response to RAI 430.218 to indicate that the IA system can be used as a backup to the HPIN system when nitrogen pressure drops below the system low pressure setpoint and recovery efforts have failed. IA would be used until repairs to the HPIN system are completed. This information resolved DSER Open Item 74, however, incorporation of this information into the SSAR was identified as DFSER Confirmatory Item 9.3.1-5. GE supplied the required information in Amendment 22 which is acceptable to the staff. DFSER Confirmatory Item 9.3.1-5 is resolved.

In evaluating the IA system as a potential backup to the HPIN system, the staff stated in the DSER (SECY-91-355) that it had found that the system complies with all aspects of the ANSI MC 11.1-1976 criteria except for particulate size. The ABWR design proposes a 5-micron criterion for particulate size that is contrary to the 3-micron criterion of the ANSI standard. This was identified as DSER Open Item 75. GE had not justified this aspect of the CA system design, therefore, the IA system's compliance with the requirements of GDC 1 remained an outstanding issue. The staff reclassified DSER Open Item 75 as Open Item 9.3.1-2 in the DFSER. The staff reviewed Section 9.3.6.2 of Amendment 24 of the SSAR and concludes that GE has clarified that any equipment using this air will be capable of operating with air containing 5micron particulates. The staff finds the modification rcceptable. DFSER Open Item 9.3.1-2 is resolved.
The ataff reviowed the preoperational teeting of the CA syetom and compliance with RO 1.68.3 as addreeced in Section 14 of this report.

OE aubmitted the design deacription and the ITAAC relating to the CA systems. This was identified as DFSER Open Item 9.3.1-3. The adequacy and acceptability of the dosign deacription and the ITAAC are ovaluated in Section 14.3 of this report. On the basis of this ovaluntion, DFSER Open Item 9.3.1-3 is resolved.

The CA ayatems include all components and piping and the points of connection with other systems. The safetyrelated HPIN aystem provides a continuous nitrogen aupply to anfoty-rolated components and is classified as soismic Catogory I and QG C. The staff reviowed the applicant's design and design criteria for the safety-related CA systems to verify that they conform to the Commission's regulations in the GDC, and to applicable regulatiory guides and industry standards. As discussed in detail above, the staff concludes that the design of the CA systems is acceptable and conforms to the requirements of GDC 1, 2, and 5 for quality standards, protection from natural phenomena, and sharing of systems and components, and moets the guidelines of SRP Soction 9.3.1.

\subsubsection{Process and Post-Accident Sampling Systems}

\subsubsection{Process Sampling System}

The process sampling system (PSS) is designed to collect water and gaseous samples contained in the reactor coolant system and associated auxiliary system process streams during all normal modes of operation. Provisions are made to ensure that representative samples (except from gaseous streams) are obtained from well-mixed streams or volumes of effluent by the proper selection of sampling oquipment, sampling points, and sampling procedures. Additionally, grab samples are obtained for confirmatory analyses and to test for other chemicals. The reactor coolent sample lines penetrating the containment are each equipped with two normally closed, isolation valves which if open, automatically close on a containment isolation actuation signal.

In DSER (SECY-91-355) Open Item 98, the NRC staff determined that SSAR Section 9.3.2.1 contained insufficient information for the staff to evaluate conformance with SRP Section 9.3.2 in the following areas:

1. Under SRP Section 9.3.2, the PSS should include the capability to obtain samples from at least the following points: main condenser evacuation system off gas, SLCS tank, and sumpe inside containment and other 
location given in SRP Section 11.5 and those eppecified in the SSAR.

2. The guidelines in Poaition C.2 of RO 1.21, "Menauring, Evaluating and Reporting Redionctivity in Solid Wattes and Reloneses of Radionctive Materials in Liquid and Gasoous Bffluent from Light-Water-Cooled Nuclear Power Plants" and pocitions of RO 1.56, "Maintenance of Water Purity in Boiling Water Reactors," Revision L, should bo ueed to meet tho requirements of GDC 13, 14, 26, 63, and 64 unleas otherwise sceeptable alternatives were proposed. The SSAR did not indicate conformance with these guidelines.

3. In sccordance with ANSI N13.1-1969 provisions should be made to ensure that representative eamples are taken from gaseous proceses atreams and tanks. This needed to be addreesed in the desizn.

4. To moet 10 CFR 20.1003 in keoping radiation exposures ALARA, and the requirement of GDC 60 to control the release of radionctive materials to the environment, passive flow restrictions to limit reactor coolant lose from a rupture of the sample line should be provided.

5. To meet the requirements of GDC 1 and 2, the seismic design and quality group classification of sampling lines for the PSS should conform to the classification of the systom to which each sampling line and component is connected.

GE responded in its March 11, 1992, letter entitled "GE Responses to the Resolution of Issues Related to ABWR DSER Chapters 1, 2, 3, 4, 5, 6, 9, 10, 12, 13, 14, and 15 (SECY-91-355)." In an attachment to this letter (Reeponeo to Open Item 98), GE stated that a capability is provided to obtain samples from the main condenser ovecuation off gas, SLCS tank, sumpe inside containment, liquid radwasto system process lines, and liquid radwasto system collection and sampling tanks. They said that the guidelines of RGs 1.21 and 1.56, and ANSI N13.1-1969 will be used, except that passive flow restrictors are not provided in reactor sampling lines to control the release of radioactive materials from a ruptured sample lise. These devices become crud trape during normal operation and overly reatrict sampling flow rate during shutdowns when the reactor is at low pressure. They stated that each reactor water sampling line is provided with two remotely operable isolation valves to limit reactor water loss from a sample line rupture. GE also indicated that the soismic design and group claseification of sampling lines and their components will conform to the classification of the system into which thoy aro connected. The staff finds this response accept- able and, therefore, DSER Open Item 98 was resolved. The itaff concludes that the syetom meots the cited requirements and guidence and is, therefore, acceptable.

OE has aubmitted ITAAC and design description in Section 2.11.20 of the CDM for the PSS. This was DFSER Open Itom 9.3.2.1-1. OE provided a reviced set of design deacription and ITAAC. The adequacy and accoptability of the ABWR deaign descriptions and ITAAC are ovaluated in Section 14.3 of this report. On the basis of the above, this itom is recolved.

\subsubsection{Post-Accident Sampling System}

After the sccident at Three Milo Island Unit 2, the staff recognized the need for an improved post-accident sampling system (PASS) to determine the extent of core degradation following a severe reactor accident. Criteria for an acceptable sampling and analysis systom are apecified in 10 CFR $50.34(f)(2)$ (viii) and Item II.B.3 of NUREG-0737. According to these documents, the PASS should have the capability to obtain and quantitatively analyze reactor coolant and containment atmosphere samples without exposing any individual to radiation exceeding 5-rem to the whole body or 75-rem to the extremities (GDC 19) during and following an accident in which there is core degradation. Materials to be analyzed and quantified include certain radionuclides that are indicators of the severity of core damage (e.g., noble gases, isotopes of iodine and cesium, and nonvolatile isotopes), hydrogen in the containment atmosphere, and total dissolved gases, boron, and chloride in reactor coolant samples.

In DSER (SECY-91-355) Open Item 99, the NRC staff determinod that the PASS design as described in SSAR Section 9.3.2 was not adequate. The staff stated that $\mathrm{GE}$ noeded to address the Item II.B.3 of NUREG-0737 and indicate the PASS provisions required to satisfy each of the 11 specified criteria. The staff said that the upper limit for activity lovels in liquid samples of $1 \mathrm{Ci} / \mathrm{cm}^{3}$ in GE's PASS design (SSAR Section 9.3.2.3.1) was not justified. Itom II.B.3 of NUREG-0737, Criterion 9, and RG 1.97, "Instrumentation for Light Water-Cooled Nuclear Power Plants to Assess Plant and Environs Conditions During and Following an Accident," Revision 3, specify reactor coolant and sump gross activity sampling capability in the $1 \mu \mathrm{Ci} / \mathrm{ml}$ to $10 \mathrm{Ci} / \mathrm{ml}$ range. Delaying sampling until the PASS sample radioactivity decays to $1 \mathrm{Ci} / \mathrm{ml}$ is unacceptable because inordinate and unjustified delay in obtaining sample radioactivity results. All PASS systems in operating reactor plants are presently designed with the capability to sample liquids with up to $10 \mathrm{Ci} / \mathrm{ml}$ radionctivity. 
OB reopoendod (March 11; 1992, letter) axplaining that the ABWR PASS tha been doaigned to moet the intent of the 11 requirements lieted in NURBO-0737. OB aleo ideatified coveral exceptions to some of the requirements of NURBO-0737. The NRC theff reviowed this information and found it acceptable, mubject to rovising the SSAR to include the following deaign featurea:

1. SSAR Section 9.3.2 indicates that PASS is doaigned for upper limit for ectivity samples of $1 \mathrm{Ci} / \mathrm{cm}^{3}$. All PASs aystems in operating reactor plante are deaigned with capability of ampling liquids up to $10 \mathrm{Ci} / \mathrm{ml}$ redioestivity. OB neede to decipm PASS with the capability of ampling liquids up to $10 \mathrm{Ci} / \mathrm{ml}$. This is DFSER Open Itom 9.3.2.2-1.

2. The ABWR PASS does not have capability to obtain preecurized or unpresaurized reactor water mamples for diseolved gas analyais. GB needa to dexign PASS to be capable of obtaining reactor water sumples 24 hours after the end of power generation in order to evaluate concentrations of diseolved gaces and chlorides in the reactor coolant. The information on the amounts of diveolved hydrogen, oxygen and chlorides in the reactor coolant is an important factor in ovaluating posteccident conditions exiating in the resctor veasel. This is DFSER Open Item 9.3.2.2-2.

The etaff concluded in the DFSER that, subject to the resolution of DFSER Open Iteme 9.3.2.2-1 and 9.3.2.2-2 deacribed above, GE will have adequately described the ABWR PASS.

GE addreseed DFSER Open Item 9.3.2.2-1 in its SSAR, Section 9.3.2.3.1, which etates that the area radiation is considered safo when the sample radionctivity is about $1 \mathrm{Ci} / \mathrm{cm}^{3}$. When the sample redioactivity lovel is higher then $1 \mathrm{Ci} / \mathrm{cm}^{3}$, abnormal or emergency conditions will be used to seceses the situation. This is acceptable.

GE reeponded to DFSER Open Itom 9.3.2.2-2 in its letter of January 28, 1993. The staff also discuseed this iseve in a telephone conference with GE on January 28, 1993. GE explained that whenever core uncovering is suspected, the reactor veseel is rapidly depressurized, and thus preesurized reactor water samples are not noceseary. In a letter dated April 26, 1993, GE revised SSAR Section 9.3.2.3.1 to document this explanation. $G E$ has also included this information in the SSAR. On the basis of the actions above, DFSER Open Item 9.3.2.2-2 is resolved.

In SECY-93-087, the staff recommended that the Commission approve its position that for ovolutionary and passive ALWR of boiling water reactor design, there would be no noed for the PASS to analyze diesolved gases in eccordance with the requirements of 10 CFR S0.34(1)(2)(viii) and Itom III.B.3 of NUREG-0737. In it April 2, 1993, SRM, the Commineion approved the ctaff position to exempt the PASS for the ovolutionary and paceive ALWR of boiling water reactor deaign from andyzing diesolved gaves in accordance with the requiroments of 10 CFR 50.34(f)(2)(viii) and Itom III.B.3 of NURBO-0737.

In SECY-93-087, the atuff also recommended that the Commisaion approve the deviation from the requirements of Item II.B.3 of NUREG-0737 with regand to the requirements for ampling reactor coolent for boron coscentration and setivity measurements using tho PASS in ovolutionary and paseive ALWRs. The modified requirement would require the capability to take boron conceatration samples and activity measurements 8 hours and 24 hours, respectively, following the accident. In its April 2, 1993, SRM, the Commission approved the staff position to require the capability to take boron concentration samples and activities measurements 8 hours and 24 hours, respectively, following the accident.

The ABWR design will have PASS which moets the requirements of 10 CFR 50.34(f)(2)(viii) and Item II.B.3 of NUREG-0737 with the modifications described in SECY-93-087. The aystem will have the capability to ample and analyze for activity in the reactor coolent and containment atmosphere 24 hours following the accident. This information is needed for evaluating the conditions of the core and will be provided during the accident management phase by the containment high-range area monitor, the containment hydrogen monitor and the reactor veasel water level indicator. The need for PASS activity mearurements will arise only during the accident recovery phase and 24 hours sampling time is, therefore, adequate. PASS will also be able to determine boron concentration in the reactor coolant. It will be capable to make this determination within 8 hours following the accident. The concentration of boron is required for providing insights for accident mitigation measures. Immediately after the eccident this information will be obtained by the neutron flux monitoring instrumentation which is designed to comply with the criteria of RG 1.97 , and which has fully qualified redundant channels capable to monitor over the full power range. Boron concentration measurements will not be, therefore, required for the first 8 hours after the accident.

In order to approve an exemption from the requirements of 10 CFR 50.34(f)(2)(viii) concerning the elimination of analyses for dissolved gases and chlorides in the reactor coolant, special circumstances must exist. For the ABWR, whenever core uncovering is suspected, the reactor vessel 
is depresourized to approximataly the preneure within the wetwell and tho drywell which reaults in partial releace of the diecolved gaves. Under these conditions, preseurized amples would not be meaningful. Therefore, application of the regulation in this particular circumatance would not servo the underlying purpose of the rulo. During sccidents when the reactor veseel hes not bese depreseurized (auch as when a small amount of cladding damage has occurred), reactor coolant amples could bo obtained by the procens sampling system.

With regards to the neod for chloride analyais, determination of chloride concentrations is of a secondary importance because it is needed only for determining the likelihood of accolerated primary system corrovion which is a slow-occurring phenomenon. Chloride analyeces could be performed on the samples taken by the procens sampling systom. In this case, therefore, the intended purpoes of the rule could be achieved without the need for the PASS to have chloride sampling capabilities.

Accordingly, special circumstances required by 10 CFR 50.12(2)(ii) exist for the ABWR in that the regulation would not serve the underlying purpose of the rule in one circumstance and is not necessary in the other circumstance to achieve the underlying purpose of the rule because the intent of rule could be mot with alternate design requirements proposed by the applicant. On this besis, the staff concludes that the exemption from analyzing dissolved gases and chlorides in the reactor coolant sample is justified.

GE has submitted ITAAC and design description of the post-accident sampling system as a part of the process sampling systom in ITAAC Section 2.11.20. This was DFSER Open Item 9.3.2.2-3. GE provided a revised set of design description and ITAAC. The adequacy and scceptability of the ABWR design descriptions and ITAAC are ovaluated in Chapter 14.1 of this report. On the basis of the above, DFSER Open Item 9.3.2.2-3 is resolved.

\subsubsection{Non-Radioactive Drain System}

The staff reviewed the non-radioactive drain (NRD) system in accordance with SRP Section 9.3.3. The NRD system is acceptable if it meets the requirements of GDC 2 as it relates to safety-related portions of the system being capable of withstanding the effects of natural phenomena; GDC 4 as it relates to the capability of the system to withstand the offects of and to be compatible with the environmental conditions associated with normal operation, maintenance, testing, and postulated accidents; and GDC 60 as it relates to providing a means to control the release of radioactive materials in liquid effluent, including anticipated operational occurrences.
SSAR Section 9.3.3 diceunese the NRD, which is a noncafety-rolated aystem designed to transfor offluents that are not redionctive or potentially radionctive. Redionetive offlueats are tranaferred by the redionctive drain transfer aystem (DTS), which is discusced in SSAR Section 9.3.8 and reviownd in Soction 9.3.8 of this report.

Initially the NRD was not convidered part of the ABWR deaige in the DFSBR. Subeoquently, OB brought portions of this syetem within the ABWR design scope. The portions of the aystem within atandard plant buildings are within the ABWR decign scope, while those portions outaide these building are outside of the ABWR deaign scope. The portions of the system outside the design ccope, as well as the dectign details of the in-ecope portion of the system, will be provided by the COL applicant refereacing the ABWR design. $\mathrm{OE}$ has provided a conceptual dosign and interface requirements for the outof -ecope portion of the system as required by 10 CFR Part 52.

The NRD system consists of sump pumps, valves, and aseociated piping and instrumentation to direct waste liquids, valve and pump leakoffs, and component drains and vents to the sanitary drainage portion of the PSW system. SSAR Table 3.2-1 states that the system serves all areas of the plent within the ABWR scope except for the primary containmeat and the MST. The areas of secondary containment housing the EDGs contain no drains. The system drains by gravity and contains no active components from the point of drainage to the sumps. Valves that are relied upon to prevent beckflow can be inspected and tested and are designed to withstand the offects of a SSE. Flooding is prevented by designing the system with sufficient capacity to accommodate expectod flooding as well as placing safety-related equipment on raised peds or gratings (seo Section 3.4.1 of this report for the stafi's reviow of flood protection). Based on this information, the staff concludes that the system can withetend the effects of natural phenomena and, therefore, meots the requirements of GDC 2.

The NRD system is arranged with separate piping in each quadrant. Flooding or beckflow in one quadrant cannot affect other quadrants. This system has no connections to the radioactive drains transfor system, and drains are designed to withstand the adverse effects (including high pressure) associated with pipe and equipment failures in building compartments. Open drainage lines that are needed to maintain an air pressure differential are provided with a water seal. Based on this information, the staff concludes that the NRD system meets GDC 4 as it relates to protection of the system from environmental and dynamic effects associated with piping and components failures. ' 
The NRD syctom deeign ensures that radionctive meterial cannot be diecharged. However, efiluent is campled for rediation prior to discharge. In addition, lovel switches are provided in each sump to monitor leakage (ces Section 5.2.5 of this report for the evaluation of leakage detection mothods). OB included a COL ection item in Ameadment 29 of the SSAR requiring COL applicents reforeacing the ABWR design to develop a campling and analysis program to ensure that redionotive liquids are not inadverteatly being diecharged from the nonradionctive drain system. This was identified as DFSER COL Action Itom 9.3.3-1. Based on these deaign and operational provisions, the staff concludes that the aystom contains adequate moans to detect and control the release of radionctive matorials in the syetem offluent and moets the requirements of ODC 60 and is acceptable.

SSAR Amondment 29 includes a conceptual deaign and interfice requirements for the part of the NRD system outside of the ABWR design scope. The COL applicant reforeacing the ABWR design shall provide the details of the systom dosign from the standard plant buildings to the site discharge structure. The system collects wastewater from plant buildings, procipitation, and other aurface runoff and directs this water to dual settling basins whore auspended solids are settled and oil is collected. Teats and analyses are performed to moet the plants discharge permit. Failure of this portion of the system will not adversely affoct any safety-rolated equipment. Based on this information, the staff concludes that the out-of-scope portion of the nonradioactive drain system will also meet the requirements of GDC 2,4 , and 60 .

The staff concludes that the design criteris, conceptual design, and interface requirements provided in the SSAR will allow the applicant to design a nonradioactive drainage systom which will comply with the GDC.

GE submitted the design description, ITAAC, and the relevent interface requirements relating to the NRD syatem. The adequacy and accoptability of the deaign description, the ITAAC, and the interface requirements are ovaluated in Section 14.3 of this report.

The basis for the staff review has been conformance of the COL applicant's system design and design criteria to the Commission's regulations as set forth in the GDC. The staff concludes that the nonradioactive equipment and floor drain system provides adequate design criteria to ensure complience with GDC 2, 4, and 60 with respect to protection from natural phenomena, seismic design, eavironmental conditions, and control of potentially radioactive material, respectively. Therefore, the staff concludes that the design will comply with the guidelines of SRP 9.3.3 and is acceptable.

\subsubsection{Chemical and Volume Control Syatem}

The ABWR does not include this aystem.

\subsubsection{Standby Liquid Control Syetem}

The SLCS was reviowed in accordance with SRP Section 9.3.5 (NUREO-0800). An audit reviow of each of the areas lieted in the "Areas of Reviow" yortion of the SRP section was performed eccording to the guidelines provided in the "Reviow Procedures" portion of the SRP. Conformence with the acceptance criteria formed the basis for our ovaluation of the SLCS with reepect to the applicable regulations of 10 CFR Part 50.

Tho SLCS is a reactivity control system, which will inject sodium pentaborate solution into the reactor coolent to provide an independent means for shutting down the reactor. The SLCS can bring the reactor from rated power to cold shutdown any time during core life if the normal reactivity control system becomes inoperable. Thus, together with the control rod systom, it satisfies the requirements of GDC 26 for reactivity control systoms redundancy and capability. (Rofer to Section 4.6 of this report for a discussion of reactivity control.)

The aystem consists of a storage tank, a test tank, and two positive displacement pumps with a motor-operated injection valve at each pump discharge, a motor-operated valve at each pump suction, piping, and controls.

All of the SLCS is located within the secondary containment. The maximum temperature at which the solid material would precipitate from solution is $15^{\circ} \mathrm{C}$ $\left(59^{\circ} \mathrm{F}\right)$; the room in which the equipment containing the borated solution is located is kept at a temperature of about $38^{\circ} \mathrm{C}\left(100^{\circ} \mathrm{F}\right)$. An electrical resistance heating system maintains the solution between $24^{\circ} \mathrm{C}$ and $29^{\circ} \mathrm{C}\left(75^{\circ} \mathrm{F}\right.$ and $85^{\circ} \mathrm{F}$ ) to prevent precipitation of the sodium pentaborate solution during storage. Both the high and low liquid lovel and temperature in tho tank are alarmed in the control room.

The two pumps in parallel trains take suction on the storage tank through separate suction lines and discharge it into the reactor vessel through a common injoction line.

The liquid is piped into the reactor through the HPCF line downstream of the HPCF inboard check valve. The discharge from each pump is provided with a check valve (to provent backflow) and a croseover line. Similarly, the piping at the pump suction is also connected by a crossover line. To meet the 10 CFR $\$ 0.62$ requirements for poison injection, the system is designed for both pumps to start 
simultaneously and inject $379 \mathrm{~L} / \mathrm{m}(100 \mathrm{gpm})$ pentaborate solution.

The ABWR SLCS design includes motor-operated ac valves instead of the squib-activated (exploeive) injection valves ueed in current BWRs. On earlier BWR plants, the SLCS piping was not completely isolated from the SLCS atorage tank and it was possiblo for boron to be precent in the SLCS piping. Consequently, GE decided to provide leakproof explosive valves 80 that boron would not leak into the reactor during SLCS teeting. In the ABWR SLCS design, the boron storage tank is provided with normally cloeed isolation valves and a suction pipe keep fill system to provent the boron solution from entering the SLCS piping. Because of this design change, $O B$ concluded that the leak-tight explosive valves are not required in the ABWR pump discharge piping.

Each pump and its associated valves are powered from a redundant emergency power supply. They are arranged so that failure of a single pump or valve will not prevent adequate amounts of sodium pentaborate solution from entering the resctor vessel to effect shutdown.

The SLCS is automatically initiated after recoiving an anticipated transient without scram (ATWS) signal or can be manually actuated by either of two keylocked springreturn switches in the control room. The SLCS system meets the ATWS rule 10 CFR 50.62 because the SLCS pumps are started automatically (see Section 15.5 of this report). Originally, in the DSER SLCS was started manually, which was identified as an open item (DSER Open Item 15). With the SLCS now modi.ued to be automatically initisted, this open item is resolved.

The ATWS initiation sigmals for SLCS automatic start are high RPV pressure or low RPV water level 2, and startup range neutron monitor (SRNM) ATWS permissive for 3 minutes. The time delay of 3 minutes is provided to allow completion of electric scram which will take about 2 minutes. When the SLCS is automatically initiated to inject the boron into the reactor, the two injection valves and two storage tank discharge valves are opened, the two injection pumps are started, and both pumps run simultaneously. The CUW isolation valves are also closed automatically to prevent a loss of the sodium pentaborate from the vessel.

Turning either key-locked switch in the control panel switch to the "run" position starts an injection pump, opens one motor operated injection valve on the pump discharge, opens a pump suction valve (which is also the tank outlet valve), and closes the reactor cleanup system isolation valves to prevent loes or dilution of boron. If the instrumentation provided indicate that the solution is not entering the reactor veseel, the operator cen tum the other koy-operated switch to the "run" position to sctuate the alternate train.

The SLCS is located in a compartment outside the drywell and below the refueling floor in the seismic Catogory I secondary containment, which protects the SLCS from floods and tornadoes. All portions of the SLCS neceseary to inject sodium pentaborate solution into the renctor are seismic Category I, QG B (or QG A if they are part of the reactor coolant pressure boundary). Thus, the SLCS meets the requirements of $G D C 2$, and the guidolines of RG 1.29, "Seismic Design Classification," Position C.1.

The secondary containment protects the SLCS against externally or internally gecrenated missiles. The SLCS is separated from non soismic system components and from the offects of breaks in other high and moderato-energy piping systems (see Sections 3.5.1.2 and 3.6.1 of this report). Thus, the SLCS meets the requirements of GDC 4.

To ensure the availability of the SLCS, the system includea two parallel sets of components required to actuate the system (pumps and injection valves). The injection portion of the system can be functionally tosted by injecting demineralized water from a test tank into the reactor. To ensure the storage tank discharge valves are reliable, the staff requires $\mathrm{COL}$ to confirm that the valves will have adequate reliability requirements and that the valves be incorporated into the operational reliability assurance program (ORAP). This issue is a COL Action Item 9.3.5-1. This was previously identified as Confirmatory Item 9.3.5-1 and the Confirmatory item is resolved.

GE submitted the design description and the inspections, tests, analysis, and acceptance criteria (ITAAC) for the SLCS. This was Open Item 9.3.5-1. GE has provided a revised set of descriptions and ITAAC. The adequacy and acceptability of the ABWR design descriptions and ITAAC are evaluated in Section 14.3 of this SER. On the basis of this evaluation, this item is resolved.

The SLCS meets the acceptance criteria of SRP Section 9.3.5 and concludes that the SLCS meets the requirements of 10 CFR 50.62 and GDC 2, 4, 26, and 27 as they relate to protected against natural phenomena, system function and redundancy, and testability, and the guidelines of Position C.1. of RG 1.29, as related io seismic classification of the system, and is, therefore, acceptable. 


\subsubsection{Instrument Air System}

Because the IA system is one of the four systems that perform functions addresed in SRP Section 9.3.1, the staff roviowed this aystem as part of an integrated roviow of the ABWR CA systems. The result of this review are presented in Section 9.3.1 of this report.

\subsubsection{Service Air System}

Because the SA system is one of the four systems that performs functions addresed in SRP Section 9.3.1, the staff roviowed this system as part of an integrated reviow of the ABWR CA systems. The recults of this review are presented in Section 9.3.1 of this report.

\subsubsection{Radianctive Drain Transfer System}

The staff reviewed the DTS in eccordance with SRP Section 9.3.3. Staff acceptance is besed on meeting the requirements of GDC 2 as it relates to safety-related portions of the system being capable of withstanding the effects of natural phenomena; GDC 4 as it relates to the capability of the system to withstand the effects of the environmental conditions associated with normal operation, maintenance, testing, and postulated accidents and to be compatible with these conditions; and GDC 60 as it relates to providing a means to control the release of radioactive materials in liquid effluent, including anticipated operational occurrences.

The DTS is designated as non-safety-related (except for containment penetrations and piping in the drywell) and designed to collect radionctive or potentially radioactive effluents in equipment or floor sumps and then transfer the effluents to the LWMS for processing. The DTS system is within the scope of the ABWR design certification. The system includes floor' drains, drain lines from the equipment to the sumps, the sumps, the two sump pumps for each sump (each 100-percent capacity), sump instrumentation, and pipisg and valves from the sumps to the radwaste system.

The drains, piping, pumps, instrumentation, and valves of the DTS system are classified as non-safety-related, except for the containment (drywell) penetrations and containment isolation valves, which are safety Class 2, and designed in accordance with seismic Category I and QG B criteria, and the reactor building penetrations that meet ASME Code III, Section 3, requirements. In DSER (SECY-91-355) Open Item 76, the staff noted a discr-fis cy in the identification of these containment isolation valves between Figure 11-2 and Table 6.2-7. Figure 11-2 identified these valves as air-operated vaives, while Table 6.2-7 showed these valves as motor-operated valves. In SSAR Amendment 20,
Figure 11-2 was modified to indicate that these valves are motor-operated valves. This modification resolved DSER (SECY-91-355) Open Item 76.

All syetem piping is designed to remain intact following a seismic event. The drain system is not the only method of loak detection available for any of the areas served by the syatom and this mothod is not considered in the facility flood analysis. However, the staff indicated in DSER (SECY-91-355) Open Item 77 that the check valves that provide backflow protection for sumps in the ECCS equipment rooms should be classified as safety Class 3 and designed to seismic Category I and QG C criteria. GE committed to revise SSAR Table 3.2-1 and Figure 11-2 to include the designation of these valves as being non-safety designed to seismic Category I and QG C criteria. This information resolved DSER Open Item 77, however, incorporation of the information into the SSAR was identified as DFSER Confirmatory Item 9.3.8-1. The staff reviewed Amendment 26 of the SSAR and concludes that GE modified Section K11 of Table 3.2-1 to require that the check valves be non-safety class and meet seismic Category I and QG C requirements. GE modified Section 9.3.8.1.1 to require that the check valves be inspectable, testable, and able to withstand an SSE. The staff finds that these modifications ensure that the check valves will provide adequate protection from backflow into areas containing safety-related equipment. DFSER Confirmatory Item 9.3.8-1 is resolved.

All drywell sumps are automatically isolated on a LOCA signal to prevent the uncontrolled release of primary coolant outside primary containment.

In the DSER (SECY-91-355), the staff discussed two additional items in its review of the systems and components shown in SSAR Figures 11.2-1 and 11.2-2. First, Figure 11.2-1 showed the shower facility discharging into the high conductivity waste collector tank. In all other figures, and in the text, the shower facility discharges to the hot shower drain (HSD) receiver tank. Second, GE did not identify the points at which changes in component qualification requirements occur (e.g., for the containment isolation valves described in the preceding paragraphs). The staff designated resolution of the discrepancy in Figure 11.2-1 and the addition of component qualification requirements to the figures as Open Item 78.

SSAR Amendment 20 revised the figure to show the shower facility discharging into the HSD receiver tank. In addition, the staff reviewed Amendment 27 of the SSAR and concludes that GE clarified the description of the containment (drywell) sump isolation valves. The valves moet seismic Category I, safety Class 2, and QG B, requirements. 
The staff noted in the DSER (SECY-91-355) that a GE interface requirement in the SSAR prevents connections botween radioactive and nonradioactive syetems. Upon further evaluation, the staff determined that this requirement can be accomplished by identifying a $\mathrm{COL}$ Action Item requiring this information. This was identified as DFSER COL Action Item 9.3.8-1. OE has included this information in the SSAR. This is acceptable.

IE Bulletin No. 80-10 identified an isswe concerning the potential contamination of nonradioactive systems which could result in unmonitored, uncontrolled roleases of radiosctivity to the environment. The ABWR design employs several methods to prevent such an occurrence. The methods include ensuring that no cross-connections exist between nonradioactive and potentially radioactive systems (such as with the DTS system), by providing sampling and monitoring of both radiosctive and nonradioactive effluents before discharge, and by separating nonradioactive systems from potentially radioactive systems by barriers, along with radiation monitors to detect leakage across the barrier (such as with the RCW system). These methods are discussed in detail in various SSAR sections (e.g., 9.2.11 and 11.5) and are reviewed in various sections of this repurt (e.g., 9.2.11 and 11.5). These methods ensure that all discharges to the environment are monitored and controlled. Based on this information, the staff concludes that the ABWR design has provided sufficient desigh features and design requirements to ensure that the issues discussed in IE Bulletin No. 80-10 are resolved.

In the DSER (SECY-91-355), the staff discussed a GE interface requirement for monitoring the effluent from nonradioactive systems before discharge to ensure that no unacceptable (radioactive) effluents are discharged from the nonradioactive drain systems. This requirement for monitoring nonradioactive effluents will allow the COL applicant to design a NRD system that will satisfy the requirements of GDC 60 (the nonradioactive drain system is evaluated in Section 9.3.3 of this report). Upon further evaluation, the staff has determined that this requirement can be accomplished by establishing a COL Action Item requiring this information. This was identified as DFSER COL Action Item 9.3.8-2. GE included this information in the SSAR, which is acceptable.

The staff stated in the DSER (SECY-91-355) that SSAR Section 9.3.8.2 inaccurately referred to SSAR Section 9.3.9.1, when the interface requirements discussed in SSAR Section 9.3.12 would be the appropriate reference. The staff stated that GE should revise the first design basis discussed in SSAR Section 9.3.8.1 to clearly indicate, consistent with the staff's dialogue hwith GE, that only portions of the drain system are considered safety- related. GE corrected the SSAR reference and revised SSAR Section 9.3.8.1, which resolved DSER Open Itom 79. Incorporation of the revisions in the SSAR was identified as DFSER Confirmatory Item 9.3.8-2. The staff roviowed Amendment 29 of the SSAR and determined that the required corrections were made. The staff determined that the classifications in Section K1 of Table 3.2-1 clarify which parts of the system are safety-related and which are not. The staff has determined that these classifications will ensure that the check valves will provide adequate backflow protection. Therefore, the staff finds these modifications acceptable. Therefore, DFSER Confirmatory Item 9.3.8-2 is resolved.

GE rubmitted the design description and the ITAAC relating to the DTS systom. This was identified in the DFSER as Open Item 9.3.8-1. GE provided a revised set of design description and ITAAC. The adequacy and acceptability of the design description and the ITAAC are evaluated in Section 14.3 of this report. On the basis of this ovaluation, DFSER Open Item 9.3.8-1 is resolved.

The staff concludes that the design of the RD system is acceptable and conforms to the requirements of GDC 2, 4, and 60 for protection against natural phenomena, environmental conditions, missiles, and the release of radionctivity to the environment. Therefore, the staff finds that the design complies with guidelines of SRP Section 9.3.3, and is acceptable.

\subsubsection{Hydrogen Water Chemistry System}

Hydrogen water chemistry (HWC) reduces intergranular stress corrosion cracking (IGSCC) by using feedwater additions of hydrogen to decrease the oxidizing power of water and reduce its aggressiveness toward plant material. To suppress IGSCC, reactor coolant conductivity must be maintained below 0.3 micro-Siemens per centimeter and sufficient hydrogen must be added to the feedwater to reduce the electro-chemical potential below -0.23 volts (Standard Hydrogen Electrode). These conditions are specified in EPRI Report NP-4947-SR, "BWR Hydrogen Water Chemistry Guidelines: 1987 Revision," October 1988. SSAR Section 9.3.9 references this report and commits to use its guidelines for design and operation of the HWC system.

Section 9.3.9 of the SSAR also addresses the means of storing and handling of hydrogen. These operations will be performed in accordance with the recommendations of EPRI Report NP-5283-SR-A, "Guidelines for Permanent BWR Hydrogen Water Chemistry Installations."

The staff finds that the EPRI guidelines presented in these reports describe a satisfactory means for storing and 
handling hydrogen for the ABWR, and the $G E$ commitments in the SSAR to the EPRI guidelines are thus scceptable. The staff concludes that DSER (SECY-91-355) Open Item 100 is resolved.

\section{Certified Desion Material}

GE has proposed ITAAC and included Tier 1 design description of the hydrogen water chemietry system in Section 2.11.17 of the CDM. This was identified as DFSER Open Itom 9.3.9-1. The adequacy and acceptability of GE's design descriptions and ITAAC are evaluated in Section 14.3 of this report. On the basis of this ovaluation, DFSER Open Item 9.3.9-1 is resolved.

\subsubsection{Oxygen Injection System}

The oxygen injection system is designed to add sufficient oxygen (20 to $50 \mathrm{ppb}$ ) to suppress erosion/corrosion, general corrosion, and the release of corrosion products in the condensate and feedwater systems. The requirements for design, operation, maintenance, surveillance, and testing of the oxygen storage facility are specified in EPRI Report NP-5283-SR-A. The staff finds that the EPRI guidelines describe a satisfactory means for storing and handling oxygen for the ABWR, and are thus acceptable. Section 9.3.10 of the SSAR references this report and commits to use these guidelines. The staff concludes that DSER (SECY-91-355) Open Item 101 is resolved.

\section{Certified Desion Material}

GE had not proposed ITAAC nor a Tier 1 design description of the oxygen injection system in Section 2.11.7 of the CDM. This was DFSER Open Item 9.3.10-1.

The adequacy and acceptability of GE's design descriptions and ITAAC are evaluated in Section 14.3 of this report. On the basis of this evaluation, DFSER Open Item 9.3.10-1 is resolved.

\subsubsection{Zinc Injection System}

The control of build-up of radiation in reactor systems has been of concern in BWR plants. GE found that operating BWR plants having 5 to $15 \mathrm{ppb}$ of soluble zinc in the reactor water had lower piping dose rates than plants that had only trace amounts of zinc.

Laboratory tests confirmed that $\mathrm{CO}-60$ deposition is greatly reduced in both normal and hydrogen water chemistry with the presence of soluble zinc. Zinc injection into the feedwater system to provide reactor water concentrations of 10 to $15 \mathrm{ppb}$ zinc during initial conditioning and 5 to 10 ppb over the fuel cycle will help keep radiation levels as low as possible; thereby, reducing personnel exposure especially during outages.

Based on the foregoing, the staff concludes that Section 9.3.11 of the ABWR SSAR is acceptable.

\section{Certified Desien Material}

At the time of the DFSER, GE had not proposed ITAAC nor a Tier 1 design description of the zinc injection system in Section 2.11.18 of the CDM. This was DFSER Open Item 9.3.11-1. GE has provided a final version of the CDM and it has been evaluated in Chapter 14.3 of this report. Based on this evaluation, DFSER Open Item 9.3.11-1 is resolved.

\subsection{Heating, Ventilation, and Air Conditioning Systems}

\section{Certified Desien Material}

GE submitted in Sections 2.15.5 of the CDM Tier 1 design description and the ITAAC for HVAC systems which were under staff review. The results of the staff's review were to be provided in the FSER. This was DFSER Open Item 9.4-1, GE provided a revised set of design description and ITAAC on August 31, 1993. The adequacy and acceptability of the design description and the ITAAC are evaluated in Section 14.3 of this report. On the basis of this evaluation, this open item is resolved.

\subsubsection{Control Building Heating, Ventilating, and Air Conditioning System}

The staff reviewed the control building HVAC systems in accordance with SRP Section 9.4.1. The system consists of two separate HVAC systems: one for the MCR habitability area and another for the control building safety-related equipment area. The staff evaluated these systems as described in Sections 9.4.1.1 and 9.4.1.2, respectively, of this report, and are evaluated for compliance with the SRP acceptance criteria as discussed below.

\subsubsection{Control Room Habitability Area Heating, Ventilating, and Air Conditioning System (CRHA HVACS)}

The CRHA HVAC system serves the main control area envelope (MCAE) containing the control room proper (including the critical document file), computer room, cortrol equipment room, upper and lower corridors, office and chart room, instrument repair room, and sleeping area, as described in SSAR Section 6.4.2.1. The MCAE is maintained at a minimum positive pressure of $3.2 \mathrm{~mm}$ 
(1/8 in.) of water gauge relative to the surrounding spaces with outside makeup air of not more than $360 \mathrm{~m}^{3} / \mathrm{hr}$ (212 cfm) $760 \mathrm{~mm} \mathrm{Hg}\left(30 \mathrm{in}\right.$.), $0^{\circ} \mathrm{C}\left(32^{\circ} \mathrm{F}\right)$. The kitchen and lunch rooms, men's lavatory, and women's lavatory and lounge facilities are in the Service Building.

The system consists of two fully redundent trains of equipment, including ductwork, air handling units (AHUs), control dampers, fire zone dampers, and aupply and exhaust fans. Each AHU consist of a bag-type filter, a chilledwater cooling coil, an electric heating coil, and a humidifier as described in SSAR Section 9.4.1.1.3. Each train also incorporates an emergency filtration unit (EFU) which is an ESF. The EFU is comprised of an electric heating coil, pro-filter, pro-high officiency particulate air (HEPA) filter, charcoal adsorber (50 mm (2 in.) deep, as a minimum), post-HEPA filter, and two circulating fans. Independent and separate discharge to and return from the MCAE is provided to each EFU. Chilled water to the cooling coils is supplied by the HVAC emergency cooling water (HECW) system. The CRHA HVAC system is designed to maintain a controlled temperature environment under normal and accidept conditions, and provides for detection and removal of smoke and filtration of radionctive material. The range of design conditions for the MCAE is $21^{\circ} \mathrm{C}$ through $26^{\circ} \mathrm{C}\left(70^{\circ} \mathrm{F}-79^{\circ} \mathrm{F}\right)$ and 10 percent to 60 percent relative humidity. SSAR Section 6.4.4.2 discusses the protection from exterior smoke, toxic chemicals, and chlorine releases.

Normally, one AHU, one supply CRHA HVAC system fan, and one exhaust fan are in operation. During normal operation, the CRHA HVAC system performs HVAC functions and pressurizes the MCAE using a combination of filtered outdoor air and recirculated indoor air. The combined air stream is passed through an AHU. Two parallel, 100-percent capacity supply fans (one standby) draw air from the instrument panel areas, corridors, $\mathbf{M C R}$, computer room, office areas, and the switch and tag room, and return it to the AHU. The exhaust fan starts automatically when the supply fan starts. Two parallel, 100-percent exhaust fans (one standby), controlled by a pressure controller, draw air from the areas and exhaust it to the environment to maintain positive pressure of $3.2 \mathrm{~mm}$ (1/8 in.) of water gauge relative to the surrounding spaces. The pressure controller is located in the instrument panel area of the MCR. The supply and return ducts have manual balancing dampers that are locked in place after the system is balanced. The supply and retum ducts also have modulating dampers to maintain the required positive pressure. Sufficient air is provided to pressurize the control room equipment HVAC envelope. As described in SSAR Section 6.4.2.1, the control room area envelope is maintained at a positive pressure of $3.2 \mathrm{~mm}$ through $6.4 \mathrm{~mm}$ (1/8 in. through $1 / 4 \mathrm{in}$.) water gauge with respect to the surrounding spaces at all times. The CRHA HVAC system flow diagram is shown in SSAR Figure 9.4-1, Sheots 1 and 2, flow rates are given in SSAR Table 9.4-3, and component descriptions are given in SSAR Tables 9.4-4 and 9.4-4a through 9.4-4c.

GE aubmitted a draft of a revised SSAR Section 9.4.1.1.4 which addresses IE Bulletin 80-03 compliance by stating that the charcoal tray and screen will be of all welded construction to preclude the potential loss of charcoal from adsorber cells per this bulletin. Therefore, the emergency air filtration system of the CRHA HVAC system precludes the potential loss of charcoal from adsorber cells as reflected in SSAR Amendment 34.

The CRHA HVAC system and components are located in a soismic Category I control building that is protected against tornado missiles and floods and are operable during LOOP. All essential control room HVAC equipment, including ductwork, is of seismic Category I design. SSAR Table 3.2-1 states that those nonessential portions of the system which, by their failure during a seismic event can affect safety-related portions, of the system are designed in accordance with Position C.2 of RG 1.29. Outside air intake valves are protected against freezing and other environmental conditions, and tornado missile barriers protect the intake vents. The CRHA HVAC system meets the requirements of GDC 2 by complying with the provisions of Position C.1 of RG 1.29 for the essential portions, and Position C.2 for the applicable nonessential portions.

SSAR Figures 1.2-15 and 1.2-21 show that the redundant CRHA HVAC system trains are located in separate rooms. In SSAR Amendment 7, GE stated that the walls, floor, and ceiling of the room that houses each safety-relatod system act us missile barriers or shields from missiles generated outside the room. In SSAR Amendment 17, GE stated that non-safety-related components are arranged in such \& way that any missile-generating component is in a separate room away from safety-related components. For these reasons, the staff concludes that the redundant CRHA HVAC system trains are protected against internallygenerated missiles. The CRHA HVAC system complies with GDC 4 with respect to protection of the system against environmental and dynamic effects, as discussed in Section 3.6.1 of this report regarding the effect of postulatod piping failures outside the containment on the system. Therefore, the first part of DSER Open Item 60 which deals with staff's concern relating to compliance of this system with the requirements of GDC 4, is resolved.

Smoke detectors in the MCAE will actuate an alarm on detection of smoke when smoke is detected in a division of the CRHA HVAC system, MCR operators will manually 
switch the appropriate divisional HVAC system to a smoke removal mode, in which the exhaust fan is stopped, the recirculation damper is clooed, and the exhaust bypass damper is opened. The MCR operators can exhaust 100 percent of the conditioned air to the atmosphere by manually activating a switch, which closes rotum dampers and opens exhaust dampers. In SSAR Amendment 32, GE stated that the CRHA HVAC system fire dampers are equipped with fusible links and aro capable of closing under anticipated air flow conditions after the fusible link melts. Tests will be performed to verify these conditions at a test facility.

In the DSER (SECY-91-235), the staff stated the system design meets the control room habitability requirements of TMI Action Item III.D.3.4 of NUREG-0737 with regard to smoke removal, contingent upon GE submitting revised P\&IDs showing smoke detection capability (second part of DSER Open Item 60). The staff stated the above contingency, since the earlier P\&IDs for the control room and the control equipment room did not include smoke detectors at the sir intakes. However, GE committed to place smoke detectors at the air intakes which will cause the control room HVAC system to shift to the recirculation mode, if smoke is detected in the air supply. Since this commitment resolved the second part of DSER Open Item 60, the staff classified the SSAR commitment as DFSER Confirmatory Item 9.4.1.1-1. SSAR amendments through Amendment 32 included revised P\&IDs which show the smoke detectors at the air intakes. Therefore, this confirmatory item is resolved.

The evaluation of requirements for protection against hazardous chemical releases will be site specific as stated in Section 6.4 of this report. Therefore, the staff stated in the DFSER that COL applicants should provide information regarding compliance with RG 1.78, "Assumptions for Evaluating the Habitability of a Nuclear Power Plant Control Room During a Postulated Hazardous Chemical Release," and RG 1.95, "Protoction of Nuclear Power Plant Control Room Operators Against an Accidental Chlorine Release," if the potential for hazardous chemical, including chlorine, releuse exists at their sites. The staff further stated in the DFSER that COL applicants should identify plant design features that will automatically isolate the control room from the outside when necessary, and thus protect the control room operators from toxic substances in the plant vicinity. The need for providing the above information was identified as DFSER COL Action Item 9.4.1.1-1. By SSAR amendments up to and including Amendment 32, GE identified $\mathrm{COL}$ license information (Section 6.4.7.3) which states that the design acceptance is based upon meeting the guidelines of the subject guides.
A four-channel radiation monitoring system is provided in the outside air intake ducts. A radiation monitor is provided in the MCR to monitor MCR area radiation levels. These monitors alarm in the MCR upon detection of high radiation levels. On receiving a high radiation signal, the redundant normal outside air intake dampers and oxhaust dampers close, the emergency outside makeup air intake dampers open, and only the corresponding EFU of the operating division starts automatically. Also, the emergency recirculation mode can be started manually. In the emergency recirculation mode, the makeup air and part of the roturn air pass through the ESF-grade filter train, which filters the radionctive particles and iodine to keep the control room operator exposures below the GDC 19 limit of 5 rem whole body or its equivalent for the duration of a design-basis accident (DBA). The control room equipment HVAC system thus meets the requirements of GDC 19 regarding protection of the control room. For further information on system compliance with GDC 19 limits, see Section 6.4 of this report. Radioactivity monitors at the inlets allow operator selection of inlet vent manually. Connections are provided for testing the HEPA and charcoal filters pressure drops and radioiodine removal efficiency. A differential pressure switch across the emergency filtration system alarms on high pressure. A flow switch in the emergency filtration fan discharge duct initiates an alarm if the fan fails and automatically starts the standby system.

After the May 5, 1992 meeting between the NRC and GE, in a telephone conversation on May 12, 1992, GE committed to provide SSAR appendices identifying the compliance of (1) the ESF-grade filter train in the system with RG 1.52 guidelines and (2) control room filter train instrumentation with the minimum instrumentation requirements listed in SRP Table 6.5.1-1. These appendices were to be similar to those provided for the SGTS. GE provided the information in the SSAR, Appendices 9C and 9D. The staff reviewed GE's justifications for compliance with RG 1.52 and NUREG-0800, Standard Review Plan, Table 6.5.1-1, "Minimum Instrumentation, Readout, Recording and Alarm, Provisions for ESF Atmosphere Cleanup Systems, " for the CRHA HVAC system and found that the proposed RG 1.52 conformance and SRP Table 6.5.1-1 instrumentation and controls in the MCR, as well as selected local panels, meet the intent of the above guidance. While the staff would prefer that GE provide all of the local instrumentation and controls described in the above guidance for operational efficiency and convenience, the staff finds that the CRHA HVAC system instrumentations and controls meet the intent of the above guidance based on the following:

1. The instrumentation and controls (i.e., readout, recordings, and alarms) provisions for the related 
parameters (i.e., pressure drop, temperature, humidity, flow) are available and would be mado acceasible in the MCR.

2. The COL applicant will prepare plant-epecific procedures to respond to the instrumentation and controls.

3. The filtration train fully complies with the regulatory position of RG 1.52.

4. The acceptance, pre-operational, and surveillance testing meet the intent of ASME Codes N509 and N510.

5. GE revised SSAR Sections 9.4.1.1.4 and 9.1.1.1.5, stating that the unfiltered in-leakage is controlled by the use of welded ducts, except galvanized steel is used for outdoor air intake and exhaust ducts, and unfiltered inleakage testing will be performed periodically on all system ductwork outside MCAE, in accordance with ASME Code N510.

6. CRHA HVAC system dose analysis is bounded by the minimum outside air intake flow, and any higher flow will be filtered through the EFUs.

Based on the above, the staff has determined that the CRHA HVAC system's EFUs will havd a creditable removal efficiency of 95 percent for all forms of radioiodine.

In DFSER Open Item 9.4.1.1-1, the staff stated that the SSAR did not specify heaters to maintain proper humidity (less than 70 percent) to ensure proper operation of the charcoal adsorbers. GE revised SSAR Section 9.4.1.1 and Table 9.4-4 to include electric beaters in the ESF filter trains. Therefore, this item is resolved.

Based on the above, the staff concludes that the control room habitability area HVAC system complies with GDC 2, 4, 19, and 60 as they relate to protection against natural phenomena, maintaining proper environmental limits for equipment operation, and protecting those who access the control room under accidental radionctive releases. This system also complies with the guidelines of RGs 1.29 and 1.52 relating to the system seismic classification and system capability to clean the control room atmosphere during emergency operation, and thereby meets the applicable acceptance criteria of SRP Section 9.4.1. Therefore, the staff concludes that the system is acceptable.

\subsubsection{Control Building Safety-Related Equipment Aree (CBSREA) HVAC System}

The ABWR design includes three similar, but independent, HVAC systems to service the safoty-rolated electrical, HVAC, and mechanical equipment (including the refrigerator, pump, and heat exchanger equipment) of Divisions A, B, and C of the CBSREA HVAC system. Safoty-related areas serviced by each system includo a safety-related battery room(8), HECW refrigerator room, reactor building cooling water pump and heat exchanger room, HVAC equipment room, and safety-related electrical equipment room. The systems differ with regard to safoty-related areas serviced, in that the system serving Division B includes two safety-related battery rooms, while the syetems serving Divisions $A$ and $C$ include one safetyrelated battery room each. Each divisional system serves non-safety-related passages. In addition, Division A serves a non-essential battery room, and a non-essential electrical equipment room, and Division C serves the non-safetyrelated MG sets. Each divisional system draws outside air through a normal air supply unit, and system exhaust fans discharge to the atmosphere. Chilled water to the cooling coil is supplied by the emergency cooling water (HECW) system. Each supply unit consists of a bag filter and cooling coil. Each divisional system contains an air supply unit with two 100-percent capacity supply fans and exhaust fans. The supply and exhaust fans of each system (Divisions A, B, and C) are powered from the correeponding Class 1E Electrical Divisions I, II, or III. One of the two supply fans is started manually for normal operation. When the ACU supply fan is started, one of the two exhaust fans start automatically. The exhaust fans can be started manually to exhaust the air to the atmosphere as needed such as to remove hydrogen and smoke.

In normal operating mode, one ACU, one supply fan, and one exhaust fan in each division operate. The HVAC system includes fire dampers for the supply and exhaust duct penetrations of firewalls for Division IV safety-related electrical equipment room and battery room, served by Division B of CBSREA HVAC system. The smoke removal mode is manually initiatod by closing the recirculation damper, closing the exhaust fan, and opening the exhaust fan bypass damper to allow outside air purging of the affected area. The smoke removal mode of the HVAC systems is discussed in CBSREA Section 9.5.1 of this report. SSAR Amendment 32 stated that the CBSREA HVAC system fire dampers separating safety-related electrical equipment and battery Divisions II and IV rooms use fusible links in HVAC ductwork which will close under anticipated air flow conditions after the fusible link melts, and that tests will be performed to verify these conditions at a test facility. 
The HVAC subeystems and components are located in a seismic Catogory I structure that is tornedo missiloprotected and flood-protected. The cesential components of eaph systom are of soismic Catogory I design. The lowpressure safoty-grado ESF ductwork is designed to withstand the maximum positive preacure to which it can be subjected under normal or abnormal conditions. The outdoor air intake and exhaust are conducted of galvanized steol, and all other ducts are of wolded black steol construction. Tornado missile barriers protect the air intake and exhaust vents. Applicable noneseential portions of the systom which, by their failure during a soismic ovent can offect safoty-related portions, are designed in accordance with Position C.2 of RO 1.29, and as atated in the SSAR Table 3.2-1. The oystems moet the requirements of GDC 2 regarding protection from natural phenomena by complying with the provisions of Positions C.1 of RG 1.29 for the eseontial portions and Position C.2 for the applicable nonessential portions.

Each system is designed to maintain hydrogen concentration below 2 percent by volume in the battery rooms, and temperature controllers regulate heating and cooling to maintain conditions within pro-set limits. SSAR Figures 1.2-15 and 1.2-21 show that the divisional CBSREA HVAC systems are located in separate rooms. SSAR Amendment 7 stated that the walls, floor, and ceiling of the room that houses each safety-related system act as missile barriers or shields from missiles generated outside the room. SSAR Amendment 17 stated that nonsafety-related components are arranged in such a way that any missile-generating component is in a separate room away from safety-related components. For these reasons, the staff concludes that the redundant essential electrical equipment HVAC systems aro protected against internallygenerated missiles. The CBSREA HVAC systems comply with GDC 4 with respect to protection of the system against environmental and dynamic effects (seo SeCtion 3.6.1 of this report for an evaluation of the effect of postulated piping failures outside the containment on the system).

In DSER (SECY-91-235) Open Item 61, the staff stated that the RCW pump rooms are located in the secondary containment and that the design of the HVAC systom as constituted did not account for the potential for radioactivity contamination following an accident. The staff reexamined this issue and finds that SSAR Figure 1.2-15 shows that the subject rooms serviced by the HVAC system are in the control building and are unlikely to be contaminated to the extent that the exhaust from the subject areas has to be filtered. The staff further discusses this in Section 11.5 of this report and concludes that no munitoring of this exhaust is required. Therefore, this resolved DSER Open Item 61.
The rooms served by this system are not occupied under sccident conditions and the syetom is not reviowed againat the requirements of GDC 19 regarding protection of the control room and the provisions of RG 1.78 and RG 1.95.

The staff concludes that the system complies with GDC 2 and 4 as they relate to protection against natural phenomena and maintaining proper environmental limits for equipment operation, and with the guidelines of RO 1.29 relating to the system soismic classification, and thereby meets the acceptance criteria of SRP Section 9.4.1. Therefore, the staff concludes that the CBSRBA HVAC systom is design accoptable.

\subsubsection{Spent Fuel Pool Area Ventilation System}

The spent fuel pool area ventilation system is part of the reactor building ventilation system and is ovaluated in Section 9.4.5 of this report.

\subsubsection{Auxiliary Area Ventilation System}

The auxiliary area ventilation system is part of the reactor building ventilation system and is ovaluated in Section 9.4.5 of this report.

\subsubsection{Turbine Island HVAC System}

The staff reviowed the turbine island ventilation system in accordance with SRP Section 9.4.4. The system consists of the turbine building (TB) HVAC system and the electrical building (EB) HVAC system. The TB HVAC and EB HVAC systems supply filtered and tompered air to all turbine island spaces during normal, plant startup, and shutdown operations. The TB HVAC and EB HVAC systems do not serve or support any safety function and have no safety design basis. The system description, equipment list, and figures are given in SSAR Section 9.4.4, Tables 9.4-5 and 9.4-5a through 9.4-5c, and Figures 9.4-2a through 2c. Failure of the system does not compromise the operation of essential systems, the ability to shut down the reactor, or result in unacceptable releases of radioactivity. Both the TB HVAC and EB HVAC systems comply with GDC 2 because the applicable nonessential portions of the systems are designed in accordance with Position C.2 of RG 1.29 as stated in SSAR Table 3.2-1. The requirements of GDC 60 for control of releases of radioactive materials to the environment do not apply because the ventilation exhausts of these systems do not include HEPA filters or charcoal adsorbers. The TBVS exhausts, including turbine building compartment exhaust and lube oil areas exhaust (SSAR Figures 9.4-2a through and 2c), will be monitored at the plant vent. The EB HVAC system will exhaust directly to the atmosphere (for additional information on 
offluent monitoring, see Section 11.5 of this report). The atuff coacludes that the turbino ialand HVAC syetem deaign complies with the applicablo GDC referenced in SRP Section 9.4.4 and consequently with the nubject SRP criteria and is, therefore, acceptablo.

\subsubsection{Reactor Building Ventilation System}

The reactor building ventilation system (RBVS) consiets of oight subsystems: (1) reactor building (RB) secondary containment HVAC system, (2) RB safety-related equipment HVAC systom, (3) RB non-eafoty-related equipment HVAC system, (4) RB safety-rolated electrical equipment HVAC system, (5) RB sufoty-related dievel generator HVAC systom, (6) RB primary contrinment supply exheust system, (7) RB main steam tunnel (MST) HVAC system, and (8) RB reactor internal pump (RIP) power supply panel adjustable speed drive (ASD) HVAC system.

The RBVS cools all areas in the reactor building serviced by these subsystems except the area serviced by the RB primary containment supply/exhaust system (cooling for this area is evaluated in Section 9.4.9 of this report). Certain subsystems including the RB secondary containment HVAC system, RB safety-related electrical equipment HVAC system, RB safety-related diesel generator HVAC system, and the primary containment supply/exhaust system have outside air intakes and exhaust air from the areas serviced by these subsystems. The HVAC systems are reviewed in accordance with SRP Section 9.4.5, as applicable, for ESF ventilation systems. The staff reviewed the RB safety-related equipment HVAC system in accordance with SRP Section 9.4.2, the subject HVAC system also services the spent fuel pool area.

\subsubsection{RB Secondary Containment HVAC System}

In the DSER (SECY-91-235), the staff included only a partial evaluation of the system, stating that the evaluation would be completed on receipt of the system P\&IDs and interface descriptions. The staff designated this lack of information as Open Item 62 in the DSER (SECY-91-235). SSAR amendments through Amendment 34 included the above information in revised SSAR Section 9.4.5.1, Figure 9.4-3, and Tables 9.4-3, 9.4-4f through 9.4-4h, 11.5-1, and 11.5-2. Therefore, the DSER Open Item 62 is resolved based on the staff's evaluation given below. SSAR Section 9.5.1.1.6 describes the smoke control mode of the secondary containment HVAC system. In Section 9.5.1.4.4 of this report, the staff evaluated the HVAC system design for smoke control in the secondary containment.
The RB secondary containment HVAC system provides the HVAC needs of the secondary containment area of the reactor building. The system provides the HVAC needs of the safety-rolated equipment areas in the secondary containment, during normal operation. The system also provides the HVAC needs of the non-eafety-related equipment areas in the secondary containment in conjunction with the RB safety-related equipment HVAC syetem during normal operation. The system is a oncothrough type. Outdoor air is filtered (bag-type filter), tompered, and dolivered to the secondary containment areas. The exhaust air from all the areas serviced by the system is filtered (bag-typo) and discharged to the monitored plant vent. The supply system consists of a bag-type filter, a cooling/heating coil, and three 50-percent aupply fans, two of which operate normally (one is standby). The exhaust system also has three fans (one standby), each of which is provided with a bag-type filter. The system includes radiation monitors for air exhaust through the refueling floor area ducting, and the common secondary containment area ducting which provide input signals to process radiation monitoring system. Isolation dampers automatically isolate the system and the SGTS is initiated on (1) secondary containment exhaust high radiation signal, (2) refueling floor tigh radiation signal, (3) LOCA signal, or (4) loss of secondary containment HVAC supply/exhaust fans signal (for SGTS evaluation, see Section 6.5.1 of this report). The secondary containment is maintained at a negative pressure with respect to the surrounding spaces during normal operation by the system and during accident conditions by the safetyrelated SGTS. The supply fans will operate only when the exhaust fans are operating. Fire dampers with fusible links in the HVAC duct work will close under anticipated air flow conditions after the fusible links melt. The system is started manually.

The secondary containment HVAC contains no equipment noeded to maintain the integrity of the reactor coolant pressure boundary or to ensure the safe shutdown of the reactor. The interface of the secondary containment HVAC system with the SGTS, which provides radioactivity filtering capability for containment releases, does include components (e.g., isolation devices and monitors) whose function is required to maintain releases below acceptable levels.

The system is located in the seismic Category I reactor building, which protects against flood and tornado missiles. Although the system is non-safety-related, SSAR Table 3.2-1 states that the radiation monitors and the inboard and outboard dampers for isolating the system under situations identified above are designed to seismic Category I requirements sand that the applicable nonessential portions are designed in accordance with 
Position C.2 of RG 1.29. Thus, the aystem complies with GDC 2 by meeting Position C.1 of RG 1.29 for the ancential portions and Ponition C.2 for the nonemential portions. The inboard and outboard isolation dampers are pneumatically opernted and thoy fril to the cloced poxition in the event of loses of pacumatic preacure or loes of power to the scturating solenoids. The safety-rolated componeats are protocted against damage from internally-generated missiles by soparation of redurdant equipmeat and aro aleo protected against piping failures. Thus,' the cesential components of the system comply with GDC 4 regarding protection from the environment and dynamic offects sseociated with equipment failures. GDC 17 is not applicable to the system because the syetem is not safoty relatod. However, because the secondary containment HVAC system air intake is filtered, the system moots GDC 17 requirements as it rolates to protection of the electrical components against eccumulation of dust and perticulates.

The system complies with GDC 60 regarding the control of releases of redioective materials to the environment because under certain situations, the system is automatically isolated to provent significant radionctivity release to the environment. When isolated, the system discharges to the SGTS, which will filter any release to the environment.

Based on the above, the staff concludes that the system design complies with applicable GDC referenced in SRP Section 9.4.5 and consequently with the subject SRP acceptance criteria, and, therefore, is acceptable.

\subsubsection{RB Safety-Related Equipment HVAC System}

The system cools the following safety-related equipment areas in the reactor building during accident conditions: the RHR pump rooms, HPCF pump rooms, RCIC pump room, FCS equipment rooms, SGTS equipment rooms, and the CAMS equipment rooms. As stated in Section 9.4.5.1 of this report, the RB secondary equipment HVAC system cools the above areas under normal conditions. Increased and reliable cooling of these rooms will be required during accident conditions when the equipment in the rooms operate. The system is designed to provide a controlled temperature environment in the rooms in accordance with equipment temperature qualification. Separate safetyrelated fan coil units (FCUs), one for each room serve the 12 rooms that house the redundant components of the five systems mentioned above and the RCIC pump room. The pump room FCUs are automatically initiated when RHR pumps, HPCF pumps, and RCIC turbines are started. The safety-related FCUs in other rooms are automatically initiated upon isolation of the RB secondary containment
HVAC system. The FCS room FCUs aro initiated upon receiving a manual FCS start signal.

All components of the RB safety-rolated equipment HVAC syetem are designed to BSF requirements and are affetyrelated. The units aro open-ended and continuoualy recirculate cooling air within the spece served. Divisional RCW is the cooling modium for the associated cooling coils. Space temperatures in the pump rooms are maintained lese then $66^{\circ} \mathrm{C}\left(150^{\circ} \mathrm{F}\right)$ during pump operation. Spece temperatures in all rooms, including the pump rooms are normally maintained less than $40^{\circ} \mathrm{C}$ (104 $\left.{ }^{\circ} \mathrm{F}\right)$. The units will receive power from the same divisional power source as that for the equipment being served. The design of the FCUs includes both remote and locel menual override of the system controls. The system deacription, figure, and tables are listed in SSAR Section 9.4.5.2, Figure 9.4-3, and Table 9.4-4e, respectively.

All components of the RB safety-related equipment HVAC system (including associated cables) serving safoty-relatod functions are located in seismic Category I structures that protect against flood and tormado missiles. The components of this safety-related system are designed to seismic Category I requirements as follows from SSAR Table 3.2-1. Thus, the system meets Position C.1 of RG 1.29, and consequently complies with GDC 2 regarding protection from natural phenomena.

In the DSER (SECY-91-235), the staff included only a partial evaluation of the system for compliance with GDC 4 as it relates to protection of the system against internally-generated missiles and piping failures. The staff stated that it would complete the evaluation upon receiving system P\&IDs and clarifying information on system compliance with GDC 4. The DSER (SECY-91-235) designated the above lack of information as Open Item 63. SSAR amendments through Amendment 34 included the required information, which the staff reviewed. The staff finds that the design satisfies the requirements of GDC 4 for protection against the effects of piping failures and internally-generated missiles by compartmentalization and separation. (For additional information, see Section 3.6.1 of this report, SSAR Section 3.6.4, and SSAR Table 3.6-2.) This resolved DSER Open Item 63.

This internally recirculating cooling system has no supply air from the outside or exhaust air from the equipment areas to the outside when the system operates. The system operates only after the secondary containment HVAC system is isolated. The normal RB secondary containment HVAC system air intake is filtered. Therefore, the system meets GDC 17 as it relates to protection of the electrical components of the system against accumulation of dust and particulates. The system does not include any HFPA 
filters or charcoul advorbers. Therefore, ODC 60, which pertains to the control of radionctive material released to the outside, does not apply to the system. Poxition C.4 of RG 1.13, (en ecceptance criterion for SRP Section 9.4.2), which doals with the ventilation and filtration basis for the relenes of redionctive materials to the environment from the epeat fuel storage facility, does not spply to that part of the enential equipment HVAC syetem that services the fuel pool cooling equipment rooms. The sOTS that rerves the fuel pool area during a DBA, including tho fuel-handling axcident, meets Poxition C.4 of RO 1.13 and, therefore, complies with GDC 61. For further information, 800 Section 6.5.1 of this report.

The staff concludes that the system complies with applicable GDC referenced in SRP Section 9.4.5 and consequently with the subject SRP ecceptunce criteria. The part of the system thet services the spent fuel pool area complies with the applicable GDC (GDC 2 and 4) refereaced in SRP Section 9.4.2, and coneequently with the subject SRP acceptance criteria. Therefore, the staff concludes that the RB safety-related equipment HVAC system design is acceptable.

\subsubsection{RB Non-Srfety-Related Equipment HVAC System, RB Mainstream Tunnel HVAC System, and RB RIP Adjustable Speed Drive (ASD) HVAC System}

DSER (SECY-91-235) Sections 9.4.5.3, 9.4.5.7 and 9.4.5.8 are consolidated in this section as part of this report.

The RB non-safety-related equipment HVAC system consists of six FCUs and four AHUs, each consisting of a cooling coil and a fan. Each fan coil unit cools the associated room during normal conditions in conjunction with the RB secondary containment ventilation system. The 10 individual rooms are identified in SSAR Section 9.4.5.3.2. The units are open-ended and continuously recirculate cooling air within the space served. This system is manually started. The system description, figure, and component description are given in ABWR SSAR Section 9.4.5.3, Figure 9.4-3, and Tables 9.4-4i, respectively.

The RB main steam tunnel HVAC system consists of two closed-loop fan-coil recirculation units that remove heat from the tunnel area. Each fan-coil unit consists of a cooling coil and two fans, one of which operates while the other is in standby. A flow switch in the operating fan discharge ductwork automatically starts the standby fan on recoiving indication of operating fan failure. The syctem description, figure, and component description are given in SSAR Section 9.4.5.7, Figure 9.4-3, and Tables 9.4-3, 9.4-4f, 9.4-4g, and 9.4-4i, reepectively.

The Divisions I and II for the RB RIP ASD HVAC syatem aro identical. Bach division consiets of two supply fans (ono atendby), one cooling coil for cach fan, and a clowedloop syetem that cools the asuociated power panel. The divisions are startod manually from the control room, and an air flow failure sensed by the flow owitch automatically starts the standby fan and activates an alarm in the control room to indicate the fan failure. The system description, figure, and component deacription are given in SSAR Section 9.4.5.8, Figure 9.4-5, and Tables 9.4-3 and 9.4-4g, respectively.

The three separate HVAC systems are not safety-related and are not required to maintain reactor coolant pressure boundary or to achieve and maintain safo-shutdown conditions. These HVAC systems include features that provide reliability over the full range of normal plant operation such as redundant components for the RB main steam tunnel HVAC system and the RB RIP power supply panel room HVAC system. HVAC normal cooling water is the cooling medium for these systems. These three systems comply with GDC 2 regarding protection from natural phenomena because the applicable nonessential portions of the system are designed in accordance with Position C.2 of RG 1.29 as stated in SSAR Table 3.2-1. The requirements of GDC 60 regarding control of releases of radioactive materials to the environment are not applicable because these systems are recirculation type systems and do not contain any HEPA filters or charcoal adsorbers. Further, because the systems do not perform any safety function and are not used during an accident, GDC 4 and 17 are not applicable.

GE provided a set of design description and ITAAC relating to the RB non-safety-related equipment HVAC system, RB main steam tunnel HVAC system, and RB RIP ASD room HVAC system. The adequacy and acceptability of the design description and the ITAAC are evaluated in Section 14.3 of this report. On the basis of this evaluation, Open Item 9.4-1 as it relates to the above systems, is resolved.

The staff concludes that the RB non-safety-related equipment HVAC system, RB MST HVAC system, and RB RIP ASD HVAC system comply with applicable GDC referenced in SRP Section 9.4.5 and consequently with the subject SRP acceptance criteria and are, therefore, acceptable. 


\subsubsection{RBSafaty-Related Electrical EquipmentHVAC Sratem}

The eycteon provides air and heat removal (cooling function) to maintain controlled tomperature cavironments to coners the continued operation of exfoty-related components (in the areas serviced by the aystem) undor recident conditions. The syetem consiats of three divisiona, each serving five areas: the day tank, dievel generator engine, dieed generator MCC aren, electrical equipment, and HVAC equipment rooms. Divisions $A$ and B aleo serve remote shutdown panel rooms A and B, repectively, and Divisions B and C also cerve RIP ASD control panel rooms. Division B of the HVAC ayetem cerven Division II electrical equipment room and the Division IV electrical equipment room. The staff evaluated these syetems in sccordance with SRP Section 9.4.5.

Ench of the throe RB safoty-related electrical equipment HVAC ayetem divisións consiats of an ACU and redundant, 100-percent capacity supply and exhaust fans. Bech ACU unit includes a modium-grade bag-type filter and a chilled water cooling coil for each supply fan and an electric heater. A safety-related divisional HECW system applies chilled water. Bach room is maintained at positive preseure with respect to the surrounding speces under normal and accident conditions. Each divisional syetem is started manually from the control room. The syetem includes temperature control features. The system and the RB anfoty-rolated, DO HVAC system supply fan maintain the DG room temperature below $45^{\circ} \mathrm{C}\left(113^{\circ} \mathrm{F}\right)$ when the DG is operating. The system maintains other areas served by it below $40^{\circ} \mathrm{C}\left(104^{\circ} \mathrm{F}\right)$. The system also has smoke removal capability. Upon receiving smoke alarm in a division of the system, operators will manually switch the system to smoke removal mode by closing the recirculation damper, stopping the exhaust fan, and opening the exhaust fan bypass damper to allow outside air to purge the affected area. No other division is affected by this action. Firo dampers separating electrical Divisions II and IV rooms that use fusible links in HVAC ductwork cloee under air flow conditions after the fusible links melt.

The system and components are located in the seismic Category I, reactor building, which protects against tornado missiles and flooding. All components are rated seismic Catogory I, and air intake and exhaust structures are protected against tornado missiles. Thus, the system meots the Position C.1 of RG 1.29 and, thereby, complies with the requirements of GDC 2 as it relates to protection from natural phenomena.

The power supply to the RB safety-related electrical equipment HVAC divisions during a LOOP. Medium- grade bag-type filtern in each of the three divisions of the HVAC aystem will remove duat and particulate matter from air intakes (aupply air). The intake louvers are located at $15.2 \mathrm{~m}$ (50 ft) above grado, thereby moeting the guidance of Item 2, Section A, of NURBO/CR-0660. Therefore, the eacential electrical equipment HVAC ayetem meets the pertinent requirements of GDC 17 relating to the protection of escential olectrical components from failure as a reault of accumulation of dunt and particulate material.

In the DSER (SECY-91-235), the staff stated that it would evaluate the system for compliance with ODC 4 for protection from the cavironmental and dynamic offects eneciatod with equipment failures upon receiving syatem P\&ID, and clarifying information on compliance with the ODC. GB submitted this information in rovised SSAR Section 9.4.5.4, SSAR Figure 9.4-4, and component deecription Tables 9.4-3, 9.4-4 9.4-4a and $b$. The ataff reviewed this information, the reactor building arrangement plan drawings, Section 3.6.1 of this report, and SSAR Section 3.6.4 and Table 3.6-2, and finds that the system components are protected against the offects of piping failures and internally-generated missiles by compartmentalization and separation, thereby satisfying the requirements of GDC 4. This resolved the unnumbered open item in DSER Section 9.4.5.4 not listed in Section 1.8 of the DSER.

In DSER (SECY-91-235) Interface Information Item 32, the staff stated that it would evaluate the monitoring of the exhaust from the areas served by the HVAC system and the electrical controls (i.e., interfaces) upon receiving additional system description. SSAR amendments through Amendment 34, GE included additional system description. The staff reviewed the information and the revised SSAR Section 11.5.2.2.4, and finds that the areas serviced by the RB safety-related electrical HVAC system contain no radionctive systems. These areas are at positive pressure with respect to the surrounding spaces (supply fan flow rate exceeds exhaust fan flow rate) and potentially contaminated adjoining areas. Because radioactive releases through exhausts from these areas to the environment are only from what would have to be brought first into these areas by their own supply fans, the exhaust from theee areas are not monitored. Therefore, the DSER Interface Information Item 32 is resolved. For the reasons stated above, no HEPA filters or charcoal adsorbers are provided to control releases from these areas to the environment. Therefore, GDC 60 is not applicable to the system.

The staff concludes that the RB safety-related electrical equipment HVAC system meets applicable GDC referenced in SRP Section 9.4.5 consequently with the subject SRP acceptance criteria and, therefore, is acceptable. 


\subsubsection{RB Safety-Related Dieud Generator HVAC Syotem}

The RB safoty-rolated DO HVAC syctem consiets of three independent and identical divisions, each of which will cervice one of the three DO rooms. The diviaions mupply freeh air to encure the continued operation of the mefotyrolated diesols under socideat conditions. The syctem and the RB anfoty-related electrical equipment HVAC ayetem maintain the DO room below $45^{\circ} \mathrm{C}\left(113^{\circ} \mathrm{F}\right)$ when the DG is operating. The staff reviowed the syetem in sccordence with SRP Section 9.4.5. Accordingly, the following criteria were considered: GDC 2 a related to the syctem being capable of withstanding the effects of earthquaken (meoting the guidance of RG 1.29, Poeition C.1, ODC 4, with respect to maintrining environmental conditions in cesential areas compatible with the design limits of the escential equipment located therein during normal, transient, and accident conditions, GDC 5, as related to shared systems and components important to safety, GDC 17, as related to asouring proper functioning of the cescential electric power syetem (protection from the offects of dust and particulate materials), and GDC 60, as related to the systems' capability to suitubly control the release of radioactive offluent to the environment.

Each division consists of two intake louvers, a mediumgrado inlet air filter, two supply fans, ductwork, and an exhnust louver. Both fans of each system draw air from outside, filter it, and distribute it to the reepective dieed generator room. The exhaust air is forced out through the oxhaust louvers. Each system is interlocked with the aseociated diesel generator starting system, but remote manual override capability is provided for the system fans. The systems are designed to facilitate inspection. The air intake louvers are located at $11.5 \mathrm{~m}(37.7 \mathrm{ft})$ and exhaust louvers at $8.5 \mathrm{~m}(28 \mathrm{ft})$ above grade, thereby meeting the guidelines of Item 2, Subsection A, of NUREG-CR-0660. Therefore, the systems meet the pertinent requirements of ODC 17 for protection of the eseential electrical components of the systems against dust accumulation and particulate material. The power supply to each of the systems allows uninterrupted operation during LOOP.

From its reviow of SSAR Table 3.2-1, the staff concludes that each essential diesel generator HVAC system is composed of seismic Category I components. The air intake and exhaust structures aro protectod against tornado missiles. Each system, by virtue of its location in the seismic Category I flood-, tornado-, and missile-protected reactor building, is protected from the offects of carthquakes, tornados and floods. Consequently, the sufety-related systems meet Position C.1 of RG 1.29, and, thereby, comply with the requirements of GDC 2.
In the DSER (SECY-91-235), the etaff included a partial evaluation of systom compliance with ODC, stating that it would complete a full ovaluation upon receiving adequate information to demonatrate the system compliance with GDC 4. Therefore, the ataff identified this iewe of ayatem compliance with ODC 4 a Open Item 64 in the DSER (SECY-91-235). After the etaff ienued the DSER (SECY-91-235), OE rubmittud a revised SSAR Section 9.4.5.5, SSAR Figure 9.4-4, and component description Tables 9.4-3, 9.4-4a and 9.4-4b. The ataff roviowed this information, the reactor building arrangomeat drawings, and SSAR Figure 9.4-4, and finds that the syatem components aro protected against the offects of piping failures and internally-generated missiles by being located in adequately separated and dedicated dieeel generator rooms, thereby atiafying ODC 4 regarding protection from environmental and dynamic effects aseociated with equipment failures. This resolved DSER Open Item 64.

In the DSER (SECY-91-235), the staff stated that it would ovaluate the monitoring of the exhaust from the areas sorved by the syatom and aseociated interfaces upon receiving P\&IDs and additional system information from GE. The staff designated this lack of information as Interface Information Itom 33 in the DSER (SECY-91-235). SSAR amendments through Amendment 34 included additional system description. Tho staff roviowed this information and the rovised SSAR Section 11.5.2.2.4 and finds that the areas serviced by the system contain no radioactive systems. Because radiosctivity releases from these areas to the environment are only from what would have to be brought first into thewe areas by their own supply fans, the system exhaust is not monitored. Therefore, the DSER Interface Information Item 33 is resolved. The system includes no HEPA filters or charcoal adsorbers to control releases from the system to the environment. Therefore, ODC 60 does not apply to the system. The cooling function of the system and smoke removal aspects are separately addreased in Sections 9.4.5.4 and 9.5.1.4.4 of this report.

The staff concludes that the RB safety-related diesel generator HVAC system complies with applicable GDC 2, 4, and 17 of SRP Section 9.4.5 as discussed above and, therefore, is acceptable.

\subsubsection{RB Primary Containment Supply and Exhaust HVAC System}

The system ventilates the primary containment, using supply from, and exhaust to, the secondary containment HVAC system. The staff roviowed operation of the system in accordance with SRP Section 9.4.5. The staff reviewed other aspects of the system in accordance with SRP 
Section 6.2.4, BTP CSB 6-4 as diacuesed in Section 6.2.4 of this report.

The ayatem has no safoty-rolated function and is not required to maintain the reactor coolant preseure boundary or to schiove and maintain safo-shutdown conditions. The syctem cosvints of a purge mupply fan, a HEPA filter, a purge exhaust fen, duct work, and controls. Tho syetem has the capability to purge the drywell and the wotwell, if required. When the aystem is in weo and the air is not highly radioactive, the ayetom diecharges to the eccondary containmeat HVAC ayctem for filtering by a bag-typo filter and exhausting to the plant veat stack. However, if the air is highly radioactive, it is discharged through the SOTS system. A high-radiation signal sctuates an alarm, clowes the isolation valves in the exhaunt duct, and initiates the SOTS (for ovaluation of SOTS, 20 Section 6.5.1 of this report). The system deacription, P\&ID, and component deccription are in SSAR Section 9.4.5.6, Figures 6.2-39 and 9.4-3, and Tablece 6.2-7, 9.4-4g, and 9.4-4h, reopectively.

SSAR Section 6.2.5 describes the wes of the primary containmeat purge system during the long-term poetaccident cleanup operation and the deinerting operation (shutdown) during which the syetem provides air to the drywell and wetwell through the purge supply. Refer to Section 6.2.4.1 of this report for the above interfaces and compliance with BTP CSB 6-4.

The purge supply is filtered twice, first by a bag-type filter (socondary containment HVAC system) and then by a system HEPA filter. The purge air supply has an isolation damper downstream of the system HEPA, and the exhaust has redundant isolation dampers in the flow path through the secondary containment HVAC system and the safetyrelated SGTS.

The system is located in the seismic Category I reactor building, which protocts against flood and tornado missiles. The system is non-safety-related. However, SSAR Table 3.2-1, the staff concludes that the radiation monitors and dampers for isolating the system are designod to seismic Category I requirements, and the applicable nonessential positions are designed in accordance with Position C.2 of RG 1.29. Thus, the system complies with ODC 2 regarding protoction from natural phenomene by meeting Position C. 1 of RG 1.29 for the cesential portions, and Position C.2 for the nonesecntial portions.

In the DSER (SECY 91-235), the staff stated that it would review the csential portions of the system for compliance with GDC 4 upon receiving detailed systom description including P\&IDs. The staff identified the lack of information pertaining to system compliance with GDC 4 as Open
Itom 65 in the DSER (SBCY-91-235). SSAR ameadmente through Ameadment 34 included the nubject syctem information. The etaff has reviowed the information and finds that the cescential portions of the syetem are protected againat damage from internally-geserated micailes by separation of redundant equipment and are also protected against piping failures. Thus, the esecential portions of the system comply with ODC 4 as they rolato to protection from the environmental and dynamic offects of equipment failures. Therefore, DSER Open Item 65 is resolved.

GDC 17 does not apply to the systom. The system complies with ODC 60 for control of relenses of radionctive materials to the environment because under cortain situations, the system is automatically isolated to prevent aignificant radionctivity releaso to the environment and facilitates the filtered release to the environment via the SOTS.

OB provided a eot of design description and ITAAC relating to the primary containment (containment purge supply/exhaust) HVAC system. The adequacy and ecceptability of tho design description and the ITAAC are ovaluated in Section 14.3 of this report. On the besis of this evaluation, DFSER Open Item 9.4-1 as it relates to the above systems, is resolved.

The staff concludes that the system design complies with applicable GDC reforenced in SRP Section 9.4.5 and discuseed above and consequently with the subject SRP acceptance criteria and, therefore, is acceptable.

\subsubsection{RB Mainsteam Tunnel HVAC System}

Seo Section 9.4.5.3 of this report.

\subsubsection{RB Reactor Internal Pump Adjustable Speed Drive (ASD) HVAC System}

See Secticn 9.4.5.3 of this report.

\subsubsection{Radwaste Building HVAC System}

The staff roviowed the radwaste building ventilation system in accordance with SRP Soction 9.4.3. The system is locatod in the radwaste building. It is non-safety-relatod, and its failure does not compromise any safety-related systom or component and does not provent reactor safo shutdown. The system is designed to provide an environment with controlled temperature and air flow patterns to ensure both the comfort and safety of plant personnel and the integrity of equipment and components. The system services two zones: the radwaste building control room and the radwaste building process area. 
Heating, cooling, and preasurization of the radwante building control room are sccomplished by an ACU which has two 100-percent supply fans (one standby). Outdoor air and recirculating air aro mixed and drawn through a pro-filter, a high officiency filter, a beating coil and a cooling coil by the aseociated fan. The aupply cources for the heating and cooling coils are the hot water beating (HWH) aystem and the HNCW ayetem, respectively. A differential presenure indicating controller modulates the inlet vanes in the supply fan air inlete to maintain the subject zone at positive preseure with respect to the surrounding apeces which includes the radwaste building proceses area. The zone has no exhaust fans; howover, it has a 100-percent smoke removal fon to release smoke directly to the atmoephere, and this fan is operated manually. An aren radiation monitor is provided in the radwaste control room and it will alarm on high radiation to alert personnel in the area.

The onco-through HVAC system for the radwaste building process area consists of two 100-percent supply fans (one standby) each associated with a pre-filter, a high officiency filter, a heating coil, and a cooling coil, and three 50-percent exhaust fans (one standby), cach aseociated with a pre-filter and a high officiency filtor. Separate filters receive oxhaust from the sorting table and compactor area. The exhaust air from the process area is monitored for radiation before it is released to the monitored plant vent. The overall air flow pattern in the zone is from the least potentially contaminated areas to the most contaminated areas. The design includes features to isolate manually affected areas on receipt of the area exhaust radiation alarm. The zone is at negative pressure with respect to surrounding spaces. The system description is given in SSAR Section 9.4.6.

The radwaste building ventilation system complies with GDC 2 regarding protection from natural phenomena because the applicable non-essential portions of the system are designed in accordance with Position C.2 of RG 1.29, as stated in SSAR Table 3.2-1. The design meets the requirements of GDC 60 (regarding control of releases of radionctive materials to the environment) for select arens in the radwaste building work areas by isolating the affected areas. Since the dosign of the system does not include HEPAs or charconi adsorbers, the system is not required to meet RG 1.140 guidelines. In a letter dated August 22, 1990 (response to RAI 430.258), GE committed to submit the P\&IDs, flow diagrams, and component description tables for the radwaste building HVAC system. However, the staff designated DFSER Open Item 9.4.6-1 because it did not receive this information until after issuing the DFSER. SSAR amendments through Amendment 32 specified COL License Information (Section 9.4.10, Item 9.4.10.2) which requires the COL applicant to submit flow rates and equipment lists. GB also submitted SSAR Figure 9.4-10, the P\&ID for the systom. The staff finds GE's approach to resolve the aubject open item acceptable. Thereforo, this item is recolved.

Baved on the above, the staff concludes that the radweate building ventilation syatem design complios with the applicable GDC reforenced in SRP Section 9.4.3 and consequently, with the subject SRP acceptance criteria and is, therefore, acceptable.

\subsubsection{Diesel Generator Area Ventilation System}

The dieed generator building ventilation system is part of the reactor building ventilation system, which is reviewed in Section 9.4.5.5 of this report.

\subsubsection{Service Building Ventilation System}

The staff reviowed the service building ventilation system in accordance with SRP Section 9.4.3. The system description is given in SSAR Section 9.4.8. The system is non-safety-related and is not required for accident mitigation, maintenance of reactor coolant pressuro boundary integrity, or achievement and maintenance of safe shutdown. It is located in the service building and operates during all nurmal conditions manually and continuously and provides an environment with controlled tomperature and air flow patterns to ensure both the comfort and safety of the plant personnel, and the integrity of equipment and components in the building. The system consists of two non-8afety-related HVAC systems: (1) the clean area HVAC system, which serves the technical support center (TSC), the operational support center (OSC), and other normally clean areas of the service building (instrument repair, locker, men and women's change and lunch rooms and laundry), and (2) the service building controlled area HVAC system, which serves the balance of the service building.

The clean area HVAC system supplies filtered, heated or cooled air to both the clean and controlled areas through a central fan system consisting of an outside air intake; an air conditioning unit consisting of filters, heating coils, cooling coils, two 50-percent capacity supply air fans; and a supply air duct. Additionally, the system has two 50-percent capacity exhaust fans and an emergency filtration unit (EFU). An automatic damper in the supply system ductwork regulates the flow of air to maintain the TSC and other clean areas at a positive pressure with respect to the surrounding spaces. The exhaust fans discharge the ventilation air from the clean areas to the outside from the service building roof top. The system also functions during high radiation mode. For this 
purpose, radiation monitors are provided to detect radiation levels in the outside air intake. On receipt of a signal for high radiation in the normal outside air intake, the normal air intake damper closes, the minimum outside air intake opens, and the ventilation air for the clean areas is routed through the EFU. The EFU consists of a heater and demister, pre-filter, HEPA filter, $5.1-\mathrm{cm}$ (2-in.) charcoal adsorber, a second HEPA filter, and two circulating fans. The EFU can remove at least 95 percent of all forms of iodine from the influent stream. If the reactor site is adjacent to a toxic gas source that could produce releases of significance to plant operating personnel in the TSC, the COL applicant will establish protection against the intrusion of toxic gas into the areas served by the system. GE has identified COL license information in SSAR Section 9.4.10 which calls for the COL applicant to locate required toxic gas monitors in the outside air intake of the clean area HVAC system, with capability to detect toxic gas concentrations at which personnel protective actions have to be initiated.

The controlled area HVAC exhaust system consists of two 50-percent exhaust fans. The controlled area exhaust is released to the environs through the monitored plant vent. The controlled area is maintained at a slightly negative pressure with respect to the surrounding spaces including the TSC and other clean areas.

The service building ventilation system complies with GDC 2 regarding protection from natural phenomena because the applicable non-safety-related portions of the system are designed in accordance with Position C.2 of RG 1.29, as stated in SSAR Table 3.2-1.

There is no need to monitor or control releases to the environment from the clean areas since these releases are from areas which do not contain radioactive sources and the only manner radioactive materials can get into these areas is due to its own HVAC system supply fans bringing outside air into the areas. The controlled area also does not contain radioactive sources; however, due to leakage from the secondary containment or turbine building, the radiation levels in the controlled area may become high. If this happens, the controlled area HVAC system can be manually isolated to prevent releases from the area to the environment. Thus, the service building HVAC system complies with GDC 60 with regard to control of releases of radioactive materials to the environment.

By letter dated August 22, 1990 (response to RAI 430.262), GE stated that the COL applicant will handle the details of the system, including P\&IDs and component description tables, and compliance with applicable guidelines of RG $\mathbf{1 . 1 4 0}$ for the system filtration unit. The staff agreed with GE's approach. The staff designated this as DFSER COL Action Item 9.4.8-1. SSAR amendments through Amendment 34, discussed COL license information (Section 9.4.10) which requires the $C O L$ applicant to submit the above information. This is acceptable to the staff.

Based on the above, the staff concludes that the service building ventilation system design complies with GDC 2 and 60 as referenced in SRP Section 9.4.3 and consequently, with the subject SRP acceptance criteria and is, therefore, acceptable.

\subsubsection{Drywell Cooling System}

The staff reviewed the drywell cooling system in accordance with SRP Section 9.4.5. The system is not designed to ensure the reactor coolant pressure boundary or to achieve and maintain safe-shutdown conditions. However, the system provides features to include redundant components to provide reliability over the full range of normal plant operation. The system provides conditioned air and nitrogen to cool equipment and maintain temperature within limits, as specified in SSAR Section 3.11, during normal operation and in the drywell head area, upper and lower drywell, shield wall annulus, and the wet-well air space. The drywell cooling unit function is manually controlled from the control room.

Two of the three fan coil units operate under normal conditions. Each fan coil unit consists of two cooling coils arranged in series, a drain pan, and a centrifugal fan. The return air passes over the first coil, which is cooled by RCW. Part of the cooled air is subsequently cooled by the second coil, which is cooled by HNCW. The twice-cooled air is mixed with the air that bypasses the second cooling coil. During a LOOP (when no LOCA signal exists), the fan coil units start automatically if power is available from the diesel generators. During such a situation, only RCW coils will provide cooling. The system description, figure, and table are in ABWR SSAR Section 9.4.9, Figures 9.4-8 and 9.4-9, and Tables 9.4-1 and 9.4-2, respectively.

The drywell cooling system complies with GDC 2 for protection from natural phenomena because the applicable nonessential portions of the system are designed in accordance with Position C.2 of RG 1.29, as stated in SSAR Table 3.2-1. The requirements of GDC 60 regarding control of releases of radioactive materials to the environment do not apply because the system is only a recirculation system and does not contain any HEPA filters or charcoal adsorbers. GDC 14 and 17 do not apply because the system will not perform or support any safety function and is not used during an accident. 
Based on the above, the staff concludes that the drywell cooling system moets the applicable scceptance criteria of SRP Section 9.4.5 and is, therefore, acceptable.

\subsection{Other Auxiliary Systems}

\subsubsection{Fire Protection System}

The Commission directed that special attention be given to measures for fire protection in addition to the staff's review of other aspects of the ABWR design in accordance with the requirements for current operating plants. For example, the Commission concluded that the ABWR design must incorporate the resolution of significant fire protection issues raised through operating experience and through the External Events Program.

The NRC established fire protection requirements for nuclear power plants in GDC 3,10 CFR 50.48, and Appendix R to 10 CFR Part 50. The Commission considered Sections III.G., III.J, and III.O of Appendix R to be of particular importance. In July 1981, NRC revised BTP APCSB 9.5-1 (SRP Section 9.5.1) to include these provisions from Appendix R.

The staff has also issued supplemental guidance on fire protection in documents such as Generic Letter (GL) 81-12 (45 FR 76602, November 19, 1981), dated February 20, 1981, and GL 86-10, dated April 24, 1986. GL 81-12 presents information on safe-shutdown methodology, and GL 86-10 presents technical information on conformance with National Fire Protection Association codes and standards.

To minimize fire as a significant contributor to the likelihood of severe accidents for the ABWR, the staff concluded that current NRC guidance must be enhanced. As stated in SECY-90-016, "Evolutionary Light Water Reactor (LWR) Certification Issues and Their Relationship to Current Regulatory Requirements," dated January 12, 1990 (and reiterated in SECY-93-087, "Policy, Technical, and Licensing Issues Pertaining to Evolutionary and Advanced Light-Water Reactor (ALWR) Designs"). The proposed applicable regulation discussed below encompasses the enhanced, NRC Guidance.

The NRC expects any new reactor design to propose fire protection systems based on the best technology available, not on the methods allowed for plants already operating or in advanced stages of design and construction. Therefore, the staff evaluated the fire protection system of the ABWR against the criteria of SRP Section 9.5.1 (BTP CMEB 9.5-1 Rev. 2), which meets the requirements of GDC 3, and against the following proposed applicable regulation for fire protection:
The standard design must comply with 10 CFR Part 50 Appendix R, Section III.G.1.a and ensure that safe shutdown can be achieved assuming that all equipment in any one fire area will be rendered inoperable by fire and that re-entry into the fire area for repairs and operator actions is not possible. The design must ensure that smoke, hot gases, or fire suppressent will not migrate into other fire areas to the extent that could adversely affect safe-shutdown capabilities including operator actions. The control room is excluded because an alternative shutdown capability is provided which is physically and electrically independent of the control room. In the reactor containment, redundant shutdown systems must be provided with fire protection to ensure, to the extent practical, that one shutdown division be free of fire damage. Because of unique design layout, other areas may be accepted on an individual basis.

\subsubsection{General Evaluation Fire Protection Program}

GE generally followed the NRC's concept of defense in depth for fire protection as described in the SSAR. The three steps of defense in depth and GE's implementation of these steps follow.

(1) To reduce the possibility of fire starting in the plant, GE used fire-resistant and fire-retardant materials in its design of the ABWR to minimize and isolate fire hazards. Low-voltage multiplexed circuits and fiber-optic circuits eliminate the need for cable-spreading rooms and thereby substantially reduce the amount of combustible cable insulation and higher voltage ignition sources in the control room.

(2) To promptly detect and suppress a fire, GE has provided automatic detection and a suitable combination of automatic and manual fire suppression capabilities in the ABWR design.

(3) GE designed the plant so that any fire that might occur will not prevent safe shutdown of the plant even if fire detection and suppression efforts fail.

SSAR Section 9.5.1 and Appendix 9A (Fire Hazards Analysis) describe a fire protection program intended to protect safe-shutdown capability, prevent release of radioactive materials, minimize property damage, and protect personnel from injury as a result of fire. 
GE also considered such features of general plant arrangement as:

- access and egress routes

- equipment locations

- structural design features separating or isolating redundant safety-related systems

- floor drains

- ventilation

- construction materials

The SSAR reflects the use of applicable National Fire Protection Association codes and standards in design and layout of the ABWR. In the DSER (SECY-91-355), the staff identified as Open Item 102, the need for GE to describe any deviations from those codes and standards and to describe in the Fire Hazards Analysis the measures taken to ensure that equivalent protection is provided. Section 9.A.3 of SSAR Appendix 9A describes three deviations from the fire codes: (1) exceptions to penetration requirements (Section 9A.3.5), (2) wall deviations (Section 9A.3.6), and (3) door deviations (Section 9A.3.7). In each case, GE described each deviation, why it was required, and how the underlying fire protection requirements are still satisfied. The staff found the $G E$ explanations acceptable. Therefore, this resolved DSER Open Item 102.

In the SSAR, Section 9.5.1, GE indicated that the ABWR design meets the commitments as specified in BTP CMEB 9.5-1 except in five cases:

1. Deviation from BTP CMEB 9.5-1, Section 7.j, "Diesel Fuel Storage Areas"

The BTP states that the diesel fuel oil tanks with a capacity greater than 4,164 L (1,100 gallons) should not be located inside buildings containing safety-related equipment. If located within $15 \mathrm{ni}(50 \mathrm{ft})$ of such buildings, the tanks should be housed in a separate building with a construction having minimum, fire resistance rating of 3 bours.

GE states that the capacity of each tank provides 8 hours supply, $12,113 \mathrm{~L}$ ( 3,200 . gallons), for the emergency diesel generators. The diesel fuel oil day tanks are located in the reactor building but outside of secondary containment. Walls, ceiling, floors, and doors are all 3-hour fire barriers. SSAR Section 9.5.1 stat is that the sunken volume of the room will accommodate (hold) the entire contents of the tank and discharge from the automatic foam sprinkler system for $\mathbf{3 0}$ minutes if an uncontrolled leak occurs.

The doors from each fuel tank room open into the respective DG equipment room which is in the same division, but in a different fire area. Therefore, should a fire occur in the fuel tank room, it will need to propagate and damage two 3-hour barriers before it can penetrate and threaten another division. Smoke removal in the fuel tank room is accomplished by the HVAC system.

The staff position is that the capacity of the fuel oil day tank exceeds the specified limits in the BTP; however, GE committed to add an automatic foam system with early detection and suppression capabilities. In addition, as required by the BTP, the SSAR indicates that the COL applicant will provide a fire brigade capable of extinguishing any oil-type fire that may occur onsite, including one in the diesel generator rooms.

Based on the above discussion, the staff finds GE's justification acceptable for having the diesel fuel oil day tanks inside the reactor building.

\section{Deviation from BTP 9.5-1, Section C.7.b, "Control Room Complex"}

The BTP 9.5-1 requires that automatic fire suppression should be provided for the control room complex subfloor if it contains cable runs unless cable is run in 4-inch or smaller steel conduit or the cables are in fully enclosed raceways internally protected by automatic fire suppression.

SSAR Section 9.5.1(2) states that the subfloor area will not contain a fire suppression system as recommended by BTP CMEB 9.5-1 Section C.7.b because the amount of cabling under the floor is substantially less than that used in current designs. The types of cables located in the raised floor area smolder for a long time and are selfextinguishing. Cables will be located within conduit. The control room is continuously staffed so that the presence of a fire will be quickly detected. There is also a fire detection system in the subflooring which will quickly detect a fire in that area. Finally, in the unlikely event that the control room were to require evacuation, the remote shutdown panels contain the necessary controls to bring the plant to cold shutdown.

The staff finds GE's justification for not installing a suppression system in the subfloor of the control room complex acceptable.

3. Deviation from BTP 9.5-1, Section C.7.b, "Control Room Complex" 
The BTP 9.5-1 requires that the office enpece in the control room complex be provided with an automatic fire suppression system.

GE SSAR indicated in Section 9.5.1(3) that the office spaces contained in the control room complex do not have automatic fire suppression systems installed.

GE SSAR indicated in Section 9.5.1(3) that the control room complex is continuously manned so that any fire will be quickly detected and manual suppression commenced without delay. Papers are limited and stored in file cabinets, book cases or other storage locations except when in use. GE indicated that fire detection will be installed in the peripheral rooms including office spaces. (Rofer to SSAR 9A.4.2.4.1.)

The staff finds GE's justification for not installing an automatic fire suppression system in the office spaces of the control room complex to be acceptable.

\section{Deviation from BTP 9.5-1, Section C.7.b, "Control Room Complex"}

The BTP 9.5-1 requires fire detectors for the consoles and cabinets in the control room complex.

SSAR Section 9.5.1(4) states that the control room complex is continuously staffed so that any fire will be quickly detected and manual suppression commenced without delay. The cabinets and consoles contain limited combustibles and are air cooled so that smoke from a cabinet fire will exhaust to the control room complex. A fire in any single cabinet or console will not disable the capability to safely shut down the plant.

The staff finds the above commitments acceptable since these consoles are not walk-in type and are small. Therefore, no detection need be installed within these consoles. If a fire was to occur, the control room detection system will alarm or a control room operator will see or smell the smoke. The automatic fire detectors and continuous presence of operators will likely result in the fire being discovered and suppressed early.

GE also indicated that fire detection is not provided in the cabinets or consoles because the control room ceiling and peripheral rooms are to be provided with early detection systems.

GE agreed to install a fire detection system in the sub-floor area of the control room.!

The staff finds GE's justification for this deviation acceptable.
5. Deviation from BTP CMEB 9.5-1, Section C.7.i, "Diesel Generator Area"

The BTP indicates that an automatic fire suppression system should be installed to combat any diesel generator or lubricating oil fire; such systems should be designed to operate when a diesel generator is running without affecting the diesel.

GE atates that the ABWR has an automatic foam sprinkler system for diesel generators and diesel day tanks. The generator is not a 100-percent sealed unit. Openings are provided for cooling purposes. When a diesel is operating and fire occurs, the automatic foam sprinkler suppression system will activate and there is a possibility that the foam could be siphoned into the generator openings, causing damage to the generator or a short circuit to occur.

The ABWR design assumes fire would result in the loss of function for one division. Thus, two more diesel generators are still available for duty. While the DG equipment is designed to continue opsrating, actuation of automatic foam system due to a fire or inadvertent actuation of the foam system should prompt an operator to shut down the affected diesel generator.

SSAR Section 9.5.1.3.7 states that the automatic foam sprinkler system is actuated by cross-zoned rate of temperature rise, rate-compensated heat detectors, and infrared detectors. The system will not discharge foam until a heat activated fusible link activates in the sprinkler head.

The applicant's automatic foam sprinkler system significantly reduces the probability of an inadvertent actuation of foam on the emergency diesel generators. The applicant's meets the design aspects of GDC 3 (BTP 9.5-1) and GI 57. Therefore, the staff finds GE's justification acceptable.

GE also indicated in the SSAR that excess water, foam, and diesel fuel oil spilled outside the reactor building will not have an adverse effect on any safety-related equipment.

\subsubsection{Specific Features of Protection}

\subsection{Protection of Safe-shutdown Equipment}

In general, the ABWR design relies on 3-hour-rated fire barriers to separate safe-shutdown equipment from the remainder of the plant and from redundant systems and components outside of primary containment. However, where safety related equipment is not divisionally separated by 3-hour fire-rated barriers, the safety-related equipment is electrically isolated from its respective division by fuses 
and/or breakers for breaker coordination and multiple high impedance faults. This is documented in the SSAR, Section 9A.5. SSAR Section 9.5.13.12 states that the COL applicent will demonstrate that multiplo high impedance faults of those circuits described in Table 9A.5-2, reoulting from a fire within any one fire area, will not negatively affect other equipment fed from the same power. The use of 3-hour-rated fire barriers exclusively for separation of safo-shutdown equipment in the nuclear power block (NPB) arees outside contrinment is in accordance with the review criteria, and is acceptable. The use of fuses and/or breakers to addrees breaker coordination and high impedance fault concerns where safoty-related equipment is not divisional, separated by 3-hour fire-barrier equipment as discussed in SSAR Section A.5, is in accordance with the reviow criteria and is acceptable. This design will ensure the capability for safo shutdown assuming all equipment in any one fire area will be rendered inoperable. In addition, this design provides the operator the ability to achieve safe shutdown without re-entry into the fire area for repairs or operator actions and meets the fire protection guidance of SECY-90-016.

The staff recognizes the need for open communication between compartments inside containment to relieve and equalize pressure following a high-energy line break. $G E$ stated in the SSAR that the safety divisions will be widely separated around containment so that a single fire will not fail any combination of active components that could prevent safe shutdown. The staff finds that this meets the fire protection requirements of SECY-90-016, SECY-93087, SRP Section 9.5.1, and 10 CFR Part 50, Appendix $R$, and is acceptable. The ABWR containment will be inerted with nitrogen during power operation, which will prevent propagation of any potential fire inside containment. In accordance with BTP CMEB 9.5-1, Section 7.a., the inerted containment significantly reduces oxygen so that combustion and/or fire will not be supported. This is an acceptable means of preventing a fire inside containment. The SSAR commits to an inerted containment. Therefore, the staff finds that this firesuppression feature meets the guidelines of BTP CMEB 9.5-1, Section 7.a., and is acceptable. Therefore, the use of structural walls inside containment as fire barriers to separate safety-related systems (cabling, components, and equipment), even though such walls may not fully enclose the equipment requiring separation, is acceptable.

GE proposes and justifies two areas outside containment and one inside containment that will not conform to the 3-hour-rated fire barrier separation criteria. The three exceptions discussed below were well justified by GE and are acceptable to the staff.
1. The MST is an exception to separation of redundant safety-rolated components outside contrinment.

SSAR Section 9A.4.1.4.26(9) states that all valves in the MST are designed to fail with acceptable consequences. For example, power-operated valves are backed up with air-operated valves not subject to damage from the same fire, or redundant valves are located in another fire area.

2. The MCR is an exception to separation of redundant safety-related components outside containment.

SSAR Section 9.5.1.1.2 describes alternative shutdown capability that is spatially remote from, and electrically isolated from, the MCR.

In the event of fire in the MCR, control room operators will have full safe-ghutdown capability available at this alternative shutdown station. In the control room, fiber optics are used to operate power, instrument, and control circuits for safe-shutdown equipment.

In discussions with the staff, $\mathrm{GE}$ stated that all controls and instrumentation (except for scram function, HPCF, and MSIV) will utilize a touch screen and touch panel. The characteristics of the specific touch screen and touch panel used and the affects of a fire on this equipment will depend on the as-procured equipment. If a fire can cause inadvertent operation of the touch screen or panels, the COL applicant will need to demonstrate that under the worst-case scenario, the reactor can be safely shutdown in a controlled manner and that long-term core cooling can be established and maintained. In addition, at no time shall top of the active fuel be uncovered. This is a COL Action Item (GI 147, "Fire Induced Alternative Shutdown Control Room Interactions").

3. Inside containment is an exception to separation of redundant safety-related components.

The entire containment is one fire area. SSAR Section 9.5.1.1.2 states that the shutdown trains will enter containment widely spaced around the perimeter. This spacing ensures that no single fire will be able to damage any combination of active components that would prevent safe shutdown. In addition, the ABWR containment will be inerted with nitrogen during power operation, which ensures that any potential ignition/fire hazards inside containment will not propagate. In accordance with BTP CMEB 9.5-1, Section 7.a., the inerted containment significantly reduces oxygen so that combustion will not be supported. This is an 
ecceptable means of proventing fire within containment. GE committed to an inerted containment in the SSAR. Therefore, the staff finds that this fire suppression feature meets the guidelines of BTP CMEB 9.5-1, Section 7.a., and is accoptable.

\subsection{Passive Fire Protection Features}

Passive fire protection features for the ABWR design consist of building assemblies such as walls, partitions, floor-ceiling assemblies, columns, beams, fire dampers, fire penetrations seals, and fire doors. Penetrations through the building assemblies, such as doorways, hoistways, stairways, and cable trays and conduits are protected by appropriate fire-rated doors, dampers, plugs, and seals. SSAR Section 9.5.1.1.3 states that it intends to select passive fire-protection components of proven design, which have previously been testerl and are listed by nationally recognized testing laboratories.

SECY-90-016 requires separation by 3-hour fire-barriers for redundent trains of all safety-related equipment, not just safe-shutdown equipment. Therefore, the staff reviewed the lack of 3-hour barriers between redundant trains of four separate systems: (1) SLCS, (2) SGTS, (3) FCS, and (4) spent fuel pool cooling system (FPC). The staff evaluations for these systems are provided below:

1. The SLCS is the alternative to the CRD system and is separated from it by 3-hour fire-rated barriers. This arrangement satisfies the SECY-90-016 requirements and is, therefore, acceptable.

2. During a meeting with the staff on May 5, 1992, GE committed to move pne train of the SGTS to an available space on a mezzanine level directly above the location presently shown (SSAR Figure 9A.4-6). In a subsequent amendment to SSAR Section 6.5.1.3.1, GE states that the SGTS has independent, redundant active trains. The two SGTS trains are mechanically and electrically separated and are located in two side-byside compartments separated by rated fire barriers and adjacent to the HVAC system exhaust. This arrangement satisfies the staff's concern because these two areas will be completely separated from each other by 3-hour fire-rated barriers.

3. GE changed SSAR Figure 9A.4-4 to show a 3-hour fire-rated barrier separating the redundant trains of the FCS. This arrangement satisfies the staff's concern and is, therefore, acceptable.

4. The FPC system is not a safety-related system. If the FPC is lost because of fire, the fuel pool will slowly heat up and eventually boil. GE calculated that the pool would begin boiling in about 16 hours under the most adverse conditions of decay heat load from a recently off-londed full-core with no emergency makeup water supplied to the pool. However, emorgency makeup water can be supplied to the fuel pool within 30 minutes from (1) the RHR system, (2) the SPCU system, (3) MUWC system, or (4) the fire protection water systom by means of hoses. The staff finds that the FPC is not required to prevent offsite releases and is not a safety-related system. Therefore, this staff concern is resolved.

\subsubsection{Fire Protection System Description}

GE submitted the design description and the ITAAC for the fire protection system. The staff designated this as DFSER Open Item 9.5.1.3-1. GE submitted a revised set of design description and ITAAC, which are evaluated in Section 14.3 of this report. Open Item 9.5.1.3-1 is resolved.

\subsection{Fire Detection Systems}

A previous amendment to the SSAR stated that the ABWR automatic fire detection systems are designed and installed in accordance with National Fire Protection Association (NFPA) Standards 72D and 72E, and will protect all safeshutdown components from all significant hazards. In the DFSER, the staff stated that NFPA 72A, 72B, 72D, and 72E have been incorporated into NFPA 72, and are no longer separate standards. Therefore, all references to NFPA 72D and 72E should be changed to NFPA 72. The staff designated this as DFSER Open Item 9.5.1.3.1-1. Amendment 33 to the SSAR states that fire detection systems are designed according to NFPA 72 Class $A$ and NFPA 70 Class 1 requirements. Therefore, DFSER Open Item 9.5.1.3.1-1 is resolved.

The ABWR will include detection capability for major cable concentrations, safe-shutdown-related major pumps, switchgear, motor-control centers, battery and inverter areas, relay rooms, fuel areas, and all other areas that may contain appreciable in-situ or transient combustibles. Detector devices will be selected on the basis of the type of unticipated fire and located on the basis of ventilation, ceiling height, ambient conditions, and burning characteristics of the involved materials. Detection systems will alarm and be annunciated in the control room and will give a distinctive audible and, if necessary, visual local alarm to aid the fire brigade in finding the fire.

Therefore, the staff concludes that the automatic fire detection capability provided for the $A B W R$ meets the guidelines of Section C.6.a of BTP CMEB 9.5-1, as discussed above, and is acceptable. 


\subsection{Fire Protection Water Supply System}

The dedicated fire protection water supply and diatribution system is designed and will be installed in accordance with NFPA Standards 11,13,14,15,16,16A, 20, and 24 to moet the anticipated needs for fixed water auppression systems and manual hose stations.

The sprinkler systems in the reactor building and the wet standpipe systems in the reactor and control buildings are designed in compliance with ANSI B31.1 and analyzed to remain functional following an SSE (seismically analyzed). Portions of the water supply system, including a tank, a pump, and part of the yard supply main, are also designed to these requirements. The remainder of the water systems are designed to appropriate fire protection standards. During normal operation, the soismically analyzed systems will be separated from those not seismically analyzed by normally closed valves and a check valve 80 that a break in the non seismically analyzed portion of the system cannot impair the operation of the seismically designed portion of the system.

The water supply system is required to be a fresh water system, filtered if necessary to remove silt and debris. The system hes two sources, each with a minimum capecity of $1,136,000$ liters $(300,000 \mathrm{gal}$. $)$. If the primary source is a volumo-limited supply such as a tank, a minimum of 455,000 liters $(120,000 \mathrm{gal}$.) must bo passively reserved for use by the seismically-designed portion of the fire suppression system. This reserve will supply two manual hose reels for 2 hours. A diesel-driven pump in the train is designed to remain functional following the SSE. A jockey pump will maintain pressure on the system.

The 'turbine bisilding will have modified Class III standpipes, hase reels, and ABC portable extinguishers throughout the building. The following fire suppression systems will have primary fire suppression capability for the following areas:

- Automatic closed-head sprinkler systems in the open grating area of the three floors under the turbine.

- Deluge foam-water sprinkler systems in the lube oil conditioning area and the lube oil reservoir area.

- A deluge sprinkler system in the hydrogen seal oil unit area.

- A preaction sprinkler system in the auxiliary boiler area.
The turbine building fire suppression systeins receive water from the portion of the supply system that is not required to be soismically analyzed for SSE.

The main power, unit auxiliary, and reserve transformen will have delugo water apray suppreseion systems. The systems are automatically actuated by flame or temperature detectors. A dike is provided to collect oil and water beneath each transformer. Drains are provided for each pit to divert oil and water away from buildings and transformers. Shadow-type fire-barrier walls separate adjacent transformers.

Alarm systems, both manual and automatic, will be in all areas of the plant as passive systems. They alarm without controlling an extinguishing function.

The two fire pumps are located in separate fire areas, separated from each other and the plant by 3-hour-rated fire barriers.

The fire-main loop in the yard will be designed and installed with sectional control valves that will deliver total fire flow and pressure design requirements to all automatic and manual fire suppression systems and manual hose stations with the shortest portion of the water distribution piping out of service.

On the basis that the fire water supply and distribution system conforms to the applicable NFPA standards mentioned above, the staff concludes that the system will meet the guidelines of Section C.6.b of BTP CMEB 9.5-1 and is acceptable

\subsection{Water Fire Suppression Systems}

The SSAR states that automatic water and foam-fire suppression systems will be installed over major fire hazards identified in the fire hazards analysis. Each system will be designed and installed in accordance with NFPA 11, 13, and 15.

Standpipe and hose stations will be installed throughout the plant as determined in the fire hazards analysis. The standpipe systems will be designed and installed in accordance with NFPA 14. Each hose station will be equipped with a maximum of $30 \mathrm{~m}(100 \mathrm{ft})$ of $3.8-\mathrm{cm}$ (1.5-in.) hose and an adjustable on/off spray nozzle listed or approved by a nationally recognized testing laboratory.

Pressure-reducing orifices will be installed at each hose station as required, to ensure that excessive pressures are not delivered to the nozzle. 
Brterior hydrants and bow houses will moet needs deacribed in the fire hemards analyais and will bo deaigned and equipped in accordance with NFPA 24.

Control and sectionalizing valves in the fire water aystem will be electrically appervieed and will be indicated in the MCR.

The ABWR will not include floor penetrations that are susceptible to the potential of channeling water from fire extinguishing operations in one redundant fire area to an adjacent fire area. Floor penetrations will only be used for interconnections within one train of afo-shutdown equipment.

The fire protection water distribution and extinguishing systems will conform to the guidelines contained in Sections C.6.b and C.6.c of BTP CMEB 9.5-1 and is scceptable. This resolved DSER (SECY-91-355) Open Item 104.

\subsection{Automatic Foam Fire Suppression Systems}

GE specified an automatic foam sprinkler fire suppression system for protection of the EDGs. GDC 3 of Appendix A of 10 CFR Part 50 states that an inadvertent operation of the foam system should not adversely affect the diesel. Section C.7.i. of BTP 9.5-1 CMEB states that "Automatic fire suppression should be installed to combat any diesel generator or lubricating oil fire; such systems should be designed for operation when the diesel is running without affecting the diesel." GI 57 addresses the potential for safety-related equipment to become inoperable due to an inadvertent operation.

The applicant committed to meet the design aspects of GDC 3, BTP 9.5-1 and GI 57, therefore, the staff concludes that the automatic foam fire suppression systems are acceptable. This item was previously discussed in Section 9.5.1.1 of this report.

\subsection{Fire Extinguishers}

Portable fire extinguishers will be provided in areas with in-situ or potentially transient combustibles. They will be chosen on the basis of the anticipated type of fire in the area and the effect of the extinguishing agent on equipment in the area. The portable extinguishers will be selected, installed, and maintained in accordance with the requirements of NFPA 10.

The portable fire extinguishers will conform to the guidelines of Section C.6.f of CMEB 9.5-1 and will, therefore, be acceptable.

\subsubsection{Fire Protection Support Systems}

\subsection{Emergency Communication and Lighting}

The BTP 9.5-1 requires portable radios be provided for fire brigade and plant operations personnel to communicate during \& fire incident. This communication system will have a distinct and separate frequency so that plant security force communications and actuation of protection relays will not be affected. The portable radio communication system will use fixed repeaters, as necessary, to ensure communications capability with any location in the station from the control room. The fixed repeaters will be arranged and protected so that exposure to fire damage will not disable the entire system. SSAR Section 9.5.2.6.2 states that "Design of fixed emergency communication and portable communication systems shall comply with BTP CMEB 9.5.1, Position C.5.g.(3) and (4)."

Sealed-beam emergency lights with individual 8-hour battery supplies will be provided in areas that must be occupied for safo shutdown and in routes used for access and egress to these locations. The lighted areas will include areas where operator actions occur if the control room is evacuated. In addition to the sealed-beam 8-hour emergency lights, portable sealed-beam battery-powered hand-held lights will be provided for use by fire brigade and plant operations personnel during a fire incident.

GE responded to staff questions about battery-powered emergency lights in harsh (extreme high or low temperature) environments by stating the following in SSAR Section 9.5.3.1.1(5):

(f) Non-essential battery pack lamps shall be self-contained units suitable for the environment in which they are located.

(g) The light fixtures for essential battery packs may be located remotely from the battery if the environment at the lemp is not within the qualified range of the battery. Alternatively, lamps powered from the station batteries may be provided.

Based on the applicant's commitments, the emergency communication and lighting design conforms to the guidelines of Section C.5.g of BTP CMEB 9.5-1 and is acceptable.

\subsection{Emergency Breathing Air}

The staff reviewed GE's commitments regarding the provision of emergency breathing air in accordance with BTP CMEB 9.5-1. Specifically, Position C.3(c) indicates that the fire protection program will include the provision 
of fire brigade equipment including self-contained breathing apparatis for brigado members.

In accordance with BTP CMEB 9.5-1, GE hes made the following commitments concerning the provition of omergency breathing air for the fire brigede ataff. Emergency breathing air will bo provided for fire brigade and control room pernonnel. The breathing air will be dolivered by a self-contained apparatus or a storage reservoir. Full-face positivo-prescure makes approved by the National Institute for Occupational Safoty and Health will be used by all personnel required to use emergency breathing air.

A minimum of 10 self-contained breathing units will be provided for fire brigade use. Each unit will be provided with two extra air bottles located on site. The rated service life for the self-contained units will be a minimum of $1 / 2$ hour. In addition to the two extra bottles for each solf-contained unit, compressors will be provided 20 that exhausted air bottles may be quickly replenished. The compressors will operate in areas free of dust and contaminants and will be powered from a vital power bus 80 that breathing air is available if off-site power is lost.

The specific provisions for emergency breathing air conform to the guidelines contained in Section C.3(c) of BTP CMEB 9.5-1 and are acceptable.

\subsection{Curbs and Drains}

Floor drains and curbs sized to remove expected firefighting water flow will drain areas protected by fixedwater fire-suppression systems or hand-held hose lines to prevent water accumulation from causing unacceptable damage to safety-related equipment. Water drained from areas that may contain radioactivity will be properly collected, analyzed, and treated before being discharged to the environment.

SSAR Section 9.5.1 states that the control room will not have floor drains. The SSAR describes the flow path that the water will travel if the subflooring was to overflow. The path traveled by the water will not jespardize safety. related equipment because of floor drains and pedestals which elevate safety-related equipment. One division outside the control room will not be in the path of the discharged water.

Floor drains in areas containing combustible liquids will be designed so that these liquids cannot flow back into safety-related areas through the drainage system.
The provisions for curbe and drains conform to the guidelines in Section A.2 of BTP CMEB 9.5-1 and are scceptable.

\subsection{Smoke Control}

In SECY-90-016, "Bvolutionary Light Water Reactor (LWR) Certification Issues and Their Relationship to Current Regulatory Requirements," datod January 12,1990, the staff stated that the ABWR design muat ensure that smoke, hot gases, or the fire suppreseant will not migrate into other fire areas to the extent that thoy could adversoly affect safo-shutdown capabilities, including operntor actions.

SSAR Section 9.5.1.1.6 states that the HVAC systems will control smoke and moot the requirements of ASHRAE's, "Design of Smoke Control Systoms for Buildings," and NFPA's "Recommendations Practice for Smoke Control Systems." GE describes the major features that will be incorporated into their design which include the following:

- Venting of the area of the fire to prevent the fire from causing pressure to increase.

- Pressure control across the fire barrier to ensure that any leakage is into the area experiencing the fire.

- Pressure control and purge air supply to prevent back flow of smoke and hot gases when fire-barrier doors are maintained open for access for manual fire-fighting activities.

Smoke will be removed from the area of the fire by the normal ventilation systems (smoke removal mode). Release of smoke that may contain radioactive materials will be monitored to ensure compliance with applicable guidelines and regulations.

The general arrangement of the ABWR design of safe-shutdown trains features a high degree of separation with no piping and minimal cabling interconnections between divisions. With such a physical arrangement, the ventilation system can become the most likely pathway for fire propagation and smoke dispersal. Outside primary and secondary containment, the ABWR employs separate, dodicated HVAC systems for each fire area containing safoshutdown equipment.

This arrangement of the ventilation systems serving the areas containing safe-shutdown equipment facilitates the venting of smoke from one area containing safe-shutdown 
equipment, and precludes the smoke from spreading to the redundant area containing safo-ehutdown equipment. This arrangement also means that ventilation air aupply, return, and oxhaust for any fire area is independent of all other fire areas and that HVAC ducting does not penetrate the 3-hour-rated fire barriers separating fire areas. Therefore, the ABWR design will not include fire dampere outside the secondary containment. This simplifies not only design of the ABWR HVAC systems, but also inotallation and maintenance of the system throughout the life of the plant.

The HVAC system removes smoke in the event of fire. For all systems, except the secondary containment and diesel generator rooms, placing a HVAC system in the smoko-removal mode causes a damper in the return line to close and a much larger exhaust damper to atmosphere to open so that the system becomes a no-return, flow-through system with the large exhaust plenum vented directly to atmosphere. The pressure in the area experiencing the fire drops to atmospheric pressure plus the duct loss in the exhaust duct and the pressure in other divisional fire areas remains at their normal positive pressure of approximately $0.06 \mathrm{Kpa}$ (1/4 of an inch of water). This assures that air leakage through any openings in the fire barriers surrounding the fires is towards the fire. GE has stated in SSAR Section 9.5.13.10, that during the detailed design phase the required differential pressure for each barrier will be calculated and the HVAC systems are to be designed to provide the required pressure. This is a COL Action Item and is not needed for design certification.

The smoke removal mode for the RB secondary containment HVAC system differs from that of the other systems, since common supply and exhaust systems are used for all three divisional areas within the secondary containment. The systems from each division are branched from the common system. Each supply and exhaust branch includes a dual purpose isolation/fire damper valve. Each exhaust branch also includes a two-position motoroperated volume damper. Upon detection of a fire, a normally non-operating exhaust fan is started to increase the negative pressure of the exhaust system. The motoroperated dampers in the exhaust ducts for the divisional/HVAC fire areas without the fire, reposition to their pre-determined fire settings to maintain normal negative pressure in their zones. The pressure in the HVAC and fire area will become more negative with the change in exhaust pressure. This establishes a differential pressure across the fire barriers surrounding the fire. As discussed above, the required differential pressure for each barrier will be calculated during the detailed design phase, and the HVAC systems will be designed to provide the required pressure.
OE also committed to inetall smoke detectors in the fremh sir intakes for the ABWR secondary containment and the control building. If smoke enters the frech air mupply for theee HVAC syatoms, they will isolate from the outride supply and start operating in the 100-percent recirculation mode.

Since the primary contrinment is inerted with nitrogen, the esparation of HVAC systems inside primary containment is not an issue during plant operation.

To remove smoke from the diesel generator room, the onco-through supply fans for the room start, and purge the room through the large exhaust opening $\left[4 \mathrm{~m}^{2}\right.$ (about $\left.43 \mathrm{ft}^{2}\right]$ ). The applicant has committed to design the smoke removal systems in accordance with ASHRAE's "Deaign of Smoke Control Systems for Buildings" and NFPA's "Recommendations Practice for Smoke Control Systems." The applicant states that a minimum of 0.06 pa $(.25$ in. $\mathrm{H}_{2} \mathrm{O}$ ) will be maintained across the fire berriers. The applicant states that sufficient flow and prescure will bo available to prevent smoke migration into the non-fire aren when doors are open to support any fire fighting operations.

Based on the above applicants commitments, the staff concludes that the design of the ABWR HVAC systems in the smoke-removal mode of operation is in accordance with the review criteria and is acceptable. This resolved DSER (SECY-91-355) Open Item 103. (See also Section 9.5.1.2.2 of this report.)

\subsection{Access/Egress Routes}

Fire exit routes will be clearly marked provided for each fire area. These routes will be designed to comply with applicable life safety codes and standards. The provisions for access and egress routes in all areas noeded for operation of safe shutdown equipment will conform to the guidelines contained in Section III.J of Appendix $R$ to 10 CFR Part 50, and are acceptable.

\subsection{Construction Materials and Combustible Contents}

GE has defined non-combustible materials used for interior wall and structural components, thermal insulation, radiation shielding, soundproofing, interior finishes, and suspended cerlings in Section 9A.2.3(4) of SSAR Appendix 9A. GE also states acceptance criteria for surface finishes in Section 9A.2.4(6) of SSAR Appendix 9A. Both the definition and the acceptance criteria are based on the technical requirements of American Society for Testing and Materials (ASTM)E84/NFPA 255, and are acceptable to the staff. 
BTP CMEB 9.5.1 Section 5.A.12 indicates that thansformers installed inside fire areas contuining safotyrelated syctems should be of the dry type or inculated and cooled with noncombustible liquid. Transformen filled with combutible fluid located indoors should bo enclosed in a transformer vault.

With regand to non-combuntible liquid-inmulated transformers, the staff identified in Section 9.5.1.4.6 of the DSER (SBCY-91-355), an interfece requirement involving considerntion of the potentially unacceptable health hrands in the event of the release of muterial from these trunsformers.

As a reault of ataff roviow of interfece requiremeats, $G E$ clarified in a letter dated March 11, 1992, that trunsformers located within fire areas contnining afetyrelated equipment will be of the dry-type only. For those areas utilizing liquid-insulated transformers, the COL applicant will include features to provent the insulating liquid from becoming an unacceptable bealth hazand to employees if the mnterial is released to the building environment. The staff will review these features on a plant-specific besis. This was DFSER COL Action Item 9.5.1.4.6-1. GE later submitted SSAR Section 9.5.13.15, requiring the COL applicant to design protective features for liquid-insulated transformers. This is acceptable to the staff.

The use of non-combustible material and the use of drytype transformers located within fire areas containing safety-related equipment conforms to ETP CMEB 9.5-1 and is acceptable.

\subsection{Interaction with Other Systems}

The aspects of the fire protection design to address interaction with other systems was reviewed in accordance with Section C.3.a of BTP 9.5.1 relative to the separation of safety-related systems from any potential fires in nonsafety-related areas, and the existence of separate redundant divisions of safety-related systems not subject to damage from a single fire.

The vulnerability of safe-shutdown equipment to fire protection water is not an issue because the ABWR design includes three trains of safe-shutdown capability and assumes separate fire areas for each shutdown train, which can survive total loss of all equipment in any fire area. Safe-shutdown equipment in the ABWR design requires no special protection from the effects of failures of the fireprotection water-suppression systems. However, GE includes such protection and assumes no credit for it.
Pipe rupture criteria will ensure that the flood inventory in firo-protection piping will not cause damage to anfoty-rolated equipmont. Driins and aumps in the NPB will be sized to control maximum flood inventory of fireprotection piping.

These provisions comply with the guidelines of BTP CMEB 9.5-1 Section C.5.a for building deaign with fire barriers and divisional separation of BTP CMEB 9.5-1 and are scceptable.

\subsection{Preoperational Testing}

All of the sctive components of the entire plant firoprotection systems are required to pass a preoperational scceptance teet in sccordance with the appropriate NPPA ctendard governing design and installation of the system. Components and systems that must pass the preoperational testing before being placed in service include the following:

- fire pumps - controls, flow volume and pressure

- water distribution - flush and hydrostatic

- control valves

- fire-detection and alarm systems, including electronic supervision for other fire-detection and fire-suppression systems

- water fire-suppression systems

- emergency radio communication systems

- emergency lights

- emergency breathing air systems and components

\subsubsection{Administrative Controls}

The staff will perform a detailed review of the administrative controls for various plant operations during the plant-specific licensing process of a COL application referencing the GE $A B W R$ design. Items of interest under the administrative controls review will include:

- control of combustible materials such as combustible or flammable liquids and gases, fire-retardant-treated wood, plastic materials, and dry ion exchange resins

- transient combustible materials and general housekeeping, including health physics materials 
- open-flame and bot-work permits, and cutting and welding operations

- quality esurnace for fire-protection system components, installation, maintenance, and operation

- qualification of firo-protection engineering perionnel, fire brigade members, and maintennnce and teating personnel for firo-protection system

- instruction, training, and drills for fire brigade mombers

The staff designated this as COL Action Item 9.5.1.5-1 in the DFSER. OE added SSAR Section 9.5.13.18 to state that the COL applicant will submit the description of administrative controls outlined in SSAR Section 9.5.1.6.4. This is acceptable to the staff.

\subsubsection{Summary}

The staff finds the fire-protection design for the ABWR acceptable. As discussed above, the fire-protection features described in SSAR Section 9.5.1 and SSAR Appendix 9A (Fire Hazards Analysis) of the ABWR application conform to the applicable sections of CMEB BTP 9.5-1 and meet the applicable regulation discussed in Section 9.5.1 above.

\subsubsection{Communications Systems}

This topic is discussed in Section 7.7.15 of this report.

\subsubsection{Lighting Systems}

This topic is discussed in Section 8.3.5 of this report.

\subsubsection{Diesel Generator Fuel Oil Storage and Transfer System}

Section 9.5.4.1 of this report addresses compliance of all the diesel generator auxiliary systems with the requirements of GDC 2, 4, and 5. Section 9.5.4.2 of this report addresses issues specific to the diesel generator fuel oil storage and transfer system.

\subsubsection{Diesel Generator Auxiliary Support Systems (General)}

There are three standby (emergency) diesel generators (DGs) in the ABWR design. Each DG has the following auxiliary systems, which are addressed in detail in the sections of this report indicated: fuel oil storage and transfer (FOST) (Section 9.5.4.2), cooling water (DGCW) (Section 9.5.5), starting air (DGSA) (Section 9.5.6), lubrication (DGLS) (Section 9.5.7), and combuation air intake and exhaust (DOCA) (Section 9.5.8).

Adequacy of the syetoms is based on compliance with the requirements of ODC 2 (protection against matural phenomena), GDC 4 (protection from environmental and dynamic offects of equipmeat failure), and ODC 5 (sharing of SSC between units) as well as the recommendations of NUREG/CR-0660, "Enhancement of Onsite Bmergency Diewel Generator Reliability." Compliance with the requirements of other GDC will be reviewed on a systemspecific basis in later sections of this report.

The diesel engine vendor has not been selected, therefore, the interaction between the diesel engine and the auxiliary systems cannot be fully defined. The staff will evaluate the COL applicant's design of specific engine and support systems on a plant-specific besis.

Most components of the diesel generators and their auxiliary support systems are located in the seismic Category I reactor building structure, which will protect against the effects of tornados, missiles, and floods. Each diesel generator and its associated auxiliary systems is physically and electrically separated and is located in separate divisional areas of the reactor building. Thus, a failure of equipment in one division cannot adversely affect the safety function of more than one division of the diesel generator and its associated auxiliaries. The diesel generator exhaust silencer is located on top of the reactor building, well above the probable maximum flood level and is designed to function during design-basis events such as seismic vibrations, wind, hail, tornados, rain, and snow storms. Fuel oil storage tanks, pump motors, valves, and piping are located underground and are of seismic Category I construction. The only portions of the FOST system located above ground are the fill, sample, and vent lines. In the DSER (SECY-91-355), the staff concluded that GE should submit additional information on provisions to minimize the effect of tornado missiles for these exposed components. SSAR Section 9.5.4 states that the FOST system is protected from damage from flying debris carried by tornados. Subject to confirmation that the fill, vent, and sample connections were adequately protected from tornado missiles, the staff concluded in the DFSER that the system designs met the requirements of GDC 2 and 4, and RGs 1.115 and 1.117. This was DSER Open Item 80 and was also identified as DFSER Open Item 9.5.4.1-1. GE submitted Amendment 24 of the SSAR, which resolved this issue, by stating that the fill, vent, and sample connections are located outside of the seismic Category I buildings at or slightly above plant grade. It is highly unlikely that one tornado missile could damage more than one redundant division because (1) these connections are not part of the fuel path from the storage 
tank to tho diecal, (2) the fuel path is loceted eatirely within the reactor building, and (3) the connections for each train are widoly apeced around the outaide of the reactor building. Tho etaff finds the deaign features ecceptable because the doaign complies with ODC 2 and 4 of the diead generator auxiliary aystems. Therefore, DFSER Open Itom 9.5.4.1-1 is rewolved.

The roquirements of GDC 5 regarding the sharing of SSCs do not apply because the ABWR is deaigned as a singlounit facility. An application for a multi-unit facility will require reviow of the deaign for compliance with GDC 5.

The staff evaluated the design of the dievel generator support (auxiliary) syetem for the offects of poetulated pipe failures as discusesed in Section 3.6 of this report. The adequacy of the firo protection for diesel generntors and the associated auxiliary support systoms is addressed in Section 9.5.1 of this report.

The applicant roferencing the ABWR design will provide information to onsure compliance with the recommendations of NUREG/CR-0660, "Enhancement of Onsite Bmergency Diesel Generator Reliability." Tho staff will review this information on a plant-specific basis. This was identified as DFSER COL Action Item 9.5.4.1-1.

The TS in SSAR Chapter 16 specify teet intervals for the diesel generator auxiliary aystoms. Moet auxiliary systoms are tested during diesel generator start/run tosts as required by RG 1.108. The TS prescribes additional tests for the fuel oil transfer system. The incorporation of these tests in the TS will resolve the open item in DSER Section 9.5.4.1 regarding the test frequency. This was TS Compliance Item 9.5.4.1-1. GE provided its set of TS in accordance with the standardized technical specifications for BWRs. Chapter 16 of this report discusses the evaluation of the TS. Based on the approval of the ABWR TS, this TS item is resolved.

Instrumentation is to be located in dust-tight steel cabinets with gasketed doors/openings and filtered louvers where ventilation is required. Ventilation is to be taken from a location high in the reactor building, approximately $11.5 \mathrm{~m}$ (38 ft) above grade. Construction-related activity will be required to use appropriate dust control techniques. Concrete flooring is to be painted with concrete or masonry paint.

GE submitted the design description and the ITAAC relating to the emergency diesel generator and its auxiliaries. This was identified as DFSER Open Item 9.5.4.1-2. GE provided a revised set of design description and ITAAC. The adequacy and acceptability of the deaign deecription and the ITAAC are ovaluated in Section 14.3 of this report. On the basis of this ovaluation, this itom is recolved.

This section applies to the emergency diesel generator suxiliary systems, which include the diesel generator fuol oil atorage and tranofer systom (FOST), diesel generator cooling water system (DOCW), diesel genorator starting air (DGSA), diesel generator lubrication (DGL), and diecel generator combustion air intake and exhaust (DOCA). The staff reviowed these auxiliaries for conformance of the deaign criteria and bases to the Commission's regulations as eot forth in the ODC of Appendix A to 10 CFR Part 50. The etaff concludes that the plant design is acceptable and meots the requirements of GDC 2 as it relates to the ability of the auxiliaries and the structures housing them to withstand the offects of natural phenomena such as earthquakes, tornados, hurricanes, and floods; GDC 4 as it relates to structures housing the auxiliaries and the auxiliaries themselves being capable of withstanding the effects of externally and internally-generated missiles, pipe whip, and jet impingement forces associated with pipe breaks; and GDC 5 as it relates to the capability of shared systems and components important to safety to perform required safety functions. In addition, $G E$ has provided adequate guidance for an applicant referencing the ABWR design to ensure compliance with the recommendations of NUREG/CR-0660.

The staff concludes that the design of the auxiliaries conforms to the above-mentioned GDC and the guidelines of SRP 9.5.4 and is, therefore, acceptable.

\subsubsection{Diesel Generator Fuel Oil Storage and Transfer System}

The staff reviewed the FOST system in accordance with SRP Section 9.5.4. The system should be designed to moet the requirements of GDC 2 (protection against natural phenomena), GDC 4 (protection from environmental and dynamic effects of equipment failure), GDC 5 (sharing of SSCs between units), and GDC 17 (availability of elestric power systems). The ability of the FOST system to meet GDC 2, 4, and 5 is discussed in Section 9.5.4.1 of this report.

The FOST system provides a separate and independent fuel oil supply division for each diesel generator. The FOST system provides minimum storage capability for full-load operation of each diesel generator for 7 days without replenishment of fuel. GE submitted the acceptance criteria of the diesel generator support systems.

The ABWR design includes three standby diesel generators. Each diesel engine fuel oil and transfer 
divinion consiets of a day tank with mufficient capacity to cupply fual oil to power the dical for 8 hourn; a fuel oil atorage tenk with a capacity sufficient to power the diecel for 7 daya; two fuel oil transfer pumpe, an engino-driven and a redundant de motor-driven fuel oil pump (both gravity fod) supplying fuol from the day tank to the eagino ful menifold; and anociatod piping, valves, inetrumentation, and controls. Each FOST ayetem division is independent and physically separated from the other two diviajons, and each division is located in a separate quadrant of the reactor building. Thus, a single failure within any one of the divisions will affect only the aseociated diesel generator.

The SSAR states that solection of the fuel oil transfer pump is an interface requirement. Upon further ovaluation, the etaff determined thet this requirement can bo sccomplished by identifying a COL sction item in tho SSAR for the applicent referencing the ABWR design to submit this information. Therefore, this interface requirement was reclassified as DFSER COL Action Itom 9.5.4.2-1. Subeequently, GE added design information for one of the fuol oil transfer pumps. The system will consist of an engine-driven fuel oil transfer pump and a second electric motor-driven transfer pump. This is acceptable.

The staff noted as DSER (SECY-91-355) Open Item 81, that the type of motive power (required to be available during a LOOP) should be provided in the SSAR. GE amended the SSAR to identify the motive source for the pump as Class 1E bus power from its respective diesel generator. This resolved DSER Open Item 81.

All FOST system piping and components up to the diesel engine interface are designed to seismic Category I requirements. All piping and components (including engine-mounted) meet RG 1.29, and will be designed, fabricated, and installed in accordance with ASME Code Section III, Class 3, requirements.

Instrumentation provided for the FOST system includes level indication for the day tank, temperature sensors at the intake and discharge of the day tank, and pressure indication for the suction of the engine-mounted and dc motor-driven fuel oil pumps. In the DSER (SECY-91-355), the staff indicated as part of DSER Open Item 83 that the sensor on the tank discyarge did not appear on the fuel oil system P\&ID. GE submitted a revised figure showing this temperature sensor, which resolved this part of DSER Open Itom 83. However, incorporation of the revised figure in the SSAR was identified as DFSER Confirmatory Item 9.5.4.2-1. Subsequently, GE modified Figure 9.5-6 in Amendment 25 of the SSAR which included this temperature sensor. Therefore, Confirmatory Itom 9.5.4.2-1 is resolved.

Lovel seneors provide signals to start the fuel oil transfor pumps, one starting on low level, a second on low-low lovol. At the low lovel, a 60-minute supply (at full dieeol genenator loed) of fuel oil is available for diesel generator operation. GE did not state whether storage tank lovel instrumentation was available. In describing its commitment for a stick gauge provision, $\mathrm{GE}$ stated that lovel awitches are provided to monitor tank level. In the DSER (SECY-91-355), the etaff identified inconsistencies in the listing of these level switches between parts of SSAR Sections 9.5.4 and 8.3. GE committod to includo the level switches and the stick gauge in the appropriate parts of SSAR Section 9.5.4, Section 8.3.1.1.8.5, and the referenced figures. This commitment resolved DSER Open Itom 82; however, incorporation of this information into the SSAR was identified as DFSER Confirmatory Item 9.5.4.2-2. GE submitted the necessary tank level information in SSAR Amendments 21,22 , and 25 . Table 8.3-5 includes an alarm on low storage tank level, Section 9.5.4.5 discusses level alarms on the storage and day tanks, and Figure 9.5-6 includes the level sensor and stick gauge. The staff finds these modifications acceptable. Therefore, Confirmatory Item 9.5.4.2-2 is resolved.

The fuel oil storage tanks are located underground in three separate areas adjacent to the reactor building. The interior and exterior of the tanks and assuciated buried piping will have a protective waterproof coating. Also, the design will use an impressed current-type cathodic protection to control corrosion of underground piping.

SSAR Figure 9.5-6 depicts the standby diesel generator fuel oil system. From the review of this figure, the staff concluded in the DSER (SECY-91-355), that the fuel oil storage tanks and associated instrumentation should be added to the figure. In addition, the staff found discrepancies between the text and Figure 9.5-6, regarding the optional characterization of the electric fuel oil pump. Responding to RAI 430.273, GE stated, in part, that "two local fuel oil temperature indicators are provided (one in the suction line and one in the discharge line) from tne day tank." Figure 9.5-6, however, shows only one temperature sensor. GE committed to include a revised Figure 9.5-6 in the SSAR that will include the fuel storage tanks and their associated instrumentation. This commitment resolved the other part of DSER Open Item 83. However, incorporation of these revisions into the SSAR was identified as DFSER Confirmatory Item 9.5.4.2-3. GE submitted the revised figure in Amendment 25 of the SSAR. The figure incorporates the tanks, their associated instrumentation, and temperature sensors at the suction and discharge of the day tanks, and 
contains a footnote which allows the motor-driven pump to he added as an option. The staff finds the revisions acceptable. Therefore, Confirmatory Itom 9.5.4.2-3 is resolved.

Section III.5 of SRP Section 9.5.4 addresees the need to minimize the creation of sediment turbulence at the bottom of the fuel oil storage tank during refueling. To ensure continuous operation of the diesel generator while refueling, the ABWR design relies on duplex filters and strainers between the storage tank and the day tank and at the fuel oil pump suction to remove any sediment. The SSAR suggests that refueling would probably occur while the day tank is full, which would allow time for sediment to settle before fuel is transferred from the storage tank to the day tank.

In the DSER (SECY-91-355), the staff stated that refueling procedures should be established as an interface requirement to verify that the day tank is full before refilling the storage tank, thereby minimizing the likelihood of sediment obstruction of fuel lines and any deleterious effects on diesel generator operation. This was identified as DSER Open Item 84. Upon further evaluation, the staff determined that this requirement can be accomplished by adding a COL action item requiring these procedures. As a result, this interface was reclassified as DFSER COL Action Item 9.5.4.2-2. GE included this information in the SSAR, which is acceptable.

GE described a program to ensure that the diesel fuel oil is tested and maintained according to the appropriate ASTM and ANSI requirements. Fuel oil is to be sampled and tested monthly for quality and contaminants. New fuel will be visually inspected before being added to the storage tank, and will be analyzed within 2 weeks for other required properties. Fuel oil not meeting all requirements will be replaced within a week. The system will be tested as part of the required diesel generator tests and hydrostatically tested before startup. Each fuel storage tank will be tested to ASME requirements every 10 years. The system design fuel oil quality and tests meet the requirements of RG 1.137. Based on the above information, the staff concludes that the FOST meets the requirements of GDC 17.

The design of the FOST system will meet the requirements of GDC 17, as related to the capability of the fuel oil system to meet independence and redundancy requirements, RG 1.9 and RG 1.137. As discussed in Section 9.5.4.1 of this report, this auxiliary system also meets the requirements of GDC 2, 4, and 5 and will incorporate the recommendations of NUREG/CR-0660. The system will also incorporate appropriate industry standards, i.e., ANSI N195-1976 and IEEE Standard 387.
Therefore, the staff concludes that the diesel generator fuel oil storage and transfer system meets the guidelines of SRP 9.5.4 and is acceptable.

\subsubsection{Diesel Generator Cooling Water Systen}

The staff reviewed the DGCW system in accordance with the GDC in SRP Section 9.5.5.

The function of the diesel generator cooling water system is to maintain the temperature of the diesel engine within a safe operation range under all load conditions and to maintain the engine coolant preheated during standby conditions. The system should be designed to meet the requirements of GDC 2 (protection against natural phenomena), GDC 4 (protection from environmental and dynamic effects of equipment failure), GDC 5 (sharing of structures, systems, and components between units), GDC 17 (availability of electric power systems), GDC 45 (inspection of cooling systems), and GDC 46 (testing of cooling systems). The ability of the ABWR diesel generator cooling water system to meet GDC 2, 4, and 5 is discussed in Section 9.5.4.1 of this report.

The DGCW system is a closed-loop system that cools the engine-jacket water, lube oil, and combustion air. The major components of this system include a jacket water heat exchanger, lube oil heat exchanger, combustion air heat exchangers (air intercooler and exhaust manifold), an expansion tank, two jacket water circulating pumps, an electric immersion heater, ' a jacket water keep-warm system, a three-way temperature control valve, and the required controls, alarms, instrumentation, piping, and valves. Heat generated during diesel generator operation is rejected to the RCW system through the jacket-water heat exchanger. All system piping and components are designated ASME Code Section III, Class 3, designed to seismic Category I requirements, and will be procured according to the requirements of 10 CFR Part 50, Appendix B.

The ABWR design includes three standby diesel generators, each having a physically separate and independent engine cooling water division, as described in the preceding paragraph. Each cooling water division is powered from the respective diesel generator's safety-related Class 1E motor-control center. Therefore, the system meets the redundancy and single-failure criteria requirements of GDC 17.

During operation of the diesel generators, the temperature of the diesel engine cooling water is regulated by three-way temperature control valves. When the standby diesel generators are idle, the cooling water is heated by an 
electric heater and maintained at $49^{\circ} \mathrm{C}\left(120^{\circ} \mathrm{F}\right)$, assuming ambient temperature of $16^{\circ} \mathrm{C}\left(60^{\circ} \mathrm{F}\right)$.

In the DSER (SECY-91-355), the staff stated that GE established interface requirements for specific information on the design and capability of the cooling water system and the keep-warm system including the following:

jacket-water circulating pump characteristics (NPSH and motive-power source, i.e., shaft, engine, otc.)

(2) the keep-warm system description (design may or may not include a keep-warm pump)

(3) temperature sensor selection (Amot-type or equivalent)

(4) heat removal capability of system (to be based on maximum permissible diesel engine overload output)

expansion tank size

(6) expected water loss over 7-day period and system volume capacity needed to ensure adequate volume is available to maintain system water level and pump NPSH without refill.

These requirements were identified as DFSER Open Item 9.5.5-1. Upon further evaluation, the staff determined that these requirements do not meet the definition of interface requirements implied in 10 CFR Part 52 and can be accomplished by adding a COL action item in the SSAR requiring the COL applicant referencing the ABWR design to submit this information. GE included this information in the SSAR, which is acceptable. This resolved DFSER Open Item 9.5.5-1.

In the DSER (SECY-91-355), the staff discussed a discrepancy between the text of SSAR Section 9.5.5 and Figure 9.5-7 regarding the circulating water pump. Section 9.5.5 described the jacket-circulating water pumps as engine- and motor-driven while Figure 9.5-7 described both as being motor-driven. (This discrepancy was considered part of DSER Open Item 85.) Additionally, the interface criteria of Section 9.5.13.6 stated that the selection of the motive power for these pumps was an interface requirement. This disagreed with the text of Section 9.5.5 and Figure 9.5-7, which clearly specified motive power for the pumps, although in an inconsistent manner. (This was the other part of DSER Open Item 85.) GE committed to submit consistent information regarding the power source for the jacket-cooling water pumps. The references to specific power sources were to be removed, and the selection of the power supply was to be incorporated as DFSER COL Action Item 9.5.5-1. These changes resolve DSER Open Item 85; however, incorporation of these changes into the SSAR was identified as DFSER Confirmatory Item 9.5.5-1. The staff reviewed Amendment 23 of the SSAR and concludes that the modification to Section 9.5.13.6, requiring the $\mathrm{COL}$ applicant to submit information on the motive power for the cooling water pumps, is acceptable. Therefore, Confirmatory Item 9.5.5-1 is resolved.

The interface criteria for selecting this valve did not specify an Amot-type or equivalent valve. The staff concluded in DSER (SECY-91-355) Open Item 86 that GE should include this selection information as DFSER COL Action Item 9.5.5-1 for temperature sensor selection. GE committed to incorporate the reference to an Amot-type temperature sensor, or equivalent into the SSAR. Therefore, DSER Open Item 86 was resolved. However, incorporation of this reference into the SSAR was identified as Confirmatory Item 9.5.5-2 in the DFSER. The staff reviewed Amendment 23 of the SSAR and concludes that the modification to Section 9.5.13.6, requiring the COL applicant to submit an Amot-type temperature sensor or its equivalent, 'is acceptable. Therefore, Confirmatory Item $\mathbf{9 . 5 . 5 - 2}$ is resolved.

The SSAR states that the diesel engine has the capability to operate at full load for 2 minutes without secondary cooling. This will ensure that the diesel engine can operate at full load in excess of the time required to restore cooling water (RSW and RCW), which are sequenced onto the emergency power supply within 1 minute after a LOPP.

The DGCW system conforms with RG 1.9 for engine cooling water protective interlocks. All trips are bypassed during LOCA conditions except low cooling water pressure and low differential pressure of secondary cooling water. Both of these trips are 2-out-of-2 logic trips (the diesel generator system protective interlocks are discussed in Section 8.3.3.7 of this report). The cooling water system is provided with an expansion tank and expansion tank vent line, both of which are to be located above the system piping and pump location. A static head will ensure that the pumps and piping are filled with water. On the basis of the discussion for resolution of DSER (SECY-91-355) Open Items 85 and 86, the system meets the requirements of GDC 44 regarding the provision for cooling systems.

The SSAR includes a commitment that the operating procedures for the diesel generator will require the loading of the engine up to a minimum of 40-percent of full load (or lower as specified in the manufacturer's recommendation) for 1 hour after up to 8 hours of 
continuous no-loed or light-load operation. Such no-load or light-load conditions would exist for a LOCA with offsite power available. Procedures including this criterion will specifically meet the guidance listed in Item III.7 of SRP Section 9.5.5.

The components of the diesel engine cooling water system can be periodically inspected through surveillance testing and monitoring instrumentation for pressure, temperature, and level. The system cooling water would be analyzed periodically to ensure that adequate quality is maintained. The diesel generator would be tested in accordance with the requirements of RG 1.108. These commitments meet the inspection and functional tosting requirements in GDC 45 and 46.

The design criteria and bases for the DGCW system will conform to GDC 17 and 44 for redundancy, physical independence, and cooling capability, and GDC 45 and 46 for inspection and testability of the system. As stated in Section 9.5.4.1 of this report, the design meets the requirements of GDC 2, 4, and 5, for the protection of equipment from environmental and dynamic effects and sharing of system components. In addition, GE has provided adequate guidance for an applicant referencing the ABWR design to iensure compliance with the recommendations of NUREG/CR-0660. The system meets the requirements of GDC 45 and 46 for inspection and testability. The design of the DGCW system will meet the requirements of GDC $\mathbf{4 4}$ for system operability. Therefore, the staff concludes that the system design meets the guidelines as specified above of SRP Section 9.5.5 and is acceptable.

\subsubsection{Diesel Generator Starting Air System}

The staff reviewed the DGCA system in accordance with SRP Section 9.5.6.

The design function of the DGSA system is to provide a supply of compressed air for starting the emergency diesel generator engines without external power. The air storage system is to perform its function in a manner that ensures that the time interval between a diesel engine start signal and a "ready-to-load" status is less than 20 seconds. The system is to be designed to meet the requirements of GDC 2 (protection from natural phenomena), GDC 4 (protection from the environmental and dynamic effects of equipment failure), GDC 5 (sharing of SSCs between units), and GDC 17 (availability of electric power systems). Compliance with the requirements of GDC 2, 4 , and 5 is discussed in Section 9.5.4.1 of this report.

The ABWR design includes three emergency diesel generators, each of which has its own starting air division, separate and independent of the starting air divisions for the other two diesel generators. Each starting air division consists of two 100-percent capacity sections, each of which is capable of supplying sufficient air for five automatic or manual start attempts without recharging the air-receiver tanks. Each starting air division consists of two air-compressors, two air-receivers, four air-admission valves (two redundant air-admission valves on each of two engine starting air manifolds), and associated piping and valves to connect system components.

One division of the DGSA system consists of two compressors and two air receivers. Controls are provided to automatically start and stop each air compressor to maintain the required pressure in each air receiver. Each compressor can be manually started to restore pressure in the air-receivers if needed. Each division is equipped with an air-receiver low-pressure alarm, which is indicated locally and displayed in the control room as part of a diesel generator trouble alarm. Each receiver is also equipped with a blowdown connection, which would be used periodically to manually blow down the receiver to remove any accumulated water from the tank.

In Amendment 16 of the SSAR, GE responded to Q430.285, stating that each air-dryer system includes an air dryer equipped with pre-filters and after- filters. SSAR Figure 9.5-8 did not specifically identify pre-filters and after-filters for the air dryers. Addition of these filters to the P\&ID (or a statement specifically identifying the filters as an integral part of the air-dryer component) was identified as DSER (SECY-91-355) Open Item 88. GE committed to revise SSAR Figure 9.5-8 to incorporate the pre- and after-filters into the design. This modification resolved DSER Open Item 88. However, incorporation of the modification into the SSAR was identified as DFSER Confirmatory Item 9.5.6-1. Subsequently, the staff reviewed Amendment 25 of the SSAR and concluded that the addition of note 4 on Figure 9.5-8 clarified the provisions for pre- and after-filters on the air dryers. Therefore, Confirmatory Item $\mathbf{9 . 5 . 6 - 1}$ is resolved.

Each diesel generator is completely separate and independent of the others so that a malfunction or failure in one starting air division does not impair the starting capability of the other diesel generators. Therefore, the design meets the independence and redundancy requirements of GDC 17.

GE identified several design parameters as future interface requirements to be determined once a diesel generator vendor has been selected. Interface requirements to be specified included the devices to crank the engine, the duration of the cranking cycle, and the number of engine revolutions per start attempt. These interface requirements 
would dictate design parameters such as the volume and design pressure of the air receivers (sufficient for five start cycles for each receiver) and compressor size (sufficient discharge flow to recharge the system in under 30 minutes). Once established, these interface criteria would provide an adequate basis for selecting component capacities. This was identified as DSER (SECY-91-355) Open Item 89 and incorporation of this information into the SSAR was identified as DFSER Confirmatory Item 9.5.6-2. Upon further evaluation, the staff hes determined that this requirement can be sccomplished by including a COL action item in the SSAR requiring the COL applicant to submit this information. GE included this information in the SSAR. Therefore, DSER Open Item 89 and DFSER Confirmatory Item 9.5.6-2 are resolved.

The air compressor's air-storage tanks, valves, and piping (up to the first connection on the engine skid) are designed in accordance with the requirements of ASME Code Section III, Class 3, requirements and are seismic Category I.

The DGSA system description did not incluble a reference to coolers at the discharge of the air compressors, although SSAR Figure 9.5-8 includes after-coolers located downstream of the starting air compressors. This discrepancy was identified as DSER (SECY-91-355) Open Item 90. GE committed to incorporate the coolers into the description of the starting air system. This modification resolved DSER Open Item 90; however, incorporation of the modifications into the SSAR was identified as DFSER Confirmatory Item 9.5.6-3. The staff reviewed Amendment 23 of the SSAR and concluded that Section 9.5.6.2 contained the required information regarding the coolers. The staff reviewed Figure 9.5-8 (Amendment 25 of the SSAR) and concluded that the aftercoolers were adequately identified. The staff finds the SSAR modifications acceptable. Therefore, Confirmatory Item 9.5.6-3 is resolved.

The SSAR states that the starting air quality complies with the diesel engine manufacturer's recommendation regarding dew point, as opposed to the requirements stated in SRP Section 9.5.6 II.4.j. The staff will determine whether the system's air quality complies with SRP Section 9.5.6.II.4.j on a plant-specific basis.

Based on the above review, the staff concludes that the DGSA system meets the requirements of GDC 17 as it W) Nates to the availability of electric power. As discussed in Section 9.5.4.1 of this report, this auxiliary system also meets the requirements of GDC 2, 4, and 5 and will incorporate the recommendations of NUREG/CR-0660.
The system, therefore, moets the guidelines of SRP 9.5.6 and is accoptable.

\subsubsection{Diesel Generator Lubrication System}

The design afety function of the DGLS system is to provide a supply of filtered 'lubrication oil to the various moving parts of the diesel engine (including pistons and bearings) during engine operation and during periods of standby to enhance first-try-start reliability. The basis for acceptance in the reviow was conformance of the design to GDC 17, regarding redundancy and physical independence, and the guidance and additional acceptance criteria of SRP 9.5.7. The staff discusses the ability of the system design to meet the requirements of GDC 2 (protection from natural phenomena), GDC 4 (protection from environmental and dynamic effects of equipment failure), and GDC 5 (sharing of SSCs between units) and the recommendations of NUREG/CR-0660 in Section 9.5.4.1 of this report.

The major components of the lubrication system include the engine lube oil pump (within the engine frame), an engine-driven pump, an oil cooler, a generator shaft lube oil cooler, an electric lube oil heater, a keep-warm circulating pump, oil filter, and strainer. Local alarms signal low oil pressure, high oil temperature, and low oil level. These signals are part of a general diesel generator trouble alarm located in the control room. The low lubrication oil level alarm is identified in SSAR Table 8.3-5, and refill is described in SSAR Section 9.5.7 as being performed on indication of low level (a lube oil supply pump actuates on a low level indication in the engine sump). In DSER (SECY-91-355) Open Item 91, the staff stated that SSAR Figure 9.5-9 did not show any level indication for the lube oil system. GE committed to correct the figure to include the level instrumentation, which had been mistakenly identified as a flow transmitter. This correction resolved DSER Open Item 91; however, incorporation of the modifications into the SSAR was identified as DFSEK Confirmatory Item 9.5.7-1. GE supplied the revised figure in SSAR Amendment 25. The staff finds the revised figure acceptable. Therefore, Confirmatory Item $9.5 .7-1$ is resolved.

Each of the DGLS divisions is completely independent of the other divisions and is dedicated to the support of a single diesel generator. A malfunction in a DGLS division will not impair the operational capability of the remaining lubrication divisions or diesel generators. This meets the requirements of GDC 17 for system independence and the single-failure criteria.

The system is designed to provide sufficient lubricating oil to support full-load diesel operation for 7 days. 
In DSER (SECY-91-355) Open Item 92, the staff requested that GE submit the following specific design criteria: pump flows, operating pressure, tomperature differentials, cooling system heat removal capabilities and electric heater characteristics for the DGLS. GE stated that the "lubrication systom design criteria will be furnished as an interface criteria after selection of the diesel vendor is finalized." Upon further svaluation, the etaff determined that this requirement can bo accomplishod by identifying a COL action item in the SSAR requiring the COL applicant to submit this information. As a result, the interface was reclassified as DFSER COL Action Item 9.5.7-1. The staff reviewed Amendment 23 of the SSAR (Section 9.5.13.5) and concludes that the COL action item would ensure that the COL applicant submits the required information. GE included this COL action item in the SSAR. This is acceptable.

GE stated that the protective features to prevent crankcase explosions and features to mitigate the consequences of such an event (such as relief ports) are vendor specific and would also be included as interface criteria after $a$ diesel engine vendor is selected. The diesel generator would be protected from crankcase explosions by activating vacuum blowers to maintain the crankcase at negative pressure and shutting down the diesel on high-pressure conditions (unless a LOCA signal is present). Inclusion of these design criteria was identified as Open Item 92 in the DSER (SECY-91-355). GE committed to incorporate the above system design characteristics into the SSAR for use when the diesel vendor is selected. This information was to be incorporated into Section 9.5.8 of the SSAR and resolved DSER Open Item 92. Incorporation of the modifications into the SSAR was identified as DFSER Confirmatory Item 9.5.7-2. Upon further evaluation, the staff determined that these requirements should be included in the system design. GE modified SSAR Section 9.5.8 (Section 9.5.8.2) and Table 8.3-5 to include these design features. Therefore, Confirmatory Item 9.5.7-2 is resolved.

The DGLS is designed to maintain lubrication oil temperature and circulate heated lubrication oil under pressure to the moving parts of the diesel engine while the engine is in the standby mode. A lube oil priming pump will operate intermittently to keep the lube oil piping pressurized. This same pump is used in conjunction with the lube oil heater to maintain system temperature. On low lube oil temperature, both the heater and priming pump will automatically start thereby circulating heated oil throughout the system. The priming pump discharge pressure switch is Class 1E. Based on the above information, the staff concludes that the DGLS conforms to the recommendations of NUREG/CR-0660, for enhancing the starting reliability of the diesel engine.
All DGLS piping and components will be designed in accordance with ASME Code Section III, Class 3, requirements or ANSI B31.1 guidance and will be seismic Category I. GE did not designate the diesel engine interface for the lubrication system because the diesel engine is vendor-specific. Therefore, the components to be designated to meet ASME Code requirements, have not been separated from those required to meet the ANSI standard. To moet NRC requirements, all components up to the diesel engine interface must meet the ASME Code requirements. The NRC staff has accepted the ANSI classification for engine-mounted components if they are pressure tested to 1.5 times design pressure and the test is documented. Recognizing that the keep-warr? heater and the priming pump do not have to be nuclear safety grade, the staff identified classification of components in the lubrication system as Open Item 93 in the DSER (SECY-91-355). The staff established Open Item 94 to have GE clarify which components meet the ASME Code requirements and which meet the ANSI requirements with the pressure testing provision. GE committed to revise the response to RAI 430.271 to clearly state which components are to meet the ASME Code requirements and which are to meet the ANSI requirements. Engine-mounted components are to be designed to the ANSI standards, all others, except the keep warm-heater and the priming pump, are to meet the ASME standard. The proposed modification resolved DSER Open Items 93 and 94; however, incorporation of the changes into the SSAR was identified as DFSER Confirmatory Item 9.5.7-3. The staff reviewed the revised response to RAI 430.271 in Amendment 22 of the SSAR and the revisions to Figure 9.5-9 in Amendment 25 of the SSAR. The staff found that the modifications to the RAI and the figure clearly state which components are to meet the ASME Code requirements and which are to meet the ANSI requirements. Therefore, Confirmatory Item $9.5 .7-3$ is resolved.

The DGLS conforms to RG 1.9 for the protective interlocks for the diesel engine lubrication system. All trips associated with the lubrication system are bypassed during LOCA conditions. The diesel generator system protective interlocks are discussed in Section 8.3 of this report.

The quality of the lubrication oil is maintained through periodic sampling and analysis of the lubrication oil. Access to the lubrication system is controlled. The system is located in locked diesel generator rooms, thereby limiting the possibility of contamination.

The staff concludes that the design of the DGLS meets GDC 2 (protection from natural phenomena), GDC 4 (protection from environmental and dynamic effects of equipment failure), and GDC 17 (availability of electric 
power), the guidelines of SRP Section 9.5.7, and the recommendations of NUREG/CR-0660 (GDC 5 does not apply to the ABWR design because it is a single-unit design). The DGLS design, therefore, is acceptable.

\subsubsection{Diesel Generator Combustion Air Intake and Exhaust System}

The design function of the DGCA system is to supply filtered air for combustion to the engine and to dispose of the engine exhaust to the atmosphere. Acceptance is based on conformance of the design to GDC 17, regarding redundancy and physical independence, the guidelines of SRP Section 9.5.8, the recommendations of NUREG/CR- 0660 , and industry codes and standards. The staff also assessed the ability of the system to supply sufficient combustion air and release sufficient exhaust gases to enable the emergency diesel generate: to perform on demand. The compliance of the system design with the requirements of GDC 2 (protection from natural phenomena), GDC 4 (protection from environmental and dynamic effects of equipment failure), and GDC 5 (sharing of SSCs between units) is discussed in Section 9.5.4.1 of this report.

Combustion air for each diesel generator is taken from the associated inlet air cubicle above the diesel generator room through floor grates into the combustion air inlet plenum, duct work, intake silencer, turbocharger and air intercooler. The exhaust gas passes through the turbocharger and the exhaust ducting to the exhaust silencer located on the roof of the reactor building. Each of the three diesel generators is provided with a separate and independent combustion air intake and exhaust division. There are no active components (such as louvers) that can fail and obstruct the inlet or outlet air flow paths. Thus, the system's independence, redundancy, and single- failure criteria meet the requirements of GDC 17. System design air flow capacity has not been specified in the SSAR. As with the other diesel generator auxiliary systems, this design characteristic will be dependent on selection of a diesel generator vendor.

The staff designated selection of a combustion air flow capacity sufficient to ensure complete combustion as an interface requirement and as Open Item 95 in the DSER (SECY-91-355). Upon further evaluation, the staff determined that this requirement can be accomplished by including a COL action item in the SSAR requiring the COL applicant to submit this information. The interface was reclassified as DFSER COL Action Item 9.5.8-1. GE included this information in the SSAR, which is acceptable.
The DGCA meets the guidelines of RG 1.9, Revision 3 (July 1993) as it relates to system protective interlocks. All DGCA piping and components are designed to seismic Category I and ASME Code Section III, Class 3, requirements. Engine-mounted piping and components beyond the engine interface are considered part of the engine assembly and are seismic Category I as part of the diesel engine package.

The combustion air intakes are located on the side of the reactor building and are protected (by vertical grills) from tornado missiles. The intakes are located $11.5 \mathrm{~m} \mathrm{(37.7} \mathrm{ft)}$ above grade and are designed to minimize any effects from dust and debris through the use of vertical grills set into the reactor building wall with filters located behind the grills. The intakes are protected from flooding by their location.

The diesel generator exhausts are partly housed within the reactor building with the exhaust silencer located on the roof of the reactor building. The design basis for the silencer requires that it be seismically qualified and able to withstand the effects of tomados. In DSER (SECY-91-355) Open Item 96, the staff stated that the means of protection from tornado missiles had not been adequately discussed. GE committed to update the SSAR to state that the silencers are seismically mounted and bolted in a horizontal position. However, this design change did not adequately address protection of the silencers from tornado missiles. Therefore, this issue was identified as DFSER Open Item 9.5.8-1. In SSAR Section 9.5.8, GE committed to house the system in a seismic Category I structure to protect against tornado-missiles. This resolved DSER Open Item 96; however, confirmation that the SSAR had been updated was identified as DFSER Confirmatory Item 9.5.8-1. The staff concluded that the system complies with GDC 4, RG 1.115, Revision 1 (July 1977) and RG 1.117, Revision 1 (April 1978) and the recommendations of NUREG/CR-0660. The staff reviewed Amendment 26 of the SSAR, which clarified that all parts of the system, except for the silencers, are housed in a seismic Category I structure (the reactor building). The exhaust silencers are seismically mounted and bolted down horizontally. Therefore, the silencers are unlikely to become missiles. The silencers are widely spaced around the top of the building so that it is unlikely that a single missile could damage more than one division of the system. A damaged silencer will not prevent a diesel from performing its safety function unless debris clogs the exhaust pipe. In such a case, the other divisions will be relied on to perform the safety function. The staff finds the additional information sufficient to conclude that the design includes adequate protection for the intake and exhaust system. Therefore, DFSER Open Item 9.5.8-1 and DFSER Confirmatory Item 9.5.8-1 are resolved. 


\section{Auxiliary Systems}

Combuation air is not taken from the diesel generator room. Instead, combustion air and ventilation air enter the reactor building through common filters into the air inlet cubicle. Before the air enters the diesel geperator room, it enters separate inlet plenums for ventilation and combustion. This design complies with NUREG/CR-0660 for combustion air and dust and dirt control in the portion of the reactor building housing the diesel generntors.

The SSAR did not deecribe the design of the portion of the DGCA which extends from the crankcase vacuum blowers to the outside eavironment. DSER Open Item 97 (SECY-91-355) requested additional information regarding this area, identified in SSAR Figure 9.5-6. GE committed to modify the response to RAI 430.294 to state that this part of the system consists of piping only. This information resolved DSER Open Item 97; however, incorporation of the modification into the SSAR was identified as DFSER Confirmatory Item 9.5.8-2. The ataff reviewed Amendment 26 of the SSAR. Amendment 26 contained the modified response to RAI 430.294 stating that the gases are exhausted through a $150 \mathrm{~mm}$ (6-in.) pipo which passes through the reactor building wall. This additional information, along with Figure 9.5-6, adequately addreseses the staff's concern. Therefore, this confirmatory item is resolved.

Based on the above review, the staff concludes that the DGCA system meets the requirements of GDC 17 as it relates to the availability of electric power. As discussed in Section 9.5.4.1 of this report, this auxiliary system also meets the requirements of GDC 2, 4, and 5 and will incorporate the recommendations of NUREG/CR-0660. The system, therefore, meets the guidelines of SRP 9.5.8 and is acceptable. 


\section{STEAM AND POWER CONVERSION SYSTEM}

\subsection{Summary Description}

The stean and power conversion system is designed to remove heat energy from the reactor and to generate electric power in the turbine generator. After the steam passes through the high- and low-pressure turbines, the main condensers (MCs) will condense and deserate the low-pressure turbine exhaust and transfer the rejected heat to the circulating water system, which, in turn, will reject the heat to the power cycle heat sink (PCHS). The condensate will be reheated and returned as feedwater to the reactor. The entire system is designed for the maximum expected energy from the nuclear steam supply system. GE states in SSAR Section 10.1 that nothing in the ABWR stendard plant design is meant to preclude the use of a once-through cooling system and a single pressure condenser nor will such changes affect the nuclear island.

A turbine steam bypass system is designed to discharge at least 33-percent of the reactor's design steam flow directly to the condenser during certain transient conditions. $\mathbf{G E}$ states that although the ABWR standard plant design is for 33-percent bypass, this capability could be increased to a full-load reject capability without affecting the nuclear island.

\subsection{Turbine Generator}

\subsubsection{Turbine Generator System}

The staff reviewed the turbine generator system (TGS) in accordance with Standard Review Plan (SRP) Section 10.2. The design of a TGS is acceptable if the integrated design meets the requirement of General Design Criteria (GDC) 4 as to protect structures, systems, and components (SSC) important to safety from the effects of turbine missiles by providing a turbine overspeed protection system to minimize the probability of generating turbine ruissiles.

The $188.5 \mathrm{rad} / \mathrm{s}$ (1800-rpm) turbine generator unit will be a compound-type unit with one double-flow high-pressure turbine and three double-flow low-pressure turbines, in tandem, coupled directly to a generator with a nominal rating of approximately $1400 \mathrm{Mwe}$. Each low-pressure turbine will exhaust to a multi-pressure three-shell, singlepass surface condenser.

The turbine generator is equipped with an electrohydraulic control system that will perform two basic functions: (1) turbine speed control for a variety of operating load conditions for which digital control and monitoring system will be used and (2) turbine overspeed protection. The design functions of the turbine speed control system are (1) to control turbine speed throughout the normal range of load conditions and ensure that a full-load turbine trip will not cause the turbine to overspeed beyond its design overspeed and (2) to provide turbine overspeed protection to minimize the probability of the generation of turbine missiles, in accordance with GDC 4. The turbine control system is, therefore, important to the overall safe operation of the plant.

The turbine is equipped with four turbine stop valves, four turbine control valves, and six combined intermediate valves collectively referred to as turbine steam admission valves. The turbine stop valves and turbine control valves are located upstream of the high pressure turbine steam inlet. The combined intermediate valves are located between the moisture separators and the steam inlets to the three low-pressure turbines. The combined intermediate valves consist of an intermediate stop valve and an intercept valve in a single casing; each will have separate operating mechanisms and controls. The turbine stop valves and the intermediate stop valves will be in the fullopen position during normal operation. The control valves are designed to modulate with load on the turbine generator. The intercept valves will modulate, as required, to control turbine speed following a load rejection. All of these valves will be capable of closing in approximately 0.2 second.

The speed control unit is designed to provide speed error signals to a load control unit. These signals, in turn, will operate to open or close the valve, as required, to maintain desired turbine steam flow. In the case of a generator load rejection up to and including full load followed by an increase in turbine speed, the speed-control unit will close both the control and intercept valves to limit turbine overspeed as follows: (1) the control and intercept valves will start to close at approximately 101 percent of rated $s_{i}$ eed and (2) the control and intercept valves will be fully closed by the time the turbine reaches approximately 104 percent of rated speed.

The turbine overspeed protection system will consist of mechanical and electrical overspeed control systems. At a predetermined speed (110 percent of rated speed), centrifugal force causes the loss of hydraulic pressure to the associated turbine steam admission valve actuators, thus closing the turbine steam admission valves. The electrical overspeed trip system will back up the mechanical overspeed trip. At a predetermined speed (111 percent of rated speed), solenoids will be deenergized. This, in turn, will actuate the electrical trip valve to release hydraulic pressure to the associated turbine steam admission valve actuators, thus closing the turbine steam admission valves.

Protection of safety-related SSC from turbine generator missiles is also assured by proper turbine-generator 
orientation. This is discussed in SSAR Section 3.5.1.1.3 and reviewed in Section 3.5.1.3 of this report.

A number of turbine generator electrical and mechanical parameters will be monitored during operation. An abnormal condition, as described in SSAR Section 10.2.2.5, in these monitored parameters will also cause a trip of turbine main stop and control valves, and combined intermediate valves by way of their disk/pump valves. These emergency trips will further reduce the possibility of a turbine missile by shutting down the turbine before overspeed or mechanical failures can occur. Some parameters that will be monitored include turbine shaft, vibration, various temperatures and fluid levels, condenser vacuum, EHC electrical power, lube oil and hydraulic pressure, generator trip, electrical and mechanical overspeed, and thrust bearing wear. All of the above trip signals excopt vibration ( 2 out of 2 per bearing) and manual trips use 2 out of 3 or 2 out of 4 coincident trip logic.

The turbine steam admission valves can be manually tripped and will automatically trip on lors of power to the hydraulic and control systems, or on lisss of both speed control signals.

An inservice inspection (ISI) program for the turbine stop and control valves and combined intermediate valves will be provided and will include: (1) dismantling and inspecting at least one turbine stop valve, one turbine control valve, one stop valve, and one intercept valve at approximately $3 \mathrm{k} / \mathrm{y}$-year intesvals during refueling or maintenance shutdowns coinciding with the ISI schedule and (2) testing the turbine stop valves, the control valves, the combined intermediate valves and the extraction steam nonreturn valves at least once a week. At least once per month, closure of each turbine stop valve, control valve, and combined intermediate valve will be verified by direct observation of the valve motion. GE has included preoperational and startup tests of the turbine generator in accordance with Regulatory Guide (RG) 1.68, "Initial Test Programs for Water-Cooled Power Plants," (Rev. 2). Testing is discussed in Section 10.2.3.6 of the SSAR. The adequacy of the test program is evaluated in Section 14.2 of this report.

GE has committed to provide turbine generator equipment shielding and access control for all areas of the turbine building (TB) that will meet the dose criteria required by 10 CFR Part 20 for operating personnel. This subject is evaluated in the discussion of the radiation protection design acceptance criteria (DAC) in Chapter 12 of this report.
The turbine generator system meets Branch Technical Positions Auxiliary Systems Branch (ASB) 3-1, "Protection Against Postulated Piping Failures in Fluid Systems Outside Containment, " and Mechanical Engineering Branch (MEB) 3-1, "Postulated Break and Leakage Locations in Fluid Systems Outside Containment." Evaluation of protection against dynamic effects associated with a postulated pipe failure is covered in Section 3.6 of this report.

GE submitted the design description and the inspections, tests, analyses, and acceptance criteria relating to the TGS. This was identified as draft final safety evaluation report (DFSER) Open Item 10.2.1-1. GE provided a revised set of design descriptions and ITAAC. The adequacy and acceptability of the final certified advanced boiling water reactor (ABWR) design description and the ITAAC are evaluated in Section 14.3 of this report. On the basis of this evaluation, this item is resolved.

The TGS includes all components and equipment, including the turbine stop and control valves and the combined intermediate valves. The scope of the review of the TGS for the ABWR included layout drawings, piping and instrumentation diagrams (P\&IDs), and descriptive information for the system and for control and supporting systems that are essential to its operation.

The basis for acceptance of the TGS was conformance of the design, design criteria, and design bases to the Commission's regulations as set forth in the GDC of Appendix A to 10 CFR Part 50. The staff concludes that the design is acceptable and meets the requirements of GDC 4 with respect to the protection of SSC important to safety from the effects of turbine missiles. GE has met this requirement by providing a turbine overspeed protection system to control the turbine action under all operating conditions and to ensure that a full-load turbine trip will not cause the turbine to overspeed beyond acceptable limits and will not result in turbine missiles.

The staff concludes that the TGS can perform its design function, meets the guidelines of SRP Section 10.2, and is acceptable.

\subsubsection{Turbine Rotor Integrity}

GDC 4 requires that structures, systems, and components important to safety shall be appropriately protected against environmental and dynamic effects, including the effects of missiles, that may result from equipment failure. Because turbine rotors have large masses and rotate at relatively high speeds during normal reactor operation, failure of a rotor may result in the generation of high energy missiles and cause excessive vibration of the turbine rotor 
assembly. The staff reviewed the measures taken by the applicant to assure turbine rotor integrity and reduce the probability of turbine rotor failure.

The staff utilized the guidelines of SRP Section 10.2.3 to roviow and evaluate the information submitted by the applicant to assure rotor integrity and low probability of turbine rotor failure with the generation of missiles.

As discussed in SSAR Section 10.2.3, turbine rotors and parts will be made from vacuum-melted or vacuumdegassed Ni-Cr-Mo-V alloy steel by processes that minimize flaw occurrence and provide adequate fracture toughness. The fracture appearance transition temperature (FATT) (50 percent FATT), as obtained from Charpy tests, will be no higher than $-17.8^{\circ} \mathrm{C}\left(0^{\circ} \mathrm{F}\right)$ for lowpressure turbine rotors. The Charpy V-notch energy at the minimum operating temperature of low-pressure rotors in the tangential direction will be at least $8.3 \mathrm{kgm}$ ( $60 \mathrm{ft}-\mathrm{lbs})$.

The ratio of fracture toughness $\left(\mathrm{K}_{\mathrm{IC}}\right)$ of the rotor material to the maximum tangential stress at speeds from normal to 115 percent of rated speed will be at least 10 square root millimeters ( $2 \mathrm{ksi}$ square root in.). However, $\mathrm{K}_{\mathrm{IC}}$ will be used only for materials that exhibit a well-defined Charpy energy and FATT curve and are strain-rate insensitive.

In the DFSER the staff stated that the applicant or a licensee referencing the ABWR standard plant design should submit the turbine rotor test data and the calculated toughness curve to the NRC staff for review. This requirement should be included in the turbine ITAAC and was identified as DSFER Open Item 10.2.2-1. The staff, upon further consideration, reclassified this as a $\mathrm{COL}$ action item. GE addressed this item in the SSAR which states the COL applicant will provide turbine inservice test and inspection requirements to the staff for review. This is acceptable to the staff and therefore, Open Item 10.2.2-1 is resolved.

Sufficient warmup time and adequate metal temperature is to be specified by the COL applicant in the turbine operating instruction to ensure that toughness will be adequate to prevent brittle fracture during startup. This was identified as DFSER COL Action Item 10.2.2-1. GE addressed this item in SSAR Section 10.2.5, which states that the COL applicant will provide the turbine material property data and assure sufficient turbine warmup time as required by Subsection 10.2.3.2 of the ABWR SSAR.

The combined stresses of low low-pressure turbine rotor at design overspeed resulting from centrifugal forces, interference fit, and thermal gradients will not exceed 75 percent of the minimum specified yield strength of the material. The design overspeed of the turbine will be
5 percent above the highest anticipated speed resulting from a loss of load. In the DFSER, the staff stated that the applicant or licensee referencing the ABWR standard plant design should provide the basis for the turbine design overspeed to the NRC. This requirement should be included in the turbine ITAAC and was identified as DFSER Open Itom 10.2.2-2. The staff, upon further consideration, reclassified this as a COL action item. GE addreased this item in the SSAR Section 10.2.5, which states that the COL applicant will provide the basis for the turbine overspeed design to the staff for review. This is acceptable to the staff and therefore, Open Item 10.2.2-2 is resolved.

The ABWR ISI for the turbine assembly will include the high- and low-pressure turbine rotor, low-pressure turbine buckets, turbine shafts, couplings, and coupling bolts. During plant shutdown, coinciding with the ISI schedule for ASME Code, Section III components, turbine inspection will be performed in sections so that a complete turbine inspection will be performed at least once every 10 years. The low-pressure turbines in curreatly operating nuclear plants are inspected on an average of once every 5 operating years. However, most of these turbines are of shrunk-on design, which is more susceptible to stress corrosion cracking than the forged monoblock rotor in the ABWR turbine. Thus, the extended inspection interval for the ABWR is acceptable.

The turbine rotor design will be a solid forged monoblock rotor rather than one with shrunk-on disks. The current practice employed by the turbine manufacturers is to bore the center of the monoblock rotor to remove metal impurity and permit internal inspection. A forged or welded rotor will not be as susceptible to stress corrosion cracking as experienced in the shrunk-on disks. However, the one-piece rotor design requires stringent partmachining inspections. Therefore, the applicant referencing the ABWR design must submit inspection requirements for one-piece rotor to the NRC staff for review and approval before plant operation. Further, the applicant must submit an actual turbine inspection schedule following the third refueling outage. The actual turbine inspection schedule should be based on a probability calculation of turbine missile generation. The calculated probability for turbine missile generation is expected to be less than or equal to $1.0 \mathrm{E}-4$ per year since GE specified that the turbine be favorably oriented. The NRC-approved methodology for calculating probability for turbine missiles is discussed in NUREG-1048 (Supplement 6, July 1986). This was identified as DFSER COL Action Item 10.2.2-1. GE addressed this item in the SSAR Subsection 3.5.1.1.1.3 to state that the COL applicant will submit for NRC approval, within 3 years of obtaining a COL, a turbine maintenance program including 
probability calculations of turbine missile generation based on methodology approved by the NRC. Further, during the preservice inspection of the turbine, each machined turbine rotor is subjected to 100-percent ultrasonic examination and surface visual examinations, using established acceptance criteria. The ISI program for the turbine assembly includes the disessembly of the turbine and complete inspection of all normally inaccescible parts, such as couplings, coupling bolts, turbine shafts, lowpressure turbine brackets, and low-pressure and high pressure rotors. This is acceptable to the staff.

The staff concludes that the integrity of the turbine rotor is acceptable and meets the relevant requirements of GDC 4 of 10 CFR Part 50. GE has met the requirements of GDC 4 of 10 CFR Part 50 with respect to the commitment to use material of acceptable fracture toughness and elevated temperature properties, adequate design, and the requirements for preservice and ISIs. GE has also described its program for ensuring the integrity of lowpressure turbine rotor through the use of suitable materials of adequate fracture toughness and conservative design practices. The GE program will provide reasonable assurance that the probability of failure with missile generation will be low dur ung normal operation, including transients in which the tuibine speed may reach its design overspeed.

\subsection{Main Steam Supply System}

\subsubsection{System Description and Operation}

The staff reviewed the main steam supply system (MSSS) in accordance with SRP Section 10.3. The design of the MSSS is acceptable if the design is in accordance with GDC 2 as it relates to safety-related portions of the system being capable of withstanding the effects of natural phenomena such as earthquakes, tornados, hurricanes, and floods, GDC 4 as it relates to safety-related portions of the system being capable of withstanding the effects of missiles, pipe whip, and jet impingement forces associated with pipe breaks, and GDC 5 as it relates to the capability of shared systems and components important to safety to perform required safety functions. Compliance with RG 1.115, "Protection Against Low-Trajectory Turbine Missiles," is evaluated in Section 3.5.1.3 of this report. The system design should adequately consider steam hammer and relief valve discharge loads to ensure that system safety functions can be achieved and should ensure that operating and maintenance procedures include adequate precautions to avoid steam hammer and relief valve discharge loads. The system design should also include protection against water entrainment.
The MSSS is designed to supply the required amount of ateam at the required pressure and tomperature to the turbine, reheaters, condenser evacuation system, turbine gland sealing system (TOSS), and offges systom.

The MSSS extends from the seismic interface restraint to the turbine stop valves and also includes connected piping up to and including the first shutoff valve on the connected lines. The safety-relief valves, which will be mounted on the main steamlines upstream of the containment isolation valves for the system, are evaluated separately in Section 5.2.2 of this report.

The steam generated in the reactor vessel will be routed to the turbine and power cycle auxiliary equipment via four 70-cm (28-in.) nominal diameter MSL. Each MSL will bo equipped with a flow restrictor and two main steam isolation valves (MSIVs), thus ensuring MSL isolation in the ovent of a steamline break outside the containment and a concurrent failure of an MSIV. One MSIV is located immodiately inside the drywell and the other immediately outside the drywell. The MSIVs are designed to provide positive isolation against steam flow associated with a MSL break. They will be pneumatic or spring-operated (to close), fast-closing (3-4.5 seconds), Y-pattern, globe valves. Operating fluid will be supplied to the valves from the nitrogen supply system. Nitrogen accumulators will supply backup operating nitrogen for the MSIVs in the event of a loss of the normal nitrogen supply system. Open Item 66 in the draft safety evaluation report (DSER) (SECY-91-235) required GE to clarify whether the backup nitrogen accumulators were seismic Category I. Subsequently, in a meeting with the staff on May 5, 1992, GE clarified that these accumulators are seismic Category I as shown on the nuclear boiler (NB) system P\&Ds, ABWR Figure 5.1-3, page 3 of 11 . Therefore, this item was resolved in the DFSER.

Downstream of the outboard MSIVs and upstream of the turbine stop valves, the MSLs that will be routed to the turbine contain no other shutoff valves. From the MSL header, in addition to the four steamlines to the turbine, two steamlines will supply steam to the power cycle auxiliary equipment. One of the branch steamlines will supply steam to the TGSS and to two reheaters. The other branch line will supply steam to the offgas system, the steam jet air ejectors (SJAE), the condenser sparger, and two other reheaters. Each of these steamlines contains a power-operated pneumatic gate shutoff valve. These valves are $41-\mathrm{cm}(16-\mathrm{in}$.) diameter, Quality Group (QG) B, seismic Category I, shut within approximately 2 seconds following an MSIV closure signal, and are equipped with air operators and spring closure mechanisms. These valves fail closed on loss of electrical power to the valve actuating solenoid or on loss of 
pneumatic preseure and are analyeed to demonstrate structural integrity under SSE loading conditions.

SSAR Section 5.4.9 and Table 3.2-1 tate that the MSL from the reactor veasel, out to and including the outboard MSIVs, are designed to QG A standards. From the outbourd MSIV st the turbine stop valves, the steamlines and associated equipment are designed to QO B standards. Tho MSL that will extend from the reactor veseel up to and including the seismic interface restraint (which is downstream of the outboard MSIVg) are seismic Category I. Downstream of the soismic interface restraints, the main steam (MS) piping and equipment is classified as nonnuclear, safety-related. This includes the shutoff valves on the two branch steamlines (inside the TB) that will supply steam to the power cycle auxiliary equipment (QG D).

SSAR Section 3.2.5.3, however, states that the MSLs from the containment outboard isolation valves, up to and including the turbine stop valves and all branch lines $6.3 \mathrm{~cm}$ (2.5 in) and larger and up to and including the first valve and its supports, are designed using an erpropriato dynamic seismic system analysis to withstand the safe shutdown earthquake (SSE) design loads in combination with appropriate loads within the limits specified. In the DSER (SECY-91-235), the staff stated that the design for the MSLs downstream of the outboard MSIVs up to the turbine stop valves, the connecting lines up to the turbine bypass valves, and all other connecting lines up to and including the first shutoff valves, did not comply with the staff's requirement for seismic and $Q G$ classifications as stated in SRP Section 10.3, Criterion III.3.b, which requires that the subject portions of the MSSS be designed to seismic Category I and QG B requirements. Therefore, the staff identified the lack of seismic Category I classification of the subject portions as DSER Open Item 3 (SECY-91-153). Although the subject piping portions will not be seismic Category I, by letter dated April 1, 1992, GE committed to apply the quality assurance criteria of 10 CFR Part 50, Appendix B, to these portions. The combination of appropriate dynamic seismic system analysis, QG B classification, and application of the Appendix B criteria to these portions are adequate and acceptable. Therefore, this open item was resolved in the DFSER (this issue is further discussed in Section 3.2.1 of this report).

In addition to meeting the acceptance criteria of SRP Section 10.3, the MS system for the ABWR must also be capable of mitigating the radiological consequences of an accident that could result in potential offsite exposures comparable to the dose reference values specified in 10 CFR Part 100. Most of the currently licensed BWRs rely on the MSIV leakage control system to mitigate the radiological consequences of MSIV leakage following a design-basis lowe-of-coolant accident (LOCA) and to stay within 10 CRR Part 100 limits if tho MSIV leakage rato exceeded the technical epecification limit of $0.3 \mathrm{~m} / \mathrm{hr}$ $\left(11.5 \mathrm{ft}^{3} / \mathrm{hr}\right)$. The ABWR will not have an MSIV leakage control ayatom and, therefore, will rely on the MS system coupled with the main condenser (MC) to contain MSIV leakage, relying on plateout and holdup of radioactive iodine and to limit the radiological consequences to within 10 CFR Part 100 limits.

In the DFSER, the staff stated that in order to take credit for the MSSS and MC for containment and boldup of MSIV leakage, the MSSS and the MC and connections from the MSLs to the condenser must be capable of maintaining their integrity during and following an SSE. Subeequently, GE added SSAR Subsection 3.2.5.3 which clarified the seismic requirements for the MSL leskage paths. Section 3.2 of this report contains a detailed evaluation of the seismic analysis requirements for the MSSS and the MC. To process the MSIV leakage through the MC, a leakage path must be ensured either through the MS drain line to the condenser or through the turbine bypass system (TBS) to the condenser. In the DFSER, the staff stated that, whichever of these two paths is chosen, reliable power sources must be available so that a control operator can establish the flow path assuming a single active failure. The staff stated they would review this issue on a case-by-case basis for each ABWR COL applicant. GE subsequently stated that the MS drain lines have parallel motor operated and air operated valves to ensure a leakage path to the MC. The motor operated valves are powered from their respective Class $1 \mathrm{E}$ bus and the air operated valves fail open on loss of pneumatic pressure or on loss of power to the actuating solenoid. Additionally, the turbine bypass valves are hydraulically operated and powered by redundant uninterruptable non-Class $1 E$ power supplies. Therefore, the staff concludes that reliable power sources are available to establish the flow path.

In the DFSER, the staff stated that the amount of allowable MSIV leakage will also be reviewed for each ABWR COL applicant. This was identified as DFSER COL Action Item 10.3.1-1. Subsequently, the staff reviewed the final SSAR and concluded that the modifications to SSAR Subsections 10.3.2 and 10.3.7 will ensure that the COL applicant referencing the $A B W R$ design will provide the amount of allowable MSIV leakage to the staff for review. This is acceptable to the staff.

The steam lines in the reactor building (including the containment and some portion of the steam tunnel) and in the steam tunnel portion in the control building, are located in seismic Category I, flood-protected and tornadoprotected structures. Thus, these portions of the MSSS 
meet the requirements of GDC 2 and the guidelines of RO 1.29, "Seismic Design Classification," (Rov. 3) Positions C.1 and C.2.

In the DFSER, the staff explained that SSAR Appendix 3F stated that since the safety-related portions of the condensate and feedwater system (CFS) and the MSSS (from the reactor up to and including the seismic interface restraints) are qualified for the leak-before-break (LBB) criterion, a high-energy pipe break does not need to be considered in those portions of the above systems solely for considering the local dynamic effects associated with such breaks. In SSAR Appendix 3F, GE provided generic LBB evaluation procedures and methodology for the systems to support this claim. In Section 3.6.3 of this report, the staff states that a LBB analysis should use plant-specific data such as piping geometry, materials, fabrication procedures, loads, degradation mechanisms, and pipe support locations. Therefore, the staff will evaluate the acceptability of the LBB methodology on a plant-specific basis to determine if the essential portion of the MSSS will be adequately protected against dynamic effects associated with high-energy pipe breaks. In a meeting with the staff on May 5, 1992, GE committed to remove references to LBB from the SSAR. This was identified as DFSER Confirmatory Item 10.3.1-1. Subsequently, the staff reviewed the final SSAR and found that GE had deleted Appendix 3F from the SSAR as agreed. GE has also removed this information from the SSAR. Therefore, Confirmatory Item 10.3.1-1 is resolved. GE has provided, in SSAR Section 6.2.3, an analysis of a MSL and main feedwater line pipe failure inside the MS tunnel. The results of the staff's review of this analysis are contained in Section 6.2.1.7 of this report. Features to protect the MSIVs from the effects of a pipe failure inside the main steam tunnel (MST) are evaluated in Section 3.6.1 of this report.

Regarding the other aspect of GDC 4, which deals with the environmental design basis for SSCs important to safety, GE states in SSAR Appendix 3I that the essential equipment of the system is environmentally qualified to function following a postulated high-energy pipe break. Specifically, this means that the MSIVs will be required to function to ensure MSL isolation and will be qualified to function in the expected steam environment resulting from a steumline break. Further, GE identified an interface requirement for the $\mathrm{COL}$ applicant to provide any additional protective features (e.g., shields and other barriers) that may be needed to protect the MSIV functional capability against the effects of postulated pipe failures. On further evaluation, the staff determined that this requirement can be accomplished by identifying a COL action item in the SSAR requiring the applicant to provide this information. This was identified as DFSER
Confirmatory Item 10.3.1-2. GE has included this information in SSAR Section 3.6.5.1. Therefore, Confirmatory Item 10.3.1-2 is resolved.

GE addressed the issue of steam hammer and relief valve discharge loads in a submittal dated February 28, 1990. and stating that the system design accommodates steam hammer and relief valve discharge loads. In the DFSER, the staff stated that the staff would require the COL applicant to have operating and maintenance procedures that include adequato precautions to avoid steam hammer and reliof valve discharge loads. This was identified as DFSER COL Action Item 10.3.1-2. Subsequently, the staff reviewed the final SSAR and concluded that the modifications to SSAR Subsections 10.3 .3 and 10.3 .7 provided adequate assurance that the applicant referencing the ABWR design will provide the necessary procedures to assure that steam hammer and relief valve discharge loads will be minimized. This is acceptable to the staff.

The system design includes drains to protect against water entrainment. The essential equipment of the system is located in tornado-missile-protected structures (as stated above) and is protected from the effects of internally generated missiles. The appendix to RG 1.117, "Tornado Design Classification," (Rev. 1), specifies SSCs of lightwater-cooled reactors that should be protected against tornados. On this basis, the staff finds that the safetyrelated portion of the system meets the requirements of GDC 4 and the guidelines of RG 1.117 (Rev. 1), Appendix Position 4.

Because the ABWR is designed as a single-unit facility, the requirements of GDC 5 do not apply.

GE submitted the design description and the ITAAC reiating to the MSSS. This was identified as DFSER Open Item 10.3.1-1. GE provided a revised set of design descriptions and ITAAC. The adequacy and acceptability of the final certified ABWR design description and the ITAAC are evaluated in Section 14.3 of this report. On the basis of this evaluation, this item is resolved.

The MSSS includes all components and piping from the outermost containment isolation valve up to and including the turbine stop valves. The safety-related portions of the system are designed to QG B from the outermost containment isolation valve and connecting piping up to and including the first normally closed valve. Those portions of the MSSS necessary to mitigate the consequences of an accident are designed to the quality standards commensurate with the importance to its safety function. The scope of the review included layout drawings, P\&IDs, and descriptive information for the system. 
Based on the above discussion, the staff concludes that the MSSS for the ABWR from the reactor to the TB satisfies the requirements of $\operatorname{CDC} 2,4$, and 5 and the guidelines of RO 1.29 (Rov. 3), Positions C.1 and C.2, and RO 1.117 (Rev. 1), Appendix Position 4; meets SRP Section 10.3 acceptance criteria; and is accoptable.

\subsubsection{Steam and Feedwater System Materials}

GDC 1 requires that systoms important to safety shall be designed to quality standards commensurato with the importance to safety of the functions to be performed. GDC 35 requires suitable inter-connections, leak detection, isolation, and contaminant capabilities bo provided to assure that the safety system function (i.e., emergency core cooling) can bo accomplished, assumed a single failure.

The staff reviewed the steam and feedwater system materials in accordance with SRP Section 10.3.6. The steam and feedwater system materials are acceptable if they satisfy the requirements of the ASME Code, Section III and GDC 1 and 35.

The Class 2 materials specified in the SSAR for the MS and feedwater system satisfy the requirements specified in Appendix I to Section III of the ASME Code, and Parts A, $B$, and C of Section II of the Code. The fracture toughness properties of the materials meet the requirements of NC-2300 of ASME Code Section III and RG 1.26, "Quality Group Classifications and Standards for Water-, Steam-, and Radioactive Waste-Containing Components of Nuclear Power Plants" (Rev. 3).

The materials selection and fabrication follow RG 1.71, "Welder Qualification for Areas of Limit Accessibility" (original), RG 1.85, "Materials Code Case AcceptabilityASME Section III, Division 1" (Rev. 28), RG 1.37, "Quality Assurance Requirements for Cleaning of Fluid Systems and Associated Components of IWater-Cooled Nuclear Power Plants" (original) and ANSI N45.2.1. The non-destructive examination of the steam and feedwater piping meets the acceptance criteria in NC-2550 through NC-2570 of ASME Code, Section III.

Compliance with the requirements of the ASME Code, ANSI standard, and regulatory guides satisfy the applicable requirements of GDC 1 and 35 and Appendix B to 10 CFR Part 50. The staff concludes that the MS and feedwater system materials are acceptable and meet the relevant requirements of $10 \mathrm{CFR} 50.55 \mathrm{a}, \mathrm{GDC} 1$ and 35, and Appendix B to 10 CFR Part 50.

\subsection{Other Features}

\subsubsection{Main Condenser}

The staff reviewed the MC in accordance with SRP Section 10.4.1. The acceptability of the system design is based on its meeting the requirements of GDC 60 as it relates to failure of the system not result in excessive releases of radioactivity to the environment, not cause unacceptable condensate quality, and not flood areas housing safety-rolated equipment.

The MC is designed to function as a steam cycle heat sink. The MC will receive, condense, and deaerate the turbine exhaust steam and the turbine bypass steam. The MC will also collect miscellaneous steam cycle drains and vents as well as transfer heat to the circulating water system (CWS), which, in turn, will reject the heat to the PCHS. GE states in SSAR Section 10.4.1.2.2 that nothing precludes the use of a single pressure condenser and a parallel (instead of series) circulating water system since these will have no affect on the nuclear TS conditions.

The MC will not be required to serve or support any reactor safety function. However, because there is no MSIV leakage control system, the MSLs and condenser will be used to collect MSIV leakage following a LOCA. Therefore, the MC must be capable of maintaining its integrity following a SSE. The condenser supports and anchorages will be seismically analyzed to demonstrate that they are capable of sustaining the SSE loading conditions without failure (Section 3.2 of this report contains additional discussion and evaluation of the capability of the MC to meet this requirement.)

The MC consists of three multi-pressure, at least two-tube bundle, single-pass shells. Each of the shells is located under its respective low-pressure turbine. The MC hotwell is sized and designed to retain all condensate for 4 minutes from the time it enters the hotwell until it is removed by the condensate pumps. Condensate will be retained in the condenser for a minimum of 2 minutes to permit radioactive decay (primarily of nitrogen-16) before it enters the condensate system. Offgas from the $\mathrm{MC}$ will be processed in the gaseous waste management system, which is described in Section 11.3 of this report. The MC is designed to (1) deaerate the condensate, (2) remove air and noncondensable gases, and (3) remoye hydrogen and oxygen formed in the steam. 

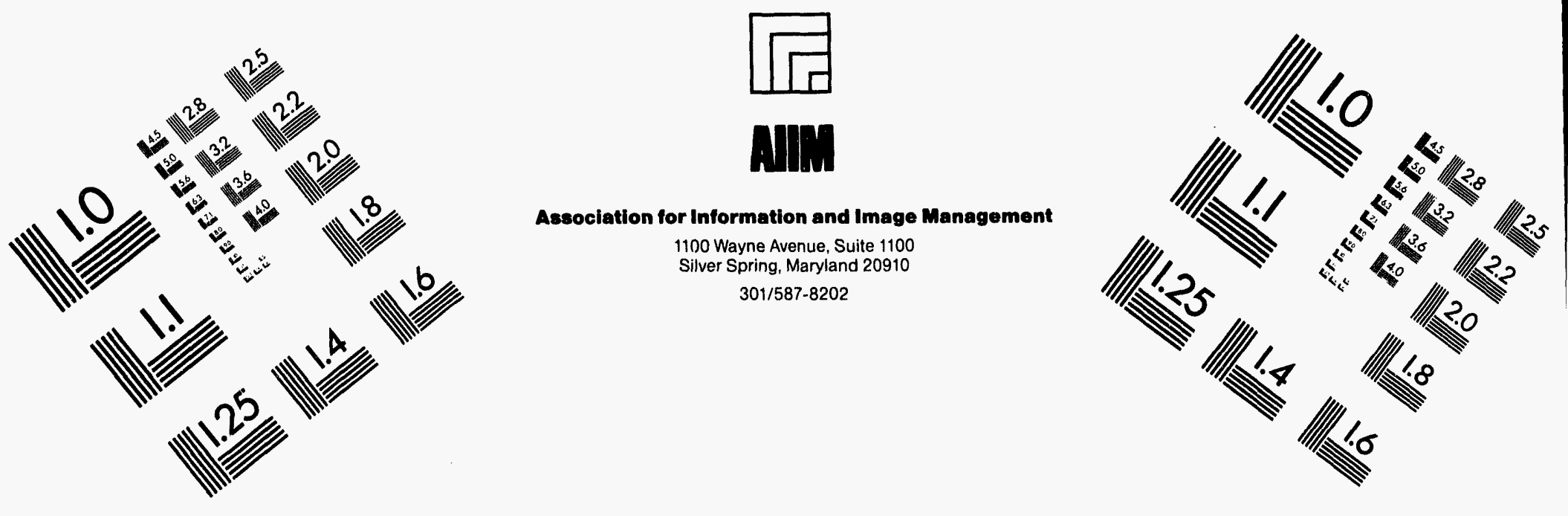

\section{Centimeter}

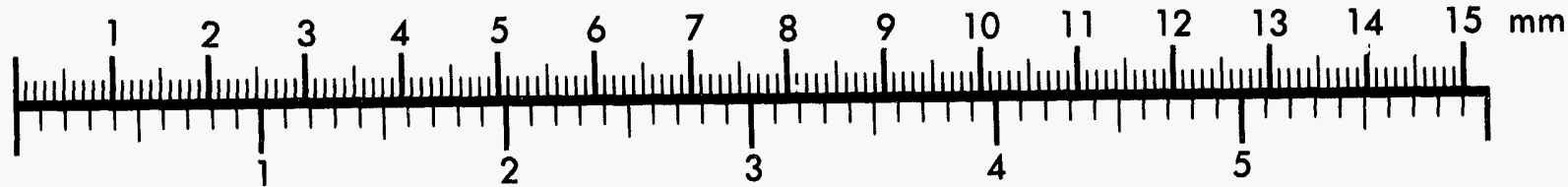
Inches
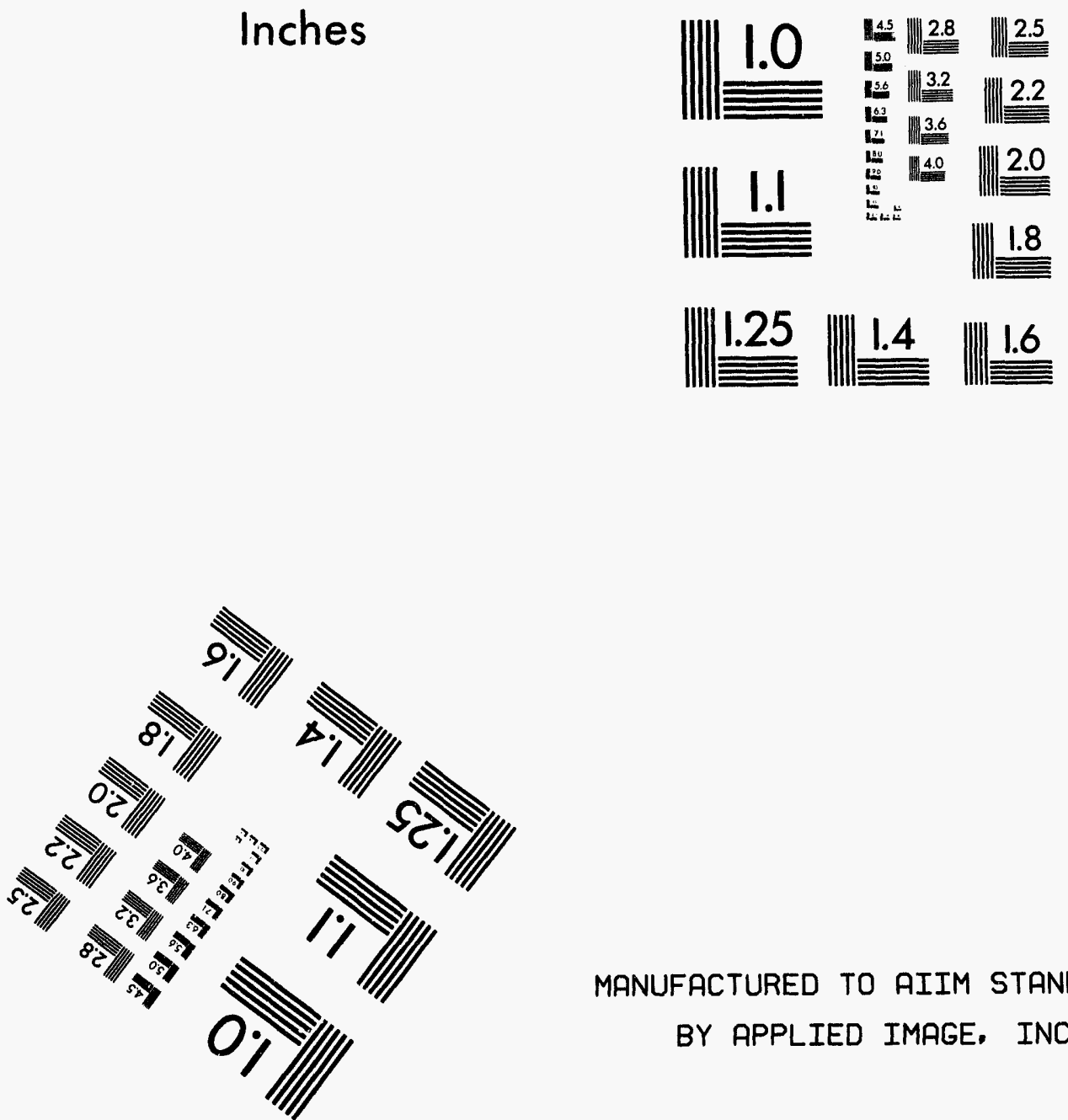

MANUFACTURED TO AIIM STANDARDS

BY APPLIED IMAGE, INC.

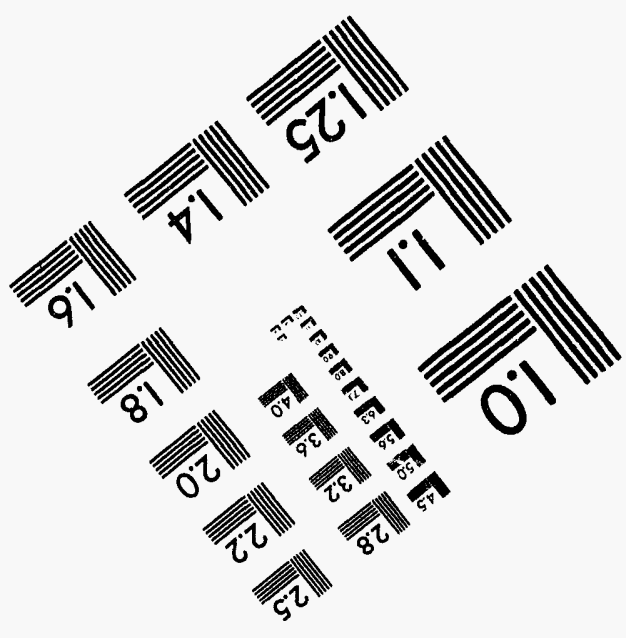



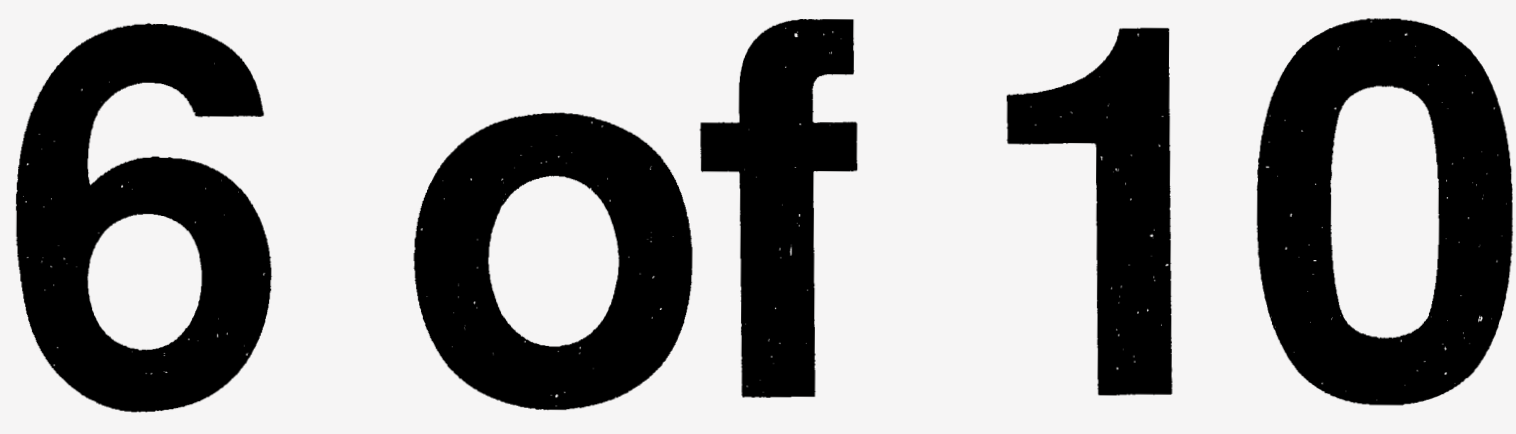
Circulating water on the tube side of the MC will be treated with chemicals to limit algae growth and to minimize long-term corrosion of the tubes. Corrosion on the shell side of the condenser will be controlled by adhering to strict water quality. The construction materials used for the MC will be chosen so that corrosion as a result of galvanic and other effects can be kept to a minimum.

Condenser leakage will be in-leakage since the MC will normally be operated under vacuum. Tube leakage will be monitored by monsuring the conductivity of water samples taken beneath the tube bundles. Additionally, since the condensate wiil be monitored at the condensato pump discharge, any tube leakage will also be detected at this monitoring point. Conductivity of the condensate will be continuously monitored at selected locations in the condenser. Condenser vacuum will also be monitored. The loss of the MC vacuum will cause a turbine trip and MSIV closure. An alarm actuates at $-81 \mathrm{kPa}$ at $0^{\circ} \mathrm{C}$ (24 in. $\mathrm{Hg}$ vacuum at $32^{\circ} \mathrm{F}$ ), and a high condenser pressure turbine trip will occur at $-75 \mathrm{kPa}$ at $0^{\circ} \mathrm{C}(22 \mathrm{in}$. $\mathrm{Hg}$ vacuum at $\left.32{ }^{\circ} \mathrm{F}\right)$. Additionally, MSIV closure occurs at -24 to $-34 \mathrm{kPa}$ at $0^{\circ} \mathrm{C}\left(7\right.$ to $10 \mathrm{in}$. $\mathrm{Hg}$ vacuum at $\left.32^{\circ} \mathrm{F}\right)$ while turbine bypass valve closure will take place at $-41 \mathrm{kPa}$ at $0^{\circ} \mathrm{C}\left(12 \mathrm{in} . \mathrm{Hg}\right.$ vacuum at $\left.32{ }^{\circ} \mathrm{F}\right)$.

The MC is designed to condense at least 33 percent of the full-rated turbine steam flow as bypass steam.

During the initial phase of startup, the mechanical vacuum pump establishes a vacuum in the MC. The discharge from the vacuum pump is routed to the Turbine Building Compartment Exhaust System. Radiation monitors in the TBCE and plant vent alarm in the MCR if abnormal radioactivity is detected. In addition, radiation monitors are provided on the main steam lines which trip the vacuum pump if abnormal radioactivity is detected in the steam being supplied to the condenser. This is discussed in Section 10.4.2 of the SSAR and evaluated in Sections 10.4.2 and 11.5 of this report.

The low-pressure turbine exhaust and the MC will be connected by a stainless steel expansion joint. Since no safety-related equipment is located in the condenser area, failure of the joint will have no adverse effect on safetyrelated equipment. Protection of safety-related equipment from flooding in the TB is reviewed in Section 3.4.1 of this report.

Based on this information, the staff concludes that the main condenser design includes provisions which assure that failures of the system will not result in excessive releases of radioactivity to the environment, do not cause unacceptable condensate quality, or result in flooding of areas housing safety-related equipment and therefore meets the requirements of GDC 60 .

GE submitted the design description and the ITAAC relating to the MC system. This was identified as DFSER Open Item 10.4.1-1. GE provided a revised set of design descriptions and ITAAC. The adequacy and acceptability of the final certified ABWR design description and the ITAAC are evaluated in Section 14.3 of this report. On the basis of this evaluation, this item is resolved.

The MC includes all components and equipment from the turbine exhaust to the connections with the CFS and other systems. The scope of the review of the MC system included layout drawings, P\&IDs, and descriptive information for the MC system and supporting systems that are essential to its operation.

The basis for acceptance of the MC system was conformance of the design, design criteria, and design bases to the Commission's regulations as set forth in GDC 60. The staff concludes that the MC system design is acceptable and meets the requirements of GDC 60 with respect to failures not resulting in excessive releases of radioactivity to the environment, not causing unacceptable condensate quality, and not flooding areas bousing safetyrelated equipment.

The staff concludes that the design of the MC is in conformance with SRP Section 10.4.1, can perform its design function, and is acceptable.

\subsubsection{Main Condenser Evacuation System}

The staff reviewed the main condenser evacuation system (MCES) in accordance with the acceptance criteria in SRP Section 10.4.2, and guidelines contained in RG 1.26, "Quality Group Classifications and Standards for Water-, Steam-, and Radioactive-Waste-Containing Components of Nuclear Power Plants," (Rev. 3); RG 1.33, "Quality Assurance Program Requirements (Operation)," (Rev. 2); and in the Heat Exchanger Institute's "Standards for Steam Surface Condensers," 6th Edition (1970). To be acceptable, the MCES must meet the requirements of GDC 60 for controlling releases of radioactive materials to the environment and the requirements of GDC 64 for monitoring the release of radioactive material to the environment.

The MCES is designed to establish and maintain condenser vacuum by removing noncondensable gases from the MC and directing them to the offgas system for processing before release through the plant stack during normal plant operation. The MCES will not perform or support any safety function. 
Tho MCES is designed to QO D standards and consists of a mechanical vacuum pump for use during startup, and two 100-percent capucity, double stage, steam jot air ejector (SJAE) units (complete with intercondenser) for normal operating conditions. During startup, the mechenical vecuum pump will bo used to establish a vacuum in the MC and the exhaust gas will be vented to the turbine building (TB) compartment exhaust system. High radioactivity in the MSL will trip the mechanical vacuum pump. The TB compartment exhaust will pass through a medium efficiency filter and be monitored for radioactivity before discharge to the plant vent. After the mechanical vacuum pump has created an absolute pressure of about -34 to $-50 \mathrm{kPa}$ at $0^{\circ} \mathrm{C}\left(10\right.$ to $15 \mathrm{in} . \mathrm{H}_{8}$ at $\left.32^{\circ} \mathrm{F}\right)$ in the MC and adequate nuclear steam pressure is available, one of the two SJAEs will be put in service to remove noncondensable gases from the condenser.

Steam supply to the second stage of the SJAE will be kept at a minimum predetermined flow to help ensure adequate dilution of hydrogen (below 4 percent by volume) to prevent the hydrogen in the offgas system from reaching a flammable concentration. Low flow of the dilution steam will result in automatic isolation of the MC from the offgas system.

GE submitted the design description and the ITAAC relating to the MCES. This was identified as DFSER Open Item 10.4.2-1. GE provided a revised set of design descriptions and ITAAC. The adequacy and scceptability of the design description and the ITAAC are ovaluated in Section 14.3 of this report. On the basis of this ovaluation, this item is resolved.

The MCES includes equipment and instruments to establish and maintain condenser vacuum and to prevent an uncontrolled release of radionctive material to the cavironment. The scope of the review included the system capability to transfer radioactive gases to the offgas system and the design provisions incorporated to monitor and control releases of radioactive materials in effluents. The staff has reviewed the applicant's system descriptions, P\&IDs, and design criteria for the components of the MCES.

The staff concludes that the MCES design is acceptable and meets the requirements of GDC 60 and 64 and the guidelines of SRP Section 10.4.2 for controlling and monitoring releases of radionctive material to the environment.

\subsubsection{Turbine Gland Sealing System}

The staff roviowed the TGSS in accordance with SRP Section 10.4.3. Acceptance is based on TOSS meeting the requirements of GDC 60 for controlling the releases of radioactive materials to the environment and the requirements of GDC 64 for monitoring the release of radionctive material to the environment.

The TGSS is designed to prevent release to the TB of radioactive steam from the turbine shaft/casing penetrations and valve stems and to prevent air leakage into the steam cycle via the subatmospheric turbine glands. TOSS will be accomplished by providing continuous supply of relatively clean (i.e., practically free of radioactivity) sealing steam to the turbine shaft seals and the steam packings of the stop valves, control valves, and combined intermediate and bypass valves. The TGSS will not perform or support any safety function. The TGSS will consist of a sealing steam pressure regulator, a sealing ateam header, a gland steam condenser, and two 100 percent capacity, motor-driven blowers. The system is designed to QG D standards.

The annular space between the turbine shaft and the casing will be sealed with sealing steam supplied to the shaft seals. At all gland seals, the vent annulus will be kept under a slight vacuum condition and also will receive outside air as in-leakage. The steam mixture from the vent annulus then will be pulled to the gland steam condenser, which will be operated under a slight vacuum condition created by one of the two exhaust blowers. The steam mixture will be condensed in the gland steam condenser and the condensate will be returned to the MC. The blower is designed to discharge the air in-leakage and the noncondensable gases to the TB compartment exhaust system, which eventually will discharge to the plant vent. As mentioned above, the TGSS is also designed to provide sealing steam to the turbine stop and control valves and combined intermediate valve packings. The staff stated Open Item 67 in DSER (SECY-91-235) that SSAR Table 11.5-2 did not indicate any separate process radiation monitoring solely for TGSS exhaust. GE addressed this issue by including monitoring and sampling provisions for the turbine gland seal exhausts in SSAR Tables 11.5-1 and 11.5-7. The staff reviewed these submittals and found them acceptable. This item was resolved in the DFSER.

During startup, sealing steam will bo provided from the MSL or the plant auxiliary steam header. The use of MS as sealing steam will not pose a significant long-term average release of radionctive material to the environment because the startup time will be relatively short and plant startup radionctivity is relatively low. If the MS sealing steam supply has an abnormally high radionctivity content, the sealing steam supply can be switched to the plant auxiliary steam beader, which contains clean steam (i.e., radiosctivity free) from a conventional auxiliary boiler. 
During normal operation (above approximately 50-percent load), process steam will be used for the sealing steam supply. The high-pressure heater drain tank vent header, which is designed to provide relatively clean steam for turbine gland sealing, will provide the process steam. Again, if this normal source of sealing steam is observed to have high radioactivity content, the source for the sealing system will be switched to the plant auxiliary steam system, which provides 100 percent backup capability. Thus, the long-term average amount of radioactive material released to the environment should be minimal. In the DSER (SECY-91-235), the staff agreed with this approach for providing sealing steam, subject to the identification of an interface requirement to provide procedures for the switchover to the plant auxiliary steam. In response to Open Item 67 in the DSER (SECY-91-235), GE included in SSAR Section 10.4.10 that COL applicants will provide the necessary procedures for switchover to the auxiliary steam system if the monitored radiation level in the gland sealing system exhaust exceeded an acceptable preset level. The staff agreed with GE's approach for providing sealing steam for the turbine gland seals. However, upon further evaluation, the staff determined that this requirement could be accomplished by identifying a COL action item in the SSAR requiring the applicant to provide the necessary procedures. This was identified as DFSER COL Action Item 10.4.3-1. GE has included this action item in the SSAR. This is acceptable to the staff.

GE submitted the design description and the ITAAC relating to the TGSS. This was identified as DFSER Open Item 10.4.3-1. GE provided a revised set of design descriptions and ITAAC. The adequacy and acceptability of the final certified ABWR design description and the ITAAC are evaluated in Section 14.3 of this report. On the basis of this evaluation, this item is resolved.

The TGSS includes the equipment and instruments to provide a source of sealing steam to the annulus space where the turbine and large steam valve shafts penetrate their casings. The scope of the review included the source of sealing steam and the provisions incorporated to monitor and control releases of radioactive material in effluents.

The staff concludes that the TGSS is acceptable because it meets the requirements of GDC 60 and 64 for controlling and monitoring releases of radioactive material to the environment. Therefore, the system meets the guidelines of SRP 10.4.3 and is acceptable.

\subsubsection{Turbine Bypass System}

The staff reviewed the TBS in accordance with SRP Section 10.4.4. The design is acceptable if, in accordance with GDC 4, failure of the system (due to a pipe break or system malfunction) does not adversely affect safety-related systems or components and if, in accordance with GDC 34, the system can shut down the plant during normal operations. Use of this system will eliminate the need to rely solely on safety systems.

The TBS is designed to bypass at least 33 percent of the rated MS flow to the MC. It is also designed to bypass steam to the MC during plant startup and to permit a normal manual cooldown of the reactor coolant system (RCS) from hot shutdown to the point at which the residual heat removal function cen be placed in service. In addition, during a power operation transient (i.e., when steam produced by the reactor cannot be entirely used by the turbine), the TBS, in conjunction with the RCS, will allow - step load reduction up to $\mathbf{4 0}$ percent of the turbine generator rated electrical load without causing a reactor trip. TBS will also allow a turbine trip or a full load rejection from 100 percent power with reactor trip, without lifting the MS relief and safety valves. Thus, the TBS minimizes step-load reduction transient effects as well as turbine trip effects on the RCS.

The TBS consists of three control valves that are housed in a common valve chest connected to the MSLs upstream of the turbine stop valves and three dump lines that separately connect each regulating valve outlet to one condenser shell. Each bypass valve is operated by hydraulic fluid pressure with spring action to close. The valve chest assernbly will include hydraulic supply and drain piping, hydraulic accumulators, servo valves, fast-acting servo valves, and position transmitters. Each bypass valve is operated by the turbine hydraulic fluid power unit or it may be provided with \& separate hydraulic fluid power unit.

The bypass valves are designed to open whenever the actual steam pressure exceeds the preset steam pressure. Fast-acting servo valves will be used to allow the bypass valves to open rapidly in case a turbine trip or generator load rejection occurs. The turbine bypass valves are designed to trip closed on loss of MC vacuum, loss of electrical power, or loss of hydraulic system pressure.

The TBS is designed to be tested during operation. Periodic inspections will be performed on 2 rotating basis within a preventive maintenance program recommended by the manufacturer. As stated in GE's submittal dated February 28, 1990, the detailed design of the bypass valves will follow standard industry practice and reduce the bypassed steam pressure sequentially through orifices before the steam enters the condenser.

The TBS will not serve or support any safety function. No safety-related equipment is located inside the TB. All high-energy lines associated with the TBS are located in 
the TB. Therefore, failure of the TBS are any safetyrelated equipment or hamper the capability for safe shutdown of the plant.

Although the TBS will not be required to serve or support any reactor safety function, it will have a post-LOCA function for the ABWR. In the absence of an MSIV leakage control system, the MSLs and condenser will be used to collect MSIV leakage following a LOCA. Therofore, the TBS must be capable of maintaining its integrity following a SSE. The turbine bypass line from the bypass valve to the condenser will be seismically analyzed to demonstrate that it is capable of sustaining the SSE loading conditions without failure (Section 3.2 of this report contains additional discussion and evaluation of the capability of the turbine bypass piping to meet this requirement.)

GE submitted the design description and the ITAAC relating to the TBS. This was identified as DFSER Open Item 10.4.4-1. GE provided a revised set of design descriptions and ITAAC. The adequacy and acceptability of the final certified ABWR design description and the ITAAC are evaluated in Section $\mathbf{1 4 . 3}$ of this report. On the basis of this evaluation, this item is resolved.

The TBS includes all components and piping from the branch connection at the MS to the MC. The scope of the review included layout drawings, P\&IDs and descriptive information for the TBS.

The basis for acceptance was conformance of the design, design criteria, and design bases to the Commission's regulations as set forth in GDC 4 and 34. The TBS has met the requirements of GDC 4 with respect to the system being designed such that a safe shutdown will not be precluded as a result of a TBS failure. The system has also met the requirements GDC 34 with respect to the ability to use the TBS for shutting down the plant during normal operations.

The staff concludes that the design of the TBS meets the guidelines of SRP Section 10.4.4 and is acceptable.

\subsubsection{Circulating Water System}

The staff reviewed the CWS in accordance with SRP Section 10.4.5. The design of the CWS is acceptable if, in accordance with GDC 4, the system can accommodate the effects water that may be discharged because a component or piping in the CWS fails.

The CWS is partially within the ABWR scope. The inscope portion of the system includes all piping, valves, instrumentation, and controls within the TB. All other equipment outside the TB, including the CWS pumps is outside the ABWR scope and is the responsibility of the COL applicant.

GE has provided a conceptual design and interface requirements for that portion of the CWS outside the scope of the ABWR design, as required by 10 CFR Part 52.

The CWS is designed to remove the power cycle water heat from the MC and transfer this heat to the PCHS. The CWS will not be required to maintain the reactor in a safe shutdown condition or support any safety-related systems or components. The system is nonseismic and QG D.

The CWS consists of at least three fixed-speed, motor-driven pumps for circulating water throughout the system, screenhouse and intake screens, condenser water boxes, piping and valves, water box fill and drain subsystem, and general support facilities. A chemical addition subsystem minimizes biological buildup and chemical deposits within the system.

The CWS pumps will be vertical, wet pit-type, capable of delivering approximately $45,430 \mathrm{~m}^{3} / \mathrm{hr}(200,000 \mathrm{gpm})$ per pump. The discharge line of each pump will be equipped with a butterfly valve to allow isolation and maintenance of any one pump while the others are in operation. The CWS pumps will be tripped and the pump and the condenser isolation valves closed on a high-high level condenser pit signal. A condenser pit high-level alarm will actuate in the control room.

The PCHS will be designed to maintain the temperature of the water entering the CWS within the range of $0^{\circ} \mathrm{C}$ to $38^{\circ} \mathrm{C}\left(32^{\circ} \mathrm{F}\right.$ to $\left.100^{\circ} \mathrm{F}\right)$. The CWS is designed to deliver water to the $\mathrm{MC}$ within a temperature range of $4^{\circ} \mathrm{C}$ to $38^{\circ} \mathrm{C}\left(39^{\circ} \mathrm{F}\right.$ to $\left.100^{\circ} \mathrm{F}\right)$. The $4^{\circ} \mathrm{C}\left(39^{\circ} \mathrm{F}\right)$ minimum temperature will be maintained by recirculating warm water from the discharge side of the condenser back to the screenhouse.

In the DFSER, the staff stated that GE had not included an analysis of flooding in the TB and could affect safetyrelated equipment. The staff requested GE to provide a flood analysis which characterized the nature of the hazards and the design features to protect safety-related equipment from flooding in the TB. This was identified as DFSER Open Item 3.4.1-1. Subsequently, GE provided a flood analysis for the TB. The major flood hazard in the TB is from a failure in the CWS, which is an open-cycle system. Leak detectors in the condenser pit will alert the control room and automatically isolate the CWS on indication of building flooding. A postulated failure of the isolation function can result in flooding of the TB up to grade level. A non-watertight truck door at grade level 
will allow release of the flood water onto the ground. As stated in Section 3.4.1 of this report, the below-plant-grade tunnel connecting the radwaste, reactor, and TB is sealed to prevent water from entering the reactor building. The staff finds that the design adequately protects safety-related SSCs from the effects of flooding as result of pipe failures in the CWS. GE has also included this information in the SSAR. Open Item 3.4.1-1 is resolved.

CWS performance will be monitored by temperature and pressure indicators in the main control room. CWS-related valve positions also will be indicated in the control room.

GE submitted the design description and the ITAAC relating to the CWS. This was identified as DFSER Open Item 10.4.5-1. GE provided a revised set of design descriptions and ITAAC. The adequacy and acceptability of the final certified ABWR design description and the ITAAC are evaluated in Section 14.3 of this report. On the basis of this evaluation, Open Item 10.4.5-1 is resolved.

The CWS includes all components and equipment necessary to provide the MC with a continuous supply of cooling water. The system is designed to nonnuclear safety and QG D requirements. Based on the review of the applicant's proposed design criteria and bases for the CWS, the staff concludes that the design is acceptable and meets the requirements of GDC 4 and the guidelines of SRP Section 10.4.5.

\subsubsection{Condensate Purification System}

The condensate cleanup system (CCS) will remove dissolved and suspended solids from the condensate to maintain a high quality of feedwater to the reactor under all normal plant conditions (startup, shutdown, hot standby, and power operation). The CCS will accomplish this task by directing the full flow of condensate to five of the six polishing vessels, which will be piped in parallel. The sixth polisher will be on standby or in the process of being cleaned, emptied, or refilled. The six polishing vessels will contain mixed bed ion exchange resin with a strainer installed downstream of each vessel. The strainers will be used to prevent gross resin leakage into the feed system in the event of vessel underdrain failure and to minimize resin fine leakage. The CCS will include all components and equipment needed to remove dissolved and suspended impurities present in the condensate.

The staff has reviewed the design of the sampling equipment, sampling locations, and instrumentation to monitor and control the CCS parameters and finds the design acceptable. However, in the DSER (SECY-91-355), the staff identified that SSAR Section 10.4.6 contained insufficient information for the staff to evaluate conformance with SRP Section 10.4.6 in the following areas:

- Under SRP Section 3.6.1, the effects of high and moderate onergy piping failures to assure that other safety-related systems are not rendered inoperable must be evaluated.

- Under SRP Section 12.2, the adequacy of the shielding design of the CCS polisher vessels must be ovaluated.

- Although the SSAR indicates conformance with RG 1.56, "Maintenance of Water Purity in Boiling Water Reactors," to meet the requirements of GDC 14 and to mitigate the potential of intergranular stress corrosion cracking, GE should state conformance with EPRI NP-4947-SR, "BWR Hydrogen Water Chemistry Guidelines," (1987 Revision, October 1988).

- GE should state that the CCS will remove condensate system corrosion products and impurities from condenser leakage in addition to radioactive material, activated corrosion products, and fission products carried over from the reactor.

The staff concluded in the DSER that the adequacy of the CCS was Open Item 105 in DSER (SE.CY-91-355).

The effects of high and moderate energy piping failures on safety-related equipment are discussed in Section 3.6.1 of this report. However, as previously stated, the TB contains no safety-related equipment and, therefore, safetyrelated systems should not be affected by a CCS piping failure. This item is resolved.

The adequacy of the shielding design of the CCS polisher vessels will be evaluated as part of the radiation protection DAC discussed in Chapter 12 of this report. This item is resolved.

GE responded to the last two parts of this open item in its letter of March 11, 1992. GE revised SSAR Section 10.4.6.3 to state that condensate system corrosion products and impurities from condenser leakage will also be removed and that the CCS will comply with EPRI NP-4947-SR. The NRC staff finds this response acceptable; therefore, this DSER (SECY-91-355) issue number 105 is resolved. The staff concludes that the design of the CCS and its supporting systems conforms to staff guidelines and is acceptable. 


\subsubsection{Condensate and Feedwater System}

The staff reviewed the condensate and foedwater system (CFS) in accordance with SRP Section 10.4.7. Acceptance of the system is based on the system's meeting the requirements of GDC 2 that the system can withstand the offects of earthquakes, the requirements of GDC 4 that the system be protected against dynamic offects associated with fluid flow instabilities during normal operation as well as during upset or accident conditions, the requirements of GDC 5 that shared systems and components important to safety can perform 'required safety functions, the requirements of GDC 44 that the system can reliably transfer heat loads from the reactor to a heat sink during both normal and accident conditions and can isolate components, subsystems, or piping if necessary to maintain the system safety function, and GDC 45 and 46 as they relate to ISI and testing, respectively.

The CFS consists of the piping, valves, pumps, heat exchangers, and associated controls and instrumentation that extends from the MC outlet to the nuclear boiling (NB) system at the seismic interface restraint and to the heater drain system. The system is designed to receive condensate from the MC hotwell; supply condensate to the condensate purification cleanup system; supply cooling water to the gland steam exhauster, SJAE, and offgas recombiner coolers; and deliver high-purity feedwater to the reactor at the required flow rate, pressure, and temperature. The major equipment in the CFS includes: (1) four identical fixed-speed, motordriven condensate pumps, of which three are normally operating and one is on standby; (2) three identical and independent, 33-65 percent capacity variable speed motor-driven reactor feed pumps; (3) three parallel and independent trains of four closed, low-pressure feedwater heaters; (4) two parallel and independent trains of two high-pressure feedwater heaters; (5) two heater drain tanks; and (6) two independent, motor-driven heater drain pumps that take suction from a heater drain tank and discharge into the suction side of the feedwater pumps. The CFS is described in SSAR Sections 5.4.9 and 10.4.7.

The CFS flow begins at the MC hotwell. Three normally operated condensate pumps take suction from the hotwell and pump condensate through the condensate filters and demineralizers. The condensate is discharged into a common header that feeds five parallel auxiliary condenser coolers (one gland steam exhauster condenser, two SJAE condensers, and two offgas recombiner coolers). The condensate then flows to three parallel trains of low-pressure feedwater heaters that discharge into a common header routed to three reactor feedwater pumps arranged in parallel. The reactor feedwater pumps then discharge into two parallel high-pressure feedwater heater trains. Downstream of the high-pressure feedwater heaters, the feedwater is combined into a common header that discharges into the reactor through two parallel $56-\mathrm{cm}$ (22-in.) nominal diameter feedwater lines, as stated in SSAR Section 5.4.9.3.

On each of the feedwater lines from the common feedwater header to the resctor, there is a seismic interface restraint. A remote manual motor-operated gate valve powered by a non-safety-grade bus serves as a feedwater shutoff valve. Downstream of this motor-operated gate valve, there is a spring-closing check valve that is held open by air and serves as the outboard containment isolation valve. On the other side of the containment, a check valve serves as the inboard containment isolation valve, and downstream of this check valve is a manual maintenance valve. However, the staff stated Open Item 69 in the DSER (SECY-91-235) that the provision of a non-8afety-grade power source for the remote manual shutoff gate valve was inappropriate because the valve and the portion of piping in which it is located are designed as seismic Category I and the valve serves as a long-term isolation for the containment. In a meeting with the staff on May 5, 1992, GE stated that insights from the probabilistic risk assessment (Chapter 19 of the SSAR) indicate that the ability to open the valve using diverse non-safety-grade on-site power instead of safety-related power to initiate feedwater flow reduces the risk. Furthermore, this valve is not relied upon as a longterm leakage barrier. Instead, GE has provided high reliability check valves. Additionally, the spring-closing check valves are testable and provide a positive means of isolation. Therefore, the use of diverse non-safety-grade power for the manual shutoff gate valve was acceptable subject to GE providing documentation of the information discussed in the May 5, 1992, meeting. This information was identified as DFSER Confirmatory Item 10.4.7-1. Subsequently, the staff reviewed the final SSAR and concluded that the modification to Subsection 5.4.9.3 regarding the power sources for the shutoff valves was acceptable. This is acceptable to the staff, and therefore, Confirmatory Item 10.4.7-1 is resolved.

As indicated in SSAR Section 5.4.9 and Table 3.2-1, the feedwater piping is QG A from the reactor pressure vessel out to and including the outboard isolation valve, QG B from the outboard isolation valve up to and including the shutoff valve and QG D beyond the shutoff valve. The feedwater piping and all connected piping of $6.5 \mathrm{~cm}$ $(2-1 / 2 \mathrm{in}$.) or larger nominal size, is seismic Category I from the reactor pressure vessel out to and including the seismic interface restraint. The safety-related equipment is physically separated and protected against the effects of internally generated missiles. The staff concludes that the design of the CFS meets the requirements of GDC 2 and the guidelines of RG 1.29, Positions C.1 and C.2. 
In a meeting with the staff on May 5, 1992, GE committed to remove references to LBB from the SSAR. This commitment was identified as DFSER Confirmatory Item 10.3.1-1. In SSAR Section 6.2.3, GE has analyzed a MSL and main feedwater line pipe failure inside the MST and has removed Appendix 3F from the SSAR. The results of the staff's review of this analysis are found in Section 6.2.1.7 of this report. This is acceptable to the staff, and therefore, Confirmatory Item 10.3.1-1 is resolved.

Regarding the other aspect of GDC 4, that deals with the environmental design basis for SSC important to safety, SSAR Appendix 3I states that the essential equipment of the system is environmentally qualified to function following a postulated high-energy pipe break. GE has also addressed the issue of water-hammer loads as a result of hydraulic transients that can occur when feedwater control valves rapidly interrupt feedwater flow (submittal dated February 28, 1990). The ABWR design uses a modified CFS design that has only a low feedwater flow control valve specifically designed to minimize cycling in feedwater nozzles. The valve is used only at low-power operating conditions. During normal power operations, feedwater flow is varied as needed by using adjustable speed, motor-driven feed pumps, thus eliminating the need for any flow control valve. As discussed in Section 10.3.1 of this report, the staff will require COL applicants to provide operating and maintenance procedures to ensure that water hammer and its effects are avoided or minimized. Finally, the system piping is analyzed for loads from anticipated flow transients. On this basis, the staff finds that the CFS design complies with GDC 4. Protection of safety-related equipment from flooding in the TB is discussed in Section 3.4.1 of this report.

Because the ABWR is designed as a single-unit facility, the requirements of GDC 5 do not apply.

The system is sized to provide adequate flow to the reactor. The system contains parallel trains that will allow for isolation, inspection, and testing during normal operation. Therefore, GDC 44, 45, and 46 are met.

GE submitted the design description and the ITAAC relating to the CFS. This wes identified in the DFSER as Open Item 10.4.7-1.

GE provided a revised set of design descriptions and ITAAC. The adequacy and acceptability of the final certified ABWR design description and the ITAAC are evaluated in Section 14.3 of this report. On the basis of this evaluation, this item is resolved.
The CFS includes all components and equipment from the condenser outlet to the connection with the NB system and heater drain system. Based on the review of the applicant's proposed design criteria, design bases, and safety classification for the system, the staff concludes that the design of the CFS and supporting systems conforms with GDC 2, 4, 5, 44, 45, and 46 and with the guidelines of SRP Section 10.4.7 and is, therefore, acceptable.

\subsubsection{Power Cycle Heat Sink}

The staff reviewed the conceptual design and the design interface requirements for the PCHS. The PCHS was included in SSAR Section 10.4.5.8 and was reviewed in accordance with SRP Section 9.2.5. Acceptance of the design is based on meeting GDC 2 as it relates to structures housing the system and the system itself being capable of withstanding the effects of natural phenomena, GDC 5 as it relates to shared systems between units, GDC 44 as it relates to the capability to transfer heat loads from safety-related SSCs to the heat sink under normal and accident conditions as well as providing suitable redundancy of components to ensure adequate safety function given a single active component failure and the capability to isolate parts of the system so that the safety function is not compromised, and GDC 45 and 46 as they relate to ISI and operational functional testing, respectively, of safety-related systems and components.

GE designated the PCHS as being outside the scope of the ABWR design. GE has provided a conceptual design and interface criteria, as required by 10 CFR Part 52, to allow an applicant referencing the ABWR to provide a plantspecific PCHS design capable of dissipating turbine plant heat. The PCHS will be designed to accept the heat loads of the turbine service water (TSW) system (Section 9.2.16 of this report) and the CWS (Section 10.4.5 of this report). The TSW in turn accepts the heat loads of the turbine building cooling water (TCW) system (Section 9.2.14 of this report) while the CWS accepts the heat load from the MC (Section 10.4.1 of this report).

GE has provided a conceptual design for the PCHS. The PCHS is a non-safety-related, non-seismic Category I system and will consist of a natural draft cooling tower from which the TSW and CWS systems will receive cooling water. Water circulation, makeup, chemical control, and inventory blowdown are part of the CWS.

The PCHS is designed to maintain the temperature of the water entering the CWS within the range of $0{ }^{\circ} \mathrm{C}$ to $38^{\circ} \mathrm{C}$ $\left(32^{\circ} \mathrm{F}\right.$ to $\left.100^{\circ} \mathrm{F}\right)$. 
The PCHS is designed to ensure that its failure will not adversely affect safety-related equipment. A flooding analysis of the TB was performed using the CWS and postulating that a complete rupture of a single expansion joint thus introducing PCHS water into the TB. In this situation, high-level sensors in the condenser pit will isolate the CWS on sensing a high water level in the pit. Should this isolation fail, excess flood water will rise to grade level and exit on site. As discussed in Section 10.1 of the SSAR, safety-related instrumentation is provided in the TB which dete s the oil pressure of the main turbine control valves and the turbine first-stage pressure and main condenser pressure. As discussed in SSAR Section 3.4.1 and Subsection 10.4.5.6 and as reviewed in Section 3.4.1 of this report, this equipment is protected from both internal and external flooding. Based on this, the staff concludes that failure of the PCHS will not adversely affect safety-related equipment and that the PCHS meets the requirements of GDC 2.The plant design is for a single-unit site and, therefore, the requirements of GDC 5 regarding the sharing of SSCs between units do not apply.

Because the PCHS is a non-safety-related system and is not required to remove reactor heat, the requirements of
GDC 44 do not apply.All active and passive system components will be accessible for inspection, maintenance, and testing during normal power operation. Therefore, the inspection and testing requirements of GDC 45 and 46 are met.

GE submitted the interface requirements relating to the PCHS. The adequacy and acceptability of the interface requirements are evaluated in Section 14.3 of this report.

The conceptual design and interface requirements provided for the PCHS provide adequate guidelines to ensure that the plant-specific design can meet the requirements of GDC 2, 5, and 44 with respect to protection against natural phenomena, shared systems, and heat removal. The system will be designed to allow periodic inspections and tests and will, therefore, meet the requirements of GDC 45 and 46. Use of the interface criteria will allow an applicant referencing the ABWR to design a PCHS that will meet all applicable regulatory requirements. Therefore, the staff concludes that the design of the PCHS system is acceptable. 


\section{RADIOACTIVE WASTE MANAGEMENT}

The advanced boiling water reactor (ABWR) design has three radionctive waste management eystems: the liquid waste management system, the gaseous wasto management system, and the wolid weste management system. The systems are decigned to provide for the controlled bandling and treatment of liquid, gaseous, and colid wastes. The liquid radioactive waste syetom will collect and proceses liquid wasteo from equipment and floor drains; sampling, decontamination, and laboratory wastea; reactor water cleanup docent wastes; chemical wasten; and detergent wastes. The gaseous waste system consists of (1) catalytic recombinen to reduce the volume of offgeses from the main condenser air ajoctor, (2) charcoal delay beds to allow decay of ahort-lived noble gases from the main condenser air ejector and to adeorb radioiodines, and (3) high-officiency particulate air (HEPA) filters to retain particulates in the offges stream. Thus, the system will control the release of gaseows radionctive effluents to the site environs 10 as to keep the exposure of persons in unreatricted areas a low as reasonably achievable in accordance with 10 CFR Part 20 and Appendix I to 10 CFR Part 50. The solid wasto systom will package spent resins and backwash slurries, solidify concentrator bottoms, incinerate and package combustible dry radioactive materials, compect and package noncombustiblo materials, and store procesesed solid wastes before they are ahipped off site to a licensed facility for burial. Radionctive wasto management also includes monitoring and ampling system to detect and measure radioactive materials in plant proceas and offluent atroams.

The staff reviewed the applicant's design, design criteria, and design bases for the radionctive waste management systems for the ABWR design. The acceptance criteria that the staff used for this ovaluation are set forth in Section II of Standard Reviow Plan (SRP) Sections 11.1, 11.2, 11.3, 11.4, and 11.5, which include 10 CFR $50.34(a)$ as it relates to the tochnical information contents in safety analysis reports, 10 CFR 20.106 as it relates to radionctivity in offluents to unreatricted arees and 10 CFR Part 71, as it relaten to packaging of processed solid wastes. In lieu of 10 CFR 20.106, the staff used 10 CFR 20.1302, which is the current requirement. The staff also used complience with 10 CFR 50.34(f)(2)(xvii) as it relates to instrumentation for monitoring noblb gases and continuous sampling of radioiodines and particu-lates in gaseous effluents during an accident and onsito capability to analyze and measure these samples, as acceptance criteria for the gaseous effluent monitoring and sampling systems. Additionally, the staff used compliance with 10 CFR 61.56 as it relates to wasto characteristics for the waste products that result from solid wasto processing. The above SRP sections, additionally, include the following general design criteria (GDC) of 10 CFR Part 50, Appendix A, as acceptance criteria for radioactive wasto management systems and liquid and gaseous process and offluent monitoring and sampling systems: GDC 3 as it relates to providing protection to gaseous waste handling and treatmont systems from the effects of an explosive mixture of hydrogen and oxygen; GDC 60 as it relates to the radioactivo waste management systems being designed to control releases of radioactive materials to the environment; GDC 61 as it relates to the liquid and geseous radioective wasto management systems and ventilation syatems for the fuel storage and handling areas being designed to assure adequate safety under normal and postulated accident conditions; and GDC 63 and 64 as they relate to solid radioactive waste management system and liquid and gaseous process and effluent monitoring and sumpling systems being designed to monitor radiation leakages and radioactivity releases to the environment. The compliance of radioactive waste management systems and liquid and gaseous process and effluent monitoring and sampling systems with the above regulations are discussed in the sections that follow. Because specific compliance with Appendix I to 10 CFR Part 50 and the guidelines given in American National Standards Institute (ANSI) N13.1, "Guide to Sampling Airborne Radioactive Materials in Nuclear Facilities," Regulatory Guide (RG) 1.21, "Measuring and Reporting Radioactivity in Solid Wastes and Releases of Radioactive Matorials in Liquid and Gessous Effluents from Light-Water-Cooled Nuclear Power Plants," and RG 4.15, "Quality Assurance for Radiological Monitoring Programs (Normal Operation)-Effluent Streams and the Environment," is not within the scope of ABWR design, the staff will roview individual combined license (COL) applications for the ABWR design to ensure their conformance with these documents. Therefore, this was identified as draft final safety evaluation report (DFSER) COL Action Item 11.0-1. By amended standard safety analysis report (SSAR) GE included COL License Information (Section 11.2.5.1, Item 1) which states Chapter 11 that the COL applicant will show compliance with 10 CFR Part 50, Appendix I and the guidelines given in ANSI N13.1 and the RGs 1.21 and 4.15. This approach by $O E$ is acceptable. $O E$ has also included this action itom in the final certified SSAR.

\section{Certified Desion Material}

Tier 1 design information and inspections, tests, analyses, and acceptance criteria (ITAAC) are required for the radwaste system. GE submitted the radwaste system ITAAC for staff roviow. This was identified as DFSER Open Item 11.0-1. GE provided a revised set of design descriptions and ITAAC. The adequacy and acceptability of the design description and the ITAAC are evaluated in Section 14.3 of this report. On the basis of this evaluation, this item is resolved. 


\subsection{Source Terms}

The staff calculated the expected releases of radionctive materials via gaseous effluents using the boiling water reactor (BWR) GALE Code methodology described in NUREG-0016, Revision 1, January 1979. The calculations in the code for estimating the liquid and gaseous effluents during normal plant operation, including anticipated operational occurrences, are based on (1) data from operating reactors, (2) field and laboratory tests, (3) standardizod coolant activities derived from American Nuclear Society 18.1 working group recommendations, (4) release and transport mochanisms that result in the appearance of radionctive matorial in liquid streams, and (5) the plant's radwaste system design features used to reduce the quantities of radioactive materials ultimately released to the environs. The principal parameters used in these calculations based on dat given in ABWR SSAR Sections 11.1, 11.2, and 11.3 tables and the gaseous source terms are given in Tables 11.1 and 11.2, respectively, of this report. Capacities of the principal components of the liquid and gaseous waste management systems for a singlo-unit plant are listed in Table 11.3 of this report. The liquid effluent source terms will be reviewed on a plant-specific basis as discussed below.

\subsection{Liquid Waste Management System}

\subsubsection{System Description and Review Discussion}

The liquid radioactive waste management system will consist of process equipment and instrumentation necessary to collect, process, monitor, and recycle or discharge the processed radioactive liquid wastes. The processing equipment for the system will be located in the radwaste building. Treatment of liquid waste will depend on the source, activity, and composition of the particular liquid waste and on the intended disposal procedure. The liquid wastes generated during operation will bo collected and processed in throe liquid radwasto management subsystems. The three subsystems are (1) the low-conductivity waste (LCW) (high purity) subsystem, (2) the high-conductivity waste (HCW) (low purity) subsystem, and (3) the detergent waste subsystem. These systems are described in detail in SSAR Section 11.2. The LCW subsystem will use high efficiency filters that require less backwash water than the precoat filters used in current designs. The LCW suibsystem will receive less wastes because the ABWR will not have recirculation pumps and associated valves and will not regenerate the deep bed condensate demineralizers or use ultrasonic resin cleaning as older BWR designs do. For these reasons, the staff expects less generation of waste in the LCW subsystem than in the systems of older BWRs.
The liquid radwaste treatment systems are designed to completely recycle of processed liquids from the LCW and HCW subsystems during normal operation. Processed liquids will bo handled on a batch basis to permit optimum control and release of radicactive materials from the LCW, $\mathrm{HCW}$, and detergent waste subsystems. Discharge of processed LCW or HCW water will be solely governed by the plant water balance considerations. Before being released, samples will be analyzed to determine the types and amounts of radionctivity present. On the basis of the results of the analyses, the waste from the HCW and LCW subsystoms will be recycled for eventual reuse in the plant, retained for further processing, or released under controlled conditions to the environment through the liquid patbway. All detergent wastes are expected to be released. A common radiation monitor (RM) in the discharge line will automatically terminate liquid waste discharges to the discharge canal from the LCW, HCW, or the detergent waste subsystem if radiation measurements exceed a predetermined level set by the COL applicant in order to moet 10 CFR Pust 20, Appendix B, Table 2, Column 2 effluent concentration limits for the applicable subsystem. The predetermined level will be based on the ratio of instantaneous radionuclide concentration in any unrestricted ares to the effluent concentration limit for that radionuclide given in the above table summed over all the radionuclides present in the liquid effluent not exceeding 10 . This was identified as DFSER COL Action Item 11.2.1-1. By amended SSAR Chapter 11, GE identified COL License Information Section 11.2.5.1, Item 5, which states the COL applicant will provide a RM in the liquid radwaste discharge line to the environment to perform the function stated above. This approach by GE is acceptable. GE has also included this action item in the final certified SSAR.

The LCW subsystem will collect and process clean wastes such as those from equipment drains (from the drywell, reactor, radwaste, and turbine buildings) and spent resin backwash transfer water. The wastes will be collected in one or two parallel LCW collector tanks, filtered in one or two parallel high efficiency filters (for the normal waste generation rate, one collector tank and one filter are used) for removal of insolubles and demineralized in a mixedbed demineralizer and a backup polishing demineralizer. Conductivity instrumentation on the demineralizer discharge will route the effluent either to the LCW sample tanks or back to the LCW collector tanks for reprocessing. From the sample tanks, the liquid stream will normally be routed to the condensate storage tank for reuse. However, a small fraction of the processed waste may be discharged from one of the sample tanks should the plant's water balance considerations dictate such a discharge. The staff estimates that approximately 1 percent of the processed LCW will be discharged. The staff estimates that the 
Table 11.1 Principal parameters used in the calculation of gaseous and liquid effluents from ABWR

\section{Penmoter}

Thermal Power, MWt

Total steam flow rate, $\mathrm{kg} / \mathrm{h}$

Reactor coolant mass, $\mathrm{kg}$

Steem/water concentration, reactor vessel:

Halogens

Particulato

RWC deminieralizer flow rate, $\mathrm{kg} / \mathrm{h}$

Fraction of $5 \mathrm{~W}$ through condensate demineralizer

Reactor bldg. iodine relense fraction

Reactor bldg. particulato release fraction

Radwaste bldg. iodine release fraction

Radwasto bldg. particulato release fraction

Turbine bldg. iodine release fraction

Turbino bldg. particulato release fraction

Mechanical vacuum pump iodine release fraction

Charcoal delay system:

$\mathrm{Kr}$ dynamic adsorption coefficient, $\mathrm{cm}^{3 / /}$

$X e$ dynamic adsorption coefficient, $\mathrm{cm}^{3} / \mathrm{g}$

Ar dynamic adsorption coefficient, $\mathrm{cm}^{3 / \mathrm{g}}$

Mass of charcoal, $t$

\section{Liquid Waste inputs}

High purity (low conductivity subsystem)

Waste collection rate, $\mathrm{m}^{3} / \mathrm{day}$

Reactor coolant activity (RCA) fraction

Collection, and processtimo, days

DF for halogens; Cs and Rb; others*

Fraction discharged

Low purity (high conductivity subsystem)

Waste collection rate, $\mathrm{m}^{3} / \mathrm{day}$

RCA fraction

Collection, and process time, days

IF for halogens; Cs and Rb; others*

Fraction discharged

Detergent Wastes

DF for radionuclides

Fraction discharged
Velue

3926

7.63E6 $(1.68 \mathrm{E} 7 \mathrm{lb} / \mathrm{h})$

3.06E5 (6.75E5 lb)

0.015

0.001

$1.52 \mathrm{ES}(3.35 \mathrm{ES} \mathrm{lb} / \mathrm{h})$

0.67

1.0

1.0

1.0

1.0

1.0

1.0

1.0

16.0

260.0

6.4

113.4 (125 tons)
$57.5 \quad(15200 \mathrm{gpd})$

0.23

$5.98,0.96$

1000; $100 ; 1000$

0.01

$23.8 \quad(6300 \mathrm{gpd})$

0.0028

$1.52,0.67$

10,$000 ; 100,000 ; 100,000$

0.1

1.0

1.0

* Excludes dissolved noble gases and tritium

** Includes chemical wastes 
Radioactive Waste Management

Table 11.2 Calculated annual release of radioactive materials in gaseous effluents from single ABWR unit

\begin{tabular}{|c|c|c|c|c|c|c|c|c|c|c|}
\hline \multirow{2}{*}{ Nuclide } & \multicolumn{2}{|c|}{ Buildin Vente* } & \multicolumn{2}{|c|}{ Oland Seal } & \multicolumn{2}{|c|}{$\begin{array}{l}\text { Mechanical Vacuum } \\
\text { Pump }\end{array}$} & \multicolumn{2}{|c|}{ Ofiras System } & \multicolumn{2}{|l|}{ Total } \\
\hline & $\mathrm{MBg} / \mathrm{yr}$ & $\mathrm{Ci} / \mathrm{yr}$ & $\mathrm{MBg} / \mathrm{yr}$ & $\mathrm{Ci} / \mathrm{yr}$ & MBg/yr & $\mathrm{C}$ i/yr & $\mathrm{MBg} / \mathrm{yr}$ & $\mathrm{Ci} / \mathrm{yr}$ & MBg/yr & $\mathrm{Ci} / \mathrm{yr}$ \\
\hline$A r-41$ & $5.6 \mathrm{ES}$ & 1.5E1 & 0.0 & $0.0 * *$ & 0.0 & 0.0 & $3.7 \mathrm{E} 4$ & 1.0 & $5.9 \mathrm{ES}$ & $1.6 \mathrm{E} 1$ \\
\hline KR-83M & 0.0 & 0.0 & $1.5 \mathrm{ES}$ & 4.0 & 0.0 & 0.0 & 0.0 & 0.0 & $1.5 \mathrm{ES}$ & 4.0 \\
\hline KR-85M & $1.1 \mathrm{E} 6$ & $2.9 \mathrm{E} 1$ & $2.6 \mathrm{ES}$ & 7.0 & 0.0 & 0.0 & $3.1 \mathrm{E6}$ & $8.5 \mathrm{E} 1$ & $4.4 \mathrm{E} 6$ & $1.2 \mathrm{E} 2$ \\
\hline KR-85 & 0.0 & 0.0 & 0.0 & 0.0 & 0.0 & 0.0 & $1.0 \mathrm{E7}$ & 2.7E2 & $1.0 \mathrm{E7}$ & $2.7 \mathrm{E} 2$ \\
\hline KR-87 & $2.3 E 6$ & $6.3 \mathrm{E} 1$ & 8.9ES & 2.481 & 0.0 & 0.0 & 0.0 & 0.0 & $3.2 \mathrm{E} 6$ & 8.7E1 \\
\hline KR-88 & $3.5 \mathrm{E} 6$ & $9.5 \mathrm{E} 1$ & 8.9ES & 2.4E1 & 0.0 & 0.0 & 2.285 & 6.0 & $4.8 \mathrm{E} 6$ & $1.3 \mathrm{E} 2$ \\
\hline KR-89 & $2.3 \mathrm{E7}$ & $6.1 \mathrm{E} 2$ & $4.8 \mathrm{E} 6$ & $1.3 \mathrm{E} 2$ & 0.0 & 0.0 & 0.0 & 0.0 & 2.7E7 & $7.4 \mathrm{E} 2$ \\
\hline XE-131M & 0.0 & 0.0 & 0.0 & 0.0 & 0.0 & 0.0 & $1.3 \mathrm{E} 6$ & $3.6 \mathrm{E} 1$ & $1.3 \mathrm{E} 6$ & $3.6 \mathrm{E} 1$ \\
\hline XE-133M & 0.0 & 0.0 & 0.0 & 0.0 & 0.0 & 0.0 & 0.0 & 0.0 & 0.0 & 0.0 \\
\hline $\mathrm{XE}-133$ & $1.8 \mathrm{E} 7$ & $4.8 \mathrm{E} 2$ & 3.3ES & 9.0 & $4.8 \mathrm{E} 7$ & $1.3 \mathrm{E} 3$ & 8.5E7 & $2.3 \mathrm{E} 3$ & 1.5E8 & $4.1 \mathrm{E} 3$ \\
\hline XE-135M & 3.7e7 & $9.9 \mathrm{E2}$ & $1.1 \mathrm{E6}$ & $2.9 \mathrm{E} 1$ & 0.0 & 0.0 & 0.0 & 0.0 & 3.7E7 & $1.0 \mathrm{E} 3$ \\
\hline XE-135 & $2.7 \mathrm{E7}$ & 7.4E2 & 9.6E5 & $2.6 \mathrm{E1}$ & $1.9 \mathrm{E7}$ & $5.0 \mathrm{E} 2$ & 0.0 & 0.0 & $4.8 \mathrm{E} 7$ & $1.3 \mathrm{E} 3$ \\
\hline XE-137 & $4.8 \mathrm{E7}$ & $1.3 \mathrm{E3}$ & $5.6 \mathrm{~B} 6$ & $1.5 \mathrm{E} 2$ & 0.0 & 0.0 & 0.0 & 0.0 & $5.2 \mathrm{E} 7$ & $1.4 \mathrm{E} 3$ \\
\hline XE-138 & 3.7E7 & $1.0 \mathrm{E} 3$ & $3.5 E 6$ & 9.5E1 & 0.0 & 0.0 & 0.0 & 0.0 & 4.1E7 & $1.1 \mathrm{E3}$ \\
\hline I-131 & $5.9 \mathrm{E} 3$ & $1.6 \mathrm{E}-1$ & $5.9 \mathrm{E} 1$ & $1.6 \mathrm{E}-3$ & $3.3 \mathrm{E} 3$ & $8.8 \mathrm{E}-2$ & 0.0 & 0.0 & 9.3E3 & $2.5 \mathrm{E}-1$ \\
\hline 1-133 & 8.5E4 & 2.3 & $2.1 \mathrm{E} 2$ & $5.8 \mathrm{E}-3$ & $3.6 \mathrm{E} 4$ & 9.7E-1 & 0.0 & 0.0 & $1.2 \mathrm{ES}$ & 3.3 \\
\hline C-14 & 0.0 & 0.0 & 0.0 & 0.0 & 0.0 & 0.0 & $3.5 \mathrm{ES}$ & 9.5 & $3.5 \mathrm{ES}$ & 9.5 \\
\hline H-3 & $2.2 \mathrm{~B} 6$ & $5.9 \mathrm{EI}$ & 0.0 & 0.0 & 0.0 & 0.0 & 0.0 & 0.0 & $2.2 \mathrm{E} 6$ & $5.9 \mathrm{E} 1$ \\
\hline CR-51 & $1.0 \mathrm{E} 2$ & $2.7 \mathrm{E}-3$ & 0.0 & 0.0 & $3.7 \mathrm{E}-2$ & $1.0 \mathrm{E}-6$ & 0.0 & 0.0 & $1.0 \mathrm{E} 2$ & 2.7E-3 \\
\hline MN-54 & $2.2 \mathrm{E} 2$ & $6.0 \mathrm{E}-3$ & 0.0 & 0.0 & 0.0 & 0.0 & 0.0 & 0.0 & $2.2 \mathrm{E} 2$ & $6.0 \mathrm{E}-3$ \\
\hline CO-58 & $5.6 \mathrm{E} 1$ & $1.5 \mathrm{E}-3$ & 0.0 & 0.0 & 0.0 & 0.0 & 0.0 & 0.0 & $5.6 \mathrm{E} 1$ & $1.5 \mathrm{E}-3$ \\
\hline FE-59 & $2.9 \mathrm{E} 1$ & $7.9 \mathrm{E}-4$ & 0.0 & 0.0 & 0.0 & 0.0 & 0.0 & 0.0 & $2.9 \mathrm{E} 1$ & $7.9 \mathrm{E}-4$ \\
\hline$c 0-60$ & $4.8 \mathrm{E} 2$ & $1.3 \mathrm{E}-2$ & 0.0 & 0.0 & $2.1 \mathrm{E}-2$ & $5.6 \mathrm{E}-7$ & 0.0 & 0.0 & $4.8 \mathrm{E} 2$ & $1.3 \mathrm{E}-2$ \\
\hline $2 N-65$ & $4.1 \mathrm{E2}$ & $1.1 \mathrm{E}-2$ & 0.0 & 0.0 & $1.3 \mathrm{E}-2$ & $3.4 \mathrm{E}-7$ & 0.0 & 0.0 & $4.1 \mathrm{E2}$ & $1.1 \mathrm{E}-2$ \\
\hline SR-89 & $2.3 \mathrm{E} 2$ & $6.1 \mathrm{E}-3$ & 0.0 & 0.0 & 0.0 & 0.0 & 0.0 & 0.0 & 2.3E2 & $6.1 \mathrm{E}-3$ \\
\hline SR-90 & 1.1 & $3.0 \mathrm{E}-5$ & 0.0 & 0.0 & 0.0 & 0.0 & 0.0 & 0.0 & 1.1 & $3.0 \mathrm{E}-5$ \\
\hline NB-95 & 3.7E2 & $1.0 \mathrm{E}-2$ & 0.0 & 0.0 & 0.0 & 0.0 & 0.0 & 0.0 & $3.7 \mathrm{E} 2$ & $1.0 \mathrm{E}-2$ \\
\hline
\end{tabular}

* Does not include the HEPA filtered offgases resulting from incineration of certain types of dry solid wastes. The total release is expected to be $592 \mathrm{MBg} / \mathrm{yr}(0.016 \mathrm{Ci} / \mathrm{yr})$ in particulate form.

** For noble gases and C-14, 0.0 means less than $37,000 \mathrm{MBg} / \mathrm{yr}(1 \mathrm{Ci} / \mathrm{yr})$. For others, it means that the release is a negligible fraction of the total release for the isotope. 
Radioactive Waste Management

Table 11.2 Calculated annual releases of radioactive materials in gaseous effluents from single ABWR unit (continued)

\begin{tabular}{|c|c|c|c|c|c|c|c|c|c|c|}
\hline \multirow{2}{*}{ Nuclide } & \multicolumn{2}{|c|}{ Building Vente } & \multicolumn{2}{|c|}{ Gland Seal } & \multicolumn{2}{|c|}{$\begin{array}{l}\text { Mochanical } \\
\text { Vacuum Pump }\end{array}$} & \multicolumn{2}{|c|}{ Offras System } & \multicolumn{2}{|l|}{ Total } \\
\hline & $\mathrm{MBq} / \mathrm{yr}$ & $\mathrm{Ci} / \mathrm{yr}$ & $\mathrm{MBq} / \mathrm{yr}$ & $\mathrm{Ci} / \mathrm{yr}$ & $\mathrm{MBq} / \mathrm{yr}$ & $\mathrm{Ci} / \mathrm{yr}$ & $\mathrm{MBq} / \mathrm{yr}$ & $\mathrm{Ci} / \mathrm{yr}$ & $\mathrm{MBg} / \mathrm{yr}$ & $\mathrm{Ci} / \mathrm{yr}$ \\
\hline ZR-95 & 6.7E1 & $1.8 \mathrm{E}-3$ & 0.0 & 0.0 & 0.0 & 0.0 & 0.0 & 0.0 & 6.7 1 & $1.8 \mathrm{E}-3$ \\
\hline MO-99 & $2.5 \mathrm{E} 3$ & $6.8 \mathrm{E}-2$ & 0.0 & 0.0 & 0.0 & 0.0 & 0.0 & 0.0 & 2.5E3 & $6.8 \mathrm{E}-2$ \\
\hline RU-103 & $1.6 \mathrm{E} 2$ & $4.3 \mathrm{E}-3$ & 0.0 & 0.0 & 0.0 & 0.0 & 0.0 & 0.0 & $1.6 \mathrm{E} 2$ & 4.3E-3 \\
\hline As-110M & $8.9 \mathrm{E}-2$ & $2.4 \mathrm{E}-6$ & 0.0 & 0.0 & 0.0 & 0.0 & 0.0 & 0.0 & $8.9 \mathrm{E}-2$ & $2.4 \mathrm{E}-6$ \\
\hline SB-124 & 8.1 & $2.2 \mathrm{E}-4$ & 0.0 & 0.0 & 0.0 & 0.0 & 0.0 & 0.0 & 8.1 & $2.2 \mathrm{E}-4$ \\
\hline CS-134 & $2.7 \mathrm{E} 2$ & $7.3 \mathrm{E}-3$ & 0.0 & 0.0 & $1.2 \mathrm{E}-1$ & $3.2 \mathrm{E}-6$ & 0.0 & 0.0 & 2.7 2 & 7.3E-3 \\
\hline CS-136 & $2.2 \mathrm{E} 1$ & $6.0 \mathrm{E}-4$ & 0.0 & 0.0 & $7.0 \mathrm{E}-2$ & $1.9 \mathrm{E}-6$ & 0.0 & 0.0 & $2.2 \mathrm{E} 1$ & $6.0 \mathrm{E}-4$ \\
\hline CS-137 & $4.1 \mathrm{E2}$ & $1.1 \mathrm{E}-2$ & 0.0 & 0.0 & 3.3E-1 & $8.9 \mathrm{E}-6$ & 0.0 & 0.0 & 4.1E2 & $1.1 \mathrm{E}-2$ \\
\hline BA-140 & $1.2 \mathrm{E3}$ & $3.2 \mathrm{E}-2$ & 0.0 & 0.0 & 4.1E-1 & 1.1E-5 & 0.0 & 0.0 & $1.2 \mathrm{E3}$ & 3.2E-2 \\
\hline CE-141 & $4.1 \mathrm{E} 2$ & $1.1 \mathrm{E}-2$ & 0.0 & 0.0 & 0.0 & 0.0 & 0.0 & 0.0 & $4.1 \mathrm{E} 2$ & $1.1 \mathrm{E}-2$ \\
\hline
\end{tabular}

* Does not include the HEPA filtered offgases resulting from incineration of certain types of dry solid wastes. The total release is expected to be $592 \mathrm{MBg} / \mathrm{yr}(0.016 \mathrm{Ci} / \mathrm{yr})$ in particulate form.

normal wast generation rate for the LCW system will be about $58 \mathrm{~m}^{3} /$ day $(15,200 \mathrm{gpd}) ;$ GE estimates $55 \mathrm{~m}^{3} /$ day (14,530 gpd). The capacity of the limiting processing equipment is $720 \mathrm{~m}^{3} /$ day $(190,080 \mathrm{gpd})$. The difference between the expected normal waste generation rate and the design process flow rate provides adequate reserve for processing a surge in LCW generation rate.

The HCW subsystem will collect and process water of relatively high conductivity, such as the wastes from the floor drains (from drywell, reactor, radwaste, turbine, and service buildings). The HCW subsystem will also collect and process chemical wastes from chemical laboratories and laboratory drains. The wastes will be collected in one of two parallel HCW colloctor tanks, chemically adjusted to a suitable $\mathrm{pH}$ for evaporation, and concentrated in one of two parallel forced-circulation concentrators or evaporators to reduce the volume of water and decontaminate the distillate. The distillate will be demineralized by the HCW demineralizer and normally will be routed to the LCW system upstream of the polishing demineralizer. During normal processing, the LCW polishing demineralizer will be bypassed and the processed HCW will be directed to the LCW sample tanks. The processed stream will then be routed to the condensate storage tank for reuse. A small fraction of the processed HCW may be discharged from one of the LCW sample tanks should the plant's water balance dictate such a discharge. The staff estimates that approximately 10 percent of the processed HCW will be discharged. The distillate from the HCW demineralizer also can be routed to an HCW distillate tank to be reprocessed by the HCW demineralizer, if required. The concentrated waste from the evaporator will be routed to the concentrated waste storage tank for further processing by the solid waste system. The staff estimates that the normal waste generation rate for the HCW system will be approximately $24 \mathrm{~m}^{3} /$ day (6300 gpd); GE estimates $15 \mathrm{~m}^{3} /$ day (4000 gpd). The capacity of the limiting processing equipment in this system is $142 \mathrm{~m}^{3} /$ day (37,440 gpd), leaving adequate reserve for processing a surge in the HCW generation rate.

The detergent waste subsystem will collect and process detergent wastes from personnel showers and laundry operations. Detergent wastes will be collected in the single hot shower drain (HSD) receiver tank, processed through one or two HSD filters, and routed to the HSD sample tank before discharge. GE estimates that the normal generation of detergent waste will be approximately $11 \mathrm{~m}^{3} /$ day (3000 gpd); the staff's estimate is $4 \mathrm{~m}^{3} /$ day (1000 gpd). In a June 7, 1990, submittal, GE further stated that, if storm drains are included, the waste 
Table 11.3 Design capacities of principal components in the liquid and gaseous radwaste treatment systems for ABWR single unit

Component

Liquid Systems*

High purity (low conductivity) subsystem Low conductivity collection tank

Waste high efficiency filter

Waste demineralizer (mixed bed)

Sample tank** ,

Low purity (high conductivity) subsystem

High conductivity collection tank

Waste evaporator

Distillate demineralizer

Sample tank **

Distillate tank

Detergent Waste Subsystem

Hot shower drain receiver tank

Hot shower drain sample tank

Detergent filter

\section{Gaseous Systems*}

Ambient temperature RECHAR system

Catalytic recombiner

Condenser

Charcoal adsorber beds

Mass of activated charcoal
No. Capacity or Flow Rate

$\begin{array}{lll}2 & 430 \mathrm{~m}^{3} & (114,000 \mathrm{gal}) \\ 2 & 15 \mathrm{~m}^{3} / \mathrm{h} & (66 \mathrm{gpm}) \\ 2 & 30 \mathrm{~m}^{3} / \mathrm{h}, 36 \mathrm{~m}^{3} / \mathrm{h} & (130 \mathrm{gpm}, 160 \mathrm{gpm}) \\ 2 & 430 \mathrm{~m}^{3} & (114,000 \mathrm{gal})\end{array}$

$\begin{array}{lll}2 & 45 \mathrm{~m}^{3} & (12,000 \mathrm{gal}) \\ 2 & 3 \mathrm{~m}^{3} / \mathrm{h} & (13 \mathrm{gpm}) \\ 1 & 6 \mathrm{~m}^{3} / \mathrm{h} & (26 \mathrm{gpm}) \\ 2 & 430 \mathrm{~m}^{3} & (114,000 \mathrm{gal}) \\ 1 & 16 \mathrm{~m}^{3} & (4,200 \mathrm{gal}) \\ & & \\ 1 & 33 \mathrm{~m}^{3} & (8,700 \mathrm{gal}) \\ 2 & 210 \mathrm{~m}^{3} & (55,500 \mathrm{gal}) \\ 2 & 6 \mathrm{~m}^{3} / \mathrm{h} & (26 \mathrm{gpm})\end{array}$

2

$2413 \mathrm{kPa}$

$232^{\circ} \mathrm{C}$

1

9

$482^{\circ} \mathrm{C}$
$2413 \mathrm{kPa} * *$ tube side

$\left(900^{\circ} \mathrm{F}\right) \dagger$

$2413 \mathrm{kPa} * * *$

$4.4^{\circ} \mathrm{C}$ to $121^{\circ} \mathrm{C}$

$\left(40^{\circ} \mathrm{F}\right.$ to $\left.250^{\circ} \mathrm{F}\right) \dagger$

$113.4 t$

(125 tons)

$\Delta \quad$ For each component (e.g., for each tank, filter, demineralizer or evaporator)

* In accordance with RG 1.143

** Shared by high and low conductivity subsystems. Acts as a surge tank for both systems when condensate storage of the processed liquids is unavailable. In addition, serves as a sample tank for the high conductivity or low conductivity subsystem from where discharge to the environment can occur.

$\begin{array}{ll}* * * & \text { Design pressure } \\ \dagger & \text { Design temperature }\end{array}$ 
generation for this subsystem will be approximately $31 \mathrm{~m}^{3} /$ day $(8300 \mathrm{gpd})$. The storm drain water will be normally nonradioactive, but can become radioactive on contact with radioactive liquids. The storm drain water will be collected in one, of the two HSD sample tanks and discharged after processing by the HSD filters, if needed. The staff estimates that all of the detergent wastes and storm drain water will be discharged. The capacity of the limiting processing equipment in this system is $284 \mathrm{~m}^{3} /$ day (75,000 gpd), which, together with the system's tanks will ensure adequate margin to collect and process any surge in the waste generation.

The liquid radwaste system has one discharge line to the environs for liquid waste. Radiation-monitoring equipment placed on this line will measure the activity discharged. At any one time, this line can be fed only by one HSD sample tank or one of the two LCW sample tanks. GE stated that administrative controls will limit the total plant release per year to $3,700 \mathrm{MBq}(0.1 \mathrm{Ci})$, excluding tritium. The staff estimates a total annual release of about $7,400 \mathrm{MBq}(0.2 \mathrm{Ci})$ for the liquid wastes, primarily as a result of $3330 \mathrm{MBq}(0.09 \mathrm{Ci})$ of untreated detergent wastes and $3,700 \mathrm{MBq}(0.1 \mathrm{Ci})$ because of adjustment for anticipated operational occurrences such as operator error, and $2.2 \times 10^{6} \mathrm{MBq}(59 \mathrm{Ci})$ for tritium. Administrative controls for meeting GE's commitment to limit the liquid wastes to $3700 \mathrm{MBq} / \mathrm{yr}(0.1 \mathrm{Ci} / \mathrm{yr})$ are not within the scope of the ABWR design, but will be the responsibility of the COL applicant. Therefore, this was identified as DFSER COL Action Item 11.2.1-2. By amended SSAR Chapter 11, GE identified COL License Information Section 11.2.5.1, Item 3 which states that the COL applicant will provide the specific administrative controls and liquid effluent source terms. This approach by GE is acceptable. GE has also included this action item in the final certified SSAR.

The tanks containing spent resin, filter/demineralizer, and filter sludges are part of the liquid radwaste management system. Separation of filter sludges and filter/demineralizer sludges from process and transfer water will take place in phase separator decant tanks. The liquid from the separator tanks will be routed to the LCW collector tanks. The spent resins from the condensate polishing sy/stem (i.e., part of the condensate/feedwater system) LCW and HCW demineralizers will be collected in a spent resin tank. The sludges from the separator tank, remaining after decant, and the spent resins from the spent resin tank will be treated either by a thin film dryer or by vendorsupplied mobile dewatering systems. The water will be routed to the LCW collector tank and the dewatered slurry will be loaded in high-integrity containers (HICs) for eventual shipment.

\subsubsection{Conclusion}

In evaluating of the liquid radioactive waste management system, the staff considered (1) the capability of the system to maintain releases below the limits in 10 CFR Part 20 during periods of fission-product leakage at design levels from the fuel, (2) the capability of the system to meet the processing demands of tho station during anticipated operational cocurrences, (3) the quality group and seismic design classification applied to the equipment, components, and structures housing the system, and (4) the design features that are incorporated to control the release of radionctive materials in accordance with GDC 60 . The staff reviewed all applicable information provided in the amended SSAR Chapter 11 and GE's submittals dated June 7 and 29, and November 5, 1990, and August 2, 1991, in response to the staff's request for additional information.

The staff concludes that the liquid radwaste system includes the equipment necessary to control the releases of radioactive materials in liquid effluents in accordance with GDC 60 and radwaste system aspects of GDC 61 and that the design of the liquid waste managemunt system is acceptable and meets the requirements of 10 CFR 20.1302 and GDC 60 and the applicable portion of GDC 61 for control of releases of radioactive material to the environment.

The staff further concludes that there is reasonable assurance that the COL applicant will be able to meet the Appendix I to 10 CFR Part 50 dose guidelines for radioactive materials released through liquid effluents with regard to the minimum discharge canal flow rate of $340 \mathrm{~m}^{3} / \mathrm{hr}(1500 \mathrm{gpm})$ and the additional dilution credit of at least a factor of 10 between the point of release and the region in the unrestricted are where the water is used. The staff considers demonstrating compliance with 10 CFR Part 50, Appendix I, is the COL applicant's responsibility. So the staff will evaluate this compliance individually for each COL application. This was identified as DFSER COL Action Item 11.2.2-1. By amended SSAR Chapter 11, GE identified COL License Information (Section 11.2-5.1, Items 1 and 4) which requires the COL applicant to demonstrate the above compliance. This approach by GE is acceptable. GE has also included this action item in the final certified SSAR.

The staff's conclusions are based on the following findings:

On the basis of ABWR parameters that govern reactor coolant system concentrations of radionuclides and design of the liquid radwaste treatment systems, as stated in Section 11.2.1 of 
this report, the staff estimates that the total of radioactive wastes discharged via the liquid offluent during normal plant operation including anticipatod opentional occurrences will be no more then $7,400 \mathrm{MBg} / \mathrm{yr}$ (0.2 Ci/yr) (excluding tritium) and $2.2 \times 10^{6} \mathrm{MBg} / \mathrm{yr}(59 \mathrm{Ci} / \mathrm{yr}$ ) for tritium. This finding, in conjunction with SSAR Section 11.2.3.2 assumed minimum dilution flow rate of $340 \mathrm{~m}^{3} / \mathrm{hr}$ (1500 gpm) and at least an additional credit of a fector of 10 (as stated in SSAR Section 11.2.3.2) between the point of discharge and the region in the unrestricted area where water is used, provides reasonable assurance that the ABWR liquid waste management system will meet the applicable 10 CFR Part 50, Appendix I drse guidelines for liquid effluents.

GE's ABWR design has met the requirements of 10 CFR Part 20 that will have the minimum discharge flow rate of $340 \mathrm{~m}^{3} / \mathrm{hr}(1500 \mathrm{gpm})$ and for which liquid waste can only be discharged from either the HSD sample tank or the LCW sample tank. The staff has considered the potential consequences resulting from reactor operation and has determined that the concentrations of radioactive materials in liquid effluent averaged over a year, as permitted by 10 CFR 20.1302 for the above case, will be well below the limits in 10 CFR Part 20, Appendix B, Table 2, Column 2. Instantaneous discharge concentrations of the radionuclides in liquid effluents to an unrestricted area will also be within these limits because GE has stated in a submittal dated November 5, 1990, that the discharge rate via the single discharge line will be administratively controlled to conform to these limits. The staff will review the administrative controls to limit the instantaneous discharge concentrations of the radionuclides in liquid effluents to an unrestricted area to comply with the limits in 10 CFR Part 20, Appendix B, Table 2, Column 2, as explained in Section 11.2.1 of this report, on a plant-specific basis for the COL applicants. Therefore, this was identified as DFSER COL Action Item 11.2.2-2. By amended SSAR Chapter 11, GE included COL License Information Section 11.2.5.1, Item 5 which states the COL applicant will provide administrative controls to ensure the limits mentioned above. This approach by GE is acceptable. GE has also included this action item in the final certified SSAR.

GE's ABWR design has met the requirements of GDC 60 and 61 with respect to system design for controlling releases of radioactive materials to the environment. The staff considered the capabilities of the proposed liquid radwasto treatment system to meet the demands of the plant resulting from anticipated operational occurrences and has concluded that the system's capacity and design flexibility are adequate to meet the anticipated needs of the plant as discussed in Section 11.2.1 of this report. The staff also reviewed GE's quality group classifications which are used for the system components and the seismic design applied to structures housing these systems. In the DFSER, the staff stated that quality assurance (QA) (Operation) provisions of the liquid radwaste ystems will be reviewed individually for each COL application and identified this as DFSER COL Action Item 11.2.2-3. By amended SSAR Chapter 11, GE included COL License Information Section 11.2.5.1, Item 6 which states the COL applicant will provide QA (Operations) provisions of the liquid radwaste systems. This approach by GE is acceptable. GE has also included this action item in the final certified SSAR.

The design of the systems and structures housing these systems meets the applicable criteria given in RG 1.143, Revision 1. Specifically, the base mat and outside walls of the housing structures are seismic Category I to a height necessary to retain spilled liquids within the building. In the draft safety evaluation report (DSER) (SECY-91-235), the staff stated that the provisions incorporated in the ABWR design to control the release of radioactive materials in liquids resulting from inadvertent tank overflow were consistent with the criteria given in RG 1.143 except for the lack of a local alarm capability for the condensate storage tank (CST). This was identified as Open Item 70 in the DSER (SECY-91-235). GE responded in Amendment 20 to SSAR Section 9.2.9.2, Item (9), by stating: "Instrumentation shall be provided to indicate CST water level in the main control room. High water level will be alarmed both locally and in the main control room." This satisfies the staff concern regarding RG 1.143 requirements for a local high level alarm for CST which will be located in the radwaste building control room as stated in SSAR Section 11.2.1.2.1. Therefore, Open Item 70 is resolved.

IE Bulletin 80-05 identified an issue: cooling hot water in a low pressure tank could create a low vacuum condition and buckle the tank, releasing radioactive material or having other detrimental effects. In a fax dated May 21, 1992, GE stated that several low-pressure tanks that could contain primary system water have vents to prevent the development of a low vacuum condition. In the DFSER, 
the staff stated that the above information resolved the tank failure concern in IE Bulletin 80-05, subject to documentation of the information in the SSAR. Therefore, the staff identified the resolution of the issue as DFSER Confirmatory Item 11.2.2-1. By amended SSAR Section 11.2.4, GE included the above information by stating that the only tanks in the LWMs that can contain reactor water, diluted by other wastes are the LCW and HCW collector tanks and that these tanks are vented to preclude their vacuum collapse. This is acceptable to the staff, and therefore, this item is resolved.

The staff concludes that the liquid waste management system for the ABWR meets the acceptance criteria of SRP Section 11.2 and is, therefore, acceptable.

\subsection{Gaseous Waste Management System}

\subsubsection{System Description and Review Discussion}

The gaseous radioactive waste processing and plant ventilation systems are designed to collect, store, process, monitor, and discharge potentially radionctive gaseous wastes that will be generated during normal operation of the plant, including anticipated operational occurrences. The systems will consist of equipment and instrumentation necessary to reduce release of radioactive gases and particulates to the environment.

The principal sources of gaseous wastes in the plant will be the offluents from the offgas system, condenser mechanical vacuum pump, turbine gland seal system (TGSS), and ventilation exhausts from the radwasto building, containment purge, reactor building, and turbine building. All these effluents will be routed into the plant stack either directly or indirectly (TGSS and mechanical vacuum pump) and monitored continuously.

The major source of gaseous radwaste during normal plant operation before treatment will be the offgases from the main condenser air ejector. These will principally contain hydrogen and oxygen from the radiolytic decomposition of water, air from condenser in-leakage, fission and activation gases, and water vapor. To treat this effluent, the ABWR design uses an offgas processing system consisting of redundant catalytic hydrogen-oxygen recombiners, charcoal absorber delay beds, and a HEPA filter operating at ambient conditions.

The offgases will be diluted with sufficient steam in the last stage of the air ejector to reduce the hydrogen concentration to less than 4 percent by volume upstream of the recombiner. The offgases will be preheated in the first stage of the recombiners to approximately $177^{\circ} \mathrm{C}\left(350^{\circ} \mathrm{F}\right)$ to remove moisture before recombination and reduced in hydrogen concentration to less than 1 percent by volume by the recombiner(s). The recombiner effluent will subsequently be cooled to between $57^{\circ} \mathrm{C}\left(135{ }^{\circ} \mathrm{F}\right)$ and $68^{\circ} \mathrm{C}$ $\left(154^{\circ} \mathrm{F}\right)$ by the offgas condenser. The offgas condenser will also includo baffles to reduce moisture entrainment. The offges stream will be further cooled to $18^{\circ} \mathrm{C}\left(65^{\circ} \mathrm{F}\right)$ by the cooler condenser. The pressure boundary of the system will be detonation resistant, with a design pressure of $2413 \mathrm{kPa}$ (350 psig). Redundant, nonigniting, detonation-resistant hydrogen analyzers will monitor hydrogen concentration downstream of the recombiners and alarm both locally and in the control room when appropriate.

Fission and activation gases will be held for decay in the charcoal absorber system downstream from the offges condensers. Before entering the delay beds, these gases decay for 2.5 minutes during their transit from the main condenser to the delay beds. The charcoal absorber beds consist of one guard bed absorber followed by four parallel trains of two absorber beds in series. The total mass of charcoal will be $114,000 \mathrm{~kg}(250,000 \mathrm{lb})$. The offgas system is also designed to prevent, monitor, and suppress the potential ignition and combustion propagation of charcoal in the charcoal absorber tanks, with the necessary temperature elements in the charcoal tanks and connections for nitrogen purge and blanketing.

Before discharge, the offgas system effluent stream will be pessed through an HEPA filter assembly to remove particulates. The holdup times in the ambient offgas treatment system charcoal beds at $38^{\circ} \mathrm{C}\left(100^{\circ} \mathrm{F}\right)$ with a dew point of $18^{\circ} \mathrm{C}\left(65^{\circ} \mathrm{F}\right)$ were calculated according to the methodology of NUREG-0016, Revision 1, and GE proprietary report NEDO-10751. The staff estimates these times to be approximately 30 days for xenon, 44 hours for krypton, and 18 hours for argon; GE estimates 42 days for xenon and 46 hours for krypton. These beds will also absorb iodines from the treatment system effluent. The offgas system is designed to withstand a hydrogen explosion.

The ventilation exhausts from all plant areas such as the reactor building (RB) (which includes the primary containment when it is vented or purged, the fuel handling area, the area housing the emergency core cooling system equipment, other areas such as the standby gas treatment system (SGTS) rooms, the fuel pool cooling system equipment rooms, and areas housing nonessential equipment), the service building controlled area, the radwaste building, and the turbine building, will be directed to the plant vent and monitored continuously before being released to the environs. The RB areas mentioned above will be serviced either directly or indirectly (for the primary containment purging or venting) by the secondary 
containment ventilation system during normal plant operation. However, ventilation exhuusts from RB areas serviced by the RB enfety-related olectrical equipment heating, ventilation, and air conditioning (HVAC) syatom and the RB afety-related diesel generator HVAC systom, the turbine islend serviced by the electrical building ventilation aystom, and the control building areas serviced by the control building afoty-related equipment area HVAC systom will bo diecharged directly to the environs unmonitored. The lack of monitoring for the exhaust from these areas is evaluated in Section 11.5 of this report which concludes that this is acceptable. Although SSAR Section 9.4.8.1.2 states that the ervice building controlled area ventilation exhaust will be monitored before its release, SSAR Table 11.5.1 doses not indicate any explicit monitoring provision for the subject exhaust. Therefore, the staff concluded in Open Item 71 in the DSER (SECY-91-235) that this discharge will not be monitored. In its response of December 19, 1991, to the issues raised in the DSER, GE stated: "The service building ventilation exhaust is sent to the plant release point where the offgeses aro monitored and sampled during release." By amended SSAR Section 11.5.2.2.4, GE further clarified the issue by stating that the exhaust from the service building controlled area will be diecharged to the environs via the monitored plant vent. Therefore, the iscue of eervice building ventilation exhaust monitoring is resolved. Open Item 71 in the DSER (SECY-91-235), is resolved.

On the basis of SSAR Section 9.4 and GE's responses dated May 23 and August 27, 1990, the staff stated in Open Item 72 in the DSER (SECY 91-235) that neither the mechanical vacuum pump exhaust nor the normal ventilation exhaust system of any building includes either charcoal adsorbers or HEPA filters to remove elemental and organic forms of iodine and particulate from the applicable offluent stream. In calculating the gaseous effluents, the staff, therefore, assumed that all the exhausts will be discharged to the environs untreated. In its response of December 19, 1991, GE confirmed the staff's assumption. The staff's assumption does not invalidate its conclusion that the gaseous waste management system discussed in Section 11.3.2 of this report is acceptable. Therefore, the issue of lack of charcoal absorbers and HEPA filters is resolved and Open Item 72 in the DSER (SECY-91-235) is resolved.

The calculated release values for iodines and particulate in Table 11.2 of this report reflect the above assumption. SSAR Sections 6.5.1, 9.4.5.1.3, and 9.4.5.1.5 etate that, if high radiation is detected in the secondary containment exhaust or in the refueling floor atmosphere, the secondary containment normal ventilation system will be secured and the exhaust discharged through the safety-related SOTS, which consists of charcoal adsorbers and HEPA filters.
The SOTS exhaust also will go through the monitored plant veat.

The plant stack and the major streams feeding the plant stack (offgas system and buiiding ventilation systoms) will be monitored to facilitate appropriate corrective action in - timoly manner to prevent offsite release exceeding applicable limits. Additionally, the offgas treatment oystem includes an automatic control feature to terminato the post-treatment releace if it exceods a preset radiation level in the effluent. However, as part of Open Item 73 in the DSER, the staff questioned whether the monitors for the recondary containment exhaust will be sufficiently ecensitive to dotect a high-radiation lovel in the primary contrinment purge exhaust as specified by Branch Technical Position CSB 6-4, "Containment Purging Di ring Normal Plant Operations." In SSAR Section 11.5.2.1.2, GE confirmed the sensitivity of these monitors to detect a high-radiation level in the primary containment purge exhaust. This part of Open Item 73 in the DSER (SECY-91-235) is resolved.

As the second part of Open Itom 73 in the DSER (SECY91-235), the staff notod that whilo SSAR Section 9.4.4.2.1.1 atates that the turbine building ventilation exhaust will be monitored before its discharge to the monitored plant vent, SSAR Table 11.5-2 did not indicate any auch process monitoring provision for that exhaust. GE amended SSAR Tables 11.5-1 and 11.5-2 to indicate that the turbine building ventilation exhaust will be monitored. This part of Open Item 73 is resolved. Both parts of Open Itom 73, in DSER (SECY-91-235) aro, therefore, resolved.

As atated above, all airborno radioactivity releases except offgeses from the incinerator will be through the monitored plant vent. The plant vent is located on the reactor building at $76 \mathrm{~m}$ (249 ft) above grade and is the talleat point on the site. Incinerator offgeses will also be monitored prior to their release to the atmosphere, through incinerator exhaust stack.

\subsubsection{Conclusion}

In evaluating the gaseous radwaste management system, the staff used the SRP criteria pertaining to (1) the capability of the systom to maintain releases below the limits in 10 CFR Part 20 during periods of fission-product leakage at design levels from the fuel, (2) the capability of the aystem to meet the processing demands of the station during anticipated operational occurrences, (3) the quality group and seismic design classification applied to the equipment and to components and structures housing the system, (4) the design features that are incorporated to control the releases of radioactive materials in accordance 
with GDC 60, and (5) the potential for geseous relenses resulting from hydrogen explosions in the gaseous radwaste system. The staff also reviewed the capability of the offgas system to limit the whole-body dose to less than 10 percent of the 10 CFR Part 100 limits for an individual exposuro of 2 hours at the nearest exclusion area boundary (EAB) as a result of radioactive releases from a postulated offges system leak or failure as assumed in BTP ETSB 11-5, Revision 0, July 1981. The staff roviewed all the applicable information provided in the amended SSAR as well as GE's submittals dated May 23, Juno 29, August 22, Soptember 14, and October 26, 1990, Docomber 19, 1991, and June 23, 1993.

The staff concludes that the gaseous radionctive waste management system design for the ABWR moets the applicable requirements of 10 CFR 20.1302 and GDC 3, 60 , and 61 with regard to radioactivity in gaseous offluents released to unrestricted areas, fire protection, control of releases of radioactive materials, and radioactivity control in the gaseous waste management system and ventilation system associated with fuel storage and handling areas.

The staff expects that the COL applicant will provide an operational demonstration that the system design complies with Appendix I to 10 CFR Part 50 numerical guidelines for offsite radiation doses as a result of gaseous or airborne radioactive effluents during normal plant operation, including anticif ated operational occurrences. Therefore, this was identified as DFSER COL Action Item 11.3.2-1. By amended SSAR Chapter 11, GE included COL License Information in Section 11.3.11.1, which states that the COL applicant will demonstrate this above compliance. This approach by GE is acceptable. GE has also included this action itom in the final certified SSAR.

Nonetheless, the staff has evaluated the ABWR design to determine if there is reasonable assurance that the COL applicant will be able to meet the Appendix I dose guidelines for design objectives. The ingestion, inhalation, and external irradiation of ground contamination pathway doses to applicable organs resulting from release of radioactive iodines, radioactive material in particulate form, and tritium and carbon-14 via airborne effluents depend on a number of site-dependent parameters. The population exposures (person-rem) and associated cost-benefit analysis are also site dependent. Therefore, the staff considered only if the standard design for the gaseous waste management system complies with Appendix I guidelines for external doses to any individual in an unrestrictod area as a result of noble gas radionuclides in gaseous effluents. The staff concludes that there is reasonable assurance that $A B W R s$ at sites that have an atmospheric dispersion factor $(\chi / Q)$ equal to or lese than $9.8 \times 10^{-6} \mathrm{sec} / \mathrm{m}^{3}$ will meet the above dose guidelines (.05 mSv (5 mrem) per year to the total body).

Using the assumptions given in BTP ETSB 11-5 for analyzing a postulated leak or failure of a waste gas system and the EAB 0-2 hour $X / Q$ of $1.37 \times 10^{-3} \mathrm{sec} / \mathrm{m}^{3}$ (used in Chapter 15 of this report), the staff has determined that the wholebody dose at the EAB is less than 10 percent of the 10 CFR Part 100 limit. Therefore, the staff concludes that for all sites that have equal to or less than the above $\chi / Q$ at the EAB, the offges system design will meet the above dose criterion and will be acceptable. This will be verified for each COL applicent.

These conclusions referred to above are based on the following findings:

(1) The ABWR design meets the requirements of ODC 60 and 61 by ensuring that the gaseous waste management system includes the equipment and instruments necessary to detect and control the release of radionctive materials in gaseous effluents.

(2) On the besis of expected radweste inputs over the life of the plant, the staff has determined the roleases of radioactive materials (noble gases, iodines, particulate, tritium and carbon-14) in gaseous effluents resulting from normal operation, including anticipated operational occurrences. The staff used the calculated releases for noble gases (Table 11.2 of this report) to determine the bounding value for $X / Q$ and assumed a 4-minute decay of the noble gas radionuclides during transit from the release point to the unrestricted area. The staff used the dose models and values for parameters given in RG 1.109 (Rev. 1) to evaluate compliance with Appendix I to 10 CFR Part 50. To calculate the external dose of noble gas radionuclides, the staff assumed a semi-infinite cloud model for the gaseous effluents. For the bounding $X / Q$ value quoted above, the staff calculated a total body dose (the limiting external dose) of $0.05 \mathrm{mSv} / \mathrm{yr}$ (5 mrem/yr), which meets the applicable Appendix I dose guideline.

(3) The ABWR design meets the requirements of 10 CFR Part 20 because the staff has considered the potential consiquences resulting from reactor operation with a postulated fission product release rate consistent with an offgas noble gas release rate of $3.7 \times 10^{6} \mathrm{~Bq} / \mathrm{MWt}-\mathrm{sec}(100 \mu \mathrm{Ci} / \mathrm{MWt}-\mathrm{sec})$ at 30 minutes decay for a BWR and estimated that, under these conditions, the concentration of radionuclides in gaseous effluents in unrestricted areas with a value of $X / Q$ that is equal to or less 
than $9.8 \times 10^{-6} \mathrm{sec} / \mathrm{m}^{3}$ will be below the concentration values in 10 CFR Part 20, Appendix B, Table 2, Column 1. For KR-89 and $\mathrm{XE}-137$, whose specific concentration values are not explicitly given in this table, the ataff used relovant concentration values based on ratios of whole-body dose factors of nobleges radionuclides given in RG 1.109 (Rev. 1).

(4) The staff has considered the capability of the proposed gaseous wasto management systom to moet the anticipatod demands of the plent remiting from anticipated operational occurrences and concludes that the system capacity and flexibility of design are adequate to meet the anticipated needs of the plant. (See item 3 above.)

(5) The staff reviewed the seismic design criteria including the quality group classifications used for the gaseous waste management system components and the structures housing the radwaste system and concludes that the design of the system and the structures meets the applicable criteria specified in RO 1.143.

(6) The staff reviewed the provisions incorporated in the ABWR design to control relenses resulting from hydrogen explosions in the gaseous waste management system (SSAR Section 11.3, GE submittal dated June 29, 1990). The taff concludes that the features built into the design are adequate to prevent the occurrence of an explosion or adequate to withstand the effects of an explosion in accordance with GDC 3. (See Section 11.3.1 of this report regarding hydrogen recombiners and bydrogen analyzers.)

The staff concludes that the gaseous waste management system for the ABWR meets the scceptance criteria of SRP Section 11.3 and is, therefore, acceptable.

\subsection{Solid Waste Management System}

\subsubsection{System Description and Review Discussion}

The solid radioactive waste management system will consist of the equipment and instrumentation necessary to collect, solidify, incinerate, package, and store radioactive wastes resulting from the operation of the reactor water cleanup system, the fuel pool cooling and cleanup system, the suppression pool cleanup system, the condensate polishing system, the liquid radwaste system, the building ventilation systems, the SGTS, the offgas system, and miscellaneous solid wastes' (e.g., paper, rags, contaminated clothing, gloves, shoe coverings) arising from the operntion and maintenance of the plant. The solid redwasto management system is located in the radwaste building.

The ABWR colid waste system is designed to procese two genernl types of solid wastes: wet solid wastes, which will bo colidified or dewatered before being shipped off site, and dry solid wastes, which will be either incinerated or compacted and/or packaged before being shipped. Combuatible dry wastes (e.g., rags, uniforms, paper) will be burned in an incinerator and discharged to an ash storage drum. The offges from the incinerator will be passed through two ceramic filters in series and a HEPA filter before boing released into the atmosphere through a monitored vent. On the basis of GE's submittal dated June 29, 1990, the staff estimates this release to bo $592 \mathrm{MBq} / \mathrm{yr}(0.016 \mathrm{Ci} / \mathrm{yr})$ and to be in particulate form. Incinerated ash will be discharged to an ash storage drum by ash discharge equipment located on the bottom of the incinerator. The description of the incinerator to be used, source of incinerntor heat, storage facility for the heat source, and specific fire protection features to prevent any undue fire hazard resulting from incineration, were identified as DFSER COL Action Item 11.4.1-1. By amended SSAR Section 11.4.3.1 and June 2, 1993 abmittal, GE included COL License Information (Section 11.4.3-1, Item 1) which states the COL applicant will provide the above information. The staff finds that GE's identification of the COL License Information pertaining to the incinerator, and testing of the major components of the incinerator and description of the incinerator operation in the SSAR (Section 11.4.2.2.6, and Figure 11.2-2, Sheot 26) are acceptable. GE has also included this action item in the final certified SSAR.

Noncombustible dry solid wastes will bo compacted and placed in dry active waste drums for shipment.

There will be two forms of wet wastes: (1) slurries of opent resins and sludges from filters and filter demineralizer backwashes and (2) concentrated wastes from the HCW concentrators of the liquid radwaste treatment system. As stated in Section 11.2.1 of this report, the spent resins and the sludges will be dewatered and the resulting slurry will bo loaded in HICs for eventual shipment.

The concentrated waste from the HCW concentrators will be routed through a thin-film dryer for dewatering. The water from this operation will be routed back to the HCW collector tanks. Air will be exhausted through the radwaste building HVAC exhaust. The dewatered, 
powdered waste will be pelletized, and the pellets will be mixed with cement glass in drums for eventual offsite shipment or an approved solidification procese will bo used. Air from the pelletizing and colidification procean will be routed to the radwaste building HVAC exhaust via a particle filter and a HEPA filter.

SSAR Interface Requirement 11.4.3.1 stated the first COL applicant will provide detailed information to demonstrate that the wet waste solidification process using cement glase as the solidification agent will result in a product that complies with 10 CFR 61.56. In Open Item 74 in the DSER (SECY-91-235), the staff stated that the interface itom should be modified to require all COL applicants to provido this information. After ro-reviowing all interface items, GE committed to revise the SSAR to reclassify the need to demonstrate compliance of wet wasto solidification product with 10 CFR 61.56, as a COL Action Item. In the DFSER, the staff found the GE commitment acceptable and, therefore, identified demonstration of the above compliance as DFSER COL Action Itom 11.4.1-2. By amended SSAR Section 11.4.3.1, GE included COL License Information 11.4.3.1, Item (2) which states the COL applicant will provide detailed information to demonstrate that the wet waste solidification process will result in a product that complies with 10 CFR 61.56. This is acceptable. GE has also included this action ivem in the final certified SSAR.

On the basis of the Electric Power Research Institute report EPRI-NP-5528, Volume 1 and NUREG/CR-2907 (annual reports for 1986 and 1987, Volumes 7 and 8, only BWRs were considered), the staff estimates the processed wet wastes requiring shipment to be about $370 \mathrm{~m}^{3} / \mathrm{yr}$ $\left(13,000 \mathrm{ft}^{3} / \mathrm{yr}\right)$ containing approximately $4.4 \times 10^{7} \mathrm{MBq}$ $(1,200 \mathrm{Ci})$. The spent resin and filter and filter/demineralizer sludge slurries will be stored in HICs before shipment. The solidified concentrates will be stored in $0.21 \mathrm{~m}^{3}$ (55-gal) drums before shipment. On the basis of NUREG/CR-2907 and GE's submittal dated June 29, 1990 , the staff estimates that the processed dry wastes requiring shipment will be about $340 \mathrm{~m}^{3} / \mathrm{yr}\left(12,000 \mathrm{ft}^{3} / \mathrm{yr}\right)$ containing approximately $4.4 \times 10^{5} \mathrm{MBq}(12 \mathrm{Ci})$. However, with incineration of combustible dry wastes, the shipment volume will be less than $340 \mathrm{~m}^{3} / \mathrm{yr}$ $\left(12,000 \mathrm{ft}^{3} / \mathrm{yr}\right)$. The processed dry wastes will be stored in boxes or in $0.21 \mathrm{~m}^{3}$ (55-gal) drums.

Because the establishment and implementation of a process control program (PCP) for solidifying the ovaporator concentrates, using an approved solidification agent, and the dewatering process for the spent resins and filter sludges are dependent on the as-procured equipment for the ABWR standard design, the staff will review the PCP and the dewatering process for each $\mathrm{COL}$ applicant against
BTP ETSB 11-3. This was identified as DFSER COL Action Itom 11.4.1-3. By amended SSAR Section 11.4.3.1, $O E$ included COL License Information in Section 11.4.3.1, Item 3 which states the COL applicant will provide a PCP for solidifying the evaporator concentrates using an approved colidification agent and the dowatering process for the apent resins and filter sludges. This is acceptable. GE has also included this action item in the final certified SSAR.

\subsubsection{Conclusion}

In ovaluating the solid radionctive waste management syatem, the ataff considered (1) aystem design objectives in terms of expected types, volumes, and activities of wastes proceseed for offsite shipment; (2) provisions for onsite atorage of proceseed solid wastes before shipment; (3) procedures for dispoeal of incinerated waste; (4) system deaign to moot acceptance critoria of SRP Section 11.4; and (5) piping and instrumentation diagrams for the system.

On the basis of its review of amended SSAR Section 11.4 and GE's submittals dated June 7, June 29, Octrber 26, and November 5, 1990, August 2, 1991, May 18, 1992, and June 2, 1993, the staff concludes that the solid wasto management system dosign moets the requirements of 10 CFR 20.302(a), and GDC 60, 63, and 64. The design also complies with 10 CFR 61.56 and 10 CFR Part 71. The dowatered resin and filter sludge wastes will be Type B per 10 CFR 61.55 classification. As noted above, they will not be processed to a stable form. They will be stored in HICs to comply with 10 CFR 61.56 and 10 CFR Part 71 requirements. The conclusion on solid waste management aystem is besed on the following findings:

(1) The design includes equipment and instrumentation for processing, packaging, and storing of radianctive solid wastes before shipment off site. Dedicated radwaste storage areas in the radwaste building can accommodate $2210.21 \mathrm{~m}^{3}$ (55-gal) drums and 13 boxes with storage capacity of approximately $62 \mathrm{~m}^{3}\left(2200 \mathrm{ft}^{3}\right)$ of processed wet wasto (solidified concentrate) and dry solid wastes. Howover, before issuing the DSER (SECY-91-235), $G E$ did not specify the capacity and maximum number of HICs that can be stored. Further, the staff was concerned that the dedicated radwaste storage areas mentioned above may not be able to accommodate the HICs before shipment. Therefore, the staff identified this concern as Open Item 75 in the DSER (SECY-91-235). By amended SSAR Chapter 11, GE responded to the above concern in SSAR Section 11.4.2.3.6. From its review, the staff finds that normally the HICs will 
be shipped promptly after boing filled, in tho ovent of a shipping dolay they will be stored with ahiolding in the truck area. SSAR Section 11.4.2.3.6 atates that the truck aren can sccommodato 5 HICs containing approximataly $24 \mathrm{~m}^{3}\left(840 \mathrm{t}^{3}\right)$ of proceseed (i.e., downtered) resins and aludges and the shiolding for the HICs. On the besis of the available storage space for proceesed wot and diy solid wastes given above and the estimates of annual shipment volumes for theee wastes given in Section 11.4.1 of this report, the staff concludes that the available storage space is sufficient to sccommodate one full offsite waute shipment of dry wastes and 30 days of wet waste at normal generation rato in accordance with BTP ETSB 11-3, Positions B.III.2 and 3. Therefore, Open Itom 75 is reeolved. The capacities of tanks eccumulating spent resins and filter sludyes also meet BTP Position B.II.1.

Besides the GE submittals and SSAR revisions discuesed above, in a teleconference on May 20, 1992, GE stated that onsite storage of low-lovel waste beyond that discussed above would be addreaeed by the COL applicent. Therefore, the staff identified the GE position as DFSER COL Action Item 11.4.2-1. By amended SSAR Section 11.4.3.1, GE included COL License Information in Section 11.4.3.1, Item 4 which states that the COL applicant will provide a discussion of onsite storage of low-lovel waste beyond that diecussed in the SSAR. This is acceptable. The staff will review the COL applicant's discussion against the guidance provided in Generic Letter 81-38, "Storage of LowLovel Radioactive Wastes at Power Reactor Sites." (This guidence is similar to the one provided in Appendix 11.4-A to SRP Section 11.4.) GE has also included this sction item in the final certified SSAR.

(2) The aystem will have the capability to process the types and volumes of wastes expected during normal plant operation, including anticipated operational occurrences, in secordance with GDC 60. Provisions for handling wastes meet the requirements of 10 CFR Parts 20 . Specifically, the staff has determined that the offgases (resulting - from incineration of combuatible wastes) that will bo exhausted through coramic filters and a HEPA filter to a monitored vent will have minimal effect on compliance with 10 CFR 20.1302 relating to concentrations of radionuclides in gaseous or airborne effluents in unrestricted areas for sites with $x / Q$ equal to or less than $9.8 \times 10^{-6} \mathrm{sec} / \mathrm{m}^{3}$. As stated in Section 11.3.2(3) of this report, the staff concludes that the subject concentrations will be below the applicable regulatory limit. By identifying the type, the expected quantity, the curio content, and the manner of disposal of the combustible wastes that will be incinerated, GE complies with 10 CFR 20.302 with regard to disposal of incinerator offgases that lies within the ABWR scope.

(3) The system for monitoring radiation levels and leakage complies with GDC 63 and 64. Radiation monitors at the end of a drum conveyor will monitor the radiation resulting from mixture in the drums and surface contamination of the drums. Devices auch as position switches, weight elements, and lovel sensors will be used to prevent spillage while filling, pouring (solidification of evaporator concentrates), aud overfilling the drums. Additionally, safety interlocks provided for the solidification procees system will ensure that solidification will be performed only under certain conditions (identified in SSAR Section 11.4.2.2.5). In addition, the effluents resulting from the system inputs to the liquid radwaste and gaseous radwasto management systems are monitored by the respective monitors for these systems (together with other effluents from these systems).

(4) SSAR Sections 11.4.1.2 and 11.4.2.1 and GE's submittals dated June 7 and 29, 1990, and June 2, 1993, state that the quality group classification, seismic design, and otier design features (such as heat tracing concentrate piping and tanks, and flushing connections for all components and piping that contain slunies) meet the guidelines of RG 1.143 and BTP ETSB 11-3, Position B.V.

(5) The staff finds that the proposed dewatering method for spent resin and filter sludges, namely, treatment by a thin-film dryer or by a vendor-supplied mobile dowatering system, is acceptable. However, as stated in Section 11.4.1 of this report, the staff will review the details demonstrating compliance of the dowatering process and solidification process with applicable positions of BTP ETSB 11-3 and 10 CFR 61.56, on a plant-specific basis for each COL application.

(6) Since radioactive material packaging is within the scope of the COL applicant, GE has included COL License Information in SSAR Section 11.4.3.1, Item (5) which states that the COL applicant will demonstrate the compliance of all radioactive waste shipping packages with 10 CFR Part 71 requirements for packaging such wastes. The staff 
finds this acceptable and will reviow compliance with 10 CFR Part 71 on a plant-specific basis for each COL application.

(7) As part of Open Itom 76 in the DSER (SECY-91-235), the staff stated that GE should identify the specific fire protection features available in the applicable area to provent any undue fire hazard resulting from incineration. By amended ISAR Section 11.4.3.1, GE providad COL License Information in SSAR Section 11.4.3.1, Item 1 which addresses the issue raised in this part of Open Item 76. As discuseed in Section 11.4.1 of this report, the staff finds this COL License Information acceptable. Therefore, part of Open Item 76 is resolved.

In the DSER (SECY-91-235), the staff stated that SSAR Section 11.4.2.3.5 (last paragraph), Table 11.4-2, and the response to Question 430.171 were inconsistent and confusing. For example, the section sated that Table 11.4-2 represents the shipped volume of solid wastes and that Table 11.4-3 gives the corresponding curie content; however, the two tables could not be correlated since Table 11.4-2 gave the shipped volume only for the solidified concentrates (not the total volume of all solid wastes) and Table 11.4-3 gave curie content for the spent resin and filter sludges. Therefore, the staff requested GE to correct this section and Table 11.4-2 (Open Item 76). GE provided the requested information in Table 11.4-3. This information provides the volumes of various kinds of solid wastes expected to be shipped annually and their corresponding total curie content. Therefore, this part of Open Item 76, in the DSER (SECY-91-235), is resolved. Therefore, this resolved both parts of Open Item 76.

On the basis of these findings, the staff concludes that the solid radwaste management system design for the ABWR meets the acceptance criteria of SRP Section 11.4 and complies with 10 CFR 61.56 and is, therefore, acceptable.

\subsection{Process and Effluent Radiological Monitoring and Sampling Systems}

\subsubsection{System Description and Review Discussion}

The process and effluent radiological monitoring systems are designed to provide information about radioactivity levels in systems throughout the plant, indicate radjoactive leakage between systems, monitor equipment performance, and monitor and cortrol radioactivity levels in plant discharges to the environs.

On the besis of GE's telefax dated May 26, 1993, its submittal dated Juno 23, 1993, and SSAR Section 11.5.2.2.4, the staff finds that all airborne radioactive releases from the plant to the environment except the offgases from the ivisiesrator to the environment will be exhausted through the plant vent. The major sources that will be combined and routed to the plant vent are the offges exhaust, the radwaste building exhaust, the RB (secondary containment) exhaust, the service building controlled area exhaust, and the turbine building exhaust, which includes the gland seal system and the mechanical vacuum pump exhausts. A radiation-monitoring system (RMS) will monitor the plant vent discharge for grose radiation level and collect halogen and particulate samples. The offgases from the incinerator will be monitored and released to the environs via the incinerator exhaust stack. Besides the main plant vent 'gaseous effluent monitor and samplers, as indicated in ABWR SSAR Table 11.5-1, radiation monitors will be provided for monitoring the offgas post-treatment exhaust, TGSS exhaust, RB (recondary containment) exhaust, radwaste building vent exhaust, and turbine building exhaust. These monitors will be used to identify sources of airborne activity before mixing in the main plant vent. Gaseous process stream monitoring will include the offgas pretreatment RM, the carbon bed vault RM, and the control rod drive maintonance area exhaust RM.

The liquid effluent and process RMS include the liquid radwaste effluent and the RB closed cooling water system RMS.

The RMs, which will monitor the discharges from the gaseous and liquid radwaste treatment systems (i.e., offgas posttreatment effluent and processed liquid radwaste effluent), are designed to alarm and provide a signal :automatically close the waste discharge valve of the affected treatment system before exceeding the normal operation limits. The radiation monitor for the incinerator offgas discharge is also designed to alarm and initiate automatic termination of the exhaust to the environs before the radiation level in the exhaust exceeds the technical specification (TS) limit. The DFSER stated that the normal operation limits will be specified in the ABWR Radiological Effluent Technical Specifications (RETS) and, therefore, identified it as TS Item 11.5.1-1. However, GL 89-01 allows the RETS to be relocated in the Offsite Dose Calculation Manual (ODCM) which is plant specific. Since the requirement for the ODCM will be included in Section 5.0 (Administrative Controls) of the plant specific TSs to be provided by the COL applicant, TS Item 11.5.1-1 is resolved. Before being discharged from 
the radwaste treatment syetoms, liquid in the tanks will be sampled and analyzed. Release and dilution rates will be specified on the basis of the results of these analyses.

In addition to the gaseous and liquid effluent and proceasing RMS, there are aystoms required to initiate appropriate protective action in cese of postulated sccidents. Thewe aystoms include the min stenmline RMS, the fuol aren (of the reactor building) veatilation exhaust RMS, the control building HVAC RMS, the SOTS RMS (the exhaust from this aystem soes to the plant atack), and the containment speco-rofueling modo RMS.

The ABWR deaign includes provisions for grab sampling and analysis of liquid sources (0.8., reactor coolant crud and filtrate, liquid radwasto system tanks, condensato storage tank, renctor building cooling water (RCW) system, reactor water cleanup syatom) and both liquid and gaseous offluent and procen streams, including renctor service water and the circulating water system docant line for determination of groses radiation level and ideatity and quantity of specific radionuclides in the applicable stream or source. The stream or the source sampled, the parameters analyzed, the analysis froquency, and the sensitivity for analysis are listed in SSAR Tables 11.5-4 through 11.5-7.

The ABWR design includes accident monitoring instrumentation for monitoring noble gases, iodines, and particulate in geseous or sirborne offluent streams during an acicident. As atated in SSAR Sections 1.A.2.15 and Section 7.5, GE considers that wh inetrumentation provided for the ABWR is geserally in ecpordance with RG 1.97, Revision 3, and that, therefore, it meets the guidelines of NUREG-0737, Action Item II.F.1, Attachments 1 and 2, which is incorporated into 10 CFR 50.34(f)(2)(xvii). Seo the detailed discussion of this item in the following section.

\subsubsection{Conclusion}

The staff reviowed the amended SSAR Section 11.5 and GE's submittals dated June 2, 1989, February 28, 1990, December 19, 1991, and June 23, 1993, and GE's telefaxes dated May 26 and September 24, 1993, with regard to the process and offluent radiological monitoring and sampling systems for the ABWR. The review included piping and instrumentation diagrams (P\&IDs) for the liquid and gaseous radwasto systems; SSAR Tables 11.5-1 through 11.5-7, which list the liquid and geseous process and offluent RMSs and summaries of radiological analysis for liquid and gaseous process and effluent stream samples; information provided in SSAR Section 7.5.1.1 and Tables 7.5-1 and 7.5-2 (i.e., tables comparing ABWR design provisions for monitoring radioective gaseous offluents during an accident with applicable RO 1.97 guidelines); and descriptions of the various building ventilation systems, the main condenser ovecuation systom, and the TOSS in 80 far as they relato to the radiation-monitoring provisions for these systems. However, in Open Item 77 in the DSER (SECY-91-235), the ataff atated it could not review the location of the monitoring points relative to the effluent release points in the gaceous offluent stroams because GE had not provided the correeponding P\&IDa. Subsequently, GE submitted P\&IDE that identify the location of monitoring points relutive to the effluent release points. Therefore, Open Itom 77 in the DSER (SECY-91-235), is resolved.

As etated at the beginning of Chapter 11 of this report, the staff will reviow specific compliance of the COL sampling program and quality assurance (QA) for radiological monitoring programs with ANSI N13.1 and RGs 1.21 and 4.15 on a plant-specific basis for each COL applicant. During such a plant-specific review, the staff will evaluate the plant-specific features and programs provided by the COL applicant to address the issue discussed in IE Bulletin 80-10 of possible contamination of nonradioactive systems and the resulting potential for unmonitored, uncontrolled rolease to the environment. Therefore, the staff's review of the sampling and analysis program for the ABWR standard design is limited to the identification of the streams required to be sampled, monitored and controlled.

The staff concludes that the design of the ABWR process and offluent radiological monitoring and sampling systems complies with the requirements (1) 10 CFR 20.1302 relating to radioactivity monitoring of effluents to unreatricted areas, (2) of GDC 60 that radioactive waste management systems be designed to control release of radioactive materials to the environment, and (3) of GDC 63 and 64 that radioactive waste management systems be designed to monitor radiation levels, leakage and releases to environment. The staff's conclusion is besed on the following findings:

The design includes provisions for monitoring the radioactivity of effluents to unrestricted areas. The exhausts from certain areas of the RB (serviced by the safety related RB electrical equipment and safety related RB diesel generator HVAC subsystems) and the turbine island (serviced by the electrical building ventilation system) will be directly released to the environs unmonitored. In addition to the above areas, the staff stated in Open Item 78 in the DSER (SECY-91-235) that the exhausts from the battery rooms and lube oil area in the turbine island and the reactor internal pump 
(RIP) control panel room in the reactor building were unmonitored. However, the SSAR currently shows the lube oil exhaust being monitored at the plant veat and does not ahow a battery room in the turbine island (Figures 9.4-2a and 2b). The SSAR also shows the RB RIP ASD HVAC system (RIP control panel room HVAC systom renamed) as a closed cooling HVAC system with no outside air supply to the room or exhaust from the room to the environs (Figure 9.4-5). Further, by telefax dated June 9, 1992, GE proposed to revise Section 11.5.2.2.4 to state that the exhausts from the areas serviced by the HVAC systems mentioned above are not monitored since the subject areas do not contain any radioactive systems and that the only releases to the environment by these systems would first have to be brought into the areas by their own HVAC system's supply fans. On the basis of the above telefax design information, the DFSER stated that lack of radiation monitoring of certain exhausts identified above is acceptable since GDC 64 does not require radiation monitoring of plant exhausts to the environs that do not have potential to be radioactive. Therefore, in the DFSER, the staff re-classified this part of DSER (SECY 91-235) Open Item 78 as DFSER Confirmatory Item 11.5.2-1 and required GE to incorporate the tolefax design information in the applicablo SSAR section. By submittal dated June 23, 1993, GE incorporated the subject information as a footnote to SSAR Section 11.5.2.2.4 after revising the subject information to include also the exhaust from the service building clean area since the exhaust from this area also qualifies for non-monitoring as explained above. In the above submittal, GE also stated that the exhaust from the area served by the control building essential electrical HVAC system will not be monitored prior to discharge to the environs though it contains (RCW) system components. This is because, the RCW, which is considered as a clean water system, is monitored to alarm at any radiation level in the system above background from potential leakage sources. Such contamination will require dumping the cooling water to radwaste treatment and replacing it with clean water. Therefore, the system will remain clean. Furthermore, at the system operating temperature below $35^{\circ} \mathrm{C}\left(95^{\circ} \mathrm{F}\right)$, airborne ovolution of radioactivity from the cooling water system will be negligible. The staff has roviewed the above GE's justification for not monitoring this exhaust prior to its release to the environs and finds the justification, acceptable. GE has also included this information in the final certified SSAR. Therefore, Confirmatory Itom 11.5.2-1 is resolved.
The etaff further stated as part of Open Item 78 in the DSER (SECY-91-235) that GE had not provided cufficient information in its submittal dated April 26, 1991, to clarify that the service building ventilation system exhaust will be routed through the plant vent where radiation monitoring occurs. By amended SSAR Section 11.5.2.2.4, GE clarified that the service building controlled area ventilation system exhaust will be routed through the plant vent, where radiation monitoring occurs. This is acceptable. Therefore, this part of DSER (SECY-91-235) Open Item 78 is resolved.

(2) The design includes provisions for monitoring process streams (0.8.) offgas post-treatment exhaust, secondary containment exhaust, RCW systom) and provisions for initiating appropriate action in case of postulated accidents. Automatic control features include termination of liquid offlueni release, incinerator offgas release, and the offyes system release as appropriate, when the preset radiation level for the applicable stream is exceeded. The automatic control features also include securing the normal secondary containment ventilation system and initiation of the SGTS under certain conditions identified in the SSAR. Also, since GE indicated a single monitor for the gland seal exhaust and mechanical vacuum pump exhaust, and totally clean steam will not normally be supplied for sealing the TGSS, the staff required in the DSER (SECY-91-235) that plant procedures include manual switchover to the auxiliary (backup clean) steam source whenever the monitor indicates that the exhaust stream concentration exceeds a preset level. As discussed in Section 10.4.3 of this report, $G E$ has committed to provide a COL action item stating that the COL applicant will provide the necessary procedures for switchover to the auxiliary steam system when monitored radiation level in tho TOSS exhaust exceeds an acceptable preset level. The staff identified the development of the procedures as DFSER COL Action Item 11.5.2-1. By amended SSAR Section 10.4.10, GE identified COL License Information in Section 10.4.10 for the TGSS effluents. The subject information among other requirements, spells out the requirement for switchover mentioned above. The staff agrees with GE's approach for providing sealing steam to the TOSS. GE has also included this action item in the final certified SSAR.

As part of Open Item 78 in the DSER (SECY-91-235), the staff questioned whether the secondary containment ventilation exhaust monitor will be sensitive enough to detect high-radiation level in the primary containment 
purge exhaust. In response to the above concern, GE has revised Section 11.5.2.1.2 to state that the detector in the secondary containment ventilation exhaust will be sensitive enough to detect high-rndiation levels during primary containment purge to alert the operator and to initiats appropriate mensures. This part of Open Item 78 is resolved.

(3) As stated earlier in this section, the design includes provisions for campling and enalysis of radioiodines, particulates, and tritium in the process and offluent streams (for tritium, only in the effluent stream). However, as part of Open Item 78 in the DSER (SECY-91-235), the staff noted that SSAR Table 11.5-5 did not include grab sampling and analysis provisions for the gland seal process stream. SSAR Table 11.5-7 also did not include sampling and analysis provisions for the plant stack exhaust. In response to the above concern, GE added the sampling and analysis provisions for the gland steam condenser and plant sack exhausts (SSAR Table 11.5-7). Therefore, this part of Open Item 78 is resolved.

SSAR Tables 7.5-1 and 7.5-2 provide design and qualification criteria for accident-monitoring instrumentation and the concentration ranges covered by the instrumentation. The staff finds that the design complies with RG 1.97 with regard to ranges and design and qualification criteria. However, as part of Open Item 78 in the DSER (SECY-91-235), the staff stated that neither these tables nor SSAR Section 11.5 contained sufficient information and that the following information was to be provided:

- type of instrumentation to be used, including the calibration frequency and technique

- monitoring locations (or points of sampling), including description of methods used to ensure representative measurements and background correction (the P\&IDs for building ventilation systems were not provided to determine monitoring locations relative to the applicable release points for the gaseous effluent streams)

- location of instrument readout(8) and method of reconding, including description of the method or procedure for transmitting or disseminating the data
- assurance of capability to obtain readings at least every 15 minutes during and following an accident

- description of procedures or calculational methods to be used for converting instrument readings to release rates per unit time, based on exhaust air flow and considering radionuclide spectrum distribution as a function of time after shutdown

- description of the sampling system design, including the sampling medium to demonstrate how the design meets the requirements identified in Clarification 2 of NUREG-0737, page II.F.1-7

- description of the sampling technique to be used under accident conditions to demonstrate how the technique meets the requirements identified in Clarification 3 of NUREG-0737, pages II.F.1-7 and II.F.1-8

- description of the sampling technique to ensure the system capability to collect and analyze or measure representative samples of radioactive iodines and particulate in plant gaseous effluents during and following an accident as identified in Table II.F.1-2 of NUREG-0737, page II.F.1-9

In response to the above request for information, $\mathrm{GE}$ provided COL License Information 11.5.6.1 through 11.5.6.5. The COL license information calls for the COL applicant to provide an operation and maintenance manual that describes or demonstrates (as appropriate) the following: calculation of radiation release rates from radiation measurements, sampling system design and its compliance with the shielding requirements identified in Clarification 2 of Attachment 2 to TMI Item II.F.1 of NUREG-0737, sampling technique and its compliance with the requirements identified in Clarification 3 of Attachment 2 to TMI Item II.F. 1 of NUREG-0737, collection technique for extracting representative samples of radioiodines and particulates and calibration frequencies and techniques for the radiation sensors. The staff concludes that this part of Open Item 78 is resolved.

On the basis of these findings, the staff concludes that the design of the ABWR process and effluent radiological and sampling systems meets the acceptance criteria of SRP Section 11.5 and is, therefore, acceptable. 


\section{RADIATION PROTECTION}

Standard safety analysis report (SSAR) Chapter 12 provides information on the rediation protection features and cotimated occuppation exposure associated with the advanced boiling water reactor (ABWR) deaign. The radiation protection measures for the ABWR are intended to ensure that internal and external occupetional radiation exposures to plant personnel, contractors, and the general population, as a result of plant operations, including shutdown periods and anticipated operational occurrences (AOOs), will be within applicable limits of regulatory criteria and will be as low as is reacomably achiovablo (ALARA). The staff reviewed the SSAR for completeness against the guidolines of Regulatory Guide (RG) 1.70 (Rev. 3), "Standard Format and Content of Safety Analysis Reports for Nuclear Power Plants, " and agaihst the criteria of Sections 12.1 through 12.5 of NUREG-0800, the standard roviow plan (SRP).

The staff reviowed GE's SSAR and supplemental information to determine if the ABWR design is sufficient to permit plant operations whilo maintaining radiation doses to personnel within the limits of 10 CFR Part 20, and if the design features are consistent with the guidelines of RG 8.8 (Rev. 3) "Information Relovant to Ensuring that Occupational Radiation Exposures at Nucloar Power Stations will be As Low As Is Reasonably Achievable." On May 21, 1991, the Commission issued a revision of 10 CFR Part 20 that changed the system of radiation dose limitation. The previous occupational dose limit for whole-body radiation exposure was $12.5 \mathrm{mSv}(1.25 \mathrm{rem})$ per quarter year with a provision to extend it to $30 \mathrm{mSv}$ (3 rem) per year. The new limit is $50 \mathrm{mSv}(5 \mathrm{rem})$ per year with a provision to extend it to $100 \mathrm{mSv}(10 \mathrm{rem})$ per quarter year. The previous 10 CFR Part 20 limits for doses from licensed radioactive material inside the body (deposited through injection, absorption, ingestion, or inhalation) were separate from the dose limits for exposure to licensed sources outside the body. The new Part 20 limits the sum of the external whole-body dose (deep dose equivalent) and the committed effective equivalent doses resulting from radioactive material deposited inside the body. In addition, the new Part 20 requires that this sum (the total effective dose equivalent) be maintained ALARA for each individual. These changes to the regulation do not affect the acceptance criteria used by the staff to review the ABWR design. The SRP acceptance critoria provide assurance that the radiation doses resulting from exposure to licensed radiosctive sources outside the body and inside the body can each be maintained well within the limits of 10 CFR Part 20 and ALARA. The balancing of internal and external exposure neceseary to ensure that their sum is ALARA is an operational concern that will be reviewed in conjunction with a combined license (COL) application. The Part 20, as amended, contrins a number of new programmatic requirements that do not affect plant design. Programmatic and operational radiation protection concerns will be addressed by the COL applicant.

The staff finds that the radiation protection measures incorporated in the ABWR design will provide rensonablo assurance that occupational doses can be maintained ALARA and below the limits of 10 CFR Part 20 during all plant operations.

\subsection{Ensuring That Occupational Radiation Doses Are As Low As Is Reasonably Achievable}

The staff reviewed the ABWR design to ensure that $G E$ had either committed to following the criteria of the RGs and staff positions referenced in SRP Section 12.1 or provided acceptable alternatives.

\subsubsection{Policy Considerations}

SSAR Section 12.1.1 describes GE's policy to ensure that ALARA considerations are factored into each stage of the ABWR design process. GE committed to ensure that the $A B W R$ will be designed and constructed in a manner consistent with RG 8.8 (Rev. 3). The ALARA policy was applied through detailed engineering reviews and design modifications to ensure that the resulting plant design can maintain radiation exposures ALARA. This policy is consistent with the guidelines of RG 8.8 and is acceptable.

The policy considerations regarding plant operations contained in RG 8.8 (Rev. 3), RG 1.8 (Rev. 2) "Qualification and Training of Personnel for Nuclear Power Plants, " and RG 8.10 (Rev. 1), "Operating Philosophy for Maintaining Occupational Radiation Exposures As Low As Is Reasonably Achievable," are outside the scope of this review of the ABWR design. The COL applicant referencing the ABWR design will address these operational policy considerations to ensure that radiation doses are ALARA. This was identified as draft final safety evaluation (DFSER) COL Action Item 12.1.1-1. In Amendment 23 to the SSAR, GE revised Section 12.1.1 to clarify the policy considerations that will be addressed by the COL applicant. This is acceptable to the staff.

\subsubsection{Design Considerations}

The ABWR design aims to minimize the costs, both in terms of maintenance time and radiation exposure, aseociated with plant operation. The ABWR design employs features that will (1) eliminate the need for certain maintenance, (2) facilitate the required maintenance, and (3) minimize the sources of radiation exposure in the plant. 
The ABWR design includes several design features consistent with the guidelines in RG 8.8 (Rev. 3). The plant layout has shiolded rooms or cubicles for components that are the source of high radiation levels. Components in redundant systems are located in separate shielded rooms or cubicles so that radiation levels associated with an operating train of equipment will not significantly contribute to the radiological hazards associated with performing maintenance on the redundant train. The design of shielded rooms or cubicles have labyrinth access ways to reduce scattered radiation in adjecent areas. Removable shielded walls or hatches will be provided if space limitations in a room or cubicle prevent an adequate laydown area for maintenance of equipment. Appropriato use of remote operators and instrumentation will minimizo the need to enter shielded rooms or cubicles. The remote back-flushing capability for plant filters and demineralizers will use gravity drains and piping that slope toward the backwash tank to minimize traps that would become radiation hot spots. Grafoil valve stem packing will reduce leakage of contaminated water from reactor systems and will minimize the need to repack the stems of these valves. These design features are consistent with the guidance in RG 8.8 (Rev. 3).

In addition to these design features, operational experience with previous boiling water reactor (BWR) designs has been factored into the ABWR design in several areas. Many unique $A B W R$ features, designed to eliminate difficulties encountered in operating current BWRs, should also reduce occupational radiation exposure. An example is the elimination of reactor coolant recirculation piping inside primary containment. Several BWRs have experienced significant stress corrosion cracking, requiring replacement of this piping at the cost of thousands of person-rem radiation doses. Eliminating the coolant recirculation piping from the $A B W R$ reactor not only eliminates the radiation exposure associated with recirculation pipe inspection and replacement but should also reduce the source of radiation in the drywell, thus reducing exposure to personnel performing other maintenance activities in the primary containment.

Other examples of design features that will reduce radiation exposure include the control rod drive (CRD) mechanism, layout of the lower drywell, and safety relief valve (SRV) design and layout. Current BWRs have extermal restraints on CRDs to prevent a rod ejection in the event of a CRD housing failure, which have to be cleared out of the way during CRD maintenance. The internal CRD restraint feature in the ABWR design will allow easier CRD removal and reduce radiation exposure associated with CRD maintenance. The arrangement of the lower drywell will also reduce radiation exposures during CRD maintenance by allowing easy access to the lower reactor veseel head for CRD and reactor internal pump (RIP) removal. A transpori systom is also provided to remove CRDs and RIPs from the drywell so that maintenance can be performed in a lower radiation area. Direct-action SRVs that require less maintenance than current pilot-operated valves are provided in the ABWR design. These SRVs are placed around the outside of the reactor vessel and have a dedicated hoist to facilitate maintenance.

In the draft safety evaluation report (DSER) (SECY-91-355), the staff identified two areas where the current BWR operating experience was not adequately accounted for in the ABWR design. These areas are the dose rates in the upper drywell during the transfer of irradiated spent fuel assemblies (SFA) (Open Item 112) and exposures resulting from a complete withdrawal of the traversing incore probe (TIP) (Open Item 106).

In a March 26, 1992, SSAR markup, GE provided additional information concerning the radiation protection design features of the ABWR TIP system in response to Open Item 106. These features include a shielded room for the TIP drive units and a separate shielded room for the parked TIP. Additional shielding is provided for the parked TIP and its drive cable to allow personnel to enter this room when the TIP is out of the reactor. The TIP drive units also have an electro-mechanical switch that will cut power to their drive spooler to prevent the activated portions of the TIP from being completely withdrawn into the drive housings. These features are designed such that radiation exposures resulting from TIP operations, and related abnormal AOOs, can be maintained ALARA. This was identified as DFSER Confirmatory Item 12.1.2-1. GE hes also included this information in Amendment 20 of the SSAR and the staff finds it to be acceptable.

The potential for creating extremely high dose rates in the upper drywell during spent fuel handling operations and the potential for high dose rates around unshielded portions of the TIP conduit are discussed in Section 12.3.2 of this report.

\subsubsection{Operational Considerations}

Operational considerations regarding the implementation of a radiation protection program are outside the scope of this design certification review. The COL applicant referencing the ABWR design will address these operational considerations to the level of detail provided in RG 1.70 (Rev. 3). This was identified as DFSER COL Action Item 12.1.3-1. In Amendment 23, GE revised Section 12.1.3 of the SSAR to identify these operational considerations as an are to be addreseed by the COL applicant. The staff finds it to be acceptable. 


\subsubsection{COL License Information}

Section 12.1.4 of the DSER (SECY-91-355) identified three issues concerning compliance with RGs 8.10 (Rev. 1) and 1.8 (Rev. 2), and procedures for keeping occupational exposures ALARA, as outside the scope of this roviow. This was identified as DFSER COL Action Item 12.1.4-1. In Amendment 20 to the SSAR, GE revised Section 12.1.4 to properly chanacterize these issues. The staff finds it to be acceptable.

In Open Item F1.9-1, the staff identified the need for GE to include a COL action item related to the use of appropriate materials in the ABWR design which would reduce the potential for personnel exposures. GE provided a submittal dated February 7, 1994, which included a markup of SSAR Section 12.3.7.4, that added a COL action item stating that the applicant, following the design commitments included in SSAR Section 12.3.1.1.2, is responsible for material selection to ensure that radiation exposures are ALARA. The staff found this commitment for a COL action item to be acceptable.

\subsection{Radiation Sources}

The staff has audited the contained source terms and airborne radioactive material source terms in Section $\mathbf{1 2 . 2}$ and Chapter 11 of the ABWR SSAR for completeness against the guidelines in RG 1.70, (Rev. 3), and against the criteria set forth in Section 12.2 of SRP. The contained source terms are used as the basis for designing radiation protection features (including radiation shielding) and for personnel dose assessment. Airborne radionctive source terms are used in the design of ventilation systems and personnel dose assessment. The staff reviewed the source terms in the SSAR to ensure that GE had either committed to following the criteria of RGs and staff positions contained in SRP Section 12.2 or provided acceptable alternatives. In addition, the staff selectively compared source terms for specific systems against those used for plants of similar design. The staff finds that source term descriptions in the SSAR are not adequate to meet the criteria of RG 1.70 (Rev. 3) and NUREG-0800.

At the current stage of the ABWR design, GE does not have the specifications for the as-built systems or the asprocured hardware that would be available for a completed plant. Therefore, GE' cannot describe the radioactive system components, which will be significant in-plant radiation sources, to the level of detail specified in RG 1.70 and the SRP. Although these details, such as radioactivity content, source geometry, equipment leakage, and plant location, are needed for the staff to verify the adequacy of the radiation shielding, ventilation and airborne radioactivity monitoring systems, the staff has determined that providing this information goes beyond the design requirements spocified in 10 CFR Part 52. As an alternative, $\mathrm{GE}$ has provided a eet of design acceptance criteria (DAC) that, if met, will verify the adequacy of the ABWR shielding design, plant ventilation design, and the deaign of the airborne radioactivity monitoring systems. Compliance with these DAC, as with other inspections, tests, analyese, and accoptance criteria (ITAAC), would be verified during plant construction prior to loading fuel into the reactor. The DAC in Table 3.2.a of the ABWR certified design material (CDM) specify the methods and assumptions for verifying the shielding design, including those for estimating the source terms to be used in the shielding analysis. Similarly, the DAC in Table 3.2.b of the CDM specify the acceptance methods for determining the airborne radioactivity concentrations used to verify the adequacy of the ventilation and airborne monitoring system designs. This alternative is acceptable to the staff.

\subsubsection{Contained Sources and Airborne Radioactive Material Sources}

GE describes radionctive sources in the ABWR design is contained in SSAR Chapters 11 and 12. Section 11.1 provides information on the radioactive source terms in reactor water and steam. Section 12.2 provides descriptions of plant components that will become significant sources of radiation during plant operations, including shutdown, and sources of airborne radioactive material.

During power operations, the greatest potential for personnel radiation dose is inside the primary containment drywell from nitrogen-16, noble gases, reactor neutrons, and prompt gammas. The steam and condensate systems outside the drywell are also significant sources of radiation because nitrogen-16 is generated during power operations. In other areas outside of the drywell, and inside the drywell after shutdown, the primary sources of personnel radiation exposure are the fission products in the coolant from fuel cladding defects and the activation products transported to and deposited in plant systems and components. Tables 12.1-7 through 12.2-30 in the SSAR list the radionctivity (or source terms) for typical components. These source terms are based on the assumed component geometry and locations listed in Table 12.2-5.

The estimates of concentrations of fission and activation products in the ABWR systems containing reactor water are based on American National Standards Institute/American Nuclear Society (ANSI/ANS)-18.1 "Radioactive Source Term for Normal Operation of LWRs" (1984), adjusted using the assumptions in RG 1.112 (Rev. 0), "Calculation of Releases of Radioactive Materials in Gaseous and Liquid Effluents from Light-Water-Cooled Power Reactors." Allowances 
are included for the buildup of activation products resulting from corrosion and wear on the basis of operating experience of reactors of similar design. Neutron and prompt gamme source terms are based on reactor core physics calculations. The source terms used to determine in-plant post-accident radiution levels meet the provisions in RG 1.3, "Assumptions used for Evaluating the Potential Radiological Consequences of a Loss of Coolant Accident for Boiling Water Reactors," as further discussed in Item II.B.2 of NUREG-0737, "Clarification of the TMI Action Plan Requirements."

In Open Item 107 in the DSER (SECY-91 355), the staff identified several deficiencies in GE's description of the contained radionctive source terms for the ABWR: sources inside the drywell and in the turbine building were omitted, sources in vital areas after an accident were not described, and source characterization was insufficient. GE amended SSAR Section 12.3.5 to indicate that the post-accident sources of concern in plant vital areas are limited to gamma radiation shine from the reactor building and the radioactive material in the post-accident coolant and effluent monitoring systems. GE also amended the tables of source terms in Section 12.2 to include sources inside the drywell and turbine building. SSAR Tables 12.2-7 through 12.2-30 provided nominal source strengths on the basis of expected system configuration and approximate component geometry. As discussed in Section 12.2 of this report, the actual source terms used in confirmatory shielding calculations will be determined as required by the DAC in Table 3.2.2 of the CDM. The staff considers this item resolved.

Almost all of the airborne radioactivity within the plant results from equipment leakage. As discussed below, the leakage of contaminated fluids from system components cannot be quantified at this stage in the ABWR design. GE has proposed DAC in Table 3.2.b of the CDM to ensure that the airborne source terms in each room and operating area of the plant are calculated prior to fuel load. The lack of airborne source term description in the SSAR was also identified as Open Item 107 in the DSER (SECY-91-355). On the basis of the following discussion of DAC, the staff considers this item resolved.

\subsubsection{Certified Design Material}

As discussed in Section 12.2 of this report, the SSAR does not provide system layouts within rooms or cubicles or information about the typo and size of components in these systems. Without this as-built or as-procured information, source term parameters needed to calculate radiation shielding for these systems cannot be provided as specified in the SRP. Similarly, since leakage characteristics of this unidentified equipment are not known, the concentrations of airborne radioactive material in equipment rooms or cubicles cannot be provided. As an alternative, GE provided DAC that require the COL applicant to determine source term parameters that will be verified during plant construction. DAC are discussed in Section 12.3.5 of this report. DAC describing the bases for the source term are consistent with the SRP acceptance criteria. Compliance with these DAC, supplemented by the information in SSAR Sections 12.2 and 12.3 , is acceptable to adequately address the requirement to identify the kinds and quantities of radioactive materials expected to be produced by plant operation in 10 CFR 50.34(b)(3) and will ensure that the appropriate source terms (as supplemented by the guidance of RG 1.112 (Rev. 0), NUREG-0737, and ANSI/ANS 18.1) are used to demonstrate that the ABWR design meets the relevant requirements in 10 CFR Part 20 concerning the limitation of radiation does to personnel; 10 CFR 50.34(f) and GDC 19 with respect to operator access to plant areas during and following a reactor accident; and GDC 61 regarding adequate shielding, containment and confinement of fuel storage and handling, radioactive waste, and other systems which may contain radioactivity. The adequacy and acceptability of the ABWR design descriptions and ITAAC (including DAC) are evaluated in Section 14.3 of this report.

\subsubsection{COL License Information}

In the DFSER, the staff stated that two items were mischaracterized as interface items by the applicant: (1) the compliance with 10 CFR Parts 20 and 50 in Section 12.2.2.3 and (2) the determination of gamma shine from the turbine building in Section 12.2.1.3 of the SSAR. These SSAR sections referenced Section 12.2.3, which identified the issues as design interfaces. This was DFSER Confirmatory Item 12.2.3-1. In an SSAR markup of Chapter 12 dated April 16, 1993, GE deleted the discussion of interfaces in Sections 12.2.1.3, 12.2.2, and 12.2.3. Se tion 12.2 .3 has been revised to identify the issues regarding compliance with 10 CFR Parts 20 and 50 as COL license information. As indicated in Section 12.2.2.4 of the SSAR, gamma shine from the turbine building is addressed in the DAC listed in Table 3.7 (see Section 12.3.5.1 of this report). GE has included this information in the SSAR. This change is acceptable. Therefore, this confirmatory item is resolved.

\subsection{Radiation Protection Design}

The staff has audited the facility design features in the SSAR, including the shielding, the ventilation, and the radiation and airbome radioactivity monitoring instrumentation for completeness against the guidelines in RG 1.70 (Rev. 3) and against the criteria set forth in SRP Section 12.3. The staff reviewed these design features to 
ensure that GE had either committed to following the criteria of RGs and staff positions referenced in SRP Section 12.3 or provided acceptable alternatives.

The staff concludes that GE has demonstrated that the ABWR design can meet the relevant requirements of 10 CFR Parts 20 and 50 and GDC 19 and 61 in all areas of the plant, as set forth below.

\subsubsection{Facility Design Features}

Several features in the ABWR design will help ALARA radiation doses associated with tasks such as maintenance, refueling, radioactive material handling, in-service inspection, decommissioning, and accident recovery (seo Section 12.1.2 of this report). These features will facilitate access to work areas, reduce or allow the reduction of radioactive source intensity, reduce the occupancy requirements in high radiation fields, and provide for portable shielding, and remote-operation and instrumentation of radioactive systems. These ABWR features are consistent with the guidance of RG 8.8 (Rev. 3) and the SRP and are acceptable.

GE's drawings of the plant layout indicate six radiation zones which are the basis for occupancy and access restrictions for various areas within the plant during normal operations and accident conditions. Maximum design dose rates are established for each zone and are used as the basis for shielding each zone. This method of plant zoning is consistent with the guidance in RG 1.70 (Rev. 3) and the SRP and is acceptable.

In Open Items 108 through 110 in the DSER (SECY-91-355), the staff identified several deficiencies in SSAR Chapter 12 Figures 12.3-1 through 12.3-73, which depict plant radiation zones (during normal operations, normal shutdown, and accident conditions) and area radiation monitor locations. This was identified as DFSER Confirmatory Item 12.3.1-1. Amendments 21 and 22 to the SSAR provided more legible figures for the reactor, control, and radwaste buildings and resolved the discrepancies noted in the figures of the turbine building. These updated figures also indicate the normal controlled and uncontrolled access routes to the plant as well as the access and egress routes to and from plant vital areas under accident conditions. In response to a staff question, GE acknowledged the radiation zone designation above the spent fuel pool (from greater than $1.0 \mathrm{mSv} / \mathrm{hr}$ (100 mrem/hr)) was an error. GE revised the radiation zone designation for this area to less than $0.05 \mathrm{mSv} / \mathrm{hr}$ (5 mrem/hr). This dose rate for the area above the spent fuel pool is consistent with industry experience and, therefore, is acceptable to the staff. GE has also included this information in the SSAR and the staff finds it to be acceptable.

The buildup of activation products from corrosion and wear is a major contributor to occupational radiation doses. As discussed in Section 12.1.4 of this report, the COL applicant is responsible for material selection to ensure that radiation exposures are ALARA. Design features provided in the SSAR to minimize exposure sources include a reduction of cobalt-bearing components used in reactor systems (activated cobalt is a major contributor to plant radiation levels) and pre-filming (establishing a corrosion resistant layer on internal surfaces) of reactor systems before plant operation to minimize activated material deposition on system interior surfaces. Main condenser tubes and tube sheets will be made of titanium alloys to minimize the introduction of foreign material (which become activated and/or promote corrosion) into the reactor system as a result of condenser tube leakage. Other features, such as the use of seamless piping, straight-through valve design wherever possible, butt-welded piping connections, and back-flushing connections on instrument lines, will minimize buildup of radioactivity in plant piping systems.

In Open Item 111 in the DSER (SECY-91-355) concerned the provision in the ABWR design to facilitate chemical decontamination of heat exchangers in systems that carry radionctive water. The staff identified DFSER Confirmatory Item 12.3.1-2 on the basis of an April 9, 1992. draft SSAR amendment. Subsequently, Amendment 20 to the SSAR stated that the reactor water cleanup (CUW) non-regenerative and regenerative heat exchangers have separate decontamination connections. Heat exchangers in the residual heat removal (RHR) system and the heat exchangers for RIP cooling have fittings that will allow flushing with clean water. GE's corrosion product control features are consistent with the guidance in RG 8.8 (Rev. 3) and the SRP and are acceptable. The staff finds it to be acceptable. This item is resolved.

The ABWR is designed so that operation will not require alternate high-radiation area controls (pursuant to 10 CFR 20.203(c)(5)), as used in current operating BWRs. All high radiation areas (with greater than $1.0 \mathrm{mSv} / \mathrm{hr}$ (100 mrem/hr)) can be locked to control unauthorized access. No credit is taken for the relief provided in Section 12.6 of the BWR standard technical specifications (i.e., area locked at $10.0 \mathrm{mSv} / \mathrm{hr}(1,000 \mathrm{mrem} / \mathrm{hr}))$. This design position meets the requirements of 10 CFR Part 20 and is acceptable. 


\subsubsection{Shielding}

Radiation shielding will protect personnel against radiation exponure inside and outside the plent during normal operation, including $\mathrm{AOO}$, and during reactor accidents. All radionctive sources will be shielded on the basis of the acceses and exposure lovel requirements of the designed rediation zoning. Concreto used for radiation shielding meets tho design guidance provided in RG 1.69, "Concrete Rediation Shields for Nuclear Power Plants" (Rev. 0). GE performed shielding calculations with the QAD-F, GGG, and DOT.4 computer codes. These are commonly eccepted shielding calculational codes referenced in the SRP and are acceptable.

GE has not provided the thickness of specific radiation shiolds, contrary to the guidance of RG 1.70 (Rev. 3) and the acceptance crituria of the SRP. GE's position is that, because the system layouts and the physical dimensions of the as-procured radioactive system components are not known, the shielding requirements for these systems cannot be provided at this stage of the ABWR design. Therefore, the staff cannot conduct confirmatory calculations of shielding effectiveness. As an alternative method, GE has provided DAC to verify the adequacy of the $A B W R$ shielding design. The staff's review of these DAC is discussed in Section 12.3.5.1 below. This alternative is accoptable, and the staff considers this item resolved.

The adequacy of the shielding in the upper drywell was identified as an Open Item 112 in the DSER (SECY-91-355). The biological shield surrounding the reactor vessel did not cover a significant portion of the top of the reactor vessel. A fuel handling mishap resulting in dropping an SFA across the reactor flange would result in extremely high dose rates in the upper drywell with this design. In addition to the radiological hazard presented by this AOO, it appears that raising an SFA in proximity of the vessel wall could result in significant radiation dose rates in the upper drywell. Amendment 21 revised the SSAR to reflect a design change to the shielding in the upper drywell, raising the biological shield to within 4 inches of the upper drywell ceiling. This design change would provide sufficient shielding during the normal withdrawal of SFAs from the reactor. However, a dropped SFA resting across the reactor flange would still produce significant radiation streaming into the upper drywell. Personnel in the upper drywell during this AOO could receive lethal radiation doses before they could escape. This was DFSER Confirmatory Item 12.3.2-1. In response to the staff's concerns, GE revised the design change to add a shielding ledge to the opening in the upper drywell ceiling. This ledge significantly reduces the radiation streaming into the upper drywell from a SFA resting on the reactor vessel flange. According to the staff's analysis, this shield design would reduce the dose rates in the upper drywell to lese then $5 \mathrm{~Sv} / \mathrm{hr}$ (500 rem) during a worse-case fuel-drop AOO. Therefore, the staff concludes that there is reasonable essurance that individuals could escape the upper drywell without recoiving lifo-threatening radiation doses. Amendment 23, which revised the SSAR to reflect this final design, is acceptable to the staff. This itom is resolved.

The shielding of the TIP system was identified as Open Item 106 in the DSER (SECY-91-355). As discuseed in Section 12.1.2 of this report, the TIP drive and the TIP storage are located in separate shielded rooms. However, the conduit that guides the TIP from the reactor to its storage is virtually unshielded. This conduit shares the primary containment penetration with the lower drywell personnel access. Personnel at the lower drywell access hatch or in the access tunnel would be exposed to the unshielded activated TIP and the drive cable as they are retracted from the reactor core. DFSER Confirmatory Item 12.3.2-2 was identified on the basis of a March 26, 1992, draft SSAR amendment. Amendment 21 revised the description of the radiation design features associated with the TIP system. This amendment notes that the lower drywell access is located in a separato shielded room that can be locked to prevent access to these areas while the TIP is being withdrawn from the core. In addition, flashing alarms at the door to this room and at the lower drywell access hatch will warn personnel when power is applied to the TIP drives. Also, the TIP system will operate so that the TIP will be withdrawn in the high-speed mode, minimizing the transit time of the activated components through the unshielded portions of the system. These features ensure that the personnel radiation exposures resulting from the operation of the TIP system can be maintained ALARA and are acceptable. The staff finds it to be acceptable.

\subsubsection{Ventilation}

The ABWR ventilation systems are designed to protect personnel and equipment from extreme environmental conditions and to ensure that plant personnel are not inadvertently exposed to airborne contaminants excoeding the concentration limits given in 10 CFR Part 20. Design features intended to maintain personnel exposures ALARA include the following:

- Airflow between areas potentially having airborne contamination will always be from the area of lower potential contamination to the area of higher potential contamination. 
- Negative or positive pressure will be used in areas to prevent exfiltration or infiltration of possible airborne contamination, respectively.

- The control room ventilation hes dual fresh air intakes deaigned 20 that at least one intake will be free of contamination following $\bullet$ loss-of-coolant accident.

These design features are in accordance with the guidelines of RG 8.8 (Rov. 3) and are acceptable. However, as noted in Section 12.2 of this report, the expected leakage of radiaactive fluids from plant systems cannot be determined at this stage of the ABWR design. Without this source term, GE is not able to provide the concentrations of airborne contamination in cubicles, rooms, and corridors as specified in the SRP. Therefore, the staff cannot verify that the plant ventilation system design meets the criteria in the SRP. This was identified as Open Item 113 in the DSER (SECY-91-355). As an alternative, $G E$ provided DAC that require the $C O L$ applicant to calculate the expected concentrations of airborne radionuclides as specified in the SRP, to verify that adequate ventilation is provided. The staff identified DFSER Confirmatory Item 12.3.3-1 on the basis of a May 1, 1992, draft SSAR amendment. Section 12.3.5.2 of this report contains the staffs evaluation of these DAC. Amendment 21 added Appendix 12A to the SSAR which describes the calculational methods and assumptions that will be used to satisfy the DAC in Table 3.2.b of the CDM. These calculational methods and assumptions are consistent with provisions of the SRP and are acceptable. The staff finds it to be acceptable. This item is resolved.

\subsubsection{Area Radiation and Airborne Radioactive Monitoring Instrumentation}

Open Item 114 in the DSER (SECY-91-355), questioned the description of the ABWR aren radiation monitoring system. GE revised the SSAR with the following information. The are radiation monitoring system consists of 25 gamma sensitive detectors and their associated digital monitors. The detectors are in key locations of the plant and will have operating ranges (sensitivity) commensurate with the expected radiation levels in the areas. Monitored radiation levels will be recorded and indication will be provided in the control room. These area monitors will be powered from the non-1E vital 120-Vac bus. The monitors will have local audible alarms with adjustable sottings (both up-scale and down-scalo) to warn personsel of abnormal conditions such as higherthan-normal radiation lovels or detector failuro. Highrange radiation accident monitors that meet the criteria of RG 1.97, "Instrumentation for Light,Water-Cooled Nuclear Power Plants to Assess Plant and Environs Conditions During and Following an Accident" (Rev. 3), are provided in the RHR equipment area. In addition, to assees the magnitude of the release of radioactive material from the core during an accident, four high-range gamma sensitive ion chambers in the containment will be able to measure up to $0.72 \mathrm{c} / \mathrm{K}_{8}$ per' second $\left(10^{7} \mathrm{R} / \mathrm{hr}\right)$. The staff concludes that the area radiution monitoring system meets the applicable criteria in RG 8.8 (Rov. 3), RG 1.97 (Rev. 3), and the provisions in Item II.F.1.3 of NUREG-0737 that are required by 10 CFR $50.34(f)(2)(x v i i)(D)$ and is acceptable. The COL applicant will address the operational considerations, such as monitor alarm set points, listed in RG 1.70 (Rev. 3) Section 12.3.4. This was DFSER COL Action Item 12.3.4-1. GE has included this information in a markup of SSAR Section 12.3.4 dated April 16, 1993. GE has also included this action item in the SSAR and the staff finds it to be acceptable.

The staff noted in the DSER (SECY-91-355) that criticality accident monitors were not provided in the ABWR design to meet the requirements of 10 CFR 70.24 as provided in the SRP. In response to the siaff's request, GE amended the SSAR to state that these monitors are unnecessary because the ABWR is designed to ensure subcritical conditions during fuel handling and storage. Several licensees of operating BWRs with similar design features and fuel handling procedures have received a license condition exempting them from this 10 CFR 70.24 requirement. The requirements of $10 \mathrm{CFR}$ Part 70 are outside the scope of this review. The COL applicant will provide information showing that their plant meets the requirements of 10 CFR 70.24 or request an exemption. This was DFSER COL Action Item 12.3.4-2. GE has included this action item in markup of SSAR Section 12.3.4 dated April 16, 1993. GE has also included this action item in the SSAR and the staff finds it to be accoptable.

Monitoring of airborne radioactive materials in nuclear power plants typically is provided by fixed continuous air monitors. These monitors sample the ventilation air exhausted from plant areas having the highest potential for radioactivity release. Movable continuous air monitors are positioned in plant areas that have a potential for airborne radionctivity release during certain operating modes (i.e., an area where a radioactive system is opened during maintenance) to supplement the fixed monitors. GE has not described the airborne monitoring for the $A B W R$ design. As discussed in Section 12.3.3 of this report, the expected concentrations of airborne radionuclides cannot bo determined at the current level of the ABWR design detail. As an alternative, GE has provided DAC that would require the COL applicant to verify that airbome monitors provided in the final ABWR design meet the criteria of the SRP. The staff's roview of these DAC is in 
Section 12.3.5 below. The COL applicant will address the operational conviderationis, such is the procedures for operation and calibration of the monitors as well as the placoment of tine movable monitors, in the COL application. This was DFSER COL Action Item 12.3.4-3. OB has included this information in a markup of SSAR Section 12.3.4 dated April 16, 1993. OE has also included this action item in the SSAR and the staff finds it to be accoptablo.

\subsubsection{Certified Design Material}

The staff initially identified three areas where the lovel of design detail in the SSAR did not allow the staff to conclude that the ABWR design meots the acceptance criteria in Chapter 12 of the SRP. These areas are the adequacy of the plant radiation shielding, the adequacy of the plant ventilation system, and the adequacy of the plant airborne radionuclide monitoring system. As an alternative, GE provided DAC requiring the COL applicent to perform shielding analysis and airborne radionuclide concentration calculations that will be verified by the ITAAC during plant construction to verify that the final ABWR design is acceptable. Details of the staff's roview of these DAC follow.

\subsubsection{Plant Shielding DAC}

Chapter 12 of the SSAR contains layout drawings of the plant that indicato the designed maximum radiation level (or zone) for each room, equipment cubicle, and operating space during normal power operations, shutdown operations and accident conditions. As discussed in Section 12.2 above, the piping layout and component selection have not been set for the ABWR systems; therefore, parameters such as source strength and geometry needed to verify the adequacy of the radiation shields around these systems are not available. In addition, nitrogen-16 gammes from the plant can significantly contribute to offsite dose rates. The adequacy of the plant shielding needed to comply with the radiation dose limits for individual members of the public in 10 CFR Part 20 cannot be verified since the turbine design and site-specific parameters such as distance to the site boundary are unknown.

GE has submitted DAC for plant shielding in Table 3.2.a of the CDM. These DAC require the COL applicant to verify the adequacy of (1) the shielding around rooms and spaces during normal operations and shutdown conditions, (2) the shielding and temporary shield space provided between plant systems during maintenence activities, (3) the shielding provided around vital plant areas during accident conditions (Three Mile Island (TMI) Action Plan Item II.B.2 (10 CFR 50.34((f)(2)(vii)), and (4) the plant ahielding needed to limit public dose. The staffe reviow indicates that the analysis esoumptions, mothode, and acceptance criteria in theee DAC are consistent with the critoria in the SRP. Therefore, the ataff concludes that compliance with these DAC, as supplemented by the information in SSAR Sections 12.3.2, is acceptable to edequatoly addreas the relovant requirements in 10 CFR 50.34(b)(3) and 10 CFR Part 20 concerning the limitation of radiation exposures to personnel, including the requirement to maintain doses ALARA as supplemented by the guidance in RO 8.8 (Rov. 3); 10 CPR 50.34(f) and ODC 19 with respect to operator access to plaut areas during and following a reactor accident as supplemented by the guidance in Itom II. B.2 of NUREG-0737; and GDC 61 regarding adequate shielding of fuel storage and bandling, radioactive waste, and other systems which may contain radioactivity. GE provided a revised set of design descriptions and ITAAC (including DAC). The adequacy and acceptability of the ABWR Tier 1 material and ITAAC (including DAC) are ovaluated in Section 14.3 of this report.

\subsubsection{Ventilation and Airborne Monitoring DAC}

The level of detail in the current ABWR design is not sufficient to provide the expectod airborne concentrations in rooms and operating areas within the plant as specified in RO 1.70 (Rev. 3). Therefore, GE has not providod a description of the sirborne monitoring system consistent with the criteria in the SRP.

GE has submitted DAC for ventilation and airbome monitoring in Table 3.2.b of the CDM. These DAC requires the $\mathrm{COL}$ applicant to calculate the expected concentrations of airborne radioactivity in each equipment cubicle, corridor, and operating area that require personnol access. These DAC also require an analysis by the COL applicant to identify those areas of the plant that require continuous monitoring of airborne radioactive materials. The staff's review indicates that the assumptions and acceptance criteria in these DAC are consistent with the criteria in the SRP. Therefore, the staff concludes that compliance with these DAC, as supplemented by the information in SSAR Sections 12.3.3 and 12.3.4 and Appendix 12A, will meet the relevant requirements in 10 CFR 50.34(b)(3) and 10 CFR Part 20 concerning the limitation of radiation exposures to personnel from airborne radioactive material, including the requirement to maintain doses ALARA as supplemented by the guidance in RG 8.8 (Rev. 3); GDC 61 regarding adequate shielding of fuel storage and handling, radioactivo waste, and other systems which may contain radionctivity; and the requirements in 10 CFR Part 20, 10 CFR 50.34(f) and GDC 64 related to in-plant monitoring of airborne radioactive materials during routine operating conditions. 
The adequacy and acceptability of the ABWR Tier 1 material and ITAAC (including DAC) are ovaluated in Section 14.3 of this report.

\subsubsection{Radiation Design Features}

In the DSER (SEC'Y-91-355), the ataff identified a number of radiation design features to be addreseed in the ABWR Tier 1 design description and ITAAC. This was identified a DFSER Open Item 12.3.5.3-1. GE provided a revised set of design descriptions and ITAAC (including DAC). The adequacy and acceptability of the ABWR Tier 1 matorial and ITAAC (including DAC) are evaluated in Section 14.3 of this report. On the besis of this evaluation, this item is resolved.

\subsubsection{CFR 50.34(ก): TMI-Related Items}

SSAR Section 12.3 addresses two items from the TMI Action Plan (NUREG-0660), II.F.1.3 (10 CFR 50.34(f)(2)(xvii)(D), and II.B.2 (10 CFR 50.34(f)(2)(vii)). Item II.F.1.3 requires that high-range radiation accident monitors be provided in the contrinment. Item II.F.1.3 specifies that high-range dose monitors be capable of detecting dose rates up to $10^{8}$ rads per hour. NUREG-0737 modified this position to specify that gamma sensitive monitors be capable of reading up to $10^{-} R$ per hour. As discussed in Section 12.3.4 of this report, the ABWR design has four monitors (two in the drywell and two in the suppression chamber) that meet the provisions of Item II.F.1.3. Item II.B.2 specifies that radiation shielding be provided so that operators can access vital equipment in the plant during an accident without receiving excessive radiation dose. As discussed in Section 12.3.5.1 of this report, the DAC in Table 3.2.a of the CDM require the COL applicant to demonstrate compliance with Item II.B.2, as part of the analysis to verify the adequacy of the plant's radiation shielding.

The COL applicant will be responsible for demonstrating compliance with II.B.2 because the final hardware and system design specifications need as inputs to shielding calculations are not available now.

\subsection{Dose Assessment}

The staff has audited the dose assessment in Section 12.4 of the SSAR for completeness against the guidelines in RG 1.70 (Rev. 3) and against the criteria set forth in SRP Section 12.3.11.5. This review consisted of ensuring that GE had either committed to following the criteria of RGs and staff positions in Section 12.3 of the SRP or provided acceptable alternatives. In addition, the staff selectively compared the dose assessment made by GE for upecific functions against the experience of operating BWR. Details of the reviow follow.

GE provided an sscossment of the radiation dose that would be received by operating a plant of the ABWR deaiga. Estimated person-rem doses for major work within areas of the plant during maintenance and refueling periods and for power operations aro given in SSAR Table 12.4-1 and result in an estimated total annual dose of 0.989 person-sievert ( 98.9 person-rem).

In Open Itom 115 in the DSER (SECY-91-355), the staff identified several deficiencies in GE's dose assessment, including mathematical errors, inconsistencies between toxt and tables, a lack of bases for assumptions, and a level of detail that was not consistent with the guidance in RG 8.19, "Occupational Radiation Dose Assessment in Light-Water Reactor Power Plants--Design Stage Man-Rem Estimates" (Rov. 1). GE amended the SSAR to correct the math errors and inconsistencies noted and to give the bases for the assumptions and values used in the assessment.

In GE's dose assessment, the stay times and frequencies for each task aro based on a detailed task analysis of maintenance activities in $\mathrm{BWR}$ with a similar containment design (MARK III containment). Average dose rates are based on past experiences for similar tasks. These values were then adjusted to account for $A B W R$ design features to obtain the expected doses. The cumulative annual dose of 0.989 person-sievert (98.9 person-rem) for personnel operating an ABWR plant is consistent with the Electric Power Research Institute design guideline of 1.0 person-sievert (100 person-rem) per year and compares favorably with the average current BWR experience (which is more than twice the ABWR projected dose). Although not in the format specified in RG 8.19, this detailed dose assessment meets the intent of RG 8.19 and is acceptable. The staff considers this item resolved.

\subsection{Organization}

The organization required to implement an effective bealth physics program and ensure that radiation exposures are within the limits of 10 CFR Part 20 and are ALARA is outside the scope of this review. The COL applicant seeking an operating license by referencing the ABWR certified design will address this concern to the level of detail discussed in RG 1.70 (Rev. 3). This was DFSER COL Action Item 12.5-1. GE has included this information in a markup of SSAR Section 12.5.3.1 dated April 16, 1993. GE has also included this action item in the SSAR and the staff finds it to be acceptable. 
-

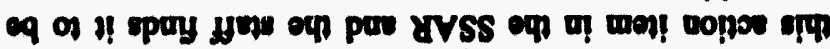
pepnjou! ax 80 'E661 '9l ludy poup Z'C'S'Z1 oopoes

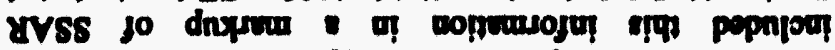

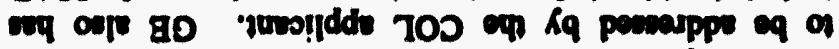

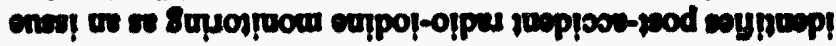

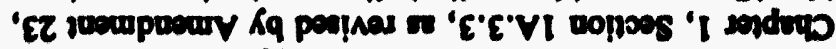

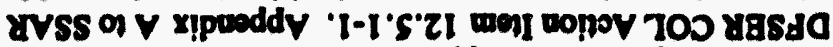

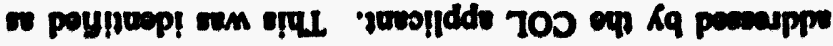

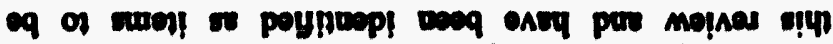

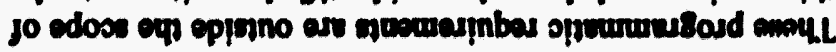

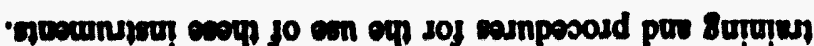

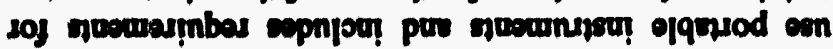

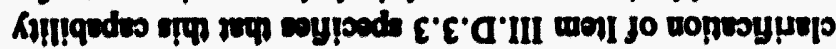

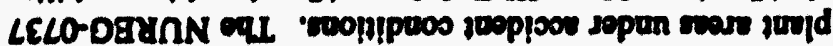

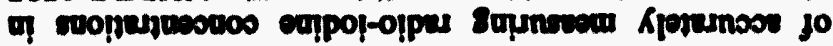

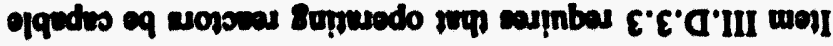
'Und nolfor IWL op 10 E'E'G'III wenl m!m coupsoos

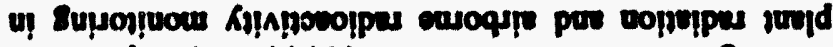

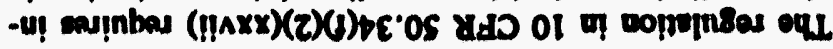

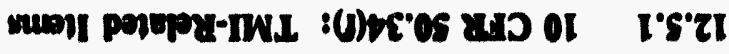




\section{CONDUCT OF OPERATIONS}

\subsection{Organizational Structure of Applicants}

The etaff comploted its roviow of Stundard Safaty Analyais Report (SSAR) Section 13.1, "Organizational Structure of Applicants," and finds this ecction to be edequate. The ataff agrees that the information rolated to the combined license (COL) applicant's organizational structure is outride the scope of the advanced boiling water reactor (ABWR) standard plant design. This information will be the responsibility of the COL applicant reforencing the ABWR design at the COL phase described in 10 CFR 52.79(b).

\subsection{Training}

The staff's reviow of SSAR Section 13.2 was based on the current regulatory requirements in 10 CFR 52.47, 10 CFR 50.34(g), and 10 CFR 50.34(f) and the guidence in SRP Section 13, NUREG-0700, and NUREO-0933. The staff developed additional review criteria to provido a basis for the review of aspects of the ABWR buman factors engineering (HFE) program that were not fully addressed by the previously mentioned documents. These criteria are contained in the staff's "HFE Program Reviow Model (PRM) and Acceptance Criteria for ABWR," which was forwarded to the Commission in SECY-92-299 dated August 27, 1992, and is attached as Appendix J of this report. The HFB PRM considered espects of training as it pertained to the verification and validution (V\&V) of the main control room and remoto shutdown system designs.

GE has not included training dovelopment in the scope of the ABWR desiga certification application and has stated that development of training will be the responsibility of the COL applicant. However, information on the incorporation of operating experience (Three Mile Island (TMI) I.C.5) and preoperational and low power testing (TMI I.G.1) into training programs is provided by GE to the COL applicant in SSAR Soction 13.2.

Although training is not considered to be part of the information required for certification of the ABWR design, the staff identified the following issues related to training during its review of SSAR Chapter 18, "Human Factors Engineering:" training materials, the use of a simulator for training, and the incorporation of operational experience into training programs. Each of these items is discussed below.

\section{DSER Issue 18.22:Trainine Materials}

In the DSER the staff stated that it "expects GE to develop and submit for certification a detailed program description for developing the training material as part of the design certification for the ABWR." Following issuance of the
DSER, the staff dotermined that training matorials were alroady a part of the established licensing roviow procest under 10 CFR Part 50 for the COL applicant and, therefore, did not need to be addreased in the ABWR design certification reviow under 10 CFR Part 52. The staff agrees that the submittal of training materials is boyond the scope of the ABWR deaign cortification and finds GE's approech to be acceptable; therefore, this item is resolved.

\section{TMLAction Itom J.A.4.2}

10 CFR 50.34(f)(2)(i) corresponds to TMI Action Item 1.A.4.2, "Long Term Simulator Training Upgrado," with regard to simulator capabilities. $\mathrm{GE}$ statos that "simulator facilities for use in performing operator training are outside the scope of the standard plant design certification." This is acceptable because training will bo addresed by the COL applicant. This was draft final safety ovaluation report (DFSER) COL Action Item 18.7.2.2-1. GE has included the COL action item, that the operator training program meets 10 CFR Part 50, as Item 18.8.8 in SSAR Section 18.8, and the staff finds this approach to be acceptable.

\section{TMLAction Item L.C.5}

The staff roviewed TMI Action Item I.C.5, "Feedbeck of Operating Experience, " on the incorporation of operational experience into the training and procedure development programs. The staff determined that development of detailed procedures and training materials is beyond the scope of the ABWR design certification and is the responsibility of the COL applicant. GE has included the training and procedure development process as a COL license information item in SSAR Sections 13.2 and 13.5, and the staff finds this approach to be acceptable.

\section{TMLAction Item L.G.1}

The staff reviewed TMI Action Item I.G.1, "Training Requirements for Preoperational and Low-Power Testing." The staff determined that I.G.1 is beyond the scope of ABWR certification and is the responsibility of the COL applicant. $G E$ has included the training requirements for preoperational and low power testing activities as a COL license information item in SSAR Section 13.2.3.2, and the staff finds this approach to be acceptable.

The staff also notes that V\&V of training materials will be oxamined further during the V\&V of the $A B W R$ main control room and remote shutdown system as described in Appendix 18E of the SSAR. Therefore, the issue of training is resolved for the ABWR design certification. 


\subsection{Emergency Planning}

In Section 13.3 of the SSAR, GE states that emergency planning is not within the scope of the ABWR design and that the COL applicant will provide emergency plans in accordance with 10 CFR 50.33(g) and 52.72(d). The staff agrees that the requirement to provide the emergency plans is the responsibility of the COL applicant referencing the ABWR design and will depend significantly on both plant and sito-epecific characteristics. This was identified as DFSER COL Action Item 13.3-1. GE included this action item in Amendment 31 of the SSAR. The staff finds it to be accoptable.

Nevertheless, GE also acknowledges that there are design features, facilities, functions, and equipment neceseary for emergency planning that must be considered in the design basis of a standard plant. These are addreseed in SSAR Table 13.3-1, "ABWR Design Considerations for Emorgency Planning Requirements," which specifies a technical support center (TSC) that complies with all of the TSC design requirements and is located in the service building adjacent to the control room. (The TSC is shown in SSAR Figure 1.2-19, "Control and Service Building, Arrangement Plan at Elevation $7900 \mathrm{~mm}$. ") GE further states that the TSC will contain the necessary facilities and equipment called for in Section 2 of NUREG-0696 ("Functional Criteria for Emergency Response Facilities, " U.S. NRC, February 1981).

The staff performed its review in accordance with the requirements of 10 CFR 50.47(b), Appendix E to 10 CFR Part 50, and 10 CFR 50.34(f)(2)(xxv), which requires an onsite TSC, an onsite operational support center (OSC), and a nearsite emergency operations facility (EOF). The staff's review also considered the guidance provided in NUREG-0654 and NUREG-0696. It is the staff' 8 position that the facilities and equipment for the ABWR standard plant TSC should be compatible with the control room and moet the applicable criteria of NUREG-0696. In this regard, the staff noted in the DFSER that whereas GE specified a TSC to support 20 people, NUREG-0696 specifies the following:

The TSC working space shall be sized for a minimum of 25 persons, including 20 persons designated by the licensee and five NRC personnel. This minimum size shall bo increased if the maximum staffing level specified by the licensee's emergency plan exceeds 20 persons.

Therefore, the staff stated in the DFSER that the TSC for the ABWR standard plant should be sized for 25 persons and be compatible with the control room in order to meet the criteria of NUREG-0696. This was DFSER Open
Itom 13.3-1. GE rovised Table 13.3-1 in Amendment 25 to the SSAR to indicate that the TSC will be of sufficient sizo to support 25 people. The staff finds it to be scceptable. This item is resolved.

The ABWR standard plant design also includes considentions for decontamination of onsite individuals in the service building adjacent to the main change rooms as shown in Figure 1.2-20 of the SSAR. The staff finds these design considerations for an onsite decontamination facility acceptable for meeting the requirements of $10 \mathrm{CFR}$ Part 50, Appendix E, Section IV.E.3.

GE considers other facilities that support emergency planning to be outside the scope of the ABWR standard plant design scope. These include an offsite EOF for the management of overall licensec emergency response, including coordination with Federal, State and local officials. The staff agrees that the EOF is not within the scope of the ABWR standard plant design, but must be addressed by the COL applicant referencing the ABWR standard plant design. This was identified as DFSER COL Action Item 13.3-2. GE included this action item in Amendment 31 of the SSAR. The staff finds it to be acceptable.

GE originally considered an onsite OSC (assembly area) separate from the control room and TSC where licenseo operations support personnel report in an emergency to be outside the scope of the ABWR standard plant design. However, the staff noted in the DFSER that an OSC should be provided as part of the ABWR standard plant design. This was DFSER Open Item 13.3-2. GE revised Table 13.3-1 in Amendment 25 to the SSAR to state that the ABWR standard plant will comply with all of the OSC design requirements, and that the lunch room adjacent to the TSC in the service building will be identified as the OSC. The staff finds it to be acceptable. This item is resolved.

\section{Certified Desian Material}

The requirements for the TSC and OSC were not covered in the Tier 1 design descriptions or inspections, tests, analyses, and acceptance criteria (ITAAC). This was DFSER Open Item 13.3-3. GE has provided a revised set of design descriptions and ITAAC. The adequacy and acceptability of the ABWR design descriptions and ITAAC are evaluated in Section 14.3 of this report. On the basis of this evaluation, this item is resolved.

10 CFR 50.34(f):TMI-Related Items

SSAR Section 13.3 addresses TMI Action Plan (NUREG-0660)Item III.A.1.2(10 CFR50.34(f)(2)(xxv)). 
This itom requires the COL applicent to upgrade its emergency support facilities by establishing a TSC, OSC, and a near site EOF for command and control, support, and coordination of onsite and offsite functions during reactor accident situations. As discussed in Section 13.3 of this report, the ABWR design provides for a TSC and an OSC. The near-site EOF is considered by the staff not to be within the scope of ABWR standard plant design and will be addressed by the COL applicant referencing the ABWR standard plant design (DFSER COL Action Item 13.3-2). GE has included this action item in the SSAR. The staff finds it to be acceptable.

\subsection{Review and Audit}

The staff determined that the review and audit information is outside the scope of the ABWR standard plant design. The COL applicant will provide the necessary information on reviews and audits for plant operation. It will be reviewed in detail during the COL stage. GE has included this action item in the SSAR and the staff finds it to be acceptable.

\subsection{Plant Procedures}

The staff's review was based on the current regulatory requirements established in 10 CFR 52.47, 10 CFR 50.34(g), and 10 CFR 50.34(f) and the guidance contained in SRP Section 13, NUREG-0700 and NUREG-0933. The staff developed additional review criteria to provide a basis for the review of aspects of the ABWR HFF program that were not fully addressed by the previously mentioned documents. These criteria are contained in the staff's HFE PRM, which is attached as Appendix J of this report. The HFE PRM considered aspects of plant procedures as they pertained to the $V \& V$ of the main control room and remote shutdown system designs.

GE has not included procedure development in the scope of its ABWR design certification application and has identified procedure development as a COL responsibility in SSAR Section 13.5. GE's description of this COL license information item is consistent with the staff's HFE PRM - Element 7, procedures, developed to support the review of the ABWR HFE effort. The HFE PRM is described in Appendix $J$ of this report.

Although plant procedures are not considered to be part of the information required for certification of the ABWR design, the staff identified several issues related to procedure development during the review of SSAR Chapter 18, "Human Factors Engineering." Items regarding procedure development as well as differences between Element 7 of the HFE PRM and SSAR Section 13.5 are discussed below.
(1)

\section{General Criterion 5 of Element 7 of the HFE PRM}

Ceneral Criterion 5 of Element 7 of the HFE PRM states: "All procedures shall be verified and validated. A review shall be conducted to assure procedures are correct and can be performed. Final validation of operating procedures shall be performed in a simulation of the integrated system es part of V\&V activities described in Element 8." Although $G E$ has not included a requirement for final validation of operating procedures, in its design scope, as a COL action item, GE has stated that procedures will be available for the humansystem interface (HSI) V\&V activities (as specified in SSAR Section 13.5.3.3, - Item e). These activities are described further in SSAR Appendix 18E and SSAR Table 18E-4. The details of GE's V\&V process are provided in SSAR Table 18E-4 and require that final procedures be included by the COL applicant in the V\&V activities for both the main control room and the remote shutdown system. On the basis of SSAR Section 13.5.3.3 and the inclusion of procedures in SSAR Table 18E-4, the staff finds specification of this criterion in the SSAR as a COL action item to be acceptable.

General Criterion 6 of Element 7 of the HFE PRM

General Criterion 6 of Element 7 of the HFE PRM states: "An analysis shall be conducted to determine the impact of providing computer-based procedures and to specify where such an approach would improve procedure utilization and reduce operating crew errors related to procedure use." This activity is not part of GE's design scope. GE states that an analysis of computer-based procedures will be conducted as part of the task analysis to be conducted by the COL applicant and evaluated further as part of the HSI. The description of the HSI requirements is contained in Table 3.1 of the ABWR certified design material. Because the computerization of procedures is an aspect of the HSI design implementation, the incorporation of the analyses as part of HSI Element 4 is acceptable. Therefore, the staff finds the specification of COL completion of this criterion to be acceptable.

Although plant procedures are not considered to be part of the information required for design certification of the ABWR, the staff identified the following issues related to procedures during its review of GE's HFE program: procedure development (DSER - SECY-91-320 Issue 18.21), guidelines for updating procedures (HF-4.4), short-term accident procedures review (TMI Action 
Item I.C.1), incorporation of operating experience (TMI Action Item I.C.5) and a long-term plan for upgrading procedures (TMI Action Item I.C.9). Each of these items is addressed below.

\section{DSER (SECY-91-320) Isque 18.21: Procedure} Development

In the DSER, the stuff stated that system-level operating procedures would be developed concurrent with the development of the ABWR systems design. Theis procedures and the associated task analyses on which the HSI requirements are based are not included in the design certification; thus, they could not be evaluated.

The staff determined that development of detailed procedures and associatbd truining materials is beyond the ecope of the ABWR design certification and is the responsibility of the COL applicant. This was DFSER Confirmatory Item 18.9.2.2.7-1. GE has included the COL license information in the SSAR Section 13.5 which adequately addresees procedure development for the certification of the ABWR design. The staff finds GE's approach to be acceptable. Therefore, Confirmatory Itrm 18.9.2.2.7-1 is resolved.

\section{USI/GSI Item HE-4.4 and TMI Action Items I.C.1, I.C.5 and I.C.9}

The staff reviewed Item HF-4.4, "Guidelines for Upgrading Other Procedures," TMI Action Item I.C.1, "Short-Term Accident and Procedures Review," TMI Action Item I.C.5, "Feedback of Operating Experience," and TMI Action Item I.C.9, "Long Term Plan for Upgrading Procedures." It was determined that development of detailed procedures is beyond the scope of the ABWR certification and is the responsibility of the COL applicant. GE has included the procedure development process as a COL license information item in SSAR Section 13.5.3. SSAR Section 13.5.3.1 states that the methods and criteria for the development, V\&V, implementation, maintenance and revision of procedures will include consideration of TMI Action Items I.C.1, I.C.5, and I.C.9. The staff finds GE's approach to be acceptable. The staff interprets this process to include the analysis of $\mathrm{HF}-4.4$.

The staff also notes that $V \& V$ of plant procedures will be examined further during the V\&V of the ABWR control room and remote shutdown system as described in GE's certified design material, Table 3.1, "Human Factors Engineering," and in Appendix 18E of the SSAR. Therefore, GE's proposed treatment of plant procedures is acceptable for the purposes of ABWR design certification.

\subsection{Physical Security}

\subsubsection{Preliminary Ptanning}

SSAR Section 13.6 states that preliminary planning is not required because the security plan will be the responsibility of COL applicants who reference the ABWR standard plant design. The staff finds this approach to be acceptable. Since the COL application will include a physical security plan, safeguards contingency plan, and a guard qualification and training plan, a preliminary planning submittal is not necessary for the design certification.

\subsubsection{Security Plan}

The SSAR states that the development of the security plan is beyond the scope of the ABWR standard plant desigra. The staff finds this approach to be acceptable. In addition to the action items listed in Section 13.6.3 of the SSAR, the COL applicant will provide site-specific security, contingency, and guard training plans in accordance with 10 CFR 50.34 and 10 CFR Part 73. This was identified as DFSER COL Action Item 13.6.2-1. By SSAR Amendment 25, GE identified in Section 13.6.3.8 that the COL applicant will provide site-specific security, contingency, and guard training plans. The staff finds it to be acceptable.

The staff requires that at least 60 days before loading fuel, the COL applicant will confirm that the security systems and programs described in its physical security plan, safeguards contingency plan, and guard qualification and training plan have achieved operational status and are available for NRC inspection. Operational status means that the security systems and programs are functioning in entirety as they would when the reactor is operating and will remain so. The COL applicant's determination that operational status has been achieved must be based on tests conducted under realistic operating conditions of sufficient duration to demonstrate (1) that the equipment is properly operating and capable of long-term, reliable operation; (2) that procedures have been developed, approved, and implemented; and (3) that personnel responsible for security operations and maintenance have been appropriately trained and have demonstrated their capability of performing their assigned duties and responsibilities. This was identified as DFSER COL Action Item 13.6.2-2. GE has included this action item described above in the SSAR and the staff finds it to be acceptable. 


\subsubsection{Control of Access to Areas Containing Vital Equipment}

Section 13.6.3 of the SSAR identifies number of interfaces between the ABWR standard plant deaign and the remainder of the plant that must be addrewed by COL applicants who roforence the ABWR stundard plant design.

The staff roviowed the interfaces and determined that thene were not interfaces as described in 10 CFR 52.47 but were actions to be accomplished as part of the COL application. The staff found them to be acceptable as COL action items subject to the addition of the requirement that the applicant provido plant-specific eecurity, contingency, and guard training plans in accordance with 10 CFR 50.34 and 10 CFR Part 73. This was identified as DFSER COL Action Item 13.6.3-1. OB hes included this action item as deacribed above in the SSAR and the ataff finds it to be acceptable.

\subsubsection{Introduction}

Section 13.6.3.1 of the SSAR states that SSAR Section 13.6.3 deals with the control of acceas to areas containing vital equipment.

\subsubsection{Design Bases}

Section 13.6.3.2 of the SSAR states that security functions described in Section 13.6.3 are incorporated into the overall ABWR deaign so that the plant is in compliance with the requirements of 10 CFR Part 73.

The Electric Power Research Institute (EPRI) Advanced Light Water Reactor (ALWR) Utility Requirements Document (Volume II, Revision 1, Chapter 11, Section 8.4.1) specifically requires the protected area lighting to be powered from an uninterruptible power source. In its response to a request for additional information (RAI) Q910.18, GE identified a site eccurity load on the non-Cless 1E vital (uninterruptible) loed list (SSAR Table 20B-1), but the staff considered the description of this interconnection to be insufficiently defined. In response to ataff comments, GE added SSAR Section 19B.3.12, which clarified the connection between the security systom uninterruptible power requirements (to be later 80 determined by the plant-specific security system designer as to meet required security system performance) and the non-Class IE vital power supply capecity. SSAR Section 19B.3.12 requires that the sito security system be powered from a non-Class 1E vital (uninterruptible) ac power source. The protected are boundary lighting subsystem is the only exception. At the discretion of the COL applicant, the protected area boundary lighting subsystem may be powered from non-Class IE vital (uninterruptible) ac power source or from an interruptible power source provided adequate compensatory measures are eatablished by the site's physical security implementation plan. The ataff corsiders this resolution acceptable and this portion of DFSER Open Item 1.1-1 is recolved.

In NRC Information Notice 83-83, the staff suggested that now plant designs that make extensive use of solid-state dovices in instrument and control circuits may experience reactor system malfunctions and spurious actuation as a result of portable communication devices in their vicinity. In RAI Queations (Q)910.10 and Q910.17, the staff asked that radio-frequency interference design criteria be establishod to eneure that eocurity personnel within the reactor and control building could maintain radio communication without advernoly affecting plant operation. OE's response to Q910.17 taif anced diecussions of system tolerance to electromagnetic interference. The staff finds that the plant cocurity ayetem criteria in SSAR Section 9.5.13.11 and the amondment to SSAR Appendix 7A, in response to a concern raised in DSER Section 7.1.3.3, adequately resolve staff's concern.

\subsection{3.? Vital Areas}

Section 13.6.3.3 of the SSAR itemizes by location the plant equipment to be considered vital equipment pursuant to 10 CFR 73.2 and the vital areas containing that equipment. SSAR Figures 13.6-1 through 13.6-14 outline the vitul areas.

In RAls Q910.9, Q910.11, and Q910.20, the staff questioned the completeness of the ust of vital equipment in SSAR Section 13.6.3.3. GE clarified this list on February 22, 1991, after discussions with staff. The staff is satisfied that the list of vital equipment includes all active and passive plant equipment essential to safo shutdown of the reactor, including necessary support systems, the reactor veseel and the remainder of the reactor coolant system pressure boundary within the primary containment, the suppression pool, spent fuel in the fuel pool, and any aseociated piping, equipment, and controls whose failure could result in an offeite release in exceses of 10 CFR Part 100 limits. The staff finds this to bo compatible with NRC Review Guideline 17 (January 23, 1978, memorandum from R. Clark to safeguards licensing staff). Prior to issuance of a COL, the etaff's review of the designation of equipment as vital in plant-specific applications will focus on plant support equipment outside the scope of the certified ABWR design. In addition, 10 CFR 73.55(e) requires that the central alarm station be considered vital area and secondary power supply system for alarm annunciator equipment and that non-portable communications equipment be located in 
vital areas. The secondary alarm station also is typically on site and treated as a vital area. Vital area classification of the central and secondary alarm stations was identified as DFSER COL Action Item 13.6.3.3-1. In SSAR Amendment 25, GE stated in Section 13.6.3.8 that the COL applicant will provide site-specific security, contingency, and guard training plans. Specifically, as stated in Section 13.6.3.10, the COL applicant will provide the classification of the control and secondary alarm stations. Vital area classification will be addressed at the time of the plant-specific sexurity plan review. The staff finds it to be acceptable.

The staff expects that at least 60 days before loading fuel, a licensee will have confirmed that no portion of as-built vital systems is located outside of designated vital areas or can be prevented from performing their safety functions from outside the vital areas (e.g., by reach-rod valve manipulation). This verification should include piping, valves, and motor control centers that are required for maintaining boundary integrity, for performing the safe reactor shutdown cooling function, and for isolating safetyrelated equipment from non-safety-related equipment. This was identified as DFSER COL Action Item 13.6.3.3-2. In SSAR Amendment 25, GE specified in Section 13.6.3.11 that the COL applicant will confirm that locations of vital systems and system operations meet the above requirements. The staff finds it to be acceptable.

The plant-specific licensing review of the security and contingency response plan also will include an evaluation of whether the security response force's capability to interdict the violent external assault postulated in 10 CFR 73.1(a)(1)(i) properly accounts for the minimum penetration delay provided by the vital area barriers and doors. This was identified as DFSER COL Action Item 13.6.3.3-3. In SSAR Amendment 25, GE stated in Section 13.6.3.12 that the COL applicant will provide an evaluation of the interdiction capability of the security response force. The security response force's capability to interdict the violent external assault postulated in 10 CFR 73.1(a)(1)(i) will be addressed at the time of the plant-specific security plan review. The staff finds it to be acceptable.

\subsubsection{Methods of Access Control}

SSAR Section 13.6.3.4 describes, in general terms, the types of door controls that will be used to control access to vital areas. In response to RAIs Q910.12, Q910.21, and Q910.22, GE added statements to the SSAR that all doors and hatches connecting vital to non-vital areas are to be alarmed and emergency egress will not require keys or card readers. The staff finds this approach to be acceptable.
13.6.3.5 Access Control and Security Measures Through Exterior Doors to the Nuclear Island

SSAR Section 13.6.3.5 describes the specific security measures at portals into the reactor and control buildings from exterior areas and facilities of the remainder of the plant. For the DSER (SECY-91-235), the staff stated the types of door controls specified in SSAR Section 13.6.3.4 were generally acceptable, but insufficient detail was provided to determine compatibility with RG 5.12, Revision 0. This description of access control methods also did not address the positive control requirement of $10 \mathrm{CFR} 73.55(\mathrm{~d})(7)(\mathrm{i})(\mathrm{B})$ and the record-keeping requirement of 10 CFR 73.70 (d), which requires logging individuals' times of entry to and exit from each vital area. This was identified as DSER (SECY-91-235) Open Item 36 and DFSER COL Action Item 13.6.3.5-1. In SSAR Amendment 25, GE stated in Section 13.6.3.13 that the COL applicant will demonstrate that door controls are compatible with RG 5.12, the positive control requirement of 10 CFR 73.55(d)(7)(i)(B) and the record-keeping requirement of $10 \mathrm{CFR} 73.70(\mathrm{~d})$. This issue will be considered during review of the plant-specific security plan. The staff finds it to be acceptable.

In RAI Q910.19, the staff asked why the parameters for environmental conditions in SSAR Appendix 3I should not apply to the design and qualification of security access control components. TMI Action Item II.B.2 (NUREG-0737) identifies areas for which envimnmental qualification of equipment necessary to ensure post-accident access may need to be considered. Although the "security center" is not safety related, it is included in NUREG-0737 because access to it may be necessary to give access to the rest of the plant. In NRC Information Notice 86-106, Supplement 2, the staff discussed an event at the Surry Power Station in which condensed steam saturated a security card reader and caused a short circuit in the card reader system for the entire plant. As a result, key cards would not open doors controlled by the security system. In the same event, a security communications system radio repeater was temporarily degraded because a thick layer of ice had formed on it from actuation of a carbon dioxide discharge nozzle. In response to RAI Q 910.19, GE stated that (1) this equipment is not safety related and is not required to operate under accident conditions, (2) the card reader design is required to preclude the possibility of failure of one card reader affecting the operation of any other card reader, (3) card reader doors are required to have a key-operated override, and (4) emergency exits are required to be designed so that personnel can exit without using keys or card readers. The staff considers this response to be consistent with currently accepted industry practice and is, therefore, acceptable. 
Furthermore, SSAR Chapter 19, Appendix 19B.3.10, requires a COL applicant to evaluate the effects of the security system on required operator actions during all emergency modes of operation. The staff's position is that this analysis should include consideration of an emergency requiring evecuation of the control room in the control building to the remote shutdown panel in the reactor building. This was identified as DSER (SECY-91-235) Open Item 37 and DFSER COL Action Item 13.6.3.5-2. In SSAR Amendment 25, GE stated in Section 13.6.3.8 that the COL applicant will provide sito-specific security, contingency, and guard training plans. Evaluation of compliance with the vital equipment prompt access requirements of 10 CFR 73.55(d)(7)(ii) will be resolved during review of the plant-specific security plan. The staff finds it to be acceptable.

\subsubsection{Bullet-Resistant Walls and Doors, Security Grills, and Screens}

SSAR Section 13.6.3.6 discusses bullet-resistant walls and doors and security grills and screens incorporated into the building design, with the stated intent of minimizing forcible access to the control room. In its responses to RAIs Q910.13, Q910.23, and Q910.24, GE did not resolve staff uncertainty as to the adequacy of barriers in all man-sized openings in physical barriers that separate other vital from non-vital areas. Also, the staff position on the effectiveness of the ventilation system barriers described in SSAR Section 13.6.3.6 remained as described in RAI Q910.13; that is, consideration may need to be given to how accessible, isolated, and hidden from view these barriers will be, as well as whether they can be penetrated with hand tools available on site. While SSAR Section 13.6.3.6 only addresses the main control room heating, ventilation, and air conditioning (HVAC) ducting and exterior air exhaust systems, SSAR Chapter 19, Appendix 19B.2.4(13) was changed to include the EPRI ALWR requirements on utility port openings (e.g., HVAC, cooling, and piping) through all vital or protected are boundaries, in accordance with EPRI
Evolutionary Requirements Document, Chapter 9, Section 5.2.5.1, Revision 0. Specifically, the SSAR states that the ABWR design will minimize the use of utility port openings through all vital or protected area boundaries and will provide security access control of these utility ports. GE's change in Appendix 19B.2.4, which clarifies that the ABWR design will comply with the above ALWR requirements, satisfactorily resolved this issue.

\section{Certified Desien Material}

The staff expects that at least 60 days before loading fuel, the COL applicant referencing the ABWR design will have confirmed that the as-built bullet-resistant feature of walls and doors and the penetration-resistant feature of barriers in HVAC ducting and exhausts, committed to in SSAR Section 13.6.3.6, have been installed in all locations required by the commitment. This inspection requirement should be included in appropriate building ITAAC and was identified as DFSER Open Item 13.6.3.6-1. In its submittal dated May 30, 1992, GE stated that the issue was not a Tier 1 ITAAC issue. Additional review by the staff agreed with GE that the issue did not meet the criteria to be a Tier 1 ITAAC requirement. This issue is discussed in detail in Section 14.3.2.5. Therefore, this item is resolved.

\subsubsection{Compatibility With the Remainder of the Plant}

SSAR Section 13.6.3.7 states that access control for the remainder of plant buildings, including the turbine building side of the main steam tunnel, must be compatible with the site-specific physical security program which will be the responsibility of the $\mathrm{COL}$ applicant who references the ABWR standard plant design. The staff agrees and notes that an acceptable security barrier to bar unsuthorized access from the turbine building into the steam tunnel must also permit venting of steam into the turbine building in accordance with SSAR Section 9A.3.2 of Appendix A to Chapter 9. 


\section{INITIAL TEST PROGRAM}

\subsection{Preliminary Safety Analysis Reports Information}

Section 14.1 of the standard safety analysis report (SSAR) is spocified in Regulatory Guide (RG) 1.70 and the standard review plan (SRP). However, the preliminary safety analysis report information specified by RG 1.70 is only required for facilities licensed under 10 CFR Part 50, and is not required for a design certification under 10 CFR Part 52. This is because under Part 52, the staff gives its final design approval (FDA) for the design, rather than its preliminary design approval as done under Part 50. Thus, the design information in the SSAR is final rather then preliminary, and therefore, no information is required to be in this section of the ABWR SSAR.

The staff provided its preliminary ovaluation of GE's draft certified design material in Section 14.1 of the DFSER. Subsequently, as requested by the staff, GE provided SSAR information discussing the certified design material in a new Section 14.3 of the SSAR. The staff's review of the certified design information is summarized in Section 14.3 of this report, which conforms with SSAR Section 14.3.

This section is not applicable to the ABWR application. The DFSER included a discussion of piping design in this section. This discussion has been moved to Section 3.12 of this report.

\subsection{Initial Plant Test Programs}

\section{Introduction}

Chapter 14, Section 14.2, of the ABWR SSAR, "Specific Information to be Included in Final Safety Analysis Reports, " describes the plant initial test program (ITP) for the ABWR. The GE ABWR ITP consists of a series of tests categorized as construction, preoperational, or initial startup tests. The construction acceptance tests determine installation and functionality of equipment. Preoperational tests are those tests normally conducted prior to fuel loading to demonstrate the capability of plant systems to moet performance requirements. Initial startup tests begin with fuel loading and demonstrate the capability of the integrated plant to meet performance requirements. This report documents the staff's evaluation of the GE ABWR ITP.

The staff performed the review of the plant ITPs in accordance with Section 14.2, of NUREG-0800, the SRP, and RG 1.68 (Rev. 2), "Initial Test Program for Water Cooled Nuclear Power Plants." The staff reviewed thirteen areas relating to initial plant test programs, described in Chapter 14 of the SSAR, and submitted by GE as part of its design certification application. These areas of review are listed below:

- Summary of the Test Program and Objectives

- Organization and Staffing

- Test Procedures

- Conduct of Test Program

- Review, Evaluation, and Approval of Test Results

- Test Records

- Conformance of Test Program With Regulatory Guides

- Utilization of Reactor Operating and Testing Experience in the Development of Test Program

- Trial Use of Plant Operating and Emergency Procedures

- Initial Fuel Loading and Initial Criticality

- Test Program Schedule

- Individual Test Descriptions

- Combined License (COL) Information - ITP

The acceptance criteria used by the staff for this review were contained in SRP Section 14.2, Subsection II.

\section{Backoround}

A meeting was held with GE, on May 7, 1991, in order to discuss list of questions, comments, and errata information generated by the staff's initial review of the SSAR and GE's potential responses to these items. Subsequently, a draft SSAR amendment was submitted by GE via a letter dated May 20, 1991, from R.C. Mitchell (GE) to C.L. Miller (NRC), in response to these items.

The DSER (SECY-91-355), dated November 5, 1991, consisting of acceptable and open items, was subsequently forwarded to GE for its use in further revising the SSAR. In October 1991, GE formally submitted SSAR Chapter 14, Amendment 20. GE subsequently submitted a response to the DSER open items via letter dated March 11, 1992, from R.C. Mitchell (GE) to R.C. Pierson (NRC) and additional SSAR markups were subsequently provided to the staff. These changes were incorporated in SSAR Amendments 21, 22, and 23. 


\section{Evaluation}

The staff reviewed the GE ABWR ITP in accordance with SRP Section 14.2. This evaluation includes information in staff requests for additional information (RAls) following its earlier review, GE's letter of May 20, 1991, in response to the staff's RAIs and the staff's findings regarding each response. The staff also evaluated GE's responses to DSER open items as contained in its letter of March 11, 1992. This evaluation also includes all other information supplied to the staff as docketed markups to the SSAR, as well as changes contained in subsequent SSAR amendments. This evaluation for the ABWR included open items, confirmatory items, and resolution of those sections of the SSAR that the staff initially found to need modification or additional information.

Based on the review of the GE ABWR ITP description in SSAR Chapter 14 and the responses to the RAIs and the DSER open items, DFSER open items and confirmatory items, the staff concludes that the ITP was generally comprehensive and covered all areas of staff concern. The staff also conducted an in-depth review of system-specific testing requirements within each test abstract. The staff concludes that GE provided a sufficient level of detail to adequately describe system-specific test prerequisites and acceptance criteria. The staff also reviewed cross references to acceptance criteria information in other parts of the SSAR and finds them acceptable.

\subsubsection{Summary of Test Program and Objectives}

As stated in SSAR Section 14.2.1, the objectives of the ITP will be to

- ensure that construction is completed and acceptable

- demonstrate the capability of structures, components, and systems to meet performance requirements

- effect fuel loading in a safe manner

- demonstrate, where practical, that the plant is capable of withstanding anticipated transients and postulated accidents

- evaluate and demonstrate, to the extent possible, that plant operating procedures provide assurance that the operating group is knowledgeable about the plant and procedures and fully prepared to operate the facility in a safe manner

- bring the plant to rated capacity and sustained power operation

\subsubsection{Construction Test Objectives}

SSAR Section 14.2.1.1 states that construction tests will be performed to demonstrate that components and systems are correctly installed and operational. These tests will include, but will not be limited to; flushing and cleaning, hydrostatic testing, initial calibration of instrumentation, checks of electrical wiring and equipment, valve testing, and initial energization and operation of equipment and aystems. Completion of this phase will ensure that systems are ready for preoperational testing.

\subsubsection{Preoperational Test Objectives}

SSAR Section 14.2.1.2 states that preoperational tests will be conducted before fuel loading to verify that plant systems are capable of operating in a safe and officient manner compatible with the system design bases. The general objectives of the preoperational test phase will be to:

- ensure that design specification and test acceptance criteria are met

- provide documentation of the performance and safety of equipment and systems

- provide baseline test and operating data on equipment and systems for future reference

- nun-in new equipment for a sufficient period s1, that any design, manufacturing, or installation defec is can be detected and corrected

- ensure that plant systems operate together on an integrated basis to the extent possible

- give maximum opportunity to the permanent plant operating staff to obtain practical experience in the operation and maintenance of equipment and systems

- help demonstrate safe and efficient system operating and surveillance testing procodures to the extent possible

- demonstrate that safety systems and equipment are operated to allow fuel loading and entry to the startup phase

\subsubsection{Startup Test Objectives}

SSAR Section 14.2.1.3 states that after the preoperational test phase has been completed, the startup phase will begin with fuel loading and extend to commercial operation. The tests conducted during the startup phase consist of major 
and minor plant transients, steady-state tests, and process control system tests. These tests will be directed toward demonstrating correct performance of the nuclear boiler and the various plant systems whilo at power and the validation of analytical models used in the design.

The general objectives of the startup phase will be to:

- achieve an orderly and safe initial core loading

- accomplish all testing and measurements necoseary to ensure that the approach to initial criticality and subsequent power ascension is safo and orderly

- conduct low-power physics tests sufficient to ensure that test acceptance criteria have been met

- conduct initial heatup and hot functional testing so that hot integrated operation of all systems is shown to meet test acceptance criteria

- conduct an orderly and safo power ascension program, with requisite physics and systems testing, to ensure that integrated plant operation at power meets test acceptance criteria

- demonstrate, to the extent possible, the adequacy of various component, system, and plant procedures

- conduct a successful warranty demonstration

\subsubsection{Conclusion}

The staff finds that the objectives for the ITP moet the acceptance criteria in SRP Section 14.2 and are acceptable.

\subsubsection{Organization and Stafring}

\subsubsection{Normal Plant Staff}

SSAR Section 14.2.2.1 states that the normal plant staff responsibilities, authorities, and qualifications are given in SSAR Chapter 13. DFSER Confirmatory Item 14.2.2.1-1 addressed an issue that plant organizational staff was outside the scope of the ABWR SSAR. GE added information in Amendment 30 of SSAR Section 14.2.2.1 to state that plant organizational staff will be provided by the COL applicant. The staff finds this acceptable. This resolved DFSER Confirmatory Item 14.2.2.1-1.

\subsubsection{Startup Group}

SSAR Section 14.2.2.2 states that the startup group will be an ad hoc organization created to ensure that the ITP is conducted in an efficient, safe, and timely manner. The startup group will be responsible for planning, executing, and documenting all startup and testing activities that occur between the completion of the construction phase and commencement of commercial operation of the plant. Upon completion of the startup program, the startup group will be dissolved and the normal plant staff will assume complete responsibility for the plant. The normal plant staff will be included in as many aspocts of the teat programs as is practicable, considering their normal dutios in the operation and maintenance of the plant.

\subsubsection{General Electric Company}

SSAR Section 14.2.2.3 states that GE will be the supplier of the boiling water reactor (BWR) nuclear steam supply system and is responsible for generic and specific BWR designs. During the construction and testing phases of the plant cycle, GE personnel will be on site to offer consultation and technical direction with regard to GE-supplied systems and equipment.

\subsubsection{Others}

SSAR Section 14.2.2.4 states that other concerned parties outside the plant staff organization--such as the architectengineer, the constructor, the turbine-generator supplier, and vendors of other equipment--will be involved in the testing program to various degrees.

\subsubsection{Interrelationships and Interfaces}

SSAR Section 14.2.2.5 states that the effective coordination between the various site organizations involved in the test program will be achieved through the startup coordinating group (SCG) that will be composed of representatives of the plant owner/operator, GE, and others. The duties of the SCG will be to review and approve project testing schedules and to effect timely changes to construction or testing in order to facilitate execution of the preoperational and initial startup test programs.

\subsubsection{Conclusion}

The staff finds that the organization and staffing plan meet the acceptance criteria in SRP Section 14.2 and are acceptable. As discussed in Section 14.2.2.1, the normal plant staff aspects will be evaluated during the COL roview.

\subsubsection{Test Procedures}

SSAR Section 14.2.3 states that testing during all phases of the ITP will be conducted using detailed, step-by-step written procedures to control the conduct of each test. 
Such test procedures will specify testing prerequisites, deacribe desired initial conditions, include appropriate mothods to direct and control test performance (including the sequencing of testing), specify acceptance criteria by which the teet will be evaluated, and provide for or specify the format by which dats or obeervations will be recorded. The procedures will be developed, reviowed, and controlled by personnel with appropriate technical beckgrounds and experience in accordance with the startup administrative manual. This will include participation of principal design organizations in the establishment of test performance requirements and accoptance criteria. $\mathrm{GE}$ will provide the COL applicant with scoping documents (i.e., preoperational and startup test specifications) containing testing objectives and acceptance criteria applicable to its scope of design responsibility. Such documents also will include, as appropriate, delineation of specific plant operational conditions at which tests will be conducted, testing methodologies to be used, specific data to be collected, and acceptable data reduction techniques as well as any reconciliation methods needed to account for test conditions, methods, or results if testing is performed at conditions other than representative design operating conditions. Available information on operating and testing experiences of operating power reactors will be factored into test procedures as appropriate.

The staff finds that the content, development, and review of test procedures meet the criteria in SRP' Section 14.2, and are acceptable. However, a COL applicant will need to provide the following for staff review:

- The scoping document (i.e., preoperational and startup test spocifications) containing testing objectives and acceptance criteria applicable to its scope of design responsibility. This was DFSER COL Action Item 14.2.3-1.

- The scoping document that delineate and any other documents which delineate plant operational conditions at which tests are to be conducted, testing methodologies to be utilized, specific data to be collected, and acceptable data reduction techniques to be reviewed by the staff at the time of combined operating license. This was DFSER COL Action Item 14.2.3-2.

- The scoping document that delineate any reconciliation methods needed to account for test conditions, methods or results if testing is performed at conditions other than representative design operating conditions. This was DFSER COL Action Item 14.2.3-3.

- The approved preoperational test procedures approximately 60 days before their intended use and etartup teet psocedures approximately 60 days before fuel loading. This was DFSER COL Action Item 14.2.3-4.

GE incorporated the above COL action itoms in SSAR Sections 14.2.3 and 14.2.13. This is acceptable.

\subsubsection{Conduct of Test Program}

SSAR Section 14.2.4 states that the ITP will be conducted by the startup group in accordance with the startup administrative manual. This manual will contain the administrative procedures and requirements that govern the activities of the startup group and their interfaces with other organizations. The startup administrative manual will receive the same level of review and approval as do other plant administrative procedures. It will define the specific format and content of preoperational and startup test procedures as well as the review and approval process for both initial procedures and subsequent revisions or changes. The startup manual also will specify the process for review and approval of test results and for resolution of failures to meet acceptance criteria and of other operational problems or design deficiencies. It will describe the various phases of the ITP and establish the requirements for progressing from one phase to the next as well as those for moving beyond selected hold points or milestones within a given phase. It will also describe the controls in place that will ensure the as-tested status of each system is known and track modifications, including retest requirements, deemed necessary for systems undergoing or already having completed specified testing. Additionally, the startup manual will delineate the qualifications and responsibilities of the different positions within the startup group.

\section{Staff Evaluation of DSER Items}

In the DSER, the staff determined that GE should specify whose approval must be obtained before increasing power to the next higher test plateau. (This was incorrectly identified as an interface requirement in Section 14.2.5 of the DSER). GE indicated that such specifics will be a function of the plant owner/operator's unique organizational structure and detailed plant administrative procedures and thus left to the COL applicant. GE revised SSAR Section 14.2.13 to reflect that the COL applicant should specify whose approval is needed to proceed to the next testing plateau. This is acceptable.

The staff finds that the conduct of the test program meets the acceptance criteria in SRP Section 14.2 and is acceptable. However, a COL applicant will need to provide a startup administrative manual (procedures) and any other documents that delineate the conduct of the test 
program to be reviewed by the staff at the time of the COL application. This was DPSER COL Action Item 14.2.4-1. OE included the above action item in SSAR Section 14.2.13 and the ataff finds this acceptable.

\subsubsection{Review, Evaluation, and Approval of Teat Reaults}

SSAR Section 14.2.5 states that individual teat resulte will bo evaluated and roviewed by cognizant membere of the startup group. Teat exceptions or acceptance critoria diecrepencies will be communicated to the affected and responsible organizations who will belp reeolve the iseuce by suggeating corrective actions, design modifications, and retests. GE and othere outside the plant ataff organization, as appropriate, will have the opportunity to review the results for conformance to predictions and exceptions. Test results, including final resolutions, then will be reviowed and approved by designated startup group supervisory personnel.

\section{Staff Evaluation of DSER Items}

In the DSER, the staff determined that GE should specify whoce approval must be obtained before increasing power to the next higher test plateau. GE indicated that auch specifics will be a function of the plant owner/opesaior's unique organizational structure and dotailed plant administrative procedures and are thus will be defined by the COL applicant. GE revised SSAR Section 14.2.13 to reflect that the COL applicant should specify whose approval is needed to proceod to the next testing plateau. This is acceptable.

The staff finds that the process for reviow, ovaluation, and approval of test results moets the acceptence criteria described in SRP Section 14.2 and is acceptable. However, a COL applicant will need to provide a startup administrative manual (procedures) and any other documents that delineate the review, evaluation, and approval of test results for staff review. This was DFSER COL Action Item 14.2.5-1. GE included the above COL sction item in SSAR Section 14.2.13 and the staff finds this acceptable.

\subsubsection{Test Records}

SSAR Section 14.2.6 states that the ITP results will be compiled and maintained according to the startup manual, plant administrative procedures, and applicable regulatory requirements. Test records that demonstrato the adequacy of anfety-related components, systems, and structures will be retained for the life of the plant. Retention periods for other test records will be based on consideration of their usefulnew in documenting initial plant performance characteristics. As discuesed in SER Section 14.2.4, the atartup administrative manual is identified as a COL action itom.

The atuff finds that the teat records compilation, mainteannce, and retention program moets the ecceptance criteria in SRP Soction 14.2, and is acceptable.

\subsubsection{Conformance of Teat Program With Regulatory Guides}

SSAR Section 14.2.7 lists the NRC RGs that will be used in the development of the ITP and states that the applicable toste will comply with these guides. The applicable revisions to these RGs are listed in SSAR Table 1.8-20.

In the DSER, the staff determined that GE needed to add additional RO references to Table 1.8-20 and SSAR Section 14.2.7. This was DSER Open Item 6.C. The DFSER tracked this issue as DFSER Confirmatory Item 14.2.7-1.

In its letter of May 20, 1991, GE agreed to amend the SSAR to include RGs 1.95, "Protection of Nuclear Power Plant Control Room Operators Against an Accidental Chlorine Release," Revision 1, and 1.139, "Guidance for Residual Heat Removal," Revision 0, and to document the applicable revision number of each RO listed in SSAR Section 14.2.7 or to amend the section to reference Table 1.8-20 for the applicable revision numbers of the tisted guide. GE mado these changes in Amendment 18 of the SSAR. GE further agreed to correct the reference to RO 1.68.3, "Preoperational Testing of Instrument and Control Air," Revision 0, contained in SSAR Table 1.8-20 or Section 14.2.7, as appropriate, to Revision 0, issue date of April 1982. GE stated this change in its response on March 11, 1992. The staff determined that GE made the required changes in Amendment 21 of the SSAR. The staff finds this acceptable. This resolved the above portions of DFSER Confirmatory Item 14.2.7-1.

The staff s reviow identified that SSAR Section 14.2.7 lists RG 1.140 as applicable to the ABWR, however, SSAR Table 1.8-20 indicates RG 1.140 is not applicable to the ABWR. SSAR Section 14.2.12.1.34(3)(1) includes RG 1.140 guidance as acceptance criteria for visual inspection and airflow distribution, testing for penetration of dioctyl phthalate and bypass leakage testing for highofficiency particulate air (HEPA) and charcoal absorber sections where installed. The staff found that the utilization of RG 1.140 guidance for normal ventilation exhaust system air filtration and absorber units was not clear. GE was asked to make the appropriato clarifications to Table 1.8-20, Section 14.2.7, and individual test 
abetracts, as appropriate, to clearly and consiatently describe the degree of conformance to RO 1.140, any exceptions taken, and to identify any sepects of RO 1.140 that are not applicablo to the ABWR.

OB responded by deleting the reference to RO 1.140 in SSAR Amendment 30 from the list of ecoeptunce criteria in SSAR Section 14.2.12.1.34 and from the liat of ROs in SSAR Section 14.2.7 to make thow rections connisteat with Table 1.8-20. OB added RO 1.52 to Section 14.2.12.1.34 and Section 14.2.7 in SSAR Amendment 30 to address teating of engineered safety feature (ESF) beating, ventilation, and air conditioning (HVAC) systoms that require in place teating of HEPA and carbon adsorber filtere. The staff finds this scceptable. This resolved DFSER Confirmatory Itom 1A.2.7-1.

\subsubsection{Utilization of Reactor Operating and Teating Experience in the Development of Teat Program}

SSAR Section 14.2.8 states that since overy reactor/plant in a GE BWR product line is an evolutionary development of the previous plant in the product line it is ovident that the ABWR plants will benefit from the experience scquired with the successful and safo startup of more than 30 previous BWR plants. The operational experience and knowledge gained from these plants and other reactor types have been factored into the dosign and tost specifications of GE-supplied systems and equipment that will bo demonstrated during the preoperational and startup test programs. Additionally, reactor operating and testing experience of similar nuclear power plants obtained from NRC licensee ovent reports and through other industry sources will be used to the extent practicable in developing and carrying out the ITP.

The staff finds that the use of reactor operating and teating experience in the develupment of the test program moets the acceptance criteria in SRP Section 14.2, and is accoptable.

\subsubsection{Trial Use of Plant Operating and Emergency Procedures}

SSAR Section 14.2.9 states that, to the extent practicable, throughout the preoperational and initial startup tost program, operating, emergency, and abnormal procedures will be incorporated, where applicable, in the performance of tests. The use of these procedures is intended to

- prove the adequacy of the specific procedure or illustrate changes that may be required
- provide training of plant personnel in the use of these procedures

- increace the lovel of knowledge of plant pereonnel on the aystems boing toeted

OB further indicated, that to meet the above goals, teat procedures will ectually reference or extract steps from operating, emergency, or abnormal procedures.

The etaff finds that the mothod of incorporating operating, emergency, or abnormal procedures into the teat program moots the acceptance criteria in SRP Section 14.2, and is scceptable. However, a discussed in SSAR Soction 14.2.3, \& COL applicint will need to provide the approved preoperational test procedures 60 days before their intended use and the startup test procedures approximately 60 days before fuel loading.

\subsubsection{Initial Fuel Loading and Initial Criticality}

SSAR Section 14.2.10 states that the fuel loading and initial criticality will be conducted in a very controlled manner in accordance with specific written procedures as part of the startup teet phase. The NRC approves fuel loading after it has verified that prerequisite testing has been satisfactorily completed or after the COL applicant provides appropriate justification to proceed with fuel loading and complete the preoperational testing after fuel loading.

The inteat of the testing program is to complete all preoperational tests and approve the results before commencement of fuel loading. However, there may be unforeseen circumstances that arise that would prevent this from occurring, but that would not necessarily justify the delay of fuel loading.

In the DFSER, the staff determined that SSAR Section 14.2.10 should address the completion of prooperational testing (including the review and approval of test results required before fuel loading). If portions of any preoperational tests are intended to be conducted, or their results approved, after fuel loading, GE should (1) list each test, (2) state which portions of each test will be delayed until after fuel loading, (3) provide technical justification for delaying these portions, and (4) state when each test will be completed and the results approved.

GE revised SSAR Section 14.2.10 in Amendment 18 to require that the above stated conditions be appropriately documented should the COL applicant decide to request permission from the NRC to proceed with fuel loading under such circumstances. In the DFSER, the staff found that the methods of controlling pre-fuel load checks, initial 
ful loading, precritical teating and initial criticality outlined in Section 14.2.10 mot the acceptance criteris in SRP Section 14.2, and were accoptable. However, referencing applicant will need to provide a startup administrative manual (procedures) and any other documeats that delineate the methods of controlling pro-fuel load chocks, initial fuel loading, precritical toeting and initial criticality. These are to be reviewed by the stafi before issuing a COL. This was DFSER COL Action Item 14.2.10.4-1. GE included this COL sction item in SSAR Sections 14.2.10 and 14.2.13. The ataff finds this accoptable.

\subsubsection{Pre-Fuel Load Checks}

SSAR Section 14.2.10.1 states that once the plant has been declared ready to load fusl, there are a number of apecific checks that must be made before proceeding. These include a final review of the preoperational test results and the status of any design changes, work packages, and/or retests that were initiated as a result of exceptions noted during this phase. Also, the technical specifications (TS) surveillance program requirements, as described in the ABWR TS Chapter 16, will be instituted at this time to assure the operability of systems required for fuel loading. Just before the initiation of fuel loading, the proper vessel water level and chemistry will be verified and the calibration and response of the nuclear instruments will be chocked. This was DFSER TS Item 14.2.10.1-1.

The staff roviewed GE submittals dated March 31 and April 16, 1993, which contained GE's response to resolve TS Item 14.2.10.1-1. SSAR Section 14.2.12.2.3(2), prerequisites (c) and (d) will require neutron detectors instrument channels to be properly calibrated and operable prior to fuel loading. A cross-reference to a response dated March 31, 1993, of TS LCO 3.3.1.3, Surveillance Requirements (SR) for startup range nuclear monitor instrumentation, excluded calibration of neutron detectors. The staff determined that calibration of neutron detector instrumentation is required before fuel loading.

The ABWR Standardized Technical Specification (STS) bases section for SR 3.3.2.1.6 states "the neutron detectors are excluded from channel calibration because they cannot readily be adjusted. The detectors are fission chambers that aro designed to have relatively constant sensitivity over the range, and with an accuracy specified for a fixed useful life." The staff determined that the startup test program prerequisite requirements verify calibration of the neutron detectors instrumentation channels before fuel loading and before startup. Neutron sources would be used to verify proper calibration and instrument response of the detectors. The ABWR STS do not require the detectors to be calibrated during startup, therefore, the staff determined that the crove reforence to the STS in SSAR Section 14.2.12.2-3 should be deleted. The staff verified that the croes reforeace to the STS was deleted from ecceptance criteria 14.2.12.2-3(2)(c) and (d) in SSAR Ameadment 31. The ecceptability of the ABWR TS is diecuesed in Chapter 16 of this report. This recolved DFSER TS Itom 14.2.10.1-1.

\subsubsection{Initial Fuel Loading}

SSAR Section 14.2.10.2 atates that fuel loading will require the movement of the full core complement of anemblies from the fud pool to the core, with ach sesembly being ideatified by number before boing placed in the correct coordinate position. The procedure controlling this movement will epecify that partial core shutdown margin and subcritical checks bo mado at predetermined intervals throughout the loading, thus censuring afo loading increments as deacribed in teat abstract 14.2.12.2.3, Fuel Loading. In-veseel neutron monitore will provide continuous indication of the core flux level as ench aseombly is added. A complete check will be made of the fully loaded core to ascertain that all aseomblies are properly installed, correctly oriented, and occupying their desigated positions.

\subsubsection{Pre-Criticality Testing}

The control rods shall be verified functional and scram tested with the fuel in place. The post-fuel-load flow test of the reactor intornals vibration assessment program, if applicable, shall be conductod at this time. Additionally, a final verification shall bo made that the required TS surveillances have been performed.

\subsubsection{Initial Criticality}

SSAR Section 14.2.10.4 states that during initial criticality, the full core shutdown margin shall be verified for the fully loaded core as described in startup test abstract 14.2.12.2.4, "Full Core Shutdown Margin Demonstration." SSAR Section 14.2.10.4 also states that initial criticality shall be achieved in an orderly, controlled fashion following specific detailed procedures in an approved rod withdrawal sequence. Core neutron flux shall be continuously monitored during the approach to criticality and periodically compared to predictions to allow carly detection and evaluation of potential anomalies.

\subsubsection{Test Program Schedule}

SSAR Section 14.2.11 states that the schedule, relative to the initial fuel load date, for conducting each major phase of the ITP will be provided by the COL applicant. This includes the time table for generation, review, and 
approval of procedures as well as tho actual tooting and analyais of results. As a minimum, at leact 9 monthe before the fuel loading date should bo allowed for conducting the preoperational phese and at least 3 monthe should be allowed for conducting the etartup and power secension tenting that commences with full loading. To allow for NRC neview, teat procedure preparation for power accension will be echeduled so that approved proceduree are available :approximately 60 daye prior to fuel loed. Although there will be considerable flexibility available in the sequencing of teating within a given phase, teating should be performed as ayatems are turned over from construction. However, the interdependency of syateme should aleo be considered to that common aupport syatam, wuch as electrical power diatribution, sorvice and instrument air, and the various makeup water and cooling water systoms, will be teated as arly as poasible. Sequencing of testing during the startup phese will depend primarily on epecified power and flow conditions and intoraystem prerequisites. To the exteat practicable, the schedule should eatablish that, before exceeding 25-percent power, the teat requirements will be mot for those plant etructures, ayatems, and components (SSC) that are relied on to prevent, limit, or mitigate the consequences of poetulated accidents. Additionally, tecting will bo requenced so that the cafety of the plant is never totally depeadeat on unteated aystems, components, or features.

\section{Stnff Evaluntion of DSER Items}

In the DSER, the ataff determined that SSAR Section 14.2.11 should be modified to include the following:

- A figure that illustrates the power-flow operating map

- A table that lists the startup teats and states at which tost condition(8) each test is to be conducted

The staff stated in DSER Open Itoms 116 and 117 that SSAR Figure 4.4-1 did not provide sufficient detail regarding test condition identification to determine that each startup tost will be conductod at appropriate power-flow conditions in accordance with RO 1.68, "Initial Test Programs for Water Cooled Nuclear Power Plant" (Rev. 2), Appendix A.5, "Power Ascension Tests." In addition, the SSAR did not contain a table of startup tests.

GE subsequently submitted a power-to-flow operating map, SSAR Figure 14.2-1, that provides an appropriate indication of tost conditions and GE provided a table of startup tests, SSAR Table 14.2-1, "Startup Test Matrix." This was acceptable subject to incorporation into a future SSAR rovision and staff roviow. This resolved DSER
Open Itome 116 and 117, and became DFSER Confirmatory Itom 14.2.11-1. The staff finds that the power-toflow map and the table of startup tats that were incorported into Ameadmeat 23 of the SSAR moet the cocopitances eritoris of SRP Section 14.2, and are coceptable. This resolved DPSER Confirmatory Item 14.2.11-1.

OB indicated that SSAR Section 14.2.11 would be revised to include the following additional information on the teat program schedule. Power ancension teating will bo conducted in cecentially threo phasen: (1) initial fuel loading and open veceel toating, (2) teating during nuclear beat up to rated tomperature and preasure, and (3) power opertition teating from 5-percent to 100-percent rated power. Further, powor operation teating will be divided into three requential toating plateaus as shown on SSAR Figure 14.2-1. The teating plateaus consist of low-power teating at leas than 25-percent power, mid-power testing up to 75-percent power between approximately the 50-percent and 75-percent rod lines, and high-power tosting along the 100-percent rod line up to rated power. Thus, there will be a total of five different toeting plateaus doaignated as shown on SSAR Figure 14.2-1. Table 14.2-1 indicates in which teating plateaus the various power ascension teats will be performed. Although the order of teating within a given plateau will be comowhat flexible, the normal recommended sequence of tests will be; (1) core performance analysis, (2) steady state toats, (3) control system tuning, (4) system transient tests, and (5) major plant trancients (including trips). Also, for given testing plateau, testing at lower power levels generally should be performed before that at higher power lovels. The detailed teoting echedulo will be generated by the COL applicant and will bo made available to the NRC before actual implementation. The schedule then will be maintained to reflect actual progreses and subeequent revised projections. The information above was acceptable subject to incorporation into a future SSAR revision. This was DFSER Confirmatory Itom 14.2.11-2.

GE revised the test program schedule in SSAR Section 14.2.11 and Table 14.2-1 in SSAR Amendments 23 and 33. The staff finds the changes acceptable. This resolved DFSER Confirmatory Item 14.2.11-2.

Additionally, a COL applicant will need to provide a startup administrative manual (procedures) and any other documents that delineate the test program schedule for staff reviow. GE identified this as a COL action item in a respones dated April 6, 1993. This information was incorporated into SSAR Amendment 31. This was DFSER COL Action Itom 14.2.11-1. OE included this COL action item in SSAR Section 14.2.3, and the staff finds this acceptable. 


\subsubsection{Individual Teat Description}

\subsubsection{Preoperational Teat Procedures}

SSAR Section 14.2.12.1 staten that the general descriptions relate the objectives of each preoperational teet. During the find construction phee, it my be necesanry to modify the preoperational teat mothods as operating and preoperational test procedures are developed. Consequently, methods in the descriptions are general, not specific.

Specific teating to be performed and the applicable acceptance critoria for each preoperational teat will be documented in detailed test procedures to be made available to the NRC approximately 60 days before their intended use. Preoperational testing will be in accordance with the detailed system specifications and associated equipment specifications for equipment in those systems (provided as part of scoping documents to be supplied by GE and others as described in SSAR Subsection 14.2.3). The teats will demonstrate that the installed equipment and systems will perform within the limits of these specifications. To allow for verification that the detailed test procedures are developed in accordance with established methods and appropriate acceptance criteria, the plant and system preoperational test specifications will also be made available to the NRC.

The preoperational tests anticipated for the ABWR standard plant design are listed and described in the SSAR Subsection 14.2.12.1. The staff finds that the scopo of preoperational tests described in SSAR Subsection 14.2.12.1 meets the scceptance criteria of SRP Section 14.2, and is ecceptable. Testing of systems out of the scopo of the SSAR are discussed in SSAR Section 14.2.13 along with other COL information related to the ITP.

\subsubsection{General Discussion of Startup Tests}

SSAR Section 14.2.12.2 discusses those tests proposed and expected to comprise the startup test phase. For each test a general description is provided for test purpose, test prerequisites, test description, and test acceptance criteria, where applicable. Because changes will occur as the test program is developed and implemented, the descriptions remain genoral in scope. However, an attempt is made in describing a test to identify those operating and safetyoriented characteristics of the plant design that are being explored and evaluated.

Where applicable, the relevant acceptance critcria for the test are discussed. Some of the criteria rulate to the value of process variables assigned in the design or analysis of the plent, component syctom, and sescocinted equipment. If a criterion of this nature is not atisfied, the plant will be pleced in a suitable bold condition until resolution is obtrined. Teats compatible with this hold condition may be continued. Following resolution, applicable teats or portions of these teats my be repeated to verify that the requirements of the criterion are ultimately entisfied. Other criterin may be ascociated with expectations relating to the performance of syctems. If this type of criterion is not antisfied, openting and teating plens would not necenarily be altered. However, investigations of the menaurements and of the analytical tochniques used fs: 5 the predictions would be started. Specific actions for dealing with criteria failures and other testing exceptions or anomalies will be described in the startup administrative monual.

The specifics of the startup tests relating to test methodology, plant prerequisites, initial conditions, acceptance criteria, and analysis techniques will come from the appropriate design and engincering organizations of the COL applicant in the form of plant, systom, and componeat performance and teating specifications. The COL applicant shall provide teat documents for the Office of Nuclear Reactor Regulation reviow as discussed in SSAR Section 14.2.3.

\subsubsection{Staff Evaluation of DSER Items}

In the DSER, the staff determined that testing of systems outside the scope of the ABWR stendard plant design should be included or referenced in SSAR Section 14.2.12. (This was not tracked as a separate open item.)

GE revised Section 14.2.12.1 in SSAR Amendment 18 to state that testing of systems outside the scope of the ABWR standard plant design are discuseed in SSAR Section 14.2.13. The staff finds this acceptable.

In the DSER, the staff determined that SSAR Section 14.2.12 test abstracts should be modified to address the following concerns:

Several preoperational and startup test prerequisites include the requirement that interfacing support systems will be available.

The staff asked GE to identify which support systems will be required for each test and to specify which individuals or groups will be authorized to make this determination. (This was incorrectly identified as an interface requirement.)

GE stated that the interfacing support system requirements will be specified in the detailed test 
procedures (and operating and maintenance procedures, if appropriate) that are required by RO 1.68 to be made available to NRC personnel at least 60 days before the intended une of preoperational toets procedures and 60 days before fuol loeding for attartup teat procedures. Additionally, tho startup adminietrative manual will dolineate how auch determinations of operability and availability will be authorized. Thus, theee dotails are the responsibility of the COL applicunt. This was DFSER COL Action Item 14.2.12.3-1. OE included this action itom in Section 14.2.13, and the staff finds this accoptable.

In the DSER, the etaff determined that the lovel of detail in the test abstracts was insufficient to determine conformance with RO 1.68, Position C.2. This was DSER Open Itom 118 . The individual test abstracts in SSAR Sections 14.2.12.1.1, 14.2.12.1.4, 14.2.12.1.7, 14.2.1.11, 14.2.12.1.12, 14.2.12.1.13, 14.2.12.1.18, $14.2 .12 .1-21, \quad 14.2 .12 .1 .22$, 14.2.12.1.43, 14.2.12.1.44, 14.2.12.1.45.1, 14.2.12.1.45.2, 14.2.12.1.45.3, 14.2.12.1.45.4, 14.2.12.1.53, 14.2.12.1.59, 14.2.12.1.67, 14.2.12.1.68, and 14.2.12.1.69 did not spocify besic systems required to be available, interface systems, or criteria required as prerequisite or initial conditions for the preoperational teats. Specific prerequisites should be addreseed in these individual lest abstracts. This was tracked in the DFSER as Open Item 14.2.12.3-1.

The staff completed its review of GE's February 12, 1993, submittal, which addresses DFSER Open Item 14.2.12.3-1. The staff determiliod that the level of detail for specific preoperational test prerequisites was sufficient with the exception of two individual test abstracts. GE provided revisions to the prerequisite sections of preoperational test abstracts 14.2.12.1.4 and 14.2.12.1.44 in responses dated May 13 and 21, 1993. The staff finds both of these revisions acceptable. The revisions were incorporated into SSAR Amendment 30. This resolved DFSER Open Item 14.2.12.3-1.

(2) The use of the word "should" in most, if not all test abstracts, is not a commitment by the COL applicant to perform certain tasks. It should, therefore, be reevaluated and revised accordingly (i.e., "will," "must"). This was DSER Open Item 119.
In the DFSER, the staff verified that $\mathrm{OB}$ incorporated the word change from "should" to oither "will" or "shall" into most test abatracts. This was acceptable subject to incorporation into a future SSAR revision. This resolved DSER Open Itom 119, and was tracked in the DFSER a DFSER Confirmatory Itom 14.2.12.3-1. The above word change was incorporated into the applicable tout abetracts in SSAR Amendment 23. The staff finds this acceptable. This resolved DFSER Confirmatory Itom 14.2.12.3-1.

Soveral preoperational and startup tost abstracts included imprecise acceptance criteria (0.g., "applicable intervals," "applicable design epecifications," "specified amounts," "specified tolerances," "perform as specified," and "function properly"). This was DSER Open Item 120.

In the DFSER, the staff determined that GE should addrese in the individual test abstracts the bases for determining acceptable system and component performance. Acceptable criteria includes specific references to RGs, TS, assumptions used in the safety analysis, other ABWR SSAR soctions, and applicable codes and standards.

GE indicated that SSAR Chapter 14 was written primarily to document the appropriate testing commitments contained in RO 1.68. In its May 20, 1991, submittal, GE indicated that precise acceptance criteria would be provided as part of the inspections, tests, analyses, and acceptance criteria (ITAAC) offort. However, GE did not provide this information in either the ITAAC or in SSAR Chapter 14. This was tracked in the DFSER as DFSER Open Item 14.2.12.3-2.

The staff reviewed the individual test abstracts submitted on February 12 and May 13, 1993, to assess the adequacy of the test abstract coverage of system-specific test requirements. Clarifications and additional cross- reference information for roughly half of the preoperational tests were determined necessary. The staff requested GE to supplement the SSAR with this additional information in order to determine that these tests adequately address system-specific test requirements.

GE submitted Amendment 30, Revision 0, dated June 7, 1993, to the staff which provided crossreference acceptance criteria information for all but two of the preoperational test abstracts. The two tests were the integrated emergency core cooling 
systems (ECCS) loss of offsite power (LOOP)/law of coolant accident (LOCA) prooperational teat and the extraction steam system preoperational test. $\mathrm{GE}$ provided the necessary crose references for these test abstracts in Revision 1 of SSAR Amendment 30 . The staff found all of the crossreferences acceptable. Additional information on system-specific testing requirements were also provided for all test abstracts. The staff finds this information acceptable. This resolved DFSER Open Item 14.2.12.3-2.

SSAR Section 14.2.12.2 states that failuro to satisfy some acceptance criteria (e.g., those related to values of process variables important to plant design) will result in the plant being placed in a suitable hold position until resolution is obtained, while failure to satisfy other acceptance criteria (e.g., expectations relating to system performance) may only resul: in the need for further data analysis. This was DSER Open Item 121.

In the DFSER, the staff determined that the distinction between these types of acceptance criteria was unclear, and that GE should clearly address the various types of acceptance criteria and the resultant actions for each type if unsatisfactory test results were obtained.

SSAR Section 14.2.12.2, as modified by GE, stated: "Specific actions for dealing with criteria failures and other testing exceptions or anomalies will be described in the startup administrative manual." This response to the staff's open item was not acceptable. Of 35 individual startup test abstracts in SSAR Section 14.2.12.2, 33 did not specify the required actions or presautions for dealing with criteria failures and other testing exceptions or anomalies. GE did not adequately modify Section 14.2.12.2 or the individual test abstracts to address the subject acceptance criteria or actions. This was DFSER Open Item 14.2.12.3-3.

The staff requested GE provide a general distinction between startup test level 1 and level 2 acceptance criteria, and to specify individual startup test abstract acceptance criteria as level 1 or level 2. Level 1 criteria relates to the value of the process variables assigned in the design or analysis of the plant, component systems, or associated equipment. If a level 1 criteria is not satisfied, the plant will be placed in a hold condition until resolution is obtained. A level 2 criterion is associated with expectations relating to the performance of systems.
If $\bullet$ level 2 criteria requirement is not satisfied then an engineering evaluation must be completed to verify that overall system performance is acceptable.

The staff reviewed a submittal by GE on April 16, 1993, of SSAR Section 14.2.12.2 which identified the distinction between startup test level 1 and level 2 acceptance criteria. The distinction between levels 1 and 2 acceptance criteria is found to be acceptable. This information was incorporated into SSAR Amendment 30.

The staff's review of individual startup test abstracts, submitted by GE on June 7, 1993, identified that more precise acceptance criteria has been provided and the criteria is acceptable. The staff also determined that the system-specific test requirements are adequately addressed. GE incorporated the individual startup test abstract scceptance criteria information, the startup test levels 1 and 2 acceptance criteria, and the systemspecific startup test requirements into SSAR Amendment 30. The staff finds the startup testing abstracts as described in SSAR Amendment 30 acceptable. This resolved DFSER Open Item 14.2.12.3-3.

(5) GE should identify startup tests listed in SSAR Section 14.2.12.2 that are not essential to the demonstration of conformancs with design requirements for $\mathrm{SSCs}$ and design features that

- will be used for safe shutdown and cooldown of the reactor under normal plant conditions and for maintaining the reactor in a safe condition for an extended shutdown period

- will be used for safe shutdown and cooldown of the reactor under transient (infrequent or moderately frequent events) conditions and postulated accident conditions and for maintaining the reactor in a safe condition for an extended shutdown period following such conditions

- will be used for establishing conformance with safety limits or limiting conditions for operation that will be included in the facility TS

- are classified as engineered safety features (ESFs) or will be, used to support or ensure the operations of ESFs within design limits 
- are assumsd to function or for which credit is taken in the accident analysis for the facility, as described in the SSAR

- will be used to process, store, control, or limit the release of radiosctive materials

GE stated that the test abstracts contained in SSAR Section 14.2.12.2 are intended to meet the requirements of RG 1.68, updated and/or modified as necessary to reflect the actual $A B W R$ design. In the DSER it was stated that a required screening will bo performed by GE to identify and document any testing that is currently specified for systems that are not essential for demonstrating conformance with the aforementioned criteria. This was DSER Open Item 122.

GE revised SSAR Section 14.2.13 (in draft) to state that criteria contaiued in the RG 1.68, Position C.1, will be used to determine if any testing is currently specified for systems that are not essential for demonstrating conformance with the aforementioned criteria. The staff found this item acceptable subject to incorporation into a future SSAR revision. This resolved DSER Open Item 122 and was tracked in the DFSER as DFSER Confirmatory Item 14.2.12.3-2.

The testing described in Section 14.2.12.2 includes testing of a limited number of ABWR SSCs, and design features that do not mot the referenced RG 1.68 criteria. The staff subsequently determined that it was premature to develop a specific list of tests that do not meet the criteria in RG 1.68, Position C.1. The staff has not yet defined the applicable COL license conditions related to such tests (i.e., timely notification to the NRC for major test changes that affect systems that meet the criteria in RG 1.68, Position C.1). This aspect will be further reviewed for a COL applicant as part of the COL action items listed in SSAR Section 14.2.13. Therefore, GE did not include this information in the SSAR. The staff finds this acceptable. This resolved DFSER Confirmatory Item 14.2.12.3-2.

\subsubsection{Conformance of the ABWR with RG 1.68, Revision 2}

In the DSER, the staff's review of the preoperational and startup test phase descriptions disclosed that the operability of several of the systems and components listed in RG 1.68 may not be adequately demonstrated by the tests described in the SSAR. This was DSER Open Item 123.
Each item is evaluated separately below. This evaluation resolved DSER Open Item 123.

\section{Staff Evaluation of DSER Items}

The staff determined that GE should either expand the test descriptions to address the following items, insert cross-references in SSAR Section 14.2.12 if complete test descriptions for the following items are provided elsewhere in the SSAR, or modify SSAR Section 14.2.7 or Table 1.8-20 of the SSAR, as appropriate, to provide technical justification for any exception to RG 1.68. It was stated in the DSER that the following items should be reflected in a subsequent amendment to the SSAR. (Note: Each item is numbered in accordance with RG 1.68.)

\section{- 1.8.(2)(d) Supports and restraints for discharge piping of safety relief valves (SRVs)}

GE stated in its response of May 20, 1991, that a statement had been added to SSAR Section 14.2.12.1.1 indicating that testing of SRV discharge piping supports and restraints is specifically covered by that testing described in SSAR Section 14.2.12.1.51.

GE incorporated into SSAR Section 14.2.12.1.51 crossreferences to SSAR Sections 3.9.2.1 and 5.4.14.4. The references were acceptable subject to incorporation into a future SSAR revision. This was DFSER Confirmatory Item 14.2.12.4-1.

The staff reviewed these cross-references in SSAR Amendment 23, Chapters 3 and 5, respectively and finds them to be acceptable. This resolved DFSER Confirmatory Item 14.2.12.4-1.

\section{- 1.8.(4) Pressure boundary interrity tests}

GE stated in its response of May 20, 1991, that integrity tests of the reactor coolant pressure boundary are specified in SSAR Section 5.2.4.6.2.

The staff verified this and the staff also determined that a cross-reference to Section 5.2.4.6.2 was incorporated into Subsection 14.2.12.1.1 in SSAR Amendment 18. The staff evaluated this reference in Chapter 5 of this report, and finds this acceptable.

- 1.c Protection of facility for anticipated transients without a scram (ATWS)

GE stated in its response of May 20, 1991, that ATWS protection functions will be tested as part of the respective systems that perform such functions (i.e., standby liquid control system, rod control and information system 
(RCIS), fine motion control rod system, recirculation flow control system). For the purpose of more explicitly demonstrating compliance with RG 1.68, GE revised the appropriate parts of SSAR Section 14.2.12.1 (in SSAR Amendment 18) as shown below to more specifically indicato where ATWS-related teeting requirements are being fulfilled, particularly those related to the alternate rod insertion function.

- 14.2.12.1.3(3)(a) - Recirculation Flow Control

- 14.2.12.1.6(3)(b) - CRD (Control Rod Drive) System

- 14.2.12.1.7(3)(b) - RCIS

The staff finds this acceptable.

- 1.h.(4) Demonstration that contrinment hydrogen monitorine is functional without the operation of the hydrogen recombiner

GE stated in its response of May 20,1991, that in the ABWR design, containment hydrogen monitoring is accomplished separately from the bydrogen recombiners. Therefore, the specific test described in RG 1.68 is not applicable. Proper functioning of containment hydrogen monitors is verified by the testing described in SSAR Section 14.2.12.1.26. The staff finds this accoptable.

- L.h.(9) Demonstration that contrinment recirculation fans can opernte in eccordance with desien requirements at the containment desion peak sccident pressure

GE stated in its response of May 20,1991, that the ABWR design does not use containment recirculation fans during normal operation or accident conditions. Therefore, the specific test described in RG 1.68 is not applicable. The staff finds this acceptable.

\section{- L.i.(1) Containment design over pressure structural tests (and vacuum tests)}

GE stated in its response of May 20, 1991, that containment structural integrity testing requirements are specified in SSAR Section 3.8.1.7.1. GE also incorporated into Section 14.2.12.1.40.2 in SSAR Amendment 18 a cross-reference to Section 3.8.1.7.1. This issue was ovaluated in SER Chapter 3. The staff finds this acceptable.

\section{- 1.j.(12) Failed fuel detection system}

GE stated in its response of May 20,1991, that the ABWR design failed fuel detection function will bel performed by the leak detection and isolation system and the process radiation monitoring system. In particular, gross fuel failure would be detected first by the main steamline radiation monitors and then by the offges pre-treatment radiation monitors. In addition, the normal reactor water sampling system will allow for identification of trends indicative of possible fuel failure. Testing of the applicable features of the associated systems, as described in SSAR Sections 14.2.12.1.13 and 14.2.12.1.23, will cosure proper operation of the failed fuel detection function.

GE revised Soction 14.2.12.2.1 in SSAR Amendment 18 to include specific reference to proper operation of failed fuel detection functions. The staff finds this accoptable.

\section{- 1.j.(15) Automatic dispatcher control systems}

GE stated in its response of May 20,1991, that automatic load following will be performed by the automatic power regulator for which testing is described in SSAR Section 14.2.12.1.17. This system will have the capability, if enabled, to accept external demand signals (e.g., from the load dispatcher). If the COL applicant decides to soek approval for using this capability, designation of the appropriate testing will be included in that application.

GE revised SSAR Section 14.2.13 to include automatic dispatcher control systems as a responsibility of the COL applicant. This is acceptable. This was also DFSER COL Action Item 14.2.12.4-1. GE incorporated this action item in SSAR Section 14.2.13, and the staff finds this acceptable.

\section{- 1.k.(2) Personnel monitors and radiation survey instrn- ments}

GE stated in its response of May 20, 1991, that traditional preoperational testing of personnel monitors and radiation survey instruments is not appropriate in the ABWR design because these instruments will be subject to very specific calibration programs. It is the responsibility of the plant operator to verify and maintain the proper calibration and operation of such devices. Therefore, GE revised the SSAR to indicate that any required testing of personnel monitors and radiation survey instruments would be a COL responsibility. Section 14.2.13 in SSAR Amendment 18 was modified to include this as a COL License Information. This is acceptable. This was also DFSER COL Action Item 14.2.12.4-2. GE incorporated this action item into SSAR Section 14.2.13, and the staff finds this acceptable.

- 1.n.(14)(f) Control room habitability systems. Demonstrate proper operation of smoke and toxic chemical detection systems and ventilation shutdown 
devices including leak tiphtnes: of ducts and flow retes. proper direction of air flows and proper control of epace temperntures

GE revised the test description in SSAR Section 14.2.12.1.34 (Amendment 18) to indicate that the control room habitability function is to be included in the testing specified for the dedicated HVAC system of the main control room. Additionally, GE added a specific requirement to demonstrate the system capability to detect smoke and/or toxic chemicals and to remove and/or prevent in-leakage of smoke or chemicals. The staff finds this acceptable.

- 2.c Final functional testing of the reactor protection system to demonstrate proper trip points lc pice and operability of scram breakers and valves. Demonstrate the operability of manual scram functions

GE stated in its response of May 20, 1991, that final functional testing will have been completed as part of the preoperational testing described in SSAR Section 14.2.12.1.14. Additionally, these tests are part of the plant TS surveillance program that will be required to be instituted before fuel loading, as specified in SSAR Section 14.2.10.1.

GE revised Section 14.2.12.2.3 in SSAR Amendment 18 to specifically require that the final functional testing required by $R G$ 1.68, Position 2.c, be completed as prerequisites to fuel loading. This is acceptable. This was also tracked as DFSER TS Item 14.2.12.4-1.

The staff found that GE's response to TS Item 14.2.12.4-1 dated April 16, 1993, stated: "Final functional surveillance testing will demonstrate operability of scram breakers and valves prior to fuel loading. Such demonstrations will be assured as part of the TS program (LCO 3.3.1.1 and 3.3.1.2) which must be instituted prior to entry into mode 5." The staff found GE's response acceptable; however, GE had not submitted a response to the ABWR STS LCO 3.3.1.1 and LCO 3.3.1.2, which incorporates surveillance testing of scram breakers and valves to demonstrate their operability before fuel loading. The staff concluded that STS SR 3.3.1.2.1 or STS Bases Section 3.3.1.2 should be revised to include testing the operability of scram breakers, scram solendid valves, and backup scram solenoid valves. The staff revised the bases portion of the STS to include a description of scram valves and backup scram valves that are tested under STS SR 3.3.1.2. The description does not include testing of scram breakers since these breakers do not exist in the ABWR design. The description for testing the solenoid valves is in the final revision to STS Bases Section B 3.3.1.2 which was issued to GE on August 30, 1993. The scceptability of the ABWR technical specifications is discuseed in Chapter 16 of this report. This resolved DFSER TS Item 14.2.12.4-1.

\section{- 2.d Final reactor coolent system leak nate test to verify that system leak rates are within specified limits}

GE stated in its response of May 20, 1991, that final reactor coolant leak rate testing will have been completed as part of the preoperational testing described in SSAR Section 14.2.12.1.1, which references the required reactor coolant leak rate tests specified in SSAR Section 5.2.4.6.1.

GE revised Section 14.2.12.2.3 in SSAR Amendment 18 to specifically require that the leak rate tests required by RG 1.68, Position 2.d, be completed as prerequisites to fuel loading. This is acceptable.

\section{- 4.k Steam driven plant auxiliaries and power conversion equipment}

The staff verified that Section 14.2.12.2 was revised in draft to add SSAR Section 14.2.12.2.39 to address testing of steam and power conversion systems. This was acceptable subject to incorporation into a future SSAR revision. This was DFSER Confirmatory Item 14.2.12.4-2.

The staff verified that Section 14.2.12.2.39 was revised to address testing of steam and power conversion systems in SSAR Amendment 23. The staff finds the revisions acceptable. This resolved DFSER Confirmatory Item 14.2.12.4-2.

- 4.L Branch steamline valves and bypass valves used for protective isolation functions at rated temperature and pressure conditions

GE stated in its response of May 20, 1991, that the only branch steamline valves used for ABWR protective isolation functions will be those on the reactor core isolation cooling (RCIC) steamline and the common drainline from the main steamlines.

GE revised the description of the RCIC system testing in Section 14.2.12.2.22 in SSAR Amendment 18 to include specific testing of the RCIC steamline isolation valves and revised Section 14.2.12.2.26 in the same amendment to include specific testing of the main steamline branch drain line isolation valves in addition to the main steam isolation valve (MSIV) testing already specified. The staff finds this acceptable. 
- Si Plant performance is as expected for rod runback and partial scram

GE stated in its response of May 20,1991, that the ABWR design has no partial scram function. Rod runback will be accomplished by the select control rod run-in (SCRRI) function. GE revised Section 14.2.12.2.5 in SSAR Amendment 18 to ensure that appropriate testing will be performed to demonstrate proper functioning of SCRRI logic and hardware. GE also revised Section 14.2.12.2.30 to ensure that proper plant response is demonstrated during sn event that will result in initiation of SCRRI. The staff finds this acceptable.

\section{- 5.n Reactor coolant system loose parts monitoring eystem}

GE added Section 14.2.12.2.36 to address loose parts monitoring system baseline data collection. This was acceptable subject to incorporation into a future SSAR revision. This was DFSER Confirmatory Item 14.2.12.4-3.

GE added Section 14.2.12.2.36 in SSAR Amendment 23 to address loose parts monitoring system baseline data collection. The staff finds Section 14.2.12.2.36 acceptable. This resolved DFSER Confirmatory Item 14.2.12.4-3.

\section{- 5,0 Reactor coolant leak detection systems}

GE stated in its response of May 20,1991, that testing of reactor coolant leak detection systems will be completed during the preoperational stage. The staff finds this acceptable.

\section{- 5,q Proper operation of failed fuel detection systems}

GE stated in its response of May 20, 1991, that the failed fuel detection function is performed by the process radiation monitoring system, the testing of which is described in SSAR Section 14.2.12.2.1.

GE revised Section 14.2.12.2.1 in SSAR Amendment 18 to require the appropriate demonstration of the related failed fuel detection function. (Also see Item 1.j.(12) above.) The staff finds this acceptable.

- 5.4 Branch steamline isolation valve operability and response times

GE revised Sections 14.2.12.2.22 and 14.2.12.2.26 in SSAR Amendment 18 to address branch steamline isolation valve operability and response times. The staff finds this acceptable.
- 5.w Demonstmation that concrete temperatures mrroundine hot penetrntions do not exceed desian limits with the minimum desion capability of cooling cystem components available

GE agreed to add SSAR Section 14.2.12.2.37 to address concrete penetration temperature surveys. This was acceptable subject to incorporation into a future SSAR revision. This was DFSER Confirmatory Item 14.2.12.4-4.

GE added Section 14.2.12.2.37 to address concrete penetration temperature surveys in SSAR Amendment 23. The staff finds Section 14.2.12.2.37 acceptable. This resolved DFSER Confirmatory Item 14.2.12.4-4.

\section{- 5.x Auxiliary systems required to support operation of} enpineered safety features

GE stated in its response of May 20, 1991, that the auxiliary systems required to support operation of ESFs include the cooling water and HVAC systems for which testing is described in SSAR Sections 14.2.12.2.23 and 14.2.12.2.24, respectively.

GE revised Sections 14.2.12.2.23 and 14.2.12.2.24 in SSAR Amendment 18 to ensure that the testing performed and results obtained will ultimately demonstrate the adequacy of a particular auxiliary system's performance under limiting accident conditions. The staff finds this acceptable.

- 5.2 Demonstration that process and effluent radiation monitorine systems are responding correctly by performing independent laboratory or other analyses

GE stated in its response of May 20,1991, that this testing is part of that described in SSAR Section 14.2.12.2.1(3).

GE revised Section 14.2.12.2.1(3) in SSAR Amendment 18 to specifically address, RG 1.68, Position 5.z. The staff finds this acceptable.

- 5.c.c Demonstration that gaseous and liquid redioactive waste processing, storage, and release systems operate in accordance with design

GE agreed to add Section 14.2.12.2.38 to address radioactive waste system testing. This was acceptable subject to incorporation into a future SSAR revision. This was DFSER Confirmatory Item 14.2.12.4-5.

GE added Section 14.2.12.2.38 to address radioactive waste system testing in SSAR Amendment 23. The staff 
finds Section 14.2.12.2.38 acceptable. This resolved DFSER Confirmatory Item 14.2.12.4-5.

- 5.e.e Demonstration of desion features to prevent or mitipate anticipated transients without scram (ATWS)

GE stated in its response of May 20, 1991, that ATWS design features will consist primarily of dedicated logic and some hardware, which will be thoroughly checked as part of the preoperatiopal test program. Most hardware design features perform ATWS-related functions in their normal mode only when initiated by dedicated ATWS logic. Therefore, the functioning of these features has already been adequately verified during the preoperational testing. Thus, no dedicated testing of ATWS-related features will be planned during the power ascension test phase.

GE incorporated in SSAR Amendment 18 specific ATWSrelated testing requirements into individual test abstracts (see Item 1.c above). The staff finds this acceptable.

- 5.h.h Demonstration that the dynamic response of the plant to load swings for the facility. includine step and ramp changes, is in accordance with desion

GE stated in its response of May 20,1991, that this testing is intended to be a part of that described in SSAR Section 14.2.12.2.16.

GE revised Section 14.2.12.2.16 in SSAR Amendment 18 to demonstrate the dynamic response of the plant to load swings for the facility, including step and ramp changes, is in accordance with design. The staff finds this acceptable.

\subsubsection{Three Mile Island (TMI) Items}

\section{Staff Evaluation of DSER Items}

Appendix A to SSAR states that testing described in Chapier 14 is consistent with the BWR Owner's Group response to Action Itom I.G.1 of NUREG-0737 as documented in a letter dated February 4, 1981, from D.B. Waters to D.G. Eisenhut. The staff determined that the test abstracts in SSAR Section 14.2.12 that describe testing outlined in Appendix $E$ of this letter should be identified or modified accordingly. This was DSER Open Item 124.

GE stated in its response of May 20, 1991, that testing outlined in Appendix E of the referenced document would be specified in the applicable test abstracts.

GE revised test abstracts 14.2.12.1.1(3)(a), 14.2.12.1.9(3)(j), and 14.2.12.1.44(3)(a) to include a reference to 1A.2.4 of Appendix A to SSAR Chapter 1, and GE revised 1A.2.4 to discuss the requirements of Action Item I.G.1 Appendix E applicable to the ITP. The staff found this item acceptable subject to incorporation into a future SSAR rovision. This resolved DSER Open Item 124, and was tracked in the DFSER as DFSER Confirmatory Item 14.2.12.5-1.

GE revised the above test abstracts in SSAR Amendment 23. The staff finds the changes acceptable. This resolved DFSER Confirmatory Item 14.2.12.5-1.

\subsubsection{Conformance With Other Regulatory Guides}

\section{Staff Evaluation of DSER Items}

In the DSER, the staff determined that GE should address the concerns of RG 1.56, "Maintenance of Water Purity in Boiling Water Reactor," (Rev. 0), in SSAR Sections 14.2.12.1.19, 14.2.12.1.54, and 14.2.12.2.21. This was DSER Open Itom 125.

GE stated in its response of May 20, 1991, that RG 1.56 deals mainly with design related issues, specifically the equipment and instrumentation needed to ensure proper BWR reactor water chemistry. SSAR Sections 14.2.12.1.19, 14.2.12.1.54, and 14.2.12.2.21 describe preoperational and power ascension testing that is adequate to demonstrate that accoptable reactor water chemistry will be maintained by the reactor water clean up system and the condensate filter/demineralizer system. Subeection 14.2.12.1.22 describes the preoperational testing intended to demonstrate the proper functioning of the instrumentation required by RG 1.56. Likewise, SSAR Section 14.2.12.2.1 indicates that a proper reactor water chemistry monitoring program will be in place.

GE agread to revise SSAR Sections 14.2.12.1.22 and 14.2.12.2.1 to more specifically address functioning of conductivity meters, which are a major focus of RG 1.56. In the DFSER, the staff found this item accoptable subject to incorporation into future SSAR revision. This resolved DSER Open Item 125, and the issue was tracked in the DFSER as DFSER Confirmatory Item 14.2.12.6-1.

GE made the above revisions to Sections 14.2.12.1.22 and 14.2.12.2.1 in SSAR Amendment 23. The staff finds the revisions acceptable. This resolved DFSER Confirmatory Item 14.2.12.6-1.

In the DSER, the staff determined that Section 14.2.12.2.14, "Foedwater Control, "should address the following items in accordance with RG 1.68, "Prooperational and Initial Startup Testing of Feedwater 
and Condensate Systems for Boiling Water Reactor Power Plants," Revision 1:

(1) Modify the test description for demonstration of the required functionality of the foedwater system at low reactor power (less than or equal to 15-percent reactor power) (RG 1.68. Position 1.C.2.a). This Was DSER Open Item 126.

GE stated in its response of May 20,1991, that this testing is already specified in the current description, and supplemented by information to be included in a test inatrix.

The staff verified that GE's proposed test matrix, to be included in the SSAR, identified feedwater system performance and feedwater control system adjustment/confirmation tests to be performed at the nuclear heat-up and low-power testing plateaus. In the DFSER, the staff found this acceptable subject to incorporation into a future SSAR revision. This resolved DSER Open Item 126, and this issue became DFSER Confirmatory Item 14.2.12.6-2.

GE added the test matrix in SSAR Amendment 23. The test matrix contained feedwater system performance and feedwater control system adjustment/ confirmation tests which are performed at the nuclear beat-up and low-power testing plateaus. The staff finds this to be acceptable. This resolved DFSER Confirmatory Item 14.2.12.6-2.

(2) Modify or clarify the test acceptance criteria to provide essurance that vibration levels for system components and piping are within predetermined limits (RG 1.68, Position 1C.2.f); piping movement during beat up and steady state and transient operation are within predetermined limits (RG 1.68, Position 1.C.2.8); and adequate margins exist between system variables and set points of instruments monitoring these variables to prevent spurious actuation or loss of system pumps and motor-operated valves (RG 1.68, Position 1.C.2.h). This was DSER Open Item 127.

GE stated in its response of May 20,1991, that the testing called for by Positions C.2.f and C.2.8 is included in the test abstracts of SSAR Sections 14.2.12.1.51, 14.2.12.1.53(3)(b) and (k), 14.2.12.2.10, 14.2.12.2.11, and 14.2.12.2.18. GE further stated that it revised Section 14.2.12.2.18 in SSAR Amendment 18 to more specifically address Position C.2.h. In the DFSER, the staff verified the above, and found it acceptable. This resolved DSER Open Item 127.
In the DSER, the staff determined that, for SSAR Section 14.2.12.1.27, GE should addrees the following items in accordance with RG 1.68:

Determine that the total air demand at normal steady-state conditions, including leakage from the system, is in accordance with design (RG 1.68, Position 3.C.5). This was DSER Open Item 127.

GE revised Section 14.2.12.1.27(3)(f) in SSAR Amendment 18 to include testing of the total air demand at normal steady state-conditions, including leakage from the system, in accordance with the design as specified in Position 3.C.5. The staff finds this acceptable. This resolved DSER Open Item 127.

(2) Demonstrate that the plant equipment designated by design to be supplied by the instrument and control air system is not being supplied by other compressed air supplies (such as service air (SA)) that may have less restrictive air quality requirements (RG 1.68, Position 3.C.9). This was DSER Open Item 128.

For Position 3.C.9, GE stated in its response of May 20, 1991, that the SA system acts as a backup to instrument air upstream of the instrument air filters. Furthermore, although totally separate (except for the manual backup cross-tie), the design of the two systems is essentially identical. Thus, the air supplied to the inlet of the instrument air filters is of the same quality, whether it is sourced from the instrument or SA system; therefore, the outlet air will be of the same quality. Because the design precludes occurrence of the conditions hypothesized, no specific test demonstration is needed beyond the construction verification and preoperational testing already planned. The staff finds this acceptable. This resolved DSER Open Item 128.

(3) Demonstrate that functional testing of instrument and control air systems important to safety is performed to ensure that credible failures resulting in an increase in the supply system pressure will not cause loss of operability (RG 1.68, Position 3.C.11). This was DSER Open Item 129.

For Position 3.C.11, GE revised Section 14.2.12.1.27 in SSAR Amendment 18 to include testing that will demonstrate continued operability of supplied loads in response to credible failures that result in an increase in the supply 
system pressure. The staff finds this item acceptable. This resolved DSER Open Item 129.

In the DSER, the staff determined that GE should address the control room habitability concerns of RO 1.95 in SSAR Section 14.2.12.1.34. This was DSER Open Item 130.

GE revised Section 14.2.12.1.34 in SSAR Amendment 18 to indicate that the control room habitability function will be included in the testing specified for the dedicated HVAC system of the main control room. GE also added a specific requirement to demonstrate the system capability to detect smoke and/or toxic chemicals and to remove and/or prevent in-leakage of such. (Also see RG 1.68, Position 1.n.(14)(f), in Section 14.2.12.4 of this report.) The staff finds this acceptable. This resolved DSER Open Item 130.

In the DSER the staff determined that GE should address, in SSAR Section 14.2.12.1.34, HVAC Systems Preoperational Tests, or other appropriate preoperational tests, the concerns for in-place testing of HEPA and charcoal filters of Position C.5, In-Place Testing Criteria, of RG 1.140. This was DSER Open Item 131.

GE revised Section 14.2.12.1.34 in SSAR Amendment 18 to include testing requirements specified by RC 1.140 and by the industry standards referenced therein. The staff finds this acceptable.

GE later determined that Position C.5, of RG 1.140 only discussed testing criteria for HEPA and carbon absorber filters in HVAC systems. The HVAC systems described in Section 14.2.12.1.34 do not contain HEPA or carbon absorber filters, therefore, Position C.5 of RG 1.140 does not apply. RG 1.52 addresses testing of HEPA and carbon absorber filters in ESF systems. GE added RG 1.52 and removed RG 1.140 in Sections 14.2.12.1.34 and 14.2.12.1.36 of a markup dated June 7, 1993, to address testing of ESF HVAC systems (i.e., control room habitability HVAC system and the standby gas treatment system (SGTS)) that require in place testing of HEPA and carbon adsorber filters. This information was incorporated into Amendment 30 of the SSAR. The staff finds this acceptable. This resolved DSER Open Item 131.

Finally, the staff determined in the DSER that GE should address the following items in accordance with RG 1.139 in SSAR Section 14.2.12.1.8.

(1) Residual heat removal (RHR) system isolation (RG 1.139, Position C.2). This was DSER Open Item 132.
GE stated in its response of May 20, 1991, that the applicable demonstrations were intended to be a part of the testing described in SSAR Section 14.2.12.1.8(3)(i).

Further, GE agreed to revise SSAR Section 14.2.12.1.8 (1) to specifically address testing of features designed to ensure isolation of low-pressure portions of the RHR system from the reactor coolant system (RCS) at high pressure. In the DFSER, the staff found this item acceptable subject to incorporation into a future SSAR revision. This was DFSER Confirmatory Item 14.2.12.6-3.

GE revised SSAR Section 14.2.12.1.8 (1) in SSAR Amendment 23 to include testing of fentures designed to ensure isolation of the low pressure portions of the RHR system at high pressures. The staff finds this acceptable. This resolved DFSER Confirmatory Item 14.2.12.6-3.

(2) RHR system pressure relief (RG 1, Position 139.C.3). This was DSER Open Item 133.

GE stated that the design of the RHR system will include the relief capacity required by Position C.3 in accordance with the applicable ASME Code. GE indicated that no specific additional preoperational test was needed because verification of the proper setting of relief valves was a vendor bench test required per the same ASME Code.

Section 14.2.12.1.8 was revised to allow for verification of proper set points of system relief valves per ASME code requirements (including those intended to meet the requirements of RG 1.139 using the results of vendor tests and the appropriate documentation of such). In the DFSER, the staff found this item was acceptable subject to incorporation into a future SSAR revision. This was DFSER Confirmatory Item 14.2.12.6-4.

GE added system pressure relief valve verification tests per ASME code and RG 1.139 requirements into Section 14.2.12.1.8 (3) in SSAR Amendment 23. The staff finds the above tests acceptable. This resolved DFSER Confirmatory Item 14.2.12.6-4.

\subsubsection{Certified Design Material}

The staff reviewed the GE certified design material and determined that the ITPs were not included in the Tier 1 or ITAAC material. The staff expected that this Tier 1 
material would be at a bigh lovel limited to a commitment to an ITP and a description of the program and the major program documents (i.e., a sito-epecific startup administrative manual, teet epecifications, and teet procedures). This was DFSER Open Itom 14.2.12.7-1.

GE provided the Tier 1 ITP information. An ovaluation of the ITP information is contained in Section 14.3.3.5 of this report. The staff has found the description acceptable. This resolved DFSER Open Itom 14.1.12.7-1.

\subsubsection{COL License Information - Initial Teat Program}

The preceding discussion of preoperational and startup tests were limited to those systems and components within the scope of, or directly related to, the ABWR standard plant. Other testing, with respect to utility specific aspects of the plant will be necessary to satisfy certain ABWR requirements. Testing of such systems and components should be adequate to demonstrate conformance to such requirements as defined throughout the specific chapters of the SSAR. Below are systems that may require such testing

(1) electrical switchyard and equipment

(2) the site security plan

(3) personnel monitors and radiation survey instruments

(4) the sutomatic dispatcher control system (if applicable)

Also to be supplied by the applicent referencing the ABWR design is the startup administrative manual described in Section 14.2.4, which will describe, among other things, what specific permissions are required for the approval of test results and the permission to proceed to the next testing plateau.

The staff received a GE response dated May 7, 1993, containing a new section (i.e., Section 14.2.13, COL License Information). Section 14.2.13 lists all the COL Action Items (i.e., DFSER COL Action Items 14.2.3-1 through 14.2.12.4-2) that were identified in the DFSER. The staff found that the new section lists all COL license information that will be provided by the COL applicant. The COL Action Items list was subsequently incorporated into the SSAR. The staff finds the COL license information provided in Section 14.2.13 ecceptable.

\section{Conclusion}

The staff performed the review of the plant ITPs in accordance with Section 14.2, of NUREG-0800, the SRP, and RG 1.68 (Rev. 2), "Initial Test Programs for Water Cooled Nuclear Power Plants." The staff reviewed thirteen areas rolating to initial plant test program, deacribed in Chaptor 14 of the SSAR, and aubmitted by GE as part of its design certification application. These areas of roviow included:

- aummary of the test program and objectives

- organization and staffing

- teat procedures

- conduct of teet program

- reviow, evaluation, and approval of teat results

- test records

- conformance of test program with regulatory guides

- utilization of reactor operating and testing experience in the dovelopment of test program

- trial use of plant operating and emergency procedures

- initial fuel loading and initial criticality

- test program schedule

- individual test descriptions

- combined license (COL) information - ITP

The acceptance criteria used by the staff for this review were contained in SRP Section 14.2, Subsection II.

Based on the review of the GE ABWR ITP description in SSAR Chapter 14 and the responses to the RAIs and the DSER open items, DFSER open items and confirmatory items, the staff concluded that the ITP was generally comprebensive and covered all areas of staff concern. The staff also conducted an in-depth review of system-specific lesting requirements within each test abstract. The staff concluded that GE provided a sufficient level of detail to adequately describe system-specific test prerequisites and acceptance criteria for design certification. The staff also reviewed cross-references to acceptance criteria information in other parts of the SSAR and found them acceptable. An additional review of COL action items and interfacing systems will be performed at the time a COL applicant referencing the $A B W R$ design submits an application for a license under 10 CFR Part 52. 


\subsection{Certined Deaign Material}

Introduction

The objective of this section of the report is to provide the bacis for the atafi's approval of the oertified deaign material (CDM) for the ABWR dexign. This soction of the report is based on the staff's review of the OB documeat titled "ABWR Cortified Deaiga Material" and andand afoty analyais report (SSAR) Section 14.3, "Cortified Deaign Material." The requirement to eubmit this information as part of an application for deaign certification is contained in 10 CFR 52.47.

The GB document titled "ABWR Certified Design Material" contains the information that will be certified by the rule that approves the ABWR design. The CDM consiats of an introductory section, design descriptions and corresponding inspections, teets, analyeen, and acceptance criteria (ITAAC) for the systome of the deaign, design material applicable to multiple syatem of the deaign, interface requirements, and sito parameters for the ABWR docien. This information is aleo reforrod to as Tier 1 information. The ABWR SSAR Section 14.3, "Certified Deaign Material," provides the bases and mothods that were uned to dovelop the information for each of thewe CDM itoms for the ABWR. This report documents the atafi's review of the ABWR CDM, as supported by the dexign information contained in the ABWR SSAR.

The information in the CDM and SSAR Section 14.3 is derived from the detailed information contained in the SSAR. Further, the purpoee of the ITAAC, which are part of the CDM, is to verify that a facility that references the deaiga certification has been built and will operate in accordance with the design certification and the applicable regulations. Consequently, there is no design information presented in the CDM or SSAR Section 14.3 that is not also contained in the various sections of the SSAR. Therefore, the staff did not base its safety evaluations for the design on the information in the CDM.

\section{Bagiz for Approval of the CDM}

The ABWR was the lead design for the initial development of CDM for design certification. Although the etaff was able to make its anfety determinations for the design based on its roviow of the information in the SSAR, this was the first time design material had been developed for certification. Therefore, there was no precedent for GE to follow to develop information for the CDM. Furthermore, the staff had no regulatory guidance on which to base its review. Recognizing this, the staff sought and received Commission guidance on several key issues associated with the design certification reviews in the staff requirements momorundum (SRM) datad Pebruary 15, 1991, rolating to SBCY-90-377, "Requiromente for Deaign Certification Under 10 CFR Part 52." These insues included the dovalopment of regulatory guidance, the role of ITAAC, the lovel of dexign dotail neoded for deaign certification, ievo finulity, the two-tiered approech to the deaign certification rulo atructure, and floxibility in deaign change proceses. In its roviow, the etaff evaluated the CDM in the contaxt of Part 52 requirements and the Commimion guidance contained in that SRM.

As the lead deaign, OE aubmitted the CDM to the ataff for roviow in stagen, 20 that leacons learned at each stage could be incorporated into later submittals. The staff reviowed the material in an iterative manner and provided comments on the CDM to $\mathrm{GE}$ at each stage. The staff informed the Commiscion of the development of the CDM in multiplo SECY papors isoued in 1991 and 1992 (SECY. 91-178, 91-210, 92-053, 92-196, 92-214, 92-287 and 287A, 92-299, and 92-327). These papers aro listed as roferences in Appendix B of this report.

In SSAR Section 14.3, GE provided the proceses it used in the developmeat of the CDM, based on the design prosented in the appropriate sections of the SSAR. GE provided CDM baed on the structures and systems of the ABWR design rather than based on the format of the ABWR SSAR. In addition, GE adoptod a graded approach to the lovel of design detail for the information in the CDM, besed on the eafoty significance of particular structures, systems, and components (SSC). GE applied various selection criteria to the information in the SSAR to dotermine the level of design information for a given structure or system in the CDM. The results of this proceses were illustrated with cross-references from the SSAR information to the CDM for important parameters that were selected for treatment in the CDM. Although many issues and analyses could have been crosereferenced, the listings in Section 14.3 were developed only for selected integrated plant safety analyses for the ABWR design. GE provided additional cross-references of key insights and assumptions from probabilistic risk analyses (PRA) and analyses for severe accidents which are contained in SSAR Chapter 19. GE provided more detailed cross-references to the CDM for these analyses in a letter datod March 31, 1994.

The staff also utilized a graded approach to the level of detail in its review of the CDM based on the safety significance of the SSCs. Thus, consistent with the guidance of Part 52 and the SRM related to SECY-90-377, the staff recognized that although many aspects of the design were important to safety, the level of design detail in the CDM and verification of the key design features and 
performance chanacteriatice should be commeneurate with the significance of the safoty functions to be performed.

The intent of the CDM is to enoure that the key characteriatica and performance requirements of afotyvignificant SSCs are implemented in an a-built facility referencing the certified deaiga. Although all these aspects of the design are described in the CDM, not all can be verified by the ITAAC because Part 52 requires that the ITAAC be satisfied prior to fwol loading. The initial toet program (ITP) erves to verify the remaining acpects of the design after fuel loed, but prior to operation. Examples of these requirements are the post-fivel load etartup and power ascension test program verification of fuel, control rod, and core characteriatics, as well as systom and intograted plant operating characteristics. The treatment of these issues will be similar to their treattonent at fecilities licensed under 10 CFR Part 50, in that verification of the satisfectory completion of these requirements will be a condition of the license.

The staff recognized that other programs also canure the continued safe operation of a facility after fuel load. For example, the continued operability of a facility after the ITAAC are satisfied is ensured through the tochnical specifications (TS), as well as various programs ouch as the maintenance program, quality aseurance program, and the in-service inspection and touting program. The operator ensures the facility is operated as designed, through the use of appropriate plant operating and emergency procedures. Additionally, a utility reforencing the design is required by 10 CFR Part 50, Appendix B, to have a quality assurance (QA) program that ensures these SSCs are appropriately designed, procured, and perform satisfactorily in service.

The above considerations provided an overall framework for OE's development of the CDM and the staff's reviow. The staff utilized multiple sources of information to determine the safety significance of SSCs in the CDM. These sources included the SRP, applicable rules and regulations, general design criteria (GDC), regulatory guides (RGs), unresolved safety iseves (USIs) and generic safety issues (GSIs), NRC generic correspondence, operating experience, NRC inspection programs, facility testing programs, PRA, and insights from ABWR safety and sovere accident analyses. For solected portions of the review, the staff aleo utilized the regulatory guidance from the Commission related to SECY-90-016, "Evolutionary Light Water Reactor Certification Ieques and Their Relationship to Curreat Regulatory Requirements," as modified by the Commission guidance related to SECY-93-087, "Policy, Technical, and Licensing Issues Pertaining to Evolutionary and Advanced Light-Wator Reactor Designs."
Nonetholoes, becaune this wae the firet tim CDM had bees doveloped for a decign, becaune there was no precedeat for OE to follow and so detailed roviow guidance for the staff to bace its roviow on, and becauke of the iterative neture of the ITAAC dovelopment proceses, considerable judgemeat was inhereat in the approval of the final meterial for the CDM.

\section{Backeround}

Part 52 of Title 10 of the Code of Federal Regulations was iemued April 18, 1989. The concept in Part 52 of certifying a design and epecifying the required ITACC in a rule prior to conatruction of a facility had not been attompted before. Consequently, OE and the Nuclear Management and Renourcen Council (NUMARC) bold extencive discusedions with the staff in 1990 and 1991 on the CDM, especially the form and content of the ITAAC. After several cenior menagement meotinge in mid-1991, the OE ABWR emerged at the lead plant in the dovelopment of tho firt CDM for a standandized deaign.

The dovelopmeat of the CDM was an iterntive proceses. As the lead dosign, OE submitted the CDM to the staff for reviow in etages, 20 that leesons learned at each stage could bo incorporated into later aubmittals. The staff reviowed the material as it was submitted and provided commonts on the CDM to $\mathrm{GE}$ at each stage. Senior management moeting between GE and the staff were hold at intervals of approximately six to eight weeks to reeolve difficult policy and technical iseves seeciated with the dovelopment and roviow of the material.

GE aubmitted the first stage of the CDM, consisting of a set of nino "pilot" ITAAC, in a submittal dated September 20, 1991. The staff provided comments on this submittal in a letter of October 23, 1991, and after soveral meetinga with the staff to discuse the comments, genoral agreement was reached on the pilot ITAAC in January 1992.

GE submitted the recond stage of the CDM, consiating of approximately ono-half the ITAAC, in a submittal titled "Tier 1 Design Certification Material for the GE ABWR Design - Stage 2 Submittal," dated March 31, 1992. The etaff provided preliminary comments to GE on the Stage 2 submittal in a letter dated May 7, 1992, as well as during severnl senior management meetings.

OE submitted the thind stage of the CDM, consisting of the remainder of the Tier 1 material, in its nubmittal titled "Tier 1 Design Cortification Material for tho GE ABWR," dated June 1, 1992, as aupplomented by a lotter datod June 17, 1992. The etaff provided dotailed comments on the CDM in a letter to GE dated Auguat 12, 1992, including the comments of an NRC reviow group 
comprised of conior managers from coveral badquarten and regional offices of the NRC.

In September 1992, a group compribed of reprecentatives from various vendorn, utilitien, and induntry groupe providad induatry comments on the CDM to OB. OB revied the CDM 10 incorporate the commentu provided by both the NRC and this reviow group in late 1992. Suberqueatly, a team of NRC reviowere mot with OB in Jenuary, Fobruary, and March 1993, to reviow the revised ITAAC.

OB nubmitted the next atage of the CDM, conaiating of a revined, complete CDM that incorporated all provious lescons leamed and roviow comments, in incremeatal aubmittals in April, May, and June of 1993. In May 1993, the etaff formed several takk groups to perform a multidisciplinary roviow of the CDM. The tack groups provided extensive comments on the submittals $10 \mathrm{OB}$ in a letter dated July 9, 1993. The task groups met with GE on July 27 through 29, 1993, to discues the comments, and the dispocition of all of the comments were documented in a moeting aummary dated Auguet 10, 1993.

OE nubmitted the next atage of the CDM, consiating of a revied, complete CDM that incorporated the comments from the stafi's tack group roviow, in a submittal titled "ABWR Cortified Deaign Material," dated Auguat 31, 1993. OE supplemented this material with CDM Revision 1 in Septomber 1993, and with CDM Rovision 2 in December 1993. Chenges to the detailed CDM supporting information in the SSAR were contained in various amendments to the SSAR, up to and including Amendment 33.

The ataff had ideatified multiple inconsistencies between the SSAR, the Tier 1 denign deacriptions, and the related ITAAC during the reviews. Consequently, the etaff formed an independent roviow group to ensure consistency of the CDM and the SSAR in November 1993. The independent reviow group completed its roview in Fobruary 1994, and its comments were provided to GE after roview by the staff. $\mathrm{GE}$ provided satisfactory resolutions to all the comments in CDM Revision 3 and SSAR Amendment 34. In addition to resolving the comments of the independent roviow group, CDM Revision 3 aleo included resolutions to commente by the ACRS and the staff. Subeequent revisions to the CDM prior to the atart of the edminiatrative review of the ABWR deaign were minor in nuture.

\section{Eormit of the CDM}

GE developed a format for the design certification information to meet the requirements of 10 CFR 52.47, including bounding parumetors for siting of the atendard dacign, deaigen deccriptions end corresponding ITAC, and interfece requirements for the deaign. The CDM is the portion of the devign information that is certified by the rulo centifying the deaign, and will bo incorpornted into tho rule as the Tier 1 part of the deaign control document (DCD). The DCD is the mater document that contrins the information that must be conformed with by an applicant who references the rulo. The format for this material is listed bolow, and is discused in more dotail in the following sections of this report.

(1) Introduction - Dofinitions of terms unad in the CDM, and a liating of general provisions that are applicable to all CDM entries.

(2) Sytem Detion Decriptione and ITAAC - Syetom deaign deacriptions and ITAAC are provided for: (a) structures and aystems that are fully within the scopo of the ABWR dexign certification, and (b) the in-ecope portions of those ayetems that are only partially within the scope of the ABWR decign certification. The syetem design descriptions aro eccompanied by tho appropriale ITAAC.

(3) Additions Centified Dexien Mnteris - Deaign deacriptions and their related ITAAC for docign and conetruction ectivition that are applicable to more then one system of the design. This additional material was provided because in solected areas of the design, OE did not provide sufficient design detril in the SSAR. GE did not provido complete design information in these areas because they were oither areas of rapidly changing technology where OE believed it was unwise to prematurely freeze the design, or because the information was dependeat on as-built or a-procured information. For thewe areas, OE provided the decign related procesese in the CDM and in the SSAR, with appropriate codes and standards, that a COL applicant or licensee would follow to complete the design.

(4) Interface Requirements - Requirements that must be mot by the sito-epecific portions of a facility that are not within the scope of the certified deaign. This rection also identifies the scope of the design to be certified. Interfece requirements aro dofined for: (a) eystems that are entirely outside tho scope of the deciga, and (b) the out-of-ecopo portions of thowe systems that are only partially withis the scope of the ABWR design.

(5) Site Panmeten - Bounding parameters of the design to be used in the selection of a suitable sito 
for a facility reforencing the ABWR certified deaign. The deaign was ovaluated in terms of these parameters. A suitable site must bo demonatrated to be within the bounding parameters and charactorintics, and a facility muat bo constructed at the sito in sccordance with their wee in the approved doeign. If a site cannot meot them, an exemption must be requested and the facility must be reevaluated in torms of these paramoters for the sctual selected sito.

\subsubsection{Introduction to CDM}

\subsubsection{Defnition}

This section of the CDM provides terms used in the CDM that could be subject to various interprotations. The intent of the terms used in the CDM was to be consistent and as closely aligned as possible with the terminology in the SSAR, in common industry use, industry codes and standands, and NRC rules, regulations, and guidance. Thus, should questions on terminology arise, these reforeaces would aid in understanding the intent of the informetion in the CDM.

\subsubsection{General Provisions}

This section of the CDM provides general provisions that are applicable to the design descriptions, figures, and the ITAAC.

\subsection{Verifications for Basic Configuration for} Structures and Systems

This section of the CDM includes provisions related to the verification of the ITAAC for besic configuration for systems and structures of the design. This ITAAC is contained in the buildings and many of the systems described in Section 2 of the CDM. The verification consiats of an inspection of the systom functional arrangement in its final as-built condition at the plant site, and includes the elements of the design descriptions and the system figures in the CDM. This functional arrangement inspection verifies, using as-built system drawings, design documentation, and in-situ plant walkdowns, that the as-built facility is in conformance with the certified design and applicable rogulations.

Several other aspects of the design were considered to have significance to the performance of safoty functions of SSCs of a facility. The besis for selecting these aspects included its importance to safety as well as its past experience with construction and operating problems. Thus, specific inspections for these aspects are part of the basic configuration ITAAC for systems and structures. The ocber inopections to be conducted to satisfy this ITAAC include, and are limited to, verification of the following:

(1) Verifications of the quality of prescure boundary wolds for ASME Code Clase 1, 2, and 3 components and systems described in the design descriptions and figures. Detailed supporting information for verification of welding requirements in accordance with ASME Code requirements is contained in SSAR Chapter 3.

(2) Verifications of the dynamic qualification (0.8., soismic, LOCA, and sufety reliof valve diecharge loads) of soiemic Catogory I mechanical and electrical equipment (including connected instrumentation and controls) deacribed in the design descriptions and figures. Detailed supporting information for dynamic qualification requirements, including qualification records, is contained in SSAR Chapter 3.

(3) Verifications of the environmental qualification of Class 1E electrical equipment described in the design deecriptions and figures. Detailed supporting information for environmental qualification requirements is contained in SSAR Chapter 3.

Verifications of the design qualification of motoroperated valves (MOVs) described in the desizn descriptions and figures. Detailed supporting information for design qualification of MOVs is contained in SSAR Chapter 3.

\subsection{Treatment of Individual Items}

A licenses is not prohibited from utilizing an item not doecribed in the CDM. However, the as-built facility must be consistent with the rule approving the design, including both tiers of information. The change proceseses for the certified design are described in the design cortification rule for the ABWR.

The term "operate" as utilized in the CDM is intended to refer to the actuation and running of equipment. This is not meant to include the term "operable" in the context of the ongoing reliability and availability of equipment. In doveloping the ITAAC, the staff recognized that other programs ensure the continued safe operation of a facility after fuel load. For example, the continued operability of a fecility after the ITAAC are satisfied is ensured through the Technical Specifications, Startup and Power Ascension Test Programs, as well as various programs such as the maintenance program, quality assurance program, and the in-service inspection and in-service testing program. Also, 
the operator enwures the facility is opernted as denigned, through the use of appropriate plant opernting and emergency procedures.

The torm "exists," when used in the Acceptance Critoria, means that the itom is present and moets the design description. Detaiied supporting information on what must be present to conclude that an itom "exists" and moets the design description is contained in the appropriate sections of the SSAR.

\subsection{Implementation of ITAAC}

GE developed a three column format for the ITAAC. The design commitments in the first column are derived from the design information in the design descriptions. The inspections, tests, and analyses in the middle column provide the intended means of verifying the design commitment. The acceptance criteria in the third columa provide the criteria used to determine whether the design commitment is mot.

The licensee is required by 10 CFR Part 52 to perform the required inspections, tests, and analyses for the design, and certify to the NRC that the acceptance criteria have been met. A licensee may utilize the efforts of subordinate vendors, contractors, or consultents. However, the licensee referencing the certified design retains responsibility for ensuring that the ITAAC are met. Additionally, the ITAAC can be satisfied using other programs, such as the pre-operational testing portion of the ITP required by CDM Section 3.5, or the QA program required by 10 CFR Part 50, Appendix B.

The ITAAC may be satisfied at any time prior to fuol load, including prior to issuance of a combined license. However, the primary intent of the ITAAC is to verify that the as-built plant on the final site has been constructed and will perform in accordance with the design certification and applicable regulations.

\subsection{Discussion of Matters Related to Operations}

Descriptions in the CDM may refer to matterd of operation, such as normal valve or breaker alignment during normal operational modes. These descriptions are not intended to require operators to take any particular action. The operational matters referred to in the CDM are governed by existing programs to ensure the ongoing safe operation of a facility, such as plant operating and emergency procedures.

\subsection{Interpretation of Figures}

The deaign deacriptions include the figuren in the CDM, where the figures are provided. They are intended to dopict the functional arrangement of the significant SSC. of the ABWR design. An an-built facility reforencing tho certified design must be consistent with the performance chancteriatics and functions deacribed in the design descriptions and figures. Any changes to the detailed information in the SSAR must be in eccordance with the "50.59-like" change proceses in the design cortification rule for the ABWR, which allows the COL applicant or licensee to make design changes, provided the changes do not impact the information in the CDM.

\subsection{Rated Reactor Core Thermal Power}

The rated reactor core thermal power for the ABWR is 3926 MW(th).

\subsubsection{Conclusions}

As discussed above, the staff reviewed the definitions and general provisions that are contained in CDM Section 1.0, and the supporting material contained in SSAR Section 14.3.1, in accordance with the requirements in Part 52 and the guidance in SRMs related to design certification applications provided by the Commission. Based on this, the staff concludes that the dofinitions and general provisions in the CDM ace appropriate to support the design descriptions and ITAAC, and are acceptable.

\subsubsection{Certified Design Material for Structures and Systems}

GE developed design descriptions and ITAAC for the structures and systems of the ABWR design, and these are contained in CDM Section 2.0. General provisions that apply to most of the structures and systems are contained in CDM Section 1.2. Additional CDM material for design issues that apply to many of these structures and systems are contained in CDM Section 3.0. Intorface requirements for these systems are provided in the system design descriptions for the in-scope portions of the systems. The interface requirements for the out-of-scope portions of the systoms of the design are contained in CDM Section 4.0. GE provided an entry in the CDM for every system of the design to define the full scope of the design. 


\subsubsection{Design Descriptions}

The design descriptions address the most safoly-significant espects of each of the systems of the design, and were derived from the detailed design information contained in the SSAR. The design descriptions include the figures associated with the systems. GE's selection criteria and methodology for the system design descriptions are specified in SSAR Section 14.3.2.1. In its review of the material, the staff followed the general guidance for the reviews specified in the SRM related to SECY-90-377, as discussed previously in the introduction to Section 14.3 of this report.

The Tier 1 design descriptions will serve as commitments for the lifetime of a facility. Once completion of ITAAC and the supporting design information demonstrate that the facility has been properly constructed, it then becomes the function of existing programs such as the technical specifications, the in-service inspection and in-service testing program, the quality assurance program, and the maintenance program, to demonstrate that the facility continues to operate in accordance with the certified design and the license. Nevertheless, the Tier 1 design descriptions will remain in effect throughout the plant life to assure that the plant does not deviate from the certified design. In general, a COL applicant or licensee may change the information in the SSAR in accordance with the "50.59-like" change process described in the rule certifying the design, provided that the change does not impact the information in the design descriptions.

GE pmvided the selection criteria for information in the design descriptions in Section 14.3.2.1. Essentially, GE put the top-level design features and performance standards that were most significant to safety in the design descriptions. The criteria GE utilized in determining the safety significance of SSCs in the design descriptions included the NRC's regulations, whether or not the information pertained to safety-related SSCs, the importance in the SRP, the relative importance based on PRA or severe accident analysis, operating experience, or the technical specifications. GE also included other SSCs based on their importance to safety. Non-safety aspects of SSCs were generaliy not discussed in the design descriptions. Thus, although a Tier 1 entry was provided for every system that is either fully or partially within the scope of the ABWR design certification, the amount of information provided in CDM Section 2.0 for a given system, if any, was basid on the safety siguificance of the system.

GE provided additional certified design material applicable to the systems of the design in CDM Section 3.0. The design descriptions in CDM Section 3.0 describe the scope and applicability of the additional certified design material to the systems of the design in CDM Section 2.0. Amplifying information on CDM Section 3.0 is provided in SSAR Section 14.3.3, and the staff's review of CDM Section 3.0 is contained in Section 14.3.3 of this report.

The CDM utilizes a system-based structure which is different than the structure of the SSAR. Consequently, developing the CDM design description entries for any one system was based on a review of the multiple SSAR chapters having technical information related to that system. GE illustrated this approach in SSAR Section 14.3.2.1, showing how the many design aspects of any single system in the CDM were derived from multiple chapters of the SSAR.

The staff was particularly interested in ensuring that the assumptions and insights from key safety and integrated plant safety analyses in the SSAR, where plant performance was dependent on contributions from multiple systems of the design, were adequately considered in the CDM. Addressing these assumptions and insights in the CDM ensures that the integrity of the fundamental analyses for the design are preserved in an as-built facility referencing the certified design. These analyses included flooding analyses, overpressure protection, containment analyses, core cooling analyses, fire protection, transient analyses, and radiological analyses.

GE provided information regarding these analyses in the SSAR, and documented the important design information and parameters from the various chapters of the SSAR that are addressed in the CDM in Tables 14.3-1 through 14.3,10. GE provided more detailed cross-references to the CDM for these analyses in a letter dated March 31, 1994. GE also provided cross-references in SSAR Chapter 19 showing how key insights and assumptions from PRA and severe accident analyses are addressed in the CDM. A COL applicant or licensee proposing to change design information in the SSAR that pertained to these analyses via the "50.59-like" change process can use these crossreferences when considering whether the proposed change impacts the treatment of these parameters in the CDM.

\subsubsection{ITAAC}

The purpose of the ITAAC is to verify that an as-built facility conforms to the approved plant design and applicable regulations. When coupled in a $\mathrm{COL}$ with the ITAAC for site-specific portions of the design, they constitute the verification activities for a facility that must be successfully met prior to fuel load. If the licensee demonstrates that the ITAAC are met and the staff agrees that they are successfully met, then the licensee will be permitted to load fuel. 
The scope of the ITAAC is consistent with the SSC that are in the design descriptions. In general, each system hes one or more ITAAC that verify the information in the design descriptions. This is not true in all cases. Reasons for not requiring an ITAAC verification for a Tier 1 design commitment include: (1) the information is only included for context, (2) fulfillment of other ITAAC are sufficient to show verification of the design commitment, (3) a single ITAAC can verify more than one design commitment, or (4) verification of the item can only occur after fuel loading. For the last item, the staff reviewed the power ascension testing program described in SSAR Chapter 14 to ensure that all important design features and commitments that could not be verified prior to fuel load were addressed where appropriate.

The staff reviewed the system ITAAC to ensure that the verifications were consistent with the safety significance of the key design characteristics and performance requirements of the SSC verified by that ITAAC. The certified design descriptions for an SSC contain the significant functions and bases for that SSC. Therefore, the ITAAC have been reviewed to ensure they are necessary and sufficient to provide the NRC with reasonable assurance that the facility should be authorized to load fuel. As a result, the ITAAC verify the significant design features from the design descriptions and the applicable requirements that are necessary and sufficient to authorize fuel loading and subsequent operation.

The staff and industry reached agreement on a threecolumn format for ITAAC, as discussed below.

\section{Column 1 - Desiqn Commitment}

This column contains the text for the specific design commitment that was extracted from the design descriptions discussed above. Any differences in text were minimized, unless intentional. Differences in text were generally intended to better conform the commitments in the design description with the ITAAC format.

\section{Column 2 - Inspections, Tests, and Analyses}

This column contains the specific method to be used by the licensee to demonstrate that the design commitment in Column 1 has been met. The method is either by inspection, test, or analysis or some combination of inspections, tests, or analyses.

The SSAR contains detailed supporting information for the CDM about various inspections, tests, and analyses that can, and should be, used to verify the Tier 1 design information and satisfy the acceptance criteria. If questions on interpretation should arise, the material in the
SSAR provides the background material and context for the CDM. The SSAR contains information reviewed by the staff which was the basis for the staff's safety determination for the design. Therefore, the information in the SSAR provides an acceptable means of satisfying an ITAAC.

Inspections are defined in CDM Section 1.1, and include visual and physical observations, walkdowns or record reviews. The inspections required for the "Basic Configuration Walkdown" ITAAC invoke the general provisions contained in CDM Section 1.2 for as-built structures and systems.

Tests are defined in CDM Section 1.1, and mean the actuation, operation, or establishment of specified conditions to evaluate the performance or integrity of the as-built SSCs. This includes functional and hydrostatic tests for the systems. The term "as-built" is intended to mean testing in the final as-installed condition at a facility. The term "type tests" is used in this column to mean manufacturer's tests or other tests that are not necessarily intended to be in the final as-installed condition. The results of pre-operational tests can be used to satisfy an ITAAC. In its review, the staff did not rely on the prooperational tests described in SSAR Section 14.2 or RG 1.68 to substitute for ITAAC. Where testing is specified, appropriate conditions for the test should be established in accordance with the ITP described in CDM Section 3.5, SSAR Section 14.2 and RG 1.68. Conversion of the test results from the test conditions to the design conditions may be required to satisfy the ITAAC.

During its review, the staff emphasized in-situ testing, where possible, of the as-built facility as the preferred means to satisfy the ITAAC. Also, the staff recognized that the results and documentation from facility programs such as the quality assurance program or the ITP may be used to satisfy an ITAAC.

Analyses are defined in CDM Section 1.1, and may refer to detailed supporting information in the SSAR, simple calculations, or comparisons with operating experience or design of similar SSCs. For example, detailed analysis methods of seismic and environmental qualification supporting CDM Section 1.2 are contained in SSAR Chapter 3, and detailed piping design information supporting CDM Section 3.3, are also contained in SSAR Chapter 3.

\section{Column 3 - Acceptance Criteria}

This column contains the specific acceptance criteria for the inspections, tests, or analyses described in Column 2 
which, if mot, demonstrato that the deeign commitment in Column 1 has been mot.

In general, the acceptance criteria wero doveloped to be objective and unambiguous. In some cases, the acceptance criteria were more general because the detailed supporting information in the SSAR did not lend itself to concise verification. For example, the ecceptance criteria for the design integrity of piping and structures is that a report "exists" that concludes the design commitments are met. In these cases, the SSAR provides the detailed supporting information on multiple interdependent parameters that must be provided in order to demonstrate that a satisfactory report exists.

Numeric performence values for SSCs were specified as ITAAC acceptance criteria when the design commitment so lent itself, or when failure to meet the stated acceptance criterion would clearly indicate failure to properly implement the design. The staff did not require that numeric performance values be specified in the design description unless there was a specific reason to include them (e.8., important to be maintained for the life of the facility).

\section{ITAAC Implementation}

The ITAAC may be satisfied at any time prior to fuel load, including prior to issuance of a combined license. However, the primary intent of the ITAAC is to verify that the as-built facility on the final site has been constructed and will operate according to the design certification and applicable regulations.

The implementation of a construction verifichtion program, including ITAAC, and other licensee programs, is the responsibility of the licensee. The successful completion of the ITAAC in the combined license will constitute the basis for the NRC's determination to allow fuel loading for the facility.

The licensee will periodically certify to the NRC that the inspections, tests, and analyses have been performed, and that the acceptance criteria have been met. These notifications should document the basis for the successful completion of the ITAAC. In accordance with 10 CFR 52.99 , the staff will assure that the required inspections, tests, and analyses have been performed and that the prescribed acceptance criteria have been met. At appropriate intervals, the NRC will publish in the Federal
Reginter, notices of the ruccessful completion of the inspections, tests, and analyses.

\subsubsection{Staff Review Approach}

GE developed the CDM based on the systems of the design rather than on the format of the SSAR and SRP. In order to ensure that the safety-significent design information in the SSAR was adequately reflected in the CDM, the staff adopted a multidisciplinary roview approach, rather than the more traditional review approach based on the individual chapters of the SSAR. The staff formed several task groups comprisod of various disciplines to ensure that the CDM would provide reasomable assurance that a facility would be built and operated in accordance with the design certification and applicable regulations.

The task groups were composed of various representatives from the technical branches of the staff, depending on the primary area of review by the task group. The task groups were formed based on the following discipline areas: plant systoms, reactor systems, electrical, human factors, radiation protection, structural, and instrumentation and controls.

The task groups had primary review responsibihities for systems that were predominantly in their discipline area, and secondary review responsibilities for systems in other discipline areas where appropriate based on the safety significance of the issues. Thus, the groups had overlapping system review responsibilities. All information in the CDM was reviewed by one or more task groups. For example, the reactor core isolation cooling system was reviewed primarily by the Reactor Systems Task Group, and that task group received technical input and comments from the Instrumentation and Controls Task Group. Specialists were designated to provide input to the task groups for selected design issues. Examples of these issues included severe accident issues, testing issues and the ITP, treatment of alarms, displays, and controls, insights from PRA, and functionality of MOVs.

The task groups with primary review responsibility for systems maintained overall responsibility for the reviews of those systems. Overall continuity and consistency of the reviews was maintained through frequent meetings with all task groups and with the projects branch of the staff. Significant policy and technical issues, or issues of concern to multiple task groups, were identified for discussion at periodic senior management meetings between the staff and GE. 
The etaff developed preliminary draft guidance for use in the reviews of the CDM, and incorporated lessons learned during the course of the reviews into the draft guidance. The draft guidance contained checklists for use in the reviews. The applicability of the ienves identified in the checkliats to the systems was besed on the safety significance of the epecific SSCs. The draft guidence also contained standard ITAAC entries that were used to verify solected issues in the appropriate systems of the design. Examples of these standard ITAAC entries are those for the basic configuration of systems, verification of control room and remote shutdown features, and electrical independence. The issues in the checklist and the use of the standard ITAAC entries are discussed in the following sections of this report.

The task groups utilized multiple sources of information to determine the afety-significance of SSCs in the CDM. These sources included the SRP, applicable rules and regulations, GDCs, RGs, USIs and GSIs, NRC generic correspondence, operating experience, NRC inspection programs, facility testing programs, PRA, and insights from ABWR safety and severe accident analyses.

For selected portions of the review, the staff also utilized the regulatory guidance from the Commission related to SECY-90-016, "Evolutionary Light Water Reactor Certification Issues and Their Relationship to Current Regulatory Requirements, " as modified by the Commission guidance related to SECY-93-087, "Policy, Technical, and Licensing Issues Pertaining to Evolutionary and Advanced Light-Water Reactor Designs." These issues included staff positions that deviated from or were not embodied in current regulations applicable to the ABWR design. The staff's positions and design-specific requirements are addressed where appropriate in this section of this report, and in the ABWR design certification rule as "applicable regulations."

The staff determined that selected material in the SSAR that supports the CDM, if considered for a change by an applicant or licensee that references the certified ABWR design, would constitute an unreviewed safety question, and therefore, would require NRC review and approval prior to implementation of the change. The material supporting the CDM is discussed where appropriate in this section, in the applicable chapters of this report, and in the ABWR design certification rule.

The task groups utilized a graded approach to the level of detail in its review of the CDM based on the safetysignificance of the SSCs. Thus, consistent with the guidance of Part 52 and the SRM related to SECY-90-377, the staff recognized that although many aspects of the design were important to safety, the level of design detail in the CDM and verification of the key features and performance characteristics should be commensurate with the significance of the aafety functions to be performed. In addition, the SSAR was reviewed to ensure that the information was consistent with the design description and that the information supporting the Tier 1 material was comprohensive and tochnically adequate. Thus, the individual task groups reviewed the CDM based on the safety significance of the material, as discussed in the following paragraphs.

\subsection{Plant Systems Task Group Review}

The Plant Systems Task Group had primary review responsibility for must of the fluid systems in CDM Section 2.0 that were not part of the core reactor systems. The scope of the plant systems review included new and spent fuel handling systems, power generation systems, air systems, cooling water systems, radioactive waste systems and heating, ventilation and air conditioning systems. The group also reviewed selected interface requirements within those systems. The grcup reviewed issues which affect multiple SSCs such as equipment qualification and protection from fires, floods and tornado missiles, and had secondary review responsibilities for most of the fluid systems and the structures of the design.

The task group primarily utilized the SRP in its review of the CDM to determine the safety significance of SSCs. Other sources included applicable rules and regulations, GDCs, RGs, USIs and GSIs, NRC generic correspondence, PRA, insights from ABWR safety and severe accident analyses, and operating experience. The task group also used the draft review guidance for the design control document as an aid in its review of the systems. For selected portions of the review, the staff also utilized the regulatory guidance from the Commission related to SECY-90-016, "Evolutionary Light Water Reactor Certification Issues and Their Relationship to Current Regulatory Requirements, " as modified by the Commission guidance related to SECY-93-087, "Policy, Technical, and Licensing Issues Pertaining to Evolutionary and Advanced Light-Water Reactor Designs." The task group reviewed the Tier 1 submittals (including the design description, figures, and ITAAC) of the design using the guidelines provided in the draft review guidance for the CDM as an aid for establishing consistency and completeness.

The task group reviewed the CDM for treatment of design information proportional to the safety significance of the SSC for that system. Many items were judged to be important to safety, and were thus included in the CDM. The following issues were identified to ensure comprehensive and consistent treatment in the CDM based on the safety significance of the system being reviewed: 
(1) Syetem purpose and functions

(2) Location of aystem

(3) Key design features of the syctem

(4) Soismic and ASMB codo claseifications

(5) Syctom operation in various modes

(6) Controls, alarms, and dieplaya

(7) Logic

(8) Interlocks

(9) Clase 1E electrical power sources and divisions

(10) Equipment to be qualified for harsh environments

(11) Interface requirements

(12) Numeric performance values

(13) Accuracy and quality of figures

Additionally, atendard ITAAC entries wero utilized to verify soloctod iscues, where appropriato. Examples of these included basic configuration, physical separation, and divisional power supplies. In particular, the general provision for convironmental qualification aspects of SSCs invoked by the basic configuration ITAAC was reviowed to ensure appropriate treatment in the CDM.

Environmental qualification (EQ) of kafo-shutdown equipment is verified as part of the basic configuration ITAAC for eafety-related systems. EQ treatment in the ITAAC is discussed in the General Provisions section of the CDM. Verification includes type tests or a combination of type tests and analyses of Class 1E electrical equipment identified in the Design Description or accompanying figures to show that the equipment can withstand the conditions associated with a design basis accident without loss of safety function for the time that the function is needed.

The task group reviewed integrated plant safety analyses auch as fires, floods and missile protection to ensure they were adequately addressed in the CDM. The insights from these analyses that were addressed in the CDM are contained in SSAR Section 14.3. The issues of floods, fires, missiles, pipe failures, and environmental protection are verified by the ITAAC on a system-specific basis, rath: than generically. Divisional separation (both physical and electrical) is the primary means of ensuring protection of safety-related equipment from these events. Verification of divisional separation is performed as part of both individual system ITAACs and building ITAACs. Physical and electrical separation is verified in each safetyrelated system ITAAC and divisional barriers are verified in the reactor and control building ITAACs.

The design features in the CDM were selected to ensure that the integrity of the analyses would be preserved in an as-built facility. For example, 3-hour fire boundaries and divisional separation were shown in the building figures. Also, flooding features spch as structure elevations were specified in the site parameters, flood doors were shown on the building figures, and elevations where shown on the buildinge to verify that the approximato physical location of components and relative elevations of buildings minimized the offects of flooding. As-built reconciliation reports for fires and floods to ensure consistency with the SSAR analyees are required by the fire protection system ITAAC and solected building ITAAC, respectively.

Other specific issues that were addressed include heat removal capabilities for design-basis accidents and tornado and missile protection. Heat removal capabilities were verified through heat removal requirements for core cooling system heat exchangers and interface requirements for sito-epecific systems. Tornado and missile protection was provided by inlet and outlet dampers in ventilation ayetems, and through the structural design of buildings.

The etaff was ovaluating ACRS comments regarding the need for verification of fires and flooding analyses in the ITAAC for buildings when the advance SER was issued. This was Open Item F14.3.2.3.1-1. GE provided satisfactory resolutions to the ACRS comments in CDM Revision 3 and SSAR Amendment 34. The CDM contained provisions for reconciliation analyses to be conducted for the ABWR design for fires and floods, to ensure that the as-built facility is consistent with the assumptions and analyses for these issues in the design certification. The staff finds this acceptable. This resolved Open Item F14.3.2.3.1-1.

The task group received inputs from other task groups such as the structural, electrical and I\&C task groups. The task group also reviewed the ITAAC for consistency with the initial test program described in SSAR Chapter 14. In addition, specialists provided key insights and assumptions from PRA and severe accident analyses, as well as inputs for issues such as treatment of alarms, displays and controls, and functionality of MOVs. A cross-reference from the SSAR to the CDM providing these key insights and assumptions is contained in SSAR Section 19.8.

The issue of containment isolation is addressed by a combination of the system ITAACs and the Leak Detection and Isolation System ITAAC. The containment isolation valves are shown on the system figures. The verification of the design qualification of the motor operated containment isolation valves will be verified by the basic configuration check in the system ITAAC as discussed in the general provisions discussion. In addition, in-situ tests are required for containment isolation MOV and check valves in each system ITAAC. The Leak Detection and Isolation System ITAAC verifies that the containment isolation valves close on receipt of an isolation signal. Actual closure of the containment isolation valves is 
checked using the manual isolation owitches in the main control room (MCR). A separate ITAAC entry verifies that a containment icolation signal is generated for each the process veriables that will cause \& contrinment isolation. This precludes multiple cycling of the contrinment isolation valves during the testing.

The staff decided during the roview of the ITAAC that the MCR ITAAC would verify only the minimum inventory as derived from the Emergency Procedure Ouidelines, the requirements of RO 1.97, and probabilistic risk assecsement insights. Other controls, indications and alarms aro identified in the syetem ITAAC and verified to exiet in the MCR. The ability of these controls, indications, and alarms to function will be checked during operation of the system for the functional tests required by the system ITAAC. The operation of the systoln during the completion of the functional tests required in the system ITAAC will be conducted from the MCR. Therefore, it was decided that the verification that the aystem can be operated from the MCR need not be a separate ITAAC. The staff also decided that since the operation of the equipment from the control room demonstrates the control function, continuity checks between the remote shutdown panel (RSP) and the equipmeat demonstrates that the control signal will be received by the component and provides adequate assurance that the equipment can be operated from the RSP. Additionally, the Initial Test Program will adequately cover the technical verifications of the ability to operate plant equipment from the RSP.

\subsection{Reactor Systems Task Group Review}

The reactor systems task group had primary roviow responsibility for the, reactor systems and core cooling systems in CDM Section 2.0. The group had secondary reviow responsibilities for those systems that could affect the operation of the reactor and core cooling systoms.

The task group primarily utilized the SRP in its review of the CDM to determine the safety significance of SSCs. Other sources included applicable rules and regulations, GDCs, RGs, USIs and GSIs, NRC generic correspondence, PRA, insights from ABWR safety and severe accident analyses, and operating experience. The task group also used guidelinies provided in the draft review guidance for the design control document as an aid for establishing consistency and completeness in its roview of the systems. For selected portions of the review, the staff also utilized the regulatory guidance from the Commission related to SECY-90-016, "Evolutionary Eight Water Reactor Certification Issues and Their Relationship to Current Regulatory Requirements," as modified by the Commission guidance related to SECY-93-087, "Policy,
Technical, and Licensing Ireves Pertaining to Evolutionary and Advanced Light-Water Reactor Designs."

The tack group reviowed the CDM systems in a similar manner as the plant systems task group because the reactor and core cooling systems were primarily fluid systems. Thus, the group examined the systems for comprehensive and consistent treatment of the issues listed in Section 14.3.2.3.1 of this report, besed on the safety significance of the respective systems being reviewed. The task group found that many of the systems in this area of roviow were classified as anfety rolatod, and thus many of the characteristics and features of these syatems were judged to have safety significance. This is reflected in a higher lovel of detail in the CDM for these systems.

The task group reviewed the CDM to verify that plant safety analyses, such as for core cooling, transients, overpressure protoction, and anticipated transient without scram (ATWS), were adequately addreseed. The takk group used the tables contained in SSAR Section 14.3 to asseses that the important input parameters used in the transient and accident analyses were verified by the ITAAC. The task group also interacted with specialists in PRA and covere accident analyses to ensure important insights and design features from these analyses were incorporated into the CDM. For the severe accident analyses in particular, the basis for the staff's review was the Commission guidance related to SECYs 90-016 and 93-087. For both PRA and severe accident analyses, although large uncertainties and unknowns may have been associated with the ovent phenomena, design features important for severe accident prevention and mitigation resulting from these analyses were selected for treatment in the CDM. The supporting information regarding the detailed design and analyset remained in the SSAR. For many of the design features, it was impractical to test their functionality. Consequently, the existence of the feature on a figure, subject to a besic configuration walkdown, was considered sufficient CDM treatment.

The staff determined that the detailed supporting information in the SSAR for the nuclear fuel, fuel channel, and control rod CDM, if considered for a change by a COL applicant or licensee that references the certified ABWR design, would constitute an unroviowed safety question. Thus, the staff has concluded that the fuel cycle and control rod dosign criteria in SSAR Sections $4 B$ and 4C, the first cycle fuel, control rod and core design and the methods used to analyze these components may not be changed without prior NRC review and approval. The specific fuel, control rod, and core designs presented in SSAR Chapter 4 will constitute, based on staff review and approval, an approved design that may be used for the COL first cycle core loading, without further NRC staff 
roviow. If any other coro decign is requeated for the firet cycle, the COL applicant or liceasee will be required to aubmit for ataff roviow that epecific fuel, control rod, and core design analyese as described in SSAR Chapters 6 and 15.

No ITAC are required for the CDM information in theee areas becauve of the requirement for prior NRC reviow and approval of any propoeed changen to the approved donign. Poet full load teating progrnm (0.8., startup terting and power ascension testing) verify that the actual core performs in sccordance with the analyzed core design.

Examples of the ieves that the task group examined for treatment in Tier 1 included net positive suction head for key pumps (etandand ITAAC entry epecified in the applicable syetems), and intersystem LOCA (the design prescure of the piping of the aystems that interface with the reactor coolant preasure boundary is specified in the design deacriptions of the applicable systems). The task group also reviewed the ITAMC for consistency with the initial teat program described in SSAR Chapter 14.

\subsection{Electrical Task Group Review}

The electrical task group had primary roview responsibility for the station electrical systems in CDM Section 2.12. The scope of the ABWR electrical design includes the entive Clase 1B portion of the olectrical system as well as - major portion of the non-Clase 1E electrical system. It also includes portions of the plant lighting system. The group also reviewed selected interface requirements. The group had secondary review responsibilities for somo systems using Class IE power.

In eetablishing the top level requirements for the electrical dexign, the staff used the Codo of Federal Rogulations including the GDC of Appendix A and Parts 50.49, "Environmental Qualification," and 50.63, "Station Blackout," as its main beses. In addition, IEEE nuclear ctandards wero used, as appropriate, to further establish top level requirements. The staff also considered significant leacons learned from operating experience problems and insights gained from the PRA for the ABWR.

GDC 17, in part, requires that an onsite and an offsite electric power system be provided to permit functioning of atructures, systems and components important to safety. It further requires that the onsite electric power system have independence and redundancy and the electric power supplied by the offaite system be supplied by two physically independent circuits.
10 CFR 50.49 requires that certain electrical equipment be qualified for accident (referred to as hareh) environments.

10 CFR 50.63 requires that a nuclear power plant be able to withstand and recover from a station blackout event.

IEEE 308 "IEEE Standard Criteria for Class IE power Systems for Nuclear Power Generating Stations," in conjunction with other related IEEE atandards, cotablish specific design criteria for nuclear power plant electrical systems and equipment.

The staff's reviow of the ABWR standard plant was conducted to ensure, in part, that the certified design contains top lovel design, fabrication, testing, and performance requirements for SSCs important to safety. Design descriptions and ITAAC were established to verify that these top level (Tier 1) requirements (or design commitments) aro met when the plant is built.

\section{Clese IE Eloctrical Systems}

The ABWR Class IE electrical systems include: (1) the Clase IE electrical power distribution system, (2) the emergency diesel generators, (3) the Clase IE direct curreat power supply, and (4) the Class 1E vital ac and Class IE instrument and control power supplies. Using the above regulations, IEEE standards, operating experience, and PRA as its beses, GE established top-lovel dosign commitments for the Class IE electrical systems of the ABWR to be included in the design descriptions and verified by ITAAC.

The top-level design commitments for the Class 1E eloctrical systems includo design aspocts relatod to:

(1) Equipment qualification for seismic and harsh environment

(2) Redundancy and independence

(3) Capacity and capability

(4) Electrical protection features

(5) Displays/controls/alarms

Equipment Qualification

To ensure that the seismic design requirements of GDC 2 and the environmental qualification requirements of 10 CFR 50.49 have been adequately addreseed, "basis configuration" ITAAC were established for applicable systems to verify these design aspects of electrical equipment important to safety. 
The deaign description identifies that Clas 1B equipment is seismic Catogory 1 and equipment located in a barah environment is qualified. A "benic configuration" ITAAC whes doveloped to include these areas.

\section{Redundancy and Independence}

To censure that the Clase 1B electric syctems meet the single failure requirements of ODC 17 (and other ODC), ITAC were established to verify the redundancy and independence of the Clase IB portion of the electrical deaign.

For the electrical systems, ITAAC verified the Clsas 1B divisional asaignments and independence of electric power by both inspections and tests. The independence is established by both electrical isolation and physical separation. Identification of the Class 1E divisional equipment is included to aid in demonstrating the separation. (The detailed requirements are epecified in the SSAR. For example, separation distances and identification are outlined in the SSAR.) Thees attributes aro verified all the way to the electrically powered loads by a combination of the electrical system ITAAC and the ITAAC of the individual fluid, I\&C, and HVAC ayetoms which also cover the electrical independence and divisional power mupply requirements.

\section{Capacity and Capability}

To casure that the oloctrical syetoms have tho capecity and capability to mupply the eafety-rolated electrical loads, ITAAC were eetablished to verify the adequate sizing of the electrical system equipment and its ability to respond (e.8., automatically in the times needed to support the accident analyees) to poetulated events. This includes the Class IE portion and the non-Class IE portion to the extent that it is involved in supporting the Class $1 E$ system.

ITAAC are included to analyzo the as-built electrical systom and installed equipment (diesel generators, transformers, switchgear, batteries, otc.) to verify its ability to power the loads. In addition, the ITAAC also includes teats to demonstrate the operation of the equipment.

To ensure that the Clase 1E portions of the electrical power system have the capability to respond to postulated evenis including LOCA, loss of normal preferrod power, and degraded voltage conditions, ITAAC were established to verify the initiation of the Class IE equipment necessary to mitigate the eveat.
ITAAC are included to analyzo the an-built electrical power aystem for its respones to a LOCA, lose of voltage, combinations of LOCA and loss of voltage, and degraded voltage. In addition, teats are included to demonstrate the ectuation of the electrical equipment in response to poetulated events.

\section{Eloctrical Protection Features}

To ensure that the eloctrical power system is protectod againet potential olectrical faults, ITAAC were established to verify the adequacy of the electrical circuit protection included in the design. Operating experience and NRC Electrical Distribution System Functional Inspections (EDSFIs) have indicated somo problems with the short circuit rating of some electrical equipment and breaker and protective device coordination.

ITAAC are included to apalyze the as-built electrical system equipment for its ability to withstand and clear electrical faults. ITAAC are also included to analyzo the protection feature coordination to verify its ability to limit the lows of equipment due to postulated faults.

\section{Displays, Alarms and Controls}

To help ensure that the electrical power system is available when required, ITAAC aro included to verify the existence of monitoring and controls for the electrical equipment. The minimum set of displays, alarms, and controls is based on the emergency procedure guidelines. In some cases, additional displays, alarms, and controls are epecified based on special considerations in the design and/or operating experience.

ITAAC are included to inspect for the ability to retrieve the information (displays and alarms), and to control the olectrical power system in the main control room and/or at locations provided for remote shutdown.

\section{Other Electrical Equipment Important to Safety}

In addition to the Class 1E syiciems addressed above, other aspects of the electrical design were deemed to be important to safety and the top-level design commitments were included in the CDM.

\section{Offsite Power}

To ensure that the requirements of GDC 17 for the adequacy and independence of the preferred offsite power sources within the ABWR scope were met, ITAAC were developed to verify the capacity and capability of the offsite sources to feed the Class 1E divisions, and the independence of those sources. 
ITAAC are included to inspect the direct connection of the offaile sources to the Clase 1E divisions and to inspect for the independence/separation of the offsite cources. Lightning protection and grounding features are inspected ss part of the configuration ITAAC.

In addition, the design description includes "interface" requirements for the portions of the offaite power outside of the ABWR scope, however no ITAAC aro included for the interfaces. The interfices dofino the requirements that the offaite portion of the design (that is out-of-ecope) must meet to support and not degrado the in-scope design.

\section{Containment Electrical Penetrations}

To ensure the containment electrical penetrations (both those containing Class 1E circuits and those containing Non Class 1E circuits) do not fail duo to electrical faults and potentially breach the containment, ITAAC were developed to verify that all eloctrical containment penetrations are protected against postulated currents greater than their continuous current rating.

ITAAC are included to inspect and analyze the electrical penetrations and their protectiun.

\section{Combustion Turbine Generator}

To ensure the availability of the combustion turbine generator (CTG) as an alternate AC source for station blackout events, ITAAC were developed to verify its inclusion in the design and its independence from other AC sources. In addition, the PRA has indicated that the CTO is relatively important from a risk perspective.

ITAAC are included to inspect and test the CTG and its auxiliaries.

\section{Lighting}

To ensure that portions of the plant lighting remain available during power failures, ITAAC were developed to verify the continuity of power sources for the lighting systems.

ITAAC are included to inspect and test the lighting and its power sources.

\section{Electrical Power For Non-Safety Plant Systems}

To ensure that electrical power is provided to support the non-safety plant systems, Design Descriptions cover portions of the non-Class 1E electrical systems. A basic configuration ITAAC verifies the functional arrangement and the Tier 1 design commitments for these areas.

\subsection{Fuman Factors Task Group Review}

The Human Factors task group had primery review responsibility for the main control penel, remote shutdown panol, and local control panels, deacribed in CDM Section 2.0. The group also reviewed CDM Section 3.1, "Human Factors Engineering." CDM Section 3.1 is discuseed further in Section 14.3.3.1 of this report. The teck group provided input to other tack groupe on the minimum inventory of alarms, controls, and indications for the control room and the RSS.

The besis for the task group's roviow in this area was a human factors cogineering (HFE) prognam review model (PRM) doveloped by the etaff. The staff's cortification reviow in the control room dosign area was based on a design and implementation process plan. The etaff informed the Commission of the development of the DAC in this are in SECY-92-299, "Development of Design Acceptance Criteria (DAC) for the Advanced Boiling Water Reactor (ABWR) in the Areas of Instrumentution and Controls (I\&C) and Control Room Design," dated August 27, 1992. In addition, the task group utilized the SRP in its review of the CDM. Other sources included applicable rules and regulations, RGs, USIs and GSIs, and operating experience.

The staff developed the HFE PRM, contained in Appendix J of this report, to serve as a tochnical basis for the review of the design process and DAC proposed by GE for certification of the ABWR control room and remote shutdown station design. The HFE PRM is (1) based upon currently accepted HFE practices, (2) well-defined, and (3) validated through experience with the development of complex, high-reliability systems in other industrial and military applications. The review model identifies the important HFE elements in a system dovelopment, design, and evaluation process that are necessary and sufficient requisites to successful integration of human factors in complex systems. The roview model also identifies aspects of each HFE element that are key to a safety review, and describes acceptance criteria by which the HFE elements can be evaluated. The HFE PRM has eight program elements, each of which contain both general and more specific acceptance criteria.

Part 52 requires applicants for design certification to meet the TMI requirements in 10 CFR $50.34(f)(2)$ (iii) for providing a control room design that reflects state-of-theart buman factors principles. GE did not develop a final control room and RSS design before design certification because this is an area of rapidly changing technology. Instead, GE provided the processes and acceptance criteria in CDM Section 3.1 and the detailed supporting information in SSAR Chapter 18 by which the details of 
the deaign in this area would bo doveloped, deaigned, and ovaluated. In lieu of having a completed control room deaign for review, the ataff concluded that it could make its safoty determination if $\mathrm{OB}$ mubmitted for certification an ecceptable proceses for the deaign of the control room. In addition, OB must have aubmitted a description of a minimum inventory of displays, controls, and alarms neceseary to accomplish the emergency proceduro guidelines (EPGs) and critical operator actions identified through GE's PRA analysis.

The proceenes and design acceptunce criteria in CDM Section 3.1, "Humen Factor Bngineering," apply to the human factore deaign of the control room and the RSS systems of the ABWR design. The detailed rupporting information for the human factors aspects of the ABWR control room and RSS design are provided in SSAR Chapter 18, "Human Factors," and together with the associated DAC in CDM Section 3.1, are evaluated in Chapter 18 of this report. OE provided amplifying information regarding the proceseses and CDM selection criteria in this aren in SSAR Section 14.3.3.1. The implementation of the process and the design is the responsibility of the COL applicant or licensee.

The staff requested that the minimum inventory of displays, controls, and alarms be developed through a task analysis of the operator actions necessary to carry out the EPGs and PRA critical actions. The staff's evaluation of the resulting minimum inventory encompassed a multidisciplinary effort consisting of human factors, I\&C, PRA, and plant, reactor, and electrical system engineering. The criteria used to determine acceptability of the inventory included assuring that: (1) the scope of these itoms in the EPGs and PRA effort were adequately considered, (2) the task analysis was detailed and comprehensive, (3) RG 1.97, category I variables for accident monitoring were included, and (4) important system displays and controls described in the Tier 1 system design descriptions necessary for transient mitigation were included.

The minimum inventory list for the control room was included in the CDM Section 2.7.1, "Main Control Room Panels." The controls and indicators required on systems to remotely shutdown the reactor are contained in CDM Section 2.2.6, "Remote Shutdown System." The items required for operation of the RSS are shown with an "R" on the figures for the individual systems. Detailed supporting information is contained in Chapter 7 of the SSAR. The individual systems that contained the sensors for the displays, controls, and alarms were reviewed to ensure that standard ITAAC entries were used to verify their function. The design processes and acceptance criteria specified in the DAC for I\&C equipment contained in CDM Section 3.4, particularly the verification and validation aspects of the IRC DAC, will verify proper operation of the LeC aspecti of the equipment. Similarly, the denign proceseses and DAC for HFB contrined in CDM Section 3.1, particularly the verification and validation aspects of the HFE DAC, will verify proper deaign of the equipment for human factors aspects.

\subsection{Radiation Protection Task Group Review}

The Radiation Protection Task Group had primary reviow reponsibility for the area radiation monitoring system, contrinment atmoepheric monitoring system, and emergency respones fecilities in CDM Section 2.0; the additional matorial in CDM Section 3.2, "Radiztion Protection," applicable to multiple systems of the dcsign; and solected sito parameters. CDM Section 3.2 is discuseed further in Section 14.3.3.2 of this report. Tho group had secondary review responsibility for all other ITAACs which addressed the plant radiation protection design or systems relied upon in the design-basis accidents (DBAs) dose essesement. These ITAACs included buildings, ventilation and filtration systems, primary containment, drywell bypass, post-accident sampling system, and site parameters (atmospheric dispersion).

The task group primarily utilized the SRP in its review of the CDM to determine the safety significance of SSCs. Other sources included applicable rules and regulations, GDCs, RGs, USIs and GSIs, NRC generic correspondence, and operating experience. The task group also used the draft review guidance for the design control document as an aid for consistency in its review of the systems.

The task group relied heavily on the material in CDM Section 3.2 during its review of the design. The design processes and acceptance criteria in this section were developed because GE did not provide sufficient information to stipulate the source terms needed to verify the design of the shielding, ventilation, and airborne radioactivity monitoring systems. Therefore, GE extracted the most important acceptance criteria for these design features from Chapter 12 of the SRP and put them into the DAC in CDM Section 3.2. A COL applicant or licensee must meet these criteria in the design of the plant, and the staff can audit the facility's design documentation to ensure that the criteria are met. The DAC are general criteria which apply to the design of shielding and ventilation systems throughout the plant. Therefore, there are no references to the DAC in the ITAACs for the buildings and systems.

The group reviewed the ITAAC for the are radiation monitoring system to ensure that the system provides information on radiation dose rates in the plant during normal operation and accidents and provides alarms to 
warn plent pernoned of chenges in thowe dow rates. The group reviewed the ITAMC for the contrinment atmoepheric monitoring systom to casure thet the syetem provides information on rediation dose rutes and gas concentrations during accideats and provides alarms to warn plant pernonnel of high levels of thew parameters. The group reviowed the ITAMC for emergency respones facilities to enmure that adequate fecilities are provided for the tochnical support center (TSC) and operational aupport center including espece, data retrieval and communications equipment, and a veatilation aystom to provido radiation protection.

The group reviowed several ITAAC for which the group had secondary review responsibility. The review of thees ITAAC was focused on verifying dokign foatures and assumptions upon which the radiological doee consequence assessment of the design basis accidents (DBAs) in this SER is based. The following discussion provides examples of some of the important design features and assumptions that are addressed in the CDM. The maximum MSIV closure time and maximum MSIV leakage rates will be verified by the ITAAC for the nuclear boiler system. The maximum primary containment leakage rate will be verified by the ITAAC for the primary containment system. The minimum radioiodine removal efficiency of the charcoal adsorbers in the atandby gas treatment systom (SGTS) filter trains and the maximum time for the SGTS to draw a specified negative pressure in the secondary containment will be verified by the ITAAC for the SGTS. The minimum radioiodine removal efficiency of the charcoal adsorbers in the control room and TSC ventilation system filter trains will be verified by ihe ITAAC for the HVAC systems. Capability of the main steam system to maintain structural integrity in an safe-shutdown earthquake (SSE) will be verified by the ITAAC for the turbine main steam system. Capability of the off-gas system to withstand an internal hydrogen explosion will be verified by the ITAAC for the off-gas system. In addition, the meteorological dispersion values assumed in the accident analyses were identified as bounding parameters for a site in CDM Table 5.0, ABWR Site Parameters. Also, the radiological analysis table in SSAR Section 14.3 was used to ensure that GE had addressed in the CDM the most important, though not necessarily all, of the key parameters in the accident dose analyses.

\subsection{Structural Task Group Review}

The Structural Task Group had primary review responsibility for building structures, chemical engineering systems, site parameters, piping DAC, reactor pressure vessel (RPV) system, and the legend for figures. The piping DAC contained in CDM Section 3.3 is discussed in Section 14.3.3.3 of this report. The task group had econdary reviow responalbilition for other ayctems a they relatad to MOVs, check valven, hydrontutic teats, and wiemic and afoty clanification of aystom, and for obiber structural aspects of sycteme. The tank sroup was componed of reviowere with experience in etructural, mechanical, muterials, and chomical cagincering. In addition, the tack group was augmentod by a upecialiat in MOVa, chock valves, and pumpe, a epecialist in soismic and afoty clasaification, and a epecialiat in chemical engineering.

The tank group primarily utilized rules and regulation to review the top lovel commitments in the CDM. Other cources included ROs, SRP guidelines, and PRA insights from ABWR safoty and sovero accident analyses and oparating experience. For selected portions of the reviow, the staff also adhered to policy discuesions by the Commission in the SRM related to SECY-90-016, "Evolutionary Light Water Reactor Certification Isaves and Their Relationship to Current Regulatory Requirements," as modified by the Commisaion guidance in the SRM related to SECY-93-087, "Policy, Technical, and Licensing Iseves Pertaining to Evolutionary and Advanced LightWater Reactor Designs." In addition, the task group roviowed the Tier 1 submittals (including the design deecription, figures, and ITAAC) of the deaign using the guidelines provided in the draft review guidance for the CDM as an aid for oetablishing consistency and completeness.

The task group reviewed the design description for those assigned systems to ensure that the certified design was consistent with the NRC regulations and policy decisions as discussed in SECY-93-087. The task group reviewed the Tier 1 material to assess whether a conclusion could bo reached that the ITAAC were necessary and sufficient to provide reasonable assurance that the facility has been constructed and will be operated in conformity with the license, the provisions of the Atomic Energy Act, and the Commission's rules and regulations.

The task group reviewed the design descriptions, figures, ITAAC, and the SSAR for consistency. The task group reviewed the CDM for all the systems to ensure consistency with the seismic and safety classification described in Section 3.2 of the SSAR. The task group ensured that the seismic classification of the system as described in the design description and the ASME Codo Class boundaries of the system as depicted on the figures was consistent with SSAR Section 3.2.

The task group reviewed the ITAAC for consistency with the preoperational tests specified in Chapter 14 of the SSAR. The task group reviewed the tests identified in the ITAAC tables to determine whether those tests have been 
appropriataly inoludad in SSAR Chapter 14 and aleo whether the preoperational teats huve been adequately incorponted into ITAAC. The tack group aleo reviowed teats in Chapter 14 of the SSAR or in the ITAAC that would require an enalyais to convert preoperational teat conditions to sccident conditions to ensure that the mothodology for performing the analyais was apecified adequatoly. In eddition, the tank group reviowed all syctem ITAAC to casure that eolected isaves were adequately and consietently treated in the CDM through the ues of the atandard ITAAC catries for besic configuration, hydrontatic teet, MOVs, and check valves.

The tack group ueod the following general spproach in roviowing tho deaign description, figures, and ITAAC and for cetablishing what information ahould reside in each tier. The certified deaign (design dexcription) should contain top lovel design, fabrication, testing, and performance requirements for SSCs important to safety. ITAAC are extablished, in part, to verify that these top-lovel (Tier 1) decign, fabrication, testing and performance requirements are met when the plant is built.

Although the eetablishment of what apecific information was to bo included in the dosign description was esentially a matter of judgemeat, the draft review guidance provided some guidance for consiatency in certain areas regarding what information should be in which tier as well as whether an inspection, test or analysis was required to be performed. The draft roviow guidance also provided a besis for the staff's judgement in selecting which tier the information should reside and why an ITAAC wus deemed necessary. These areas include component welding, equipment soismic qualification, pumps, valves, and piping systems. The basis for selecting these areas included its importance to anfety as well as its past experience with construction and operating problems.

Design descriptions and ITAAC were developed and grouped by systems and building structures. These Tier 1 requirements for systems and building structures are typically verified by inspections, tests, and analyses specified in the system ITAAC. For example, system-specific performance tests are typically conducted to demonstrate that the system can perform its intended function. For building structures, the structural capability is typically verified by performing an analysis to reconcile the as-built data with tho structural design beses for each safety-related building.

For components, the verification of design, fabrication, testing, and performance requirements are partially addressed in conjunction with the specific system ITAAC. For example, a teat is typically performed to verify the ability of a motor-operated valve to close under design- beais fluid conditions. However, performance teuts are not protical for verifying certain component design requirements such wo its soismic deaign or cafoty clasificatioa. Therefore, ITAAC have been doveloped to verify cortain areas where performance teats aro not practical. These areas include seismic design qualification and fabrication (i.e., welding) of components. The ITAAC for coismic deaign qualification and fabrication of components are cutabliahed on a generic basis in the genoral proviaions for verifying the besic configurations of systems rather then on an individual component basis.

The Tier 1 treatmeat of the desigm qualification and fabrication of components was reviewed to ensure that the isaves were verified by ITAAC as discuseed below:

\section{Fabrication of Components}

A besic configuration check (system) is required in each individual system ITAAC. The configuration check includes an inspection of the welding quality for all ASME Codo Class 1, 2, and 3 piping systems. A hydrotest is also required in each aystem ITAAC for ASME Code Class 1, 2, and 3 piping syatems to verify that, in the process of fabricating thr overall piping systom, the welding and bolting iequirements for ensuring the pressure integrity have been met. The methods to be used by the COL applicant or licensece to verify the acceptability of the welds are discussed in the SSAR in the sections applicable to the specific component or structure.

\section{(2) Design Qualification of Components}

(a) Safety Classification - The safety classification of SSCs are describel in each system's design description. The functional drawings identify the boundaries of the ASME Code classification that are applicable to the safety class. The piping DAC includes a verification of the design report to ensure that the appropriate code design requirements for the system's safety class have been implemented.

(b) Mechanical and Electrical Equipment (including I\&C) - A basic configuration check (system) is required in each individual system ITAAC. The configuration check includes an inspection of the as-built equipment (including anchorages) and a review of the qualification records to verify that the equipment in its as-built condition is seismically qualified. The material in SSAR 
Section 3.10.1 providen dotuiled supporting information for the CDM regarding the mothods to be used by the COL applicant or licenses for the dynamic qualification of equipment. This material, if considered for a change by an applicant or liceasco that seferences the certified ABWR desiga, would conatituto an unroviowed safoty queation, and therefore, would require NRC roviow and approval prior to implementation of the change. This material supporting the CDM is discuesed further in Section 3.10 of this report.

(c) Valves - The verification of the deaign qualification of valves is performed in conjunction with the basic configuration check for mochanical equipment as discuseed above. Specifically, for MOVs, a special inspection is required as a part of the basic configuration check to verify the records of vendor tests that demonstrate the ability of MOVs to function under design conditions. In addition, in-situ tests are required for MOVe and check valves in anch system ITAAC. These tests will be performed during the initial test program. Tho material in SSAR Section 3.9.6.2.2 provides detailed supporting information for the CDM regarding the methods to be used by the COL applicant or licenseo for the design, qualification, and testing of MOVs to demonstrate their design basis capability. This material, if considered for a change by an applicant or licensee that reforences the certified ABWR design, would constituto an unreviewed anfety question, and therefore, would require NRC review and approval prior to implementation of the change. This material supporting the CDM is discussed further in Section 3.9.6 of this report.

(d) Piping - The verification of the overall piping design including the effects of highenergy line breaks and the application of leak-before-break (as applicable) is performed in conjunction with the piping DAC. The ss-built piping system is required to be reconciled with the design commitments. The material in SSAR Section 3.12 provides detailed supporting information for the CDM tegarding the analysis mothods and design criteria to be used by the COL applicant or licensee to complete the piping design. This material, if considered for a change by an applicant or licensece that roforences the certified ABWR deaign, would conetitute an unroviowed anfety queation, and therefore, would require NRC review and approval prior to implementation of the change. This material aupporting the CDM is discuseed further in Section 3.12 of this report.

\section{Beviey of the ABWR StructumL Dexion Integrity}

The scope of structural dosign cover the major structural syctems in the ABWR plant including the RPV, ASME Code Class 1, 2, and 3 piping systems, and major building atructures (primary containment, reactor building, control building, turbine building, service building, and radwasto building). The RPV, piping systems, and primary containmeat are included because they provide the defensein-depth principle for nuclear plants. The major building etructures house those systems and components that aro importent to safoty.

In establishing the top level requirements for structural design, the staff used the General Design Criteria (GDC) of 10 CFR Part 50, Appendix A, as its basis. The primary general design criteria pertaining to the major structural system design aro GDC 1, "Quality Standards and Records," GDC 2, "Design Bases for the Protection Against Natural Phenomena," ODC 4, "Environmental and Dynamic Effocts Design Basis," ODC 14, "Reactor Coolent Pressure Boundary," GDC 16, "Containment Design," and GDC 50, "Containment Design Basis."

GDC 1 requires, in part, the need for structures, systems and components important to safety to be doaigned, fabricatod, erectod, and testod to quality standards commensurate with the importance of the safety functions to be performed.

GDC 2 requires, in part, the need to design structures, systems, and components important to safety to withstand tho effects of natural phenomena such as earthquakes, tornados, hurricanes, and floods without loss of capability to perform their safety functions, including the appropriate combinations of the effects of normal and accident conditions with the effects of the natural phenomena.

ODC 4 requires, in part, the need to protect structures, systems, and components important to safety from dynamic effects including the effects of missiles, pipe whipping, and discharging fluids that may result from equipment failures and from events and conditions outside the nuclear power unit. 
ODC 14 requires, in part, the need for the resctor coolant preasure boundary to be deaigned, fabricated, erected, and toeted so as to have an axtremely low probability of abnormal leakage, of rapidly propagating failuro, and of grose rupture.

ODC 16 requires, in part, the need for the reactor containment to provide an caveatially leak-tight barrier against uncontrolled release of radioactivity to the environment.

ODC 50 requires, in part, the need for the reactor containment etructure including ecceses openinge and penotrations to be deaigned so that the containement structure and its internal compartments can sccommodato, without exceeding the design leakage rate and with aufficient margin, the calculated preseure and tomperature conditions resulting from any loes-of-coolant accident.

Using the above GDC as its basis, the ataff eatablished the following top-level attributes to be verified by ITAAC:

(1) preamuro boundary integrity (GDC 14, 16 and 50)

(2) normal loads (ODC 2)

(3) soiamic loads (ODC 2)

(4) suppression pool hydrodynamic loads (ODC 4)

(5) flood, wind, and tornado (ODC 2)

(6) rain and snow (GDC 2)

(7) pipe rupture (ODC 4)

(8) codes and standards (GDC 1)

In addition, to ensure that the final as-built plant conforms to the certified design, GE provided ITAAC to reconcile the as-built plant with the etructural decign basis. A summary of the top-lovel structural design requirements for the major structural systems that are verified by the structures and systems in CDM Section 2.0 and the piping design information in CDM Section 3.3 is provided below.

\section{Pressure Boundary Integrity}

To ensure that the applicable requirements of GDC 14,16, and 50 have been adequately addreseed, ITAAC were established to verify the preseure boundary integrity of the RPV, piping, and primary containmeat for tho ABWR. ODC 16 and 50 apply 'to the primary containment and GDC 14 applies to the RPV and the reactor coolant pressure boundary piping systems. The preesure integrity for these major structural systems are needed to ensure the defenso-in-depth principle.

For the RPV and piping, hydrostatic tests performed in conjunction with the ASME Boiler and Pressure Vessel
Cods, Section III are required by ITAAC. For the priasary containment, a structural integrity teat is required by ITAC to be performed on the preseure boundary composeats of the primary containment in accordance with the ASME Boiler and Preasure Veasel Codo, Section III. Because the requirements of GDC 14, 16, and 50 do not apply to the reactor, control, turbino, service, and mdwatt buildinge, ITAAC were not required to verify the preacure integrity for these other buildings.

\section{Normilloadr}

To eneure that the applicable requirements of ODC 2 have been adequatoly addreseed, ITAAC were established to verify that the normal and accideat loads have been appropriately combined with the offects of natural phecomena.

For piping systoms, ITAAC require an analysis to reconcile the a-built piping design with the design-basis loads (which include the appropriate combination of normal and accident loads). For the RPV, the fabrication is performed primarily in the vendor's shop where edherence to design drawings is tightly controlled. Therefore, ITAAC for the as-built reconciliation of normal loade with eccident loads for the RPV were deemed to be inappropriate. Instead, ITAAC verify that the ASME Codo-required reports exist to document that the RPV hes been dosigned, fabricated, inspected, and tested to Code requirements to ensure adequate safety margin.

Similarly, for safety-related buildings, ITA AC require an analyeis for reconciling the as-built plant with the structural deaign basis loads (which include the combination of normal and sccident loads with the effects of natural phesomena). The analysis results are to be documented in a aructural analysis report, the scope and contents of which are deecribed in the SSAR. The staff determined that the derign of certain structures did not require verification by ITAAC, based on their safety significance. In particular, these ITAAC apply only to safety-related structures and are not applicable to the service and turbine buildinge.

\section{Soinmic Load}

To ensure that the applicable requirements of GDC 2 have been adequately addressed, ITAAC were established to verify that the safety-related systems and structures have been designed to seismic loadings. Component qualification for soismic loads is addressed by ITAAC that were established for verifying the basic configuration of systems. 
As discussed above for normal loads on piping systems and the RPV, ITAAC require an analysis to reconcile the asbuilt piping design with the design basis loads (which include seismic loads). For the RPV, ITAAC for the asbuilt reconciliation of seismic loads for the RPV were deemed to be inappropriate as previously discussed. Instead, ITAAC verify that the ASME Code-required reports exist for the RPV ensuring that the RPV has been designed, fabricated, inspected, and tested to ASME Code requirements.

For safety-related buildings, ITAAC require an analysis for reconciling the as-built plant with the structural designbasis loads (which include seismic loads). The analysis results are to be documented in a structural analysis report, as discussed above. These ITAAC apply only to safetyrelated structures and are not applicable to the service and turbine buildings. However, because the leakage path for fission products includes components within the turbine building, the turbine building is required to withstand the effects of a safe-shutdown earthquake. Therefore, ITAAC were established to verify that, under seismic loads, the collapse of the turbine building will not impair the safetyrelated functions of any structures or equipment located adjacent to or within the turbine building.

For non-seismic Category I SSCs, the need for ITAAC to verify that their failure will not impair the ability of nearby safety-related SSCs to perform their safety-related functions was assessed. Because the design detail and asbuilt and as-procured information for many non-safetyrelated systems (e.g., field-run piping and balance-of-plant systems) are not required for design certification and the spatial relationship between such systems and seismic Category I SSCs cannot be established until after the asbuilt design information is available, the non-seismic to seismic (II//) interaction cannot be evaluated until the plant has been constructed. Accordingly, the design criteria for ensuring acceptable II// interactions and a commitment for the COL applicant to describe the process for completion of the design of balance-of-plant and non-safety related systems to minimize II/I interactions and proposed procedures for an inspection of the as-built plant for II/I interactions have been specified as a COL action item in the SSAR.

\section{Suppression Pool Hydrodynamic Loads}

To ensure that the applicable requirements of GDC 4 have been adequately addressed, ITAAC were established to verify that the safety-related systems and structures have been designed to suppression pool hydrodynamic loadings, which include safety relief valve discharge and loss-ofcoolant accident (LOCA) loadings. Component qualification for suppression pool hydrodynamic loads is addreseed by ITAAC established for verifying the basic configuration of systems.

As discussed above for seismic loads on piping systems and the RPV, ITAAC require an analysis to reconcile the as-built piping design with the design-basis loads (which include suppression pool hydrodynamic loads). For the RPV, ITAAC verify that the ASME Code-required reports exist to ensure that the RPV has been designed, fabricated, inspected, and tested to ASME Code requirements.

For the reactor building and primary containment including the internal structures, ITAAC require an analysis for reconciling the building as-built configuration with the structural design basis loads (which include suppression pool hydrodynamic loads). The as-built analysis results are to be documented in a structural analysis report as discussed above. The effects of suppression pool hydrodynamic loads do not extend beyond the reactor building, and, thus, ITAAC are not required to verify these loadings for the other ABWR building structures.

ITAAC also require the verification of the horizontal vent system, water volume, and the safety-relief valve discharge line quencher arrangement to ensure adequacy of the suppression pool hydrodynamic loads used for design.

\section{Elood Wind Tomado Rain, and Snow}

To ensure that the applicable requirements of GDC 2 have been adequately addressed, ITAAC were established to verify that the safety-related systems and structures have been designed to withstand the effects of natural phenomena other than those associated with seismic loadings. The offects include those associated with flood, wind, tornado, rain, and snow.

These loadings do not apply to the RPV, the ASME Code Class 1, 2, and 3 piping systems and components, nor tho primary containment because they are all housed within the safety-related buildings. For safety-related buildings, ITAAC require an analysis for reconciling the as-built plant with the structural design basis loads (which include the flood, wind, tornado, rain, and snow loads). Based on their safety significance, these ITAAC apply only to safety-related structures and are not applicable to the service and turbine buildings.

For flooding, ITAAC also require inspections to verify that water-tight doors exist, penetrations (except for water-tight doors) in the divisional walls are at least $2.5 \mathrm{~m}$ above the floor, and safety-related electrical, instrumentation, and control equipment are located at least $20 \mathrm{~cm}$ above the floor surface. In addition, for safety-related buildings, ITAAC require that external walls below flood level are 
equal to or greater than $0.6 \mathrm{~m}$ to protect against water seopage, and penetrations in the external walls below flood lovel are provided with flood protection features.

\section{Pipe Break}

To ensure that the applicable requirements of ODC 4 have been adequately addressed, ITAAC were established to verify that the safety-related SSCs have been designed to the dynamic effects of pipe breaks. Component qualification for the dynamic effects of pipe breaks is addressed by ITAAC established for verifying the besic configuration of systoms.

For the RPV, ITAAC that verify the besic configuration of the RPV system require an inspection of the critical locations that establish the bounding loads in the LOCA analyses for the RPV to ensure that the as-built areas not exceed the postulated break areas assumed in the LOCA analyses.

In addition, ITAAC have been established to verify by inspections of as-built, high-energy pipe break mitigation features and of the pipe break analysis report that safetyrelated SSCs be protected against the dynamic and environmental effects associated with postulated high-energy pipe breaks. ITAAC to verify pipe break loads are not required for the turbine, service, and radwaste buildings either because they are not safetyrelated structures or there are no high-energy lines located within the structure.

\section{Codes and Standards}

To ensure that the applicable requirements of GDC 1 have been adequately addressed, ITAAC were established to verify that appropriate codes and standards were used in the design and construction of safety-rolated systems and components. In general, the staff considered those codes and standards endorsed by the regulations under 10 CFR $50.55 \mathrm{a}$ in determining which codes and standards were appropriate for Tier 1 verification. The ASME Boiler and Pressure Vessel Code, Section III for Code Class 1, 2, and 3 systems and components was established as the code for the design and construction of ABWR piping systems and the RPV. For safety-related building designs, the staff based its safety findings on audits of ABWR design calculations which relied on specific codes and standards. These codes and standards are contained in SSAR Sections3.8.1, 3.8.2, 3.8.3, 3.8.4, and 3.8.5, and were identified in Section 3.8 of this report as material that, if considered for a change by an applicant or licensee that references the certified ABWR design, would constitute an unreviewed safety question, and therefore, would require NRC review and approval prior to implementation of the change.
Inspections will be conducted as a part of ITAAC to verify that ASME Code-required documents exist that demonstrate that the RPV, piping systems and containment pressure boundaries have been designed and constructed to their appropriate Code requirements. For other ASME Code components and equipment, the verification of Code compliance will be performed in conjunction with the quality assurance programs and by the authorized inspection agency as required by the ASME Boiler and Pressure Vessel Code.

\section{As-built Reconciliation}

To ensure that the final as-built plant structures are built in accordance with the certified design as required by 10 CFR Part 52, structural analyses will be performed which reconcile the as-built configuration of the plant structures with the structural design bases of the certified design. The structural analyses will be documented in structural analysis reports. Structural analysis reports will be verified in conjunction with ITAAC for the primary containment and the reactor, control, radwaste, and turbine buildings. The detailed supporting information on what is required for an acceptable analysis report is contained in SSAR Chapter 3.

Similarly for piping systems, an as-built analysis will be performed using the as-designed and as-built information. ITAAC will verify the existence of acceptable final as-built piping stress reports that conclude the as-built piping systems aro adequately designed.

For the RPV, the key dimensions of the RPV system will be verified in conjunction with the basic configuration check of the system. The key dimensions of the RPV system and the acceptable variations of the key dimensions are provided in the certified design description.

For component qualification, tests, analyses, or a combination of tests and analyses will be performed for seismic Category I mechanical and electrical equipment (including connected instrumentation and controls) to demonstrate that the as-built equipment and associated anchorages are qualified to withstand design basis dynamic loads without loss of safety function. These test and analyses will be performed as a part of ITAAC to verify the basic configuration of the system in which the equipment is located.

\subsection{Instrumentation and Controls (I\&C) Task Group Review}

The I\&C Task Group's primary review responsibilities included a review of the CDM for I\&C systems involving core protection and control, other miscellaneous I\&C 
Initial Test Program

systems, the additional I\&C material in CDM Section 3.4 applicable to multiple systems of the desiga, and selected interface requirements. The material in CDM Section 3.4 is discussed further in Section 14.3.3.4 of this report. The group's secondary seview responsibilities included ESF systems, reactivity control systems, and other systems using I\&C equipment.

The figures in CDM Section 3.4 depict both safety-related and non-safety-related systems of the design. The block concept was used for developing the system control interface diagrams that were needed for depicting the configuration of the I\&C system architecture. The I\&C design described in the SSAR was to the level of control functional blocks, and therefore, the configuration in the CDM was to the same level.

The CDM entries were reviewed to confirm that the safety-related I\&C system met the protection systems requirements of 10 CFR $50.55 \mathrm{a}(\mathrm{h})$, as well as the quality standards and records requirements of GDC 1 , the protection against natural phenomenon requirements of GDC 2, the environmental and dyamic effects requirements of GDC 4, the instrumentation and control requirements of GDC 13, the control room requirements of GDC 19, the protection system design requirements of GDC 20, the protection system reliability and testability requirements of GDC 21 , the protection system independence requirements of GDC 22, the protection system failure modes requirements of GDC 23, the protection system requirements for reactivity control malfunctions of GDC 25, and the protection against anticipated operational occurrences requirements of GDC 29. To meet the criteria of 10 CFR 50.55a(h), "Criteria for Protection Systems for Nuclear Generating Stations," and IEEE Standard 279-1971, the ITAAC entries were reviewed considering the following design issues:

(1) General fuactional requirements for the system

(2) Single failure criterion

(3) Quality of components and modules (hardware and software)

(4) Equipment qualification

(5) Channel integrity and channel independence

(6) Classification of equipment

(7) Isolation devices

(8) Single random failure
(9) Systom inputs

(10) Capability for sensor checks, tests and calibration

(11) Channel bypasees, operating bypasses, indication of bypasses, and access to means for bypassing

(12) Completion of protective action once initiated

(13) Manual initiation

(14) Information read-out

(15) Identification

Standard ITAAC entries for several attributes of the I\&C system were developed and used for basic configuration, divisionalized power supply, electrical isolation and physical separation (independence), and control room and remote shutdown system configuration. For those systems reviewed that were not safety-related systems, appropriate criteria from the SRP applicable to those systems were used.

For the microprocessor and digital control technology aspects of the I\&C system design of the ABWR, GE did not provide complete design information in the SSAR. This was because the technology in this area is rapidly evolving and it is, therefore, important that the certified design description and ITAAC not "lock in" a design which could be obsolete at the time of construction. The process to complete the design, with appropriate acceptance criteria, is specified in CDM Section 3.4, with detailed supporting information in SSAR Chapter 7. The issues discussed in that material include the SSLC system, hardware and software development, electromagnetic compatibility, instrument setpoint methodology, environmental qualification of I\&C equipment, and I\&C system diversity and defense-in-depth considerations. Since the additional CDM information in CDM Section 3.0 apply to both safety- and non-safety-related I\&C systems, the staff relied heavily on the information contained in those references in its reviews of the I\&C systems.

The CDM Section 3.0 and SSAR contain criteria which describe the method to develop plans and procedures that will guide the design process throughout the lifecycle stages. The ITAAC provides the acceptance criteria for verifying the design through the stages while the SSAR adds the set of guidelines and standards that will provide more detailed criteria for the development of the design. The CDM has been written to incorporate the most important and general aspects (top-level requirements) from the 
standards. The set of standards and criteria in the SSAR encompass the guidance for generating the plans that will be used in the computer software and hardware design process for the computer design throughout the lifecycle.

The certified design description and design dovelopment process continue for the lifetime of the plant. Any safetyrelated software that is changed or added after plant startup is required to either be developed using the certified design development process described in the computer CDM, or the licensee must submit a design process (together with the design bases) description that will produce software of the same or higher quality than the original certified design process, consistent with the CDM. The licenser will be required to use the approved software change procedure (SCP) based upon the certified design development process for the operation stage of the lifecycle.

\subsubsection{Approval of the CDM for Structures and Systems}

The staff performed a multidisciplinary review, utilizing several task groups, of the SSCs of the ABWR, in accordance with 10 CFR Part 52 and the guidance provided in SRMs related to design certification applications provided by, the Commission. This review included information contained in multiple CDM and SSAR submittals to the staff, as discussed in the background portion of Section 14.3 of this report.

Based on the task group reviews, the staff concludes that the top-level design features and performance characteristics of the SSCs important to safety in the ABWR are appropriately described in the design descriptions of the CDM, and are acceptable.

Further, these top-level design features and performance characteristics can be adequately verified by the ITAAC provided by GE. Therefore, the staff concludes that the ITAAC in the CDM are necessary and sufficient to provide reasonable assurance that if the inspections, tests, and analyses are performed and the acceptance criteria met, the SSCs important to safety in a facility that references the design have been constructed and will operate in accordance with the design certification and applicable regulations.

\subsubsection{DFSER Issues}

Section 2.0, "Tier 1 Material for ABWR Systems, " of the "Tier 1 Design Certification Material for the GE ABWR," was under staff review at the time the DFSER was issued. The staff stated that the final evaluation would be provided in the FSER. This was DFSER Open Item 14.1.2-1.
The DFSER contained preliminary comments on the second stage submittal of the CDM, titled "Tier 1 Design Certification Material for the GE ABWR Design - Stage 2 Submittal," dated March 31, 1992. These preliminary comments were documented in many sections of the DFSER based on their relationship to the detailed design information in various SSAR sections. The preliminary comments provided in the DFSER were intended to discuss the philosophy of development of the Tier 1 design certification material, to establish early staff positions on the material, and to provide an indication of the status of development of the material.

GE provided resolutions to all of the staff's comments in various revisions to the Tier $1 \mathrm{CDM}$, and provided revised supporting design information in various SSAR amendments, as discussed in the background part of Section 14.3 of this report. In these submittals, GE addressed all of the comments of the staff, the ACRS, and an independent review group. Based on the revised material in the CDM and SSAR submittals, the CDM development process, criteria, and methodology described in SSAR Section 14.3, and the review process discussed in this section of this report, the staff concluded that these issues were adequately addressed where appropriate in the CDM. This resolved DFSER Open Item 14.1.2-1.

The following is a list of issues identified in the DFSER that specifically cited the Tier 1 material, and that were resolved as discussed above. This list of issues considered for treatment in the CDM is not all-inclusive, nor were all issues listed necessarily incorporated into the final CDM. The staff considered many issues for treatment in the CDM, using general approach and criteria discussed in this section of this report. Other specific issues considered for treatment in the CDM may also be discussed where applicable in other sections of this report.

\section{ITAAC Open Items In DFSER}

Item Number Description of Item

2.6-1 Additional Site Parameters from Tier 1

3.2.1-3 ITAAC-plant specific walkdown

3.4.1-2 ITAAC-flood protection

3.5.1.1-1 ITAAC-protect SSCs from internally-generated missiles

3.5.1.2-2 ITAAC-protection of safety-related (SR) equipment from missiles 
ITAAC Open Itoms In DFSER

Item Number Description of Item

3.5.1.4-1

ITAAC-missiles generated from natural ovents

3.5.2-1

ITAAC-protect S/R SSCs from failure of non-S/R SSCs

3.5.2-2 ITAAC-protect SSCs from externally-generated missiles

3.6.1-1 ITAAC-protection of safety equipment from DBA

3.8.6-1 ITAAC-generic building design concerns (11 items)

3.8.6-2 ITAAC-SW design concerns (2 items)

3.8.6-3 ITAAC-containment design concerns (4 items)

3.8.6-4

3.8.6-5

ITAAC-containment structures design concerns ( 2 items)

ITAAC-reactor vessel pedestal design concerns (3 items)

ITAAC-reactor building design concerns (6 items)

ITAAC-control building design concerns (4 items)

ITAAC-radwaste building design concerns ( 2 items)

3.8.6-9 ITAAC-yard structures-stack systems design concerns (3 items)

3.9.6.4-1 ITAAC-generic MOV sizing

3.11.3-1 ITAAC-equipment qualification (EQ) radiation concern

4.4-2 ITAAC-LPMS consistent with

RG 1.133

4.6-1 ITAAC-control rod drive system

5.2.2-1 ITAAC-safety relief valve and fuel

5.2.5-1 ITAAC-reactor coolant system leakage detection

$5.4 .1-1$

ITAAC-recirculation flow control

$5.4 .6-1$

ITAAC-reactor core isolation cooling
7.1.4-1

7.2.2.3-1

7.2.8-1

Item Number

$5.4 .7-1$

6.2.1.7-1

6.2.3.1-1

6.2.4-1

6.2.4.1.4

6.2.6-9

6.3.6-1

6.4-1

6.4-2

7.1.3.3-1

(2.2.3.1

7.4.1-1

7.4.2-1

7.6.1-1

7.7.1-1

8.2.1.4-1

8.2.2.1-1

8.2.2.1-2

8.2.2.2-1

8.2.2.3-1

8.2.2.4-1
ITAAC-residual heat removal

ITAAC-containment design

ITAAC-functional of secondary containment

ITAAC-standby gas treatment system

ITAAC-containment isolation system

ITAAC-containment leak testing

ITAAC-high pressure core flooder

ITAAC-control room habitability

ITAAC-control room environmental design

ITAAC/DAC-instrument setpoints, safety system logic and control, EQ, computer development

ITAAC/DAC-neutron monitoring systems

ITAAC-timeout predetermined safe states

ITAAC-safety hazards, sneak circuit, timing analyses

ITAAC-systems required for safe shutdown

ITAAC-use of remote shutdown panel

ITAAC-interlock systems

ITAAC-key features of the control system

ITAAC-interfaces

ITAAC-physical separation (circuits and transformers)

ITAAC-circuit separation

ITAAC-physical separation (power, instrumentation, etc.)

ITAAC-electrical independence

ITAAC-testing of the offsite power system 
ITAAC Open Item In DFSER

Item Number Description of Item

8.2.2.6-1 ITAAC-capacity and capability of the offsito power system

\subsubsection{7-1 ITAAC-electrical grounding}

8.2.3.1-1 ITAAC-independence between offsite circuits and Cless 1E

8.3.2.8-1

ITAAC-independence during parallel operations operations

8.2.3.3-2

ITAAC-LOOP during parallel operations

8.3.3.1-1

8.3.3.2-1

Practediesel generator (DG)

8.2.3.3-3

8.2.3.3-4

8.2.3.4-1

8.2.3.4-2.

8.2.3.4-3

8.3-1

8.3.1.2-1

8.3.2.1-1

8.3.2.2-1

8.3.2.3-1

8.3.2.4-1

8.3.2.4-2

8.3.2.4-3

8.3.2.5-1 operating
8.3.3.3-1

8.3.3.4-1

8.3.3.6-1

8.3.3.7-1

8.3.3.8-1

8.3.3.10-1

8.3.3.11-1

8.3.3.12-1

8.3.3.13-1

8.3.3.14-1

8.3.3.15-1

8.3.3.16-1
ITAAC-separation of non-Class $1 E$ from Class 1E

ITAAC-separation/protection of cables outside cabinets and panels

ITAAC-separation between Class IE \& non-Class $1 E$

ITAAC-separation between Class 1E penetrations

8.3.4-1

8.3.4.1-1
8.3.3.5-2
ITAAC-separation of cables inside cabinets/panels

ITAAC-separation of cables approsching/exiting cabinets

ITAAC-independence/physical separation of equipment

ITAAC-ID power, instrumentation, control equipment

ITAAC-ID neutron monitoring, scram solenoid

ITAAC-protection of electrical penetrations

ITAAC-design and qualification of electrical equipment

ITAAC-seismic qualification of light bulbs

ITAAC-submergence

ITAAC-protection of redundant Class IE (environment)

ITAAC-associate circuits

ITAAC-diesel generator protective relaying bypass

ITAAC-thermal overload

ITAAC-protective relay

ITAAC-fault interrupting capacity

ITAAC-control of design parameters for MOV

ITAAC-separation of raceways

ITAAC-electrical protection for scram and MSIV

ITAAC-safety buses grounding

ITAAC-control of access to Class 1E equipment

ITAAC-electrical independence

ITAAC-interconnections 
UTAC Open Itoms In DESER

Item Numbar Description of Item

8.3.4.2-1 ITAAC-CVCF power supplies

8.3.4.4-1 ITAAC-isolation between safety and non-safety buses

8.3.5-1 ITAAC-lighting system under design basis accident

8.3.5-2 ITAAC-lighting requirements

8.3.6.1-1 ITAAC-control of the electrical design process

8.3.7-2 ITAAC-testing surveillance

8.3.8.1-1 ITAAC-non-safety dc power system

8.3.8.2-1 ITAAC-capacity of the Class 1E 125v dc battery supply compliance

8.3.9.2-1 ITAAC-SBO copir \& capability

8.3.9.3-1 ITAAC/DAC

9.1.1-1 ITAAC-change new fuel storage interface to ITAAC

9.1.2-1 ITAAC-change spent fuel storage interface to ITAAC

9.1.2-2 ITAAC-review fuel storage facility ITAAC and T1

ITAAC-fuel pool cooling and cleanup system

9.1.4-1 ITAAC-light load handling system

9.1.5-1 ITAAC-reactor building crane capability under safe shutdown earthquake

9.2.4-2 ITAAC-sanitary and potable water system
9.2.12-1

9.2.13-1

9.2.14-1

9.2.15-2

9.2.16-2

9.3.1-3

9.3.2.2-3

9.3.5-1

ITAAC Open Items In DFSER

Item Number Deacriotion of Item

9.2.5-1 ITAAC-ultimato heat sink

9.2.8-1 II,AAC-makeup water system (preparation)

ITAAC-makeup water condensate system

ITAAC-makeup water (purifiod) systom

ITAAC-reactor building cooling water system

ITAAC-heating, ventilation, and air conditioning (HVAC) normal cooling water

ITAAC-HVAC emergency cooling water system

ITAAC-turbine building cooling system

ITAAC-reactor service water system

ITAAC-turbine service water system

ITAAC-compressed air systoms

ITAAC-post accident sampling system (PASS)

ITAAC-standby liquid control system (SLCS)

9.3.8-1 ITAAC-radianctive drain transfer system

9.3.9-1 ITAAC-hydrogen wator chemistry

9.3.10-1 ITAAC-oxygen injection

9.3.11-1 ITAAC-zinc injection system

9.4-1

ITAAC-HVAC systems

9.5.1.3-1 ITAAC-fire protection system

9.5.4.1-2 ITAAC-DG and auxiliary system, fuel oil storage and transfer

9.5.5-1 ITAAC-put interfaces into ITAAC

10.2.1-1 ITAAC-turbine generator

10.2.2-1 ITAAC-turbine disk test data 
Initial Test Program

\section{ITAAC Open Itoms In DESER}

Item'Number Description of Item

10.2.2-2 ITAAC-design beses for turbine design overspeed

10.3.1-1 ITAAC-main steam (7 itoms)

10.4.1-1 ITAAC-main condenser

10.4.2-1 ITAAC-main condenser evacuation system (7 items)

10.4.3-1 ITAAC-turbine gland seal system (7 items)

10.4.4-1 ITAAC-turbino bypass (7 items)

10.4.5-1 ITAAC-circulating water system (10 items)

10.4.7-1 ITAAC-condenser/feedwater (7 items)

11.0-1 ITAAC-radwaste syitiem

12.3.5.3-1 ITAAC and Tier 1 radiation design submittal

13.3-3 ITAAC and Tier 1 for technical support center and operations support center

13.6.3.6-1 ITAAC-verify HVAC bulletproof features

14.1.1.5.2-1 ITAAC-roadmap of key analyses

14.1.1.5.3-1 ITAAC-certain systems may not have ITAAC

14.1.2-1 ITAAC-staff evaluation of system ITAAC

14.1.3.1-1 ITAAC-staff evaluation of generic ITAAC

14.1.3.3.3.6-1 ITAAC-structural design of small bore piping

14.1.3.3.3.9-1 ITAAC-buried piping design

14.1.3.3.4.1-1 ITAAC-confirmatory analysis on computer model adequacy

14.1.3.3.4.3-1 ITAAC-piping benchmark program

14.1.3.3.4.4-1 ITAAC-small bore piping decoupling criteria
ITAAC Open Itemis In DFSER

Item Number Descriotion of Item

14.1.3.3.5.2-1 ITAAC-60 year life cycle factor of 1.5

14.1 3.3.5.7-1 ITAAC-environmental effects in fatigue design, Cl. 1

14.1.3.3.5.7-2 ITAAC-method of including environmental effects of fatigue

14.1.3.3.5.8-1 ITAAC-environmental effect in fatigue design, $\mathrm{Cl} .2$

14.1.3.3.5.10-1 ITAAC-methodology to address thermal striping

14.1.3.3.5.13-1 ITAAC-inertial and seismic motion effocts

14.1.3.3.5.17-1 ITAAC-modal damping for composite structures

14.1.3.3.5.18-1 ITAAC-minimum temperature for thermal analyses

14.1.3.3.6-1 ITAAC-pipe support criteria (8 items)

14.1.3.3.7-1 ITAAC-high energy line break criteria

14.1.3.3.9.1-1 ITAAC-fatigue cumulative usage factor of 1.0

14.1.3.3.9.13-1 ITAAC-Tier 1 piping design description

14.1.3.8-1 ITAAC-reliability assurance program

14.1.3.9-1 ITAAC-welding

14.1.4-1 ITAAC-interface requirements

14.1.5-1 ITAAC-site parameters

14.2.12.7-1 ITAAC-design certification material initial test program

18.9.1-1 ITAAC-design description

19.1.2.2.2-2 ITAAC-fire barriers/separation

19.1.2.2.2-3 ITAAC-interface design for fires

19.1.2.4.2-1 ITAAC-PRA for intermal, external ovents

19.1.5.2-3 ITAAC-interfacing piping 
ITAAC Open Items In DESER

\section{Item Number Description of Item}

19.1.5.4-3 ITAAC-reliability of interfacing systems

19.1.5.6.3-1 ITAAC-human reliability analyses

ITAAC Confirmatory Items

19.1.6.3.2-3 ITAAC-seismic capacity of equipment

19.1.6.4-4 ITAAC-fire barrier installation, smoke mitigation

19.1.6.4-5 ITAAC-fire for COL design

5.2.4-1 ITAAC-add discussion of PSE and 89 code

7.2.2.1-1 ITAAC-verify maximum transmission distance

7.2.2.1-2 ITAAC-include sccuracy in setpoint methods

7.2.2.5-2 ITAAC-Tier 1-eliminate teet jumpers and lifted leads

7.2.3-1 ITAAC-verify bypasses are annunciated

7.2.8-1 ITAAC-Tier 1-software metrics to track error rate

7.2.8-4 ITAAC-equipment to be tested for low range EMI

7.7.1.5-1 ITAAC-reactor protection system trip ID in computer

7.10.2-1 ITAAC-follow EPRI for operating experience

8.2.3.4-1 ITAAC-independence safety vs non-safety systems

12.2.3-1 ITAAC/DAC include former interfaces

14.1.3.3.3.8-2 ITAAC-verification of seismic/nonseismic interactions

18.9.2.2.8-4 ITAAC-tests and analyses in CDM Table'3.6
The following issues were incorrectly classified in the DPSER a ITAAC COL Action Items, but were also reeolved based on the revised CDM material, supporting SSAR information, the discussion in SSAR Section 14.3, and the discuseion in this section of this report.

\section{ITAAC COL_Action Items}

Item Number Description of Action Item

9.5.7-1 ITAAC-DG lube oil system design
criteria

9.5.8-1 ITAAC-DO combustion air system flow cepacity

\subsubsection{Additional Certified Design Material}

This soction of the ABWR CDM provides additional certified design material for design and construction activities that are applicable to more than one system. There are five entries in this CDM section, and these are discuseed in the appropriate paragraphs that follow. The firat four entries describe design related processes and associated DAC for the ABWR, and the fifth entry describes the ITP for a facility referencing the certified design. The design description for each entry describes its cope and applicability to the ABWR design. Amplifying information on CDM Section 3.0 is contained in SSAR Section 14.3.3. The material in this section of the CDM applies to the individual systems of the ABWR design contained in CDM Section 2.0, and the staff's review of the material in CDM Sertion 2.0 is contained in Section 14.3.2 of this report. The staff's safety evaluation for each design are where the DAC are used is contained in the section of this report applicable to the area.

\section{Desien Acceptance Criteria (DAC)}

Design and engineering information for some areas of the design was not provided by GE at a level of detail customarily reviowed by the staff in making a final safety determination. GE provided less detailed information in thewe areas because GE believed they were either areas of rapidly changing tochnology and it would have been detrimental to freeze the details of the design many years before an actual plant was ready to be constructed, or because GE believed they were areas for which GE did not have sufficient as-built or as-procured information to complete the final design. Areas of rapidly changing technology included control room and RSS design (human factors) and advanced instrumentation and controls. Areas dependent on as-built or as-procured information included piping design and radiation shielding, ventilation, and airbome monitoring design.; The staff provided its views 
on the DAC to the Commission in SECY-92-053, "Uee of Design Acceptance Criteria During 10 CFR Part 52 Deaign Certification Reviews," dated Fobruary 19, 1992.

The design information and appropriato design mothodologies, codes, and atandards provided in the SSAR, together with the design deecriptions and DAC, are aufficiently detailed to provide an adequate basis for the staff to make a final safety determination regarding the design, subject only to satisfactory design implementation and verification of the DAC by the COL applicant or licensee. The DAC are at of prescribed limits, parameters, procedures, and attributes upon which the NRC relies, in a limited number of technical areas, in making a final safety determination in support of the ABWR design certification. The acceptance criteria for the DAC are objective; that is, they are inspectable, testable, or subject to analysis using pro-approved methods, and must bo verified as a part of the ITAAC performed to demonstrate that the as-built facility conforms to the certified design. Thus, the acceptance criteria for DAC are epecified together with the related ITAAC in the Tier 1 material, and both are part of the design certification. The DAC and the ITAAC, when met, ensure that the completed design and as-constructed plant conforms to the design certification. The material in the SSAR for each of the DAC areas includes, as appropriate, sample calculations or other supporting information to illustrate methods that are acceptable to the staff for meeting Tier 1 DAC commitments.

The structure of each area where DAC are used is the same as for the other areas of the design that are verified by ITAAC. The structure consists of three parts: the Tier 1 design description, the corresponding DAC, and the Tier 2 supporting information in the SSAR for the DAC. The stafi has based its safety findings for the areas where DAC are used on the Tier 2 information specified in the SSAR, including applicable design methodologies, codes and standards, contingent on verification that the design has been properly implemented according to the Tier 1 design descriptions and the corresponding DAC.

For the two areas of rapidly changing technology, control room and RSS design (humen factors) and instrumentation and controls design, the design descriptions and DAC delineate the process and requirements that a COL applicant or licensee must implement to develop the design information required in each area. Acceptance criteris are specified in the CDM for the development process at various stages of detailed design and subsequent construction and testing. The COL applicant or licensee is required to develop the procedures and test programs necessary to demonstrate that the DAC requirements are mot at ench stage. Similar to ITAAC, the COL applicant or licenees will certify to the NRC that the deaign through that atage is in compliance with the certified design. The NRC will review and inspect the work to confirm that the COL applicant or licensee has adequately implemented the commitments of the DAC at these stages. The process is referred to as a phased DAC because it consists of a set of sequential steps or stages that require successful completion. A COL applicant or licensee is not required to certify that each phase is completed sequentially. However, if the staff determines that a DAC was not auccessfully met, the design process may be required to be repeated to meet the DAC, possibly requiring a change to the as-built system design.

\subsubsection{Human Factors Engineering DAC}

The human factors aspects of the ABWR control room and remote shutdown system (RSS) design are provided in SSAR Chapter 18, "Human Factors," and together with the aseociated DAC in CDM Section 3.1, "Human Factors Engineering," are evaluated in Chapter 18 of this report. GE did not develop a final control room and RSS design before design certification because this is an area of rapidly changing technology. Instead, GE provided the processes and acceptance criteria by which the details of the design in this area would be developed, designed, and evaluated. GE provided amplifying information regarding the processes in this area in SSAR Section 14.3.3.1. The material in CDM Section 3.1 applies to the human factors design of the control room and the RSS. The implementation of the process and the design is the responsibility of the COL applicant or licensee.

Complete detailed human-system interface (HSI) design information was not available for staff review. The basis for the staff's review in this area was a HFE Program Review Model (PRM) developed by the staff. The staff's certification review in the control room design area was based on a design and implementation process plan. The staff informed the Commission of the development of the DAC in this area in SECY-92-299, "Development of Design Acceptance Criteria (DAC) for the Advanced Boiling Water Reactor (ABWR) in the Areas of Instrumentation and Controls (I\&C) and Control Room Design," dated August 27, 1992.

The staff developed the HFE PRM, contained in Appendix J of this report, to serve as a technical basis for the review of the design process and DAC proposed by GE for certification of the ABWR control room and remote shutdown station design. The HFE PRM is (1) based upon currently accepted HFE practices, (2) well-defined, and (3) validated through experience with the development of complex, high-reliability systems in other industrial and 
military applications. The review model identifies the important HFE eloments in a system development, design, and ovaluation process that are necessary and sufficient requisites to successful integration of human factors in complex systoms. The roview model also identifies aspects of each HFE olement that are key to a safety roviow, and deecribes acceptance criteria by which the HFE olements can be ovaluated. Tho HFE PRM hes eight program olements, each of which contain both general and more specific accoptance criteria.

The CDM deecribes the process to develop the HSI design information for the control room and RSS based on human factors systems analyses and human factors principles. The design offort will be directed by a multi-disciplinury HFE design team comprised of personnel with expertise in HFE and other technical areas relevant to the HSI design, ovaluation and operations. The HSI design team shall devolop a program plan to establish methods for implementing the HSI design through a process of human factors system analyses as discussed in CDM Figure 3.1, "Human-System Interface Design Implementation Process." The details of implementation of each stage of the development process are described in CDM Section 3.1, together with the related acceptance criteria. Detailed supporting information is contained primarily in SSAR Chapter 18, Appendix 18E.

The staff conducted a complete and tho' ough review of the ABWR CDM to ensure that the gecueral criteria of the eight program elements in the HFE PRM were appropriately addressed in the Tier $1 \mathrm{CDM}$. The Tier 2 SSAR material contains more detailed guidelines and applicable guidance documents. The staff also conducted a review of the SSAR material to ensure that the specific acceptance criteria in the HFE PRM were appropriately addressed. The staff ' reviewed the CDM and SSAR Section 14.3.3.1 in accordance with the requirements in Part 52 and the guidance provided in SRMs related to design certification applications provided by the Commission. This review included information contained in multiple submittals to the staff as listed in the background part of Section 14.3 of this report.

The material in SSAR Chapter 18 provides design information and defines design processes that are acceptable for use in meeting the acceptance criteria in the CDM. However, the SSAR information may be changed by a COL applicant or licensee referencing the certified design in accordance with a "50.59-like" process. The staff's evaluation of the ABWR design for the control room is based on the design processes and acceptance criteria material in the DAC and the SSAR, especially those defined in SSAR Section 18E. Consequently, the staff indicated in Section 18 of this report that any proposed changes to SSAR Section 18E constitutes an unreviowed safety question and, therefore, must be submitted to the NRC for reviow and approval prior to implementation.

\section{Conclusions}

On the basis of the above, the staff concludes that the toplovel dosign proceseses, features and performance characteristics of the humen factors aspects of SSCs important to safety in the ABWR are appropriately described in the design descriptions of the CDM, and are acceptable.

Further, these top-lovel design processes, fentures and performance characteristics can be adequately verified by the DAC provided by GE. Therefore, the staff concludes that the DAC in the CDM are necessary and sufficient to provide reasonable assurance that if the inspections, tests, and analyses are performed and the acceptance criteria mot, the human factors aspects of SSCs important to safety in a facility that references the design have been designed, constructed and will operate in accordance with the design certification and applicable regulations.

\subsubsection{Radiation Protection DAC}

The radiation protection aspects of the ABWR design are provided in SSAR Chapter 12, "Radiation Protection," and together with the associated DAC in CDM Section 3.2, "Radiation Protection," are evaluated in Chapter 12 of this report. GE did not provide the complete design information in this design area before design certification because the radiation shielding design and the calculated concentrations of airborne radioactive material were dependent upon as-built and as-procured information of plant systems and components. Therefore, GE was not able to describe the ABWR radiation source terms (i.e., the quantity and concentration of radioactive materials contained in, or leaking from plant systems) in sufficient detail to allow the staff to verify the adequacy of the shielding design, ventilation system designs, or the design and placement of the airborne radioactivity monitors. Instead, GE provided the processes and acceptance criteria by which the details of the design in this area would be developed, designed, and evaluated. GE provided amplifying information regarding the processes in this are in SSAR Section 14.3.3.2. This material in CDM Section 3.2 applies to the radiological shielding and ventilation design of the reactor building, turbine building, control building, service building, and radwaste building. The implementation of the process and the design is the responsibility of the COL applicant or licensee. 
The acceptance criteria in the DAC are taken from the acceptance criteria in the applicable section of Chapter 12 of the SRP. The analysis mothode and source term ascumptions specified in the DAC are consistent with approved methods and assumptions listed in the SRP. The SRP is the basis for the staff's safoty roviow of the ABWR design. Therefore, demonstrating that the final design meets these DAC with the methods and assumptions specified in Tier 1 ensures that the as-built ABWR design meets the applicable acceptance criteria of the SRP and the aseociated regulations and staff technical positions. The staff informed the Commission of the development of the DAC in this area in SECY-92-196, "Dovelopment of Design Acceptance Criteria (DAC) for the Advanced Boiling Water Reactor (ABWR)," dated May 28, 1992.

The DAC in the Tier 1 information address the verification of the plant radiation shielding design and the plant airborne concentrations of radioactive materials (e.g., the ventilation system and airborne monitoring system designs). The DAC require the COL applicant to calculate radiation levels and airborne radioactivity levels within the plant rooms and areas to verify the adequacy of these design features during plant construction (concurrently with the verification of the ITAAC). The plant renms and areas to which the DAC apply are given in the figures in CDM Section 3.2. Detailed supporting information is contained in SSAR Chapter 12.

The criteria in CDM Table 3.2a, Items 1 and 2, ensure that the radiation shielding design (either that provided for by the plant structures, or design permenent or temporary shielding) is adequate to ensure that the maximum radiation levels in plant areas are commensurate with the area's access requirements so radiation exposures to plant personnel can be maintained as low as reasonably achievable (ALARA) during normal plant operations and maintenance. Item 4 in Table 3.2a ensures that adequate shielding is provided for those areas of the plant that may require occupancy to permit an operator to aid in the mitigation of or the recovery from an accident. Item 4 of Table 3.2a ensures that the contribution to the radiation dose from gamma shine (particularly from the turbine building) to a member of the public (off site) will be a small fraction of the EPA dose limit in 40 CFR Part 190.

The criteria in CDM Table 3.2b, Item 1, ensures that the plant provides adequate containmen' and ventilation flow rates to control the concentrations of airborne radioactivity to levels commensurate with the access requirements of areas in the plant. Item 2 in Table 3.2b ensures that once the concentrations of airborne radioactivity are determined per Item 1 above, the required airborne monitors are provided in the appropriate locations in the plant.
The ataff conducted a complete and thorough reviow of the GE ABWR CDM material to ensure that the SRP guidelines for radiation protection design were appropriately addressed in both the Tier 1 CDM and the SSAR. The staff's evaluation included the analysis methods, design procedures, acceptance criteria, and related ITAAC that are to be used for the completion and verification of the ABWR radiation protection design. The SSAR information contains more detailed guidelines and applicable documents. The staff reviewed the CDM and SSAR Section 14.3.3.2 in accordance with the requirements in Part 52 and the guidance provided in $\mathrm{SRMs}$ related to design certification applications provided by the Commission.

\section{Conclusions}

On the basis of the above, the staff concludes that the toplevel design processes, features and performance characteristics of the radiation protection aspects of SSCs important to safety in the ABWR are appropriately described in the design descriptions of the CDM, and are acceptable.

Further, these top-level design processes, features and performance characteristics can be adequately verified by the DAC provided by GE. Therefore, the staff concludes that the DAC in the CDM are necessary and sufficient to provide reasonable assurance that if the inspections, tests, and analyses are performed and the acceptance criteria met, the radiation protection aspects of SSCs important to safety in a facility that references the design have been designed, constructed and will operate in accordance with the design certification and applicable regulations.

\subsubsection{Piping Design DAC}

The piping design aspects of the ABWR design are provided in SSAR Chapter 3, "Structures, Components, Equipment, and Systems," and together with the associated DAC in CDM Section 3.3, "Piping Design," are evaluated in Section 3.12 of this report. GE did not provide the complete design information in this design area before design certification because the piping design was dependent upon as-built and as-procured information. Instead, GE provided the processes and acceptance criteria by which the details of the design in this area would be developed, designed, and evaluated. GE provided amplifying information regarding the processes in this area in SSAR Section 14.3.3.3. The material in CDM Section 3.3 applies to ABWR piping systems classified as nuclear safety-related, and to non-nuclear safety systems as specified in the Tier 1 material for the individual systems in CDM Section 2.0. The implementation of the process 
and the denign is the responsibility of the COL applicant or licenseo.

The staff used the SRP guidelines to ovaluate the piping design information in the ABWR CDM and SSAR and performed a detailed audit of the piping design criteria, including sample calculations. The staff evaluated the adequacy of the structural integrity and functional capability of safety-related piping systems. The review was not limited to the American Society of Mechanical Engineers (ASME) Boiler and Preasure Vessel Code Class 1, 2, and 3 piping and supports, but included buried piping, instrumentation lines, the interaction of non-seismic Catogory I piping with soismic Category I piping, and any safety-related piping designed to industry standards other than the ASME Code. The staff's evaluation included the analysis methods, design procedures, acceptance criteria, and related ITAAC that are to be used for the completion and verification of the ABWR piping design. The staff's evaluation included both CDM and SSAR information regarding the applicable' codes and standards, analysis methods to be used for completing the piping design, modeling techniques, pipo stress analyses criteria, pipe support design criteria, high-energy line break criteria, and leak-before-break (LBB) approach applicable to the ABWR. The staff informed the Commission of the development of the DAC in this area in SECY-92-196, "Development of Design Acceptance Criteria (DAC) for the Advanced Boiling Water Reactor (ABWR)," dated May 28, 1992.

The material in CDM Section 3.3 provides the design process to develop the piping for the nuclear safety-related (seismic Category I) systems of the ABWR design. Piping systems that must remain functional during and following an SSE are designated as seismic Category I and are further classified as ASME Code Class 1, 2, or 3. The piping systems and their components are designed and constructed in accordance with the ASME Code requirements identified in the individual systems of the ABWR design. The CDM ensures that the piping systems will be designed to perform their safety-related functions under all postulated combinations of normal operating conditions, system operating transients, postulated pipe breaks, and seismic events. The material in the CDM section also addresses the consequential effects of pipe ruptures such as jet impingement, potential missile generation, and pressure and temperature effects.

GE specified three ITAAC in the CDM to ensure the design process for piping systems was as described in the design description. The first ITAAC specified in the CDM requires that an ASME Code certified stress report exists to ensure that the ASME Code Class 1, 2, or 3 piping systems are designed to retain their pressure integrity and functional capability under internal design and operating preesures and design basis loads. The specific contents and requirements of the certified streas report are contained in the ASME Code. As used in this report, an ASME Code certified strese report is the design document required by ASME Code, Section III, Subarticlo NCA-3550. A certified piping stress report provides aseurance that requirements of the ASME Code, Section III for design, fabrication, installation, examination, and testing have been met and that the design complies with the design specifications.

The second ITAAC requires that a pipe break analysis report exists that documents that SSCs that are required to be functional during and following an SSE have adequate high-energy pipe break mitigation features, or alternatively, that a leak-before-break report exists for those sections of piping systems qualified for leak-beforebreak design. As discussed in the design description, the pipe break analysis report specifies the criteria used to postulate pipe breaks and the analytical methods used to perform pipe breaks and confirms the adequacy of the results of the pipe break analyses. This verification provides assurance that the high-energy line break analyses have been completed and meet the following certified design commitments. For postulated pipe breaks, the Pipe Break Analysis Report shall confirm that: (1) piping stresses in the containment penetration area shall be within their allowable stress limits, (2) pipe whip restraints and jet shield designs shall be capable of mitigating pipe break loads, (3) loads on safety-related SSCs shall be within their design load limits, and (4) SSCs are protected or are qualified to withstand the environmental effects of postulated failures. The Pipe Break Analysis Report shall conclude that, for each postulated piping failure, the reactor can be shut down safely and maintained in a safe, cold shutdown condition without offsite power. Detailed information that supports this ITAAC is contained in SSAR Chapter 3.

The third ITAAC requires that an as-built piping stress report exists that documents the results of an as-built reconciliation analysis confirming that the final piping system has been built in accordance with the ASME Code certified stress report. The report provides an overall verification that the as-constructed piping system is consistent with the certified design commitments. Although similar to the first ITAAC, this verification also provides assurance that modification of any document used for construction from the corresponding document used for design analysis bas been reconciled with the certified stress report discussed above. This documentation may become part of the certified stress report. 
As discureed in the advance SER, GE atatod that it intended to provide, in a future SSAR ameadment, amplifying information in the SSAR to support the piping DAC. This was Confirmatory Itom F14.3.3.3.1-1. OB provided this amplifying information in Amendment 34. The etaff finds this scceptable. This resolved Confirmatory Itom F14.3.3.3-1.

The ataff conducted a complete and thorough roview of the OB ABWR CDM material to encure that the SRP suidelines for piping design were appropriately addreaced in both the Tier 1 CDM and the SSAR. The stafi's ovaluation included the analysis mothods, dosign procedures, acceptance critoria, and relatod ITAAC that are to be used for the completion and verification of the ABWR piping design. The Tier 2 SSAR material contain more detailed guidelines and applicable documents. The staff reviowed the CDM and SSAR Section 14.3.3.3 in accordance with the requirements in Part 52 and the guidanco provided in SRMs related to design certification applications provided by the Commission. This roviow included information contained in multiple submittals to the staff as listed in the introductory part of Section 14.3 of this report.

Selected material in SSAR Chapter 3 provides design information and defines design processes that aro acceptable for use in moeting the piping DAC in the CDM. However, the SSAR information may be changed by a COL applicant or licensee referencing the certified design in accordance with a "50.59-like" process. The staffs evaluation of the ABWR design for piping systems is based on the design processes and acceptance criteria material in the DAC and the SSAR. Consequently, the staff indicated in Section 3.12 of this report that any proposed changes to selected aspects of these piping design processes described in the appropriate SSAR sections constitutes an unreviewed safety question and, therefore, must be submitted to the NRC for review and approval prior to implementation.

\section{Conclusions}

On the basis of the above, the staff concludes that the toplevel design processes, features and performance characteristics of the piping design aspects of SSCs important to safety in the ABWR are appropriately described in the design descriptions of the CDM, and are acceptable.

Further, these top-level design processes, features and performance characteristics can be adequately verified by the DAC provided by GE. Therefore, the staff concludes that the DAC in the CDM are necessary and sufficient to provide reasonable assurance that if the inspections, tests, and analyses are performed and the acceptance criteria mot, the piping design appeots of SSCs importent to safety in a facility that references the design have been designed, constructed and will operato in accordance with the design certification and applicable regulations.

\subsubsection{Instrumentation and Controls (1\&C) DAC and Other I\&C ITAAC}

The I8C aspects of the ABWR design are provided in SSAR Chapter 7, "Instrumeatation and Control Systems," and together with the aseociated DAC and other multiaystem I\&C related ITAAC in CDM Section 3.4, "Instrumentation and Control," are ovaluatod in Chapter 7 of this report. OE did not dovelop a final design for I\&C before design certification because this is an area of rapidly changing tochnology. Instond, GE provided tho proceseses and acceptance criteria by which the details of the design in this area would be developed, designed, and ovaluatod. GB provided amplifying information regarding the procesees in this area in SSAR Section 14.3.3.4. The material in CDM Section 3.4 applies to the design of both safety related and non-safety related I\&C systems of the ABWR. These I\&C systems are described in CDM Section 2.0, and the staff's review of these systems is described in Section 14.3.2 of this report. The implementation of the process and the design is the responsibility of the COL applicant or licensee.

The staff used the SRP guidelines to review the I\&C design information in the ABWR CDM and SSAR to confirm that both the safety-related and non-safety-rolated I\&C systems met the appropriate acceptance criteria of the SRP. The staff also used the Commission guidance contained in a SRM of July 15, 1993, related to SECY-93-087, "Policy, Technical, and Licensing Issues Pertaining to Evolutionary and Advanced Light Water Reactor (ALWR) Designs," dated April 2, 1993. The staff informed the Commission of the development of the DAC in this are in SECY-92-299, "Development of Design Acceptance Criteria (DAC) for the Advanced Boiling Water Reactor (ABWR) in the Areas of Instrumentation and Controls (I\&C) and Control Room Design," dated August 27, 1992.

CDM Section 3.4 has multiple entries addressing three key issues associated with the I\&C design. These issues include the design of the SSLC system, the development and qualification processes for I\&C systems, and design features that provide diverse backup as protection against common-mode failures in the SSLC. These issues and their relationships to other systems of the design are illustrated in the figures in CDM Section 3.4, which contain a block diagram showing the SSLC logic and control, a depiction of the integrated hardware and 

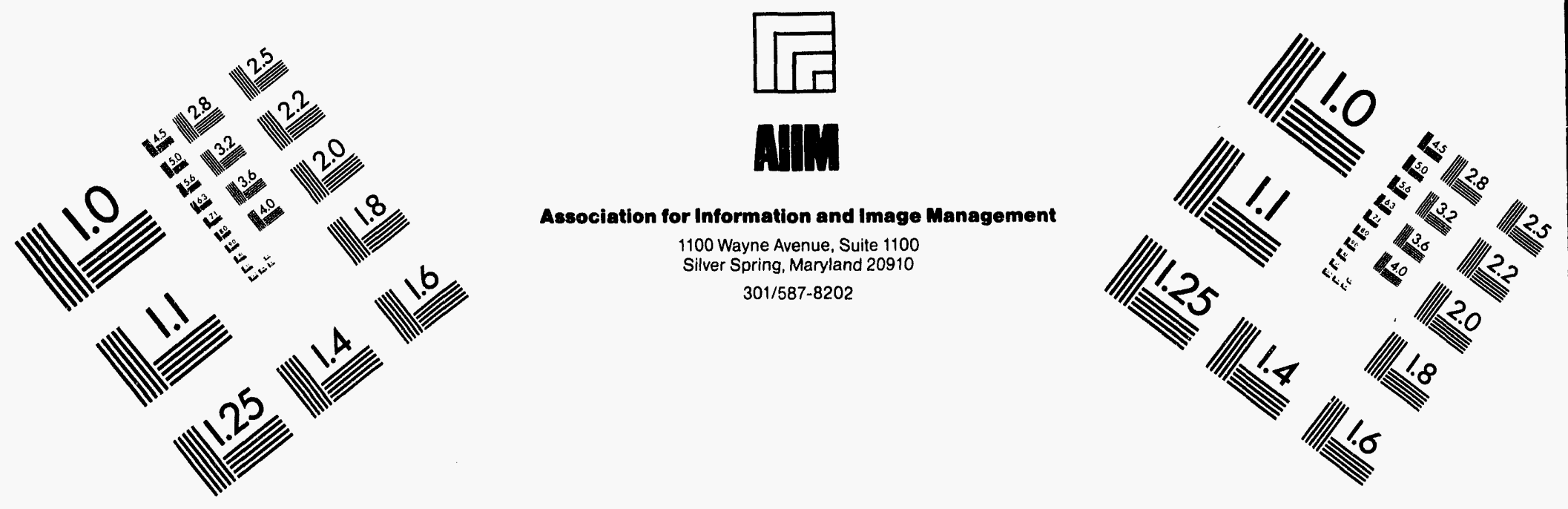

Centimeter

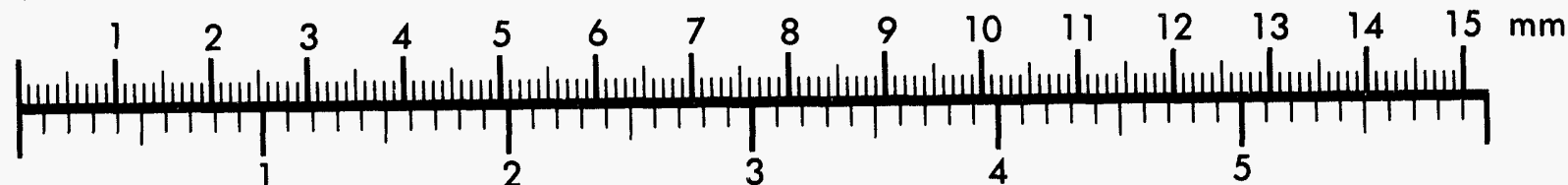
Inches
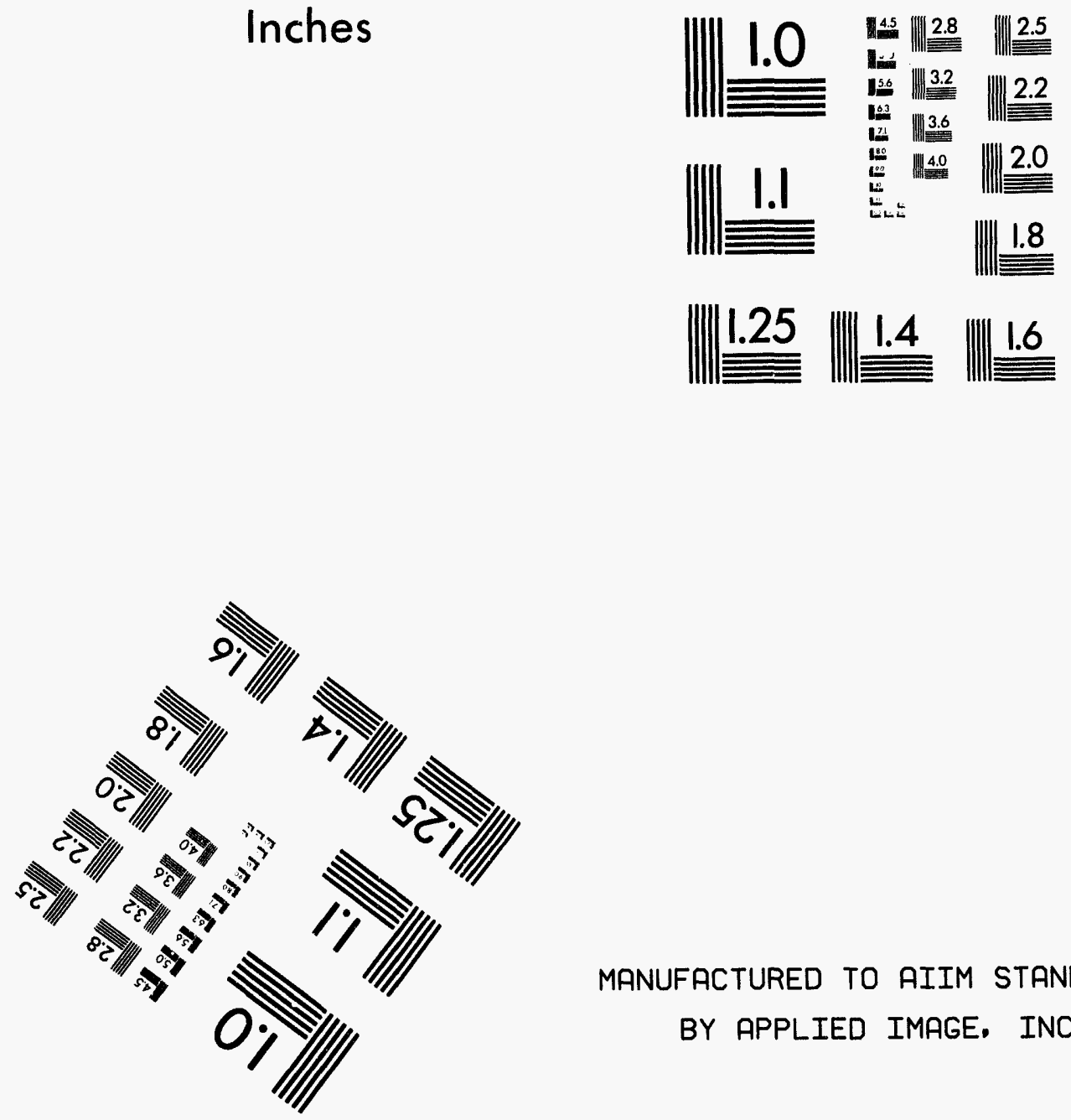

MANUFACTURED TO AIIM STANDARDS

BY APPLIED IMAGE, INC.

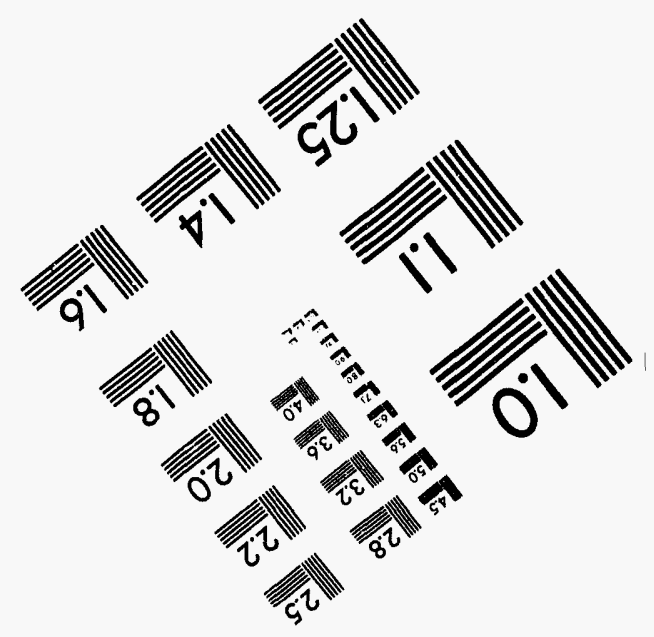



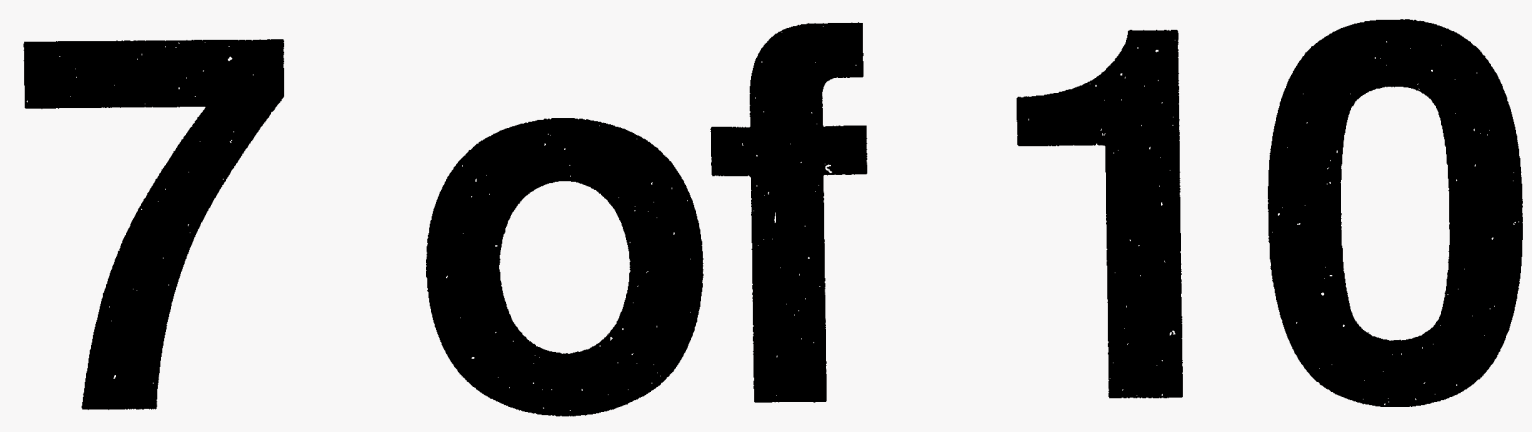
software development process for I\&C systems, and a diagram showing the interfaces of the SSLC system with other I\&C systems in the design. Detailed supporting information for the CDM is contained in SSAR Chapter 7.

CDM Section 3.4A, "Safety System Logic and Control," contains material for the SSLC. The SSLC integrates the automatic decision-making and trip logic functions, and manual initiation functions associated with the safety actions of the safety-related systems. Safety-related trip logic and monitoring of plant protection system resides in \$SLC equipment. SSLC equipment comprises microprocessor-bused, software-controlled signal processors that perform signal conditioning, setpoint comparison, trip logic, system initiation and reset, selftest, calibration, and bypass functions. The signal processors associated with particular safety-related system are an integral part of that system and do not belong to SSLC.

CDM Section 3.4B, "I\&C Development and Qualification Processes," contains the DAC for the I\&C area of the design. The DAC are contained in four subsections that describe (1) design processes and acceptance criteria to be used for safety-related systems using programmable microprocessor-based control equipment, (2) a program to assess and mitigate the effects of electromagnetic interference on I\&C equipment, (3) a program to establish setpoint for safety-related instrument channels, and (4) a program to qualify safety-related I\&C equipment for inservice environmental conditions.

The subsection of CDM Section 3.4B titled, "Hardware and Software Development Process," describes hardware and software development processes to be used in the design, testing, and installation of I\&C equipment. The following discussion addresses the considerations mado in reviewing the entries for this subsection of the CDM.

The primary function of this development process is to implement the functional instrumentation and control requirements described in the CDM and the SSAR for the systems which comprise the ABWR. The decomposition of the functional system (SSLC, RPS, ARI, otc.) requirements to specific computer hardware and software components to perform the various tasks is accomplished using the structured design process described below.

The CDM includes the description of the design procese to be followed for hardware and software development, design commitments, the inspections, tests, and analysis to be performed to verify that the design is consistent with the commitments, and the appropriate acceptance criteria against which the design will be judged. This ITAAC describes attributes of the process to be used to develop the software as well as attributes of the final softwaro product. The ITAAC for software and hardware describes the following design stages within the design process:
(1) Planning
(2) Design definition
(3) Software design
(4) Software coding
(5) Integration
(6) Validation
(7) Change control

The CDM and SSAR contain criteria which describe the method to develop plans and procedures that will guide the design process throughout the lifecycle stages. The ITAAC provides the acceptance criteria for verifying the design through the stages listed above, while the SSAR adds the set of guidelines and standards that will provide more detailed criteria for the development of the design. The CDM has been written to incorporate the most important and general aspects (top-level requirements) from the standards. The set of standards and criteria in the SSAR encompass the guidance for generating the plans that will be used in the computer software and hardware design process for the computer design throughout the lifecycle. These plans are described below.

The software QA (SQA) plan describes the softwarespecific activities that are to be performed and controlled in addition to the approved QA plan (in accordance with 10 CFR Part 50, Appendix B, "Quality Assurance Criteria for Nuclear Power Plants and Fuel Reprocessing Plants") for the total ABWR design. The SQA plan establishes the criteria under which the other software development plans will be generated. The software management plan (SMP) establishes the organization and authority structure for the design, the procedures to be used, and the interrelationships between major activities. The software configuration management plan (CMP) provides the means to identify software products, control and implement changes, and record and report change implementation status. The software development plan (SDP) describes a development process, tools documentation, and products developed according to the software lifecycle. The verification and validation plan (V\&VP) describes the method to ensure that the requirements of each phase or stage of the design process (lifecycle) are fully and accurately implemented into the next phase. The software safety plan (SSP) describes the safety and hazards analyses that will be performed. The software operation and maintenance plan (SOMP) includes the procedures required to ensure that the software will be operated correctly and that the quality of the software is maintained. GE has combined these plans into a software management plan, a 
configuration management plan, and a verification and validation plen.

The ITAAC activities completed by the COL applicant will bo inspected by the NRC to verify conformeace with the requirements at several stages during the digital control system design process or stage of the lifecycle. The documents which demonstrate satisfactory implementation of the ITAAC will be available for inspection during the NRC audit at the completion of each of the above stages. The stages or phases described by GE aro shown in Figure 3.4d. The NRC audit and the COL applicant conformance review points are shown in Figure 7.1-2 of the ABWR FSER. These stages correspond with the phases described by GE in the CDM. The actual stages, including the conformance review and audit points, will be determined for each of the software products to be developed when design implementation is scheduled to begin.

At each stage, the design development must be verified by the COL applicant to be in accordance with the certified design process and the detailed design developed (through that stage) to be in conformance with the certified design. Upon completion of ITAAC activities for each stage, the COL applicant will certify to the NRC that the stage has been completed and the design and construction completed up through that stage is in compliance with the certified design. Although not required, the COL applicant should satisfactorily complete ITAAC activities at each stage prior to proceeding to the next stage of the design development process. Failure to successfully complete the ITAAC at a stage, as determined by the conformance review or the NRC audit, may require repeating an earlier stage ITAAC or changing the system design. The NRC staff will identify any open issues which require resolution for each stage of the ITAAC. Significant open issues which are not resolved could result in the NRC staff concluding that the ITAAC had not been satisfactorily completed.

The subsection of Section 3.4B titled "Electromagnetic Compatibility" describes the process to ensure that I\&C equipment is able to function properly when subjected to an electromagnetic environment. An electromagnetic compatibility (EMC) compliance plan to confirm the level of immunity to electrical noise is included in the design, installation, and testing of I\&C equipment. The plan is structured on the basis that EMC of I\&C equipment is verified by factory testing and site testing of both individual components and interconnected systems to meet electromagnetic compatibility requirements.

The subsection of Section 3.4B titled "Instrument Setpoint Methodology" describes the process to ensure that setpoints for initiation of safety-related functions are determined, documented, installed, and maintained. The procese (the instrument setpoint methodology) establishes a program for epecifying requirements for documenting the bases for election of trip setpoints, accounting for instrument inaccuracies, response testing, and replacement of instrumentation.

The subsection of Section 3.4B titled "Equipment Qualification" describes the process to ensure that qualification of safety-related 1\&C equipment is able to complete its safety-related function under the eavironmental conditions that exist up to and including the time the equipment has finished performing that function. An equipment qualification program is established that ensures qualification specifications consider conditions that exist during normal, abnormal, and design-basis accident events in terms of their cumulative effect on equipment performance for the period up to the end of equipment life.

CDM Section 3.4C, "Diversity and Defense-In-Depth Considerations," addresses the concern that software design faults or other initiating events common to redundant, multidivisional logic channels of I\&C protection syetems could disable significant portions of the plant's safety functions at the moment when these functions are needed to mitigate an accident, and addresses the divereo beckup features that are provided for the primary automatic logic. Diversity is provided in the form of hardwired backup for reactor trip, diverse display of important process parameters, defense-in-depth arrangement of equipment, and other equipment diversity.

The staff conducted a complete and thorough review of the GE ABWR CDM material to ensure that the SRP guidelines and Commission guidance for I\&C design were appropriately addressed in both the CDM and the SSAR. The staff's evaluation included the analysis methods, design procedures, acceptance criteria, and related ITAAC that are to be used for the completion and verification of the ABWR I\&C design. The SSAR material contains more detailed guidelines and applicable guidance documents. The staff reviewed the CDM and SSAR Section 14.3.3.4 in accordance with the requirements in Part 52 and the guidance provided in SRMs related to design certificetion applications provided by the Commission. This review included information contained in multiple submittals to the staff as listed in the background part of Section 14.3 of this report.

Selected material in SSAR Section 7.2 provides detailed design information and defines design processes that are acceptable for use in meeting the I\&C DAC in the CDM. However, the SSAR information may be changed by a COL applicant or licensee referencing the certified design 
in accordance with a "50.59-like" process. The staff"s evaluation of the ABWR design for I\&C systems is based on the design processes and acceptance criteria material in the DAC and the SSAR. Consequently, the staff indicated in Section 7.2 of this report that any propgsed changes to the appropriate SSAR sections constitutes an unreviewed safety question and, therefore, must be submitted to the NRC for reviow and approval prior to implementation.

\section{Conclusions}

On the basis of the above, the staff concludes that the toplevel design processes, features and performance characteristics of the I\&C aspects of SSCs important to safety in the ABWR are appropriately described in the design descriptions of the CDM, and are acceptable.

Further, these top-level design processes, features and performance characteristics can be adequately verified by the DAC provided by GE. Therefore, the staff concludes that the DAC in the CDM are necessary and sufficient to provide reasouable assurance that if the inspections, tests, and analyses are performed and the acceptance criteria met, the I\&C aspects of SSCs important to safety in a facility that references the design have been designed, constructed and will operate in accordance with the design certification and applicable regulations.

\subsubsection{Initial Test Program (ITP)}

This section of the CDM consists of a high level commitment to in ITP and a description of the program and major program documents (i.e., a site-specific startup administrative munual, test specifications, and test procedures). The ABWR: SSAR Chapter 14.2 contains a complete description of the ITP, and the staff's evaluation of the ITP is contained in Section 14.2 of this report.

The staff reviewed this CDM Section for consistency with the guidelines contained in the SRP and RG 1.68, "Initial Test Program for Water-Cooled Nuclear Power Plants." RG 1.68 describes the general scope and depth of testing that is acceptable to the staff for conduct of preoperational and startup testing as part of the ITP.

The key facets of the ITP are described in the Tier 1 CDM to ensure that subsequent changes in the conduct of the ITP cannot be initiated unilaterally by the COL applicant. This ITP is described in Tier 1 because of the essential role of a test program in the verification that SSCs have been constructed and will perform satisfactorily in service. The Tier 1 description requires that the ITP be performed under suitably controlled conditions and processes. The development of test procedures, conduct of the tests, and safe execution of the test program, are important considerations in ensuring that as-built facility is in accordance with the design certification and applicable regulations. Thus, the staff will have the confidence that the ITP will be implemented effectively, so that the appropriato testing methodologies, and associated programmatic controls for testing plant systems will be ensured.

A corresponding ITAAC for this design description is not required for several reasons:

The Tier 1 certified design material consists of a high level commitment to an ITP, and a description of the program and major program documents that constitute an acceptable ITP (i.e., \& site-specific startup administrative manual, test specifications, and test procedures). The specific testing necessary to verify design features and performance aspects of the design is delineated in the system-specific ITAAC.

(2) The ITP covers a broader spectrum of time than the ITAAC. While ITP pre-operational testing shall be completed prior to fuel load, the ITP startup and power ascension testing will be conducted after fuel load. As the ITP involves testing post-fuel load, it is not appropriate to define associated ITAAC entries as Part 52 specifies that the ITAAC will be completed prior to fuel load.

In summary, the top-level ITP commitments in the CDM ensure that suitable controls are imposed over the prooperational and start-up testing programs, which provide reasonable assurance that the facility can be operated without undue risk to the public. The staff concludes that the ITP information in the CDM is acceptable.

\subsubsection{Interface Requirements}

The requirements for interfaces for $a$ design are contained in 10 CFR 52.47(a)(1)(vii-ix). An applicant for design certification is required to provide (1) the interface requirements to be met by those portions of the plant for which the application does not seek certification, (2) justification that compliance with the interface requirements is verifiable through inspection, testing , or analysis, and the method to be used for verification of interface requirements, and (3) a representative conceptual design for those portions of the plant for which the application does not seek certification. The staff evaluated these interface requirements and the ABWR design in the appropriate sections of this report.

GE defined the interface between the systems of the design and the site-specific systems to be at the walls of the turbine building, reactor building, and control building, as 
depicted in Figure 1.2-1 of this report. This section of the CDM specifies interface requirements for those portions of the certified design that interface with site-specific portions of the design, and specifies the systems that are completely or partially out of scope of the certified design. The interface requirements define the design attributes and performance characteristics that must be met by the sitospecific, out-of-scope portion of the plant so that the sitespecific portion of the design is in conformance with the certified design. The site-specific portions of the design are those portions of the design that are dependent on characteristics of the site, such as the design of the ultimate heat sink.

The review of the appropriate inspections, tests, and analyses to demonstrate compliance with the interface requirements for the site-specific portion of the design is accomplished in the review of an application and for a combined license under Subpart C of 10 CFR Part 52.

GE provided information discussing the interface requirements in the CDM and in SSAR Section 14.3.4. GE provided acceptable interface requirements in CDM Section 4.0, and in the appropriate systems in CDM Section 2.0. This information was based on the information in the various sections of the SSAR, and is evaluated by the staff in the appropriate sections of this report. In CDM Section 4.0, GE stated that the development of ITAAC for the interface requirements will be similar in nature to the development of ITAAC in CDM Section 2.0. The staff concludes that this is an acceptable justification that compliance with the interfaces is verifiable through ITAAC, and the process described in SSAR Section 14.3 provides an acceptable methodology for verification of the interface requirements. GE provided acceptable representative conceptual designs in the SSAR that enabled the staff to complete its review of the design, as discussed in the appropriate sections of this report.

Therefore, based on the above discussion, the staff concludes that the interface information provided by $G E$ meets the requirements contained in 10 CFR 52.47(a) (1)(vii - ix), and is acceptable.

\subsubsection{Site Parameters}

The requirements for site parameters for a design are contained in 10 CFR 52.47(a)(1)(iii). An applicant for design certification is required to provide the site parameters used in the design, and an analysis and evaluation of the design in terms of these parameters. The site parameters are specified in both the CDM Section 5.0 and Chapter 2 of the SSAR, and the analysis and evaluation of the design is contained in the various sections of the SSAR. The staff evaluated these parameters and the design in the appropriate sections of this report.

Site parameters are specified in this section of the CDM for establishing the bounding parameters to be used in the solection of a suitable site for a facility referencing the ABWR certified design. Because they were used in bounding evaluations of the certified design, they define the requirements for the design that must be met by a site to ensure that a facility built on the site remains in conformance with the design certification. The demonstration that the site parameters are met at a given site is accomplished in conjunction with an application and issuance of a combined license under Subpart C of 10 CFR Part 52.

GE provided information discussing the site parameters in the CDM and in SSAR Section 14.3.5. GE provided acceptable site parameters postulated for the certified design in CDM Section 5.0 and in the appropriate sections of the SSAR. The appropriate sections of the SSAR information also provided an acceptable analysis and evaluation of the design in terms of these parameters, and the staff found the design acceptable in the related sections of this report. Therefore, the staff concludes that the site parameter information provided by GE meets the requiroments of 10 CFR 52.47(a)(1)(iii), and is acceptable.

\subsubsection{Summary}

The staff reviewed the GE ABWR CDM and SSAR Section 14.3 in accordance with the requirements in Part 52 and the guidance provided in SRMs related to design certification applications provided by the Commission. This review included information contained in multiple submittals to the staff, as listed in the background portion of Section 14.3 of this report.

Based on the staff's review of the material in the CDM, and a review of the selection methodology and criteria for the development of the CDM contained in SSAR Section 14.3, the staff concludes that the top-level design features and performance characteristics of the ABWR SSCs important to safety are appropriately described in the CDM, and are acceptable.

Further, these top-lovel commitments can be adequately verified by the ITAAC and additional certified design material provided by GE. Therefore, in the appropriate parts of Section 14.3 of this report, the staff concludes that the CDM are nocessary and sufficient to provide reasonable assurance that, if the inspections, tests, and analyses are performed, and the acceptance criteria met, a facility referencing the certified design will be constructed and will operate in conformity with the design certification and applicable rogulations. 
The staff also concludes in the appropriate parts of Section 14.3 of this report that the interface requirements and site parameters provided by $\mathrm{GE}$ for tho ABWR moet the requirements for design certification applications in 10 CFR 52.47, and are acceptable.

\subsubsection{DRSER Issues}

\subsubsection{Treatment of Non-Traditional Items in ITAAC}

GE incorporated into the SSAR any insights into the design that were obtained from non-traditional items such as PRA and severe accident issue resolutions. Additionally, the staff followed the Commission's guidance in its review of the evolutionary designs for the resolution of non-traditional issues such as those discussed in SECY-90-016, "Evolutionary Light Water Reactor Certification Issues and Their Relationships to Current Regulatory Requirements," and SECY-93-087, "Policy, Technical, and Licensing Issues Pertaining to Evolutionary and Advanced LightWater Reactor (ALWR) Designs." In 10 CFR 52.47, the Commission specified that the ITAAC must provide reasonable assurance that "a plant which references the design is built and will operate in accordance with the design certification." Therefore, by verifying key aspects and features of the design, the ITAAC implicitly confirm the implementation of these non-traditional items and the safety findings contained in the safety ovaluation report.

The staff requested GE to develop a cross-reference of key aspects, analyses, and features of the design from the SSAR to the CDM in order to document how these issues had been incorporated into the CDM. Specifically, the cross- references were to show how key aspects of the accident analyses, PRA, and severe accident issue resolutions were included in the CDM. This was DFSER Open Item 14.1.1.5.2-1.

GE provided the cross-references in SSAR Amendment 33 and updated the cross-references in Amendment 34. In those submittals, GE provided cross-roferences for key safety and integrated plant analyses in SSAR Section 14.3, and cross- references for PRA and severe accident analyses in SSAR Section 19.8. GE also provided more detailed cross-references for these analyses in a letter dated March 31, 1994.

The treatment of non-traditional items in the CDM for the ABWR design is discussed further in Section 14.3.2 of this report. Based on the discussion in Section 14.3.2, the staff found the cross-references, and the treatment of nontraditional items in the CDM acceptable. This resolved DFSER Open Itom 14.1.1.5.2-1.

\subsubsection{Relationship of the Design Description to the ITAAC}

GE proposed that certain systoms could have Tier 1 design descriptions, but may not require any corresponding ITAAC to verify the design for those systems. Examples of these systems were the fuel service equipment, the internal pump maintenance facility, and the fuel cask cleaning facility. The staff was reviewing this proposal at the time the DFSER was issued. This was DFSER Open Item 14.1.1.5.3-1.

GE adopted a graded approach to the level of detail in the development of the CDM, based on the safety significance of the ABWR structures, systems, and components. In SSAR Section 14.3, GE provided the process it used in the development of the CDM, based on the design presented in the appropriate sections of the SSAR. GE applied various selection criteria to the information in multiple chapters of the SSAR to determine the level of design information for a given system in the CDM.

GE provided its selection criteria and methodology for the ITAAC in SSAR Section 14.3.2.2. In general, each ABWR system with information in the design description has one or more ITAAC, based on the its safety significance. A single ITAAC may verify one or more provisions in the design description. Other aspects of systems may be satisfied by ITAAC contajned in other systems or other sections of the CDM. For example, the piping design information in CDM Section 3.3 provides acceptance criteria for seismic Category I and ASME Codo Class 1, 2, and 3 components. Additionally, since Part 52 requires that the ITAAC be satisfied prior to fuel loading, there are no ITAAC to verify any information dependent on post-fuel load conditions (e.g., nuclear fuel, fuel channels, and control rods). This information will be verified by the ITP as part of start-up and power ascension testing.

In Section 14.3 of this report, "Basis for Approval of the CDM," the staff discussed its graded approach to the review of the CDM based on the safety significance of the SSCs. Thus, consistent with the guidance of Part 52 and the SRM related to SECY-90-377, the staff recognized that although many aspects of the design were important to safety, the level of design detail in the CDM and verification of the key features and performance characteristics should be commensurate with the importance of the safety functions to be performed.

The relationship of design descriptions and ITAAC for the ABWR design is discussed further in Section 14.3.2 of this report. Based on the discussion in Section 14.3.2, the staff found the treatment of design descriptions and ITAAC in 
the CDM acceptable. This resolved DFSER Open Item 14.1.1.5.3-1.

\subsubsection{System Design Descriptions and ITAAC}

Section 2.0, "Tier 1 Material for ABWR Systems, " of the "Tier 1 Design Certification Material for the GB ABWR," was under staff review at the time the DFSER was issued. The staff stated that the evaluation would be provided in the FSER. This was DFSER Open Item 14.1.2-1.

GE provided revised CDM information and supporting information in various SSAR submittals to the staff as discussed in the background part of this report. In these submittals, GE addressed all of the comments of the staff, the ACRS, and an independent review group. As discussed in Section 14.3 of this report, "Basis for Approval of the CDM," the staff reviewed the GE ABWR CDM and selection, methodology and criteria for the development of the CDM contained in SSAR Section 14.3 in accordance with the requirements in Part 52 and the guidance provided in SRMs related to design certification applications provided by the Commission.

System design descriptions and ITAAC for the ABWR design are discussed further in Section 14.3.2 of this report. Based on the discussion in Section 14.3.2, the staff found the treatment of system design descriptions and ITAAC in the CDM acceptable. This resolved DFSER Open Item 14.1.2-1.

\subsubsection{Equipment Qualification (EQ)}

Section 3.1, "Equipment Qualification," of the "Tier 1 Design Certification Material for the GE ABWR," was under staff review at the time the DFSER was issued, and the staff stated that the evaluation would be provided in the FSER. This was DFSER Open Item 14.1.3.1-1.

GE provided revised CDM information in a submittal dated August 31, 1993, and supporting information in Amendment 32. GE eliminated the proposed CDM Section 3.1, and put the required equipment qualification information in CDM Section 1.2, General Provisions. GE provided supporting information on equipment qualification in the SSAR. The equipment qualification of safetysignificant portions of the design will be verified as part of the basic configuration walkdown of individual SSCs.

The basic configuration walkdown for equipment qualification is discussed in greater detail in Sections 14.3.1.2 and 14.3.2.3.1 of this report. Based on the discussion in Sections 14.3.1.2, and 14.3.2.3.1 the staff found the treatment of equipment qualification in the
CDM acceptable. This resolved DFSER Open Item 14.1.3.1-1.

\subsubsection{Reliability Assurance Program}

Section 3.8, "Reliability Assurance Program," of the "Tier 1 Design Certification Material for the GE ABWR," was under staff roview at the time the DFSER was issued. The staff stated that the evaluation would be provided in the FSER. This was DFSER Open Item 14.1.3.8-1.

When the DFSER was written the staff's position on a reliability assurance program (RAP) was that a high-level commitment to a RAP applicable to design certification (D-RAP) was required. GE committed to provide the required D-RAP commitments in the CDM in a letter dated July 12, 1994. The staff finds GE's commitments to D-RAP acceptable, subject to incorporation in the CDM. DFSER Open Item 14.1.3.8-1 becomes Confirmatory Item F14.3.7.5-1.

\subsubsection{Welding}

Section 3.9, "Welding," of the "Tier 1 Design Certification Material for the GE ABWR, " was under staff review at the time the DFSER was issued. The staff stated that the evaluation would be provided in the FSER. This was DFSER Open Item 14.1.3.9-1.

GE provided revised CDM information in a submittal dated August 31, 1993, and supporting information in Amendment 32. GE eliminated the proposed CDM Section 3.9, and put the required welding information in CDM Section 1.2, General Provisions. GE provided supporting information on welding in the SSAR. The welding aspects of safety-significant portions of the design will be verified as part of the basic configuration walkdown of individual SSCs.

The basic configuration walkdown for welding is discussed in greater detail in Section 14.3.1.2 of this report. Based on the discussion in Section 14.3.1.2, the staff found the treatment of welding in the CDM acceptable. This resolved DFSER Open Item 14.1.3.9-1.

\subsubsection{Interface Requirements}

Section 4.0, "Interface Tier 1 Material," of the "Tier 1 Design Certification Material for the GE ABWR," was under staff review at the time the DFSER was issued. The staff stated that the evaluation would be provided in the FSER. This was DFSER Open Item 14.1.4-1. 
The staff provided comments on interfaces during a meeting with GE on July 27, through 29, 1993. These comments are documented in a moeting summary dated August 10, 1993. GE provided information to resolve these comments in revised Tier 1 material dated August 31,1993 , and provided supporting information in SSAR Amendment 32. In those submittals, GE modified the CDM Section 4.0 to provide consistent treatment of interface requirements for systems, clarify the in-scope and out-of-scope portions of the design, and modify the SSAR listing of systems so that it was consistent with the CDM.

Interfaces are discussed further in Section 14.3.4 of this report. Based on the discussion in Section 14.3.4, the staff found the treatment of interface requirements in the CDM acceptable. This resolved DFSER Open Item 14.1.4-1.

\subsubsection{Site Parameters}

Section 5.0, "Site Parameters," of the "Tier 1 Design Certification Material for the GE ABWR," was under staff review at the time the DFSER was issued. The staff stated that the evaluation would be provided in the FSER. This was DFSER Open Item 14.1.5-1.

The staff provided comments on site parameters in a letter to GE dated July 9, 1993. These comments were discussed during a meeting with GE on July 27 through 29, 1993, and were documented in a meeting summary dated August 10, 1993. GE provided information to resolve these comments in revised Tier 1 material dated August 31, 1993, and provided supporting information in SSAR Amendment 32. In those submittals, GE modified the CDM Section 5.0 to provide consistent treatment of site parameters with the site parameters and design basis analyses contained in the SSAR.

Site parameters are discussed further in Section 14.3.5 of this report. Based on the discussion in Section 14.3.5, the staff found the treatment of site parameters in the CDM acceptable. This resolved DFSER Open Item 14.1.5-1. 


\section{TRANSIENT AND ACCIDENT ANALYSIS}

The staff reviewed the transient and accident analysis for the advanced boiling water reactor (ABWR) in accordance with Standard Roview Plan (SRP) Section 15. Conformance with the acceptance criteria, except as noted for each of the sections, formed the besis for deciding if the design of the facility for each of the areas reviewed was acceptable.

Three groups of design-besis events are ovaluated in this section: anticipated operational occurrences, enticipated operational occurrences involving common-mode software failure, and accidents. A conservative model of the reactor is used for the analysis of events in each group and all appropriate systoms whose operations (or postulated misoperations) would affect the ovent are included. Anticipated operational occurrences (AOOs) are expected to occur during the life of the plant and are analyzed to ensure that they will not cause damage to either the fuel or to the reactor coolant preecure boundary. $\mathrm{AOO} s$ involving common-mode software failures have a lower probability of occurrence and are discussed in Section 15.2 of this report. Design-besis accidents (DBAs) are not expected to occur but are postulated because their consequences would include the potential for the release of significant amounts of radioactive material. These postulated accidents are analyzed to determine the extent of fuel damage expected and to ensure that reactor coolant pressure boundary damage, beyond that assumed initially to be the DBA, will not occur and that the radiological dose is maintained within 10 CFR Part 100 guidelines.

For loss-of-coolant accidents (LOCAs), the acceptance criteria for the emergency core cooling system (ECCS) specified in 10 CFR 50.46 are as follows:

- The peak cladding tomperature must remain below $1204^{\circ} \mathrm{C}\left(2200^{\circ} \mathrm{F}\right)$.

- Maximum cladding oxidation must nowhere exceed 17 percent of the total cladding thickness before oxidation.

- Total hydrogen generation must not exceed 1 percent of the hypothetical amount that would be generated if all the metal in the cladding cylinders surrounding the fuel, excluding the cladding surrounding the plenum volume, were to react.

- The core must be maintained in a coolable geometry.

- Calculated core temperatures after successful initial operation of the ECCS must be maintained accoptably low, and decay heat must be removed for the extended period of time required by the long-lived radioactivity remaining in the core.
The staff evaluation of GE Nuclear Energy (GE) LOCA analysis is given in Sections 15.4.4 and 6.3 of this report.

To demonstrate the adequacy of the plant's engineered safety features (ESF8), GE calculated the offsite consequences that could result from the occurrence of each of several DBAS and presented the results of these computations in the standard safety analysis report (SSAR).

\subsection{Anticipated Operational Occurrences}

$\mathrm{AOOs}$ which include infrequent and moderate frequency events are those transients expected to occur during normal or planned modes of plant operation. The acceptance criteria for these transients are based on GDC 10,15, and 20. ODC 10 specifies that the reactor core and associated control and instrumentation systems shall be designed with appropriate margin to ensure that specified acceptable fueldesign limits are not exceeded during any condition of normal operation, including the effects of AOOs. GDC 15 specifies that sufficient margin shall be included to ensure that design conditions of the reactor coolant pressure boundary are not exceeded during any condition of normal operation, including AOOs. GDC 20 specifies that a protection system be provided that automatically initiates appropriate systems to ensure specified acceptable fuel design limits are not exceeded during any condition of normal operation including AOOs.

Acceptance criteria contained in Chapter 15 of the SRP for AOOs are as follows:

- Pressure in the reactor coolant and main steam systems should be maintained below 110 percent of the design values according to American Society of Mechanical Engineers (ASME) Code, Section III, Article NB-7000. For ABWR, which has a design pressure of $8722 \mathrm{kPa}$ (1250 psig), the pressure should not exceed $9584 \mathrm{kPa}$ (1375 psig) during any AOO.

- Fuel-cladding integrity should be maintained by ensuring that the reactor core is designed with appropriate margin during any conditions of normal operation, including the effects of AOOs. For BWRs, the minimum value of the critical power ratio reached during the transient should be such that 99.9 percent of the fuel rods in the core would not be expected to experience boiling transition during core-wide transients. This limiting value of the minimum critical power ratio (MCPR), called the safety limit for the ABWR, is 1.07 .

- An incident that occurs with moderate frequency should not generate a more serious plant condition unless other faults occur independently. 
- An incident that occurs with moderato frequency in combination with any single active component failure, or operator error, should not result in loss of function of any barrier other than the fuel cladding. A limitod number of fuel-rod-cledding perforations is acceptable. (Seo the discussion of Three Mile Island (TMI) Item II.K-3.44, NUREG-0737, in Chapter 20 of this report.)

For ABWR transient analysis, GE used the ODYNA computer code (proprietary) to simulate pressurization events and the REDYA computer code (proprietary) for other transient events.

The ODYNA code (proprietary) is designed to simulate selected transient conditions for the ABWR. Major features of this code are one dimensional description of kinetics and thermal-hydraulics of the core; reactor internal pumps (RIPs); option for two- and eight-node steamline model; and system models consisting of the core, bypass, and upper plenum. The coro thermal-hydraulics is calculated using a fivo-equation formulation consisting of mass and energy balances for the vapor and liquid phases and momentum balance for the mixture. The code also contains models for ECCS, boron injection, and detailed control system for turbine control and pressure relief. The code includes modifications to the upper plenum model to allow for subcooled liquid.

The REDYA code (proprietary) is designed to simulate selected transient conditions for the ABWR. Major fentures of this code are point kinetics description of the core; lumped pressure calculation from a volume consisting of the core, bypass, and upper plenum; and multiple RIPs. Additionally, the code has models for internal separators; options for two- and eight-node steamline models; wide range of turbine control, pressure relief, and rod motion; reactor protection system (RPS) options; and boron injection models.

Both ODYNA and REDYA codes are similar to previous models, ODYN (NEDO-24154) and REDY (NEDO-10802), which the staff approved for transient analysis of operating BWRs. The ODYNA and REDYA versions have been revised to reflect the recirculation model and ECCS unique for the ABWR. The REDYA code also incorporated some model improvements already included in the ODYN code (e.g., safety/relief valve model and steamline model).

The recirculation model was the major modification in both ODYNA and REDYA codes. This new recirculation model consists of three groups of RIPs. RIP characteristics, initial conditions, and pump trip and runback functions are assumed to be identical for all RIPs in the same group. The performance of this recirculation model has been qualified against plant startup data obtained from European plants with similar RIPs. The events simulated for qualification purposes included pump constdown during a trip of all pumps (data from two plants), during a trip of one pump, and during momentary voltage drop. GE compared the calculated results and plant data to verify the adequacy of the codes. GE also conducted model-to-model comparison and comparison with other test data (e.g., Peach Bottom turbine trip test) to ensure that the models perform correctly.

The staff, with the technical assistance of Brookhaven National Laboratory, audited ODYNA and REDYA during January 1992 at GE offices in San Jose, California. The staff audited three major areas: (1) formulation and models, (2) quality assurance (QA) procedures, and (3) verification and validation. The staff concluded that the modifications to the ODYN and REDY codes for the $A B W R$ were adequately justified. It found the changes to ODYN and REDY to be acceptable. However, there was no documentation to verify that the coding changes to implement new models were independently checked. As stated in the DFSER, GE was to inform the staff, in writing, to confirm that the implementation of the code modifications had been independently verified as correct. This was DFSER Confirmatory Item 15.1-1. (Previously DSER SECY-91-355 Open Item 134.)

In the letter dated February 26, 1993, GE submitted the necessary information describing its verification process. The staff reviewed the documents governing GE QA requirements, and found that the code modifications were performed in accordance with the applicable design control provisions contained within the GE QA program and the GE design control procedures. Therefore, the staff has concluded that GE properly controlled the coding changes for ODYNA and REDYA. Thus, DFSER Confirmatory Item 15.1-1 is resolved.

The staff concludes that the ODYNA and REDYA computer codes are acceptable for design analysis of the ABWR.

In conducting its analyses of anticipated transients, GE used conservative assumptions with regard to initial power, scram reactivity, reactivity coefficients, and power profiles. It used conservative time delays to trip for each scram signal in the analyses. GE analyzed the following transients:

- decrease in core coolant temperature

- increase in reactor pressure

- decrease in reactor coolant system flow rate 


\section{Decrease in Core Coolant Temperature}

Transients analyzed in this group included loss of foedwater heaters, foedwater control failure, runout of one feedwater pump, feedwater controller failure during maximum domand, opening of turbine control and bypass valves, pressure regulator failure in the open direction, inadvertent opening of a safety/rolief valve, and inadvertent residual heat removal (RHR) shutdown cooling operation.

For transients categorized under Decrease in Core Coolant Temperature, the most severe transient is feedwater controller failure during maximum demand (runout of two feedwater pumps). The resultant minimum critical-power ratio (MCPR) reached is 1.07, and the peak veseel pressure is $1262 \mathrm{kPa}$ (168 psi) below the ASME Code limit.

For the loss of feedwater heating transient, GE assumed a drop of $38^{\circ} \mathrm{C}\left(68^{\circ} \mathrm{F}\right)$ in feedwater temperature, although a drop of $66^{\circ} \mathrm{C}\left(119^{\circ} \mathrm{F}\right)$ occurred at a domestic BWR following an electrical component failure. In a letter dated January 10, $1992, \mathrm{GE}$ stated that the drop of $66^{\circ} \mathrm{C}\left(119^{\circ} \mathrm{F}\right)$ was a unique condition for that particular BWR design. The feedwater temperature will not drop as far in the ABWR design during this transient because the ABWR is designed 80 that no single failure of equipment can cause a temperature drop of more than $38^{\circ} \mathrm{C}\left(68^{\circ} \mathrm{F}\right)$. The staff agrees with GE that the $66^{\circ} \mathrm{C}\left(119^{\circ} \mathrm{F}\right)$ drop was caused by a plent-specific design feature not present in the ABWR. Therefore, the $38^{\circ} \mathrm{C}\left(68^{\circ} \mathrm{F}\right)$ drop analyses is acceptable.

Inadvertent opening of a safety relief valve will cause a decrease in reactor coolant inventory and result in a mild depressurization event that will have only a slight effect on fuel thermal margins. Changes in surface heat flux are calculated to be negligible indicating an insignificant change in the MCPR. Thus, the transient response is acceptable and is bounded by the more severe feedwater controller failure transient.

GE initially inappropriately categorized the inadvertent RHR shutdown cooling operation event as an accident rather than an AOO. This was identified as DSER (SECY-91-355) Open Item 135, which was a significant doviation from the SRP. GE recategorized this event as a moderato frequency ovent (an AOO) and applied the appropriate acceptance criteria in the SSAR. The reanalysis of the event shows that the AOO acceptance criteria are mot. This is acceptable and resolved DSER SECY-91-355 Open Item 135.

\section{(2) Increase in Reactor Pressure}

Transients in this group included generator load rejection and turbine trip with and without turbine bypass, inadvertent main steam isolation valves (MSIV) closure, loss of condenser vacuum, loss of auxiliary power transformer, loss of all grid connections, loss of all feedwater flow, and failure of RHR shutdown cooling.

The transient resulting in the highest system pressure was a generator load rejection without turbine bypass, which would result in a peak system pressure of about $1138 \mathrm{kPa}(151 \mathrm{psi})$ below the allowable maximum pressure of $9584 \mathrm{kPa}$ (1375 psig). In the overpressure protection report, the most limiting transient is an inadvertent MSIV closure with failure of the position switch scram (see Section 5.2.2 of this report). The reactor pressure increase for the transient turbine trip without bypass is bounded by the MSIV closure transient and is acceptable.

\section{Decrease in Reactor Coolant System Flow Rate}

Transients in this group included trip of three RIPs, trip of all RIPs, runback of RIPs, and failure of the recirculation flow control to decrease flow.

Traditionally, loss of all forced circulation has been classified as a moderate frequency event and subject to the associated acceptance criteria. The ABWR will use motor-generator (MG) sets to power siz of the ten RIPs. On loss of offsite power, the inertia of the MG provides a longer flow coastdown period. Analysis of this event shows that AOO acceptance criteria are met. However, the staff asked GE to consider the possibility of failures of other systems or components that could result in the loss of forced circulation without the availability of MG set coastdown. GE identified loss-of-flow transients both with and without offsite power available. The case with offsite power available was found more limiting because it did not result in an immediate reactor scram. 
The most severe transient in this group is the simultancous trip of all RIPs with offsito power available which is discussed in Section 15.2 of this report.

\section{Reactivity and Power Distribution Anomalies}

Transients in this group included rod withdrawal error, abnormal startup of one RIP, fast runout of RIPs, and control rod misoperations.

The startup of an idle RIP is categorized under reactivity anomalies. This event is not a limiting transient and neither primary pressure boundary nor fuel damage criteria are exceoded.

\section{(a)}

\section{Rod Withdrawal Error at Low Power}

GE examined the design of the rod control system to ascertain if a single failure can lead to the uncontrolled withdrawal of a control rod during refueling and during startup and low-power operation. During refueling operations, interlocks ensure that all control rods are inserted while fuel is being handled over the core. When no fuel is being handled, a maximum of one rod may be withdrawn. However, the control system is designed (see Section 4.3.2 of this report) so that the core is subcritical with the highest worth rod withdrawn. Finally, a control rod cannot physically be removed (from the top) without removing the four fuel assemblies that surround the rod. Therefore, GE has not provided an analysis of control rod removal orror during refueling. This is in accord with approvals for current BWRs and is acceptable.

GE claims that the uncontrolled withdrawal of a rod during reactor startup is prevented by the rod block control system function of the rod control and information system (RCIS). This system enforces the banked position withdrawal sequence and precludes rod withdrawals other than those permitted in normal operation SRP Section 15.4.1 states that this transient need not be considered if single failures cannot cause the sequence. The single failure evaluation of the RCIS is given in Chapter 7 of this report. However, in accordance with staff requirements on current BWRs, GE also analyzed the erroneous withdrawal of a high worth control rod and found that the results fall well within the MCPR and other fuel criteria limits. This analysis is acceptablo for the postulated event.

\section{(b) Bod Withdrawal Error at Power}

The rod withdrawal error transient can result from oither a procedural error by the operator so that a gang of control rods is withdrawn continuously or from a malfunction of the automated rod withdrawal control logic during automated operation in which a gang of control rods is withdrawn continuously.

In the ABWR, the automated thermal limit monitor (ATLM) and the multi-channel rod block monitor (RBM) subsystem logic issues a rod block signal used in the RCIS logic to enforce rod blocks. This feature acts to prevent fuel damage by ensuring that tho MCPR and maximum average planar linear heat generation rate (MAPLHGR) do not violate the fuel thermal operating and safety limits. The operating thermal limits rod block function will block rod withdrawal when the operating thermal limit is reached.

The rod block algorithms and set point are based on online core information (e.g., core flow and local power range monitor (LPRM) readings used to calculate the fuel status relative to limits). In response to staff questions and DSER (SECY-91-135) Open Item 137, GE presented (enclosures to its letter dated January 10, 1992, "GE Response to Agenda Item 12 Discussed During ... . Meeting on November 20 and 21, 1991") a description of the algorithms, their development and bases, and examples of the functions (correlating MCPR or MAPLHGR with LPRM set points) programmed into the microprocessor-based ATLM for a given fuel and core design.

The functions for both MCPR and MAPLHGR are developed statistically with a database developed by analyzing control rod withdrawals for a wide range of initial power and flow conditions for a core design. These cases are used to provide a statistically derived bounding ( $95 / 95$ probability and confidence) function for the rod block set point. The method is similar to the approach previously approved for BWR/5 rod block set point analysis. The functions will be updated for each fuel and core design used in the ABWR. This resolved DSER SECY-91-355 Open Item 137.

The RBM algorithms are simple relationships between power (LPRM readings) and operating limits (MCPR and MAPLHGR) and are reasonable and acceptable. The statistical approach is similar to previous staff-approved rod block methodology 
and is appropriate and conservative for use as propoeed for the ABWR.

\section{Increase in Reactor Coolant Inventory}

GE analyzed inadvertent startup of the highpressure core flooder (HPCF) pump. (Feedwater flow control failure to maximum demand is covered in Category (1).)

The transient which could cause unplanned addition to coolant inventory is the inadvertent actuation of the HPCF system. The HPCF system actuation has little effect because its flow is small compared to the recirculation flow. Becsuse the HPCF full flow is a small contributor to total core flow, the increase in total coolant inventory is also small. GE's analysis shows that the consequences of this small inventory increase has little effect on fuel thermal margins and reactor system pressure. In accordance with SRP Section 15.5.1, this is acceptable.

\section{(6) Decrease in Reactor Coolant Inventory}

The anticipated operational occurrence of the inadvertent opening of a safety relief valve is covered in Category (1) above.

GE indicated that non-safety-grade equipment is credited for the high water level 8 trip, use of turbine bypass valves, and recirculation pump trip on load/turbine trip.

The staff questioned the appropriateness of $\mathrm{GE}$ taking credit for equipment that is not safety grade in the transient analysis as stated in DSER (SECY-91-355) Open Item 138. GDC 1 through 4 require that components important to safety be designed to be coimmensurate with the quality standards, and GDC 21 requires that the protection system be designed for high functional reliability. GE listed in a table the redundancy, isolation, environmental, seismic, periodic testing, and QA requirements for the equipment.

Even though the equipment discussed above will not be categorized as safety grade, it is of high quality and has sufficient redundancy to ensure its operability. To ensure an acceptable level of performance for the ABWR, GE committed to identify the above equipment in the $A B W R$ tochnical specifications (TS) with regard to availability, set points and surveillance testing. This was DFSER TS Item 15.1-1. GE included the level 8 trip, the RIP trip and the turbine bypass in the proposed ABWR TSs. This is acceptable and TS Item 15.1-1 is resolved.

By letter dated August 23, 1989, GE informod Gulf States Utilities Company of a condition that could be reportable under 10 CFR Part 21, applicable to the River Bend Station. This condition involves a slow closure of one main turbine control valve. This low probability event, which was not previously considered, results from a turbine control valve that GE assumes to close as a result of an unspecified failure in the turbine control circuit or in the servo-mechanism hardware. According to GE, if the valve closes in less then 2.3 seconds, a reactor scram will be initiated as a result of high neutron flux and no safety limits will be exceoded. However, if the valve closes in more than 2.3 seconds, the reactor scram will be initiated by high reactor pressure. During this slow-closure case, the MCPR safety limit may be exceeded if the maximum combined flow limiter is set for less the? 113 percent of rated steam flow. GE based the consequences of this postulated event on its assessment of a generic BWR/6 analysis. This was identified as DSER (SECY-91-355) Open Item 139. The staff, however, requested that GE address the event for ABWR applicability. In response, $G E$ performed an ABWR-specific analysis for the slow closure of one turbine control valve with the remaining three control valves remaining open. In this case, the neutron flux increase will not reach the high neutron flux scram set point. Since the available turbine bypass capacity will be high enough to bypass all steam flow not passing through the remaining three turbine control valves, the reactor power settles back to its steady state. (The total steam flow through three control valves will increase to about 85 percent, and the remaining 15 percent of flow will pass through the slowopening control valve and the bypass valves.) During this transient, the peak fuel surface heat flux will not exceed 104 percent of its initial value. The MCPR remains above the safety limit and is acceptable. Therefore, DSER Open Item 139 was resolved.

\subsection{Trip of All Reactor Internal Pumps and Pressure Regulator Down-Scale Failure}

For the postulated trip of all of the RIPs with offsite power available, GE postulated a common-mode failure of the adjustable speed drives. GE estimated that a fraction of low burnup fuel rods will achieve boiling transition during this event although test results indicate no fuel failures 
would occur. The staff classified this postulated event in the special category of anticipated transients involving a common-mode software failure and established a special acceptance criterion for the radiological dose calculation. The staff will not require that fuel failure be assumed in dose calculations for fuel rods that are under approximately $600^{\circ} \mathrm{C}\left(1111^{\circ} \mathrm{F}\right)$ for less than 60 seconds. This time and temperature criterion is based on test data for fuel that has achieved up to 20 gigawatts days per metric ton (GWD/MtU) (18 GWD/t) burnup; thus, it may be applied only to fuel with burnup of less than $20 \mathrm{GWD} / \mathrm{MtU}$ $(18 \mathrm{GWD} / \mathrm{t})$. For fuel with greater burnup, the dose calculations must assume fuel failure for all fuel rods that achieve transition boiling. In the equilibrium cycle, the higher burnup fuel accounts for about 45 percent of the total fuel bundles. The power generated by these bundles is usually $\mathbf{2 0}$ percent less than that of the hottest bundles, and less than 0.2 percent of these rods are expected to enter transition boiling. Because none of the hottest fuel rods exceed the time and temperature failure criterion, the radiological dose requirements limit of 10 percent of 10 CFR Part 100 are satisfied.

For the pressure regulator down-scale failure to occur, all three channels would have to suffer a common-mode failure before the pressure regulator would go either up or down the scale. If the pressure regulator failed downscale, the steam control valves would close causing the reactor pressure and reactivity to increase. When reanalyzing this postulated event, GE proposed to assume that any fuel rods that achieve transition boiling fail for the purposes of the radiological dose calculation. The staff includes this postulated event in the special category of anticipated transients involving a common-mode software failure because of the uncertainty that such an event will occur during the plant lifetime. GE originally categorized this event as an accident. The staff believes that it is more appropriate to apply a special classification for such an event. The staff required that GE demonstrate that this special event will not exceed the limits of 10 percent of 10 CFR Part 100, which the staff considers appropriate for an event of such postulated frequency.

According to GE analysis, during this event, it is estimated that less than 0.2 percent of fuel rods enter transition boiling and the requirement that the limit of 10 percent of 10 CFR Part 100 not be exceeded is met.

The staff will treat the above two postulated events as special cases, applicable only for the ABWR. This is due to the unique design features of the $A B W R$ instrumentation and control systems, which reduce the frequency of such events; therefore, allowing these events to be recategorized as special cases. This resolved DSER (SECY-91-355) Open Item 136.

\subsection{Accidents}

GE analyzed RIP seizure and shaft break accidents. In the unlikely evest of the pump motor shaft of 1 of the 10 RIPs stops instantaneously, a very rapid decrease of pump flow will result from the large hydraulic resistance introduced by the stopped rotor or shaft and cause pump seizure or shaft break. Consequently, core inlet flow and core cooling capability decreases. However, GE's analysis shows that with only 1 out of 10 RIPs seized, the core flow decrease is small ( $<10$ percent), so the event is mild. The RIP seizure and shaft break do not result in any fuel failure. This satisfies the dose limit criteria of 10 CFR Part 100 and is acceptable.

GE's analyses of the mislocated fuel bundle accident, misoriented fuel bundle accident, rod ejection accident, and control rod drop accident are discussed below.

\section{Mislocated Fuel Bundle Accident}

Three errors must occur for this event to take place: (a) a bundle must be misloaded into a wrong location in the core; (b) the bundle, which was supposed to be loaded where the mislocation occurred, also is put in an incorrect location or discharged; and (c) the misplaced bundles are overlooked during the core verification process after core loading. A fuel loading error not detected by in-core instruments after fueling operations may result in an undetected reduction in thermal margin during power operations. However, GE evaluated the probability and consequences of a misplaced fuel bundle accident in equilibrium, first cycle, and subsequent cycle cores for current operating reactors and concluded that no fuel failure will occur and no radioactive material will be released from the fuel. The staff approved this analysis for operating plants and it is also applicable for the ABWR. This satisfies the criteria of 10 CFR Part 100 as required by the SRP for this event and is acceptable.

\section{Misoriented Fuel Bundle Accident}

GE notified the staff by a 10 CFR Part 21 report (GE letter dated June 19, 1992, from S.J. Stark, " 10 CFR Part 21, Reportable Condition, Rotated C or S-Lattice Fuel Assembly") that a fuel misorientation event may lead to fuel damage in BWR/6 designs. The staff required GE to evaluate the applicability of the issue for the ABWR and discuss its evaluation in the SSAR. This was DFSER Open Item 15.3-1. 
For this event the fuel bundle is located correctly, but is rotated by $90^{\circ}$ or $180^{\circ}$, requlting in nonuniform adjacent water gaps. While this does not result in exceeding specified acceptable fuel design limits for some fuel bundle configurations during normal operation, for other configurations the limit might be exceeded. GE prepared a generic probabilistic risk model (GB letter dated September 30, 1992, from J.F. Klapproth, "Rotated Bundle Event Licensing Basis Change"), based on experience from recommended procedures for verifying fuel loading instituted in 1981, this model applies to current operating reactors and the $A B W R$, to demonstrate that the event may be classified as an accident. Since the staff had not completed the review of the GE probabilistic study, GE chose to reanalyzo the misoriented fuel bundle event for a core loading with a bundle very similar to the reference fuel bundle design. GE made only slight modifications to the radial enrichment distribution to reduce the delta $R$ factor. The analysis reflected that the energy capabilities were equivalent to the reference bundle design and the 15 percent thermal margin requirement was maintained. The infinite lattice void coefficient was also unchanged. This assures that the fuel safety limits are not exceeded for a misorientation event and is acceptable to the staff. Therefore, DFSER Open Item 15.3-1 is resolved.

\section{(3) Rod Ejection Accident}

The rod ejection accident is caused by a major break on the fine motion control rod drive (FMCRD) housing, outer tube, or associated control rod drive (CRD) pipe lines. The consequences of a rod ejection accident are similar to those of the rod drop accident in that the fuel enthalpy criteria may be violated if the speed of the ejected rod and/or the reactivity added are large enough. The same criterion of $280 \mathrm{cal} / \mathrm{gm}$ $(1172 \mathrm{E}+3$ joules $/ \mathrm{kg})$ is applied to the rod ejection accident.

A redundant brake mechanism is installed in the FMCRD system (two brakes in each FMCRD) to prevent severe consequences resulting from this accident. Even if this accident does happen, the brake effectively terminates this event and prevents any severe consequences.

The radiological consequences are bounded by the analysis of the control rod drop accident. Therefore, the plant response is acceptable.
(4)

\section{Rod Drop Accident}

The locking piston CRD mechanism in current BWRs cannot detect separation of the control rod from the drive mechanism during normal rod movements. Therefore, a latch mechenism is provided on the control rod to restrict the control rod freo-fall distance to scceptable limits to prevent damage to the nuclear system process barrier by the rapid reactivity increase that would result from a free fall of a control rod (rod drop accident) from its fully inserted position to the position where the drive mechanism is withdrawn.

In contrast to the locking piston CRD, the FMCRD is designed to detect the separation of the control rod from the drive mechanism. Two redundant and separate Class IE switches are provided to detect the separation of either the control rod from the hollow piston or the hollow piston from the ball nut. Actuation of either of these switches cause an immediate rod block and initiate an alarm in the control room, thereby reducing the probability of a rod drop accident from occurring. The radiological consequences of the control rod drop accident are provided in Section 15.4.1 of this report.

\subsection{Radiological Consequences of Accidents}

(Throughout this chapter there are statements indicating that 10 CFR Part 100 guidelines and criteria have been met. This means that the design basis accident being evaluated would result in a fission product release that would result in an exposure to an individual located in the plant's exclusion area for a period of two hours immediately after the release, of no more than $250 \mathrm{mSv}$ (25 rem), or a whole body dose of no more than $3000 \mathrm{mSv}$ (300 rem), or a total thyroid exposure from iodine of no more than $3000 \mathrm{mSv}$ (300 rem). Further, a person located in the plant's low population zone for the duration of the release would receive no more than a whole body dose of $250 \mathrm{mSv}(25 \mathrm{rem})$ or a total iodine dose to the thyroid of $3000 \mathrm{mSv}$ (300 rem). These dose limits are listed in 10 CFR 100.11.)

In Chapter 15 of the SSAR, GE assessed the radiological consequence of the following six reactor DBAs (1) failure of small lines carrying primary coolant outside containment, (2) main steamline failure outside containment, (3) LOCA, (4) fuel handling accident, (5) spent fuel cask drop accident, and (6) reactor water cleanup system failure outside containment. GE concluded that the ABWR design using (1) reactor accident source term assumptions given in Technical Information Document (TID)-14844, "Calculation of Distance Fac- 
tors for Power and Teet Reactor Siten," (2) certnin ESF systems in the ABWR design, and (3) the bounding sets of atmospheric rolative concentretion values $(X / Q)$ which determine certain distances to the exclusion area boundary (EAB) and the low-population zone (LPZ) for a given aite, are sufficient to provide reasonable sesurance that the radiological consequences of ruch DBAs will bo within the dose reference values established in 1C CFR Part 100 and the dose limits given in GDC 19 of Appendix A to 10 CFR Part 50. (A maximum whole body does of $50 \mathrm{mSv}$ (5 rem) or its equivalent to any part of the body for the duration of an eccident).

To verify GE's conclusion, the staff independently ascesced the radiological consequences of the above six DBAs and reactor control rod drop accident. In its asecesments, the staff used assumptions and methods deecribed in the SRP Section 15 and in Regulatory Guide (RG) 1.3 (Rev. 2), "Assumptions Used for Evaluating the Potential Radiological Consequences of a Loss-of-Coolant Accident for Boiling Water Reactors," and the bounding atmospheric relative concentration values for EAB and LPZ proposed by GE. The major parameters and assumptions used in the staff's radiological consequence assesements are listed in Tables 15.2 through 15.9 of this report.

In its evaluation of the radiological consequences in the DFSER, the staff used an EAB of $800 \mathrm{~m}(0.5 \mathrm{mi})$ and an LPZ ranging from $1500(0.9 \mathrm{mi})$ to $4800 \mathrm{~m}$ (3 mi), with Pasquill F stability and persistent (greater than 95 percent of time) and a wind velocity of $1 \mathrm{~m} / \mathrm{sec}(3 \mathrm{ft} / \mathrm{sec})$. The staff also stated that the median values of EAB and LPZ of current operating reactor sites are $800 \mathrm{~m}(0.5 \mathrm{mi})$ and $4800 \mathrm{~m} \mathrm{(3} \mathrm{mi),} \mathrm{respectively.} \mathrm{In} \mathrm{the} \mathrm{DFSER,} \mathrm{the} \mathrm{staff}$ accepted and used, in its radiological consequence assesements, the atmospheric relative concentration values corresponding to these distances as proposed by GE. GE calculated these values using the acceptable regulatory methodology given in RG 1.3.

Subsequently, as agreed to by the staff, GE proposed in Amendment 32 to the SSAR the use of the bounding atmospheric relative concentrations for EAB and LPZ for the ABWR design rather than median EAB and LPZ distances used by the staff in the DFSER. Table 15.5 of this report and in Table 15.6-13 of the SSAR list the bounding atmospheric relative concentration values proposed by GE and accepted by the staff in its radiological consequence assessments. The staff's recalculated offsite doses resulting from DBAs using the bounding atmospheric relative concentration values are listed in revised Table 15.1 of this report.
The atmoepheric relative concentration for the 2-hour BAB was determined by the most limiting DBA (fuel-handling eccident) not to excoed the dose acceptance criteria epecified in the SRP Section 15.7.4 (750 mSv (75 rem) for the thyroid and $60 \mathrm{mSv}$ (6 rem) for the whole-body doses).

The bounding atmospheric relative concentration values for LPZ (the 8-hour time period from 0 to 8 hours, the 16-hour period from 8 to 24 hours, the 3-day period from 1 to 4 days, and the 26-day period from 4 to 30 days) were also determined by the most limiting DBA (LOCA) not to exceed the dose reference values given in 10 CFR Part 100 (3000 mSv (300 rem) for the thyroid and $250 \mathrm{mSv}(25 \mathrm{rem})$ for the whole-body). Two-hour LPZ atmoapheric relative concentration and an annual average ( 8760 hours) concentration values were obtained by logarithmic interpolation of the celculated LPZ bounding atmospheric relative concentrations. In determination of these $\times / Q$ values, GE followed the guidelines provided in RG 1.145, "Atmospheric Dispersion Models for Potential Accident Consequence Assessments at Nuclear Power Plants," (Rev. 1). The bounding atmospheric relative concentration values for the EAB, 2-hour LPZ, and annual average (8760-hours) are specified in Table 5.0, "ABWR Site Parameters," of the ABWR Certified Design Material (Tier 1 Design Control Document) and in Table 2.0-1, "Envelope of ABWR Standard Plant Site Design Parameters," of the SSAR.

The staff will independently assess $\chi / Q$ values for potential accident consequence assessments on a site-specific basis using onsite meteorological data (hourly cumulative frequency distributions) submitted by a $\mathrm{COL}$ applicant in accordance with RG 1.70, "Standard Format and Content of Safoty Analysis Reports for Nuclear Power Plants." In its evaluation, the staff will use the guidance provided in (1) RO 1.23, "Onsite Meteorological Programs," (2) RG 1.145, (3) RG 1.111, "Methods for Estimating Atmospheric Transport and Dispersion of Gaseous Effluent in Routine Releases from Light-Water-Cooled Reactors," and (4) SRP Section 2.3.4, Short-Term Dispersion Estimates. As discussed in Section 2.3.4 of this report, this was DFSER COL Action Item 2.3.4-1.

If sito-specific atmospheric relative concentration values are greater than the bounding values (e.g., less dispersion) used in this report, a COL applicant may have to augment ABWR ESF systems to meet the relevant requirements of 10 CFR Part 100 and GDC 19. However, this condition is not expected to arise frequently since the bounding values for atmospheric relative concentrations envelope most of the current operating reactor site meteorological characteristics. 
Transient and Accident Analysis

Table 15.1 Revised radiological consequences of design-basis accidents

\begin{tabular}{|c|c|c|c|c|}
\hline \multirow[b]{2}{*}{ Postulated Accident } & \multicolumn{2}{|c|}{$\mathrm{EAB}, \mathrm{mSv}$ (rem) } & \multicolumn{2}{|c|}{ LPZ, mSv (rem) } \\
\hline & Thyroid & Whole Body & Thyroid & Whole Body \\
\hline \multicolumn{5}{|l|}{ Loss of coolant } \\
\hline \multicolumn{5}{|l|}{ Containment leakage } \\
\hline 00- 02 hours & 331 (33) & $40(4)$ & 38 (4) & $3(0.3)$ \\
\hline 02- 08 hours & & & $198(20)$ & 11 (1) \\
\hline 08- 24 hours & & & $244(24)$ & $15(1.5)$ \\
\hline 24- 96 hours & & & $417(42)$ & $6(0.6)$ \\
\hline $96-720$ hours & & & $248(25)$ & $2(0.2)$ \\
\hline Exfiltration & & & $172(17)$ & $6(0.6)$ \\
\hline Total containment leakage & 331 (33) & $40(4)$ & $1317(132)$ & $43(4)$ \\
\hline Emergency core cooling systems component leakage & $20(2)$ & $10(1)$ & 72 (7) & $<10(1)$ \\
\hline Main steam isolation valve leakage & $125(13)$ & $10(1)$ & $1302(130)$ & $<10(1)$ \\
\hline Total & $476(48)$ & $60(6)$ & $2691(269)$ & $63(6)$ \\
\hline \multicolumn{5}{|l|}{ Main stealine failure outside containment } \\
\hline With concomitant iodine spike & $110(11)$ & $<10(1)$ & $13(1)$ & $<10(1)$ \\
\hline With preaccident iodine spike & $270(27)$ & $<10(1)$ & $30(3)$ & $<10(1)$ \\
\hline Rod drop accident & $6(0.6)$ & $<10(1)$ & $20(2)$ & $<10(1)$ \\
\hline Fuel-handling accident & $750(75)$ & $<10(1)$ & $20(2)$ & $<10(1)$ \\
\hline Small line break accident & $46(5)$ & $<10(1)$ & $<10(1)$ & $<10(1)$ \\
\hline \multicolumn{5}{|l|}{ Reactor water cleanup line break } \\
\hline With concomitant iodine spike & $92(9)$ & $<10(1)$ & 13 (1) & $<10(1)$ \\
\hline With preaccident iodine spike & 225 (23) & $<10(1)$ & $30(3)$ & $<10(1)$ \\
\hline
\end{tabular}

Note: $\mathrm{EAB}=$ exclusion aree boundary

I.PZ = low population zone. 
Parameter
Power level
Peaking factor
Number of fuel rods perforated
Number of fuel rods melted
Condenser leak rate
Fraction of fission product inventory release to coolant
from melted fuel rods

\section{Iodines}

Noble gases

Fraction of fission product inventory released to coolant from perforated fuel rods

$$
\text { Iodines }
$$

Noble gases

Iodine fraction released to condenser

Iodine fraction available for release from condenser after plate-out and partitioning

$10 \%$

$100 \%$

$10 \%$

$100 \%$

$10 \%$

\section{Value}

$4005 \mathrm{MWt}$ (4.2 E+6 BTU/sec)

1.55

770

6

$1.0 \% /$ day

Atmospheric diffusion values

0-2 hour, exclusion area boundary

1.37E-3 sec/m $/ \mathrm{m}^{3}\left(3.88 \mathrm{E}-\mathrm{S} \mathrm{sec} / \mathrm{ft}^{3}\right)$

$0-8$ hour, low population zone 
Table 15.3 Assumptions used to evaluate the main steamline and small line break accidents outside the containment

Paramoter

Value

Mass of primary coolent released before main steam isolation valve closure

Steam mass roleased

$1.29 \mathrm{E}+4 \mathrm{~kg}$

$(2.8 \mathrm{E}+4 \mathrm{lb})$

Water mass released

$2.2 \mathrm{E}+4 \mathrm{~kg}$

(4.84E+4 lb)

Mass of primary coolant released through small line

$5.5 \mathrm{E}+3 \mathrm{~kg}$

$(1.2 \mathrm{E}+4 \mathrm{lb})$

Mass of primary coolant flashed

$2.3 \mathrm{E}+3 \mathrm{~kg}$

(5E+3 lb)

Fraction of iodine in the primary coolant released

$100 \%$

Fraction of noble gases in the primary coolant released

$100 \%$

Primary coolant concentration (dose equivalent I-131)

Technical specification limit, normal long-term operation

7.4E-3 mBq

$(0.2 \mu \mathrm{Ci} / \mathrm{gm})$

Technical specification limit, normal sbort-term operation

$1.5 \mathrm{E}-1 \mathrm{mBq}$

$(4.0 \mu \mathrm{Ci} / \mathrm{gm})$

Atmospheric diffusion values

0-2 hour, exclusion area boundary

1.37E-3 sec/ $\mathrm{m}^{3}$

(3.88 E-5 sec/ $\left./ \mathrm{ft}^{3}\right)$

0-8 hour, low population zone

$1.56 \mathrm{E}-4 \mathrm{sec} / \mathrm{m}^{3}$

$\left(4.42 \mathrm{E}-6 \mathrm{sec} / \mathrm{ft}^{3}\right)$ 
Transient and Accident Analysis

Table 15.4 Assumptlons used to evaluate the loss-of-coolant accident

Paramoter

Fraction of core inventory released

Noble gases

Value

Iodines

4005 MWt

(4.2E+6 BTU/sec)

Iodines initial plate-out fraction

$100 \%$

$50 \%$

Iodire chomical species

Elemental

Particulato

$5 \%$

Organic

$50 \%$

Suppression pool decontamination factor

Noble gas

Organic iodine

Elemental iodine

Particulate

$4 \%$

Pool bypass

1

1

2

2

$50 \%$

Iodine dose conversion factors

ICRP-30*

Primary containment leakage

$0.5 \% /$ day

Main steam isolation valve leakage (total)

$3.96 \mathrm{~m}^{3} / \mathrm{hr}$

$\left(140 \mathrm{ft}^{3} / \mathrm{hr}\right)$

Standby gas treatment system

Filter efficiency

$97 \%$

Flow rate

$113 \mathrm{~m}^{3} / \mathrm{min}$

$\left(4000 \mathrm{ft}^{3} / \mathrm{min}\right)$

Drawdown time

20 minutes

Emergency core cooling system (ECCS) system leakage

$3.785 \mathrm{~L} / \mathrm{min}$

(1.0 gpm)

Iodine core inventory in suppression pool

0.5 fraction

Suppression pool water volume

3.785E $+6 \mathrm{~m}^{3}$

$(1 \mathrm{E}+6 \mathrm{gal})$

Iodine partition factor for ECCS leak

0.1

Primary containment free volume

$1.33 \mathrm{E}+4 \mathrm{~m}^{3}$

$\left(4.7 \mathrm{E}+5 \mathrm{ft}^{3}\right)$

Secondary containment free volume

$8.5 E+4 \mathrm{~m}^{3}$

$\left(3 \mathrm{E}+6 \mathrm{ft}^{3}\right)$

Secondary containment mixing efficiency

$50 \%$

- ICRP-30 International Commission on Radiation Protection Publication 30. 
Table 15.5 Atmospheric dispersion $(\alpha / Q)$ values used in accident evaluations

Timo Period

$$
\begin{gathered}
x / Q \text { Value } \\
\left(\mathrm{sec} / \mathrm{m}^{3}\right)\left(\mathrm{Sec} / \mathrm{ft}^{3}\right)
\end{gathered}
$$

0-02 hour EAB

0-08 hour LPZ

8-24 hour LPZ

$1-04$ day LPZ

4-30 day LPZ
1.37E-3 (3.88 E-5)

$1.56 \mathrm{E}-4(4.42 \mathrm{E}-6)$

9.61E-5 (2.72 E-6)

3.36E-5 (9.51 E-7)

7.42E-6 (2.10 E-7)

\section{Note: $\quad \mathrm{EAB}=$ exclusion area boundary \\ LPZ = low population zone.}

\begin{tabular}{|c|c|c|c|c|c|}
\hline \multicolumn{3}{|l|}{ Parameter } & \multicolumn{3}{|c|}{ Value } \\
\hline \multicolumn{3}{|c|}{$\begin{array}{l}\text { Source term } \\
\text { Main steam isolation valve leakage rate } \\
\text { Leakage duration } \\
\text { Condenser volume }\end{array}$} & \multicolumn{3}{|c|}{$\begin{array}{l}\text { Regulatory Guide } 1.3 \\
3.96 \mathrm{~m}^{3} / \mathrm{hr}\left(140 \mathrm{ft}^{3} / \mathrm{hr}\right) \\
30 \text { days } \\
9.85 \mathrm{E}+8 \mathrm{cc}\left(3.47 \mathrm{E}+4 \mathrm{ft}^{3}\right)\end{array}$} \\
\hline & $\begin{array}{l}\text { Deposition } \\
\text { Temperature } \\
\text { (K) (F) }\end{array}$ & $\begin{array}{l}\text { Velocities } \\
(\mathrm{cm} / \mathrm{sec})\end{array}$ & $\begin{array}{l}\text { Resuspen- } \\
\text { sion Rate } \\
\text { (in./sec) }\end{array}$ & \multicolumn{2}{|c|}{$\begin{array}{l}\text { Fixation } \\
\text { Rate }\end{array}$} \\
\hline $\begin{array}{l}\text { Elemental and } \\
\text { particulate } \\
\text { iodine }\end{array}$ & $\begin{array}{l}500(81) \\
400(261) \\
500(441) \\
560(549)\end{array}$ & $\begin{array}{l}3.2 \mathrm{E}-2 \\
5.0 \mathrm{E}-3 \\
1.0 \mathrm{E}-3 \\
6.2 \mathrm{E}-4\end{array}$ & $\begin{array}{l}1.2 \mathrm{E}-2 \\
2.0 \mathrm{E}-3 \\
3.9 \mathrm{E}-4 \\
2.4 \mathrm{E}-4\end{array}$ & $\begin{array}{l}3.14 \mathrm{E}-6 \\
7.05 \mathrm{E}-6 \\
8.10 \mathrm{E}-6 \\
9.20 \mathrm{E}-6\end{array}$ & $\begin{array}{l}4 \mathrm{E}-6 \\
8 \mathrm{E}-6 \\
1 \mathrm{E}-5 \\
2 \mathrm{E}-5\end{array}$ \\
\hline Organic iodine & $\begin{array}{l}300(81) \\
400(261) \\
500(441) \\
560(549)\end{array}$ & $\begin{array}{l}1.4 \mathrm{E}-3 \\
3.5 \mathrm{E}-4 \\
1.0 \mathrm{E}-5 \\
1.3 \mathrm{E}-6\end{array}$ & $\begin{array}{l}5.5 \mathrm{E}-4 \\
1.4 \mathrm{E}-4 \\
3.9 \mathrm{E}-6 \\
5.2 \mathrm{E}-7\end{array}$ & $\begin{array}{l}9.5 \mathrm{E}-8 \\
2.0 \mathrm{E}-7 \\
3.0 \mathrm{E}-7 \\
3.6 \mathrm{E}-7\end{array}$ & $\begin{array}{l}4 E-6 \\
8 E-6 \\
1 E-5 \\
2 E-5\end{array}$ \\
\hline & $\begin{array}{l}\text { Inside } \\
\text { Diameter } \\
\text { (cm) (in.) }\end{array}$ & $\begin{array}{l}\text { Length } \\
(\mathrm{cm})(\mathrm{ft})\end{array}$ & $\begin{array}{l}\text { Thickness } \\
\text { (cm) (in.) }\end{array}$ & & \\
\hline \multicolumn{6}{|l|}{ Component } \\
\hline $\begin{array}{l}\text { Main steamline } \\
\text { Drain line }\end{array}$ & $\begin{array}{l}64(25) \\
6.7(2.6)\end{array}$ & $\begin{array}{l}4773(157) \\
610(240)\end{array}$ & $\begin{array}{l}2.5(1.0) \\
1.1(.4)\end{array}$ & & \\
\hline
\end{tabular}

Table 15.6 Method to evaluate iodine removal in main steamlines and main condenser 
Transient and Accident Analysis

Table 15.7 Iodine releases* GBq (curies)

\begin{tabular}{llll}
\hline Hours & Inlet to Main Steamlines & Inlet to Main Condenser & \multicolumn{1}{c}{ Outlet From Main Condenser } \\
\hline $00-002$ & $4.8 \mathrm{E}+05$ & $1.6 \mathrm{E}+04$ & $8.9 \mathrm{E}+02$ \\
& $(1.3 \mathrm{E}+04)$ & $(4.2 \mathrm{E}+03)$ & $(2.4 \mathrm{E}+01)$ \\
$02-008$ & $1.3 \mathrm{E}+06$ & $1.7 \mathrm{E}+04$ & $3.5 \mathrm{E}+03$ \\
& $(3.5 \mathrm{~B}+04)$ & $(4.6 \mathrm{E}+03)$ & $(9.5 \mathrm{E}+01)$ \\
$08-024$ & $1.8 \mathrm{E}+06$ & $1.7 \mathrm{E}+04$ & $1.8 \mathrm{E}+04$ \\
& $(4.9 \mathrm{E}+04)$ & $(4.6 \mathrm{E}+03)$ & $(4.8 \mathrm{E}+02)$ \\
$24-096$ & $6.7 \mathrm{E}+06$ & $5.9 \mathrm{E}+05$ & $2.0 \mathrm{E}+05$ \\
& $(1.8 \mathrm{E}+05)$ & $(1.6 \mathrm{E}+04)$ & $(5.4 \mathrm{E}+03)$ \\
$96-720$ & $2.1 \mathrm{E}+07$ & $1.7 \mathrm{E}+06$ & $1.1 \mathrm{E}+06$ \\
& $(5.6 \mathrm{E}+05)$ & $(4.6 \mathrm{E}+05)$ & $(2.9 \mathrm{E}+04)$ \\
\hline
\end{tabular}

*Based on total MSIV leakage rate.

Table 15.8 Assumptions used in computing fuel handling accident doses

Parameter

Value

Power level

Peaking factor

4,005 Mwt

1.55

Number of fuel rods damaged

$124^{(1)}$

$5,120^{(2)}$

Number of fuel rods in cask

1,116

Filter iodine removal efficiencies:

Organic

Elemental

$99 \%$

$99 \%$

Shutdown Times

24 hours $^{(1)}$

7 days $(2)$

120 days $^{(3)}$

Inventory released from damaged rods:

Iodine and noble gases

$\mathrm{Kr}-85$

Iodine fraction:
Organic
0.25
Elemental
0.75

Atmospheric diffusion values

0-2 hour, exclusion boundary

$\left(\mathrm{sec} / \mathrm{m}^{3}\right) \quad\left(\mathrm{sec} / \mathrm{ft}^{3}\right):$

0-8 hour, low population zone

1.37E-3 (3.88 E-5)

$1.56 \mathrm{E}-4 \quad(4.42 \mathrm{E}-6)$

(1) single fuel assembly dropping

(2) heavy object dropping

(3) fuel cask dropping 
Table 15.9 Assumptions and extimates of the radiological consequences to control room operators after a loss-of-coolant accident

Control room free volume

\section{Recirculation rates}

Filtered intake

Unfiltered intake

Filterod recirculation

Filter efficecy

Unfiltered control room infiltration rate (assumed)

Duration of accident

Breathing rate of operators in control room for course of accident

Meteorology (wind speeds for all sectors
$00-008$ hours
$08-024$ hours
$24-096$ bours
96 - 720 hours

Iodine protection factor

Iodine dose conversion factors*

Iodine reduction factor for dual air intake

Control room operator occupational factors

$$
\begin{aligned}
& 00-008 \text { hours } \\
& 08-024 \text { hours } \\
& 24-096 \text { hours } \\
& 96-720 \text { hours }
\end{aligned}
$$

Doses to control room operators

$$
\begin{aligned}
& 00-008 \text { hours } \\
& 08-024 \text { hours } \\
& 24-096 \text { hours } \\
& 96-720 \text { hours } \\
& \text { Total }
\end{aligned}
$$

$$
7,000 \mathrm{~m}^{3}\left(2 \mathrm{E}+5 \mathrm{ft}^{3}\right)
$$

$$
\begin{aligned}
& 1.8 \mathrm{~m}^{3} / \mathrm{sec} \\
& 0.0 \\
& 0.8 \mathrm{~m}^{3} / \mathrm{ecc} \\
& 95 \%
\end{aligned}
$$

$$
\text { 4.7E-3 } \mathrm{m}^{3} / \mathrm{sec}\left(1.0 \mathrm{E}-1 \mathrm{ft}^{3} / \mathrm{min}\right)
$$

30 days

$$
3.47 \mathrm{E}-4 \mathrm{~m}^{3} / \mathrm{sec}\left(1.22 \mathrm{E}-2 \mathrm{ft}^{3} / \mathrm{sec}\right)
$$

$$
\begin{aligned}
& 4.0 \mathrm{E}-3 \mathrm{sec} / \mathrm{m}^{3}\left(1.1 \mathrm{E}-4 \mathrm{sec} / \mathrm{ft}^{3}\right) \\
& 2.4 \mathrm{E}-3 \mathrm{sec} / \mathrm{m}^{3}\left(6.8 \mathrm{E}-5 \mathrm{sec} / \mathrm{f}^{3}\right) \\
& 1.5 \mathrm{E}-3 \sec / \mathrm{m}^{3}\left(4.3 \mathrm{E}-5 \mathrm{sec} / \mathrm{f}^{3}\right) \\
& 6.6 \mathrm{E}-4 \sec / \mathrm{m}^{3}\left(1.9 \mathrm{E}-5 \mathrm{sec} / \mathrm{f}^{3}\right)
\end{aligned}
$$

27

ICRP-30**

$$
4
$$

$$
\begin{aligned}
& 1 \\
& 1 \\
& 0.6 \\
& 0.4
\end{aligned}
$$

Thyroid dose* mSv (rem)

10 (1)

30 (3)

$100(10)$

$130(13)$

270 (27)
Whole-body dose**** mSv (rem)

$10(1)$

$3(0.3)$

$1(0.1)$

$1(0.1)$

$15(1.5)$

* Unweighted dose equivalent.

* ICRP-30 International Commission on Radiation Protection Publication 30.

** Unweighted dose equivalent - rod bone marrow. 
The bounding atmoepheric relative concentrations eliminate the need for either the COL applicant with the certified ABWR design or the ataff to seeese the offaite radiological consequence aswesements for DBAs for the reactor site proposed if a COL applicent cen demonstrate that (1) its atmoepheric relative concentrations at the proposed ABWR reactor sito aro lese then tho bounding values used in this report, and (2) its design characteristics of main steamlines, stoem drain lines, and condenser can remove equal or greater amounts of iodine then that claimed in the staff aseosement in this report.

\subsubsection{Control Rod Drop Accidents}

In SSAR Section 15.4.9.6, GE states that the radiological consequences of a control rod drop accident need not be considered because auch an eccident is extremoly unlikely with the improved dexign of the ABWR. The ABWR design employs the FMCRD system, which has soveral now features not found in current BWR locking piston CRDs.

In SSAR Section 15.4.9.2, GE states that for the rod drop accident to occur, it is necessary for such highly unlikely ovents as failures of both Class IE separation-detection devices or the failure of the rod block interlock, and the failure of the latch mechanism to occur bimultaneously with the occurrence of a stuck rod on the same FMCRD. GE further states that, thereforo, there is no basis to postulate the occurrence of this eveat because of the low probability of such simultancous occurrence of these multiple independert events.

The staff considered past licensing reviows, such as Clinton, Perry, and River Bend, and concluded that a control rod drop accident for the ABWR design results in radiological consequences less than a small fraction of the dose reference values apecified in 10 CFR 100.11 oven with conservative sesumptions. SRP Section 15.4.9 (III) states that a specific calculation of the rediological consequences for this accident is not necessary unless unusual plant or site features are present, or the applicant's calculation shows an unusually large amount of fuel damage. However, the staff specifically evaluated this accident because it is the first application involving the ABWR standard design with hypothetical site boundaries. This ovaluation should establish a reference for comparison of future applications incorporating the ABWR design.

To evaluate the radiological consequence of this accident, the staff postulated that the highest worth control rod becomos decoupled from its drive mochanism at a fully inserted position in the core. The drive mechanism is withdrawn, but the decoupled control rod is assumed to be stuck in place. At a later moment, the control rod suckeneny falle free and drops out of the core. This results in the insertion of a large positive reactivity into the core, causing a localized power excursion. An automatic safety feature would terminate this excursion with required operator action. The rod pattern control function of the RCIS limits the worth of any control rod by regulating the withdrawal sequence.

The staff eatimated that such a rod drop would cause no more than $\mathbf{7 7 0}$ fuel rods to reach the threshold for cladding damage, with 6 fuel rods melting. Table 15.2 of this report lists the assumptions used for estimating this fuel damage which are consistent with those given in Appendices A (Physics and Thermal-Hydraulics) and B (Rediological Assumption) of RG 1.77, "Assumptions Used for Evaluating a Control Rod Ejection Accident for Preasurized Water Reactors," (Rev. 0). The computed doese are listed in Table 15.1 of this report and are well within the doee reference values of 10 CFR 100.11. Therefore, the staff concludes that the ABWR design is adequate to control the release of fission products following a postulated control rod drop accident.

\subsubsection{Failure of Small Lines Carrying Primary Coolant Outside Containment}

GDC 55 contains provisions to ensure isolation of all pipes carrying reactor coolant that penetrate the containment building. Exempted from these specifications are smalldiameter pipes (instrument lines) that must be continuously connected to the primary coolant system in order to perform necessary functions. The design must include methods of mitigating the consequences of a rupture of an instrument line because the lines cannot be automatically isolated. GE submitted a radiological analysis for an instrument line failure in SSAR Section 15.6.2.5, and the results of the analysis are provided in SSAR Table 15.6.3.

GE postulated that a small steam or liquid line breaks inside or outside the primary containment and that a small instrument line, instantaneously and circumferentially, breaks at a location where it may not be able to be automatically isolated and where detection is not automatic or apparent.

GE estimated that $5,448 \mathrm{~kg}(12,000 \mathrm{lbs})$ of primary coolant would be released through the break before it is isolated. GE estimated that $2,270 \mathrm{~kg}(5,000 \mathrm{lbs})$ of the $5,448 \mathrm{~kg}$ released would flash to steam and bo available for release.

While conducting past licensing reviews, such as Clinton, Perry, and River Bend, the staff determined that a small line break accident is expected to result in radiological consequences less than a small fraction of the dose reference values specified in 10 CFR 100.11. Further- 
more, the staff believes that these postulated breaks are subcumed by the design-basis LOCA radiological coneoquencen, as atated in SRP Section 15.6.2. Howover, the etaff did perform a specific ovaluation of this accident because this application is the firt involving the ABWR atandand design with hypothetical site boundaries. This ovaluation should establish a reference for compariecon of future applications incorporating the ABWR doaign.

The assumptions used for the ovaluation aro listed in Table 15.3 of this report. The computed doses are listed in Table 15.1 and are well within the dose reference values of 10 CFR 100.11. Therefore, the staff concludes that the $A B W R$ design is adequate to control the release of fission products following a postulated small line break sccident.

\subsubsection{Mas. Steamline Failure Outside Containment}

GE postulated one of the four main steamlines to rupture botween the outer isolation valve and the turbine control valves. GE analyzed this hypothetical accident in SSAR Section 15.6.4.5 and concluded that no more than $34,800 \mathrm{~kg}(76,770 \mathrm{lb})$ of reactor coolant would be lost through the break before automatic isolation and lese than $12,870 \mathrm{~kg}(28,373 \mathrm{lb})$ of that would be lost as steam. The results of the GE analysis are provided in SSAR Table 15.6.7.

The staff accepted GE's estimated value and calculated the potential radiological consequences assuming $34,000 \mathrm{~kg}$ $(74,957 \mathrm{lb})$ of reactor coolant are released directly to the environment. The staff assumed that 100 percent of the iodine and noble gases present in the released coolant are released to the atmosphere within 2 hours as stated in RG 1.5, "Assumptions Used for Evaluating the Potential Radiological Consequences of a Steamline Break Accident for Boiling Water Reactors," (Rev. 0). Other assumptions are listed in Table 15.3 of this report.

In Section 3.6 of this report, the staff evaluatod the ABWR design for protection against postulated piping failures in fluid systoms outside the containment. The staff's evaluation of the protection provided against adverne environmental offects (excluding radiation effects) resulting from postulatod piping failure is discussed in Section 3.11 of this report.

The staff assumed two reactor coolant conditions for the evaluation. In Case 1, the lost coolant was contaminated with radionctive iodine at the limits included in the standard tochnical specifications (STS) (i.e., 7.4E-3 mBq $(0.2 \mu \mathrm{Ci})$ of dose-equivalent I-131 per gram) for BWRs at continued full-power operation. In Case 2, a concentration of $1.5 \mathrm{E}-1 \mathrm{mBq}(4.0 \mu \mathrm{Ci})$ of dose-equivalent I-131 per gram was assumod (the limits in the STSs above which the reactor is required to be shut down). The SRP acceptance criteris ane the dowe reference values of 10 CFR 100.11 for Cave 2, and lese then 10 percent of these values for Case 1. Doso-equivalent I-131 is defined as any mixture of iodise isotopes yielding the samo inhalation thyroid doee so the atated amount of pure I-131. The staff also considered the amounts of 13 noble gas isotopes that also would be released.

The major parameters and assumptions used in the staff: radiological consequence assessment are given in Table 15.3 of this report. The calculated doses are listed in Table 15.1 and are within the acceptance criteria of SRP Section 15.6.4. Therefore, the staff concludes that the ABWR dosign is adequato to control the release of fission products following a postulated steamline break accident.

\subsubsection{Lose-of-Coolant Accidents}

In SSAR Section 15.6.5, GE solected and analyzed a hypothetical design-basis LOCA and concluded that certain bounding eets of atmospheric relative concentration values in conjunction with the use of ESF systems provided in the ABWR design are sufficient to provide reasonable assurance that the radiological consequences of such an uccident will bo within the dose reference values establishod in 10 CFR Part 100.

To verify GE's conclusion, the staff independently assessed the radiological consequences of a hypothetical LOCA. In its assocsment, the staff used assumptions and mothods doscribed in the appendices to SRP Section 15.6.5 and in RG 1.3, "Assumptions Used for Evaluating the Potential Radiological Consequences of a Loss-of-Coolant Accident for Boiling Water Reactors," (Rev. 2). The major parameters and assumptions used in the staff's evaluation are listed in Table 15.4 of this report.

Since no specific sito is associated with the ABWR plant, GE previously defined these two boundaries only in terms of various hypothetical atmospheric relative concentrations at fixed BAB and LPZ distances. Subsequently, GE proposed and the staff accepted the bounding $X / Q$ values as stated in Section 15.4 of this report. Using these bounding $X / Q$ values, the recalculated offsite doses reculting from a hypothetical LOCA are listed in Table 15.1. The computed doses in Table 15.1 are expreseed as thyroid and whole-body exposure for 2 hours at the EAB and for 30 days at the boundary of the LPZ to allow direct comparison with the dose reference values eetablished in 10 CFR 100.11.

The staff evaluated offsite radiological consequences using the current TID-14844 source torm assumptions that are consistent with the guidelines in the applicable SRP 
sections and regulatory guides, except for the following two deviations: The staff (1) provided a credit for radioactive iodine removal in the main steamlines and in the main condensers by holdup for decay and deposition and (2) accepted the ABWR design without an MSIV leakage control system' (LCS) (see Section 15.4.4.2 for technical bases).

The staff postulated a hypothetical LOCA to determine the adequacy of the ESF systoms designed to prevent release of fission products into the environment, using bounding meteorological conditions. The passive ESF systems for this purpose in the ABWR design are the primary containment and secondary containment (reactor building). The staff considered these in conjunction with the standby gas treatment system (SGTS) and the pressure suppression pool scrubbing, both of which are active ESF systems.

The primary containment spray system, which is designed as a containment heat removal feature, has not been given credit in any drywell airborne fission product removal calculations. The spray system is designed as a safetyrelated system but is not automatically initiated as required in the SRP for iodine removal credit. $G E$ has not requested any iodine removal credit for the spray system. In its assessment, the staff included containment leakage, main steam isolation valve leakage, and post-LOCA leakage from ESF systems outside containment as sources and radioactivity transport paths to the environment following a LOCA.

\subsubsection{Containment Leakage Contribution}

The ABWR primary containment design consists of a drywell, a wetwell, and supporting systems to limit fission product leakage during and following a LOCA with rapid isolation of all pipes or ducts that penetrate the containment boundary. It is designed to prevent the uncontrolled release of airbome radioactivity to the environment. GE proposed that the primary containment will be built and tested periodically to have a leak rate at design pressure of less than 0.5 percent by weight per day at the calculated peak containment pressure associated with a LOCA. The staff used this leak rate in its radiological assessment.

The secondary containment structure and supporting systems will collect and process radioactive material that may leak from the primary containment following a LOCA or that may result from a fuel-handling accident. The secondary containment is a seismic Category I reinforcedconcrete structure with a volume of approximately $8.5 E+4 \mathrm{~m}^{3}\left(3 \mathrm{E}+6 \mathrm{ft}^{3}\right)$.
In SSAR Section 15.6.5.5.1, GE assumed that the primary containment leak rate into the reactor building through penetrations and ESF system components will not be greater than an equivalent release of 0.5 percent by weight per day of the primary containment free air weight for the first 24 hours after 2 LOCA and half of that value ( 0.25 percent/day) after 24 hours. GE based its assumption of a reduced leak rate on the finding that the primary containment pressure is reduced by more than a factor of $1 / 2$ during the 12 hours following initiation of a LOCA; therefore, the driving force for leakage through the pathway is correspondingly reduced.

RG 1.3 (Rev. 2) assumes a constant containment leak rate for the duration of a LOCA, although it permits a reduced leak rate with supporting justification. Two rationales support a constant containment leak rate: (1) the pressure profile for a BWR does remain high for a long period of time and (2) for most plants, the leakage is only measured at the maximum value in accordance with Appendix $J$ to 10 CFR Part 50. Therefore, the primary containment leak rate was identified as Open Item 143 in the DSER (SECY-91-355). Subsequently, GE revised the primary containment leak rate of 0.5 percent by weight per day for the entire duration of a LOCA, accepting the staff's position in a draft revision to the SSAR. This was identified as DFSER Confirmatory Item 15.4.4.1-1. In Amendment 24 to the SSAR Section 15.6.5.5.1, GE revised the leak rate to 0.5 percent by weight per day for the duration of a LOCA and this resolved DFSER Confirmatory Item 15.4.4.1-1.

The pressure within the reactor building is maintained slightly negative during normal operation by exhausting the reactor building air through the normal reactor building ventilation system. On receipt of an ESF actuation signal, the normal ventilation system is automatically switched off and the SGTS actuated. Following a postulated LOCA, the pressure in the secondary containment could increase from its initially negative pressure to a slightly positive value as a result of inleakage, air expansion because of heat, and the time required for the startup of the SGTS.

The SGTS is designed to achieve a negative pressure of $0.635 \mathrm{~cm}(0.25 \mathrm{in}$.) water gauge in the secondary containment within 20 minutes (drawdown time). Following the drawdown time, the staff assumed an iodine removal efficiency of 97 percent by the SGTS charcoal absorber with a depth of $15.24 \mathrm{~cm}$ (6 in.). In accordance with SRP Section 6.5.3, the staff assumed reactor building air mixing efficien:y of 50 percent for the primary containment leakage before the release to the environment.

The staff estimates that wind speed in excess of $10 \mathrm{~m} / \mathrm{s}$ $(33 \mathrm{ft} / \mathrm{sec}$ ) may create potential exfiltration of the reactor 
building due to the low atmospheric pressure created outside the reactor building. The loss of the SGTS for the eatire period of an accident (720 hours) will increase the offsite radiological consequences by a factor of 100 , while this increased wind speed will improve atmospheric dispersion parameters by a factor of 33 based on the metoorological data submitted by GE on November 17, 1992. In the submittal, :GE also stated that wind speed will exceed $10 \mathrm{~m} / \mathrm{s}(33 \mathrm{ft} / \mathrm{eec})$ no more than 5 percent of the timo, based on moteorological data oblined from 28 BWR sites in the United States. Therefore, the loss of the SGTS for 36 bours (5 percent of 720 hours) could increase the offsite radiological consequences by 15 percent. This increase is reflected in revised Table 15.1 of this report.

Because the secondary containment (reactor building) is designed to completely enclose the primary containment, the staff assumed no bypass leakage to the environment from the primary containment except that directed through the main steamlines. In Section 6.2.3.1 of the DSER (SECY-91-355), the staff concluded that GE adequately addressed the criteria in Branch Technical Position CSB 6-3 of the SRP and that the design of barriers to preclude the secondary containment bypass flow (excluding that through main steamlines) is acceptable.

The fundamental characteristic of an BWR pressuresuppression containment is that steam released from the reactor coolant system will be condensed and scrubbed of radionuclides in a pool of water (the suppression pool) and the pressure rise in the containment will thereby be limited. This is accomplished by directing the steam from the reactor coolant system to the suppression pool through a vent system. However, leakage paths could exist in the pathway between the drywell and the wetwell airspace that could allow steam to bypass the suppression pool, potentially overpressurizing the containment. Potential sources of steam bypass include leakage through the vacuum relief valves, cracking of the drywell structure, and penetrations through the drywell structure.

In SSAR Section 15.6.5.5.1, GE assumed that any elemental and particulate iodine species purged to the suppression pool wouid be subject to a decontamination factor (DF) of 10. In the DSER (SECY-91-355), the staff found that credit may be given for the removal of fission products by the suppression pool if suppression pool DFs are evaluated in accordance with the methodology prescribed in revised SRP Section 6.5.5, "Pressure Suppression Pools or Fission Product Cleanup Systems" (issued in December 1988), which states that suppression pools are capable of scrubbing airborne fission products and that it is unduly consorvative to ignore this capability.
However, the staff also stated in the DSER (SECY-91-355) that GE should provide the drywell leakage capability to justify the suppression pool DF of 10 . The suppression pool DF was identified as Open Item 141 in the DSER (SECY-91-355).

In the DFSER, the staff conservatively assumed, in its radiological consequence analysis, that a DF of 2 is provided by the ABWR pressure suppression pool (equivalent to suppression pool steam bypass of 50 percent) for airborne radioactive iodine in elemental and particulate forms. This assumption is further supported by safety-related drywell and wetwell containment sprays in the drywell or wetwell, or both, which also would reduce the effect of suppression pool bypass leakage on containment performance; therefore, the staff statsd in the DFSER that this DSER Open Item 141 was resolved. In Amendment 31 to the SSAR, GE accepted the staff position amending Section 15.6.5.5.1.1 of SSAR to reflect a DF of 2 by the suppression pool for airborne radioactive iodine in elemental and particulate forms. This item re:uains resolved.

The staff recently accepted the drywell leakage value of $\left(.05 \mathrm{~m}^{2}\right)\left(.06 \mathrm{yd}^{2}\right)$ of effective leakage pathway) proposed by GE for the ABWR design. GE submitted a letter dated August 31, 1993, enclosing a revised set of design description and ITAAC on the suppression pool bypass issue. The adequacy and acceptability of the ABWR design descriptions and ITAAC are evaluated in Chapter 14.3 of this report.

While containment sprays in the drywell and/or wetwell also would reduce the effect of suppression pool bypass leakage on containment performance lowering its temperature and pressure, the sprays also scrub the containment atmosphere of fission products (even though the staff has not given a credit for scrubbing) and mitigate the effects of bypass on fission product distribution.

The staff will review, for each COL applicant, plantspecific TS, which require periodic inspections to confirm supprassion pool depth, and surveillance tests to confirm drywell leak tightness. In DFSER, the staff identified this as TS Item 15.4.4.1-1. GE included this inspection requirement in the ABWR STS for such surveillance tests. Thersfore, this item is resolved. The calculated doses for the ABWR resulting from the containment leak of 0.5 percent by weight per day are shown in Table 15.1 of this report. 


\subsubsection{Main Steam Isolation Valve Leakage}

The main steamlines in BWR plants contain dual quickclosing main steam isolation valves (MSIVs) which isolate the reactor system in the event of a break in a steamline outside the primary containment, a design-basis LOCA, or other events requiring containment isolation. Although the MSIVs are designed to provide a leaktight barrier, it is reco'gnized that they allow some leakage. The current BWR TS limit for MSIV leakage is typically $0.325 \mathrm{~m}^{3} / \mathrm{hr}$ $\left(11.5 \mathrm{ft}^{3} / \mathrm{hr}\right)$ per valve. Operating experience has indicated that degradation has occasionally occurred in the leaktightness of MSIVs and that the valves may exceed their specified leakage limit.

Because of recurring problems with excessive leakage of MSIVs, the staff recommended in RG 1.96, "Design of Main Steam Isolation Valve Leakage Control Systems for Boiling Water Reactor Nuclear Power Plants," (Rev. 1), installation of a supplemental leakage control system (LCS) to ensure that the isolation function of the MSIVs complies with the specified limits. Most of the currently operating BWRs have an LCS.

In response to the MSIV leakage concerns, the BWR Owners Group (BWROG) commissioned a program of studies to determine the causes of high leak rates and the means to eliminate them. The results of these studies were submitted to the Nuclear Regulatory Commission (NRC) in General Electric proprietary reports, NEDO-31643P (November 1988) and NEDO-31858P (February 1991), both entitled, "Increasing Main Steam Isolation Valve Leakage Rate Limits and Elimination of Leakage Concrol Systems." GE referenced these reports as the besis for not including an LCS and requesting a substantially higher $\left(0.99 \mathrm{~m}^{3} / \mathrm{hr}\left(35 \mathrm{ft}^{3} / \mathrm{hr}\right)\right.$ per valve) MSIV leakage limit.

The MSIVs generally have not provided a leak-tight containment pressure boundary to the extent intended in the plant design. Although substantial progress has been made in recent years to identify the causes of the leakage and reduce the amount of leakage, the current typical TS limit of $0.325 \mathrm{~m}^{3} / \mathrm{hr}\left(11.5 \mathrm{ft}^{3} / \mathrm{hr}\right)$ per valve is still difficult to achieve when the valve is rapidly closed against a full-flow condition at reactor operating pressure and temperature.

The staff conservatively assumes for operating plants that the TS leakage limit of $0.325 \mathrm{~m}^{3} / \mathrm{hr}\left(11.5 \mathrm{ft}^{3} / \mathrm{hr}\right)$ per MSIV is released directly into the environment in calculating offsite radiological consequences of potential accidents (10 CFR Part 100). No credit is currently given for the integrity and leaktightness of the main steam piping and condenser to provide boldup and plato-out of fission products.
The BWROG proposed an approach adopted by GE which would allow higher leakage limits of $3.96 \mathrm{~m}^{3} / \mathrm{hr}$ $\left(140 \mathrm{ft}^{3} / \mathrm{hr}\right)$ total for four steamlines and would not include an LCS for the ABWR design. In this alternative approach, GE used the main steam piping (and its associated piping) and the condenser to mitigate the radiological consequences of an accident that could result in offsite exposures comparable to the dose reference values specified in 10 CFR Part 100.

In the DSER (SECY-91-355), the staff stated that it was ovaluating whether a credit for the fission product attenuation in the main steamlines and for the condenser is appropriate and reasonable for BWRs even though the main steamlines downstream from the MSIV and its condensers are not designed to withstand the safe shutdown earthquake (SSE), as defined in Appendix A, Section III(c), to 10 CFR Part 100. This was identified as DSER (SECY-91-355) Open Item 142. The staff completed its evaluation, and has accepted the BWROG and GE proposals for the ABWR design based on the following radiological and seismic anaiyses.

\subsection{Radiological Analysis}

\section{- MSIV Leakage Pathways}

Following a LOCA, three potential release pathways exist for main steam leakage through the MSIVs:

(1) main steam drain lines (typically $5.08 \mathrm{~cm}$ ( 2 in.) in diameter) to the condenser with delayed release to the environment through the lowpressure turbine seals

(2) turbine bypass lines (typically $15.2 \mathrm{~cm} \mathrm{(6} \mathrm{in.)} \mathrm{in}$ diameter) to the condenser with delayed release to the environment through the low-pressure turbine seals

(3) main steamline (typically $61 \mathrm{~cm}$ (24 in.) in diameter) turbine stop and control valves through and high-pressure turbine seals to the environment bypassing the condenser

The consequences of leakage from pathways 1 and 2 will bo essentially the same because the condenser can be used to process MSIV leakage. The condenser iodine removal efficiency will vary depending on the inlet location of the bypass or drain line piping, but in either case, iodine removal will occur. However, for pathway 3, MSIV leakage through the closed turbine stop and control valves will not bo processed via the condenser. For this case, iodine will be removed in the high-pressure turbine, which has a large internal 
surface area associated with the turbine blades for plate-out of the radionctive material.

The staff assumed that turbino bypass, stop, and control valves will be closed upres loss of the electrohydraulic control system following a LOCA, and the drain valve can be manually opened to provide a leakage pathway from the control room to the condenser via a safety-related power sourco following a LOCA. GE submitted on August 31, 1993, a rovised set of Tier 1 design descriptions of the nuclear boiler system. In Section 2.1.2 and corresponding Figure 2.1.2b of this document, GE stated that the main control room will include main steam drain valve controls and status displays. The staff finds that the remote control requirement placed in the ABWR Tier 1 document is acceptable. The overall adequacy and acceptability of the ABWR Tier 1 design descriptions are evaluated in Chapter 14.3 of this report.

In the DFSER, the staff stated that the TS must address operability of the drain valve. Subsequently, the staff agreed with GE that the operability of the drain valve need not to be included in the ABWR STSs but should be included in the plant operating procedures. This position makes GE's TS consistent with the BWR STS developed under the Commission's TS improvement program. See the general discussion in Chapter 16 of this report. Therefore, this resolved DFSER TS Item 15.5.1.2.1-1.

The BWROG has also identified the same three leakage pathways as discussed above. Of these, the BWROO and GE proposed to use the drain line downstream of the MSIVs as a leakage pathway to the condenser. The staff also chose to use the main steamline drains for the MSIV leakage pathway in assessing iodine holdup and deposition for the ABWR design.

The BWROG and GE indicated that the bypass piping of the main steamline is another appropriate leakage pathway that can be used for MSIV leakage control. Either pathway is an acceptable approach, provided that the chosen pathway will be available for MSIV steam leakage to reach the main condenser. Comparing the two pathways, more iodine is removed (by holdup and deposition) through the turbine bypass pathway than through the drain line pathway because of the larger pipe size, which will have more surface area for deposition.

The staff believes that as long as either the turbine bypass or the drain line leakage pathway is available, MSIV leakage through the closed turbine stop and control valves (pathway 3) will be negligible and casentially all of the releases will be through the main condenser. This is because there wi": be essentially no differential preasure in the main steamline downstream of the MSIVs following the closure of the valves.

Furthermore, any MSIV leakage through pathway 3, if any, will have been subjected to the same iodine removal processes in the main steamlines (up to turbine etop valves) as the other pathways, and it will be further subjected to iodine removal by deposition in the high-presoure turbine internal surfaces. The main condenser does not remove iodine in pathway 3.

In calculating the contribution to the LOCA dose, the staff assumed that one of the inboard isolation MSIVs failed to close, thus allowing contaminated steam to travel to the outboard valve. This outboard valve and the outboard valves from the other three steamlines were assumed to have a total leak rate of $3.96 \mathrm{~m}^{3} / \mathrm{hr}$ $\left(140 \mathrm{ft}^{3} / \mathrm{hr}\right)$.

\section{- Lodine Trunsport Model}

Basic chemical and physical principles indicate that gascous iodine and airbome iodine particulate material will deposit on surfaces. Several laboratory and inplant studies have demonstrated that gaseous iodine deposits will occur by chemical adsorption, and particulate iodine deposits will occur through a combination of sedimentation, molecular diffusion, turbulent diffusion, and impaction. Gaseous iodine exists in nuclear power plants in several forms: elemental $\left(\mathrm{I}_{2}\right)$, hypoiodous acid (HIO), organic $\left(\mathrm{CH}_{3}\right)$, and particulates. In accordance with RG 1.3, the staff assumed 91 percent of iodine will be in the elemental form (inhypoiodous acid), 5 percent in the particulate form, and 4 percent in the form of organic iodides.

Each of these forms deposits on surfaces at a different rate, described by a parameter known as the deposition velocity. The elemental iodine form, being the most reactive, has the largest deposition velocity, and organic iodide has the smallest. Further, studies of inplant airborne iodine show that elemental and particulate iodine deposited on the surface undergoes both physical and chemical changes and can either be resuspended as an airborme gas or become permanently fixed to the surface. The data also shows that the iodine can change its form so that iodine deposited as one form (usually elemental) can be resuspended in the same or in another form (usually organic). Conversion can be described in terms of resuspension rates that are different for each iodine species. Chemical surface fixation can similarly be described in terms of a surface fixation rate constant. 
The transport of gaseous iodine in elemental and particulate forms has been studied for many years and several groups have proposed different models to describe the observed phenomean. Examples of the studies are listed below.

(1) NUREG/CR-2713, "Vapor Deposition Velocity Measurement and Consolidation for Iodine and Cesium Iodine," S.L. Nicolosi and P. Baybutt, May 1982.

(2) NUREG/CR-4397, "In-Plant Source Term Measurements at Prairio Island Nuclear Generating Station," J.W. Mandler et al., September 1985.

(3) IN-1394, Idaho Nuclear/National Reactor Testing Station, "Deposition of Iodine 131 in CDE Experiments," Nebecker at al., 1969.

(4) BMI-1863, Fission Product Deposition and Its Enhancement Under Reactor Accident Condition: Deposition on Primary System Surfaces, J.M. Genco et al., May 1969.

(5) "Transmission of Iodine Through Sampling Lines," 18th DOE Nuclear Airborne Waste Management and Air Cleaning Conference, P.J. Unrein et al., October 1984.

The staff used the model developed by an NRC contractor (J.E. Cline and Associates, Inc., 1991) for iodine removal in BWR main steamlines and the main condenser following a LOCA.

The staff model treats the MSIV leakage pathway as a sequence of small segments for which instantaneous and homogeneous mixing is assumed; the mixing computed for each segment is passed along as input to the next segment. The number of segments depends on the parameter of the line and flow rate and can be as many as 100,000 for a long, large-diameter pipe and a low flow. Each line segment is divided into five compartments that represent the concentrations of the three airborne iodine species, the surface that contains iodine available for resuspension, and surface iodine that has reacted and is fixed on the surface. The staff's model considers three iodine species: elemental, particulate, and organic. A fourth species, hypoiodous acid, is considered for the purpose of the staff's model to be a form of elemental iodine. All iodine in the segment undergoes radioactive decay. The resulting concentration from each segment of the deposition compartment serves as the input to the next segment.
The staff's transport model also assumes iodine transport through the condenser as a dilution flow rather than the plug flow as in the steamlines. The staff assumes that the iodine entering the condenser mixes instantaneously with a volume of air in the condenser and that the diluted air exhausts at the same time and same rate as the input air (MSIV leakage) flows into the condenser.

The staff developed the equations for iodine deposition velocities, resuspension rates, and surface fixation rates as a function of temperature using published data from the above-mentioned literature. The equations and data are contained in the report by Cline and Associates. The equation for the deposition velocity of elemental iodine is based on the least-squares fit to the available data. Deposition velocity equations for $\mathrm{HOI}$ and organic iodine are based on the values at $30^{\circ} \mathrm{C}$ $\left(86^{\circ} \mathrm{F}\right)$; because of the lack of data at elevated temperatures, their termperature dependence is assumed to be similar to that of elemental iodine. The staff based its resuspension and fixation equations as a function of temperatures available in the literature based on measurements taken at ambient temperature. The staff assumed that resuspension and fixation rates will increase with increasing temperature.

The parameter and assumptions used in the development of the iodine transport model are listed in Table 15.6 of this report. Calculated iodine releases from the condenser after holdup and plate-out in the main steamlines and condensers are shown in Table 15.7 of this report.

The technical references mentioned above and the staff's model indicate that particulate and elemental iodine would be expected to deposit on surfaces at rates varying with temperature, pressure, gas composition, surface material, and particulate size. The staff, therefore, concludes that an appropriate credit for the removal of iodine in the main steamlines and main condensers should be provided in the radiological consequence assessment following a design-basis accident for the ABWR. The staff considers DSER Open Item 142 resolved.

The amount of iodine removal credit for the ABWR design is shown in Table $\mathbf{1 5 . 7}$ of this report. In the DFSER, the staff stated that the COL applicant will need to recalculate removal credit on the basis of its design characteristics of main steamlines, drain or bypass line, and main condenser. This was identified as COL Action Item 15.4.4.2.1. In Sections 15.6.5.5.1.2 and 15.6.5.5.1.3 of the SSAR, GE stated that COL applicants will recalculate iodine 
removal credit on the basis of its design characteristics of main steamlines, drain lines, and main condenser. The staff finds this acceptable.

\subsection{Seismic Analysis}

Section III(c) and VI of Appendix A to 10 CFR Part 100 require that structures, systems, and components (SSCB) necessary to ensure the capability to mitigate the radiological consequences of accidents that could result in exposures comparable to the dose guideline exposures of Part 100 be designed to remain functional during and after an SSE. Thus, the main steamline, portions of its associated piping, and the main condenser are required to remain functional if the SSE occurs. Consequently, these components are required to be classified as safety-related and seismic Category I. In addition, Appendix A to 10 CFR Part 100 requires that the engineering method used to ensure that the safety functions are maintained during and after occurrence of an SSE involve the use of either a suitable dynamic analysis or a suitable qualification test.

For the purpose of giving credit to iodine holdup and plateout in the main steamlines and condensers, the staff's model requires that the main steam piping (including its associated piping to the condenser) and the condenser to remain structurally intact following an SSE, so it can act as a holdup volume for fission products.

In the DFSER, the staff stated that the ABWR design did not fully comply with the requirements of 10 CFR Part 100 because portions of the main steamlines, bypass and drain piping, and the condenser were not classified as seismic Category I. This DFSER statement was incorrect. The staff's position as discussed in detail in Section 3.2.1 of the DFSER and of this report is that the ABWR design provides reasonable assurance that the main steam piping from the outmost isolation valve up to the turbine stop valve, the MSIV leakage pathway (i.e., the drain line or bypass line) up to the condenser, and the main condenser will remain structurally intact and leaktight, so that they can act as a holdup volume for fission product during and following an SSE. The staff has determined that the ABWR design does comply with the requirements of 10 CFR Part 100 because the SSCs described above are designed to remain functional during and following a SSE. This issue is also discussed in the staff's SECY-93-087 entitled, "Policy, Technical, and Licensing Issues Pertaining to Evolutionary and Advanced Light-Water Reactor (ALWR) Designs," dated July 21, 1993.

Open Item 15.4.4.2.2-1 in the DFSER indicated that the staff would have to describe new ABWR design requirements which would enable it to meet 10 CFR
Part 100 in a different manner or require that GE requed exemption from 10 CFR Part 100 and provide an ovaluation of the request in the SSAR. Section 3.4.1 of this report describes the key design requirements for the ABWR that resolve DFSER Open Itom 15.4.4.2.2-1.

\subsubsection{Post-LOCA Leakage Contribution from Engineered Safety Features Systems Outside Containment}

Any leakage of water from ESF components (valve stems and pump seals) located outside of the primary containment releases fission products to the secondary containment during the recirculation phase of long-term core cooling following a LOCA. GE estimated such leakage from the RHR system, HPCF system, and reactor core isolation cooling (RCIC) system to be less than 6.2E-3 L/min (1.6E-3 gpm). GE's leakage estimate indicated valve stem leakage of $4.5 \mathrm{E}-3 \mathrm{~L} / \mathrm{min}$ (1.2E-3 gpm) from a total of 45 valves and 1.7E-3 L/min (4.4E-4 gpm) from a total of 5 pumps in these systems. In Section 5.2.5 of this report, the staff states that an identified leakage within the drywell (inside of the primary containment) could reach $5.8 \mathrm{~m}^{3} / \mathrm{hr}$ (25 gpm) at which point it would activate an alarm in the control room.

The staff used a conservative leakage value of $3.8 \mathrm{~L} / \mathrm{min}$ $(1.0 \mathrm{gpm}$ ) (instead of $6.2 \mathrm{E}-3 \mathrm{~L} / \mathrm{min}$ (1.6E-3 gpm) proposed by GE), which is the typical BWR leakage value used by the staff in its radiological consequence assessment. The COL applicant will provide this leakage value in its plant-specific TS. Section 17.6.3 (limiting condition for operation (LCO) 3.4.3 of the $A B W R$ TS) requires unidentified reactor coolant system leakage to be less than $1 \mathrm{gpm}$. This resolved DFSER TS Item 15.4.4.3-1.

The staff further assumed that 10 percent of the waterborne iodine that leaks from the ECCSs (RHR, HPCF, and RCIC) systems will become airborne and be released to the environment through the SGTS after 20 minutes of the secondary building drawdown time (no filtration credit is given prior to the drawdown time). The offsite radiological consequences of an ESF component leak outside the primary containment are relatively small and are given in Table 15.1 of this report.

\subsubsection{Conclusion}

The staff reviewed GE's analysis and performed an independent analysis of the radiological consequences resulting from each of the transport paths described in Section 15.4.4 of this report. The calculated thyroid and whole-body doses are listed in Table 15.1. Based on the above evaluation and the recalculated radiological 
consequences shown in Table 15.1, the etaff concludes that the MSIV leak rete limit of $3.96 \mathrm{~m}^{3} / \mathrm{hr}\left(140 \mathrm{f}^{3} / \mathrm{hr}\right)$ total and the proposed ABWR deaign without an MSIV LCS are scceptable. It further concludes that GE's propoced bounding atmompheric relative concentrations $(x / Q)$ for the BAB and to the LPZ of the ABWR plant, in conjunction with the BSF sytoms provided in the ABWR design are auficicient to provido reasonablo aseurnece that the radiological consequences of a postulated LOCA will bo within the dose reference values in 10 CFR Part 100.

\subsubsection{Fuel Handling and Duel Cask Drop Accidents}

In SSAR Sections 15.7.4 and 15.7.5, GE presented radiological consequence amalyses of fuel handling and spent fuel cask drop accidents. The staff analyzed the radiological consequences for the following three different types of fuel handling accidents resulting from an unspecified failure of a lift mechanism due to (1) a single fuel assembly with 124 spent fuel rods dropped onto the irradiatod fuel stored in the spent fuel pool, (2) a raised single fuel cask contrining 18 fuel assemblies in it dropped from the level of the refueling floor to ground level through the refuoling floor maintenance hatch, and (3) a raised heavy object (i.e., steam dryer, moisture soparator) dropped onto the fuel in the reactor veseel during refueling operation.

For the single fuel assembly accident, the kinetic energy of a single falling fuel assembly was assumed to break open the maximum possible number of fuel rods (124 spent fuel rods) using perfect mechanical efficiency. Instantaneous release of noble gases and radioiodine vapor from the gaps of the broken rods ( 10 percent of noble gases and iodine inventories in the reactor core except 30 percent assumed for krypton-85) was assumed to occur, with the released gases bubbling up through the fuel pool water (with an overall effective DF of $1 \mathrm{CO}$ for iodines and of 1 for noble gases) Radiation monitors located within the normal ventilation system are designed to isolate that system automatically and direct all fuel handling building exhaust to the SGTS.

The SGTS is deeigned to achieve a negative pressure of $0.635 \mathrm{~cm}(0.25 \mathrm{in}$.$) water gauge in the secondary$ contrinment within 20 minutes (drawdown time). During the drawdown time, the staff assumed that radionctive iodines would bo released directly to the environment without credit for filtration. Following the drawdown time, the staff assumed the SGTS charcoal absorber with a depth of $15.24 \mathrm{~cm}(6 \mathrm{in}$.) would remove iodine from the released gas at a 99 percent efficiency.

The fuel cask drop accident was assumed to result from an unspecified failure of the cask-lifting mechanism, thereby allowing the cask to fall approximatoly $19.5 \mathrm{~m}$ (64 ft) from tho lovel of the refueling floor to ground lovel through the rofueling floor maintenance hatch. GE stated that each cack will have the maximum capacity of 1116 epent fuel rods (18 fuel assemblies) besed on the largest capacity cask projected to be available. GE proposed, and the staff accepted, the minimum fuel storage (decay) time of 120 days before cask-loading operation commences after reactor fueling. The minimum storage time of 120 days is based on the administrative controls currently used by operating BWRs.

In NUREG-0612, "Control of Heavy Loads at Nuclear Power Plants," the staff discusses the potential for an accidental load drop on nuclear fuel or safety-related equipment causing excessive offsite radioactivity releases, inadvertent criticality, loss of water inventory in the reactor or spent fuel pool, or loss of safo-shutdown equipment. The NUREG also recommends guidelines to prevent or mitigate these potential consequences and states that the guidelines in NUREG-0554, "Single-Failure-Proof Cranes for Nuclear Power Plants," can be followed in lieu of upgrading existing crane and lifting devices. NUREG-0554 provides guidence for the design, fabricution, installation, and testing of now cranes that are of a high reliability design and it defines that a singlofailure-proof crane system as a system designed so that a single failure will not result in the loss of the capacity of the system to safely retain the load.

In Section 9.1.5.2.1 of the SSAR, GE states that the reactor building crane will be designed to meet the singlefailuro-proof requirements of NUREG-0554, and in Section 9.1.6.6 of the SSAR, GE states that the COL applicant should provide, among other things, heavy load handling system operating and equipment maintenance procedures for NRC roview. This review will confirm that a heavy load drop is not a design-basis event by determining that the crane system meets (1) single-failureproof criteria, and (2) prevention of load unbalancing (e.8., improper placement of slings) which could potentially defeat the single-failure-proof criteria.

For the heavy load drop accident to occur, the following steps must occur in sequence: (1) a heavy load is slung wrong (procedural), (2) the heavy load is transported to an incorrect position over the core (procedural), (3) the sling fails (equipment failure), and (4) an alternate slung hook fails (equipment failure).

Nevertheless, the staff assumed in the DFSER that the heavy load drop accident occurs because the lifting device fails (unspecified cause), drops, or tips a heavy object onto the fuel in the reactor vessel and breaks open all fuel rods in 10 percent of fuel assemblies (approximately 
80 ascemblies) in the reactor veseol. The staff assumed the minimum radioactivity docay timo of 7 days from the timo of reactor shutdown until the lifting of the heavy object based on a conservative BWR refueling schedule.

The ataff evaluated a postulated fuel handling accidents for the ABWR in eccordance with the guidence of SRP Section 15.7.4, using assumptions consistent with Positions C.1.a through C.1.k of RO 1.25 (Rev. 0), "Assumptions Used for Evaluating the Potential Radiological Consequences of a Fuel Handling Accident in tho Fuel Handling Storage Facility for Boiling and Presourized Water Reactors," (Rev. 0).

The assumptions used for the spent fuel handling accidents are listed in Table 15.8. The offsite doses recalculated for these accidents are given in Table 15.1. The calculated offsite doses for all three cases considered are within the dose guidelines specified in SRP Section 15.7.4, specifically, the estimated doses resulting from this type of accident are less than or equal to 25 percent of the 10 CFR Part 100 dose limits (listed in Section 15.4 above). Therefore, the staff concludes that the standard ABWR design is adequate to control the release of fission products following postulated spent fuel handling accidents.

\subsubsection{Postulated Radioactive Releases Resulting from Liquid Tank Failures}

The staff reviewed this accident in accordance with SRP Section 15.7.3. Tanks and associated components containing radioactive liquids outside containment are acceptable if the failure of the equipment does not lead to radioactive concentrations that exceed the limits of 10 CFR Part 20, Appendix B, Table II, Column 2, at the nearest potable water supply in an unrestricted area or if special design features to mitigate the effects of the accident are incorporated in the design of systems that do not meet the requirements of 10 CFR Part 20.

All the liquid radwaste tanks, including the evaporator concentrate tanks, that could adversely affect the potable water supply if they fail are located in the radwaste building. The base mat and outside walls of the building are seismic Category I to a height necessary to retain spill liquids within the building (SSAR Section 11.2.1.2.2). Additionally, in accordance with SSAR Section 15.7.3.1, all compartments containing liquid radwastes are steel lined up to a beight capable of containing the release of all the liquid radwastes into the compartments. For the above reasons, GE considers it as remoto that any major accident that involves the release of liquid radwastes into these volumes would result in the release of liquid radwastes to the environment via the liquid pathway. In SSAR Section 15.7.3.1, GE states that initially the releases would be contained in other bolding tanks or omorgency tanks. GE further atates that plant operating techniques and administrative procodures will contain detailed syetom and equipment operating instructions and, therefore, will significantly minimize the potential for operator error that cen cause liquid radwaste release. In addition, the liquid mowaste system design will include a positive action interlock system to prevent inadvertent opening of a drain valve. GE concludes that if a release of liquid radwaste occurs, the steel lining would contain the release until the operator could use the floor door sump pumps to pump the reloase into holding tanks or emergency tanks.

ODC 60 requires the control of releases of radionctive materials to the environment including both gaseous and liquid offluents under both normal and enticipated operntional occurrences. Further, sufficient holdup capecity is required. As discussed above, GE's liquid radwaste design provides the necessary control and liquid offluent storage capacity to reduce the potential offect of a failure of a radionctive liquid containing tank and its associated components. Therefore, GE's design complies with GDC 60 and any potential release associated with a liquid tank failure will not result in radionuclide concentrations in water exceeding the limits of 10 CFR Part 20, Appendix B, Table II, Column 2, in any unrestricted area. The staff finds this aspect of the design ecceptable.

\subsubsection{Reactor Water Cleanup System Pipe Break Accident}

In Section 15.6.6 of the SSAR, GE postulated a reactor water cleanup system pipe break outside the primary containment as a DBA in response to an inquiry by the Advisory Committee on Reactor Safeguards (ACRS) Subcommittee on ABWRs during its meeting on June 17, 1993, at San Jose, California. The break was assumed to be instantaneous, circumferential, and to occur on the downstream side of the outmost containment isolation valve but on the upstream side of the reactor water demineralizer. GE further assumed 75 seconds of break flow time (45-second builtin delay time for flow differential pressure instrumentation to activate an isolation signal and 30 seconds for the motor-operated isolation valve to close).

GE analyzed this hypothetical accident and concluded that no more than $28,800 \mathrm{~kg}(61,670 \mathrm{lb})$ of reactor coolant would be lost through the break before automatic isolation occurred and less than $9,900 \mathrm{~kg}(21,800 \mathrm{lb})$ of that would be lost es steam. The break line is equipped with a $140-\mathrm{cm}^{2}\left(23 \mathrm{in.}^{2}\right)$ flow limiter. The staff accepted and used in its assessment the reactor coolant break flow of $28,800 \mathrm{~kg}$ estimated by GE. 
The current SRP noither lists nor clesifies the renctor water deanup oystem pipe break scoident as a DBA. However, the athf asseased the radiological consequencen of this sccideat sasuming two reactor coolent conditions for the evaluntion. In Case 1, the lost coolant was contaminated with redionctive iodine at the limits in the STS (i.e., 7.4E-3 mBq) of dowo-equivalent I-131 per gram ( $90.8 \mathrm{mCl}$ of dose-quivaleat I-131 per pound) at continued full-power operation. In Case 2, a concentration of $1.5 \mathrm{E}-1 \mathrm{mBq}$ of doso-equivalent I-131 per gram (1816.0 mCiq doeo-equivalent I-131 per pound) was assumed (the limits in the STSs above which the reactor is required to be shut down).

The staff chose the dose reference values of $10 \mathrm{CFR}$ 100.11 for Case 2 and leas then 10 percent of these values for Case 1 as two scceptance criteria. Theee are the anmo s those given for the min stentine break outside conthinment in SRP Section 15.6.4. Doso-equivalent I-131 is defined as any mixture of iodine isotopes yielding the same inhalation thyroid dose as the stated amount of puro I-131. The staff also considered the amounts of 13 noble gas isotopes that also would be released.

Tho calculated doses are listed in Table 15.1 and are within the staff's acceptance criteris listed above. Therefore, the staff concludes that the ABWR design is adequate to control the release of fission products following a postulated reactor cleanup system pipe break accident.

\subsection{Anticipated Transient Without Scram}

\subsubsection{Design Features}

The ABWR design incorporates electric-hydraulic fine motion control rod drives (FMCRDs) to perform motordriven scram and hydraulic scram. In response to a scram signal, the control rods will be inserted hydraulically by means of the stored energy in the scram accumulator, similar to the current operating BWR CRDs. A scram signal also will be given simultaneously to insert the FMCRD electrically via the FMCRD motor drive. This diversity, hydraulic and electric methods of scramming, provides a high degree of assurance of rod insertion on demand.

The ABWR is designed with an alternate rod insertion (ARI) system that will bo independent from the existing reactor protection system (RPS) from the sensor output to the final actuation device. The ARI system will have redundant scram air header exhaust valves. The ARI system is designed to perform its function in reliable manner. Detailed evaluations of the ARI and RPS ayotem are given in Chapter 7 of this report.

The ABWR aleo is derigned with a atendby liquid control syetem (SLCS) that will automatically inject $379 \mathrm{~L} / \mathrm{min}$ (100 $\mathrm{spm}$ ) of sodium pentaborate solution into the reactor preasure veacel (RPV) with the simultaneous operation of both pumps. The $326 \mathrm{~L} / \mathrm{min}$ (86 gpm) equivalency epacified in the ATWS rule (10 CFR 50.62) for the 638-cm (251-in.) RPV is satisfied by the $379 \mathrm{~L} / \mathrm{min}$ (100 gpm) provided for the 706-cm (278-in.) ABWR veasel. Tho ABWR SLCS initiation is eutomatic as required by the ATWS rule and is designed to perform its function in a reliable manner. The detailed evaluation of SLCS is given in Section 9.3.5 of this roport.

ABWR has equipment to trip the RIPs automatically under conditions indicative of an ATWS. The RIPs are automatically tripped on reactor high preseure (7,860 kPa (1125 paig)) and RPV Lovel 2. The RIP trip equipment is deaigned to perform its function in a roliable manner as required by the ATWS rule.

The ABWR design aleo provides recirculation runback for all ceram signals and feedwater runback on reactor high preasure and startup range neutron monitoring system (SRNM) not downscale for 2 minutes. Automatic depreseurization system automatic inhibit is also provided with reactor water level 1.5 and average power range monitor ATWS permissive. This feature is discussed in Section 7.4.1.1 of this report.

The ABWR complies with the prescriptive design requirements of the ATWS rule and is designed to mitigate the effects of an ATWS ovent.

\subsubsection{Analysis}

GE aubmitted the ATWS analysis in SSAR Appendix 15E. GE analyzed the limiting transients identified in NEDO-24222 (proprietary) (a supporting document used for the ATWS rule). GE used the NRC-approved ODYNA and REDYA computer codes for the analysis. GE analyzed cases with the ARI system operational, without the ARI system but with FMCRD system operational, and without the ARI and FMCRD systems but with SLCS operational. GE compared the results with the performance guidelines for fuel integrity (coolable core geometry), containment integrity (45 psi (414 kPa)), suppression pool temperature $\left(207^{\circ} \mathrm{F}\left(97^{\circ} \mathrm{C}\right)\right.$ ), primary system pressure (1,500 psis (10446 kPa)) and long-term shutdown cooling and found them accoptable.

The staff performed audit calculations to verify that the ABWR design is satisfactory to mitigate the effects of an 
ATWS. The etudy focused on the coneequences of manual SLCS sctuation and no recirculation pump runback on scram signals other than reactor high presoure and reactor low loval. Ono problom that was identified initially was the potential for fuel dainage if only the FMCRD aystem provides slow scrum (motor-driven scrum) and there were no other actions to lower power. In this case, the power abifted to the top of the core when the control rods entered from the bottom and, in combination with the dolay in shutting down the reactor because of the slowness of the FMCRD systom, could lead to higher linear power densities and the potential for fuel damage. If the use of the FMCRD system was always in combination with a reactor internal pump trip or recirculation runbeck, then overall power would be reduced sufficiently to avoid excessive power densities when the power shifted to the top of the core.

The now design feature of recirculation runback on any scram signals or any ARI/FMCRD run-in tignals ensures that there is no potential for any unacceptable power shift to the top of the core.
Another feature included of the initial study was the time available for SLCS actuation. Assuming the failure of ARI and FMCRD, the original design called for manual operation of SLCS; however, if the system was not started within a fow minutes, contrinment integrity would bo threatened. OB resolved this issue by changing the ABWR deaign 20 that the SLCS is automatically started at 3 minutes into an ATWS event.

The recults of celculations to evaluate the thermal hydraulic stability of $A B W R$ under the recirculation runbeck and feedwater runbeck conditions aseociated with ATWS ovents have been provided for staff review. ABWR design response to ATWS enables avoidance of large oscillations and the staff audit of stability calculations is complete. This is discussed in detail in Section 4.4 of this report (DFSER Open Itom 4.4-1).

DSER (SECY-91-355) Open Items 140 and 144 are dependent on and are superseded by the DFSER Open Itom 4.4-1. Since Open Itom 4.4-1 has been resolved the DSER open items aro also resolved. 


\section{TECHNICAL SPECIFICATIONS}

\subsection{Introduction}

As part of its deaign certification application for the advanced boiling water reactor (ABWR) and as required by pangraph (1)(i) of 10 CFR 52.47(a), OE must provide Technical Specifications (TS) that are technically rolovant and not sito-epecific for the ABWR design. The TS provided must comply with the requirements of paragraph (b)(6)(vi) 10 CFR 50.34, which atates that proposed TS are to be prepared in eccordance with the requirements of 10 CFR 50.36. 10 CFR 50.36 details the epecific items (wuch as afoty limits, limiting safoty uystem sottings, limiting control settings, limiting conditions for operation, etc.) that must be included in the TS.

In roviowing propoeed TS for compliance with 10 CFR 50.36, the etaff evaluates the conformence of the propoced TS to atandand technical epecifications (STS) which most clowely recemble the plant doeign.

The staff reviow of the ABWR TS was closely coupled to the development of the improved STS under the TS Improvement Program in accordance with the interim Commisaion Policy Statoment on TS Improvements for Nuclear Power Plants (52 FR 3788 dated February 6, 1987). Since the ABWR design evolved primarily from the BWR/6 design, most of the ABWR TS were modeled after NUREG-1434, "Standard Technical Specifications General Electric Plants, BWR/6." However, since the ABWR contrinment most closely resembles plant containments covered by NUREG-1433, "Standard Technical Specifications - General Electric Plants, BWR/4." the ABWR containment TS were modeled after NUREG-1433. These improved STS reflect the accumulated operating experience of currently operating light water reactors.

The proposed ABWR TSs were developed from the $B W R / 6$ and the BWR/4 STS. The staff reviewed the proposed ABWR TS to confirm similarities between them and the STS, as appropriate. The staff then concentrated its review on the parts of the ABWR TS that are unique because of ABWR-epecific design features. Dispositions of comments reoulting from the staff review were incorporated into the proof-and-review ABWR TS. The proof-and-roviow ABWR TS were then iseved to GE and made available to the ataff for comment. Dispositions of comments from $G E$ and the staff on the proof-and-review TS have been incorporated into the final ABWR TS. The final ABWR TS will be produced in the industry format and certified as accurate by GE.

In the DFSER, the staff stated that GE should prepare the relevant portions of the TS for review by the staff in the
WordPerfect 5.1 format. This was DFSER Open Item 16-1. The NRC TS staff aceinted OB in doveloping

the ABWR proof-and-roview TS in the WordPerfect 5.1 format. GE committed to maintain the ABWR TS in this format. This resolved Open Item 16-1.

\subsection{Evaluation}

The etaff ovaluated the ABWR TS to confirm that they will prewerve the validity of the design plant SSAR by censuring thet ABWR plants will bo operated within the required conditions bounded by the SSAR and with operable equipment that is escential to prevent accidents and to mitigate the consequences of accidents postulated in the SSAR.

In the DFSER, the ataff noted that for the ABWR dexign, OE had attempted the ueo of a three-aubsystem concept for the engineered anfety feature (ESF) systems in order to facilitate maintenance on one subsystem by axtending the completion times (CTs) for one inoperable subsystem from 7 days to 30 days. OE was asked to provide justification that the emergency core cooling systems design consists of three independent redundant subsystems. This was DFSER Open Itom 16-3. GE stated that it could not provide this justification. Instead, it stated that the ABWR design includes additional redundancy, beyond that for currently operating BWR plants, for the ESF systems. The staff reviewed GE's response and determined that, although this added redundancy does not allow extending the CT for an inoperable system from 7 to 30 days, it does allow extending the associated CTs bejond those specified for ESF systems in currently operating BWR plants. The staff's finding on the relexed CTs, ranging from 8 hours to 14 days, is besed on probabilistic risk evaluation, engineering ovaluation, and operating experience and judgment for various components and combinations of components. The staff noted that these evaluated configurations match the configurations of inoperable components delineated in the TS limiting conditions for operation. The rationale for the relaxed CTs is given in Chapter 19 of the SSAR and the TS bases. On the basis of the above, DFSER Open Item 16-3 is resolved.

The ABWR instrumentation and controls (I\&C) systems design concept incorporates microproceseor-besed digital technology and multiplexed fiber optic signal transmission. TS limits for the reactor protection system are based on a four-sensor channel design. This requires that the applicable portions of the BWR/6 STS be restructured to address the unique $A B W R$ data collection and transmission design features. In the DFSER, the staff asked GE to submit the ABWR TS so that it could complete its review of the ABWR I\&C TS. This was DSER Open Item 16-2. 


\section{Technical Specifications}

As part of the rewolution of DFSBR Open Item 16-1 noted previoualy, the I\&C TS were iraved by the staff to OB for commeat. After mootinge during which OB's comments were roolved, the etaff isaued the ABWR TS to OB for certification. This resolved DFSER Opea Itom 16-2.

In the DFSER, the ataff atated that the COL applicant chould include plent- and silo-epecific information in the ABWR TS. This was DFSER COL Action Item 16-1. SSAR Chapter 16, "Tochnical specifications," contain ruidelines canbling the COL applicant to complete the plant- and sito-apecific portions of the TS on the basis of ae-procured hardwaro and software. This is acceptable.

As part of the TS Improvement Program, the etaff concluded that portions of STS Section 5.0, "Administrative Controls," could be relocated to licenseo-controlled documents. This improvement was incorporated into the ABWR TS.
COL applicants will have to enaure that the portions of Section 5.0 relocated to licenece-controlled documents are controlled in eccordance with an adminiatrative control ayatem scceptable to the staff. To complete its reviow of tho ABWR TS, the atafi performed an independent audit to verify the sccuracy and completences of the TS. The staff provided comments to $\mathrm{OB}$ in a series of letters dated Fobruary 2, 10, 14, and 16, 1994, which were addroceed by OB in the certified final ABWR TS provided in SSAR Amendinent 34.

\subsection{Conclusion}

The atafi concludes that the ABWR TS are consistent with the regulatory guidance in the BWR/6 and BWR/4 STS and contrin design-epecific parameters and additional TS requirements considered appropriate by the staff. Therofore, the ABWR TS satisfy 10 CFR 50.34 and 50.36 and are accoptable. 


\section{QUALITY ASSURANCE}

\subsection{Quality Assurance During the Design Phase}

\subsubsection{General}

Standand afoty analyvis report (SSAR) Chapter 17 describes the quality escounnce (QA) program for the deaigm phase of the advanced boiling water reactor (ABWR) and reforences OB Nuclear Bnergy (GE) QA topical roport, NBDO-11209-04A, which the ataff ro viowed and found acceptable. SSAR Chapter 17 also provides additional QA information specifically applicable to the ABWR. The ataff aceoceed OB's deacription of the QA program for the decign phace of the ABWR to determine if it complies with the requirements of 10 CPR Part 50, Appeadix B, and with applicable QA-related regulatory guides listed in Table 17.1 of this report.

The basis of the staff's review was Standard Roviow Plan (SRP) Section 17.1, which addresese both design and construction QA. The development and implementation of the construction QA program were identified in the draft final safety evaluation report (DFSER) as DFSER combined license (COL) Action Item 17.1.1-1. GE addreseed this itom in Amendment 31 of the SSAR (SSAR Section 17.0.1.1), which is scceptable to the staff. GE also included this action item in the SSAR.

\subsubsection{Organization}

The structure of the organization responsible for the design of the ABWR and for the establishment and execution of the design-phase QA program is shown in Figure 17.1 of this report. The line organizations have been assigned specific QA responsibilities, including both internal audits and audits of suppliers, to ensure compliance with the QA program. Audits conducted by GE's Nuclear Quality Assurance (NQA) organization are superimposed on these audits.

The General Manager of Nuclear Operations is responsible for ensuring that (1) the intent of GE's nuclear quality policy is reflected in its nuclear products and services, (2) a system is in place to independently assess the performance of organizations that affect the quality of these products and services, and (3) a system is in place to resolve issues that could affect GE's ability to satisfy its nuclear quality policy and other quality-related commitments.

NQA is a staff organization responsible for establishing the nuclear quality policy and procedures that are issued by the Vice President and General Manager of GE. NQA is also responsible for (1) auditing the various line organizations involved in the nuclear business and ensuring conformance of thew organizations' procedures and practices with applicablo corporato and nuclear quality-rolated policy and procedures, (2) ennuring integration of the organizations" quality planning into an offective QA program, (3) participating in management reviow bourde that operato independently of the design verification by the line orgenizations, and (4) specifying how the line orgenizations are to comply with tho nucleur quality policy and procedures. For the ABWR denign, NQA is reeponsiblo for coordinating and integrating the QA program as it relates to engineering and management of the project.

A quality council aids NQA in fulfilling its responsibilitios. The council's reeponsibility is to ensure total quality syetem coverage, uniformity, convinteacy, and continuity and to eliminate system deficiencies. The Manager of NQA chairs the quality council. Members of this council, as shown in Figure 17.1, are the managers responsible for QA in each of the major nuclear orgenizations. The council provides theee managers direct accoses to top-lovel management and acts as a forum for the roviow of quality problems and corrective actions.

The line organizations are responsible for planning and implementing the QA functions performed within thoir areas of responsibility so that each organization's QA program complies with the nuclear QA policy and procedures established by NQA. The individual QA managers report to their department-level management and bave the organizational independence and authority to identify quality-related problems; initiate, recommend, or provide solutions pertaining to conditions adverse to quality; and verify implementation of such solutions.

GE and its major technical associates, Hitachi and Toshiba, are designing the ABWR. The lead responsibility to produce each specification (through the major purchasing specifications) and drawing is assigned to one design organization within GE, Hitachi, or Toshiba. The content of each of these common engineering documents is reviewed and approved by GE engineering personnel, and GE is responsible for the design and the supporting calculations and records for the ABWR.

GE engineering organizations are responsible for the U.S. ABWR design and design control by

- ensuring incorporation of applicable regulatory requirements, codes, standards, criteria, and design bases into the design

- ensuring incorporation of project design requirements into the design 
Table 17.1 Quality assurance regulatory guide commitments

\begin{tabular}{|c|c|c|c|}
\hline No. & Title & Revision & Date \\
\hline 1.8 & Pernonnol Selection and Training & 1 & Septomber 1975 \\
\hline 1.26 & $\begin{array}{l}\text { Quality Group Classification, and Standards for Water-, } \\
\text { Stonm-, and Radioactive-Wasto-Containing Components of } \\
\text { Nuclear Power Plants }\end{array}$ & 3 & February 1976 \\
\hline 1.28 & $\begin{array}{l}\text { Quality Asourance Program Requirements (Design and Con- } \\
\text { struction), using NQA-1 and NQA-2* }\end{array}$ & 3 & August 1985 \\
\hline 1.29 & Soismic Design Classification & 3 & September 1978 \\
\hline 1.30 & $\begin{array}{l}\text { Quality Assurance Requirements for the Installation, Inspec- } \\
\text { tion, and Teeting of Instrumentation and Electric Equipment }\end{array}$ & 0 & August 1972 \\
\hline 1.37 & $\begin{array}{l}\text { Quality Assurance Requirements for Cleaning of Fluid } \\
\text { Systems and Associated Components of Water-Cooled Nuclo- } \\
\text { ar Power Plants" }\end{array}$ & 0 & March 1973 \\
\hline 1.38 & $\begin{array}{l}\text { Quality Asourance Requirements for Packaging, Shipping, } \\
\text { Receiving, Storage, and Handling of Items for Water-Cooled } \\
\text { Nuclear Power Plants" }\end{array}$ & 2 & May 1977 \\
\hline 1.39 & $\begin{array}{l}\text { Housekeeping Requirements for Water-Cooled Nuclear Power } \\
\text { Plants }\end{array}$ & 2 & September 1977 \\
\hline 1.58 & $\begin{array}{l}\text { Qualification of Nuclear Power Plant Inspection, Examina- } \\
\text { tion, and Testing Personnel" }\end{array}$ & $*$ & \\
\hline 1.64 & $\begin{array}{l}\text { Quality Assurance Requirements for the Design of Nuclear } \\
\text { Power Plants* }\end{array}$ & $*$ & \\
\hline 1.74 & Quality Assurance Terms and Definitions & $*$ & \\
\hline 1.88 & $\begin{array}{l}\text { Collection, Storage, and Maintenance of Nuclear Power Plant } \\
\text { Quality Assurance Records }\end{array}$ & $*$ & \\
\hline 1.94 & $\begin{array}{l}\text { Quality Assurance Requirements for Installation, Inspection, } \\
\text { and Testing of Structural Concrete and Structural Steel Dur- } \\
\text { ing the Construction Phase of Nuclear Power Plants }\end{array}$ & 1 & April 1976 \\
\hline 1.116 & $\begin{array}{l}\text { Quality Assurance Requirements for Installation, Inspection, } \\
\text { and Testing of Mechanical Equipment and Systems" }\end{array}$ & 0-R & June 1976 \\
\hline 1.123 & $\begin{array}{l}\text { Quality Assurance Requirements for Control of Procurement } \\
\text { of Items and Services for Nuclear Power Plants* }\end{array}$ & $\cdots$ & \\
\hline 1.144 & $\begin{array}{l}\text { Auditing of Quality Assurance Programs for Nuclear Power } \\
\text { Plants }\end{array}$ & $*$ & \\
\hline 1.146 & $\begin{array}{l}\text { Qualification of Quality Assurance Program Audit of Person- } \\
\text { nel for Nuclear Power Plants* }\end{array}$ & $*$ & \\
\hline
\end{tabular}

- NRC accepted the GE positions given in Topical Report NEDO-11209-04A, Revision 8, March 31, 1989.

- Superseded by Revision 3 of Regulatory Guide 1.28. 
Quality Assurance

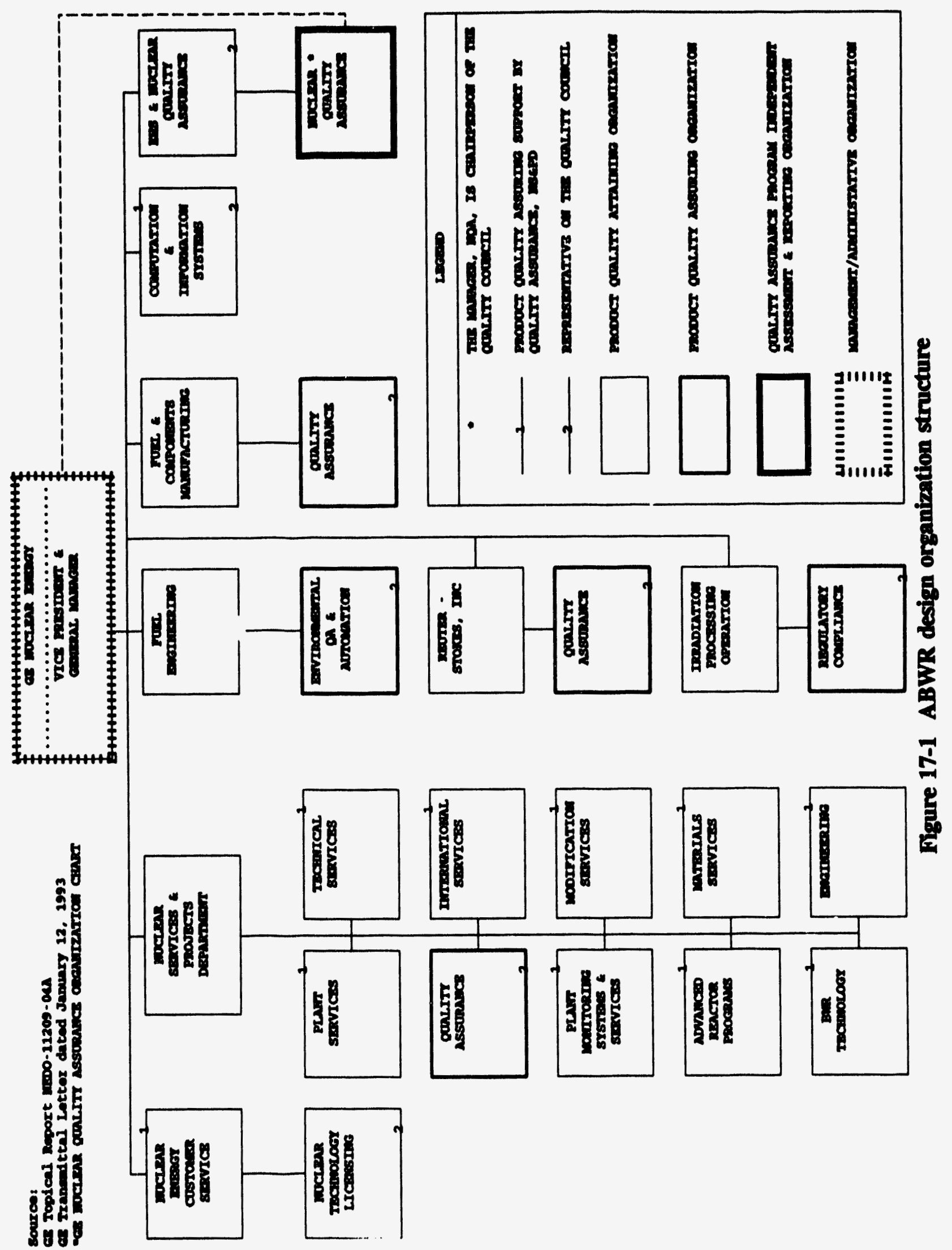


- translating the design information into the appropriate design documents

- verifying tho design adequacy either through independent design review, the use of alternative or simplified calculational methods, or the performance of a suitable testing program

- coordinating design activities among interfacing design engineers and design organizations

- reviewing, approving, issuing, and distributing design documents under a controlled document system

- controlling design changes and changes to design documents in accordance with documented procedures

- providing for the retention, storage, control, and retrievability of design record documents

- taking corrective action as necessary to correct design errors and to improve the design control function

\subsubsection{Quality Assurance Program}

GE structured its nuclear QA program to satisfy Appendix B to 10 CFR Part 50 and the provisions of the applicable Nuclear Regulatory Commission (NRC) regulatory guides identified in Table 17.1 of this report. GE uses this QA program to control its design of the ABWR. GE has written policies, procedures, and instructions to implement the program. These documents control quality-related activities in accordance with the requirements of Appendix B to 10 CFR Part 50 and with applicable regulations, codes, and standards. The GE QA organizations ensure that procedures and instructions are provided for meeting the QA requirements. In addition, QA personnel conduct reviews and audits to verify the effective implementation of the program.

GE's nuclear QA program requires that implementing documents encompass detailed controls for (1) translating codes, standards, regulatory requirements, technical specifications, engineering requirements, and process requirements into drawings, specifications, procedures, and instructions; (2) developing, reviewing, and approving procurement documents and changes thereto; (3) prescribing all quality-related activities by docupented instructions, procedures, drawings, and specifications; (4) issuing and distributing approved documents; (5) purchasing items and services; (6) identifying materials, parts, and components; (7) performing special processes; (8) inspecting and/or testing materials, equipment, processes, and services; (9) calibrating and maintaining measuring and test equipment; (10) handling, storing, and shipping items;
(11) identifying the inspection, test, and operating status of items; (12) identifying and dispositioning nonconforming items; (13) correcting conditions adverse to quality; (14) preparing and maintaining QA records; and (15) auditing activities that affect quality.

Training and experience requirements are defined for each position in the GE organization. In addition, GE indoctrinates and trains personnel performing activities affecting quality to ensure that appropriate proficiency is achieved and maintained and that personnel responsible for quality-related activities are instructed as to the purpose, scope, and implementation of the quality-related manuals, instructions, and procedures. The indoctrination and training are carried out through documented procedures, on-the-job training, personal contacts, and meetings.

The ABWR design and changes to it are formally verified. Design verification is a process for an independent review of the design against design requirements to confirm that the designer's methods and conclusions are consistent with requirements and that the resulting design is adequate for its specified purpose. Design verification is performed and documented by persons other than those responsible for the design, using the method specified by the design organization. Designs are verified by one or more of the following methods: design review, qualification testing, alternative or simplified calculations, or checking. Team design reviews are continuing reviews of a design, selected by engineering management, to evaluate design adequacy that includes concepts, the design process, methods, analytical models, criteria, materials, applications, or development programs. When appropriate, team design reviews are used to verify that product designs meet functional, contractual, safety, regulatory, industrial codes and standards, and GE requirements. The selection of the design review team depends on the product design and the type of review. The technical competence of the members of each team encompasses three broad categories: (1) those with broad experience on similar products; (2) those with specialized technical expertise such as in heat transfer, materials, and structural analysis; and (3) those with a functional expertise such as QA, manufacturing, engineering, and product service.

For the international ABWR design, the lead design organization prepares the common engineering design document and circulates it internally for engineering review, approval, and design verification. Evidence of verification is entered into the design records of the responsible design organization. Each document is distributed to the design organizations of the other parties for their review and approval of technical content and design interfaces. All comments resulting from this process are resolved. After the comments are resolved, 
the design verification is reviewed and, when neceseary, updated to ensure that changes did not invalidate the original verification. After final agreement is reached, the document is finalized by the lead design organization, circulated to the other parties for their approval signatures, and issued. Changes to ABWR documents are handled similarly. Differences betwoen international and U.S. ABWR designs are identified in a controlled list (called the design action list) for future design action and application.

GE's QA organizations are responsible for establishing and implementing the audit program. Audits are performod in accordance with preestablished written checklists by qualified personnel not having direct responsibilities in the areas being audited. Periodic audits are performed to evaluate all aspects of the QA program, including the offectiveness of implementation. The QA program requires the review of audit results by the person having responsibility in the area audited to determine and take corrective action where necessary.

Followup audits are performed to determine if nonconformances and deficiencies have been effectively corrected and the corrective action precludes repetitive occurrences. Audit reviews, which indicate performance trends and the effectiveness of the QA program, are reported to responsible management for review and assessment.

The staff concludes that GE's QA program for the design phase of the ABWR describes requirements, procedures, and controls that, when properly implemented, will comply with the QA requirements of Appendix B to 10 CFR Part 50, applicable QA-related regulatory guides, and the acceptance criteria in SRP Section 17.1, related to QA during design and construction. In addition, SSAR Chapter 17 references GE QA topical report, NEDO-11209-04A, which the staff has reviewed and found scceptable.

During its review of the QA program dgscribed in the ABWR SSAR, the staff audited the implementation of the program at GE's offices in San Jose, California, during the weok of February 6, 1989. The report of this rudit is in the Commission's Public Document Room, the Gelman Building, 2120 L Street NW, Washington, DC. On the basis of the sample of design activities audited, which included Hitachi and Toshiba documents requested by the staff and translated into English, the auditors concluded that the design QA programs implemented by GE, Hitachi, and Toshibe met the applicable requirements of Appendix B to 10 CFR Part 50 and were acceptable for designing the $A B W R$.
An inspection of the $A B W R$ design process was performed from September 7 through 10, 1993. The inspection results are documented in NRC Inspection Report 99900403/93-02: The inspection scope included an examination of GE QA controls applied to the ABWR project. This included a review of design record files (DRFs), selected computer codes used for accident analysis and transient modeling, test activities, design calculations, and audits. The inspection questioned the technical adequacy of supporting calculations generated by the international technical associates (TAs). Some test data for the Full Integral Simulation Test could not be retrieved by $G E$, and some calculation notebooks were poorly maintained. The staff evaluation of GE's response to the findings of that inspection was Open Item F17.1.3-1.

GE provided a response to the staff's inspection report on November 24, 1993, which addressed the items of concern and proposed corrective and preventive actions such as: verifying the accuracy of an input parameter for a LOCA analysis and performing related sensitivity studies, disseminating training reminders to technical staff about the $Q A$ requirements for design analysis and DRFs, increasing the GE audit emphasis on the content of DRFs, verifying that installed test instrumentation was within specified tolerances, supplementing transient analysis code DRFs, confirming that engineering services were provided under the auspices of an Appendix B quality program, correcting SSAR inaccuracies, and performing design verification on a design calculation. The staff found these proposed actions to be acceptable with a few exceptions. $A$ request for further information and clarification was sent to GE on December 22, 1993, fur the issues involving the technical oversight by GE of supporting calculations generated by the TAs and the conduct of computer code design verification. GE's response dated January 17, 1994, was found to be acceptable with one exception discussed as follows.

During the course of the inspection in September 1993, the staff identified that the common engineering documents (design specifications, process flow diagrams (PFDs), instrument block diagrams (IBDs), and piping and instrument diagrams (P\&IDs)) have received a considerable level of GE design review. However, the level of GE review performed on the supporting calculations generated by the international TAs was not found to be rigorous. For example, the NRC inspection found that the depth of technical review afforded by the GE program reviews (QA audits) was minimal as the audit teams had not been supplemented by technical reviewers. In addition, little documented evidence was found in the DRFs to substantiate GE's review of the supporting calculations. 
GE informed the staff that a sufficient level of confidence was obtained in the supporting calculations through the performance of GE program reviews of each TA, the GE engineering reviews of the common engineering documents, and participation by GE staff in numerous design review meetings. In addition, GE provided amplifying information during meetings with the staff on March 14 and 15, 1994, with respect to the extensive GE involvement during the $\mathrm{ABWR}$ design evolution. $\mathrm{GE}$ stated that, during the period from 1978 through 1985, extensive technical interaction transpired between GE and the TAs.

On March 22 through 24, 1994, a second NRC inspection was performed to substantiate the extent of the GE technical oversight of the TA's supporting design and analysis efforts. The inspection spanned a representative sampling of ABWR systems for which a TA had lead design responsibility. The staff examined the associated GE DRFs, interviewed cognizant GE design engineers, reviewed engineering correspondence from the TAs, and searched for examples of GE verification of TA calculations.

The three-day inspection resulted in the identification of evidence of GE's technical oversight of the supporting design as documented by the Phase 3 "Advanced BWR Plant Evaluation Report," GE comparisons of the ABWR design parameters with respect to the BWR 5 and 6 plant designs, thorough $G E$ review of the common engineering documents that included proposed design revisions and independent GE calculations, the existence of selected TA supporting calculations in the GE DRFs, and GE review of system analysis, system performance, and capacity calculations generated by the TAs.

The inspection determined that reasonable assurance was provided by the depth, extent, and duration of the GE technical oversight of the joint design process to resolve the remaining issue from the September 1993 inspection. During the March 1994 inspection the staff additionally reviewed selected GE corrective and preventive actions that had been implemented in response to other concerns raised during the September 1993 inspection and found them satisfactory. Therefore, Open Item F17.1.3-1 is resolved based on the March 1994 inspection findings and the corrective and preventive measures instituted by GE in response to the QA and design control concerns identified in NRC Inspection Report 99900403/93-02.

An applicant for a COL, when completing its detailed design and equipment selection during the $\mathrm{COL}$ design phase, will submit its QA program for the design phase for staff review. This will be in addition to the staff review of the COL applicant's QA program for both the construction and the operation of the facility. When the COL applicant's QA programs are submitted, whether they are the GE QA programs augmented with information by the COL applicant, or a completely now QA program, the staff will perform the necessary reviews in ensure compliance to 10 CFR Part 50, Appendix B. This was DFSER COL Action Item 17.1.1-1.

\subsection{Quality Assurance During the Operations Phase}

The operations QA program is beyond the scope of GE's application for design certification (DC) and was identified by the staff in the DFSER as DFSER COL Action Item 17.2-1. This item was addressed by GE Amendment 31 of the SSAR (SSAR Section 17.0.1.1), which is acceptable to the staff. GE has also included this action item in the SSAR. For a discussion on the relationship of the COL applicant's Operational Reliability Assurance Process to the QA program, see Section 17.3 of this report.

\subsection{Reliability Assurance Program}

\section{Introduction}

SSAR Section 17.3 describes the reliability assurance program (RAP) for the design phase of the ABWR. GE implements the design reliability assurance program (D-RAP) for its scope of design during detailed design and specific equipment selection phases to ensure that the important ABWR reliability assumptions of the probabilistic risk assessment (PRA) will be considered throughout plant life. The COL applicant will augment and implement the D-RAP for its scope of design and equipment selection (See SSAR 17.3.13). Additionally, the COL applicant should develop and implement a process whose objectives are to monitor equipment performance and evaluate equipment reliability to provide reasonable assurance that the plant is operated and maintained commensurate with PRA assumptions so that the overall safety is not unknowingly degraded and remains within acceptable limits (See SSAR 17.3.13). This process could be described as an operational reliability assurance process (O-RAP) that should be included under existing programs for quality assurance and maintenance. When structures, systems, and components (SSCs) monitoring and evaluation identifies performance or condition problems, appropriate corrective action will be taken to ensure SSCs remain capable of performing their intended functions. However, the RAP does not attempt to statistically verify the numeric values used in the PRA through performance monitoring.

The staff has evaluated SSAR Chapter 17.3, which included the GE response (dated March 5, 1992) to the 
staff's request for additional information (RAI) contained in its requeat for reeolution of iseves relatod to SSAR Chapter 19, Appendix K (letter dated September 19, 1991). The acceptability of the particular method to identify and prioritize risk-significant etructures, systems, and components (SSCs) associated with PRA was roviewed as part of SSAR Chapter 19 and is addressed in Chapter 19 of this report.

\section{Backeround}

The need for a safety-oriented reliability offort for the nuclear industry was identified by the NRC in Three Mile Island (TMI) Action (NUREG-0660) Item II.C.4. Subeequently, initial NRC research in the area of reliability assurance began in the carly $1980 \mathrm{~s}$. The results of this research showed that an operational reliability program based on a feedbeck process of monitoring performance, identifying problems, taking corrective action, and verifying the effoctiveness of these actions was needed and that other NRC initiatives (e.8., maintenance inspections, performance indicators, aging programs, and tochnical specification improvements) would address this need. The NRC concluded from this research that an operational reliability program could be implemented most effectively in a performanco-besed, nonprescriptive regulation, where NRC mandates the level of safety performance to be achieved. For example, licensees could be required to set availability and reliability targets for selocted systems and to measure performance compared to the targets.

The TMI item was closed out for operating reactors in October 1988 without further action because several NRC initiatives had effectively subsumod the operational reliability program effort. These initiatives included efforts to (1) improve maintenance and better manage the effects of aging, (2) improve tochnical specifications, (3) develop and use plant performance indicators, and (4) develop an operational reliability program as an acceptable means of meeting the station blackout rule (10 CFR 50.63).

NUREG-1070, "NRC Policy on Future Reactor Designs" included the concept of a systems reliability program to ensure that the reliability of components and systems important to safety would remain at a sufficient level. To ensure that reliability objectives are met and to prevent degradation of reliability during operation, the NRC envisioned that the PRA, performed at the design stage, would be used as a tool in making detailed design decisions affecting procurement, testing, and the formulation of operations and maintenance procedures.

In a fow specific instances, the NRC is studying or has established reliability targets for systems and components.
For example, SRP Section 10.4.9 requires that an acceptable auxiliary feedwater system design have an unreliability in the range of $10 \mathrm{E}-4$ to $10 \mathrm{E}-5$ per demand. The resolution of Generic Issue B-56 involves efforts to determino, monitor, and maintain emergency diesel generator reliability levels. Additional regulatory beses for key elements of a RAP can be found in Appendices $A$ and B to 10 CFR Part 50 and 10 CFR 50.65.

In SECY-89-013, "Design Requirements Related to the Evolutionary Advanced Light Water Reactors," dated January 19, 1989, the staff identified several issues for next-generation light water reactors that go beyond present acceptance criteria defined in the SRP. RAP, as one of these issues, was defined as a program to ensure that the design reliability of safoty-significant SSCs is maintained over the life of a plant. In SECY-89-013, the staff informed the Commission that RAP would be required for final design approval or design certification (DC). In November 1989, potential applicants for DC were informed by letter that "the NRC staff was considering matters that went beyond the current SRP . . . that [the NRC] expects these advanced reactor designs to embody." Reliability assurance was identified as one of these matters.

In SECY-93-087, "Policy, Technical, and Licensing Isques Pertaining to Evolutionary and Advanced Light-Water Reactor (ALWR) Designs, " dated April 2, 1993, the staff recommended that the Commission approve its interim position that a high-level commitment to a RAP application to design certification be required as a non-system generic Tier 1 requirement with no associated inspections, tests, analyses, and acceptance criteria (ITAAC). The details of the D-RAP, including the conceptual framework, program structure, and essential elements, should be provided in the SSAR. The SSAR for the D-RAP should also (1) identify and prioritize a list of risk-significant $\mathrm{SSC}_{8}$ basod on the DC PRA and other sources; (2) ensure that the vendor's design organization determines that significant design assumptions, such as equipment that satisfies the design reliability and unavailability, are realistic and achievable; (3) provide input to the procurement process for obtaining equipment that satisfies the design reliability assumptions; and (4) provide these design assumptions as input to the COL applicant for consideration in the O-RAP. A COL applicant would augment the D-RAP with site-specific design information and would implement the balance of the D-RAP, including input to the procurement process (See SSAR 17.3.13).

The RAP consists of two distinct parts: (1) D-RAP and (2) O-RAP. D-RAP involves a top-level program at the design stage that is used to define the scope, conceptual framework, and essential elements of an effective RAP. D-RAP is also used to implement those aspects of the 
program that are applicable to the design process. In addition, D-RAP is used to identify the relevant aspects of plant operation, maintenance, and performance monitoring for the risk-aignificant SSCs for the operator's consideration in developing an O-RAP. The O-RAP objectives should be incorporated into existing programs (i.e., quality sesurance and maintenance) that will be used to monitor equipment performance and evaluato equipment reliability to provide reasonable sseurance that the plant is operated and maintained commensurate with PRA assumptions 80 that the overall safety is not unknowingly degraded and remains within scceptable limits. When SSC monitoring and ovaluation identifies performence or condition problems, appropriate corrective action will be taken to assure SSCs remain capable of performing their intended functions. However, the RAP does not attempt to statisticaily verify the numerical values used in the PRA through performance monitoring.

The staff's final position on RAP was presented in the Commission peper on the Regulatory Treatment of NonSafety Syatems (RTNSS) SECY-94-084 dated March 28, 1994. The Commission approved the following applicable regulation for D-RAP:

An application for design certification or for a combined license must contain:

(a) the description of the reliability assurance program used during the design that includes, scope, purpose, and objectives;

(b) the process used to evaluate and prioritize the structures, systems, and components in the design, besed on their degree of risksignificance;

(c) list of structures, systems, and components designated as risk-significant; and

(d) for those structures, systems, and components designated as risk-significant:

(i) A process to determine dominant failure modes that considered industry experience, analytical models, and applicable requirements; and

(ii) Key assumptions and risk insights from probabilistic, deterministic and other methods that considered operation, maintenance and monitoring activities.
Each COL applicant that references the ABWR design must implement the D-RAP approved by the NRC.

The ataff evaluated the SSAR on the basis of the applicable regulation stated above.

A COL applicant would augment the designer's RAP to reflect plant-specific information and implement those elements applicable during the construction and operation pheses. The staff's COL application review will be similar to the design certification review and include an evaluation of the updated (site-specific) PRA, probabilistic, deterministic and other insights (e.g., operating experience) to aseess any changes to risk-significant SSCs and siteepecific vulnerabilities. The staff will review the COL applicant's proposed design reliability assurance program plan to determine if it satisfies the above requirements at the time of the COL application.

\section{Evaluation}

In its RAI dated September 19, 1991, the staff stated that the GE ABWR RAP submittal should (1) describe the basic framework of a RAP including the scope, purpose, objective, basic definitions, and elements (RAI Question (Q)1); (2) when describing the RAP concepts and elements, include a discussion on performance goal or targets, problem prediction and recognition, problem prioritization and correction, and problem closeout (RAI Q2); (3) describe how RAP will address plant aging concerns (RAI Q3); (4) describe the organizational and administrative aspects for implementing an effective RAP (RAI Q4); (5) describe the approach for providing feedback to the designer when actual plant performance data consistently differ from the designers PRA and RAP assumptions (RAI Q5); (6) describe the major programmatic interface between the RAP and areas such as design, construction, startup testing, operations, maintenance, engineering, safety, licensing, quality assurance, and procurement (RAI Q6); and (7) provide an example of how the GE RAP would be implemented using a specific SSC identified as risk significant in the PRA (RAI Q7). These questions included the use of the term "RAP;" however, the intent was for the questions to apply to that portion of the RAP that GE is responsible for preparing and implementing (e.g., the ABWR D-RAP). The RAI questions provided an outline of the staff's expectations on RAP for evolutionary designs and explicitly stated the details of these expectations.

In its letter dated March 5, 1992, GE stated that a new SSAR Section 17.3 would address the staff's RAI questions. After reviewing the initial $\mathrm{GE}$ response and the modifications to SSAR Section 17.3 in Amendment 26 
(dated March 24, 1993) the staff determined that (1) RAI Q1 was answered by Sections 17.3.2, 17.3.3, 17.3.4, 17.3.6, 17.3.7, and 17.3.8; (2) RAI Q2 was answered by Sections 17.3.6, 17.3.9, and 17.3.10; (3) RAI Q3 was answered by Section 17.3.10; (4) RAI Q4 was answered by Section 17.3.5; (5) RAI Q5 was answered by Section 17.3.10; (6) RAI Q6 was answered by Section 17.3.10; and (7) RAI Q7 was answered by Section 17.3.11. Therefore, the answers to the RAI questions contained in SSAR Section 17.3 address the staff's expectations on RAP for evolutionary designs and explicitly state GE's response to these expectations. The details of the staff's evaluation are presented in Sections 17.3.1 through 17.3.11 below.

\subsubsection{General}

RAP for the design phase of the ABWR described in SSAR Section 17.3 ensures that the important ABWR reliability assumptions of the PRA will be considered throughout plant life. The PRA is used to evaluate the anticipated plant response to initiating events. The PRA evaluates the plant response to initiating events to substantiate, in part, that plant damage has a very low probability and risk to the public is very low. Input to the PRA includes details of the plant design and assumptions about the reliability of the plant risk-significant SSCs. Changes to equipment and system reliabilities will be reevaluated and as necessary will be reflected in a revised PRA throughout plant life. GE started the D-RAP during design of the ABWR. The COL applicant will utilize the ABWR D-RAP during the detailed design and specific equipment selection phases to complete the D-RAP. The COL applicant will complete the D-RAP and will also incorporate the objectives of the O-RAP into existing programs (i.e., maintenance and quality assurance) that will be used to monitor equipment performance and evaluate equipment reliability to provide ressonable assurance that the plant is operated and maintained commensurate with PRA assumptions so that the overall safety is not unknowingly degraded and remains within acceptable limits. When SSC monitoring and evaluation identifies performance or condition problems, appropriate corrective action will be taken to assure SSCs remain capable of performing their intended functions.

GE states that the D-RAP will include the design evaluation of the ABWR. It will be used to identify relevant aspects of plant operation, maintenance, and performance monitoring of important plant SSCs for the COL applicant's consideration in ensuring safety of the equipment and limited risk to the public. The COL applicant will specify the policy and implementation procedures for using D-RAP information provided by GE
(See SSAR 17.3.1-13). SSAR Section 17.3 aleo includes a descriptive example of how the D-RAP will apply to the standby liquid control system (SLCS). This example shows how the principles of D-RAP will be applied to other systems identified by the PRA as significant with regard to risk.

The staff concludes that Section 17.3.1 of the SSAR moets the requirement of the applicable regulation for D-RAP to provide a description of the RAP used during the initial design as discussed above in Section 17.3 of this report and is acceptable.

\subsubsection{Scope}

In response to the part of RAI Q1 associated with the RAP scope, GE provided the additional information in Section 17.3.2 of the SSAR. In that section, GE states that the scope of the ABWR D-RAP includes identifying relevant aspects of plant operation, maintenance and monitoring of plant risk-significant SSCs. The PRA and other industry sources are used to identify and prioritize those SSCs that are important to prevent or mitigate plant transients or other events that could present a risk to the public.

The staff reviewed SSAR Section 17.3.2 with r.ppect to the scope of the ABWR D-RAP and concludes that it is responsive to the staff's RAI question, meets whe requirement of the applicable regulation for D-RAP 0 include the scope of the RAP as described in Section 17.3 of this report and is acceptable.

\subsubsection{Purpose}

In response to the part of RAI Q1 associated with the RAP purpose, GE provided the additional information in Section 17.3 .3 of the SSAR. In that section, GE states that the purpose of the ABWR D-RAP is to ensure that plant safety, as estimated by the PRA, is maintained as the detailed design evolves through the implementation and procurement phases. Additionally, GE states that pertinent information is to be provided in the design documentation to the COL applicant so that equipment reliability, as it affects plant safety, can be maintained through operation and maintenance during the entire plant life.

The staff reviewed SSAR Section 17.3.3 with respect to the purpose of the ABWR D-RAP and concludes that it is responsive to the staff's RAI question, meets the requirement of the applicable regulation for D-RAP to include the purpose of the RAP as described in Section $\mathbf{1 7 . 3}$ of this report and is acceptable. 


\subsubsection{Ohjective}

In reaponse to the part of RAI Q1 aeeociated with the RAP objective, GE provided the additional information in Section 17.3.4 of the SSAR. In that section, GE states that the objective of the ABWR D-RAP is to identify those plant SSCs that are significant contributors to risk, as shown by the PRA or other sources, and to ensure that, during the implementation phase, the plant design continues to utilize risk-significant SSCs whose reliability is commensurate with the PRA assumptions. The D-RAP also will be used to identify key assumptions regarding any operation, maintenance, and monitoring activities that the COL applicant should consider in developing its approach to implementing an O-RAP using existing programs such as quality assurance and maintenance to provide reasonable assurance that such SSCs can be expected to operate with reliability commensurate with that assumed in the PRA. A major factor in the ABWR D-RAP is risk-focused maintenance that considers all plant modes and equipment directly relied on in ABWR emergency operating procedures (EOPs).

The staff reviewed SSAR Section 17.3.4 with respect to the objective of the ABWR D-RAP and concludes that it is responsive to the staff's RAI question, meets the requirement of the applicable regulation for D-RAP to include the objective of the RAP as described in Section $\mathbf{1 7 . 3}$ of this report and is acceptable.

\subsubsection{GE Organization for D-RAP}

In response to RAI Q4 associated with the RAP organizational aspects, GE provided the additional informution in Section 17.3.5 of the SSAR dated March 5, 1992. However, in its DFSER, the staff identified an inconsistency between the SSAR Section 17.3.5 narrative and SSAR Figure 17.3-1. Additionally, GE described the D-RAP organizational structure in the future tense in SSAR Section 17.3.5. This item remained open subject to a revision of SSAR Section 17.3.5 (DFSER Open Item 17.3.5-1). On January 18, 1993, GE submitted a markup to SSAR Section 17.3.5 that satisfactorily addressed DFSER Open Item 17.3.5.1 and deleted the organization chart (SSAR Figure 17.3-1). This markup was incorporated into SSAR Section 17.3.5 as Amendment 26 dated March 24, 1993. GE has also included this information in the SSAR. On the basis of this evaluation, this item is resolved.

In SSAR Section 17.3.5, GE states that the reliability analyses and the PRA, including SSAR Appendix 19K, were performed by GE. GE also developed the D-RAP definition. Responsibility for the design of key equipment, components, and subsystems was shared by $G E$ and external organizations, including the organization performing architect-engineoring functions. The $G E$ manager assigned the responsibility of managing and integrating the D-RAP program had direct access to the ABWR project manager and kept him abreast of D-RAP critical items, program needs, and status. He had organizational freedom to (1) identify D-RAP problems; (2) initiate, recommend, or provide solutions to problems through designated organizations; (3) verify implementation of the solution; and (4) function as an integral part of the final design process.

The staff reviewed Amendment 26 of SSAR Section 17.3.5, which incorporated the markup submitted on January 18, 1993, with respect to the GE organizational description and accountability for implementing the ABWR D-RAP for DC, and concludes that it is responsive to the staff's DFSER open item concern, is responsive to the staff's original RAI Q4, satisfies the staff position that the D-RAP ensures that the vendor's design organization determine that significant design assumptions are realistic and achievable as discussed in SECY-93-087 and Section $\mathbf{1 7 . 3}$ of this report, and is acceptable. The staff also concludes that the GE organizational description and accountability for implementing the ABWR D-RAP were acceptable and resolved DFSER Open Item 17.3.5-1.

A COL applicant completing its detailed design and equipment selection during the $\mathrm{COL}$ design phase will submit its specific D-RAP 'organization for staff review (See SSAR 17.3.13).

\subsubsection{SSC Identification and Prioritization}

In response to the part of $R A I Q 1$ associated with the RAP definitions and elements and the part of RAI Q2 associated with the RAP scope, GE provided the additional information in Section 17.3.6 of the SSAR.

In SSAR Section 17.3.6, GE states that the PRA prepared for the ABWR will be the primary source for identifying risk-significant SSCs that should be given special consideration during detailed design and procurement phases and considered for inclusion in the COL applicant's O-RAP. It also is possible that risk-significant SSCs will be identified from sources other than the PRA, such as nuclear plant operating experience, other industrial experience, and relevant component failure databases. SSAR Chapter 19 describes the method of identifying risksignificant SSCs using the PRA.

The staff reviewed SSAR Section 17.3.6 with respect to identifying and prioritizing risk-significant SSCs for the ABWR D-RAP and concludes that it is responsive to the 
ctaff. RAI queations, meets the requitement of the applicable regulation for D-RAP to dencribe the methodology used to ovaluato and prioritize rick aignificunt SSCs as described in Section 17.3 of this report, and is accoptable. The acceptability of the PRA methoda or techniques to prioritize SSCs is addreseed in Chapter 19 of this report.

\subsubsection{Deaign Consideration}

In reaponse to the part of RAI Q1 ancociated with the RAP definitions and elements, $\mathrm{GB}$ provided the additional information in Section 17.3.7 of the SSAR. In SSAR Section 17.3.7, GE states that the reliability of SSCs identified by the PRA as risk significant will be evaluated at the detailed design etage by appropriate design reviows and reliability analysis. Current databases will be used to identify appropriate values for failure rates of equipment as designed, and these failure rates will bo compared with those used in the PRA. 'Normally, the failure rates will be similar, but in some cases they may differ because of recent design or database changes. Whenever failure ratee of designed equipment are significantly greater than those assumed in the PRA, an evaluation will be performed to determine if the equipment is acceptable or if it must be redesigned to achieve a lower failure rate.

For those SSCs identified by the PRA or other sources as risk significant redesign will be considered as a way to reduce the core damage frequency (CDF) contribution. If there are practical ways to redesign a risk-significant SSC, it will be redesigned and the change in system fault tree results will be calculated. Following the redesign phase, dominant SSC failure modes will be identified so that protection against such failure modes can be accomplished by appropriate activities during plant life. (See Chapter 19 of this report.)

For the COL applicant, GE will identify in the PRA, or other design documents, the risk-significant SSCs and the associated reliability assumptions, including any pertinent bases and uncortainties considered in the PRA (Seo Chapter 19 of this report). GE will also provide this information for the COL applicant to consider in developing an O-RAP to help acsure that PRA results will be achieved over the life of the plant. The COL applicent can use this information for establishing appropriate reliability targets and the associatod maintenance practices for achieving them.

The staff reviewed SSAR Sections 17.3.6, 17.3.7, and 17.3.8 and concludes that GE has provided a process for ovaluating risk-significant SSCs for rodosign and a process for providing information to a COL applicant for establishing appropriate reliability targets and the anociated maintenunce practices for an O-RAP. The ataff also concludes that SSAR Section 17.3.7 is responsive to its RAI queation, meots the requirement of the applicable regulation for D-RAP to describo the methodology used to ovaluato and prioritizo riak significant SSCs as doscribed in Section $\mathbf{1 7 . 3}$ of this report, and is accoptable.

\subsubsection{Defining Fallure Modes}

In reeponse to the part of RAI Q1 associated with the RAP dofinitions and elements, $\mathrm{GE}$ provided the additional information in Section 17.3.8 of the SSAR. In SSAR Section 17.3.8, GE uses the methodology of NUREG/CR-5695, Section 5, to determine dominant failure modes of risk-significant SSCs in the D-RAP. The method includes using historical information, analytical models, and existing requirements.

The etaff roviewed SSAR Sections 17.3.6, 17.3.7, and 17.3.8 and concludes that GE has provided a method for determining dominant failure modes for risk-significant SSCs in the ABWR D-RAP. The staff also concludes that SSAR Section 17.3.8 is responsive to its RAI question, meets the requirement of the applicable regulation for D-RAP to define failure modes as described in Section $\mathbf{1 7 . 3}$ of this report, and is acceptable.

\subsubsection{Operational Reliability Assurance Activities}

In response to the part of RAI Q2 associated with the RAP performance goals and targets, problem prediction, and problem recognition, $G E$ provided the additional information in Section 17.3.9 of the SSAR. In SSAR Section 17.3.9, GE states that once the dominant failure modes are determined for risk-significant SSCs, an assessment is required to determine suggested O-RAP activities that will ensure acceptable performance during plant life. Such activities may consist of periodic surveillance inspections or tests, monitoring of SSC performance, or periodic preventive maintenanco (PM).

Periodic teating of SSCs may include startup of standby systems, surveillance testing of instrument circuits to ensure that they will respond to appropriate signals, and inspection of passive $\mathrm{SSC}_{8}$ to show that they are available to perform as designed. Performance monitoring, including condition monitoring, can consist of mossurements of output, measurement of magnitude of an important variable, and testing for abnormal conditions. Periodic PM will be performed at regular intervals to preclude problems that could occur before the next PM interval.

Planned maintenance activities will bo integrated with regular operating plans. Maintenance that will be 
performed more frequently then during refuling outagen muat bo planned to avoid dianupting enfo operation or causing a resctor somm, engincored safety fouture sctuation, or abnormal transieat. Maintenunce performed during rofueling outages must not adversely affect plant safoty.

The staff roviowed SSAR Section 17.3.9 and 17.3.10 and concludes that GB has provided a process to determine operational reliability' ascurance sctivities uning the dominant failure modes identified in the ABWR D-RAP. The staff also concludes that SSAR Section 17.3.9 is reeponsive to its RAI queetion, to include a deacription of O-RAP ectivitien, and is acceptable. Tho COL applicant should incorporate O-RAP sctivities into exiating program such as maintenance and quality acourunce and provide the staff with a description of how thewe sctivitien are mot at the time of the COL application. (See SSAR 17.3.13).

\subsubsection{COL Applicant's Reliability Asourance Proces}

In response to the part of RAI Q2 aesociated with the RAP performance goals and targets, problem prediction, and recognition, problem prioritization and correction, and problem closeout, GE provided the edditional information in Section 17.3.10 of the SSAR. Additionally, the O-RAP description of plant aging, feedbeck to designer, and programmatic intorfaces responds to RAI Q3, Q5, and Q6, respectively. In SSAR Section 17.3.10, GE states that the O-RAP will be prepared and implemented by the COL applicant, using the information provided by GE. The information will belp the COL applicant determine activities that should be included in the O-RAP. Examples of activities that might be included in an O-RAP are:

- reliability performance monitoring

- reliability methodology

- problem prioritization

- root cause analysis

- corrective action determination

- corrective action implementation

- corrective ection verification

- plant aging

- feedback to designer

- programmatic interfaces
The COL applicant will addiese in its O-RAP the interfices with construction, atartup testing, operations, muintenance, engineering, safoty, licensing, QA, and procurement of replecement equipment.

The ataff concludes that the outline of an O-RAP provided by GE to be used by the COL applicant in SSAR Section 17.3.10 is responsive to its RAI questions, to include a description of O-RAP activities, and is acceptable. The COL applicant should also incorporate O-RAP setivitien into existing programs such as maintenance and quality ancurance and provids the staff with a description of how these setivities are mot. The COL applicant will provide the D-RAP for completion of the detailed design and epecific equipment selection phases (e.8., procurement of risk-aignificant SSC8), and a completo O-RAP to be roviowed by the staff as deacribed in Sections 17.3.1 and 17.3.9 of this report.

\subsubsection{D-RAP Implementation}

In reeponse to RAI Q7, GE provided in Section 17.3.11 of the SSAR, an example of how the GE RAP would be implemented using a specific SSC identified as risk significant in the PRA. For example purposes only, the SLCS was assumed to be a significant contributor to CDF or to offsite risk. The system description (including operation and differences from current BWRs) and a system fault tree were provided in the example. Seven SLCS risk-aignificant components identified in the example a having high importance in the SLCS fault tree were considered for redesign. Also, failure modes and maintenance requirements for the seven components were identified.

The staff concludes that the SSAR Section 17.3.11 example using the SLCS satisfactorily demonstrated GE's coenitive understanding of the RAP concept and their ability to incorporate it into the design, is responsive to its RAI queation, and is acceptable. The process description for the implementation of the ABWR D-RAP by a COL applicant will be reviewed by the staff at the time a COL application is submitted.

\subsubsection{Conclusion}

The staff has reviewed Section 17.3 of the ABWR SSAR. The staff finds that the ABWR SSAR satisfies the requirements of the applicable regulation for $D-R A P$ for the ABWR design phase of the reliability assurance program as described in Section 17.3 of this report, and is therefore scceptable. 


\section{HUMAN FACTORS ENGINEERING}

To parform its ovaluation of Standard Safoty Analyais Report (SSAR) Chapter 18, the etaff reviowed tho information deccribed in Section 18.1.2 of thin report. The roviow was beced on the current regulationy requirements in 10 CFR 52.47, 10 CFR 50.34(9), and 10 CFR 50.34(f) and the guidance in Standard Roviow Plen (SRP) Section 13 and 18; NUREG-0700, "Ouidolines for Control Room Dexign Roviow," September 1981; and NURBG-0933, "Prioritization of Oeneric Safety Ienves Main Report," April 1983. The ataff doveloped additional roviow criteria to provida a basis for its roviow of appects of the advanced boiling water reactor (ABWR) human factore engineering (HFE) program that wero not fully addreseed by the previously mentioned documents. Thees criteria are contained in the etaff's "Humen Factors Bngincering Program Reviow Model (PRM) and Acceptunce Criteria for Evolutionary Reactors" which was forwanded to the Commiasion in SBCY-92-299 dated Auguet 27, 1992, and is attachod as Appendix J to this report.

Section $\mathbf{1 8 . 1}$ of this report describes the methodology used to conduct the reviow, including the development of general roviow criteria that supplement the regulatory requirements and established guidelines. The results dencribed in Sections 18.2 through 18.9 address tho following eight major topica:

- docign goals

- main control room (CR) standard design features

- inventory of controls, displays, and alarms

- remote shutdown system (RSS)

- local valve position indication (VPI)

- unresolved and generic safoty issues

- emergency procedure guidelines (EPGs)

- decign and implementation process

Section 18.10 gives a summary of the evaluation findings and overall conclusions.

As a reoult of the staff's initial reviow of the SSAR, many outatunding issues were identified and documented in tho draft safety ovaluation report (DSER) (SECY-91-320), and subeequently in the DFSER (SECY-92-349). One of the major iscues to emorge from the initial reviow was that detailed human-system interface (HSD) information concerning the final design was not available for staff roviow as part of the design certification ovaluation. OE's HSI analysis and design efforts resulted in a list of key CR design features characterized at a genoral level (not a detailed specification) and a minimum inventory of fixed safety-significant information and control requirements derived from an analysis of the ABWR EPGs and probabilistic risk assessment (PRA). Evaluation of the key features and the inventory is part of the certification soviow. Howover, thoy reflect a decign in its proliminary atages (not a dotuiled deaign or epecification) and by themealves do not provide a basis on which a eafety determination cen be mado.

In SECY-92-053, "Une of Dexign Acceptance Criteria During 10 CFR Part 52 Dexign Cortification Roviewn," dated Fobruary 19, 1992, the etaff proposed uaing deaign ecceptunce criteria (DAC) as an approech to the ABWR decign roviow because detuiled decign information was unavailable for electod areas of rapidly changing technology, including humen factors appects of the CR and remote shutdown station doaign. Therefore, it was inadvirable to require detailed decign specifications at this point. The inclunion of DAC in specific aystem inspection, teets, analyese, and acceptance critoria (TTAC) is discuesed in Soction 14.3 of this report.

The ataff will verify conformance with the ITAAC at everal points during the CR design procesen. Tho documents that demonstrate atisfactory implemeatation of the ITAAC will bo available for inspection as they are completed. In the DFSER the ataff introduced the concept of conformance reviow points as part of the DAC process. These points would bo koy points during the DAC process at which the staff would complete an adequacy roviow. As its reviow of the dovelopment of the ITAAC and DAC continued, the etaff dotermined that five epecific conformance points wero unneceseary and wero impractical. The deletion of the discuscion of epecific conformance reviow points was the recult of the staff? continued roviow of the design certification applications from eoveral vendors. At the time the DFSER was written, the staff envisioned that a design would progreses in such a fashion that at a given time (e.g., a conformence roviow point) all information related to a particular apect of the design process aseociated with that particular conformance point would be available; for example, all implementation plans would be available at one timo. Because of the nature of the design proceses, it is not practical to assumo that all documentation on a specific conformance roviow would be available at one point in time.

DAC are prescribed limits, parameters, procedures, and attributes on which the staff relies to make a final safety determination to support design certification. The DAC are measurable or testable and must bo verified in order for the staff to accept the final design. DAC delineate the process and requirements that a combined license (COL) applicant must implement during the development of detailed design information for the $\mathrm{CR}$ and the remote shutdown station. The adequacy of the dotailed design will be periodically assessed as it develops. Tho COL applicant must demonstrate that the DAC are met. Failure to 
ancemafully complete ITAAC and any aupporting DAC may require repeatiag enilier ITAAC and/or changing the gyctem doaign.

Becunso the oriteria for roviow of the deaign and implementation procen for a CR or other control ayetem were not clearly dofined in curreat rogulations and guidance documents, the etaff doveloped criteria as part of this reviow. These criteria provided the basis with which to (1) anes if the appropriate HFB elements are included in tho deaign and implementation procen, (2) identify what materials need to be roviowed for each element, and (3) ovaluate the adequacy of DAC and ITAAC to be uned by the etaff to verify each of the reviow demeats, as doveloped by OB.

The taff dovign certification ovaluation is baced partially on deaign information and partially on an implemeatation procese plan that deceribes the HFB program elements required to develop the koy featuree and inventory into an scoeptable detriled deaign epecification. Along with the deaign and implementation procees plan, GB has mubmitted the neceecary DAC and ITAAC to cenoure that the deaign and implementation process is properly executed by the COL applicant. $O B$ has aubmitted a deaign and implementation procees plen for the major deaign ectivition for the ABWR HFE offort. The firt part of the plan presents GE's plant and syetem deaign elements; the eccond part describes the elements that muat be implemented by a COL applicant to complete the deaign activity. The etaff required that the design and implementation proceses plan contain deecriptions of all required human fectors activitien (elements) that are neceseary and aufficient for the development and implementation of the ABWR HSI.

\subsection{Methodology}

The staff noviow was performed in two phaces. A proliminary roviow was performed on carly vernions of the SSAR and was documented in the DSER (SECY-91-320). This review is cummarized in Section 18.1.1 of this roport. DSER (SECY-91-320) isaue recolution and further dovelopment of the SSAR were then reviewed and documented in the DFSER (SECY-92-349). The scopo of this aubsequeat reviow is described in Section 18.1.2. As part of the final roviow, the staff doveloped the HFE PRM, or the reviow model, identified above for the evaluation of a design process. Development of the HFE PRM, found in Appendix J of this report, is described in Section 18.1.3.

\subsubsection{Preliminary Review and Draft Safaty Evaluation Report Isoues}

The primary cource of information reviowed by the thaff for the DSER (SECY-91-320) was SSAR Chapter 18 (updated through Ameadmeat 15) and Chapter 13 (updated through Ameadment 7) and GB's responses to etaff requede for additional information (RA), Queations 620.1 through 620.37, as documented in Chapter 20 of the SSAR. The review focused on four important aspects of ABWR humnn factors considerations:

- the organizational structure of the buman factors function

- decign goals and seaumptions

- dacien procesces

- the epecification of HSI design requirements

In addition, the roview included OE's resolution of thowe afoty inawes (unresolved afoty isoues, generic anfety isvas and the construction permit/manufacturing license (CP/ML) rule of 10 CFR 50.34(f)) related to humen fuctors considerations addroesed in SSAR Chapters 13 and 18.

From its initial review, the staff concluded that the humnn factore program for the HSI was generally inadequate as prosented in GE's initial documentation and that SSAR Chapter 18 and Sections 13.2 and 13.5 did not provide afficient information to support a determination that the ABWR design as proposed by GE for certification would adequately incorporate accepted human factors considerations in a manner that would achiove required afety and reliability. The principal reasons for this finding were: (1) design bases were specified in the SSAR without supporting rationale, (2) a design process was presented in insufficient detail and without results, (3) HSI deaign requirements were presented without evidence that they were derived from the design process and without wupporting teats and ovaluations, and (4) the documentation did not provide sufficient detail to support the reviow of the ABWR humen factors efforts to a level necessary for deaign certification. Twenty-four issues were identified as requiring resolution. The issues are listed in Table 18.1 of this report. The tablo shows the section in this chapter where cach DSER (SECY-91-320) open issue is addressed. In the discussions with $\mathrm{GE}$ that followed issuance of the DSER (SECY-91-320), two issues identified below were added in order to address the overall lack of design detail. These two issues are discussed in detail in Sections 18.4 and $\mathbf{1 8 . 9}$ of this report. 


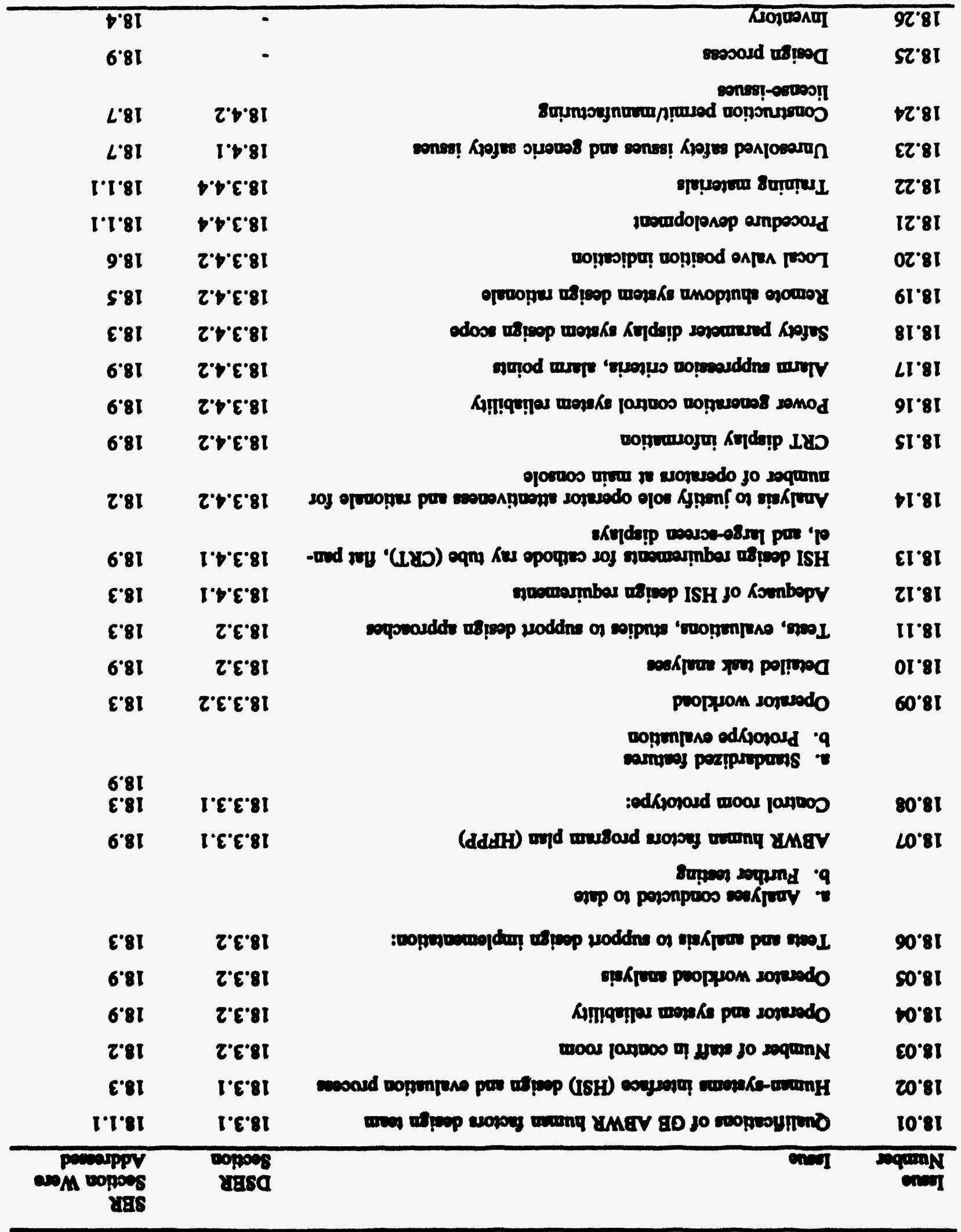

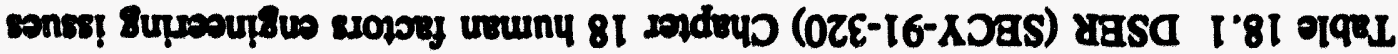


- Impe 18.25 - Dedign Proceses

- Inove 18.26 - Inveatory

DSER (SECY-91-320) Inven 18.01, 18.21, and 18.22 were resolved before the SSAR reviow for mencons discuesed bolow.

\section{DSER (ABCY -21-320) Inne 18.01: Onlifiction of the GBARYR Hum Bretom Deim Ten}

In Section 18.3.1 of the DSBR (SBCY-91-320), the thaff atated that "additional detailed information on the human fuctore qualification of the OB ABWR bumen fectorn decien team is required." This information was deemed important in the DSER roviow because of the aseumption thet tho SSAR was to include an eacentially complete decien for the HSI. GB responded by providing dexign team information in its letter of October 1, 1991.

Bvaluation: Since HFB is to be primarily performed by the COL applicant, the iane is no longer a concern. Inetend, the focus on the doeign team was shifted toward cotablishing the qualification requirements of the design team that will ectually implement tho HFB program discused in Soction $\mathbf{1 8 . 9}$ of this report. Because of the change in focus for certification from an HFE decign to a deaign proceses, OE's initial response to this isewe in its letter of October 1, 1991, provided aufficient information for the staff's ovaluation of this issue. Since OB hes addreseed the qualification requirements for its HFE design toam, this item is resolved.

\section{DSER (SECY-91-320) Isgue 18.21: Procedure} Development

In the DSER (SECY-91-320), the staff stated that systemlovel operating procedures had been doveloped concurrently with the development of the ABWR systems dosign. These procedures and the aseociated task analyesen on which the HSI requirements are based were not included in the references (SSAR Section 18.6); thus, they could not be evaluated. For the ABWR design certification, the etaff expects the COL applicent to provide detriled program descriptions for the development of standardized plant procedures and standardized plant personel training materials. Further, the staff expects the COL applicant to dovelop intograted operating procedures that reflect the full leval of detail consistent with and included as part of the final plant deaign. In addition, the COL applicant should develop procedure dovelopment guidelines (e.8., procedure writers guide, verification and validation (V\&V) guidelines, and generic tochnical guidelines) with sufficient detail to ensure that the COL applicant's implementation of the proceseces and criteria delineated in theee guidelines, when revising procedures will precerve the humen fectore insights and tho overall ABWR deaign.

Bvaluation: The atafi determined that the dovelopment of doteiled precedures and training matorials was beyoad the scope of the ABWR deaign certification and was the responsibility of the COL applicent. This was DRSER Confirmatory Item 18.9.2.2.7-1. Chapter 13.5.3.3 of the SSAR ctates that procedures will bo uned during tho V\&V proceses as described in Articlo VII of Tablo 18B-1. Tho etaff escepts OB's determination that procedure development is beyond the scope of the ABWR decign certification, and OB has included a COL sction item that is ecceptable. Therefore, this item is resolved.

\section{DSER (SECY-91-32.0) Ieave 18.22: Trining Mnteriale}

In the DSER (SECY-91-320), the staff stated that it "expects OB to develop and submit for certification a dotailed program dencription for developing the training material as part of the decign certification for the ABWR." After the DSER was ievued, the staff determined that training materials were already a part of the cetablished licensing reviow process under 10 CFR Part 50 for the COL applicant and did not need to be addreseed in the certification review under 10 CFR Part 52. The staff accepts that the dovelopment of training materials is beyond the scope of tho ABWR decign certification and that the materials will be developed and submitted by the COL applicant as part of the licensing process; therefore, this itom is resolved. A specific COL action item was deemed unneceseary for this itom, because 10 CFR Part 50 requirements are sufficiently explicit and the COL action item list is not intended to be exhaustive.

\subsubsection{Ninal Standard Safety Analyais Report Review}

The sources of information used for the final review deacribed in this chapter wero SSAR Chapter 18 through Ameadment 34, GE's responses to the DSER (SECY-91-320) issues as documented in the SSAR, and GE's responses to the RAls as documented in Chapter 20 of the SSAR. In support of design certification, GB personnel precented additional information on the standard design features to the NRC staff at a meeting during a visit to Japan to obeerve the Japanece ABWR CR prototypes ("Advanced Reactor Program - ABWR Control Room Design" - presented to the United States Nuclear Regulatory Commission, M.A. Ross (GE), April 3 and 4, 1992, Tokyo, Japan - GE Proprietary). This information wes latter summarized and included in tho design certification application as Appendix $18 \mathrm{G}$ to the SSAR. These standard decign features aro ovaluated in Section 18.3 of this report. 


\subsubsection{Development of Review Criteria}

\subsubsection{Ohjectives}

As unted in the beginning of this chapter, complete detailed HSI deaign information would not be available for review before design certification. Certification is based on the staff's approval of GE's deaign and implomentation proceses plan. For a design and implementation proceas plan to reault in an scceptable design, it muat contrin (1) deccriptions of all required HFE program elements for the deaign and dovelopment and implementation of the ABWR HSI and (2) DAC for the conformence reviows under the ITAAC.

To review the GB-proposed HFE process, the athff had to (1) assess if all the appropriate HFE elements were included, (2) identify what materials needed to be reviewed for each element, and (3) ovaluate the proposed DAC and ITAAC to verify each of the elements. To conduct the review, the staff identified (1) which aspects of the HSI design process wero requirod to ensure that HFE safoty design in support of safe plant operation is achieved and (2) the review criteria by which each element is asesesed. Review criteria independent of that provided by GE were required to ensure that OE's plan reflects currently accepted HFE practices and is a thorough, complete, and workable plan. To support anch a review, the staff developed a technical basis for review of the HSI design process. The specific objectives of this effort were:

(1) To dovelop an HFE PRM to servo as a technical basis for the review of the GE-proposed process for certification. The HFE PRM is (a) besed on currently accepted HFE practices, (b) well defined, and (c) validated through experience with the development of complex, high-roliability systems.

(2) To identify the HFE elements in a system development, design, and evaluntion process that are necessary and sufficient for auccessful integration of the humen component in compl. systems.

(3) To identify which aspects of each HFE element are key to a safety review and are required to monitor implementation of the process.

(4) To epecify the ecceptance criteria by which HFE elements can be evaluated as design development progreseses.

\subsubsection{HTE FRM Development}

The etafi roviowed curreat HPB guidnace and practices dencribed in a wide range of nuclear induntry and nonnuclear industry documents to identify important human factors program plan (HPPP) elements relevant to a deaign procens review. A generic system dovelopment, deaign, and evaluation proceses was dofined with eight koy HFB elements that included criteria by which thoy could bo anceased. This is roferred to as the HFB PRM, or the roview model.

The HPB PRM was beed largely on applied geaernl oyctom theory and the Department of Defense (DOD) eyctem dovelopment process (which is rooted in syatems theory). Applied genernl systems theory provides a broad approach to system design and development that is based on a ceries of clearly defined dovelopmental steps, each with clearly defined goals and specific manngement proceses to attain them. Systems eagineering has been dofined as "the management function which controls the total system development effort for the purpose of schioving an optimum balance of all systom elements. It is o process which transforms an operational need into a description of aystem parameters and integrates those parameters to optimize the overall system effectiveneas." (F. Kockler, of al., Systems Enpineerine Manngement Guide (AD/A223 168), Defense Systems Management College, Fort Belvoir, Virginia, 1990.)

Use of the DOD system dovelopment process and procedure in the dovelopment of the HPE PRM was besed on several factors. DOD policy identifies personnel is a specific component of the total system. A systems approach implies that all system components (hardware, software, personnel, support, procedures, and training) are given adequate consideration in the developmental process. A besic aseumption is that the personnel component receives serious consideration from the very beginning of the design process. In addition, DOD has the most experience in applying HFE to the dovelopment of complex, technical systems (as compared with nonmilitary systern 'ovelopers); thus, its process is mature, formalized, and : presents the most highly developed and well defined model of the HFE process svailable.

Within the DOD system, the development of a complex eyctem begins with the mission or purpose of the system and the capability requirements needed to satisfy mission objectives. Systems engineering methods must be used as early as possible to develop the system concept and to 


\section{Human Factors Engnineering}

define the system requirements. During the detniled design of the system, systems engineering ensures

- balanced influence of all required design epecialties

- resolution of interface problems

- effective conduct of tradeoff analyses

- effective conduct of design reviews

- V\&V of system performance

The effective intogration of HFE considerations into the design is accomplished by providing (1) a structured topdown approsech to system development that is iterative, integrative, and interdisciplinary and (2) a management structure that details the HFE considerations in each step of the overall process. A structured topdown approach to nuclear power plent (NPP) HFE is consistent with the approach to new CR design as described in Appendix B to NUREG-0700 and the more recent internationally accepted industry standard, International Electrotechnical Commission 964, for advanced CR design. The approach also is consistent with the recognition that human factors issues and problems emerge throughout the NPPP design and evaluation process; therefore, human factors issues are best addressed with a comprehensive topdown program.

The scope of the HFE PRM excluded a training program development element because training is edequately addreseed by existing NRC requirements. In addition, human reliability analysis was excluded and is addrossed in Section $\mathbf{1 9 . 1}$ of this report.

The HFE PRM incorporates the requirements (as discussed below in Section 18.1.3.3) of 10 CFR 50.34(t)(2)(iii) as required by 10 CFR 52.47(a)(1)(ii). The HFE PRM is briefly described below and is included in Appendix $J$ of this report.

\subsubsection{HFE PRM Model Description}

The overall purpose of the HFE PRM review is to ensure that

- the applicant has integrated HFE into plant development and design

- the applicant has provided HSIs that make possible safe, efficieat, and reliable operator performance of operation, maintenance, test, inspection, and surveillance tasks

- the HSIs reflect "stato-of-tho-art human factors principles" as required by 10 CFR 50.34(f)(2)(iii).

Stato-of-tho-art human factors principles are defined as those principles currently accepted by human factors practitioners. "Current" refers to the time when a program management or implementation plan is prepared. "Accepted" refers to a practice, method, or guide that is (1) documented in the humen factors literature within a standard or guidance document that has undergone a peerroview process or (2) can be justified through scientific or industry research and practices.

All aspects of HSI will be developed, designed, and ovaluated on the basis of a structured topdown system analysis using accepted HFE principles besed on current HFE practices. HSI is used here in the very broad sense and shall includo all operations, maintenance, test, and inspection interfaces and procodures materials.

The model developed to achiove this commitment contains oight eloments:

(1) human factors engineering program management

(2) operating experience review (OER)

(3) system functional requirements analysis

(4) allocation of function

(5) task analysis

(6) human-system interface design

(7) plant and emergency operating procedure development

(8) buman factors verification and validation

The elements and their interrelationships are illustrated in Figure J.1 of Appendix J of this report. Also illustrated are the minimal set of items to be submitted by the COL applicant for NRC staff review of the applicant's HFE efforts. A description of the purpose of each element follows.

\section{Element 1 - Human Factors Engineering Program Mangrement}

To ensure the integration of HFE into system development and the achievement of the goals of the HFE effort, an HFE design team and an HFE program plan must be established to ensure the proper development, execution, oversight, and documentation of the HFE program. An HFE issue tracking system (to document and track HFE-related problems, concerns, and issues, and their solutions throughout the HFE program) will be established as part of the program plan. The HFE issue tracking system will be used as a mechanism to $\log A B W R$-specific design issues as part of the COL applicant's overall design process.

\section{Element 2 - Operatine Experience Review}

The accident at Three Mile Island (TMI) in 1979 and other reactor incidents have illustrated that significant problems 


\section{Human Factors Engineering}

in the actual design and design philosophy of NPP HSIs exist. There have been many studies as a result of these accidents and incidents. Utilities have implemented both NRC-mandated changes and additional improvements on their own initiative. However, the changes were formed on the besis of the constraints aseociated with beckfits to existing CRs using early 1980s technology, which limited the ecope of corrective actions that might have been considered (i.e., more effective changes can be made in the case of a new CR with the modern technology typical of advanced CRs). Problems and issues encountered in similar systems of previous designs must be identified and analyzed 80 that they are avoided in the development of the current system, or in the case of positive features, to ensure their retention.

\section{Element 3 - System Functional Requirements Analysis}

System requirements shall be analyzed to identify those functions that must be performed to satisfy the objectives of each functional area. System function analysis shall (1) determine the objective, performance requirements, and constraints of the design and (2) establish the functions that must be accomplished to meet the objectives and required performance.

\section{Element 4 - Allocation bf Function}

Functions shall be allocated to take advantage of human strengths and to avoid functions that would bo affected by human limitations. To ensure that functions are allocated according to accepted HFE principles, a structured and well-documented methodology of allocating functions to personnel, system elements, and personnel-system combinations shall be developed.

\section{Element 5 - Task Analysis}

Task analysis shall include the systematic study of the behavioral requirements of the tasks personnel are required to perform in order to achieve the functions allocated to them. The task analysis shall

- provide one of the bases for making design decisions (e.g., determining before hardware fabrication, to the extent practicable, whether system performance requirements can be met by combinations of anticipated equipment, software, and personnel)

- ensure that human performance requirements do not excerd human capabilities

- be used as basic information for developing procedures

- be used as basic information for developing staffing, skill, training, and communication requirements of the system
- form the basis for specifying the requirements for the displays, data processing, and controls needed to carry out tasks

\section{Element 6 - Human-System Interface Desion}

Human engineering principles and criteria shall be applied along with all other design requirements to identify, select, and design the particular equipment to be operated, maintrined, and controlled by plant personnel.

Blement 7 - Plant and Emergency Opernting Procedure Development

Plant and emergency operating procedures (EOPB) shall bo doveloped to support and guide human interaction with plant aystem and to control plant-related ovents and activities. Human engineering principles and criteria shall be applied along with all other design requirements to develop procedures that are technically accurate, comprehensive, explicit, easy to use, and validated. The types of procedures covered in the element are

- normal plant and system operations (including startup, power, and shutdown operations)

- abnormal and emergency operations

- alarm response

\section{Element 8 - Human Factors Verification and Validation}

Using HFE procedures, guidelines, standards, and principles, the acceptability of the final HSI design shall be evaluated as an integrated system. The integrated system includes all

- human-hardware interfaces

- human-software interfaces

- communications (human-human interfaces)

- procedures

- workstation and console configurations

- control room design

- remote shutdown system (RSS)

- design of the overall work environment

High fidelity with regard to the final design is expected (i.e., only minor differences between the actual final design and the evaluated design are acceptable). Validation should be accomplished through dynamic task performance of trained operating personnel using evaluation tools that are appropriate to the accomplishment of this objective as stated in Table 3.1 of the certified design material (CDM) and SSAR Appendix 18E. 


\subsection{Design Goals}

\subsubsection{General Discussion in the Standard Safety Analysis Report}

Tho HSI design goals are described in SSAR Section 18.2. GE's "primary goal for the openator interface decign is to facilitate anfo, officient, and reliablo operator performance during all phases of normal plant operation, abnormal ovents, and accident conditions." It further atates that, to achieve thew goals, the HSIs will bo designed and provided in a manner consistent with "good human factors engineering practices."

Within the context of this review, GE's eight specific design bases are considered to bo design sesumptions since thoy are "givens" and, as precented, have ndt been derived from analysis. They thus become design drivers. These dosign ascumptions aro evaluated in Section 18.2.2.2 of this report.

\subsubsection{Analygis}

\subsubsection{DSER (SECY-91-320) Issue Resolution}

Two DSER (SECY-91-320) issues related to the design goals are summarized below, including the resolution that was achioved.

DSER (SECY-91-320) Isque 18.03: Number of Stgff in the Control Room

In the DSER (SECY-91-320), the staff stated that the number of main control room (CR) oporating staff needed to be clearly established for the ABWR. Design Basis 1 in the original SSAR stated that for "normal operations, the ABWR shall be operable by one senior reactor operator who. will be directly involved in manipulation of the reactor controls, one assistant CR SS (shift supervisor), one CR SS (shift supervisor), and two auxiliary equipment operators." The operating crew could be increased during accident conditions. In the DSER (SECY-91-320), the staff stated that the specification of a single operator at the control boards during normal operations was considered to be a significant design driver.

Evaluation: This issue is related to DSER (SECY-91-320) Issuo 18.03 and was similarly resolved. GE satisfactorily clarified this issue in amended SSAR Section 18.2 by indicating that the ABWR operating crew will be consistent with the requirements of 10 CFR 50.54(m) and that two operatore will be available during all phases of ABWR operation. Therefore, this item is resolved.
DSER (SECY-91-320) Ingue 18.14: Annlyric To Jutify Sole Operntor Attentivenese and Retionsle for Number of Operntor at Min Console

In the DSER (SECY-91-320), the staff stated that in appropriate analysis ahould be provided to juatify how one operator at the main console will remain attentive to his/her duties, and that the maximum number of operators who are expected to monitor and opernte the plent during an emergency at the main control console needs to be epecified with the rationale to support this number. The staff stated that this rationale should be based on the function and task analysis performod to aupport the CR design. The staff required the rationale for the number of operators anticipatod to monitor and control functions on the main control console while the operator is performing other functions.

Evaluation: GE eatisfactorily clarified this iseas in amended SSAR Section 18.2 by indicating that the ABWR operating crew will be consistent with the staffing requirements of 10 CFR 50.54(m) and that two operators will be available during all pheses of ABWR operation. Therefore, this item is resolved.

\subsubsection{Evaluation of the Current SSAR Design Bases}

GE defined the following eight discrete design bases for use in the design development of the ABWR CR:

Design Basis 1 - The ABWR will be operated by two reactor operators, and four licensed operators will be on shift at all times, consistent with the requirements of 10 CFR 50.54(m).

Design Basis 2 - Efficient and reliable operation will be promoted through increased automation.

Design Basis 3 - Only proven technology will bo used for the HSI design.

Design Basis 4 - Safety-related systems monitoring displays and control capability will meet the requirements for independence and electrical separation.

Design Basis 5 - The operator interface design will be highly reliable and provide functional redundancy.

Design Basis 6 - The principal functions of the ABWR safety parameter display system (SPDS) will be integrated into the HSI design. 
Deaign Basis 7 - ODC 19 will be met (ODC 19 atates that a control room shall bo provided from which setions can bo taken to operate the nuclear power unit and that equipment outside of the control room shall be provided to chutdown the reactor.)

Dexign Basis 8 - Dexign beces for the RSS will be epecified in SSAR Soction 7.4.

The staff roviowed the GE doaign bases which will be met through the design and implementation precen deacribed in SSAR Chapter 18. For two of the baces isaves were identified which are described in detail below.

Design Basis 1 states that the ABWR will be operated by two reactor operators and that four licensed operatore will be on shift at all times consistent with the requirements of 10 CFR 50.54(m). These will include a licensed cenior reactor operator SS and ewaietant SS. While this may bo a reasonable design goal on the besis of the proliminary analyses and evaluations conducted thus far, the capability of the main control console to accommodate two operatore will have to be validated as part of HFE V\&V activities (Element 8). Further, it will have to be verified that no more than two operators need to accees the controls and displays at the main control console under all normal, abnormal, and accident conditions. The roles and responsibilities of the SS and assistant SS also will noed to be defined, including their information requirements and access to displays. As reported in the preliminary validation tests, using the Japancee CR prototypes, in SSAR Appendix 18G, the main console would bo crowded if more then two operators were required there. SSAR Table 18E-1 states that the COL applicant will validate that the CR design will support acceptable performance of all tasks assigned to the operating crew under a varicky of plant conditions. In the DFSER the evaluation of the number of operators needing access to controls at the main console and the specification of the roles and responsibilities of the SS and assistant SS was identified as DFSER COL Action Items 18.2.2.2-1 and 18.2.2.2-2. GE has adequately incorporated these issues in the SSAR as Item 18.8.2 in SSAR Section 18.8. The staff agrees with GE's assertion that this issue (results of the evaluation shall be placed in the HFE Issue Tracking System - Item II. 2 of SSAR Table 18E-1) should be resolved by the COL applicant as noted in SSAR Section 18.8.2 as part of the design and implementation procees.

Design Basis 2 states that efficient and reliable operation will be promoted through increased automation. This design basis is acceptable only if it can be demonstrated that the increases in automation promote operational reliability and that automation is not introduced in such an arbitrary manner that it may impair human and/or system performance. This basis must bo ovaluated as part of the requirements of Element 4, "Allocation of Function." Decisions regarding which functions should be automated are more offectively made after the function analyees have been conducted and functions have been allocated a documented in NURBG/CR-3331, "A Methodology for Allocating Nuclear Power Plant Control Functions to Humen or Automatic Control." In the DPSER, the ovaluation of automation etrategies and their effects on operntor reliability wes identified a COL Action Itom 18.2.2.2-3. OB hne acceptably incorporated thin iseve (recults of the ovaluation ahall be placed in the HFE Iseve Tracking System - Itom II.2 of SSAR Table 18E-1) as noted in SSAR Section 18.8.3 as part of tho design and implementation process.

No insues wero identified for SSAR Deaign Besen 3 through 8 listed above. Therefore, thewe items are recolved.

\subsubsection{Finding}

As discussed in Section 18.2.2.1 of this report, DSER (SECY-91-320) Isewes 18.03 and 18.14 are resolved. In addition, the staff identified three issues to be addreseed, as part of the design and implementation process, as described in SSAR Table 18E-1.

- evaluation of the number of operators needing access to controls and dieplays at the main console

- epecification of the roles and responsibilities of the SS and assistant SS

- evaluntion of the impact of automation on operator reliubility

SSAR Section 18.8 states that these issues will be resolved by the COL applicant after system functional requirements andyces, the allocation of functions, and tho task analysis are performed.

\subsection{Main Control Room Standard Design Features}

\subsubsection{General Discussion in the Standard Safety Andalysis Report}

The CR is characterized by 18 standand foatures, each of which is reviowed in Section 18.3.2.2 below. The features were derived from $\bullet$ aystem analyais and verified through V\&V testing using two Japaneec CR prototypes. The 
standard design features are described in SSAR Section 18.4, and their dovelopment is described in SSAR Sections 18.3.1 and 18.3.2.

A possible ABWR main CR is partially cnaracterized in SSAR Appendix 18C. Since this serves as an example of how the standard features might bo implemented, it has no specific application in the safety roviow of the ABWR for design cortification. SSAR Appendix 18C should not bo misinterpreted as providing any information specific to the ABWR CR design safety finding.

\subsubsection{Analysis}

\subsubsection{DSER (SECY-91-320) Issue Resolution}

DSER (SECY-91-320) Issues 18.02, 18.06, 18.08, 18.09, $18.11,18.12$, and 18.18 were related to the standard features that are described in SSAR Section 18.4. Eech of these issues is summarized below, the path to resolution that was proposed in the discussions with GE after the DSER (SECY-91-320) was iseved is given, and issuo resolution is evaluated. These issues generally address the need for information regarding the design process and analyses leading to the standard features and their teat and evaluation.

DSER (SECY-91-320) Issues 18.13 (HSI design requirements for the cathode ray tube (CRT), flat panel, and large-screen displays), 18.15 (CRT display information), and 18.17 (alarm suppression criteria, alarm points) address a level of design detail beyond the description of the standard features in the SSAR. Thus, these DSER issues are addressed in Section 18.9 because they will be resolved by the COL's design and implementation process.

DSER (SECY-91-320) Issue 18.02; HSI Desien ind Evaluation Process and Issue 18.06: Tests and Analysis To Support Desion Implementation

In the DSER (SECY-91-320), the staff stated that additional detailed information regarding the HSI design and evaluation process was necessary (Iscue 18.02). Additional detailed information also was necessary about the methods, criteria, and results of analyses performed to aupport the level and type of staffing, automation, and function allocation to achieve the goals of anfe and reliable performance of the operating crew and overall system (Issue 18.06).

Evaluation: These issues are addressed in SSAR Section 18.4 and Appendix 18G. The standard design features were the result of a 5-year development program that included
- the preparation of implementation plans for major deaign and evaluation sctivities

- the derivation of general HSI requirements from the design of individual systems

- tack analyses for safety-related functions based on manual operations

- systematic allocation-of-function strategy based on workloud analysis and an analysis of such task characteristics as degree of repetitiveness and complexity

- an analysis of current trends and technology asesesments of the major CR features including approaches to automation, console design, video display units (VDUs), display techniques, large display panels, use of fixed-position displays, alarms, and CR layout

After the features were identified, GE assessed them in a validation testing program using two Japanese CR prototypes that had the standard features. Three teams of operators participated in the validation tests by performing range of operational tasks, including normal operation, equipment failures, scrams, and accidents. Information collected for the validation tests included that collected by videotape and observations and operator opinion.

The test results generally supported the use of the standard features. However, the staff noted several limitations in the tests:

- The standard fentures were not individually tested; instead, the entire design as a package (which included standard features and other design detail) was ovaluated. Also, the features as implemented in the validation tests were designed at a considerably greater level of detail when compared with their SSAR definition as standard features. Thus, it is possible that the same set of standard features (as defined in the SSAR) could bo improperly designed and/or poorly integrated to result in an unacceptable design.

- The data collected were limited mainly to observations and subjective evaluations. A more complete performance measurement evaluation such as that described by HFE PRM, Element 8, was not used.

- The selection of accident and transient test scenarios was limited. More extensive tests will be needed but will be performed as part of the Element 8 validation test program (as defined in the HFE PRM). 
- The results were expressed in general terms without the compilation of specific findings related to each of the general features (e.g., the relative merits and problems encountered for each specific feature).

- The test program showed that the main control console would be crowded if more than two operators were required there. The result is specific to the design configuration and teat scenarios used in the test program. The SSAR level of detail does not include console dimensions; therefore, the test results from the Japanese prototypes do not directly pertain to the key feature as represented in the SSAR. Analysis of the console's suitability under maximum staffing demands should be evaluated as part of the detailed task analysis and validation test program.

Although the limitations noted above of the testing of the standard features were identified, the staff determined that the level of validation provided by the testing was sufficient to support the use of these features for the ABWR design because the suitability of these features would be revisited in more detail during the V\&V of actual ABWR CR designs by the COL applicant.

DSER (SECY-91-320) Issues 18.02 and 18.06 became DFSER Confirmatory Item 18.3.2.1-1. GE has provided the description of the design development and validation testing in SSAR Appendix 18G. The staff agrees that GE's description of the design development and validation testing as discussed above is acceptable and therefore considers this item resolved.

In addition, the standard features are defined at a very general level and provide a general approach to CR design. They are not a final design specification and not at the level of detail needed for a final safety determination without consideration in the context of the design development process. Therefore, the detailed design implementation of the standard features and their integration into the CR and RSS designs will be included as part of the staff's review of the COL's DAC submittals related to the activities of HFE PRM Elements 6 and 8. In addition, the validation of the final design of the standard fentures is specifically identified as COL Action Item 18.8.5 in SSAR Section 18.8.

DSER (SECY-91-320) Issue 18.08: Standardized Features and Prototype Evaluation

In the DSER (SECY-91-320), the staff stated that additional detailed information was necessary to precisely indicate the aspects of the $C R$ design that are part of the standardized design and that are unique to a $\mathrm{COL}$ applicant's implementation consistent with accepted human factore principles and practices and the requirements of 10 CFR Part 52. The ataff believes dovelopment of a fully functional CR prototype of the standard design is appropriate in order to demonstrate acceptable human performance. Thus, there are three parts to this issue: (1) the aspects of the CR that are part of the standardized design, (2) the level of detail with which the standard features are described, and (3) the use of a prototype.

Evaluation: For Parts 1 and 2 of this issue, the staff conducted a feature-by-feature ovaluation to determine the lovel of design detail that was supported by GE's design efforts. GE agreed to modify the description of the standard features to a level of detail supported by the design and evaluation efforts discussed with respect to Issue 18.06 above. The results were provided in GE's letter of February 18, 1992. This was DFSER Confirmatory Item 18.3.2.1-2.

SSAR Section 18.4 gives a revised description of the standard CR design features. The description has been modified to a level of detail commensurate with the test and evaluation program. The staff has determined that the design development description provided by GE is acceptable on the basis of the approved DAC.

In regard to Issue Part 3, the use of a prototype in design and evaluation is addressed as part of the design process discussed in Section 18.9 of this report.

GE has submitted the description of the design development and validation testing and revised the description of the standard features in SSAR Section 18.4. On the basis of its review, the staff finds GE's submittals acceptable; therefore, this item is resolved.

\section{DSER (SECY-91-320) Issue 18.09: Operator Workload}

In the DSER (SECY-91-320), the staff stated that GE had not indicated how the workload was defined and measured (in the context of allocation of functions) or what constitutes an appropriate operator workload level. The staff further stated that it was unclear how validating allocationof-function decisions by a COL applicant at this late point in the design process could result in a standardized design. Thus, there are three parts to this issue: (1) workload definition for allocation-of-function studies, (2) determination of satisfactory workload, and (3) implications for postcertification evaluations that require modification of certified aspects of the design, in this case, allocation of function.

Evaluation: GE addressed this issue in its letter of February 18, 1992. Parts 1 and 2 of this issue are addressed in the evaluation of Issue 18.06 above. The 
specification of workload ovaluations during postcertification is addreseed in the discussion of the design proceses in Section 18.9 of this report and is required by the COL applicant in SSAR Table 18.E-1. This was DFSER Confirmatory Itom 18.3.2.1-3. GE has submitted the information requedted by the staff on operator wortloed in SSAR Appendix 180. The ataff has roviowed GE's arbmittal and found it to be acceptable; therefore, this item is resolved.

DSER (SBCY-91-32.0) Irane 18.11: Teets. Bysiuntions, Studien to Supoort Dexim Aporonches

In the DSER (SECY-91-320), the staff stated that information was noedod on teets, evaluations, and trade studies performed to support the selection of design approseches (0.8., the use of touch-screen interfaces).

Evaluation: GE addreseod this issue in its letter of Fobruary 18, 1992, and it is discuseed under Isewe 18.06. After discuscions with the staff, GE oliminated revoral deaign dotails from the eppecification as standard features, including the use of touch-ecroen interfaces. Thowe that remain are those supported by the test program. DSER (SECY-91-320) Issue 18.11 was to bo resolved subject to receipt of the ameaded SSAR. This was DFSER Confirmatory Item 18.3.2.1-4. GE has provided, in SSAR Appeadix 180, the information to support the staff's determination that GE's design details, as well as the appropriate DAC, are acceptable. Therefore, this item is resolved.

DSER (SECY-91-320) Irove 18.12; Adequacy of HSI Desien Requinements

In the DSER (SECY-91-320), the stuff stated that, in the absence of a systems analysis and test and evaluation results, there was no basis to ovaluate the reasonableness and adequacy of the HSI design requirements from a top-down (or bottom-up) perspective.

Evaluation: GE addressed this issue in its letter of February 18, 1992, as is discussed under Issue 18.06 above. DSER (SECY-91-320) Isove 18.12 was to be resolved subject to receipt of the amended SSAR. This was DFSER Confirmatory Item 18.3.2.1-5. GE has provided, in SSAR Appendix 18G, the information to support the staff's determination that the HSI design requirements and appropriate DAC are acceptable. Therefore, this item is resolved.
DSER (SECY-91-320) Isque 18.18; Snfety Panmeder Displey System Desion Scope

In the DSER (SECY-91-320), the staff stated that, at the precent stage of dosign, it could not detormine if the ABWR eafoty parumotor dieplay systom (SPDS) will moot all the NRC SPDS design criteria in NUREG-0737, Supploment 1, "Clarification of TMI Action Plen Requirements," 1982. The requirements regarding the SPDS in the ABWR CR are discussed in detail under "Standard Feature N."

The SPDS function and the list of critical parametere, as described in SSAR Section 18.4.6, did not include parameters that would provide operators with information about radioactivity control should there be a release of radioactive materials. The SSAR further stated that the COL applicant may provido a radioactivity release control information display. GE's initial approach to moeting NRC requirements for the SPDS function was not eufficieat.

Evaluation: SPDS design is part of the ABWR standard features. Therefore, it is reviewed in the next eection under "Standard Feature N." The commitment to the requirements of NUREG-0737, Supplement 1, has been incorporatod into the description in SSAR Section 18.2, which states that the SPDS functions will comply with the NUREG report requirements. Therefore, this item is resolved.

\subsubsection{Evaluation of the Current SSAR}

As a result of the DSER (SECY-91-320) issue resolutions discussed above, GE agreed to

- clarify how the standard features were defined from the design process

- provide support for the validation of the standard features

- redefine tho SSAR descriptions of the standard features to bring them in line with the supporting design and validation efforts

The list of standard feature descriptions below was the sesult of that process. It is important to reemphasize that a final safety determination for the detailed design of the standard features will be made by the staff using the DAC as part of ITAAC. 


\section{Stondand Fenture A}

Feature Description - The use of a single, integrated control console staffed by two operators; the console has a low profilo so that the operators can see over the console from a seated position.

Feature Evaluation - This feature, as presented, is generally supportod by GE's design analyses and evaluations as discussed in Section 18.3.2.1 above.

\section{Standard Feature B}

Feature Description - The use of an on-screen control video display unit (VDU) for safety system monitoring and non-safety system control and monitoring that is driven by the plant process computer system.

Feature Evaluation - This feature, as presented, is generally supported by GE's design analyses and evaluations as discussed in Section 18.3.2.1 above.

\section{Standard Feature C}

Feature Description - The use of a separate set of onscreen control VDUs for safety system control ind monitoring and separate on-screen control VDUs for nonsafety system control and monitoring; the operation of these two sets of VDUs is entirely independent of the process computer system. Further, the first set of VDUs and all equipment associated with their functions of safety system control and monitoring are divisionally separate and qualified to Class $1 \mathrm{E}$ standards.

Feature Evaluation - This feature, as presented, is generally supported by GE's design analyses and evaluations as discussed in Section 18.3.2.1 above.

\section{Standard Feature D}

Feature Description - The use of dedicated function switches on the control console.

Feature Evaluation - This feature, as presented, is generally supported by GE's design analyses and evaluations as discussed in Section 18.3.2.1 above. GE's rationale for specifying the use of dedicated switches for the identified functions is consistent with human factors engineering practices and is acceptable for this application. This feature is described in SSAR Section 18.4.2.5, indicating that several different types of switches are used, incorporating a technology that has been retained from the previous BWR designs. The type of switch will be determined by the design implementation process addressed in Section 18.9 of this report.
Standand Features E. E. and O

Feature Descriptions -

E - Operator selectable automation of predefined plant operational sequences.

F - The incorporation of an operator selectable somiautomated mode of plant operations. This mode will provide procedural guidance to the operators using the plant operating procedures as a basis for that guidance. This "feature" is stated at the general level and will be further specified during the design implementation process.

G - The capability to conduct plant operations in an operator manual modo.

Feature Evaluation - These features, as presented, are generally supported by GE's design analyses and evaluations as discussed in Section 18.3.2.1 above. The features as stated are at the level of general requirements for the levels of automation available to the operator. The operator maintains the capability to assume manual control at any time. This basic approach is consistent with current human factors engineering practice and is acceptable for this application.

\section{Standand Feature H}

Feature Description - The incorporation of a large display panel that presents information for use by the entire CR operating staff.

Feature Evaluation - This feature, as presented, is generally supported by GE's design analyses and evaluations as discussed in Section 18.3.2.1 above. It should be noted that the safety significance of this display approach will be dependent on the final design of display formats and distribution of information between the main control console and the large display. This is addressed as part of the COL's HSI design and V\&V ITAAC.

\section{Standard Reature I}

Feature Description - The inclusion on the large display panel of fixed-position displays of key plant parameters and major equipment status

Feature Evaluation - This feature, as presented, is generally supported by GE's design analyses and evaluations as discussed in Section 18.3.2.1 above. Information on the large panel will be designed so that it can be observed from the supervisor's console (which is 
further from the panel than the main control coneole). As the CnL applicant dovolops the design after certification, ovaluations are required by the HFE PRM to confirm the allocation of information between the large panel and the main control console. This is addreesed as part of the COL's HSI design and V\&V ITAAC.

\section{Standard Features J and $K$}

Fenture Descriptions -

J- The inclusion in the fixed-position displays of both Class 1E qualified (those that contain eafoty-related information) and non-Class 1E display elements.

$\mathrm{K}$ - The independence of the fixed-position displays from the plant process computer.

Feature Evaluation - The SSAR acceptably requires that the fixed-position displays of safety-related information conform to Class 1E standards and be independent of the plant process computer.

\section{Standard Feature L}

Feature Description - The inclusion in the large display panel of a large VDU that is driven by the plant process computer system.

Feature Evaluation - This feature, as presented, is generally supported by GE's design analyses and evaluations as discussed in Section 18.3.2.1 above.

\section{Standard Feature $\mathbf{M}$}

Feature Description - The incorporation of a "monitoring only" supervisor's console that includes VDUs on which display formats available to the operators on the main control console also are available to the supervisors.

Feature Evaluation - The role of the supervisor and the supervisor's information requirements need to be more completely specified by the COL applicant before a determination of the design requirements of the console can be made. The present design of the main control console is for two seated operators. Making no provisions for control capability from the supervisor's console leads to the assumption that under no circumstances would control capability beyond that of the two operators be required. This will be considered by the COL applicant in the design process under Element 8 of the HFE PRM and will be resolved by the COL applicant on completion of the functional analysis as required by SSAR Table 18.E-2(II).

\section{Stundund Benture N}

Feature Deacription - The incorporation of the SPDS function as part of the plant atatus summary information that will continuoualy bo displayed on the fixed-position displays on the large display panel.

Feature Evaluation - This feature, as presented, is generally mupported by OE's design analyses and ovaluations as discuseed in Section 18.3.2.1 above. Details pertinent to the SPDS are discussed below.

The ataff roviewed GE's proposed approach to SPDS dovelopment in accordance with the requirements in 10 CFR 50.34(f)(2)(iv) and NUREG-0737, Supplement 1, and the guidance in NUREG-1342 "A Status Report Regarding Industry Implomentation of Safety Parameter Display Systems" (1989), which describes SPDS implementation methods acceptable to the NRC staff as well as problem areas identified in operating plant SPDS reviews. GE describes its SPDS design in SSAR Section 18.4.2.11, as well as in DSER (SECY-91-320) Responses 3.b.1(n), 3.b.5, Table 3.b-1, and 5.e (GE letter of February 18, 1992).

The SPDS review for the ABWR is part of the staff's reviow to be conducted as part of HFE PRM Elements 6 (Design) and 8 (V\&V). The ABWR CR and SPDS design, while not complete, is described in the SSAR. The discussion below addresses several SPDS requirements.

Paragraph 3.8a of NUREG-0737, Supplement 1, discusses the integration of the SPDS with related emergency response capabilities and includes the following comment on the SPDS:

(1) Review the functions of the NPP operating staff that are necessary to recognize and cope with raro ovents that (a) pose significant contributions to risk, (b) could cause operators to make cognitive errors in diagnosing them, and (c) are not included in routine operator training programs.

This guidance was not specifically addressed in GE's response. Therefore, the COL applicant will need to consider incorporation of insights from the PRA into the SPDS selection process. For example, loss of power/station blackout (SBO) was very important to risk in the ABWR PRA (90 percent of core damage frequency (CDF) in the first revision of the PRA). Hence, there should be some monitoring of electric power sources as part of the SPDS. Also, with the addition of a gas turbine generator to the design to reduce the dominance of the SBO sequence, parameters related to the gas turbine should be included on the SPDS. Other safety-system failures that 
appear prominently in the accident equences are thoes of the high-preseure core flooder, reactor core isolation cooling (RCIC) system, low-preenure core floodor, retidual heat removal system, and automatic depreanurization system (ADS).

Additionally, cognitive errors made by operators and iteme not covered in operator training programs would need to be addressed similarly to the risk-significant itoms. Addressing the criteria of Paragraph $3.8 \mathrm{a}$ of NUREG-0737, Supplement 1, will be part of the COL applicant's CR design responsibility. This was DFSER COL Action Item 18.3.2.2-1. The commitment to the criteria in NUREG-0737, Supplement 1 , is epecified in SSAR Section 18.2 and is incorporated in the DAC. This is acceptable to the staff.

Eech of the paragraphs of Section 4.1 of NUREG-0737, Supplement 1, contains specific details pertaining to the SPDS. Some areas that require further consideration by the COL applicant in the design process are noted below.

- Paragraph 4.1a calls for " "concise" SPDS display. The concept of a "concise" display is further amplified in NUREG-1342, Section III.A.1. It is not clear from the description of the ABWR SPDS how the "concise" criteria will be met. This issue will be part of the COL applicant's detailed design development process.

- Paragraph 4.1c requires procedures and training on the SPDS. This will bo addressed by the COL applicant in the development of procedures as addressed in SSAR Chapter 13.

- Paragraph 4.1d was addressod in GE's DSER (SECY-91-320) response, in which GE stated that the selection of information for inclusion in the SPDS display was based on the current BWR Owners Group (BWROG) EPGs rather then the ABWR EPG. GE stated that this would be corrected to specifically address the ABWR EPGs. This was DFSER Confirmatory Itom 18.3.2.2 1 . The SSAR bas been modified to state that "selection of the parametete for inclusion in the SPDS display is based upon the Advancod Boiling Water Reactor Emergency Procedure Guidelines ...." Therefore, this item is resolved.

- Paragraph 4.1f addresses the functional information required in the SPDS. While the specific parameters are to be determined by the COL applicant, GE has provided specific parameters in SSAR Chapter 18.4.2.11 that follow the NUREG-1342 recommendations, except as noted below.
- The COL applicent should consider the need for some standby liquid control (SLC) indication along with the reactivity control covered in the ABWR parameters. Existing BWR designs do not have this indication; however, because the ABWR is a now reactor design, the COL applicant should consider the items listed in NUREG-1342 as "desirable cahancements." Also, the comment on PRA insighte from Paragraph 3.8a above and the fact that SLC is neoded to mitigato the anticipated transient without scram (ATWS) sequence (which is 31 percent of CDF in the probabilistic riak analyais) in the ABWR illustrates the importance of having SLC indication.

- GE state that indication of radioactivity control will be selected by the first ABWR license applicent. Thus, parameter solection and display implementation will bo the responsibility of the COL applicant as part of the design development.

DSER (SECY-91-320) Issue 18.18 concerning the SPDS was resolved, and the remaining issues listed above will bo addreased as part of the COL applicant's design process through incorporation into the HFE issue tracking system. This was DFSER Confirmatory Issue 18.3.2.2-2. GE has included the SPDS design in SSAR Section 18.8, "COL License Information," as Item 18.8.4 and has committed to meeting NUREG-0737, Supplement 1, and the SPDS guidance in SSAR Sections 18.2 and 18.4.2.11. This is acceptable; therefore, this item is resolved.

EXEMPTION FROM 10 CER 50.34(F)(2)(iv) FOR AN SPDS CONSOLE

The regulation 10 CFR 50.34(f)(2)(iv) requires that an application:

Provide a plant safety parameter display console that will display to operators a minimum set of parameters defining the safety status of the plant, capable of displaying a full range of important plant parameters and data trends on demand, and capable of indicating when process limits are being approached or exceeded (1.D.2).

GE, as part of the ABWR SSAR, commits to meet the intent of this requirement. However, as discussed below, the functions of the SPDS will be integrated into the control room design rather than on a separate "console." The purpose of the requirement for an SPDS, as stated in NUREG-0737, Supplement 1 , is to ". . provide a concise display of critical plant variables to the 
control room operation to aid them in rapidly and reliably determining the cafoty tatus of the plant. ... and in ancuaing whother abeormal conditions warmat corrective cetion by operatorn to avoid a dograded core."

The ABWR decign does not provide a eepartio SPDS, but rather, the function of the SPDS are integrated into the overall control room dieplay capabilities. In liou of the requirements in 10 CFR 50.34(D)(2)(iv) for a "console," OB hes proposed the following commitments in the ABWR SSAR:

(1) Section 18.2(6) vates that the functions of the SPDS will be intograted into the deaign,

(2) Section 18.4.2.1(14) atales that the SPDS function will be part of the plant summary information which is continuoualy dieplayed on the fixedposition displays on the large display panel,

(3) Section 18.4.2.8 states that the information presented in the fixed-position displays includes the critical plant parameter information, and

(4) Section 18.4.2.11 deecribes the SPDS for the ABWR and atates that the displays of critical plant variables sufficient to provide information to plant operatore about tho following critical safety functions are continuously dieplayed on the large display panel as an integral part of the fixedposition displays:

(a) Reactivity control,

(b) Reactor core cooling and beat removal from the primary system,

(c) Reactor coolant system integrity,

(d) Redionctivity control, and

(e) Containment conditions.

The Commission may, upoa its own initiative or at the request of an applicant, grant exemptions from the requirements of the regulations of Part 50. The exemption must comply with 10 CFR 50.12(a) criteria regarding epecial circumstances. An exemption from the "console" of the SPDS may bo granted since not having an SPDS "console" (1) does not present in undue risk to the public bealth and afety, and is consistent with the common defenso and security (10 CFR 50.12(a)(1)); and (2) special circumstances exist that application of the regulation to the ABWR design of the SPDS rule is not neceseary to achieve the underlying purpoes of the SPDS rule (10 CRR 50.12(a)(2)(ii)). As presented bere, the ataff unes the epecial circumetances in $10 \mathrm{CFR} 50.12(a)(2)$ (ii) to juntify tho deviation from the regulation (exemption) for an SPDS "console" for the ABWR deaign.

In conclusion, the ataff finde an exemption from the requirement for an SPDS "coneolo" to be appropriate baced upon (1) the deacription in the OB SSAR of the inteat of the ABWR deaign to incorporate the SPDS function as part of the plant status nummary information which is continuoualy displayed on the fixed-position dieplays on the large dieplay panel; and (2) a ceparate "console" is not neceseary to echiove the underlying purpoce of the SPDS rule which is to display to operators a minimum et of paramoten dofining the safoty status of the plant. The staff, therefore, finds that GF has adequately supported an exemption from 10 CFR 50.34(f)(2)(iv) because SSAR Sections 18.2(6), 18.4.2.1(14), 18.4.2.8 and 18.4.2.11 schiove the underlying purpose of the rule by consuring that the SPDS functional sequiroments are satisfactorily incorporated in the control room design without a exparate "console."

\section{Stundund Feature 0}

Feature Deacription - The use of fixed-position alarm tiles on the large display panel.

Feature Evaluation - This feature, as presented, is cupported by GE's design analyses and ovaluations a discuseed in Section 18.3.2.1 above. In addition, the use of fixed-position alarms for koy parameters is supported by research and industry experience with advanced alarm sysiems.

\section{Standard Fenture $P$}

Feature Description - The application of alarm processing logic to prioritize alarm indications and to filter unnocesany alarms.

Feature Evaluation - This feature, as presented, is supported by GE's design analyses and ovaluations a discuseed in Section 18.3.2.1 above. GE's alarm prioritization scheme is based on three basic principles: mode suppression, redundancy suppression, and consequence suppression. GE does not propose advanced alarm suppreasion tochniques, such as expert system-besed analyses. Thus, the suppression is besed on wellunderstood tochniques that have been tested in other nuclear industry studies and have been found to be beneficial. In addition, the design epecifies operator 
control over aupprescion. Operntore may tum supprescion on or off. As with other CR fatures, the alarm procesening tochniques must be verified and validated as required by the V\&V ITAAC in Table 3.1 of the CDM and SSAR Appondix 18B andyecs.

It should be soted that this standard feature only includes the spplication of alarm procesaing logic to prioritize alarm indications and to filter unnecesenry slarm. The general ieves of alarm procecesing is the rubject of much induetry and NRC resourch, and much additional recearch data pertaining to alarm implementation will be availablo for tho COL applicant during the CR deaign procees.

\section{Sindud Renture 0}

Feature Description - A epatial arrangemeat between the large display panel, the main control console, and the shift supervicor's console allowe the cutiro CR oporating crew to conveniently viow the information precented on the large dieplay panel.

Feature Evaluation - This feature, as presented, is generally supported by GE's design analyeses and ovaluations as discuseod in Section 18.3.2.1 above.

\section{Standund Feature $B$}

Feature Description - The use of VDUs to provide alarm information in addition to the alarm information provided by the fixod-position alarm tiles on the largo display panel.

Feature Evaluation - This feature, as presented, is generally supported by GE's design analyses and ovaluations as discuseed in Section 18.3.2.1 above. Component-lovel alarms will be provided on main console VDUs whilo importent alarms and aystem-lovel alarms will be provided on the fixed-position tiles on the large display panel. The slarms preecented on the large panel also will be available on the VDUs.

\subsubsection{Finding}

The staff did not identify any safety issues in the description of the stendard features for the lovel of design detail presented. It is important to note that the description of the standard features is at a general lovel and cesceatially presents a general approach to CR decign. The features are not a final deaign epecification and are not deacribed at a lovel of detail sufficient for a final rafety determination without consideration of the design development process. When the design becomes more detailed as part of the implementation and integration of the design process, the COL applicant will ovaluate the etandard features in accordance with Item 18.8.5 in SSAR Section 18.8, the
VaV ITAAC in Table 3.1 of the CDM, and the SSAR Appendix 188 andyen.

DSBR (SBCY-91-320) Imaven 18.02, 18.06, 18.08, 18.09, 18.11, and 18.12 became DFSBR Confirmatory Item 18.3.3-1. As discuesed above, GB ameaded the SSAR and included Appeodix 180, which atiafectorily addreand each of these iserven. Therefore, these iteme are recolved.

DSER (SE.CY-91-320) IEve 18.18, "SPDS Intogration With Related Bmergency Rexponeo Capabilitien," will bo addround by the COL applicent and hes been included as Itom 18.8.4 in SSAR Section 18.8. This is acceptable; cherefore, this item is recolved.

\subsection{Inventory of Controls, Displays, and Alarms}

\subsubsection{General Discuscion in the Standard Safety Analysis Report}

OB's initial SSAR contrined insufficient information about controls, displays, and alarms to be utilized for the ABWR CR, reculting in a DSER (SECY-91-320) open isove. As part of the general reeolution of the leck of CR dotail, $O B$ provided the detailed $\mathrm{CR}$ design implementation proceses through which the epecific controls, displays, and alarms will be specified and designed. However, to provide an initial set of controls, displays, and alarms for transient mitigation bofore design certification, OE doveloped the inveatory presented in SSAR Appendix 18F. This inventory was developed by analyzing the ABWR EPG. and the important operator actions specified as a result of the ABWR PRA analysis (rofer to SSAR Section 19.D.7). Subeequeatly, $O B$ deecribed an additional fixed-position subeet of these controls, displays, and slarms (i.e., a minimum inventory) for inclusion in the design description (DD) and ITAAC (CDM Section 2.7.1 and Table 2.7.1.A) for the main $C R$ panels.

As part of the reviow, OE submitted to the staff dotailed task analysis information (formerly SSAR Table 18F-1 through 18F-12, Amendmeat 21) to support the identification of important displays, controls, and alarms for EPO implementation. The staff's reviow and its comments were given in the DSER (SECY-91-320) and DFSER, respectively. In response to the staff comments, OB submitted revised inventory analyees in SSAR Amendmeats 25 and 30 and in a letter providing proprietary task analysis information dated Juno 9, 1993. In Ameadment 34, GE submitted SSAR Appendix 18H which provided the supporting analysis for the investory of controls, dieplays, and alarms in SSAR Appendix 18F. The staff reviewed these submittals and confirmed that the 
innes decoribed in the DSBR and DRSER were atiofuctorily addreased. Bech confirmatory itom is diecused bolow. The staffe review of the isure is complete, the DFSBR confirmatory item are considered resolved, and the minimum inventory of dieplays, controls, and clarm is edequate.

\subsubsection{Analysir}

\subsubsection{DSER (SECY-91-320) Insue Recolution}

One DSER (SBCY-91-320) isane related to the inventory is aummarized below along with the path to resolution that wes proposed in the diecustions with OB. The evaluntion of the isere is given in the following cection.

\section{DSER (SECY-91-320) Jenve 18.26: Inyentory}

The staff raised general questions in the DSER (SECY-91-320) about the abeence of level of detail for controls, displays, and alarms to be incorporated into the min CR. GE and the staff agreed that alnce a detailed doaign regarding controls and displays would not bo available for the deaign certification reviow, GB would use the EPOs to develop an inventory of the key minimum information and control requirements for the operntor to perform neceseary seffety-related functions. This epproach to developing an inventory is discuseed below.

\subsubsection{Evaluation of the Current SSAR}

\subsection{Review Methodology}

The staff reviewed SSAR Sections 18.3.1, 18.3.3, and Appendices 18A, 18F, and 18H to determine if the inventory in Appendix 18F provided ressonable minimum sot of fixed controls, displays, and alarms to adequately implement the EPGs for the ABWR.

The analysis methods used for this ovaluation included

- EPG Review: Solected steps of the EPGs were compared with the corresponding portions of SSAR Tables 18H-1 through 18H-14 to determine accuracy and technical validity of conclusions.

- PRA/Human Reliability Annlygis (HRA) Review: Tho PRA/HRA was compared with SSAR Tables 18H-1 through 18H-14 to determine whether vignificent buman actions wero selectod and if the anelyais was correct.

- Summiry Table Review: Summary SSAR Tables 18H11 through $18 \mathrm{H}-13$ wero selectively compared with SSAR Tables 18H-1 through 18H-10 for accuracy.
GB's analysis procen for the BPGe provided a lare amount of epecified equipment. Bech tep, cantion, and note in the large body of EPGs was exparately reviowed, analyzed, and documeated in a tablo contuining 14 columns. A number of important controls, dieplays, and alarms were identified. On the basis of discumions with $\mathrm{OB}$, the staff determined that the remilt of the analyair would bo provided to the COL applicant for une in the CR design implementation process. This will belp cosure that the important indications, controls and alarme derived from tho analyais aro appropriately implemented in the HSI deaign. The etaff has determined that OB's analyais process is acceptablo.

\subsection{General Reoults}

\section{Level of HSI Detnil}

Discussions in carlier SSAR Section 18F.1 indicated that GB had made significent HSI docign implementation decisions reganding dieplaye and controls in the min CR. This contrudicted other statements in SSAR Chapter 18. For example, GB stated: "In Tables 18F-1 through 18F-12, the particular method of design implementation for cach control, display, and alarm function is indicated in brackets as part of each relovent table catry." Particular implementation methods wero described for hundreds of items. In genern, the bracketed information in the inventory was more detailed then what the rest of the SSAR supported. OE also stated that "all remoto control equipment of a particular system can be acceseed and controlled by touch operations when the VDU operate mode is selected." However, touch operations are not part of the standard features identified in the SSAR. OB committed to revise the discussions in Table 18R-1 and the output from the inventory to make them consistent with the remainder of SSAR Chapter 18.

In Amendment 25 of tho SSAR, GB provided a revised version of the inventory that addreaed the staff concurns about the level of HSI detail. The staff reviowed the revisions and found OB had adoquately removed the specification of deaign implementation for each control, dieplay, and alarm and had adequately revised the introduction to Appendix 18E to reflect this. The staff found thece revisions acceptable; therefore, the isave is resolved.

\section{Eixed Versus VDU Selection Rationale}

For each step of the EPGs and each important PRA operator sction, GE defined the information 
(Colum 4) and control functions (Columen 5) necenary to perform that etep. The parameter displayu (Column 6), controls (Column 7), and alarme (Column 8) that ane seodad also were defined. OB further epecified whether they were fixed or on VDUs. GB, however, did not provide information as to how the ues of fixed dieplays or VDU displays was determined. GB committed to provide the appropriate criteria and rationsle for this detormination in SSAR Appeadix 18F.

As a result of further discussion with the staff, $O B$ agreed to remove the VDU designation from the inventory list since apecifying an implemeatation strategy bofore implementing the human-machine interfece dexign implementation proceses would be , premature. In SSAR Amendment 30, GE provided a revised version of the inventory that addreesed the staff concerns about VDU selection rationalo by removing the reference to design implementation detail (e.8., VDU). This is acceptable; therefore, the issue is resolved.

(3)

\section{HEE Input}

Although the inventory contains a list of key minimum displays, controls, and alarms neceseary to carry out operator actions associated with the EPGs, the COL applicant will need to identify and further define additional detailed characteristics of these displays and controls (0.8., ranges, rcales, physical dimensions, and actual information presentation) during the detailed task analysis and HSI design efforts. On the basis of its discussions with GE, the staff concluded that at the time in the design implementation process tho inventory is used for the actual CR design, the COL applicant will review the minimum inventory against the results of the detailed task analyses to cosuro that the appropriate information is displayed for operations activities. Any discrepancies identified from this comparison will be documented and resolved by the COL applicant through the design procees. As a result, the minimum inventory has been added to the required information to be used in the detailed HSI design element of the human-machine interface design implementation process. Therefore, the staff concerns regarding HFE input have been addreseod as noted before and this issue is resolved.

\section{Use of Important Operator Actions}

GE's earlier SSAR Section 18F-2 listed five actions considered to be important based on the results of GE's PRA sensitivity study. However, the SSAR did not contain a dincuscion of the rationale for the celection of these as the important setions. Additionally, Item 7 of the PRAMRA noviow of March 1991 contrined a diccuasion of the number of humen errors in the HRA. Six errors were noted to be the only ones deacribed in any detail in the PRA. Of these six errors, which were treated as importent in tho PRA, only one was on the liat of five setions considered in the inventory dovelopmeat (failure to inject water from the facility fire protection auppreasion system into the reactor preesure veesel (RPV)). The others related to inhibiting ADS during an ATWS, initiating SLC during an ATWS, controlling flow during an ATWS, failing to deproanurize the reactor, and failing to isolate a failed beat exchenger. Thewe orrors did not appear to be analyzed for inclusion in the inventory. GE stated that nome of thece were covered in EPG stepe and, bence, were addreaced in the inventory. Others were not included because of automation decisions that removed the noed for certain operator actions (e.8., ATWS control). GE agreed to provido a discussion of the rationale for the selection of the important operator setions included in the inventory in the PRA discusecion in Chapter 19 of the SSAR. GE also agreed to ideatify each operntor action already covered in the body of the EPGs that was also identified through the PRA study. Finally, OB committed to update the inventory based on any additional importent bumen actions from PRA after the PRA/HRA had been completed.

As a result of further discussion with the staff, $O B$ rovised SSAR Section 19.D.7 to discuss the operator actions considered important in the ABWR PRA. Additionally, the GE revised dotniled decign files (0.8., SSAR Tables 18F-1 through 18F-11) cubmitted on June 9, 1993, to roflect the operator actions identified through the PRA. Currently, SSAR Appendix $18 \mathrm{H}$ contrins those detriled deaign files. Therefore, the staff concerns about the use of important operator actions as identified in Chapter 19 have been addreesed in the inventory described in Appendix 18F of the SSAR. The staff finds this approach to be acceptable; therofore, this issue is resolved.

\section{Scope of the Inventory}

GE has doveloped a minimum set of fixed displays, controls, and alarms required to mitigate transients and accidents associated with the BPGs and the PRA sensitivity study. It should be noted, however, that GE committed to providing additional 
fixed displays (e.g., in SSAR Section 18.4.2.11 on the SPDS and in Section 18.4.2.11 on dedicated handware alarm windows of entry conditions for EOPs) beyond those identified in SSAR Tables 18H-1 through 18H-14. GE also identified additional fixed displays as part of the inventory analysis that were not considered las part of the minimum inventory.

GE committed to revising the SSAR to describe the scope of the inventory as limited to the EPGs and the PRA sensitivity study and to clarify that additional required fixed displays would not be superseded by this inventory. GE also agreed to provide a discussion in the introduction to Appendix 18F of the SSAR on the scope of the inventory and to describe the integration of the inventory with the detailed design process by the COL applicant.

SSAR Amendment 30 included a discussion on the scope of the inventory that was consistent with the scope previously established by the staff for the inventory specification. In addition, the introduction to Appendix $18 \mathrm{~F}$ notes that other requirements on the $C R$ panel inventory stemming from other design commitments were not necessarily incorporated into the minimum inventory. The staff reviewed the revised introduction to this appendix and found that it addressed its concerns about the scope of the minimum inventory. The issue is resolved.

\subsubsection{Findings}

In the DFSER, the staff concluded that GE had developed an acceptable minimum set of displays, controls, and alarms that will mitigate transients and accidents associated with the EPGs and the PRA sensitivity study subject to the incorporation of the comments in the DSER (SECY-91-320). As a result of further discussions with GE, the staff determined that the revision to SSAR Amendment 30, Appendix 18F, addressed its concerns and was, therefore, acceptable. The minimum inventory of displays, controls, and alarms described by GE is adequate; therefore, DSER (SECY-91-320) Issue 18.26 is resolved.

\subsection{Remote Shutdown System}

\subsubsection{General Discussion in the Standard Safety Analysis Report}

SSAR Sections 7.4 and 18.5 describe the RSS. The RSS will use conventional hardwired controls and indicators to maintain diversity from the main CR. Discussion of other HSIs outside the CR are tied to GE's design and implementation process contained in SSAR Appendix 18E.

\subsubsection{Analysis}

\subsubsection{DSER (SECY-91-320) Issue Resolution}

DSER (SECY-91-320) Issue 18.19: Remote Shutdown System Design Rationale

In the DSER (SECY-91-320), the staff stated that additional information (i.e., tests, evaluations, and results) addressing how human performance is affected when operators are required to use mixed control and display technologies (i.e., digital and analog) during emergency plant operations was needed to support GE's position and rationale on the RSS design for the ABWR. (This issue is discussed further in Section 18.5.2.2 below.)

Evaluation: GE stated that the RSS will not use digital technology in order to maintain diversity from the CR. An assessment of the mix of analog and digital technologies in the plant as a whole was to be included in the postcertification test activities conducted by the COL applicant as part of the V\&V element. The staff noted that independence (i.e., isolation and separation) and diversity were needed for the RSS. This was DFSER Confirmatory Item 18.5.2.1-1. GE has included information regarding the RSS as a COL action in Item 18.8.6 of SSAR Section 18.8 and in the HFE design acceptance criteria (ITAAC) of Table 3.1 of the CDM. This approach is acceptable; therefore, this item is resolved.

\subsubsection{Evaluation of the Current SSAR}

SSAR Sections 18.5 and 7.4 describe the RSS. GE intends the RSS to use conventional, hardwired controls and indicators to maintain diversity from the main CR. One generally acknowledged HFE design principle is to maintain consistency across HSIs when similar tasks are being performed in order to (1) minimize the time operators must spend "switching gears" to adopt operations to different HSIs for similar tasks and (2) minimize the potential for human errors that arise from incorrect transfer of learned activities from one HSI to another. In response to RAI Question $\mathbf{6 2 0 . 3 2}$ concerning the possible human factors implications of using analog hardware in the RSS design rather than a digital design consistent with the main CR, GE submitted a rationale for the diversity that included protecting "against the improbable event of common mode hardware or software failure in the plant instrumentation and control systems." The importance of diversity is acknowledged; however, caution should be exercised with regard to when the diversity is applied. 
The staff was, therefore, concerned with GE's rationale for using mixed HSI technology. In its response to RAI Question 620.32, GE stated that the human factors testing of the RSS would be conducted during part of the plant power ascension test program and that, because RSS operations are relatively simple, training the operators to adjust to the analog RSS should not be an undue burden on them. GE did not give the basis or rationale to support these conclusions. As discussed above, the issue is being incorporated as Item 18.8.6 in GSAR Section 18.8 as a COL action item, thus addressing the staff's concern.

An NRC human factors generic issue includes the RSS. An evaluation of the risk significance of this issue for an RSS and a value-impact assessment of proposed human factors fixes is documented in NUREG/CR-5572, "An Evaluation of the Effects of Local Control Station Design Configurations on Human Performance and Nuclear Power Plant Risk" (1992). This study showed that functionally centralizing (integrating many functions into one panel) the RSS into one integrated panel was risk significant. Since the issue of RSS HSI design versus the CR HSI can only be addressed when design detail is developed, the staff expects that RSS functional centralization will be addressed by the COL applicant during the detailed design process described in SSAR Appendix 18E.

\subsubsection{Finding}

The design of the RSS is covered under the COL applicant's design and implementation process addressed by the HFE ITAAC in Table 3.1 of the CDM and detailed in SSAR Appendix 18E. DSER (SECY-91-320) Issue 18.19 is resolved on inclusion of Item 18.8.6, a CCL action item, in SSAR Section 18.8.

\subsection{Local Valve Position Indication}

\section{DSER (SECY-91-320) Issue 18.20: Local Valve Position Indication}

In the DSER (SECY-91-320), the staff stated that the ABWR design should include complete local valve position indicator (VPI) based on accepted human factors principles and practices. "Local" in this instance means at the location of the valve in the plant. However, GE's commitment to VPI was unclear. This was identified as DSER (SECY-91-320) Issue 18.20.

Evaluation: In its response of October 1, 1991 (Response $5 \mathrm{~g}), \mathrm{GE}$ stated that only valves in the $\mathrm{CR}$ task analysis are required to have positive position indication. In the DSER (SECY-91-320) issues response dated February 18, 1992, GE stated that "the ABWR design does not include requirements for local position indication on all valves."
However, the response did not indicate which local valves will have position indication.

In the process of plant and aystem deaign development, including CR task analyses, a nuclear power plant vendor will determine the valves that require remote position indication in the $\mathbf{C R}$. In the large majority of cases, the valves with remote VPI in the CR are motor-operated valves. However, in some cases of hydraulically operated valves, pneumatic valves, and even manual or check valves (e.g., valves for the low-pressure coolant injection line for BWRs) have CR VPI. The ABWR should have a full complement of CR VPI, with specific detrils (0.8., which valves and what type of displays) determined by the COL applicant through the approved CR design implementation process plan.

While the NRC has focused on CR VPI, developments over the past few years have shown the importance of VPI at the valve itself. The recognition of the need to know valve position has come about through review of operating events and an increased attention to good human-systems interface design, including VPI for manual valves. These developments indicate the need for local VPI at various types of valves (e.g., manual and motor operated).

Brookhaven National Laboratory (BNL) reviewed historic records (BNL Report A-3972-4-91) to determine the extent and type of human engineering deficiencies that exist at local control stations (LCSs) in actual plants and to determine the type of plant-level problems caused by these deficiencies. Table 4.b of the BNL report catalogues a number of such problems as a result of inadequate VPI identified in licensee event reports (LERs), NUREG/CR reports, and EOP inspections. Table 5 in the BNL report also identifies problems related to inadequate VPI and discusses an Institute of Nuclear Power Operations recommendation for local means of visually verifying actual and normal position of valves.

During an NRC research project, related to potential upgrades to LCSs, both the costs and benefits associated with improved VPI for manual valves were investigated. This project showed that human factors improvements (which included VPI as a key component) to only selected important manual valves could result in risk changes of about $10^{-5}$ core damage events per reactor-year. Additionally, cost analyses showed these upgrades or backfits to the important manual valves were cost beneficial. Further, cost analysis showed that most of the costs were related to the backfit situation. That is, when local VPI was included as part of the original valve design specification, the added costs were minimal, especially 
when compared to the increased assurance that valves were positioned properly at all times. Thus, it was concluded that most local valves for now plents should have VPI. For certain small local manual valves (0.8., root valves), VPI was determined not to be neceseary.

The staff's position is that remote VPI should be provided in the CR as discussed above and local VPI should be provided for

- all power-operated valves (e.g., motor, hydraulic, and pneumatic)

- all large manual valves (5 cm (2 in.) or greater)

- those small manual valves ( $<5 \mathrm{~cm}$ (2 in.)) determined to be important

The staff noted that DSER (SECY-91-320) Issue 18.20 will be addressed by the COL applicant as part of the design development process. This was DFSER COL Action Item 18.6-1. GE has included a COL action item regarding VPI in Itom 18.8.7 of SSAR Section 18.8. This is acceptable.

\subsection{Unresolved and Generic Safety Issues}

\subsubsection{General Discussion in the Standard Safety Analysis Report}

As required by 10 CFR 52.47, the applicant for design certification must demonstrate compliance with any technically relevant portions of the TMI requirements in 10 CFR 50.34(f), which is sometimes referred to as the CP/ML rule. 10 CFR 52.47 also requires proposed technical resolutions of USI/GSI. The safety issues that relate to human factors are addressed in Section 18.7.2, which follows.

GE discusses its approach and proposed resolution of these issues in Appendix 19B to the SSAR. The staff's initial review of the issues related to human factors is documented in DSER (SECY-91-320) Chapter 18. Several of the items were left outstanding at that time. This section will address the human factors aspects of these issues, as well as those items left as outstanding in the DSER (SECY-91-320).

\subsubsection{Analysis}

\subsubsection{DSER (SECY-91-320) Issue Resolution}

Two DSER (SECY-91-320) issues related to the standard features are summarized below along with the path to resolution that was proposed in the discussions with GE. The evaluation of these issues is given in the following eection.

Inve 18.23: Unreolved Safety Isener and Generic Safety Isave (UST/GSIs)

In the DSER (SECY-91-320), the staff identified several USIe/OSIs (see discussion below in Section 18.7.2.2).

Evaluation: This issue was to be resolved as part of the design implementation process roviow (seo discussion below in Section 18.7.2.2).

Inve 18.24: Construction Permit/Manufacturiwe License (CPMI) Rule Issues

In the DSER (SECY-91-320), the staff identified soveral CP/ML rule issues (see discussion below in Section 18.7.2.2).

Evaluation: This issue was to be resolved as part of the design implementation process roview (seo discussion below in Section 18.7.2.2).

\subsubsection{Evaluation of the Current SSAR}

In its response dated February 21, 1992, GE addressed the specific outstanding items associated with 10 CFR 50.34(f) that were identified in the DSER (SECY-91-320). These are summarized below.

\section{USU/GSI Item HF-1.1 and related items}

The staff considers Items HF-1.1, "Shift Staffing," and I.A.1.4, "Long Term Upgrade of Operating Personnel and Staffing," to be beyond the scope of the design certification. The COL applicant will be responsible for addressing these issues as part of the licensing process. This was DFSER COL Action Item 18.7.2.2-8. As Item 18.8.1 in SSAR Section 18.8, GE has included a general COL action item to conduct the detailed HFE design according to the design and implementation process defined by the DD and Table 3.1 of the CDM and SSAR Appendix 18E. The staff interprets this process to include the analysis of these USI/GSI items; therefore, this approach is acceptable.

\section{USI/GSI Items HF-5.1 and related items}

The staff considers Items HF-5.1, "Local Control Stations," HF-01.3.4.a, "Local Control Stations," and II.K.1(5), "Safety Related Valve Position Indication," to be beyond the scope of the design certification; the COL applicant will need to address these issues. This was 
DFSER COL Action Itom 18.7.2.2-7. GE has includod information regarding these two iseves as Item 18.8.11, "Local Control Stations," and 18.8.7, "Local Valve Potition Indication, " in SSAR Section 18.8. This approech is scceptable.

\section{USU/OSL Items HF-5.2, B-17, and related items}

The staff has reviewed the GE detailed CR design process and finds that the COL applicant will address several USI/GSI items as part of the detailed design implementation process. Among these items are (1) HF-5.2, "Roview Criteria for Humen Factors Aspects of Advanced Control Room Instrumentation"; (2) B-17, "Criteria for Safoty Related Operator Actions"; (3) HF-01.3.4b, "Interfaco Annunciators"; (4)HF-01.3.4c, "Operational Aids"; (5) HF-01.3.4d, "Automation and Artificial Intelligence"; and (6) HF-01.3.40, "Computers and Computer Displays." This was DFSER COL Action Item 18.7.2.2-6. As Item 18.8.1 in SSAR Section 18.8 $G E$, has included a general COL action item to conduct the detailed HFE deaign according to the design and implementation process defined by the DD and Table 3.1 of the CDM and SSAR Appendix 18E. The staff interprets this process to include the analysis of these USI/GSI items. In addition, for resolving Itom B-17, GE has included en evaluation of the adequacy of the HSI to provide necosary controls, displays, and alarms for the timely performance of critical tasks as Item 18.8.15 in SSAR Section 18.8. This approach is acceptable.

\section{TMI Action Item $\mathrm{I} \cdot \mathbf{A . 4 . 2}$}

10 CFR 50.34(f)(2)(i) corresponds to TMI Action Item I.A.4.2 on simulator capabilities. GE states that "simulator facilities for use in performing operator training are outside the scope of the standard plant design certification." This is consistent with the treatment of training in SSAR Chapter 13 and is acceptable bocause training is to be addreased by the COL applicant. This was DFSER COL Action Item 18.7.2.2-1. GE, with the agreement of the ataff, has included the requirement that the operator training program moet 10 CFR Part 50 as Item 18.8.8 in SSAR Section 18.8. This approach is acceptable.

\section{TMI Action Item I.D.1}

10 CFR 50.34(f)(2)(iii) corresponds to TMI Action Item I.D.1 on CR design. Item I.D.4 and Item I.D.5(1) also relate to CR design issues. GE states in the SSAR that these issues will be addressed by the COL applicant in the detailed design implementation process. This is acceptable and is further addressed by the HFE design process discussed in Section 18.8 below. This was DFSER COL Action Item 18.7.2.2-3. GE has included detailed
CR development in Table 3.1 of the CDM, Item 5, and in SSAR Appendix 18E. Information regarding this isswe is given a a COL action item in Item 18.8.1 of SSAR Section 18.8. This approsech is acceptable.

\section{TML Action Itom I.D.2}

Section 50.34(f)(2)(iv) corresponds to TMI Action Item I.D. 2 on the SPDS. GE addressed this item in SSAR Section 18.4.2.11 (seo the previous discussion of the SPDS in Section 18.3 of this report). Additionally, Item 125.I.3 in NUREG-0933 on SPDS availability will be addressed as part of the detailed CR design process. This was DFSER COL Action Item 18.7.2.2-4. GE has included the COL action of SPDS design in Item 18.8.4 of SSAR Section 18.8 and, in SSAR Soctions 18.2 and 18.4.2.11, has committod to mooting NUREG-0737, Supplement 1, SPDS requirements. This approach is acceptable.

\section{TMLAction Itom L.D.3}

10 CFR 50.34(f)(2)(v) corresponds to TMI Action Item I.D.3 on the status of bypassed and inoperable systems. This issue is covered in SSAR Chapter 7; bowever, the human factors aspects are not addressed. GE states that these will be addressed by the COL applicant in the detailed CR design implementation process. In addition, the COL applicant will be required to meet RO 1.47, which requires automatic indication at the system level of the bypassed or deliberately induced inoperable protection system and systems activated or controlled by the protection system. This was DFSER COL Action Item 18.7.2.2-5. GE has included a general COL action item to conduct the detailed HFE design according to the design and implementation process (defined by Table 3.1 of the CDM and SSAR Appendix 18E) in Item 18.8.1 of SSAR Section 18.8. The staff interprets this process to include the analysis of these USI/GSI items; therefore, this approach is accoptable.

\section{TMI Action Items II.E. L and II.F.2}

These items address detailed CR design issues related to instrumentation (II.F.1, "A'dditional accident monitoring instrumentation" and II.F.2, "Instrumentation for Detection of Inadequate Core-Cooling"). GE states that these issues will be addressed by the COL applicant in the detailed design implementation process. This is acceptable and is further addressed by the HFE design process discussed in Section 18.8 of this report. This was DFSER COL Action Item 18.7.2.2-3. GE has included detailed $C R$ development in Table 3.1 of the CDM, Item 5, and in SSAR Appendix 18E. The COL applicant's action with the process is included in Item 18.8.1 of SSAR Section 18.8. Further, GE has specifically identified $\mathrm{COL}$ 
actions for each of these TMI issues in Items 18.8.13 and 18.8.14, respectively, of SSAR Section 18.8. This approsch is acceptable.

\subsubsection{Finding}

The staff concludes that detailed resolution of the TMI, USI, and GSI tochnical iesues are adequately addreased by GE's design and implementation process as reflected in SSAR Appendix 18E and COL license information given in SSAR Section 18.8.

\subsection{Emergency Procedure Guidelines}

The staff approved Revision 4 of the BWROG EPGs, in an NRC letter (A.C. Thadani to D. Grace) dated September 12, 1988. This revision of the EPGs formed the basis for the ABWR EPGs. In Appendix 18B of the SSAR, GE submitted to the staff a list of differences between the ABWR EPGs and the BWROG EPGs, Revision 4. The following is a summary of the major differences and a description of the unresolved item, F18.8.4-1, when the advance version of the SER was issued. The resolution of this item is addressed in Sections 18.8.2 and 18.8.4 of this report.

\subsubsection{Containment Temperature}

Section CN/T of the BWROG EPGs contains guidelines for monitoring and controlling containment temperature by using available containment cooling. The control functions specified in this section - operation of contrinment cooling, initiation of suppression pool sprays, and RPV depressurization when containment temperature cannot be maintained below a prescribed limit - are specified in Sections SP/T and DW/T of the ABWR EPGs. The steps in these sections are carried out concurrently. Step SP/T-1 directs the operator to initiato all available suppression pool cooling. Step SP/T-3 directs the operator to depressurize the RPV in accordance with the heat capacity temperature limit (HCTL) curve. Step DW/T-2 calls for the initiation of containment sprays.

Section CN/T of the BWROG EPGs was developed specifically for the BWR/6 Mark III containment where temperature can be controlled by the previously stated control functions. Although the ABWR containment design incorporates the concept of a Mark III suppression pool, it is analogous to a Mark II BWR containment design for the purpose of controlling the wetwell space temperature.

Because Section CN/T is design specific for the BWR/6 Mark III containment and the control functions specified in this dection are carried out concurrently in other sections in the ABWR EPGs, this section has been eliminated from the ABWR EPGs.

\subsubsection{Venting}

Revision 4 of the BWROG EPGs directs the operator to manually vent the contrinment before the primary containment presenure limit (PCPL) is reached in order to prevent uncontrolled containment failure. The PCPL is defined as the lowest pressure of the following: (1) presoure capability of the containment, (2) maximum containment pressure for vent valves to open and close, (3) maximum containment pressure at which eafety/reliof valves (SRVB) can open and remain opea, and (4) maximum containment pressure for RPV vent valves to open and close for containment flooding. In the ataff'. SER for Revision 4 of the BWROG EPGs, the etaffe stated goal was to limit venting to a "last recort" action. The major staff concern was centered on the appropriate containment pressure for venting. As a recult, the venting preseure should be established to be as high as reasonably achievable.

In the $A B W R$, primary containment overpreasure protection will not be accomplished through manual venting. This will be the function of the passive containment overpressuro protection system (COPS), which is described in Section 19.2.3.3, "ABWR Containment Vent Design," of this report. The COPS is a passive system that is designed to actuate at $0.62 \mathrm{MPaG}$ (90 psig) at $93^{\circ} \mathrm{C}\left(200^{\circ} \mathrm{F}\right)$ before the primary containment reaches a pressure corresponding to the ASME Service Lovel C of $0.67 \mathrm{MPaG}(97 \mathrm{psig})$ at $260^{\circ} \mathrm{C}\left(500{ }^{\circ} \mathrm{F}\right)$.

The COPS meets the primary containment overpreasure protection philosophy described in the SER for Revision 4 of the BWROG EPGs because the set point is set as high as is reasonably achievable. Therefore, this change in veat design and the associated changes to the EPGs are acceptable.

The low pressure venting issue following the November 4, 1993, conference call with $G E$ required $G E$ to address the following items:

(1) Revise EPGs (PC/P) to show that venting is restricted to the $5 \mathrm{~cm}(2 \mathrm{in}$.) line in the drywell.

(2) Address suppression pool bypass mechanism through interconnection in the ACS and show the effect on the existing bypass analysis. Ensure that no other bypass pathways exist that have not been accounted for. 
(3) Addreen contrinment isolation configuration of interconnoction in tho ACS between the wetwell and drywall. GB should justify automatic control of the ACS over a normally closed penetration enouring contrinment intogrity.

(4) Addrese cuppreation pool lovel inswe in EPGs relating to the wetwell to drywell interconnoction level. The EPGs appear to be inconsistent with the deaign.

(5) Address auppreasion pool level and preesure control BPG. for injection from sources outside of containment. The EPGs appear to direct conflicting sctions in that SP/L-3.3 directs operatore to etop injection from eources outside containment when the euppreasion pool lovel reaches $27.2 \mathrm{~m}$ (89.5 ft). Whereas, PC/P-6 directs operators to epray the containment when the water level reache $27.2 \mathrm{~m}$ (89.5 ft) with use of sources external to the containment.

Rewolution of Items 1 and 5 was provided in Amendment 33. GE provided rovised deaign information for Itoms 2 , 3, and 4 in SSAR Amendment 34. For Itom 2, the auppression pool bypess mechanism was shown to be ineignificant when compared to the suppression pool bypass capability discuseod in Section 6.2.1.1.5 of the SSAR. For Item 3, GE provided a description of the icolation provisions. For Item 4, GE modified the EPGs to specify the correct water level. The staff finds the information acceptable; therefore, the low pressure venting portion of Open Itom F18.8.4-1 is resolved.

\subsubsection{Drywell Spray Initiation Limit}

The drywell spray initiation limit (DSIL) curvo, used in Revision 4 of the BWROC EPGs, is defined to be the highest drywell temperature at which initiation of drywell sprays will not result in en evaporative cooling pressure drop to below either (1) the drywell-below-wetwell differential preesure capability or (2) the high drywell prescure scram set point. The curvo contains a single peak. The curve to the left of the peak is a function of the high drywell pressure scram set point, while the right-hand side of the curve is limited by the drywell-below-wetwell differeatial preesure capability.

The DSIL curve used in the ABWR EPGs differs from the one used in Revision 4 of the BWROC EPGs. The curve to the right of the peak has been eliminated fc: the ABWR because a large pressure differential between the wetwell and the drywell at the onset of drywell sprays is not likely since the drywell and wetwell sprays are designed to acturate simultaneously. There will be some differential preanure between the wetwell and the drywall as epraying proceeds because of different injection lino-filling times and rates of epray flow into the two volumes.

OB calculated the differential presaure between the wetwell and drywell with concurreat epraying in the two volumes wing the GE computer code SHEX. For the SHEX calculation, only six of eight vecuum breakers wero asoumed operable. Initial drywell preseuro varied from maximum normal operating to maximum doaign, and relative humidity varied from 0 to 100 percent. Wetwell preecure varied from one atmoephere to normal operating and a wetwell temperature of $35^{\circ} \mathrm{F}\left(95^{\circ} \mathrm{F}\right)$ was ascumed along witi 100-percent relativo humidity. The maximum drywell-to-wetwell preanure differential did not exceed $3.45 \mathrm{kPaD}$ ( -0.5 psid), which is leas than tho detign valve of $-13.7 \mathrm{kPaD}(-2.0 \mathrm{psid})$ design value.

Actuation of drywell spray only is possible through a series of operator actions or following failure of the wetwell spray injection valvo to open when containment eprays (both wetwoll and drywell) are actuatod. In a letter dated May 26, 1994, GE analyzed the effect of drywell epray actuatioc alone on the negative preacure capability of the containment and drywoll/wetwell interface. OB concluded that the analysis supports all modes of spray actuation on the right side of the curve.

The staff finds the revised DSIL curve acceptable because the drywell and wetwell sprays will normally actuato simultaneously in the ABWR, thus eliminating the possibility of a significent preseure differential between the wetwell and the drywell at the onset of drywell sprays. This effect was confirmed by calculations performed by GE using the SHEX computer code. In the event of drywell spray actuation alone, GB provided analyais to demonstrate that the negative differeatial preesure capability of the contrinment would not bo exceeded.

\subsubsection{Heat Capacity Temperature Limit}

The advance version of the SER identified Open Itom F18.8.4-1 which consisted of two issues - the heat capacity temperature limit and the low pressure venting. The low pressure venting issue is discussed in Section 18.8.2 of this report.

For the ABWR, GE proposes the use of HCTL which would require reactor vessel depressurization when the suppression pool temperature reaches $103.9^{\circ} \mathrm{C}\left(219^{\circ} \mathrm{F}\right)$. Increasing the allowable suppression pool temperature before reactor vessel depressurization would begin permits the operation of the RCIC system for vessel injection when all other dedicated plant systems would be postulated to fail. This could occur during a SBO. This proposal raises 
everal phenomenology isuve related to hydrodynnmic loads.

Concerns were raised regarding the muppression pool with ateam diechargee from SRV or the RCIC turbine exhauet during pump operntion, since the auppresecion pool temperature hes traditionally been restricted by HCTL curves to ensure reactor vesed deprecourization a $66^{\circ} \mathrm{C}$ $\left(151^{\circ} \mathrm{F}\right)$. With a ateam discharge from a SRV quencher or RCIC turbine exhrust eparger at suppression pool tomperatures approaching $103.9^{\circ} \mathrm{C}\left(219^{\circ} \mathrm{F}\right)$, should a unstable steam condensation process occur, the containment liner may be subjected to an exceceive buckling load from a low presmure region occurring at the containment liner/suppression pool water interface. Aleo, - auppression pool bypass issue arieces if a steam plume oxtends from the quencher to the suppression pool surface. This wes HCTL part of Open Itom F18.8.4-1.

To resolve the above iscue on unstable collupee for an extended plumo where the steam jet extends beyond the quencher condeneation zone, GE relied on teeting performed by Drs. Chun and Sonin as described in OB's submittal of January 20, 1994. In current generation reactors, steam discharge from a SRV quencher is condeneed within a cylindrical region about the quencher arms called a condensation zone. The radius is in part of function of the amount of sub-cooling which exists within the suppreasion pool during a discharge, with the basis for ab-cooling being set forth in NUREG-0783, "Suppreesion Pool Tempereture Limits for BWR Containments."

With the proposal of permitting steam discharge in the suppreaeion pool at a higher pool tomperature then what hes been traditional discuseod with the NRC, the ataff pursued the potential consequences, as follows;

(1) Potential generation of a high quality stoum plume extending beyond the quencher condensation zone with the plume being ingeated by the ECCS inlet piping,

(2) Potential for audden collapso and an unacceptably high condensation oscillation ( $\mathrm{CO}$ ) load, should the stenm plume discussed above become sufficiently buoyent to detach from the quencher source,

(3) Potential extension of a steam plume from the quencher to the pool surface, thereby leading to a pool bypass path for particle scrubbing,

(4) Poteatial for a steam discharge from the RCIC turbine exhaust sparger, causing $\mathrm{CO}$ or chugging land higher than the CO or chugging loed for LOCA or discharge of all SRVs.
The ABWR ECCS inlet piping is located epproximately 1 m (3.3 ft) below the SRV quencher dovices. The utaff coscluded that eteam plumo injection by the BCCS is not poesible due to the buoyant nature of the steam plumo.

In the January 20, 1994, aubmittal, OB presented a discuseion by Dr. A. Sonin addreseing the potential largo steam plumes drifting into cooler region of the pool, thereby creating the initial conditions for audden collapse of the plume. The conclusion that was reached in the above stated paper was that the cooler regions (with respect to the local tomperature about the quencher which is discharging) of the suppression pool are a a low devation and eximuthally away from the quencher. During the quencher discharge, a circulatory drift motion occurs as the surrounding water is catrained into the plume. As the pool temperature increases during in extended discharge, the arta about the expanding steam plume is expected to be relatively well mixed horizontally. Thermal atratification will be primarily vertical, with the higheat temperature being in the warm buoyant layer near the surface and the colder temperature near the bottom of the pool. The staff finds that GE's position that a condition where the steam plume could move from a warm region of the pool to a aignificantly colder region to be implausible is justified based on the above stated paper and experiments performod by Drs. Chun and Sonin.

A question was also discused concerning a steam plume extending from the SRV quencher to the pool surface and creating a potential ouppression pool bypase pathway, which would negate any scrubbing action by the water. This issued appears to be unfounded based on the discuseion in the January 20,1994, submittal. The argument against the notion of a long continuous high quality steam plume extending to the pool surface appears unlikely duo to turbulence about the buoyent bigh velocity jet formed at the queacher hole. The turbulence caused at the plume in close proximity to the quencher entrains water into the plume from the sides causing rupid lose of plume tomperature and steam volume fraction with increasing distance from the quencher. In addition, independent calculations by the staff show that the wetwell airupace pressurization during pool heatup produces sufficient preasure to maintain a minimum of 40 degreces $K$ subcooling in the pool, based on bulk pool temperature. The staff concludes that a pool bypass is not a concern based on the proposed HTCL curve.

RCIC turbine exhaust discharge during suppression pool heat was reviewed for the poteatial of producing pool boundary loads which may exceed LOCA loads. This issued was raised because the turbine exhaust is discharged into the pool via a sparger which may not have tho same performance features for condensing steam as a X- 
Quencher. GE evaluated the sparger and has dotermined that the potential for producing CO and chugging loads greater than a LOCA scems unlikely based on a steam mass flux of about $48 \mathrm{~kg} / \mathrm{m} 2-8 e c\left(9.83 \mathrm{lbm} / \mathrm{ft}^{2}-\mathrm{sec}\right)$. At a mass flux of this magnitude, it is unlikely that CO and chugging loeds could be produced which would be of the same magnitude as LOCA loads. In addition, the ABWR SSAR specifies a bounding asymmetric load case which assumes that half the drywell vents are 180 degrees out of phase with remaining vents for chugging. Based on the asymmetric loading requirement for chugging, the low mass flux at the sparger and that the sparger design has been in use on current-generation BWR without a reported failure or problem, the staff finds that the HCTL curve as drawn would not produce higher loads on the containment then LOCA londs currently assumed. This is acceptable and resolved HCTL portion of Open Item F18.8.4-1.

\subsubsection{Primary Containment Mooding}

An override statement has been placed in front of ABWR EPG Step C6-2. This step directs the operator to terminate all injection into the primary containment when drywell water level reaches the bottom of the RPV if containment radiation is greater than the core damage radiation level (CDRL) and RPV water level is below the top of the active fuel.

GE stated that containment flooding is to be terminated when the drywell water level reaches the bottom of the RPV during severe accident conditions when the core has melted through the vessel and dropped to the lower drywell. Flooding will be terminated to avoid covering the wetwell vent path, which has the containment rupture diaphragms. The wetwell vent is located at an elevation above the bottom of the RPV.

GE stated that it had set the CDRL at a level that will differentiate between an accident that has led to the melting of most of the fuel and an accident that results in damage of a few fuel pins. Once most of the fuel has melted the possibility of an ex-vessel event that leads to pressurization of the primary containment becomes much more likely. This pressurization may require actuation of the COPS. The staff finds this approach to primary containment flooding acceptable.

\subsubsection{ATWS Stability Strategy}

GE, in SSAR Amendment 32, submitted changes to the EPGs (departed from the Rev. 4 BWROG EPGs) incorporating ATWS stability strategy related to initiation of the SLC system and lowering of the RPV water level. This strategy is similar to that proposed by the BWROG for current BWRs and, in that context, is still a subject of discussion between the staff and the BWROG. On the basis of its review (see Section 4.4 of this report), the staff concludes that the proposed processes for boron insertion and lowering of the RPV water level below the feodwater sparger level are acceptable for reducing large power oecillations to acceptable levels, should they occur, and for reducing power level in general for ATWS.

\subsection{Design and Implementation Process}

The final $C R$ design is an area of rapidly changing tochnology and it is important that the Tier 1 certified DD and the ITAAC do not "lock in" a CR design that would be obsolete at the time of construction. The staffs approach for ensuring CR human factors considerations for design certification is to "lock in" a design process and specific DAC that, if met, would result in a design that is acceptable. GE provides an overview of the design process in SSAR Sections 18.3.4 and 18.7 and gives details in SSAR Appendix 18E. Section 3.1 of the CDM gives the HFE ITAAC and DAC associated with the design and implementation process. At the time of the DFSER review, the ITAAC and DAC "Design Description" for Section 3.1 of the CDM were not complete. This was identified as DFSER Open Item 18.9.1-1. The material was submitted by GE in SSAR Amendment 32 and is reviewed below in this section.

The DAC will be in the same format as the ITAAC used for other systems in that they will specify the certified design process commitment and the method of demonstration that the commitment has been met. The method of demonstration will be inspection, test, or analysis against established acceptance criteria. The $\mathbf{C R}$ acceptance criteria will describe a formal design implementation process with test, analysis, and acceptance criteria.

General acceptance criteria are specified in the Tier 1 ITAAC and DAC material for each of the program elements shown, along with specific criteria for submitting several COL applicant technical reports. The general criteria are derived from accepted HFE practices. The Tier 2 SSAR (Appendix 18E) material contains applicable guidance documents for the development of the material for each of the program elements.

The staff performed the safety evaluation of the design and implementation process using Tier 1 HFE ITAAC and DAC described in Table 3.1 of the CDM and the Tier 2 criteria that appear in SSAR Tables 18E-1 through 18E-4. Each table provides the Tier 2 acceptance criteria. The design and implementation process review is described in Section 18.9.2, which follows. The Tier 2 material contains all the requirements identified in the Tier 1 
material and gives additional dotail regarding how Tier 1 requirements are atisfied. The evaluation of the Tier 1 material is provided in Section 18.9.3, which follows.

The Tier 2 commitments described in the SSAR provide methods and descriptions of the implementation of the Tier 1 requirements. The determination that the plant has been constructed in sccordance with the design certification will require the use of the information contained in both the Tier 1 and Tier 2 documents. The Tier 2 material contained in SSAR Appendix 18E was used to support the safety finding with regard to the design and implementation process. Thus, any change to the SSAR Appendix 18E commitments by the COL applicant would involve an unreviewed safety queetion and, therefore, would require NRC review and approval before implementation. Any requested change to SSAR Appendix 18E commitments shall either be specifically described in the COL application or be submitted for license amendment after COL issuance.

\subsubsection{General Discussion in the Standard Safety Analysis Report}

In GE's design and implementation process (as described in SSAR Appendix 18E and Table 3.1 of the CDM), the following HFE activities are defined:

- HFE design team

- HFE program and implementation plans

- system functional requirements analysis

- allocation of functions

- task analyses

- HSI design

- human factors V\&V

GE's key HFE design activities and their acceptance criteria were developed to address the staff's HFE PRM. It is important to note that the ITAAC and DAC description as presented in Table 3.1 of the CDM and the Tier 2 criteria that appear in SSAR Tables 18E-1 through 18E-4 have a scope limited to the main CR and the RSS (as agreed to by the NRC), whereas the HFE PRM has a broader scope. In addition, although procedures are within the scope of the HFE PRM as Element 7, GE has not included procedures within the scope of SSAR Appendix 18E. Procedure development is addressed as a COL responsibility in SSAR Section 13.5. In addition to scope, there are other differences between the staff's HFE PRM and GE's design and implementation process. However, a high degree of similarity exists between the two. The relationship between the PRM elements and the SSAR Tier 2 criteria is given below.

\begin{tabular}{cl} 
HER PRM Element & SSAR Tier 2 \\
\hline 1 & Table 18E-1 \\
2 & Table 18E-1 \\
3 & Tables 18E-1, 18E-2 \\
4 & Tables 18E-1, 18E-2 \\
5 & Tables 18E-1, 18E-2 \\
6 & Tables 18E-1, 18E-3 \\
7 & Section 13.5 \\
8 & Tables 18E-1, 18E-4
\end{tabular}

The following review focuses on (1) the evaluation of the acceptability of the differences between GE's proceses and tho staff's PRM and (2) the closure of DSER (SECY-91-320) issues. Since the GE process was ovaluated against the criteria depicted in the PRM, the organization of the report design and implementation plan roviow follows the organization of the PRM (i.e., Bloments 1 to 8).

\subsubsection{Analysis}

\subsubsection{DSER (SECY-91-320) Issue Resolution}

The initial SSAR provided little detailed information about the ABWR HSIs. As part of the general resolution of the lack of design detail, GE committed to provide a detailed HFE design and implementation process through which the HSIs will be designed and evaluated. This became DSER (SECY-91-320) Issue 18.25. However, because many other DSER (SECY-91-320) issues addressed design detail and were, therefore, beyond the scope of the certified design review, they too became incorporated into the design process review for subsequent consideration by the COL applicant as design development proceeds. These DSER (SECY-91-320) issues are identified in Table 18.2. As indicated previously in Section 18.1 of this report, an eight-element HFE PRM was developed to provide review criteria for the process. Table 18.2 shows which HFE PRM element addresses each DSER (SECY-91-320) issue. The issue is discussed in the section of this report identified in the table.

\subsubsection{Evaluation of the Current SSAR}

One general open issue pertained to Tier 2 guidance descriptions for each of the GE process elements. Element 1 (in the HFE PRM), for example, specifies the documents that are to be used as guidance. Each element has a similar specification. When the DFSER was issued, GE had not incorporated the specific documents, to serve as guidance, from the staff's review model into its process. The list of guidance documents was identified as DFSER Open Item 18.9.2.2-1. 
Table 18.2 DSER (SECY-91-320) HFE issues to be addressed in the process plan

\begin{tabular}{|c|c|c|c|}
\hline $\begin{array}{l}\text { Ieswe } \\
\text { Number }\end{array}$ & Iseue & $\begin{array}{l}\text { SER } \\
\text { Section }\end{array}$ & HFE PRM Element \\
\hline 18.04 & Operator and system reliability & 18.9.2.2.8 & Element 8 - Verification \& Validation \\
\hline 18.05 & Operator workload analysis & 18.9.2.2.8 & Element 8 - Verification \& Validation \\
\hline $18: 06$ & $\begin{array}{l}\text { Tosts and analysis to mupport dosign } \\
\text { implomentation }\end{array}$ & 18.9.2.2.8 & Eloment 8 - Verification \& Validation \\
\hline 18.07 & ABWR HFPP & 18.9.2.2.1 & Element 1 - HFE Program \\
\hline 18.08 & Control room prototype & 18.9.2.2.8 & Elemeat 8 - Verification \& Validation \\
\hline 18.10 & Detailed task analyses & 18.9.2.2.5 & Eloment 5 - Task Analysis \\
\hline 18.13 & $\begin{array}{l}\text { HSI design requirements for CRT, flat } \\
\text { panel, and large-screen displays }\end{array}$ & 18.9.2.2.6 & Element 6 - Interface Design \\
\hline 18.15 & CRT display information & 18.9.2.2.6 & Element 6 - Interface Design \\
\hline 18.16 & POCS display reliability & 18.9.2.2.8 & Element 8 - Verification \& Validation \\
\hline 18.17 & Alarm suppression criteria, alarm points & 18.9.2.2.6 & Element 6 - Interface Dosign \\
\hline 18.21 & Procedure development & 18.9.2.2.7 & Element 7 - Procedure Development \\
\hline
\end{tabular}

GE has incorporated the list into SSAR Appendix 18E, and the staff finds it acceptable based on a comparison to the HFE PRM; therefore, all of the basic docuthents necessary to conduct the design and implementation process that are identified in the HFE PRM have been incorporated into SSAR Appendix 18E. Therefore, this item is resolved.

For each of the following elements, the staff compared the criteria in the HFE PRM with GE's element criteria. If GE's criterion differs from the "general criterion" described in the HFE review model, the analysis of the difference is given.

\subsection{Element 1 - Human Factors Engineering Program Management}

GE addresses human factors engineering program management in its HFE program plan of the HFE ITAAC and DAC described in Table 3.1 of the CDM and in the Tier 2 description in SSAR Table 18E-1(II). GE's description of this element is substantially the same as the HFE PRM, Element 1 description. However, the staff identified and evaluated the following three exceptions. It also evaluated DSER (SECY-91-320) Issue 18.07 as part of this element:

\section{(1) Operating Experience Review (QER)}

GE incorporated OER (HFE PRM Element 2) into its HFE program plan instead of presenting it as a separate element. The main purpose of this element is to ensure that the designer identifies HFE issues from current and past operating experience to be incorporated into the HFE issue tracking system. The merger of these elements does not compromise the contribution of the OER and is acceptable.

(2) Absence of System Safety Engineerine Expertise on the Desion Team

GE's design team does not include system safety engineering expertise as specified in the HFE PRM. In the May 1992 meeting, GE stated that the system safety engineers will be included as needed and not as full permanent members of the HSI design team. The staff finds GE's approach acceptable, because this area of engineering expertise is applicable to the HFE design rather than the other HFE elements of the process.

(3) Absence of Reliability. Availability, Maintainability and Inspection Expertise on the Desien Team

GE's design team does not include reliability, availability, maintainability, and inspection expertise as specified in the HFE PRM. In the May 1992 meeting, GE agreed to include this expertise in the description of the HSI design. This 
is ecceptable because this aren of cogineering expertice is applicable to the HSI deaign nather than the other HFE elements of the proceses.

\section{DSER (SFCY-91-320) JEnY 18.07: ABWR Humm Exctor Progrm Plen (HEPP)}

In the DSER (SECY-91-320), the staff atated that SSAR Section 18.3 gave an outline for ayetems analyais and HSI deaign, but because the ABWR HFPP was not provided or referenced, the ecetion contrined littlo dotril about actual analyais eteps and procedures and discuscion of reaults. The ataff peoded additional dotriled information to complete its reviow.

Evaluation: The design and implementation proceses described in the SSAR and in the HFE certification deaign material DD document adequately addresses the HFPP and the types of analyses to be performed. All relevant portions of the HFE model were incorporated into the GE documents. Therefore, DSER (SECY-91-320) Issue 18.07 was to be resolved aubject to receipt of final ITAAC and DAC. This was DFSER Confirmatory Item 18.9.2.2.1-1. GE has provided an acceptable plan as described in the ITAAC and in SSAR Appendix 18E (the following section addreses the technical justification of the plan's acceptability).

\subsection{Element 2 - Operating Experience Review}

As indicated above, GE addresses CER as part of the HFE program plan of the HFE ITAAC and DAC described in Table 3.1 of the CDM and in the SSAR Tier 2 description in SSAR Table 18E-1 (II).

In the DFSER the staff identified an open item with regard to the OER. The OER for a specific list of issues still needed to be performed. The list of items had not been identified when the DFSER review was conducted. The list of issues was DFSER Open Item 18.9.2.2.1-1. GE has provided an acceptable approach to OER in Table 18E-1(II) in SSAR Appendix 18E. The main treatment of OER is included as Article $e$ in that SSAR section. For the first ABWR implementation, a list of issues is identified and organized into topical areas such as CR design, computers, CRT displays, and anthropometrics. These issues were identified through a preliminary OER performed by GE and are required, according to the design and implementation process, to be included in the COL HFE issues tracking system. The issues were identified on the basis of a reviow of pertinent industry experience literature and detailed control room design reviews of predecessor plants. The basis for the identification of operating experience is consistent with the requirements of the PRM. In addition, experience reviews are required in six selected areas, which OE has identified as ones for which further industry dovelopment is enticipated; thus, now iesues are likely to emerge. These areas include on-screen controls, wide display panels, alarm prioritization ayetem, automation, VDU doaign, and worketation intogration. The staff agrees that thees are aignificant areas of HSI deaign and areas where aignificant tochnology development and operating experience are likely to occur. COL roviows in these arous include source material consistent with the PRM. Now iseves identified will bo incorporated into the HSI tracking system. Subeequeat ABWR COL applications would ues the OER firet implemented if no deaign changes wero made. When changes are to be mado, an OER is to be conducted using operator intorviews and LERs of provious ABWR implementations. The staff interprets this requirement as also including a review of the documentation identified under Article 2e.(i)(b) of SSAR Appendix 18E; that is, the roviows will include industry experience, design, and research reports applicable to the areas of the design being modified. Where the changes represent a significant departure from the previous ABWR implementation, the staff expects applicablo elements of the certified design and implementation process to be followed.

OER also is included as part of Article d of Appendix 18B for applications of HSI technologies that are different from those specified in SSAR Section 18.4.3.

On the basis of GE's commitment in SSAR Tablo 18E-1(II) for an OER to be conducted, this item is resolved.

\subsection{Element 3 - System Functional Requirements Analysis}

GE addresses system functional requirements analysis as part of the HFE ITAAC and DAC described in Table 3.1 of the CDM and in the Tier 2 description in Table 18E-1(III). GE's description of this element is substantially the same as the HFE PRM description for Element 3. However, the staff identified and evaluated the following three exceptions:

\section{Modification of General Criterion 2}

This criterion defined critical functions as "those functions required to achieve major system performance requirements; or those functions which, if failed, could degrade system or equipment performance or pose a safety hazard to plant personnel or to the general public." GE has deleted from the definition the words "degrade system or equipment performance." The staff agrees with this 
change because the initial model definition was so broed that, if applied, it could define all functions a critical. OE's later definition of critical functions is scceptable.

(2)

\section{Elimination of Genern L Criterion 8}

This criterion stated: "The function analysis shall be kept current over the life cycle of design development." $\mathrm{GB}$ justified the deletion of this criterion by stating that an iterative approach to design dovelopment does not affect the reviow process. The staff reviow focusen on the acceptability of the end products of the deaign proceses as defined by the ITAAC requirements in Table 3.1 of the CDM, regardleas of the number of iterations the designers weat through to derive the requirements. Therofore, GE's deletion of this criterion is acceptable.

\section{(3) Elimination of General Critoriong}

This criterion addressed verification that "all the functions neceseary for the achiovement of safo operation are identified" and that "all requirements of each function are identified." GE's justification for eliminating this criterion was that it was covered by the quality assurance (QA) requiremonts of Appendix B to 10 CFR Part 50. The staff finds this change accoptable because (1) general verification is covered by $Q A$ and is addressed in the Tier 2 analysis report criteria for this element and (2) the HFE design team evaluation report will adequately address the verification aspects of this element. Therefore, GE's deletion of this criterion is acceptable.

\subsection{Element 4-Allocation of Function}

GE addresese function allocation as part of the HFE ITAAC and DAC deecribed in Table 3.1 of the CDM and in the SSAR Tier 2 description in SSAR Table 18E-1(IV).

GE's description of this element is substantially the same as the HFE PRM description for Element 4. However, the staff identified and evaluated the following two exceptions:

\section{(1) Elimination of General Criterion 5}

This criterion stated: "Functions shall bo roallocated in an iterative manner, in response to developing design specifics and the outcomes of ongoing analyses and trade studies." As in the case of the systems requirements analysis, as the design is modified as a result of design tradeoffs and analyses, it is important to reovaluato the functionewaignments; however, an itorative approsch to design does not affect the roview procese since the staff roviow focuses on the sccoptability of the and products of the design procese regardless of the number of iterations the designers went through to derive the results. Therefore, GE's deletion of this criterion is acceptable.

\section{Elimination of Genenl Criterion 6}

This criterion stated: "Function assignment shall be evaluated." Although this was eliminated as a general criterion (Tier 1) it was not removed from the Tier 2 requirements that elaborate on the ovaluation specification. Because the general criterion did not provide any specific information and the evaluation of function assignment is maintained in the Tier 2 description, GE's deletion of this criterion is acceptable.

\subsection{Element 5 - Task Analysis}

GE addresses task analysis as part of the HFE ITAAC and DAC described in Tablo 3.1 of the CDM and in the SSAR Tier 2 description in SSAR Table 18E-1 (V). GE's description of this element is substantially the same as the HFE PRM description for Element 5. However, the staff identified and evaluated the following exceptions; it also ovaluated DSER (SECY-91-320) Issue 18.10 as part of this element.

\section{Elimination of Part of General Criterion 4}

This criterion stated: "The task analysis shall bo iterative and become progressively more detailed over the design cycle. The task analysis shall be detailod enough to identify information and control requirements to enable specification of detailed requirements for alarms, displays, data processing, and controls for human task accomplishment." GE deleted the first sentence dealing with the iterative aspects of the analysis. This change is acceptable because an iterative approach to design does not affect the review process since the staff review focuses on the acceptability of the end products of the design process regardless of the number of iterations the designers went through to derive the results. Therefore, GE's partial deletion of this criterion is acceptable.

\section{Definition of PRA Critical Tasks}

In SSAR Table 18E-1(V), "Trsk Analysis Implementation Plan," Item (1)(c) states: "Human 
sotions which aro identified through PRA censitivity analyes to have significant impect on eafety shall sleo be considered critical tacke." Tho etaff expects that the dofinition of critical taske will include all PRA-dofined human actions that are britical and that the definitions will not be limited to sensitivity snalyes slone. SSAR Section 19D.7.6 defines importunt operalor setions from the ABWR PRA as derived from the ABWR Lovel 1, Lovel 2, fire, flood, seismic, and shutdown snalyese. These sctions are to be included in the definition of critical tacke for task analycis and the HFE offorts aseociated with aubeequent eloments - HSI design, procedure dovelopment, and V\&V. Therefore, the definition of critical task is acceptable.

\section{DSER (SECY-91-320) Jane 18.10: Detniled Tnek} Anilyes

In the DSER (SECY-91-320), the staff stated that detailed task analyes, which should cover the full range of normal and off-normal plant operations, had not been performed. GE stated that the tank analyais will be performod as part of the hardware and eoftware procurement and deaign implementation setivities.

Evaluation: Although the design commitment, ITAAC, and general criteria for task analysis in Table 3.1 of the CDM and in the SSAR Tier 2 deacription adequately addrese detailed task analyees, DSER (SECY-91-320) Isove 18.10 was to be reeolved subject to recoipt of the final ITAAC and DAC. This was DFSER Confirmatory Item 18.9.2.2.5-1. Task analysis is described in Tablo 3.1 of the CDM, Item 4. The analyses will address "the range of plant operating modes, including startup, normal operations, abnormal operations, transient conditions, low power and shutdown operations." This approach is acceptable and this itom is resolved.

\subsection{Element 6 - Human-System Interface Design}

GE addresses HSI design as part of the HFE ITAAC and DAC described in Table 3.1 of the CDM and in the Tier 2 description in SSAR Table 18E-1(Item VI). The description of this olement is different from the HFE PRM Element 6 description. The staff identified and evaluated the following two exceptions. In addition, it evaluated DSER (SECY-91-320) Issues 18.13, 18.15, and 18.17 as part of this element.

\section{Elimination of Genenal Criterion 6}

This criterion stated: "The selection and design of HSI hardware and software approeches shall be

baced upon demonatrated critoria that support the schiovemeat of human tack performance requirements. Critoria can be based upon teat results, demonatrated experienco, and trado studies of identified options." GE eliminated this element from its proceses description. It atates that the list for Element 6 of epecific documents to serve w guidance will be used by the COL applicant for the election and design of HSI hardware and software approsebes. The ataff finds this to be an acceptable approach; therefore, GE's deletion of this criterion is acceptable.

(2)

\section{Eliminntion of Cenerel Criterion 7}

This critorion stated: "HFE standards shall be omployed in HSI solection and design. Humen engineering guidance rogarding the design of particular foatures, shall be doveloped by the HSI designer to (1) insure that the HSIs are designed to currently accepted guidelines and (2) insure proper consideration of human capabilities and limitations in the doveloping system. This guidance shall be derived from sources such as expert judgement, deaign guidelines and standards, and quantitative (0.8., anthropometric) and qualitative (0.8., relative effectiveness of differing types of displays for different conditions) data. Procedures shall bo employed to ensure HSI adherence with standards." GE states that th:s specific documents listed in SSAR Appendix $18 \mathrm{E}$ will be used by the COL applicant to comply with this general criterion. The staff finds that the information in SSAR Appendix 18E rolated to this issue and GE's deletion of this criterion is acceptable.

DSER (SECY-91-320) Issue 18.13; HSI Desion Bequirements for Cathode Ray Tube (CRT). Flat Panel and Large-Screen Displays

In the DSER (SECY-91-320), the staff stated that additional detailed information was needed on the ABWR HSI design requirements for the control station CRT, flat panel, and large-screen displays.

Evaluation: Althougi the design commitment, ITAAC, and general criteria for HSI design described in the CDM and in the SSAR Tier 2 description adequately address the detriled design of the HSI, DSER (SECY-91-320) Issue 18.13 was to be resolved subject to receipt of the final ITAAC and DAC. This was DFSER Confirmatory Item 18.9.2.2.6-1. Design Commitment 5 of Table 3.1 of the CDM and SSAR Appendix 18E states that the HSI will be based on requirements derived from task analyses and 
deaigned waing HFB critoria and guidance. The ataff ba compared OB's Design Commitment 5 and SSAR Appeodix 18E with the HFE PRM and found OE's deecription to be seceptable. Therefore, this itom is recolved.

DSBR (SECY-21-32.0) Inne 18.15: CRT Dirplay Information

In the DSER (SECY-91-320), the etaff atated that no details of the CRT dieplays were provided to permit visualization of the actual information available to the operator. The staff needed this information to completo its noviow.

Evaluation: The deaign commitment, ITAAC, and general criteria for HSI desizm described in the DD of the CDM and in the SSAR Tier 2 deecription adequately addreas the dotailed deaign of the HSI. DSER (SECY-91-320) Isave 18.15 was to be reeolved aubject to recoipt of the final ITAAC and DAC. This was DFSER Confirmatory Item 18.9.2.2.6-2. Design Commitment 5 of Table 3.1 of the CDM and SSAR Appendix 18E state that the HSI will be based on requirements derived from task analyses and designed by the COL applicant using HFE criteria and guidance. This is acceptable based on a comparison of the design commitments with the HFE PRM. Therefore, this item is resolved.

DSER (SECY-91-320) Is:ue 18.17: Alarm Suppression Criteria Alarm Points

In the DSER (SECY-91-320), the staff stated that additional detailed information about the ABWR alarm suppresaion criteria and rationale ueod to determine the limit number of alarm points that operators can simultaneously recognize was necessary for the staff to complete its roviow.

Evaluation: Although the design commitment, ITAAC, and genoral criteria for HSI design deecribed in the CDM and in the SSAR Tier 2 description adequately address the detailed design of the HSI, DSER (SECY-91-320) Issue 18.17 was to be resolved subject to receipt of the final ITAAC and DAC. This was DFSER Confirmatory Item 18.9.2.2.6-3. Design Commitment 5 of Table 3.1 of the CDM and SSAR Appendix 18E state that the HSI will be based on requirements derived from task analyses and designed using HFE criteria and guidance. This is acceptable based on a comparison of Design Commitment 5 with the HFE PRM. Therefore, this item is resolved.

\subsection{Element 7 - Ptant and Emergency Operating Procedure Development}

As atated in Section 18.9.1 above, OE has not included procedure dovelopment in the scope of its HFE deaign and implementation plan. Since procedure development is addroeeced an a COL applicent responsibility in SSAR Section 13.5, it is ovaluated in Chapter 13 of this report.

\subsection{Element 8 - Human Factors Verification and Valldation (V\&V)}

OB addresece bumen factors V\&V as part of the HFE ITAAC and DAC deacribed in Table 3.1 of the CDM and in tho SSAR Tier 2 doecription in Tables 18E-1(VII). OE's description of this element is the samo as the HFE PRM doecription for Element 8. However, the staff identified and evaluatod the following exception. It also ovaluated DSER (SECY-91-320) Isuves 18.04, 18.05, 18.06, 18.08, and 18.16 as part of this element.

Elimingtion of PRA/HRA-Defined Critical Actions Erom Geneml Criterion 8

This critorion stated: "A verification shall bo mado that all critical human actions as defined by tho task analysis and PRA/HRA havo been adequately supported in the design. The design of teets and ovaluations to be performed as part of HFE V\&V activities shall specifically examine these actions." Risk-critical human actions (those to which tho plant design is especially sénsitive in a risk model) should receive special attention in the V\&V process. $G E$ committed to having all critical tasks confirmed as part of the V\&V process and defined critical tasks under the task analysis olement to include all PRA/HRA items included in SSAR Appendix 19D, Section D.7. These would include those operator actions that had significant safety impect. The staff considered this approach acceptable. The incorponation of the commitment was DFSER Confirmatory Item 18.9.2.2.8-1. SSAR Table 18E-1 states that critical tasks will include those buman actions identified through PRA sensitivity analyses to be critical. Table 3.1 of the CDM, Item 6a, (4)(a), states that one V\&V objective will be the "confirmation that the identified critical functions can be achieved using the integrated HSI design." GE's deletion of PRA/HRA-defined critical actions from this criterion is acceptable; therefore, this item is resolved. 
DSER (SECY-91-320) Issue 18.04: Evaluntion of Opentor and Systers Reliability Durine Shift From Normal to Abnormal Operations

In the DSER (SECY-91-320), the staff statod that the net offect on operator and system reliability should be ovaluated for normal operations and for the shift, or transition, from normal to emergency operations.

Evaluation: Incorporation of this analysis into the V\&V ITAAC was DFSER Confirmatory Item 18.9.2.2.8-2. Table 3.1 of the CDM, Item 6a, states that the dynamic performance evaluations conducted as part of validation "shall be conducted over the range of operational conditions and upsets." The staff interprets this as including transitions from normal to emergency operations to permit the evaluation of the crew's ability to assume plant control under abnormal conditions, and notes that a detailed oxamination of operator transition from normal to abnormal operations will be performed during the V\&V of the main CR and RSS by the COL applicant. Therefore, this item is resolved.

\section{DSER (SECY-91-320) Issue 18.05: Opentor Worklond Analysis}

In the DSER (SECY-91-320), the staff stated that GE did not make it clear what analyses had been performed in support of the design and dovelopment of the ABWR and what tests and analyses are yet to be dowe by the COL applicent.

Evaluation: In the DFSER, the staff stated that the V\&V analyses conducted by the COL applicant as part of the HFE ITAAC and DAC described in Table 3.1 of the CDM specifically would address this issue, which would bo resolved subject to receipt of the final ITAAC and DAC. This was DFSER Confirmatory Item 18.9.2.2.8-3. Design Commitment 6, Acceptance Criteria 6a(6)(d) of Table 3.1 of the CDM, and SSAR Appendix 18E state that workload will be used as a performance measure in dynamic performance tests. On the basis of a comperison of Design Commitment 6 and SSAR Appendix 18E with the HFE PRM, this item is resolved.

\section{DSER (SECY-91-320) Issue 18.06: Tests and Analysis To} Support Design Implementation

In the DSER (SECY-91-320), the staff stated that additional detailed information was needed about the methods, criteria, and results of analyses that support the level and type of staffing, automation, and function allocation to achieve the goals of safe and reliable performance of the operating crew and overall system. The staff further stated that the design bases in SSAR Section 18.2 would be more appropriate as design requirements if they had been derived and justified on the basis of the systems analysis. The staff considered it more appropriate to develop design beses that are stated in terms that would help achieve the primary goal of developing interfaces (and a system) that make possible safe, efficient, and reliable operator performance. The bases could be described in "operatorcentered" terms that can objectively be linked with achieving the design goals and serve as criteria for test and ovaluation activities. There were two aspects of this issue to consider: (1) the analyses conducted to date and (2) the analyses that will be done in the future.

Evaluation: The analyses conducted to dato were included in SSAR Appendix 18G and evaluated by the staff as acceptable (see detailed discussion of this review in Section 18.3.2.1 above). Although the V\&V analyses to be conducted by the COL applicant as part of the HFE ITAAC and DAC described in Table 3.1 of the CDM specifically address this issue, it was to be resolved subject to receipt of the final ITAAC and DAC. This was DFSER Confirmatory Item 18.9.2.2.8-4. Design Commitment 6 of Table 3.1 of the CDM and SSAR Appendix 18E include a commitment that the V\&V analyses will be performed. These analyses are acceptable (as stated above) on the basis of a comparison of Design Commitment 6 and SSAR Appendix 18E with the HFE PRM. Therefore, this item is resolved.

\section{DSER (SECY-91-320) Issue 18.08: CR Prototype}

In the DSER (SECY-91-320), the staff stated that dovelopment of a fully functional CR prototype of the standard design was appropriate to demonstrate acceptable human performance.

Evaluation: Although V\&V analyses conducted by the COL applicent as part of the HFE ITAAC and DAC described in Table 3.1 of the CDM specifically require prototype evaluation, this issue was to be resolved subject to receipt of the final ITAAC and was DFSER Confirmatory Item 18.9.2.2.8-5. Design Commitment 6 of Table 3.1 of the CDM requires dynamic task performance test evaluations to be performed for HSI validation. SSAR Table 18E-1(VII), Item (1)(d), states that the dynamic task performance evaluations will be performed using "dynamic HSI prototypes, i.e., prototypical HSI equipment which is dynamically-driven by real time plant simulation computer models. " On the basis of a comparison of Design Commitment 6 and SSAR Appendix 18E with the HFE PRM, the staff finds that GE's proposal is acceptable and, therefore, this item is resolved. 
DSER (SECY-91-320) Issue 18.16: Power Generntion Control System (PGCS) Reliability

In the DSER (SECY-91-320), that staff stated that additional detailed information was necessary regarding the reliability of the PGCS and the offect on operator performance and workload should it malfunction.

Evaluation: Since system malfunctions are required to be analyzed as part of the V\&V effort under HFE model Element 8, the COL applicant will analyze malfunctions of the PGCS. This issue was resolved as DFSER COL Action Item 18.9.2.2.8-1 to be addressed as part of the HFE issue tracking system. GE has included this analysis in Item 18.8.10 of SSAR Section 18.8, which the staff finds acceptable. Therefore, this item is resolved.

\subsubsection{Design Description Tier 1 ITAAC and DAC Review}

While the above review was directed toward the acceptability of the design and implementation process as a whole, the staff performed a separate evaluation of the HFE ITAAC and DAC provided in Table 3.1 of the CDM to ensure that significant features of the design certification application contained in the SSAR were captured by Table 3.1 of the CDM. It should be noted that the materials reviewed in SSAR Appendix 18E were used to support the safety finding with regard to the design and implementation process. Thus, any change to the commitments in SSAR Appendix 18E would involve an unreviewed safety question and, therefore, require NRC review and approval before implementation. Any requested change to commitments in SSAR Appendix 18E shall either be specifically described in the COL application or be submitted for license amendment after COL issuance.

The review of the SSAR using the HFE PRM led to the staff's conclusion that the design and implementation process contained the necessary and sufficient aspect of an HFE program that were sufficient to result in an acceptable HSI design. The general guidance in SECY-92-287 was used to support the review of Table 3.1 of the CDM.
Table 3.1 of the CDM was compared to the major PRM elements to determine whether they were captured. No omissions were identified. Table 3.1 of the CDM was then evaluated to ensure that they accurately reflected the design and implementation process and that they were at a level of detail consistent with the staff's intent to not constrain the use of state-of-the-art, proven technology at the time the HSI is designed (one of the stated intents of the DAC process). All necessary and sufficient ITAAC were identified based upon comparison with the HFE PRM, and no concerns were identified.

Therefore, the staff concludes that the design commitments in the HFE ITAAC and DAC accurately summarize the DD for HFE; that the inspections, tests, and analyses identified are acceptable methods for determining whether the design commitments have been met; and that the acceptance criteria are sufficient to establish, if they are met, that the design commitments have been met.

\subsection{Conclusion}

The staff has reviewed the HSI design development and implementation process presented by GE in SSAR Sections 18.0 through 18.8 and Appendices 18A, 18B, $18 \mathrm{D}, 18 \mathrm{E}, 18 \mathrm{~F}, 18 \mathrm{G}$, and $18 \mathrm{H}$, up through SSAR Amendment 34. SSAR Appendix $18 \mathrm{C}$ represents only one illustration of a possible $C R$ design for the $A B W R$; therefore, it is NOT a part of the certified design and was NOT subject to the review process. The staff concludes that the design and implementation process discussed in the SSAR describes an acceptable HFE program, and if applied, will result in an acceptable HSI designs for the main CR and RSS. In addition, the design commitments and ITAAC in Table 3.1 of the CDM accurately summarize the minimum HFE requirements for an acceptable design, development, implementation, and $V \& V$ process for the main CR and RSS. All previously identified DSER (SECY-91-320) and DFSER issues are resolved. 


\section{SEVERE ACCIDENTS}

\subsection{Probabilistic Safety Assessment}

\subsubsection{Executive Summary}

As part of its advanced boiling water reactor (ABWR) design certification application, GE Nuclear Energy (GE) has performed a design-specific probabilistic risk assessment (PRA) as required by 10 CFR 52.47(a)(1)(v). GE submitted a Level 3 PRA (i.e., the PRA calculated core damage frequencies, conditional containment failure probabilities, and conditional offsite consequences) that addresses internal initiating events. The PRA also evaluates seismic, internal flood, and fire-initiating events.

The staff reviewed the ABWR PRA to investigate design insights and to determine its quality. The staff concluded that the quality of the ABWR PRA is adequate for supporting and improving the $A B W R$ design process; providing relative importance of sequences (as well as identifying important structures, systems, and components (SSCs)) leading to core damage or containment failure; and searching for design and procedure vulnerabilities that could be eliminated on a cost-benefit basis.

The draft safety evaluation report (DSER) (SECY-91-309) and the draft final safety evaluation report (DFSER) included a number of unresolved issues. Since both evaluations were too detailed and extensive to be repeated in this safety evaluation, the staff totally revised its evaluation as reflected in this report. As stated herein, those issues that were individually listed in the previous two evaluations have been adequately addressed by $G E$ in its application.

The staff concludes, based on its review of the ABWR PRA, that the ABWR is of a robust design, that the design is an improvement over existing designs, and that the design meets the Commission's safety goals described in 51 FR 28044 and 51 FR 30028 published August 21, 1986, for internal events (see FSER Section 19.1.3.8.3). The Commission has determined that it is acceptable for GE to submit external event analyses that provide insights needed to identify design and procedure vulnerabilities; provide insights needed for inclusion in areas such as the reliability assurance program (RAP); and inspections, tests, analyses, and acceptance criteria (ITAAC); but do not provide core damage frequency estimates suitable for use in comparison to the Commission's safety goals or in comparison to the Electric Power Research Institute's (EPRI's) Public Safety Requirement, which states

"The design is considered to have met the EPRI risk requirement if the mean complementary cumulative distribution function (CCDF) for wholebody dose developed for a $0.8 \mathrm{~km}$ (one-half mile) radius falls outside the region bounded by a lower limit for frequency at 1E-6 per year and has a lower limit for consequences of 25 rem whole-body dose at $0.8 \mathrm{~km}$ (one-half mile). The EPRI goal is based on consideration of both internal and external initiators"

Although direct comparison of external-event results to these goals is not possible, the ABWR design has significant margins above the design bases for seismic, fire, and internal flood-initiating events and, where computed, has low estimated core damage frequencies from these bounding analyses. The staff believes that the ABWR design meets the Commission's safety goals.

The staff finds that there is an acceptable balance of preventative and mitigative features in the ABWR design. The core damage frequency estimates for internal events reported in the ABWR PRA are on the order of 1E-7 per year. Table 19.1-1 lists the most important internal initiating events and Table 19.1-2 lists the top 20 internal event sequences leading to core damage. Station blackout (SBO) contributes about 70 percent of the internal events core damage frequency (i.e., its absolute value is about $1 \mathrm{E}-7$ per year, which is low when compared to the figures in most recent boiling water reactor (BWR) PRA studies). Table 19.1-3 lists the most important sequences leading to core damage from seismic, internal flood, and fire event initiators.

\section{Table 19.1-1 ABWR PRA initiating event contributors to CDF (Level 1, internal events)}

Initiating Event

Events Per Yr.

CDF $\times 1 E-8$

\section{7}

2.6

Station blackout $2<\mathrm{X}<8 \mathrm{hrs}$

4.5E-7

Station blackout $>8 \mathrm{hrs}$

$1.6 \mathrm{E}-8$

Isolation/loss of feedwater

0.18

1.0
1.7

1.7

1.2
Percent CDF

$43 \%$

$16 \%$

$11 \%$

$11 \%$

Unplanned manual reactor shutdown 
Table 19.1-2 Important sequences leading to core damage (internal events)

\begin{tabular}{|c|c|c|c|}
\hline $\begin{array}{l}\text { Sequence Description } \\
\text { (Top } 20 \text { sequences) }\end{array}$ & $\begin{array}{c}\text { CDF } \\
\text { (Per Year) }\end{array}$ & $\begin{array}{l}\text { Percent } \\
\text { CDF }\end{array}$ & $\begin{array}{l}\text { Plant } \\
\text { Damage } \\
\text { Class }\end{array}$ \\
\hline $\begin{array}{l}\text { SBO from } 0.5 \text { to } 2 \mathrm{hrs,} \text { RCIC unavail. because of test or main- } \\
\text { tenance }(\mathrm{T} / \mathrm{M})\end{array}$ & 2.4E-8 & 15.6 & ID \\
\hline SBO more than $8 \mathrm{hrs}$ & $1.6 \mathrm{E}-8$ & 10.4 & IB-2 \\
\hline SBO from 0.5 to $2 \mathrm{hrs,}$ RCIC turbine mech. failure & $1.3 \mathrm{E}-8$ & 8.6 & ID \\
\hline SBO from 2 to $8 \mathrm{hrs}, \mathrm{RCIC}$ unavail. because of T/M & 8.9E-9 & 5.7 & IB-1 \\
\hline SBO from 0.5 to $2 \mathrm{hrs}, \mathrm{RCIC}$ pump fails & 8.3E-9 & 5.3 & ID \\
\hline SBO from 0.5 to 2 hrs, RCIC lubrication system fails & $5.1 E-9$ & 3.3 & ID \\
\hline SBO from 2 to $8 \mathrm{hrs,} \mathrm{RCIC} \mathrm{turbine} \mathrm{mech.} \mathrm{fails}$ & 4.9E-9 & 3.1 & IB-1 \\
\hline $\begin{array}{l}\text { Loss of feedwater/isolation, failure to inject with feedwater, con- } \\
\text { ditional containment failure (CCF) of MUX, operator fails to } \\
\text { manually initiate feedwater after } 30 \mathrm{~min} \text {. }\end{array}$ & 4.6E-9 & 2.9 & IA \\
\hline $\begin{array}{l}\text { Reactor trip, failure to inject feedwater, CCF of MUX, operator fails } \\
\text { to manually initiate feedwater after } 30 \mathrm{~min} \text {. }\end{array}$ & $3.1 \mathrm{E}-9$ & 2.0 & IA \\
\hline SBO from 2 to $8 \mathrm{hrs,} \mathrm{RCIC} \mathrm{pump} \mathrm{fails}$ & $3.0 \mathrm{E}-9$ & 1.9 & IB-1 \\
\hline $\begin{array}{l}\text { Loss of feedwater/isolation, failure to inject feedwater, CCF of } \\
\text { system logic unit, operator fails to manually initiate feedwater after } \\
30 \mathrm{~min} \text {. }\end{array}$ & 2.3E-9 & 1.5 & IA \\
\hline $\begin{array}{l}\text { Loss of feedwater/isolation, failure to inject feedwater, operator fails } \\
\text { to manually initiate feedwater after } 30 \mathrm{~min} \text {., CCF of remote MUX }\end{array}$ & 2.3E-9 & 1.5 & IA \\
\hline $\begin{array}{l}\text { SBO from } 0.5 \text { to } 2 \mathrm{hrs,} \mathrm{valve} \mathrm{E51-F011} \mathrm{fails} \mathrm{to} \mathrm{close} \mathrm{after} \mathrm{RCIC} \\
\text { pump has started }\end{array}$ & 2.2E-9 & 1.4 & ID \\
\hline SBO from 0.5 to $2 \mathrm{hrs,}$ valve F037 fails closed (NCFC) & 2.1E-9 & 1.3 & ID \\
\hline SBO from 0.5 to $2 \mathrm{hrs,}$, valve F004 fails closed (NCFC) & 2.1E-9 & 1.3 & ID \\
\hline $\begin{array}{l}\text { SBO from } 0.5 \text { to } 2 \mathrm{hrs,} \text { valve E51-F011 fails to open when RCIC } \\
\text { pump starts }\end{array}$ & 2.1E-9 & 1.3 & ID \\
\hline $\begin{array}{l}\text { Loss of feedwater/isolation, failure to injèct feedwater, battery CCF, } \\
\text { loss-of-offsite line } 1 \text { power }\end{array}$ & 2.0E-9 & 1.3 & IA \\
\hline SBO from 2 to $8 \mathrm{hrs,} \mathrm{RCIC} \mathrm{lubrication} \mathrm{fails}$ & $1.9 \mathrm{E}-9$ & 1.2 & IB-1 \\
\hline $\begin{array}{l}\text { Turbine trip, failure to inject feedwater, CCF of MUX, operator fails } \\
\text { to manually initiate feedwater after } 30 \mathrm{~min} \text {. }\end{array}$ & $1.8 \mathrm{E}-9$ & 1.2 & IA \\
\hline SBO from 0.5 to $2 \mathrm{hrs,} \mathrm{isolation} \mathrm{signal} \mathrm{logic} \mathrm{fails}$ & 1.7E-9 & 1.1 & ID \\
\hline Totals & $1.1 E-7$ & 71.9 & \\
\hline
\end{tabular}




\section{Table 19.1-3 Important sequences for external events (seismic, fire, and internal floods)}

\section{Seismic Events}

Sequences chosen for having low HCLPF ${ }^{1}$ values or needing fow SSC failures

Sequence HCLPF

Failure of emergency dc power

Emergency ac/emergency SW and fire water

Emergency ac/emergency SW and scram

Reactor or control building, containment, RPV pedestal, or RPV supports $1.11 \mathrm{~g}$

ATWS and SLCs failure

$0.62 \mathrm{~g}$

ATWS and SLCs and high-pressure core flood

0.628

\section{Internal Wlood Events}

Sequences chosen as being most challenging and having worst consequences

Estimated CDF

Control building: large pipe break in RSW, operator fails to isolate flooding, auto RSW pump trip fails, water flows to remaining RSW pump rooms, operator fails to 2E-9 per year respond to flooding alarm, RSW fails.

Reactor building: break in fire water standpipe or line from CST, operator does not respond to alarm to isolate flood, overfill lines to corridor ure clogged, all three electrical

2E-10 per year rooms on floor B1F flood, ac power is lost to all mako-up systems.

Turbine building: break in CWS system, isolation valves in CWS lines fail to close, water fills up and runs out of the condenser pit, fire door between the turbine building and the service building is either open or fails open allowing water into service building, service building floods and a door between the service building and the control building fails open or is open, water entering the control building causes electrical power supplies and all three divisions of RCW to fail.

Fire

Sequences chosen that had a core damage frequency of 1E-6 or higher before the plant design was improved

Estimated CDF (considered conservative)

Fire in the control room causes its evacuation, feedwater fails, RCIC or one highpressure core flood train fails, either one train of low-pressure core flood train or less than $1 E-6$ per year manual depressurization fails.

1 - High confidence with low probability of failure that the structure, system, or component will fail at the given peak ground acceleration.

Note: Because of the assumptions and methods used in the ABWR shutdown risk evaluation, no dominant sequences leading to core damage could be determined. NUREG-1449 did identify various important scenarios that were potential contributors to core damage in BWRs during shutdown. Conclusions from NUREG-1449 are based on actual nuclear power plant operating experience. 
The internal events core damage frequency estimate is very low and is a reflection of GE's efforts to systematically minimize the effect of sequences or initiators that have been important contributors to core damage frequency in previous BWR PRAs. A brief discussion is necessary on the implications of the low estimated core damage frequency for internal events for the ABWR. Estimated core damage frequency values with absolute values less than 1 in a million years should not be taken literally is the expectation of the "true" core damage frequency of the design. Rather, this value should be taken as a reflection of the conscientious engineering and design effort to reduce or eliminate the contributors to core damage frequency found in previous PRAs. When core damage frequencies of one in a hundred thousand or a million years are estimated in a PRA, it is the areas of the PRA where modeling is least complete, supporting data are sparse, or even nonexistent that actually could be the more important contributors to risk. Areas not modeled or incompletely modeled include errors of commission, sabotage, rare initiating events, construction errors, design errors, control systems, ageing, systems interactions, human interaction with smart control rooms, and human errors.

For seismic initiating events, GE submitted a PRA-based seismic margins analysis. This method eliminates the uncertainties associated with picking an appropriate seismic hazard curve, while still providing the insights needed to judge the ability of the design to withstand beyond-designbasis earthquakes. With a PRA-based seismic margins analysis, rather than developing an estimated core damage frequency, the method estimates the margin the design has beyond the design basis safe shutdown earthquake (SSE) (which is $0.3 \mathrm{~g}$ for the $\mathrm{ABWR}$ ) and identifies any weak links in the design. GE reported that all sequences leading to core damage from a purely seismic event were found to have a high confidence with low probability of failure (HCLPF) value of $0.6 \mathrm{~g}$ or higher. An HCLPF roughly represents the $\mathrm{g}$-level acceleration at which a SSC is believed to fail 5 percent or less of the time with a 95 percent confidence level. The staff finds that the ABWR's HCLPF ( $\geq 0.5 g$ ) demonstrates that a significant margin exists beyond the design basis earthquake level.

For internal floods that occur at power, GE performed a PRA internal flood analysis that assumed that once flood water reaches a level high enough to cause the failure of any piece of equipment in an area, then all the equipment in that area instantly fails and is unrecoverable. This analysis estimated that the core damage frequency from internal floods was on the order of 1E-8 per year. This number was particularly low because the ABWR design has three safety divisions that are physically separated. For internal floods during shutdown, GE developed guidelines for the COL applicant for configuring shutdown cooling divisions such that one division would be in operation, one isolated and in standby, and one in maintenance. It is believed that the core damage frequency from this configuration should not exceed 1E-6 per year and probably can be at least an order of magnitude lower, given the conservatism of the assumptions in the analysis.

For fires, GE submitted a fire analysis that was a combination of the Fire Induced Vulnerability Evaluation (FIVE) methodology developed by EPRI and the internal events PRA. This analysis assumed that, if a fire occurred in any portion of a fire area, all equipment in the area failed instantly. The GE fire analysis estimated the core damage frequency from fires to be on order of 1E-6 per year.

The design basis analysis for tornados in the ABWR is such that the ABWR is designed to be able to withstand tormados that occur with a frequency in the range of 1E-7 per year. Since the plant is designed to handle these low frequency tornados and is already analyzed for loss-ofoffsite power events, the staff does not consider it necessary to analyze design basis tornados probabilistically.

The staff finds that the ABWR design is adequate to limit exposure to risk when the plant is operated in Modes 3, 4, and 5 (hot shutdown, cold shutdown, and refueling, respectively). The staff finds that the ABWR design includes enhanced features that reduce risk during shutdown operations when compared to operating BWRs. These features specifically address the more risk-significant operations during shutdown identified in NUREG-1449 including three independent residual heat removal (RHR) divisions, three emergency diesel generators (EDGs), an ac-independent water addition (ACIWA) system, an alternate onsite combustion turbine generator (CTG), and proper plant electrical and physical separation and layout.

The results of the Levels 2 and 3 portion of the ABWR PRA indicate that the ABWR containment is quite robust and able to accommodate severe accidents with a low attendant probability of containment failure. Both GE and staff estimates of the ABWR conditional containment failure probability (CCFP) are within the Commission's containment performance goal $(0.10)$. Using the structural integrity definition, GE's estimate of CCFP is 0.005 , whereas the staff's estimate is $\mathbf{0 . 0 2 6}$.

Based on the Level 3 PRA, the estimated total risk to the public for the ABWR is extremely small. GE's analysis indicates a total dose of about 0.3 person-rem over the 
60-year plant life. The staff's ostimate is about 1 person-rem. The staff estimated that total risk is dominated by events that lead to early containment failure and containment bypass. This is consistent with results from PRAs for operating plants.
GE made a number of design modifications to the $A B W R$ both early in the design and later during the staff's reviow of the ABWR PRA that were motivated by the results of the PRA. Table 19.1-4 describes some of the modifications made to the design by GE.

Table 19.1-4 Examples of cost-effective PSA-inspired design/procedure modifications to the ABWR design

Area Modified

Modification

Core cooling systems

Reactivity control

Instrumentation

AC-independent water addition

(ACIWA) system

Combustion turbine

Lower drywell flooder (LDF)

Containment Overpressure Protection System (COPS)

Control for fourth SRV on remote shutdown panel

Water-level sensors, pump trip and valve isolation circuits

Containment concrete
GE found it only needed three, not four, ECCS divisions.

GE found alternate rod insertion reliability was such that less expensive ATWS mitigation system was acceptable.

GE found that it cnuld eliminate 60 percent of sensor instrumentation in the reactor safety systems without affecting plant safety.

System added to ABWR design. Staff believes that it is the most important system for helping to prevent severe accidents.

System added to ABWR design. In combination with ACIWA, it virtually eliminates SBO as a consideration.

System added to ABWR design. Floods lower drywell in event that vessel fails and corium enters lower drywell.

System added to ABWR design. If an accident occurs that pressurizes containment, the COPS allows for release of the pressure (90 psig set point) with the capability to reclose vent path.

Extra SRV control added based on ABWR fire analysis. Mitigates control room fire.

Pump trips added for floods in turbine and control building as well as valve isolation signals on high water level. Pipe length between first RSW isolation valve and control building limited to help assure pipe break will not cause unacceptable results.

Basaltic concrete used rather than limestone concrete to limit production of noncondensible gases from a core on floor event. 
GE and the staff have drawn a substantial number of significant safety insights from the ABWR PRA that have or will affect the design, construction, operation, maintenance, and regulation of the ABWR. These insights are discussed in more detail in Section 19.1.3 in the final safety evaluation report (FSER) and in Section 19.8 in the SSAR. Appendix 19K in the SSAR lists those SSCs that are to be included in a COL action item that lists proposed inputs for the COL applicant's operational reliability assurance process (O-RAP) and design reliability assurance program (DRAP) based on the ABWR PRA. Appendix $K$ in the FSER lists those safety insights that were motivated by the PRA. The disposition of these insights is documented in the appendix and indicates if the insights are in ITAAC, Tier 2 information, technical specifications (TS), COL action items, Interface Items, or RAP.

It is the staff's view that the mean core damage frequency for the ABWR from internal, external, and shutdown events is probably on the order of $1 E-6$ or less assuming the plant is constructed, maintained, and operated in accordance with the SSAR. This judgment is based on the staff's understanding of operating plant experience and PRA results, design improvements in the ABWR relative to operating reactors, and insights from the staff's review of the ABWR PRA. Furthermore, it should be emphasized that there are large uncertainties in internal event core damage frequency estimates. The external event analyses for the ABWR were quasi-probabilistic and were designed to uncover vulnerabilities in the design rather than generate specific core damage frequency estimates. Also, the shutdown risk evaluation was quasi-probabilistic, using PRA-based techniques to determine the reliability of shutdown cooling and to examine the possibility of determining plant configurations that would limit exposure to risk. The staff's review of the shutdown risk evaluation reflected the insight from provious PRAs that human orror was the greatest contributor to shutdown risk. However, human error analysis methods still cannot accurately predict human response to various circumstances. This fact increases the uncertainty of the estimated bottom-line core damage frequency numbers for shutdown events.

GE conducted uncertainty analyses for the Level 1 portion of the ABWR PRA. GE reported that the internal event core damage frequency distribution had a mean value of 1.6E-7 per year and an error factor (EF) of about 4.2 (where the EF is the ratio of the 95 th percentile to the median of the lognormal distribution). The 95th and Sth percentiles reported by GE were 4.5E-7 per year and 3.8E-8 per year, respectively. GE used a lognormal distribution for most random variables in the ABWR PRA, which is a mathematical simplification and assumption that is commonly used in PRA evaluations. The actual distribution for most variables is not known. Use of the lognormal distribution in lieu of the "actual" distribution adds an unquantifiable uncertainty to the evaluation, particularly in the bottom-line numbers.

GE performed importance analyses in order to determine the most important structures, systems, and components (SSCs) to be added to the RAP. GE used two importance measures: risk achievement worth ratio and fussell-vesely importance. The analysis identified scram function and its attendant equipment as very important. Station batteries are similarly important, since dc power controls the automatic depressurization system (ADS) as well as many pumps and valves. Another insight is the importance of reactor core isolation cooling (RCIC). This is because it is ac-independent, reliable, and provides high-pressure injection. These attributes are important for mitigating SBOs.

The probabilistic shutdown risk evaluation performed by GE concluded that the ABWR design could be maintained in configurations during Modes 3,4 , and 5 so that the estimated conditional core damage frequency was very low. The staff noted that estimates of core damage frequency and risk at shutdown for the $A B W R$ design have much larger uncertainties than do such estimates for internal events in Modes 1 and 2. In the SSAR, GE presented sample plant configurations that help limit risk when shutdown occurs. The staff finds that the ABWR design, through appropriate shutdown planning, contingency planning, and operator instrumentation, can be configured and maintained in Modes 3, 4, and 5 in a manner that helps to reduce the chances of core damage or releases to the environment to a point where shutdown risk does not represent a disproportionate risk to the public.

\subsubsection{Introduction}

As part of the ABWR design certification application, GE submitied the ABWR PRA in response to 10 CER 52.47, the Commission's Policy Statement on Severe Reactor Accidents Regarding Future Designs and Existing Plants, described in ER Vol. 50, No. 153, dated August 8, 1988, p. 32138 dated August 8, 1991, and the ABWR Licensing Review Bases. The staff's assessment included the traditional evaluation of events that could lead to core damage and offsite consequences as well as an evaluation of what the ABWR PRA revealed about the ABWR design.

The general objectives of the staff's review of the ABWR PRA were (a) to identify safety insights based on the performance of systematic risk-based evaluations of the ABWR design; (b) to determine in a quantitative manner whether the ABWR design represents a reduction in risk over existing plants; (c) to examine the balance of preventive and mitigative features of the design; (d) to 
assess the reasonableness of the risk estimates documented in the PRA and other risk-related documents submitted as part of the FDA application package, and (e) to support pre- and postcertification activities such as ITAAC, RAP, TS, and completion of site-specific design details (e.g., ultimate heat sink). In addition, the ABWR PRA was used to both determine how the ABWR design related to various safety goals and discover design and procedural vulnerabilities.

The objectives are drawn from 10 CFR 52.47, the Commission's Policy Statement on Severe Reactor Accidents Regarding Future Designs and Existing Plants, the Commission's Safety Goal Policy Statement, the Commission approved positions concerning the analyses of external events contained in SECY-93-087, and the Commission's interest in the use of PRA to belp improve future reactor designs. In general, these objectives have been achieved by the ABWR PRA and the staff's review. The staff's proposed applicable regulation for the analysis of external events for the ABWR PRA is as follows:

The application for design certification must contain a probabilistic risk assessment that includes an assessment of internal and external events. Simplified probabilistic methods and margins methods may be used to assess the capacity of the standard design to withstand the effects of external events such as fires and earthquakes. Seismic margin analysis must consider the effects of earthquakes with accelerations approximately one and two-thirds the acceleration of the safe-shutdown earthquake.

The staff believes that if its review were to concentrate on bottom-line numbers or merely on the quality of a PRA, the most important insights from a PRA could receive inadequate attention. In Section 19.1.3, the staff reported on its investigation of those safety insights that are revealed by the ABWR PRA about the ABWR design. These insights include those that are to be passed on to the COL applicant, insights into the balance of prevention and mitigation, design vulnerabilities, and aspects of the design that tend to reduce or exacerbate risk estimates. The results of this broadened perspective are multifold. GE's systematic evaluation of the ABWR design has accomplished the following:

- Identified important areas where minor design modifications will help confirm that the potential for severe accidents is maintained at a low level

- Helped GE to identify the most safety-important equipment to be included in the RAP
- Provided the COL applicant with information about what is most important about the ABWR design and operation from a safety standpoint

- Helped confirm for the staff that the ABWR design is robust against internal and external events.

GE provided a list of important safety insights from the ABWR PRA including internal and external events and events during all modes of operation. This list, which was developed from a systematic process, is described in detail in SSAR Section 19.9 and is detailed in Appendix $K$ in the FSER. As indicated in this table, GE recommended and staff agreed that a subset of these insights be included in the design control document (DCD) as ITAAC, Interface Items, or Tier 1 or Tier 2 material.

During the construction stage, the COL applicant will be able to consider as-built information. The staff concludes that updated PRA insights, if properly evaluated and utilized, could strengthen programs and activities in areas such as training, development of emergency operating procedures, reliability assurance, maintenance, and 10 CFR 50.59 evaluations. The staff recommends that the design-specific PRA developed to meet 10 CFR 52.47 be revised to account for site-specific information, as-built (plant-specific) information refinements in the level of design detail, and design changes. These updates are the responsibility of the COL applicant. As plant experience data accumulate, failure rates (taken from generic data bases) and human errors assumed in the design PRA are to be updated and incorporated, as appropriate, into ORAPs.

\subsubsection{Advanced Boiling Water Reactor Probabilistic Risk Assessment-Based Safety Insights}

Insights gleaned from a PRA can provide significant perception into the design and operation of a nuclear power plant. This section documents the insights derived by GE and the staff about the ABWR design based on the ABWR PRA.

\subsubsection{Technical Insights Summary}

In developing the $A B W R$ design, GE significantly reduced the dominant contributors to core damage frequency found in most current BWR plant-specific design PRAs. The success of this attempt is substantiated by the low estimated core damage frequency for internal events recorded in the ABWR PRA (1.6E-7 per year) and the staff's conclusion documented in Section 19.1.4 that, on balance, the ABWR PRA was performed in an acceptable manner. The estimated core damage frequency from internal floods is about 7E-9 per year. The fire analysis performed by GE for the ABWR produced a core damage 
frequency estimate of about 1E-6 per year. Because of conservatism in the analyses, the staff does not believe that the fire and internal flood core damage frequency estimates should be compared to those of internal events. The seismic analysis performed by GE was a PRA-based margins analysis that does not provide core damage frequency estimates. The margins analysis demonstrated that the ABWR design' is robust for seismic events well beyond the design basis. The staff finds that the ABWR design, if built, maintained, and operated as assumed in the ABWR PRA, represents a reduction in risk when compared to the current design of BWRs.

It is important to understand what contributes to core damage frequency and risk in the $A B W R$ design. Internal initiating events that are dominant contributors to core damage frequency include SBO, loss of offsite power, and vessel isolation or loss of feedwater. Failure of RCIC, the multiplexing transmission network, the station batteries, and the trip logic units are the most important contributing fuilures. SSAR Section 19K discusses the SSCs found to be most important in the PRA for internal and external events and when the plant is in modes other than full power. Table 19.1-2 provides a list of important sequences leading to core damage or risk for internal events. Table 19.1-3 provides a list for external events sequences.

For events occurring during modes other than full power, the ABWR design provides enhanced protection over the designs of many operating plants in that it has three fully separated safety divisions. To make use of this redundancy for maintenance purposes and still maintain an appropriate level of protection when in modes other than full power, GE has developed tables (See SSAR Tables 19Q.7-2 to $19 Q .7-4$ ) that list combinations of equipment that, if kept operable while in Modes 3, 4, and 5 , will help ensure that a severe accident does not occur. These tables have the goal of maintaining a conditional core damage frequency of less than 1E-5 per year should the operating train of RHR cooling become unavailable. Since GE assumed that a loss of RHR cooling (i.e., of the operating train) has an occurrence rate of once per 10 years (GE's assumption is that during a 10-year period with all its included shutdowns there will be one loss of shutdown cooling event -0.1 per year), this gives a frequency of core damage of less than 1E-6 per year when operating in Modes 3, 4, and 5. In the shutdown analysis, it is conservatively sssumed that all equipment not specifically referred to in the tables as "operable" is "inoperable." During shutdown, it is conservatively assumed that any core damage would result in a large release, since the containment would be open much of the time. The staff and GE noted that separation of safety divisions is not always maintained during maintenance outages. To help assure that fires and floods cannot become common cause failures of all three divisions when in modes other than full power, GE has developed guidelines for plant operation. These guidelines would have one division isolated and in standby, another division operating in the shutdown cooling mode but not necessarily isolated, and another in maintenance. The staff believes that a safety-oriented approach to planning and controlling an outage is needed and that such an approach will reduce risk during Modes 3, 4, and 5. It recommends that COL applicants make use of the guidance provided by $G E$ in Section $19 Q$ of the SSAR regarding outage planning and control.

For seismic events, fires, and internal floods, the ABWR design has specific advantages over many current designs. The seismic design bases for the ABWR is a $0.3 \mathrm{~g}$ SSE. In simple terms, the ABWR design can be built at any site that has its site-specific spectrum bounded by the design bases spectrum. Such a site might normally have an SSE of $0.2 g$ assigned to it. However, the ABWR will be built to the $0.3 \mathrm{~g}$ SSE standard, regardless. This creates an additional explicit seismic robustness at most potential sites east of the Rocky Mountains. For fires and internal floods, the existence of three separated safety divisions along with a diesel-driven fire water pump and an alternative water supply (that will remain functional following a design bases earthquake) external to the reactor building provide design improvements that significantly reduce potential core damage.

External events such as external flooding and hurricanes may be analyzed by a designer in a bounding manner in order to minimize the chances that the design has vulnerabilities to site-specific external events. GE did not chose to evaluate such external events at the Design Certification stage. The staff worked with GE to assure that GE was aware of the potential for vulnerabilities to such external events. It is possible that some sites may not be appropriate for the ABWR design because they could introduce vulnerabilities into the $A B W R$ design that were not taken into account in the Design Certification process. For each site, the COL applicant must provide a sitespecific PRA-based analysis to help determine if the ABWR design has any vulnerabilities to previously unanalyzed external events applicable to the site (e.g., river flooding or soil liquefaction from seismic events).

Human reliability analyses (HRAs) of the ABWR design show that it is not particularly sensitive to operator errors during operation in Modes 1 and 2. This is true, in part, because of the multitude of paths by which water can be provided to the core and the inherent attributes of the design (in most sequences of actions, it takes a long time before an operator needs to make a critical decision, if 
such a decision is neoded at all). GE conducted a sensitivity analysis to investigato the influence of variations in the PRA-modeled humin error rates of the ABWR core damage frequency estimate. The analysis suggests that, while there is little room for reducing core damage frequency by improving human performance, core damage frequency can increase if human performance significantly degrades. The potential increase in core damage frequency appears to be about two orders of magnitude above the base case frequency under an assumption that all human error probabilities are simultaneously increased by a factor of 30. However, such a magnitude of increase is unrealistic because the human error probabilities used in the ABWR human performance analyses were either screening values or reasonable values for the actions defined based on previous HRAs for existing PRAs. Even though some recovery actions (such as offsite power and emergency ac) were not included in this analysis, the results of the sensitivity analysis provide a proper indication of the ABWR tolerance of human errors.

Since the ABWR design was not detailed in a number of areas important to evaluating human actions and potential errors (e.g., control room design or plant-specific emergency procedures), GE's HRA was essentially a scoping analysis, based largely on a generalization of results from previous HRAs (which reflect conventional BWR human-machine interface desijns) and the use of screening-type human error probabilities collected from various sources. GE contends that this treatment is conservative for the ABWR because of the significant improvements envisioned for the ABWR human-machine interface design relative to earlier designs. However, the validity of the scoping analysis for the as-built $A B W R$ design will need to be confirmed as part of the implementation of the detailed control room design process. This process and associated ITAAC/DAC are described in Chapter 18 of this report. The focus of that effort with regard to the HRA will be on confirming that the final control room design has not introduced any human engineoring deficiencies that would significantly increase the error rates for human actions modelled in the HRA or the potential for additional, risk-significant errors not modelled in the HRA.

Every nuclear power plant PRA is incomplete to some extent. Ordinarily, a PRA is performed on a plant for which the site is known, the equipment has been procured, and the plant is nearly or completely built. For the ABWR PRA, the PRA practitioners had to develop their models using a design that lacks many of the details available for an existing plant. The lack of detail was recognized by the staff as well as by GE. For this reason, the staff developed several processes to which the COL applicant must comply, including (a) the ITAAC process, (b) the reliability assurance process and program (O-RAP and DRAP) that the COL applicant should implement to confirm that the as-built plant conforms to the assumptions of the ABWR PRA, and (c) interface items that the COL applicant must address in its application for a COL. To help confirm that the assumptions in the PRA are realized in the as-built design, GE provided a systematic list of SSCs that are to be included in the COL applicant's RAP, PRA-besed insights into the ITAAC, and a systematic list of safoty insights derived from the ABWR PRA that will be passed on to future COL applicants. One of the significant benefits of having a PRA at early stages in the design is that GE took advantage of PRA insights to improve the final design and provide guidance to $\mathrm{COL}$ applicants or holders.

Based on the information provided in the SSAR, this design has achieved a significant reduction in expected core damage frequency and risk compared to operating plant PRA results. The staff compared the numerical results of internal events in the ABWR PRA to the Commission's safety goals and found that the ABWR design meets each safety goal.

As part of its investigation of the ABWR design, the staff endeavored is determine if a balance had been achieved between the prevention of accidents and accident mitigation capabilities. The staff concludes that the design has an appropriate balance of prevention and mitigation. Details of this discussion are provided in Section 19.1.3.9.2 of this report.

GE searched for design and procedure improvements that were prudent to include in the ABWR. The staff concludes that the search made by GE was adequate to identify design and procedure vulnerabilities for the ABWR design. Details of the design improvements motivated by the ABWR PRA are discussed in Section 19.1.3.2.3 of this report.

The staff believes that the ABWR PRA is capable of supporting pre- and post- certification activities such as ITAAC, RAP, and TS. The PRA can be modified to include site-specific design details for areas outside the design certification such as the ultimate heat sink.

\subsubsection{Level 1 - Internal Events}

\subsection{Dominant Accident Sequences}

GE estimated the total core damage frequency from internal events for the ABWR design to be 1.6E-7 per year. The internal events initiators that contribute the most to core damage frequency are loss of offsite power, SBO, and loss of feedwater/isolation of the vessel (See 
Table 19.1-1). Of theee, SBO is the largest contributor to coro damage frequency. This is consistent with risk profile estimates for many other BWR PRAs that have identified SBO as one of, if not the leading, contributor to core damage frequency. For the ABWR, SBO and loss of offsite power sequences have an estimated core damage frequency of about 1E-7 per year.

The top soven sequences that in aggregate contribute 52 percent of the internal event core damage frequency are SBO events in which RCIC fails or is unavailable or where the blackout outlasts the capacity of the emergency batteries. Of the top 20 sequences, 14 involve SBO. The reason SBO events in the ABWR have very low estimated absolute core damage frequency value is the low overall core damage frequency estimate for the ABWR design. This is primarily because the ABWR design has three independent EDGs and because of the addition of the onsite CTG. With respect to SBO events, the staff noted that the removal of a steam-driven high-pressure system (such as the high- pressure core injection system (HPCI) in earlier designs) is well compensated for by a substantial improvement in the reliability of backup power resulting from the addition of a CTG in the ABWR design.

Anticipated transients without scrum (ATWS) has a very low absolute value for the $A B W / R$ design for several reasons, including the following: (1) the ABWR design has diverse means of inserting control rods into the core (by hydraulic or electric means), (2) initiation of the standby liquid control system (SLCS) is automated, (3) the hydraulic system that inserts control rods includes additional backup scram valves to relieve scram air header pressure, and (4) the ABWR design does not have a scram discharge volume.

\subsection{PRA as a Design Tool}

The ABWR design was influenced by PRA insights. Table 19.1-4 summarizes design changes that GE made to the ABWR that were motivated by PRA insights. GE used PRA insights and mini-PRA studies to help decide on a number of important design options. The performance of the ABWR PRA and several mini-PRAs early in the ABWR design process made important contributions to improving the ABWR design. The PRA influenced the design positively, not only early in the design process, but also during the design certification.

GE indicated that the use of PRA evaluations in the early stages of the $A B W R$ design helped $G E$ to simplify the design in a manner that maintains or improves core damage frequency estimates compared to estimates for operating plants. Examples of the design simplification by GE include the following:
- The reduction in the number of emergency core cooling systom (ECCS) divisions from four to three by upgrading the RCIC system and by modifying the automatic depressurization system (ADS) logic to begin operation when a low water level is reached (improved design for transient response)

- The elimination of 60 percent of the sensor instrumentation in the reactor safety systems without its affecting plant safety.

In its initial ABWR PRA submittal, GE concluded that the Commission's safety goals and goals proposed by EPRI for evolutionary reactors (core damage frequency, CCFP, and dose at the boundary of the plant following an accident) were met and that the design had many means of severe accident prevention and mitigation. After discussions with the staff and in order to come to more complete agreement with EPRI evolutionary plant design guidelines, GE decided to make several design improvements that significantly added to defense in depth and reduced uncertainty that the design would moet its intended goals. GE made the following design changes:

- Added an AC-independent water addition (ACIWA) system. This system provided benefits for SBO, fires, internal floods, and seismic events. It has both preventative and mitigative capabilities in that it can either inject to the vessel or spray the drywell. It can provide water from a seismically robust diesel-driven pump or a fire truck.

- Added a non-safety grade combustion turbine generator that starts automatically with safety grade loads added manually. This system used in conjunction with the ACIWA system significantly reduces the estimated core damage frequency from SBO.

- Made recommendations for the improvement of emergency procedures following examination of the dominant severe accident sequences.

- Changed the lower drywell basemat concrete composition from limestone to basaltic concrete to limit production of noncondensible gases.

- Added a containment overpressure protection system (COPS).

- Increased the pressure capacity of the drywell head.

- Surveillance testing of the microprocessor-based controllers was increased to quarterly to improve the ability to detect failures left undetected by the continuous self-test feature. This action was taken 
based on a study of potential failures of the safoty system logic and control.

\subsection{Plant Features and Operator Actions Important to Risk}

Insights as to what features, procedures, or operator actions are important to risk have been gathered from soveral areas of Chapter 19 of the SSAR, including Appendices 19K, 19L, 19M, 19Q, and 19R as well as from discussions with $G E$. The staff considers the following plant features, procedures, and operator actions to be the most important to risk reduction or prevention for Lovel 1 internal events.

\section{Plant Fearures Important to Risk}

Combustion Gas Turbine Generator - The combustion gas turbine generator (CTG) provides non-safety grado power that is diverse and independent from the normal and emergency ac power sources. It is capable of providing ac power to any of the three safety divisions or to a condensate pump. The CTG requires no plant support systerns to start or run. The gas turbine, in conjunction with the ACIWA system, is a significant factor in reducing the likelibood of an SBO (a leading contributor to core damage).

ACIWA System - The ACIWA system has two pumping sources available: a diesel-driven pump and a fire truck. The diesel-driven pump is designed to survive a design bases earthquake. Its pumping sources are located outside the reactor building. Manual valves to direct the flow from the ACIWA system into the RHR system and then on to either the core or to the drywell or wetwell spray are located in the reactor building and can be operated successfully following an internal event.

Lack of Recirculation Piping - The ABWR design has done away with external reactor recirculation piping and pumps. This means that there are no large pipes that penetrate the vessel below the core. This design detail has significantly reduced the already low chances of a loss-ofcoolant accident (LOCA) leading to core damage.

Three ECCS Trains - The redundancy of the divisions improves the chances of the design preventing transients from developing into core damage events.

Reactor Core Isolation Cooling (RCIC) - RCIC is a safety-grade system that provides the ABWR with a diverse high-pressure system that can delay the onset of core damage following an SBO event to about 8 hours. Importance analyses from the ABWR PRA indicate that
RCIC is one of the most important systems in proventing core damage accidents.

Multiplexing Systom - The high reliability of the multiplexing system is very important in the ABWR PRA. Significant degradation of this function could result in a largo increase in the likelihood of the plant's having an event that leads to core damage.

High-pressure Core Flooder (HPCF) Pump - One of the high-pressure core flood pumps can be operated independently of the essential multiplexing system. This design feature is an important factor in reducing the chances of the plant experiencing core damage, since this design should reduce the chance of a common cause control system failure, that would disable all ECCS pumps.

Electrically Driven Control Rod Insertion - The diverse ability to drive in rods with electrical motive power as well as hydraulic power significantly reduces the chances of an ATWS occurring.

Automatic Depressurization System - The ADS is needed to enable the use of low-pressure core flooder pumps and the ACIWA system. ADS is important in SBO, small LOCAs, and transients.

Reactor Water Cleanup (RWCU) Isolation Valves - The isolation valves in the RWCU system must be capable of isolating against a differential pressure equal to the operating pressure of the reactor coolant system (RCS) in the event that there is a LOCA in the RWCU.

\section{Operator Actions Important to Risk}

- Five specific human actions have been identified as most important to the Level 1 PRA analysis because of their impact on core damage frequency. All five of these relate to makeup of reactor inventory - the first four with the reactor at high pressure and the last with the reactor at low pressure (the acronyms in parentheses correspond to the basic event identifier in the ABWR PRA):

- Backup manual initiation of HPCF (HOOBOPHL)

- Recovery of feedwater in events without MSIV closure (Q)

- Recovery of feedwater in ovents with MSIV closure (Q2)

- Reopening of HPCF injection valves following maintenance (HBMAER1) 
- Une of condensato injection following ecram with reactor depreasurized (COND).

A sixth humen setion - control of reactor water lovel in an ATWS (LPL) - was also identified as critical to the Lovel 1 analysis based on its impact on offsite consequences rather than on its impact on core damage frequency. Because of their importance, these human actions are included as "critical tasks" that will be ovaluated further by the COL applicant as part of the advanced plant design (seo SSAR Section 19.9).

- Although miscalibration of sensors is not a significant contributor to core damage frequency (partly because of the low assigned probabilities), instrument calibration is an important maintenance action requiring that a special maintenance procedure be developed by the COL applicant.

- A limited number of human actions were identified as having a significant impact on containment performance and the results of the Level 2 analysis. These involve the following:

- Emergency depressurization of the reactor to mitigate core damage in-vessel and reduce the potential for containment failure from direct containment beating (OP)

- Alignment and initiation of firewater (ACIWA mode of RHR) for injection into the depressurized reactor pressure vessel (ARV)

- Alignment and initiation of firewater for injection to the drywell sprays to prevent drywell overtemperature (HTF)

- Initiation of drywell sprays in response to suppression pool bypass

- Use of a fire truck as a backup to the diesel-driven firewater pump.

Because of their importance, the actions are included in COL Action Items (See SSAR Section 19.9). Some of these actions would also be addressed by the COL applicant as part of its Accident Management Program discussed in Section 19.2.

Appendix 19K in the FSER lists those PRA-based safety insights motivated by the PRA. The disposition of these insights is documented in the table and indicates if the insights are in ITAAC, Tier 2 information, TS, COL action items, Interface Items, or the RAP.

\subsection{Interface and COL Applicant Action Items}

The Design Cortification Rule 10 CFR Part 52 does not requiro vendor to provide complete design details, eopecially in areas where there is evolving technology (e.8., the control room) or where it is very difficult to bound the possible design options (e.8., the ultimate heat sink and the service water pump house). Other areas such as accident management are the responsibility of the COL applicant. OE identified Interface Itoms (hardware) and COL Action Itoms (primarily procedural or analytical) that define the areas dorived from performance of the ABWR PRA that the COL applicant needs to perform or complete. The following COL action item addressed in Section 19.9 in the SSAR is of particular interest to the staff:

- The COL applicant should update the design-specific ABWR PRA to include site-specific information (i.e., a site-specific PKA) and additional design details (0.8., once the COL applicant designs the structures, systems, and components that were not part of the design certification). The PRA is to be maintained by the COL holder (living PRA) so that the PRA can be useful in helping to make 50.59-like decisions as well as belping to determine the safety significance of operational events or data from ABWR operation or other nuclear power plants.

These actions are cetailed in Section 19.9 and Table 1.9.1 in the SSAR. The staff finds the Interface Items in Section 1.9 in the SSAR to be adequate for performing the $A B W R$ design-specific PRA. The staff finds the COL action items in Section 19.9 of the SSAR to be acceptable and finds that GE identified those actions that the COL applicant must take in order to help make the PRA assumptions come true in the as-built, as-operated plant.

\subsection{Insights From Uncertainty, Importance, and Sensitivity Analyses}

GE has conducted a traditional uncertainty analyses for the Level 1 portion of the ABWR PRA. GE calculated importance analyses in order to determine the most important SSCs to be added to the RAP. GE also conducted selected sensitivity analyses to determine the robustness of the design to biases in numerical assumptions.

The uncertainty analyses started with GE's assuming that all basic events (in the fault trees) have lognormal distributions. These distributions were propagated using Monte Carlo techniques. As shown in Figure 19.1-1, the core damage frequency distribution had a mean value of 1.6E-7 per year and an error factor (EF) of about 4.2 

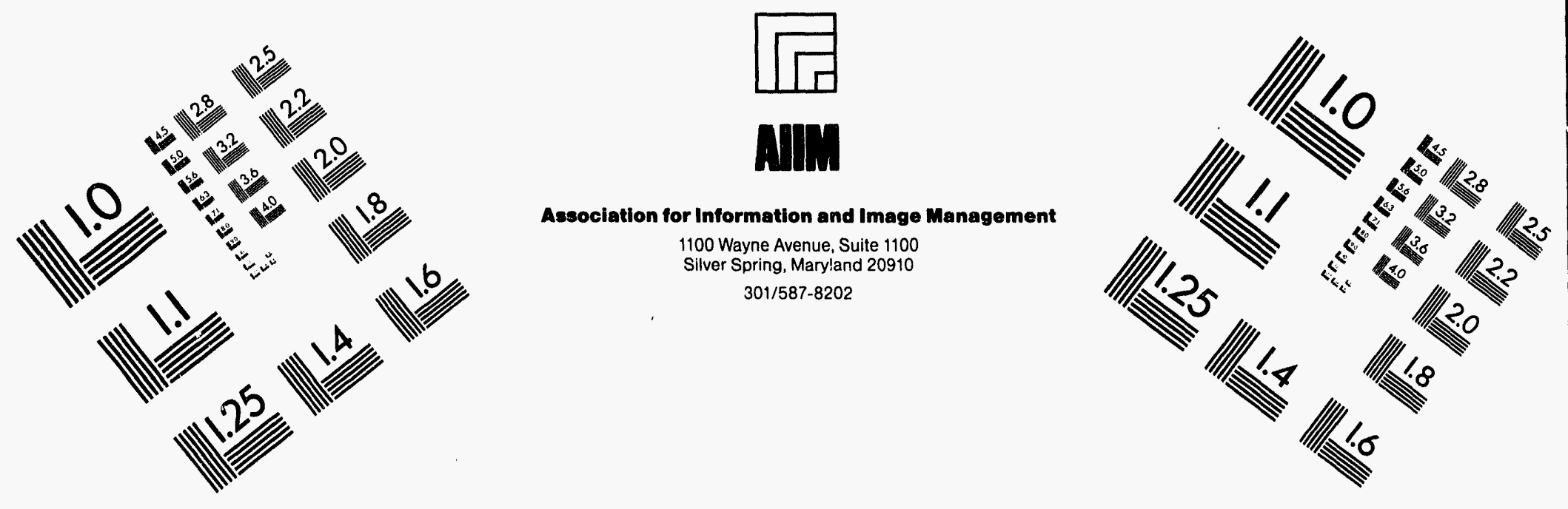

\section{Centimeter}

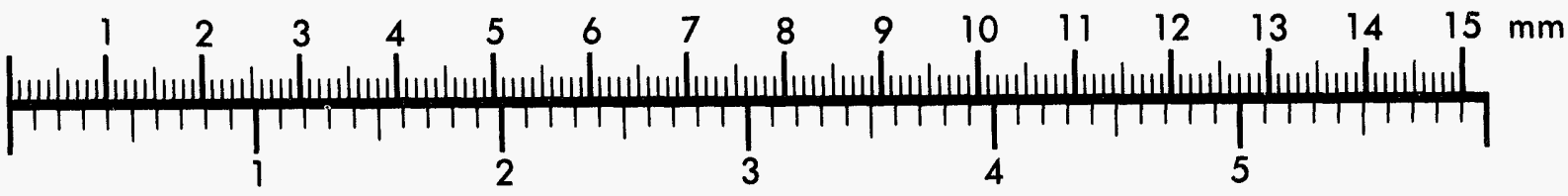
Inches
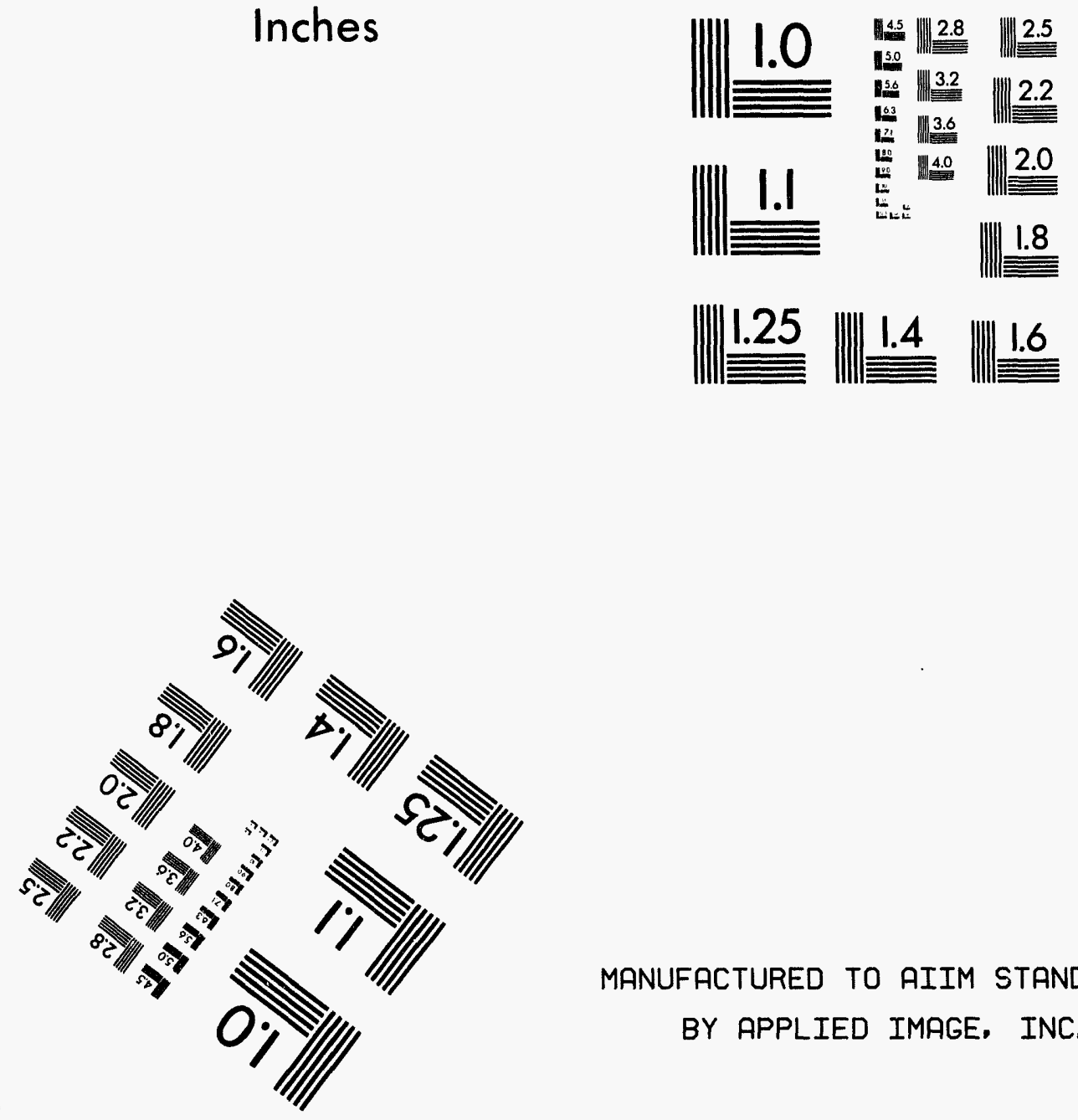

MANUFACTURED TO AIIM STANDARDS

BY APPLIED IMAGE, INC.

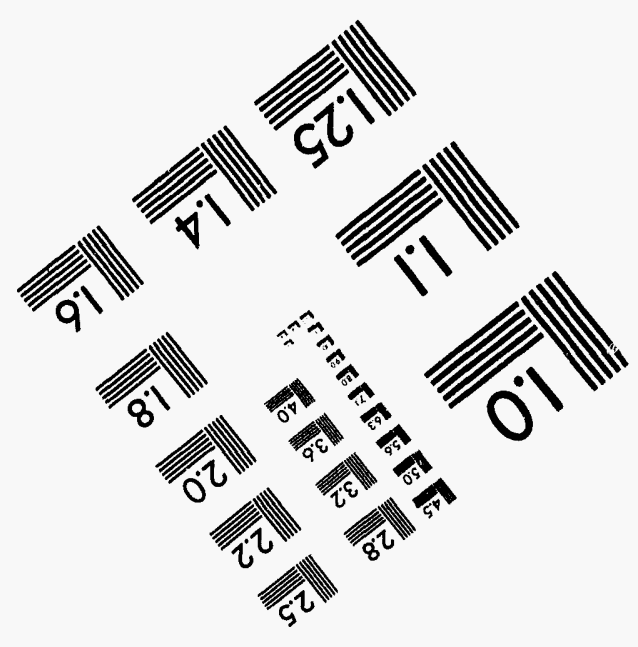




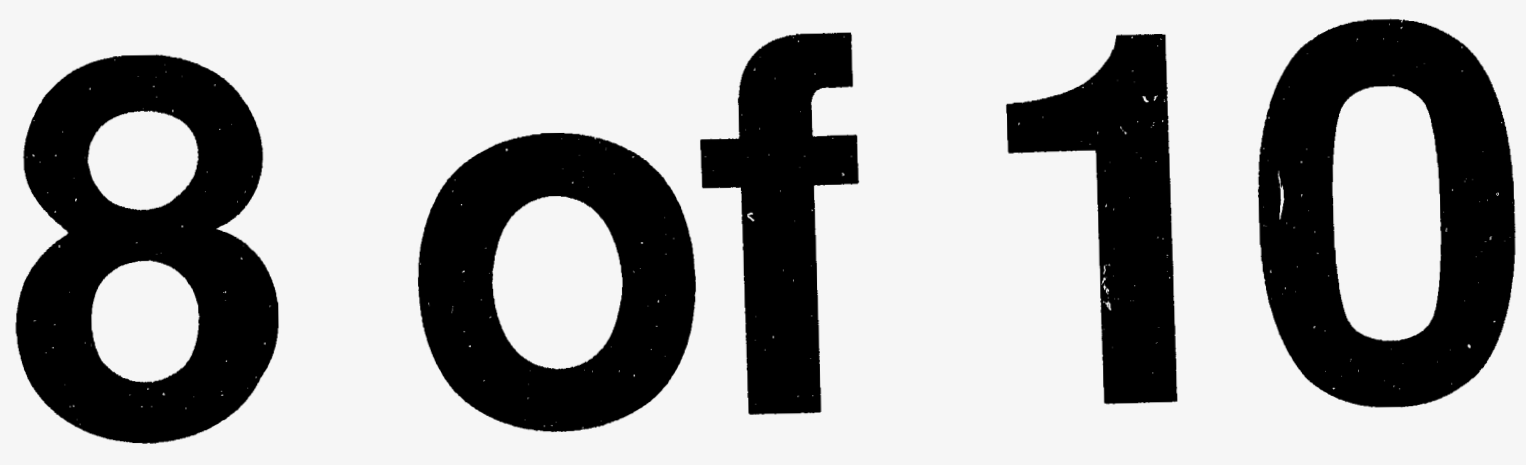


(where the EF is the ratio of the 95th percentilo to the median of the lognormal distribution). The 95th and Sth percentiles reported by GE were 4.5E-7 per year and 3.8E-8 per year, respectively.

The uncertainty studies revealed that the majority of baxic events that were part of the dominant core damage sequences (i.e., involved in the failure of SSCs needed to prevent core damage) were also identified by the importance analyses as the top contributors to core damage frequency. Similarly, the relative importance of the topranked sequences and top-ranked basic ovents was shown to change only slightly when the input data were biased by a fector of two.

GE performod importance analyses on internal events using "change in core damage" as the underlying variable. GE used the importance analyses reoults to help determine SSCs to be included in Appendix 19K of the SSAR that deals with SSCs that are to be included in the COL applicant's RAPs. GE used two importance measures: rick achievernent worth ratio and fussell-vesely importance. The rick achiovement worth ratio is calculated by taking the ratio of (a) the core damage frequency with the particular SSC always failed to (b) the base core damage frequency. Rick achievement identifies those SSCs for which it is particularly important to do good maintenance, since poor reliability or availability of this equipment would increase estimated core damage frequency significantly. The Fussell-Vesely importance mensure is calculated by (a) finding the difference between the base case core damage frequency and the core damage frequency with the SSCs operating perfectly, and (b) dividing by the base case core damage frequency. The Fuseoll-Vesely importance measure identifies which SSCs would benefit the most from improved testing and maintenance that would minimize equipment unavailability and failures. The staff believes that the risk achievement worth is a particularly important measure when deciding which SSCs to include in a RAP.

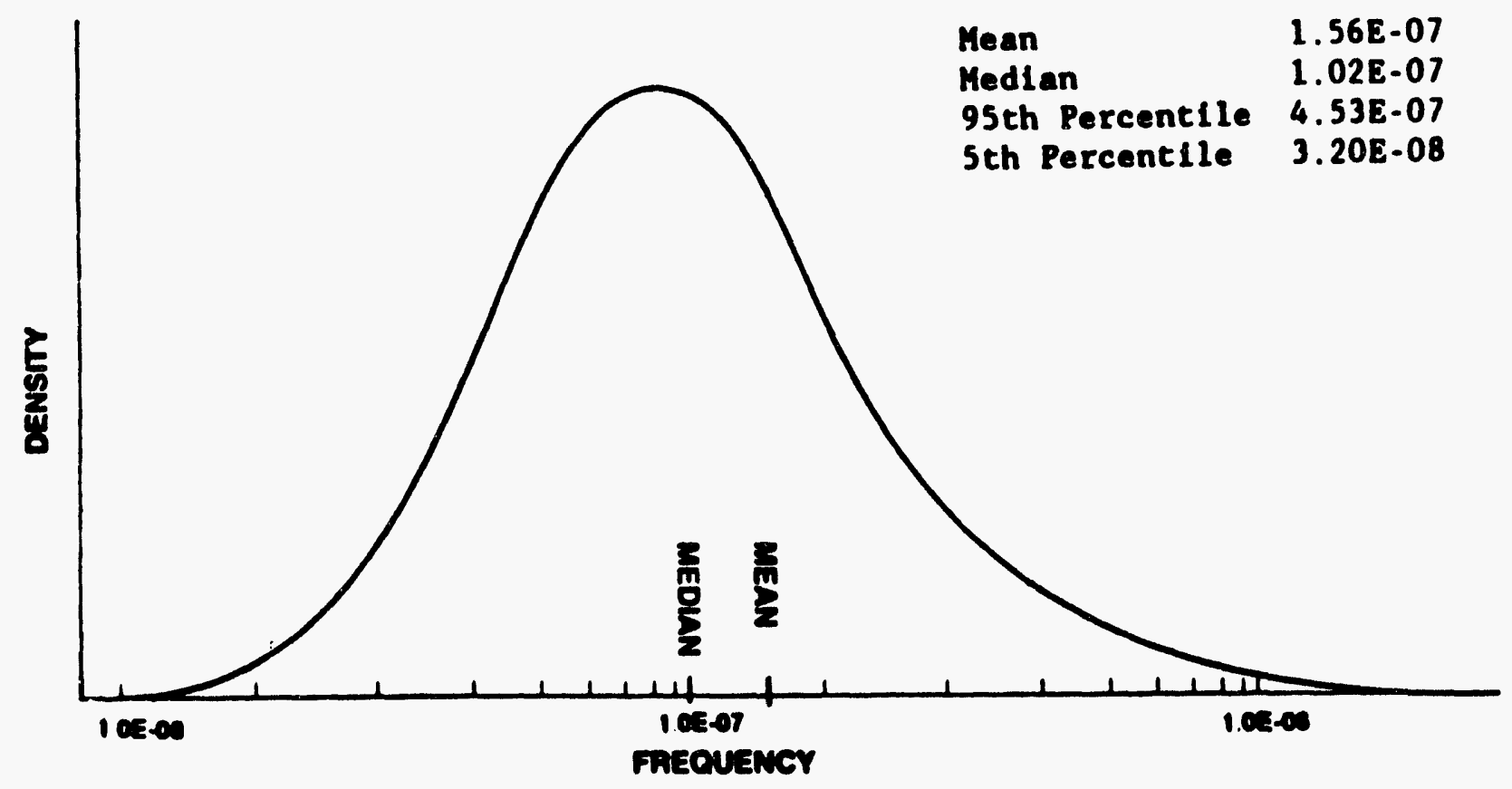

Figure 19.1-1 ABWR core damage frequency distribution 
Table 19.1-5 in this report provides a listing of the most important SSCs and their importance. The table highlights the importance of the scram function and its attendant equipment. Similarly important are the station batteries, since dc power controls ADS as well as many pumps and valves. The table also points out the importance of the CTG and RCIC. This is because SBO is the largest contributor to internal event core damage frequency estimates.

Table 19.1-6 in this report shows the sensitivity of core damage frequency to test and maintenance outage assumptions for ECCS equipment. Increasing RCIC unavailability was found to cause the greatest increase in estimated core damage frequency. This results in large part from RCIC's contribution to mitigation of SBO sequences. This outcome supports the results of importance analyses discussed above. GE found that increasing high-pressure core flooder B (HPCFB) unavailability resulted in the second highest core damage frequency increase. This is because HPCFB is important in mitigating a common-cause failure of the essential multiplexing system.

GE performed a sensitivity study on the effect of increasing the test and maintenance outage times for ECCS equipment (i.e., the period each piece of ECCS equipment is assumed to bo unavailable during the year because of testing or maintenance). RCIC was found to be the ECCS system most sensitive to increased outage time. This would be expected based on the Fussell-Vesely importance measure results. Second in importance is high-pressure core flooder " $B$ " that includes a diverse (resulting from the multiplexing system), hard-wired manual-initiation backup in the control room. The sensitivity study indicated that other individual systems are not sensitive to test and maintenance outage time. GE noted that even with RCIC out of service all the time, the ABWR core damage frequency estimate is still below $1 E-5$ per year. It should be noted that the CTG and the EDGs have the largest Fussell-Vesely importance measure value, since 100-percent availability of the CTG or an EDG would eliminate SBO as an estimated core damage contributor.

\subsubsection{Level 1 - External Events}

Three external events were analyzed in the ABWR PRA: seismic, fire, and internal flood. In many PRAs performed to date, these external events have had combined core damage frequencies that are the same magnitude as internal events. It is not unusual to see the combined core damage frequencies for these events in the area of 1E-4 per year. The varying methods used in the ABWR PRA to evaluate external events are acceptablo to the staff because they provide the insights necessary to determine if any design or procedural vulnerabilities exist for these external events and because the methods provide insights needed for the RAP, ITAAC, TS, and other important programs.

To help confirm that no vulnerabilities are introduced when a site is chosen for an ABWR (e.g., site-specific external floods can flood higher than assumed in the design basis so a vulnerability, such as an external, nonwatertight door, could exist), the following steps need to be taken. The staff requires COL applicants to perform a sitospecific PRA-based analysis that searches for vulnerabilities from site-specific external events not evaluated in the ABWR PRA and that are not enveloped by the ABWR PRA assumptions (e.g., seismic-induced soil liquefaction). This PRA-based analyses must also search for vulnerabilities in the parts of the ABWR design that were not part of the design certification (e.g., the service water pump house).

The ACIWA system is very important to preventing and mitigating severe accident external events. GE and the staff understand the importance of the ACIWA system being able to function following various external initiators. For this reason, GE developed a COL action item (detailed in Section 19.9 and Table 1.9 in the SSAR) that outlines the following:

- The COL applicant should design the building to house the ac-independent water addition (ACIWA) pumps in such a manner that the building is capable of withstanding high seismic events, river flooding, and other site-specific external events such as high winds (e.g., hurricanes). The capability of the building housing the ACIWA pumps should be evaluated in the site-specific PRA to assure that vulnerabilities do not exist for the specific site.

\subsection{Seismic Events}

A PRA-based margins analysis systematically evaluates the capability of SSCs in the design to withstand an earthquake, but does not estimate the core damage frequency from seismic events. The margins analysis is a way of estimating how much larger an earthquake than the SSE the design should be able to withstand without sustaining core damage. 
Table 19.1-5 SSCs identified by importance measure values

\begin{tabular}{|c|c|c|}
\hline Structure, System, or Component (SSC) & $\begin{array}{c}\text { Risk } \\
\begin{array}{c}\text { Achievement } \\
\text { Worth }\end{array} \\
\end{array}$ & $\begin{array}{c}\text { Fussell-Vesely } \\
\text { Importance } \\
\text { Meesure (\%) }\end{array}$ \\
\hline Multiplex Transmission Network (CCF) & 204,400 & 12.1 \\
\hline Trip Logic Units & 204,300 & 6.0 \\
\hline Remote Multiplexing Units & 204,300 & 6.0 \\
\hline Station Batteries & 13,160 & 3.3 \\
\hline Digital Trip Modules (CCF) & 281 & 0.1 \\
\hline Level 2 Sensors (CCF) & 273 & 0.1 \\
\hline SRV (CCF) & 189 & 0.1 \\
\hline RHR Flow Transmitters (CCF Miscalibration & 32 & 0.2 \\
\hline Level 8 Sensors (CCF Miscalibration) & 28 & 0.1 \\
\hline Combustion Turbine Generator (CTG) & 14 & 69.6 \\
\hline Both Offsite Power Sources & 14 & 1.3 \\
\hline Division 1 Transmission Network Failure (EMS) & 13 & 0.70 \\
\hline 1st ESF RMU Division 1 Fails & 13 & 0.34 \\
\hline 2nd ESF RMU Division 1 Fails & 13 & 0.34 \\
\hline RCIC Turbine & 12 & 12.0 \\
\hline RCIC Pump & 12 & 7.4 \\
\hline RCIC System (Unavailable, Test or Maintenance) & 12 & 21.8 \\
\hline RCIC Flow Sensor E51-FT007-2 Fails & 12 & 0.32 \\
\hline RCIC Isolation Valve F036 Fails (NOFC) & 12 & 0.18 \\
\hline RCIC Isolation Valve F035 Fails (NOFC) & 12 & 0.18 \\
\hline RCIC Isolation Valve F039 Fails (NOFC) & 12 & 0.18 \\
\hline RCIC Check Valve E51-F003 Fails to Open & 12 & 0.15 \\
\hline RCIC Check Valve F038 Fails to Open & 12 & 0.15 \\
\hline RCIC Outboard Check Valve F005 Fails to Open & 12 & 0.15 \\
\hline NBS Isolation Check Valve B21-F003B (FW Isolation) Fails Closed & 12 & 0.15 \\
\hline NBS Isolation Check Valve B21-F004B (FW Isolation) Fails Closed & 12 & 0.15 \\
\hline NBS Manual Valve B21-F005B (FW Isolation) Fails Closed (NOFC) & 12 & 0.14 \\
\hline RCIC Pres Sensor PIS-Z605 Miscalibrated & 12 & 0.054 \\
\hline RCIC Flow Sensor FT-007-2 Miscalibrated & 12 & 0.054 \\
\hline RCIC Pressure Sensor E51-PIS-Z605 Fails & 12 & 0.013 \\
\hline Failure of Division I Distribution Panel & 12 & 0.0064 \\
\hline SLU/EMS Link for Division I SLU I Fails (RCIC Fails) & 12 & 0.00046 \\
\hline SLU/EMS Link for Division I SLU 2 Fails (RCIC Fails) & 12 & 0.00046 \\
\hline RCIC Turbine Exhaust Isolation Valve F039 Limit Switch Fails & 12 & 0.74 \\
\hline RCIC Steam Supply Bypass Valve F045 Limit Switch Fails & 12 & 0.74 \\
\hline RCIC Turbine Lubrication System & 12 & 4.6 \\
\hline RCIC Min. Flow Bypass Valve E51-F011 (NOFO) & 12 & 2.0 \\
\hline RCIC Min. Flow Bypass Valve E51-F011 (NCFC) & 12 & 1.9 \\
\hline RCIC Injection Valve E51-F004 (NCFC) & 12 & 1.9 \\
\hline RCIC Steam Supply Valve E51-F037 (NCFC) & 12 & 1.9 \\
\hline RCIC Isolation Signal Logic & 12 & 1.5 \\
\hline All 3 Diesel Generators, CCF & 11 & unknown \\
\hline SP Temp High (Loss of Pump Head) & 6.6 & 0.00055 \\
\hline SRVs & 4.3 & 1.0 \\
\hline Single Offsite Power Line & 4.1 & 3.1 \\
\hline HPCF Maintenance Valve E22-F005B & 2.7 & 1.7 \\
\hline HPCF Pump & 2.6 & 1.1 \\
\hline
\end{tabular}


Table 19.1-6 Sensitivity to test or maintenance (T/M) outages

Single system perturbations (factor of five) to base case $T / M$ of two percent unavailability

\begin{tabular}{|l|r|r|r|r|r|r|r|}
\hline \multicolumn{1}{|c|}{ System } & & & & & & & \\
\hline RCIC & 0.02 & 0.1 & 0.02 & 0.02 & 0.02 & 0.02 & 0.02 \\
\hline HPCFB & 0.02 & 0.02 & 0.1 & 0.02 & 0.02 & 0.02 & 0.02 \\
\hline HPCFC & 0.02 & 0.02 & 0.02 & 0.1 & 0.02 & 0.02 & 0.02 \\
\hline RJRA & 0.02 & 0.02 & 0.02 & 0.02 & 0.1 & 0.02 & 0.02 \\
\hline RHRB & 0.02 & 0.02 & 0.02 & 0.02 & 0.02 & 0.1 & 0.02 \\
\hline RHRC & 0.02 & 0.02 & 0.02 & 0.02 & 0.02 & 0.02 & 0.1 \\
\hline Core Damage Frequency & $1.6 \mathrm{E}-7$ & $2.9 \mathrm{E}-7$ & $1.8 \mathrm{E}-7$ & $1.6 \mathrm{E}-7$ & $1.6 \mathrm{E}-7$ & $1.6 \mathrm{E}-7$ & $1.6 \mathrm{E}-7$ \\
\hline Percent Increase & N.A. & 86 & 13 & $<1$ & $<1$ & $<1$ & $<1$ \\
\hline
\end{tabular}

- Unavailabilities in bold type represent perturbations to the base case in the first column.

Effect of single systems completely removed from service

\begin{tabular}{||l|r|r|r|r|r|r|r||}
\hline System & & & & & & \\
\hline RCIC & 0.02 & 1.0 & 0.02 & 0.02 & 0.02 & 0.02 & 0.02 \\
\hline HCPFB & 0.02 & 0.02 & 1.0 & 0.02 & 0.02 & 0.02 & 0.02 \\
\hline HPCFC & 0.02 & 0.02 & 0.02 & 1.0 & 0.02 & 0.02 & 0.02 \\
\hline RHRA & 0.02 & 0.02 & 0.02 & 0.02 & 1.0 & 0.02 & 0.02 \\
\hline RHRB & 0.02 & 0.02 & 0.02 & 0.02 & 0.02 & 1.0 & 0.02 \\
\hline RHRC & 0.02 & 0.02 & 0.02 & 0.02 & 0.02 & 0.02 & 1.0 \\
\hline Core Damage Frequency & $1.6 \mathrm{E}-7$ & $1.8 \mathrm{E}-6$ & $4.1 \mathrm{E}-7$ & $1.6 \mathrm{E}-7$ & $1.6 \mathrm{E}-7$ & $1.6 \mathrm{E}-7$ & $1.6 \mathrm{E}-7$ \\
\hline Percent Increase & N/A & 1073 & 162 & 4 & 5 & 2 & $<1$ \\
\hline
\end{tabular}

- Unavailabilities in bold type represent single systems that have been removed from service. 
Table 19.1-6 Sensitivity to test or maintenance (T/M) outages (continued)

Multiple system perturbations (factor of five) to base case

\begin{tabular}{|c|c|c|c|c|c|c|c|}
\hline System & & & & & & & \\
\hline RCIC & $0.1^{*}$ & 0.02 & 0.02 & 0.1 & 0.02 & 0.1 & 0.1 \\
\hline HPCFB & 0.02 & 0.1 & 0.02 & 0.1 & 0.1 & 0.1 & 0.1 \\
\hline HPCFC & 0.02 & 0.02 & 0.1 & 0.02 & 0.1 & 0.1 & 0.1 \\
\hline RHRA & 0.1 & 0.02 & 0.02 & 0.02 & 0.02 & 0.02 & 0.1 \\
\hline RHRB & 0.02 & 0.1 & 0.02 & 0.02 & 0.02 & 0.02 & 0.1 \\
\hline RHRC & 0.02 & 0.02 & 0.1 & 0.02 & 0.02 & 0.02 & 0.1 \\
\hline Core Damage Frequency & $2.9 \mathrm{E}-7$ & $1.8 \mathrm{E}-7$ & $1.6 \mathrm{E}-7$ & 3.1E-7 & $1.8 \mathrm{E}-7$ & $3.2 \mathrm{E}-7$ & $3.2 \mathrm{E}-7$ \\
\hline Percent Increase & 88 & 14 & $<1$ & 101 & 13 & 102 & 104 \\
\hline
\end{tabular}

- Unavailabilities in bold type represent perturbations to a base case value of 0.02 .

The capability of a particular SSC to withstand beyond design bases earthquakes is measured in terms of an HCLPF given a certain input acceleration. The HCLPF has units of acceleration. An HCLPF value represents the acceleration that approximates the concept of having about 95 percent confidence that the SSC will fail less than about 5 percent of the time. The ABWR is designed to withstand a $0.3 \mathrm{~g}$ SSE. Since the analysis used in evaluating the capability of SSCs to withstand the SSE has significant margin in it, the staff expects that a plant built to withstand a $0.3 \mathrm{~g}$ SSE actually will be able to withstand a much larger earthquake. The staff indicated that it expects that a plant truly designed to withstand a 0.38 SSE should have a plant HCLPF at least 1.67 times the SSE. In SSAR Section 19H.5, GE provided a COL action item to assess how the as-built facility corresponds to the assumptions in the seismic margins analysis. As discussed below, the ABWR design as analyzed meets the 1.67 times the SSE expectation. Thus, GE and the staff believe that the ABWR can be designed and built in a reasonable, costeffective manner to achieve a plant HCLPF of $0.5 g$ or higher. The staff notes that the ABWR seismic margins analysis assumes that no soil liquefaction will occur (regardiess of the g-level) or that liquefaction would not affect the plant HCLPF. COL applicants will need to confirm (with their site-specific seismic risk assessment) that soil liquefaction does not introduce any vulnerabilities. The staff finds this acceptable.

\subsection{Dominant Accident Sequences}

In the PRA-based margins method, the event trees and fault trees for internal events are modified to accommodate seismic events. In this way, the random failures and human errors modeled in the internal events portion of the PRA are captured in the seismic analysis.

In Table 19.1-7 in this report, 25 sequences are identified that lead to core damage in the ABWR PRA-based seismic margins analysis, listed by plant danage class. The first HCLPF value given for each sequence is the HCLPF assuming that only seismic failures can occur (i.e., without any random failures or human errors). Additional HCLPF entries under a sequence include various combinations of random failures and human errors. The underlying assumption that earthquakes exceeding the SSE will happen less frequently than once in a 1,000 years allows us to exclude random failures or human errors less than 1E-3. This is because the combination of seismic events more than 1.67 times the SSE with random failures lower than 1E-3 would result in core damage frequency estimates much less than 1E-6 per year. We also exclude seismicrandom combinations where the seismic portion has an HCLPF at least as high as the seismic-only HCLPF.

Further details are provided in Table 19.1-8 in this report, which provides the "dominant" cut sets for each plant damage state. The word "dominant" appears in quotes to emphasize that the use of this terminology in the context of a margins study should not be taken in the same way as it would be for a conventional PRA. While these sequences and cut sets dominate the HCLPF values for the plant, the margins approach does not permit a determination that these are the dominant contributors to seismic risk in a probabilistic sense. 
Severe Accidents

Table 19.1-7 Results of GE HCLPF quantification using the MIN/MAX approach (by plant damage class)

\begin{tabular}{|c|c|c|c|c|}
\hline \%orp & $8 \%$ & 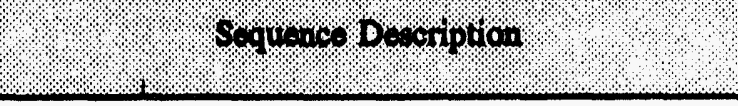 & $\begin{array}{l}\text { Soismis: } \\
\text { HCLPF }\end{array}$ & $\begin{array}{l}\text { Seismich Rerilom } \\
\text { HCLPF }\end{array}$ \\
\hline \multirow[t]{6}{*}{14} & 5 & ISI*LOP*APW*/DP*/C*/UR*X*/HX & $0.74 \mathrm{~g}$ & None \\
\hline & 9 & ISI*LOP*APW*/DP*/C*UR*X*/HX & $0.74 \mathrm{~g}$ & None \\
\hline & 13 & ISI*LOP*AW*DP*/HX & $0.74 g$ & None \\
\hline & 18 & /SI*LOP*/APW*/C*/PC*UR*UH*X & $0.74 \mathrm{~g}$ & None \\
\hline & 20 & /SI*LOP*/APW*/C*PC*UH*X & $0.74 \mathrm{~g}$ & None \\
\hline & row & & $0.74 \mathrm{~s}$ & None: \\
\hline \multirow[t]{2}{*}{$18 \%$} & 3 & ISI*LOP*APW*/DP*/C*/UR*/X*FA*/HX & $0.62 \mathrm{~g}$ & None \\
\hline & Toul1: & & $0.62 \mathrm{~g}$ & None \\
\hline \multirow[t]{4}{*}{ IC } & 21. & ISI*LOP*/APW*C*/C4*/LPL*/PC*/PA*UH*UR & . & $0.62 g * 6 \mathrm{E}-2$ \\
\hline & 23 & ISI*LOP*IAPW*C*/CA*/LPL*PC*/PA*UH & 0.748 & $0.62 \mathrm{~g} * 1 \mathrm{E}-1$ \\
\hline & 27 & ISI*LOP*/APW*C*C4*UH & $0.62 \mathrm{~g}$ & None \\
\hline & rotal & & $0.62 \%$ & None \\
\hline \multirow[t]{4}{*}{ 10 } & 7 & ISI*LOP*APW*/DP*/C*UR*/X*FA*/HX & $0.70 \mathrm{~g}$ & $0.62 g * 6 \mathrm{E}-2$ \\
\hline & 17 & ISI*LOP*/APW*/C*/PC*UR*UH*/X*V1*V2 & $0.70 \mathrm{~g}$ & $0.62 \mathrm{~g} * 6 \mathrm{E}-2$ \\
\hline & 19 & ISI*LOP*/APW*/C*PC*UH*/X*V1*V2 & $0.74 \mathrm{~g}$ & $0.62 \mathrm{~g} * 2 \mathrm{E}-3$ \\
\hline & Tolil & & $0.70 \mathrm{~g}$ & $0.62 \mathrm{~g} * 6 \mathrm{~B} 2$ \\
\hline \multirow[t]{2}{*}{18} & 15 & SI*/HX & $1.11 \mathrm{~g}$ & None \\
\hline & rots. & & 1.118 & None \\
\hline \multirow{7}{*}{$\frac{1}{(10,0)}$} & 11 & ISI*LOP*APW*/DP*C*/HX & $0.62 \mathrm{~g}$ & None \\
\hline & 12. & ISI*LOP*APW*/DP*C*HX & $0.70 \mathrm{~g}$ & None \\
\hline & 22 & ISI*LOP*/APW*C*/C4*/LPL*/PC*PA & $0.74 \mathrm{~g}$ & $0.62 \mathrm{~g} * 2.4 \mathrm{E}-3$ \\
\hline & 24 & /SI*LOP*/APW*C*/C4*/LPL*PC*PA & $0.74 \mathrm{~g}$ & None \\
\hline & 25 & /SI*LOP*/APW*C*/C4*LPL & 0.748 & $0.62 \mathrm{~g} * 1 \mathrm{E}-2$ \\
\hline & 26 & ISI*LOP*/APW*C*C4*/UH & $0.62 g$ & None \\
\hline & Total & & $0.62 \mathrm{~g}$ & None. \\
\hline
\end{tabular}


Table 19.1-7 Results of GE HCLPF quantification using the MIN/MAX approach (by plant damage class) (continued)

\begin{tabular}{|c|c|c|c|c|}
\hline P. & $\begin{array}{l}\text { Squirice } \\
\text { Number: }\end{array}$ & Soquenco Doscription. & Sismis & 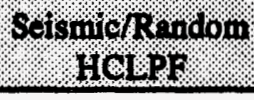 \\
\hline \multirow{7}{*}{ 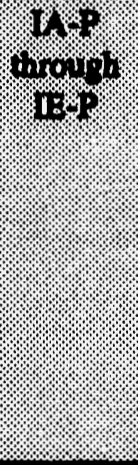 } & 4(IB2-P) & ISI*LOP*/APW*DP*/C*/UR*/X*FA*HX & $0.70 \mathrm{~g}$ & None \\
\hline & $6(\mathrm{AA}-\mathrm{P})$ & ISI*LOP*APW*/DP*/C*/UR*X*HX & $0.74 \mathrm{~g}$ & None \\
\hline & 8_(ID-P) & /SI*LOP*APW*/DP*/C*UR*/X*FA*HX & $0.70 \mathrm{~g}$ & None \\
\hline & 10 (IA-P) & ISI*LOP*APW*/DP*/C*UR*X*HX & 0.74 .8 & None \\
\hline & 14 (IA-P) & ISI*LOP*AW*DP*HX & $0.74 \mathrm{~g}$ & None \\
\hline & 16 (IE-P) & SI*HX & $1.11 \mathrm{~g}$ & None \\
\hline & rotal & & $0.20 \%$ & None: \\
\hline
\end{tabular}

NOTE: An entry of "none" in the seismic/random HCLPF column means that either (1) there were no combinations in which the random portion was greater than 1E-3 or (2) there were no combinations in which the HCLPF of the seismic portion of the combination was less than the HCLPF from seismic only.

\section{LEGEND:}

APW = Failure of Emergency AC Power or Service Water

C = Failure of Reactivity Control System

C4 = Failure of Standby Liquid Control System

DP = Failure of dc Power

FA $=$ Failure of Fire Water System

HX = Rupture of RHR Heat Exchanger

LOP $=$ Loss of Offsite Power

LPL $=$ Failure of Primary Level and Pressure Control

PA $=$ Failure to Inhikit ADS Actuation

$P C=\quad$ Failure of SRVs to Close

SI $=\quad$ Collapse of Plant Essential Structures

UH $=$ Failure of High Pressure Core Flooder

UR = Failure of Reactor Core Isolation Cooling System

V1 = Failure of Low Pressure Core Flooder

V2 = Failure of Condensate Injection

$\mathbf{X}=\quad$ Failure of Primary Depressurization

A slash (I) appearing before a designator means the occurrence of the opposite condition (i.e., success rather than failure). 
Table 19.1-8 "Dominant" contributors to HCLPF using the MIN/MAX approach (by plant damage class)

\begin{tabular}{|c|c|c|c|c|}
\hline o. & \multicolumn{3}{|c|}{ 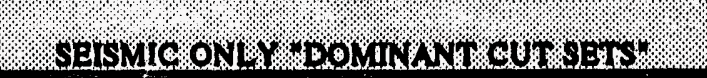 } & 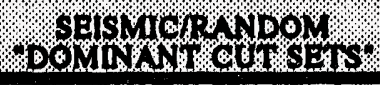 \\
\hline \multirow[t]{2}{*}{18} & \multicolumn{3}{|c|}{ Do Cable Trays $(0.74 \%)$} & None \\
\hline & \multicolumn{2}{|c|}{$\begin{array}{c}\text { SW HVAC }(0.63 \mathrm{~g}) \\
\text { or } \\
\text { SW Pump }(0.62 \mathrm{~g}) \\
\text { or } \\
\text { SW Pump House }(0.60 \mathrm{~g}) \\
\text { or } \\
\text { Diesel Gen. }(0.62 \mathrm{~g}) \\
\text { or }(0.62 \mathrm{~g}) \\
\text { Transformer or } \\
\text { or } \\
\text { MCC }(0.62 \mathrm{~g}) \\
\text { Switch (0.63 g) } \\
\text { or } \\
\text { HPCF Pump }(0.62 \mathrm{~g})\end{array}$} & S/Rvs $(0.748)$ & \\
\hline 182 & \multicolumn{2}{|c|}{$\begin{array}{c}\text { SW HVAC }(0.63 \mathrm{~g}) \\
\text { or } \\
\text { SW Pump }(0.62 \mathrm{~g}) \\
\text { or } \\
\text { Diesel Gen. }(0.62 \mathrm{~g}) \\
\text { of } \\
\text { Transformer }(0.62 \mathrm{~g}) \\
\text { MCC }(0.62 \mathrm{~g}) \\
\text { of } \\
\text { Switch }(0.63 \mathrm{~g})\end{array}$} & Fire Pum & None \\
\hline 10 & $\begin{array}{c}\text { Fuel Ass. } \\
(0.62 \mathrm{~g}) \\
\text { or } \\
\text { HCU } \\
(0.63 \mathrm{~g})\end{array}$ & $\begin{array}{c}\text { SLC Tank } \\
(0.62 \mathrm{~g}) \\
\text { or } \\
\text { SLC } \\
\text { Pump } \\
(0.62 \mathrm{~g})\end{array}$ & $\begin{array}{c}\text { HPCF } \\
\text { Pump } \\
(0.62 \mathrm{~g})\end{array}$ & None \\
\hline
\end{tabular}

How to reed this table:

The columns for seismic only and soismic random are independent. Within each of those columns, the or function is obvious, and the and function is represented by a horizontal dotted line. Thus, for Damage Class IA, the seismic only column represents the Boolean expression [(SW HVAC + SW Pump + Diesel Gen. + Transformer + MCCs + Switch + HPCF Pump) * S/Rvs] and the same column for Damage Class IC represents the Boolean expression [Fuel Ass. * (SLC Tank + SLC Pump) * HPCF Pump]. 

Table 19.1-8 "Dominant" contributors to HCLPF using the MIN/MAX approach (by plant

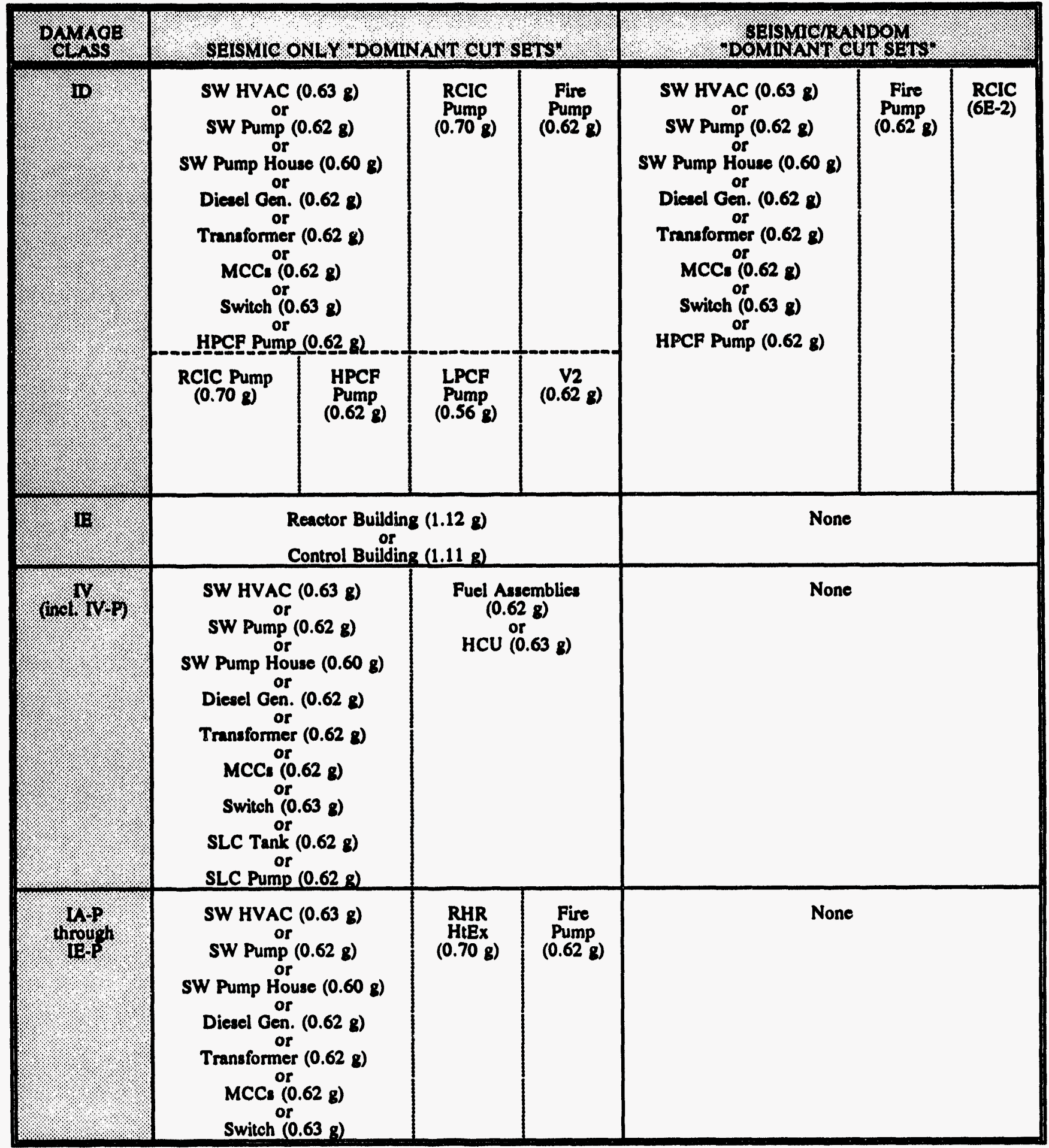

How to read this table:

The columns for seismic only and seismic random are independent. Within each of those columns, the or function is obvious, and the and function is represented by a horizontal dotted line. Thus, for Damage Class IA, the seismic only column represents the Boolean expression [(SW HVAC + SW Pump + Diesel Gen. + Transformer + MCCs + Switch + HPCF Pump) * S/Rvs] and the same column for Damage Class IC represents the Boolean expression [Fuel Ass. * (SLC Tank + SLC Pump) * HPCF Pump]. 
GE used two mothods to calculato its HCLPFs: $\min / \max$ and convolution. The $\mathrm{min} / \mathrm{max}$ method provides more safety insights. The convolution method may more appropriately (in a pure mathematical sense when a margins analysis is performed) take into account the fact that when one combines HCLPFs, one is working with the tails of probability distributions. If random failures and human errors are ignored when the $\min / \max$ method is used, the plant HCLPF is $0.6 \mathrm{~g}$. With the $\mathrm{min} / \mathrm{max}$ method, if random failures and human errors are included, the most significant combination of HCLPF, human errors, and random failures for the plant is also $0.6 \mathrm{~g}$. When the convolution method is used, the plant HCLPF is about 0.698 if random failures and human errors are ignored. All of these values exceed the 1.67 times SSE that represents the seismic robustness the staff expects to find.

For earthquakes that generate higher accelerations than the plant HCLPF, the staff no longer has the same high degree of confidence that core damage will not occur. However, the staff does not believe that a cliff-effect will exist for the ABWR design at or near the plant HCLPF and expects that the plant will have margin (perhaps quite a bit) above the HCLPF value.

The staff defines the most important seismic core damage sequences as those that have the lowest HCLPF8 (seismic only) or the lowest combination of HCLPF with random failure or human error. Using these as the selecting criteria, none of the most important seismic core damage sequences involve random failures or human errors. The following are the most important sequences:

- (loss of emergency ac power or luss of emergency service water) and (fire water injection fails)

- (loss of emergency ac power or loss of emergency service water) and (scram fails)

- (scram fails) and (standby liquid control fails)

- (scram fails) and (standby liquid control fails) and (high-pressure core flood fails).

These results are similar to those from seismic margins analyses and PRAs performed previously.

The staff focused on the performance of and insights drawn from the ABWR seismic margins analysis. Because of the large uncertainty in hazard curves and the fact that seismic PRA results are dominated by the tails of the site hazard and SSC's fragility curves, it is expected that if a seismic PRA had been performed, it would have been one of the largest contributors to core damage frequency (though still a low absolute value). This is particularly true for the ABWR design since design changes or improvements have greatly reduced the estimated core damage frequency from internal events. As it is, the ABWR design should be better able to resist seismic events than most, if not all, existing nuclear power plants east of the Rocky Mountains because of its built-in safety margins.

The staff did not require GE to examine the HCLPFs of paths by which the containment could be bypassed, fail to isolate, or fail, since the containment structure was considered to be very rugged and none of the sequences that led to core damage had HCLPFs less than 1.67 times the SSE. Nevertheless, GE performed an evaluation of beyond-design-basis earthquakes to see how the containment would perform under high 8 -levels. This ovaluation showed that no bypass paths are expected to occur with an HCLPF of less than 1.67 times the SSE. The lowest $\mathrm{min} / \max$ HCLPF for bypass reported by GE was $0.74 \mathrm{~g}$.

\subsection{PRA as a Design Tool}

The following are examples of ways in which the ABWR design or procedures were modified by $G E$, based on the ABWR PRA-based seismic margins analysis:

- GE switched the seismic qualifications of the fire water pumps (i.e., the diesel-driven fire water pump took the place of the motor-driven pump as the pump capable of surviving an SSE) because failure of the diesel generators following a seismic event (by seismic or random failure) would otherwise have left the plant with no fire water addition capability.

- GE chose to lower the capacities of a few SSCs since it might have been difficult for a COL applicant to achieve the capacities in a cost-effective manner. The staff found this acceptable, since the lowered capacities did not affect the overall HCLPF of the plant and the original capacity assumptions seemed to be slightly higher than normally assumed in eastern U.S. seismic fragility analyses.

- GE developed recommendations for improving emergency operating procedures by instructing the operator to manually operate heat removal system valves if seismic-induced transformer loss should make power operation of these vaives impossible.

\subsection{Plant Features and Operator Actions Important to Risk}

The margins approach does not allow a determination of which plant features are most important to risk. It does allow one to determine which plant features are important 
to the plant-level HCLPF and the redundancy or diversity available in achieving that HCLPF. In order to make this determination, the staff examined each sequence that led to core damage on the seismic event trees. None of the sequences has a seismic-only HCLPF of less than 0.58 . The sequences were examined to determine if lowering the HCLPF value of a single SSC (to a much lower HCLPF value) or increasing the demand failure rate of a single system (to \& much higher demand failure rate) would result in a plant HCLPF of less than 0.58. A review of the cut sets in Table 19.1-8 shows that most of the important sequences require at least two failures of SSC with HCLPFs above $0.5 \mathrm{~g}$. The two cases where this is not true are discussed below:

- Structural integrity - Most of the safety-significant structures (except for the service water pump house) are assumed to have an HCLPF of $1.11 \mathrm{~g}$ or higher. If any of these structures were to be built with an HCLPF much lower than $0.5 g$, it would result in a much lower plant HCLPF. These structures include the control building, reactor building, containment, service water pump house, reactor pressure vessel (RPV) supports, and RPV pedestal.

- Batteries - In a seismic event, it is assumed that offsite power will be lost and ac power must be supplied by the EDGs. For the EDGs to start and load, they require dc power. The battery chargers or inverters, which provide dc power when ac power is available, are lost on loss of offsite power, until the EDGs start and load. However, the EDGs will not start and load unless dc power is available. Therefore the EDGs rely on the batteries to start and load in these circumstances. If the batteries or the dc cable trays were to bave an HCLPF of less than 0.58 , it would lower the plant HCLPF accordingly.

All other seismic sequences require multiple failures of SSC the HCLPF of which is greater than $0.5 g$ in order to cause the plant to experience core damage. As noted in SSAR Sections 19.9.5 and 19.H.5, a check of the capacity of as-built SSCs to meet the HCLPFs assumed in the ABWR PRA will be provided by a seismic walkdown. Details are to be developed by the COL applicant.

\subsection{Human Reliability Insights and Important Human Actions}

In the margins analysis, GE used the same human error rates and random failure rates that were used in the ABWR internal events analysis. The PRA-based seismic margins analysis did not identify any human reliability insights that were not already identified in the internal events analyses.
There were no human actions or random failures that contributed to the plant HCLPF.

\subsection{COL Action Items}

GE identified COL actions that define the areas derived from performing the ABWR PRA-based seismic margins analysis that the COL applicant needs to perform or complete. These actions, including plant walkdowns, are detailed in SSAR Section 19.9 and are acceptable.

\subsection{Insights from Uncertainty, Importance, and Sensitivity Analyses}

One of the reasons for performing an uncertainty analysis is to help to display the range of values within which the results of an analysis could reasonable be expected to fall. The use of a PRA-based seismic margins analysis inherently makes use of the breadth of information being considered. This is because HCLPF values can be thought of as the $\mathrm{g}$-level at which one has a 95 percent confidence that less than 5 percent of the time the equipment will fail (i.e., we are dealing with the tails of the curves). In addition, the staff does not require that a seismic hazards analysis be convoluted with equipment fragilities, since hazard curves have a large uncertainty that reduces their value in helping to make judgements about the seismic risk. From seismic PRA analyses, it is clear that uncertainties in the hazard curves would dominate the uncertainties in equipment or structure fragilities. For the ABWR PRA-based seismic margins analysis, no uncertainty analysis was performed because uncertainty is directly reflected in the margins method. Similarly, sensitivity studies were nat performed on the margins analysis. Finally, the margins method does not result in either core damage frequency or risk results. Therefore, importance analyses were not performed.

\subsection{Fire}

In a number of PRAs for operating plants, fires have shown up as important contributors to core damage frequency and risk. GE has taken a unique and effective approach to analyzing beyond-design-basis fires. In performing its fire analysis (a combination of the FIVE methodology and the ABWR internal events PRA), GE chose to simplify its analysis by assuming that any fire that started in a divisional fire area while the plant was at power would immediately cause all equipment to fail in that divisional fire area. While this assumption greatly simplifies the performance of a fire analysis, it biases the numerical results in a conservative manner. GE suggests and the staff agrees that it would be inappropriate to compare the numerical results from the ABWR fire rnalysis to the results of the more realistic internal events 
analyses. Analysis of the potential consequences of a fire while in Modes 3, 4, and 5 are investigated in the shutdown risk analysis discussed in Section 19.1.3.4.

The ABWR design has a number of attributes that have significantly improved the detection, suppression, and confinement potential of fires. The most important improvement is that the ABWR was designed with fire prevention and mitigation in mind. The ABWR does not need to rely on spatial separation as a barrier between safety divisions. The three safety divisions are separated by 3-hour fire barriers throughout the plant, with few exceptions (See SSAR Section 9A.5). Detection systems and suppression systems will be placed for optimal advantage.

\subsection{Dominant Accident Sequences}

Because GE did not perform a fire PRA, but rather used a combination of the FIVE methodology and the ABWR internal events PRA, one cannot determine dominant sequences in the sense normally used when working with a PRA. For the fire analysis, the word "dominant" appears in quotes to emphasize that the use of this terminology in the context of a fire analysis should not be taken in the same way as it would be for a PRA (i.e., no cut sets were developed for the fire analysis and therefore importance analyses cannot be performed). The staff identified the "dominant" sequences leading to core damage in the systematic fire analysis performed by GE on the basis of engineering judgement, core damage frequency point estimates, and descriptions provided by GE of what it considers the most important sequences. The staff believes this approach is adequate to identify fire vulnerabilities.

GE identified the most important sequences as those that begin with a fire in the control room. In these "dominant" sequences, a control room fire starts, feedwater is lost, RCIC or one high-pressure core flood train is lost, and either one train of low-pressure core flooder or manual depressurization fails. The fire analysis screened out all additional sequences and fire areas because the estimated screening core damage frequency associated with each fire area was less than $1 \mathrm{E}-6$ per year.

The staff finds $1 E-6$ per year to be an acceptable screening level for the ABWR since the fire analysis methodology used by GE assumes that any fire that starts in a physically separated divisional area instantaneously causes all the equipment in that division to fail. Although this assumption is conservative, the separation of divisions in the ABWR design still results in low core damage frequency estimates.

\subsection{PRA as a Design Tool}

On the basis of the ABWR fire analysis, GE made a design change to assure that certain fire protection capabilities existed in the as-built plant. The change was rade because GE determined that unless the capability to crstrol ADS valves from the remote shutdown control pariel was improved (controls for a fourth safety relief valve (SRV) were added) and unless it was possible to control the RCIC system locally (RCIC could not be controlled from the remote shutdown panel), the control room would not pass the 1E-6 per year screening value.

\subsection{Plant Features and Operator Actions Important to Risk}

Several plant features and operator actions are important to reducing the consequences of a fire in an ABWR.

\section{Design Features}

- Separation of the three safety divisions - The roost important is the 3-hour fire barrier that is to be in place among the three safety divisions. The fire analysis assumes that there will be no spreat of fire or suppressants among the divisions; once a fire begins.

- Smoke control system - This system helps prevent the migration of smoke to other divisions if a fire occurs. This is accomplished by pressurizing the surrounding areas so that the smoke will be contained in the fire zone. Smoke control is particularly important in secondary containment.

- Inerting of containment at power - The inerting of containment precludes the need to analyze fires in containment while at power. Containment is one of the few areas in the plant where all four divisions (three safety, one non-safety) are in the same fire area. The control room is another area where multiple divisions coexist.

- Capability to operate RCIC from outside the control room - The largest contributor to core damage frequency among fire-initiating events is a control room fire. For control room fires, it is important to be able to control RCIC locally, since it cannot be controlled directly from the remote shutdown panel. This is both a design feature and an important operator action.

- Capability to operate four SRVs from the remote shutdown panels - As with RCIC, for control room fires, it is important to be able to operate four SRVs from the remote shutdown panel. Successful 
depressurization is achieved by manual operation of three of the four SRVs. If only three SRVs were on the panel, a single failure of one of the SRVs would prevent successful mitigation of the control room fire. This is both a design feature and an important operator action.

- Remote shutdown panel - The panel is required for shutdown of the plant in the event that the control room needs to be evacuated.

\subsection{Human Reliability Insights and Important Human Actions}

The ABWR fire analysis considered random failures and human errors modeled in the internal events analysis. Operator control of the RCIC system from outside the control room was found to be an important human action, should the control room needs to be evacuated.

\subsection{Insights From Uncertainty, Importance, and Sensitivity Analyses}

Because the methodology used in performing the ABWR severe accident fire analysis (a combination of the FIVE analysis, which is primarily a deterministic evaluation of fires, and portions of the ABWR PRA internal events analysis) is bounding in nature, the results of uncertainty, sensitivity, or importance analyses would be biased. Since the purpose of performing an uncertainty analysis is to better understand the subject being investigated and since in the case of the fire analysis it is unclear what the results of an uncertainty analysis would represent physically given the bounding nature of the assumptions in the analysis, the staff finds that an uncertainty analysis was not required. The, staff concludes that the fire methodology used by GE provides the insights needed to determine whether fire vulnerabilities exist for severe accident firtes and whether fires represent a disproportionate risk.

\subsection{Internal Floods}

At some plants, PRAs have shown that internal floods are leading contributors to core damage frequency. Utilities that have performed a systematic internal floods analysis have generally found design modifications that they deemed prudent to implement in order to maintain adequate prevention and mitigation capability for internal floods. GE performed a comprehensive internal flood PSA for ABWR power operation. In the shutdown heat removal analysis, GE performed a separate flooding analysis that evaluated the flood protection provided by the plant during shutdown by controlling barriers between divisions and by controlling equipment configurations.

\subsection{Dominant Accident Sequences}

The ABWR Probabilistic Flooding Analysis (flood analysis) in Appendix 19R of the SSAR estimates that the chances of an internal flood causing core damage is very small (about 7E-9 per year).

For the intemal flooding analysis, the word "dominant" appears in quotes to emphasize that the use of this terminology in the context of the flooding analysis should not be taken in the same way as it would be for a PRA performed using more realistic assumptions or for an analysis that has cutsets on which importance analyses can be performed. The ABWR internal flooding analysis made several conservative assumptions that could bias the results. GE has identified the "dominant" sequences leading to core damage in the internal flooding analysis on the basis of sequences with the largest estimated core damage frequency and on engineering judgment.

The "dominant" sequences that are initiated in the turbine building are those associated with the circulating water system (CWS) or the turbine service water (TSW) system. The following sequence is "dominant" for the turbine building: a large pipe breaks in the CWS system, the isolation valves in the CWS lines fail to close, water fills up and runs out of the condenser pit, and the fire door between the turbine building and the service building is either open or fails open allowing water into the service building. The service building floods and a door between the service building and the control building fails open or is open. Water enters the control building and causes electrical power supplies and all three divisions of reactor building cooling water (RCW) to fail. The estimated frequency of this event is $3 E-9$ per year.

The most important internal floods initiated in the control building are those associated with the reactor service water (RSW) system. This sequence involves the following: a large pipe breaks in the RSW piping in the RSW/RCW room and the operator fails to isolate the flooding. The automatic RSW pump trip fails and the water flows into the remaining RSW pump rooms. The operator fails to respond to the flooding alarm and the RSW fails. The estimated frequency of this event is $2 E-9$ per year.

Floods that begin inside the reactor building are divided into two parts: those inside and those outside secondary containment. The most important internal flood sources that initiate inside secondary containment are the suppression pool, condensate make-up, and fire water. The lowest floor of the reactor building is entirely within the secondary containment. On this level, each of the three safety divisions has a separate ECCS room that has an alarmed watertight door and a sump pump. Floods 
inside these rooms would cause the HPCF, RCIC, RHR, and control rod drive (CRD) pumps, and the CRD hydraulic control unit to fail. A common hallway into which the watertight doors open runs around the perimeter of the division rooms. There are three worst- case flood sequences for the reactor building. The three flood sequences are developed in event trees in SSAR Appendix R, Figures 19R.5-4, -5, and -6 . The largest estimated contributor to core damage among these three flood sequences occurs inside an ECCS room resulting from a leak in the suppression pool suction line upstream of the isolation valve. This is a nonisolable break.

In the reviow of the risk resulting from internal floods, several concerns were identified. The main concerns identified for turbine building floods were (1) the assumptions regarding the likelihood of the truck door failing and allowing turbine building flood waters to exit the turbine building without challenging the fire door between the turbine building and the service building and (2) the justification for the assumed reliability for the fire door. GE satisfactorily addressed these staff concerns in Section 19R of the SSAR. In the reactor building, the chief concern identified was the lack of any common-cause failure analysis for the failure of the isolation measures credited in the analysis. GE performed an improved common-cause failure analysis that resulted in no change in internal flood insights. For control building floods, the staff was concerned that failure of the discharge or intake valves following a service water system pipe break in an RSW or RCW room would result in an unisolable flood that could affect all three divisions of the RSW system. GE added design requirements for antisiphon capability to prevent continued flooding in the event the RSW pump is tripped but the isolation valves do not close. In addition, GE stated that the ABWR would be designed so that the ABWR ultimate heat sink (UHS) cannot gravity drain into the control building.

\subsection{Comparison of Dominant Sequences}

Conservatism in the ABWR flooding analysis biases the results and may make it unsuitable for comparison to the more realistic internal events results. Conservatisms include the assumptions that all piping breaks are doubleended shears and once a flood in a division causes one piece of equipment to fail, all equipment in that division is assumed to fail.

\subsection{PRA as a Design Tool}

In performing its internal flooding analysis, GE determined that several areas of the design needed to be modified or strengthened to help make sure that internal floods do not present an unacceptable lovel of risk for the ABWR design. These modifications include the following:

- GE modified the motor control centers (MCCs) to have NEMA Type 4 enclosures to protect the MCCs from water spray from a pipe break or leak.

- GE added four water-level sensors in the condenser pit. When actuated, these sensors send an alarm to the control room, trip the CWS and TSW pumps, and close isolation valves in both systems. This isolates floods in the turbine building caused by pipe breaks in the TSW and CWS.

- GE added four room-floor water-level sensors, which send an alarm to the control room when water is first detected in the room, and four diverse sensors, which automatically trip the reactor water service water/RCW pumps at a higher water level in the RCW/RSW room. The sensors will alert the operators to RCW leakage and will isolate the flood.

- GE added to the Tier 1 description of the control building in the design control document (DCD) the design requirement that no more than 4,000 meters $(4,374 \mathrm{yds})$ of pipe exist between the isolation valves at the RSW pump house and the control building (2,000 meters each, for supply and return lines). This limits the amount of water that can be drained into the RCW/RSW room following RSW pump trip during flooding.

- GE added antisiphon capabilities to the RSW system to end a flood if the RSW pump trips but the isolation valves do not close.

\subsection{Plant Features and Operator Actions Important to Risk}

Several plant features are important in reducing the chances or consequences of an internal flood. These fertures are discussed below:

- Separation of the three safety divisions - Whenever the three safety divisions are in a building, they are separated by barriers. The most important barrier is the 3-hour fire barrier that must be in place between the three safety divisions. The flooding analysis assumes that there is a limited spread of water among the divisions, once a flood begins. The primary assurances that flooding will not get high enough to affect SSCs in multiple divisions are that (1) the 3-hour barriers are in place, (2) there are elevator shafts with no sills that carry water to lower reactor building levels, (3) stairwells on all floors have doors that 
provide a leak path (up to a $1.9 \mathrm{~cm}(0.75$ in.) gap at bottom of fire door) down the stairs to the lowest building level, (4) there is at least one drain in every room, (5) all pipes penetrating floors have $200 \mathrm{~mm}$ (8 in.) sills that help prevent sneak-path leaks, (6) all hatches and electrical penetrations through floors are to be able to withstand $200 \mathrm{~mm}$ (8 in.) of standing water without leaking, and (7) except as noted in SSAR Section 19R.4.2.3, equipment from multiple divisions does not occupy the same divisional area. Barriers include concrete fire barrier floors, ceilings, and walls; partitions; rated watertight doors; penetration seals for process pipes and cable trays; and special assemblies and constructions.

- Auto trip of the CWS and TSW pumps - The three CWS pumps and the two TSW pumps provide tunlimited supplies of water to the turbine building. If a flood were to occur, level sensors would alert the control room operators, trip all five pumps, and close all isolation valves in both systems.

- Maximum length of RSW pipe - TheíCOL applicant will have to limit the RSW piping distance between the control building and the RSW isolation valves to 4000 meters (4,374 yds)(2,000 meters each, for supply and return lines). A longer length would provide enough water to flood one RCW room, overflow, and start to flood another RCW room.

- Auto trip of the RSW pumps - The RSW pumps trip and the RSW isolation valves close in the affected division should flooding occur in the control building. The trips limit the volume of water that can be added to a controi building flood. Trip sensors are diverse from sensors that alert the operators early on (i.e., at a lower level) to a flood in the room.

- Antisjphon capability - If the RSW pumps trip on a high water level caused by a line break, but the isolation valves fail to close, antisiphon capabilities will be needed to prevent further flooding because otherwise the siphon effect will continue to draw water from the ultimate heat sink into the rooms.

- $3 C C S$ room watertight doors - The doors hatween the ECCS rooms and the outside corridor in the reactor building are watertight. These doors have dogs and alarms. The doors do not send an alarm if they are physically closed, but not "dogged." The doors are designed to limit flooding in a division to the particular ECCS divisional area.
- Reactor building corridor volume - The volume of the reactor building corridor surrounding the three ECCS divisions at the lowest level of the reactor building is sufficiently large to handle large breaks. The corridor can hold water from a suppression-pool-driven flood at the equilibrium water level with the suppression pool and have the water level not exceed the ceiling of the corridor. This limits the flood potential to one ECCS division and the corridor.

- Drip-proof designs and NEMA Type 4 enclosures All electric motors have drip-proof designs and all motor control centers have NEMA Type 4 enclosures that protect electrical equipment from water spray from above.

Further details of the ABWR design features that help to prevent or mitigate internal flooding are given in SSAR Appendix 19R, Table 19R.6-2. In addition, the following are important insights into the ABWR internal flooding analysis:

- The only buildings modeled in the PRA for flooding where internal flooding could ciamage safety-related equipment or cause plant transients are the turbine building, control building, and reactor building.

- The service water pump house, which is outside the ABWR certification scope, is a building that must be designed to prevent internal floods from impairing multiple safety trains. Flooding of the pump house would cause all ECCS pumps to fail except for RCIC. For injection to the vessel, the operators also would have the fire water pumps and the condensate pumps.

- Secondary containment in the reactor building is designed to mitigate internal floods that begin at elevations above the lowest elevations by directing flood water to floor drains and stairwells that are routed to the lowest elevation. It is important that the drains be sized to drain at a rate that does not permit a flood on a particular level to rise high enough to damage safety-related equipment, pressurize the volume within which it is contained, or spill over to other divisior.s.

- From SSAR Appendix 19Q, the recommended shutdown configuration is as follows: one RHR division and its support systems should be operating, the second safety division should be administratively controlled to not be in maintenance and its barriers should be intact, and the third safety division may be undergoing maintenance. 
- Fire doors generally are not considered to be capable of holding back a large head of water.

- If a watertight door is physically shut but not "dogged," it will not alarm to indicato it is incapable of holding back a flood inside the door.

- The service water system and the CWS are assumed to be designed and located so that they cannot gravity feed to the plant.

- The ACIWA system can provide water to the core or spray the drywell in the event of a catastrophic internal flood. Manual valves to direct the flow to either the core or to the drywell ans located in the reactor building and can be operated successfulily following an internal flood.

\subsection{Insights Into Human Reliability and Important Human Actions}

Although postulated floods can be mitigated from a risk perspective with fow operator actions, because of the inherent ABWR flooding capability (the frequency of internal floods leading to core damage without taking any credit for operation action is still quite low), timely implementation of the following operator actions can limit potential flood damage:

- Isolation of flood sources following detection by sump pump operation and alarms or floor water-level detectors (for floods in the turbine building, the operator should attempt to isolate the leak and shut down the plant without losing condenser vacuum to avoid a "turbine trip without bypass" scenario)

- Closure of watertight doors to prevent damage to equipment in more than one safety division

- Opening of certain nonwatertight doors or hatches to divert water from safety-related equipment.

\subsection{3.3.6 Combined License Applicant Action Items}

GE has identified COL Action Items that define the actions derived from performing the $A B W R$ internal flood analysis that the COL applicant needs to perform or complete. These actions are detailed in SSAR Section 19.9. The staff finds these COL Action Items to be acceptable.

\subsection{Insights From Uncertainty, Importance, and Sensitivity Analyses}

The ABWR internal flooding analysis methodology made bounding assumptions to simplify the task of evaluating floods. This resulted in an evaluation that cannot readily be manipulated to provide uncertainty, importance, or censitivity insights because of its internal biases. Therefore, GE did not perform any uncertainty, importance, or sensitivity analyses on its internal flooding analysis nor did the staff require these analyses to be performed. GE identified important design features through engineering judgement. The staff finds this approach to be acceptable.

\subsection{External Floods}

In SECY-93-087, the staff identified the need for a sitespecific probabilistic safety analysis and analysis of external events. GE did not perform an analysis (PRA or bounding) of the capability of the ABWR design to withstand external flooding. Instead, GE assumed that the ABWR standard design would be sited such that its grade lovel would be $30.5 \mathrm{~cm}$ (1 ft) higher than the probable maximum flood level as stated in Section 2.6.2 of the SSAR. However, estimates of the return periods of river floods at various auclear power plant sites that would exceed the probable maximum flood level range from probable to very improbable. For some sites where the return period of large floods is high, the ABWR design may have vulnerabilities to external flooding.

Therefore, the staff will require, where applicable to the site, that the COL applicant perform a site-specific PRAbased analysis for external flooding to search for sitospecific vulnerabilities.

\subsubsection{Operation in Modes Other Than Full Power and Startup - Level 1}

This section details the staff's safety insights drawn from the review of the ABWR shutdown heat-removal reliability study performed by GE. Although the staff found that the most significant events to date have occurred at pressurized water reactors (PWRs), the potential vulnerability of BWR plants to shutdown and low-power events cannot be ignored. GE submitted a shutdown risk evaluation of the ABWR design (SSAR Appendix 19Q). The evaluation covered Modes 3 (hot shutdown), 4 (cold shutdown), and 5 (refueling). It included all aspects of the nuclear steam supply system (NSSS), containment, and all systems that support the NSSS and containment. It did not address fuel handling outside the primary containment or fuel storage in the spent fuel pool.

The evaluation covered important aspects of draft NUREG-1449, "NRC Staff Evaluation of Shutdown and Low Power Operation," such as decay heat removal (DHR), inventory control, containment integrity, electrical power, reactivity control, and instrumentation. The 
analysis examined 70 loss-of-power and more than 100 loss-of-DHR precursor ovents at operating BWRs. For new features of the ABWR design, GE developed a failure-modes-and-effects-analysis to determine if the new features would introduce additional shutdown vulnerabilities. GE performed a detailed reliability study of the ABWR DHR function. This study included fault and ovent trees for all DHR and mako-up systems. The analysis separately investigated fire and flooding at shutdown, along with the potential effect of increased maintenance of important equipment.

The staff finds that the ABWR design includes enhanced features that reduce risk during shutdown operations when compared with operating BWRs. These features, including three independent RHR divisions, three EDGs, an ACIWA system, an alternate onsite CTG, and proper plant electrical and physical separation and layout, specifically address the more risk-significant operations during shutdown identified in NUREG-1449. GE provided appropriate safety guidance for effective outage planning and control and provided TS to ensure adequate systems are available to respond to events that may occur during shutdown. Implementation of these recommendations by a $\mathrm{COL}$ applicant will be reviewed by the staff.

The staff concludes, based on previous shutdown analyses (both international and U.S. operating reactors) and the ABWR Shutdown Risk Evaluation, that the chances of a core damage event occurring when in Modes 3, 4, or 5 is probably on the same order of magnitude as that of internal events occurring in Modes 1 and 2.

\subsection{Dominant Accident Sequences}

GE and the staff determined that it would not be useful to attempt to identify dominant accident sequences during Modes 3, 4, and 5. This is because, among all possible plant shutdowns and even on a minute-by-minute basis during any shutdown, the plant configuration could and probably would change. During each of these different configurations, one could conceivably have different dominant sequences and therefore different insights. Because of this, no dominant sequences based on the ABWR Shutdown Risk Evaluation were identified. NUREG-1449 identified that the majority of shutdown precursors and actual shutdown events were caused by human error. Operating, administrative, and emergency procedures as well as aspects of the ABWR design that minimize the chances of human error are discussed below.

\subsection{PRA as a Design Tool}

GE made no design changes spocifically based on the ABWR shutdown risk evaluation. However, it did develop procedural guidance for outage planning and did develop for COL applicants a short list of acceptable system configurations, minimum combinations of systems to ensure adequate shutdown safety margins, when in Modes 3, 4, and 5. This guidance is located in SSAR Section 19.Q.7.9, Tables 19Q-3 through 19Q-5 and is repeated in Table 19.1-9 in this report. The tables were developed based on a single initiating event during shutdown (the failure of the operating DHR division), but are valid for initiating events during shutdown including loss of offsite power and the loss of the operating service water division.

\subsection{Vulnerabilities}

The staff believes that the results of the ABWR shutdown risk evaluation provide the information needed to decide if there are shutdown vulnerabilities and whether operation in modes other than full power represent a disproportionate risk in the ABWR. GE did not identify any shutdown vulnerabilities. With the use by a COL applicant of the tables (and accompanying or similarly acceptable methodology) that define sets of equipment that should remain operable for the ABWR to meet GE's proposed goal for conditional core damage frequency, 1E-5 given the loss of a DHR train, when in Modes 3, 4, and 5, the staff finds that operation of the ABWR in Modes 3, 4, and 5 does not represent a disproportionate risk. In SSAR Appendix 19Q.9, GE has investigated whether the new features in the ABWR design might have introduced vulnerabilities when in modes other than full power. GE concluded that they did not introduce new vulnerabilities, and the staff concurs with GE's conclusion. The staff reviewed the ABWR shutdown evaluation and found no unreported shutdown vulnerabilities.

\subsection{Plant Features and Operator Actions Important to Risk}

A detailed list of ABWR features that are important to risk in Modes 3, 4, and 5 are provided in Tables 19Q.4-1 in the SSAR. The following list outlines those areas of the ABWR design that are important to maintaining risk during shutdown operations at a low level.

\section{Features and Actions Minimizing Loss of DHR}

- Having three divisions of RHR that are physically separated lowers the frequency of loss of DHR. 
Severe Accidents

Table 19.1-9 Examples of configurations that meet 1E-5 CCDF goal in Modes 3, 4, and 5

Example Minimum Sets of Systems for Modes 3 and 4

\begin{tabular}{|c|c|c|c|c|c|c|c|c|c|}
\hline & RHRB & Main Cond. & CUW & HPCFB & CRD & ADS & RHRB (CF) & Condensate & Fire Water \\
\hline 1 & $\mathrm{X}$ & & & & $\mathrm{X}$ & $\mathrm{X}$ & $\mathrm{X}$ & & $\mathrm{X}$ \\
\hline 2 & $\mathrm{X}$ & & $\mathrm{X}$ & & & $\mathrm{X}$ & $\mathrm{X}$ & & $\mathrm{X}$ \\
\hline 3 & $\mathrm{X}$ & & & & & $\mathrm{X}$ & $\mathrm{X}$ & $\mathrm{X}$ & $\mathrm{X}$ \\
\hline 4 & $\mathrm{X}$ & $\mathrm{X}$ & & & & $\mathrm{X}$ & $\mathrm{X}$ & & $\mathrm{X}$ \\
\hline $\mathbf{5}$ & $\mathrm{X}$ & & & $\mathrm{X}$ & $\mathrm{X}$ & $\mathrm{X}$ & & $\mathrm{X}$ & \\
\hline
\end{tabular}

Examples of Minimum Secs of Systems for Mode 5 (Unflooded) (2 to 3 Days After Shutdown)

\begin{tabular}{|c|c|c|c|c|c|c|}
\hline & RHRB & HPCFB & CRD & Condensate & Fire Water & RHRB (CF) \\
\hline 1 & $\mathrm{X}$ & & $\mathrm{X}$ & & $\mathrm{X}$ & $\mathrm{X}$ \\
\hline 2 & $\mathrm{X}$ & & & $\mathrm{X}$ & $\mathrm{X}$ & \\
\hline 3 & $\mathrm{X}$ & $\mathrm{X}$ & $\mathrm{X}$ & $\mathrm{X}$ & & \\
\hline
\end{tabular}

Examples of Minimum Sets of Systems for Mode 5 (Flooded) (3 or More Days After Shutdown)

\begin{tabular}{|l|c|c|c|c|c|c|c|c|}
\hline & RHRB & FPC & CUW & HPCFB & CRD & RHR (CF) & Condensate & Firo Water \\
\hline 1 & $\mathrm{X}$ & & & & & & $\mathrm{X}$ & $\mathrm{X}$ \\
\hline 2 & $\mathrm{X}$ & & & & $\mathrm{X}$ & $\mathrm{X}$ & & \\
\hline 3 & $\mathrm{X}$ & & & $\mathrm{X}$ & $\mathrm{X}$ & & $\mathrm{X}$ & \\
\hline 4 & $\mathrm{X}$ & & & & & $\mathrm{X}$ & $\mathrm{X}$ & $\mathrm{X}$ \\
\hline $5^{*}$ & & & $\mathrm{X}$ & & $\mathrm{X}$ & & & $\mathrm{X}$ \\
\hline $6^{*}$ & & & $\mathrm{X}$ & & & & $\mathrm{X}$ & $\mathrm{X}$ \\
\hline $7^{* *}$ & & $\mathrm{X}$ & & & $\mathrm{X}$ & & $\mathrm{X}$ & \\
\hline $8^{* *}$ & & $\mathrm{X}$ & & & & & $\mathrm{X}$ & $\mathrm{X}$ \\
\hline $9^{* *}$ & & $\mathrm{X}$ & & & $\mathrm{X}$ & & & $\mathrm{X}$ \\
\hline
\end{tabular}

- After 8 days

- After 10 days 
- If all RHR loops were unavailable, (a) steam from the reactor could be directed to the main condenser (if available) and make-up could be supplied to the veesel by many sources discussed in Inventory Control below, or (b) the suppression pool could be used as a heat sink via the SRVB, or (c) the reactor water cleanup systom could be a heat sink, or (d) the spent fuel pool inventory could be a heat sink if the reactor water level were raised to the refueling level, or $(0)$ if the vesel head were removed, bulk boiling of reactor coolant in the vessel with adequate make-up would prevent fuel damage.

- There is no isolation of shutdown cooling on the loss of reactor protection system (RPS) logic power.

\section{Eeaturas and Actions Minimizing Loss of Inventory}

- The vessel level is displayed for the operator in the control room during all shutdown configurations, including refueling.

- Multiple sources of make-up exist such as the suppression pool, condensate storage tank, main condenser hotwell, and ac-independent water addition system.

- RHR system valves are interlocked with reactor system pressure to help ensure that RHR system low-pressure piping is not subject to full system pressure. However, oven if it were exposed to full system pressure, the RHR piping should withstand full reactor pressure without rupture.

- Make-up can be provided by the CRD hydraulic system, the reactor water cleanup system, the condensate pumps in conjunction with the hotwell, the ACIWA system, and the RHR system.

- The mode selector switch automatically realigns the valves, as required, for the RHR mode selected. In the past, operator errors led to sending water to the wrong place. Now, all the operator has to do is change the mode switch to realign the system automatically.

- The shutdown cooling piping connects to the nozzle in the vessel above the level of the active fuel, so fuel cannot be uncovered by a siphoning effect.

- Suppression pool drain down has been identified as a period during which there is a diminished level of protection against core damage. It is important that a COL applicant properly coordinate suppression pool drain down with TS equipment configuration requirements and the DHR core damage frequency goal (1E-5 conditional core damage frequency).

\section{Eentures Minimizine Loss of Contrinment Interrity}

- During shutdown with the drywell head removed, the ABWR has a secondary containmeat that will automatically be isolated on high radiation from a madiological boundary breach or fuel-handling accident. If the radiological accident is one that does not preenurize secondary containment, the filtering function of atundby gas treatment system (SGTS) will bo a benefit. If the radiological breach is caused by boiling in Mode 5, secondary containment will overproesurizo and fail. In this circumstance, the SOTS filterios function will be lost; however, plate out via a tortuous path will tend to reduce consequences. If the core can continue to be covered by water, then boiling is a relatively benign event (with respect tc radiological consequences). If, however, the core subsequently becomes uncovered for an extended period with the head off and secondary containment breached, there would be a massive radiological roleave. It takes approximately 3 hours to boil down the water above the core and longer to heat up the core. This should be an extremely low probability event since the ABWR design includes multiple means to provide water to the core in all modes of operation.

\section{ABWR Eeatures Minimizing Loss of Electrical Power}

- There are three physically independent IE diesel generators.

- There is a CTG that can be used to power any of the Clase 1E or non-Class 1E buses. This generator can start a feedwater or other pump for DHR or inventory make-up if required.

- There are four divisions of dc power.

Other Desim Features and Operator Actions Minimizins the Chances of Core Damage When Not at Power

- Fires and floods during shutdown can be mitigated by ensuring, through administrative procedures, that at least ono safety division is not in maintenance and its physical boundaries remain intact. If it is decided to breach the boundaries of two safety divisions to complete maintenance tasks, an evaluation could indicate if the minimum set of systems capable of moeting the shutdown safety criteria would be available if a fire or flood were to occur. The analysis would indicate if a minimum set were available should a flood 
or fire occur in the intact division or the breached divisions.

- The staff believes that the most important element in control of shutdown risk is adequate planning of maintenance on systems and support systems that can be used to remove decay heat or supply inventory make-up to the vessel. Maintenance planning is the responsibility of the COL applicant, but $G E$ has provided guidance in its shutdown risk evaluation (SSAR Appendix 19Q.10) to help ensure that the planning will not place the plant in an unfavorable configuration from the standpoint of expected core damage frequency.

Appendix $\mathrm{K}$ of this report lists those PRA-based safety insights that were drawn from the PRA. The appendix documents the disposition of these insights and indicates if the insights are in ITAAC, Tier 2 information, TS, COL Action Items, Interface Items, or the RAP.

\subsection{Insights Into Human Reliability and} Important Human Actions

A total of eight human actions were identified as important for controlling risk during shutdown. Five actions were treated probabilistically in the evaluation, and three were treated deterministically (i.e., they were assumed to be taken if needed):

- Recognition of failure of an operating RHR system

- Initiation of standby RHR following loss of the operating division

- Lse of non-safety grade equipment for DHR (e.g., reactor water cleanup (CUW) and main condenser)

- Use of non-safety grade equipment for inventory makeup (e.g., CRD, feedwater, condensate)

- Use of boiloff for DHR with the RPV head removed

- Implementation of fire or flood watches during periods of degraded safety equipment integrity

- Firefighting during shutdown operations, possibly with part of the fire protection system in maintenance

- Use of the remote shutdown panel during shutdown operation.
Because these actions and instrument requirements are considered significant, they are included in COL Action Items (Seo SSAR Section 19.9).

\subsection{Combined License Applicant Action Items}

COL Action Items based on the shutdown evaluation are identified in SSAR Appendix 19Q.12.3. These actions are contained in the detailed discussion of Chapter $19 \mathrm{COL}$ Action Items given in SSAR Section 19.9.11. The staff finds these COL Action Items to be acceptable.

\subsection{Insights From Uncertainty, Importance, and Sensitivity Analyses}

The greatest uncertainty in a shutdown evaluation is the actual configuration of the plant. This is particularly true since there is no agreed-upon method of modeling plant configurations during shutdown. To bound this concern, the ABWR shutdown evaluation made conservative assumption that all equipment not included in the minimum combinations of equipment needed to meet the goal of conditional core damage frequency was unavailable. GE and the staff believe that this conservatism would overshadow any uncertainty analysis or sensitivity analysis that might be performed. No importance analyses were performed since the importance of an SSC will vary depending on the particular configuration the plant is in.

\subsubsection{Level 2 Analysis}

\subsection{Containment Performance and CCFP}

The results of the Level 2 and 3 portions of the ABWR PRA indicate that the ABWR containment is quite robust and able to accommodate severe accidents with a low attendant probability of containment failure. In assessing the probability of containment failure, two alternative definitions of containment failure were considered: (1) loss of containment structural integrity, and (2) releases that result in doses of 25 rem or greater at a distance of $0.8 \mathrm{~km}(0.5 \mathrm{mile})$ from the reactor. The GE and staff estimates of CCFP are presented in Table 19.1-10. The staff estimates are based on a "staff-adjusted" ABWR risk profile that reflects staff views on selected issues. The most significant staff adjustment was to increase the frequency of early containment failures to account for uncertainty in the magnitude of direct containment heating loads and the contribution to CDF from unisolated LOCAs outside containment and ATWS events. Adjustments to account for uncertainties in source terms and consequence modelling were also made but affect only the dose definition of CCFP. 
Table 19.1-10 GE's point estimates and the stafr's mean estimates of the internal events risk

\begin{tabular}{|l|c|c|c|c|}
\hline \multirow{2}{*}{ Performance Measure } & \multicolumn{2}{|c|}{ GE Updated PRA } & \multicolumn{2}{c|}{ Staff-Adjusted Resul. } \\
\cline { 2 - 5 } & CFP & CCFP & CFP & CCFP \\
\hline Structural Integrity & 7.7 E-10 2/ & $0.005^{2 /}$ & $4.1 \mathrm{E}-9$ 1/ & $0.026^{1 /}$ \\
\hline Dose Definition & 3E-10 & 0.002 & $1.6 \mathrm{E}-8$ 3/ & $0.10^{3 /}$ \\
\hline
\end{tabular}

Notes:

$1 /$ Staff estimates reflect: (1) contribution from unisolated LOCAs outside containment and (2) increased probability of containment failure because of DCH.

2/ Based on GE's estimates of early and late containment failure frequency.

3/ Staff estimates include all frequency from Cases 7, 8, and 9, plus 58 percent of the frequency of Case 1 based on staff calculations using MACCS.

Both the GE and the staff estimates of the ABWR CCFP aro within the Commission's containment performance goal (0.10) using either containment failure definition. Combined with the core damage frequency estimate from the Lovel 1 portion of the. PRA (1.6E-7), this results in an extremely low likelihood of containment failure in absolute terms (i.e., on the order of 1E-8 to 1E-9 per year). GE's estimate of CCFP using the structural integrity definition

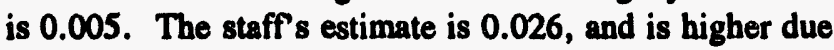
to the treatment of LOCAs outside containment as containment failures, and the higher loads associated with DCH in the staff's assessment. GE's estimate of CCFP based on the dose definition is $\mathbf{0 . 0 0 2}$. In contrast, the staff's estimate of CCFP using the dose definition of containment failure is about 0.1 . The staff's estimate is higher because of primarily (1) a higher source term used by the staff to represent scenarios with vented containment and suppression pool scrubbing, and (2) the use of the Melcor Accident Consequence Code System (MACCS) code for the consequence in calculations. However, the staff concludes that CCFP does not exceed 0.1, even under conservative staff assumptions, and therefore, meets the Commission's safety goal.

\subsection{Leading Sequences for Containment Failure}

The breakdown of contributors to containment failure for internal events is presented in Figure 19.1-2 in the form of a pie chart. For internal events, the bulk (about 85 percent) of the core melt events in the ABWR are successfully contained, with the releases to the environment limited to leakage on the order of the designbasis containment leak rate. A small fraction (about 13 percent) of core damage events result in actuation of tho COPS and releases to the environment via the stack. While this is the dominant release mode for the ABWR, the consequences of these releases are significantly reduced because of the relatively late time of the release (about 20 hours from accident initiation), and fission product removal by the suppression pool. As a result, these releases do not dominate the ABWR risk profile.

Based on the staff assessment, only about 3 percent of coro melt accidents result in containment failure. The bulk of these failures (about 90 percent of the 3 percent) are classified as early failures, relative to the time of core melt. Major contributors are DCH, LOCAs outside containment that proceed to core melt, and overpressure as a result of ATWS (The DCH frequency is based on a GE sensitivity study, as discussed in FSER Section 19.1.3.5.4; the LOCA and ATWS frequencies are based on GE's baseline Level I PRA). Late failures constitute only about 10 percent of the containment failure frequency. Drywell head or penetration overtemperature and rupture disk failure (i.e., failure of the drywell before rupture disk actuation) are the major contributors. 
Severe Accidents

Figure 19.1-2 Breakdown of ABWR containment release frequency from CET analysis
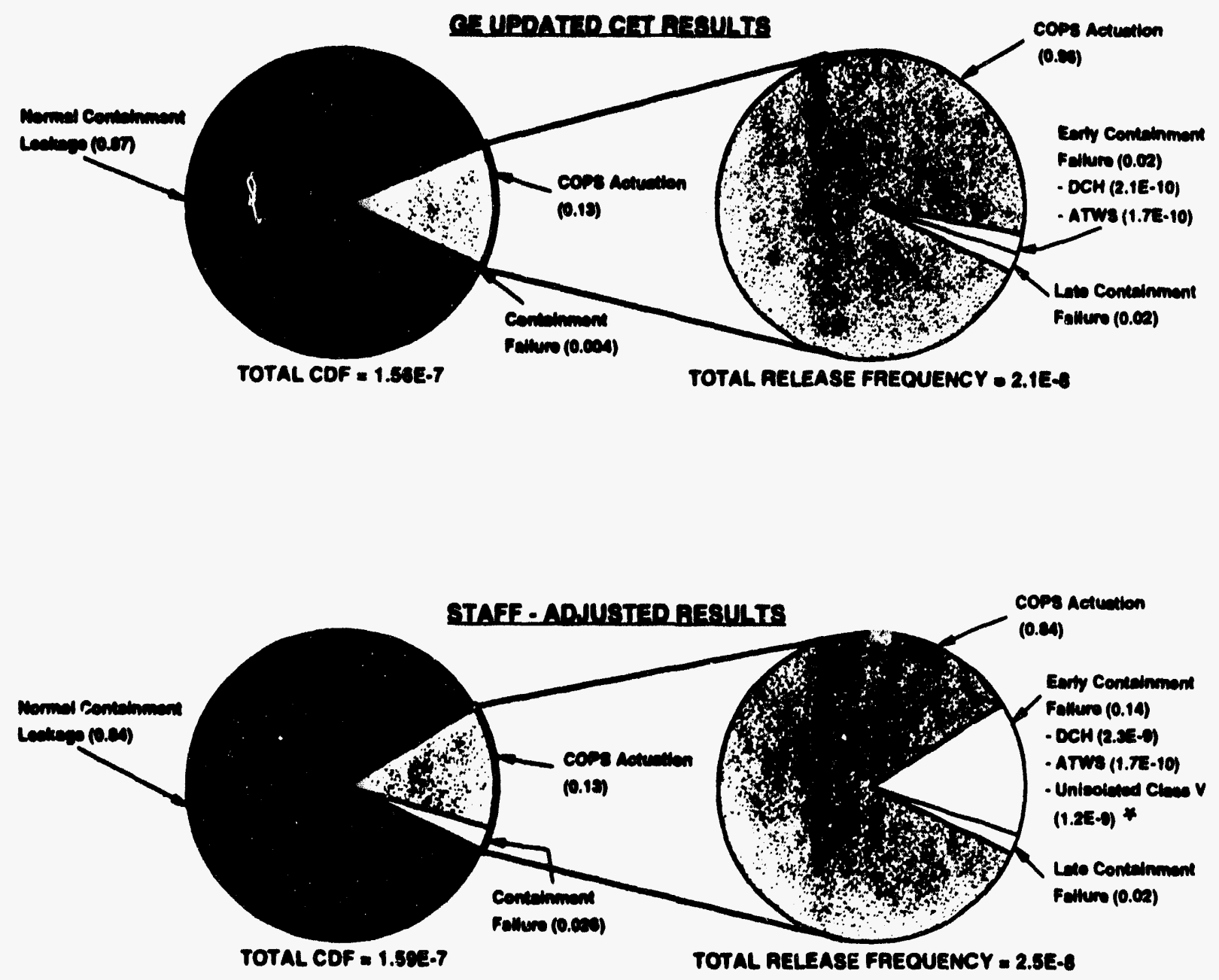

- Based on GE results before Amendmeat 32. OE values for unisolated LOCAs outside containment reported in Ameadment 32 are about a factor of 10 lower, however this does not affect the overall staff findings. 


\subsection{Important Design Peatures for Containment Performance}

GB added a passive flooder system to the lower drywell to improve the chances that a core-on-the-floor (following a postulated reactor vessel failure) would be covered by water. This is designed to help quench the corium and reduce the drywell temperature and preseure from noncondensable gas generation.

GE added a COPS to protect the integrity of the containmut (i.e., to sssuire that fission products must pass through the pool rather than bypass it by preventing failure of the drywell bead) in slow containment overpreenure eveats. The COPS allows isolation of the contrinmeat after the opening of the COPS rupture dieks.

Suppression Pool - The suppression pool is an important containment feature to prevent severe sccident progression and to promote fission product removal, since relenses from the reactor vessel are either directly routed to the pool (e.8., transients with sctuation of ADS) or pase through the pool via the drywell-wetwell connecting vents. However, the suppression pool function can be comprowised in the ABWR design by a single failure of a wetwell or drywell vacuum breaker (i.e., a stuck open vacuum breaker) or by excessive leakage of one or more vacuum breakers. While a similar containment challenge exists for all operating BWRs, the frequency of auppreasion pool bypass is expected to be somowhat greater for the ABWR since the ABWR has only a single vacuum breaker in each wetwell-drywell connecting path, in contrast to two valves in series in each path in operating BWRs. The impact of suppression pool bypass is minimized in the $A B W R$ by assuring: (1) a low probability of vacuum breaker leakage and failure through periodic surveillance, and (2) availability of drywell or wetwell eprays to condense steam that bypasses the auppression pool.

Vecuum Breaker Position Indication - Each vacuum breaker will be equipped with a position indication switch that will be sensitive enough to detect the allowable appreasion pool bypass capability of the containment. Vacuum breaker position indication and aseociated alarms will be provided in the main control room. This reduces the potential for suppression pool bypass by sesuring that the plant is not operated with a stuck open vacuum breaker, and that preexisting leakage paths will bo limited to small flow areas.

Drywell Sprays - The drywell spray system is critical for mitigating the consequences of severe accidents in the ABWR. The drywell spray system serves to: (1) reduce containment overpressure and delay the time to actuation of COPS, (2) eliminate the potential for drywell failure resulting from overhenting in those events in which debris my be dispersed to the upper drywell, and (3) mitigate the consequences of auppression pool bypass by condensing steam produced in the drywell. The ACIWA mode of RHR as a backup source of water to the sprays is pertaps the single-most important feature for reducing the consequences of severe accidents in the ABWR.

Lower Drywell Design - The design of the ABWR lower drywell or reactor cavity is such that there is a low probability that the cavity will be flooded at the time of reactor veasel failure, but a high probability that the cavity will be flooded after veasel failure. A dry cavity at tho time of veseal failure reduces the potential for large exvesiel steam explosions, whereas the subsequent flooding of the cavity belps minimize the impact of core concrete internctions (CCls). The following ABWR design fenture are important to assuring a dry cavity at the timo of veased failure: (1) lack of any direct pathways by which water from the upper drywell (e.g., from drywell sprays) can drain to the lower drywell, other than by overflow of the suppression pool, (2) negligible probability of premature or spurious actuation of the passive flooder valves at cemperatures lower than $260^{\circ} \mathrm{C}\left(500^{\circ} \mathrm{F}\right)$ or under differential pressures associated with reactor blowdown and pool hydrodynamic loads, and (3) a capability to accommodate approximately $7.2 \mathrm{ES} \mathrm{kg}$ of water in the auppression pool from external sources before the pool overflows into the lower drywell. Additional design features are included to increase the chances of a flooding a cavity following veseel failure, as discussed below.

Lower Drywell Flooder (LDF) System - The LDF system in the ABWR provides a passive means of adding water to the lower drywell following reactor vesed breach. This water would cover the core debris, thereby enbencing debris coolability, cooling the drywell, and providing fiscion product scrubbing. The passive flooder systom is a backup to other means of lower drywell water addition in the ABWR, including: (1) continued water addition through the breached reactor veseel, (2) suppression pool overflow as a result of water addition from water sources outside containment, and (3) ingress of suppression pool water after the core debris has penetrated the wetwelldrywell connecting vents (DCV8). PRA-based sensitivity studies indicate that the incremental risk rediction offered by the passive flooder system is minimal. This is because of credit taken in the ABWR for continued water addition using the ACIWA mode of RHR.

Reactor Pedestal and Drywell Floor - The effect of CCls is minimized in the ABWR by the use of a robust reactor pedestal and the use of basaltic concrete in the floor of the lower drywell. The reactor pedestal is $1.7 \mathrm{~m}$ (5.6 ft) thick 
and capable of withstanding $1.55 \mathrm{~m}(5 \mathrm{ft})$ of core-concreto erosion without loss of ptructural integrity. The use of basaltic concrete in the floor minimizes the production of noncondensable gases, thereby delaying the time of COPS sctuation.

Containmeat Ultimate Pressure Capacity - The ultimate pressure capacity of the ABWR containment is limited by the drywell head, the failure mode of which is plastic yield of the torispherical dome. After the original SSAR submittal, $\mathrm{GE}$ increased the pressure capability of the drywell head from 100 pounds per square inch (psig) to 134 psig, and increased the COPS setpoint from the original value of 80 psig to the final value of 90 psig. The strengthening of the drywell head increases the ability of the containment to withstand rapid presourization ovents, such as DCH, without loss of structural integrity, and provides additional margin between the COPS setpoint and the drywell failure pressure, thereby reducing the potential for drywell failure before COPS actuation.

COPS - COPS is part of the atmospheric control system in the ABWR and consists of a pair of rupture disks installed in a 10-in. diameter line, which connects the wetwell airspace to the stack. COPS provides for a scrubbed release path in the event that containment pressure cannot be maintained below 90 psig. Without this system, late containment overpressure failures would be expected to occur in the drywell, resulting in unscrubbed releases. COPS provides a significant benefit by reducing the source terms for late releases, and minimizing the potential for containment-failure-induced loss of core cooling (e.g., in Class II sequences).

Containment Inerting - The ABWR containment will be made inert during power operation. As a result, the threat of containment failure as a result of hydrogen combustion is essentially eliminated for power operation.

Containment Sump Protection - To preclude significant debris from entering the containment sump following a severe accident, a protective barrier was added around the sumps to prevent the entrance of molten' debris, while allowing water to enter the sumps during normal operations.

\subsection{Impact of Severe Accident Phenomena on Containment Performance}

DCH occurs only in sequences with reactor vessel failure at high pressure. For the ABWR, reactor veseel failures at high pressure constitute about 30 percent of the reactor vessel failures (about 4.3E-8 per year). In viow of the large uncertainties inherent in estimating the pressure loads associated with DCH, the staff conservatively based its findings on the results of a $\mathrm{GE}$ sensitivity analysis for DCH which reflected an increased contribution to preasurization due to higher baseline containment pressure, and combustion/recombination of hydrogen with residual oxygen. As such, DCH is the principal contributor to contrinment failure for the ABWR. The staff thas cotimated the containment failure probability for DCH to be about 5 percent, conditional upon reactor vecsel failure at high precoure. This results in a very low irspuency of contninment failure from DCH (2.3E-9 per year). The low frequency of reactor vessel failure at high pressure is a result of the highly reliable depressurization system. There are no specific ABWR containment design features to deal with DCH loads other than the general arrangement of the drywell, wetwell, and connecting vents, which provides for a series of 90 -degree bends that debris must traverse in order to reach the upper drywell.

Fuel-coolant interactions (FCl) or steam explosions are considered negligible in the ABWR design because of the very low probability that the lower drywell will be flooded at the time of reactor vessel failure $(0.3$ percent). In addition, the ABWR reactor pedestal is capable of withstanding the best-estimate loads associated with an exvessel steam explosion as predicted by GE and staff calculations. The design features that contribute to the low probability of a flooded lower drywell at the time of vessel failure were discussed above in the context of the lower drywell design. The structural capability of the reactor pedestal is discussed further in Section 19.2 of this report.

CCls have a minimal impact on $A B W R$ containment structural integrity because of the inclusion of: (1) a thick reactor pedestal, (2) the use of basaltic concrete in the floor of the lower drywell, and (3) a sump shield to prevent core debris from entering the lower drywell sump. These features provide significant confidence in reactor pedestal and containment integrity for well beyond 24 bours following reactor vessel failure and reader CCI-induced containment failure a relatively insignificant contributor to risk.

Hydrogen combustion is not an important containment challenge in the ABWR since the atmosphere is made inert during normal operation.

\subsubsection{Level 3 Analysis Insights}

\subsection{Risk to the Public}

Based on the Lovel 3 PRA, the estimated total risk to the public from the ABWR is extremely small. GE's analysis indicates a total dose of about 0.2 person-rem over the 60-year period. The staff's estimate is about 1 personrem. The difference is largely a result of the contribution 
from unisolated LOCAs outside containment, and an increased probability of early containment failure from DCH. It should be noted that while vented scenarios are the dominant contributor to the staff's estimate of contrinment failure using the dose definition of contrinment failure, these sequences do not contribute significantly to total risk when measured in terms of person-rem exposure. Rather, total risk is dominated by ovents that lead to early containment structural failure and containment bypass. This is consistent with results from PRAs for operating plants.

\subsection{Leading Contributors to Risk}

Despite their small contribution to total core damage frequency ( 0.8 percent based on the staff's assessment), unisolated LOCAs outside containment dominate the ABWR risk profile. The frequency of these sequences is extremely low in absolute terms (1.2E-9 per year). In the staff's assessment, these sequences dominate risk because of the severe releases associated with complete bypass of containment. These sequences also dominate risk because of the fact that the baseline core damage frequency and the contribution of more familiar sequences and containment challenges that dominate PRAs for operating plants have been reduced in the ABWR design. The fact that these sequences dominate risk is, in a way, a reflection of the low estimated risk of the ABWR.

Other early containment failures (DCH and ATWS) are the second most dominant contributor to risk for the ABWR. Although the frequency of these early failure mechanisms (2.5E-9) is higher than unisolated LOCAs outside containment, fission product releases are reduced somewhat because of holdup in containment.

It should be noted that the reported frequency of unisolated LOCAs reported in Amendment 32 of the SSAR is about a factor of 10 lower than the above value on which the staff based its finding. This would result in the total risk's contribution, as well as the contribution of bypass scenarios to risk, being lower than described above.

\subsubsection{PRA-Based Input to the Certified Design}

\subsection{Reliability Assurance Program}

The ABWR is the lead plant for development of a RAP for advanced reactors as required by 10 CFR Part 52. GE made a particularly strong effort in identifying important SSC for inclusion in RAP based on insights from the ABWR PRA. In Appendix 19K of the SSAR, GE hes listed the reliability and maintenance actions that it believes should be considered throughout the life of the plant so that the PRA remains an adequate basis for quantifying plant safety and determining safety insights. It is anticipated that a COL applicant will make these insights (given in Table 19K.11-1 in the SSAR) the comerstone of its programs (DRAP and ORAP).

Internal and external event sequences, both for Lovels 1 and 2, were considered in drawing up the list of reliability and maintenance actions. In developing the list, $\mathrm{GE}$ performed systematic search that involved both quantitative and qualitative considerations. For Lovel 1 internal events, the key considerations were the results of risk achievement worth and Fussell-Vesely importance mensures. These results are reported in Tables 19K.3-1 and 19K.3-2 in the SSAR and Appendix $K$ in this report. From risk achievement worth measures, one gets a list of SSCs where maintenance or testing resources should be focused to help assure high lovels of availability. A Fussell-Vesely importance measure answers the question, "For which SSCs would improvement of current unavailabilities be most beneficial in order to best lower the estimated core damage frequency?"

\subsection{Tiers 1 and 2 Information or Requirements}

In its review, the staff believed that it was important to systematically search a PRA for safety insights. As part of this search for insights, GE identified important safety insights that need to be passed on to a COL applicant. Appendix $\mathrm{K}$ of this report provides a cross-reference between the PRA insights and the ITAAC, Tier 1 design descriptions, and Tier 2 material in the DCD. Appendix $K$ explains the disposition of these ABWR PRA safety insights. The staff has reviewed the COL action items proposed by GE and finds them to be appropriate dispositions of these insights, and finds they are acceptable.

\subsubsection{PRA Insight Conclusions and Safety Findings}

This section documents the overall conclusions about the insights drawn from the ABWR PRA about the ABWR design.

\subsection{Vulnerabilities}

In its performance of the ABWR PRA, GE did not specifically identify any design features or procedures that constituted a vulnerability to severe accidents. GE did search for and identify many cost-effective design and procedure improvements that it included in the ABWR design. Details of the design improvements motivated by the ABWR PRA are discussed previously in Section 19.1.3 and listed in Table 19.1-4. The search by the staff and GE for design anci procedure vulnerabilities (or areas of 
potential improvement) included internal and external events (seisnic, fire, and internal floods) as well as ovents in Modes 3, 4, and 5.

\subsection{Balance of Prevention and Mitigation}

The staff examined the ABWR design to determine if the design has an inappropriate reliance on either prevention of severe accidents or mitigation of severe accidents to the exclusion or detriment of the other. The staff finds the balance to be acceptable for the following reasons:

In the area of prevention of core damage, GE has reported that the ABWR PRA estimates internal event core damage frequency to be in the range of 1E-7 per year. This estimate reflects the design modifications incorporated into the ABWR design that have eliminated or roduced most of the important sequences that have led to core damage in other BWR PRAs. The NRC does not endorse the absolute value of the core damage frequency reported by GE, but does endorse the insights drawn from the PRA by GE and the NRC, which are based on relative and other considerations. For the external events seismic, fije, and internal floods, the ABWR design is an improvement over those of existing operating plants. The seismic design is built to an SSE of $0.3 \mathrm{~g}$ while most siteq in the United States east of the Rocky Mountains would have lower SSEs when determined on a site-specific basis. In addition, the ABWR PRA-based seismic margins analysis demonstrated that the design has significant margin to earthquakes well above the SSE. For fires and floods, the ABWR design has three physically separated safety divisions that limit the chances of a fire or flood affecting more than one division. This capability is a design enhancement for advanced reactors. For mitigation of a severe accident in which core damage has occurred, the ability of the containment design to withstand severe accidents is at least as robust as that of operating BWRs today and has some additional features not in current designs. Additional features include the acindependent water addition system, an increased drywell head ultimate pressure capacity, and the passive flooder system.

\subsection{Comparison With NRC and EPRI Safety Goals}

In the DSER (SECY-91-309), the staff compared the integrated risk results for the A.BWR with the Commission's quantitative health objectives and safety goals, NRC and EPRI requirements or goals for advanced light-water reactors (ALWRs), and GE's design goal. GE and staff estimates of various risk measures based on the original GE analysis (Amendment 8 to the SSAR), are reported in Figures 19.1-1 and 19.1-2 of the DSER. Based on these comparisons, the staff reached tentative conclusions on how the various objectives and goals were met. After the DSER, GE modified the ABWR design and submitted the results of the updated ABWR PRA (Levels 1,2 , and 3 ) reflecting modifications to the plant design, as well as modeling enhancements and corrections identified by GE and staff since the original PRA. The staff committed itself to reporting the results of its review of the integrated risk estimates in this report.

The staff's evaluation of GE's updated PRA analyses is presented in the preceding portions of Section 19.1 of this report. Based on a review of the updated PRA analysis, the staff performed a limited update of the comparisons with the safety goals. The updated comparisons with safety goals are not as exhaustive as the one provided in the DSER since: (1) the staff did not attempt to requantify uncertainties in core damage frequency and containment performance as part of the final evaluation, and (2) only doses at the site boundary were recalculated as part of the final evaluation, rather than the full set of offsite consequence measures. However, for certain performance measures, such as individual risk of early fatality, the original comparisons indicated significant margins between the PRA results and the health objectives or safety goals, even when the uncertainty associated with various phenomenological issues and other issues raised in the staff review were factored into the assessment. In those cases, the staff's tentative conclusions presented in the DSER are still considered valid for the updated $A B W R$ PRA and have been used as the basis for the staff's final conclusions. Limited reliance on the original analyses is considered acceptable on the basis that the updated core damage frequency and containment release characteristics are not significantly dif'erent from those on which this original assessment was based. Furthermore, the analyses and plant modifications performed after Amendment 8 to the SSAR did not identify any plant vulnerabilities and are expected to further reduce risk.

The comparison of the ABWR PRA results with the various health objectives and safety goals follows. As discussed in Section 19.1.1 of this report, the staff does not believe that it is appropriate, or possible, to directly compare the results of the updated ABWR external events analyses with the safety goals because in the updated PRA these events were analyzed using either a margins approach (seismic) or bounding analyses (internal floods and fire). Accordingly, the comparisons with safety goals are limited to internal events.

\section{Individual risk of early fatality - Goal: $\leq 5 E-7$}

The staff concluded in the DSER that the ABWR meets the Commission's quantitative health objective for individual risk of early fatality by a wide margin. The calculated 
mean estimate, as well as the upper bound of the uncertainty distribution (95th percentile), were orders of magnitude below the goal. Because the updated core damage frequency and containment release characteristics are not significently different from those on which this original assessment was based, the staff concludes that the final ABWR design would also meet this health objective by a wide margin, even if the effects of unisolated LOCAs outside containment are taken into account. The staff further believes that the remaining margin provides rensonable assurance that consideration of the impact of those portions of the analysis for which full PRA quantification was not performed (e.g., seismic events) will not result in the mean value's exceeding the goal.

\section{Individual risk of cancer fatality - Goal: < 2E-6}

The staff concluded in the DSER that the ABWR meets the Commission's quantitative health objective for individual risk of cancer fatality by a wide margin. The calculated mean estimate, as well as the upper bound of the uncertainty distribution, were several orders of magnitude below the goal. Because the updated ABWR core damage frequency and containment release characteristics are not significantly different from those on which this original assessment was based, even if the effects of unisolated LOCAs outside containment are taken into account, the staff concludes that the final ABWR design would also meet this health objective by a wide margin. The staff further believes that the significant margin between the calculated risk and this goal provides reasonable assurance that consideration of the impact of those portions of the analysis for which full PRA quantification was not performed will not result in the mean value's exceeding the goal.

Core damgre frequency - Commission Goal: $<1 \mathrm{E}-4$ EPRI Goal: < 1E-5

The staff concluded in the DSER that the ABWR meets both the Commission and the EPRI goals for internal event core damage frequency by a wide margin. The calculated mean value was below the goal, with the upper bound of the uncertainty distribution about 1 order of magnitude below the Commission goal. Based on the updated PRA and a supporting Lovel 1 uncertainty analysis, GE has estimated the ABWR mean core damage frequency at 1.6E-7 per year, with an upper bound (95th percentile) value of 4.5E-7 per year. Based on review of the ABWR PRA, the staff concludes that the final ABWR design meets the Commission's goal for internal events, even if uncertainties in the calculated core damage frequency are taken into account. The analyses performed by $G E$ for ABWR external and shutdown events do not lend themselves to comparison with the Commission's core damage frequency goals, based on methods and assumptions used. The staff determined that this is acceptable, since the GE analyses of external events and shutdown events included an appropriate search for vulnerabilities.

Probability of larre ndease (one or more early fatalities) Goal: $<1 \mathrm{E}-6$

The staff concluded in the DSER that the ABWR meets the Commission's goal for the probability of large release by a considerable margin, recognizing that the definition of "large" was still under Commission consideration. The calculated mean estimate was well below the goal, with the upper bound of the uncertainty distribution (95th percentile) about 2 orders of magnitude below the goal. Because the updated core damage frequency and containment release characteristics are not significantly different from those on which this original assessment was based, the staff concludes that the final ABWR design would also meet this objective by a wide margin. The staff notes that this goal can be met as a result of the very low calculated core damage frequency for internal events, even without taking credit for the containment. Compliance with the Commission's containment performance goal provides added assurance that the probability of a large release will remain below the goal.

Conditional containment failure probability (structural integrity definition - Goal: $<0.1$

The staff concluded in the DSER that the ABWR did not strictly meet the Commission's goal for CCFP using the structural integrity definition of containment failure. The staff's uncertainty distribution bridged the goal with a median value slightly above the goal, suggesting that the bulk of the distribution was slightly above the goal.

GE's updated point estimate of CCFP based on structural integrity definition is $\mathbf{0 . 0 0 5}$. The staff adjusted this value to account for: (1) uncertainties in DCH, and (2) treatment of unisolated LOCAs outside containment. These adjustments increased CCFP to about 0.026, which is still below the Commission goal. However, the staff did not attempt to requantify the uncertainties associated with this estimate. It believes that if these uncertainties were requantified reflecting the final $A B W R$ design and additional severe accident analyses completed since the DSER (e.8., increased containment pressure capacity and additional information supporting a low probability of a flooded reactor cavity at the time of vessel failure), the resulting CCFP estimate and associated uncertainties would be somewhat lower than reported in the DSER, but would still be significant. 
Conditional containment failure probability (dose definition - Goal: $<0.1$

The staff concluded in the DSER that the ABWR did not strictly meet the Commission's goal for CCFP using GE's definition of containment failure (dose). The staff's uncertainty distribution bridged the goal, with a mean estimate above the goal and median estimate slightly below the goal. This indicated that about half of the distribution is below the goal.

GE's updated point estimate for CCFP (based on the dose definition) is $\mathbf{0 . 0 0 2}$. The CCFP based on the dose definition is not significantly different than the CCFP based on the structural integrity definition (where containment venting is not considered as a containment failure). The reason for this is that in GE's analysis, doses in excess of $25 \mathrm{rem}$ at $0.8 \mathrm{~km}$ ( 0.5 miles) primarily occur only when structural integrity is breached. In contrast, the staff's consequence calculations indicate a high probability (about 60 percent) of exceeding 25 rem at the boundary for vented scenarios. Thus, the staff's estimate of containment failure frequency using the dose definition of containment failure includes essentially all of the frequency of events leading to loss of structural integrity, plus about 60 percent of the frequency of sequences with COPS actuation. This results in a staff estimate of CCFP of about 0.10 , which still meets the Commission's safety goal.

The staff did not attempt to requantify the uncertainties associated with this estimate. It expects that if these uncertainties were requantified reflecting the final $A B W R$ design, additional severe accident analyses completed since the DSER, and more deterministic estimates of source terms for vented scenarios, the resulting CCFP estimate and associated uncertainties would be lower than reported in the DSER. Nevertheless, the uncertainties would still be significant and would extend above the goal. Although the uncertainty bands are different, the staff and GE both concludes that the mean values of their risk estimates meet the Commission's safety goal.

\subsection{Comparison With Operating BWRs}

The staff evaluated the ABWR design and its improved or unique features to prevent or mitigate severe accidents such as the three full (high and low pressure) ECCS divisions, the COPS, and the passive flooder. The staff evaluated the ABWR PRA and concluded that the absolute value of the estimated core damage frequency for the ABWR is lower than those of operating BWRs in the United States. Based on these reviews, the staff finds that the ABWR design represents an improvement in safety over operating BWRs in the United States.

\subsection{ABWR Design Acceptability}

Based on the staff's review of the ABWR PRA and ABWR design as set forth in this section (19.1) of this report, the staff finds that the ABWR design and the submittals mado for the ABWR in the SSAR meet the intent of the Commission's Policy Statement on Severe Reactor Accidents Regarding Future Designs and Existing Plants, dated August 8, 1985, the requirement of 10 CFR 50.34(f)(1)(i) to perform a plant-specific PRA that secks improvement in the reliability of core and containment heat removal systems, the staff's proposed applicable regulation for analysis of external events for the ABWR PRA, and the requirement of $10 \mathrm{CFR} 52.47(\mathrm{a})(1)(v)$ for an evolutionary plant design vendor to submit a PRA.

\subsubsection{ACRS Concerns Related to the ABWR PRA}

\subsection{Adequacy of the ABWR PRA}

The Advisory Committee on Reactor Safeguards (ACRS) asked the staff to explain how it intends to use the ABWR PRA in the design certification process and when PRA guidance will be provided.

In preparing for design certification, the staff and GE used the ABWR PRA in a number of traditional as well as new areas. The staff expects that the PRA will continue to prove to be useful throughout the entire process - from design certification through the end of the life of an operating $A B W R$. Examples of traditional areas in which the ABWR PRA was used include estimating core damage frequencies and risk significance and identifying design vulnerabilities. Innovative ways in which the PRA has been used include the following:

- helping to identify systems and components to be included in the RAP, increasing the safety of the design of the $A B W R$ by examining design options

- helping to identify human errors that need to be considered when designing an advanced control room

- identifying areas that should receive special attention under ITAAC

- helping to determine the balance of prevention and mitigation capabilities

- providing a structure for helping to determine procedural and TS needs during modes other than full power. 


\subsection{Adequacy of GE's Treatment of the Reactor Water Cleanup System}

The ACRS performed a review, independent from the staff, of the reactor water cleanup (RWCU) system. GE's treatment of this system in the PRA was not reviewed in detail as part of the staff's initial review. Several of the questions raised by the ACRS review applied to the ABWR PRA. First, the ACRS review concluded that the ABWR PRA did not evaluate RWCU system line breaks as initiators. Second, the ACRS review concluded that GE erroneously took credit for the RWCU system as a potential heat removal path at high pressure during nonLOCA transients. The ACRS found credit to be inappropriate, in part, because the RWCU system was designed to isolate on high temperature (to protect resin beds) and because even if the resin beds were bypassed, the outlet temperatures of the heat exchanger piping would have exceed the design limits of the piping.

The ACRS correctly noted that GE did not treat RWCU system line breaks, or other LOCAs outside the primary containment, as initiating events in the PRA. Rather, the approach taken by GE (SSAR Section 19E.2.3.3) was to show that the risks associated with such events constitute a small fraction of the risk from all non-bypass paths, and that these ex-containment LOCAs therefore need not be included in the PRA. The ACRS questioned the validity of this analysis, and the fact that it failed to consider that the RWCU system line break could be the initiator for the core damage event. Based on concerns identified by the ACRS, the staff performed a more detailed review of GE's treatment of the RWCU system in the PRA. After further review of GE's treatment of ex-containment LOCAs, the staff identified additional concerns related to flow area assumptions on which the split fractions were based and isolation valve failure probability assumptions in the analysis (i.e., whether the assigned values adequately account for environmental effects and common cause failure).

In response to ACRS and staff concerns, GE revised its suppression pool bypass analysis and provided additional clarification regarding the effects of a break in the RWCU suction line. GE indicated that the system arrangement and emergency procedure guidelines (EPGs) provide assurance that unisolated breaks in the RWCU suction line will not result in core uncovery and long-term releases. The staff required that GE develop a COL Action Item that would have a COL applicant develop postaccident recovery procedures for an unisolated CUW line break.

As part of its review, the staff required GE to provide an analysis of LOCAs outside containment that was based on event trees and fault trees rather than on split fraction arguments.

The ACRS correctly stated that GE erroneously took credit for the RWCU system at high pressure during transients. GE has corrected this design deficiency by redesigning the isolation logic of the RWCU system, realigning the isolation configuration so that only the heat-vulnerable resin beds are isolated on high temperature, and limiting the total isolation of the RWCU to those periods when the containment isolation function is actuated. In addition, the RWCU will only be put into operation by emergency procedure after the RHR fails. Thereafter, cooling water will be diverted by procedure from the RHR heat exchangers to the RWCU heat exchanger to limit the temperature increase across the RWCU heat exchanger. GE calculates that this temperature increase is only a few degrees above the design temperature and argues that this is acceptable because the RWCU is a backup system that only will have to be used in this configuration for very low probability, beyond-design-basis events.

\subsubsection{Evaluation of the Quality of the ABWR Probabilistic Risk Assessment}

The staff has completed its review of the quality of the ABWR PRA. It finds that the ABWR PRA is of sufficient quality that, at a minimum, it can be used in the following ways:

(1) to assess (within the limits of PRA methods and uncertainties) the risks associated with the $A B W R$ design

(2) to identify strengths and weaknesses of $A B W R$ design features

(3) to evaluate ABWR containment failure probabilities for early and late failure modes

(4) to compare the $A B W R$ risk results with the Commission's safety goal and the "safety margin basis design requirements" provided in the EPRI ALWR Requirements Document within the limitations of the latest technology in risk assessment

(5) to provide an integrated perspective of the overall risk estimates for the design

(6) to identify major contributors to uncertainty in estimated core damage frequency. 
The staff concludes that the quality of the ABWR PRA is adequate for its intended functions such as supporting and improving the ABWR design process, providing relative importance of sequences (as well as identifying important SSC) leading to core damage or containment failure, and searching for design and procedure vulnerabilities that could be eliminated on a cost-effective basis.

\subsubsection{Open Item Closure}

All Open and "Outstanding" Items identified in Chapter 19 of the staff's ABWR DSER and DFSER are resolved satisfactorily. The staff is issuing a letter separate from this report documenting the resolution of these issues. All important issues related to containment performance are discussed in Section 19.2.

\subsection{Severe Accident Performance}

\subsubsection{Introduction}

The purpose of this section is (1) to describe the NRC's approach to resolution of severe accident issues for evolutionary light water reactors as specified in SECY-90-016, SECY-91-262, SECY-93-087, and the corresponding SRMs and (2) to evaluate the approach proposed by GE for resolution of severe accident issues for the ABWR design.

To provide adequate protection of the public health and safety, current NRC regulations require conservatism in design, construction, testing, operation, and maintenance of nuclear power plants. A defense-in-depth approach has been mandated in order to prevent accidents from happening and, if accidents should occur, to mitigate their consequences. Siting of nuclear power plants in less populated areas is emphasized. Furthermore, the NRC, State, and local governments mandats emergency response capabilities that provide additiunal defense-in-depth protection to the surrounding population.

The reactor and containment systems design provides a vital link in the defense-in-depth philosophy. Current reactors and containments are designed to withstand a LOCA and to meet the siting criteria of 10 CFR Part 100 and General Design Criteria (GDC) of 10 CFR Part 50, Appendix A. The large-break LOCA and other accidents analyzed in accordance with the NRC's Standard Review Plan (NUREG-0800) and documented in Chapter 15 of the SSAR are commonly referred to as "design-basis accidents" (DBAs) for nuclear power plants. This high level of confidence in a defense-in-depth approach results, in part, from stringent requirements for meeting singlefailure criterion, redundancy, diversity, quality assurance, and utilization of conservative models.
The NRC also has requirements to mitigate adverse conditions associated with transients or ovents considered outside the design basis such as ATWS (10 CFR 50.62), station blackout (SBO) (10 CFR 50.63), and combustible gas control (10 CFR 50.44); however, a definitive set of regulatory requirements for addressing specific sovere accident phenomenon does not exist. Existing regulations that require conservative analyses and inclusion of mitigative features for design-basis events, provide margin for severe accident challenges. In addition, the staff, in keeping with the Commission's Policy Statement on Severe Accidents that future designs for nuclear power plants achieve a higher standard of severe accident safety performance, concluded that severe accidents should be considered in the design of future nuclear power plants.

In an SRM, dated January 28, 1992, on SECY-91-262, the Commission approved the staff's recommendation to proceed with design-specific rulemakings through individual design certificstions to resolve selected technical and severe accident issues. The effect of these actions on the $A B W R$ is that the criteris specified for resolution of severe accident issues in SECY-90-016 and SECY-93-087 will be incorporated into the ABWR design certification rulemaking as applicable regulations. The following discussion describes the criteria that were used for the deterministic evaluation of severe accident issues.

\subsubsection{Deterministic Assessment of Severe Accident Prevention}

\subsubsection{Severe Accident Preventative Features}

Accident initiators can be separated into two general groups: transients and LOCAs. Transients include planned reactor shutdowns and transients that result in reactor scrams. Examples of transients include manual shutdown, main steam isolation valve closure, loss of condenser vacuum, loss of feedwater, nonisolation event (trip with bypass), inadvertent open relief valve, and loss of orfsite power. LOCAs generally fall within three categories, small, medium, and large, based on the size of the line break.

Following the accident initiator, plant systems respond to control reactivity, reactor pressure, reactor water level, and containment parameters within the design basis spectrum. Ensuring sufficient heat removal from the core to prevent overheating and subsequent fuel damage is of paramount importance. Failure to provide this heat removal can result in fuel overheating and the potential for oxidation and melting of the reactor core.

Transient-induced accidents are usually accompanied by actuation of the safety or relief valves that transfer steam 
from the reactor directly to the suppression pool, thus limiting an increase in containment pressuro. LOCAs blow down into the drywell atmosphere until the suppression pool horizontal vents' are uncovered, resulting in containment pressurization lower than the containment design pressure. In the event that the steam from the reactor bypasses the suppression pool and travels directly to the wetwell atmosphere, significant pressurization of the containment may reoult. The issue of suppression pool bypass is addressed in Sections 6.2.1.8 of this report for design-basis accident (DBA) bypass and 19.2.3.3.5 for severe accident bypass.

In response to accident initiators identified through operating reactor experience and analyses of the results of probabilistic safety assessment, the staff developed criteria for evolutionary light-water reactors (LWRs) to prevent the occurrence of such initiators from leading to a severe accident. These criteria were specified in SECY-90-016 and SECY-93-087 and include design provisions for anticipated transient without scram (ATWS), SBO, fires, and intersystem LOCAs.

\subsection{Anticipated Transient Without Scram}

An ATWS is an anticipatod operational occurrence followed by the failure of the trip portion of the reactor protection system (RPS). Anticipated operational occurrences (transients) are those conditions of normal operation that are expected to occur one or more times during the life of the nuclear power plant and include, but are not limited to, loss of power to all recirculation pumps, tripping of the turbine generator set, isolation of the main condenser, and loss of all offsite power. Dependent upon the transient and its severity, the plant may recover and continue normal operation or the plant may automatically shut down (scram) via the RPS. The RPS is designed to safely shutdown the reactor to prevent core damage.

These transients when coupled with a failure of the RPS may lead to conditions beyond the design basis of the plant. In these cases, the reactor must be manually scrammed in order to avoid reactor fuel damage or coolant system damage. Subsequent failure of the manual scram systom and inadequate core cooling may lead to coro damage.

Transients with the greatest potential for significant damage to the reactor core and containment are those leading to an increase in reactor pressure and temperature, a loss of heat sink, or a failure of the RPS to scram the reactor. During an ATWS event, reactor power, pressure, and temperature must be controlled or the potential exists for a severe accident.
The ATWS rule (10 CFR 50.62) was promulgated to reduce the probability of an ATWS event and to enhance mitigation capability if such an event occurrod. For BWRs, the ATWS rule specifies inclusion of an alternate rod insertion system, an SLCS, and equipment to trip the renctor recirculation pumps. In Section 15.5 of this report, the NRC concluded that the ABWR complies with the ATWS rule.

\subsection{Preventive and/or Mitigative Features}

In SECY-90-016, the staff recommended that the Commission approve its position that diverse scram systems should be provided for evolutionary LWRs. In its June 26, 1990 SRM, the Commission approved the staff's position, but directed that if the applicant can demonstrate that the consequences of an ATWS are acceptable, the staff should accept the demonstration as an alternative to the diverse scram system.

The ABWR has a number of design features that reduce the risk from an ATWS event including a diverse scram system with both hydraulic and electric run-in capabilities for the fine motion control rod drives (FMCRD), an automatic SLCS, and a reactor internal pump (RIP) trip capability. In addition, the scram discharge volume has been removed from the ABWR, eliminating some of the potential problems that could affect the scram function associated with older BWR designs.

The ABWR has an alternate rod insertion system that is diverse, when compared with that of the RPS, from sensor output to the final actuation device. The ARI system has rodundant scram air beader exhaust valves and is designed to perform its function in a reliable manner.

\subsection{Basis for Acceptability}

In SECY-90-016, the NRC concluded that evolutionary LWR designs should provide diverse methods of inserting control rods to mitigate a potential ATWS and to ensure a safe reactor shutdown. The ABWR incorporates a diverse method for inserting control rods. The ABWR complies with the ATWS rule, as concluded in Section 15.5 of this report, and the design is capable of satisfactorily mitigating the effects of an ATWS and preventing an ATWS ovent from ovolving into a severe accident with coro damage. The staff concludes that the ABWR meots the criteria specified in SECY-90-016 through incorporation of the features discussed above.

\subsection{Station Blackout}

An SBO involves the complete loss of ac electrical power to the essential and nonessential switchgear busses in a 
nuclear power plant (i.e., loss of offeite electric power aystem concurreat with turbine trip and unavailability of the pa-site emergency ac power system). SBO does not include the loss of available ac power to buses fod by station batteries through inverters or by alternato ac sources, nor does it asume a concurrent single failure or DBA.

During normal plant operation, power is supplied to the Class IE distribution system from the main generator. Following plant shutdown, the preforred power source is the offisite grid, which provides a continuous source of ac electric power to equipment required to maintain core coolability. If the power from the offaito grid is not available, the on-site distribution system will sense an undervoltage condition and initiate a transfor to the emergency dieeel generators (EDGs) for continued power. In the oveat of the loss of both the offsite grid and EDGs, an SBO has occurrod. As most DHR and containment heat removal systems are dependent upon ac power for operation, failure to provide core cooling during an SBO will likely result in core temperature and pressure increases and may lead to a severe accident.

The SBO rule (10 CFR 50.63) allows several design alternatives to ensure that a plant is able to withstand an SBO for a specified duration and rocover. A complete evaluation of the ABWR relative to the SBO rule is provided in Section 8.3.9 of this report.

\subsection{Preventive and/or Mitigative Features}

In SECY-90-016, the staff stated that the preferred method of demonstrating compliance with 10 CFR 50.63 is through the installation of a spare (full- capacity) alternate ac power source of diverse design that is consistent with the guidance in Regulatory Guide (RG) 1.155 and is capable of powering at least one complete set of normal shutdown loads. The staff recommended that the Commission approve the requirement for an alternate ac cource for ovolutionary LWRs. In its June 26, 1990 SRM, the Commission approved the staff's position. Therefore, the etaff's proposed applicable regulation for an alternate ac souce is as follows:

The standard design must provide an alternate ac power souce for the purposes of dealing with station blackout.

The ABWR design includes three independent electrical divisions, each capable of providing power to highpressure and low-pressure water injection division, each powered by a full-capacity EDG, and each division capable of independently shutting down the reactor. In addition, the ABWR design includes an alternate ac combustion turbine to back up the diesel generators. The RCIC system (with its supporting systems) is deaigned to perform its function without ac power for at loast 2 bours and also have an ultimate capability to function for 8 hours without ac power. Extended bleckout capabilities aro also provided by the ACIWA system. This system allows for makeup to the reactcr vessel following depressurization or to the containment sprays from a direct-drive diesel fire pump or by connecting an external pumping source, wuch as a fire truck, to a yard standpipe into the RHR system.

\subsection{Basis for Acceptability}

In SECY $-90-016$, the NRC concluded that designers ahould meet the SBO rule by including in alternate ac power source (i.e., CTG) of diverse design capable of powering at least one complete set of normal shutdown loads. To cope with SBOs, the ABWR has included an alternate CTG. Based on the proventive and mitigative featurea doscribed above, the staff concludes that the ABWR has met the criteria of SECY-90-016 and the staff's proposed applicable regulation for station blackout.

\subsection{Fire Protection}

The Commission concluded that fire protection issues that have been raised through operating experience and the external events program must bo resolved for evolutionary light water reactors. In SECY-90-016, the staff recommended that current NRC guidance to resolve fire protection issues be enhanced to minimize fire as a significant contributor to the likelihood of severe accidents and DBAs. As indicated in SECY-90-016, the ABWR design must ensure that safo shutdown can be achieved, assuming that all equipment in any area will be rendered inoperable by fire and that reentry into the fire area for repairs and operator actions will be impossible. Becaune of its physical configuration, the control room is excluded from this approach, provided an independent alternative shutdown capability that is physically and electrically independent of the control room is included in the design. The ABWR design must also provide firo protection for redundant shutdown systems in the reactor containment building that will ensure, to the extent practical, that one shutdown division will be free of fire damage. Additionally, the ABWR design must ensure that smoke, hot gases, or fire suppressant will not migrate into other fire areas to the extent that they could adversely affect safo-shutdown capabilities, including operator actions. These fire protection measures are for both DBAs and severe accidents.

\subsection{Preventive and/or Mitigative Features}

Section 9.5.1 of this report provides a description and evaluation of the ABWR features provided to prevent and 
mitigate fires. In particular, this coction addresces protection of afo-shutdown equipment, pasaive fire protection features, fire detoction, fire protection water aupply aystem, water fire suppreseion systems, gaseous firo cuppression systoms, fire extinguichor, emergency communication and lighting, omorgency breathing air, curbs and drains, smoke control, wecess and routes, construction materials and combustible contents, and internction with other systems.

\subsection{Basis for Acceptability}

Based on the ovaluation in Section 9.5.1 of this report and on the discussion above, the staff concludes that the ABWR deaign meets the criteria ideatified in SECY-90-016 and is accoptablo for preventing and mitigating threats from fires for DBAs and covero sccidents.

\subsection{Intersystem Loss-of-Coolant Accident}

Intersystem loss-of-coolant accidents (ISLOCAs) are defined as a class of LOCAs in which the RCS pressure boundary is breached and coolant is lost through an interfacing system with a lower design pressure. The breach may occur in portions of piping located outside the primary containment, causing a direct and potentially unisolable discharge from the RCS to the environment. An ISLOCA is of concern because of potential direct releases to the environment, loss of core cooling, and loss of core makeup.

High or low pressure interfaces occur on many lines including low-pressure injection lines and the RHR heat exchangers. An ISLOCA occurs when high pressure is introduced in low-pressure system because of valve failure or an inadvertent valve actuation. In either case, the overpressurization can cause the low-pressure system or components to fail. An ISLOCA concurrent with a loss of all core cooling may lead to core damage.

\subsection{Preventive and/or Mitigative Features}

In SECY-90-016, the staff recommended that evolutionary LWR designs reduce the possibility of a LOCA outside containment by designing (to the extent practicable) all systems and subsystems connected to the RCS to an ultimate rupture strength (URS) at least equal to the full RCS pressure. The "extent practicable" phrase shows a realization that all systoms must oventually interface with atmospheric preasure and that for certain large tanks and heat exchangers, it would be difficult or prohibitively expensive to design such systems to a URS equal to full RCS pressure. The staff further recommended that systems tha! have not been designed to withstand full RCS presoure should include (1) the capability for leak teating of the presoure isolation valves, (2) indication in the control room of valve position when isoletion valve operntors are deenergized, and (3) high-preseure alarms to warn control room operators when rising RCS preseure appronchen the design pressure of attached low-precoure systeme and both isolation valves are not closed.

In its June 26, 1990 SRM, the Commission approved the staff's position on ISLOCA provided that all elements of the low-pressure system are considered (0.g., instrument lines, pump seals, heat exchanger tubes, and valve bonnets).

The atructural capability of low-pressure piping systems interfacing with the reactor coolant pressure boundary to withstand the consequences of an ISLOCA is discussed in Section 3.9.3.1.1 of this report. In eddition, $O E$ performod a systematic evaluation of interfacing systoms to ensure that the SECY-90-016 requirements were satisfied. The resolution of this issue is provided in Section 20.2.19 of this report.

\subsection{Basis for Acceptability}

As indicatod in Chapter 20 and Section 3.9.3.1.1 of this report, the staff concludes that $G E$ has met the criteria from SECY-90-016, as approved by the Commission, regarding ISLOCA prevention and mitigation for the ABWR.

\subsubsection{Deterministic Assessment of Severe Accident Mitigation}

\subsubsection{Overview of the ABWR Containment Design}

The ABWR containment maintains the pressure suppression design of other BWR containments. The containment is a reinforced concrote cylindrical structure with a steel upper drywell head and internal stool liner to reduce leakage. The ABWR containment atmosphere is made inert to preclude hydrogen combustion and a slightly positive pressure is maintained to prevent air from leaking in. The containment basemat is $5.5 \mathrm{~m}(18 \mathrm{ft})$ thick with several layers of reinforcements. The top slab is an integral part of the fuel pool. The containment wall is a right circular cylinder $2 \mathrm{~m}(6.56 \mathrm{ft})$ thick with an inside radius of $14.5 \mathrm{~m}$ (47.57 ft) and height of $29.5 \mathrm{~m}$ (96.78 ft). Its internal space is divided by the diaphragm floor and the reactor pedestal into an upper drywell chamber, a lower drywell chamber, and a wetwell. The upper drywell volume surrounds the RPV and houses the steam and foedwater lines and other connections of the reactor primary coolant system and safety/relief valves, 
and tho lower drywell volume houses the reactor internal pumpe and FMCRD.

The cylindrical RPV pedestal separates the lower drywell from the wetwell. Ten DCVs are built into the RPV pedeetal and connect the upper drywell and lower drywell. The DCVs are extended downward by steel pipes, each of which has three horizontal vent outlets into the suppression pool. The wetwell consists of an air volume and suppression pool. Steam from a reactor vessel blowdown or from a break in a major pipe inside the drywell condenses in the suppression pool through the SRV8 or the DCV8. A vacuum breaker system is provided between the drywell and wetwell to prevent excessive differential pressures.

The containment beat-removal system is an integral part of the RHR system. Suppression pool temperature is controlled in the suppression pool cooling mode of RHR. RHR also includes the containment spray feature to cool the containment air space. A capability also exists to directly connect the drywell spray header to the fire protection system pumps, one of which is driven by a diesel engine.

The ABWR design includes a passive flooder system. This system consists of a group of pipes that horizontally passes through the pedestal wall and connects tho suppression pool to the lower drywell. These pipes terminate in the lower drywell with fusible plugs. These plugs are designed to melt and open a connection between the suppression pool and the lower drywell region when the drywell airspace temperature reaches $260^{\circ} \mathrm{C}\left(500^{\circ} \mathrm{F}\right)$.

A COPS consisting of two relief rupture disks in succession from the wetwell airspace is provided. The inner rupture disk, which controls the actual pressure, actuates at a pressure of $617.8 \mathrm{kPa} g a g e(90 \mathrm{psig})$. This is above the containment design basis pressure of $309.9 \mathrm{kPa} g a g e$ (45 psig), but bolow the ASME Service Lovel C limit of $666.9 \mathrm{kPa}$ gage (97 psig).

\subsubsection{Severe Accident Progression}

This section provides a description of the processes, both physical and chemical, that may occur during the progression of a severe accident and how these phenomena affect containment performence. This description is intended to be generic in nature. However, many aspects of severe accident phenomena depend on the specific reactor type or on the containment design features. This information has been extracted from NUREG/CR-5132 Severe Accident Insights Report, NUREG/CR-5597 InVessel Zircaloy Oxidation/Hydrogen Generation Behavior During Severe Accidents, and NUREG/CR-5564 Core-
Concrete Internctions Using Molten $\mathrm{UO}_{2}$ With Zirconium on a Basaltic Basomat.

Sovere accident progression can be divided into two phases: an in-veseel stage and an ex-veseel stage. Tho invessel stage generally begins with insufficient DHR and can lead to molt-through of the reactor veseel. The exvessel stage involves the release of the core debris from the reactor vessel into the containment and reculting phenomena such as CCI, FCI, and DCH.

\subsection{In-Veseel Melt Progression}

In sovero accidents that proceed to veseol failure and release of molten core material into the containment, the in-vessel melt progression establishes the initial conditions for assessment of the thermal and mechanical loads that may ultimately threaten the integrity of the containment. In-vessel melt progression encompasses the phenomena and processes involved in a severe core damage accident: These phenomena and processes start with uncovering of the core and initial heat-up, and continue until either (1) the degraded core is stabilized and cooled within the reactor vessel, or (2) the reactor vessel is breached and molten core material is released into the containment. The phenomena and proceseses in the ABWR that can occur during in-vessel melt progression include the following:

- Core heat-up resulting from loss of adequate cooling

- Metal-water reaction and cladding oxidation

- Eutectic interactions between core materials, 0.8., control blades and fuel assembly channel boxes, resulting in relocation of molten material. Butectices are mixtures of materials with a molting point lower than that of any other combination of the same components.

- Melting and rolocation of cladding, structural matorials, and fuel

- Formation of blockages near the bottom of the core resulting from the solidification of relocating molten materials (a wet-core scenario)

- Drainage of molten materials to the veesel lower head region (a dry-core scenario)

- Formation of a melt pool, natural circulation beat transfor, crust formation, and crust failure (a wet-core scenario)

- Lower head breach resulting from failure of penetration or from local or global creep-rupture. 
Adequate core cooling cen be defined as providing enough cooling water flow to the reactor core to remove the decay heat produced. Or, if the decay heat is transforred to the containment, providing enough cooling water to containment heat removal systems to remove the decay heat truneferred from the core. The mechaniems by which sufficient cooling is provided to the reactor core or the containmont are numerous, diverse, and redundant. These mechanisms includo both safoty and non-eafoty aystems. Examples of eafety systems include the RCIC aystem, high-pressure core flooder systems, RHR aystem, and ADS. Examples of non-safoty systems include the condensate and feedwater systems, condenser, relief valves, and the ACIWA system.

In the event of failure of all safety and non-wafety systems to remove the decany heat produced, the core will beat up to the point where damage to the fuel and fuel cladding may occur. Decay beat is transferred through radiative, conductive, and convective heat transfer to the steam, other core materials, and nonfuel materials within the reactor. The insufficient cooling supply results in coolent boiloff and a decreasing level within the reactor veasel as the decay heat generation exceeds the heat removal rate. The coolant level within the core further decreases 80 that the fuel rods above the coolant level are only cooled by rising steam. The fuel rods begin to overheat and cladding oxidation begins in the presence of steam at high temperatures. As the cladding oxidizes in the presence of steam, hydrogen and additional beat are generated. The fuel cladding is mado of a zirconium alloy callod zircaloy.

The initial zircaloy oxidation involves oxygen diffusion through $\& \mathrm{ZrO}_{2}$ surface layer. As the fuel rods continue to heat up from decay heat and the exothermic zirconium oxidation reaction, the 'materials within the reactor with low melting points are expected to molt first and may form outectics.

Zircaloy with melting point of $1,757^{\circ} \mathrm{C}\left(3,194^{\circ} \mathrm{F}\right)$ begins to melt breeking down the protective $\mathrm{ZrO}_{2}$ layer, exposing unoxidized zircaloy. Following this, local melting of the fuel rods may cause changes in the core geometry resulting in different steam flow paths. On the one hand, this can lead to an increase in the oxidation process as access to the unoxidized zircaloy is available. On the other hand, the melt formation or changes in the steam flow path could reduce the zircaloy surface available for oxidation and thereby decrease the overall reaction process. In some accident scenarios in which residual amounts of water remain in the bottom of the core and lower plenum, substantial steaming and oxidation can take place.
In addition to oxidation, the potential exists for the zircaloy to interact with the $\mathrm{UO}_{2}$ fuel, forming outectics. Formation of eutectice may decrease the offective eurface area for oxidation and the overall oxidation rate. The molting point of zircaloy is dependent upon its oxidation atate and lattice atructure. It has three molting points which include $1,877^{\circ} \mathrm{C}\left(3,410^{\circ} \mathrm{F}\right)$ (bota-Zr), $1,977^{\circ} \mathrm{C}$ $\left(3,590^{\circ} \mathrm{F}\right.$ ) (alpha-Zr(O)), and $2,677^{\circ} \mathrm{C}\left(4,850^{\circ} \mathrm{F}\right)$ $\left(\mathrm{Z} \mathrm{O}_{2}\right)$. When partially oxidized zircaloy is in contact with $\mathrm{UO}_{2}$, an alpha-Zr(0)/UO $\mathrm{O}_{2}$ besed eutectic will form with a liquefaction temperature of approximatoly $1,897^{\circ} \mathrm{C}$ $\left(3,446^{\circ} \mathrm{F}\right)$. Therefore, in the presence of good fuel or cledding contact, fuel liquefaction and melt relocation will commence around this temperature. This has the potential to affect the oxidation behavior of zircaloy-based melt.

Various covero-fuel damage (SFD) toat programs discuseed in the NUREG's listed above eponeored by the NRC indicate that oxidation of the zircaloy is largely controlled by the availability of a steam supply and that high rates of hydrogen generation can continue after molt formation and relocation. Some of these experiments indicate that the majority of the hydrogen generated occurs after onset of zircaloy melting and fuel diseolution. In steam-rich experiments, oxidation took place over most of the fuel bundle leagth, and most of the hydrogen is generated early. For steam-etarved experiments, oxidation was limited to local regions of the fuel bundle and the majority of the hydrogen is genenated after the onset of $\mathrm{Zr} / \mathrm{UO}_{2}$ liquefaction and relocation.

The ABWR contains more than $72,000 \mathrm{~kg}(158,700 \mathrm{lbm})$ of zirconium in the active fuel region that has the potential to generate more than $3,100 \mathrm{~kg}(6,834 \mathrm{lbm})$ of hydrogen. Hydrogen production and accumulation may represent challeages to the containment in numorous ways including deflagration, detonation, and pressurization. The ABWR containment will be made inert with nitrogen to prevent the occurrence of any deflagration or detonation. Preasurization of the containment from the generation of hydrogen gases will not exceed ASME Service Lovel C limits.

The SFD tests indicated the potential for incoherent meltrelocation due to noncoherent temperatures within the test bundles. This is because of the different core materials present with a wide range of melting points and eutectic temperatures. Formation of eutectics would result in a nonuniform molting and relocation process. Further differences in the melt-relocation process can be attributed to aymmetric bundle beating that can increase because of zircaloy oxidation. This process begins when one area of the fuel bundle is initially at a temperature higher than the other areas. The higher-temperature zircaloy will consume the available steam through oxidation at a quicker rate. 
The oxidation reaction makes the botter areas bottor still, which further increases the oxidation rate and the local comperatures. This autocatalytic nature of zircaloy oxidation appears to contribute to anymmotric bundle beatup and the poteatial for incobereat molt-rolocation.

As the temperature of the core increases, fiscion products in vapor form are released. The mixing and transport of these fistion products within the primary system depend upon flow paths set up by any existing steam or hydrogen and any interactions with surfaces within the reactor. Such surfaces as the upper internal structures of the reactor vecsel may act as a filter where microscopic fisvion product aerosols suspended in the gas can settle on comparatively cool surfaces by thermophorisis and diffusiophoresis. In addition, retention mechenisms such as turbuleat deposition and gravitational settling occur.

The core molt progression, including relocation and fission product release, becomes increasingly difficult to predict as it continues to degrade. The core melt could relocate into the lower reactor vessel plenum. If water is present in the lower plenum, the potential exists for in-vessel steam explosions, where molten fuel rapidly fragments and transfere its energy causing rapid steam generation and ahock waves. Another possibility is that the core debris within the lower plenum may quickly melt through the rector veseel or interact with available water before molting through and entering the lower drywell.

The in-vessel coro melt progression, including core degradation, relocation, and failure of the reactor vessel, is rather urcertain. This uncertainty includes the potential for in-vessel steam explosion, the interaction of core debris with internal vessel structures, the time and mode of vessel failure, the composition of the core debris released at vessel failure, the amount of in-vessel hydrogen generation, the in-vessel. fission product release, and the transport and retention of fission products and other core materials in the RCS.

\subsection{Ex-Vessel Melt Progression}

Ex-vessel severe accident progression is affected by the mode and timing of the reactor vessel failure; the primary system pressure at reactor vessel failure; the composition, amount, and character of the molten core debris expelled; the type of concrete used in containment construction; and the availability of water to the lower drywell. The initial response of the containment to ex-vessel severe accident progression is largely a function of the pressure of the RCS at reactor vessel failure and the existence of water within the reactor cavity. If not prevented through design features, risk consequences are usually dominated by early containment failure mechanisms that could result from onergetic eovere accident phonomens such as HPME with DCH and ex-veceal steam explosions. The long-ierm response of the containment from ex-veseol severe sccident progreasion is largely a function of the containment preasure and temperature reculting from core-concreto interaction and the availability of containment heat removal mechenisms.

At high RCS preseures, the molten core debris could be ejected from the reactor vesel in jet form causing it to fragment into small particles. The potential exists for the core debris ejected from the veseel to be swept out of the lower drywell and into the upper drywell. Finely fragmented and dispersed core debris could heat the containment atmosphere and lead to large pressure spikes. In addition, chemical reactions of the core debris particulate with oxygen and steam could add to the pressurization loads. This sovero accident phenomenon is known as HPME with DCH.

To prevent this phenomenon, the ABWR has incorporated a reliable depressurization system to provido assurance, that in the event of a core melt scenario, that failure of the RPV would occur at a low pressure. Should the RPV fail at a high pressure, the design of the ABWR containment would provide an indirect pathway from the lower to the upper drywell in an effort to decrease the amount of core debris that could contribute to DCH.

The equipment tunnels are located on the periphery of the lower drywell at a midlevel elevation. Core debris exiting the reactor vessel or entrained from the lower drywell during HPME has the potential to reach the tunnels. An accumulation of core debris within the tunnels could lead to melt-through and development of a suppression pool bypass mechanism. GE had not addressed this issue in the SSAR. The staff indicated that it believed that an acceptable resolution to this issue would be for GE to provide reasonable assurance that an appreciable amount of core debris would not enter the tunnels. This could be done by showing that the existing equipment within the lower drywell provides a tortuous pathway to the lower drywell periphery or providing an additional shield structure over the tunnels. This was Open Item F19.2.3.2.2-1.

GE addressed this issue in a letter dated February 7, 1994, which proposed a new SSAR Section 19.E.2.3.6. GE indicated that the equipment tunnels will be partially covered with 1.2 meters of suppression pool water at the low water level allowed by technical specifications. In the event core debris melts through the equipment tunnel, the debris will enter the suppression pool and any additional gases from the lower drywell will pass through the indicated suppression pool level. Also, a HPME results in 
core debris and elevated temperatures within the upper drywell. In ordor for the containment penetrations to withatand the elevated temperatures, the operator must sctuate the containment spray system. The water from the containment spray system eventually sccumulates in the suppression pool, raising the water level to provide additional water coverage of the equipment tunnels. Therefore, the suppreasion pool water lovel covering the lower section of the equipment tunnels is sufficient to preclude this potential suppression pool bypass pathway. The staff finds this acceptable. Therefore, Open Itom P19.2.3.2.2-1 is resolved.

RPV failure at high or low pressure coincident with water present within the lower drywell could lead to $\mathrm{FCI}$ with the potential for rapid steam generation or steam explosions. Rapid steam generation involves the pressurization of containment compartments from nonexplosive steam generation beyond the capability of the compartment to relieve the pressure so that local overpressurization failure of the compartment occurs. Steam explosions involve the rapid mixing of finely fragmented core debris with surrounding water resulting in rapid vaporization and acceleration of surrounding water creating substantial pressure and impact loads. The ABWR is designed so that there is a very low likelihood of water within the lower drywell at the time of reactor vessel failure.

The eventual contact of molten core debris with concrete in the lower drywell will lead to core-concrete interaction (CCI). CCI involves the decomposition of concrete from core debris and can challenge the containment in various mechanisms, including (1) pressurization resulting from the production of steam and noncondensible gases to the point of containment rupture, (2) the transport of high temperature gases and aerosols into the upper drywell leading to high-temperature failure of the containment seals and penetrations, (3) liner melt-through, (4) reactor pedestal melt-through leading to relocation of the reactor vessel and tearing of containment penetrations, and (5) the production of combustible gases such as hydrogen and carbon monoxide. $\mathrm{CCI}$ is affected by many factors including the availability of water to the lower drywell, the containment geometry, the composition and amount of core melt, the core melt superheat, and the type of concrete involved.

The ABWR has incorporated several design features to mitigate the effects of $\mathrm{CCI}$. These include an LDF system, an ACIWA system, basaltic concrete for the lower drywell floor, and the COPS. The LDF system provides suppression pool water to assist in cooling core debris once it has entered the lower drywell. The ACIWA system provides for both reactor vessel injection and drywell spray capability to cool core debris or control containment preserurization. Basaltic concrete protects the containment liner from molt-through and docreases the amount of noncondensible gaves geaerated during CCI when compared with limestono-based concretes. The COPS is designed to passively reliove containment preasure to prevent groses contrinment failure during severe accidents when the containment precaure approaches ASME Service Lovel C limits. This roliof pathway takes advantage of the scrubbing capability of the suppression pool to limit any offaito releases.

\subsubsection{Severe Accident Mitigative Features}

\subsection{Hydrogen Generation and Control}

Generation and combuation of large quantities of hydrogea is a severo accident phenomenon that can threaten containment integrity. The major source of hydrogen generated is from the oxidation of zirconium with steam when the zirconium reaches temperatures well above normal operating lovels. This reaction is commonly referred to as the motal-water reaction.

Research indicates that in-vessel hydrogen generation associated witb core-damage can vary over a wide range. The specific amount of oxidation is dependent on a variety of parameters related to sequence progression. These include the RCS pressure, the timing and flow rate of reflooding if it occurs, and the temperature profile of the reactor core during the course of the accident sequence. In addition, ex-vessel hydrogen generation must be considered. Hydrogen is produced as a result of ex-vessel core debris reacting with steam or concrete.

\subsection{Preventive and/or Mitigative Features}

10 CFR 52.47(a)(1)(ii) requires applicants for a standard design certification to provide demonstration of compliance with any technically relevant portions of the Three Mile Island Requirements set forth in $10 \mathrm{CFR}$ 50.34(f). 10 CFR 50.34(f)(2)(ix) requires a system for hydrogen control that can provido with reasonable assurance that uniformly distributed hydrogen concentrations in the containment do not exceed 10 percent during and following an accident that releases an equivalent amount of hydrogen as would be generated from a 100 percent fuel-clad metalwater reaction, or that the postaccident atmosphere will not support bydrogen combustion.

In SECY-90-016, the staff recommended that the Commission approve the staff's position that the requirements of 10 CFR 50.34(f)(2)(ix) remain unchanged for evolutionary LWRs. In its June 26, 1990 SRM, the Commission approved the staff's position. 
To comply with 10 CFR 50.34(f)(2)(ix), the ABWR will have an inert atmosphere during normal operation. The inert containment prevents hydrogen combuation and/or detonations from occurring.

10 CFR $50.34(f)(3)(v)$ requires containmeat integrity to be maintained bolow ASMB Service Lovel C limitu for ated containments and the factored load catogory for concrete containmente during an sccident that releaces hydrogen generated from 100 percent fuel-clad metal-water reaction. OE performed an analysis in Section 19B.2.3.2 of the ABWR SSAR of the capability of the containment to withstand preasurization from a 100-percent, fuel-clad, metal-water reaction coupled with a largo-break LOCA. The analysis indicatod a peak containment proceure of about $618 \mathrm{kPa}$ abeoluto (75 psig).

The ABWR has a concrete containment with a steel upper drywell bead. The steel upper drywell head, based on OE structural analyses, has been shown to be the most limiting structural component of the containment, with a Service Level C limit of $666.9 \mathrm{kPa}$ gage (97 psig). Therefore, the containment pressurization from a 100-percent, fuel-clad, metal-water reaction coupled with a large-break LOCA is below the Service Lovel C limit.

\subsection{Basis for Acceptability}

The ABWR design moets the requirements of SECY-90-016 and 10 CFR 50.34(f)(2)(ix) by utilizing a nitrogen-inerted atmosphere within its containment. The ABWR design is capable of withstanding the pressurization loadings resulting from a large-break LOCA and hydrogen generation equivalent to a 100-percent fuel-clad metalwater reaction as required by 10 CFR $50.34(f)(3)(v)$.

\subsection{Core Debris Coolability}

Coolability and quenchability have been the subject of extensive research over the past decado. However, much uncertainty still exists about these phenomena, which will most likely not be resolved in the near future. Because of this uncertainty, the NRC decided not to address the question of whether coolability or quenchability has been achieved or can be achieved, but rather, what the impact on the containment design is if they are not achieved.

CCI is a severe accident phenomenon that involves the melting and docomposition of concrete in contact with molten corium. This phenomenon may occur following accident sequences that result in molten corium's breaching the reactor vessel and spreading onto the lower drywell floor. The thickness of the corium layer within the lower drywell depends upon the amount of core debris, its apreadability, and the lower drywell floor area. Once on the drywell floor, the molten corium may react with the concrete and any available water, producing noncondensible gases, water vapor, and heat from oxothermic reactions.

$\mathrm{CCl}$ can challenge the containment by various mechanisms including preseurization from noncondensible gas and steam generated, destruction of structural support mombers, and molt-through of the containment liner. Noncondensible gases, primarily carbon dioxido, carbon monoxide, and hydrogen, are released from the concrete as it docomposes and are formed from reactions between water and motals within the molten corium. The corium and concrete are heated from the combined offects of docay beat and oxothermic chemical reactions.

\subsection{Preventive and/or Mitigative Features}

In SECY-93-087, "Policy, Technical, and Licensing Issues Pertaining to Evolutionary and Advanced Light-Water Reactor (ALWR) Designs, "the staff recommended that the Commission approve the position that both the evolutionary and passive LWR designs meet the following criteria: (1) provide reactor- cavity floor space to enhance debris spreading, (2) provide a means to flood the reactor cavity to assist in the cooling process, (3) protect the containment liner and other structural members with concrete, if nocesaary, and (4) ensure that the best-estimate environmental conditions (pressure and temperature) resulting from core-concrete interactions do not exceed Service Lovel C for steel containments or factored load category for concrete containments, for approximately 24 bours. In addition, they must ensure that the containment capability has margin to accommodate uncertainties in the environmental conditions from coroconcrete interactions. In its July 21, 1993 SRM, the Commission approved the staff's position.

Therefore, the staff's proposed applicable regulation for core dobris coolability is as follows:

The standard design must include features that reduce the potential for and effect of interactions with molten core debris by:

(1) providing reactor cavity floor space to enhance debris spreading;

(2) providing a means to flood the reactor cavity to assist in the cooling process;

(3) protecting the containment liner and other structural members with concrete, if nocessary; and 
(4) providing design features that ensure that the beat-eatimate environmental conditions (preseure and temperature) resulting from core-concrete interactions do not exceed ervice level C for steel containments or fuctored load catogory for concreto containments, for approximately 24 hours.

OB incorporated numerous features in the ABWR to help mitigate the effects of core-concrete interaction. The following features were judged by the staff as boing most important: a large lower drywell floor area with minimal obetructions to the spreading of core debris, an LDF syctem, an ac-independent water addition system, use of acrificial bacaltic concrote for the lower drywell floor, a thick reactor podestal wall, and a COPS.

\subsection{1 Lower Drywell Floor Area}

The lower drywell is 10.6 moters $(34.8 \mathrm{ft}$ ) in diameter, which provides a floor area of $88 \mathrm{~m}^{2}\left(947.2 \mathrm{ft}^{2}\right)$. The lower drywell contains embedded sump pits that could lead to the accumulation of core debris and accelerated CCI. To preveat this, the sumps are provided with protection to preveat the eatrance of core debris. The sump protection is deccribed in 19.2.3.3.8 below.

Even with the prevence of the sumps, the lower drywell will have an unobstructed floor area greater than $79 \mathrm{~m}^{2}$ $\left(850.4 \mathrm{t}^{2}\right)$. This is sufficient floor ares to satisfy the EPRI design criterion of $0.02 \mathrm{~m}^{2} / \mathrm{MWt}$ for debris coolability. This value represents the EPRI Requirements Document eatimate of what is required to adequately cool corium debris. The staff does not support or dispute the EPRI floor rizing criterion. Instead, the staff concludes that an unobatructed floor area, along with the design features meationed above, provides measures to promoto the potential for core debris coolability, but does not necenearily ensure it.

To determine whether the lower drywell meets the criteria within SECY-93-087 relative to providing reactor cavity floor apece to enhance debris spreading, the staff evaluated the total wize of the lower drywell, the number of obetructions present to prevent the spreading of molten cose debris, and the impact on the containment design of requiring further modifications. Baed on minimal obetructions on the floor ares described above, the staff concludes that the design is acceptable.

\subsection{2 Lower Drywell Flooder System}

An LDF was incorporated into the ABWR design to supply water from the suppression pool to the lower drywell to aseist in the cooling process of the corium. The water also cools and condenses gases that ovolved during CCI, thereby limiting containment temperature and presenre increases. The LDF is discussed in Sections 9.5.12 and 19E.2.8.2 of the SSAR.

The LDF consists of ten $100 \mathrm{~mm}$ (4 in.) stainless stoel piping lines from the suppression pool to the lower drywell with thermally activated flooder valves attached to them. The thermally activated flooder valves open when the lower drywell air temperature reaches $260^{\circ} \mathrm{C}\left(500^{\circ} \mathrm{F}\right)$. Bach flooder valve has a minimum flow rate of $10.8 \mathrm{Kg}$ (2.77 gallons/sec) and contains four components: a stainless steol disk, a toflon disk, a fusible motal plug, and a plastic cap. The stainless steol disk provents suppression pool water from corroding the teflon disk and fusible motal plug. The toflon disk provides an insulating barrier to provent the suppression pool water from contacting the fusible metal plug. This insulating barrier is needed to aseure that the fusible metal plug is not cooled by the suppreasion pool water and provented from melting. The teflon disk will not melt or stick in the valve because its eoftening tomperature is approximately $400{ }^{\circ} \mathrm{C}\left(769^{\circ} \mathrm{F}\right)$ and its chemical resistance is higher. It therefore will not adhere to the stainless steel plug or to the fusible plug. The fusible metal plug has a small, raised, annular ring around its circumference approximately $2.0 \mathrm{~mm}(0.08 \mathrm{in}$.) bigh. It is this annular ring that has to molt in order for the LDF to actuate.

The fusible metal plug is made of an alloy mixture of two or more metals so that the plug melts when its temperature reaches $260^{\circ} \mathrm{C}\left(500{ }^{\circ} \mathrm{F}\right)$. The end of the flooder valve line is covered with a plastic cover with a low molting point below $130^{\circ} \mathrm{C}\left(266^{\circ} \mathrm{F}\right)$. This plastic cover prevents corrosion of the fusible metal material from intrusion of moisture. The flooder valves are mounted in the vertical position so that the fusible metal faces downward to facilitate opening of the valve when the melting tomperature of the fusible motal is reached. Heat transfer resulting in molting of the fusible plug occurs through a combination of conduction, convection, and radiation. Heat is conducted from the stainless steel pipe to the fusible plug causing it to melt. This heat is recoived from the atmosphere within the lower drywell through convection. In addition, the stainless steol pipe also receives radiative heat from the corium on the lower drywell floor. The LDF is safoty-related and soismic Catogory 1.

During each refueling outage, the 10 fusible plug flanges and outlets will bo inspected to ensure there is no leakage. Once every two refueling outages, 2 of the 10 fusible plugs will bo removed, inspected, and tested to confirm their function and verify the temperature setpoint. 
In Section 19E.2.8.2.2, GE calculated the minimum scceptable flow rate to remove decay heat and heat generated during $\mathrm{CCI}$ to be a total of $0.018 \mathrm{~m}^{3} / \mathrm{sec}$ (5 gallcns/sec) compared to the system flow rate of $.099 \mathrm{~m}^{3} / 100 \mathrm{c}(26 \mathrm{gall}$ ons/ $/ \mathrm{sec}$ ) assuming the failure of one of the ten flooder lines to open. This indicates that ouly two of the flooder lines are needed to remove decay heat and exothermic heat frox zirconium oxidation. Opening of additional flooder lines contributes to the flooding within the lower drywell.

In Section 19E.2.8.2.4, GE calculated approximate values for the minimum time (21 minutes) and maximum time (1.3 hours) to fill the lower drywell. These times are very sensitive to the assumptions used and are strongly dependent upon the accident sequence selected. For instance, the calculations assume a 100-percent core debris at 1-percent-rated thermal power, no heat from exothermic reactions, all heat rejection to the water, and failure of one passive flooder valve to operate. The staff concludes that this is acceptable as it provides a relative time frame to judge the adequacy of the LDF design, but the actual flooding rate and time to complete flooding are accidentsequence specific.

Based on the above discussions, the staff concludes that the LDF meets the criteria of SECY-93-087 for providing a means to flood the reactor cavity to assist in the cooling process of core debris.

\subsection{3 AC-Independent Water Addition System}

In addition to the three electrically and mechanically independent divisions of the RHR system of the ABWR that provide reactor vessel injection and containment spray, an ACIWA system has been incorporated. The ACIWA system consists of piping and manual valves connecting the fire protection system to the loop C RHR pump discharge line downstream of the pump's discharge check valve. The C loop is capable of providing low-pressure injection to the reactor vessel or containment spray to the upper drywell. Within the fire protection system, an independent diesel-driven pump exists that would provide the pumping capability. Additionally, an external hookup outside the reactor building for connection of a fire truck pump to an alternate water source is provided. An ac-driven fire pump is included within the fire protection system. However, its contribution to severe accident prevention and mitigation has been excluded because of its dependence on electrical power. The ACIWA system is discussed in Sections 5.4.7 and 19K.11.5 of the SSAR.

Injection to the reactor vessel using the ACIWA system is intended to prevent core damage. In the event that it is not initiated in time to prevent core damage and reactor vessel melt-through, the ACIWA, when operated in the reactor vessel injection mode, would provide water to the lower drywell through the breech in the reactor vessel to assist in cooling ex-vessel core debris. This flooding of the lower drywell could be in addition to or in-place of the flooding provided by the LDF. The actual circumstances are accident-sequence specific. For example, if the ACIWA provides flooding to the lower drywell immodiately following veesel breach, then the temperature within the lower drywell may sever reach the initiation temperature for the LDF or if initiation of the ACIWA is delayed, the LDF would open followed by the ACIWA.

Operation of the ACIWA in the containment spray mode controls atmospheric temperatures in the upper drywell and provides fission product acrubbing. This system is very beneficial in delaying the time to or preventing the opening of the COPS as is indicated in Appendix 19E to Section 19 of the SSAR.

In both the vessel injection mode or containment spray mode, the ACIWA supplies water to the containment thus increasing the thermal mass, which in turn slows the overail pressure rise. Operation of the ACIWA is manual. The diesel-driven fire pump can be operated from the control room; the injection valves, which must be opened or closed, are located in the same loop C ECCS valve room. The ACIWA system can supply, from either the diesel-driven fire pump or fire truck pump, between $0.04 \mathrm{~m}^{3} / \mathrm{sec}(630 \mathrm{gpm})$ and $0.06 \mathrm{~m}^{3} / \mathrm{sec}(950 \mathrm{gpm})$ for conditions between runout and back pressure equal to the COPS initiation setpoint. Inspection and testing of the ACIWA system are discussed in SSAR Section 19K.11.5.

Based on the above discussions, the staff concludes that the ACIWA provides another means of flooding the lower drywell to assist in the cooling process of core debris, as specified in SECY-93-087.

\subsection{4 Sacrificial Basaltic Concrete}

Basaltic concrete is a type of siliceous concrete used in the construction of nuclear power plants and is found throughout the United States. This concrete melts over a range of $1,077^{\circ} \mathrm{C}-1,376^{\circ} \mathrm{C}\left(1970-2,510^{\circ} \mathrm{F}\right)$ and typically liberates 1.5 weight-percent carbon dioxide gas and 5 weight-percent water vapor when heated to melting (NUREG/CR-5564).

In Section 6.2.1.1.10.3 of the SSAR, GE stated that the ABWR will use $1.5 \mathrm{~m}$ layer of basaltic concrete above the containment liner with a low gas content. The basaltic concrete selected will have less than 4 weight-percent of calcium carbonate, which results in low gas generation 
rates when subjected to CCI. This concrete is designed to protect the containment liner in the ovent that CCI occurs. Basaltic concrete was chosen as it reduces the production of noncondensible gases when compared with other forms of concrete, auch as limestone and limestone-common sand concrete. Reduced noncondensible gas and water vapor production from basaltic concrete has been observed during toeting (NUREG/CR-5564 and NUREG/CR-5423). However, basaltic concrete does have a lower melting point and quicker ablation rate when compared with limeatone and limestone-common sand concrete.

Using the observations discussed above, based on engineoring judgment, the staff concludes that the $1.5 \mathrm{~m}$ layer of basaltic concrete meets the criteria specified in SECY-93-087 relating to protecting the containment liner and provides sufficient protection for the containment liner.

\subsection{5 Reactor Pressure Vessel Pedestal}

The basaltic concrete discussed above protects the containment liner from core-concrete attack in the axial direction. Core-concrete attack in the radial direction could affect the RPV pedestal. The cylindrical RPV pedestal is formed from two concentric steel rings interspaced with internal stiffeners and filled with concrete. The RPV pedestal is rigidly connected to the diaphragm floor and separates the lower drywell from the wetwell while supporting the loads from the RPV and the diaphragm floor. Built into the RPV pedestal is the drywell-to-wetwell connecting vent system that directs steam from the lower drywell to the suppression pool and upper drywell.

The inner diameter of the RPV pedestal is the outer boundary of the lower drywell. As such, the pedestal is the radial bearrier to the horizontal flow of corium. If corium contacts the RPV pedestal, the inner steel cylinder would be attacked and the concrete fill would be subject to ablation. Unabated ablation could lead to failure of the pedestal and subsequent collapse of the RPV and diaphragm floor leading to gross containment failure.

The width of the RPV pedestal is $1.7 \mathrm{~m}(5.6 \mathrm{ft})$. The steel rings and internal stiffeners provide the design strength for the RPV pedestal, while the concrete strength is not considered. In Section 19EC of the ABWR SSAR, GE presents the results of an analysis that indicate that only the stcel outer shell and $15 \mathrm{~cm}$ ( 6 in.) of internal stiffeners are required to maintain RPV pedestal loads below 90 percent of yield strength.

The staff performed an estimate of the stresses in the RPV pedestal based on the methodology in "Formulas for Stress and Strain," by R. J. Roark and W. Young, McGraw Hill,
1982. Based on these approximate calculations, the staff concludes that adequate margin exists to the yield strength of the RPV pedestal following $1.5 \mathrm{~m}(5 \mathrm{ft})$ of radial ablation and that the RPV pedestal is thick enough to withstand tine effects of radial ablation resulting from CCI. These attributes moet the criteria specified in SECY-93-087 for protecting structural members with concrete.

\subsection{6 Containment Overpressure Protection System}

The COPS passively relieves containment pressurization before containment pressure reaches ASME Service Lovel C limits. This system provides for a controlled release through a containment vent pathway with fission product scrubbing provided by the suppression pool. With respect to CCI, the COPS prevents catastrophic overpressurization failure of the containment for severe accident sequences involving prolonged periods of $\mathrm{CCI}$. The COPS ensures that containment pressurization resulting from $\mathrm{CCI}$ does not exceed the ASME Service Level C limit of $666.9 \mathrm{kPa}$ gage (97 psig), as the actuation setpoint is $617.8 \mathrm{kPa}$ gage (90 psig).

\subsection{Analyses}

In SECY-93-087, the staff concluded that the evolutionary light water reactors should ensure that the best estimate environmental conditions (pressure and temperature) resulting from core-concrete interactions do not excoed service Level C for steel containments or factored load category for concrete containments, for approximately 24 hours. In addition, designers should ensure that the containment capability has a margin to accommodato uncertainties in the environmental conditions from coroconcrete interactions.

The staff concluded that twenty-four hours was an appropriate time period based on sufficient time to allow for decay of fission products, operator intervention, utilization of accident management strategies, fission product deposition in the containment through natural mechanisms, and offsite protective measures. It was developed as a guideline and not a strict criterion in recognition of the uncertainties in severe accident progression and phenomenology.

\subsection{1 GE Analyses}

In Section 19E.2 of the ABWR SSAR, GE provided the results of its deterministic evaluation for several specific accident challenges to evaluate the containments performance. To perform this evaluation, GE used the MAAP3.OB code modified to model the configuration of 
the ABWR. The now version of the code is referred to as MAAP-ABWR.

Using the ABWR probabilistic safety assessment, GE considered accident classes representing the largest frequencies in selecting the accident sequences to be studied. Eight accident sequences were selected for analysis using MAAP-ABWR. These accident sequences include loss of core cooling with the reactor vessel failing at low and high pressure, SBO, loss of containment heat removal, large break loss-of-coolant accident, and ATWS at low and high prosenure and ATWS concurrent with an SBO. For each accident sequence, several mitigating systeme could be used to prevent or reduce the release of fiesion products into the environment. These mitigating systems include in-vessel recovery, passive flooder system, ACIWA, containment heat removal, and containment sprays.

The results of the analyses for each accident sequence are preeented in summary form in Table 19E.2-16 of the ABWR SSAR. These analyses generally indicate core debris coolability and little, if any, CCI. The timo-torelease of fission products ranges from 8.6 to 50 hours from the start of the transient with the most likely fission product release location through the COPS. The COPS prevents the containment pressure from reaching the ASME Service Level C limit. However, for some sequences, the time to COPS actuation is less than 24 bours. For example, the accident sequence resulting in a release time of 8.6 hours is of extremely low probability involving an SBO with failure of the combustible gas turbine concurrent with an ATWS in which all reactivity control fails. However, if credit is given to operation of the ACIWA in the containment spray mode, the timo-torelease of fission products increases to 26.4 hours.

A benchmark of the containment's passive pressure capability is its ability to accommodate the loss of containment heat removal sequence analyzed by $G E$ in ection 19E.2.2.4 of the ABWR SSAR. This analysis assumes that reactor vessel injection is maintained with all the decay heat being transferred to the suppression pool. Core damage does not occur. This analysis indicates that tho COPS would actuate in approximately 21.7 hours. COPS actuation results from saturation of the suppression pool pressurizing the containment. This sequence indicates that the timo to COPS actuation, even without the added pressurization and energy sources from sovere accidents, cannot be extended much beyond 20 hours in the absence of active decay heat removal.

With the addition of noncondensible gases from $\mathrm{CCI}$ and heat from the exothermic metal-water reactions during a eevere accident, the time to COPS actuation will be less.
This is an important point in that COPS actuation before 24 hours cunnot be prevented unless additional heat capacity is added to the containment or a containment heat removal system is recovered. The ACIWA system, as discussed above in Section 19.2.3.3.2.1.3, can provide additional heat capacity to prolong the time to COPS actuation. Based on GE's analysis provided in Table 19E.2-16 of the ABWR SSAR, the time to COPS actuation is delayed by at least 10 hours for cases in which additional water is added to the containment by the ACIWA, when compared with the same sequence in which only the LDF system actuates to cool the core debris. The ACIWA is crucial to delaying the time to COPS actuation.

Section 19EC presents the results of an uncertainty analyses performed by GE using MAAP-ABWR to investigate the uncertainties associated with debris coolability. These analyses evaluated the impact of parameters such as the amount of core debris, debris-towater heat transfor, amount of steel in the debris, delayed flooding of the lower drywell, and use of the ACIWA system on CCI, containment pressurization, COPS actuation, and fission product release.

As discussed in Soction 19.2.3.3.2.1.4 above, the ABWR will have a $1.5 \mathrm{~m}(4.9 \mathrm{ft}$ ) layer of basaltic concrete above the containment liner. This concrete layer is designed to protect the containment liner from being breached in the event that significant CCl occurs. In Section 19EC using the MAAP-ABWR code, GE provided the results of an uncertainty analyses that calculated the extent of axial ablation. The results, provided in Table 19ED.5-2 of the ABWR SSAR, indicate that axial ablation will not exceed $1 \mathrm{~m}(3.3 \mathrm{ft})$ in a 24-hour period.

As discussed in Section 19.2.3.3.2.1.5 above, $G E$ indicated that the distance the molten corium must ablato in the radial direction is $1.55 \mathrm{~m}(5.1 \mathrm{ft})$ before the minimum wall thickness of the pedestal is reached. In Section 19EC using the MAAP-ABWR code, GE provided the results of an uncertainty analyees that calculated the extent of radial ablation by multiplying the axial ablation depth by 1/5. GE selected the 1/5 value based on the results of previous $\mathrm{CCI}$ experiments. This multiplying factor was necessary, as MAAP assumes that radial and axial penetration are identical. The results, provided in Table 19ED.5-2 of the ABWR SSAR, indicate that radial ablation does not represent a significant threat to the containment.

\subsection{2 Staff Analyses}

The staff analyzed in-house the response of the ABWR using the MELCOR code. In addition, the staff contractor Sandia National Laboratories (SNL) porformed 
additional analysee using the MELCOR code. The results of the SNL ovaluation were sent to $G E$ and placed on the docket. The MELCOR results generally reproduced the event sequences predicted by MAAP, albeit usually with timing shifts. These timing shifts did not affect the safety insights for the containment analyses.

\subsection{3 Conclusions}

The staff did not rely on any one specific sequence or scenario performed by GE using the MAAP-ABWR code nor by the staff's contractor (Sandia National Laboratories) in determining whether the ABWR met the criterion in SECY-93-087 for ensuring that containment conditions do not exceed Service Level C for approximately 24 hours from CCI. Rather, the staff evaluated the range of results provided by these codes, with due consideration of the uncertainties inherent within them, and the capability of the design to extend the time period to COPS actuation through intervention. The ACIWA is fundamental to prolonging the period to COPS actuation. Once COPS is actuated, containment pressurization is relieved through a controlled pathway that takes advantage of scrubbing by the suppression pool. The staff recognizes that there are sequences in which COPS actuation in under 24 hours is required to maintain containment stresses below ASME Service Level C limits.

The staff concludes that the ABWR design meets the criterion when use of the mitigation systems incorporated into the design is factored in, such as the LDF and ACIWA system.

\subsection{Basis for Acceptability}

The ABWR meets the criteria of SECY-93-087 and the staff's proposed applicable regulation for core debris coolability through (1) providing a lower drywell unobstructed floor area greater than $79 \mathrm{~m}^{2}\left(850 \mathrm{ft}^{2}\right)$ to enhance debris spreading, (2) providing an LDF system and ACIWA system to flood the lower drywell, (3) providing a $1.5 \mathrm{~m}(4.92 \mathrm{ft})$ layer of basaltic concrete to protect the containment liner, (4) providing a thick reactor vessel pedestal, and (5) providing a COPS. Containment conditions resulting from $\mathrm{CCI}$ can be maintained below Service Level C for approximately 24 hours, through incorporation of the above-listed design features.

\subsection{High-Pressure Core Melt Ejection}

High-pressure core melt ejection (HPME) and subsequent DCH are severe accident phenomena that could lead to early containment failure resulting in large radioactive releases into the environment. HPME is the ejection of core debris from the reactor vessel at a high pressure.
DCH is the sudden beatup and pressurization of the containment resulting from the fragmentation and dispersal of core debris within the containment atmosphere.

\subsection{Preventive and/or Mitigative Features}

In SECY-90-016, Evolutionary Light-Water Reactor (LWR) Certification Issues and Their Relationship to Current Regulatory Requirements, the staff concluded that evolutionary LWR designs should include a depressurization system and cavity design features to contain ejected core debris. In its June 26, 1990, SRM, the Commission approved the staff's position that ovolutionary LWR designs include a depressurization system and cavity design to contain core debris. In addition, the Commission stated that the cavity design, as a mitigating feature, should not unduly interfere with operations including refueling, maintenance, or surveillance activities.

In SECY-93-087, Policy, Technical, and Licensing Issues Pertaining to Evolutionary and Advanced Light-Water Reactor (ALWR) Designs, the staff recommended that the Commission approve the general criteria that the evolutionary LWR designs provide a reliable depressurization system and cavity design features to decrease the amount of ejected core debris that reaches the upper containment. In its July 21, 1993, SRM, the Commission approved the staff's position.

Based on engineering judgment, the staff believes that examples of cavity design features that will decrease the amount of ejected core debris that reaches the upper containment include ledges or walls that would deflect core debris and an indirect path from the lower drywell to the upper containment. The staff position within SECY-93-087 evolved from the staff position in SECY $-90-016$ and forms the basis for the staff's review and evaluation.

Therefore, the staff's proposed applicable regulation for high-pressure core melt ejection is as follows:

The standard design must provide a reliable means to depressurize the reactor coolant system and cavity design features to reduce the amount of ejected core debris that may reach the upper containment so that the potential for and effects of interactions with molten core ejected under high pressure are reduced.

The ABWR has an ADS that is discussed in Sections 5.2.2, 6.3, 7.3, and 19D.6.2.5 of the SSAR. The staff's evaluation of the ADS is provided in Sections 6.3 and 7.3.1.2 of this report. The ADS is a safety grade 
system that can be used to depressurize the reactor when it is shut down and isolated. The ADS consists of 8 SRVs, which are $\bullet$ subset of a total of 18 SRVs. The SRVs provide three main functions: overpressure relief operation using preumatic actuators, safety operation using steam overpressure, and depressurization operation using the ADS valves. The eight ADS SRVs can function in either the ADS or SRV mode. All of the SRVs are located on the main steamlines and discharge to the suppression pool. The ADS is automatically initiated or can be manually initiated. ADS requires de power for the solenoid valves and a nitrogen gas supply for the servo valves and pneumatic actuators. Nitrogen gas is supplied from either the high-pressure nitrogen gas supply system or two backup safety-grade nitrogen gas supplies through an accumulator. The SRVs of the ADS each have two accumulators: one for the ADS function and one for the relief function. The accumulator capacity is sufficient for one actuation at drywell design pressure or five actuations at normal drywell pressure.

The ADS SRVs must remain open during the in-vessel phase of a severe accident to ensure that any potential vessel failure occurs at low pressure. Once the reactor vessel has failed, the ADS system is no longer needed. GE indicated that the capability of the depressurization system will not be degraded as a result of the radiation exposure or thermal loads. The DBA radiation environment (TID-14484) is more limiting than, that predicted through best-estimate analysis for a severe accident. The thermal loads on the valve actuators are expected to be similar to those used for equipment qualification, and therefore the ADS valves will not be subject to degradation. Nitrogen, which is used to hold the ADS valves open, is supplied from outside of containment and therefore will not be exposed to the harsh severe accident environment. GE indicated that the nitrogen supply will be adequate to assure SRV operability over a full range of hypothetical accidents.

The design of the lower drywell of the ABWR is expected to decrease the amount of ejected core debris that reaches the upper drywell. This decrease is anticipated through the following: (1) capture and trapping of some debris in the lower drywell, (2) impaction and removal of core debris as it is transported between the lower and upper drywell, and (3) division of exiting core debris and gas from the lower drywell into both the upper drywell and wetwell. The lower drywell is a cylindrical cavity with horizontal vent openings to the downcomers at two-thirds of the cavity height. The upper portion of the lower drywell contains the CRD mechanisms. Debris circulating within the lower drywell may be trapped on the CRD mechanisms and other stagnant areas.
For debris to travel from the lower cavity floor to the upper drywell, it must travel vertically from the lower drywell, borizontally to the downcomer vent, and then vertically through the downcomer to the upper containment. This tortuous path, which contains two 90-degree turns, provides an indirect path from the lower drywell to the upper drywell and is expected to enhance removal of core debris from the gas jet stream through impaction. As pressurization of the lower and upper drywell increases, the suppression pool level within the lower downcomers will be forced down to expose the horizontal vents to the suppression pool. Once the horizontal vents have been cleared, the gas and debris leaving the lower drywell will split into two paths: one to the upper drywell and the other to the suppression pool.

The pathway alongside of the reactor vessel is closed off by the reactor vessel skirt. This prevents core debris from the lower drywell from being ejected alongside of the vessel into the upper drywell.

The ABWR containment is inert. A postulated loading from an HPME/DCH event results from hydrogen generation and combustion generated from the oxidation of metallic debris ejected with the core melt. As the ABWR is inerted, any combustion of hydrogen and resulting pressurization loadings is limited to the amount of residual oxygen present within the containment atmosphere.

\subsection{Basis for Acceptability}

In SECY-93-087, Policy, Technical, and Licensing Issues Pertaining to Evolutionary and Advanced Light-Water Reactor (ALWR) Designs, the staff recommended that the Commission approve the general criteria that the evolutionary LWR designs provide a reliable depressurization system and cavity design features to decrease the amount of ejected core debris that reaches the upper containment. In its July 21, 1993 SRM, the Commission approved the staff's position.

The ADS of the ABWR is provided with a reliable nitrogen supply and dc power to ensure its operability. The containment design of the ABWR is expected to decrease the amount of ejected core debris that reaches the upper drywell. This decrease is anticipated through the following: (1) capture and trapping of debris in the lower drywell, (2) impaction and removal of core debris as it is transported between the lower and upper drywell, and (3) division of exiting core debris and gas from the lower drywell into both the upper drywell and wetwell. Based on the above, the staff concludes that the criteria of SECY-93-087 and the staff's proposed applicable regulation for high-pressure core melt ejection have been met. 


\subsection{ABWR Containment Vent Design}

In SECY-90-016, the staff discussed the incorporation of a containment vent system in the ABWR. The containment vent system is identified as the COPS. The design basis of the COPS is discussed in Sections 6.2.5.2.6.2, 19.E.2.8.1, and 19K.11.6 of the ABWR SSAR.

The desirability of venting a BWR containment to mitigate multiplo-failure accidents beyond the design basis has been accepted for some time. Since 1981, the BWR EPGs, developed by the BWR Owners' Group and approved by the NRC for existing BWRs, have called for venting the containment wetwell airspace. The ABWR has a COPS that is designed to avoid gross containment failure resulting from postulated slow-rising overpressure scenarios. The COPS vents the containment from the wetwell airspace, thereby taking advantage of the scrubbing capability of the suppression pool. In transient events, fission products will be directed to the suppression pool through the SRVs. For LOCAs and severe accident scenarios in which the reactor vessel fails, fission products will be directed through the DVCs to the suppression pool.

Without incorporation of the COPS, overpressurization of the containment could lead to failure of the drywell head and fission product releases that have not been scrubbed. The COPS provides a coptrolled scrubbed vent patb from the wetwell with provisions that allow for reisolation of the containment.

\subsection{System Description}

The COPS consists of two containment isolation valves (CIVs) (F007 and F010) and two $200 \mathrm{~mm}$ (8 in.) diameter overpressure relief rupture disks (D001 and D002) mounted in succession in a $250 \mathrm{~mm}$ (10 in.) diameter line that connects the wetwell airspace to the plant stack. The CIVs are located in the reactor building as close as practical to the containment. Downstream of the CIVs is the first rupture disk (D001) with a pressure setpoint of $617.8 \mathrm{kPa}(90 \mathrm{psig})$ at $93^{\circ} \mathrm{C}\left(200^{\circ} \mathrm{F}\right)$. This rupture disk is expected to have a mean opening tolerance of \pm 5 percent pressure. Further downstream, before the entrance to the plant stack, is the second rupture disk (D002) with pressure setpoint of approximately $0.03 \mathrm{MPa}$ (4.35 psig).

The area between the rupture disks is made inert with nitrogen to eliminate the potential for combustion within the portion of the vent path within the reactor building. The rationale for setting the second rupture disk setpoint much lower than that of the first rupture disk is to eliminate the possibility of pressurization between the rupture disks adversely affecting the actuation pressure.
For example, if some type of in-leakage occurred between two high-pressure rupture disks, the containment pressure required to burst the first rupture disk could exceed the design bursting pressure of the disk. By utilizing a highpressure rupture disk in succession with a low-pressure rupture disk, it is expected that significant in-leakage would pressurize the airspace and burst the low-pressure rupture disk and thereby not affect the required containment pressure for bursting the high-pressure nupture disk.

The CIVs in the COPS pathway are subject to the leaktesting requirements associated with $10 \mathrm{CFR}$ Part 50, Appendix J as specified in the SSAR Section 6.2 and the Inservice Testing Requirements as specified in the SSAR Section 3.9. These CIVs are normally open so that the containment atmospheric pressure is exposed to the first rupture disk during all modes of operation. The CIVs are intentionally not provided with an automatic isolation signal to ensure that they remain open in the event that the COPS is needed to mitigate the consequences of a severe accident. With the CIVs open, the first rupture disk provides the barrier to releases during DBA scenarios. In addition, the CIVs are designed to fail-open upon loss of actuating power. This failure position ensures the availability of the COPS during se vere accident scenarios involving multiple failures. If under design-basis conditions, leakage past the rupture aisks occurs, the CIVs can be remotely isolated from the cont $\mathrm{N} / \mathrm{room}$. In-line radiation monitoring of the vent pathway coild be used to detect leakage. However, no leakage is expated within the containment design-basis spectrum 309.9 ' $\mathrm{Pa}$ gage (45 psig). This is based on the design presst ire of the rupture disk being substantially above the containment design- basis pressure and pressures associated with a DBA.

The rupture disks will be tested and replaced every 5 years providing additional confidence of actuation pressure. When the rupture disks are procured, a number will be procured at the same time to provide uniformity in the relief pressure.

The purpose of the CIVs is to contribute to the control of the venting process. Following rupture disk actuation, plant operators may decide to reclose the vent path based upon accident management guidance or procedures to be developed by the COL applicant. The CIVs are designed to be capable of fully opening and closing against the pressures associated with venting. GE indicated that the sizing of the COPS vent path is sufficient to allow $35 \mathrm{~kg} / \mathrm{sec}(77.2 \mathrm{lbm} / \mathrm{sec})$ of steam flow at the opening pressure of $617.8 \mathrm{kPa}$ gage (90 psig), which corresponds to an energy flow of about 2.4 percent rated power. At the time of rupture disk actuation, the decay power is 
expected to be well below 1 percent rated power. The staff concludes that a sufficient margin exists to ensure pressure relief once the rupture disk has been actuated. The sizing of the COPS also prevents suppression-poollevel swell that could force water into the COPS pathway.

The rupture disk cetpoint was selected to assure an adequate margin prior to drywell head failure while maximizing the time before fission product releases through COPS. The rupture pressure of the COPS is slightly below the containment's Service Lovel C capability of $666.9 \mathrm{kPa}$ gage (97 psig), which provides confidence that the integrity of the containment will be maintained before rupture disk actuation.

\subsection{Basis for Acceptability}

In SECY-90-016, the, staff recommended that the Commission approve the use of an overpressure protection system that used a dedicated containment vent for the ABWR. In its June 26, 1990, SRM, the Commission approved the staff's recommended use of the COPS on the ABWR, subject to the results of a comprehensive regulatory reviow, which should fully weigh the potential "downside" risks with the mitigation benefits of the system. In addition, the Commission directed the staff to ensure that the design should provide full capability to maintain control over the venting process.

\subsection{1 Regulatory Review of the Downside Risks and Mitigation Benefits}

The COPS is intended to protect the containment against sequences in which containment integrity is challenged by overpressurization. Without the COPS, the containment failure location is expected to be the upper drywell head with a mean ultimate pressure capability of $1,025 \mathrm{kPa}$ absolute (134 psig). The staff concludes that COPS actuation is preferable to failure of the upper drywell head for the following reasons: (1) releases through the COPS have the advantage of auppression pool scrubbing of fission products, (2) following COPS actuation, the vent pathway can be reisolated, and (3) the actuation setpoint and relief capacity of COPS are selected for optimal containment performance.

The staff evaluated the potential downside risks of COPS on the containment failure frequency and source term.

The pressure setpoint for COPS actuation has an impact on the containment failure frequency. If set too high, the potential exists for failure of the upper drywell head before COPS actuation. GE evaluated the variability in the pressure setpoint at which COPS is actuated, as well as the uncertainty of the drywell head failure pressure. Based on this ovaluation, GE concluded that there is between a 2 percent and 5 percent probability of drywell head failure before COPS actuation, dependent upon the specific accident scenario.

The temperature of the rupture disks has an impact on its bursting pressure. GE evaluated a range of temperatures from 38 to $149^{\circ} \mathrm{C}\left(100\right.$ to $\left.300^{\circ} \mathrm{F}\right)$ for the time various temperatures would take to the nupture disk's opening. Higher temperatures cause a decrease in the bursting pressure, whereas lower temperatures cause an increase. GE concluded that for the range of the temperatures evaluated, the time to rupture disk's opening was within 0.8 bours of the base case and the probability of drywell head failure before rupture disk's opening varied slightly. These results indicate that temperature variations have only a minor effect on the COPS.

A potential adverse impact of the COPS involves its actuation when it might have been possible to recover a containment heat removal system in the time period after COPS initiation and before failure of the upper drywell head. The recovery of the containment heat removal system would therefore prevent the fission product release through the COPS. GE estimated the probability of this to be about 4 to 11 percent depending upon the accident scenarios.

In Section 19E.2.8.1.4 of the ABWR SSAR, GE provided a comparison of ABWR performance with and without the use of the COPS. This included comparisons of the time and magnitude of fission product release for the frequencydominant sequence for the ABWR, as well as an assessment of the impact of COPS on the frequency of core damage and drywell head failure for various accident classes. These results indicate that for the dominant sequence, COPS reduces the time of fission product release from 27 to 20 hours if drywell sprays are not available and from 35 to 31 hours if drywell sprays are available. The cesium iodide release fractions are reduced from about 4 percent without COPS to less than 1E-7 with COPS as a result of suppression pool scrubbing.

Table 19E.2-27 of the ABWR SSAR provides the results of the probability of release modes with and without COPS. The probability of drywell head failure increases by about a factor of $\mathbf{4 0}$ for accident classes involving transients and loss-of-coolant accidents without COPS. For accident classes that include loss of containment heat removal but successful core cooling before containment failure, the frequency of both drywell head failure and resulting core damage would increase by 2 orders of magnitude without COPS. 
In summary, the major benefit of COPS is that it provides asourance that releases from the containment are scrubbed. This fission product scrubbing is provided by the suppression pool. Operators can control roleases via COPS through manual isolation valves. While actuation of COPS results in an earlier release of fission products when compared with failure of the upper drywell head, the magnitude of the release is significently less. Additionally, COPS is expected to reduce the frequency of core damage resulting from accident sequences involving loss of core cooling induced by containment failure.

A major concern related to COPS is that it could lead to carlier, and pertaps unnecessary, releases. However, this does not seem to bo a significant factor for the ABWR. In particular, the selection of the system retpoint appears to provide a reesenable balance between the competing goals of minimizing the probability of drywell head failure and maximizing the time before fission product release into the eavironment. The setpoint is sufficiently high that the time of rolease will generally still be on the order of 15 to 20 hours, yet low enough that the probability of containment failure before COPS actuation is very small (about 5 percent). Also, the probability of unnecessary system actuation (when it might have been possible to prevent a release by recovering containment beat removal systems before containmont failure) is reasonably low (about 10 percent) and COPS is capable of being manually isolated from the control room.

The staff concludes that the COPS has a significant net benefit that outweighs the potential negative aspects of the system.

\subsection{2 Control Over the Venting Process}

The staff roviewed the provisions provided by GE for ensuring full capability to maintain control over the venting process. These provisions include:

(a) selection and justification of the containment pressure when the COPS will actuate

(b) provisions for reclosure of the vent pathway using CIVs that are designed to be capable of fully opening and closing at pressures up to the COPS actuation pressure

(c) providing radiation monitoring within the vent pathway to monitor the potential for an early release or provide guidance for accident management strategies for reclosure of the vent pathway

(d) sizing of the vent pathway to prevent further containment pressurization, once the venting process is actuated, and prevent suppression-poollovel swell into the system piping.

The use of a passive rupture disk prevents the opportunity for veating at presoures below the actuation pressure of the rupture disks. This was a deliberate decision made by $\mathrm{GE}$ to prevent early venting and maintain the integrity of the containment as long as possible. To allow for carly venting, $G E$ could have installed motor-operated valves instead of a rupture disk.

The ataff believes that good engineering rationale can be doveloped to support either position - to allow for carly venting or to maintain containment intogrity as long as possible. The decision to provide rupture disks and therefore prevent early venting is philosophical in nature, with the underlying theme of maintaining an intact containment and venting only as a last resort. The containment is the final berrier preventing release of radioactivity into the environment. As such, it should not be unnecessarily or prematurely breached by plant staff.

GE evaluated severe accidents in Chapter 19 of the ABWR SSAR. This evaluation included use of the COPS, where needed, with the rupture disks installed. The ovaluation did not include carly venting. In this Section (19.2) and Section 19.1 of this report, the staff concludes that GE's analysis in Chapter 19 is acceptable. This acceptability includes the COPS as an integral part of the containment.

\subsection{Conclusions}

The ABWR dedicated containment vent is the COPS, which consists of a vent path from the wetwell airspace to the plant stack. The COPS actuates at a pressure less than ASME Service Lovel $C$ and has provisions for isolation following actuation. Control over the venting process is assured through selection of the actuation pressure and the capability for vent path reclosure. The results of the regulatory review indicate that the net benefits of the system outweigh the potential negative aspects. Based on the above, the staff concludes that the GE ABWR design moets the Commission-approved staff's position in SECY-90-016 for inclusion of a dedicated containment vent path.

\subsection{Suppression Pool Bypass}

Although suppressinn pool bypass is not a severe accident phenomenon, it car become a significant contributor to plant risk. Suppression pool bypass is associated with the failure of the containment system to channel steam and fission product releases through the suppression pool. 
The fundameatal characteristic of a BWR proseuresuppreasion containmeat is that stoum roleased from tho RCS will be condeneod and ecrubbed of radionuclides in the suppreasion pool and that the presenure rise in the containment will therefore bo limited. This is sccomplisbed by directing the steam from the RCS to the mppreasion pool through a drywell to wetwell connecting vent syetom. However, leaknge paths could exiet in the pathway between the drywell and wetwell that could allow steam to bypase the suppreasion pool, preceurize the contuinment, and lead to a rolease. Potential sources of eteam bypase include leakage through the vacuum reliof valves, cracking of the drywell structure, and penetrations through the drywell structure.

\subsection{Preventive and/or Mitigative Features}

In SECY-90-016, the staff concluded that a special offort abould be made to eliminate or further reduce the likelihood of a sequence that could bypass the containment. In SECY-93-087, the staff atated that veadors should make reasonable efforts to minimize the possibility of bypass leakage and should account, in their containment designs, for a certain amount of bypass leakage.

The bypass scenario with the greatest threat to containment integrity in the ABWR is suppression pool bypass through the wetwell-to-drywell vacuum breakers. The vacuum breakers provent the passage of stoam from the drywell to the wetwell by use of a single chock valve. However, pressure transients in the wetwell and drywell or suppression pool swell could force the vacuum breaker check valve to open. If the vacuum breaker disk fails to reseat, a bypass path would be created and allow drywell steam passage directly to the wetwell airspace. Such a scenario allows steam to bypass the condensation function of to the suppression pool, to pressurize the wetwell, and challenge containment integrity. If sufficient steam bypass occurs, containment pressurization rates would increase, thereby decreasing the time to opening of the COPS.

GE analyzed the maximum allowable leakage path area of the ABWR design for DBA-type scenarios. The DBA results are in Section 6.2.1.1.5 of the SSAR. The staff's evaluation of the DBA results are provided in Section 6.2.1.8 of this report.

To mitigate the consequences of suppression pool bypass for both DBAs and severe accidents, the ABWR design includes a containment spray system in the wetwell and upper drywell. The B or C train of the RHR system supplies the water flow to the safety-grade sprays. The spray flow is split with about $800 \mathrm{~m}^{3} / \mathrm{hr}(211,000 \mathrm{gal} / \mathrm{hr})$ going to the drywell spray header and $114 \mathrm{~m}^{3} / \mathrm{hr}$ $(30,100 \mathrm{gal} / \mathrm{hr})$ going to the wetwell spray header.
Nithough RHR pumpe are automatically aligned for thair ECCS function, the flow cen be munually diverted to the containment aprays to mitigate the preceurization of the wetwell airepece during suppreasion pool bypass.

In the event of failure of the RHR system, the ecindependent water addition (ACIWA) oystem can bo interconnected with the C loop of the RHR syatem to provide o flow of between $2385 \mathrm{litera} / \mathrm{m}(630 \mathrm{gpm})$ and 3596 litern/m (950 gpm) to the upper drywell containment epray header. The COPS provents gross contrinment failure for bypase scenarios in which the contrinment preesure would exceed the rupture preseure of the rupture disk. COPS allowa for a controlled releace through reclosure of isolation valves in the vent pathway.

\subsection{GE Analyses}

In Section 19EE of the SSAR, GE performed an analysis to determine the impact on the containment from varying amounts of supprescion pool bypass. Tho study examined the offect of varying a vacuum broaker's bypass leakage are (from zero leakage to leakage from one full opea vacuum breaker) on the timo to fission product releace and the Cesium Iodine (CsI) release fraction at 72 hours for five different scenarios. These scenarios are as follows:

(1) Bypass leakage bogins after passive flooder activation; serosol plugging is neglected.

(2) Bypass leakage is present from the beginning of the accident; aerosol plugging is neglected.

(3) Bypass leakage begins after passive flooder activation; aerosol plugging of the vacuum breaker opening is considered.

(4) Bypass leakage is present from the beginning of the accident; aerosol plugging of the vacuum breaker opening is considered.

(5) Bypase leakage is present from the beginning of the accident and the operator initiates the firewater spray systom.

The effective vacuum breaker area was varied from 0 to $2030 \mathrm{~cm}^{2}$, the latter figure corresponding to one fully open vacuum breaker. The time to fission product relense and the CsI release fractions were determined from MAAP. ABWR runs. The dominant severe accideat sequeace, LCLP (loss of all core cooling with vessel failure occurring at low pressure), was chosen to evaluate plant performance. 
A reference point for comparicon of the recults of OB's analyais is the can with zero bypase leakage and without tho firowneter epray syctem. For this case, tho olapeed timo bofore rupture dick opeaing is about 20 hours and the Cal releass frection is lase then 10B-07.

Cal releave fructions aro orden of magnituds larger for canes with bypase leakage then for the caes without bypaes leakage. For caces with offective aupprestion pool bypan areas greater than $400 \mathrm{~cm}^{2}\left(62 \mathrm{in}^{2}\right)$, the 72 -hour $\mathrm{Cal}$ release fractions are approximatoly 17 perceat.

Socanario 5 examined the offects of drywell epray from the ACIWA on cases with bypass leakage present from the beginning of the secident. Asmuming the operator initiates the firewater epray within 2 bours of the start of the eccident, the olapeod time to rupture dick opening can be delayed to nearly 30 houre for bypase patbways experieacing up to one fully open vecuum breaker.

\subsection{Badis for Acceptability}

The ABWR has the containment spray system and COPS to mitigate the offects of containment bypass and prevent a bypase ccenario from progreasing to containment failure. The contrinment spray system can be supplied from either the RHR or ACIWA syetem. In SECY-90-016, the staff ctated that veating should be delayed for approximately 24 hours following the onset of core damage. For the cases in which one vecuum breaker is fully open, the ABWR moets the intent of this criterion when the initiating of contrinment sprays through the ACIWA system within 2 bours (as described in scenario 5 above) is factored in. The staff concludes that OE has performed a relatively complete analyais to allow an understanding of the capability of the ABWR containment to accommodate a range of bypass conditions through the vecuum breakers. This analyais highlights the importance of the containment epray aystom to mitigating the consequences of suppreseion pool bypass.

\subsection{Duel-Coolant Interaction}

The contrinment fusiction can be challenged by energetic or rapid energy releases. One such energetic or rapid coergy release is an FCI that results in a steam explosion. The term "steam explosion" refers to a phenomenon in which molten fuol rapidly fragments and transfers its energy to the coolant resulting in rapid steam generation, shock waves, and possible mochanical damage. To be a aignificant afety concern, the internction must be very rapid and must involve a large fraction of the coro mass. Steam explosions can occur either in-vessel or ex-vessel.

\subsection{In-Veasel Steam Explodion}

NUREO-1116, A Reviow of the Curreat Underatanding of the Potential for Containmeat Failure From In-Veacel Stanm Explosions, nummarized the deliberations of the Stoum Explosion Roview Oroup's (SERO's) undertanding of the poteatial for containmeat failuro arising from inveenel stanm explosions during core molt sccidents. The consenous reached by the SERO was that the occurreace of in in-veceel steam explocion of mufficient energetics to lead to containment failure was enfficieatly low in probability to allow elimination as a credible threat.

This conclusion was reached despite the expreasion of differing opinions on the modeling of basic steam explocion requence phenomenology. An opinion supported by moat members of the group is that the probability of contrinmeat failure is reduced because of the expectation of limited molt mase involvement in the explosion and/or low thermal-to-mechanical ceergy conversion.

This conclusion was reaffirmed at the meeting of the Committice on the Safoty of Nuclear Installations (CSNI), "Specialiat Meeting on Fuel-Coolant," in Jenuary 1993. The conclusion of the mooting was that alpha-mode failure was highly unlikely because of the structures in the lower reactor veseel head. These structures, such as the CRD guide tubet, would limit the melt mess involvemeat by causing incoherent relocation of the molten corium.

\subsection{Ex-Veasel Steam Explosion}

In SECY-93-087, the staff stated that any dynamic forces resulting from ex-veseel FCI on the integrity of the containment ahould be evaluated. One of the conditions necessary for an ex-veseel FCI in the ABWR is for the molten corium to be discharged from the reactor vessel into a body of water in the lower drywell. The design of the ABWR containment substantially roduces the probability of a preexiating body of water in the lower drywell at the time of reactor vessel failure.

The reactor vesel skirt is solid, preventing water transfer from the upper drywell to the lower drywell. In addition, there are no active injection systems in the lower drywell, and the passive flooder system does not actuate until the atmoephere within the lower drywell is approximately $260^{\circ} \mathrm{C}\left(500^{\circ} \mathrm{F}\right)$. The connection between the upper drywell and lower drywell is through the vertical connecting vent system, which contains a horizontal 90-degreo bend proventing water from reaching the lower drywell. 
In Section 19EB.1.1 of the ABWR SSAR, OB atated that only 0.3 perceat $(5.1 \mathrm{E}-10)$ of all core damage sequences would recult in water in the lower drywell at the timo of veasel failure. In Section 19.1.3.5.4 of this report, the staff ovaluated OB's eatimato and concluded that the probability of a flooded lower drywell at the time of reactor veecel failure is oxtremoly small.

The ataff believes that the low likelibood (5.1B-10) of a flooded lower drywell at the time of reactor veceal fillure provides a sufficient besis to conclude that the probability of an ex-vereal steam explosion has beca reduced to an acceptably low valuo and is therofore coceptable. Nevertheleas, OB and the ataff performed analyen to determine the capability of the ABWR contuinment to withstand ex-veseol steam explosions.

\subsection{1 GE Analysis}

OE provided an uncertainty and sonsitivity analysis of the FCI phenomenon in Section 19EB of the ABWR SSAR. This analysis eatimated the ability of the ABWR containment, epecifically the lower drywell, to withetend - large coergetic FCI (ateam explosion). The analyais determined the peak presenure the ABWR podectal is capable of withstanding and the amount of molicen corium interacting with water that would be neceseary to produce this poak preasure.

OE calculated the peak preasure the podeatal was capable of withstanding during a steam explosion by determining the average preacure of an impulee the amplitude of which can be estimated by the maximum prescure rise expected during an FCl. The ratio of reciatance to doformation to the average preanure of an impules is given by a series of curves. Using this approach, OB calculated the pedactal's resistance to deformation to be $1.7 \mathrm{MPa}$ (246.5 paia).

When an impulse duration of $5 \mathrm{msec}$ is used, which appears to be reasonable based on pules widthe obwerved during $\mathrm{FCl}$ experiments involving corium simulates, the ratio of resistence to deformation to the average preasure of an impulee is approximately 1.0. This implies that the pedeatal can withstand a peak preacure of $1.7 \mathrm{MPa}$ (246.5 puia). For additional conservatiom, OB oliminated the need for a specific pulse duration by uning the curve with the largeat ratio of resistance to deformation to the everage preasure of an impulse, which is 2.0. This resulted in a peak preesure capability of $0.85 \mathrm{MPa}$ (123 psia).

To detormine the amount of corium neceasary to cause this peak presoure, OE calculated the steam formation rate assuming a mass of corium fragments into droplets of an identical radius $2.5 \mathrm{~mm}$ (.1 in.) and interacts with water.
The mace of corium necencary to produce a peak premsure of 0.85 MPa (123 paia) was $22,400 \mathrm{~kg}$ (49,383 lbm), which is approximately 9.5 percent of the catise corium inventory. The peak precenure celculated by $O B$ is at the location of the FCI and doen not account for decay of the abock wave as it propagetes lowards the pedectal wall. OB concluded that the reactor pedeatal wall could withetand en FCl involving 9.5 perceat of the corium inventory.

\subsection{2 Start Analyais}

The ctaff performed an independent sacesement of the ABWR containmeat to withotend a steam explosion uding the TBXAS-II computer code. The remults of the acescoment are documented in report EPRI/NRC 93-203, An Acesesment of Bx-Veasel Fuol-Coolant-Internction Energetices for the Oeneral Electric Advanced Boiling Water Reactor (Lotter dated March 12, 1993, Richard Borchardt, NRC, to Patrick Marriott, OE).

This acesesment ovaluated two different possible sccident progreacion requences, one baeed on the MAAP code and the other baced on the BWRSAR code. The MAAP code ecenario used a relatively large (540 kg/ece) $(1,190 \mathrm{lbm} / \mathrm{ecc})$ corium rolense compoeed of a lot of oxides; wherens, the BWRSAR code scenario is more gradual $(16.7 \mathrm{~kg} / \mathrm{moc})(36.8 \mathrm{lbm} / \mathrm{ecc})$ and compoend of moetly metallics. The results from the MAAP code ceenario were identified as being coneervative because of the large rolease rate, whereas the BWRSAR codo ccenario was identified as being best eatimate. The reactor pedeatal presecure loads were determined to be approximately 1.1 MPa (160 pria) for tho beet cetimato case and 1.6 MPa (232 peia) for the conservative case. These entimates correepond to local presenure impulse loads of $2.6 \mathrm{kPatac}$ (0.38 paia/eec) and $3.7 \mathrm{kPa}-60 \mathrm{c}(0.54 \mathrm{pria} / \mathrm{ecc})$.

In a ceparate analyais, the staff concluded that the pedeatal wall could withstand an FCl-genenated presenre impulse of $3.7 \mathrm{kPa}-20 \mathrm{c}(0.54 \mathrm{psia} / \mathrm{sec})$ uning a ductility ratio of 1.6. It aleo concluded that the aseociated radial doflection at this ductility ratio would not compromise the integrity of the reactor veacel and other anfoty-rolated piping and equipmeat.

\subsection{Basis for Acceptability}

Baned on the conclurions reached in NUREQ-1116 and reaffirmed in the recent CSNI mooting, the staff concluden that in-vesect steam explotions are not a threat to the ABWR containment.

As diecuesed above in Section 19.2.3.3.6.2, the ABWR containment substantially reduces the probability of a presexiating body of water in the lower drywell at the time 
of reactor veasel failure. The athef belleves that the low likelihood of a flooded lower drywall at the time of reactor venal filure provides a aufificient basis to conclude that the probubility of an ex-vesed stenm axplosion has been reduced to an ecceptably low valus and it therofore ecceptible.

\subsection{Equipment Survivabillity}

The purpoes of this section is to diecuse the aurvivability of equipment, both electrical and mochenical, that is needed to provent and mitigate the consequeaces of covere eccidents. GE sddreesed equipment arvivability in Section 19B.2.1.2.3 of the ABWR SSAR.

Dexign beses events are defined a conditions of normal operntion, including anticipated operationd occurresces, deaign basis sccidents, external ovents, and natural phenomenn for which the plant must be deaigned. Safotyrelated equipmeat, both olectrical and mechnnical, must perform its safoty function during design bases ovents. Section 3.11 of the ABWR SSAR defines the environmental conditions with respect to limiting design conditions for all safoty-related mechanical and electrical equipment. The common terminology used for the level of aseurance provided for equipment neceseary for deaign beses ovents is "environmental qualification" or "equipment qualification."

Boyond design besis events can generally be categorized into in-veasel and ex-veseel severe sccidents. Tho environmental conditions resulting from these events are generally more limiting than those from design bases ovents. The NRC established a criterion to provide a reasonable level of confidence that the necessary equipment will function in the severe accident environment for the time span for which it is needed. This criterion is commonly referred to as "equipment survivability" and is fundamentally different from equipment qualification.

In its SRM of June 16, 1990, relating to SECY-90-016, the Commission approved the staff position that features provided only (not required for design basis eccidents) for sovere-accident protection (prevention and mitigation) need not be subject to the 10 CFR 50.49 environmental qualification requirements; 10 CFR Part 50, Appendix B quality assurance requirements; and 10 CFR Part 50, Appendix A redundancy/diversity requirements. The reason for this judgement is that the staff does not believe that severe core damage eccidents should be design basis accidents in the traditional sense that DBAs have been treated in the past. Therefore, the staff's proposed applicable regulation for equipment survivability is as follows:
The standard decign must include analyen, baced on beat-available methode, to demonetrate that:

Bquipaneat, both dectrical and mechunical, neoded to prevent and mitigate the coneequences of sovere cocidente is capable of performing its function for the timo period needod in the beot-eatimeto environmental conditions of the eovere sccident (0.8., preacuro temperature, radiation) in which the equipment is relied upon to function.

Inetrumeatation neodod to monitor plant conditions during a severo sccident is capable of performing it function for the time period needed in the beatcotimate cavironmental conditions of the covere eccident (0.8., proseure, temperature, rediation) in which the inetrumentation is rolied upon to function.

\subsection{In-Vemel Severe Accidents}

The applicable criterion for equipment, both mochanical and olectrical, required for recovery from in-veseal severe accidents is provided in 10 CFR 50.34(f).

Part 50.34(f)(2)(ix)(C) atates that equipment neceseary for achioving and maintaining safo shutdown of the plant and maintaining containment integrity will perform its safoty function during and after being exposed to the environmental conditions attendant with the release of hydrogen generated by the equivalent of a 100 percent fuel-cied metal-water reaction including the environmental conditions created by activation of the hydrogen control systom.

Part 50.34(f)(3)(v) states that systems necessary to ensure containment intogrity shall be demonstrated to perform thoir function under conditions associated with an accident that releases hydrogen generated from 100 percent fuelclad motal-water reaction.

Part 50.34(f)(2)(xvii) requires instrumentation to measure containment pressure, containment water lovel, containment hydrogen concentration, containment radiation intensity, and noble gas effluents at all potential accident release points.

Purt 50.34(f)(2)(xix) requires instrumentation adequate for monitoring plant conditions following an accident that includes core damage.

These regulations collectively indicate the need to perform a systematic evaluation of all equipment, both electrical and mechanical, and instrumentation to ensure its survivability for intervention into an in-veseel severe 
cocident. OB did not perform this systematic evaluation a of SSAR Ameadment 32.

The ataff atated in the advance SER that it believed that an ecceptable resolution of this isoue would entail the following:

OE should perform an evaluation using bestcetimate means of a degraded in-veasel core damage accident that results in a 100 percent motal-water reaction. The basis for the ovaluation should be included. The evaluation should identify the most likely sequences resulting in substantial oxidation of the fuel cladding as a result of the probabilistic safoty assesesment (PSA). An example of an acceptable sequence would involve accident condition in which ECCS performance is degraded for a sufficient time to cause cladding oxidation but is later recovered to ensure a safo shutdown. If the analysis assumes an intact primary loop, the basis for this should be supported by the results of the PSA (i.e., LOCA does not contribute significently to core melt). The impact on the reactor system and containment system from the preseure, temperature, and radiation released should be ovaluated. As an example, the safe shutdown and containment equipment identified below sbould be ovaluated. Plots showing pressure and temperature as a function of time should be provided.

If the in-vessel severe accident environment has no effect on the equipment performance, this should be clearly indicated along with the supporting rationale. Examples of such instances include cases in which the equipment has already performed its function before the onset of the accident conditions or the equipment is located in an area not exposed to the environmental conditions, such as being located outside the primary containment. For equipment in which environmental conditions as a result of the in-vegsel severe accident are in excess of the equipment qualification range, an engineering rationale must be developed as to why the equipment would survive the environment for the needed time span. This rationale could include such factors as limited time period in the environment; the use of similar equipment in commercial industry exposed to the same environment; the use of analytical extrapolations; or

- the results of tests performed in the nuclear industry or at national laboratories.

An accoptable example using this rationale is the work that GE performed for electrical penetration assemblies in Section 19F.3.2.2 of the SSAR. In particular, GE reforred to experimental tests performed at Sandia National Laboratories on actual electrical penetration seeemblies (EPAs) used in operating plants. The teats were performed representative under sovere accident conditions with temperatures up to $371^{\circ} \mathrm{C}\left(700^{\circ} \mathrm{F}\right)$ and presecures up to $965 \mathrm{kPa}$ (140 psig). Using the results of this work, OE committed to providing EPAs that will maintain leak tightness up to containment preseure of $924 \mathrm{kPa}$ (134 psig) and a temperature of $371^{\circ} \mathrm{C}$ $\left(700^{\circ} \mathrm{F}\right)$. The end reoult of this is that the aseumptions used for equipment performance in GB's sovere accident ovaluation are consistent with the as-built plant.

Safe shutdown equipment that should be addreseed include scram equipment, HPCF motor and pump, HPCF isolation valves, HPCF controls, RCIC turbine and pump, RCIC steam valves and cables, RCIC controls, RHR, ADS, shutdown cooling, and others.

Equipment for containment integrity should include containment structure, ClVs - inboard and outboard, electrical penetrations, mechanical penetrations, hatches, sealing mochanisms (welds, bellows, O-ring), as well as others.

With respect to instrumentation requirements, the staff believes that sufficient instrumentation should exist to inform operators of the status of the reactor and the containment at all times as the in-vessel severe accident is intended to be recoverable from and lead to safe shutdown with containment integrity maintained. The emergency operating procedures (EOPs) direct specific manual operator actions based on instrumentation readings and as such all instrumentation should exist where manual operator actions are specified within the EOPs. As a minimum, the instrumentation identified below should be evaluated.

The instrumentation is designed to survive the environment as specified in RG 1.97. However, RG 1.97 only ensures that the instrumentation will survive in the worst environment resulting from a design bases ovent and not a severe accident. Therefore, engineering rationale must be developed as to why the instrumentation would survive the environment. This rationale could include such factors as limited time period in the environment; the use of similar equipment in commercial industry exposed to the same environment; the use of analytical extrapolations; or the results of tests 
performed in the nuclear industry of at national laboratories.

Instrumentation should include neutron flux, RPV water level, RPV pressure, sup pool temperature, sup pool level, drywell/wetwell (CW/WW) $\mathrm{H}_{2}$ concentration, DW/WW $\mathrm{O}_{2}$ concentration, DW temperature, DW pressure, WW pressure, WW temperature, DW water level, among others.

In response to the open item, GE provided the environmental profiles, a table of the necessary equipment, and the accompanying rationale for in-vessel severe accidents in Section 19E.2.1.2.3 of SSAR Amendment 34. The staff finds this information acceptable. Therefore, Open Item F19.2.3.3.7.1-1 is resolved.

\subsection{Ex-Vessel Severe Accidents}

The applicable criteria for equipment, both electrical and mechanical, required to mitigate the consequences of exvessel severe accidents is discussed in the Equipment Survivability section of SECY-90-016. This section indicates that features provided only (not required for design basis accidents) for sovere-accident protoction (prevention and mitigation) need not be subject to the 10 CFR 50.49 environmental qualification' requirements; 10 CFR Part 50, Appendix B quality assurance requirements; and 10 CFR Part 50, Appendix A redundancy/diversity requirements. The reason for this judgement is that the staff does not believe that severe core damage accidents should be design basis accidents in the traditional sense that DBAs have been treated in the past.

However, mitigation features must be designed to provide reasonable assurance that they will operate in the severeaccident environment for which they are intended and over the time span for which they are needed. In cases where safety-related equipment (equipment provided for DBAs) is relied upon to cope with severe accident situations, there should be reasonable assurance that this equipment will survive accident conditions for the period that is needed to perform its intended function.

According to SECY-90-016, GE was to review the various severe accident scenarios analyzed and $i$ atify the equipment needed to perform various functions during a severe accident and the environmental conditions under which the equipment must function. Equipment survivability expectations under severe accident conditions should include consideration of the circumstances of applicable initiating events (e.g., SBO and earthquakes) and the environment (e.g., pressure, temperature and radiation) in which the equipment is relied upon to function. The staff concluded that GE had not performed the ovaluation as outlined by SECY-90-016 as of Amendment 32 to the SSAR. This wes identified as Opea Item $\mathrm{F} 19.2 .3 .3 .7 .2-1$.

As stated in the Advance SER, the staff believed that an acceptable resolution of this issue would entail the following:

(1) GE should provide an evaluation of the dominant accident sequences identified in Section 19E.2.2 of the SSAR. For each accident sequence, GE should identify the mitigation features. Mitigation features should include ADS, ACIWA, and RCIC as appropriate.

In addition, the specific environment profile (pressure, temperature, radiation fields) should be specified. For each mitigation feature, an assessment of survivability should be done using ground rules similar to those specified above for invessel accidents. At least the following mitigation features should be evaluated SRVs, containment structure, vacuum breakers, inboard and outboard CIVs, electrical penetrations, mechanical penetrations, hatches, sealing mechanisms (welds, bellows, 0-rings), passive flooders, COPS, COPS CIVs, and others.

With respect to instrumentation requirements, the staff believes that sufficient instrumentation should exist to inform operators of the status of the containment at all times. This instrumentation should also inform the status of the reactor during the early stages of the accident to ensure reactor failure at low pressure or to allow for low-pressure injection from the ac-independent water addition system.

As a minimum, the list of instrumentation identified below should be evaluated. Where extended ranges of operation of the instrumentation is needed, it should be identified along with the environment to which the instrumentation will be exposed.

The instrumentation is designed to survive the environment as specified in RG 1.97. However, RG 1.97 only ensures that the instrumentation will survive in the worst environment resulting from a design bases event and not from a severe accident. Therefore, engineering rationale must be developed as to why the instrumentation would survive the environment. This rationale could include such factors as limited time period in the environment; the use of similar equipment in commercial industry exposed to the same environment; the use of 
analytical extrapolations; or the results of tests performed in the nuclear industry or at national laboratories.

At least the following instrumentation should be evaluated: RPV water level, RPV pressure, sup pool temperature, sup pool level, DW/WW $\mathrm{H}_{2}$ concentration, DW/WW $\mathrm{O}_{2}$ concentration, DW temperature, WW pressure, WW temperature, and others.

In response to the open item, GE provided the environmental profiles, a table of the necessary equipment, and the accompanying rationale for ex-vessel severe sccidents in Section 19E.2.1.2.3 of SSAR Amendment 34. The staff finds this information acceptable. Therefore, Open Item F19.2.3.3.7.2-1 is resolved.

\subsection{Basis for Acceptability}

GE developed a set of curves representing the bounding environmental conditions for both in-vessel and ex-vessel severe accidents. The environmental conditions were then compared to the equipment capabilities to provide a mensure of confidence that the necessary equipment would survive the expected conditions. The staff concludes that the systematic process used by GE for assessing equipment survivability is acceptable and consistent with the assumptions used in GE's deterministic severe accident assessment. Further, the staff concludes that this meets the requirements of $10 \mathrm{CFR} 50.34$ discussed in Section 19.2.3.3.7.1, and the staff's proposed applicable regulation for equipment survivability.

\subsection{Protection of Containment Sumps}

The lower drywell contains two sumps: an equipment dmin sump (EDS) and a floor drain sump (FDS). Figures 1.2-3b and 1.2-13e of the ABWR SSAR indicate that the sumps are embedded in the lower drywell floor with dimensions of approximately $1 \mathrm{~m}$ (3 ft) wide, $2 \mathrm{~m}$ ( $7 \mathrm{ft}$ long, and $1.25 \mathrm{~m}(4 \mathrm{ft}$ ) deep. Figure 1.2-3b of the ABWR SSAR indicates that the lower drywell has approximately $1.6 \mathrm{~m}(5.75 \mathrm{ft})$ of concrete protecting the liner, while SSAR Section 6.2.1.1.10.3 indicates that there are $1.5 \mathrm{~m}(5 \mathrm{ft})$ of concrete protecting the liner. Therefore, in the sump region, there is approximately 0.25 to $0.35 \mathrm{~m}$ (1 $\mathrm{ft}$ ) of concrete protecting the containment liner. An accumulation of core debris within the sumps could lead to accelerated core-concrete interactions and, given the decreased thickness of concrete protecting the containment liner, the time to liner melt-through in the sump region from core-concrete interactions could be adversely affected.
To prevent liner melt-through in the sump region, the $A B W R$ will have a protective layer of refractory bricks (corium shield) built around each sump to prevent corium ingression. The corium shield design is discussed in Sections 6.2.1.1.10.4 and 19ED of the ABWR SSAR.

\subsection{Sump Design Criteria}

The following general criteria included in Amendment 32 , were developed by GE for designing the sumps:

- Corium shield height greater than maximum height of core debris bed

- Melting point of corium shield material above initial contact temperature

- Corium shield material having good chemical resistance to siliceous slags and reducing environments

- Seismic adequacy determined during the detailed design phase

- Shield roofs have provisions to allow water to flow into the sumps when the lower drywell is flooded.

- Shields extend to the floor of the sumps to prevent debris tunneling.

The EDS and FDS have different functions and therefore specific design criteria in addition to the above General Design Criteria (GDC) were developed. The specific design criteria are discussed below.

\subsection{1 Equipment Drain Sump}

The purpose of the EDS is to collect water leaking from valves and piping within the containment. The water enters and exits through piping from above the sump. As such, the following additional design criteria were specified in Amendment 32:

- Solid corium shield, except for the inlet and outlet piping through the roof

- Corium shield walls thick enough to withstand ablation

\subsection{2 Floor Drain Sump}

The purpose of the FDS is to collect water that falls onto the lower drywell floor. The water flows across the drywell floor and runs into the FDS at a height equal to the lower drywell elevation. As such, the following additional design criteria were specified in Amendment 32: 
- The corium shield will have channels, which do not face the center of the lower drywell, at the lower drywell elevation to allow for water collection during normal operation.

- The channel leagth must ensure that debris will freeze before reaching the sump.

- The width and number of channels must ensure the required water flow rate during normal operation.

- Corium shield walls must be thick enough to allow residence time for debris solidification within the channels.

- The corium shield will extend beneath the lower drywell floor.

- The corium shield must be high enough to ensure longterm debris solidification.

\subsection{Corium Shield Design}

In Section 6.2.1.1.10.4.2, GE indicated in Amendment 32 that the corium shields are made of alumina with a height of $0.4 \mathrm{~m}(1 \mathrm{ft})$. The shield walls extend to the floor of the sumps.

For the FDS corium shield, GE analyzed in Amendment 32 the ability of the corium shield to initially freeze molten debris as it enters the channels and to transfer sufficient heat so that the debris remains solid in the long term. This analysis was in Sections 19ED.4 and 19ED.5 of the ABWR SSAR. It was used along with the GDC and the apecific design criteria specified above to determine the actual corium shield desiga. The channels in the FDS corium shield are $1 \mathrm{~cm}(.4 \mathrm{in}$.) high and at least $0.5 \mathrm{~m}(1.64 \mathrm{ft})$ long; however, the width has not been specified.

\subsection{Discussion}

The staff stated in the advance SER that it believes that the sump shield designs proposed by GE have considerable merit and that some conservatism exists in the specified design criteria. For example, the design criteria are intended to ensure that no core debris enters the sumps. However, in actuality, the sumps could withstand limited amounts of core debris. In addition, GE in Amendment 32 did not take into account or factor in flooding the lower drywell with the LDF system or ac-independent water addition system.

Based on engineering judgment, the staff believes that the sump stields would prevent a substantial accumulation of core debris and that the channels within the FDS would lead to freezing of debris within them. However, the analysis provided to support the proposed shield designs in Amendment 32 was not sufficient to reach this conclusion. In particular, OE did not make use of existing experimental data and analytical tools in justifying its design in SSAR Amendment 33. This was Open Item $F$ 19.2.3.3.8.2-1.

In the advance SER, the staff stated that an acceptable resolution to this issue would entail the following:

(1) GE should evaluate related experimental and analytical work performed in this area to lend additional credibility to its design. In particular, GE should address how the results of its previous work supports its design. This would include a discussion of the prototypicality of the core debris, important parameters, and results. The staff has performed a quick review of related work and tools in this area and believes that they are relevant and readily uvailable.

(a) Experiments performed at (1) Kernforschungszentrum Karlsrube (KfK) on ingression of molten debris into small cracks and openings, (2) Winfrith in the United Kingdom and (3) Grenoble in France.

(b) Analytical tools such as PLUGM computer code (NUREG/CR-3190) and BUCOGEL computer code developed in France.

(c) Work performed in the forging and casting industries.

(2) The analysis performed by GE in Amendment 32 for sizing the FDS ovaluated an oxidic melt of around $2,227^{\circ} \mathrm{C}\left(4,040^{\circ} \mathrm{F}\right)$ and a eutectic melt of around $1,427^{\circ} \mathrm{C}\left(2,600^{\circ} \mathrm{F}\right)$. However, GE used the same correlations and key parameters for both, such as thermal conductivity and latent beat of fusion. To account for uncertainty in the progression of a severe accident and a range of material properties (such as density, melting point, and thermal conductivity), $G E$ should perform separate analyses for oxidic, metallic, and eutectic molts clearly identifying the material properties and providing suitable references. In addition, $G E$ should identify the parameters that the shields are most sensitive to (e.8., freezing point, heat of fusion, velocity of debris in channel, atmosphere temperature, and melt superheat). GE can use the results of its MAAP runs to identify the core debris composition at the time it enters the lower drywell. 
In addition, GE could use the results of other code predictions (BWRSAR, MELCOR) as documented in NUREGs for similar BWRs.

(3) GE should address why the velocity of the debris in the FDS channels is not affected by the initial velocity of debris falling from the reactor presesure vessel (RPV)

(4) GE should modify the design criteria to do the following:

(a) Specify that the EDS extend below the lower drywell floor and that both shields prevent tunneling of core debris under them.

(b) Specify sloping of the shield roof to prevent accumulation of core debris or show that the long-term debris solidification in the channels is not affected by minor amounts of debris on the roof.

(5) GE should provide the thickness of the EDS corium shield necessary to withstand ablation.

GE has addressed these 5 issues in an SSAR markup of Sections 6.2.1.1.10.4 and Appendix 19ED dated February 7, 1994. Specifically, GE provided a markup of SSAR Section 19ED.6 providing an overview of reiated experimental and analytical work concerning the freezing of molten fuel in narrow channels to address Item 1. For Item 2, GE modified the analysis of channel length in Subsection 19ED.4 to account for three debris scenarios covering the expected range of melt phenomena. For Item 3, GE clarified the FDS shield design to clarify the location of channels. For Item 4, GE modified Subsections 19ED.3 and 19ED.5.2 and added 19ED.5.3 to estabiish that the EDS and FDS shields extend to the sump floor to prevent debris tunneling. Further, GE modified its long-term analysis in Subsection 19ED.5.1 to credit flooding of the lower drywell. Lastly, for Item 5, GE added Subsection 19ED.5.3 to address the thickness of the EDS shield walls and the shield wall of the FDS without channels. In addition, GE modified its general and specific design criteria for the EDS and FDS. This resulted in a revision to the design dimensions. Further, GE takes credit for the lower drywell flooder in determining the sump shield design. The staff concludes that the sump shield design proposed by GE is acceptable. This is based on GE's development of design criteria, proposed analytical solution, evaluation of the shield design to variations in key parameters, and review of existing related experimental and analytical work. GE has included the above information in SSAR Amendment 34 and the staff finds it to be acceptable. Therefore, Open Item F19.2.3.3.8.3-1 is resolved.

\subsubsection{Containment Performance}

The NRC approach for ensuring containment survivability from severe accident challenges consists of requiring inclusion of accident provention and consequence mitigation features and the containment performance goal (CPG). The CPG ensures that the containment would perform its function in the face of most severe accident challenges and that the design (including its mitigation features) would be adequate if called upon to mitigate a sovero accident.

Two alternative CPGs were identified in SECY-90-016: a conditional containment failure probability (CCPP) of 0.1 or a deterministic containment performance goal that offers comparable protection. In its June 26, 1990, SRM, the Commission approved the use of a 0.1 CCFP as a basis for establishing regulatory guidance for evolutionary LWRs. Two definitions of containment failure were discussed in SECY-91-309, "Draft Safety Evaluation Report on the General Electric Boiling Water Reactor Design Covering Chapter 19 of the Standard Safety Analysis Report, Response to Severe Accident Policy Statement." These include a CCFP based on a structural integrity definition and on a dose definition. For internal ovents, Section 19.1.3.5.1 of this report provides the results of the CCFP analyses and concludes that the ABWR design limits the CCFP to approximately 0.1. The treatiment of external events for the ABWR is discussed in Section 19.1.2 of this report.

The Commission directed that the use of 0.1 CCFP should not be imposed as a requirement, and that the use of the CCFP should not discourage accident prevention. Therefore, the staff's proposed applicable regulation for containment performance is as follows:

The standard design must include design features to limit the conditional containment failure probability for the more likely severe accident challenges.

Section 19.1.3.5 of this report provides the staff's analysis of the design features that contribute to limiting the CCFP. The severe accident phenomena that are mitigated by these design features are ovaluated in Sections 19.2.3.3 and 19.2.6 of this report. Based on the evaluations in these sections, the staff concludes that the acceptance criteria in SECY-90-016, SECY-93-087, and the staff's proposed applicable rogulation for containment performance have been mot. 


\subsubsection{Accident Management}

The staff concluded, based on PRAs and sovere accident analyeses, that the risk associated with eovere accidents could bo further reduced through effective accident management (AM). AM encompasses those actions taken during the course of an accident by the plant operating and tochnical staff to (1) prevent coro damage, (2) terminate the progress of core damage if it begins and retain the core within the reactor vessel, (3) maintain containment integrity as long as possible, and (4) minimize offsite releases. AM, in effect, extends the defense-in-depth principle to plant operating staff by extending the operating procedures well beyond the plant design basis into severe fuel damage regimes, using existing plant equipment and Operator skills and creativity to terminate sovere accidents and limit offsito relenses.

In SECY-88-147 and Generic Letter 88-20, the staff identified the development of an "accident management plan" by each operating reactor licensee for severe accident "closure." A somprehensive description of the major 8oals, framework, and elements of an AM plan was subsequently provided in SECY-89-012, Staff Plans for Accident Management Regulatory and Research Programs. The AM plan provides a framework for evaluating information on severe accidents, for preparing and implementing severo accident operating procedures, and for training operators and managers in these procedures. An effective AM plan could reduce the risk associated with severe accidents by incorporating improvements in five general areas:

- Accident Management Strategies and Implementing Procedures

- Training in Severe Accidents

- Guidance and Computational Aids for Technical Support

- Instrumentation

- Delineation of Decision Making Responsibilities

In response, the nuclear industry has initiated an $\mathrm{AM}$ program, as described in SECY-90-313, Status of Accident Management Program and Plans for Implementation. Key issues to be resolved in establishing the AM program include industry completion and NRC review of (1) the industry-proposed process for evaluating $A M$ capabilities, and (2) vendor-specific AM guidance. The industry-proposed AM program was scheduled for completion in 1993.

The overall responsibility for AM, including dovelopment, implementation, and maintenance of the AM plan, lies with the COL applicant, since the applicant is ultimately responsible for the safety of the plant and for establishing and maintaining an emergency response organization capable of effectively responding to potential accident situations.

The COL applicant should submit the AM plen es part of the COL application. The plan should provide the applicant's commitment to perform a systematic evaluation of the plant's ability to deal with potential severe accidents and to implement the necessary enhancements within the detailed plant design and organization. The staff will review the AM plan at the COL stage to assure that the evaluation process and commitments proposed by the COL applicant provide an acceptable means of systematically assessing, enhancing, and maintaining $A M$ capabilities, consistent with staff expectations. The COL applicant would later implement the plan and submit the results for staff reviow before plant operation.

\subsubsection{Capacity of the ABWR Primary Containment Vessel}

\subsubsection{Introduction}

In Appendix 19F to Chapter 19 of the ABWR SSAR, the applicant (GE) discussed the ultimate capacity of its primary containment. The pressure boundary of the containment consists of the reinforced concrete containment vessel (RCCV) and steel torispherical upper drywell head (STUDH). The staff's evaluation of the adequacy of the containment to withstand the postulated design basis loads is provided in Sections 3.8.1 and 3.8.2 of this report. The purpose of this evaluation was to assess the containment's capability beyond the design basis.

\subsubsection{Evaluation}

The ABWR's containment consists of an RCCV, a right cylindrical structure built of steel-lined reinforced concrete, and a STUDH. In order to establish the ultimate capacity of the containment, GE discussed in Appendix 19F of its SSAR (Reference (Ref.) 1) the analyses performed for the RCCV. It also provided the calculated capacity of the STUDH and related the potential leak path under pressures and temperatures that could represent the environment inside the containment during severe accident conditions. This evaluation was based on a reviow of the information provided in Reference 1.

GE arrived at the following conclusions regarding the structural capability and functionality of the containmont structure:

The STUDH of the containment will have an internal pressure capacity of $770.1 \mathrm{kPa}(97 \mathrm{psig})$ at 
$260.0^{\circ} \mathrm{C}\left(500^{\circ} \mathrm{F}\right)$ when the allowable stresses in the steel drywell head are held to the Level $C$ Service Limit of the ASME Code Section III, Subarticle NE-3220 (Ref. 1, Section 19F.3.1.2).

(2) The pressure capacity of the STUDH at the median fragility (as defined by the conditional failure probability at 50 percent confidence level) is determined to be $1025.3 \mathrm{kPa}(134 \mathrm{psig})$ at $260.0^{\circ} \mathrm{C}$ $\left(500^{\circ} \mathrm{F}\right)$, and $928.7 \mathrm{kPa}(120 \mathrm{psig})$ at $371.1^{\circ} \mathrm{C}$ $\left(700^{\circ} \mathrm{F}\right)$ (Ref. 1, Section 19F.3.1.2).

(3) The equivalent ASME Level C Service Limit of the RCCV is $1232.1 \mathrm{kPa}$ (164 psig); the ultimate capacity of the RCCV, being higher, is not estimated by the applicant (Ref. 1, Sections 19F.1, 19F.2, and 19F3.1.1).

(4) Liner plate and its anchorages will maintain their integrity when subjected to a severe accident pressure of $1025.3 \mathrm{kPa}$ (134 psig) and a temperature of $260.0^{\circ} \mathrm{C}\left(500^{\circ} \mathrm{F}\right)$ (Ref. 1, Section 19F.3.2.1).

(5) The total leak area through various penetrations at $928.7 \mathrm{kPa}$ (120 psig) is estimated to be $67.55 \mathrm{~cm}^{2}$ (10.47 $\mathrm{in}^{2}$ ) (Ref. 1, Section 19F.3.2.2).

The acceptability of GE's five conclusions is discussed and evaluated by the staff in the following sections.

\subsection{Level C Service Limit}

\subsection{Steel Torispherical Upper Drywell Head}

\section{Membrane Stress Intensity}

On the basis of NASTRAN analysis and the stress intensity criterion provided in the ASME Code, Section III, Paragraph NE-3221, GE stated that the general primary membrane stress controls the design at the Level C Service Limit for an internal pressure of $832.2 \mathrm{kPa}(106 \mathrm{psig})$ at $171.1^{\circ} \mathrm{C}\left(340^{\circ} \mathrm{F}\right)$. At $260.0^{\circ} \mathrm{C}\left(500^{\circ} \mathrm{F}\right)$, the allowable internal pressure at the Lovel C Service Limit for membrane stress intensity was found to be $770.1 \mathrm{kPa}$ (97 psig). To verify GE's results concerning the stresses using NASTRAN computer code, the staff independently calculated the membrane stresses using ALGOR computer code. The staff's comparison (Table 19.2-1) confirmed the applicant's conclusion.
Buckling

Galletly (Ref. 2) developed, on the basis of the actual test data, a simple parametric equation to calculate limiting internal pressure that would prevent buckling of steel torispherical heads. Based on the equation and the analysis of the data in Reference 2, GE calculated a best-estimate internal pressure value of $1838.8 \mathrm{kPa}(252 \mathrm{psig})$ and a lower bound value of $1245.9 \mathrm{kPa}$ (166 psig) as values corresponding to buckling failure values of torispherical heads tested.

When test data are used to establish the ASME Code Section III, NE-3222, Allowable Buckling Stress, it is appropriate to use the best estimate test data. Accordingly, when the best-estimate test data values are used in NE-3222, the allowable internal pressure at the Level C Service Limit for buckling stress is $797.7 \mathrm{kPa}$ (101 psig). An alternate method of computing the allowable buckling stress is provided in ASME Code, Section III, Code Case N-284. The factor of safety at the Level C Servico Limit in Code Case in N-284 (1.67) is less than that in NE-3222 (2.5). However, the factor of safety has to be applied to the lower-bound test data. When the lower-bound test date are used in Code Case N-284, the allowable internal pressure at the Level C Service Limit is $783.9 \mathrm{kPa}$ (99 psig). This evaluation is based on the staff's position on the shell buckling as a result of internal pressure (See Appendix A to Section 3.8.1 of this report).

From the above three limiting pressure values of $770.1 \mathrm{kPa}$ (97 psig) based on membrane stress intensity criterion, $797.7 \mathrm{kPa}$ (101 psig) from buckling criterion of NE-3222, and $783.9 \mathrm{kPa}$ (99 psig) from buckling criterion of $\mathrm{N}-284$, the staff finds that because the $770.1 \mathrm{kPa}$ (97 psig) is the least of the pressure values, it controls the internal pressure capacity of STUDH corresponding to the ASME Lovel C Service Limit stress criterion. Thus, the staff finds the proposed internal pressure of $770.1 \mathrm{kPa}$ (97 psig) as an acceptable value for the STUDH.

\subsection{Concrete}

For the concrete portion of the RCCV, the staff considers the factored load acceptance standards of ASME Code Section III, Division II, Article CC-3000 as an appropriate acceptable criterion. It should be noted that in applying the criterion, a factor of 1.0 (instead of 1.5) should be Table CC-3230-1 for the internal pressure generated by severe accidents. The pressure capability estimate for the RCCV using this criterion is discussed in the following paragraphs. 
Table 19.2-1 GE ABWR drywell head comparison of membrane stresses

75 psig internal pressure, $0.03175 \mathrm{~m}(1.25 \mathrm{in}$.$) thickness, 171^{\circ} \mathrm{C}\left(340^{\circ} \mathrm{F}\right)$

\begin{tabular}{|l|c|c|c|l|}
\hline & $\begin{array}{c}\text { Hoop } \\
\text { MPa (psi) }\end{array}$ & Longitudinal MPa (psi) & $\begin{array}{c}\text { Intensity } \\
\text { MPa (psi) }\end{array}$ & \multicolumn{1}{|c|}{ Remarks } \\
\hline NASTRAN & $101.5(-14,725)$ & $59.57(8,640)$ & $161.1(23,365)$ & $5^{\circ}$ wedge \\
\hline ALGOR ${ }^{1}$ & $101.0(-14,650)$ & $58.05(8,420)$ & $159.1(23,070)$ & $\begin{array}{l}5^{\circ} \text { wedge } \\
1^{\star} \text { quadrant }\end{array}$ \\
\hline ALGOR & $92.91(-13,475)$ & $59.50(8,630)$ & $152.4(22,105)$ & $\begin{array}{l}1^{\circ} \text { wedge } \\
\text { Full model }\end{array}$ \\
\hline
\end{tabular}

From NASTRAN,

Stress intensity, $\mathbf{P}_{\mathbf{m}}$ :

161.1 $\mathrm{MPa}(23,365 \mathrm{psi})\left(0.618 \mathrm{MPa}(75 \mathrm{psig})\right.$ and $171^{\circ} \mathrm{C}\left(340^{\circ} \mathrm{F}\right)$

Yield strength $\left(S_{y}\right)($ SA-516, Gr. 70):

$$
\begin{array}{ll}
229.7 \mathrm{MPa}(33,300 \mathrm{psi}) & 171^{\circ} \mathrm{C}\left(340^{\circ} \mathrm{F}\right) \\
211.7 \mathrm{MPa}(30,700 \mathrm{psi}) & \quad 260^{\circ} \mathrm{C}\left(500^{\circ} \mathrm{F}\right)
\end{array}
$$

Allowable stress intensity $\left(\mathrm{S}_{\mathrm{mc}}\right)$ (SA-516, Gr. 70): $133.1 \mathrm{MPa}(19,300 \mathrm{psi})$

Level C Service Limit Criteria (NE-3221): $\quad P_{m} \leq \max .\left(1.0 S_{y}, 1.2 S_{m c}\right)$,

$$
\begin{array}{ll}
\mathrm{P}_{\mathrm{m}} \leq 229.7 \mathrm{MPa}(33,300 \mathrm{psi}) & \text { (171 }{ }^{\circ} \mathrm{C}\left(340^{\circ} \mathrm{F}\right) \\
\mathrm{P}_{\mathrm{m}} \leq 211.7 \mathrm{MPa}(30,700 \mathrm{psi}) & \left(160^{\circ} \mathrm{C}\left(500^{\circ} \mathrm{F}\right)\right.
\end{array}
$$

$$
\begin{aligned}
\text { Allowable pressure } & =(75) *(33,300) /(23,365) \\
& =0.832 \mathrm{MPa}(106 \mathrm{psig}) @ 171^{\circ} \mathrm{C}\left(340^{\circ} \mathrm{F}\right) \\
& =(106) *(30,700) /(33,300) \\
& =0.770 \mathrm{MPa}(97 \mathrm{psig}) @ 260^{\circ} \mathrm{C}\left(500{ }^{\circ} \mathrm{F}\right)
\end{aligned}
$$

1 ALGOR is a three-dimensional finite element program for structural analysis and design and has been used by the staff for its independent evaluation. 
Initially, in Amendment 21 of Ref. 1, the applicant provided the information related to the RCCV ultimate capacity based on the scaled model test of the RCCV. Later, in Amendment 30 of Ref. 1, to avoid inclusion of proprietary information in the SSAR and recognizing the differences in the model and the proposed RCCV (having a significantly higher percentage of reinforcement) $G E$ decided to perform analyses of the RCCV for severe accident conditions. The FINEL computer program developed by Bechtel Corporation is used for the nonlinear finite element analysis of the RCCV. In the analysis, the RCCV and the internal structures are considered as axisymmetric, and the reinforced concrete girders integral with the top slab of the RCCV are represented by solid elements with appropriate stiffness. The pressure capacity of the top slab is calculated based on the extrapolation of the elastic 3-D STARDYNE analysis results.

Within the elastic range of response, both codes have been well recognized and benchmarked against the structural integrity tests of containments. Though the FINEL computer program permits the specification of bilinear, brittle, and ductile material properties, it is not benchmarked against results of any containment test with nonlinear responses. However, within the pressure range of interest, the RCCV responses are in the linear range and hence the use of these codes to compute pressure capacities of the RCCV is reasonable.

The results of the combined analyses indicate that the weakest link in the RCCV is the top slab where the equivalent ASME Level C Service Limit acceptance criterion is reached at a pressure of $1232.1 \mathrm{kPa}$ (164 psig).

Thus, the staff finds the containment performance under an internal pressure of $770.1 \mathrm{kPa}$ (97 psig) to be acceptable and is aware that it is limited by the capacity of the STUDH. The RCCV has higher capacity and does not limit the containment performance.

\subsection{Median Fragility Level for the Containment}

\subsection{Steel Torispherical Upper Drywell Head}

GE stated that the limit pressure for plastic deformation was found to be $940.4^{\circ} \mathrm{kPa}$ (121.7 psig) at $260.0^{\circ} \mathrm{C}$ $\left(500^{\circ} \mathrm{F}\right)$ by Shield and Drucker's proposed equation (Ref. 3). The minimum yield strength of material SA-516, Gr. 70, as specified in Appendix I of ASME Section III was increased by 10 percent for the realistic estimate of the structural strength. Thus, the limiting internal pressure is determined to be $1025.3 \mathrm{kPa}(134 \mathrm{psig})$ at $260.0^{\circ} \mathrm{C}$ $\left(500^{\circ} \mathrm{F}\right)$ and $928.7 \mathrm{kPa}(120 \mathrm{psig})$ at $371.1^{\circ} \mathrm{C}\left(700^{\circ} \mathrm{F}\right)$ to account for the lower yield strength of the material.
From the STUDH buckling capability, the applicant predicted a best-estimate internal pressure value of $1838.8 \mathrm{kPa}$ (252 psig) and a lower bound value of $1245.9 \mathrm{kPz}$ (166 psig) as values corresponding to buckling failure of the STUDH. These values are besed on the results of the tests (Rof. 2) performed on stainless steel and carbon steel torispherical heads fabricated using the preased and apun (PS) technique as well as the crown and segment tochnique (CS). Out of 43 tests, six date points were from the actual failure resulting from internal pressure on the carbon steel CS heads. These are the most relevant data for the drywell bead. The lower-bound value is estimated to be $1245.9 \mathrm{kPa}$ (166 psig). As these values are based on a limited data base and as they correspond to actual buckling failure of the heads, use of them to arrive at the actual median fragility internal pressure for the STUDH should be made with some margin on the lower bounds. Providing an arbitrary knockdown factor of 1.2, the internal buckling pressure of the median fragility level can be derived as $1052.8 \mathrm{kPa}$ (138 psig). However, GE adopts $1025.3 \mathrm{kPa}$ (134 psig) as the capability pressure and uses it as the median fragility value at $260.0^{\circ} \mathrm{C}\left(500^{\circ} \mathrm{F}\right)$. Based on this median fragility value of $1025.3 \mathrm{kPa}$ (134 psig), a containment pressure capacity fragility curve was provided with the following uncertainty parameters in Appendix 19FA to Reference 1 .

In Appendix 19FA to Reference 1, the applicant estimated the uncertainties associated with the median fragility value using engineering judgment and the results from prior analysis. The uncertainties in the prediction of the failure pressure generally result from uncertainties in modeling and material strength. The lognormal distribution is selected to characterize the fragility curve and defined in terms of the median pressure capacity and the combined logarithmic standard deviation. The logarithmic standard deviations from uncertainties for modeling and material properties of steel structures $\left(B_{m}\right.$ and $\left.B_{y}\right)$ are estimated as 0.14 and 0.08 , respectively, and the combined logarithmic standard deviation $\left(B_{c}\right)$ is estimated to be 0.16 .

The use of 0.14 for $B_{m}$ is acceptable because it is consistent with Reference 4 in which the coefficient of variation (COV) [defined as (exp $\left.\left(B^{2}\right)-1\right)^{1 / 2}$ ] associated with the modeling error by the use of approximate methods including torispherical heads is $\mathbf{0 . 1 2}$.

The use of 0.08 for $B_{1}$ is acceptable because the variability associated with material strength is expected to be the same regardless of temperature (Ref. 5). The statistical data for SA-516, Gr. 70, show that the average yield strength of the material is $48.62 \mathrm{ksi}$ and the standard deviation is $3.525 \mathrm{ksi}$ (Ref. 6). The COV is 0.073 , which is less than 0.08 used for $B_{\text {. }}$. 
Therefore, the combined logarithmic standard deviation (Bd) of $0.16\left(\left(B_{m}^{2}+B_{s}^{2}\right)^{1 / 2}\right)$ is acceptable.

Based on the staff's evaluation and by taking the above factors into account, the staff considers the median fragility value for the STUDH of $1025.3 \mathrm{kPa}$ (134 psig) at $260.0^{\circ} \mathrm{C}\left(500^{\circ} \mathrm{F}\right)$ with the combined logarithmic standard deviation of 0.16 to be reasonable. If the temperature reaches $371.1^{\circ} \mathrm{C}\left(700^{\circ} \mathrm{F}\right)$, the median fragility internal prossure value is reduced to $928.7 \mathrm{kPa}$ (120 psig).

\subsection{Concrete}

As discussed in A.2 above, the equivalent Lovel C Service Limit internal pressure capacity of the RCCV is estimated as $1130 \mathrm{kPa}$ (164 psig). As this capacity is higher than the median fragility internal pressure capacity of the STUDH, GE decided not to spend resources in estimating the ultimate (modian fragility) pressure capacity value for the RCCV. The staff considered this approach acceptable provided GE demonstrated the integrity of the RCCV liner plate and its anchorages under $1025.3 \mathrm{kPa}(134 \mathrm{psig})$ and $260.0^{\circ} \mathrm{C}\left(500^{\circ} \mathrm{F}\right)$ temperature.

In Section 19F.3.2.1 (Ref. 1), GE provided an evaluation of the liner plate and its anchorages under the specified conditions. The applicant determined the maximum hoop strain in the liner plate at $1025.3 \mathrm{kPa}$ (134 psig) to be 0.13 percent. With a strain concentration factor of 33 to account for a failure mode similar to that in the Sandia test (Ref. 7), GE uses the argument that the resulting strain in the ABWR RCCV is 4.3 percent, which is significently lower than the ultimate tensile strain (i.e., 21 percent) of the liner plate material. The staff recognizes that the geometry and type of anchors to be used for the ABWR RCCV are quite different and the strain concentration factors may be different between the Sandia test and the ABWR. Nevertheless, a factor of 33 is conservative and the staff finds it acceptable.

Additionally, GE evaluated the effects of thermal loading on the liner and the anchorages using Bechtel's topical report, BC-TOP-1, Rev. 1, Containment Building Liner Plate Design Report. For this evaluation, the temperature inside the RCCV is considered as $260.0^{\circ} \mathrm{C}\left(500^{\circ} \mathrm{F}\right)$, and that outside the $\mathrm{RCCV}$ is assumed as $37.8^{\circ} \mathrm{C}\left(100^{\circ} \mathrm{F}\right)$. The liner is shown to be buckled (because of temperatureinduced compressive stresses) between the continuous anchorages, but the force on the anchorages is shown to be less than its yield capacity.

Although the staff finds this approach reasonable, it should be recognized that there is a difference in the duration and magnitude of the temperature loading that would be applied during a design-basis accident (DBA) (which is of a smaller and magnitudo shorter duration) compared with that postulated to occur during a controlling severe accident (SA) scenario. Also, the condition of the RCCV structure would be different in the two cases. The pressure loading during an SA would reduce the stiffness of the structure considerably. Thus, the assumptions used in the BC-TOP-1 report are not necessarily applicable. However, they provided a besis for calculating an upperbound value for compressive buckling of the plate and for the forces on the liner anchorages. Alternatively, under an $S A$, the liner together with the extensively cracked concrete can be considered to grow because of high $\left(260.0^{\circ} \mathrm{C}\left(500^{\circ} \mathrm{F}\right)\right)$ temperature. Considering the differential temperature of $204.4^{\circ} \mathrm{C}\left(400^{\circ} \mathrm{F}\right)$, the staff calculated the tensile strain in the liner to be 0.24 percent. The combined tensile strain in the general shell liner could be as bigh as 0.37 percent. When the same strain concentration factor of 33 is used again, the maximum tensile strain in the liner at a discontinuity could be as high as $\mathbf{7 . 9}$ percent. This strain is $\mathbf{4 0}$ percent of the ultimate tensile strain of the liner material. Under this condition, the continuous anchorages could detach themselves from the cracked concrete, but, the liner would still provide the required leaktightness.

Thus, the staff finds the median fragility internal value of $1025.3 \mathrm{kPa} \quad(134 \mathrm{psig})$ at $260.0^{\circ} \mathrm{C}\left(500^{\circ} \mathrm{F}\right)$ and $928.7 \mathrm{kPa}(120 \mathrm{psig})$ at $371.1^{\circ} \mathrm{C}\left(700^{\circ} \mathrm{F}\right)$ acceptable as limiting values.

\subsection{Interface Between STUDH and RCCV}

GE performed the pressure capacity calculations for the interface between the STUDH flanges and the top slab of the RCCV and arrived at the following pressure capacities: (a) $1176.9 \mathrm{kPa}$ (156 psig) for the maximum allowable concrete peripheral shear stress of the top slab using the acceptance criteria of ASME Section III, Division II, CC-3421.6, (b) $1687.1 \mathrm{kPa}$ (230 psig) for anchorage steel ring plate using the Level C acceptance criteria of ASME Section III, Division I, NE-3221, and (c) $1528.5 \mathrm{kPa}$ (207 psig) for the anchorage steel gusset plates using the Lovel C acceptance criteria of ASME Section III, Division I, NE-3227.2. The staff finds the pressures to be above the median fragility value of $1025.3 \mathrm{kPa}$ (134 psig), with the stresses in the interface area well within the ASME Section III Code allowables, and thus acceptable. Therefore, the staff agrees with GE's conclusion that the probable leakage path would be through the STUDH flanges. The leakage through the STUDH flanges is discussed in Section 2D of this report. 


\subsection{Leakage Through Penetrations}

In Section 19F.3.2.2 (Ref. 1), GE diecuseses the leakages through various RCCV penetrations and from the seal area between the flanges in the STUDH under severe accident temperatures and pressures. The essumptions and rationale used in the discussions by the applicant are besed upon the experimental work performed at SNL and Argonno National Laboratory (ANL). OE determined that under the poetulated SA ccenarios, the leakage through the fixed olectrical and mechanical penetrations was negligible.

In a facsimile dated September 7, 1993, GE revised Subsection 19F.3.2.2 of the SSAR to discuss the leakage performance of the containment EPAs under conditions. GE stated that the EPAs to be used in the ABWR containment would be capable of maintaining leaktightness up to the containment pressure of $1025.3 \mathrm{kPa}$ (134 psig) at $371.1^{\circ} \mathrm{C}\left(700^{\circ} \mathrm{F}\right)$. The staff finds GE's assessment regarding the fixed electrical and mechanical penetrations acceptable. GE has included this information in Subsection 19F.3.2.2 of the SSAR.

The containment has five operable penetrations: two pressure-seating airlocks, two pressure unseating equipment hatches, and the pressure-unseating STUDH. In Section 19F.3.2.2 of Ref. 1, GE estimated the leakage areas from the three pressure-unseating penetrations with conservative assumptions; such as, (1) the seal is assumed lost at $260.0^{\circ} \mathrm{C}\left(500^{\circ} \mathrm{F}\right)$, and (2) the springback capability of degraded seals was not factored in. The total leakage area is estimated as 110 percent of the leakage areas of the three pressure-unseating penetrations to account for the potential for small leakages through the airlocks. The leakage areas are provided for the pressures above the structural integrity test pressure at an interval of $170.3 \mathrm{kPa}$ (10 psig). The total leakage area at $928.7 \mathrm{kPa}$ (120 psig) is estimated as $67.5 \mathrm{~cm}^{2}\left(10.47 \mathrm{in}^{2}\right)$.

The staff considers the estimate of these leakage areas to be reasonable.

\subsubsection{Summary and Conclusion}

Based on the review of the information GE providad and the staff's evaluation as discussed above, the staff concludes the following:

(1) The staff evaluation indicates that the ABWR containment structure has an internal pressure capacity of $770.1 \mathrm{kPa}(97 \mathrm{psig})$ and $260.0^{\circ} \mathrm{C}$ $\left(500^{\circ} \mathrm{F}\right)$ when the allowable stresses in the steel drywell head are held to the Level C Service Limit.
(2) As diecused in 2B of the evaluation, the ataff considers the modian fragility of the contrinment atructure of $1025.3 \mathrm{kPa}\left(134\right.$ paig) at $260.0^{\circ} \mathrm{C}$ $\left(500^{\circ} \mathrm{F}\right)$ to be a conservative value.

\section{Beferences:}

1. Appendix 19F to Chapler 19 of the General Blectric Nuclear Energy, Advance Boiling Water Reactor Standard Safety Analyais Report (asp to and including Amendmeat 34).

2. Galletly, G. D. "A Simple Design Equation for Preventing Buckling in Fabricated Torispherical Shells Under Internal Pressure," ASME Journal of Pressure Vessel Technology, Vol. 108, November 1986.

3. Shield, R. D., Drucker, D. C. "Design of Thin-Walled Torispherical and Toriconical Pressuro-Veseel Heads," Transactions of ASME, June 1961.

4. NUREG/CR-2442, "Roliability Analysis of StcolContrinment Strength," June 1982.

5. NUREG/CR-5405, "Analysie of Shell-Rupture Failure Due to Hypothetical Elevated-Temperature Pressurization of the Sequoyah Unit 1 Steel Containment Building," February 1990.

6. NUREG/CR-2137, "Realistic Design Margins of Pumps, Valves, and Piping," June, 1981.

7. NUREG/CR-5341, "Round-Robin Analysis of the Behavior of a 1:6-Scale Reinforced Concrete Containment Model Pressurized to Failure: Posttest Evaluations," Sandia National Laboratory, October 1989.

\subsection{Shutdown Risk}

\subsubsection{Introduction}

Various incidents occurring at nuclear power plants during low power and shutdown operation modes over the past several years have raised NRC staff concerns regarding plant vulnerability during these operating modes. The shutdown events have caused plants to lose their ability to maintain core cooling, provide make-up coolant to the reactor, and to maintain electrical power to essential equipment. The April 10, 1987, event at the Diablo Canyon Nuclear Power Plant emphasized the sensitivity of operating a pressurized-water reactor (PWR) with a reduced inventory in the RCS. Following an evaluation, the staff issued Generic Letter 88-17, "Loss of Heat Decay Removal, " on October 14, 1988, requesting PWR licensees 
to sddress numerous generic doficiencies to improve safety during operation at reduced inventory.

On March 20, 1990, Vogtio Unit 1 experienced a complete loes of decay heat removal (DHR) capability during shutdown and refueling operations from a lows of the required offaito sc eource and failure of the available onsite dieal generator to provide and maintain power to safetyrelated buses. In June 1990, the staff ienued NUREG-1410, Lose of Vital AC Power and the Residual Heat Removal System During Mid-Loop Operations at Vogtlo Unit 1 on March 20, 1990. In the NURBO, the ataff discused the loses of vital ac power and DHR capability during midloop operations and the need to manage riak for shutdown operations.

These eveats, as well as others, prompted the staff to begin a comprebensive review of low-power and shutdown operations including bot shutdown, cold shutdown, and refueling at all nuclear plants and other shutdown-related isoue ideatified by foreign regulatory organizations and the NRC. The objective of the reviow was to aseess riak during ahutdown, refueling and low-power operation. In February 1992, the staff issued Draft NUREG-1449, Shutdown and Low Power Operation at Commercial Nuclear Power Plants in the Unitod States, for public comment to document technical findings aseociated with shutdown conditions. In September 1993, the staff issued NUREG-1449 final report, which incorpornted and responded to comments received on draft NUREG-1449. The staff is using these technical findings to prepare appropriate regulatory actions to address shutdown risk.

The fundamental conclusion of NUREG-1449 is that public health and anfety have been adequately protectod while plante were in shutdown conditions. However, numorous and significant ovents have indicated that subetantial affety improvements should be made in the areas of:

- outage planning and control

- fire protection

- TS

- instrumentation.

The staff utilized the technical findings and insights from NUREG-1449 in its safoty evaluation of the ABWR.

\subsubsection{Evaluation Scope}

On January 12, 1990, the Office of the Secretary of the Commission iroued SECY-90-016, Evolutionary Light Water Reactor (LWR) Certification Iseues and Their Relationship to Current Regulatory Requiremeats. In this Commission paper, the staff identified reduced inventory operation and number of other issues significant to reactor safoty that were considered tundamental to the agency's decisions on the ecceptability of ovolutionary ALWR designs. On July 12, 1993, the ataff mubmitted SECY-93-190, Regulatory Approach To Shutdown and Low-Power Operations, in which it discueved the advantages and dimadvantages of a proposed rulemaking to catablish now regulatory requirements for shutdown and low-power operations in the following areas: outage planning and control, TS, fire protection, and instrumentation. The proposed now regulatory requirements, which will bo doveloped further as part of the shutdown risk rulemaking process, were a result of technical findinge and invights from NUREO-1449.

Based on the sbove, the NRC requeated OB, as part of the dexign reviow procen for the ABWR, to perform a systematic examination of shutdown risk, including ovaluation of specific ABWR deaign fontures that minimizo shutdown risk, quantification of the reliability of the DHR systoms, identification of any vulnembilities introduced by new doaign features and considoration of fires and floods with the piant in modes other than full power.

OB nubmitted its Shutdown Riak Bvaluation on July 2, 1992, for staff roviow. In this report, OB atated that a total of 70 lowe-of-power and over 100 lowe- of-DHR oveats that occurred at operating BWRs were reviowed and ovaluated from NUREG-1410, NSAC-88, Reeidual Heat Removal Experience Reviow and Safety Analyais Boiling Water Reactor, Institute of Nuclear Power Operation (INPO) reports, and NRC information notices. OE stated that the ABWR deaign features would prevent or mitigate the most anfety significant of these events. $\mathrm{OB}$ also addreseed what it belioved to be all shutdown risk isanes, concerns, and design features to minimize riak aseociated with low-power and shutdown operations.

GE evaluated the ABWR design for risks seecoiated with plant conditions in Modes 3 (hot shutdown), 4 (cold shutdown), and 5 (refueling), as well as areas that are considered operational improvemente for shutdown risk operation which will be further addressed by COL holders implementing guidance provided by the reactor veador (0.8., outage planning and control and operator training and procedures). Other shutdown risk concerns, such as DHR capability during low-power and shutdown operation, are addreased by epecific deaign features and TS.

The staff evaluated this mubmittal besed on technical findings and insights from NUREG-1449, a number of studies from the international community, and PRA of shutdown and low-power operating modos for a BWR to screen for important accident requences. The staff also considered reports on operating plant ovents aseociated 
with shutdown operation and enfi-eponsored rewearoh inanes anocinted with low-power and shutdown opention.

The puppose of the atafi reviow is to enme that the ABWR deaign hes appropriately addroesed the shutdown risk concerns baned on experience with operating plants, including appropriate vendor guidance for COL applicants in areas of outage planning and control, fire protection, and instrumentation. Deaign improvements and/or design modificutions GE identified were reviowed to ensure innights from shutdown operntion experiences were addresead and thet the desizn improvements reduce the likelibood of core damage and enhance public bealth and eafoty. Aleo, the etafi ovaluated vulnerabilities that may result from now deaign features; DHR capability; treatment of fires and floods with plant in modes other than full power; and nlated technical findings discused in NUREG-1449.

Therefore, the stafi's proposed applicable regulation for chutdown risk is as followa:

Tho spplication for design certification must include a systematic examination of shutdown risk including an asceasmeat of:

(1) epecific design features that minimize shutdown riak;

(2) the reliability of decay heat romoval systems;

(3) vulnembilities introduced by new design features; and

(4) fires and floods with the plant in modes other than full power.

These items are discused in the sections below.

\subsubsection{ABWR Design Features Minimizing Shutdown Risk}

GE stated that the risks associated with shutdown operations have been reduced in the ABWR design by auch features as the enhanced DHR system, improved electrical systems, instruments that give important safoty parameters during shutdown, and alternate features that mintain core cooling in case of a loss of DHR. The applicant concluded that ABWR TS and utility operating and maintenance procedures will ensure that, during shutdown conditions, the ABWR is adequately protected against accidents.

\subsubsection{Decay Heat-Removal Capability}

In NUREG-1449, the staff stated that DHR can be lost at shutdown because of a loas of flow in the RHR system or a loss of an intermediate or ultimate heat sink caused by the loss of electric power or by valve failures. Events during shutdown an lead to ful's boing uncovered and damaged. Past eveats have led to interrupted chutdown cooling (SDC) at BWR oporating plants becaurs of a low of power to the RPS logic that caused the RHR system isolation valves to fail closed.

The applicent deecribed the ABWR DHR capability in SSAR Section 19.Q.4.1 of the ABWR PRA Stuudown Rick Find Report. The DHR capability conviste of evern! features that minimize the loss of DHR. One of thewe features consists of the three independent divisions of RHR syatems and is the fint line of dofense in mintuining DHR. Three auction lines for shutdown cooling will be connected directly to the reactor preacure veacel (RPV). This is an improvement over the current BWR deaigns in which one common shutdown cooling line drawe auction from the external reactor recirculation loops. This single suction line in current BWRs is moro vulnerable to a low of shutdown cooling by single failure of valves in the suction line. The RHR shutdown cooling rotum for RHR abaystem A will be routed to the RPV veasel through the foodwater aystem. RHR shutdown cooling roturn for RHR subayatems B and C will be routed directly to the RPV. If a single failure occurred in the operating RHR locp while a eccond loop was in mintenance, the thind loop could be pleced in service. Under certain conditions, all three RHR loops or any two RHR loops would be run in parallel. In these cases, failure of one loop would not result in a loss of RHR. The ABWR DHR systoms include a mode selector control for choosing among five modes of operation: low preseure flooding, supprecuion pool cooling, shutdown cooling, wetwell epray, and drywell spray. If any one of these modes is selected, the DHR systems will automatically align the valves as required for the mode selected. This feature will reduce the chance of operator error from incorrectly aligning the required valves, thus increasing the availability of the DHR capability during shutdown operations.

The applicant indicated that a loes of power to the RPS will not result in isolation of the shutdown cooling (SDC) system. A loss of power to the multiplexed anfety syctem logic would cause each SDC isolation valve to fail in its current position (fail as-is), thus proventing closure of the CIVs between the RHR system and the RCS. Shutdown cooling is thereby maintrined.

Upon recoiving a low RPV water-lovel signal, RHR shutdown cooling isolation valves will close to stop all flow out of the RPV. The RPV low-level set point is $3.18 \mathrm{~m}$ (10.43 $\mathrm{ft})$ above the top of the active fuel. If the RPV low-lovel isolation feature fails, inventory low resulting from flow out of the RPV will stop when the RHR suction cooling nozzle is uncovered. At this point, $1.7 \mathrm{~m}(5.58 \mathrm{ft})$ of water will remain above the top of the 
cotive fual. The applicant will deaign two-out-of-four logic to control the initiation of ABWR RPV water-lovel tignals. This will reduce the likelihood of a fales lowe-of-coolent cocident (LOCA) signal.

The enff finds thene provisions scceptable and concludes the $O B$ hes appropriately addreased concerns in NURBG-1449 related to inedvertent loes of RHR.

\subsection{ABWR Altermate Decay Heat Removal Features}

In NURBO-1449, the staff stated that in can of a low of RHR, BWR operatore can significantly extend the time available for recovering the aystem by adding water to the corv from sovernl cources, including the condensate system and the CRD system, to raise water to a lovel that can support natural circulation and continue to romove decay heat, thus reducing the probability of damage to the core.

The applicant diecuseed the altornate DHR capability for the ABWR in SSAR Table 19.Q-1 of the ABWR PRA Shutdown Risk Final Report. In the event that RHR is not available, operatore can use soveral non-safety-rolated systems as alternate methods to remove decay heat:

- Main steam SRVs can be used to vent steam to the suppression pool thus depressurizing the RPV and allowing the use of other low-pressure systems.

- During shutdown, the reactor water cleanup (CUW) system can be used under certain conditions to remove decay beat. Water is moved through a line attached to the RPV bottom head, through a series of heat exchangers and filter demineralizers and then returned to the RPV through an attachment to the upper head or the feedwater lines.

- The fuel pool cooling (FPC) system can be used for DHR during Mode 5 (refueling).

- RPV water boiling with the vessel head off is an effective way to remove heat but is not a preferred mothod because of the potential for offsite releases. However, it can be used as long as the RPV level can be maintained by available make-up sources.

The staff asked GE to discuss the impact of direct RPV water boiling to the containment as an acceptable altornate DHR method. In a letter dated January 13, 1993, GE ataled that analysis results indicato that offsite doses from direct boiling in the RPV during Mode 5 will be much lower than required by regulatory limits of 10 CFR Part 100. Component operability is ensured because the RHR components will bo qualified for a harsh eavironment. Reliable components wuch as the CRD pumpe are expected to aurvive for a significant period of time in a low-preanure eteam environment to mupport alternate make-up capability. Minimum operator sctions required to initiate direct boiling of RPV water with the bead removed include opening three menual valves inside cocondary containmeat and ectuating the ACIWA syatem. Since the timo to reach steam boiling is several bours after DHR cooling is lost, the operator actions to manually open the valves are reasonably assured. The staff concludes that direct boiling in the containment can be ueod as an alternato DHR mothod, but should be used only after attempts to reatore other DHR methods, such as use of the FPC system, have been unsuccessful.

The ABWR dosign will enable operators to cool the core using alternate DHR mothods as deacribed above. The loes of RHR during shutdown can be responded to as long as non-safety-related equipment used for the alternate methods is mado available and clear procedures have been prepared for applying the mothods. Maintenance of the decay heat capability and procedures are discuseed in Section 19.3.7.2 of this report. The staff concludes that the applicant has sufficiently addressed concerns in NUREO-1449 regarding the capability to provide alternate core cooling in case of a loss of RHR.

\subsubsection{Inventory Control}

In NUREO-1449, the staff stated that loss of inventory is more likely to occur during shutdown or refueling than during normal operating conditions because of system ropairs, maintenance, and component replacement. Activities such as test and maintenance during shutdown that require seldom-used valve lino-ups and plant configurations increase the probability of operator error associated with inventory control. Loss of inventory cen lead to fuel damage by overheating if no mako-up water is added to the core.

GE discussed the ABWR inventory control in SSAR Section 19.Q.4.2 of the ABWR PRA Shutdown Risk Final Report. In the event that the RPV lovel decreases during shutdown conditions, Modes 4 and S, the ABWR design will automatically initiate, on low reactor water lovel, the high-pressure core flooder (HPCF), and the low-pressure flooder (LPFL) systems to inject water from the suppression pool. These features are part of the ECCS, and the TS require automatic actuation of the BCCS to be operable in these modes. Other manually initiated systems could also be used to inject water from the main condenser hotwell, CRD system, and ACIWA system. These features will bo part of the ABWR alternate DHR capability and the COL applicant will dovelop administrative control procedures, with appropriate 
suidance from the reactor vendor, to ensure that altermate DHR capability is availablo. All isolation valves used in the shutdown cooling modo of RHR and CUW, except those in the injection lines, will automatically close on a low RPV water level signal to isolate the inventory loseses. If the HPCF and LPFL aystoms are in the teat mode and on RPV low-lovel signal is received, the systems will automatically switch to the vessel injection modo. Additionally, the ABWR design uses renctor internal pumps that eliminate recirculation piping external to the RPV, hence the probability of LOCAs during normal and ahutdown operations will likely be reduced.

To further reduce the likelihood of a lose of inventory, RHR eyctem valves will be interlocked with the reactor system preasure to ensure that low-preasure RHR piping will not be exposed to full system pressure. The lowprescure portions of RHR piping are designed to withstand the full reactor pressure without rupture in the ovent that the interlocks fail or aro bypassed.

In NUREG-1449, it was noted that draindown of the RPV water to the suppression pool could occur if the motoroperated valves in the RHR system inadvertently opened or by operator error. The ABWR decign includes provisions for preventing inadvertent draining of the RPV to the suppreasion pool. Interlocks require that the RPV uhutdown cooling suction valve be fully closed before the muppreasion pool return or auction valves can be opened. In the reveres situation, interlocks require that suppression pool return or suction valves must be fully closed before SDC ruction valve can be opened. The permanently installed RPV lovel indication system will give level indications and alarms to operators in the control room during shutdown operations.

\subsection{Temporary Reactor Coolant System Boundaries}

\subsection{Use of Freeze Seals in ABWR}

The RCS in the ABWR design includes significantly less piping than does the RCS in currently operating BWR decigns. For example, the design includes no external recirculation loops, and the RHR piping connected to the RPV will enter at a higher level than the top of the active fuel. Therefore, inadvertent draining from these lines will stop without exposing the fuel. The ABWR will contain no pipes larger than $5.08 \mathrm{~cm}(2 \mathrm{in}$.) in diameter below the core, thus allowing opesators more time to recover coolant inveatory if coolant is lost as a result of maintenance, valve failures, or pipo breaks. However, freeze seals are cometimes used and are discussed in SSAR Section 19.Q.8 of the ABWR PRA Shutdown Risk Final Report. Freeze ecals are often used to isolate system piping for the repair and replacement of components such as valves, pipo connections, pipe fittings, and pipe stops, where it is imposesible to perform the task without isolating the piping syetem in such a way. The use of freeze seals to perform such activity in the RCS boundary is of concern becaune a failed seal would compromise the structural intogrity of tho boundary, thus creating a loss of inventory control. In NUREG-1449, the staff discuseed ovents in which a freese seal used in secondary system equipmont failed, resulting in a loss of inventory, causing flooding, and readering equipment inoperable. These incidents occurred becaune plant personel failed to follow the procedures and properly maintain the freezing modia.

OE stated that the COL administrative procedures will ensure the integrity of the temporary boundary when freese ceals are ueed. Mitigative measures will be identified in advance, and appropriate back-up systoms will be mado available to minimize the offects of a lose of coolant inventory.

The staff considers this a COL action itom and will easure that COL applicants provide guidance on controlling and maintaining the integrity of freeze seals. The guidance should address the use of an engineoring safoty analyais on a case-by-cese basis to ensure that the use of freezo seals, where a failure could result in lows of inveatory, will not result in any unresolved safoty roviow queations. $O E$ bas included this COL action item in SSAR Amendment 34 and the staff finds it to be acceptable.

\subsection{Reactor Internal Pump Motor and Impeller Replacement}

The ABWR reactor internal pumps (RIPs) are used to supply coolant circulation and to replace the external coolant recirculation system used in the BWR designs. This is a design improvement over the BWR designs in which an unisolable pipe break or component repair in the external recirculation system could result in a major loss of inventory control. The RIP concept was adopted from European BWTs that have been operating for more then 15 years and have had no indications of difficulty in maintenance or in operation that resulted in a lose of inventory. GE discuseed the procedures to maintain and to replace the RIPs in SSAR Section 19.Q.4.2 of the ABWR PRA Shutdown Risk Final Roport.

Removal of the RIP motors for maintenance is accomplishod by using integral inflatable seals that act as backup sealing dovices to' assure that no RPV water leakage occur. Following anch motor removal, a temporary cover plate is bolted to the bottom of the motor's housing, which forms part of the reactor veseel. The impeller is then removed from the top. Upon the 
removal of the impoller, the bolted cover plate acts as the RPV boundary and prevents leakage of reactor water. A plug is then installed on the RPV bottom head at the impeller nozzlo to provide additional protection againat drining the RPV.

The staff akked OB to discuse the offect the increased temperature from a lose of DHR cooling during RIP replecement or maintenance could have on inflatable ceals. In a letter dated January 13, 1993, OB stated that the inflatable seals on the RIP shaft will bo permenently installed and will bo designed to handle normal operating temperatures. Increased temperatures from a lows of DHR cooling will not affect the performance of the seals since the coolent temperature during shutdown conditions will be lese than the design temperature of the seal.

The ataff reviowed the RIP maintenance and replacement equences and found that if leakage occurred during the removal of the RIP motor, the temporary cover plate could be installed to eliminato RPV water leakage. The pump internal primery and inflatable secondary seals would minimize the potential RPV water drainage, thus making the RIP motor removal process acceptable. However, the staff noted that during the RIP impeller and shaft removal, possible unisolable LOCA with an opening of about $20.32 \mathrm{~cm}(8 \mathrm{in}$.$) exists in the event that operators failure$ to follow the maintenance procedure or possibly as a result of miscommunication. In addition, during pump impeller and ahaft replacement, the containment would be opened, thus allowing a direct release path to the onvironmont. The staff, therefore, requires that RIP impeller and shaft replacement be conducted only after fuel has been removed from vessel. This was Open Item F 19.3.3.2.1-1.

In a letter dated January 14, 1994, and subsequent responses to staff questions, GE provided additional information with regard to RIP impeller-shaft removal and CRD replacoment. During the RIP shaft and impeller removal, the following teplacement sequence, maintenance requirements, and pump design features together with the refueling platform auxiliary hoist design are intended to minimize the likelihood of an unisolable LOCA.

- Upon completion of the RIP motor removal, a maintenance cover is bolted to the bottom of the motor housing, which forms a temporary RPV boundary. the motor housing is then pressurized to verify that the maintenance cover is providing a seal. The secondary inflatable seal is then depressurized. At this point, two seals (internal primary metal-to-metal, and maintenance cover) are still provided. Upon removal of the pump impeller-shaft, only the maintenance cover seal remains. To protect against removal of the impeller- shaft in the ovent that maintenance seal is not in place, an auxiliary hoist interlock is provided. The refueling platform auxiliary boist interlocks will interrupt the boisting power if the load exceeds a specified setpoint. The hoiet load extpoint is leas then the sum of the impollor-ahaft weight and the hydrostatic hoad on tho impeller. To overcoms the static head, the motor houving muat be preasurized, which requires tho maintenance cover plate to be secured in place, and thus sealing is sesuring.

- When the pump impellor-shaft has been removed, a maintenance diffuser plug is then installed over the shat opening. The diffuser plug provides sealing and is the only means to prevent possible unisolable LOCA when the motor housing is drained and the maintenance cover plate is removed for secondary inflatable seal and atrotch tubo inspection or replacement. To prevent this potontial unisolable LOCA, the diffuser plug is designed with break-away lifting lug. If the maintenence cover is not secured in place and presesurized, the lifting lug will break during the attempted removal due to the static head pressure excoeding the lug's design force, thus ensuring that the diffuser plug seal is maintained. In the event that the operator inadvertently removed the plug, abnormal or excessive drainage will be discovered when the motor housing is partially drained through the drain line. At this point, RIP sealing is still provided by the maintenance cover plate. Discontinued drainage of the motor bousing will oliminate the loss of reactor coolant and allow corrective actions.

To further ensure that there is no leakage with the motor bottom cover installed, $\mathrm{GE}$ specifically states that $\mathrm{COL}$ applicant develops procedure to visually monitor for potential leakage from the motor housing during pump shaft lifting and maintenance plug removal. The staff finds these provisions acceptable and that the potential unisolated LOCA is minimized during RIP maintenance and replacement. Therefore, Open Item F19.3.3.2.1-1 is rosolved. However, the staff considers this a COL action item and will reviow the COL procedures to ensure appropriate installation and verification of motor bottom cover, as well as visual monitoring of the potential leakage during impeller-shaft and maintenance plug removal have been considered. Also, the staff will ensure that COL applicant develops a contingency plan (0.8., close personnel access hatch, safety injection), which assures that core and spent fuel cooling can be provided in the event that a loss-of-coolant occurs during RIP maintenance. $\mathrm{GE}$ hae included this COL action item in SSAR Amendment 34 and the staff finds it to bo scceptable. 


\subsection{Control Rod Drive Replacement}

CRD replacement for the ABWR is similar to that of current BWRs, and will use the same maintenance procedures. The CRD is withdrawn to the point where its blade fits onto the CRD guide tube. This provides a metal-to-metal seal that minimizes the RPV water drainage when the CRD is removed. The staff reviewed the replacement process and found that unisolated LOCA with an opening of about $5.08 \mathrm{~cm}$ ( 2 in.) exists at the bottom of the vessel head if the CRD blade and drive are simultaneously removed because of operator failure to follow the procedures. In the DFSER, the staff stated that its position was that TS should be included to prohibit the removal of the blade and drive of the same assembly. This was Open Item F19.3.3.2.1-2.

The procedure for removal of the line motion control rod drive (FMCRD) for maintenance or replacement is similar to current BWRs. The control rod is first withdrawn until the CRD blade is backseated onto the control rod guide tube. This provides a metal-to-metal seal that minimizes the RPV drainage when the FMCRD is subsequently lowered and removed. The CRD blade normally remains in this backsented condition at all times with the FMCRD out. In the event that the CRD blade is required to be removed for replacement, a temporary blind flange will be first installed on the end of the CRD housing to prevent draining of the reactor water.

During the FMCRD removal, personnel are required to monitor under the RPV for water leakage out of the CRD housing. If abnormal or excessive leakage occurs after only a partial lowering of the FMCRD, which is the indicative of a metal-to-metal seal that has not yet been established, the FMCRD can then be raised back into its installed position to eliminate the leak and allow corrective action. In the event that the CRD blade and drive of the same assembly were inadvertently removed due to operator failures to follow procedures during refueling operations with water level greater than $23 \mathrm{ft}$ above the vessel flange, the analysis results indicated that it would take approximately 36 minutes for the water to fill the lower drywell sump, reach the tunnel entrances, and begin flowing into the access tunnels. With the expected flow rate of 174 cubic meters per hour $\left(6,145 \mathrm{ft}^{3} / \mathrm{hr}\right)$ from the CRD opening, the water in the spent fuel would drop approximately $.3 \mathrm{~m} / \mathrm{hr}(.98 \mathrm{ft} / \mathrm{hr})$. The high drywell sump level and the low spent fuel level would alarm in the main control room approximately 2 minutes and 28 minutes, respectively, into the transient. The normally operating non-safety-related makeup water condensate system (MUWC) will automatically start upon receiving a low level alarm in the spent fuel pool and transfer water to the spent fuel pool cooling and cleanup (FPCCU) system. The
RHR spent fuel cooling mode can be manually initiated to provide makeup injection and the suppression pool cleanup system also can provide backup if the MUWC is not available. In the event of loss-of-offsite power, backup water also can be provided by RHR ac independent water addition system.

Upon identified leakages from the bottom of the RPV, it is expected that personnel door and equipment hatch in the lower drywell areas will be closed within $\mathbf{3 0}$ minutes before the water level would reach the tunnel entrances and begin flowing into the access tunnel. Appropriate actions will then be taken to reinsert the CRD blade and to mitigate the event using various water sources and injection systems and mentioned.

Additionally, the FMCRD design also allows partial removal of certain mechanical assemblies without the need to withdraw the associated CRD. These mechanical components include the stepping motor, position indication probe (PIP), and spool piece. While these components are removed for maintenance, the associated CRD will be maintained in the fully inserted position by one of two mechanical anti-rotation locking devices, which are part of the FMCRD design. Details of the anti-rotation locking devices and verification process are discussed in SSAR Section 4.6.2.3.4

The staff reviewed the FMCRD and its associated antirotation locking devices design and concluded that adequate locking mechanisms are provided to assure that control rods remain fully inserted with the FMCRD subassemblies removed. In addition to the locking devices, TS prohibits removal of any two adjacent CRD subassemblies to prevent a potential inadvertent criticality event during refueling operation.

The staff also notes that only two or three complete FMCRDs are required to be removed for inspection each refueling outage. This is an improvement relative to the CRD system design at current BWRs which have piston seal replacement needs such that 20 to 30 drives are typically removed each refueling outage.

The staff finds that the FMCRD design improvements, provisions to control potential loss of reactor water, and ample time available for operators to initiate corrective actions in the event of coincident removal of the CRD blade and drive of the same assembly during refueling outage acceptable, and therefore, Open Item F19.3.3.2.1-2 is resolved. However, the staff considers this issue a COL action item and will ensure that maintenance procedures have provisions prohibit coincident removal of the CRD blade and drive of the same assembly. The staff also will ensure that COL applicant develops contingency 
procedures to provide core and spent fuel cooling capability and mitigative actions during CRD replacement with fuel in the vessel. GE has included this COL action item in SSAR Amendment 34 and the staff finds it to be acceptable.

\subsection{Alternate Reactor Inventory Control Feature}

The ABWR design includes a non-safety-related feedwater and condensate system, cunsisting of three electric pumps and associated piping, that can be used as an alternate means for make-up during shutdown operation. The CRD pump can also be used to provide inventory control during shutdown by injecting water from the condensate storage tank to the RPV through the FMCRD system. An ACIWA system is also available to supply make-up water to the RPV if no ECCS make-up water is available.

The staff finds these provisions acceptable and concludes that GE has sufficiently addressed the concerns in NUREG-1449 related to alternate make-up capability to provide core decay heat removal. The alternate inventory control features using the feedwater, the condensate system, and the CRD pump will provide alternate core cooling upon loss of normal RHR capability. The staff also finds that an ACIWA system will further enhance the capability of the ABWR to maintain core cooling in the event that no ECCS make-up is available.

\subsubsection{Containment Integrity}

During refueling of the $A B W R$, the primary containment head is removed and cannot be readily repositioned to restore containment integrity. This is also the case for operating BWR plants with Mark I and II containments. NUREG-1449 stated that BWR secondary containments were judged unlikely to prevent an early release following initiation of boiling with an open RCS or during potential severe-core-damage scenarios. This is also the case for the ABWR.

In NUREG-1449, the staff evaluated the need to reestablish containment integrity for all operating plants under shutdown conditions. Based on operating experience, thermal-hydraulic analyses, and PRA assessments, it was concluded that containment integrity under some shutdown conditions may be necessary for pressurized water reactor (PWR) plants. However, this conclusion was not reached for BWR plants. This is a result in part, of the decreased frequency and significance of precursor events involving reduction in reactor vessel level or loss of RHR (or both) in BWRs as compared to PWRs. In addition, BWRs do not enter a midloop operating condition as do PWRs.
In NUREG-1449, the staff stated that operating BWR altemate DHR methods provide significant depth and diversity. For these reasons, the staff concluded that loss of RHR in BWRs during shutdown is not a significant safety issue as long as the equipment (pumps, valves, and instrumentation) needed for these methods is operable and clear procedures exist for applying the methods. As discussed in Sections 19.3.3.1, 19.3.3.1.1, and 19.3.3.2 of this report, GE provided design features to minimize the risk from shutdown events and ensure the availability of DHR and reactor inventory. GE stated that ABWR TS required that secondary containment automatically bo isolated on high radiation from a radiological boundary breach or fuel handling accident. Also, procedures should be developed by the COL applicant to ensure that (1) the primary containment is available during Modes 3 and 4 (if appropriate), and (2) the secondary containment can be maintained functional as required, especially during higherrisk evolutions.

Based on the conclusions reached in NUREG-1449 and the improvements, beyond that of operating BWRs, provided in the $A B W R$ design, the staff concludes that additional requirements are not necessary for the primary containment. The requirements to isolate secondary containment on high radiation and fuel- handling accidents, and procedures to ensure the availability of secondary containment during high-risk evolutions could contribute to the mitigation of a low-power and shutdown event.

\subsubsection{Electrical Power}

In NUREG-1449, the staff concluded that the availability of electrical power is vital to maintaining shutdown cooling. A loss of power could range from the complete loss of ac power to the loss of a dc bus or an instrument bus. Loss of electrical power generally leads to other events, such as a loss of SDC.

The staff reviewed the design for the electrical system described in SSAR Section 19.Q.4.4 of the ABWR PRA Shutdown Risk Evaluation Final Report. The ABWR electrical system design includes three diesel generators one diesel generator for each safety division. A nonsafety-related combustion gas turbine is an alternate means of supplying power. The combustion gas turbine can start a feedwater or other pump for DHR or inventory make-up, if required upon a loss of offsite power and diesel generator failure.

Two independent offsite power sources, three unit auxiliary transformers powering three Class $1 \mathrm{E}$ and non-1E buses, and four safety divisions of dc power would increase the availability of power for equipment. 
The staff finds that the ABWR electrical power system design contains redundant electrical power sources. The availability of electrical power during shutdown is discussed in Section 19.3.7.3 of this report.

\subsubsection{Reactivity Control}

In NUREG-1449, the staff indicated that inadvertent criticality events at BWR plants have resulted in reactor trips. Inadvertent reactivity is most often caused by human error (the operator selecting the wrong control rod) and feedwater transients. GE addressed reactivity excursion events in SSAR Section 19.Q.4.5 of the ABWR PRA Shutdown Risk Final Report, and in Chapter 15 of the SSAR. GE stated that reactivity events during shutdown could result in critical events by moving control rods or making errors in handling fuel, which could jeopardize DHR or fuel integrity. These events could result from any the following:

- Control rod drop

- Control rod ejection

- Refueling error

- Rod withdrawal error

- Fuel loading error.

\subsection{Control Rod Drop}

A control rod drop event could occur during control rod testing at shutdown. The applicant discussed the control rod drop accidents in details in Chapter 15 of the GE ABWR SSAR. To limit the reactivity increases that would result from a free-falling control rod, the ABWR will include a latch mechanism to restrict the distance of rod free-fall to an acceptable limit. The FMCRD design will detect the separation of the CRD mechanism. A rod block signal will prevent a second control rod from being withdrawn, if any one control rod is fully withdrawn. The latch mechanism would limit to $20.32 \mathrm{~cm}(8 \mathrm{in}$.) the distance a rod could drop if (1) the rod block signal failed, (2) the operator incorrectly selected an adjacent control rod for withdrawal, and (3) the incorrectly selected rod became stuck and decoupled from its drive. Two redundant and separate Class 1E switches will detect the separation of either the control rod from the hollow piston or the hollow piston from the ball nut. If either the FMCRD or the Class 1E separation detection system were actuated, an alarm would annunciate in the control room, thus reducing the probability of rod drop accidents going undetected. These features provide acceptable plant response as discussed in Section 15 of the FSER.

\subsection{Control Rod Ejection}

During shutdown operation, a major break on the CRD housing or associated CRD pipelines from RPV bydrostatic testing of a control rod could cause a control rod to bo ejected. The FMCRD system will include redundant brake mechanisms to prevent this accident from causing severe consequences. The rod drop detection system also will provide the same protection against a rod ejection accident and will include alarms in the control room to alert operators to this accident. Details of the control rod ejection accidents and plant response are discussed in Section 15 of the FSER.

\subsection{Rod Withdrawal Error}

The staff stated that certain inadvertent criticality events resulted in reactor trips. Inadvertent criticality is most often caused by human error (such as the operator's selocting the wrong control rod). GE stated that the reactor could become critical if two adjacent control rods were withdrawn at the same time during refueling operations. To prevent a rod from being inadvertently withdrawn, the ABWR design will include interlocks to ensure that all control rods are inserted while fuel is being handled over the core. The design also will include an interlock to prevent more than one control rod from being withdrawn at a time. If the interlock fails and the control rod is withdrawn, the reactor would trip on a high-flux signal received in the control room. Details of the rod withdrawal errors are discussed in Chapter 15 of the ABWR SSAR and are evaluated in Section 15 of the FSER.

The ABWR refueling interlocks that prevent more than one control rod from being withdrawn at a time and the highflux signal scram features will provide diverse protection against rod withdrawal errors during shutdown operations. The staff judged that there is only a small probability of the coincident failures of the refueling interlock and RPS occurring together with operator errors.

\subsection{Refueling Error}

A reactivity excursion event in an $A B W R$ could occur during refueling operations if a fuel bundle is inserted at the maximum fuel grapple speed into a fueled region of the core. Details of the refueling error events are discussed in Chapter 15 of the ABWR SSAR. The ABWR will include the following design features to prevent or mitigate refueling errors: 
(1) An interlock with a mode switch in the REFUEL position prevents another fuel assembly from being hoisted over the' vessel if a control blade has been removed.

(2) While the mode switch is in the REFUEL position, only one rod can be withdrawn at a time. Any attempt to withdraw a second control rod would result in a rod block signal from the refueling interlocks.

(3) A refueling error will cause the start-up neutronmonitoring system to send an alarm and alert operators to the condition.

Details of the refueling errors are discussed in Section 15 of this report.

\subsection{Tuel Loading Error}

A fuel loading error is similar to a refueling error. $G E$ stated that if the refueling procedure were not followed, the core reactivity would increase to a value higher than tho design value, and if the operator, in performing the core verification process, failed to identify a misplaced fuel bundle, subsequent control rod testing could result in an inadvertent critical event and a power excursion. The likelihood and accoptability of plant response to this event is discussed in Section 15 of this report.

\subsubsection{ABWR Reactor Instrumentation}

In NUREG-1449, the staff stressed the importance of dedicated shutdown annunciators and instruments used during shutdown operation to provide RCS coolant temperature indication, reactor water level fudication, and RHR system status.

The applicant discussed ABWR instruments in SSAR Section 19.Q.5 of the GE ABWR PRA Shutdown Risk Final Report. The applicant stated that, to minimizo risk during shutdown, the instrument system must monitor the RPV lovel, the water temperature, the make-up sources, and heat ainks, and must display these parameters in the control room to the operators in a reliable manner that is easily understood. These instruments can also supply signals to actuato ECCS functions upon receiving a signal for low reactor water lovel, to automatically insert control rods on high flux, and to close appropriate isolation valves.

The staff asked GE to discuss the reliability of power available for the CUW system to measure coolant temperatures and the adequacy of the DHR system parameters monitored by the ABWR instrument system.
The applicant stated in letters dated Janury 13 and 28, 1993, that resistance temperature detectors (RTDs) in the CUW system suction lines and the RHR pump discharge will be used to measure reactor water temperatures. The temperature indications and alarms will be located in the control room to enable operators to monitor coolant temperature during shutdown operations. Upon a loss of offsite power, the RHR systems will be powered from the EDGs and the CUW system can be powered by either the EDG or an alternate onsite ac power source combustion turbine generator (CTG). When an alarm is received from the CUW system, the operator would retrieve the associated system on a computer display to determine the specific cause for the alarm condition. GE also gave specific DHR system parameters that will be monitored in shutdown conditions.

Instrument features important to shutdown operations include the following:

- Automatic initiation of ECCS to ensure adequate RPV make-up during Modes 4 and 5

- Four channels of instruments to allow for bypass during maintenance and testing while retaining the redundancy of the system (the two-out-of-four logic reverts to two-out-of-three during maintenance bypass)

- Continuous monitoring to detect fires or flooding in safety-related and other areas

- Operability of the RPS during shutdown conditions to mitigate any reactivity excursions

- Interlocked refueling bridge operation to prevent reactivity excursions

- Automatic isolation of SDC valves (F-010 and F-011) on low level in the RPV to prevent fuel from being uncovered

- Interlocked RHR valves (SDC and suppression pool) to reduce the possibility of diverting coolant from the RPV to the suppression pool

- Ability to shut down the plant from the remote control panel if the control room becomes uninhabitable

- Ability to monitor radiation levels throughout the plant to detect breaches in radiological barriers.

Parameters that are monitored by the instrument system include the following:

- RPV level, water temperature, and pressure 


\section{- Neutron flux}

- Drywell and wetwell pressure and temperature

- Suppression pool temperature and level

- Turbine building condenser pit and reactor component cooling water (RCW) rooms in the control building flooding lovel

- RHR flow rate, pump motor trip, loop logic power failure

- Fire detection in various buildings

- Electric power distribution system parameters (e.g., power, voltage, current, and frequency)

- Operation of the fire water system

- CUW outlet temperature high.

The staff finds these provisions acceptable and concludes that GE has appropriately addressed concerns in NUREG-1449 related to the importance of dedicated shutdown annunciators and instruments used during shutdown operations to provide RCS coolant temperature indication, reactor water level indication, and RHR system status.

\subsubsection{Flooding and Fire Protection}

In NUREG-1449, the staff stated that the safety significance of flooding or spills during shutdown depends on the equipment affected by the spills and that such spills are most often caused by human error. Plant activities during shutdown and refueling operations may increase fire hazards in safety-related systems essential to the plant's capability to maintain core cooling. Further, Appendix R to 10 CFR Part 50, Fire Protection Program for Nuclear Power Facilities Operating Prior to January 1, 1979, and current NRC fire protection philosophy do not address shutdown and refueling conditions and the effect that a fire may have on the plant's ability to remove decay heat and to maintain shutdown cooling. SSAR Section 19.Q.6 of the ABWR PRA Shutdown Risk Evaluation Final Report addresses the capability of the plant design to protect safeshutdown equipment from fire and floods.

The physical layout of the ABWR design is the primary means of ensuring that this requirement will be met should these hazardous conditions occur. The ABWR design incorporates such methods as proper plant layout, proper system layout and operation, physical and electrical separation, and the use of administrative controls to be established by the referencing applicant to provide DHR function and to mainta in safe shutdown operation.

The layout of the plant will minimize the propagation of fires and floods by locating the control building (CB) between the reactor building (RB) and the turbine building (TB). Most safe-shutdown equipment will be located in the RB and most non-safety-rolated equipizent will bo located in the TB; therefore, failures of systems in the TB because of fires or floods will not adversely affect safetyrelated equipment.

GE stated that the ABWR includes three independent safety-related RHR divisions. These divisions will be separated by 3-hour fire barriers, and divisional equipment will be electrically isolated from redundant divisions of equipment except for equipment in the main control room (MCR), remote shutdown panels (RSP8), primary containment, and several special cases in which divisional equipment is in close proximity to equipment in another division as described in SSAR Section 9A.5, Special Cases. Also, there are some cases where cables of more than one division are in relatively close proximity and require special justification. In each of these areas, the applicant has provided recommendations concerning fire protection during shutdown conditions to ensure that DHR capability remains intact.

The ABWR design and TS in Modes 3, 4, and 5 ensure physical and electrical separation that no more than one of the three redundant divisions of safe-shutdown equipment can be rendered inoperable because of a fire or flood. Physical and electrical separation of redundant safetyrelated divisions ensures that, if a division is rendered inoperable because of fire or flood, at least one division will be operable and available to provide DHR function. The ABWR will not include fire walls inside primary containment to provide divisional separation because of the need to rapidly equalize pressure among these divisions after a high-energy line break. In the ABWR SSAR, GB stated that the divisions of safe-shutdown equipment will be widely separated (at intervals of 120 degrees around the containment) 80 that a single fire will not be able to render inoperable any combination of active componenis that are used to ensure maintenance of a safe-shutdown condition. During normal plant operation, the primary containment will be made inert, therefore, the potential for fire in the containment is reduced substantially. During shutdown or refueling activities, the primary containment will not be made inert and, therefore, would be susceptible to fires because of maintenance activities that involve increased amounts of combustible loading and a number of ignition sources (cutting and welding equipment). The COL applicant referencing the ABWR design will prepare 
edministrative procedures to limit storage of combustibles and control ignition sources inside primary containment.

Nthough the divisions of safo-shutdown equipment located in the primary containment will not be located in the eepanted fire areas, cther methods will be available to deal with fires in the primary containmeat such as minimizing the afo-ehutdown components, maximizing dietance between divisional equipment, and providing eprinkler coverage from the containment spray mode of RHR.

Within the primary containment, check valves and automatic depreseurization system (ADS) SRVs are the only components that noed to operate to achieve safo uhutdown. A fire cannot disable the check valves or the epring-actuated SRVs, and the high-pressure injection pumps will provide enough pressure to lift the SRVs. Therefore, the eafo shutdown capability will not be compromised as a result of a fire. GE stated that containment apray can be used to mitigate the consequences of a fire inside primary containment. The ataff does not consider this to be a primary fire mitigation feature. It believes that the design of the SRVs and check valves, along with the wide spaces between divisional equipmeat and administrative procedures, provides sufficieat assurance that safe-shutdown equipment will remain functional, should a fire or flood occur inside the primary containment during shutdown conditions.

Although the MCR includes controls and indications for afo-ahutdown divisions, redundancy is achieved by providing the RSP in a separate area of the RB. The MCR and the RSP will be separated by 3-hour fire barriers and the RSP will bo hard-wired to field devices and power aupplies. Fiber optic cables from the MCR will transmit two identical digital control signals to operate equipment. In the event of major fire in the MCR, the instrumentation and control power for safety-related cooling systems will be transferred from the MCR to the two RSPs, each of which is capable of serving one division of safety-related cooling systems. It is not likely that a fire in the MCR would cause spurious operation of equipment (barring inadvertent control switch operation) because two simultaneous identical signals are needed at the demultiplexer for control action to be taken at the field device (element).

The RSP rooms will be separated from each other by a fire barrier and fire door assembly. The transfer switches will be located in each room. GE stated that if a fire involved one of the safo-shuidown rooms and caused inadvertent operation of safety-related equipmeni, only one of the iwo remaining divisions would be needed to bring the reactor to a hot shutdown and then cold shutdown condition.
The beating, ventilating, and air-conditioning (HVAC) systems will be used during shutdown conditions to prevent smoke, hot gaves, beat, or fire suppressant in one fire area from migrating into other fire areas to the extent that they could adversely affect the safo shutdown capability of redundant equipment. When the HVAC syetems are operated in the smoke-removal mode, the system in the aree experiencing fire will be maintained at a lower preasure than the other fire areas. This will ensure that any leakage acroes a barrier will be drawn into the area experiencing the fire and will provide a clean air esace for pereonnel acceses to the fire. The fire suppression and detection eystem used in conjunction with edminietrative controls will enable the COL applicant to offectively fight the fire.

While the plant is in shutdown modes, the licensee will commonly bring additional personnel and materials to the site for various refueling and maintenance activities. During this time, some safe-shutdown systems may be inoperable for maintenance at a time when fires are more likely to occur. Administrative controls proposed by $O E$ will ensure that at least one safety-related division is operable (the operable division) and that another safetyrelated division is operable with fire and flood barriers fully in place (the standby division). Thus while one division may be in maintenance, another division will bo operable (although its fire or flood barriers may be breached), and the third division will be in standby. If the operable division is rendered inoperable by a fire or flood, the standby division will be available to perform the DHR function. Likewise, if a fire or flood renders the standby division inoperable, the operable division will continue to perform the DHR function. The COL applicant refer to the ABWR design will establish administrative procedures to ensure that an unanticipated breach of a fire barrier will be discovered and compensated for in a timely manner. The staff considers fire protection administrative procedures a plant-specific issue. In addition, the staff will ensure that the COL applicant has appropriately addreseed the availability of the safe-shutdown equipment using the physical and electrical separation concept to provide DHR function and to maintain safo-sbutdown operation. The staff also will ensure that the COL administrative procedures provide appropriate controls of combustibles and ignition sources during shutdown operations. GE has included this COL action item in SSAR Amendment 34 and the staff finds it to be acceptable.

The physical and electrical separation of redundant safoshutdown equipment provides for flood protection. The ABWR will include barriers to protect against both flood and fires. Doors that protect against flood are watertight with seals that will seat with increased water pressure from outside the room. These watertight doors also will be 
alarmed so that if the door is opened (i.e., the flood barrier is breached), socurity will be alerted and will take appropriate actions. The ABWR will also reduce flood hazands by minimizing sources of flood water near safetyrelated equipment and by alarming and isolating water sources on indication of high water levels. Safety-related equipment will be installed at a minimum level of $200 \mathrm{~mm}$ (8 in.) off the floor with adequate drainage in the floor spaces. GE will give COL applicants guidance on administrative controls to effectively deal with a flood situation.

The staff reviewed the protection philosophy for the ABWR, the design features used to protect safe-shutdown equipment from fires and floods and their effects, and concludes that the design provides for adequate fire and flood protection for systems and components required to achieve and maintain safe-shutdown and is acceptable.

\subsubsection{Shutdown Risk Insights}

In supporting the design certification of the ABWR design, the NRC required GE to prepare a suitable, systematic risk analysis for those operating modes other than full power. On July 2, 1992, GE submitted its shutdown risk evaluation for the NRC staff to review. The staff reviewed GE's shutdown risk PRA for the ABWR design. This PRA included discussion of dominant accident sequences; calculation of core damage frequency from internally initiated events in Modes 3, 4 and 5; and vulnerabilities while operating the plant in modes other than full power. The staff also considered human reliability insights, important human actions, insights from uncertainty, importance, and sensitivity analyses.

In SSAR Table 19.Q-6 of the shutdown risk evaluation final report, GE performed a failure modes and offects andysis (FMEA) of the ABWR new design features to determine if any vulnerabilities were introduced by the now tochnology. OE concluded that the new design features would not introduce now vulnerability. The staff discussed these assessments in Section 19.1.3.4 of this report.

The staff reviewed the shutdown risk PRA for the ABWR design. It concluded that the results of the shutdown risk ovaluation provide sufficient information to determine that there would not be a disproportionate risk of operating the plant in modes other than full power. The staff also found no unreported shutdown risk vulnerabilities.

\subsubsection{Technical Findings in NUREG-1449}

In NUREG-1449, the staff identified several operationalrelated issues for regulatory action. These issues are the following:
- Outage planning and control

- operator training and procedures

- TS

\subsubsection{Outage Planning and Control}

In the absence of strict TS controls, licensees have considerable freedom in planning their outage activities. NUREG-1449 indicated that outage planning dictates what equipment will be available and what and when maintenance activities will be undertaken. It effectively establishes if and when a licensee will encounter circumstances that are likely to challenge safety functions and the level of mitigation equipment available to deal with such a challenge. The staff believes that a safety-oriented approach to planning and controlling an outage is needed and that such an approach will reduce risk during shutdown, thereby reducing the incidence of precursor ovents and improving the defense-in-depth concept.

In the GE ABWR PRA Shutdown Risk Final Report, SSAR Sections 19.Q.7 and 10, GE discussed the generic procedure guidelines for planning outages. In responso to a staff RAI regarding the guidelines for conducting and planning outages, GE stated in a letter dated January 13, 1993, that the plant-specific operating procedures, and the GE ABWR procedure guidelines for outages and planning will endorse NUMARC 91-06, Guidelines for Industry Actions to Assess Shutdown Risk Management. The staff believes that in addition to NUMARC 91-06 guidelines, fire protection and appropriate use of instrumentation also should be considered. Fire protection provisions for plants during shutdown operation and tho use of plant instruments important to shutdown to monitor and detect a loss of DHR cooling during reduced inventory are discussed in Sections 19.3.5 and 4 of this report, respectively. The procedure guidelines for outage and control planning will be based on an engineering evaluation including engineering safety analyses and will addross the offective planning and control of outages and the maintenance of important shutdown functions: DHR capability, electrical power availability, reactivity control, and containment (primary/secondary) integrity.

The plant-specific guidelines for planning and controlling outages will include the following:

- An outage philosophy including a list of organizations responsible for scheduling outages. These guidelines should address both the initial outage plan and all safety-significant changes to schedule.

- Provisions to ensure that all activities receive adequate resources. The plan should also consider unanticipated changes and increases of the scope. 
- Provisions to ensure defense in depth during shutdown and to ensure that safety margins are not reduced. An alternate or backup system must bo mado available if a safety system is removed from service.

- Provisions to ensure that all personnel involved in outage activities are adequately trained. This should include operator simulator training to the extent practicable. Other plant personnol, including temporary personnel, should recoive training commensurate with the outage tasks they will be performing.

- Provisions for an independent safety review team that would be assigned to perform final review and grant approval.

The staff finds that improvement in safe operation of the ABWR plant in low-power and shutdown modes can be reasonably accomplished by implementing GE's guidelines for proparing and implementing an outage plan. It concludes that GE has adequately addressed important areas described in NUREG-1449 regarding outage planning and control. The staff also notes that specific shutdown TS requirements and guidelines for preparing and implementing an outage plan, will significantly improve safe shutdown operation. ABWR shutdown TS requiroments are discussed in detail in Section 19.3.7.3 of this report.

The staff considers outage planning and control a plantspecific issue and will verify that each COL applicant has appropriately implemented GE's guidance and rocommendations to improve low-power and shutdown operation. The staff will review the COL applicant's outage planning and control program to ensure that the safety principle is clearly defined and documented. The controlled procedure should clearly define an outage planning process and should incorporate preplanning for all outages. GE has included this COL action item in SSAR Amendment 34 and the staff finds it to be acceptable.

\subsubsection{Operator Training and Procedures}

In NUREG-1449, the staff stated that conditions and plant configurations during shutdown outages for refueling can place control room operators in an unfamiliar situation. Personnel that is properly trained and understand the problems that could arise during outages is essential in reducing risk associated with the outage activities.

GE stated in SSAR Section 19.Q.10 of the GE ABWR PRA Shutdown Risk Final Report that each utility must prepare plant-specific operating procedures based on individual site characteristics and training program requiroments. GE gave broad guidance to ensure important safety functions aro maintained during shutdown operations as follows:

- Decay Hear Removal Capability. The RHR system will be the normal method of removing decay heat. The COL applicant will use recovery strategy to address loss of normal RHR including determining an alternate DHR system and personnel responsible for executing the recovery. In planning for an outage, the COL applicant will emphasize the need for RHR systems during periods of high heat decay loads and the later maintenance of the RHR system when decay heat loads have been reduced or when the core has been unloaded to the spent-fuel pool. Procedures will bo provided to maintain spent-fuel cooling during core unloading.

- Inventory Control. The COL applicant will implement appropriate procedures to ensure that adequate coolant inventory is maintained at all times during shutdown. Plant activities or configurations in which single failure can result in loss of inventory will be identified, and compensatory measures will be provided. Specific activities that could result in a loss of inventory such as use of freeze seals, removal of control rods, CRDs, reactor internal pumps, and RHR valve actuation or other activities that could lead to diversion of RPV coolant to the suppression pool will be reviewed, compensatory measures will be provided.

- Electrical Power Availability. The COL applicant will implement procedures to ensure the defense in depth of electrical power sources. Maintenance of power sources will reflect the current plant configurations and conditions. GE recommended normal and alternate power sources be made available during high-risk conditions. The COL applicant will review all maintenance and switchyard activities to identify single failures or procedural errors that could result in loss of power to vital buses during shutdown. Procedures will be written to govern the use of alternate sources of power.

- Reactivity Control. Shutdown reactivity control for the ABWR will be maintained by core design analysis and interlocks to restrict the movement of fuel and CRDs. The COL applicant will provide procedures to ensure that the core is loaded according to design requirements and that fuel movements are not to be permitted while a CRD mechanism is in maintenance. If a refueling sequence must be altered, a new shutdown margin analysis must be performed. All fuel movements will be verified by knowledgeable trained personnel. 
- Contninment Integrity. The COL upplicant will develop procedures to ensure the availability of primary containment during Modes 3 and 4 (if appropriate). In addition, procedures will be available to ensure that the secondary containment function can be maintained, as required, in all modes.

GE has recommended ways for COL applicants to maintain key safety functions during shutdown. However, the effectiveness of these recommendations would depend on the procedures, characteristics and training program requirements of each plant. The staff considers plantspecific procedures a COL action item and will require COL applicants to appropriately address and incorporate plant-specific safety-related issues and the vendor's operating guidance on safo operations during shutdown. GE has included this COL action item in SSAR Amendment 34 and the staff finds it to be acceptable.

\subsubsection{Technical Specifications}

The TS for current operating plants are the primary sources of operational requirements. The standard technical specifications (STS) include general requirements for reactivity control, inventory control, RHR, and containment capability during all plant conditions. The STS also include general requirements for fire protection.

The staff asked GE to provide shutdown TS requirements for the ABWR design. In letters of June 30 and July 9 , 1993, GE submitted shutdown TS for the staff to review.

In the ABWR shutdown TS, GE established systematic requirements for operating the plant in modes other than full-power conditions. The staff reviewed the ABWR shutdown TS using insights from technical findings discussed in NUREG-1449 and the staff's proposed model TS improvements to enhance the safe shutdown operation of all nuclear plants. These proposed improvements were made available for public comment and industry review in July 1993. Table 19.3-1 of this report indicates additional limiting conditions, beyond those currently listed in the improved STS (NUREG-1434), for operation during reduced inventory that GE proposed. The staff compared TS requirement improvements for $A B W R$ design with the BWR-6 TS. The ABWR shutdown TS reflects redundant onsite AC power sources (diesel generators), one offsite power source, and associated support systems to ensure the DHR capability can be maintained and to minimize the loss of DHR from a loss of electrical power. The ABWR shutdown TS closely follows the staff's guidance on the proposed model TS improvements. Therefore, the staff concludes that the ABWR shutdown TS will include requirements needed for managing risk during shutdown operations.

\subsubsection{Summary}

The ABWR design provides flexible combinations of DHR systems, alternate features, and associated safoty parameters monitored by the ABWR instrumentation and control system during shutdown operations. These combinations of safoty-related systems and normally operating non-safety-related systems ensure that the ABWR is adequately protected against accidents during low-power and shutdown operations.

GE considered fire and flood hazards and plant damage that could occur during shutdown operation as evidenced by proper plant layout, proper system layout and operation, physical separation, and electrical separation. GE took appropriate actions for adequate fire and flood protection to ensure that at least one safety-related division is operable and the standby safety-related division also is operable with fire and flood barriers fully in place.

Outage planning and control will include specific operating procedures to address key safety features such as DHR capability, inventory control, electrical power availability, reactivity control, and containment control. Specific guidelines for planning and controlling outages will include organizations responsible for scheduling outages. Personnel involved in outage activities will be adequately trained and proper safety reviews will be conducted. Implementations of these operating procedures are COL action items.

The ABWR design includes specific TS requirements for operating the plant in modes other than full power. These TS requirements will provide appropriate redundancy in equipment during higher-risk evolutions during shutdown. These TS are consistent with the staff's proposed model TS developed from evaluation of shutdown and low-power operations.

\subsubsection{Conclusion}

Based on the above, the staff finds the ABWR PRA Shutdown Risk Evaluation Final Report acceptable, and meets the staff's proposed applicable regulation for shutdown risk. Further, the staff concludes that GE has adequately addressed the shutdown risk concerns in NUREG-1449 and has demonstrated that the ABWR design will not introduce significant risk during shutdown operntions. 
Table 19.3-1 Comparison of ABWR shutdown TS and BWR-6 TS

\begin{tabular}{|c|c|c|c|}
\hline ABWR Shutdown TS & Modes & BWR-6 TS & Modes \\
\hline $\begin{array}{l}\text { RCW/RSW and UHS - Shutdown } \\
\text { Two RCW/RSW divisions and UHS openable }\end{array}$ & $\begin{array}{l}4 \text { and } 5 \text { except when } \\
\text { water lovel } \geq 23 \mathrm{ft}\end{array}$ & No requirements & \\
\hline $\begin{array}{l}\text { RCW/RSW and UHS - Refueling } \\
\text { One RCW/RSW division and UHS } \\
\text { aubsystoms operable }\end{array}$ & $\begin{array}{l}5 \text { with water lovel } \\
\geq 23 \mathrm{ft}\end{array}$ & $\begin{array}{l}\text { SSW and UHS - Refueling } \\
\text { No requirements }\end{array}$ & \\
\hline $\begin{array}{l}\text { AC Sources - Shutdown (low lovel) } \\
\text { One offsite power source } \\
\text { Two diesel generator (DC) (onsite) power } \\
\text { sources }\end{array}$ & $\begin{array}{l}4 \text { and } 5 \text { with water } \\
\text { lovel } \leq 23 \mathrm{ft}\end{array}$ & $\begin{array}{l}\text { AC source - sutdown one } \\
\text { offite power source } \\
\text { One DO (onsitb) power source }\end{array}$ & 4 and 5 \\
\hline $\begin{array}{l}\text { AC Sources - Shutdown (high level) } \\
\text { One offsite power source } \\
\text { One DG (onsite) power source }\end{array}$ & $\begin{array}{l}4 \text { and } 5 \text { with water } \\
\text { level } \geq 23 \mathrm{ft}\end{array}$ & & \\
\hline
\end{tabular}

- A new LCO has been added as a result of the shutdown risk program. 


\section{GENERIC ISSUES}

This chapter covers the staff's evaluation of several topics: (1) unresolved enfoty issues (USIs) and generic safety isoues (GSIs), (2) conatruction permit/menufacturing license (CP/ML) rule compliance, and (3) incorporation of operating experience in the advanced boiling wator reactor (ABWR) dowign.

Since there is a large number of USIs, GSIs, and CP/ML rule items, the staff bas grouped its evaluations according to issue type. Section 20.1 contains task action plan itoms, which include both USIs and OSIs. Sections 20.2 and 20.3 address now generic issues and human factors issues, respectively, all of which belong to the GSI category. Section 20.4 includes items listed by Three Mile Island (TMI) Action Plen (NUREG-0660) item number, but many are ectually evaluated in Section $\mathbf{2 0 . 5}$ since they are also CP/ML items. TMI Action Plan items are in the GSI catogory. Section 20.5 deals with the CP/ML items, which are listed by their 10 CFR 50.34(f) paragraph number. CP/ML items can also be considered as GSIs. All issues are listed consecutively within each section.

Because of the considerable amount of overlap among CP/ML rule items and USIs and GSIs, Table 20-1 lists all the USIs and GSIs that are tochnically relevant to the ABWR design or that the staff needed to otherwise address. Table 20-2 lists all the CP/ML issues. These tables provide the issue designation, title, and a reference to the appropriate section(s) of this report containing the evaluation.

Section 20.6 covers incorporation of operating experience in tho $A B W R$ design.

Compliance with paragraph (1)(iv) of 10 CFR 52.47(a)

Paragraph (1)(iv) of 10 CFR 52.47(a) requires an application for design certification to include proposed technical resolutions of those USIs and modium- and high-priority GSIs identifisd in the version of NUREG-0933, "A Prioritization of Generic Safety Issues, " current on the date 6 months prior to application and which are technically relovant to the design.

In the draft final safety evaluation report (DFSER), the staff required GE to modify the standard safety analysis report (SSAR) to explicitly discuss the resolution of each technically relevant USI and GSI per 10 CFR 52.47 (a)(1)(iv) in the appropriate SSAR soction for clarity and to enable the staff to evaluate each item. These were identified in the DFSER as Open Items 20.1-1 and 20.2-1, respectively.
As a result of the ABWR licensing reviow besas document (lotter from T. Murloy, NRC to R. Artigas, GE, dated August 7, 1987), GB agreed to address issues boyond the date 6 months prior to the ABWR application. During a conforence call on January 13, 1993, the etaff and OE mutually agreed that iecues identified in NUREG-0933, with Supplements 1 through 15, would be addreased in the ABWR deaign cortification review. It was also agreed that the list of issues contained in NUREG-0933, Appendix B, "Applicability of NUREG-0933 Iseues to Operating Reactors and Future Plants, " would be used as the baseline list of issues to be addressed for the ABWR design, excluding any issues that were shown in the list to be not applicable to BWR vendors or to future plants. In addition, GE agreed to address five other issues (A-17, A-29, B-5, 29, and 82) that were resolved without the issuance of now requirements, but for which the Office of Nuclear Reactor Research had recommended the devolopment of specific guidance for future plants (although action to develop such guidance is suspended at this time). The staff also asked GE to address one other issue (C-8), the subject of which was an important ABWR roviow topic.

During the time frame of the review, several issues (113, 120,121 , and 151) were resolved by the NRC without the issuance of now requirements. Since the staff was already pursuing an ABWR response for those items, they were evaluated.

The advance safety evaluation report (SER) stated that based on the staff's evaluation of the issues listed in Table 20-1 of the SER and contingent on GE's incorporation of agreed-to issue mark-ups in the SSAR, the staff concluded that GE adequately demonstrated compliance with or proposed a method of compliance for the USIs and medium- and high-priority GSIs that aro technically relevant to the ABWR design as required by 10 CFR 52.47(a)(1)(iv), with some exceptions that required further $G E$ or staff action. These exceptions were that (1) Issue II.F.2 was still open pending the resolution of the differences of views between the staff and $G E$ on the need for diverse instrumentation for reactor pressure vessel water lovel indication, and (2) Issues II.B.1 and II.K.3(15) required incorporation of COL action items in the ABWR SSAR. These exceptions havo been addressed as discussed in Sections 20.5.30, 20.5.18, and 20.4.64, respectively, of this report, and GE has incorporated agreed-to issue mark-ups in the ABWR SSAR. Based on this information and the staff's reviow of the issues listed in Table 20-1 of this report, the staff concludes that GE has adequately demonstrated compliance with 10 CFR S2.47(a)(1)(iv) for the ABWR design. Therefore, DFSER Open Items 20.1-1 and 20.2-1 are resolved. 


\section{Table 20-1 ABWR - Relevant USI and GSIs}

Ieave

Darimation Title

BRER Section(n)

A-1 Water Hammer (former USD)

20.1.1

A-7 Mark I Long-Term Program (former USI)

20.1.2

A-8 Mark II Containment Pool Dynamic Loads - Long-Term Program

20.1.3

A-9 ATWS (former USI)

20.1 .4

A-10

BWR Feodwater Nozzlo Cnecking (formor USI)

20.1.5

A-13

Snubber Operability Acournoce

20.1.6

A-17 Syatom Interaction (formor USI)

20.1.7

A-24 Qualification of Clase 1B Safoty-Related Bquipmeat (former USI)

20.1.8

A-25

Non-Safoty Loada on Clase 1E Power Sourcee

20.1 .9

A-29

Nuclear Power Plant Deaign for the Reduction of Vulnerability to Induetrial Sabotage

20.1.10

A-31

RHR Shutdowa Requirements (former USI)

20.1.11

A-35

Adequacy of Offaito Power Systems

20.1.12

A-36 Control of Heavy Loads Near Spent Fuel (former USI)

20.1.13

A-39 Determination of Safoty Relief Valve Pool Dynamic Loads and Temperature Limits (former USI)

20.1.14

A-40

Soismic Design Criteria - Short-Term Program (formor USI)

20.1.15

A-42

Pipe Cracks in BWR (former USI)

20.1.16

$\dot{A}-44$

Station Blackout (former USI)

20.1.17

A-47 Safety Implications of Control Systems (formor USI)

20.1.18

A-48 Hydrogen Control Measures and Effects of Hydrogen Burns on Safety Equipment

20.1.19

B-5 Ductility of Two-Way Slabs and Sholls and Buckling Behnvior of Steel Containments

20.1.20

B-10

Behavior of BWR Mark III Containments

20.1.21

B-17

Criteria for Safety-Related Operator Actions

20.1.22

B-36 Dovelop Design, Teating, and Maintenance Criteria for Atmosphere Cleanup System Air Filtration and Adsorption Units for ESF Syatems and Normal Ventilation Systems 


\section{Table 20-1 (Continued)}

Inave

Daimantion Title

ESER Section(s)

B-56 Dieal Rolimbility

20.1.27

B-61 Allowable BCCS Bquipmeat Outage Periode

20.1.28

B-63 Inolation of Low-Preseurs Syetem Connected to the Reactor Coolant

20.1.29

Preacure Boundary

B-66 Control Room Infiltration Mecenurements

20.1.30

C-1 Aequnnce of Continuous Long-Term Capability of Hermetic Seals on Instrumentation and Electrical Equipmeat

C-8 Main Stenm Line Loakage Control Systems

20.1.32

C-10 Bffective Operation of Containmeat Sprays in a LOCA

20.1.33

C-17 Interim Acceptanca Critoria for Solidification Agents for Radionctive Solid Wastes

20.1.34

Radiation Effects on Reactor Veasel Supports

20.2.1

Reactor Coolant Pump Seal Failures

20.2.2

Automatic Air Header Dump on BWR Scram Syatem

Bolting Degradation or Failure in Nuclear Power Plants

20.2.4

40

Safoty Concerns Aseociated With Pipe Breaks in the BWR Scram System

20.2.5

Inoperability of Instrumentation Due to Extreme Cold Weather

20.2.6

Propoed Requiroments for Improving the Reliability of Open Cycle SWSs

20.2.7

Effects of Fire Protection Syatem Actuation on Safoty-Related Equipment

67.3.3 Steam Generator Staff Actions - Improved Accident Monitoring

Generic Implications of ATWS Events at the Salem Nuclear Plant

20.2.10

Monitoring of Fatigue Transient Limits for RCS

20.2.11 


\section{Table 20-1 (Continued)}

\begin{tabular}{|c|c|c|}
\hline $\begin{array}{l}\text { Issue } \\
\text { Desianation }\end{array}$ & Title & ESER Section(a) \\
\hline 103 & Design for Probable Maximum Precipitation & 20.2 .17 \\
\hline 105 & Interfacing Systems LOCA at LWRs & $\begin{array}{l}20.1 .29 \\
20.2 .19\end{array}$ \\
\hline 106 & Piping and Use of Highly Combuatible & 20.2 .20 \\
\hline 113 & Dynamic Qualification Tocting of LBHS\& & 20.2 .21 \\
\hline 118 & Tondon Anchorage Failure & 20.2 .22 \\
\hline 120 & On-Line Testability of Protection Systems & 20.2 .23 \\
\hline 121 & Hydrogen Control for Large, Dry PWR Containments & 20.2 .24 \\
\hline 124 & Auxiliary Foedwater System Roliability & 20.2 .25 \\
\hline 128 & Electrical Power Reliability & 20.2 .26 \\
\hline 142 & Leakage Through Eloctrical Isolators in Instrumentation Circuits & 20.2.28 \\
\hline 143 & Availability of Chilled Water Syatems & 20.2.29 \\
\hline 145 & Actions to Reduce Common Cause Failures & 20.2.30 \\
\hline 151 & Roliability of RPT During an ATWS & 20.2.31 \\
\hline 153 & Loss of Essential Service Water in LWRs & 20.2.32 \\
\hline 155.1 & More Realistic Source Torm Assumptions & 20.2.33 \\
\hline HF 1.1 & Staffing and Qualifications - Shift Staffing & 20.3.1 \\
\hline HF 4.4 & Procedures - Guidelines for Upgrading Other Procedures & 20.3 .2 \\
\hline HF 5.1 & Man-Machine Interface - LCSs & 20.3.3 \\
\hline HF 5.2 & $\begin{array}{l}\text { Man-Machine Interface - Reviow Criteria for Humas Factors Aspects of Advanced } \\
\text { Controls and Instrumentation }\end{array}$ & 20.3.4 \\
\hline I.A.1.1 & Operating Personnel -- Operating Personnel and Staffing - STA & 20.4 .1 \\
\hline 1.A.1.2 & $\begin{array}{l}\text { Operating Personnel -- Operating Personnel and Staffing - Shift Supervisor } \\
\text { Administrative Duties }\end{array}$ & 20.4.2 \\
\hline I.A.1.3 & Operating Personnel -- Operating Personnel and Staffing - Shift Manning & ¿0.4.3 \\
\hline I.A.1.4 & Operating Personnol -- Operating Personnel and Staffing - Long-Term Upgrading & 20.4.4 \\
\hline
\end{tabular}




\section{Table 20-1 (Continued)}

Issue

Desionation Title

ESER Section(s)

I.A.2.1 Operating Personnel - Training and Qualification of Operating Personnel Immediate Upgrading of Operator and Senior Operator Training and Qualifications

20.4.6

I.A.2.3 Operating Personnel -- Training and Qualifications of Operating Personnel Administration of Training Programs

I.A.2.6(1) Operating Personnel -- Training and Qualifications of Operating Personnel Long-Term Upgrading of Training and Qualifications; Revise RG 1.8

I.A.3.1 Operating Personnel -- Licensing and Requalification of Operating Personnel Revise Scope of Criteria for Licensing Examinations

I.A.4.1(2) Operating Personnel -- Licensing and Requalification of Operating Personnel 20.4 .9 Initial Simulator Improvement; Interim Changes in Training Simulators

I.A.4.2 Operating Personnel -- Simulator Use and Development - Long-Term Training Upgrade

18.7.2.2

20.4.10

20.5.13

I.C.1 Operating Procedures - Short-Term Accident Analysis and Procedures Revision

I.C.2 Operating Procedures - Shift Relief and Turnover Procedures

20.4.12

1.C.3 Operating Procedures - Shift Supervisor Responsibilities

I.C.4 Operating Procedures - Control Room Access

I.C.5 Operating Procedures - Procedures for Feedback of Operating Experience to Plant Staff

I.C.6 Operating Procedures - Procedures for Verification of Correct Performance of

I.C.7 Operating Procedures -- NSSS Vendor Review of Procedures

I.C.8 Operating Procedures -- Pilot Monitoring of Selected Emergency Procedures for NTOL Applicants

I.D.1 Control Room Design - Control Room Design Reviews

I.D.2 Control Room Design - Plant Safety Parameter Display Console 
Generic Issues

Table 20-1 (Continued)

Issue

Designation Title

FSER Section(s)

I.D.3 Control Room Design - Safety System Status Monitoring

18.7.2.2

20.4.22

20.5.17

I.D.5(2) Control Room Design - Plant Status and Post-Accident Monitoring

I.D.5(3) Control Room Design - On-Line Reactor Surveillance System

20.4 .24

I.F.2 Quality Assurance - Develop More Detailed Quality Assurance (QA) Criteria

20.4.26

20.5.43

I.G.1 Preoperational and Low-Power Testing - Training Requirements

13.2

20.4.27

I.G.2 Preoperational and Low-Power Testing - Scope of Test Program

20.4.28

14.2

II.B.1 Consideration of Degraded or Melted Cores in Safety Review - RCS Vents

5.2 .2

20.4.29

20.5.18

II.B.2 Consideration of Degraded or Melted Cores in Safety Review - Plant Shielding to Provide Access ,to Vital Areas and Protect Safety Equipment for Post-Accident Operation

12.3.5.1

12.3 .6

13.6.3.5

20.4.30

20.5.19

II.B.3 Consideration of Degraded or Melted Cores in Safety Review - Post-Accident Sampling

9.3.2.2

20.4.31

20.5.20

II.B.4 Consideration of Degraded or Melted Cores in Safety Review - Training for Mitigating

20.4 .32 Core Damage

II.B.8 Consideration of Degraded or Melted Cores in Safety Review - Rulemaking Proceeding on Degraded Core Accidents

II.D.1 RCS Relief and Safety Valves - Testing Requirements 


\section{Table 20-1 (Continued)}

Issue

Designation Title

FSER Section(s)

II.D.3 RCS Relief and Safety Valves - Relief and Safety Valve Position Indication

20.4.35

20.5.23

6.3 .3

5.2 .2

II.E.1.3 System Design -- AFW System - Update the SRP and Develop Regulatory Guidance

20.4 .38

II.E.4.1 System Design -- Containment Design - Dedicated Penetrations

20.4.40

20.5.46

6.3.5

II.E.4.2 System Design -- Containment Design - Isolation Dependability

20.4.41

20.5.26

6.2.4.1

II.E.6.1 System Design -- In-Situ Testing of Valves - Test Adequacy Study

20.4 .44

II.F.1 Instrumentation and Controls (I\&C) - Additional Accident Monitoring Instrumentation

20.4.46

20.5.29

12.3 .6

12.3 .4

11.5.2

11.5.1

II.F.2 I\&C - Identification of and Recovery from Conditions Leading to Inadequate Core Cooling

20.4.47

20.5.30

6.3

II.F.3 I\&C - Instruments for Monitoring Accident Conditions

20.4 .48

20.5.31

II.J.4.1 General Implications of TMI for Design and Construction Activities - Revise Deficiency Reporting Requirements

II.K.1(5) Measures to Mitigate SBLOCAs and Loss-of-Feedwater Accidents -- IE Bulletins Safety-Related Valve Position Description

II.K.1(10) Measures to Mitigate SBLOCAs and Loss-of-Feedwater Accidents -- IE Bulletins -

20.4 .53 Review and Modify Procedures for Removing Safety-Related Systems from Service

II.K.1(13) Measures to Mitigate SBLOCAs and Loss-of-Feedwater Accidents -- IE Bulletins Proposed TS Changes Reflecting Implementation of All Bulletin Items 
Issue

Desionation Title

FSER Section(8)

II.K.1.(22) Measures to Mitigate SBLOCAs and Loss-of-Feedwater Accidents -- IE Bulletins -

20.4.55

Describe Automatic and Manual Actions for Proper Functioning of Auxiliary Heat

20.5.33

Removal Systems When Feedwater System Not Operable

5.4 .6

II.K.1(23) Measures to Mitigate SBLOCAs and Loss-of-Feedwater Accidents -- IE Bulletins -

Describe Uses and Types of Reactor Vessel Lovel Indication for Automatic and Manual

Initiation Safety Systems

II.K.3(3) Measures to Mitigate SBLOCAs and Loss-of-Feedwater Accidents -- Final

Recommendations of Bulletins and Orders Task Force - Report Safety and Relief Valve

Failures Promptly and Challenges Annually

II.K.3(11) Measures to Mitigate SBLOCAs and Loss-of-Feedwater Accidents -- Final

Recommendations of Bulletins and Orders Task Force - Control Use of Power-Operated

Relief Valves Supplied by Control Components, Inc., Until Further Review Complete

20.4.61

II.K.3(13) Measures to Mitigate SBLOCAs and Loss-of-Feedwater Accidents -- Final

20.4 .63

Recommendations of Bulletins and Orders Task Force - Separation of HPCI and

RCIC System Initiation Levels

20.5.5

5.4 .6

II.K.3(15) Measures to Mitigate SBLOCAs and Loss-of-Feedwater Accidents -- Final

Recommendations of Bulletins and Orders Task Force - Modify Break Detection

Logic to Prevent Spurious Isolation of HPCI and RCIC Systems

II.K.3(16) Measures to Mitigate SBLOCAs and Loss-of-Feedwater Accidents -- Final

Recommendations of Bulletins and Orders Task Force - Reduction of Challenges and

Failures of Relief Valves; Feasibility Study and System Modification

II.K.3(17) Measures to Mitigate SBLOCAs and Loss-of-Feedwater Accidents -- Final

Recommendations of Bulletins and Orders Task Force - Report on Outage of ECCSs;

Licensee Report and TS Changes

II.K.3(18) Measures to Mitigate SBLOCAs and Loss-of-Feedwater Accidents -- Final

Recommendations of Bulletins and Orders Task Force - Modification of ADS Logic;

Feasi bility Study and Modification for Increased Diversity for Some Event Sequences

II.K.3(21) Measures to Mitigate SBLOCAs and Loss-of-Feedwater Accidents -- Final

20.4 .68

Recommendations of Bulletins and Orders Task Force - Restart of Core Spray and

20.5.8

LPCI Systems on Low Level; Design and Modification

II.K.3(22) Measures to Mitigate SBLOCAs and Loss-of-Feedwater Accidents -- Final

Recommendations of Bulletins and Orders Task Force - Automatic Switchover of RCIC System Suction; Verify Procedures and Modify Design

II.K.3(24) Measures to Mitigate SBLOCAs and Loss-of-Feedwater Accidents -- Final

Recommendations of Bulletins and Orders Task Force - Confirm Adequacy of 
Issue

Desienation Title

FSER Section(s)

II.K.3(25) Measures to Mitigate SBLOCAs and Loss-of-Feedwater Accidents --

20.4.72

Final Recommendations of Bulletins and Orders Task Force - Effect of Loss of

20.5.3

ac Power on Pump Seals

5.4 .1

II.K.3(27) Measures to Mitigate SBLOCAs and Loss-of-Feedwater Accidents --

20.4.73

Final Recommendations of Bulletins and Orders Task Force - Provide Common

Reference Lovel for Vessel Lovel Instrumentation

II.K.3(28) Measures to Mitigate SBLOCAs and Loss-of-Feedwater Accidents --

20.4 .74

Final Recommendations of Bulletins and Orders Task Force - Study and Verify

Qualification of Accumulators on ADS Valves

20.5.10

7.3

6.3

5.2 .2

3.11

II.K.3(30) Measures to Mitigate SBLOCAs and Loss-of-Feedwater Accidents --

Final Recommendations of Bulletins and Orders Task Force - Revised SBLOCA

Methods to Show Compliance with 10 CFR Part 50, Appendix A

II.K.3(31) Measures to Mitigato SBLOCAs and Loss-of-Feedwater Accidents --

20.4 .76

Final Recommendations of Bulletins and Orders Task Force - Plant-Specific

6.3

Calculations to Show Compliance with 10 CFR 50.46

II.K.3(44) Measures to Mitigate SBLOCAs and Loss-of-Feedwater Accidents --

20.4.77

Final Recommendations of Bulletins and Orders Task Force - Evaluation of Anticipated

Transients with Single Failure to Verify no Significant Fuel Failure

II.K.3(45) Measures to Mitigate SBLOCAs and Loss-of-Feedwater Accidents --

Final Recommendations of Bulletins and Orders Task Force - Evaluate Depressurization

with Other Than Full ADS

20.5.11

9.6.3

6.3 .3

II.K.3(46) Measures to Mitigate SBLOCAs and Loss-of-Feedwater Accidents -- Final

20.4.79

Recommendations of Bulletins and Orders Task Force - Response to List of

Concerns from ACRS Consultant

III.A.1.1(1) Emergency Preparedness and Radiation Effects -- Improve Licensee Emergency

Preparedness - Short Term; Upgrade Emergency Preparedness, Implement Action Plan

Requirements for Promptly Improving Licensee Emergency Preparedness

III.A.1.2 Emergency Preparedness and Radiation Effects -- Improve Licensee Emergency

20.4.81

Preparedness - Short Term; Upgrade Emergency Preparedness

20.5.37

13.3

III.A.2.1 Emergency Preparedness and Radiation Effects -- Improve Licensee Emergency

20.4.82

Preparedness - Long Term; Amend 10 CFR Part 50 and 10 CFR Part 50, Appendix E

III.A.2.2 Emergency Preparedness and Radiation Effects -- Improve Licensee Emergency

Preparedness - Long Term; Development of Guidance and Criteria 
Generic Issues

\section{Table 20-1 (Continued)}

Issue

Desimation Title

ESER Section(s)

III.A.3.3 Emorgency Preparedness and Radiation Effects -- Improving NRC Emergency

20.4.84

Proparedness - Communications

III.D.1.1 Radiation Protoction - Rediaticn Source Control - Primary Coolant Sources

20.5.85

Outside the Containment Structure

20.5.38

III.D.3.3 Radiation Protection --Worker Radiation Protection Improvement - Inplant

20.4.86

Radiation Monitoring

20.5.39

12.5.1

III.D.3.4 Radiation Protection -Worker Radiation Protection Improvement - Control Room

20.4.87

Habitability

20.5.40

9.4.1.1

6.4 
10 CFR 50.34(f)

Pangrenh

(1)(i)

II.B.8

(1)(ii)

(1)(iii)

II.K.2(16)

(1)(iii)

II.K.3(25)

(1)(iv)

II.K.3(2)

(1)(v)

II.K.3(13)

(1)(vi)
Title

ESER Section(8)

Consideration of Degrailed or

20.5.1

Melted Cores in Safety Review -

Rulomaking Proceeding on Degraded

Core Accidents, "Design Alterna-

tives from PRA"

System Design - AFWS - AFWS

20.5.2

Evaluation

20.4.36

20.5.3

20.4.59

5.41

Commission Orders on B\&W Plants -

Impact of RCP Seal Damage Following SBLOCA With Loss of Offsite Power

Measures to Mitigate SBLOCAs and Loss-of-Feedwater Accidents -Final Recommendations of Bulletins and Orders Task Force - Effect of Loss of ac Power on Pump Seals

Measures to Mitigate SBLOCAs and Loss-of-Feedwater Accidents -Final Recommendations of Bulletins and Orders Task Force - Report on Overall Safety Effect of PowerOperated Relief Valve Isolation

Measures to Mitigate SBLOCAs and Loss-of-Feedwater Accidents -Final Recommendations of Bulletins and Orders Task Force - Separation of HPCI and RCIC System Initiation Levels

Measures to Mitigate SBLOCAs and 20.5 .6 Loss-of-Feedwater Accidents -20.4.65 Final Recommendations of Bulletins 5.2 .2 and Orders Task Force - Reduction of Challenges and Failures of Relief Valves; Feasibility Study and System Modification 
10 CFR 50.34(f) Paraqraph

(1)(vii)

TMI Item

II.K.3(18)

(1)(viii)

II.K.3(21)

(1)(ix)

$(1)(x)$

(1)(xi)

(1)(xii)

N/A

(2)(i)

(2)(ii)
II.K.3(28)

II.K.3(45)
I.C.9
Title

Measures to Mitigate SBLOCAs and

Loss-of-Feedwater Accidents --

Final Recommendations of Bulletins

and Orders Task Force - Modifica-

tion of ADS Logic; Feasibility

Study and Modification for Increased Diversity for Some Event

Sequences

Measures to Mitigate SBLOCAs and

Loss-of-Feedwator Accidents --

Final Recommendations of Bulletins

and Orders Task Force - Restart of

Core Spray and LPCI Systems on Low

Level; Design and Modification

Measures to Mitigate SBLOCAs and

Loss-of-Feedwater Accidents --

Final Recommendations of Bulletins and Orders Task Force - Confirm Adequacy of Space Cooling for HPCI and RCIC Systems

Measures to Mitigate SBLOCAs and Loss-of-Feedwater Accidents --

Final Recommendations of Bulletins and Orders Task Force -

Study and Verify Qualification of Accumulators on ADS Valves

Measures to Mitigate SBLOCAs and

Loss-of-Feedwater Accidents --

Final Recommendations of Bulletins and Orders Task Force -

Evaluate Depressurization with

Other Thari Full ADS

Evaluation of Alternative Hydrogen Control Systems

Operating Personnel -- Simulator

Use and Development - Long-Term

Training Upgrade
Operating Procedures - Long-Term

Program Plan Procedures for Upgrading of Procedures
ESER Section(8)

20.5.7

20.4.67

6.3.3

20.5.8

20.4.68

6.3

20.5 .9

20.4.71

6.2 .5

5.4 .6

20.5.10

20.4.74

7.3

6.3

5.2 .2

3.11

20.5.11

20.4.78

9.6.3

6.3.3

20.5.12

20.5.13

20.4.10

18.7.2.2

20.5.14

20.4.19

18.7.2.2

13.5 
Table 20-2 (Continued)

10 CFR 50.34(f)

Pangreph

(2)(iii)

I.D.1

(2)(iv)

I.D.2

(2)(v)

I.D.3

(2)(vi)

II.B.1

(2)(vii)

II.B.2

(2)(viii)

II.B.3

(2)(ix)

II.B.8

(2)(x)

II.D.1

II.D.3

II.E.1.2
Title

Control Room Design - Control

Room Design Roviows

20.5.15

20.4.20

18.7.2.2

Control Room Design - Plant

20.5.16

Safety Paramoter Display Consolo

20.4.21

18.7.2.2

7.5 .2

20.5.17

20.4.22

18.7.2.2

System Status Monitoring

20.5.18

20.4.29

5.2 .2

Melted Cores in Safety Reviow RCS Veats

20.5.19

20.4.30

13.6.3.5

12.3.6

12.3.5.1 tect Safety Equipment for PostAccident Operation

Consideration of Degraded or Melted Cores in Safety Review -

20.4.31

9.3.2.2

Post-Accident Sampling

20.5.21

Consideration of Degraded or Melted Cores in Safety Review -

Rulemaking Proceeding on Degraded Core Accidents, "Hydrogen Control System"

RCS Relief and Safety Valves -

20.5.22

20.4.34

5.2 .2

3.9.3.2

20.5.23

20.4.35

6.3 .3

5.2 .2

20.5.247

System Design - AFWS - AFWS Sys-

20.4.37

Indication 
10 CFR 50.34(f)

Paramph

(2)(xiii)

II.E.3.1

(2)(xiv)

II.E.4.2

(2)(xv)

(2)(xvi)

II.E.5.1

(2)(xvii)

II.F.1

(2)(xviii)

II.F.2

(2)(xix)

II.F.3

(2)(xx)

(2)(xxi)

II.K.1(22)

(2)(xxii)

TMUItem
Title

ESER Section(8)

System Deaiga - Döcay Heat Romo-

20.5.25 val - Reliability of Power Supplies for Natural Circulation

20.4.39

20.5.26

20.4.41

6.2.4.1

Design - Isolation Dependability

20.5.27

20.4.42

6.2 .5

Design - Purging

20.5.28

20.4.43

vity of B\&W Reectors - Design

Evaluation

I\&C - Additional Accident Monitoring Instrumentation

20.5.29

20.4.46

12.3.6

12.3.4

11.5 .2

11.5 .1

20.5.30

20.4.47

Recovery from Conditions Leading to Inadequate Core Cooling

6.3

I\&C - Instruments for Monitoring

20.5.31

Accident Conditions

20.4.48

20.5.32

Electrical Power - Power Supplies

for Pressurizer Relief Valves,

20.4.49

Block Valves, and Lovel Indicators

20.5.33

Measures to Mitigate SBLOCAs and

20.4.55

Loss-of-Feedwater Accidents -

IE Pulletins - Describe Automatic

5.4 .6

and Manual Actions for Proper Func-

tioning of Auxiliary Heat Removal

Systems When Feedwater System Not

Operable

Measures to Mitigate SBLOCAs and

Loss-of-Feedwater Accidents --

20.4.57

Commission Orders on B\&W Plants

- Analysis and Upgrading of Integrated Control System 
Table 20-2 (Continued)

10 CFR 50.34(f)

Paragraph

(2)(xxiii)

TMI Item

II.K.2(10)

(2)(xxiv)

II.K.3(23)

(2)(xxv)

III.A.1.2

(2)(xxvi)

(2)(xxvii)

III.D.3.3

(2)(xxviii)

III.D.3.4

III.D.1.1

(3)(i)

I.C.5

(3)(ii)

I.F.1

I.F.2

(3)(iii)

(3)(iv)

II.B.8
Title

FSER Section(s)

Measures to Mitigate SBLOCAs and

20.5.35

Loss-of-Feedwater Accidents --

Commission Orders on B\&W Plants

- Hard-Wired Safety-Grade Anticipatory Reactor Trips

Measures to Mitigate SBLOCAs and 20.5.36 Loss-of-Feedwater Accidents -20.4.70 Final Recommendations of Bulletins and Orders Task Force - Central Water Level Recording

Emergency Preparedness and Radiation Effects -- Improve Licensee Emergency Preparedness - Short Term; Upgrade Emergency Preparedness

Radiation Protection -- Radiation Source Control - Primary Coolant Sources Outside the Containment Structure

Radiation Protection --Worker Radiation Protection Improvement - Inplant Radiation Monitoring

20.4.86

12.5.1

Radiation Protection --Worker Radiation Protection Improvement 20.4.87

- Control Room Habitability

9.4 .1 .1

6.4

Operating Procedures - Procedures 20.5.41 20.4.16 for Feedback of Operating Experience to Plant Staff

Quality Assurance (QA) - Expand QA List

Quality Assurance - Develop More Detailed QA Criteria

Consideration of Degraded or 20.5.44 Melted Cores in Safety Review Rulemaking Proceeding on Degraded Core Accidents, ".91-Meter (3-Foot) Diameter Equivalent Dedicated Containment Penetration" 
Generic Issues

Table 20-2 (Continued)

10 CFR 50.34(f)

Paragraph

TMLItem

(3)(v)

II.B.8

(3)(vi)

II.E.4.1

(3)(vii)
Title

Consideration of Degraded or Melted Cores in Safety Review -

Rulemaking Proceeding on Degraded

Core Accidents, "Containment Intogrity During an Accident Involving 100-Percent Fuel Clad Metal-Water Reaction"

System Design -- Containment

Design - Dedicated Penetrations

General Implications of TMI for

Design and Construction Activities - Management for Design and Constriction - Organization and Starfins to Oversee Design and Construction
ESER Sections)

20.5.45

20.5.46

20.4 .40

6.3.5

20.5.47

20.4.50

NUREG-1503

20-16 
Compliance with paragraph (1)(ii) of 10 CFR 52.47(a)

Paragraph (1)(ii) of 10 CFR 52.47(a) requires an application for a design certification to include a demonstration of compliance with any technically relevant portions of the TMI requirements identified in 10 CFR 50.34(f), often called the CP/ML rule.

GE addressed the TMI requirements of paragraph (1)(ii) of 10 CFR 52.47(a) in SSAR Appendix 19A and in other SSAR sections. In the DFSER, the staff provided evalurtions for the majority of GE's submittal relating to compliance with this regulatory requirement and indicated that the additional items not insluded in the DFSER would be included in the final safety evaluation report (FSER). A number of the staff's evaluations contained open items, combined operating license (COL) action items, and/or technical specification (TS) items that needed to be addressed by GE. The closure of these items for the ABWR design certification review is discussed in the appropriate issue evaluations.

The advance SER stated that based on the staff's evaluation of the issues listed in Table 20-2 of the SER and contingent on GE's incorporation of agreed-to issue markups in the SSAR, the staff concluded that GE adequately demonstrated compliance with or proposed a method of compliance for the technically relevant portions of 10 CFR $50.34(f)$ as required by 10 CFR $52.47(a)(1)$ (ii) for the ABWR design, with some exceptions that required further GE or staff action. These exceptions were that (1) 10 CFR50.34(f)(2)(xviii) (TMI Item II.F.2) was still open pending the resolution of the differences of views between the staff and GE on the need for diverse instrumentation for reactor pressure vessel water level indication, and (2) 10 CFR 50.34(f)(2)(vi) (TMI Item II.B.1) required incorporation of a COL action item in the ABWR SSAR. These exceptions have been addressed as discussed in Sections 20.5.30 and 20.5.18, respectively, of this report, and GE has incorporated agreed-to issue mark-ups in the ABWR SSAR. Based on this information and the staff's review of the issues listed in Table 20-2 of this report, the staff concludes that GE has adequately demonstrated compliance with 10 CFR 52.47(a)(1)(ii) for the ABWR design.

Incorporation of operating experience in the ABWR design

In a staff requirements memorandum dated February 15, 1991, on SECY-90-377, "Requirements for Design Certification Under 10 CFR Part 52," the Commission directed the staff to ensure that the design certification process preserves operating experience insights in the certified design. As discussed in Section 20.6 of this report, the staff concludes that $G E$ has adequately considered operating experience identified by generic letters or bulletins issued since 1980 in the ABWR design.

\subsection{Task Action Plan Items}

This section addresses staff evaluation of USIs and GSIs that are categorized as "task action plan items" in NUREG-0933. All the following issues, with the exception of Issues B-29 and B-32, are relevant to the ABWR design. Issues B-29 and B-32 were evaluated in the DFSER and are discussed here for continuity only.

\subsubsection{Issue A-1: Water Hammer (former USI)}

Water hammer is defined as a rapid change in pressure caused by a change in velocity of a fluid in a closed volume. Water hammer occurs in various piping systems, such as emergency core cooling, residual heat removal (RHR), containment spray, service water, and feedwater and in steam lines. Water hammer may be caused by rapid condensation of steam pockets, steam-driven slugs of water, pump startup with partially empty lines, and rapid valve motion. Regardless of the cause, water hammer may result in a rapid acceleration of the fluid and may affect the piping system. Severity of the damage from water hammer may range from overstressing of pipe hangers to major damage of restraints, piping, and components.

The review criteria for this issue are stated in the following sections of NUREG-0800, "Standard Review Plan" (SRP): 5.4.7, 6.3, 9.2.1, 9.2.2, and 10.4.7 and Branch Technical Position (BTP) ASB 10-2. Specifically, the feedwater system, containment spray system, shutdown cooling, and other safety-related systems that may be adversely affected by water hammer should be designed to withstand the dynamic loads associated with water hammer. BTP ASB 10-2 requires that the feedwater system be subjected to preoperational testing to demonstrate the effectiveness of the design and operating procedures to mitigate the effects of water hammer.

SSAR Section 19B.2.2 indicates that all of the ABWR systems having potential for water hammer have been analyzed. Different forms of initiating events that could occur and which cause water hammer were considered, such as steam condensation, steam-driven slugs of water, pump startup with partially empty lines, and rapid valve cycling. Section 19B.2.2 states that GE has evaluated various systems for potential water hammer, including the condensate and feedwater system, main steam lines, and all components of the main steam supply system.

With regard to leak before break, GE states that feedwater lines were demonstrated to be immune to failure from 
water hammer effects. Reactor core isolation cooling (RCIC), high pressure core flooder (HPCF), and RHR systems are precluded from water hammer by keop-full features and the absence of fast-acting valves.

GE also states that the systems susceptible to water hammer effects will bo kept full of water, thus proventing water hammer when pumps are started from a steady condition. These systems include the reactor service water (RSW); turbine service water; RHR; HPCF; RCIC; and heating, ventilation, and air conditioning (HVAC) emergency cooling water system. Based on the above, the staff concludes that the ABWR design meets the guidelines in the SRP sections listed above with respect to the dynamic effects associated with possible fluid flow instabilities, such as water hammer. The staff further concludes that GE adequately addressed this issue for the ABWR design.

\subsubsection{Issue A-7: Mark I Long-Term Program (former USI)}

During testing for an advanced BWR containment system design (Mark III), GE identified suppression pool hydrodynamic loads that had not been considered in the original design of the Mark I containment system. To address this issue, a Mark I Owners Group was formed and the assessment was divided into a short-term and a long-term program. The long-term program was conducted to provide a generic basis to define suppression pool hydrodynamic loads and the related structural acceptance criteria so that a comprehensive reassessment of each Mark I containment system would be performed. A series of experimental and analytical programs was conducted by the Mark I Owners Group. The program proposed to the NRC and reviewed and modified by the staff was to be used to perform plant-unique analyses and identify modifications, as necessary.

The review criteria for this issue are to establish designbasis, conservative loads that are appropriate for the anticipated life of each Mark I BWR containment and to restore the originally intended design margin of safety for the containment system. The principal thrust of the longterm program has been the development of generic methods for the definition of suppression pool hydrodynamic, loadings and the associated structural assessment techniques for the Mark I configuration.

It is recognized that the Mark I torus pool and vent configuration is different from the ABWR annular pool and vent design. Therefore, the local loads evaluated within the issue are not applicable to the ABWR design. However, while the results of the Mark I Owners Group investigation cannot be directly applicable for definition of the safety-relief valve (SRV) loads in the ABWR design, they are used as a data base for definition of the SRV loads that are specified in Issue A-39 as discussed in Section 20.1.14 of this report.

\subsubsection{Issue A-8: Mark II Containment Pool Dynamic Loads - Long-Term Program}

This issue deals with the now containment loads associated with the postulated loss-of-coolant accidents (LOCAs) that were identified as a result of tests by GE. These loads result from the dynamic effects of drywell air and steam being rapidly forced into the suppression pool during a postulated LOCA ovent. These loads, as well as the loads from actuation of SRVs in the Mark II containment, had not been previously accounted for.

The review criteria for this issue are contained in NUREG-0808, "Mark II Containment Program Evaluation and Acceptance Criteria, " and SRP Section 6.2.1.1C and Appendices A and B. SRP Section 6.2.1.1C, Appendix A pertains to steam bypass from the drywell to the suppression pooi air volume in the Mark I, II, and III containment designs and states that the system used to quench steam bypassing the suppression pool should be designed so that the steam bypass capability for small breaks satisfies the specified criteria. It also states that the bypass leakage should not substantially increase over the life of a plant. SRP Section 6.2.1.1C, Appendix B summarizes the generic loads acceptable to the NRC and provides information regarding load identification, a summary of the load specification, load specification clarifying criteria, and a reference to the NRC NUREG section that describes the NRC-specific load evaluation.

SSAR Section 3B.4.2.1 states that pool swell response calculations to quantify pool swell loads were based on a simplified, one-dimensional analytical model (described in NEDE-21544-P, "Mark II Pressure Suppression Containment Systems: Analytical Model of the Pool Swell Phenomenon"), which is the same as that reviewed and accepted by the staff in NUREG-0808 for application to Mark II plants. This analytical model was qualified against Mark II full-scale test data. It is recognized that although ABWR wetwell airspace is similar to that of the Mark II design, its vent system design is quite different. Therefore, recognizing the difference in vent system design, additional studies comparing model versus Mark III horizontal vent test data were performed to assure adequacy of the model for application to the ABWR. The staff concludes that this approach adequately addresses this issue for the ABWR since the differences between the ABWR design and the Mark II and Mark III containments have been taken into account in the analysis. 

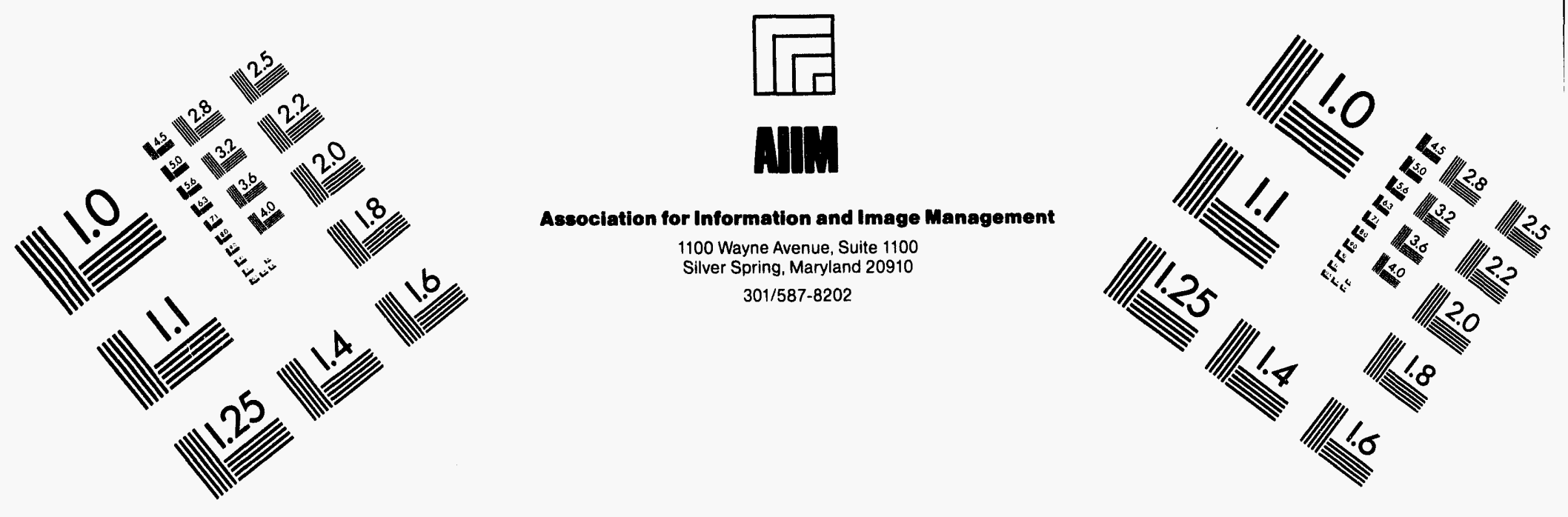

Centimeter

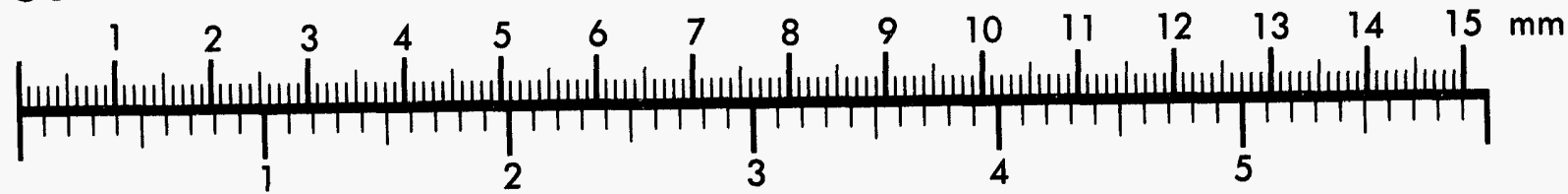
Inches
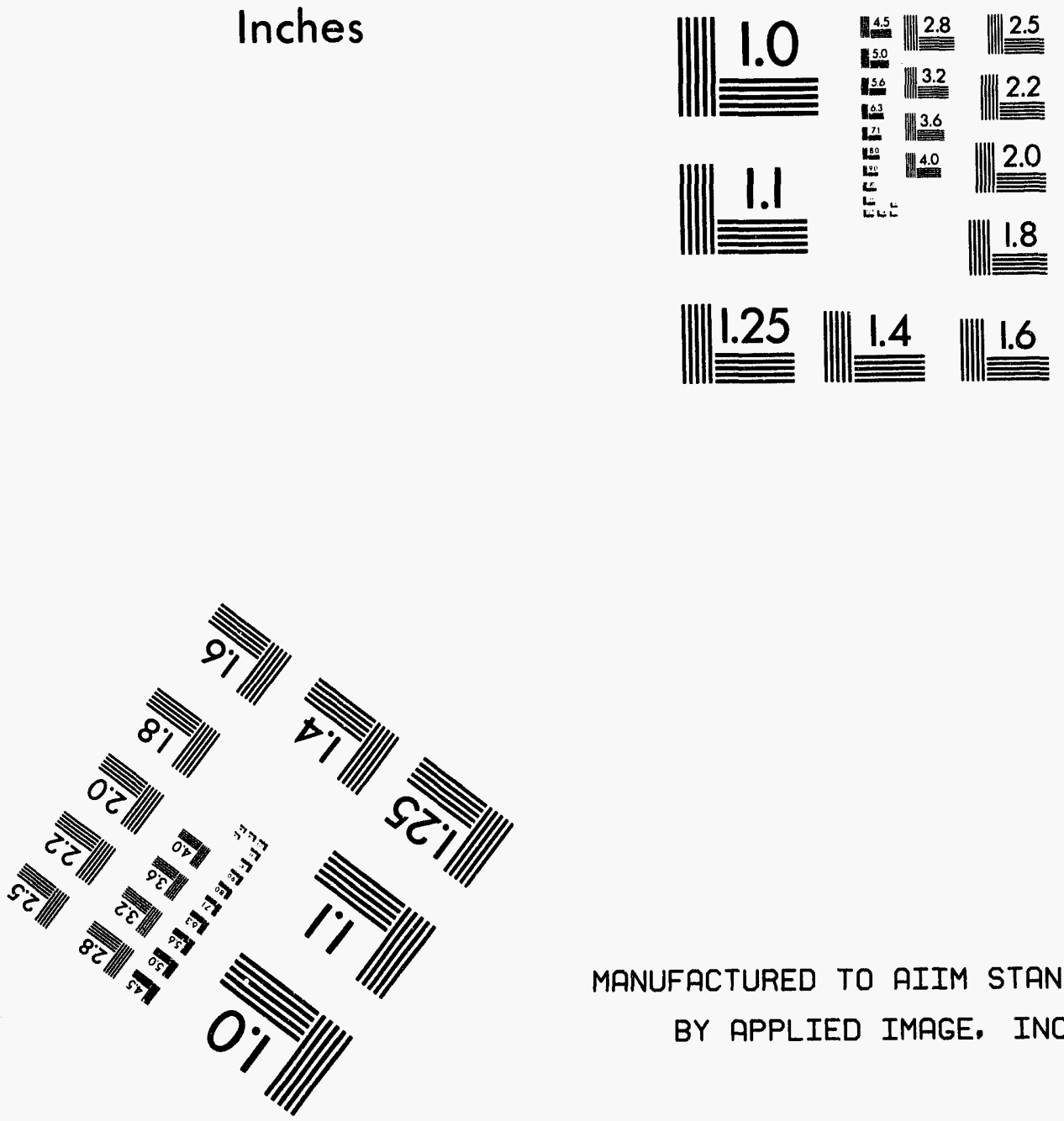

MANUFACTURED TO AIIM STANDARDS

BY APPLIED IMAGE, INC.

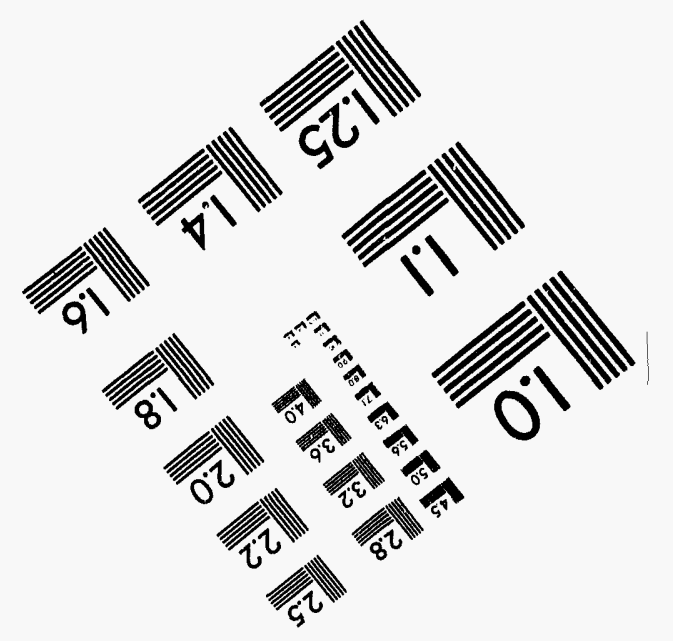



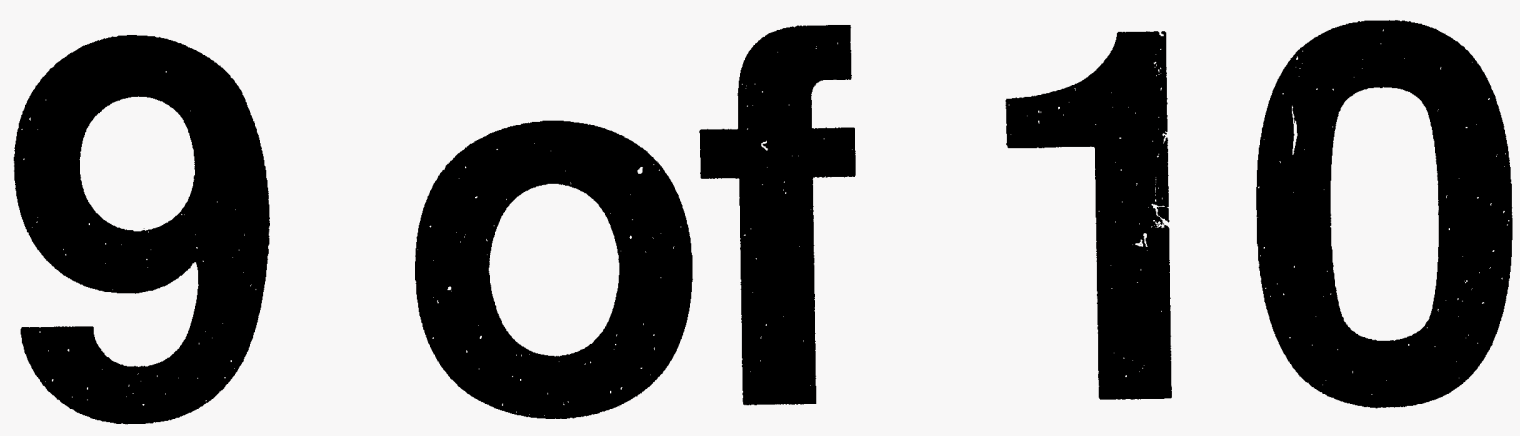


\subsubsection{Issue A-9: Anticipated Transient Without Scram (ATWS) (former USI)}

This issue deals with the problem of occurrence of transients that require scram but for which scram does not occur. It involves devising measures, both design and operational, that can be taken to avoid or compensate for such occurrences.

The staff's technical findings on this issue were documented in NUREG-0460, "Anticipated Transients Without Scram for Light Water Reactors," and the requirements for resolution are contained in 10 CFR 50.62 (also known as the ATWS rule). For BWRs, 10 CFR 50.62 requires the reactor to have an alternate rod injection (ARI) system that is diverse (from the reactor trip system) from the sensor output to the final actuation device. This system is also required to have redundant scram air header exhaust valves and must be designed to perform its function reliably and be independent of the existing reactor trip system from sensor output to final actuation device. The ATWS rule also requires that each BWR have a standby liquid control system (SLCS) that has the capability of injecting a borated water solution into the reactor pressure vessel (RPV). The borated water must be of such flow rate, boron concentration, and boron-10 isotope enrichment that, when accounting for the RPV volume, the resulting reactivity control is equivalent to that resulting from the injection of $326 \mathrm{Lpm}(86 \mathrm{gpm})$ of 13 weight percent sodium pentaborate decahydrate solution at the natural boron-10 isotope abundance into a $638 \mathrm{~cm}$ (251 in.) internal diameter reactor pressure vessel for a given core design. The SLCS must be automatically initiated and the system and its injection location must be designed to perform their functions in a reliable manner. Each BWR must also have equipment designed to reliably trip the reactor coolant recirculation pumps under conditions indicative of an ATWS.

SSAR Sections 15.8 and 19B.2.5 indicate that there are two ways to provide scram in the ABWR design: a motordriven way and a hydraulic way. In response to a scram signal, the control rods are inserted hydraulically, by the stored energy in the scram accumulator, similar to the current operating BWRs. A scram signal is given simultaneously to insert the fine motion control rod drives (FMCRDs) electrically; via the FMCRD motor drive. This diversity (hydraulic and electric methods of scramming) provides a high degree of assurance that control rods will be inserted when needed.

The ABWR has equipment to trip the reactor internal pumps (RIPs) automatically under ATWS conditions. The RIPs are automatically tripped on reactor high pressure $7860 \mathrm{kPa}$ (1125 psig) (RIPs not connected to the motor- generator set) and RPV Level 2 (RIPs connected to the motor-generator set).

The ABWR design provides recirculation runback for all scram signals, feedwater runback on reactor high pressure and startup range neutron monitoring system ATWS permissive for 2 minutes.

In SSAR Appendix 15E, GE provides ATWS performance evaluation for fuel integrity, containment integrity, primary system, and long-term shutdown cooling. GE states that all requirements of satisfactory performance in the case of an ATWS are met.

As discussed in Section 15.5.2 of this report, the staff performed audit calculations to verify that the ABWR design is satisfactory to mitigate the effects of an ATWS. The review focused on the consequences of manual SLCS actuation and no recirculation pump runback on scram signals other than reactor high pressure and reactor low level. Under some circumstances, a problem was identified regarding the power shift to the top of the core. The staff concluded that the new design of recirculation runback on any scram signal and any ARI FMCRD run-in signal ensure that there is no potential for any unacceptable power shift to the top of the core.

Based on the information provided by GE and the staff evaluation cited above, the staff concludes that GE bas adequately addressed this issue for the ABWR. The ABWR complies with the ATWS rule (10 CFR 50.62), as discussed in Section $\mathbf{1 5 . 5}$ of this report.

\subsubsection{Issue A-10: BWR Feedwater Nozzle Cracking (former USI)}

Inspections of operating BWRs conducted up to April 1978 revealed cracks in the feedwater nozzles of 20 reactor vessels. These cracks ranged in depth from $1.3-1.90 \mathrm{~cm}$ ( $0.5-0.75$ in.), including cladding. One crack penetrated the cladding to the base metal for a total depth if approximately $3.8 \mathrm{~cm}(1.5 \mathrm{in}$.). It was determined that cracking resulted from high-cycle thermal fatigue caused by fluctuations in water temperature within the vessel in the nozzle region. These fluctuations occurred during periods of low feedwater circulation when the flow was unsteady and intermittent. Once started, the cracks grew because of thermal cycling during startups and shutdowns.

The review criteria for this issue are stated in NUREG-0619, "BWR Feedwater Nozzle and Control Rod Drive Return Line Nozzle Cracking." This document states that the thermal fatigue and crack initiation of feedwater nozzles are caused by the incoming feedwater, which is considerably colder than the water in the reactor 
vessel. This is espocially true during reactor startup (before feedwater heaters are in service) and during shutdown (after heaters are taken out of service). Turbulent mixing of the hot water retuming from the steam separators and dryers and the incoming cold feedwater causes thermal stress cycling of the nozzle unless it is protected by a thermal sleeve.

The proposed design for the ABWR will require that an inner thermal sleeve leading the cooler feedwater to the feedwater sparger be welded to the nozzle safe end. The welded thermal sleeve will assure that there is no leakage of cold feedwater between the thermal sleeve and the safe end. A secondary thermal sleeve is to be placed concentrically in the annulus between the inner thermal sleeve and the nozzle bore to prevent cold water that may be shedding from the outside surface of the inner sleeve from impinging on the nozzle bore and the inside nozzle corner. This proposed double-sleeve design gives a low fatigue usage factor in the nozzle bore and at the inner nozzle corner.

The material of the nozzle forging is SA-508, Class 3, low-alloy steel and the material of the safe end is SA-508, Class 1, carbon steel. The carbon steel safe end is welded to the nozzle forging with a carbon steel weld.

The double thermal sleeve as applied to the ABWR has not been used in earlier plants, although the Monticello (U.S.) and Tsuruga (Japan) plants are using similar designs. A telephone conference with Northern States Power, owner of the Monticello Power Plant, disclosed that the double thermal sleeve performs satisfactorily.

GE proposed an inservice inspection (ISI) program consisting of the following:

- Ultrasonic examination from the external surface of the nozzle ends, nozzle bores, and nozzle blend radius every second outage. If indications are found in the safe ends, the indications will be evaluated per the American Society of Mechanical Engineers Boiler and Pressure Vessel Code (ASME Code), Section XI.

- Visual inspection of flow holes and welds in sparger arms and sparger tees every fourth outage.

- Visual inspection of accessible areas of the nozzles from the inner diameter surface on the ASME Code, Section XI, schedule as core internal components.

The ISI program described above is acceptable to the staff because the reactor feedwater nozzles will be ultrasonically and visually examined in service according to ASME Code, Section XI, schedules and inspection criteria. This should ensure that the reactor vessel nozzles will perform in service as designed.

On the basis of the above, the staff concludes that GE adequately addressed this issue for the ABWR design.

\subsubsection{Issue A-13: Snubber Operability Assurance}

In May 1978, the Advisory Committee on Reactor Safeguards (ACR:3) staff observed that there are many licensee event reports (LERs) related to the malfunction of snubbers. The most common LERs involve (1) seal leakage in hydraulic snubbers and (2) high rejection rate during functional testing of snubbers. Snubbers are used as seismic and pipe whip restraints at operating plants. Their safety function is to provide supports to systems or components under dynamic load conditions such as earthquakes and severe hydraulic transients, e.g., pipe breaks. When snubbers are used as vibration arrestors, their fatigue strength must be considered.

The review criteria for this issue are contained in SRP Section 3.9.3. This section states that systems and components that utilize snubbers as shock and vibration arrestors must be analyzed to ascertain their interaction with the systems and components to which they are attached. Snubbers used as shock arrestors do not require fatigue evaluation if it can be demonstrated that certain conditions are satisfied. The criteria for inspection and testing of snubbers are also provided.

SSAR Section 19B.2.7 refers to Section 3.9.3.4.1(3), which in turn, provides the information pertinent to snubber operability assurance. The information consists of the design parameters regarding the required load capacity and snubber location, inspection, testing, replacement, design and testing, installation requirements, and preservice examination. As discussed in Section 3.12.6.6 of this report, the staff concluded that the information provided by GE is consistent with applicable portions of SRP Section 3.9.3 and, therefore, is acceptable. On the basis of the above, the staff concludes that GE adequately addressed this issue for the ABWR design.

\subsubsection{Issue A-17: Systems Interaction (former USI)}

Nuclear power plants contain many structures, systems, and components (SSCs), some of which are safety related. Some of these SSCs are designed to interact to perform their intended functions and are usually well recognized and accounted for in the evaluation of plant safety by designers and in plant safety assessments. Several significant, plant-specific events have involved unintended or unrecognized dependencies among various SSCs. Some of these events have involved subtle dependencies between 
safety-related and non-safety-related SSCs and some have even invoived subtle dependencies between redundant and supposedly independent SSCs. These dependencies have been termed "adverse systems interactions" (ASIs). This issue was instituted to investigate the potential that these ASIs have remained hidden and could lead to safetysignificant events. Seismically induced systems interactions, originally covered in Issue A-46 (which applies only to operating plants), is covered for the ABWR in current licensing requirements.

The staff's technical findings are documented in NUREG-1174, "Evaluation of Systems Interactions in Nuclear Power Plants," and the regulatory analysis in NUREG-1229, "Regulatory Analysis for Resolution of USI A-17." The staff informed the Commission of the resolution in SECY-89-230, "Unresolved Safety Issue A-17, 'Systems Interactions in Nuclear Power Plants'." These documents provide adequate guidance on this issue, although it was resolved by the staff without the establishment of new requirements. Generic Letter (GL) 89-18 was issued to licensees and applicants on September 6,1989 , to inform them about the resolution of this issue.

SSAR Section 19B.2.59 describes the studies on the subject of ASIs that were carried out over the last 10 years and the ABWR design features that could prevent and/or mitigate them. These studies were performed by various organizations, such as NRC's Office of Analysis and Evaluation of Operational Data (AEOD), the Institute of Nuclear Power Operations (INPO), nuclear steam supply system (NSSS) vendors, and the NRC staff based on the operating experience that is available in various publications, such as generic letters, information notices, and bulletins. These studies allowed plant system designers to formulate certain attributes that could be incorporated into design of the ABWR. These attributes consist of the separation criteria, consideration of failure aspects (such as fail safe, diversity, redundancy), protective actions (such as auto versus manual), and so on.

GE states that consideration of ASIs has resulted in designing the ABWR to explicitly avoid unwanted, unacceptable, or unknown ASIs. This has been accomplished through such features as multiple fission barriers, inherent shutdown features and mechanisms, a redundant and diverse engineered safety features (ESFs) network, and a redundant and diverse instrumentation and controls (I\&C) protection network.

The SSAR also compares the ABWR-unique features that are designed to prevent, mitigate, and accommodate ASIs with the features of other BWRs. These features include more redundant, diverse and independent power sources, RPV and containment makeup and cooling capabilities, decay heat removal capabilities, and operator action capabilities. Also, the ABWR has more redundant faulttolerant I\&C protection and a more secure and protected ESF housing from fire and flood.

Based on review of the design aspects of the ABWR described above, the staff concludes that the ABWR reflects the proven technology and accepted design requirements and that GE adequately addressed the concerns of this issue.

\subsubsection{Issue A-24: Qualification of Class 1E Safety- Related Equipment (former USI)}

Construction permit (CP) applicants for which SERs were issued after July 1974 were required by the NRC to qualify all safety-related equipment in accordance with IEEE 3231974, "Qualifying Class 1E Equipment for Nuclear Power Generating Stations. " From the time that this standard was originated, methods to qualify equipment to IEEE 323 were developed by the industry, but some of them, such as testing margins, aging effects, and the simulation of the worst-case environments, have not been accepted by the NRC.

All major NSSS vendors and architect engineers submitted topical reports that describe their methods of qualification. These reports were reviewed by the NRC and the results documented in NUREG-0588, "Interim Staff Position on Environmental Qualification of Safety-Related Electrical Equipment." These requirements were later established in 10 CFR 50.49 and revised Regulatory Guide (RG) 1.89, "Environmental Qualification of Certain Electric Equipment Important to Safety for Nuclear Power Plants, " which describes acceptable methods for complying with 10 CFR 50.49. Dynamic and seismic qualification of Class 1E electrical equipment was not included in the scope of 10 CFR 50.49. Guidance on dynamic and seismic qualification is contained in RG 1.100 (Rev. 2), "Seismic Qualification of Electric and Mechanical Equipment for Nuclear Power Plants. "

The criteria for this issue are contained in NUREG-0588 and in 10 CFR 50.49 for environmental qualification and RG 1.100 (Rev. 2), for dynamic and seismic qualification of Class $1 \mathrm{E}$ electrical equipment.

Dynamic and seismic qualification testing and analysis of the electrical equipment identified in SSAR Appendix 3I are addressed in SSAR Section 3.10, except for pump motors and valve motor operators which are addressed in Section 3.9. The tests and analyses are to be performed in accordance with IEEE-344, "IEEE Recommended Practices for Seismic Qualification of Class 1E Equipment 
for Nuclear Power Generating Stations," as modified and endorsed by RG 1.100 .

Environmental qualification of safety-related mechanical and electrical equipment is described in SSAR Section 3.11. ABWR Class 1E electrical equipment, including pump and valve motors and electrical accessories, will be environmentally qualified by the methods documented in the NRC-approved report, NEDE-24326-1-P, "General Electric Environmental Qualification Program." These methods are in accordance with the guidance of IEEE 323-1974, NUREG-0588, RG 1.89 (Rev. 1), and the generic requirements of 10 CFR 50.49. Typical environmental conditions (temperature, pressure, humidity, integrated radiation dose, and exposure to chemicals) are provided in SSAR Appendix 31 and cover the design lifetime. Conditions are tabulated for normal operation in and outside of containment and for LOCAs and HELBs inside containment.

Environmental qualification tests and analyses are addressed in SSAR Section 3.11.2. The safety-related equipment in the areas of SSAR Appendix $3 I$ is required to remain functional in the environmental conditions expected at the equipment location during and after the limiting DBA. Qualification tests and analyses of electrical equipment for the effects of aging, radiation, temperature, humidity, chemical spray, submergence, and power supply variation, as applicable, are to be performed and the results documented in accordance with NEDE-24326-1-P.

The proposed qualification program for ABWR electrical equipment is acceptable as discussed further in Sections 3.10 and 3.11 of this report. Therefore, the staff concludes that GE adequately addressed this issue for the ABWR design.

\subsubsection{Issue A-25: Non-Safety Loads on Class $1 E$ Power Sources}

Class $1 \mathrm{E}$ power sources provide the electric power for the plant systems that are essential to reactor shutdown, containment isolation, reactor core cooling, and containment heat removal, and are otherwise essential in preventing significant release of radioactive material to the environment. In some cases, non-safety loads are supplied from the Class $1 E$ power sources and if this is allowed, it is possible that the non-safety loads may cause degradation of the Class $1 \mathrm{E}$ power system by introducing loss of redundancy or by other failure mechanisms.

Resolution of this issue required that non-safety-related electrical equipment connected to the Class $1 \mathrm{E}$ power systems be limited and, if connected, conform to requirements (for example, independence, electrical isolation, and physical separation) so that the Class $1 \mathrm{E}$ system to which the non-safety-related equipment is connected continues to meet the capacity, capability, independence, redundancy, and testability requirements of GDC 17.

The ABWR design incorporates three independent Class 1E diesel generators and a non-Class $1 \mathrm{E}$ combustion turbine generator. The combustion turbine generator is designed to automatically assume the majority of nonsafety-related electrical equipment independently from the Class 1E diesel generators. Therefore, it is not necessary for non-safety-related electrical equipment to be connected to the Class $1 \mathrm{E}$ system.

The ABWR design excludes non-safety-related electrical equipment from the Class $1 \mathrm{E}$ system, with the exception of the fine-motion control rod drive subsystem and a portion of the lighting subsystem. :The fine motion control rod drive subsystem meets Class $1 \mathrm{E}$ requirements from the Class 1E system buses to and including zone-select interlocks (isolation devices). In addition, the fine motion control rod drive subsystem is restricted to Division $I$ in order to assure that the Class $1 \mathrm{E}$ subsystems do not violate their independence requirements. The lighting subsystem meets Class $1 E$ requirements from the Class $1 E$ system buses to and including the subsystem load. Because lighting fixtures and bulbs are not seismically qualified in accordance with Class $1 \mathrm{E}$ requirements, protective devices (breakers or fuses) and their coordination is provided to assure that Class 1E systems meet their independence and redundancy requirements. The Class $1 \mathrm{E}$ system is also sized with sufficient capacity to accommodate operation and failure of the connected non-safety-related subsystems.

The staff concludes that the connection of non-safetyrelated electrical equipment to the Class $1 \mathrm{E}$ system has been appropriately limited. It also concludes that the Class 1E system (with the limited number of connected non-safety-related electrical subsystems) meets the capacity, capability, independence, redundancy, and testability requirements of GDC 17 . Therefore, the staff concludes that GE adequately addressed this issue for the ABWR design.

\subsubsection{Issue A-29: Nuclear Power Plant Design for the Reduction of Vulnerability to Industrial Sabotage}

Reduction of the vulnerability of reactors to radiological sabotage is currently treated as a plant physical security function and not as a plant design requirement. Although present reactor designs provide a great deal of inherent protection against industrial sabotage, extensive physical security measures are still required to provide an 
acceptable level of protection. An alternative approach would be to consider more fully reactor vulnerabilities to sabotage during the preliminary design phase. Because emphasis is being placed on standardizing plants, it is especially important to consider measures that could reduce the vulnerability of reactors to sabotage. Any design features to enhance physical protection must be consistent with system safety requirements.

The staff resolved this issue without the establishment of new requirements. However, future plants may decrease vulnerability to sabotage by several means. Each division of safety system functions should be totally independent and separated, both mechanically and electrically. Each division should also include 3-hour fire barriers, physical protection of each division from flooding, and physical protection from pipe breaks, both inside and outside the containment. The site security system requirements should be compatible with the plant arrangement and safety system design, definition of vital systems, layout of vital components, security barriers, intrusion detection systems, isolation zone requirements, security alarms, access control, security communications, power supply, and data management. Since there exists a potential for sabotage by a "knowledgeable insider" with authorized access or for acts of sabotage that could occur during maintenance activities, advanced light water reactor (ALWR) plant designers should also analyze the vulnerability of their designs to insider sabotage before finalizing the designs.

SSAR Section 19B.2.4 contains a summary that describes this issue, the Electric Power Research Institute (EPRI) ALWR requirements document, and the proposed resolution of Issue A-29 for the ABWR. It states that the $A B W R$ design will comply with the ALWR requirements document as defined in the SSAR. It also indicates that the ABWR design will mitigate the acts of sabotage through physical separations in the plant arrangement of engineering safety systems and the design and location of barriers to resist threats.

In SSAR Section 19B.2.4, GE states that a sabotage vulnerability analysis will be conducted before the design is finalized. The staff verified that GE established a COL action item in Table 1.9-1 to perform this analysis. This is an acceptable approach. Based on the above, the staff concludes that GE adequately addressed this issue for the ABWR design.

\subsubsection{Issue A-31: RHR Shutdown Requirements (former USI)}

This issue addresses the safe shutdown of the reactor following an accident or abnormal condition other than a LOCA from a hot standby (that is, the reactor is shut down, but the primary system temperature and pressure are still at or near normal operating values) to a cold shutdown condition. Considerable emphasis has been placed on long-term cooling, which is achieved by the RHR system. The RHR starts to operate when the reactor coolant system (RCS) pressure and temperature are substantially lower than their hot-standby condition values.

Even though it may generally be considered safe to maintain a reactor in a hot-standby condition for a long time, experience has shown that there have been events that required eventual cooldown and long-term cooling until the reactor coolant is cool enough to perform inspection and repairs. For this reason, the ability to transfer heat from the reactor to the environment after a shutdown is an important safety function. It is essential that a power plant be able to go from hot-standby to a cold-shutdown condition after any abnormal occurrence.

The review criteria for this issue are contained in SRP Section 5.4.7, Revision 3. Specifically, the RHR system should meet the intent of the following:

- The design should be such that the reactor can be taken from normal operating to cold shutdown using only safety-grade systems that satisfy the criteria of GDC 1 through 5 of 10 CFR Part 50, Appendix A.

- The system(s) should have suitabie redundancy in components and features, and suitable interconnections, leak connections, and isolation capabilities to assure that for onsite electrical power system operation (assuming that offsite power is not available), the system function can be accomplished assuming a single failure.

- The system is capable of being operated from the control room with either onsite or offsite power available.

- The system(s) should be capable of bringing the reactor to a cold shutdown condition, with either onsite or offsite power available, within a reasonable time following a shutdown, assuming the most limiting single failure.

In SSAR Section 19B.2.10, GE stated that the RHR system consists of three electrically and mechanically independent divisions, except for the outboard containment isolation valves, which are in different electrical divisions than the inboard valves. The system will be redundant so that its functional integrity will be assured for onsite electrical power system operation, when offsite power is not available, assuming a single failure. The RHR shutdown cooling subsystem will be activated manually by the 
operator from the control room following insertion of the control rods and normal blowdown to the main condenser. For eme gency conditions, when one of the RHR loops has failed, the RHR system will be capable of bringing the reactor to the cold shutdown condition, i.e., $100^{\circ} \mathrm{C}$ $\left(212^{\circ} \mathrm{F}\right)$, within 36 hours following reactor shutdown with two divisions. When all three RHR loops are functioning together, the RHR can remove residual heat (decay and sensible) from the reactor vessel water at a rate sufficient to cool it to $60^{\circ} \mathrm{C}\left(140^{\circ} \mathrm{F}\right)$ within 24 hours after the rods are inserted.

The ABWR RHR design does not meet SRP Section 5.4.7, BTP RSB 5-1, Sections B.1(b) and (c), which require the RHR suction side isolation valves to have independent diverse interlocks to prevent the valves from being opened unless RCS pressure is below the RHR system design pressure. Instead, the pressure signal that provides the interlock function is supplied from a 2-out-of-4 logic, which has four independent pressure sensor and transmitter inputs, each of which is in a separate instrument division. The staff concluded in Section 5.4.7 of this report that they satisfy the intent of BTP RSB 5-1. Therefore, the staff concludes that $\mathrm{GE}$ adequately addressed this issue for the ABWR design.

\subsubsection{Issue A-35: Adequacy of Offsite Power Systems}

GDC 17 of 10 CFR Part 50, Appendix A, requires provisions be included in the design to minimize the probability of losing electric power from any of the remaining supplies as a result of, $x$ coincident with, the loss of power generated by the nuclear power unit, the loss of power from the transmission network, or the loss of power from the onsite electric power supplies.

To meet these requirements of GDC 17, the NRC, in the past, depended on (1) the results of transient and steadystate stability analyses documented in the safety analysis reports for license applications which indicated that the offsite power source remained stable and (2) on design provisions for the disconnection of the offsite power source on its loss of voltage. However, abnormal occurrences at several operating plants indicated that a sustained undervoltage condition of the offsite power can occur and not be detected by the existing loss of voltage design provisions. Failure to disconnect from the undervoltage condition could cause redundant safety-related equipment to be exposed to voltage levels below that for which they are designed. The sustained undervoltage condition could thus result in failure of redundant safety-related equipment.

To resolve this issue, the NRC evaluated the power systems of operating plants to determine the susceptibility of safety-related electrical equipment to: (1) sustained undervoltage condition on the offsite power source, (2) interaction of the offsite and onsite power sources, and (3) adequacy of the existing testing requirements. From this evaluation, the NRC developed an additional requirement for a second level of loss of voltage protection. This second level of protection assures disconnection from offsite power when there is a sustained undervoltage condition on the offsite power source. This additional requirement for a second level of protection was imposed on all operating and future plant designs. In order to assure implementation on future plant designs, Appendix A to SRP 8.3.1 was revised to incorporate this requirement as BTP PSB-1, "Adequacy of Station Electric Distribution System Voltages." In the advance SER, the staff also stated that in resolving A-35 it evaluated the susceptibility of safety-related electrical equipment to the rapid rate of decay of the offsite power source. The advance SER stated that the staff determined this was not a significant safety concern. Details of this determination may be found in an NRC memorandum for K. Kniel from M. Srinivasan dated July 31, 1981.

The review guideline for this issue is that the design of the undervoltage protection schemes for the Class $1 \mathrm{E}$ buses of the onsite power system conform to the requirements of BTP PSB-1. Specifically, a second level of voltage protection should be provided for Class $1 \mathrm{E}$ equipment, in addition to the existing protection based on detecting the complete loss of offsite power to the Class $1 \mathrm{E}$ buses. The second level should have two separate time delays: one before alerting the control room operator and the other automatically separating the Class $1 E$ buses from the offsite power source. The time delays should be long enough to ensure protection from sustained low voltage while avoiding disconnection from the offsite source because of short-term transients such as motor starting. The undervoltage protection scheme should have the capability to be tested and calibrated during power operation. Voltage levels at the safety-related buses should be optimized for the maximum and minimum load conditions that are expected throughout the anticipated range of offsite power source voltage variations. TS are to include limiting conditions of operation, surveillance requirements, and protection equipment set points.

The ABWR design provides two levels of protection for independence of offsite and onsite systems during loss of or degraded voltage conditions. During loss of voltage condition, that is, when the bus voltage decays to less than 70 percent of its normal rated value, a bus transfer to the diesel generator is initiated by the first level of protection. During degraded voltage conditions, that is, when the bus voltage decays to between 70 and 90 percent of its normal rated value for a sustained period of time, the bus is 
tripped by the second level of protection. With the bus tripped, bus transfer to the diesel generator is initiated by the first level of protection. Equipment will be qualified for voltages below 90 percent for the period of time the equipment will bo subjected to these voltage conditions.

The staff reviewed the ABWR design for a second level of protection in accordance with the guidelines of BTP PSB-1, and concluded in Section 8.2.3.2 of this report that the design meets the requirements of GDC 17 defined above. Therefore, the staff concludes that GE adequately addressed this issue for the ABWR design.

\subsubsection{Issue A-36: Control of Heavy Loads Near Spent Fuel (former USI)}

Overhead cranes are used at all nuclear plants to lift heavy objects in the vicinity of spent fuel. If a heavy object such as a spent fuel shipping cask or shielding block were to fall onto spent fuel in the storage pool or reactor core during refueling and damage the fuel, radioactivity could be released to the environment. Such an occurrence also has the potential of overexposing plant personnel to radiation. If the dropped object were large and the damaged fuel contained a considerable amount of undecayed fission products, radiation releases could exceed the guidelines of 10 CFR Part 100. With the advent of increased and longer-term storage of spent fuel, the NRC determined that there is a need for a systematic review of requirements, facility designs, and TS regarding the movement of heavy loads to assess safety margins and improve them where necessary.

The review criteria for this issue are stated in NUREG-0612, "Control of Heavy Loads at Nuclear Power Plants." They provide for the safe path of the load, training of the operators, inspection and tests of the equipment involved, safety interlocks, and limit switches, etc. The review of the proposed resolution of this issue consists of determining incorporation of the guidelines provided in NUREG-0612 in the ABWR design.

SSAR Section 19B.2.12 states that a number of measures are required to preclude an accident involving heavy loads, in general, and in the vicinity of the storage pool, in particular. These measures include the following:

- The COL applicant will perform a study on all planned heavy-load-handling moves to evaluate and minimize safety risks. The study will establish the heavy-loadshandling paths and routing plans. The COL applicant will also be required to provide the NRC a confirmatory structural evaluation of the spent fuel racks.
- The major heavy-load-handling equipment components (such as cranes and hoists) will be provided with an operating instruction and maintenance manual, in conformance with the guidelines of NUREG-0612, for reference and utilization by operation and maintenance personnel.

- Crane inspections and testing will comply with the requirements of American National Standards Institute (ANSI) B30.2, "Overhead Gantry Cranes," and NUREG-0612, Section 5.1.1(6).

- The equipment-handling components used over the spent fuel pool are designed to meet the single-failureproof criteria, according to the guidelines of NUREG-0554, "Single Failure Proof Crances for Nuclear Power Plants." Safety interlocks and limit switches are provided to prevent transporting heavy loads, other than spent fuel by the refueling platform crane, over any spent fuel that is stored in the spent fuel storage pool.

- The reactor vessel head lifting strongback and the dryer/separator lifting strongback are designed in accordance with the guidelines of NUREG-0612 and ANSI N14.6, "Standard fo. Special Lifting Devices for Shipping Containers Weighing 10,000 Pounds $(4500 \mathrm{Kg})$ or More for Nuclear Materials."

- The design bases of the system will conform to the requirements of GDC 2, as it relates to the ability of structures, systems, and mechanisms to withstand the effects of earthquakes; GDC 4 as it relates to protection of safety-related equipment from the effects of internally generated missiles (i.e., dropped loads); and GDC 61 as it relates to the safe handling and storage of fuel.

The staff verified that GE established a COL action item in Table 1.9-1 to provide design details for the load handling equipment. This approach is acceptable to the staff. Based on the above information, the staff concludes that GE adequately addressed this issue for the ABWR design.

\subsubsection{Issue A-39: Determination of Safety Relief Valve Pool Dynamic Loads and Temperature Limits (former USI)}

Operation of BWR primary system pressure relief valves can result in hydrodynamic loads on the suppression pool retaining structures or those structures located within the pool. These loads result from initial vent clearing of relief valve piping and steam quenching because of high local pcol temperatures. Overall, the definition methodology 
used for the ABWR containment is similar to that used for prior BWR containment designs. In spite of the unique features in the $A B W R$, such as pressurization of the wetwell gas space, the presence of a lower drywell, the smaller number of horizontal vents (30 in the ABWR versus 120 in the Mark III containment), and extension of horizontal vents into the pool, the hydrodynamic loads addressed in this issue are similar to those in other BWR designs.

The review criteria pertinent to this issue are contained in SRP Section 6.2.1.1.C, Appendix B, which lists the generic loads acceptable to the NRC, including load identification, a summary of load specification, load specification clarifying criteria, and reference to the NRC NUREG section that describes the NRC-specific load evaluation. The staff considers that this issue summarizes and incorporates the pertinent results of the studies described in Issues A-7 and B-10, Sections 20.1.1 and 20.1.21, respectively of this report.

SSAR Appendix 3B describes containment hydrodynamic loads, such as those resulting from the SRVs, quencher discharge loads, pressure and temperature transients, and submerged structure loads. The ABWR containment design has some unique features that differ from previously approved designs, such as the Mark III containment. These unique features include pressurization of the wetwell airspace, the presence of a lower drywell, the smaller number of horizontal vents into the pool, vent submergence, and suppression pool width. GE states in the SSAR that SRV discharge is completely condensed in the pool and steam condensation loads are low compared to those of other submerged structures loads because of SRV line air clearing and LOCAs. Consequently, dynamic loads on submerged structures during quencher steam condensation will not be defined and considered for containment evaluation. This is appropriate for the dynamic loads associated with the SRV.

Based on this information and the staff's evaluation of the ABWR containment analysis in Section 6.2.1.6 of this report, the staff concludes that GE adequately addressed this issue for the ABWR design.

\subsubsection{Issue A-40: Seismic Design Criteria - Short-Term Program (former USI)}

Seismic design of nuclear plants is reviewed in accordance with the provisions of SRP Sections 2.5.2, 3.7.1, 3.7.2, and 3.7.3. Over the years, there has been an evolution of seismic design requirements and technology. The objective of this issue was to investigate selected areas of the seismic design sequence to determine their conservatism for all types of sites, to investigate alternative approaches where desirable, to quantify the overall conservatism of the design sequence, and to modify the NRC criteria in the SRP where justified. Studies were conducted and the results were documented in NUREG/CR-1161, "Recommended Revisions to Nuclear Regulatory Commission Seismic Design Criteria," with specific recommendations for changes in seismic design requirements.

SRP sections were then revised with the following principal areas of change: Section 2.5.2 was updated to reflect the current NRC staff review practice; Section 3.7.1, to reflect design time history criteria; Section 3.7.2, to reflect development of floor response criteria, damping values, soil-structure interaction uncertainties, and combination of modal responses; and Section 3.7.3, to reflect seismic analysis of above-ground tanks and Category 1 buried piping.

The review criterion for the resolution of this issue is conformance with the seismic design acceptance criteria of Revision 2 to SRP Sections 2.5.2, 3.7.1, 3.7.2, and 3.7.3. Specifically, these SRP sections cover review of the site characteristics and earthquake potential, the parameters to be used in seismic design, methods to be used in seismic analysis of the overall plant, and methods to be used in seismic analysis of individual systems and components.

SSAR Section 19B.2.14 states that the design ground motions, site parameters, and system and subsystem analyses criteria and methods described in SSAR Sections 2.3.2.22, 3.7.1, 3.7.2, and 3.7.3 meet the intent of the corresponding SRP sections, except that the operating-basis earthquake (OBE) requirement is not a requirement for the $A B W R$. Elimination of the $O B E$ from the ABWR design is consistent with the Commissionapproved staff position on the policy issue regarding elimination of the OBE addressed in SECY-93-087, "Policy, Technical, and Licensing Issues Pertaining to Evolutionary and Advanced Light Water (ALWR) Designs," April 2, 1993.

Based on this information, the staff concludes that GE adequately addressed this issue for the ABWR design.

\subsubsection{Issue A-42: Pipe Cracks in BWR (former USI)}

Pipe cracking has occurred in the heat-affected zones of welds in primary system piping in BWRs since mid-1980. These cracks have occurred mainly in Type 304 unstabilized austenitic stainless steel, which is the pipe material used in most operating BWRs. The major problem is recognized to be intergranular stress corrosion cracking (IGSCC) of austenitic stainless steel components. These components have been made susceptible to this 
failure by being exposed to a sensitizing temperature range $427-816^{\circ} \mathrm{C}\left(800-1500{ }^{\circ} \mathrm{F}\right)$ during welding or post-weld heat treatment.

The review criteria for this issue are contained in NUREG-0313, Revision 2, "Technical Report on Material Selection and Processing Guidelines for BWR Coolant Pressure Boundary Piping."

The ABWR design complies with RG 1.44, "Control of the Use of Sensitized Stainless Steel," and with the guidelines of NUREG-0313, Revision 2. These documents specify that low-carbon austenitic stainless steels are used in the construction of BWR piping and that low carbon (with a minimum of 8 percent ferrite) weld metal as deposited, is utilized in the fabrication of BWR piping. This will ensure that sensitization of ABWR components will be avoided. Based on this information, the staff concludes that GE adequately addressed this issue for the ABWR design.

\subsubsection{Issue A-44: Station Blackout (former USI)}

The complete loss of ac electrical power to the essential and nonessential switchgear buses in a nuclear power plant is referred to as a "station blackout" (SBO). Because many safety systems required for reactor core decay heat removal are dependent on ac power, the consequences of an SBO could lead to a severe core damage accident. This issue involves the likelihood and duration of the loss of all ac power and the potential for severe core damage after a loss of all ac power.

The issue arose because of experience with the reliability of ac power supplies. Numerous reports of standby diesel generators failing to start and run had been received and a number of operating plants had experienced a total loss of offsite electrical power. In almost every one of these latter events, the onsite ac power supplies were available to supply power to the safety equipment. However, in some instances, one of the redundant onsite ac power supplies had not been available and, in a few cases, ac power was completely lost (although during these latter events, ac power was restored in a short time and no serious consequences resulted).

The results of WASH-1400/NUREG-75/014, "Reactor Safety Study, An Assessment of Accident Risks in U.S. Commercial Nuclear Power Plants," showed that for one of the evaluated plants, an SBO could be an important contributor to the total risk from nuclear power plant accidents. Although the total risk was found to be small, the relative importance of an SBO was established.
To resolve this issue, the NRC designated SBO as an unresolved safety issue and implemented a task action plan to determine the need for additional safety requirements. The results, described in NUREG-1109, "Regulatory/Backfit Analysis for the Resolution of Unresolved Safety Issue A-44, Station Blackout," indicated that actions could be taken to reduce the risk from SBO events. The NRC amended its regulations in 10 CFR Part 50 to include the SBO rule (10 CFR 50.63) and issued an associated regulatory guide (RG 1.155, "Station Blackout") that provides guidance on an acceptable means to comply with the SBO rule.

Paragraph (a) of 10 CFR 50.63 requires that each lightwater-cooled nuclear power plant be able to withstand and recover from an SBO of a specific duration. The specified SBO duration must be based on (1) the redundancy of the onsite standby ac power sources, (2) the reliability of the onsite standby ac power sources, (3) the expected frequency of loss of offsite power, and (4) the probable time needed to restore offsite power. During the specified SBO duration, the reactor core and associated coolant, control, and protection systems, including station batteries and any other necessary support systems, must provide sufficient capacity and capability to ensure that the core is cooled and appropriate containment integrity is maintained.

Paragraph (c)(2) of 10 CFR 50.63 allows an alternate ac (AAC) source to be used to meet the above defined requirements of 10 CFR $50.63(\mathrm{a})$ provided that:

- Either the AAC source can be demonstrated by test to be available within 10 minutes to supply power to switchgear buses that are capable of supplying power to required shutdown equipment, or the reactor core and associated coolant, control, and protection systems, including station batteries and any other necessary support systems, have sufficient capacity and capability to ensure that the core is cooled and appropriate containment integrity is maintained from the onset of SBO until the AAC source and required shutdown equipment are started and lined up to operate,

- The time required for startup and alignment of the AAC source and shutdown equipment is demonstrated by test, and

- The AAC source, as a minimum, has the capacity and capability to ensure the plant can be brought to and maintained in safe shutdown.

To meet the SBO rule, GE has provided a combustion turbine generator (CTG) as an AAC source. The CTG has the capability of being aligned with any one of the three 
Class 1E divisions within 10 minutes. The CTG has sufficient capacity and capability to supply the loads that can be connected to one Class 1E division. Each of the three Class IE divisions has sufficient capacity and capability to ensure the plant can be brought to and maintained in safe shutdown. The capability of aligning the CTG with a Class $1 E$ bus within 10 minutes can be demonstrated by test. In addition, the time required for startup and alignment of the CTG and shutdown equipment can be demonstrated by test.

The staff reviewed the ABWR design for its ability to withstand and recover from an SBO in accordance with the guidelines of RG 1.155, and concluded in Section 8.3.9 of this report that the design meets the above defined requirements of 10 CFR 50.63(c)(2). Therefore, the staff concludes that $G E$ adequately addressed this issue for the ABWR design.

\subsubsection{Issue A-47: Safety Implications of Control Systems (former USI)}

Concerns have been raised regarding the potential for accidents or transients being made more severe as a result of control system failures, including control and instrumentation power supply faults. During the licensing review process, the staff performs an audit review of the non-safety-grade control systems to ensure that an adequate degree of separation and independence is provided between these non-safety-grade systems and the safety systems. On this basis, it is generally believed that control system failures are not likely to result in safety function losses that could lead to serious events or result in conditions that the safety systems are not able to mitigate. However, in-depth studies for all non-safety-grade systems have not been performed.

Generic Letter 89-19, "Request for Action Related to Resolution of Unresolved Safety Issue A-47, 'Safety Implication of Control Systems in LWR Nuclear Power Plants'," recommended that all GE BWR plant designs provide (1) automatic reactor vessel overfill protection to mitigate main feedwater (MFW) overfeed events and (2) plant procedures and TS to periodically verify the operability of overfill protection during power operation.

The ABWR reactor vessel overfill protection is described in SSAR Section 7.7.1.4(9). The level control system provides interlocks and control functions to other systems. When the reactor water level reaches the Level 8 trip set point, the feedwater control system (FWCS) simultaneously (1) annunciates a control room alarm, (2) sends a trip signal to the turbine control system to trip the turbine generator, and (3) sends trip signals to the condensate, feedwater, and condensate air extraction
(CF\&CAE) system to trip all foed pumps and to close the MFW discharge valves. This interlock is enacted to protect the turbine from damage from high moisture content in the steam caused by excessive carry over while preventing the reactor water level from rising any higher.

In the event that the foedwater pump discharge valves fail to close following the Level 8 trip signal, the FWCS automatically issues another signal to the CF\&CAE system to trip all condensate pumps in order to avoid overpressurization of the vessel.

Based on the information above and in SSAR Section 19B.2.17, which states that the COL applicant will develop plant procedures including reactor vessel overfill considerations as shown in SSAR Figure 7.7-8, "Feedwater Control System IED," the staff finds that the proposed Issue A-47 resolutions are acceptable. Therefore, the staff concludes that GE adequately addressed this issue for the ABWR design.

\subsubsection{Issue A-48: Hydrogen Control Measures and Effects of Hydrogen Burns on Safety Equipment}

This issue concerns the control of large quantities of hydrogen in reactors with small volume containments. As a result of the accident at TMI-2, the Commission issued requirements on hydrogen control in 10 CFR 50.34(f) and 50.44. 10 CFR 50.34(f) requires a hydrogen control system. This system must be based on a 100 -percent, fuel clad metal-water reaction and a hydrogen concentration limit of 10 percent on uniformly distributed hydrogen in the containment or on a post-accident atmosphere that will not support hydrogen combustion.

Provision of a noncombustible containment atmosphere (inerting) is an acceptable approach to addressing this issue and is mandated for those reactors with a Mark I or II type of containment. These plants must also have hydrogen recombiners, either internal or external. Reactors with a Mark III type of containment are required to provide a hydrogen control system.

During the TMI-2 accident, it became apparent that metalwater reactions generated hydrogen in excess of the smounts specified in 10 CFR 50.44. In June 1990, the Commission approved the staff's recommendations in SECY -90-016 as the requirements for evolutionary LWRs. These requirements are set forth in 10 CFR $50.34(f)(2)(i x)$.

The plant-specific design must also comply with $10 \mathrm{CFR}$ 50.34(f) for combustible gas control. 10 CFR $50.34(f)(2)(i x)$ requires that a hydrogen control system be 
based on a 100-percent, fuel clad metal-water reaction and a hydrogen concentration limit of 10 percent on uniformly distributed hydrogen in the containment or on a postaccident atmosphere that will not support hydrogen combustion. $10 \mathrm{CFR} 50.34(f)(3)(v)$ requires that containment integrity be maintained below Service Level C limits for steel containments and the factored load category for concrete containments during an accident that releases hydrogen generated from a 100-percent, fuel clad metal-water reaction.

This issue was resolved by the requirements contained in 10 CFR 50.34(f) and 10 CFR 50.44. SSAR Section 19B.2.18 states that there are no design-basis events for the ABWR that result in core uncovery or core heatup sufficient to cause significant metal-water reaction. It further states that this is equivalent to the reaction of the active clad to a depth of $0.00058 \mathrm{~cm}(0.00023 \mathrm{in}$.) or 0.72 percent of the active clad. SSAR Section 6.2.5.3 states that the atmospheric control system (ACS) is designed to maintain the containment in an inert condition, except for nitrogen make-up needed to maintain a positive containment pressure and prevent air leakage from the secondary into the primary containment.

GE analyzed consequences of hydrogen release and concluded that for 100-percent, fuel clad metal-water reaction, the resulting peak containment pressure would be about $517 \mathrm{kPa}(75 \mathrm{psig})$. The ABWR has a concrete containment with a steel upper drywell head. This head, based on GE structural analysis, has been shown to be the most limiting structural component of the containment, with a Service Level C limit of $669 \mathrm{kPa}$ (97 psig). Therefore, the containment pressurization resulting from a 100-percent, fuel clad metal-water reaction, coupled with a large-break LOCA, is below the Service Level C limit.

On the basis of this information and the staff's evaluation of ABWR compliance with 10 CFR 50.34(f)(2)(ix), as discussed in Sections 20.5.21 and 19.2.3.3.1 of this report, the staff concludes that $\mathrm{GE}$ adequately addressed this issue for the ABWR design.

\subsubsection{Issue B-5: Ductility of Two-Way Slabs and Shells and Buckling Behavior of Steel Containments}

This issue addresses two concerns relating to containment design: (1) that sufficient information is not available to predict the behavior of two-way reinforced concrete slabs, and (2) that the structural design of a steel containment vessel subjected to unsymmetrical dynamic loadings may be governed by the instability of the shell. The safety significance of the first concern is that in the event of the collapse of a floor that may be caused by an earthquake or a LOCA, there would be a possibility that other portions of the RCS or safety-related systems could be damaged. The damage could lead to an accident sequence resulting in the release of radioactivity to the environment.

The other concern, identified in NUREG-0471, "Generic Task Problem Descriptions (Categories B, C, and D), "is over the lack of a uniform, well-defined approach to design evaluation of steel containments. The structural design of a steel containment vessel subjected to unsymmetrical dynamic loadings may be govemed by the instability of the shell. For these types of loads, the current criteria and the current analytical techniques may not be as comprehensive as they should be.

The review criterion for the first concern is that the design code, American Concrete Institute code ACI 349, "Code Requirements for Nuclear Safety Related Structures," contains sufficient information pertaining to the design of two-way slabs subjected to dynamic loads and biaxial tension to enable a reasonably accurate analysis. ACI 349 should be used in conjunction with the pertinent regulatory documents such as SRP Section 3.5.3, Appendix A, and RG 1.142, "Safety-Related Concrete Structures for Nuclear Power Plants (Other than Reactor Vessels and Containments). "

The review criterion for the second concern is that all applied loads must be adequately addressed by the steel containment design. RG 1.57, "Design Limits and Loading Combinations for Metal Primary Reactor Containment System Components," recommends a minimum factor of safety of 2 against buckling for the worst loading condition, provided that a detailed, rigorous analysis that considers inelastic behavior is performed. Also, the allowable stress values for buckling are contained in the ASME Code, Section III, Subsection NE-3222.

SSAR Sections 3.8.3, 3.8.4, and 19B.2.61 state that the design of the ABWR safety-related structures (other than the containment vessel), including consideration of the ductility requirements for the two-way slabs, is based on the ACI 349-80 Code. The approach used by GE for the design of two-way reinforced concrete slabs meets the guidelines of SRP Sections 3.8.3 and 3.8.4 and is, therefore, acceptable.

The applicant indicated that the ABWR containment is a concrete structure and the steel component not backed by concrete, that is, the ABWR reactor closure head, is designed in accordance with the ASME Code, Section III, Subsection NE. This approach meets the guidelines of SRP Section 3.8.2 for shell buckling and, therefore, is acceptable. 
Based on the above discussions, the staff concludes that GE adequately addressed this issue for the ABWR design.

\subsubsection{Issue B-10: Behavior of BWR Mark III Containments}

This issue deals with the dynamic loads present in the Mark III containment following a postulated LOCA when escaping steam forces the suppression pool water out of the drywell and into the wetwell. This action results in pool swell and loads from vent clearing, jets, chugging, impact of water, impact of froth impingement, pool fallback, condensation, and containment pressure. The concern is that these loadings may damage structures and components located within the wetwell. Although many of these structures (e.g., walkways) are by themselves not related to safety, the various emergency core cooling systems (ECCSs) take suction from the wetwell and, therefore, damage in the wetwell may affect the performance of the ECCSs.

The review criteria for this issue are provided in NUREG-0978, "Mark III LOCA-Related Hydrodynamic Load Definition," Appendix C. These criteria have been developed on the basis, of large-scale tests conducted between 1973 and $1979^{\circ}$ by GE in order to define the LOCA-related hydrodynamic loads for use in the design of the standard Mark III containment.

The ABWR horizontal vent confirmatory test program was performed to obtain data that could be used to determine condensation oscillation and chugging loads for design evaluation of containment structures. The test matrix included tests at conditions that produce bounding loads and additional tests to examine the sensitivity of the loads to system parameters. The test specifically documents work performed, including general evaluation of the test data and the specification of prrcuedures that can be used to define containment loads.

The ABWR design utilizes a horizontal vent system, which is similar to that of the Mark III containment design, but includes some ABWR-unique design features. These unique features include pressurization of the wetwell airspace, the presence of a lower drywell, a smaller number of horizontal vents (30 in the ABWR containment versus 120 in the Mark III containment), extension of horizontal vents into the pool, vent submergence, and suppression pool width.

The ABWR horizontal vent test program has been based on resolution of several other issues (A-7, A-8, and B-10), which produced test data to confirm and define condensation oscillation and chugging loads for design application. SSAR Section 3B.2.2 describes a spectrum of postulated LOCAs that was considered in assessing the design adequacy of the ABWR containment system. The results obtained from small-scale tests conducted within the scope of the ABWR design confirmed the applicability of Issue B-10 test data.

Based on this information and the staff's evaluation of the ABWR containment analysis in Section 6.2.1.6 of this report, the staff concludes that $G E$ adequately addressed this issue for the ABWR design.

\subsubsection{Issue B-17: Criteria for Safety-Related Operator Actions}

Current plant designs are such that reliance on the operator to take action in response to certain transients is necessary. Consequently, it becomes necessary to develop appropriate criteria for safety-related operator actions (SROAs). The criteria would include a determination of actions that should be automated rather than manual and developminas? of a time criterion for SROAs.

The review criteria for this issue are contained in ANSI/American Nuclear Society (ANS) 58.8-1984, "Time Response Design Criteria for Nuclear Safety Related Operator Actions," and ANSI/ANS 52.2-1983, "Nuclear Safety Criteria for the Design of Stationary Boiling Water Reactor Plants." Plants should perform task analysis, simulator studies, and analysis and evaluation of operational data to assess ESF and safety-related control system designs for conformance to the criteria. Where nonconformance is identified, modification of the design and hardware may be required.

SSAR Appendix 18E describes the program of humanfactors-related activities conducted throughout the development of the ABWR plant system designs, including the development of the main control room (MCR) and remote shutdown system (RSS) designs. Appendix 18E describes the process through which the MCR and RSS human-system interface (HSI) design implementations will be conducted and evaluated through the application of human factors engineering (HFE) practices and principles.

The COL applicant is responsible for addressing B-17 as part of the detailed design implementation. The staff verified that $\mathrm{GE}$ has established a general COL action item in SSAR Section 18.8 (Item 18.8.1) to conduct the detailed HFE design according to design and implementation as defined by the $A B W R$ certified design material (CDM) Table 3.1 Inspection, Tests, Analyses, and Acceptance Criteria (ITAAC) and SSAR Appendix 18E. The staff considers the SSAR to include commitments for the COL applicant to conduct the necessary analyses of the critical operator tasks. In addition, the staff verified that $G E$ 
established another COL action item in SSAR Section 18.8 (Item 18.8.15) to evaluate the adequacy of the HSI to provide the necessary controls, displays, and alarms for the timely performance of critical tasks. This approach is acceptable to the staff as discussed in Section 18.7.2.2 of this report.

Based on this information, the staff concludes that GE adequately addressed this issue for the ABWR design.

\subsubsection{Issue B-29: Effectiveness of Ultimate Heat Sinks}

This issue addressed the adequacy of existing NRC mathematical models for the prediction of the ultimate heat sink (UHS) performance by comparing model performance with field data. The issue also addressed the selection of site-specific meteorological data for use as UHS design basis meteorology.

The DFSER stated that the design of the UHS is not within the scope of the ABWR design. GE provided several interface requirements to be used as guidance for the design of systems not within the ABWR design scope. The DFSER contained a lengthy discussion of these interface requirements and concluded that $G E$ provided sufficient information to allow the COL applicant to provide a plant-specific response to Issue B-29. The plantspecific response was identified in the DFSER as COL Action Item 20.1-1.

Issue B-29 is categorized in NUREG-0933 as a licensing issue and as such, is not required to be considered in meeting the requirements of 10 CFR 52.47(1)(a)(iv). The purpose of the issue was to confirm the validity of the NRC models used to make an independent assessment of UHS design safety. NRC's studies have confirmed that the capability of NRC's models and existing guidance are adequate. The determination of the adequacy of a specific UHS design is to be made by the staff during the review process using the models and guidance. The design of the UHS for the ABWR will be provided by the COL applicant as part of the COL application in accordance with the interface requirements discussed in Section 9.2.5 of this report. The UHS design will be reviewed at the COL application stage. This approach is acceptable to the staff.

Upon further consideration, the staff determined that because Issue B-29 is a licensing issue and not required to be considered in meeting the requirements of 10 CFR $52.47(1)(a)(i v)$ as discussed above, no specific response to Issue B-29 is necessary from either GE or the COL applicant. On this basis, the staff concludes that DFSER
COL Action Item 20.1-1 was not warranted and need not be addressed.

\subsubsection{Issue B-32: Ice Effects on Safety-Related Water Supplies}

This issue addressed the potential effects associated with extreme cold weather and ice buildup on the reliability of various plant water supplies. Of particular concern are events that could affect safety-related water systems and affect the ability of the plant operations staff to safely shut down the plant and provide adequate core cooling.

The DFSER contained a discussion of interface requirements for the UHS necessary to the reliability of this water source. The evaluation concluded that GE needed to require the COL applicant to use site weather conditions to establish the severe weather design envelope for the site. This was identified in the DFSER as COL Action Item 20.1-2.

The staff's evaluation in the DFSER also identified that the interface requirements for the UHS did not explicitly include the RSW system, portions of which have exposed piping that may be vulnerable to the adverse effects of ice, and required GE to address this concern. This was identified in the DFSER as Open Item 20.1-2. The DFSER stated that subject to the acceptable resolution of DFSER Open Item 20.1-2, the staff could conclude that the ABWR design addresses the concerns of Issue B-32.

In the DFSER, the staff also required GE to establish a requirement for the COL applicant to address the capability of the plant-specific RSW system and UHS designs to address the concerns of Issue B-32. This was identified in the DFSER as COL Action Item 20.1-3.

NUREG-0933 shows that Issue B-32 was subsumed by Issue 153 (discussed in Section 20.2.32 of this report). As such, Issue B-32 is not required to be considered separately in meeting the requirements of 10 CFR 52.47(a)(1)(iv). The UHS design and the out-of-scope portions of the RSW will be provided by the COL applicant as part of the COL application in accordance with the interface requirements discussed in Sections 9.2.5 and 9.2.15 of this report. The UHS design and the out-ofscope portions of the RSW will be reviewed at the COL application stage. This approach is acceptable to the staff. In addition, GE has included a COL action item in SSAR Section 2.3.2.14 for the COL applicant to demonstrate that safety-related facilities and water supply are not affected by ice flooding or blockage.

Because Issue B-32 was subsumed by Issue 153, upon further consideration of this information, the staff 
determined that no specific response to Issue B-32 is necessary from either GE or the COL applicant. On this basis, the staff concludes that

DFSER Open Item 20.1-2 was not warranted and need not be addressed. Therefore, DFSER Open Item 20.1-2 is resolved.

DFSER COL Action Items 20.1-2 and 20.1-3 were not warranted and need not be addressed.

See Section 20.2.32 of this report for the staff's evaluation of Issue 153.

\section{1:25 Issue B-36: Develop Design, Testing, and Maintenance Criteria for Atmosphere Cleanup System Air Filtration and Adsorption Units for Engineered Safety Features Systems and Normal Ventilation Systems}

This issue involves developing revisions to current guidance and staff technical positions regarding ESF and normal ventilation system air filtration and adsorption units. Any technological advances leading to better methods and/or standards for the design, testing, and maintenance for these systems in light water-cooled nuclear power plants need to be documented for NRC staff guidance and technical positions.

Guidance on controlling the release of gaseous radioactive effluents to the environment is contained in Revision 1 to RG 1.140, "Design, Testing, and Maintenance Criteria for Normal Ventilation Exhaust System Air Filtration and Adsorption Units of Light-Water-Cooled Nuclear Power Plants, " and Revision 2 to RG 1.52, "Design, Testing and Maintenance Criteria for Postaccident Engineered-SafetyFeature Atmosphere Cleanup System Air Filtration and Adsorption Units of Light-Water-Cooled Nuclear Plants." RG 1.52 provides guidance relating to the design, testing, and maintenance of post-accident ESFs, whereas RG 1.140 applies to the normal ventilation exhaust features.

GE provided the information pertinent to this issue in SSAR Sections 6.4 and 6.5. SSAR Section 6.5.1 states that the filter systems required to perform safety-related functions following a design-basis accident are the standby gas treatment system (SGTS) and the control room portion of the HVAC system.

The SGTS has the capacity to filter the gaseous effluent from the primary containment or from the secondary containment, when required, to limit the discharge of radioactivity to the environment to meet the guidelines of 10 CFR Part 100. GE described the SGTS power generation design basis, safety design basis, system design,
SGTS operation (automatic and manual), and the design evaluation. Compliance with RG 1.52 is also discussed.

SSAR Sections 9.4.1 and 6.4 and Appendices 6A, 6B, 9C, and 9D describe the HVAC system pertinent to control room habitability. The system is designed in conformance with the requirements of GDC 19 and guidelines of RG 1.52 related to the design, testing, and maintenance of post-accident ESFs and ASME N509 and N510.

The radwaste building incinerator offgas exhaust is directed to a separate monitored vent, as described in SSAR Section 9.4.6.5.3. The COL applicant is to provide conformance with RG 1.140 for the radwaste building HVAC system.

Based on this information, the staff concludes that $G E$ adequately addressed this issue for the ABWR design.

\subsubsection{Issue B-55: Improved Reliability of Target Rock Safety-Relief Valves}

The majority of valves in BWR pressure-relief systems are Target Rock SRVs. A significant number of failures of these valves have occurred, which include valves that (1) failed to open properly on demand, (2) opened spuriously and then failed to reseat properly, and (3) opened properly and then failed to reseat properly. The performance of these valves is under continual surveillance and the consequences of their failures are subject to review.

SSAR Section 19B.2.22 states that Target Rock SRVs are not to be used in the ABWR design. The SRVs to be used in the ABWR do not have a pilot stage such as that present in the Target Rock pilot-operated SRVs. The ABWR will use a direct-acting SRV design. Therefore, the mechanisms that cause the pilot valve to fail to open properly have been eliminated from the ABWR design.

Based on this information, the staff concludes that GE adequately addressed this issue for the ABWR design.

\subsubsection{Issue B-56: Diesel Reliability}

If a loss of normally available ac power from the offsite preferred systems occurs at a nuclear power plant, redundant onsite standby ac power sources (diesel generators) provide power for necessary safety functions, which include reactor core decay heat removal, emergency core cooling, and containment heat removal. Therefore, the reliability of the diesel generators is a major factor in ensuring acceptable plant safety.

This issue was promulgated by a review of licensee event reports (LERs) which indicated that the diesel generators 
at operating plants were demonstrating an average starting reliability of about $\mathbf{0 . 9 4}$ per demand. The NRC's goal for new plants, as expressed in Regulatory Guide 1.108, "Periodic Testing of Diesel Generator Units Used as Onsite Electric Power Systems at Nuclear Power Plants," is a diesel generator starting reliability of 0.99 per demand. As part of the resolution of Issue A-44 on station blackout (see Section 20.1.17 of this report), diesel reliability was considered one of the main factors affecting plant risk from station blackout. Thus, attaining and maintaining high diesel generator reliability was a necessary part of the resolution of Issue $A-44$. The Federal Register notice (53 FR 23217) which accompanied 10 CFR 50.63 (station blackout rule) indicated that the resolution of Issue B-56 would provide specific guidance for diesel generator reliability consistent with the resolution of Issue A-44. The specific guidance (the resolution of B-56) has been included as part of Revision 3 of RG 1.9, "Selection, Design, and Qualification of Diesel-Generator Units Used as Standby (Onsite) Electric Power Systems at Nuclear Power Plants" and as part of RG 1.160, "Monitoring the Effectiveness of Maintenance at Nuclear Power Plants." RG 1.160 endorses the guidelines in NUMARC 93-01, "Industry Guideline for Monitoring the Effectiveness of Maintenance at Nuclear Power Plants" (May 1993) as an acceptable method for meeting the requirements of 10 CFR 50.65 (the maintenance rule). With regard to systems and components such as diesel generators, 10 CFR 50.65 requires that:

- the performance or condition of diesel generators be monitored against established goals in a manner sufficient to provide reasonable assurance that the diesel generators are capable of fulfilling their intended functions,

- goals be established commensurate with safety and to take into account industry wide operating experience,

- appropriate corrective action be taken when the performance or condition of the diesel generators do not meet established goals,

- diesel generator performance and condition monitoring activities and associated goals and preventive maintenance activities be periodically evaluated, taking into account industry wide operating experience, and

- adjustments be made where necessary to ensure that the objective of preventing failure of diesel generators through maintenance is appropriately balanced against the objective of minimizing unavailability of diesel generators due to monitoring or preventive maintenance.
Revision 3 of RG 1.9 integrated into a single regulatory guide guidance previously addressed in other documents such as Revision 2 of RG 1.9, Revision 1 of RG 1.108, and Generic Letter 84-15.

With respect to diesel generator reliability (compliance with Issue B-56), the ABWR SSAR indicates the following:

a. Diesel generators will be required to be capable of reaching full speed and voltage within 20 seconds after the signal to start (Section 8.3.1.1.8.2(4) of SSAR Amendment 34).

b. For the COL license, the COL applicant will be required to have appropriate plant procedures for periodic testing of diesel generator start capability (Section 8.3.4.36 of SSAR Amendment 33). In particular,

- Appropriate plant procedures will include the requirement that the interval between periodic start test for diesel generators will be no longer than 31 days (Section 6.5.1 of IEEE 387-1984), and

- Diesel generator start testing may, once per 6 months, be replaced with a modified diesel generator start involving idling and gradual acceleration to synchronous speed as recommended by the manufacturer (Technical Specification guidelines in Section 16.3.8 (SR 3.8.1.2) of SSAR Amendment 34).

c. As part of the COL license, the COL applicant will be required to demonstrate the start reliability of the diesel generators (Section 8.3.4.2 of SSAR Amendment 34). Specifically,

- The preoperational test program will demonstrato the required reliability by means of 25 start demands without failure on each installed diesel generator unit (Section 14.2.12.1.45.3(l) of SSAR Amendment 34 and Position C.2.3.1 of RG 1.9 (F.ev. 3)).

- Periodic testing at intervals of no longer than 31 days will commence within 31 days following completion of preoperational testing for diesel generator start reliability (Position C.2.3.2.1 of RG 1.9, Rev. 3)).

- Performance criteria and goals for diesel generator start and loading reliability will be set at 0.975 per demand as part of the COL licensee's program for 
assuring diesel generator reliability. The SSAR indicates:

- Diesel generator start reliability of 0.986 per demand can be achieved as shown by industry experience (Section 19B.2.23 of SSAR Amendment 34).

- A diesel generator reliability of 0.975 per demand was assumed for station blackout considerations (Table 1C-1 of SSAR Amendment 32).

- A diesel generator reliability of 0.975 per demand was used in the ABWR PRA analysis (Table 1C-1 of SSAR Amendment 32).

- Performance criteria for both diesel gencrator reliability and unavailability will be established to assure that the performance or condition of the diesel generators is being effectively controlled through the performance of appropriate preventive maintenance, such that the diesel generator remains capable of performing its intended function (Section B of RG 1.160). The SSAR states:

- Performance criteria for reliability will be met by the absence of a maintenance-preventable failure, or the occurrence of a single maintenance. preventable failure, followed by appropriate root cause determination and corrective action.

- Performance criteria for unavailability will be met by having fewer unavailable hours, on a rolling 1-year basis, than required by the established performance criteria.

- If performance criteria is not met or a second diesel generator maintenance-preventable failure occurs, diesel generator performance goals will be established and the performance or condition of the diesel generators will be monitored in a manner sufficient to provide reasonable assurance that the diesel generators are capable of fulfilling their intended functions consistent with an appropriate balance between diesel generator reliability and unavailability (Section B of RG 1.160).

- Periodic adjustments will be made where necessary to ensure that the objective of preventing failures of the diesel generator through maintenance will be appropriately balanced against the objective of minimizing unavailability of the diesel generator due to monitoring or preventive maintenance (Section B of RG 1.160).
The staff concludes that a diesel generator testing and reliability program which meets the above described commitments will assure an acceptable level of diesel reliability in accordance with the objectives of Issues B-56 and $A-44$ and will meet the above defined requirements of 10 CFR 50.65. Because COL applicants will be required to have a diesel generator test and reliability program for their license which meets the above described commitments, or an acceptable alternative method, the staff concludes that GE adequately addressed this issue for the $A B W R$ design.

\subsubsection{Issue B-61: Allowable ECCS Equipment Outage Periods}

This issue concerns establishing surveillance test intervals and allowable equipment outage periods, using analytically based criteria and methods for TS. The present TS allowable equipment outage intervals and test intervals were determined primarily on the basis of engineering judgement. Studies performed by the NRC on operating reactors indicated that from 30 to 80 percent of the ECCS system unavailability was a result of testing, maintenance, and allowed outage periods. Therefore, by optimizing the allowed outage period and the test and maintenance interval, the equipment unavailability and public risk can be reduced.

The review criteria for this issue consist of the techniques and methods available and the modeling from the Interim Reliability Evaluation Program (IREP) and the National Reliability Evaluation Program (NREP), the optimum equipment test intervals and allowable equipment downtimes. Also, since the ABWR evolved primarily from the BWR/6 design, most of the ABWR TS that control the ECCS outage periods, were modeled after NUREG-1433, "Standard Technical Specifications General Electric Plants, BWR/6." Furthermore, the criteria for resolution of this issue incorporated the accumulated experience from currently operating light water reactors.

SSAR Section 19B.2.24 states that the ABWR design incorporates many design enhancements to improve the operation and safety of the plant, and the most significant advances are in the area of ESFs. Based on the review of the information provided in the SSAR, the staff agreed with GE that the $A B W R$ design includes redundancy for the ESF systems beyond that for currently operating BWR plants. This added redundancy allows for extending the associated completion times (CTs) beyond those specified for ESF systems on currently operating BWR plants, thereby facilitating maintenance on certain subsystems. This relaxation ranges from 8 hours to 14 days, and is based on probabilistic risk analysis (PRA), engineering 
evaluation, operating experience, and judgement for various components and combinations of components.

The PRA performed by GE used a system fault tree approach to quantify system accident sequences that result in severe core damage. Data related to the ESF used in the quantification included:

- Component failure rates

- Component repair times and maintenance frequencies

- Component inspection and test times and frequencies

- Allowable equipment completion times

The data used were in accordance with the guidance in NUREG/CR-2815, "Probabilistic Safety Analysis Procedures Guide," and basic failure rate data were obtained from the EPRI ALWR Requirements Document, supplemented by other nuclear sources. The staff reviewed the ABWR TS and concluded that the CTs contained therein are considered appropriate by the staff. The staff concludes that GE adequately addressed this issue for the ABWR design.

\subsubsection{Issue B-63: Isolation of Low-Pressure Systems Connected to the Reactor Coolant Pressure Boundary}

These generic issues, combined with Issue 96, "RHR Suction Valve Testing," (subsumed by Issue 105, "Interfacing Systems LOCA at LWRs") concern the common area of the ABWR, namely, the systems connected to the RCS pressure boundary that are considerably below the RCS operating pressure. The NRC has required that valves forming the interface between these high and low systems and the associated piping have sufficient redundancy to assure that the low-pressure systems are not subjected to pressure that exceeds their design limits.

Issue B-63 was resolved by the staff and implemented by MPA B-45, "Event V, Primary Coolant System Pressure Isolation Valves," which required leak testing of these check valves in accordance with plant-specific technical specifications. For the ABWR, SSAR Section 19B.2.25 states that test requirements for these valves are in SSAR Section 3.9.6, "Testing of Pumps and Valves." SSAR Table 3.9-9 provides a list of all the ABWR reactor coolant system pressure isolation valves. Section 3.9.6 states that all of the valves in this table will be periodically leak tested in accordance with the surveillance requirements in SSAR Chapter 16, "Technical Specifications." As discussed in Section 3.9.6.2.4 of this report, the staff reviewed the applicable information in SSAR Section 3.9.6 and concluded that it is acceptable.
On the basis the above discussion, the staff concludes that GE adequately addressed these issues for the ABWR.

\subsubsection{Issue B-66: Control Room Infiltration Measurements}

This issue addresses the concerns that the control room may not be in a safe, habitable condition under accident conditions and may not provide adequate protection for the plant operators against the effects of accidental releases of airborne radioactivity and toxic gases. The rate of air infiltration into the control room is a significant factor in maintaining habitability, and the NRC measured air exchange rates in selected operating reactor plant control rooms to improve the data base for evaluating its effects. No new design requirements were established by the NRC as a result of this and other work related to control room habitability in an accident. However, more specific review procedures were incorporated in SRP Sections 6.4, 6.5.1, and 9.4.1, including the habitability review provisions of TMI Action Plan Item III.D.3.4 (see Section 20.4.87 of this report) regarding analyses of toxic gas concentrations and operator exposures from airborne radioactive material and direct radiation, to ensure more effective implementation of existing requirements.

The review criterion for the resolution of this issue is that the control room ventilation and air conditioning systems be designed to maintain the room's environment within acceptable limits for the operation, testing, and maintenance of the unit controls and the uninterrupted safe occupancy during normal and accident conditions.

SSAR Sections 9.4.1, 6.4, and 19B.2.26 state that the systems incorporated in the design of the control room ventilation and air conditioning will meet the intent of the guidance given in SRP Sections 6.4, 6.5.1, and 9.4.1. More specifically, these systems are designed to meet the intent of the guidance given in SRP Sections 6.4, 6.5.1, 9.4.1, and 15.6.5.5 (all Rev. 2). Under normal operation, the control room HVAC provides HVAC functions and pressurization inside the main control area envelope (MCAE) using a combination of filtered outdoor air and recirculated indoor air.

The emergency recirculation system consists of an electric heating coil, a prefilter, pre-high-efficiency particulate (HEPA) filter, charcoal absorber, post-HEPA, and two 100-percent capacity circulating fans. Independent and separate discharge to and return from the MCAE to each filtration unit is provided. All control room HVAC equipment, including the ductwork (which is termed ESF), 
and surrounding structures are seismic Category I design and operable during loss of offsite power supply.

ABWR design features regarding control room habitability and the HVAC are described in the SSAR Sections 9.4.1 and 6.4. The filtration units conform to the guidance of RG 1.52, and the requirements of ANSI ASME N509 and ASME N510, "Testing of Nuclear Air-Cleaning Systems." SSAR Appendices 9C and 9D provide detailed information regarding $A B W R$ conformance with $R G 1.52$ and SRP Table 6.5.1-1.

In Amendment 32, GE revised SSAR Sections 9.4.1.1.4 and 9.4.1.1.5 to state that the galvanized steel (American Society for Testing and Materials (ASTM) A526 or A527) is used for outdoor air intake and exhaust ducts and all other ducts (CRHS HVAC system) are welded, black steel ASTM A570, Grade A or Grade D. In Amendment 34, GE revised SSAR Section 9.4.1.1.5 to stats that unfiltered in-leakage testing will be periodically performed on all ductworks and housing outside the MCAE in accordance with ASME N510. Based on the information provided in SSAR Sections 19B.2.26, 9.4.1, and 6.4 and Appendi$\operatorname{ces}$ 9C and 9D that the appropriate plant-specific procedures will be developed to address MCR infiltration measurements, to preclude any unfiltered in-leakage not credited in dose analysis, in accordance with the above requirements.

On the basis of this information, the staff concludes that GE adequately addressed this issue for the ABWR design.

\subsubsection{Issue C-1: Assurance of Continuous Long- Term Capability of Hermetic Seals on Instrumentation and Electrical Equipment}

This issue concerns the long-term capability of hermetically sealed instruments and equipment that must function in post-accident conditions. More specifically, certain classes of instrumentation that are equipped with seals are sensitive to steam and vapor. If the seals become defective as a result of personnel error in the maintenance of such equipment, such errors could lead to the loss of a seal and of equipment functionality. The objective of this issue is to establish confidence that sensitive equipment has an effective seal for the lifetime of the plant.

The review criterion for this issue is compliance with the review criteria of SRP Section 3.11 for environmental qualification of electrical equipment.

SSAR Section 19B.2.17 refers to SSAR Section 3.11, "Environmental Qualification of Safety-Related Mechanical and Electrical Equipment," which defines the environmental conditions with respect to limiting design conditions for all safety-related mechanical and electrical equipment. Safety-related equipment located in a harsh environment must perform its proper safety function during normal, abnormal, test, DBA, and post-accident environments, as applicable. A list of all safety-related electrical and mechanical equipment required for safo shutdown that is located in a harsh environment are will be included in the Environmental Qualification Document as stated in SSAR Section 3.11.6.1.

Environmental conditions for the zones where safetyrelated equipment is located are calculated for normal, abnormal, test, accident, and post-accident conditions and are documented in SSAR Appendix 3I, "Equipment Qualification Environmental Design C cteria." Environmental conditions are tabulated by zones contained in the referenced building arrangements.

Safety-related electrical equipment that is located in a harsh environment is qualified by test or other methods, as described in IEEE 323 and permitted by 10 CFR 50.49(f). The qualification methodology is described in detail in the NRC-approved report, NEDE-24326-1-P. This report also addresses compliance with the applicable portions of 10 CFR Part 50, Appendix A and the quality assurance criteria of 10 CFR Part 50, Appendix B. Additionally, the report describes conformance to NIJREG-0588 and the RGs and IEEE standards referenced in SRP Section 3.11.

Based on the above discussion, since safety-related electrical equipment for the ABWR will be qualified in accordance with applicable guidance, including NUREG0588, the staff concludes that GE adequately addressed this issue for the $A B W R$ design.

Details on the staff's evaluation of environmental qualification of safety-related electrical equipment are provided in Section 3.11 of this report.

\subsubsection{Issue C-8: Main Steam Line Leakage Control Systems}

Dose calculations in 1975 by NRC's former Accident Analysis Branch indicated that operation of the main steam isolation valve leakage control system (MSIVLCS) required for some BWRs could result in higher offsite accident doses than if the system were not used and the integrity of the steam lines and condenser was maintained. This issue was initiated to investigate whether the MSIVLCS recommended in RG 1.96, "Design of Main Steam Isolation Valve Leakage Control Systems for Boiling Water Reartor Nuclear Power Plants," was desirable. This issue was resolved without the establishment of now requirements. The main steam system of BWR designs is expected to meet GDC 54. RG 1.96 describes a means 
accuptable to the staff for implementing GDC 54 with regard to the design of an MSIVLCS that ensures that total radiological effects do not exceed the guidelines of 10 CFR Part 100 in the event of a postulated design-basis LOCA.

Since this issue was resolved without the establishment of new requirements, it does not need to be addressed in the ABWR design certification review. A discussion of the ABWR approach to the MSIVLCS issue is provided here for information purposes only.

The A.BWR design does not incorporate a MSIVLCS, but utilizes an alternative approach as permitted by RG 1.96 . RG 1.96 indicates that an LCS is not required if the main steam line leakage path can be relied on to remain intact and capable of providing significant dose reduction factors for postulated accident conditions. A description and the staff's evaluation of the ABWR's method of containing and holding up MSIV leakages following a design-basis LOCA are addressed in Section 10.3.1 of this report. Evaluation of the seismic and radiological analyses of the main steam and condenser systems' capability to perform this postLOCA function is provided in Sections 3.2.1 and 15.4.4.2, respectively, of this report.

\subsubsection{Issue C-10: Effective Operation of Containment Sprays in a LOCA}

This issue deals with the effectiveness of various containment sprays to remove airborne radioactive materials that could be present within the containment following a LOCA. This concern includes the possible damage to equipment located inside the containment because of inadvertent actuation of the sprays.

The review criteria for this issue are that the containment spray system will be designed to meet the requirements of GDC 41, 42, and 43 of 10 CFR Part 50, Appendix A, related to fission product removal, periodic inspection, and functional testing, respectively, by conforming to the guidance of SRP Section 6.5.2, Revision 2.

SSAR Section 19B.2.28 states that the RHR system provides two independent containment spray cooling systems (on loops B and C), each having a common header in the wetwell and a common spray in the drywell, and sufficient capacity for containment depressurization by removing heat and condensing steam in both the drywell and wetwell air volumes following a LOCA. All components of the RHR containment spray system can be inspected and tested during normal plant operation or during refueling and maintenance outages. The ABWR design does not take credit for any fission product removal provided by the drywell and wetwell spray portion of the RHR system. The removal of fission products is controlled by the SGTS, which has the redundancy and capability to filter the gaseous effluent from the primary and secondary containment. However, the drywell sprays off the RHR system also function to provide removal of fission products during a LOCA, as well as in the event of failure of the drywell head. The drywell spray is initiated by operator action post-LOCA in the presence of high drywell pressure and is terminated by operator action. It is also terminated automatically as the RHR injection valve starts to open.

The water in the $304 \mathrm{~L}$ stainless-steel-lined suppression pool is maintained at high purity by the suppression pool cleanup (SPCU) system. The $\mathrm{pH}$ range is maintained between 5.3 and 8.6 to minimize any corrosive attack on the pool liner over the life of the plant. The protective epoxy coatings applied on the carbon steel containment liner, internal steel structures and equipment inside the drywell and wetwell meet the guidance of RG 1.54, "Quality Assurance Requirements for Protective Coatings Applied to Water-Cooled Nuclear Power Plants, " and are qualified using the tests in accordance with ANSI N101.4, "Quality Assurance for Protective Coatings Applied to Nuclear Facilities."

On the basis of this information, the staff concludes that $G E$ adequately addressed this issue for the ABWR design.

\subsubsection{Issue C-17: Interim Acceptance Criteria for Solidification Agents for Radioactive Solid Wastes}

This issue concerns lack of criteria for acceptability of solidification agents for radioactive solid wastes.

The review criteria for this issue are contained in 10 CFR Part 61, which was published in the Federal Register on December 27, 1982, and includes Section 61.56, which addresses waste characteristics. Also, BTP ETSB-11-3, "Design Guidance for Solid Radioactive Waste Management Systems Installed in Light-Water-Cooled Nuclear Power Plants, " was developed under TMI Action Plan Item IV.C. 1 before the issuance of 10 CFR 61.56. Evaluation of this issue is based on these documents.

SSAR Section 19B.2.29 states that the ABWR design will comply with the requirements of the 10 CFR 61.56 regarding waste characteristics. The establishment and implementation of a process control program (PCP) for solidifying the evaporator concentrates (the applicable plant waste will be solidified) using an approved solidification agent is dependent on the as-procured equipment for the ABWR standard design. Therefore, the staff will review the PCP on a plant-specific basis. The staff verified that GE established a COL action item in SSAR 
Section 11.4.3.1 to provide a PCP for solidifying the ovaporator concentrates using an approvad solidification agent and to demonstrate that the wet solidification process will result in a product that complies with 10 CFR 61.56 regarding waste characteristics. The staff finds this approach acceptable, and therefore, concludes that GE adequately addressed this issue for the ABWR design.

\subsubsection{Other Issues}

\subsubsection{Issue A-43: Containment Emergency Sump Performance}

This issue concerns the availability of adequate recirculation cooling water following a LOCA when longterm recirculation of cooling water (from the PWR containment sump or the BWR RHR system suction intake) must be initiated to prevent core melt. This water must be sufficiently free of LOCA-generated debris and potential air ingestion so that pump performance is not impaired, thereby seriously degrading long-term recirculation flow capability. Issue A-43 was resolved with the issuance of RG 1.82 (Rev. 1), "Water Sources for Long-Term Recirculation Cooling Following a Loss-of-Coolant Accident."

NUREG-0933, Appendix B indicates that this issue is not applicable to BWRs, therefore, GE did not specifically address it in SSAR Appendix 19B. However, the staff evaluated GE's compliance with RG 1.82 (Rev. 1) and supplemental staff positions and found it to be acceptable. Refer to Sections 6.2.1.9 and 6.2.2 of this report for the staff's evaluation.

\section{$20.2 \quad N e w$ Generic Issues}

This section addresses staff evaluation of GSIs that are categorized as "new generic issues" in NUREG-0933. All the following issues, with the exception of Issue 130 (which was evaluated in the DFSER) are relevant to the ABWR design. Issue 130 is discussed here for continuity oniy.

20.2.1

Issue 15: Radiation Effects on Reactor Vessel Supports

This issue addresses the potential problem of radiation embrittlement of reactor vessel support structures. Neutron damage of structural materials causes embrittlement that may increase the potential for propagation of flaws that might exist in the materials. The potential for brittle fracture of these materials is typically measured in terms of the material's nil ductility transition temperature (NDTT), which is the lowest temperature at which the material would not be susceptible to failure by brittle fracture. As long as the operating environment in which the materials are used has a higher temperature than the material's NDTT, no failure by brittle fracture would be expected. Recent studies of steel materials indicate that the NDTT may shift upwards (towards the operating temperature) as a result of exposure to neutron irradiation.

For a structural material to be susceptible to a brittle failure, several conditions must be met simultaneously. These conditions are that (a) there must be a flaw of critical size, (b) there must be a load that develops a tensile stress, and (c) the service temperature must be at or below the NDTT of the material. This last condition is affected by the neutron flux to which the element is exposed. Thus, the evaluation of the resolution of this issue depends on the assessment of the conditions stated above.

The ABWR RPV support consists of a support skirt bolted to the support pedestal. The skirt is located below the core beltline and slightly below the core support plate. It follows that the skirt is in a low neutron flux area because it is located below the core beltline. Additional shielding is provided by water flow between the vessel shroud and the vessel wall. In this situation, the effects of neutron flux would be negligible. Based on this information, the staff determined that this issue is not applicable to the ABWR design and concludes that GE adequately addressed this issue for the $A B W R$ design.

\subsubsection{Issue 23: Reactor Coolant Pump Seal Failures}

This issue concerns the high rate of reactor coolant pump (RCP) seal failures that challenge the makeup capacity of the ECCS in pressurized water reactors (PWRs) which could result in a small-break loss-of-coolant-accident (SBLOCA) and possibly in core damage. RCP seal failures in BWRs occur at a frequency similar to that experienced in PWRs, but the operating experience indicates that the problem in BWRs is mitigated by smaller leak rate, larger RCIC, high-pressure coolant injection (HPCI), and feedwater makeup capabilities.

The review criteria for RCP seal acceptability is to limit the possibility of an SBLOCA (which might lead to core damage) resulting from an RCP shaft seal failure. In particular, susceptibility of the auxiliary systems to failure because of an SBO should be addressed.

SSAR Section 1A.2.30 states that the ABWR wet motor RIPs do not include seals. During a loss of preferred power (LOPP), the RIPs shutdown automatically. There are no shaft seals which require cooling water restoration. Based on this information, the staff determined that this 
issue does not apply to the ABWR design and concludes that GE adequately addressed this issue for the ABWR design.

\subsubsection{Issue 25: Automatic Air Header Dump on BWR Scram System}

This issue concerns the slow loss of control air pressure in the scram system of BWRs. Air pressure dropping at a certain rate will first allow some of the control rod drive (CRD) scram outlet valves to open slightly, thus filling the scram discharge volume (SDV) with water, but allowing little or no control rod movement. Eventually, the rods will try to scram but the scram will bo impaired. Meanwhile, the dropping air pressure may cause a transient (e.g., via controller lockup), which would normally call for a scram.

The review criteria for this issue are stated in an NRC memorandum for G. Lainas, et al., from P. Check, "BWR Scram Discharge System Safety Evaluation," dated December 1, 1980.

SSAR Section 19B.2.32 states that the ABWR is different from other BWRs in that there is no SDV exploying the locking piston control rod drive in this design. For the ABWR fine motion control rod drive (FMCRD) design, scram water is discharged directly into the reactor vessel, instead of the discharge volume, as was done in previous BWR designs. The ABWR has no SDV as does previous BWR designs.

Two other features are incorporated in the design of the ABWR:

- A scram air header low-pressure alarm to alert the operator of a low pressure in the header. The pressure in the header is maintained higher than that at which the scram valves start to open and the set point is set at a sufficient margin to alert the operator to take corrective action.

- A rod block and alarm initiated by low pressure and a scram initiated by low-low pressure in the common header supplying the charging water to the scram accumulators. The accumulators have sufficient water volume to scram the associated control rods as long as the CRD system pump maintains the pressure in the charging header above the minimum required accumulator charging pressure. If pressure in the header drops below the acceptable level, the instrumentation located in the charging header will initiate an immediate scram. Thus, the accumulator charging header low pressure causes the automatic shutdown before the accumulator is depleted.

The ABWR design incorporates two features to prevent the loss or impairment of the scram function because of slow loss of control air in the system: (1) a low pressure alarm to alert the operator to trouble in the scram air header and (2) an accumulator charging header low pressure scram to automatically shut down the plant before the accumulator is depleted. Based on this information, the staff concludes that GE adequately addressed this issue for the ABWR design.

\subsubsection{Issue 29: Bolting Degradation or Failure in Nuclear Power Plants}

This issue addresses degradation of bolts in nuclear power plants, especially those constituting an integral part of the primary pressure boundary, such as closure studs and bolts on reactor vessels, reactor coolant pumps, and other safety-related equipment and components. Failure of these bolts or studs could result in a loss of reactor coolant and thus jeopardize the safe operation of a plant. There is also a concern regarding bolts used as component supports or embedment anchor bolts that are essential for withstanding transient loads resulting from abnormal or accident conditions. This issue was resolved without the establishment of any new requirements.

The review criteria used for evaluating this issue are taken from NUREG-1339, "Resolution of Generic Safety Issue 29: Bolting Degradation or Failure in Nuclear Power Plants." More specifically, proven bolting designs and selection of proper materials and fabrication techniques should be employed to assure acceptable performance of bolts and studs used in vital areas of nuclear power plants.

In SSAR Section 19B.2.62, GE states that for the ABWR designs only proven materials for the specific application and environment will be employed. The materials will be selected after evaluation of the potential for corrosion wastage and IGSCC. Also, the RCPB components and their integral bolts, including the reactor vessel, renctor coolant pumps, and piping will be fabricated, tested, and installed in accordance with the requirements of the ASME Code, Sections III and XI. The ABWR design will also comply with the guidelines of NUREG-1339; EPRI NP-5769, "Degradation and Failure of Bolting in Nuclear Power Plants;" and GL 91-17, "Generic Safety Issue 29, 'Bolting Degradation of Failure in Nuclear Power Plants'."

This approach is acceptable to the staff and, therefore, the staff concludes that GE adequately addressed this issue for the ABWR design. 


\subsubsection{Issue 40: Safety Concerns Associated With Pipe Breaks in the BWR Scram System}

This issue is concerned with a possibility of a break or leak in the scram discharge volume (SDV) during a reactor scram. If such a leak or break develops, it would result in the release of water and steam at $100^{\circ} \mathrm{C}\left(212^{\circ} \mathrm{F}\right)$ into the reactor building at a maximum flow rate of $2,082 \mathrm{Lpm}$ $(550 \mathrm{gpm})$ and it is postulated to result in 100-percent relative humidity in the reactor building. This could be mitigated by closing the scram exhaust valves that are located on the hydraulic control units, but this depends upon ability to reset the scram, which cannot be absolutely assured immediately following the scram. Therefore, a rupture of the SDV could result in an unisolable break outside of primary containment. This break is postulated to threaten emergency core cooling equipment by flooding areas in which this equipment is located and by causing ambient temperature and relative humidity conditions for which this equipment is not qualified.

The review criteria for this issue are stated in the NUREG-0803, "Generic Safety Evaluation Report Regarding Integrity of BWR Scram System Piping," which provides guidance to ensure pipe integrity, detection capability, mitigation capability, and qualification of the emergency equipment to the expected environment.

This issue is not applicable to the ABWR design. SSAR Sections 4.6 and 19B.2.33 state that for the FMCRD design, scram water is discharged through the drive directly into the reactor vessel. There are no CRD withdraw lines or SDV as used in previous BWR designs employing the locking piston control rod drive. Consequently, the safety concerns associated with pipe break are not applicable to the ABWR. The staff concludes that $G E$ adequately addressed this issue for the ABWR design.

\subsubsection{Issue 45: Inoperability of Instrumentation Due to Extreme Cold Weather}

This issue was raised after an event at Arkansas Nuclear One, Unit 2, in which all four refueling water storage tank (RWST) instrumentation channels were lost when the level transmitters froze. The system heat-tracing circuit was deenergized because the main line fuse was removed. This situation would have prevented the automatic changeover of the ECC from the injection to the recirculation mode under LOCA conditions, that is, a loss of safety function could have occurred. Typical safety-related systems employ pressure and level sensors that use small bore instrumentation lines. Most operating plants contain safety-related equipment and systems, parts of which are exposed to the ambient environment. These lines contain liquid that is susceptible to freezing. Where systems or components and their associated instrumentation are exposed to subfreezing temperatures, heat tracing and/or insulation should be used to mitigate the effects of cold temperatures.

The review criterion for this issue is that the fluid in safety-related instrument sensing lines must bo protected from freezing and maintained above the precipitation point. Guidance on the design of protective measures against freezing in instrument lines of safety-related systems are stated in the RG 1.151, "Instrument Sensing Lines." RG 1.151 endorses and augments the Instrument Society of America (ISA) standard ISA-S67.02 (1980), "NuclearSafety-Related Instrument Sensing Line Piping and Tubing Standards for Use in Nuclear Power Plants." RG 1.151 augments ISA-S67 by indicating that freezing temperatures be added to the environmental and installation conditions of the standard and that special considerations in the design of instrument sensing lines include freezing temperatures. Further guidance is provided in SRP Sections 7.1, Revision 3; Section 7.1, Appendix A, Revision 1; Section 7.5, Revision 3; and Section 7.7, Revision 3. SRP Section 7.1 provides for identification of the I\&C systems important to safety. The acceptance criteria consist of the GDC (identified is SRP Table 7.1) and IEEE 279, "Criteria for Protection Systems for Nuclear Power Generating Stations." SRP Section 7.5 provides that the information systems impurtant to safety provide the operator with the information on the status of the plant to allow manual safety actions to be performed when necessary. SRP Section 7.7 provides that the control systems used for normal operation, that are not relied upon to perform safety functions, but which control plant processes having a significant impact on plant safety, be acceptable and meet the relevant requirements of GDC 13 and 19.

As a proposed resolution of this issue, SSAR Section 19B.2.34 states that all safety-related systems and components used in the $A B W R$ design, including instrument sensing lines, will be located in temperaturecontrolled environments. These environments will be maintained above the freezing (or precipitation) point of the contained fluid. SSAR Appendix 3I demonstrates that the temperature of these environments is not expected to be below $10^{\circ} \mathrm{C}\left(50^{\circ} \mathrm{F}\right)$. The section also states that the ABWR will meet the guidance of RG 1.151.

Based on this information, the staff concludes that GE adequately addressed this issue for the ABWR design. 
20.2.7 Issue 51: Proposed Requirements for Improving the Reliability of. Open Cycle Service Water Systems

This issue addresses the subject of service water system (SWS) fouling at operating plants by aquatic bivalves. The SWS is the UHS that, during an accident or transient, cools the reactor building component cooling water heat exchangers, which in turn cool the RHR heat exchangers, as well as provide cooling for safety-related pumps and area cooling coils. Fouling of the safety-related SWS either by mud, silt, corrosion products, or aquatic bivalves has led to plant shutdowns, reduced power operation for repairs and modifications, and degraded modes of operation.

The review criteria for this issue consist of elimination of the possible effects of fouling of SWS and UHSs.

SSAR Section 19B.2.35 indicates that the COL applicant is given specific requirements and guidance on achieving this goal, iucluding instructions to consider designs and new requirements that further mitigate the fouling effects. Additionally, the COL applicant is directed to investigate the problem with ice as a flow blockage mechanism and to dispose of and/or dissolve such ice, as required.

The staff studied the conditions that allow fouling and compared alternative surveillance and control programs to minimize SWS fouling. The staff's technical findings were published in NUREG/CR-5210, "Technical Findings Document for Generic Issue 51: Improving the Reliability of Open-Cycle Service-Water Systems."

SSAR Section 19B.2.35 states that the design basis for the SWS is in accordance with the EPRI ALWR Requirements Document and RG 1.27, "Ultimate Heat Sink for Nuclear Power Plants" (Rev. 2). The specifics of the design basis are given in SSAR Section 19B.2.35 as follows. Section 19B.2.35 states that the direct service water will not be used for component cooling. A closed-loop component cooling system will be used to transfer heat from the component heat loads via a heat exchanger to the SWS and ultimate heat sink. This design will minimize the number of pieces of equipment that could be in contact with the problem-causing service water. Additionally, the COL applicant will treat raw service water to reduce the effects of mud, silt and/or organisms, will select the materials for piping, pumps, and heat exchangers to offer greater resistance to the probable water chemistry, and will provide for inspections and replacements of piping during plant life. The COL applicant will also provide sufficient redundancy of makeup pumps for the UHS to allow for malfunction of one of them according to the guidelines of RG 1.27 (Rev. 2) and provide the safety-related portions of the systems to meet the design bases during a loss of power. These systems will be designed to perform their cooling function assuming a single active failure in any mechanical or electrical system.

GE identified this issue as a COL applicant action in SSAR Section 9.2.15.2.2, "Power Generation Design Bases (Interface Requiremints)," and in SSAR Section 9.2.15.2.3, "System Description (Conceptual Design)." The staff verified that GE established a COL action item (Item 9-12) in SSAR Table 1.9-1. The staff also verified that SSAR Section 9.2.17.2, "COL License Information, Reactor Service Water System Requirements," addresses measures that will be used to prevent organic fouling, erosion, and corrosion. This approach is acceptable to the staff. However, the staff will review the COL applicant's proposed resolution of this issue on a case-by-case basis.

Based on this information, the staff concludes that GE adequately addressed this issue for the ABWR design.

\subsubsection{Issue 57: Effects of Fire Protection System Actuation on Safety-Related Equipment}

This issue addresses fire protection system (FPS) actuations that have resulted in adverse interactions with safety-related equipment at operating nuclear power plants. Events have shown that safety-related equipment subjected to FPS water spray could be rendered inoperable and that numerous spurious actuations of the FPS have been initiated by operator testing errors or by maintenance activities, steam, or high humidity in the vicinity of FPS detectors. The NRC issued Office of Inspection and Enforcement (IE) Information Notice 83-41, "Actuation of Fire Suppression System Causing Inoperability of SafetyRelated Equipment," to alert licensees and provide recent examples in which FPS actuations caused damago or inoperability of systems important to safety. In addition, the staff is considering the need for modifying FPS requirements or licensing review procedures.

The review criterion for this issue is to verify, per GDC 3 of 10 CFR Part 50, Appendix A, that a fire detection and fighting system of appropriate capacity shall be provided and designed to minimize the adverse effects of fires on structures, systems, and components important to safety. It further states that fire fighting systems shall be designed to assure that their rupture or inadvertent operation does not significantly impair the safety capability of those structures and components. Criteria in BTP CMEB 9.5-1, Section C.7.1, state that automatic fire suppression should be installed to combat any diesel generator or lubricating oil fires; such systems should be designed for operation when the diesel is running without affecting the diesel. 
SSA'R Section 19B.2.36 stutes that the ABWR incorporates design features that prevent the inadvertent actuation of fire protection systems and limit the effects of water spray onto safety-related equipment. The automatic fire suppression systems protecting the safety-related equipment are of the preaction automatic type that require the detection of a fire by infrared and/or rate-of-rise heat detectors, and that require the opening of the fusible link sprinkler heads. Furthermore, each division has its own dedicated detection and actuation equipment for the control of the automatic closed head sprinklers in that divisional area. The first of the two actuation signals required to initiate the fire suppression system will annunciate an alarm to alert the operator to any potential problem. The operator has the capability of terminating the flow of fire suppressant locally by manual isolation valve.

The safety-related equipment that could be damaged because of flooding discharge of a sprinkler system is further protected by being elevated and by providing adequate drainage.

Based on this information, the staff concludes that GE adequately addressed this issue for the ABWR design.

\subsubsection{Issue 67.3.3: Steam Generator Staff Actions - Improved Accident Monitoring}

This issue addresses several weaknesses in accident monitoring that were observed at the Ginna Nuclear Plant. More precisely, they included (1) non-redundant monitoring of RCS pressure, (2) failure of the position indication for the steam generator relief and safety valves, and (3) the limited range of the charging pump flow indicator for monitoring charging flow during accidents. Under these conditions, it is difficult for the operating personnel to decide what corrective action they should take in situations when such an action is needed.

The review criteria used for this issue are those contained in the RG 1.97, (Rev. 3), "Instrumentation for LightWater-Cooled Nuclear Power Plants to Assess Plant Conditions and Environs During and Following an Accident." RG 1.97 describes the methods acceptable to the NRC staff for complying with the Commission's requirements to provide instrumentation to monitor plant variables and systems during and following an accident in a nuclear plant. It describes the parameters that are necessary for the operating personnel to be monitored so that an appropriate corrective action could be taken. It also sets the requirements for the instrumentation to be functional in case of an emergency.

SSAR Section 19B.2.37 states that the ABWR has implemented into its basic design the guidance of RG 1.97 and the TMI Action Plan requirements of NUREG-0737 and NUREG-0737, Supplement 1. Section 19B.2.37 refers also to Section 7.5.1.1, Table 7.5.2, and SSAR Section 18.2. Section 7.5.1.1 describes the design features of the plant that indicate its conformance to the provisions of RG 1.97. Plant variables are defined in conformasuce to the definitions contained in the RG and consist of five "types" and three "categories," also according to the RG. SSAR Table 7.5-3 lists 12 Type A "variables," such as neutron flux, RPV water level, and RPV pressure.

SSAR Section 18.2 states that during all phases of normal plant operation, abnormal events, and emergency conditions, the ABWR will be operable by two reactor operators. In addition, the operating crew will include one assistant control room shift supervisor, one control room shift supervisor, and two or more auxiliary equipment operators. Four licensed operators will be on shift at all times, consistent with the staffing requirements of 10 CFR $50.54(\mathrm{~m})$. The main control room staff size and roles will be evaluated and implemented by the COL applicant. The staff verified that GE established a COL action item in SSAR Section 18.8.2 regarding the adequacy of control room staffing. The design acceptance criteria (DAC)/ITAAC will further ensure compliance with the HFE design and implementation process with regard to the control room and the remote shutdown station.

Based on this information, the staff concludes that $G E$ adequately addressed this issue for the ABWR design.

\subsubsection{Issue 75: Generic Implications of ATWS Events at the Salem Nuclear Plant}

On two occasions in 1983, Salem Unit 1 failed to scram automatically because both reactor trip breakers (RTBs) failed to open on receipt of an actuation signal. In both cases, the unit was successfully tripped manually. The failure of the breakers was attributed to excessive wear from improper maintenance of the undervoltage relays that receive the trip signal from the protection system and result in the breaker's opening mechanically.

Three separate actions were initiated to address this problem. One was plant specific and was addressed before restart of Salem Unit 1. The second action was an investigation of the Salem events and the circumstances leading to them. The third action was the formation of an NRC task force to study the overall generic implications of this event. The results of the task force's work were reported in NUREG-1000, Volume 1, "Generic Implications of ATWS Events at the Salem Nuclear Power Plant." 
The results of investigations of the Salem Generic Implications Task Force published in NUREG-1000, Volume 1, were later outlined in proposed actions for licensees, applicants, and the NRC staff in SECY-83-248, "Generic Actions for Licensees and Staff in Response to the ATWS Events at Salem Unit 1." Furthermore, in July 1983, NRC issued the required actions for licensees and applicants in GL 83-28, "Required Actions Based on Generic Implications of Salem ATWS Events," and the internal staff actions as NUREG-1000, Volume 2.

SSAR Section 19B.2.38 describes acceptable criteria pertinent to the issue that would satisfy the regulatory requirements. These criteria state that:

- The plant must have a program for a post-trip review of unscheduled reactor shutdowns.

- The plant must have a program for safety-related equipment classification and vendor interface.

- The plant must have a program for post-maintenance operability testing.

- The plant must have a program to control vendorrelated modifications, preventive maintenance, and surveillance for reactor trip breakers.

SSAR Section 19B.3.1 indicates that the COL applicant is responsible for providing resolutions of issues identified as "COL Applicant" in the "Safety Issues Index" of SSAR Appendix 19B. The SSAR indicates that issues are identified for $\mathrm{COL}$ action because they pertain to operating personnel issues, operating procedures, and other topics beyond the scope of the ABWR design certification review. SSAR Section 19B.1.1 lists specific documentation the COL applicant is to provide for resolution of such issues.

GE identified this issue for COL applicant action in the "Safety Issues Index." The staff verified that GE established a COL action item (Item 19-28) in SSAR Table 1.9-1 to address unresolved generic and TMI safety issues. This approach is acceptable to the staff. The staff will review the COL applicant's proposed resolution of this issue on a case-by-case basis.

\subsubsection{Issue 78: Monitoring of Fatigue Transient Limits for Reactor Coolant System}

This issue concerns the fact that repeated thermal cycling of RCS components produces some degree of fatigue degradation of the material that could lead to failure, thereby increasing the likelihood of a LOCA. The staff expressed the concern that for many older operating reactors, no TS requirements exist for monitoring the actual number of transient occurrences. For newer operating reactors, it is required that the licensees keep account of the number of transient occurrences to ensure that transient limits, based on design assumptions, are not exceeded. Additionally, the staff determined that the fatigue curves used in ASME Code, Section III, may not be adequate in taking into account environmental effects. Recent data indicated that the existing code fatigue curves may have less margin than originally intended when the effects of fatigue induced by the operating environment were considered.

The review criteria for this issue are that plants implement TS to monitor plant transients and environmental of fects on the fatigue life of ASME Code, Section III, Class I carbon steol piping. For ASME Code, Class 2 and 3 or Quality Group D components that are subjected to cyclic loading, an appropriate analysis is required.

SSAR Section 19B.2.39 states that the ABWR TS 5.7.2.9 requires that the monitoring of plant transients be performed to ensure that RCPB components are maintained within design limits, and that environmental effects will be included in the design bases for materials. The calculated core damage frequency (CDF) includes the environmental effects on fatigue resistance of materials.

The tentative procedure to evaluate the environmental offects on material fatigue that is currently used for a foreign BWR plant design was presented to the staff during an audit at the GE offices in San Jose, California, on March 23 through 26, 1992. In SSAR Section 3.9.3.1.1.7, GE commits to perform additional evaluations for environmental effects on the fatigue design of ASME Code, Section III, Class 1 carbon steel piping in accordance with GE document 408HA414 (nonproprietary). As discussed in Section 3.12.5.7 of this report, the staff found that the conditions and the methodology proposed by GE constitute supplemental guidelines that enhance the design margins beyond the requirements of the ASME Code, Section III, for fatigue ovaluation and are acceptable.

Based on this information, the staff concludes that GE adequately addressed this issue for the ABVVR design.

\subsubsection{Issue 82: Beyond Design-Basis Accidents in Spent Fuel Pools}

A typical spent fuel storage pool with high-density storage racks can hold about five times the fuel in the core. If the pool were to be drained of water, the discharged fuel from the last two refuelings might still be "fresh" enough to melt under decay heat. Additionally, the zircaloy cladding of this fuel could be ignited during the heatup. The 
resulting fire, in a pool equipped with high-density storage racks, could spread to most or all of the fuel in the pool. This could cause a release of fission products from the fuel matrix.

The review criteria for this issue are contained in SRP Sections 9.1.2 through 9.1.5 and RG 1.13, "Spent Fuel Storage Facility Design Basis." The highlights of the guidelines contained in these documents are as follows:

- The spent fuel pool should be a seismic Category I structure.

- The spent fuel pool should be designed to withstand heavy load drops without pool leakage that would uncover the top of the fuel. The spent fuel pool will be arranged to prevent cask movement over the pool.

- There should be no connections to the pool that could allow the pool to be drained below the minimum level over the spent fuel.

Although the likelihood of the complete draining of the spent fuel pool is low, the use of bigh-density storage racks does increase the probability of a zircaloy cladding fire as compared with the use of low-density or open frame racks. The use of low-density storage racks, for the most recently off loaded fuel, as a minimum, is justified by a favorable value-impact ratio for new designs.

In SSAR Section 19B.2.63, GE listed several design features that have been incorporated into the ABWR to provide the degree of safaty for the spent fuel pool required for resolution of the issue. These features are as follows:

- The spent fuel pool is located inside the reactor building, a seismic Category I structure, and is, therefore, protected against seismic loads, tomadic winds and the associated missiles, as well as turbine missiles. It is also protected from other type of missiles because of the absence of non-seismic systems, high- or moderate-energy piping, and rotating machinery in the vicinity of the spent fuel pool. Also, connections from the RHR system to the fuel pool cooling and cleanup (FPC) and suppression pool cleanup (SPCU) systems provide a seismic Category I, safety-related makeup capability to the spent fuel pool. In SSAR Section 9.1.3.3, GE states that following an accident or seismic event, the filter-demineralizers are isolated from the cooling portion of the fuel pool cooling and cleanup system and the SPCU system by two block valves in series at both the inlet and outlet of the common filter-demineralizer portion. Seismic Category I Quality Group C bypasc lines are provided on both the fuel pool cooling and cleanup system and SPCU system to allow continued flow of cooling and makeup water to the spent fuel pool.

- Spent fuel is protected against heavy loads, including the fuel cask, by means of interlocks that prevent travel of the reactor building crane over the spent fuel storage pool.

- The SGTS limits the potential release of radioactive iodine and other radioactive materials because it is located inside the renctor building.

- No inlets, outlets, or drains are provided that might permit the pool to be drained below a safe shielding level.

In addition to the above features, SSAR Section 9.1.3 states the following:

- Fire protection is provided by means of standpipes in the reactor building and the water supplies of which are seismically designed. GE states that an analysis indicates that under the maximum abnormal heat load with the pool gates closed and no pool cooling taking place, the pool temperature will reach about $100{ }^{\circ} \mathrm{C}$ $\left(212^{\circ} \mathrm{F}\right)$ in about 16 hours. This provides sufficient time for the operator to hook up fire hoses for the pool makeup.

Based on the above information, the staff determined that the ABWR meets the guidelines or the pertinent regulatory documents listed above. Based on this information, the staff concludes that GE adequately addressed this issue for the ABWR design.

\subsubsection{Issue 83: Control Room Habitability}

This issue emphasizes the significant discrepancies found during a survey of uxisting plant control rooms. These discrepancies highlighted deficiencies in the maintenance and testing of ESFs designed to maintain control room habitability. They also provided examples of design and installation errors, including degradation of control room leak tightness, and pointed out a shortage of NRC and licensee personnel knowledgeable about HVAC systems and nuclear air-cleaning technology.

Loss of control room habitability following an accidental release of external airborne toxic or radioactive material or smoke can impair or cause loss of the control room operator's capability to safely control the reactor and could lead to a core damaging accident. Use of the remote shutdown station outside the control room following such events in unreliable since this station has no emergency 
habitability or radiation protection provisions similar to the control room's.

The review criterion for this issue is to verify that the control room is designed to provide adequate protection to the operating personnel during and following an accident. The design must meet the guidance given in the SRP Sections 6.4, 6.5.1, 9.4.1, and 15.6.5.5. The design must be in accordance with the requirements of GDC 2,4 , and 19 of 10 CFR Part 50, Appendix A, and ASME AG-1, "Code on Nuclear Air and Gas Treatment" (1991) and the ASME AG-1a-92 Addenda, ASME 509, and ASME N510.

SSAR Sections 9.4.1 and 6.4 describe control room habitability. The control room is designed to withstand the effects of natural phenomena, missiles, and postulated accidents in accordance with GDC 2 and 4. Design of the ambient conditions (HVAC system) permits safe occupancy during abnormal conditions. Radiation exposure of control room personnel during any of the postulated design-basis accidents does not exceed the requirements of GDC 19 , that is, $0.05 \mathrm{~Sv}$ (5 rem) whole-body radiation exposure. Smoke and toxic gas protection will be provided by the use of noncombustible materials, purging by the HVAC, individual respirators, and site-specific considerations of potential chemical releases. SSAR Section 9.4.1.1.7 states that ESF filter trains comply with the design, testing, and maintenance provisions of RG 1.52. SSAR Appendices 9C and 9D provide information on how the ABWR design meets RG 1.52 and SRP Table 6.5.1-1, respectively. The staff's review of this section found that the ABWR conforms with the design, testing, and maintenance provisions of RG 1.52..

Based on this information, the staff finds that the ABWR is adequately designed to ensure the habitability of the control room under normal and accident conditions and meets the requirements of GDC 2 regarding the systems being capable of withstanding the effects of earthquakes; GDC 4 as it relates to maintaining environmental conditions in the control room compatible with the design limits of essential equipment located therein during normal, transient, and accident conditions; and GDC 19 with regard to providing adequate protection to permit access and occupancy of the control room under accident conditions. Therefore, the staff concludes that GE adequately addressed this issue for the ABWR design.

Three other issues are related to this issue: B-36, B-66, and III.D.3.4. They are discussed in Sections 20.1.25, 20.1.30, and 20.4.87, respectively, of this report.

\subsubsection{Issue 86: Long-Range Plan for Dealing with Stress Corrosion Cracking in BWR Piping}

This issue addresses leaks that were detected in the heataffected zones of the safe-end-to-pipe welds in two of the 71-cm (28-in.) diameter recirculation loop safe ends at Nine Mile Point Unit 1. Subsequent ultrasonic examination revealed extensive cracking at many weld joints in the recirculation system. The cause of the cracking was determined to be IGSCC. Addressing existing power plants, this issue offers four possible solutions for proventing or mitigating the effects of IGSCC. These recommendations are contained in NUREG-0313, Revision 2, "Technical Report on Material Selection and Processing Guidelines for BWR Coolant Pressure Boundary Piping."

The ABWR design meets RG 1.44, "Control of the Use of Sensitized Stainless Steel," and NUREG-0313. This will ensure that significant sensitization in ABWR components will be avoided. Further, the ABWR design does not utilize recirculation piping and, therefore, the issue as it relates to cracking of the recirculation loop piping in BWRs does not apply to the ABWR. Based on this information, the staff concludes that GE adequately addressed this issue for the ABWR design.

\subsubsection{Issue 87: Failure of High Pressure Coolant Injection Steam Line Without Isolation}

This issue addresses a postulated break in the HPCI steam supply line and the uncertainty regarding the operability of the HPCI steam supply line isolation valves under those conditions. A similar situation can occur in the RWCU system. The HPCI steam supply line has two containment isolation valves in series (one inside the containment and one outside), both of which are normally open in most plants (two plants do operate with the outboard isolation valve normally closed). An HPCI supply valve located adjacent to the turbine and the turbine stop valve are normally closed. The RWCU system also has two normally open containment isolation valves that must remain open if the system is to function.

At the valve manufacturers' facilities, only the opening characteristics are tested under operating conditions (because of flow limitations). Although the operation of the valves is tested periodically without steam, the capability of the valves to close against the forces created by the steam flow resulting from a downstream line break has not been demonstrated. The valve type is not under 
GE's (BWR vendor) scope of control, but is selected by the plant architect-engineer. This results in a diversity of valves and valve types ( $\mathrm{Y}$-type globe valves and gate valves) and increases the difficulty of demonstrating valve operating capability.

This issue is addressed in GL 89-10, "Safety-Related Motor-Operated Valve Testing and Surveillance," dated June 28, 1989, with Supplements 1-4. The staff's specific concern is the adequacy of testing, maintenance, and inspection of motor-operated valves (MOVs) so as to assure that they will remain functional when subjected to the design-basis conditions that are to be considered during both normal operation and abnormal events within the design basis of the plant.

SSAR Section 3.9.6.2.2 provides commitments for the design, qualification, testing, and inspection of MOVs. The details of the staff's evaluations are contained in Section 3.9.6.2.2 of this report. The staff's evaluation concludes that the commitments as described in SSAR Section 3.9.6.2.2 provide reasonable assurance for demonstrating the adequacy of the MOV isolation capability for the design-basis conditions and are, therefore, acceptable. Furthermore, SSAR Section 3.9.7.3 also states that the COL applicant will address the design qualification and testing for MOVs as discussed in SSAR Section 3.9.6.2.2 prior to plant startup.

Based on this information, the staff concludes that GE adequately addressed this issue for the ABWR design.

\subsubsection{Issue 89: Stiff Pipe Clamps}

Stiff pipe clamps were installed because of requirements for piping systems to withstand dynamic loads such as SRV discharges to suppression pools, LOCA-induced loads, and seismic loads. A preloading of pipe clamp U-bolts or straps, which imposes a constant compressive load on the piping, is necessary to prevent stiff pipe clamps from lifting under dynamic loading. In addition to the large preloading of the clamps, four other design features were identified as requiring additional analyses because of their differences from conventional pipe clamps. Those were (1) use of high-strength or nonASME- approved materials; (2) local surface contact on the pipe; (3) uncommonly thick and/or wide design of clamp; and (4) clamp applications to piping components other than straight pipe, such as pipe elbows.

It was found that piping designers often assumed that the clamp effects on piping systems were negligible and did not warrant any explicit consideration. Although this assumption was acceptable for most clamp applications, in some cases, piping systems coupled with specific pipe clamp design requirements sould experience interaction effects that need to be evaluated to determine the magnitude of pipe stresses induced.

The ASME Code, Section III, requires that the effects of attachments in producing thermal stresses, stress concentrations, and restraints on pressure-retaining members be taken into consideration in checking for compliance with stress criteria. The review criteria for this issue are that the effects of stiff clamps on piping stresses should be included in the piping system design. That is, in designing a piping system, cumulative stress contribution, such as due to thermal expansion of the pipe and clamp, discontinuity stresses in the pipe, stresses from thermal gradient through the pipe wall, and the external loads from dynamic events such as earthquake should also include the stresses attributed to the stiff clamps.

SSAR Section 19B.2.43 states that a study was performed in 1980 for typical stiff pipe clamps on BWR main steam and recirculation piping systems. For each system, the stiff clamps were installed on straight pipe or on bends with a radius of at least five pipe diameters. The purpose of these analyses was to evaluate the additional stresses at clamp locations resulting from the following:

- Differential thermal expansion of the pipe and clamp

- Discontinuity stresses in the pipe from internal pressure restraint

- Thermal gradient through the pipe wall in the vicinity of the pipe clamp

- External loads resulting from dynamic events such as earthquakes.

The results of these calculations showed that the total primary and secondary stresses, including clamp-induced stresses, were less than 70 percent of code-allowable stresses. GE states that the governing stress locations occurred at pipe branch connections, elbows, and shear lugs, and that they did not occur at stiff clamp locations. GE says this indicates that the stress intensification that occurs at elbows, branch connections, and shear lugs is greater than that occurring at stiff pipe clamps. Based on these calculations GE concluded, and the staff concurred, that explicit consideration of clamp-induced piping stresses is not required when the clamps are installed on straight pipe or on bends with a radius of at least five pipe diameters.

GE states in the SSAR section referred to above that the stiff clamp pipe analysis described above will be extended to the ABWR design and the pipe design specifications on other than NSSS piping will also consider these stress requirements. 
Based on this information, the staff concludes that GE adequately addressed this issue for the ABWR design.

\subsubsection{Issue 103: Design for Probable Maximum Precipitation}

This issue concerns the use of the most recent National Oceanic and Atmospheric Administration (NOAA) procedures for determining probable maximum precipitation (PMP). More specifically, the issue was centered upon the NRC use of NOAA Hydrometeorological Reports (HMRs) Nos. 51 and 52, published in June 1978 and August 1982, respectively. The PMP values are used in estimating design flood levels at reactor sites. Objections were raised against use of these reports because by using HMR-52, higher values of flood levels were obtained than those when earlier reports were used. That would constitute unauthorized backfit under NRC procedures.

The procedures for estimating PMP and, therefore, the probable maximum flood (PMF) acceptable to the NRC are given in Appendices A and B of RG: 1.59, "Design Basis Floods for Nuclear Power Plants," (Appendix A has since been superseded by ANSI N170-1976, "Standards for Determining Design Basis Flooding at Power Reactor Sites." ANSI N170-1976 defines the PMF as a hypothetical flood that is considered to be the most severe reasonably possible, based on comprehensive hydrometeorological application of PMP and other hydrologic factors favorable for maximum flood runoff. Thus, PMP is an integral component of PMF determination.

GDC 2 of 10 CFR Part 50, Appendix A, requires that the design bases for floods reflect consideration of the most severe historical flood data, with sufficient margin for the limited accuracy, quantity, and period of time in which the data have been accumulated. Additional guidance for estimating PMP and PMF is contained in SRP Sections 2.4.2, Revision 3, and 2.4.3 Revision 3, and in GL 89-22, "Potential for Increased Roof Loads and Plant Area Flood Runoff Depth at Licensed Nuclear Plants Due to Recent Change in Probable Maximum Precipitation Criteria Developed by the National Weather Service."

SSAR Section 19B.2.44 states that the ABWR design meets the requirements of GDC 2. In SSAR Table 2.0-1, GE provides the envelope of the ABWR site design parameters, among which is the maximum precipitation (for roof design) expressed in terms of a maximum rainfall rate of $49.3 \mathrm{~cm} / \mathrm{hr}(19.4 \mathrm{in} . / \mathrm{hr})$, and a maximum snow load of $2.354 \mathrm{kPa}(.341 \mathrm{psi})$. In Section 4.5.2.2 of the EPRI Evolutionary SER (NUREG-1242, "NRC Review of Electric Power Research Institute's Advanced Light Water Reactor Utility Requirements Document "), the staff stated that a 5-minute PMP is reasonable and that the $49.3 \mathrm{~cm} / \mathrm{hr}$ (19.4 in./hr) PMP, together with $2.6 \mathrm{~km}^{2}\left(1.0 \mathrm{mi}^{2}\right)$, 5-minute PMP of $15.7 \mathrm{~cm}(6.2$ in.) appears to be acceptable to the staff. However, that might exclude a number of sites in the Great, Lakes area. GE further states that the ABWR meets the intent of SRP Sections 2.4.2, Revision 3 and 2.4.3, Revision 3 and GL 89-22. Detailed site characteristics based upon historical site environmental data will be provided by the site owner-operator for any specific applications. The staff verified that GE established a COL action item in SSAR Section 2.3 to provide site characteristics information. This approach is acceptable to the staff.

Based on this information, the staff determined that the ABWR is designed in accordance with the requirements of GDC 2 for the most severe environmental conditions, including floods, tornadoes, and hurricanes, that are expected and meets the intent of SRP Section 2.4.2 Revision 3, SRP Section 2.4.3 Revision 3, and GL 89-22. Therefore, the staff concludes that GE adequately addressed this issue for the ABWR design.

\subsubsection{Reserved.}

\subsubsection{Issue 105: Irterfacing Systems LOCA at LWRs}

To protect against an intersystem LOCA (ISLOCA), designers of future ALWR plants should reduce the possibility of a LOCA outside containment by designing, to the extent practicable, all systems and subsystems connected to the RCS to an ultimate rupture strength (URS) at least equal to the normal RCS operating pressure.

Enhancements of isolation capability or the number of intersystem barriers (e.g., three isolation valves) are not considered to be adequate alternatives in systems that can be practically designed to the URS criteria. For example, piping runs should be designed to meet the URS criteria, as should all associated flanges, connectors, and packing, including valve stem seals, pump seals, heat exchanger tubes, valve bonnets, and RCS drain and vent lines. The designer should also make every effort to minimize the pressure loading experienced by each system and subsystem connected to the RCS should an ISLOCA occur. The staff does recognize, however, that all systems must eventually interface with atmospheric pressure and that it would be difficult or prohibitively expensive to design certain large tanks and heat exchangers to an URS equal to normal RCS operating pressure.

Applicants must provide justification demonstrating that it is not practicable to reduce the pressure challenge any 
further for each interfacing system and component that dous not meet the RCS URS. This justification must be based upon an engineering feasibility analysis and not solely on the ratio of risk to benefit. Applicants must also demonstrate a compensating isolation capability for each interface for which it submits acceptable justification on the impracticability of normal RCS operating pressure capability. This would include a discussion of how the degree and quality of isolation or the reduced severity of the pressure challenges compensate for the low-pressure design of the interfacing system or component. The vendor may also need to consider the adequacy of pressure relief and piping of relief back to primary containment. In SECY-90-016, the staff stated that systems that have not been, designed to full RCS pressure must include the following protection measures:

- the capability for leak testing of the pressure isolation valves,

- valve position indication that is available in the control room when isolation valve operators are deenergized, and

- high-pressure alarms to warn control room operators when rising RCS pressure approaches the design pressure of the attached low pressure systems and both isolation valves are not closed.

In the DFSER, the staff reported on its review of GE's preliminary evaluation of the RHR, HPCF, SLC, and RCIC systems and indicated that it would complete its review of Issue 105 upon receiving and reviewing additional information from $G E$. This was identified in the DFSER as Open Item 20.2-3.

In the original $A B W R$ design, low-pressure piping that indirectly interfaces with the RCS (such as the RHR system suction piping) was designed to $1,277 \mathrm{kPa}$ (200 psig). This design pressure was not considered to be acceptable since the piping was susceptible to pipe break because of ISLOCA. The staff required GE to upgrade the pressure rating of the piping that interfaces with the RCS. GE provided its implementation of the issue resolution in a submittal dated October 8, 1992, from J. Fox to C. Poslusny (NRC), "Proposed Resolution of ISLOCA Issue for ABWR." The staff reviewed the GE submittal and concluded that the design pressure for the low-pressure piping systems that interface with the RCS pressure boundary should be equal to 0.4 times the normal reactor operating pressure of $6,965 \mathrm{kPa}$ (1025 psig), that is, $2,786 \mathrm{kPa}(410 \mathrm{psig})$, and the minimum wall thickness of the low-pressure piping should be no less than that of a standard weight pipe. The staff concluded that this minimum pressure will ensure reasonable protection against burst failure should the low-pressure system be subjected to full pressure.

GE agreed with the staff position and made the necessary design changes as described below. All the low-pressure piping was changed to 2,786 $\mathrm{kPa}$ (410 psig). Furthermore, the staff will continue to require periodic surveillance and leak rate testing of the pressure isolation valves per TS requirements as a part of the ISI program. The details of the staff position on this issue is given in Section 3.9.3.1.1 of this report.

The following items form the basis of what constitutes practicality and set forth the test of practicality used to establish the boundary limits of URS for ABWR.

It is impractical to construct large tank structures to the URS design pressure that are vented to the atmosphere and have a low design pressure. Tanks included in this category are:

- Condensate storage tank

- SLCS main tank

- Low-conductivity waste receiving tank

- High-conductivity waste receiving tank

- FPC skimmer surge tank

- FPC spent fuel storage pool and cask pit

- Condensate hotwell.

Also included as impractical to upgrade were the suppression pool and primary containment. The suppression pool provides a low-pressure sink, approximately $-96.31 \mathrm{kPa}(0.75 \mathrm{psig})$ for its interfacing systems, and the first closed valve is rated to at least $2,786 \mathrm{kPa}$ (410 psig). The ABWR containment is designed to $209 \mathrm{kPa}$ (45 psig) and is designed to seismic Category I.

GE upgraded the design pressure of the following small tanks as a result of the review:

- SLCS test tank

- RCIC turbine barometric condenser tank.

Based on the staff guidance described above, GE evaluated in SSAR Appendix 3MA the following systems that interface with the RCS to verify that they are designed for an ISLOCA "to the extent practicable":

- RHR system

- HPCF system

- Standby liquid control system

- RCIC

- Control rod drive (CRD) system

- Reactor water cleanup system

- FPC system 
- Nuclear boiler system (NBS)

- Reactor recirculation system (RRS)

- Makeup water (condensate) (MUWC) system

- Makeup water (purified) (MUWP) system

- Radwaste system

- Condensate and feedwater (CFS) system

- Sampling (SAM) system

The pressure of each system piping boundary was reviewed to identify where changes were needed to provide the URS protection. Where low-pressure piping interfaces with higher-pressure piping that is connected to the RCS, design pressure values were increased to $2,786 \mathrm{kPa}$ (410 psig). The low-pressure piping boundaries were upgraded to URS pressures and extended to the lest closed valve connected to the piping interfacing a low-pressure sink, such as the suppression pool or the condensate storage tank. For some systems, with low-pressure piping and normally open valves, the valves were changed to locked-open valves to ensure a pathway from the last URS boundary to the tank or low-pressure sink. Also, the minimum wall thickness for all the piping was changed to the standard weight pipe.

It is the staff's position that components such as heat exchangers, flanges, and pump seals should also be designed to a pressure of $2,786 \mathrm{kPa}$ (410 psig). These changes have been implemented and are indicated in the SSAR by revised boundary symbols in the P\&IDs. $A$ stated parameter (e.g., design pressure) of a boundary symbol on the P\&ID applies to all the piping and components on the P\&ID that extend away from the boundary symbol, including any branch line, until another boundary symbol occurs on the P\&ID.

GE upgraded the design pressure of piping in 14 systems that interface with the RCS and changed the design pressure of two tanks as the result of the ISLOCA review. Based on the above, the staff concludes that using the staff guidance, GE has modified the ABWR systems design "to the extent practicable" and, hence, has adequately addressed this issue for the ABWR design. Therefore, DFSER Open Item $20.2-3$ is resolved.

Based on the above discussions, the staff concludes that the ABWR design meets the criteria of SECY-90-016 regarding ISLOCA prevention and mitigation.

\subsubsection{Issue 106: Piping and Use of Highly} Combustible Gases in Vital Areas

Issue 106 addresses the risk associated with the use of hydrogen and other combustible gases, such as propane and acetylene, during normal plant operation. This issue does not cover the use of large quantities of liquid hydrogen at hydrogen water chemistry (HWC) installations at BWRs or liquified petroleum gases (which are covered under Licensing Isere 136).

The review criteria for this issue are taken from EPRI Report NP-5283-SR-A, "Guidelines for Permanent BWR Hydrogen Chemistry Installations," and SRP Section 9.5.1. The current SRP Section 9.5.1, with the BTP CMEB 9.5-1, Part C.5.d(5), should be modified as follows: "Hydrogen lines in safety-related areas should follow the guidance of RG 1.29, "Seismic Design Classification," Section C.2. The lines should (1) be equipped with an excess flow valve or equivalent protection located outside the building 80 that in case of a line break, the hydrogen concentration in affected areas does not exceed 2 percent volume or (2) be sleeved with the outer pipe vented directly to the outside." The criteria should be applied to systems that supply hydrogen for cooling of the electric generators.

The system design should comply with the following general guidance:

- Design features and administrative controls should be provided to prevent inadvertent bypass of small or normally isolated hydrogen supplies.

- Flow limiting devices should be used to limit hydrogen relenses to a leak or pipe break.

- Equipment and controls to mitigate the consequences of a hydrogen fire or explosion should be accessible and remain functional during an event.

- Design features and administrative controls should be provided to isolate the hydrogen supply if normal building ventilation is lost.

- Backflow to a leak or line break of hydrogen contained in components (e.g., generator) should be considered in evaluating the consequences of leaks or breaks and measures taken to mitigate these consequences.

- Threaded joints in the hydrogen distribution lines within safety-related areas should be back welded.

EPRI Report NP-5283-SR-A provides guidelines for HWC installations. With the exception of information dealing specifically with the HWC application (e.g., certain trips, injection points, and main steam line radiation), most of the EPRI guidelines dealing with hydrogen are applicable to these other uses. The guidelines give a number of system design features and administrative controls that are in addition to, or more restrictive than, those in SRP Section 9.5.1. In addition, safety-related equipment should 
not be located in the turbine building because of the hazards associated with hydrogen fires or explosions and largo oil fires and the large uncertainties in estimating the consequences.

According to SSAR Section 9.3.9.1.2, hydrogen is used in the $A B W R$ design to reduce the dissolved oxygen in the reactor water in order to mitigate the potential for IGSCC of sensitized austenitic stainless steels. The amount of hydrogen required is in the range of 1.0 to $1.5 \mathrm{ppm}$, but the exact amount, which depends on many factors, including for instance, incore recirculation rates, will be determined by tests performed during initial operation of the plant.

SSAR Section 19B.2.48 states that the ABWR design uses hydrogen for IIWC and the main generator bulk hydrogen supply system. These systems are non-nuclear and nonsafety-related and are located in the turbine building, which is a non-safety-related structure in a nonvital area.

SSAR Section 10.2.2.1 states that there are no safetyrelated systems or components located within the turbine building, hence any local failure associated with the turbine-generator (T-G) unit will not affect any safetyrelated equipment. It further states that failure of $T-G$ equipment cannot preclude safe shutdown of the RCS. SSAR Sections 9.3.9.1.2 and 10.2.2.2 state that the HWC system and the bulk hydrogen system, respectively, utilize the guidelines given in EPRI Report NP-5283-SR-A with respect to those portions of the guidelines involving hydrogen which do not deal specifically with the HWC system. Specifically, the bulk hydrogen system and HWC system piping and components will be located to reduce risk from their failures. The bulk hydrogen storage is located outside but near the turbine building. Tho arrangement of buildings at the facility and location of building doors and the bulk hydrogen storage tanks will be designed to ensure that damage to buildings containing safety-related equipment due to combustion of hydrogen or an explosion is unlikely.

Hydrogen lines are provided with a pressure-reducing station before the piping enters the turbine building which limits the maximum flow of hydrogen to less than 100 standard cubic meters per minute (3530 scfm). The hydrogen piping inside the turbine building will be designed in accordance with the guidence of RG 1.29, Position C.2, regarding the seismic design of non-safetyrelated equipment whose failure could affect safety-related equipment. This is in order to comply with the modified BTP CMEB 9.5-1, Part C.5.d(5). Additionally, all threaded joints in the hydrogen distribution piping will be back welded. Equipment and controls used to mitigate the consequences of a hydrogen fire or explosion will be designed to be accessible and remain functional during the postulated post-accident condition. Design features and/or administrativo controls will be provided to ensure that the hydrogen supply is isolated when normal building ventilation is lost.

Based on this information, the staff concludes that $G E$ adequately addressed this issue for the ABWR design.

\subsubsection{Issue 113: Dynamic Qualification Testing of Large Bore Hydraulic Snubbers}

Large bore hydraulic snubbers (LBHSs) have a loed rating greater than 22.68 tonnes (50 kips). They are ective mechanical devices used to restrain safety-related piping and equipment during seismic or other dynamic events (e.g., high-energy line breaks), yet also allow sufficient piping and component flexibility to accommodate system expansion and contraction resulting from thermal transients, such as normal plant heatups and cool downs. Dynamic qualification testing and periodic functional testing are important to verify that the LBHSs are properly designed and maintained for the lifo of the plant. Issue 113 addresses the need for requirements for dynamic testing of LBHSs.

SSAR Section 19B.2.64 states that for the ABWR design, LBHSs will only be used for piping systems when dynamic supports are required at locations where large thermal displacements prohibit the use of rigid supports. They will not be used in applications other than piping restraints. Section 19B.2.64 refers the reader to SSAR Section 3.9.3.4.1(3) for information on design, testing, installation, and pre-service examination of mechanical and hydraulic snubbers, including LBHSs. To assure snubber functionality under various normal and abnormal conditions, snubbers are to be designed in accordance with provisions of the ASME Code, Section III, Subsection NF. This design requirement includes analysis for normal, upset, emergency, and faulted loads. These calculated loads are then compared with the allowable loads to verify that the stresses are below the code-allowable limits.

GE described the tests that the snubbers will be subjected to, and they will consist of the following:

- Force or displacement versus time loading at frequencies within the range of significant modes of the piping systom.

- Dynamic cyclic tests to determine the operational characteristics of the snubber control valve. 
- Dieplacomont tosts to dotermine the epecified performance characteristics.

The suubbers will be tested for various abnormal environmental conditions. Upon completion of the abnormal environmental transient test, the snubbers will be tested dynamically at a frequency within a specified frequency range.

Based on this information, the staff concludes that GE provided acceptable commitments to dynamically test LBHSs, and therefore, adequately addressed this issue for the ABWR design.

\subsubsection{Issue 118: Tendon Anchorage Failure}

An inspection of a PWR prestresed concrete containment structure showed that three lower vertical tendon anchor heads were broken. The failures appeared to be caused by stress corrosion cracking. Quantities of water ranging from a few milliliters (oz.) to about 5.7 liters (1.5 gals.) were found in the grease caps.

A reinforced concrete contrinment for BWRs will be used. Since a prestressed concrete containment is not specified, no specific requirements for tendon anchorage are provided.

SSAR Sections 3.8.1 and 19B.2.48 state that the primary containment of the ABWR standard plant is designed as a reinforced concrete structure. Since the technique of prestressed concrete design has not been used by GE, the issue of tendon anchorage failure is not applicable for the containment structure design of the ABWR standard plant. Therefore, the staff concludes that $G E$ adequately addressed this issue for the ABWR design.

\subsubsection{Issue 120: On-Line Testability of Protection Systems}

During its 1985 review of several plant TS, the staff discovered that the design of protection systems of some plants did not provide as complete a degree of on-line, at-power surveillance testing capability as did other plants undergoing staff review, and evaluation at that time. This raised questions about the on-line testability of protection systems and the possibility that some nuclear power plants might not provide complete testing capability. Issue 120 was established to examine these questions. Protection systems consist of the reactor protection system (RPS) and the engineered safety features actuation system (ESFAS). The main concern of this issue, however, is the on-line testability of the actuation subgroup (slave) relays in the ESFAS.
The requirements for at power testability of components are included in GDC 21 of 10 CFR Part 50, Appendix A. ROs 1.22, "Periodic Teating of Protection System Actuation Functions," and 1.118, "Periodic Testing of Electric Power and Protection Systems," and IEEE 338-1977, "Criteria for the Periodic Testing of Nuclear Power Generating Station Safety Systems," provide supplemental guidance. This guidance is intended to ensure that protection systems (including logic, actuation devices, and aseociated actuated equipment) will be designed to permit testing while a plant is operating at power without adversely affecting the plant's operation. The scope of testing covered consists of functional tests, checks, calibration verifications, and time- response measurements. Criteria are provided for determining system operational availability, status, and necessary documentation, and for establishing test intervals and test procedures during operation.

The review criteria applied for this issue included an assessment of the capability for periodic functional testing of the systems. This periodic testing should be manually initiated, but automatically performed once initiated, and should meet the guidance of RGs 1.22 and 1.118 and IEEE 338. Automatic initiation of periodic testing may be provided where the testing does not degrade the system functionality. Built-in, automated test features are expected to be provided for periodic, functional testing, as necessary, to eliminate physical reconfiguration of systems (e.g., adding jumpers, lifting leads, swapping cables) to perform the required tests. The safety-related systems are to have automatic test foatures that are sufficient to moot TS requirements for periodic surveillance of the system's functionality as defined by RGs 1.22 and 1.118 and IEEE 338.

This issue was resolved during the staff's USI-GSI review for the ABWR without the establishment of now requirements. Nevertheless, the staff evaluated the capability of the ABWR for continuous on-line self-testing of hardware and system integrity as detailed above.

SSAR Sections 7.1.2.1.6 and 19B.2.49 indicate that the ABWR design's RPS and ESFAS can be tested at power during reactor operation by six separate tests. The first five tests are primarily manual tests and although each individually is a partial test, combined with the sixth test they constitute a complete system test. The sixth test is the self-test of the system logic and control that automatically tests the complete system excluding sensors and actuators.

The sixth test is an integrated self-test provision built into the microprocessors within the safety system logic and control (SSLC). It consists of on-line, continuously operating, self-diagnostic, monitoring network and an off- 
line semi-automatic (operator initiated, but automatic to completion), end-to-end surveillance program. This testing includes the following:

- On-line continuous testing, which is a solf-diagnostic program monitoring each signal-processing module from input to output (actuation of the trip functions is not performed during this test)

- Off-line semi-automatic end-to-end testing, which exercises the trip outputs of the SSLC logic processors.

All testing features adhere to the single-failure criterion.

Since the design of the systems permit periodic testing of their functioning when the reactor is in operation, including a capability to test channels independently to determine failures and losses of redundancy that may have occurred, the staff determined that the ABWR meets the requirements of GDC 21 of 10 CFR Part 50, Appendix A. Therefore, the staff concludes that $G E$ adequately addressed this issue for the ABWR design.

\subsubsection{Issue 121: Hydrogen Control for Large, Dry PWR Containments}

As a result of the TMI-2 accident, the Commission promulgated regulatory requirements on hydrogen control in 10 CFR 50.34(f) and 50.44. 10 CFR 50.34(f) requires a hydrogen control system based on 100-percent, fuel-clad metal-water reaction and hydrogen concentration limit of 10 percent on uniformly distributed hydrogen in the containment or on a post-accident atmosphere that will not support hydrogen combustion.

The review criterion for this issue is that the control of hydrogen generated in the containment in a degraded core accident shall meet the requirements of 10 CFR 50.34(f) on limiting the distributed hydrogen concentration to 10 percent, on limiting the combustible concentration, and on maintaining safe-shutdown equipment and containment integrity.

This issue is relevant to large, dry containments, such as those used in PWRs. Therefore, this issue does not apply to the ABWR design. Additionally, the ABWR primary containment is inerted and is, therefore, protected from hydrogen combustion regardless of the amount or rate of hydrogen generation.

Based on this information, the staff concludes that GE adequately addressed this issue for the ABWR design. See also the staff's evaluation of 10 CFR 50.34(f)(2)(ix) in Section 20.5.21 of this report.

\subsubsection{Isove 124: Auxillary Feedwater System Reliability}

In 1985, it was observed by the NRC staff and induatry that the auxiliary feedwater systems (AFWSs) continued to fail at a high rate. These studies also indicatod that plants with similar AFWS reliabilities (as calculated in eccordance with the SRP guidance) did not neceasarily exhibit similar AFWS availabilities. Based on thewo studies and on engineering judgement, the staff concluded that the PWR AFW system reliabilities calculated in accordance with the SRP guidance may have represented the relative reliability of AFW system hardware configurations for various plants, but did not represent the real availability of the system.

A function of the AFWS in most cases is to supply water to the secondary side of the steam generator during system fill, normal plant heatup, normal plant standby, and normal plant cold shutdown. The AFWS also functions following loss of normal feedwater flow, including loss because of offsite power supply failure, and provides emergency feedwater (EFW) following such postulated events as main feedwater line break or main steam line break.

The AFWS reliability criterion has been specified in SRP Section 10.4.9. For the ABWR, SSAR Section 19B.2.51 states that the acceptance criteria for resolution of this issue will be that the AFWS will be designed for a high degree of reliability (that is, using reliability analyses the system will attain 0.0001 to 0.00001 unavailability per demand).

As it has been pointed out above, the function of the AFWS in most cases is to supply water to the secondary side of the steam generator under various conditions. Since this condition does not exist in case of the ABWR, this issue is not applicable to the ABWR.

\subsubsection{Issue 128: Electrical Power Reliability}

Concerns have been raised regarding the dependence on Class IE power, especially dc power, of the decay heat removal systems required for long-term heat removal. Failure of one division would generally result in a reactor scram, which would then require removal of decay heat. The frequency of reported failures of single dc divisions gives rise to the concern that the second de division may not be available. This issue combines three interrelated issues, namely, A-30, "Adequacy of Safoty-Related DC Supplies;" 48, "LCOs for Class 1E Vital Instrument Buses in Operating Reactors;" and 49, "Interlocks and LCOs for Redundant Class 1E Tie Breakers." 
Issue A-30 involves the power source to the inverters for the vital 120-Vac instrument power supplies that are related to Issues 48 and 49 . It is also related to Isawe 76, "Instrumentation and Control Power Interactions, "because a loss of 120-Vac vital instrument power could challenge emergency safeguards systems and could cause reactor trips, loss of foedwater, loss of emergency core and containment cooling systems, and loss of post-accident monitoring instrumentation.

Issue A-48 concerns the fact that in some plants, there are no administrative controls governing operational restrictions for their Class 1E 120-Vac vital instrument buses (VIBs) and associated inverters. Without such restrictions, these power sources could be out of eervice indefinitely and might place certain safety systems in a situation where they could not meet the singlo-failure criterion. This is of particular concern during the period before the start and load of diesel generators following a loss of offsite power. In this condition, some VIBs may be subjected to power failure modes that may not have been considered during the safety analysis of the plant.

Issue $A-49$ arises from the fact that in some plants there is lack of adequate procedural and administrative controls that are used to monitor and provide assurance that the tie breakers between redundant Class 1E divisions of electrical power and multi-units are always open during plant operation. Such controls are necessary to provide assurance that the Class $1 E$ power buses are not compromised. There is also a related concern, when a tie breaker is closed, involving electrical interlocks to prevent out-of-synchronization interconnections of a diesel generator to either the off-site power source or another diesel generator.

The review criteria for this issue are contained in NUREG/CR-5414, "Technical Findings for Proposed Intograted Resolution of Generic Issue 128, Electric Power Reliability." Generally, this document states that the plant design should provide for the separation and isolation of electrical power systems to preclude interactions that could adversely affect such functions as diesel generator loading and offsite to diesel generator power transfers.

Each division of the ESFs requiring electric power will bo provided with an onsite source of $a c$ and dc power. At least two separate and independent connections will be provided to offsite power sources capable of starting and running all Class IE loads required for safe shutdown. The specified functions of the ESFs will be met by the use of redundant divisions and that the divisions will be totally independent and separated both mechanically and electrically. The DHR systems will be redundant and safety grade.
The plant designs will have three independent divisions for the core coolant inventory control and DHR systems and each division will have its own independent ac and dc power source.

Separation of electrical power systems will be such as to preclude interactions that could adversely affect the functioning of the dc power systems. Specifically, the use of bus ties between safety divisions is prohibited.

Non-safety-related loads will be placed on power supplies that are completely separate from those on which safetyrelated loads are placed.

The loes of any plant battery or de bus concurrent with a single independent failure in any other system required for shutdown cooling will not result in a total loss of reactor cooling capability.

Each reactor protection chanrel will be normally powered from a dedicated Class IE source that is normally independent of other dc sources.

SSAR Section 19B.2.52 describes the ABWR design features pertinent to the resolution of Issues 128, A-30, 48, and 49.

For Issue A-30, the dc buses for the safety-related dc power system meet the acceptance criteria because of the following:

- The safety-related de power system does not supply power to any non-Class 1E loads.

- Consists of four separate and independent dc battery systems.

- Does not contain any direct bus tie between dc battery systems. However, it does contain two standby battery charges, each of which is capable of supplying one of the divisional dc systems. Redundant key-locked breakers are provided to prevent manual paralleling between divisions, and no automatic connections are provided between dc divisions.

The ABWR design moets the acceptance criteria for the resolution of Issue 48 by the system design and TS. The ABWR design consists of four separate and independent Class 1E 120-Vac vital instrument buses with their respective inverters. TS contain the appropriate operating restrictions, to assure the onsite Class $\mathrm{IE}$ ac and dc power distribution system availability and thus, an uninterruptable power source for safety-related systems and components. The TS contain specific requirements regarding a periodic evaluation of the onsite power system bus condition which 
addresses such availability items as correct breaker and bus alignment and bus voltage.

The ABWR meets the scceptance criteris with regards to Isou 49. The ABWR Class 1B system dosign does not contain bus tio breakers botween Clas IE divisions, but it is possible to manually crose-connect the Class $1 \mathrm{E}$ diesel buses through the CTO connections, vince the power to each diesel bus can be provided from the CTO. Eech diesel generator is provided with a synchronizing equipment for paralleling offsite supplies. The normal and alternate offsite feeder breakers to Clase $1 \mathrm{E}$ buses are interlocked to prevent paralleling offsite circuits.

Based on this information, the staff concludes that $\mathrm{GE}$ adequately addreseed this issue for the ABWR design.

\subsubsection{Issue 130: Eseential Service Water Pump Failures at Multiplant Sites}

This issue addresses shared eseential corvice water (ESW) systems between PWR units located on the same site. Specifically, this issue deals with multiplant sites that have only two ESW pumps per plant with crose-tie capability and the impact of auch sharing on the availability of the ESW pumps. The safety concern is that the needed ESW pumps may not be available during all possible operating conditions for the multiple units, thereby increasing the core melt and radiological risks at the site. Other multiplant and single plant configurations may also contain similar ESW system vulnerabilities. Therefore, the concern of this issue is equally applicable to other multiplant and single plant PWR sites. According to Appendix B to NUREG-0933, Issue 130 is not applicable to BWR vendors.

Issue 130 was resolved with the issunnce on September 19, 1991, of GL 91-13, "Request for Information Related to the Resolution of Generic Issue 130, 'Essential Service Water System Failures at Multi-Unit Sites,' Pursuant to 10 CFR 50.54(f)." This letter contained TS and emergency procedures improvements for seven specific multiplant PWR sites.

Although this issue is not applicable to BWR plants, the staff included an evaluation of the concerns as related to the ABWR RSW design in the DFSER. In the DFSER, the staff said that the SSAR stated that the ABWR has been designed as a single unit with no specific consideration of possible shared systems. (Note that in all system analysis reviews, the requirements of GDC 5 have been identified as not being applicable to the ABWR docign.) Shared systems are, therefore, not a concern for the ABWR design.
The staff reported in the DFSER that SSAR Appendix 19B, "Resolution of Applicable Unreeolved Safoty Inever and Generic Safety Isewes," Sections 19B.2.10 and 19B.3.5, allowed for the possible modification of the ABWR design by plant-specific applicents. The guidelines provided by GE to assure that the modified design would address the concerns of Isove 130 included reforence to two design requirements from the EPRI ALWR Requirements Document. The first requirement was for limiting the number of shared systems to the "tost programs which have been made" and further states that these systems "shall incorporate the pertinent results into the design of the ALWR." The second requirement can be interproted to address shared systems at multiplant sites stated that each division of any ESW system must have two heat exchangers and two pumpe sized $s 0$ that each division can provide the capacity to abeorb the system heat loads. generated by the plant during all operational (normal and emergency) modes.

The staff stated in the DFSER that the requirements mentioned above did not provide sufficient guidance to an applicant referencing the ABWR design for a multiplant site to design ESW systems for the units that reflect an acceptable resolution of the concern of Issue 130. Specifically, the staff indicated that the first EPRI requiroment as iclentified by GE is confusing. The subject requirement as stated in the Requirements Document (see Volume 2, Chapter 1, Section 6.2.B.1) limits the number of shared systems to auxiliary support systems such as sower, auxiliary steam, or site security. Further, another EPRI requirement (see Requirements Document, Volume 2, Chapter 8, Item B.1.4.2) clarifies the above EPRI requirement by specifically ruling out sharing of ESW pumps between divisions and between units of a multiplant site and by requiring the ESW system for each unit to be designed to the same requirements as for a single unit. The EPRI requirement as identified by GE, on the other hand, implies that the ESW system can be shared between the units, provided certain conditions are satisfied. However, the staff related that the ABWR SSAR provided little or no guidance regarding whether the ESW system pumps will be shared between the units and if so, how they will be shared, the number of shared as well as non-shared ESW pumps for each unit, the capacity of each ESW pump, and the operational limitations required to minimize system misoperation (human errors associated with the wrong train or the wrong plant identification). In addition, the staff said that $\mathrm{GE}$ should address the applicable reliability concerns of Issue 130 for single-plant units.

In the DFSER, the staff required GE to address all the above concerns and modify the two identified interface requirements accordingly to provide sufficient guidance to the applicants referencing the ABWR design. The staff 
stated that such guidance is needed so that each plantspecific applicent will be ablo to provide supporting documentation and analysis to justify modifications to the ABWR eseential cooling water systems if a multi-unit site is to incorporate shared cooling water systems in the modified designs. The staff indicated that the analyois and documentation should demonstrate that the rovised plant dosign meots the concerns identified in Issue 130, as well as the requirements of GDC 5 with regard to the sharing of structures, systems, and components at multi-unit sites. This was identified in the DFSER as Open Itom 20.2-4.

Further, the staff required in the DFSER that the COL applicant address the plant-specific resolution of Issue 130. This was identified as COL Action Item 20.2-3. The staff stated that it would review the plant-specific response to the concerns of Issue 130 and that the roview would include, among other things, the available redundancy in ESW pumps within a division to achieve any licensingbasis requirement, available flexibility for needed recovery actions, and specific measures to preclude potential operator errors.

GE revised the SSAR to delete the discussion of Issue 130, because it is not applicable to BWR plants. The SSAR discussions and EPRI requirements that are the subject of DFSER Open Item 20.2-4 no longer exist in SSAR Sections 19B.2.10 and 19B.3.5. SSAR Section 1.1.6 still states that the ABWR has been designed as a single-unit plant, therefore, the staff need not be concerned with specific consideration of possible shared systems and with addressing Issue 130. Because Issue 130 is not applicable to BWR plants and based on the subsequent revisions to the SSAR discussed above, the staff concludes that DFSER Open Item 20.2-4 is resolved.

Because this issue is not applicable to the ABWR and based on the above discussion of the ABWR design as a single-unit plant without any shared systems, the staff concludes that the COL applicant need not prepare a plantspecific response to the issue. On this besis, the staff concludes that DFSER COL Action Item 20.2-3 was not warranted and need not be addressed.

\subsubsection{Issue 142: Leakage Through Electrical Isolators in Instrumentation Circuits}

This issue addresses electrical isolators used to maintain electrical separation between safety-related and non-safetyrelated electrical systems in nuclear power plants, preventing malfunctions in the non-safety-related systems from degrading the performance of safety-related circuits. The primary concern is that the amount of energy that could pass through certain types of isolation devices (and be transmitted to safety-related circuitry) during certain electrical transionts might damage or seriously degrade the performance of Clases IE components. Or, this energy could cause the isolation devices to give falee output, or the olectrically generated noise on the circuit might cause the ieolation device to give a false output.

The roviow criteria for this iscue are contained in a letter from T. Murloy (NRC) to R. Artigas (GE), "Advanced Boiling Water Reactor Licensing Roview Bases," dated August 7, 1987. This letter contains the staff's expectations regarding isolation dovices. The letter describes the design and environmental qualifications that insulators must satisfy. It requires that description of tosts be provided, as woll as other requirements, as appropriate. The letter also addresses guidance for fiber-optic cable, and etates that the staff is working to dovelop comprehensive guidance on this subject, and that it will be based on the oxieting IEEE cable standards, wuch as IEEE 323 and 384, and applicable ANSI standards.

Therefore, the reviow criteria for this isoue must contain guidance for:

- Inspection and testing of all electrical insulation devices between Class 1E and non-Class 1E systems.

- Replacement or repair of isolators that fail the tests, including description of accoptable hardware fixes to the isolators.

- Implementation of an annual program to inspect and test all electrical isolators between Class IE and nonClass IE systems.

SSAR Appendix 7A and Section 19B.2.53 state that the isolating devices used in the ABWR design are similar to those in Group 1 referred to in NUREG/CR-3453, "Electronic Isolators Used in Safety Systems of U.S. Nuclear Power Plants." Review of this reference confirmed that lest results demonstrated that only minor amounts of high-frequexcy energy pass through the barrier during testing. These isolators, though they provide the best isolation and are recommended as the safest units, they are the most susceptible to damage. The report indicates that they are 80 fragile that some were damaged during the electromagnetic interference (EMI) tests.

GE indicates that the ABWR design will use a fiber-optic system for electrical isolation of logic and analog signals between protection divisions and from protection divisions to non-safety equipment. This selection of isolation devices appears to be scceptable, in viow of the statement in the referenced report that "optical-fiber isolators are the newest of the isolators and consist of both analog and digital types." 
Another positive feature of the design is the fact that the ABWR RPS and ESF functions are not aupplied directly from a commercial power eource, but from difforent plant power sources. Thus, the low voltage de aupplies fed from theee sources are regulated and filtered. This is important, because as the reference states, when power is oupplied from commercial sources to the input power supply through the common ac power line, as it is in most PWRs, power surge appears to be high.

The advance SER stated that as part of the resolution of this issue, there should be a requirement stated in the accoptance criteria in SSAR Section 19B.2.53 that the following will bo implomented:

- Annual inspection and testing of all olectrical isolation devices between Class IE and non-Class IE systoms.

- Repair or replacement of insulators that fail the teats.

These changes were incorporated in SSAR Amendment 34.

In the advance SER, the staff concluded that GE provided an acceptable system of isolators to resolve this issue, assuming that the testing, inspection, and replacement of isolators, when needed, would bo incorporated in resolution of this issue. The staff verified that GE established a COL action item in SSAR Section 19B.3.2 and Table 1.9-1 addressing testing, inspection, and replacoment of isolators. On the basis of this information, the staff concludes that GE adequately addreseed this issue for the ABWR design.

\subsubsection{Issue 143: Availability of Chilled Water Systems}

This issue concerns partial or complete loss of the HVAC system. Many of these problems exist because of the desire to provide increased fire protection and the need to avoid severe temperature changes in equipment control circuits. The improvements in this area, which started after the Browns Ferry fire, consist mainly of enclosing the affected equipment in small, isolated rooms. This resulted in a significant reduction in room cooling rate. Plant control and safety have improved with the introduction of electronic integrated circuits. However, these circuits are more susceptible to damage from severe changes in temperature caused by the loss of room cooling.

It is believed that failures of air cooling systems for aress housing key components, such as RHR pumps, switchgear, and diesel generators, could contribute significantly to core-melt probability in certain plants. Because corrective measures are often taken at the affected plants once such failures occur, the impact of these failures on the proper functioning of air cooling systems may not have been considered. Thus, plants with similar inherent deficiencies may not be aware of these problems.

Operability of some safety-related components is dependent upon operation of HVAC and chilled water systoms to remove heat from the rooms containing the components. If chilled water and HVAC systems are unavailable to remove heat, the functionality of the equipment within the rooms may bo destroyed.

The review criterion for this issue is to assure that the equipment can be functional during the period of loss of room cooling.

SSAR Section 19B.2.54 states the following criteria as the acceptable ABWR design:

- An ovaluation of the dependencies or nondependencies of anfety-related equipment on HVAC cooling will be performed. This ovaluation will include assessment of room heat load and heatup rates, and establish equipment operating conditions. Equipment ability to withstand these conditions without loss of function will be established.

- For equipment found to be significantly dependent on the HVAC cooling, an assessment of the HVAC system reliability will be performed. PRA analyses will be carried out to assess plant risk and determine whether any modifications are necessary.

- Corrective design measures will be identified where necessary to reduce plant risk.

SSAR Section 19B.2.54 states that the following features have been incorporated into the ABWR design to satisfy the criteria stated above:

- RCIC pump and turbine are designed to operate for at least 8 hours without room cooling. This system will provide core cooling during a prolonged loss of HVAC cooling.

- Operation of other injection systems (HPCF, LPFL, RHR) is more dependent on the availability of room cooling. However, these systems are designed to operate for at least 10 minutes without room cooling. The equipment in question is designed to be operational at the highest temperature expected during that time.

- Detailed design specifications for ABWR safety-related equipment will specify the room conditions under which equipment must operate without room cooling. 
Room heat aseossment will be performod to establish environmental conditions for equipment specification.

- Potential modifications including procedure changes or hardware changes will be evaluated through PRA analyses to ensure acceptable risk.

GE also listed the safety-related HVAC systems that will provide room cooling under most circumstances. These includo the secondary containmeat safety-related HVAC, reactor building safety-related electrical equipment HVAC, reactor building safety-rolated diesel generator HVAC, and HVAC emergency cooling water (three divisions).

The staff concludes that GE adequately addressed this issue for the ABWR design.

\subsubsection{Issue 145: Actions to Reduce Common Cause Failures}

This issue concerns the fact that common cause failures (CCFs) can be a major cause of a system failure.

Testing of equipment has its limitations; in fact, testing can be an important cause of CCF that occur when the testing does not reflect true demands of the equipment under operating conditions. For example, MOVs may work during a test but not during a true demand when there exists a high differential pressure across them. Much design-basis testing cannot be performed in situ. Prototypical testing, on the other hand, is expensive and the application of it to equipment in plants is sometimes not practical. Effective maintenance is important to ensure that design assumptions and margins in the original design bases are maintained. In the design of nuclear plants, an important safety margin is the redundancy of equipment to perform safety functions. This redundancy, however, can be degraded by CCFs. Thus, measures are needed to identify CCF precursors before they occur so that corrective mensures can be taken.

The reviow criterion for the resolution of Isque 145 is to demonstrate compliance with the maintenance rule, 10 CFR 50.65, which requires that a program of performance and condition monitoring activities be ovaluated at least every refueling cycle (provided the interval between evaluations does not exceed 24 months) and that industry-wide experience bo incorporated in the program. When monitoring and preventive maintenance activitios aro performod, an assessment of the total plant equipment that is out of service should be taken into account to determine the overall effect on performance of safety functions.
Implementation of $10 \mathrm{CFR} 50.65$ is an effective and practical way to prevent or reduce CCFs.

SSAR Section 19B.2.55 states that compliance with 10 CFR 50.65 will be responsibility of the COL applicant. This approach is acceptable to the staff.

In addition, the ABWR capability to respond to system interactions and CCFs is described in the SSAR Soction 19.2.3.4. Five factors are considered and incorporated in the analysis of system interactions and CCFs:

- Component commonality at the system level, such as common initiating signal.

- Common divisional services, such as common electric power buses or common service water loops.

- System dependency, such as automatic depressurization system (ADS) dependency on the operability of at least one of the five (two high-pressure and three low-pressure) ECCS pumps.

- Past experience of losing onsite power.

- Human errors.

Actions to reduce CCFs fall into the Owner/Operator's Reliability Assurance Process (O-RAP), described in SSAR Section 17.3.10 and which bas been reviewed by the staff and found to be acceptable as discussed in Sections 17.3.9 and 17.3.10 of this report. The COL applicant will specify the policy and implementation procedures for the O-RAP and submit it for staff review. The staff verified that GE established a COL action item in SSAR Section 17.9.13 to make use of information provided by $G E$ to help the owner/operator determine activities that should be included in the O-RAP. This approach is acceptable to the staff.

Based on this information, the staff concludes that GE adequately addressed this issue for the ABWR design. The staff will evaluate compliance with 10 CFR 50.65 as part of its inspection activities during plant operations.

\subsubsection{Issue 151: Reliability of Recirculation Pump Trip During an ATWS}

This issue concerns reliability of breakers used to trip the recirculation pumps at high pressure or low-water-level signals during ATWS mitigation in BWRs.

If a plant transient requiring reactor scram occurs and the scram function does not occur, then an ATWS ovent 
exists. To lessen the effects of an ATWS event, negative reactivity must be added to the reactor core by tripping the recirculation pumps. Negative reactivity is added as a result of the ensuing stean voiding in the core area as the core flow decreases, thereby decreasing the power generation and limiting the power or pressure disturbance. If the recirculation $\mathrm{pu}$ up trip (RPT) Rails to trip on demand, the reactor could experience continued power generation resulting in a high suppression pool temperature.

Plants equipped with GE AKF-25 circuit breakers have experienced failures of the field breakers in the RPT system that were caused by binding of the trip latch mechanism and misadjustment of the breakers' mechanical linkage.

The review criterion for this issue is determining the use of reactor RPT hardware or a RPT method that is more reliable than the previously used AKF 2-25 breaker hardware or RPT method.

Since the design for the ABWR reactor recirculation systom and RPT method is completely different from the previously designed BWR reactor recirculation systems and RPT trip methods, resolution of this issue was evaluated on the basis of the ABWR RPT information about the new design for the recirculation pump system provided by GE in SSAR Sections 7.7.1.3(7) and 7.7.1.3(8). A summary of the important design changes is provided in the following paragraphs.

GE states that the ABWR reactor recirculation system and the RPT design is completely different from the previously designed BWR reactor recirculation systems and RPT methods. They state that it is more diverse and more redundantly reliable. The ABWR uses 10 pumps and multiple pump and RPT trip logic, circuits and hardware, rather than only two recirculation pumps, as has been generally used in BWRs. The recirculation flow control (RFC) system consists of three redundant process controllers, adjustable-speed drives (ASDs), switches, sensors, and alarm devices provided for operational manipulation of the 10 RIPs and the surveillance of the associated equipment. RFC is achieved either by manual operation or by automatic operation if the power level is above 70 percent of rated power.

In the event of (a) a turbine trip or generator load rejection when reactor power is above a predetermined level, (b) the reactor pressure exceeds the high dome pressure set point, or (c) the reactor water level drops below the Lovel 3 set point, the RPT logic will automatically trip off a group of four RIPs. If the reactor water level continues to drop and reaches Lovel 2 after the first group of four RIPs have been tripped, the remaining six RIPs will be tripped. The implementation of the second RPT function is similar to that of the first RPTs, using 2-out-of-4 confirmation logic.

It is known that plants with GE AKF-25 circuit breakers have experienced failures of the field breakers in the RPT system. In the ABWR design, instead of using AKF-25 breaker switching hardware to provide an RPT, RFC controller switching and ADS gate inverter turn-off circuit hardware provide the RPT.

The staff determined that the system described above appears to be more reliable than the previously used AKF-2-25 breaker hardware and method and, therefore, provides reasonable assurance that in the event of an ATWS, the RIPs will be tripped, thus lessening the effect of the ATWS. Based on this determination, the staff concludes that GE adequately addressed this issue for the ABWR design.

\subsubsection{Issue 153: Loss of Essential Service Water in LWRs}

This issue concerns reliability of the ESW supply that is critical in the transfer of heat from various safety-related and non-safety-related systems and equipment to the UHS. The ESW is needed in every phase of plant operations and, under accident conditions, supplies adequate cooling water to systems and components that are important to safe plant shutdown or to mitigate consequences of an accident. Under normal operating conditions, the ESW provides component and room cooling (mainly via the component cooling water system). During shutdowns, it also ensures that the residual heat is removed from the reactor core, cooling towers, and water treatment systems at a plant. A complete loss of the ESW system could lead to a core-melt accident, posing a significant risk to the public.

Loss of ESW can be caused by a number of reasons: various fouling mechanisms (sediment decomposition, biofouling, corrosion ard erosion, foreign materials, and debris intrusion), ice effects, single failures and other design deficiencies, flooding, multiple equipment failures, and personnel and procedural errors. Additionally, the design and operational characteristics of the ESW system differ significantly from plant to plant within each reactor type. For these reasons, it is practically impossible to formulate generic ESW design criteria that would be universally applicable. The design bases of the system will conform to the requirements of GDC 2 relating to the ability of structures, systems, and mechanisms to withstand the effects of earthquakes; GDC 4 regarding the protection of safety-related equipment from the effects of internally generated missiles, pipe whip, and environmental conditions resulting from high and modorate energy line 
breaks and the dynamic offects associated with flow instabilities and loads (e.8., water hammer); GDC 5 relating to shared systems and components; and GDC 44 as is relates to transferring heat from structures, systems, and components important to safety, to an ultimate heat sink. More specific review criteria are contained in SRP Section 9.2.1.

The ABWR RSW system removes beat from the reactor building cooling water (RCW) and transfers it to the UHS. The RSW system is provided in three divisions. Each division has two pumps that send cooling water to three heat exchangers. Normally, one pump 'and two heat exchangers are operating in each division. The remaining pump and the third heat exchanger are automatically put in operation when heat-removal requirements increase.

In case of failure of any of the three RSW divisions, the remaining two divisions are sufficient to moet safe shut down requirements for the plant. The ABWR RSW system is protected from common-cause effects by the fact that the three divisions are separated both physically and electrically from each other.

Degradation of the RSW system is prevented by periodic inspection and testing to ensure integrity and functional capability. All three divisions of the RSW system are designed to allow periodic inservice inspection of ail the system components. This testing capability consists of structural and leak-tightness visual inspection, entire system operability, and system component operability and performance.

SSAR Section 19B.2.57 lists the design features for the portions of system that are not within the ABWR standard plant scope that will be provided by the COL applicant.

Based on the above, the staff concludes that GE adequately addressed this issue for the ABWR design.

\subsubsection{Issue 155.1: More Realistic Source Term Assumptions}

This issue is a result of the study conducted by the TMI-2 Safety Advisory Board, and is one of the seven recommendations forwarded to the NRC. The subject issue deals with the fact that during the TMI-2 accident, fission products did not behaye as predicted by the analytical methods and assumptions used in the licensing process at the time and delineated in RG 1.3, "Assumptions Used for Evaluating the Potential Radiological Consequences of a Loss-of-Coolant Accident for Boiling Water Reactors," RG 1.4, "Assumptions Used for Evaluating the Potential Radiological Consequences of a Loss-of-Coolant Accident for Pressurized Water Reactors," and TID-14844,
"Calculation of Distance Factors for Power and Test Reactor Sites." Contrary to the original predictions that during the TMI-2 accident major core damage had occurred, NRC determined that approximately 50 percent of the core was in a molten state, and only about 55 percent of the highly volatile fission products and noble gases were released from the reactor vessel with a major portion retained in the reactor building. There is also evidence that less then 5 percent of the medium- and low-volatile fission products were released from the reactor vessel.

The review of this issue consists of determining that the plant is designed to ensure that the dose commitment to the public, in the event of a licensing design-basis accident, will be within those limits prescribed by existing regulations based upon the guidelines of 10 CFR Part 100.

SSAR Section 19B.2.58 states that in view of lack of adequate guidance as to acceptance methods and conditions, i.e., revised RGs and SRP, it is premature for the ABWR to use the revised source terms. It also states that the ABWR design bas been analyzed in accordance with the current RGs, SRP, and the GDC, all of which are be sd on TID-14844. The staff evaluated offsite radiological consequences using the TID-14844 source term procedures that are consistent with the guidelines provided in the applicable SRP sections and RGs. (See Section 15.4.3 of this report.) Two deviations from the current staff position were noted: (1) credit was given for radioactive iodine removal in the main steam lines and in the main condensers by holdup for decay and deposition and (2) the staff accepted the ABWR design without an MSIV leakage control system.

The advance SER indicated that in response to the staff's concern, the BWR Owners' Group (BWROG) performed further studies to determine the consequences, if any, of the ABWR design regarding radionctive offsite releases. The staff subsequently evaluated the results of the BWROG and GE proposals and found them to be acceptable. In particular, in SSAR Chapter 15, GE performed radiological consequence assessments of certain DBAs and concluded that the ABWR design, using TID-14844 source terms with the two deviations stated above, will moet the dose reference values established in 10 CFR Part 100 and the dose limits given in GDC 19 of 10 CFR 50, Appendix A. To verify GE's conclusion, the staff independently assessed the radiological consequences resulting from DBAs, also using TID-14844 and the deviations discussed earlier, and found GE's assessments to be acceptable. The staff assessments and conclusion are discussed further in Section 15.4 of this report.

Based on this information, the staff concludes that GE adequately addressed this issue for the ABWR design. 


\subsection{Human Factors Issues}

This section addresses staff evaluation of GSIs categorized as "human factors issues" in NUREG-0933. All the following issues are relevant to the ABWR design.

\subsubsection{Issue HF 1.1: Stafring and Qualifications - Shift Stafring}

The purpose of this issue is to assure that the number and capabilities of the staff at nuclear power plants are adequate to provide safe operation. To meet this goal, consideration should be given to: (1) the number and functions of the staff needed to safely perform all requirod plant operations, maintenance, and technical support for each operational mode; (2) the minimum qualifications of plant personnel in terms of education, skill, knowledge, training experience, and fitness for duty; and (3) appropriate limits and conditions for shift work including overtime, shift duration, and shift rotation. More specifically, this issue refers to determination of the minimum appropriate shift crew staffing composition.

The review criteria for this issue are contained in the 10 CFR 50.54, SRP Section 13.1.2-13.1.3, and RG 1.114, "Guidance on Being Operator at the Controls of a Nuclear Power Plant."

This issue is beyond the scope of the ABWR design certification review and the COL applicant will be responsible for addressing it. The staff verified that $\mathrm{GE}$ established a general COL action item (Item 18.1.1 in SSAR Section 18.8) to conduct the detailed HFE design according to design and implementation. The staff considers this to include the resolution of Issue HF 1.1. This approach is acceptable to the staff as discussed in Section 18.7.2.2 of this report.

\subsubsection{Issue HF 4.4: Procedures - Guidelines for Upgrading Other Procedures}

The objective of this issue is to provide assurance that plant procedures are adequate and can be used effectively and to guide operators in maintaining plants in a safe state under all operating conditions. This latter includes the ability to control upset conditions without first having to diagnose the specific initiating event. This objective is to be met by: (1) developing guidelines for preparing and criteria for evaluating emergency operating procedures (EOPs), normal operating procedures, and other procedures that affect plant safety and (2) upgrading the procedures, training the operators in their use, and implementing the upgraded procedures.
The review criteria for this issue are contained in SRP Sections 13.5.1 and 13.5.2 and NRC Information Notice 86-64, "Deficiencies in Upgrade Programs for Plant Emergency Operating Procedures."

The development of detailed procedures and training materials is beyond the scope of the ABWR design cortification review and the COL applicant will be responsible for addressing this generic issue. The staff verified that GE established a COL action item in SSAR Section 13.5.3 for procedure development. SSAR Section 13.5.3.1 indicates that the methods and criteria for the development, verification and validation $(V \& V)$, implementation, maintenance, and revision of procedures will include considerations of Issues I.C.1, I.C.5, and I.C.9. The staff considers this to also include the resolution of Issue HF 4.4. This approach is acceptable to the staff as discussed in Section 13.5 of this report.

\subsubsection{Issue HF 5.1: Man-Machine Interface - Local Control Stations}

The objective of this issue is to ensure that the manmachine interface is adequate for the safe operation and maintenance of nuclear power plants. The regulatory guidance has been limited to the control room and the remote shutdown panel. Further guidance is necessary regarding local control stations and auxiliary operator interfaces. To accomplish this task, analyses of control room crew and local control activities should be conducted to establish and describe communication and control links between the control room and the auxiliary control stations.

The review criteria for this issue are contained in SRP Section 18.2, Appendix A.

This issue is beyond scope of the ABWR design certification review and the $\mathrm{COL}$ applicant will be responsible for addressing it. The staff verified that GE established a COL action item (Item 18.8.11 in SSAR Section 18.8) to analyze this issue. This approach is acceptable to the staff as discussed in Section 18.7.2.2 of this report.

\subsubsection{Issue HF 5.2: Man-Machine Interface - Review Criteria for Human Factors Aspects of Advanced Controls and Instrumentation}

With the outcome of advanced technologies utilizing improved annunciator systems, guidelines for evaluation of these longer-term annunciator improvements are necessary. These guidelines will be based upon evaluations of results from advanced concept activities being performed by the 
Government and commencially sponsored research programs.

The existing HFE guidelines for nuclear power plant control rooms primarily address the control, display, and information concepts and technologies that are now being used in process control systems. Whilo these guidelines were adequate in the past, they may not be sufficient for advanced and developing tochnologies that are being introduced in more advanced designs.

The review criteria for this issue are contained in SRP Section 18.2, Appendix A.

In SSAR Section 18.3, GE described an integrated design implementation process to incorporate HFE principles. The process includes an integrated design of control and instrumentation systems and HSI of the ABWR. The design implementation process facilitates selection of design features that satisfy the top level requirements and goals of individual systems and the overall plant.

In its review of GE's detailed control room design process, the staff found that this issue is beyond the scope of the ABWR design certification review and that it is to be addressed by the COL applicant as part of the detailed design implementation. The staff verified that GE established a general COL action item in SSAR Section 18.8 (Item 18.8.1) to conduct the detailed HFE design according to the design and implementation as defined by the HFE ITAAC and DAC described in ABWR CDM Table 3.1 and SSAR Appendix 18E. The staff considers this to include the analysis of this generic issue. This approach is acceptable to the staff as discussed in Section 18.7.2.2 of this report.

\subsection{TMI Action Plan Items}

This section addresses staff evaluation of GSIs that are categorized as "TMI Action Plan items" in NUREG-0933. Except as noted, all the following issues are relevant to the ABWR design.

\subsubsection{Issue I.A.1.1: Operating Personnel - Operating Personnel and Stafring - Shift Technical Advisor}

This issue requires the provision of an on-shift technical advisor, with specific education and training, to the shift supervisor.

SSAR Section 19B.3.1 states that the COL applicant is responsible for providing resolutions of issues identified as "COL Applicant" in the "Safety Issues Index" of SSAR Appendix 19B. The SSAR states that issues are identified for COL action because they pertain to operating personnel issues, operating procedures, and other topics beyond the scope of the ABWR design certification review. SSAR Section 19B.1.1 lists specific documentation the COL applicant is to provide for resolution of such issues.

GE identified this issue for COL applicant action in the "Safety Issues Index." The staff verified that GE establishod a COL action item (Item 19-28) in SSAR Table 1.9-1 to address unresolved generic and TMI safety issues. This approach is acceptable to the staff. The staff will review the COL applicant's proposed resolution of this issue on a case-by-case basis.

\subsubsection{Issue I.A.1.2: Operating Personnel -- Operating Personnel and Staffing - Shift Supervisor Administrative Duties}

This issue requires review of the administrative duties of the shift supervisor by the senior officer responsible for plant operations. It also requires that when administrative functions detract from or are subordinate to the management responsibility for assuring the safe operation of the plant, they are to be delegated to other operations personnel not on duty in the control room.

SSAR Section 19B.3.1 indicates that the COL applicant is responsible for providing resolutions of issues identified as "COL Applicant" in the "Safety Issues Index" of SSAR Appendix 19B. The SSAR indicates that issues are identified for COL action because they pertain to operating personnel issues, operating procedures, and other topics beyond the scope of the ABWR design certification review. SSAR Section 19B.1.1 lists specific documentation the COL applicant is to provide for resolution of such issues.

GE identified this issue for COL applicant action in the "Safety Issues Index." The staff verified that GE established a COL action item (Item 19-28) in SSAR Table 1.9-1 to address unresolved generic and TMI safety issues. This approach is acceptable to the staff. The staff will review the COL applicant's proposed resolution of this issue on a case-by-case basis.

\subsubsection{Issue I.A.1.3: Operating Personnel -- Operating Personnel and Staffing - Shift Manning}

This issue requires adherence to the shift manning and overtime requirements for normal plant operation established by the NRC.

SSAR Section 19B.3.1 indicates that the COL applicant is responsible for providing resolutions of issues identified as "COL Applicant" in the "Safety Issues Index" of SSAR 
Appendix 19B. The SSAR indicates that issues are identified for COL action because they pertain to operating personnel issues, operating procedures, and other topics beyond the scope of the ABWR design certification review. SSAR Section 19B.1.1 lists specific documentation the COL applicant is to provide for resolution of such issues.

GE identified this issue for COL applicant action in the "Safety Issues Index." The staff verified that GE established a COL action item (Item 19-28) in SSAR Table 1.9-1 to address unresolved generic and TMI safety issues. This approach is acceptable to the staff. The staff will review the COL applicant's proposed resolution of this issue on a case-by-case basis.

\subsubsection{Issue I.A.1.4: Operating Personnel -- Operating Personnel and Stafing - Long-Term Upgrading}

The purpose of this fissue was to develop changes to 10 CFR 50.54 concerning shift staffing with licensed operators and their working hours.

The resolution of this issue is beyond the scope of the ABWR design certification review and the COL applicant will be responsible for addressing it. This was identified in the DFSER as COL Action Item 18.7.2.2-8. The staff verified that GE established a general COL action item (Item 18.1.1 in SSAR Section 18.8) to conduct the detailed HFE design during design and design implementation. The staff considers this to include the resolution of Issue I.A.1.4. This approach adequately addresses DFSER COL Action Item 18.7.2.2-8 as discussed in Section 18.7.2.2 of this report.

20.4.5 Issue I.A.2.1: Operating Personnel - Training and Qualification of Operating Personnel Immediate Upgrading of Operator and Senior Operator Training and Qualifications

This issue requires that, effective December 1, 1980, all senior reactor operator (SRO) applicants must have been a licensed operator for at least 1 year.

SSAR Section 19B.3.1 states that the COL applicant is responsible for providing resolutions of issues identified as "COL Applicant" in the "Safety Issues Index" of SSAR Appendix 19B. The SSAR indicates that issues are identified for COL action because they pertain to operating personnel issues, operating procedures, and other topics beyond the scope of the ABWR design certification review. SSAR Section 19B.1.1 lists specific documentation the COL applicant is to provide for resolution of such issues.
GE identified this issue for COL applicant action in the "Safety Issues Index." The staff verified that GE established a COL action item (Item 19-28) in SSAR Table 1.9-1 to address unresolved generic and TMI safety issues. This approach is acceptable to the staff. The staff will review the COL applicant's proposed resolution of this issue on a case-by-case basis.

\subsubsection{Issue I.A.2.3: Operating Personnel -- Training and Qualifications of Operating Personnel - Administration of Training Programs}

This issue requires that, subject to the accreditation of training institutions, licensees and applicants assure that training center and facility instructors who teach systems, integrated responses, transients, and simulator courses demonstrate SRO qualifications and be enrolled in appropriate requalification programs.

SSAR Section 19B.3.1 states that the COL applicant is responsible for providing resolutions of issues identified as "COL Applicant" in the "Safety Issues Index" of SSAR Appendix 19B. The SSAR indicates that issues are identified for COL action because they pertain to operating personnel issues, operating procedures, and other topics beyond the scope of the ABWR design certification review. SSAR Section 19B.1.1 lists specific ciocumentation the COL applicant is to provide for resolution of such issues.

GE identified this issue for COL applicant action in the "Safety Issues Index." The staff verified that GE established a COL action item (Item 19-28) in SSAR Table 1.9-1 to address unresolved generic and TMI safety issues. This approach is acceptable to the staff. The staff will review the COL applicant's proposed resolution of this issue on a case-by-case basis.

20.4.7 Issue I.A.2.6(1): Operating Personnel -Training and Qualifications of Operating Personnel - Long-Term Upgrading of Training and Qualifications; Revise Regulatory Guide 1.8

This issue required NRC development of a revised RG 1.8 to incorporate recommendations on upgrading personnel training and qualifications.

SSAR Section 19B.3.1 states that the COL applicant is responsible for providing resolutions of issues identified as "COL Applicant" in the "Safety Issues Index" of SSAR Appendix 19B. The SSAR indicates that issues are identified for COL action because they pertain to operating personnel issues, operating procedures, and other topics beyond the scope of the ABWR design certification review. 
SSAR Section 19B.1.1 lists specific documentation the COL applicant is to provide for resolution of such issues.

GE identified this issue for COL applicant action in the "Safoty Issues Index." The staff verified that GE established a COL action item (Itom 19-28) in SSAR Table 1.9-1 to address unresolved generic and TMI safety issues. This approach is acceptable to the staff. The staff will review the COL applicant's proposed resolution of this issue on a case-by-case basis, evaluating compliance with the version of RG 1.8 current at the time of the review.

\subsubsection{Issue I.A.3.1: Operating Personnel - Licensing and Requalification of Operating Personnel - Revise Scope of Criteria for Licensing Examinations}

This issue requires the inclusion of simulator examinations as part of the licensing examinations.

SSAR Section 19B.3.1 states that the COL applicant is responsible for providing, resolutions of issues identified as "COL Applicant" in the "Safety Issues Index" of SSAR Appendix 19B. The SSAR states that issues are identified for COL action because they pertain to operating personnel issues, operating procedures, and other topics beyond the scope of the ABWR design certification review. SSAR Section 19B.1.1 lists specific documentation the COL applicant is to provide for resolution of such issues.

GE identified this issue for COL applicant action in the "Safety Issues Index." The staff verified that GE established a COL action item (Item 19-28) in SSAR Table 1.9-1 to address unresolved generic and TMI safety issues. This approach is acceptable to the staff. The staff will review the COL applicant's proposed resolution of this issue on a case-by-case basis.

20.4.9 Issue I.A.4.1(2): Operating Personnel Simulator Use and Development - Initial Simulator Improvement; Interim Changes in Training Simulators

This issue requires the following capabilities for simulators: modeling saturation conditions; providing multiple-failure accident training, including incorrect instrument responses; providing training for both active and passive failure of ESF components; providing training on natural circulation operation under solid water conditions; and other simulator weaknesses that may have been identifiod under I.A.2.6 and I.A.4.2.

SSAR Section 19B.3.1 states that the COL applicant is responsible for providing resolutions of issues identified as "COL Applicant" in the "Safety Issues Index" of SSAR
Appendix 19B. The SSAR states that issues are identified for COL action because they pertain to operating personnel iseves, operating procedures, and other topics beyond the scope of the ABWR design certification review. SSAR Section 19B.1.1 lists specific documentation the COL applicant is to provide for resolution of such issues.

GE identified this issue for COL applicant action in the "Safety Issues Index." The staff verified that GE establishod a COL action item (Item 19-28) in SSAR Table 1.9-1 to address unresolved generic and TMI safety issues. This approach is acceptable to the staff. The staff will roview the COL applicant's proposed resolution of this issue on a caso-by-case basis.

\subsubsection{Issue I.A.4.2: Operating Personnel - Simulator Use and Development - Long-Term Training Upgrade}

Refer to the evaluation of 10 CFR $50.34(f)(2)(i)$ in Section 20.5.13 of this report.

\subsubsection{Issue 1.C.1: Operating Procedures - Short- Term Accident Analysis and Procedures Revision}

The objective of this issue was to improve the analysis of design-basis and off-normal transients and arcidents and the procedures for handling them. Actions to add'ress this issue include the performance of analyses of smali-break LOCAs, inadequate core cooling, transients, and acc dents; preparation of emergency procedure guidelines (LPGs); implementation of appropriate emergency procedures; and training of operators.

The development of detailed procedures and training materials is beyond the scope of the ABWR design certification review and the COL applicant will be responsible for addressing this TMI item. The staff verified that GE established a COL action item in SSAR Section 13.5.3 for procedure development. SSAR Section 13.5.3.1 states that the methods and criteria for the development, $V \& V$, implementation, maintenance, and revision of procedures will include considerations of I.C.1. This approach is acceptable to the staff as discussed in Section $\mathbf{1 3 . 5}$ of this report.

\subsubsection{Issue 1.C.2: Operating Procedures - Shift Relief and Turnover Procedures}

This issue requires that plant procedures include provisions to assure that shift and relief turnover is adequately prescribed to ensure that each oncoming shift is aware of critical plant status information and system availability prior to assuming duties. 
SSAR Section 19B.3.1 states that the COL applicant is responsible for providipg resolutions of issues identified as "COL Applicant" in the "Safoty Ireves Index" of SSAR Appendix 19B. The SSAR states that issues are identified for COL action because thoy pertain to operating personnel issues, operating procedures, and other topics beyond the scope of the ABWR design certification review. SSAR Section 19B.1.1 lists specific documentation the COL applicant is to provide for resolution of such issues.

GE identified this issue for COL applicant action in the "Safety Isowe Index." The staff verified that GE established a COL action item (Itom 19-28) in SSAR Table 1.9-1 to address unresolved generic and TMI safety issues. This approach is acceptable to the staff. The staff will review the COL applicant's proposed resolution of this issue on a caso-by-case basis.

\subsubsection{Issue I.C.3: Operating Procedures - Shift Supervisor Responsibilities}

This issue requires review and revision of plant procedures and directives to assure that duties, responsibilities, and authority are properly defined to establish a definite line of command and clear delineation of the command decision authority of the supervisor in the control room relative to other plant management personnel. It also requires training programs for shift supervisors to emphasize and reinforce the responsibility for safe operation and the management function of the shift supervisor to assure safe operation of the plant.

SSAR Section 19B.3.1 states that the COL applicant is responsible for providing resolutions of issues identified as "COL Applicant" in the "Safety Issues Index" of SSAR Appendix 19B. The SSAR states that issues are identified for COL action because they pertain to operating personnel issues, operating procedures, and other topics which are beyond the scope of the ABWR design certification review. SSAR Section 19B.1.1 lists specific documentation the COL applicant is to provide for resolution of such issues.

GE identified this issue for COL applicant action in the "Safety Issues Index." The staff verified that GE established a COL action item (Item 19-28) in SSAR Table 1.9-1 to address unresolved generic and TMI safety issues. This approach is acceptable to the staff. The staff will review the COL applicant's proposed resolution of this issue on a case-by-case basis.

\subsubsection{Issue I.C.4: Operating Procedures - Control Room Access}

This issue requires that the authority and responsibilities of the person in charge of control room access and clear lines of authority and responsibility in the control room in the ovent of an emergency be established in conformance with itom 2.2.2.a of NUREG-0578, "TMI-2 Lessons Loarned Task Force Status Report and Short-Term Recommendations," dated July 1979.

SSAR Section 19B.3.1 states that the COL applicant is responsible for providing resolutions of issues identified as "COL Applicant" in the "Safety Issues Index" of SSAR Appendix 19B. The SSAR states that issues are identified for COL action because they pertain to operating personnel iseves, operating procedures, and other topics beyond the scope of the ABWR design certification review. SSAR Section 19B.1.1 lists specific documentation the COL applicant is to provide for resolution of such issues.

GE identified this issue for COL applicant action in the "Safety Issues Index." The staff verified that GE established a COL action item (Item 19-28) in SSAR Table 1.9-1 to address unresolved generic and TMI safety issues. This approach is acceptable to the staff. The staff will review the COL applicant's proposed resolution of this issue on a case-by-case basis.

\subsubsection{Issue I.C.5: Operating Procedures - Procedures for Feedback of Operating Experience to Plant Staff}

Refer to the evaluation of $10 \mathrm{CFR} 50.34(\mathrm{f})(3)(\mathrm{i})$ in Section 20.5.41 of this report.

\subsubsection{Issue I.C.6: Operating Procedures - Procedures for Verification of Correct Performance of Operating Activities}

This issue requires review and revision, as necessary, of procedures to assure that an effective system of verifying the correct performance of operating activities is provided as a means of reducing human errors and improving the quality of normal operations. Such a verification system may include automatic system status monitoring and human verification of operations and maintenance activities independent of the people performing the activity.

SSAR Section 19B.3.1 states that the COL applicant is responsible for providing resolutions of issues identified as "COL Applicant" in the "Safety Issues Index" of SSAR Appendix 19B. The SSAR states that issues are identified for COL action because they pertain to operating personnel issues, operating procedures, and other topics beyond the scope of the ABWR design certification review. SSAR Section 19B.1.1 lists specific documentation the COL applicant is to provide for resolution of such issues. 
GE identified this issue for COL applicant action in the "Safety Issues Index." The staff verified that GE established a COL action item (Item 19-28) in SSAR Table 1.9-1 to address unresolved generic and TMI safety issues. This approach is'acceptable to the staff. The staff will review the COL applicant's proposed resolution of this issue on a case-by-case basis.

\subsubsection{Issue 1.C.7: Operating Procedures - NSSS Vendor Review of Procedures}

This issue requires that applicants for near-term operating licenses (NTOLs) obtain the NSSS vendor's reviow of the low-power and power-ascension test and emergency procedures to further verify the adequacy of the procedures.

SSAR Section 19B.3.1 states that the COL applicant is responsible for providing resolutions of issues identified as "COL Applicant" in the "Safety Issues Index" of SSAR Appendix 19B. The SSAR states that issues are identified for COL action because they pertain to operating personnel issues, operating procedures, and other topics beyond the scope of the ABWR design certification review. SSAR Section 19B.1.1 lists specific documentation the COL applicant is to provide for resolution of such issues.

GE identified this issue for COL applicant action in the "Safety Issues Index." The staff verified that GE established a COL action item (Item 19-28) in SSAR Table 1.9-1 to address unresolved generic and TMI safety issues. This approach is acceptable to the staff. The staff will review the COL applicant's proposed resolution of this issue on a case-by-case basis.

\subsubsection{Issue I.C.8: Operating Procedures - Pilot Monitoring of Selected Emergency Procedures for NTOL Applicants}

This issue requires an interdisciplinary and interoffice NRC task force review of emergency procedures received from NTOL applicants and of the training related to the symptoms of the postulated transients.

SSAR Section 19B.3.1 states that the COL applicant is responsible for providing resolutions of issues identified as "COL Applicant" in the "Safety Issues Index" of SSAR Appendix 19B. The SSAR indicates that issues are identified for COL action because they pertain to operating personnel issues, operating procedures, and other topics beyond the scope of the ABWR design certification review. SSAR Section 19B.1.1 lists specific documentation the COL applicant is to provide for resolution of such issues.
GE identified this issue for COL applicant action in the "Safoty Issues Index." The staff verified that GE established a COL action item (Item 19-28) in SSAR Table 1.9-1 to address unresolved generic and TMI safety issues. This approach is acceptable to the staff. However, the COL applicant's responsibility for resolution of this issue extends only to providing the necessary procedures to the task force, accommodating the task force review, and addressing the review findings to the satisfaction of the NRC.

20.4.19 Issue 1.C.9: Operating Procedures - LongTerm Program Plan Procedures for Upgrading of Procedures

Refer to the evaluation of 10 CFR 50.34(f)(2)(ii) in Section 20.5.14 of this report.

\subsubsection{Issue I.D.1: Control Room Design - Control Room Design Reviews}

Refer to the evaluation of 10 CFR 50.34(f)(2)(iii) in Section 20.5.15 of this report.

\subsubsection{Issue I.D.2: Control Room Design - Plant Safety Parameter Display Console}

Refer to the evaluation of 10 CFR 50.34(f)(2)(iv) in Section 20.5.16 of this report.

\subsubsection{Issue I.D.3: Control Room Design - Safety System Status Monitoring}

Refer to the evaluation of 10 CFR $50.34(f)(2)(v)$ in Section 20.5.17 of this report.

\subsubsection{Issue I.D.5(2): Control Room Design - Plant Status and Post-Accident Monitoring}

The objective of this issue is to improve the ability of nuclear power plant control room operators to prevent, diagnose, and properly respond to accidents and concentrates on the operator's information needs.

The review criteria for this issue are contained in RG 1.97 (Rev. 3). This document provides guidance for the design of instrumentation to help the operators (1) to determine the nature of an accident and whether the reactor trip and engineered safety features are functioning properly, (2) to provide information regarding the potential for breaching the barriers to radioactivity release, and (3) furnish data for deciding on the need to take manual action if an engineered safety feature malfunctions. 
SSAR Section 19B.2.65 states that the ABWR information system provides information for manual initiation and control of safety systems. These systems provide information sufficieat for the operators to take an appropriate action when needed. Section 19B.2.65 refers to SSAR Section 7.5, "Information Systems Importent to Safety," which describes safoty-related display systoms that provido information for the safo operation of the plant during normal operation, anticipated operational occurrences, and accidents. SSAR Section 7.5.2.1, "Pout Accident Monitoring System," describes Typo A Variables, which are plant-specific parameters needed to alert the control room operators to take actions menually, initiating a system or function that otherwise would not be automatically initiated in the course of an event. In conformance with the guidelines provided in RG 1.97, SSAR Table 7.5-2 lists post-accident monitoring variables which are common to BWR designs. The staff concludes that the features discussed above adequately addrese this issue for the ABWR design.

\subsubsection{Issue 1.D.5(3): Control Room Design - On-} Line Reactor Surveillance System

This issue addresses noise surveillance and diagnostic techniques associated with the on-line reactor surveillance system. More specifically, it focuses on neutron noise monitoring in BWRs to detect the impact of instrument tubes against fuel channel boxes or detect other loose internal reactor parts.

The review criteria for this issue are addressed in RG 1.133, "Loose Parts Detection Program for the Primary System of Light-Water Cooled Reactor." SSAR Section 4.4.4, "Loose-Parts Monitoring System," describes the ABWR design features to provide detection of loose metallic parts within the RPV. The loose-parts monitoring system (LPMS) is designed to provide detection and operator warning of loose parts in the RPV to avoid or mitigate damage to or malfunction of reactor components. Additional design considerations provide for the inclusion of electronic features to minimize operator interfacing requirements during normal LPMS operation. These electronic features improve the LPMS capability when operator action is required. GE provided a general description of the LPMS, including the design bases, system description, system operation, safety evaluation, test, inspection, and application. The LPMS includes sensors (accelerometers located at neutral loose parts collection regions, e.g., steam outlet nozzle, feedwater inlet nozzle, control rod drive housings), signal conditioning, signal analysis, alarms, and calibration. The staff reviewed the LPMS description and concluded in Section 4.4.4.2 of this report that it conforms with RG 1.133 and, therefore, concludes that GE adequately addresced this iseve for the ABWR design.

\subsubsection{Issue 1.F.1: Quality Assurance (QA) - Expand QA List}

Refor to the evaluation of 10 CFR $50.34(f)(3)(i i)$ in Section 20.5 .42 of this report.

\subsubsection{Issue I.F.2: Quality Assurance - Develop More Detailed QA Criteria}

Refer to the evaluation of 10 CFR 50.34(f)(3)(iii) in Section 20.5.43 of this report.

\subsubsection{Issue I.G.1: Preoperational and Low-Power Testing - Training Requirements}

The objective of this iesue is to increase the capability of shift crows to operate facilities in a safo and competent manner by assuring that training for plant changes and offnormal events is conducted.

The review criterion for this issue is the definition of training plans prior to fuel loading and the conduct of training prior to full-power operation for each operating shift. The resolution of this issue is beyond the scope of the ABWR design certification review, and the COL applicant will be responsible for addressing it. SSAR Section 13.2 discusses training requirements for reactor operators. The staff verified that GE established a COL action item in SSAR Section 13.2.3.2 to include training requirements for preoperational and low-power testing activities. This approech is acceptable to the staff as discussed in Section 13.2 of this report.

\subsubsection{Issue 1.G.2: Preoperational and Low-Power Testing - Scope of Test Program}

The objective of this issue is to reviow the comprehensiveness of test programs to identify anomalies in a plant's response to transients.

The review criteria for resolution of this issue are specified in SRP Chaptor 14, "Initial Test Program - Final Safety Analysis Report," and RG 1.68, "Initial Test Programs for Water-Cooled Reactor Power Plants." SRP Section 14.2 sets forth the acceptable test procedures to establish the degree of conformance with the applicable tests identified in RG 1.68. RG 1.68, in turn, describes the general scope and depth of initial test programs acceptable to the NRC staff for light-water cooled reactors. RG 1.68, Appendix A provides a representative listing of plant structures, systoms, and components design features and 
performance capability teats that should be demonstrated during the initial teet program.

The atafi reviowed the teat program proposed by OE for the ABWR and concludes in Section 14.2 of this report that it conforme to SRP Chapter 14 and RO 1.68. Therefore, the stuff concludes that $\mathrm{OB}$ adoquately addreseed this ienve for the ABWR.

20.4.29 Iseve I.B.1: Consideration of Degraded or Melted Cores in Safety Review - Reactor Coolant System Vents

Refer to the evaluation of 10 CFR $50.34(f)(2)(v i)$ in Section 20.5.18 of this report.

20.4.30 Issue II.B.2: Consideration of Degraded or Melted Cores in Safety Review - Plant Shielding to Provide Access to Vital Areas and Protect Safety Equipment for Post-Accident Operation

Refer to the evaluation of 10 CFR $50.34(f)(2)$ (vii) in Section 20.5.19 of this report.

20.4.31 Issue II.B.3: Consideration of Degraded or Melted Cores in Sofety Review - Post-Accident Sampling

Refer to the evaluation of 10 CFR $50.34(f)(2)$ (viii) in Section 20.5.20 of this report.

\subsubsection{Issue II.B.4: Consideration of Degraded or Melted Cores in Safety Review - Truining for Mitigating Core Damage}

This issue requires development and implementation of a training program to teach the use of installed equipment and systems to control or mitigate accidenfs in which the core is severely damaged.

SSAR Section 19B.3.1 indicates that the COL applicant is responsible for providing resolutions of issues identified as "COL Applicant" in the "Safety Issues Index" of SSAR Appendix 19B. The SSAR states that issues are identified for COL action because they pertain to operating personnel issues, operating procedures, and other topics which are beyond the scope of the ABWR design certification review. SSAR Section 19B.1.1 lists specific documentation the COL applicant is to provide for resolution of such issues.

GE identified this issue for COL applicant action in the "Safety Issues Index." The stuff verified that GE established a COL action item (Item 19-28) in SSAR Table 1.9-1 to address unresolved generic and TMI safety iences. This approach is scceptable to the staff. The staff will roviow the COL applicant's propoeed recolution of this iense on a caes-by-caes basis.

20.4.33 Isave 11.B.8: Consideration of Degraded or Melted Core in Safety Review - Rulemaking Proceeding on Degraded Core Accidents

Refor to the evaluations of 10 CFR $50.34(f)(1)(i)$, $50.34(f)(2)(i x), 50.34(f)(3)(i v)$, and $50.34(f)(3)(v)$ in Sections 20.5.1, 20.5.21, 20.5.44, and 20.5.45, respectively, of this report.

20.4.34 Isave II.D.1: Reactor Coolant System Relief and Safety Valves - Testing Requirements

Refor to the ovaluation of 10 CFR $50.34(f)(2)(x)$ in Section 20.5.22 of this report.

\subsubsection{Issue II.D.3: Reactor Coolant System Relief and Safety Valres - Relief and Safety Valve Position Indication}

Refer to the evaluation of 10 CFR $50.34(f)(2)(x i)$ in Section 20.5 .23 of this report.

20.4.36 Issue II.E.1.1: System Design -- Auxiliary Feedwater System - Auxiliary Feedwater System Evaluation

This isoue is not applicable to the ABWR as discussed in the evaluation of 10 CFR 50.34(f)(1)(ii) in Section 20.5.2 of this report.

20.4.37 Issue II.E.1.2: System Design - Auxiliary Feedwater System - Auxiliary Feedwater System Automatic Initiation and Flow Indication

This issue is not applicable to the ABWR as discussed in the ovaluation of $10 \mathrm{CFR} 50.34(f)(2)(x i i)$ in Section 20.5.24 of this report.

20.4.38 Issue II.E.1.3: System Design - Auxiliary Feedwater System - Update the Standard Review Plan and Develop Regulatory Guidance

This issue requires the NRC to update SRP Section 10.4.9 and issue a regulatory guide on AFWSs.

The staff determined that this issue is not applicable to the ABWR, since a BWR plant does not incorporate an AFWS. Therefore, this issue is not technically relevant to the ABWR design and does not need to be addressed. 
20.4.39 Issue II.E.3.1: System Deaign - Decay Heat Removal - Reliability of Power Suppliee for Natural Circulation

This issue is not applicable to the ABWR as discuned in the evaluation of $10 \mathrm{CFR} 50.34(f)(2)(x i i)$ in Section 20.5.25 of this report.

20.4.40 Issue II.E.4.1: System Dedign - Contrinment Design - Dedicated Penetration

Refor to the evaluation of 10 CFR $50.34(f)(3)$ (vi) in Section 20.5.46 of this report.

\subsubsection{Issue II.E.4.2: System Design - Containment Design - Isolation Dependability}

Refer to the ovaluation of 10 CFR $50.34(f)(2)(x i v)$ in Section 20.5.26 of this report.

20.4.42 Issue II.E.4.4: System Deaign -- Containment Design - Purging

Refer to the evaluation of 10 CFR $50.34(f)(2)(x v)$ in Section 20.5.27 of this report.

\subsubsection{Issue II.E.5.1: System Design - Deeign Sensitivity of Babcock \& Wilcox (B\&W) Reactors - Design Evaluation}

This issue is not applicable to the ABWR as diecuesed in the evaluation of $10 \mathrm{CFR} 50.34(f)(2)(x v i)$ in Section 20.5.28 of this report.

\subsubsection{Iscue II.E.6.1: System Desitn - In-Situ Testing of Valves - Test Adequacy Study}

The objective of this issue is to establish the adequacy of current requirements for safety-related valve teating. It recommends a study that would reeult in recommendations for alternate means of verifying performence requirements. This issue was divided into four parts during its recolution: (1) pressure isolation valves (PIV8), (2) check valves, (3) reevaluation of thermal-overload protection provisions of RG 1.106, "Thermal Overload Protection for Electric Motors on Motor-Operated Valves," for MOVs, and (4) in-situ testing of MOVs.

Relative to in-situ testing of PIV8, SSAR Section 3.9.6 requires that all the PIVs listed in Table 3.9-9 be leak tested in accordance with the ABWR TS. This approach is an acceptable way of addressing this part of the issue.
Regarding in-situ touting of check valves, SSAR Section 3.9.6.2.1 indicates that the COL applicant is responsible for performing in-situ full-flow teating of check valven, in addition to the ASME Section XI inservice teeting requirements. Advanced, nonintrusive techniques will be ueed to aseese degradation and performance characterietics of the check valves. In addition, the COL applicant is to dovelop a program to eatablish the frequency and extent of disaseombly and inspection of check valves. This approech is responsive to the applicable guidelines of SECY-90-016 regarding ineervice teating of pumps and valves and is an accoptable moans of addressing this part of the issue.

For reovaluation of MOV thermal-overload protection, SSAR Tables 1.8-20 and 1.8-22 state that the ABWR deaign complies with RG 1.106 and NUREG-129, "Thermal Overload Protection for Eloctric Motors on Motor-Operated Valves - Genoric Isove II.E.6.1," respectively. In addition, SSAR Section 3.9.6.2.2 states that the guidelines of OL 89-10 will be implemented. Since the staff determined that the guidelines of RO 1.106 adequatoly address thermal-overload protection and OL 89-10 addresses control switch settings, which include thermal overload, the staff concludes that GE's approech to this part of the issue is acceptable.

With respect to in-situ tosting of MOVs, SSAR Section 3.9.6.2.2 discusses implementation of the guidelines of GL 89-10 in sufficient detail for the staff to conclude in Section 3.9.6.2 of this report, that the staff's positions in SECY-90-016 as an applicable regulation reganding inservice testing of pumps and valves are addreseed and that $\mathrm{OE}$ took an acceptablo approach to this part of the isoue.

\subsubsection{Reserved.}

20.4.46 Issue II.F.1: Instrumentation and Controls Additional Accident Monitoring Instrumentation

Refer to the evaluation of 10 CFR $50.34(f)(2)(x v i i)$ in Section 20.5.29 of this report.

\subsubsection{Issue II.F.2: Instrumentation and Controls - Identification of and Recovery from Conditions Leading to Inadequate Core Cooling}

Refer to the ovaluation of 10 CFR $50.34(f)(2)(x v i i i)$ in Section 20.5.30 of this report. 
20.4.48 lave II.F.3: Instrumentation and Controbs Instruments for Monitoring Accident Conditions

Refor to the evaluation of 10 CFR $50.34(f)(2)$ (xix) in Section 20.5.31 of this report.

\subsubsection{Isuse II.G.1: Electrical Power - Power Supplies for Pressurizar Relled Valves, Block Valves, and Level Indicators}

This issus is not applicable to the ABWR as discussed in the evaluation of $10 \mathrm{CFR} 50.34(f)(2)(x x)$ in Section 20.5.32 of this report.

20.4.50 Issue II.J.3.1: General Implications of TMI for Design and Construction Activitie Management for Deaign and Construction. Organization and Stafring to Oversec Design and Construction

Refer to the evaluation of 10 CFR $50.34(f)(3)(v i i)$ in Section 20.5.47 of this report.

20.4.51 Isove II.J.4.1: General Implications of TMI for Design and Construction Activities - Revise Deficiency Reporting Requirements

This issue requires the NRC to improve the event-reporting requirements of 10 CFR 50.55(e) and 10 CFR Part 21 to ensure that all reportable items are reportal promptly and that information submitted is complete.

SSAR Section 19B.3.1 states that the COL applicant is responsible for providing resolutions of isstes identified as "COL Applicant" in the "Safety Issues Index" of SSAR Appendix 19B. The SSAR states that issues are identified for $\mathrm{COL}$ action because they pertain to operating personnel issues, operating procedures, and other topics beyond the scope of the ABWR design certification review. SSAR Section 19B.1.1 lists specific documentation the COL applicant is to provide for resolution of such issues.

GE identified this issue for COL applicent action in the "Safety Issues Index." The staff verified that GE established a COL action item (Item 19-28) in SSAR Table 1.9-1 to address unresolved generic and TMI safety issues. This approach is acceptable to the staff. However, the COL applicant's responsibility for resolution of this issue extends only to complying with the current regulations. The staff will review the COL applicant's proposed resolution of this issue on a case-by-case basis, evaluating compliance with the versions of 10 CFR 50.55(e) and 10 CFR Part 21 current at the time of the review.
20.4.52 Inve I.K.1(5): Measures to Mitigate SmallBreak Loss-of-Coolant Accidents and Lose-ofFeedwater Accidents - IE Bulletins - SafetyRelated Valve Position Description

The objective of this isave is to have plants (1) reviow all valve positions and positioning requirements and positive controls, along with all related tost and maintenance procedures, to aseure proper ESF functioning, if required, and (2) verify that AFW valves are in the open position.

The verification that AFW valves are in the open position is applicablo to PWRs only, since a BWR design does not include an AFWS. Therefore, this portion of the issue it is not technically relevant to the ABWR design and does not need to be addreseed.

The reviow of valve positions and positioning requirements and positive controls is beyond the scope of the ABWR deaign certification review, and the COL applicant will bo responsible for addressing this portion of the TMI item. This was identified in the DFSER as COL Action Itom 18.7.2.2-7. The staff verified that GE established a COL sction item (Item 18.8.7) in SSAR Section 18.8 for an ovaluation of the indication of local valve position. This approach adequately addresses DFSER COL Action Itom 18.7.2.2-7 as discussed in Section 18.7.2.2 of this report.

20.4.53 Issue II.K.1(10): Measures to Mitigate SmallBreak Loss-of-Coolant Accidents and Loss-ofFeedwater Accidents -- IE Bulletins - Review and Modify Procedures for Removing SafetyRelated Systems from Service

Between April 1, 1979, and July 26, 1979, the former NRC Office of Inspection and Enforcement (IE) issued nine bulletins to various operating plant licensees. This issue requires compliance with the requirements of the IE Bulletins related to operability determination and criteria needed to be met bofore removing safety-related equipment from service.

The DFSER reported that the SSAR stated that the COL applicant will reviow all maintenance and test procedures during the preoperational test phase. It also stated that the COL applicant will ensure that the maintenance and test procedures require verification of operability of redundant safety-related systems before removing the safety system from service. The SSAR also stated that the COL applicant will verify the operability of safety-related systems after performing maintenance or tests as part of the test to restore a system to service. The staff concluded that these requirements satisfied this TMI item, but stated 
that compliance with the TMI itom was DFSER COL Action Item 20.3.1-2.

The staff verified that GE established a COL action itom in SSAR Section 1A.3.2 for reviewing and modifying, as required, the procedures for removing enfety-related systems from and restoring them to service to sesure that their operability status is known. (The staff will vorify that the procedures satisfy these requirements, which correspond to Item 8 of IE Bulletin 79-08, while reviewing the preoperational testing.) The staff concludes that this approach adequately addresses DFSER COL Action Item 20.3.1-2 and GE adequately addreseed this TMI itom for the ABWR design.

\subsubsection{Issue II.K.1(13): Mensures to Mitigate Small- Break Loss-of-Coolant Accidents and Loss-of- Feedwater Accidents - IE Bulletins - Propoced Technical Specification Changes Relecting Implementation of All Bulletin Items}

Between April 1, 1979, and July 26, 1979, IE issued nine bulletins to various operating plant licensees. This issue requires operating plants to propose TS changes reflecting implementation of all bulletin items, as required.

Since 1969, there has been a trend to include in TS not only those requirements derived from safety analyses and evaluations, but also many other Commission requirements governing the operation of nuclear power reactors. Therefore, to make TS more operator oriented and to focus on the more important requirements, in its interim "Commission Policy Statement on Technical Specifications Improvements for Nuclear Power Plants," (52 FR 3788 dated February 6, 1987), the Commission established criteria to determine which requirements should remain in TS and which requirements could be relocated to licenseecontrolled documents. Based on these criteria and with industry input, the staff developed improved standard technical specifications (STS). The bulletin items covered by this TMI item were considered in the development of the improved STS.

Future TS, including those for advanced reactors such as the ABWR, are to be based on the improved STS. Consequently, this approach supersedes the need to specifically address the builletin items covered by this issue for the ABWR. Section 16 of this report discusses the development and acceptability of the ABWR TS.
20.4.55 Inen II.K.1.(22): Measures to Mitigate SmallBreak Lose-of-Coolant Accidents and Loss-ofFeedwater Accidents - IE Bulletins - Describe Automatic and Manual Actions for Proper Functioning of Auxiliary Heat Removal Systems When Feedwater System Not Operable

Refer to the ovaluation of 10 CFR $50.34(f)(2)(x x i)$ in Section 20.5.33 of this report.

20.4.56 Issue II.K.1(23): Measures to Midigate SmallBreak Loss-of-Coolant Accidents and Loss-ofFeedwater Accidents - IE Bulletins - Describe Uses and Types of RV Level Indication for Automatic and Manual Initiation Safety Systems

Between April 1, 1979, and July 26, 1979, IE issued nine bulletins to various operating plant licensees. This issue requires the performance of systems reliability analyses and changes in EOPs and operator training to improve the capability of plants to mitigate the consequences of the SBLOCAs and loss-of-foedwater events.

The reviow criterion for this issue is that the reactor water level must be known to the operators under all normal and abnormal conditions. The instrumentation that serves this purpose must be functional under all conditions, and must provide the operators all the information necessary to aseose the state of the plant and what corrective action to be taken when needed.

SSAR Section 1A.2.21, describes the instrumentation that give the operator the information necessary to assess plant status. It provides information for the following conditions:

- Shutdown water level range - used to monitor the reactor water lovel during shutdown conditions when the reactor is flooded for maintenance and head removal.

- Narrow water level range - RPV taps at the elevation above the main steam outlet nozzle and a tap at an elovation near the bottom of the dryer skirt. This range is used for the water-level control and indication inputs of the feedwater control system. 
- Wido water lovel range - RPV tape at the olovation above the main steam outler nozzlo and tape at the elovation near the top of the sctive fuel. These instruments provide inputs to various safety systems and ESF8.

- Fuel zone, water lovel range - RPV taps at the elevation above the main steam outlet nozzle and tape just above reactor internal pump deck. These instruments provide input to water-level indication only.

The instrumentation described above will improve the capability of the plant to mitigate the consequences of the SBLOCAs and loss-of-feedwater ovents, which is the objective of this issue. Therefore, the staff concludes that $\mathrm{GE}$ adequately addressed the requirements of this TMI item for the ABWR design.

20.4.57 Issue II.K.2(9): Measures to Mitigate SmallBreak Loss-of-Coolant Accidents and Loss-ofFeedwater Accidents - Commisejon Orders on B\&W Plants - Analysis and Upgrading of Integrated Control System

This issue is not applicable to the ABWR as discuseed in the evaluation of 10 CFR $50.34(f)(2)$ (xxii) in Section 20.5.34 of this'report.

20.4.58 Issue II.K.2(10): Measures to Mitigate SmallBreak Loss-of-Coolant Accidents and Lose-ofFeedwater Accidents - Commission Orders on B\&W Plants - Hard-Wired Safety-Grade Anticipatory Reactor Trips

This issue is not applicable to the ABWR as discussed in the evaluation of $10 \mathrm{CFR} 50.34(f)(2)(x \times i i i)$ in Section 20.5.35 of this report.

20.4.59 Issue II.K.2(16): Measures to Mitigate SmallBreak Loss-of-Coolant Accidents and Lose-ofFeedwater Accidents - Commission Orders on B\&W Plants - Impact of RCP Seal Cumage Following SBLOCA With Loss of Offsite Power

This issue is not applicable to the ABWR as discussed in the evaluation of 10 CFR 50.34(f)(1)(iii) in Section 20.5.3 of this report.
20.4.C0 Isove II.K.3(2): Mensures to Mitigate SmallBreak Loes-of-Coolant Accidents and Loes-ofFeedwater Accidents - Final Recommendations of Bulletins and Orders Task Force - Report on Overall Safety Effect of Power-Operated Relief Valve (PORV) Isolation

This issue is not applicable to the ABWR as discussed in the ovaluation of 10 CFR 50.34(f)(1)(iv) in Section 20.5.4 of this report.

20.4.61 Issue II.K.3(3): Measures to Mitigate SmallBreak Loss-of-Coolant Accidents and Loss-ofFeedwater Accidents -. Final Recommendations of Bulletins and Orders Task Force - Report Safety and Relief Valve Failures Promptly and Challenges Annually

This issue requires all operating plants and operating license applicants to report safety and relief valve failures promptly and challenges annually.

In the DFSER, the staff reported that SSAR Section 1.9 committed the COL applicant to report the failures of safety and relief valves in the annual report to the NRC in eccordance with the requirement of this TMI item and that this approach was acceptable. COL applicant compliance with the requirement was identified as DFSER COL Action Item 20.3.1-3. The staff verified that GE atablished a COL action item in SSAR Section 1A.3.4. This approach adequately addresses DFSER COL Action Itom 20.3.1-3.

20.4.62 Issue II.K.3(11): Measures to Mitigate SmallBreak Loes-of-Coolant Accidents and Loss-ofFeedwater Accidents - Final Recommendations of Bulletins and Orders Task Force - Control Use of PORV Supplied by Control Components, Inc., Until Further Review Complete

This issue requires all plants to justify the use of PORVs supplied by Control Components, Inc., that had failed during testing.

SSAR Chapter 15 demonstrates the ABWR's capability to respond to the full spectrum of line breaks and loss-offoedwater accidents without loss of containment or ignificant core damage. SSAR Section 5.2 describes the 
overpressure protection provided by the SRVs performing an overpressure relief valve function, an overpressure safety valve function, or an ADS function. SSAR Section 19B.2.70 states that the SRV for the ABWR is not a PORV by Control Components, Inc. For the safety valve function, the ABWR will use a spring-loaded safety valve with a pneumatic cylinder or piston for power operation in the ADS and relief function. Further, SSAR Section 3.9.3.2.4.2 describes the qualification by type test of the SRVs to IEEE 344, "Recommended Practice for Seismic Qualification of Class 1E Equipment for Nuclear Power Generating Stations," for operability during a dynamic event.

The staff concludes that since the ABWR design does not use Control Components, Inc. PORVs and that the safety valve for the $A B W R$ design will be appropriately qualified, this issue is adequately addressed for the ABBW design.

20.4.63 Issue II.K.3(13): Measures to Mitigate SmallBreak Loss-of-Coolant Accidents and Loss-0fFeedwater Accidents -- Final Recommendations of Bulletins and Orders Task Force. Separation of HPCI and RCIC System Initiation Levels

Refer to the evaluation of 10 CFR $50.34(f)(1)(v)$ in Section 20.5.5 of this report.

20.4.64 Issue II.K.3(15): Measures to Mitigate SmallBreak Loss-of-Coolant Accidents and Loss-ofFeedwater Accidents -- Final Recommendations of Bulletins and Orders Task Force - Modify Break Detection Logic to Prevent Spurious Isolation of HPCI and RCIC Systems

The HPCI and RCIC systems use differential pressure sensors on elbow taps in the steam lines to their turbine drives to detect and isolate pipe breaks in the systems. In NUREG-0737, the staff stated that the pipe-break-detection circuitry has resulted in spurious isolation of the HPCI and RCIC systems because of the pressure spike that accompanies the actuation of the systems. This TMI item requires applicants to modify the pipe-break-detection circuitry so that pressure spikes resulting from HPCI and RCIC system initiation will not cause inadvertent system isolation.

SSAR Section 1A.2.23 states that the ABWR design will maintain the high-pressure inventory using the motordriven HPCF system rather than the turbine-driven $\mathrm{HPCl}$ system. Therefore, this TMI item only applies to the turbine-driven RCIC system of the ABWR.
SSAR Section 1A.2.23 states that the ABWR high leak detection and isolation system processes the differential pressure signals that isolate the RCIC turbine. Spurious trips are avoided because the RCIC has a bypass startup system controlled by valves F037 and F045. Upon receiving RCIC start signals, bypass valve F045 opens to pressurize the line downstream and accelerate the turbine. The bypass line through F045 is small (diameter of 1 in.) and naturally limits the initial flow surge to prevent a differential pressure spike in the upstream pipe.

After approximately 5 to 10 seconds, steam supply valve F037 opens to admit full steam flow to the turbine. At this stage, the line downstream is already pressurized. This design feature will reduce the possibility that a pressure spike would occur during any phase of the normal startup process. In the DFSER, the staff concluded that the ABWR design adequately addresses the requirements of this TMI item. However, the staff stated that the COL applicant should test the RCIC bypass startup system during plant startup and designated this as DFSER [COL] Action Item 20.3.1-4. In the advance SER, the staff concluded that since GE had not yet included a COL action item in the SSAR addressing this test, DFSER COL Action Item 20.3.1-4 would remain open until GE had done so. In Amendment 34, GE provided revised SSAR Section 1A.2.23 and provided a new Section 1A.3.8 that establish a COL action item for the COL applicant to test the RCIC bypass startup system during plant startup. This approach adequately addresses DFSER COL Action Item 20.3.1-4.

20.4.65 Issue II.K.3(16): Measures to Mitigate SmallBreak Loss-of-Coolant Accidents and Loss-ofFeedwater Accidents -- Final Recommendations of Bulletins and Orders Task Force - Reduction of Challenges and Failures of Relief Valves; Feasibility Study and System Modification

Refer to the evaluation of 10 CFR 50.34(f)(1)(vi) in Section 20.5.6 of this report.

20.4.66 Issue II.K.3(17): Measures to Mitigate SmallBreak Loss-of-Coolant Accidents and Loss-ofFeedwater Accidents -- Final Recommendations of Bulletins and Orders Task Force - Report on Outage of ECC Systems; Licensee Report and Technical Specification Changes

This TMI item required all GE plants to review data on ECC system outages to determine if cumulative outage time limitations should be incorporated in TS. It also required submittal of a report detailing outage dates, lengths of outages, and causes of the outages for all ECCSs. 
The DFSER reported that the STS permit several components of the ECCS to have substantial outage times (0.8., 72 hours for one diesel generator; 14 days for the HPCF system). The ABWR TS contain limits on allowable outage times for ECCSs and ECC components but do not specify cumulative outage time limitations for the ECCSs. This was identified in the DFSER as TS Item 20.3.1. The advance SER stated that cumulative outage times were not required to be in the ABWR TS, but would be implemented in plant administrative procedures as discussed in Chapter 16 of the SER. The DFSER, also reported that SSAR Section 1.9 established an action itom for the COL applicant to report ECCS outages in annual summary reports to the NRC. The staff also reported in the DFSER that it would review compliance with this requirement during the $\mathrm{COL}$ review. This was identified in the DFSER as COL Action Item 20.3.1-5.

The staff verified that GE established a COI. action item in SSAR Table 1.9-1 (Item 1.9) to prepany and submit annual reports on ECCS unavailability that also include information on outage dates, lengths, and causes; ECCSs or ECC components involved; and any corrective action taken. SSAR Section 1A.2.25 also states that operating license applicants will establish a plan to meet these reporting requirements. This is approach adequately addresses DFSER COL Action Item 20.3.1-5.

20.4.67 Issue II.K.3(18): Measures to Mitigate SmallBreak Loss-of-Coolant Accidents and Loss-ofFeedwater Accidents - Final Recommendations of Bulletins and Orders Task Force Modification of ADS Logic; Feasibility Study and Modification for Increased Diversity for Some Event Sequences

Refer to the evaluation of 10 CFR $50.34(f)(1)$ (vii) in Section 20.5.7 of this report.

20.4.68 Issue II.K.3(21): Measures to Mitigate SmallBreak Loss-of-Coolant Accidents and Loss-ofFeedwater Accidents -- Final Recommendations of Bulletins and Orders Task Force - Restart of Core Spray and LPCI Systems on Low Level; Design and Modification

Refer to the evaluation of 10 CFR $50.34(f)(1)$ (viii) in Section 20.5.8 of this report.
20.4.69 Issue II.K.3(22): Measures to Mitigate SmallBreak Loss-of-Coolant Accidents and Loss-ofFeedwater Accidents -- Final Recommendations of Bulletins and Orders Task Force Automatic Switchover of RCIC System Suction; Verify Procedures and Modify Design

This TMI item required that until the automatic switchover of RCIC system suction from the condensate storage tank to the suppression pool when the condensate storage tank level is low was implemented in BWRs, licensees and applicants would need to verify that clear and cogent procedures existed for the manual switchover of the RCIC system suction.

The RCIC system in the ABWR design includes an automatic switchover feature to change the pump suction source from the RCIC condensate storage tank to the suppression pool. The safety-grade switchover will automatically occur when the RCIC system receives a lowlevel signal from the condensate storage tank or a highlevel signal from the suppression pool. The staff concludes that since the ABWR design incorporates this automatic switchover, there is no need for verification of the manual switchover procedures and that GE's approach adequately addresses the requirements of this TMI item for the ABWR design.

20.4.70 Issue II.K.3(23): Measures to Mitigate SmallBreak Loss-of-Coolant Accidents and Loss-ofFeedwater Accidents -- Final Recommendations of Bulletins and Orders Task Force - Central Water Level Recording

Refer to the evaluation of 10 CFR 50.34(f)(2)(xxiv) in Section 20.5.36 of this report.

20.4.71 Issue II.K.3(24): Measures to Mitigate SmallBreak Loss-of-Coolant Accidents and Loss-ofFeedwater Accidents -- Final Recommendations of Bulletins and Orders Task Force - Confirm Adequacy of Space Cooling for HPCI and RCIC Systems

Refer to the evaluation of 10 CFR 50.34(f)(1)(ix) in Section 20.5.9 of this report. 
20.4.72 Issue I.K.3(25): Measures to Mitigate SmallBreak Loss-of-Coolant Accidents and Loss-ofFeedwater Accidents - Final Recommendations of Bulletins and Orders Task Force - Effect of Loss of ac Power on Pump Seals

Refer to the evaluation of 10 CFR $50.34(f)(1)$ (iii) in Section 20.5.3 of this report.

20.4.73 Issue II.K.3(27): Measures to Mitigate SmallBreak Loss-of-Coolant Accidents and Loss-ofFeedwater Accidents - Final Recommendations of Bulletins and Orders Task Force - Provide Common Reference Level for Vessel Level Instrumentation

This issue required all resctor vessel level instruments on GE plants to be referenced to the samo point to avoid potential confusion of operators if different reference points were used for various reactor vessel water level instruments. It recommended the use of either the bottom of the vessel or the active fuel as reasonable common reference points.

The review criterion for this issue is to confirm that the ABWR design has a common zero reference for all water level indications. SSAR Section 19B.2.71 states a common reference for the reactor vessel water level has been set at the top of the active fuel level as described in SSAR Section 7.7. The staff confirmed that SSAR Section 7.7.1.1 (6)(c) indicates that the zero of the reactor vessel water level instruments has been set at the top of the active fuel and the instruments are calibrated to be accurate at the normal power operating point. Therefore, the staff concludes that the ABWR design adequately addresses the requirements of this TMI item.

20.4.74 Issue II.K.3(28): Measures to Mitigate SmallBreak Loss-of-Coolant Accidents and Loss-ofFeedwater Accidents - Final Recommendations of Bulletins and Orders Task Force - Study and Verify Qualification of Accumulators on ADS Valves

Refer to the evaluation of 10 CFR $50.34(f)(1)(x)$ in Section 20.5.10 of this report.
20.4.75 Issue II.K.3(30): Measures to Mitigate SmallBreak Loss-of-Coolant Accidents and Loss-ofFeedwater Accidents - Final Recommendations of Bulletins and Orders Task Force - Revised SBLOCA Methods to Show Compliance with 10 CFR Part 50, Appendix A

This issue requires all licensees and applicants to revise, document, and submit for NRC approval the analyses used by NSSS vendors and/or fuel suppliers for SBLOCA analysis in compliance with 10 CFR Part 50, Appendix K. The revised analyses were to account for comparisons with experimental data, including data from the loss-of-fluid test (LOFT) and Semiscale test facilities.

In response to this issue, the BWROG conducted a study that was later endorsed by GE as being applicable to the ABWR within this area. In a letter from R.H. Buchholz (GE) to D.G. Eisenhut (NRC) dated June 26, 1981, GE submitted information on the results of its study and NRC's concerns with the smali-break model. The GE information consisted of modeling in SAFE, treatment of pressure variation, and overall model assessment. The staff reviewed this information and concluded that it was acceptable. The staff concluded that the SBLOCA model need not be changed because the test data comparisons and other information submitted by GE acceptably demonstrate that its small-break model complies with the analysis requirements in 10 CFR Part 50, Appendix K.

The staff also reviewed the applicability of the BWROG evaluation to the ABWR design. It concurs that no model changes are required for the ABWR, because it is similar in design to the current BWRs and thus will respond similarly to SBLOCAs. Therefore, the staff concludes that the requirements of this TMI item have been adequately addressed for the ABWR SBLOCA model.

20.4.76 Issue II.K.3(31): Measures to Mitigate SmallBreak Loss-of-Coolant Accidents and Loss-ofFeedwater Accidents - Final Recommendations of Bulletins and Orders Task Force - PlantSpecific Calculations to Show Compliance with 10 CFR 50.46

This issue requires licensees and applicants to submit for NRC approval plant-specific calculations, using NRCapproved models for SBLOCAs, to show compliance with 10 CFR 50.46. 
The ABWR-specific SBLOCA calculations in SSAR Section 6.3 show compliance with 10 CFR 50.46, as discussed in Section 6.3 of this report. Therefore, the staff concludes that GE has adequately addressed the requirements of this TMI item for the ABWR design.

20.4.77 Issue II.K.3(44): Measures to Mitigate SmallBreak Loss-of-Coolant Accidents and Loss-ofFeedwater Accidents -- Final Recommendations of Bulletins and Orders Tasik Force Evaluation of Anticipated Transients with Single Failure to Verify no Significant Fued Failure

This issue requires licensees and applicants of GE plants to demonstrate that the core remains covered or provide analysis to show that no significant fuel damage results from core uncovery for anticipated transients combined with the worst single failure and proper operator actions. This category includes transients that result from a stuckopen relief valve.

GE has endorsed the results of the BWROG study (NEDO-24708, "Additional Information Required for NRC Staff Generic Report on Boiling Water Reactors," which had been accepted by the staff) as applicable to ABWR in this area. In a letter dated Docember 29, 1980, from D.B. Walters (BWROG) to NRC, the BWROG enclosed an evaluation (NEDO-24708) in which it stated that the worst-case transient with single failure combination for BWR/2-6 plants is the loss-of-feedwater event with a failure of the high-pressure ECCS. However, since the ABWR design includes three high-pressure core injection systems, the probability of a loss of all high-pressure ECCS is low. GE also considered an event with a stuckopen relief valve, and a high-pressure ECCS failure, and concluded that the core remained covered throughout the transient either because the RCIC system operated or because the RCS was depressurized by automatic or manual means, permitting low-pressure inventory makeup. GE also assumed the operator would manually depressurize the vessel to permit low-pressure injection.

The staff has reviewed the results of the BWROG's study and its applicability to $A B W R$ and finds that GE has shown that the ABWR design can keep the core covered and have no fuel damage from core uncovery for transients combined with the worst single failure. Therefore, GE adequately addressed the requirements of this TMI item for the ABWR design.
20.4.78 Issue II.K.3(45): Measures to Mitigate SmallBreak Loss-of-Coolant Accidents and Loss-ofFeedwater Accidents - Final Recommendations of Bulletins and Orders Task Force - Evaluate Depressurization with Other Than Full ADS

Refer to the evaluation of 10 CFR $50.34(f)(1)(x i)$ in Section 20.5.11 of this report.

20.4.79 Issue II.K.3(40): Measures to Mitigate SmallBreak Loss-of-Coolant Accidents and Loss-ofFeedwater Accidents -- Final Recommendations of Bulletins and Orders Task Force - Response to List of Concerns from ACRS Consultant

This TMI item includes 16 questions, developed by Mr. C. Michaelson of the ACRS staff, most of which pertain to PWRs, to which all licensees and applicants were required to respond. GE responded to Mr. Michaelson's concorns as they related to BWRs in a letter dated February 21, 1980.

The staff required GE to review each of Mr. Michaelson's questions and verify that the responses given for BWRs in its February 21, 1980, letter were valid for the ABWR design. In SSAR Table 1A-1, GE responds to all 16 questions. One question pertains to the adequacy of the net positive suction head (NPSH) since the ABWR RCIC and HPCF systems share a common suction line from the condensate storage tank. It is an ABWR design requirement that adequate NPSH be available to the RCIC and HPCF pumps for simultaneous operating modes of these systems. Other questions pertain to the isolation of small breaks, the adequacy of auxiliary feedwater, the recirculation mode of $\mathrm{HPCl}$ pumps at high pressure, and the simultaneous operation of HPCI and RHR pumps.

The staff reviewed the responses in SSAR Table 1A-1 and found them to be similar to GE's responses to Mr. Michaelson's questions for operating BWRs that it proviously accepted. This approach is acceptable for the ABWR design. Therefore, the staff concludes that GE adequately addressed the requirements of this TMI item for the ABWR design.

20.4.80 Issue III.A.1.1(1): Emergency Preparedness and Radiation Effects -- Improve Licensee Emergency Preparedness - Short Term; Upgrade Emergency Preparedness, Implement Action Plan Requirements for Promptly Improving Licensee Emergency Preparedness

This issue requires approval of the overall state of preparedness, primarily with respect to the capability of 
offsite agencies to take appropriate emergency actions in the event of nuclear power plant accidents.

SSAR Section 19B.3.1 states that the COL applicant is responsible for providing resolutions of issues identified as "COL Applicant" in the "Safety Issues Index" of SSAR Appendix 19B. The SSAR states that issues are identified for COL action because they pertain to operating personnel issues, operating procedures, and other topics beyond the scope of the ABWR design certification review. SSAR Section 19B.1.1 lists specific documentation the COL applicant is to provide for resolution of such issues.

GE identified this issue for COL applicant action in the "Safety Issues Index." The staff verified that GE established a COL action item (Item 19-28) in SSAR Table 1.9-1 to address unresolved generic and TMI safety issues. This approach is acceptable to the staff. However, the COL applicant's responsibility for resolution of this issue extends only to providing support to the review and approval process and addressing the review findings to the satisfaction of the NRC.

\subsubsection{Issue III.A.1.2: Emergency Preparedness and Radiation Effects -- Improve Licensee Emergency Preparedness - Short Term; Upgrade Emergency Preparedness}

Refer to the evaluation of 10 CFR $50.34(f)(2)(x \times v)$ in Section 20.5.37 of this report.

\subsubsection{Issue III.A.2.1: Emergency Preparedness and Radiation Effects -- Improve Licensee Emergency Preparedness - Long Term; Amend 10 CFR Part 50 and 10 CFR Part 50, Appendix $\mathbf{E}$}

This issue required the NRC to revise 10 CFR Part 50, as appropriate, to upgrade the emergency preparedness of nuclear power plants and to revise the inspection program to cover the upgraded requirements.

SSAR Section 19B.3.1 states that the COL applicant is responsible for providing resolutions of issues identified as "COL Applicant" in the "Safety Issues Index" of SSAR Appendix 19B. The SSAR states that issues are identified for COL action because they pertain to operating personnel issues, operating procedures, and other topics beyond the scope of the ABWR design certification review. SSAR Section 19B.1.1 lists specific documentation the COL applicant is to provide for resolution of such issues.

GE identified this issue for COL applicant action in the "Safety Issues Index." The staff verified that GE established a COL action item (Item 19-28) in SSAR
Table 1.9-1 to address unresolved generic and TMI safety issues. This approach is acceptable to the staff. However, the COL applicant's responsibility for resolution of this issue extends only to complying with the current regulations. The staff will review the COL applicant's proposed resolution of this issue on a case-by-case basis, ovaluating compliance with the version of the emergency preparedness requirements of 10 CFR Part 50, as well as 10 CFR Part 50, Appendix E, current at the time of the review.

\subsubsection{Issue III.A.2.2: Emergency Preparedness and Radiation Effects - Improve Licensee Emergency Preparedness - Long Term; Development of Guidance and Criteria}

This issue requires the emergency plans to include information on meteorological criteria, means for promptly notifying the population, and emergency response facilities as detailed in Revision 1 to NUREG-0654 (FEMA-REP-1), "Criteria for Preparation and Evaluation of Radiological Emergency Response Plans and Preparedness in Support of Nuclear Power Plants."

SSAR Section 19B.3.1 states that the COL applicant is responsible for providing resolutions of issues identified as "COL Applicant" in the "Safety Issues Index" of SSAR Appendix 19B. The SSAR states that issues are identified for COL action because they pertain to operating personnel issues, operating procedures, and other topics beyond the scope of the ABWR design certification review. SSAR Section 19B.1.1 lists specific documentation the COL applicant is to provide for resolution of such issues.

GE identified this issue for COL applicant action in the "Safety Issues Index." The staff verified that GE established a COL action item (Item 19-28) in SSAR Table 1.9-1 to address unresolved generic and TMI safety issues. This approach is acceptable to the staff. The staff will review the COL applicant's proposed resolution of this issue on a case-by-case basis.

\subsubsection{Issue III.A.3.3: Emergency Preparedness and Radiation Effects -- Improving NRC Emergency Preparedness - Communications}

This issue requires the availability of communication means that will enable the NRC, in the event of a nuclear accident, to (1) monitor and evaluate the situation and (2) potentially advise the plant operating staff, as noeded, and (3) in extreme cases, be able to issue orders governing such operations.

SSAR Section 19B.3.1 states that the COL applicant is responsible for providing resolutions of issues identified as 
"COL Applicant" in the "Safety Issues Index" of SSAR Appendix 19B. The SSAR states that issues are identified for COL action because they pertain to operating personnel issues, operating procedures, and other topics beyond the scope of the ABWR design certification reviow. SSAR Section 19B.1.1 lists epecific documentation the COL applicant is to provide for resolution of such issues.

GE identified this issue for COL applicant action in the "Safety Issues Index." The staff verified that GE established a COL action item (Item 19-28) in SSAR Table 1.9-1 to address unresolved generic and TMI safety issues. This approach is acceptable to the staff. The staff will review the COL applicant's proposed resolution of this issue on a case-by-case basis.

\subsubsection{Issue III.D.1.1: Radiation Protection - Radiation Source Control - Primary Coolant Sources Outside the Containment Structure}

Refer to the evaluation of 10 CFR $50.34(f)(2)(x \times v i)$ in Section 20.5.38 of this report.

20.4.86 Issue III.D.3.3: Radiation Protection Worker Radiation Protection Improvement Inplant Radiation Monitoring

Refer to the evaluation of 10 CFR $50.34(f)(2)(x x v i i)$ in Section 20.5.39 of this report.

20.4.87 Issue III.D.3.4: Radiation Protection Worker Radiation Protection Improvement Control Room Habitability

Refer to the evaluation of 10 CFR $50.34(f)(2)$ (xxviii) in Section 20.5 .40 of this report.

\subsection{CFR 50.34(f), Additional TMI Requirements}

This section addresses staff evaluation of paragraphs (1)(i) through (3)(vii) of 10 CFR 50.34(f).

20.5.1 10 CFR 50.34(f)(1)(i): Consideration of Degraded or Melted Cores in Safety Review Rulemaking Proceeding on Degraded Core Accidents (TMI Item II.B.8), "Design Alternatives from PRA"

Paragraph (1)(i) of 10 CFR 50.34(f) requires the applicant to "perform plant/site specific probabilistic risk assessment, the aim of which is to seek such improvements in the reliability of core and containment heat removal systems as are significant and practical and do not impact excessively on the plant."

\subsubsection{Introduction}

GE has made extensive use of the results of the PRA to arrive at a final $A B W R$ design. As a result, the estimated core damage frequency and risk calculated for the ABWR is very low both relative to operating plants and in abeolute terms. The low core damage frequency and risk for the ABWR is a reflection of GE's efforts to systematically minimize the effect of initiators or sequences that have been important contributors to core damage frequency in previous BWR PRAs. This has been done largely through the incorporation of a number of hardware improvements in the ABWR design. These include the provision of: three separated divisions of ECCSs, a diverse and independent combustion gas turbine capable of providing ac power to any of the three divisions, an ac-independent water addition system, and an FMCRD system as a backup to the hydraulic drive system. Several improvements have also been incorporated in the ABWR design to mitigate the consequences of a core damage event, including inerting of the containment atmosphere, inclusion of a lower drywell flooder system and a containment overpressure protection (vent) system, the use of basaltic concrete in the lower drywell, and an increased ultimate pressure capacity. These and additional ABWR design features which contribute to low core damage frequency and risk for the ABWR are discussed further in FSER Section 19.1.

In response to 10 CFR 50.34(f)(1)(i), GE provided an initial evaluation of further $A B W R$ design improvements in a February 25, 1992 submittal. This submittal was besed on the original PRA results, and included consideration of risk from both internally and seismically initiated events. Based on this evaluation, GE concluded that none of the design improvements considered were cost beneficial.

The initial evaluation was subsequently revised to reflect the results of the updated Level 1 PRA and containment analyses, and was resubmitted on June 30, 1992. The revised assessment was based on the risk reduction potential for internal events only, in contrast to the original evaluation which considered both internally and seismically initiated events. This more limited scope was a consequence of GE's change in methodology from a quantitative treatment of seismic risk to a qualitative, margins-type analysis of seismic events. The net result of the new analysis was an order of magnitude reduction of estimated risk from severe accidents -- from 0.047 perronSv to 0.0048 person-Sv (4.7 person-rem to 0.48 personrem) over a 60 -year plant life - largely due to removal of seismic events from the risk profile. The reduced risk in the revised analysis further strengthened GE's original conclusion that none of the design improvements, beyond 
those already incorporated in the ABWR design, were cost beneficial.

In response to staff comments, GE further modified their evaluation of design improvements to include additional discussion of selected design altematives, further clarification of the basis for risk-reduction estimates, and additional factors in estimating costs for the modifications. The risk estimates were also adjusted to reflect the results of the final Level 2 analysis and the updated offsite consequence calculations performed as part of the Level 3 portion of the PRA. The final evaluation was submitted as SSAR Appendix 19P.

GE's evaluation of potential design improvements was submitted in response to the requirements of $10 \mathrm{CFR}$ $50.34(f)(1)(i)$. The staff's review of GE's final evaluation of potential ABWR design improvements is presented below.

\subsubsection{Estimate of Risk for ABWR}

\subsection{GE Risk Estimates}

GE estimated offsite consequences at five different sites, each representing a different geographic region of the U.S. Offsite consequences were calculated for each release class or case from the Level 2 analysis using the CRAC2 code. The meteorological and population data were obtained from previously developed information contained in NUREG/CR-2239, "Technical Guidance for Siting Criteria Development." The source terms were determined using the MAAP code for each of the release categories as discussed in Section 19.1 of the FSER. The results of the five sets of consequence calculations were averaged together, to represent a typical site in the U.S.

GE's estimate of the cumulative offsite risk to the population within $80 \mathrm{~km}$ (50 miles) of the site is provided in SSAR Table 19P-1. The total cumulative exposure calculated by GE is about 0.003 person-Sv (0.3 personrem), assuming a 60-year plant life. The extremely small level of risk calculated by GE is primarily due to the low estimated core damage frequency for the ABWR (1.6E-7 per reactor year). As a case in point, even if all core damage accidents resulted in the worst release, based on GE's core damage frequency estimates for internal events, the total exposure would only be about 0.3 person-Sv (30 person-rem).

As a result of the low estimated core damage frequency and associated risk levels for the ABWR, any potential modifications which cost more than a few dollars would not be cost-effective, even if the design modification were to totally eliminate the severe accidents or their consequences.

The staff notes that the frequencies of core damage accidents and release bins on which GE based its evaluation of design alternatives are slightly different than those reported in SSAR Section 19D.5. However, these differences are minor and would not alter the essential conclusions of the analysis.

\subsection{Staff Review of GE's Risk Estimates}

The staff independently estimated the risk associated with severe accidents in the ABWR. A comparison of GE and staff estimates of the person-Sv (person-rem) exposure for each of GE's release classes is provided in FSER Table 20.5.1-1 for internally initiated events. GE's estimates are based on the use of the MAAP and CRAC2 computer codes, and metoorology for five different sites, as described previously. The staff estimates of person-Sv (person-rem) are based on use of the 50th percentile source terms developed during the initial staff review of the ABWR (FSER Table 20.5.1-2), the MACCS offsite consequence code, and meteorology for the Zion site. The staff estimates of the frequency of occurrence of each release class are as reported in FSER Section 19.1.

The GE and staff estimates of person-Sv (person-rem) exposure per event are generally consistent for the large release classes (Cases 7, 8, and 9). The staff's dose estimate is significantly higher for vented scenarios (Case 1) due to the higher fission product release fractions used in the staff's assessment. Similarly, the staff's estimate is much lower for sequences with normal containment leakage (NCL) due to a significantly smaller staff source term for this case. The differences between staff and GE estimates for both these release classes are insignificant, however, since these release classes do not contribute appreciably to total risk.

The estimated total risk over a 60-year reactor operating lifetime is extremely small in both the GE and staff assessment. GE's analysis indicates a total dose of about 0.003 person-Sv (0.3 person-rem) over the 60-year period. The staff's estimate is about 0.01 person-Sv ( 1 personrem). The difference is due largely to an increased frequency of early releases in the staff assessment to account for: (1) the contribution from unisolated LOCAs outside containment, and (2) an increased probability of early containment failure from direct containment heating. It can be noted that total risk is dominated by events which lead to early containment failure, and containment bypass. This is consistent with the results from PRAs for operating plants. 
Table 20.5.1-1a Comparison of GE and staff adjusted offsite consequences (person-Sv)

\begin{tabular}{|c|c|c|c|c|c|c|c|c|}
\hline \multirow[b]{2}{*}{ Case" } & \multicolumn{4}{|c|}{ GE Extimates I/ } & \multicolumn{4}{|c|}{ Staff-Adjusted Estimatea } \\
\hline & Prequency & $\begin{array}{c}\text { Perwon- } \\
\text { Sv }\end{array}$ & $\begin{array}{c}\text { Person- } \\
\text { Sv per } 60 \text { y }\end{array}$ & Frection & Prequency 2 & $\begin{array}{c}\text { Perwon- } \\
\text { Sv } 3 /\end{array}$ & $\begin{array}{c}\text { Perwon- } \\
\text { Sv per } 60 \text { y }\end{array}$ & Frnction \\
\hline NCL & $1.3 \mathrm{E}-7$ & 96 & .00075 & .28 & $1.34 E-7$ & .1 & .000008 & $<.01$ \\
\hline Case 1 & $2.1 \mathrm{E}-8$ & $1.4 \mathrm{E2}$ & .00018 & .07 & $2.08 \mathrm{E}-8$ & $1.4 \mathrm{E3}$ & .0017 & .13 \\
\hline Case 7 & $3.9 \mathrm{E}-10$ & $2.7 \mathrm{EA}$ & .00063 & .23 & $3.6 E-10$ & $1.6 \mathrm{EA}$ & .00035 & .03 \\
\hline Case 8 & $4.1 E-10$ & $3.2 \mathrm{EA}$ & .00079 & .29 & $3.6 \mathrm{R}-9 \mathrm{4I}$ & $4.5 \mathrm{E} 4$ & .0097 & .77 \\
\hline Case 9 & $1.7 \mathrm{E}-10$ & $3.3 \mathrm{E} 4$ & .00034 & .13 & $3.3 \mathrm{E}-10$ & $4.5 \mathrm{E} 45$ & .00089 & .07 \\
\hline Total & $1.6 \mathrm{E}-7$ & & .00269 & 1.0 & $1.6 \mathrm{E}-7$ & & .0126 & 1.0 \\
\hline
\end{tabular}

Table 20.5.1-1b Comparison of GE and staff adjusted offsite consequences (person-rem)

\begin{tabular}{|c|c|c|c|c|c|c|c|c|}
\hline \multirow[b]{2}{*}{ Case" } & \multicolumn{4}{|c|}{ GE Estimates 11} & \multicolumn{4}{|c|}{ Staff-Adjusted Estimate } \\
\hline & Frequency & $\begin{array}{c}\text { Person- } \\
\text { Rem }\end{array}$ & $\begin{array}{c}\text { Perron- } \\
\text { Rem per } 60 \text { y }\end{array}$ & Fraction & Frequency ${ }^{\prime}$ & $\begin{array}{l}\text { Person- } \\
\text { Rem } 3 /\end{array}$ & $\begin{array}{c}\text { Pereon- } \\
\text { Rem per } 60 \text { y }\end{array}$ & Fraction \\
\hline $\mathbf{N C L}$ & 1.3E-7 & 9600 & .075 & .28 & 1.34E-7 & 100 & .0008 & $<.01$ \\
\hline Case 1 & $2.1 \mathrm{E}-8$ & $1.4 E 4$ & .018 & .07 & $2.08 \mathrm{E}-8$ & $1.4 \mathrm{ES}$ & .17 & .13 \\
\hline Case 7 & $3.9 \mathrm{E}-10$ & $2.7 \mathrm{E} 6$ & .063 & .23 & $3.6 \mathrm{E}-10$ & $1.6 \mathrm{E} 6$ & .035 & .03 \\
\hline Case 8 & 4.1. $\mathrm{E}-10$ & $3.2 \mathrm{E} 6$ & .079 & .29 & $3.6 \mathrm{E}-9 \leq$ & 4.5E6 & .97 & .77 \\
\hline Case 9 & $1.7 \mathrm{E}-10$ & $3.3 \mathrm{E} 6$ & .034 & .13 & 3.3E-10 & $4.5 E 65$ & .089 & .07 \\
\hline Total & $1.6 \mathrm{E}-7$ & & 0.269 & 1.0 & $1.6 \mathrm{E}-7$ & & 1.26 & 1.0 \\
\hline
\end{tabular}

Notes:

* For case deacription, refer to Table 20.5.1-2.

1/ Baced on information reportod in SSAR Tablo 19P-1.

2] Based on GE's containment eveat troo end stale frequencies with staff corrections.

3/ Based on staff 50th percentile source terms (see Table 20.5.1-2) and use of MACCS consequence code with Zion site meteorology.

4) Staff frequency cotimate includes: (1) contribution from unisolated LOCAs outside containment, and (2) increased probability of early containment failure from direct contrinment heating.

5/ Based on the staff's counce term estimate for Case 8. 
Generic Issues

Table 20.5.1-2 Cesium and Iodine release fractions, as estimated by the staff and GE

\begin{tabular}{|c|c|c|c|c|c|}
\hline & \multirow{2}{*}{$\begin{array}{l}\text { GB Case } \\
\text { Identifier }\end{array}$} & \multicolumn{3}{|c|}{ Suffes Btimnte } & \multirow[t]{2}{*}{ GB's Estimate } \\
\hline & & Sth & soth & 95th & \\
\hline & NCL & $2.1 \times 10^{-11}$ & $3.2 \times 10^{9}$ & $3.9 \times 10^{-8}$ & $5.1 \times 10^{-5}$ \\
\hline & Case 1 & $2.7 \times 10^{-6}$ & $2.7 \times 10^{4}$ & $5.3 \times 10^{-2}$ & $1.3 \times 10^{-5}$ \\
\hline \multirow[t]{5}{*}{ Cesium } & Caso 7 & $6.6 \times 10^{-6}$ & $2.4 \times 10^{-3}$ & $1.4 \times 10^{-1}$ & $9.9 \times 10^{-2}$ \\
\hline & Case 8 & 0.002 & 0.06 & 0.75 & 0.25 \\
\hline & Case 9 & $8.3 \times 10^{-4}$ & $7.8 \times 10^{-3}$ & $1.7 \times 10^{-1}$ & 0.36 \\
\hline & $\mathrm{NCL}$ & $3.4 \times 10^{-11}$ & $2.3 \times 10^{-6}$ & $3.8 \times 10^{-4}$ & $3.8 \times 10^{-6}$ \\
\hline & Caso 1 & $8.5 \times 10^{-6}$ & $9.2 \times 10^{-4}$ & $6.1 \times 10^{-2}$ & $1.5 \times 10^{-7}$ \\
\hline \multirow[t]{3}{*}{ lodine } & Case 7 & $4.7 \times 10^{-4}$ & $9.7 \times 10^{-2}$ & $3.2 \times 10^{-1}$ & $8.9 \times 10^{-2}$ \\
\hline & Case 8 & 0.007 & 0.19 & 0.69 & 0.19 \\
\hline & Case 9 & 0.002 & 0.10 & 0.16 & 0.37 \\
\hline
\end{tabular}

Case Description

NCL Normal containment leakage, no containment failure.

Case 1 Fission products scrubbed by suppression pool before release, includes the "venting" sequences.

Case 7 Late containment failure due to overpressurization, spray available, no suppression pool scrubbing.

Case 8 Early containment failure, no suppression pool scrubbing.

Case 9 Late containment failure due to overpressurization, no spray, no suppression pool scrubbing. 
As discused bolow, the staff baed its amomencent of rictreduction potential for the varioun ABWR devign improvemeats on the taff catimate of rict for internally initiated ovents, that is, 0.01 pereon-Sv (1 percen-rom). However, the validity of the conclueions of this analysis were teated by considering the uncertainties in core damage frequency catimates, as well as the potential frequency of core damage dus to external eveats.

\subsubsection{Identinication of Potential Design Improvements}

\subsection{List of Potential Dedign Improvements}

GE identified a sel of potential design improvements for the ABWR based on a curvey of provious industry- and NRC-eponsored studies of preventative and mitigative features which addreses severe accidents. Through this effort OE developed a composite list of 68 potential design improvements, organized into 14 general catogories. Theso categories and many of the design improvements are the same as considered for the General Electric Standard Safety Application Report (GESSAR) II deaign. The resulting list of potential design improvements for the ABWR is presented in SSAR Table 19P-3.

GE eliminated certain design improvements from further consideration on the basis that they are either already incorporated into the ABWR design, or not applicable to the ABWR design. Examples of design improvements already included in the design are: improved low-prescure injection system (fire pump), RWCU decay heat removal, low flow unfiltered vent, and combustible gas control (inerted containment). On the basis of this screening, 21 potential design improvements covering 12 of the 14 general categories were retained for further consideration. The set of design improvements selected for further evaluation is listed in Table 20.5.1-3, and summarized in Section 20.5.1.3.2 of this report.

The staff and its contractor, Brookhaven National Laboratory (BNL), have reviewed the set of potential design improvements identified by GE (SSAR Table 19P-3) and find it to be comprehensive. The list includes all improvements identified as part of the GESSAR II review, and the NRC Containment Performance Improvement (CPI) program. The staff notes that the set of design improvements is not all-inclusive, in that additional, perhaps less expensive design improvements can always be postulated. However, the staff concludes that the benefits offered by any additional modifications would not likely exceed those for the modifications evaluated. The staff also concludes that the costs of altemative improvements would not likely be less than that of the lowest cost improvements evaluated, when

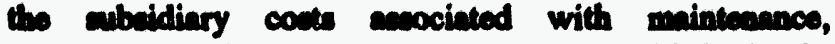
procedures, and training are considered. Dn this bacis, the refaf concluder that the of potential deaizn improvements ideatified by GE is scceptable.

The of dosign improvemeats solected for further ovaluation aleo appean to be seavonablo. The staff notes that the improvements considered include a filtered containment vent, and flooded rubble bed core retention dovice, which are two improvements epecifically cited in NUREG-0660 for evaluation as part of TMI Itom II.B.8. A modification intended to dolay the time of renctor veseol failure through the use of alternative materials for the bottom head pesetration piping was also considered by $\mathrm{OE}$. This modification was instigated by the reeults of recent analyses of resctor veesel bottom head failure as documented in draft NUREG/CR-5642.

Finally, it should be noted that certain features of several of the improvements selectod for further ovaluation have been or will be incorporated as part of the ABWR design, independent of this ovaluation of design improvements. For example, severe sccident EPGs or sccident management guidelines (AMGs) will be implemented by the COL applicant as part of its accident management program, as discuseed in FSER Soction 19.2, and much of the benefits of improved maintenance procedures or menuals will be achieved through the COL applicent's reliability assurance program, as discussed in Section 19.1.3.7 of this report.

\subsection{Description of Design Improvements}

A description of the design improvements selocted by GE for cost-benefit evaluation is provided in SSAR Sections 19P.3 and 19P.4, and summarized below.

- Severe accident EPGs or AMGs - extend the EPGs and EOPs to address arrest of a core melt, emergency planning, radiological release assessment and other areas related to severe accidents. This modification would lead to increased reliability of manual actions in response to core-damage events.

- Computer-aided instrumentation - provide artificial intelligence-based improvements to plant status monitoring, including human-engineered displays of important variables in the EPGs and AMGs, and procedural options for the operator to evaluate during severe accidents. This modification would lead to increased reliability of manual actions to prevent core damage. 
Table 20.5.1-3 Potential Design Improvements and Ascociated Costs (Provided by GE)

\section{Modiriention

Eetimated Perwonst
Coet
(SM) \\ $\operatorname{Cot}($ BM)/Pumoms (Perem-Rem) Averted}

\section{Aceident Mansement}

1a. Sovere sccident BPGs

1b. Computer-aided instrumeatation

0.60

0.00015

(0.015)

4,000

1c. Improved maintenence procedurea/manuals

0.60

0.00010

(0.01)

$>4,000$

$(>40)$

0.30

0.00016

(0.016)

1,880

2. Decay Heat Removal

2a. Pasaive high presaure aystem

1.75

0.00138

(0.138)

1,270

2b. Improved depresourization

0.60

0.00042

(0.042)

1,430

2c. Suppreasion pool jockoy pump

0.12

0.00002

(0.002)

$>4,000$

2d. Safoty-related condensalo storage tank

1.0

0.00010

(0.01)

3. Contrinment Capability

3a. Larger volume containment

3b. Increased containmont preseure capacity

$8.0 \quad 0.00150$

(0.15) $>4,000$

$(>40)$

12.0

0.00020

(0.02)

$>4,000$

3c. Improved vacuum breakers

0.10

0.0000003

$(0.00003)$

$(>40)$

3d. Improved bottom head penctration design

0.75

0.00057

(0.057)

1,320

4. Contrinment Heat Removal

4a. Larger volume auppression pool

8.0

5. Contrinment Atmosphere Mass Removal

5.a Low-flow filtpred vent

3.0

0.00014

$(0.014)$

$(>40)$

7. Containment Spray Syatems

7a. Drywell boed flooding

0.10

0.00060

(0.06)

1,700

8. Prevention Concepts

8a. Additional service water loop

6.0

0.00016

$(0.016)$

$(>40)$

9. AC Power Supplies

9a. Steam driven turbine generator

$\begin{array}{rrrrr}6.0 & 0.00052 & (0.052) & >4,000 & (>40) \\ 1.2 & 0.00069 & (0.069) & 1,740 & (17.4)\end{array}$

9b. Altemate pump power source

1.2

0.00069

(0.069)

10. DC Power Supplies

10a. Dedicated RHR de Power Supply

3.0

0.00069

(0.069)

(>40)

11. ATWS Capability

11. ATWS-sized vent

0.30

0.00030

$(0.03)$

1,000

13. System Simplification

13. Reactor building sprays

0.10

0.00017

(0.017)

5,900

14. Core Retention Devices

14a. Flooded rubble bed

18.8

0.00001

$(0.001)$

$>4,000$ 
- Improved maintensace procodures or manuals - provido improved mintenences manuals and edditional information on the components importent to the rist of the plant within the OB ecopo of anply. Them manuals and information would lead to increased roliability of important equipmeat.

- Paceivo high preasure system - add an isolation condeneer-type high preseure syetem for removing decay beat from both the core and contrinment. Tho benefit of this system would bo equivaleat to an additional RCIC systerm and containment heat-removal aystom.

- Improved depreseurization - provide munually controlled, seiemically protected air operators to permit manual depreseaurization in the event of loss of de control power or control air ovents. Improved depreacurization would reduce the threat of containment failure due to high presesure melt ejection, and allow more reliable access to low-preesure systems.

- Supprossion pool jockey pump - add a small, acindependent makeup pump to provide low-pressure decay heat removal from the reactor preesure veesel using suppression pool water as the source. This modification would have a benofit similar to that provided by the ac-independent water addition mode of RHR (fire water), but without the associated long-term contrainment inventory concerns.

- Safety-related condensato storage tank - upgrade the structure of the condensate storage tank such that it would be available to provide makeup to the reactor following a large seismic event. This would enhance core injection capabilities in seismic ovents, by providing an alternative to the suppression pool as a source of water for imjection.

- Larger volume containment - increase the volume of containment by a factor of two. This would reduce the peak pressures associalod with energetic events, thereby reducing the potential for drywell bead failure, and would also reduce the rate of long-term containment pressurization, thereby delaying the timo of fission product release.

- Increased containment preseure capecity - increase the ultimate pressure capacity of containment (including seals) to a level at which all release modes except normal containment leakage are eliminated.

- Improved vacuum breakers - add a scocond vacuum breaker valve in each of the eight drywell-to-wetwell vacuum breaker lines to make these valves redundant. This modification would reduce the potential for aupprewion pool bypaes due to stuck-opea or leaking vecuum breaker valves.

- Improved bottom hoed pecetration decign - change tho trancition piecos (uned to connect the stainlew ateel RPV drain line io tho RPV) from carbon ateel to a meterial with a higher molting point, auch as inconel. Also, cetabliah external wolds or rectraints on the CRD. external to the veseed so that the drives would not be ejected following failure of thu internal welds. This modification would dolay the time of reactor veeeel failure by several hours, thereby increasing the poteatial to arreat core damage in the veecel, but may also increase the potential for groas failure of the lower bead.

- Larger volume suppression pool - increase the size of the suppreseion pool to provide reduced pool heatup rates. This modification would reduce the frequency of core melt from Class II sequences (loss of containment heat removal), and ATWS sequences by providing additional time for operator actions and recovery of heat removal systems.

- Low-flow filtered veat - add a filter system external to the containment to further reduce the magnitude of radionctive releases vis containment venting. The system would be similar to the multi-venturi scrubbing systems implemented in some plants in Europe. The system would provide fission product scrubbing beyond that presently offered by the suppression pool, but would not affect releases due to drywell head failure and containment bypass sequences.

- Drywell head flooding - provide an additional line to permit intentional flooding of the upper drywell head using the existing fire water additional system. Drywall head flooding would cool the drywell head seal and provide fission product scrubbing in the ovent of drywell beed leakage. Instrumentation and controls to permit manual control from the control room were considered part of this modification.

- Additional servico water loop - provide an additional sorvice water cooling loop (pump and heat exchanger) to improve the overall reliability of the service water network. This cooling loop would be capable of removing heat from any one of the three divisions. This would reduce the frequency of sequences involving failure of injection due to loes of component cooling.

- Steam-driven turbine generator - add a stoam-driven turbine generator that uses reactor steam and exhausts to the suppression pool. The benefits of this modifi- 
cation would be a further reduction in the frequeacy of station bleckout sequences, similar to that which might be obtuined by adding another gas turbine generator.

- Alternate pump power source - provide a separate dienel generetor and aupporting auxiliaries to power the feodwater or condensate pumpe. This modification would remove the relience of thewe pumpe on offisite power, and permit them to be uned as a backup to HPCF and low-preanure core flooder.

- Dedicated de power aupply - provido a exparate, diverno de power cource (fid cell or esparate battery) to aupply a de motor-pump combination for RPV and containment cooling. This modification would further reduce the riak from loes of offinite power and station bleckout.

- ATWS-eized vent - provido a wetwell veat line capable of passing the stoam flow aseociated with ATWS. The system would be significantly larger then the exiating contrinment overpressure protection system (COPS) design, and manually initiated from the control room. This system would prevent contrinment overpressure failure in ATWS ovents, and thereby prevent core damage.

- Reactor building sprays - modify the firo water spray systom in the reactor building to spray in areas vulnorable to relense. This modification would reduce the risk aseociated with releases into the reactor building, such as drywell head failures and containment bypass ovents, but would not impact releases via COPS.

- Flooded rubble bed - provide a bed of refractory pebbles that would be flooded with water. The rubble bed would impede the flow of molten corium to the concrete drywell structures, and increase the available beat trunsfer area, thereby enhancing debris coolability. This modification would further reduce the potential for core concrete interactions in the ABWR. A major drawbeck of the modification is that additional experimental teeting would be necessary to validate the concept for the ABWR application.

\subsubsection{Risk Reduction Potential of Design Improvements}

\subsection{GE Evaluation of Risk Reduction Potential}

GE used the reduction in cumulative risk of accidents occurring during the life of the plant as the basis for estimating the benefit that could be derived from plant improvements. Estimates of risk reduction were developed by determining the approximete offect of each modification on the frequency of the various relense clacese in the PRA. OE's beais for catimating the risk reduction for cach deaign improvement is provided in SSAR Section 19P.4, and aummarized in Table 20.5.14 of this report.

The ataff reviewed GE's basen for eatimating the risk reduction seecciated with the various decign improvements. The staff notes that considerable judgemeat was exercied in extimating the risk reduction potential, but that in general, the rationalo and aesumptione on which the rits reduction cetimater are baced (center colume of Trbble 20.5.1-4) are reneonablo, and in may canes coneservative. However, this is not to any that the cetimntes of percon-Sv (porron-sem) averted are coneervative, since the theff is not in completo agreement with GE's chancterization of baseline risk. For example, the risk-reduction potential for improved vecuum brenkers appears to be undereatimated in GE's analysis. $G B$ cetimates that improved vecuum breakers (addition of a second vacuum breaker valve in series with each of the exiating valves) would roduce risk by about 3E-7 pernonSv (0.00003 person-rem). This value is in large part due to significant credit for fission product removal by wetwell aprays (when available), and the failure to sccount for the impact of the design improvement on bypase scenarios in which sprays are not available. GE's risk-reduction cetimate for this improvement would increase by at lowst three orders of magnitude if just the latter factor was eccounted for. Novertholess, the risk reduction would remain small since the probability of the ovents involved is on the order of $1 \mathrm{E}-10$ per reactor year.

\subsection{Staff Evaluation of Risk-Reduction Potential}

In viow of the extromely small residual risk for the ABWR, rather then perform an independent assessment of the risk-reduction potential of each $A B W R$ design improvement, the staff used a bounding assumption that each improvement would eliminate all of the risk for the ABWR (0.01 person-Sv (1 person-rem) for the 60-year plant lifo). This approech tends to overestimate the benefits because the $A B W R$ risk profile reflects contributions from several unique types of sequences (e.g., station blackout, containment bypass, and LOCAs). An individual design improvement would generally reduce or eliminate some of these contributors but would not be effective on others. Moreover, there a.e numerous and diverse modes of contrinment failure which must be dealt with to ensure containment integrity in a severe accident. Thus, a carefully selected set of plant improvements would generally be needed, each one acting on particular components of risk, to effectively and significantly reduce total risk. 
Summary of GE's ascessment of risk reduction for candidate dealgn improvements

\begin{tabular}{|c|c|c|}
\hline Potential ABWR dacton modification & $\begin{array}{l}\text { GE's bacis for mothanting riek } \\
\text { reduction }\end{array}$ & 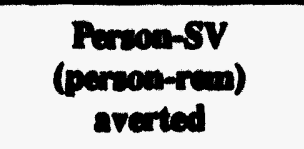 \\
\hline $\begin{array}{l}\text { Accidant Manngensient } \\
\text { Severe socident EPOL/AMOS }\end{array}$ & $\begin{array}{l}\text { 10\% reduction in failure rates for } \\
\text { manually initiated mitigative setions }\end{array}$ & $0.00015(0.015)$ \\
\hline $\begin{array}{l}\text { Computer-aided inetrumeatation } \\
\text { Improved maintenance procedurea/menuals }\end{array}$ & $\begin{array}{l}10 \% \text { reduction in frilure metes for } \\
\text { menually initieted preventive sctions } \\
10 \% \text { improvement in reliability of } \\
\text { HPCF, RCIC, RHR, LPCF }\end{array}$ & $\begin{array}{l}0.00010(0.01) \\
0.00016(0.016)\end{array}$ \\
\hline $\begin{array}{l}\text { Decay Heat Removal } \\
\text { Passive high preseuro system }\end{array}$ & $\begin{array}{l}\text { Equivaleat to adding a diverno RCIC and } \\
\text { RHR aystom with 10\% unavailability }\end{array}$ & $0.00138(0.138)$ \\
\hline Improved depressurization system & $\begin{array}{l}\text { Factor of } 2 \text { reduction in deprescurization } \\
\text { failure rates }\end{array}$ & $0.00042(0.042)$ \\
\hline Safety-selated condensate storage tank & $\begin{array}{l}\text { 10\% improvement in reliability of low } \\
\text { presoure makeup (resulting in } \\
2 \% \text { roduction in core damage frequency } \\
\text { from low pressure sequences } \\
\text { Engineering judgement }\end{array}$ & $0.00010(0.01)$ \\
\hline Containment Capability & & \\
\hline Larger volume containment & $\begin{array}{l}\text { Elimination of all containment release } \\
\text { modes involving drywell head failure } \\
(\text { Cases } 3,6,7,8,9)\end{array}$ & $0.00150(0.15)$ \\
\hline Increased containment pressure capacity & $\begin{array}{l}\text { Elimination of all containment release } \\
\text { modes except normal containment } \\
\text { leakage }\end{array}$ & $0.00020(0.02)$ \\
\hline Improved vacuum breakers & $\begin{array}{l}\text { Elimination of releases from Release } \\
\text { Class } 2\end{array}$ & $.0000003(0.00003)$ \\
\hline Improved bottom head penetration design & $\begin{array}{l}\text { Factor of } 2 \text { incroase in the probability of } \\
\text { arresting core damage in-vessel }\end{array}$ & $0.00057(0.057)$ \\
\hline
\end{tabular}




\begin{tabular}{|c|c|c|}
\hline Potential ABWR design modification & $\begin{array}{c}\text { GE's basis for estimating risk } \\
\text { reduction }\end{array}$ & $\begin{array}{l}\text { Person-SV } \\
\text { (person-rem) } \\
\text { averted }\end{array}$ \\
\hline $\begin{array}{l}\text { Containment Heat Removal } \\
\text { Large volume suppression pool }\end{array}$ & Elimination of Class II Sequences & $.000002(0.0002)$ \\
\hline $\begin{array}{l}\text { Containment Mass Removal } \\
\text { Low-flow filtered vent }\end{array}$ & $\begin{array}{l}\text { Elimination of the risk associated with } \\
\text { releases via COPS }\end{array}$ & $0.00014(0.014)$ \\
\hline $\begin{array}{l}\text { Containment Spray Systems } \\
\text { Drywell head flooding }\end{array}$ & $\begin{array}{l}\text { Elimination of drywell head over- } \\
\text { temperature failures and reduction in } \\
\text { releases from drywell head over-pressure } \\
\text { failures }\end{array}$ & $0.00060(0.06)$ \\
\hline $\begin{array}{l}\text { Prevention Concepts } \\
\text { Additional service water Loop }\end{array}$ & $\begin{array}{l}10 \% \text { increase in reliability of HPCF, } \\
\text { RCIC, RHR, LPCF }\end{array}$ & $0.00016(0.016)$ \\
\hline $\begin{array}{l}\text { AC Power Supplies } \\
\text { Steam-driven turbine generator } \\
\text { Alternate pump power source }\end{array}$ & $\begin{array}{l}80 \% \text { reduction in the diesel generator } \\
\text { common mode failure rate } \\
\text { Equivalent to adding a diverse RCIC } \\
\text { system }\end{array}$ & $\begin{array}{l}0.00052(0.052) \\
0.00069(0.069)\end{array}$ \\
\hline $\begin{array}{l}\text { DC Power Supplies } \\
\text { Dedicated dc power supply }\end{array}$ & $\begin{array}{l}\text { Factor of } 10 \text { increase in RCIC } \\
\text { availability in LOOP and SBO sequences }\end{array}$ & $0.00069(0.069)$ \\
\hline $\begin{array}{l}\text { ATWS Capability } \\
\text { ATWS-sized vent }\end{array}$ & Elimination of risk from ATWS (Case 9) & $0.00030(0.03)$ \\
\hline $\begin{array}{l}\text { System Simplification } \\
\text { Reactor building sprays }\end{array}$ & $\begin{array}{l}10 \% \text { reduction in risk from releases } \\
\text { through the reactor building }\end{array}$ & $0.00017(0.017)$ \\
\hline $\begin{array}{l}\text { Core Retention Devices } \\
\text { Flooded rubble bed }\end{array}$ & $\begin{array}{l}\text { Elimination of sequences with core } \\
\text { concrete interactions, except those with } \\
\text { failure of containment heal removal (1\% } \\
\text { of Cases } 1,6 \text {, and } 7 \text { ) }\end{array}$ & $0.000010(0.001)$ \\
\hline
\end{tabular}




\subsubsection{Cost Impacts of Candidate Design Improvements}

GE determined the approximate costs for cach design improvement. The costing methodology and assumptions are described in SSAR Section 19P.1.3. The coet besis for each plant improvement is provided in SSAR Section 19P.5 on an item-by-item besis.

GE stated in the SSAR that the cost estimates represent the incremental costs that would be incurred in a new plant, rather than costs that would apply on a beckfit basis. GE also stated that the costs were intentionally biased on the low side, but that all known or reasonably expected costs were accounted for so that a reasonable assessment of the minimum cost would be obtained.

For modifications which reduce core damage frequency, GE reduced the costs of the design improvements by an amount proportional to the reduction in the present worth of the risk of averted onsite costs. Onsite coets considered

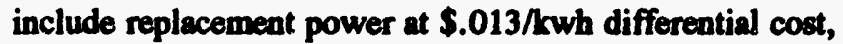
direct accident costs including onsite cleanup at $\$ 2$ billion, and the economic loss of the facility at $\$ 1.4$ billion. The resulting costs for each of the design improvements are provided in Table 20.5.1-3.

The staff reviewed the bases for GE's cost estimates and finds them to be reasonable. For certain improvements, the staff also compared GE's cost estimates with estimates developed elsewhere for similar improvements, even though the bases for some of these cost estimates were different. The staff considered the cost estimates developed as part of: the evaluation of design improvements for GESSAR II (NUREG-0979, Supplement 4), and the review of SAMDAs for Limerick and Comanche Peak (NUREG-0974 and -0775, respectively).

The staff noted a number of inconsistencies in the cost estimates. For example, GE's cost estimates for certain improvements such as improved vacuum breakers $(\$ 100,000)$, modified reactor building sprays $(\$ 100,000)$, and ATWS-sized vent $(\$ 300,000)$ were are considerably less than expected. The costs for certain other improvements was much higher than expected, such as improved bottom head penetration design $(\$ 750,000)$ and flooded rubble bed (approximately $\$ 19$ million).

It should be noted that only rough approximations of the costs of specific improvements are possible at this time. Large uncertainties exist because detailed designs are not available and because experience with construction and licensing problems that could surface with this type of work is limited. Nevertheless, the staff views GE's approximate cost estimates as adequate, given the uncertainties surrounding the underlying cost estimates, and the level of precision neceseary given the greater uncertainty inherent on the benefit side, with which these coets were compared.

\subsubsection{Cost-Benefit Comparison}

A cost-benefit comparison was performed to determine whother any of the potential severe socident desizn features could be justified. GE's estimates of the cost per personSv (person-rem) averted for the various design improvoments are precented in Table 20.5.1-3. The GE values aro based on the risk- reduction extimates reported in Tables 20.5.1-3, and 20.5.1-4 of this report. The ataff analysis is based on the conservative assumption that each design improvement would eliminate all of the residual risk (0.01 person-Sv (1 person-rem) over the 60-year plant life).

Consistent with current NRC practice (NUREG-3568), GE used a screening criterion of $\$ 100,000$ per person-Sv ( $\$ 1000$ per person-rem) averted to identify whether any of the design improvements could be cost-ffective. As shown in Table 20.5.1-3, the potential cost per averted person-rem ranges from about $\$ 1.7$ million to far-in-excess of $\$ 40$ million for the various suggested modifications according to the GE evaluation. Thus, this far exceeds the $\$ 100,000$ per person-Sv ( $\$ 1000$ per person-rem) criterion. On this basis, GE concluded that no additional modifications to the ABWR design are warranted.

The staff's assessment similarly indicates that none of the design improvements approach a level where they could be considered cost-effective, in spite of the significant conservatisms in assessing risk-reduction potential in the staff's analysis. The staff notes that the lowest cost modifications were estimated to cost about $\$ 100,000$, and realistically would only partially reduce the residual risk for the ABWR. Even though the cost of implementing design improvements in the ABWR may be less than for an existing plant, given that the ABWR has not yet been constructed, relatively large costs are still to be anticipated for many of the design improvements because they would involve first-of-a-kind engineering, and would need to be integrated within the existing design. In addition, the introduction of a new system will trigger a series of related requirements such as incremental training, procedural changes, and possible licensing requirements. These are all legitimate costs that require consideration in a comprehensive cost estimate. The staff concludes that none of the modifications evaluated would be cost effective given the low residual risk for the $A B W R$, and the $\$ 1000$ per person-rem criterion. 
The staff has considered the robustress of this conclusion relative to a number of critical aseumptions in the analysis as described below. These involve: the offect of uncertainties in estimating core damage frequency, the use of alternative cost-benefit criteria, and the inclusion of external events within the scope of the analysis.

Based on uncertrinty analyses performed by GE for the Level 1 portion of the PRA (s00 FSER Section 19.1.3.2.6), the 95th percentile core damage frequency is 4.5E-7 por reactor yoar. This is a factor of three higher than the mean value on which the cost-benefit analysis is based, but still very low both compared to operating plants and in absolute terms. Even if the benefits of the various design improvements were requantified on the besis of this upper-bound value, none of the improvements would become cost beneficial. This would remain the case even if the cost-benefit criterion was also increased by a factor of 10 to $\$ 1$ million per person-Sv (\$10,000 per person-rem) averted.

If external events are included, the estimate of ABWR risk could be one or possibly two orders of magnitude higher than considered in this analysis. For example, based on the BNL review of GE's original seismic PRA, as documented in the DSER (SECY-91-309), the total risk from internal and seismic events for the 60-year plant life would range from about 0.4 to 2 person-Sv ( 40 to 200 person-rem) depending on the site population. However, the value for the final ABWR design would be somewhut less since these estimates do not account for plant improvements incorporated in the design subsequent to the original PRA analysis, including upgrading the seismic capability of the diesel-driven fire water pump.

Even assuming the higher of these two risk estimates and complete elimination of all risk, any design modifications or combinations which cost more than $\$ 200,000$ would not be cost-effective. This would eliminate most of the candidate design modifications from further consideration. Based on the GE analysis, those modifications which were estimated to cost less than $\$ \mathbf{2 0 0 , 0 0 0}$ have a relatively low risk-reduction potential, and would generally eliminate only about 10 percent of the residual risk from internal events. The improvements are also not expected to be effective in eliminating most of the added risk from seismic events. Since the minimum cost of these systems would be about $\$ 100,000$, none of these improvements are expected to be cost-effective when their actual effectiveness in reducing risk is taken into account.

The staff concludes that with the significa" margins in the results of the cost-benefit analysis, the findings of the analysis would be unchanged even considering the above factors.

\subsubsection{Conclusions}

As discussed in Chupter 19.1.3.2.2 of this report, GE has made extensive use of the results of the PRA to arrive at a final ABWR design. As a result, the estimated core damage frequency and risk calculated for the $A B W R$ is very low both relative to operating plants and in absolute terms. The low core damage frequency and risk for the ABWR is a reflection of GE's efforts to systematically minimize the effect of initiators or sequences that have been important contributors to core damage frequency in previous BWR PRAs. This has been done largely through the incorporation of a number of hardware improvements in the ABWR design. These include providing three separated divisions of ECCSs, a diverse and independent combustion gas turbine capable of providing ac power to any of the three divisions, an ac-independent water addition system, and an FMCRD system as a backup to the hydraulic drive system. Several improvements have also been incorporated in the ABWR design to mitigate the consequences of a core damage event, including inerting of the containment atmosphere, inclusion of a lower drywell flooder system and a containment overpressure protection (vent) system, the use of basaltic concrete in the lower drywell, and an increased ultimate pressure capacity. These and additional ABWR design features which contribute to low core damage frequency and risk for the ABWR are discussed further in Section 19.1.3.2.3 of this report.

Because the ABWR design already includes numerous plent features oriented towards reducing core damage frequency and risk, the benefits and risk- reduction potential of additional plant improvements is significantly reduced. This is true for both internally and externally initiated events. For example, the ABWR seismic design basis ( $0.3 \mathrm{~g}$ safe shutdown earthquake) has been shown to result in significant ability to withstand earthquakes well beyond the design basis, as characterized by a high confidence with low probability of failure (HCLPF) value of $0.6 \mathrm{~g}$. Moreover, with the features already incorporated in the ABWR design, the ability to estimate core damage frequency and risk approaches the limitations of probabilistic techniques. Specifically, when core damage Srequencies of one in a hundred thousand or a million years are estimated in a PRA, it is the areas of the PRA where modelling is least complete, or supporting data is sparse or even nonexistent that could actually be the more important contributors to risk. Areas not modelled or incompletely modelled include human reliability, sabotage, rare initiating events, construction or design errors, and systems interactions. Although improvements in the modelling of these areas may introduce additional contributors to core damage frequency and risk, the staff 
does not expect that they would be significant in absolute terms.

10 CFR 50.34(f)(1)(i) requires the applicant to perform a plant- or site- specific probabilistic risk assessment, the aim of which is to seek such improvements in the reliability of core and containment heat removal systems as are significant and practical and do not impact excessively on the plant. The staff concludes that the ABWR PRA, and GE's use of the insights of this study to improve the design of the ABWR meets this requirement. The staff concurs with the GE conclusion that none of the potential design modifications evaluated are justified based on costbenefit considerations. The staff also concludes that it is unlikely that any other design changes would be justified on the basis of person-Sy (person-rem) exposure considerations, because the estimated core damage frequencies would remain very low on an abeolute scale.

\subsubsection{CFR 50.34(1)(1)(ii): System Design - Auxiliary Feedwater System - Auxiliary Feedwater System Evaluation (TMI Item II.E.1.1)}

Paragraph (1)(ii) of 10 CFR 50.34(f) requires the performance of an evaluation of the proposed AFWS of PWR plants to include a simplified AFWS reliability analysis using event-tree and fault-tree logic techniques, design review of AFWS, and an evaluation of AFWS flow design bases and criteria.

This requirement is applicable to PWRs only, since \& BWR design does not include an AFWS. Therefore, it is not technically relevant to the ABWR design and does not need to be addressed.

\subsubsection{CFR 50.34(I)(1)(iii):}

Measures to Mitigate Small-Break Loss-ofCoolant Accidents and Loss-of-Feedwater Accidents - Commission Orders on B\&W Plants - Impact of RCP Seal Damage Following SBLOCA With Loss of Ofrsite Power (TMI Item II.K.2(16)) and

Measures to Mitigate Small-Break Loss-ofCoolant Accidents and Loss-of-Feedwater Accidents - Final Recommendations of Bulletins and Orders Task Force - Effect of Loss of ac Power on Pump Seals (TMI Item II.K.3(25))

TMI Item II.K.2(16) is applicable to PWRs only and does not need to be addressed for the ABWR, but II.K.3(25) applies to BWRs. Paragraph (1)(iii) of 10 CFR 50.34(f) requires analyses or experiments to determine the consequences at each plant of a loss of cooling water to the reactor recirculation pump seal coolers. Pump seals should be designed to withstand a complete loss of ac power for at least two hours and the adequacy of the seal design should also be demonstrated. The design should prevent an excessive loss of reactor coolant inventory after an anticipated operational occurrence. It is assumed that the loss of ac power constitutes a loss of offsite power.

SSAR Sections 5.4.1 and 1A.2.30 state that the ABWR design features reactor internal pumps (RIPs) that do not require pump shaft seals. During a loss of ac power, the RIPB are shut down automatically, but there are no shaft seals that require restoration of cooling. During its review of this issue, the staff required GE to confirm that the failure of the following systems would not cause a LOCA

- recirculation motor cooling system

- recirculation motor seal purge system

- recirculation motor inflatable shaft seal subsystem.

GE confirmed in SSAR Section 1A.2.30 that an ac failure would temporarily disrupt the operation of these systems, but their failure would not generate a LOCA. Therefore, the staff concludes that GE adequately addressed the requirements of this TMI item for the ABWR design.

20.5.4 10 CFR 50.34(I)(1)(iv): Measures to Mitigate Small-Break Loss-of-Coolant Accidents and Loss-of-Feedwater Accidents - Final Recommendations of Bulletins and Orders Task Force - Report on Overall Safety Effect of PORV Isolation (TMI Item II.K.3(2))

Paragraph (1)(ii) of 10 CFR 50.34(f) requires performance of an analysis of the probability of a SBLOCA caused by a stuck-open PORV of PWR plants. If the probability is a significant contributor to the probability of SBLOCAs from all causes, it also requires a description and evaluation of the effect on SBLOCA probability of an automatic PORV isolation system that would operate when the RCS pressure falls after the PORV has opened.

This requirement is applicable to PWRs only, therefore, it is not technically relevant to the ABWR design and does not need to be addressed. 


\subsubsection{CFR 50.34(1)(1)(v): Measures to Mitigate Small-Break Loss-of-Coolant Accidents and Loss-of-Feedwater Accidents - Final Recom- mendations of Bulletins and Orders Task Force - Separation of HPCI and RCIC System Initiation Levels (TMI Item II.K.3(13))}

Paragraph (1)(v) of 10 CFR 50.34(f) requires an evaluation of the safety effectiveness of providing for separation of the HPCI and RCIC system initiation lovels so that the RCIC system initiates at a higher water lovel than the HPCI system, and of providing that both systems restart on low water level. For plants with high pressure core spray (HPCS) systems in lieu of HPCI systems, HPCS system is to be evaluated in lieu of the HPCI system.

In NUREG-0737, the staff stated that the initiation levels of the HPCI and RCIC systems should be separated so that the RCIC system initiates at a higher water level then the HPCI system. Further, the initiation logic of the RCIC system should be modified so that the RCIC system will restart upon receiving a low water level signal. These changes could reduce the number of challenges to the HPCI system and could result in less stress on the reactor vessel from cold water injection. Applicants were required to submit the analyses of these changes to the NRC staff and implement the changes if justified by the analyses.

The ABWR design is consistent with this position. The ABWR incorporates an HPCF system that initiates at reactor vessel level 1.5 and an RCIC system which initiates at level 2. At level 8, the injection valves for the HPCF and the RCIC steam supply and injection valves automatically close to prevent water from entering the main steam lines.

If the RPV again reaches a low level, the RCIC steam supply and injection valves automatically reopen to allow the RCIC to continue flooding the vessel. The HPCF injection valves will also automatically reopen unless the operator previously closed them manually.

The ABWR has three high-presenure makeup systems, two HPCFs and one RCIC. Current BWRs have the HPCS or HPCI, and RCIC. Thus, the water level set points for ABWR must moet the following requirements:

- During anticipated abnormal transients, including the loss of all feodwater flow event, the RCIC system will prevent the minimum water level from dropping below vessel level 1.5. This requirement is to minimize the challeage to the HPCFs.

- The ADS will not likely be ectuated duiring eny abnormal transient with a failure of RCIC. Therefore, the reactor isolation and two HPCFs initiated at vessel level 1.5 will prevent the water level from dropping below level 1 during a loss-of-all-feedwater-flow transient with RCIC failure.

The staff found that GE provided different initiation levels for HPCF and RCIC so that the RCIC system initiates at a higher water level than the HPCF system, as well as the automatic restart of RCIC on low level. GE's proposed response adequately addresses the requirements of this TMI item for the ABWR design. An in-depth discussion of the RCIC system is provided in Section 5.4.6 of this report and of RCIC and HPCF in Section 6.3.1 of this report.

20.5.6 10 CFR 50.34(f)(1)(vi): Measures to Mitigate Small-Break Loss-of-Coolant Accidents and Loss-of-Feedwater Accidents - Final Recommendations of Bulletins and Orders Task Force - Reduction of Challenges and Failures of Relief Valves; Feasibility Study and System Modification (TMI Item II.K.3(10))

Paragraph (1)(vi) of 10 CFR 50.34(f) requires the performance of a study to identify practicable system modifications that would reduce challenges and failures of relief valves in BWRs, without compromising the performance of the valves or other systems.

In 1980, the staff determined that in the prior three years of operation of all BWR plants, there were approximately 30 failures of relief valves to close in 73 reactor-years (0.41 failures per reactor-year). This demonstrated that the failure of a relief valve to close was the most likely cause of an SBLOCA. The high failure rate is the result of a high relief-valve challenge rate and a relatively high probability of failure for each challenge ( 0.16 failures per challenge). Typically, five valves are challenged per event. This results in an equivalent failure rate for each challenge of 0.03 . In NUREG-0737, the staff stated that the challenge and failure rates can be reduced in many ways.

To resolve this iseve, the staff required GE to invectigate the feasibility of reducing challenges to relief valves and implement those changes shown to reduce challenges to the anfety and reliof valves without compromising the performance of the relief valves or other systems. Challenges to the relief valves were expected to be reduced substantially (by an order of magnitude).

GE evaluated the possible ways for reducing the challenges and failure rate of SRVs, and reduced the MSIV isolation ot points from RPV level 2 to level 1.5. The staff concludes that this modification will reduce SRV challenge 
rates and concludes that GE's response adequately addresses the requirements of this TMI item for the ABWR design. Further discussion of SRVs is provided in Section $\mathbf{5 . 2 . 2}$ of this report.

\subsubsection{CFR 50.34()(1)(vii): Measures to Mitigate} Small-Break Loss-of-Coolant Accidents and Loss-of-Feedwater Accidents - Final Recommendations of Bulletins and Orders Task Force - Modification of ADS Logic; Feasibility Study and Modification for Increased Diversity for Some Event Sequences (TMI Item II.K.3(18))

Paragraph (1)(vii) of 10 CFR 50.34(f) requires performance of a feasibility and risk assessment study to determine the optimum ADS design and modifications that would eliminate the need for manual activation to ensure adequate core cooling for BWRs.

In NUREG-0737, the staff stated that the ADS actuation logic should be modified to eliminate the need for manual actuation to ensure adequate core cooling. The applicant was required to conduct a feasibility and risk assessment study to determine the best approach. For example, the applicant was to consider actuating the ADS on a low reactor vessel water level signal if the instruments indicate no HPCI or HPCS flow and a low-pressure ECCS is running. This logic would complement, not replace, the existing ADS actuation logic. The ADS must be manually actuated to cool the core adequately for transient and accident events that do not directly produce a high drywell pressure signal (e.g., stuck-open relief valve or steam line break outside containment), and are degraded by the loss of high-pressure ECCSs. This TMI item requires that the ADS logic be modified to eliminate operator action.

In the DFSER, the staff reported that GE proposed to modify the ABWR design in a manner consistent with option 4 of the BWROG response to TMI Item II.K.3(18). GE discussed this proposal in a letter dated October 28, 1982, from T.J. Dente (GE) to D.G. Eisenhut (NRC), "NUREG-0737 Item II.K.3.18 Modification of Automatic Depressurization System Logic." This modification involves a manual inhibit switch and a timer that bypasses the high drywell pressure permissive if the reactor water level is low for a sustained period. GE added an 8-minute high drywell pressure bypass timer to the ABWR ADS initiation logic. This timer will initiate on a low water level-1 signal. When it times out, it bypasses the need for a high drywell pressure signal to initiate the standard ADS initiation logic.

The DFSER reported that the bypass timer would be tested periodically as required by the STS and stated that this was identified in Chapter 6 of the DFSER as TS Item 6.3.3-1.
It also indicated that GE documented the results of its evaluation of the adequacy of the 8-minute bypass timer in the SSAR (s00 GE letter to NRC, MFN No. 038-92, dated Fobruary 14, 1992). The staff agreed with the analysis and results and concluded that the modifications to the ADS design were acceptable. In response to TS Item 6.3.3-1, GE modified the ABWR TS to require periodic tosting of the ADS bypass timer. The staff concludes that GE has adequately responded to this item as discussed further in Section 6.3.3 of this report.

On the basis of its review of the ADS design and resolution of the DFSER TS item, the staff concludes that GE's response adequately addresses this TMI requirement.

\subsubsection{CFR 50.34(f)(1)(viii): Measures to Mitigate} Small-Break Loss-of-Coolant Accidents and Loss-0f-Feedwater Accidents - Final Recommendations of Bulletins and Orders Task Force - Restart of Core Spray and LPCI Systems on Low Level; Design and Modification (TMI Item II.K.3(21))

Paragraph (1)(viii) of $10 \mathrm{CFR} 50.34(f)$ requires performance of a study of the effect on all core-cooling modes of BWRs under accident conditions of designing the core spray and low-pressure coolant injection systems to ensure that the systems will automatically restart on loss of water level, after having been manually stopped, if an initiation signal is still present.

In NUREG-0737, the staff identified a concern that the operator may stop the required flow of the core spray and LPCl system. These systems will not restart automatically on a loss-of-water level signal if an initiation signal is still present. The staff indicated that the vendor should modify the core spray and LPCI system logic so that these systems will restart, if required, to ensure adequate core cooling. Before modifying the design, the staff also stated that the vendor should submit a preliminary design to the staff for approval because it affects several core-cooling modes under accident conditions.

In the DFSER, the staff reported that for the ABWR, GE endorses the conclusions of the study performed by the BWROG which was forwarded to the staff in a December 29, 1980, letter from D.B. Waters (BWROG) to D.G. Eisenhut (NRC). The BWROG concluded that the current BWR ECCS design is adequate and that the proposed changes would decrease the overall safety of the plant. For example, the BWROG stated that the modification would significantly escalate the control system complexity, restrict the operator's flexibility when dealing with anticipated events, and reduce system reliability. The BWROG concluded that the current ECCS design is 
adequate because the BWR operator training is comprehensive and thoroughly addreases reactor-waterlovel control, the BOPs addreses this iesue, the operator hes sufficient timo to correct errors, and the low reactor-waterlevel conditions are clearly displayed and alarmed in the control room.

The staff reported that it reviewed the results of the BWROG study and considered the emphasis placed on water-lovel control in BWR operator training. The staff found GE's response acceptable and agrees that the ABWR design need not be modified to provide an automatic restart of the low-pressure ECCS. Therefore, the staff concludes that the ABWR design meets the requirements of this TMI itom.

\subsubsection{CFR 50.34(f)(1)(ix): Measures to Mitigate} Small-Break Loss-of-Coolant Accidents and Loss-of-Feedwater Accidents -. Final Recommendations of Bulletins and Orders Task Force - Confirm Adequacy of Space Cooling for HPCI and RCIC Systems (TMI Item II.K.3(24))

Paragraph (1)(ix) of 10 CFR 50.34(f) requires a determination of the adequacy of space cooling for the high pressure coolant injection systems at BWRs. Long-term operation of these systems during a complete loss of offsite power, for up to two hours, may require space cooling to maintain the HPCI pump rooms within allowable temperature limits. The HPCI systems and their respective support systems should be designed to withstand the consequences of a complete loss of offsite $a c$ power for 2 hours. For plants with HPCS systems in lieu of HPCI systems, the HPCS system is to be evaluated in lieu of the HPCI system.

The ABWR design contains two systems to provide room cooling to the HPCF and RCIC systems. During normal operation, the two HPCF pump rooms and the single RCIC pump room are cooled by the non-safety-related secondary containment, HVAC system. During accident conditions, the room-cooling function is transferred to the safety-grade essential equipment HVAC system and the secondary containment HVAC system is isolated. The essential equipment HVAC system consists of a fan coil unit in each of the pump rooms. Cooling for each fan coil is provided by the safety-related portion of the applicable train of the RCW system. The fan coil unit in the applicable pump room, the HPCF subsystem or the RCIC system which the fan coil unit is serving, and the associated RCW train are all on the same essential electrical power division, which includes the divisional onsite ac power source, that is, emergency onsite diesel generator. The fan coil unit is necessary to keep the temperature of the aseociated pump room within its design limits. It is sutomatically initiated upon startup of the respective HPCF or RCIC pump. Besed on the above, the staff concludes that space cooling for the HPCF and the RCIC systems will be available as required by this TMI item following a complete loss of offsite ac power to the plant for at least 2 hours.

In the DFSER, the staff noted that the design chancteristics for the fan coil units were not specifically identified in SSAR Section 9.4.5. The staff was not able to confirm the ability of the fan coil units to remove sufficient heat to maintain the pump room temperatures within deaign limits. Also, SSAR Tables 8.3-1 and 8.3-2, which list diesel generator loads, did not include the fan coil units. These concerns were identified in the DFSER as Open Item 20.3-1. Subeequently, in Amendment 32 of the SSAR, GE stated in Section 9.4.5.2.2.1 that the fan coil units are sized to maintain the rooms within $40^{\circ} \mathrm{C}$ $\left(104^{\circ} \mathrm{F}\right)$ operational temperature, which is well below the temperature limits specified in SSAR Appendix 31 regarding environmental qualification. Based on this information, the staff determined that there is sufficient margin to provide adequate space cooling during a LOCA. Further, GE added the fan coil units and their capacities to SSAR Table 9.4-40, and their associated loads in SSAR Table 8.3-1 (the operational loads are one-half of the connected loads). Based on this additional information, the staff concludes that the fan coil units receive emergency power from the diesel generators and are sized to remove the worst-case heat load from the rooms. This additional information adequately resolved the concerns of DFSER Open Item 20.3-1.

The staff concludes that the HPCF and RCIC room cooling units are adequately sized and powered to maintain the rooms within design environmental conditions following a complete loss of offsite ac power to the plant for at least 2 hours, and therefore, the ABWR design adequately addresses the requirements of this TMI item.

\subsubsection{CFR 50.34(f)(1)(x): Measures to Mitigate Small-Break Loss-of-Coolant Accidents and Loss-of-Feedwater Accidents -- Final Recommendations of Bulletins and Orders Task Force - Study and Verify Qualification of Accumulators on ADS Valves (TMI Item I.K.3(28))}

Paragraph (1)(x) of $10 \mathrm{CFR} 50.34(f)$ requires the performance of a study to ensure that the ADS valves, accumulators, and associated equipment and instrumentation of BWRs will be capable of performing their intended functions during and following an accident situation, taking no credit for non-safety-related equipment 
or instrumentation, and accounting for normal expected air (or nitrogen) leakage through valves.

The ABWR has 18 quality Group A, seismic Catogory I SRVs, eight of which can also perform the ADS function. One 189-liter (50-gallon) capecity nitrogen accumulator with a design pressure of $1379 \mathrm{kPa}(200 \mathrm{psig})$ is provided for each ADS SRV to support its ADS function during and following an accident situation. The accumulator supplies compressed nitrogen gas to the valve for its actuations. The staff's evaluation is based on SSAR Sections 1A.2.31 and 6.7 and is limited to the adequacy of the accumulators and associated equipment to perform their intended functions during and following an accident situation. Tho staff's evaluation regarding the system's compliance with other regulatory requirements, such as the adequacy of the ADS SRV valves and their associated instrumentation and controls to perform their intended functions during and following an accident situation, is provided in Sections 5.2.2, "Overpressure Protection," 6.3, "Emergency Core Cooling Systems," and 7.3, "Engineered Safety Features Systems," of this report.

Each accumulator is sized to provide sufficient nitrogen gas for one associated ADS valve actuation at drywell design pressure or five actuations at normal drywell pressure with nominal pneumatic supply. Makeup supply for the accumulators is provided by the safety-related portions of the nitrogen gas supply system, which includes two redundant safety-related nitrogen gas supply trains. Each train consists of 10 high-pressure nitrogen gas bottles and associated piping, valves, and instrumentation. The nitrogen bottles in each train have sufficient stored compressed nitrogen gas to supply makeup nitrogen gas to the accumulators associated with four ADS valves to compensate for an expected nitrogen leakage of 28 liters per hour (L/hr) (1 standard cubic foot per hour (scth)) for each valve for a 7-day period. Additionally, the accumulators can be refilled after the system is operating using the non-safety-related portion of the nitrogen gas supply system in conjunction with the non-safety-related atmospheric control system (ACS) described in SSAR Section 6.2.5. GE determined that a maximum of three ADS valves will be needed to meet short-term demands and one ADS valve will be needed to meet long-term needs and so, one safety-related train of the nitrogen gas supply system will be sufficient to provide the needed nitrogen makeup to the associated ADS accumulators. The system has alarm provisions to indicate failure of any redundant nitrogen supply train due to a loss of nitrogen supply prestsure to the ADS valve accumulator.

The accumulators, including the associated equipment to the ADS valves, and the safety-related portions of the nitrogen gas supply system are designed to seismic
Catogory I, quality Group B or C, as appropriate, and quality ascurnece B requirements. The accumulators, including the aseociated equipment to the ADS valves, are designed to operate in the environmental conditions to be found in the drywoli after a design-basis accident ( 800 SSAR Section 7.3.1.1.1.2 for specific additional information and Section 3.11 of this report for general information on environmental qualification design criteria for equipment important to safety). SSAR Section 7.3.1.1.10 states that the safety-related equipment in the nitrogen gas supply system are selected to accommodate the hostile environment to which they may be exposed during an accident situation. The nitrogen supply system is designed to $1379 \mathrm{kPa}$ (200 psig) and $66^{\circ} \mathrm{C}\left(151^{\circ} \mathrm{F}\right)$. In the DFSER, the staff expressed concern regarding the design temperature. The $66^{\circ} \mathrm{C}$ $\left(151^{\circ} \mathrm{F}\right)$ design temperature is significantly lower than the temperature to which some portions of the system (e.g., inside the drywell and the reactor building) may be exposed during an accident situation. The staff also expressed concern that SSAR Section 6.7.4 did not explicitly specify a requirement for periodically testing the leakage through each valve to verify that such leakage is within the assumed value of $28 \mathrm{~L} / \mathrm{hr}(1 \mathrm{scth})$. These concerns were identified in the DFSER as Open Item 20.3-2.

Subsequently, in Amendment 31, GE modified SSAR Sections 6.7.4 and Figure 6.7-1. The figure now indicates that the high pressure nitrogen (HPIN) system piping from inside primary containment to the outboard containment isolation valve is designed to $171^{\circ} \mathrm{C}\left(340^{\circ} \mathrm{F}\right)$, while the remainder of the system outside primary containment is designed to $66^{\circ} \mathrm{C}\left(151^{\circ} \mathrm{F}\right)$. These specifications ensure that the system can withstand the worst postulated environmental conditions. SSAR Section 6.7.4 now states that periodic testing will be performed on system components to ensure that leakage will not exceed $28 \mathrm{~L} / \mathrm{hr}$ $(1 \mathrm{scth})$. Based on this additional information, the staff concludes that the system is designed to ensure proper ADS SRV valve operation. This additional information adequately resolved the concerns of DFSER Open Item 20.3-2.

Based on its evaluation, the staff concludes that (1) GE's criteria for sizing each nitrogen gas accumulator and the provision for supply of makeup nitrogen gas to the accumulator is appropriate, and (2) the nitrogen accumulators and the associated equipment, including the safetyrelated portions of the nitrogen gas supply system, will perform their intended functions during and following an accident situation. Therefore, the ABWR design adequately addresses the requirements of this TMI item. 
20.5.11 10 CIR 50.34(h)(1)(xi): Micasure to Mitigate Small-Breals Loso-of-Coolant Aceldents and Loss-of-Feodwater Aceidonts -. Final Recommendations of Bulletin and Order Task Force - Evaluate Deprescurization with Other Than Full ADS (TMI Item II.K.3(45))

Paragraph (1)(xi) of 10 CFR 50.34(f) requires provision of an evaluation of depressurization modes, other than full sctuation of the ADS, such as early depreacurization with one or two SRVs, that would reduce the possibility of exceeding veseel integrity limits during rapid cooldown of BWRs. Slower depreseurization would reduce the possibility of exceeding vessel integrity limits by rapidly cooling down.

Since the ABWR design provides three high pressure core injection systems, the probability of ADS actuation is lower then for current BWRs. In the report dated September 27, 1982 (momorandum from T. Speis to G. Lainas), the staff ovaluation which addressed this subject concurred with the BWROG study in this area. In the analyses conducted for the study, it was asoumed that all high-preseure injection systems would fail, but that all low-pressure systems would operate. The time at which the operator is assumed to actuato the ADS varied. The effects of depressurization over a 10-minute interval and a 20-minute interval were compared to the case in which the RCS is completely depressurized in 3.3 minutes. Vessel fatigue usage was the key parameter studied regarding vessel integrity. The BWROG analyzed the extent to which a longer depressurization period would reduce fatigue usage and then considered the effect of this reduced fatigue usage on the core cooling capability. The BWROG concluded that

- vessel integrity limits are not exceeded for full depressurization using the ADS

- for slower depressurization rates (longer than the approximate 3.3 minute interval for the normal depressurization rate), the usage assignable to the full depressurization using the ADS would not significantly affect vessel fatigue usage relative to that usage assignable to the full ADS blowdown

- slower depressurization rates reduce the core cooling capability, except when the operator begins to depressurize the RCS very early in the accident.
The reaults aleo atated that core cooling capability could bo improved using a 10-minute depreseurization period if the operator sctuated the ADS within 1 to 6 minutes after the eccident begins. However, it was considered more prudent to sctivate the high-preasure injection systems during this initial period to avoid using the ADS.

GE performed the analysis for a standard BWR, which has an RPV and ADS similar to the ABWR. Thus, the RPV cooldown rate and material design of the RPV veasel for the ABWR are similar to those features in current designs. Hence, the results should be the same for the ABWR. Based on its reviow, the staff concludes that the current mode of depresesurization using the ADS in the samo manner as current operating BWRs for the ABWR is satisfactory and adequately addresses the requirements of this TMI itom.

\subsubsection{CFR 50.34(1)(1)(xii): Evaluation of Alternative Hydrogen Control Systems}

Paragraph (1)(xii) of 10 CFR 50.34(f) requires performence of an evaluation of alternative hydrogen control systems that would satisfy the requirement of paragraph (2)(ix) of 50.34(f) (see Section 20.5.21 below). As a minimum, the evaluation must consider a hydrogen ignition and post-accident inerting system and include:

- A comparison of costs and benefits of the alternative systems considered.

- For the selected system, analyses and test data to verify compliance with the requirements of paragraph (2)(ix) of 50.34(f).

- For the solected system, preliminary design descriptions of equipment, function, and layout.

In the DFSER, the staff required GE to provide this information since it had not yet done so. This was identified in the DFSER as Open Item 20.3-3. Subeoquently, GE modified SSAR Section 19A.2.12 to state that Section 6.2.7.1 contained COL license information requiring the applicant referencing the $\mathrm{ABWR}$ design to provide this information, if appropriate. The staff agrees that evaluating an alternative hydrogen control system is beyond the scope of the ABWR design certification reviow, and should a COL applicant wish to provide an alternative system, it should provide the supporting information for staff review. Based on the clarifying information provided in the SSAR, the staff concludes that GE has adequately addressed the requirements of 10 CFR 50.34 (f)(1)(xii). Therefore, DFSER Open Item 20.3-3 is resolved. 
20.5.13 $10 \mathrm{CRR}$ 50.34(1)(2)(i): Oparating Perround Simulator Use and Development - Lone-Term Training Upgrade (TMI Item I.A.4.2)

Paragraph (2)(i) of 10 CFR 50.34(f) requires the provition of simulator capability that correctly models the control room and includes the capability to simulate SBLOCAs.

GE stated that simulator facilities for use in performing operator training are beyond the roope of the ABWR design cortification roviow and the COL applicant will be responsible for addressing this requirement. This is consistent with the treatment of training in SSAR Chapter 13 and is acceptablo because training will be addreseed by the COL applicant. This was identified in the DFSER as COL Action Itom 18.7.2.2-1. The staff verified that GE established a COL sction item (Item 18.8.8 in SSAR Section 18.8) for an oporator training program to moet 10 CFR Part 50. This approech adequately addresses DFSER COL Action Item 18.7.2.2-1 as discussed in Sections 13.2 and 18.7.2.2 of this report.

20.5.14 10 CFR 50.34(I)(2)(ii): Operating Procedures Long-Term Program Plan Procedures for Upgrading of Procedures (TMI Item I.C.9)

Paragraph (2)(ii) of 10 CFR 50.34(f) requires establishment of a program, to begin during construction and follow into operation, for integrating and expanding current efforts to improve plant procedures. The scope of the program is required to include emergency procedures, reliability analyses, HFE, crisis management, operator training, and coordination with INPO and other industry efforts.

The development of detailed procedures is beyond the scope of the ABWR design certification review and the COL applicant will be responsible for addressing this TMI item in the detailed design implementation. This was identified in the DFSER as COL Action Item 18.7.2.2-2. The staff verified that GE established a COL action item in SSAR Section 13.5.3 for procedure development. Additionally, SSAR Section 13.5.3.1 states that the methods and criteria for the development, V\&V, implementation, maintenance, and revision of procedures will include considerations of I.C.9. This approech is adequately addresses DFSER COL Action Item 18.7.2.2-2 as discussed in Section 13.5 of this report.

\subsubsection{CFR 50.34(f)(2)(iii): Control Room Design - Control Room Design Reviews (TMI Item I.D.1)}

Paragraph (2)(iii) of $10 \mathrm{CFR} 50.34(f)$ requires the provision, for NRC review, of a control room design that reflects stato-of-tho-art human fector principles prior to committing to fabrication or revision of fabricated control room panels and layouts.

GE stated that this requirement is beyond the ecope of the ABWR design certification roview and the COL applicant will be responsible for addreesing it in the detailed design implementation. This was identified in the DFSER as COL Action Itom 18.7.2.2-3. Tho ataff verified that $O E$ addrosed this requirement further in the HFE design (SSAR Section 18.8), included detuiled CR development in ABWR CDM Table 3.1 ITAAC and in SSAR Section 18E, and eatablished a COL action itom (Item 18.8.1) in SSAR Section 18.8. This approach adequately addreseses DFSER COL Action Item 18.7.2.2-3 discussed in Section 18.7.2.2 of this report.

\subsubsection{CFR 50.34(n)(2)(iv): Control Room Design - Plant Safety Parameter Display Console (TMI Item I.D.2)}

Parkgraph (2)(iv) of 10 CFR 50.34(f) requires provision of a plant eafety parameter display console that will display to operators a minimum set of parameters defining the safoty status of the plant, capable of displaying a full range of important plant parameters and data trends on demand, and capable of indicating when process limits are being approached or exceeded.

GE addresses this requirement in SSAR Section 18.4.2.11 (ovaluatod in Section 18.3 of this report). This requirement is beyond the scope of the ABWR design certification review and the COL applicant will be responsible for addressing it in the SPDS design. This was identified in the DFSER as COL Action Itom 18.7.2.2-4. The staff verified that GE established a COL action item in SSAR Section 18.8 (Item 18.8.4) to evaluate the SPDS design against the applicable provisions of NUREG-0737, Supplement 1. This approach adequately addresses DFSER COL Action Item 18.7.2.2-4 as discussed in Section 18.7.2.2 of this report.

It should be noted that Section 18.7.2.2 of this report states that the ABWR design will not provide a separato SPDS console, but rather, the functions of the SPDS will be integrated into the overall control room display capabilities. The staff concludes that an exemption from the requirements of 10 CFR 50.34(f)(2)(iv) for a separate SPDS console are appropriate for the ABWR for the reasons set forth in Sections 18.3 and 18.7.2.2 of this report. 


\subsubsection{CFR 50.34(h)(2)(v): Control Room Design . Safety System Status Monitoring (TMI Item I.D.3)}

Paragraph (2)(v) of 10 CFR 50.34(f) requires provisions for automatic indication of the bypaseed and inoperable status of safoty systoms.

SSAR Section 7.1.2.10.2 states that the ABWR standard plant design complies with the requirements of IEEE 279, paragraph 4.13; RG 1.47; and BTP ICSB 21. IEEE 279, paragraph 4.13 and RG 1.47 state that if the protective action of some part of the I\&C system has been bypassed or deliberately readered inoperative for any purpose, this fact will be continuously indicated in the control room. The ABWR design also provides for automatic indication at the system lovel when the system losen power or when it is out of service. In addition, a switch will be provided for manual initiation of bypess indication for out-of-service conditions under limited circumstances when bypass is not automatically annunciated. On this basis, the staff concludes that the ABWR standard design meets the stated guidance of RG 1.47, and therefore, meets the requirements of $50.34(f)(2)(v)$ with respect to the I\&C design of safety system status monitoring. See also Section 7.2.3 of this report.

The human factors details of this requirement are beyond the scope of the ABWR design certification review and GE stated that they will be addressed by the COL applicant in the detailed design implementation. This was identified in the DFSER as COL Action Item 18.7.2.2-5. The staff verified that GE established a COL action item in SSAR Section 18.8 (Item 18.8.1) to conduct the detailed HFE design according to design and implementation as defined by the ABWR CDM Table 3.1 ITAAC and SSAR Appendix 18E. The staff considers this to include the resolution of the human factors aspects of this requirement. This approach adequately addresses DFSER COL Action Item 18.7.2.2-5 as discussed in Section 18.7.2.2 of this report.

20.5.18 10 CFR 50.34(f)(2)(vi): Consideration of Degraded or Melted Cores in Safety Review Reactor Coolant System Vents (TMI Item II.B.1)

Peragraph (2)(vi) of 10 CFR 50.34(f) requires that each applicant and licensee install high-point vents for the RCS and the reactor vessel head. These vents will be remotely operated from the control room. Although the purpose of the system is to vent noncondensable gases, from the RCS which may inhibit core cooling during natural circulation, the vents must not lead to an unacceptable increase in the probability of a LOCA or a challenge to containment integrity. Theee veats are part of the reactor coolent preacure boundary and thus, shall conform to the regulatory requirements of 10 CFR Part 50. The vent syatem shall bo designed with sufficient redundancy to casire a low probability of inadvertent or imevervible ectuation.

This TMI item also requires the submittal of the following information on the design and operation of the high-point vent system:

- A description of the design, location, size, and powver supply for the vent system, along with recults of analyses for LOCAs initiated by a break in the vent pipe. The results of the analyses should demonetrate compliance with the acceptance criteria of 10 CFR 50.46 .

- Procedures and supporting analysis for the operator to use in operating the vents. This information should include the information available to the operator for beginning or ending the use of the vents.

In the ABWR design, the 18 power-operated anfety and relief valves are the primary venting capability. Each SRV is seismically qualified. The high-pressure nitrogen gas supply to the eight SRVs which comprise the ADS is aleo seismically qualified. To vent the RCS, cach SRV can bo operated in the power-actuated mode by remoto manual controls in the main control room. The discharge line for each SRV will include linear variable differential traneformers (LVDTs) and a thermocouple to monitor the position and leakage of the SRV. Each SRV discharges to the suppression pool.

The RCS can also be vented through the RCIC system, which directs steam from one of the main steam lines to a turbine-driven pump, from which the steam is exhausted to the suppression pool. The RCIC system cen vent the RCS during hot standby mode or during reactor isolation.

The top head vent line of the RPV can also direct steam and noncondensable gases from the reactor's upper dome. This line is used principally to vent the reactor during the final stages of normal shutdown from power operation. A reactor head vent line is a continuous vent which is normally open to discharge to a main steam line.

The COL applicant will develop plant-specific procedures to govern the operator's use of the relief mode for venting the reactor. This was identified in the DFSER as COL Action Item 20.3-1. In the advance SER, the staff concluded that since GE had not yet included a COL action item in the SSAR addressing the development of these procedures, DFSER COL Action Item 20.3-1 would 
remain opea until $O E$ had done so. In Ameadmeat 33, OB revised SSAR Soctions 1A.2.5 and 1A.3.6 to extablish a COL action item for the COL applicant to dovelop the indicated plant procedures. This approsech adoquately addreaces DPSBR COL Action Item 20.3-1.

OE has submittod no additional accideat analyees to addrees a broak in any of the veat lines becaues the plant's denign basis includes a complete stonm line break, which is more bounding.

The staff concurs with the applicant's asecesment becauve it include adequate capecity, operation, and procedural provisions of the ABWR vent syetom. The staff concludes that $\mathrm{CB}$ has adequately addreseed the requirements of this TMI itom for the ABWR design.

\subsubsection{CFR 50.34(1)(2)(vii): Concideration of} Degraded or Melted Cores in Safety Review Plant Shielding to Provide Access to Vital Areas and Protect Safety Equipment for PostAccident Operation (TMI Item II.B.2)

Paragraph (2)(vii) of 10 CFR 50.34(f) requires rediation and shielding design roviows of speces around syetems that may, as a result of an accident, contain source torm radionctive materials, and design as necescary to permit adequate access to important areas and to protect anfety equipment from the radiation environment. OE's response adequately addresses the requirements of this TMI item for the ABWR design as discussed in Sections 12.3.6 and 13.6.3.5 of this report.

\subsubsection{CFR 50.34(f)(2)(viii): Consideration of Degraded or Melted Cores in Safety Review - Post-Accident Sampling (TMI Item II.B.3)}

Paragraph (2)(viii) of $10 \mathrm{CFR} 50.34(f)$ requires the capability to promptly obtain and analyzo samples from the reactor coolant system and containment that may contain TID-14844 source term radioactive materials without radiation exposure to any individual exceeding $0.05 \mathrm{~Sv}$ $(5 \mathrm{rem})$ to the whole-body or $0.50 \mathrm{~Sv}(50 \mathrm{rem})$ to the extremities.

GE's response adequately addresses the requirements of this TMI item for the ABWR design as discussed in Section 9.3.2.2 of this report.
20.5.21 $10 \mathrm{CIR}$ 50.34(n)(2)(ix): Conaideration of Degraded or Melted Cores in Safety Review Rulemaling Proceding on Dagraded Core Aceidents (TMI Item II.B.8), "Hydrogen Control Syatem"

Parngraph (2)(ix) of 10 CFR 50.34(f) requires a syctom for bydrogen control that can iafoly eccommodate hydrogen seneratod by the equivalent of a 100-percent, fuel clad motal-water reaction. The hydrogen control system and areociated systoms sball provide with reasonable ascunnce that:

(A) Uniformly distributed hydrogen concentrations in the containment do not exceed 10 percent during and following an accident that releases an equivaleat amount of hydrogen as would be generatod from a 100-percent, fuol clad motal-water reaction, or that the poet-accideat atmosphere will not support hydrogen combustion.

(B) Combustible concentrations of hydrogen will not collect in arews where unintended combustion or dotonation could cause lows of containment intogrity or loss of appropriate mitigating features.

(C) Equipment necossary for achieving and maintaining eafo shutdown of the plant and maintaining containment intogrity will perform its safoty function during and after being exposed to the eavironmental conditions attendant with the release of hydrogen generated by the equivalent of a 100-percent, fuel clad metal-water reaction including the environmental conditions created by activation of the hydrogen control system.

(D) If the method chosen for hydrogen control 18 a postaccident inerting system, inadvertent actuation of the system can be safely accommodated during plent operation.

SSAR Section 6.2.5 discusses the provisions for combustible gas control within the ABWR containment, which include an inerted containment and inclusion of thermal hydrogen recombiners. In Sections 6.2.5 and 19.2.3.3.1 of this report, the staff concludes that these provisions for hydrogen gas control within the ABWR containment, for both design-basis accidents and sovere accidents, are acceptable. 
Criteria (A) and (B) are mot through an inerted containment which ensures that tho post-eccident containment atmoephere will not support hydrogen combustion. Criterion (C) is mot as discussed in Section 19.2.3.3.7 of this report. Critorion (D) is not applicable to the ABWR design, as inerting is accomplished prior to the onset of the sccident. The staff concludes that the ABWR design meots the requirements of 10 CFR 50.34(f)(2)(ix).

\subsubsection{CFR 50.34(O)(2)(x): Reactor Coolant System} Relief and Safety Valves - Testing Requirements (TMI Item II.D.1)

Paragraph $(2)(x)$ of 10 CFR 50.34(f) requires that the licenseo provide a test program and associated model dovelopment and conduct tests to qualify reactor coolant system relief and safoty valves for all fluid conditions expected under operating conditions, transients, and accidents. The staff concludes that GE's approach adequately addresses the requirements of this TMI item for the ABWR design as discussed in Section 3.9.3.2 of this report.

\subsubsection{CFR 50.34(f)(2)(xi): Reactor Coolant System Relief and Safety Valves - Relief and Safety Valve Position Indication (TMI Item II.D.3)}

Paragraph (2)(xi) of 10 CFR 50.34(f) requires that the relief and safety valves for the RCS shall include a positive indication in the control room derived from a reliable valve-position detection device or a reliable indication of flow in the discharge pipe.

The ABWR SRVs are equipped with position sensors that will be qualified as Class 1E components. All SRV positions will be indicated in control room. The ABWR design also includes a backup method using thermocouples. The pipe downstream of the SRV is equipped with thermocouples which signal the annunciator and the plant process computer when the temperature in the tail pipe exceeds the predetermined set point.

The staff has reviewed the design, compared it with the position and clarification contained in NUREG-0737, "Clarification of TMI Action Plan Requirements," and determined that GE's response adequately addresses the requirements of this TMI item for the ABWR design as discussed in Section 5.2.2 of this report.
20.5.24 10 CFR 50.34()(2)(xii): System Design Auxilliary Feedwater System - Auxiliary Feedwater System Automatic Initiation and Fow Indication (TMI It m II.E.1.2)

Paragraph (2)(xii) of 10 CFR 50.34(f) requires the provision of automatic and manual AFWS initiation and the provision of AFWS flow indication in the control room of PWR plants.

This requirement is applicable to PWRs only, since a BWR design does not include an AFWS. Therefore, it is not tochnically rolovant to the ABWR design and does not need to be addressed.

20.5.25 10 CFR 50.34(n)(2)(xiii): System Design Decay Heat Removal - Reliability of Power Supplies for Natural Circulation (TMI Item II.E.3.1)

Paragraph (2)(xiii) of 10 CFR 50.34(f) requires provision of a pressurizer heater power supply and associated motive and control power interfaces for PWR plants that is sufficient to establish and maintain natural circulation in hot standby conditions with only onsite power available.

This requirement is applicable to PWRs only, since \& BWR design does not include a pressurizer. Therefore, it is not technically relevant to the ABWR design and does not need to be addressed.

20.5.26 10 CFR 50.34(n)(2)(xiv): System Design Containment Design - Isolation Dependability (TMI Item II.E.4.2)

Paragraph (2)(xiv) of $10 \mathrm{CFR} 50.34(f)$ requires the provision of containment isolation systems that do the following:

- Ensure all non-essential systems are isolated automatically by the containment isolation signal

- Have two isolation barriers in series for each nonessential penetration, except instrument lines

- Do not result in reopening of the containment isolation valves on resetting of the isolation signal

- Utilize a containment set point pressure for initiating containment isolation as low as is compatible with normal operation 
- Includo automatic closing on a high radiation signal for all systems that provide a path to the environs.

The staff roviewed GE's containment isolation system for compliance with these requirements. The ovaluation results and findings regarding ach requirement are as follow:

- All non-essential systems are isolated automatically by the containment isolation system in accordance with the TMI Item II.E.4.2 requirements.

- As discussed in DFSER Sections 6.2.4 and 6.2.4.1, some penetrations do not have two isolation barriers in series that conform to the containment isolation requiremonts of ODC 56. This was identified in the DFSER as Open Item 20.3-4. (This issue was also identified in the DFSER as Open Item 6.2.4.1-1.) As discussed in Section 6.2.4.1 of this report, GE subsequently provided adequate justification for the alternative containment isolation design that resolved these open items. Therefore, DFSER Open Item 20.3-4 and DFSER Open Item 6.2.4.1-1 are resolved.

- Resetting the containment isolation signal will not result in the automatic reopening of containment isolation valves. The reopening of any containment isolation valve is on a valve-by-valve basis once the isolation signal has cleared and following subsequent logic reset.

- GE has committed to using a high drywell set point pressure of $14 \mathrm{kPag}$ (2 psig) to isolate non-essential penetrations. This is a minimum value and compatible with normal operating conditions. The staff finds a set point value of $14 \mathrm{kPag}$ ( 2 psig) acceptable.

- The containment purge and vent isolation valves isolate on high radiation levels in the reactor building HVAC air exhaust or in the fuel bandling adea HVAC air exhaust. As discussed in SSAR Section 6.2.4.1, the containment purge provision has not been found acceptable for $A B W R$.

Based on the above evaluation, the staff concludes that the ABWR design meets this TMI requirement.

\subsubsection{CFR 50.34(f)(2)(xv): System Design - Containment Design - Purging (TMI Item II.E.4.4)}

Paragraph (2)(xv) of 10 CFR 50.34(f) requires provision of containment venting/purging capability to minimize purging time, consistent with the as-low-as-is-reasonablyachievable (ALARA) principles for occupational exposure.
It also requires ascurance that the purge system will reliably isolato under accident conditions.

SSAR Section 19A.2.27 stated that during normal power operation, all large valves in the containment ventilation lines are closed and that only the 5-cm (2-in.) nitrogen makeup valves are open. These valves are characterized as air-operated valves with fart closure timos which prevent substantial releases from containment should containment isolation be required. GE also stated that the 5-cm (2-in.) nitrogen bleed lines are sufficient to maintain normal containment pressure during normal operation when used in conjunction with containment spray and the drywell cooling system. In the DFSER the staff found that the use of the 5-cm (2-in.) nitrogen bleed lines for normal pressure control is consistent with ALARA considerations and there is high assurance that the purge system will reliably isolate under accident conditions.

SSAR Section 19A.2.27 also stated that the large ventilation valves will be tested not only on a regular basis, but also after any valve maintenance in order to ensure that closing times are within allowable limits. In the DFSER, the staff noted that these tests should include valve T31-F007, that the details of these tests should be submitted by the applicant referencing the ABWR design, and that this should be identified in the SSAR as a COL action item. This was identified in the DFSER as COL Action Item 20.3-2. Subsequently, GE modified SSAR Table 3.9-8, "Inservice Testing of Safety-Related Pumps and Valves", to include both T31-F007 and T31-F010, the isolation valves for the COPS rupture disk. The staff verified that GE established a COL action item to develop the inservice testing program for the components in Table 3.9-8. The test requirements in this table ensure that these valves will be adequately tested. This approach adequately addresses DFSER COL Action Item 20.3-2.

In response to the staff's request for additional information (RAI) dated June 5, 1990, GE stated that the isolation signal to valve T31-F007 would be deleted from SSAR Figure 6.2-39a. As of SSAR Amendment 11, this figure still contained an isolation signal to this valve, the DFSER identified this as Open Item 20.3-5. Subsequently, GE provided SSAR Figure 6.2-39, Sheet 1, which deleted the isolation signal. Therefore, DFSER Open Item 20.3-5 is resolved.

In another response to this RAI, GE agreed to amend the ABWR TS to allow a 24-hour (rather than a 72-hour) window at the beginning and end of a fuel cycle, during which the large diameter $56-\mathrm{cm}$ (22-in.) purge lines can be open in accordance with the STS. This was identified in the DFSER as TS Item 6.2.5-1 and was discussed in Chapter 6 of the DFSER. In addition to proper operaition 
during normal conditions, the staff stated in the DFSER that GE should provide justification that these valves will close during accident conditions. This was identified in the DFSER as Open Item 20.3-6. The staff has confirmed that SSAR Section 6.2 .5 has been modified to clarify that these valves receive close signals during accident conditions. Therefore, DFSER Open Item 20.3-6 is resolved.

Based on the additional clarifying information provided in the SSAR, the staff concludes that the ABWR design meets this TMI requirement.

20.5.28 10 CFR 50.34(f)(2)(xvi): System Design Design Sensitivity of B\&W Reactors - Design Evaluation (TMI Item II.E.5.1)

Paragraph (2)(xiv) of 10 CFR 50.34(f) requires establishment of a design criterion for the allowable number of actuation cycles of the ECCS and RPS of B\&W plant designs consistent with the expected occurrence rates of severe overcooling events, considering both anticipated transients and accidents.

This requirement is applicable to B\&W-designed plants only, therefore, it is not technically relevant to the ABWR design and does not need to be addressed.

\subsubsection{CFR 50.34(f)(2)(xvii): Instrumentation and Controls - Additional Accident Monitoring Instrumentation (TMI Item II.F.1)}

Paragraph (2)(xvii) of 10 CFR 50.34(f) requires provisions for instrumentation to measure, record, and read out in the control room containment pressure, water level, hydrogen concentration, radiation intensity (high level), and noble gas effluent at all potential accident release points. In addition, it requires continuous sampling of radioactive iodines and particulates in gaseous effluent from all potential accident release points, and an onsite capability to analyze and measure samples. Under TMI Item II.F.1, NUREG-0660 restates these requirements with additional guidance and clarification. NUREG-0660 calls for a human factors analysis, which is to include the use of the indicators listed above by the operator during both normal and abnormal plant conditions, integration of these indicators into plant emergency procedures and operator training, the use of other alarms during an emergency, and the need for prioritization of alarms.

In the DFSER, the staff stated that GE's responses to its RAI dated June 5, 1990, were still under review and that cornpletion of this review was DFSER Open Item 20.3-7. SSAR Section 7.5 compares the ABWR design against the criteria of RG 1.97 (R.ev. 3), addressing accident monitoring instrumentation. Section 7.5 lists the variables that are considered essential safety-related information for the operators, and identifies specific exceptions to the guidance of RG 1.97. The capability to monitor the parameters required by the regulation is provided in the control room. Based on its review of SSAR Section 7.5, the staff concludes that the ABWR I\&C design meets RG 1.97 as discussed further in Section 7.5.2 of this report and, therefore, also meets this TMI requirement. Therefore, DFSER Open Item 20.3-7 is resolved.

In the DFSER, the staff also reported that GE stated that the human factors aspects of this requirement were beyond the scope of the ABWR design certification review and the COL applicant will be responsible for addressing them in the detailed design implementation. This was identified in the DFSER as COL Action Item 18.7.2.2-3. The staff verified that GE established a COL action item (Item 18.8.1) in SSAR Section $\mathbf{1 8 . 8}$ for the detailed control room development as defined in ABWR CDM Table 3.1 ITAAC and in SSAR Section 18E. Further, GE established a COL action item (Item 18.8.13) in SSAR Section 18.8 to address II.F.1. This approach adequately addresses DFSER COL Action Item 18.7.2.2-3 as discussed in Section 18.7.2.2 of this report.

\subsubsection{CFR 50.34(f)(2)(xviii): Instrumentation and Controls - Identification of and Recovery from Conditions Leading to Inadequate Core Cooling (TMI Item II.F.2)}

Paragraph (2)(xviii) requires provision of instrumentation or controls (primary or backup) proposed for the plant to supplement existing instrumentation (including primary coolant saturation monitors) in order to provide an unambiguous, easy-to-interpret indication of inadequate core cooling (ICC). It also requires a description of the functional design requirements for the system, a description of the procedures to be used with the proposed equipment, the analysis used in developing these procedures, and a schedule for installing the equipment.

Reactor pressure vessel level is the only issue to be considered with respect to this issue since BWRs operate at saturation pressure and saturation monitors are not required for the $A B W R$. As in operating BWRs, the level instruments for the ABWR RPV are all delta $p$ (dp) instruments. Each instrument uses a reference leg, which is maintained full by a condensing chamber connected directly to the steam space in the RPV, and uses a variable leg which is connected to the RPV water space. All the dp level instruments operate on the same physical principle. Therefore, common-cause failures caused by a design deficiency or maintenance error could result in inaccurate indication of reactor vessel water level. 
The 'staff's concern about common-cause failures is besed on experience with potential common-mode failure mechanisms in the reactor water level instruments. For example, during the past two years, anomalies have been observed in reactor vessel water level indication at several BWRs (Millstono-1, Pilgrim, LaSalle, and Washington Nuclear (WNP-2) during controlled depressurization to commence plant outages. These anomalies consisted of "spiking" or "notching" of level indication, and in one instance, a sustained error in level indication. The effect of noncondensable gas in the condensate chamber and reference leg of the cold-leg type of water level instruments has been determined to be the root cause of these level indication anomalies. Testing has shown that under depressurization conditions, noncondensable gases can cause significant errors in the level indication.

The ABWR design for the reactor vessel water level measurement system has the following features:

(1) The ABWR has temperature-compensated RPV level indication for post-accident monitoring of the RPV.

(2) The vertical drop in the drywell for the ABWR RPV water level reference leg instrument lines from the condensing chamber to the drywell wall has been limited to three feet.

(3) The ABWR uses analog levol transmitters.

(4) The ABWR safety system utilizes two-out-of-four logic for the automatic safety systems initiated on RPV water level.

The staff reviewed the ABWR design for the reactor vessel water level measurement system and found that it meets the requirements specified in GL 84-23, "Reactor Vessel Water Level Instrumentation in BWRs," dated October 26, 1984. To ensure high functional reliability of the instrumentation, the staff issued GL 92-04, "Resolution of the Issues Related to Reactor Vessel Water Level Instrumentation in BWRs Pursuant to 10 CFR 50.54(f)," dated August 19, 1992, and Bulletin 93-03, "Resolution of Issues Related to Reactor Vessel Water Level Instrumentation in BWRs," dated May 28, 1993, requesting hardware modifications for operating reactors. In response to these generic communications, all BWR licensees have committed to implement hardware modifications to their level instrumentation systems. Similar cold-leg instruments are used in the ABWR design.

Before the noncondensible gas level inaccuracies, there were other problems with dp level instrumentation used in BWRs. The staff issued GL 84-23 to address concerns related to high containment temperature during a depressurization event. High containment temperature combined with reector depressurization can lead to false water level readings as a result of flashing or boiling in the reference leg within the containment.

In the DFSER, the staff stated that the design of the ABWR reactor vessel water level measurement system met the requirements specified in GL 84-23. However, the staff required GE to discuss GL 92-04 in the SSAR and include any design changes necessary to preclude the potential for false reactor coolant level readings. The staff also required GE to determine if compliance with this TMI requirement was affected by any design changes. This was identified in the DFSER as Open Item 20.3-8. In response to these generic communications, GE changed the design of the ABWR RPV level instrumentation system. GE incorporated a backfill modification system that will constantly purge the reference leg with a very low flow rate of water supplied by the CRD system. The constant flow of water up the reference leg will prevent dissolved gases from migrating down the reference leg.

The known common-mode deficiencies in BWR level instrumentation systems have been addressed at operating BWRs and by GE in the ABWR design. It should also be noted that these yarticular deficiencies would not have compromised the automatic protective functions of the level instrumentation for accident scenarios initiated while at power, and that no previous incidents at BWRs of inaccurate level indication have been misinterpreted by plant operators so as to lead to unsafe actions. The staff concluded in the advance SER that the ABWR level instrumentation system without the proposed level diversity meets the requirements of 10 CFR Part 50. However, in view of the importance of level instrumentation for safety in BWRs, and the experience discussed above where the potential existed to fail redundant level instruments due to a common cause, the staff believes that the addition of level instrumentation which operates on a diverse physical principle is desirable and prudent for the purpose of guiding operator emergency actions.

GE did not agree with the staff recommendation for diverse water level instrumentation and presented its position in a letter dated October 26, 1993. As part of the letter, GE presented the following summary:

ABWR water level instrumentation is rugged, simple and highly redundant for failure tolerance. All known operating problems have been addressed in this design and it is incredible to postulate simultaneous common-mode failures which would yield identical errors in all the dp instrumentation. 
Alternate technologies are unqualified for this application; further, there is no need to add this complexity, since the plant operating staff has ample additional indications of an impending problem without relying solely on water level. The EPGs direct the operator to use all information available to him and make conservative (safe) decisions.

In the attachment to the letter, GE also provided a list of indications of inadequate RPV water level which are independent of the dp RPV water level instrumentation. The staff recognizes that other parameters could aid the operator in assessing the adequacy of core cooling under accident conditions. These include instrumentation for indication of reactor power, core neutron flux, the recirculation flow control system response, and feedwater flow and steam flow mismatch. However, the staff believes that these indications could be easily misinterpreted or could be insufficient because they are only indirect methods of inferring reactor water level or core cooling.

Other evolutionary designs, such as the ABB-Combustion Engineering, Inc. (ABB-CE) System $80+$, provide diverse methods of RPV level measurement. The inadequate core cooling instrumentation package in the CE System 80+ plant includes reactor vessel level monitoring system probes employing both $\mathrm{dp}$ sensors and the heated junction thermocouple concept. The staff is aware of a diverse method of level monitoring that is currently in use in at least one nuclear power plant in Germany employing ultrasonic measurement techniques. In addition, a diverse level measurement system which uses heated junction thermocouples has been in use for the past 5 years at a Swedish BWR, and another Swedish BWR uses float switches for diverse level indication and automatic systems actuation. Other Swedish BWRs have decided in principle to install diverse level measurement systems.

The staff indicated in the advance SER that the diverse method of level measurement is recommended for indication in the control room only (there is diverse instrumentation, namely high drywell pressure, in both the operating BWRs and the ABWR design which provides diverse signals for automatic safety systems actuation for many event scenarios). This would provide a direct and back-up means for the operator to identify inadequate core cooling and to take appropriate manual actions to initiate and control safety systems as identified in the plant EOPs. The staff also recommended that the diverse level measurement device be reliable, redundant, and capable of being powered by onsite power sources. This was Open Item F20.5.30-1 in the advance SER.

The staff issued the draft Commission paper, "Diversity in the Method of Measuring Reactor Pressure Vessel Lovel in the Advanced Boiling Water Reactor and Simplified Boiling Water Reactor, " on November 15, 1993, for public and industry comments. The ACRS discussed the issue in its 430th meeting on December 9 through 11, 1993, and sent its recommendation to the Commission in a letter dated December 16, 1993. The ACRS did not support the staff recommendation on diversity. Based on ACRS deliberations and GE's position, the staff reconsidered the need for the requirement for instrumentation diversity.

All the known common-mode deficiencies in BWR level instrumentation systems bave been addressed by GE in the ABWR design. It should also be noted that these deficiencies would not have compromised the automatic functions of the level instrumentation for accident scenarios initiated while at power, and that no previous incidents at BWRs of inaccurate level indication have been misinterpreted by plant operators so as to lead to unsafe actions. In addition, for many events, the ECCS is started in the ABWR on high drywell pressure, as well as low reactor water level, thus providing some diversity. The ABWR EPGs will be used to develop the EOP that will be used with the reactor water level instrumentation.

Even though it may be desirable to provide instrumentation diversity in the ABWR design, there is not sufficient basis to postulate an unidentified potential common-mode failure. Further, diverse level measurement devices have not been demonstrated to be adequate. In light of the enhanced LOCA response in the ABWR and the guidance provided in the ABWR EPGs to address the use of the RPV instrumentation, the staff concludes that reactor vessel level instrumentation diversity is not required for the ABWR. On the basis of the above discussion, Open Item F20.5.30-1 (DFSER Open Item 20.3-8) is resolved. Based on the above discussion, the staff also concludes that the ABWR RPV level instrumentation will provide adequate indication of ICC as required by this TMI item.

In the DFSER the staff reported that GE stated that the human factors aspects of this requirement were beyond the scope of the ABWR design certification review and the COL applicant will be responsible for addressing them in the detailed design implementation. This was identified in the DFSER as COL Action Item 18.7.2.2-3. The staff verified that GE establisked a COL action item (Item 18.8.1) in SSAR Section 18.8 for the detailed control room development as defined in ABWR CDM Table 3.1 ITAAC and in SSAR Section 18E. Further, GE established a COL action item (Item 18.8.14) in SSAR 
Section 18.8 to addrese II.F.2. This approech adequately addresecs DFSER COL Action Itom 18.7.2.2-3 as discussed in Section 18.7.2.2 of this report.

\subsubsection{CFR 50.34(7)(2)(xix): Instrumentation and Controls - Instruments for Monitoring Accident Conditions (TMI Item II.F.3)}

Paragraph (2)(xix) of 10 CFR 50.34(f) requires instrumentation adequate for monitoring plant conditions following an accident that includes core damage.

SSAR Section 7.5 compares the ABWR design against the criteria of RG 1.97 (Rev. 3), addressing accident monitoring instrumentation. Section 7.5 lists the variables that are considered essential safety-related information for the operators, and identifies specific exceptions to the guidance of RG 1.97. The list incorporates adequate monitoring capability for post-accident plant conditions that include core damage, including reactor pressure, water lovel and temperature, containment pressure, temperature and radiation level, and shutdown operation status. Based on its reviow of SSAR Section 7.5, the staff concludes that the ABWR I\&C design meets RG 1.97 as discussed further in Section 7.5.2 of this report and, therefore, also meets this TMI requirement.

20.5.32 10 CFR 50.34(f)(2)(xx): Electrical Power Power Supplies for Pressurizer Relief Valves, Block Valves, and Level Indicators (TMI Item II.G.1)

Paragraph (2)(xx) of 10 CFR 50.34(f) requires power supplies for pressurizer relief valves, block valves, and level indicators for PWRs such that the level indicators are powered from vital buses, motive and control power connections to the emergency power sources are thorough devices qualified in accordance with requirements applicable to systems important to safety, and electric power is provided from emergency power sources.

This requirement is applicable to PWRs only, therefore, it is not technically relevant to the ABWR design and does not need to be addressed.

20.5.33 10 CFR 50.34(f)(2)(xxi): Measures to Mitigate Small-Break Loss-of-Coolant Accidents and Loss-of-Feedwater Accidents - IE Bulletins Describe Automatic and Manual Actions for Proper Functioning of Auxiliary Heat Removal Systems When Feedwater System Not Operable (TMI Item Issue II.K.1.(22))

Paragraph (2)(xxi) of 10 CFR 50.34(f) requires design of auxiliary heat removal systems such that necessary automatic and manual actions can be taken to ensure proper functioning when the main feedwater system is not operable.

SSAR Section 7.7.1.4(9) states that if the ABWR main feedwater system is not operating, the reactor will be tripped automatically when reactor water lovel falls to reactor vessel level 3. The operator can manually initiate the RCIC system from the main control room or, if the operator takes no ection, reactor water lovel will continue to decrease as the steam boils off until the low-low level eot point (level 2) is reached. At low-low level, the RCIC system is automatically initiated to supply makeup water to the reactor pressure vessel. If level 1.5 is reached, both HPCF pumps will start automatically. These systoms will continue automatic injection until the reactor water level reaches level 8, at which time the HPCF and RCIC systems are trippod. The HPCF will restart automatically once the high-level trip signal clears and the level 1.5 signal is received. The RCIC will automatically start after a level 8 trip and a level 2 signal.

If the vessel is isolated, reactor vessel pressure is regulated by automatic or remote manual operation of the main steam relief valves, which exhaust to the suppression pool. In this case, the automatic suppression pool cooling mode of the RHR system will transfer heat to the ultimate heat sink.

The HPCF system will automatically provide the required makeup flow for the accident situations with the reactor vessel at high pressure. No manual operations are required since the HPCF system will cycle on and off automatically as water level reaches vessel level 1.5 and level 8, respectively. If the HPCF system fails under these conditions, the operator can manually depressurize the reactor vessel using the ADS to permit the low-pressure emergency core cooling systems to provide makeup coolant. The RCS will automatically be depressurized if all of the following signals are present: high drywell pressure, level 1 water level, and pressure in at least one low-preseure injection system or one HPCF system. If the low level persists in the RPV, the ADS will also activate without drywell high pressure after a delay of about 8 minutes.

The ABWR design incorporates appropriate automatic and munual action capability to ensure proper heat removal when the main feedwater system is not operable. Therefore, the staff concludes that GE has adequately addressed the requirements of this TMI item for the ABWR design. 
20.5.34 10 CFR 50.34(f)(2)(xxii): Measures to Mitigate Small-Break Loss-of-Coolant Accidents and Loss-of-Feedwater Accidents - Commission Orders on B\&W Plants - Analysis and Upgrading of Integrated Control System (TMI Item II.K.2(9))

Paragraph (2)(xxii) of 10 CFR 50.34(f) requires performance of a failure modes and effects analysis of the integrated control system (ICS) of B\&W-designed plants to include consideration of failures and effects of input and output signals to the ICS.

This requirement is applicable to B\&W-designed plants only, therefore, it is not technically relevant to the ABWR design and does not need to be addressed.

\subsubsection{CFR 50.34(f)(2)(xxiii): Measures to Mitigate Small-Break Loss-of-Coolant Accidents and Loss-of-Feedwater Accidents - Commission Orders on B\&W Plants - Hard- Wired Safety-Grade Anticipatory Reactor Trips (TMI Item II.K.2(10))}

Paragraph (2)(xxiii) of $10 \mathrm{CFR} 50.34(f)$ requires provision, as part of the RPS of B\&W-designed plants, an anticipatory reactor trip that would be actuated on loss of main feedwater and on turbine trip.

This requirement is applicable to $B \& W$-designed plants only, therefore, it is not technically relevant to the ABWR design and does not need to be addressed.

\subsubsection{CFR 50.34(f)(2)(xxiv): Measures to Mitigate} Small-Break Loss-of-Coolant Accidents and Loss-of-Feedwater Accidents -- Final Recommendations of Bulletins and Orders Task Force - Central Water Level Recording (TMI Item II.K.3(23))

Paragraph (2)(xxiv) of 10 CFR 50.34(f) requires the capability to record reactor vessel water level in one location on recorders that meet normal post-accident recording requirements for BWRs.

SSAR Section 7.5.8 states that the reactor vessel water level wide range instruments and fuel zone instruments are utilized to provide post-accident monitoring indication. The four divisions of wide range level instruments cover the zone from above the core to the main steam lines. The two channels of fuel zope instruments cover the range from below the core to the top of the steam separator shroud.
The SSAR also states that in the event that the vessel water level is below the range of the wide range level sensor and the two channels of fuel zone level instrumentation disagree, the EOPs instruct the operator to use the lower level indicated in the two channels and to return the water level to the range of the wide range level instrumentation. GE adds that by using the four divisions of wide range level instruments, an unambiguous indication of vessel water level can be determined despite a postulated failure of a single instrument channel or division, thereby permitting the operator to implement the EOPs.

The staff concludes that GE's approach acceptably meets the requirements of this TMI item regarding post-accident reactor vessel water level recording for the ABWR design.

\subsubsection{CFR 50.34(f)(2)(xxv): Emergency} Preparedness and Radiation Effects -- Improve Licensee Emergency Preparedness - Short Term; Upgrade Emergency Preparedness (TMI Item III.A.1.2)

Paragraph (2)(xxv) of $10 \mathrm{CFR} 50.34(f)$ requires the provision of an onsite Technical Support Center (TSC), an Operational Support Center (OSC), and a nearsite Emergency Operations Facility (EOF).

GE's proposal is discussed and evaluated in Section 13.3 of this report. The staff verified that GE established a COL action item in SSAR Section 19A.3.4 to detail a TSC and an OSC in the ABWR service building. This SSAR section also states that the COL applicant has an interface requirement to provide a near site emergency operational facility. On the basis of the staff's evaluation in Section 13.3 of this report and GE's establishment of the COL action item, the staff concludes that GE has adequately addressed the requirements of this TMI item for the ABWR design.

20.5.38 10 CFR 50.34(f)(2)(xxvi): Radiation Protection - Radiation Source Control - Primary Coolant Sources Outside the Containment Structure (TMI Item III.D.1.1)

Paragraph (2)(xxvi) of 10 CFR 50.34(f) requires provision of leakage control and detection in the design of systems outside containment that contain (or might contain) TID-14844 source term radioactive materials following an accident. Applicants are required to submit a leakage control program, including an initial test program, a schedule for retesting these systems, and the actions to be taken for minimizing leakage from such systems. The goal is to minimize potential exposures to workers and the public and to provide reasonable assurance that excessive 
leakage will not prevent the use of systems needed in an emergency.

The advance SER stated that the staff reviewed SSAR Section 1A.2.34, as well as GE's response (soo page 20.3.15-22 of the SSAR) to staff Question 430.227 relating to this TMI item. It also stated that these references identify the applicable systems and the leak reduction measures for the ABWR design. Based on its review, the staff found in the advance SER that the leakage control program for the systems outside the containment for the ABWR design would include periodic leak testing and leak reduction measures for eight listed systems. GE revised and expanded the list of systems in Section 1A.2.34 to include the following: (1) RHR, (2) HPCF, (3) low pressure core flooder, (4) RCIC, (5) suppression pool cleanup, (6) reactor water cleanup, (7) fuel pool cooling and cleanup, (8) post-accident sampling, (9) process sampling, (10) containment atmospheric monitoring, (11) fission product monitor (part of leakage detection system), (12) hydrogen recombiner, and (13) standby gas treatment.

In the advance SER, the staff also found that the COL applicant will be required to develop plant procedures that will prescribe the leak testing methods for the above systems and schedule maintenance programs to monitor leakages and reduce detected leakages to lowest practical levels. GE stated that the leak tests will be conducted periodically at each refueling outage. Furthermore, the staff found that GE identified Item 5.5.2.2 in the administrative controls section of the ABWR TS, which calls for the COL applicant to establish a leakage control program for the subject systems. The TS item further stipulates that the program include preventive maintenance and periodic visual inspection requirements and integrated leak test requirements for each system at refueling cycle intervals or less.

Based on the above, the staff concludes that the ABWR design adequately addresses the requirements of this TMI item for the ABWR design.

The staff will review and evaluate the individual leakage control programs, including the initial test programs, of the COL applicant on a plant-specific basis.

\subsubsection{CFR50.34(f)(2)(xxvii): Radiation Protection - Worker Radiation Protection Improvement - Inplant Radiation Monitoring (TMI Item III.D.3.3)}

Paragraph (2)(xxvii) of $10 \mathrm{CFR} 50.34(f)$ requires provisions for monitoring of inplant radiation and airborne redioectivity as appropriate for a broad range of routine and accident conditions.

GE's response adequately addresses the requirements of this TMI item for the ABWR design as discussed further in Section 12.5.1 of this report.

\subsubsection{CFR 50.34(f)(2)(xxviii): Radiation Protection - Worker Radiation Protection Improvement - Control Room Habitability (TMI Item III.D.3.4)}

Paragraph (2)(xxviii) of 10 CFR 50.34(f) requires an evaluation of the potential pathways for radioactivity and radiation that may lead to control room habitability problems under accident conditions resulting in a TID-14844 source term release, and to make necessary design provisions to preclude such problems.

The staff's review of control room habitability is provided in Section 6.4 of this report. The staff concludes that the ABWR control room design provides an acceptable means of maintaining the control oom in a safe and habitable condition by providing adequate protection under accident conditions in accordance with the requirements of this TMI item.

20.5.41 10 CFR 50.34(f)(3)(i): Operating Procedures Procedures for Feedback of Operating Experience to Plant Staff (TMI Item I.C.5)

Paragraph (3)(i) of $10 \mathrm{CFR} 50.34(f)$ requires the provisions for administrative procedures for evaluating operating, design, and construction experience and for ensuring that applicable important industry experiences will be provided in a timely manner to those designing and constructing the plant.

The development of detailed procedures is beyond the scope of the ABWR design certification review and the COL applicant will be responsible for addressing this TMI item. The staff verified that GE established a COL action item in SSAR Section 13.5.3 for procedure development and a COL action item in SSAR Section 13.2 regarding the incorporation of operating experience into training programs. Additionally, SSAR Section 13.5.3.1 states that the methods and criteria for the development, V\&V, implementation, maintenance, and revision of procedures will include considerations of I.C.5. This approach is acceptable to the staff as discussed in Sections 13.5 and 13.2 of this report. 


\subsubsection{CFR 50.34(1)(3)(ii): Quality Assurance (QA) - Expand QA List (TMI Item I.F.1)}

NUREG-0660 states that several systems important to safety of the TMI plant were not designed, fabricated, and maintained at a level equivalent to their safety importance. In accordance with the requirements of Criterion 1 of Appendix A to 10 CFR Part 50 and the guidance provided in SRP Section 17.3, "Quality Assurance Program Description," applicants are to include these types of nonsafety-related items within the scope 'of their QA programs. This requirement was incorporated into Paragraph (3)(ii) of 10 CFR 50.34(f).

SSAR Table 3.2-1, "Classification Summary," identifies safety-related and non-safety-related items of the ABWR. Note " $e$ " in the table and SSAR Section 3.1.2.1.1.2 state

the total QA program described in SSAR Chapter 17 is applied to the safety-related items

(2) the non-safety-related items are controlled by the QA program described in SSAR Chapter 17 in accordance with the functional importance of the item

The staff concludes that GE's approach adequately addresses the requirements of this TMI item for the ABWR design.

20.5.43 10 CFR 50.34(f)(3)(iii): Quality Assurance Develop More Detailed QA Criteria (TMI Item I.F.2)

Paragraph (3)(iii) of $10 \mathrm{CFR} 50.34(f)$ requires the establishment of a quality assurance program. NUREG-0660, Item I.F. 2 lists 11 considerations that the NRC should use to develop additional guidance to clarify requirements for the $\mathrm{QA}$. function. These considerations resulted in Revision 2 of SRP Section 17.1, "Quality Assurance During the Design and Construction Phases, " in July 1981 .

SSAR Chapter 17 references NEDO-11209, "Nuclear Energy Business Operation Quality Assurance Program Description," Revision 7 dated May 1987. The staff reviewed this report against the acceptance criteria of Revision 2 of SRP Section 17.1 and found it to be acceptable. The staff concludes that GE's approach adequately addresses the requirements of this TMI item for the ABWR design.
20.5.44 10 CFR 50.34(f)(3)(iv): Consideration of Degraded or Melted Cores in Safety Review Rulemaking Proceeding on Degraded Core Accidents (TMI Item I.B.8), ".91-Meter (3-Foot) Diameter Equivalent Dedicated Containment Penetration"

Paragraph (3)(iv) of 10 CFR 50.34(f) requires one or more dedicated containment penetrations, equivalent in size to a single .91-m (3-ft) diameter opening, in order not to preclude future installation of systems to prevent containment failure, such as a filtered vented containment system. This requirement is intended to ensure provision of a containment vent design feature with sufficient safety margin well ahead of a need that may be perceived in the future to mitigate the consequences of a severe accident situation. The staff's evaluation of ABWR compliance with the requirement is limited to the effective penetration size for venting provided in the ABWR primary containment design.

In the DFSER, the staff found that the size of the primary containment penetration that could be used during a severe accident situation for venting the containment was smaller than the specific size identified in the TMI requirement. The staff required GE to submit a request for exemption from the requirement and supporting justification. The justification was expected to demonstrate that the penetration size was adequate to permit a vent relief path that is capable of providing the needed overpressure relief for the primary containment to prevent its uncontrolled failure during any credible severe accident situation. This was identified in the DFSER as Open Item 20.3-9.

SSAR Section 19A.2.44 states that the COPS precludes the need for a dedicated penetration equivalent in size to a single .91-m (3-ft) diameter opening. The COPS is part of the atmospheric control system and is discussed in SSAR Section 6.2.5.6. The COPS consists of two $200-\mathrm{mm}$ (8-in.) diameter rupture disks mounted in series in a 250 -mm (10-in.) line and is sized to allow $35 \mathrm{~kg} / \mathrm{sec}$ $(15.86 \mathrm{lbm} / \mathrm{sec})$ of steam flow at the opening pressure of $6.3 \mathrm{~kg} / \mathrm{cm}^{2} \mathrm{~g}$ (90 psig), which corresponds to an energy flow of about 2.4 percent of rated power. The SSAR states that the COPS is capable of keeping containment pressures below ASME Service Level C limits for an ATWS event with failure of the SLCS and containment heat removal systems. 
In Section 19.2.3.3.4 of this report, the staff concludes that the COPS design is acceptable. Although the diameter of the COPS pathway is only $200 \mathrm{~mm}(8 \mathrm{in}$.), the staff determined that this exception from the requirement of a .91-m (3-ft) diameter opening is acceptable since: (1) the limiting diameter of the COPS pathway is adequate to permit the needed vent relief path, and (2) a need for venting capability beyond that provided by the COPS has not been identified. This resolved DFSER Open Item 20.3-9. The staff concludes that GE's approach adequately addresses the requirements of this TMI item for the ABWR design. An exemption in accordance with 10 CFR 50.12(a)(2)(ii) is justified since the COPS provides sufficient venting capability to preclude the need for a

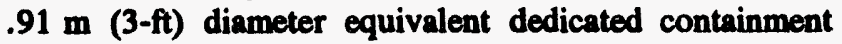
penetration. This exemption is in order based on the staff's conclusion that the underlying purpose of the regulation has been met.

20.5.45 10 CFR 50.34(f)(3)(v): Consideration of Degraded or Melted Cores in Safety Review Rulemaking Proceeding on Degraded Core Accidents (TMI Item II.B.8), "Containment Integrity During an Accident Involving 100-Percent, Fuel Clad Metal-Water Reaction"

Paragraph (3)(v) of 10 CFR 50.34(f) requires design information to demonstrate that:

(1) Containment integrity will be maintained during an accident that releases hydrogen generated from a 100-percent, fuel clad metal-water reaction accompanied by either hydrogen burning or the added pressure from post-accident inerting, assuming carbon dioxide is the inerting agent. Systems necessary to ensure containment integrity shall also be demonstrated to perform their function under these conditions.

(2) Containment structure loadings produced by an inadvertent full actuation of a post-accident inerting hydrogen control system, but not including seismic or design-basis accident loadings will not produce stresses in steel containments in excess of the limits set forth in the ASME Code.

SSAR Section 19E.2.3.2 provides an evaluation of the capability of the containment to withstand pressurization from a 100-percent, fuel clad metal-water reaction. The staff finds the evaluation acceptable in Section 19.2.3.3.1 of this report. The staff evaluation of GE's assessment of systems necessary to ensure containment integrity under these conditions is provided in Section 19.2.3.3.7 of this report. Criterion (2) is not applicable to the ABWR design, as inerting is accomplished prior to the onset of the accident. On this basis, the staff concludes that GE's approach adequately addresses the requirements of this TMI item for the ABWR design.

\subsubsection{CFR 50.34(f)(3)(vi): System Design - Containment Design - Dedicated Penetrations (TMI Item II.E.4.1)}

Paragraph (3)(vi) of 10 CFR 50.34(f) requires redundant, dedicated containment penetrations for plant designs with external hydrogen recombiners so that, assuming a single active failure, the recombiner systems can be connected to the containment atmosphere.

SSAR Section 1A.2.13 states that the flammability control system (FCS) uses two permanently installed recombiners located in secondary containment which ensure that the FCS remains operable assuming a single active failure. In the DFSER, the staff noted that the FCS was not described in SSAR Section 6.2.5 and that GE had not demonstrated that redundant dedicated containment penetrations existed for the hydrogen recombiners. The staff required GE to provide

- information to clearly demonstrate that the permanently installed hydrogen recombiners have redundant, dedicated containment penetrations and that the penetrations meet all applicable design requirements. This information was to include

- how long after a LOCA and at what hydrogen concentration the recombiners are to be utilized

- line sizes as related to flow requirements

- duration of recombiner operation

- interface requirements for referencing applicants with regard to the recombiners

- clearer copy of SSAR Figure 6.2-40, "Flammability Control System."

This was identified in the DFSER as Open Item 20.3-10. GE provided a new, clearer copy of Figure $6.2-40$ and modified SSAR Section 6.2.5 to clarify FCS operation. Based on this additional information, the staff concludes that the FCS can adequately accommodate the effects of hydrogen and mitigate the consequences of hydrogen generated as a result of a LOCA, assuming a single active component failure. Therefore, Open Item 20.3-10 is resolved. The staff concludes that the ABWR design meets the requirements of this TMI item. 


\subsubsection{CFR 50.34()(3)(vii): General Implications of TMI for Design and Construction Activities - Management for Deaign and Construction - Organization and Stafing to Oversee Design and Construction (TMI Item II.J.3.1)}

Paragraph (3)(vii) of 10 CFR 50.34(f) requires provision of a description of the management plan for design and construction activities that includes:

- the organizational and management structure singularly responsible for direction of dosign and construction of the proposed plant .

- technical resources directed by the applicant

- details of the interaction of design and construction within the applicant's organization and the manner by Which the applicant will ensure close integration of the architect engineer and the nuclear steam supply vendor

- proposed procedures for handling the transition to operation

- the degree of top-level management oversight and technical control to be exercised by the applicant during design and construction, including the preparation and implementation of procedures necessary to guide the effort.

The development of the management plan for organization and staffing to oversee design and construction is beyond the scope of the ABWR design cirtification review and the $\mathrm{COL}$ applicant will be responsible for addressing it. The staff verified that GE established a COL action item in SSAR Section 19A.3.7 to develop the necessary management plan. This approach is acceptable to the staff.

\subsection{Generic Communications}

As part of its program to disseminate information on operating experience to the industry, the NRC issues generic communications when a significant safety-related event or condition at one facility is believed to potentially apply to other facilities. Using the basic criteria of safety significance and generic implications, many safety issues have been highlighted in generic communications. These generic communications encompass and address both staff positions (in the form of bulletins and most generic letters) and information alerts (in the form of information notices, circulars, and some generic letters). Potential concerns addressed initially by these generic communications may be subsequently revised or amplified. The resolution of these concerns may be incorporated into formal regulatory requirements, such as rules in $10 \mathrm{CFR}$, or an analysis of such $\bullet$ concern may result in it becoming a USI or GSI.

The staff roviewed the ABWR design for incorporation of important lessons leamed from operating experience using NRC bulletins and generic letters. These two classes of documents are used to communicate staff positions on issues potentially affecting operating facilities, thereby ensuring consideration of those issues judged to have significant public health and safety implications. The issues covered by bulletins and generic letters originate in a number of ways, including the staff's systematic review of operating experience. In the context of the NRC program to review and incorporate operating experience, bulletins and generic letters convey the most safetysignificant lessons distilled from numerous sources of information. As a contrast, another product of that program, information notices, do not contain any requests for action on the part of licensees. Thus, bulletins and generic letters comprise a sufficient basis for reviewing the ABWR design against operating experience.

In SSAR Section 1.8, GE identifies the experience information that has been or will be included in the design of the ABWR. Experience information is routinely made available and distributed to design personnel. In addition, as a focused effort for the ABWR design activities, GE management surveyed a listing of all regulatory reports in its possession that contain operating experience information. If $\mathrm{GE}$ determined a report did not apply to the ABWR, the report was set aside. Each of the remaining reports on the list of potentially applicable experiences was then reviewed individually to determine tochnical applicability. As a result of this effort, GE prepared a listing of applicable regulatory documents (that is, information notices, generic letters, bulletins, and NUREGs) issued in 1980 or later. Some documents that addressed resolutions of concerns were not included on the resulting summary list to avoid repetition. In addition to these regulatory documents which are publicly available, GE has a collection of in-house proprietary documents that it has prepared over the years as part of its continual and ongoing assistance to various BWR licensees. GE also considered pertinent information from these experience reports.

Although the SRP provides acceptance criteria (some of which are based upon operating reactor experience) for review of a reactor facility design, this document was last revised in 1981. Therefore, potential concerns addressed in generic communications issued subsequent to the issue period of the SRP must be addressed. To ensure the staff's operating experience review is comprehensive, operating experience documents issued in 1980 and later were considered by the staff for applicability to the ABWR 
design. Becrues the roview of operating experience should include those items that are believed to have the highest safety significance, the staff limited its augmented reviow to those documents that rose to the status of a bulletin or a generic letter with a staff position or a request for licensece action. The last bulletin and generic letter considered in the roviow were NRC Bulletin 91-01 (original issuance) and GL 91-17, respectively. This consists of approximately $\mathbf{4 5 0}$ documents. Approximately 220 of these documents were excluded because they were not pertinent to the design reviow of the ABWR. The remaining list of 230 documents was augmented by any additional bulletins and generic letters GE thought applicable. About 160 on the combined listing were related to GSIs, USIs, TMI item implementation, or an NRC regulation. Operating experience concerns related to these issues are required to be explicitly addressed by GE and acceptability of the ABWR design with respect to these concerns is discussed in appropriate sections of this report. Thus, the staff excluded the disposition of these concerns from the task of ensuring and addressing how operating experience was considered in the ABWR design.
The remaining 71 applicable documents identify undesirable situations that have occurred and should be avoided and that could affect ABWR issues related to either equipment design, analytical methods, construction, operation or maintenance activitios, or major programmatic activities. The staff reviewed these documents to determine if additional action is necessary to ensure that this experience has been reflected in the ABWR design and properly resolved. Of the 71 documents considered by the staff, 31 addressed issues that are being resolved during the ongoing preparation of TS or during future equipment procurement process, and 27 had been superseded by technical developments after the document was issued. The remaining 13 documents raised questions that were considered by the staff in their overall evaluation process of the ABWR design.

Based on the above, the staff concludes that GE has adequately considered operating experience identified by generic letters or bulletins issued since 1980 in the ABWR design. 


\section{REPORT OF THE ADVSORY COMMITTEE ON REACTOR SAFEGUARDS}

The edvanced boiling water reactor (ABWR) Subcommittee of the Advieory Committee on Reactor Saferuards (ACRS) conducted a reviow of GE Nuclear Energy's (OE's) application for deaign cettification, which began in February 1988 and was completed in April 1994. Tho Subcommitteo conducted a limited reviow of OB's certified deaign material (CDM) and a complote roviow of the various drat vercions of the etaff's affety ovaluation reports on the ABWR atandard deaign. The ACRS conducted its final moeting on the ABWR during its 408th meoting on April 7 and 8, 1994, and subsequently isened its letter regarding the ABWR on April 14, 1994. This letter, which follows this discuseion, roflects approval of the epplication and includes no recommended actions by either the ataff or the applicant. During the full committee meeting held on
March 10 through 12, 1994, the Chairman of the ABWR Subcommitteo indicated that GE had provided him with in axtensive set of draft revisions and markups to the standard arfety analyair report (SSAR) and CDM in response to ACRS concern, which were found to bo scceptable but had not yet been incorporated into en SSAR amendment or final CDM aubmittal. The staff agreed to reviow OE's SSAR Ameadmeat 34 and the aseociated CDM revision to casure that the proposed revisions were included in GE's aubmittals. Accordingly, a roviow of Amendments 34 and 35, and the associated CDM was conducted and the staff determined that GE has adequately included the technical and editorial changes in its application for design certification in response to the previous ABWR Subcommittee concerns. 


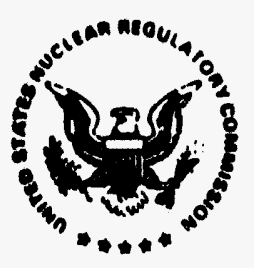

\author{
UNITEO STATES \\ NUCLEAR REGULATORY COMMISSION \\ ADVISORY COMMITTEE ON REACTOR SAFEGUARDS \\ WABHINOTON, D. C. 20885
}

April 14, 1994

The Honorable Ivan Selin

Chairman

U.S. Nuclear Regulatory Commission

Washington, D.C. 20555

Dear Chairman Selin:

SUBJECT: REPORT ON SAFETY ASPECTS OF THE GENERAL ELECTRIC NUCLEAR ENERGY APPLICATION FOR CERTIFICATION OF THE ADVANCED BOILING WATFR REACTOR DESIGN

During the 408 th meeting of the Advisory Committee on Reactor Safeguards, April 7-8, 1994, we completed our review of the General Electric Nuclear Energy (GENE) application for certification of 1ts U.S. version of the Advanced Boiling Water Reactor (ABWR) standard design. This final report is intended to fulfill the requirement of 10 CFR 52.53 that the ACRS "... report on those portions of the application which concern safety." During our review we had the benefit of discussions with representatives of GENE and the NRC staff. We also had the benefit of the documents referenced.

\title{
AHKR Application
}

The U.S. version of the ABWR standard design utilizes a significant portion of the detailed design information developed jointly by GENE, Hitachi, and Toshiba for the international version which is being built in Japan. The application for certification of the U.S. version was filed by GENE in september 1987 under the provisions of Appendix 0 to 10 CFR Part 50 and the NRC Policy statement on Nuclear Power plant Standardization (Ref. 1). The application was docketed in February 1988. In December 1991, GENE requested that the application be considered under 10 CFR 52.45. This request was made effective in March 1992.

The application is based on the ABWR Standard Safety Analysis Report (SSAR), which was submitted in modular form between September 1987 and March 1989. Since then it has been amended frequently, the last submittal for our review was Amendment 34 in March 1994. The application also includes the ABWR Certif: :d Design Material (CDM). The CDM contains the design information from the SSAR that will become a part of the design certificaition rule. The CDM has been revised, the last submittal that we received was Rev. 2 in December 1993. 


\section{ABWR Desian Description}

The ABWR is a forced circulation bolling water reactor with a rated power of $3926 \mathrm{MWt}$. The reactor core consists of $8728 \times 8$ fuel assemblies and 205 control rods. The reactor utilizes internal recirculation pumps and fine-motion control rod drives. It is located inside a steel-1ined reinforced concrete pressure suppression containment which is enclosed by a reinforced concrete secondary containment, both of which are located in the Reactor Building. The Reactor Bullding also houses a standby gas treatment system, refueling area, main steam pipe tunnel, and essential systems for emergency core cooling, AC power (including diesel generators), and environmental conditioning.

The Control Building is located between the Reactor Building and the Turbine Building. The Control Building houses a continuation of the main steam pipe tunnel, the main control room, a computer facility, and essential systems for DC power, environmental conditioning, and cooling water. During emergencies, technical support is provided by the Technical support and operational support centers, which are located in the service Building, which is immediately adjacent to the control Building.

The Turbine Building houses equipment for power generation. steam is supplied to an $1800 \mathrm{rpm}$ turbine-generator which 18 oriented to minimize damage to safety-related equipment should a turbine failure occur. The Turbine Building also houses systems and equipment that provide various nonessential services for the plant. These include the standby combustion-gas-turbine generator, house boiler, air compressors, and systems for AC and DC power and environmental conditioning.

The Radwaste Building houses equipment for the collection and processing of radioactive waste generated by the plant. An underground pipe tunnel connects the Turbine and Reactor Builaings to the Radwaste Building.

The ABWR design includes a number of features that we believe will enhance safety relative to past BWR designs. Some of these features resulted from the use of PRA methodology by GENE in evaluating the ABWR design as it progressed.

- The use of reactor internal pumps removes the large reactor recirculation piping and connections to the reactor vessel, thereby reducing the size of the largest loss-of-coolant accident (LOCA).

- The use of a fine-motion control rod drive arrangement removes the scrai discharge volume and associated piping, provides two reliable means for inserting the rods, and is intended to eliminate the rod drop and rod ejection accidents. 
The Honorable Ivan Selin $3 \quad$ April 14, 1994

- The Emergency Core Cooling system and supporting auxiliaries are arranged into three physically separated electrical and mechanical divisions, only one of which is needed for handing transients and virtually all accidents.

- A combustion-gas-turbine generator 1s provided for enhanced on-site AC power capability.

- An AC-independent reactor water addition feature, a depressurization system, lower drywell flooder, cavity floor spreading area, sacrificial layer of basaltic concrete, and containment overpressure protection system are provided to mitigate severe accidents.

- The greatly increased application of digital control systems offers the potential for improved operator interface with the plant and the reliability of control and protection systems. In addition, the use of digital multiplexers and fiber optics reduces the amount of cabling in the plant thereby reducing the fire hazard.

- The reactor vessel is fabricated using ring forgings that eliminate the need for beltline longitudinal welds. This, in combination with improved material specifications, reduces concern for reactor vessel integrity.

\section{Chronology of ACRS Review}

Our review of the ABWR application commenced after it was docketed in February 1988. The NRC staff issued a Draft Safety Evaluation Report (DSER) on the first module of the SSAR in August 1989 (Ref. 2). We reviewed this draft and reported our findings in November (Ref. 3). At that time we questioned, in particular, the adequacy of the level of design detail available for review and recommended that the staff revisit the issue of what constitutes an "essentially complete" design.

Subsequent to November 1989, our review activities focused on several ABWR-related design concerns including control Building flooding, physical separation, environmental protection of sensitive equipment, performance of essential chilled water systems, use of leak-before-break methodology, use of integral low-pressure turbine rotors, and the capability of the floor area beneath the reactor vessel to cope with severe accidents. These preliminary concerns were brought to the attention of the NRC staff in our July 1991 report (Ref. 4).

During 1991 the DSER was completed by the NRC staff in the form of siX SECY papers (SECY-91-153, 235, 294, 309, 320, and 355). These papers generally covered most sections of the SSAR through the first eighteen amendments, but contained numerous open items. We 

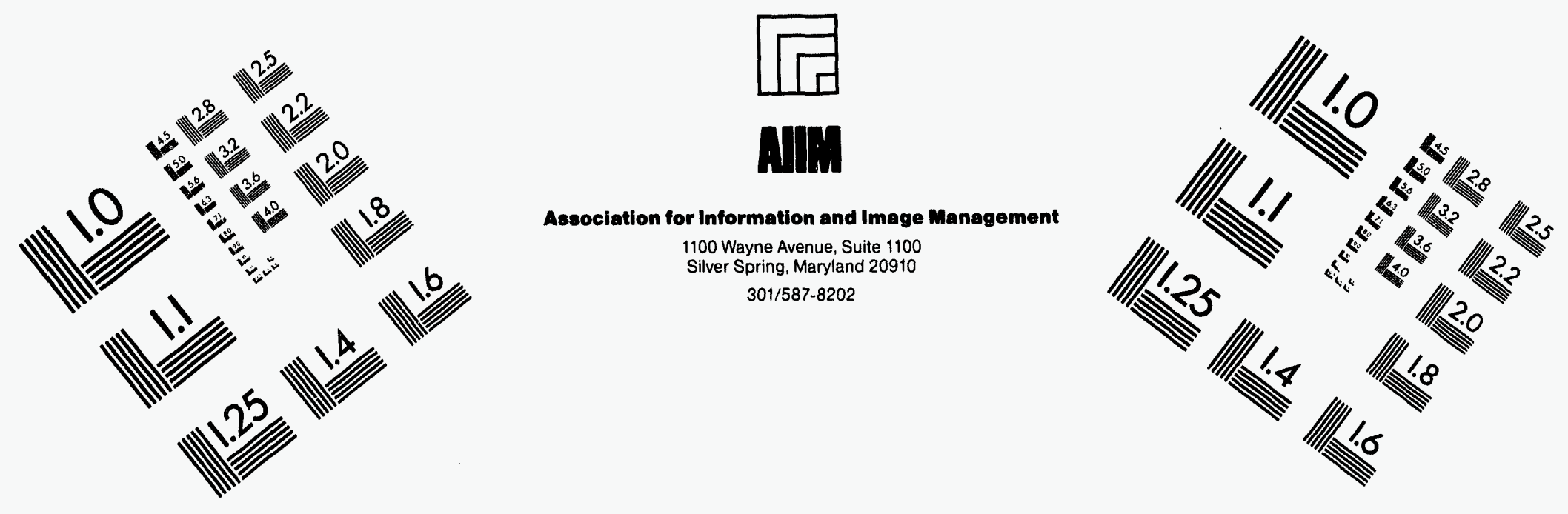

\section{Centimeter}

|

Inches
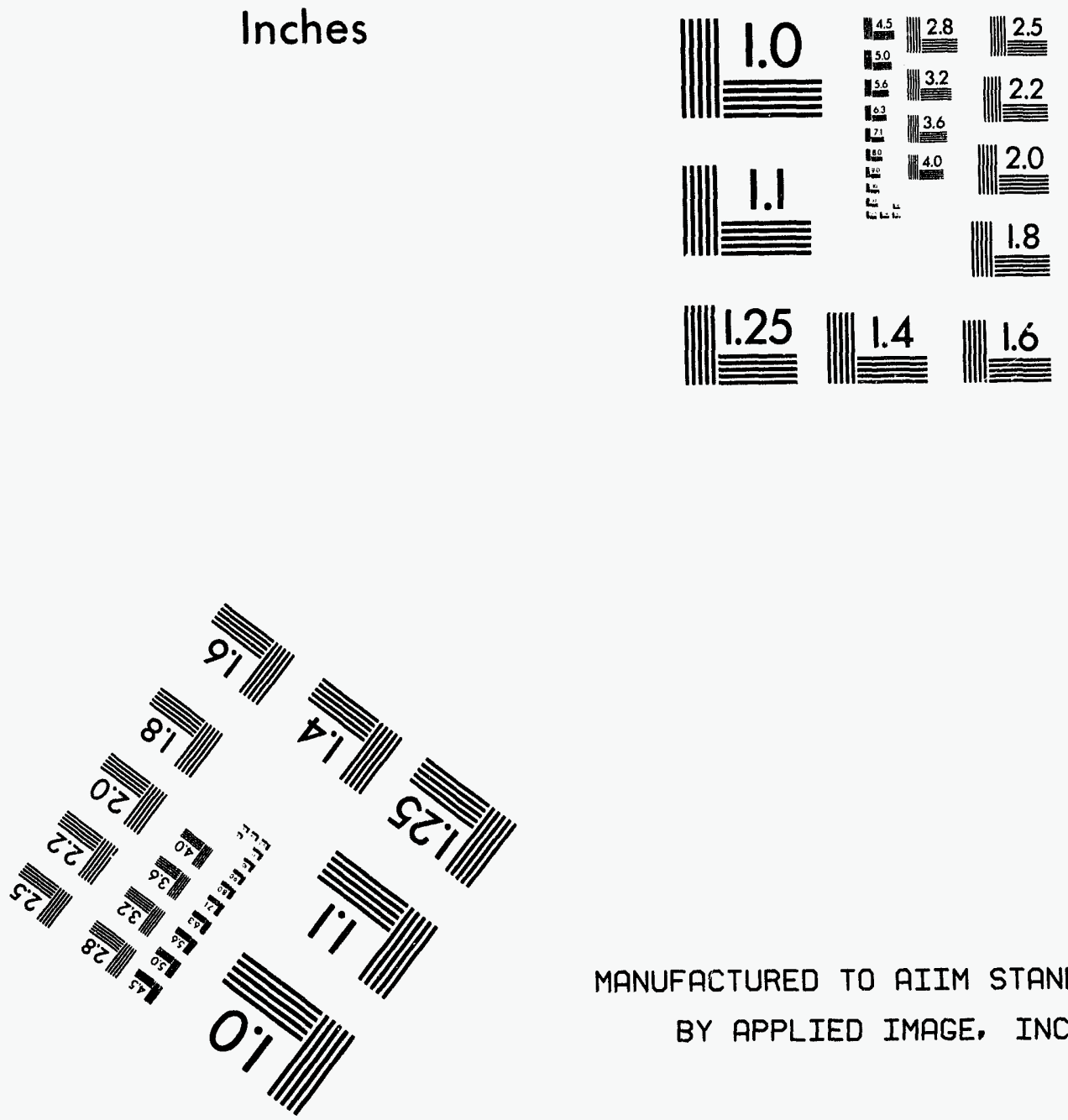

MANUFACTURED TO AIIM STANDARDS

BY APPLIED IMAGE, INC.

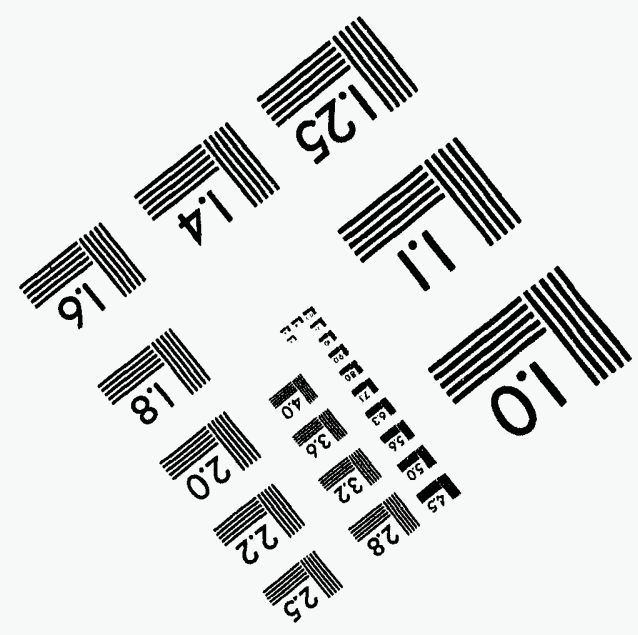



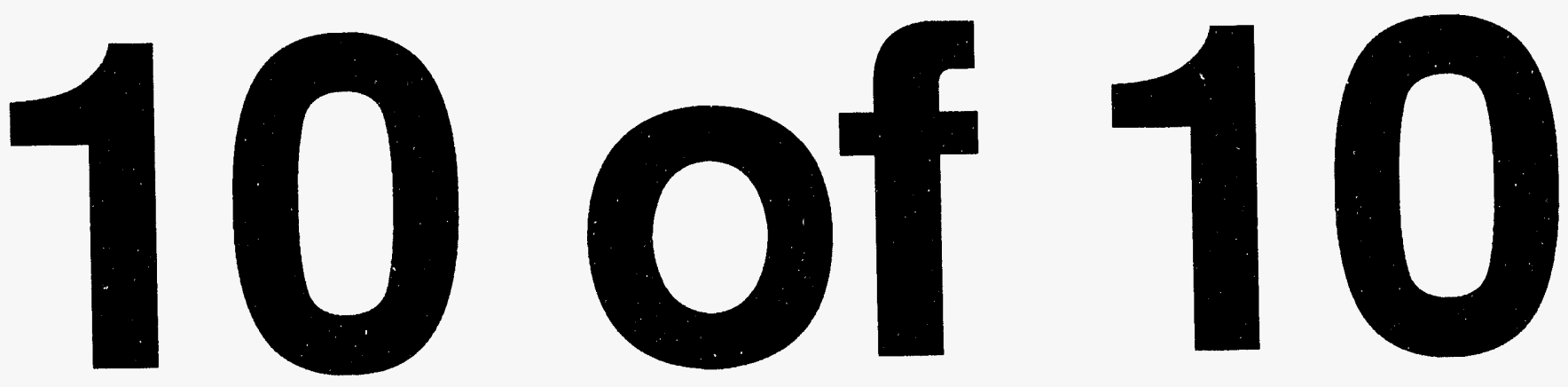
reported our findings in April 1992 (Ref. 5). In this report, we reconfirmed the preliminary concerns expressed in our July 1991 report and added several more including adequacy of the PRA, containment hydrodynamic loads, Reactor Water Cleanup System safety implications, plant design life and aging management, station grounding and surge protection, and corrosion control for structures.

In October 1992, the NRC staff issued a Draft Final safety Evaluation Report (DFSER) (Ref. 6) covering the entire SSAR through amendment 20. This draft euperseded the six SECY papers. The final version of the staff safety evaluation report which we reviewed was the "Advance Copy of Safety Evaluation Report related to the certification of the Advanced Boiling-Water Reactor Design," dated December 1993 (Ref. 7). This copy covered the NRC staff review of SSAR information through about Amendment 32 . Additional changes, including those which reflect Amendments 33 and 34 , were reviewed by us as page changes to Reference 7 .

Between February 1988 when the ABWR application was docketed and April 1992 when we issued our report on the DSER, our ABWR subcommittee held numerous meetings to review the SSAR and the NRC staff rafety evaluations. During this same period, our subcomittee on Improved Light Water Reactors held several meetings to review the Electric Power Research Institute (EPRI) Utility Requirements Document (URD) and associated NRC staff safety evaluations for the Advanced Light-Water Reactor (ALWR) evolutionary plant. (The EPRI URD prescribes ALWR design requirements from the utility industry perspective.) Meetings were also held by our subcommittees on Auxiliary and secondary systems, Computers in Nuclear Power Plant Operations, Human Factors, and Severe Accidents. These subcommittees reviewed a number of specialized aspects of the proposed ABWR design including those related to fire, digital control and protection systems, human factors, and severe accidents.

Between April 1992 and today, our ABWR subcommittee held additional meetings to review design features proposed beyond Amendment 20 of the SSAR and to review the DFSER and Reference 7 . This review covered significant design changes in the SSAR (through Amendment 34) and closure of all open items in the DFSER. It also included a review of written responses by GENE to numerous questions and concerns raised by the subcomittee.

During this time our subcommittee on Improved Light Water Reactors held several meetings to complete its review of the EPRI URD. In addition,. ABWR-related meetings were held by our subcommittees on Auxiliary and secondary Systems, Computers in Nuclear Power Plant Operations, Human Factors, Severe Accidents, Safeguards and security, and our Ad Hoc Subcommittee on Design Acceptance Criteria $(D A C)$. We did not review most of the CDM portion of the applica- 
tion because we were assured by the NRC staff that it did not contain design features and requirements beyond those found in the SSAR. We did, however, review and comment (Ref. 8) on the viability of the DAC process as a suitable method for establishing future design acceptance requirements in certain areas (1.e., human factors engineering, radiation protection, piping design, and instrumentation and control). We also reviewed the CDM related to these DAC areas.

During our review of the ABWR SSAR, we considered the design-specific requirements which relate to the varlous evolutionary and advanced light water reactor policy, technical, and licensing issues included in SECY-90-016 (Ref.9) and 1ts successor, SECY-93-087 (Ref. 10). These issues incorporate staff positions that deviate from or are not embodied in current regulations. Their resolutions will become "applicable regulations" through incorporation into the design certification rule for the ABWR. We have commented previously (Refs. 11 and 12) concerning these issues.

\section{ACRS conclusion concerning ABWR Safety}

Based on the results of our review of those portions of the GENE ABWR application which concern safety, we believe that acceptable bases and requirements have been established in the application to assure that the U.S. version of the ABWR standard design can be used to engineer and construct plants that with reasonable assurance can be operated without undue risk to the health and safety of the public.

Additional comments by ACRS Members Carlyle Michelson and Charles J. Wylie are presented below.

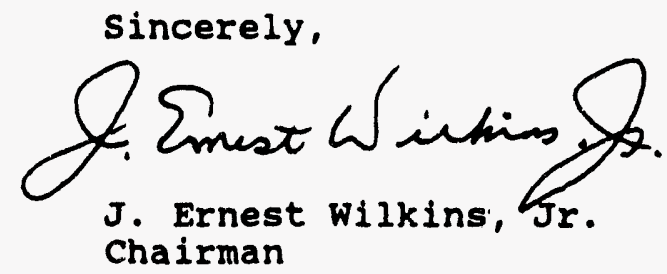

Additional Comments by ACRS Members Carlyle Michelson and charles J. Wylie

Although the committee has arrived at a favorable conclusion concerning ABWR safety with which we agree, it is our view that this report should discuss the resolution of various issues that were considered $i y$ the committee (Refs. 4 and 5) prior to reaching the favorable conclusion. Some of the resolutions were based on findings that were unanticipated and led to significant design changes. We believe that these findings should be made available 
to those who must make the final safety and design certification decisions.

As an example, it was found that the rupture of an 8-inch pipe in the non-safety-grade Reactor Water Cleanup (CUW) System which is housed inside of secondary containment creates serious environmental disruption throughout the three separate divisional areas of secondary . containment which house redundant portions of the Emergency Core Cooling system (ECCS). Since this 8-inch pipe contains reactor coolant at operating temperature and pressure, the break results in an immediate 1088 of reactor coolant until isolated and it requires an ECCS response. Steam from the break permeates the entire secondary containment because the divisional barrier doors are forced open by a bulldup of steam pressure. This occurs before the primary containment isolation valves for the CUW system have time to close. A similar situation exists for the Reactor Core Isolation Cooling (RCIC) System; however, the resulting environmental conditions for most locations are bounded by those produced by the CUW 8-inch pipe break.

Since these pipe break events cannot be confined, GENE now proposes that safety-related equipment inside of the ABWR secondary containment be environmentally qualified for steam at $15 \mathrm{psig.} \mathrm{and}$ about $248^{\circ} \mathrm{F}$. It is our view that this is an acceptable, although undesirable, alternative to a design which provides separation barriers and pressure relieving pathways that are capable of isolating a sufficient amount of ECCS equipment from the harsh environment. In addition, GENE has added a third break isolation valve in the 8-inch CUW supply line and located it inside of primary containment. This valve can be closed after the blowdown is over to ensure the interruption of any prolonged loss of ECCS water to secondary containment. It is needed only if both primary containment isolation valves fail to fully close due to the severe blowdown loads or other challenges common to both valves. The added environmental qualification and the third valve are new features.

References:

1. U.S. Nuclear Regulatory Commission, Policy Statement, 10 CFR Part 50, "Nuclear Power Plant Standardization," 52 FR 34884, September 15,1987

2. Letter dated August 17, 1989, from Charles L. Miller, NRC Office of Nuclear Reactor Regulation, to Patrick w. Marriott, General Electric Company, enclosing Draft Safety Evaluation Report Related to the Final Design Approval and Design Certification of the Advanced Boiling water Reactor, August 1989

3. ACRS report dated November 24, 1989, from Forrest J. Remick, ACRS Chairman, to James M. Taylor, NRC Executive Director for Operations, Subject: Module I of the Draft Safety Evaluation Report for the Advanced Boiling Water Reactor Design 
4. ACRs report dated July 18, 1991, from David A Ward, ACRS Chairman, to James M. Taylor, NRC Executive Director for Operations, Subject: Concerns Related to the General Electric Advanced Boiling Water Reactor Design

5. ACRS report dated April 13, 1992, from David A. Ward, ACRS Chairman, to James M. Taylor, NRC Executive Director for operations, subject: Review of the Draft safety Evaluation Reports on the GE Advanced Boiling Water Reactor Design

6. U. S. Nuclear Regulatory Commiseion, NUREG-1469, "Draft Final Safety Evaluation Report Related to the Design Certification of the General Electric Nuclear Energy Advanced Bolling water Reactor," October 1992

7. U.S. Nuclear Regulatory Commission, office of Nuclear Reactor Regulation, "Advance Copy of Safety Evaluation Report related to the certification of the Advanced Boiling-Water Reactor Design," December 1993

8. ACRS report dated January 14, 1994, from J. Ernest wilkins, Jr., ACRS Chairinan, to Ivan selin, NRC Chairman, subject: Finat Report on the Use of the Design Acceptance Criteria Process in the Certification of the General Electric Nuclear Energy Advanced Boliling Water Reactor Design Approval

9. SECY-90-016, dated January 12, 1990, from James M. Taylor, NRC Executive Director for Operations, for the commissioners, Subject: Evolutionary Light Water Reactor (LWR) Certification Issues and Their Relationship to Current Regulatory Reguirements

10. SECY-93-087, dated April 2, 1993, from James M. Taylor, NRC Executive Director for Operations, for the Commissioners, subject: Policy, Technical, and Licensing Issues Pertaining to Evolutionary and Advanced Light-Water Reactor (ALWR) Designs

11. ACRS report dated April 26, 1990, from Carlyle Michelson, ACRS Chairman, to Kenneth M. Carr, NRC Chairman, subject: Evolutionary Light Water Reactor Certification Issues and Their Relationship to Current Regulatory Requirements.

12. ACRS report dated April 26, 1993, from Paul shewmon, ACRS Chairman, to Ivan selin, NKC Chairman, subject: SECY-93-087, "Policy, Technical, and Licensing Issues Pertaining to Evolutionary and Advanced Light-Water Reactor (ALWR) Designs" 


\section{CONCLUSIONS}

The staff performod its review of the U.S. ABWR atundard safety analysis report, certified design material, and technical spocifications in accordance with the standards for review of design certification applications set forth in 10 CFR \$52.48 that are applicable and technically relevant to the U.S. ABWR standard design, including the exemptions and applicable regulations identified in Section 1.6 of this report. On the besis of its evaluation and independent analyses as discussed in this report, the staff concludes that, subject to satisfactory resolution of the confirmatory items identified in Section 1.8 of this report, GE Nuclear Energy's application for design certification meets the requirements of 10 CFR 852.47 that are applicable and technically relevant to the U.S. ABWR standard design. A copy of the report by the Advisory Committes on Reactor Safeguards required by 10 CFR 852.53 is provided in Chapter 21 of this report.
The ataff aleo concludes that iseunance of a final design approval, in accordance with Appendix $O$ to 10 CFR Part 52, will not be inimical to the common defense and security or to the health and safety of the public. The financial qualifications of the applicable utility and the indemnity requirements of 10 CFR Part 140 will be addresed during the plant-specific licensing process for an application that references the U.S. ABWR standard design.

A final design approval, issued on the basis of this SER, does not constitute a commitment to issue a permit or license, or in any way affect the authority of the Commission, the Atomic Safety and Licensing Board, and other presiding officers, in any proceeding pursuant to Subpart G of 10 CFR Part 2. 


$$
\begin{aligned}
& \text { DATE } \\
& \text { FILMED } \\
& 9 / 20 / 94
\end{aligned}
$$

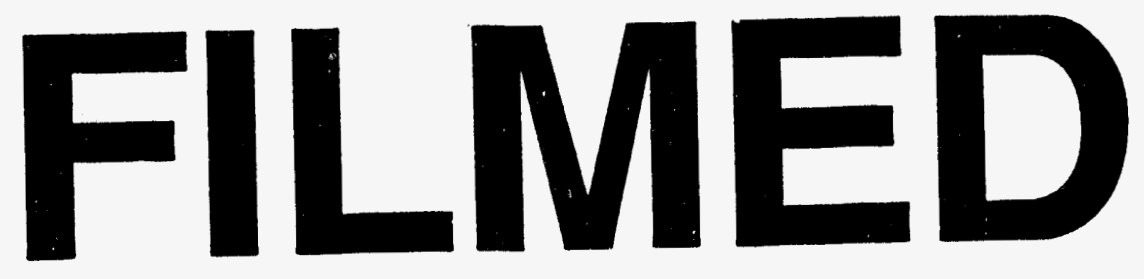

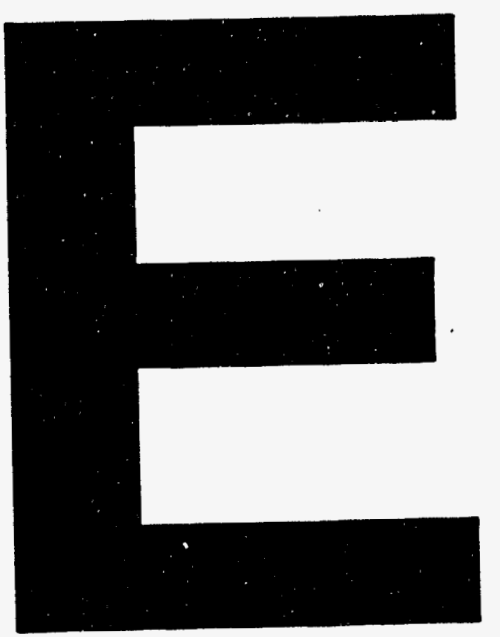
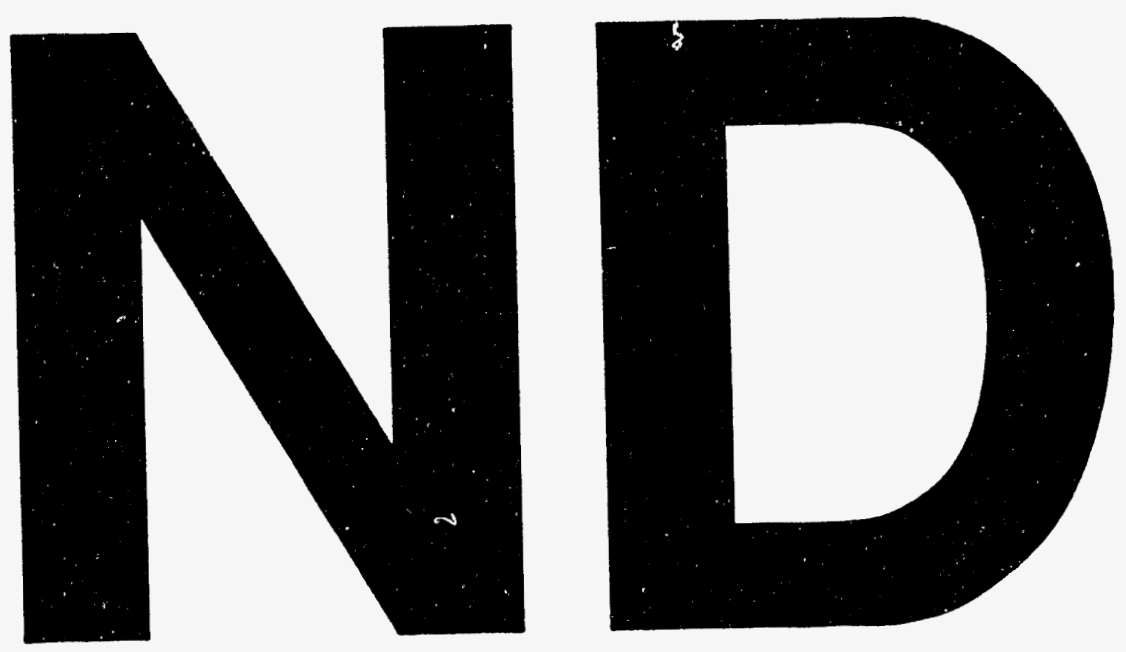


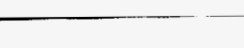

